AlllOI H I

NATL INST OF STANDARDS \& TECH R.I.C.

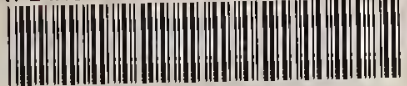

A11101110125

National Instituta o/Publications of tha
QC100.U57 NO.305 SUPPL.9 SUPP C.1 NBS-P 




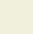



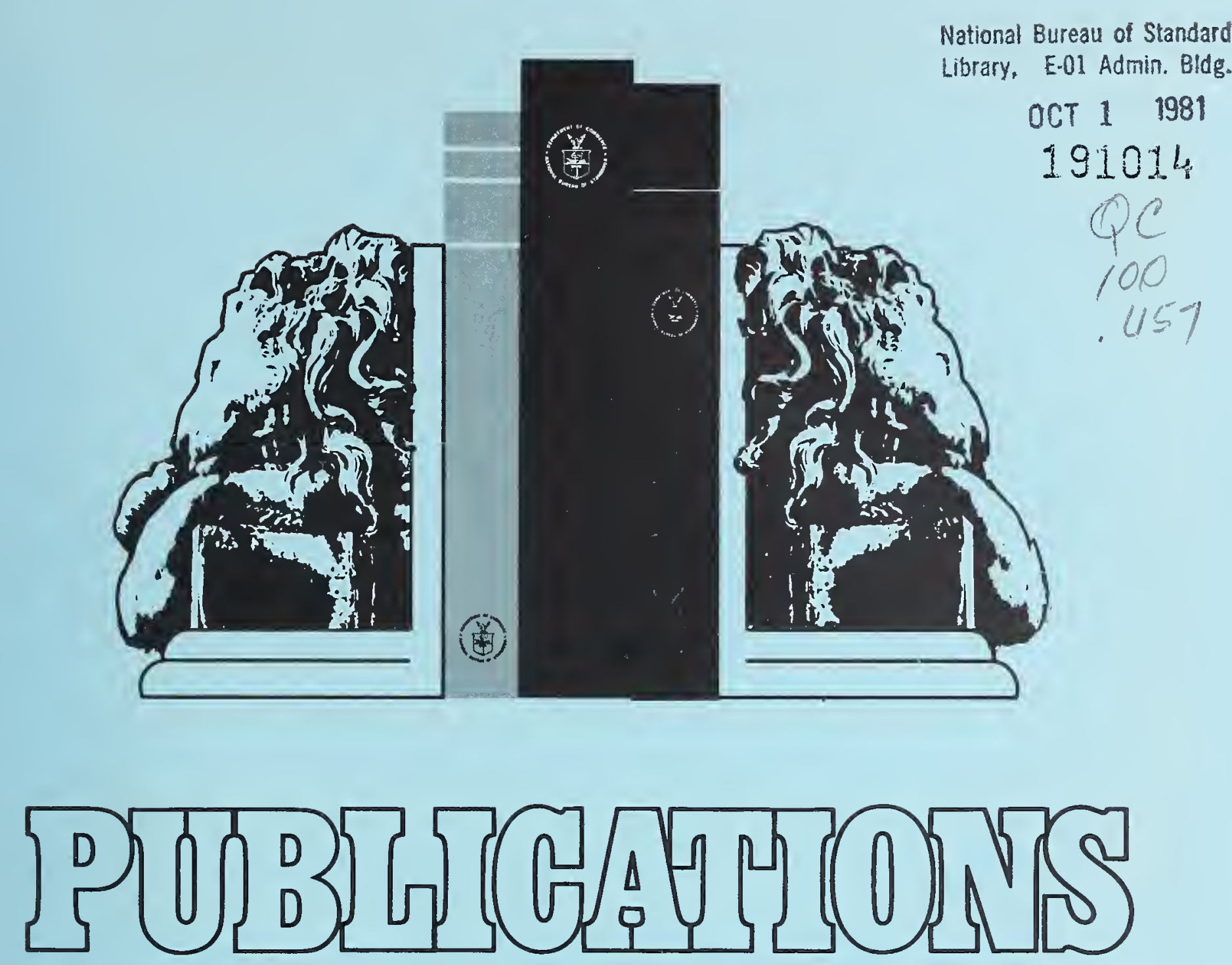

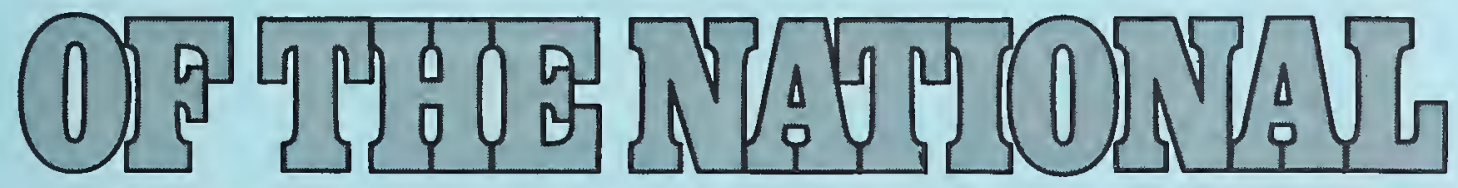

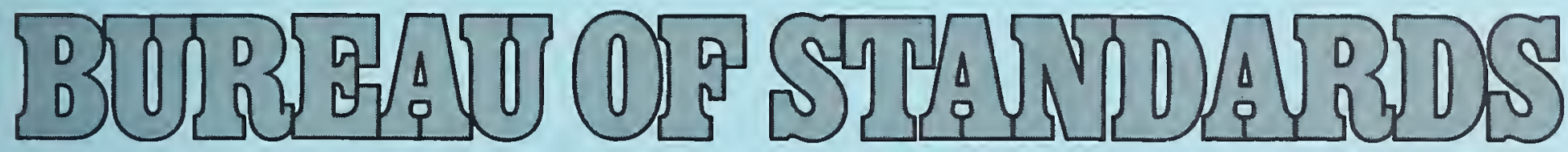

\section{CATALOG/SUPPLEMENT 9}





\section{Publications of the National Bureau of Standards 1977 Catalog}

A Compilation of Abstracts and Key Word and Author Indexes

Betty L. Burris, Editor

Technical Information and Publications Division

National Bureau of Standards

Washington, D.C. 20234

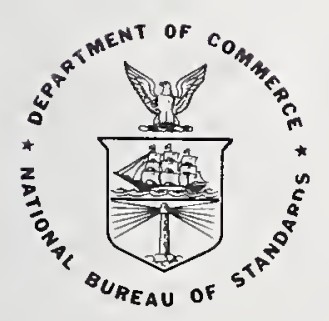

U.S. DEPARTMENT OF COMMERCE, Juanita M. Kreps, Secretary

Dr. Sidney Harman, Under Secretary

Jordan J. Baruch, Assistant Secretary for Science and Technology

U.S. NATIONAL BUREAU OF STANDARDS, Ernest Ambler, Director 


\section{Library of Congress Catalog Number: 48-47112}

\section{National Bureau of Standards Special Publication 305 Supplement 9}

To Accompany National Bureau of Standards Special Publication 305; and its Supplements 1,2,3,4,5,6,7 and 8 Nat. Bur. Stand. (U.S.), Spec. Publ. 305 Suppl. 9, 601 pages (June 1978)

CODEN: XNBSAV

Issued June 1978 


\section{PREFACE}

Publications constitute an important means of transmitting the results of NBS and NBSsponsored research to the diverse audiences served by the National Bureau of Standards. NBS research covers the wide range of physics, chemistry, engineering, mathematics, and computer sciences, all related to the specific program areas listed on the inside cover. An overall total of 46,021 pages was published by NBS in 1977, 64 percent issued in the Bureau's own publication series, with the other 36 percent appearing in non-NBS journals, books, and proceedings.

The NBS Journal of Research, previously issued in two sections (A: Physics and Chemistry, and B: Mathematical Sciences), was consolidated during 1977 into a single journal which now reports on all areas of NBS research and development: This catalog reports the final issues of the two-section Journal and the beginning issues of its single-volume successor.

The present catalog again includes citations for patents issued to NBS inventors and for reports prepared under NBS contracts. Also included, as in past years, are citations for papers published in the Journal of Physical and Chemical Reference Data, which is published for NBS by the American Institute of Physics and the American Chemical Society.

All papers are cited by full title, author(s), place of publication, abstract, and key words. Permuted author and key word indexes facilitate use of the listings, as does the edge index on the back cover. Citations for papers published in the Bureau's formal program are organized by NBS publications series. NBS-authored papers in non-NBS media are cited separately in numerical sequence. In addition, for the convenience of specialists, the titles of all NBS publications for 1977, categorized by major primary subject area, are listed in a special section of this catalog.

NBS papers published by the Government Printing Office are sold by the Superintendent of Documents and also, in microcopy form, by the National Technical Information Service (NTIS). The NBS Federal Information Processing Standards Publications (FIPS PUBS) are sold only by NTIS.

For the convenience of researchers, this issue contains information on previous NBS catalogs and on the availability of NBS papers published in past years. Also included, for completeness, are those NBS papers published prior to 1977 but not reported in previous issues of this annual catalog. This 1977 catalog, Supplement 9 to NBS Special Publication 305 , was produced by means of computer-assisted photocomposition under the direction of Rebecca J. Morehouse.

W. R. Tilley

Chief, Technical Information and Publications Division 


\section{CONTENTS}

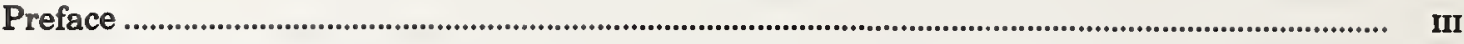

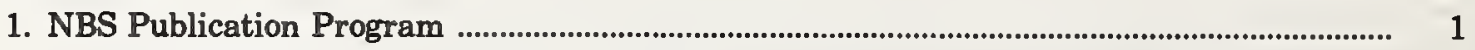

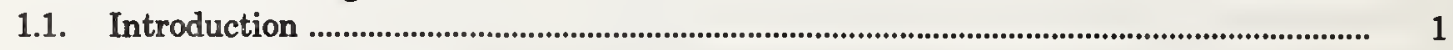

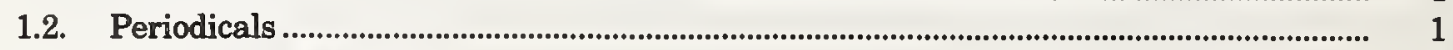

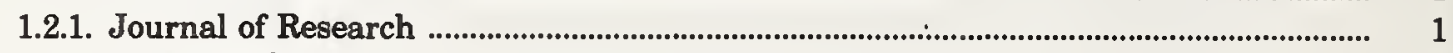

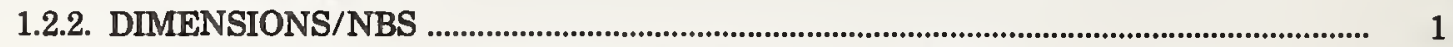

1.2.3. Journal of Physical and Chemical Reference Data (JPCRD) ........................................ 1

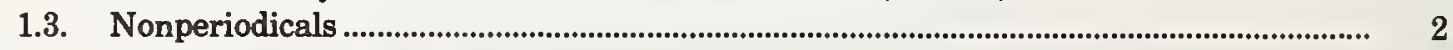

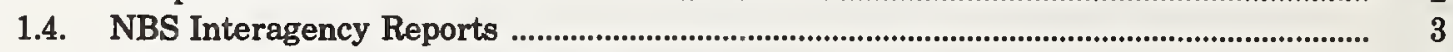

1.5. Grantee/Contractor Reports and Patents ................................................................... 3

1.6. NBS Bibliographic Subscription Services ...................................................................... 3

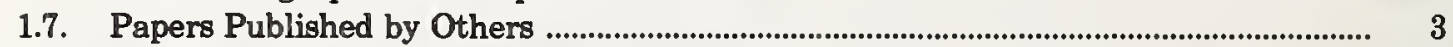

2. Purchase Procedures and Document Availability ..................................................................... 3

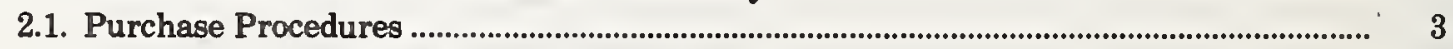

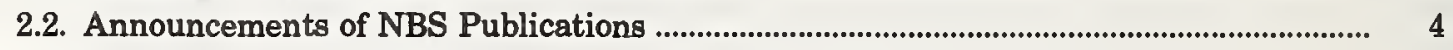

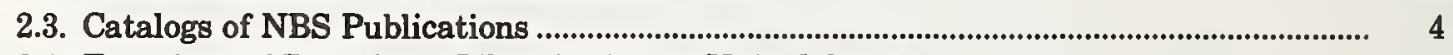

2.4. Functions of Depository Libraries in the United States............................................... 5

2.5. Functions of U.S. Department of Commerce District Offices ........................................... 5

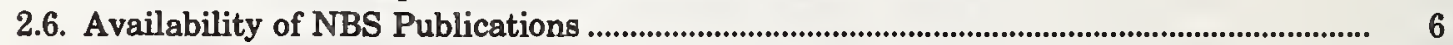

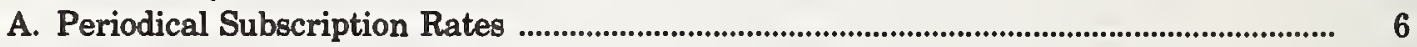

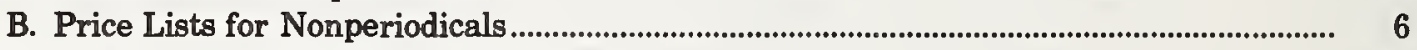

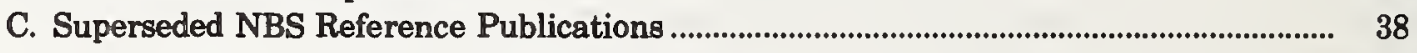

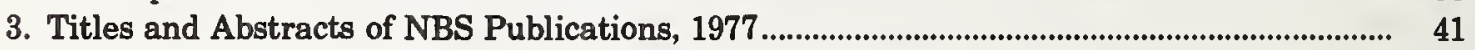

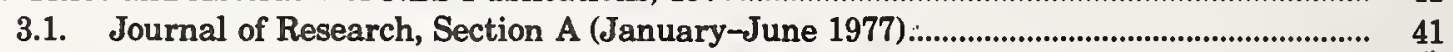

3.2. Journal of Research, Section B (January-June 1977) .............................................. 44

3.2.1. Journal of Research (July-December 1977) *................................................................. 45

3.3. Journal of Physical and Chemical Reference Data ..................................................... 48

3.4. DIMENSIONS/NBS, article titles only ...................................................................... 52

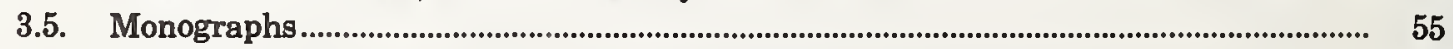

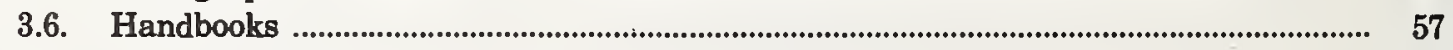

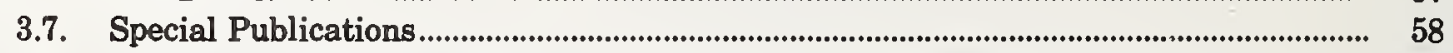

3.8. Applied Mathematics Series ....................................................................................... 137

3.9. National Standard Reference Data Series ...................................................................... 137

3.10. Building Science Series .................................................................................................... 138

3.11. Federal Information Processing Standards Publications ........................................... 144

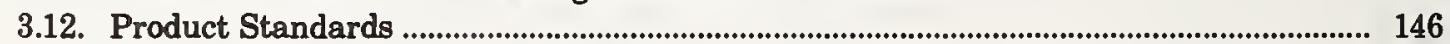

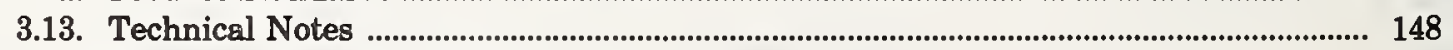

3.14. Consumer Information Series ................................................................................. 154

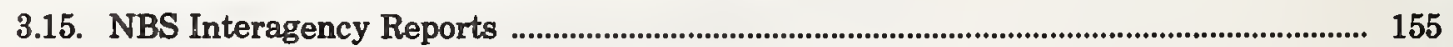

3.16. Grantee/Contractor Reports and Patents ............................................................... 182

4. Titles and Abstracts of Papers Published in Non-NBS Media, 1977 ........................................ 191

5. Listing of NBS Papers by Major Subject Areas ..................................................................... 293

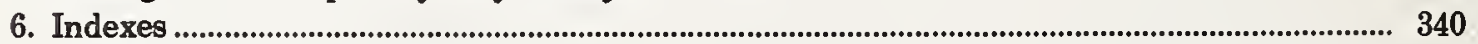

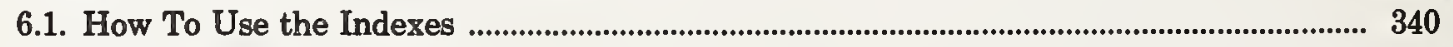

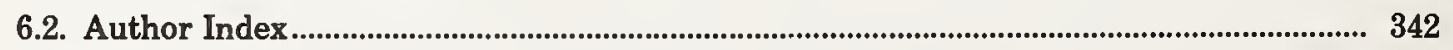

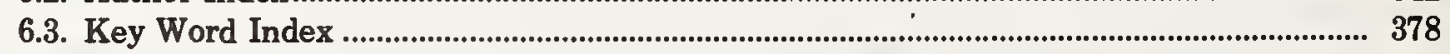

Appendix A. List of Depository Libraries in the United States ................................................. 581.

Appendix B. List of District Offices of the U.S. Department of Commerce ............................ 595

- See Section 1.2.1. for information on changes in this Journal. 


\section{NBS PUBLICATION PROGRAM}

\subsection{INTRODUCTION}

The formal publication of the National Bureau of Standards-some, 1878, papers in 1977 provide the primary means of communicating the results of NBS programs to its varied technical audiences, as well as to the general public. Publications thus constitute a major end product of the Bureau's efforts. These take the form of the Bureau's three periodicals, its ten nonperiodical series, interagency reports, and articles in the journals of professional organizations and technological associations.

This annual catalog, Publications of the National Bureau of Standards, cites the 1977 output of papers that document the results of the $\mathrm{Bu}$ reau's current programs. The various media in which these papers appeared are as follows:

\subsection{PERIODICALS}

\subsubsection{JOURNAL OF RESEARCH}

This catalog reports the concluding issues (from January to June 1977) of the National Bureau of Standards Journal of. Research, Section A. Physics and Chemistry and Section B. Mathematical Sciences. Section A covered NBS physical and chemical research, with major emphasis on standards of physical measurements, fundamental constants, and properties of matter. Section B, designed mainly for the mathematician and theoretical physicist, published papers on methematical statistics, theory of experiment design, numerical analysis, theoretical physics and chemistry, logical design and programming of computers and computer systems and also short numerical tables.

Effective July 1977, the National Bureau of Standards Journal of Research, as one section on a bi-monthly basis, superseded the two-section Journal. It reports NBS research and development in those physical and engineering disciplines where the Bureau is active. These include physics, chemistry, engineering, mathematics, and computer sciences. Papers cover a broad range of subjects, with major emphasis on measurement methodology and on the basic technology underlying standardization. Also included from time to time are survey articles on topics closely related to the Bureau's technical and scientific programs. As a special service to subscribers, each issue contains complete citations for all recent NBS publications. Papers published during 1977 in the new Journal are reported in this catalog.

Board of Editors:

Churchill Eisenhart,

Executive Editor (Mathematics)

John W. Cooper (Physics)

Donald D. Wagman (Chemistry)

Andrew J. Fowell (Engineering)

Joseph O. Harrison (Computer Science)

Stephen J. Smith (Boulder Labs.)

\subsubsection{DIMENSIONS/NBS}

This magazine is published to inform both the technical expert and the interested layman of the latest advances in science and technology, with primary emphasis on the work at NBS. The magazine highlights and reviews such issues as energy research, fire protection, building technology, metric conversion, pollution abatement, health and safety, and consumer product performance. In addition, it reports the results of Bureau programs in measurement standards and techniques, properties of matter and materials, engineering standards and services, instrumentation, and automatic data processing.

The table of contents for each issue in 1977 are listed in Section 3.4. pages 52-54. Issued monthly.

Editor: Juli Kelley

\subsubsection{JOURNAL OF PHYSICAL AND CHEMICAL REFERENCE DATA (JPCRD)}

This Journal is published quarterly by the American Chemical Society and the American Institute of Physics for the National Bureau of Standards. The objective of the Journal is to provide critically evaluated physical and chemical property data, fully documented as to the original sources and the criteria used for evaluation. Critical reviews of measurement techniques, whose aim is to assess the accuracy of available data in a given technical area, are also included. The principal source for the Journal is the National Standard Reference Data System (NSRDS). The Journal is not intended as a publication outlet for original experimental measure- 
ments such as are normally reported in the primary research literature, nor for review articles of a descriptive or primarily theoretical nature. (See also Section 1.3. National Standard Reference Data Series.)

\subsection{NONPERIODICALS}

Ten categories of nonperiodical publications, described as follows, are listed in this catalog:

MONOGRAPHS-major contributions to the technical literature on various subjects related to the Bureau's scientific and technical activities.

HANDBOOKS-recommended codes of engineering and industrial practice (including safety codes) developed in cooperation with interested industries, professional organizations, and regulatory bodies.

SPECIAL PUBLICATIONS-include proceedings of conferences sponsored by NBS, NBS annual reports, and other special publications appropriate to this grouping such as wall charts, pocket cards, and bibliographies.

Special subject-matter subseries include Semiconductor Measurement Technology (SP400- ), Standard Reference Materials (SP 260- ), Precision Measurement and Calibration (SP300- ), Law Enforcement Technology (SP480- ), and Computer Science and Technology (SP500- ).

\section{APPLIED MATHEMATICS SERIES-math-} ematical tables, manuals, and studies of special interest to physicists, engineers, chemists, biologists, mathematicians, computer programmers, and others engaged in scientific and technical work.

\section{NATIONAL STANDARD REFERENCE DATA} SERIES-provides quantitative data on the physical and chemical properties of materials, compiled from the world's literature and critically evaluated. Developed under a worldwide program coordinated by NBS, under authority of National Standard Data Act (Public Law 90-396). This series supplements the JPCRD, see also Section 1.2.3.

BUILDING SCIENCE SERIES-disseminates technical information developed at the Bureau on building materials, components, systems, and whole structures. The series presents research results, test methods, and performance criteria related to the structural and environmental functions and the durability and safety characteristics of building elements and systems.

TECHNICAL NOTES-studies or reports which are complete in themselves but restrictive in their treatment of a subject. Analogous to monographs but not so comprehensive in scope or definitive in treatment of the subject area. Often serve as a vehicle for final reports of work performed at NBS under the sponsorship of other government agencies.

Special subject-matter subseries include Optical Radiation Measurements (TN594- ) and Self Calibrations Manual for Optical Radiation (TN910- ).

VOLUNTARY PRODUCT STANDARDS-developed under procedures published by the Department of Commerce in Part 10, Title 15, of the Code of Federal Regulations. The purpose of the standards is to establish nationally recognized requirements for products, and to provide all concerned interests with a basis for common understanding of the characteristics of the products. The National Bureau of Standards administers the Voluntary Product Standards program as a supplement to the activities of the private sector standardizing organizations.

\section{FEDERAL INFORMATION PROCESSING} STANDARDS PUBLICATIONS (FIPS PUBS)publications in this series collectively constitute the Federal Information Processing Standards Register. Register serves as the official source of information in the Federal Government regarding standards issued by NBS pursuant to the Federal Property and Administrative Services Act of 1949 as amended, Public Law 89-306 (79 Stat. 1127), and as implemented by Executive Order 11717 (38 FR 12315, dated May 11, 1973) and Part 6 of Title 15 CFR (Code of Federal Regulations).

Public distribution of FIPS PUBS is by purchase from the National Technical Information Service, Springfield, VA 22161.

CONSUMER INFORMATION SERIES-practical information, based on NBS research and experience, covering areas of interest to the consumer. Easily understandable language and 
illustrations provide useful background knowledge for shopping in today's technological marketplace.

\subsection{NBS INTERAGENCY REPORTS}

A special series of interim or final reports on work performed by NBS for outside sponsors (both government and non-government). In general, initial distribution is handled by the sponsor; public distribution is by the National Technical Information Service (Springfield, VA 22161) in paper copy or microfiche form. (See pages 28 to 35 for price lists.)

\subsection{GRANTEE/CONTRACTOR REPORTS AND PATENTS}

Grantee/contractor reports are prepared by non-NBS persons or organizations working under grant or contract from the National Bureau of Standards. Those contract reports not incorporated into the formal NBS publication series are available directly from the National Technical Information Service (NTIS), Springfield, VA 22161 , in paper copy or microfiche form unless otherwise stated. When ordering a report from NTIS you must order it by the "COM, PB, AD, or N" number as indicated.

Patents-are obtained on NBS inventions of high commercial potential, in order to establish Government ownership of the patent rights. The patents are then made available for the grant of nonexclusive licenses to all qualified applicants. A limited exclusive license may be granted under a particular patent, however, if it appears that some period of exclusivity is necessary as an incentive for the investment of risk capital. For information on licensing any of the NBS held patents, write to the Office of the Legal Adviser, National Bureau of Standards, Washington, DC
20234. Copies of patents may be obtained from the U.S. Patent and Trademark Office, Washington, DC 20231 for 50 cents each.

\subsection{NBS BIBLIOGRAPHIC SUBSCRIPTION SERVICES}

The Cryogenic Data Center of the National Bureau of Standards, Boulder, CO has developed specialized bibliographic issuances designed to provide interested audiences with information on latest developments in certain specialized fields. These issuances, together with subscription information, are listed below:

CRYOGENIC DATA CENTER CURRENT AWARENESS SERVICE (Publications and Reports of Interest in Cryogenics). A literature survey issued weekly. Annual subscription: Domestic, $\$ 25.00$; Foreign, $\$ 30.00$.

LIQUEFIED NATURAL GAS. A literature survey issued quarterly. Annual subscription: $\$ 20.00$.

SUPERCONDUCTING DEVICES AND MATE-

RIALS. A literature survey issued quarterly. Annual subscription: $\$ 30.00$.

Send subscription orders and remittances for the preceding bibliographic services to the National Bureau of Standards, Cryogenic Data Center (736.00), Boulder, CO 80303.

\subsection{PAPERS PUBLISHED BY OTHERS}

Many significant contributions by NBS authors are published in other journals. Up-todate listings of these articles are carried regularly in each section of the Journal of Research, along with selected abstracts. A complete listing is published annually in NBS SP305, along with abstracts, key words, and author/subject indexes.

\section{PURCHASE PROCEDURES AND DOCUMENT AVAILABILITY}

\subsection{PURCHASE PROCEDURES}

Publications of the Bureau are available from the Superintendent of Documents, U.S. Government Printing Office, Washington, DC 20402, at the prices listed in this publication. However, prices are subject to change without notice. You may also order through the U.S. Department of Commerce Field Office nearest you (see Appen- dix B for list of Field Offices of the U.S. Department of Commerce). Microfiche copies of all recent NBS publications, and paper copies of many non-periodicals, may be ordered through the National Technical Information Service, U.S. Department of Commerce, Springfield, VA 22161.

This section includes price lists of available 
publications, plus instruction on how to acquire reprints of articles by NBS authors, and how to get out-of-print material.

How To Make Remittances. Remittances for publications for which individual sales or subscription prices are shown should be mailed to Superintendent of Documents, U.S. Government Printing Office, Washington, DC 20402, by postal money order, express money order, or check. Postage stamps will not be accepted. Publications cannot be mailed before remittances are received. Foreign remittances should be made either by international money order, draft on an American bank or UNESCO coupons.

The letter symbol, publication number, full title of the publication, SD catalog or SD stock number MUST be given when ordering. The Superintendent of Documents allows a discount of 25 percent on orders of 100 or more copies of one publication.

Persons who make frequent purchases from the Superintendent of Documents may find a deposit account convenient. Deposits of $\$ 50$ or more are accepted against which orders may be placed without making individual remittances or first obtaining quotations. Order blanks are furnished for this purpose. After the order has been processed, the order itself is returned, showing the publications supplied, explanations regarding those not sent, the amount of charge, and the balance on deposit.

No charge is made for postage on documents sent to points in the United States and its possessions. In computing foreign postage, the charge is approximately one-fourth of the current selling price of the publication. The charge is to cover the special handling required to comply with the customs and international mailing regulations.

Orders for publications purchased from the National Technical Information Service (NTIS) must be accompanied by postal money order, express money order, or check made out to the NTIS and covering total cost of the publications order. All inquiries or orders should be addressed to: National Technical Information Service, Springfield, VA 22161.

SD and NTIS order forms are included at the end of this publication for your convenience in ordering.

\subsection{ANNOUNCEMENT OF NBS PUBLICATIONS}

The National Bureau of Standards and the agencies mentioned below regularly issue the following official announcements dealing with NBS publications.

DIMENSIONS/NBS. Issued monthly by the National Bureau of Standards. In addition to publishing technical news of the Bureau, this periodical announces selected new publications in an NBS series. Available from the Superintendent of Documents, U.S. Government Printing Office, Washington, DC 20402. Annual subscription, $\$ 12.50 ; \$ 15.65$ foreign. Single copies, $\$ 1.00$ each.

NBS JOURNAL OF RESEARCH. The Journal carries a listing of all NBS publications as issued. See Section 2.6. for subscription information.

Monthly Catalog of United States Government. Publications. Issued monthly by the Superintendent of Documents, U.S. Government Printing Office, Washington, DC 20402. Annual subscription, with consolidated annual index, $\$ 45.00$; $\$ 56.00$ foreign.

Selected List of U.S. Government Publications. Issued monthly by the Superintendent of Documents. Each list is arranged by subject, with annotations, prices, and order form. May be obtained free from the U.S. Government Printing Office, Superintendent of Documents, Mail List Section, Stop SSOM, Washington, DC 20402.

Business Service Check List. Bi-weekly announcement of publications of the Department of Commerce. Lists titles and prices of National Bureau of Standards publications, as well as those of other offices of the Department of Commerce. Available from the Superintendent of Documents, U.S. Government Printing Office, Washington, DC 20402. Annual subscription, $\$ 9.00 ; \$ 11.25$ foreign.

\subsection{CATALOGS OF NBS PUBLICATIONS}

Previous catalogs, plus this publication, constitute a complete list of the titles of the Bureau's publications through December 31, 1977. The catalogs are available from the Superintendent of Documents, U.S. Government Printing Office, Washington, DC 20402, unless otherwise stated, or may be consulted in a library which maintains sets of National Bureau of Standards publications. 
Circular 460: Publications of the National Bureau of Standards 1901 to June 30, 1947. 375 pages including subject and author indexes. Brief abstracts are included for the period January 1, 1941 to June 30, 1947

Supplement to Circular 460: Publications of the National Bureau of Standards, July 1, 1947 to June 30, 1957. 373 pages, including subject and author indexes...

Miscellaneous Publication 240: Publications of the $\mathrm{Na}$ tional Bureau of Standards, July 1, 1957 to June 30, 1960. First NBS Catalog to include Titles of Papers Published in Outside Journals 1950 to 1959. 391 pages, including subject and author indexes.

Supplement to Miscellaneous Publication 240: Publications of the National Bureau of Standards published by NBS, July 1960 through June 1966; published by others, 1960 through 1965 . 740 pages, including subject and author indexes

Special Publication 305: Publications of the National Bureau of Standards, published by NBS, July 1966 through December 1967; published by others, 1966-1967. 223 pages, a citation of titles and abstracts, with key words and author indexes...

Supplement 1 to Special Publication 305: Publications of the National Bureau of Standards, 1968 through 1969. 497 pages, a citation of titles and abstracts, with key words and author indexes ....

Supplement 2 to Special Publication 305: Publications of the National Bureau of Standards, 1970. 378 pages, a citation of titles and abstracts, with key words and author indexes

Supplement 3 to Special Publication 305: Publications of the National Bureau of Standards, 1971. 342 pages, a citation of titles and abstracts, with key words and author indexes

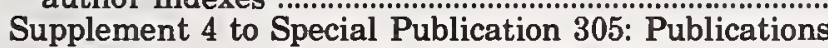
of the National Bureau of Standards, 1972. 449 pages, a citation of titles and abstracts, with key words and author indexes

Supplement 5 to Special Publication 305: Publications of the National Bureau of Standards, 1973. 349 pages, a citation of titles and abstracts, with key words and author indexes

Supplement 6 to Special Publication 305: Publications of the National Bureau of Standards, 1974. 523 pages, a citation of titles and abstracts, with key words and author indexes

Supplement 7 to Special Publication 305: Publications of the National Bureau of Standards, 1975. 595 pages, a citation of titles and abstracts, with key words and author indexes

Supplement 8 to Special Publication 305: Publications of the National Bureau of Standards, 1976.728 pages, a citation of titles and abstracts, with key words and author indexes

Supplement 9 to Special Publication 305: Publications of the National Bureau of Standards, 1977 . pages, a citation of titles and abstracts, with key words and author indexes

-Available by purchase from the National Technical Information Service, Springfield, VA 22161.

\subsection{FUNCTIONS OF DEPOSITORY LIBRARIES IN THE UNITED STATES}

The Superintendent of Documents, United States Government Printing Office, is authorized by law to furnish Government publications to designated depository libraries.
Under provisions of Title 44 of the United States Code, certain libraries are designated depositories for Government publications. Through them Federal Government documents are made available to residents of every State, District of Columbia, Guam, Puerto Rico, and the Virgin Islands. Distribution to the libraries is made by the Office of the Superintendent of Documents.

It is sometimes impossible to obtain desired publications by purchase from the Superintendent of Documents. Stocks may have been exhausted or the document may be permanently out of print. In these instances the depositories render an invaluable service by keeping such publications permanently available. Every Government publication cannot be consulted at all depository libraries. Designated Regional Depositories are required to receive and retain one copy of all Government publications made available to depository libraries either in printed or microfacsimile form. All other libraries are allowed to select the classes of publications best suited to the interest of their particular clientele.

The libraries listed in Appendix $\mathrm{A}$ are now receiving selected publication series of the $\mathrm{Na}$ tional Bureau of Standards for general reference use. Whether a given library has a copy of a particular publication can be determined by inquiring at the library.

\subsection{FUNCTIONS OF U.S. DEPARTMENT OF COMMERCE DISTRICT OFFICES}

\section{Department of Commerce District Offices} are maintained in the cities listed in Appendix B. Their purpose is to provide ready access, at the local level, to the services of the Department of Commerce as well as to its reports, publications, statistical statements, and surveys. Each District Office serves as an official sales agent of the Superintendent of Documents, U.S. Government Printing Office, making available for purchase locally a wide range of Government publications. The reference library maintained by each District Office contains many Government and private publications, periodicals, directories, reports, and other reference materials. 
2.6. AVAILABILITY OF NBS PUBLICATIONS

A. PERIODICAL SUBSCRIPTION RATES

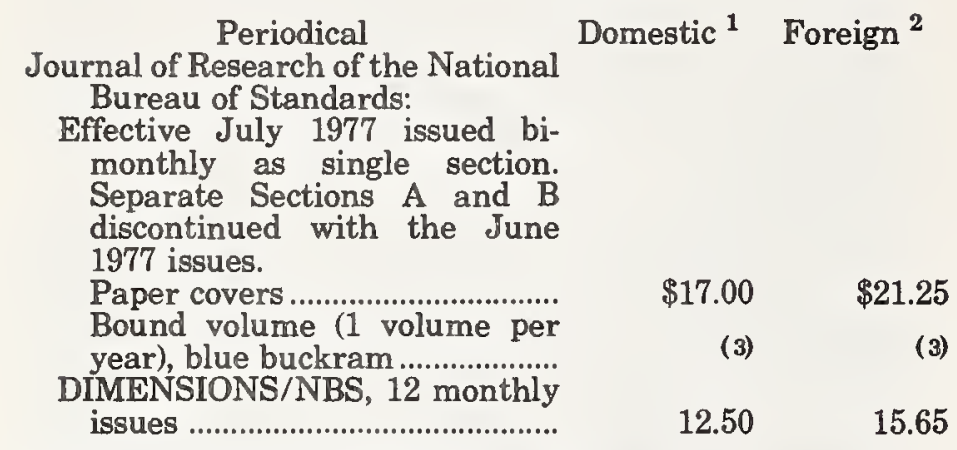

NOTE. -Send order, with remittance, to Superintendent of Documents, U.S. Government Printing Office, Washington, D.C. 20402.

${ }^{1}$ United States and its possessions.

${ }^{2}$ Foreign price includes the cost of the publication and postage.

Prices of the bound volumes vary. The Superintendent of Documents will furnish prices on request.

B. PRICE LISTS FOR NONPERIODICALS

The following lists give the numbers and prices of all NBS publications issued from 1901 through 1977 which are still in print. Those items in boldface denote the 1977 publications cited in this supplement. The prices shown herein supersade prices quoted in previous catalogs of NBS publications. The prices shown are those in effect as of the date this publication went to press. Prices are subject to change without notice, and the prices that will be charged on your order will be those in effect as of the date your order is processed. Except for the Federal Information Processing Standards Series which are only available by purchase from the National Technical Information Service, Springfield, VA 22161, publications may be ordered from the Superintendent of Documents, U.S. Government Printing Office or from, the U.S. Department of Commerce District Office nearest you. SD order forms are included at the end of this publication. Some NBS publications may be purchased from the National Technical Information Service. (See Section 2.1.)

For availability and price of Patents see page 3. Publications not listed are out of print. In such cases, your nearest depository library may still have a copy of that item. (See Section 2.4 and Appendix A.)

6 
CIRCULARS

\begin{tabular}{|c|c|c|c|c|c|}
\hline No. & Price & No. & Price & No. & Price \\
\hline 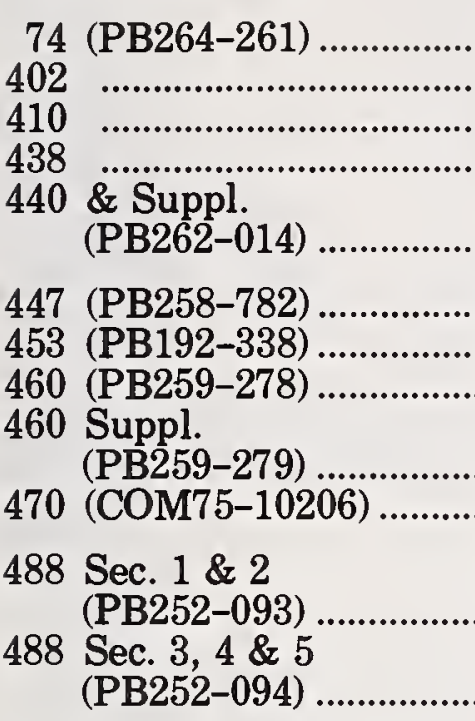 & $\begin{array}{l}* * \\
* 35 \\
* \\
* * \\
* * \\
* * \\
* * \\
* * \\
* * \\
* * \\
* *\end{array}$ & $\begin{array}{l}499 \\
510 \text { (PB192-399) } \\
510 \begin{array}{l}\text { Suppl. } 1 \\
\text { (PB192-340) }\end{array} \\
510 \begin{array}{l}\text { Suppl. } 2 \\
\text { (PB192-341) }\end{array} \\
524 \text { (PB259-780) } \\
536 \\
539 \text { Vol. } 1 \text { to } 10 \text { are } \\
\text { (PB178-902 to } \\
\text { PB178-911) } \\
542 \text { (PB188-806) } \\
556 \text { (COM73-50843) } \\
564 \\
571 \text { (PB175-659) } \\
574 \text { (PB272-292) }\end{array}$ & $\begin{array}{l}* \\
* * \\
* * \\
* * \\
* * \\
.55 \\
* * \\
* * \\
* * \\
* \\
* * \\
*\end{array}$ & 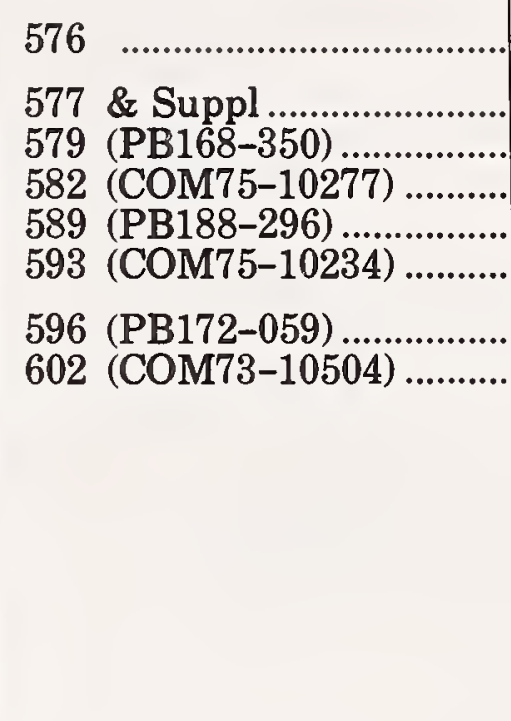 & $\begin{array}{l}* \\
* \\
* * \\
* * \\
* * \\
* * \\
* * \\
* *\end{array}$ \\
\hline
\end{tabular}

*See page 38 for additional information.

"*Available from the National Technical Information Service; use "PB". "COM" or NBS publication identification if no specific NTIS number is assigned. 


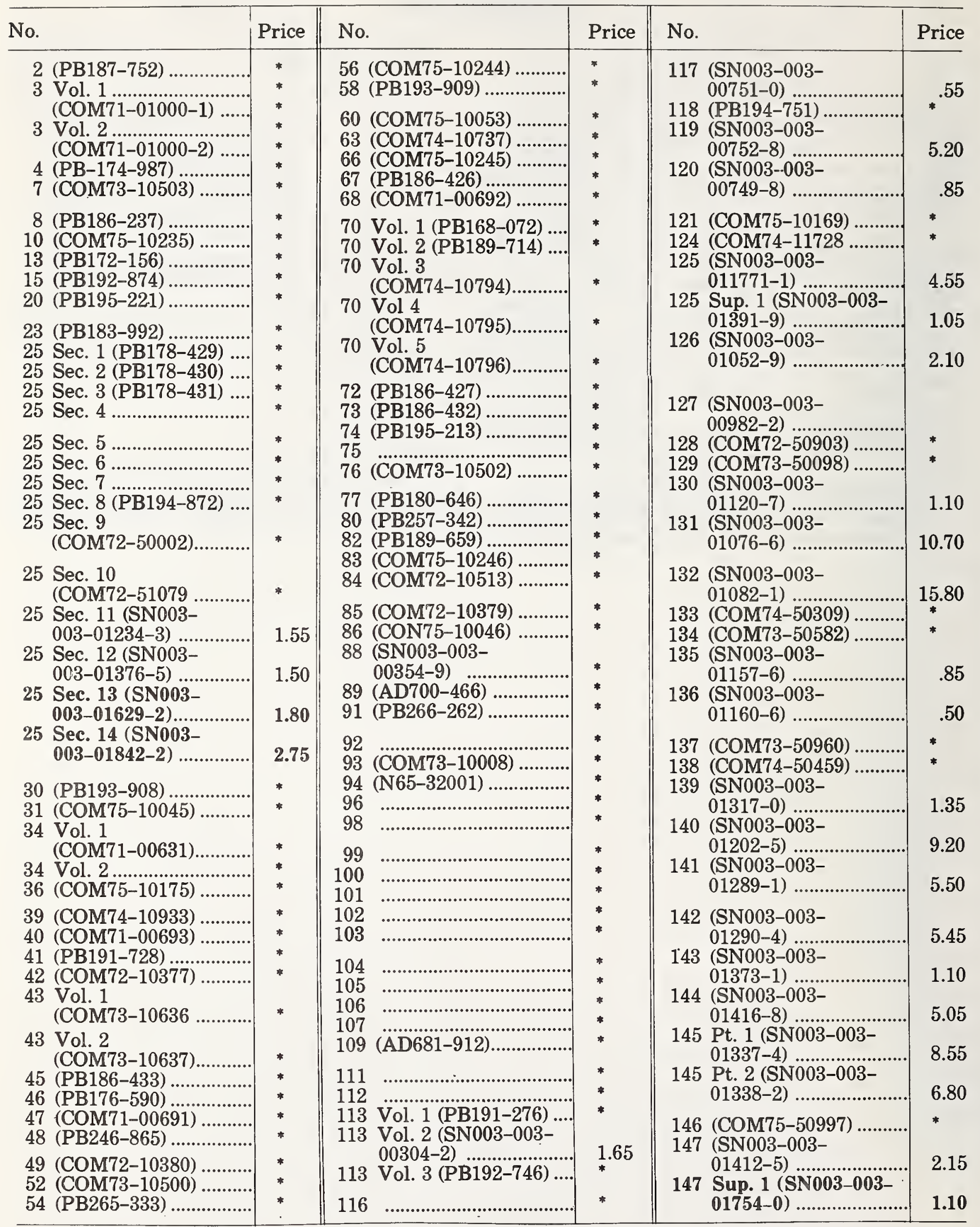


MONOGRAPHS (Continued)

\begin{tabular}{|c|c|c|c|c|c|}
\hline No. & Price & No. & Price & No. & Price \\
\hline $\begin{array}{r}148 \text { (SN003-003- } \\
01370-6)\end{array}$ & \multirow{2}{*}{$\begin{array}{l}1.15 \\
1.35\end{array}$} & \multirow{2}{*}{$\begin{aligned} & \text { (SN003-003- } \\
& 01651-9) \\
154 & (\text { SN003-0..... } \\
& 01612-8 . . . . . . . . .\end{aligned}$} & 1.35 & \multirow{2}{*}{$\begin{aligned} 158 & \text { (SN003-003- } \\
& 01788-4) \ldots . . . . \\
159 & (\text { SN003-003- } \\
& 01782-5) . . . . . .\end{aligned}$} & \multirow{2}{*}{$\begin{array}{l}1.60 \\
5.00\end{array}$} \\
\hline $\begin{array}{l}149 \begin{array}{l}\text { (SNO03-003- } \\
01390-1)\end{array} \\
\text {............. }\end{array}$ & & & 1.70 & & \\
\hline $150 \begin{array}{l}\text { (SN003-003- } \\
01287-3)\end{array}$ & \multirow{2}{*}{$\begin{array}{r}.85 \\
4.50\end{array}$} & $\begin{array}{c}155 \text { (SN003-003- } \\
01650-1)\end{array}$ & 4.00 & \multirow[t]{3}{*}{$160 \begin{array}{r}\text { (SN003-003- } \\
01793-1)\end{array}$} & \multirow[t]{3}{*}{2.10} \\
\hline 151 (SN003-003- & & 156 (SN003-003- & 450 & & \\
\hline $152 \begin{array}{c}\text { (SN003-003- } \\
01552-1)\end{array}$ & & $157 \begin{array}{c}\text { (SN003-003- } \\
01681-1)\end{array}$ & 4.55 & & \\
\hline
\end{tabular}

"Available from the National Technical Information Service: use "PB", "AD", "COM", or NBS publication identification number if not specific NTIS number is assigned.

MISCELLANEOUS PUBLICATIONS

\begin{tabular}{|c|c|c|c|c|c|}
\hline No. & Price & No. & Price & No. & Price \\
\hline $179 \quad \ldots . .$. & $*$ & $260-11 \quad \ldots \ldots$. & $* *$ & 286 (PB252-212).... & * \\
\hline 187 (Сом73-10871) & ** & $260-12 \quad \ldots \ldots \ldots$ & *** & 287 & ${ }^{* *}$ \\
\hline 240 & $* *$ & $260-14$ & ** & 291 & ** \\
\hline 240 Suppl & $* *$ & 262-1 (PB261-051) ........... & $*$ & 294 & $* *$ \\
\hline $\begin{array}{l}260-1 \text { (COM74-11061) ....... } \\
260-2 \text { (COM74-11063) ..... } \\
260-3 \text { (COM74-11060) ..... } \\
260-4 \text { (COM74-11059) ...... } \\
260-5 \text { (PB168-068) ............ }\end{array}$ & $\begin{array}{l}* * \\
* * \\
* * \\
* *\end{array}$ & 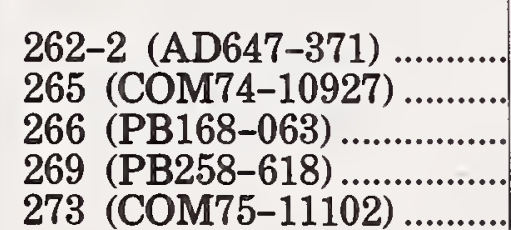 & $\begin{array}{r}* \\
* \\
* * \\
* \\
*\end{array}$ & $\begin{array}{l}\text { This series name was } \\
\text { changed to Special } \\
\text { Publications beginning } \\
\text { with SP295 }\end{array}$ & \\
\hline $\begin{array}{l}260-6 \text { (COM74-11068) ....... } \\
260-7 \text { (COM74-11067) ..... } \\
260-8 \text { (COM74-11066)..... } \\
260-9 \text { (COM74-11065)..... } \\
260-10(\text { COM74-11064) ... }\end{array}$ & $\begin{array}{l}* * \\
* * \\
* * \\
* *\end{array}$ & $\begin{array}{l}274 \\
275 \\
281 \\
284\end{array}$ & $\begin{array}{l}* * \\
8.50 \\
* *\end{array}$ & & \\
\hline
\end{tabular}

*See page 38 for additional information.

**Available from The National Technical Information Service; use "AD", "PB", "COM", or NBS publication identification if no specific NTIS number is assigned. 


\begin{tabular}{|c|c|c|c|c|c|}
\hline No. & Price & No. & Price & No. & Price \\
\hline $260(\mathrm{SN}$ & & $200-$ & & & \\
\hline $\begin{array}{c}014 \\
-16\end{array}$ & 1.50 & 01836-8) & 2.20 & $306-$ & \\
\hline-18 & & 250 & & 307 & \\
\hline 19 & & & * & 309 Vol. 2. & * \\
\hline 0 & & 300 Vol. 1 (SN003- & & 312 (Vol. $1 \& 2$ (COM73- & \\
\hline $260-22(\mathrm{CO}$ & & 002 & 9.00 & 11439) & \\
\hline $\begin{array}{l}260-23(\mathrm{C}) \\
260-24(\mathrm{C}\end{array}$ & & 300 vol. & 9.75 & $313 \ldots \ldots$ & \\
\hline $\begin{array}{l}260-25(\mathrm{COM} 74-11356) \ldots \\
260-26 \text { (SN003-003- }\end{array}$ & & 300 Vol. 3 (SN003- & 8.05 & $\begin{array}{l}314 \begin{array}{l}\text { (SN003-003- } \\
00091-4)\end{array} . . . . . . .\end{array}$ & 6.45 \\
\hline 0078 & .85 & 300 Vol. 4 (SN003- & & $\begin{array}{l}317 \text { Vol. } 1 \text { (COM71- } \\
50268-01)\end{array}$ & \\
\hline $\begin{array}{l}260-27 \text { (COM } \\
260-28 \text { (COM }\end{array}$ & & $\begin{array}{l}003-00778-1) \\
300 \text { Vol. } 5 \text { (SN003- }\end{array}$ & 7.65 & $\begin{array}{l}317 \text { Vol. } 2 \text { (COM71- } \\
50268-02)\end{array}$ & \\
\hline $260-29$ (COM & & $003-00916-4) \ldots$ & 8.65 & 319 (COM7 & * \\
\hline $\begin{array}{l}-30(C O M 71-50283) \ldots . . . \\
-30(C O M 71-50563) \ldots .\end{array}$ & & $\begin{array}{l}300 \text { Vol. } 6 \text { (SN003- } \\
003-00696-3)\end{array}$ & 7.10 & $320\left(\mathrm{AD}^{\prime}\right.$ & * \\
\hline )-32 (SN003-003- & & 300 Vol. & 965 & $\begin{array}{l}320 \mathrm{Su} \\
320 \mathrm{Su}\end{array}$ & \\
\hline $01213-1$ & .55 & 300 Vol. 8 (SN003- & & 5003 & \\
\hline $\begin{array}{l}260-33 \text { (COM7 } \\
260-34 \text { (COM7 }\end{array}$ & & 00 & 8.75 & $321(\mathrm{~PB})$ & * \\
\hline $260-36$ (COM7 & : & 300 Vol. 9 (SN003- & 7.65 & & \\
\hline 260-37 (COM72-50692) & * & 300 Vol. 10 (SNO03- & 11 & $327(\mathrm{PF}$ & \\
\hline 260-39 (COI & ${ }^{*}$ & 301 & 11.8 & $\begin{array}{l}329 \text { (CO } \\
329 \text { Sur }\end{array}$ & \\
\hline $260-40(\mathrm{COI}$ & 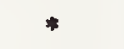 & 302 & & 506 & \\
\hline 26 & * & 303 & * & 329 Sup. 2 & $935>->$ \\
\hline $260-42(\mathrm{CON}$ & * & $304 \begin{array}{l}\text { (SN003- } \\
01072-3\end{array}$ & .65 & 330 & \\
\hline $\begin{array}{l}260-44(\mathrm{COM} \\
260-45\left(\mathrm{COM}^{2}\right.\end{array}$ & * & $\begin{array}{l}\text { 304A (SN003-003- } \\
01713-2)\end{array}$ & .35 & $331 \quad \ldots 0$ & \\
\hline $260-4$ & & $\begin{array}{l}305 \\
305\end{array}$ & & $\begin{array}{l}332(\mathrm{~PB} \\
333(\mathrm{~PB}\end{array}$ & \\
\hline & & 305 Sup & & 334 (COM74-11482 & \\
\hline 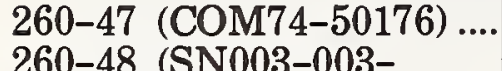 & * & & & $335(\mathrm{COM}$ & * \\
\hline 0127 & .60 & 305 Sup. 3 & * $>2>2$ & 336 (SN & $9^{\prime}+2>-5$ \\
\hline $\begin{array}{r}260-49 \text { (SN003-003- } \\
01344-7)\end{array}$ & .75 & 305 Sup. 4 (SN003-003- & & $\begin{array}{l}337 \text { (COM71-00182) } \\
338 \text { (COM74-10736) }\end{array}$ & \\
\hline $\begin{array}{r}260-50 \text { (SN0 } \\
01425-7)\end{array}$ & 1.00 & 305 Sup. 5 (SN003-003- & & 339 (COM71-50080) ..... & * \\
\hline $\begin{array}{l}260-51 \text { (SN003-003- } \\
01481-8 \text { ) .................. }\end{array}$ & 1.90 & 305 Sup. 6 (SN003-003- & & $\begin{array}{l}344 \text { See SP398 } \\
345 \text { (SN003-0......................... }\end{array}$ & 5 \\
\hline 260-52 (SN003-003- & & 305 Sup. 7 (SN003-003- & 7.5 & $\begin{array}{r}00 \xi \\
345-1\end{array}$ & \\
\hline $260-53$ & & N003-003 & & $345-2$ & \\
\hline 01 & 1.05 & 017 & 8.25 & 008 & 3. \\
\hline 01828 & 3.00 & $\begin{array}{l}306 \\
306-2\end{array}$ & * & $\begin{array}{r}345-3 \\
00\end{array}$ & 1.75 \\
\hline
\end{tabular}

"Available from the National Technical Information Service, use "AD", "COMM", or "NBS" publication identification if no specific NTIS number is assigned. 
SPECIAL PUBLICATIONS (Continued)

\begin{tabular}{|c|c|c|c|c|c|}
\hline No. & Price & No. & Price & No. & Price \\
\hline $\begin{array}{r}45-4 \text { (SN003-003- } \\
00825-7)\end{array}$ & 3.20 & $\begin{array}{l}366-2 \text { (S } \\
015\end{array}$ & 1.35 & $\begin{array}{r}396-2(\mathrm{SN} \\
01457\end{array}$ & 1.10 \\
\hline $\begin{array}{r}345-5 \text { (SN003-003- } \\
00898-2)\end{array}$ & 215 & & 1.00 & $396-3(\mathrm{P}$ & \\
\hline $45-6$ (SN & 2.18 & 300 (SN & & & \\
\hline $345-7$ & 2.30 & $\begin{aligned} 016 \\
369 \text { (SN }\end{aligned}$ & $\begin{array}{rl}4 & 4.65 \\
\text { (per } 100 \\
\text { cop) }\end{array}$ & 398 (SN & 1.00 \\
\hline $\begin{array}{r}0086 \\
45-8(\mathrm{~S})\end{array}$ & 1.75 & 0112 & 1.85 & $\begin{array}{r}01331-5) \\
399-1 \text { (SN003-003-. }\end{array}$ & .35 \\
\hline $\begin{array}{l}45-8 \text { (SN003- } \\
00895-8) .\end{array}$ & 2.10 & $\begin{array}{r}370 \text { (SN003-003- } \\
01057-0)\end{array}$ & .55 & 01339-1) & 2.35 \\
\hline 345-9 (COM71-50305) & * & $\begin{array}{l}371 \text { (COM73-50245) } \\
371-1 \text { (SN003-003- }\end{array}$ & & 01 & 2.85 \\
\hline $\begin{array}{r}345-10 \text { (SN003- } \\
00879-6) \ldots .\end{array}$ & 3.05 & $01422-2)$ & 1.45 & N003-003- & \\
\hline $\begin{array}{l}\text { 345-11 (SN003-003- } \\
00835-4)\end{array}$ & 2.70 & 372 (SN003-003- & 2.35 & $400-1$ & 2.90 \\
\hline $\begin{array}{r}345-12 \text { (SN003-003- } \\
00865-6)\end{array}$ & 2.00 & $\begin{array}{l}373 \text { (COM72-51036) .. } \\
374 \text { (SN003-003- }\end{array}$ & & 400-2 (SN00: & 1.50 \\
\hline $\begin{array}{r}348 \text { (SN003-003- } \\
00893-1)\end{array}$ & 7.45 & $\begin{array}{l}01061-8) \\
375 \text { (COM73-50839) ............ } \\
376 \text { (SN003-003- }\end{array}$ & 5.20 & $\begin{array}{r}400-3 \text { (SN003-003- } \\
01236-0) \\
400-4 \text { (SN003-003-..... }\end{array}$ & .60 \\
\hline $\begin{array}{r}349 \text { (COM72- } \\
50807) \ldots . . . .\end{array}$ & & 01081 & .35 & & 1.70 \\
\hline $\begin{array}{l}350 \text { (COM71-50276) ....... } \\
351 \text { (SN003-003- }\end{array}$ & * & $\begin{array}{r}377 \text { (SN003-003- } \\
01107-0) . . . . . . .\end{array}$ & .85 & $\begin{array}{r}400-5(\mathrm{SI} \\
01372\end{array}$ & 1.10 \\
\hline $01027-8$ & 6.45 & $\begin{array}{l}378 \text { (COM73-50585 } \\
380 \text { (SN003-003- }\end{array}$ & & $\begin{array}{r}400-6 \text { (SN00 } \\
01313-7)\end{array}$ & .60 \\
\hline 353 (COM71-5 & 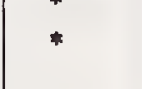 & 381 (COM73-50932).. & 2.10 & $\begin{array}{r}400-7 \text { (SN003-003- } \\
01635-7)\end{array}$ & .75 \\
\hline $\begin{array}{l}354(\mathrm{CO} \\
355(\mathrm{CO}\end{array}$ & * & $\begin{array}{l}382 \text { (SN003-003- } \\
01176-2) . . . . . . .\end{array}$ & 3.30 & 400-8 (SN003 & 1.30 \\
\hline 356 (SN003-003- & 2.05 & $383 \begin{array}{l}\text { (SN003-003- } \\
01171-1)\end{array}$ & 2.10 & 01 & 1.00 \\
\hline $\begin{array}{l}357 \text { (SN003-003- } \\
\quad 00928-8) \ldots \ldots \ldots . . \\
359 \text { (COM72-50057) .... }\end{array}$ & 5.40 & $\begin{array}{l}384 \text { Rev. } 1976 \text { (SN003- } \\
003-01670-5) \\
385 \text { (COM74-50307) ....... }\end{array}$ & 2.45 & 400-10 (SN003-003- & 3.55 \\
\hline $\begin{array}{l}361 \text { Vol. } 1 \text { (COM72- } \\
\text { 10309) }\end{array}$ & * & $\begin{array}{l}386 \text { (SN003-003- } \\
01593-8) \ldots \ldots . . .\end{array}$ & 1.90 & 400-12 (AD-A011121) & 1.00 \\
\hline $\begin{array}{l}361 \text { Vol. } 2 \text { (COM72- } \\
50850)\end{array}$ & * & 388 (COM74- & * & $\begin{array}{r}400-13 \text { SN003-003- } \\
01382-0)\end{array}$ & .75 \\
\hline 362 (SN003-003- & 1.15 & $\begin{array}{l}389 \text { Superseded by } \\
\text { LC1070 ................. }\end{array}$ & *" & $\begin{array}{r}400-15 \text { (SN003-003- } \\
01566-1)\end{array}$ & 1.25 \\
\hline 363 (SN003-003- & 1.45 & $\begin{array}{l}390 \text { (COM74-50352) ... } \\
391 \text { (SN003-003- }\end{array}$ & & $\begin{array}{l}400-17 \text { (SN003-003- } \\
01480-0 \text { ) }\end{array}$ & \\
\hline $\begin{array}{r}363-1 \text { (SNO03-003- } \\
01673-0) \ldots \ldots \ldots \ldots . . .\end{array}$ & 2.50 & 392 (SN003-................ & 2.50 & $\begin{array}{l}400-18 \text { (SN003-003- } \\
01577-6)\end{array}$ & 1.25 \\
\hline $\begin{array}{l}364 \text { (COM72-50746) ........... } \\
365 \text { (SN003-003- }\end{array}$ & ${ }^{*}$ & 393 (COM74 & $\begin{array}{l}1.30 \\
*\end{array}$ & $\begin{array}{r}400-19 \text { (SN003-003- } \\
01606-3) \ldots \ldots \ldots . . . . . . .\end{array}$ & 2.10 \\
\hline $366 \stackrel{01}{(\mathrm{~S}}$ & & $\begin{array}{l}394 \text { (COM74-50523) } \\
395 \text { (SN003-003- }\end{array}$ & & $\begin{array}{r}400-20 \text { (SN00 } \\
01473-7)\end{array}$ & 1.00 \\
\hline 366-1 (COM74-50063) & 2.80 & $\begin{array}{c}01300-5) \\
396-1\end{array}$ & 4.25 & 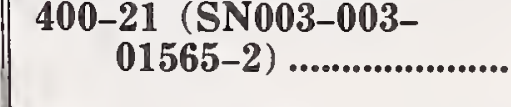 & 1.30 \\
\hline
\end{tabular}

"Available from the National Technical Information Service; use "AD", or "COM" number when ordering.

${ }^{* *}$ Free from Office of Technical Publications, National Bureau of Standards, Washington, D.C. 20234 
SPECIAL PUBLICATIONS (Continued)

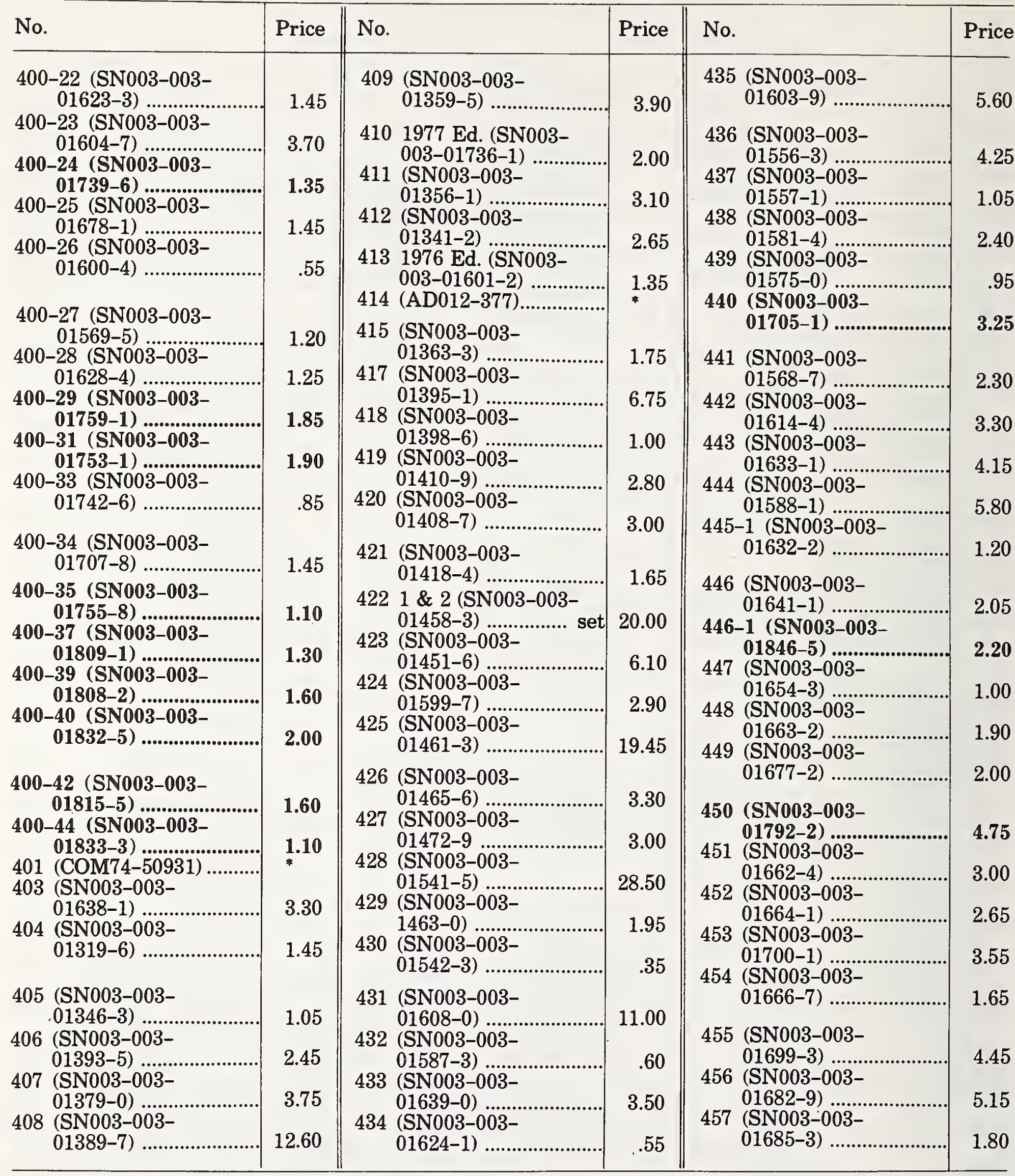

"Available from the National Technical Information Service, use "AD", or "COM", number when ordering. 
SPECIAL PUBLICATIONS (Continued)

\begin{tabular}{|c|c|c|c|c|c|}
\hline No. & Price & No. & Price & No. & Price \\
\hline $\begin{array}{r}457-1(\text { SN00 } \\
01802-3)\end{array}$ & 3.20 & $\begin{array}{r}480-4 \text { (SNO03-003- } \\
01745-1)\end{array}$ & 2.75 & $\begin{array}{l}493 \text { (SN003-003- } \\
01847-3) . . . . . . .\end{array}$ & 8.50 \\
\hline $\begin{array}{l}458 \text { (SN003-003- } \\
01684-5) \text {............. }\end{array}$ & .75 & $\begin{array}{r}480-5 \text { (SN003-003- } \\
01747-1 \text { ) } \ldots . . . . . . . . . . .\end{array}$ & 2.20 & $\begin{array}{c}494 \text { (SN003-003- } \\
01844-9) . . . . . . . .\end{array}$ & 4.50 \\
\hline 459 (SN003-003- & 3.40 & $\begin{array}{r}480-6 \text { (SNO03-003- } \\
01748-5) \text {.............. }\end{array}$ & 2.20 & $\begin{array}{c}500-1 \text { (SN003-003- } \\
01724-8)\end{array}$ & 1.10 \\
\hline 460 (SN003-003- & 2.35 & $\begin{array}{l}480-7 \text { (SN003-003- } \\
01766-3)\end{array}$ & 2.40 & $\begin{array}{l}500-2 \text { (SNO03-003- } \\
01726-4)\end{array}$ & 2.65 \\
\hline 461 (SN003-003- & 3.25 & 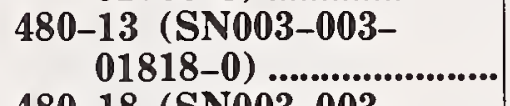 & 2.00 & $\begin{array}{r}500-3 \text { (SN003-003- } \\
01725-6)\end{array}$ & 1.05 \\
\hline $\begin{array}{l}462 \text { (SN003-003- } \\
01729-9) \ldots \ldots . . .\end{array}$ & 4.60 & 480-18 (SN003-003- & 1.60 & $\begin{array}{l}500-4 \text { (SN003-003- } \\
01756-6)\end{array}$ & 1.45 \\
\hline $\begin{array}{l}463 \text { (SN003-003- } \\
01701-9) \ldots . . . . . .\end{array}$ & 3.35 & $\begin{array}{c}480-19 \text { (SNO03-003- } \\
01773-6)\end{array}$ & 2.10 & $\begin{array}{c}500-5 \text { (SN003-003- } \\
01758-2)\end{array}$ & 1.40 \\
\hline $464 \begin{array}{l}\text { (SN003-003- } \\
01704-3)\end{array}$ & 11.00 & $\begin{array}{r}480-21 \text { (SN003-003- } \\
01777-9)\end{array}$ & 1.00 & 500-6 (SN & \\
\hline $\begin{array}{c}465 \text { (SN003-003- } \\
01728-1)\end{array}$ & 2.50 & $\begin{array}{l}\text { 480-22 (SN003-003- } \\
\text { 01774-4) }\end{array}$ & 1.00 & $\begin{array}{r}01757-4) \ldots \ldots . . . . . . . \\
500-7 \text { (SN003-003- }\end{array}$ & 1.45 \\
\hline $\begin{array}{l}466 \text { (SN003-003- } \\
01791-4) . . . . . . .\end{array}$ & 5.25 & 480-24 (SN003-003- & 3.00 & $\begin{array}{r}01780-9) \\
500-8 \text { (SN003-0.......... }\end{array}$ & 1.60 \\
\hline $\begin{array}{c}467 \text { (SN003-003- } \\
01716-7) \ldots . . . . .\end{array}$ & 1.20 & $\begin{array}{l}480-25 \text { (SN003-003- } \\
01855-4)\end{array}$ & .90 & $\begin{array}{r}01771-0) \ldots \ldots \ldots \ldots . . . \\
500-9 \text { (SN003-003- }\end{array}$ & 2.50 \\
\hline $\begin{array}{r}468 \text { (SN003-003- } \\
01760-4)\end{array}$ & 3.00 & $\begin{array}{r}480-26 \text { (SN003-003- } \\
01821-0)\end{array}$ & & $\begin{array}{l}500-10 \text { (SN003-003- } \\
01787-6)\end{array}$ & $\begin{array}{l}2.00 \\
1.40\end{array}$ \\
\hline 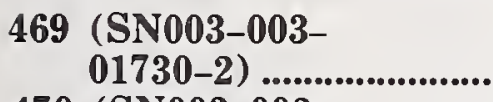 & 1.05 & $\begin{array}{r}480-27 \text { (SN003-003- } \\
01838-4)\end{array}$ & 1.50 & 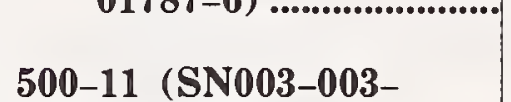 & 1.40 \\
\hline $\begin{array}{l}470 \text { (SN003-003- } \\
01762-1) \ldots . . . . .\end{array}$ & 5.60 & $\begin{array}{l}481 \text { (SN003-003- } \\
01783-3)\end{array}$ & 1.40 & $01785-7$ ) & 2.00 \\
\hline $471 \begin{array}{c}\text { (SN003-003- } \\
01806-6)\end{array}$ & 3.75 & 482 (SN003-003- & 250 & $01797-3)$ & 1.50 \\
\hline $\begin{array}{l}472 \text { (SN003-003- } \\
01767-1) . . . . . . .\end{array}$ & 2. & 483 (SN003-003- & 2.00 & 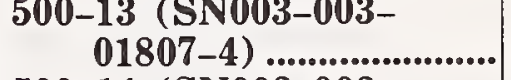 & 2.00 \\
\hline $\begin{array}{l}473 \text { (SN003-003- } \\
01775-2) . . . . . . . .\end{array}$ & 6.00 & 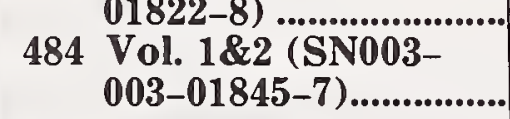 & $\begin{array}{r}2.75 \\
12.75 \\
\text { set }\end{array}$ & $\begin{array}{l}500-14 \text { (SN003-003- } \\
01823-6) \ldots \ldots \ldots \ldots . . . \\
500-15 \text { (SN003-003- }\end{array}$ & 2.10 \\
\hline $\begin{array}{l}475 \text { (SN003-003- } \\
01764-7 \text { ) .......... }\end{array}$ & 2.80 & 485 (SN003-003- & 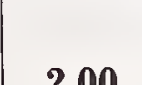 & & 2.10 \\
\hline $\begin{array}{l}476 \text { (SN003-003- } \\
01804-0)\end{array}$ & 1.40 & $486 \begin{array}{l}\text { (SN003-003- } \\
01827-9)\end{array}$ & 2.10 & 500-16 (SN003-003- & 2.50 \\
\hline $\begin{array}{l}477 \text { (SN003-003- } \\
01772-8) . . . . . . .\end{array}$ & 6.25 & $\begin{array}{l}487 \text { (SN003-003- } \\
01829-5)\end{array}$ & 5.25 & 500-17 (SN003-003- & 4.00 \\
\hline 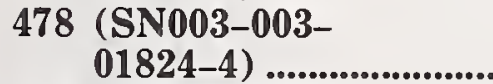 & 2.00 & 488 (SN003-003- & 3.0 & $\begin{array}{r}\text { 500-18 (SN003-003- } \\
01839-2) \text {................... }\end{array}$ & 4.00 \\
\hline $\begin{array}{l}479 \text { (SN003-003- } \\
01826-1 \ldots . . . . . . . .\end{array}$ & 3.75 & $\begin{array}{l}489 \text { (SN003-003- } \\
01830-9)\end{array}$ & 3.00 & $\begin{array}{r}500-19 \text { (SN003-003- } \\
01848-1) \ldots \ldots \ldots . . . \\
500-20 \text { (SN003-003- }\end{array}$ & 4.00 \\
\hline $\begin{array}{l}480-1 \text { (SN003-003- } \\
01722-1) . . . . . . . . . . . . . . .\end{array}$ & 3.00 & $490 \begin{array}{l}\text { (SN003-003- } \\
01841-4)\end{array}$ & $\mathbf{3 . 0 0}$ & & 1.60 \\
\hline $\begin{array}{r}480-2 \text { (SN003-003- } \\
01723-0) \ldots . . . . . . . . .\end{array}$ & 2.75 & 491 (SN003-003- & 3.25 & $\begin{array}{r}500-22 \text { (SN003-003- } \\
01867-3)\end{array}$ & 3.25 \\
\hline $\begin{array}{r}480-3 \text { (SN003-003- } \\
01744-2) \ldots . . . . . . . . . .\end{array}$ & 2.50 & $\begin{array}{l}492 \text { (SN003-003- } \\
01858-9)\end{array}$ & 7.50 & $\begin{array}{r}\text { 500-23 (SN003-003- } \\
01874-1 \text { ) ................. }\end{array}$ & 4.25 \\
\hline
\end{tabular}




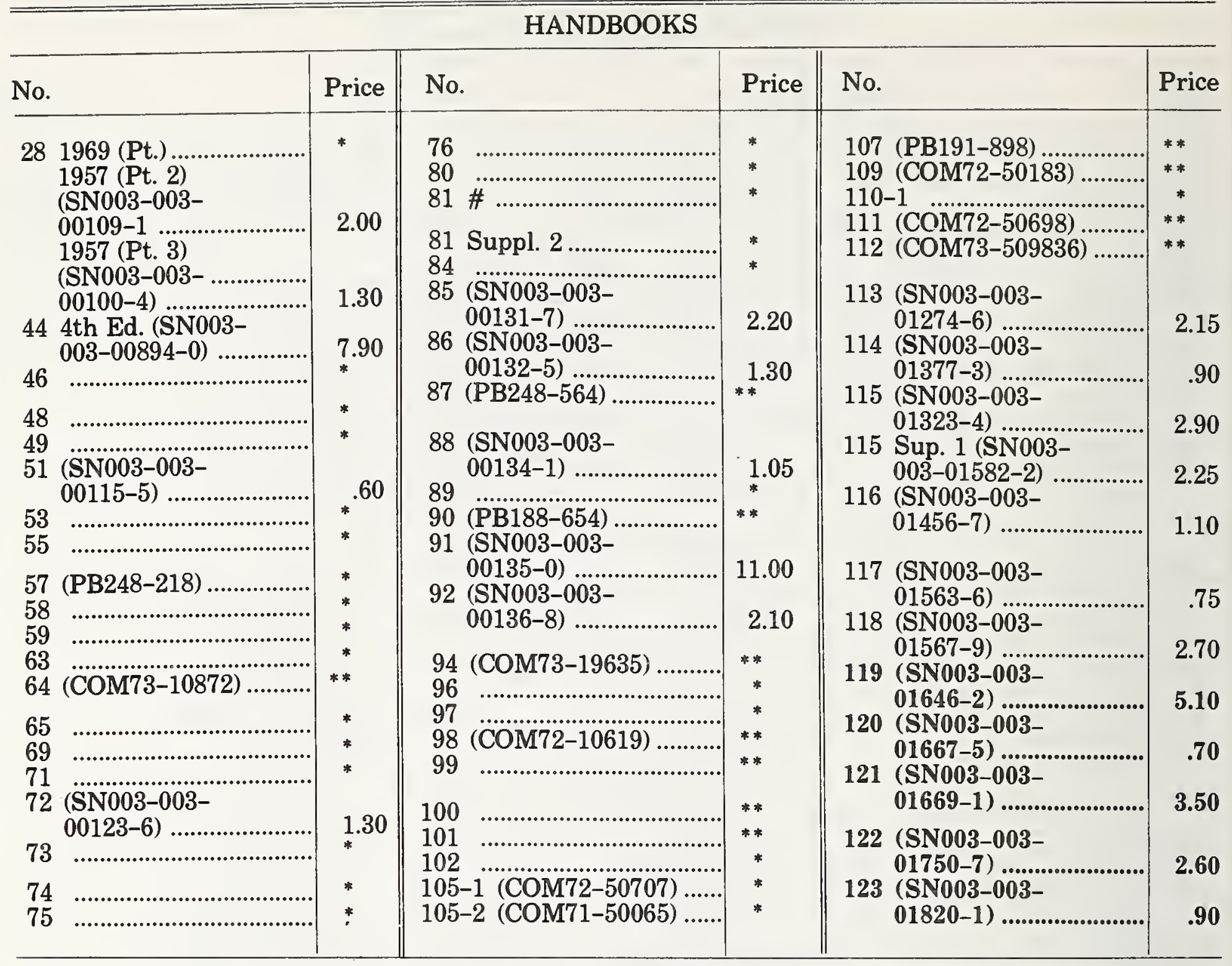

\#81 amends in part: Part 2, Definitions and the Grounding Rules of these Handbooks.

* See page 38 for additional information.

**Available from the National Technical Information Service; use "PB", "COM", or NBS publication identification if no specific NTIS number is assigned. 


\section{NATIONAL STANDARD REFERENCE DATA SERIES}

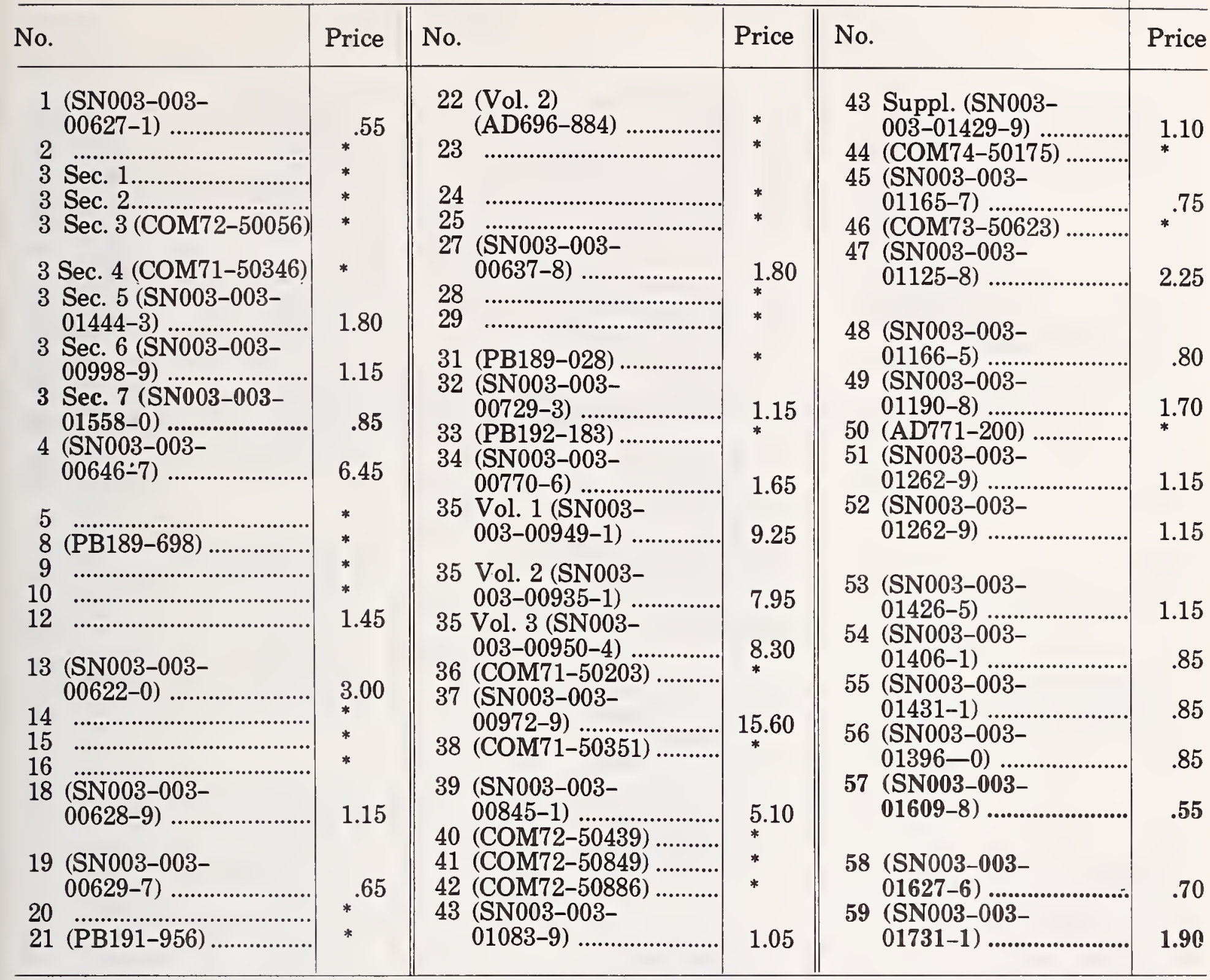

"Available from the National Technical Information Service, use "PB", "COM" or NBS Publication identification if not specific NTIS number is assigned. 


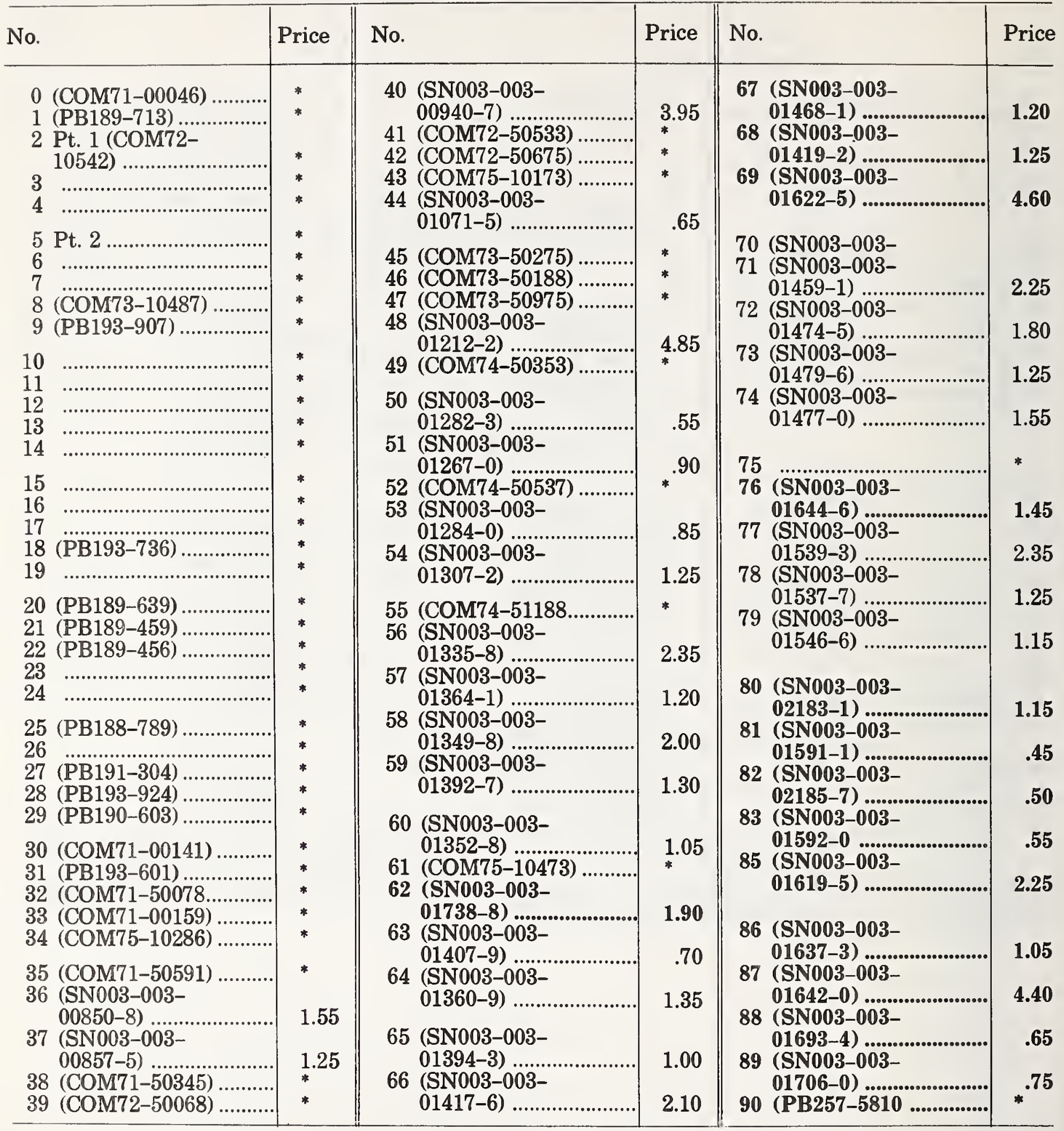


BUILDING SCIENCE SERIES (Continued)

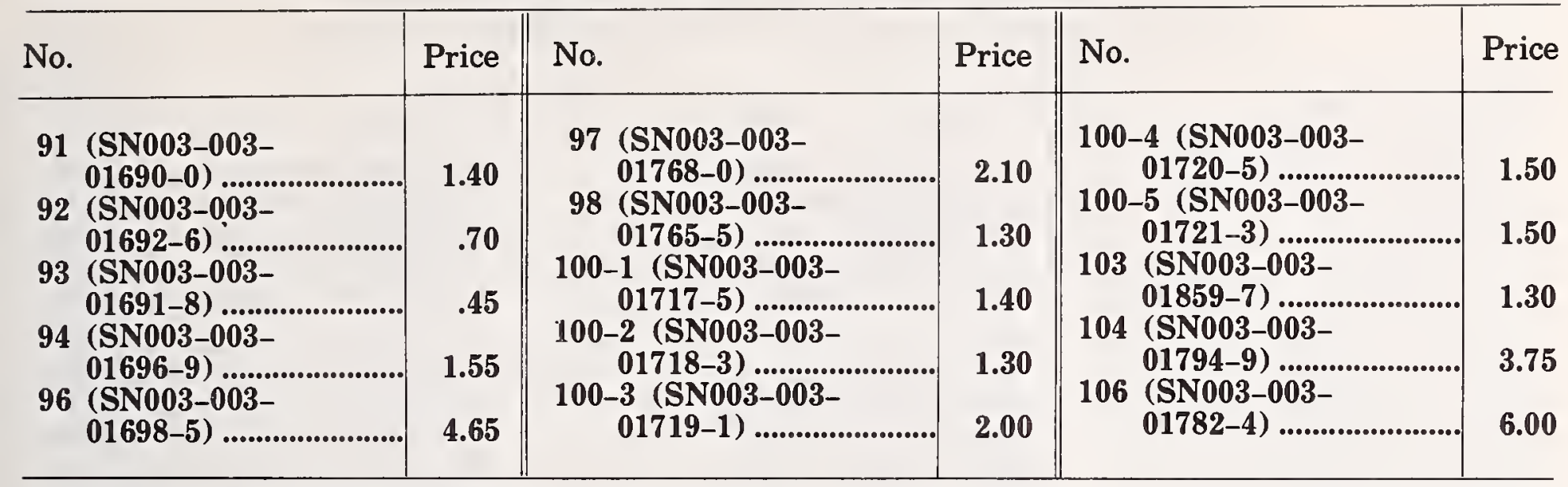

"Available from the National Technical Information Service; use "PB", "COM" or NBS Publication identification if no specific NTIS number is assigned. 
BUILDING MATERIALS AND STRUCTURES REPORTS

\begin{tabular}{|c|c|c|c|c|c|}
\hline No. & Price & No. & Price & No. & Price \\
\hline 2 (COM73-10942) & * & $71(\mathrm{COM} 73-10968) \ldots . .$. & $*$ & 118 (COM73-11014) & * \\
\hline 5 (COM73-10943) & * & 76 (COM73-10969) & 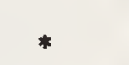 & 119 (COM73-11016) & * \\
\hline 17 Suppl. 1 \& 2, & & 78 (COM73-10970) & * & 120 (COM73-11054) & $*$ \\
\hline see Mono 77 & & 79 (COM73-10971). & $*$ & $\begin{array}{l}123 \text { (COM73-11050) } \\
124 \text { (COM73-11051) }\end{array}$ & * \\
\hline $\begin{array}{l}\text { (PB180646) } \\
19 \text { see BM...... }\end{array}$ & OP & & * & 126 (COM73-11052).... & $*$ \\
\hline $21(\mathrm{CC}$ & * & 92 (COM73-10974) & * & 132 (COM73-11053) & * \\
\hline 23 (COM73-10946). & * & 93 (COM73-10975) & * & 133 (COM73 & * \\
\hline 24 (COM73-10947) & * & 94 (COM73-10978). & * & $\begin{array}{l}134 \text { (COM7 } \\
135 \text { (COM7 }\end{array}$ & $*$ \\
\hline 32 (COI & * & $\begin{array}{r}96(\mathrm{COM73-10979)} . . . . \\
100(\mathrm{COM73-10980)}\end{array}$ & * & 136 (COM73-11058) & * \\
\hline $41(\mathrm{CO}$ & * & & & 138 (COM73-11059) & * \\
\hline $\begin{array}{l}45 \text { (COM73-10961) } \\
52 \text { (COM74-50537) }\end{array}$ & * & $\begin{array}{l}101 \text { (COM73-10981) } \\
103 \text { (COM73-10982) }\end{array}$ & $*$ & $\begin{array}{l}141 \text { (COM73-11060) } \\
142 \text { (COM73-11062) }\end{array}$ & * \\
\hline 54 (COM73-10963) & * & 104 (COM73-10983).. & & 143 (COM73-11061) & * \\
\hline 55 (COM73-10964) & $*$ & 106 (COM73-10984) ........ & & 144 (PB180647) ........ & * \\
\hline $56(\mathrm{CO}$ & $*$ & 108 (COM73- & & 146 (COM73-11063). & ${ }^{*}$ \\
\hline $63(\mathrm{COI}$ & * & 109 (COM' $^{\prime}$ & & 147 (COM73-11064) & * \\
\hline 64 (PB17798 & + & 114 (COM7: & & 149 (COM73-11 & * \\
\hline 65 (COM73-10967) ... & * & 115 (COM73-10988) & * & 150 (COM73-11066) & $*$ \\
\hline $66 \quad \ldots .$. & .80 & 117 (COM73-11015) & & 151 (PB177987) ..... & \\
\hline
\end{tabular}

*Available from the National Technical Information Service, use "PB" or "COM" number when ordering.

VOLUNTARY PRODUCT STANDARDS

\begin{tabular}{|c|c|c|c|c|c|}
\hline No. & Price & No. & Price & No. & Price \\
\hline 1-74 (SN003-003- & \multirow{3}{*}{$\begin{array}{l}.85 \\
.40\end{array}$} & \multirow{7}{*}{ 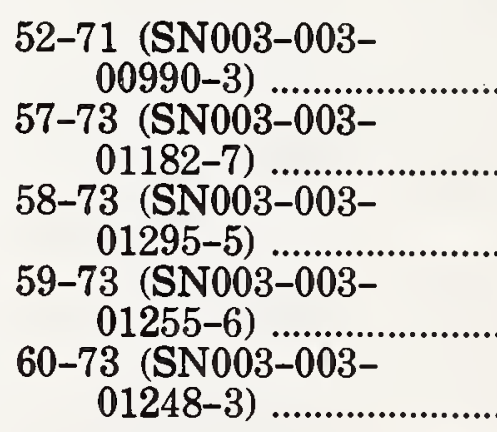 } & \multirow{2}{*}{.35} & \multirow{7}{*}{ 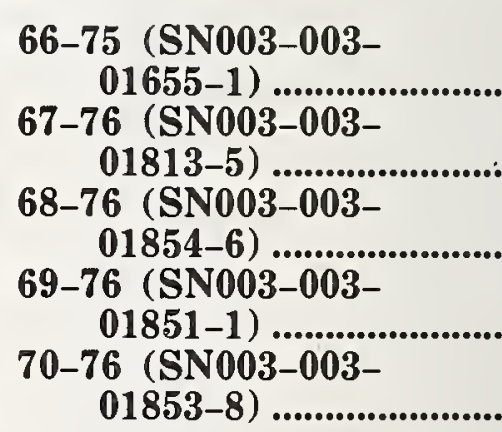 } & \multirow{7}{*}{$\begin{array}{r}.45 \\
.70 \\
.70 \\
1.00 \\
.70\end{array}$} \\
\hline 15-69 (SN003-003- & & & & & \\
\hline $\begin{array}{r}00188-1) \\
20-70 \text { (SN003-003- }\end{array}$ & & & \multirow{2}{*}{$\begin{array}{l}.40 \\
.40\end{array}$} & & \\
\hline $00192-9)$ & \multirow{4}{*}{$\begin{array}{l}.40 \\
.45 \\
.65\end{array}$} & & & & \\
\hline 38-70 (SN003-003- & & & & & \\
\hline $\begin{array}{r}00842-7) \\
39-70 \text { (SNo....... }\end{array}$ & & & .45 & & \\
\hline $\begin{array}{r}39-10(\text { SNOU3-003- } \\
00840-1)\end{array}$ & & & .40 & & \\
\hline $\begin{array}{r}42-70 \text { (SN003-003- } \\
00901-6)\end{array}$ & .65 & $\begin{array}{r}61-74(\mathrm{SN} 003-003- \\
01421-4)\end{array}$ & .45. & $\begin{array}{l}71-76 \text { (SN003-003- } \\
01702-7)\end{array}$ & 10 \\
\hline 46-71 (SNO03-003- & & 62-74 (SN003-003- & & 73-77 (SN003-003- & \\
\hline $\begin{array}{r}00936-9) \\
48-71 \text { (SN003-003- }\end{array}$ & 35 & $\begin{array}{r}01375-7) \\
63-75 \text { (SN003-003- }\end{array}$ & 55 & & \\
\hline 00925-3) ................ & .35 & 01415-0) $\ldots$ & .50 & & \\
\hline 50-71 (SN003-003- & 35 & 64-75 (SN003-003- & 3 & & \\
\hline 51-71 (SN003-003- & & 65-75 (SN003-003- & & & \\
\hline 0096 & .35 & 0158 & .35 & & \\
\hline
\end{tabular}


CONSUMER INFORMATION SERIES

\begin{tabular}{l|r||r|r||r|r}
\hline No. & Price & \multicolumn{1}{|l|}{ No. } & Price & No. & Price \\
\hline 1 (SN003-003-00608-7) & .90 & 4 (SN003-003-00920-2) & 1.10 & 7 (SN003-003-01688-8) & .35 \\
2 (SN003-003-00681-5) & .90 & 5 (SN003-003-00941-5) & .70 & 8 (SN003-003-01446-0) & .70 \\
3 (SN003-003-00682-3) & .60 & 6 (SN003-003-01536-9) & 1.70 & & \\
\hline \hline
\end{tabular}

TECHNICAL NOTES

\begin{tabular}{|c|c|c|c|c|c|}
\hline No. & Price & No. & Price & No. & Price \\
\hline 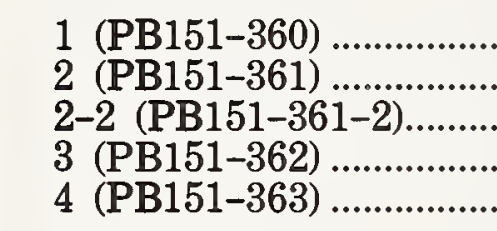 & $\begin{array}{l}* \\
* \\
* \\
* \\
*\end{array}$ & $\begin{array}{l}18-19 \text { (PB195-218) .......... } \\
18-20 \text { (PB168-044) ......... } \\
18-21 \text { (PB195-219) ......... } \\
18-22(\text { (N661-3994) ......... } \\
18-23 \text { (COM74-10437) .... }\end{array}$ & $\begin{array}{l}* \\
* \\
* \\
* \\
*\end{array}$ & $\begin{array}{l}40-9 \text { (PB189-933) ........... } \\
40-10 \text { (PB189-934) ......... } \\
40-11 \text { (PB189-935) ......... } \\
40-12 \text { (PB189-936) ........ } \\
40-13(\mathrm{~PB} 151-399-13) \ldots\end{array}$ & $\begin{array}{l}* \\
* \\
* \\
* \\
*\end{array}$ \\
\hline $\begin{array}{ll}5 & (\mathrm{~PB} 151-364) \\
6 & (\mathrm{~PB} 151-365) \\
7 & (\mathrm{~PB} 151-366) \\
8 & (\mathrm{~PB} 151-36 \ldots \ldots \ldots \ldots \ldots \\
9 & (\mathrm{~PB} 151-368)\end{array}$ & $\begin{array}{l}* \\
* \\
* \\
*\end{array}$ & $\begin{array}{l}18-24 \text { (COM74-10438) .... } \\
18-25 \text { (COM74-10473) .... } \\
18-26(\mathrm{COM} 74-10439) . . . \\
19(\mathrm{~PB} 151-378) \\
20(\mathrm{~PB} 151-379)\end{array}$ & $\begin{array}{l}* \\
* \\
* \\
* \\
*\end{array}$ & 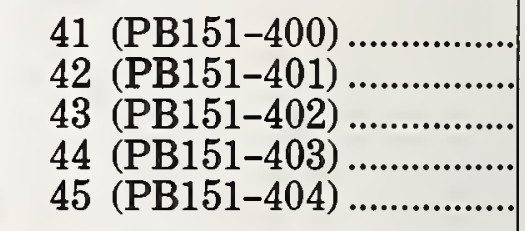 & $\begin{array}{l}* \\
* \\
* \\
* \\
*\end{array}$ \\
\hline 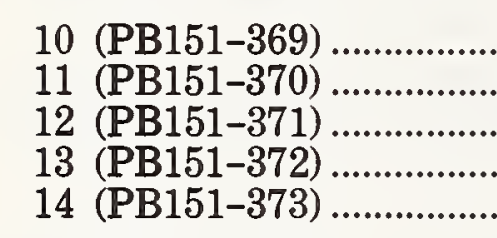 & $\begin{array}{l}* \\
* \\
* \\
* \\
*\end{array}$ & 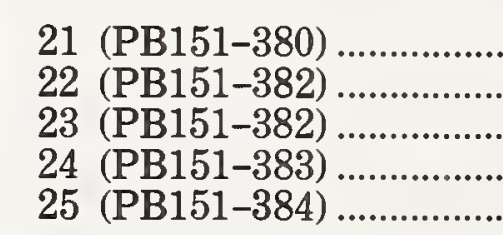 & $\begin{array}{l}* \\
* \\
* \\
* \\
*\end{array}$ & $\begin{array}{l}46 \text { (PB151-405) ........ } \\
47 \text { (PB151-406) ........ } \\
48 \text { (PB151-407) ....... } \\
49 \text { (PB151-408) ........ } \\
50 \text { (PB151-409) ........ }\end{array}$ & $\begin{array}{l}* \\
* \\
* \\
* \\
*\end{array}$ \\
\hline 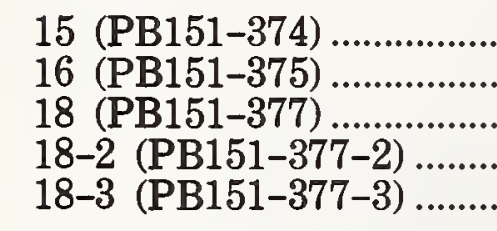 & $\begin{array}{l}* \\
* \\
* \\
* \\
*\end{array}$ & $\begin{array}{ll}26 & (\mathrm{~PB} 151-385) \\
27 & (\mathrm{~PB} 151-386) \\
28 & (\mathrm{~PB} 151-38 . . . \\
29 & (\mathrm{~PB} 151-388) \\
30 & (\mathrm{~PB} 151-38 . . . \\
& \ldots . . . . \\
& \ldots . . .\end{array}$ & $\begin{array}{l}* \\
* \\
* \\
* \\
*\end{array}$ & 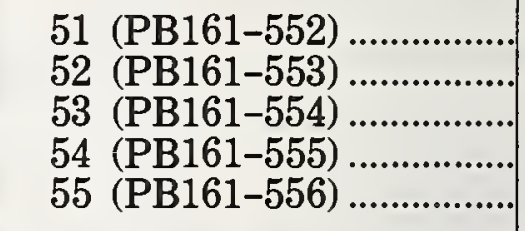 & $\begin{array}{l}* \\
* \\
* \\
* \\
*\end{array}$ \\
\hline 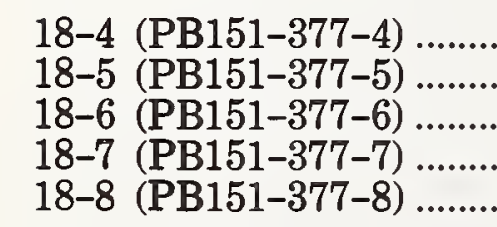 & $\begin{array}{l}* \\
* \\
* \\
* \\
*\end{array}$ & 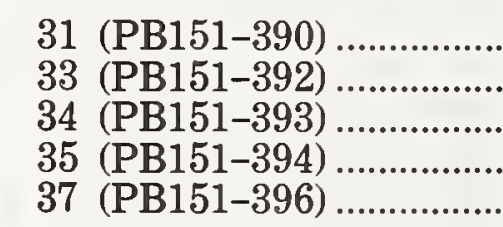 & $\begin{array}{l}* \\
* \\
* \\
* \\
*\end{array}$ & 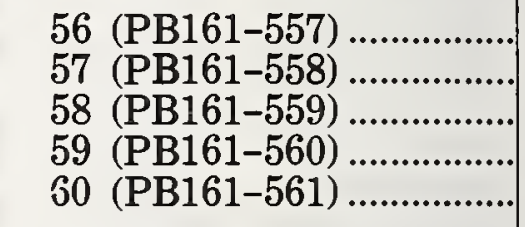 & $\begin{array}{l}* \\
* \\
* \\
* \\
*\end{array}$ \\
\hline $\begin{array}{l}18-9 \text { (PB151-377-9) ....... } \\
18-10 \text { (PB151-377-10) ... } \\
18-11 \text { (PB151-377-11) .... } \\
18-12(\text { PB151-377-12) ... } \\
18-13(\mathrm{~PB} 151-377-13)\end{array}$ & $\begin{array}{l}* \\
* \\
* \\
*\end{array}$ & $\begin{array}{l}38 \text { (PB151-397) ................ } \\
39 \text { (PB151-398) ............... } \\
40-1 \text { (PB151-399-1) ........ } \\
40-2 \text { (PB151-399-2) ........ } \\
40-3 \text { (PB151-399-3) ....... }\end{array}$ & $\begin{array}{l}* \\
* \\
* \\
* \\
*\end{array}$ & 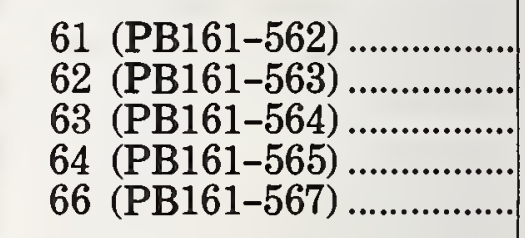 & $\begin{array}{l}* \\
* \\
* \\
* \\
*\end{array}$ \\
\hline 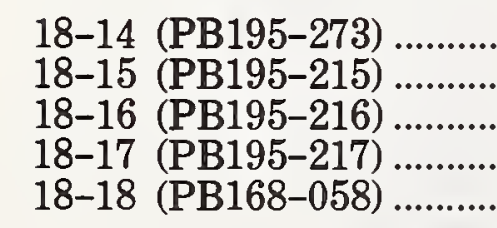 & $\begin{array}{l}* \\
* \\
* \\
* \\
*\end{array}$ & $\begin{array}{l}40-4 \text { (PB151-399-4) ........ } \\
40-5 \text { (PB151-399-5) ........ } \\
40-6 \text { (PB151-399-6) ....... } \\
40-7 \text { (PB151-399-7) ....... } \\
40-8 \text { (PB189-932) ............ }\end{array}$ & $\begin{array}{l}* \\
* \\
* \\
* \\
*\end{array}$ & 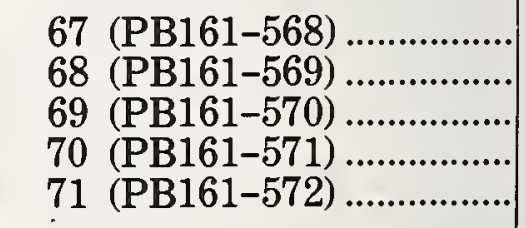 & $\begin{array}{l}* \\
* \\
* \\
* \\
*\end{array}$ \\
\hline
\end{tabular}

*Available from the National Technical Information Service; use "PB", "AD”, "N", “COM", or NBS publication number when ordering. 
TECHNICAL NOTES (Continued)

\begin{tabular}{|c|c|c|c|c|c|}
\hline No. & Price & No. & Price & No. & Price \\
\hline 72 (PB1 & * & $120 \mathrm{~A}(\mathrm{~PB} 190-611)$ & 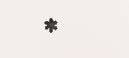 & 196 (COM73-10483) & 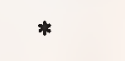 \\
\hline 73 (PB1) & * & 121 (PB161-622) ..... & * & 197 (AD419-866)...... & * \\
\hline 74 & * & 122 (PB161-623) & & 199 (AD683-408). & $*$ \\
\hline $75(\mathrm{P}$ & * & $\begin{array}{l}122 \\
123\end{array}$ & $*$ & 200 (N64-14272) & * \\
\hline 76 (PB1 & * & 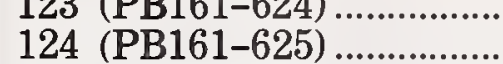 & $*$ & 201 (PB182-539) & $*$ \\
\hline 77 (PB1 & $*$ & 125 (PB161-626). & * & 202 & * \\
\hline 78 (PB) & * & 128 (PB161-629). & * & 204 (PB184-118) & * \\
\hline 79 (PB1 & * & 129 (PB161-630 & * & 205 (COM73-10 & * \\
\hline 80 (PB1 & $*$ & $129 \mathrm{~A}$ & * & $206-1(\mathrm{COI}$ & * \\
\hline 81 (PB1 & * & 130 (PB161-631) & * & 206-2 (COM73- & * \\
\hline 82 (PB1 & $*$ & 131 (PB161-632) & $*$ & $206-3$ (COM & * \\
\hline 83 (PB) & $*$ & 132 (PB161-63 & * & 206-4 (COM73 & * \\
\hline 84 (PB1 & * & 133 & * & 206-5 (COI & * \\
\hline 85 (PB1 & * & 134 (PI & * & 207 (COM73-10 & * \\
\hline $86(\mathrm{~PB}$ & ${ }^{*}$ & $135(\mathrm{PE}$ & * & 209 (PB168-04 & * \\
\hline 87 (PB1 & $\begin{array}{l}* \\
*\end{array}$ & $\begin{array}{l}136 \text { (PB161 } \\
137 \text { (PB161 }\end{array}$ & * & 210 (PB189-930) .......... & * \\
\hline $\begin{array}{l}88 \text { (PB161-589) } \\
89 \text { (PB161-590) }\end{array}$ & * & 151 & ${ }^{*}$ & 214 (PB189-931)... & $*$ \\
\hline 90 (PB161-591) & $*$ & $\begin{array}{l}138 \\
139\end{array}$ & ${ }^{*}$ & 215 (PB188-808) & * \\
\hline $91(\mathrm{~PB} 1$ & $*$ & 140 (PB161-641). & * & 217 (PB1 & * \\
\hline 92 (PB & * & 141 (PB161-729) & * & $218(\mathrm{PF}$ & * \\
\hline $93(\mathrm{PI}$ & $*$ & $142(\mathrm{~PB} 161-$ & * & 219 (PH & * \\
\hline $94(\mathrm{~PB})$ & * & 143 & $*$ & 220 (COM & * \\
\hline 95 (PB & & 146 & * & 221 (COM71-00 & * \\
\hline $96(1$ & * & 147 (1) & * & 223 (PB16 & $*$ \\
\hline 97 (PB1 & & 148 (PB161- & * & 224 (PB184-119) ....... & * \\
\hline $98(\mathrm{P}$ & * & $151(\mathrm{H}$ & * & 225 (AD614-056). & * \\
\hline $\begin{array}{r}99(\mathrm{~PB}) \\
100(\mathrm{CO})\end{array}$ & * & $154(\mathrm{PE}$ & & 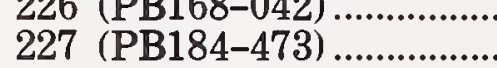 & * \\
\hline 1 & $*$ & $\begin{array}{l}154 \mathrm{~A}(\mathrm{~F} \\
160 \ldots\end{array}$ & $*$ & 228 (PB191-731) ........ & * \\
\hline (2) & $*$ & 163 (COM71-0 & & $229(\mathrm{PI}$ & $*$ \\
\hline-2( & $*$ & $164(\mathrm{~N}$ & * & 231 (COM72-10587). & * \\
\hline$(\mathrm{PB} 1$ & * & 165 & & 233 (COM75-10054) & * \\
\hline (PB & $*$ & 166 (PB181-454 & & 234 (COM7: & * \\
\hline & & & & $235(\mathrm{COM}$ & * \\
\hline $\mathrm{DF}$ & * & 172 (PB193- & & 236 (AD4 & * \\
\hline 109 (P] & \pm & $173(\mathrm{COM}$ & & 237 (COM75-10166). & * \\
\hline $110(\mathrm{PF}$ & * & $174(\mathrm{COM}$ & . & 245 (PB184-177) ...... & \\
\hline 11 & & 177 (C & * & $249(\mathrm{P}]$ & * \\
\hline 11 & & $190-917) \ldots .$. & * & $252(\mathrm{AD}$ & * \\
\hline $113(P$ & * & 179 (P) & & 253 (PB18 & * \\
\hline & * & 180 (COM7 & & 255 (AD614-257).. & t \\
\hline $115(\mathrm{P}$ & * & $182(\mathrm{C}$ & 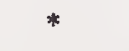 & 260 (PB168-041) ............... & $*$ \\
\hline 11 & & $183(\mathrm{C}$ & * & 261 & $* *$ \\
\hline & & 187 (PB188-807).. & 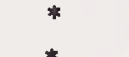 & 262-A (COM73-10486). & 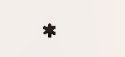 \\
\hline $\begin{array}{l}118 \\
119\end{array}$ & * & $\begin{array}{l}191 \text { (PB182-538). } \\
194 \text { See NSRDS1 }\end{array}$ & .55 & 263 (COM75-10486). & * \\
\hline 120 (PB161- & * & 195 (COM73-10418). & * & 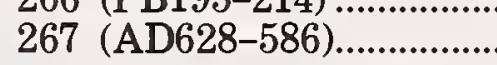 & * \\
\hline
\end{tabular}

"Available from the National Technical Information Service, use "PB", “AD”, “COM", “N”, or NBS publication identification if no specific NTIS number is assigned. 
TECHNICAL NOTES (Continued)

\begin{tabular}{|c|c|c|c|c|c|}
\hline No. & Price & No. & Price & No. & Price \\
\hline 268 & * & 347 & * & 414 (PB176 & * \\
\hline 270-1 See T & 3.25 & 349 & ${ }^{*}$ & 416 & \\
\hline 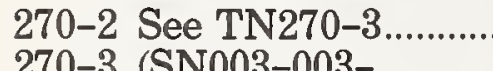 & 3.25 & $\begin{array}{l}355 \\
360\end{array}$ (PB190-125) & * & 417 & * \\
\hline $00406-5) \ldots$ & 3.25 & 361 (COM75-50052) ...... & * & $\begin{array}{l}419 \text { (PB179-432) } \\
420\end{array}$ & * \\
\hline $\begin{array}{r}270-4 \text { (SN003-003- } \\
00407-3)\end{array}$ & 2.10 & $361 \begin{array}{c}\text { (SN003-003- } \\
01321-8)\end{array}$ & 1.25 & 421 & * \\
\hline $270-5$ (COM71-50171).. & .010 & (Metric Version) & & & $*$ \\
\hline 270-6 (SN003-003- & & 362 (COM74-104 & * & 425 & * \\
\hline 270-7 (SN003-003- & 1.90 & $\begin{array}{ll}363 & \cdots \\
364 & \ldots\end{array}$ & * & 428 & ${ }^{*}$ \\
\hline 0113 & 1.25 & $365 \ldots . .$. & * & 431 & * \\
\hline $\begin{array}{l}270-8 \\
273 \text { (PB248-534). }\end{array}$ & & $\begin{array}{l}365-1 \text { (COM71-00048) } \\
366\end{array}$ & * & 402 & \\
\hline 275 (COM73-10484) .......... & * & 367 & & $\begin{array}{l}434 \\
435\end{array}$ & * \\
\hline $\begin{array}{l}277 \\
278\end{array}$ & * & $\begin{array}{l}368 \\
370\end{array}$ & * & $\begin{array}{l}436 \\
437\end{array}$ & * \\
\hline 279 (COM75-10375). & * & $372 \ldots$ & * & 438 (AD665-245) & * \\
\hline 280 (COM72-10590). & & 373 & & & \\
\hline 285 (AD633-354).. & & 374 & * & $\begin{array}{l}459 \\
440\end{array}$ & \\
\hline 287 (PB182-436)....... & * & 375 & * & 444 & * \\
\hline $\begin{array}{l}288 \\
291\end{array}$ & , & $\begin{array}{l}377 \\
378\end{array} \quad \cdots \ldots . .$. & * & 445 & * \\
\hline 292 (COM75-1 & * & 379 (SN003-003- & & 401 & \\
\hline 293 & * & & .65 & $\begin{array}{l}464 \\
465\end{array}$ & \\
\hline $294(\mathrm{~PB} 176-289) \ldots \ldots . . .$. & * & $\begin{array}{l}381 \\
382\end{array}$ & * & 467 (COM72-50871) ..... & * \\
\hline 297 (PB188-657). & & 383 & & & " \\
\hline 298 (F & $*$ & $384(\mathrm{CC}$ & * & & \\
\hline 303 (AI & $*$ & $\begin{array}{l}385 \text { (PB190- } \\
386 \text { (PR191_- }\end{array}$ & $*$ & $\begin{array}{l}472(\mathrm{AD} 681-330) \ldots . . . \\
473\end{array}$ & * \\
\hline $\begin{array}{l}303 \text { (AD611-400). } \\
304 \text { (AD615-936). }\end{array}$ & ${ }^{*}$ & $387(\mathrm{C}$ & $*$ & 474 (AD681-351). & * \\
\hline $07(\mathrm{P}$ & $*$ & $\begin{array}{l}388 \text { (COM }^{\prime} \\
389\end{array}$ & $*$ & 476 & * \\
\hline 310 (AD615-937)...................... & * & 390 (PB191-639) & & 477 & * \\
\hline 318 (COM75-10374) ..... & * & 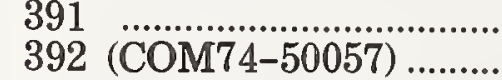 & * & 478 (PB190-6C & * \\
\hline 321 & & $393(\mathrm{CC}$ & * & 480 & * \\
\hline $322(C$ & & 397 (COM71-50060). & & 483 & * \\
\hline $323(\mathrm{CC}$ & * & $\begin{array}{r}398(\text { (SIN003-003- } \\
00814-1) \ldots . . . . .\end{array}$ & .40 & $484($ AD692-231)... & * \\
\hline 324 (AD654-887)... & ${ }^{*}$ & 399 (COM71-50294) & & 485 & $*$ \\
\hline & * & $\begin{array}{ll}400 & \ldots . . \\
403 & \ldots . .\end{array}$ & * & 487 & 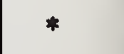 \\
\hline 34 (PB173-291) & & 406 & * & 488 (AD692-232).......... & \\
\hline & & 409 & & 490 & * \\
\hline $\begin{array}{l}343 \\
345\end{array}$ & ${ }^{*}$ & $\begin{array}{l}410 \\
411\end{array}$ & * & 491 A605-820). & $*$ \\
\hline 346 (PB194-282) & * & 412 & * & 496 & * \\
\hline
\end{tabular}

"Available from the National Technical Information Service, use "PB", "AD", "COM", "N", or NBS publication identification if no specific NTIS number is assigned. 
TECHNICAL NOTES (Continued)

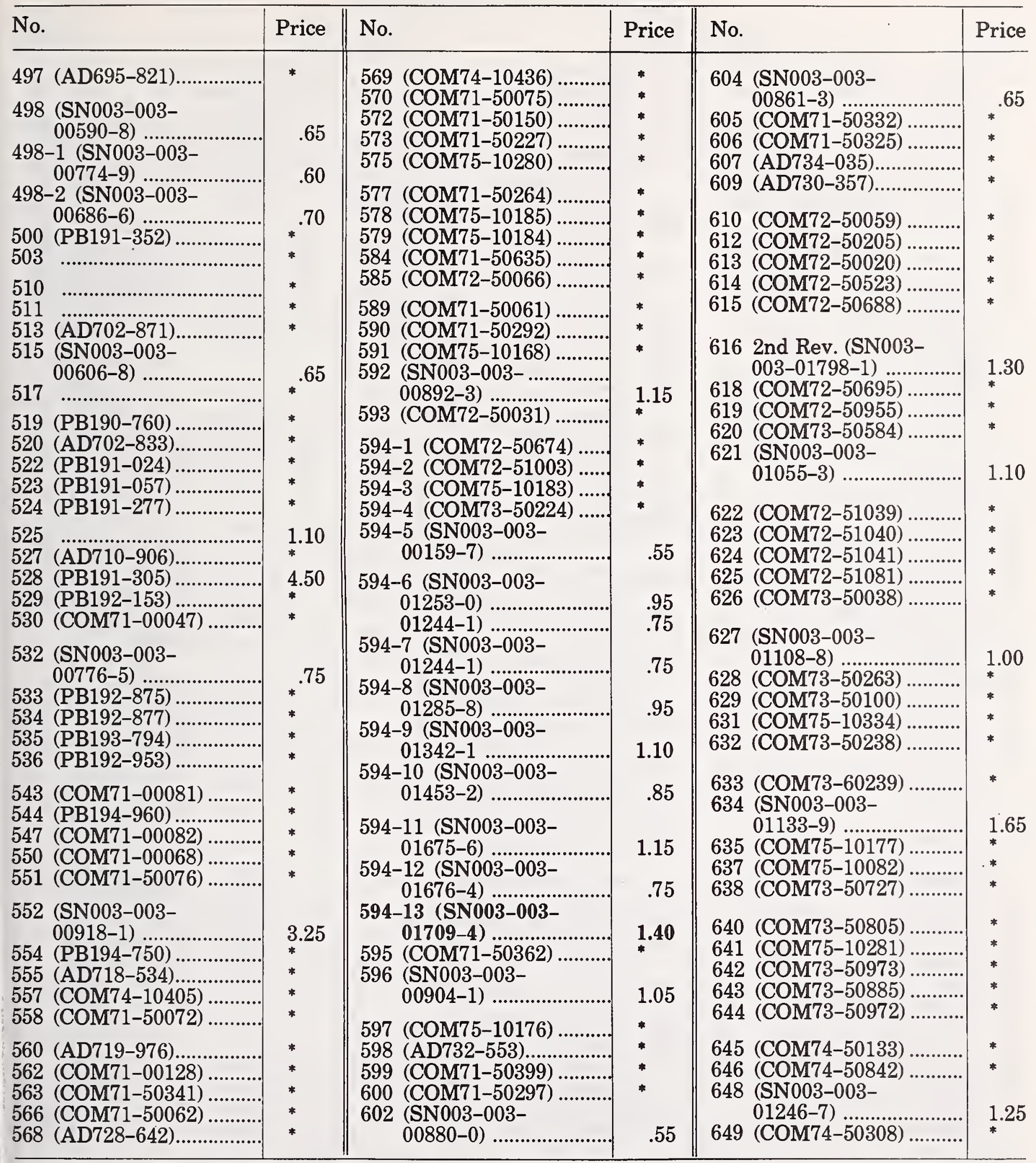

"Available from the National Technical Information Service, use "PB", "AD", "COM", "N", or NBS publication identification if no specific NTIS number is assigned. 
TECHNICAL NOTES (Continued)

\begin{tabular}{|c|c|c|c|c|c|}
\hline No. & Price & No. & Price & No. & Price \\
\hline $650(\mathrm{COM} 74-50430) \ldots . .$. & * & 683 (SN003-003- & & $718(\mathrm{C}$ & * \\
\hline 651 (SN & & 684 (SN003-003- & 1.0 & $\begin{array}{r}720 \text { (SN } \\
009\end{array}$ & \\
\hline 01 & .50 & 01732-9) ........ & 3.85 & 721 (COM72-50467) & \\
\hline $\begin{array}{r}652 \text { (SN003-003- } \\
01299-8) \ldots \ldots . . .\end{array}$ & 50 & 685 (SN003-003- & & 723 (COM72-50535) & * \\
\hline $653(\mathrm{COM}$ & & 0 & .65 & $725(\mathrm{~S}$ & 75 \\
\hline $\begin{array}{l}654 \text { (COM74-50698) } \\
655 \text { (COM74-51542). }\end{array}$ & & $\begin{array}{l}686 \text { (PB260-666) } \\
687 \text { (SN003-003- }\end{array}$ & & 01 & \\
\hline $657(C$ & & 0171 & .75 & 727 (COM72-50538) & * \\
\hline $58(\mathrm{~S}$ & 10 & $\begin{array}{l}688 \text { (SN0 } \\
01715\end{array}$ & .65 & $\begin{array}{l}728 \text { (COM7 } \\
729 \text { (COM7 }\end{array}$ & \\
\hline 659 (SN & 1.10 & 689 (PB263-104). & & 731 (SN003-003- & \\
\hline 01 & .85 & $690(\mathrm{P}$ & & $01023-5)$ & .95 \\
\hline $\begin{aligned} & 660 \text { (SN } \\
& 013\end{aligned}$ & 1.00 & $\begin{array}{l}691 \text { (PB2 } \\
692 \text { (SNO }\end{array}$ & * & $1026+3$ & \\
\hline $\begin{array}{r}661 \text { (SN00 } \\
01350-\end{array}$ & .80 & $\begin{array}{l}01734 \\
693 \text { (SNo }\end{array}$ & .55 & 733 (COM7 & .75 \\
\hline $662(\mathrm{~S}$ & & $01710-8) \ldots \ldots$ & 1.20 & 734 (COM72-50732) & \\
\hline 663 (SN003-0 & .70 & $\begin{array}{r}695 \text { (SN003-003- } \\
01781-7) \ldots . . . . . . . . . . . .\end{array}$ & 2.80 & 736 (COM72-5092 & * \\
\hline 01405-2) & 1.10 & 696 Rev. 1977 (SN003- & 1.5 & $101(1$ & \\
\hline $\begin{array}{l}664 \text { (COM75-10289) ... } \\
665 \text { (SN003-003- }\end{array}$ & * & 003-018 & 1.0 & 738 (COM72-50810) & * \\
\hline 01403-6) ............. & 1.00 & $\begin{array}{r}697 \quad(\text { SNO03-003- } \\
01862-7) \ldots \ldots \ldots\end{array}$ & 2.20 & $747 \underset{01}{(\mathbf{S} 1}$ & 1.2 \\
\hline 666 (CON & & 698 (SN003-003- & $190+25+5$ & 748 (COM7 & \\
\hline $\begin{array}{r}667 \underset{\mathrm{SN}}{\mathrm{S}} \\
0156\end{array}$ & 1.85 & $699 \begin{array}{l}01864-3) \\
(\text { SN003-003- }\end{array}$ & 1.30 & 749 (COM7 & * \\
\hline 668 (SN0C & & 01865-1) & 2.75 & $750(\mathrm{C}$ & * \\
\hline $669 \stackrel{014}{(\mathrm{CC}}$ & 1.05 & $\begin{array}{l}700 \text { (COM73- } \\
702 \text { (AD734- }\end{array}$ & & 751 (SN & \\
\hline 670 (SN003-003- & & 700 & & 752 (COM73-50624) & \\
\hline 015 & 1.60 & $\begin{array}{l}703 \text { (COM71-50607) } \\
706 \text { (COM72-50892) }\end{array}$ & & 753 (SNOC & \\
\hline $\begin{array}{r}672 \text { (SN003-003- } \\
01550-4)\end{array}$ & 2.40 & $\begin{array}{l}707 \text { (COM72-50054) } \\
708(\mathrm{COM} 72-50062)\end{array}$ & * & $754\left(\begin{array}{l}01097-9) \\
(\text { COM73-50225) }\end{array}\right.$ & $\begin{array}{l}1.1 \\
*\end{array}$ \\
\hline 673 (SN003-003- & 8 & $710-1$ (COM72-50276) & * & 755 (SN) & \\
\hline 674 (SN003-003- & & $710-2(\mathrm{CO}$ & * & 756 & .70 \\
\hline $675 \stackrel{01559-8)}{(\text { SN003-0...... }}$ & 1.50 & $\begin{array}{l}710-4 \text { (COM72-50521) } \\
710-5 \text { (COM72-50694) }\end{array}$ & & 757 (SNO03-003 & \\
\hline 015 & 1.30 & 710-6 (SN003-00 & & 758 (SN003-003- & \\
\hline $\begin{array}{r}677 \begin{array}{l}\text { (SN003-003- } \\
01597-1)\end{array} \text {........ }\end{array}$ & 1.20 & $\begin{array}{r}01087-1) \\
710-7 \text { (COM73-50483) }\end{array}$ & 1.00 & 01115-1) & 2.10 \\
\hline $\begin{array}{r}680 \text { (SN003-003- } \\
\quad 01616-1)\end{array}$ & .50 & 711 (COM72-50064) & * & $\begin{array}{r}759 \text { (SN003-003- } \\
01102-9) \text {........ }\end{array}$ & .65 \\
\hline 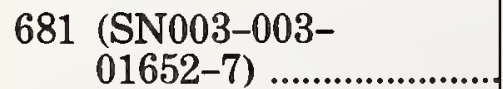 & 1.05 & $\begin{array}{c}714 \begin{array}{l}\text { (SN003-003- } \\
00974-1)\end{array} \text {........... }\end{array}$ & .5 & $\begin{array}{r}760 \text { (SN003-003- } \\
01112-6) . . . . . .\end{array}$ & .90 \\
\hline $\begin{array}{r}682 \text { (SNO } \\
01655\end{array}$ & .80 & $\begin{array}{l}716 \text { (COM72-50361) } \\
717 \text { (AD740-674)...... }\end{array}$ & * & $\begin{array}{l}761 \text { (SN003-003- } \\
\text { 01132-1) ........ }\end{array}$ & 1.15 \\
\hline
\end{tabular}

*Available from the National Technical Information Service, use "PB", "AD", "COM", "N", or NBS publication identification if no specific NTIS number is assigned. 
TECHNICAL NOTES (Continued)

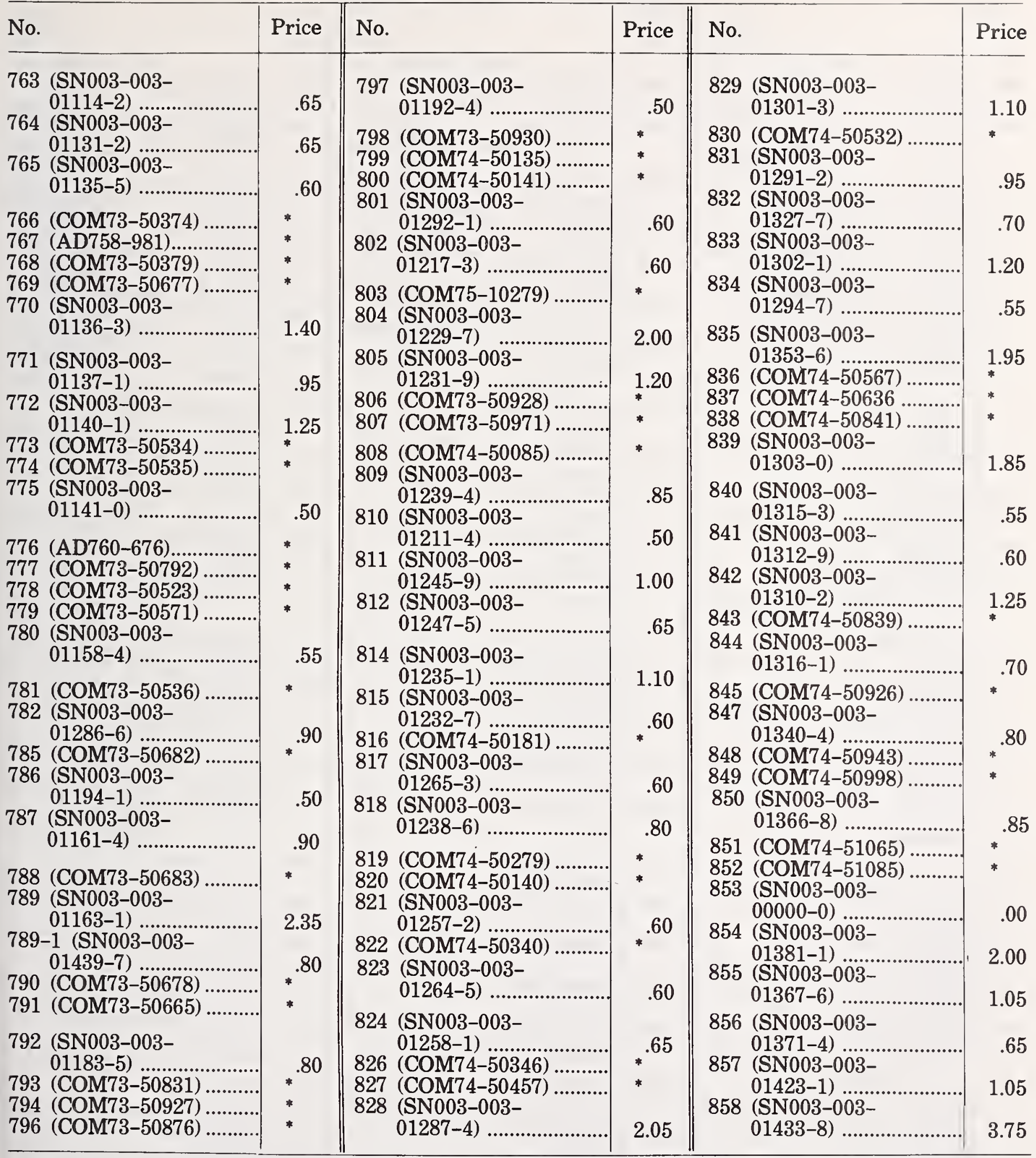

"Available from the National Technical Information Service, use "PB", "AD", "COM", "N", or NBS publication identification if no specific NTIS number is assigned. 
TECHNICAL NOTES-(Continued)

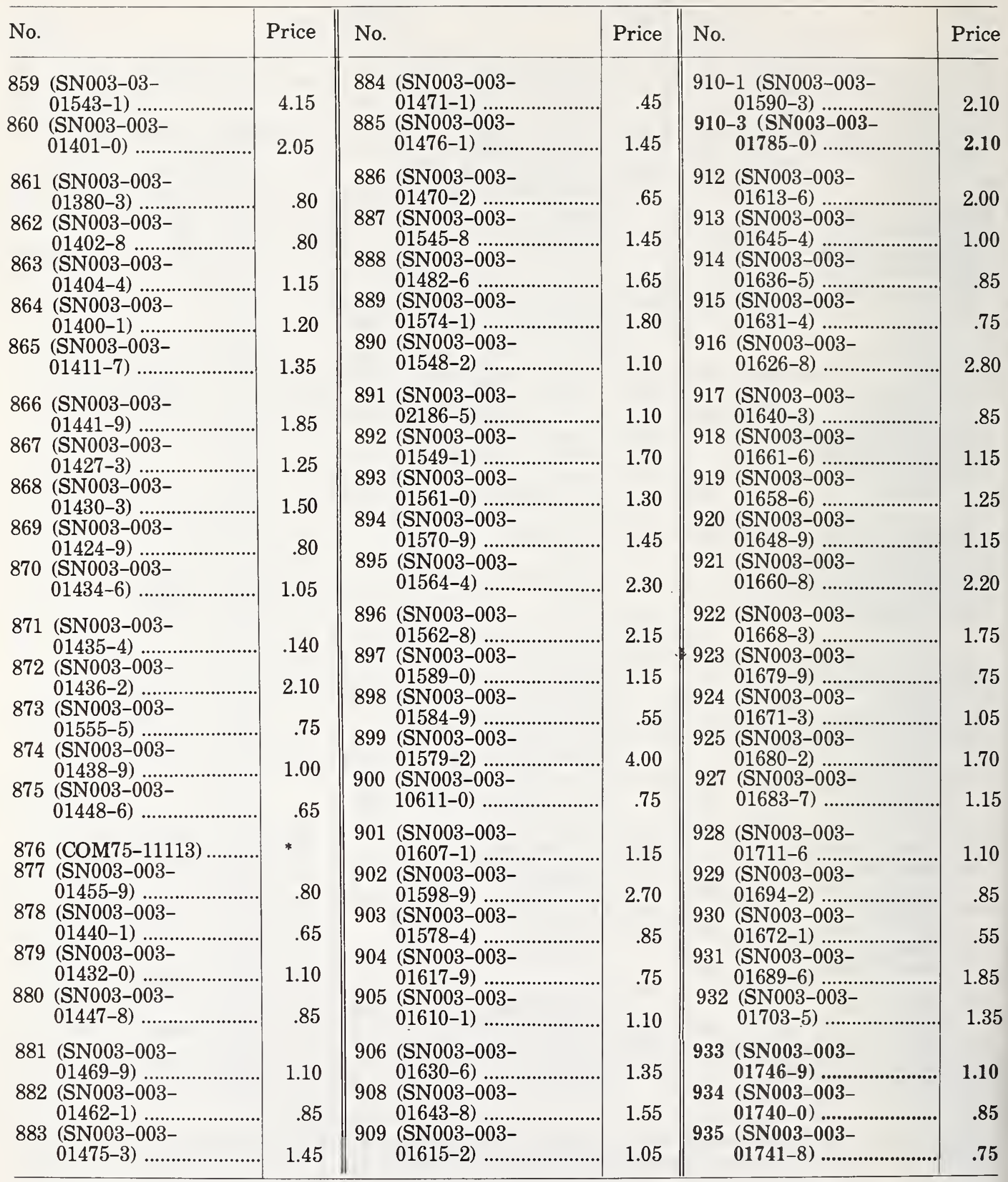

*Available from the National Technical Information Service; use "AD", or "COM" number when ordering. 
TECHNICAL NOTES (Continued)

\begin{tabular}{|c|c|c|c|c|c|}
\hline No. & Price & No. & Price & No. & Price \\
\hline 936 (SN003-003- & 145 & 945 (SN003-003- & 220 & 954 (SN003-003-... & \\
\hline $\begin{array}{c}937 \text { (SN003-003- } \\
01763-9) \ldots \ldots . . . . .\end{array}$ & 1.30 & 946 (SN003-003-. & 2.30 & 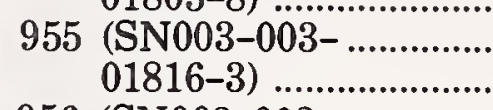 & 2.00 \\
\hline $\begin{array}{c}938 \text { (SN003-003- } \\
01761-2) \ldots . . . . . .\end{array}$ & 1.60 & 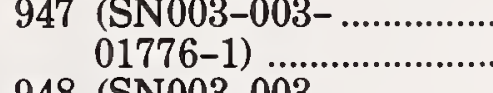 & 2.20 & 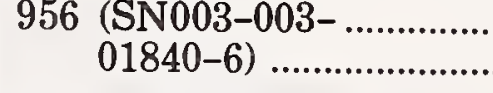 & 2.00 \\
\hline 939 (SN003-003- & 275 & 948 (SN003-003- & 3.25 & 957 (SN003-003- & 150 \\
\hline $\begin{array}{l}940 \text { (SN003-003- } \\
01790-6)\end{array}$ & 2.00 & $01810-4) \ldots . . . .$. & 1.10 & $\begin{array}{c}958 \text { (SN003-003-. } \\
01866-0) \text {......... }\end{array}$ & 1.40 \\
\hline $\begin{array}{l}941 \text { (SN003-003- } \\
01727-2 \ldots \ldots \ldots . . .\end{array}$ & 2.30 & 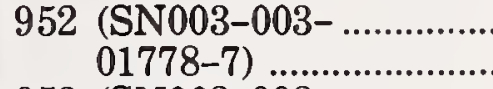 & 2.10 & 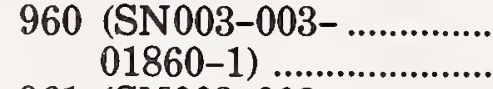 & 2.30 \\
\hline $\begin{array}{c}943 \begin{array}{l}\text { (SN003-003- } \\
01799-0)\end{array} . . . . . . . .\end{array}$ & 2.30 & 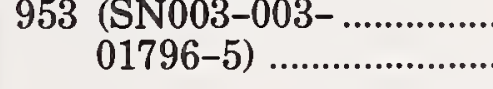 & 2.00 & 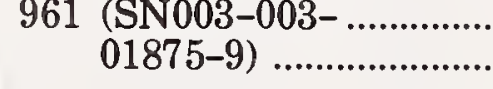 & 2.30 \\
\hline
\end{tabular}




\section{NBS INTERAGENCY REPORTS}

These reports are available by purchase from the National Technical Information Service, Springfield, VA 22161. Those items in boldface denote the publications cited in this supplement. The prices are those in effect as of the date this publication went to press. When ordering, use the

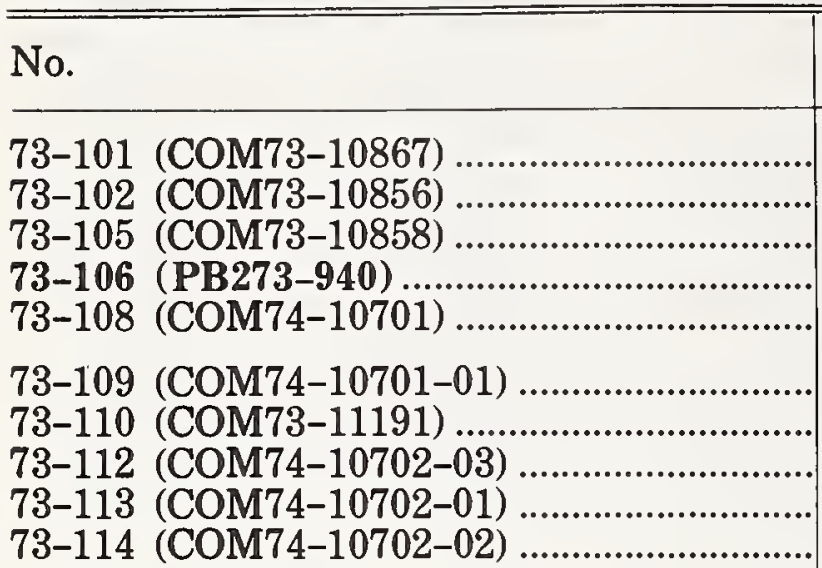

73-115 (PB226907)

73-119 (AD757789).

73-121 (COM73-10860)

73-125 (COM73-11189)

73-126 (COM73-10854)

73-127 (COM73-10857)

73-128 (AD760150).

73-129 (COM73-10853)

73-131 (COM73-10863)

73-132 (PB222300)

73-135 (COM73-10840)

73-136 (PB273-995)

73-138 (COM73-10868)

73-140 (COM73-10842)

73-141 (COM73-10841)

73-144 (PB220-849)

73-145 (COM75-10541)

73-146 (COM73-10989)

73-147 (AD759737).

73-151 (COM73-10866)

73-152 (AD914258)

73-153 (AD758-730)

73-154 (COM73-10865)

73-156 (COM73-11286)

73-157 (COM74-10394)

73-159 (COM73-11174)

73-160 (PB243540)

73-161 (PB225310)

73-163 (COM74-10542)

73-164 (COM73-10834)

73-165 (COM73-10837)

73-166 (COM73-10835)

73-167 (COM73-10836)

73-168 (COM73-10838)

73-169 'COM73-10839)

73-170 (COM73-10843)

73-172 (COM73-11175)
Price

5.00

4.50

4.00

5.25

300.00

4.50

6.00

4.50

9.25

9.25

4.50

4,50

5.50

4.50

5.50

5.00

4.50

5.00

4.50

6.00

4.00

4.00

4.00

3.50

4.00

6.00

4.00

4.50

4.00

3.50

6.00

3.50

3.50

4.50

4.00

3.50

4.00

4.50

5.50

4.00

3.50

3.50

3.50

4.00

3.50

4.00

5.00
"AD", "PB", "N" or "COM" number. The prices quoted are for paper copy domestic, add $\$ 2.25$ additional for foreign mailing. Microfiche are available for $\$ 2.25$ per set. Prices are subject to change without notice.
No.

Price

73-173 (COM73-10844)

4.00

73-175 (COM74-10395)

73-176 (AD761197)

4.50

4.00

73-177 (COM75-10336)

73-180 (COM74-10130)

4.00

4.00

73-182 (COM73-11284)

5.00

73-183 (COM73-11177)

73-184 (COM73-11110)

4.50

5.00

73-185 (COM73-11287)

73-187 (PB221-188)

73-188 (PB221-183)

73-189 (COM73-11173)

73-190 (COM73-10831)

4.00

4.50

5.00

4.00

3.50

73-191 (PB221-695)

3.50

73-192 (COM73-10832)

73-196 (PB273-941)

3.50

4.50

4.50

73-198 (COM74-11289)

73-199 (COM74-10129)

73-200 (COM74-10478)

73-201 (COM73-11221)

73-202 (COM74-10479)

73-203 (See NBSIR 74-430

COM74-10724)

73-206 (COM73-11262)

73-207 (AD769-266)

73-208 (COM74-10127)

73-209 (COM74-10469)

73-210 (COM74-11767)

73-211 (COM74-10950)

73-212 (COM74-11009)

73-213 (COM74-11771)

73-214 (COM74-11239)

73-215 (COM74-11010)

73-216 (COM74-11011)

73-218 (COM75-10144)

73-219 (PB273-939)

73-220 (PB222-437)

73-221 (COM73-11113)

73-223 (COM73-11220)

73-228 (PB222-425)

73-231 (PB224-645)

73-232 (PB273-947)

73-233 (COM74-11770)

73-234 (COM74-10128)

73-239 (PB273-962)

73-240 (COM74-10986)
97.50

5.50

4.00

5.00

4.00

5.50

5.50

6.00

4.00

8.00

7.75

6.75

6.00

6.00

5.50

5.50

6.00

4.00

4.50

3.50

5.00

5.00

3.50

4.00

4.50

4.50

4.00

4.00

4.00 
NBS INTERAGENCY REPORTS-(Continued)

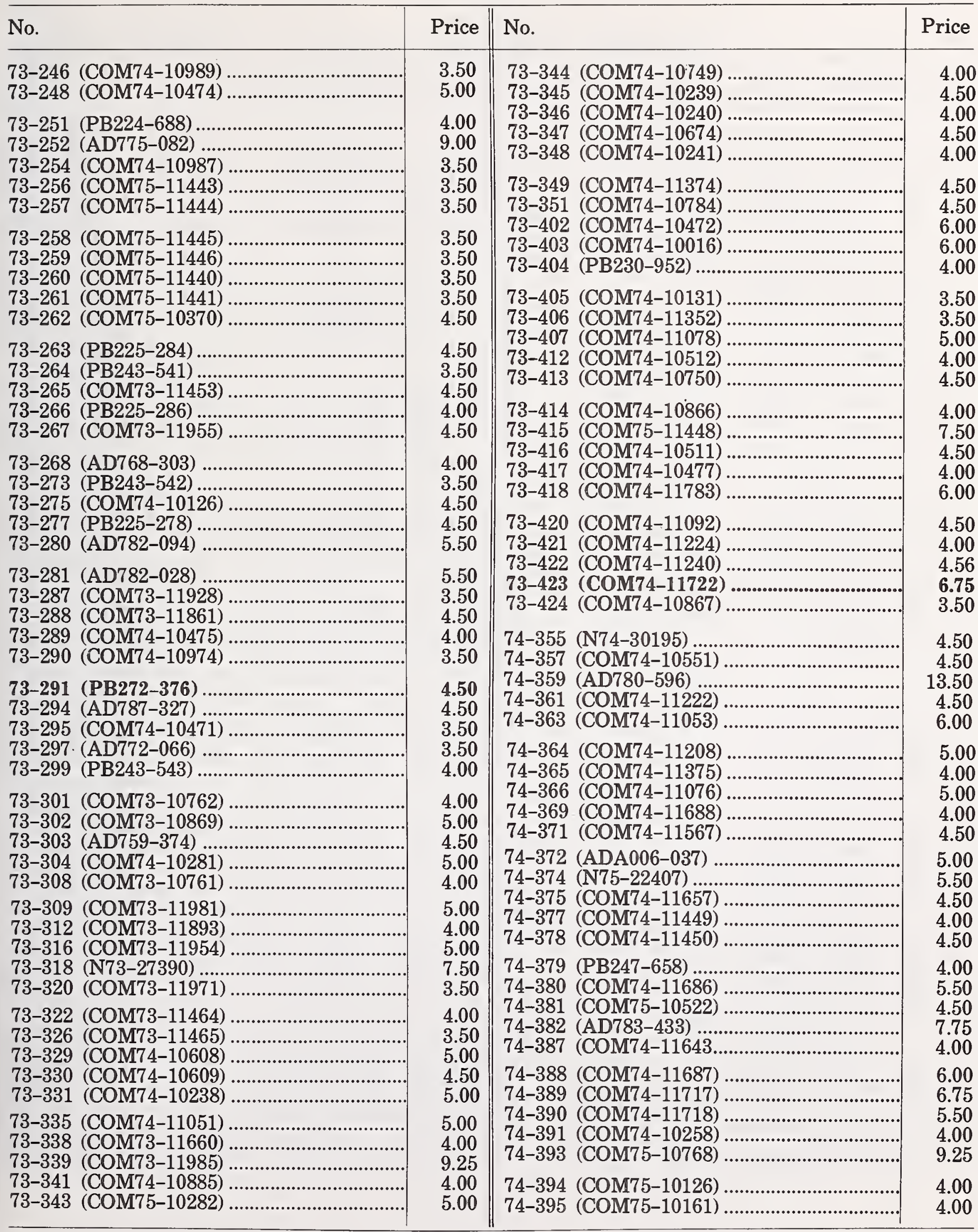


NBS INTERAGENCY REPORTS (Continued)

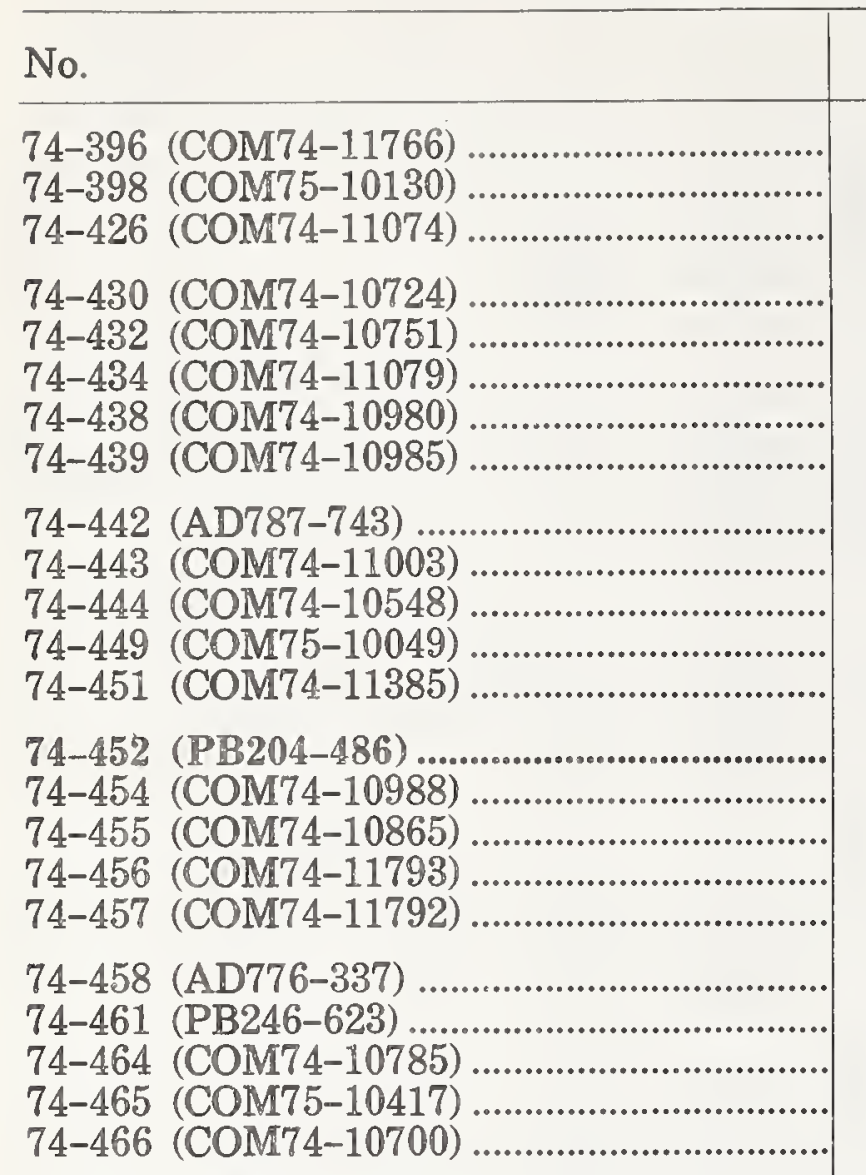

Price

4.00

10.00

5.50

5.50

4.50

3.50

4.00

3.50

4.00

3.50

4.00

4.00

3.50

5.50

3.50

4.00

3.50

5.00

3.50

4.00

5.00

4.50

12.50

74-467 (COM74-11754)

74-469 (PB234-348) .

74-470 (PB232-629)

74-471 (COM74-10981)

74-473 (COM74-11719)

\section{4-474 (AD778-340)}

74-477 (COM74-11784)

74-479 (PB239-420)

74-481 (COM74-11794)

74-482 (COM75-10147)

74-485 (AD780-704)

74-486 (AD780-705)

74-487 (COM74-10886)

74-488 (COM75-10088)

74-493 (PB243-545)

74-495 (COM74-11575)

74-496 (COM74-11576)

74-497 (COM74-11269)

74-499 (COM74-11378)

74-500 (PB265-694)

74-501 (COM75-10131)

74-506 (COM74-11632)

74-507 (AD/A0001343)

74-509 (COM74-11377)

74-510 (AD782-793)

4.50

4.50

5.00

3.50

4.50

4.00

4.00

6.00

4.50

7.75

3.50

4.50

13.00

5.50

3.50

5.00

5.00

3.50

4.00

6.00

3.50

5.00

4.00

3.50

4.00

74-511 (COM74-11448)

3.50

74-514 (COM75-10102)

74-515 (COM74-11498)

74-516 (COM74-11384)

74-517 (COM74-10470)

74-518 (PB239-633)

74-519 (PB238-284)...

74-520 (COM74-11480)

74-521 (COM75-10187)

74-522 (COM75-10080)

74-523 (COM75-11126)

74-524 (COM74-11568)

74-525 (AD782-564)

74-526 (COM75-10087)

74-527 (COM74-11720)

74-529 (COM74-11495)

74-530 (COM75-10041)

74-533 (PB238-573) ..

74-535 (COM74-11659)

74-537 (COM74-11577)

74-539 (COM74-11574)

74-541 (COM75-10618)

74-542 (COM75-10081)

74-543 (COM74-11772)

74-544 (COM74-11525)

74-545 (COM74-11656)

74-550 (COM74-11721)

74-551 (COM74-11658)

74-552 (COM74-11644)

74-553 (COM75-10058)

Price

74-554 (COM74-10703)

74-555 (COM74-10704)

74-556 (COM74-10703)

74-557 (COM75-11439)

74-561 (COM75-10413)

74-564 (COM74-11726)

74-567 (COM74-11631)

74-568 (COM74-11578)

74-569 (AD/A002-289)

74-572 (COM74-11791)

74-577-1 (COM74-11723)

74--577-2 (COM74-11724)

74-578 (COM74-11765)

74-580 (PB248-465)

74-581 (COM75-10127)

4.50

7.50

4.50

4.00

5.00

4.00

6.00

4.50

3.50

3.50

4.00

3.50

4.50

4.50

4.50

4.00

5.50

5.00

3.50

5.00

4.00

4.00

6.00

4.00

4.50

5.00

5.50

5.00

4.50

3.50

4.00

5.00

4.00

4.00

4.50

9.25

4.50

4.00

4.50

7.50

9.75

3.50

3.50

4.00

4.00

5.00

3.50

4.00

3.50

$74-588$ (COM75-10040)
$74-590$ (COM75-11434)

3.50 


\section{NBS INTERAGENCY REPORTS (Continued)}

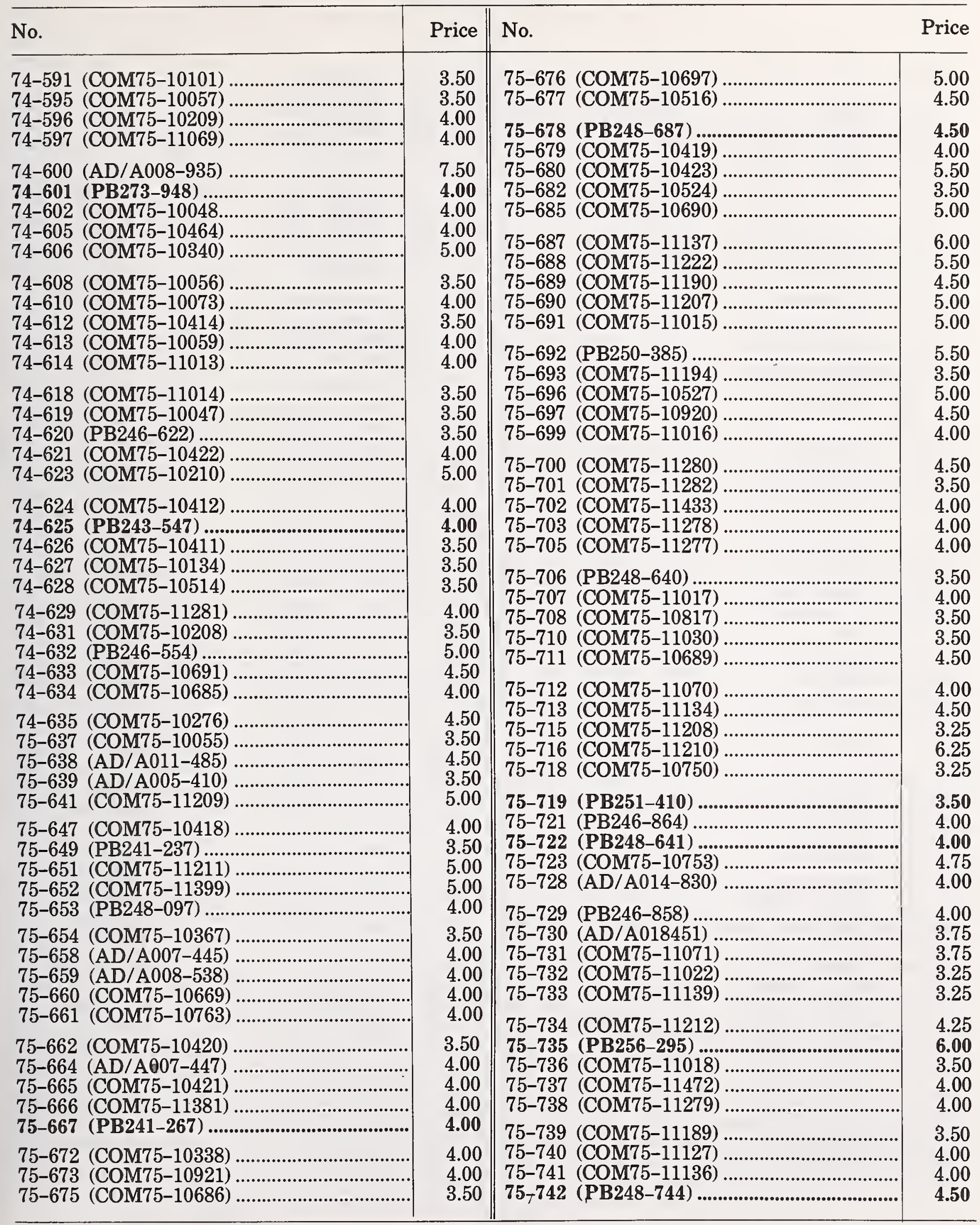




\begin{tabular}{|c|c|c|c|}
\hline No. & Price & No. & Price \\
\hline 75-744 (COM75-11072) & 3.50 & 5-822 (PB246933) & 4.00 \\
\hline 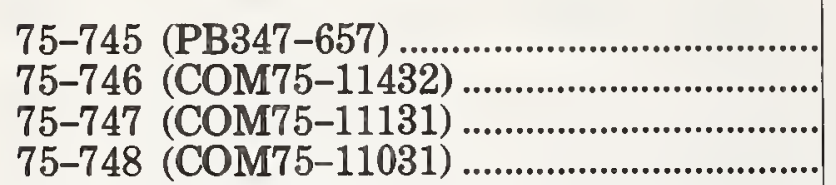 & $\begin{array}{l}4.00 \\
4.50 \\
4.00 \\
5.00\end{array}$ & $\begin{array}{l}75-825 \\
75-827 \\
75 B 248-913) \\
75-828\end{array}$ & $\begin{array}{l}5.00 \\
4.50 \\
3.50 \\
7.50\end{array}$ \\
\hline 75-750 (PB249-934) ......................................... & 4.00 & 75-829 (PB248-855). & 4.00 \\
\hline $\begin{array}{l}75-771 \\
75-752 \\
75-(\mathrm{AD} 245-013) \\
75-754 \\
75-755\end{array}$ & $\begin{array}{l}4.00 \\
5.00 \\
5.00 \\
4.00\end{array}$ & $\begin{array}{l}75-900(\mathrm{PB250}-859) \\
75-901(\mathrm{~PB} 246-860) . . \\
75-902(\mathrm{PB249-539)} . \\
75-903(\mathrm{~PB} 246859) \ldots\end{array}$ & $\begin{array}{l}4.00 \\
4.00 \\
4.00 \\
4.00\end{array}$ \\
\hline 75-757 (PB248-914) ...................................... & 4.00 & $75-908$ (PB247- & \\
\hline 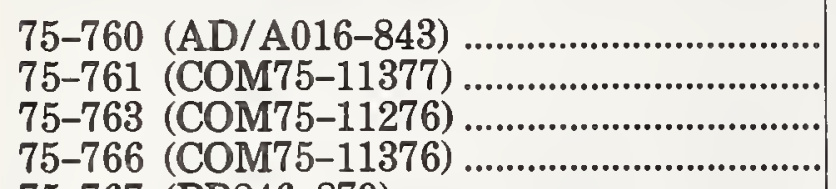 & $\begin{array}{l}7.75 \\
5.50 \\
7.75 \\
4.50\end{array}$ & $\begin{array}{l}75-909(\text { PB246-863).. } \\
75-910 \text { (PB248-646). } \\
75-913 \text { (PB248-911). } \\
75-915 \text { (PB249-775). }\end{array}$ & $\begin{array}{l}3.50 \\
5.50 \\
4.00 \\
3.50\end{array}$ \\
\hline 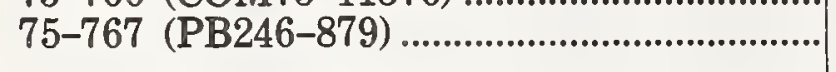 & 4.00 & (................................ & 5.00 \\
\hline 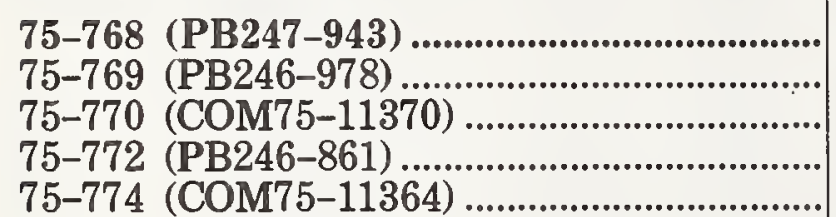 & $\begin{array}{l}4.00 \\
8.00 \\
4.00 \\
4.50 \\
4.50\end{array}$ & 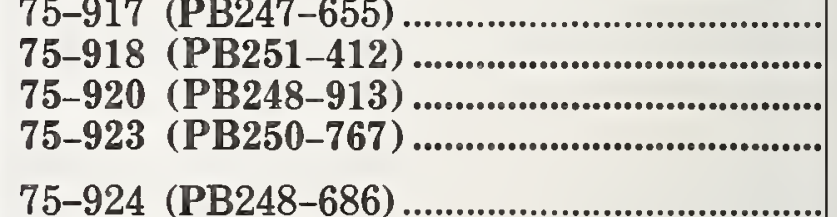 & $\begin{array}{l}3.50 \\
5.00 \\
4.00 \\
3.50\end{array}$ \\
\hline 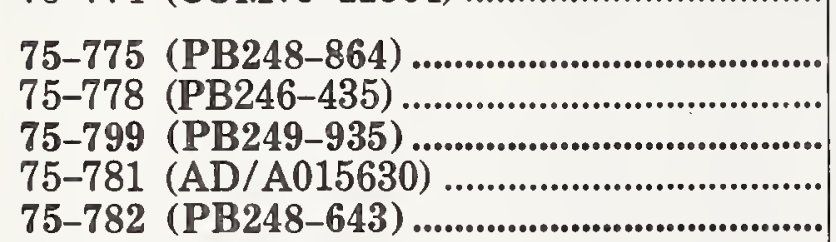 & $\begin{array}{l}4.50 \\
4.50 \\
5.50 \\
3.50 \\
4.00\end{array}$ & 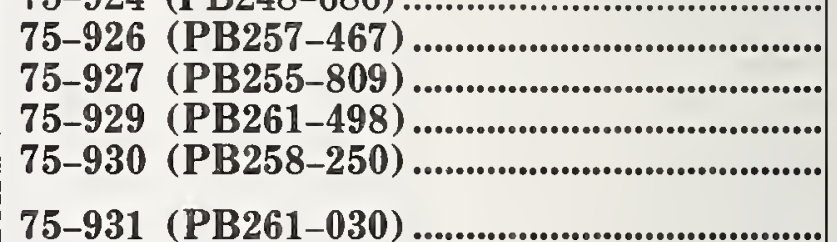 & $\begin{array}{l}5.50 \\
4.50 \\
4.00 \\
4.50 \\
4.00\end{array}$ \\
\hline 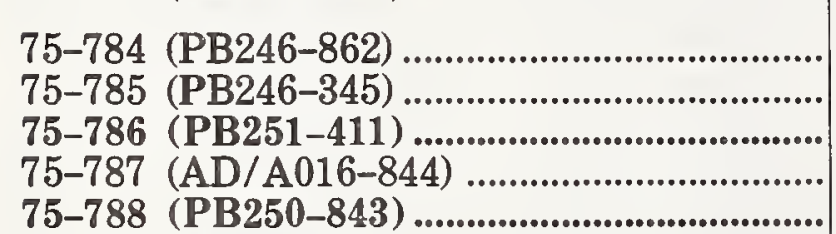 & $\begin{array}{l}4.50 \\
3.50 \\
4.50 \\
4.50 \\
4.00\end{array}$ & $\begin{array}{l}75-932 \\
75-933 \\
75-937\end{array}$ & $\begin{array}{l}4.50 \\
4.50 \\
3.50 \\
6.00 \\
4.50\end{array}$ \\
\hline 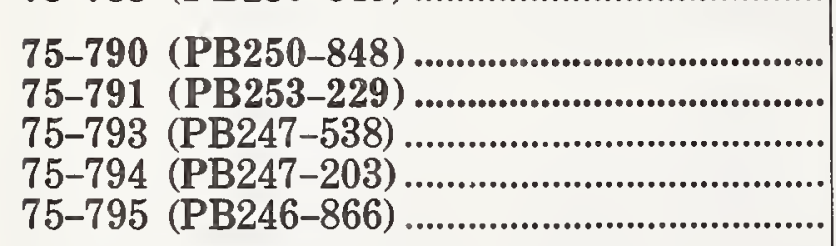 & $\begin{array}{r}10.50 \\
4.50 \\
4.50 \\
4.00 \\
4.50\end{array}$ & 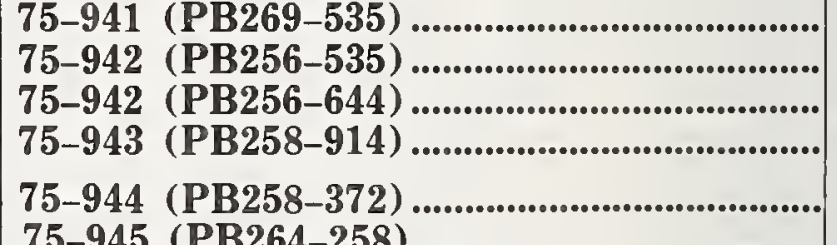 & $\begin{array}{l}5.25 \\
5.25 \\
4.50 \\
5.00 \\
4.00\end{array}$ \\
\hline 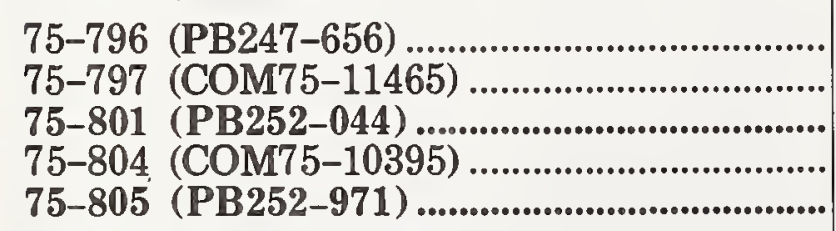 & $\begin{array}{l}3.50 \\
3.50 \\
6.75 \\
4.00 \\
4.00\end{array}$ & $\begin{array}{r}75-945 \\
75-947 \\
75-948\end{array}$ & $\begin{array}{l}5.25 \\
4.50 \\
4.50 \\
7.25 \\
4.00\end{array}$ \\
\hline 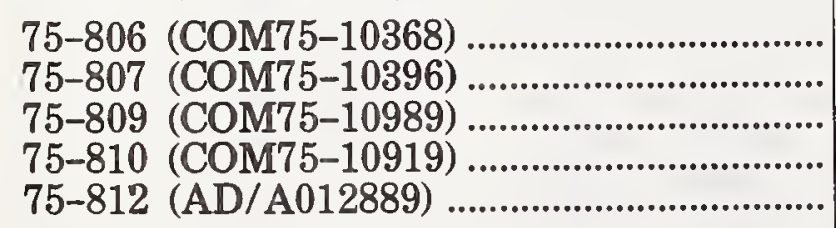 & $\begin{array}{l}4.50 \\
5.00 \\
4.00 \\
5.50 \\
4.00\end{array}$ & 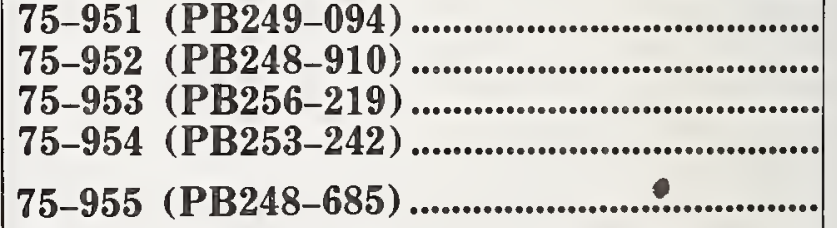 & $\begin{array}{l}4.00 \\
4.00 \\
4.00 \\
4.00 \\
6.75\end{array}$ \\
\hline 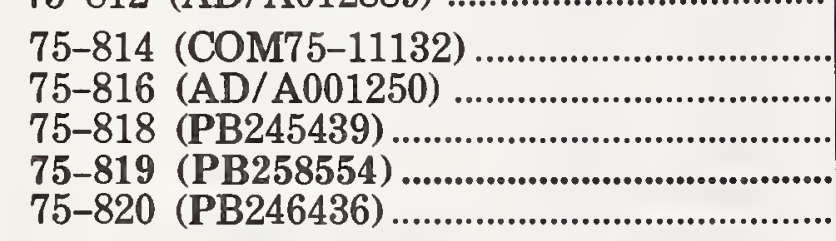 & $\begin{array}{l}4.50 \\
4.50 \\
4.00 \\
5.50 \\
4.50\end{array}$ & 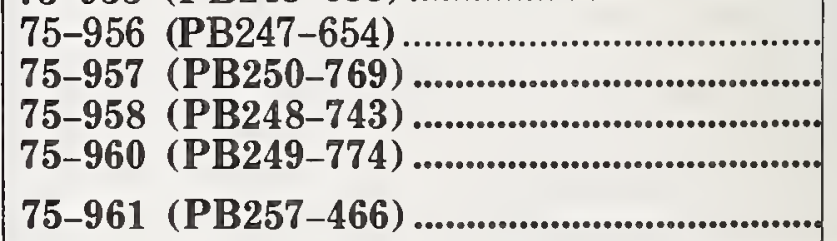 & $\begin{array}{l}3.50 \\
3.50 \\
3.50 \\
4.50 \\
8.00\end{array}$ \\
\hline
\end{tabular}




\begin{tabular}{|c|c|c|c|c|}
\hline \multicolumn{2}{|l|}{ No. } & \multirow{2}{*}{$\begin{array}{l}\text { Price } \\
3.50 \\
3.50 \\
3.50 \\
4.00\end{array}$} & \multirow{2}{*}{ 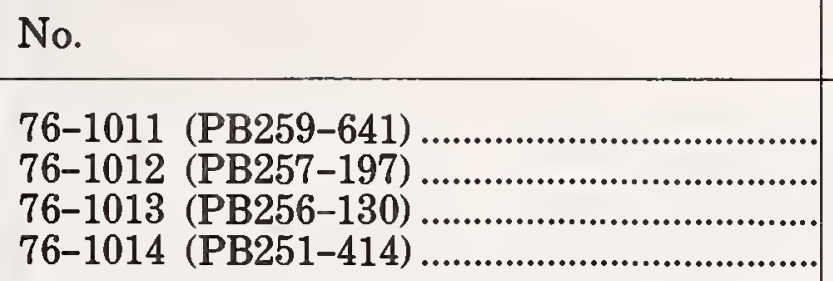 } & \multirow{2}{*}{$\begin{array}{l}\text { Price } \\
4.00 \\
4.50 \\
4.00 \\
3.50\end{array}$} \\
\hline & ) & & & \\
\hline & , & $\begin{array}{l}4.00 \\
5.00 \\
4.50 \\
5.50 \\
4.00\end{array}$ & $\begin{array}{l}76-1015 \text { (PB249-530) } \\
76-1016 \text { (PB254-177) } \\
76-1017 \text { (PB251-917) } \\
76-1018 \text { (PB257-779) } \\
76-1019 \text { (PB251-944) }\end{array}$ & $\begin{array}{l}9.2 \\
4.5 \\
4.0 \\
4.5 \\
3.5\end{array}$ \\
\hline & . & $\begin{array}{l}4.00 \\
4.00 \\
4.00 \\
4.00 \\
4.00\end{array}$ & $\begin{array}{l}76-1020 \text { (PB258-2 } \\
76-1021 \text { (PB257-1 } \\
76-1022 \text { (PB259-6 } \\
76-1023 \text { (PB256-1 } \\
76-1024 \text { (PB255-8 }\end{array}$ & $\begin{array}{l}3.5 \\
3.5 \\
4.5\end{array}$ \\
\hline & $\begin{array}{l}(\mathrm{PB} \\
(\mathrm{PB} \\
(\mathrm{PB} \\
\left(\mathrm{PB}^{\circ}\right. \\
(\mathrm{PB}\end{array}$ & $\begin{array}{l}6.00 \\
6.75 \\
4.00 \\
4.00 \\
3.50\end{array}$ & $\begin{array}{l}76-1025 \text { (PB251-7 } \\
76-1027 \\
\text { (PB-1028 } \\
76-1025-2 \\
76-1029 \\
76-1030\end{array}$ & 50 \\
\hline & $\begin{array}{l}(\mathrm{PB} \\
(\mathrm{PB} \\
(\mathrm{PB} \\
(\mathrm{PB} \\
(\mathrm{PB}\end{array}$ & $\begin{array}{l}4.50 \\
4.00 \\
\mathbf{9 . 0 0} \\
9.75 \\
\mathbf{5 . 2 5}\end{array}$ & $\begin{array}{l}76-1031 \text { (PB } \\
76-1034 \text { (PB } \\
76-1037 \text { (PB } \\
76-1038 \text { (PB } \\
76-1039 \text { (PB }\end{array}$ & $\begin{array}{l}4.0 \\
3.5 \\
4.0\end{array}$ \\
\hline & $\begin{array}{l}(\mathrm{PB} \\
(\mathrm{PB} \\
(\mathrm{PB} \\
(\mathrm{PB} \\
(\mathrm{PB}\end{array}$ & $\begin{array}{r}4.00 \\
3.50 \\
7.75 \\
10.00 \\
4.00\end{array}$ & $\begin{array}{ll}1 & (\mathrm{~PB} \\
3 & (\mathrm{~PB} \\
6 & (\mathrm{~PB} \\
0 & (\mathrm{PD}\end{array}$ & 5.5 \\
\hline & $\begin{array}{l}(\mathrm{PB} \\
(\mathrm{PB} \\
(\mathrm{PB} \\
(\mathrm{PB} \\
(\mathrm{PB}\end{array}$ & $\begin{array}{l}6.00 \\
4.50 \\
4.50 \\
3.50 \\
5.00\end{array}$ & $\begin{array}{ll}0 & (\mathrm{~PB} 253-1 \\
3 & (\mathrm{AD}-\mathrm{A} 02 \\
2 & (\mathrm{~PB} 258-1 \\
4 & (\mathrm{~PB} 253-1\end{array}$ & 5.5 \\
\hline & 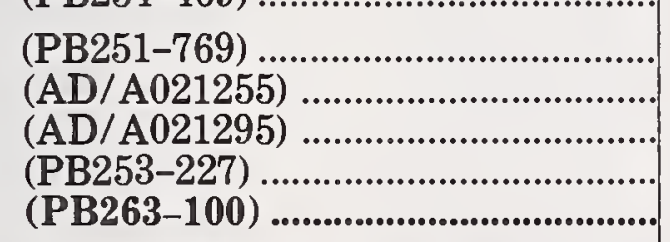 & $\begin{array}{l}3.50 \\
3.50 \\
4.50 \\
4.00 \\
\mathbf{9 . 0 0}\end{array}$ & $\begin{array}{l}58(\mathrm{~PB} 2 \\
59 \text { (PB2 } \\
00 \text { (PB2 } \\
01(\mathrm{~PB} 2\end{array}$ & 4.5 \\
\hline $\begin{array}{l}76-996 \\
76-997 \\
76-998 \\
76-999 \\
76-1000\end{array}$ & $\begin{array}{l}(\mathrm{PB} 2 \\
(\mathrm{PB} 2 \\
(\mathrm{PB} 2 \\
(\mathrm{PB} \\
(\mathrm{PB} 2\end{array}$ & $\begin{array}{l}4.00 \\
5.00 \\
3.50 \\
6.00 \\
4.50\end{array}$ & $\begin{array}{l}064 \text { (PB2 } \\
066 \text { (PB2 } \\
067 \text { (PB2 } \\
069 \text { (PB2 }\end{array}$ & $\begin{array}{l}4.0 \\
4.0\end{array}$ \\
\hline $\begin{array}{l}76-1002 \\
76-1003 \\
\mathbf{7 6 - 1 0 0 5}\end{array}$ & $\begin{array}{l}(\mathrm{PB} 2 \\
(\mathrm{PB} 2 \\
(\mathrm{PB}) \\
(\mathrm{PB} 2 \\
(\mathrm{PB} 2\end{array}$ & $\begin{array}{l}4.50 \\
3.50 \\
5.25 \\
4.50 \\
4.00\end{array}$ & $\begin{array}{l}76-1070 \text { (PB260 } \\
76-1072 \text { (PB255 } \\
76-1074 \text { (PB261 } \\
76-1075 \text { (PB274 } \\
76-1076 \text { (PB254 }\end{array}$ & $\begin{array}{l}4.0 \\
4.0 \\
4.0\end{array}$ \\
\hline $76-1010$ & (PB250-654) & 4.00 & , & \\
\hline
\end{tabular}


NBS INTERAGENCY REPORTS (Continued)

No.

76-1081 (PB256-329)

76-1082 (PB258-235)

76-1083 (PB255-803)

76-1084 (PB257-180)

76-1087 (PB257-202)

76-1088 (PB273-949)

76-1089 (PB254-475)

76-1090 (PB255-505)

76-1091 (PB257-768)

76-1092 (PB265-961)

76-1093 (PB256-318) ...

76-1094 (AD-A030-098)

76-1095 (PB255-808)

76-1096 (PB257-076)

76-1097 (PB257-141)

76-1098 (PB259-523)

76-1099 (PB258-612)

76-1100 (PB258-371)

76-1102 (PB257-729)

76-1103 (PB268-425)

76-1107 (PB258-322)

76-1108 (PB269-337)

76-1109 (PB257-194)

76-1110 (PB257-073)

76-1112 (PB259-636)

76-1113 (PB263-526)

76-1115 (PB257-196)

76-1117 (PB269-341)

76-1120 (PB257-837)...

76-1124 (PB261-846) .

76-1125 (PB273-666)

76-1126 (PB260-878)

76-1128 (PB259-199)

76-1130 (PB257-347)

76-1131 (PB259-242)

76-1132 (PB260-363)

76-1133 (PB261-228)

76-1135 (PB263-630)

76-1136 (PB261-965)

76-1137 (PB257-770)

76-1138 (PB259-522) ...

76-1140 (PB259-626)

76-1141 (AD/A031530)

76-1142 (PB263-099)

76-1143 (PB257-769)

76-1144 (PB259-243)

76-1145 (PB265-110)

76-1146 (PB269-355)

76-1147 (PB259-637)

\begin{tabular}{|c|c|c|}
\hline Price & No. & Price \\
\hline 5.00 & 76-1148 (PB264-689) & 4.50 \\
\hline $\begin{array}{l}6.75 \\
5.50\end{array}$ & 76-1149 (PB266-925) & 8.00 \\
\hline 4.00 & 76-1152 (PB265-719) & 6.50 \\
\hline 4.00 & $\begin{array}{l}76-1153 \text { (PB259-638) } \\
76-1154 \text { (PB260-400) }\end{array}$ & $\begin{array}{l}3.50 \\
7.50\end{array}$ \\
\hline 5.25 & $76-1154$ (PB260-401) & 6.00 \\
\hline $\begin{array}{l}7.75 \\
4.00\end{array}$ & 76-1159 (PB261-994) & 4.00 \\
\hline 4.00 & $76-1162$ (PB260-879) & 4.50 \\
\hline 6.00 & 76-1169 (PB273-306) & 5.25 \\
\hline 3.50 & $76-1172$ (PB261-217) & $\begin{array}{l}5.25 \\
4.00\end{array}$ \\
\hline $\begin{array}{l}6.50 \\
500\end{array}$ & 76-1174 (PB262-366) & 4.50 \\
\hline 4.50 & 76-1175 (PB276-530) & 6.00 \\
\hline 4.00 & 76-1176 (PB261-995) & 4.00 \\
\hline & $76-1177$ (PB267-829) & 4.50 \\
\hline 4.00 & 76-1178 (PB264-211) & \\
\hline $\begin{array}{l}5.50 \\
4.50\end{array}$ & 76-1179 (PB276-536) & 9.00 \\
\hline 6.75 & 76-1180 (PB265-087) & 6.00 \\
\hline 5.25 & 76-1182 (PB263-883) & 6.50 \\
\hline & 76-1184 (PB267-221) & $\begin{array}{l}4.50 \\
5.95\end{array}$ \\
\hline 4.50 & 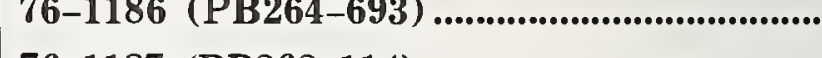 & \\
\hline $\begin{array}{l}5.25 \\
4.50\end{array}$ & 76-1187 (PB262-114) & 5.50 \\
\hline $\begin{array}{l}4.00 \\
400\end{array}$ & 76-1190 (PB264-917) & 6.00 \\
\hline $\begin{array}{l}4.00 \\
4.00\end{array}$ & 76-1191 (PB263-534). & 4.50 \\
\hline & 76-1193 (PB265-103).. & 4.00 \\
\hline 6.00 & 年 & 4.00 \\
\hline 3.50 & 77-852 (PB263-776) & 4.50 \\
\hline $\begin{array}{l}4.00 \\
3.50\end{array}$ & ......................................... & 6.00 \\
\hline 5.00 & 77-855 (PB265-075) & 4.00 \\
\hline & 77-856 (AD-A038725) .................................. & 4.50 \\
\hline 11.00 & 77-857 (PB266-944) & 4.50 \\
\hline 4.50 & 77-858 (PB272-358) & 4.00 \\
\hline 4.50 & (........................................ & 4.50 \\
\hline 7.50 & $77-860(\mathrm{~PB} 272-355) \ldots \ldots \ldots \ldots \ldots \ldots \ldots \ldots \ldots \ldots \ldots \ldots \ldots \ldots \ldots$ & 9.50 \\
\hline 4.00 & $77-861(\mathrm{PB2} 74-057) \ldots \ldots \ldots \ldots \ldots \ldots \ldots \ldots \ldots \ldots \ldots \ldots \ldots \ldots$ & 4.50 \\
\hline 5.00 & n.............................. & 5.25 \\
\hline 6.75 & 77-863 (AD-A046831) & 8.00 \\
\hline 4.50 & 77-1195 (PB263-771) & 8.00 \\
\hline 4.50 & 77-1196 (PB274-647). & 4.50 \\
\hline 5.00 & $77-1197(\mathrm{~PB} 268-081)$ & 4.00 \\
\hline 4.50 & $202($ PB276-652) & 4.00 \\
\hline 11.75 & 77-1207 (PB264-427 & 4.00 \\
\hline 4.00 & 77-1208 (PB264-286) & 6.50 \\
\hline 3.50 & 77-1209 (PB269-866).. & 4.50 \\
\hline 4.00 & $77-1210(\mathrm{~PB} 264-297)$ & 5.25 \\
\hline & 77-1212 (PB265-697) ....... & 5.25 \\
\hline 4.50 & $77-1213$ (PB265-102) & 7.25 \\
\hline 9.25 & 77-1214 (PB269-878) & 9.25 \\
\hline 4.00 & 77-1215 (PB269-534) ..................................... & 9.50 \\
\hline
\end{tabular}


NBS INTERAGENCY REPORTS (Continued)

\begin{tabular}{|c|c|c|c|}
\hline No. & Price & No. & Price \\
\hline $\begin{array}{l}77-1217(\mathrm{~PB} 264-691) \ldots \ldots \ldots \ldots \ldots \ldots \ldots \ldots \ldots \ldots \ldots \ldots \ldots \ldots \ldots \ldots \ldots \ldots \ldots \ldots \ldots \ldots \ldots \\
77-1218(\mathrm{~PB} 264-666)\end{array}$ & $\begin{array}{l}4.50 \\
6.50\end{array}$ & $\begin{array}{l}77-1265 \\
77-1270\end{array}$ & $\begin{array}{l}4.50 \\
\mathbf{5 . 2 5}\end{array}$ \\
\hline $\begin{array}{l}77-1219 \\
77-1221\end{array}$ & $\begin{array}{l}4.50 \\
5.25 \\
4.50 \\
9.00 \\
4.00\end{array}$ & 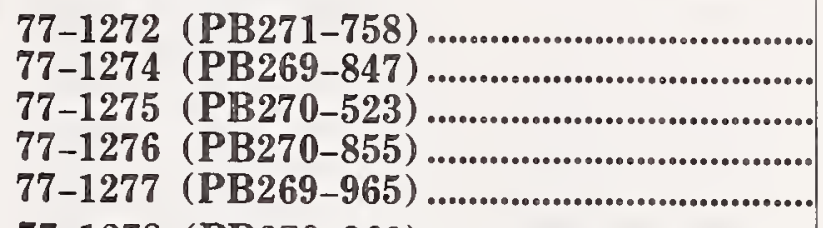 & $\begin{array}{l}8.00 \\
8.00 \\
4.50 \\
9.00 \\
4.00\end{array}$ \\
\hline $\begin{array}{l}77-1228 \\
77-1229 \\
7(\mathrm{~PB} 265-950) \\
77-1230\end{array}$ & $\begin{array}{l}4.50 \\
4.00 \\
4.50 \\
4.50 \\
5.25\end{array}$ & $\begin{array}{l}77-1278)(\mathrm{PB} 270-868) \\
77-1279 \\
\mathbf{7 7 - 1 2 8 2}\end{array}$ & $\begin{array}{l}4.50 \\
4.00 \\
4.50 \\
5.25 \\
7.25\end{array}$ \\
\hline $\begin{array}{l}77-1233 \\
77-1234\end{array}$ & $\begin{array}{l}5.25 \\
4.50 \\
4.50 \\
4.50 \\
4.50\end{array}$ & $\begin{array}{r}77-1291 \\
77-1293 \\
(\mathrm{PBB} 271-745) \\
77-1294\end{array}$ & $\begin{array}{r}5.25 \\
9.00 \\
5.25 \\
4.50 \\
10.75 \\
6.00\end{array}$ \\
\hline $\begin{array}{l}77-1239 \\
77-1240 \\
77-1243\end{array}$ & $\begin{array}{l}9.50 \\
4.00 \\
9.00 \\
5.25 \\
6.00\end{array}$ & $\begin{array}{r}77-1302 \\
7 \text { (PB275-173) } \ldots \ldots \ldots \ldots \ldots \ldots \ldots \ldots \ldots \ldots \ldots \\
77-1303 \\
77-1304 \\
77-1305\end{array}$ & $\begin{array}{l}4.50 \\
6.00 \\
4.50 \\
5.25 \\
6.50\end{array}$ \\
\hline 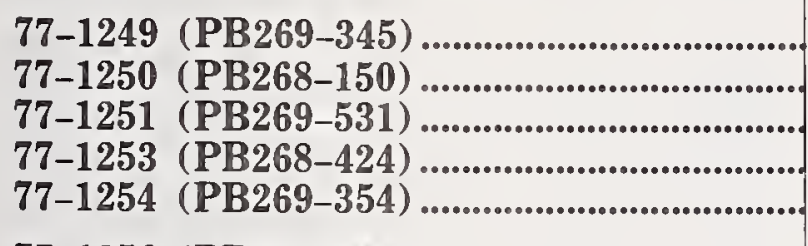 & $\begin{array}{l}6.00 \\
6.50 \\
6.50 \\
6.50 \\
5.25\end{array}$ & $\begin{array}{l}77-1308)(\mathrm{PB} 273-589) \\
77-1309 \\
77-1310\end{array}$ & $\begin{array}{l}9.00 \\
4.50 \\
4.00 \\
4.50 \\
5.25\end{array}$ \\
\hline 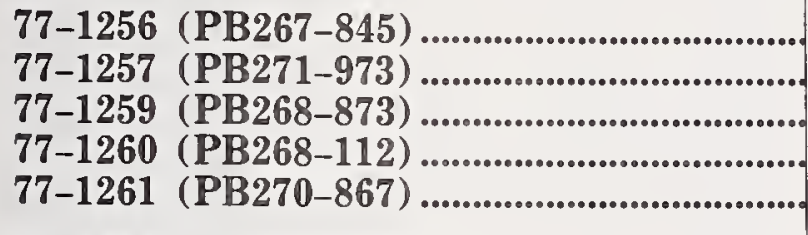 & $\begin{array}{l}4.50 \\
4.50 \\
6.50 \\
5.25 \\
5.25\end{array}$ & 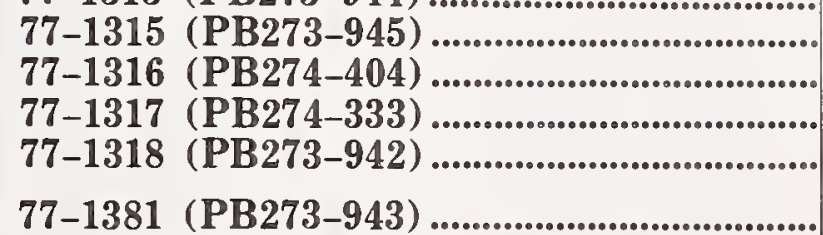 & $\begin{array}{l}4.50 \\
8.00 \\
4.50 \\
5.25 \\
4.50\end{array}$ \\
\hline $\begin{array}{l}77-1262(\text { PB269-346) } \ldots \ldots \ldots \ldots \ldots \ldots \ldots \ldots \ldots \ldots \ldots \ldots \ldots \ldots \\
77-1263 \\
77-1264\end{array}$ & $\begin{array}{l}4.50 \\
4.50 \\
7.25\end{array}$ & $\begin{array}{l}77-1390 \\
77-1394 \\
77-1396\end{array}$ & $\begin{array}{l}6.50 \\
4.00 \\
4.50\end{array}$ \\
\hline
\end{tabular}


GRANTEE/CONTRACTOR REPORTS

\begin{tabular}{|c|c|c|c|c|c|}
\hline \multicolumn{2}{|l|}{ No. } & \multirow{2}{*}{$\begin{array}{r}\text { Price } \\
4.00\end{array}$} & \multicolumn{2}{|l|}{ No. } & \multirow{2}{*}{ Price } \\
\hline-1 & (PB 192-3 & & $75-48$ & o........................... & \\
\hline-2 & & .00 & & 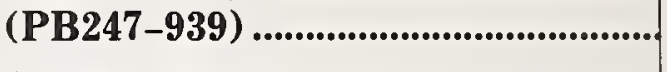 & 6.00 \\
\hline & & & $75-51$ & (PB247 & 10.0 \\
\hline & ............................... & 4.50 & & & \\
\hline & .................................... & & & ................................ & \\
\hline & o......................................... & & & . & \\
\hline $3-7$ & & 4.50 & & (....................... & 5.5 \\
\hline & .................................... & 7.75 & $76-58$ & $(\mathbf{P B}$ & \\
\hline & [.................................... & 4.00 & & ...................... & \\
\hline & ........................................ & 6.75 & & 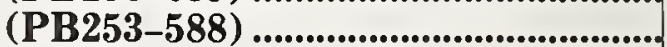 & 0. \\
\hline & .................................... & & & (........................... & \\
\hline $3-12$ & 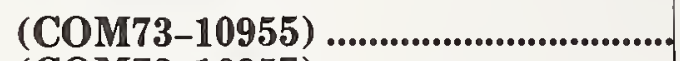 & 50 & $76-63$ & $(\mathbf{P E}$ & \\
\hline & ................................. & 5.00 & $76-64$ & (PB2 & \\
\hline & o................................. & 4.50 & & & \\
\hline & . o...................................... & 10.00 & 76 & (PB & 4.0 \\
\hline & ......................................... & 4.50 & & 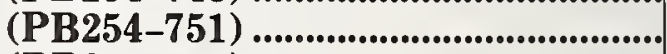 & \\
\hline-17 & ( & 6.00 & $76-72$ & (PB2 & 5. \\
\hline & .................................... & 4.00 & $76-73$ & $(\mathbf{P}$ & \\
\hline & ....................................... & 4.50 & 74 & & \\
\hline & o......................................... & 6.00 & $76-75$ & (PB2) & 4.0 \\
\hline & ...................... & 10.50 & $76-76$ & 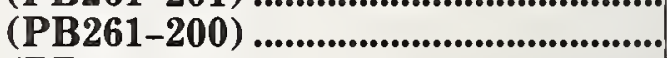 & \\
\hline $4-23$ & ( & 00 & $76-77$ & ...... & 6. \\
\hline $74-24$ & ) & 5.00 & 78 & $(\mathbb{P}$ & $6.2^{\prime}$ \\
\hline $74-25$ & 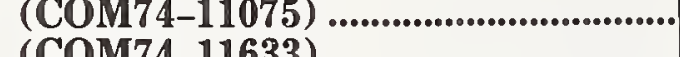 & 6.00 & 79 & . .......................... & 4.5 \\
\hline $\begin{array}{l}74-26 \\
74-27\end{array}$ & $74-11633)$ (16143) & $\begin{array}{l}5.50 \\
5.50\end{array}$ & & $\ldots$ & 5 \\
\hline-28 & & 00 & $77-83$ & $(\mathrm{~PB} 265-228)$ (P) & 6.5 \\
\hline & & 4.50 & 84 & & 6.5 \\
\hline-30 & & 4.00 & $77-85$ & (n...... & 11.7 \\
\hline $74-31 \quad-\quad$ & 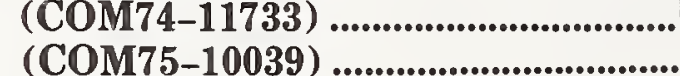 & $\begin{array}{l}3.50 \\
4.50\end{array}$ & $77-86$ & ........................................... & 9.2 \\
\hline & 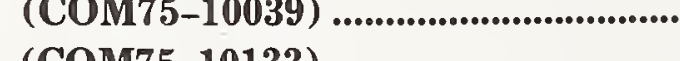 & & $77-87$ & $(\mathrm{~PB} 268-132)$............................................. & 0.4 \\
\hline $\begin{array}{l}75-33 \\
75-34\end{array}$ & o................................... & $\begin{array}{l}8.00 \\
4.50\end{array}$ & 7709 & (PB268-131) ....................... & \\
\hline $73-35$ & ............... & 5.00 & $77-89$ & (PB & 8.0 \\
\hline & (n............................ & 10.50 & $77-90$ & $(\mathbf{P B} 2$ & 9.0 \\
\hline & 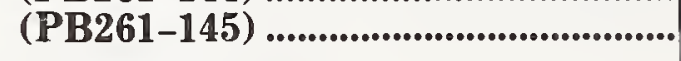 & 550 & 91 & .......................................... & 6.0 \\
\hline $75-38$ & & 500 & & & \\
\hline & & & & & \\
\hline & ) & 13.50 & $77-94$ & . & 1.7 \\
\hline & & 5.50 & & ......................................... & $\because$ \\
\hline $75-4$ & n............................. & 775 & $77-97$ & (PB272-069) ….................................... & .5 \\
\hline $75-45$ & ( & 3.50 & $\begin{array}{l}77-99 \\
77-102\end{array}$ & (PB273-165) & \\
\hline $\begin{array}{l}75-46 \\
75-47\end{array}$ & $\begin{array}{l}(\mathbf{P B} \\
(\mathbf{P B}\end{array}$ & $\begin{array}{r}7.50 \\
10.75\end{array}$ & 77-103 & (P) & \\
\hline & & & & & \\
\hline
\end{tabular}




\begin{tabular}{|c|c|c|c|}
\hline No. & Price & No. & Price \\
\hline \multirow{3}{*}{ 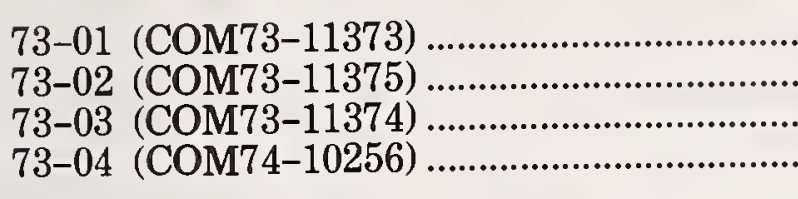 } & \multirow{3}{*}{$\begin{array}{l}6.25 \\
4.75 \\
4.25 \\
3.00\end{array}$} & 76-16 (PB256-129) & \multirow{2}{*}{$\begin{array}{l}8.00 \\
7.75\end{array}$} \\
\hline & & 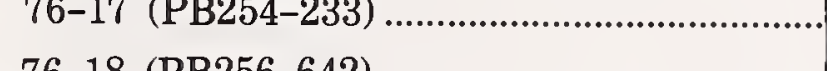 & \\
\hline & & \multirow{3}{*}{$\begin{array}{l}76-18(\mathrm{~PB} 256-642) \\
76-19(\mathrm{~PB} 256-643) \\
76-22 \\
76-23 \\
\text { (PB257-884) }\end{array}$} & \multirow{3}{*}{$\begin{array}{r}4.00 \\
4.00 \\
12.00 \\
4.00 \\
8.00\end{array}$} \\
\hline \multirow{3}{*}{ 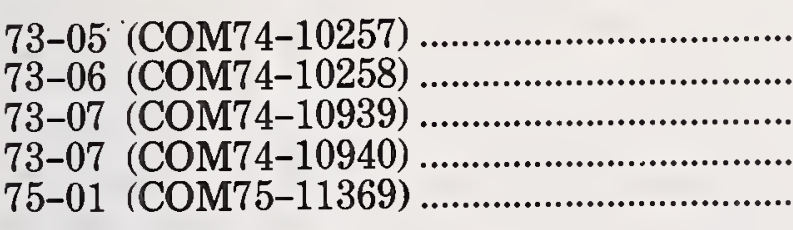 } & \multirow{3}{*}{$\begin{array}{l}4.50 \\
4.00 \\
5.00 \\
9.75 \\
5.75\end{array}$} & & \\
\hline & & & \\
\hline & & 76 & \multirow{4}{*}{$\begin{array}{l}6.00 \\
4.50 \\
4.50 \\
8.00 \\
9.25\end{array}$} \\
\hline \multirow{4}{*}{$\begin{array}{l}76-03 \\
76-04 \\
76-05 \\
76-0251-683) \\
76-06 \\
76-07\end{array}$} & \multirow{4}{*}{$\begin{array}{r}4.50 \\
10.00 \\
4.00 \\
7.50 \\
21.50\end{array}$} & 76-27 (PB260-523) & \\
\hline & & 76-28 (PB264-387). & \\
\hline & & & \\
\hline & & 76-30 (PB264-38 & \multirow{4}{*}{$\begin{array}{r}6.50 \\
9.50 \\
10.75 \\
13.00 \\
6.00\end{array}$} \\
\hline \multirow{4}{*}{ 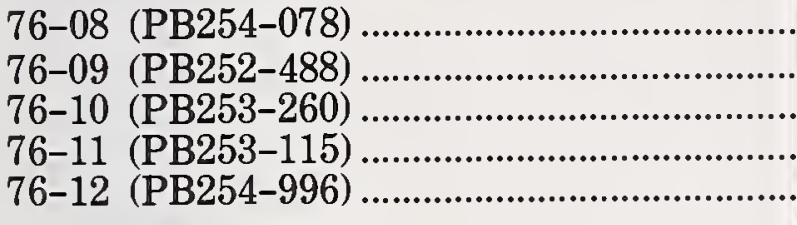 } & \multirow{4}{*}{$\begin{array}{r}4.00 \\
4.00 \\
4.00 \\
5.50 \\
11.75\end{array}$} & 2 (PB264 & \\
\hline & & 1 & \\
\hline & & & \\
\hline & & (n) & \multirow{3}{*}{$\begin{array}{r}4.50 \\
10.75 \\
6.50 \\
9.25 \\
4.50\end{array}$} \\
\hline & & $77-$ & \\
\hline & 4.00 & $77-39$ (PB273-950) & \\
\hline
\end{tabular}


Those NBS publications not listed in the Price Lists are out of print and are not available from the Superintendent of Documents. Many can be consulted at libraries. Also, in many cases, photoduplicated copies can be purchased from the Library of Congress. For full information concerning this service, write to the Photoduplication Service, Library of Congress, Washington, DC 20540.

Certain NBS publications are out of print because they have been replaced, or partially replaced, by material issued by other organizations. In this connection NBS is able to offer the following information:

Circular 410, National Standard Petroleum Oil Tables. Information in this Circular has been incorporated in the ASTM-IP petroleum Measurement Tables issued by the American Society for Testing and Materials, 1916 Race Street, Philadelphia,PA 19103. Available at $\$ 12.75,20 \%$ off to ASTM members. Tables 5 and 7 of the ASTM-IP Tables may also be purchased from the ASTM in separate reprint form at $\$ 2.25$ and $\$ 2.00$ per copy respectively.

Circular 438, Static Electricity. The National Fire Protection Association, 60 Batterymarch Street, Boston, MA 02110, has issued a publication by the same title, available from them as NFPA Publication 77, at $\$ 2.00$.

Circular 499, Nuclear Data. Replaced by Atomic and Nuclear Data Tables, published by Academic Press, 111 Fifth Avenue, New York, NY 10003. Available by subscription for $\$ 88.00$ per year.

Circular 564, Tables of Thermal Properties of Gases. A reprinted edition is available from University Microfilms, Inc., Ann Arbor, MI 48106. Order as OP 12,192 for $\$ 56.80$, Microfiche of this Circular is available from Cryogenic Data Center, National Bureau of Standards, Boulder, CO 80302.

Circular 576, Automotive Antifreezes. For information on this subject consult American National Standards Institute, 1430 Broadway, New York, NY 10018.

Circular 577 and Supplement, Energy Loss and Range of Electrons and Positrons. These have been superseded by. NASA Special Publication 3012 , available from the National Technical Information Service, Springfield, VA 22161, at $\$ 6.75$ hardcopy and $\$ 3.00$ microfiche number N65-12506.

Miscellaneous Publication 179, American Standard Building Code Requirements for Minimum Design Loads in Buildings and Other Structures. The American National Standards Institute, 1430 Broadway, New York, NY 10018, has issued a publication on this subject. Available from them as A58.1-1969-1972, at $\$ 7.50$.

Miscellaneous Publication 18\%, Directory of Commercial and College Laboratories. A new Directory of Testing Laboratories is published by the American Society for Testing and Materials, 1916 Race Street, Philadelphia, PA 19103, at $\$ 3.75$.

Miscellaneous Publication 211, American Standards Building Code Requirements for Masonry. The American National Standards Institute, 1430 Broadway, New York, NY 10018, has issued a publication on this subject. Available from them as A41.1-1953-R1970, at $\$ 4.50$.

NBS Handbook 28, Parts 1, 2, and 3, Screw Thread Standards. Responsibility for screw thread standards for Federal Government has been transferred to General Services Administration (GSA). Standards will be promulgated as Federal Standard 28 by GSA. Technical Questions should be addressed to Mr. John McGlone, Directorate of Engineering and Standardization, Defense Logistics Agency (DISC), 700 Robbins Ave., Philadelphia, PA 19111, telephone (215) 697-4349. Questions regarding administration of the program should be addressed to Mr. Grant Beattie, Standards Control and Support Division, General Services Administration (Federal Supply Service), attn: FMHS, Washington, DC 20406, telephone (703) 557-0506. Part 1 is now out-ofprint.

Handbook 30, National Electrical Safety Code (also H81 and its Supplements and H110-1). All NBS publications on this subject have been superseded by National Electrical Safety Code, 1977 Edition, issued by the American National Standards Institute, 1430 Broadway, New York, NY 10018. Available from them as ANSI C2, at $\$ 6.50$. 
Handbook 46, Code for Protection Against Lightning. A United States of America Standards Institute Code for protection Against Lightning (NFPA-78-1969) is available from the American National Standards Institute, 1430 Broadway, New York, NY 10018, at $\$ 4.25$, as C5.1-1969-1975.

Handbook 48, Control and Removal of Radioactive Contamination in Laboratories. Reprints of this Handbook can be purchased as NCRP Report 8 at $\$ 2.00$ from NCRP Publications, Post Office Box 30175, Washington, DC 20014.

Handbook 49, Recommendations for Waste Disposal of Phosphorus-32 and Iodine-131 for Medical Users. Reprints of this Handbook can be purchased as NCRP Report 9 at $\$ 2.00$ from NCRP Publications, Post Office Box 30175, Washington, DC 20014.

Handbook 53, Recommendations for the Disposal of Carbon-14 Wastes. Reprints of this Handbook can be purchased as NCRP Report 12 at $\$ 2.00$ from NCRP Publications, Post Office Box 30175, Washington, DC 20014.

Handbook 55, Protection Against Betatron-Synchrotron Radiations up to 100 Million Electron Volts. February 26, 1954 has been combined with NBS Handbook 97. Available as NCRP Report 51, Radiation Protection Design Guidelines for 0.1-100 MeV Particle Accelerator Facilities from NCRP Publications, Post Office Box 30175, Washington, DC 20014 at $\$ 5.00$.

Handbook 58, Radioactive Waste Disposal in the Ocean. Reprints of this Handbook can be purchased as NCRP Report 16 at $\$ 2.00$ from NCRP Publications, Post Office Box 30175, Washington, DC 20014.

Handbook 59, Permissible Dose from External Sources of Ionizing Radiations. Reprints of this Handbook can be purchased as NCRP Report 39 at $\$ 4.00$ per copy from NCRP Publications, Post Office Box 30175, Washington, DC 20014.

Handbook 63, Protection Against Neutron Radiation up to $30 \mathrm{MeV}$. Reprints of this Handbook can be purchased as NCRP Report 38 at $\$ 5.00$ per copy from NCRP Publications, Post Office Box 30175, Washington, DC 20014.
Handbook 65, Safe Handling of Bodies Containing Radioactive Isotopes. Reprints of this Handbook can be purchased as NCRP Report 37 at $\$ 4.00$ per copy from NCRP Publications, Post Office Box 30175, Washington, DC 20014.

Handbook 69, Maximum Permissible Body Burdens and Maximum Permissible Concentrations of Radionuclides in Air and in Water for Occupational Exposure. Reprints of this Handbook can be purchased at $\$ 3.00$ per copy from NCRP Publications, Post Office Box 30175, Washington, DC 20014.

Handbook 71, Specifications for Dry Cells and Batteries. Available as C18.1-1972 from the American National Standards Institute, 1430 Broadway, New York, NY 10018, at $\$ 6.25$.

Handbook 73, Protection Against Radiations from Sealed Gamma Sources (Supersedes H54). Reprints of this Handbook can be purchased as NCRP Report 40 at $\$ 4.00$ per copy from NCRP Publications, Post Office Box 30175, Washington, DC 20014.

Handbook 74, Building Code Requirements for Reinforced Masonry. The American National Standards Institute, 1430 Broadway, New York, NY 10018 has issued a publication on this subject. Available from them as A41.2-1960 (R1970), at $\$ 3.25$.

Handbook 75, Measurement of Absorbed Dose of Neutrons and of Mixtures of Neutrons and Gamma Rays. Reprints of this Handbook can be purchased as NCRP Report 25 at $\$ 2.00$ per copy from NCRP Publications, Post Office Box 30175, Washington, DC 20014.

Handbook 76, Medical X-ray Protection Up to Three Million Volts. Now NCRP 33 and 34 respectively. Purchase from NCRP Publications, Post Office Box 30175, Washington, DC 20014, at $\$ 3.00$ and $\$ 4.00$ respectively.

Handbook 80, A Manual of Radioactivity Procedures. Reprints of this Handbook can be purchased as NCRP Report 28 at $\$ 3.00$ per copy from NCRP Publications, Post Office Box 30175, Washington, DC 20014.

Handbook 81 and its Supplements, Safety Rules for the Installation and Maintenance of Electric 
Supply and Communication Lines (also H30 and H110-1). All NBS publications on this subject have been superseded by National Electrical Safety Code, 1977 Edition, issued by the American National Standards Institute, 1430 Broadway, New York, NY 10018. Available from them as ANSI C2, at $\$ 6.50$.

Handbook 84, Radiation Quantities and Units. Reprints of this Handbook can be purchased as ICRU Report 19 at $\$ 5.00$ per copy from ICRU Publications, Post Office Box 30165, Washington, DC 20014.

Handbook 89, Methods of Evaluating Radiological Equipment and Materials. Reprints of this Handbook can be purchased as ICRU Report 10F at $\$ 2.50$ per copy from ICRU Publications, Post Office Box 30165, Washington, DC 20014.

Handbook 96, Inspection of Processed Photographic Record Films for Aging Blemishes. Reprints of this Handbook can be purchased as $\mathrm{PH}$ $1.28-1973$ at $\$ 4.00$ per copy from the American National Standards Institute, 1430 Broadway, New York, NY 10018.

Handbook 97, Shielding for High-Energy Electron Accelerator Installations. July 1, 1964 has been combined with NBS Handbook 55. Available as NCRP Report 51, Radiation Protection Design Guidelines for 0.1-100 MeV Particle Accelerator Facilities from NCRP Publications, Post Office Box 30175, Washington, DC 20014 at $\$ 5.00$.
Handbook 102, ASTM Metric Practice Guide. Available as Z 210.1-1976 from the American National Standards Institute, 1430 Broadway, New York, NY 10018 at $\$ 4.00$.

Handbook 110-1, National Electrical Safety Code. Part 1. Rules for Installation and Maintenance of Electric Supply and Communication Lines (also H30 and H81 and its Supplements). All NBS publications on this subject have been superseded by National Electrical Safety Code, 1977 Edition, issued by the American National Standards Institute, 1430 Broadway, New York, NY 10018. Available from them as ANSI C2, at $\$ 6.50$

Technical Note 724. Properties of Selected Superconductive Materials has been superseded by an article in the Journal of Physical \& Chemical Reference Data. Vol. 5, No. 3, pp. 581-821, Reprint 84 (1976), $\$ 12.50$ from the American Chemical Society, 1155 16th St., N.W., Room 616, Washington, DC 20036.

'I'echnical Note 825. Properties of Selected Superconductive Materials has been superseded by an article in the Journal of Physical \& Chemical Reference Data. Vol. 5, No. 3, pp. 581-821, Reprint 84 (1976), $\$ 12.50$ from the American Chemical Society, 1155 16th St., N.W., Room 616, Washington, DC 20036. 


\section{TITLES AND ABSTRACTS OF NBS PUBLICATIONS, $1977^{1}$}

\subsection{PAPERS FROM THE JOURNAL OF RESEARCH OF THE NATIONAL BUREAU OF STANDARDS, SECTION A. PHYSICS AND CHEMISTRY, VOLUME 81A, JANUARY-JUNE $1977^{2}$}

\section{January-February 1977}

On the atomic weight of gallium, G. Marinenko, J. Res. Nat. Bur. Stand. (U.S.), 81A (Phys. and Chem.), No. 1, 1-4 (Jan.Feb. 1977).

Key words: atomic weight; coulometry; electrochemical equivalent; gallium arsenide; gallium atomic weight; stoichiometry.

Accurate measurement of stoichiometry of GaAs provides new data which are used for calculation of the atomic weight of Ga. Using the IUPAC accepted value for the atomic weight of As (74.9216), the atomic weight of $\mathrm{Ga}$ based on this work is $69.737 \pm 0.006$. The mean of two independent chemical values for the atomic weight of $\mathrm{Ga}$, one obtained by Lundell and Hoffman and the other in this work, is 69.735 .

Vapor pressure formulation for ice, A. Wexler, J. Res. Nat. Bur. Stand. (U.S.), $81 \mathrm{~A}$ (Phys. and Chem.), No. 1, 5-20 (Jan.Feb. 1977).

Key words: Clausius-Clapeyron equation; saturation vapor pressure over ice; thermal properties of ice; vapor pressure; vapor pressure at the triple point; vapor pressure of ice; water vapor.

A new formulation is presented for the vapor pressure of ice from the triple point to $-100{ }^{\circ} \mathrm{C}$ based on thermodynamic calculations. Use is made of the definitive experimental value of the vapor pressure of water at its triple point recently obtained by Guildner, Johnson, and Jones. A table is given of the vapor pressure as a function of temperature at 0.1 -degree intervals over the range 0 to $-100{ }^{\circ} \mathrm{C}$, together with the values of the temperature derivative at 1 -degree intervals. The formulation is compared with published experimental measurements and vapor pressure equations. It is estimated that this formulation predicts the vapor pressure of ice with an overall uncertainty that varies from 0.016 percent at the triple point to 0.50 percent at $-100{ }^{\circ} \mathrm{C}$

Standard $\mathrm{pH}$ values for the potassium hydrogen phthalate reference buffer solution from 0 to $60^{\circ} \mathrm{C}, \mathrm{H}$. B. Hetzer, R. A. Durst, R. A. Robinson, and R. G. Bates, J. Res. Nat. Bur. Stand. (U.S.), $81 \mathrm{~A}$ (Phys. and Chem.), No. 1, 21-24 (Jan.Feb. 1977).

Key words: acidity; emf; pH; phthalate buffer; potassium hydrogen phthalate; standard for $\mathrm{pH}$.

\footnotetext{
'The various NBS publications series are grouped under subheadings within this section. The several volumes of the Joumal of Research are presented consecutively within their appropriate subheadings. If a particular publications series is sought, consult the table of contents or the edge index on the back cover.

See Section 1.2.1 for information on the change of the two Section Journal of Research, A and B, to a single Section.
}

The standard $\mathrm{pH}$ values of the solution of potassium hydrogen phthalate (molality $0.05 \mathrm{~mol} \mathrm{~kg}^{-1}$ ) have been redetermined over the temperature range 0 to $60^{\circ} \mathrm{C}$, using SRM 185d. Extensive measurements were made of the emf of cells of the type

\section{$\mathrm{Pd} ; \mathrm{H}_{2}(\mathrm{~g}, 1 \mathrm{~atm}) \mid \mathrm{KH}$ phthalate $(m=0.05), \mathrm{KCl}(m) \mid \mathrm{AgCl} ; \mathrm{Ag}$}

where $m_{K C l}$ was $0.015,0.01$, or $0.005 \mathrm{~mol} \mathrm{~kg}^{-1}$, from which values of the acidity function $\mathrm{p}\left(a_{k} \gamma_{c l}\right)$ were derived. The $\mathrm{pH}$ convention defines $\gamma_{C l}$ in the range of ionic strengths 0 to 0.1 mol kg-1 and permits conventional values of $p a_{H}$ to be obtained. According to NBS procedures, $\mathrm{p} a_{H}$ for selected reference solutions is identified with the standard $\mathrm{pH}(\mathrm{S})$ in the operational definition of $\mathrm{pH}$. The new values, given in terms of the thermodynamic temperature $(T)$ by

$\mathrm{pH}(\mathrm{S})=(2073.44 / T)-13.3270+0.045199 T-3.4846 \times 10^{-5} T^{2}$

differ, on the average, by 0.003 unit from the results based on the 1944 data of Hamer and Acree.

Atlas of the $I_{2}$ spectrum from 19000 to $18000 \mathrm{~cm}^{-1}, \mathrm{~J}$. D. Simmons and J. T. Hougen, J. Res. Nat. Bur. Stand. (U.S.), 81A (Phys. and Chem.), No. 1, 25-80 (Jan. Feb. 1977).

Key words: high-resolution spectrum; iodine spectrum; line identification atlas; rovibronic assignments; spectral analysis; visible absorption spectroscopy.

A line identification band atlas is presented for a $1000 \mathrm{~cm}^{-1}$ segment, from 19000 to $18000 \mathrm{~cm}^{-1}$, of the molecular iodine absorption spectrum. Each page of the atlas covers a $20 \mathrm{~cm}^{-1}$ region of the spectrum and contains a CALCOMP produced photodensitometer trace of the spectrum together with accompanying tabular identification data. The tabular data includes: line identification numbers, observed wavenumbers, calculated wavenumbers, and rotational and vibrational assignments.

The NBS two-pressure humidity generator, Mark 2, S. Hasegawa and J. W. Little, J. Res. Nat. Bur. Stand. (U.S.), $81 \mathrm{~A}$ (Phys. and Chem.), No. 1, 81-88 (Jan.-Feb. 1977).

Key words: calibration; dew point; humidity; hygrometer; mixing ratio; relative humidity; two-pressure generator; volume ratio; water vapor.

A new humidity calibration facility which uses the two-pressure principle for generating gas of known humidity has been developed at NBS for calibrating and testing hygrometers. The relative humidity range of the two-pressure humidity generator is 3 to 98 percent for ambient temperatures -60 to $80^{\circ} \mathrm{C}$ and test chamber pressures 5 to $200 \mathrm{kPa}$ (absolute). This is equivalent to a nominal dew/frost point range of -80 to $80^{\circ} \mathrm{C}$. Intercomparison tests were made with the NBS standard gravimetric hygrometer over a portion of the generator's operating range. The estimated maximum uncertainty (three standard deviations) is 0.2 percent $R H$ for temperatures 0 to 
$80{ }^{\circ} \mathrm{C}$ which in units of dew point corresponds to an estimated maximum uncertainty of $0.04{ }^{\circ} \mathrm{C}$ for dew points -35 to $80^{\circ} \mathrm{C}$.

Humidity fixed points of binary saturated aqueous solutions, $L$. Greenspan, J. Res. Nat. Bur. Stand. (U.S.), 81A (Phys. and Chem.), No. 1, 89-96 (Jan.-Feb. 1977).

Key words: aqueous solution; equilibrium; humidity; relative humidity; salt; saturated salt solution; vapor pressure; water vapor.

An evaluated compilation of equilibrium relative humidities in air versus temperature from pure phase to approximately $10^{5}$ pascal $(1 \mathrm{~atm})$ in pressure is presented for 28 binary saturated aqueous solutions. The relative humidities of the solutions range from about 3 to 98 percent. Using a data base from 21 separate investigations comprising 1.106 individual measurements, fits were made by the method of least squares to regular polynomial equations with two through four coefficients. Equations and tables are presented along with the estimated uncertainties in the correlated results.

Frequency dependence of intrinsic stress and birefringence tensor of bead/spring model of polymer solutions, A. Peterlin and J. T. Fong, J. Res. Nat. Bur. Stand. (U.S.), $81 \mathrm{~A}$ (Phys. and Chem.), No. 1, 97-107 (Jan.-Feb. 1977).

Key words: bead-spring model; eigenvalues; frequency response; intrinsic optical tensor; intrinsic stress tensor; polymer solution.

The recently obtained complete solution of the simultaneous diagonalization of matrices $\underline{H A}$ and $\underline{\underline{H}}$ in the hydrodynamic diffusion equation has basically changed the diagonal values $\nu_{p}$ of the symmetric matrix $\stackrel{H}{=}$ of hydrodynamic interaction between all the beads of the elastic random coil model of the isolated macromolecule in solution. Since these values enter explicitly the expression for the intrinsic stress and refractive index tensor in an alternating flow field if based on the concept of internal viscosity of the model one had to recalculate all values obtained formerly by using the then generally accepted erroneous set of $\nu_{p}$ data. The new $\nu_{p}$ equal unity independent of $p$ while the old values were larger than 1 for small $p$ and smaller for large $p$. Hence their too large contributions in the former range are partially compensated by their too small contributions in the latter region. As a consequence in the whole range investigated, between 3 and 300 chain links, the differences in rheological and rheooptical effects are relatively small, up to a factor of 2, although at higher link number the differences tend to grow with the logarithm of this number.

\section{March-June 1977}

Diffusion with discontinuous swelling. III. Type II diffusion as a particular solution of the conventional diffusion equation, $\mathrm{A}$. Peterlin, J. Res. Nat. Bur. Stand. (U.S.), $81 \mathrm{~A}$ (Phys. and Chem.), Nos. 2 and 3, 243-250 (Mar.-June 1977).

Key words: concentration dependent diffusion coefficient; concentration front; discontinuous swelling; unconventional diffusion; velocity of concentration front propagation.

Very often a non-solvent diffuses into a glassy polymer with a steep concentration profile proceeding at an almost constant rate $v$ yielding a weight gain proportional to time. Such a diffusion is called type II diffusion in order to distinguish it from the more usual "Fickian" diffusion proceeding without such a constant concentration front and yielding, at least in the beginning, a weight gain proportional to the square root of time. It turns out that the conventional diffusion equation without any special new term but with a diffusion coefficient rapidly increasing with concentration has a series of solutions representing exactly such type II diffusion with $v$ as a completely free parameter which determines the steepness of concentration front. With the usual boundary conditions and infinite medium the diffusion coefficient has to become infinite at the highest penetrant concentration. This case can be considered as an extreme limit which is approached to a high degree in an actual experiment. The finite sample thickness, however, requires only a very large but not an infinite diffusion coefficient. Hence type 11 diffusion is only a special case of possible diffusion processes compatible with the conventional diffusion equation without any need for new terms if only the diffusion coefficient increases sufficiently fast with penetrant concentration.

Thermophysical measurements on 90Ti-6Al $4 \mathrm{~V}$ alloy above 1450 $\mathbf{K}$ using a transient (subsecond) technique, A. Cezairliyan, J. L. McClure, and R. Taylor, J. Res. Nat. Bur. Stand. (U.S.), 81A (Phys. and Chem.), Nos. 2 and 3, $251-255$ (Mar.-June 1977).

Key words: electrical resistivity; heat capacity; high-speed measurements; high temperatures; melting; normal spectral emittance; radiance temperature; specific heat capacity; thermal radiation properties; thermodynamics; titanium alloy.

Simultaneous measurements are described of specific heat capacity, electrical resistivity and hemispherical total emittance of the ternary allow $90 \mathrm{Ti}-6 \mathrm{Al}-4 \mathrm{~V}$ in the temperature range 1450 to $1900 \mathrm{~K}$, and the melting point and the radiance temperature at the melting point of the alloy by a subsecond duration transient technique. The results are expressed by the relations:

$$
\begin{aligned}
& c_{p}=1.3833-9.943 \times 10^{-4} \mathrm{~T}+3.745 \times 10^{-7} \mathrm{~T}^{2} \\
& \rho=152.65+1.9304 \times 10^{-2} \mathrm{~T}-3.9548 \times 10^{-6} \mathrm{~T}^{2}
\end{aligned}
$$

where $c_{p}$ is in $\mathrm{J} \cdot \mathrm{g}^{-1} \cdot \mathrm{K}^{-1}, \rho$ is in $\mu \Omega \cdot \mathrm{cm}$, and $T$ is in $\mathrm{K}$. The value of the hemispherical total emittance is 0.39 in the range 1700 to $1900 \mathrm{~K}$. The melting point and the radiance temperature at the melting point are 1943 and $1796 \mathrm{~K}$, respectively; the corresponding value for the normal spectral emittance at the melting point and at $653 \mathrm{~nm}$ is 0.395 . Estimated inaccuracies of measured properties are: 3 percent for specific heat capacity, I percent for electrical resistivity, 5 percent for hemispherical total emittance and $8 \mathrm{~K}$ for melting point and radiance temperature at the melting point.

Evaporation of a liquid droplet, R. Kayser, Jr., and H. S. Bennett, J. Res. Nat. Bur. Stand. (U.S.), 81A (Phys. and Chem.), Nos. 2 and 3, 257-266 (Mar.-June 1977).

Key words: confluent hypergeometric functions; droplet; moving boundary problem; preheat; transient heat conduction.

Two idealized models for the preheat stage of liquid droplets are analyzed theoretically. These models contain the effects of transient heat conduction and evaporation. It is assumed that the droplet surface area decreases linearly with time. This assumption necessitates the solution of moving boundary problems. These models, however, do not consider gas-phase mass transport. In the finite-gradient model, the temperatures of both the droplet and surrounding hot gases vary spatially and temporally. In the zero-gradient model the gas temperature varies spatially and temporally but the droplet temperature varies only temporally, i.e., the droplet temperature is spatially uniform. Numerical examples, which require extensive calculations of confluent hypergeometric functions, are presented for typical values of the droplet latent heat and evaporation rate constant. The temperature profiles given by the finite-gradient and zero-gradient models agree to within 20 percent of each other for all cases examined.

Isotope effects in the association reactions of methyl and ethyl iodide cations, L. W. Sieck, J. Res. Nat. Bur. Stand. (U.S.), 
81A (Phys. and Chem.), Nos. 2 and 3, 267-271 (Mar.-June 1977).

Key words: alkyl iodides; ion-molecule reactions; isotope effects; mass spectrometry; photoionization; rate constants.

Rate coefficient for production of stabilized dimeric parent cations at $295 \mathrm{~K}$ have been determined in $\mathrm{CH}_{3} \mathrm{l}, \mathrm{CD}_{3} \mathrm{I}$, $\mathrm{CH}_{3} \mathrm{I}-\mathrm{CD}_{3} \mathrm{I}$ mixtures, $\mathrm{C}_{2} \mathrm{H}_{5} \mathrm{I}, \mathrm{CH}_{3} \mathrm{CD}_{2} \mathrm{I}, \mathrm{CD}_{3} \mathrm{CH}_{2} \mathrm{I}$, and $\mathrm{C}_{2} \mathrm{D}_{5} \mathrm{I}$. These processes are the most rapid reported for association reactions, the various individual values falling within the limits $0.33 \times 10^{-24}\left(\mathrm{CH}_{3} \mathrm{I}\right)$ and $10.1 \times 10^{-24} \mathrm{~cm}^{6} \mathrm{molecule}^{-2} \mathrm{sec}^{-1}\left(\mathrm{C}_{2} \mathrm{H}_{5} \mathrm{I}\right)$. The temperature dependence of the stabilization coefficients in $\mathrm{CH}_{3} \mathrm{I}$ and $\mathrm{CD}_{3} \mathrm{I}$ was also measured over the range $220 \pm 3$ to $320 \pm 1 \mathrm{~K}$, as well as the efficiencies of other third bodies in the stabilization process. The differences observed for the variously labelled analogues are interpreted in terms of vibrational level (energy) depression upon deuteration, which affects the intrinsic lifetime of the collision complex.

Solubility of $\mathrm{Ca}_{5}\left(\mathrm{PO}_{4}\right)_{3} \mathrm{OH}$ in the systern $\mathrm{Ca}(\mathrm{OH})_{2}-\mathrm{H}_{3} \mathrm{PO}_{4}-\mathrm{H}_{2} \mathrm{O}$ at 5, 15, 25, and $37^{\circ} \mathrm{C}$, H. McDowell, T. M. Gregory, and W. E. Brown, J. Res. Nat. Bur. Stand. (U.S.), $81 \mathrm{~A}$ (Phys. and Chem.), Nos. 2 and 3, 273-281 (Mar.-June 1977).

Key words: dissolution; hydroxyapatite; ion pairs; solubility; solubility isotherms; solubility product; thermal coefficient of solubility; thermodynamics; tooth mineral.

Solubility isotherms of hydroxyapatite, $\mathrm{Ca}_{5}\left(\mathrm{PO}_{4}\right)_{3} \mathrm{OH}$ (OHAp), prepared by titrating a boiling aqueous suspension of $\mathrm{Ca}(\mathrm{OH})_{2}$ with $0.5 \mathrm{M} \mathrm{H}_{3} \mathrm{PO}_{4}$, were determined in the ternary system $\mathrm{Ca}(\mathrm{OH})_{2}-\mathrm{H}_{3} \mathrm{PO}_{4}-\mathrm{H}_{2} \mathrm{O}$ at $5,15,25$, and $37^{\circ} \mathrm{C}$ in the $\mathrm{pH}$ range 3.7-6.7 by equilibration with dilute $\mathrm{H}_{3} \mathrm{PO}_{4}$ solutions. The solubility product $K_{8}$, determined as a function of temperature by a generalized least-squares procedure from 41 experimental points, is given by the equation

$$
\log K_{s}=-8219.41 / T-1.6657-0.098215 T \text {. }
$$

The values of $K_{s}$ and its dispersion at 25 and $37{ }^{\circ} \mathrm{C}$ are 3.04 $(0.25)$ and $2.35(0.27) \times 10^{-59}$. There is a maximum in $K_{8}$ near $16^{\circ} \mathrm{C}$, which may be due to the form of temperature dependence found earlier for the stability constants of the ion pairs $\mathrm{CaH}_{2} \mathrm{PO}_{4}{ }^{+}$and $\mathrm{CaHPO}_{4}{ }^{\circ}$.

The relative positions of the isotherms show that OHAp has a negative thermal coefficient of solubility. Thermodynamic functions for the dissolution of the salt are reported

The solubility data previously reported by others for OHAp at $25{ }^{\circ} \mathrm{C}$ were reviewed. The solubility products obtained by three of these investigators were comparable with our value of $3.0 \times 10^{-59}$; their data were reevaluated by the method described here. We conclude that the best value for the solubility product at $25^{\circ} \mathrm{C}$ is $4.7(2.0) \times 10^{-59}$.

Thermodynamics of the densification process for polymer glasses, J. E. McKinney and R. Simha, J. Res. Nat. Bur. Stand. (U.S.), 81A (Phys. and Chem.), Nos. 2 and 3, 283297 (Mar.-June 1977).

Key words: compressibility; densification; glass; glass transition; liquid; polymer; pressure; PVT; pyrolysis; refractive index; thermal expansion; thermodynamic.

A quantitative description is given for the densification process of glasses resulting from glass formation at elevated pressures. Phenomenological relations are derived, or justified, which allow estimation of the densification rate $\kappa^{\prime}$ (with respect to formation pressure) from various thermodynamic quantities and glass transition behavior. In addition, the estimation of $\kappa^{\prime}$ may be facilitated by the application of the hole theory of Simha and Someynsky. Using these relations $\kappa^{\prime}$ is estimated, and the results from the different methods are compared for data from 23 different organic polymers with glass transition temperatures ranging from 150 to $455 \mathrm{~K}$. The amount of densification appears to be limited by the apparcnt convergence of the glass temperature and effective decomposition temperature with increasing pressure. Some estimates of limiting values are presented. Finally, changes of refractive index resulting from densification are estimated from the observed, or predicted, densification rates. 


\subsection{PAPERS FROM THE JOURNAL OF RESEARCH OF THE NATIONAL BUREAU OF STANDARDS, SECTION B. MATHEMATICAL SCIENCES, VOLUME 81B, JANUARY-JUNE 1977}

\section{January-June 1977}

Electromagnetism in non-Riemannian space, C. H. Page, J. Res. Nat. Bur. Stand. (U.S.), $81 \mathrm{~B}$ (Math. Sci.), Nos. 1 and 2, 1 3 (Jan.-June 1977).

Key words: anholonomic; constraint; electromagnetism; Hamilton; Maxwell; momentum; Poynting; variational.

Maxwell's equations can be interpreted as two conservation laws in a four-dimensional geometric manifold, expressed as the vanishing of a divergence and of a curl. These natural derivatives are invariant under holonomic coordinate transformations in any geometric manifold, and contain no reference to properties of the manifold such as its metric tensor and linear connection.

The relation between the $D-H$ and $E$ - $B$ fields is classically determined by the metric tensor. If a general asymmetric connection is considered, the field relations can still be derived from Hamilton's principle with the addition of an anholonomic constraint.

The basic effect of the inclusion of asymmetry (a nonvanishing torsion) is to destroy the paralleilism between the Poynting vector $\mathbf{E} \times \mathbf{H}$ and the momentum vector $\mathbf{D} \times \mathbf{B}$.

Tables of one- and two-dimensional inverse Laplace transforms of complete elliptic integrals, S. Okui, J. Res. Nat. Bur. Stand. (U.S.), $81 B$ (Math. Sci.), Nos. 1 and 2, 5-39 (Jan.-June 1977).

Key words: complete elliptic integrals; inverse Laplace transforms.

This paper gives an exrensive rabulation of one- and twodimensional inverse Laplace transforms of complete elliptic integrals.

Off-diagonal elements of normal matrices, R. Grone, J. Res. Nat. Bur. Stand. (U.S.), $81 \mathrm{~B}$ (Math. Sci.), Nos. 1 and 2, 41 44 (Jan.-June 1977).

Key words: constrained extrema of quadratic forms; numerical range.
Let $A$ be an $n \times n$ complex matrix, and let $W(A)$ denote the numerical range of $A$. In this paper, results of Parker and Mirsky are shown to be consequence of the following fact. If $A$ is normal, then the maximum value of $\{(A x, y) \mid$ as $x$ and $y$ run over all ortho-normal pairs in $C^{n}$ coincides with the radius of the smallest closed disk in $C$ which contains $W(A)$.

Laminar flow induced by a point source of heat, H. R. Baum, J. Res. Nat. Bur. Stand. (U.S.), 81 B (Math. Sci.), Nos. 1 and 2, 45-60 (Jan.-June 1977).

Key words: analysis; buoyancy; laminar flow; plume; pressure distribution; streamlines; temperature distribution.

An asymptotic description of the laminar flow pattern generated by a point source of heat is derived. Existing solutions of the boundary layer equations are shown to be valid in a limited domain where buoyancy forces are dominant. These solutions are supplemented by new results for the buoyant plume and are matched asymptotically to solutions valid everywhere outside the plume. Composite analytical formulae for the pressure, enthalpy and velocity fields are obtained and applied to the computation of the streamline pattern, pressure, and enthalpy distribution for Prandtl numbers 0.7 and 1.0.

Distant coordinates in matrix form, K. Goldberg, J. Res. Nat. Bur. Stand. (U.S.), 81 B (Math. Sci.), Nos. 1 and 2, 61-72 (Jan.-June 1977).

Key words: barycentric coordinates; distance coordinates; Euclidean plane; matrices of order three; triangle of reference.

In the Euclidean plane: given three noncolinear points (vertices of the "triangle of reference") any point is uniquely determined by its distances to those vertices. These are called the "distance coordinates" of the point. The main result of our first paper was to determine which vectors of three nonnegative numbers could be distance coordinates for the given reference triangle. In this paper we put that result, and others, into matrix form. This leads to generalizations, and to the effect of a change of the reference triangle on the distance coordinates and the formulas in which they are involved. 


\subsubsection{PAPERS FROM THE JOURNAL OF RESEARCH OF THE NATIONAL BUREAU OF STANDARDS, VOLUME 82, JULY-DECEMBER 1977}

\section{See Section 1.2.1. for information on this Journal.}

\section{July-August 1977}

Photodecomposition of chloromethanes adsorbed on silica surfaces, P. Ausloos, R. E. Rebbert, and L. Glasgow, J. Res. Nat. Bur. Stand. (U.S.), 82, No. 1, 1-8 (July-Aug. 1977).

Key words: chloromethanes, photochemistry; quantum yields; quartz; sand; surface reactions; tropospheric sink.

Irradiation of $\mathrm{CCl}_{4}, \mathrm{CFCl}_{3}$, and $\mathrm{CF}_{2} \mathrm{Cl}_{2}$ in the presence of $\mathrm{C}_{2} \mathrm{H}_{4}$ in vessels containing silica sand or fused quartz tubing results in the formation of chlorine-containing products. The formation of these compounds occurs at wavelengths extending up to approximately $400 \mathrm{~nm}$, that is, at wavelengths well beyond the absorption threshold of the chloromethanes in the gas phase. It is suggested that $\mathrm{CCl}_{4}$ adsorbed on silica surfaces photodissociates to yield $\mathrm{CCl}_{3}$ and $\mathrm{CCl}_{2}$ species. The poor material balance obtained in these experiments indicates that several of the chlorine-containing fragments are strongly adsorbed on the surface. At a $\mathrm{CCl}_{4}$ pressure of $13 \mathrm{~Pa}$ (0.1 torr), photolysis with $366 \mathrm{~nm}$ light in the presence of sand results in the decomposition of one molecule for every $10^{4}$ photons striking the surface. Under otherwise identical conditions, the photo-induced breakdown of $\mathrm{CFCl}_{3}$ and $\mathrm{CF}_{2} \mathrm{Cl}_{2}$ is respectively only 10 percent or 3 percent as efficient.

Heat capacity and thermodynamic properties of poly(vinyl chloride), S. S. Chang, J. Res. Nat. Bur. Stand. (U.S.), 82, No. 1, 9-18 (July-Aug. 1977).

Key words: calorimetry; enthalpy relaxation; glass transition; heat capacity; polymer; poly(vinyl chloride); pressure effects; thermodynamic properties.

Heat capacities, $C_{p}$, of three different samples of poly(vinyl chloride), PVC, have been determined from 6 to $375 \mathrm{~K}$ by adiabatic calorimetry. These three samples were derived from either bulk- or suspension-polymerization processes and were measured either as received or after pelleting under pressure. The heat capacities of the samples are almost identical if the thermal and pressure histories are the same. Below the glass transition temperature, $T_{g}$, of about $355 \mathrm{~K}, C_{p}$ of $\mathrm{PVC}$ was found to be exceptionally linear over a wide temperature range. $C_{p}$ of annealed PVC may be represented by $(10+0.166 T) \mathrm{J}$ $\mathrm{K}^{-1} \mathrm{~mol}^{-1}$ to within 1 percent of the measured values from 80 to $340 \mathrm{~K}$. Approximately $200 \mathrm{~J} \mathrm{~mol}^{-1}$ of energy were stored in the samples by the pelleting processes. The stored energies begin to release at about 30 to $40 \mathrm{~K}$ below the glass transition temperature. $T_{g}$ for powdery or relaxed samples occurs around 352 to $356 \mathrm{~K}$ for the suspension-polymerized PVC sample and 348 to $351 \mathrm{~K}$ for bulk-polymerized sample.

Enthalpy of solution of sodium nitrite, J. C. Cases, V. B. Parker, and M. V. Kilday, J. Res. Nat. Bur. Stand. (U.S.), 82, No. 1, 19-28 (July-Aug. 1977).

Key words: calorimetry, soln.; $\mathrm{NaNO}_{2}$, enthalpy of dilution; $\mathrm{NaNO}_{2}$, enthalpy of soln.; $\mathrm{NaNO}_{2}$, relative apparent molar heat content; $\mathrm{NaNO}_{2}$, enthalpies of transition and fusion; $\mathrm{NaNO}_{2}$, melting temperature.

An adiabatic solution calorimeter was used to measure enthalpies of solution and dilution of sodium nitrite in water in the concentration range of 5 to $200 \mathrm{mmol} \cdot \mathrm{kg}^{-1}$. For the solution reaction where molality, $m=100 \mathrm{mmol} \cdot \mathrm{kg}^{-1}, \Delta C_{p}=-$ $1.394 \pm 0.014 \mathrm{~J} \cdot \mathrm{g}^{-1} \cdot \mathrm{K}^{-1}\left(-23.0 \pm 0.2 \mathrm{cal} \cdot \mathrm{mol}^{-1} \cdot \mathrm{K}^{-1}\right)$. Other $\Delta C_{p}$ values for some dilution reactions were also measured. The value selected for the enthalpy of solution at infinite dilution is

$$
\begin{aligned}
\Delta H^{\circ}(298.15 \mathrm{~K}) & =14.006 \pm 0.015 \mathrm{~kJ} \cdot \mathrm{mol}^{-1} \\
=3.347 & \pm 0.004 \mathrm{kcal} \cdot \mathrm{mol}^{-1}
\end{aligned}
$$

Values for the relative apparent molal heat content $\phi_{L}$, are tabulated and the enthalpy of transition and of fusion derived from differential thermal analysis measurements are also given.

Establishing a scale of directional-hemispherical reflectance. Factor I: The Van den Akker Method, W. H. Venable, Jr., J. J. Hsia, and V. R. Weidner, J. Res. Nat. Bur. Stand. (U.S.), 82, No. 1, 29-55 (July-Aug. 1977).

Key words: absolute reflectance; diffuse reflectance; error analysis; reflectance; reflectance factor; spectrophotometry.

A thorough study and error analysis was made of the Van den Akker or "auxiliary sphere" method of determining a scale of directional-hemispherical reflectance factor. The effects of a non-Lambertian distribution of the reflected radiation, including retroreflection, were included in this study. Three working standards were measured to an uncertainty in reflectance of less than \pm 0.0015 and these will be used as a basis for a new, more accurate NBS scale of $6^{\circ}$-hemispherical reflectance factor. The new scale and the NBS scale established in 1965 are in agreement to within the uncertainty of \pm 0.005 assigned to the 1965 scale.

Uniaxial extension and compression in stress-strain relations of rubber, L. A. Wood, J. Res. Nat. Bur. Stand. (U.S.), 82, No. 1, 57-63 (July-Aug. 1977).

Key words: extension and compression in rubber; MartinRoth-Stiehler equation; modulus of rubber; Mooney-Rivlin equation; rubber; stress-strain relations; stress-strain relations in rubber; uniaxial extension and compression in rubber.

A survey of experimental data from the literature in cases where the deformation of a specimen is varied continuously from uniaxial compression to tensile deformation shows that Young's Modulus $M$, defined as the limit of stress to strain in the undeformed state, is independent of the direction of approach to the limit. The normalized stress-strain relation of Martin, Roth, and Stiehler (MRS, 1956) is $F / M=\left(L^{-1}-L^{-2}\right)$ $\exp A\left(L-L^{-1}\right)$ where $F$ is the stress on the undeformed section, $L$ is the extension ratio, and $M$ and $A$ are constants. Values of $M$ and $A$ are obtained from the intercept and slope of a graph of experimental observations of $\log F /\left(L^{-1}-L^{-2}\right)$ against $\left(\mathrm{L}-\mathrm{L}^{-1}\right)$ including observations of uniaxial compression if available. They found the value of $A$ to be about 0.38 for pure-gum vulcanizates of natural rubber and several synthetics.

In later work several observers have now found that the equation is also valid for vulcanizates containing a filler, but $A$ is higher, reaching a value of about 1 for large amounts of filler. In extreme cases $A$ is not constant at low deformations. 
The range of applicability in many cases now is found to extend from the compressive region where $L=0.5$ up to the point of tensile rupture or to a point where $A$ increases abruptly because of crystallization. Taking $A$ as a constant parameter in the range 0.36 to 1 , graphs are presented showing calculated values if (1) F/M as a function of $L$ and (2) the normalized Mooney-Rivlin plot of $F /\left[2 \mathrm{M}\left(\mathrm{L}-\mathrm{L}^{-2}\right)\right]$ against $\mathrm{L}^{-1}$. Each of the latter graphs has only a limited region of linearity corresponding to constant values of the Mooney-Rivlin coefficients $C_{1}$ and $\mathrm{C}_{2}$. Since this region does not include the undeformed state, where $L=1$, or any of the compression region, the utility of the Mooney-Rivlin equation is extremely limited, since it can not be used at low elongations. The coefficients are dramatically altered for rubbers showing different values of the MRS constant $A$. For rubbers showing the higher values of $\mathrm{A}$, the coefficients are radically altered and the region of approximate linearity is drastically reduced.

Minimax location problems with nonlinear costs, P. M. Dearing, J. Res. Nat. Bur. Stand. (U.S.), 82, No. 1, 65-72 (July-Aug. 1977).

Key words: facility location; location theory; minimax; networks.

Previous studies of one-facility minimax location problems are extended by permitting the cost of travel to be given by any (strictly) increasing, continuous function of travel distance. Previous solution procedures for the rectilinear distance problem in the plane and for the problem on a tree network are extended to these general cost functions.

A note on a nonlinear minimax location problem in tree networks, R. L. Francis, J. Res. Nat. Bur. Stand. (U.S.), 82, No. 1, 73-80 (July-Aug. 1977).

Key words: facility location; location theory; minimax; networks.

We present some new derivations of properties of a nonlinear version of a minimax tree network location problem. They provide necessary and sufficient conditions for optimality, a means of computing the optimum objective function value, and a means of constructing the unique optimum location.

\section{September-October 1977}

Fundamentals of building heat transfer, T. Kusuda, J. Res. Nat. Bur. Stand. (U.S.), 82, No. 2, 97-106 (Sept.-Oct. 1977).

Key words: air-leakage; dynamic heat transfer; energy analysis; heat and cooling loads; heat loss and heat gain; multiroom problems.

Basic problems and unique features of building heat transfer are described in relation to the heating and cooling load calculation, which is a starting point for building energy consumption analysis and equipment sizing. Detailed discussion is given of the relationship between heat loss (heat gain) and heating load (cooling load). Also outlined is a discussion of the multispace heat transfer problems in which the air and heat exchange equations among adjacent spaces in a building are solved simultaneously with the radiant heat exchange equations for the surfaces of each room.

Static pressure measurements of enclosure fires, B. J. McCaffrey and J. A. Rockett, J. Res. Nat. Bur. Stand. (U.S.), 82, No. 2, 107-117 (Sept.-Oct. 1977).

Key words: buoyancy pressure; enclosure fires; entrainment; fire induced flows; models; physical scale; plumes.
Some enclosure-fire static pressure measurements are presented for both full and scale model rooms and are compared with the present hydraulics-orifice flow model for fire induced flows into and out of enclosures. Results indicate that the vertical pressure differential (enclosure to ambient) follows the expected hydrostatic distribution quite well and accurately reflects the doorway inflow and outflow gas velocities.

Measurement of ceiling and floor differential pressure using different numbers of gas burners yields insight into gross plume entrainment and illustrates how the neutral plane and thermal discontinuity vary with upper gas temperature. Correlating upper gas temperature with fire size and enclosure height makes it possible to predict at what heat release rate a given enclosure might become fully involved, i.e., by using the temperature at which the thermal discontinuity approaches the floor

In terms of present fire plume modeling large entrainment coefficients (0.3-0.4) are required in order to reproduce the enclosure flows for both the small and, large scale results. A noted deficiency in the plume model appears in the small scale results where the data suggest that the entrainment should exhibit a much stronger dependence on the fuel injection rate than that predicted by the theory.

Melting point, normal spectral emittance (at the melting point), and electrical resistivity (above $1900 \mathrm{~K}$ ) of titanium by a pulse heating method, A. Cezairliyan and A. P. Miiller, J. Res. Nat. Bur. Stand. (U.S.), 82, No. 2, 119-122 (Sept.-Oct. 1977).

Key words: electrical resistivity; emittance; high-speed measurement; high temperature; melting point; radiance temperature; titanium.

A subsecond duration pulse heating method was used to measure the melting point, the normal spectral emittance (at the melting point), and the electrical resistivity (above $1900 \mathrm{~K}$ ) of $99.9+$ percent pure titanium. The results, based on the International Practical Temperature Scale of 1968 , yield a value of $1945 \mathrm{~K}$ for the melting point. The normal spectral emittance (at $653 \mathrm{~nm}$ ) at the melting point is 0.40 . Estimated inaccuracies are: $5 \mathbb{K}$ in the melting point, 5 percent in the normal spectral emittance, and 3 percent in the electrical resistivity.

A method for the numerical evaluation of the second virial coefficient for polyatomic molecules, P. M. Holland, J. F. Ely, H. J. M. Hanley, J. Res. Nat. Bur. Stand. (U.S.), 82, No. 2, $123-$ 127 (Sept.-Oct. 1977).

Key words: dipolar gas; numerical in tegration; polyatomic molecule; Pople expansion; quadrupolar gas; second virial coefficient.

A numerical integration procedure to calculate the second virial coefficient polyatomic molecules is proposed. The intermolecular pair potential is assumed to be a sum of a spherically symmetric contribution and an unsymmetric, angular dependent, contribution. The method is based on evaluating the possible different numerical values for this latter term. Quadrupolar and dipolar molecules are considered. Calculations for the virial coefficient for quadrupolar molecules are judged to be correct to within one part in 2500 or better, and to within one part in 300 or better for polar molecules. Results from the method are compared to corresponding results from the wellknown Pople expansion procedure. It is shown that care must be taken to ensure this latter technique yields a convergent answer.

Minimum polynomials and control in linear systems, J. Z. Hearon, J. Res. Nat. Bur. Stand. (U.S.), 82, No. 2, 129-132 (Sept.-Oct. 1977).

Key words: control theory; linear algebra; matrix; minimum polynomials. 
Given the constant coefficient system $x=A x+B \mu$, relationships are established among the minimum polynomial (with respect to $A$ ) of the range of $B$, the degree and null space of this polynomial, the rank of the controllability matrix and the degrce of the minimum polynomial of $A$. These relations lead to a simple proof of a theorem on reduction of control.

Eigenset generalizations of the eigenvalue concept, $C$. R. Johnson, J. Res. Nat. Bur. Stand. (U.S.), 82, No. 2, 133-136 (Sept.-Oct. 1977).

Key words: bound set; convex hull; eigenvalue-eigenvector equation; root of unity.

For an $n-b y-n$ complex matrix $A$ some generalizations of the cigenvalue-eigenvector cquation

$$
A x=\lambda x, 0 \neq x \in C^{n}
$$

are investigated. These take the form

$$
A S=\lambda S \text { or } A S \subseteq \lambda S
$$

where $S$ is a subset of $C^{n}$ about which various assumptions are made. For cxample, it is shown that there exists a finite set $S$ $\subset C^{n}$, the sum of whose elements is not 0 , such that $A S=\lambda$ $S$, if and only if $\lambda$ is an eigenvalue of $A$ in the usual sense. The requirement that the sum of the elements of $S$ is not 0 should bc viewed as a natural analog of the requirement $x \neq 0$ in the classical eigenvalue-eigenvector cquation.

\section{November-December 1977}

Phase equilibria and crystal chemistry of rubidium niobates and rubidium tantalates, D. B. Minor, R. S. Roth, H. S. Parker, and W. S. Brower, J. Res. Nat. Bur. Stand. (U.S.), 82, No. 3, $151-165$ (Nov.-Dec. 1977).

Key words: crystal chemistry; ionic conductivity; nonstoichiometry; phase equilibria; rubidium niobate; rubidium tantalate.

The phasc equilibria relations and crystal chemistry of portions of the $\mathrm{Rb}_{2} \mathrm{O}-\mathrm{Nb}_{2}^{-} \mathrm{O}_{5}$ and $\mathrm{Rb}_{2} \mathrm{O}-\mathrm{Ta}_{2} \mathrm{O}_{5}$ systems were investigated for structures potentially useful as ionic conductors. A hexagonal tungsten bronze-type (HTB) structure was found in both systems as well as three hexagonal phases with mixed HTB-pyrochlore type structures. lon exchange experiments between various alkali ions are described for several phases. Unit cell dimensions and $\mathrm{x}$-ray diffraction powder patterns are reported.

Investigation of calcium aluminate cement phases under high gaseous pressure, J. L. Waring, R. S. Roth, W. S. Brower, and C. A. Harding, J. Res. Nat. Bur. Stand. (U.S.), 82, No. 3, 167-172 (Nov.-Dec. 1977).

Key words: alumina cements; $\mathrm{CaO} \cdot \mathrm{Al}_{2} \mathrm{O}_{3} \cdot \mathrm{H}_{2} \mathrm{O}$; coal gasification; refractory cements.

The chemical degradation of refractory cement castable liners is important in the coal gasification process. The system $\mathrm{CaO}-\mathrm{Al}_{2} \mathrm{O}_{3}-\mathrm{H}_{2} \mathrm{O}$ has been investigated at high temperature and pressure. A pseudobinary reaction diagram was constructed for the system $\mathrm{CaO}-\mathrm{Al}_{2} \mathrm{O}_{3}-\mathrm{H}_{2} \mathrm{O}$ in steam at 1000 psig. Several experiments were conducted in the $\mathrm{CaO}-\mathrm{Al}_{2} \mathrm{O}_{3}-\mathrm{H}_{2} \mathrm{O}$ system in $\mathrm{CO}_{2}, \mathrm{CH}_{4}$, and $\mathrm{CO}$.

Stimulated multiphoton bremsistrahlung in electron-ion collisions, S. Geltman, J. Res. Nat. Bur. Stand. (U.S.), 82, No. 3, 173 179 (Nov.-Dec. 1977).
Key words: bremsstrahlung; electron-ion collisions; freefree transitions; multiphoton processes; plasma absorption.

A review is presented of the basic classical mechanism whereby an electron can absorb energy from an-elcctromagnetic field while undergoing a collision with an atom or ion. The process is also described for a quantum mechanical collision and the absorption or emission of photons. The appropriate formulations are described for weak and strong applied fields. A brief review is given for the resulting plasma absorption coefficients.

Transport coefficients in the one-fluid approximation, H. J. M. Hanley, J. Res. Nat. Bur. Stand. (U.S.), 82, No. 3, 181-182 (Nov.-Dec. 1977).

Key words: critical point; mixture; one-fluid theory; plait point; thermal conductivity coefficient; viscosity coefficient.

Some comments of the justification of writing the viscosity and thermal conductivity coefficients of a mixture in the onefluid approximation are presented. Anomalous behavior in the critical region is discussed.

Mathematical models of the transient heat flow to fuel droplets, H. S. Bennett and R. Kayser, Jr., J. Res. Nat. Bur. Stand. (U.S.), 82, No. 3, 183-195 (Nov.-Dec. 1977).

Key words: combustion; emulsified fuel droplet; fuel droplet; heat flow; micro-explosion; preheat.

Two models for the preheat stage of conventional liquid fuel droplets and of emulsified fuel droplets in combustion gases are analyzed theoretically. These models contain the effects of transient heat conduction to the droplets. In the first model, the droplet and gas temperatures vary temporally but only the gas temperature varies spatially; i.e., the droplet temperature is spatially uniform. Numerical examples, computed from this model, for both the droplet and gas temperatures are given. In the second model, both the droplet and gas temperatures vary spatially and temporally. Numerical examples computed from this second model for the surface and average temperature of the droplet are given. These analyses show that the temperature gradients inside droplets of oil and water are small compared to those in the combustion gases near the droplet; that temperature profiles given by both models are very similar. In particular, the predicted times at which micro-explosions are expected to occur agree within 10 percent of each other.

Enclaveless sets and MK-Systems, P. J. Slater, J. Res. Nat. Bur. Stand. (U.S.), 82, No. 3, 197-202 (Nov.-Dec. 1977).

Key words: dominating set; enclaveless set; graph; hypergraph; König System; KM-System; Menger System; MKSystem.

A hypergraph $H=(X, \mathscr{E})$ is called a Mcnger System if the maximum cardinality of a family of pairwise disjoint edges $\left(\nu_{1}(H)\right)$ is equal to the minimum cardinality of a subset of vertices which meets every edge $\left(\tau_{0}(H)\right)$. A set $S \subseteq X$ is defined to be enclaveless if each vertex in $S$ is adjacent to at least one vertex in $X-S$. A parameter $\pi_{0}$ related to the formation of maximal enclaveless sets is defined, and it is shown that if $\boldsymbol{H}$ has no singleton edges then $\nu_{1}(H) \leqslant \pi_{0}(H)$. MK-Systems are defined to be those hypergraphs $H$ without singleton edges for which $\nu_{1}(H)=\pi_{0}(H)$; simple graphs which are Menger Systems are shown also to be MK-Systems. 


\subsection{PAPERS FROM THE JOURNAL OF PHYSICAL AND CHEMICAL REFERENCE DATA, VOLUME 6, JANUARY-DECEMBER 1977}

This journal is published quarterly by the American Chemical Society and the American Institute of Physics for the National Bureau of Standards. The objective of the Journal is to provide critically evaluated physical and chemical property data, fully documented as to the original sources and the criteria used for evaluation. Critical reviews of measurement techniques, whose aim is to assess the accuracy of available data in a given technical area, are also included. The principal source for the Journal is the National Standard Reference Data System (NSRDS). The Journal is not intended as a publication outlet for original experimental measurements such as are normally reported in the primary research literature, nor for review articles of a descriptive or primarily theoretical nature.

\section{Volume 6, No. 1}

Diffusion in copper and copper alloys. Part V. Diffusion in systems involving elements of group VA, D. B. Butrymowicz, J. R. Manning, and M. E. Read, J. Phys. Chem. Ref. Data 6, No. 1, 1-50 (1977).

Key words: alloys; antimony; arsenic; bismuth; copper; diffusion; electromigration; liquid metals; nitrogen; phosphorus; ternary diffusion; thermomigration.

A survey, comparison, and critical analysis is presented of data compiled from the scientific literature concerning diffusion in copper alloy systems involving elements in Group VA (As, $\mathrm{Bi}, \mathrm{N}, \mathrm{P}, \mathrm{Sb}$ ). Here the term "copper alloy system" is interpreted in the broadest sense. For example, the review of diffusion in the $\mathrm{Cu}-\mathrm{M}$ system reports all diffusion situations which involve both copper and element $\mathrm{M}$, including diffusion of $\mathrm{Cu}$ in $\mathrm{M}$ or in any binary, ternary, or multicomponent alloy containing $\mathrm{M}$; diffusion of $\mathrm{M}$ in $\mathrm{Cu}$ or in any alloy containing $\mathrm{Cu}$; and diffusion of any element in any alloy containing both $\mathrm{Cu}$ and $\mathbf{M}$. Topics include volume diffusion, grain boundary diffusion, tracer diffusion, alloy interdiffusion, electromigration, thermomigration, strain-enhanced diffusion and diffusion in molten metals. An extensive bibliography is presented along with figures, tabular presentation of data, and discussion of results.

The calcullated thermodynamic properties of superfluid helium4, J. S. Brooks and R. J. Donnelly, J. Phys. Chem. Ref. Data 6, No. 1, 51-104 (1977).

Key words: computed thermodynamic properties; entropy; equation of state; excitation spectrum; helium-4; normal fluid helium-4; phonons; protons; specific heat; superfluid helium-4.

Comprehensive tables of the primary thermodynamic properties of superfluid helium- 4 , such as the specific heat and entropy, are presented as computed from the Landau quasiparticle model, with the aid of inelastic neutron scattering data. The neutron data are represented by continuous functions of temperature, pressure, and wave number and certain excitation properties such as number density, normal and superfluid densities are calculated directly from it. A discussion of the methods used in our computations is included, and comparisons of computed and experimental results are made where applicable. Certain inadequacies of present theoretical methods to describe the thermodynamic properties are reported, and the use of an effective spectrum is introduced to offset some of the difficulties.
Considerable experimental effort is also needed to improve the present situation.

Thermodynamic properties of normal and deuterated methanols, S. S. Chen, R. C. Wilhoit, and B. J. Zwolinski, J. Phys. Chem. Ref. Data 6, No. 1, 105-112 (1977).

Key words: enthalpy of formation; Gibbs energy of formation; ideal gas thermodynamic properties; intermolecular association; normal and deuterated methanols; potential barrier to internal rotation; principal and reduced moments of inertia; structural parameters; vibrational fundamentals; virial coefficients of the equation of state.

Structural and spectroscopic data on $\mathrm{CH}_{3} \mathrm{OH}, \mathrm{CH}_{3} \mathrm{OD}$, $\mathrm{CD}_{3} \mathrm{OH}$, and $\mathrm{CD}_{3} \mathrm{OD}$ were reviewed. The selected values were utilized to calculate the ideal gas thermodynamic properties in the temperature range of 0 to $1500 \mathrm{~K}$, using the rigid-rotor and harmonic-oscillator model. Experimental data for the standard enthalpy of formation at $298.15 \mathrm{~K}$, the heat capacities, and the third-law entropies at elevated temperatures are available only for $\mathrm{CH}_{3} \mathrm{OH}$ in the vapor phase where intermolecular association occurs. The agreement between the observed thermal data and our calculated values is satisfactory within the experimental uncertainties. Finally, the standard chemical thermodynamic values for $\Delta H f^{\circ}, \Delta G f^{\circ}$, and $\log K f$ were generated in the temperature range of 0 to $1500 \mathrm{~K}$.

The spectrum of molecular nitrogen, A. Lofthus and P. H. Krupenie, J. Phys. Chem. Ref. Data 6, No. 1, 113-307 (1977).

Key words: critical review; Franck-Condon integrals; molecular constants; molecular nitrogen; potential energy curves; radiative lifetimes.

This is a critical review and compilation of the observed and predicted spectroscopic data on the molecule $\mathrm{N}_{2}$ and its ions $\mathrm{N}_{2}{ }^{-}, \mathrm{N}_{2}{ }^{+}, \mathrm{N}_{2}{ }^{2+}$, and the molecule $\mathrm{N}_{3}$. Each electronic band system is discussed in detail, and tables of band origins and heads are given. In addition to the gas phase electronic, electron and Raman spectra, there are also examined the spectra of condensed molecular nitrogen as well as the pressure- and field-induced infrared and microwave absorption. Dissociation energy of $\mathrm{N}_{2}$, predissociations, and perturbations are discussed. Potential energy curves are given, as well as radiative lifetimes, $f$-values, and Franck-Condon integrals. Molecular constants are listed for the known electronic states. Electronic structure and theoretical calculations are reviewed.

\section{Volume 6, No. 2}

Energy levels of chromium, $\mathrm{Cr}, \mathrm{through} \mathrm{Cr}$ xxIv, J. Sugar and C. Corliss, J. Phys. Chem. Ref. Data 6, No. 2, 317-384 (1977).

Key words: atomic energy levels; atomic spectra; chromium.

The energy levels of the chromium atom in all of its stages of ionization, as derived from the analyses of atomic spectra, have been completed. In cases where only line classifications are given in the, literature, level values have been derived. The percentages for the two leading components of the calculated eigenvectors of the levels are given where available. Ionization energies and $g$-factors are also given. 
The activity and osmotic coefficients of aqueous calcium chloride at 298.15 K, B. R. Staples and R. L. Nuttall, J. Phys. Chem. Ref. Data 6, No. 2, 385-408 (1977).

Key words: activity coefficient; calcium chloride; critical evaluation; electrolyte; excess free energy; osmotic coefficient; solutions; thermodynamic properties.

A critical evaluation of the mean activity, $\gamma_{ \pm}$, and osmotic coefficients, $\phi$, of aqueous calcium chloride at $298.15 \mathrm{~K}$ is presented for the concentration range of 0 to $10 \mathrm{~mol} \cdot \mathrm{kg}^{-1}$. Osmotic coefficients were calculated from direct vapor pressure measurements, from isopiestic measurements or from freezing point depression measurements. Activity coefficients were calculated from electro-motive force measurements of galvanic cells, both without liquid-junction and with transference, and from diffusion data. A nonlinear least-squares program was used to fit data from all sources using both $\phi$ and $\ln \gamma_{ \pm}$, as a function of molality. An eight-parameter extended DebyeHuckel equation describes the osmotic coefficient, the mean activity coefficient, and the excess free energy as a function of molality. The scientific literature has been covered through July, 1976.

Molten salts: Volume 4, part 3. Bromides and mixtures; iodides and mixtures. Electrical conductance, density, viscosity, and surface tension data, G. J. Janz, R. P. T. Tomkins, C. B. Allen, J. R. Downey, Jr., and S. K. Singer, J. Phys. Chem. Ref. Data 6, No. 2, $409-596$ (1977).

Key words: bromides; data compilation; density; electrical conductance; iodides; molten salt mixtures; standard reference data; surface tension; viscosity.

Data on the electrical conductance, density, viscosity, and surface tension of bromide mixtures and iodide mixtures have been systematically collected and evaluated. Results are given for eighty-five binary mixtures over a range of compositions and temperatures. Values of the above properties for twentythree single bromide and iodide salts are also given.

The viscosity and thermal conductivity coefficients for dense gaseous and liquid methane, H. J. M. Hanley, W. M. Haynes, and R. D. McCarty, J. Phys. Chem. Ref. Data 6, No. 2, $597-$ 610 (1977).

Key words: correlation; critical point anomaly; methane; tables; thermal conductivity coefficient; viscosity coefficient.

Data for the viscosity and thermal conductivity coefficients of dense gaseous and liquid methane have been evaluated. Selected data were fitted to a function derived in our previous work and tables of values were generated for temperatures from 95 to $500 \mathrm{~K}$ and for pressures up to $50 \mathrm{MPa}$ ( $\sim 500 \mathrm{~atm}$ ). The uncertainties of the tabular values are estimated to be approximately 3 and 5 percent for the viscosity and thermal conductivity coefficients, respectively. The contribution for the thermal conductivity enhancement in the critical region is included in the tables. Care has been taken to ensure that the calculated values are consistent with reliable equation-of-state data and also with dilute gas transport coefficients determined previously.

\section{Volume 6, No. 3}

Phase diagrams and thermodynamic properties of ternary copper-silver systems, Y. A. Chang, D. Goldberg, and J. P. Neumann, J. Phys. Chem. Ref. Data 6, No. 3, 621-674 (1977).

Key words: critically evaluated data; phase diagrams; ternary copper-silver alloy systems; thermodynamic properties.
Phase diagram and thermodynamic data for twenty ternary copper-silver-X alloy systems-where $\mathrm{X}$ represents $\mathrm{Al}, \mathrm{Au}, \mathrm{Cd}$, $\mathrm{Fe}, \mathrm{Ge}, \mathrm{In}, \mathrm{Mg}, \mathrm{Mn}, \mathrm{Ni}, \mathrm{P}, \mathrm{Pb}, \mathrm{Pd}, \mathrm{Re}, \mathrm{S}, \mathrm{Sb}, \mathrm{Se}, \mathrm{Sn}, \mathrm{Te}, \mathrm{Ti}$ or $\mathrm{Zn}$-were compiled and critically evaluated. Of the twenty ternary systems, thermodynamic data are available for only the seven systems containing $\mathrm{Au}, \mathrm{Pb}, \mathrm{Pd}, \mathrm{S}, \mathrm{Sn}, \mathrm{Te}$ and $\mathrm{Zn}$. The high-temperature phase relationships in the iron-rich region of the $\mathrm{Cu}-\mathrm{Fe}$ binary system were also evaluated and a recommended phase diagram is presented.

Crystal data space-group tables, A. D. Mighell, H. M. Ondik, and B. B. Molino, J. Phys. Chem. Ref. Data 6, No. 3, $675-$ 830 (1977).

Key words: crystal; isostructural materials; lattice; point group; polymorphism; space group; symmetry.

Crystal Data Space-Group Tables lists over 17,000 materials whose space groups and symmetry have been determined mainly by $x$-ray diffraction. These tables comprise a companion publication to Crystal Data Determinative Tables. The space groups are listed in the same order and orientation as in International Tables for X-Ray Crystallography. Within each space group, the materials are arranged in increasing order of the ratios of the cell parameters. The space-group tables enable the user to find crystals of any specified symmetry, to locate isostructural molecules, and to compare the population frequencies of the various space groups.

Energy levels of one electron atoms, G. W. Erickson, J. Phys. Chem. Ref. Data 6, No. 3, $831-870$ (1977).

Key words: atomic structure; electron structure; energy levels; fine structure; hydrogenic atoms; Lamb shift; level shifts; quantum electrodynamics; radiative corrections; relativistic corrections.

The table of precise one-electron atomic energy levels given by Garcia and Mack in 1965 is expanded to include all atomic numbers and more energy levels, updated by using more recent values of fundamental constants and radiative corrections, and extended to the maximum precision allowed by quantum electrodynamics (QED) calculations. All levels with $n \leqslant 11$ are given for $Z \leqslant 15$, with $n \leqslant 5$ for $Z \leqslant 39$, and with $n \leqslant 3$ for $Z$ $\leqslant 1 \overline{0}$. In addition, the $\bar{S}_{1 / 2}$ and $\bar{P}_{1 / 2}$ and $j \leqslant n-1 / 2$ levels with $n$ $\leqslant 20$ are given for $Z \leqslant 15$, and with $n \leqslant 13$ for $Z \leqslant 39$. The uncertainty in the QED calculations is given for each level, and the level is given to that precision. Conversions to different units and corrections for changing the Rydberg or nuclear mass values are pointed out. The paper includes a comprehensive listing and brief discussions of all effects considered and of the uncertainties for the calculated and neglected terms. The Fine Structure Interval (difference between the $j=l \pm 1 / 2$ levels for given $n$ and $l$ ) and its reduced mass and QED contributions are discussed in detail. All known measurements of Lamb shifts and other fine structure differences are compared with calculated values.

Rate constants for reactions of $\mathbf{C l O}_{x}$ of atmospheric interest, $\mathrm{R}$. T. Watson, J. Phys. Chem. Ref. Data 6, No. 3, 871-918 (1977).

Key words: absorption spectra; chemical kinetics; chlorine; chlorine oxides; chlorocarbon; chlorofluorocarbon; data compilation and evaluation; nitrosyl chloride; rate constant.

Chemical kinetics measurements on 82 gas phase reactions of chlorine containing species are reviewed. Recommended rate constants are given. The principal species of interest are $\mathrm{Cl}$, $\mathrm{Cl}_{2}, \mathrm{ClO}, \mathrm{Cl}_{2} \mathrm{O}, \mathrm{ClOO}, \mathrm{OClO}, \mathrm{ClNO}, \mathrm{HCl}$ and halo derivatives of methane and ethane. Absorption spectra are given for 21 species. In addition the chemical kinetics methods used to ob- 
tain thcse data are discussed with regard to their applicability and reliability.

NMR spectral data: A compilation of aromatic proton chemical shifts in mono- and di-substituted benzenes, B. L. Shapiro and L. E. Mohrmann, J. Phys. Chem. Ref. Data 6, No. 3, 919. 992 (1977).

Key words: aromatic proton chemical shifts; mono- and disubstituted benzenes; NMR spectral data.

NMR chemical shifts for protons directly attached to monoand di-substituted benzenes are conpiled from the literature. Data for $1053 \mathrm{~s}$ ' s of data are presented. The data have been examined for reliability using criteria which include high spectral quality, rigorous experimental technique, and sufficient description to assure correct interpretation of results. The data, presented in tabular form, include compound name and formula, solvent employed, concentration, temperature, chemical shift, and observation frequency. Other NMR-related data are not given. An author index is included. The data and references cover the literature to June 1976.

Tables of molecular vibrational frequencies-Consolidated Volume II, T. Shimanouchi, J. Phys. Chem. Ref. Data 6, No. 3, 993-1102 (1977).

Key words: fundamental frequencies; infrared spectra; polyatomic molecules; Raman spectra; vibrational frequencies.

The compilations of fundamental vibrational frequencies of molecules previously published as Tables of Molecular Vibrational Frequencies Part 5, Part 6, Part 7, and Part 8, which appeared in the Journal of Physical and Chemical Reference Data in 1972, 1973, and 1974, have been revised. This Consolidated Volume II includes data on a total of 212 molecules in addition to those on 223 molecules included in Volume I (NSRDS-NBS 39 ). Selected values of the fundamental vibrational frequencies are given for each molecule, together with observed infrared and Raman spectral data and citations to the original literature. The selection of vibrational fundamentals has been based on careful studies of the spectral data and comprehensive normalcoordinate analyses. An estimate of the accuracy of the selected values is included. The tables provide a convenient source of information for those who require vibrational energy levels and related properties in molecular spectroscopy, thermodynamics, analytical chemistry, and other field of physics and chemistry.

\section{Volume 6, No. 4}

Effects of isotopic composition, temperature, pressure, and dissolved gases on the density of liquid water, G. S. Kell, J. Phys. Chem. Ref. Data 6, No. 4, $1109-1132$ (1977).

Key words: aqueous solutions of gases; compressibility; equation of state; heavy water; isotopic waters; partial molar volume of aqueous gases; PVT; thermal expansivity; water.

A review is made of measurements of the effect of temperature, pressure, isotopic composition, and dissolved atmospheric gases on the density of liquid water at temperatures to $100{ }^{\circ} \mathrm{C}$. The molar volume is expanded as a multiple power series in the variables, and the coefficients determined. A number of gaps become evident in our knowledge of properties that are within the capacity of current measurements. For example, there appears to be no measurement of the effect of oxygen isotopes on the compressibility. Data on the thermal expansion of $\mathrm{D}_{2} \mathrm{O}$ are strikingly inconsistent. The partial molar volumes of dissolved gases are only sketchily known. At $0{ }^{\circ} \mathrm{C}$, equilibration with the oxygen, nitrogen, and argon of the atmosphere lowers the density about 3 p.p.m., while atmospheric carbon dioxide raises it about 0.3 p.p.m. Appendix 1 discusses the care needed to obtain various degrees of precision in practical density measurements, and the effect of isotopic uncertainties on them. Appendix II treats the representation of the equation of state of water at slightly higher pressures.

Viscosity of water substance-new International Formulation and its background, A. Nagashima, J. Phys. Chem. Ref. Data 6, No. 4, $1133-1166$ (1977).

Key words: critically evaluated data; International Formulation; steam; viscosity of water and steam; water.

The paper traces the development of our knowledge of the viscosity of water and steam over the last decade, that is over the period of intense experimental and analytic activity which separates the promulgation of the 1964 Supplementary Release on Transport Properties of the Sixth ICPS from the recently announced Release on Dynamic Viscosity of Water Substance. As a result of this work, which was largely stimulated by the activities of the International Association for the Properties of Steam, the new internationally recognized skeleton table and the internationally recommended interpolation equations cover the wide range of pressures and temperatures of $0-100 \mathrm{MPa}$ and $0-800^{\circ} \mathrm{C}$.

A correlation of the existing viscosity and thermal conductivity data of gaseous and liquid ethane, H. J. M. Hanley, K. E. Gubbins, and S. Murad, J. Phys. Chem. Ref. Data 6, No. 4, 1167-1180 (1977).

Key words: critical point enhancement; data evaluation; ethane; thermal conductivity coefficient; viscosity coefficient.

Data for the viscosity and thermal conductivity coefficients of ethane have been evaluated and represented by an empirical function. Tables of values have been prepared for the range $200-500 \mathrm{~K}$, for pressure to $75 \mathrm{MPa}(\approx 750 \mathrm{~atm})$. The tables include an estimate of the anomalous contribution to the thermal conductivity in the neighborhood of the critical point. The estimated uncertainties of the tabular values are \pm 5 percent and \pm 8 percent for the viscosity and thermal conductivity coefficient, respectively.

Elastic properties of zinc: A compilation and a review, H. M. Ledbetter, J. Phys. Chem. Ref. Data 6, No. 4, 1181-1204 (1977).

Key words: bulk modulus; compressibility; Debye temperature; elastic constants; Poisson's ratio; shear modulus; single-crystal elastic coefficients; sound velocities; Young's modulus; zinc.

The elastic constants of zinc are compiled and reviewed; one hundred references are cited. The included elastic constants are: Young's modulus, shear modulus, bulk modulus, compressibility, Poisson's ratio, second-order single-crystal elastic stiffness and compliances, and third-order elastic stiffnesses. Temperatures and elastic-anisotropy effects are also reviewed. Other topics are: sound velocities, elastic Debye temperature, Cauchy relationships, elastic stability, pressure effects, and theoretical studies. New polycrystalline data are computed from single-crystal data by tensor-averaging methods.

Behavior of the AB-type compounds at high pressures and high temperatures, L. Merrill, J. Phys. Chem. Ref. Data 6, No. 4, 1205-1252 ( 1977 ).

Key words: AB-type compounds; çalibration; critically evaluated data; crystallographic data; experimental melting curves; high pressure; solid-solid phase boundaries. 
The results of the published work on the high pressure-high temperature properties of the AB-type compounds have been compiled and evaluated. All pressure studies above the rage of 1 kilobar have been included with an emphasis on the accurate characterization of the solid-solid phase boundaries and the experimental melting curves. Whenever $x$-ray diffraction data are available for the high pressure phases, they have also been reviewed. Phase diagrams are included for all compounds in which measurement of more than one point along the phase boundary was made. This review discusses a total of $87 \mathrm{com}$ pounds and 212 distinct high pressure-high temperature phases.
Energy levels of manganese, Mn I through Mn xxv, C. Corliss and J. Sugar, J. Phys. Chem. Ref. Data 6, No. 4, 1253-1330 (1977).

Key words: atomic energy levels; atomic spectra; manganese.

The energy levels of the manganese atom in all of its stages of ionization, as derived from the analyses of atomic spectra, have been compiled. In cases where only line classifications are given in the literature, level values have been derived. The percentages for the two leading components of the calculated eigenvectors of the levels are given where available. Ionization energies and $g$-values are also given. 


\subsection{DIMENSIONS/NBS, ARTICLE TITLES ONLY}

This monthly magazine is published to inform scientists, engineers, businessmen, industry, teachers, students, and consumers of the latest advances in science and technology, with primary emphasis on the work at NBS.

DIMENSIONS/NBS highlights and reviews such issues as energy research, fire protection, building technology, metric conversio i, pollution abatement, health and safety, and consumer product performance. In addition, DIMENSIONS/NBS reports the results of Bureau programs in measurement standards and techniques, properties of matter and materials, engineering standards and services, instrumentation, and automatic data processing. Issued monthly.

\section{January 1977}

DIM/NBS 61, No. $1,1-32$ (1977).

Key words: Alaska pipeline; calibration; CMAC; computers; consumer sounding boards; data; electron probe microanalysis; laser ionization; metrication; noise; nondestructive evaluation; research associate program; standards.

Will the Real John Hancock Please Sign In?

Meeting a Measurement Challenge in Alaska

Utilizing Consumer Insight

Good Data, Bad Data?

Transition to Ametrica

Fire Research With the Gypsum Industry

The U.S. Voluntary Standards System: NBS Role May Be Changing

Highly Efficient Laser Ionization of Dense Vapors Achieved

A Winning Invention: The Cerebellar Model Arithmetic Computer

Neutron Diffraction for NDE Being Studied

Standard Reference Materials for Electron Probe Microanalysis

Humidity Calibration Service Extended to Broader Temperature, Pressure Range

Extended Calibration Service Available for Low Vacuum Gages

Put a Damper on Noise-Prevent Deafness

\section{February 1977}

DIM/NBS 61, No. 2, 1-32 (1977).

Key words: building collapse; computer security; cryogenic temperature; dentistry; dielectric measurements; dye lasers; dynamic calibration; electron microscopy; electronic technology; energy conservation; interferometric wavemeter; metric; pressure transducers; synchrotron radiation.

New Energy Efficient Office Building

The Measurement Challenge in Electronic Technology

Destroying to Build Better

Cooperative Research in Dentistry

First Federal Computer Security Standard

Interferometric Wavemeter for CW Dye Lasers Developed

Dynamic Calibration Methods Developed for Space Shuttle Pressure Transducers

Synchrotron Radiation Facility Now Available to Outside Users

Dielectric Measurements at Cryogenic Temperatures

Standard Reference Materials for Scanning Electron Microscopy

A New "Metric Style Guide" from NBS
Applications of Thermography for Industrial Energy C\&nservation

Critical Survey of Data Sources on Electric and Magnetic Properties of Metals

Accuracy in Trace Analysis Proceedings

\section{March 1977}

DIM/NBS 61, No. 3, 1-32 (1977).

Key words: adobe; air pollution; corrosion; electrical; energy management; graphic pen; halocarbons; infrared lasers; international standard; neutron xeroradiography; problemsolving; radiation safety; smoke detectors; solar heating; SRM's.

Evaluating Incentives for Solar Heating Systems

Clearing the Air on Smoke Detectors

A Legacy of Adobe

The State of NBS, Part 1: Technical Quality and Problem Solving

How Sweet It Is?

Copper Benchmark Standard Reference Materials

Thermal Neutron Xeroradiography

Possible Mechanism for Removal of Halocarbons from Lower Atmosphere

Electrically Tuned Far Infrared Lasers

The Graphic Pen-An Economical Semiautomatic Fingerprint Reader

New Air Pollution Standard Reference Materials

Electrical Measurement Seminar

Conference on Corrosion

New Energy Management Guide for Small Business

Measures for Radiation Safety

\section{April 1977}

DIM/NBS 61, No. 4, 1-32 (1977).

Key words: American electroplaters'; calorimeter; cryogenic flow measurement; dental restorations; deep ocean research; federal science; governmental environment; laser energy; space flight; spectroscopy; SRM; television captioning; thermophysical; weights and measures.

Television Watching Could Become Meaningful Out of the Classroom, Into the Laboratory

New Device Aids Deep Ocean Research

The State of NBS

NBS, Aluminum Association, and American Electroplaters' Society Form Program

NBS Cryogenic Flow Measurement Code Approved

New Technique for Dental Restorations

New Calorimeter Unit Measures High Laser Energy

Use of Vibrational Spectroscopy for NDE

New Standard Reference Materials to Aid Research on Role of Chromium on Nutrition

Materials and Space Flight Conference

Thermophysical Properties Symposium

Weights and Measures Standards of the United States, A Brief History 


\section{May 1977}

DIM/NBS 61, No. 5, 1-32 (1977).

Key words: computer use; conservation; data; earth's measurement; energy; health records; hydrogen; law enforcement; liquefied natural gas; metric tons; polyethylene; sound; spinach; SRM; systems and software; telecommunications.

Going to Extremes in the Study of Sound

Things Your Mother Never Told You About Spinach

Liquefied Natural Gas

NBS Issues Landmark Study on Privacy in Health Records

Resource Conservation and Recovery

Standards for Law Enforcement

Measurements on Earth's Motion Agree With General Relativity Theory

Limits of Hydrogen Liquefier Efficiency Defined

NBS Microcopy Resolution Test Chart SRM Accepted for International Use

Polyethylene Proposed for Biocompatibility Studies

Reference Data Report

Telecommunications Technology and Libraries Conference

ACM/NBS Systems and Software Symposium

New SRM Price List Available from NBS

Is Hydrogen Safe?

Thermophysical Properties Data Published

\section{June 1977}

DIM/NBS 61, No. 6, 1-32 (1977).

Key words: computerized data; data elements; equity; federal technology; fire modeling; heat; hydrocarbon; ionized molybdenum; measurement assurance; metric; neutron diffraction; recycling oil; research and innovation; safety; ultrasonic tissue.

Metrication Australian Style

Recycling Oil: A Question of Quality

What's The Password?

Building Safety

Measurement Assurance Program

Measures for Equity: NCWM

Profile Analysis of Neutron Diffraction Powder Patterns

Fire Modeling Group Organized

Hydrocarbon-In-Air Standard Reference Materials

Spectra of Highly lonized Molybdenum and Heavy Elements Provided for Fusion Diagnostics

Mechanism for Transferring Federal Technology to State and Local Governments

Research and Innovation in the Building Process Conference

Data Elements Management Symposium

Landmark Volume on Ultrasonic Tissue Characterization Published

Why Waste Heat?

\section{July 1977}

DIM/NBS 61, No. 7, 1-32 (1977).

Key words: coal conversion; consumer products; cryogenic; crystalline materials; dosimeter calibrations; energy; energy related inventions; heterodyne receiver; international standards code; NCSL; NMR knight shifts; neutron beams; piezo-flex micropositioning; pressure; thermodynamic tables.

A Primer on Pressure

Summer Tips for Saving Energy and Money

When is a Product Portable?
The Key to Marketing New Energy-Related Inventions

An International Standards Code for Products

Single-Crystal Method for Identifying Crystalline Materials

NBS Standard Neutron Beams Extend Energy Range for Personnel Dosimeter Calibrations

New "Piezo-Flex" Micropositioning Stage Permits Smooth Control of Displacements in Microscope Systems

Improved Heterodyne Receiver at $300 \mathrm{GHz}$ Developed

New Thermodynamic Tables Being Prepared

1977 Combined Cryogenic Conference

NCSL Annual Meeting at Boulder, Colorado

Comprehensive Review on NMR Knight Shifts

A Guide for Law Enforcement Agencies on Use of Voice Scramblers

Prevention of Failures in Coal Conversion Systems

\section{August 1977}

DIM/NBS 61, No. 8, 1-32 (1977).

Key words: computer memories; computer performance; inventor; molecular identity; preserving stone; pressure measurements; rf-power meter; roofing; safety; security alarms; SRM's; time and frequency; ultraviolet.

Preserving Stone Art and Architecture

User's Guide to Pressure Measurement Services

Profile of an Inventor: Louis Marzetta

Home Security Alarms

NBS/ASTM Research Associate Program Develops Urgently Needed SRM's

Shedding More Light on the Ultraviolet

Molecular Identity of Power Plant Stack Particulates

Technology Assessment of Computer Memories

A New Self Balancing DC-Substitution RF Power Meter

Time and Frequency Seminar

Roofing Symposium

Computer Performance Evaluation Users Group

Teacher Aids

\section{September 1977}

DIM/NBS 61, No. 9, 1-32 (1977).

Key words: calibration; consumers; energy; energy savings; grain moisture; mass spectra; radiation sterilizing; screw thread standards; SHIVA laser; silicon; tinekeeping; ultraviolet radiation.

Ultraviolet Radiation: Problems and Issues

Let the Buyer Be Aware

Material Aspects of the Energy Problem

Don't Let Your Furnace Guzzle Oil

Participants Wanted for IC Linewidth Calibration Study

Coordination of Federal Screw Thread Standards Shifts to GSA

Glass Developments for SHIVA Laser

Worldwide Timekeeping Better Than Previously Believed

NBS, NIH Offer New Mass Spectra Data Base

Study of Grain Moisture Meters Begun

Silicon for Infrared Imaging Creates New Measuremenı Problems

New Calibration Services for Radiation Sterilizing and Processing Industries

Cardiac Pacemakers Workshop

9th Materials Research Symposium Papers Solicited

Metric Conversion Guidelines for Building Community

Teacher Aids 


\section{October 1977}

DIM/NBS 61, No. 10, 1-32 (1977).

Key words: cryocooler; EMI problems; energy problems; energy savings; exchange program; lead detection; metric; oxygen; technology.

NBS Inventiveness: Still a Winning Commodity Energy Tips for Winter Savings

Harnessing Technology for State and Local Use

NBS Guidelines for Use of the Metric System

Industry Calls for More Federal Initiative in Solving EMI Problems

Conversion of U.S. Customary Units of Length, Area, and Volume to SI

Data Center Investigates Oxygen and Sulfur in Copper

Cryocooler Invention Disclosed

Reference Materials Available for Calibrating Lead Detection Instruments

NBS Undertakes Data Work for Energy Problems

Exchange Program for State and Local Government Employees

Materials for Coal Conversion and Utilization Conference

Winter Simulation Conference

Ncw Edition of Official Publication on the International System of Units (SI)

Orthopaedic Implants Publication

\section{November 1977}

DIM/NBS 61, No. 11, 1-32 (1977).

Key words: air pollution; attic ventilation; data encryption; dental materials; fire safety; metric; miniature electric field; organic sulfur; radiometric detector; smog formation; SRM's.
Scientific Detectives Track Smog Formation Operation Firestop

What Won't Change as We "Go Metric"

The Dental Materials of Tomorrow Are Here Today

Validating Data Encryption Device

Temperature SRM Will Aid Accuracy of Clinical Tests

Miniature Electric Field Probe Developed

Two-Year Study Begun on Attic Ventilation

Radiometric Detector Calibration Capability Increased

Air Pollution Research Focuses on Organic Sulfur Chemistry

Micromeasurement for IC Industry Seminar

IEEE/NBS Computer Networking Symposium

SI Revisited

\section{December 1977}

DIM/NBS 61, No. 12, I-32 (1977).

Key words: AC high voltage; AC voltmeter calibrator; marine studies; microelectronic industry; monitoring system; photodetectors; radiopharmaceuticals; ultraviolet radiation; windows.

Making the Most of Windows

Toward a National Environmental Monitoring System UItraviolet Radiation Standards for Health Safety

Radiopharmaceuticals

Photodetectors Lose Dynamic Range With Modulated Signals

AC High Voltage Measurements on Firmer Footing

AC Voltmeter/Calibrator Developed

Upcoming Dimensional Standard Aimed at Needs of Microelectronic Industry

New SRM's Aid Industrial Hygiene Analysts

Research Material Now Available for Marine Studies

Precision Thermometry Seminars 


\subsection{MONOGRAPHS}

Major contributions to the technical literature on various subjects related to the Bureau's scientific and technical activities.

Monogr. 25, Section 14. Standard x-ray diffraction powder patterns. Section 14-Data for 68 substances, M. C. Morris, H. F. McMurdie, E. H. Evans, B. Paretzkin, J. H. deGroot, and R. Newberry, Nat. Bur. Stand. (U.S.), Monogr. 25, Sec. 14, 143 pages (Sept. 1977) SNO03-003-01842-2

Key words: crystal structure; integrated intensities; lattice constants; peak intensities; powder patterns; reference intensities; standard; $\mathbf{x}$-ray diffraction.

Standard x-ray diffraction patterns are presented for 68 substances. Twenty-seven of these patterns represent experimental data and 41 are calculated. The experimental $x$-ray powder diffraction patterns were obtained with an $x$-ray diffractometer. All d-values were assigned Miller indices determined by comparison with computed interplanar spacings consistent with space group extinctions. The densities and lattice constants were calculated, and the refractive indices were measured whenever possible. The calculated $x$-ray powder diffraction patterns were computed from published crystal structure data. Both peak height and integrated intensities are reported for the calculated patterns.

Monogr. 147, Suppl. 1. Relativistic many-body bound systems: Electromagnetic properties, M. Danos and V. Gillet, Nat. Bur. Stand. (U.S.), Monogr. 147, Suppl. 1, 52 pages (Apr. 1977) SNO03-003-01754-0.

Key words: electromagnetic properties; form factors; magnetic moments; quadrupole moments; quantum field theory; relativistic many body systems; vector dominance.

The formulae for the calculation of the electron scattering form factors, and of the static magnetic dipole and electric quadrupole moments, of relativistic many-body systems are derived. The framework, given in NBS Monograph 147, is relativistic quantum field theory in the Schrödinger picture; the physical particles, i.e., the solutions of the interacting fields, are given as linear combinations of the solutions of the free fields, called the parton fields. The parton-photon interaction is taken as given by minimal coupling, $\vec{p} \rightarrow \vec{p}-e \vec{A}$; in addition the contribution of the photon-vector meson vertex of the vector dominance model is derived.

Monogr. 155. From sundials to atomic clocks-Understanding time and frequency, J. Jespersen and J. Fitz-Randolph, Nat. Bur. Stand. (U.S.), Mongr. 155, 177 pages (Dec. 1977) SN003-003-01650-1.

Key words: astronomy; automation; clocks; communication; frequency; history; mathematics; navigation; physics; time; time broadcasts; time scales.

This book is a layman's introduction to time: its generation, its uses, its distribution, and its physical and scientific nature. The book begins with an historical review of clocks and watches, leading into a discussion of today's most sophisticated "time piece," the atomic clock. The need for highly accurate atomic time, to a millionth of a second or better, is described as it relates to a number of modern-day activities and systems such as advanced electronic communication systems, satellite navigation systems, and precise scientific measurements in radio astronomy and in tests of the theory of relativity. Several chapters are devoted to the legal aspects of time, both national and international. Who, for example, decides the length of a second, and why was the leap second introduced? Another portion of the book describes a variety of special short-wave broadcasts of time which are maintained by many nations of the world. There is also a discussion of the impact of satellites on time broadcasts. The book concludes with a discussion of the relationship of time to mathematics, physics, astronomy, and automation. It is shown how the science of time measurement has both contributed to and profited from advancements in each of these disciplines.

Monogr. 156. Stress corrosion cracking control measures, B. F. Brown, Nat. Bur. Stand. (U.S.), Monogr. 156, 81 pages (June 1977) SN003-003-01674-8.

Key words: aluminum alloys; copper álloys; high strength steels; nickel alloys; stainless steels; stress corrosion cracking; titanium alloys.

Stress corrosion cracking is a failure mode which has occurred with incresing frequency in all sectors of technology. This publication attempts to diminish the incidence of stress corrosion failures by assembling the available practical measures to avoid or minimize the problem and present these measures in a form comprehensible to those persons responsible for the design, fabrication and maintenance of new structures. The alloys covered are copper, aluminum, titanium and nickel alloys and high strength and stainless steels.

Monogr. 158. Corrosion and protection of steel piles in a natural seawater environment, E. Escalante, W. P. Iverson, W. F. Gerhold, B. T. Sanderson, and R. L. Alumbaugh, Nat. Bur. Stand. (U.S.), Monogr. 158, 42 pages (June 1977) SN003003-01 788-4.

Key words: cathodic protection; coating systems; corrosion protection; offshore corrosion; sand corrosion; seawater corrosion; splash zone corrosion.

This report describes the first eight years of a long term program in which twenty-three coating systems and five cathodic protection systems are evaluated on their ability to protect steel piles in offshore conditions. These systems are made up of nonmetallic coatings, metallic pigmented coatings, nonmetallic coatings on metal filled coatings, nonmetallic coatings on metallic coatings, metallic coatings, and cathodic protection on bare and coated piles.

It includes a description of the annual on site electrochemical coating evaluation and a description of the final physical evaluation made on the piles after removal. The results of these electrochemical and physical evaluations are presented graphically and in tabular form.

Monogr. 159. Visual range: Concepts, instrumental determination, and aviation applications, C. A. Douglas and R. L. Booker, Nat. Bur. Stand. (U.S.), Monogr. 159, 362 pages (June 1977) SN003-003-01782-5.

Key words: ceilometer; runway visual range; scattering; transmissometer; visibility; visual range.

This document is a review of the principles, procedures, and instruments used in the measurement of visual range. The fundamental concepts of the visual range of objects and lights are 
discussed. The principles of operation of the several classes of atmospheric attenuation meters are reviewed and representative instruments are described. The course of development of the NBS transmissometer, its validation and application to aviation operations is reported. An error analysis is made of the effects of instrument errors and of differences in observer thresholds on visibility measurements. A chronological review of the development and application of the runway visual range consept is included together with a discussion of cloud height mensurements.

Monogr. 160. Geometrical considerations and nomenclature for reflectance, F. E. Nicodemus, J. C. Richmond, J. J. Hsia, I. W. Ginsberg, and T. Limperis, Nat. Bur. Stand. (U.S.), Monogr. 160, 36 pages (Aug. 1977) SN003-003-01793.

Key words: bidirectional reflectance-distribution function; diffuse reflectance; directional reflectance; nomenclature of reflectance; optical reflection; reflectance; reflectance factor; reflectance geometry; reflectance nomenclature; reflection; specular reflectance; sub-surface scattering.

A unified approach to the specification of reflectance, in terms of both incident- and reflected-beam geometry, is presented. Nomenclature to facilitate this approach is proposed.

Under specified conditions -including uniform irradiance, a uniform, isotropic, plane surface, and allowance for edge offects due to subsurface scattering -the geometrical reflecting properties of a reflecting surface arc readily characterized or specified in terms of the bidirectional reflectance-distribution function (BRDF). The BRDF is denoted symbolically as $f_{r}$ :

$$
f_{r}\left(\theta_{i}, \phi_{i} ; \theta_{r}, \phi_{r}\right) \equiv d L_{r}\left(\theta_{i}, \phi_{i} ; \theta_{r}, \phi_{r} ; E_{i}\right) / d E_{i}\left(\theta_{i}, \phi_{i}\right)\left[s r^{-1}\right]
$$

where $\theta$ and $\phi$ together indicate a direction, the subscript $i$ indictates quantities associated with incident radiant flux, the subscript $r$ indicates quantities associated with reflected radiant flux, $E_{t}$ is incident irradiance, $L_{r}$ is reflected radiance, and $d$ indicates a differential quantity.

The BRDF is a derivative, a distribution function, relating the irradiance incident from one given direction to its contribution to the reflected radiance in another direction. Nomenclature (concepts, terms, symbols, and units) for categorizing and specifying reflectance quantities for a variety of different beam configurations (both incident and reflected beams) is described, and all are defined and interrelated in terms of the BRDF. The conditions under which the formalism can be applied, including situations involving considerable subsurface scattering, are carefully established. The entire treatment is limited to the domain of classical geometrical-optics radiometry and does not take into account interference and diffraction phenomena, such as are frequently encountered with highly coherent radiant flux. The other radiation parameters such as wavelength, (temporal) modulation, and polarization and the effects of fluorescence (or phosphorescence) are discussed briefly.

56 


\subsection{HANDBOOKS}

Recommended codes of engineering and industrial practice (including safcty codes) developed in cooperation with interested industrics, professional organizations, and regulatory bodies.

H121. Waste heat management guidebook, K. G. Kreider and M. B. McNeil, Eds., Nat. Bur. Stand. (U.S.), Handb. 121, 174 pages (Feb: 1977) SN003-003-01669-1.

Key words: boilers; economics; energy conservation; instrumentation; recuperators; waste.

Sources of waste (i.e., discarded) heat in industrial processcs are rcvicwed, and an overview of off-the-shelf technology available for its use is given. Discussions of waste heat measurement technology and economics are included, as are fourteen case studies of successful industrial waste-heat recovery installations.

H122. Noise emission measurements for regulatory purposes, D. R. Flynn, W. A. Leasure, Jr., A. I. Rubin, and M. A. Cadoff, Nat. Bur. Stand. (U.S.), Handb. 122, 193 pages (Mar. 1977) SN003-003-01750-7.

Key words: acoustics; environmental pollution; machinery and equipment; noise; noise abatement and control; noise emission; regulation; sound.

A review is given of the measurement needs attendant to regulation of the noise generated and emitted by commercial products. The emphasis is primarily on measurement procedures for use in conjunction with point-of-sale regulations as opposed to regulations on the noise which a source actually emits when in operation. The report is divided into three major parts. Part I is a discussion of overall measurement requirements and the type of data and information which are needec in order to promulgate regulations based on appropriate mea- surement techniques. Part II is designed as a checklist for the evaluation of the suitability of a noise measurement standard for a particular class of products or, in the absence of a suitable standard, as a framework for development of one. The intent is to identify and discuss in some detail those factors which can impact on the accuracy, precision, and applicability of a noise measurement process. Part III consists of a series of flow charts depicting the development of appropriate procedures for the measurement of product noise emission.

H123. American National Standard N537; Radiological safety standard for the design of radiographic and fluoroscopic industrial x-ray equipment. ( $A N S I$ N537-1976), E. H. Eisenhower, Chairman, ANSI Subcommittee N43-7, Nat. Bur. Stand. (U.S.), Handb. 123, 15 pages (Aug. 1977) SN003003-01820-1.

Key words: design standard; fluoroscopy; national standard; radiation safety; radiography; $x$-ray equipment; $x$-ray safety; $x$-ray tube.

This standard provides guidelines specific to the radiatior. safety aspects of the design of industrial $x$-ray cquipment operating at energies below $1 \mathrm{MeV}$ for radiographic and fluoroscopic applications, wherein the $x$ rays are generated by electronic means. The objective is to achieve safe design of industrial $x$-ray equipment by establishing requirements for some of the components which are critical for radiation safety. These include controls, panel displays, warning indicators, tube assembly, and shielding. Other considerations which are generally the responsibility of the manufacturer are also included, such as instructions, provision of means for connecting interlocks, and labelling. This standard does not include safety considerations outside the realm of radiation safety, nor does it apply to safe operation of such equipment. 


\subsection{SPFCIAL PUBLICATIONS}

Include prcceedings of conferences sponsored by NBS, NBS annual reports, and other special publications appropriate to this grouping such as wall charts, pocket cards, and bibliographies.

SP260-54. Standard reference materials: Certification and use of acidic potassium dichromate solutions as an uItraviolet absorbance standard-SRM 935, R. W. Burke and R. Mavrodineanu, Nat. Bur. Stand. (U.S.), Spec. Publ. 260-54, 157 pages (Aug. 1977) SN003-003-01828-7.

Key words: absorbance linearity; accuracy of transmittance or absorbance scale; acidic potassium dichromate solutions; calibration of ultraviolet spectrometers; certification of apparent specific absorbance; isosbestic wavelengths; liquid filters; standard reference material; transfer standards.

The apparent specific absorbances of $0.001 \mathrm{~N}$ perchloric acid solutions of a high purity potassium dichromate salt, Standard Reference Material (SRM) 935, have been certified at four wavelengths in the ultraviolet-235, 257, 313 and $350 \mathrm{~nm}$. This publication describes in detail the measurements leading to the certification, and discusses the use of this SRM as a transfer standard for verifying the accuracy of the absorbance scale of narrow bandpass absorption spectrometers in this important wavelength region. Apparent specific absorbance data are also reported near two predicted isosbestic wavelengths in the acidic $\mathrm{HCrO}_{4}-/ \mathrm{Cr}_{2} \mathrm{O}_{7}=$ system. The apparent specific absorbances at $345 \mathrm{~nm}$ are sufficiently independent of concentration that absorbance measurements at this wavelength can be used for verifying absorbance linearity to about one part in a thousand.

SP260-55. Standard reference materials: Enthalpy and heat capacity standard reference material: Molybdenum SRM 781, from 273 to $2800 \mathrm{~K}$, D. A. Ditmars, A. Cezairliyan, S. Ishihara, and T. B. Douglas, Nat. Bur. Stand. (U.S.), Spec. Publ. 260-55, 80 pages (Sept. 1977) SN003-003-01836-8.

Key words: drop calorimetry; emittance; enthalpy; heat capacity; high-speed measurements; high temperature; molybdenum; pulse calorimetry; standard reference material; thermodynamic functions.

The relative enthalpy of NBS Standard Reference Material No. 781 (99.95 mass-percent pure, polycrystalline molybdenum: a metallic, high-temperature enthalpy and heat-capacity standard) has been measured with two differently designed, receiving-type calorimeters in the temperature ranges 273 to $1173 \mathrm{~K}$ and 1173 to $2100 \mathrm{~K}$, respectively. The smoothed enthalpy data derived from these measurements are believed to have an inaccuracy not exceeding 0.6 percent at any temperature in these ranges. The heat capacity of Standard Reference Material No. 781 has also been measured in the temperature range 1500 to $2800 \mathrm{~K}$ using a millisecond-resolution pulse technique with resistive self-heating. This technique measured, in addition, hemispherical total emittance. In this highest temperature range, the smoothed heat-capacity data are believed to be in error by no more than 3 percent. A complete description of all the NBS experimental techniques and a detailed analysis of all suspected sources of errors are presented. Equations representing the smoothed NBS enthalpy and heat-capacity data for SRM-781 molybdenum in the range 273.15 to $2800 \mathrm{~K}$ are presented along with a table of these data calculated from the equations at selected temperatures. A bibliography of all known publications on the enthalpy and heat capacity of molybdenum has been compiled. The NBS-measured enthalpy and heat-capacity data for molybdenum have been compared with those of all the principal investigators and compilers reported in the literature.

SP305. Supplement 8. Publications of the National Bureau of Standards 1976 catalog. A compilation of abstracts and key word and author indexes, B. L. Burris, Ed., Nat. Bur. Stand. (U.S.), Spec. Publ. 305 Suppl. 8, 728 pages (June 1977) SN003-003-01743-4.

Key words: abstracts, NBS publications; key words; publications.

This supplement to Special Publication 305 supplements 1 through 7 of the National Bureau of Standards lists the publications of the Bureau issued between January 1, 1976 anci December 31,1976 . It includes an abstract of each publication (plus some earlier papers omitted from Special Publication 305 Supplement 7), key word and author indexes, and general information and instructions about NBS publications.

Miscellaneous Publication 240 (covering the period July 1 , 1957 through June 30,1960 ) and its suppleinent (covering the period July 1, 1960 through June 30, 1966), Special Publication 305 (covering the period July 1966 through December 1967), and Special Publication 305 Supplement 1 (covering the period 1968-1969), Special Publication 305 Supplement 2 (covering the period 1970), Special Publication 305 Supplement 3 (covering the period 1971), Special Publication 305 Supplement 4 (covering the period 1972), Special Publication 305 Supplement 5 (covering the period 1973), Special Publication 305 Supplement 6 (covering the period 1974), and Special Publication 305 Supplement 7 (covering the period 1975) remain in effect. Two earlier lists, Circular 460 (Publications of the National Bureau of Standards, 1901 to June 1947) and its supplement (Supplementary List of Publications of the National Bureau of Standards, July 1, 1947 to June 30, 1957) are also still in effect.

SP330. The International System of Units (SI), (Supersedes NBS Special Publication 330, 1974 Edition), Nat. Bur. Stand. (U.S.), Spec. Publ. 330, 46 pages (Aug. 1977) SN003-00301784-1.

Key words: General Conference on Weights and Measures; International System of Units; SI; Système International des Unités; Units of Measurements.

This translation from the French "Le Système International d'Unités," (SI) published originally by the International Bureau of Weights and Measures (BIPM) has been prepared jointly by the National Physical Laboratory, UK, and the National Bureau of Standards, USA. Included are Resolutions and Recommendations of the General Conference on Weights and Measures (CGPM) on the International System of Units, (ISO) for the practical use of the system.

Appendix I gives in chronological order the decisions promulgated since 1889 by CGPM and the International Committee for Weights and Measures (CIPM) on units of measurement and on SI. Appendix II outlines the measurements, consistent with the theoretical definitions given in this document, which metrological laboratories can make to realize the units and to calibrate precision material standards. Appendix II lists the organs of the Metric Convention. 
SP363. Supplement 1. Bibliography on atomic energy levels and spectra (July 1971 through June 1975), L. Hagan, Nat. Bur. Stand. (U.S.), Spec. Publ. 363 Suppl. l, 186 pages (Jan. 1977) SN003-003-01673-0, \$2.50.

Key words: atomic energy levels; atomic spectra; bibliography; energy levels, atomic; spectra, atomic; wavelengths, atoms and ions.

This is the first supplement to the NBS Special Publication 363, "Bibliography on Atomic Energy Levels and Spectra, July 1968 through June 1971," and it covers the most recent literature from July 1971 through June 1975. It contains approximately 2150 references classified by subject for individual atoms and atomic ions. A number index identifies the references. An author index is included. References included contain data on energy levels, classified lines, wavelengths, Zeeman effect, Stark effect, hyperfine structure, isotope shift, ionization potentials, or theory which gives results for specific atoms or atomic ions.

SP400-24. Semiconductor measurement technology: A laser scanner for semiconductor devices, D. E. Sawyer and D. W. Berning, Nat. Bur. Stand. (U.S.), Spec. Publ. 400-24, 72 pages (Feb. 1977) SNO03-003-01739-6.

Key words: electronic reliability; electronics; laser scanner; measurement method; mixer; optics; pre-amplifier; radio receiver; semiconductor device studies.

This is a construction guide and operators manual for a laser scanner built for semiconductor device studies. A very brief discussion of the theory of operation of the scanner is given. The scanner's operation from a systems point of view is described in detail with emphasis on block diagrams. The scanner is described from a hardware point of view with a detailed description of the function of the various controls on the electronic equipment that was built for the laser scanner. A quick guide for the use of the scanner is given so that a person unfamiliar with the instrument can use it effectively. Specifications relating to the scanner's data gathering ability are also given. Mechanical drawings and circuit schematics are given to enable others to build a similar scanner. The optics and their alignment are discussed. Various display modes including color are discussed to enhance operator viewing.

SP400-29. Semiconductor measurement technology. Progress report, January 1 to June 30, 1976, W. M. Bullis, Ed., Nat. Bur. Stand. (U.S.), Spec. Publ. 400-29, 119 pages (Apr. 1977) SN003-003-01759-1, \$1.85.

Key words: acoustic emission; Auger electron spectroscopy; beam-lead bonds; capacitance-voltage methods; carrier mobility; C-MOS circuits; dopant profiles; electrical properties; electronics; four-probe method; hermeticity; ion implantation; Irvin's curves; leak tests; line-width measurement; measurement methods; microelectronics; optical flying-spot scanner; oxidation particle impact noise detection test; passivation overcoats; photovoltaic method; powerdevice grade silicon; radioisotope method; resistivity; resistivity variations; safe operating area, transistor; scanning acoustic microscope; scanning electron microscope; scanning low energy electron probe; semiconductor devices; semiconductor materials; semiconductor process control; silicon; silicon dioxide; silicon on sapphire; sodium contamination; spreading resistance; surface roughness; test patterns; thermally stimulated current; transistors, power; TTL circuits; ultrasonic wire bonding; ultraviolet reflectance; $x$-ray damage.

This progress report describes NBS activities directed toward the development of methods of measurement for semiconduc- tor materials, process control, and devices. Both in-house and contract efforts are included. The emphasis is on silicon device technologies. Principal accomplishments during this reporting period included (1) development of theoretical expressions for electron mobility in silicon based on combinations of scattering mcchanisms; (2) successful low-temperature processing of MOS capacitors to permit measurement of thermally stimulated current and capacitance without subjecting the specimens to potentially degrading heat treatments; (3) completion of a study of the thermodynamics of reactions in an oxidation furnace tube which provides a basis for models of the effect of water vapor, chlorine, and tube wall conditions on sodium contamination levels; (4) development of a rapid, nondestructive method for reverse decoration of defects in passivation overcoats; (5) development of the theoretical basis for accurate measurement of small line widths by analysis of a spatially filtered image of the line; (6) extension of the acoustic emission technique to the nondestructive testing of tape-bonded chips and hybrid components; and (7) analysis of the results of a first exploratory interlaboratory evaluation of the radioisotope method for testing hermeticity of semiconductor devices. New tasks were undertaken to develop techniques for measuring resistivity uniformity of and nondopant impurities and defects in power-device grade silicon and to investigate the particle impact noise detection method for screening devices for the presence of loose particles in the package; initial results were obtained in the study of scanning acoustic microscopy which was begun during the previous reporting period. Because of technical limitations in the methods, efforts to develop both the automated scanning low energy electron probe and in-process ultrasonic bond monitor were terminated. Also reported is other on-going work on materials characterization by electrical and physical analysis methods, materials and procedures for wafer processing, photolithography, test patterns, and device inspection and test procedures. Supplementary data concerning staff, publications, workshops and symposia, standards committee activities, and technical services are also included as appendices.

SP400-31. Semiconductor measurement technology: Techniques for measuring the integrity of passivation overcoats on integrated circuits, W. Kern and R. B. Comizzoli, Nat. Bur. Stand. (U.S.), Spec. Publ. 400-3l, 120 pages (Mar. 1977) SN003-003-01753-1.

Key words: corona charging decoration; dielectric defect detection; electrophoretic decoration; integrated circuit quality control; selective chemical etching; semiconductor device reliability.

Conventional test methods to evaluate the quality of glass passivation overcoats on semiconductor devices are generally inadequate and/or destructive. Three new methods have been devised that overcome these problems: (1) Sequential selective chemical etching of metal/dielectric structures to detect buried, latent, or partial defects as a function of dielectric layer depth. (2) Electrophoretic cell decoration with uv phosphor particles suspended in an insulating liquid, the sample forming one electrode of the cell. (3) Electrostatic corona-charging, to selectively deposit surface ions from a high voltage dc discharge on the insulating surfaces of the sample, followed by placing of the charged sample in a suspension of charged carbon black particles in an insulating liquid; depending on the polarity of the ions the particles can be deposited on the insulator surface or at the defect sites. The etching method is most suitable in process research studies, and the electrophoretic technique for demarcating relatively large defects. The corona decoration method, coupled with automated instrumental read-out based on measuring the reflected light intensity, is ideal for routine testing of devices because it is fast, simple sensitive, and non- 
destructive to devices such as glass passivated bipolar and MOS 1Cs. The practical benefits of the new test methods can be considerable in production and product control, with cost savings through early detection of production line defects and rapid corrective action.

SP400-33. Semiconductor measurement technology: The dopant density and temperature dependence of electron mobility and resistivity in $n$-type silicon, S. S. Li, Nat. Bur. Stand. (U.S.), Spec. Publ. 400-33, 36 pages (Mar. 1977) SN003-003-017426.

Key words: dopant density; electron mobility; ionized impurity scattering mobility; lattice mobility; neutral impurity scattering mobility; n-type silicon; resistivity; scattering mechanisms; temperature.

Traditional analysis of electron mobility in $n$-type silicon neglects the effects of electron-electron scattering and scattering anisotropy in the mobility calculations. As a result, theory fails to conform with experiment when dopant density exceeds $2 \times 10^{16} \mathrm{~cm}^{-3}$.

In this work, an improved theoretical model for computing mobility and resistivity as functions of dopant density and temperature has been formulated for $n$-type silicon. The model has been applied to phosphorus-doped silicon for dopant densities from $10^{13}$ to $10^{19} \mathrm{~cm}^{-3}$, temperatures between 100 and $500 \mathrm{~K}$.

The electron mobility was calculated analytically by appropriately combining lattice, ionized impurity, and neutral impurity scattering contributions. The effect of electron-electron scattering on both lattice and ionized impurity scattering mobilities was incorporated empirically for dopant densities greater than $2 \times 10^{16} \mathrm{~cm}^{-3}$. Additionally, the anisotropic scattering effect was also considered in the mobility calculations.

Theoretical calculations of resistivity and ionized donor density were made for phosphorus-doped silicon for temperatures between 100 and $500 \mathrm{~K}$.

Resistivity measurements on seven phosphorus-doped silicon slices with dopant densities from $1.2 \times 10^{14}$ to $2.5 \times 10^{18} \mathrm{~cm}^{-3}$ were carried out for temperatures between 100 and $500 \mathrm{~K}$. Electron mobility at $300 \mathrm{~K}$ was deduced from resistivity and junction $\mathrm{C}-\mathrm{V}$ measurements for dopant densities from $10^{14}$ to $10^{18} \mathrm{~cm}^{-3}$

Agreement between theory and experiment for both electron mobility and resistivity of phosphorus-doped silicon was within \pm 7 percent in the range of dopant densities and temperatures studied.

SP400-35. Semiconductor measurement technology: Notes on SEM examination of microelectronic devices, J. R. Devaney, K. O. Leedy, and W. J. Keery, Nat. Bur. Stand. (U.S.), Spec. Publ. 400-35, 54 pages (Apr. 1977) SN003-003-01755-8.

Key words: backscattered emission; EB1C; microelectronic devices; scanning electron microscope; secondary emission; voltage contrast.

This report reviews selected scanning electron microscope (SEM) techniques which are appropriate for the examination of microelectronic devices. lllustrated are the results of individual variations in SEM operating parameters such as accelerating voltage, specimen tilt, scan line time, and frame time. Techniques which utilize secondary and backscattered electron emissions are compared and electron-beam-induced current and voltage contrast nodes are discussed. Specimen preparation and beam-induced charging artifacts are also discussed. This report demonstrates the need for flexibility in selecting and using SEM parameters and analytic procedures to obtain the maximum information when examining semiconductor devices.
SP400-37. Semiconductor measurement technology: Suppression of premature dielectric breakdown for high-voltage capacitance measurements, A. M. Goodman, Nat. Bur. Stand. (U.S.), Spec. Publ. 400-37, 27 pages (July 1977) SN003-00301809-1.

Key words: capacitance-voltage measurements; dielectric breakdown suppression; discharge suppression; electronics; extended-range MIS C (V) measurements; high-voltage C (V) measurements; MIS capacitor; premature dielectric breakdown; semiconductor devices.

Surface-initiated premature dielectric breakdown is encountered in extended-range MIS C(V) measurements at appliedbias voltages above some sample-dependent threshold value, e.g., 3 to $5 \mathrm{kV}$ across a $150-\mu \mathrm{m}$-thick wafer of sapphire. It is necessary to suppress this premature breakdown in order that a much larger applied-bias voltage may be used without damaging the sample. This may be accomplished by eliminating the air space adjacent to the sample surface at the junction of the dielectric and the electrode edge. A simple, easy-to-use apparatus (sample holder and probe assembly) which allows this to be done conveniently and quickly by using a silicone rubber washer to cover the edge of the electrode and the adjacent area is described. Construction details of the apparatus and a test chamber which have been tested to $30 \mathrm{kV}$ are provided in an appendix.

SP400-39. Semiconductor measurement technology: Some aspects of dose measurement for accurate ion implantation, D. M. Jamba, Nat. Bur. Stand. (U.S.), Spec. Publ. 400-39, 44 pages (July 1977) SNO03-003-01808.

Key words: accurate ion beam current measurement; current integrators; ion beam scanning; ion implantation; ion implantation dose measurement and control; secondary particle suppression.

An investigation of various phases of ion implantation dose measurement was carried out, covering in detail ion beam scanning, secondary particle suppression, and current measurement instruments. Problems are discussed and preferred techniques, electrode structures, and measurement circuitry are presented. Five current integrators were tested and are compared, especially in regard to pulsed current measurement.

SP400-40. Semiconductor measurement technology: A 25-kV bias-isolation unit for $1-\mathbf{M H z}$ capacitance and conductance measurements, A. M. Goodman, Nat. Bur. Stand. (U.S.), Spec. Publ. 400-40, 57 pages (Sept. 1977) SN003-003-018325.

Key words: bias-isolation unit; capacitance and conductance measurements at high applied-bias voltage; capacitance/conductance-meter; capacitance-voltage measurements; electronics; extended-range $C(V)$ and $G(V)$ measurements; high voltage $\mathrm{C}(\mathrm{V})$ and $\mathrm{G}(\mathrm{V})$ measurements; MIS capacitors; modified MIS C(V) measurements; semiconductor devices; silicon-on-sapphire measurements; SOS measurements.

The measurement of small signal (differential) capacitance (C) and conductance (G) at $1 \mathrm{MHz}$ as a function of appliedbias voltage can be carried out with a commercially available capacitance/conductance $(\mathrm{C} / \mathrm{G})$ meter at moderate applied-bias voltage ( $\leqslant 100 \mathrm{~V}$ ). However, C and $\mathrm{G}$ measurements of metalsapphire-silicon capacitors for characterizing silicon-on-sapphire require the use of much larger applied-bias voltage.

This report describes a technique for using a commercially available C/G-meter with a Bias-lsolation Unit (BIU) for $\mathrm{C}$ and $\mathrm{G}$ measurements at bias-voltage magnitudes up to $25 \mathrm{kV}$ without damage to the measurement equipment. The basic 
principles of operation and the details of the electrical design of a BIU are presented.

The use of the BIU imposes certain limitations on the range of sample capacitance and conductance that may be measured without introducing excessive error. The theory of these limitations is presented and compared with experimental results obtained from the use of the BlU. The measurement capability demonstrated by these results is adequate for the intended silicon-on-sapphire measurement application and may be described in terms of a measurement range for a maximum added error due to the use of the BIU. For less than \pm 1 percent added error in the indicated (measured) capacitance, the measurable range of the sample capacitance is found to be from 0 to about $100 \mathrm{pF}$. In this application, it is also important to be able to accurately measure small changes in the sample capacitance; for less than \pm 1 percent added error in the indicated (measured) value of a small change in the sample capacitance, the measurable range of the sample capacitance is found to be from 0 to about $38 \mathrm{pF}$. Conductance measurements may be made with less than about 2 percent added error for samples whose capacitance is in the range 0 to $50 \mathrm{pF}$.

SP400-41. Semiconductor measurement technology: A versatile high-voltage bias supply for extended range MIS $C(V)$ and G(V) measurements, P. Kuczer, H. O. Hook, and A. M. Goodman, Nat. Bur. Stand. (U.S.), Spec. Publ. 400-41, 69 pages (Dec. 1977) SN003-003-01869-4.

Key words: high-voltage bias supply; high-voltage $\mathrm{C}(\mathrm{V})$ and $G(V)$ measurements; high-voltage function generator; high-voltage sweep; semiconductor devices; silicon-on-sapphire measurements.

Recently developed technology has enabled the measurement of MIS C(V) and $G(V)$ at bias-voltage magnitudes as large as $25 \mathrm{kV}$. This report describes a versatile high-voltage power supply intended for use as a bias source in carrying out such measurements.

The design allows the user a wide variety of options in the selection of the sweep function (waveform), sweep time, initial bias voltage, and the amplitude of the bias sweep. There are six possible sweep functions: (i) increasing ramp, (ii) decreasing ramp, (iii) positive polarity half-wave sawtooth (increasing ramp followed by decreasing ramp), (iv) negative polarity halfwave sawtooth (decreasing ramp followed by increasing ramp), (v) full-wave sawtooth starting with increasing ramp, and (vi) full-wave sawtooth starting with decreasing ramp. Either single or repetitive sweeps may be selected. The sweep time from the initial value to the end of the first ramp segment may be varied from 1 to $2000 \mathrm{~s}$. Operator convenience is enhanced by certain features of the design; among these are light-emitting diodes which display the state of the sweep and automatic pen control if the sweep is used with an $x-y$ recorder.

SP400-42. Semiconductor measurement technology: Reliability technology for cardiac pacemakers II-A workshop report. Proceedings of a Workshop held at the National Bureau of Standards, Gaithersburg, MD, July 19-20, 1976, H. A. Schafft, Ed., Nat. Bur. Stand. (U.S.), Spec. Publ. 400-42, 45 pages (Aug. 1977) SN003-003-01815-5.

Key words: batteries; cardiac pacemakers; hermeticity; hybrid devices; leak testing; measurement technology; microcalorimetry; pacemaker leads; process control; reliability; screen tests; semiconductor devices.

Summaries are presented of 12 invited talks on the following topics: the procurement and assurance of high reliability electronic parts, leak rate and moisture measurements, pacemaker batteries, and pacemaker leads. The workshop, second in a series, was held in response to strong interest expressed by the pacemaker community to address technical questions relevant to the enhancement and assurance of cardiac pacemaker reliability. Discussed at the workshop were a process validation wafer concept for assuring process uniformity in device chips; screen tests for assuring reliable electronic parts; reliability prediction; reliability comparison of semiconductor technologies; mechanisms of short-circuiting dendritic growths; details of helium and radioisotope leak test methods; a study to correlate package leak rates, as measured with test gases, and actual moisture infusion; battery life prediction; microcalorimetric measurements to nondestructively evaluate batteries for pacemakers; and an engineer's and a physician's view of the present status of pacemaker leads. These proceedings include the following papers (indented):

Process validation wafers for use in procuring reliable custom integrated circuit chips, M. G. Buehler, SP400-42, pp. 5-8 (Aug. 1977).

High reliability microcircuit procurement controls, W. J. Kitchen, Jr. and T. H. Brown, SP400-42, pp. 9-12 (Aug. 1977).

Mechanisms of dendritic growth, R. P. Frankenthal, SP4OO42, pp. 12-13 (Aug. 1977).

Use of epoxies in hybrid microcircuits, R. F. Redemske, SP400-42, pp. 14-15 (Aug. 1977).

Microcalorimetric study of cardiac pacemakers and batteries, E. J. Prosen and J. C. Colbert, SP400-42, pp. 16-18 (Aug. 1977).

Statistical methods for estimating the longevity of pacemaker batteries, D. J. Gerrard, SP400-42, pp. 18-19 (Aug. 1977).

Applications and pitfalls of reliability prediction, J. H. Maness and S. Kus, SP400-42, pp. 19-20 (Aug. 1977).

A reliability comparison of semiconductor and microcircuit technologies, H. A. Lauffenburger, SP400-42, pp. 20-22 (Aug. 1977).

Moisture measurement, leak rate, and reliability, R. E. Sulouff, SP4O0-42, pp. 22-24 (Aug. 1977).

The fundamentals of leak testing for cardiac pacemakers, S. Ruthberg, SP400-42, pp. 25-30 (Aug. 1977).

Pacemaker leads-A physician's view, V. Parsonnet, SP40O42, pp. 30-32 (Aug. 1977).

The performance of implantable pacing leads-A status report, P. P. Tarjan, SP400-42, pp. 33-37 (Aug. 1977).

SP400-44. Semiconductor measurement technology: Safe operating area limits for power transistors, D. L. Blackburn, Nat. Bur. Stand. (U.S.), Spec. Publ. 400-44, 20 pages (Sept. 1977) SN003-003-01833-3.

Key words: hot spots; junction temperature; measurement technology; nondestructive test; reliability; safe operating limits; second breakdown; semiconductor devices; thermal characterization; thermal instability; thermal resistance; transistors.

This is a script of a videotape presentation which addresses deficiencies of present methods for measuring and specifying the power dissipation capabilities and safe operating area (SOA) limit\$ for power transistors. These deficiencies result from not including adequately the effects of significant temperature nonuniformities which occur, primarily for high-volt- 
age, low-current conditions. Firstly, the specified thermal resistance of a transistor can be applied strictly only when the junction temperature is relatively uniform, otherwise the power capability of the device can bc grossly overestimated. Secondly, the use of the standard method for measuring junction temperature can lead to a serious underestimate of the peak junction temperature if the temperature distribution is not uniform. Finally, the traditional SOA limits do not consider the phenomenon of thermal instability and the hot spots that ensue. As a result, devices can operate with potentially dangerous hot spots within operating limits that traditionally have been considered to be safe. It is proposed that the SOA limits be revised to exclude operating conditions where thermal instability and hot spots can occur. A method for detecting the onset of thermal instability and triggering a circuit to turn-off the transistor under test is described. This approach can be used to develop the revised SOA limits in a nondestructive way.

SP440. COLOR-Universal language and dictionary of names, K. L. Kelly and D. B. Judd, Nat. Bur. Stand. (U.S.), Spec. Pı:bl. 440, 184 pages (Dec. 1976) SN003-003-01705-1.

Key words: centroid colors; color; color designations; calorimetry; color names; color-order systems; Munsell Color System; Universal Color Language; variable accuracy of color designations.

The Universal Color Language (UCL) has been revised and will be published together with the 7 th printing of the Color Names Dictionary. It serves as the means of updating the Dictionary. The UCL brings together all the well-known colororder systems and methods of designating color. It interrelates them in six correlated levels of fineness of color designation, each higher level indicating a finer division of the color solid. It follows closely the original requirements for the ISCC-NBS Method of Designating Colors stated in the Color Names Dictionary. They were: a) accurate enough to satisfy a scientist, b) usable enough to satisfy a manufacturer and c) simple enough to be understood by the average person on the street. The first requirement is satisfied by levels 6 and 5 , the second by levels 5,4 and 3, and the third by levels 3,2 and 1. The UCL is being increasingly used by science, art and industry. Instructions are included for the application of the UCL at each level.

SP446-1. Building technology project summaries 1976, M. Olmert, and CBT Management Group, Nat. Bur. Stand. (U.S.), Spec. Publ. 446-l, 83 pages (Sept. 1977) SN-003-003-018465.

Key words: building research; building technology; codes; criteria; project summaries; standards; technical bases.

The Center for Building Technology provides the technical and scientific bases for criteria and standards that improve the usefulness, safety, and economy of buildings while conserving building materials and energy. The Center's activities support the building technology program of the Federal, State and local government; assist design professions, building officials and the research community by developing design criteria that improve buildings; and assist manufacturers of building products by developing criteria for evaluating innovative building materials. This report summarized the Center's projects for calendar year 1976. It enables individuals to get a clear impression of CBT research activities.

SP450. Blood pH, gases, and electrolytes. Proceedings of the Workshop on $\mathrm{pH}$ and Blood Gases, held at the National Bureau of Standards, Gaithersburg, MD, July 7-8, 1975, R. A. Durst, Ed., Nat. Bur. Stand. (U.S.), Spec. Publ. 450, 338 pages (June 1977) SN003-003-01792-2.
Key words: acid-base status; blood electrolytes; blood gases; blood pH; calcium; carbon dioxide; hydrogen ion concentration; nomograms: oxygen; $\mathrm{PCO}_{2} ; \mathrm{pH}$; potassium; $\mathrm{PO}_{2}$; sodium.

On July 7-8, 1975, a workshop was held at the National Bureau of Standards to discuss the status and needs of this very important area of clinical measurement. A major goal of this workshop was the initiation of cooperative efforts on an international level toward the standardization of $\mathrm{pH}$ and blood gas measurements and the various quantities and terms used in this field.

To this end, the first technical session was concerned with the acid-base status of blood and included the topics: Definitions of Quantities and Concepts; Recommendations of Nomenclature, Physiological Terminology and Symbols; Reference Values; and the Evaluation of Nomograms and Algorithms. The second session addressed itself to the more practical aspects of this subject and included the topics: Blood Sampling, Handling, and Storage; Instrument Specifications; Quality Control and Standards; and the Development of Reference Methods. Finally, a brief session was concerned with the newer topic of the electrometric measurement of blood electrolytes.

This volume contains all of the papers invited for presentation at the workshop by some of the leading clinical and medical authorities on this subject and also includes a transcription of the extensive discussion sessions. These proceedings include the following papers (indented):

Definitions of acid-base quantities: Terminology, symbols, and SI units, O. Siggaard-Andersen, SP450, pp. 1-9 (June 1977).

The buffer value of plasma, erythrocyte fluid and whole blood, O. Siggaard-Andersen, M. Rørth, and D. A. P. Strickland, SP45O, pp. 11-19 (June 1977).

Acid-base algorithms, O. Siggaard-Andersen, SP450, pp. 21-26 (June 1977).

Determination of total $\mathrm{CO}_{2}$ concentration in blood or plasma, P. Rispens, E. J. van Kampen, and W. G. Zijlstra, SP45O, pp. 27-31 (June 1977).

The apparent overall first dissociation constant of $\mathrm{CO}_{2}$ in plasma, P. Rispens and W. G. Zijlstra, SP45O, pp. 33-38 (June 1977).

Quantitative relationships between total $\mathrm{CO}_{2}$ concentration in blood and plasma, plasma bicarbonate concentration, plasma $\mathrm{pH}$ and carbon dioxide tension between $16-42{ }^{\circ} \mathrm{C}, \mathrm{P}$. Rispens, J. P. Zock, and W. G. Zijlstra, SP450, pp. 39-45 (June 1977).

$\mathrm{PCO}_{2}$ independent quantities, why or why not, $\mathrm{P}$. Rispens, W. G. Zijlstra, and E. J. van Kampen, SP450, pp. 47-52 (June 1977).

Base excess. Why. reopen the acid-base debate?, P. J. N. Howorth, SP450, pp. 53-56 (June 1977).

Use of in vivo $\mathrm{CO}_{2}$ titration curves in the physiological assessment of acid-base balance, P. J. N. Howorth, SP450, pp. 57-67 (June 1977).

Relative activity and SI units, B. F. Visser and A. H. J. Maas, SP450, pp. 69-72 (June 1977).

Semi-empirical acid-base program, B. F. Visser, A. J. Hoelen, J. A. Kreuger, and A. H. J. Maas, SP450, pp. 7374 (June 1977). 
"Acid-base semantics"-A century of the Tower of Babel, H. F. Weisberg, SP450, pp. $75-89$ (June 1977).

Tri-slide ${ }^{T M}$ calculator for Henderson-Hasselbalch equation and $\mathrm{CO}_{2} \mathrm{RREC}^{\circ} \mathrm{t}-\mathrm{O}_{2}-\mathrm{SLIDE}^{T M}$ for temperature corrections of pH, $\mathrm{PCO}_{2}$, and $\mathrm{PO}_{2}, \mathrm{H}$. F. Weisberg, SP45O, pp. 91-101 (June 1977).

Aids for evaluation of acid-base imbalance-Diagrams, nomograms, and slide-rules, H. F. Weisberg, SP450, pp. 103 117 (June 1977).

The overall first ionization equation of carbonic acid as related to $\mathrm{CO}_{2}$ in gas phase: $\mathrm{A}$ new $\mathrm{p} K, \mathrm{~A} . \mathrm{H}$. J. Maas and $\mathrm{B}$. F. Visser, SP45O, pp. 119-126 (June 1977).

Towards a physiological nomenclature for in vivo disturbances of acid-base balance, J. J. Cohen, SP450, pp. 127-129 (June 1977).

Minimal acceptance criteria for acid-base nomograms, J. J. Cohen, SP4SO, pp. 131-132 (June 1977).

A physiological approach to acid-base diagnostics, P. Kildeberg and K. Engel, SP450, pp. 133-141 (June 1977).

$\mathrm{CO}_{2}$ solubility, $\mathrm{pK}^{\prime}$ and related factors in acid-base balance, W. H. Austin, SP450, pp. 143-151 (June 1977).

Definition of oxygen saturation and characterization of oxygen-hemoglobin affinity, A. L. Malenfant, SP450, pp. 153162 (June 1977).

Problems associated with the definition of measured and calculated quantities in blood $\mathrm{pH}$ and gas analysis, R. W. Burnett, SP450, pp. 163-165 (June 1977).

Arterial and venous blood samples in acid-base balance, $W$. H. Austin, SP450, pp. 167-170 (June 1977).

Blood sampling and handling in the determination of blood pH and blood gases, A. H. Richards, SP4SO, pp. 171-173 (June 1977).

Non-analytical sources of laboratory error in $\mathbf{p H}$ and blood gas analysis, J. H. Ladenson, SP4SO, pp. 175-190 (June 1977).

Instrument specifications, S. R. Gambino, SP4SO, pp. 191193 (June 1977).

Effects of the liquid junction on pH measurement in blood; the $0.160 \mathrm{~mol} / \mathrm{l}$ sodium chloride bridge, A. H. J. Maas, SP450, pp. 195-200 (June 1977).

The critical care laboratory: A 10-year perspective, M. B. Laver and D. R. Misiano, SP450, pp. 201-206 (June 1977).

A theoretical and practical analysis of $\mathbf{P O}_{2}$ microelectrode behavior: The three-shell model, R. G. Buckles, H. Heitmann, and M. B. Laver, SP450, pp. 207-225 (June 1977).

Dynamic response of a $\mathbf{p C O}_{2}$ electrode, S. J. Pace and $\mathrm{M}$. J. D. Brand, SP45O, pp. 227-234 (June 1977).

Monitoring of oxygen pressure in human and animal blood, H. P. Kimmich and F. Kreuzer, SP450, pp. 235-238 (June 1977).

Alternative methods of $\mathrm{CO}_{2}$ measurement, with particular reference to continuous recording, $L$. H. J. van Kempen and F. Kreuzer, SP450, pp. 239-246 (June 1977).
NBS standards for $\mathrm{pH}$ and ion activity measurements in biological fluids, R. A. Durst and R. G. Bates, SP450, pp. 247-255 (June 1977).

Use of carbon dioxide- and oxygen tonometered phosphatebicarbonate-chloride-glycerol-water mixtures for calibration and control of $\mathrm{pH}, p \mathrm{CO}_{2}$, and $p \mathrm{O}_{2}$ electrode systems, $\mathrm{A} . \mathrm{H}$. J. Maas, A. H. Veefkind, R. A. M. Van den Camp, A. J. Teunissen, A. B. T. J. Boink, and T. J. C. Ruigrok, SP450, pp. 257-265 (June 1977).

Calibration of blood gas analyzers, A. H. Runck, SP45O, pp. 267-272 (June 1977).

Quality control, S. R. Gambino, SP450, pp. 273-274 (June 1977).

Quality control and standards, D. C. Noonan, SP45O, pp. 275-278 (June 1977).

Development of reference methods: Blood gas analysis, A. L. Malenfant and K. D. Fallan, SP4SO, pp. 279-283 (June 1977).

Quality control and standards, S. K. Sorensen, SP450, pp. 285-287 (June 1977).

Development of reference methods, S. K. Sørensen, SP450, pp. 289-29l (June 1977).

Standardization of ion-selective electrodes for serum analysis, M. S. Mohan and R. G. Bates, SP450, pp. 293-299 (June 1977).

Electrolyte activities in human blood plasma, M. J. D. Brand and W. J. Scott, SP450, pp. 301-310 (June 1977).

The King's College Hospital ion-selective electrode serum electrolyte analyzer, A. D. Hirst, P. Gay, P. Richardson, and P. J. N. Howorth, SP450, pp. 311-314 (June 1977).

SP457-1. Building technology publications 1976-Supplement 1,

J. R. Debelius, Ed., Nat. Bur. Stand. (U.S.), Spec. Publ. 457 -

I, 78 pages (June 1977) SN003-003-01802-3.

Key words: bibliography; building technology publications; Center for Building Technology; key word-author indexes; publication abstracts.

The complete citations for publications of the NBS Center for Building Technology (CBT) are given for the period January-December 1976. This supplement to NBS Special Publication 457, "Building Technology Publications 1965-1975," includes the titles and abstracts for CBT papers published during 1976 in both NBS and non-NBS media; key-word and author indexes are also included, along with general information and the availability of CBT publications.

Publications constitute the major end product of CBT programs and provide the primary means of communicating the results of NBS programs to its varied technical audiences, as well as to the general public.

SP458. Metrication and dimensional coordination-A selected bibliography, R. E. Clark and C. L. Roat, Nat. Bur. Stand. (U.S.), Spec. Publ. 458, 32 pages (Apr. 1977) SN003-00301684-5.

Key words: building codes and standards; construction industry; dimensional coordination; metrication; metric system; modular coordination; SI.

The United States changeover to the use of the SI (International metric) measurement language presents our construction industry with the need to review and adapt many 
product standards and practices for the use of metric measurement units. These adaptations and changes can bring substantial benefits to the industry in the form of permanently recurring cost savings. A practice of potentially great benefit would be the incorporation of dimensional coordination in the new metric standards for sizes of building products. For such benefits to be realized, however, the involved issues must be effectively addressed and the requisite decisions made and implemented. Considerable literature pertinent to the issues and decisions has been published in the United States and in the other (primarily English-speaking) countries that have been implementing metrication and dimensional coordination in the past decade. This report aids construction industry consideration and resolution of metrication decisions by providing a guide to the best available sources relevant to the issues.

SP461. Radiation physics. Proceedings of the International Symposium on Radiation Physics, held at Bose Institute, Calcutta, India, Nov. 30-Dec. 4, 1974, A. M. Ghose, D. V. Gopinath, J. H. Hubbell, and S. C. Roy, Eds., Nat. Bur. Stand. (U.S.), Spec. Publ. 461, 268 pages (Jan. 1977) SNO03003-01733-7.

Key words: cross sections; dosimetry; electrons; neutrons; photons, radiation physics; symposium.

These proceedings contain invited and contributed papers presented at the International Symposium on Radiation Physics organized by and held at the Bose Institute, Calcutta, India, Nov. 30-Dec. 4, 1974. The purpose of this symposium, recognizing radiation physics as the thread held in common by a variety of medical, engineering and scientific disciplines, was to bring together specialists from these disciplines to report on, exchange, and make available through these proceedings, information and experiences of common interest to workers in these diverse disciplines. Topics thus brought together in this symposium include new measurements, theoretical developments, compilations and applications of basic cross section and transport data for photon, electron, neutron and heavy ion beams interacting with matter. These proceedings include the following papers (indented):

Present status of photon cross section data $100 \mathrm{eV}$ to 100 GeV, J. H. Hubbell, SP461, pp. 3-16 (Jan. 1977).

Key words: atomic form factor; attenuation coefficients; cross sections; gamma rays, incoherent scattering function; pair production; photoelectric effect; photons; $x$ rays.

Recent developments in theoretical and experimental cross sections for the basic photon interactions with atoms (photoeffect, coherent and incoherent scattering, and electron-positron pair production) are reviewed. Emphasis is on the extensive total and subshell photoeffect calculations by J. Scofield, and on atomic form factor and ineoherent scattering function data calculated by D. Cromer and by R. Brown. Some comparisons of these theoretical results with available explicit cross section and total attenuation coefficient measurements are presented.

Semiempirical formulation of coherent scattering of gamma rays, S. C. Roy and A. M. Ghose, SP461, pp. 17-19 (Jan. 1977).

Key words: analytical formula; coherent scattering; cross section; gamma rays; photons; Rayleigh scattering.

An empirical formula to estimate Rayleigh scattering cross-section of gamma rays depending on photon energy and momentum transfer involved was first developed by Nath and Ghose by considering the available theoretical and experimental cross-section values. With availability of much accurate cross-section values in recent times by using large volume Ge(Li) detectors (M. Schumacher et al., Nucl. Phys. A206, 531 (1973); Nucl. Phys. A213, 306 (1973)] it becomes necessary to recheck the existing formula. We observe reasonable difference in cross-section values in the region where theoretical calculations are not available due to the uncertainties in earlier measurements. In the present paper an analytical formula of coherent scattering cross-sections of photons valid for photon energy below $1.5 \mathrm{MeV}$ and up to momentum transfer 2.0 in units of $\mathrm{mc}$ has been developed. The calculated values for different photon energies have been compared with experimental results and are in good agreement within experimental uncertainty.

Experimental photoionization cross sections of gamma ray photons for low, medium and high $\mathrm{Z}$ atoms, $\mathrm{B}$. Sinha and $\mathrm{N}$. Chaudhuri, SP461, pp. 20-22 (Jan. 1977).

Key words: coherent scattering; cross sections; gamma ray; incoherent scattering; pair-production; photoionization.

Direct measurements of subshell and total photoionization cross sections reported so far are relatively few. Total photoionization cross sections have been determined previously from the measured total photon attenuation cross sections using the available theoretical estimates of incoherent and coherent scattering cross sections and above $1.02 \mathrm{MeV}$ the electron-positron pair production cross section. This method is suitable at an energy region for such atoms for which photo absorption contribution is larger than or at least comparable to other individual contributions to the total photon attenuation coefficient. Theoretical investigations have been continued to improve the accuracy of individual cross sections. J. H. Scofield has calculated screened relativistic photoionization cross sections for all 100 atoms $(Z=1-100)$ in the energy range from $1 \mathrm{keV}$ to $1.5 \mathrm{MeV}$. Refined incoherent and coherent scattering calculations for all 100 elements over a wide energy range using SCF Hartree-Fock wave functions have been reported recently. Improved pair production cross sections are also available. In view of these accurate theoretical results and inadequacy of experimental information on photoionization in the energy from 10 to $100 \mathrm{keV}$ and above, we have evaluated experimental total photoionization cross sections for low, medium and high $\mathrm{Z}$ elements in the range $Z=12$ to 92 , from the very accurately measured total cross sections using the accurate theoretical estimates of partial cross sections. An analysis of the experimental results has been made and interpreted in a comparison of the theoretical photoionization results recently published. The $Z$ dependence and photon energy dependence of total cross sections have also been studied.

Inner bremsstrahlung accompanying electron capture in ${ }^{7} \mathbf{B e}$ and ${ }^{51} \mathrm{Cr}, \mathrm{H} . \mathrm{S}$ Sanjeevaiah and B. Sanjeevaiah, SP461, pp. 23 25 (Jan. 1977).

Key words: coincidence; electron capture; excited state; gamma ray; ground state; inner bremsstrahlung; Jauch plot; spectrum; transition.

The inner bremsstrahlung spectra accompanying electron capture in ${ }^{7} \mathrm{Be}$ and ${ }^{51} \mathrm{Cr}$ are studied in coincidence with the 477 and $325 \mathrm{keV}$ gamma rays respectively. The random coincidence counts are subtracted from the true plus random coincidence counts to get the inner bremsstrahlung spectra. The disintegration energies of ${ }^{7} \mathrm{Be}$ and ${ }^{51} \mathrm{Cr}$ leading to the first excited states of ${ }^{7} \mathrm{Li}$ and ${ }^{51} \mathrm{~V}$ respectively are determined from the Jauch plots. Using these values the total disintegration energies of ${ }^{7} \mathrm{Be}{ }^{7} \mathrm{Li}$ and ${ }^{51} \mathrm{Cr}{ }^{51} \mathrm{~V}$ decay processes are calculated. The total disintegration energies 
are also measured directly by studying the inner bremsstrahlung spectra emitted in the ground-to-ground transitions. The results obtained by these methods will be presented and discussed.

Inelastic scattering of $279-\mathrm{KeV}$ gamma rays by bound electrons in heavy atoms, D. S. R. Murty, V. G. Reddy, E. Narasimhacharyulu, and S. T. Swamy, SP461, pp. 26-28 (Jan. 1977).

Key words: bound electrons; cross section; gamma rays; inelastic scattering; $\mathrm{K}$-shell electron; photon; $\mathrm{x}$ ray.

The differential cross section for the inelastic scattering of $279-\mathrm{KeV}$ photons by $\mathrm{K}$-shell electrons of thorium was experimentally determined and expressed in terms of free electron scattering cross section at scattering angles of $30^{\circ}$, $50^{\circ}, 70^{\circ}, 105^{\circ}, 125^{\circ}$ and $150^{\circ}$. Two scintillation spectrometers and a fast-slow coincidence circuit were used. The differential cross section for the inelastic scattering vanishes as the scattering angle approaches zero and becomes larger than the free electron scattering cross section at very large angles. The experimental results were compared with those computed on the basis of different theories. Total cross section for the bound electron scattering was also obtained by graphical method.

Gamma ray attenuation coefficient measurements at 1115 , 1173 and $1332 \mathrm{keV}, \mathrm{S}$. Gopal and B. Sanjeevaiah, SP461, pp. 29-31 (Jan. 1977).

Key words: attenuation coefficient; counting sequence; cross section; gamma ray; photon.

Gamma ray attenuation coefficients in $\mathrm{C}, \mathrm{Al}, \mathrm{Cu}, \mathrm{Zr}, \mathrm{Sn}$ and $\mathrm{Pb}$ were measured for gamma ray energies 1115,1173 and $1330 \mathrm{keV}$ using the technique employed earlier by the authors for similar measurements at lower energies. The results will be presented here and discussed.

Radiation physics and nuclear technology, P. K. lyengar, SP461, pp. 32-40 (Jan. 1977).

Key words: cross section; energy transfer; gamma rays; moderator; neutron; radiation damage; reactor; scattering; spectrometer.

Understanding of basic interaction processes of radiations with atoms, nuclei and bulk matter contributes a lot towards the advances in nuclear technology. Yet it seems that more accurate and wide ranging measurements are required to make accurate predictions for the design of reactors, accelerators etc. The present article is a birds-eye view of the problems which need solution in new technologies-problems due to radiation effects, study and solution of which can arise from use of accelerators.

Variation of total to K-shell photoelectric cross section ratios with atomic number and photon energy, R. Gowda and B. Sanjeevaiah, SP461, pp. 41-43 (Jan. 1977).

Key words: atomic number; cross section; K-shell; measurement; photoelectric effect; photon.

The total to $\mathrm{K}$-shell photoelectric cross section ratios are calculated from the measured total and $\mathrm{K}$-shell photoelectric cross sections (using a well type plastic scintillation spectrometer) in copper, zirconium, silver, tin, tantalum, gold, and lead for $145.4,279.1,411.8$ and $661.6 \mathrm{keV}$ gamma rays. The ratios are plotted against the atomic number and also the photon energy. The theoretical ratios obtained from the cross sections of Scofield [UCRL Report No. 51326] are also plotted and a comparison is made. The dependence of these ratios on the atomic number of the element and the photon energy is discussed.
Optical model analysis of nonelastic interaction of $14.2 \mathrm{MeV}$ neutrons, B. Pal, A. Chatterjee, and A. M. Ghose, SP461, pp. 44-46 (Jan. 1977).

Key words: cross section; multiple bias; neutron; nonelastic; optical model; parameter; polynomial extrapolation; sphere transmission.

Nonelastic cross sections of several nuclei for $14.2 \mathrm{MeV}$ neutrons have been measured using sphere transmission technique. The measured data together with the results of others have' been analyzed with optical model using a least square criteria over a wide range of mass number $(12 \leqslant$ $A \leqslant 207$ ).

Geometric factors in radiation physics measurements, A. $M$. Ghose, SP461, pp. 47-54 (Jan. 1977).

Key words: absorption; accuracy; cross section; fast neutrons; geometric factors; photon; polarimeter; radiation physics; scattering; spectrometers.

Optimization of geometrical factors through symmetry considerations is a powerful means of improving the accuracy of measurements in Radiation Physics. This has been illustrated for the cases of spherical and axial symmetries. Design of double scattering fast neutron polarimeters as well as of gamma ray linear polarimeter systems have been discussed. Applications of the surface of revolution geometries to various fields have also been considered.

Measurement of angular distribution of incoherently scattered gamma rays from atoms, B. Sinha (Goswami) and N. Chaudhuri, SP461, pp. 55-56 (Jan. 1977).

Key words: angular distribution; cross section; gamma rays; photon; scattering, incoherent; $x$ rays.

There has been comparatively little experimental investigation on the whole-atom incoherent scattering of photons in the $x$-ray and gamma-ray regions. A rigorous theoretical treatment of this type of scattering has not yet yielded enough results and the incoherent scattering function approach is taken to calculate the incoherent scattering cross section. Recently, Cromer and Mann calculated using SCF Hartree-Fock wave functions the incoherent scattering function over a wide range of momentum transfer in the photon scattering process. These data are more accurate than the earlier Hartree-Fock data in the low momentum transfer range and form the only available most comprehensive set of data over the range of momentum transfer up to $3.9 \mathrm{mc}$. In the present work, the angular distribution has been measured for incoherent scattering of $662 \mathrm{keV}$ and $1.115 \mathrm{MeV}$ photons by atoms with low, medium and high $\mathrm{Z}$ in the angular range from $1^{\circ}$ to $165^{\circ}$. The experimental values of the incoherent scattering function have been interpreted on the basis of Cromer's theory.

Measurement and analysis of a few $14 \mathrm{MeV}$ neutron capture cross sections, M. Majumdar and B. Mitra, SP461, pp. 57-59 (Jan. 1977).

Key words: activation; capture reaction; cross section; measurement; neutron; $\beta$-counting error.

Total $14 \mathrm{MeV}$ neutron capture cross sections of seven representative nuclei have been measured by activation method, in a relative way. Data with an estimated error of \pm 2 percent have been presented. Analysis of $\sigma(n, \gamma)$ total has been attempted with (a) Statistical evaporation type formula presented by Naguib and Lukyanov and (b) Direct reaction formula presented by Lane and Lynn. It has been shown that D.l. gives absolute estimate of values agreeing 
with experimental ones. Statistical model analysis with carefully adjusted neutron width function yiclds rather high radiative strength function.

Intermediate energy approximation of the Bethe-Heitler formula for the bremsstrahlung cross-sections, $K$. Gopala and B. Sanjeevaiah, SP461, pp. 60-63 (Jan. 1977).

Key words: approximation; bremsstrahlung; cross section; electron; intermediate energy; photons.

Bremsstrahlung cross section calculations are still attracting attention because of the inadequacy of the existing formulae. The Sommerfeld-Elwert formula holds good up to $0.1 \mathrm{MeV}$. Bethe and Heitler gave a relativistic expression for the bremsstrahlung cross sections using Dirac's electron theory and Born approximation. Coulomb and screening effects were not included in their calculations. Calculations of the bremsstrahlung cross sections using the $\mathrm{B}-\mathrm{H}$ formula are tedious. Approximations of the $\mathrm{B}-\mathrm{H}$ formula in the nonrelativistic and extreme relativistic regions exist. But no such approximation is available in the intermediate energy region. An attempt is made to obtain an approximation of the $\mathrm{B}-\mathrm{H}$ formula in the intermediate energy region. Several approximations are made to reduce the $\mathrm{B}-\mathrm{H}$ formula into a polynomial in $\mathrm{x}$, the ratio of the photon energy to the total energy of the incident electron. The coefficients of the polynomial turn out to be a long series of terms which are functions of incident electron energy. The validity of the approximate formula in the intermediate energy region will be discussed.

A new method for the measurement of differential elastic scattering cross sections of fast neutrons, S. Nath, A. Chatterjee, and A. M. Ghose, SP461, pp. 64-66 (Jan. 1977).

Key words: cross section; differential; elastic; multiple bias technique; neutron; scattering.

A new method has been described which successfully reduces the problem of low scattering intensity. The scatterer has been taken in the form of a spheroid. The elastically scattered neutrons have been discriminated from the inelastically scattered ones by using multiple bias technique. Experimentally measured values of differential elastic scattering cross sections for sulphur at four angles for $14 \mathrm{MeV}$ neutrons have been presented. The results have also been compared with the optical model prediction.

Compton scattering of $1.12 \mathrm{MeV}$ gamma rays by $\mathrm{K}$-shell electrons, P. N. B. Prasad, G. Basavaraju, and P. P. Kane, SP461, pp. 67-69 (Jan. 1977).

Key words: Compton scattering; differential cross section; electron binding; gamma rays; K-shell; photons.

Two sodium iodide counters in coincidence and a twenty channel pulse height analyzer have been used to determine the pulse height distribution of $1.12 \mathrm{MeV}$ gamma rays which are Compton scattered by the K-shell electrons of gold, lead and thorium. The angular variations of the differential cross section ratio, $\mathrm{d} \sigma \mathrm{K} / \mathrm{d} \sigma \mathrm{F}$, have already been reported. The present measurements were made at 60 and $100^{\circ}$ scattering angles. At $60^{\circ}$, lead targets of $30 \mathrm{mg} / \mathrm{cm}^{2}$ and $143 \mathrm{mg} / \mathrm{cm}^{2}$ were used. At $100^{\circ}$, targets of gold $(13$ $\mathrm{mg} / \mathrm{cm}^{2}$ ), lead $\left(143 \mathrm{mg} / \mathrm{cm}^{2}\right)$ and thorium $\left(14 \mathrm{mg} / \mathrm{cm}^{2}\right)$ were used. In all cases, pulse height distributions of false coincidence events were determined and subtracted from the measured distributions in order to obtain the true distributions. A broadening of the K-shell electron Compton peak has been observed. The results of these measurements are discussed.
Nuclear theory based cross sections of TH-232, TH-233 and U-233 and their applications in reactor technology, S. B. Garg and A. Kumar, SP461, pp. $70-73$ (Jan. 1977).

Key words: calculation; cross section; optical model; reactor technology; scattering-elastic, inelastic, total; thorium; uranium.

Thorium. fuel cycle is an active subject of research-more so for us since we have large deposits of thorium. Because of various reasons thorium has not found much favour with the reactor technologists and therefore its cross sections have not been studied with the desired accuracy. Cross sections make their impact on reactor design right from its inception to its completion and therefore a coherent study of the cross sections of thorium and uranium-233 has been made. In Reactor Physics studies emphasis is placed on total, fission, capture, elastic and inelastic scattering cross sections. Generally, the measured information on inelastic scattering cross section of heavy nuclides is not sufficient in the $\mathrm{MeV}$ energy range for reactor applications. In order to correctly predict the neutron spectrum and its effect on reactor parameters the inelastic cross sections have been evaluated with the local optical and statistical models. The total and elastic scattering cross sections have also been evaluated together with the angular distributions of elastically and inelastically scattered neutrons. Multigroup temperature dependent cross sections have also been generated for thorium and uranium-233 in the entire energy range extending up to $10 \mathrm{MeV}$.

The development of radiation shielding standards in USA, D. K. Trubey, SP461, pp. 74-78 (Jan. 1977).

Key words: American Nuclear Society; radiation; shielding; standard.

The American Nuclear Society (ANS) is a standardswriting organization-member of the American National Standards Institute (ANSI). The ANS Standards Committee has a subcommittee denoted ANS-6, Shielding, whose charge is to establish standards in connection with radiation shields, to provide shielding information to other standards writing groups, and to prepare recommended sets of shielding data and test problems. This paper is a progress report of this subcommittee.

Integral equation methods in radiation transport, $D . V$. Gopinath, SP461, pp. 79-86 (Jan. 1977).

Key words: integral equation; radiation; scattering; seminumerical; transport.

This paper presents a review of the work done on the development of integral equation methods for different problems in radiation transport. The cases considered are: (i) Three-dimensional (XYZ) geometry and (ii) One dimensional time-dependent transport for the transport of (a) Charged particles and (b) Optical radiation. The methods are developed for arbitrary degree of anisotropy, and their simplification in the case of isotropic scattering are discussed. Few typical results are presented and the advantages of integral equation methods are discussed.

Neutron transport problems in spherical geometry, D. C. Sahni, SP461, pp. 87-90 (Jan. 1977).

Key words: density transform; expansion coefficient; Green's function; neutron; spherical; symmetric; transport.

The density transform method has been extended to cover spherically symmetric neutron transport problems. The density transform is expanded in plane geometry nor- 
mal modes and explicit singular integral equations are derived for the expansion coefficients. The method is thus an extension of Case's method of singular eigen-functions to spherical geometry problems. The Green's function approach for transport problems in spherical geometry has been considered. It is shown that the reduction operators used in this method can solve only some of the problems in the intcrior of a solid homogeneous spherc.

Transport of neutrons during reactor transients, S. K. Kapil, SP461, pp. 91-93 (Jan. 1977).

Key words: approximations; fast-thermal couple reactor; neutron; reactor transients; solution; time-dependent; transport; transport equation.

The study of time dependent behaviour of nuclear reactors is important from operational and safety considerations. 'In this papcr, situations requiring an explicit time dependent solution of the transport equation are identified. The range of validity of the approximation methods in different situations is discussed. Finally, severe transients in a Fast-Thermal coupled reactor are computed with various commonly used approximations and also by an explicit time-dependent solution of the Boltzmann equation, using a set of computer codes which were specially developed for the purpose. It is shown that the commonly used approximate methods can lead to erroneous results. The reasons for the deviation of the solutions for the different approximations from the correct behaviour of the reactor under transient are discussed.

Criticality calculations by source-collision iteration technique for cylindrical systems, V. K. Sundaram and D. V. Gopinath, SP461, pp. 94-96 (Jan. 1977).

Key words: criticality; collision; cylindrical; energy; integral; iterative; neutron; transmission matrix.

This paper presents a fast-converging iterative technique using first collision probabilities developed for obtaining criticality parameters in two-region cylindrical systems with multigroup structure in energy of the neutrons. The space transmission matrix is obtained part analytically and part numerically through evaluation of a single-fold integral. Critical dimensions for condensed systems of uranium and plutonium computed using this method are presented and compared with published values.

Stochastic method of calculations for fast systems, B. K. Godwal and M. P. Navalkar, SP461, pp. $97-99$ (Jan. 1977).

Key words: BESM-6; JEZEBEL; Markov process; neutron; PURNIMA; Rossi- $\alpha$; slowing down; stochastic.

Neutron slowing down is a Markov process in which the probability for being in a certain volume element in phase space (space-time-energy) at some future time depends only on the present state of the system and not on the past. The process has been approximated to a discrete time, discrete state by Williamson et al., to determine state transition probabilities. In this paper, this approach has been extended to calculate Rossi- $\alpha$ which is an important dynamic parameter of the system. The values of $\mathbf{K}_{\text {eff }}$ as a function of $\mathbf{B}^{2}$ for the bare core of Zero Energy Fast Critical Facility, PURNIMA calculated from this method showed good agreement with the bare critical experimental parameters obtained from fission rate distribution. A method to extend this method of calculations to reflected system has also been described.

A random sampling technique for choosing scattering angles from arbitrary angular distributions in dosimetric and shield- ing computations, P. S. Nagarajan, C. P. Raghavendran, P. Sethulakshmi, and D. P. Bhatia, SP46I, pp. 100-105 (Jan. 1977).

Key words: angle; centre of mass; coefficients; computations, cross-section; Legendre polynomial; neutron; random sampling; scattering; shielding.

A random sampling technique has been developed for sampling the cosine of the scattering anglc of the neutron in the centre of mass system. This technique could be incorporated in existing shielding and dosimetry codes. Recent differential scattering cross section data (from BNL-400 (1970)) is expanded in double Legendre polynomials of incident neutron-energy and a random number. The necessary coefficients for the elements $C, N$, $\mathrm{O}, \mathrm{Si}, \mathrm{Ca}, \mathrm{Fe}$ and $\mathrm{Pb}$ for incident neutron energies upto 15 $\mathrm{MeV}$ have been obtained and the same are presented along with typical results, checking the method and coefficients.

Monte Carlo calculations on dose distributions from plane infinite oblique electron sources, C. R. Gopalakrishnan and V. Sundararaman, SP461, pp. 106-109 (Jan. 1977).

Key words: aluminium; carbon; collision; copper; distribution; dose; electron; Gaussian; Monte Carlo; scattering.

A modified Monte Carlo method has been developed for tracking electrons. In this method individual collisions wherein the electron suffers a large deflection or loses large fraction of its energy (denoted as catastrophic) are treated separately. The history of the particle is divided into sections, within which no catastrophic collisions occur and in which continuous-slowing down is assumed. The angular distribution at the end of a section follows a Gaussian distribution. In this method the correlation between energy-loss fluctuations and multiple scattering deflections is preserved more faithfully. Dose distributions for electrons in carbon, aluminium and copper have been calculated for oblique incidence using this method. Data have been obtained for five different initial angles and covering a range of energies from 0.05 to $10 \mathrm{MeV}$ electrons.

Backscattering of gamma rays, T. Hyodo, SP461, pp. $110-$ 118 (Jan. 1977).

Key words: albedo; backscattering; distribution; dose rate; gamma rays; Monte Carlo; photon.

A survey of principal research on the backscattering of gamma rays is described. This is a macroscopic phenomena composing many photons scattered backward from a surface of material. After a historical survey as an introduction, principal theme of research is described; nomenclature of albedo, Monte Carlo calculation, measurement of albedos, semi-empirical formula of the differential albedo, exposure dose rate distribution outside a scatterer, distribution of scattered gamma rays on the surface.

Transmission of ${ }^{252} \mathrm{Cf}$ fission neutrons through various shields, Y. T. Song, SP461, pp. 119-123 (Jan. 1977).

Key words: ANISN; code; configuration; dose equivalent; energy; gamma rays; neutron; scattering; shield; transmission; ${ }^{252} \mathrm{Cf}$.

Measurements have been made of neutron transmission through various shield configurations. $A{ }^{252} \mathrm{Cf}$ source, having a neutron yield of $1.02 \times 10^{6} \mathrm{n} / \mathrm{sec}$ was used with a U.S. Navy neutron dosimeter, AN/PDR-70. This detector was used to measure the integrated neutron dose equivalent (DE). 3 by $5 \mathrm{ft}$. slab shields of various materials were used, such as iron, lead, polyethylene, combinations 
of iron-polyethylene, lead-polyethylene, and iron polyethylene-iron. The measured data were corrected for room-scattered contributions. The scattered neutron DE was calculated using the differential dose albedo formula of Song, et al. The experimental data thus obtained were compared with calculated values. The one-dimensional discrete ordinates neutron transport code, ANISN, with 40 energy groups, 22 groups for neutron and 18 groups for $\gamma$-rays, was used for the transmission calculations. Comparisons were made in terms of attenuation factors, the ratio of transmitted neutron $D E$ to free-field neutron $D E$ at the detector point. Agreement was within the expected dosimeter range of 20 percent for all cases. For the case of two inches of iron and five inches of polyethylene, placing the iron on the source side was more effective than placing it on the opposite side.

Back-scattering (sky-shine) of gamma-rays from a 650 Curie cobalt -60 source by infinite air, J. Swarup and A. K. Ganguly, SP461, pp. 124-128 (Jan. 1977).

Key words: back scattering; gamma rays; sky-shine; spectrum; ${ }^{60} \mathrm{Co}$

The paper reports the preliminary results obtained on the sky-shine spectra from a $650 \mathrm{Ci}{ }^{60} \mathrm{Co}$ source located at the centre of a gamma irradiation field of radius $90 \mathrm{~m}$ fenced by a stone wall of thickness $\sim 75 \mathrm{~cm}$ and height $3.66 \mathrm{~m}$. The source is in the form of small pellet. The height of the source when raised for irradiation is $1.2 \mathrm{~m}$ above ground level and it is shielded on top by a lead cylinder of $10 \mathrm{~cm}$ diameter and $25 \mathrm{~cm}$ length. Thus, only the scattered radiation can reach the ground level beyond the fencing wall. There is a field of $100 \mathrm{mR} / \mathrm{hr}$ on the inner side and $2 \mathrm{mR} / \mathrm{hr}$ on the outer side of the wall with the source raised. Experiments are carried out for the measurement of sky-shine with a well-shielded Nal detector assembly coupled to a 400-channel analyzer. The detector is placed $55 \mathrm{~cm}$ above ground looking vertically up through a lead collimator of diameter $12 \mathrm{~mm}$ (or $20 \mathrm{~mm}$ ) at distances from $150 \mathrm{~m}$ to $325 \mathrm{~m}$ away from the source. Energy calibrations of the spectra have been carried out before and after each experiment using standard sources of gamma-energy ranging from $60 \mathrm{keV}$ to $662 \mathrm{keV}$. It is found that the spectrum extends up to $400 \mathrm{keV}$ with a pronounced peak at $72 \mathrm{keV}$ for all the distances. There is no evidence of the presence of primary gamma-photons in the spectra. Total counts under the sky-shine are observed to follow an exponential decline with distance, with a slope of $-0.50 \pm 0.02$ for both the collimators used. The ratio of peak counts ( $72 \mathrm{keV}$ ) to total sky-shine is $0.24 \pm 0.02$ for both the collimators. Also, the nature and intensity of the spectra remain unchanged when the lead shield around the detector is provided with an internal lining of $2.5 \mathrm{~cm}$ thick aluminium.

Backscattering of gamma rays by barriers from various media, D. B. Pozdneyev, SP461, pp. 129-131 (Jan. 1977).

Key words: albedo; angular; backscattering; barrier; differentials; distribution; gamma rays; integral; medium; Monte Carlo.

Quantitative data about albedo of gamma radiation must be known to solve some problems of radiation shielding, radiometry, nuclear instruments.' Spatial-energy differential and integral characteristics of gamma rays albedo for the case of the barriers of different thicknesses from beryllium, graphite, aluminium, concrete, iron, tin, and lead were determined both experimentally and by means of Monte Carlo method. Energies of gamma rays from the point isotropic source and of monodirectional beam were $145,279,511,662,1000$ and $1250 \mathrm{keV}$. Spectral-angular distribution of back-scattered gamma rays escaping from various portions of the barrier surface as a function of thickness and material of barrier, distance from the source, geometry of the source and energy of primary gamma radiation was also investigated. Systematized data about differential and integral albedo of gamma rays of various energies for the case of barriers of different thickness from various media are presented in the form convenient for practical uses.

Gamma ray streaming through annular cylindrical duct, $K$. P. N. Murty, R. Vaidyanathan, and R. S. Singh, SP461, pp. 132-135 (Jan. 1977).

Key words: annular; computation; duct; gamma ray; integration; kernel; radiation; streaming.

In this paper we present the study of gamma ray streaming through an annular cylindrical duct from an infinite plane source. A rigorous formulation based on the rayanalysis procedure has been developed to compute the resultant dose in the vicinity of the duct exit. A parametric study has been carried out to evaluate the accuracies obtained with the present rigorous treatment as compared to the simple formula developed for hand calculations. Attempts are being made to incorporate the scattering component to the dose at the exit, in our present study.

Multiple scattering of 12 to $\mathbf{4 0} \mathrm{MeV}$ heavy ions through small angles, B. W. Hooton, J. M. Freeman, and P. P. Kane, SP461, pp. 136-139 (Jan. 1977).

Key words: angular distribution; chlorine; foils; ions; iron, oxygen; measurement; Moliere theory; multiple; scattering.

Collimated beams of heavy ions were allowed to pass through thin foils. The angular distributions of the transmitted beams were measured with a position sensitive silicon detector. Oxygen, chlorine and iron ions of energy between 12 to $40 \mathrm{MeV}$ were used in conjunction with carbon, aluminium, nickel and gold foils of thicknesses between 12 to $250 \mu \mathrm{g} / \mathrm{cm}^{2}$. Values obtained for the halfangles of the distributions at half height are in fair agreement with the recent theoretical predictions of Meyer (1971). The data deviate substantially from the values calculated on the basis of the Moliere theory (1948) and even more markedly from those based on the theory of Nigam, Sundaresan and Wu (1959). Reasons for the success of the recent Meyer theory in the interpretation of the new data will be clarified.

Charged particle transport in one-dimensional finite systems, G. Muthukrishnan, K. Santhanam, and D. V. Gopinath, SP461, pp. 140-143 (Jan. 1977).

Key words: anisotropy; charged particle; computer code; energy-angle; integral; legendre polynomial; scattering; semi analytical; spatial; transmission.

A semi-analytical technique for the charged particle transport in one-dimensional finite media is developed which can be applied to multi-energy multi-region systems with arbitrary degree of anisotropy in scattering. For this purpose the transport equation is cast in the form of coupled integral equations separating spatial and energy-angle transmission. The spatial transmission is evaluated using discrete ordinate representation in space, energy and direction cosine for the particle source and flux. The collision integral is evaluated using discrete ordinate representation in energy and legendre polynomial approximation in the direction cosine. A computer code based on the above iurmulation is described. 
Passage of heavy charged particles through matter, S. Mukherii and B. K. Srivastava, SP461, pp. 144-148 (Jan. 1977).

Key words: charge; charged particle; collision; electron; ionic charge; ionization potential; stopping power; stripped particle; velocity.

The energy loss of charged particles (much heavier than electrons) at energies where electronic collision predominates may be studied conveniently by separating the particles into two groups: completely stripped particles and partially stripped particles. Bethe's quantum mechanical stopping power equation is of limited applicability for the first group of particles and inapplicable for the second group. A general stopping equation valid for all ions up to relativistic energies has been developed which predicts the experimentally measured stopping powers and ranges of partially stripped heavy ions accurately. From the detailed analysis of the equation a simple formula to predict the number of orbital electrons with velocity less than a given velocity in an element of atomic number $\mathrm{Z}$ has been developed. Assuming the above equation to be valid for all the orbital electrons except the two K-shell electrons, it has been possible to calculate the mean excitation potential for any medium.

Neutron thermalization in hydrogenous moderators, L. S. Kothari, SP461, pp. 149-162 (Jan. 1977).

Key words: cross section; diffusion; kernel; lattice vibration; model; moderator; neutron; scattering; thermalization.

The mechanism of neutron scattering from various moderators is a poorly understood subject. Exact calculations of neutron scattering properties of commonly used moderators namely light and heavy water and graphite are extremely difficult. Calculations of neutron scattering from light and heavy water are complicated because of our imperfect understanding of liquid structures. Therefore one has to depend on various approximations or models for such calculations. This paper first stresses on investigations carried out in this field for hydrogenous moderators. A scattering kernel for light and heavy water and its mixtures developed by us considering the low-frequency collective oscillations in the quasicrystalline approximation using Debye distribution has then been described. The total scattering cross section, diffusion coefficient and various other physical parameters calculated on the basis of this kernel has been presented and compared with the available experimental and theoretical results.

Neutron transport studies in fast reactor shields, $R$. Vaidyanathan, K. P. N. Murty, and R. S. Singh, SP461, pp. 163-165 (Jan. 1977).

Key words: approximations; diffusion; neutron; NIOBE; Rapsodie; reactor; shielding; transport calculation.

The present study aims at evaluating the relative accuracies with which the different approximations to the transport theory represent the spatial and spectral distribution of neutrons in a typical fast reactor shield. Diffusion, removal diffusion and discrete ordinate transport calculations, with and without the inclusion of anisotropic scattering effects, have been performed for the lateral and axial shield configurations of the French fast reactor Rapsodie. The results have been compared, with the measurements made in Rapsodie and the NIOBE calculations made earlier.

Shielding for the variable energy cyclotron at Calcutta, G. Muthukrishnan, H. Singh, and R. Mukherjee, SP461, pp. 166-170 (Jan. 1977).
Key words: calculation; concrete; cyclotron; design; earth shield; neutron spectra; shielding; shield thickness.

Shielding calculations are done for the AVF Cyclotron under construction at Calcutta. Concrete shields are designed to reduce the fast neutron flux to less than the maximum permissible levels outside the shields. Earth shields are designed to reduce the fast neutron flux outside the building to less than the maximum permissible levels for public exposure. Experimentally measured values of half-value layer thickness are used in the calculations. Neutron source strengths are obtained by extrapolation to higher energies from published values at lower energies. Total neutron spectra consisting of both cascade and evaporation neutrons are computed for the bombardment of $60 \mathrm{MeV}$ protons on a $\mathrm{Li}$ target, using semiempirical relations. In order to calculate the roof shield thicknesses calculated total neutron emission spectrum due to the bombardment of $60 \mathrm{MeV}$ deuterons on a Be target is considered. Shield thicknesses thus obtained, are comparable with values calculated for a similar cyclotron at Texas A and $M$ University. The calculated neutron dose outside the shield agrees well with the values predicted by Monte Carlo calculations.

Computer codes and data available from the radiation shielding information center, D. K. Trubey, B. F. Maskewitz, and R. W. Roussin, SP461, pp. 171-173 (Jan. 1977).

Key words: computer code; data library; information; radiation; radiation analysis; $\mathrm{RSIC}$; shielding.

The Radiation Shielding Information Center (RSIC) is a technical institute serving the international shielding community. It acquires, selects, stores, retrieves, evaluates, analyzes, synthesizes, and disseminates information on shielding and ionizing radiation transport. The major activities include: (1) operating a computer-based information system and answering inquiries on radiation analysis, (2) collecting, checking out, packaging, and distributing large computer codes and evaluated and processed data libraries. The data packages include multigroup coupled neutron-gamma-ray cross sections and kerma coefficients, other nuclear data, and radiation transport benchmark problem results.

Gamma ray build-up factors for finite media, K. John and D. V. Gopinath, SP461, pp. 174-176 (Jan. 1977).

Key words: ASFIT; build-up factor; empirical; energy; gamma ray; mean free path.

Using the transport code ASFIT, energy build-up factors are calculated for various energies and different systems. The results presented here are the energies $0.05,0.1,0.2$, $0.4,0.66,0.8,1.0,1.25,1.5$, and $2.0 \mathrm{MeV}$. Media considered -are air, aluminium, beryllium, calcium, carbon, hydrogen, iodine, iron, lead, magnesium, molybdenum, oxygen, silicon, sulphur, tin, uranium and water and their thicknesses are 1.0,2.0,4.0,6.0,8.0,10.0, 15.0 and 20.0 mean free paths. Empirical formulae of the exponential polynomial type have been obtained for these finite region build-up factors. Dependence of the constants in the empirical formulae on the material property $\mathrm{Z}$ has been discussed.

Physical principles of photon dosimetry, W. S. Snyder, SP461, pp. 177-182 (Jan. 1977).

Key words: dose; dosimetry; Monte Carlo; organ; phantom; photon; reciprocity theorem; source; target; tissue. 
Estimation of dose absorbed in the human body is important from the point of view of health physics as well as because of the increased utilization of nuclear radiation in clinical and diagnostic medicine or therapy. An idealized mathematical model of the human body was developed and Monte Carlo calculation was applied to evaluate the photon dose. In this paper the attention is restricted to certain physical results or principles which are a by-product of such studies. These relate to evidence on the validity of the reciprocity theorem, use of the build-up factor for an infinite medium of tissue in calculating absorbed fractions, scaling absorbed fractions for the weight of the target organ, and the effects on nonhomogeneity of the body on absorbed dose to the organs.

Track theory applied to physical, chemical and biologicaI systems, S. C. Sharma and R. Katz, SP461, pp. 183-187 (Jan. 1977).

Key words: cell; delta ray; dose; ions; LET; model; neutron; OER; one-hit detector; pion; radiation; track.

The conceptual structure of the $\delta$-ray model of track effects will be presented. Its universal applicability to a wide spectrum of radiation detectors and radiation environments will be shown. For l-hit detectors, the response with LET variation is described by two parameters, the D-37 dose for gamma-rays and the size of the sensitive element. The role of 1-hit detectors in the measurement of radiation quality will be briefly outlined. A simple cellular model which applies to cells whose radiosensitivity parameters have been determined experimentally yields the cellular survival, RBE, OER etc. for heavy ions, neutrons and pions.

Spectrum shapes of low-energy photon sources, R. C. Sharma, S. Somasundaram, K. Unnikrishnan, and S. Datta, SP461, pp. 188-192 (Jan. 1977).

Key words: detector; Monte Carlo; perspex; photon energy; pulse height; resolution; scattering media; tissue; water.

The spectrum shapes of low-energy photon (LEP) sources undergo interesting changes in the presence of scattering media of low atomic numbers. Two readily observed changes in the spectrum shape are (a) downward shift of the peak energy and (b) apparent deterioration of the energy resolution of the detector. A study of these changes is useful for in vivo assessment of LEP-emitters such as ${ }^{241} \mathrm{Am},{ }^{239} \mathrm{Pu}, \mathrm{U},{ }^{210} \mathrm{~Pb}$ etc. A computer program, based on Monte Carlo principles, has been evolved to compute the magnitudes of these changes in pulse-height distribution. Calculations were performed for point sources of low-energy photons located on the axis of the detector and for different thicknesses of the scattering medium interposed between the source and the detector. The variable parameters considered in these calculations are initial photon energy, thickness of the interposed material and type of detector. The magnitudes of both the above-mentioned changes in the pulse-height spectra of LEP sources embedded under media of low effective atomic number, such as water $(\bar{Z}=7.42)$, tissue $(\bar{Z}=7.33)$ and perspex $(\bar{Z}$ $=6.47$ ), are found to be dependent to a great extent on the energy resolution of the detector employed, apart from the electron density and effective atomic number of the scattering medium. The theoretical results are presented and compared, wherever possible, with experimental values obtained with $\mathrm{NaI}$ (T1) detector.

Dose function for beta dosimetry, S. J. Supe and S. Datta, SP461, pp. 193-196 (Jan. 1977).
Key words: air dose; arbitrary shaped field; back-scatter factor; Clarks' method; depth dose; dosimetry; surface dose.

The feasibility of using various shapes and sizes of field limiting devices and collimators with beta ray eye applicators has necessitated the study of dosimetry for these fields. A method of obtaining dosimetry for any shaped field from the data for circular fields is presented. The method is based on a similar procedure for $\mathrm{X}$ and gamma rays. The surface dose computation is done based on Clarkson's method but without splitting the surface dose into air dose and back-scatter dose. The depth dose evaluation is based on depth dose function which is defined as the dose rate at a particular depth for particular circular field. The usual method of splitting depth dose into primary and scatter doses was not found necessary. The evaluated values for the surface and depth dose were compared with experimentally obtained values for three noncircular fields. The good agreement in these data indicates the practicability of the method suggested.

Actual problems in photon dosimetry, D. F. Regulla and G. Drexler, SP461, pp. 197-208 (Jan. 1977).

Key words: dosimetry units; photon dosimetry; radiation; solid state dosimetry.

A brief review of the evolution of quantities and units in dosimetry is given, and the relevance of the dosimetry concept to applications in medicine, technique and health physics is pointed out. While radiation dosimetry seems to have, from a physical point of view, achieved an adequate status, handling of the physical fundamentals as well as practical application of quantities, units and measurement methods to operational dosimetry appears to be limited mainly to the level of highly competent authorities in dosimetry, such as ICRU or, on a national basis, to primary standard laboratories. This consequence is based on the authors' experience, that there is hardly a country, in which the numerical value of a dosimetrical quantity can be determined reproducibly through the different institutions engaged with practical dosimetry. WHO and IAEA, for this reason, started to establish a net-work of secondary standard laboratories, recently, with the aim of an improvement of dosimetry in medicine, radiation protection and radiation research. Details of this joint international effort on standardization are given, results already evident in some countries are presented. Recent advances, particularly in solid state dosimetry, are discussed together with the scientific aspects of physics in diagnostic radiology. To the authors' opinion almost every effort in the field of diagnostic radiology is worthy and promising for reasons of reduction of population dose and amelioration of information but also due to the broad interdisciplinary possibilities, the immediate output of applied research and, last not least, the benefit to mankind. Some examples on new results of medical physics as well as an outlook to future developments are given.

Neutron dosimetry by thermoluminescence dosimeter, Y. Furuta and S. Tanaka, SP461, pp. 209-2 18 (Jan. 1977).

Key words: charged particle; dosimeter; dosimetry; efficiency; gamma ray; kerma; neutron.

In this report, a historical survey of neutron dosimetry by thermoluminescence dosimeter (TLD) is made to begin with and then, as the basic problems for neutron dosimetry, the energy response to neutrons, gamma-ray discrimination performance in gamma neutron mixed fields, and sensitivity improvement are described. Further- 
more, two types of conversion efficiencies are introduced to obtain the integral glow value of TLD from its kerma value. These efficiencies are given for any charged particle and may serve not only to estimate neutron energy response of any TLD but also to study the energy transfer to material from charged particles. As applications of these studies, the possibility of development of a rem response TLD or absorbed dose measurements for neutrons by TLD are also described.

Effect of heat treatments on thermoluminescence of pure $\mathrm{AI}_{2} \mathbf{O}_{3}$, A. S. Basu and A. K. Ganguly, SP461, pp. 219-221 (Jan. 1977).

Key words: aluminium oxide; glow; heat treatment; impurity; temperature; thermoluminescence.

Six TL glow-peaks at the temperatures $100{ }^{\circ} \mathrm{C}, 150{ }^{\circ} \mathrm{C}$, $200{ }^{\circ} \mathrm{C}, 275{ }^{\circ} \mathrm{C}, 310^{\circ} \mathrm{C}$ and $415^{\circ} \mathrm{C}$ are observed in pure $\mathrm{Al}_{2} \mathrm{O}_{3}$ after gamma irradiation. For higher exposures ( $>$ $1000 \mathrm{R}$ ) the $275^{\circ} \mathrm{C}$ TL glow-peak is masked by the lower temperature peaks and is not seen. Thermoluminescence of this pure $\mathrm{Al}_{2} \mathrm{O}_{3}$ is investigated after different thermal treatments. The overall sensitivity increases with annealing temperatures and reaches a maximum at about $1200{ }^{\circ} \mathrm{C}$. The results are explained in terms of the structural change in alumina during these heat treatments.

Thermoluminescence mechanisms in lithium fluoride, S. P. Kathuria, V. N. Bapat, C. M. Sunta, and V. K. Jain, SP461, pp. 222-226 (Jan. 1977).

Key words: gamma rays; irradiation; LiF; optical absorption; spectral distribution; thermoluminescence.

Five glow peaks upto $200{ }^{\circ} \mathrm{C}$ are well known in lithium fluoride after gamma irradiation. Seven new glow peaks above $200{ }^{\circ} \mathrm{C}$ are reported in the present work. They are designated as I to XII in the ascending order of temperature of appearance. Activation energies are determined by initial rise method for five glow peaks, which could be well isolated by partial annealing from the lower temperature glow peaks. TL emission from the prominent glow peaks is similar and contains four bands with maxima at $370 \mathrm{~nm}$, $390 \mathrm{~nm}, 415 \mathrm{~nm}$ and $470 \mathrm{~nm}$ approximately. The spectral distribution of the total TL emission and emission from glow peaks $\mathrm{V}\left(195^{\circ} \mathrm{C}\right)$ and $\mathrm{XII}\left(400^{\circ} \mathrm{C}\right)$ are obtained also by plotting the integrated intensities of individual glow curves recorded at every $5 \mathrm{~nm}$ interval from $250 \mathrm{~nm}$ to $800 \mathrm{~nm}$. The TL emission spectra obtained in this way are corrected for the instrument response. Optical absorption spectrum of lithium fluoride crystal is recorded after gamma irradiation. Distinct absorption bands are observed at $225 \mathrm{~nm}, 250 \mathrm{~nm}, 310 \mathrm{~nm}$ and $380 \mathrm{~nm}$. Absorption spectra are recorded also after various thermal annealing treatments. The spectral similarity of individual glow peaks and the continuous bleaching of $F$ band $(250 \mathrm{~nm})$ with the annealing of individual peaks, shows that $F$ centre takes part in recombination process at each stage of glow peak emission. The thermally released carrier at individual glow peaks is therefore of hole type.

Thermoluminescence response of $\mathbf{L i F}$ to gamma rays, V. K. Jain and S. P. Kathuria, SP461, pp. 227-230 (Jan. 1977).

Key words: dose; gamma rays; LiF; response; sensitivity; supralinear; thermoluminescence.

The thermoluminescence of lithium fluoride shows twelve peaks, of which II $\left(100{ }^{\circ} \mathrm{C}\right)$, III $\left(135^{\circ} \mathrm{C}\right)$ and $\mathrm{V}$ $\left(190{ }^{\circ} \mathrm{C}\right)$ grow linearly first and then become nonlinear, eventually saturate and finally show decreased response or damage. Peaks beyond the $V$ th peak on the other hand seem to grow supralinearly right from the beginning. None of the available explanations for the supralinearity of the dosimetry peak (V) is entirely satisfactory. Similarly damage too is not understood. In this paper it has been shown that the radiation induced sensitisation is linked with the XIlth peak $\left(400{ }^{\circ} \mathrm{C}\right)$. It is postulated that this peak is created as a result of irradiation and hence is supralinear right from the beginning. The other high temperature peaks, though supralinear, are not found to be responsible for radiation induced increase in sensitivity of lower temperature peaks. It is shown that the trap centres (TC's responsible for the XIIth peak) are generated as a result of the break up of complex centres TCLC's on irradiation. This break also causes the addition of luminescence centres (LC's) which leads to increase in sensitivity. The complex centres (TCLC's) themselves are formed due to the $400{ }^{\circ} \mathrm{C}$ annealing. Decreased response or damage after saturation is the result of loss of luminescence centres while the traps remain unaffected.

Change in TL sensitivity of quartz due to stress, $M$. David and A. K. Ganguly, SP461, pp. 231-233 (Jan. 1977).

Key words: quartz; sensitivity; stress; thermoluminism.

Stress and strain caused by progressive and impact pressure loading can change the TL sensitvity of natural quartz. Stress due to progressive loading enhances the TL sensitivity considerably. It is found that sensitisation increases as the amount of stress increases and reaches a maximum at about $1400 \mathrm{~kg} \mathrm{~cm}^{-2}$. The TL sensitisation obtained is correlated to "strain hardening" by the dislocation nets produced by stress. In the case of stress caused by impact loading, TL sensitivity is reduced. This may be due to the conversion of quartz to a glassy state at a high stress.

ESR-TL correlation studies in $\mathrm{CaSO}_{4}(\mathrm{RE})$ phosphors, K. S. V. Nambi, SP461, pp. 234-237 (Jan. 1977).

Key words: $\mathrm{CaSO}_{4}$; correlation; dose; ESR; gamma ray; glow curve; irradiation; TL.

ESR and TL glow curve measurements were done after gamma irradiation at room temperature of $\mathrm{CaSO}_{4}$ samples doped individually with all the lanthanide series rare earth (RE) elements, an yttrium doped sample and a few undoped samples of different origins. Samples were prepared in the laboratory using standardized techniques and concentration of the dopant in individual doped samples was maintained at a typical value of 0.1 percent by weight in $\mathrm{CaSO}_{4}$. ESR as well as the TL glow curve patterns of all the sixteen samples were almost identical excepting for relative intensity differences. By observing the build up of these signals with increasing gamma dose and also by following the decay of these for storage at room temperature, it could be inferred that the nature of the trapping species indicated in the ESR and TL glow curve patterns are the same. The behaviour of these patterns for various thermal annealings at different temperatures have revealed that the trapping species might have configurations like $\mathrm{SO}_{4}^{-}, \mathrm{SO}_{3}{ }^{-}$, $\mathrm{O}_{3}{ }^{-}$etc. having different thermal stabilities and these are responsible for the observation of the multi-peak TL glow curve structure involving a variety of thermal activation energies. The increased intensities observed in the ESR and TL signals of the differently doped samples indicate that presence of various $\mathrm{RE}$ impurities in $\mathrm{CaSO}_{4}$ enhances to different extents the stabilities of these trapped species after gamma irradiation.

Neutron dosé evaluation using calculated neutron spectra, $\mathbf{S}$. Makra, SP461, pp. 238-246 (Jan. 1977). 
Key words: computer code; dose; dosimetry; monitor; neutron; shielding; spectrum.

Measurements carried out at shielded neutron sources such as nuclear reactors and neutron generators showed the importance of intermediate energy neutrons not recorded by most of the commonly used monitors. Based on these measurements correction factors were established for scintillation survey instruments, track plates, activation detectors and other routinely used devices. Although this simple technique has proved to be very useful, the need for a more sophisticated evaluation method was evident. With this in mind we started with the calculation of neutron spectra transmitted through and reflected from shielding slabs. Calculations were performed by using the MUSPALB albedo code developed in our Institute as well as with the 05R code written in Oak Ridge, USA. Over the last four years spectra for different reactor and neutron generator sources with $\mathrm{H}_{2} \mathrm{O}$, polythene, concrete, beryllium, aluminium, graphite, iron, boron loaded polythene and iron-concrete mixture shields were calculated for thicknesses ranging from $5 \mathrm{~cm}$ to $200 \mathrm{~cm}$. Calculated spectra were used for personnel-, survey-, and nuclear accident dosimetry evaluation. International comparison measurements have shown the value of this evaluation method. For illustration several examples are given.

Utilization of plastic scintillator in the measurement of uncharged radiations, P. K. Sarkar and K. N. Kirthi, SP46I, pp. 247-251 (Jan. 1977).

Key words: Apsara; energy distribution; gamma ray; iterative; neutron; plastic; recoil; scintillator; UNFOLD.

Uncharged radiations like neutrons and gamma rays produce scintillations in plastic scintillator through secondary charged particles. The energy distributions of these recoil particles are related to the energy distribution of the incident radiation. An attempt has been made in the present work to get back the original incident spectrum from the recoil distribution. The computer code UNFOLD designed for the purpose makes a minimum-variance, maximum likelihood estimate of the incident spectrum by iterative least square technique. Neutron spectra from different $\mathrm{BE}(\alpha, n)$ source and ${ }^{252} \mathrm{Cf}$ spontaneous fission have been measured. The results agree well with those published. Plastic scintillator proves to be more useful when the incident gamma spectrum is continuous in nature because the Compton continuum produced in the scintillator has a well defined integral relationship with the incident gamma spectrum. Continuous gamma spectrum in Apsara reactor beam hole has been estimated using the technique developed.

Neutron spectrometry by sandwich surface barrier technique, O. P. Joneja, SP461, pp. 252-254 (Jan. 1977).

Key words: 'detector; energy leakage; Monte Carlo; neutron; sandwich; spectrometry; surface barrier; ${ }^{6} \mathrm{LiF}$.

A neutron spectrometer using silicon surface barrier detectors employing $\mathrm{LiF}$ as a radiating material is developed. An incident neutron interacts with the radiating atom resulting in two charged particles, which are detected by sandwich detector geometry and the corresponding sum pulses from both the detectors shall uniquely define the incident neutron energy. This paper also presents results obtained by Monte Carlo simulation of all the correction factors for the detector head employed. A new concept for resolution correction is developed which brings down the lower energy limit of the detector system. The spectrometer is employed for incore spectrum studies in case of a thermal reactor "Kather" and the results obtained exhibit a good agreement with that of calculations by GAM THERMOS EXTERMINATOR Code.

Role of high resolution $\mathrm{Ge}(\mathrm{Li})$ detector in trace element study in water activated with thermal neutrons, J. M. Chatterjee, E. Peeters, and M. A. Castiaux, SP46l, pp. 255-256 (Jan. 1977).

Key words: activation; analysis; element; gamma rays; $\mathrm{Ge}(\mathrm{Li})$ detector; neutron; nondestructive; resolution; spectrometry; water.

While chemical analysis is limited in its application of element detection, gamma-ray spectrometry plays a big role in the nondestructive element detection in the neutron activated samples with large volume high resolution $\mathrm{Ge}(\mathrm{Li})$ detector. The water samples from the volcanic region of the island SANTORINI (Greece) have been activated with thermal neutrons, and the gamma-rays emitted by the longlived radioisotopes have been detected with high resolution $\mathrm{Ge}(\mathrm{Li})$ detector. The analyzed results show the high concentrations of alkaline and magnetic elements if compared with that of these elements in the normal sea water samples. The presence of some rare earth elements has been observed as well.

SP463. Materials Information Programs-An interagency review of Federal agency activities on technical information about materials. Proceedings of a Conference held at the National Bureau of Standards, Gaithersburg, MD, Apr. 16 and 17, 1974, S. A. Rossmassler, Ed., Nat. Bur. Stand. (U.S.), Spec. Publ. 463, 271 pages (Jan. 1977) SN003-003-01701-9.

Key words: Commerce; Defense; E.R.D.A.; Federal agencies; interagency review; Interior; Library of Congress; materials; materials data; materials information; N.A.S.A.; U.S.D.A.

The Conference on Materials Information Programs was held on April 16 and 17, 1974, at the National Bureau of Standards, Gaithersburg, Maryland. It was planned, with sponsorship by the Interagency Council for Materials (ICM), as an interagency review of Federal agency activities on technical information about materials. The program was organized by the ICM Working Group on Materials Information and Data. The intent of the review was to develop a common awareness, among operators and sponsors of information activities, of opportunities to help each other solve problems and to improve their services to users. Federal agencies which took part in the Conference, and whose materials information programs are covered in this report, include U.S. Department of Agriculture, Energy Research and Development Administration (formerly A.E.C.), Department of Defense, Department of Interior, National Aeronautics and Space Administration, Department of Commerce, and Library of Congress. Dr. Franklin P. Huddle, of the Congressional Research Service, was the Keynote Speaker; Dr. Emanuel Horowitz, of the National Bureau of Standards, gave the Summary address. These proceedings include the following papers (indented):

The National significance of materia ls information, $F$. P. Huddle, SP463, pp. I.2.1-I.2.2 (Jan. 1977).

Key words: energy; environmental quality; management; materials information; national programs; policy; technology assessment.

Review of agriculture information program materials information in the Forest Service, J. I. Zerbe, SP463, pp. II.1.1iI.1.4 (Jan. 1977). 
Key words: AIDS; bark; forest products; glues and gluing; information service; lumber; mechanical properties; paper; pulp; timber; wood; wood products.

The Current Research Information System (CRIS) as a source for materials information in the agricultural and allied sciences, P. L. Dopkowski, SP463, pp. II.2.1-11.2.10 (Jan. 1977).

Key words: agricultural materials; agricultural research; biological properties; chemical properties; engineering properties; food products; information retrieval systems; management information systems; materials; nonfood products; physical properties; research information.

How the Extension Service-Land Grant University-ARSUSDA information exchange functions, O. Bay, SP463, pp. II.3.1-II.3.4 (Jan. 1977).

Key words: agricultural research service; agriculture; extension service; information services; land grant university.

MateriaIs information in the Radiation Shielding Information Center, B. F. Maskewitz, D. K. Trubey, and R. W. Roussin, SP463, pp. III.1.1-III.1.10 (Jan. 1977).

Key words: computer codes; materials properties; nuclear data; radiation transport; reactor; RSIC; shielding; weapons.

Rare-Earth Information Center (RIC), K. A. Gschneidner, Jr. and B. L. Evans, SP463, pp. III.2.1-III.2.9 (Jan. 1977).

Key words: information center; rare earths.

The Research Materials Information Center, T. F. Connolly and J. W. Cleland, SP463, pp. Ill.3.1-III.3.8 (Jan. 1977).

Key words: availability; crystal growth; crystal structure; electronic properties; magnetic properties; optical properties; phase diagrams; research materials; thermal properties.

Materials information services of the Environmental Information System Office and the Toxic Materials Information Center, E. D. Copenhaver and G. U. Ulrikson, SP463, pp. III.4.1-III.4.15 (Jan. 1977).

Key words: air pollution; analysis; ecology; energy; environmental impact; land pollution; mutagenicity; toxic materials; toxicology; trace contaminants; water pollution.

Government-Industry Data Exchange Program, F. M. Nelson, SP463, pp. III.5.1-IIl.5.8 (Jan. 1977).

Key words: ALERT; calibration procedures; engineering technical data, metrology; failure mode; failure rate, quality, reliability, safety; technology transfer; urgent data request.

Introductory remarks, "The DoD Program for Technical Information about Materials", J. L. Blue, SP463, pp. IV.1.1IV.1.5 (Jan. 1977).

Key words: DDC; Defense Documentation Center; DoD technical information; Information Analysis Centers; technical information.

Metals and Ceramic Information Center, J. F. Lynch and H. D. Moran, SP463, pp. IV.2.1-IV.2.7 (Jan. 1977).

Key words: ceramic technology; current awareness services; databooks; information analysis center; inquiry services; metals technology; structural materials; technical reports.
Plastics Technical Evaluation Center (PLASTEC), H. E. Pebly, SP463, pp. IV.3.1-IV.3.2 (Jan. 1977).

Key words: adhesives; composites; computerized information system; foams; plastics information; Plastics Technical Evaluation Center; specifications; technical reports; testing methods; tooling.

Thermophysical and Electronic Properties Information Analysis Center [TEPIAC] a DoD Information Analysis Center operated by Center for Information and Numerical Data Analysis and Synthesis [CINDAS], Y. S. Touloukian, SP463, pp. IV.4.1-IV.4.3 (Jan. 1977).

Key words: computerized information system; data bank; electrical properties; electronic properties; magnetic properties; optical properties; Retrieval Guide; technical reports; Thermophysical and Electronic Properties Information Analysis Center; thermophysical properties.

Machinability Data Center-Data Publications and Services, J. F. Kahles, SP463, pp. IV.5.1-IV.5.8 (Jan. 1977).

Key words: data banks; information analysis centers; Machinability Data Center; machining costs; machining data banks; Machining Data Handbook; machining data publications.

Nondestructive Testing Information Amalysis Center, G. Darcy, SP463, pp. IV.6.1-IV.6.2 (Jan. 1977).

Key words: Army Materials and Mechanics Research Center; electromagnetics; materials testing; nondestructive testing; Nondestructive Testing Newsletter; radiography; technical reports; ultrasonics.

Concrete Technology Information Analysis Center (CTIAC), B. Mather, SP463, pp. IV.7.1-IV.7.7 (Jan. 1977).

Key words: analytical procedure; bibliographies; computerized information system; concrete; concrete technology; construction material; construction methods; portland cement; state-of-the-art summaries; technical reports; test methods.

The Mechanical Properties Data Center Products, services and informational content, R. C. Braden, SP463, pp. IV.8.1 = IV.8.10 (Jan. 1977).

Key words: data storage/retrieval; handbooks; mechanical properties; Mechanical Properties Data Center; structural metals and alloys; technical information; user awareness.

Water Resources Scientific Information Center (WRSIC), W. Z. Ignatieff, SP463, pp. V.1.1-V.1.6 (Jan. 1977).

Key words: information exchange; information management; information network; information retrieval; information services; information systems; specialized information center; water resources information.

Materials activity in the Office of Saline Water, F. H. Coley, SP463, pp. V.2.1-V.2.6 (Jan. 1977).

Key words: corrosion; desalination; distillation; hot sea water and materials.

Bureau of Mines Information-Publication Program, R. P. Willing, SP463, pp. V.3.1-V.3.9 (Jan. 1977).

Key words: Bureau of Mines; energy; health and safety; metallurgy; mining; Office of Mineral Information.

Materials information in the NASA Scientific and Technical Information System, F. G. Drobka, SP463, pp. VI.1.1-VI.1.7 (Jan. 1977). 
Key words: aerospace; computer information system; international aerospace abstracts; materials; mechanical properties; metallic materials; nonmetallic materials; physical properties; RECON; scientific and technical aerospace reports; thesaurus.

The National Standard Reference Data System as a materials information resource, D. R. Lide, Jr., SP463, pp. VII.1.1 VIl.1.15 (Jan. 1977).

Key words: chemical; critical evaluation; mechanical; numerical data; physical properties; thermodynamics; transport.

The Flammable Fabric Accident Case and Testing System (FFACTS), A. K. Vickers, SP463, pp. VII.2.1-VII.2.11 (Jan. 1977).

Key words: apparel fires; burn injury; fabric flammability; FFACTS; flammability standards; Flammable Fabrics Act; ignition sources.

National Technical Information Service-Its products and services, G. K. Kudravetz, SP463, pp. VII.3.1-VII.3.5 (Jan. 1977).

Key words: computerized information system; document dissemination; government reports; NTIS; patent licensing; technical reports.

Standard Reference Materials-The data and the material, R. W. Seward and H. T. Yolken, SP463, pp. VII.4.1-VII.4.14 (Jan. 1977).

Key words: accuracy; certification; precision; SRM; standard reference data; standard reference materials.

NBS Standards Information Services-Description of data, information system and services, W. J. Slattery, SP463, pp. VII.5.1 -VII.5.9 (Jan. 1977).

Key words: American National Standards Institute; computerized information system; engineering standards; mandatory standards; national standards; plastics standards; standards; standards information service; voluntary standards.

The Library of Congress MARC system, L. J. Rather, SP463, pp. VIII.1.1-VIII.1.4 (Jan. 1977).

Key words: bibliographic information; data bases; information retrieval; library automation; machine-readable; MARC; standards.

The National Referral Center, J. F. Price, SP463, pp. VIII.2.1 - VIII.2.4 (Jan. 1977).

Key words: computerized information system; directories; information resource; National Referral Center; referral; scientific and technical information; thesaurus.

Increased demand for data and information in the materials cycle, E. Horowitz, SP463, pp. IX.1.1-IX.1.22 (Jan. 1977).

Key words: information demand; materials information and data system; national commission on materials policy; technology transfer; total materials cycle.

SP464. Methods and standards for environmental measurement. Proceedings of the 8 th Materials Research Symposium held at the National Bureau of Standards, Gaithersburg, MD 20234, Sept. 20-24, 1976, W. H. Kirchhoff, Ed., Nat. Bur. Stand. (U.S.), Spec. Publ. 464, 659 pages (Nov. 1977) SNO03-003-01 704-3.
Key words: accuracy; aerosol; air; collaborative testing; laboratory accreditation; laser technology; multielement analysis; pollutants; speciation; Standard Reference Materials; trace organics; water.

This book presents the Proceedings of the 8th Materials Research Symposium on "Methods and Standards for Environmental Measurement" held at the National Bureau of Standards, Gaithersburg, Maryland, on September 20 through September 24, 1976. The Symposium was sponsored by the NBS Institute for Materials Research in conjunction with the Office of Air and Water Measurement.

The volume contains extended abstracts of the invited and contributed papers in topics of concern at the time of the symposium: Accuracy, the analysis of trace organic compounds in water, multielement analysis, the physical and chemical characterization of aerosols, in situ methods for water analysis, the application of laser technology to atmospheric monitoring, ambient air quality monitoring, the chemical characterization of inorganic and organometallic constituents, reference materials for environmental measurement and finally, environmental laboratory certification and collaborative testing. These proceedings include the following papers (indented):

Accuracy-An industrial viewpoint, W. O. Fitzgibbons, SP464, pp. 3-8 (Nov. 1977).

UItraviolet photometer for ozone calibration, A. M. Bass, A. E. Ledford, Jr., and J. K. Whittaker, SP464, pp. 9-13 (Nov. 1977).

Accuracy of ozone calibration methods, R. J. Paur, SP464, pp. $15-19$ (Nov. 1977).

Interrelationships between primary calibration standards for nitric oxide, nitrogen dioxide and ozone as applied to test gas atmospheres generated by gas phase titration, D. G. Muldoon and A. M. Majahad, SP464, pp. 21-35 (Nov. 1977).

An analysis of the measurement accuracy and validity of results from the charcoal tube sampling technique, $G$. Moore, SP464, pp. 37-42 (Nov. 1977).

Achieving accuracy in environmental measurements using activation analysis, D. A. Becker, SP464, pp. 43.46 (Nov, 1977 ).

A comparison of factors affecting accuracy in atomic emission and atomic absorption spectrometry using a graphite furnace for trace metal analysis in water, M. S. Epstein, T. C. Rains, and T. C. O'Haver, SP464, pp. 47-5I (Nov. 1977).

Improved accuracy in background corrected atomic absorption spectrometry, A. T. Zander and T. C. O'Haver, SP464, pp. 53-59 (Nov. 1977).

Standard addition uses and limitations in spectrophotometric analysis, R. Klein, Jr. and C. Hach, SP464, pp. 61-66 (Nov. 1977).

Unmet needs in the analysis of trace organics in water, $W$. T. Donaldson, SP464, pp. $69-72$ (Nov. 1977),

GCIR-A versatile and powerful tool for analysis of pollutants, L. V. Azarraga, SP464, pp. 73-74 (Nov. 1977).

The MSDC/EPA/NIH mass spectral search system, S. R. Heller, SP464, pp. 75-80 (Nov. 1977).

Methods for analysis of trace levels $(\mu \mathrm{g} / \mathrm{kg})$ of hydrocarbons in the marine environment, S. N. Chesler, B. H. Gump, H. S. Hertz, W. E. May, and S. A. Wise, SP464, pp. 81-85 (Nov. 1977). 
Potential carcinogens in water: GC/MS analysis, R. A. Hites, SP464, pp. 87-89 (Nov. 1977).

A new simple method for the recovery of trace organics from water, T. D. Kaczmarek, SP464, pp. 91-96 (Nov. 1977).

Determination of trace organic pollutants in water by spectrophotofluorescence after treatment with activated carbon, J. G. Montalvo, Jr. and C. G. Lee, SP464, pp. 97-100 (Nov. 1977).

Polyurethane foam plugs for concentration of trace quantities of benzo(a)pyrene from water, J. Saxena, J. Kozuchowski, and D. K. Basu, SP464, pp. 101-104 (Nov. 1977).

Thousands of metal analyses per man day -A reality in U.S. EPA's central regional laboratory: Multielement (23) analysis by an inductively coupled argon plasma atomic emission system (ICAP-AES), R. J. Ronan and G. Kunselman, SP464, pp. 107-111 (Nov. 1977).

Multielement analysis of river water, R. Schelenz, SP464, pp. 113-120 (Nov. 1977).

Multielement analysis in rainwater, J. G. van Raaphorst, J. Slanina, D. Borger, and W. A. Lingerak, SP464, pp. 121-123 (Nov. 1977).

Quantitative multi-element analysis of environmental samples by x-ray fluorescence spectrometry, P. A. Pella, K. Lorber, and K. F. J. Heinrich, SP464, pp. 125-127 (Nov. 1977).

Multielement analysis of air and water pollutants in gold mines by thermal and epithermal neutron activation, C. S. Erasmus, J. Sargeant, J. P. F. Sellschop, and J. I. W. Watterson, SP464, pp. 129-136 (Nov. 1977).

A multielement-direct reading method for the spectral analysis of sediment leachates, M. M. Moselhy, D. W. Boomer, J. N. Bishop, and P. L. Diosady, SP464, pp. 137-150 (Nov. 1977).

High efficiency solvent extraction of trace elements in aqueous media with hexafluoroacetylacetone, M. Janghorbani, M. Ellinger, and K. Starke, SP464, pp. 151-156 (Nov. 1977).

Determination of trace and minor elements in the combustible fraction of urban refuse, W. J. Campbell, H. E. Marr, III, and S. L. Law, SP464, pp. 157-161 (Nov. 1977).

Physical characterization of aerosols, K. T. Whitby, SP464, pp. 165-173 (Nov. 1977).

Measurement of aerosol size distribution with a particle doppler shift spectrometer, I. Chabay, SP464, pp. 175-178 (Nov. 1977).

Instrumental analysis of light element composition of atmospheric aerosols, E. S. Macias, SP464, pp. 179-188 (Nov. 1977).

X-R-D analysis of airborne asbestos preparation of calibration standards, M. Fatemi, E. Johnson, L. Birks, J. Gilfrich, and R. Whitlock, SP464, pp. 189-190 (Nov. 1977).

Respirable ambient aerosol mass concentration measurement with a battery-powered piezobalance, G. J. Sem, SP464, pp. 191-197 (Nov. 1977).

A cascade impaction instrument using quartz crystal microbalance sensing elements for "Real-Time" particle size distribution studies, D. Wallace and R. Chuan, SP464, pp. 199-211 (Nov. 1977).

A limitation on electrical measures of aerosols, W. H. Marlow, SP464, pp. 213-218 (Nov. 1977).

The use of a modified beta density function to characterize particle size distributions, A. S. Goldfarb and J. W. Gentry, SP464, pp. 219-226 (Nov. 1977).

In-situ monitoring with ion-selective electrodes-Advantages and pitfalls, or what the instructions didn't say, R. A. Durst, SP464, pp. 229-232 (Nov. 1977).

Problems of mercury determination in water samples, S. Yamazaki, Y. Dokiya, and K. Fuwa, SP464, pp. 233-235 (Nov. 1977).

Sampling for water quality, W. R. Curtis, SP464, pp. 237 244 (Nov. 1977).

Monitoring bacterial survival in seawater using a diffusion chamber apparatus in situ, G. J. Vasconcelos, SP464, pp. 245-247 (Nov. 1977).

Clean laboratory methods to achieve contaminant-free processing and determination of ultra-trace samples in marine environmental studies, C. S. Wong, W. J. Cretney, J. Piuze, and P. Christensen, SP464, pp. 249-258 (Nov. 1977).

A modified procedure for determination of oil and grease in effluent waters, G. M. Hain and P. M. Kerschner, SP464, pp. 259-261 (Nov. 1977).

Variability of trace metals in bed sedime.nts of the Po river: Implications for sampling, M. T. Ganzerli-Valentini, V. Maxia, S. Meloni, G. Queirazza, and E. Smedile, SP464, pp. 263-273 (Nov. 1977).

Application of laser technology to atmospheric monitoring, A. Mooradian, SP464, pp. 277-286 (Nov. 1977).

Laser monitoring techniques for trace gases, W. A. McClenny and G. M. Russwurm, SP464, pp. 287-290 (Nov. 1977).

Long-path monitoring with tunable lasers, E. D. Hinkley and R. T. Ku, SP464, pp. 291-294 (Nov. 1977).

Development of a two frequency downward looking airborne lidar system, J. A. Eckert, D. H. Bundy, and J. L. Peacock, SP464, pp. 295-300 (Nov. 1977).

Remote analysis of aerosols by differential scatter (disc) lidar systems, M. L. Wright, J. B. Pollack, and D. S. Colburn, SP464, pp. 301-303 (Nov. 1977).

Dial systems for monostatic sensing of atmospheric gases, E. R. Murray, J. E. van der Laan, J. G. Hawley, R. D. Hake, Jr., and M. F. Williams, SP464, pp. 305-314 (Nov. 1977).

Coherent anti-Stokes Raman scattering in gases, J. J. Barrett, SP464, pp. 315-316 (Nov. 1977).

Highly selective, quantitative measurement of atmospheric pollutants using carbon monoxide and carbon dioxide lasers, D. M. Sweger, S. M. Freund, and J. C. Travis, SP464, pp. 317-320 (Nov. 1977).

Chemical characterization of aerosols: Progress and problems, W. E. Wilsun, SP464, pp. 323-325 (Nov. 1977). 
Detection of individual submicron sulfate particles, $Y$. Mamane and R. G. de Pena, SP464, pp. $327-334$ (Nov. 1977).

An analysis of urban plume particulates collected on Anderson 8-stage impactor stages, P. A. Russell, SP464, pp. 335 336 (Nov. 1977).

Size discrimination and chemical composition of ambient airborne sulfate particles by diffusion sampling, R. L. Tanner and W. H. Marlow, SP464, pp. 337-342 (Nov. 1977).

The identification of individual microparticles with a new micro-Raman spectrometer, E. S. Etz and G. J. Rosasco, SP464, pp. 343-346 (Nov. 1977).

A compact $x$-ray fluorescence sulfur analyzer, L. S. Birks, J. V. Gilfrich, and M. C. Peckerar, SP464, pp. 347-349 (Nov. 1977).

The $x$-ray identification and semi-quantification of toxic lead compounds emitted into air by smelting operations, P. F. Lott and R. L. Foster, SP464, pp. 351-366 (Nov. 1977).

Flameless atomic absorption determinations of cadmium, lead and manganese in particle size fractionated aerosols, $M$. E. Peden, SP464, pp. 367-378 (Nov. 1977).

Ambient air quality monitoring, G. B. Morgan, SP464, pp. 381-385 (Nov. 1977).

Applications of remote monitoring techniques in air enforcement programs, F. J. Biros, SP464, pp. 387-389 (Nov. 1977).

Individual air pollution monitors, S. C. Morris and M. G. Morgan, SP464, pp. 391-392 (Nov. 1977).

Intercalibration of nitric oxide/nitrogen dioxide/ozone monitors, D. H. Stedman and R. B. Harvey, SP464, pp. 393-396 (Nov. 1977).

A reactive gas generator, $W$. Tsang and $\mathrm{J}$. A. Walker, SP464, pp. 397-403 (Nov. 1977).

Semiconductor gas sensor equations for predicting performance characteristics, S. M. Toy, SP464, pp. 405-414 (Nov. 1977).

Monitoring nonmethane hydrocarbons in the atmosphere by photoionization, J. N. Driscoll, SP464, pp. $415-417$ (Nov. 1977).

A study of vertical diffusion in the atmosphere using airborne gas chromatography and numerical modelling, $R$. S. Crabbe, SP464, pp. $419-433$ (Nov. 1977).

In situ quantitation of background halofluorocarbon levels, L. Elias, SP464, pp. 435-438 (Nov. 1977).

Origin and residence times of atmospheric pollutants: Application of ${ }^{14} \mathrm{C}$, L. A. Currie and R. B. Murphy, SP464, pp. 439-447 (Nov. 1977).

Chemical characterization of inorganic and organometallic constituents, R. S. Braman, SP464, pp. $451-458$ (Nov. 1977).

Analytical techniques for the study of the distribution and speciation of heavy metals in aquatic systems, H. J. Tobschall, N. Lawkowski, and K. Kritsotakis, SP464, pp. 459-460 (Nov. 1977).

Inorganic speciation of copper in estuarine environments, $D$. Burrell and M. L. Lee, SP464, pp. 461-465 (Nov. 1977).
Use of ion-specific electrodes in studying heavy metal transformation in aquatic ecosystem, S. Ramamoorthy and D. J. Kushner, SP464, pp. 467-471 (Nov. 1977).

Electrochemical studies of the methylmercury cation, R. A. Durst, F. E. Brinckman, K. L. Jewett, and J. E. Doody, SP464, pp. 473-483 (Nov. 1977).

An element-specific technique for the analysis of organometallic compounds, Y. K. Chau and P. T. S. Wong, SP464, pp. 485-490 (Nov. 1977).

Chromatography-atomic spectroscopy combinations. Applications to metal species identification and determination, $D$. A. Segar and A. Y. Cantillo, SP464, pp. 491-493 (Nov. 1977).

Changes in the chemical speciation of arsenic following ingestion by man, E. A. Crecelius, SP464, pp. 495-496 (Nov. 1977).

The determination of lead in aqueous solutions by the Delves cup technique and flameless atomic absorption spectrometry, H. J. Issaq, SP464, pp. 497-500 (Nov. 1977).

The status of reference materials for environmental analysis, J. K. Taylor, SP464, pp. 503-507 (Nov. 1977).

Reference type samples for water/waste analyses in EPA, J. A. Winter, SP464, pp. 509-513 (Nov. 1977).

The preparation and analysis of trace elements in water standard reference material, J. R. Moody, H. L. Rook, P. J. Paulsen, T. C. Rains, I. L. Barnes, and M. S. Epstein, SP464, pp. 515-518 (Nov. 1977).

The standard fineparticle, B. H. Kaye, SP464, pp. $519-526$ (Nov. 1977).

Thin film standards for $x$-ray and proton induced $x$-ray fluorescence, D. N. Breiter, P. A. Pella, and K. F. J. Heinrich, SP464, pp. 527-529 (Nov. 1977).

Reference materials for automotive emissions testing, T. G. Eckman, SP464, pp. 531-534 (Nov. 1977).

Long term investigation of the stability of gaseous standard reference materials, E. E. Hughes and W. D. Dorko, SP464, pp. 535-539 (Nov. 1977 ).

Standard reference materials for the analysis of organic vapors in air, B. C. Cadoff, SP464, pp. 541-543 (Nov. 1977).

Working reference materials for lead contamination analyses of air and water, A. C. Eckert, Jr. and D. M. Mongan, SP464, pp. 545-551 (Nov. 1977).

Collaborative testing of air pollution methods, J. B. Clements, SP464, pp. 555-564 (Nov. 1977).

Interlaboratory comparison of neutron activation and atomic absorption analyses of size-classified stack fly ash, J. M. Ondov, R. C. Ragaini, R. E. Heft, G. L. Fisher, D. Silberman, and B. A. Prentice, SP464, pp. 565-572 (Nov. 1977).

Collaborative testing of a continuous chemiluminescent method for measurement of nitrogen dioxide in ambient air, J. H. Margeson, P. C. Constant, Jì., M. C. Sharp, and G. W. Scheil, SP464, pp. 573-574 (Nov. 1977).

Collaborative testing of EPA method II, J. E. Knoll, M. R. Midgett, and G. W. Scheil, SP464, pp. 575-579 (Nov. 1977). 
Evaluation of interlaboratory comparison data by linear regression analysis, D. E. King, SP464, pp. 581-596 (Nov. 1977).

Potential enforcement uses of emission test collaborative studies, L. Paley and W. S. Smith, SP464, pp. 597-599 (Nov. 1977).

Ion chromatography-A new analytical technique for the assay of sulfate and nitrate in ambient aerosols, J. D. Mulik, R. Puckett, E. Sawicki, and D. Williams, SP464, pp. 603-607 (Nov. 1977).

The use of a gas chromatograph-microwave plasma detector for the detection of alkyl lead and selenium compounds in the atmosphere, D: C. Reamer, T. C. O'Haver, and W. H. Zoller, SP464, pp. 609-612 (Nov. 1977).

The Dutch National air pollution monitoring system-A focal and reference point, T. Schneider, SP464, pp. 613-615 (Nov. 1977)

Analysis and calibration techniques for measuring of airborne particulates and gaseous pollutants, I. Delespaul, $\mathbf{H}$. Peperstrate, and T. Rymen, SP464, pp. 617-623 (Nov. 1977).

Factors governing the contents of metals in water, D. J. Swaine, SP464, pp. 625-626 (Nov. 1977).

Effects of water soluble components of refined oil on the fecundity of the copepod, Tigriopus Japonicus, C. Finney and A. D'Agostino, SP464, pp. 627-631 (Nov. 1977).

A comparison of electron microscope techniques for the identification of asbestos fibers, C. O. Ruud, P. A. Russell, C. S. Barrett, and R. L. Clark, SP464, pp. 635-636 (Nov. 1977).

Determination of reducing agents and sulfate in airborne particulates by thermometric titration calorimetry, L. D. Hansen, D. J. Eatough, N. F. Mangelson, and R. M. Izatt, SP464, pp. 637-642 (Nov. 1977).

Determination of acidic and basic species in particulates by thermometric titration calorimetry, D. J. Eatough, L. D. Hansen, R. M. Izatt, and N. F. Mangelson, SP464, pp. 643-649 (Nov. 1977).

Single-particle analysis of the ash from the Dickerson coalfired power plant, J. A. Small and W. H. Zoller, SP464, pp. 651-658 (Nov. 1977).

Laser-Raman monitoring of ambient sulfate aerosols, R. G. Stafford, R. K. Chang, and P. J. Kindlmann, SP464, pp. 659 667 (Nov. 1977).

Chemical characterization of particulates in real time by a light scattering method, C. C. Gravatt, SP464, pp. 669-671 (Nov. 1977).

The National voluntary laboratory accreditation program, T. R. Young, SP464, pp. 675-676 (Nov. 1977).

The National laboratory certification program for water supply, C. Hendricks, SP464, pp. 677-679 (Nov. 1977).

Laboratory accreditation, C. E. Hamilton, SP464, pp. 681 684 (Nov. 1977).

Certification of water and wastewater laboratories: A professional chemists view, H. G. Swope, SP464, pp. 685-687 (Nov. 1977).
Lessons to be learned from clinical laboratory accreditation, W. F. Vincent, SP464, pp. 689-691 (Nov. 1977).

SP465. Science and technology in America-An assessment, E. Teller, N. Ramsey, W. O. Baker, H. Eyring, G. Birkhoff, A. Perlis, R. C. Seamans, Jr., S. Ramo, and R. M. Thomson, Ed., Nat. Bur. Stand. (U.S.), Spec. Publ. 465, 166 pages (June 1977) SNO03-003-01728-1.

Key words: National Bureau of Standards; physical sciences; science and technology in America; technology; 75 th anniversary.

On the occasion of its 75 th anniversary, the National Bureau of Standards presented a series of eight lectures by distinguished scientists and engineers assessing the current state and future prospects of broad physical sciences and technologies which underlie the mission of NBS and which also relate to many. other technological issues of national concern.

SP466. Standardization in spectrophotometry and luminescence measurements. Proceedings of a Workshop Seminar held at the National Bureau of Standards, Gaithersburg, MD, Nov. 19-20, 1975, K. D. Mielenz, R. A. Velapoldi, and R. Mavrodineanu, Eds., Nat. Bur. Stand. (U.S.), Spec. Publ. 466, 155 pages (May 1977) SNO03-003-01791-4

Key words: accuracy; critical parameters; diffuse reflectance; fluorescence; instrumentation; luminescence; quantum yield; spectrophotometry; standard reference materials; standardization.

This volume contains 15 papers presented at the Workshop Seminar on Standardization in Spectrophotometry and Luminescence Measurements organized by the Analytical Chemistry Division, Institute for Materials Research, at the National Bureau of Standards, and held from November 19 to 20, 1975.

These papers discuss the problems encountered where accurate measurements are required in the fields of luminescence quantum yields, diffuse reflectance spectroscopy, and ultraviolet absorption spectrometry. They also define the needs for standardization of measurements in these fields and suggest materials that could be used as Standard Reference Materials. Considerations on some applications of such standards in the field of environmental pollution and health are included. These proceedings include the following papers (indented):

Fluorescence quantum yield measurements, J. B. Birks, SP466, pp. 1-11 (May 1977).

Key words: fluorescence lifetime; fluorescence quantum efficiency; fluorescence quantum yields; fluorescence spectrum; fluorescence standards; molecular fluorescence parameters; observed (technical) fluorescence parameters; polarization; radiative and non-radiative transition probabilities; real fluorescence parameters.

Four molecular fluorescence parameters describe the behaviour of a fluorescent molecule in very dilute $\left(\sim 10^{-6}\right.$ $M$ solution: (i) the fluorescence spectrum $F_{M}(\bar{\nu})$; (ii) the fluorescence polarization $P_{M}$; (iii) the radiative transition probability $k_{F M}$; and (iv) the radiationless transition probability $k_{I M}$. These parameters and their temperature and solvent dependence are those of primary interest to the photophysicist and photochemist. $F_{M}(\bar{\nu})$ and $P_{M}$ can be determined directly, but $k_{F M}$ and $k_{I M}$ can only be found indirectly from measurements of the secondary parameters: (v) the fluorescence lifetime $\tau_{M}$, and (vi) the fluorescence quantum efficiency $q_{F M}$, where $k_{F M}=q_{F M} / \tau_{M}$ and $k_{I M}=(1-$ $\left.q_{F M}\right) \tau_{M}$.

The real fluorescence parameters $F(\bar{\nu}), \tau^{\prime}$ and $\phi_{F}$. of more concentrated $\left(c>10^{-5} \mathrm{M}\right)$ solutions usually differ from the molecular parameters $F_{M}(\bar{\nu}), \tau_{M}$ and $q_{F M}$ due to concentra- 
tion (self) quenching, so that $\tau \geq \bar{\tau}_{M}$ and $\phi_{F^{*}}<q_{F M}$. The concentration quenching is due to excimer formation and dissociation (rates $k_{D M C}$ and $k_{M D}$, respectively) and it is often accompanied by the appearance of an excimer fluorescence spectrum $F_{V}(\bar{\nu})$ in addition to $F_{M}(\bar{\nu})$, so that $F(\bar{\nu})$ has two components. The excimer fluorescence parameters $F_{D}(\bar{\nu}), \mathrm{P}_{D}, k_{F D}$ and $k_{I D}$, together with $k_{D M}$ and $k_{M V}$, and their solvent and temperature dependence, are also of primary scientific in terest.

The observed (technical) fluorescence parameters $F^{\top}(\bar{\nu})$, $\tau^{T}$ and $\dot{\phi}_{F}{ }^{T}$ in more concentrated solutions usually differ from the real parameters $F(\bar{v}), \tau$ and $\phi_{F}$, due to the effects of self-absorption and secondary fluorescence. The technical parameters also depend on the optical geometry and the excitation wavelength. The problems of determining the real parameters from the observed, and the molecular parameters from the real, will be discussed.

Methods are available for the accurate determination of $F^{T}(\bar{v})$ and $\tau^{T}$. The usual method of determining $\phi_{F}{ }^{T}$ involves comparison with a reference solution $R$, although a few calorimetric and other absolute determinations have been made. For two solutions excited under identical conditions and observed at normal incidence

$$
\frac{\phi_{F}^{T}}{\phi_{F \cdot R}^{T}}=\frac{n^{2} \int F^{T}(\bar{\nu}) d \bar{\nu}}{n_{R}^{2} \int F_{\mu}^{T}(\bar{\nu}) d \bar{\nu}}
$$

where $n$ is the solvent refractive index.

Two reference solution standards have been proposed, quinine sulphate in $\mathrm{N} \mathrm{H}_{2} \mathrm{SO}_{4}$.which has no self-absorption, and 9,10-diphenylanthracene in cyclohexane which has no self-quenching. The relative merits of these solutions will be discussed, and possible candidates for an "ideal" fluorescence standard with no self-absorption and no selfquenching will be considered.

Some methods of luminescence efficiency measurements, A. Bril and A. W. de Jager-Veenis, SP466, pp. 13-19 (May 1977).

Key words: cathode-ray excitation; luminescence; luminescence standards; phosphors; quantum efficiencies; radiant efficiencies; UV excitation; $x$-ray excitation.

Methods of absolute and relative radiant and quantum efficiency measurements are described for ultraviolet, visible, cathode-ray, and x-ray excitations. Data on some standard luminescent materials are given.

On the actinometric measurement of absolute luminescence quantum yields, J. N. Demas and B. H. Blumenthal, SP466, pp. 21-24 (May 1977).

Key words: absolute yield; chemical actinometry; correction factors; luminescence; quantum-flat actinometer; quantum yield.

The theory of the measurement of luminescent quantum yields using chemical actinometry is described. The sample's emission intensity is measured by nearly completely surrounding the sample with an actinometer solution, and the excitation intensity is directly measured with the same type of actinometer. The ratio of the measured sample emission intensity corrected for the fraction escaping through the excitation ports to the measured excitation intensity is the absolute luminescence yield. Equations, a suitable cell design, and computer calculated correction factors for different cell dimensions and optical densities are given. The absolute yield of the actinometer is not needed, only its relative response with wavelength. New quantum-flat actinometers which should greatly simplify the measurements are described

The calorimetric detection of excited states, J. B. Callis, SP466, pp. 25-31 (May 1977).
Key words: absolute quantum efficiency; absolute quantum yield; calorimetry; luminescence; photoacoustic spectrometer; piezocalorimeter; transducers; triplet formation.

Calorimetric techniques offer the photophysicist and photochemist the opportunity to measure a number of parameters of excited states which may be difficult to obtain by other techniques. The calorimetric strategy seeks to measure the heating of a sample resulting from radiationless decays or chemical reactions of excited states. Heating is best measured through volume and pressure transducers, and four calorimeters based on these are described. With calorimetric instrumentation one can perform measurements on samples in the gas, liquid and solid phases over a wide temperature range. Moreover, time dependent processes with time constants ranging from microseconds to seconds are amenable to study. Examples of the application of calorimetric techniques to the determination of quantum yields of fluorescence, triplet formation and photochemistry are given.

Fluorescence efficiency of laser dyes, K. H. Drexhage, \$P466, pp. 33-40 (May 1977).

Key words: aminocoumarins; carbazine dyes; deuterium effect; fluorescence quantum yield; laser dyes; molecular structure; oxazine dyes; quenching; xanthene dyes.

The fluorescence efficiency of xanthene dyes, oxazine dyes, and 7-aminocoumarins is discussed. Relations with the molecular structure are pointed out and dependence on solvent and temperature is explained. Several new fluorescence standards are suggested.

Diffuse reflectance spectroscopy; applications, standards, and calibration (with special reference to chromatography), $R$. W. Frei, SP466, pp. 41-55 (May 1977).

Key words: chromatography; color matching; color measurement; diffuse reflectance; Kubelka-Munk function; reflectance; reflectance standards; thin layer chromatography.

The multitude of areas in which diffuse reflectance spectroscopy can be applied has been described in several books and reviews and ranges from color measurements of textiles, pharmaceuticals, building materials, paper and pulp materials, etc., to adsorption studies and other basic investigations in physical, inorganic and organic chemistry.

The major area of application is still the measurement of color which has become indispensible in the quality control of colored products, dyes and pigments. Color matching practices and techniques with sophisticated instrumentation which can be fully computerized as well as the use of simpler filter instruments for quality control are mentioned.

Transferability of reflectance data, i.e., color coordinates, depends on the quality of standards particularly when absolute measurements are desired. The difficulty of finding suitable "white standards" with good reflection properties at low UV and with a good long term stability is discussed. Similar arguments hold for sphere coating materials. For the measurement of fluorescing surfaces suitable standards are lacking which renders transfer of such data almost impossible.

The usefulness of diffuse reflectance techniques to study adsorption phenomena on small particle adsorbents is demonstrated with a malachite green-o-carboxylic acid lactone system studied by Kortüm. This or similar systems could be adopted to the measurement of relative surface areas on certain chromatographic adsorbents yielding more realistic values than the BET-method. 
The most recent area of application has been in the field of chromatography for the in situ evaluation of chromatographic zones in flat-bed chromatography, electrophoresis and isoelectric focusing.

In chromatography, standardization is less problematic since usually relative measurements are sufficient. On the other hand one has to find suitable calibration procedures. The use of the Kubelka-Munk function is often questionable since we are usually not dealing with layers of infinite thickness and below $300 \mathrm{~nm}$ the conventional adsorbents such as silica gel, alumina or cellulose are strongly absorbing. Experiences with a new function combining the laws of Kubelka-Munk and Lambert-Beer are therefore presented.

The problem is also to find calibration techniques which account for chromatographic parameters. Until recently it was believed that a quantitative evaluation of chromatograms required a number of reference zones to be developed on the same chromatogram. In our experience this is no longer true. A novel calibration technique which utilizes the concept of transferable calibration factors is discussed. With this approach a quantitative evaluation of a chromatogram with only one reference spot is possible. Here again scanning and data acquisition can be fully automated. The application of proper calibration procedures to differential reflectance techniques and the measurement of multi-component systems is briefly mentioned.

Finally it is demonstrated that it is possible to carry out in situ quantitative measurements on low UV absorbing compounds (down to $190 \mathrm{~nm}$ ) separated on silica gel surfaces, provided suitable techniques and instrumentation are used.

The interpretation of diffuse reflectance spectra, $H$. G. Hecht, SP466, pp. 57-73 (May 1977).

Key words: absolute absorptivities; continuum models; diffuse reflectance; radiative transfer; reflectance spectra; scattering coefficients; statistical models.

Numerous treatments of the diffuse reflecting properties of scattering media have been described. Many theories give an adequate account of the reflectance for a specific set of conditions for which the model was constructed and the solution tested experimentally. Only those models which are considered to be fairly general are considered here.

It is convenient to divide the theories into those based upon continuum models and those based upon statistical models. The continuum models typically describe the scattering and absorbing properties of a given medium in terms of two phenomenological constants. These models may all be regarded as varying levels of approximate solution to the general equation of radiative transfer. This provides a convenient basis for comparison of the various theories.

The statistical models are based upon a summation of transmittances and reflectances from individual layers or particles. Thus, some assumptions must be made about the nature of the fundamental units, and the validity of the ultimate result will depend upon how closely these assumptions correspond with reality. Only the statistical models lead to expressions from which absolute absorptivities and scattering coefficients can be calculated and related to the actual particle characteristics.

The relationship between the various models will be discussed and the features which typify the absorptivity and scattering coefficient according to each will be compared and related to the available experimental data. This leads to a consideration of the characteristics of appropriate model systems and standards.
Calibration of reflectance standards, W. Budde, SP466, pp. 75-85 (May 1977).

Key words: barium sulfate; diffuse reflectance spectra; magnesium oxide; opal glass; radiant flux; reflectance standards; standards calibration.

Measurements of the diffuse spectral reflectance are usually not made as direct measurement of the incident. and the reflected radiant flux but rather as measurements relative to a standard of known reflectance value.

For the calibration of such standards, different methods have been described in the literature: (1) goniophotometric methods, also called Indicatrix methods or point-bypoint methods; (2) methods based on the Kubelka-Munk theory; and (3) integrating spherc methods according to Taylor, Benford, Sharp-Little, van den Akker, Korte.

Various materials such as magnesium oxide, barium sulfate or opal glass are being used as standards. Their suitability as transfer or as working standards will be discussed.

The results of comparative measurements between some of these methods will be given.

Understanding bidirectional reflectance and transmission for space applications, J. B. Schutt, SP466, pp. 87-93 (May 1977).

Key words: bidirectional radiometry; canopies; diffuse reflectance; diffuse transmission; reflectance standards; scattering surfaces.

Applications for optical diffusers in space projects are presented which include the functions of reflection, trans-. mittance, and collection. These modes encompass such diverse uses as temperature regulation and ozone concentration monitors. Discussed is the cooperative aspect of diffuse reflectance and environmental stability. Magnesium oxide, sodium chloride and barium sulphate are evaluated in some detail. The importance of scene scattering behavior to modeling the earth's radiation budget and in determining thermal inertias of the earth's surface are discussed, because solar albedo serves as the weighting function in the solar input irradiance. Finally, work in the area of canopy reflectance modeling is reviewed with verification data included whenever available. Some knowledge of the bidirectional reflectance properties of vegetation is necessary for identification, acreage computations, and scene transferrance.

Standardization of light scattering measurement in conjunction with immunochemical analysis, G. J. Buffone, SP466, pp. 95-98 (May 1977).

Key words: antibodies; antigens; biological polymers; immunochemical analysis; light scattering; polymers; proteins; solid standards.

Light scattering methods for the physical analysis of synthetic and biological polymers necessitates the use of scattering standards and absolute light scattering measurements. Standardization has not been employed when light scattering has been used to monitor immunochemical reactions using a kinetic or thermodynamic mode.

The concentration of a specific protein present in a complex matrix such as urine, serum or cerebrospinal fluid, is measured by reacting the protein of interest with its specific antibody and then measuring the excess light scattering of the solution produced by the formation of antigen antibody complexes. The lack of established light scattering standards in the area of immunochemical measurements makes instrumental quality control difficult and has 
hindered direct comparison of data among investigators. Both solid and liquid light scattering standards would be necessary to encompass the wide range of instrumentation currently in use. Several solid standards which have been used in the past include reflecting diffusers such as vitrolite, magnesium carbonate crystals with a ground surface, magnesium oxide coatings on magnesium carbonate crystal, casein paint on vitrolite, and solid opal glass transmitting diffusers such as flashed opal glass and solid opal glass. These standards, while applicable to manual light scattering photometers, are not suitable for recently developed automated instrumentation. Liquid standards in the form of Ludox $($, solutions of polystyrene, suspensions of small diameter latex spheres and even pure organic solvents could be used more easily with the continuous flow and discrete automated analyzers. The introduction of instrumental standards at this levêl of analysis would result in improved overall quality control and facilitate data and method comparison between laboratories.

Errors in spectrophotometry and calibration procedures to avoid them, A. G. Reule, SP466, pp. 99-1 14 (May 1977).

Key words: bandwidth; calibration; errors in spectrophotometry; interferences; multiple reflections; photometric linearity; polarization; sample characteristics; stray light; wavelength accuracy.

Based on simple principles, spectrophotometry nevertheless demands a lot of precautions to avoid errors. The following properties of spectrophotometers will be discussed together with methods to test them:

Spectral properties-wavelength accuracy, bandwidth, stray light; photometric linearity; interactions between sample and instrument-multiple reflections, polarization, divergence, sample wedge, sample tilt, optical path length (refractive index), interferences.

Calibration of master instruments is feasible only by complicated procedures. With such a master instrument standards may be calibrated which greatly simplify performance checks of instruments used for practical work. For testing high quality spectrophotometers the use of emission lines and nearly neutral absorbing solid filters as standards seems to be superior, for some kinds of routine instruments the use of absorption bands and liquid filters may be necessary.

Standardization in transmission spectrophotometry in the visible and ultraviolet spectral regions, A. R. Robertson, SP466, pp. 117-120 (May 1977).

Key words: errors in spectrophotometry; photometric scale; slit width; spectral transmission; spectrophotometer standards; stray light; wavelength scale.

In an instrument as complex as a spectrophotometer there are many potential sources of error. Because of this it is useful to have available standard materials whose spectral transmittances are known accurately. Periodic measurement of such standards provides a useful indication of whether a spectrophotometer is producing accurate results.

If the spectral transmittance functions of these standards are chosen suitably, the measurements can provide diagnostic information to indicate what type of error is occurring. Among the factors that most often lead to errors in spectrophotometry are the slit-width, the wavelength scale, the photometric scale, and stray radiation. Suitable material standards can provide indications of the occurrence of these errors. However, it is sometimes difficult to identify a particular error since of ten several errors will occur at the same time.
Several sets of standards for testing spectrophotometers are available or can be constructed easily. Most of these are glass filters, but interference filters, perforated screens, and rotating sectors are also used. Liquid filters have some advantages, especially in the ultraviolet where glass filters absorb too strongly to be useful. However, difficulties in preparing and handling liquid filters can introduce uncertainties.

It is important that standard materials are insensitive to environmental conditions (such as temperature) and that they are stable over a long period of time. Unfortunately, many of the materials with the most suitable spectral characteristics are least suitable in these respects, and it would be very useful if new and better materials could be developed.

Acidic potassium dichromate solutions as ultraviolet absorbance standards, R. W. Burke and R. Mavrodineanu, SP466, pp. 121-126 (May 1977).

Key words: absorbance linearity; accuracy; acidic potassium dichromate solutions; calibration of ultraviolet spectrophotometers; liquid filters; transfer standards; ultraviolet absorbance standards.

The absorbances of five concentrations of potassium dichromate in $0.001 M$ perchloric acid have been determined at eight wavelengths in the ultraviolet on the $\mathrm{Na}$ tional Bureau of Standards Institute for Materials Research high-accuracy spectrophotometer. Four of the wavelengths - 235, 257, 313, and $350 \mathrm{nm-correspond} \mathrm{to}$ absorbance maxima or minima in the $\mathrm{HCrO}_{4}^{-}$spectrum and are useful wavelengths for checking the accuracy of the absorbance scale of narrow bandpass spectrophotometers. Although partial dimerization of $\mathrm{HCrO}_{4}{ }^{-}$to $\mathrm{Cr}_{2} \mathrm{O}_{7}=$ produces small positive deviations from Beer's law at these wavelengths, the apparent absorptivities calculated for each concentration are reproducible to one part in a thousand. The estimated uncertainties in the absorptivity values are \pm 0.7 percent at 0.1 absorbance $(A)$ and \pm 0.2 percent near $A=1$. These uncertainties include all known sources of possible systematic error and the 95 percent confidence level for the mean. The remaining four wavelengths used for measurement are near two predicted isosbestic points in the $\mathrm{HCrO}_{4}^{-} / \mathrm{Cr}_{2} \mathrm{O}_{7}{ }^{=}$spectra. The absorptivities at $345 \mathrm{~nm}$ are sufficiently independent of concentration that this wavelength can be used for checking absorbance linearity to one part in a thousand over the range $A=0.2-1$.

Considerations for the use of semi-transparent metallic thin films as potential transmittance standards in spectrophotometry, R. Mavrodineanu, SP466, pp. 127-131 (May 1977).

Key words: evaporated metal-on-quartz; filters, transmittance; neutral filters; standard reference materials; transmittance characteristics; ultraviolet-visible filters.

Various characteristics of evaporated metal-on-fused silica filters are discussed in relation to their optical transmission properties. Special metal holders provided with shutters were designed to be used with these filters, and are described in detail. Transmittance measurements, performed in various conditions, are reported and indicate that the evaporated metal-on-fused silica filters might present an acceptable material as transfer standards in spectrophotometry.

Structure-related optical characteristics of thin metallic films in the visible and ultraviolet, $H$. E. Bennett and J. L. Stanford, SP466, pp. 133-148 (May 1977). 
Key words: absorption; dielectric layers; irregularities; metallic thin films; microirregularities; overcoating; plasmons; scatter.

Surface irregularities and crystalline order strongly influence both the scattered light and absorption of metallic films. These effects extend through all spectral regions but are particularly important in the visible and ultraviolet. Scattered light arises from several scattering mechanisms. Macroscopic irregularities such as dust, scratches and particulates are typically much less important than are microirregularities only a few tens of angstroms in height but covering the entire surface. For metals such as silver and aluminum, which have plasma edges in the ultraviolet, the excitation of surface plasmons resulting from these microirregularities causes additional incoherently reemitted or "scattered" light. Surface plasmon excitation also causes increased absorption in some wavelength regions. These effects are enhanced by dielectric overcoating layers, which both increase the absorption and scattering and shift the wavelength at which the peak occurs. Surface plasmon excitation is particularly important in the ultraviolet region, where the dielectric overcoating applied to prevent formation of an oxide film on aluminized mirrors, for example, can significantly change the mirror reflectance. Plasmon excitation is made possible by a momentum conserving process associated with material inhomogeneities and hence can presumably be caused by crystalline disorder in the metal surface as well as surface irregularities. If the disorder is present on a sufficiently fine scale, it also affects the band structure of the metal and hence its optical absorption. Examples of the effect of film structure on the optical properties of evaporated and sputtered metal films will be given.

SP467. Activities of the National Bureau of Standards, $M$. Jacobs and S. A. Washburn, Eds., Nat. Bur. Stand. (U.S.), Spec. Publ. 467, 40 pages (Mar. 1977) SN003-003-01716-7.

Key words: annual report; computer; energy; environmental; measurement; product safety; research; science; standards; technology.

This publication highlights the major achievements of the $\mathrm{Na}$ tional Bureau of Standards and shows how this work contributes to the solution of many problems of national concern. In addition, the report contains sections featuring the Bureau's interaction with the public and private sectors and emphasizes the historical perspective in relation to the Bureau's 75 th anniversary and the Nation's bicentennial.

Sections of the report feature: A Word to Our Readers; Introduction; Increasing Measurement Capabilities; Transferring Research and Technology; Promoting Better Materials Use; Aiding Environmental Protection; Conserving Energy Resources; Advancing Building Technology; Protecting Public Safety; Improving Product Performance; Expanding Computer Applications; Providing Information Resources; People; Funds and Facilities; Selected Publications; Directory.

SP468. MFPG-Prevention of failures in coal conversion systems. Proceedings of the 24th Meeting of the Mechanical Failures Prevention Group, held at Battelle, Columbus Laboratories, Columbus, OH, Apr. 21-23, 1976, T. R. Shives and W. A. Willard, Eds., Nat. Bur. Stand. (U.S.), Spec. Publ. 468, 233 pages (Apr. 1977) SN003-003-01760-4.

Key words: coal conversion; coal gasification; coal liquefaction; corrosion; failure analysis; failure prevention; quality assurance; reliability.

These Proceedings consist of a group of twenty submitted papers and discussions from the 24th meeting of the Mechani- cal Failures Prevention Group which was held at Battelle, Columbus Laboratories in Columbus, Ohio, on April 21-23, 1976. Prevention of failures in coal conversion systems is the central theme of the Proceedings. A series of overview lectures dealing with reliability problems in coal conversion systems, economics of failures in energy generating systems, corrosion, and gaps in engineering data are presented. In addition, failure analysis, materials problems, and related materials research are discussed. These proceedings include the following papers (indented):

Reliability problems in coal gasification and liquefaction, $\mathrm{H}$. E. Frankel and J. R. Ogren, SP468, pp. 3-25 (Apr. 1977).

Economics of failures in energy generation systems, $M$. E. Lapides, SP468, pp. 27-39 (Apr. 1977).

Demonstration of a reliability methodology using two coal conversion plant models, J. R. Hoffman, W. T. Long, and R. L. Williams, SP468, pp. 41-48 (Apr. 1977).

Critical materials problems in coal conversion, $R$. W. Staehle, SP468, pp. 50-78 (Apr. 1977).

The AGA-ERDA-MPC program on materials for the gasification of coal, A. O. Schaefer, SP468, pp. 80-92 (Apr. 1977).

Failure analysis of components from coal-gasification pilot plants, S. Greenberg and K. Natesan, SP468, pp. 97-106 (Apr. 1977).

Erosion problems in letdown valves, J. J. Mueller, SP468, pp. 107-118 (Apr. 1977).

ERDA information center for failure prevention in fossil energy plants, J. H. Smith and W. A. Willard, SP468, pp. 121-128 (Apr. 1977).

Steel plant coke-ovens: An energy conversion process with warpage problems, H. W. Lownie, Jr. and A. O. Hoffman, SP468, pp. $131-133$ (Apr. 1977).

Selection of materials used in coal gasification plants, M. A. H. Howes, SP468, pp. 137-142 (Apr. 1977).

Particle erosion measurements on metals at elevated temperatures, L. K. Ives, J. P. Young, and A. W. Ruff, SP468, pp. $145-157$ (Apr. 1977).

High-temperature corrosion, K. Natesan, SP468, pp. 159 170 (Apr. 1977).

Development on nondestructive evaluation methods for coalconversion systems, W. A. Ellingson, G. C. Stanton, and N. P. Lapinski, SP468, pp. 172-181 (Apr. 1977).

Potential materials problems in coal gasification systems, A. M. Hall, SP468, pp. 183-188 (Apr. 1977).

Low ductility, high temperature failure of austenitic materials, F. B. Hamel, SP468, p. 191 (Apr. 1977).

The SRC plant, L. G. Samuels, SP468, pp. 192-194 (Apr. 1977).

High Btu gasification pilot plant experience, A. J. Mac Nab, SP468, pp. 195-198 (Apr. 1977).

$\mathrm{CO}_{2}$ acceptor process, C. A. Schulz, SP468, pp. 199-201 (Apr. 1977).

Consol pilot plant materials problems, J. F. Leterle, SP468, pp. 202-204 (Apr. 1977). 
The synthane coal to gas pilot plant, R. Lewis, SP468, pp. 205-206 (Apr. 1977).

SP469. A policy analysis of citizen rights issues in health data systems, A. F. Westin and F. Isbell, Ed., Nat. Bur. Stand. (U.S.), Spec. Publ. 469, 48 pages (Jan. 1977) SN003-00301730-2.

Key words: citizen rights; computers, confidentiality; data systems; health records; information policy, management principles; medical records; privacy; recordkeeping practices; security.

This is a condensation of the report "Computers, Health Records, and Citizen Rights," by Alan F. Westin, NBS Monograph 157, which investigates the impact of computers on citizen rights in the health recordkeeping area. Under Dr. Alan F. Westin's direction, from July of 1974 to April of 1976, a small interdisciplinary team did the following: (1) examined published literature from medicine and health, law, computing, and social science; (2) conducted interviews with major computer manufacturers, systems developers, health professionals and civil liberties, public interest, consumer, and minority-rights groups; (3) made on-site visits to six representative health-care organizations using computers to handle personal records; (4) corresponded with 70 organizations in the health field; and (5) subjected an initial draft report to review by a conference of experts in September 1975 and subsequently by about 50 outside reviewers. The findings of this investigation were then combined into this four-part report. Part One describes the world of medical data and citizen rights within the framework of three zones-primary health care (by health professionals), service payers and health care reviewers and social uses of health data (such as in employment, life insurance, and welfare); Part Two treats patterns of computerization in health care in each of the above zones; Part Three contains the profiles of the six health-care organizations that were studied in depth; and Part Four analyzes the impact of computerization on personal health records, presents comparisons with six other democratic nations, and states 12 recommended management principles for health care data systems. The full report also contains a 28 page bibliography and 12 appendices with support documents and information.

SP470. Wind and seismic effects. Proceedings of the Seventh Joint Panel Conference of the U.S.-Japan Cooperative Program in Natural Resources, May 20-23, 1975, Tokyo, Japan, H. S. Lew, Ed., Nat. Bur. Stand. (U.S.), Spec. Publ. 470, 513 pages (Apr. 1977) SN003-003-01762-1.

Key words: accelerograph; bridges; buildings; codes; disaster; dynamic analysis; earthquakes; ground failures; hydraulic structures; seismicity; soils; standards; structural response; vessels and wind.

The Seventh Joint Meeting of the U.S.-Japan Panel on Wind and Seismic Effects was held in Tokyo, Japan on May 20-23, 1975. The proceedings of the Joint Meeting include the program, the formal resolutions, and the technical papers. The subject matter covered in the papers includes characteristics of strong wind; response of full-scale structures to wind action; geological distribution of seismic activity; maintenance of strong motion accelerographs and data processing; strong earthquake motions and ground failures; response of hydraulic and building structures to seismic forces; aseismic considerations for vessels; recent revisions of design standards on wind and seismic effects; joint research program utilizing large scale testing facilities; and technological assistance to developing countries. These proceedings include the following papers (indented):

Present status of wind characteristics in Japan, $K$. Takeuchi, SP470, pp. I-I -I-17 (Apr. 1977).
Key words: field measurements; model; towers; wind; wind observation; wind tunnel.

The present status of a study on the wind characteristics in Japan is given herein. Observational studies constructed from a tower and an array of towers are described in addition to results obtained from tethered balloons.

The observations obtained from towers in Tokushima Pref. and analysis of the data, which were made by Shiotani (1972 and 1974), are detailed and unique. Also other observations from towers located at Tarama Island, Okinawa Pref. are being conducted by Mitsuta (1974). Detailed analysis of these observations are also presented.

Finally some model experiments on the local wind, using a tunnel, are also presented.

A reexamination of hurricane Camille, A. R. Hull, SP470, pp. I-18-I-27 (Apr. 1977).

Key words: hurricane; storm surge; tropical storms; wind; wind data; wind speed.

Newly available oceanographic and meteorological data on major storms and hurricanes striking the Gulf of Mexico during a 31 -month period provided by eight petroleum firms present an opportunity to reexamine and reevaluate Hurricane Camille, one of the most severe and destructive storms ever to strike the Gulf. (Maximum wave heights of 72 feet were recorded as the eye of the hurricane passed within 15 miles of one measurement station.) The new data on Camille comprise one of the most comprehensive sets of oceanographic and meteorological information available for such an extreme weather event and should prove invaluable in basic research and offshore engineering applications. With increasing availability of this type of information likely as the Nation develops its offshore energy resources, questions arise as to what procedures should be followed to access, disseminate, and use these data most effectively and what contributions this important new data source may make to current knowledge of extreme storm events and their effects on engineering structures. The data available for Camille are examined to provide tentative answers to these questions.

Fire tornado and its maximum wind-speed, S. Soma and $\mathrm{K}$. Suda, SP470, pp. I-28-I-4l (Apr. 1977).

Key words: fires; fire tornados; tornado model; tornados; wind speed.

Very few studies have been conducted on fire tornados, owing to its rare occurrence. However, in Japan, much public attention has been directed to this phenomenon in view of the fact that catastrophic damage has been caused by two fire tornados. One such tornado developed during the Great Kanto Earthquake in 1923 and another at Wakayama City in 1945. The cause of such catastrophic damage, due to these fire tomados is two-fold. One is the formation of a tornado, in burning of the urban area, and the other is the peculiar feature that the tornado is accompanied by strong winds.

In the present report, the characteristirs of the fire tornados, which have been experienced in Japan are reported and the estimated maximum wind speed in the tornados are given.

A research project on the wind flow around tall buildings, T. Murota and K. Nakano, $S P 470$, pp. I-42-i- 49 ' Apr. 1977).

Key words: building; wind; wind effects; wind loads; wind observation; wind speed. 
The problem of wind effects, produced by the construction of tall buildings, is analyzed. A research project designed to obtain information about this problem and to study the counterpart for the prevention of high winds around tall buildings, has been initiated. Some preliminary observations are described herein.

Wind engineering research program supported by the National Science Foundation, M. P. Gaus, SP470, pp. II-I-II10 (Apr. 1977).

Key words: education; research; research programs; wind engineering; wind studies.

The National Science Foundation is an Agency of the Federal Government established in 1950 to advance scientific and technical progress in the United States. The Foundation fulfills this responsibility primarily by sponsoring scientific research, encouraging and supporting improvements in science education, and fostering scientific information exchange. NSF does not itself conduct research or carry out education projects.

Operating under this charter the Foundation supports a substantial amount of research in Wind and Seismic effects. The Division of Engineering has for the past years had an organized area activity in Wind Engineering Research. The primary emphasis of this research has been toward developing a better understanding of the structure and flow of the earth's boundary layer to develop new knowledge and techniques for predicting and coping with the interaction between the boundary layer wind and manmade or natural objects and to develop methods to assess or predict environmental effects related to wind flow. Almost all of the current research programs being supported are at academic institutions. A summary of these current research projects is given herein.

Study of the wind pressure and the response of roof corners, T. Murota and M. Nakahara, SP470, pp. II-11-II-19 (Apr. 1977).

Key words: buildings; dynamic effects; high winds; roofs; typhoon; wind pressure.

In 1972, a number of prefabricated dwellings in the Nagoya district, Japan, suffered damage from high winds caused by Typhoon No. 7220. Much of the damage to the dwellings caused by this typhoon was the removal of the flat roofs of the buildings. It is known that the corners of flat roofs, when subjected to high winds have high suctions with periodic fluctuating force components. The cause of this type of damage has created a need for studying the dynamic effect of wind pressure on roof comers. Such a study has been conducted since 1973 by the Building Research Institute. The results of the 1974 field observations, by the BRI, will be given herein.

On the wind response of the Kanmon Bridge, T. Okubo, $\mathbf{N}$. Narita, and K. Yokoyama, SP470, pp. II-20-II-46 (Apr. 1977).

Key words: bridges; displacements; field tests; wind measurements; winds; wind speed.

The resistance against wind of long-span suspension bridges is one of the important design problems because this type of bridge is flexible and sensitive to wind action. The Kanmon Bridge, opened to the public in November 1973, is a typical long-span suspension bridge in Japan. The design of this bridge against wind initiated during the early design phases and its stability against wind was confirmed through wind tunnel experiments on section models. However, confirmation between theory and model tests can only be confirmed by considering field studies and the resulting data. Such studies can reconfirm the bridge safety when the bridge behavior is examined under strong wind conditions. Considering these thoughts, a long-term observation plan system was established on the Kanmon Bridge, with actual observations initiated in April 1974.

In this paper, the research plan for the long-term observation system is reviewed. Then, the characteristics of the approaching wind and the response of the suspended structure are presented. A comparison is then made between observed and theoretical wind gust responses. The results show that the observed response is less than the theoretical response and thus shows the need for accumulation of data which can improve analytical techniques.

Luling, Louisiana cable-stayed bridge wind tunneI section modeI tests, R. H. Gade, W. Podolny, Jr., and H. R. Bosch, SP470, pp. II-47-II-67 (Apr. 1977).

Key words: bridge; cabled stayed; displacements; flutter; models; wind angles; wind tunnel.

Results of wind tunnel section model tests of five orthotropic superstructure configurations for the Luling, Louisiana, cable-stayed bridge are presented.

The 1,235-foot (376.4 meters) long main span crossing of the Mississippi River is designed for 150 miles per hour (67 meters per second) hurricane wind velocity

The section models, 1/60 scale, are tested at six wind angles: $-4^{\circ},-2^{\circ}, 0^{\circ}, 2^{\circ}, 4^{\circ}$, and $6^{\circ}$. Flutter coefficients are plotted for all tests.

The tests show freedom from flutter at the design wind speed. Vortex excitation, vertical and torsional, is exhibited.

Testing is performed in smooth flow conditions at the Fairbank Highway Research Station of the Federal Highway Administration, utilizing the George S. Vincent Wind Tunnel.

The regional distribution of the earthquake danger in Japan, S. Hattori, Y. Kitagawa, and T. Santo, SP470, pp. III1-III-17 (Apr. 1977).

Key words: earthquake distribution; earthquakes; field data; frequency maps; ground displacement; Japan.

The values of $\mathrm{m}$ and $\log \mathrm{k}$ in Ishimoro-Iida's statistical Formula are derived for each component of the maximum displacement amplitude observed at many stations of the network maintained by the Japan Meteorological Agency (JMA).

A distribution map of expected maximum displacement amplitudes for the earthquake recurrence period of 100 years is made based on the derived values of $\mathrm{m}$ and $\log$ k. The map indicates quantitatively the regional distribution of earthquake danger in and around Japan. It is seen from this map that the general level of the earthquake danger varies throughout Japan. This variation is also found to reflect the pattem of seismic activity throughout the area. The earthquake danger increases along the Pacific side of Hokkaido, Tohoku and Kanto districts and decreases in the southwestern and inland areas of Japan. Small variations are also recognized, which might suggest that the earthquake danger is affected by local geological and subsoil effects.

Quantification of seismicity, T. Terashima and T. Santo, SP470, pp. III-18-III-28 (Apr. 1977).

Key words: earthquake distributions; epicenters; maps; seismicity index.

A new seismicity index is proposed in this paper. This index is defined by the following equation: 


$$
\mathrm{S}_{T}=\left(\mathrm{M}_{2 \mathrm{G}} / \mathrm{T}\right) \Delta \leqslant 100 \mathrm{~km} \mathrm{M} \geqslant 6
$$

where, $N(M)$ represents the number of shallow earthquakes with $M \geqq 6$ which have occurred within a epicentral distance $\Delta$ of $100 \mathrm{~km}$ during the period $\mathrm{T}$ (year). Using this criterion, seismicity index maps in or near Japan for two different periods have been made.

Application of this index indicates that a remarkable change of $S_{T}$ was found in southern part of Boso Peninsula before and after Great Kanto Earthquake of 1923. Therefore, in the field of earthquake engineering, these seismicity index maps can be used as a zoning map of earthquake risk.

Maintenance of the strong-motion accelerograph and the data processing of the records, E. Kuribayashi, H. Tsuchida, and M. Watabe, SP470, pp. IV-1-IV-34 (Apr. 1977).

Key words: accelerographs; earthquake data; earthquake records; field observations; strong-motion accelerographs.

The observation of strong-motion earthquakes, located at harbour, public works and buildings throughout Japan by the national research institute has been made. These observations will be discussed, herein, in addition to such items as the maintenance and checks of the strong-motion accelerographs, main records, processing and analyses of records, and the availability of the data to the public.

The United States strong-motion network: Field operations, R. P. Maley, SP470, pp. IV-35-IV-52 (Apr. 1977).

Key words: accelerographs; earthquake data; earthquake records; field stations; strong-motion network.

The national strong-motion instrumentation network operated by the Seismic Engineering Branch of the U.S. Geological Survey is the system established to record the strong motions of damaging earthquakes in the United States. From the original $50 \mathrm{C} \&$ GS Standard instruments installed in the 1930's, the network has expanded to more than 1300 accelerographs, with 9 different models, located in 35 states and 9 Central and South American countries.

The network operations section of SEB conducts three interrelated field programs: instrument installation, routine maintenance, and earthquake record recovery. At the present time the large majority of instruments being installed are self-contained three-component accelerographs that record on $70-\mathrm{mm}$ film. Some remote-sensor accelerographs are also being located on structures. Routine maintenance intervals have been lengthened from 2 months a few years ago to 4 months, with the exception of a trial area in Los Angeles where a 6 month interval is now in effect. The higher reliability of modern instrumentation has made this extended maintenance schedule possible. As the network expands, it may be necessary to develop a Remote Interrogation System to provide a method of determining the criterion of the instruments' vital functions by telemetry. After significant earthquakes, SEB personnel promptly collect and develop earthquake records and attach permanent labels providing sufficient data for most analyses. The records are then transmitted to the data management section for further processing.

Strong-motion data management, C. Rojahn, SP470, pp. IV-53-IV-66 (Apr. 1977).

Key words: accelerographs; data processing; earthquake records; strong-motion data.

The Seismic Engineering Branch (SEB), of the Office of Earthquake Studies, U.S. Geological Survey, is funded by the National Science Foundation and is responsible for the development and maintenance of a national network of strong-motion instruments and for the processing, management, and dissemination of data obtained from those instruments. Data management is central to the entire strong-motion program; it serves as a focal point for the functions of archiving the records, processing the data, and disseminating both the data and information about the program to the user community. In the archival phase, all records are stored by station and cataloged both by event and by station. In data processing, all significant ground and basement level records are digitized after which the raw digitized data is used to generate the following: uncorrected acceleration time-histories; velocity and displacement time-histories; and various forms of frequency domain spectra. Both SEB and the Environmental Data Service of the National Oceanic and Atmospheric Administration are involved in the data and information dissemination operation. Each organization distributes data, whereas SEB is solely responsible for the dissemination of information about the strong-motion program. Various U.S. Geological Survey professional papers and circulars are the primary media through which the latter function is accomplished.

Brief review on liquefaction during earthquakes in Japan, E. Kuribayashi and F. Tatsuoka, SP470, pp. V-1-V-15 (Apr. 1977).

Key words: alluvial deposits; earthquakes; epicentral distance; liquefaction; settlement; soils.

To correlate the actual liquefaction phenomena and site conditions, a literature survey about the liquefaction phenomena caused by earthquakes during the last century in Japan was performed. A liquefaction distribution map of Japan and the regional maps of Kanto, Nobi and Hokuriku are presented and the factors related to liquefaction are discussed. During the last century liquefaction in sub-soils have been observed at some hundred sites during 44 earthquakes where the sites were limited to alluvial deposits and reclaimed lands. Furthermore, it was found that liquefaction occurred repeatedly in different earthquake zones. The estimated JMA intensity scale factor, at the liquefied sites was more than five which means a maximum acceleration of 80 to 250 gals. The extent of the liquefied zones are limited, depending on the magnitude of the earthquake.

Vibration test on settlement of submerged sand layer, $K$. Sawada and Y. Koga, SP47O, pp. V-16-V-35 (Apr. 1977).

Key words: earthquakes; liquefaction; sand layer; shake table; vibration tests; void ratios.

A series of vibration tests on submerged sand layer model, using a large shaker table, was performed in order to establish a method which can predict the liquefaction and settlement phenomenon of sandy ground during earthquakes. As a result of these tests, information concerning the vibration behaviour during the liquefaction phenomenon and subsequent settlement behaviour was obtained. Examining these test results and assuming that the vibration and settlement behaviour of a sand layer in the sand container is one-dimensional, it has been found that the test and analysis results agree quite favorably. Therefore, if the shear stress in the ground can be reasonably estimated, the amount of settlement of the sand due to earthquakes can be estimated by this analysis method proposed herein.

Study on earthquake response of structures by considering non-deterministic variables, $Y$. Yamazaki and $Y$. Koizumi, SP47O, pp. VI-1-VI-21 (Apr. 1977). 
Key words: deterministic; dynamics; earthquake; probability; random vibrations; safety; structures.

The seismic design coefficient has been widely used because of its simplicity. This design technique provides a safeguard against earthquakes but contains many problems when replacing the dynamic forces with static forces. In addition, the earthquake resistant properties of high-rises or buildings can be investigated by a simulation analysis, using many past earthquake records as input excitation. This type of dynamic analysis of a structure has been made possible by use of electronic computers. In this analysis, an actual structure is transformed into a vibration model, then the structure is subjected to earthquake ground motions, which are simulated by an electronic computer. As an alternate scheme, from a stochastic point of view, vibrational properties of structures subjected to earthquake ground motions have been investigated by utilizing the concept of random vibrations. The theory of random vibration, for dynamic response of structures, considers that earthquake ground motions can be essentially predicted as deterministic phenomena and that the vibrational behaviour of structures during these earthquakes can be predicted stochastically. Studies on developing a more reasonable design method have been conducted using the experiences obtained from earthquake disasters and the analyses of earthquake phenomena. The nondeterministic phenomena of earthquake ground motions will be treated essentially by the application of the theory of random vibration to the earthquake engineering. However, it is also true that a structure cannot be handled as a deterministic system, because the dynamic property variables of an actual structure, such as the masses, spring constants and damping constants, cannot be evaluated deterministically when the structure is designed. Hence, a structure must be designed by considering the nondeterministic properties of the structure as well as those of earthquake ground motions. In this thesis, a theoretical treatment of the earthquake response problems of a structure with nondeterministic variables have been discussed and a reasonable design technique of a structure with appropriate safety has been suggested.

Least weight structures for threshold frequencies, R. D. McConnell, SP470, pp. VI-22_-V1-32 (Apr. 1977).

Key words: frequency response; least weight; optimization; structures.

This paper demonstrates a method for designing leastweight, or optimized, structures when a threshold frequency (within appropriate force factors) is known. The process is highly amenable to a job-by-job application due to its simplicity. Small mathematical models of a structure can be analyzed by a hand-calculator while standard staticload finite element programs can be used for large structures.

Ductile shear walls in earthquake-resistant multistory buildings, M. Fintel, SP470, pp. VI-33-VI-46 (Apr. 1977).

Key words: buildings; damage; dynamic response; earthquakes; safety; shear wall; stiffness.

Slender shear walls in multistory buildings are discussed in this paper and answers are given to such questions as "Why do we need them?" and "What do we know about their design?". Also discussed are the historical development of the use of shear walls, their performance in earthquakes of the past 10 years (both good and bad), and finally, the available design information and our future needs in the area of design of shear walls for strength, stiffness and ductility, as well as needs in the area of analysis for the dynamic response of shear wall structures.
Surveillance of corps of engineers structures in earthquakeprone areas, K. O. O'Donnell, SP470, pp. Vl-47-Vl-63 (Apr. 1977).

Key words: earthquakes; hydraulic structures; inspection; instrumentation; strong-motion accele rographs.

This paper explains the program which the corps of Engineers has adopted to assess the effects of earthquake activity concerning the structural behavior of Civil Works hydraulic structures. The program encompasses reporting earthquake effects and an instrumentation system on dams and appurtenant structures for monitoring. Post-earthquake inspections will be conducted to detect significant structural distress and provide information for the necessary remedial measures for damaged structures. The strong motion instrumentation will provide a record of ground and structure motion during earthquakes. Data provided from this program should be an aid in selecting design earthquakes and may provide preliminary guidance in design procedures for use in predicting, from small earthquakes, the behavior of structures subjected to larger design earthquakes. The accumulated information from the entire program should help in improving the design criteria for future designs.

School and hospital construction in California, J. F. Meehan, SP470, pp. VI-64-VI-73 (Apr. 1977).

Key words: building codes; building regulations; design criteria; earthquakes; hospitals; schools.

The California State Legislature has adopted statutes concerning the regulation of the design and construction of public school buildings and hospitals. These statutes were brought about because of the rather poor performance of these types of buildings in California earthquakes. Events leading up to these statutes and the methods of their enforcement will be discussed.

Improved earthquake resistive design and construction of single-family residential dwellings, G. R. Fuller, SP470, pp. VI-74-VI-88 (Apr. 1977,).

Key words: building codes; buildings; construction; dwellings; earthquakes; seismic design criteria.

This paper presents results of the research program being carried out by the Applied Technology Council (ATC) of the Structural Engineers Association of California (SEAOC) under the sponsorship of the U.S. Department of Housing and Urban Development. The objective of this project was to review and evaluate available manuals, literature and standards concerning design and construction of residential dwellings and response of such structures to earthquake motions; and to then develop a manual of recommended practice for earthquake resistive design and construction. This manual would be primarily directed toward builders, building officials, field inspectors, and house designers and would contain recommended construction details, architectural layouts, design recommendations and types of construction recommended or to be avoided. The manual is now in draft form and copies are available for review. A synopsis of research results developed to date will be presented in this paper. Code comparisons, problem areas, tentative recommendations will be discussed.

The research contract with ATC is not due for completion until June 30,1975 , therefore this paper is an interim report. The final report with the completed manual will be distributed to members of the U.S.-Japan Panel on Wind and Seismic Effects, when available. 
Dynamic tests of structures for oil tanks and nuclear power plants, S. Inaba, SP470, pp. VII-1-VI1-6 (Apr. 1977).

Key words: aseismic design; dynamic tests; nuclear reactors; oil tanks; power plants; shake table.

In Japan, it is necessary to build an increasing number of nuclear power plants in order to overcome the energy problem. Also, an increasing number of large oil tanks have been built in order to increase the amount of standard crude oil. It has, therefore, become important in engineering to dcsign aseismic structures for nuclear power plants, oil plants, gas tanks, and other industrial plants for the purpose of preventing disasters due to the earthquake. Under these circumstances, several dynamic tests of plant structures have been conducted by using a large-scale shake table of the National Research Center for Disaster Prevention (VRCDP) in Tsukuba New Town. This report will present in general the results of dynamic tests on a graphite shielding structure, oil tanks, fuel assemblies of nuclear reactor, and a container vessel of thin shell.

Sheet pile foundation and its structural characteristics against horizontal loads, K. Kawakami, T. Okubo, K. Komada, and M. Okahara, SP470, pp. VII-7-VII-60 (Apr. 1977).

Key words: foundation; lateral loads; sheet piles; structural analysis; tests.

The general response of sheet pile foundations, relative to analytical and experimental studies, are discussed. Test results are given, in addition to the development of general design equations.

On specifications for earthquake-resistant design of highway bridges (January, 1971), K. Kawakami, E. Kuribayashi, T. Iwasaki, and Y. Iida, SP470, pp. VIII-1-VIII-30 (Apr. 1977).

Key words: earthquakes; highway bridges; seismic provisions; specifications; structural engineering.

This paper presents the details of new specifications for Design of Highway Bridges to Resist Earthquakes, completed in January 1971 by the Highway Bridge Committee of the Japan Road Association.

On specifications for earthquake-resistant design of the Honshu-Shikoku Bridges (JSCE 1974), I. Kawasaki and E. Kuribayashi, SP470, pp. VIII-3 I -VIII-4I (Apr. 1977).

Key words: bridges; earthquake design; earthquake forces; seismic provisions; specifications.

The following describes the general specifications for earthquake-resistant design of the Honshu-Shikoku Bridges, as developed by JSCE in 1974, after significant study.

Recent revision of design standards on seismic effects for port and harbour structures, S. Hayashi, H. Tsuchida, and S. Noda, SP470, pp. VIII-42-VIII-55 (Apr. I977).

Key words: design; earthquakes; harbours; ports; specifications; structures.

The design standards for port structures have been compiled four times in Japan. In thesc design standards, provisions on earthquake resistant design of wharves are included.

In 1950 the first design standard was published, and in 1959 and 1967 new design standards as an expansion of preceding one were compiled. Those design standards were recognized as the most advanced design procedure in the times and used very widely for design of port structures. However, the standards were not related to any law.

In 1973 Port and Harbour Law was revised and to secure the safety in ports it was assigned to establish engineering requirement of facilities in ports. The requirement has been effective since 1974 and the earthquake resistant design of the facilities are specified in it.

JSCE specifications for earthquake resistant design of submerged tunnels (1975), E. Kuribayashi and $H$. Tsuchida, SP470, pp. VIII-56-VIII-68 (Apr. 1977).

Key words: aseismic design criteria; design provisions; earthquakes; specifications; structural engineering; tunnels.

In response to the request from Ministry of Construction and Ministry of Transport, the Japan Society of Civil Engineers has concluded in March 1975 the final draft of the Specifications for Earthquake Resistant Design of Submerged Tunnels. The writers of this paper have worked on the drafting of these Specifications in cooperation with colleagues of the Public Works Research Institute and Port and Harbor Research Institute during the last four years.

The draft of the Specifications was adopted as Specifications for Earthquake Resistant Design of the Proposed Tunnel across Tolyo Bay. This paper presents the principal provisions and articles of the draft of the Specifications, and contains the following five chapters; General, Investigation, Earthquake Resistant Design, Dynamic Analyses, and Preservation and Countermeasure in Earthquakes.

Joint research program utilizing the large scale testing facilities (free discussion), M. Watabe, M. Hirosawa, and S. Nakata, SP470, pp. IX-1 -IX-5 (Apr. 1977).

Key words: dynamic testing; lateral load simulation; models; shake tables; testing.

Recently the United States and Japan have made progress in aseismic design of $\mathbf{R}$. C. Structures based on the testing of R. C. members, in which these tests have shown the importance of ductility in columns. However there are a few seismic studies based on the loading tests of full size structures. Fortunately, in Japan there are the greatest loading test facilities in the world, with new larger facilities now under construction. By using these facilities full size aseismic tests can be conducted. This proposal provides a plan for the testing of reinforced concrete structures with shear walls, which should be the first step toward developing an international aseismic code.

Earthquake disaster mitigation: $A$ joint research approach, C. C. Thiel and J. B. Scalzi, SP470, pp. IX-6-IX-16 (Apr. 1977).

Key words: buildings; earthquakes; research; structural engineering; structures.

This paper discusses the current earthquake research being undertaken in the USA under sponsorship of the NSF. In addition, possible cooperative research studies between the USA and Japan are described.

High wind study in the Philippines, N. J. Raufaste, SP470, pp. X-1-X-1 I (Apr. 1977).

Key words: field studies; high winds; instrumentation; Philippines; wind tunnel test.

A review of the National Bureau of Standards three-year high wind study in the Philippines is presented. Accomplishments during the first two years of the study are discussed. Principal accomplishments include: 1) formation 
of a Philippine Advisory Committee to coordinate local wind research, 2) selection of three field test sites, 3 ) construction and instrumentation of six test buildings with wind recording equipment at the test sites, 4) instrumentation of the University of Philippines wind tunnel, and 5) participation in two international workshops on high winds in Manila.

Survey on seismology and earthquake engineering in India, Iran and Turkey, M. Watabe and $\mathrm{H}$. Tokuhiro, SP470, pp. X-12-X-16 (Apr. 1977).

Key words: carthquake engineering; earthquakes; education; India; lran; training; Turkey.

A series of earthquake engineering courses have been held in Japan in cooperation with Iran, India and Turkey. This paper presents the details of these courses and the aid such courses have provided to the supporting countries.

SP471. Report of the 61 st National Conference on Weights and Measures 1976, P. A. Raschella, Ed., Nat. Bur. Stand. (U.S.), Spec. Publ. 471, 304 pages (June 1977) SN003-003-018066.

Key words: checking prepackaged commodities; computer assisted check-out systems; consumer affairs; cordage products; drained weight; laws and regulations; metrication; national laboratory accreditation; retail meat identity standards; tolerance application; vapor recovery; weights and measures.

This is a report of the proceedings (edited) of the Sixty-First National Conference on Weights and Measures, sponsored by the National Bureau of Standards, held in Washington, D.C., July 12-16, 1976 and attended by State, county, and city weights and measures officials, the Federal Government, business, industry, and consumer organizations. These proceedings include ihe following papers (indented):

Metrication-A one-time opportunity, R. L. Thompson, SP471, pp. 1-4 (June 1977).

A different view on tolerance application, O. K. Warnlof, SP471, pp. 5-12 (June 1977).

Tare weight in computer assisted checkout systems, H. Morris, SP471, pp. 13-16 (June 1977).

EPA gasoline vapor recovery programs, R. L. Ajax, SP471, pp. 17-22 (June 1977).

Documentation of interpretations and methods of sale, $E$. W. Johnson, SP471, pp. 23-24 (June 1977).

What everyone should know about those Supreme Court cases having to do with moisture losses-As of the Fourth of July, 1976, M. S. Thompson, SP471, pp. 24-28 (June 1977).

Uniform retail meat identity standards, H. K. Johnson, SP471, pp. 29-43 (June 1977).

An introduction to weights and measures for cordage products, W. H. Hagenbuch, SP47I, pp. 44-48 (June 1977).

Report and recommendations to the National Conference on Weights and Measures on the measurement of kiln dried hardwood lumber, E. H. Gatewood, SP471, 49-52 (June 1977).

Metrication USA, M. E. O'Hagan, SP47I, pp. 53-62 (June 1977).

The metrication of Seven-Up-The liter leader, B. H. Wells, SP471, pp. 63-68 (June 1977).
Metric training seminars, J. H. Landvater and M. Perkins, SP471, pp. 69.76 (June 1977).

A background for understanding sampling plans, $M$. G. Natrella, SP471, pp. 77-83 (June 1977).

National conference of State legislatures, T. Jensen, SP471, pp. 84-89 (June 1977).

National voluntary laboratory accreditation program, G. A. Rowland, SP471, pp. 90-102 (June 1977).

Consumer affairs forum (introduction), O. D. Mullinax, SP471, p. 103 (June 1977).

A new road for consumers, M. Dana, $S P 471$, pp. 103-109 (June 1977).

Drained weight regulations, B. M. Gutterman, $S P 471$, pp. 110-120 (June 1977).

What the consumer needs to know about metric, B. Beizer, SP471, pp. 120-124 (June 1977).

NBS and NCWM-Past, present, and future, E. Ambler, SP471, p. 128 (June 1977).

SP472. Retrieval and analysis of orthopaedic implants. Proceedings of a Symposium held at the National Bureau of Standards, Gaithersburg, MD, Mar. 5, 1976, A. Weinstein, E. Horowitz, and A. W. Ruff, Eds., Nat. Bur. Stand. (U.S.), Spec. Publ. 472, 130 pages (Apr. 1977) SN003-003-017671.

Key words: analysis; implants; metallic; orthopaedic; retrieval.

This book is the formal report of a symposium on Retrieval and Analysis of Orthopaedic Implants. This volume contains the invited lectures that provide a state-of-the-art information base about implant characteristics related to performance; the discussions of a panel addressed to the problems associated with, and the information generated from, implant retrieval analysis; and the reports resulting from a workshop on "What Is the National Need?" These proceedings include the following papers (indented):

Opening remarks, P. G. Laing, SP472, p. 1 (Apr. 1977).

Overview: Performance feedback via device retrieval and analysis, A. M. Weinstein, SP472, pp. 3-9 (Apr. 1977).

A review of metallurgical failure modes in orthopaedic implants, D. F. Williams, SP472, pp. 11-20 (Apr. 1977).

Models for systemic effects of metallic implants, G. K. Smith and J. Black, SP472, pp. 23-28 (Apr. 1977).

Tissue reaction to biomaterials, $P$. G. Laing, $S P 472$, pp. 31 38 (Apr. 1977).

Clinical biomechanics, G. Piotrowski, SP472, pp. 41-48 (Apr. 1977).

Femoral stem performance, D. L. Bartel and S. G. Desormeaux, SP472, pp. 51-59 (Apr. 1977).

Orthopaedic implant retrieval analysis, A. U. Daniels and H. K. Dunn, SP472, pp. $61-70$ (Apr. 1977).

Legal aspects of device retrieval, T. R. Lemon, SP472, pp. 73-79 (Apr. 1977). 
SP473. Research and innovation in the building regulatory process. Proceedings of the First NBS/NCSBCS Joint Conference hcld in Providence, R1, on Sept. 21-22, 1976, in conjunction with the Ninth Annual Meeting of the National Conference of States on Building Codes and Standards (NCSBCS), Inc., P. W. Cooke, Ed., Nat. Bur. Stand. (U.S.), Spec. Publ. 473, 504 pages (June 1977) SN003-003-017752.

Key words: administrative procedures; building codes; building regulations; buildings; economic impacts; environmental considerations; innovative practices; regulatory research; standards development.

The First NBS/NCSBCS Joint Conference on Research and Innovation in the Building Regulatory Process was held in Providence, Rhode Island on September 21-22, 1976. The proceedings of the Joint Conference include the opening remarks, the Keynote Address, the technical papers presented at each session, and a summary of a panel discussion on the future of building regulatory research. The subject matter covered in the papers includes: New Alternatives, Environmental Research and the Building Regulatory Process; Energy Conservation, Solar Energy and Building Standards; Coping with Building Innovations and Environmental Considerations; Issues in Building Regulation and Administration; Organization and Structure of Building Regulations; Information Processing and the Building Regulatory Process; Impact, Economics and Metrication of Building Regulation; Preservation, Rehabilitation and the Building Regulatory Process. These proceedings include the following papers (indented):

Incentives and constraints in building and the regulatory process, U. P. Gauchat and D. L. Schodek, SP473, pp. 1733 (June 1977).

Key words: altcrnatives; building codes; building process; constraints; costs; incentives; regulation.

This paper discusses three specific ways to improve the balance between incentives and constraints in the building regulatory proccss:

1. Reorganizing and controlling the building process with the aim of making the interests of individual participants more congruent.

2. Offering tax incentives at the federal level that would distinguish between those parts of a building which reflect a common objective such as health and safety and those which respond to the wishes of a particular client.

3. Developing federal legislation that prohibits, on thc basis of restrictive trade practice, the establishment of arbitrary local code restrictions, particularly those measures which inhibit the national marketing of highly factored building components or sub-assemblies.

How environmental research may affect the technical provisions and enforcement of regulations, S. T. Margulis, SP473, pp. $35-53$ (June 1977).

Key words: codes and standards; environmental studics; fire safety; health dangcrs; research needs.

Two case studies illustrate the consequences of knowledge voids on the technical provisions and enforcement of regulations. The first case deals with legal decisions about the reasonableness (and, by implication, the scientific justification for) certain health provisions of a model housing code adopted by a local government. The second case focuses on a situation in which enforcement of the Life Safety Code could have resulted in the forced relocation of institutionalized elderly. In this situation, code enforcement (leading to forced relocation) could have contributed to more deaths than nonenforcement of this fire safety code. The application of environmental research to solve the problem posed by this situation is described. Problems of obtaining and applying environmental research, with regard to policy decisions such as building regulations, are noted.

Interior architecture by consent decree and court order, W. Kleeman, Jr. and R. Reeves, SP473, pp. 55-67 (June 1977).

Key words: court orders; human behavior; institutional occupancies; interior design; physical environment; regulation; research; standards.

Mental hospital patients, mental retardates, handicapped pcople and prisoners in jails are suing various governmental authorities saying, among many other things, that the physical interior environments of these institutions do not mect their needs. Conscnt decrees and court orders in 16 leading cases are examined. The question is raised as to the origin of the vcry specific standards in several of the cases. The long-range suitability of these standards is questioned and contrasted with more humane, less specific approaches to the same concerns in Sweden and Canada. The need for further research to establish more useful determinations of the effects of the immediate physical environment on human well-being and behavior is pointed out. The problems of the designer in meeting the special needs of these four types of plaintiffs are also examined.

Residential energy consumption: Socio-physical determinants of energy use in single family dwellings, B. M. Morrison, SP473, pp. 69-83 (June 1977).

Key words: energy consumption; input/output models; lifestyle factors; physical environment; residential housing; socio-physical determinants; systems theory.

The paper rcports research designed to establish the factors that detcrmine energy consumption, especially in single family detached dwelling units. The research asks the question is it the physical structural components of the housing or the life patterns carried on by the residents or both that make the difference in energy consumption? Using a human/environment ecosystem model, this question comes under scrutiny.

A void tunnel vision in implementation of energy conservation building standards, W. J. van der Meer, SP473, pp. 85101 (June 1977).

Key words: alternatives; ASHRAE 90-75; building standards; buildings; energy conservation; minimum property standards; multiple glazing; "U" values.

Aside from recommendations to improve mechanical systems and components or to reduce lighting, most of the present thinking on cnergy conservation in buildings has the tunnel vision of looking almost exclusively toward lower "U" values. The FHA fell into the "U" value trap. in revising their Minimum Property Standards. Even the more permissive and performance oriented ASHRAE Standard 90-75 has succumbed in part to the lower "U" value syndrome because, even though they permit alternative mcthods in achieving energy conservation, the criterion for allowable energy use by the alternative methods is based upon the estimated energy use of a similar hypothetical building using the appropriate ASHRAE average " $U$ " values $\left(U_{n}\right)$.

Lower "U" values are not the only way to achieve thermal energy efficiency, nor need they necessarily form the criterion for energy conservative building standards. There are many alternatives in energy conservation which are 
relatively independent of " $U$ " values, several of which will be discussed in this paper.

Standards for solar heating and cooling applications, R. D. Dikkers, SP473, pp. 103-112 (June 1977).

Key words: buildings; cooling; heating; performance criteria; solar collectors; solar energy; standards.

The "Solar Heating and Cooling Demonstration Act of 1974," along with the "National Program for Solar Heating and Cooling (Residential and Commercial Applications)," call for the development and implementation of performance criteria, consensus standards, certification procedures and design guidelines relating to solar heating and cooling systems and components. This paper describes activities being carried out by the National Bureau of Standards (NBS) in support of the previously cited Federal legislation and program plan.

In cooperation with ERDA and HUD, NBS is developing: (1) performance criteria for solar heating and cooling systems to be used in residential and commercial buildings; (2) standards for solar heating and domestic hot water systems that can be used in conjunction with HUD's Minimum Property Standards; (3) draft standards for materials to be used in solar systems; (4) plans for establishing a solar collector testing laboratory accreditation program; and (5) plans for identifying and developing other needed standards in cooperation with various organizations.

Regulatory barriers to the diffusion of innovation: Some evidence from building codes, S. Oster and J. M. Quigley, SP473, pp. 113-135 (June 1977).

Key words: building official; building regulation; education; housing demand; innovation; regulatory barriers; residential construction; unionization.

Previous studies, including most prominently the reports of the Douglas and the Kaiser Commissions, have suggested that outmoded local regulation of residential construction has impeded technical progress in the industry. In this paper, we try to identify the determinants of differences across communities in building regulation. In particular, we use as our dependent variable the permissibility of four particular innovations in a cross section of political jurisdictions in 1970 and try to explain this permissibility using variables measuring attributes of building officials, local firms, labor unions, and housing demand. The data was taken from a special survey of local building departments conducted by Fields and Ventre in 1970. Our results indicate that the education of the chief building official and the level of unionization in the area are the two major factors explaining the probability that a jurisdiction will adopt a construction innovation in its code.

Effectiveness of U.S. municipal design review programs-Preliminary findings, S. Cohn, SP473, pp. 137-187 (June 1977).

Key words: architectural controls; buildings; design review; land use; municipalities; regulation; site design.

Design review and architectural controls as regulatory devices for improving building and site design began in the United States in 1930. By 1949, there were some $30 \mathrm{mu}$ nicipalities in the United States using such controls. The desire for more flexible regulatory instruments which could deal with unique contextual situations and designs as well as provide the means for designers to exercise their ingenuity in solving complex problems has resulted in this quasi-judicial regulatory technique becoming increasingly popular throughulit the United States. In spite of this growing popularity there has been neither a systematic inventory or evaluation of this particular technique. This study has attempted a comprehensive analysis of design review and architectural control boards in municipalities in the United States with a population of greater than 25,000. In general, it tries to identify the goals, functions, structures, and techniques used by such boards and attempts to relate these to the effectiveness of such boards in achieving these goals.

Natural environmental carrying capacity and building regulation, P. G. Rowe, J. L. Gevirtz, and J. B. Blackburn, Jr., SP473, pp. 189-202 (June 1977).

Key words: building codes; carrying capacity; environment; land use; natural system; performance standards; regulatory process.

This paper is an attempt to examine the concept of "natural environmental carrying capacity" in relationship to building regulation. Principally it is an examination of the representational problem involved in achieving conformance between building regulatory mechanisms and understanding of the fundamental characteristics and processes of the natural system.

The first part of the paper presents the concept of "natural environmental carrying capacity" and the problem of translating this into performance standards. Within this framework some of the difficulties of incorporating these concepts in present building regulation formats are described. An attempt is also made to distinguish those environmental issues that seem to be most appropriately regulated at the building code level.

The second part of the paper briefly describes a systematic approach whereby building performance standards can be developed that reflect the ability of different geographic areas within a region to absorb building developments without upsetting the balance of the natural system. This approach takes into consideration the interaction between various building and land-use types with a broad range of natural environmental characteristics.

Decision-aiding communications in the regulatory agency: The partisan uses of technical information, F. T. Ventre, SP473, pp. 203-223 (June 1977).

Key words: building codes; decision making; public policy; regulation.

This paper, based on a nationally representative survey of 1,200 municipal building departments, describes the partisan uses of information in a regulatory setting. Each of the agencies was facing a specific decision to alter its regulations to accommodate innovative building techniques. The agencies identified the various members of the building community-builders, designers, vendors, users, regulators-who came forward to initiate the change, to discuss its advantages or disadvantages, and then to assert a position either supporting or resisting the agency decision to modify the regulation. The local building industry, accused by many of being the greatest source of resistance to technical innovation, was found to be the strongest force for change, equaling sometimos surpassing the positive influence of the model code groups.

Oregon's experience in statewide code uniformity-Third year, W. M. Friday, SP473, pp. 225-240 (June 1977).

Key words: building regulation; code administration; enforcement; funding; local government; model codes; statelocal relations; statewide codes; uniformity. 
This paper has its genesis in an article written in mid1974 and appearing in the Building Standards magazine of November-December, 1975. The information has been updated with the latest Oregon experiences. Prior to 1971, Oregon had four independent agencies enforcing building regulations, with all of the related problems of code conflicts, duplication and nonuniformity of interpretation. In 1971, all of these functions were transferred to the Department of Commerce. New responsibilities were added in 1973, including a law setting statewide code uniformity, state-local government relations, personnel training and certification, adoption of model codes, appeals, statistical reporting, and energy conservation. Model codes have been adopted for all specialty codes. Some of the model codes are almost "pure"; others have significant amendments. A struggle is now under way between advocates of pure model codes and those who have amended it, over the number and auality of amendments.

Regulation and communication in the implementation of a building code for accessibility to the physically handicapped, T. J. R. Raper, SP473, pp. 241-251 (June 1977).

Key words: accessibility standards; building code; code administration; communication; enabling legislation; physically handicapped; regulation.

The State of North Carolina pioneered enabling legislation and development of building code requirements for accessibility to the physically handicapped. The "Handicapped Section" of the North Carolina State Building Code encompasses almost every occupancy classification in publicly- and privately-owned buildings. Requirements extend from small equipment items, such as water fountains, to spatial arrangements including site development, seating and laboratory space. Consequences of implementing these laws, effective in 1973, were profound for code administrators, the building community and the public

The approach to implementation is an "extension" approach to code administration, which is exemplary of regulatory reform for the public benefit. Access to public buildings is mandated by law (Public Law 90-480); annually more states and model codes are adopting standards for accessibiblity. As a possible model for others, this paper seeks to explain how the "Handicapped Section" of the Code was developed and enacted, how it is being publicized and enforced and how it is being maintained.

Catalogue of buildirg safety instruments, R. S. Ferguson and C. C. Gordon, SP473, pp. 259-278 (June 1977).

Key words: building codes; building safety; control; instruments; knowledge; legislation; life safety; regulation; standards.

A building regulation is an instrument to achieve a goal-building safety. At any time and place the building ordinance, bylaw, or act is seen as "the" instrument and little thought is given to other instruments (existing or possible), attention is usually focused inwardly on the bylaw or code. The focus of this paper encompasses many instruments all of which have been or are being used. These instruments ranging from custom to research include law, authority, training, education, standards, guidelines, and administrative techniques. The characteristics of each instrument are discussed. This is an aid to their selective use. Building safety can be likened to a garden which flourishes with the use of many tools, or instruments, from hoes, picks, and rakes to watering cans and fertilizers but only when the right tool is chosen for a specific task at the right time and place. The paper is written in definitive form as a contribution for discussion and subsequenct inclusion in a proposed manual of building safety knowledge.

Performance vs producer-controlled codes, O. Richards, SP473, pp. 279-284 (June 1977).

Key words: building codes; concrete testing; evaluation; innovations; in-place testing; performance approach; regulatory domination; standards development.

This is intended to speed evaluation and implementation of innovations in standards and codes, which too often await change initiated by large producer corporations. Such producers tend to take such action only when no damage is done to a status quo that favors them and, further, when they stand to benefit from a change.

The writer, a would-be innovator in in-place field evaluation of concrete insulation and strength for twenty years, would leaven producer domination of codes with more vigorous participation of users. Products and methods should be evaluated not under artificial conditions, but under conditions of intended use. Examples include performance vs potential in thermal insulation and nondestructive in-place strength testing by the pullout method.

Logical analysis of building code provisions, J. R. Harris, SP473, pp. 285-316 (June 1977).

Key words: building codes; computer model; decision table; decision theory; networks; specifications; standards; system engineering.

The paper describes a systematic analysis of a set of related building code provisions. The analysis is a part of an overall methodology being developed for the systematic formulation and expression of clear, correct, anci complete building regulatory documents. Provisions for the allowable size of buildings are represented with decision tables and networks. The analysis shows the complete hierarchy of decision making necessary to arrive at the final answer. Alternate schemes of arranging the information are developed, and the relation of the information content to the overall organization of the document is shown. The applicability of the analysis for various factions of the building regulatory system is evaluated.

The evolution of the performance approach in plumbing, $R$. S. Wyly, L. S. Galowin, and M. J. Orloski, SP473, pp. 317348 (June 1977).

Key words: performance approach; performance characteristics; performance criteria; performance evaluation; performance testing; plumbing research; plumbing research needs; reduced-size venting.

The performance approach is reviewed as it relates to plumbing. The approach described provides for the systematic development of performance criteria, reproducible evaluation or test methods, and inspection guidelines, with significant benefits derived for innovators, contractors, code administrators, and the consumer through the utilization of new methods and materials for water supply and drainage in buildings. Performance specifications are seen as complementary or supplementary to the traditional prescriptive-type language of standards and code documents. They have the primary purpose of simplifying, systematizing, and hastening the process of acceptance of innovation. Traditionally, acceptance has occurred through a lengthy trial period during which satisfactory service history is accumulated with great difficulty and considerable expense to the proponents. The gradual movement to performance concepts in the requirements for sanitary drain- 
waste-vent systems is discussed. An example is described in which planned laboratory and subsequent field research with a performance orientation have provided a technological basis for acceptance of reduced-size venting. This economically attractive new method has only recently been considered by the prescriptive codes and is not yet fully accepted by them.

A theoretical basis and implementation for computer assisted architectural design evaluation, D. A. Bryant and R. B. Dains, SP473, pp. 349-368 (June 1977).

Key words: architectural criteria; automated system; building codes; buildings; computer applications; criteria maintenance design evaluation; design guides.

$S E A R C H$ : Systematic Evaluation And Review of Criteria for Habitability (SEARCH) is an automated architectural criteria maintenance and design evaluation system. A prototype system is now in the Office of the Chief of Engineers (OCE). SEARCH is used in two phases of Corps of Engineers design work. First, performance type architectural design criteria and selected building code requirements are checked for consistency, documented as to information location, and stored for later use. Second, design layouts produced by Architect/Engineers (A/E) are put into SEARCH. The result is full, unbiased evaluation based on the previously checked and stored criteria. SEARCH is intended to be used by OCE personnel for both criteria maintenance and design evaluation type of work. An example of criteria maintenance would be in checking and storing criteria of the Design Guides now being developed. Design evaluation use will involve evaluating selected architectural designs submitted by Corps Districts as well as design layouts and relationship diagrams in the Design Guides.

The development of computer based systems for building codes, C. Masterson, SP473, pp. 369-375 (June 1977).

Key words: building regulation; computer-based systems; computer technology; information processing; performance evaluation; plan review; research and development.

The Purpose is to explain, in a brief fashion, the most important aspects of four years of research into computerbased systems for building regulation. The topics of automated plan review and performance evaluations through computer technology are covered. And, the basic strategies of a master plan for applications oriented development are outlined. The basic thrust of the argument is that computer-based systems can provide major assistance in moving the regulatory process towards a performance-oriented basis.

The use of computers and microfilm in the code enforcement program of the Chicago department of buildings, W. J. Burke and R. P. Moran, SP473, pp. $377-382$ (June 1977).

Key words: building code; building permits; computers; enforcement; information retrieval; inspection; management control; microfilm.

The Chicago Department of Buildings uses three principal types of computer-supported systems. 1) Several systems use automated devices to issue documents to the public. Notices of violation are prepared on minicomputers using stored violation texts. "Certificates of Inspection" for buildings and elevators are prepared by computer. 2) Computers are used extensively for information retrieval. An on-line system allows access to selected information on specific buildings via CRT display and hard copy. Monthly reports summarizing building permit activity are generated from computer files. 3) Management control reporting is an important computer-based application. Permits, complaints, and follow-up inspection requests are aged by computer; and items open beyond a control age are listed on exception reports. A system to report on inspectional performance is currently in development. About eight years ago the Department was literally forced by the volume of its paper to convert its files to microfilm. We now have approximately 10 million documents on film and are expanding at a rate of approximately 1.5 million documents per year.

Improved communications between code officials and building design and construction groups through education, C. L. Charriere, SP473, pp. 383-389 (June 1977).

Key words: building construction groups; certification; code enforcement officials; communications; criteria; education programs; professional competence.

This paper stresses the necessity of developing educational programs in order to provide more effective communication between code enforcement officials and the various branches of the building construction field-architects, engineers and building contractors. The major premise is that code enforcement officials must be elevated to a professional status to communicate more effectively with the building construction groups. To accomplish this, educational background criteria and professional requirements must be established through educational and certification programs. These programs can be offered through two channels: continuing education courses and formal degree programs. The Pennsylvania State University's continuing education program is presented as a model of how educational programs can be offered effectively to upgrade the status of building code officials. Included is a review of Penn State's certificate programs wherein code officials, through evening courses and seminars, are provided the technical background needed to increase their professional competence. Also covered are examples of the development of special programs utilizing the information obtained through the above educational programs, specifically, the Energy Conservation Seminar which provides terminology and principles of heat gain and loss. The program includes a workshop session on the ASHRAE 90-75 requirements. This enables code enforcement officials to interpret and apply ASHRAE 90-75.

Regulation and the housing industry, A. Trellis, SP473, pp. 391-396 (June 1977).

Key words: builder-developer; construction; consumers; cost analysis; cost benefits; housing; regulation.

The National Association of Home Builders (NAHB) has become increasingly aware of the disproportionate increase in the cost of owning a new home, in relationship to the general increase in consumer prices. These increases are rapidly raising the cost of housing out of the reach of an ever increasing percentage of the population. What are the reasons for this inordinate increase in housing costs? NAHB has embarked on a major national study effort to answer this question. The study is intended to pinpoint the causes of this cost escalation, and in particular, determine the impact of increasing state, local, and Federal regulations on spiralling housing costs. It is a growing feeling among consumers and homebuilders alike, that a significant portion of the increased regulations associated with housing construction, do not provide benefits in relation to the overall costs incurred by the builder, which of course are ultimately passed on to the home buyer. 
Economic impacts of building codes, J. S. McConnaughey, Jr., SP473, pp. 397-419 (June 1977).

Key words: accidents; benefit-cost analysis; building codes; building economics; building regulations; economic impact; electric shock; ground fault circuit interrupters; national electric code; safety regulations; standards.

This paper presents an impact evaluation approach for building officials faced with making building code decisions. Types of building code impacts are defined and categorized. A standardized method to measure and evaluate the potential benefit and cost impacts of a specific building code provision is described. The approach is intended to be a relatively simple, easy to apply system which uses available, or easily obtainable information. Benefit and cost impacts of code provisions intended to reduce the risk of death from a building hazard are examined. The paper concludes with case study of the 1975 National Electric Code requirement for the use of Ground Fault Circuit Interrupters (GFCI) in residences to illustrate the approach.

Building codes: Preservation and rehabilitation, R. J. Kapsch, SP473, pp. 437-452 (June 1977).

Key words: adaptive reuse; architecture; building codes; building regulations; building safety; construction; performance; preservation; rehabilitation; renovation.

There has been a large rise in interest in the last ten years in building reuse, rehabilitation and preservation projects. This trend is expected to continue in the foreseeable future. Such projects pose difficulties for the building regulatory system since many of these buildings were originally constructed prior to the existence of building codes. Most of these buildings do not meet modern levels of building regulation and application of building regulations to them poses difficulties as these regulations are essentially designed for new construction. The potential impact of these regulations includes the increase of project costs and damage to the fabric of the building intended to be preserved. Yet safety and health must be achieved in existing buildings as well as new. This paper summarizes studies and other activities that are presently being conducted by a number of organizations on this subject. One such study conducted by NBS has indicated that numerous State and local jurisdictions and model code organizations are adopting historic building waiver clauses and similar regulations as a partial answer to this problem. The National Trust for Historic Preservation sponsored the first national conference, in 1974, on this question and is currently cooperating with NBS in a study of the effectiveness of selected historic building waiver clauses. The National Endowment for the Arts has sponsored a grant that would identify tradeoffs that could be used in building regulations. NBS has also sponsored a study, reported in a separate paper in these Proceedings, on how a standard designed for existing buildings might be structured and formatted. NBS is also studying, for the Department of Housing and Urban Development, technological aspects of neighborhood conservation, including the role of building regulations. As of this writing, no final or definitive answer has been developed for the problem of achieving contemporary levels of safety and health in existing buildings.

Information structure of building codes and standards for the needs of existing buildings, B. Smith, SP473, pp. 453-489 (June 1977).

Key words: building codes and standards; building code structure; existing buildings; historic preservation; performance attributes; performance evaluation.
With the increased occurrence of rehabilitation and preservation projects, the problem of code compliance for these buildings is growing in magnitude. We are no longer dealing with isolated historic buildings, but with both entire historic districts and an ever increasing number of recycled, adaptively used buildings. The problem of code compliance for these projects frequently causes the destruction of the historic integrity of the building, the replacement of serviceable materials and, at the same time, increases project costs. The compliance problems may stem from the organization and format of the model codes which are based on new construction materials and techniques. This study examines the present organization and format of the three model codes, and develops a decision flow chart which analyzes how these model codes are used. The regulatory problems facing rehabilitation and preservation projects are then reviewed. From this investigation, a proposed decision process, based on the needs of rehabilitation and preservation projects is developed. Such a decision process could be used if and when building regulations are developed for the unique needs of these type projects.

Contractor understanding relative to rehab costs, R. S. Harrington, SP473, pp. 491-497 (June 1977).

Key words: building codes; community development; construction costs; contractors; housing; rehabilitation; standards.

The nature of rehabilitation, with its nonvisible elements and its potential for self-help, makes it extremely difficult to accurately estimate the costs involved. The uncertainty is passed on by the Contractor in the fees he charges. Uncertainty exists, as well, in the standards for accomplishing the work at hand. Specifications are normally cumbersome, Work Write-Ups lacking in detail. Therefore understanding is diminished, and costs rise, while quality falls below standards.

With the pending increase in neighborhood code rehabilitation projects, there is the need to increase the supply of competent contractors interested and experienced in rehab. This requires both a method for offering standardization of specifications and work-write-ups with more detail, and the ability to assure a steady flow of work into bidding channels.

SP475. The electron factor in catalysis on metals. Proceedings of a workshop held at the National Bureau of Standards, Gaithersburg, MD, Dec. 8-9, 1975, L. H. Bennett, Ed., Nat. Bur. Stand. (U.S.), Spec. Publ. 475,217 pages (Apr. 1977) SN003-003-01764.

Key words: catalysis; characterization; chemisorption; electronic factor; geometric factor; metals; surfaces.

This book presents the proceedings of a Workshop on the Electron Factor in Catalysis on Metals held at the National Bureau of Standards, Gaithersburg, Maryland, on December 8-9, 1975. The Workshop was sponsored by the Institute for Materials Research, NBS, the Devision of Materials Research of the National Science Foundation, and the Division of Conservation Research and Technology of the Energy Research and Development Administration. The purpose of the Workshop was to review the most recent experimental and theoretical investigations on catalysis on metals and related topics, and to bring together chemists, chemical engineers, surface scientists, and solid state physicists and chemists involved in research related to this topic. These proceedings summarize the four panel sessions into which the Workshop was organized: Experimental Techniques, Effect of Alloying, Geometrical Effects, and Elec- 
tronic Structure. These proceedings include the following papers (indented).

Welcome, E. Ambler, SP475, p. 1 (Apr. 1977).

Overview of the workshop, L. H. Bennett, SP475, pp. 3-4 (Apr. 1977).

Catalysis by metals: Concepts, factors and reactions, $M$. Boudart, SP475, pp. 5-12 (Apr. 1977).

Experimental techniques, J. Katzer, R. Park, T. Rhodin, J. T. Yates, and G. Haller, Panel members, SP475, p. 13 (Apr. 1977).

Experimental methods in heterogenous catalysis, J. T. Yates, Jr., SP475, pp. 15-29 (Apr. 1977).

Investigation of support catalysis by $x$-ray absorption spectroscopy, F. W. Lytle, SP475, pp. 34-41 (Apr. 1977).

Catalysis by alloys and bimetallic clusters, J. H. Sinfelt, SP475, pp. 56-67 (Apr. 1977).

Surface composition of nickel-copper alloys, V. Ponec, SP475, pp. $71-80$ (Apr. 1977).

Heat of formation of $3 \mathbf{d}$ and $4 \mathrm{~d}$ transition metal hydrides, G. D. Gelatt, J. A. Weiss, and H. Ehrenrich, SP475, pp. 8386 (Apr. 1977).

Geometric factors in chemisorption and catalysis on metals, G. Ertl, SP475, pp. 94-118 (Apr. 1977).

The geometry of solid surfaces, C. B. Duke, SP475, pp. 127-130 (Apr. 1977).

Bonding properties of stepped transition metal surfaces, G. S. Painter, R. O. Jones, and P. J. Jennings, SP475, pp. 136149 (Apr. 1977).

The role of model Hamiltonians in chemisorption and catalysis, J. W. Gadzuk, SP475, pp. 154-161 (Apr. 1977).

Theory for chemisorption and catalysis, A. B. Anderson, SP475, pp. 166-170 (Apr. 1977).

A comparison of SCF-X $\alpha$ and extended Huckel methods for metal clusters, R. P. Messmer, C. W. Tucker, Jr., and K. H. Johnson, SP475, pp. 174-177 (Apr. 1977).

A new role for theory in surface science, D. R. Hamann, SP475, pp. 183-192 (Apr. 1977).

SP476. Opening the doors to better buildings, S. A. Kliment, Nat. Bur. Stand. (U.S.), Spec. Publ. 476, 32 pages (July 1977) SNO03-003-01804.

Key words: building performance; building process; building systems; construction management; design/build; lifecycle costing; project procurement.

Several problem areas were identified in three workshops and one national symposium which was held to pinpoint choices open to the building community for improved building procurement practices. Some of the problem areas identified are: inconsistency in building codes an'd standards; inadequate bridges between design and construction; and the dissemination of post-construction information. Other problems which were addressed were: long-term economy; technical innovation; performance data; interdisciplinary training and education; and traditional attitudes in building practices.
SP477. Wind and seismic effects. Proceedings of the Eighth Joint Panel Conference of the U.S.-Japan Cooperative Program in Natural Resources, May 18-21, 1976, National Bureau of Standards, Gaithersburg, Md., H. S. Lew, Ed., Nat. Bur. Stand. (U.S.), Spec. Publ. 477, 626 pages (May 1977) SN003-003-01772-8.

Key words: accelerograph; bridges; buildings; codes; disaster; dynamic analysis; earthquakes; ground failures; nuclear facilities; seismicity; soils; standards; structural response; winds.

The Eighth Joint Meeting of the U.S.-Japan Panel on Wind and Seismic Effects was held in Gaithersburg, Maryland on May 18-21, 1976. The proceedings of the Joint Meeting include the program, the formal resolutions, and the technical papers. The subject matter covered in the papers includes wind effects on structures and design criteria; extreme winds for structural design; earthquake ground motions and instrumentation; seismicity and earthquake risk; seismic effects on structures and design criteria; lessons learned from recent natural disasters; design of nuclear reactor facilities. These proceedings include the following papers (indented):

Aspects of hurricane winds as recorded at an instrumented suspension bridge, R. H. Gade and R. H. Scanlan, SP477, pp. I-1-I-11 (May 1977).

Key words: wind; wind velocity spectra.

Velocity spectra of the winds of tropical storm Doria in its passage over the Newport, Rhode Island, Suspension Bridge is presented for four mean wind speeds. Data was acquired with five 3-component Gill propeller anemometers, spaced at approximately 350 feet $(108 \mathrm{~m})$ intervals along the semispan of the bridge. This paper presents final information on the wind mean angle of attack, turbulence levels, vertical and horizontal spectra of wind of various velocity levels, derived surface drag coefficients, and a comparison of results with standard spectra and other applicable data from the Japanese, United States, and Canadian wind literature.

Study on the wind effect on eaves, T. Murota, SP477, pp. l-12-1-20 (May 1977).

Key words: dynamics; failure; roofs; wind.

Recently in Japan damage to flat roofs of light weight roofing is increasing. The damage is often very severe to the extent that complete removal of the roofs occurs. The dynamic behavior of the eaves is related to the damage. A current research project is also described.

Measurements of wind loads and tie-down forces on mobile homes, R. D. Marshall and R. A. Crist, SP477, pp. 1-21-133 (May 1977).

Key words: aerodynamics; buildings; full-scale testing; mobile homes; wind loads.

This paper describes instrumentation, experimental techniques and progress to date on a program of research into the effects of wind on mobile homes. Direct measurements of lift and drag forces on a nominal $12 \times 60 \mathrm{ft}$. $(3.66$ $\times 18.3 \mathrm{~m}$ ) mobile home provide more reliable information on load fluctuations than is possible with the usual approach of measuring surface pressure alone. Results of spectral analysis conducted on time histories of overturning forces suggest that a simple quasi-static approach, when used with appropriate gust factors, can be employed to calculate loads for the design of mobile home anchoring systems. 
On the wind resistant design specifications for the proposed Honshu-Shikoku bridges (1975), T. Okubo and N. Narita, SP477, pp. 1-34-l-48 (May 1977).

Key words: bridges; specifications; wind.

The newly revised specifications for the wind resistant design of the proposed Honshu-Shikoku Bridges are introduced in this paper. The previous specifications (the first edition was issued in 1964, and the second edition in 1972) have been revised by taking into account recent research activities, resulting in final edition as established in the fall of 1975 .

The main subjects discussed in this paper are: 1. Scope of application; 2. Basic wind and design wind speed; 3 . Drag coefficients; 4 . Gust response; 5 . Wind resistibility of structures under construction.

Equivalent static wind loads for tall building design, E. Simiu, SP477, pp. 1-49-1-65 (May 1977).

Key words: design; equivalent loads; tall buildings; wind loads.

Certain shortcomings of current procedures for computing along wind structural response have been shown to result in unrealistic estimates of tall building behavior under the action of strong winds. Differences between predictions of fluctuating response based on various such procedures have been shown to be in certain cases as high as 200 percent. In recent years, advances in the state of the art have been made which provide a basis for significantly improved alongwind response predictions. The purpose of the present work is to present a procedure for calculating alongwind response, including deflections and accelerations, which incorporates these advances. The meteorological and aerodynamic models on which the procedure is based are briefly described. The practical use of the procedure is illustrated in a numerical example. Estimates are provided of errors inherent in the models employed. The range of applicability of the procedure is defined, and it is indicated that for structures with unusual modal shapes or for which the influence of higher vibration modes is significant, a recently developed computer program should be employed in lieu of the procedure presented herein.

A wood house will resist wind forces, B. Bohannan, SP477, pp. 1-66-1-69 (May 1977).

Key words: concentrated loads; design criteria; mode of failure; racking resistance; structural performance; uniform loads.

Experience tells us that wood-frame houses built by conventional construction practices will be long-lived structures. Why then should we be doing research on lightframe wood construction.

The answer seems simple. There are reasons to believe that the conventional wood frame systems are overbuilt in many respects. Initial evaluations have indicated that significant material savings are possible without sacrificing any of the structural integrity of wood-frame systems.

The actual structural performance of the conventional wood-frame house is not well understood. Little or no structural engineering goes into its design. While a lot of research effort has gone into defining pieces and parts of houses, much of this research has been aimed at very narrow objectives. Little attention was given to the house as a complete structural system. The interaction of components has not been evaluated.
It is assumed that the resistance to wind-caused racking or shear would be provided solely by the end-walls of a conventional wood-frame house. There are no known formulae for calculating the racking resistance of these walls. In fact, there is even some question as to how much of the total wind force actually reaches the end-walls.

Wind loads on low-rise buildings, N. J. Raufaste, Jr., SP477, pp. 1-70-1-78 (May 1977).

Key words: codes and standards; disaster mitigation; housing; low-rise buildings; socio-economics; structural connections; wind loads.

The National Bureau of Standards is continuing its project to develop improved design criteria for low-rise buildings in developing countries to better withstand the effects of extreme winds. This paper is an overview of the results of the project, some of which have occurred since the Seventh meeting of the U.S.-Japan Panel on Wind and Seismic Effects, that is to say, the third year of this $3 \mathrm{1} / 2$ year project. To date, most data analyses have been completed and presented in several NBS published progress reports. The final report is expected to be published in the Fall of 1976.

Characteristics of the high wind at Hachijojima Island on the occasion of typhoon No. 7513, S. Somá, SP477, pp. II1-11-14 (May 1977).

Key words: damage; effects; houses; typhoon; wind speeds.

A typhoon that attacked Hachijojima Island on October 5, 1975 brought to this island very strong winds which were beyond expectations. The value of the peak gust observed at the weather station, located at the central part of the Island, was $67.8 \mathrm{~m} / \mathrm{s}$. Moreover, in the premises of the lighthouse situated on the southeastern part of the lsland, an incredible wind of $82.4 \mathrm{~m} / \mathrm{s}$ was recorded. This wind was extraordinarily strong and was the third strongest recorded wind in our country. Due to this high wind, a great deal of damage was caused in various parts of the Island. Houses and buildings suffered the most from the high wind. The damage rate to houses which varied in different areas, had a high of 7.3 percent, which were completely destroyed, and 21 percent in which half of the houses were completely destroyed. Whether this strong wind was innate in the typhoon, or whether it was brought about due to the peculiar topographic features of the Island was the subject of this study. However, it was not possible to clarify these points quantitatively. Although, in certain areas, it was realized that topographic influences were apparent.

While making this survey on the typhoon's effect, it was noted that severe damage occurred to the windowpanes in tall buildings. An administrator of the building told us that these panes were broken by fragments of houses that were scattered in the high wind. This, therefore, indicates that a problem exists when tall buildings are surrounded by houses which have low wind-resistance in their vicinity. Therefore, the damage indicates that in town planning, not only a wind resistant design of individual buildings is required but also wind resistant planning of the entire environment is essential.

High winds in the United States, 1975, A. R. Hull, T. D. Potter, and N. B. Guttman, SP477, pp. 11-15-II-29 (May 1977).

Key words: extra-tropical storms; hurricanes; thunderstorms; tornadoes; wind; wind damage. 
During 1975, high winds in the United States were associated with tornado and thunderstorm activity, major extra-tropical storms and Hurricane Eloise.

Hurricane Eloise reached the coast of Florida with an observed minimum pressure of $95.5 \mathrm{kPa}$ and sustained surface winds estimated at $202 \mathrm{~km} / \mathrm{h}(56 \mathrm{~m} / \mathrm{s})$. Associated gale winds were rcported from Cedar Key, Florida, to southeastern Louisiana and northward over most of Alabama, wcstern Georgia, and extreme southeastern Tennessee. A unique set of hourly meteorological data and some oceanographic data was collected by two buoys during the approach and passage of the eye of Hurricane Eloise. These data, along with simultaneous ship, aircraft, and satellite data are being assembled and packaged for hurricane research studies.

During 1975, 918 tornadoes and numerous storms with high winds caused damage estimated in excess of 2 billion dollars.

A devastating January blizzard dumped up to $58 \mathrm{~cm}(.58$ $\mathrm{m}$ ) of snow in some areas of the North Central States and was accompanied by winds of up to $130 \mathrm{~km} / \mathrm{h}(36 \mathrm{~m} / \mathrm{s})$. In contrast, a severe sandstorm struck southern California on June $17-18$, bringing near zero visibility and windspeeds of $144 \mathrm{~km} / \mathrm{h}(40 \mathrm{~m} / \mathrm{s})$. Damage to power lines, poles, and other facilities exceeded $\$ 100,000$.

Mean speed profiles of hurricane winds, E. Simiu, V. C. Patel, and J. F. Nash, SP477, pp. II-30-II-40 (May 1977).

Key words: boundary layer; hurricanes; loads (forces); natural analysis; tall buildings; wind profiles.

A numerical solution of the hurricane boundary layer problem is presented in which the hurricane is modeled as a steady, axisymmetric, neutrally stratified flow. The turbulence effects in the flow are accounted for by the phenomenological relations proposed by Bradshaw et al., and Nash, which provide a considerably more realistic picture of the actual flow than the pseudolaminar model used in previous solutions of the boundry layer problem. The results of the calculations obtained on the basis of the model just described suggest that: (1) in the height range of interest to the structural designer, say up to a height of $400 \mathrm{~m}$ above ground, it is permissible to use the logarithmic law to represent the mean velocity profile of hurricane winds and (2) if the relation between wind speeds in different roughness regimes which is valid in extratropical storms is applied to hurricane winds, the speeds over built-up terrain, calculated as functions of speed over open terrain, may be underestimated by about 10 percent and 10-20 percent in suburban and in urban exposure, respectively. The corresponding mean loads are then underestimated by about 15 percent and 30 percent, respectively.

Planning and design of strong-motion instrument networks, R. B. Matthiesen, SP477, pp. III-1-III-15 (May 1977).

Key words: cost effectiveness; ground motion; network design; strong-motion record.

The types of research studies that utilize strong-motion data may be classified as: source mechanism studies, ground motion studies, soil failure studies, studies of the response of typical structures (including soil-structure interaction effects), and studies of the response of equipment.

In planning networks and arrays to make these studies, criteria must be established based on the tectonic setting, the seismicity or recurrence of strong ground motions, the reliability of operations in different regions, and a cost/benefit analysis of the data that may be obtained. A review of the strong-motion records that have been obtained during the past 40 years indicates significant variations in the recurrence of strong ground motions in the scismically active regions of the western United States. When combined with instrument costs, maintenance costs, and the reliability of operations, these recurrence relations can be interpreted in terms of the cost per record for different levels of motion. The benefits to be derived from each type of study in each region need to be established.

Current plans call for additional arrays to be installed in California, the Mississippi embayment, the Yellowstone Park region, and Alaska to study the spectral characteristics of strong ground motions in these regions. Special studies of local site effects and structural response are being planned in the more seismically active regions of California. Similar criteria and planning should be applied in the establishment of arrays of strong-motion instruments on a worldwide basis.

Observation of earthquake response of ground with horizontal and vertical seismometer arrays, S. Hayashi, H. Tsuchida, and E. Kurata, SP477, pp. III-16-III-25 (May 1977).

Key words: arrays; earthquakes; ground motion; records; results; seismometers.

A horizontal seismometer array, having six observation points along a straight line of 2500 meters in length, have been established at the Tokyo International Airport. Each observation point is equipped with two horizontal seismometers. Downhole seismometer arrays have also been established at two points, one at the end of the observation line and the other at a point 500 meters inside from the other end of the line. The observation started in April 1974 and since then 28 earthquakes have been recorded as of June 1975. Correlations among the ground motions at the points on the ground surface and the two points in the ground where the downhole seismometers have been installed, have been studied. The relative displacements between the points have also been studied.

It was assumed that there had been a straight pipeline made of steel along the observation line and the pipe motions had been equal to the observed ground motions. Then, the stresses in the pipe were estimated, and it was found that the stresses due to axial deformations were remarkably larger than those due to the bending deformations.

Building strong-motion earthquake instrumentation, $C$. Rojahn, SP477, pp. III-26-III-40 (May 1977).

Key words: buildings; instruments; strong motion.

Based on the recommendations of a special ad-hoc committee, twenty-one geographic areas will be instrumented under the building instrumentation phase of the California Strong-Motion Instrumentation Program, a statewide program established by law in 1971 and funded through an assessment of estimated construction costs collected statewide from building permits. Tlie areas were selected on the basis of population density, locations of buildings already instrumented, and the probability for potentially damaging earthquakes. Buildings to be instrumented will be of typical construction, simple in framing and design, and of various heights with the instrumentation of low-rise buildings emphasized. Remote recording instrumentation, consisting of single or multiaxial accelerometers connected via data cable to a central recorder, will be installed in each building. The accelerometers will be placed on the lowest level, at the roof level, and, in many cases, at one or more inter- 
mcdiate levels. The instrumentation will be situated so as to separately record both translational and torsional responsc.

On the basis of current projected revenues, and instrument procurement, installation and maintenance expenses, it is estimated that as many as 400 buildings may be instrumented under the State program.

Characteristics of underground seismic motions at four sites dround Tokyo Bay, T. Iwasaki, S. Wakabayashi, and F. Tatsuoka, SP477, pp. III-4I -III-56 (May 1977).

Key words: acceleration records; dynamic behavior; earthquakcs; response spectra; soils.

This paper discusses the dynamic behavior of subsurface soil and rock laycrs on the basis of acceleration records triggered during actual small to moderate earthquakes. Borehole accelerometers are installed at four sites around the Bay of Tokyo. These were installed in 1970-74, in conncction with the Tokyo Bay Loop Highway Project proposed by the Ministry of Construction.

Important acceleration records were obtained during sixteen moderate earthquakes (Magnitude-4.8-7.2) which occurred near the area in September 1970 through February 1975. From distributions of maximum accelerations at the four stations, it seems that the surface magnification factors (ratios of the surface acceleration to the base acceleration) are large (2.5 to 3.5 ) at the soft clayey soil site. small (about 1.5) at the rocky site, and medium (1.5 to 3 ) at sandy soil sites.

Response spectrum curves from typical acceleration records are shown. Comparison of the spectral curves from records obtained at three (or four) levels of one station during an earthquake suggests that frequency characteristics at the several depths arc comparatively similar. Also it seems that frequency characteristics of earthquake ground motions are influenced by seismic conditions (such as magnitudes, epicentral distance, etc.) as well as soil conditions at the sites.

Relationship between earthquake damage of existing wooden houses and seismic intensities, E. Kuribayashi, T. Tazaku, and T. Hadate, SP477, pp. IV-1-IV-17 (May 1977).

Key words: classification; damage; intensity; seismic; wooden house.

This report discusses a quantitative relationship between a ratio of earthquake damage of existing wooden houses and seismic intensities.

The ratio of earthquake damage of the houses is useful not only for understanding house and building design criteria but for presuming the damage ratio of other structures such as bridges, roads, public utilities, etc.

Using statistics of disaster documents on short distant earthquakes; Fukui Earthquake ( $M=7.3,1948)$, IsuhantoOki Earthquake $(M=6.8,1974)$ and Ebino Earthquake $(M=6.1,1968)$ the relationship between the ratio of razed houses and épicentral distances or magnitudes of earthquakes was analyzed. The equivalent ratio of razed houses in earthquakes (D1) and the orignal ratio of razed houses (D2) are defined as; $D_{1}=$ (Number of Razed Houses $+0.5 \times$ Number of Half Razed Houses/Total Number of Existing Houses) $\times 100(\%) ; D_{2}=($ Number of Razed Houses/Total Number of Existing Houses $) \times 100$ (\%).

Conclusively $D_{1}$ in the area of diluvium or tertiary (given as $\mathrm{D}_{u}$ ) and in the area of alluvium (given as $\mathrm{D}_{u l}$ ) can be tentatively expressed as follows:

$$
\begin{aligned}
\mathrm{D}_{1 /} & =\mathrm{K}_{l} \times 10^{k_{I}} \\
\mathrm{D}_{1 / I} & =\mathrm{K}_{l l} \times 10^{k_{I J}}
\end{aligned}
$$

where $K_{l}$ and $K_{\| \prime}$ are respective constant values, $K_{l}$ and $K_{\| \prime}$ are functions of epicentral distances and earthquake magnitudes.

Moreover $D_{1}$ and $D_{2}$ correlatc with each other and $D_{2 \mu \prime}$ (in the area of alluvium) is greater than $D_{21}$ (in the area of diluvium or tertiary).

A method for calculating nonlinear seismic response in two dimensions, W. B. Joyner, SP477, pp. IV-18-IV-46 (May 1977).

Key words: bedrock; modeling; rheological; seismic response; two-dimensions.

A method is presented for calculating the seismic response of two-dimensional configurations of soil testing on bedrock. The method, which is based on a rheological model suggested by Iwan, takes account of the nonlinear, hysteretic behavior of soil and offers considerable flexibility for incorporating laboratory data on soil behavior. An approximate treatment of the boundary conditions is employed which permits energy to be radiated into the underlying medium. Examples are shown to illustrate the method.

A new scale representing the "quake-sensitivity" at a certain region, T. Terashima and T. Santo, SP477, pp. IV47-IV-54 (May 1977).

Key words: earthquake; index; quake-sensitivity; seismic index; seismicity.

The nature of ground motions due to earthquakes, depends on the property of the superficial materials of the ground, which vary in different areas. In this paper, the different characteristics of the ground motions is normalized by a new scale designated as "Quake-Sensitivity." This scale is defined as a ratio of $N(I) / S$, where $N(I)$ is the annual mean frequency of seismic intensity of more than III (in J.M.A. scale) and $S$ is seismicity index which has been defined previously by the authors.

A seismic zoning map was then made for Japan Islands relative to the "Quake-Sensitivity." The area having a large value of $N(I) / S$ means that the area is sensitive to earthquake motions or the neighboring area has moderate earthquakes.

Damage to the civil engineering structures in Hachijojima Island by typhoon 7513, T. Okubo, N. Narita, and K. Yokoyama, SP477, pp. V-1-V-20 (May 1977).

Key words: damage; structures; typhoon; wind; wind effects.

Typhoon 7513 passed across Hachijojima Island on 16:40, October 5, 1975 and caused damage to property, houses and public service. The Public Works Research Institute performed a field investigation in Hachijojima Island. In this paper the record of strong wind and the state of damage are introduced. Typhoon 7513 is classified as a small but strong typhoon, and the maximum wind speed, averaged over ten minute intervals was $35.5 \mathrm{~m} / \mathrm{s}$, and the maximum instantaneous wind speed was $67.8 \mathrm{~m} / \mathrm{s}$.

The number of the wounded was 85 , but fortunately no one was killed. A great deal of damage was done to houses, trees, poles and fences. The damage, with regard to public service was the destruction of a school and hospital building, and the interruption of electric power, telephone, and roads. The damage to large scale structures 
consisted of the destruction of a guyed tower 80 meters high, a panzer-mast, a bridge and four arc lamp standards.

Cyclone Tracy, R. D. Marshall, SP477, pp. V-2I-V-53 (May 1977).

Kcy words: buildings; cyclones; disasters; structural engincering; tides; wind.

During the carly morning hours of December 25, 1974 , the city of Darwin was devastated by the most damaging cyclonc ever to strike the Australian Continent. Winds of up to $75 \mathrm{~m} / \mathrm{s}$ causcd extensive damage to housing in particular, requiring the evacuation of approximately half of the 45,000 residents to other major cities in Australia. This rcport is a result of the author spending several days on tcmporary assignment with the Department of Housing and Construction-Australian Government to inspect the damagc, and to participate in discussions regarding the establishment of new design criteria and construction practices for cyclone areas. The fact that most of the damage was caused by wind forces rather than a combination of wind and storm surge greatly simplified the assessment of damage and structural performance. The experience at Darwin points out the danger in depending too heavily upon past experience and intuition in the design of housing. It also makes clear the need for additional research into the behavior of certain building materials under repeated loads and missile impact, and the racking strength of walls subjected to uplift loads.

On the damage to buildings in Hachijojima caused by typhoon No. 7513, T. Murota, SP477, pp. V-54-V-59 (May 1977).

Key words: damage; typhoon; wind; wind effects.

On October 5, 1975 Typhoon No. 7513 hit Hachijojima 1sland, Tokyo and the maximum peak gust of $67.8 \mathrm{~m} / \mathrm{s}$ was ohserved. The damage to this island was severe and widespread, damage to buildings, services, crops, trees, electric power lines and telephone lines occurred. The wind records and the rate of damage to buildings was one of the largest in Japan.

The Building Research Institute investigated the damage to the buildings in Hachijojima Island from 9 to 16 , October. This paper describes results of the investigation.

Description of the typhoon and meteorological environment in the Island during the passage of the typhoon are referred in detail by Soma (1) and therefore are not referred to herein.

Seismic response of reinforced concrete highway bridges, $J$. Penzicn, W. G. Godden, M. C. Chen, D. Williams, and K. Kawashima, SP477, pp. V1-I-VI-9 (May 1977).

Key words: bridges; design; experiments; nonlinear response; reinforced concrete.

Presented is a brief progress report of an investigation entitled "An Investigation of the Effectiveness of Existing Bridge Design Methodology in Providing Adequate Structural Resistance to Seismic Disturbances" which was initiated in 1971 within the Earthquake Engineering Research Center, University of California, Berkeley, under the sponsorship of the U.S. Department of Transportation, Federal Highway Administration.

An evaluation method for the earthquake resistant capacity of reinforced concrete and steel reinforced concrete columns, M. Ozaki and Y. Ishiyama, SP477, pp. V1-10-VI-27 (May 1977).
Key words: columns; concrete; earthquake; hysteretic envelope; reinforced; strength.

An evaluation method for the earthquake resistant capacity of reinforced concrete and steel reinforced concrete columns by utilizing the force deflection relationship of column specimens subjected to axial force and repeated and reversed lateral loading of considerable intensity is proposed.

An approximate response analysis for a nonlinear structural system was developed based on random vibration theory and was applied to models represented by a singledegree-of-freedom system subjected to a constant white noise acceleration. The mean expected maximum response values of the models with two different natural periods 0.1 and $0.5 \mathrm{sec}$. were calculated. Each model has a degrading stiffness system and various hysteretic envelope slopes after four different yield point levels. The viscous damping ratio is considered to be 5 percent of the critical damping for the entire processes of the models, and the hysteretic damping ratio after yielding is assumed to increase according to the increase of ductility factor. The ductility factors of the models calculated by the nonlinear response analysis are shown in tables and figures.

The maximum strength of the linear model having the equivalent earthquake resistant capacity of a column specimen can be assumed if the yield point, hysteretic envelope slope tangent, coefficient of hysteretic damping ratio and ductility factor of the specimen are measured by testing.

A facility was designed for testing large models of reinforced concrete and steel reinforced concrete columns under action simulating gravity load and ground motion in order to standardize the testing techniques and to forestall possible errors that may be induced by the use of different types of testing facilities.

An example of evaluation for the earthquake resistant capacity of a reinforced concrete column is presented by utilizing the force deflection relationship of the specimen obtained by the testing facility.

It is confirmed that yield point level, hysteretic envelope slope, hysteretic damping ratio and ductility factor are the most important components of earthquake resistant capacity.

The earthquake engineering program of the National Science Foundation, J. B. Scalzi, SP477, pp. VI-28-VI-36 (May 1977).

Key words: earthquake; program; research; seismic.

The general research program, supported by the $\mathrm{Na}$ tional Science Foundation, is given in general terms. The required interaction between the social, economic and technology is described.

Large-scale testing programs related to wind and seismic effects currently underway in Japan, S. Inaba, SP477, pp. VI37-V1-43 (May 1977).

Key words: earthquake; research programs; seismic; testing; wind.

This list has been prepared in order to discuss cooperative research problems in the area of large-scale testing of structures at the 8th Joint Meeting of U.S.-Japan Panel on Wind and Seismic Effects. The Japan Panel selected the following four members to work on the task committee on the large-scale testing program: Seiichi Inaba, National Research Center for Disaster Prevention; Makoto Watabe, Building Research Institute; Kenkichi Sawada, Public Works Research Institute; Nobuyuki Narita, Public Works Research Institute. 
In accordance with the exchange of letters between Dr. C. Culver of the National Bureau of Standards of the U.S. Panel and Mr. S. Inaba of the Japan Panel, this list has been drafted to inform thc U.S.-Japan Panel of work being conducted in this area. The list includes the large-scale testing programs currently underway in Japan, the organization, the name of individuals in charge, and a brief description of the objectives, status and time schedule.

Earthquake damages to earth structures, K. Sawada, SP477, pp. VI-44-VI-49 (May 1977).

Key words: construction; dams; earthquake; earth structures; roads; survey.

This paper will present the problems associated with the damage to earth structures during earthquakes, and how some of the problems have been solved. In addition this paper will present the principle of the design of earth structures, that to date have not been discussed.

Initially, data has been collected on the amount of damage to earth structures during earthquakes, how they have failed and relationships to such failures. These data are then used in formulating the mechanics of the failure.

Finally, the details of the repair work required, as listed by field engineers engaged in this repair work was examined.

Dynamic test ot a circuit breaker for transformer substaion, S. Inaba and S. Kinoshita, SP477, pp. VI-50-VI-60 (May 1977).

Key words: circuit breaker; data; experiment; shake table; testing; transformer.

During earthquakes, dependability of electric power supply systems, is required. However, earthquake damage to the electric power industry has resulted from the structural failure of porcelain insulators, which are commonly used for electric transmission equipment.

Dynamic tests of a circuit breaker of capacity 72/84 kilovolts used for a transformer substation were conducted using the large-scale shaking table of the National Research Center for Disaster Prevention in 1975. The test was performed under the sponsorship of Meidensha, a Japanese Manufacturer of electric power equipment. The purpose of the test was to determine the dynamic characteristics of the prototype structure shielded with the porcelain insulator. Sinusoidal waves of resonant frequency and earthquake simulated waves were applied to the test structure. It was found that the failure of the porcelain insulator governs the seismic resistibility of the circuit breaker and the maximum allowable acceleration at the top of the structure is $8.0 \mathrm{~g}$.

Comprehensive seismic design provisions for buildings-A status report, C. G. Culver, SP477, pp. V1-61-VI-68 (May 1977).

Key words: building codes; buildings; design; earthquakes; structural engineering.

A review of the first draft of recently developed U.S. seismic design provisions for building is presented. The draft includes regulatory provisions suitable for inclusion as part of a building code and technical criteria for earthquake resistant design. The provisions are intended for implementation by standards organizations, model code groups, Federal agencies and other regulatory groups. Technical criteria for structural design, architectural and mechanical-electrical design, and existing buildings are discussed.
Retrofitting of vulnerability in earthquake disaster mitigation problems, K. Ichihara, E. Kuribayashi, and T. Tazaki, SP477, pp. VI-69-V1-84 (May 1977).

Key words: costs; existing structures; optimization; retrofitting; seismic.

This paper discusses a criterion for retrofitting of existing structures vulnerable to disastrous earthquakes.

It would be ideal if all structural damage could be avoided during earthquakes, however, to completely strengthen structures is not practical because of the limitation of resources and land-space. On the basis of execution, it is necessary to classify the structures by functional importance and structural vulnerability. The first category of classification deals with the structure load. In the category dealing with the location, the densely inhabited and effectively utilized structure, should have preferential earthquake resistance, and this consideration is the basic philosophy of urban design including the countermeasure to earthquakes. The second category is classified according to the purpose of the structure. Life lines, such as traffic, transportation, water and energy transmission, and communication are indispensable during evacuation and rescue, so that these structures would be required to retain safety. This is especially true for roads, which are used not only for a path of evacuation but also for rescue space, fire fighting etc. immediately after earthquakes. However, it seems impossible that all existing roads can be modified to such a high standard of earthquake resistance because of the extreme cost involved. It is therefore more practical and rational to select the important routes which should be modified to meet specific earthquakes.

In this situation the following principles have been chosen in the retrofitting and the vulnerability for such a decision-making process.

If given certain model routes, retrofitting costs can be obtained for several methods, for example, perfect, medium and rough, for which the retrofitting cost should not be more than the cost of reconstruction. Next, suitable load-retrofitting relations and suitable load-safety relations are examined. Using these quantitative results a final decision can be made.

Dynamic response characteristics of a model arch dam, C. D. Norman, R. D. Crowson, and J. P. Balsara, SP477, pp. VI-85-VI-1 17 (May 1977).

Key words: arch dam; deflections; dynamic tests; model; structural analysis; velocities; vibrations.

The dynamic response characteristics of a model arch dam are given in detail. These characteristics were determined by subjecting the model to a vibratory loading. Resulting deformations and velocities are given.

The measurement of the dynamic $k$-value in site and its application to design, T. Kunihiro, K. Yahagi, and M. Okahara, SP477, pp. VI-118-VI-140 (May 1977).

Key words: bore hole; k property; property; soil; stiffness; testing.

The determination of the dynamic soil $k$ property is determined by a series of bore hole tests. Results from these tests are discussed and the significance of these data are presented.

Laboratory investigation of undisturbed sampling and standard penetration tests on fine sands, $M$. F. Marcuson, S. S. Cooper, and M. A. Bieganousky, SP477, pp. VI-141-VI-157 (May 1977). 
Key words: density; liquefaction; sand; soils; tests; undisturbed sampling.

Determination of density of sand is presented. Densities determined from using undisturbed samples and from the standard penetration tests are compared. It is shown that the standard penetration test is not sufficiently accurate to be recommended for final evaluation of the density at a site unless site specific correlations are developed.

Dynamic soil properties with emphasis on comparison of laboratory tests and field measurements, $T$. Iwasaki and $F$. Tatsuoka, SP477, pp. VI-158-VI-178 (May 1977).

Key words: dynamics; field tests; laboratory tests; relationships; soil properties.

In order to evaluate analytically the motion of the ground during earthquakes, it becomes necessary to obtain the dynamic deformation properties of the soil deposits, especially the strain amplitude-dependent shear moduli and the damping coefficients. At two sites, Iruma, Minami-Isucho and Ohgi-shima, Kawasaki-shi, insitu seismic surveys were performed. At the former site, a sand embankment was damaged during the Off-Izu-peninsula earthquake on May 9, 1974 and at the latter is located reclaimed land where borehole accelerometers are installed. Furthermore, sand sampled from these sites was tested with the resonantcolumn apparatus of the Drnevich type in order to obtain the shear moduli and damping capacities at small strains. Laboratory test results showed that the two natural sands, which are well-graded and include fine particles, have smaller shear moduli than does uniform clean sands such as Toyoura-sand and Ottawa-sand.

A comparison of the shear moduli from shear wave velocities and those from resonant column tests was performed, giving excellent correlation for sands from both sites.

Design earthquakes, E. L. Krinitzsky and F. K. Chang, SP477, pp. VI-179-VI-191 (May 1977).

Key words: data; displacements; intensity; seismic records; velocity.

Relationships between earthquake intensity and epicentral distance are presented. Peak motion results, from 187 field records, are also given for examination. Also presentcd is data on displacements, velocities and intensities.

Relation between seismic coefficient and ground acceleration for gravity quaywall, S. Hayashi, S. Noda, and T. Uwabe, SP477, pp. VI-192-VI-198 (May 1977).

Key words: acceleration; accelerogram; gravity quaywall; rock motion; seismic coefficient.

The present design standard for port and harbor structures, utilizes seismic coefficients which were obtained from records of 129 gravity quaywalls in 49 ports damaged by 12 earthquakes. The maximum ground accelerations in the ports were estimated by calculating the ground response during the earthquake with reference to the attenuation curves of the base rock acceleration based on the accelerograms in port area.

The seismic coefficients in past earthquakes had upper values of 0.25 , and this upper limit can be related between the coefficient and the maximum ground acceleration by the following equation:

$$
\mathrm{e}_{A}=1 / 3(\alpha / \mathrm{g})^{1 / 3}
$$

Where $\mathrm{e}_{A}$ : seismic coefficient; $\alpha$ : maximum ground acceleration (gal); g: acceleration of gravity (gal).
Investigation of earthquake resistance of structural (shear) wall buildings carried out at Portland Cement Association, $M$. Finkel, SP477, pp. VI-199-VI-219 (May 1977).

Key words: design procedures; earthquake excitation of structures; earthquake resistant structures; reinforcing details; structural walls.

In July of 1974, PCA started (with NSF-RANN sponsorship) a comprehensive analytical and experimental study to investigate the response to earthquake excitation of reinforced concrete structures containing structural (shear) walls. The aim of the study is to develop design procedures and reinforcing details for earthquake resistant multistory reinforced concrete structures containing structural walls.

A philosophy for structural integrity of large panel buildings, M. Fintel and D. M. Schultz, SP477, pp. VI220-VI-251 (May 1977).

Key words: buildings; collapse; concrete; panels; structural integrity.

The paper reviews the various methods to reduce risk from abnormal loads. To limit the occurrence of progressive collapse in large panel residential structures, a philosophy for establishing General Structural Integrity is developed to assure bridging of local damage while maintaining overall stability, thus eliminating the need to design for any particular abnormal load. In this approach, tensile continuity and ductility of the elements, and their connections as well as of the overall structure, is stressed. The rationale for a minimum tie system consisting of transversal, longitudinal, vertical and peripheral ties to establish this General Structural Integrity is developed.

The objective of this approach is not to afford absolute safety in regard to any exceptional event in any part of every building; rather, the intention is to limit and substantially reduce the general risk of collapse, as compared to that existing if no such measures were taken.

Wind and seismic design of United States nuclear power plants, L. C. Shao, R. J. Stuart, and C. H. Hofmayer, SP477, pp. VII-1 - VII-28 (May 1977).

Key words: nuclear power plant; seismic effects; tornado; wind.

All U.S. Nuclear Power Plants are currently designed to resist the effects of severe and extreme environmental loads in combination with operating and accident loads (tornado and accident loads are not combined). This affords two levels of resistance to wind and seismic loads i.e., the plant can remain operational during and following the operating basis earthquake or the design wind, and shall be able to safely shut down following the design basis tornado or safe shutdown earthquake. The design wind parameters are normally selected based upon a one hundred year recurrence interval. These parameters (wind velocity, velocity vertical profiles, and applicable gust factors) are transformed into applied pressures on exposed surfaces of safety related structures considering the effects of ground exposure, shape coefficients and pressure profiles at discontinuities. The design basis tornado is selected as the most severe tomado that can reasonably be predicted at a site based on the geographical distribution of the frequency of tomado occurence. The continental United States is divided into three tornado regions and for each region the following tornado characteristics are specified: the rotational wind speed, the translational wind speed, the pressure drop across the tornado, the rate of pressure drop and the radius of maximum rotational wind speed. The conver- 
sion of these parameters to design pressures must consider the orientation of the tornado relative to the structure as well as the other factors considered for the design wind. Various design tornado missiles and corresponding velocities are specified for each plant. Safety related structures are designed to resist both local damage (penetration and spalling) and overall structural response due to these missiles. The SSE (Safe Shotdown Earthquake) is chosen as the maximum earthquake expected to occur at the site and normally has a probability of occurrence of less than $10^{-5}$. The OBE is chosen as the earthquake which could reasonably be expected to affect the plant during its operating life; however, its magnitude cannot be less than one half that of the SSE. Vertical and horizontal ground acceleration values and broad band ground response spectra are specified for each plant site. A detailed dynamic analysis is required for each plant, including the consideration of the effects of damping, soil-structure interaction, three components of earthquake motion, combination of modal responses, etc. These considerations are detailed in recently published U.S. Nuclear Regulatory Commission's Standard Review Plans 3.7.1 Seismic Input, 3.7.2 Seismic System Analysis, 3.7.3 Seismic Subsystem Analysis and 3.7.4 Seismic Instrumentation.

Outline of basic philosophy and practices of aseismatic design for nuclear facilities in Japan, M. Watabe and Y. Ohsaki, SP477, pp. VII-29-VIl-35 (May 1977).

Key words: design guides; nuclear facilities.

In Japan, consistent standard specifications or guide lines for the aseismatic design of nuclear facilities has not officially been established. Only recently, in March 1975, has the Regulatory Guide of Design Earthquake Ground Motions for Nuclear Power Facilities been proposed. The proposed Regulatory Guide has already had an effect in a practical sense in spite of its interim nature. It is the purpose of this paper to briefly summarize the design philosophies and procedures of this aseismatic design currently being used in practice in Japan.

Tornado-borne missiles, J. F. Costello, SP477, pp. VII36-VII-4I (May 1977).

Key words: dynamics; missiles; power plants; structural engineering; tornadoes; trajectories.

Nuclear power plants are designed to withstand the effects of severe environmental events, including tornadoes, without endangering public health and safety. Along with high wind velocities and drops in pressure, an effect which must be considered is the fact that objects of varying sizes are displaced by tornadoes. Predictions of what objects are likely to fly and at what velocities are difficult. Knowledge of the actual windfields present in a tornado is sketchy as is information about the aerodynamics of bluff bodies. This paper outlines methods which have been developed in order to make conservative estimates of the effects of tornado-generated missiles.

Structural damage to bridges resulting from the Guatemala earthquake, J. D. Cooper, SP477, pp. VIII-1-VIII-27 (May 1977).

Key words: bridges; earthquake damage; Guatemala earthquake.

The Guatemala earthquakes of February 4 and 6, 1976 , caused severe economic hardships because of highway bridge failures and damage. The damage to three major bridges, Agua Caliente, LaAsuncion, and Incienso is described. A general discussion of damage to bridges and the roadway along a major highway, the Atlantic Highway, (Route CA9), is also presented.

SP478. Nitrogen oxychlorides: A bibliography on data for physical and chemical properties of $\mathrm{CINO}, \mathrm{CINO}_{2}$, and $\mathrm{CINO}_{3}, \mathrm{~F}$. Westley, Nat. Bur. Stand. (U.S.), Spec. Publ. 478, 54 pages (Aug. 1977) SNO03-003-01824-4.

Key words: bibliography; chemical kinetics; chemistry; chlorine nitrate; molecular properties; nitrosyl chloride; nitryl chloride; physical properties; spectral properties; thermodynamic properties.

A data oriented list of references is provided for published papers and reports containing measured or calculated data for the physical and chemical properties of nitrosyl chloride, nitryl chloride, and chlorine nitrate with particular emphasis on the chemistry and chemical kinetics of these compounds. More than 387 papers are listed. The period covered extends from 1874 through 1977.

SP479. Corrosion and metal artifacts-A dialogue between conservators and archaeologists and corrosion scientists, B. F. Brown, H. C. Burnett, W. T. Chase, M. Goodway, J. Kruger, and M. Pourbaix, Eds., Nat. Bur. Stand. (U.S.), Spec. Publ. 479, 252 pages (July 1977) SNO03-003-01826-1.

Key words: archaeological finds, preservation of; conservation of metal artifacts; corrosion, inhibiting of; corrosion, treatment methods; metal artifacts, restoration of; patina, artificially produced; patina, natural.

This book is the formal report of the proceedings of the seminar on Corrosion and Metal Artifacts. The volume contains the tutorial lectures on the aspects of corrosion science and engineering of relevance to conservators and archaeologists and background lectures which are addressed to corrosionists with activities and problems in the conservation of metallic artistic artifacts. The report also contains the full discussion (attendee) of the structured questions distributed before the meeting. The report is well documented with illustrations. These proceedings include the following papers (indented):

Electrochemical corrosion and reduction, M. Pourbaix, SP479, pp. 1-16 (July 1977).

Corrosion product characterization, N. A. Nielsen, SP479, pp. 17-37 (July 1977).

Principles of gaseous reduction of corrosion products, C. E. Birchenall and R. A. Meussner, SP479, pp. 39-57 (July 1977).

Some brief remarks on electrochemical reduction, J. Kruger, SP479, pp. 59-65 (July 1977).

Measures for preventing corrosion of metals, R. T. Foley, SP479, pp. 67-76 (July 1977).

A review of the history and practice of patination, P. D. Weil, SP479, pp. 77-92 (July 1977).

The production of artificial patination on copper, D. C. Hemming, SP479, pp. 93-102 (July 1977).

Beta iron oxide hydroxide formation in localized active corrosion of iron artifacts, F. Zucchi, G. Morigi, and V. Bertolasi, SP479, pp. 103-105 (July 1977).

The current status of the treatment of corroded metal artifacts, R. M. Organ,'SP479, pp. 107-142 (July 1977).

Some constructive corrodings, C. S. Smith, SP479, pp. 143153 (July 1977). 
Conservation of rusty iron objects by hydrogen reduction, L. Barkman, SP479, pp. 155-166 (July 1977).

Restoration of large gilded statues using various electrochemical and metallurgical techniques, F. Ogburn, E. Passaglia, H. C. Burnett, J. Kruger, and M. L. Pickelsimer, SP479, pp. 167-178 (July 1977).

Problems of retrieval and retention of artifacts in field excavations, W. Trousdale, SP479, pp. 179-189 (July 1977).

SP480-1. LEAA police equipment survey of 1972, Volume I. The Need for Standards: Priorities for police equipment, R. $\mathrm{Ku}$, E. Bunten, and P. Klaus, Nat. Bur. Stand. (U.S.), Spec. Publ. 480-1, 166 pages (June 1977) SN003-003-01722-1.

Key words: police; police equipment; standards.

The report describes the methodology of and summarizes a portion of the data from the LEAA Police Equipment Survey of 1972 . One of a series of seven reports resulting from this nationwide mail survey of a stratified random sample of 1386 police departments, the present report summarizes the answers of 1100 police departments concerning the need for performance standards for items of law enforcement used in their departments. Each sample department was asked to rank one list of equipment categories and nine lists of equipment items within those categories in terms of the need for standards for those equipment within their own departments. The data are presented by all responding departments, by all city departments, by seven department types, and by ten LEAA geographical regions. Data describing the characteristics of the responding departments are also presented.

SP480-2. LEAA police equipment survey of 1972, Volume II. Communications equipment and supplies, S. Mumford, P. Klaus, E. Bunten, and R. Cunitz, Nat. Bur. Stand. (U.S.), Spec. Publ. 480-2, 127 pages (June 1977) SN003-003-017230 .

Key words: communications; mobile radio; police; police equipment; portable radio; standards.

The report outlines the methodology of and summarizes a portion of the data from the LEAA Police Equipment Survey of 1972. One of a series of seven reports resulting from this nationwide mail survey of a stratified random sample of police departments, the present report summarizes the answers of 428 police departments concerning their communications equipment and supplies: Use of Mobile Radios and Portable Radios; Power Supplies for portable radios; Scramblers; Portable/mobile Radios; Helmets with Built-in Communications; Needs for standards and problems associated with communications equipment and supplies. The data are presented by all responding departments and by seven department types.

SP480-3. LEAA police equipment survey of 1972, Volume III. Sirens and emergency warning lights, P. Klaus and E. Bunten, Nat. Bur. Stand. (U.S.), Spec. Publ. 480-3, 110 pages (June 1977) SN003-003-01744-2.

Key words: emergency warning lights; police equipment; sirens; standards.

The report outlines the methodology of and summarizes a portion of the data from the LEAA Police Equipment Survey of 1972 . One of a series of seven reports resulting from this nationwide mail survey of a stratified random sample of police departments, the present report summarizes the answers of 437 police departments concerning their sirens and emergency warning lights: use of sirens and lights; experience with most commonly used electronic sirens, electromechanical sirens, and emergency warning lights; purchasing, repair and replacement of this equipment; and training of officers in use of this equipment. The data are presented by all responding departments and by seven department types.

SP480-4. LEAA police equipment survey of 1972, Volume IV. Alarms, security equipment, surveillance equipment, J. L. Eldreth, E. D. Bunten, and P. A. Klaus, Nat. Bur. Stand. (U.S.), Spec. Publ. 480-4, 115 pages (June 1977) SN003003-01745-1.

Key words: alarm systems; cameras; police; police equipment; security equipment; surveillance equipment.

The report outlines the methodology of and summarizes a portion of the data from the LEAA Police Equipment Survey of 1972. One of a series of seven reports resulting from this nationwide mail survey of a stratified random sample of police departments, the present report summarizes the answers of 447 police departments concerning their use of alarm systems, cameras, security equipment, and surveillance equipment: purchasing practices, typical patterns of use, and needs for standards for such equipment. The data are presented by all responding departments and by seven department types.

SP480-5. LEAA police equipment survey of 1972, Volume $V$. Handguns and handgun ammunition, S. Bergman, E. Bunten, and P. Klaus, Nat. Bur. Stand. (U.S.), Spec. Publ. 480-5, 83 pages (June 1977) SNO03-003-01747-7, \$2.20.

Key words: ammunition; handguns; policc; police equipment; standards.

The report outlines the methodology of and summarizes a portion of the data from the LEAA Police Equipment Survey of 1972 . One of a series of seven reports resulting from this nationwide mail survey of a stratified random sample of police departments, the present report summarizes the answers of 445 police departments concerning their officers' use of handguns and handgun ammunition: on-duty and off-duty use, types and calibers in use, and problems encountered. The data are presented by all responding departments and by seven department types.

SP480-6. LEAA police equipment survey of 1972, Volume VI. Body armor and confiscated weapons, G. B. Hare, P. A. Klaus, and E. D. Bunten, Nat. Bur. Stand. (U.S.), Spec. Publ. 480-6, 77 pages (June 1977) SN003-003-01748-5.

Key words: ballistic protective equipment; body armor; confiscated weapons; police; standards

The report outlines the methodology of and summarizes a portion of the data from the LEAA Police Equipment Survey of 1972. One of a series of seven reports resulting from this nationwide mail survey of a stratified random sample of police departments, the present report summarizes the answers of 440 police departments concerning body armor and confiscated weapons: Preference for hidden or visible body armor; Use of other ballistic protective equipment; Routine operations where body armor would be most useful; Current problems and failures with present equipment; Needs for standards for the testing and assessment of penetration capabilities of body armor; Disposition of confiscated weapons. The data are presented by all responding departments and by seven department types.

SP480-7. LEAA police equipment survey of 1972, Volume VII.

Patrol cars, E. D. Bunten and P. A. Klaus, Nat. Bur. Stand. (U.S.), Spec. Publ. 480-7, 97 pages (June 1977) SN003-00301766-3.

Key words: patrolcar; police; police vehicles; standards. 
The report outlines the methodology of and summarizes a portion of the data from the LEAA Police Equipment Survey of 1972. One of a series of sevcn reports resulting from this nationwide mail survey of a stratified random sample of police departments, the present report summarizes the answers of 449 police departments conceming their patrolcars: Purchasing practices; types of options and accessories usually selected; types of equipment stored in the patrolcar; typical patterns of use; and needs for standards for systems or aspects of patrolcars. The data are presented by all responding departments and by seven department types.

SP480-8. A guide to voice scramblers for law enforcement agencies, R. E. Nelson, Nat. Bur. Stand. (U.S.), Spec. Publ. 4808, 44 pages (Dec. 1976) SN003-003-01735-3.

Key words: LESL; NILECJ; privacy; scramblers; speech scramblers; voice privacy; voice scramblers.

This guideline presents information and suggestions which will assist law enforcement agencies in the selection, procurement, and implementation of voice scramblers in their communications systems. Important points are discussed that need to be considered in choosing the proper scrambler, negotiating the procurement contract, installing the scramblers, and evaluating their performance.

SP480-13. Police communications equipment survey of $1976, \mathrm{~W}$. A. Shand and M. J. Treado, Nat. Bur. Stand. (U.S.), Spec. Publ. 480-13, 54 pages (Aug. 1977) SN003-003-01818-0.

Key words: communications equipment priorities; equipment standards; Law Enforcement Standards Laboratory; police equipment; reports and guidelines; survey.

This report discloses the results of a survey conducted by NBS for the Law Enforcement Assistance Administration. The survey was designed to determine the degree of utilization of law enforcement communications equipment documentation developed by the Law Enforcement Standards Laboratory of NBS and the need, if any, for additional documentation. 176 of 254 questionnaires were returned by respondents for a 69 percent rate of return.

SP480-18. Report on an investigation of the high speed hazards of steel belted radial tires on police cars, J. J. Collard, Nat. Bur. Stand. (U.S.), Spec. Publ. 480-18, 40 pages (June 1977) SN003-003-01786-8.

Key words: high speed tire hazard; police patrol car tires; radial tire failures.

At least two police fatalities and one permanent disability were caused by catastrophic failures of steel-belted, radial-ply tires during high speed police operations. More than 200 other failures were reported by one State highway patrol department. The report concludes that general-use tires, whether steelbelted, radial, fabric-belted radial, bias ply, or bias belted, are not suited to high speed use. It recommends that police departments use for high speed patrol only those models that tire manufacturers have tested and certified for use at speeds of at least 125 miles per hour. Tires of all four types are available for such use.

SP480-19. Digital data transmission tests on voice channels, Urban Sciences, Inc., Nat. Bur. Stand. (U.S.), Spec. Publ. 480-19, 63 pages (July 1977) SN003-003-01773-6.

Key words: Allegheny County; data transmission tests, digital data; mobile digital equipment; modulation technique; transmission rate; voice channel.

In order to better understand the ramifications of transmitting and receiving digital data over typical voice channels, a series of tests were performed in Allegheny County, Pennsylvania, using existing local government transmitting sites and a specially equipped mobile unit. Carrier frequency, digital data transmission rate, modulation technique; range of transmission, speed of the mobile unit and the time of day were varied for test purposes. Tests were conducted in both urban and suburban environments. This paper discusses test procedures, sites, routes, test equipment and the results obtained.

SP480-21. The hazard of benzidine to criminal justice personnel, H. Steinberg, Nat. Bur. Stand. (U.S.), Spec. Publ. 480-21, 16 pages (May 1977) SN003-003-01777-9.

Key words: benzidine hazard; blood testing; carcinogen; fingerprints; forensic science; hazardous materials.

Benzidine is a hazardous material which can cause bladder cancer in man. Yet it is used by criminalists and by investigative personnel in the detection of blood and in the preparation for photography of fingerprints found on bloody substrates; significant benzidine uptake by these personnel is possible. The forensic techniques which utilize benzidine, and the most likely routes by which contamination of personnel may occur, are described. Recommendations regarding its handling and use are presented

SP480-22. Terms and definitions for door and window security, J. S. Stroik, Nat. Bur. Stand. (U.S.), Spec. Publ. 480-22, 16 pages (May 1977) SN003-003-01774-4.

Key words: definitions; doors; glossary; security terms; windows.

This is a glossary of definitions for those terms most frequently encountered in the spoken and written vocabulary concerning door and window security. Compiled from dictionaries, glossaries, professional literature and technical publications, the definitions were either used as found or rewritten into simpler and more descriptive language. Terms and definitions for alarm systems are not included.

SP480-24. The role of behavioral science in physical security. Proceedings of the first annual symposium, Apr. 29-30, 1976, J. J. Kramer, Ed., Nat. Bur. Stand. (U.S.), Spec. Publ. 48024, 122 pages (Nov. 1977) SN003-003-01868-6.

Key words: behavioral science; human factors; human reliability; perpetrator attributes; physical security; psychological deterrence; sophisticated crime; threat analysis; terrorism; vigilance.

This document contains the proceedings of a Symposium/Workshop along with many formal papers assembled to provide a collection of current behavioral science contributions to physical security. The formal papers are divided into three topical sections (1) Threat Analysis-Behavioral Factors and Consequences, (2) Human Reliability-Response Forces vs. Adversary, and (3) Methods of Measuring Behavioral Impact-Quantitative vs. Qualitative. Timely questions and challenges were explored in open discussion sessions following many of the presentations. The proceedings concludes with a brief summary of the Panel-type Workshop Session dealing with the topic of threat analysis held on the second day. These proceedings include the following papers (indented):

Analyzing threats from terrorism, a working paper, E. D. Shaw, L. Hazlewood, R. E. Hayes, and D. R. Harris, SP48024, pp. 1-16 (Nov. 1977).

Federal Aviation Administration's behavioral research program for defense against hijacking, E. Pickrel, SP480-24, pp. 19-24 (Nov. 1977). 
Perpetrator attributes in threat analysis, A. Fine, SP480-24, pp. 27-34 (Nov. 1977).

Profiles of computer criminals, S. Nycum, SP480-24, pp. 37-4l (Nov. 1977).

Some human factors that influence reliability of signal detection and identification in surveillance systems, $R$. Mackie, SP480-24, pp. 43-56 (Nov. 1977).

Human reliability factors, J. J. Cappucci, SP480-24, Pp. 59-61 (Nov. 1977).

Human engineering in decision theory, K. A. Plant, SP48024, pp. 63-73 (Nov. 1977).

Final report-Joint services perimeter barrier penetration evaluation, R. A. Fite and S. Kilpatrick, SP480-24, pp. 75106 (Nov. 1977).

Preliminary observations of complex fence and barrier assaults-Phase II, J. Kramer and P. Meguire, SP480-24, pp. 107-113 (Nov. 1977).

SP480-25. Image quality of monochrome television cameras, J. C. Richmond, Nat. Bur. Stand. (U.S.), Spec. Publ. 480-25, 14 pages (Oct. 1977) SNO03-003-01855-4.

Key words: contrast; contrast transfer function; image quality; limiting resolution; relative spectral response; signal-to-noise ratio; square wave patterns; television cameras.

The camera operating characteristics most frequently quoted by manufacturers of monochrome television cameras are the (1) limiting resolution, (2) signal-to-noise ratio, and (3) sensitivity. These characteristics are coupled to each other and to the scene parameters (1) spatial frequency, (2) contrast, and (3) brightness. The camera characteristics are evaluated under limiting conditions of the scene parameters, and hence define in a general way the range of scene parameters over which the camera will produce useful pictures, but they do not give much information about the quality of the image produced. The contrast transfer function and the responsivity curve of the camera give more information about image quality. A fourth camera operating characteristic, relative spectral response, which is independent of the other camera characteristics and scene parameters, may also affect image quality.

SP480-26. The reduction of airborne lead in indoor firing ranges by using modified ammunition, A. A. Juhasz, Nat. Bur. Stand. (U.S.), Spec. Publ. 480-26, 27 pages (Nov. 1977) SN003-003-01821-0.

Key words: airborne lead; ammunition; firing ranges; law enforcement; lead; lead poisoning.

A study was conducted to evaluate the feasibility of decreasing or eliminating aerosol lead contamination at firing ranges by selectively modifying the ammunition fired. A 38 Special police revolver was used in the study and firings were conducted in a specially designed container which allowed trapping of particulate effluents from this weapon for subsequent analysis. Under the conditions of the experiment, conventional 38 Special ammunition yielded an average of 5,638 micrograms of lead per round at the position of the shooter. Under identical conditions, experimental ammunition, using jacketed soft point projectiles and a special non-lead-container primer composition yielded an average of 13 micrograms of lead per round. The data indicate a decrease of the particulate lead produced per round by a factor greater than four hundred. The ballistic characteristics of the ammunition were also examined. The manufacture of no-lead primers which will reproduce the interi- or ballistics of conventionally-primed ammunition appears to be well within the state of the art.

SP480-27. Security lighting for nuclear weapons storage sites: A literature review and bibliography, P. G. Meguire, J. J. Kramer, and A. Stewart, Nat. Bur. Stund. (U.S.), Spec. Publ. 480-27, 38 pages (Nov. 1977) SNO03-003-01838-4.

Key words: contrast; detection; illumination; incapacitation; psychological deterrence; recognition; security lighting; security systems; visibility level; visual processes.

The Defense Nuclear Agency (DNA) program to improve the security of nuclear weapons storage facilities includes consideration of requirements for not only physical barriers and alarm systems but security lighting to aid response force personnel as well. This report presents a literature review and bibliography dealing with optimization of Nuclear Weapons Storage Site (NWSS).security lighting systems design through the application of established principles of human psychological and behavioral functioning. Three distinct psychological/behavioral processes are relevant to the design of security lighting system design: (1) intruder psychological deterrence, (2) detection, and (3) incapacitation. General recommendations for NWSS security lighting system design are provided, based on the literature review and analysis.

SP481. The gallium melting-point standard, B. W. Mangum and D. D. Thornton, Eds., Nat. Bur. Stand. (U.S.), Spec. Publ. 481, 35 pages (June 1977) SNO03-003-01783-3.

Key words: clinical laboratory; fixed-point; gallium; melting-point standard; temperature; thermometric fixed-point.

This Special Publication contains a series of papers published in Clinical Chemistry concerning our temperature measurement system, the gallium melting-point as a thermometric fixed-point, how the gallium melting-point fits into the measurement system, and applications of the gallium melting-point standard.

SP482. Rare event/accident research methodology. Proceedings of a Workshop held at the National Bureau of Standards, Gaithersburg, MD, May 26-28, 1976, V. J. Pezoldt, Ed., Nat. Bur. Stand. (U.S.), Spec. Publ. 482, 112 pages (July 1977) SN003-003-01 800-7.

Key words: accident research; human factors; methodology; rare events; safety; system safety.

This volume contains the formal papers presented at a Workshop on Rare Event/Accident Research Methodology sponsored by the Human Factors Section of the Center for Consumer Product Technology, National Bureau of Standards held at NBS May 26-28, 1976. The topics addressed at the workshop and reflected in the papers in this volume include system safety engineering, hypothesis generation in accident research, epidemiological approaches to injury research, observational techniques for studying complex tasks, accident simulation, and methodological considerations being forced by the law. These proceedings include the following papers (indented):

System safety engineering as the integrator of accident prevention activities, W. Hammer, SP482, pp. 1-10 (July 1977).

Investigative methods useful in safety, W. G. Johnson, SP482, pp. 11-23 (July 1977).

Hypothesis generation for rare events research, L. A. Benner, Jr., SP482, pp. 25-28 (July 1977).

Epidemiologic approaches to injury research, J. A. Waller, SP482, pp. 29-46 (July 1977). 
Needed human research and new methodological considerations being forced by the law, G. A. Peters, SP482, pp. 4753 (July 1977).

Methods for studying complex homemaking tasks, R. E. Steidl, SP482, pp. 55-69 (July 1977).

Data collection for hand tool injury: An approach, M. M. Ayoub, SP482, pp. 71-103 (July 1977).

Simulation in accident research, S. Rubinsky, SP482, pp. 105-109 (July 1977).

SP483. Index of U.S. nuclear standards, W. J. Slattery, Nat. Bur. Stand. (U.S.), Spec. Publ. 483, 127 pages (Aug. 1977) SN003-003-01822-8.

Key words: engineering standards, index of; index of nuclear standards; KWIC index of standards.

This Index contains the pcrmuted titles of more than 1,200 nuclear and nuclear-related standards, specifications, test methods, codes and recommended practices published by 34 U.S. Government agencies, technical societies, professional organizations, and trade associations. Each title can be found under all the significant key words which it contains. These key words are arranged alphabetically down the center of each page together with their surrounding context. Each entry includes the date of publication or last revision, the standard number, an acronym designating the standards-issuing organization, any cross reference standard number, and price.

SP484, Volumes 1 and 2. Flow measurement in open channels and closed conduits. Proceedings of the Symposium on Flow Measurement in Open Channels and Closed Conduits held at the National Bureau of Standards in Gaithersburg, MD on Feb. 23-25, 1977, L. K. Irwin, Ed., Nat. Bur. Stand. (U.S.), Spec. Publ. 484, Vol. I, 479 pages, Vol. 2, 490 pages (Oct. 1977) SNO03-003-01845-7.

Key words: acoustic flow meters; closed conduit flows; current meters; dye-dilution methods; errors in flow measurement; flow measurement; fluid flow modeling; fluid velocity; flumes; gas flow standard; hot-wire anemometry; international flow standards; laser anemometry; open channel flows; orifice meters; pitot-static meters; turbine meters; weirs.

The wide range and complexity of problems and potential solutions that must be considered for useful flow measurements are emphasized by the papers contained in these proceedings. Fifty-three presentations cover: characteristics of new and improved instruments; applications of traditional and new measuring devices in field environments; procedures for identifying and analyzing errors or uncertainties in data under specific conditions; uses of physical and numerical models; politicoeconomic changes that affect international standards for flow measurement; and philosophical bases for making measurements. The fluids of most interest are water and waste water, petroleum and related refined products, air, natural gas and stack gas.

Experimental and analytical investigations on instrument performance and interpretation of results include innovative applications of traditional and new flow measurement techniques to fluid flows in open channels and closed conduits. The traditional devices or techniques include weirs, flumes, current meters, orifice plates, turbines, hot-wires, pitot-static tubes, velocity traverses, dye-dilution, and others. More recent instrumentation developments and procedures such as laser doppler anemometry, acoustic and thermal imaging, acoustic pulse velocity and doppler anemometry, numerical modeling, vortex shedding and digital computation are covered for particular measurement purposes.
The most significant trend reflected in these presentations is the general awareness that uncertainties in measured quantities at the lowest point in the measurement chain, i.e., in the field or plant, are more important than accuracy statements derived from controlled laboratory studies. Other trends in evidence are the rising importance of turbine meters for use as transfer standards and in-line measurements of liquids and gases in filled pipes and the increasing number of applications for acoustics and laser technology for flow measurements in both open channels and closed conduits. These proceedings include the following papers (indented):

Measuring the repeatability of flowmeters, A. T. J. Hayward, SP484, pp. 1-24 (Oct. 1977).

Key words: flowmeter calibration; flowmeter drift; flowmeter measurements; flowmeter repeatability.

A technique for measuring the repeatability of flowmeters has been investigated in an extensive series of tests. The technique involves installing a pair of nominally identical flowmeters in series and comparing their readings in a batch of repeat tests; the repeatability is then given by $\operatorname{to} \sqrt{2}$, where $\sigma$ is the standard deviation of the ratio of the simultaneous readings of the two meters and $t$ is Student's $t$.

The method shows great promise, and has revealed small but significant drift (sometimes as low as a few parts per million over a short series of tests) in meters where drift had not previously been suspected. Extensions of the method have also been used successfully to determine the repeatability of a flowmeter calibration system, and to measure the intra-rotational linearity of a positive displacement meter.

The Navy Liquid Flow Correlation Program, J. H. Tabler and C. G. Kullmann, SP484, pp. 25-32 (Oct. 1977).

Key words: metrology system; Navy Flow Correlation Program; turbine flowmeters; volumetric standards.

A brief history of the Navy Flow Correlation Program is described. The present flow correlation program is outlined in detail. The object of the on-going program is to assure compatibility of all primary liquid flow stands in the Navy Metrology System to within \pm 0.15 percent. This is accomplished by first assuring that the primary weigh/time dynamic liquid flow stands at the Navy Type I Laboratory are in agreement with those at the National Bureau of Standards. The method of maintaining compatibility of the four flow provers at the Type I Laboratory is discussed. Application of process control charts is described.

Approximately 15 primary volumetric and dynamic weighing flow stands are located at various Navy Metrology Laboratories and Test Centers throughout the Continental U.S. The technique used to maintain control is the use of turbine type flowmeters at discrete frequencies and the use of a common very stable calibrating fluid. The excellent short term repeatability of these transfer devices lends itself to this type of correlation program. The Type I Laboratory calibrates the turbine meters before and after a participating laboratory calibration is performed. The report issued to participating laboratories is described.

A laboratory study of turbine meter uncertainty, G. E. Mattingly, P. E. Pontius, H. H. Allion, and E. F. Moore, SP484, pp. 33-54 (Oct. 1977).

Key words: accuracy; calibration; flow conditioning; meter performance; perturbations; precision; turbine meter; uncertainty. 
A scrics of laboratory tests arc conducted to assess, quantitatively, the uncertainties produced in making fluid flow mcasurcments using turbine meters. The patterns of unccrtainty are analyzed statistically and remedial modifications are described and evaluatcd.

Using a tandemly connccted pair of conventional turbine metcrs with rccommcnded mcter tubes and straightening vane sections, calibration procedures are performed with a weigh-time reference for the liquid flow. The calibration data are analyzed using a varicty of techniques. The results indicate that turbine meter performance can, within the realm of "normal" operating conditions, bc perturbed to exceed specified valucs. Modifications, both to hardware and conventional tcsting procedures, arc described which enhance metering assurance.

Evolution of a modern petroleum measurement manual, L. M. Davis, SP484, pp. 55-60 (Oct. 1977).

Key words: measurement practices; metering; oil measurement documents; petroleum measuring; tank gaging.

Progress from early applications of positive displacement mcters to modern measurement practices are reviewed with particular attention to liquid petroleum metering. Comments on somc advantages of metering vs tank gaging arc made. The rcalism of the new API Measurement Manual is discussed and an outline of its contents provided.

Building blocks towards flowmeter reliability, D. Halmi, SP484, pp. $61-82$ (Oct. 1977).

Key words: flow measurements; flow properties; flowmeter rcliability; reliability.

The need to analyze the question of flow measurement reliability as a special subject is pointed out. Attempt is made to give a definition to flow measurement reliability, review its types, and uncover the means by which it can be attained, in terms of "building blocks" which may be found in the nature of a mcter, or in the method of its flow metering performance investigation.

Open channel flow monitoring or metering, that is the question, K. W. Martig, Jr., SP484, pp. 83-89 (Oct. 1977).

Key words: closed conduit flow; instrumentation; measuring flow; metering flow; monitoring flow; open channel flow; public law 92-500; sewerage flow; wastewater flow.

For generations we have accurately MEASURED clean fluid flow conveyed in closed cinduits employing precise, reliable flow meters. Clean fluids, historically, have had "Value." This "Value" has motivated precise METERING to apportion, buy, and sell said "Value." In contrast, most open channel conveyed fluids have by nature been low "value," liability "Value" or waste liquids containing debris. Therefore, there has been no incentive to MEASURE open channel flow: We simply have ignored or only applied loose MONITORING practices to these flows.

The advent of P.L. 92-500 in late 1972, has provided an instant incentive to MEASURE open channel flow more accurately, using METERING practices instead of less accurate MONITORING practiccs.

Instrumentation state-of-the-art does not lend itself to producing reliable, precise, cost effective METERING equipment to replace previously employed MONITORING equipment for use in existing systcms. Recognizing this point is a significant step toward advancing open channel flow MEASURING technology and reducing the costly mistakes continuously being madc by those who believe as gospel, the output from many new open channel flow devices being marketed and employed today.
Instrument errors in open channel flow measurement systems, D. M. Grant, SP484, pp. 91-108 (Oct. 1977).

Key words: flow measurement, water; flow meters; instruments, flow measurement; level measurement; level-to-flow rate conversion; liquid flow; open channel flow measurement; secondary measuring device.

Certain aspects of open channel flow measurement systems are briefly discussed, including primary and secondary measuring devices. The two functions of a secondary measuring dcvice (opcn channel flow meter) are discussed: level measurement and level-to-flow rate conversion. Some of the common methodologies uscd to accomplish each of the two functions of a secondary device are described, and the possible sources and magnitudes of errors associated with each of these methodologies are analyzed. Level measurement methods discussed are: float, electrical, ultrasonic, bubbler, and dipping probe. Level-to-flow rate conversion methods discussed are: mechanical cam, electronic analog function generator, electronic memory device, and opto-electronic function generator. In the interest of promoting a uniformity of specifications, a standard general format for open channel flow meters is proposed.

Marine dynamics and its effects on current measuring transducers, T. Mero, G. Appell, and R. S. McQuivey, SP484, pp. 109-122 (Oct. 1977).

Key words: current measuring transducers; current velocities; dynamic response characteristics; fluctuating flow characteristics; marine environment.

A growing interest in measuring current velocities in coastal zone and estuaries prompted the creation of a Dynamic Analysis Program at T\&EL (formerly NOIC). The dynamics of near-shore current flows are more severe than that of the deep ocean. Therefore, it is important to qualify the performance of current measuring transducers in a dynamic environment. A study was contracted to determine what scales and intensities of turbulence exist in the near-shore environment. The major effort of the study is concerned with turbulence from 1 to $20 \mathrm{~Hz}$ and scales up to $30 \mathrm{~cm}$.

Tests are being conducted to determine the response characteristics of several current measuring transducers including both rotor and electromagnetic instruments. These tests include grid-produced turbulence measurements as well as simulated mooring-line dynamics' tests. Measurements have revealed several transducers that have 10 to 20 percent sensitivity increases when turbulence intensities of 6 to 12 percent are present.

This paper contains a description of turbulence that exists in the marine environment along with dynamic response characteristics of several current measuring transducers.

Some error sources in Price and Pygmy current meter traverses, G. Kulin, SP484, pp. 123-144 (Oct. 1977).

Key words: current meter calibrations; current meters, water; flow measurement; Price meter suspensions; Pygmy meter performance; velocity-area method.

Some performance characteristics and effects of methods of calibration and use of Price and Pygmy water current meters are examined with emphasis on their application to velocity-area traverses for flowrate determination. The limits of applicability of group rating equations relative to individual ratings are discussed using available calibration data. The repeatability of meter performance at low veloci- 
ties, $0.1<\mathrm{V}<0.5 \mathrm{ft} / \mathrm{s} \quad(3.0<\mathrm{V}<15.2 \mathrm{~cm} / \mathrm{s})$, is investigated. The effect of cable-and-weight suspcnsion relative to rod suspcnsion of Price meters is examined experimentally and analytically for Columbus and Elliptic weights. Errors duc to lateral velocity gradients and bottom and sidewall proximity effccts on both types of meters are also investigated.

Flow measurements in the canals of power plant closed loop cooling systems, J. F. O'Brien, J. Skridulis, J. Annett, G. W. Singley, and H. L. Kocnig, SP484, pp. 145-172 (Oct. 1977).

Kcy words: closed-loop cooling system; cooling lake; dye dilution method; error analysis; flow rate mcasurement; open channel flow measurement; power plant; spray canal; stage-discharge equation; velocity-area method; weir equation.

Measurements were made of the flows in the intake and discharge canals of thrce large power plants as part of a comprehensive study on the thermal performance of various closed-loop cooling systems. The types of cooling systems studied were spray canal, cooling lake, and spray canal/cooling lake combination. The flows were measured using velocity-area and dye dilution tcchniques. Velocityarea flow measurements were made at two of the plants under constant plant operational conditions. Analysis showed that the experimental error in these measurements was generally less than the estimated total standard error. This result was expected because of the relatively uniform nature of the canal cross-sections. At one of the plants, dye dilution and velocity-area flow measurements were used to develop a stage-discharge equation for a wingtipped weir. Subsequent validation measurements indicated that the variation of the measured flow rates from the flow rates predicted by the weir equation was less than the probable experimental error. Discharges calculated by the velocity distribution method were compared to those found by the one-point and two-point methods for various numbers of verticals per transect. It was found that the calculated discharge was not particularly sensitive to the number of points per vertical, but was affected by the number of verticals per transect.

Errors in flow measurement and their importance in infiltration/inflow analysis, D. L. Guthrie, D. R. Washington, and C. Vincenty, SP484, pp. 173-186 (Oct. 1977).

Kcy words: error reduction strategy; flow measurement errors; infiltration/inflow analysis; Parshall flume.

For infiltration/inflow analysis, flow measurement problems encountered in warm weather and humid climates include rapid build-up of floc particles and solids caused by high bacterial growth rates. Environmental in situ factors not only have a tendency to shorten equipment life but also to reduce the accuracy of flow determinations and to lengthen the time required for field study of infiltration/inflow problems.

Several common flow-measurement devices including the weir, Parshall flume, and scow were used in field studies of infiltration/inflow in Puerto Rico. Mathematical determinations of infiltration/inflow were made by calculating the hydraulic gradient, the height of water in the sewer, and the velocity head loss. Both of these instrumental and physical-mathematical methods for flow determination are reviewed, stressing the advantages and disadvantages of each, their sources of error, and methods used to resolve that error, whercver possible.

Results of infiltration/inflow studies are presented, emphasizing flow determination errors and their effect upon the inherent errors in infiltration/inflow assessment. Sewer system evaluations are not discussed because they are concerned with the evaluation of the physical problems of the existing sewer system which would increase infiltration/inflow.

Errors resulting from operational problems with physical flow-measurement devices are presented, along with a strategy to reduce these errors. The impact of operational problems in flow determination on infiltration/inflow assessment are also presented, along with field-tested resolutions for those problems.

Rating broad-crested V-notch weirs with narrow, sloping approach channels and sediment deposits, J. F. Ruff, K. Saxton, and C. Dang, SP484, pp. 187-200 (Oct. 1977).

Key words: approach channels; broad-crested V-notch weirs; calibration; small watersheds; stream gages; streamflow measurements; weirs.

An accurate and reliable precalibratcd streamflow measuring device is required to determine the discharge from small watersheds because rapidly rising and falling streamflow stages prevent accurate field determination of flow rates by conventional stream gaging techniques. Broadcrested, V-notch weirs were developed and calibrated by the U.S. Soil Conservation Service about 1940 to meet these requirements and they have been used extensively. Because field calibration of these weirs is difficult and inaccurate, the calibration curves often have not been verified. Recent evidence has shown that different approach channels cause significant deviations from the original calibrations.

Model studies were conducted to investigate the effects of the different approach channels slopes, cross-sections, and sediment deposits on the weir calibrations. The fixedboundary channels were tested at slopes of $0.0,0.5,1.0$, and 1.5 percent. Rectangular, trapezoidal, and circular cross-sections were tested with sediment deposits of 0.0 , 0.5 , and 1.0 feet depth. The calibration curves developed from the broad-crested $V$-notch weirs, will provide more accurate discharge measurements for small watersheds with narrow sloping channels.

Compensating for construction errors in critical-flow flumes and broad-crested weirs, J. A. Replogle, SP484, pp. 201-218 (Oct. 1977).

Key words: broad-crested weirs; errors; flow measurement; flumes; open-channel flow.

Critical-flow flumes and broad-crested weirs can now be routinely and accurately calibrated $( \pm 2 \%)$ by computer techniques over a wide range of flow rates and flume cross sections, including trapezoidal and complex shapes. This ability permits detailed compensation for errors introduced by construction anomalies. Procedures were developed and used on a series of primary devices in irrigation canals, including trapezoidal flumes and broad-crested weirs, which identified construction errors and accurately related a readout mechanism to the primary device, as constructed, so that the original intended accuracy could be restored. Templates were used to accurately define field dimensions of the flume throat section, its most sensitive portion. Errors in defining the throat cross-sectional area can be shown to be nearly equal to the error in discharge. Errors in the approach and converging sections are about onetenth as important. The accurate field measurements of flume dimensions were then used to compute a tailored calibration table for the particular construction. The template can also be used to accurately relate the readout 
device to the flume. Direct reading discharge gages that wcre prestamped could be mounted, using a modification of the technique, to reserve the highest accuracy for any selected flow ratc on the range. Discharge errors, if any, could thus be relegated to the least used flow range.

Numerical modeling of two-dimensional flumes, $R$. W. Davis, SP484, pp. $219-242$ (Oet. 1977).

Key words: flumes; hydraulic models; hydraulics; numerical models; open-channel flow; weirs.

Flumes are eommonly used dcviccs for the measurement of open-ehannel flow rates. Their range of operation has bccn limited, however, because outside of experimentally calibrating each configuration used, one has had to rcsort to one-dimensional theory for flow rate determination. This theory is restricted to fairly low values of upstream-head to erest-length ratio, as well as to almost level flumes with a rcasonably uniform incoming vclocity profile and nonconverging sidcwalls. The prescnt study is concerned with cxtending the operational range of a particular type of flumc (the two-dimensional version of the Palmer-Bowlus flumc) into areas where one-dimensional theory loses its validity. The determination of the head-discharge relationship for this flume is done numerieally by use of the SOLA finite difference routine for two-dimensional free-surface flows. Effects of changes in flume geometry, channel slope, and upstream velocity profile are investigated. The numerical results are verified experimentally.

The design of open channel acoustic flowmeters for specified accuracy: Sources of error and calibration test results, F. C. Lowell, Jr., SP484, pp. 243-266 (Oet. 1977).

Key words: acoustic flow rate; acoustic velocity; flow rate; liquid flow rate; liquid velocity; open ehannel flow rate; open channel velocity.

The design of open channel acoustie flowmeters is more difficult than the design of pipeline flowmeters because of errors introduced by the free surface, as well as because the open channel environment is usually more susceptible to attenuation and multipath eonditions which can inject large errors unless special signal recognition and filtering techniques are employed. The sources of error in open channel acoustic flowmeters are tabulated and diseussed. These include 1 ) line veloeity errors, 2 ) level measurement errors, and 3) integration errors. Assuming that the required sophisticated techniques are used to prevent the large errors (20-50\%) which can oecur due to signal attenuation and multipath, the total flow rate error contribution of items 1 and 2 above can be kept below 1 percent for liquid velocities greater than 0.5 FPS. Any error in excess of 1 percent of flow is contributed by item 3, integration error. For an accurately known cross seetion, this error is a function of the number and spacing of acoustic paths and the integration method used, and can be predicted in advance. Therefore, the desired overall system accuracy should be taken into account during the design phase in order to establish the minimum number of paths required. Two design examples are given for 2 percent specified accuracy with maximum flow rates of 1000 and 6000 CFS. In both cases the meters were calibrated using standard stream gauging techniques and demonstrated accuracies of better than 2 percent.

Application considerations and performance capability of the time differential clamp-on ultrasonic flowmeter, J. Baumoel, SP484, pp. 267-276 (Oct. 1977).

Key words: clamp-on ultrasonic flowmeter; flowmetering; ultrasonic flowmeter.
Substantial information has been developed on the application history and performance eapability of the time differcntial clamp-on ultrasonic flowmeter during approximatcly four years of in-scrvice expcriencc. These applieation considerations and performance capabilities are reviewed together with a review of the principles of operation and listings of the types of uses to which this instrument has been applied.

Theoretical and experimental assessment of uncertainties in non-intrusive, ultrasonic flow measurement, R. F. Bruner, SP484, pp. 277-291 (Oct. 1977).

Key words: acoustic rays; flow measurement; ultrasonic flowmeter.

In recent years the development of eommereially available, externally mounted, ultrasonic flow measuring systcms has made it possible to measure liquid flow rate without disturbing the flow or modifying the ducting. Such systems rely on the highly accurate measurement of both the timc for sound pulses to travel from an upstream transducer to an oppositely mounted downstream transdueer, and the time for sound pulses to travel from downstream to the upstream transducer. (This teehnique does not employ the Doppler shift, and scattered sound is undesirable.) This paper treats only the steady flow of homogeneous liquid in full ducts, although the theory is easily extended to open channel and gas flow.

In making such measurements the duet itself beeomes part of the measuring system, as the path and intensity of the transmitted sound depend on the material composition, wall thickness, and surface condition of the duct. Furthermore, the outside dimension of the duct (i.e., diameter), velocity of sound in the liquid, and flow velocity field also figure in the theoretical determination of the flow rate. Add to the uncertainties in the above parameters the positional (i.e., mounting) uncertainties plus uncertainties in the electronic equipment, and the feasibility of accurate flow measurement outside the laboratory becomes questionable.

A theoretieal analysis is developed which aims to quantify the uncertainties associated with these paramcters, and to determine their effects on overall system accuracy and repeatability. Experimental data have been obtained for estimating the uneertainties whieh might normally be encountered. These are presented for comparison with the theory. The result is a elearer picture of what we can realistically expect for the overall ace uraey of nonintrusive, ultrasonic flow measurement both in the field, and under controlled conditions.

A new ultrasonic flowmeter for the natural gas industry, $\mathrm{N}$. E. Pedersen, J. E. Bradshaw, L. C. Lynnworth, and P. R. Morel, SP484, pp. 293-318 (Oct. 1977).

Key words: flowmeter for natural gas; ultrasonic flowmeter; ultrasonic pulses.

An ultrasonic flow metering system is being developed for the measurement of the flow of natural gas in pipclines having diameters from less than $1 \mathrm{ft}$ to $3 \mathrm{ft}$ or more. The system is designed to measure flow over a line pressure range from less than 100 psig to 1500 psig. Problems relating to high frequeney dispersion and attenuation by the gas are avoided by the use of a patented ultrasonic flow metering technique which utilizes the accurate measurement of the absolute phases as well as the phase difference of various discrete low frequeney ( $25 \mathrm{~Hz}$ and $5 \mathrm{kHz}$ ) components in the identical but sequential upstream and downstream transmitted waveforms. The measurement system utilizes a 
dedicated microcomputer which has been programmed to provide outputs of flow rate $(\mathrm{ft} / \mathrm{sec})$, supercompressibility, flow rate (std cu ft/hr), totalized flow ( $s t d \mathrm{cu} f$ ), Reynolds number, energy flow rate (btu/hr) and totalized energy flow (btu), as well as a real time statistical analysis of intermediate data. A prototype system has been tested on an in-service gas line of $2 \mathrm{ft}$ diameter. Good tracking was observed between the ultrasonic meter and a downstream orifice station on a point-by-point basis at 30 second intervals, although the flow rate varied rather substantially over such intervals. Representative preliminary data are presented.

A new non-intrusive flowmeter, R. S. Flemons, SP484, pp. 319-333 (Oct. 1977).

Key words: cross-correlation analysis; liquid velocity measurement; non-intrusive flowmeter; ultrasonic beams.

A new type. of flowmeter is described which can be clamped to the outside of existing pipes and can measure liquid velocity without calibration. Two diametral ultrasonic beams are used to interact with the liquid and to detect passage of inherent tracers such as turbulent eddies. Cross-correlation analysis is used to determine the transit time of the eddy pattern and thus the liquid velocity. The operating principles of the signal processing electronics and the digital cross-correlator are outlined. Comparisons with accurate gravimetric flow measurements and field applications are briefly described.

Reconstructing three-dimensional fluid velocity vector and temperature fields from acoustic transmission measurements, S. A. Johnson, J. F. Greenleaf, M. Tanaka, and G. Flandro, SP484, pp. 335-359 (Oct. 1977).

Key words: acoustic transmission measurements; algebraic reconstruction techniques; temperature fields.

A theory with supporting experimental evidence is presented for reconstructing the three-dimensional fluid velocity vector field and temperature field in a moving medium from a set of measurements of the acoustic propagation time between a multiplicity of transmitter and receiver locations on a stationary boundary surface. The inversion of the integrals rclating the acoustic propagation path to the propagation time measurements is affected by linearization and discrete approximation of the integrals and application of an algebraic reconstruction technique (ART). The inversion of these integrals provides reconstructions of both acoustic refractive index and vector fluid velocity. Temperature reconstructions are obtained from the temperature dependence of acoustic refractive index. The problem of the presence of certain invisible fluid functions is treated. Since this technique does not require the presence of scattering centers or the optical transparency of the medium, it may be applied in many cases (i.e., turbid, opaque, or chemically pure media) where Doppler or optical (e.g., laser holography) methods fail.

Validation of use of dye-dilution method for flow measurement in large open and closed channel flows, W. H. Morgan, D. Kempf, and R. E. Phillips, SP484, pp. 361-394 (Oct. 1977).

Key words: dye dilution method; flume calibration; turbidity variations; validity testing; water soluble tracers.

The use of water soluble tracers for determining flow rates of rivers and streams has been practiced for several decades, both in the United States and abroad. During the last 15 years the economical availability of water soluble dyes, coupled with the considerable technical improvement in fluorometry equipment, has made feasible the use of dye-dilution methods for in situ calibration of flumes and other flow measurement devices.

In July 1976 a validation of the precision of flow measurement by dye-dilution techniques was undertaken at the St. Anthony Falls Hydraulic Laboratory, University of Minnesota, by comparing volumetrically measured flows over the range of 50,000 to 80,000 GPM. Subsequently, the method was applied in a field acceptance test of a large variable speed vertical turbine pump handling effluent from a wastewater treatment plant.

In both the validation and acceptance tests a dye of the Rhodamine family was continuously injected at a low precisely controlled rate into the flow stream. Several precise dilutions of the injected dye concentrate were prepared so as to bracket the anticipated dilution expected of the measured flow. A fluorometer was used to detect levels of dye concentration in the fully mixed flow at downstream sampling point as well as that of the prepared volumetric diluents.

The most serious of the measuring problems encountered, at the field test site, was the variation in turbidity which was overcome by a change in the type of Rhodamine dye used and through carefully controlled volumetric dilution of samples.

This paper describes the apparatus and procedures used during the validation test as well as those of similar activities pursued during the conduct of verification tests of hydraulic performance for the two installed variable speed pumps. Results of the validation tests are demonstrated to be within 3 percent of volumetrically determined flows and the field application of the dye-dilution method for determining hydraulic performance are shown to be within 1.5 percent of the predicted head-capacity pump curve.

Dilution method of discharge measurement in pipes, E. R. Holley, SP484, pp. 395-421 (Oct. 1977).

Key words: dilution method; discharge measurement in pipes; method of mixtures; mixing; tracer technique.

The dilution method, or the method of mixtures, is a tracer technique for discharge measurement in steady flow. The method is based on the mass balance of a tracer injected at a steady rate into the pipe flow and depends on measuring the concentration at one or more points downstream of the injector in order to evaluate the average concentration of the tracer. The accuracy of the method depends on the tracer, on the injection and measurement equipment, and on the locations of the sampling ports since these locations determine the accuracy with which the concentration measurements represent the actual average concentration.

Minimizing the errors associated with the locations of the sampling ports depends on being able to predict the rates at which mixing takes place for the applicable injection and pipe flow conditions. The mixing can be viewed as being either initial mixing associated with the injection or ambient mixing associated with the pipe flow. Both analytical work and experimental work on ambient mixing are presented with attention being focused on injection and sampling at the pipe wall. If the available mixing distance is restricted, multiple-point injection or multiple-point sampling can be used. However, analytical work and the limited available data indicate that the inherent asymmetry of the flow may have a strong influence on the rates of mixing for multiple-point systems.

Relatively little definitive information is available on initial mixing. Analytical and experimental work on one type of jet injection is reviewed. 
Equipment errors can be analyzed if a sufficient number of experiments are done in advance of the discharge measurement. Based on data from the literature, an error analysis is presented for a situation where a radioactive tracer was used. The total error in the calculated discharge was determined to be approximately 0.5 percent at the 95 percent confidence level.

Some possible areas for additional research are presented.

Application of a fluorescence technique to dye-concentration measurements in a turbulent jet, H. Liu, J. Lin, D. P. Delisi, and F. A. Robben, SP484, pp. 423-447 (Oct. 1977).

Key words: auto-correlation; convective velocity; cross-correlation; exit concentration; exit velocity; flow visualization; fluorescence; fluorescent dye; laser; laser dyefluorescence technique; mean concentration; mean velocity; measuring volume; remote sensing; root-meansquare concentration; Schmidt number; simultaneous measurements; spectra; water jet.

A laser dye-fluorescence technique for measuring the concentration of Rhodamine-6G dye in a turbulent water jet is presented. The measurement device consists of a 1 watt argon laser, which was used to excite the fluorescent dye, and an optics assembly, which was used to detect the radiated energy from the dye.

The dye-fluorescence technique is a remote-sensing method, which does not interfere with the flow field. Thus, a unique feature of this technique is that it provides the ability to conduct simultaneous measurements at many positions, which are as close as desired, parallel to the jet axis. Measurements show that the detecting device has an extremely high frequency response and that the sensing volume can be as small as $0.1 \mathrm{~mm}^{3}$. This technique can measure a wide range of concentrations with ratios larger than $10^{4}$. In the concentration range from $10^{-3}$ to $10^{-7} \mathrm{~g} / l$, the calibration of the photomultiplier tube output to the dye concentration is linear.

Measurements of the mean and fluctuating dye concentrations in a round, turbulent water jet are reported. The Reynolds number of the jet was approximately 1600 . The jet was tripped inside the nozzle to ensure a turbulent jet. Results show that the mean and rms concentrations on the jet axis decrease with the distance from the nozzle as $x^{-1}$. The profile of the axial mean concentration agrees very well with the profiles other investigators have measured in an air jet traced by oil smoke. The axial rms concentration, however, tends to have a relatively high value in the case reported here. Spectra of the concentration fluctuations are also discussed.

Simultaneous measurements of mean and fluctuating concentrations parallel to the jet axis were conducted to demonstrate the unique features of this technique. The results for tests made with two sensors focused at the same point show that the two sensors indeed measured the same signal. Both on- and off-axis measurements were conducted at $x / D=30$, with three sensors separated by 0.3 and 0.7 $\mathrm{cm}$. Cross-correlations and the convective velocity estimated from the cross-correlation are presented.

The application of Monte Carlo and Bayesian probability techniques to flow prediction and determination, F. J. Berté, SP484, pp. 447-470 (Oct. 1977).

Key words: Bayes' Rule; flow determination; flow prediction; Monte Carlo; statistics; stratified sampling.

The prediction of flow rate through a flow network, which is in the design stage, requires a detailed analysis of component resistance and pump performance uncertainties. In order to evaluate the predicted best estimate flow rate and its associated probability distribution, a combination of the Monte Carlo and Stratified Sampling techniques can be utilized. The use of these techniques permits the required results to be obtained even when non-gaussian probability distributions are associated with network flow resistances and/or pump performance parameters. The calculations necessary to produce the best estimate predicted flow rate and its associated probability distribution, are performed using a computer code, which embodies the Monte Carlo and Stratified Sampling techniques. After the flow network has been constructed, and flow measurements have been made, the problem becomes one of determining the best estimate true flow rate and its associated probability distribution. Ordinarily if a number of different techniques were available for measuring the flow in the network, the one with the smallest uncertainty would be utilized to determine the true flow rate. An alternate technique exists whereby the predicted flow as well as the flows measured by the available techniques are combined to produce one best estimate flow rate and its associated probability distribution. The statistical technique which can be used to accomplish this combination is Bayes' Rule. This combination of predicted and measured flow rates and their associate uncertainties is performed by a computer code which embodies Bayes' Rule as well as the Monte Carlo and Stratified Sampling techniques.

Laser doppler anemometry for flow measurement, W. W. Durgin and L. C. Neale, SP484, 471-477 (Oct. 1977).

Key words: flow measurement; He Ne laser; laser doppler anemometry.

Laser doppler anemometers are noninvasive, linear, and inherently precise. Calibration, in the usual sense, is not necessary; length and frequency measurements suffice to establish velocity at a spatial point. Measurements were made at points in the cross-sections of two square ducts containing water flow. The points were selected in conformance with a numerical integration scheme to be used for volumetric flow rate determination from the velocity measurements. The experiments were performed in a primary calibration facility at flows up to $1.25 \mathrm{~m}^{3} / \mathrm{sec}$ using ducts with sides 46 and $92 \mathrm{~cm}$. The anemometer, operating in forward scatter differential mode with a $15 \mathrm{mw} \mathrm{He} \mathrm{Ne}$ laser, was positioned with a special traversing frame. Windows in the ducts allowed transmission of the beams into the flow and reception of scattered light. Two grid patterns, $4 \times 11$ and $11 \times 11$, were used so that 44 and 121 velocities were measured for each test. A total of eight tests were conducted covering a Reynolds number range from 1.1 to $3.9 \times 10^{6}$. After accounting for errors due to the discrete integration scheme of 0.61 and 0.13 percent for the $4 \times 11$ and $11 \times 11$ schemes, respectively, comparison with the calibration facility indicated extreme errors of $+0.81 / 0.16$ and $+0.84 /-0.61$. The major limitation of the setup used was the time required to move the anemometer and obtain a new velocity value. It was pointed out that either better mechanical positioning or optical scanning could be employed to reduce the time required for a flow determination.

On improving the Pitot-tube determination of flows in large pipes, J. M. Robertson and M. E. Clark, SP484, pp. 479-489 (Oct. 1977).

Key words: flow in large pipes; flow metering; pipe flow; Pitot tubes; velocity indication. 
Reliable and accurate flow measurements in large pipes are becoming increasingly important in assessing the performance of power plant equipment in these days of energy crises. Since the Pitot-static tubes that are used for the determination of flows in large (diameters from 4 to $8 \mathrm{ft}$ ) pipes are being calibrated in a smaller (24-in) pipe, various uncertainties arise in the use of the Pitot and in the interpretation of its coefficient. These uncertainties include the correction for the area blockage by the Pitot tube, the effect of tip proximity to the wall on velocity indications, and the effect of asymmetric velocity profiles on the accuracy of the flow rate prediction. Additionally, the problems associated with fluctuating manometer readings and vibration of the Pitot tube can be significant. Studies and considerations of these uncertainties are reported. Specifically, the blockage correction has been studied via traverses with several Pitot tubes in the 24-in pipeline and with a reduced-size model in 8 - and 24 -in pipelines. Test results indicate that this type of correction is necessary to achieve true flow rate predictions but that it needs a better definition and is not unique. Velocity gradients and proximity to the far wall also significantly affect velocity indications. Conventional integration techniques applied to asymmetric velocity profiles, obtained from laboratory measurements following a pipe bend, are shown to yield inaccurate flow rate predictions. A study of Pitot tube vibration effects suggests that the resultant over-indicated velocities should be discarded from the average and more appropriate values, estimated from the trend of the profile, should be substituted for them.

Numerical modeling of turbulent flow through thin orifice plates, R. W. Davis and G. E. Mattingly, SP484, pp. 491-522 (Oct. 1977).

Key words: closed conduit meter; differential pressure; flow measurement; mathematical modeling; meter performance; orifice meter; turbulence flow.

A study is presented which uses the two-equation turbulence model developed at Imperial College, London to model high Reynolds number flow through orifice plates. This turbulence model employs the eddy viscosity concept for the Reynolds stresses. Two transport equations are solved for turbulence variables and are combined to form a spatially dependent eddy viscosity. This eddy viscosity is used in the numerical solution of the time-averaged momentum equations. The resulting solution is in terms of velocities, pressure, and turbulence intensity. The flow fields modeled are axisymmetric; the orifice plates are infinitely thin with beta ratios from 0.4 to 0.7 . Reynolds numbers are in the approximate range $10^{4}-10^{6}$. The incoming velocity profile at one pipe diameter upstream of the orifice plate is varied to assess its effect on meter performance. The results of the calculations give such orifice flow features as discharge coefficients for various tap locations, vena contracta, points of minimum pressure, and reattachment locations, and overall pressure loss through the meter. The numerical results are compared with available experimental data, and the agreement between computed and experimental discharge coefficients is within 4 percent. It is concluded that this type of computer simulation can be extremely useful in conjunction with experiments in future investigations of the performance of numerous types of differential pressure meters.

Studies of pulsating incompressible flow through orifice meters, R. A. Bajura and M. T. Pellegrin, SP484, pp. 523-548 (Oct. 1977).
Key words: differential pressure; flow metering error; flow oscillations; jet flow; orifice meters; pulsating flow measurements; pulsations; turbulence; vortex.

The differential pressure-flow relationship for standard ASME concentric sharp-edged orifice meters subjected to pulsating incompressible flow was investigated experimentally and analytically. Tests were conducted with water at pipe Reynolds numbers between 8,000 and 24,000 . Strouhal numbers of pulsation were varied between 0 and 1.8. The source of pulsation was located 15 diameters downstream of the orifice and provided flow pulsation amplitudes of up to 30 percent of the mean flow with differential pressure pulsation amplitudes of up to 250 percent of the mean differential pressure across the orifice. Three orifices with beta ratios of $0.35,0.50$ and 0.70 were used in the tests. A vortex shed from the edge of the orifice during pulsatile flow distorts the downstream flow channel as the vortex is convected away from the orifice. A marked distortion of the orifice flow channel occurs for pulsation conditions where the wavelength of the pulsation is approximately equal to the bore diameter of the orifice. The effect of the inertia of the fluid mass between pressure taps was determined over a range of pulsation Strouhal numbers. The effective discharge coefficient of the orifice decreases during pulsatile flow conditions. An analytical model which included the effects of fluid inertia and the increased friction losses which occur during pulsatile flow was developed and compared with the experimental data.

A vortex flowmeter-Calibration results and application experiences, R. W. Miller, J. P. DeCarlo, and J. T. Cullen, SP484, pp. 549-570 (Oct. 1977).

Key words: linearity; shedding frequency; vortex flowmeter; vortex generating element; vortex shedding.

Over the past few years the vortex flowmeter has come into prominence because of its potentially high degree of accuracy and low cost. Although several meter manufacturers offer this type flowmeter, little calibration data has been published to support specifications that are claimed.

The purpose of this paper is to present a substantial body of calibration data on a particular vortex flowmeter design. Over 1300 data points on $167^{-}$meters in $2^{\prime \prime}(50 \mathrm{~mm})$, $3^{\prime \prime}(75 \mathrm{~mm})$, and $4^{\prime \prime}(100 \mathrm{~mm})$ line sizes were obtained in a high quality hydraulic test laboratory. These data are statistically analyzed to arrive at specifications for this particular type of vortex flowmeter. These results are not necessarily representative of the performance of any other vortex flowmeter design.

This paper will not deal with the theoretical aspect of vortex shedding, of which little is known, but will describe the broad fundamentals of vortex shedding. Details of the experimental and fluid mechanic studies necessary to design a practical industrial type flowmeter are left to the reader's imagination.

Temperature field measurements in turbulent thermals, $M$. Gad-el-Hak, SP484, pp. 571-596 (Oct. 1977).

Key words: buoyant thermals; entrainment coefficient; fireballs; turbulent thermals; vortex bubbles.

Laboratory studies of buoyant vortex bubbles and thermals in an unstratified atmosphere are presented. Thermals are generated by filling a soap bubble with a combustible mixture and igniting.it with an electrical spark. These are compared to the thermals produced by igniting a similar mixture inside a cylindrical box with a sharp-edged orifice at its top. Detailed temperature field measurements are ob- 
tained using an array of hot-wire probes operating at low overheat. The temperature signals are digitized and different statistical quantities are obtained using an ensembleconditional averaging technique. It is found that initial conditions do have a strong effect on the development and growth of a thermal, even for gross parameters such as the "entrainment cocfficient."

Flow measurement up-date, R. B. Suhoke, SP484, pp. 597 619 (Oct. 1977).

Key words: error reduction; flow measurement techniques; flow vs. temperature techniques; pressure drops; thermal devices.

The intention of this paper is to provide insight into basically two flow measurement techniques. Consideration is given to the latest innovations in both the thermal and optical methods and the sources of possible error. Many of these error contributions can be reduced or eliminated by various techniques which will be explored and evaluated.

Near wall velocity measurements for wall shear inference in turbulent flows, F. J. Pierce, D. S. Gold, and E. I. Dupont, SP484, pp. 621-648 (Oct. 1977).

Key words: turbulent flow; velocity profiles; wall shear inference; wall velocity measurements.

The existence of logarithmic near wall similarity for twodimensional turbulent flows permits the inference of local wall shear stress from ordinary velocity profile data. In cases of minimal logarithmic similarity, it would be helpful to use the velocity measurements closer to the wall, in the "very" near wall region. Regrettably, this data is all too often inconsistent, deviating considerably from the proposed similarity laws, and thus invalidating its use for wall shear inference. In an attempt to explain such inconsistent behavior, velocity profiles were systematically measured with four different probes under six different flow conditions. Additionally, classical displacement corrections were considered as was the effect of the choice of similarity laws and "universal" law of the wall constants. While small, consistent differences were identified with different probes and different flow conditions, none of the probes or flow variations studied were able to explain the frequently encountered kind of inconsistency between measurements and proposed similarity laws in this very near wall flow.

On reduction of errors arising in hot-wire anemometry of thin turbulent shear layers, J. Gaviglio and J. P. Dussauge, SP484, pp. 649-658 (Oct. 1977).

Key words: error reduction; hot-wire anemometry; supersonic flows; thin turbulent shear layers.

In supersonic flows, turbulent fluctuations can be classified into vorticity, entropy and acoustic "modes." The first represents the vortical part of the fluctuating velocity field, which will be called "turbulent velocity field," or "turbulence field"; the second comes from turbulent heat transfers, involving nonisentropic temperature fluctuations; the latter expresses local pressure fluctuations, which in the case of waves radiated by the turbulent flow, is associated with irrotational and isentropic motions. Measurements of the level of these modes are performed advantageously by using a constant-current type hot-wire anemometer. Only this type of instrument will be discussed in this paper. It is well known that, due to the imperfections of the anemometer, the intensity of modes are often underestimated. In some cases this can be attributed to the low value of the impedance of the circuit feeding the hotwire or to the nonlinear response of the associated amplifier; then the defects can be easily reduced or corrected.
Probe and method for simultaneous measurements of "true" instantaneous temperature and three velocity components in turbulent flow, G. Fabris, SP484, pp. 659-685 (Oct. 1977).

Key words: fluid mechanics; nonisothermal flow; three velocity components in turbulent flow; true instantaneous temperatures; turbulent flow.

Need has always existed in the measurement of turbulent flows to obtain correct instantaneous values of temperature and three components of velocity at a particular point. Many proposed lengthy approximate correction methods, that attempt to account for "nonlinear" effects (cross contamination between different quantities) in hot-wire measurements, cannot be considered satisfactory.

The availability of powerful digital computers for theoretical and experimental studies has placed pressures on experimentalists to develop better probes and methods. This paper attempts to answer these pressures by describing the development of a special four wire probe and a method of processing the obtained signals. The use of four 0.000025 inch sensors makes the probe practically interference free. The processing method is based on the simultaneous solution of four complete nonlinear response equations for the sensors yielding in principle exact instantaneous values of velocity components and temperature. Additional features of the processing method includc: instantaneous full correction for tunnel free stream velocity and temperature fluctuations, first order correction for DC drifts of the signals during data acquisition, subtraction of all $60 \mathrm{~Hz}$ related noise, correction for streamwise displacement of sensors based on instantaneous streamwise velocity.

Measurement of bocindary layer transition using acoustic techniques, D. C. Sachs, T. F. V. Meagher, and V. D. Peckham, SP484, pp. 687-704 (Oct. 1977).

Key words: acoustic monitor; BLAM; boundary layer transition; hypersonic velocities.

The acoustical properties of boundary layers on the surface of bodies moving at hypersonic velocities have not been characterized fully by detailed measurements. It is known that boundary layer conditions (i.e., laminar, transitional, or turbulent) are dependent on a number of factors, including the Reynolds number of the flow, body orientation with respect to the flow, body geometry, et al. The essential acoustical parameters associated with boundary layers in general are well known to those who have worked in this field; among these parameters are pressure fluctuations in time which vary greatly with flow condition, spatial correlation of the fluctuations, and intermittency during marginal transition conditions.

A Boundary Layer Acoustic Monitor (BLAM) has been developed to take advantage of some of these acoustic properties to measure transition. In the design of this transducer, consideration has been given to measure and level, dynamic range, directionality, response frequency, packaging design for aerospace environments, installation requirements, and calibration techniques. Figures 1 and 2 are photographs of a monitor set; the set consists of a sensor connected with a cable to an electronics signal conditioning amplifier.

Measurement of recirculating flow behind a cylinder with spray cooling, R. S. Rudland, SP484, pp. 705-718 (Oct. 1977).

Key words: anemometer; cylinder; frequency; hot film anemometer; recirculating flow; spray; two component flow; vortex street; wake flow. 
A hot-film anemometer was used to measure the recirculating flow behind a heated cylinder which was cooled with spray water. The anemometer was electrically insulated from the water by a thin quartz film which was heated by the anemometer to help keep it dry. To measure air velocity in an air stream containing water droplets requires a sturdy anemometer which can withstand the droplet impact without breaking. The anemometer must also be able to measure the air velocity in less than a millisecond in the presence of water droplets. The hot-film anemometer was selected because it is a sturdy, fast response instrument which detects changes in heat transfer related to changes in fluid velocity. Since the heat transfer to water and to air are quite different, it is necessary to keep the anemometer dry when measuring air velocity. When the anemometer was calibrated it was found that the anemometer could dry itself in about a millisecond. This meant that the anemometer could measure air velocities with as many as a thousand drops a second hitting the anemometer. Also, the calibration revealed that the calibration curve shifted upward in proportion to the amount of spray present due to the heat loss at the probe support.

Once the anemometer was calibrated it was used to measure air flow patterns behind a cylinder. These measurements helped evaluate the change in vortex patterns due to the spray. The test results indicated that the vortex shedding pattern was noticeably changed by the spray. The shedding frequency increased about 20 percent when the spray was present and the recirculating flow over the trailing surface was also increased. This improvement in flow over the trailing surface is expected to improve the heat transfer from the cylinder noticeably.

A new type of velocity probe, W. B. Brower, Jr. and A. Servoz, SP484, pp. $719-735$ (Oct. 1977).

Key words: calibration; Pitot-static tube; Reynolds number; sphere flow; transition; trip-wire probe; turbulent boundary layer.

A trip-wire velocity probe has been designed and tested which employs a sphere as the mechanism for producing a pressure difference. To render this pressure difference independent of Reynolds number a trip-wire is placed on the upstream side of the sphere, which trips the boundary layer to turbulent flow. The resulting design has greater sensitivity than the Pitot-static tube, and can fit through smaller openings than a comparable Pitot-static tube. The dimensions of a typical probe are given, as are the results of a series of wind-tunnel tests at "low" Reynolds numbers.

The influence of turbulence on static and total pressure probes, V. E. Scottron, SP484, pp. 737-753 (Oct. 1977).

Key words: impact pressure probe; Pitot tubes; static pressure probe; turbulence; turbulent boundary layers; velocity measurement.

In the course of studying boundary layer flows over a rough boundary in an adverse pressure gradient in a wind tunnel, measurements of mean and turbulent velocities were taken using a hot-wire anemometer. Comparative velocity measurements were taken with static and impact probes attached to a micromanometer. Attempts have been made to determine the influence of the turbulence components on the readings obtained by these probes. Also comparisons have been made with the results of similar studies made by other investigators, such as Toomre, Bradshaw and de Haan.

The probes used in these tests were $1 / 16$ and 1/8 inch diameter separated probes. Combined probes could not be used near the wall due to the local pressure disturbances caused by the roughness. The boundary layer thicknesses were large, of the order of 10 to 12 inches so that it was possible to obtain a wide variation of turbulence levels by positioning of the probes. Pressure differences were referenced to a fixed static probe outside the boundary layer in a very low turbulence region.

Pressure indications were sufficiently large that it was possible to obtain reasonable verification of the theoretical estimates obtained by Toomre.

Determination and elimination of errors in velocity readings at ventilation tubing inlets, R. A. Haney, SP484, pp. 755-763 (Oct. 1977).

Key words: air velocity; error elimination; vane anemometer; velocity readings; ventilation tubing.

Accurate air velocity measurements have been obtained by applying a methods factor to vane anemometer readings at the inlet of an exhaust tubing installation. Methods factors were determined by comparing simultaneous 4 -inch rotating vane anemometer readings at the centerline of the tubing inlet to a Pitot-static tube traverse of the duct. Test velocities ranged from approximately 600 to $8,600 \mathrm{fpm}$. Methods factors were independent of velocity but dependent on tubing diameter and tubing entrance configurations. For straight unflanged tubing, the methods factors for 12-, 14-, 16-, 18-, and 20-inch diameter rigid tubing and 24-inch diameter spiral reinforced tubing were 0.69 , $0.68,0.66,0.74,0.75$ and 0.72 , respectively.

Indirect two-phase flow measurement: Analysis and reduction of methods errors, N. N. Kondic, SP484, pp. 765-782 (Oct. 1977).

Key words: error reduction; indirect flow measurement; turbulent two-phase flow; two-phase flow.

Flow measurement systems characterized by adverse features (high temperature and/or pressure, aggressive fluids, chemically reacting materials, vibrations, etc.) often require the application of indirect methods. Although more complex, due to instrumentation and data processing involved, such methods sometimes offer an additional advantage, when they are devised to be contactless (i.e. when pick-up probes and similar flow-field disturbing elements are eliminated). This family of methods introduces either tracers (chemical, radioactive, colorimetric, etc.) within the flow, or wave-transmitting and receiving devices (sound, ultra-sound, photons of various wavelength). Tracer concentration and wave-field characteristics (energy, flux) are functionally dependent on the characteristics of the original flow-field (velocity, gas fraction, particle concentration, etc.). This functional dependence, i.e. its accuracy (which depends on the assumptions and approximation in the mathematical analysis of all phenomena involved) is an important component of the overall method's accuracy. In addition, statistical fluctuations within the basic flow-field (turbulent in most practical cases) are generally independent of statistical fluctuations which are often inherent with the measurement method employed: fluctuations of tracer density or of the radioactive decay rate or other wave-source intensity variations. An appropriate analysis of these sources of errors-which are different from the usually listed errors when direct-reporting instrumentation is being utilized-can give an assessment of their magnitudes and indicate approaches to reduce them, including experimental procedures and data analysis improvements. 
Measurements of density and density gradient with an oscillating conductivity probe, D. P. Delisi and R. H. Kirchhoff, SP484, pp. 783-802 (Oct. 1977).

Key words: conductivity probe; density; density gradient; experimental; internal wave; laboratory; oscillating probe.

Density measurements obtained using single-electrode conductivity probes in a stratified salt solution are reported. A comparison of vertical density profiles obtained from upward and downward traversing probes show that measurement errors take the form of a hysteresis loop. Nondimensional plots of these mcasurements characterize probe performance in terms of the size of the hysteresis loop as a function of the parameters in the experiment.

A series of experiments werc performed with vertically oscillating conductivity probes to decrease the hysteresis effect in the density measurements. Typically, a probe was oscillated at a peak-to-peak amplitude of $1 \mathrm{~mm}$ at a frequency of $20 \mathrm{~Hz}$. Analysis of the data yields, for a single dimensionless parameter, a range of values over which the hysteresis effect is negligible. This parameter is a simple combination of the probe dimensions, gravity, and the oscillation charactcristics. The data indicate that, above a certain value of the parameter, the hysteresis effect is negligible regardless of the local density gradient.

Also reported are a theoretical development and results of additional experiments, in which the oscillating conductivity probe signal is analyzed to calculate the local density gradient. It is shown that phase synchronous detection of the probe signal can result in the direct measurement of the local density gradient. Experimental data showing satisfactory agreement with the theoretical results are reported.

New techniques for automotive fuel flow measurements, $M$. Baker, SP484, pp. 803-820 (Oct. 1977).

Key words: automotive fuel; flow measurement errors; fuel economy measurements; fuel flow mcasurements; in-line flow transducer.

This paper discusses techniques for making accurate automotive fuel economy measurements using an in-line flow transducer and an electronic display unit. The paper reviews the fuel delivery system of a conventionally carbureted vehicle and describes some of the sources of flow measurement errors this system introduces. Design requirements for automotive fuel flow measurement instrumentation are developed and techniques are presented for making accurate flow measurements in the presence of these error conditions.

The descriptive material presented is general in format as each vehicle manufacturer has different design requirements for the fuel delivery system. Testing, however, has shown this information applicable to vehicles from a number of different vehicle manufacturers.

Digital compensation techniques for positive-displacement and turbine flowmeters, R. Jennings, SP484, pp. 821-846 (Oct. 1977).

Key words: digital compensation techniques; fossil fuel limitations; linear specific gravity compensation; positive displacement flowmeters; turbine flowmeters.

Limitations in the availability of fossil fuels, natural gas, and other energy resources due to physical and geopolitical factors have, in recent years, increased the price of these products by as much as a factor of five. During the next 20 years, prices of both petroleum and natural gas are expected to increase at a rate substantially in excess of, and will thus contribute greatly to, the rate of inflation. While conservation of these resources by the fundamental laws of economics combined with government intervention in the production and consuming segments of the economy will undoubtedly result in improved conservation practices, virtually all projections show increasing usage of these vital raw materials through at least the year 2000 .

The first step in any conservation program must be the accurate determination of production and consumption quantities. For conservation programs to be effcctive, these measurements must be made with sufficient accuracy and resolution to allow the determination of the effects of incremental conservation measures. Further, because of increasing cost of petroleum-based fuels and their petrochemical derivatives, accurate measurement of product delivery and consumption, whether in pipelines, tank trucks, rail cars or ships, as well as within energy and raw material consuming processes themselves, must be made to assure proper billing for these products or to allocate their costs for accounting purposes.

Viscosity effects on the turbine flowmeter, J. M. Ball, SP484, pp. 847-869 (Oct. 1977).

Key words: accuracy; calibration; characteristic factor ( $\mathrm{K}$ or C); curve fitting; pickoffs (magnetic and RF); turbine flowmeter; universal curve; viscosity measurement.

The so called universal viscosity curve has been a common medium for the presentation of turbine flowmeter performance characteristics for some time. This paper shows that the most common types of turbine flowmeters do not usually perform according to a single curve when the viscosity is changed. We also present data which demonstrates that certain modulated carrier type turbine flowmeters do respond predictably when the fluid properties change. Errors produced by the misuse of the universal curve are demonstrated, and errors in the characteristic value ( $\mathrm{K}$ factor or $\mathrm{C}$ factor) due to fluid property measurement errors are described.

Turbine meters for the measurement of gaseous hydrocarbons, P. J. LaNasa, SP484, pp. $871-880$ (Oct. 1977).

Key words: design considerations; field testing; fuel gas measurement; fundamentals; gaseous hydrocarbons; installation; performance characteristics; turbine meter.

Turbine meters for the measurement of gaseous fluids have been available for many years. However, their application in the United States to the measurement of hydrocarbon fuel gases has occurred over the last fifteen years. The evolution of the turbine meter for this particular application has resulted in specific design consideration to insure its continued reliability and performance. In addition to specific design considerations, this particular measurement application requires the accuracy of the turbine meter be verified on location, thus necessitating the development of accurate high pressure field testing methods.

On a new method of gas flow measurement using cryogenic techniques, D. B. Mann and J. A. Brennan, SP484, pp. 881893 (Oct. 1977).

Key words: cryogenic; flow; gas; liquid; mass flow; measurement.

Direct comparison of ambient temperature gas flow measurements to mass is made possible by a new continuous closed-loop measurement method. The direct comparison is made possible by modification of a proven flow reference system based on mass-time. 
The complete gas flow reference system has, as yet, not bccn dcmonstrated physically; however, the liquefied gas portion has been continuously proven over a period of six years and is the flow standard for the recently developed cryogenic flowmeter code. Modifications are state-of-theart additions of heat exchangers and proccss control. It is believed that the accuracy of the liquid system (less than $\pm 0.2 \%$ ) will be maintained after modification.

If implemented, the method would be extremely valuable in improving and redefining many of the present gas flow measurements and standards. Gas and liquid mcter coefficients could be related directly to mass and to each other without the tedious reliance on state equations and critical pressure and temperature measurements. The validity of liquid calibration for gas service could be confirmed on a mass basis. Current codes and recommended practices could be supported and improved with new, more accurate empirical data. The method can be extended to mixtures such as natural gas and would improve the accuracy of these measurements.

It is believed that this modification is a significant and timely improvement within measurement science which could have major impact on custody transfer and energy conservation.

An anatomy of the international standards producing system-Flow measurement, L. K. Irwin, SP484, pp. 895-920 (Oct. 1977).

Key words: closed conduit flow; flow measurement; international standards; open channel flow; petroleum product standards.

The several international organizations that, collectively, form the "system" to promulgate and maintain the documents and publications that are explicit or de facto international standards are described. Included in this review are the International Organization for Standardization, International Electrotechnical Commission, International Organization of Legal Metrology, European Economic Community, European Committee for Standardization, World Metrological Organization, and International Bureau of Weights and Measures. Also, elements of organizations, that are not international by design but that generate standards used internationally, are reviewed. This second group includes the American Society of Mechanical Engineers, American Society for Testing and Matcrials, American Petroleum Institute, and British Standards Institution.

Summary information is given for the current activities of most of these organizations and the scope and technical output of selected technical committees as they affect standards for flow measurement or the quantitative determination of volume or mass of fluids. The efforts on coordination and apparent overlap of the work are noted. Some discussion of the existing and needed relationships between physical measurement standards and international documentary standards is given.

OIML and EEC, their impact on the international standards producing system, D. E. Edgerly, SP484, pp. 921-927 (Oct. 1977).

Key words: flow measurement; industry; intergovemmental; international standards; legal metrology; measurement: trade facilitation.

Existing relationships of three major international organizations involved in producing standards are explored. These are the International Organization of Legal Metrology (OIML), the International Organization for Standardization (ISO), and the International Electrotechnical Commis- sion (IEC). Emphasis is given to differing government versus industry needs in the production and use of standards and examples are provided in the flow measurement field which illustrate these differing needs. The technical directives program of the European Economic Community and its impact on the international standards producing system is also considered. Discussion is provided on existing and needed relationships among these organizations to ensure compatibility of technical requirements and to prevent duplication of effort.

The interface between industrial, national and international standards, W. N. Seward, SP484, pp. 929-934 (Oct. 1977).

Key words: application of standards; international standards; measurement standards; national standards.

The oil and gas industries, throughout more than 100 years of historical development, have been able to capitalize on the rationalization of sophisticated document and technology through industry-wide standardization efforts. The essential incentives of the original industrial standardization programs were threefold:

First, to decrease capital costs and long-term maintenance expenses through the interchangeability of parts and the establishment of uniform operating, procurement, and training procedures.

Second, to ascertain and develop optimum levels of performance, safety, and reliability without inhibiting technological development.

Third, to promote economic viability and incentive among supply and service organizations associated with the resource industries.

There are essentially two end uses for proprietary measurement standards developed by industry. A significant number were developed by industrial users to aid in the purchase, operation and maintenance of equipment common to various companies making up the industry. Conversely, as the product line of a manufacturing industry multiplied, the manufacturers themselves generated quality or definition standards to describe common product characteristics to the customer or user level.

The adequacy of the data bases available for promulgating international standards, H. H. Dijstelbergen and N. V. N. Gasunie, SP484, pp. 935-944 (Oct. 1977).

Key words: data bases; EEC regulations; flow rate; international standards; orifice plates.

The number of international standards for measuring flow rate or quantity is gradually increasing. In the light of experience with existing ones questions rise with respect to the validity of certain figures or tolerances. To answer the questions raised implicitly in the title, for all fields of standardization is beyond the competence of the author and the rest of the paper will therefore be limited to two specific fields. From the observations in these fields some conclusions might be drawn which are more generally valid.

In general international standards are based on national ones which have been in existence for some time. In some instances, the data bases underlying these standards have not been published and are lost in forgotten file cabinets. If they would be found, hardly anybody would be able to find his way in the chaos of insufficiently specified data. The adequacy of the data basis can, therefore, be rarely tested directly on the data itself. If, however, the claims put in the standards show not to hold, it can be concluded indirectly that the data base must be inadequate. Instead of speaking of adequacy of the data base one could put the 
question more gently by asking whether the right standard is based on the available data. The paper restriets itself to two standards. The first is not an international standard in the usual sense but the EEC regulations on gas turbine flowmeters. The seeond one is the international standard on flow measurement by means of orifiee plates.

Equitable implementation of national and international allocation programs (Summary of remarks to the panel), J. A. West, SP484, pp. 945-946 (Oet. 1977).

Key words: implementation of alloeation programs; international alloeation programs; International Energy Ageney; national alloeation programs.

Following the 1973-74 Arab Oil Embargo of the United States and the Netherlands and a reduetion of Arab oil supplies, the United States and 18 other nations formed the International Energy Ageney (IEA). These nations eonsume about 85 pereent of the world's oil supplies and formed IEA in order to establish cooperative measures in the event of any future large-seale interruptions in petroleum supplies. Its major programs inelude an international emergency alloeation program, oil market monitoring, produeer-eonsumer relations, and long-term eooperation on energy problems.

The Federal Energy Administration (FEA) was formed to administer the national regulatory programs in petroleum produet alloeations and prieing. FEA has the major role in the U.S. Government's partieipation in the IEA international alloeation program. Flow measurement standards are not a major eoneern in national alloeations but are of very eonsiderable eoneern in the international emergency program (IEP).

Of form and substance for effective standards, $E$. A. Spencer, SP484, pp. 947-956 (Oet. 1977).

Key words: flow measurement; ISO; methods of tests; need for international standardization; produet speeifieations.

With the expansion of demand and eonsequent inerease in world trade, the need for international standardization has intensified. The various types of sueh standards inelude produet speeifications, methods of test and codes of praetice: all are relevant to flow measurement. Their effeetiveness ean be measured by how well the operator attains in praetice the objeetives set out in the standards and these are reviewed.

Three ISO Draft International Standards, which ean be used for hydrocarbon fluid flow measurement, are taken as examples of produet speeifieations and eodes of praetice. The importanee of their interrelationship with national regulations is examined.

Comments on: Role of international standards in measuring and allocating hydrocarbons-A program for solution of our present problems, F. H. Abernathy, SP484, pp. 957-959 (Oet. 1977).

Key words: alloeating hydroearbons; hydroearbon measurement; international standards.

The four members of the panel eoneentrated their diseussion on different aspeets of the hydrocarbon measurement problem, which are assoeiated with the international trade in hydroearbons. There are a number of features of the present problem that makes the situation qualitatively different from that whieh existed in the past. Inereasingly the buyers and sellers of hydrocarbon are units of government rather than individual eorporations. The total mass or volume of hydrocarbons in international trade is rising and likely to eontinue to rise over the next deeade. The amount of hydrocarbons primarily transshipped through nations is also rising. Lastly the value of a unit of hydroearbons has risen by at least a factor of four in so short a period of time that it ean be thought of as a diseontinuous ehange.

SP485. A bibliography of sources of experimental data leading to activity or osmotic coefficients for polyvalent electrolytes in aqueous solution, R. N. Goldberg, B. R. Staples, R. L. Nuttall, and R. Arbuekle, Nat. Bur. Stand. (U.S.), Spec. Publ. 485, 53 pages (July 1977) SNOO3-003-01812-1.

Key words: aetivity eoeffieients; aqueous systems; bibliography; eleetroehemistry; isopiestic; osmotie eoeffieients; thermoehemistry; vapor pressure.

Contained herein is a bibliography of sourees of experimental data that ean be used to ealculate either aetivity or osmotie eoeffieients in water. The data types ineluded are eleetromotive foree measurements on cells with and without transferenee, vapor pressure data (relative and absolute), ultracentrifuge measurements, diffusion measurements, and other miseellaneous techniques. The compounds are given aceording to the standard thermochemical order of arrangement and referenees to the primary literature are ineluded.

SP486. User evaluation of "Phase Diagrams for Ceramists" and implications for related data and research programs, R. S. Roth, L. P. Cook, T. Negas, G. W. Cleek, and J. B. Waehtman, Jr., Nat. Bur. Stand. (U.S.), Spec. Publ. 486, 70 pages (Aug. 1977) SN003-003-01827-9.

Key words: Ameriean Ceramie Soeiety; eeramies; phase diagrams; "Phase Diagrams for Ceramists"; phase equilibria; user evaluation.

A survey was made of the needs of the users of "Phase Diagrams for Ceramists," a eontinuing speeial publieation series published by the Ameriean Ceramie Soeiety under the general editorship of the National Bureau of Standards. The results overwhelmingly support eontinuation of the series, but point to needs for expanded coverage, fuller commentaries, and redueed publieation time. The results also identify needs for greater effort on speeifie types of experimental and theoretieal phase equilibria studies ineluding the effeets of variable oxygen pressure and eomplex metal-eeramie systems.

SP487. MFPG-Engineering design. Proceedings of the 25th Meeting of the Meehanieal Failures Prevention Group, held at the National Bureau of Standards, Gaithersburg, MD, Nov. 3-5, 1976, T. R. Shives and W. A. Willard, Eds., Nat. Bur. Stand. (U.S.), Spec. Publ. 487, 367 pages (Aug. 1977) SN003-003-01829-5.

Key words: eoating materials; eomposite materials; design; failure avoidanee; failure prevention; lubrieants; materials of design; produet liability; reliability of design; teehniques of design; validation of design.

These Proeeedings eonsist of a group of twenty-three submitted papers from the 25th meeting of the Meehanieal Failures Prevention Group which was held at the National Bureau of Standards in Gaithersburg, Maryland on November 35, 1976. The eentral theme of the Proeedings is the applieation of design failure prevention, with emphasis on the techniques of design, materials of design, design validation, and the goals, purposes, and requirements of design as related to produet liability. These proceedings include the following papers (indented):

The growing web around the designer, C. O. Smith, SP487, pp. 1-15 (Aug. 1977). 
Key words: checklist for design; design; factors in design; requiremcnts in design.

The task of the designcr has never been easy since he has had to consider a number of factors, not all of which are necessarily compatible. He has always had to make iterative tradeoffs among various requirements, including the very important one of cost. In the context of today's technical and societal climate, the designer's task has become even morc difficult, if not almost impossible.

This paper summarizes the interrelated factors the designer must consider. There is further complexity as not all of the factors apply with equal weight in all designs, and some requirements conflict with others, yet all must be considered. None should be discarded without full justification, much less be ignored. The paper is essentially a checklist for the complex, confusing, and (sometimes) frustrating task of designing a product, not a "how to design" paper.

A systems approach to materials in design, B. P. Bardes, SP487, pp. 19-24 (Aug. 1977).

Key words: engineering design; manufacturing processes; materials selection; systems approach to design.

A systems oriented approach to the problems of materials selection and choice of manufacturing processes in engineering design is presented. The goal of this approach is to select the best combination of shape, material and manufacturing process by optimization with respect to several previously established criteria, such as performance, cost, availability of materials and manufacturing facilities and personnel. A flow chart is used to describe the process of evaluating the interactions between shape, material and process to determine the best combination. The flow chart also illustrates the use of prototype testing and reports of performance in service to provide feedback which may indicate changes in the design.

Probabilistic methods in design, E. B. Haugen, SP487, pp. 25-38 (Aug. 1977).

Key words: algebra of normal functions; correlation; probability; random variable; reliability.

It has sometimes been the case during the development of the various branches of science and engineering that, on looking back, initial solutions turned out to be special cases of more general problems. Such has been the case with mechanical design and analysis.

Until recently, many of the implications arising from the probabilistic nature of engineering phenomena were not fully realized, even though with the announcement of "Heisenberg's uncertainty principle," the whole of science (including engineering) was recognized as ultimately based philosophically on the concepts of experimental probability. A partial explanation is that some of the necessary supporting science and technology had not, until recently, sufficiently evolved to provide a base for a probabilistic design theory and methodology.

Beginning with a probability based design theory and reducing the variability (in the design variables) to the vanishing point, the residue amounts to a special case, i.e., a theory based on the deterministic assumption. It is essentially this special case into which classical deterministic design theory in its main features has evolved. Over the past several centuries an enormous methodology and supporting literature has been developed around the special case of assumed determinism.

Although in many classes of engineering problems the variables have been identified and the forms of their func- tional rclationships correctly described, the behavior of many individual variablcs has until recently remained imperfectly understood. In addition, probability mathematics, for coping with functions of random variables, has only recently been developed in forms lending themselves to the support of design synthesis and analysis.

In this paper, the focus of discussion is on a probabilistic design theory and methodology. Several points of theory in which the assumptions of determinism have led to untenable statements are examined. Other points are identified whose existence under deterministic assumptions were not suspected.

The task undertaken here is to discuss points of theory and methodology such that the practicing engineer can readily appreciate its power. Design examples are given, to a reliability specification, in which both over and under designing is avoided and variability information is used, not suppressed.

The finite element method in structural analysis, $H . G$. Schaeffer, SP487, pp. 41-61 (Aug. 1977).

Key words: finite element method; structural analysis.

NASTRAN thermal analyzer in interdisciplinary thermostructural analyses, H. P. Lee, SP487, pp. 62-81 (Aug. 1977).

Key words: finite-element method; general purpose heat transfer computer program; interdisciplinary thermo-structural analyses.

The NASTRAN Thermal Analyzer ( $\bar{N} T A$ ) is a unique, general purpose heat transfer computer program that is an integral part of the NASTRAN (NASA STRuctural ANalysis computer program) system. The $\bar{N} T A$ is based on the finite-element method and was developed at GSFC but implemented by a contractor. This paper stresses the role played by $\bar{N} T A$ in interdisciplinary thermo-structural analyses and illustrates the versatility and capability of this computer program. $\bar{N}$ TA, together with its host program, NASTRAN, is best suited for analyzing large and complex thermo-structural problems such as those dealing with stresses, deflections or deformations, vibration, buckling, etc., that are induced by thermal effects. A comparison is made between (1) a unified approach to the thermo-structural problem, and (2) an approach that is a combination of using (A) a thermal analysis computer program employing a lumped-nodal network which is based on the finitedifference method, and (B) a structural analysis computer program which is based on the finite-element method. Solution accuracy, procedural efficiency and savings of engineering efforts are discussed.

The use of cathode ray tube graphics as a computer aided design tool, A. Branum, SP487, pp. 82-90 (Aug. 1977).

Key words: cathode ray tubes; computer aided design; design; graphics.

Considering how efficiently the human mind functions when communicating in pictorial terms, many graphics experts expected the use of CRT's to sweep through the engineering community much as the use of TV's had swept through the home entertainment marketplace. In addition to discussing this "boom that never happened" and why, the paper will provide a general background in display technology and its progress over the past decade. Particular emphasis will be placed on refresh calographic CRT's and their use in the design process. 
Review of the processing and properties of PAN graphitealuminum composites, R. T. Pcpper, H. Gigerenzer, and T. A. Zack, SP487. pp. 93-107 (Aug. 1977).

Key words: composite material; fabrication techniques; graphite fibers-aluminum: mechanical behavior; pultrusion/drawing; wire preform.

The development of a liquid metal infiltration process and successful fiber-matrix interface barrier coatings has led to an exciting new class of graphite fiber reinforced metals. Composite wire preforms are continuously cast on a pilot production basis using the liquid infiltration technique. Aluminum composites reinforced with PAN graphite fibers have shown strengths in excess of 150,000 psi and modulus of up to 20 million psi. Work is currently underway to develop low-cost fabrication processes for hardware, using the wire preform material, by the modification of conventional mechanical working techniques such as metal drawing. A review of the processes and meehanical behavior of graphite fiber reinforced aluminum is given in the paper below.

Composite inlays for jet engines, W. Troha and K. Swain, SP487, pp. 108-120 (Aug. 1977).

Key words: blade flutter control; composite materials; jet engines.

A method of using composite material to improve turbine engine blade vibration stability has been demonstrated on a TF 41 fan rig and engine. The procedure uses the high strength and stiffness properties of $\mathrm{B} / \mathrm{SiC}$-titanium composite material, bonded into the leading edge trip section of an all titanium fan blade. Comparisons are made between the blade response characteristics with and without the composite inlay. These comparisons are made for blade natural frequency, untwist due to rotational speed, and shift in flutter boundary. Engine performance improvements due to blade shroud removal are also presented.

Stress concentrations in composite materials, G. Kardos, SP487, pp. 121-134 (Aug. 1977).

Key words: anisotropy; composite laminates; failure; strain concentration; stress concentration.

The use of high strength laminated composites has added a new dimension to the structural designer's arsenal. The designer may now tailor the properties of the material to match the load requirements of his structure. But the use of laminated composites is a mixed blessing; many design concepts have to be revised when applying these composites. The most important of these is the significance of stress and strain concentrations.

The analysis of simple laminated eomposite panels containing a hole demonstrate that neither the stress nor the strain concentration has the same significance as in isotropic homogeneous materials. Comparison with published test data shows that proceeding on the basis of older concepts can lead to erroneous results.

Elastohydrodynamic lubrication, L. B. Sibley, SP487, pp. 137-153 (Aug. 1977).

Key words: bearings: computer programs; elastohydrodynamics; failure analysis; film thickness; gears: Hertz contacts; lubrication; rheology; starvation; traction.

The basic mechanism of elastohydrodynamic (EHD) lubrication is described, including the historical development of the mathematical formulations and their experi- mental verification. The results of recent studies of the thermal, chemical and rheological conditions existing at the EHD contacts in machine elements are reviewed, as well as new developments in EHD starvation theory and experiments. Critical effects of EHD phenomena as they influence the performance of rolling bearings are illustrated, and their implications are given for the performance of other machine elements having concentrated contacts, such as gears, cams, seals, foil bearings and articular cartilage. The use of computers is described both for obtaining theoretical EHD solutions and for EHD calculations in rolling bearing design and application engineering. Typical computer computations of EHD film thickness, traction, power loss and starvation effeets are presented, showing how EHD analysis can be used to design ball bearing lubricants and lubrication systems for minimum friction torque with maximum lubrication effectiveness and reliability.

Polyfluoroalkyl-alkyl polysiloxane grease for instrument lubrication, J. B. Christian, SP487, pp. 154-171 (Aug. 1977).

Key words: antimony dialkyldithiocarbamate; antiwear; bearing lubrication; extreme pressure; fluorinated ethylenepropylene; gear lubrication; grease; polyfluoroalkyl-alkyl polysiloxane; polytetrafluoroethylene.

A wide temperature range grease has been developed for instruments which operate under light to heavy loads and low to moderately high speeds. It is especially suited for use in applications involving rolling, sliding or oscillating motions and where very little wear can be tolerated. The grease is based on a fluorinated ethylenepropylene or polytetrafluoroethylene thickener in a polyfluoroalkyl-alkyl polysiloxane fluid. The grease's outstanding qualities are its wide temperature range $\left(-100\right.$ to $\left.450{ }^{\circ} \mathrm{F}\right)$ capability, its extreme pressure and antiwear characteristics, its nonmigratory nature, and its low foreign and/or opaque partiele content.

The grease is suitable for use in aircraft actuators, gears, gimbal rings, oscillation bearings, antifrietion bearings, and plain spherical bearings. It is especially suitable for use in applications employing miniature bearings, and has yielded thousands of hours of operation in some of these applieations including blower motors, motor generators, plastic clutches and gears, servo motors, and others.

Antiwear and lubricity additives for lubricants, S. M. Hsu, SP487, pp. 172-185 (Aug. 1977).

Key words: antiwear additives; interaction; lubricant; metals; properties; tricresyl phosphate; zinc dithiophosphate.

The physical and chemical eharacteristics of the common antiwear additives such as zinc dithiophosphate, tricresyl phosphate are discussed. Effective region of these additives is defined by the load, speed, bulk and junction temperatures, and oxygen concentration. Interactions among additives in a lubricant are important. One additive can completely blank-out another additive. Some additivemetal interactions can also be critical. Proper consideration of these factors in choosing the additive/lubricant system during the design phase is crucial in preventing costly premature failures.

Piezoelectric polymers and their applications, S. Edelman, SP487, pp. 189-196 (Aug. 1977).

Key words: acoustic emission; damage detection; failure prevention; noise spectrum; piezoelectric polymer; vibration sensor. 
Polymers with significant piezoelectric activity have been developed. This activity has been used to make measuring instruments of thin polymer sheets. Sensors have been made to measure dynamic stress, strain, acceleration, sound, vibration, and the effects of mechanical impact or shock. Polymer sensors differ from conventional instruments in being light, flexible, thin, highly damped, easily attached to curved, twisted, or compliant surfaces, uniform in response over a wide range of frequencies, and cheap. Neither the instrument nor its leads is subject to mechanical fatigue. Polymer instruments have obvious applications in failure prevention. For example, the condition of bearings can be monitored by cementing polymer gages to any available portion of a bearing, the signal analyzed to provide the noise spectrum of the bearing, and the spectrum checked at periodic intervals so that deterioration in the condition of the bearing is noticed in time to prevent catastrophic failure. Other components of machinery can be monitored in similar ways. Typical noise spectra will be shown. The process of poling the material will be outlined. The construction, characteristics, and uses of typical sensors will be described.

Exoelectron emission-Past experience and future expectations, W. J. Baxter, SP487, pp. 197-209 (Aug. 1977).

Key words: assessment of fatigue damage; exoelectron emission; failure prediction; laser scanner; oxide rupture; surface deformation.

During fatigue testing of metallic components there is a gradual accumulation of "damage," leading ultimately to total failure. An early manifestation of this damage is the development of surface deformation which eventually provides sites for fatigue cracks to nucleate. However, prior to the development of a crack in the metal itself, the surface deformation produces microscopic cracks in the natural layer of surface oxide. Under ultraviolet illumination photoelectrons from the underlying metal can escape more easily through these microcracks, such emission being referred to as exoelectron emission.

Thus exoelectron emission provides a measure of the accumulation of fatigue deformation. By scanning the surface with a spot of ultraviolet radiation the distribution of emission (i.e., deformation) can be displayed, and the severity of the damage assessed from the localized intensity of the emission. After only 2 percent of life the ultimate fatigue life may be reliably predicted. This technique should be applicable to all metallic materials, but the range of variables such as stress level, yield strength, oxide thickness, etc., has yet to be completely explored.

Detecting structural degradation by acoustic emission, $M$. P. Kelly and R. J. Schlamp, SP487, pp. 2 10-238 (Aug. 1977).

Key words: acoustic emission; crack growth; drill pipe; failure; Kaiser Effect; pressure vessels; sources.

The application of acoustic emission techniques to the detection and location of structural defects in a variety of materials and geometries is presented. Results obtained during the preservice inspection of the Baltimore Gas \& Electric Company Calvert Cliffs Unit 2 Nuclear Power Plant will be discussed. Additional results obtained during proof testing of two petrochemical hydrotreaters will also be presented.

A multichannel computerized source location system was utilized to monitor petroleum drill pipe during proof loading. Several sections of new and used, corroded and sandblasted drill pipe were monitored. Initial results indicate an ability to detect, locate and identify fatigue cracks, coating cracks and corrosion during proof loading. Test results from high reliability petrochemical vessels demonstrate that incremental crack growth during pressurization can be accurately located and assessed.

Negligence charges in products liability law can be used in engineering as safety design criteria, R. R. Hagglund, SP487, pp. $241-246$ (Aug. 1977).

Key words: product liability; safety.

Society expects manufacturing companies to make products that are safe but the meaning of the word safe is not very clear. In products liability law, the legal requirement is that a product be "reasonably safe." The charges of negligence, as used in products liability suits, can be used as safety design criteria in design and manufacturing to insure that reasonable care will be exercised in producing products that are reasonably safe.

Prescription to reduce products liability losses. A. The defendant and products liability, J. P. Arness, SP487, pp. 247. 252 (Aug. 1977).

Key words: defendant and products liability; liability losses; products liability losses.

Prescription to reduce products liability losses. B. The plaintiff and products liability, M. Heller, SP487, pp. 253-256 (Aug. 1977).

Key words: liability losses; plaintiff and products liability; products liability losses.

Safety analysis: Qualitative, quantitative and cost effective, H. D. Wolf, SP487, pp. 265-277 (Aug. 1977).

Key words: accident prevention; hazard analysis; risks; safety.

No system involving man can be 100 percent safe since he is not error-free. The objective of any safety analysis effort is to identify what to "worry" about in the system and how to take steps to eliminate that "worry." With the proper attention to (1) past history of similar systems; (2) development of safety controls in all program phases; (3) reviews of program efforts; (4) aggressive accident/incident analysis, corrective action and closeout; and (5) an educational program for all project personnel from corporate managers on down, a system can approach "failure-free" conditions. The various approaches to safety analysis are described in this paper, including preliminary, system and operational hazard analyses. The advantages and limitations of the several methods are discussed. Examples are used to emphasize specific points and to enhance the reader's understanding. Some ideas on safety ieature decisionmaking are included.

A failure mode and effect analysis program to reduce mechanical failures, R. R. Landers, SP487, pp. 278-288 (Aug. 1977).

Key words: critical item list; failure mode and effect analysis; failure reduction; reliability; system safety.

Described is an interdisciplinary technique to reduce the number of mechanical failures in an ongoing torpedo program through the use of failure mode and effect analysis techniques. The paper describes the procedure and forms for completing the analysis and provides representative examples. FMEA's are performed at the component level early in the design phase to find possible ways that equipment can fail and to determine the effect of such failures on the system. The FMEA is used to assure that: all com- 
ponent failure modes and their effect have been considered and either eliminated or controlled; information for design reviews, maintainability analysis and quantitative reliability analysis is generated; data for maintenance and operational manuals are provided; and that inputs to safety and hazard analyses are available in a Critical ltem List (CIL).

Fault tree analysis as a part of mechanical systems design, J. B. Fussell and D. P. Wagner, SP487, pp. 289-308 (Aug. 1977).

Key words: availability; fault tree analysis; probabilistic analysis; reliability; systems analysis.

Fault tree analysis is a method of system reliability and safety analysis that is rapidly gaining favor as a design tool. Fault tree analysis has the potential of offering an objective basis for analyzing system design, performing trade-off studies, analyzing common cause failures, demonstrating compliance with safety requirements, and justifying system changes and additions.

In this paper emphasis is placed on the use of fault tree analysis in mechanical system design with particular concern for: (1) introductory concepts; (2) schemes for integration into the design process; (3) limitations; and (4) related application.

In addition, a review of the latest production computer programs is given.

Ion plating-Concepts and applications, D. M. Mattox, SP487, pp. 311-323 (Aug. 1977).

Key words: adhesion; coatings; films; gas discharges; sputtering.

Ion plating is a generic term applied to deposition processes in which the substrate is subjected to a flux of high-energy ions prior to and possibly during film deposition. This flux of ions cleans the substrate surface to allow intimate substrate-film interactions. Ion bombardment during deposition may be used to control the properties of the deposit and to increase the "throwing power" of the deposition technique. Recent advances in the understanding of ion plating processes and applications will be reviewed. These include sputter cleaning, reactive plasma cleaning, gasless (or vacuum) ion plating, and several new source configurations. Related deposition processes, such as activated reactive evaporation, will be discussed and specific large scale and small scale industrial applications of ion plating will be detailed.

Sputtering, T. Spalvins, SP487, pp. 324-337 (Aug. 1977).

Key words: protective coatings; sputtering; thin films.

This paper primarily reviews the potential of using the sputtering process as a deposition technique; however, the manufacturing and sputter etching aspects are also discussed. Since sputtering is not regulated by classical thermodynamics, new multicomponent materials can be developed in any possible chemical composition. The basic mechanism for dc and $\mathrm{rf}$ sputtering is described. Sputterdeposition is described in terms of the unique advantageous features it offers such as versatility, momentum transfer, stoichiometry, sputter-etching, target geometry (coating complex surfaces), precise controls, flexibility, ecology, and sputtering rates. Sputtered film characteristics, such as strong adherence and coherence and film morphology, are briefly evaluated in terms of varying the sputtering parameters. Also described are some of the specific industrial areas which are turning to sputterdeposition techniques.
SP488, Measurements and standards for recycled oil. Proceedings of a Workshop held at the National Bureau of Standards, Gaithersburg, MD, Nov. 22-23, 1976, D. A. Becker, Ed., Nat. Bur. Stand. (U.S.), Spec. Publ. 488, 140 pages (Aug. 1977) SN003-003-01831-7.

Key words: engine oil; fuel oil; hydraulic oil; industrial oils; lubricating oil; oil specifications; petroleum standards; petroleum test methods; recycled oil; re-refined oil; used oil; waste oil.

This publication is the formal report of the workshop on measurements and Standards for Recycled Oil, held at the National Bureau of Standards on November 22 and 23, 1976. There were seven sessions on specific subject areas at the meeting, with a total of 26 formal presentations, plus extensive discussion periods. The subject areas were as follows: (1) The NBS Responsibilities and Program, (II) Used Oil Reused as Fuel, (III) Recycled Industrial and Hydraulic Oils, (IV and V) Recycled Engine Oils, (VI) Barriers to the Utilization of Recycled Oils, and (VII) Problems and Needs in Establishing Quality for Recycled Oil Products. Included in this volume are the invited talks that were given and summaries of the extended discussions that were held on each of these subject areas. These proceedings include the following papers (indented):

The NBS workshop objectives and the NBS recycled oil program, D. A. Becker, SP488, pp. 7-11 (Aug. 1977).

Burning used oil at a military installation, C. F. Schwarz, SP488, pp. 17-18 (Aug. 1977).

Fuel oil and the Defense Supply Agency, E. J. French, SP488, p. 19 (Aug. 1977).

Fuel oil specifications, B. L. Weller, SP488, pp. 21-26 (Aug. 1977).

Automotive crankcase drainings used for fuel, B. R. Williams, SP488, pp. 27-31 (Aug. 1977).

ASTM test methods for industrial oils, L. B. Sargent, Jr., SP488, pp. 37-38 (Aug. 1977).

Industrial oil recycling at Chrysler, W. Katzenstein, SP488, pp. 39-40 (Aug. 1977).

Industrial oils: Descriptions, additives, and test methods, J. W. Swain, Jr., SP488, pp. 41-43 (Aug. 1977).

The use of recycled industrial and hydraulic oils at Ford, J. W. Hunt, SP488, pp. 45-46 (Aug. 1977).

Industrial lubricants, reclaimed oils, and test methods, C. J. Flake, SP488, pp. 47-49 (Aug. 1977).

DOD experiences in testing lube oils, T. C. Bowen, SP488, pp. 55-56 (Aug. 1977).

Waste oil recycling-An idea whose time has come, C. J. Thompson and M. L. Whisman, SP488, pp. 57-60 (Aug. 1977).

Comments on additive response to different base oils, T. P. Sands, SP488, pp. 61-62 (Aug. 1977).

Activities of the ASTM used oil task force, W. W. Crouse, Jr., SP488, p. 63 (Aug. 1977).

Activities of the API used oil task force, B. W. Hutchings, SP488, pp. 65-67 (Aug. 1977).

Chevron research's experiences with re-refined oils, F. Sam, SP488, pp. 69-71 (Aug. 1977). 
Engine sequence tests for determination of lube oil quality, R. H. Kabel, SP488, pp. 73-75 (Aug. 1977).

Screening tests on lube oils, P. A. Asseff, SP488, pp. 77 78 (Aug. 1977).

Laboratory testing on re-refined motor oil, B. R. Williams, SP488, pp. $79-87$ (Aug. 1977).

Diesel lube oil test methods, J. A. MacLean, SP488, pp. 89-94 (Aug. 1977).

Recent used oil legislation, H. B. Kaufman, SP488, pp. 101102 (Aug. 1977).

The Iead problem associated with recycled oil, J. S. Cooper, SP488, pp. 103-104 (Aug. 1977).

Factors affecting used oil recovery/utilization and effects of proposed policy alternatives, S. P. Maltezou, SP488, pp. 105 107 (Aug. 1977).

Energy conservation aspects of re-refined oil, G. J. Mascetti, SP488, pp. 109-113 (Aug. 1977).

Marketing barriers for recycled oil, P. M. Cukor, SP488, pp. 115-121 (Aug. 1977).

SP489. Abstracted reports and articles of the HUD Modular Integrated Utility Systems (MIUS) Program, J. D. Ryan and B. Reznek, Eds., Nat. Bur. Stand. (U.S.), Spec. Publ. 489, 153 pages (Aug. 1977) SN003-003-01830-9.

Key words: abstracted reports and articles; HUD Modular Integrated Utility Systems (MIUS) Program; total energy; utility systems.

This document provides a complete listing of reports and articles relating to the HUD-MIUS Program. Reports from 1970 through August 1976 are included. The entry for each report contains an abstract and other pertinent information, including procurement sources and procedures. Reports are presented by 4 general subject categories; Program and Concept Description, Systems Analysis, Technology Evaluation, and Hardware Evaluation and Demonstration. The reports are further classified into 3 publication/availability categories: government publications (Published Reports), nongovernment publications and articles (Outside Publications) and unpublished reports and data (Open-File Reports).

SP490. Observations on the behavior of buildings in the Romania earthquake of March 4, 1977, G. Fattal, E. Simiu, and C. Culver, Nat. Bur. Stand. (U.S.), Spec. Publ. 490, 168 pages (Sept. 1977) SNO03-003-01841-4, \$3.00.

Key words: buildings; building codes; earthquakes; natural disasters; structural enginee ring.

Observations are presented of the damage to buildings resulting from the earthquake of March 4, 1977 in Romania. The report was prepared by engineers from the National Bureau of Standards who participated as members of the U.S. government team dispatched to Romania under the auspices of the Office of Foreign Disaster Assistance, Agency for International Development. A summary of the team's activities is included. Background data on the seismic history of Romania, the characteristics of the earthquake and descriptions of damage to specific buildings are also included. The types of building construction and the history of the development of seismic design requirements for buildings in Romania are discussed. Recommendations are presented for needed building research based on the observations.
SP491. Thermal analysis-Human comfort-Indoor environments. Proceedings of a Symposium held at the National Bureau of Standards, Gaithersburg, MD, Feb. 11, 1977, B. W. Mangum and J. E. Hill, Eas., Nat. Bur. Stand. (U.S.), Spec. Publ. 491, 197 pages (Sept. 1977) SN003-003-01849-0.

Key words: energy conservation in buildings; heat stress; human comfort; indoor environment; mean radiant temperature; thermal comfort.

These are the proceedings of a symposium sponsored by the National Bureau of Standards and held in Gaithersburg, Maryland on February 11, 1977. The symposium was held for the purpose of exploring new aspects of indoor thermal environments, caused primarily by the impact of energy conservation in new and existing buildings. Included in these proceedings are eleven formal papers which were presented by leading researchers in the field of thermal comfort and heat stress. The contributed papers were from Denmark, Sweden, and several research institutions within the United States including the John B. Pierce Foundation at Yale University, Kansas State University, and Pennsylvania State University. Information was presented on a variety of approaches to determining human response to thermal environments. These included laboratory studies in environmental chambers utilizing instrumented human subjects, field studies involving surveys and questionnaires, mathematical modeling of humans, an analysis of some types of instruments used in assessing the quality of the environments, and a discussion of the relationships between productivity and the thermal environment. These proceedings include the following papers (indented):

Thermal comfort in indoor environments, P. O. Fanger, SP491, pp. 3-17 (Sept. 1977).

Key words: human comfort; indoor climate; indoor environment; thermal comfort; thermal environment; thermal neutrality.

A review is given of existing knowledge regarding the conditions for thermal comfort for man, emphasizing research data obtained during recent years.

Equations, indices, and diagrams predicting man's thermal sensation, comfort, and discomfort as a function of air temperature, mean radiant temperature, air velocity, humidity, clothing, and activity are discussed. The influence on comfort conditions of age, adaptation, sex, seasonal, and circadian rhythm, temperature swings, color, and noise are dealt with. The term "climate monotony" is considered.

Local discomfort due to radiant asymmetry, vertical air temperature gradients, and nonuniformity of clothing are discussed.

New preliminary research data are presented on limits for draft and on comfort limits for floor temperatures.

Future research needs are identified.

The use of modeling human responses in the analysis of thermal comfort of indoor environments, N. Z. Azer and S. Hsu, SP491, pp. 18-40 (Sept. 1977).

Key words: core temperature; energy conservation; modeling; OSHA Standards; thermal sensation; WBGT.

Modeling the thermoregulatory system is used in evaluating the threshold WBGT Values of OSHA Heat Stress Standards. It is shown that physiological reactions above or within the tolerance limits can be experienced during exposure to environments having the same threshold WBGT Values, particularly at heavy work loads. Also, the use of modeling human subjective reactions in planning energy conservation strategies in buildings is also discussed 
Industrial heat stress monitoring, F. N. Dukes-Dobos, SP491, pp. 41-51 (Sept. 1977).

Key words: environmental monitoring; heat stress control; heat stress indices; heat stress monitoring; industrial heat stress; metabolic heat load.

When assessing the heat load which is imposed on a worker by his job, the method of choice will depend on the purpose for which this information is needed. If the question is whether the heat load exceeds the threshold limit value (TLV) adopted by the American Conference of Governmental Industrial Hygienists (ACGIH) or whether the job is in compliance with the standards recommended by NIOSH or by the OSHA Standards Advisory Committee, the method to be used is the WBGT index. There are some important differences, however, between the monitoring requirements in the three documents which will be discussed in detail.

Since work metabolism is fairly constant for a given job, once it has been reliably established, no further monitoring is required. However, since environmental conditions of the job-site vary with changing outdoor temperatures, environmental monitoring has to be either continuous or at least measurements have to be repeated in certain intervals. To eliminate the need for either continuous or repetitive monitoring, $\mathrm{N} 1 \mathrm{OSH}$ initiated studies for the development of mathematical models to predict job-site WBGT values from outdoor temperatures. Such a model is of particular value when jobs have to be rated according to the heat load they impose on the worker throughout a year. This information is necessary for studying the long range health effects of work in hot environments.

If the question is how to reduce the heat load most efficiently or if human responses to heat stress are analyzed, monitoring has to be performed by one of the physical heat stress indices. Several investigators recommended that industrial heat exposure limits shall also be expressed in terms of physical indices. However, this cannot be done until the permissible exposure limits expressed in units of these indices are validated for all combinations of environmental factors, clothing, metabolic rates and then displayed in a simple graph, such as the present TLV. The limits must also be validated to be safe for the worker population, as it was done with the WBGT index.

Establishment of the boundaries to comfort by analyzing discomfort, R. F. Goldman, SP491, pp. 52-64 (Sept. 1977).

Key words: clothing effects; comfort; heat storage; work effects.

The simple word "comfort" confounds a variety of social, psychological and physiological perceptions. Even if one delimits the comfort area to the physiological correlates of human thermal comfort, there are still a number of facets which must be addressed. Physiologically, thermal comfort is an integrated system state, with primary inputs from the mean weighted skin temperature $\left(\overrightarrow{\mathrm{T}}_{\boldsymbol{s}}\right)$, the percent skin wettedness and the temperature of the extremities (particularly $\mathrm{T}_{\text {loe }}$ and $\mathrm{T}_{\text {finger }}$ ) and secondary inputs from alterations of deep body temperature $\left(T_{r e}\right)$ and heart rate (H.R.). These secondary inputs result from the body attempting to compensate for the strain imposed changes in the resting level of body heat content $(\Delta S)$ by the environment and work load. As one might expect, comfort exists across a range of these various parameters, rather than at any single, unique, state point. It is easier to delineate the boundary between comfort and discomfort, or between comfort and performance decrement, than it is to delineate comfort per se. A table provides some representative values for comfort, discomfort and performance decrement levels, and adds the confounding factor that the comfort zone can be dramatically altered by clothing insulation (clo).

Heat stress, work function and physiological heat exposure limits in man, A. R. Dasler, SP491, pp. 65-92 (Sept. 1977).

Key words: exposure limits; heat stress; thermal analysis.

Various operational trials using tolerance criteria available in the literature revealed that predictions of physiological exposure limits were rarely compatible with the observed status of men in a wide range of heat stress and work conditions. Computer integration of laboratory and industrial-type data led to establishing a comprehensive set of physiological criteria for tolerance limits appropriate to man at work within time-weighted-mean $\left(\mathrm{t}_{\mathrm{x} m}\right)$ metabolic rates from $76-126 \mathrm{kcal} /\left(\mathrm{m}^{2} \cdot \mathrm{hr}\right)$ [88.4-146.5 $\left.\mathrm{W} \cdot \mathrm{m}^{-2}\right]$. These criteria and work rates were integrated with industrial-type heat stress conditions over the $t_{u^{\prime} m}$ WBGT Index range of $82-130{ }^{\circ} \mathrm{F}$ [27.8-54.4 $\left.{ }^{\circ} \mathrm{C}\right]$; which resulted in developing the Physiological Heat Exposure Limits (PHEL) concept. Several electronic heat stress monitordevices were evaluated and employed in determining environmental conditions. In all laboratory and field studies the dry- and wet-bulb and globe temperatures were recorded. Physiological data were obtained at the same time as the environmental data. Although the physiological data obtained in the laboratory were much more broad in scope than in the field settings, the field approach included physical characteristics of the subjects, body temperatures (skin and rectal), cardiovascular (heart rates and blood pressures) and metabolic-respiratory $\left(\mathrm{O}_{2}\right.$ consumption, respiratory minute volume and respiration rates) data during rest and performance of dynamic work; sweat rates were determined by body weight changes when feasible in the nonlaboratory trials. Coefficients for physiological factors in the heat stress and strain equations were automatically adjusted for physiological changes determined in the actual situations. Comparison of over 200 sets of environmental and physiological data supported the PHEL concept and permitted more definitive identification of material areas requiring corrective engineering actions in the industrial-type settings. Corrective engineering actions based upon results of the data analyses have permitted nearly a sixfold increase of the maximum physiological exposure times; simultaneously, the estimated cardiovascular reserve increased from 15 percent to as much as 85 percent during routine work.

Effect of energy conservation guidelines on comfort, acceptability and health, A. P. Gagge and R. G. Nevins, SP491, pp. 93-116 (Sept. 1977).

Key words: clothing insulation; effective temperature (ET*); energy conservation; summer temperature guidelines; thermal acceptability; thermal preference survey; winter temperature.

Both the Winter and Summer Surveys in a New York government building validate the recommendations of ASHRAE STANDARD 55-74 that the optimum acceptable thermal environment, in which at least 80 percent of normally clothed men and women living in the United States and Canada would express thermal comfort, lies in the range $72-78^{\circ}\left({ }^{\circ} \mathrm{F}\right) \mathrm{ET}^{*}\left(22.2-25.6^{\circ} \mathrm{C}\right)$. The ASHRAE ET* is the dry bulb temperature of a uniform thermal environment at 50 percent $\mathrm{r}$ with air movement in range 20-25 fpm (0.1-0.125 m/s) for sedentary man (1.-1.2 mets) while wearing an intrinsic thermal insulation of 0.6 Clo. 
The FEA Summer Conservation Temperature limits of 78-80 ${ }^{\circ} \mathrm{F}$ (25.6-26.7 ${ }^{\circ} \mathrm{C}$ ) can be made 80 percent acceptable ( 1 ) by use of light clothing with insulation less than 0.4 $\mathrm{Clo}$, (2) by increasing the air movement above $50 \mathrm{fpm},(3)$ by reducing the relative humidity, or (4) by all. These FEA Guidelines, which require the elimination of thermostats and reheat processes, make (1) and (2) the more desirable approaches to 80 percent acceptability. In summer time heat, men tend to wear 50 percent more clothing (insulation) than women, while at work. In summer the practical minimum level of clothing insulation for men appears to be 0.4-0.5 Clo while for women, 0.2-0.3 Clo.

For the $68-70{ }^{\circ} \mathrm{F}\left(20-21.1{ }^{\circ} \mathrm{C}\right)$ FEA Conservation Guideline temperatures for winter, the 80 percent acceptability is possible for pcrsons wearing 0.9-1.2 Clo insulation, provided proper care is made to cover legs with socks and trousers or wear dresses with stockings and with shoes without open toes.

Except for the seriously ill and those in hospitals, there appears to be no serious health hazard for properly clothed individuals due to exposure to the FEA Winter and Summmer Guideline Temperatures.

For simple sedentary tasks, no decrements in performance can be expected for the FEA Guideline temperatures-winter or summer-as long as the applicable ASHRAE ET* falls within the 80 percent acceptability range defined by our Comfort Charts in terms of $\mathrm{T}_{n}$, Clo, air movement and relative humidity. A loss of dexterity may occur when air temperature falls below $65^{\circ} \mathrm{F}(18.3$ ${ }^{\circ} \mathrm{C}$ ). Decrements in the performance of simple manual and mental tasks may occur when the ASHRAE ET* rises above $90^{\circ} \mathrm{F}\left(32.2{ }^{\circ} \mathrm{C}\right)$.

Comfort Charts are presented to show how various clothing insulations can be used to convert any combination of dry bulb temperature, relative humidity, air movement to an equivalent ASHRAE Effective Temperature ET*. From these charts the reader can recognize for himself additional strategies possible to meet the $72-78{ }^{\circ} \mathrm{F}$ (22.2-25.6 $\left.{ }^{\circ} \mathrm{C}\right) \mathrm{ET}^{*}$ necessary for 80 percent acceptability.

Radiation measurement for thermal comfort assessment in the built environment, L. G. Berglund, SP491, pp. 117-130 (Sept. 1977).

Key words: directional radiant temperature; mean radiant temperature; radiation measurement; radiometer; thermal comfort; thermal radiation.

The major properties of the environment that affect thermal comfort include: air temperature, humidity, air velocity, and thermal radiation. The first two can be readily and accurately measured. Field instrumentation for measuring air velocity has greatly improved in recent years. The fourth quantity, thermal radiation, is still elusive to the HVAC engineers and has often been overlooked or neglected because of the difficulty in measuring it accurately. Thermal radiation as a factor in attaining comfort has traditionally been expressed in terms of the "Mean Radiant Temperature" of the environment. Various instruments have evolved to measure mean radiant temperature. Some are passive and elementary like the Vernon Black Globe while others are active and complex like the Panradiometer, for example. The present paper summarizes the operating principles and the technique of application of the various types of instruments developed in the past, and compares their advantages and disadvantages as to inherent accuracy, ease of operation, simplicity of design, and speed of response. Reviewed are those instruments applicable to the needs of environmental scientists and HVAC engineers for thermal radiation measurement in the built environment. Some development needs and design suggestions are also presented.

Experimental analysis of thermal acceptability, R. R. Gonzalez, SP491, pp. 131-151 (Sept. 1977).

Key words: clothing; cold discomfort; energy conservation; humidity; temperature; thermal acceptability.

This paper reviews recent laboratory studies and research needs in human physiology that will be important in specifying thermal acceptability; it compares these results with guidelines proposed by the Federal Energy Administration for summer and winter months. Male and female subjects, in both younger and older age groups, were exposed while sedentary or slightly active, to fluctuating dry bulb temperature (at $50 \% \mathrm{RH}$ ) and to constant dry bulb temperatures (at $40,60,80 \% \mathrm{RH}$ ) in summer experiments. In winter experiments, subjects were exposed to 20 ${ }^{\circ} \mathrm{C}$ and colder environments and were allowed the use of extra outer clothing to avoid cold discomfort. Clothing insulation was directly evaluated. In both studies judgments of whole body thermal discomfort and thermal sensation were made; in addition, in winter studies direct votes of acceptability, as well as regional thermal sensation (face, trunk and extremities) were taken. A method of estimating preferred comfort and neutral thermal sensation temperatures is described for fluctuating air temperature conditions.

The results of summer studies indicate that 60 percent RH ( 16 torr) at $26.7^{\circ} \mathrm{C}$ is the maximum limit for thermal acceptability which corresponds to a $28 \mathrm{ET}^{*}$ or $2{ }^{\circ} \mathrm{C} \mathrm{ET*}$ above the optimal ASHRAE neutral/comfort zone. The results of the winter experiments showed that the FEA winter temperature guideline lower limit $\left(20^{\circ} \mathrm{C}\right)$ proved 80 percent acceptable. Specific groups of individuals have been identified for whom winter and summer guidelines will not be wholly acceptable.

Rating of environments for human thermal comfort by "Resultant Surface Temperature", T. H. Benzinger, SP491, pp. 152-168 (Sept. 1977).

Key words: indoor environmental measurement; rating of indoor environments; thermal comfort.

A concept is introduced for rating thermal environments on their potential for human comfort. It involves the measurement of the surface temperature (designated Resultant Surface Temperature) of an object placed in a building environment and producing heat per unit surface area at a rate equal to that of a human body. A detailed description is given of a prototype RST-Meter that has been built. The intended applications for the instrument and how it could be used for rating environments is described.

Aspects of indoor environments: Tolerable vs comfortable thermal environments, E. R. Buskirk and J. L. Loomis, SP491, pp. 169-173 (Sept. 1977).

Key words: environmental control; temperature and performance; temperature control; thermal comfort; thermal sensation; thermal tolerance; work conditions.

Thermal comfort depends on a variety of factors including the level of physical activity, clothing worn and how the occupied space is heated, cooled or ventilated. Sufficient attention has not been paid to the importance of physical activity or the types of jobs workers need to perform in a given environment. Their metabolic heat production and modes of heat loss are important modifiable components in the energy balance equation. Both relatively cool and warm environments can be tolerated by the physi- 
cally active worker. Similarly, modification of clothing ensembles can extend the tolerable range depending on the type of task performed. Comfort and tolerable conditions can be quite different, but when energy must be conserved maintenance of tolerable conditions will, of necessity, take precedence over "comfort." The limits of tolerable conditions for various tasks remain ill-defined and largely a happening of the work place. Use of tolerable conditions may provide thermal stress and result in physiological and psychological strain. Thus, research is needed to provide guidance regarding tolerable conditions and their periodicity, physical activity, clothing worn, work-rest cycles and productivity. The cumulative effects of prolonged thermal stress and the resultant strain need to be assessed.

Assessing productivity decrements in heat and cold: On-site simulation of industrial work in a mobile climate chamber, $D$. P. Wyon, SP491, pp. 174-189 (Sept. 1977).

Key words: energy conservation research; heat and cold stress; mobile climate chamber.

This paper describes the establishment in Africa of a major research project whose aim is to quantify the effects on productivity of heat and cold stress in factory buildings. The intention is to provide design criteria for the intermediate levels of thermal stress-beyond comfort but not involving any risk to health-which are likely to occur in the industrialization of developing countries with warm climates and limited resources. The background to the project is given, and relevant published work is summarized. On-site simulation of industrial work in a mobile climate chamber was chosen in preference to conventional field or laboratory studies. The development and construction of the mobile climate laboratory, including the performance testing equipment, is described. The currently proceeding research program is given. It is suggested that the rationale and methods of this project are appropriate for energy conservation research elsewhere.

SP492. Procedures used at the National Bureau of Standards to determine selected trace elements in biological and botanical materials, R. Mavrodineanu, Ed., Nat. Bur. Stand. (U.S.), Spec. Publ. 492, 295 pages (Nov. 1977) SN003-003-018589.

Key words: analytical disciplines; analytical procedures; atomic absorption spectrometry; biological materials; blanks; botanical materials; chemical species; flame emission spectrometry; fluorescence spectrometry; molecular absorption spectrometry; neutron activation analysis; polarography; pure reagents; sample preparation; spark source mass spectrometric isotope dilution; tissues.

This volume consists of thirteen papers describing the analytical procedures selected at the National Bureau of Standards (NBS) for the determination of $\mathrm{Ag}, \mathrm{Al}, \mathrm{As}, \mathrm{Be}, \mathrm{Bi}, \mathrm{Ca}$, $\mathrm{Cd}, \mathrm{Cr}, \mathrm{Cu}, \mathrm{Fe}, \mathrm{Hg}, \mathrm{K}, \mathrm{Mg}, \mathrm{Mn}, \mathrm{Mo}, \mathrm{Na}, \mathrm{Ni}, \mathrm{Pb}, \mathrm{Pt}, \mathrm{Sb}, \mathrm{Se}$, $\mathrm{Te}, \mathrm{T}, \mathrm{V}$, and $\mathrm{Zn}$ in biological and botanical materials. These procedures are used at the present time for the certification of various substances issued by NBS as Standard Reference Materials, and belong to the following analytical disciplines: sample preparation, neutron activation analysis, spark source mass spectrometric isotope dilution, atomic absorption and flame emission spectrometry, molecular absorption spectrometry, fluorescence spectrometry, and polarography. Further details on the analytical methods including sample preparation, purity of reagents, and problems associated with blanks are given in sixteen additional papers which are reproduced in the Appendix to this volume. These proceedings include the following papers (indented):
Sample preparation, T. J. Murphy, SP492, pp. 5-8 (Nov. 1977).

Determination of arsenic, antimony and copper in biological and botanical materials using neutron activation analysis, $T$. E. Gills, SP492, pp. 9-12 (Nov. 1977).

Determination of platinum in biological and botanical materials using neutron activation analysis, D. A. Becker and T. E. Gills, SP492, pp. 12-14 (Nov. 1977).

Determination of vanadium and manganese in biological and botanical materials by neutron activation analysis, $\mathrm{S}$. $\mathrm{H}$. Harrison, SP492, pp. 15-19 (Nov. 1977).

Radiochemical separation for the determination of mercury and selenium in biological and botanical materials using neutron activation analysis, H. L. Rook, T. E. Gills, and G. J. Lutz, SP492, pp. 20-22 (Nov. 1977).

Determination of chromium in biological and botanical materials using neutron activation analysis, L. T. McClendon, SP492, pp. 23-26 (Nov. 1977).

Rapid, quantitative separation for the determination of selenium using neutron activation analysis, $H$. L. Rook, SP492, pp. 26-32 (Nov. 1977).

Determination of cadmium, copper, iron, lead, mercury, molybdenum, nickel, selenium, silver, tellurium, thallium, and zinc, P. J. Paulsen, SP492, pp. 33-48 (Nov. 1977).

Determination of beryllium, cadmium, copper, magnesium, manganese, mercury, nickel, and zinc by atomic absorption, and of calcium, potassium, rubidium, and sodium by flame emission spectrometry, in biological and botanical materials, T. C. Rains, SP492, pp. 49-65 (Nov. 1977).

Determination of calcium, potassium, and sodium in flour by emission flame spectrometry, J. R. Baldwin and R. Mavrodineanu, SP492, pp. 66-71 (Nov. 1977).

Procedures for the determination of arsenic, copper, and nickel by molecular absorption spectrometry, R. W. Burke and B. 1. Diamondstone, SP492, pp. 73-84 (Nov. 1977).

Determination of beryllium by fluorescence spectrometry, $\mathrm{S}$. A. Wicks and R. W. Burke, SP492, pp. 85-89 (Nov. 1977).

Analysis of botanical standard reference materials by cathode ray polarography, E. J. Maienthal, SP492, pp. 91105 (Nov. 1977).

SP493. Neutron standards and applications. Proceedings of the International Specialists Symposium on Neutron Standards and Applications held at the National Bureau of Standards, Gaithersburg, MD, Mar. 28-31, 1977, C. D. Bowman, A. D. Carlson, H. O. Liskien, and L. Stewart, Eds., Nat. Bur. Stand. (U.S.), Spec. Publ. 493, 379 pages (Oct. 1977) SN003-00301847-3.

Key words: cross section standards; dosimetry; fission; flux; measuring techniques; neutrons; standards.

These proceedings contain forty-seven papers, which were presented at the International Specialists Symposium on Neutron Standards and Applications held at the National Bureau of Standards on March 28-31, 1977. The topics addressed at the Symposium include light-element cross section standards, capture and fission cross section standards, integral neutron standards, flux measuring techniques, and medical and personnel dosimetry. These proceedings include the following papers (indented): 
Survey of recent experiments for the ${ }^{7} \mathbf{L i}$-system, $H . H$. Knitter, SP493, pp. 3-9 (Oct. 1977).

Kcy words: measurements review; polarization; ${ }^{3} \mathrm{H}\left(\alpha,{ }^{6} \mathrm{Li}\right) \mathrm{n}$, ${ }^{4} \mathrm{He}(\mathrm{t}, \mathrm{t}){ }^{4} \mathrm{Hc}$; ${ }^{6} \mathrm{Li}$ neutron cross sections; ${ }^{7} \mathrm{Li}$ system.

Recent experiments on reactions relevant to the ${ }^{7} \mathrm{Li}$ system are described. It concerns the reactions ${ }^{6} \mathrm{Li}(n, t)^{4} \mathrm{He}$, ${ }^{6} \mathrm{Li}(\mathrm{n}, \mathrm{n})^{6} \mathrm{Li},{ }^{4} \mathrm{He}(\mathrm{t}, \mathrm{n}){ }^{6} \mathrm{Li}$ and ${ }^{4} \mathrm{He}(\mathrm{t}, \mathrm{t})^{4} \mathrm{He}$, for which differential cross sections $\sigma_{i}(E, \Theta)$, angle integrated cross sections $\sigma_{i}(E)$ and neutron total cross sections $\sigma_{T}(E)$ were measured. Also polarization experiments yielding the analyzing power $A_{i}(E, \theta)$ are described.

Angular anisotropy in the ${ }^{6} \mathrm{Li}(\mathrm{n}, \alpha)^{3} \mathrm{H}$ reaction below 100 keV, J. A. Harvey and I. G. Schrödcr, SP493, pp. 10-13 (Oct. 1977).

Key words: angular distribution; fast neutrons; linac; reactor filtered beam; standard; ${ }^{6} \mathrm{Li}(\mathrm{n}, \boldsymbol{\alpha}) \mathrm{T}$.

The data on the differential $(n, \alpha)$ cross section of ${ }^{6} \mathrm{Li}$ has been reviewcd bclow a neutron energy of $100 \mathrm{keV}$. Measurements in this region, compared to that above 100 $\mathrm{keV}$, have been few. Only recently has interest increased as large and unsuspected anisotropies have been observed in this energy region. Thus, at $25 \mathrm{keV}$ an anisotropy amounting to 67 percent in the forward-to-backward direction has been observed; while in the region between $1 \mathrm{eV}$ and $10 \mathrm{keV}$ measurements indicate that in the forward-to-backward $66^{\circ}$ cone the asymmetry has an energy dependence, in the laboratory system, which can be expressed analytically as $1+0.0055 \vee \mathbb{E}_{n}(\mathrm{eV})$. These angular anisotropies seem to arise from interference between the large p-wave resonance at $247 \mathrm{keV}$ and many s-wave resonances which account for the large $1 / v(n, \alpha)$ thermal cross section. New and detailed measurements of the differential $(n, \alpha)$ cross section are nceded not only to be able to account analytically for these interference effects but also because it is necessary to consider these anisotropies when the ${ }^{6} \mathrm{Li}(\mathrm{n}, \alpha)^{3} \mathrm{H}$ cross section is used as a standard.

Experimental data base for the Li-7 system, H. Derrien and L. Edvardson, SP493, pp. 14-29 (Oct. 1977).

Key words: elastic scattering; neutrons; review of measurements; ${ }^{6} \mathrm{Li}(\mathrm{n}, \boldsymbol{\alpha}) ;{ }^{6} \mathrm{Li}$ total; ${ }^{7} \mathrm{Li}$ system.

A review of the experimental data available for the Li7 system is given, including reactions induced by neutrons and those induced by $\mathrm{He}-4$ on $\mathrm{H}-3$ or by $\mathrm{H}-3$ on He-4. For reactions induced by neutrons only, the energy range up to about $5 \mathrm{MeV}$ has been considered. Some recommendations are given concerning possible future measurements and the validity of the recent evaluations for the $\mathrm{Li}-6(\mathrm{n}, \alpha)$ cross section.

R-matrix analysis of the ${ }^{7} \mathrm{Li}$ system, G. M. Hale, SP493, pp. 30-36 (Oct. 1977).

Key words: resonance parameters; R-matrix; standard; ${ }^{6} \mathrm{Li}(\mathrm{n}, \mathrm{t}) ;{ }^{7} \mathrm{Li}$ system.

We describe a multichannel, multilevel, R-matrix analysis of reactions in the ${ }^{7} \mathrm{Li}$ system which was used to provide the ENDF/B-V neutron cross sections for ${ }^{6} \mathrm{Li}$ at low energies. Resonance parameters obtained from the R-matrix levels are presented. Various features of the data are interpreted in terms of these resonances.

Special problems with ${ }^{6} \mathbf{L i}$ glasses, G. P. Lamaze, SP493, pp. 37-42 (Oct. 1977).

Key words: glass scintillators; Monte Carlo; multiple scattering; neutron detection; photomultipliers; ${ }^{6} \mathrm{Li}(\mathrm{n}, \boldsymbol{\alpha}) \mathrm{T}$.
Properties of Ce activatcd $\mathrm{Li}$ loaded glass scintillators are discussed as well as their applications as neutron dctectors. Three special prohlems that may arise in their use for neutron detection are nonuniformity of the ${ }^{6} \mathrm{Li}$ content, multiple scattering, and after pulsing of the photomultiplier. These problems and thcir consequences are discussed as well as some possible solutions.

Instruments for use of ${ }^{6} \mathbf{L i}$ as a standard, L. W. Weston, SP493, Pp. 43-46 (Oct. 1977).

Key words: external particle detectors; gaseous ionization detectors; instruments; scintillation detcctors; ${ }^{6} \mathrm{Li}(n, \alpha){ }^{3} \mathrm{H}$.

A review is given of the instruments which use the ' $\mathrm{L}(\mathrm{n}, \boldsymbol{\alpha}) \mathrm{B}^{\mathrm{T}} \mathrm{H}$ reaction as a standard in the measurement of neutron flux. These instruments consist of scintillation detectors, gaseous ionization detectors, and external particle detectors. The Li glass scintillator is the most versatile because of minimized effects of the angular distribution of the reaction products and simplicity. The gaseous ionization detector has lower gamma-ray sensitivity than does the scintillation detector. Surface-barrier diodes may be used to detect the reaction products when a neutron spectromcter is desired. A choice of instruments to use this reaction must consider gamma-ray sensitivity, effects of the angular distribution of the reaction, and the range of the triton in the detector.

Experiments and theory for differential n-p scattering, C. A. Uttley, SP493, pp. 47-53 (Oct. 1977).

Key words: calculated $\sigma(\theta)$; experimental $\sigma(\theta)$; model predictions; nuclear reactions np scattering $E \leqslant 30 \mathrm{MeV}$; phase shift analyses.

The present status of the n-p differential scattering cross section is presented over the energy range bclow $30 \mathrm{MeV}$. This energy range covers the application of this cross section for the flux or relative flux spectrum measurements which are used to produce differential cross section data for fission and fusion reactor systems. Recent neutronproton scattering experiments between 20 and $30 \mathrm{MeV}$ have improved the isospin-zero phase shifts, particularly $\delta\left({ }^{1} P_{1}\right)$, which largely determine the anisotropy and the asymmetry about $\pi / 2$ in neutron-proton scattering below $20 \mathrm{MeV}$.

Use of the $n, p$ scattering reaction for neutron flux measurements, J. B. Czirr, SP493, pp. 54-60 (Oct. 1977).

Key words: detectors; flux; neutrons; proton-recoil; scattering; standards.

Several contemporary proton-recoil detectors are described and compared. These detectors have been used for neutron-spectrum measurements over various portions of the 10-keV-to-20-MeV energy range. Several factors which limit the accuracy of the results are compared quantitatively. General suggestions are given for setting and using standard cross sections and for future developments using the $n, p$ scattering reaction.

Surface harrier spectrometers for calibration of fast neutrons in $\mathrm{MeV}$ range, O. P. Joneja, R. V. Srikantaiah, M. R. Phiske, J. S. Coachman, and M. P. Navalkar, SP493, pp. 61-66 (Oct. 1977).

Key words: energy and flux calibration; fast neutrons; isotropic neutrons; $\mathrm{Li}^{6}$ sandwich surface barrier spectrometer; proton recoil surface barrier spectrometer.

At present there are very few methods available for calibrating fast neutrons in the $\mathrm{MeV}$ range. In the present 
paper methods employing $\mathrm{Li}^{6}$ sandwich and proton recoil spectrometers using surface barrier detectors for calibration of neutron energies and fluxes have been described. The results obtained with mono-energetic neutron sources in the energy range of $1-4 \mathrm{MeV}$ are given. The accuracies for energy and flux calibrations are also discussed.

Review of ${ }^{10} \mathrm{~B}(\mathrm{n}, \alpha)^{7} \mathrm{Li}$ cross-section measurements in the energy range from $10 \mathrm{keV}$ to $1 \mathrm{MeV}, E$. Wattecamps, $S P 493$, pp. 67-84 (Oct. 1977).

Key words: alpha; boron; branching ratio; compilation; cross-section; elastic; lithium; measurements; neutron; total.

Cross-section data of the ${ }^{10} \mathrm{~B}(\mathrm{n}, \alpha){ }^{2} \mathrm{Li}$ and of the ${ }^{10} \mathrm{~B}\left(\mathrm{n}, \alpha_{1}\right)$ $\tau_{\mathrm{Li}}$ reaction are compiled together with related cross-section data such as $\sigma\left(\mathrm{n}, \alpha_{0}\right), \sigma_{t o t}, \sigma_{n, t}$, branching ratio and the ratio of $\sigma(n, \alpha)$ of ${ }^{6} \mathrm{Li}$ to ${ }^{10} \mathrm{~B}$. For each type of crosssection a characterisation of the measurements and some comments are listed in a table. The data are illustrated in plots together with ENDF/B-IV data. Measurements of different origin are compared, agreement or disagreement is discussed. Qualitative statements on accuracies that recommendable sets might achieve are made, and motivation for some new measurements is argued.

Instruments for use of ${ }^{10} \mathrm{~B}$ as a standard, $\mathrm{A}$. D. Carlson, SP493, pp. 85-92 (Oct. 1977).

Key words: boron scintillators; $\mathrm{Ge}(\mathrm{Li})$; ionization chambers; Nal; neutron flux determination; proportional counters; solid-state detectors; standard cross section; ${ }^{10} \mathrm{~B}\left(\mathrm{n}, \alpha_{0}+\alpha_{1} \gamma\right)^{7} \mathrm{Li} ;{ }^{10} \mathrm{~B}\left(\mathrm{n}, \alpha_{1} \gamma\right)^{7} \mathrm{Li}$.

The interaction of neutrons with ${ }^{10} \mathrm{~B}$ provides two commonly used neutron cross section standards. The ${ }^{10} \mathrm{~B}\left(\mathrm{n}, \alpha_{1} \gamma\right)$ $\mathrm{Li}$ reaction is implemented with detectors such as $\mathrm{NaI}$ or $\mathrm{Ge}(\mathrm{Li})$ to detect the $478-\mathrm{keV}$ gamma ray emitted in this reaction. The ${ }^{10} \mathrm{~B}\left(\mathrm{n}, \alpha_{0}+\alpha_{1} \gamma\right)^{7} \mathrm{Li}$ (commonly referred to as $\left.{ }^{10} \mathrm{~B}(\mathrm{n}, a)^{\top} \mathrm{Li}\right)$ reaction is used with proportional counters, ionization chambers, solid-state detectors and boron scintillators. A discussion of the use of these detectors for implementing these cross sections will be presented.

Evaluation and use of carbon as a standard, J. C. Lachkar, SP493, pp. 93-100 (Oct. 1977).

Key words: carbon; elastic scattering cross section; evaluation; optical model; R-function analysis; standard; total cross section.

Available data on the carbon total and elastic scattering cross sections are reviewed. Major emphasis is placed on two neutron-energy regions below $5 \mathrm{MeV}$ and between 8.5 and $15 \mathrm{MeV}$. The overall consistency of the recommended values has been established with the aid of previously performed theoretical analyses. It is concluded that carbon elastic data below $5 \mathrm{MeV}$ can be adopted as a standard except at the location of resonances. 1 t is also suggested that the present need for high energy neutron standards could be satisfied by carbon data.

Need for improved standards in neutron personnel dosimetry, J. A. Auxier, SP493, pp. 101-105 (Oct. 1977).

Key words: criteria, accuracy; criteria, performance; dose equivalent; elements, transuranic; glove box; intercomparison; neutrons, high energy; neutrons, low energy; nonuniform exposures; quality factor; standards.

There is a continuing need for standards in neutron monitoring. A discussion of special problem areas and the benefits of intercomparisons is given. The RBE for leu- kemia induction in the survivors of the nuclear bombings of Hiroshima and Nagasaki is greater than ten for absorbed doses in the bone marrow of less than 100 rads; this may have an important impact on neutron standards preparation.

Standards in medical neutron dosimetry, J. J. Broerse, SP493, pp. 106-114 (Oct. 1977).

Key words: basic physical data; medical; mixed $n-\gamma$ fields; neutron dosimetry; standards.

Ciinical and radiobiological experience has shown that differences in absorbed dose of less than 10 percent can be recognized for tumour eradication probability as well as for normal tissue damage. These observations determine the degree of precision and overall accuracy required in medical neutron dosimetry. Standard neutron fields are available only for restricted conditions; the feasibility of a number of detectors as standard dosimeters will be considered. Uncertainties in basic physical parameters will be discussed and recommendations for future research in neutron dosimetry for biology and medicine will be included.

NBS facilities for standardization of neutron dosimetry from 0.001 to $14 \mathrm{MeV}$, O. A. Wasson, SP493, pp. 115-120 (Oct. 1977).

Key words: calibration; detection; dosimetry; facilities; fluence; flux; moderation; monitor; neutron; shielding; sources; standardization.

The neutron sources available at NBS for use in neutron dosimetry are described in terms of fluence, beam size, and background contamination. Operational details and neutron fluence monitoring of the recently installed standardized beam line of the $3 \mathrm{MV}$ Van de Graaff Laboratory are given for the $200 \mathrm{keV}$ to $1 \mathrm{MeV}$ energy region along with plans for measurements at $14 \mathrm{MeV}$. Measurements of he response of typical laboratory dose rate meters and iilms to monoenergetic neutrons of accurately known fluence in the $250 \mathrm{keV}$ to $1 \mathrm{MeV}$ energy region are given. The problem of the neutron fluence to dose equivalent conversion is discussed.

International neutron dosimetry intercomparisons, $R$. S. Caswell, SP493, pp. $121-127$ (Oct. 1977).

Key words: intercomparisons; medical; neutron dosimetry; radiation effects; standards.

Three recent international neutron dosimetry intercomparisons are discussed: the International Neutron Dosimetry Intercomparisons (INDI) sponsored by the International Commission on Radiation Units and Measurements (ICRU); the European Neutron Dosimetry Intercomparison Project (ENDIP) sponsored by EURATOM; and the intercomparison carried out by the centers doing neutron radiotherapy. Physical dosimetry to an accuracy of two or three percent is desired in order to achieve a generally-accepted 5 percent accuracy in dose to the tumor. In general it is found that 3 percent accuracy has not been achieved by the intercomparison participants; however, the radiotherapy centers agree on an arbitrary (but not absolutely known) scale with in this uncertainty.

Reactor core dosimetry standards, W. L. Zijp, SP493, pp. 128-136 (Oct. 1977).

Key words: comparative evaluation; cross sections; fission spectra; integrals; neutrons; radioactivation; resonance integrals; spectral functions. 
Reactor neutron metrology serves to determine directly flux densities, fluences, spectra, and indirectly effects like burn-up, depletion and displacements. There are tendencies to require an accuracy of 2 to 5 percent. This gives requirements for the accuracy of nuclear data, of which the cross section data are most important.

Average fission neutron cross sections for many reactions of interest arc at present not accurate enough, owing to inadequacy of the spectral cross section data and to inadequacy of the knowledge of the fission neutron spectrum of ${ }^{235} \mathrm{U}$ above about $8 \mathrm{MeV}$.

More experiments in benchmark fields, performed in interlaboratory experiments and in international collaboration are necessary to arrive at accuracies specified in reactor development programs.

Standards for dosimetry beyond the core, F. J. Rahn, K. E. Stahlkopf, T. U. Marston, R. Gold, and J. H. Roberts, SP493, pp. 137-145 (Oct. 1977).

Key words: dosimetry; licensing; measurements; nuclear powcr.

The need for well understood, standardized neutron dosimetry techniques is increasingly evident for several applications in thermal and fast reactors beyond the core region. This need for dosimetry comes mainly from separate but related interests, namely: pressure vessel surveillance, materials testing, design and shielding requirements. The needs of the controlled thermo-nuclear program are addressed in another session of this symposium.

Fission yields: Measurement techniques and data status, $W$ J. Maeck, SP493, pp. 146-155 (Oct. 1977).

Key words: data compilations; fission yield measurement techniques, counting, mass spectrometry; fission yields, thermal, fast, absolute, relative; fission yields versus neutron energy.

Techniques for the measurement of absolute and relative fission yields are reviewed. The preferred techniques are isotope dilution mass spectrometric measurement of the individual fission products, and the heavy element mass difference or the fission product summation method to establish the number of fissions. The accuracy of most thermal fission yields appears adequate, and the status of the various yield compilations is reviewed. For fast fission yields, the data are not nearly as well established. For many heavy nuclides, fast fission yield data are nearly nonexistent. Because fast fission yields change with neutron energy, it is imperative that fast yield data be evaluated as a function of neutron energy to generate the most complete and accurate compilation.

Fission reaction rate standards and applications, J. Grundl and C. Eisenhauer, SP493, pp. 156-164 (Oct. 1977).

Key words: cross sections; fission; neutron reactions; neutron spectrum; reactor fuels; reactor materials.

Fission rate measurements in and around prototype and power reactors of all kinds, as well as in the criticals of reactor physics are vital elements in understanding nuclear energy generation rates, neutron transport, and the integrity of materials exposed to reactor radiation fields. Standardization and interlaboratory referencing for this historic measurement activity have improved significantly since the last neutron standards symposium in 1970 . This advancement will be summarized along with a general orientation and description of fission detector response characteristics and interpretation. For the last, necessary analytic formulations and a brief treatment of error propagation are in- cluded. Also included is an updated look at observed versus predicted fission cross sections for fission spectrum neutrons and the related fast criticals of reactor physics.

Utility and use of neutron capture cross section standards and the status of the $\mathrm{Au}(\mathrm{n}, \boldsymbol{\gamma})$ standard, A. Paulsen, SP493, pp. 165-169 (Oct. 1977).

Key words: accuracy; $\mathrm{Au}(\mathrm{n}, \boldsymbol{\gamma})$ cross section; cross section fluctuations; mcasurement; neutron capture cross section; normalization; reference standard; review.

The main application of a neutron capture cross section standard should be found in ratio measurements using the prompt $\boldsymbol{\gamma}$-ray detection method. A review of neutron capture cross section measurements in the last six years shows that the $\operatorname{Au}(n, \gamma)$ standard is increasingly used for this purpose. But the majority of all measurements is still based on other normalization methods than ratio measurements, although the accuracy established for the $A u(n, \gamma)$ cross section below $3 \mathrm{MeV}$ competes now well with that of other normalization methods. On the other hand this accuracy has scarcely reached the accuracy of necessary corrections associated with prompt $\gamma$-ray detection measurements below $3 \mathrm{MeV}$ neutron energy, and is completely insufficient above $3 \mathrm{MeV}$. Below $200 \mathrm{keV}$ the cross section fluctuations due to level statistics in the compound system ${ }^{198} \mathrm{Au}$ are seriously disturbing measurements aiming at high accuracy and high resolution.

Remarks on the $2200 \mathrm{~m} / \mathrm{s}$ and $20{ }^{\circ} \mathrm{C}$ Maxwellian neutron data for U-233, U-235, Pu-239 and Pu-241, H. D. Lemmel, SP493, pp. 170-173 (Oct. 1977).

Key words: fission-neutron yields; fission standards; neutron nuclear data evaluation; Pu-239; Pu-239 half-life; Pu-241; thermal neutron cross-sections; U-233; U-235.

Attention is drawn to the still existing systematic discrepancy between experimental cross-sections for $2200 \mathrm{~m} / \mathrm{s}$ neutrons and those for a $20{ }^{\circ} \mathrm{C}$ Maxwellian neutron spectrum for U-235 and U-233.

Assessment of the "thermal normalization technique" for measurement of neutron cross sections vs. energy, $R$. W. Peelle and G. de Saussure, SP493, pp. 174-181 (Oct. 1977).

Key words: cross section; neutron; normalization; resonance; shape; standards; thermal; ${ }^{6} \operatorname{Li}(n, \alpha) ;{ }^{10} B(n, \alpha)$; ${ }^{235} \mathrm{U}(\mathrm{n}, \mathrm{f})$.

Refined knowledge of the thermal neutron cross sections of the fissile nuclides and of the $(n, \alpha)$ reaction standards, together with the reasonably well-known energy dependence of the latter, have permitted resonance-region and low-keV fissile nuclide cross sections to be based on these standards together with count-rate ratios observed as a function of energy using a pulsed "white" source. As one evaluates cross sections for energies above $20 \mathrm{keV}$, optimum results require combination of cross section shape measurements with all available absolute measurements. The assumptions of the "thermal normalization method" are reviewed and an opinion is given of the status of some of the standards required for its use. The complications which may limit the accuracy of results using the method are listed and examples are given.

For the ${ }^{235} \mathrm{U}(\mathrm{n}, \mathrm{f})$ cross section, the option is discussed of defining resonance-region fission integrals as standards. The area of the $\sim 9 \mathrm{eV}$ resonances in this nuclide may be known to one percent accuracy, but at present the fission integral from 0.1 to $1.0 \mathrm{keV}$ is known to no better than about two percent. This uncertainty is based on the scatter among independent results, and has not been reduced by 
the most recent measurements. This uncertainty now limits the accuracy attainable for the ${ }^{2.35} \mathrm{U}(n, f)$ cross section below about $50 \mathrm{keV}$.

Suggestions are given to indicatc how future detailed work might overcome past sources of error.

Review of $\bar{\nu}$ for ${ }^{2.52} \mathrm{Cf}$ and thermal neutron fission, J. W. Boldeman, SP493, pp. 182-193 (Oct. 1977).

Key words: ncutron standards; $\bar{\nu} ;{ }^{233.235} \mathrm{U}(\mathrm{n}, \mathrm{f}) ;{ }^{239.2+1} \mathrm{Pu}(\mathrm{n}, \mathrm{f})$; ${ }^{2 \cdot 2} \mathrm{Cf}$.

A rcvicw is presented of absolute measurements of $\bar{\nu}$ for the spontaneous fission of ${ }^{252} \mathrm{Cr}$ and of relative measurements for thermal neutron induced fission of ${ }^{2 \times 3.235} \mathrm{U}$ and $239.2+1 \mathrm{Pu}$. The discussion includes the consideration of a number of sources of revision that have been suggested for sume of the measurements. No evidence is found in the revised data of any experiment-dependent systematic error. A set of recommended values is given.

Measurement of the ${ }^{252} \mathrm{Cf}$ spontaneous fission neutron spectrum, M. V. Blinov, V. A. Vitenko, and V. T. Touse, SP493, pp. 194-197 (Oct. 1977).

Key words: fission neutron spectrum; neutron detectors; neutron standard; time-of-flight; ${ }^{252} \mathrm{Cf}$.

The ncutron energy spectrum of ${ }^{252} \mathrm{Cf}$ spontaneous fission has been measured by the time-of-flight method using two neutron detectors--a ${ }^{6} \mathrm{Lil}$ (Eu) crystal and a fast ionization chamber with ${ }^{205} U$ layers. The influence of scattered ncutrons and fission ncutron emission time on the spectrum shape was studicd. In the range from $10 \mathrm{keV}$ to 7 $\mathrm{MeV}$, the ncutron energy spectrum is satisfactorily described by a Maxwellian distribution within the experimental errors with $\mathrm{T}=1.41 \pm 0.03 \mathrm{MeV}$.

Prompt fission neutron spectra, L. Stewart and C. M. Eisenhauer, SP493, pp. 198-205 (Oct. 1977).

Kcy words: californium-252; Maxwellian spectrum; plutonium-239; prompt fission spectrum; uranium-235; Watt spectrum.

Recent measurements of the spectra of prompt neutrons emitted from neutron-induced fission in ${ }^{235} \mathrm{U}$ and ${ }^{239} \mathrm{Pu}$ are reviewed. Results are discussed in terms of departures of the data from a simple Watt representation. An evaluation of the neutron spectrum from neutron-induced fission in ${ }^{2.35} \mathrm{U}$ and spontaneous fission in ${ }^{252} \mathrm{Cf}$, made by NBS in 1975 , is also reviewed. Recent measurements on the fission spectra of ${ }^{235} \mathrm{U}$ and ${ }^{239} \mathrm{Pu}$ seem to indicate a harder energy spectrum than indicated by the earlier data available for the NBS evaluation. Possible reasons for this trend in the experimental data are discussed.

On quantitative sample preparation of some heavy elements, A. H. Jaffey, SP493, pp. 206-211 (Oct. 1977).

Kcy words: absolute counting; aliquotting; analysis (plutonium, uranium); isotope dilution; sample preparation; spccific activity; $\alpha$-activity.

A discussion is given of some techniques that have been useful in quantitatively preparing and analyzing samples uscd in the half-life determinations of some plutonium and uranium isotopcs. Application of these methods to the preparation of uranium and plutonium samples used in ncutron cxperiments is discussed.

Black and grey neutron detectors, F. Gabbard, SP493, pp. 212-220 (Oct. 1977).
Key words: black and grey neutron detectors; neutron flux measurement; review.

Recent progress in the development and use of "black" and "grey" detectors is reviewed. Such detcctors are widely used for counting neutrons in $(p, n)$ and $(\alpha, n)$ experiments and in neutron cross section measurements. Accuracy of each detector is stressed.

Associated particle methods, M. M. Meier, SP493, pp. 221 226 (Oct. 1977).

Key words: calibration; efficiency; neutron beams; neutron flux; neutrons; ${ }^{3} \mathrm{H},{ }^{2} \mathrm{H},{ }^{4} \mathrm{He},{ }^{3} \mathrm{He}$, protons.

Developments in the associated particle method for the last ten years are summarized with emphasis on the rcactions $\left.{ }^{3} \mathrm{H}(\mathrm{d}, \mathrm{n})\right)^{4} \mathrm{He},{ }^{2} \mathrm{H}(\mathrm{d}, \mathrm{n})^{3} \mathrm{He}$ and ${ }^{3} \mathrm{H}(\mathrm{p}, \mathrm{n})^{3} \mathrm{He}$. Recent progress on the associated particlc calibration of a black detector in the energy range 250 to $1000 \mathrm{keV}$ is reported. Current accuracies for the time uncorrelated and time correlated approaches are noted and prospects for future improvement are estimated.

Associated gamma-ray technique for neutron fluence measurements, J. D. Brandenberger, SP493, pp. 227-233 (Oct. 1977).

Key words: cross sections; detector efficiency; neutron fluence.

The use and development of the ${ }^{7} \operatorname{Li}\left(p, n_{1} \gamma\right)^{7} B e$ reaction as an example of the associated gamma-ray technique for neutron flucnce and detector efficiency measurements are described. Present limits on energy range and accuracy are stated for this method, and current extensions of this work are discussed.

Associated activity method, K. K. Sekharan, SP493, pp. 234-236 (Oct. 1977).

Key words: description of method; possible improvements; uncertainties in efficiency.

A bricf description of the associated activity method is given and its application for the calibration of flat response neutron dctectors in three laboratories is described. The uncertainties involved in the associated activity method have been discussed and suggestions for improving the accuracy of the efficiency for neutron detection have becn made.

Accuracies and corrections in neutron bath techniques, E. J. Axton, SP493, pp. 237-243 (Oct. 1977).

Key words: bath techniques; manganese sulphate baths; neutron.

The corrections and currently attainable accuracy in the neutron source emission rate measurements with the manganese sulphate bath technique are discussed in detail, followed by a review of other bath techniques and their adaptation for neutron flux measurement.

International comparison of flux density measurements for monoenergetic fast neutrons, V. D. Huynh, SP493, pp. 244249 (Oct. 1977).

Key words: fast neutron flux density; international comparison.

An intcrnational flux density intercomparison of fast neutrons has been organized by the Bureau International des Poids et Mesures during the past three years. Nine laboratories have carried out measurements. Three neutron 
energies were selected ( $250 \mathrm{keV}, 2.5 \mathrm{MeV}$ and 14.8 $\mathrm{MeV}$ ), to which two optional energies were added (565 $\mathrm{keV}$ and $2.2 \mathrm{MeV}$ ). A polyethylene sphere with a small $\mathrm{BF}_{3}$ counter at the center was used as a transfer instrument at all energies except for $14.8 \mathrm{MeV}$. A ${ }^{3} \mathrm{He}$ proportional counter was used at the two lower energies as the second transfer instrument. At $14.8 \mathrm{MeV}$ a fission chamber $\left({ }^{238} \mathrm{U}\right)$ and the iron foil activation method using ${ }^{56} \mathrm{Fe}(\mathrm{n}, \mathrm{p})^{56} \mathrm{Mn}$ reaction were used. The results concerning the sensitivity of each transfer instrument measured by all the participating laboratories are summarized.

Calibration and use of filtered beams, R. B. Schwartz, SP493, pp. 250-254 (Oct. 1977).

Key words: dosimeter calibration; monoenergetic neutrons; neutron beams; neutrons; resonant scatterer.

Using a combination of resonant scatterers and filters, very pure beams of $2 \mathrm{keV}, 24 \mathrm{keV}$, and $144 \mathrm{keV}$ neutrons are produced at the NBS reactor. The calibration of these beams and their application to dosimeter calibration will be discussed.

Much ado about nothing: Deep minima in ${ }^{45} \mathrm{Sc}$ and ${ }^{56} \mathrm{Fe}$ total neutron cross sections, R. E. Chrien, H. I. Liou, R. C. Block, U. N. Singh, and K. Kobayashi, SP493, pp. 255-260 (Oct. 1977).

Key words: deduced neutron resonance parameters; neutron total cross sections; ${ }^{45} \mathrm{Sc}$ measured from 0.4 to 22 $\mathrm{keV} ;{ }^{56} \mathrm{Fe}$ measured from 0.4 to $1000 \mathrm{keV}$.

The deep minima in ${ }^{45} \mathrm{Sc}$ and ${ }^{56} \mathrm{Fe}$ neutron total cross sections have been measured at the Gaerttner Linac Laboratory by using thick, ultra-pure samples in transmission experiments. The samples are used to produce quasimonoenergetic beams at the BNL High Flux Beam Reactor. For the ${ }^{45} \mathrm{Sc}$ minimum near $2.05 \mathrm{keV}$ we obtain $\sigma_{\text {totat }}$ $=0.71 \pm 0.03$ barns, in sharp contrast to a previously reported value of $\sim 0.05$ barns. The ${ }^{56} \mathrm{Fe}$ measurement was carried out with a $6 \mathrm{~kg}, 68.58-\mathrm{cm}$-long sample of 99.87 percent isotopically pure sample of ${ }^{56} \mathrm{Fe}$; a minimum cross section of $0.0085 \pm 0.004$ barns at $24.39 \mathrm{keV}$ is inferred. This may be compared to a value of 0.420 barns for natural iron.

The U-235 neutron fission cross section from 0.1 to 20.0 MeV, W. P. Poenitz, SP493, pp. 261-268 (Oct. 1977).

Key words: data; evaluations; status; U-235 (n,f); 0.1-20.0 $\mathrm{MeV}$.

The status of the U-235 fast neutron fission cross section is discussed based primarily on material contributed and considered at the NEANDC/NEACRP Specialists Meeting on Fast Neutron Fission Cross Sections held at Argonne National Laboratory in June 1976. However, some newer measurements and evaluations are discussed as well. Specifically, recent measurements at ANL over the energy range 0.2-8.2 MeV, using several BND's, are reported. Data from the last 10 years are found to be in good agreement with an evaluated average of these data. Suggested problem areas are investigated in terms of their actual significance. It is found that the presently suggested version of ENDF/B-V for the U-235 (n,f) cross section does not represent the data base well and a reconsideration is recommended.

Propagation of uncertainties in fission cross section standards in the interpretation and utilization of critical benchmark measurements, $C$. R. Weisbin and R. W. Peelle, SP493, pp. 269-277 (Oct. 1977).
Key words: criticals; cross section; ENDF/B; fission; standards; uncertainties.

This work explores the constraints imposed on the ${ }^{22.5} \mathrm{U}(\mathrm{n}, \mathrm{f})$ standard (proposed ENDF/B version $\mathrm{V}$ ) by information deduced from clean integral measurements and demonstrates how uncertainties in fission cross section standards propagate in an uncertainty analysis and interpretation of those experiments. The question of what a significant improvement in the accuracy of the ${ }^{2235} U(n, f)$ standard would accomplish is addressed in the limited context of analysis of GODIVA and JEZEBEL measurements.

The CSEWG integral benchmark results and uncertainties were updated in accordance with more recent information. Sensitivity coefficients were developed and used to estimate calculated results which should be obtained using the subsequent release of ${ }^{238} U(n, f),{ }^{235} U(n, f)$, and ${ }^{2 \pi 9} \mathrm{Pu}(\mathrm{n}, \mathrm{f})$ at version $\mathrm{V}$ status. Covariance files were evaluated and processed for all important cross sections with the sole exception being inelastic scattering for all levels and the continuum. Uncertainties due to the ${ }^{23 s} \mathrm{U}(\mathrm{n}, \mathrm{f})$ standard were estimated to comprise more than half of the calculated uncertainty for criticality and $\left\langle{ }^{28} \sigma_{S}{ }^{25} \sigma_{f}\right\rangle_{c}$ spectral index in JEZEBEL as well as GODIVA; though the JEZEBEL assembly contained no ${ }^{235} \mathrm{U}$. We are not able at this time, to predict criticality or $\left\langle{ }^{28} \sigma_{c} /{ }^{28} \sigma_{f}\right\rangle_{e}$ to anywhere near the accuracy obtained by direct measurements, and therefore the integral results are significant to our analysis capability. Inclusion of integral information from GODIVA and JEZEBEL in an adjustment procedure was effective in reconciling all parameters other than $\left\langle{ }^{28} \sigma_{f} f^{25} \sigma_{f}\right\rangle_{c}$ measurement in JEZEBEL for which current calculation and measurement are in disagreement. The adjustment procedure made changes of less than one standard deviation in the cross sections for ${ }^{235} U(n, f),{ }^{236} U(n, \gamma),{ }^{236} U(n, f),{ }^{238} U(n, y)$, and ${ }^{239} \mathrm{Pu}(\mathrm{n}, \mathrm{f})$ including an increase of $\sim 1.5$ percent for the ${ }^{235} \mathrm{U}(\mathrm{n}, \mathrm{f})$ cross section above $1.3 \mathrm{MeV}$. This specific adjustment result could change with inclusion of inelastic covariance files and must be viewed cautiously at this time.

${ }^{237} \mathrm{~Np}$ and ${ }^{239} \mathrm{U}$ as possible standards for the $\mathrm{MeV}$ region, $\mathrm{S}$. Cierjacks, SP493, pp. 278-289 (Oct. 1977).

Key words: $E_{n}=0.1-20 \mathrm{MeV}$; summary of experimental results; ${ }^{237} \mathrm{~Np},{ }^{238} \mathrm{U}(\mathrm{n}, \mathrm{f})$ as neutron standards.

The aspects of using the fission cross sections of ${ }^{237} \mathrm{~Np}$ and ${ }^{2238} \mathrm{U}$ as possible standards in the $\mathrm{MeV}$ region are considered. In comparison to other neutron standards their application is particularly advantageous for experiments involving white-source techniques. Major distortions in fast neutron measurements due to frame-overlap problems and contributions from slow neutrons events can be avoided by spectrum cut-off at threshold energies. The present data basis for both nuclei is discussed and critically examined. Some suggestions are made of how to achieve an ultimate accuracy of 2 percent with measurements employing ${ }^{237} \mathrm{~Np}$ or ${ }^{238} \mathrm{U}$ as secondary standards.

Standard integral measurement facilities, A. Fabry, SP493, pp. 290-298 (Oct. 1977).

Key words: cross sections; ENDF/B; fission; integral measurements; standard neutron fields.

The usefulness of integral measurements in standard and reference neutron fields is examined in terms of the validation of microscopic differential-energy neutron fission cross section standards needed for fission reactor technology. This synthesis encompasses a summary description of the identified neutron fields and of the status of their spectral characterization, discussion of the corrections and uncer- 
tainties involved in such experiments, and an appraisal of the accuracy of integral fission cross sections, in particular at the light of interlaboratory comparisons. The significance of such integral measurements to the testing and improvement of evaluated nuclear data is illustrated by a limited confrontation with the ENDF/B IV cross section file.

Integral measurement results in standard fields, D. M. Gilliam, SP493, pp. 299-303 (Oct. 1977).

Key words: cross sections; fission yields; neutrons; nuclear data; standard fields.

Measured spectrum-averaged fission cross sections are reported for several benchmark fast neutron fields. For the Cf-252 spectrum, absolute cross section measurements at NBS and the University of Michigan are compared. Cross section ratios (relative to $\mathrm{Pu}-239$ ) are reported for $\mathrm{U}-235$, U-238, and Np-237 for the following fields: U-235 fission spectrum, BIG-10, CFRMF, SIGMA SIGMA, and the Intermediate-Energy Standard Neutron Field (ISNF) at NBS.

Fission product yields measured by the Interlaboratory LMFBR Reaction Rate Program (ILRR) are reported in two categories: (1) Consensus Yields from thorough interlaboratory studies and (2) Subsidiary Yields for isotopes studied less intensively (usually by a single laboratory). All measured yields were determined by $\mathrm{Ge}(\mathrm{Li})$ counting of fission activation foils, with specific fission rates determined by counting fissions from a separate light deposit in an ionization chamber. The fission product yields for the CFRMF and BIG-10 rields are reported first separately and then combined, to provide a single set of yields for a Fast Reactor Spectrum.

Absolute fission cross section measurements using fixed energy neutron sources, G. F. Knoll, SP493, pp. 304-310 (Oct. 1977).

Key words: absolute cross sections; neutron sources.

Quasi-monoenergetic neutron sources of fixed energy can permit generation of absolute cross section data at well-known and isolated neutron energies. These data can serve as independent normalization points for cross section shape measurements made using other techniques. Several examples of their application to fission cross section measurements are given.

Impact of ENDF standards on fast reactors, U. Farinelli, SP493, pp. 310-312 (Oct. 1977).

Key words: adjustment; benchmark; cross-sections; fast reactors; integral experiments; standards.

ENDF/B is widely used throughout the world by fast reactor designers, either directly or as a basis for adjustment procedures. Neutron standards have at least potentially a value that goes beyond their intrinsic function in the production of evaluated nuclear data files; they could be used as standards also for integral measurements, especially in connection with benchmark experiments, and could provide a reference set for adjustment procedures. The conditions under which this new use of the standards would be possible are briefly reviewed in the paper.

Absolute ${ }^{235} \mathrm{U},{ }^{238} \mathrm{U},{ }^{237} \mathrm{~Np}$ fast neutron fission cross-section measurements, V. M. Adamov, B. M. Alexandrov, I. D. Alkhazov, L. V. Drapchinsky, S. S. Kovalenko, O. I. Kostochkin, G. Y. Kudriavzev, L. Z. Malkin, K. A. Petrzhak, L. A. Pleskachevsky, A. V. Fomichev, and V. I. Shapakov, SP493, pp. 313-318 (Oct. 1977).
Key words: absolute measurements; fission cross sections; fission spectrum neutrons; $14.8-\mathrm{MeV}$ neutrons; ${ }^{235} \mathrm{U} ;{ }^{238} \mathrm{U}$; ${ }^{237} \mathrm{~Np} ;{ }^{252} \mathrm{Cf}$.

The fission cross sections of ${ }^{235} \mathrm{U},{ }^{238} \mathrm{U}$ and ${ }^{237} \mathrm{~Np}$ for ${ }^{252} \mathrm{Cf}$ fission spectrum neutrons and $14.8 \mathrm{MeV}$ neutrons have been absolutely measured. Coincidence method fission fragment-associated particle was used. Measurement accuracy is better than 2 percent. Error sources are discussed.

Neutron energy standards, G. D. James, SP493, pp. 319328 (Oct. 1977).

Key words: accurate neutron energy determination; energy standards.

In recent years there have been several examples of discrepancy between the neutron energy scales from different spectrometers. Some of the work undertaken to review and improve neutron energy determination is noted and some suggestions on how errors can be reduced are listed. The view advocated by Youden that the only worthwhile estimates of systematic error are those made experimentally is presented. Comparison of energy determinations for a few resonances show that at best resonance energies can be quoted to an accuracy of about one in 10,000. A list of 41 narrow resonances, over the energy range $0.6 \mathrm{eV}$ to 12.1 MeV, which should prove suitable as energy standards is given. At present, not all the energies listed are known to the highest accuracy attainable.

Neutron transport calculations for the intermediate-energy standard neutron field (ISNF) at the National Bureau of Standards, C. M. Eisenhauer, J. A. Grundl, and A. Fabry, SP493, pp. 329-334 (Oct. 1977).

Key words: benchmark spectrum; discrete ordinates; intermediate energy; measurement assurance; neutron standard; reaction rates.

The intermediate-energy standard neutron field (ISNF) established in the thermal column of the NBS reactor is designed to produce a benchmark neutron spectrum concentrated between $10 \mathrm{keV}$ and $3 \mathrm{MeV}$. Design principles and physical description of the spherically-symmetric system are summarized. Neutron transport calculations of the ISNF spectrum at the center of the facility by the discrete-ordinates method are discussed and results are given for 40-group and 240-group computations. The sensitivity of the calculated spectrum to variations in important physical parameters such as material densities and carbon and boron- 10 cross sections is explored.

Standardization of fast pulse reactor dosimetry, A. H. Kazi, E. D. McGarry, and D. M. Gilliam, SP493, pp. 335-341 (Oct. 1977).

Key words: califomium-252; dosimetry; neutron flux standard; pulse reactor calibration; radiation effects.

A dosimetry method, developed at the National Bureau of Standards and known as the Flux Transfer Technique, is proposed for accurately determining the total fast flux in the vicinity of a fast-pulse reactor or bare-critical assembly. The method is to determine the fast flux from the comparison of free-field ${ }^{239} \mathrm{Pu}$ fission-rate measurements made at the reactor facility to calibration measurements made in a standard ${ }^{252} \mathrm{Cf}$ neutron flux. Use of the technique at the Army Pulse Radiation Facility shows that total fluxes can be measured in and near the reactor to a determinable accuracy of \pm 5 percent. For comparison, but with less accuracy of \pm 8 percent, the same total fluxes were verified using ${ }^{237} \mathrm{~Np},{ }^{234} \mathrm{U},{ }^{236} \mathrm{U}$ and ${ }^{238} \mathrm{U}$. 
The technique has several important advantages. It uses a recognized standard neutron source for calibration. Accurate fission rates are measured and compared with dualisotope fission chambers that are easily calibrated. The method is independent of errors in foil masses. The method does not require the use of an unfolding code and the effects of cross section errors are lessened because of the need to evaluate only cross section ratios. The method is simple and is readily amenable to absolute crror analysis and interlaboratory calibrations.

Dosimetry standards for neutrons above $10 \mathrm{MeV}, H$. H. Barschall, SP493, pp. 342-346 (Oct. 1977).

Key words: activation; Bragg-Gray; dosimetry; energy per ion pair; fluence; kerma factor; neutrons.

Dosimetry of neutrons in the energy range $10-50 \mathrm{MeV}$ is needed for applications in radiation damage studies and in biomedical work. Dose determinations use either a fluence measurement or the Bragg-Gray principle. Better knowledge of activation cross sections, kerma factors, and energy per ion pair is needed to reduce uncertainties in dosimetry.

SP494. MFPG. Detection, diagnosis and prognosis. Proceedings of the 26th Meeting of the Mechanical Failures Prevention Group held at the IIT Research Institute, Chicago, IL, May 17-19, 1977, T. R. Shives and W. A. Willard, Eds., Nat. Bur. Stand. (U.S.), Spec. Publ. 494, 296 pages (Sept. 1977) SN003-003-01 844-9.

Key words: failure detection; failure diagnosis; failure prevention; ferrography; land vehicle diagnostics; oil analysis; railroad system diagnostics; signature analysis; wear.

These proceedings consist of a group of twenty-four submitted papers from the 26th meeting of the Mechanical Failures Prevention Group which was held at the IIT Research Institute in Chicago, Illinois on May 17-19, 1977. The central theme of the proceedings is detection, diagnosis and prognosis as related to mechanical failure. Papers are presented that discuss oil analysis, signature analysis techniques, new detection, diagnosis and prognosis techniques and equipment, railroad system diagnostics, and land vehicle diagnostics. These proceedings include the following papers (indented):

Statistical analysis of wear metal concentration measurements in oil; calculation of significant wear metal production rates, K. Scheller and K. J. Eisentraut, SP494, pp. 3-23 (Sept. 1977).

Effective fluid analysis of oil-wetted systems through proper planning and interpretation, R. K. Tessmann and G. E. Ma:oney, SP494, pp. 24-26 (Sept. 1977).

Oil analysis/wear particle analysis, P. B. Senholzi, SP494, pp. 27-32 (Sept. 1977).

Application of ferrographic lube oil analysis to U.S.N. ship systems, G. F. Rester, SP494, pp. 33-48 (Sept. 1977).

Effectiveness of the real time ferrograph and other oil monitors as related to oil filtration, $R$. Valori, SP494, pp. 49-72 (Sept. 1977).

Ferrographic separation of organic compounds, E. R. Bowen and V. C. Westcott, SP494, pp. 73-74 (Sept. 1977).

Mechanical signature analysis as a first step in quantifying the characteristics of operating machinery, J. S. Mitchell, SP494, pp. 77-78 (Sept. 1977).
Spectrum analysis and machinery monitoring, G. F. Lang, SP494, pp. 79-81 (Sept. 1977).

Comparison of vibration signature analysis techniques, J. L. Frarey, SP494, pp. 82-83 (Sept. 1977).

The role of signal processing in machinery vibration analysis, J. H. Hamilton, SP494, pp. 93-96 (Sept. 1977).

Diagnostic techniques for steam turbines, R. L. Bannister, R. L. Osborne, and S. J. Jennings, SP494, pp. 97-116 (Sept. 1977).

Experimental determination of radial magnetic forces as a function of rotor offset in a large induction motor, $R$. $L$. Leon, SP494, pp. 117-120 (Sept. 1977).

A new chip detector-reliable, versatile, and inexpensive, $T$. Tauber, SP494, pp. 123-132 (Sept. 1977).

Another look at time waveform analysis, J. B. Catlin, SP494, pp. 133-137 (Sept. 1977).

The advent of sophisticated fluid power systems and its impact on preventative maintenance in the military, $M$. W. Wigton, SP494, pp. 138-145 (Sept. 1977).

Tire degradation monitoring, W. Lichodziejeswki, SP494, pp. 146-151 (Sept. 1977).

Use of microprocessors in analysis of acoustic emission weld monitoring data, R. N. Clark and T. A. Mathieson, SP494, pp. 152-166 (Sept. 1977).

Pictorial history of the development of proximity probes for use in high temperature liquid metals environment, $L$. Hoogenboom, SP494, pp. 167-187 (Sept. 1977).

Department of Transportation System for Train Accident Reduction (DOT-STAR), J. K. O'Steen, SP494, pp. 191-204 (Sept. 1977).

Comparison of vibration analysis techniques for railroad roller bearing diagnostics, W. D. Waldron, SP494, pP. 205222 (Sept. 1977).

Maintenance management through diagnosis, R. G. Salter, SP494, pp. 225-237 (Sept. 1977).

Vehicle monitoring system, S. C. Hadden, R. E. Hanson, and M. W. Stewich, SP494, pp. 238-248 (Sept. 1977).

Systemized diesel engine diagnostics, H. J. Mercik, Jr., SP494, pp. 249-258 (Sept. 1977).

SP500-1. Computer science \& technology: Foreign and domestic accomplishments in magnetic bubble device technology, R. B. J. Warnar and P. J. Calomeris, Nat. Bur. Stand. (U.S.), Spec. Publ. 500-1, 50 pages (Jan. 1977) SN003-00301724-8.

Key words: amorphous materials; bubble; field-access; garnet; guide-pattern; magnetoresistance; nonvolatility; orthoferrite; photolithography; uniaxial structures.

This document assesses the status of magnetic bubble technology as displayed by non-U.S. research and manufacturing facilities. Non-U.S. research and U.S. accomplishments are described while both technical and economic factors are addressed. Magnetic bubble devices are discussed whenever their application could impact future computer system design. Generally the magnetic bubble device can be applied to a computer system as a peripheral mass memory. Magnetic bubble devices are produced from either synthetic garnet or 
amorphous materials rather than from familiar silicon material. The document contains a significant bibliography to support certain main points which are supplemented by information supplied by the library of the Information Technology Division (ICST-NBS) and from private interviews with various U.S. technical experts.

SP500-2. Computer science \& technology: Accessing individual records from personal data files using non-unique identifiers, G. B. Moore, J. L. Kuhns, J. L. Trefftzs, and C. A. Montgomery, Nat. Bur. Stand. (U.S.), Spec. Publ. 500-2, 203 pages (Feb. 1977) SN003-003-01726-4.

Key words: data retrieval; file validation; name lookup; nonunique identifiers; personal data files; Privacy Act; probability model; retrieval.

The Privacy Act of 1974 places restrictions on the Federal, state and local agencies' use of the Social Security account number as an identifier. For some agencies, compliance will involve changes in implementation of retrieval algorithms. This report describes methodology applicable to these changes in the more general context of the problem of retrieving individual records from files using nonunique identifiers. State-ofthe-art retrieval techniques are discussed, a method for assigning reliability weights to various personal data elements is presented, file validation techniques for the error and omission rates of data items are suggested, and a retrieval probability model-designed to show likelihood of retrieval of a subject's record given a variety of populations, combinations of identifiers, and error/omission rates-is described. A methodology is developed for forming confidence factors from the established error/omission rates for combinations of nonunique identifiers that are candidates for use as retrieval keys. Use of these confidence factors as indices into the precision tables produced by the probability model is described.

SP500-3. Computer science \& technology: Technical profile of seven data element dictionary/directory systems, B. LeongHong and B. Marron, Nat. Bur. Stand. (U.S.), Spec. Publ. 500-3, 45 pages (Feb. 1977) SN003-003-01725-6.

Key words: computer software; data base management systems; data element dictionary; data element dictionary/directory; software tool.

A Data Element Dictionary/Directory $(\mathrm{DED} / \mathrm{D})$ is a software tool that is used to control and manage data elements in a uniform manner. It can serve data base administrators, systems analysts, software designers, and programmers by providing a central repository for information about data resources across oraganization and application lines. This report describes and classifies DED/D systems and discusses the potential benefits from their use. A technical profile of seven commerciallyavailable DED/D systems is presented with side-by-side exposition of technical features.

SP500-4. Computer science \& technology: Survey of remote terminal emulators, S. W. Watkins and M. D. Abrams, Nat. Bur. Stand. (U.S.), Spec. Publ. 500-4, 80 pages (Apr. 1977) SN003-003-01756-6.

Key words: evaluation; interactive; measurement; performance evaluation; performance measurement; remote terminal emulation; remote terminal emulators; teleprocessing.

This report describes twelve Remote Terminal Emulators (RTE's). The key terminology associated with remote terminal emulation is defined and possible application areas are discussed. Technical implementation details and operational considerations are addressed for each RTE. Summary tables are provided to indicate current RTE capabilities and capacities, as claimed by the RTE developers.
SP500-5. Computer science \& technology: Impact of chargetransfer device technology on computer systems, R. B. J. Warnar, Nat. Bur. Stand. (U.S.), Spec. Publ. 500-5, 48 pages (Apr. 1977) SN003-003-01758-2.

Key words: bucket-brigade; buried channel; Canada; charge-coupled device; Great Britain; imager CCD's; Japan; peristaltic CCD's; surface channel; The Federal Republic of Germany; The Netherlands; transfer channel.

This document assesses the status of charge-transfer device technology as displayed by foreign research and manufacturing facilities for a period up to September 1975. Capabilities and accomplishments of charge-transfer device research facilities in Japan, Canada, Great Britain, The Netherlands, The Federal Republic of Germany, and the United States are described. Technical and economic factors are addressed and compared. Conclusions are presented which suggest future impacts of charge-transfer devices on current electronic systems, especially computers. Information contained in this report was derived from the open technical literature and from interviews with various U.S. technical experts. The technology assessment resulting in this report was conducted by the Information Technology Division of the Institute for Computer Sciences and Technology, National Bureau of Standards, as part of an "Advanced Computer Technology Survey" project.

SP500-6. Computer science \& technology: Computer network interconnection: Problems and prospects, I. W. Cotton, Nat. Bur. Stand. (U.S.), Spec. Publ. 500-6, 83 pages (Apr. 1977) SNOO3-003-01757-4.

Key words: communications networks; computer networks; data communications; interconnection; networks; packet switching; standards.

This report examines the current situation regarding the interconnection of computer networks, especially packet switched networks (PSNs). The emphasis is on identifying the barriers to interconnection and on surveying approaches to a solution, rather than recommending any single course of action.

Sufficient organizational and technical background is presented to permit an understanding and appreciation of the problem. Four major types of interconnections are then surveyed: (1) Circuit Switched Network to PSN, (2) Star Network to PSN, (3) Simple Terminal to PSN, and (4) PSN to PSN. The major barriers to interconnection, both political/legal and technical, are then outlined. The report concludes with some comments on the prospects for overcoming these barriers.

An extensive bibliography, glossary with list of abbreviations, and listing of existing data communications standards relevant to interconnection are also included.

SP500-7. Computer science \& technology: Computers in the Federal Government: A compilation of statistics, M. M. Gray, Nat. Bur. Stand. (U.S.), Spec. Publ. 500-7, 41 pages (June 1977) SN003-003-01780-9.

Key words: ADP costs; Federal ADP statistics; Federal Government computers; Federal minicomputers; statistics.

The material in this report is a compilation of some of the data on the status of computer technology in the Federal Government. This compilation is a combination of existing statistics from Federal Government and computer industry sources, and original statistics based on these sources. Information is included on numbers of computers installed in the Federal Government, dollar value of computers installed, numbers of computers installed by agency, Federal ADP costs by agency and minicomputers in the Federal Government.

SP500-8. Computer science \& technology: Workshop on standards for image pattern recognition. Proceedings of a 
Workshop held at the National Bureau of Standards, Gaithersburg, MD, June 3-4, 1976, J. M. Evans, Jr., R. Kirsch, and R. N. Nagel, Eds., Nat. Bur. Stand. (U.S.), Spec. Publ. 5008, 115 pages (May 1977) SNO03-003-01771-0.

Key words: automation; calibration; data formats; documentation; image content language; image processing; pattern recognition; prototype images; standards.

Automatic image pattern recognition techniques have been successfully applied to improving productivity and quality in both manufacturing and service applications.

Automatic Image Pattern Recognition Algorithms are often developed and tested using unique data bases for each specific application. Quantitative comparison of different approaches and extrapolation of existing techniques to new applications is difficult or impossible.

To facilitate data interchange in this area a two day workshop was held at the National Bureau of Standards in Gaithersburg, Maryland, on June 3 and 4, 1976.

The workshop considered the issues involved with interchange of images as data in standard formats on magnetic tape. Specifically, the workshop addressed the following objectives: 1 . To define mechanisms for achieving a standard format for magnetic tape interchange; 2 . To define requirements for documentation of the recording environment of an image; 3 . To recommend mechanisms for selecting and distributing prototype images; 4 . To consider the requirements and to explore the prospect for a language to describe image content and structure. These proceedings include the following papers (indented):

Introductory address, R. M. Davis, SP500-8, pp. 1-4 (May 1977).

The NATO RSG-4/SGIP tape format, J. S. Dehne, SP50O8, pp. 11-25 (May 1977).

Tape formats, T. Pavlidis, SP500-8, pp. 26-27 (May 1977).

Earth observation image data format, J. Y. Sos, SP500-8, pp. 28-34 (May 1977).

On communicating about pictures, M. A. Fischler, SP5OO8, pp. $41-42$ (May 1977).

Syntactic approach to the description of image structure and content, K. S. Fu, SP500-8, p. 43 (May 1977).

Languages for image content and structure, J. F. O'Callaghan, SP5OO-8, p. 44 (May 1977).

Constructive descriptions of images, R. F. Sproull, SP50O8, p. 45 (May 1977).

Instrument parameters in image digitization, W. R. Huelskoetter, SP500-8, pp. 52-54 (May 1977).

Calibration of television microscopes, K. Preston, Jr., SP500-8, pp. 56-57 (May 1977).

Digitization of ultrasonic signals for biomedical investigation, J. F. Greenleaf, SP500-8, pp. 59-62 (May 1977).

A suggestion for the calibration of digitized imagery, W. Frei, SP500-8, pp. 64-65 (May 1977).

Factors which influence acoustic images of medical objects, J. K. Zieniuk, SP500-8, pp. 67-69 (May 1977).

Documentation of the recording environment, $M$. Ritter and M. S. Maxwell, SP500-8, pp. 71-75 (May 1977).
Correcting gray scale distortions in photographic images, B. S. Baxter, SP500-8, pp. 77-79 (May 1977).

The recording environment in pathology, L. Boccia, SP50O8, p. 81 (May 1977).

Prototype images-Selection problems, R. Nagel, SP500-8, pp. 89-90 (May 1977).

Prototype radiographs, J. Sklansky, SP500-8, pp. 92-98 (May 1977).

Thoughts on standardization of parameters for image evaluation, F. C. Billingsley, SP500-8, pp. 99-107 (May 1977).

SP500-9. Computer science $\&$ technology: The use of passwords for controlled access to computer resources, H. M. Wood, Nat. Bur. Stand. (U.S.), Spec. Publ. 500-9, 59 pages (May 1977) SN003-003-01770-1.

Key words: computer networking; computer security; controlled access; identification; passwords; personal authentication.

This paper considers the generation of passwords and their effective application to the problem of controlling access to computer resources. After describing the need for and uses of passwords, password schemes are categorized according to selection technique, lifetime, physical characteristics, and information content. Password protection, both in storage and transmission, is dealt with in the next section, followed by brief sections on current implementations and cost considerations. A glossary and an annotated bibliography of all referenced material are included.

SP500-10. Computer science \& technology: A data base management approach to privacy act compliance, E. Fong, Nat. Bur. Stand. (U.S.), Spec. Publ. 500-10, 34 pages (June 1977) SN003-003-01787-6.

Key words: computer utilization; data base functions; data base management systems; Privacy Act of 1974; privacy compliance techniques.

The Privacy Act (PL 93-579) provisions on personal record handling present new issues concerning effective use of commercial data base management systems (DBMS) by Federal agencies. The widespread use of such systems in recordkeeping activities will definitely have an impact on methods of administering compliance with the Privacy Act. This report proposes a technical approach to compliance with certain Privacy Act requirements through the use of generalized data base management system. Requirements are translated into a set of computer data file and procedures. These procedures, incorporated at pivotal points of data base soft-ware, can implement those Privacy Act compliance procedures amenable to automation. The use of DBMS appears to be a viable and technologically feasible solution to the effective and efficient implementation of many Privacy Act provisions.

SP500-11. Computer science \& technology: Computer software management: A primer for project management and quality control, D. W. Fife, Nat. Bur. Stand. (U.S.), Spec. Publ. 50011, 58 pages (July 1977) SN003-003-01 795-7.

Key words: computer management; computer programming; computer project control; computer software; software engineering; software quality; software reliability.

Today, providing computer software involves greater cost and risk than providing computer equipment, because hardware is mass produced by industry using proven technology, while 
software is still produced mostly by the craft of individual computer programmers. This brief guide is intended for managers who are responsible for computer projects, to explain the use of quality controls and software management methods. The typical problems of software development are explained. Over twenty distinct quality controls are defined, and recommendations are given for software management actions. Empirical information is included that would help top executives to appreciate the potential problems and importance of software management.

SP500-12. Computer science \& technology: Data compression-A comparison of methods, J. A ronson, Nat. Bur. Stand. (U.S.), Spec. Publ. 500-12, 39 pages (June 1977) SN003003-01797-3.

Key words: coding; coding theory; computer storage; data compaction; data compression; data elements; data management; data processing; information management; information theory.

One important factor in system design and in the design of software is the cost of storing data. Methods that reduce storage space can, besides reducing storage cost, be a critical factor in whether or not a specific application can be implemented. This paper surveys data compression methods and relates them to a standard statistical coding problem-the noiseless coding problem. The well defined solution to that problem can serve as a standard on which to base the effectiveness of data compression methods. A simple measurc, based on the characterization of the solution to the noiseless coding problem, is stated through which the effectiveness of a data compression method can be calculated. Finally, guidelines are stated concerning the relevence of data compression to data processing applications.

SP500-13. Computer science \& technology: Features of seven audit software packages-Principles and capabilities, A. J. Neumann, Nat. Bur. Stand. (U.S.), Spec. Publ. 500-13, 58 pages (July 1977) SN003-003-01807-4.

Key words: audit packages; audit routines; audit software; auditing; auditing standards; computer assisted auditing; computer auditing.

The objectives of the auditing process are illustrated by a review of auditing standards for external and internal auditors. Some basic concepts of auditing are defined. Methods for computerized internal control are outlined. Characteristics and features for seven major commercially available audit software packages are described under common headings dealing with the computer environment, input file characteristics, history, availability and cost, and general system characteristics. Basic functions and specialized audit functions of software packages such as numerical and logical operations, stratification and aging, selection, and summarization are described for the various packages.

SP500-14. Computer science \& technology: Software tools: A building block approach, I. T. Hardy, B. Leong-Hong, and D. W. Fife, Nat. Bur. Stand. (U.S.), Spec. Publ. 500-14, 66 pages (Aug. 1977) SN003-003-01823-6.

Key words: building blocks; programming aids; software tools; syntax analysis; text editing.

The present status of software tools is described; the need for special-purpose tools and for new techniques with which to construct such tools is emphasized. One such technique involving the creation of general-purpose "building blocks" of code is suggested; an initial application of the technique to the construction of a text editor and syntax analyzer tool is described. An annotated bibliography of current literature relevant to software tools is provided.
SP500-15. Computer science \& technology: Documentation of computer programs and automated data systems. Proceedings of a Symposium held at the National Bureau of Standards, Gaithersburg, MD, Oct. 12, 1976, M. A. Krasny, Ed., Nat. Bur. Stand. (U.S.), Spec. Publ. 500-15, 66 pages (July 1977) SN003-003-01814-7.

Key words: automated data systems; computer programs; documentation; documentation content guidelines; FIPS guidelines; software, symposium proceedings.

This symposium was organized to introduce the Government ADP-community to the concepts of when and how to apply the government-wide guidelines of FIPS PUB 38 "Guidelines for Documentation of Computer Programs and Automated Data Systems"-in developing both agency standards and operational documentation. The proceedings contain all of the papers presented in the plenary session, and the papers plus summaries of question and answer sessions presented in three parallel sessions for management, operations, and staff attendees. These proceedings include the following papers (indented):

Why document?, T. D. Puckorius, SP500-15, pp. 5-8 (July 1977).

Life cycle concepts and document types, R. A. Young, SP500-15, pp. 10-18 (July 1977).

Flexibility provisions and document type selection, R. R. Hegland, SP50O-15, pp. 19-21 (July 1977).

Content guidelines, T. M. Kurihara, SP500-15, pp. 22-25 (July 1977).

USDA application management, R. V. Head, SP500-15, pp. 27-28 (July 1977).

Documentation standards-A management view, E. B. Smith, SP500-15, pp. 29-31 (July 1977).

Key elements in the ADP system development process at HUD, M. Goer, SP500-15, pp. 32-35 (July 1977).

Problems in using the documentation guideline, $R$. $R$. Hegland, SP500-15, pp. 44-45 (July 1977).

FIPS PUB 38-Implementation philosophy in HEW, J. J. Strnad, SP500-15, pp. $51-52$ (July 1977).

The role of the auditors in the development and evaluation of automated systems, P. L. Morrison, SP500-15, pp. 53-56 (July 1977).

SP500-16. Computer science \& technology: A survey of eleven government-developed data element dictionary/directory systems, H. McEwen, Coordinator for FIPS Task Group 17C-Data Element Dictionary/Directory, Nat. Bur. Stand. (U.S.), Spec. Publ. 500-16, 111 pages (Aug. 1977) SNO03003-01817-1.

Key words: ADP; automated data processing; computer software; data element dictionary; data element dictionary/directory; data management; software tool.

This report presents the current state-of-the-art of government-developed Data Element Dictionary/Directory (DED/D) systems. DED/D's are software tools used for managing and controlling information and data. Eleven DED/D systems are described, first using a side-by-side features presentation approach, and followed by narrative systems descriptions which highlight special capabilities and experiences with each system. Information presented in this report is intended to serve both the technical and administrative ADP community. 
SP500-17. Computer science \& technology: Copyright in computer-readable works: Policy impacts of technological change, R. G. Saltman, Nat. Bur. Stand. (U.S.), Spec. Publ. 500-17, 267 pages (Oct. 1977) SN003-003-01843-1.

Key words: computer; computer program; copyright; data base; economic efficiency; information technology; policy analysis; policymaking; public goods; technological change; transaction costs.

The findings, recommendations, and conclusions of a policyoriented, multi-disciplinary study of copyright in computerreadable works are reported.

The foundations of copyright are examined for basic principles, and the theory of public goods is applied to develop the rationale for copyright protection. The judicial history of copyright in the twentieth century is reviewed with respect to advances in information technology. The impact of technological change on judicial decisionmaking in copyright is analyzed.

The problem of transaction costs in the marketplace for copyrighted works is examined and methods for the reduction of such costs are described. Models of policymaking are developed which clarify the roles of interest groups and the branches of Government, demonstrating their interactions and providing insights into possible futures.

Recommendations on the conditions of copyrightability for computer-readable data bases and computer programs are presented and are based on findings of basic principles developed during the study and described in the report.

SP500-18. Computer science \& technology: Computer Performance Evaluation Users Group (CPEUG). Proceedings of the Thirteenth Meeting held at New Orleans, LA, Oct. 1114, 1977, D. M. Conti and J. L. Walkowicz, Eds., Nat. Bur. Stand. (U.S.), Spec. Publ. 500-18, 241 pages (Sept. 1977) SN003-003-01839-2.

Key words: ADP life cycle; computer performance evaluation; computer performance measurement; computer performance prediction; computer system acquisition; conference proceedings; CPEUG; hardware monitoring; online system evaluation; prediction methods; queuing models; simulation; software monitoring; workload definition.

The Proceedings record the papers that were presented at the Thirteenth Meeting of the Computer Performance Evaluation Users Group (CPEUG) held October 11-14, 1977 in New Orleans. The technical presentations were organized around the three phases of the ADP Life Cycle: the Requirements Phase (workload definition), the Acquisition Phase (computer system and service selection), and the Operational Phase (performance measurement and prediction methods). The program of CPEUG 77 is also included and serves as a Table of Contents to the Proceedings. These proceedings include the following papers (indented):

Functional workload characteristics and computer response time in the design of on-line systems, J. D. Williams and J. S. Swenson, SP500-18, pp. 3-11 (Sept. 1977).

Key words: computer response time; human factors; online systems; system design; task variables; workload characteristics.

This paper presents two human factors studies which explored the relationship between user performance (data entry speed and errors) and on-line computer system response time. The studies investigated user performance with response times of zero to 45 seconds, during both data entry and on-line data correction types of work. The users experienced each response time condition for about one to two hours.
The results indicate that user performance was not degraded by long response times. In addition, the data indicates that the type of work that the user was doing had a much greater effect on user performance than did the computer response time. Finally, the results indicate that longer response times may be appropriate for certain types of work because they reduce the time that the computer waits for the user while potentially causing no decrease in system through-put.

Functional workload characterization, J. E. McNeece and R. J. Sobecki, SP500-18, pp. 13-21 (Sept. 1977).

Key words: benchmarking; computer procurement; computer selection; workload characterization.

This paper addresses functional workload characterization in the benchmark process covering the: (1) past-several early references to standard benchmarks are reviewed and their findings summarized, as are two large Federal computer procurements; (2) present-the current state of functional workload specification is briefly described, as is the approach currently being taken by the U.S. Department of Agriculture (USDA); and (3) future - the trends and problems uncovered in the literature gained through USDA experience and resulting from discussions with other Government agencies and ADP equipment manufacturers are identified and discussed. Finally, those areas which need more study are outlined. These experiences and observations are presented with a view toward precipitating discussion. The main emphasis in workload characterization in this paper is on batch and online transaction processing utilizing a DBMS.

Some results on the clustering approach to workload modelling, A. K. Agrawala and J. M. Mohr, SP500-18, pp. 23-38 (Sept. 1977).

Key words: clustering; workload characterization.

In this paper we discuss two of the issues involved in the use of clustering techniques to characterize a computer system's workload. First we examine the results of clustering one data set with three distinctly different types of feature sets. In the second half of this paper we present results showing that the clusters that are obtained are stable and that they represent natural groupings in the workstep population.

Workload characterization and performance measurement for a CDC CYBER 74 computer system, J. R. Bear and T. E. Reeves, SP500-18, pp. 39-67 (Sept. 1977).

Key words: accounting data; computer performance; computer resource unit; probability density function; statistics; turnaround; workload.

Characterizing the workload of a computer system is directly related to interest in evaluating and predicting the performance of a computer system. Developing an accurate description of the workload is a major requirement which should precede the performance evaluation of a computer system.

This paper reports on research aimed at using existing data collected by an operating system for accounting purposes to characterize the workload of the system. The workloads presented in this paper are for a Control Data Corporation CYBER 74 computer system located at WrightPatterson Air Force Base, Ohio.

The observed workloads obtained from the accounting data are subjected to numerical derivations using cubic spline computer subroutines in generating cumulative frequency distributions and continuous probability density 
functions. Tables and graphs are presented for the derived functions. Four performance measures are given for the CYBER 74 system. The measures are total jobs executed per day, CPU utilization, an economic measure called computer resource unit (CRU), and turnaround time for jobs. Histograms, tables, and graphs are used to illustrate these performance measures.

Selection of ADPS for the Air Force Academy: A case study, R. E. Waters, SP500-18, pp. 71-74 (Sept. 1977).

Key words: Air Force Academy; benchmark tests; development of benchmarks; live test demonstrations; selection of ẠDPS.

This paper reviews the competitive acquisition of a large scale ADP system capable of supporting numerous interactive terminals while concurrently processing a large batch workload. The system was designed to act as an educational tool for the cadets while simultaneously supporting research in aerospace mechanics, applied mathematics, and other related areas.

Emphasis is placed on the examination of the techniques used in workload analysis and benchmark development associated with this acquisition. This paper cites examples of sound approaches used in these two areas and also discusses a major shortcoming in the benchmarking of teleprocessing systems.

Validation-All important in benchmarking, L. A. Johnson, SP500-18, pp. 75-83 (Sept. 1977).

Key words: benchmark audit procedures; bcnchmarking; benchmarks associated with government procurement of computers; validation.

This paper discusses validation of benchmarks associated with Government procurement of data processing equipment. It is not uncommon, after a procurement, to find that the computer system obtained did not have the processing capability or capacity required by the Request for Proposal (RFP), even though the vendor successfully passed a benchmark. In many cases this insufficiency can be attributed to inadequate validation of the benchmarking process. The benchmark is a tool for validating the capability of a vendor's computer system and there are certain characteristics which the benchmark must have. This paper describes these characteristics and some techniques for incorporating them into a benchmark. Benchmark preparation, benchmark execution, and software configuration are three areas which may affect the representativeness of the benchmark. Improper validation of the software configuration for the benchmark or the optimization applied to benchmark programs, for example, may result in a benchmark implementation which would be uncharacteristic of the production workload.

The approach taken to benchmark validation can greatly affect the ease and timeliness with which the benchmark demonstration can be performed. A well-defined set of audit procedures and a multiple-step validation, with appropriate contingency plans, are essential to reduce benchmark reruns and vendor protests. An approach for developing benchmark audit procedures is presented together with an outline of the steps in the benchmark validation process.

Determination of non-steady state conditions in performance measurement runs, N. N. Tendolkar, SP500-18, pp. 87-94 (Sept. 1977).

Key words: interactive computer system; performance measurement; renewal theory; statistical analysis; steady state.
An analytical technique is proposed for determining whether a performance measurement run of an interactive computer system is in steady state. The technique is illustrated by applying it to some measurements of a benchmark workload processed by IMS/VS under OS/VS2 (MVS). An approach is suggested to determine the length of measurement runs required to predict system transaction rate with a given reliability.

Capturing terminal traffic using a hardware monitor, T. M. Marter, SP500-18, pp. 95-105 (Sept. 1977).

Key words: data input bus; DATANET 355; data output bus; high-speed line adaptor; HIS 6080; interactive terminal; probe point development; programmable monitor; stimulator; terminal data.

This paper presents a detailed technical discussion of the HIS 6000 hardware monitoring project performed under subtasks 3 and 5 of task 398 of Contract Number DCA 100-74-C-0002. This paper presents a statement of the problem, a conceptual ovcrview of the DATANET 355 (and specifically the HSLA), the equipment selected, the probe points uscd and their development, and the overall measurement strategy for the terminal data capturing effort. Some additional discussion is presented on direction for continuing work in this area.

A new tool for measuring response time, G. Carlson and D. Ferreira, SP500-18, pp. 107-115 (Sept. 1977).

Key words: measuring response time; software monitor.

A new software monitor was recently announced that measures the response time of up to 100 terminals for over 9 hours with only 32 seconds of CPU time and $8 \mathrm{~K}$ bytes of core overhead. The data reported includes the minimum, maximum, average, standard deviation, and distribution of response times by terminal, by hour. Various other reports can be obtained.

Comparative study of task dispatching algorithms in an IBM MVT/ASP environment, S. E. Freeman and F. C. Green, SP500-18, pp. 119-135 (Sept. 1977).

Key words: benchmarking; dispatching algorithms; synthetic benchmarking.

The study presents the results of a comparison of three dispatching algorithms available in the IBM MVT/ASP environment. The three algorithms investigated are: MVT/ASP with standard dispatching; MVT/ASP with dynamic dispatching; and MVT/ASP using APG from the LSPS package. The comparisons were made using the synthetic benchmark approach described in the NBS publication "Use of Synthetic Benchmarks for Estimating Service Bureau Processing Charges." A relationship for the synthetic benchmark in terms of elapsed running time is also developed in addition to those described in the NBS publication. A discussion of the dispatching algorithms as well as the procedure used for construction of the benchmark are described.

Computer performance comparisons, W. D. Bennett, SP500-18, pp. 137-142 (Sept. 1977).

Key words: availability; basis statistics; offered load; performance.

This paper enumerates the necessary and sufficient conditions under which system accounting log data collected over one time interval of normal operations may be statistically compared to that over a second interval, obviating the need for benchmark experiments. It is determined that 
since major modifications to hardware and system software, as well as shifts in workload character occur at identifiable points in time, the actual operational environment may, in fact, be considered sufficiently "controlled" to permit the inspection of one random variable and its effect on system performance over two carefully selected intervals. Included is an account of such a comparison as performed at NARDAC Washington DC which uses these concepts to investigate the effect of a modification to the system scheduling algorithm on an HIS-6000 computer.

A study on the effectiveness of data blocking in an MVS environment, R. E. Paulhamus and G. E. Ward, SPSO0-18, pp. 143-158 (Sept. 1977).

Key words: blocking factor; data record; multiple regression; processing time; regression model.

In a production oriented computer center with IBM equipment, blocking of program data can be very advantageous yielding reduced resource utilization. This paper outlines the theory of data blocking, derives equations for two system variables, and interprets sample data in light of these equations. Regression tests help to show the similarity of theoretical and practical results.

A new methodology for computer system data gathering, $\mathbf{R}$. A. Orchard, SP500-18, pp. 159-182 (Sept. 1977).

Key words: boolean random sampling; computer system monitoring; data gathering.

Many computer system monitoring, data gathering, and reduction efforts ignore unbiased sampling techniques. The approaches generally taken are expensive and can make no scientifically based statement about the accuracy of the data gathered or consequent data reduction. The approach outlined in this paper attempts to correct these inadequacies by using the theory of random sampling.

Several new techniques are introduced for obtaining optimal error bounds for estimates of computer system quantities obtained from random samples. A point of view is taken (boolean variable random sampling) which makes it unnecessary to have any a priori knowledge of the population parameters of the phenomena being sampled. It is expected that the techniques introduced will significantly reduce monitoring overhead for computer systems while increasing the quality of the data gathered

The use of a validated event model in a comprehensive performance evaluation of an on-line minicomputer system, S. G. Gangwere, Jr., J. R. Hosler, and L. H. Stewart, SPS00-18, pp. 185-211 (Sept. 1977).

Key words: credit authorization system; critical resource; disk modelling; event model; measurement; modelling; resource dependency; system capacity; validation.

A performance evaluation technique is described that has been successfully applied to several on-line systems implemented on a NOVA minicomputer with a disk file. The technique is based on the use of a system event model, validated by direct, hardware-assisted measurement of system behavior. The event model is necessary for successful evaluation of system limits and for prediction of the effect of various design changes on system behavior. The fidelity required of the model is such that the hardware and software actions of the disk file system must be simulated in detail; considerations of disk modelling are examined.

Approximate evaluation of the effect of a bubble memory in a virtual memory system, W. T. K. Lin and A. B. Tonik, SP500-18, pp. 213-217 (Sept. 1977).
Key words: bubble memory; performance evaluation; system modeling; virtual memory system.

This paper uses an approximate queuing model to evaluate how a bubble memory will affect a virtual memory paging system. Specifically, we compare the throughput of two systems: one uses bubble memory, the other uses a fixedhead disk. We found that if we replace the fixed-head disk by a bubble memory, we can reduce the main memory size by at least two million bytes and still maintain the same system throughput. Although we make several assumptions about the model, these assumptions have been shown to be quite accurate by various authors.

The use of measured utilizations in queuing network analysis, J. Bouhana, SP500-18, pp. 219-225 (Sept. 1977).

Key words: operational analysis; queuing networks; queuing theory; utilization.

For closed queuing networks having simple, load-independent servers, computationally efficient equations are derived relating several interesting network properties to server utilization. The equations permit measured utilizations to be used in computing the probability of a specific number of jobs at a server, the expected number of jobs at a server, and the mean queue length at a saturated server. The expressions in the derived equations require far less knowledge about the detailed stochastic parameters of a network than is needed in classical queuing network analysis.

Applications of queuing models to ADP system performance prediction: A workshop summary, M. G. Spiegel, SP500-18, pp. 227-234 (Sept. 1977).

Key words: computer-communication networks; configuration analysis; model validation; performance management; performance prediction; queuing networks; sizing studies; system design.

The objective of this presentation is to summarize the state-of-the-art of queuing models from the position of Workshop Chairman of a recently completed workshop on the "Applications of Queuing Models to ADP System Performance Prediction." Over sixty queuing model practitioners gathered together at the National Technical Information Service (NTIS) on 7-8 March 1977. Topics discussed were divided into four general areas: (1) Application of Queuing Models to Feasibility and Sizing Studies; (2) Application of Queuing Models to System Design and Performance Management; (3) Queuing Model Validation; and (4) New Queuing Model Implementations. Eighteen speakers provided a broad viewpoint of applied queuing model issues.

A simulation study of initiator/terminator policy in OS/MVT, E. Fiegl and N. Schneidewind, SP500-18, pp. $235-$ 248 (Sept. 1977).

Key words: IBM OS/MVT; initiator policy; job scheduling; simulation.

An initiator is a task in IBM's OS/MVT which selects a job for execution and attempts to obtain the main storage, file space and devices which are necessary for job execution. A related task, the terminator releases these resources upon completion of the job. The order in which job classes are served by an initiator from the job queue is determined by the order of assigning job classes to an initiator. Initiators and their job class assignments are specified by the operator with start initiator commands at the console. The number of initiators started and the job class assignments 
significantly influence system performance. The number of initiators corresponds to the maximum degree of multiprogramming available. However, too many initiators could be detrimental to system performance because an initiator and terminator consume main storage during the execution of thcir functions. If the job input rate is low and there are many initiators, resources will be wasted. On the other hand, if the job input rate is high and there is an insufficient number of initiators, a large job queue will develop.

SP500-19. Computer science \& technology: Audit and evaluation of computer security. Proceedings of the NBS Invitational Workshop held at Miami Beach, Florida, Mar. 22-24, 1977 , Z. G. Ruthberg and R. G. McKenzie, Eds., Nat. Bur. Stand. (U.S.), Spec. Publ. 500-19, 256 pages (Oct. 1977) SNO03-003-01848-1.

Kcy words: audit standards; audit techniques; audit tools; audit training; communications security; computer controls; computer security; data integrity; interactive audit; internal audit; post-processing audit; program integrity.

The National Bureau of Standards, with the support of the U.S. General Accounting Office, sponsored an invitational workshop on "Audit and Evaluation of Computer Security," held in Miami Beach, Florida on March 22-24, 1977. Its purpose was to explore the state-of-the-art in this area and define appropriate subjects for future research. Leading experts in the audit and computer communities were invited to discuss the subject in one of ten sessions, each of which considered a different aspect. A consensus report was produced by each of the ten sessions and these reports form the body of these Proceedings. The ten topics reported on are: Internal Audit Standards, Qualifications and Training, Security Administration, Audit Considerations in Various System Environments, Administrative and Physical Controls, Program Integrity, Data Integrity, Communications, Post-Processing Audit Tools and Techniques, and Interactive Audit Tools and Techniques.

SP500-20. Computer science \& technology: Validating the correctness of hardware implementations of the NBS data encryption standard, J. Gait, Nat. Bur. Stand. (U.S.), Spec. Publ. 500-20, 46 pages (Nov. 1977) SN003-003-01861-9.

Key words: communications security; computer security; cryptography; encryption standard; interface requirements; Monte-Carlo testing; testbed; test cases; validating correctness.

This publication describes the design and operation of the NBS testbed that is used for the validation of hardware implementations of the Federal Information Processing Data Encryption Standard (DES). A particular implementation is verified if it correctly performs a set of 291 test cases that have been defined to exercise every basic element of the algorithm. As a further check on the correctness of the implementation an extensive Monte-Carlo test is performed. This publication includes the full specification of the DES algorithm, a complete listing of the DES test set and a detailed description of the interface to the testbed.

SP500-22. Computer science \& technology: Guide to computer program directories, A. G. Chattic, Compiler, Nat. Bur. Stand. (U.S.), Spec. Publ. 500-22, 168 pages (Dec. 1977) SN003-003-01867-8.

Key words: computer. program index; Federal Software Exchange Program; proprietary software; public domain software; software exchange; software guide; software index; software sharing.

The Guide is a product of the Computer Information Section's efforts to establish and maintain a reference index to computer programs. CIS has over the past several years collected catalogs that contain proprietary and public domain software and answered queries on the availability of computer programs already developed, tested on in use.

Included here are abstracts of catalogs from the collection; no computer program abstracts are included individually. Information concerning specific programs may be obtained from the catalogs abstracted here.

Key word indexes for applications and systems programs are included to help users identify catalogs which list programs in their area of interest.

SP500-23. Computer science \& technology: An architecture for a robot hierarchical control system, A. J. Barbera, Nat. Bur. Stand. (U.S.), Spec. Publ. 500-23, 227 pages (Dec. 1977) SN003-003-01874-1.

Key words: adaptive; automation; computer; control; goaloriented; hierarchical control; robot; sensors.

Complex automation systems, such as industrial robots, require a computer-based control system for the effective utilization of this advanced technology. This report describes such a control system developed at the National Bureau of Standards. The approach has been to partition the control system into a hierarchy of different functional levels. This has proven to be a powerful technique in obtaining sensor-controlled robot behavior at a minimum cost of programming time and computer size. Further, this partitioning has greatly simplified the implementation of additional functions and sensors. This report discusses the control system, its implementation and use, and provides a documented listing of all of the control programs.

\subsection{APPLIED MATHEMATICS SERIES}

Mathematical tables, manuals, and studies of special interest to physicists, engineers, chemists, biologists, mathematicians, computer programmers, and others engaged in scientific and technical work.

No publications issued in this series during this period.

\subsection{NATIONAL STANDARD REFERENCE DATA SERIES}

Provides quantitative data on the physical and chemical properties of materials, compiled from the world's literature and critically evaluated. Developed under a worldwide program coordinated by NBS. Program under the authority of National Standard Data Act (Public Law 90-396).

NSRDS-NBS59. Selected specific rates of reactions of transients from water in aqueous solution. III. Hydroxyl radical and perhydroxyl radical and their radical ions. Farhataziz and A. B. Ross, Nat. Stand. Ref. Data Ser., Nat. Bur. Stand. (U.S.), 59, 122 pages (Jan. 1977) SN003-003-01731-1.

Key words: aqueous solution; chemical kinetics; data compilation; hydroxyl radical; oxide radical ion; perhydroxyl radical; radiation chemistry; rates; superoxide ion.

Rates of reactions of $\mathrm{OH}$ and $\mathrm{HO}_{2}$ with organic and inorganic molecules, ions, and transients in aqueous solution have been tabulated, as well as the rates for the corresponding radical ions in aqueous solution $\left(\mathrm{O}^{-}\right.$and $\left.\mathrm{O}_{2}^{-}\right)$. Most of the rates have been obtained by radiation chemistry methods, both pulsed and steady-state; data from photochemistry and thermal methods are also included. Rates for over one thousand reactions are listed. 


\subsection{BUILDING SCIENCE SERIES}

Disseminates technical information developed at the Bureau on building materials, components, systems, and whole structures. The series presents research results, test methods, and performance criteria related to the structural and environmental functions and the durability and safety characteristics of building elements and systems.

BSS62. Evaluation of structural properties of masonry in existing buildings, S. G. Fattal and L. E. Cattaneo, Nat. Bur. Stand. (U.S.), Bldg. Sci. Ser. 62, 127 pages (Mar. 1977) SN003-003-01738-8.

Key words: analysis; compressive strength; deflection; design; flexural strength; masonry walls; racking strength; seismic loading; shear strength; shear wall; stiffness.

The current state of knowledge on the structural behavior of masonry is synthesized to develop a methodology for the evaluation of the load capacity of masonry walls in existing buildings. A procedure is described for direct sampling and testing of specimens removed from masonry walls of buildings to determine their strength in shear, flexure and compression, and to measure their load-deformation characteristics. A documentation of strength and stiffness properties obtained from available test data is included to provide an alternate source of information on masonry of comparable construction. Sample calculations of masonry building analysis for seismic forces are given in Appendices $\mathbf{A}$ and $\mathbf{B}$.

BSS93. Dynamic performance of a residential air-to-air heat pump, G. E. Kelly and J. Bean, Nat. Bur. Stand. (U.S.), Bldg. Sci. Ser. 93, 18 pages (Mar. 1977) SN003-003-01691-8.

Key words: cooling and heating coefficients of performance; effective seasonal heating COP; heat pumps; heat pumps and energy conservation; part-load performance; seasonal performance factor.

Information is presented on the dynamic performance of a 5-ton air-to-air heat pump, which was installed in a residence in the Washington, D.C. area. The effect of part-load operation on the heat pump's COOLING and HEATING coefficients of performance (COP) was determined. When the pump operated in the heating mode at outdoor temperatures below $40^{\circ} \mathrm{F}(4.4$ ${ }^{\circ} \mathrm{C}$ ), a considerable discrepancy was found to exist between the measured performance and the performance data supplied by the manufacturers. This discrepancy is apparently due to the adverse effects of frost buildup and defrosting of the outdoor coil. The seasonal performance factor (SPF) of the heat pump was estimated and then traced back to the power plant to obtain an "EFFECTIVE SPF" which is then compared with the performance which might be expected from fossil-fuel heating equipment.

BSS94. Investigation of the Skyline Plaza Collapse in Fairfax County, Virginia, E. V. Leyendecker and S. G. Fattal, Nat. Bur. Stand. (U.S.), Bldg. Sci. Ser. 94, 91 pages (Feb. 1977) SNO03-003-01696-9.

Key words: apartment building; collapse; concrete; concrete strength; construction; flexure; progressive 'collapse; shear; strength.

The collapse of the Skyline Plaza apartment building A-4 has been studied by using information contained in case records of the Occupational Safety and Health Administration (OSHA),
U.S. Department of Labor and obtained from on-site inspections by investigators from the National Bureau of Standards.

Noncompliance with OSHA construction standards has been identified with regard to formwork, field-cured concrete specimens and crane installation. Specifically, the construction procedures did not comply with standards for the removal of supporting forms. It is concluded that premature removal of forms was a contributing factor to the collapse in building A4.

An analysis of the 23rd-floor slab indicates that its most likely mode of failure was in shear around one or more columns in section 3 of the floor slab. The strength of the 23rd-floor slab on the day of collapse has been estimated to be at a level that removal of shoring could have produced shear failure in the slab.

BSS96. Hourly solar radiation data for vertical and horizontal surfaces on average days in the United States and Canada, $T$. Kusuda and K. Ishii, Nat. Bur. Stand. (U.S.), Bldg. Sci. Ser. 96, 412 pages (Apr. 1977) SNO03-003-01698-5.

Key words: computer; energy; radiation; solar.

The majority of the available solar radiation data for the United States and Canada are in the form of either monthly averages of daily total radiation on a horizontal surface or hourly values for cloudless days on horizontal, tilted, and vertical surfaces. Hourly solar radiation data for walls and roofs under "average" solar conditions were computed in order to be able to make estimates of the effect that incident solar radiation has on a building and/or its heating and air conditioning system over a heating and/or cooling season. Calculation procedures developed by Liu and Jordan were modified and hourly solar radiation data were compiled for 80 locations in the United States and Canada. Data were also computed and tabulated for a new parameter called "sol-air temperature for glass."

'BSS97. Evaluation of ventilation requirements and energy consumption in existing New York City school buildings, S. T. Liu, C. M. Hunt, and F. J. Powell, Nat. Bur. Stand. (U.S.), Bldg. Sci. Ser. 97, 69 pages (Apr. 1977) SN003-003-017680 .

Key words: computerized thermal simulation; $\mathrm{CO}_{2}$ concentration; energy conservation in schools; energy consumption; energy utilization in schools; oxygen content; reduced ventilation rate; school operation schedule; ventilation test.

A study was made, under the sponsorship of the National Science Foundation and in collaboration with the New York City Board of Education, of the energy consumption and ventilation requirements of typical existing urban public schools, for the purpose of determining the pattern of energy usage in such public schools so that effective energy conservation measures can be taken both for existing schools and for future new school design.

Electricity and fuel-oil consumption data from May 1970 through April 1973 on 19 existing schools provided by the New York City Board of Education were analyzed. Analysis showed that the overall energy consumption of 17 of the 19 schools varied by a factor of less than 2 . Average yearly consumptions per $1,000 \mathrm{ft}^{2}\left(92.9 \mathrm{~m}^{2}\right)$ gross floor area of $5,250 \mathrm{kWh}$ of electrical energy and 417 gallons of No. 6 fuel oil $\left(2.03 \times 10^{8} \mathrm{~J}\right.$ and $0.017 \mathrm{~m}^{3}$ per $\mathrm{m}^{2}$ of gross floor area), were selected as a norm 
typical of the existing schools. These figures correspond to $82,400 \mathrm{Btu} /$ year-(gross) $\mathrm{ft}^{2}\left(29.7 \mathrm{~W} / \mathrm{m}^{2}\right)$ at the building line or an estimated $126,000 \mathrm{Btu} /$ year-(gross) $\mathrm{ft}^{2}\left(45.4 \mathrm{~W} / \mathrm{m}^{2}\right)$ when calculated in terms of raw fuel at the generating plant. The figures can be used for future comparison purposes with a new energy conservation school. A computerized thermal energy simulation, using the program NBSLD, was performed on one of the schools having an energy consumption close to the norm. The results showed good agreement between the predicted and measured monthly electricity and fuel-oil consumption data. Detailed analysis of the pattern of energy consumption showed that 75 percent of the thermal energy during the heating season was used for the heating of outdoor air for ventilation purposes, and 80 percent of the electrical energy was used for lighting.

A ventilation test was conducted over a 4-day period in a typical classroom. It was found that a reduction of the air change rate from the normal 4.6 changes per hour to 1.3 changes per hour did not significantly change the indoor environment as expressed in terms of temperature, relative humidity, oxygen content level, and $\mathrm{CO}_{2}$ concentration level. However, computation indicates that, when no mechanical ventilation was provided, the $\mathrm{CO}_{2}$ concentration level would exceed the 0.5 percent safety limit, indicating that natural air infiltration alone will not provide adequate ventilation for the general health and safety of the students.

BSS98. Design methods for reducing the risk of progressive collapse in buildings, E. V. Leyendecker and B. R. Ellingwood, Nat. Bur. Stand. (U.S.), Bldg. Sci. Ser. 98, 68 pages (Apr. 1977) SN003-003-01765-5.

Key words: abnormal loading; alternate path; building code; design criteria; probability; progressive collapse; reliability; structural engineering; uncertainty.

A progressive collapse is described as a chain reaction of failures following damage to a relatively small portion of a structure. The damage which results characteristically is out of proportion to the damage which initiated the collapse. The basic concepts associated with progressive collapse are described and the background leading to the concepts is summarized. Possible causes of progressive collapse are discussed, with concentration on abnormal events which have a low probability of occurrence but may have catastrophic consequences. A case study of the probability of structural failure as a consequence of one type of abnormal load (a gas explosion) shows that these probabilities exceed levels generally considered acceptable to engineers.

Direct design strategies for reducing progressive collapse are described as (1) the Alternate Path Method and (2) the Specific Local Resistance Method. Equations for load combinations, including appropriate load factors, are presented for each design method. The advantages and disadvantages of each approach are described and it is concluded that the alternate path method affords the designer more flexibility. Although the design strategies are applicable to any type of structure at any time in its life cycle, this report provides detailed recommendations for completed buildings.

BSS100-1. Building to resist the effect of wind. Volume 1: Overview, R. D. Marshall, N. J. Raufaste, Jr., and S. A. Kliment, Nat. Bur. Stand. (U.S.), Bldg. Sci. Ser. 100-1, 34 pages (May 1977) SNO03-003-01717-5.

Key words: codes and standards; disaster mitigation; housing; low-rise buildings; socio-economics; structural connections; technology transfer; wind loads.

This document presents the background, goals, procedures and results of a project to develop improved design criteria that would make low-rise buildings in developing countries better able to withstand the effects of extreme winds. The project stemmed from the belief that additional research on wind was needed to reduce loss of life and property, human suffering, disruption of productive capacity and costs of disaster relief. The $31 / 2$ year project began in early 1973 and produced these results: the development of improved design criteria; a methodology for the estimation of extreme wind speeds; the development of wind tunnel modeling techniques; a heightened awareness of the wind problem and the need to guard against it; the emergence of useful working relationships between NBS/AID and public and private decisions makers in developing countries subject to extreme winds, especially the Philippines, Jamaica and Bangladesh; and the documentation of important information in the areas of wind design speeds and pressure coefficients, economic forecasting, socio-economic and architectural concerns, and construction detailing practices. Also during the project, a program began in the training of professionals and technicians in developing countries to carry out wind measurements and analyses. In addition, methods to ensure transfer of information to user groups were employed.

BSS100-2. Building to resist the effect of wind. Volume 2: Estimation of extreme wind speeds and guide to the determination of wind forces, E. Simiu and R. D. Marshall, Nat. Bur. Stand. (U.S.), Bldg. Sci. Ser: 100-2, 29 pages (May 1977) SN003003-01718-3.

Key words: building codes; buildings; codes and standards; housing; hurricanes; pressure coefficients; probability distribution functions; risk; statistical analysis; storms; structural engineering; tropical storms; wind loads; wind speeds.

The Agency for International Development sponsored with the National Bureau of Standards, a three and a half year research project to develop improved design criteria for lowrise buildings to better resist the effects of extreme winds.

Project results are presented in five volumes. Volume 1 gives a background of the research activities, accomplishments, results, and recommendations. In Volume 3 , a guide for improved use of masonry fasteners and timber connectors are discussed. Volume 4 furnishes a methodology to estimate and forecast housing needs at a regional level. Socioeconomic and architectural considerations for the Philippines, Jamaica, and Bangladesh are presented in Volume 5.

Volume 2 consists of two reports. The first reviews the theoretical and practical considerations that are pertinent to the estimation of probabilistically defined wind speeds. Results of the statistical analysis of extreme wind data in the Philippines are presented and interpreted. Recommendations based on these results are made with regard to the possible redefinition of wind zones, and tentative conclusions are drawn regarding the adequacy of design wind speeds currently used in the Philippines. Report two describes some of the more common flow mechanisms which create wind pressures on low-rise buildings and the effects of building geometry on these pressures. It is assumed that the basic wind speeds are known and a procedure is outlined for calculating design wind speeds which incorporates the expected life of the structure, the mean recurrence interval, and the wind speed averaging time. Pressure coefficients are tabulated for various height-to-width ratios and roof slopes. The steps required to calculate pressures and total drag and uplift forces are summarized and an illustrative example is presented.

BSS100-3. Building to resist the effect of wind. Volume 3: A guide for improved masonry and timber connections in buildings, S. G. Fattal, G. E. Sherwood, and T. L. Wilkinson, Nat. Bur. Stand. (U.S.), Bldg. Sci. Ser. 100-3, 56 pages (May 1977) SN003-003-01719-1. 
Key words: codes and standards; connectors; fasteners; low-rise buildings; masonry walls' structural design; technology transfer; timber roofs; timber walls; wind effects.

The Agency for International Development sponsored with the National Bureau of Standards, a $3 \frac{1}{2}$ year research project to develop improved design criteria for low-rise buildings to better resist the effects of extreme winds. This report contains information gathered from this project.

This report investigates the use of connectors for masonry and timber elements in low-rise buildings. Connector characteristics and construction details that improve a building's response to extreme wind effects are given primary emphasis. Recommendations include improvements through better utilization of connector technology showing good feasibility of introduction in developing countries. The building systems considered in this study fall within the low to moderate cost category.

Project results are presented as five volumes. Volume 1 gives an overview of the research activities, accomplishments, results, and recommendations. Volume 2 presents a methodology to estimate design wind speeds and a guide to determine wind forces. In Volume 3, a guide for improved use of masonry fasteners and timber connectors are discussed. Volume 4 furnishes a methodology to estimate and forecast housing needs at a regional level. Socio-economic and architectural considerations of the Philippines, Jamaica, and Bangladesh are presented in Volume 5.

BSS100-4. Building to resist the effect of wind. Volume 4: Forecasting the economics of housing needs: A methodological guide, J. G. Kowalski, Nat. Bur. Stand. (U.S.), Bldg. Sci. Ser. 100-4, 36 pages (May 1977) SN003-003-01720-5.

Key words: development; forecasts; growth; housing needs; projections

The Agency for International Development sponsored with the NBS, a $3 \frac{1}{2}$ year research project to develop improved design criteria for low-rise buildings to better resist the effects of extreme winds. Housing is probably the single most important consumer good in most economies. Measuring the size of a region's unmet housing need is a first step to planning and implementing improvements in housing conditions. This report analyzes the concept of housing needs in an economic framework. A methodology for estimating and projecting housing needs at the regional level is developed. The methodology attempts to make explicit the income redistribution intent which is the core meaning behind the concept of housing needs.

Project results are presented in five volumes. Volume 1 gives an overview of the research activities, accomplishments, results and recommendations. Volume 2 presents a methodology to estimate design wind speeds and a guide to determine wind forces. Volume 3 discusses a guide for improved use of masonry fasteners and timber connectors. Volume 4 furnishes a methodology to estimate and forecast housing needs at a regional level. Socio-economic and architectural considerations of the Philippines, Jamaica and Bangladesh are presented in Volume 5.

BSS100-5. Building to resist the effect of wind. Volume 5: Housing in extreme winds: Socio-economic and architectural considerations, S. A. Kliment, Nat. Bur. Stand. (U.S.), Bldg. Sci. Ser. 100-5, 37 pages (May 1977) SN003-003-01721-3.

Key words: architectural; design; housing; low income; lowrise buildings; sites and services; socio-economic; structural design; wind-resistant.
Typical socio-economic conditions in the Philippines, Jamaica, and Bangladesh are identified. These conditions include strong respect for traditional materials and methods of house construction, and suspicion of innovative forms and approaches; a rising proportion of urban poor who live in squatter settlements; and a rising ratio of inhabitants whose incomes are at a level where they cannot afford housing of any kind. The importance of land from a social standpoint is stressed. The report reviews the sites and services concept whereby low income persons are provided a site equipped with basic utilities but must erect and maintain a house upon it. Recommendations include: placement of buildings to exploit terrain; adherence to good practices in the configurations of the main elements of a house (these are shown by means of simple drawings); use of cheap, strong and locally available materials.

This report is one of a five volume series describing the results of a three and a half year research study to develop improved design criteria for low-rise buildings to better resist the effects of extreme winds. The project was sponsored by the Agency for International Development, Dept. of State. Vol. 1 gives a background of the research activities, accomplishments, results and recommendations. Vol. 2 presents a methodology to estimate design wind speeds and a guide to determine wind forces. In Vol. 3, a guide fór improved use of masonry fasteners and timber connectors are discussed. Vol. 4 furnishes a methodology to estimate and forecast housing needs at a regional level.

BSS103. Exploratory study of glowing electrical connections, W. J. Meese and R. W. Beausoliel, Nat. Bur. Stand. (U.S.), Bldg. Sci. Ser. 103, 29 pages (Oct. 1977) SNO03-003-01859-7.

Key words: arcing/sparking; branch circuit; contact resistance; electrical connections; fire hazard; glowing electrical connections.

This report describes and characterizes with quantifiable electrical and thermal measures the extent to which loose electrical connections in residential-type branch circuits have overheated in the laboratory. With loose electrical connections, which conceivably could be inadvertently duplicated in field installations, but with otherwise normal installation and operating conditions, visible glows have been observed under laboratory test conditions in normal 120-volt, 15 and 20 ampere branch circuits with both copper and aluminium wire. Characteristics of the glow condition are differentiated from arcing/sparking as sometimes observed in making or breaking electric circuits.

Glowing electrical connections may dissipate as much as 35 watts of power with a current of 15 amps in the circuit and as much as 5 watts with a current of $0.8 \mathrm{amp}$ in the circuit. Temperatures over $7500^{\circ} \mathrm{F}$ were measured on the "break-off tab" of receptacles. Metal outlet boxes housing glowing connections in an insulated wall test set-up representative of a common type of residential construction attained temperatures in excess of $450{ }^{\circ} \mathrm{F}$. In laboratory tests under repetitive, intermittent and periodic cycles, a connection on a steel wire-binding screw of a receptacle open to the air had sustained glow conditions maintained for over 100 hours. Glowing connections will not perceptibly affect the electrical performance function of lights, appliances or other electrical loads, and will not "blow" fuses, trip circuit breakers or operate ground fault circuit interrupters.

BSS104. Window design strategies to conserve energy, S. R. Hastings and R. W. Crenshaw, Nat. Bur. Stand. (U.S.), Bldg. Sci. Ser. 104, 209 pages (June 1977) SN003-003-01794-9.

Key words: air-tightness; daylighting; energy-conservation; insulation; shading; solar-heating; ventilation; windows.

A multitude of design strategies are available to achieve energy-efficient windows. Opportunities for improving window 
performance fall into six groups: site, exterior appendages, frame, glazing, interior accessories, and building interior. Design strategies within these groups can improve one or more of the six energy functions of windows: solar heating, daylighting, shading, insulation, air tightness, and ventilation. Included in this report are 33 strategies; an explanation of the physical phenomena responsible for each strategie's energy performance, summarized energy and non-energy advantages and disadvantages; aesthetic considerations; cost approximations; example installations, laboratory studies, or calculations by the authors; and references. Intended readers include professional designers, lessors and owners of commercial space, home buyers and owners, window component manufacturers, and researchers. The report's purpose is to draw attention to the wide range of options currently available to conserve energy with windows.

BSS106. Earthquake resistant masonry construction: National workshop. Proceedings of a National Workshop held at the National Bureau of Standards, Boulder, CO, Sept. 13-16, 1976, R. A. Crist and L. E. Cattaneo, Eds., Nat. Bur. Stand. (U.S.), Bldg. Sci. Ser. 106, 372 pages (Sept. 1977) SN003003-01872-4.

Key words: building codes and standards; design criteria; earthquake resistance; masonry construction; seismic design; structural design; structural engineering; structural research.

The National Workshop on Earthquake Resistant Masonry Construction provided an exchange of information between researchers and practicing engineers for the purpose of orienting pertinent research toward national needs concerning current problems related to design criteria. These proceedings contain the reports presented by researchers and by users of design criteria, as well as transcripts of the discussions which followed the individual presentations. In addition, the proceedings include recommendations which emanated from working sessions held by five working groups of participants. Technical areas covered by the groups were (1) code requirements, (2) design criteria, (3) mathematical models, (4) test standardization and material properties, and (5) retrofit and repair. The recommendations were derived to identify research which would lead to improved output in each of the technical areas in order to benefit national needs. These proceedings include the following Dapers (indented):

A perspective view: Brick masonry construction in the U.S.A., A. H. Yorkdale, BSSI06, pp. 9-16 (Sept. 1977).

A perspective view: Concrete masonry construction in the U.S.A., T. B. Redmond, BSS1 06, pp. 17-39 (Sept. 1977).

Earthquake resistant masonry construction: A perspective view of needed research, R. A. Crist, BSS106, pp. 40-59 (Sept. 1977).

Key words: building codes and standards; design criteria; earthquake resistance; limit states design; masonry construction; materials testing standardization; mathematical models; rehabilitation; retrofit; seismic design; structural design; structural research.

An overview of the areas of research needed for improved engineering design of earthquake resistant masonry construction is given and followed by a presentation of the information in the form of a 3-dimensional matrix model. The elements of the matrix representing areas of research and their coordinate intersections (combinations) are used to develop the structuring of a workshop in which 5 major areas of consideration are shown to emerge. These 5 categories of: design criteria; standardized tests for materi- al properties; mathematical models; rehabilitation and retrofit; and code requirements; together with respective task statements are each described, in order to organize corresponding workshop groups for accomplishment of the tasks. In conclusion, an order of assigning priorities to needed research is established.

Seismic research on masonry-University of California, Berkeley, 1972-1977, R. L. Mayes, R. W. Clough, and Y. Omote, BSS106, pp. 60-90 (Sept. 1977).

Key words: connections; houses; masonry; piers; research; seismic; shear walls; spandrel beams.

This paper describes the scope of the seismic research program that has been ongoing at the Earthquake Engineering Research Center, University of California, Berkeley since September, 1972. The program currently has two major parts. The first is an experimental and analytical study of multistory buildings and the second is an experimental study of housing construction. A summary of results of tests completed to date is included together with a description 'of tests currently in progress and those planned in the near future.

Expected performance of uniform building code designed masonry buildings, R. L. Mayes, R. W. Clough, Y. Omote, and S. W. Chen, BSS106, pp. 91-113 (Sept. 1977).

Key words: codes; design; dynamic analysis; masonry; shear walls.

The paper presents a summary of a study on the evaluation of the seismic design sections of the 1972, 1973, 1974 and 1976 Uniform Building Codes, and the recommended Comprehensive Seismic Design Provisions for Buildings prepared by the Applied Technology Council (ATC-3). In order to evaluate the various codes a three, a nine and a seventeen story building of similar floor plan were studied. The seismic design stresses were calculated in these buildings by the specific code procedures as well as the stress state predicted by a realistic dynamic earthquake response procedure. The adequacy of the codes was then evaluated by comparison of the two types of stress predictions.

The conclusion of the study was that the increasing conservatism of the more recent codes is justified and that greater conservatism is necessary in the most recent codes in buildings of moderate height, such as the nine and seventeen story buildings considered in this study.

An experimental study of concrete masonry under seismictype loading, G. A. Hegemier, G. Krishnamoorthy, and R. O. Nunn, BSS106, pp. 114-153 (Sept. 1977).

Key words: earthquake damage analysis; masonry; rheology, material.

This paper outlines portions of a comprehensive research program on concrete masonry. Objectives, scope, methodology, and sample results obtained to date are presented. Where appropriate practical implications of the latter are delineated. Future experiments are discussed.

An experimental study of connections in reinforced concrete masonry: Masonry structures under seismic loading, J. Isenberg, G. A. Hegemier, and A. Anvar, BSS106, pp. 154-165 (Sept. 1977).

Key words: masonry; masonry panels; seismic loading.

This paper describes a University of California, San Diego test program to determine the behavior of typical floor-to-wall connections utilized in reinforced concrete 
masonry structures. The experiments are part of an extensive research effort on the seismic response of reinforced concrete masonry buildings.

Masonry research and codes in the United Kingdom, W. B. Cranston, BSS106, pp. 166-176 (Sept. 1977).

Key words: masonry codes, United Kingdom; masonry research.

A brief description of the various research projects known to the author is given, defining the objectives, conclusions and tentative conclusions where appropriate. Selected references are also given. The second part of the paper gives details of some of the proposed changes and additions to the United Kingdom Masonry Code.

The capacity of unreinforced masonry shear walls under membrane loads, S. G. Fattal, BSSI06, pp. 177-197 (Sept. 1977).

Key words: brick; clay masonry; concrete block; concrete masonry; failure modes; load capacity; masonry walls; shear walls; splitting strength; ultimate capacity.

Four different types of unreinforced masonry walls and miscellaneous companion prisms were subjected to various configurations of membrane forces to study shear wall limit states in both clay brick and concrete masonry. The specimens that were subjected to diagonal compression, in combination with edge loads applied normal to the bed joint, generally displayed failure modes characterized by diagonal splitting through the masonry units or by separation along the mortar joints. The test results exhibited a dependence between diagonal load capacity and the intensity of normal lodas. Square specimens of dissimilar size but similar in composition developed comparable strength when subjected to diagonal loading alone, providing an experimental basis for evaluating the diagonal compressive strength of masonry by standard tests using small prisms. The directional variation of strength was investigated by means of diametral compression tests of circular walls and diagonal compression tests of rectangular prisms having different aspect ratios.

Canadian code requirements for masonry in earthquake zones, A. H. P. Maurenbrecher, BSSI06, pp. 198-213 (Sept. 1977).

Key words: bricks; buildings; Canada; concrete blocks; design standards; earthquake resistant structures; masonry.

This paper gives a short review of Canadian seismic requirements for masonry buildings contained in the 1975 National Building Code of Canada and in the proposed revision to the masonry code-CSA draft Standard S304-Masonry Design and Construction for Buildings.

HEW, activity in masonry design and construction, $R$. M. Webb, BSSI06, pp. 215-217 (Sept. 1977).

NAVFAC interests in earthquake resistant masonry construction, J. V. Tyrrell, BSSI 06, p. 220 (Sept. 1977).

Summary of the Veterans Administration Engineering Program, P. M. Sears, BSS106, pp. 221-227 (Sept. 1977).

Seismic requirements of the Phoenix Construction Code, $\mathbf{R}$ C. Hildebrandt, BSSI06, pp. 228-237 (Sept. 1977).

Concerns of the NYC Housing Authority in the design of multifamily masonry residential structures, E. Nadel, BSS106, pp. 238-242 (Sept. 1977).
Requirements of a seismic resistant masonry construction code, C. C. Lederer, BSS106, pp. 243-248 (Sept. 1977).

Some research needs of earthquake-resistant masonry, J. E. Amrhein, BSS106, pp. 255-258 (Sept. 1977).

Key words: anchor bolts; bond; damping; ductility; earthquake resistance; energy absorption; modulus of elasticity; partial reinforcing; risk; shear modulus; testing; ultimate strength.

This paper outlines in general terms many specific needs of the masonry industry to obtain information, establish performance parameters, improve the final product and develop design criteria. It points up the many areas where information is lacking as related to dynamic seismic performance and reliability.

Suggested researchable items relating to masonry construction, J. F. Meehan, BSSI 06, pp. 259-274 (Sept. 1977).

Key words: allowable bolt loads, end distance, edge distance and spacing; drift; face shells, reinforcing splices; high lift grouting; shotcrete, surface wave instrumentation; veneer anchorage.

The purpose of this paper is to present a brief overview of needs believed necessary to improve the resistance of masonry construction to earthquake forces.

A view on some prerequisites for improved earthquake resistant masonry construction, M. E. Werner, BSSI06, pp. 275-282 (Sept. 1977).

Arching in masonry walls subjected to out-of-plane forces, B. L. Gabrielsen and K. Kaplan, BSSI06, pp. 283-313 (Sept. 1977).

Key words: arching; masonry walls.

Nonreinforced masonry walls, confined between rigid supports that restrict in-plane motions and rotation of wall elements about the supports, can display very high resistance to out-of-plane forces by forming three-hinged arches after cracking in flexure. Analysis indicates that two different types of arching can occur depending on whether a wall is tightly fitted between supports (rigid arching), or is separated from one support by a small gap (gapped arching).

Special static tests were devised to investigate the kinds of loading that occur at the hinges of the arches (line loadings). These tests indicated that rigid arching walls can resist 6 to 8 times the loads that gapped arching walls can, although gapped arching walls are still considerably stronger than either cantilevered walls or walls mounted as simple beams.

An extensive dynamic test program involving full-scale walls, $81 / 2 \mathrm{ft}(2.6 \mathrm{~m})$ high and $12 \mathrm{ft}(3.7 \mathrm{~m})$ wide, subjected to blast waves in a large shock tunnel, confirmed that brick walls undergoing rigid arching could withstand loadings as high as $19 \mathrm{psi}\left(131 \mathrm{kN} / \mathrm{m}^{2}\right)$ equivalent to about $34 \mathrm{~g}$. These walls cracked in flexure but did not fail, and then withstood many cycles of reversing loadings with maxima equivalent to accelerations greater than $1 \mathrm{~g}$.

Some thoughts on minimum requirements for the seismic design of load bearing masonry buildings, R. M. Gensert, BSS106, pp. 314-326 (Sept. 1977).

Key words: current research; ductility; full scale testing; high-rise masonry; scale factors; shear walls.

A shear wall is analyzed for a 5, 10 and 15-story building for two typical wind zones and four seismic zones. The 
result shows that one might design a tall unreinforced building in all zones but 3 and $\mathbf{4}$ for seismic conditions. It is suggested that the need for criteria regarding ductility should come from the testing of actual buildings. 


\subsection{FEDERAL INFORMATION PROCESSING STANDARDS PUBLICATIONS}

Publications in this series collectively constitute the Federal Information Processing S،andards Register. Register serves as the official source of information in the Federal Government regarding standards issued by NBS pursuant to the Federal Property and Administrative Services Act of 1949 as amended, Public Law 89-306 (79 Stat. 1127), and as implemented by Executive Order 11717 (38 FR 12315, dated May 11, 1973) and Part 6 of Title 15 CFR (Code of Federal Regulations). This series is available only from the National Technical Information Services, Springfield, VA 22161 . See page 17 for price list.

FIPS PUB 10-2. Countries, dependencies, and areas of special sovereignty, H. E. McEwen, Standards Coordinator, Nat. Bur. Stand. (U.S.), Fed. Info. Process. Stand. Publ. (FIPS PUB) 10-2, 31 pages (Mar. 1977).

Key words: ADP standards; computers; data elements and codes; data processing; Federal Information Processing Standards; geography; information processing standards; information system; representations and codes; standards; statistical data.

This publication provides a list of geographical-political entities of the world and associated standard codes. These entities include independent states, dependent areas, areas of quasi-independence, noncontiguous territories, possessions without population, areas with special sovereignty associations, areas without sovereignty, political regimes not recognized by the United States, and outlying areas of the United States.

FIPS PUB 11-1. Dictionary for information processing, J. Walkowicz, Standards Coordinator, Nat. Bur. Stand. (U.S.), Fed. Info. Process. Stand. Publ. (FIPS PUB) $I I-I, 4$ pages (Sept. 1977).

Key words: computers; data processing; definitions; dictionary for information processing; Federal Information Processing Standards Publication; information processing; terms; vocabulary.

This publication adopts X3/TR-1, AMERICAN NATIONAL DICTIONARY FOR INFORMATION PROCESSING, which provides a common reference within the Federal Government for terms and definitions used in such information processing activities as the representation, communication, interpretation and processing of data by human or automatic means.

The DICTIONARY consists of a single alphabetic listing of over 4000 terms and their definitions. The usage label (ISO) is used in the DICTIONARY to indicate terms and definitions that have been approved by the International Organization for Standardization.

FIPS PUB 16-1. Bit sequencing of the Code for Information Interchange in serial-by-bit data transmission, G. Clark, Standards Coordinator, Nat. Bur. Stand. (U.S.), Fed. Info. Process. Stand. Publ. (FIPS PUB) 16-1, 4 pages (1977).

Key words: American Standard Code for Information Interchange; ASCII; communications; data communications equipment; data processing terminal equipment; data transmission; Federal Information Processing Standards; serialby-bit; serial-by-character; telecommunications; teleprocessing

This standard specifies the method of transmitting the Standard Code for Information Interchange (FIPS 1) in the serial- by-bit, serial-by-character data transmission. This revision supersedes FIPS PUB 16 and reflects changes necessary to accommodate FIPS 1 when operating in either 7 or 8 bit coded environments. This standard is identified also as Federal Standard Number 1010.

FIPS PUB 17-1. Character structure and character parity sense for serial-by-bit data communication in the Code for Information Interchange, G. Clark, Standards Coordinator, Nat. Bur. Stand. (U.S.), Fed. Info. Process. Stand. Publ. (FIPS PUB) 17-1, 4 pages (1977).

Key words: American Standard Code for Information Interchange; ASCII; character parity sense; character structure; communications; data transmission; Federal Information Processing Standards; serial-by-bit; telecommunications; teleprocessing.

This standard specifies the method of transmitting the Standard Code for Information Interchange (FIPS 1) in the serialby-bit, serial-by-character data transmission. This revision supersedes FIPS PUB 17 and reflects changes necessary to accommodate revisions prescribed by FIPS 1 when operating in either 7 or 8 bit coded environments. This standard is identified also as Federal Standard Number 1011.

FIPS PUB 18-1. Character structure and character parity sense for parallel-by-bit data communication in the code for information interchange, G. Clark, Standards Coordinator, Nat. Bur. Stand. (U.S.), Fed. Info. Process. Stand. Publ. (FlPS $P U B)$ ) 18-1, 4 pages (1977).

Key words: American Standard Code for Information Interchange; ASCII; character structure; communications; data transmission; Federal Information Processing Standards; parallel-by-bit; parity sense; serial-by-character; telecommunications; teleprocessing.

This standard specifies the channel assignment for transmitting the Standard Code for Information Interchange (FIPS 1) in parallel-by-bit serial-by-character data transmission. This revision supersedes FIPS PUB 18 and reflects changes necessary to accommodate revisions prescribed by FIPS 1 when operated in either 7 or 8 bit coded environments. This standard is identified also as Federal Standard Number 1012

FIPS PUB 22-1. Synchronous signaling rates between data terminal and data communication equipment, G. Clark, Standards Coordinator, Nat. Bur. Stand. (U.S.), Fed. Info. Process. Stand. Publ. (FIPS PUB) 22-1, 4 pages (1977).

Key words: data communication equipment; data processing terminal equipment; data transmission (voice band); Federal Information Processing Standards; synchronous signaling rates; teleprocessing.

This standard specifies the rates of transferring binary encoded information in synchronous serial or parallel form between data processing terminal and data communications equipments that employ voice band communication facilities. This revision supersedes FIPS PUB 22 and reflects changes made to the corresponding American National Standard X3.11976. This standard is identified also as Federal Standard Number 1013. 
FIPS PUB 42-1. Guidelines for benchmarking ADP systems in the competitive procurement environment, J. F. Wood, Ed., Nat. Bur. Stand. (U.S.), Fed. Info. Process. Stand. Publ. (FIPS PUB) 42-I, 27 pages (May 1977).

Key words: benchmarking; benchmark mix demonstration; computer selection; Federal Information Processing Standard; workload representation.

This publication provides general guidelines to best practice for use by Federal agencies in benchmark mix demonstrations for validating hardware and software performance in context with processing an expected actual workload. The publication provides an overview and general discussion of the benchmarking process; guidelines for reducing the problems in benchmarking at the management level and at the technical staff level including a discussion of how these problems can be resolved or minimized; and procedural benchmarking guidelines, a discussion of the four phases of benchmarking, workload analysis, construction and validation of the benchmark, procedural documentation and preparation of the benchmark for the vendors, conducting benchmark tests. The document is written such that the various hierarchical levels in an organization's structure can direct itself toward applicable sections of these Guidelines.

FIPS PUB 46. Data Encryption Standard, D. K. Branstad, Ed., Nat. Bur. Stand. (U.S.), Fed. Info. Process. Stand. Publ. (FIPS PUB) 46, 17 pages (1977).

Key words: ADP security; computer security; encryption; Federal Information Processing Standard.

The selective application of technological and related procedural safeguards is an important responsibility of every Federal organization in providing adequate security to its ADP systems. This publication provides a standard to be used by Federal organizations when these organizations specify that cryptographic protection is to be used for sensitive or valuable computer data. Protection of computer data during transmission between electronic components or while in storage may by necessary to maintain the confidentiality and integrity of the information represented by that data. The standard specifies an encryption algorithm which is to be implemented in an electronic device for use in Federal ADP systems and networks. The algorithm uniquely defines the mathematical steps required to transform computer data into a cryptographic cipher. It also specifies the steps required to transform the cipher back to its original form. A device performing this algorithm may be used in many applications areas where cryptographic data protection is needed. Within the context of a total security program comprising physical security procedures, good information management practices and computer system/network access controls, the Data Encryption Standard is being made available for use by Federal agencies.

FIPS PUB 47. Federal Standard COBOL Pocket Guide, Nat. Bur. Stand. (U.S.), Fed. Info. Process. Stand. Publ. (FIPS PUB) 47, 37 pages (1977).

Key words: COBOL; COBOL programming aids; Federal Standard COBOL; programming aids; programming languages.

This document contains a composite language skeleton of Federal Standard COBOL. It is intended to display complete and syntactically correct formats for the High Level of the standard. In addition, the document contains other selected prompts for the COBOL programmer to assist in expediting the programming task.

FIPS PUB 48. Guidelines on evaluation of techniques for automated personal identification, P. Meissner, Nat. Bur. Stand. (U.S.), Fed. Info. Process. Stand. Publ. (FIPS PUB 48), 22 pages (Apr. 1977).

Key words: ADP security; computer networks; controlled accessibility; encryption; evaluation criteria; key; password; personal identification; terminals; verification.

This publication provides a guideline to be used by Federal organizations in the selection and evaluation of techniques for automatically verifying the identity of individuals seeking access to computer systems and networks via terminals, where controlled accessibility is required for security purposes. The guideline describes various techniques for verifying identity and provides a set of criteria for the evaluation of automated identification systems embodying these techniques.

FIPS PUB 49. Guideline on computer performance management: An introduction, D. M. Conti, Nat. Bur. Stand. (U.S.), Fed. Info. Process. Stand. Publ. (FIPS PUB) 49, 14 pages (1977).

Key words: computer performance evaluation; computer performance management; Federal Information Processing Standards; performance measures.

A Computer Performance Management (CPM) program is any structured effort to measure and evaluate the performance of installed computer systems in support of established management goals and objectives. The purpose of this publication is to introduce the Federal ADP manager to the subject of CPM, to provide general assistance to Federal ADP managers in planning and organizing a CPM program, and to recommend the establishment of CPM programs at all Federal ADP facilities. Guidance is presented on the use of performance measures in four major areas of management responsibility. The role of the ADP manager and the expected resources required in instituting a CPM program are discussed. 


\subsection{PRODUCT STANDARDS}

Developed under procedures published by the Department of Commerce in Part 10, Title 15, of the Code of Federal Regulations. The purpose of the standards is to establish nationally recognized requirements for products, and to provide all concerned interests with a basis for common understanding of the characteristics of the products. The National Bureau of Standards administers the Voluntary Product Standards program as a supplement to the activities of the private sector standardizing organizations.

PS67-76. Marking of gold filled and rolled gold plate articles other than watchcases. (ANSI/VPS PS 67-76), C. W. Devereux, Technical Standards Coordinator, Nat. Bur. Stand. (U.S.), Prod. Stand. 67-76, 6 pages (Aug. 1977) SN003-00301813-9.

Key words: jewelry, marking of; "Gold Filled," marking of; "Gold Overlay," marking of; "Gold Plate," marking of;

"Rolled Gold Plate," marking of.

This Voluntary Product Standard covers the marking of gold filled and rolled gold plate articles other than watchcases, as herein defined, offered for sale in the United States of America. Requirements include application of quality marks, "Rolled Gold Filled," "Gold Overlay," "Gold Plate," and/or "Rolled Gold Plate" to articles made of other metals. Definitions of trade terms used and methods for identifying products that comply with the standard are included.

PS68-76. Marking of articles made of silver in combination with gold. (ANSI/VPS PS 68-76), C. W. Devereux, Technical Standards Coordinator, Nat. Bur. Stand. (U.S.), Prod. Stand. 68-76, 6 pages (Sept. 1977) SNO03-003-01854-6.

Key words: jewelry; "Silver/Gold," marking of.

This Voluntary Product Standard covers the marking of articles made of silver in combination with gold, as herein defined, offered for sale in the United States of America. Requirements are given for the marking of articles made of two metals Definitions of trade terms used and methods for identifyin products that comply with this standard are included.

PS69-76. Marking of articles made wholly or in part on platinum. (ANSI/VPS PS 69-76), C. W. Devereux, Technica' Standards Coordinator, Nat. Bur. Stand. (U.S.), Prod. Stand. 69-76, 6 pages (Sept. 1977) SN003-003-01851-1.

Key words: "Iridium," marking of; jewelry, marking of; "Osmium," marking of; "Palladium," marking of;

"Platinum," marking of; "Rhodium," marking of;

"Ruthenium," marking of.

This Voluntary Product Standard covers the marking of articles made wholly or in part of platinum, as defined herein, offered for sale in the United States of America. Requirements given apply to marking of "Platinum," "Iridium," "Palladium," "Ruthenium," "Rhodium," and/or "Osmium." Definitions of trade terms used and methods for identifying products tha' comply with the standard are included.

PS70-76. Marking of articles made of karat gold. (ANSI/VPS PS 70-76), C. W. Devereux, Technical Standards Coordinator,
Nat. Bur. Stand. (U.S.), Prod. Stand. 70-76, 6 pages (Sept. 1977) SN003-003-01853-8.

Key words: jewelry, marking of; "Karat," "Karat gold," " Kt," "Kt gold," “K," or "K gold," marking of.

This Voluntary Product Standard covers the marking of articles made of karat gold, as herein defined, offered for sale in the United States of America. Requirements are given for the marking of "Karat," "Karat gold," "Kt," "Kt gold," " $\mathrm{K}$," or " $\mathrm{K}$ gold," preceded by a whole number. Definitions of trade terms used and methods for identifying products that comply with this standard are included.

PS7 1-76. Marking of jewelry and novelties of silver. (ANSI/VPS PS $7(-76), C$. W. Devereux, Technical Standards Coordinator, Nat. Bur. Stand. (U.S.), Prod. Stand. $7 I-76,4$ pages (Aug. 1977) SN003-003-01852-0.

Key words: "Coin" or "Coin Silver," marking of; jewelry, "Silver," marking of; novelties, "Silver," marking of; "Sterling Silver," "Silver," or "Solid Silver," marking of.

This Voluntary Product Standard covers the marking of jewelry and novelties of silver, as herein defined, (other than flatware, hollow-ware, and toilet ware) offered for sale in the United States of America. Requirements are given for marking of "Sterling Silver," "Silver," or "Solid Silver" and for the marking of "Coin" or "Coin Silver." Definitions of trade terms used and methods for identifying products that comply with this standard are included.

PS72-76. Toy Safety. (ANSI/VPS PS 72-76), J. M. Tascher, Technical Standards Coordinator, Nat. Bur. Stand. (U.S.), Prod. Stand. 72-76, 30 pages (Jan. 1977) SN003-003-017027. $\mathrm{c} 170$

Key words: cautionary labeling for toys; hazardous characteristics of toys; safety, toy; toy safety; use and reasonably foreseeable abuse testing for toys.

The purpose of this Voluntary Product Standard is to establish nationally recognized safety requirements for toys intended for use by children in age groups through 14 years. The standard relates to possible hazards that may not be readily recognized by the public, and which may be encountered in the normal use for which a toy is intended, or after reasonably foreseeable abuse. Requirements are included for material quality; flammability; toxicology; packaging film; strings and elastics; electrical/thermal energy; impulsive noise; edges; hazardous points; projections; wheels, tires, and axles; folding mechanisms and hinges; holes, clearances, and protection of mechanisms; stability of ride-on toys and seats; overload requirements for ride-on toys and seats; tipping of stationary floor toys; confined spaces; small objects; simulated protective devices, such as helmets, hats, and goggles; projectiles; and labeling, literature, and marking.

PS73-77. Carbonated soft drink bottles. ( $A N S I / V P S$ PS 73-77), C. W. Devereux, Technical Standards Coordinator, Nat. Bur. Stand. (U.S.), Prod. Stand. 73-77, 11 pages (Nov. 1977) SN003-003-01877-5.

Key words: glass, returnable and nonreturnable bottles; glass, soda-lime-silica; manufacturing requirements. 
This Voluntary Product Standard covers conventional returnable and nonreturnable glass bottles manufactured from soda-lime-silica glass with nominal capacity of up to and including 36 fluid ounces, intended for use in the packaging of soft drinks carbonated to a maximum of five volumes. This standard also covers conventional returnable and nonreturnable glass bottles manufactured from soda-lime-silica glass and nominal capacity in excess of 36 fluid ounces, but not in excess of 68 fluid ounces, intended for use in packaging soft drinks carbonated to a maximum of four volumes. The standard provides manufacturing requirements for temper number, thermal shock resistance, internal pressure strength, simulated impact resistance, abrasion resistance, detection of visual defects, wall thickness, dimensional tolerances for height and major body diameter, tolerances for capacity and weight, perpendicularity, bottom characteristics, and bottle identification. A statement to be used on manufacturing orders and invoices specifying the maximum carbonation volumes intended for use. with the bottles is included.

These requirements apply only to glass containers currently being used and described as conventional containers; they do not apply to bottles which are plastic clad or encapsulated, chemically tempered, or the result of other novel or innovative engineering or design developments. Definitions of the trade terms used and methods for identifying products which conform to this standard are included. Included in an appendix is information showing the relation of apparent to real temper number. 


\subsection{TECHNICAL NOTES}

Studies or reports which are complete in themselves but restrictive in their treatment of a subject. Analogous to monographs but not so comprehensive in scope or definitive in treatment of the subject area. Often serve as a vehicle for final reports of work performed at NBS under the sponsorship of other Government agencies.

TN594-13. Optical radiation measurements: The 1973 NBS scale of spectral irradiance, R. D. Saunders and J. B. Shumaker, Nat. Bur. Stand. (U.S.), Tech. Note 594-13, 36 pages (Apr. 1977) SNO03-003-01709-4.

Key words: calibrations; interpolation formula; irradiance drift formula; projected solid angle; spectral irradiance; standards.

This note describes the measurement apparatus and techniques used in deriving the 1973 scale of spectral irradiance. The uncertainty of this scale is believed to be less than 2 percent in the spectral region $250 \mathrm{~nm}-500 \mathrm{~nm}$ and less than 1 percent in the spectral region $500 \mathrm{~nm}-1600 \mathrm{~nm}$. This uncertainty represents a threefold improvement over the previous NBS scale of spectral irradiance. The complete derivation of the projected solid angle, which is crucial when transferring from radiance to irradiance, is given. Also described in this note is a model for interpolating the spectral irradiance at wavelengths between the wavelengths measured. Measurement details are presented and sources of error are discussed.

TN616, 2d Revision. Frequency standards and clocks: A tutorial introduction, H. Hellwig, Nat. Bur. Stand. (U.S.), Tech. Note 616 (2d Rev.), 70 pages (June 1977) SN003-003-01798-1.

Key words: cesium beam; clocks (atomic); crystal oscillator; frequency accuracy; frequency stability; frequency standards; hydrogen maser; quartz crystal; rubidium gas cell; timekeeping.

The topic of frequency standards and clocks is treated in a tutorial and nonmathematical way. The concepts of time, frequency, frequency stability and accuracy are introduced. The general physical principles and design features of frequency standards and clocks are described. The design, performance, and limitations of quartz crystal oscillators and atomic devices (cesium, hydrogen, rubidium) are discussed in detail and critically compared for laboratory devices as well as for devices intended for field usage.

TN685. A system for calibrating laser power meters for the range 5-1000 W, E. D. West and L. B. Schmidt, Nat. Bur. Stand. (U.S.), Tech. Note 685, 27 pages (May 1977) SN003003-01789-2.

Key words: calorimeter; laser calorimeter; laser energy; laser power.

This technical note describes the National Bureau of Standards measurement system for calibration and test of laser power and energy devices at power levels up to $1 \mathrm{~kW}$ and total energies of several $\mathrm{kJ}$. The main parts of the system are two electrically calibrated calorimeters and several beam splitters of different materials. The estimated limits of systematic error in measurements with the two calorimeters are \pm 1.9 percent for one and \pm 2.0 percent for the other. The two calorimeters have the same precision, and the standard deviation of an electrical calibration is the same as the standard deviation of a laser ener- gy measurement, indicating that the laser beam does not affect the precision of the measurement. The standard deviation of an energy measurement depends on the total energy to the calorimeter and is about 0.8 percent at $1 \mathrm{~kJ}$.

TN692. Servo techniques in oscillators and measurement systems, F. L. Walls and S. R. Stein, Nat. Bur. Stand. (U.S.), Tech. Note 692, 23 pages (Dec. 1976) SN003-003-01734-5.

Key words: atomic frequency standard; frequency discrimination; frequency domain stability; frequency-lock loop; phase-lock loop; phase noise; servo techniques; time domain stability.

Nearly every precision oscillator includes a frequency or phase servo system. In the case of cesium standards, a crystal oscillator is frequency locked to a particular resonance line in atomic cesium; in the case of an oscillating hydrogen maser, a crystal oscillator is phase locked to the very weak signal coming from the microwave cavity. The first section of this note treats the errors and offsets of frequency-lock loops which result from background, noise and other effects. Third harmonic lock systems and square wave frequency modulation are analyzed as possible solutions to some of these problems. The second section is a general treatment of servo system response which is applicable to both frequency and phase-lock loops. The effects of noise on such servo systems are discussed in detail, and an example is given of how to obtain optimum performance from a pair of phase-locked oscillators. A simple circuit is suggested for phase-locking high quality oscillators, which has many advantages over previous circuits.

TN693. Predicted values of the viscosity and thermal conductivity coefficients of nitrous oxide, H. J. M. Hanley, Nat. Bur. Stand. (U.S.), Tech. Note 693, 64 pages (Mar. 1977) SN003003-01780-8.

Key words: carbon dioxide; corresponding states; mixtures; nitrous oxide; prediction; thermal conductivity; transport property; viscosity.

The viscosity and thermal conductivity coefficients of nitrous oxide are calculated for temperatures between 180 and $900 \mathrm{~K}$ ( 330 to $1600^{\circ} \mathrm{R}$ ) for pressures to $23 \mathrm{MPa}(\sim 3500 \mathrm{psi})$. Tables of values are presented. Two mixtures with carbon dioxide are also discussed. These transport coefficients (for the pure fluid and for the mixtures) were predicted from thermodynamic data. Details of the prediction procedure are presented. Estimates of the accuracy of the tabular values are \pm 6 percent for the viscosity and $\pm \dot{8}$ percent for the thermal conductivity.

TN695. Time and frequency user's manual, G. Kamas, Ed., Nat. Bur. Stand. (U.S.), Tech. Note 695, 217 pages (May 1977) SN003-003-01781-7.

Key words: frequency calibration; high frequency; LoranC; low frequency; radio broadcasts; standard frequencies; television color subcarrier; time and frequency calibration methods; time calibration; time signals.

This manual has been written for the person who needs information on making time and frequency measurements. It has been written at a level that will satisfy those with a casual interest as well as laboratory engineers and technicians who use time and frequency every day. It gives a brief history of time and frequency, discusses the roles of the National Bureau of 
Standards and the U.S. Naval Observatory, and explains how time and frequency are internationally coordinated. It also explains what time and frequency services are available and how to use them. It discusses the accuracy that can be achieved using the different services as well as the pros and cons of using various calibration methods.

TN696. Near-field antenna measurements on a cylindrical surface: A source scattering-matrix formulation, A. D. Yaghjian, Nat. Bur. Stand. (U.S.), Tech. Note 696, 40 pages (July 1977) SN003-003-01850-3.

Key words: cylindrical scanning; near-field measurements; source-scattering matrix.

The theory for probe-corrected measurement of antennas by scanning on a circular cylindrical surface enclosing the test antenna in the near-field is formulated from a source scattering matrix description of the test and probe antennas. The basic transmission formula is derived without recourse to reciprocity, and from a common center approach which separates as an isolated problem the probe characterization and transformation. Moreover, it is shown how an experimental technique can, in principle, determine the required transformed probe coefficients without the use of addition theorems. Computer inversion of the transmission formula is accomplished accurately and efficiently with the aid of the sampling theorem and FFT algorithm.

TN696, 1977 Revision. Near-field antenna measurements on a cylindrical surface: A source scattering-matrix formulation, A. D. Yaghjian, Nat. Bur. Stand.(U.S.), Tech. Note 696, (Revised Sept. 1977), 40 pages (Sept. 1977) SN003-00301850-3.

Key words: cylindrical scanning; near-field measurements; scattering matrix.

The theory for probe-corrected measurement of antennas by scanning on a circular cylindrical surface enclosing the test antenna in the near-field is formulated from a source scattering matrix description of the test and probe antennas. The basic transmission formula is derived without recourse to reciprocity, and from a common center approach which separates as an isolated problem the probe characterization and transformation. Both an experimental technique and an approximate analytical technique are presented to determine the required transformed probe coefficients without the use of addition theorems. The approximate technique, which is developed from the exact addition theorem transformation, yields the probe coefficients directly in terms of the far-field of the probe, provided the rotation axis of the test antenna lies in the far-field of the probe. Computer inversion of the transmission formula is accomplished accurately and efficiently with the aid of the sampling theorem and FFT algorithm.

TN697. An evaluation of commercial densimeters for use in LNG, J. D. Siegwarth, B. A. Younglove, and J. F. LaBrecque, Nat. Bur. Stand. (U.S.), Tech. Note 697, 52 pages (Oct. 1977) SN003-003-018627.

Key words: cryogenic densimeters; density reference system; liquid methane; LNG.

The cryogenic fluids density reference system has been used to evaluate three basic types of densimeters: the vibrating element type, the dielectric cell type and the displacement type. These meters were used to measure densities in liquid methane and liquid methane mixtures with ethane, propane, normal butane, and nitrogen. Measurements were made over the density range from 400 to $480 \mathrm{~kg} / \mathrm{m}^{3}$, temperatures from $108 \mathrm{~K}$ to 130 $\mathrm{K}$, and pressures from 1 to 3 bar. $\mathrm{A}$ hundred measurements were made at various densities, temperatures, pressures and compositions.
TN698. Cryogenic fluids density reference system: Provisional accuracy statement, J. D. Siegwarth, B. A. Younglove, and J. F. LaBrecque, Nat. Bur. Stand. (U.S.), Tech. Note 698, 32 pages (Nov. 1977) SN003-003-01864-3.

Key words: densimeters; density reference system; liquid methane; LNG

The density reference system of the Cryogenic Division of the National Bureau of Standards is described. This system is used in making density measurements of cryogenic liquids. The methods of computation and the accuracy to which the density of the liquid can be measured are discussed in detail.

At this time the estimate of sample standard deviation for a single density measurement made using this system is 0.016 percent (at $422.63 \mathrm{~kg} / \mathrm{m}^{3}$ ). Using three times this standard deviation as a limit for random error and using 0.028 percent as the bound for known sources of possible systematic error, the uncertainty of a single determination with this system is \pm 0.076 percent. This statement of accuracy applies for the density range 400 to $480 \mathrm{~kg} / \mathrm{m}^{3}$, pressures from 0 to $3 \mathrm{bar}$, and temperatures from $110 \mathrm{~K}$ to $125 \mathrm{~K}$. Because of the densimeter design, this accuracy statement is expected to apply to the density range from 400 to $1000 \mathrm{~kg} / \mathrm{m}^{3}$ and to the temperature range of 77 to $300 \mathrm{~K}$ at least, and to pressures of $7 \mathrm{bar}$, though these ranges of application have yet to be verified.

TN699. Spectrum Amplitude-Definition, generation and measurement, J. R. Andrews and M. G. Arthur, Nat. Bur. Stand. (U.S.), Tech. Note 699, 100 pages (Oct. 1977) SN003-00301865-1.

Key words: electromagnetic interference; Fourier transformation; impulse; impulse generator; spectrum amplitude.

This technical note is a detailed discussion of the electromagnetic quantity, spectrum amplitude, which is used to characterize broadband signals and noise. The definition of spectrum amplitude is presented in detail. Several practical means of generating electrical signals with broadband spectrum amplitude are described along with experimental comparisons. The NBS measurement service for the calibration of impulse generator spectrum amplitude is described along with an-error analysis.

TN910-3. Self-study manual on optical radiation measurements: Part I-Concepts, Chapter 6, F. E. Nicodemus, Ed., Nat. Bur. Stand. (U.S.), Tech. Note 910-3, 62 pages (June 1977) SN003-003-01785-0.

Key words: Mueller matrix; polarization; polarizer; retarder; Stokes parameters.

This is Chapter 6 of a SELF-STUDY MANUAL ON OPTICAL RADIATION MEASUREMENTS. It develops and illustrates the concepts necessary to include polarization rigorously in classical radiometry. The treatment is based upon the Stokes polarization vector of spectral radiance and Mueller transmittance matrices. The Mueller matrices of many common polarizing optical components are discussed. Considerable attention is paid to the measurement of the Stokes spectral radiance vector components and to the measurement of the Mueller-transmittance matrix elements. The concepts and techniques are illustrated by discussions of such subjects as radiometer calibrations, three-polarizer attenuators, depolarizers, and the characterization of Polaroid-type polarizers. Also included are an appendix on matrix multiplication and an appendix showing one way by which, in principle, any Mueller transmittance matrix may be measured.

TN933. An infrared technique for heat-loss measurement, D. M. Burch, T. Kusuda, and D. G. Blum, Nat. Bur. Stand. (U.S.), Tech. Note 933, 52 pages (Apr. 1977) SN003-003-01746-9. 
Key words: heat-flow measurements; infrared heat-loss measurement technique; measurement technology; thermography.

This paper describes a newly developed technique for measuring heat-loss rate utilizing an infrared television system. A device called a heat-flow reference pad was developed that makes it possible to measure quantitatively the heat-loss rate through the surface of a building without the need for a conventional heat-flow meter to be mounted on the surface. Technical considerations for the design of a heat-flow reference pad are presented. The infrared measurement technique predicted heat-loss rates in the laboratory and field within approximately 12 percent.

TN934. Preservation of historic adobe structures-A status report, J. R. Clifton, Nat. Bur. Stand. (U.S.), Tech. Note 934, 35 pages (Feb. 1977) SN003-003-01740-0.

Key words: adobe building materials; adobe soil; mechanical properties; moisture determination; preservation technology.

The physicochemical and mechanical properties of adobe soils and building materials, and the technology of preserving historic adobe structures have been critically reviewed. In most cases, the deterioration of adobe structures can be directly or indirectly correlated with the presence of excess moisture. Therefore, the successful preservation of most historic adobe structures depends largely on effectively protecting these structures from water. This review indicates that the technology of preserving adobe structures needs further development to ensure the longevity of the structures.

Areas in which research is needed have been identified and include: (1) the development of standard methods to characterize the composition and physical properties of adobe soils, and the mechanical properties of adobe brick; (2) nondestructive methods to measure the water contents of and water movement in adobe structures; and (3) the evaluation of the effectiveness of different types of preservation materials and methods.

TN935. Measurement of energy irradiance from single puIse sources, A. R. Schaefer and E. F. Zalewski, Nat. Bur. Stand. (U.S.), Tech. Note 935, 32 pages (Feb. 1977) SN003-00301741-8.

Key words: curve fitting; energy irradiance; flashtube; pulsed source; radiometry.

A method of measuring the energy irradiance from a single pulsed source, such as a xenon flashtube, is presented. Details of the approach used in this particular measurement are given, along with a discussion of the data analysis. In particular, we consider some of the inherent problems encountered in curve fitting which are also common to other radiometric and photometric measurements.

TN936. A FORTRAN program for desmearing small-angle $x$ ray scattering curves, J. Mazur, Nat. Bur. Stand. (U.S.), Tech. Note 936, 83 pages (Apr. 1977) SN003-003-01752-3.

Key words: FORTRAN program; integral equation; interpolating polynomial; numerical stability; slit correction; small angle scattering; unsmearing.

A FORTRAN program is presented that corrects for collimation effects in small angle $x$-ray scattering measurements. The method employed in calculations is based on numerical solution of an integral equation, which is written as a Volterrra equation of the first kind. This equation is reduced to a system of simultaneous equations, which are solved by a matrix inversion method. Several different algorithms are tried, based on dif- ferent interpolating polynomials for $l(x)$, the true scattering intensity which is expressed as a function of the scattering angle $x$. The problem of numerical stability, which is inherent to the computations algorithms employed in the algebraic solution of integral equation is discussed and exemplified with actual computations.

TN937. Estimation of net enthalpies of combustion of some aviation fuels expressed in the International System of Units (SI), R. L. Nuttall and G. T. Armstrong, Nat. Bur. Stand. (U.S.), Tech. Note 937, 63 pages (Apr. 1977) SN003-003-01763-9.

Key words: aniline point; API gravity; aviation fuels; enthalpy of combustion; fuels; gasoline; gravity; heat content; heat of combustion; kerosine.

A new correlation has been made of the net enthalpy of combustion of some aviation fuels with their aniline point, density, and sulfur content. Previous correlations gave a set of five equations relating the enthalpy of combustion to the aniline point gravity product for five classes of fuels ranging from aviation gasoline to kerosine. These equations were in non-SI units.

The correlation reported here gives similar sets of equations using SI units and also gives a single equation which can be used to adequately predict the net enthalpy of combustion of all five classes of fuels from measurements of aniline point, density and sulfur content. This equation is: $Q=[B(0)+B(1)$ $\times A+B(2) \times(1 / D)+B(3) \times(A / D)+B(4) \times(A)^{2}+B(5) \times$ $\left.(1 / D)^{2}+B(6) * S\right] M J / k . B(0)=22.9596 \mathrm{MJ} \cdot \mathrm{kg}^{-1} ; \mathrm{B}(1)=-$ $1.26587 \times 10^{-2} \mathrm{MJ} \cdot \mathrm{kg}^{-1} \cdot{ }^{\circ} \mathrm{C}^{-1} ; \mathrm{B}(2)=26.6409 \mathrm{MJ} \cdot \mathrm{kg}^{-1} \cdot \mathrm{g}^{-1} \cdot \mathrm{cm}^{3}$; $\mathrm{B}(3)=0.032622 \mathrm{MJ} \cdot \mathrm{kg}^{-1} \cdot{ }^{\circ} \mathrm{C}^{-1} \cdot \mathrm{g}^{-1} \mathrm{~cm}^{3} ; \mathrm{B}(4)=-6.6903 \times 10^{-5}$ $\mathrm{MJ} \cdot \mathrm{kg}^{-1} \cdot{ }^{\circ} \mathrm{C}^{-2}, \mathrm{~B}(5)=-9.21776 \mathrm{MJ} \cdot \mathrm{kg}^{-1} \cdot \mathrm{g}^{-2} \cdot \mathrm{cm}^{6} ; \mathrm{B}(6)=$ $50 . \mathrm{MJ} \cdot \mathrm{kg}^{-1} \cdot \mathrm{S}^{-1}$.

TN938. Recommended practice for the use of metric (SI) units in building design and construction, H. J. Milton, Nat. Bur. Stand. (U.S.), Tech. Note 938, 47 pages (Apr. 1977) SN003003-01761-2.

Key words: International System of Units (SI); metric design and construction; recommended SI practice.

This Technical Note contains a comprehensive set of recommendations for the use of metric (SI) units in building design and construction.

It includes descriptive material dealing with the structure of the International System of Units (SI); rules and recommendations for the presentation of SI units and symbols, and of numerical values associated with SI; a set of tables showing working units and typical applications for SI units in building design and construction; and a section dealing with special considerations in the selection and use of SI units in design and construction. Appendixes show conversion factors for the most common units; superseded metric units not recommended for use with SI; an SI units and relationships chart; and appropriate references.

This document was prepared to provide the technical basis for an ASTM reference standard on recommended practice for the use of metric (SI) units in building design and construction.

TN939. NBS reactor: Summary of activities July 1975 to June 1976, F. J. Shorten, Ed., Nat. Bur. Stand. (U.S.), Tech. Note 939, 140 pages (May 1977) SN003-003-01769-8.

Key words: activation analysis; crystal structure; diffraction; isotopes; molecular dynamics; neutron; nuclear reactor; radiation.

This report summarizes all those programs which depend on the NBS reactor. It covers the period from July 1975 through June 1976. The programs range from the use of neutron beams to study the structure and dynamics of materials through nuclear physics and neutron standards to sample irradiations 
for activation analysis, isotope production and radiation effects studies.

TN940. The representation and use of design specifications, $S$. J. Fenves and R. N. Wright, Nat. Bur. Stand. (U.S.), Tech. Note 940, 51 pages (June 1977) SNO03-003-01790-6.

Key words: building codes; computer programming; decision tables; graph theory; performance specifications; standards.

Design specifications are presented as the primary communication and control tool for the design and construction industry. Requisite properties of completeness, uniqueness and correctness are identified, and the role of performance and limit state concepts in specifying intent of the specifications are emphasized. Formal representation methods are presented at three levels: decision tables for specification provisions, an information network for related provisions, and argument trees for organizing and outlining. An idealized process for specification development is presented, and the use of the representational tools for checking specifications and providing strategies for textual expression is described and illustrated. Development of computer aids for specification processing in design and conformance checking is described.

TN941. Stone preservatives: Methods of laboratory testing and preliminary performance criteria, G. A. Sleater, Nat. Bur. Stand. (U.S.), Tech. Note 941, 79 pages (May 1977) SN003003-01727-2.

Key words: accelerated laboratory testing; performance criteria; stone decay; stone preservatives.

Although numerous materials have been proposed as preservatives for stone in historic buildings and monuments, their efficacy is difficult to establish. In the work described here, a laboratory research program of accelerated simulated stone decay was used to obtain data on stone preservatives and to suggest criteria for their selection. Over 50 materials usable as stone preservatives were tested.

Tests to simulate stone decay were of two types: 1 . exposure to combined weathering factors using a special test chamber for accelerated decay (CAD), in which chemical attack, salt and water action, and thermal effects were simulated in one operation; 2. exposure to single causes of stone decay using sulfurous acid fog, sodium chloride fog, water condensation/evaporation cycling, sodium sulfate penetration and crystallization, and ultraviolet radiation.

Methods for measuring the effects of the exposures are given together with the test data; these have been used to set limits of acceptable performance in preliminary performance criteria for the selection of stone preservatives. The behavior of each stone preservative tested in meeting these criteria is given. No one stone preservative met all criteria.

TN943. Evaluation of automotive fuel flowmeters, B. Robertson and G. P. Baumgarten, Nat. Bur. Stand. (U.S.), Tech. Note 943, 95 pages (June 1977) SN003-003-01799-0.

Key words: automotive environment; automotive fuel flowmeters; effect of environment on flowmeter performance; flowmeter calibration; flowmeter evaluation; procedure for testing flowmeters.

Fuel economy measurement procedures being developed by the Transportation Systems Center of the Department of Transportation require flowmeters to measure the gasoline consumed by the engine of an automobile either on the road or on a dynamometer. The contribution of the National Bureau of Standards to this work was to ascertain the environment in which the flowmeters will probably be used, to develop procedures for measuring their performance in a laboratory simulation of that environment, and to carry out illustrative measurements on a number of flowmeters.

This report discusses: (1) the environment of the flowmeter in an automobile, i.e., flowmeter temperature; fuel temperature, pressure, density, viscosity, color, opacity, flow pulsations, back flow, and swirl due to elbows; line voltage fluctuations; electromagnetic radiation from ignition; vehicle attitude with respect to the vertical; and vibration, (2) the test set-up and procedure used for evaluating and calibrating these meters in the laboratory under conditions simulating the automotive environment, (3) a discussion of possible sources and magnitudes of errors in the calibration, and (4) results of illustrative tests on seven flowmeters.

TN945. An investigation of the fire environment in the ASTM E 84 tunnel test, W. J. Parker, Nat. Bur. Stand. (U.S.), Tech. Note 945, 75 pages (Aug. 1977) SN003-003-01819-8.

Key words: ASTM E 84; fire tests; flame spread; heat flux; heat release rate; oxygen depletion; smoke; Steiner Tunnel Test.

Measurements were made of heat flux, oxygen concentration, temperature, velocity and pressure in a series of instrumented ASTM E 84 tunnel tests using (1) standard length specimens, (2) $0.91-\mathrm{m}$ (3-ft) long specimens, and (3) a reference specimen consisting of asbestos-cement board and an auxiliary controlled supply of methane. Five different flow rates of methane to the auxiliary burner provided constant and known heat inputs simulating the gaseous decomposition products from regular test specimens. Incident heat fluxes on an inert specimen surface as high as $6.3 \mathrm{~W} / \mathrm{cm}^{2}\left(5.5 \mathrm{Btu} / \mathrm{ft}^{2} \cdot \mathrm{s}\right)$ were measured within the flame impingement zone with a water-cooled heat flux meter $0.61 \mathrm{~m}$ ( $2 \mathrm{ft}$ ) downstream from the burner. While oxygen depletion in the tunnel did not appear to be a dominating factor in controlling the flame spread, the oxygen depletion measured in the exhaust duct beyond the tunnel correlated with the total rate of heat production of the specimens. It appears that the differences in the observed burning behavior of materials in the tunnel test and in a room may be mainly due to differences in the incident heat flux distribution in the two cases. These distributions reflect the different geometries, orientations, and ignition sources. The potential for rapid flame spread of some low flame spread classification (FSC) low density materials is evident from observations of the flame propagation along these materials during the tunnel test, but is not adequately reflected in the flame spread classification.

TN946. Urea-formaldehyde based foam insulations: An assessment of their properties and performance, W. J. Rossiter, Jr., R. G. Mathey, D. M. Burch, and E. T. Pierce, Nat. Bur. Stand. (U.S.), Tech. Note 946, 92 pages (July 1977) SN003003-01801-5.

Key words: cellular plastics; foam insulation; insulation; materials properties; performance; urea-formaldehyde.

The properties and performance of urea-formaldehyde based foams pertinent to their use as insulation in buildings were assessed based essentially on existing information. Pertinent materials properties were identified and guidelines prepared for the suggested values of these properties along with corresponding methods of test. For certain materials properties information was not found to enable suggested values of these properties. The factors affecting performance of urea-formaldehyde based foam insulations were also identified and discussed. Some performance factors could not be adequately evaluated because of insufficient or contradictory data in the literature. Methods of foam application were studied and suggested general application guidelines were prepared. 
The advantages and disadvantages of using urea-formaldehyde based foam insulations were discussed and problem areas identified. Recommendations were made pertaining to the use and assessment of urea-formaldehyde based foam insulations for residential construction.

TN947. Critical evaluation of data in the physical sciences-A status report on the National Standard Reference Data System, January 1977, S. A. Rossmassler, Ed., Nat. Bur. Stand. (U.S.), Tech. Note 947, 84 pages (May 1977) SN003003-01776-1.

Key words: atomic and molecular data; chemical kinetics data; energy data; environmental data; industrial process data; materials utilization data; mechanical properties; nuclear data; physical science data; solid state data; standard reference data; thermodynamic data; transport properties.

This is a report on the status of the National Standard Reference Data System as of January 1977. Current activities and functions of the Office of Standard Reference Data are summarized. A complete list of data evaluation projects supported by the Office of Standard Reference Data during Fiscal Year 1977 is included; this list also includes projects which received financial support during the previous fiscal year, and which are still actively involved in some aspect of data compilation and evaluation. The list of projects includes continuing data centers in the United States whose activities fall within the scope of the system, but which are not formally affiliated with it. A list of publications resulting from the National Standard Reference Data program is provided.

TN948. Tabulation of voluntary standards and certification programs for consumer products, W. J. Slattery, Nat. Bur. Stand. (U.S.), Tech. Note 948, 187 pages (June I977) SN003-00301779-5.

Key words: certification programs; consumer products; household products; industry standards; international recommendations; national standards; product standards; recommended practices; specifications; test methods.

This tabulation is a revised and enlarged version of NBS Technical Note 762, "Tabulation of Voluntary Standards and Certification Programs for Consumer Products," issued March 1973.

The original draft of the tabulation was developed by the Council of the American National Standards Institute (ANSI) in 1970. The product categories covered in the ANSI tabulation were based on those listed in the Consumer Product Safety Index (CPSI) of the National Commission on Product Safety, issued in July I970. In 1971, at the Consumer Council's request, the Bureau's Office of Engineering and Information Processing Standards revised the draft tabulation and issued it as NBS Technical Note 705. In March 1973, the tabulation was again revised based on the product categories developed for the National Electronic Injury Surveillance System (NEISS) of the Food and Drug Administration. The NEISS listings used in Technical Note 762 were an expansion and revision of the CPSI. The product categories in the current revision are based on the NEISS Coding Manual published by the Consumer Product Safety Commission in July 1975.

The tabulation lists over I000 product areas and over 2000 standards titles covering products found in and around the home. (The major consumer product areas not included are foods, beverages, and drugs.) The tabulation also indicates the applicable national, industrial, and international standards which deal primarily with either safety or performance or both aspects of the products listed. For some of the product areas, there are no applicable standards. Available information on certification programs and standards under development, and the Standard Industrial Classification (SIC) numbers for the products is also provided.

TN950. The NBS detector response transfer and intercomparison package: The instrumentation, M. A. Lind, E. F. Zalewski, and J. B. Fowler, Nat. Bur. Stand. (U.S.), Tech. Note 950, 23 pages (July 1977) SN003-003-01810-4.

Key words: absolute radiant power measurements; detector radiometry; detector response transfer instrumentation; radiometers; silicon detectors.

A system has been designed to transfer the NBS absolute radiant power base in the 250 to $1150 \mathrm{~nm}$ wavelength range. The silicon detector based radiometer and its accompanying test materials can be used to measure the absolute spectral response of detectors and to provide a diagnosis of some common measurement problems. The instrumentation and accompanying components are described in this publication.

TN952. Designs for the calibration of standards of mass, J. M. Cameron, M. C. Croarkin, and R. C. Raybold, Nat. Bur. Stand. (U.S.), Tech. Note 952, 64 pages (June 1977) SN003003-1778-7.

Key words: design of experiments; least squares; mass calibration; statistical design; weighing design.

This report presents a collection of designs for the intercomparison of sets of weights for use in precision calibration of standards of mass. These include a number of previously unpublished designs which have an additional weight in each set to serve as the check standard for monitoring the performance of the weighing process. Also included are the classical designs of Benoit and Hayford. The complete least squares analysis is presented in integer form (i.e., with a common division) for the most widely used designs; and for the others, the standard deviations are given for various weight combinations when used as an ascending or as a descending series. Designs for sets of nominally equal objects, the $22 \ldots$ I $1 \ldots$ series, the binary sequences, the 52211 series, and the 53211 and some miscellaneous series are given.

TN953. A new portable tester for the evaluation of the slip-resistance of walkway surfaces, R. J. Brungraber, Nat. Bur. Stand. (U.S.), Tech. Note 953, 5 I pages (July I977) SN003003-01796-5.

Key words: flooring; floor treatments; shoe sole and heel materials; slip-resistance tester; walkway surfaces; waxes and polishes.

The paper describes the available devices for testing the slipresistance developed between walkway surfaces and shoe sole or heel materials. The limitations of available testers are detailed, and the need for a more reliable tester that can be used on actual floors under true field conditions, such as in the presence of water, is shown. The design and development of the new NBS-Brungraber Slip-Resistance Tester is described, including a discussion of the test programs that were employed to evaluate it.

TN954. Spectral radiometry: A new approach based on electrooptics, J. Geist, M. A. Lind, A. R. Schaefer, and E. F. Zalewski, Nat. Bur. Stand. (U.S.), Tech. Note 954, 23 pages (July 1977) SNO03-003-01805-8.

Key words: absolute radiometry; detector; electrically calibrated detectors; laser power measurements; pyroelectric detectors; radiometry; silicon cell; silicon detector; silicon photodetector. 
Progress in developing a new approach to radiometry based on electro-optical technology is discussed. A feasibility experiment that demonstrates and motivates the new approach is described. The laser-based, characterization facility that plays a central role in the new approach, including the electrically calibrated pyroelectric radiometer that provides the absolute radiant power measurements, and recent investigations of silicon photovoltaic detectors that were performed on the facility are all described. Alternatives for extending the wavelength range of the new approach are also discussed.

TN955. Electromagnetic interactions from 5 to $500 \mathrm{MeV}$ and nuclear research-A position paper as of March 1977, L. C. Maximon, Nat. Bur. Stand. (U.S.), Tech. Note 955, 51 pages (Aug. 1977) SN003-003-01816-3.

Key words: bremsstrahlung spectrum tip; Delbrück scattering; electromagnetic interactions; electron scattering; radiative corrections; total photon absorption cross sections; virtual photon theory.

We present the current status of both experimental measurements and theoretical expressions for cross sections for the majority of the electromagnetic processes that are intimately connected with nuclear research using electromagnetic probes, emphasizing in particular those theoretical papers which are both reliable and useful for an analysis of the experiments, and indicating those regions in which the theoretical calculations are inadequate. Serving as a structure for this presentation, four areas of experimental research have been chosen, and we discuss in reasonable detail the status of the latest experiments in these areas: total photoabsorption cross section measurements, elastic photon scattering and Delbrïck scattering, electron scattering and its corrections-radiative, recoil, dispersive and relativistic-and the bremsstrahlung spectrum tip. In addition, a guide to the more pertinent articles (experiment and theory) on the subject of virtual photons is presented.

TN956. FORTRAN program to determine length of gage blocks using single wavelength interferometry, R. N. Varner, Nat. Bur. Stand. (U.S.), Tech. Note 956, 55 pages (Sept. 1977) SN003-003-01840-6.

Key words: FORTRAN computer program; gage blocks; interferometry.

A description of a computer program which computes the length of a gage block from a process using single wavelength interferometry is given. The computer program has been written in American National Standards Institute FORTRAN, with emphasis on making it as machine-independent as possible. A sample of input and output is given.

TN957. Threshold photo and electroproduction of pions from nuclei, E. T. Dressler, Nat. Bur. Stand. (U.S.), Tech. Note 957, 38 pages (Sept. 1977) SN003-003-01834-0.

Key words: effective Lagrangian; electroproduction; impulse approximation; photoproduction; pseudoscalar and pseudovector coupling; threshold pion production.

The nonrelativistic amplitudes for photo and electroproduction of pions are derived using effective pseudoscalar and pseudovector Lagrangian densities. The results for pseudoscalar and pseudovector coupling are compared at threshold for charged and neutral pion photo and electroproduction. Cross section formulas and kinematical conditions are also presented.

TN958. Four versatile MIDAS compatible modules, M. A. Lind and J. B. Fowler, Nat. Bur. Stand. (U.S.), Tech. Note 958, 34 pages (Nov. 1977) SNOO3-003-01866-0.
Key words: data acquisition system; MIDAS; MIDAS amplifier controller; MIDAS digital to analog converter; MIDAS modules; MIDAS stepping motor indexer; MIDAS up/down counter.

Four versatile MIDAS compatible modules are documented. These modules include a precision digital to analog converter, a programmable up/down counter, a high speed stepping motor indexer, and an amplifier controller-filter-V/F converter.

TN960. A survey of the National Metric Speakers Bureau, J. M.

Tascher, Nat. Bur. Stand. (U.S.), Tech. Note 960, 56 pages (Nov. 1977) SN003-003-01860-1.

Key words: metric information, sources of; metric speakers; Metric Speakers Bureau, National; National Metric Speakers Bureau.

The National Metric Speakers Bureau was established by the Metric Information Office of the National Bureau of Standards (NBS) in January 1976 in response to the rapidly growing interest in the metric system and metrication. The number of speakers at the end of 1976 was 273 with at least one in every State. NBS supplied a script and other materials to each speaker. A survey of all of the speakers was conducted during November and December 1976. The purpose of the survey was to determine how the Speakers Bureau is working, and how it can be made to work better. NBS wanted to know, for example, what the speakers thought of the speaker materials supplied by NBS, where additional speakers may be needed, what types of expertise the speakers have, and how NBS could further assist the speakers. This report summarizes the findings of the survey. The report also gives a survey of the sources of information on the metric system and metrication. A roster of speakers of the National Metric Speakers Bureau, dated July 1977, appears in an appendix.

TN961. Experimental investigation of means for reducing the response of pressure transducers to thermal transients, J. S. Hilten, C. F. Vezzetti, J. F. Mayo-Wells, and P. S. Lederer, Nat. Bur. Stand. (U.S.), Tech. Note 961, 58 pages (Dec. 1977) SN003-003-01875-9.

Key words: coatings; delayed response; dynamic; dynamic response; pressure step; pressure transducer; protective coatings; shock tube; tape; thermal protection; thermal radiant-energy response; thermal transient response; transducer; zero shift.

Experimental efforts are described in the evaluation of protective diaphragm coatings as a means to reduce the effects produced by thermal radiant-energy transients on pressuretransducer response.

A series of tests was carried out to investigate the effects of a variety of protective coatings on the amount and rate of thermal energy transmission through thin metal disks (used to simulate transducer diaphragms) as revealed by measurements of the disk back-side temperature. The temperature histories of both bare and protected disks were measured with thermocouples during and after exposure of the disks to thermal radiantenergy transients (of approximately $20 \mathrm{~mJ} / \mathrm{mm}^{2}$ at the disk) generated by No. 22 photographic flashbulbs. Protective coatings investigated include various tapes, greases, and roomtemperature-vulcanizing rubbers (RTVs).

Based on the results from these tests, the effectiveness of nine selected coatings in reducing thermally-induced zero shifts of four types of pressure transducers was investigated. In these tests, a pair of transducers - one protected and the other unprotected, but otherwise nominally identical - were exposed to a thermal radiant-energy transient as described above. The resulting zero shift was measured and taken as an index of coating effectiveness. 
The effect of the mass of the coatings on transducer dynamic response was investigated by means of a shock tube, in which a protected and unprotected pair were simultaneously exposed to a pressure step of approximately $280 \mathrm{kPa}$ ( $40 \mathrm{psi}$ ). Also, the effect of selected coatings on transducer accelerating sensitivity was investigated by monitoring the outputs of pairs of transducers mounted on a vibration exciter.

Test results indicate the validity of the simulated diaphragm test as a predictor of protection effectiveness. Results from both disk and transducer tests show that some coating combinations appear to be an order of magnitude more effective than others in delaying and reducing zero shift. Coatings of multi-layer black tape, red RTV silicone rubber, and "heat sink" compound appear most effective, other materials less. Silicone grease is found least effective while single-layer black tape appears to produce results ranging from very limited protection to actual degradation of response, based on the limited sampling carried out in this investigation.

\subsection{CONSUMER INFORMATION SERIES}

Practical information, based on NBS research and ex. perience, covering areas of interest to the consumer. Easily un. derstandable language and illustrations provide usefu! background knowledge for shopping in today's technologica' marketplace.

No publications issued in this series during this period. 


\subsection{NBS INTERAGENCY REPORTS}

A special series of interim or final reports on work performed by NBS for outside sponsors (both government and non-government). In general, initial distribution is handled by the sponsor; public distribution by the National Technical Information Service (NTIS), Springfield, VA 22161, in paper copy or microfiche form unless otherwise stated. When ordering this series from NTIS you must order it by the "COM, PB, or AD" number listed at the end of each entry.

NBSIR 73-106. A system for computerized surface roughness measurement, D. A. Swyt, 61 pages (Feb. 1973). Order from NTIS as PB273940.

Key words: surface profile instrumentation; surface roughness calibrations; surface roughness measurement.

An overall system for computerized surface roughness measurements, involving a commercial stylus profile instrument and a minicomputer, is described. The method allows: direct displacement calibration of the stylus instrument by means of interferometrically measured gage block steps; the elimination of roughness artifacts as calibration standards; and access to punched-tape surface profile data which may be given detailed analysis on a larger, faster computer. Details of system operation and precision are included.

NBSIR 73-136. Measurements of cylindrical standards, R. C. Veale, 24 pages (Mar. 1973). Order from NTIS as PB273995.

Key words: calibration; cylinders; plug gages; rolls; wire standards.

Cylinders are widely used in industry and standards labs as a form of length transfer. The measurement algorithm used by the dimensional technology section to determine the diameters of master cylinders is given in detail. It has been found that a mechanical transfer from interferometrically measured gage blocks is the most satisfactory method.

NBSIR 73-196. Surface finish, friction and wear: The need for more than one parameter, D. A. Swyt, 28 pages (May 1973). Order from NTIS as PB273941, \$4.50.

Key words: AA roughness; surface autocorrelation; surface finish; surface finish average wavelength; surface periodicity.

Surface finish is most commonly described by an arithmetic average (AA) value, often coupled with a description of the process by which the surface is finally formed. Since the insensitivity of the AA parameter to the periodic nature of surface structure is well known, many supplemental "second" parameters have been suggested. This short paper gives an indication of the basis for the insensitivity of the AA parameter to periodic structure and considers briefly some "wavelength-conscious" parameters (e.g., average wavelength and correlation lengths) which may be useful in supplementing the basic AA value for a more complete description of surface finish.

NBSIR 73-219. Eight techniques for the optical measurement of surface roughness, R. D. Young, 39 pages (May 1973). Available from author.

Key words: light scattering; optical measurement of roughness; surface finish; surface roughness.
The need for a fast, on-line, nondestructive technique for measuring surface roughness has recently accelerated the decade long development of optical methods. It is anticipated that these new instruments will add a new dimension to the surface roughness measurement system which may require an appropriate NBS response. In order to formulate this response, the eight optical techniques which have been identified are briefly described and are summarized and compared in Table 1.

It is concluded that model deficiencies, questionable theoretical bases, as well as physical and analytical limitations cast serious doubt on the present accuracy of these techniques for absolute measurements. Optical techniques seem more suitable for comparison measurements, i.e., measurement after appropriate calibration using surfaces which have been measured using other techniques. Thus, it is concluded that the most appropriate NBS response to the increased use of optical techniques is to concentrate our limited resources on developing much improved instruments such as the Topografiner and traditional stylus instruments so that highly refined optical surfaces can be measured and their surface parameters determined accurately.

NBSIR 73-232. A survey of the stability of optical flats, C. P. Reeve and R. C. Veale, 27 pages (June 1973). Order from NTIS as PB273947.

Key words: calibration; optical flat, profile; stability; standard deviation.

Some optical flat owners are concerned about the long term stability of their optical flats. To examine this problem, a survey was made of several optical flats which were calibrated by the National Bureau of Standards at least three times during the period from 1959 to 1972 . The measured profiles of these flats are presented graphically so that the different calibrations can be compared. The conclusion of this survey is that optical flats are quite stable over a period of several years, but since the individual requirements for precision may vary greatly, it should be left up to the owner to weigh the appropriate factors in determining how frequently he needs his optical flat calibrated.

NBSIR 73-239. Gage block flatness and parallelism measurement, J. S. Beers and C. D. Tucker, 11 pages (Aug. 1973). Order from NTIS as PB273962.

Key words: flatness; gage blocks; interferometry; length measurement; parallelism.

Geometric properties of gage blocks are important in many length measurement applications. Methods are described for measuring the flatness of gaging faces and the parallelism between opposing gaging faces. These methods, used for many years, employ interferometers and electro-mechanical gage block comparators.

NBSIR 73-291. A systematic study of vibration standards-Mounting effects, R. S. Koyanagi, J. D. Pollard, and J. D. Ramboz, 43 pages (Sept. 1973). Order from NTIS as PB272376.

Key words: acceleration calibration; mounting variable; vibration. 
The purpose of this study was to determine the extent of the sensitivity change of laboratory quality piezoelectric accelerometers for various mounting conditions. The mounting variables included the material upon which the accelerometer was mounted, geometry, the use of commercial insulated studs, and the use of mounting stud thread size adaptors. For the stated test conditions, the cffect of different materials and geometry was insignificant below about $3000 \mathrm{~Hz}$. For stainless steel, beryllium, alumina, and tungsten, the deviations were less than 0.5 percent up to $10,000 \mathrm{~Hz}$. The aluminum alloy base showed an increase of about 2 percent at $10,000 \mathrm{~Hz}$. The effect of insulated studs showed deviations beginning at about 3000 $\mathrm{Hz}$. No significant deviation was found hetween the different stud thread size adaptors.

NBSIR 74-452. Design and evaluation criteria for energy conservation in new buildings, Staff of the Center for Building Technology, NBS, 107 pages (Revised Feb. 26, 1976). Order from NTIS as PB272511.

Key words: air leakage; building design; energy conservation; fenestration; HVAC systems; illumination; insulation; lighting; performance standard; thermal performance; ventilation; water heating.

This document contains design and evaluation criteria for energy conservation in most new buildings. It was prepared in response to a request by the National Conference of States on Buildings Codes and Standards to the National Bureau of Standards. It is intended to be the forerunner of a consensus standard to be promulgated by a national standards organization.

The requirements and criteria are performance-oriented to the extent permitted by present building design technology. The performance concept is applied at the subelement or subsystem level to synthesize an energy-efficient total system. The detailed criteria are directed toward the design of building envelopes with good thermal resistance and low air leakage, and toward practices in the design of mechanical and electrical systems which conserve energy. Design flexibility is achieved by providing for the acceptance of alternative design solutions that can be shown to save equivalent amounts of energy without following every detailed requirement. Supersedes Feb. 27, 1974 issue.

NBSIR 74-500. The CODASYL data base approach: A COBOL example of design and use of a personnel file, E. H. Sibley, 83 pages (Feb. 1974). Order from NTIS as PB265694.

Key words: COBOL; CODASYL; data base; data definition; data definition language; data structure applications.

This report introduces examples of the use of the proposed CODASYL Data Definition Language and Data Base Language extensions to COBOL. It does this by suggesting the needs and data base elements which can be expected for a set of simple personnel applications. The discussion of the data definitions centers around the decisions that the data administrator makes, and the tools that are provided for him. Then it discusses a few of the processes (programs) which are required by typical personnel departments, and shows their implementation (in outline) in three. COBOL programs. The reader is expected to have some knowledge of the CODASYL specifications.

NBSIR 74-594. Examination of failed four inch cast iron pipe natural gas main, Philadelphia Gas Works, Philadelphia, Pennsylvania, T. R. Shives, 24 pages (Oct. 1974). Order from NTIS as PB243546.

Key words: brittle fracture; cast iron gas pipe; graphitic corrosion; steadite.

The Office of Pipeline Safety submitted several pieces of four inch diameter cast iron natural gas main pipe to the National Bureau of Standards Mechanical Properties Section for ex- amination. An accumulation of gas that had escaped from a fracture in the pipeline resulted in an explosion in the 1200 block of South Markoe Street in Philadelphia, Pennsylvania on May 3, 1974. The fracture had occurred in a transverse plane that passed through a service tap hole in the top of the pipe. The fracture was brittle in nature and there was no evidence to indicate the existence of a crack prior to the failure. There was extensive graphitic corrosion in some areas of the pipe, although this does not appear to be related to the failure. A chemical analysis indicated that the phosphorus content of the pipe material was higher than desirable. The microstructure contained a considerable amount of iron-iron phosphide eutectic. Failure apparently occurred from a single stressing event caused by bending loads from an external source.

NBSIR 74-601. A survey of the temporal stability of angle blocks, R. C. Veale and C. P. Reeve, 24 pages (Nov. 1974). Order from NTIS as PB273948.

Key words: angle block; between time variation; calibration; measuring system; stability; standard deviation; statistical analysis.

The National Bureau of Standards is often asked how frequently a set of angle blocks should be calibrated. In order to provide a basis for answering that question, a survey was made of the long-term stability of several sets of angle blocks over a ten-year period. Data is given concerning the short-term and long-term variability of the measurement process as well as the observed long-term slope of the computed values. The conclusion is that a significant long-term variation in the measurement system does exist, but the long-term slope of the blocks which were surveyed is not significantly different from zero.

NBSIR 75-936. The National Electromagnetic Measurement System, R. A. Kamper, 42 pages (June 1977). (Refer all requests to Electromagnetics Division, National Bureau of Standards, Boulder, CO 80302.)

Key words: electromagnetic quantities; laser; microwave; National Measurement System; radio measurements.

This report reviews the scientific, commercial, civil, and military activities that use electromagnetic measurements, and the measurement techniques and standards, and the institutions developing and using them, that have evolved to satisfy their needs. Through the early influence of the Department of Defense, this part of the National Measurement System is well coordinated, with NBS established as the central reference point. The measurement needs of lasers are included in the discussion.

NBSIR 75-938. The National Measurement System for Acoustics, D. S. Pallett and M. A. Cadoff, 95 pages (Mar. 1977). Order from NTIS as PB264290.

Key words: acoustical measurements; acoustics; audiometry; national measurement system; noise; noise control; noise emissions; sound; sound level meters.

This report describes acoustical measurement processes which are motivated by societal concern over noise and which have broad relevance to our contemporary technological society. The emphasis of this study of the National Measurement System for Acoustics has been to review the status of the system in order to determine the adequacy of these important physical measurements and to promote improvements within the measurement system. The relevant physical quantities are indicated, and the interactions occurring between participants as well as the roles of acoustical standardization institutions are specified. Technological, social and economic impacts are outlined. Finally, the status and trends of the system and the NBS role in adapting to changing technology are discussed. 
NBSIR 75-939. The National Measurement System for radiometry and photometry, H. J. Kostkowski, 32 pages (Nov. 1977). Order from NTIS as PB274643.

Key words: detectors; National Measurement System; photometry; radiometry; sources; standards; survey.

This publication covers the National Measurement System concerned with the measurement of radiant power in the ultraviolet, visible, and infrared regions of the electromagnetic spectrum. This study was undertaken to determine the importance of such measurements in the United States, the accuracy and ease with which they can be made, the adequacy of this capability, and the nature of the program NBS has been pursuing in this measurement area. The economic and social impact of radiometry and photometry is also discussed.

NBSIR 75-941. The National Measurement System for far ultraviolet radiometry, W. R. Ott, 74 pages (June 1977). Order from NT1S as PB269535.

Key words: detectors; National Measurement System; radiometry; sources; survey; ultraviolet.

NBSIR 75-945. The National Measurement System for Surface Properties, C. J. Poweli, 81 pages (Mar. 1977). Order from NT1S as PB264258.

Key words: National Measurement System for Surface Properties; surface atomic structure; surface characterization; surface composition; surface electronic structure; surface properties.

An analysis is given of the National Measurement System for Surface Properties. Emphasis is placed on the properties needed to characterize a solid surface, particularly surface composition, surface atomic structure and surface electronic structure; these characteristics directly affect many important surface properties or processes that occur on surfaces (e.g., electrical and optical properties, adhesion, bonding, catalytic activity, plating, durability, corrosion, decoration, segregation, lubrication and reactivity). The above three forms of surface characterization are widely utilized in surface-science experiments while measurements of surface composition are routinely made to solve a wide variety of problems in the semiconductor, chemical, petroleum and metallurgical industries for applications ranging from process and device development, process control, process evaluation to failure analysis. Surface-characterization measurements in government laboratories support a variety of agency missions. Surface science and surface technology have both grown rapidly in the past ten years, and further growth is expected. At this time, there is a complete lack of standards, standard procedures, and standard materials to support surface-characterization measurements. In short, there is no established national system for the measurement of surface properties. Recommendations for NBS action are given to improve and extend the measurement services required to promote surface science and surface technology and thereby to establish a satisfactory system for the measurement of surface properties.

NBSIR 75-948. Economic analysis of the national measurement system, B. W. Poulson, Ed., 45 pages (Sept. 1977). Order from NT1S as PB274049.

Key words: economics; information; NBS; national measurement system.

This report is a comprehensive summation of all relevant work known to NBS on the state of the art of economic analysis of the national measurement system. It is written for a mixed audience of economists and physical scientists. The first part deals with the concept of measurement for economic anal- ysis, the quantitative dimensions of measurement in the economy and the relationships between measurement and economic change. Measurement information is ubiquitous in the economy; it is used by producers and consumers and as an input at the interface between buyers and sellers. Resources used in making measurements cost about 6 percent of GNP in 1963, and all major economic sectors incurred substantial expenses. Industries with rapid rates of growth and productivity advance tend to be measurement intensive. Data from the NBS metric study provide supporting insights. The second part of the study examines the measurement system from the standpoint of the private sector, including the economic rationale for measurement by producers, consumers, and in sales transactions; and case studies of costs and benefits. The third part deals with the role of government, incorporating an economic rationale for measurement activities in the public sector, and case studies of costs and benefits of activities by NBS. Information provided by measurement may be a public or collective good, and be accompanied by external economies; under such conditions the private market system may not allocate resources efficiently and governmental intervention may increase the general welfare. While none of the case studies satisfies the conditions of rigorous cost benefit or cost effectiveness analysis, they do provide insight into the economic role of NBS in the national measurement system.

NBSIR 75-949. Structure and functions of the national measurement system, R. C. Sangster, 140 pages (July 1977). Order from NT1S as PB274048.

Key words: instrumentation; measurement standards; National Bureau of Standards; national measurement system; standardization organizations; standard reference data; weights and measures.

The National Measurement System consists of the activities and mechanisms-intellectual and operational, technical and institutional-that provide physical measurement data to allow creation of the objective, quantitative knowledge required by our society. This report describes the structural and functional aspects of the system, with emphasis on the technical and institutional infrastructures, the international context, and basic impacts and trends. 16 appendices and an extended bibliography provide back-up detail. Measurement is necessary in conduct of the life of the individual, pursuit of science, operations of society, and employment of technology, for describing, predicting, communicating, deciding, controlling, and reacting in dealing with the physical universe. Our model of the system employs five structural levels: 1. Conceptual foundation-the International System of units (S1). 2. Basic technical infrastructure-documentary standards and specifications, instrumentation, reference data, reference materials, predictive methods, science and trained people. 3. Realized measurement capabilities. 4. Dissemination and enforcement network-documentary standardization institutions, instrumentation industry, state and local offices of weights and measures, standards and testing laboratories and services, regulatory agencies, and NBS. 5. End-use measurements market-place. B1PM, the International Bureau of Weights and Measures, is the central agency internationally. Major trends of the system include increased complexity and integration, improved quality control and information resources, automation, metrication, and an increasingly fundamental scientific base.

NBSIR 76-847. Electrocaloric refrigeration for superconductors, R. Radebaugh, J. D. Siegwarth, W. N. Lawless, and A. J. Morrow, 195 pages (Feb. 1977). Order from NT1S as PB265007.

Key words: beryllium; ceramics; cryogenics; dielectric-constant; electrets; electrocaloric effect; entropy; ferroelec- 
trics; glass-ceramics; heat switches; magnetothermal conductivity; polarization; potassium tantalate; refrigeration; specific heat; strontium titanate.

A solid state type of refrigeration, which utilizes the electrocaloric effect in certain dielectric materials, has been investigated. Such a refrigerator would operate with a load at 4 $\mathrm{K}$ and reject heat to a reservoir at $15 \mathrm{~K}$. Heat switches for such a refrigerator were studied. One type was a multiple leaf contact switch. The other type was a magnetothermal switch utilizing single crystal beryllium. Based upon earlier preliminary work, the refrigeration material was to be a $\mathrm{SrTiO}_{3}$ glass-ceramic. It was found here that such a material has no useful electrocaloric effect at $4 \mathrm{~K}$. Many other materials were studied but none were found with sufficiently high electrocaloric effects for a practical refrigerator. The largest effects were seen in $\mathrm{SrTiO}_{3}$ ceramics, followed by $\mathrm{KTaO}_{3}$ single crystal. Temperature reductions of about $0.5 \mathrm{~K}$ at $10 \mathrm{~K}$ were observed during depolarization. A theoretical model, based on the electret behavior of impurity-vacancy dipoles, was developed to explain the observed dielectric behavior in the materials investigated. Another theoretical model, based on the lattice dynamics of displacive dielectrics, was used to explain the observed entropy and temperature changes seen in such materials. The model points out that displacive type materials have too low entropies at $4 \mathrm{~K}$ for practical refrigeration. An investigation of certain order-disorder dielectrics is suggested.

NBSIR 76-850. Liquid helium storage at high density and discharge at high low rates, D. E. Daney, 54 pages (Dec. 1976). Order from NTTS as PB266945.

Key words: cryogenic helium supply system; cryogenic storage; helium; helium supply system; high density helium storage; liquid helium storage; supercritical helium.

Equipment to store supercritical helium at high density and to demonstrate pulsed discharge at high flow rates has been designed, fabricated and successfully tested. A storage density of $0.193 \times 10^{3} \mathrm{~kg} / \mathrm{m}^{3}\left(12.03 \mathrm{lb} / \mathrm{ft}^{3}\right)$ at $8.3 \mathrm{MPa}(81 \mathrm{~atm})$ was achieved in a 135 liter ( $35 \mathrm{gal}$ ) dewar. Pulsed discharges of 2 seconds and 4 seconds duration were demonstrated at a flow rate of $1.0 \mathrm{~kg} / \mathrm{s}(2.2 \mathrm{lb} / \mathrm{s})$, and flow fluctuations of less than \pm 1 percent were achieved without feedback control. In general, the system operated in a very stable and well behaved manner.

NBSIR 76-851. Electromagnetic remote sensing of inhomogeneous media, W. A. Bereuter and D. C. Chang, 22 pages (Jan. 1977). Order from NTIS as PB263124.

Key words: inhomogeneous dielectrics; profile inversion.

This report deals with the electromagnetic response of inhomogeneous dielectrics, i.e., media whose permittivity is a function of depth. The resulting boundary value problem is solved for a large number of permittivity functions which can model almost any medium of interest.

Since those permittivity profiles are characterized by only a few parameters, they are particularly useful for the inverse problem; i.e., the retrieval of profiles from the measured electromagnetic response.

It is shown how the nonuniformity of the permittivity changes the response and how the change is related to the profile characteristics.

NBSIR 76-994. A numerical solution of the time dependent partial differential equations which describe a one-dimensional, laminar, premixed flame, R. L. Brown, 178 pages (Jan. 1976). Order from NTIS as PB263100.

Key words: combustion; differential equations; flame chemistry; flame modeling; laminar flames; numerical solution of flame equations.
The set of time dependent, parabolic differential equations, which describe the physical and chemical processes in a onedimensional, laminar, premixed flame is solved by adapting a solution procedure originally developed to solve the two-dimensional steady state boundary layer equations. The flame equations are integrated by an implicit method until the steady state is reached. This corresponds to a flame propagating steadily through a mixture of combustible gases. By a suitable choice of boundary conditions, it is also possible to model a flame which is stabilized on a burner. Solution of the flame equations yields the concentration profiles of the different chemical species as well as the temperature profile. From these one can also calculate the production rates of each species, the rate of each chemical reaction, and the heat release rate at each point in the flame. The velocity of the freely propagating flame can be calculated from the integrals over the whole flame zone of any of the species production rates. The model incorporates realistic thermodynamic data and transport property data that are functions of both temperature and concentration. A complete documentation of the computer program which accomplishes the integration is presented.

\section{NBSIR 76-999. Surveillance test procedures, H. W. Almer and J. Keller, Eds., 78 pages (May 1977). Order from NTIS as PB268130.}

Key words: apparent mass; buoyancy; buoyancy correction; change; comparison; difference; mass; records; set; surveillance limits; surveillance test; test interval; true mass; value; weighing design; weights.

Surveillance tests are designed to monitor the values of mass standards between calibrations. Two types are described; both consist of comparisons of the weights of an ordered set of mass standards with each other. The differences found are compared with those computed from the reported mass values. Surveillance limits based on the precision of both the calibration and the surveillance test processes are computed. These limits are estimates of the departure of the measured differences from the expected, or predicted, differences as computed from the reported values. A larger change is considered significant. Additional measurements to identify individual weights which have changed are required when a given comparison indicates that the mass of one or more of the weights involved has changed. Buoyancy corrections are used to correct for the difference in the buoyant effect on weights of differing densities. Records document the surveillance test results, and control charts help detect trends. Judgments concerning recalibration can be made based on the constancy of the weights and the use requirements.

NBSIR 76-1005. A comparison of two testers in evaluating the slip-resistance of bathtub and shower base surfaces, R. J. Brungraber and T. J. R. Raper, 59 pages (Oct. 1977). Order from NTIS as PB273120.

Key words: Kollsman tester; NBS-Brungraber tester; safety of bathrooms; slip-resistance of bathtub and shower base surfaces; slip-resistance testers.

The report describes a program of tests planned by ASTM Committee F15.03 on Safety Standards for Bathtub and Shower Structures, and conducted at the National Bureau of Standards for the purpose of comparing the NBS-Brungraber and the Kollsman tester with respect to their effectiveness in evaluating the slip-resistance of , bathtub and shower base surfaces. This program represents a contribution by the National Bureau of Standards to the efforts of the American Society for Testing and Materials and the Consumer Product Safety Commission in developing safety standards for bathrooms and bathroom fixtures. Both testers employ the same material (drumheads of 
"slunk") to simulate human skin, and the report concludes that both testers will satisfactorily discriminate between different bathroom surfaces on the basis of slip-resistance. The conclusion may be made that the NBS-Brungraber tester is considerably more convenient to use.

NBSIR 76-1030. The effect of sample orientation in the smoke density chamber, L. Breden and M. Meisters, 32 pages (May 1976). Order from NTIS as PB263633.

Key words: fire performance; horizontal and vertical smoke measurements; smoke; smoke density chamber; smoke suppressants.

Smoke measurements were compared for various materials in the vertical and horizontal positions. There appeared a significant difference for thermoplastic materials because of the melting away from the incident heat flux in the vertical position. The horizontal mode in addition allows one to relate the chemistry of polymeric materials to the amount of smoke production. Finally, smoke measurements are made of products containing various amounts of smoke suppressants.

NBSIR 76-1053. Component parts assembly with joints, adhesive-mechanical. Part 4. Analysis and test of bonded and weldbonded lap joints, R. A. Mitchell, R. M. Woolley, and S. M. Baker, 75 pages (Mar. 1976). Order from NTIS as ADA029426.

Key words: adhesive-bonded joints; bonded joints; cyclic loading; debond analysis; double-lap-joint analysis; fatigue tests; finite element analysis; joints; nonlinear analysis; single-lap-joint analysis; single-lap-joint bending; spotwelded joints; weldbonded joints.

Finite element computer techniques were used to study the linear and nonlinear structural response of bonded and weldbonded lap joints. Although the techniques used are applicable to either single-lap or double-lap joints, the emphasis was on the single-lap joint problem with the attendant complication of joint bending. Nonlinear algorithms were developed to account for nonlinear stress-strain characteristics of the adhesive, and the joined metal sheet, weld-heat softening of the metal sheet, progressive debonding of the adhesive, and nonlinear cyclic loading. The nonlinear modes of response were simulated by sequences of linear solutions.

Eight different single-lap joint configurations, designed so as to constitute an experimental parameter study, were studied in a laboratory testing program. Representative specimens were subjected to quasi-static tensile strength and cyclic-load tests and to tensile fatigue tests. The quasi-static and fatigue data generally plot into clear $\mathrm{S}-\mathrm{N}$ patterns that are in a reasonable relationship to the lap joint design parameters. For the most part, strains measured on the surfaces of the test specimens were in reasonably good agreement with those computed by finite element analysis, provided out-of-plane bending effects were accounted for. The dominant failure modes were consistent with the computer analyses.

NBSIR 76-1075. The structure of slow crack interfaces in silicon nitride, N. J. Tighe, 23 pages (May 1976). Order from NTIS as PB274653.

Key words: cracks; electron microscopy; fracture interfaces; plastic deformation; silicon nitride; turbine materials.

Cracks in hot-pressed silicon nitride (HPSN) and in reaction bonded silicon nitride were studied by light and electron microscopy. Slow crack growth, resulting from plastic deformation, occurred in HPSN at $1400{ }^{\circ} \mathrm{C}$. However, the RBSN exhibited brittle fracture at this temperature. This difference in behavior can be explained by the effects of compositional and microstructural differences between the two materials. The
MgO additions to HPSN promoted sintering but its presence contributed to plastic deformation. The RBSN was made without added phases. It does not sinter as completely as the HPSN and the grain size is an order of magnitude smaller. The small grained regions offered no resistance to fracture.

NBSIR 76-1078. Piezoelectric polymer transducers for dynamic pressure measurements, A. S. DeReggi, S. Edelman, and S. C. Roth, 42 pages (June 1976). Order from NTIS as PB264125.

Key words: piezoelectric; polymer; polyvinylidene fluoride; pressure sensor; pyroelectric; transducer.

This report describes the construction, testing and calibration of piezoelectric polymer sensing transducers of two sizes. The piezoelectric material was obtained by poling $25 \mu \mathrm{m}$ thick, polyvinylidene fluoride sheet. Sensors with an active area of 1 $\mathrm{cm}$ diameter, intended for dynamic interface-pressure measurements, were calibrated in a fixture generating normal pressure transients by means of piston impact. Sensors with an active area of $2 \mathrm{~mm}$ diameter, intended for measuring dynamic pressures while implanted in the cranium of rhesus monkeys, were calibrated in an oil cell with a piston-cylinder seal which provided hydraulic pressure transients by means of impact on the piston. The larger sensors had a normal-pressure sensitivity around $3 \mu \mathrm{V} / \mathrm{Pa}(20 \mathrm{mV} / \mathrm{psi})$ and the smaller sensors a hydraulic-pressure sensitivity around $0.7 \mu \mathrm{V} / \mathrm{Pa}(5 \mathrm{mV} / \mathrm{psi}$ ).

NBSIR 76-1088. Estimating the energy conservation potential of ventilation control through weather data analysis, $T$. Kusuda and J. W. Bean, 51 pages (Aug. 1977). Order from NTIS as PB273949.

Key words: air conditioning requirements; energy conservation; intermittent ventilation; ventilation control; weather data analysis.

Hourly weather data for six selected cities in the United States covering eleven consecutive years were analyzed to aid in estimating the possible energy saving that could be achieved by closing the outdoor dampers during unoccupied hours. The analysis shows that, depending upon the local weather condition, and with some simplifying assumptions, from 74 to 83 percent of the energy used for heating the make-up air could potentially be saved by closing the outdoor dampers when the building is not occupied. Based upon a premise that the energy required for cooling the outdoor ventilation air is proportional to the average enthalpy difference between the outdoor air and the air leaving the cooling coil, from 53 to 63 percent of the energy for cooling of ventilation air could be saved by closing the outdoor dampers during unoccupied hours.

Hourly temperature and enthalpy values are presented in histogram form for occupied and unoccupied periods (office use), with the suggestion that similar data processing be carried out for other cities as well.

NBSIR 76-1092. Consumer product portability as related to warranty rulemaking, J. J. Kramer and P. G. Meguire, 91 pages (Aug. 1976). Order from NTIS as PB265961.

Key words: anthropometry; biomechanics; carrying; consumer product portability; ergonomics; human factors; lifting; manual materials handling; physiology; psychophysics; safety; warranty.

The Federal Trade Commission (FTC) has the responsibility for determining what may be reasonably expected of consumers in their fulfillment of the terms of a consumer product warranty. Such determination necessitates, in part, providing an empirical basis for defining and quantifying various factors influencing product portability. This report discusses the problem of defining consumer product portability within the context of 
a consumer product return activity, offers a working definition of product portability within this context, summarizes and discusses the results and utility of previous portability related studies, and describes the results of a controlled experiment which more directly relates to the task of establishing maximum reasonable product weight for a consumer product return activity. Statistically significant differences in maximum reasonable product weight were found for the variables of method of product carry and sex of customer. No statistically significant differences were found for the variables of consumer age and product size (at least for the sizes chosen for study). Distributions of maximum rcasonable weight for product return are presented and recommendations for warranty rulemaking are given.

NBSIR 76-1094. Standards for computer aided manufacturing, J. M. Evans, Jr., J. T. O'Neill, J. L. Little, J. S. Albus, A. J. Barbera, D. W. Fife, E. N. Fong, D. E. Gilsinn, F. E. Holberton, B. G. Lucas, G. E. Lyon, B. A. S. Marron, A. J. Neumann, M. V. Vickers, and J. C. Walker, 41 pages (July 1976). Order from NTIS as ADA030098.

Key words: CAM architectures; computer aided manufacturing; computer systems; standards; system integration; voluntary standards.

This report identifies and evaluates those existing and potential standards which will be useful to the Air Force in the development and implementation of integrated computer aided manufacturing (ICAM) systems. Such systems, when implemented by the Air Force and by Air Force contractors, will increase productivity in discrete part batch manufacturing by several thousand percent. The use and importance of standards are considered in the context of CAM systems. Since the Air Force will develop the detailed ICAM architecture after this study is complete, existing system concepts and architectures are examined to identify the common elements to guide the further presentation and discussion of relevant standards.

NBSIR 76-1103. Some institutional factors affecting MIUS-A case study and annotated bibliography, J. Elder, 65 pages (June 1977). Order from NTIS as PB268425.

Key words: institutional factors; Modular Integrated Utility System; total energy; utility system.

This report considers some of the institutional factors which might affect the development and implementation of an innovative utility project and in particular of a Modular Integrated Utility System (MIUS). A case study of the planning and implementation stages of a major utility project was undertaken along with several studies of less complex utility projects. An annotated bibliography exploring the literature on institutional response to existing or proposed utility projects and to innovation in general is included. The case studies and literature survey indicated a number of institutional factors along with a wide range of issues associated with these factors. Specifically, the institutional factors which are considered fall into the following areas: utility company response, local citizen group response, environmental group response, labor interest, builder/developer role, local planning agency and local, state and Federal agency involvement. Economic and legal/regulatory factors are not considered in any detail. In addition to the case studies and the annotated bibliography, the report contains a list of researchers currently working on related programs and a list of journals and other major references which are likely to include relevant material.

NBSIR 76-1108. Fabrication of the barium quoride film humidity sensor by industrial firms, F. E. Jones, 73 pages (Apr. 1977). Order from NTIS as PB269337.
Key words: barium fluoride; calibration equations; fast response; films; humidity sensor; industrial fabrication; isotherm equations; physical adsorption; relative humidity; routine radiosonde application.

The barium fluoride film electric hygrometer element, which was conceived and developed at the National Bureau of Standards as a fast responding humidity sensor and which has been used in a variety of research applications, has been successfully fabricated by several commercial firms. This successful transfer of technology from the Federal Government to the private sector should assure the availability of the element for general use, including missile climatology and routine radiosonde use. Calibration equations have been developed and the analysis of calibration data has provided insight into the physical processes involved in the functioning of the element.

It has been shown that the conductance-p/ps isotherm (in itself a Type II isotherm in the Brunauer designation of physical adsorption isotherms) is a composite of a Type I and two Type III isotherms. The two Type II isotherm equations are of the form of the Freundlich isotherm equation. These results represent the solution of a long-standing problem in adsorption and have general application to other adsorption systems in addition to the water vapor-barium fluoride film system.

NBSIR 76-1 I 13. A ten year history of National Bureau of Standards activities under the Brooks Act (Public Law 89-306), G. Burns and S. Radack, Eds., 93 pages (Feb. 1977). Order from NTIS as PB263526.

Key words: ADP standards; Brooks Act; computer science research; computers in the Federal Government; scientific and technological advisory services.

This report presents the principal findings of a National Bureau of Standards task force which reviewed the activities and accomplishments of NBS from I 965 to I975 under Public Law 89-306, the Brooks Act. The Brooks Act is concerned with the effective use of computers by the Federal Government and assigns the National Bureau of Standards responsibility for providing scientific and technological advisory services for automatic data processing, developing uniform Federal ADP standards and undertaking necessary research in computer science and technology. Program activities and a history of funding for each of these three major responsibilities are covered. Also included are case studies of individual program initiatives.

NBSIR 76-I 1 I7. Exposure spectra from NBS vertical-beam ${ }^{60} \mathrm{Co}$ gamma-ray source, M. Ehrlich and C. G. Soares, I 1 pages (Dec. 1976). Order from NTIS as PB269341.

Key words: collimator; exposure spectra; gamma-rays; scattered radiation; source housing; spectrometry; ${ }^{60} \mathrm{Co}$ gamma-ray source.

Exposure spectra at a distance of 1 meter from the NBS vertical-beam ${ }^{60} \mathrm{Co}$ gamma-ray source are presented in tabular form for field sizes of practical interest. Also tabulated are contributions to exposure arising from source housing and collimator, as well as from the source proper.

NBSIR 76-1125. Catalog of artifacts on display in the NBS Museum, H. L. Mason, Ed., 292 pages (Nov. 1977). Order from NTIS as PB273666.

Key words: history of science; measurement instruments; measurement standards; National Bureau of Standards; national measurement standards; physical measurement; weights and measures.

Apparatus and other memorabilia illustrative of the scientific and engineering achievements of NBS are described, with statements of their technical function and their historic place in the evolution of physical measurement. 
NBSIR 76-1128. Interaction of blood proteins with solid surfaces, L. E. Smith, R. E. Dehl, W. H. Grant, R. R. Stromberg, and B. W. Morrissey, 44 pages (Oct. 1976). Order from NTIS as PB259199.

Key words: adsorption; blood protein; ellipsometry; implants; polymer adsorption; protein adsorption; synthetic implants.

This investigation is designed to help characterize the surface properties of cardiovascular implant materials. Such properties largely determine the success or failure of implants and may therefore be used as the basis for in vitro test methods. The focus of this investigation has been on the measurement of protein adsorption on surfaces, emphasizing measurements of the conformational changes which occur upon adsorption. During this reporting period, several materials produced by contractors of the NHLI Biomaterials Program have been examined by ellipsometry and a number have been found suitable for further work. Conformational changes at very short adsorption times are of considerable importance and preliminary results indicate that our techniques are capable of measurements at times as short as two seconds. We have analyzed commercially available radiolabeled human serum albumin and found considerable amounts of dimers and higher aggregates in some commercial preparations. We have begun to assess the errors involved in the use of unfractionated proteins for adsorption measurements by using purified monomer and aggregates. The use of light scattering to measure the conformation of protein adsorbed on small particles has been evaluated in a study of $\gamma$-globulin adsorption on polystyrene. The results agree well with similar measurements made by ellipsometry.

NBSIR 76-1135. Radiation-hardness testing of electronic devices: A survey of facility dosimetry practices, J. C. Humphreys and S. E. Chappell, 45 pages (Sept. 1976). Order from NTIS as PB263630.

Key words: dosimeter calibration; electronic devices; ionizing radiation; radiation dosimetry; radiation hardness testing; radiation sources; thermoluminescence dosimeters; total dose.

As part of a program to develop better quality assurance in the measurement of total dose in the field of radiation-hardness testing of electronic devices, a survey was conducted at twelve radiation test facilities. The survey was carried out through personal visits at which time various characteristics of the test facilities and dosimetry procedures were noted. This report summarizes the results of the survey. Particular attention is given to the types of dosimetry problems perceived by the dosimetry personnel at the facilities as well as to general observations by the surveyor.

The observations and information obtained through this survey led to some conclusions on where problems in total-dose measurements may occur. Some specific recommendations result and give direction to the program plan for developing more consistent measurement procedures within the radiationhardness testing community.

NBSIR 76-1145. Interlaboratory comparison of force calibrations using ASTM method E74-74. Phase 1, R. W. Peterson and R. L. Bloss, 35 pages (Aug. 1976). Order from NTIS as PB265110.

Key words: force; force calibration; interlaboratory comparison; load cell; static force.

This report covers the first phase of an intercomparison of force calibrations coordinated by the National Bureau of Standards in conjunction with Committee E28.01 of the American Society for Testing and Materials. Results obtained show that the provisions of ASTM Method E74-74, "Standard Methods of Calibration of Force-measuring Instruments for Verifying the Load Indication of Testing Machines" can be met by a variety of calibration laboratories. In general, uncertainties computed from the data are of the magnitude expected based upon the NBS results. An important byproduct of the program is the mechanism for self-evaluation by each laboratory of its own force calibration capability.

NBSIR 76-1146. A study of personal fall-safety equipment, $H$. L. Steinberg, 219 pages (June 1977). Order from NTIS as PB269355.

Key words: body belts; body harness; fall-arrest equipment; fall-safety systems; impact accelerations; impact forces; lanyards; linemen's equipment; load-extension data; occupational safety and health; performance standard; regulation; tensile testing; worker safety equipment.

A study has been made of the basic requirements for personal safety equipment that is designed to protect workers at heights against the danger of falis. The project was undertaken for the Occupational Safety and Health Administration as part of an effort to update the Code of Federal Regulations on fallsafety equipment. The investigation included an intensive literature review, numerous field visits, and a limited laboratory examination of some components. Some unique testing and evaluation approaches were developed, and a novel extensometer was designed.

NBSIR 76-1148. Characterizing the inter-fiber bond strengths of paper pulps in terms of a breaking energy, J. C. Smith and E. L. Graminski, 39 pages (Oct. 15, 1976). Order from NTIS as PB264689.

Key words: breaking energy; inter-fiber bond strength; mixed waste paper; paper recycling; pulp characterization; $2.5 \mathrm{~g} / \mathrm{m}^{2}$ handsheets.

The inter-fiber bond strength of paper is an important but an arduous property to measure. In order to characterize a pulp completely, the quality of bondability must be known especially for pulps produced from a mixture of waste paper. It has been postulated that a measure of bond strength can be obtained by measuring $2.5 \mathrm{~g} / \mathrm{m}^{2}$ handsheets to tensile failure, recording the number of bonds broken with a sensitive tensile tester and plotting a curve of number of bonds broken as a function of cumulative work done on the system. The value of the minimum slope of this curve is equal to the average energy dissipated per bond break. Results obtained on two different softwood kraft pulps indicate the proposed method may be useful in assessing bond strengths.

NBSIR 76-1149. A second appraisal of methods for estimating self-reaction hazards, E. S. Domalski, 160 pages (Mar. 1977). Order from NTIS as PB266925.

Key words: accidental polymerization; CHETAH predictive scheme; hazard evaluation; test data; test methods; thermal explosion theory.

A literature survey was carried out to collect and evaluate test methods and test data on hazardous materials which undergo self-decomposition. Some thermal tests are regarded as valuable because they give quantitative data indicating the limit of thermal stability for specified materials. With the assistance of the CHETAH predictive scheme, a hazard evaluation was conducted on a selected group of compounds normally considered safe. Results showed a tendency to identify these safic materials as hazardous so as not to err in evaluating a truly hazardous compound. In a study of accidental polymerization of bulk chemicals, free radical polymerization involving olefins was considered the polymerization process most likely to occur 
inadvertently during transport. A calorimetric test procedure appeared to offer the promise of yielding data from which an unambiguous reactivity scale could be developed. The test procedure should have a firm relationship to the theory of thermal explosion.

NBSIR 76-1152. Report to AID on an NBS/AID workshop on standardization and measurement services, H. S. Peiser, J. Cornish, and C. C. Raley, Eds., 111 pages (Mar. 1977). Order from NTIS as PB265719.

Key words: AID; assistance; developing economies; foreign relations; industrializing nations; international relations; LDS's; measurement services; standardization.

From September 20 to October 3, 1975, a Workshop was held at the National Bureau of Standards, Gaithersburg, under the sponsorship of AID. The object of the Workshop was to give standards officials of industrializing nations insight into the standards and measurement systems of the United States and the role of the National Bureau of Standards, so that these officials might consider what parts of the U.S. System might usefully be adapted to conditions in their home countries. An exchange of standardization experience in each of the participant's countries was presented by delivered papers which are reproduced here.

NBSIR 76-1169. Rationale and recommendations for changes and revisions to the HUD noise measurement systems specifications, D. S. Blomquist and M. A. Cadoff, 58 pages (Oct. 1977). Order from NTIS as PB273306.

Key words: acoustics; community noise; environmental impact; noise; noise exposure measurement system; sound.

In 1973, the Office of Noise Abatement Research, Department of Housing and Urban Development, contracted with the Applied Acoustics Section of the National Bureau of Standards to develop a noise exposure measurement system. This system was subsequently developed, seventeen prototype units were procured, and a full-scale laboratory and field evaluation of the units were conducted. This report discusses the results of the evaluation, as well as the rationale behind and recommendations for changes and revision to the HUD noise measurement system specifications.

NBSIR 76-1170. The role of passive film growth kinetics and properties in stress corrosion and crevice corrosion susceptibility, J. Kruger and J. R. Ambrose, 56 pages (Nov. 1976). Order from NTIS as ADA034723.

Key words: crevice corrosion; iron-molybdenum alloys; localized cortosion; repassivation; sensitization; stainless steel.

This report consists of four parts as follows: I-A study of the influence of $\mathrm{Mo}$ in Fe-Mo alloys on crevice corrosion. It was found the $>5$ percent Mo is needed to affect repassivation in a crevice. II-The description of a new technique for measuring repassivation rates in a crevice. III-A description of alloys prepared to simulate the composition of metal near grain boundaries of sensitized austenitic stainless steel. These alloys are used for studies of the effect of sensitization on repassivation kinetics. IV-A review of new approaches in the study of localized corrosion.

NBSIR 76-1174. Skid resistance measurement test procedures for intercomparing FHWA national and regional reference systems, R. W. Kearns and J. F. Ward, 35 pages (Dec. 1976). Order from NTIS as PB262366.

Key words: friction, pavement; highway safety; measurement, skid resistance; pavement, skid resistance; test procedures, skid resistance measuring systems; tire-pavement interface forces.

The measurement of the skid resistance of highways, under wet weather conditions, is part of the Federal Highway Administration (FHWA) skid-accident reduction program. A national reference system and regional reference systems are operated to improve the method of measurement, to reduce differences in results between systems and to include measurement assurance in the program. State highway measuring systems are intercompared with reference systems at FHWA regional field test centers. This document describes the objectives, the scope and the general procedures of the tests used to intercompare the regional reference systems with the national reference system operated by the National Bureau of Standards. Listing of the general equipment required are included.

NBSIR 76-1 175. The static force calibration of a skid resistance measuring system, R. W. Kearns and J. F. Ward, 87 pages (Dec. 1976). Order from NTIS as PB276530.

Key words: accident reduction, skidding; highway safety; measurement, skid resistance; pavement skid resistance; skid resistance measurement; tire-pavement interface forces; wet pavement skid resistance.

A variety of skid resistance measuring systems have been designed to meet the requirements of ASTM Method E 274. When these systems are compared on the same pavement, the measurements often vary widely. This report describes procedures for the calibration and control of one such measuring system, the FHWA Interim Reference System. This system employs a tow vehicle and two-wheeled skid trailer. The procedures are chosen to minimize errors, leading to an increased confidence in the measurement results.

Equations of static equilibrium for the skid trailer are derived and experimentally verified. The motions of the system in response to static force are measured and shown to depend on tow vehicle as well as trailer characteristics. Variables affecting the force calibration are identified. These include hitch height, trailer weight, lateral force on the test tire, center of support of the test tire, temperature of the test tire and force transducer, and inflation pressure.

The use of a force plate as a calibrator is described. It is shown that the calibrator must itself have been calibrated under conditions covering its use with the trailer. Calibration of the force plate under combined vertical and traction force is described.

The procedures are adaptable to other similar skid resistance measuring systems.

NBSIR 76-1177. Comparison of computer-predicted and observed energy uses in a multi-family high-rise apartment building, J. P. Barnett and S. T. Liu, 37 pages (June 1977). Order from NTIS as PB267829.

Key words: building energy analysis; computerized energy analysis; energy consumption; heating and cooling loads.

A comparison has been made of the results of two computer programs, the National Bureau of Standards Load Determination Program (NBSLD) and the American Gas Associations ECUBE program, in predicting the energy consumption of a multi-family high-rise apartment building located in Omaha, Nebraska. Results are given on a monthly basis for the computed energy values and compared with average monthly values of metered data obtained over a five-year period. Close agreement was found between the energy consumption predicted by the two different computer programs, as well as between the predicted values and the metered data (less than $7 \%$ difference on an annual basis). 
NBSIR 76-1178. Air leakage and thermal performance of a MARK III relocatable Lewis building, C. W. Phillips, B. A. Peavy, and M. E. Kuklewicz, 42 pages (Dec. 1976). Order from NTIS as PB264211.

Key words: air leakage of buildings; building heat transfer; honeycomb panel construction; relocatable buildings; windload racking.

This report presents the findings of air leakage and heat transfer tests of a Mark III relocatable building at the National Bureau of Standards, Building Environment Division, for the U.S. Department of the Navy. Quantitative and qualitative (smoke trace) air leakage tests with the building pressurized, and the heat transfer test, were performed with the building erected in an environmental laboratory. The quantitative air leakage tests were performed in two phases. One was with the building racked to simulate a wind load and the other was without racking. The building was of prefabricated honeycomb panel construction using aluminum skins. Included are photographs of the building and test equipment and tables and charts showing the magnitude of air leaks at the windows and doors. Racking had negligible effect on the air leakage rate.

NBSIR 76-1179. Attack and release characteristics of compression hearing aids, E. D. Burnett and M. A. Bassin, 175 pages (Dec. 1976). Order from NTIS as PB276536.

Key words: attack and release characteristics; compression; hearing aids.

The attack and release time characteristics of 81 compression hearing aids are presented. The input signal used was that specified in the standard, ANSI S3.22.

NBSIR 76-1180. Standardization and measurement services in Guyana, H. S. Peiser, N. C. Beck, and K. S. Stephens, 100 pages (Feb. 1977). Order from NTIS as PB265087.

Key words: cottage industry; developing countries; Guyana; less developed countries; measurement services; standardization; testing facilities.

A survey of standardization and measurement services in Guyana was carried out in July, 1976, as part of a National Bureau of Standards program sponsored by the Office of Science and Technology of the Agency for International Development. The Survey Team included three members, one of whom was an NBS staff member and the other two, U.S. participants. The survey was conducted at the request of Dr. Dennis Irvine, Chairman of the National Science Research Council (NSRC) and Vice Chancellor of the University of Guyana.

The NBS team's specific objectives were: 1) to survey domestic and export oriented industries and related GOG and private sector organizations, and 2) to advise the NSRC on optimum means for establishing a National Bureau of Standards and related activities to assist effectively industrial development in Guyana.

NBSIR 76-1182. The thermal performance of a two-bedroom mobile home, G. J. Teitsma and B. A. Peavy, 104 pages (Jan. 1977). Order from NTIS as PB263883.

Key words: air infiltration; energy conservation; mobile home; part-load efficiency; thermography.

Tests were conducted on a mobile home located in an Environmental Climatic Laboratory for the purpose of evaluating its thermal performance. The heating demand greatly affected the part-load efficiency of a gas-fired, forced-air, sealed-combustion furnace system. The practice of installing oversized heating plants was shown to result in low seasonal operating efficiencies. Air leakage measurements were performed using a pressurization technique to quantify the amount of air leakage through the various parts of the mobile home. Separate air infiltration tests using the $\mathrm{SF}_{6}$ tracer-gas technique that somewhat higher air infiltration rates were induced by operation of the mobile home heating plant. A thermographic survey of interior surfaces showed that the technique used to install the wall insulation may allow wrinkles formed in the surface of the insulation to form air paths zunning the height of the wall cavity. Convective air flow through these paths may create heat leaks on the building surface which can have an impact on the overall heat-loss rate. Separate tests were also conducted to identify places in the mobile home envelope having high condensation potential.

NBSIR 76-1184. Performance of branch circuit electrical terminations of copper and aluminum non-metallic sheathed cable, L. W. Masters, E. J. Clark, and E. J. Embree, 35 pages (Nov. 1976). Order from NTIS as PB267221.

Key words: aluminum wiring; branch circuits; copper wiring; military buildings.

A study was performed to provide the Tri-Services Committee on Building Materials with guidelines regarding the use of aluminum branch circuit wiring in military buildings. The first part of the study consisted of identifying military bases which contain buildings with aluminum wired branch circuits. Personnel at a number of the bases were contacted in order to estimate the extent of observed problems. Laboratory tests were performed on CO/ALR and non-CO/ALR duplex receptacles wired with both aluminum and copper nonmetallic sheathed cable. Overheating of aluminum wired termination points was observed with some receptacles in a current cycling test using non-CO/ALR receptacles at screw torque levels of 0.023 and $0.069 \mathrm{~kg}-\mathrm{m}$ ( 2 and $6 \mathrm{lb}$-in). Aluminum wired non-CO/ALR receptacles tested at $0.138 \mathrm{~kg}-\mathrm{m}$ (12 lb-in) screw torque showed no signs of overheating and copper wired non-CO/ALR receptacles showed no signs of overheating regardless of screw torque.

This report presents the findings of the study and includes guidelines regarding the use of aluminum branch circuit wiring in military buildings.

NBSIR 76-1186. Piezoelectricity and pyroelectricity in crystalline polymers, G. T. Davis and M. G. Broadhurst, 57 pages (Dec. 1976). Order from NTIS as PB264893.

Key words: charge distribution; charge transfer; corona poling; dipole orientation; piezoelectricity; polarization; polyvinylidene fluoride; pyroelectricity; vinylidene fluoride copolymer.

Investigations on piezoelectricity and pyroelectricity in crystalline polymers have been carried out using a copolymer of vinylidene fluoride and tetrafluoroethylene which crystallizes directly from the melt into a polar crystal form. The crystalline fraction is easily varied from 0.35 to 0.5 . Alignment of the dipoles in an applied electric field appears to approach saturation electric fields of $250 \mathrm{kV} / \mathrm{cm}$, independent of poling temperatures between 0 and $80{ }^{\circ} \mathrm{C}$. Piezoelectric responses from samples of varying crystallinity are consistent with increased polarization and lower compressibility as the degree of crystallinity is increased.

Thermal pulse experiments reveal that when poled at room temperature, only a thin region near the positive electrode is poled but the thickness of this region increases with an increase in poling temperature.

Copolymer films crystallized from the melt in the presence of a field show greatly improved stability of piezoelectric activity when stored at elevated temperatures compared with samples poled only after crystallization. 
The room temperature poling of polyvinylidene fluoride using a corona discharge has been confirmed. Preliminary results are presented which imply that even the nonpolar $\alpha$ phase of the polymer may be poled in this way but it is unstable-especially at elevated temperatures.

NBSIR 76-1190. Report on an NBS/AID survey of standardization and measurement services in Thailand, H. S. Peiser and R. S. Marvin, Eds., 80 pages (Feb. 1977). Order from NTIS as PB264917.

Key words: measurements; quality control; standardization; testing facilities; Thailand.

A survey of standardization and measurement services available in Thailand was carried out in May and June of 1973 as part of a National Bureau of Standards program sponsored by the Office of Science and Technology of the Agency for International Development. The Survey Team included five NBS staff members, three third-country participants, and an approximately equal number of professional Thai participants, headed by the overall Survey Director, Dr. Charoen Vashrangsi of the Department of Science in the Thai Ministry of Industry. A total of universities, government departments and private organizations were visited by some or all of the Team. The schedule of visits was so heavy that no time was available for discussion and formulation of formal recommendations. Thus the report is largely a brief factual account of the various visits, although a few comments and suggestions are included.

NBSIR 76-1191. A survey of calibration techniques for atmospheric ozone monitors, J. A. Hodgeson, 30 pages (Dec. 1976). Order from NTIS as PB263534.

Key words: air pollution; calibration; iodometry; monitoring; ozone; ultraviolet photometry.

A survey is presented of recent studies on calibration techniques for atmospheric ozone $\left(\mathrm{O}_{3}\right)$ monitors. These calibration techniques are based on iodometry, ultraviolet photometry (UV) and gas phase titration (GPT). The iodometric procedures include the 1 percent neutral buffered potassium iodide (NBKI) technique used by the Environmental Protection Agency (EPA), a 2 percent NBKI method of the California Air Resources Board and a 1 percent unbuffered $\mathrm{KI}$ technique previously used by the Los Angeles Air Pollution Control District (LAAPCD). The UV and GPT approaches are of rather recent application and brief descriptions of the calibration procedures are given. In summary the data show excellent agreement between $\mathrm{O}_{3}$ determinations by UV or GPT and demonstrate that absolute measurements of trace $\mathrm{O}_{3}$ concentrations can be made by either technique. On the other hand, the NBKI methods yield $\mathrm{O}_{3}$ measurements 1 to 13 percent higher than absolute values when $\mathrm{O}_{3}$ in dry air is analyzed. In the presence of humid air the NBKI measurements are high by factors ranging from 15 to 30 percent.

NBSIR 76-1193. Earthquake related activities of the Center for Building Technology, C. G. Culver, 24 pages (Mar. 1977). Order from NTIS as PB265103.

Key words: buildings; design; disaster mitigation; earthquakes; engineering.

This report describes activities related to earthquake engineering being carried out by the Center for Building Technology as part of the Center's overall Disaster Mitigation Program. Laboratory and field research, post disaster investigations and efforts to develop comprehensive eartquake resistant design provisions are included. The professional disciplines within the Center and the laboratory facilities are discussed. Recent accomplishments and mechanisms employed for facilitating implementation of the Center's research results are also discussed.
NBSIR 76-1194. A study of fire spread in multi-family residences: The causes-The remedies, B. M. Vogel, 22 pages (Feb. 1977). Order from NTIS as PB264368.

Key words: apartments; building codes; fire; fire resistivity; firestopping; fire walls; garden apartments; multi-family residences.

This report identifies the major elements contributing to the spread of fire in multi-family buildings, where the fire is beyond the area of origin. The data has been collected from 84 separate fires involving low-rise (garden apartments) residential buildings in the Washington, D.C. metropolitan area. This report categorizes the contributing factors of the fire spread into construction deficiencies, design deficiencies, and possible code violations; and suggests the need for specific revisions to building codes.

NBSIR 77-852. Cryogenic fluids density reference system: Provisional accuracy statement, B. A. Younglove and J. D. Siegwarth, 31 pages (Jan. 1977). Order from NTIS as PB263776.

Key words: densimeters; density reference system; liquid methane; LNG.

The measurement capability of the density reference system (DRS) of the National Bureau of Standards, Cryogenics Division, is described. This system measures density, pressure, and temperature of LNG mixtures for the purpose of testing densimeters which are contained in the liquid sample. Sample composition is determined by weighing the gas samples separately before condensing them into the sample. The DRS measures density by weighing a single-crystal of silicon immersed in the LNG mixture. This process is described and the equations used in the computation of density are discussed.

At this time the estimate of sample standard deviation for a single density measurement made on this system is \pm 0.062 percent (at $0.4 \mathrm{~g} / \mathrm{cc}$ ). Using three times this standard deviation as a limit for random error and adding \pm 0.026 percent as an upper bound for known sources of possible systematic error, the uncertainty of a single determination by this system is \pm 0.21 percent. This statement of accuracy applies for the density range 380 to $430 \mathrm{~kg} / \mathrm{m}^{3}$ and 1200 to $1400 \mathrm{~kg} / \mathrm{m}^{3}$, pressures to $7 \mathrm{bar}$, and temperatures from $80 \mathrm{~K}$ to $140 \mathrm{~K}$. This statement is expected to be correct in the intermediate density range and for all temperatures up to $300 \mathrm{~K}$.

Measurement uncertainties for temperature, pressure, and composition are discussed. Comparison of measurements for liquid argon densities with the results of other laboratories is given.

NBSIR 77-853. Helium research in support of superconducting power transmission-Annual report (July 1975-September 1976), M. C. Jones, V. D. Arp, W. R. Parrish, D. E. Daney, P. R. Ludtke, N. V. Frederick, and B. A. Hands, 99 pages (Feb. 1977). Order from NTIS as PB265076.

Key words: burn-out; helium-cooled current leads; helium flow facility; helium impurities; microwave pressure transducer; thermal-acoustic oscillations.

This report is the second annual report of research on helium related problems in support of superconducting power transmission development. The report is in four sections.

In the first section; results are presented from experimental and computer modeling of the performance of current leads cooled with supercritical helium gas. Performance characteristics studied are bum-out conditions and existence of oscillation in the helium gas.

The second section, on helium measurements, reports some conclusions on the feasibility of data transmission from highvoltage regions to grounded read-out instrumentation, on ther- 
momctry and on helium impurity measurements. A major part of this section is a detailed description with test results of microwave cavity pressure transducers for use at helium temperatures.

A third section, on helium properties, reports some improvements in computer codes for helium properties and discusses some recent data on the thermal conductivity of helium.

In the final section, a description is given of a recently completed flow facility which has been built for research on flow and heat transfer dynamics of supercritical helium in channels of high aspect ratio modeling superconducting power transmission line channels.

NBSIR 77-855. Quartz crystal oscillators with low acceleration sensitivity, J. J. Gagnepain and F. L. Walls, 16 pages (Mar. 1977). Order from NT1S as PB265075.

Key words: acceleration field; acceleration sensitivity; compound crystal resonator; crystallographic axis; nonlinear elastic effect; resonance frequency.

The acceleration sensitivity of quartz crystal resonators imposes severe limitation on their use in nonlaboratory environments. This work shows that by using two resonators connected in series and properly orientated with respect to one another, it is possible to substantially reduce the net acceleration sensitivity of the composite or compound crystal resonator. First qualitative experimental results on accelcration, also some experimental theories of studies related to the introduction of the two resonators comprising the compound resonator, are presented. From these studies it appears feasible to fabricate compound crystal resonators exhibiting acceleration sensitivities at least 10 times smaller than the resonators used individually.

NBSIR 77-856. Proposed standards for ladar signatures, B. L. Danielson, 38 pages (Apr. 1977). Order from NTIS as ADA038725.

Key words: laser radar; laser radar signatures; target standards.

This report attempts to assist in providing a common basis for the reporting and intercomparison of laser radar cross section (LRCS) data generated at different laboratories for the Ballistic Missile Defense Advanced Technology Center (BMDATC) laser radar signatures program. We are concerned here with recommending preferred definitions of some of the most commonly used LRCS terms and recommending a calibration target standard.

NBSIR 77-857. Cryogenic design and safety review NASALangley Research Center 0.3 Meter Transonic Cryogenic Tunnel, R. O. Voth and T. R. Strobridge, 28 pages (Apr. 1977). Order from NTIS as PB266944, \$5.25.

Key words: cryogenic; design; nitrogen; safety; wind-tunnel.

The findings of a Cryogenic Design and Safety Review of the NASA-Langley $0.3 \mathrm{~m}$ Transonic Cryogenic Tunnel are presented in this report. The tunnel working fluid and coolant is litrogen. The nitrogen, supplied as liquid, is exhausted as a in temperature gas. The use and storage of liquid nitrogen at the facility presents several potential hazards to personnel and quipment. An appropriate cryogenic design minimizes these risks, and provides for convenient tunnel operation and for the economical use of the liquid nitrogen. The tunnel and ancilliary systems are generally well designed but several recommendations to improve the cryogenic systems are made. The cost of recovering the cold vent gas is compared to the cost of producing the required liquid nitrogen using a captive air separation plant. Although the economic analysis is preliminary, it shows that because of the periodic operation of the tunnel, a captive air separation plant has a lower annual operating cost than the vent gas rccovery systems considered.
NBSIR 77-858. Measurement procedures for the optical beam splitter attenuation device BA-1, B. L. Danielson, 24 pages (May 1977). Order from NTIS as PB272358.

Key words: attenuation; laser attenuation; optical beam splitter.

Measurement procedures are described for the step attenuation of laser beams up to $44 \mathrm{~dB}$ using a spccially constructed attcnuator box (BA-1). With the use of an additional preattenuator beam splitter, the attenuation range can be extended to over $70 \mathrm{~dB}$. The BA-1 system is designed for use at .6328 $\mu \mathrm{m}, .5145 \mu \mathrm{m}$, and $1.06 \mu \mathrm{m}$. The attenuation ratios of these wavelengths are calculated values. An analysis of the estimated uncertainties is also given.

NBSIR 77-859. The thermodynamic properties of slush hydrogen and oxygen, H. M. Roder, 43 pages (Nov. 1977). Order from NTIS as PB274186.

Kcy words: computer programs; enthalpy; entropy; hydrogen; internal energy; liquid; oxygen; PVT; quality; slush; solid; vapor.

The thermodynamic properties of hydrogen and oxygen have been calculated for temperatures both below and above the triple point. Values of the various physical properties required for the computations are either taken from the literature, or are extrapolated. If extrapolated, the extrapolations are based on the known behavior of other simple fluids. The results are presented in the form of computer programs which cover two regions of the phase diagram, solid-vapor, and solid-liquid. Input to the programs is temperature and quality. The properties returned include pressure, density, enthalpy, entropy and internal energy. The present programs for slush hydrogen and slush oxygen are an extension of and depend upon the equations of state developed previously for these gases.

NBSIR 77-860. Provisional thermodynamic functions of propane, from 85 to $700 \mathrm{~K}$ at pressures to $700 \mathrm{bar}, \mathrm{R}$. D. Goodwin, 240 pages (July 1977). Order from NTIS as PB272355.

Key words: densities; enthalpies; entropies; equation of state; internal energies; isobars; isochores; isotherms; JouleThomson inversion; latent heats of vaporization; melting line; orthobaric densities; propane; specific heats; speeds of sound; vapor pressure.

Thermophysical properties of propane are tabulated at integral temperatures over the entire range of fluid states from 85 to $700 \mathrm{~K}$ along isobars to 700 bar. A modified form of the nonanalytic equation of state is employed for the first time. Thermodynamic functions for the compressed liquid are obtained by use of heats of vaporization from the boiling point to the critical point, such that the free energies of saturated liquid and vapor are equal.

NBSIR 77-861. A relatively short cylindrical broadband antenna with tapered resistive loading for picosecond pulse measurements, M. Kanda, 47 pages (Aug. 1977). Order from NTIS as $\mathrm{PB} 274057$.

Key words: broadband antenna; measurements; picosecond pulse; resistive loading; the method of moments.

A relatively short cylindrical antenna with continuously tapered resistive loading has been studied for the purpose of picosecond pulse and extremely braodband $\mathrm{CW}$ measurements. The antenna considered is a nonconducting (glass) cylinder with continuously deposited, varying-conductivity, resistive loading. The current distributions on the antenna were numerically calculated using the method of moments. Using these cur- 
rent distributions, other quantities, such as input impedance, near-field and far-field radiation patterns, and radiation efficiency, were also numerically calculated and compared with the results using Wu-King's approximate current distribution. Agreement is relatively good except at high frequencies, $k h>$ $\pi / 2$, where the method of moment appears to give better results. To verify the theoretical results, several resistively loaded antennas were fabricated, and their picosecond pulse and extremely braodband $\mathrm{CW}$ receiving characteristics were analyzed for the frequency range between $5 \mathrm{kHz}$ and $5 \mathrm{GHz}$. The experimental results indicate excellent linear amplitude and phase response over the frequency range. This provides the unique capability of this antenna to measure fast time-varying electromagnetic fields with minimal pulse-shape distortion due to nonlinear amplitude of phase characteristics.

NBSIR 77-862. Studies of hydrogen liquefier efficiency and the recovery of the liquefaction energy, $R$. O. Voth and $W . R$. Parrish, 62 pages (Aug. 1977). Order from NTIS as PB274058.

Key words: component efficiency; cryogenics; efficiency; energy recovery; hydrogen; liquefier.

Liquid hydrogen is a potential synthetic fuel. It is nonfossil, its production and storage technology is well developed, and it is inherently nonpolluting. However, the economics of liquefying hydrogen are costly both in the energy required to produce the liquid and in the capital costs of the liquefier. These costs could be reduced by increasing the liquefier efficiency and/or by recovering a portion of the liquefaction energy at the use site. This paper provides the maximum hydrogen liquefier efficiency based on the efficiency of available components and the fraction of original liquefaction energy that can be recovered at the use site. Since the inefficient compressors and expanders are the major cause of liquefier inefficiency, no increase in liquefier efficiency above the current 30 to 35 percent is probable without a corresponding increase in compressor and expander efficiency-a difficult task since both the compressors and expanders have a long and stable history of development. However, roughly one-third to one-half of the actual energy required to liquefy hydrogen can be recovered at the use site and this represents a cost credit for liquid hydrogen.

NBSIR 77-863. RF attenuation measurement system using a SQUID, R. T. Adair, N. V. Frederick, and D. B. Sullivan, 158 pages (Sept. 1977). Order from NTIS as ADA046831.

Key words: Josephson junction; quantum interference; rf attenuation; superconductivity.

This report describes a unique portable system for measuring attenuation at $30 \mathrm{MHz}$ over a range of $50 \mathrm{~dB}$ to an accuracy of $0.005 \mathrm{~dB}$ per $20 \mathrm{~dB}$. This system does not require any reference standard. A SQUID (Superconducting QUantum Interference Device) with its associated instrumentation is used to determine attenuation in terms of Bessel Function Zeros. A SQUID is a loop of superconducting metal closed by a weak point contact called a Josephson junction, operating in liquid helium.

The system specifications, description, and theory of operation are presented. A complete system operating procedure including data reduction techniques is given along with a discussion of sources of errors.

Considerable additional information and diagrams are presented as an aid to the user in understanding and operating the system.

NBSIR 77-866. NBS type IV rf power meter operation and maintenance, N. T. Larsen, 38 pages (Oct. 1977). Order from NTIS as PB274456.
Key words: bolometer; dc substitution; microwave; power meter.

Operating, maintenance, and calibration procedures are provided for the NBS Type IV Power Meter. This is a recently developed instrument for if power measurement by means of dc substitution in a bolometer (thermistor type only). Complete parts lists, schematic diagrams, and parts placement drawings are provided. Mechanical drawings are not included, but are available from National Technical Information Service, U.S. Department of Commerce, 425 Thirteenth Street, N.W., Washington, DC 20004.

NBSIR 77-868. The characteristics of broadband, isotropic electric field and magnetic field probes, M. Kanda, 34 pages (Nov. 1977). Order from NTIS as PB274457.

Key words: broadband probe; dipole antenna; dynamic range; electric field probe; isotropic probe; loop antenna; magnetic field probe; tangential sensitivity.

A feasibility study and a preliminary engineering test program have been conducted to establish performance specification limits and preliminary engineering design for broadband, isotropic, receiving, electric field and magnetic field probes for electromagnetic emission measurements. Three electric field probes cover the frequency range from $20 \mathrm{~Hz}$ to $32 \mathrm{GHz}$. Two magnetic field probes cover the frequency range from $20 \mathrm{~Hz}$ to $32 \mathrm{MHz}$. The tangential sensitivities and the dynamic range of these broadband isotropic electric field and magnetic field probes are specified. Preliminary engineering design and supporting test data are also included.

NBSIR 77-1195. The worId of EDP standards, M. F. Hill and J. L. Walkowicz, 154 pages (Dec. 1976). Order from NTIS as PB263771.

Key words: ADP standards; international standardization; national standardization; national standards bodies; practice; procedures; regional standárdization; standardization; standards development.

This publication describes the activities and relationships of the many organizations and individuals involved at the national, regional, and international levels in the development of standards for computers and information processing. A generalized description of the standardization process is presented first and then used as a basis for describing the activities of the principal organizations that comprise The World of EDP Standards. This Second Edition of The World brings up-to-date the information contained in the First Edition and retains the format used therein. The description of each organization is structured in a uniform manner and includes the history of each organization, its objectives, membership, organization, finance, relationship to other organizations, and its technical work.

NBSIR 77-1 196. Wind tunnel studies of RP-US Bayanihan permanent school building, $R$. D. Marshall, 28 pages (Dec. 1977). Order from NTIS as PB274647.

Key words: aerodynamics; boundary layers; buildings; turbulence; wind loads; wind tunnels.

Wind pressures measured on a 1:80 scale model of the RPUS Bayanihan Permanent School Building are compared with wind pressures used in the original design calculations. The wind tunnel studies were conducted in a tunnel fitted with spires and roughness elements to generate a thick, turbulent boundary layer. This boundary layer is believed to be a reasonable simulation of the lowest portion of the atmospheric surface layer developed over rolling countryside with scattered trees or over suburban areas. While the wind tunnel test results are in fair agreement with the overall design wind pressures, 
edgcs of the roof along the end walls can be subjected to pressures which substantially exceed the design values. It is recommended that the load capacity of certain roof elcments be reexamined and that ridge ventilators be used in future construction to reduce the uplift loads on the roof structure.

NBSIR 77-1 197. How houses can better resist high wind, S. Kliment, N. J. Raufaste, and R. D. Marshall, Coordinators, 12 pages (Feb. 1977). Order from NTIS as PB268081.

Key words: architecture; buildings; connectors; design criteria; fasteners; wind

This guide presents to designers, builders, government and private building authorities, and building owners and occupants a series of effective methods for improving the resistance of new and existing buildings against high winds. The methods described may be applied to improving the construction of new buildings as well as to increase the wind resistance of existing buildings. This material offers guidelines for selecting the location and orientation of buildings and the building shapes, for suggesting methods of construction, for recommended building details, and for local production of connectors and fasteners. It covers two common types of construction-masonry and timber-as well as selected details based on local materials such as bamboo and adobe.

NBSIR 77-1202. Application of proof tests to silicon nitride, $N$. J. Tighe, S. M. Wiederhorn, and L. R. Russell, 11 pages (Mar. 1977). Order from NTIS as PB276652.

Key words: brittle materials; ceramics; ceramic turbine; proof testing; silicon nitride; strength.

In the ceramic turbine program, the high cost of turbine components and the disastrous effect of component failure require development of both destructive and nondestructive tests for detecting and rejecting defective components. Proof tests, in which a load is applied to break weak components, will ensure that the survivors will have a possibility of failure that is acceptable for the design requirements. Thus, the development of a reliable proof test program requires testing a statistically significant number of specimens. Proof tests have been applied to assure the reliability of glass components and are being developed for polycrystalline ceramic components, such as silicon nitride. The initial proof tests are being done with 4 Pt bend specimens of hot-pressed and reaction-bonded silicon nitride. The tests are conducted at room temperature and at the maximum useful temperature of the materials.

NBSIR 77-1207. Performance of the engine-generators used in the Jersey City total energy plant, J. B. Coble, M. E. Kuklewicz, and J. H. Hebrank, 22 pages (Mar. 1977). Order from NTIS as PB264427.

Key words: diesel engine performance; engine-generator efficiency; engine-generator performance; heat recovery; total energy systems.

Each of five 600-kilowatt $(\mathrm{kW})$, diesel engine-generators which were to be installed in a total energy plant was performance tested under NBS direction at the engine-generator vendor's plant. These tests provided a basis for acceptance of the engine-generators and for comparison with installed performance.

This testing was performed as a part of a comprehensive study to assess engineering, economic, and environmental aspects of a total energy plant which supplies all electrical power, hot water, and chilled water to an apartment complex in Jersey City, New Jersey. Under sponsorship of the Department of Housing and Urban Development (HUD), the National Bureau of Standards (NBS) has instrumented the total energy site for engineering data and is collecting economic and environmental data.
The engines were. tested at seven power levels ranging from 0 to 110 percent rated clectrical load. In the tests, fuel consumption, electrical output, and jacket-water heat recovery were measured, as well as many other parameters. Results are reported for fuel consumption, electrical efficiency, and electrical-plus-thermal efficiency, and comparisons are made with measured data from the total energy plant.

NBSIR 77-1208. NBS space processing research, E. Passaglia and R. L. Parker, 115 pages (Feb. 1977). Order from NTIS as PB264286.

Key words: convection; crystal growth; crystal perfection; microgravity; purification; space processing.

This report describes NBS work for NASA in support of NASA's Space Processing Program covering the period January 1, 1976-December 31, 1976.

The results obtained for each task are given in detailed summaries in the body of the report. Briefly, in Task 1-Crystal Perfection in Czochralski Growth-large nickel single crystals have been grown having dislocation densities as low as 400 lines $/ \mathrm{cm}^{2}$ as assessed by $\mathrm{x}$-ray dynamical diffraction techniques. In Task 2-Evaporative Purification of Ultra-High Purity Materials-Part A-it was determined that the use of sessile drops as a means of support for the study of molten alumina places severe restrictions on the type and validity of the data that can be obtained in view of temperature measurement and control problems encountered. In Part B, rates of evaporative purification were determined for $\mathrm{Nb}-\mathrm{Mo}$ and for $\mathrm{Mo}-\mathrm{Zr}$ alloys at elevated temperatures using R.F. levitation of molten drops. In Task 3-Vapor Transport Synthesis and Crystal Growth-the growth of $1.5 \mathrm{~cm}$ diameter crystals of mercurous chloride crystals by a vapor Bridgman technique is described. In Task 4-Melt Shape in Weightless Crystal Growth, thermocapillary forces on air bubbles in a viscous oil were measured, and the shape of axisymmetric liquid zones and their stability with respect to perturbations has been investigated numerically.

NBSIR 77-1209. Control of smoke movement in buildings: A review, 1. A. Benjamin, F. Fung, and L. Roth, 44 pages (July 1977 ). Order from NTIS as PB269866.

Key words: basic principles; computer calculations; computer modeling; experimental methods; smoke control methods; smoke movement; smoke simulation; state-of-theart review.

A state-of-the-art review of efforts in smoke movement and smoke control is presented. Basic principles, experimental techniques and results, computer models, and smoke control methods which have been employed are presented. The paper covers all work in the area of smoke movement and smoke control but emphasizes the work of NBS.

\section{NBSIR 77-1210. Equipment maintenance for energy conserva- tion, J. Levy, 56 pages (Feb. 1977). Order from NTIS as PB264297.}

Key words: dynamic programming; economic analysis; energy conservation; equipment maintenance; Markow decision process; policy improvement algorithm.

A general model of equipment performance as a function of maintenance is developed that permits quantification of the optimal level of maintenance in terms of performance attainment and relative factor costs. The model formulation is that of a finite state, finite action Markovian decision process. The report supplies a listing for a program in BASIC of the policy improvement algorithm for finding a best policy. The model will help maintenance engineers, building managers and/or others responsible for making decisions concerning maintenance policies in selecting economically efficient levels of maintenance 
for elements of building service equipment. The report also contains an illustrative example applying the model to the maintenance of an air handling unit.

NBSIR 77-1212. Life cycle costing: An assessment of practicability for consumer products, S. W. Stiefel, S. Justin Kim, and H. Hung, 66 pages (Dec. 1976). Order from NTIS as PB265697.

Key words: accelerated testing; consumer products; cost estimation; life cycle costing; life cycle performance; life testing, and performance testing

This report assesses the practicability for applying the life cycle costing ( LCC) approach to consumer products. The report provides a basis for understanding: the potential for application, benefits and effects of LCC; the basic concept of LCC; its interaction with performance, and the state-of-the-art of "life" testing as it relates to developing extended performance test methods for consumer products. The report reviews information now obtainable and barriers to labeling consumer products with LCC information. An observation is made that application of LCC to consumer products is not immediately practicable. The basic areas requiring further investigation are identified, long term research goals are suggested and activities deserving immediate attention are described.

NBSIR 77-1213. Skid resistance measurement tests of new FHWA reference systems at the Eastern Field Test Center, $R$. W. Kearns and J. F. Ward, 132 pages (Mar. 1977). Order from NTIS as PB265102.

Key words: accident reduction, skidding; correlation, skid resistance; highway safety; measurement, skid resistance; pavement, skid resistance; pavement wetting system; skid resistance, measurement; tire-pavement interface forces; wet pavement skid resistance.

The Federal Highway Administration (FHWA) is developing a program to improve the method of measuring wet weather pavement skid resistance (SN) and to reduce the variation in results. At the national level, an interim reference system (IRS) is maintained and operated by the National Bureau of Standards. At the regional level, an area reference system (ARS) is maintained and operated at each FHWA Field Test Center. Intercomparisons between these reference systems and the highway measuring systems at the state level provide measurement assurance.

In this report, the first correlations between three identical, newly manufactured systems (ARS 1, 2, 3) and the IRS are given. Computed standard deviations of midrange predicted SN values are typically less than $0.1 \mathrm{SN}$. SN is given as a function of test speed for each system, on two test surfaces. Speed gradients of $\mathrm{SN}$ are found to be characteristic of the surface.

The test program is explained, from preparations and calibrations of subsystems through dynamic measurement on the surfaces. Controlled and uncontrolled variables are identified, discussed, and in some cases, investigated experimentally. A ranking of the sources of dispersion is given.

A ground station for improved SN calculation precision and on-site statistical analysis, operated in parallel with traditional SN data acquisition methods, is found to perform reliably.

NBSIR 77-1214. Evaluation of metal volumetric standards used in the measurement of liquid hydrocarbons: A report of a U.S. National Bureau of Standards and American Petroleum Institute research associate project, D. J. Hine, 204 pages (June 1977). Order from NTIS as PB269878.

Key words: accuracy; design analysis; equipment specification; field standard; gravimetric calibration; liquid retention or clingage tests; precision; prover; Research Associate
Program; standards inspection procedure; temperature correction; test measure; test measure evaluation; "to contain"; "to deliver"; volumetric calibration.

Weights and measures jurisdictions and the petroleum industry have, for many years, used metal volumetric standards in the measurement of petroleum liquid hydrocarbons. As a result of several surveys, it was leamed that a need existed to establish uniform application procedures and investigate measurement accuracy. To answer this need, a joint project under the Research Associate Program of the U.S. National Bureau of Standards was established with the American Petroleum Institute as the sponsoring agency. Equipment and techniques were evaluated and the program resulted in an equipment specification, a recommended procedure for inspection, and a recommended procedure for the calibration of metal volumetric standards used by weights and measures jurisdictions and the petroleum industry.

NBSIR 77-1215. NBS serial holdings-1977, J. C. Tucker, Ed., 242 pages (Apr. 1977). Order from NTIS as PB269534.

Key words: annual reports; diffusion in metals; fire; journals; library holdings, NBS Library; NBS periodicals; periodicals; proceedings; serials; standards; transactions.

This publication contains holdings information for approximately 4600 titles representing current and noncurrent journals, periodicals, annuals, memoirs, proceedings, and transactions. The holdings of the NBS Library and 4 collections specializing in fire research, computer information, standards, and diffusion in metals are represented.

NBSIR 77-1217. Safety problems associated with pressure containers, S. K. Wakamiya and N. J. Calvano, 42 pages (Mar. 1977). Order from NTIS as PB264691.

Key words: container; corrosion; explosion; extinguisher; fire; gas; injury; liquefied; petroleum; standards.

Accident reports from hospital emergency rooms and reports of interviews with accident victims were reviewed to determine the probable causes of accidents involving two types of pressure containers: fire extinguishers and liquefied petroleum (LP) gas tanks. The data collected and reviewed during the study suggests that some of the safety problems associated with fire extinguishers involve: 1 ) incompatibility of the contents of an extinguisher with its shell; 2) faulty method attachment of plastic pressure gages on some dry chemical extinguishers; and 3) widespread use of obsolete extinguishers.

The primary hazard associated with LP gas containers appears to be leakage from various parts of the LP system. In many instances leaking gas accumulated in a closed area and was accidentally ignited, resulting in an explosion.

Engineering standards relevant to the safety of fire extinguishers and LP gas tanks were reviewed. Although the present standards governing these pressure containers address most safety problems adequately, a few of the requirements in some of these standards appear to be of questionable value in preventing certain types of accidents.

NBSIR 77-1218. Risks associated with certain sports activities, W. B. Beine, 106 pages (Jan. 1977). Order from NTIS as PB264666.

Key words: accident; associated factors; injuries; literature; NEISS; recommendations; review; safety; sports.

This study provides the Consumer Product Safety Commission with recommendations for assigning priorities to tasks associated with reducing the incidence and severity of sports related injuries. Recommendations were derived from an analysis of the published literature and the NEISS data. They emphasize 
the need for collecting additional data, improving surveillance capabilities, stimulating research, and developing and promulgating equipment safety standards.

NBSIR 77-1219. Optical materials characterization, A. Feldman, D. Horowitz, R. M. Waxler, M. J. Dodge, and W. K. Gladden, 37 pages (Mar. 1977). Order from NTIS as $\overline{\mathbf{P B 2}} 64692$.

Key words: $\mathrm{BaF}_{2} ; \mathrm{CaF}_{2} ; \mathrm{KBr} ; \mathrm{KCl} ; \mathrm{LiF} ; \mathrm{NaF}$; refractive index; $\mathrm{SrF}_{2}$; thermal coefficient of refractive index; $\mathrm{ZnSe}$.

The refractive indices of three prisms of chemical vapor deposited $\mathrm{ZnS}$ were measured at room temperature over the wavelength range $540 \mathrm{~nm}$ to $1.083 \mu \mathrm{m}$. The refractive indices of eight specimens of $\mathrm{CaF}_{2}$ doped with $\mathrm{Er}$ were measured from $404.7 \mathrm{~nm}$ to $1.083 \mu \mathrm{m}$. The doping range was 0.001 to $3 \mathrm{per}$ cent Er. Interferometric measurements of $\mathrm{dn} / \mathrm{dT}$ were made over the temperature range -180 to $200{ }^{\circ} \mathrm{C}$ at the wavelengths $632.8 \mathrm{~nm}$ and $3.39 \mu \mathrm{m}$ on single crystal specimens of $\mathrm{BaF}_{2}$, $\mathrm{CaF}_{2}$, reactive atmosphere processed (RAP) $\mathrm{KBr}, \mathrm{RAP} \mathrm{KCl}$, $\mathrm{KCl}$ doped with $\mathrm{KI}, \mathrm{LiF}, \mathrm{NaF}$ and $\mathrm{SrF}_{2}$, and on chemical vapor deposited (CVD) $\mathrm{ZnSe}$ and hot forged $\mathrm{CaF}_{2}$.

NBSIR 77-1221. Proceedings of a symposium: Communicating for product improvement October 13-14, 1976, C. Hulick, Ed., 52 pages (Feb. 1977). Order from NTIS as PB264919.

Key words: procurement incentives; product improvement system; product innovation; user need.

The general objective of the conference was to establish a continuing dialogue between private industry and government agencies on the ways and means of product improvement, placing particular emphasis on methods of communicating specific product needs to manufacturers and making purchasing offices more responsive to these needs at the Federal, State and local level. Workshops were organized to consider Product Improvement System, User Need and Industry Response, Procurement Incentives and Techniques, and The Role of Professional Organizations. Reports and recommendations of these Workshops are included.

NBSIR 77-1222. Reproducibility of the radiant panel test method (ASTM E 162-67) using polyurethane foam, neoprene, and hardboard specimens, T. G. Lee, 40 pages (Mar. 1977). Order from NTIS as PB265089.

Key words: ASTM E 162; coefficient of variation; flame spread tests; flexible polyurethane; hardboard; interlaboratory evaluation; neoprene; radiant panel test; round robin; test method.

Interlaboratory evaluation of the Radiant Panel Method (ASTM E 162-67) for flame spread testing of two flexible foam and one hardboard specimens was made. Results obtained by 13 laboratories based on 4 replicate tests, showed that the between-lab coefficient of variation on the flame-spread index ( $I_{3}$ ) was 21 percent for Hardboard A, 35 percent for Urethane $B$ and 45 percent for Neoprene C. The within-lab coefficient of variation for the Hardboard was 9.9 percent. The higher variability of results for the foam materials was caused by the rapid melting of the Urethane B and unstable flame front of the Neoprene $C$ specimens during the tests. An important source of error for some laboratories was in the determination of $\beta$, the calibration constants, and the inappropriate use of base stack temperature correction. Statistics on the reproducibility of the flame-spread factor $\left(F_{s}\right)$, heat evolution $(Q)$ and $I_{g}$ are also given. A new pilot burner and other modifications of the method were found useful.

NBSIR 77-1225. Test and evaluation of the smoke control capabilities of the San Diego Veterans Administration Hospital, F. C. W. Fung and R. H. Zile, 167 pages (Apr. 1977). Order from NTIS as PB270856.
Key words: air-handling units; building pressure profile; computer simulation; elevator shaft pressure profiles; parametric analysis; simulated smoke concentration; smoke control; smoke movement; smoke simulation; systematic pressurization.

A study was made by the National Bureau of Standards to evaluate the smoke control capabilities of the San Diego Veterans Administration Hospital. A unique feature of the hospital is the presence of independent air-handling units for each floor and each wing. This feature allows the air-handling units to be manipulated for smoke control following the systematic pressurization concept. Systematic pressurization is a means of smoke control whereby a building is divided into either vertical or horizontal compartmented zones such that the air-handling systems are designed to exhaust the immediate fire zone and pressurize the adjacent surrounding zones upon detection of smoke. An experimental technique of smoke simulation and smoke movement measurement was used for the study. The effectiveness of the systematic pressurization smoke control concept is demonstrated by the simulated smoke concentration profiles and pressure measurements.

An extensive series of experiments designed to evaluate the above smoke control concepts were performed by the NBS in cooperation with the VA. Two types of experiments were performed with the building air-handling system operating in normal and various smoke control modes. First, simulated smoke infiltration measurements were obtained by using the sulfurhexafluoride smoke simulation technique. Second, pressure measurements were obtained across elevator doors, and doors leading from the building central core to each wing. Both $\mathrm{SF}_{6}$ concentrations and pressure measurements are key indicators of smoke movement in this evaluation. Six basic air-handling test configurations were established and pressure difference data was collected at fifteen locations on each floor measured. At least two floors and more generally three floors were measured for each mode. Each of the six configurations tested are summarized in table 7 , and the measured data are summarized in table 8. A total of six smoke simulation experiments were conducted. The results and test conditions for each test are tabulated in tables 1 to 6 inclusively. It is concluded that airhandling systems in the San Diego VA Hospital can be effective in controlling smoke movement if the proper vertical and horizontal systematic pressurization concept as described in this report is applied. This is illustrated in figures $7,8,11$, and 12.

A computer smoke movement simulation analysis is also presented. Computer calculations compared favorably with field data. Parametric analysis was also performed on smoke control modes for varying environmental and leakage conditions to further study the smoke control uses of the air-handling system and to demonstrate the capability of the computer simulation program.

NBSIR 77-1227. Thermometry in the control of water quality, S. D. Wood, 21 pages (May 1977). Order from NTIS as PB267608.

Key words: pollution; standards committees; temperature measurements; thermal pollution; thermometry; water analysis; water pollution.

A limited study of thermometry in water pollution was made which focused on water analysis, thermal pollution, and the work of standards committees. It was concluded that the current needs in this field can be addressed most efficiently by the National Bureau of Standards with educational and calibration activities. Suggestions are made concerning possible contributions by NBS with an emphasis on those activities having large impacts for small investments of NBS resources. 
NBSIR 77-1228. Automatic data processing risk assessment, S. K. Reed, 37 pages (Mar. 1977). Order from NTIS as PB265950.

Key words: ADP availability; annual loss expectancy; application system vulnerability; computer security; data confidentiality; data integrity; data security; physical security; procedural security; risk analysis; risk assessment; systems security.

This document presents a technique for conducting a risk analysis of an ADP facility and related assets. Risk analysis produces annual loss expectancy values based on costs and potential losses estimated by a management-appointed team from within the organization using and maintaining the ADP facility. The annual loss expectancy values are fundamental to the cost-effective selection of safeguards for the security of the facility. For the purpose of clarity, the ADP facility of a hypothetical Federal agency is used for an example. The characteristics and attributes which must be known in order to perform a risk analysis are described and the process of analyzing some of the assets is demonstrated, showing how the problem of risk analysis can be reduced to manageable proportions.

NBSIR 77-1229. Accelerometer calibration-A comparison between CESTA and NBS, J. D. Pollard, 22 pages (Jan. 1977). Order from NTIS as PB265477.

Key words: accelerometers; calibration; measurements; vibration; vibration exciters; vibration standards.

This report describes a vibration measurement interchange between a French laboratory (CESTA) and the National Bureau of Standards (NBS). Methods of calibration at NBS and results of the calibration of two commercially available double ended or "piggy-back" type accelerometers are discussed. No difficulties were encountered in the calibration of System 1, however, above $4000 \mathrm{~Hz}$ difficulties were experienced in the calibration of System 2.

NBSIR 77-1230. CROSSI-A Univac processor which assembles code for Interdata minicomputers, C. V. Young, 33 pages (Apr. 1977). Order from NTIS as PB269344.

Key words: assembler; cross-assembler; machine code; relocatable code.

Instructions are given for the use of CROSSI, a computer program which assembles Interdata assembler code on the UNIVAC 1108 producing an assembler listing and relocatable code for the minicomputer. The assembler statements, relocatable output formats and the structure of the processor are described. A preprocessor is given for converting CROSSI's zoned relocatable format to Interdata's zoned relocatable format. A method of reconfiguring the CROSSI processor to assemble code for newer upward compatible minicomputer models is explained.

NBSIR 77-1231. Measurement of transistor collector-emitter saturation voltage, K. O. Leedy, 55 pages (June 1977). Order from NTIS as PB267780.

Key words: collector-emitter; saturation voltage; transistor measurement; transistor measurement repeatability.

This report presents a detailed method for the measurement of collector-emitter saturation voltage. The method which is included in the Appendix is proposed for standardization. The report also contains a description of the laboratory confirmation of the method and a discussion of the precautions to be taken to assure repeatability of the measurement. Emphasized is the necessity to determine that the conditions for saturation are met during the measurement.
NBSIR 77-1232. Development of in-situ techniques for the detection and measurement of corrosion of copper concentric neutrals in underground environments, J. Kruger, U. Bertocci, E. Escalante, and J. L. Mullen, 71 pages (Apr. 1977). Order from NTIS as PB265672.

Key words: buried cables; copper concentric neutral wires; corrosion detection methods; corrosion tests; currentpotential measurements; underground corrosion.

The report describes the work done on the first year of a three-year project, whose purpose is to develop in-situ methods for detecting corrosion on buried copper concentric neutral (CCN) wires.

Specimens of the wire underwent long term corrosion tests. Environmental variables examined were: a) composition of electrolyte, b) composition of the gaseous atmosphere, c) convective motion in solution, d) superimposed a.c. signal, and e) coupling with conducting polyethylene (CPE).

The results showed that accelerated attack with pit formation was caused by a.c. signal and that oxygen availability and presence of chloride ions in solution favored the attack of the wires.

Potentiodynamic scans on the wires as well as on pure copper and tinning alloy were performed in various solutions.

The development of a new measurement method, the analysis of the fluctuations of the corrosion potential, has been initiated in the laboratory with the aim of testing its potentiality as a corrosion detection method in the field. A burial site on NBS grounds has been prepared, and several lengths of cable as well as some other pertinent materials have been laid underground. Data collection from the buried specimens has been initiated.

NBSIR 77-1233. U.S. team visit to France on health care facilities, S. Kramer and R. Kapsch, 56 pages (Apr. 1977). Order from NTIS as PB265436.

Key words: architecture; building technology; construction; health facilities; hospitals; medical facilities; medical planning.

The U.S. Center for Building Technology (CBT), Institute for Applied Technology, National Bureau of Standards, and the French Centre Scientifique et Technique du Batiment (CSTB) regularly exchange special study teams for selected areas of building technology. This report is on the visit of the U.S. team to France on health care facilities, held in April 1972. The U.S. team consisted of representatives from the Center for Building Technology; the Department of Defense; the Veterans Administration; and the Department of Health, Education and Welfare. The team visited health facilities in Paris, Meaux, Dijon, Beaune and Lyon. Innovative methods for the planning, design and construction of French health facilities were reviewed by the team participants. This report contains the findings and observations of the team. These findings and observations were originally recorded in a letter report which was exchanged with members of the U.S. team and the respective cooperating groups in France. However, it is felt that the documentation of the observations in the open literature is important for record purposes and will provide a source document for future discussions on the planning and design of medical and health care facilities.

NBSIR 77-1234. Hazard characteristics of combustion products in fires: The state-of-the-art review, M. M. Birky, 49 pages (May 1977). Order from NTIS as PB267828.

Key words: biological assessment; chemical analysis; combustion products; fire fatalities; smoke inhalation; toxicity.

The purpose of this effort is to review what is known about the "smoke inhalation" hazard as related to human fatalities, 
the limitations of the fire fatality data and the methods that have been and are being used to assess the inhalation toxicity hazard.

Fire statistics indicate that 70 to 80 percent of the fire fatalities are attributed to smoke inhalation. In depth autopsy studies of some of these fatalities show that carbon monoxide is the predominant toxicant produced from fires. The role of new synthetic polymers and other additives is unknown as is the role of hydrogen cyanide in fire fatalities.

Chemical analysis of combustion products has been used extensively to assess the toxicological hazard in fire research. The limitations of such measurements are addressed and a combination of toxicology (animal exposures) and analytical chemistry is recommended. Recent combined biological and selected analytical measurements are critically reviewed.

The mechanism of toxic action of a few well known combustion products is discussed. Due to the extensive use of organophosphates as fire retardants in polymeric materials, the toxicity of this class of compounds is reviewed in some detail.

The role of building codes and standards and early detection and suppression of fire are discussed as a means of reducing human exposure to toxic combustion products. For example, the 1976 French regulation that limits the use of flammable materials that contain chlorine and nitrogen in their molecular structure is presented.

NBSIR 77-1235. Some aspects of using a scanning electron microscope for total dose testing, K. F. Galloway and P. Roitman, 41 pages (Sept. 1977). Order from NTIS as PB273634.

Key words: electron beam energy deposition; ionizing radiation effects; radiation dose; radiation testing; scanning electron microscope; semiconductor devices.

This report addresses a number of aspects involved in using a Scanning Electron Microscope (SEM) for radiation testing of semiconductor devices. Problems associated with using the low energy electron beam to simulate ${ }^{60} \mathrm{Co}$ exposure and a method for estimating the total absorbed dose in critical device oxides are discussed. The method is based on the experimentally determined expression for electron energy dissipation versus penetration depth in solid materials of Everhart and Hoff. An appendix giving the method of estimating the total absorbed dose in a form suitable for ASTM deliberations is included.

NBSIR 77-1236. The measurement of fabric flammability parameters in experiments simulating human movement In burn accidents, E. A. Zawistowski, J. F. Krasny, E. Braun, R. Peacock, and N. Williams, 26 pages (June 1977). Order from NTIS as PB268902.

Key words: accident; apparel; burn injury; fabric flammability; fabrics; fire; garments; heat transfer; injury hazard; simulation.

This paper describes results of experiments simulating the phenomena occurring during burns of apparel items. Fabrics were burned near a semicylinder which was covered by 54 heat sensors. The areas which received various heat loads (corresponding to various depth of burn injury in real-life flammable garment accidents) were recorded. In most cases, the semicylinder was moved during the burn, so that the burning fabrics made contact with it, simulating movement by the victim during a garment burn. This caused rapid extinguishment in some but not all fabrics. Results are reported for 40 fabrics varying in fiber content, and fabric construction and weight.

NBSIR 77-1237. Transpiration heat transfer in thermal energy storage devices, B. A. Peavy and W. E. Dressler, 31 pages (May 1977). Order from NTIS as PB267281.

Key words: porous media; thermal energy storage; transpiration heat transfer.
The storage of thermal energy at a suitable temperature level from sources such as solar energy or waste heat processes can make that energy available for space heating at a later time period. This report is concerned with sensible heat transfer that takes place in a thermal storage device composed of a porous material with a fluid (water) transpiring through it. Experiments were performed on a prototype thermal storage device and the results were compared to numerical values computed from an analytical model. The comparison can be considered very good. Further experimentation is considered necessary to define test parameters such as steady initial condition, steady input water temperatures, piston and mixing-type flows, effects of heat losses, and conduction heat flow in the heat storage container.

NBSIR 77-1239. Workshop on applications of phase diagrams in metallurgy and ceramics, L. H. Bennett and G. C. Carter, 235 pages (Apr. 1977). Order from NTIS as PB269281.

Key words: computer predictions; critical evaluations; data compilations; industrial needs; phase diagrams; theory of phase diagrams; thermodynamics.

A workshop was held at the National Bureau of Standards, Gaithersburg, Md., January 10-12, 1977, to assess the current national and international status of phase diagram determinations and evaluations for alloys, ceramics and semiconductors; to determine the needs and priorities, especially technological, for phase diagram determinations and evaluations; and to estimate the resources being used and potentially available for phase diagram evaluation. A one-day meeting was held following the workshop for the international data center representatives from France, Germany, Canada, the U.K., Japan, the USSR, and the USA, in a further attempt to assess currently on-going phase diagram data evaluation activities and to stimulate interaction and cooperation between these centers.

This report includes highlights of the workshop, description of a new poster board design used in the poster sessions, lists of attendees and demonstrations, the program, and descriptions of the presentations.

NBSIR 77-1240. Measurement assurance, J. M. Cameron, 16 pages (Apr. 1977). Order from NTIS as PB266238.

Key words: measurement assurarce; systematic error; uncertainty.

The procedures by which one establishes that the uncertainty of individual measurements is adequate to their needs have been given the title measurement assurance. This note discusses the factors involved in achieving measurement assurance, beginning with the base line which serves as a standard or reference, the determination of the uncertainty relative to this basis, and the need for control of the measurement process to assure the continuing validity of the accepted process parameters.

NBSIR 77-1243. Performance analysis of the Jersey City total energy site: Interim report, J. Hebrank, C. W. Hurley, J. D. Ryan, W. Obright, and W. Rippey, 175 pages (July 1977). Order from NTIS as PB269517.

Key words: absorption chillers; boiler performance; central utility plant; diesel engine; engine-generator efficiency; heat recovery; performance; total energy systems.

Under the sponsorship of the Department of Housing and Urban Development (HUD), the National Bureau of Standards (NBS) has gathered engineering and economic data from an operating diesel total energy plant which supplies all electrical power, hot water, and chilled water to a 485-unit apartment/commercial building complex in Jersey City, New Jersey. 
Engineering data has been continuously collected since April 1975 by a data acquisition system (DAS) which monitors approximately 200 sensors located in the plant and site buildings. In this report, data for a one-year period from November 1975 through October 1976 is presented. Electrical and thermal demands by the site and plant equipment efficiencies have been determined from this data and are reported. Reliability data is also reported.

Relative fuel savings by the total energy plant have been determined from the engineering data. Adjustments were performed to compensate for the malfunctioning absorption chillers. Calculations indicate that an alternative conventional central plant using purchased electrical power, oil-fired boilers, and absorption chillers would have required 17.3 percent more fuel than required by the JCTE plant as adjusted. These savings correspond to 160,000 gallons $\left(606 \mathrm{~m}^{3}\right)$ of fuel oil annually. Minor design modifications are suggested in this report which would improve the JCTE plant performance an additional 5.7 percent. If the JCTE plant chillers were properly adjusted and the suggested minor modifications were performed, the above alternative conventional plant would have consumed 24.5 percent more fuel oil annually. Economic data describing the capital, operating, owning, and maintenance costs during the one-year period are also presented. Unit cost of electrical, heating and cooling energy commodities are determined and compared to conventionally-supplied energy unit costs.

NBSIR 77-1244. Survey of uses of waste materials in construction in the United States, J. R. Clifton, P. W. Brown, and G. Frohnsdorff, 63 pages (July 1977). Order from NTIS as PB270854.

Key words: coal by-products; construction materials; industrial wastes; mining wastes; municipal waste; slags; waste materials.

A survey has been made of the sources, amounts and methods of disposal of major mining, industrial and municipal wastes available in the 48 counterminous states of the United States. This includes the present and potential uses of these wastes as construction materials.

While over $3 \times 10^{9}$ tons of waste materials are generated annually in the United States, only small amounts are being used by the construction industry. The low level of use does not yet reflect the advances being made in converting wastes into viable construction materials. In several cases, construction materials produced from wastes have been at least the technological equivalent of materials produced from virgin resources. Factors which are impeding the increased utilization of wastes are discussed and emerging incentives which could facilitate their increased use are covered.

NBSIR 77-1246. Evaluation of the egress provisions of the HUD mobile home construction and safety standard, S. Adler, 78 pages (May 1977). Order from NTIS as PB268389.

Key words: emergency egress; HUD; mobile home; racking; research; safety; standard; window.

Evaluative tests were carried out to assess the adequacy and sufficiency of the HUD Mobile Home Construction and Safety Standards. Project activities included library research, laboratory testing and construction of a Mobile Home Emergency Egress Demonstration Unit. The study recommended: (1) establishment of performance goals to relate the desired objective (safe egress) to the specific requirements of the standard: (2) expansion of the scope of the requirements to assure that egress devices do not adversely affect the safety or security of the mobile home under normal living conditions; and (3) support of applied research to interrelate egress requirements, device characteristics, and human capabilities.
NBSIR 77-1249. Measurement techniques for high power semiconductor materials and devices: Annual report, January 1 to December 31, 1976, D. L. Blackburn, R. Y. Koyama, F. F. Oettinger, and G. J. Rogers, 94 pages (May 1977). Order from NT1S as PB269345.

Key words: d-c transmission; energy conservation; measurement methods; photovoltaic method; power-device grade silicon; resistivity variations; silicon; thermally stimulated capacitance; thermally stimulated current; thermally stimulated measurements; thyristor materials measurements; thyristor measurements.

This annual report describes NBS activities directed toward the development of measurement methods for semiconductor materials and devices which will lead to more effective use of high power semiconductor devices in applications for energy generation, transmission, conversion, and conservation. It responds to national needs arising from rapidly increasing demands for electricity and the present crisis in meeting longterm energy demands. Emphasis is on the development of measurement methods for thyristors and rectifier diodes.

The major tasks under this project are (1) to evaluate the feasibility of the photovoltaic method as a rapid, nondestructive technique for characterizing the resistivity uniformity of highresistivity, large-diameter silicon wafers and (2) to evaluate the use of thermally stimulated current and capacitance measurements as a means for characterizing lifetime controlling or leakage source defects in power device grade silicon wafers.

NBSIR 77-1250. Analysis of housing data collected in a leadbased paint survey in Pittsburgh, Pennsylvania-Part I, D. R. Shier and W. G. Hall, 100 pages (May 1977). Order from NTIS as PB268150.

Key words: children; data analysis; housing; lead paint; lead poisoning; surveys; $x$-ray fluorescence.

This report is a companion document to a previous report (NBSIR 76-1024) on blood lead levels of children tested during a lead-based paint survey in Pittsburgh, Pennsylvania. The emphasis in this report is on the methodology used and types of housing-related information collected by the survey. Through the use of portable $x$-ray fluorescence lead detectors, measurements were taken from a variety of surfaces within rooms of the dwelling unit as well as at locations exterior to the unit. Analyses of these $x$-ray fluorescence measurements established that older housing units exhibit considerably greater lead levels than newer housing units. In addition, wet rooms (kitchen and bathrooms) have higher levels than other (dry) rooms, rooms with a poor surface/substrate condition have higher levels than rooms with a good surface/substrate condition, and trim surfaces (e.g., doors, windows, baseboards) have higher levels than walls. Also, exterior surfaces show higher readings than functionally similar interior surfaces. While the present report concentrates on the housing aspect of the survey, subsequent processing of the Pittsburgh data is under way to determine possible relationships among blood lead levels, socioeconomic variables and housing-related characteristics.

NBSIR 77-1251. Considerations in establishing performance criteria for structural firefighters' helmets, $N$. J. Calvano, 111 pages (May 1977). Order from NTIS as PB269531.

Key words: fire helmet; head injury; head protection; heat resistance; helmet; impact; penetration resistance; test methods.

The report describes the development of performance criteria for firefighters' helmets. Biomedical and physiological considerations are discussed. Fire helmet constructions and test methods for impact attenuation, penetration resistance, heat re- 
sistance and flammability are described. Results of tests on various types of fire helmets are presented. A proposed standard for fire helmets is included.

NBSIR 77-1253. Cost/benefit analysis of automated transit information systems, D. R. Shier and J. F. Gilsinn, 111 pages (June 1977). Order from NTIS as PB268424.

Key words: automation; cost/benefit; models; queuing; telephone systems; transit information; transportation.

This report discusses the costs and benefits associated with automating the route-finding portion of a telephone transit information system. The various costs of implementing such a system are categorized and compared with those of a manual system over an appropriate time span using a present value approach. A queuing model, described in the report, is used for computing manpower requirements of the two systems, manual and automated. Outputs of the queuing model for a wide range of input parameters are tabulated in an appendix. Benefits from automating transit information route-finding are discussed, and measures of performance improvement available as output from the queuing model are provided.

NBSIR 77-1254. Transportation, handling and field service loads for air mobility shelter systems, C. W. C. Yancey, 74 pages (July 1977). Order from NTIS as PB269354.

Key words: acceleration; airplanes; cargo; dynamic loads; equivalent static force; gravity load; handling devices; handling loads; military field shelters; probability distributions; shocks, snow load; static load; trains; transportation; trucks; vibrations; wind load.

To fulfill one of the prerequisites for establishing design criteria for military field shelters, transportation, handling and field service load data are presented. An extensive literature search was conducted to determine the magnitude and frequencies of shock and vibration responses produced by railroad, road and air cargo vehicles and by devices commonly used in handling field shelters. Summary data, extracted from field study reports, are presented in the form of acceleration versus frequency diagrams. The acceleration values can be used to compute an Equivalent Static Force input for the design and analysis of shelter models. The probabilities of occurrence of the acceleration amplitudes generated by the three transportation modes are indicated in cases where data reduction included statistical analyses. Sources of the dynamic load data included flatbed trucks, propeller and jet airplanes, helicopters, railroad flatcars and forklift trucks. Where possible, the shock and vibration data used in presenting the summary diagrams were restricted to that obtained from tests involving military vehicles commonly used to transport shelters. Recommendations are presented for the selection of static design loads to account for gravity, snow, ice and wind effects.

NBSIR 77-1256. Properties of 21 year old coal-tar pitch roofing membranes: A comparison with the NBS preliminary performance criteria, R. G. Mathey and W. J. Rossiter, Jr., 26 pages (June 1977). Order from NTIS as PB267845.

Key words: bituminous roof membranes; built-up roof membranes; coal-tar pitch; performance criteria; physical and engineering properties; test methods.

The properties of coal-tar pitch roof membranes approximately 21 years old were compared to the properties reported for such membranes in NBS Building Science Series 55, "Preliminary. Performance Criteria for Bituminous Membrane Roofing." Samples of the old membranes were taken from eight buildings having roof areas that range from 0.5 to 1.5 million square feet $\left(4.6\right.$ to $\left.15 \mathrm{~km}^{2}\right)$. The buildings were located at three sites in or near the state of Kentucky. The roof mem- these buildings had been subjected to different mainenance procedures.

Laboratory tests conducted on 47 membrane samples included tensile strength, modulus of elongation and coefficient of expansion. The thermal shock factor was calculated for each sample. Laboratory observations were made of the membrane samples to determine between-ply bitumen thickness, weight per unit area, ply adhesion, pliability and condition of the membrane.

The tensile strengths of the membranes determined at $0{ }^{\circ} \mathrm{F}$ $\left(-18^{\circ} \mathrm{C}\right)$ in their longitudinal and transverse directions were comparable to values reported in NBS Building Science Series 55. Values of the coefficient of expansion measured over the temperature range of 0 to $-30{ }^{\circ} \mathrm{F}\left(-18\right.$ to $\left.-34{ }^{\circ} \mathrm{C}\right)$ were also comparable to those reported in NBS Building Science Series 55. The modulus of elongation was considerably higher for the old membrane samples which resulted in lower values of thermal shock factor. The lower values of extensibility of the old membranes were attributed to their brittleness caused by aging. The type and frequency of roof maintenance procedures was considered to have had a definite effect on the properties of these old roof membranes.

NBSIR 77-1257. An analysis of employee publics and employee communication programs in the National Bureau of Standards, J. E. Grunig, 43 pages (June 1977). Order from NTIS as PB271973.

Key words: communication among scientists; coordination of research organizations; employee communication; information needs; information processing; information seeking; internal media.

An evaluative study of the employee communication program at the National Bureau of Standards was conducted in cooperation with the Seminar in Corporate Communication, University of Maryland College of Journalism to: 1) identify the information needs of different types of NBS employees, 2) relate these information needs to use of internal employee media, and 3 ) evaluate and make recommendations on these media. Information needs were identified using a communication model developed by Grunig, which predicts the probability that a public will actively seek out information or passively process it. The variables of this model were related to content preference and media use through factor analysis and canonical correlation. The study identified four types of employee publics: 1) a research-oriented employee, 2) an administrative-oriented employee, 3) an employee programs and benefits-oriented employee, 4) an employee who perceives himself to be uninvolved in most NBS programs. The study also showed that most employee media in a research organization contain information which employees do not perceive to involve them. Thus, following the logic of the Grunig theory, employees will passively process the information if it is easily available, but they will not seek it out. Recommendations are then made for how employee media should be designed for each employee type and on how to deal with the generally low level of employee involvement.

NBSIR 77-1259. Building energy conservation programs-A preliminary examination of regulatory activities at the State level, P. W. Cooke and R. M. Eisenhard, 125 pages (June 1977). Order from NTIS as PB268873.

Key words: buildings; energy conservation; enforcement; legislation; regulations; solar energy; standards; state-ofthe-art study.

Background information on the current regulatory status and degree of implementation of building energy conservation programs at the State level are described, including those programs dealing with solar energy. The objective of the study is to pro- 
vide the Federal Energy Administration (FEA) with a data base of standards implementation experience. This data base can be drawn upon to promote utilization of building thermal efficiency standards on a uniform basis throughout the country. From information collected in a survey of twenty-one selected States, the survey report presents the current state-of-the-art on common problems experienced at the State level in the promulgation and implementation of building energy conservation regulations. Based on these findings, several types of assistance that could facilitate the orderly adoption and implementation of uniform standards are identified.

NBSIR 77-1260. A computer program for the thermal analysis of the fire endurance of construction walls, F. C. W. Fung, 62 pages (May 1977). Order from NTIS as PB268112.

Key words: composite building constructions; convection; experimental data; fire endurance; heat generation or absorption; numerical solutions; one-dimensional; radiation; thermal conduction; transient heat transfer.

A general one-dimensional transient heat and mass transfer numerical program has been developed for composite building constructions. Since typical building constructions consist of a series of composite layers and intermediate air layers transient heat transfer is modeled by conduction through solids and by radiation and convection through air spaces. In addition the program has built-in features for ease of application to building constructions where various combinations of solid-to-solid and solid-to-air interfaces are encountered. The complete Fortran language program as used on the NBS Univac 1108 computer is given. A discussion of the program and instruction for its use are facilitated by the aid of examples. Numerical solutions using the present program compare favorably with experimental data in standard fire endurance tests.

NBSIR 77-1261. Laboratory tests of thermoplastic piping assemblies subjected to water hammer and intermittent hot water flow, D. E. Rorrer, J. R. Shaver, and R. S. Wyly, 51 pages (Aug. 1977). Order from NTIS as PB270867.

Key words: intermittent hot water exposure tests of thermoplastic pipe; pressure shock in thermoplastic pipe; water hammer in thermoplastic pipe.

Evaluation procedures are described that were used at the National Bureau of Standards (NBS) for simulating the longterm effects of water hammer (shock pressure) and cyclic hot water flow (thermal cycling) on chlorinated polyvinyl (CPVC) thermoplastic pressure piping assemblies. Also included are the procedures used to study the effects of thermal cycling of two (2) polyvinyl chloride (PVC) thermoplastic drainage stack assemblies. The results obtained using these test procedures are presented and, in addition, related work of other investigators is briefly reviewed.

The shock pressure results show that a fatigue life curve can be established for CPVC as a function of temperature and pressure. As the temperature is decreased the number of shock pressure applications necessary to produce failure increases. An estimated use-life of at least 50 years was indicated at the maximum test temperature of $180^{\circ} \mathrm{F}\left(82^{\circ} \mathrm{C}\right)$ with pressures of 150 psi ( $1034 \mathrm{kPa})$.

With intermittent hot water flow all test assemblies were performing satisfactorily when the test was terminated after more than 1500 cycles had been completed.

NBSIR 77-1262. Computerized site security monitor and response system, R. T. Moore, R. J. Carpenter, and A. L. Koenig, 45 pages (June 1, 1977). Order from NTIS as PB269346.
Key words: adversary scenarios; automated response systems; distributed processing; monitoring systems; physical security; sensor systems.

The Computerized Site Security Monitor and Response System (CSSMRS) was conceived as an integrated, state-of-theart, computer-based system to enhance and improve the overall physical security of storage sites for special weapons or materials.

This report is divided into three sections. Section I contains an overview summary of the findings or study results for each of the eight specific Phase 1 tasks. These are set forth in varying degrees of detail as appropriate to both the nature of the task and the results.

Section II is a description of the CSSMRS in its current (and incomplete) state of evolution. Here many of the attributes, capabilities, and features developed during the course of Phase I work are set forth. Some of the alternatives are identified as are areas where additional work will be necessary to reach clearly identifiable and attainable objectives necessary to complete the system definition.

In Section III, a proposed Phase II work plan is presented.

NBSIR 77-1263. Radiant heating in seamless flooring- $\mathbf{A}$ feasibility study, P. G. Campbell, M. A. Post, M. Godette, and W. E. Roberts, 30 pages (July 1977). Order from NTIS as PB273946.

Key words: electrical heating elements; materials performance; radiant panel-seamless flooring system; seamless flooring; temperature characteristics.

The purpose of this study was to determine the feasibility of using radiant heating in seamless flooring as a supplemental heating source in housing units. The resistance of twenty seamless flooring systems to abrasion, flow, impact, flame, stain, moisture and elevated temperature were evaluated using laboratory tests. Power requirements and the magnitude and uniformity of surface temperatures of nine electrical heating elements, functioning as radiant heating panels, were experimentally determined and evaluated. The radiant heating panels were coated with selected seamless flooring systems and the performance characteristics of the radiant panel-seamless flooring system were evaluated. The report contains a summary of test results demonstrating the feasibility of the radiant panelseamless flooring system and the identification of areas for future research.

NBSIR 77-1264. Fire research specialists: A directory, N. H. Jason, 139 pages (Sept. 1977). Order from NTIS as PB272475.

Key words: building research; chemistry; combustion research; design concepts; directories; fire prevention; fire research; hazard analysis; physics.

This Directory lists specialists from the United States and Canada who have made recent contributions to the fire literature, to the teaching of fire science or related subjects, or who have participated in or supported fire research programs. This work is an update of the "Directory of Workers in the Fire Field" by Boris W. Kuvshinoff, Stephen B. McLeod, and Richard G. Katz (NASA CR-121129; 1973). The Directory is divided into three parts. The first part, the Specialists Index, is arranged alphabetically. The first line notes the name followed by the area(s) of specialization represented by Arabic numerals. These Arabic numerals are used throughout the Directory and are defined in a separate listing on page vii. The second and subsequent lines give the specialist's affiliation, mailing address, and telephone number. The second part, the Subject Specialty Index, alphabetically lists the subject areas and the corresponding specialist names. Entries are limited to 
two areas of specialization per individual. The third part, the Affiliations Index, alphabetically lists the corporate sources, noting the specialists therein. If a specialist was not affiliated with an organization, the term "Consultant" was used to group these individuals in the Affiliations Index.

NBSIR 77-1265. An evaluation of fire properties of generic gypsum board products, J. R. Lawson, 30 pages (Aug. 1977). Order from NTIS as PB271097.

Key words: buildings; ease of ignition; fire tests; gypsum board; potential heat; properties; rate of flame spread; rate of heat release; scanning electron microscope (SEM).

An evaluation of the fire properties of generic gypsum board products was made in order to obtain a better understanding of the material's reaction to a fire environment. These gypsum board products are typically used in wall and ceiling assemblies throughout the United States. Four small-scale fire test methods were used in the examination of the materials' fire properties. The tests conducted were for potential heat, ease of ignition by flame impingement, rate of heat release, and rate of flame spread. All of these properties are of major importance in the design of a building. They influence the potential rate of fire growth in a room. Standard fire test methods were used for the development of data on rate of flame spread and potential heat characteristics. The ease of ignition and rate of heat release characteristics were determined by fire tests recently developed at the National Bureau of Standards. Test results showed that the potential heat for the materials examined ranged from 510 $\mathrm{J} / \mathrm{g}(220 \mathrm{Btu} / \mathrm{lb})$ to $2670 \mathrm{~J} / \mathrm{g}(1150 \mathrm{Btu} / \mathrm{lb})$. The ignitability of the materials spanned from 42 to 171 seconds, while the peak heat release averages ranged from a 2.5 to $4.8 \mathrm{~W} / \mathrm{cm}^{2}$ on an unpiloted $4 \mathrm{~W} / \mathrm{cm}^{2}$ exposure and 3.9 to $8.2 \mathrm{~W} / \mathrm{cm}^{2}$ on an unpiloted $6 \mathrm{~W} / \mathrm{cm}^{2}$ exposure. The flame spread index for the materials ranged from 8 to 38 .

NBSIR 77-1270. Materials for fuel cells, L. H. Bennett, M. I. Cohen, A. L. Dragoo, A. D. Franklin, A. J. McAlister, and K. F. Young, 63 pages (May 1977). Order from NTIS as PB269518.

Key words: AC impedance; automated electrochemical analysis, ceramic electrolytes, ; ceria-yttria; cyclic voltommetry; electrocatalysis; equivalent circuit; fuel cells; microprocessor; network analyzer; phosphoric acid electrolyte; refractory hard metals.

This report describes the first year's progress of the NBS program on Materials for Fuel Cells.

Transition metal carbides, borides and nitrides ("refractory hard metals") were examined with respect to stability and to catalytic oxidation of $\mathrm{H}_{2}$ as nonprecious substitutes for $\mathrm{Pt}$ as fuel electrocatalysts. Hydrogen oxidation was observed only on $\mathrm{Pt}$, WC and $\left(\mathrm{Mo}_{0.8} \mathrm{~W}_{0.2}\right) \mathrm{C}$. The activity of $\mathrm{WC}$ was found to depend upon the preparative method. The compound $\left(\mathrm{Mo}_{0.8} \mathrm{~W}_{0.2}\right)$ C, which has the WC structure, was estimated to have a specific activity from 1.5 to 3 times greater than that of the WC samples.

A versatile automated system for electrochemical analysis was designed and built utilizing the precision of digital control and readout techniques to perform essentially analog measurements. The automated system uses a microprocessor as the key element in the central processing unit. The various components and operation of the automated system are described.

Studies of $\mathrm{CeO}_{2}: \mathrm{Y}_{2} \mathrm{O}_{3}$ ceramic electrolytes were designed to measure the influence of annealing and prolonged current passage on electrical properties of these materials. Work on a high temperature facility for these experiments and preparation of $\mathrm{CeO}_{2}: \mathrm{Y}_{2} \mathrm{O}_{3}$ ceramic specimens is described.
$\mathrm{AC}$ impedance was measured on several $\mathrm{CeO}_{2}: \mathrm{Y}_{2} \mathrm{O}_{3}$ sintered specimens as a function of frequency using a network analyzer. The features of this instrument and the theory of the measurements are presented.

NBSIR 77-1272. Intermediate standards for solar domestic hot water systems/HUD initiative, J. K. Holton, et al., 153 pages (July 1977). Order from NT1S as PB271758.

Key words: solar buildings; solar collectors; solar domestic hot water systems; standards; thermal storage.

This report presents standards for the use of solar domestic hot water systems in residential applications. The standards have been developed for application in numerous housing programs of the Department of Housing and Urban Development and are a companion document to be used in conjunction with the HUD "Minimum Property Standards for One and Two Family Dwellings," 4900, and "Minimum Property Standards for Multifamily Housing," 4910. To the greatest extent possible, these standards are based on current state-of-the-art practice and on nationally recognized standards including the MPS and the HUD "Interim Performance Criteria for Solar Heating and Combined Heating/Cooling Systems and Dwellings.'

NBSIR 77-1274. Retrofitting an existing wood frame residence for energy conservation-An experimental study, D. M. Burch and C. M. Hunt, 159 pages (July 1977). Order from NTIS as PB269847.

Key words: air infiltration; condensation in buildings; energy conservation; energy measurements; fuel savings; heatloss reduction; insulation properties; residential heat loss; retrofitting houses; thermal conductivity; thermal insulation; thermography.

A wood-frame residence having only limited insulation in the attic was retrofitted in three stages to reduce its energy requirements for heating and cooling. The three retrofit stages comprised: reducing air leaks; adding storm windows; and installing insulation in the floor, ceiling, and walls. The house was extensively instrumented to evaluate energy savings and other performance factors. An economic model was used to evaluate the cost effectiveness of the retrofit options and the number of years to pay back their initial investment.

The walls of the test house were insulated with three different types of insulating material: fibrous glass wool, cellulosic fiber, and urea-formaldehyde foam. The thermal performance of these three insulating materials was measured and compared, both in the field and laboratory.

"Recommended good practices" for moisture protection were applied when insulation was installed in the test house. The effectiveness of these measures in preventing damaging moisture accumulation in crawl spaces and attics was evaluated.

Finally, thermographic surveys were performed before and after the retrofit. Based on the results of these surveys, criteria for distinguishing between insulated and uninsulated woodirame cavity walls were presented.

NBSIR 77-1275. Examination of cap screws from currency printing press flanges, T. R. Shives, 28 pages (June 1977). Order from NTIS as PB270523.

Key words: cap screw failures; cyclic loading; fatigue; fatigue failure.

The Office of Engineering of the Bureau of Engraving and Printing submitted a number of failed and intact cap screws from printing press flanges to the NBS Mechanical Properties Section for examination. All of the cap screw failures examined were due to the initiation and propagation of fatigue cracks. Based on the results of hardness measurements, some of the 
cap screws of one manufacturer did not meet the minimum ultimate tensile strength requirements for DIN 12.9 screws. One cap screw with an ultimate tensile strength significantly below the specified minimum had yielded apparently while in service.

NBSIR 77-1276. OMNITAB II user's reference manuaI-1977 supplement, D. Hogben and S. T. Peavy, 176 pages (July 1977). Order from NTIS as PB270855.

Key words: automatic printing; Calcomp plotting; data editing; interactive; label:: numerical analysis; OMNTTAB II computing system; probability plotting; selection of variables in linear regression; statistical plotting; stem-and-leaf displays; table making.

The Supplement describes all the additions and improvements made to the OMNITAB II computing system at NBS since 1970. OMNITAB 1977, as OMNITAB II is now known, is fully interactive. Major new capabilities now exist in the following areas: Use of labels, table making, plotting, numerical analysis, editing of data, stem-and-leaf displays, selection of variables in linear regression and probability plotting. The Supplement is an interim document for use until OMNITAB 1977 is released and new documentation prepared.

NBSIR 77-1277. Fire research publications, 1976, N. H. Jason, 16 pages (July 1977). Order from NTIS as PB269965.

Key words: arson; bibliographies; building fires; carpets; construction materials; fire departments; fire detection systems; fire tests; flame research; flammability tests; interior furnishings; mobile homes; polyurethanes; smoke detectors; standards; textiles; toxicity.

"Fire Research Publications, 1976" is a supplement to the previous editions which covered the years 1969-1972 (NBSIR 73-246, NTIS Order No. COM-74-10989; \$3.25), 1973 (NBSIR 74-511, NTIS Order No. COM-74-1 1448; \$3.25), 1974 (NBSIR 75-736, NTIS Order No. COM-75-11018; \$3.25), and 1975 (NBSIR 76-1120, NTIS Order No. PB-257837; \$3.50). Only publications prepared by the members of the Center for Fire Research (CFR), by other National Bureau of Standards (NBS) personnel or external laboratories under contract or grant from the CFR are cited. Articles published in NBS house organs also are cited.

NBSIR 77-1278. The air density equation and the transfer of the mass unit, F. E. Jones, 31 pages (July 1977). Order from NTIS as PB270868.

Key words: air buoyancy; air density; mass unit transfer; real gas equation.

A new formulation of the equation used for the calculation of air density has been developed. The Quinn, Colclough and Chandler value of the gas constant, currently accepted values of the atomic weights, and recent determinations of the abundances of the various constituents of air have been used. The abundance of carbon dioxide has been treated as a variable and a factor enabling convenient adjustment of the apparent molecular weight of air for deviation of carbon dioxide abundance from a background value has been derived. A new table of compressibility factor for the range of pressure and temperature of interest in standards laboratories has been calculated using recently determined values of virial coefficients. The enhancement factor, which has usually been ignored in air density equations, has been explicitly included in the equation; a table of enhancement factor has been calculated using a simple equation fitted to values in the range of pressure and temperature of interest. A table of the saturation water vapor pressure has been included; a simple equation for the calculation of saturation water vapor pressure has been fitted. Uncertainties, random and systematic, in the parameters and in the mea- surement of environmental variables and consequent uncertainties in calculated air density have been estimated.

Application of the equation to air buoyancy determination and the transfer of the mass unit at the various national standards laboratories has been made.

NBSIR 77-1279. Cross sections and yields for high energy neutron source reactions, M. A. Lone, L. Stewart, A. D. Carlson, and C. D. Bowman, Eds., 40 pages (July 1977). Order from NTIS as PB270863.

Key words: $B e(d, n)$ source; $B e(p, n)$ source; $C(d, n)$ source; $D(d, n)$ source; dosimetry; $L i(d, n)$ source; $L i(p, n)$ source; neutron angular distributions; neutron energy distributions; neutrons; nuclear reactions; thick-target yields.

Eight papers were presented at a workshop on thick-target yields from high-energy neutron source reactions on March 30 , 1977 in Bethesda, Md. Presentations were made on several source reactions including $D(d, n), \operatorname{Li}(p, n), \operatorname{Li}(d, n), B e(p, n)$, $B e(d, n)$, and $C(d, n)$ including energy and angular distributions. Special emphasis was placed on these sources due to the needs in medical applications and for studies of radiation damage expected in an operating fusion reactor. These proceedings inclucie the following papers (indented):

Neutron spectra from deuteron and proton bombardment of thick lithium targets, C. E. Nelson, F. O. Purser, P. Von Behren, and H. W. Newson, NBSIR 77-1279, pp. 1-4 (July 1977).

Key words: $E_{d}=8,12,15 \mathrm{MeV}, E_{p}=15 \mathrm{MeV}$; energy spectra, yields; neutrons; thick target; time-of-flight; ${ }^{7} \mathrm{Li}(\mathrm{d}, \mathrm{n})^{\mathrm{8}} \mathrm{Be},{ }^{7} \mathrm{Li}(\mathrm{p}, \mathrm{n})^{7} \mathrm{Be}$.

Neutron energy spectra and yields produced by the bombardment of thick lithium targets by deuterons and protons have been measured using the time-of-flight method. Measurements were made at angles up to $45^{\circ}$ for deuteron energies of 8,12 and $15 \mathrm{MeV}$ and a proton energy of 15 $\mathrm{MeV}$. The average neutron energy of the $(d, n)$ reactions is shown to vary approximately at $.44 \mathrm{E}_{d}$. The $(p, n)$ reaction has $\overline{\mathrm{E}}_{n}=4.7 \mathrm{MeV}$.

Neutron spectral distributions from proton and deuteron bombardment of thick $L i$ and Be targets at 14.8, 18 and 23 MeV, M. A. Lone, NBSIR 77-1279, pp. 5-9 (July 1977).

Key words: $\mathrm{E}=14.8,18,23 \mathrm{MeV}$; measured neutron spectral distributions for $\mathrm{E}_{n}>0.3 \mathrm{MeV}$; nuclear reactions; $\theta=$ $0^{\circ}, 10^{\circ}, 20^{\circ}, 30^{\circ}, 40^{\circ} ;{ }^{7} \mathrm{Li}\left({ }_{p}{ }^{d}, \mathrm{n}\right),{ }^{9} \mathrm{Be}\left({ }_{p}{ }^{d}, \mathrm{n}\right)$.

This report compares the spectral distributions of neutrons of energies greater than $300 \mathrm{keV}$ produced by bombarding thick ${ }^{7} \mathrm{Li}$ and ${ }^{9} \mathrm{Be}$ targets with protons and deuterons of energies $14.8,18$ and $23 \mathrm{MeV}$. The experimental technique used to measure the scattered neutron background is described and the data are compared with previously reported spectral distributions.

35 and $65 \mathrm{MeV}$ protons and $35 \mathrm{MeV}$ deuterons on lithium and beryllium, M. Awschalom, NBSIR 77-1279, pp. 10-14 (July 1977).

Key words: Be; Li; neutron sources; thick-target yields.

Protons of 35 and $65 \mathrm{MeV}$ and deuterons of $35 \mathrm{MeV}$ were used to bombard beryllium and lithium targets of various thicknesses. Energy spectra were measured by time-of-flight.

Spectral measurements of 25 to $55 \mathrm{MeV}$ neutron beams, S. W. Johnsen, NBSIR 77-1279, pp. 15-18 (July 1977). 
Key words: distributions; neutrons; resolution; spectra; uncertainties; yield.

Energy spectra of ncutron beams produced by $25,35,45$ and $55 \mathrm{MeV}$ protons stopping in beryllium havc been measured. The spcctra exhibit a large low energy component which has small angular dependence and a high energy component which is peaked in the forward direction. The dominant uncertainties in these time-of-flight measurements are the uncertainties in detector efficiency and the energy resolution for ncutrons with short flight times.

Protons and deuterons on $B e$ at $E_{p}=100 \mathrm{MeV}$ and $E_{d}=$ $80 \mathrm{MeV}$, G. H. Harrison, C. R. Cox, E. B. Kubiczek, and J. E. Robinson, NBSIR 77-1279, pp. 19-23 (July 1977).

Key words: dosimetry; energy spectra; high energy; LET; neutrons; yields.

The dose rate of neutrons produced by $80 \mathrm{MeV}$ deuterons on a thick. Be targct was measured to be $56.0 \mathrm{rad}$ $\mu \mathrm{amp}^{-1} \mathrm{~min}^{-1}$ at a target-to-surface distance (TSD) $125 \mathrm{~cm}$ and field size $10 \mathrm{~cm} \times 12 \mathrm{~cm}$. The maximum of the neutron energy spectrum occurred at $32 \mathrm{MeV}$. The LET spectrum $(L \cdot D(L))$ indicates that 33 percent of the absorbed neutron dose is due to events with $\mathrm{L}<100 \mathrm{KeV} / \mu$, and emphasizes the need for measurements of high energy neutron reaction cross sections of ${ }^{12} \mathrm{C},{ }^{14} \mathrm{~N}$, and ${ }^{16} \mathrm{O} .100$ $\mathrm{MeV}$ protons on a $\mathrm{Be}$ target $62 \mathrm{MeV}$ thick backed with aluminum yielded neutrons at $14.4 \mathrm{rad} \mu \mathrm{amp}^{-1} \mathrm{~min}^{-1}$ at TSD $100 \mathrm{~cm}$ and field size $8 \mathrm{~cm} \times 10 \mathrm{~cm}$. The maximum of the neutron energy spectrum occurred at $50 \mathrm{MeV}$.

Neutron yields and dosimetry for $\operatorname{Be}(d, n)$ and $\operatorname{Li}(d, n)$ neutron sources at $\mathrm{E}_{d}=\mathbf{4 0} \mathrm{MeV}, \mathrm{M}$. J. Saltmarsh, C. A. Ludemann, C. B. Fulmer, and R. C. Styles, NBSIR 77-/279, pp. 24-29 (July 1977).

Key words: dosimetry: $\mathrm{E}_{d}=40 \mathrm{MeV} ; \mathrm{E}_{\mathrm{n}}>2 \mathrm{MeV}$; measured thick-target neutron yields, $\operatorname{Be}(d, n), \operatorname{Li}(d, n) ; \theta=0$ $90^{\circ}$.

Time-of-flight measurements are reported for the thicktarget neutron yields from the $\operatorname{Be}(\mathrm{d}, \mathrm{n})$ and $\mathrm{Li}(\mathrm{d}, \mathrm{n})$ reactions over an angular range of $0-90^{\circ}$ at a deuteron energy of $40 \mathrm{MeV}$. Foil activation measurements are also described for the $\operatorname{Be}(d, n)$ reaction. A dosimetry technique based on these measurements is discussed.

Neutron spectra and doses from deuteron bombardment of light nuclei, H. H. Barschail, NBSIR 77-1279, p. 30 (July 1977).

Key words: deuterons; ionization; neutron spectra.

Neutron spectra measured by time of flight and doses measured with a tissue-equivalent ionization chamber have been studied at the Lawrence Livermore Laboratory for deuterons up to $20 \mathrm{MeV}$ on targets of $\mathrm{D}, \mathrm{Li}, \mathrm{Be}$, and $\mathrm{C}$. All the results have been previously published.

Neutron spectral measurements and interpretation at the Naval Research Laboratory, L. S. August, P. Shapiro, and R. B. Theus, NBSIR 77-1279, pp: 31-34 (July 1977).

Key words: energy spectra; neutrons; Rossi-counter measurements; Serber theory; thick target; time-of-flight; ${ }^{9} \mathrm{Be}(\mathrm{d}, \mathrm{n}){ }^{10} \mathrm{~B} ;{ }^{9} \mathrm{Be}\left({ }^{3} \mathrm{He}, \mathrm{n}\right)^{11} \mathrm{C}$.

The thick-target, neutron energy spectra and yields produced at $0^{\circ}$ with respect to the incident ion beam for the reaction ${ }^{9} \mathrm{Be}(\mathrm{d}, \mathrm{n})^{10} \mathrm{~B}$ at $\mathrm{E}_{d}=35 \mathrm{MeV}$ and the reaction ${ }^{9} \mathrm{Be}\left({ }^{3} \mathrm{He}, \mathrm{n}\right)^{11} \mathrm{C}$ at $\mathrm{E}_{3}{ }_{\mathrm{He}}=81.4 \mathrm{MeV}$ have been measured by time-of-flight techniques. The same data are analyzed dosimctrically in order to extract kerma-to-fluence factors for the NE 213 scintillator. The ${ }^{9} \mathrm{Be}(\mathrm{d}, \mathbf{n})^{10} \mathrm{~B}$ results are compared with predictions of the Serber theory as applied to a thick target. Rossi counter measurements in the phantom have shown that the fast neutron spectral quality does not change significantly along the beam axis from at least $2 \mathrm{~cm}$ to $20 \mathrm{~cm}$ depth in tissue-equivalent fluid.

NBSIR 77-1282. Investigation of the suitability of light duty pipe hangers for use in residential and care type sprinkler systems, W. D. Hayes, Jr. and R. L. P. Custer, 45 pages '(Oct. 1977). Order from NTIS as PB273575.

Key words: automatic sprinklers; care type occupancies; fire endurance; load failure; pipe hangers; residential occupancies.

Several sizes of various types of commonly available light duty hangers for pipe, cable and conduit were subjected to load failure tests and while under load to exposure from 70 to 140 pound ( 31.8 and $63.5 \mathrm{~kg}$, respectively) crib fires. In addition, hangers made from thin strap metal were tested for effect on performance of undersized screws and for benefit obtained from the use of washers. All sizes of the two-hole or twofastener hangers met the NFPA No. 13 Standard for the Installation of Sprinklers load requirement, while only the nominal 1-1/4 inch size of the one-hole hangers met the requirement. Washers improve the performance of hangers made of thin strap metal.

NBSIR 77-1287. Analytical and experimental study of evaporative cooling and room fire suppression by corridor sprinkler system, S. T. Liu, 58 pages (Oct. 1977). Order from NTIS as PB273576.

Key words: automatic sprinklers; compartment fire; corridor sprinkler systems; droplet size; droplet trajectory; evaporative cooling; fire suppression; full-scale test; gas temperature; oxygen content; recirculating flow; reduced scale model test; scaling criteria; spray water flow rate; water spray.

Investigations, both theoretical and experimental, are conducted to evaluate the effects of a corridor sprinkler system on the cooling and suppression of a fire in an adjacent compartment connected by an open doorway. A simplified one dimensional mathematical model is presented to predict the net reduction of the corridor ceiling hot gas temperature by evaporative cooling. Scaling criteria based on the analysis of the motion of an evaporating droplet were developed for the correlation of full-scale and small-scale experimental results and the design requirements of a small-scale experiment. Representative test results from a full-scale and a one-quarter scale model experiments are presented. These tests demonstrate the effectiveness of water spray in reducing the corridor hot gas temperature to a level low enough for safe passage, and in causing a strong recirculating flow at the room doorway. This flow reduces the oxygen content around the fire significantly, and results in a much reduced burning rate of the fuel. The effect of the spray droplet size on the cooling and on fire suppression is discussed.

NBSIR 77-1290. Combustion of mattresses exposed to flaming ignition sources. Part I. Full-scale tests and hazard analysis, V. Babrauskas, 146 pages (Sept. 1977). Order from NTIS as PB272064.

Key words: bedding; beds; compartment fires; firesafety engineering; fire tests; health care facilities; hospitals; mattresses; prisons.

A test program was conducted to assess the hazards of institutional mattresses when subjected to a sustained flaming ig- 
nition source. This report gives results on full-scale room burns of ten different mattress types under several ventilation conditions. Tenability and rapid flame spread potential criteria were applied in a hazard assessment which showed a wide range of behavior among mattresses now being used in institutions. An extensive review of previous fire tests involving mattresses is included.

NBSIR 77-1291. Report of the Workshop on Cryptography in Support of Computer Security, D. Branstad, J. Gait, and S. Katzke, 62 pages (Sept. 1977). Order from NTIS as PB27 1744.

Key words: cryptanalysis; cryptography; encryption; key management; known plaintext attack; security; work factor.

This publication reports on the Workshop on Cryptography in Support of Computer Security held at the National Bureau of Standards on September 21-22, 1976. The workshop was organized to obtain expert opinions on the mathematical and statistical characteristics of the proposed Data Encryption Standard (DES) as it relates to computer security. This report summarizes formal presentations that were made, outlines major issues that were raised, quotes statements that were made for the record and answers several of the major questions that were asked.

NBSIR 77-1293. Analysis of housing data collected in a leadbased paint survey in Pittsburgh, Pennsylvania-Part II, D. R. Shier and W. G. Hall, 190 pages (June 1977). Order from NTIS as PB27 1745 .

Key words: blood lead; children; data analysis; housing; lead paint; lead poisoning; surveys.

This report represents Part II of a two-part document describing a lead-based paint survey conducted in Pittsburgh, Pennsylvania. Part I of this document (NBSIR 77-1250) presented details of the design, methodology and findings of this survey. The current report (Part II) presents and describes a series of tables summarizing the Pittsburgh survey data base, which includes measured lead levels of various surfaces in dwelling units and blood lead levels of children resident in those units. Most of the data analyses conducted in Part I derive from these tables. Thus, the tabulations given in this report provide not only the basis for those analyses but also a potential source for additional data analyses.

\section{NBSIR 77-1294. Power lawn mowers: Evaluation of anthropometric foot probes, J. J. Persensky and A. M. Ramey, 57 pages (May 1977). Order from NTIS as PB272507.}

Key words: consumer products; generic probes; human factors; lawn mowers; safety; standards.

This document is the final report for the Consumer Product Safety Commission of an evaluation of the adequacy of existing generic foot probes. The Human Factors Section at NBS compared the dynamic characteristics of three generic probes with those of potential lawn mower users' feet.

Horizontal and vertical insertion distances for the generic probes and the foot data were used to develop safety envelopes for various simulated housing heights. Inspection of the safety envelopes at 6,8 , and $10 \mathrm{~cm}$ housing heights indicates that of the three generic probes, the UK probe most closely approximates the foot data. Only the UK probe passes through the area above the plane of the housing opening.

However, a comparison of each individual's data (rather than aggregate data) was made with each generic probe to determine the percentage of participants who would be completely protected by each generic probe. These data indicate that at least one point of each individual's foot movement data would fall outside of the safe area defined by the generic probe envelopes. Therefore, a lawn mower meeting the criteria of any of the generic foot probes would not completely protect any of the participants in the study.

Recommendations for a modification of the UK probe and for further research are discussed.

NBSIR 77-1295. Tests on insulative barriers as a method of protecting neoprene core mattresses, J. N. Bresse, 30 pages (Nov. 1977). Order from NTIS as PB275170.

Key words: compartment fires; fire-retardants; insulation; mattresses; shipboard; thermal conductivity.

Tests were performed to determine the value of noncombustible insulative barriers as a method of protecting neoprene (chloroprene) mattress cores from igniting and contributing to a shipboard fire. The mattress systems were tested in the heat release rate calorimeter and in a quarter scale model compartment. Thicknesses of up to $44 \mathrm{~mm}$ (1-3/4 in) of ceramic fiber and glass fiber insulation were used to protect the cores. Although the insulation reduced the rate of heating of the core, it also served to raise interior temperatures by the effect of heat "trapping" to a point where the core could continue to decompose and smolder after all exterior heat supply had been removed.

NBSIR 77-1297. State solar energy legislation of 1976: A review of statutes relating to buildings, R. M. Eisenhard, 255 pages (Sept. 1977). Order from NTIS as PB273899.

Key words: architecture; buildings; design; energy; legislation; solar; standards; State.

This report reviews State legislation on solar energy use in buildings enacted in 1976. Acts involve tax incentives for the installation of solar devices, support for the proposed Solar Energy Research Institute called for in Public Law 93-473, solar standards, State energy offices, studies, building requirements and solar projects. The Acts are identified and abstracted and responsible State officials listed. The Acts, as well as supporting forms and other information, are included in the appendixes.

NBSIR 77-1300. A computer-assisted evaluation of the thermochemical data of the compounds of thorium, D. D. Wagman, R. H. Schumm, and V. B. Parker, 94 pages (Aug. 1977). Order from NTIS as PB273171.

Key words: data evaluation; enthalpy; entropy; Gibbs energy; thermochemical data networks; thermochemical tables; thorium compounds.

Selected values are given for the thermochemical properties of the compounds of thorium. They are obtained from a computer-assisted least sums-least squares approach to the evaluation of thermodynamic data networks. The properties given, where data are available, are enthalpy of formation, Gibbs energy of formation, and entropy at $298.15 \mathrm{~K}\left(\Delta \mathbf{H f} \mathrm{f}^{\circ}\right.$ (298), $\Delta G f^{\circ}(298)$, and $S^{\circ}(298)$ ). The values are consistent with the CODATA Key Values for Thermodynamics. The reaction catalog from which this self-consistent set of values is generated is given with a statistical analysis. Some thermal functions are also given, as well as detailed comments when necessary.

NBSIR 77-1302. A numerical technique to correct heat release rate calorimetry data for apparatus time delay, D. D. Evans and L. H. Breden, 25 pages (Nov. 1977). Order from NTIS as $\mathrm{PB} 275173$.

Key words: calorimetry; heat release rate; response time; time delay. 
A numerical scheme is presented to correct heat release rate measurements made with the Ohio State University rate of heat release apparatus for the effects of inherent time delays in the measurement system. The magnitude of the correction is shown to increase with increasing rate of change in heat release rate. Illustrative heat release rate curves for particle board and balsa wood show that corrections to the peak heat release rate of 40 percent and 130 percent respectively are necessary. Measurements of the apparatus time response to step changes in heat release rate are reported. A simple method of determining corrections to the measured peak heat release rate is discussed.

NBSIR 77-1303. A simplified procedure for calculating the direct components of contrast rendition factor and equivalent sphere illumination, J. B. Murdoch, 75 pages (Nov. 1977). Order from NTIS as PB274331.

Key words: body shadow; contrast rendition; hand calculator; illuminating engineering; light design; luminaire effectiveness; luminance factor; office lighting; sphere illumination.

A procedure is presented which enables the user to compute the direct components of contrast rendition factor (CRF) and equivalent sphere illumination (ESI) for an interior lighting design with the aid of a card-programmable hand calculator. The underlying theory and equations of CRF and ESI are discussed, including a consideration of body shadow, intensity distribution curve interpolations, bidirectional luminance factor approximating equations and Inverse Square approximations.

The procedure is designed so that the user is a participant in the computations as they progress and thus is able to modify a lighting design in "midstream" to improve CRF or ESI. A set of user instructions is included with the calculator programs.

NBSIR 77-1304 (ARPA). Optical materials characterization, A. Feldman, D. Horowitz, R. M. Waxler, M. J. Dodge, and W. K. Gladden, 43 pages (Aug. 1977). Order from NTIS as PB272478.

Key words: $\mathrm{BaF}_{2} ; \mathrm{CaF}_{2} ; \mathrm{KBr}$; $\mathrm{KCl}$; Lexan; LiF; NaF; Plexiglas 55; refractive index; $\mathrm{SrF}_{2}$; thermal coefficient of refractive index; $\mathrm{ZnS} ; \mathrm{ZnSe}$.

The refractive index of fusion cast $\mathrm{CaF}_{2}$ was measured at room temperature over the wavelength range $0.2144 \mu \mathrm{m}$ to $8.662 \mu \mathrm{m}$ and the data were fitted to a Selmeier type equation. Measurements of refractive index of hot forged $\mathrm{CaF}_{2}$ were extended to the wavelength range $0.2024 \mu \mathrm{m}$ to $0.2483 \mu \mathrm{m}$. Data are presented for $\mathrm{dn} / \mathrm{dT}$ of single crystal specimens of $\mathrm{CaF}_{2}$, $\mathrm{BaF}_{2}$, reactive atmosphere processed (RAP) $\mathrm{KCl}$ and $\mathrm{KBr}, \mathrm{LiF}$, $\mathrm{NaF}$, and $\mathrm{SrF}_{2}$, and polycrystalline chemical vapor deposited (CVD) $\mathrm{ZnSe}$ and $\mathrm{ZnS}$. The measurements were done by the method of Fizeau interferometry over the temperature range $-180^{\circ}$ to $200{ }^{\circ} \mathrm{C}$ at the wavelengths $0.6328 \mu \mathrm{m}, 1.15 \mu \mathrm{m}, 3.39$ $\mu \mathrm{m}$ and $10.6 \mu \mathrm{m}$. Data are presented for the refractive indices, the linear thermal expansion and $\mathrm{dn} / \mathrm{dT}$ of Lexan and Plexiglas 55.

NBSIR 77-1305. Provisional flat plate solar collector testing procedures, Solar Energy Program Team, Center for Building Technology, 56 pages (Sept. 1977). Order from NTIS as PB272500.

Key words: durability/reliability; fire safety; rating criteria; solar collectors; structural performance; testing procedures; thermal performance.

The test methods contained in this report and the provisional rating criteria presented in an appendix are intended for use in determining the thermal performance, and to aid in the assessment of the safety and durability/reliability of flat plate solar collectors. These test methods and rating criteria have been selected after the review of over 400 accepted industry standards and are consistent with the intent of the U.S. Department of Housing and Urban Development (HUD) Minimum Property Standards (MPS) and the Interim Performance Criteria (IPC) prepared by the National Bureau of Standards (NBS) for ERDA and HUD respectively. These test methods and rating criteria do not, however, represent a consensus of industry and are therefore provisional in nature. It is intended that revisions will be made as more experience is gained and inputs received from appropriate industry representatives, testing laboratories, designers, etc.

NBSIR 77-1307. A review of computer software applicable to the MIUS Program, W. L. Carroll and J. R. Schaefgen, Jr., 102 pages (Oct. 1977). Order from NTIS as PB273175.

Key words: computer programs; cooling; energy analysis; financial analysis; heating; load calculation; MIUS; modular integrated utility system; simulation; utility services.

Thirteen computer programs are examined for potential application to the Modular Integrated Utility System (MIUS) program. The software programs considered calculate all or partial combinations of: heating and cooling loads, simulation of physical systems to determine the energy requirements necessary to satisfy those loads, prediction of optimal operation schedules and associated costs, and accomplishment of full life-cycle economic analyses. A set of criteria for evaluation of this software is presented. Information regarding the programs, obtained from user manuals and a series of seminar presentations, is collected and systematically summarized in a standardized format using information available as of June 1974. An evaluation summary of each program as of that date is given. Program comparison activities are discussed and evaluated. Conclusions regarding applicability, validity, and utility of programs are reached. Recommendations are made concerning future software development and utilization.

NBSIR 77-1308. Annual conference on fire research, C. Huggett, Ed., 199 pages (Oct. 1977). Order from NTIS as PB273589.

Key words: combustion products; fire hazards; fire modeling; fire research; human behavior in fires.

This report contains extended abstracts of grants and contracts for fire research sponsored by the Center for Fire Research, National Bureau of Standards and descriptions of the internal programs of the Center for Fire Research. It was prepared as a preprint for use at a conference of contractors and grantees held at NBS on August 3-5, 1977.

NBSIR 77-1309. Three proposed typical house designs for energy conservation research, S. R. Hastings, 38 pages (Oct. 1977). Order from NTIS as PB274334.

Key words: building envelope; energy conservation base; insulation; residential design practices; typical construction characteristics; typical new house materials; windows.

This report provides three house designs typifying the majority of new house construction in the U.S. Included are: scaled drawings detailing the construction of the houses, a breakdown of envelope components by surface area, a schedule of materials with supporting survey statistics from the National Association of Home Builders, a table of heat transfer properties of the specified materials, and recommendations for how these typical house designs can provide a basis for further work in the areas of fire research, durability, security, and environmental behavior in addition to energy conservation.

The background work for this report was completed in support of two other reports: "Geographic Variation in the Heating and Cooling Requirements of a Typical Single-Family 
House," and "Determination of Optimal Energy Conservation Designs in Single-Family Housing: Preliminary Results." This report is a wrap-up of the support to these two reports and provides a thorough documentation of the three designs to provide a basis for future work.

NBSIR 77-1310. Microcalorimetric study of cardiac pacemakers and batteries, E. J. Prosen and J. C. Colbert, 21 pages (Sept. 1977). Order from NTIS as PB272690.

Key words: battery; microcalorimetry; pacemaker; power cell; self-discharge.

A feasibility study was carried out to determine if microcalorimetry could be used to measure the energy loss or selfdischarge of cardiac pacemakers and power cells. Alkaline and mercury batteries, camera and watch type, were measured both under external load and open-circuit conditions. The results indicate that microcalorimetry can be both a sensitive and useful tool for measuring the self-discharge of cardiac pacemakers and power cells. Microcalorimetry can also be used to measure nondestructively, the power output from the completed (sealed) pacemaker itself.

NBSIR 77-1312. Physical properties of smokes pertinent to smoke detector technology, T. G. K. Lee and G. Mulholland, 46 pages (Nov. 1977). Order from NTIS as PB274330.

Key words: aerosol; mass concentration; number concentration; size distribution; smoke; smoke detector; test method; UL 217.

Several commercially available aerosol instruments including the electrical aerosol analyzer, nuclei condensation monitor, quartz mass monitor, and optical particle counter were used to measure particle size distribution of smokes from buming heptane and cellulosic materials. Some limitations of these instruments are discussed. Parameters such as mode of exposure (flaming versus smoldering), pyrolysis temperature, air velocity at smoke emitting site, and aging were found to have a large effect on the smoke particle size distribution. Mass and number concentrations of smokes from cotton lamp wick as a function of smoke obscuration in the standard UL 217 detector test chamber were determined. The maximum alarm threshold obscuration of $0.06 \mathrm{OD} / \mathrm{m}$ ( $4 \%$ per $\mathrm{ft}$ ), required for detector approval, was found to correspond to lamp wick aerosol mass concentration of $40 \mathrm{mg} / \mathrm{m}^{3}$ and particle concentration of about $4 \times 10^{6} \mathrm{~cm}^{-3}$ with the peak size in the number distribution of about $0.15 \mu \mathrm{m}$. The present UL 217 test method was shown to be affected by smoke coagulation and did not provide a complete measure of sensitivity in smoke detectors. An algebraic model size distribution, with number and mass concentration the only free parameters, was shown to provide a good estimate for all the smoke size distributions measured.

NBSIR 77-1313. An assessment of the technical Iiterature on emergency egress from buildings, F. I. Stahl and J. Archea, 66 pages (Oct. 1977). Order from NTIS as PB273944.

Key words: architectural psychology; architectural research; building codes; building design; building fires; building regulatory standards; emergency egress; exit capacity; fire safety; human performance; occupational safety; regulatory data.

An assessment was made of the literature on research related to current emergency egress regulations promulgated by the Occupational Safety and Health Administration (OSHA). The purposes of this assessment were to ascertain the extent to which these regulations were based upon empirical research, and to determine the adequacy of available research findings from which OSHA emergency egress regulations may be developed. Three areas of research on emergency egress were identified: research on (1) the carrying capacity of exitways, (2) signage, lighting, and visibility through smoke, and (3) occupant responses to, and experiences in building fires. Only research on the carrying capacity of exitways appears to have had direct impact on current OSHA regulations, which are based largely on empirical findings reported in 1935. Much of the available data on egress signage, lighting, visibility through smoke, and occupants' responses in real fire situations have appeared since the adoption of standards by OSHA. Consequently, these areas have had minimal impact on OSHA egress regulations. This study provides specific recommendations concerning the technical adequacy and range of applicability of the available empirical literature on emergency egress from buildings. In addition, it provides specific recommendations concerning directions and methodological requirements for future research.

NBSIR 77-1315. Simulated precipitation reference materials II, J. K. Taylor, E. R. Deardorff, and T. C. Rains, 26 pages (Sept. 1977). Order from NTIS as PB273945.

Key words: chemical analysis; rainwater analysis; reference materials.

This report describes the preparation of a series of reference materials for chemical analysis of natural precipitation. This is the second series of such materials prepared by NBS, under the sponsorship of EPA, and will be distributed by the latter as a means to intercalibrate atmospheric monitoring stations. The materials consist of ampoules of concentrates which can be diluted to simulate natural rainwater. A separate reference sample, to be used undiluted, is provided for evaluation acidity measurements. The analytical measurements made to establish the composition of the samples are also described.

NBSIR 77-1316. Performance criteria resource document for innovative construction, T. K. Faison, 165 pages (Nov. 1977). Order from NTIS as PB274404.

Key words: acoustics; appliances; atmospheric; durability; electrical; environment; housing technology; HVAC; innovative construction; maintainability; materials; minimum property standards; performance criteria; performance evaluation; plumbing; safety; structures; test methods.

Performance criteria for innovative construction are presented in this resource report in order to assist in the broad technical acceptance of new building products and materials. The leveis of performance stated are intended to be equivalent to the Minimum Property Standards (MPS) which reflects acceptable performance of conventional building materials and designs for programs sponsored by the Department of Housing and Urban Development. The report is structured so that new performance criteria can be added in the future as additional technical data and evaluation methods become available.

NBSIR 77-1317. Calibration of high-voltage pulse measurement systems based on the Kerr effect, R. E. Hebner, Jr. and M. Misakian, 38 pages (Sept. 1977). Order from NTIS as PB274333.

Key words: calibration; dielectrics; dividers; electric fields; electro-optics; high voltage measurement; insulating fluids; Kerr effect; nitrobenzene; pulse measurement; space charge.

High voltage pulse measurements have been performed using systems based on the electro-optic Kerr effect for a number of years. These systems permit state-of-the-art measurements (uncertainties $= \pm 1 \%$ ). Because the precision of the measurement can be significantly better than the accuracy, an investigation of techniques to improve the calibration of the system was undertaken. 
The investigation focused on two areas. One was the experimental determination of correction factors which would account for differences in environmental factors between the calibration of the system and its use. These measurements yielded accurate corrections for variations in temperature and quantitative evidence of the magnitude of the wavelength dependence of a Kerr system's response. The second was further study into the feasibility of calibrating the Kerr system at a number of discrete frequencies and using this calibration for pulse measurement.

NBSIR 77-1318. The impact of a room fire on a corridor with considerations of fuel load, ventilation and scaling, J. Quintiere, B. McCaffrey, T. Kashiwagi, K. Den Braven, M. Harkleroad, J. Raines, and W. Rinkinen, 61 pages (Nov. 1977). Order from NTIS as PB273942.

Key words: corridors; fuel load; heat transfer; room fires; scaling; ventilation.

A study was conducted of heat transfer and temperature field imparted to a corridor by a room fire in order to assess the potential of fire spread along the corridor. Wood cribs were used as the fuel load which ranged from 20 to $120 \mathrm{~kg}$. Also the effects of ventilation and fuel load location were examined. The results showed these effects to be significant.

A corresponding scale model study was conducted using gas burners as a fuel supply. A scaling criteria was developed which emphasized the solid wall conductive and gas phase convective transport processes. As a result limitations were encountered at high temperature when radiation became more significant. In general the convective processes appeared to scale well and radiation limitations could be assessed through analysis.

NBSIR 77-1381. Preliminary report on evaluating alternatives for reducing upholstered furniture fire losses, B. Buchbinder, S. G. Helzer, and F. L. Offensend, 30 pages (Nov. 1977). Order from NTIS as PB273943.

Key words: cost plus loss; decision analysis; fire; furniture fire; losses; residential fire; standard; upholstered furniture.

This paper presents preliminary results from a pilot project designed to test the utility of applying decision analysis to fire hazard problems. To test the methodology, an analysis is being performed to determine the effectiveness and economic consequences of alternative intervention strategies for reducing upholstered furniture fire losses in residences. A probabilistic model has been developed to assess quantitatively the expected fire losses under each alternative. This paper describes the analysis on one alternative: the proposed upholstered furniture standard currently under consideration by the Consumer Product Safety Commission. The loss model for this alternative is described in some detail. Preliminary results on costs, losses, and cost plus loss to society and the present value of these quantities are presented.

A subsequent report will update this analysis with revised data, and present a comparison of the proposed standard with other alternative strategies.
NBSIK 77-1390. A preliminary examination of building regulations adopted by the states and major cities, P. W. Cooke and R. M. Eisenhard, 124 pages (Nov. 1977). Order from NTIS as PB274335.

Key words: building construction; building regulations; cities; code uniformity; enforcement; legislation; rules and regulations; statewide codes; summary tables.

Preliminary information describing regulatory codes and standards bearing on building construction and occupancy which have been adopted by the various States and certain major cities in the U.S. are presented in a series of summary tables. The tables and accompanying notes provide information on salient elements of the enabling legislation, the type of codes and standards promulgated, and the respective agencies charged with the administration and enforcement of each regulatory program. Other features of the various regulatory programs (e.g., occupancy classifications covered, preemptive status of codes, etc.) are also enumerated. The regulatory programs and the respective code disciplines which are summarized include: building; mechanical; plumbing; electrical; fire and life safety; elevators; gas fittings; and boiler and pressure vessels.

INBSIR 77-1394. A computer code for the simulation of turbulent swirling flow through closed-conduit flow meters, $R$. W. Davis and E. F. Moore, 12 pages (Dec. 1977). Order from NTIS as PB274650.

Key words: flow meter; meter performance; numerical modeling; turbulent flow.

A computer code is presented for the simulation of turbulent swirling flow through closed-conduit flow meters. The code is reasonably fast and accurate. The response of a flow meter to changes in its operating environment is easily assessed. Through the use of computer plotting routines, a complete picture of the flowfield through a meter can be obtained. An example flowfield for a target meter is presented.

NBSIR 77-1396. Erosion of brittle materials by solid particle impact, B. J. Hockey, S. M. Wiederhorn, and H. Johnson, 27 pages (Nov. 1977). Order from NTIS as PB274648.

Key words: ceramics; erosion; fracture; plastic flow; solid particle impact; transmission electron microscopy.

Results are presented which show, that in addition to fracture, plastic deformation occurs and plays an important role in the erosion of brittle materials by solid particle impact. These conclusions are supported by transmission electron microscopy studies of impact damage produced in a wide variety of brittle materials and by erosive wear studies on silicon nitride and alumina. The erosive wear studies also indicate that while erosion resistance is primarily determined by fracture toughness and hardness, the relative importance of these materials parameters depends on the test conditions (e.g., temperature and angle of particle impingement). 


\subsection{GRANTEE/CONTRACTOR REPORTS AND NBS PATENTS}

Grantee/contractor reports are prepared by non-NBS persons or organizations working under grant or contract from the $\mathrm{Na}$ tional Bureau of Standards. Those contract reports not incorporated into the formal NBS publication series are available directly from the National Technical Information Service (NTTS, Springfield, VA 22161) in paper copy or microfiche form unless otherwise stated. When ordering a report from NTIS you must order it by the "COM, PB, AD, or N" number as indicated.

Patents are legal documents which fully describe inventions in return for the right for 17 years to exclude others from making, using, or selling the inventions. They are obtained on NBS inventions of high commercial potential in order to establish Government ownership of the patent rights. The patents are then made available for the grant of nonexclusive licenses to all qualified applicants. A limited exclusive license may be granted under a particular patent, however, if it appears that some period of exclusivity is necessary as an incentive for the investment of risk capital. For information on licensing any of the following patents, write to the Office of the Legal Adviser, National Bureau of Standards, Washington, DC 20234. Copies of patents may be obtained from the U.S. Patent and Trademark Office, Washington, DC 20231 for 50 cents each.

NBS-GCR-76-77. A basic investigation of the extinguishability of various fabrics, L. B. Miles, 95 pages (Sept. 22, 1976). Order from NTIS as PB257767.

Key words: extinguishability; fabric flammability; flammability ranking; heat flux; heat transfer rate; linear burning rate

In considering extinguishability hazards both the inherent qualities of a fabric as well as human reactions are important. This study concentrates on the former aspect. Linear burning rate and heat flux are measured for twelve fabrics within a TRI Flammability Analyzer cabinet. Initial work deals with ambient oxygen effects on the burning rate and heat flux of each fabric measured at four levels of oxygen. From the resulting data, a series of relationships were studied by regression techniques. The latter work investigates heat sink/intersticial effects on burning rate and heat flux. Two heat sink designs were evaluated using temperature and distance as variables. In studying cooling effects, each fabric was tested at three heat sink distances. Burning rate and heat flux were plotted as functions of inverse heat sink distance. In the oxygen effects study, analyses showed that linear burning rate was dependent on fiber type and construction, that heat flux was basically fiber dependent, and that mass burning rate was not entirely independent of construction. In the heat sink effects study, burning rate and. heat flux were mainly dependent on distance of the heat sink. A comparison of oxygen and heat sink data showed that in both cases oxygen supply was the controlling factor.

NBS-GCR-76-78. An investigation of certain design parameters of the mushroom apparel flammability tester, A. K. Stratton, 112 pages (July 1976). Order from NTIS as PB257836.

Key words: apparel; fabrics; flammability testing; heat transfer rates; Mushroom Apparel Flammability Tester; standards; test development; textiles.

This paper describes the effect of variations in design parameters of the apparatus on the heat transfer rates measured by the "Mushroom Apparel Flammability Tester." In this instrument, cylindrical specimens of apparel fabrics are suspended from a circular top plate, and the rate of heat transfer to the top plate and a cylinder inside the specimen are measured. The paper describes the effect of changing the cylinder diameter, and of introducing rods between the specimen and the cylinder to prevent deposition of molten polymer on the cylinder. Heat transfer rates measured on the top plate and on the cylinder are compared. Design parameters for the present version of this instrument and the corresponding test method were chosen on the basis of this investigation. The paper is in the form of a Master of Science thesis; the experimental work was performed at NBS.

NBS-GCR-76-79. A problem in fire safety: Flame spreading across liquid fuels, F. L. Dryer, 1. Glassman, W. A. Sirignano, 30 pages (Sept. 15, 1976). Order from NTIS as PB259127.

Key words: combustion models; flame spread; fluid flow; laser doppler velocimetry; liquid fuels; solid fuels; surface tension.

This report provides a brief summary of experimental and theoretical work carried out at Princeton University on flame spreading across liquid fuels. The importance of surface tension driven flows ahead of the flame front in controlling flame spread across liquids at temperatures below the flash point was demonstrated experimentally. Buoyancy and radiation effects were also present but were of lesser importance. Variations in the temperature of the liquid surface are attributed to eddies in the gas phase ahead of the flame front. These eddies may also play a role in flame propagation across solid combustibles. It is proposed to investigate these eddies by means of laser doppler velocimetry. A two-dimensional, steady-state computer program is under development for use as a tool in studying flame propagation above liquid and solid fuels.

NBS-GCR-76-80. Scaling of radiative characteristics of turbulent diffusion flames, G. H. Markstein, 51 pages (June 1976). Order from NTIS as PB259126.

Key words: flame radiation; radiant flux density; radiation measurement; radiative heat transfer; turbulent flames.

The following measurements were performed on single buoyancy-controlled turbulent propane diffusion flames within the range $44 \leqslant q \leqslant 412 \mathrm{~cm}^{3} / \mathrm{s}$ of fuel rate $q: 1$ ) total radiative power $\mathrm{P}$, determined with a wide-view-angle radiometer, 2) total radiative power $\Delta \mathrm{P}$ emitted by a horizontal flame slice of known height $\Delta z$, measured with a wide-view-angle radiometer that looks at the flame through a horizontal slit, and 3) radiance emitted along a flame diameter, $N_{\max }$, measured with a collimated beam radiometer. The latter two quantities were measured simultaneously as functions of height $\mathrm{z}$ above the burner nozzle over the entire length $L$ of the flame. Total radiative power was found to scale with the first power of flow rate, $P=\chi Q=\chi \Delta h_{r} q$, where the fraction $\chi$ of total rate of release $Q$ emitted as radiation was 0.264 and $\Delta h_{c}=86.821$ $\mathrm{J} / \mathrm{cm}^{3}$ is the heat of combustion per unit volume of fuel. From the local radiative properties $S=\Delta \mathrm{P} / \Delta \mathrm{z}$ and $\mathrm{N}_{\text {max }}$, flame diameter $\mathrm{D}=\pi^{-2} \mathrm{~S} / \mathrm{N}_{\max }$ and volumetric radiant power $\mathrm{p}=4 \pi^{3} \mathrm{~N}^{2}$ max /S were derived. It was found further that the dependence of the data on flow rate $q$ could be scaled by power law relationships, with the dependence on height $\mathrm{z}$ expressed by two dimensionless functions $s(\zeta), n(\zeta)$ of the dimensionless height $\zeta=\mathrm{z} / \mathrm{L}$. 
NBS-GCR-77-82. Detector sensitivity and siting requirements for dwellings-Phase 2, S. W. Harpe, T. E. Waterman, and W. J. Christian, 379 pages (Feb. 1977). Order from NTIS as PB263882.

Key words: detector sensitivity; detector siting; escape time; fire tests; gas detectors; heat detectors; residential fires; smoke detectors.

The contract for a field investigation of the effectiveness of residential smoke detectors was extended to cover 36 additional tests investigating details not completely covered in the first report. The objective of the second phase of the program was to gather information on fires under summer/fall conditions without air conditioning and to expand available information on high volume, two story structures. The effects of open windows, new technical developments in photoelectric detector design, and the response of semiconductor type residential gas detectors and mechanically powered heat detectors were also included.

The tests reinforced the conclusions of the first phase of testing. They showed that open windows have little appreciable affect of life safety and detection times, and that semiconductor gas sensing fire detectors exhibit fuel specific response characteristics which seriously degraded the effectiveness in certain types of fires.

NBS-GCR-77-83. Thermophysical properties of polystyrene and poly(vinyl chloride), C. Y. Ho, P. D. Desai, K. Y. Wu, T. N. Havill, and T. Y. Lee, 110 pages (Mar. 1977). Order from NTIS as PB265228.

Key words: fire research; polymers; polystyrene; poly(vinyl chloride); specific heat; thermal conductivity; thermal diffusivity.

This technical report presents the most comprehensively compiled experimental data and the critically evaluated and recommended reference values for the thermal conductivity, specific heat, density, and thermal diffusivity of polystyrene and poly(vinyl chloride). The compiled data include all the experimental data available from the literature. The recommeded values generated from critical evaluation, analysis, and synthesis of the available data and information are for solid (unexpanded) polystyrene with a density of $1.050 \mathrm{~g} \mathrm{~cm}^{-3}$, for foamed polystyrene expanded with air with densities of 0.060 and $0.010 \mathrm{~g} \mathrm{~cm}^{-3}$, for solid poly(vinyl chloride) with a density of $1.400 \mathrm{~g} \mathrm{~cm}^{-3}$, and for foamed poly(vinyl chloride) expanded with air with densities of 0.060 and $0.020 \mathrm{~g} \mathrm{~cm}^{-3}$. The temperature range covered by the compiled data on some of the properties is from cryogenic temperatures to above the melting point of the material. The recommended values for polystyrene cover the temperature range from 100 to $600 \mathrm{~K}$ and those for poly(vinyl chloride) cover the range from 100 to $400 \mathrm{~K}$.

NBS-GCR-77-84. UNDSAFE-1: A computer code for buoyant flow in an enclosure, K. T. Yang and L. C. Chang, 103 pages (Mar. 1, 1977). Order from NTIS as PB267278.

Key words: buoyant flow; compartment fires; corridor fires; fire code; fire science; fire spread model.

This report describes a numerical computer code known as UNDSAFE-1 for predicting the flow, temperature and pressure fields in a simple two-dimensional rectangular enclosure due to a volumetric heat source. It accommodates either a doorway or a window, and a variety of conditions such as location, extent and strength of the heat source as well as various thermal boundary conditions along the ceiling and the floor of the enclosure. Physical effects taken into account in this code include strong buoyancy, compressibility, and turbulence. The code is fully documented and explained in this report in terms of input data and format as well as available output options. A complete numerical example is presented.

NBS-GCR-77-85. Toxicity of plastic combustion products. Toxicological methodologies to assess the relative hazards of thermal decomposition products from polymeric materials, $Y$. Alarie and C. S. Barrow, 309 pages (Feb. 1976/1977). Order from NTIS as PB267233.

Key words: acute lethality; Douglas Fir; inhalation; mice; polyurethane; pulmonary irritation; PVC; respiratory rate; sensory irritation; stress index; thermal decomposition products; toxicity.

Sensory and pulmonary irritation effects of thermal degradation products from natural and synthetic materials were studied using mice. Mice were used to develop a sensory irritation stress index based on changes in respiratory rate. In addition, acute lethality was obtained.

Dose-response curves were generated for decomposition products from Douglas Fir, PVC, flexible polyurethane, teflon, and fiberglass reinforced polyester. Similar data were obtained for $\mathrm{CO}, \mathrm{CO}_{2}$, low $\mathrm{O}_{2}$, acrolein, $\mathrm{HCl}$ and $\mathrm{Cl}_{2}$.

Preliminary studies on the pulmonary effects of combustion products using rabbits are also reported.

NBS-GCR-77-86. Environments of fire detectors-Phase 1: Effect of fire size, ceiling height and material. Volume 1. Measurements, G. Heskestad and M. A. Delichatsios, 206 pages (May 1977). Order from NT1S as PB272882.

Key words: ceiling height; ceilings; cotton; detector location; detectors; fire detectors; polyurethanes; polyvinyl chloride; room fires; rooms; smoldering; wood.

An experimental program has been initiated to map ceiling environments to which fire detectors are exposed for various combinations of room geometry, ceiling configuration, fire type, and detector spacing. This report covers Phase 1 of the program, which considered 1) flat, extensive ceiling areas, 2) a quiescent test space, 3 ) flaming and smoldering fires of wood, cotton, foamed polyurethane, and polyvinyl chloride, 4 ) ceiling heights of 8,15 and $29 \mathrm{ft}$, and 5 ) instrument stations at 10, 20, and $40 \mathrm{ft}$ from the geometric fire axis. Measured environmental parameters included temperature, velocity, and optical density. In addition, response times of a set of five fire detectors (heat detectors of fixed temperature, rate-of-rise, and rate anticipation types; one ionization smoke detector; and one photoelectric smoke detector of the reflection type) were recorded at each instrument station. A total of 49 fire tests were conducted. The reduced data are presented in two tables, one listing detector response times and the other listing the environmental data. Analysis of the data is presented in a second volume (Volume II) and includes determination of spacing requirements for fire detectors in flaming fires.

NBS-GCR-77-87. Government-supported residential rehabilitation, M. C. McFarland, 55 pages (May 1977). Order from NTIS as PB268132.

Key words: building codes; housing; rehabilitation; remodeling; residential; urban renewal.

The NBS is developing new research to determine how best to remodel and rehabilitate existing buildings as a way of conserving the INation's resources. As background information, this report discusses the three major programs in residential rehabilitation which HUD has conducted in the past. The programs, whose needs, history, examples, and outcomes are discussed, are (1) urban renewal rehabilitation, (2) concentrated code enforcement, and (3) project rehabilitation. The author, Carter McFarland was an economist at HUD when these programs were conceived and carried out, and was involved with them either directly or indirectly. 
NBS-GCR-77-88. Self-help housing construction: Effects of regulatory codes and standards, 121 pages (May 1977). Order from NTIS as PB268131.

Key words: building codes; building regulation; do-it-yourself; home construction; housing; rehabilitation; remodeling; renewal; renovation; self-help; standards.

The NBS is pursuing new research into how best to construct buildings, including housing. This report discusses one type of housing construction-self-help, wherein the proposed occupant and owner builds his own dwelling either on his own, or collaboratively with a group of prospective homeowners. The self-help idea can also be applied to remodeling, rehabilitation, dwelling additions, or just minor repairs and improvements, for which it is also referred to as "do-it-yourself" labor. This report describes self-help, suggests how self-help projects can be supported, explores the feasibility of using component systems in self-help projects, and provides references and bibliographic materials.

NBS-GCR-77-89. Symbolic testing-Design techniques, costs and effectiveness, W. E. Howden, 168 pages (May 1977). Order from NTIS as PB268517.

Key words: computer programming; cost analysis; software engineering; software reliability; software testing; symbolic evaluation; symbolic testing.

The report is divided into two parts. The first part contains a study of the design of symbolic evaluation system. It also contains an estimate of the costs of using such a system to carry out symbolic program testing. The second part contains a study of the effectiveness of symbolic testing. It contains an analysis of the circumstances under which symbolic testing is reliable for discovering program bugs. The effectiveness of symbolic testing is compared with other reliability analysis techniques. The analysis of the effectiveness of symbolic testing which is contained in Part 2 is based on the study of six programs. Descriptions of the programs and the details of the analyses are continued in the six Appendices.

NBS-GCR-77-90. Extinguishability as a component measure of

flammability hazard, S. M. Spivak, 180 pages (Apr. 1977). Order from NTIS as PB269489.

Key words: air flow; extinguishability; extinguishment; fabric flammability; fibers; heat flux; heat sinks; oxygen concentration; textiles.

Extinguishability of flammable fabrics has been investigated under two separate basic and applied phases. Twenty-two fabrics have been investigated. The basic phase focused on the influence of extinction mechanisms which control buming behavior during extinguishment, and thus extinguishability. Mechanisms studied include effects of ambient oxygen concentration and placement of a heat sink in proximity to the flame. A modified TRI Flammability Analyzer was used. Results show that burning rate and heat flux vary linearly with oxygen concentration, and the general behavior of fiber type can be ascertained. Further analyses show the influence of both sensitivity to, and lower limits of, oxygen concentration as these influence burning behavior. Heat sink effects cause reductions in flammability with increasing impingement of the heat sink device. The applied phase concentrated on laboratory simulations of extinguishment strategies, i.e., slapping out the flames and running to blow out the flames. In slapping, the test device consisted of two boards which could be closed onto a burning fabric. Numerous experimental variables influence these results. Thus, slapping is highly method dependent and may not be a good candidate as a simple test to assess extinguishability. A method of greater promise consisted of flowing air over burning fabric to simulate running. This utilized a controlled air flow directed at burning fabric mounted on an NBS Mushroom Apparel Flammability Tester (MAFT).

NBS-GCR-77-91. Guidebook on anthropomorphic test dummy usage, D. H. Robbins, 84 pages (Mar. 1977). Order from NTIS as PB268904.

Key words: anthropomorphic dummies; building safety; dummies; guidebook; testing.

This report addresses the role which may be played by impact test dummies in developing countermeasures to cope with the high incidence of safety problems related to building structures. Possible roles are discussed in safety problem identification, countermeasure development, and in the preparation of standardized test procedures. The parameters of a test using a dummy are grouped according to: 1. representation of a human victim; 2. representation of the environment in which an injury may occur; 3 . the interaction between the victim (dummy) and his environment; and 4 . the injuries (transducer or other measurements in the case of the dummy) which occur. Dummies are classified according to sophistication ranging from anthropometric form to impact body blocks and finally to sophisticated anthropomorphic test devices used in automotive safety. Test procedures and data processing are discussed. A bibliography, coded by subject, is also included.

NBS-GCR-77-92. Simulating human behavior in high-rise building fires: Modeling occupant movement through a fire-floor from initial alert to safe egress, F. 1. Stahl, 55 pages (Aug. 1977). Order from NTIS as PB273166.

Key words: building fires; fire behavior; high-rise buildings; occupant behavior in fires; simulated behavior.

The objective of the current study is to present an alternative means through which to model the building fire system, predict human responses in building fires, and test safety policies and building design alternatives. Focusing on the case of the highrise office building, the investigation develops a methodology, and explores its implications for building design, planning and policy evaluation, and theory.

NBS-GCR-77-93. Human behavior in institutional fires and its design implications, L. Lerup, D. Cronrath, J. K. C. Liu, 185 pages (Feb. 28, 1977). Order from NTIS as PB271980.

Key words: alarm; arclitecture; design implication; emergency actions; emergency communicative; emergency decisions; escape; fires; human behavior; human response; life safety; mapping; model; nursing homes; rescue; verbal communicative.

The objective of this project is to derive design implications from the in-depth analysis of behavior in institutional settings under fire. The context and data for this pursuit are drawn from ten case studies of significant nursing home fires which occurred in the United States between 1970 and 1974. The methodology used is based on a graphical (pictorial) and narrative mapping of fire and people behavior and it is an extension of the mapping system report in Report NBS-GCR 76-73 "Mapping of Recurrent Behavior Patterns in Institutional Building Under Fire: Ten Case Studies of Nursing Facilities."

NBS-GCR-77-94. Smoke as a determinant of human behavior in fire situations (project people), J. L. Bryan, 304 pages (June 30,1977 ). Order from NTIS as PB271755.

Key words: building fires; egress; fire alarms; fire incidents; fire investigations; fires; human behavior; project people; residential buildings; smoke; statistical analysis. 
This study involved the interviewing of 584 occupants of buildings on fire by fire department officials at the scene of the fire incident. The analysis and study of the interview data involved the determination of the critical variables relative to the fire incident (e.g., area of fire origin), participant population parameters (e.g., location at time of awareness there was a fire) and the first, second and third actions of the participants after becoming aware of the fire incident. Statistical analysis were performed showing the relationship among the variables. Results were compared with those of a similar study conducted in England by Wood. The results of the two studies were in general agreement, with the differences in large part explainable by the larger percentage of residential fires in this study.

NBS-GCR-77-95. Environments of fire detectors-Phase 1: Effect of fire size, ceiling height and material. Volume 2. Analysis, G. Heskestad and M. A. Delichatsios, 129 pages (July 1977). Order from NTIS as PB272883.

Key words: ceiling height; ceilings; cotton; detector location; fire detectors; fire growth; flaming fires; heat detectors; polyurethanes; polyvinyl chloride; smoke detectors; smoldering fires; temperature rise; wood.

This volume is an analysis of experimental data presented in Volume 1 on the ceiling environment and response to this environment by various types of fire detectors. Data and the analysis pertain to flat, extensive ceilings and quiescent surroundings. The results for smoldering fires are found to be of limited utility because of dominant influence of uncontrolled variables such as pre-existing temperature stratifications; however, an anomalous smoke pattern has been explained, which should aid future investigations. The results of environmental variables versus time for the unsteady, flaming fires are found to correlate very well in coordinates which intrinsically account for variations in fire-growth rate and ceiling height. Hence, ceiling temperatures and velocities can be predicted as function of time for any combination of fire-growth rate and ceiling height. Optical densities for a given combustible material are found to be in approximately constant ratio to the local temperature rise. In flaming fires smoke detectors are found to respond at approximately constant temperature rise of the fire gases; this temperature rise depends on the combustible material and mode of fire spread. The response of heat detectors is shown to be predictable theoretically from the temperature and velocity fields and key detector characteristics. The final section of the report deals with spacing requirements of fire detectors in flaming fires as influenced by ceiling height, fire-growth rate, and detector characteristics. The results are presented in graphical and tabular forms.

NBS-GCR-77-97. An experimental investigation of the heat transfer from a buoyant gas plume to a horizontal ceiling-Part 1. Unobstructed ceiling, C. C. Veldman, T. Kubota, and E. E. Zukoski, 115 pages (Sept. 1977). Order from NTIS as PB272069.

Key words: buoyant plumes; ceilings; compartment fires; fire plumes; heat transfer; room fires; scale models.

This report presents an experimental investigation of the axisymmetric heat transfer from a small scale fire and resulting buoyant plume to a horizontal, unobstructed ceiling during the initial stages of development. A propane-air burner yielding a heat source strength between $1.0 \mathrm{~kW}$ and $1.6 \mathrm{~kW}$ was used to simulate the fite, and measurements proved that this heat source did satisfactorily represent a source of buoyancy only. The ceiling consisted of a $1 / 16^{\prime \prime}$ steel plate of $0.91 \mathrm{~m}$ diameter, insulated on the upper side. The ceiling height was adjustable between $0.5 \mathrm{~m}$ and $0.91 \mathrm{~m}$. Temperature measurements were carried out in the plume, ceiling jet, and on the ceiling. Heat transfer data were obtained by using the transient method and applying corrections for the radial conduction along the cciling and losses through the insulation material. The ceiling heat transfer coefficient was based on the adiabatic cciling jet temperature (recovery temperature) reached after a long time. A parameter involving the source strength $\mathrm{Q}$ and ceiling height $\mathrm{H}$ was found to correlate measurements of this temperature and its radial variation. A similar parameter for estimating the ceiling heat transfer coefficient was confirmed by the experimental results. This investigation therefore provides reasonable estimates for the heat transfer from a buoyant gas plume to a ceiling in the axisymmetric case, for the stagnation region where such heat transfer is a maximum and for the ceiling jet region $(\mathrm{r} / \mathrm{H} \leqslant 0.7)$. A comparison with data from experiments which involved larger heat sources indicates that the predicted scaling of temperatures and heat transfer rates for larger scale fires is adequate.

NBS-GCR-77-99. Prediction of fire hazard from fabrics and building materials, P. Durbetaki, W. C. Tincher, L. R. Lloyd, R. P. Lowery, W. J. Tingle, and V. L. Wolfe, Jr., 267 pages (Feb. 28, 1977). Order from NTIS as PB273977.

Key words: cellulosic materials; char; convective heat transfer; fabric flammability; fabrics; fire hazards; ignition time; pyrolysis; radiant heating; thermal radiation; thermoplastics.

The assessment of the fire hazard of a system (fabrics, furniture, building materials, etc.) requires, first, a quantitative measure which characterizes the fire hazard, and, second, a rational relation between the hazard and the relevant descriptions of the system and its environment. Probabilistic failure analysis was proposed as a rational measure of a system's fire hazard and this is quantitatively expressed in terms of the probability with which use of a system leads to a prescribed loss. The fire loss probability is composed of all sub-probabilities which are associated with the events and processes leading to the occurrence of the fire loss. Measurements have been carried out to provide required data on thermophysical properties, constitutive description of processes, and ignition times. Thermal radiative properties have been measured both on original and charred samples of cellulosic and thermoplastic materials. Modeling analyses have been carried out for single and pairs of thermally thin materials under radiative heating and single thermally thick materials under convective heating.

\section{NBS-GCR-77-102. Vocal emergency alarms in hospitals and nursing facilities: Practice and potential, J. P. Keating and E. F. Loftus, 33 pages (July 1977). Order from NTIS as PB273165.}

Key words: coding; communication systems; fire alarm systems; health care facilities; hospital communication systems; hospital fires; hospital personnel; human behavior; nursing home fires; nursing staff; standards; voice communication.

This report reviews current usage of voice emergency alarms in nursing homes and hospitals, and recommends guidelines for the development of alarm messages, which should facilitate effective personnel response to fires in health care facilities. A sample message is provided which can serve as the basis for a national or regional standard.

NBS-GCR-77-103. The goal oriented systems approach, J. Watts, 122 pages (July 12, 1977). Order from NTIS as PB273174.

Key words: buildings; fire protection; fire safety; goal oriented systems approach; systems analysis. 
This report is an introduction to the goal oriented systems approach to building fire safety based on a review of the available literature. Included are discussion of the environment in which the concept was conceived, the genesis of the formalized procedures, the aspects conducive to reevaluation and the present and projected impact of this concept on the discipline of fire protection cngineering. The conclusions drawn are that the goal oriented systems approach attempts to fulfill a significant need but is requisite of additional research.

NBS-GCR-ETIP 76-24. A framework for analyzing commodity supply restrictions, 242 pages (Sept. 1976). Order from NTIS as PB258093.

Key words: applied microeconomic framework; commodity supply crises; econometric analysis; economic impacts; efficiency impacts; income distribution effects; policy alternatives.

Study addresses commodity supply crises due to producer country export policies, and considers the issue of resource exhaustion only as it relates to this problem. The primary concern is with economic impacts and policies. Crises in commodity supplies may well have political impacts, but detailed treatment of such effects is beyond the scope of the study. Possible political and diplomatic constraints on U.S. policies are considered, but the primary concern is with economic impacts.

Policies differ in their effects on the distribution of income between producers and consumers. Such effects are considered, where appropriate. Concentration is on efficiency impacts, however, and there is no attempt to address effects on the size distribution of income.

The basic analytical approach is that of the applied microeconomist working in a supply and demand framework. This framework allows the use of available qualitative economic, econometric and engineering information. There has been no use of mathematical programming or input-output techniques as it is believed that the techniques employed are, for the purposes of this study, more productive within time and budget constraints.

NBS-GCR-ETIP 76-25. Cartelization in the world cobalt market: Economic analysis and policy implications, 96 pages (Sept. 1976). Order from NTIS as PB264386.

Key words: cartels; economic policy options; foreign supply disruptions; stockpiling; technology; U.S. demand structure.

This volume applies the analytical framework to study supply, demand, and price formation in the cobalt market as a background for policy formation. It also analyzes the effects and likelihood of a producer country cartel or supply disruption. Finally, it presents policy and technological strategies in response to cartel formations or supply cutoffs.

The major policy implication of this study is that maintenance of a moderate contingency stockpile of between five and ten million pounds provides adequate insurance for possible supply disruptions. This range includes both public and private contingency stocks. Promotion of research and development to find substitutes for cobalt and cobalt alloys might be warranted, but only if the costs to the public sector are very low relative to the potential reduction in consumption. Subsidies to potential domestic producers would be advisable only if a prolonged distuption seemed likely; in such a situation, promoting recovery of cobalt from undersea manganese nodules might be preferable to subsidizing landbased production.

NBS-GCR-ETIP 76-26. Value incentive program. Energy conservation compressors for computer room air conditioning systems, 39 pages (Oct. 1976). Order from NTIS as PB259998.
Key words: Experimental Technology Incentives Program (ETIP); Federal Supply Service; life cycle costing; procurement policy; specifications; value incentive.

This case study covers the use of the Value Incentive Clause by a GSA/FSS contractor to make product improvement suggestions on Energy Conservation Compressors for Computer Room Air conditioning Systems. The use of this clause allows for contractors who hold FSS contracts to make suggestions to reduce the overall cost of procurement to the government and to share in the savings resulting from their suggestion. Copies of the GSA order, and the clause itself are included in addition to the specific changes proposed for the energy conservation compressors for computer room air conditioning systems.

NBS-GCR-ETIP 76-27. Value incentive program. Reduce welding/brazing on wardrobe hinge, 41 pages (Oct. 1976). Order from NTIS as PB260523.

Key words: Experimental Technology Incentives Program (ETIP); Federal Supply Service; life cycle costing; procurement policy; specifications; value incentive.

This case study covers the use of the Value Incentive Clause by a GSA/FSS contractor to make product improvement suggestions to Reduce Welding/Brazing on Wardrobe Hinge. The use of this clause allows for contractors who hold FSS contracts to make suggestions to reduce the overall cost of procurement to the government and to share in the savings resulting from their suggestion. Copies of the GSA order, and the clause itself are included in addition to the specific changes proposed to reduce welding/brazing on wardrobe hinge.

\section{NBS-GCR-ETIP 76-28. Policy implications of producer country supply restrictions: The world platinum and palladium mar- kets, 153 pages (Sept. 1976). Order from NTIS as PB264387.}

Key words: cartels; economic policy options; foreign supply disruptions; stockpiling; technology; U.S. demand structure.

Analysis of the supply and demand conditions in the world markets for platinum and palladium and the nature of the U.S. dependence on foreign supplies. Objective is to evaluate the probability and consequences of disruptions in the supply of new platinum metals to the United States or of cartel sponsored increases in the prices of these metals. The analysis of the consequences of supply disruptions and cartelization of the platinum and palladium markets is based on both qualitative assessment of the characteristics of those industries and a theoretical model of firm behavior applied to the industries which use platinum metals as a capital good.

The study is organized into chapters on consumption, supply, market organization and price history (including past crises), qualitative analysis of the impact of supply disruptions, a theoretical analysis of the impact of supply disruptions and an analysis of alternative government policies to protect against disruptions.

\section{NBS-GCR-ETIP 76-29. Policy implications of producer country supply restrictions: The world manganese market, 210 pages (Sept. 1976). Order from NT1S as PB264388.}

Key words: cartels; economic policy options; foreign supply distuptions; stockpiling; technology options; U.S. demand structure.

This volume analyzes the likelihood and the consequences for the United States of nonmilitary disruptions in foreign supplies of higher grade manganese ores, materials which the U.S. does not mine domestically. Information about foreign producers is studied for indications of the probability and nature of 
potential nonmilitary supply disruptions which would result eithcr from formal cartels explicitly formed for economic gain, or from more tacit forms of collusion. Considerable attention is given to the demand of U.S. steelmakers for manganese at various prices, from which the cconomic cost which higher manganese prices would inflict can be inferred. Finally, economic policy options are investigated in terms of minimizing the total expected welfare loss for the economy. Stockpiling policy is investigated in detail both because it is a fundamental policy response, and because the most relevant analysis of other policy options, such as investment in technological projects, generally assumes a coordinated stockpile policy. A coordinated tariff policy is also considered.

NBS-GCR-ETIP 76-30. Policy implications of producer country supply restrictions: The world copper market, 121 pages (Aug. 1976). Order from NTIS as PB264389.

Key words: cartels; economic policy options; foreign supply disruptions; stockpiling; technology options; U.S. demand structure.

This volume examines the likelihood of future crises in copper supply and the policy alternatives available to the United States. The major conclusion is that supply crises are fairly unlikely and that the potential damage to the U.S. economy from such crises would be minimal. Even when very pessimistic assumptions are made about the ability of the United States and other countries to adapt to disruptive export policies of CIPEC (the organization of foreign copper producers), it appears that CIPEC does not have enough market power to cause severe economic damage to the principal consuming countries.

The analysis addresses the likelihood of a number of potential supply crises. Each type of supply crisis will lead to a significant welfare loss only if the United States becomes substantially dependent on imports before the interruption occurs. Therefore, an important question for analysis in this report is whether copper imports are likely to play an important role in future U.S. supply patterns, and if so, why.

NBS-GCR-ETIP 76-3 I. Policy implications of producer country supply restrictions: The world chromite market, 247 pages (Oct. 1976). Order from NTIS as PB264390.

Key words: cartels; economic policy options; foreign supply disruptions; stockpiling technology options; U.S. demand structure.

This volume presents an analysis of the likelihood and the consequences for the United States of disruptions in our foreign supplies of chromium, a material which we do not mine domestically. Information about foreign producers is studied for indications of the probability and nature of potential supply disruptions, whether caused by cartels formed for economic gain or by actions of individual supplying countries. Considerable attention is given to assessing the market behavior of U.S. consumers of chromium, from which can be inferred the economic cost which higher chromium prices would inflict. Finally, economic policy options, particularly the standard tools of stockpiles and tariffs, are investigated in terms of minimizing the total expected welfare loss for the economy. Investments in technological projects which would ameliorate U.S. vulnerability to chromium supply disruptions are subject to general analysis, assuming a coordinated stockpile and tariff policy. Finally, in a brief historical review, potential past crises in the chromite market are assessed for lessons relevant to possible future supply disruptions.

NBS-GCR-ETIP 76-32. Policy implications of producer country supply restrictions: The world aluminum/bauxite market, 275 pages (Mar. 1977). Order from NTIS as PB26439I.
Key words: applied microeconomic framework; commodity supply crises; econometric analysis; economic impacts; efficiency impacts; income distribution effects; policy alternatives.

Analyzes the impact on the world bauxite and aluminum markets of the recently formed International Bauxite Association (IBA), a cartel organized by the bauxite producing and exporting nations. Examines the probable price and output policies of the IBA and the potential effect of these policies on the U.S. economy. The resource loss to the United States resulting from the cartel's actions is estimateo, and alternate U.S. government policies for modifying the IBA's behavior and reducing the resource loss resulting from cartel pricing and possible supply cutoffs are analyzed. Particular emphasis is given to the role of innovative technology.

NBS-GCR-ETIP 76-33. Policy implications of producer country supply restrictions: The world energy market, 382 pages (Nov. 1976). Order from NTIS as PB264392.

Key words: applied microeconomic framework; commodity supply crises; econometric analysis; economic impacts; efficiency impacts; income distribution effects; policy alternatives.

A number of policies have been proposed to rcduce U.S. dependence on imported oil or to reduce U.S. vulnerability in some other way. Among the policies proposed are stockpiling, quotas and tariffs, subsidies to domestic oil producers, accelerated development of nuclear power, and conversion of oil fired generating plants to coal. Of special concern is the proposal that U.S. government subsidize or offer other incentives to the development of synthetic fuels, since these technologies have not yet been significantly developed on a commercial scale in the United States. This study examines these different policies, their benefits and costs, and compares them as instruments to reduce the impact of future supply disruptions.

The policy measures chosen for analysis are representative of types of actions currently under consideration to mitigate the effects of OPEC. The policy analysis treats the price of oil, the strength of OPEC, and the prospect for future embargoes as given, determined effectively by forces other than the policies themselves. Policy measures primarily aimed at weakening OPEC and encouraging its collapse require a different kind of analysis and are not within the scope of this study, though considerations bearing on OPEC's cohesiveness are discussed.

NBS-GCR-ETIP 76-34. Developing incentives for pest control methods. Proceedings of a conference Oct. 26-27, 1976, 92 pages (Jan. 1976). Order from NTIS as PB263275.

Key words: impact of government on the economy; pesticides; R\&D incentives; regulation; technology.

The conference, which is the subject of these proceedings, represented the culmination of a joint study effort by Experimental Technology Incentives Program/National Bureau of Standards (ETIP/NBS) and Office of Pesticide Programs/U.S. Environmental Protection Agency (OPP/EPA) to develop incentives through which the Federal Government could encourage continued research and development of pest control methods. The project is part of the regulatory programs of ETIP seeking data and policy recommendations on how regulatory process can be improved in a way that will benefit desirable technological growth in the private sector.

The purpose of the conference was to assemble representatives of the parties at interest (government agencies, industry and public interest groups) in order to examine and evaluate the incentives that had been developed by the study contractor, Arthur D. Little, Inc. The two-day meeting was organized into 
working groups who reported to a plenary session at the close of their discussions. The result is a consensus concerning the incentives and their implementation. The report contains summaries of the workshops, their recommendations for the parties at interest to follow, and the reactions of participants after the confercnce was held.

NBS-GCR-ETIP 76-35. Post-marketing surveillance of new drugs: A preliminary review of the current state-of-the-art, $W$. M. Wardell, M. C. Tsianco, H. T. Davis, and S. N. Anavekar, 46 pages (Dec. 1976). Order from NTIS as PB263273.

Key words: adverse reaction detection; biostatistics; drug regulation; pharmaceutical regulation; phase IV; post marketing surveillance; regulatory experiments; system design.

The study had the aim of gathering information to (1) identify examples of post-marketing surveillance that have been carried out, (2) review the methodology available for PMS in relation to the aims of studies involved, using the actual examples upon which data could be obtained, (3) analyze the examples in technical terms, particularly experimental design and statistical power, (4) examine their costs and benefits where sufficient data exist. The case examples selected for this study were those upon which the data could be obtained in a limited time period and in some cases published data were used. Examples of controlled experiment studies, controlled cohort surveys, uncontrolled cohort surveys, case-control surveys, and spontaneous voluntary reporting are provided. These examples are not the products of a formal system of PMS but are studies which have been carried out to meet a variety of perceived needs. A main conclusion is that no single design approach for a PMS system will by itself be sufficient to carry out all that is needed from a PMS system. As one moves from descriptive approaches to analytic studies, power, bias, and costs become dominating features.

NBS-GCR-ETIP 77-36. Policy implications of producer country supply restrictions: Overview and summary, 264 pages (Feb. 1977). Order from NTIS as PB264393.

Key words: applied microeconomic framework; commodity supply crises; cconometric analysis; economic impacts; efficiency impacts; income distribution effects; policy alternatives.

This volume summarizes the other eight volumes of the study which seeks to evaluate alternative federal policies which deal with restrictions initiated by producer countries on supplies of major imported materials. A major premise of CRA's effort was that rational policy analysis must proceed from a realistic and market specific analysis of risks to a similarly concrete evaluation of potential damage, and then to consideration of a range of policy instruments including not only government encouragement of technological change, but also stockpiling, tariffs and quotas, subsidies, and other measures.

The analytical approach combined an assessment of real dangers to the U.S. economy in various materials markets with an analysis of the costs of different policies designed to reduce the impacts of foreign supply restrictions. The assessment of the dangers involved an analysis of both the economic costs of various possible contingencies with an assessment of the probabilities of these contingencies. The analysis of the potential policies also involved the measurement of the transfer payments (income redistributions) and the identification of the noneconomic costs, such as environmental consequences, of each policy.

NBS-GCR-ETIP 77-37. Life cycle costing-Case studies, C. Hulick, Ed., 107 pages (May 1, 1977). Order from NTIS as PB268162.
Key words: life cycle costing; printer ribbons; procurement experiment; refrigerator-freezers; water heaters; window air conditioners.

This report documents the use of life cycle cost procurements of window air conditioners, water heaters, refrigeratorfreezers, and high-speed printer ribbons made by the Federal Supply Service (FSS), General Services Administration (GSA). These procurements were part of a program instituted by FSS to apply life cycle costing techniques to its procurement process. This program was instituted in conjunction with the Experimental Technology Incentives Program (ETIP) of the National Bureau of Standards. The material contained in this report explains how these products were selected for LCC, how the LCC criteria were developed, and what results were obtained. Details concerning the screening process used in selecting the products, the preparation of the invitation for bid document, the bids received and the evaluation, analysis and award process were covered in the reports.

\section{NBS-GCR-ETIP 77-38. Commodity supply policies, 211 pages (Aug. 1977). Order from NTIS as PB272700.}

Key words: bauxite; chromite; commodity supply policies; contingency planning; energy (petroleum); manganese.

Document contains text of speeches and summaries of working groups at a conference on commodity supply policies sponsored by the Experimental Technology Incentives Program (ETIP). The policies examined are those that affect the stability of critical raw materials for which the United States is heavily dependent on foreign suppliers. The subject matter covered was based on a nine volume study performed by Charles River Associates for ETIP.

The purpose of the Conference was to assess the usefulness of the study's methodology for commodity policy research and to evaluate the initial applications of the methodology to four commodity markets: bauxite, chromite, manganese, and energy (petroleum).

NBS-GCR-ETIP 77-39. Prototype procurement: A case study in experimental technology check wrapping machines of the U.S. Treasury Department, 30 pages (Nov. 1977). Order from NTIS as PB273950.

Key words: check wrapping equipment; experimental procurement; experimental technology incentives program; procurement experiment; prototype procurement; technological innovation.

This report is a case study of a prototype procurement developed by the U.S. Treasury Department for innovative check wrapping equipment now being used by the Division of Disbursement in preparing and mailing millions of government checks issued annually.

The case study provides a useful guide to other government agencies for conducting similar experimental procurements which illustrate how innovative purchasing along with management initiative can result in better government operation and lower total cost to the taxpayer. The ETIP objective of stimulating technological innovation through government procurement policies and practices is met through the Treasury study. This application of prototype procurement can be a prime example to various individual federal and other government agencies of how new technological achievements can be accomplished through their own individual initiatives within the existing procurement framework.

U.S. Patent 4,001,681. Vector voltmeter, C. A. Hoer and G. F. Engen, 6 pages (Jan. 4, 1977).

Key words: microwave voltmeter; phase angle measurements; six-port voltmeter; vector voltmeter. 
A vector voltmeter for measuring the amplitude and phase difference between two signals. A first signal is fed to a power divider in which one of its outputs is measured with a power detector and the other output is fed to a second divider, each output thereof being fed one each to a third and fourth power divider. The second signal is fed to a fifth power divider in which one of its outputs is measured by a second power detector and the other output of the fifth divider is fed to a hybrid circuit having quadrature outputs, one of which is fed to the third power divider whose output is measured by a third power detector and the other quadrature output is fed to the fourth power divider whose output is measured by a fourth power detector. The four power detectors are connected to two differential amplifiers which drive the $\mathrm{X}$ and $\mathrm{Y}$ axis of an oscilloscope.

U.S. Patent 4,006,023. Photographic polymeric composition containing a leuco dye cyanide, W. L. McLaughlin, H. Levine, and M. Rosenstein, 9 pages (Feb. 1, 1977).

Key words: gamma rays; ionizing radiation; leuco dye cyanide; radiation dosimeter; radiation sensor; triphenylmethane cyanide dye precursor; ultraviolet; $x$ rays.

A hard, clear, glassy, smooth polymer with a dry surface having a dye precursor therein which forms a permanent color at those areas of the solid polymer that have been irradiated with ultra-violet or ionizing radiation is formed by combining vinyl and/or acrylic monomers, a triphenylmethane cyanide dye precursor and a chemical initiator that is compatible with the dye cyanide and polymerizing in the presence of a slight excess of hydrogen ions in an inert atmosphere.

U.S. Patent 4,008,477. Antenna with inherent filtering action, T. M. Babij, R. R. Bowman, and P. F. Wacker, 5 pages (Feb. 15, 1977).

Key words: antenna; antenna frequency response; dielectric sheath; filtering antenna; resistive shield.

A novel antenna is disclosed which provides inherent filtering action by which the frequency response curve of the antenna can be shaped. In the preferred inventive embodiment, the antenna comprises at least one elongated receiving element, and preferably two such elements in the form of a dipole, both elements being constructed, at least in part, of an electrically resistive material. A detector, such as a diode detector, is directly coupled to the receiving elements. The resistance of the receiving element and the capacitances of the receiving element and the detector form a distributed parameter RC filter, the values of which parameters can be carefully controlled so as to provide the desired frequency response curve shaping. In the preferred inventive embodiment, a conductive strip is disposed along the length of and preferably to both sides of each receiving element, with a layer of dielectric material being sandwiched therebetween, whereby the filtering action is enhanced.

U.S. Patent 4,008,610. Self-balancing D.C.-substitution measuring system, N. T. Larsen and G. R. Reeve, 9 pages (Feb. 22, 1977).

Key words: bolometer; D.C.-substitution technique; differential operational amplifiers; microwave power meter; self-balancing two amplifier power meter.

A self-balancing D.C.-substitution R.F. power measuring system includes first and second high gain differential operational amplifiers, a bolometer element, and a reference resistor element. The amplifiers and the two elements are connected in a current loop with one of the elements connected between the output terminals from the differential amplifiers and the other of the elements connected between center points of isolated dual power supplies associated with each of the amplifiers. The inputs to one amplifier are connected from an adjacent end of one of the elements and the far end of the other element, while the inputs to the second amplifier are connected to the far end of the one element and the adjacent end of the other element. Current flows out of one amplifier and into the other. The current is driven to a value which maintains the potential between the input terminals of the first amplifier essentially equal to zero and the potential between the input terminals of the second amplifier essentially equal to zero. Thus, the current drives the value of the bolometer element to a resistance which is equal to the resistance of the reference element. An output connection to a voltmeter may be taken between corresponding ends of the elements. The bolometer element may be a thermistor or a barretter. The system may also be used in a hot-wire anemometer. In another version of the system, the current loop is established with one of the elements connnected between the output of one amplifier and the center point of the power supply of the other amplifier and the other of the elements connected between the output of the other amplifier and the center point of the power supply of the one amplifier; the input connections to the amplifiers are taken from the same points, but with the input leads to the second amplifier interchanged.

\section{U.S. Patent 4,009,704. Cool-touch cooking surfaces, L. A. Mar-} zetta, 4 pages (Mar. 1, 1977).

Key words: compressible cooking surfaces; hot plates; thermal safety covering; warming trays.

A cool-touch safety covering for the cooking surfaces of warming trays, hot plates and other cooking appliances. The covering is fibrous, springy or otherwise compressible under the weight of a pan or other cooking utensil and its contents. In the uncompressed state, the covering stores relatively little heat per unit volume and transfers the heat relatively poorly, so that it will not burn a finger or other body surface briefly contacting it, even though the covering is heated to $200-300{ }^{\circ} \mathrm{C}$ or higher. In the compressed state, the covering transfers heat relatively well, thereby permitting an ample flow of heat to the utensil and its food or other contents. In quantitative terms, the thermal inertia of the uncompressed covering should not exceed about $\left(T_{h}-60\right)^{-2} \mathrm{cal}^{2} / \mathrm{sec}-\mathrm{cm}^{4}-\operatorname{deg} C^{2}$, where $T_{h}$ is the maximum operating temperature of the appliance in $\operatorname{deg} \mathrm{C}$. The covering may include one or more of the following: a matted felt of asbestos, ceramic or other thermally stable fibers; a wool-like layer of ceramic, metal or other fibers; a rippled sheet of thermally stable plastic or metal; a sandwich of springs or rings between sheets of plastic or metal; or spaced-apart metal or plastic screens.

U.S. Patent 4,014,166. Satellite controlled digital clock system, J. V. Cateora, D. D. Davis, and D. W. Hanson, 13 pages (Mar. 29, 1977).

Key words: clock comparison and reset; digital clock; satellite clock system; satellite controlled clock; satellite time code reception.

A method and apparatus are provided for maintaining and correcting a time reference in a satellite controlled digital clock system. A time code message including time-of-year information and satellite position information is transmitted in a data stream from a transmitter on earth to a satellite orbiting the earth to be relayed back to receivers located around the world. The data is transmitted at a precise data rate. According to the invention, a local clock oscillator is phase locked with the precise data rate, thereby providing the clock system with timeof-year information by counting the pulses produced by the local oscillator. At the same time, the digital clock system assembles the time code message from the received data stream 
and compares the message with the time accumulated by counting the pulses produced by the oscillator. After a predetermined number of errors are detected by such comparisons, the clock system resets itself to coincide with the received time code message. If transmission of the time code message is interrupted, the clock continues counting pulses produced by the local oscillator and thereby continues keeping time undisturbed. In a preferred embodiment, the digital clock system is implemented with a firmware programmed micro-computer and the time-of-year and satellite position information is displayed on light emitting diode digital displays.

U.S. Patent 4,025,406. Photochemical method for chlorine isotopic enrichment, M. Lamotte, H. J. Dewey, R. A. Keller, and J. J. Ritter, 4 pages May 24, 1977).

Key words: chlorine isotope separation; isotope enrichment; laser isotope separation; photochemical enrichment; thiophosgene.
An isotopic starting material consisting of a mixture of chlorine-35 and chlorine-37 isotopic species of an isotopic compound having the formula $\mathrm{CYClX}$, wherein $\mathrm{Y}$ is $\mathrm{O}$ or $\mathrm{S}$ and $\mathrm{X}$ is $\mathrm{Cl}$ or $\mathrm{F}$, such as thiophosgene, is selectively isotopically enriched by means of a laser-induced photochemical reaction between selected chlorine isotopic species in the starting material and dialkoxyethylene, such as diethoxyethylene. The method is carried out by irradiating with laser radiation, a gaseous mixture at a reduced pressure of the isotopic starting material and the dialkoxyethylene, until a stable reaction product is formed. The wavelength of the radiation is selected so as to selectively excite at least one but less than all of the chlorine isotopic species in the starting material, thereby causing the excited species to preferentially react with the dialkoxyethylene. The resulting reaction product is readily separable from the reaction mixture thereby leaving unreacted isotopic starting material selectively enriched in the unexcited chlorine isotopic species. 


\section{TITLES AND ABSTRACTS OF PAPERS PUBLISHED IN NON-NBS MEDIA, 1977}

Reprints from the journals listed in this section may often be obtained from the authors. See page 3 for additional information.

16659. Mehlman, G., Weiss, A. W., Esteva, J. M., Revised classification of $\mathrm{Mg} n$ levels between 59 and $63 \mathrm{eV}$, Astrophys. J. 209, 640-641 (Oct. 15, 1976).

Key words: atomic processes; line identifications.

A total of 68 new resonances in the absorption spectrum of magnesium were previously identified by two of the authors. The tentative classification proposed for 10 of the $\mathrm{Mg} \|$ levels was erroneous. A revised labeling is proposed in this note for these lines.

16660. Newman, M., Asymptotic formulas related to free products of cyclic groups, Math. Comp. 30, No. 136, 838-846 (Oct. 1976).

Key words: asymptotic formulas; classical modular group; cyclic groups; free groups; free products; tables.

Asymptotic formulas for the number of subgroups of a given index of the free product of finitely many cyclic groups are given. The classical modular group $\Gamma$ is discussed in detail and a table of the number of subgroups of $\Gamma$ of index $n$ is given for $1 \leqslant n \leqslant 100$.

16661. Lawton, R. A., Andrews, J. R., Electrical strobing of a photoconductor cuts sampling oscilloscope's risetime, Laser Focus Mag., pp. 62-65 (Nov. 1976).

Key words: optical; oscilloscope; photoconductor; sampling; waveforms.

An oscilloscope capable of directly sampling optical waveforms has been developed at NBS. It uses a GaAs photoconductor strobed by an electrical impulse. The transition time of the oscilloscope is $100 \mathrm{ps}$.

16662. Dodge, M. J., Malitson, I. H., Refractive index of high purity $\mathrm{KCl}$ and $\mathrm{KI}$ doped $\mathrm{KCl}$, Proc. 5th Conf. on Infrared Laser Window Materials, Las Vegas, NV, Dec. 1-4, 1975, pp. 216-223 (Air Force Materials Laboratory, Wright-Patterson Air Force Base, OH, Feb. 1976).

Key words: potassium chloride; refractive index; temperature coefficient of index.

The refractive indexes of a sample of potassium chloride made by reactive atmosphere processing (RAP) and a sample of potassium chloride doped with potassium iodide were determined from $0.25 \mu \mathrm{m}$ to $15.5 \mu \mathrm{m}$. Measurements were made by means of the minimum-deviation method on both samples at a controlled room temperature near $20^{\circ} \mathrm{C}$ and on the RAP specimen near $34^{\circ} \mathrm{C}$. Each set of experimental data was fitted to a Sellmeier-type dispersion equation which permits refractive index interpolation within several parts in $10^{-5}$. Temperature coefficients of index as a function of wavelength are also given. A comparison of these data with values of commercially grown $\mathrm{KCl}$ is presented.

16663. Engen, G. F., Theorem giving limits for $\left|S_{22}\right|$ when $\left|S_{11}\right|$ and the two-port efficiency are known, IEEE Trans. Instrum. Meas. IM-20, No. 1, 78 (Feb. 1971).

Key words: lossless two-port; scattering parameters.
A well-known condition on the scattering parameters of a lossless two-port may be written $\left|S_{22}\right|=\left|S_{11}\right|$. For low-loss twoports it may be expected that this condition is approximately satisfied; this result is of potential value in certain types of system evaluation.

16664. Lovas, F. J., Johnson, D. R., Buhl, D., Snyder, L. E., Millimeter emission lines in Orion A, Astrophys. J. 209, No. 3, 770-777 (Nov. 1, 1976).

Key words: interstellar, molecules; line identifications; nebulae, individual; radio sources, lines.

During the course of a search of Orion A for signals from three large, organic molecules, several millimeter wave lines from known interstellar molecules were observed. Results of observations on methanol $\left(\mathrm{CH}_{3} \mathrm{OH}\right)$, methyl cyanide $\left(\mathrm{CH}_{3} \mathrm{CN}\right)$, methyl acetylene $\left(\mathrm{CH}_{3} \mathrm{CCH}\right)$, acetaldehyde $\left(\mathrm{CH}_{3} \mathrm{CHO}\right)$ and ${ }^{29} \mathrm{SiO}$ are reported here. Emission signals from two hydrogen recombination lines ( $\mathrm{H} 41 \alpha$ and $H 42 \alpha$ ) detected from the $\mathrm{H}$.1 region of Orion $\mathrm{A}$ are also reported. Negative results were obtained for several millimeter wave transitions of ethylene oxide $\left(\mathrm{CH}_{2} \mathrm{OCH}_{2}\right)$, acetone $\left[\left(\mathrm{CH}_{3}\right)_{2} \mathrm{CO}\right]$, and cyclopropenone ( $\mathrm{HCCOCH})$.

16665. Madden, R. P., Hughey, L. R., Radiometry with synchrotron radiation, Proc. Synchrotron Radiation Facilities, Quebec Summer Workshop, Quebec, Canada, June 15-18, 1976, Chapter 10.4, pp. 10-51-10-77 (1976).

Key words: calibration facilities; photodiodes; radiometry; spectrometer calibration; synchrotron radiation; transfer standard detectors.

Transfer standard detectors are calibrated at NBS by comparing their output with that of a double-ionization chamber. In this instance the synchrotron radiation from the NBS electron storage ring (SURF) is utilized as a convenient source of radiation in the wavelength range of 190 to $600 \AA$. Synchrotron radiation is also used as an absolute irradiance standard. Numerous experimental checks of Schwinger's theoretical predictions have demonstrated agreement within the limits of accuracy of the measurements. SURF is a well characterized storage ring. The magnetic field and electron radius are known to about .01 percent. The major source of uncertainty is the determination of the number of electrons in orbit $\left(n_{e}\right) . n_{e}$ is measured with a narrow band photodiode calibrated by the NBS Optical Radiation Section. This method provides $n_{e}$ to about 2.4 percent and an overall uncertainty of less than 5 percent for wavelengths in excess of $40 \AA$.

16666. Motz, J. W., Danos, M., The potential for exposure reduction in diagnostic radiology, Proc. Digest of the $4 \mathrm{th}$ Int. Conf. on Medical Physics, Special Issue of Physics in Canada, Ottawa, Canada, July 25-30, 1976, 32, 13.3 (Le DroitLeclerc, Ottawa, Canada, July 1976).

Key words: diagnostic radiography; exposure reduction; imaging information content; image processing; mammography; x-ray radiography.

Based on considerations of the statistical noise generated by the detection of a given number of particles in a given resolution element, a method is developed for determining the quantitative dependence of the image information content on the patient exposure. Data are given which show: (1) the minimum 
exposures required for the detection of image signals from six sample structures encountered in diagnostic radiology, as a function of the spatial resolution and x-ray energy, (2) the number of gray levels attainable for a given patient exposure, body thickness, and x-ray energy, and (3) the quantitative effects of $x$-ray grids in increasing the image contrast and gray level number, and in reducing the exposure required for the detection of a given image signal. The implications of these results for reducing exposures and for detecting low contrast objects below the visibility threshold will be discussed.

16667. Beeghly, H. F., Mears, T. W., Michaelis, R. E., Standard materials for analysis and testing, Paper in Treatise on Analytical Chemistry, I. M. Kolthoff and P. M. Elving, Eds., 3, Part III, 1-45 (John Wiley \& Sons, 1976).

Key words: chemical analysis; measurement systems; physical measurement units; standard reference materials.

Emphasis in this chapter is on reference materials, with particular concern for carefully characterized materials, certified by a responsible, impartial agency or organization. Attention is given to materials useful in making meaningful measurements over the span of needs by science, industry, and government for "benchmark" or reference point materials for calibrating and checking measuring instruments and methods.

16668. Crawford, M. L., Techniques for measurement of electromagnetic radiation and susceptibility of electronic equipment, Proc. Ist Symp. and Technical Exhibition on Eleciromagnetic Compatibility, Montreux, Switzerland, May 20-22, 1975, pp. 38-44 (Electromagnetic Compatibility, Montreux, Switzerland, 1975).

Key words: electronic equipment; EMC measurements; low-Q enclosures; radiated susceptibility; TEM transmission cell.

This paper describes two alternative approaches to conventional screen room measurements for determining radiation from electronic equipment and the susceptibility of equipment to continuous wave and pulsed electromagnetic fields. Details of EMC measurements performed using the two techniques: (1) use of underground mine tunnels (low- $Q$ enclosure), and (2) use of TEM transmission cells, are given along with a brief discussion of factors influencing the measurement results.

The TEM cell is particularly high-lighted because of its potential for making accurate $(\leqslant 1-2 \mathrm{~dB}$ for radiated susceptibility at levels up to $600 \mathrm{~V} / \mathrm{m}$, and $3-5 \mathrm{~dB}$ for radiated emission at levels down to $10 \mu \mathrm{V} / \mathrm{m}$ ) measurements with a minimum of additional equipment.

16669. Kanda, M., An improved solid state noise source, Proc. Int. IEEE-MTT-S Microwave Symp., Cherry Hill, NJ, June 1416, 1976, pp. 224-226 (The Institute of Electrical and Electronics Engineers, Inc., Piscataway, NJ, June 1976).

Key words: argon gas discharge noise source; silicon avalanche diode; solid state noise source; stability.

An improved solid state noise source is discussed. By implementing such modifications as 1 ) heat sinking of a silicon avalanche noise diode, 2) proper DC RF decoupling, and 3) impedance matching, the stability of the NBS solid state noise source is improved significantly over that of typical commercial solid state noise sources. The paper describes these modifications, how they are implemented, and the resulting improvement in stability.

16670. Ederer, D. L., Photoabsorption in inner-shells of atoms, (Proc. 2nd Int. Conf. on Inner Shell lonization Phenomena, Freiburg, Germany, Mar. 29-Apr. 2, 1976), Paper in Second International Conference on Inner Shell Ionization Phenomena,
W. Mehlhorn and R. Brenn, Eds., pp. 145-165 (Universität Freiburg, Freiburg, Fed. Rep. Germany, 1976).

Key words: atoms, correlation; configuration interaction; exchange interaction; inner shells; photoabsorption.

Inner-shell optical photon excitations in atomic gases are discussed in this paper. Special emphasis is given to electron correlations arising from configuration interaction and the exchange interaction. Because these interactions are largest at photon energies $\leqslant 200 \mathrm{eV}$ the scope of the paper will be limited to this part of the spectrum. The subject is approached from the point of view of experimental physics emphasizing excitations in noble gases and metal vapors. The first section of the paper deals with excitations to discrete states that decay by an Auger or an autoionization process, and the next section explores the role exchange and correlation plays in the continuum photoionization cross section of gaseous systems. Finally recent measurements will be reviewed that use the technique of photoelectron spectroscopy to measure the partial photoionization cross section of each group of subshell electrons.

16671. Wacker, P. F., Non-planar near field measurements: Spherical scanning, $A F A L-T R-75-38,55$ pages (Air Force Avionics Laboratory, Air Force Systems Command, WrightPatterson Air Force Base, OH, Apr. 1975).

Key words: antennas; arrays; coordinate transformations; data processing; group representations; measurements; near field; nonplanar; patterns; scanning; spherical; symmetry.

The advantages and limitations of near-field antenna measurements are compared with those of conventional far-field measurements. Further, the advantages and limitations of planar, circular cylindrical, and spherical scanning are compared.

Spherical scanning is advantageous for arrays steered well off-axis and for antennas with wide angle side lobes, but the data processing has been quite impractical except for very simple antennas and probes. A new highly efficient data processing scheme is given for spherical scanning with and without probe pattern correction. The translation-of-centers transformation of the probe pattern coefficients (required only with the probe pattern correction) is carried out once and for all for a given probe, scanning radius, and frequency. The routine computations involve Fast Fourier "Transforms" and multiplication by matrices with constant elements, matrices which are independent of the detailed nature of the probe, the radius of the scanning sphere, the points at which measurements are made, and the nature of the test antenna. The FFT's and matrix multiplications supplant matrix inversion, ordinary solution of simultaneous equations in more than two unknowns, ordinary numerical integration, and (in routine processing) ordinary evaluation of functions, even for computation of the far field. Except for the truncation of the infinite series of spherical modes, no analytical or data processing approximations are made, even in the use of the FFT.

So that readers may draw from their understanding of planar and cylindrical scanning, a unified theory of near-field data processing is given, treating planar, cylindrical, and spherical scanning as mere special cases.

16672. Lawn, B. R., Fuller, E. R., Wiederhorn, S. M., Strength degradation of brittle surfaces: Sharp indenters, Am. Ceram. Soc. 58, No. 5-6, 193-197 (May-June 1976).

Key words: brittle solids; ceramic surfaces; degradation; fracture; indentation; strength.

A theory of strength loss for brittle surfaces in contact situations, developed in a previous paper for "blunt" indenters, is extended to the case of "sharp" indenters. A prior fracture 
mechanics analysis of crack growth beneath ideal cone indenters serves as the basis for predetermining the prospective surface degradation of ceramic components in service. Compared to blunt indenters, sharp indenters can cause severe degradation at lower contact loads. However, at high loads, the extent of degradation becomes remarkably insensitive to details in the indenter geometry. Essential theoretical predictions are verified by bend tests on glass slabs. Effects of indenter "sharpness" and initial specimen surface flaw state are investigated systematically, along with some secondary rate effects in the contact process. The possibility of minimizing degradation via adjustment of material parameters (including hardness) or surface condition (e.g. residual stresses, frictional properties) is briefly discussed.

16673. Wasik, S., Chesler, S., Use of a nematic liquid crystal for the gas-liquid chromatographic separation of naphthalene homologues, J. Chromatogr. 122, $451-458$ (1976).

Key words: gas-liquid chromatography; liquid crystal; naphthalene homologues; nematic phase; supercooled phase.

The gas-liquid chromatographic separations of methyl-, ethyl-, and dimethyl-naphthalene isomers on the nematic and supercooled regions of $N, N^{\prime}$-bis ( $p$-methoxybenzylidene)- $\alpha, \alpha^{\prime}-b i-p$ toluidine are presented and compared with the results obtained on other materials. The unique selectivity of this liquid crystal, based upon differences in the molecular length-to-breadth ratio of the solute positional isomers, has enabled the complete separation of these naphthalene homologues.

16674. Collins, L. A., Lane, N. F., Quantum-mechanical calculations of rotational-excitation cross sections for $\mathrm{HCl}, \mathrm{DCl}, \mathrm{DF}$, and HF in slow collisions with He, Phys. Rev. A 14, No. 4, 1358-1367 (Oct. 1976).

Key words: atom-molecule scattering; collisions of He with diatomic hydrides; heavy particle collisions; rotational excitation in atom-molecule scattering.

Low-energy rotational-excitation cross sections have been calculated for collisions between ground-state helium atoms and the diatomic molecules $\mathrm{HCl}, \mathrm{DCi}, \mathrm{DF}$, and $\mathrm{HF}$ from modelpotential surfaces. Solutions of the coupled radial equations are obtained in the close-coupling coupled-channels (CC) formulation and the $j_{z}$-conserving coupled-states (CS) approximation, including as many channels (open and closed) as needed for convergence. Trends in the behavior of the cross sections with respect to variations in the potential surface and the spacing of rotational levels are discussed with particular emphasis on the isotope effects. In addition, cross sections calculated for various CS approximations are compared with CC results and comment is made on the influence of the closed channels.

16675. Clark, F. O., Asymmetric HCN line profiles from the Orion Nebula, Astrophys. J. 200, L1 15-L1 17 (Sept. 1, 1975).

Key words: molecules, interstellar; Orion Nebula.

The hyperfine components of the HCN $J=1-0$ transition in Orion are observed to be asymmetric. This asymmetry apparently indicates some inhomogeneity of the molecular cloud and is interpreted as due to radial motions in the source. The magnitude of these implied motions is discussed and the sense examined. Alternate interpretations are also discussed.

16676. Johnson, C. R., Multiplicativity and compatibility of generalized matrix norms, Linear Algebra and Appl. 16, 25 37 (1977).

Key words: compatible; generalized matrix norm; Hadamard product; multiplicative; spectral radius; vector norm.
It is well known that if a generalized matrix norm is multiplicative, then it has a compatible vector norm associated with it. The converse, however, is invalid, and the precise relation between multiplicativity and compatibility is here explored for a generalized matrix norm. In the process, certain methods for deriving one norm from another are mentioned.

16677. Costrell, L., Evolution, definition, and status of IEEE Standard 583: Standard modular instrumentation and digital interface system (CAMAC), Proc. Electro 76 Professional Program, Boston, MA, May $11-14,1976$, No. 29, Paper No. 4, 1-8 (Institute of Electrical and Electronics Engineers, Inc., New York, NY, 1976).

Key words: CAMAC; computer interfacing; instrumentation; interfacing; standards.

Incompatible instruments have long been the rule in laboratories and industrial organizations. The problems they pose are enormous and expensive. The concern is with interfaces, mechanical, electrical, and from a signal standpoint. Besides the inefficiency inherent in a multiplicity of different interfaces, the man hours of design effort is staggering and this effort is needlessly repeated for installation after installation. IEEE Standard 583 defines a standardized instrumentation system designated CAMAC, for Computer Automated Measurement and Control, that has been developed to alleviate this problem and that is gaining wide international acceptance. The system features a fully specified data highway (Dataway) together with modular functional units that are completely compatible with each other and that are available from diverse sources. Additional levels of compatibility are achieved through the use of standardized parallel and serial highways that have been developed for use with the basic CAMAC system.

16678. Costrell, L., CAMAC instrumentation system-Introduction and general description, U.S. NIM Committee on CAMAC Tutorial Articles, (Computer Automated Measurement and Control), ERDA Report No. TID-26618, 8 pages (Energy Research and Development Administration, Washington, DC, Oct. 1976).

Key words: CAMAC; Dataway; instrumentation; modules; nuclear; standards.

The CAMAC instrumentation system is described in a general way in this introductory paper which is followed by papers that discuss the system in greater detail. This paper is an updated version of the introductory paper that appeared in the April 1973 IEEE Transactions on Nuclear Science.

16679. Costrell, L., Highways for CAMAC systems-A brief introduction, U.S. NIM Committee on CAMAC Tutorial Articles, (Computer Automated Measurement and Control), ERDA Report No. TID-26618, 7 pages (Energy Research and Development Administration, Washington, DC, Oct. 1976).

Key words: CAMAC; highway; interface; instrumentation; standards.

The interconnection between CAMAC crates and between the crates and a computer is called the CAMAC highway. The purpose of this paper is to present a brief summary of CAMAC highway configurations to put in perspective the highway papers that follow and to serve as a starting point for the panel discussion on CAMAC highways.

16680. Ghigo, F. D., Shelus, P. J., Silverberg, E. C., Faller, J. E., Laser range measurements using non-Gaussian pulse shapes, Appl. Opt. 15, No. 11, $2621-2623$ (Nov. 1976).

Key words: laser range measurement; pulse shapes; ranging systems. 
Many optical ranging systems currently use laser pulses with approximately Gaussian shape of a few nanoseconds or less. In those cases where the number of photoelectrons in the return signal is small, either on a single shot basis or where a number of shots are combined to build up an "equivalent" single shot, the accuracy of the range measurement is proportional to $W / \sqrt{N}$, where $W$ is the width of the laser pulse and $N$ the number of photoelectrons received. We show that a considerable improvement in accuracy can be obtained if the unbounded, Gaussian pulse shape is modified so that it can be considered a bounded distribution of finite duration.

16681. Fong, J. T., Rehm, R. G., Graminski, E. L., Weibull statistics and a microscopic degradation model of paper, Tappi 60, No. 1, 156-159 (Jan. 1977).

Key words: durability; fatigue; fiber length; flexing; low cycle fatigue; mechanical properties; microstructure; modelling; paper; pore size; statistical analysis; Weibull distribution.

Motivated by scanning electron micrographs showing microstructural degradation of several grades of paper under repetitive loadings, a crude statistical approach in defining two micro-variables, namely, an "effective" fiber length and an "equivalent" void diameter, is presented. The approach is based on the mathematical properties of a shape-sensitive statistical distribution originally derived by Weibull. Two microstrength parameters, the fiber-breaking load and the fiber-tofiber bond strength, are also given a Weibull statistical analysis. Two distinct mechanisms for explaining the loss of modulus due to repetitive flexing are presented for constructing a self-consistent microscopic degradation model of paper.

16682. Morrison, M. A., Collins, L. A., Lane, N. F., Theoretical study of low-energy electron- $\mathrm{CO}_{2}$ scattering, Chem. Phys. Lett. 42, No. 2, 356-360 (Sept. 1, 1976).

Key words: theoretical elastic e- $\mathrm{CO}_{2}$ scattering; theoretical electron- $\mathrm{CO}_{2}$ scattering; theoretical electron-molecule scattering.

A study of electron collisions with ground-state $\mathrm{CO}_{2}$ molecules in the energy range $0.07-10.0 \mathrm{eV}$ is reported. An accurate static potential is augmented with a local exchange potential and induced polarization terms, and coupled radial equations are solved in a spherical coordinate system. Converged total and momentum-transfer cross sections are presented and discussed, and comparison is made with existing experimental measurements.

16683. McCamy, C. S., Theory of optical wedges as flux modulators, J. Opt. Soc. Am. 66, No. 12, 1350-1355 (Dec. 1976).

Key words: calibration; density; photography; reflectance; transmittance; wedges.

Many optical experiments and applications require the use of devices called optical wedges which are thin-sheet optical modulators having a continuous, usually linear, change in optical density with either distance or angle. The optical density of a sample area on an optical wedge depends on the size and shape of the aperture and the characteristics of the wedge. The relationship of the effective density of the whole sample to the density at the center of the sample has been derived for wedges of rectilinear and circular form and sampling apertures in the form of rectangles, circles, and circular sectors. The theory has applications in the microdensitometry of photographic edges.

16684. Krauss, M., Liu, B., The energy curve of XeF, $\mathrm{X}^{2} \Sigma^{+}$ Chem. Phys. Lett. 44, No. 2, 257-260 (Dec. 1, 1976).

Key words: charge transfer; dissociation energy; energy curve; overlap; van der Waals; XeF.
The energy curve of the ground state of $\mathrm{XeF}$ is obtained theoretically assuming that the energy is represented by the sum of the "first order energy" and the dispersion energy. Since the inverse power expansion of the dispersion energy is not valid when the atoms overlap significantly, the dispersion energy is estimated in the overlap region by noting that the Coulomb integrals now vary exponentially with internuclear distance. The onset of overlap was chosen to occur over a range of distances which then permits a range of well depths to be determined. Comparison with recent experimental results indicates that the $\sigma$ of the analogous van der Waals well provides agreement with the well depth. The energy curve has an unusual shape which suggests that the region around the minimum is determined by a small mixing of charge transfer into the ground state. Since this study is intended to determine the qualitative electronic basis of the binding in molecules like $\mathrm{XeF}$, no attempt was made to calculate the vibrational spectrum but it is clear from the curve shape that the spectrum could be fit only with a large anharmonicity coefficient.

16685. Halsey, N., Marlowe, D. E., Mitchell, R. A., Mordfin, L., Non-metallic antenna-support materials pultruded rods for antenna guys, catenaries and communications structures, AFML-TR-76-42, 126 pages (Air Force Materials Laboratory, Wright-Patterson Air Force Base, OH, May 1976).

Key words: aramid; composite materials; end fittings for FRP rod; environmental resistance of FRP rods; fiber-reinforced plastic (FRP); glass; guys, antenna; pultrusion; reinforced plastics; stress rupture of FRP rod; test methods; weatherability of FRP rods.

Both E-glass and Kevlar 49 (aramid) fibers were used to reinforce an isophthalic polyester resin. These materials were used, in turn, to form pultruded antenna rod hardware for structural tests. The aramid material exhibited substantially improved strength-retention properties over the glass-reinforced material under prolonged exposure to heat and humidity. The aramid material offers the promise of superior weatherability in antenna-support applications although further testing is warranted. The stress-rupture properties of pultruded rod, under high humidity, possess unusual temperature and time dependencies. These are explained in terms of the mechanisms whereby moisture is transported from the environment to the fiber/matrix interface. The stress-rupture properties, as well as the tensile properties, may be improved by appropriately modifying the pultrusion process.

Two new end fittings, generally capable of attaining the full tensile strength of glass fiber-reinforced pultruded rod, were developed.

Several new test methods were developed, including an environmental stress-rupture test, two methods for investigating the quality of the fiber/matrix interface, and a method for examining the rate sensitivity of the tensile strength. A significant rate sensitivity was observed for glass fiber-reinforced rod but not for aramid fiber-reinforced rod.

16686. Dikkers, R. D., Development and implementation of standards for solar heating and cooling applications, Proc. Joint Solar Energy Conf. on Sharing the Sun 76 Solar Technology in the Seventies, Winnipeg, Manitoba, Canada, Aug. 15-20, 1976, 1, 83-90 (Pergamon Press, Elmsford, NY, 1976).

Key words: buildings; cooling; heating; laboratory accreditation; performance criteria; solar energy; standards.

Solar energy program activities being conducted by the $\mathrm{Na}$ tional Bureau of Standards (NBS) are primarily centered around projects related to the development and implementation of standards and performance criteria for solar heating and 
cooling applications. In support of the Energy Research and Development Administration (ERDA) and the Department of Housing and Urban Development's (HUD) solar energy research and demonstration programs, NBS has prepared interim performance criteria for residential solar energy systems, and test procedures for determining the thermal performance of solar collectors and thermal storage devices. Currently, NBS is developing: ( 1 ) interim performance criteria for commercial solar energy systems; (2) intermediate standards for solar heating and domestic hot water systems that can be used in conjunction with HUD's Minimum Property Standards; (3) draft standards for materials (i.e., sealants, cover plates, insulation) to be used in solar systems; (4) plans for establishing a solar collector testing laboratory accreditation program; and (5) plans for identifying and developing other needed standards in cooperation with various standards-writing organizations such as ASTM and ASHRAE.

16687. Lindgren, R. A., Bendel, W. L., Jones, E. C., Jr., Fagg, L. W., Maruyama, X. K., Lightbody, J. W., Jr., Fivozinsky, S. P., Electroexcitation of the $T_{n}+1$ giant $M 1$ resonance in ${ }^{58.60} \mathrm{Ni}$, Phys. Rev. C 14, No. 5, $1789-1799$ (Nov. 1976).

Key words: electron scattering; inelastic; isospin; magnetic; multipolarity; sum rule.

Using inelastic electron scattering, several isobaric analog $1^{+}$ states between 9 and $13 \mathrm{MeV}$ excitation in ${ }^{58} \mathrm{Ni}$ and ${ }^{60} \mathrm{Ni}$ have been found. They are identified as components of the $T_{0}+1$ giant $M 1$ state in ${ }^{58.60} \mathrm{Ni}$.

16688. Staffa, J. A., Zervos, C., Mighell, A. D., Hubbard, C. R., S-carboxymethyl-L-cysteine sulfoxide (configuration 2R:4R), Acta Cryst. B32, Part 11, $3132-3135$ (Nov. 1976).

Key words: absolute configuration; amino acid derivative; crystal structure; $S$-carboxymethyl-L-cysteine sulfoxide; $x$ ray determination; zwitterion.

$\mathrm{C}_{5} \mathrm{H}_{9} \mathrm{SO}_{5} \mathrm{~N}$, orthorhombic, $P 2_{1} 2_{1} 2_{1} ; a=4.786(2), b=8.312$ (1), $c=18.914$ (5) $\AA ; Z=4, D_{x}=1.723, D_{m}=1.732$ (5) $\mathrm{g}$ $\mathrm{cm}^{-3}$ (flotation at $21^{\circ} \mathrm{C}$ ). The structure has been determined by standard Fourier techniques from x-ray diffractometer data and refined by least-squares methods to $R=0.035$ for 924 independent reflections. As found by $x$-ray analysis, the title compound exists as an "apparent" zwitterion. The cysteine carboxyl and the methyl carboxyl groups of adjacent molecules are involved in a very strong hydrogen bond [O...O 2.449 (3) $\AA]$.

16689. Lafferty, W. J., Suenram, R. D., Johnson, D. R., Microwave spectrum of acetylene- $d_{2}$, J. Mol. Spectrosc. 64, 147-156 (1977).

Key words: acetylene- $d_{2}$; l-type doubling constants; microwave spectrum; rotational constants; Stark effect; vibrational transition moment.

Eight $P$-branch transitions from the $\nu_{5}{ }^{1}-\nu_{4}{ }^{1}$ difference band of $\mathrm{C}_{2} \mathrm{D}_{2}$ have been observed in the microwave region. Significant improvements in the spectroscopic constants for the two states involved in the difference band have been obtained by combining infrared and microwave data. The Stark shifts for the observed $C_{2} D_{2}$ lines are discussed in some detail. The vibrational transition moment is found to be $\mu_{\text {vib }}=0.0358 \pm 0.0020 \mathrm{D}$.

16690. Fraker, A. C., The microstructural influence of a 2 wt pet Mo addition to a Ti-1.5 wt pet Ni alloy, Metall. Trans. A Commun. 7A, 1793-1796 (Nov. 1976).

Key words: corrosion resistant alloys; microstructures; molybdenum additions; precipitation; titanium alloys; transmission electron microscopy.
Microstructural changes resulting from adding 2 wt.\% Mo to the crevice corrosion resistant $\mathrm{Ti}-1.5 \mathrm{wt} . \% \mathrm{Ni}$ alloy have been studied. Light microscopy of bulk specimens and thin foil transmission electron microscopy show that the Mo addition produces a finer and more elongated grained microstructure and increases the martensitic reaction. The Mo addition also delays precipitation and growth of the intermetallic phase, $\mathrm{Ti}_{2} \mathrm{Ni}$, and increases the hardness of the material.

16691. Green, R. B., Keller, R. A., Schenck, P. K., Travis, J. C., Luther, G. G., Opto-galvanic detection of species in flames, J. Am. Chem. Soc. 98, No. 26, 8517-8518 (Dec. 22, 1976).

Key words: dye laser; flame analysis; flame fluorescence; laser; opto-galvanic effect; spectroscopy; tunable laser.

A recently reported, opto-galvanic effect (OGE) in electrical discharges has been found to occur in flames. Specifically, if the current from a constant voltage source is passed through the flame, the current is found to change when the flame is irradiated by intense monochromatic radiation (laser) corresponding to an absorption of a species present in the flame. This change in current is easily detected by standard electrical measurement techniques and can be used for spectroscopy, analytical determinations, and flame analysis. As an examiple of the analytical application of this technique, the quantitative analysis of sodium in a flame is described.

16692. Rossmassler, S. A., The National Standard Reference Data System, Proc. AGARD Conf. on Advancements in Retrieval Technology as Related to Information Systems, Arlington, VA, Oct. 20-21, 1976, AGARD-CP-207, 10-1-104 (Available from National Technical Information Service, Springfield, VA 22161, Dec. 1976).

Key words: data compilation; data evaluation; information retrieval; NSRDS; Omnidata; reference data.

The National Standard Reference Data System is a coordinated, but decentralized, effort to increase the reliability and availability of numerical data used in and produced by the physical sciences and engineering. Individual data projects on specific technical subjects are established to extract, evaluate, and compile, in a systematic manner, all relevant data from the scientific journal and technical report literature. The evaluation process compresses the original data, and the systematic treatment aids the user in filling his data needs. Sophisticated datahandling capabilities-including on-line information and data retrieval-are developed in individual data centers and also in a central data systems design group.

16693. Hermach, F. L., Flach, D. R., An investigation of multijunction thermal converters, IEEE Trans. Instrum. Meas. IM-25, No. 4, 524-528 (Dec. 1976).

Key words: ac current measurements; ac-dc comparator; ac-dc transfer standard; ac voltage measurement; multijunction converter; thermal converter.

The relative ac-dc differences of a group of multi-junction thermal converters (MJTC's) have been determined over the frequency range $30 \mathrm{~Hz}-10 \mathrm{kHz}$. These MJTC's are of different ranges and were obtained from several sources. Differences were observed at low frequencies when converters of various ranges were intercompared. For voltage measurements, the use of matched resistors in series with the MJTC heater resistors greatly reduced these errors and contributed to the reduction of other errors as well. It is believed that the average ac-dc difference of this group is less than $0.3 \mathrm{ppm}$ at $160 \mathrm{~Hz}$ and 0.5 ppm up to $10 \mathrm{kHz}$. 
16694. Hermach, F. L., Ac-dc comparators for audio-frequency current and voltage measurements of high accuracy, IEEE Trans. Instrum. Meas. IM-25, No. 4, $489-494$ (Dec. 1976).

Key words: ac current measurement; ac-dc comparator; acdc transfer standard; ac voltage measurement; thermal converter.

This paper surveys recent developments in high-accuracy acdc comparators, the basic standards for ac current and voltage measurements at audio and higher frequencies. These instruments compare the unknown ac quantity with a dc reference. The ac-dc transfer characteristics of thermal converters, the most widely used comparators, can be evaluated to about 10 ppm at audio frequencies in national metrology laboratories. With recent developments even better accuracies, and greater convenience with automatic comparisons, are feasible.

16695. Geltman, S., Theory of laser-induced inelastic collisions, J. Phys. B Letter to Editor 9, No. 18, L569-L574 (1976).

Key words: atomic collision; excitation transfer; laser stimulation; orbiting; saturation; selection rules; van der Waals.

A theory of laser-induced inelastic collisions is presented, containing atomic selection rules and specific intensity and velocity dependences. It is applied to the case of the process $\mathrm{Sr}\left(5 \mathrm{p}{ }^{1} \mathrm{P}^{\circ}\right)+\mathrm{Ca}\left(4 \mathrm{~s}^{2}{ }^{1} \mathrm{~S}\right)+\hbar \omega(6408.6 \AA) \rightarrow \operatorname{Sr}\left(5 \mathrm{~s}^{2}{ }^{1} \mathrm{~S}\right)+\mathrm{Ca}(4 \mathrm{~d}$ $\left.{ }^{1} \mathrm{D}\right)$, for which the intensity and wavelength dependence of the cross section is evaluated.

16696. Rubin, R. J., Mazur, J., Weiss, G. H., Spans of polymer chains, Pure Appl. Chem. 46, 143-148 (1976).

Key words: polymer chain statistics; random walk statistics; spans of polymer chains.

The span of an $N$-segment chain in a given direction, $e$, is defined as the maximum distance between parallel planes normal to $e$ which contain segments of the chain. We present a simple derivation of Daniel's result for the span of a random chain. We have generalized this simple derivation and have calculated: (1) $\left\langle X_{\text {ring }}\right\rangle$, the average span of an $N$-segment random polymer ring; (2) $\left\langle X_{\text {surf. }}\right\rangle$, the average span in the direction normal to the solution surface of an $N$-segment chain which is attached at one end to the surface; (3) In addition, we have obtained the exact solution of a problem treated by Hollingsworth, the calculation of $\left\langle R_{\text {Holl }}\right\rangle$, the average distance between the first segment and the most distant segment in an $N$-segment polymer chain. The results are:

$$
\begin{gathered}
\left\langle X_{\text {rino }}\right\rangle=(\pi N / 6)^{1 / 2} \cong 0.724 N^{1 / 2} \\
\left\langle X_{\text {surr. }}\right\rangle=2 \ln 2(\pi N / 6)^{1 / 2} \cong 1.003 N^{1 / 2} \\
\left\langle R_{\text {Holl. }}\right\rangle=\frac{1}{2} \pi(\pi N / 6)^{1 / 2} \cong 1.137 N^{1 / 2} .
\end{gathered}
$$

For reference'purposes we note that the average span calculated by Daniels for an $N$-segment polymer chain is $\langle X\rangle=$ $2(2 N / 3 \pi)^{1 / 2} \cong 0.921 N^{1 / 2}$ and the root-mean-square end-to-end distance is $\left\langle r_{N}^{2}\right\rangle^{1 / 2}=N^{1 / 2}$.

The spans of each chain configuration in the directions defined by the principal components of the square radius of gyration of the chain have been determined. The relative values of the average squares of the spans in the directions of the largest, intermediate, and smallest components of the square radius of gyration are found to be $6.7: 2.2: 1$ in the case of the unrestricted polymer chain model. For the same model, Solc and Stockmayer obtained the following set of relative values of the ordered principal components of the square radius of gyration, 11.7:2.7:1. We have determined that the apparent difference between these two sets of relative average dimensions arises from a different segment density distribution in the different principal directions.
16697. Williams, E. S., Thermal current converters for accurate ac current measurement, IEEE Trans. Instrum. Meas. IM-25, No. 4, 519-523 (Dec. 1976).

Key words: ac-dc difference; current comparator; current measurements; thermoelement.

A new 14-range set of thermal current converters consisting of shunted thermoelements has been constructed to measure ac-dc difference and ac current from $10 \mathrm{~mA}$ to $20 \mathrm{~A}$ at $20 \mathrm{~Hz}$ to $50 \mathrm{kHz}$. The ac-dc difference corrections for all ranges can be determined relative to two ranges by a 7-step intercomparison of certain adjacent ranges.

16698. Field, B. F., Hesterman, V. W., Laboratory voltage standard based on 2e/h, IEEE Trans. Instrum. Meas. IM-25, No. 4, 509-511 (Dec. 1976).

Key words: Josephson junction; standard cell; superconducting; voltage measurement; voltage reference.

The increased dependence of a standards laboratory on a stable voltage reference has made the maintenance of a "volt" by standard cells a costly and time consuming process. This paper describes an instrument designed to calibrate cadmium-sulfate standard cells directly against a time-invariant superconducting Josephson junction voltage reference, thus replacing the large groups of cells typically used as a voltage reference. An induced voltage of $5.2 \mathrm{mV}$ is produced across the Josephson junction by irradiating the junction with microwaves of a known frequency. A specially designed potentiometer is used to scale this voltage up to $1.01+\mathrm{V}$ where it can be compared to a standard cell. The overall accuracy $(2 \sigma)$ of the system is 0.4 ppm or better.

16699. Tsang, W., Walker, J. A., Instrument for the generation of reactive gases, Anal. Chem. 49, No. 1, 13-17 (Jan. 1977).

Key words: acetaldehyde; acrolein; calibration; diffusion cell; formaldehyde; instrumentation; pyrolysis; reactive gases.

An instrument has been constructed which is capable of generating reactive gases over wide concentration ranges [from ppm on up]. Its operational characteristics and performance have been evaluated with specific application to the generation of formaldehyde, acetaldehyde, and acrolein vapors of micrograms/minute rates.

16700. Interrante, C. G., Hicho, G. E., Removal of iron-sulfide deposits from fracture surfaces, Am. Soc. Test. Mater. Spec. Tech. Publ. 610, pp. 349-365 (1976).

Key words: crack propagation; ductility; failure; fractography; fracture tests; hydrogen; steels; stress corrosion.

Steels are most commonly used at moderate strength levels at which they have high ductility and resistance to subcritical crack growth due to hydrogen. Thus, in testing the susceptibility to hydrogen damage of these steels, severe charging conditions are commonly used, and hydrogen sulfide is often used in low-pH solutions to obtain the desired high fugacity for the test. The fracture faces of specimens tested in this type of solution become covered with iron and other sulfides that are difficult to remove without affecting the underlying metal as well. The removal of these sulfide deposits from the fracture surfaces is a prerequisite to fractographic analysis of the failure mode, and it was attempted by various methods. Hydrogen reduction of the sulfides at elevated temperatures followed by ultrasonic cleaning in alcohol was found to be much more successful than the other methods studied. This is true principally because the hydrogen-reduction treatment did not attack the fracture surface. Procedures for four different cleaning treatments are 
described, and they arc rated in terms of their relative capability for cleaning sulfidc-contaminated fracture surfaces without affecting the underlying metal. Evaluations of these methods for doublc-cantilcver-beam and Charpy V-notch specimens of a $2 \frac{1}{4} \mathrm{Cr}-1 \mathrm{Mo}$ steel with fracture surfaces that were created at various stress-intensity levels provides information needed for studying thc cracking mechanism under severe sulfide exposure conditions.

16701. Hruska, G. R., Magrab, E. B., Penzes, W. B., Environmental effects on microphones of various constructions, $J$. Acoust. Soc. Am. 61, No. 1, 206-210 (Jan. 1977).

Key words: calibration; ceramic; condenser; electret; humidity; microphones; reciprocity; sensitivity; temperature.

The prcssure sensitivities of two $1 / 2$-in electret, two 1 -in ceramic, and two back-vented 1 -in condenser microphones werc measured for numerous combinations of teniperature, percentage relative humidity, and frequency. The two condenser microphones were calibrated by the reciprocity technique at each combination of temperature, relative humidity, and frequency. The condenser microphones were then used as calibratcd sources to determine the pressure sensitivities of the other microphones. Insert voltage techniques were used to eliminate the environmental effects on the electronics. It was found that the backvented condenser microphones are insensitive to changes in relative humidity. At frequencies considerably bclow their resonance frequencies they exhibited only a very small change in sensitivity with temperature. At frequencies closer to the resonance frequency the temperature coefficient increases approximately fourfold. The temperature and humidity coefficient for the electret and ceramic microphones could not be determined due to the instability in their sensitivities which produced changes that were larger than those induced by the temperature and humidities.

16702. Magrab, E. B., Natural frequencies of elastically supported orthotropic rectangular plates, J. Acoust. Soc. Am. 61, No. 1, 79-83 (Jan. 1977).

Key words: Galerkin; natural frequencies; orthotropic; plates; rotary inertia; transverse shear; vibration.

An expression is derived from which the natural frequencies of a rectangular orthotropic plate, under any combination of simply supported, elastically supported, or clamped boundary conditions, can be obtained. The Mindlin-Timoshenko theory, which includes the effects of transverse shear and rotary inertia, is used to describe the plate motion. The solution is obtained with a previously developed extension of the Galerkin technique. Comparison of results with the limited results of previous investigations is very good. New results are presented for the fundamental frequencies of rectangular and square plates for boundary conditions on all four edges that vary continuously from simply supported to clamped, and for various combinations of length-to-thickness ratios and material constants. Additional results are presented for orthotropic plates simply supported and clamped on all four edges.

16703. Rebbert, R. E., Ausloos, P. J., Gas-phase photodecomposition of carbon tetrachloride, J. Photochem. 6, 265-276 (1976/77).

Key words: absorption cross section; carbon tetrachloride; chlorine atom; photochemistry; primary processes; quantum yields; troposphere; ultraviolet.

The gas-phase photolysis of $\mathrm{CCl}_{4}$ was investigated at 213.9 , 163.3 and $147.0 \mathrm{~nm}$ in the presence of $\mathrm{HCl}, \mathrm{HBr}$, and $\mathrm{C}_{2} \mathrm{H}_{6}$. Quantum yields of the products measured in these mixtures at a temperature of $300 \mathrm{~K}$ led to the conclusion that at $213.9 \mathrm{~nm}$ over 90 percent of the photodecomposition can be attributed to the photodissociative process:

$$
\mathrm{CCl}_{4}+h \nu \rightarrow \mathrm{CCl}_{3}+\mathrm{Cl} \text { (quantum yield } \geqslant 0.9 \text { ) }
$$

independent of pressure (5-60 torr). At $163.3 \mathrm{~nm}, \mathrm{CCl}_{2}$ is formed via the photodecomposition process:

$$
\mathrm{CCl}_{4}+h \nu \rightarrow \mathrm{CCl}_{2}+2 \mathrm{Cl} \text { (quantum yield } \sim 0.75 \text { ) }
$$

Contrary to earlier suggestions, $\mathrm{CCl}_{2}$ is unreactive toward $\mathrm{CCl}_{4}$. Combination with other radicals and insertion into $\mathrm{HCl}$ are the major modes of reaction of $\mathrm{CCl}_{2}$.

Experiments carried out at $313.0 \mathrm{~nm}$ show evidence for the occurrence of photodissociation of $\mathrm{CCl}_{4}$. On the assumption that absorption of a photon by $\mathrm{CCl}_{4}$ invariably leads to the detachment of a chlorine atom, the absorption cross-section at $313.0 \mathrm{~nm}$ is $\leqslant 3.7 \pm 0.4 \times 10^{-26} \mathrm{~cm}^{2}$ molecule ${ }^{-1}(300 \mathrm{~K})$. This result indicates that photodecomposition of $\mathrm{CCl}_{4}$ in the troposphere is of minor importance as compared to other processes including diffusion up to the earth's stratosphere.

16704. Bright, D. S., Miniature helical stirrer, Anal. Chem. 49, No. 1, 191 (Jan. 1977).

Key words: cuvette; helix; mixer; spectrophotometry; stirrer; vortex.

A novel and easily made helical stirring device is described that rapidly stirs small samples in long thin volumes, e.g., $1 \mathrm{~cm}$ spectrophotometric cuvettes. This stirring device overcomes some difficulties encountered with the conventional magnetic stirring device. Also described is a modified cuvette designed to enhance total mixing.

16705. Fenves, S. J., Wright, R. N., The representation and use of design specifications, (Proc. Symp. on Structural and Geotechnical Mechanics, Urbana, IL, Oct. 2-3, 1975), Paper in Structural and Geotechnical Mechanics, W. J. Hall, Ed., pp. 278-304 (Prentice-Hall, 1nc., Englewood Cliffs, NJ, 1977).

Key words: building codes; computer programming; decision tables; graph theory; performance specifications; standards.

Design specifications are presented as the primary communication and control tool for the design and construction industry. Requisite properties of completeness, uniqueness, and correctness are identified, and the role of performance and limit state concepts in specifying intent of the specifications are emphasized. Formal representational mcthods are presented at three levels: decision tables for specification provisions, an information network for related provisions, and argument trees for organizing and outlining. An idealized process for specification development is presented, and the use of the representation tools for checking specifications and providing strategies for textual expression is described and illustrated. Development of computer aids for specification processing in design and conformance checking is described.

16706. Steinberg, H. L., Standard Reference Collections of forensic science materials: Status and needs, LESP-RPT$0601.00,90$ pages (U.S. Department of Justice, Law Enforcement Assistance Administration, National Institute of Law Enforcement and Criminal Justice, Washington, DC, Feb. 1977).

Key words: criminalistics; evidential materials; forensic reference collections; forensic science; reference materials; standard reference collections.

An overview of criminalistics is given, stressing the potential forms and uses of Standard Reference Collections (SRCs).

A set of 34 classes of materials of Forensic Science import (FSM classes) is presented. A brief introduction to each FSM class is then given, along with a recommended action. Where a recommendation for SRC development or for further con- 
sideration is made, some elaboration of relevant factors is given. Fourteen FSM classes are so recommended. Fifteen classes were not recommended for further SRC consideration at this time. Five FSM classes were classified as "indeterminate," due to an insufficient data base.

An extensive bibliography is included.

16707. Morrow, J. J., NBS automated one-ohm resistance measurements, Quality Progress IX, No. 11, 22-25 (Nov. 1976).

Key words: automated resistance measurement; automation; dc current comparator; digital nanovoltmeter; resistance; resistance measurements.

A one-ohm resistance measurement system at NBS utilizes a dc current comparator potentiometer and a digital nanovoltmeter (DNM) with a sensitivity of one nanovolt. The circuit configuration for automated measurements is the same as that for manually balanced measurements except that the DNM replaces the galvanometer and the circuit is not balanced. Accuracies of 1 part in $10^{7}$ are easily achieved with the system.

16708. Culver, C. G., Live-load survey results for office buildings, J. Struct. Div. Proc. Am. Soc. Civil Eng. 102, No. ST12, 2269-2284 (Dec. 1976).

Key words: buildings; live loads; load surveys; structural engineering.

Live load data obtained from a survey of twenty-three office buildings located in various regions throughout the United States are presented. The buildings ranged in height from two stories to forty-nine stories. Data for government and private office buildings are included. Statisțical summaries of the data are presented and the effects of various factors such as building height, building age, geographic location, room use and room size are discussed. A mathematical model expressing the relationship between the live load in offices and the significant factors affecting the load magnitude is also presented. The data presented may be used to evaluate current requirements for design loads for buildings and also for research studies of load effects in buildings.

16709. Truhlar, D. G., Van-Catledge, F. A., Tests of INDO/1s and INDOXI/1s methods for the calculation of the static potential for electron scattering by $\mathrm{CO}, J$. Chem. Phys. 65, No. 12, 5536-5538 (Dec. 15, 1976).

Key words: carbon monoxide molecules; dipole moment; electron scattering; electrostatic potential; intermediate neglect of differential overlap (INDO); molecular orbital theory; quantum chemistry; static potential.

We have previously used semiempirical molecular orbital theory (INDO, INDO/ls and INDOXI methods) to calculate the equilibrium-geometry ground state static potential $V_{s}\left(r, \theta ; R_{l}\right)$ for $\bar{N}_{2}$ and $\overline{\mathrm{CO}}$ as functions of $r$ and $\theta$; where $V_{s}\left(r, \theta ; R_{l}\right)$ is the interaction energy of a fixed electron with the unperturbed ground-state charge distribution of a molecule fixed at its equilibrium internuclear distance, $r$ is the magnitude of the vector $\vec{r}[\equiv(r, \theta, \phi)]$ from the center-of-mass of the molecule to the electron, and $\theta$ is measured with respect to the internuclear axis. The static potential is useful for electron scattering calculations and for estimating the reactivity of molecules with electrophilic reagents.

16710. Wagner, H. L., Hoeve, C. A. J., The Mark-Houwink equation and chain dimensions of linear polyethylene in theta solvents, J. Polym. Sci. Polym. Symp. No. 54, 327-339 (1976).

Key words: biphenyl; chain dimensions; dodecanol; linear polyethylene; Mark-Houwink equation; NBS Standard
Reference Material 1475; theta solvents; 3,3,5-trimethylhexyl acetate.

In order to ascertain whether the fractions used to determine the molecular weight distribution of the NBS standard polyethylene sample SRM 1475 by gel-permeation chromatography are linear, the exponent $a$ in the Mark-Houwink equation was determined in three theta solvents: biphenyl, dodecanol, and 3,3,5-trimethylhexyl acetate. Our data indicate that $a$ might exceed the theoretical value of 0.5 . This is attributed to the fractions below molecular weight 20,000, which approach freedraining coils in their behavior. When an exponent of 0.5 is assumed and fractions below 20,000 are omitted, the characteristic size ratio $\left\langle r_{0}{ }^{2}\right\rangle / n l^{2}$ is found to be 7.21 at $140{ }^{\circ} \mathrm{C}$. The average value at $140{ }^{\circ} \mathrm{C}$ derived from available data, including ours, is 6.79 , in excellent agreement with the theoretical value of 6.89. We conclude that standard sample SRM 1475 is linear polyethylene.

16711. Mountain, R. D., Generalized hydrodynamics, Adv. Mol. Relaxation Processes 9, 225-291 (1976).

Key words: correlation function; density fluctuations; fluctuations; hydrodynamics; light scattering; liquid state; molecular dynamics; neutron scattering; shear wave; statistical mechanics; time correlation function; transverse current; ultrasonics.

Equations of motion for time correlation functions of molecular quantities, such as the density-density correlation function, can be obtained in the form of generalized hydrodynamic equations. The generalization considered here leads to wave vector dependent generalizations of thermodynamic coefficients and to wave vector and frequency dependent generalizations of transport coefficients in linear equations of motion for the correlation functions. The motivation for describing collective effects in fluids at the molecular level from this viewpoint is discussed in this review and several ways of deriving such equations of motion are compared. An explicit derivation is carried out for the density-density correlation function, the quantity studied by neutron and light scattering studies. The intent of this discussion is to provide a perspective view of the subject. Several applications of the theory are described. These include molecular dynamics, neutron scattering and light scattering studies of density-density correlations, molecular dynamics and light scattering studies of transverse current correlations, hydrodynamic studies of long time tails in molecular correlation functions of the currents of the hydrodynamic variables and ultrasonic studies of fluids in the critical region and in the rarified gas region. Some unresolved aspects of the theory are considered in the last section.

16712. Brown, P. W., Clifton, J. R., Nondestructive techniques for evaluating metallic artifacts of historical interest, Bull. Assoc. Preserv. Technol. VIII, No. 4, 2-2 1 (1976).

Key words: compositional analysis; instrumental methods; metallic artifacts; microstructural analysis; nondestructive evaluation techniques.

This paper describes a variety of nondestructive evaluation (NDE) techniques which can be used to characterize the compositions and methods of fabrication of metallic artifacts, to form a basis for approximating their ages and determining their sources. This paper was prepared with the objective of showing preservation technologists how NDE methods can be used in the course of their work. This paper was written in response to a request by Mr. L. H. Nelson, editor of the Bulletin of the Association for Preservation Technology. Because the paper is addressed to an audience not versed in this area, it has been reviewed by Mr. Nelson who approves of the format and the level of technical content. 
16713. Childers, C. B., Dziuba, R. F., Lee, L. H., A resistive ratio standard for measuring direct voltages to $10 \mathrm{kV}, I E E E$ Trans. Instrum. Meas. IM-25, No. 4, 505-508 (Dec. 1976).

Key words: direct voltage measurements; high voltage measurements; Kelvin-Varley divider; ratio standard; voltage dividers; volt boxes.

A highly accurate guarded voltage-ratio standard has been developed for measuring direct voltages from the range of a standard cell to $10 \mathrm{kV}$. The ratio standard has a resolution capability of $0.1 \mathrm{ppm}$ for ratios of $1: 1$ to $10000: 1$ with an estimated uncertainty of $0.2 \mathrm{ppm}$. 1t is designed for operation at a rating of $2 \mathrm{k} \Omega / \mathrm{V}$ and consists of an adjustable reference section in series with three resistance groups each containing nine nominally equal sections. The resistance ratios are determined by a self-calibration technique using a 1:1 bridge. A seriesparallel mode of calibration provides an additional check on the accuracies of the ratios. The standard is housed in a temperature-controlled oil bath whose oil is filtered to remove moisture and contaminants.

16714. Stroik, J. S., Physical security of door assemblies and components, NILECJ-STD-0306.00, 33 pages (U.S. Department of Justice, Law Enforcement Assistance Administration, National Institute of Law Enforcement and Criminal Justice, Washington, DC, May 1976).

Key words: burglary resistance; door assemblies; door components; doors; frames; hardware; hinges; locks; security standards.

Security standards for doors have been developed at the $\mathrm{Na}$ tional Bureau of Standards to evaluate burglar-resistance of door assemblies and components. Criteria were established by analysis of available data on burglary methods, by duplication of the attacks, and finally by measurement of the duplicated attacks applicable to the standards' scope. The scope includes development of standards designed to resist only burglary attacks defined as "common" or "opportunity" attacks on residences and small businesses. Four classes were established, from class I which includes attributes for the lowest level of resistance, up to class IV with attributes for the highest level of resistance. Requirements are specified as performance criteria with test methods described in detail. Two classification methods were established, one for door assemblies, the other for door assembly components. Included in an appendix is a description of the test equipment used at the National Bureau of Standards.

16715. Interrante, C. G., Early, J. G., Hicho, G. E., Analysis of findings of four tank-car accident reports, DOT Report No. FRA-OR\&D 75-50, 70 pages (Available as PB251097 from the National Technical Information Service, Springfield, VA 22161, Jan. 1975).

\section{Key words: metallurgy; tank cars}

A comprehensive overview of the findings and metallurgical analyses of tests conducted at the National Bureau of Standards on samples of tank-car materials submitted by the Federal Railroad Administration is presented. The submitted samples were taken from tank cars which had been involved in accidents during the period January 1970 to January 1971. The testing conducted during the metallurgical analyses included full chemical analyses, ambient temperature tensile tests on longitudinal and transverse specimens, quantitative metallography to determine ferrite grain size, peralite colony size, and inclusion content, size, and shape, hardness tests, bend tests on longitudinal and transverse specimens, and a very comprehensive program of impact testing, which is covered in a separate report on Impact Properties.
16716. Interrante, C. G., Impact properties of steels taken from four failed tank cars, DOT Report No. FRA-OR\&D 75-5I, 157 pages (Available as PB255854 from the National Technical Information Service, Springfield, VA 22161, June 1976).

Key words: metallurgical; tank cars.

An overview of the results and metallurgical analyses of the findings of impact tests conducted at the National Bureau of Standards on samples of tank-car materials submitted by the Federal Railroad Administration is presented. The submitted samples were taken from tank cars which had been involved in service accidents during the period January 1970 to January 1971. One of these tank cars had been fabricated from ASTM A212 steel and the remaining four tank cars from AAR TC128 steels. The impact test data were reported earlier in four tankcar accident reports.

16717. Early, J. G., Interrante, C. G., A metallurgical investigation of a full-scale insulated rail tank car filled with LPG subjected to a fire environment, DOT Report No. FRA-OR\&D $75-52,67$ pages (Available as PB250587 from the National Technical Information Service, Springfield, VA 22161, Jan. 1975 ).

Key words: metallurgical; tank cars.

An analysis of the failure of an insulated rail tank car, RAX 202, which had been tested to failure in a fire environment at White Sands Missile Range, New Mexico, was requested by the Federal Railroad Administration, Department of Transportation.

The tank car, filled with approximately 33,000 gallons of liquified petroleum gas (LPG), failed after approximately 94 minutes of exposure to a JP-4 jet fuel fire. The car fractured into four fragments which were examined in the field. Five plate samples from the four fragments were selected for laboratory study at the National Bureau of Standards.

16718. Early, J. G., Mechanical properties of AAR M128-69-B steel plate samples taken from insulated fire tested tank car RAX 202, DOT Report No. FRA-OR\&D 76-74, 57 pages (Available as PB255907 from the National Technical Information Service, Springfield, VA 22161, June 1976).

Key words: metallurgical; tank cars.

Studies were undertaken to measure the elevated-temperature mechanical properties and to determine the elevated-temperature fracture behavior of selected AAR M128-B steel plates. In addition, the ambient-temperature mechanical properties were measured to determine if the requirements of specification AAR M128-69-B were satisfied. The NBS results of check chemical analyses, hardness surveys, thickness measurements, macroscopic observations, and metallographic analyses of the plate samples had been reported previously. The results of ambient-temperature tensile tests showed that all plate samples met the strength and tensile ductility requirements of specification AAR M128-69-B. The results of hot-tensile tests showed a continuous decrease in strength properties and an increase in tensile ductility as the test temperature was increased from $1100 \mathrm{~F}$ to $1250 \mathrm{~F}$. An analysis of stress-rupture data for specimens from all plate samples in the same temperature range indicated that a straight line in a log-log plot of initial stress versus rupture life reasonably represented the data at each test temperature. In the temperature and stress range studied, a decrease in the initial stress of about 20 to 30 percent resulted in a twelvefold increase in rupture life from 15 minutes to three hours. A comparison of the results of the metallographic analysis of hot-tensile and representative stress-rupture specimens with the previously reported metallographic results 
on the initial rupture site in the failed shell course indicate the presence of the identical fracture mode. This mode is characterized by many intergranular voids which originate primarily at the proeutectoid ferrite-pearlite boundaries. These results confirm the previously reported finding that the initial rupture of the tank car was a stress-rupture crack.

16719. Interrante, C. G., Hicho, G. E., Harne, D. E., A metallurgical analysis of five steel plates taken from a tank car accident near Crescent City, Illinois, DOT Report No. FRA$O R \& D 75-48,87$ pages (Available as PB250530 from the National Technical Information Service, Springfield, VA 22161, Mar. 1972).

Key words: metallurgy; tank cars.

A metallurgical analysis of five steel samples (numbered FRA-1 through FRA-5) was requested by the Bureau of Railroad Safety, Federal Railroad Administration, Department of Transportation. These steel samples were taken from two tank cars (numbered SOEX 3037 and SOEX 3219) which had been involved in an accident near Crescent City, Illinois. Samples FRA-1, FRA-4, and FRA-5 were reported to be shell plates and sample FRA-3, a head plate. Sample FRA-2 was a welded sample of head plate and shell plate and it was used for most of the mechanical properties determinations in this report.

An investigation was conducted at the National Bureau of Standards to determine if the samples conformed with the appropriate specifications for tank car materials and to gather information pertinent to the question of the suitability of these steels for use as plate materials of tank cars. Samples FRA-1, -2 , and -5 were reportedly produced to the specification for ASTM A 212-65 Grade B, flange quality steel (A 212-B); and FRA-3 and -4 were reportedly produced to specification AAR M128 Grade B, flange quality steel (M128-B).

16720. Interrante, C. G., Hicho, G. E., Metallurgical analysis of a steel shell plate taken from a tank car accident near South Byron, N.Y., DOT Report No. FRA-OR\&D 75-47, 56 pages (Available as PB250063 from the National Technical Information Service, Springfield, VA 22161, Oct. 1971).

Key words: metallurgy; tank cars.

A metallurgical analysis of a steel plate sample (the South Byron sample) was requested by the Federal Railroad Administration. The steel sample was taken from a tank car (number PPGX9990) which had been involved in an accident near South Byron, New York. This sample was reported to have been produced to specification AAR-M-128-65-DTD-1966Flange Quality-Grade B, and it was reportedly taken from the second course of shell plate of car number PPGX9990. The fracture in this course circumscribed the tank car and resulted in the division of the car into two sections.

An investigation was conducted at the National Bureau of Standards to determine if the plate sample conformed with the above Association of American Railroads (AAR) Specifications for Tank Cars and to gather information pertinent to the question of the suitability of this type of steel for use as the shell plate of tank cars.

16721. Gans, W. L., Present capabilities of the NBS Automatic Pulse Measurement System, IEEE Trans. Instrum. Meas. IM25, No. 4, 384-388 (Dec. 1976).

Key words: automated measurement; pulse; rise time; sampling oscilloscope; spectrum ampiitude; time domain; transient.

In 1972, NBS began development of an Automatic Pulse Measurement System (APMS) consisting essentially of a minicomputer-controlled wide-band sampling oscilloscope. The objective of the work was to produce a fast general purpose pulse waveform acquisition and processing instrument with spectral capability in the frequency range dc-18 GHz. The purpose of this paper is to report the highlights of work done on the APMS from early 1975 to present.

The measurement applications of the APMS now consist of both publicly offered calibration services and in-house experimental measurements. In the first category, calibration services are available for the following physical parameters: a) Impulse generator spectrum amplitude; b) Wide-band coaxial attenuation/gain; c) Pulse generator transition time.

Still in the experimental stage are measurements involving reflection coefficient and impedance, group delay, pulse distortion, and wide-band antenna characteristics.

16722. Jesch, R. L., Repeatability of SMA coaxial connectors, IEEE Traris. Instrum. Meas. IM-25, No. 4, 314-320 (Dec. 1976).

Key words: insertion loss; reflection coefficient; repeatability; SMA connectors.

SMA connectors in three different configurations were investigated for variation of reflection coefficient magnitude and insertion loss for a given SMA connector connect-disconnect sequence. Repeatability measurements were taken over the frequency range of 2 to $18 \mathrm{GHz}$ on the NBS Automatic Network Analyzer. Plots are given that show the SMA connector repeatability for both reflection coefficient magnitude and insertion loss as a function of frequency.

\section{Larsen, N. T., A new self-balancing dc-substitution RF power meter, IEEE Trans. Instrum. Meas. IM-25, No. 4, 343- 347 (Dec. 1976).}

Key words: bolometer; microwave; power measurement.

Problems intrinsic in self-balancing Wheatstone bridges have led to the development of a new dc substitution microwave power meter. The new instrument allows four-terminal measurement of bolometer resistance and affords improved accuracy and lower noise at a lower cost than earlier instruments. Measurement errors due to imperfect behavior of the servo system are typically less than 0.01 percent.

16724. Hoer, C. A., Roe, K. C., Allred, C. M., Measuring and minimizing diode detector nonlinearity, IEEE Trans. Instrum. Meas. IM-25, No. 4, 324-329 (Dec. 1976).

Key words: diode detector; diode model; temperature compensation.

This paper describes two techniques for measuring the linearity of amplitude detectors in general, and for measuring the deviation from square-law $E$ of point-contact diode detectors in particular. A general mathematical model is given for determining the RF input power as a function of the detector output voltage. It is shown how to choose the value and the temperature coefficient of the video load resistance to minimize $E$ and make $E$ independent of temperature.

16725. Andrews, J. R., Impulse generator spectrum amplitude measurement techniques, IEEE Trans. Instrum. Meas. IM-25, No. 4, 380-384 (Dec. 1976).

Key words: calibration; electromagnetic interference; fast Fourier transform; impulse generator; radiometer; sampling oscilloscope; spectrum amplitude; spectrum analyzer; spectrum intensity.

Various techniques that have been used to calibrate impulse generators and to measure spectrum amplitude are surveyed. A summary of experiments comparing the various techniques is included. The NBS measurement service for calibrating impulse generators is described. 
16726. Engen, G. F., Determination of microwave phase and amplitude from power measurements, IEEE Trans. Instrum. Meas. IM-25, No. 4, $414-418$ (Dec. 1976).

Key words: automatic network analyzer; automation; microwave; microwave measurement; six-port.

Although straightforward in principle, the extension of existing designs for automatic network analyzers (ANA's) to the higher microwave frequencies is difficult in the current state of the art. What appears to be needed is a basically different approach to the microwave detection problem. One promising alternative is provided by the so-called "six-port" techniques, which eliminate the need for modulation or for frequency conversion, local oscillators, phase detectors, etc. Recent theoretical studies have provided new insights into the basic concept and lead to "five-port" configurations which require three instead of four amplitude detectors. Of particular interest is the projected measurement dynamic range of 50-60 dB corresponding to a dynamic range requirement in the amplitude detectors of a nominal $20 \mathrm{~dB}$ or less.

16727. Estin, A. J., Scattering parameters of SMA coaxial connector pairs, IEEE Trans. Instrum. Meas. IM-25, No. 4, 329 334 (Dec. 1976).

Key words: coaxial connectors; microwave connectors; RF connectors; scattering parameters.

A technique is described for making reflection and insertion loss measurements on microwave connectors, without the need for reference to calibrated or precision standards. The effects of connectors used in the measuring system are removed from the results, thus providing a means for testing and selecting cables from a group for specific critical applications. Results are given for a group of eight sections of Type 141 solid dielectric line having SMA connectors, and generic behavior is predicted for the SMA connector.

16728. Wells, J. S., Streit, G. E., Petersen, F. R., Absolute spinflip Raman laser frequency measurements with metal-insulator-metal diodes, Opt. Commun. 19, No. 2, 248-252 (Nov. 1976).

Key words: frequency measurements on tunable lasers; IFS with a tunable laser; infrared frequency synthesis; SFRL frequency measurement; spin flip Raman laser.

Infrared frequency synthesis techniques with metal-insulator. metal (MIM) diodes have been extended to include absolute frequency measurement of a spin-flip Raman laser (SFRL). As a result of this extension, spectroscopy in the $5.3 \mu \mathrm{m}$ region more readily can be put on a frequency rather than a wavelength metrology basis. Additional observations with the diode are in qualitative agreement with recent work relating to nonlinear tuning over axial SFRL modes.

16729. Maienthal, E. J., Becker, D. A., A survey on current literature on sampling, sample handling, for environmental materials and long term storage, Interface 5, No. 4, 49-62 (1976).

Key words: chemical analysis; environmental samples; longterm storage; microbiologicals; organics; pesticides; radionuclides; sample handling; sampling; trace elements.

In order to aid in the development of criteria for the possible establishment of a National Environmental Specimen Bank for the Environmental Protection Agency, a large portion of the recent literature concerning sampling and storage of environmental specimens has been examined. This has been done both manually and by use of bibliographical retrieval services such as Medline, Chemcon, Biosis, Cain, Defense Documentation
Center and others. Also, the advice and opinion of workers in various aspects of the field has been obtained. A summary of the results of this survey is found below, separated into the various areas of concern.

16730. Waxler, R. M., Horowitz, D., Feldman, A., Precision interferometer for measuring photoelastic constants, Appl. Opt. 16, No. 1, 20-22 (Jan. 1977).

Key words: crystals; fused silica; interferometers; optics; photoelasticity.

A stable polarizing interferometer has been adapted for measuring small changes in optic path induced by small stresses in optical materials. With this instrument we measured the piezooptic constants of fused silica at $0.6328 \mu \mathrm{m}$ by applying stresses up to $1.34 \times 10^{7} \mathrm{~N} / \mathrm{m}^{2}$ and found good agreement with previous workers who employed much higher stresses. The standard deviation of the fringe shift from a linear fit of optical path change as a function of stress was less than $\lambda / 500$. This technique is valuable for measuring the piezo-optic constants of materials that cannot withstand large stresses.

16731. Riad, S. M., Nahman, N. S., Application of the homomorphic deconvolution for the separation of TDR signals occurring in overlapping time windows, IEEE Trans. Instrum. Meas. IM-25, No. 4, 388-391 (Dec. 1976).

Key words: homomorphic deconvolution; time domain reflectometry.

The homomorphic transformation is used to separate a time domain reflectometry (TDR) signal into its rapidly and slowly varying components, respectively. The separation (deconvolution) technique is successful in the case where the multiple reflections cannot be viewed in nonoverlapping time windows as is required by the conventional TDR method.

16732. Chiu, H. Y., Adams, P. J., Linsky, J. L., Basri, G. S., Maran, S. P., Hobbs, R. W., High-resolution stellar vidicon spectrophotometry. I. Variable mass loss from arcturus and the hypothesis of giant convective elements, Astrophys. J. 211, No. 2, 453-462 (Jan. 15, 1977).

Key words: Ca II emission; stars, chromospheres; stars, individual; stars, late type; stars, mass loss.

High-resolution spectrophotometry of the variable Ca $11 \mathrm{~K}$ line in the K2 Illp star $\alpha$ Boo was performed on five occasions over the period 1974 April-1976 February with the McMath Solar Telescope at Kitt Peak National Observatory and an experimental SEC vidicon camera. The results are compared with Copernicus observations of the $\mathrm{Mg}$ II $h$ and $k$ lines (1973 May 19; 1974 May 20) and with earlier Ca 11 data of Griffin, and it is found that either of two states may typically occur in the Arcturus chromosphere. From comparison with the results of model calculations for expanding chromospheres, it is concluded that these correspond respectively to a "normal" state in which the mass loss $d M / d t<10^{-9} \mathrm{Mbyr}^{-1}$ and an "abnormal" state in which $d M / d t \approx 8 \times 10^{-9} M_{\odot} \mathrm{yr}^{-1}$. In the latter case, the expansion velocity is $\sim 13 \mathrm{~km} \mathrm{~s}^{-1}$ at optical depth unity in the $\mathrm{K}$-line, which exceeds the local sound speed. It is suggested that the abnormal state represents the rise to the photosphere of a very large convective element $\left(d \sim r^{*}\right)$ as hypothesized for red giants by Schwarzschild.

16733. Holton, J. K., Interfacing building design and solar energy research and standards, Proc. 1976 Joint Solar Energy Conf., on Sharing the Sun: Solar Technology in the Seventies, Winnipeg, Manitoba, Canada, Aug. 15-20, 1976, 9, 74-82 (Pergamon Press, Elmsford, NY, 1976). 
Key words: communication of research and standards; National Bureau of Standards; solar energy standards; standards users.

An extensive program of solar energy research and standards development has been undertaken by the National Bureau of Standards in support of the national effort to expedite the introduction of solar usage. The communication between researchers and the building coinmunity, who will utilize the products of this research, is of critical importance for effective conduct of this program. This paper examines a number of the programs being conducted at NBS, identifies the intended user groups, and describes some of the paths of communication that are being used. It is hoped that a clearer understanding of the research/user linkage will lead to more effective communication between those working in the field.

16734. Tucker, J. C., Alternative models of the decision-making process and their implications for information packaging, Proc. 39th Annual Meeting of the American Society for Information Science on Information-Politics, San Francisco, CA, Oct. 4-9, 1976, 13, 10 pages (American Society for Information Science, Washington, DC, 1976).

Key words: decision maker; decision model; information packaging; information processing; managment information.

The organization of data into information for decision-making depends not only on the problem addressed, but also on the decision maker's thought processes. Three types of decision makers are described: the satisficer or cybernetic decision maker, the rational decision maker, and the adaptivizer. The rational decision maker is the classic type, described in economic and management literature. The cybernetic model of the decision maker is based on studies in cognitive psychology, which attempt to model the processes of the mind. The concept of the adaptive decision maker is relatively new, growing out of the present environment of uncertainty, rapid change, and interdependence, which requires flexibility.

After examining the information processing characteristics of each of these types, the paper suggests some ways in which the information specialist might organize information to be presented to each type of decision maker to have maximum effect on the decision process. Care must be taken, however, not to cross the line between effective presentation and manipulation of the decision maker.

16735. Parks, S. I., Linzer, M., Application of pulse compression techniques to medical ultrasound, (Proc. of the Society of Photo-Optical Instrumentation Engineers, Conf., Washington, DC, Sept. 16-19, 1976), Paper in Application of Optical Instrumentation in Medicine V, R. K. Cacak, et al., Eds., 96, 349-353 (Society of Photo-Optical Instrumentation Engineers, Palos Verdes Estates, CA, 1976).

Key words: chirp radar; medical diagnosis; pulse compression; signal processing; ultrasound.

The application of pulse compression to medical ultrasound is discussed. This approach can decrease peak power and increase sensitivity in ultrasonic diagnosis. A prototype system with $8: 1$ compression ratio and $0.6 \mu$ s resolution is described. Compressed echo waveforms were obtained from an aluminum bar and from a human heart in vivo.

16736. Morton, M., Fetters, L. J., Homogeneous anionic polymerization of unsaturated monomers, Paper in Macromolecular Reviews, A. Peterlin, M. Goodman, S. Okamura, B. H. Zimm, and H. F. Mark, Eds., 2, 71-113 (Interscience Publishers, John Wiley \& Sons, New York, NY, 1967).
Key words: block copolymers; homogeneous anionic polymerization; monodisperse polymers; unsaturated monomers.

This review discusses the polymerization of unsaturated monomers by carbanionic mechanisms. Particular emphasis is placed on the synthetic possibilities of these systems, i.e., monodisperse polymers, block copolymers, and polymers having reactive end-groups.

16737. Bright, R. G., Status and problems of fire detection for life safety in the United States, (Proc. Symp. National Academy of Sciences-National Research Council on Fire Detection for Life Safety, Washington, DC, Mar. 31-Apr. 1, 1975), Paper in Fire Detection and Life Safety, pp. 3-14 (1977).

Key words: building fires; fire detection devices; heat detectors; ionization chamber detectors; photoelectric detectors; smoke detectors.

About 12,000 persons lose their lives in fires each year in the U.S. Two-thirds of these persons die in home fires. If fire detectors for life safety are to be effective, their use in dwellings is indicated.

Any of the three conventional fire detector types, flame, heat, or smoke, can serve for life safety. Comparing advantages and disadvantages of each type of detector indicates smoke detectors should be the most effective of the three. There are, however, some technical and design deficiencies with smoke detectors which must be overcome if these devices are to realize their maximum potential as life saving devices.

16738. Waterstrat, R. M., Manuszewski, R. C., The niobiumosmium constitution diagram, J. Less-Common Met. 51, 5567 ( 1977 ).

Key words: atomic ordering; constitution diagram; niobium alloys; osmium alloys; phase diagram.

The Nb-Os alloy system has been investigated over the entire composition range using metallographic, $x$-ray diffraction and electron microprobe techniques. The $\epsilon$-Os solid solution extends to about 27 at.\% $\mathrm{Nb}$ at high temperatures but this is reduced to about 20 at.\% Nb at lower temperatures. Three intermediate phases occur in this system and all of them possess topologically close-packed structures of the Frank-Kasper type. These phases are $\chi(\alpha-M n$ type $), \sigma(\sigma$-phase type) and $\beta$ (A.15 or $\beta W$-type). The $\alpha-\mathrm{Nb}$ solid solution extends to about 19 at.\% Os at high temperatures but only to about 13 at.\% Os at lower temperatures. Two eutectic reactions occur at about $2120^{\circ} \mathrm{C}$ and $2175^{\circ} \mathrm{C}$. The $x$-phase is formed by a peritectic reaction at about $2270^{\circ} \mathrm{C}$, the $\sigma$-phase melts congruently at about 2200 ${ }^{\circ} \mathrm{C}$ and the $\beta$-phase forms by a peritectoid reaction at about $1975{ }^{\circ} \mathrm{C}$. All the intermediate phases possess highly ordered structures with the larger $(\mathrm{Nb})$ atoms preferring the sites having high coordination while the smaller (Os) atoms prefer the sites of lowest coordination.

16739. Brown, W. E., Gregory, T. M., Chow, L. C., Effects of fluoride on enamel solubility and cariostasis, Caries Res. 11, (Suppl. 1), 118-141 (1977).

Key words: chemical potential; dental caries; enamel; fluorapatite; fluoride; hydroxyapatite; solubility.

The known caries-reducing effect of fluoride is frequently attributed to its ability to reduce the solubility of enamel. Solubility data are presented which show that under a caries-like condition, the difference in the amounts of enamel that would dissolve in the absence and in the presence of fluoride ions is not significant. A new theory for the physicochemical action of fluoride is proposed which is based on the view that fluoride increases the chemical potential of the component $\mathrm{H}_{3} \mathrm{PO}_{4}$ and 
decreases the chemical potential of the component $\mathrm{Ca}(\mathrm{OH})_{2}$ of the solution within the lesion, thereby lowering diffusion out of the enamel or hastening remineralization. Solid solutions between hydroxyapatite and fluorapatite are an important means of incorporation of fluoride into enamel crystals, but the thermodynamic properties exhibited by such solid solutions in the presence of $\mathrm{F}^{-}$ions and under cariogenic conditions are likely to mimic those of the end member, fluorapatite because of the formation of surface coatings. A distinction is made between "lattice" and "interfacial" fluorides; addition of acid to an equilibrated mixture would cause release of "lattice" fluoride to the solution and, at the same time, an uptake of fluoride by the "interface."

16740. Truhlar, D. G., Brandt, M. A., Srivastava, S. K., Trajmar, S., Chutjian, A., Quantum mechanical and crossed beam study of vibrational excitation of $\mathrm{N}_{2}$ by electron impact at 30 75 eV, J. Chem. Phys. 66, No. 2, 655-663 (Jan. 15, 1977).

Key words: close-coupling calculations; crossed beams; cross sections; differential cross sections; electron scattering; inelastic scattering; nitrogen molecules; resonances; scattering; vibrational excitation.

The ratios of differential cross sections for excitation of the first excited vibrational state and for elastic scattering for electron impact on $\mathrm{N}_{2}$ have been measured at scattering angles ranging from $20^{\circ}$ to $135^{\circ}$ at $30,35,40,45$, and $75 \mathrm{eV}$ impact energies and from $25^{\circ}$ to $90^{\circ}$ scattering angle at $20 \mathrm{eV}$ impact energy. The results at $20 \mathrm{eV}$ are in good agreement with two previous sets of measurements. Using previously measured and normalized elastic differential cross sections for $\mathbf{N}_{2}$, the ratios have been converted to inelastic cross sections. Calculations using a four-state vibrational-rotational basis set and an effective interaction potential developed previously are reported at the five energies in the $30-75 \mathrm{eV}$ region. It is shown that the potential scattering model can account for the magnitude and the qualitative behavior of the cross sections at $35-75 \mathrm{eV}$ but there are some significant quantitative differences between theory and experiment. The most striking of these is the way the theoretical model overestimates the scattering at scattering angles less than about $50^{\circ}$. Core-excited resonances apparently make an appreciable contribution to the vibrationally inelastic scattering at $30 \mathrm{eV}$.

16741. Jordan, T. H., Schroeder, L. W., Dickens, B., Brown, W. E., Crystal structure of stannous hydroxide phosphate, a reaction product of stannous fluoride and apatite, Inorg. Chem. 15, No. 8, 1810-1814 (1976).

Key words: asymmetric coordination; crystal structure; $\mathrm{Sn}$ bonding; tin hydroxy phosphate; tin phosphate.

Stannous hydroxide phosphate, $\mathrm{Sn}_{2}(\mathrm{OH}) \mathrm{PO}_{4}$, crystallizes in the monoclinic unit cell, $a=7.176$ (4) $\AA, b=7.051$ (1) $\AA, c$ $=10.453$ (4) $\AA$, and $\beta=103.96(3)^{\circ}$, with space group $P 2_{1} / n$ and $Z=4$. Refinement of the structure concluded with $R_{\mathrm{w}}=$ 0.035 and $R=0.053$. A total of 1332 x-ray data of measurable intensity were collected from a single crystal using Mo radiation and $\theta-2 \theta$ scans. The data were not corrected for absorption, and the refinements allowed for anomalous dispersion but not for secondary extinction. Each of the $\mathrm{Sn}$ atoms is coordinated by three oxygen atoms; with Sn...O distances of $\sim 2.1$ $\AA$. All three coordinated oxygens are within the same hemisphere about $\mathrm{Sn}$, presumably because of repulsion by a lone pair of electrons in the other hemisphere about Sn. The hydroxyl hydrogen atom has been located approximately, and forms a hydrogen bond with an oxygen of the $\mathrm{PO}_{4}$. The O-P$O$ angles in the $\mathrm{PO}_{4}$ group show little deviation from tetrahedral because there is no $\mathrm{Sn}$ coordination to $\mathrm{PO}_{4}$ edges. Each oxygen atom of the $\mathrm{PO}_{4}$ group forms one strong bond to
Sn. Three of these oxygen atoms also form weaker bonds to $\mathrm{Sn}$ and the fourth forms a hydrogen bond with the hydroxyl group. The average P-O distance is $1.539 \AA$. Structural consideration of the $\mathrm{Sn}-\mathrm{PO}_{4}$ coordinations and the $\mathrm{PO}_{4}$ geometry imply that $\mathrm{Sn} . . \mathrm{O}$ bonds are predominantly ionic in tin phosphates.

16742. Schroeder, L. W., Prince, E., Hydrogen-bonded dimers in Tin(II) hydrogen phosphate, Acta Cryst. B32, Part 12, 3309-331 I (Dec. 1976).

Key words: hydrogen-bonded dimers; neutron diffraction; stannous hydrogen phosphate.

SnHPO 4 , monoclinic, $P 2_{1} / c, a=4.608(2), b=13.603(4), c$ $=5.823$ (2) $\AA, \beta=98.76$ (1) ${ }^{\circ}, Z=4$. This neutron diffraction study has shown that the $\mathrm{HPO}_{4}{ }^{2-}$ ions are linked together by two asymmetric hydrogen bonds $[d(\dot{\mathrm{O}} . . \mathrm{O})=2.560, d(\mathrm{O}-\mathrm{H})=$ $1.017 \AA,<\mathrm{O}-\mathrm{H}$...O $\left.=178.1^{\circ}\right]$ to form dimers. Tin-phosphate-oxygen coordination takes place primarily in layers with the hydrogen bonds occurring between these layers.

16743. Henderson, M. M., The Federal sector, Chapter in The Information Age: Its Development, Its Impact, D. P. Hammer, Ed., pp. 91-121 (The Scarecrow Press, Inc., Metuchen, NJ, 1976).

Key words: Federal library and information activities; library and information sciences; review.

This chapter reviews the significant accomplishments in library and information sciences in the Federal Government over a ten year period (1965-1975). Federal librarians and information scientists were faced with a number of problems but also offered some special promises: major support for innovative developments came from Federal sources, for example, and cooperative programs have resulted in resource sharing on a number of fronts. The chapter follows a chronological path to trace developments and activities; those discussed in different context in other chapters are not covered in detail in this one. A list of sources and recommended reading is included for the reader's reference.

16744. Stein, R. J., Electron transmission measurements of electron mean free path in supported thin films from $1.5 \mathrm{keV}$, Surf. Sci. 60, 436-444 (1976).

Key words: Auger-electron spectroscopy (AES); electron attenuation lengths; electron spectroscopy for chemical analysis (ESCA); electron transmission through thin films; inelastic electron mean free path; supported thin films.

Measurements are made of the transmission of medium energy electrons through in vacuo deposited films in order to determine the inelastic electron mean free path as a function of energy. Films of $\mathrm{Al}, \mathrm{Ge}$ and $\mathrm{Au}$ are deposited in small increments on 20-30 $\AA$ carbon substrates supported by "holey" carbon films. The no-loss electron current is measured for each thickness as a continuous function of incident energy in the range of 1-5 keV: Although this preliminary experiment does not result in a precise separation of elastic and inelastic scattering effects, the attenuation lengths estimated are in reasonable agreement with measured and calculated inelastic mean free paths. Elastic scattering cross sections appear to be smaller than estimated by simple theory.

16745. Gerhold, W. F., Corrosion behavior of ductile cast-iron pipe in soil environments, J. Am. Water Works Assoc. 68, No. 12, 5506-5510 (Dec. 1976).

Key words: carbon steel; corrosion; ductile cast-iron; soils; statistical analysis; underground.

Ductile cast-iron pipe was buried for up to fourteen years in a variety of soil environments. This final report, comparing its 
performance to that of carbon steel buried in the same soils, suggests the two substances corrode at nearly the same rates when encased in some soils. Different soils, however, alter the corrosion rates considerably for both materials.

16746. Bennett, H. S., Cantrell, C. D., Inclusions in cadmium telluride: Estimates for damage thresholds, J. Appl. Phys. 48, No. 2, 522-529 (Feb. 1977).

Key words: cadmium telluride; elastic compliance tensor; elastic moduli; extrinsic damage thresholds; high-power lasers; infrared materials; tensile stress.

One problem frequently encountered in high-power laser systems is the thermal extrinsic damage to the laser materials, which arises from absorbing inclusions. Absorbing inclusions are impurities with physical and optical properties which differ substantially from those of the host material. Such inclusions may absorb sufficient radiation from the incident laser beam to produce major stresses within the host. In this paper, estimates of the maximum tensile stress as a function of inclusion size, laser pulse width, and laser power are computed for the common precipitates in CdTe. Our computations suggest that the heating of such precipitates when subjected to power densities of about $100 \mathrm{MW} / \mathrm{cm}^{2}$ may produce stresses comparable to or greater than the breaking strength of the CdTe host.

\section{Gadzuk, J. W., Angle resolved Auger surface spectrosco- py, Surf. Sci. 60, 76-84 (1976).}

Key words: adsorption; angle resolved; Auger; chemisorption; electron spectroscopy; surfaces.

The angular distribution of electrons ejected in core-valencevalence Auger transitions of atoms chemisorbed on metal surfaces is considered theoretically. Since the valence electrons participating in the Auger transition are also involved in chemical bonding to the surface, these initial states contain information pertaining to the chemisorption bonding geometry. The role of the initial state symmetry in determining the angle resolved Auger surface spectrum (ARASS) is investigated through model calculations and is found to be small. Thus the ARASS is expected to be a smoothly varying function of angle with $\leqslant \pm 15$ percent modulations due to diffraction effects, in agreement with recent experimental results for $\mathbf{S}$ adsorbed on $\mathrm{Ni}(100)$.

16748. Penn, D. R., Electron mean free paths for free-electronlike materials, Phys. Rev. B 13, No. 12, 5248-5254 (June 15, 1976).

Key words: electron mean free path; free-electron-like metal; 100 to several $1000 \mathrm{eV}$.

Mean free paths for electrons in bulk jellium are calculated for electrons with energies from a few hundred to a few thousand $\mathrm{eV}$ and for values of $r_{s}$ for 1.5 to 5 where $r_{s}$ is the average distance between valence electrons measured in units of the Bohr radius. Account is taken of exchange and correlation effects in an approximate way. The present theory is compared to previous theories and to experiments on $\mathrm{Al}, \mathrm{Be}, \mathrm{Si}$, $\mathrm{SiO}_{2}$, and $\mathrm{Al}_{2} \mathrm{O}_{3}$, and in most cases the agreement between theory and experiment is quite good.

16749. Gadzuk, J. W., Vibrational excitation in photoemission spectroscopy of condensed molecules, Phys. Rev. B 14, No. 12, 5458-5465 (Dec. 15, 1976).

Key words: adsorption; molecules; photoelectron spectroscopy; surfaces; vibrational excitation.

Photoelectron spectra of gas-phase molecules display sharp vibrational structure. The envelope of the spectrum is determined by the Franck-Condon factor. On the other hand, photoelectron spectra of the same molecules, adsorbed or condensed onto metal surfaces show a broad band whose shape resembles the gas-phase Franck-Condon envelope but with no sharp structure. The smearing out of the vibrational structure is usually attributed to lifetime effects or site inhomogeneities. A new mechanism involving intrinsic phonon sidebands in photoemission from condensed molecules is suggested and the details of the theory are worked out. Experimental ultraviolet photoelectron spectra from condensed $\mathrm{CO}$ are considered in the light of this theory.

16750. Houck, J. C., Mercury-melting-line determination by latent heat method, J. Appl. Phys. 48, No. 2, 605-609 (Feb. 1977).

Key words: high pressure; latent heat detection; melting and freezing equilibrium; mercury.

The equilibrium pressure for the melting and freezing of mercury was observed for the temperature range $-38.834-0.023$ ${ }^{\circ} \mathrm{C}$ by latent heat detection. The corresfonding pressure range was $0.14-757.32 \mathrm{MPa}\left(\mathrm{MPa}=10^{6} \mathrm{~N} / \mathrm{m}^{2}\right)$. The least-squares fit was obtained for this range of pressure with a standard deviation of the residuals of $0.055 \mathrm{MPa}$ for pressure expressed as a third-order polynomial in temperature.

16751. Tsai, D. H., MacDonald, R. A., An atomistic view of shock wave propagation in a solid, (Proc. 5th European Conf. on Thermophysical Properties of Solids at High Temperatures, Moscow, USSR, May 18-21, 1976), High Temp. High Pressures 8, 403-418 (1976).

Key words: anharmonic crystal; computer simulation; energy transport; equation of state; interatomic potential; molecular dynamics; second sound; shock wave; stress relaxation; structural relaxation; thermal relaxation.

Molecular dynamical studies of the propagation of strong one-dimensional shock wave in a perfect fcc or bcc monatomic lattice in one, two, and three dimensions are reported. Various two-body interatomic potentials ranging from a harmonic potential to one which simulates that in $\alpha$-iron are used. The classical equations of motion for the atoms are solved numerically under appropriate initial and boundary conditions, and the properties of the lattice are obtained from averages of the atomic motion. With a realistic potential the shock wave velocity $u_{a}$ increases approximately linearly with increasing particle velocity $u_{p}$, in agreement with experiment. The results show the structure of the shock wave on an atomic scale, and give such details as the thickness of the shock front and the equilibration of stresses and energies in the compressed region. Under certain conditions structural relaxation accompanied by stress relaxation is also observed. The implications of some of these details on the determination of equation of state data from shock wave experiments are examined.

16752. Cheron, B., Scheps, R., Gallagher, A., Noble-gas broadening of the $6{ }^{2} P_{1 / 2}-7{ }^{2} S_{1 / 2}(377.6 \mathrm{~nm}) 6{ }^{2} P_{3 / 2}-7{ }^{2} S_{1 / 2}(535$ $\mathrm{nm}$ ) thallium lines, Phys. Rev. A 15, No. 2, 651-660 (Feb. 1977).

Key words: line broadening; satellites; thallium.

The shapes of the thallium (T1) 535- and 377.6-nm resonance lines broadened by 500-1500 torr of noble gases have been measured at $743 \mathrm{~K}$. The reported normalized emission intensities yield absorption coefficients in absolute units for all portions of the line. The shift and broadening of the Lorentzian-shaped line cores, the wavelengths of the transition to non-Lorentzian wings, wing shapes, and satellite positions, shapes, and intensities are reported. As an example, a pair of excited and ground-state interaction potentials are given for the Xe case to explain the shift, width, and intensities in all portions of the line wings. 
16754. Lind, M. A., Measurement of the absolute spectral response of detectors, Proc. of the Technical Program-Electro-Optical Systems . Design Conf. 1976-International Laser Exposition, New York, NY, Sept. 14-16, 1976, pp. 55-58 (1976).

Key words: absolute spectral response; detector uniformity; linearity; photodetectors; silicon detectors.

There are many parameters that affect the absolute spectral response of any photodetector. The question of how to measure these parameters and thereby characterize a detector is the subject of this paper. For brevity, this paper will confine itself to the discussion of the techniques used to measure those parameters which have the greatest potential effect on silicon photodiodes operated in the short circuit or current mode. In general, these same parameters aiso affect all other photodetectors to some extent.

16755. Johnson, C. R., The inertia of a product of two hermitian matrices, J. Math. Anal. Appl. 57, No. 1, 85-90 (Jan. 1977).

Key words: eigenvalue; hermitian matrix; inertia; stability.

Given the inertias of $H$ and $K$, hermitian and nonsingular, the precise set of possible inertias of $H K$ is determined. Several consequences are given.

16756. Hodgeson, J. A., Hughes, E. E., Schmidt, W. P., Bass, A. M., Methodology for standardization of atmospheric ozone measurements, Proc. Int. Conf. on Photochemical Oxidant Pollution and Its Control, Research Triangle Park, NC, Sept. 1217, 1976, EPA-600/3-77-001a, Ecological Research Series, 1, 3-12 (Environmental Sciences Research Laboratory, Research Triangle Park, NC, Jan. 1977).

Key words: ozone; potassium iodide; techniques; ultraviolet photometer.

Preliminary intercomparisons have been made among several techniques for the calibration of atmospheric ozone monitors. These procedures include the 1 percent neutral buffered potassium iodide method; a modification of this method employing 0.1 molar boric acid rather than the phosphate buffer; a 3 meter double-beam ultraviolet photometer; and gas phase titration. The potassium iodide reagent with boric acid gave a more stable color development and much closer agreement with the ultraviolet measurements than that obtained with the neutral buffered reagent. Ozone calibration data with the 3-meter photometer agreed within 1 and 2 percent with gas phase titration and ultraviolet photometric ozone measurements respec. tively made at the Environmental Protection Agency facility in Research Triangle Park, North Carolina.

16757. Shiloh, M., Gayer, B., Brinckman, F. E., Preparation of nitrides by active nitrogen. II. $\mathrm{Si}_{3} \mathrm{~N}_{4}, J$. Electrochem. Soc. 124, No. 2, 295-300 (Feb. 1977).
Key words: activation parameters; active nitrogen; iodine; kinetics; microwave discharge; nitride; plasma; reaction mechanism; silicon; synthesis; thin film; vapor transport.

A general method for the preparation of nitrides is described by which active nitrogen, excited in a microwave cavity, is subsequently reacted with $\mathrm{Sil}_{4}$ vapors formed in situ by passing iodine vapors over heated silicon powder. The temperature dependence of the deposition of $\mathrm{Si}_{3} \mathrm{~N}_{4}$ on polished $\mathrm{Si}$ wafers was measured and compared with calculated thermodynamic data of similar reactions with nonactive nitrogen. The kinetic measurements were related to the special flow characteristics of the system. The over-all reaction

$$
4(\mathrm{~N})_{g}+3\left(\mathrm{Sil}_{4}\right)_{g} \rightarrow\left(\mathrm{SiN}_{4}\right)_{s}+6\left(\mathrm{I}_{2}\right)_{g}
$$

was found to be exothermic. Two regions of different slopes were obtained from the Arrhenius plot

$$
\begin{aligned}
& \Delta E_{\left(280^{\circ}-450^{\circ} \mathrm{C}\right)}=-3070 \mathrm{cal} / \mathrm{mole} \\
& \Delta E_{\left(450^{\circ}-600^{\circ} \mathrm{C}\right)}=-8600 \mathrm{cal} / \mathrm{mole}
\end{aligned}
$$

The calculated temperature dependence of the enthalpy change of the corresponding reaction with nonactive nitrogen was shown to be almost constant in the range studied. Similar values of negative activation energy were obtained for the assumed second-order rate-determining reaction: $\mathrm{N}+\mathrm{Sil}_{4} \rightarrow \mathrm{SiN}$ $+2 \mathbf{l}_{\mathbf{2}}$.

16758. Hummer, D. G., Line formation in expanding atmospheres, (Proc. IAU Symp. No. 70, on Be and Shell Stars, Bass River, MA, Sept. 1975), Paper in Be and Shell Stars, A. Slettebak, Ed., pp. 281-312 (Reidel, Dordrecht-Holland, 1976).

Key words: high speed aerodynamics; radiative transfer; spectral line formation; stellar atmospheres.

The current state of understanding of line formation processes in expanding atmospheres is reviewed, and the successes and limitations of current computational techniques are summarized. Some results for differential rotation are also given, although very little work has been done in this area. Special attention is given to the severe difficulties that are encountered in inferring the structure of rapidly expanding or rotating atmospheres from observed line profiles because of the failure under these conditions of the Eddington-Barbier relation in integrated light; the value in this respect of continuum and interferometric observations is emphasized.

16759. Wineland, D. J., Allan, D. W., Glaze, D. J., Hellwig, H. W., Jarvis, S., Jr., Results on limitations in primary cesium standard operation, IEEE Trans. Instrum. Meas. IM-25, No. 4, 453-458 (Dec. 1976).

Key words: cesium standard; clock, operating; magnetic shielding; microwave feed; primary cesium standard.

We report on the most recent design changes in our two primary cesium standards, their current operational use, results obtained, and limitations. NBS-4, the shorter device with an interaction length of $L=0.52 \mathrm{~m}$, has been extensively used for many months as a clock. After improvements in the magnetic shielding and microwave feed, we have obtained $\sigma_{y}$ ( 1 week 
$<\tau<2$ weeks $)=7 \times 10^{-15}$ in a $10-\mathrm{Hz}$ bandwidth for its frequency stability. NBS-6, the longer, more accurate device ( $L=3.75$ $\mathrm{m}$ ), features a linewidth ( $\widetilde{<} 30 \mathrm{~Hz}$ ), which is believed to be the narrowest linewidth ever reported for a cesium device. NBS-6 has been operated to give a short-term stability $\sigma_{y}\left(\begin{array}{ll}1 & s)=7\end{array}\right.$ $\times 10^{-13}$ in a $10-\mathrm{Hz}$ bandwidth and has capability of easy beam reversal. The current and past rates of the International Atomic Time (TAI) in terms of our primary cesium standards are reported and compared with the results of other laboratories. With NBS-6 we have calibrated the rate of the NBS time scale of an uncertainty of $0.9 \times 10^{-13}$.

16760. Lutz, G. J., Activation analysis with a californium-252 source, (Proc. Educational Seıninar on Use of Californium252 in Teaching and Research, Karlsruhe, Germany, Apr. 1418, 1975), IAEA-SR-3/3, Chapter in Some Physical, Dosimetry and Biomedical Aspects of Californium-252, pp. 7387 (International Atomic Energy Agency, Vienna, Austria, 1976).

Key words: activation analysis; californium-252; inland waters and sediments; in vivo analysis; mineral exploration; nuclear safeguards; oceanography; on-stream analysis; well logging.

Aside from the great disparity in fluxes, neutron activation analysis with a ${ }^{252} \mathrm{Cf}$ source differs in two ways from the more traditional methods with a reactor. Firstly, in situ analyses require that the bombarding source and detector conform to the requirements of the sample, e.g. material on a conveyor belt or minerals in a bore hole, and hence frequently use ${ }^{252} \mathrm{Cf}$ sources; secondly, prompt capture gamma rays, the photons produced virtually simultaneously with the capture of a neutron by the nucleus, are frequently used for detection in californium activation analysis. They are rarely used in activation analysis with a reactor. This review discusses the major "field" applications of ${ }^{252} \mathrm{Cf}$ activation analysis-on-stream analysis, well logging, terrestrial mineral exploration, in vivo analysis, oceanography, studies of inland waters and sediments, and for nuclear safeguards. This is followed by a discussion of more conventional laboratory activation analysis with the isotope source.

16761. Richmond, J. C., A simple test for evaluating the spectral responsivity of monochrome television cameras, LESPRPT-0310.00, 24 pages (U.S. Department of Justice, Law Enforcement Assistance Administration, National Institute of Law Enforcement and Criminal Justice, Washington, DC, Feb. 1977).

Key words: diffuser; interference filters; spectral responsivity; spectral transmittance; television camera tubes; television cameras; test methods.

This report describes a light source designed for measuring the spectral responsivity of monochrome television cameras, and a simple procedure for making such measurements. The light from a quartz-halogen lamp is diffused and passes through an array of twelve interference filters, of $50 \mathrm{~nm}$ bandpass each, with peak wavelengths at about $50 \mathrm{~nm}$ intervals from 400 to $950 \mathrm{~nm}$. The spectral transmittance of the diffuser, and of each interference filter-diffuser combination was measured, and factors are supplied to compute the radiance of the light transmitted by each filter from the measured luminance of the diffuser.

A step wedge, with 21 steps, in which the ratio of the transmittance of adjacent steps is about $\sqrt{2}$, is located below the array of interference filters. The gamma of the television camera is evaluated by use of the step wedge. The voltage of the video signal produced when the image of each filter impinges on the face of the camera tube is measured, and divided by the radiance of the filter raised to the gamma power, to obtain the relative spectral responsivity of the camera at the peak wavelength of the filter. The results are normalized by dividing each value by the maximum value obtained, and the quotients plotted as a function of wavelength to produce the spectral responsivity curve of the camera.

16762. Jenkins, E. B., Snow, T. P., Upson, W. L., Starrfield, S. G., Gallagher, J. S., Friedjung, M., Linsky, J. L., Anderson, R., Henry, R. C., Moos, H. W., Copernicus observations of Nova Cygni 1975, Astrophys. J. 212, No. 1, 198-202 (Feb. 15, 1977).

\section{Key words: Novae; OAO-3; spectra-ultraviolet.}

Near-ultraviolet radiation from Nova Cygni 1975 was detected by the Copernicus satellite on five occasions from 1975 September 1 to 1975 September 9. The nova was not seen in the UV after this date. The principal result was the observation of a broad emission feature from the $\mathrm{Mg} \|$ doublet at $2800 \AA$. The absence of strong UV radiation at shorter wavelengths suggests that these lines are produced by collisional excitation in the outer layers of an expanding shell with $T_{e} \sim 4000 \mathrm{~K}$. The absence of observed emission lines from highly ionized species indicates that the amount of material with $4.4<\log T<5.7$ is less than $10^{-3}$ times that which produces the $\mathrm{Mg}$ II emission. The continuum flux in the near-UV decreased as the nova evolved, showing that the total luminosity decreased as the nova faded in the visible.

16763. Pallett, D. S., Bartel, T. W., Voorhees, C. R., Recent reverberation room qualification studies at the National Bureau of Standards, Noise Control Eng. 7, No. 2, 71-80 (Sept.Oct. 1976).

Key words: acoustical measurements; acoustics; acoustics facility; automated sound measurement; computer-controlled instrumentation; reverberation room; reverberation room qualification; sound power.

A computer-controlled instrumentation system has been implemented to ascertain room "qualification" (per ANS S1.211972) for sound power measurements, to measure radiated sound power, and to measure acoustic absorption in the NBS reverberation room. Preliminary studies performed with this system indicate the effectiveness of rotating diffuser elements and the use of a 12-microphone array in achieving a qualified condition. Initial sound power measurements made under qualified conditions appear to show a measurement repeatability that is generally consistent with and within the bounds of the uncertainties indicated in Table 1 of $\$ 1.21$.

16764. Voorhees, C. R., Pallett, D. S., Laboratory measurements in acoustics, Noise Control Eng. ?, No. 2, 52-56 (Sept.Oct. 1976).

Key words: acoustical measurements; acoustics; acoustics facilities; laboratory facilities; noise measurement; sound measurement.

A detailed questionnaire on the topic of "Laboratory Measurements of Noise Emission and of Acoustical Properties of Building Elements and Materials" was initiated by the Board of Directors of the Institute of Noise Control Engineering in September 1974. Topics dealt with cover the use of facilities for sound power, acoustical absorption, transmission loss, and impact noise measurements, and the use of reference sound sources and anechoic chambers. Results of the survey, which are presented and briefly discussed, indicate the extent and type of activity in these areas. They also reveal a general feeling among respondents that acoustic measurements could be made more accurate with the implementation or improvement of existing facility qualification (performance) criteria, calibra- 
tion data, measurement standards, and measurement methodology.

16765. Lawton, S. A., Novick, S. E., Broida, H. P., Phelps, A. V., Quenching of optically pumped $\mathrm{O}_{2}\left(b^{1} \Sigma_{y}{ }^{+}\right)$by ground state $\mathrm{O}_{2}$ molecules, J. Chem. Phys. Letters to the Editor 66, No. 3, 1381-1382 (Feb. 1, 1977).

Key words: laser; metastable; oxygen molecules; photoluminescence; quenching.

A flashlamp-pumped tunable pulsed dye laser operating near the head of the $\mathrm{O}_{2}$ atmospheric $B$ band at $688 \mathrm{~nm}$ was used to excite the first vibrational level of the $b^{1} \Sigma$ state. The quenching rate constant was determined from the dependence of the $b^{1} \Sigma$ decay constant on $\mathrm{O}_{2}$ density. The rate for quenching of the $b^{1} \Sigma$ state by $\mathrm{O}_{2}$ was found to be $(3.8 \pm 0.3)$ $\times 10^{-17} \mathrm{~cm}^{3}$ molecule ${ }^{-1} \mathrm{sec}^{-1}$.

16766. Holmer, C. I., Qualification of an acoustic research facility for sound power determination, Noise Control Eng. 7, No. 2, 87-92 (Sept.-Oct. 1976).

Key words: acoustic test facility; noise; noise measurement; reverberation room; sound power measurement; standard test procedures for sound power measurement.

Modifications to a test facility that were required in order to bring the facility to within the qualification requirements of American National Standard S1.21 for sound power measurement of sources emitting pure tones are described. The facility is unique in that two nearly identical rooms, of substantially smaller volume than recommended (i.e. $90 \mathrm{~m}^{3}$ ), were found to be "qualifiable" with suitable modifications. The modifications included the use of an eight microphone array, fixed and rotating diffusers, low frequency absorption and multiple source locations. The modifications, and some of their objective effects on the qualification measurements, are discussed.

16767. Cezairliyan, A., McClure, J. L., Temperature and energy of $\boldsymbol{\alpha} \rightarrow \boldsymbol{\beta}$ transformation in hafnium-3\% zirconium, High Temp. High Pressures 8, 461-467 (1976).

Key words: hafnium; high-speed measurements; high temperature; solid-solid phase transformation; thermodynamics.

Measurements of the temperature and energy of the $\alpha \rightarrow \beta$ transformation of hafnium containing $3 \cdot 12 \%$ zirconium using a millisecond-resolution pulse-heating technique are described. The results yield $2012 \mathrm{~K}$ for the transformation temperature and $33 \cdot 1 \mathrm{~J} \mathrm{~g}^{-1}$ for the transformation energy. The normal spectral emittance (at $0.65 \mu \mathrm{m}$ ) at the transformation point is determined to be $0 \cdot 42$. Estimated maximum inaccuracies of the measured properties are: $10 \mathrm{~K}$ for the transformation temperature, 10 percent for the transformation enery, and 5 percent for the normal spectral emmittance.

16768. Brown, P. W., Berger, R. L., Clifton, J. R., Frohnsdorff, G., Limitations to fly ash use in blended cements, Proc. $4 \mathrm{th}$ Int. Ash Utilization Symp., St. Louis, MO, Mar. 24-25, 1976, pp. 518-529 (Energy Research \& Development Administration, Morgantown, WV, 1976).

Key words: blended cements; fly ash; specifications.

The production and utilization of blended cements containing fly ash is less than one million tons a year in the U.S. This accounts for only about one percent of the cement produced. It has been demonstrated that utilization of fly ash with portland cement to make blended cement results in energy and raw materials savings almost directly proportional to the amount of ash used. In view of the benefits derived from ash utilization in this way the level of production of blended cement may be expected to increase. However, additional property data need to be developed to address uncertainties and misconceptions regarding the performance of blended cements. Facilitation of blended cement use requires the development of data to be used by voluntary consensus standards organizations as a basis for standard test procedures and specifications.

16769. Chang, S. S., Stored energy in poly(vinyl chloride) from pelletizing process, J. Chem. Thermodyn. 9, 189-197 (1977).

Key words: adiabatic temperature drift; enthalpy; glass transition; heat capacity; pelletization; poly (vinyl chloride), pressure densification; relaxation; stored energy; strain energy.

From the heat capacities measured from 5 to $375 \mathrm{~K}$ on three poly(vinyl chloride) samples, evidence of residual strain energies stored in the sample appeared near the glass-transition temperature in the pelletized materials. The three samples were derived from suspension- and bulk-polymerized powder stocks and were measured either pelletized or as received. The stored energies began to be released at temperatures about 30 to 40 $\mathrm{K}$ below the glass-transition temperature of about $355 \mathrm{~K}$. The stored energies were estimated to be $(2.7 \pm 0.1)$ and $(3.5 \pm$ 0.1 ) $\mathrm{J} \mathrm{g}^{-1}$ for samples pelletized under 140 and $500 \mathrm{MPa}$ of pressure, respectively.

16770. Kusuda, T., Energy calculations for energy conservation design of buildings, APEC J., pp. 18-22 (Automated Procedures for Engineering Consultants, Dayton, $\mathrm{OH}$, Winter 1976-1977).

Key words: computerized energy analysis; energy conservation standards; new building design; retrofit design.

Since energy calculation is an essential element of energy conservation standards, an accurate and comprehensive yet "easy-to-use" computer program for such calculation is most desirable. This paper reviews the existing state of energy-analysis procedures and identifies the areas for needed improvement. The paper also points out that the computational procedures suitable for new building design could be simpler than those required to simulate the energy consumption performance of existing buildings.

Standardization of input and output is also considered a key factor for the "easy-to-use" issue for the implementation of computerized energy calculation for building energy conservation standards.

16771. Scheide, E. P., Durst, R. A., Indirect determination of sulfate in natural waters by ion-selective electrode, Anal. Lett. 10, No. 1, 55-65 (1977).

Key words: environmental analysis; ion-selective electrode; lead electrode; natural waters; rainwater; seawater; sulfate.

The indirect determination of sulfate in natural waters (seawater and simulated rainwater) was accomplished by titration with lead nitrate solution using the lead ion-selective electrode as the titration sensor. The indirect determination of sulfate is based on the formation of $\mathrm{PbSO}_{4}$ which is quantified by measurements with a lead electrode. The measurements were carried out in 80 percent isopropanol using a double-junction reference electrode. The data evaluation was performed by a Gran plot of the titration of sulfate samples with standard lead nitrate. Samples containing between 2 and 100 ppm sulfate concentration were analyzed directly, while samples of higher sulfate concentration were diluted prior to analysis. The seawater samples were diluted 100 -fold prior to analysis.

16772. Durst, R. A., Tris(hydroxy methyl)aminomethane physiologic-pH buffer-Liquid-junction error, Clin. Chem. 23, No. 2, 298 ( 1977). 
Key words: clinical $\mathrm{pH}$; liquid junction; $\mathrm{pH}$ analyzers; $\mathrm{pH}$ error; $\mathrm{pH}$; physiologic $\mathrm{pH}$; tris $\mathrm{pH}$ buffer.

Studies using clinical blood-pH instrumentation confirm the reported existence of a residual liquid junction potential which produces an error in the observed $\mathrm{pH}$ value. The magnitude of the effect depends on the type of liquid junction and may include contributions from errors in instrument temperature control. The buffer is useful as a secondary standard of $\mathrm{pH}$ for the detection of instrumental malfunctions in $\mathrm{pH}$ analyzers.

16773. Scheide, E. P., The piezoelectric-crystal mercury dosimeter, Phys. Teach. 15, No. 1, 47-51 (Jan. 1977).

Key words: environmental analysis; industrial hygiene; mercury vapor; personal dosimeter; piezoelectric sensors; quartz crystal microbalance.

A personal dosimeter for mercury vapor in air based on the use of a piezoelectric sensor with a selective coating has been developed and evaluated. The philosophy behind the use of such devices is explained along with the basic physics concerning this scientific principle. The sensor is a gravimetric device which indicates an integrated total exposure to mercury vapor. Calibration curves are given in the industrial hygiene range of interest and the device was evaluated from an industrial hygiene point of view. Short summaries are given describing current research and new directions in this field.

16774. McKinney, J. E., Application of hole theory to estimate the pressure-induced densification of polymers, Ann. N.Y. Acad. Sci. 279, 88-93 (Oct. 15, 1976).

Key words: compressibility; densification; glass; glass transition; hole theory; liquid; polymer; pressure; thermodynamic.

Forming a glass by isobaric cooling at an elevated pressure produces a larger density than that obtained by cooling at the same rate at atmospheric pressure. Simple phenomenological theory is used to obtain a relation to estimate the densification from glass transition properties obtained by experiment. It is shown how the hole theory of Simha and Somcynsky may be used to facilitate the estimation of densification through the application of a universal reduced function that replaces the quantity most difficult to obtain experimentally in this relation.

16775. Glaze, D. J., Hellwig, H., Allan, D. W., Jarvis, S., Jr., NBS-4 and NBS-6: The NBS primary frequency standards, Metrologia 13, 17-28 (Feb. 1977).

Key words: bias uncertainty; frequency accuracy; frequency bias; frequency stability; primary frequency standard; time dispersion.

The NBS primary frequency standard NBS-4 has been operating since January 1973. NBS-5 operated from January 1973 until March 1974. At this time NBS-5 was modified significantly and redesignated NBS- 6 . The extent and character of these design changes are discussed. NBS-6 operation and evaluation began in March 1975. Results obtained from NBS4 , NBS-5 and NBS- 6 are given, along with intercomparisons of some significant parameters.

During 1975, NBS-4 was operated as a clock and a time dispersion of $2.5 \mathrm{~ns}$ was obtained for one day. The NBS approach to long term clock operation of the primary standards is discussed. These techniques will probably involve "accuracy servo" methods, and may lead to very accurate clocks with time dispersion less than $1 \mathrm{~ns}$ per day.

16776. Bergquist, J. C., Lee, S. A., Hall, J. L., Saturated absorption with spatially separated laser fields: Observation of optical "Ramsey" fringes, Phys. Rev. Lett. 38, No. 4, 159-162 (Jan. 24, 1977).
Key words: nonlinear spectroscopy; Ramsey fringes; saturated absorption.

We have observed Ramsey's interference fringes in the optical region using saturated-absorption techniques in a fast atomic beam. We discuss their physical origin and describe an optical configuration that guarantees fringes of high symmetry. This technique, with its high-resolution potential, should lead to dramatic improvements in spectral measurements.

16777. Grant, W. H., Smith, L. E., Stromberg, R. R., Radiotracer techniques for protein adsorption measurements, J. Biomed. Mater. Res. Symp. 8, 33-38 (1977).

Key words: adsorption; proteins; radiotracer; techniques.

Factors which contribute to measurement errors associated with the use of radiotracers to measure protein adsorption are considered. Techniques for removal of excess adsorbent solution and for estimation of surface area are described. Artifacts induced by the incorporation of a radio-label both by specific adsorption of the labeling atom and by changes in the protein are discussed.

16778. Bridges, J. M., Ott, W. R., Vacuum ultraviolet radiometry. 3: The argon mini-arc as a new secondary standard of spectral radiance, Appl. Opt. 16, No. 2, 367-376 (Feb. 1977).

Key words: argon; light source; mini-arc; radiometry; spectral radiance; standard; ultraviolet.

A miniature argon arc has been designed and tested as a new transfer standard of spectral radiance for the wavelength range from $114 \mathrm{~nm}$ to $330 \mathrm{~nm}$. Calibration has been performed using two primary standard sources: the hydrogen arc from $130 \mathrm{~nm}$ to $330 \mathrm{~nm}$ and the blackbody line radiator from $114 \mathrm{~nm}$ to 130 $\mathrm{nm}$. The mini-arc provides an intense, stable, and reproducible uv continuum with dc power requirements of less than $1.5 \mathrm{~kW}$. The arc characteristics have been investigated, and the sensitivity of the radiant power output to various operating parameters has been measured. The rms uncertainty in the spectral radiance is estimated to be 5.3 percent above $140 \mathrm{~nm}$ and 10.1 percent between $114 \mathrm{~nm}$ and $140 \mathrm{~nm}$, due primarily to uncertainties in the primary standard sources.

16779. Lin, S. L., Bardsley, J. N., Monte Carlo simulation of ion motion in drift tubes, J. Chem. Phys. 66, No. 2, 435-445 (Jan. 15, 1977).

Key words: drift tube; ion; Monte-Carlo; swarm; theory; velocity distribution.

The motion of a swarm of ions in a uniform electric field is studied by simulating the motion of a single ion through many collisions with neutral atoms in order to obtain the drift velocity, average energy, and velocity distribution for the ions. For $\mathrm{K}^{+}$ions in $\mathrm{He}$ at low field strengths, the results agree well with the solutions of the Boltzmann equation by Kumar and Robson; and for $\mathrm{K}^{+}$in $\mathrm{Ar}$ at all field strengths, the computed mobilities demonstrate that the Viehland-Mason moment method can give useful results, especially if carried through to third order. The velocity distributions computed for $\mathrm{O}^{+}$ions in $\mathrm{He}$ and $\mathrm{Ar}$ are used in the accompanying paper by Albritton et $a l$., to analyze drift tube measurements of $\mathrm{O}^{+}$reaction rates. Significant deviations from the Maxwell-Boltzmann form have been found and are seen to have important effects in that application. Velocity distributions have also been obtained for $\mathrm{Li}^{+}$ in He. The sensitivity of ionic mobilities to changes in the ionatom interaction potential is examined with particular reference to $\mathrm{K}^{+}$ions in $\mathrm{Ar}$. 
16780. Hardy, S. C., A grain boundary groove measurement of the surface tension between ice and water, Philos. Mag. 35, No. 2, 471-484 (Feb. 1977).

Key words: grain boundary groove; ice-water interface; icewater surface tension; Nash-Glicksman theory; surface energy.

The surface tension between ice and water has been measured by observations of the equilibrium shape of grain boundary grooves at an interface stabilized by an imposed temperature gradient. The experiments have been designed to minimize the perturbing effects of heat flow in the cell walls which contain the samples. The observed grooves are in agreement with the theory of Nash and Glicksman (1971) which predicts groove shapes for the case of unequal thermal conductivities in the two phases. The measurements give a value of $29.1 \pm 0.8 \mathrm{~mJ} \mathrm{~m}^{-2}$ for the ice-water surface tension.

16781. Okabe, H., Photodissociation of thiophosgene, J. Chem. Phys. 66, No. 5, 2058-2062 (Mar. 1, 1977).

Key words: $\operatorname{CS}\left(A^{1} \pi\right)$; photodissociation; thiophosgene; $\Delta H f^{\circ}(\mathrm{SCCl}) ; \Delta H f^{\circ}\left(\mathrm{SCCl}_{2}\right)$.

The photolysis of thiophosgene produces $\operatorname{CS}\left(A^{1} \pi\right)$ below the incident wavelength $(1270 \AA)$ from which $\Delta H f^{\circ}{ }_{0}\left(\mathrm{SCCl}_{2}\right) \leqslant 7.92$ $\pm 1 \mathrm{kcal} \mathrm{mol}^{-1}\left(33.1 \pm 4 \mathrm{~kJ} \mathrm{~mol}^{-1}\right)$ is derived. The quantum yield for the production of $\mathrm{Cl}$ atoms has been determined from the amounts of $\mathrm{HCl}$ produced from the photolysis of thiophosgene-heptane mixtures. At $2537 \AA$ the yield is unity over the pressure region $0.4-80$ torr $(0.05-10 \mathrm{kPa})$ of thiophosgene, indicating that the primary photochemical process is almost entirely $\mathrm{SCCl}+\mathrm{Cl}$. Both at 3660 and 4358 $\AA$ the quantum yield of $\mathrm{Cl}$ production increases with a decrease in thiophosgene pressure and is $0.90 \pm 0.17$ and $0.38 \pm 0.19$. respectively, as the pressure approaches zero. From the pressure dependence of the quantum yield the lifetime of the excited state ${ }^{1} A_{2}$ is estimated to be about $55 \mathrm{nsec}$ at $4358 \AA$ and about $6 \mathrm{nsec}$ at $3660 \AA$. The photolysis data of the ${ }^{1} A_{2}$ state of thiophosgene are correlated with the fluorescence lifetime measured previously. $D^{\circ}{ }_{0}(\mathrm{SCCl}-\mathrm{Cl})=63.4 \pm 0.5 \mathrm{kcal}$ $\mathrm{mol}^{-1}\left(265.3 \pm 2 \mathrm{~kJ} \mathrm{~mol}^{-1}\right)$ and $\Delta H f^{\circ}{ }_{0}(\mathrm{SCCl})=43 \pm 1 \mathrm{kcal}$ $\mathrm{mol}^{-1}\left(180 \pm 4 \mathrm{~kJ} \mathrm{~mol}^{-1}\right)$ are derived. The photochemistry of thiophosgene is compared with that of phosgene and formaldehyde. A new method of $\mathrm{Cl}$ isotopic enrichment is suggested.

16782. Anderson, W. E., Davis, R. S., Measurement of ac insulation losses at cryogenic temperatures, IEEE Trans. Elec. Insulation EI-12, No. 1, 51-54 (Feb. 1977).

Key words: cryogenic; dielectric loss; dissipation factor; high voltage; low temperature polymer.

The design of superconducting high voltage transmission lines requires engineering data which, until recently, have been largely unavailable. The selection of a suitable dielectric for a tape-insulated ac cryogenic cable, for example, requires the knowledge of insulation dissipation factors at high voltage, which are typically $20 \times 10^{-6}$ or smaller. We present here dissipation factor measurements made on several dielectric tapes under consideration by a superconducting power transmission line project as well as on epoxies which appear mechanically suitable as low-temperature bushing material. The measurement technique and instrumentation are described.

16783. Braun, W., Tsang, W., Mechanism of alkyl halide photolysis by a pulsed $\mathrm{CO}_{2}$ TEA laser, Chem. Phys. Lett. 44, No. 2, 354-359 (Dec. 1, 1976).

Key words: alkyl halides; $\mathrm{CO}_{2}$ laser; infrared; kinetics; mechanisms; photochemistry; pyrolysis.
A $\mathrm{CO}_{2}$ TEA laser has been used to photolyze dilute samples of various alkyl halides in helium. The mechanism of the high intensity infrared photolysis of these molecules involves the decomposition of molecules into molecular or radical fragments. The reaction pathway is always dissociation into the lowest thermal dissociation channel(s) of the molecule photolyzed. Products from the initial process are also photo-dissociated by the laser pulse and their decomposition pathways are similarly governed. The molecules being photolyzed are not thermally equilibrated with the bath or with each other and the molecular-specific nature of the laser excitation is demonstrated.

16784. Goodman, S., Shier, D., On designing a reliable hierarchical structure, SIAM J. Appl. Math. 32, No. 2, 418 430 (Mar. 1977)

Key words: dynamic programming; graph; network; organization; probability; reliability; trees.

This paper considers the design and analysis of a class of managerial structures which are perhaps best illustrated by a spy network. The problem is formulated as a reliability problem on organizational trees, and two probabilistic performance measures are studied. With respect to either measure, it is possible to analyze the value of any given hierarchical structure. In addition, optimal organizational designs can be synthesized with respect to either criterion using for the one a dynamic programming approach and for the other a graph-theoretic solution method.

16785. Manning, R. G., Kurylo, M. J., Flash photolysis resonance fluorescence investigation of the temperature dependencies of the reactions of $\left.\mathrm{Cl}^{2} \mathrm{P}\right)$ atoms with $\mathrm{CH}_{4}, \mathrm{CH}_{3} \mathrm{Cl}$, $\mathrm{CH}_{3} \mathrm{~F}, \mathrm{CH}_{3} \mathrm{~F}^{\dagger}$, and $\mathrm{C}_{2} \mathrm{H}_{6}, J$. Phys. Chem. 81, No. 4, 291-296 (1977).

Key words: chemical kinetics; chlorine atoms; flash photolysis; hydrogen metathesis methanes; resonance fluorescence; vibrational excitation.

The flash photolysis resonance fluorescence technique was employed to investigate the temperature dependencies of the reactions $\mathrm{Cl}+\mathrm{CH}_{4} \rightarrow \mathrm{HCl}+\mathrm{CH}_{3}\left(k_{1}\right) ; \mathrm{Cl}+\mathrm{CH}_{3} \mathrm{Cl} \rightarrow \mathrm{HCl}+$ $\mathrm{CH}_{2} \mathrm{Cl}\left(k_{2}\right) ; \mathrm{Cl}+\mathrm{CH}_{3} \mathrm{~F} \rightarrow \mathrm{HCl}+\mathrm{CH}_{2} \mathrm{~F}\left(k_{3}\right) ; \mathrm{Cl}+\mathrm{CH}_{3} \mathrm{~F} \rightarrow \rightarrow \mathrm{HCl}$ $+\mathrm{CH}_{2} \mathrm{~F}\left(k_{3}^{\dagger}\right) ; \mathrm{Cl}+\mathrm{C}_{2} \mathrm{H}_{6} \rightarrow \mathrm{HCl}+\mathrm{C}_{2} \mathrm{H}_{5}\left(k_{4}\right)$. The following rate expressions were obtained in units of $\mathrm{cm}^{3}$ molecule ${ }^{-1} \mathrm{~s}^{-1}$ : $k_{1}(218-322 \quad \mathrm{~K})=(7.93 \pm 1.53) \times 10^{-12} \quad \exp [-(2529 \pm$ $101) / R T] ; k_{2}(233-322 \mathrm{~K})=(3.36 \pm 0.71) \times 10^{-11} \exp [-(2484$ $\pm 113) / R T] ; \quad k_{3}(216-296 \quad \mathrm{~K})=(4.79 \pm 1.05) \times 10^{-12}$ $\exp [-(1535 \pm 107) / R T] ; \quad k_{4}(222-322 \quad \mathrm{~K})=(7.29 \pm 1.23) \times$ $10^{-11} \exp [-(121 \pm 87) / R T]$ where $R=1.987 \mathrm{cal} \mathrm{deg}^{-1} \mathrm{~mol}^{-1}$. At 227 and $296 \mathrm{~K} k_{3} \uparrow / k_{3}$ was observed to be $\leqslant 1$...

16786. Raveché, H. J., Metastable states in the Lennard-Jones fluid, Ann. N.Y. Acad. Sci. 279, 36-42 (Oct. 15, 1976).

Key words: algorithm; Lennard-Jones; metastable states; Monte Carlo.

Metastable states associated with the fluid-solid transition in the classical Lennard-Jones system are simulated by means of the Monte Carlo algorithm in statistical mechanics. The simulations are concerned with both the thermal and structural properties of undercooled or overcompressed monatomic fluids

16787. Tung, M. S., Characterization and modification of pe. alselective properties of apatite membranes, J. Dental Res. 55, Spec. Issue D, D77-D85 (1976).

Key words: apatites; caries mechanism; caries prevention; membrane potentials; permselective properties; surface properties. 
Compressed apatite disks were used as models for tooth enamel. Their permselective properties were studied as functions of the $\mathrm{pH}$ of the gradient solutions, the composition of the apatites, and the pretreatments with anionic phosphate compounds and cationic proteins. The results are discussed in relation to the caries mechanisms.

16788. Finnegan, T. F., Holdeman, L. B., Wahlsten, S., Microwave phenomena in thin-film Josephson junctions coupled to a contiguous microstrip resonator, IEEE Trans. Magn. MAG-13, No. 1, 392-395 (Jan. 1977).

Key words: coherent microwave emission; e/h voltage standard; Josephson junction; microstrip resonator; microwave coupling; parametric plasma oscillation; thin-film device.

A half-wavelength microstrip resonator has been used to couple microwave radiation between Josephson junctions and an external $50 \Omega$ transmission line, and various microwave properties of these resonator-coupled junction devices have been studied. The advantages of these devices in applications including coherent radiation emission, $2 \mathrm{e} / \mathrm{h}$ precision voltage sources, and parametric plasma-related effects are described.

16789. Lambropoulos, M., Moody, S. E., Design of a threestage alkali beam source, Rev. Sci. Instrum. 48, No. 2, 131 134 (Feb. 1977)

Key words: atomic beam; effusive oven; sodium beam.

A three-stage effusive alkali beam source is described in detail. Among the advantages of this device over ordinary effusive ovens are greatly increased intervals between refillings, and the production of beams with significantly reduced alkali dimer densities.

16790. Grundl, J. A., Spiegel, V., Eisenhauer, C. M., Heaton, H. T. Il, Gilliam, D. M., Bigelow, J., A californium-252 fission spectrum irradiation facility for neutron reaction rate measurements, Nucl. Technol. 32, 315-319 (Mar. 1977).

Key words: calibration; californium-252; cross sections; design; errors; fission neutrons; irradiation devices; measuring methods; neutron reactions; neutron sources.

Spontaneous fission sources of ${ }^{252} \mathrm{Cf}$, lightly encapsulated and with neutron source strengths approaching $10^{10} \mathrm{n} / \mathrm{s}$, have been developed especially for integral cross-section measurements and neutron reaction rate calibrations. An irradiation facility at the National Bureau of Standards makes use of these sources in two well-investigated geometries. A free-field neutron flux in the range of $10^{7} \mathrm{n} /\left(\mathrm{cm}^{2} \mathrm{~s}\right)\left(10^{5} \mathrm{n} / \mathrm{mm}^{2} \cdot \mathrm{s}\right)$ and fluences of up to $10^{13} \mathrm{n} / \mathrm{cm}^{2}\left(10^{11} \mathrm{n} / \mathrm{mm}^{2}\right)$ are established at the facility based only on a distance measurement and the absolute source strength of the national standard $\mathrm{Ra}-\mathrm{Be}$ photoneutron source. The error in the ${ }^{252} \mathrm{Cf}$ source strength $( \pm 1.1 \%)$ dominates the total free-field flux uncertainty of \pm 1.4 percent $(1 \sigma)$. Neutron scattering effects in the source capsule and support structures and neutron return from concrete and earth boundaries have been calculated and investigated experimentally. In the worst case, they contribute \pm 0.7 percent to the total flux response uncertainty for all observed neutron reaction rates, including those with sensitivity to low-energy neutrons.

16791. Hanley, H. J. M., Prediction of the viscosity and thermal conductivity coefficients of mixtures, Cryogenics 16, No. 11 , 643-65 I (Nov. 1976).

Key words: corresponding states; dense liquid; mixture; modified Enskog theory; prediction; thermal conductivity coefficient; viscosity coefficient.

A corresponding states procedure to predict the viscosity and thermal conductivity coefficients of a pure fluid or mixture is discussed. We show the transport properties of a fluid or mixture can be calculated to within experimental error given only corresponding values for a reference fluid and equation of state data. With methane, as the reference fluid, we consider nitrogen, ethane, propane, butane, carbon dioxide, and mixtures of these fluids. LNG is also included. It is shown that the conventional corresponding states approach is not sufficient to predict correctly the transport properties. The effect of internal degrees of freedom on the thermal conductivity coefficient and the enhancement in the critical region for this coefficient is discussed briefly.

16792. Haynes, W. M., Simplified magnetic suspension densimeter for absolute density measurements, Rev. Sci. Instrum. 48, No. 1, 39-41 (Jan. 1977).

Key words: absolute measurements; barium ferrite buoy; densimeter; experimental; liquid, magnetic; modification; suspension.

A magnetic suspension densimeter, incorporating three support coils, has been reduced to a system using only one coil. This simplifies considerably the design of the apparatus and the procedures involved in the measurements. This instrument can be used for absolute density measurements; i.e., it does not have to be calibrated with reference fluids of known density.

16793. Heimbach, C. R., Lehman, D. R., O'Connell, J. S., Twobody electrodisintegration of ${ }^{3} \mathrm{He}$ : Faddeev calculation, Physics Lett. 66B, No. 1, 1-4 (Jan. 1977).

Key words: Coulomb excitation; electron scattering; Faddeev equations; helium-three; monopole transition; separable potential.

${ }^{3} \mathrm{He}\left(e, e^{\prime}\right) p d$ and ${ }^{3} \mathrm{He}\left(e, e^{\prime} p\right) d$ cross sections are calculated with Faddeev formalism. At low excitation energies, forward electron scattering cross sections are dominated by the Coulomb monopole transition. Backward electron scattering is dominated by the magnetic quadrupole transition.

16794. Hellwig, H., Design principles and characteristics of frequency and time standards, IEEE Trans. Nucl. Sci. NS-23, No. 6, 1629-1635 (Dec. 1976).

Key words: frequency; standards, time; time standards.

Today's precision oscillators and clocks are discussed. They include cesium standards, rubidium standards, hydrogen masers, and quartz crystal oscillators. A brief review of their basic design philosophy and performance characteristics is given. Block diagrams of schematics of the physics packages as well as of the electronic systems are given, and it is pointed out quantitatively (where possible) which parameter changes cause frequency shifts and/or performance deterioration. Particular attention is focused on those parameters which are likely to change under nuclear radiation.

16795. Holdeman, L. B., Holdeman, J. T., Jr., Magnetic torque on a shielded superconducting gyroscope, J. Appl. Phys. 47, No. $11,4936-4943$ (Nov. 1976).

Key words: electrodynamics; gyroscope; London moment; magnetic torque; relativity; satellite experiment; superconducting.

The torque on a superconducting sphere rotating in an arbitrary magnetic field is calculated. The result is expressed in terms of the coefficients of the expansion of the magnetic field in spherical harmonic functions, but in general a boundaryvalue problem must be-solved to obtain these coefficients. The boundary-value problem is solved and the torque calculated for configurations pertinent to the gyroscope relativity experiment, a proposed satellite experiment which is to test various theories 
of gravitation. Typical numerical results for these torques are given and compared with the predicted relativistic effects.

16796: Moulder, J. C., Clark, A. F., Time-resolved spectroscopy of laser-initiated metal combustion, (Proc. Unconventional Spectroscopy, San Diego, CA, Aug. 24-25, 1976), SPIE 82, 66-74 (Society of Photo-Optical Instrumentation Engineers, Palos Verdes Estates, CA, 1976).

Key words: laser effects; luminescence; metal combustion; spectroscopy; titanium alloys.

A rapid-scan spectrometer employing a silicon-target vidicon detector was used to study the time-resolved emission spectra of laser-ignited metals. Bulk specimens of $\mathrm{Ca}, \mathrm{Mg}, \mathrm{Zr}, \mathrm{Ti}$ and several Ti alloys were ignited with a $90 \mathrm{~W} \mathrm{cw} \mathrm{CO}_{2}$ laser in air or under a gentle flow of oxygen. Line and band emissions observed between 300 and $1100 \mathrm{~nm}$ during combustion help to identify vapor phase reactants and products and their locations in the flame. Disappearance of discrete spectra during the transient combustion of $\mathrm{Ti}$ and $\mathrm{Zr}$ gives information on the accumulation of molten oxide products. Observations of the continuum radiation emitted by laser-irradiated flames indicate a laser-stimulated luminescence from condensed metal oxide particles.

16797. Radebaugh, R., Thermal conductance of indium solder joints at low temperatures, Rev. Sci. Instrum. 48, No. 1, 93 94 (Jan. 1977).

Key words: beryllium; copper; cryogenics; indium; joints; solder; thermal conductance.

The thermal conductances of two indium solder joints were measured between 2 and $130 \mathrm{~K}$. One joint was between two copper pieces and the other joint between beryllium and copper. Both joints gave nearly the same results even though beryllium is much more difficult to wet with indium. The thermal conductances of the joints at $4 \mathrm{~K}$ were considerably higher than those of joints using alloy solders such as lead-tin. The maximum conductance per unit area was about $100 \mathrm{~W} / \mathrm{cm}^{2} \mathrm{~K}$, which occurred at about $20 \mathrm{~K}$.

16798. Siegwarth, J. D., Polarization and dielectric constant of $\mathrm{SrTiO}_{3}$ glass ceramics at low temperatures, J. Appl. Phys. 48, No. 1, 1-4 (Jan. 1977).

Key words: dielectric constant; dielectric relaxation; electret; glass ceramic; polarization; strontium titanate.

Peaks observed in the temperature dependence of the dielectric constant of $\mathrm{SrTiO}_{3}$ glass ceramics do not appear in the dc polarization. A remanent polarization is observed between 4 and $77 \mathrm{~K}$. The dielectric properties at low temperature are attributed to the relaxation of permanent dipoles to an electret state rather than to antiferroelectric ordering.

16799. Smith, E. W., Giraud, M., Calculations of rotational linewidths in $\mathrm{HCl}$ perturbed by argon, J. Chem. Phys. 66, No. 4, 1762-1764 (Feb. 15, 1977).

Key words: anisotropic interactions; $\mathrm{HCl}-\mathrm{Ar}$; linear molecules; rotational line widths; semiempirical potential; theoretical potential.

Calculations of rotational line widths in $\mathrm{HCl}$ perturbed by Argon are calculated using a recently developed theory for the broadening of linear molecules by atoms. Calculations are made with a semiempirical potential and with a recent purely theoretical potential and comparisons are made with experimental data measured for the $0-0$ and $0-1$ vibrational bands. The inaccuracy of potentials extracted solely from line profile data is discussed and the importance of high order anisotropic contributions to the interaction is stressed.
16800. Stock, M., Drullinger, R. E., Hessel, M. M., Comparison between electron beam and optically produced mercury excimer fluorescence, Chem. Phys. Lett. 45, No. 3, 592-594 (Feb. 1, 1977).

Key words: kinetics; Mercury excimers; time resolved spectroscopy.

Significant differences have been observed between the mercury excimer fluorescence produced by electron beam and optical excitation. We have used time resolved fluorescent spectroscopy to study the evolution of the excimer system following a 4 ns optical excitation pulse.

16801. Tobler, R. L., Low temperature effects on the fracture behaviour of a nickel base superalloy, Cryogenics 16, No. 11, 669-674 (Nov. 1976).

Key words: fatigue; fracture; low temperature tests; mechanical properties; nickel alloys; superalloys.

The mechanical properties of a solution treated and double aged nickel-18 percent iron-18 percent chromium alloy (Inconel 718) were studied to assess its utility at temperatures in the ambient-to-cryogenic range. Uniaxial tensile property measurements using unnotched specimens at decreasing temperatures between 295 and $4 \mathrm{~K}$ show that yield and ultimate strengths increase by 20 and 29 percent, respectively, while ductility remains virtually constant. Fracture mechanics tests using $2.54 \mathrm{~cm}$ thick compact specimens revealed that the fatigue crack growth resistance of this alloy improves slightly at extreme cryogenic temperatures, and its plane strain fracture toughness, $\mathbf{K}_{l c}$, increases from $96.3 \mathrm{MPa} \mathrm{m}^{1 / 2}$ at $295 \mathrm{~K}$ to 112.3 $\mathrm{MPa} \mathrm{m}^{1 / 2}$ at $4 \mathrm{~K}$. These results are compared with similar data for Inconel 750 alloys.

16802. Blais, N. C., Truhlar, D. G., Monte Carlo trajectory study of $\mathrm{Ar}+\mathrm{H}_{2}$ collisions. I. Potential energy surface and cross sections for dissociation, recombination, and inelastic scattering, J. Chem. Phys. 65, No. 12, 5335-5356 (Dec. 15, 1976).

Key words: argon; collisions; dissociation; hydrogen; inelastic; molecular potential; recombination; scattering; theoretical; theory.

Modified statistical electron-gas calculations using the methods of Gordon, Kim, Rae, Cohen, and Pack are carried out to obtain the interaction energy of $\mathrm{Ar}$ with $\mathrm{H}_{2}$ as a function of geometry. The results are combined with the accurate pairwise interactions, the long-range nonpairwise interaction, and the potential LeRoy and van Kranendonk fit to spectral data on the van der Waals' complex to obtain a potential energy surface which is as accurate as possible at all geometries. This surface and the pairwise additive surface are then used in a Monte Carlo quasiclassical trajectory study of the cross sections (under shock-tube high-energy collision conditions) for complete dissociation, for production of quasibound states of $\mathrm{H}_{2}$, and for $V-T, R-T$, and $V-R-T$ energy transfer. Except for $R-T$ energy transfer, the accurate surface yields smaller cross sections than the pairwise additive surface does. The cross sections for dissociation are much smaller than predicted by the available-energy hard-sphere model but are larger than the inelastic cross sections for excitation to the highest bound vibrational energy levels. Initial vibrational excitation energy is more effective than rotational energy or relative translational energy in causing dissociation. Using the full potential surface the recombination cross section of the $v=13, j=8$ quasibound state of $\mathrm{H}_{2}$ is calculated at $E_{\text {rel }}=0.026 \mathrm{eV}$ and is in good agreement with the result previously calculated by Whitlock, Muckerman, and Roberts using a less accurate, pairwise additive potential surface. 
16803. Blais, N. C., Truhlar, D. G., Monte Carlo trajectory study of $\mathbf{A r}+\mathbf{H}_{2}$ collisions. II. Vibrational and rotational enhancement of cross sections for dissociation, J. Chem. Phys. 66, No. 2, $772-778$ (Jan. 15, 1977).

Key words: argon; cross section; dissociation collisions; hydrogen; theory; vibrational and rotational enhancement.

Integral cross sections and properties of the dissociated trajectories were calculated for the reactions $\mathrm{Ar}+\mathrm{H}_{2} \rightarrow \mathrm{Ar}+$ $\mathrm{H}+\mathrm{H}$ and $\mathrm{Ar}+\mathrm{H}_{2}(q b) \rightarrow \mathrm{Ar}+\mathrm{H}+\mathrm{H}$, where $\mathrm{H}_{2}(q b)$ is a quasibound $\mathrm{H}_{2}$. Integral cross sections were also calculated for $\mathrm{Ar}+\mathrm{H}_{2} \rightleftharpoons \mathrm{Ar}+\mathrm{H}_{2}(\mathrm{qb})$. Twenty-four different ( 21 bound, 3 quasibound initial vibrational-rotational states of $\mathrm{H}_{2}$ are considered. The potential surface (which we presented previously) is based on modified statistical calculations at small distances and dissociates to an accurate potential in the van der Waals region and to accurate diatomic curves. At a total energy $1 \mathrm{eV}$ above the energetic threshold for dissociation, we find reagent vibrational energy is very effective in promoting dissociation (the vibrational bias parameter of Kiefer, Joosten, and Breshears is about 11 to 13 ), rotational energy is second most effective, and relative translational energy is least effective. Except for the topmost vibrational level we find dissociation cross sections are much smaller than predicted by the hard-sphere available-energy theory.

16804. Smeyers, P., Influence of magnetic fields on nonradial stellar oscillations, Proc. Solar and Stellar Pulsation Conf., Los Alamos, NM, Aug. 3-5, 1976, pp. 140-149 (Los Alamos Scientific Laboratory, University of California, Los Alamos, NM, Oct. 1976).

Key words: nonradial; perturbation theory; stellar oscillations; weak magnetic fields.

A perturbation method is presented which allows us to determine the effect of a weak magnetic field on the linear and adiabatic nonradial oscillations of a star. The method has been applied to a model with uniform density pervaded by a magnetic field with both a poloidal and a toroidal component, and to a polytropic model with a magnetic field which is purely toroidal and has only a $\phi$-component.

16805. Olver, F. W. J., Connection formulas for second-order differential equations with multiple turning points, SIAM J. Math. Anal. 8, No. 1, 127-154 (Feb. 1977).

Key words: asymptotic analysis; Bessel functions; boundary-value problem; connection formula; diffraction theory; error analysis; Liouville-Green approximation; ordinary differential equation; turning point.

A study is made of the differential equation

$$
d^{2} w / d x^{2}=\left\{u^{2} f(u, x)+g(u, x)\right\} w, a_{1}<x<a_{2},
$$

in which $u$ is a positive parameter. For each value of $u, \partial^{2} f(u$, $x) / \partial x^{2}$ and $g(u, x)$ are assumed to be continuous in the finite or infinite open interval $\left(a_{1}, a_{2}\right)$. The function $f(u, x)$ is real and its only zero within $\left(a_{1}, a_{2}\right)$ is a single zero of multiplicity $m-2$, where $m(\geqslant 2)$ is an arbitrary integer. For large values of $u$, asymptotic approximations for the solutions are constructed in terms of Bessel functions of order $1 / m$, subject to certain restrictions on the behavior of $f(u, x)$ and $g(u, x)$ as $u$ $\rightarrow x$. These restrictions are satisfied, for example, if $f(u, x)$ is independent of $u$ and $g(u, x)=O\left(u^{u r}\right)$, where $\omega<\min (4 / m, 1)$. Each approximation is uniformly valid throughout $\left(a_{1}, a_{2}\right)$ and is accompanied by a strict and realistic bound for the error term.

In the case in which $a_{1}$ and $a_{2}$ are singularities of the differential equation, the uniform approximations are applied to solve the problem of connecting the known asymptotic solu- tions in terms of elementary functions (the Liouville-Green approximations) valid in a neighborhood of $a_{2}$, with the corresponding asymptotic solutions valid in a neighborhood of $a_{1}$.

16806. Green, D. C., A CAMAC parallel branch driver for the Harris 6024/5 computer, IEEE Trans. Nucl. Sci. NS-24, No. 2, $931-932$ (Apr. 1977).

Key words: branch driver; CAMAC; CAMAC standards; computer interfaces; digital interfaces; Harris computer.

A CAMAC parallel Branch Driver has been developed for the Harris $6024 / 5$ series computers used in neutron physics research at the National Bureau of Standards. The Branch Driver allows either programmed transfers or programmed interrupt transfers of data between the computer and a CAMAC Branch Highway.

16807. Faulkner, D. J., Mode interaction in U TrA, Proc. Solar and Stellar Pulsation Conf., Los Alamos, NM, Aug. 3-5, 1976, pp. 66-75 (Los Alamos Scientific Laboratory, University of California, Los Alamos, NM, Oct. 1976 ).

Key words: beat Cepheids; double-mode Cepheids; Fourier analysis of stellar variations; mode interaction; stellar instabilities; U Trianguli Australis.

Photoelectric observations of the double-mode Cepheid U TrA previously reported by Oosterhoff (1957a) and Jansen (1962) have been reanalyzed using Fourier techniques. The two reported periods have been confirmed and it has been shown that no further statistically significant periodicity is present. The two observed modes are subject to a strong mode interaction, but it is not yet clear whether this will have any implications for the pulsational masses derived for double-mode Cepheids.

16808. Vorburger, T. V., Sandstrom, D. R., Waclawski, B. J., The displacement of hydrogen by carbon monoxide on the (100) face of tungsten: A photoemission and thermal desorption study, Surface Sci. 60, $211-230$ (1976).

Key words: carbon monoxide; chemisorption; coadsorption; desorption; displacement; hydrogen; photoemission; thermal desorption; tungsten; ultraviolet photoelectron spectroscopy.

Photoelectron spectra ( $h v=21.22 \mathrm{eV}$ ) and thermal desorption data were obtained for $\mathrm{CO}$ and $\mathrm{H}$ coadsorbed on W(100) at $80 \mathrm{~K}$. When the clean surface is exposed to a saturation dose of $\mathrm{H}_{2}$, subsequent exposure to $\mathrm{CO}$ results in the formation of a state whose emission spectrum is similar to that of molecular $\alpha$-CO. Upon heating to $\sim 280 \mathrm{~K}$, a structural rearrangement occurs in which most of the adsorbed $\mathrm{CO}$ is converted to the strongly bound $\beta$ form as the hydrogen is simultaneously desorbed. These data plus the observation that $\mathrm{H}_{2}$ cannot be adsorbed to any significant degree on a saturated layer of $\beta$ $\mathrm{CO}$ suggest that adsorbed $\beta-\mathrm{CO}$ and $\mathrm{H}$ occupy the same atomic sites on the $W(100)$ surface. The distinction between long and short range repulsive $\mathrm{CO}-\mathrm{H}$ interactions is discussed. For $\mathrm{CO}$ adsorbed on clean $W(100)$, the range of activation energies for virgin to $\beta$ conversion is calculated from the UPS data to be $45-62 \mathrm{~kJ} / \mathrm{mol}$.

16809. Ayres, T. R., Linsky, J. L., Rougers, A. W., Kurucz, R. L., Stellar model chromospheres. V. Alpha centauri A (G2 V) and alpha centauri B (KI V), Astrophys. J. 210, No. 1, Pt. 1, 199-210 (Nov. 15, 1976).

Key words: flare stars; stellar chromospheres; stellar evolution; stellar photospheres; stellar spectra; stellar transition regions. 
We propose models for the upper photospheres and lower chromospheres of $\alpha$ Cen $A$ and $B$ based on a partial redistribution (PRD) analysis of the $\mathrm{Ca} \| \mathrm{K}$ line cores and damping wings. Coude spectrograms of the $\mathrm{Ca} 11$ regions in these stars obtained with the Mount Stromlo 74 inch ( $1.9 \mathrm{~m}$ ) telescope are calibrated by fitting the far wing profiles of $K$ with synthetic fluxes based on radiative equilibrium ( $R E$ ) models. The RE calibrations are verified by comparison with independent calibrations using Willstrop's absolute photometry and narrow band fluxes obtained at Mount Stromlo. Deviations of the empirical profiles from the RE fluxes in the inner wings of $\mathrm{K}$ suggest departures from radiative equilibrium in the upper photosphere of $\alpha$ Cen A comparable to those found previously for the Sun and Procyon. Alpha Cen B shows similar departures from RE when the effects of $\mathrm{CO}$ cooling near the temperature minimum are taken into account. We find similar ratios of $T_{m i n} / T_{e f f}$ for both stars, which are within the range of $T_{\min } / T_{\text {eff }}$ ratios determined previously for the Sun, Procyon, and Arcturus. In addition, we find similar mass column densities at the $8000 \mathrm{~K}$ levels of the $\alpha$ Cen A and B chromospheres comparable to those determined for the Sun and Procyon. Finally, $\alpha$ Cen $A$ appears to be more evolved and possibly much older than the Sun, despite its similar chromosphere structure.

16810. Beaty, E. C., Hesselbacher, K. H., Hong, S. P., Moore, J. H., Triple-differential three-dimensional cross sections for low-energy electron impact ionization of helium, J. Phys. B: Atom. Molec. Phys. 10, No. 4, $611-620$ (1977).

Key words: cross section; differential; electron; helium; ionization; measurements.

Measurements are reported of the triple-differential cross section for ionization of helium by electron impact. Experimental conditions were chosen to help clarify the situation in the theory of ionization. Data are presented for primary energies of $100,105,125$ and $165 \mathrm{eV}$. Unlike previous measurements in this energy regime, data are included for the circumstance where the three electron trajectories are not in a plane.

16811. Parris, G. E., Blair, W. R., Brinckman, F. E., Chemical and physical considerations in the use of atomic absorption detectors coupled with a gas chromatograph for determination of trace organometallic gases, Anal. Chem. 49, No. 3, 378-386 (Mar. 1977).

Key words: arsenic; atomic absorption; gas chromatography; organometal; selenium; tin.

A commercial atomic absorption spectrophotometer with a heated graphite-tube furnace atomizer (HGA) was adapted as a detector for a gas-liquid chromatograph. The combined system was applied to the determination of elements (i.e., As, $\mathrm{Se}, \mathrm{Sn}$ ) known to be methylated by microorganisms. The system was optimized by assessing the effects of varying the atomization temperature, the inner surface of the furnace (i.e., fused silica, alumina, bare graphite and pyrolytic carbon surfaces) and the carrier gas (i.e., pure argon and argon with hydrogen). Using conservative, statistically-based numerical techniques, the system detection limits for arsenic, selenium, and tin (introduced as trimethylarsine, dimethylselenium and tetramethyltin gas solutions with nitrogen diluent) were found to be $5 \mathrm{ng} \mathrm{As,} 7 \mathrm{ng} \mathrm{Se}$, and $12 \mathrm{ng} \mathrm{Sn}$. To obtain these limits, the bare graphite furnace was run continuously at about 1800 ${ }^{\circ} \mathrm{C}$ while the compounds were eluted from the chromatograph with argon to which 10 percent hydrogen was added. Optimization of the furnace conditions requires an understanding of the thermodynamics and kinetics associated with thermal and chemical decomposition of the analyte compounds.

16812. Stone, E. J., Lawrence, G. M., Fairchild, C. E., Kinetic energies and angular distributions of oxygen atom photofrag- ments produced by photodissociation of $\mathrm{O}_{2}$ and $\mathrm{N}_{2} \mathrm{O}$ in the vacuum ultraviolet, J. Chem. Phys. 65, No. 12, 5083-5092 (Dec. 15, 1976).

Key words: atomic; experimental; lifetimes; $\mathrm{N}_{2} \mathrm{O}$; oxygen; radiation; time-of-flight.

A gas phase chemi-ionization process is used to detect $O$ atoms produced by photodissociation of $\mathrm{O}_{2}$ and $\mathrm{N}_{2} \mathrm{O}$. For the photon energies used here the accessible $O$ atom states are within the ground ${ }^{3} P$ levels and the metastable ${ }^{\prime} D$ and ' $S$ levels. Kinetic energies of the $\mathrm{O}$ atom photofragments are determined using an atomic beam time-of-flight technique, and the $O$ atom angular distributions are determined by varying the angle between the direction of the photon beam and the atomic beam flight path. Dissociative transitions within the Schumman-Runge continuum of $\mathrm{O}_{2}$ and the principal vacuum ultraviolet absorption continuum of $\mathrm{N}_{2} \mathrm{O}$ yield results in agreement with previous predictions. For the dissociation of $\mathrm{O}_{2}$ at wavelengths of 120 and $124 \mathrm{~nm}$, the principal dissociation products are $O\left({ }^{3} P\right)+$ $O\left({ }^{1} D\right)$; and, at these wavelengths, the $O$ atom angular distribution is consistent with previous conclusions that predissociation is important. Using existing theories of photofragment angular distributions, an asymmetry parameter having a value of $(-0.61$ \pm 0.05 ) is obtained for predissociation in $\mathrm{O}_{2}$ at the 10.0 and $10.3 \mathrm{eV}$ absorption features.

16813. Krasny, J. F., Peacock, R. D., Comments on "Flammability assessment of apparel fabrics", Textile Chem. Colorists 9, No. 4, 32-33 (Apr. 1977).

Key words: burn injury; flammability; Mushroom Flammability Tester; test methods.

The heat transfer rate from burning fabrics, measured on the Mushroom Apparel Flammability Tester, is compared with flammability assessments reported in a paper by Galil and Lomartire. Agreement between the two methods was found for only a few fabrics.

16814. Sparrow, J. H., Dick, C. E., Pulsed high intensity monoenergetic low energy $x$-ray source and absolute $x$-ray monitor, Nucl. Instrum. Methods 141, 283-292 (1977).

Key words: absolute $\mathrm{x}$-ray detectors; electron excitations; monoenergetic $x$ rays; pulsed $x$-ray source; $x$-ray detector calibration; $1.5-8 \mathrm{keV} \times$ rays.

An x-ray source of $1.5,4.5$, or $8.0 \mathrm{keV}$ with $10 \mathrm{~ns}$ durations has been produced utilizing a pulsed electron source to excite the characteristic $\mathbf{K}$-line radiation of elemental targets. A parallel plate ionization chamber was calibrated in the NBS standard monoenergetic $\mathbf{K}$ x-ray beams and used with Ross filters to measure the pulsed source $K$-ray fluence. Typical measured peak $x$-ray flux intensities are $10^{18}-10^{19} \mathrm{~K} x$-rays per $\mathrm{sr}$ per $\mathrm{s}$. The pulsed source contains four identical ports for simultaneous measurement of the $\mathrm{K}$ x-ray intensity by the ionization chamber and detectors being calibrated. The pulsed $\mathrm{K}$ x-ray source and the NBS standard steady state $K$-ray source, which differ in intensity by 10 orders of magnitude, have been utilized to determine the responses of a photoelectric diode, a scintillator-vacuum photodiode combination, and a silicon PIN diode.

16815. Bennett, H. S., Forman, R. A., Relative dominance of bulk or surface absorption in highly transparent materials by transient methods, J. Appl. Phys. 48, No. 3, $1217-1222$ (Mar. 1977).

Key words: absorption; barothermal gas cell; bulk absorption; highly transparent; infrared materials; optical materials; surface absorption. 
For the case in which a pulsed laser beam passes through the weakly absorbing windows of a gas cell containing a nonabsorbing gas, the time rate of change of the relative pressure rise immediately after the cessation of the laser beam correlates directly with the relative dominance of bulk and surface absorption in highly transparent materials. Whenever bulk ab'sorption dominates, the time derivative of the pressure rise in the gas for times shortly after cessation of the pulse is positive; when surface absorption dominates, it is negative; and when bulk and surface absorption are comparable, it is very close to zero. This, suggests then, a relatively simple experimental procedure by which one may determine nondestructively the relative dominance of bulk or surface absorption in highly transparent materials.

16816. Ekin, J. W., Clark, A. F., Effect of strain on the critical current of $\mathrm{Nb}_{3} \mathrm{Sn}$ and $\mathrm{NbTi}$ multifilamentary composite wires, (Proc. Joint MMM-Intermag Conf., Pittsburgh, PA, June 1518, 1976), AIP Conf. Proc. No. 34, Magnetism and Magnetic Materiais-1976, J. J. Becker and G. H. Lander, Eds., pp. 81-83 (American Institute of Physics, New York, NY, 1976).

Key words: aluminum stabilization; copper stabilization; critical current; critical-current degradation; multifilamentary wires; $\mathrm{Nb}_{3} \mathrm{Sn}$; NbTi; strain; stress.

The critical currents of flexible $\mathrm{Nb}_{3} \mathrm{Sn}$ and $\mathrm{NbTi}$ composite wires have been observed to decrease as a function of strain. Characteristic samples of the data are presented along with a brief summary and intercomparison of the results for each wire type. In the $\mathrm{NbTi}$ wires the decrease commenced at strains of about 0.5 percent, but did not become appreciable (i.e., greater than $\sim 5 \%$ ) until strains exceeded about 1.5 percent. The effect is almost totally reversible and the magnitude of the decrease is not strongly dependent on sample configuration or stabilization material. In the $\mathrm{Nb}_{3} \mathrm{Sn}$ composites the degradation in critical current is relatively much larger, becoming significant at strains ranging from 0.1 to 0.3 percent depending on the reinforcement technique used in the wires' construction. At high strains, the effect in $\mathrm{Nb}_{3} \mathrm{Sn}$ is only partially reversible. Also in the $\mathrm{Nb}_{3} \mathrm{Sn}$ composites, stress-induced resistivities as high as $10^{-10} \Omega \mathrm{cm}$ were observed at currents well below $\mathbf{L}_{c}$. This leads to significant Joule heating of the superconducting wire and ambiguities in the operational definition of "critical current."

16817. Han, C. C., Mozer, B., Conformation of PS-PMMA diblock copolymer in toluene by small angle neutron scattering, Macromolecules 10, No. 1, 44-51 (Jan./Feb. 1977).

Key words: conformation; deuterated polystyrenepoly(methylmethacrylate); diblock copolymer; radius of gyration; small angle neutron scattering.

A deuterated polystyrene-poly(methyl methacrylate) (dPSPMMA) diblock copolymer and its deuterated polystyrene homopolymer precursor were studied by small angle neutron scattering and light scattering experiments using toluene as the solvent. The radii of gyration of the deuterated PS homopolymer $(M=88000)$ measured by both methods and that of the PMMA block $(M=203000)$ in the diblock copolymer measured only by neutron scattering were determined as 210 and $85 \AA$, respectively. In addition, the second virial coefficients and the chain excluded volume exponents were also obtained. The copolymer chain conformation in toluene at $23^{\circ} \mathrm{C}$ is inferred from these measurements. It is suggested that the PMMA block forms the interior core from which the PS block exudes out as an expanded chain.

16818. Wisdom, J., Hartquist, T. W., Lane, N. F., He( $\left.2^{3} S\right)$ bubble in liquid helium, Phys. Rev. B, Comments and Addenda 14, No. 9, 4205-4208 (Nov. 1, 1976).
Key words: helium absorption; liquid helium bubble; metastable helium atoms.

Using the phenomenological model of Padmore and Cole, we have reinvestigated the nature of the "bubble" surrounding a $2^{3} \mathrm{~S}$ metastable helium atom in liquid helium. The principal result of this work is that a reasonable $2^{3} S \rightarrow 2^{3} P$ absorption line shift is obtained in good agreement with the model of Hickman, Steets, and Lane, and with experiment, and that a local liquid-helium density function is obtained in good agreement with that determined in a very different manner by Hansen and Pollock.

16819. Johnson, C. R., Functional characterizations of the field of values and the convex hull of the spectrum, Proc. Am. Math. Soc. 61, No. 2, 201-204 (Dec. 1976).

Key words: convex hull; eigenvalue; field of values; positive semidefinite; semistable.

The only compact, convex set-valued homogeneous and translatable function of square complex matrices which is an indicator function for the matrices with positive semidefinite real part is the classical field of values. An analogous characterization of the convex hull of the spectrum is given.

16820. Klebanoff, P. S., Frenkiel, F. N., On the small-scale turbulence structure, (Proc. Bat-Sheva Int. Seminar, Ben-Gurion Univ. of Negev, Beersheva, Israel, Mar. 17-20, 1975), Paper in MHD-Flows and Turbulence, H. Branover, Ed., pp. 147151 (Halsted Press, Div. John Wiley \& Sons, Inc., New York, NY, 1976).

Key words: boundary-layer; higher-order moments; hotwire anemometry; log-normal distribution; small-scale turbulence.

ithe results of an experimental investigation into the nature of the small-scale turbulence structure involving the measurement of higher-order moments of turbulent velocity gradients are described. Comparisons with atmospheric investigations and theory are given.

16821. Klebanoff, P. S., McMichael, J. M., On MHD pipe flow, (Proc. Bat-Sheva Int. Seminar, Ben-Gurion Univ. of Negev, Beersheva, Israel, Mar. 17-20, 1975), Paper in MHD-Flows and Turbulence, H. Branover, Ed., pp. 73-80 (Halsted Press, Div. John Wiley \& Sons, Inc., New York, NY, 1976).

Key words: liquid metals; magnetohydrodynamics; pipe flow; resistance coefficients; turbulence.

A description of the liquid metal flow facility at NBS is - presented. Data demonstrating the operation of the facility, including wall pressure measurements over a range of Hartmann numbers and Reynolds numbers extending up to 1350 and 340,000 , respectively, are discussed.

16822. McCrackin, F. L., Calibration of geI permeation chromatography columns using polydisperse polymer standards, $J$. Appl. Polymer Sci. 21, $191-198$ (1977).

Key words: calibration; column broadening, GPC; gel permeation chromatography; nonlinear regression.

Two methods of calibrating gel permeation chromatography columns are given. The first method uses polymer standards that may have broad molecular weight distributions. Either the weight-, number-, or viscosity-average molecular weight of each standard must be known. This method neglects column peak spreading. The second method requires polymer standards of moderately narrow molecular weight distributions for which both the weight- and number-average molecular weights are known. However, the second method determines both the 
column peak spreading and calibration of the column. The second method is applied to calibration of a column using polystyrene standards. The column peak spreading is found to be small and independent of molecular weight for this column.

16823. Maki, A. G., Sams, R. L., Pearson, R., Jr., Microwave and infrared spectra of isotopically substituted carbonyl selenide (OCSe), J. Mol. Spectrosc. 64, 452-459 (1977).

Key words: bond distances; carbonyl selenide; energy levels; force field; infrared; microwave; molecular structure; spectra; spectroscopy.

Infrared and microwave spectral measurements are given for three isotopically enriched species of carbonyl selenide. The high-resolution infrared measurements (made near 2000 and $2600 \mathrm{~cm}^{-1}$ ) provide constants for the following transitions: ${ }^{10^{\circ} 0} \mathrm{O}-00^{\circ} 0$ for ${ }^{16} \mathrm{O}^{12} \mathrm{C}^{8 n} \mathrm{Se}$; $10^{\circ} 0-00^{\circ} \mathrm{O}$ and $11^{1} \mathrm{O}-01^{1} \mathrm{O}$ for ${ }^{18} \mathrm{O}^{12} \mathrm{C}$ ${ }^{80} \mathrm{Se}$; and $10^{\circ} 0-00^{\circ} 0,11^{1} 0-01^{1} \mathrm{O}, 10^{\circ} 1-00^{\circ} 1$, and $10^{\circ} 1-00^{\circ} 0$ for ${ }^{16} \mathrm{O}^{13} \mathrm{C}^{80} \mathrm{Se}$. Microwave measurements are given for the $J=4 \leftarrow$ 3 , and $3 \leftarrow 2$ transitions of ${ }^{18} \mathrm{O}^{12} \mathrm{C}^{80} \mathrm{Se}$ and ${ }^{16} \mathrm{O}^{13} \mathrm{C}^{80} \mathrm{Se}$ in the $00^{\circ} 0,01^{1} 0,02^{n} 0,02^{2} 0$, and $00^{\circ} 1$ states. Equilibrium rotational constants are given for all three isotopic species and the equilibrium bond distances are determined to be $r_{e}(\mathrm{C}-\mathrm{O})=$ $1.1535 \pm 0.0001 \AA$ and $r_{e}(\mathrm{C}-\mathrm{Se})=1.7098 \pm 0.0001 \AA$.

16824. Needham, P. B., Jr., Driscoll, T. J., Powell, C. J., Stein, R. J., Determination of the Be-Auger-electron attenuation length in Be using $160-\mathrm{keV}$ protons, Appl. Phys. Lett. 30, No. 7, 357-359 (Apr. 1, 1977).

Key words: attenuation length; Auger-electron yield; beryllium; electron scattering; proton bombardment.

We report the first results of a method for determining the inelastic attenuation length of low-energy electrons in the surface region of a solid from a yield of characteristic Auger electrons excited by proton bombardment. Samples of evaporated beryllium were bombarded by $160-\mathrm{keV}$ protons, and the attenuation length of $100-\mathrm{eV}$ electrons in $\mathrm{Be}$ was determined to be $6.1 \AA$.

16825. Pella, P. A., Measurement of the vapor pressures of TNT, 2,4-DNT, 2,6-DNT, and EGDN, J. Chem. Thermodyn. 9, 301-305 (1977).

Key words: DNT; EGDN; electron-capture gas chromatography; measurements; TNT; vapor pressures.

The vapor pressures of 2,4,6-trinitrotoluene (TNT), 2,4dinitrotoluene (2,4-DNT), 2,6-dinitrotoluene (2,6-DNT), and ethylene glycol dinitrate (EGDN) have been measured by an electron-capture gas-chromatographic method in the temperature range from 287.15 to $329.65 \mathrm{~K}$ for TNT, 277.15 to 344.15 $\mathrm{K}$ for 2,4-DNT, 277.15 to $323.15 \mathrm{~K}$ for $2,6-\mathrm{DNT}$, and 240.15 to $298.15 \mathrm{~K}$ for EGDN. The temperature dependence of the vapor pressure is given by the equations: $\mathrm{TNT}$ : $\log _{10}(p /$ torr $)=(12.31$ $\pm 0.34)-(5175 \pm 105) \mathrm{K} / T ; 2,4-\mathrm{DNT}: \log _{10}(p /$ torr $)=(13.08 \pm$ $0.19)-(4992 \pm 59) \mathrm{K} / T ; \quad 2,6-\mathrm{DNT}: \quad \log _{10}(p /$ torr $)=(13.99 \pm$ $0.18)-(5139 \pm 52) \mathrm{K} / T ; \quad$ EGDN: $\quad \log _{10}(p /$ torr $)=(10.55 \pm$ $0.08)-(3476 \pm 22) \mathrm{K} / \mathrm{T}$.

The values for the enthalpy of sublimation are $\Delta H_{\text {sub }}($ TNT $)=$ $\left(23.7 \pm 0.5\right.$ ) $\mathrm{kcal}_{t h} \mathrm{~mol}^{-1}, \Delta H_{\text {sub }}(2,4-\mathrm{DNT})=(22.9 \pm 0.3) \mathrm{kcal}_{\text {th }}$ $\mathrm{mol}^{-1}$, and $\Delta H_{s u b}(2,6-\mathrm{DNT})=(23.5 \pm 0.2) \mathrm{kcal}_{t h} \mathrm{~mol}^{-1}$. The enthalpy of vaporization for EGDN is $(15.9 \pm 0.09) \mathrm{kcal}_{\ell h} \mathrm{~mol}^{-1}$ The indicated uncertainties are standard errors.

16826. Penn, D. R., Secondary-electron energy distribution in high-energy photoemission, J. Vac. Sci. Technol. 14, No. 1, 300-302 (Jan./Feb. 1977).

Key words: energy distribution; photoemission; secondary electron.
We have calculated the energy distribution of secondary electrons observed in core-level XPS or core-level synchroton photoemission experiments on $\mathrm{Al}$. The secondary electrons are produced when the photoexcited primary electrons scatter inelastically from the valence electrons via the mechanisms of bulk and surface plasmon production and electron-hole production. The scattering cross sections for these events are determined from the Lindhard dielectric function, although the plasmon dispersion and broadening are taken from experimental measurements. Multiple scattering is taken into account by means of the Wolff-Spencer-Fano integral equation for the electron-energy distribution. The calculated results are compared to experiment.

16827. Ruff, A. W., Characterization of debris particles recovered from wearing systems, WEAR 42, $49-62$ (1977).

Key words: debris; electron microscopy; particles; wear; $x$ ray emission.

Studies have been conducted on wear debris collected from various systems involving both sliding and rolling contacts. Results of size, shape and chemical composition analyses of typical debris particles are presented. Different techniques for debris recovery and analysis are discussed. Some results are presented on electron transmission studies of individual debris particles. The effect of small particle size on $\mathrm{x}$-ray emission microanalysis is also described.

16828. Spal, R. D., Production of uniform field gradients for magnetometers by means of current-carrying strips, J. Appl. Phys. 48, No. 3, 1338-1341 (Mar. 1977).

Key words: Faraday magnetometer design; homogeneity; magnet design; magnetic field gradients; magnetometer design.

Current-carrying strips are a convenient means to produce a uniform field gradient for use in a Faraday magnetometer. An expression is derived for the magnetic field gradient, taking into account the images of the strips in the pole pieces. Tables are presented giving the magnitude and homogeneity of the gradient for various strip widths and locations. The performance in the laboratory of a set of strips is reported.

16829. Vorburger, T. V., Waclawski, B. J., Plummer, E. W., Evidence for the distortion of $\mathrm{C}_{2} \mathrm{H}_{4}$ and $\mathrm{C}_{2} \mathrm{H}_{2}$ chemisorbed on W(100), Chem. Phys. Lett. 46, No. 1, $42-47$ (Feb. 15, 1977).

Key words: acetylene; adsorption; chemisorption; dehydrogenation; ethylene; photoemission; tungsten; ultraviolet photoelectron spectroscopy.

The adsorption of $\mathrm{C}_{2} \mathrm{H}_{4}$ on $\mathrm{W}(100)$ has been studied by ultraviolet photoelectron spectroscopy with $h v=21.22 \mathrm{eV}$. The spectrum measured after an initial saturation exposure at $80 \mathrm{~K}$ exhibits structure which correlates well with energy levels recently calculated by Demuth and Eastman (DE) for $\mathrm{sp}^{3}$ rehybridized $\mathrm{C}_{2} \mathrm{H}_{4}$. Dehydrogenation of the adsorbate, either by subsequent heating to $295 \mathrm{~K}$ or direct adsorption at $295 \mathrm{~K}$, yields a spectrum which correlates with DE's calculation for $\mathrm{sp}^{2}$ rehybridized $\mathrm{C}_{2} \mathrm{H}_{2}$. These results suggest that $\mathrm{C}_{2} \mathrm{H}_{4}$ and $\mathrm{C}_{2} \mathrm{H}_{2}$ may be distorted from their planar and linear structures respectively and that the $\mathrm{C}-\mathrm{C}$ bonds on these molecules are stretched by adsorption on $W(100)$. Qualitative arguments suggest that the bonding site for both molecules is directly over a $\mathrm{W}$ atom and that the Dewar-Chatt model for $\pi$-d bonding in organometallic compounds is applicable.

16830. Pella, P. A., Mills, R. M., A trace vapor generator for testing explosives vapor detectors, LESP-RPT-0604.00, 24 pages (U.S. Department of Justice, Law Enforcement Assistance Administration, National Institute of Law Enforcement and Criminal Justice, Washington, DC, Mar. 1977). 
Key words: DNT; EGDN; explosive detection; limits of detection; sensitivity test; TNT; vapor generator; vapor pressure.

A vapor generator for law enforcement applications was developed to produce known trace concentrations of vapors of 2,4,6 trinitrotoluene (TNT), 2,4-dinitrotoluene (2,4 DNT), 2,6dinitrotoluene $(2,6 \mathrm{DNT})$, and ethylene glycol dinitrate (EGDN). Known equilibrium vapor concentrations of these explosives are generated at several temperatures by passing dry nitrogen through a temperature-controlled column packed with the explosive dispersed on an inert support. The equilibrium vapor enters a dynamic gas-blending system in which the vapor is precisely diluted with air to provide output explosives vapor concentrations below $1 \mathrm{ppb}$. The system was evaluated by measuring output vapor concentrations of TNT, 2,4 DNT, 2,6 DNT, and EGDN using gas-chromatographic analysis. The applicability of the generator for testing sensitivities and limits of detection of commercial explosives vapor detectors is demonstrated.

16831. Quindry, T. L., Stenbakken, G. N., Sound sensing units for intrusion alarm systems, NILECJ-STD-0308.00, 18 pages (U.S. Department of Justice, Law Enforcement Assistance Administration, National Institute of Law Enforcement and Criminal Justice, Washington, DC, Mar. 1977).

Key words: alarm; audio alarm; burglar alarm; intrusion alarm; intrusion detector; sound sensing; standard.

This standard establishes performance criteria for sound sensing alarms intended for use in protective intrusion systems to monitor for attempts to enter a room or building. These devices cause the initiation of an alarm signal to a police panel, central station, or local audible alarm device. Included are requirements and test methods for performance, electrical properties and materials. The characteristics addressed are those which affect the reliability of the devices with emphasis on those performance characteristics which affect their false alarm susceptibility and its tamper resistance.

16832. Waterstrat, R. M., Müller, J., Ternary A15-phase regions in the $\mathrm{Nb}-\mathrm{Sn}-\mathrm{Si}$ and $\mathrm{Nb}-\mathrm{Sn}-\mathrm{As}$ systems, J. Less-Common Metals 52, $271-277$ (1977).

Key words: A15 phase; constitution diagram; niobium alloys; phase diagram; superconductivity; ternary alloys.

The A15-phase regions in the $\mathrm{Nb}-\mathrm{Sn}-\mathrm{Si}$ and $\mathrm{Nb}-\mathrm{Sn}-\mathrm{As}$ systems have been delineated by quantitative electron microprobe analyses. In contrast to previous reports, both systems exhibit a rather limited solubility in the binary $\mathrm{Nb}_{3} \mathrm{Sn}$ compound. The addition of $\mathrm{Si}$ to $\mathrm{Nb}_{3} \mathrm{Sn}$ produces a strong deviation from the "ideal" stoichiometry. The present results are in serious disagreement with previous reports concerning the solubility of $\mathrm{As}$ and $\mathrm{Si}$ in $\mathrm{Nb}_{3} \mathrm{Sn}$. This may be attributed to a failure of the previous investigators to recognize fully the extent of inhomogeneities in their samples and the effect of this failure on the interpretation of x-ray diffraction data.

16833. Wampler, R. H., On least squares algorithms, Am. Stat. Letter to Ed. 31, No. 1, 52-53 (Feb. 1977).

Key words: Cholesky decomposition; Givens transformations; Gram-Schmidt orthogonalization; Householder transformations; least squares algorithms; regression; statistics.

The letter cites additional references bearing on the paper, "Least Squares Programs-A Look at the Square Root Procedure," by Kopitzka, Boardman and Graybill, The American Statistician Vol. 29 (1975), pages 64-66.
16834. Waterstrat, R. M., Manuszewski, R. C., The vanadiumrhodium constitution diagram, J. Less-Common Metals 52 , 293-305 (1977).

Key words: atomic ordering; constitution diagram; phase diagram; phase transformations; rhodium alloys; vanadium alloys.

The V-Rh alloy system has been investigated over the entire composition range using metallographic, $x$-ray diffraction, electron microprobe and DTA measurements. There are six intermediate phases having structural similarities to phases which occur in the V-Ir and Nb-Rh alloy systems. A constitution diagram for the V-Rh system is presented.

16835. Alperin, H. A., Cullen, J. R., Clark, A. E., Callen, E., Amorphous magnetism in bulk samples of terbium iron alloys, Physica 86-88B, 767-769 (1977).

Key words: amorphous alloys; iron; magnetization measurements; neutron diffraction; terbium.

Magnetization measurements made on compositions $x=0.45$ and 0.75 in the series $\mathrm{Tb}_{x} \mathrm{Fe}_{1-x}$ show a decreasing average terbium moment with increasing $x$. Spontaneous moments, coercive forces and Curie temperatures for samples in the range $0.018 \leqslant x \leqslant 0.75$ are described in terms of a cluster model.

16836. Johnson, C. R., Locally compatible generalized matrix norms, Numer. Math. 27, 391 -394 (1977).

Key words: compatible; generalized matrix norm; multiplicative; spectral radius; unit ball; vector norm.

We show that the following three conditions are equivalent for a generalized matrix norm $N$ on $M_{k}(C)$ :

(i) for each $x \in C^{*}$ there is a vector norm $\|\cdot\|_{x}$ (depending on $x$ ) such that for all $A \in M_{h}(C),\|A x\|_{x} \leqslant N(A)\|x\|_{x}$;

(ii) for each $A \in M_{k}(C)$ there is a vector norm $\|\cdot\|_{A}$ (depending on $A$ ) such that for all $x \in C^{k},\left\|A_{x}\right\|_{A} \leqslant N(A)\|x\|_{A}$; and

(iii) the spectral radius $\rho(A)<N(A)$ for all $A \in M_{\kappa}(C)$.

We call generalized matrix norms satisfying (i) (and, thus, (ii) and (iii)) locally compatible and cite examples, for instance, to show that a locally compatible generalized matrix norm is not necessarily globally compatible with any single vector norm.

16837. Lide, D. R., Jr., Sources of atomic and molecular data relevant to laser chemistry, Laser Focus 13, No. 2, pp. 53. 56 (Feb. 1977).

Key words: atomic spectra; data sources; laser chemistry; molecular spectra.

Sources of data on atomic and molecular properties of interest to research workers in the field of laser chemistry are listed. Data on atomic energy levels and spectra; atomic transition probabilities; infrared, visible, and ultraviolet spectra of molecules; electron and photon cross sections; and spectra of dyes are included.

16838. Laufer, A. H., Bass, A. M., Reaction between triplet methylene and $\mathrm{CO}_{2}$ : Rate constant determination, Chem. Phys. Lett. 46, No. I, $151-155$ (Feb. 15, 1977).

Key words: $\mathrm{CO}$; combustion; $\mathrm{CO}_{2}$; methylene; rate constant.

The rate constant $\left(k_{3}\right)$ for the reaction ${ }^{3} \mathrm{CH}_{2}+\mathrm{CO}_{2} \rightarrow \mathrm{HCHO}$ $+\mathrm{CO}$ has been measured using flash photolysis in conjunction with both gas chromatography and kinetic spectroscopy. $k_{3}$ was found to be $(3.9 \pm 1.9) \times 10^{-14} \mathrm{~cm}^{3}$ molecule $\mathrm{c}^{-1} \mathrm{~s}^{-1}$. CO, vibrationally excited to at least $v^{\prime}=2$ is a product of the reaction. The rate constant for the abstraction by triplet $\mathrm{CH}_{2}$ from 
$\mathrm{CH}_{2} \mathrm{~N}_{2}$ to produce $\mathrm{CH}_{3}$ was determined to be $1.0 \times 10^{-12} \mathrm{~cm}^{3}$ molecule $\mathrm{s}^{-1}$.

16839. Joy, D. C., Newbury, D. E., A blbliography on the observation of crystailine materials by use of diffraction effects in the scanning electron microscope, (Proc. Workshop on Analytical Electron Microscopy, Chicago, IL, Mar. 28-Apr. 1, 1977), Paper in Scanning Electron Microscopy I, 445-454 (IIT Research Institute, Chicago, IL, 1977).

Key words: crystal orientation determination; crystallographic contrast; electron channeling contrast; microstructural analysis; scanning electron microscope; selected area electron channeling pattern.

A bibliography of references pertaining to the observation of crystalline materials by use of diffraction effects in the scanning electron microscope has been prepared. One hundred and eighty-three references have been collected covering the following topics: (1) theory of electron channeling contrast; (2) instrumental techniques; (3) tests of performance; (4) maps and quantitative procedures; (5) applications; (6) miscellaneous related techniques; and (7) review papers. Following the list of literature citations, the papers have been classified within these seven topics to facilitate recovery of particular information.

16840. Newbury, D. E., Fundamentals of scanning electron microscopy for physicist: Contrast mechanisms, (Proc. Workshop on Analytical Electron Microscopy, Chicago, IL, Mar. 28-Apr. 1, 1977), Paper in Scanning Electron Microscopy I, 553-568 (IIT Research Institute, Chicago, IL, 1977).

Key words: atomic number contrast; electron beam induced conductivity (EBIC) contrast; electron channeling contrast; magnetic contrast; scanning electron microscopy; topographic contrast; voltage contrast.

Contrast arises in the scanning electron microscope from a variety of mechanisms: atomic number differences, topography, crystallinity, magnetic structure, surface potential, and beam induced effects. The nature of the contrast depends on the interaction of the beam electrons with the specimen and on the characteristics of the detector. Two general forms of contrast exist, those arising from differences in the number of electrons emitted from the sample and those arising from differences in the post-specimen trajectories.

Atomic number contrast arises from differences in the backscattering of beam electrons from regions of different elemental composition due to a variation in the elastic cross-section with atomic number. Topographic contrast occurs because of differences in the numbers of backscattered and secondary electrons emitted from tilted surfaces as well as from the directionality of emission. Electron channelling contrast originates because of differences in scattering of the primary beam because of the periodic arrangement of atoms in crystalline materials. Type 1 magnetic contrast is formed by postspecimen deflection of emitted secondary electrons by leakage magnetic fields. Type 11 magnetic contrast is caused by deflection of the beam electrons within the specimen by the internal magnetic field. Voltage contrast arises from deflection of the secondary electrons by surface potentials. Electron beam induced current (EBIC) contrast originates from production of electron-hole pairs and recombination effects.

16841. Heinrich, K. F. J.; Elemental mapping in the microscopic domain, (Proc. Workshop on Analytical Electron Microscopy, Chicago, IL, Mar. 28-Apr: 1, 1977), Paper in Scanning Electron Microscopy I, 605-614 (IIT Research Institute, Chicago, IL, 1977).

Key words: electron probe; image formation; ion probe; microanalysis; microscopy; scanning; $x$-ray spectroscopy.
The production of microscopic maps depicting the variation of specimen composition over a small specimen region is a valuable tool for characterizing the microstructure of many specimens. Such maps may show the distribution of isotopes (ion probe or ion microscope), elements (autoradiography, electron and ion probes, Auger probes, back-scattered electrons), or compounds (cathodoluminescence, laser-Raman probe). Elemental maps can be obtained by contact procedures, image forming optics, or scanning.

Techniques and applications will be described, and limitations in the evaluation of elemental distributions will be discussed.

16842. Dickens, B., Pummer, W. J., Flynn, J. H., Automation of a thermogravimetry apparatus with a laboratory computer, (Proc. 3d Int. Symp. on Analytical Pyrolysis, Amsterdam, The Netherlands, Sept. 6-10, 1976), Paper in Analytical Pyrolysis, pp. 383-391 (Elsevier Scientific Publ. Co., Amsterdam, The Netherlands, 1977).

Key words: computerized experiment; experiment automation; off-the-shelf automation; polymer degradation; rapid response furnace; thermogravimetry.

We describe an automation scheme devised to implement "factor-jump" thermogravimetry. Temperature, pressure and the flow rates of oxygen and nitrogen are presently controlled and humidity control and sample irradiation are easily added. A computer uses feedback and prespecified precision levels to decide the course of the experiment. The automation is comprised in the main of commercially available components and is modular in form. A newly designed rapid-response furnace has been constructed.

16843. Vaicaitis, R., Simiu, E., Nonlinear pressure terms and alongwind response, J. Struct. Div. ASCE Tech. Notes 103, ST4, 903-906 (Apr. 1977).

Key words: aerodynamics; building (codes); pressure; spectra; structural engineering; tall buildings; turbulence; wind.

Current procedures for estimating alongwind response on structures are based upon the assumption that the fluctuations about the mean of the wind pressures are proportional to the fluctuations about the mean of the wind speeds. Preliminary time-domain calculations have been reported in Ref. 5 which suggest that the errors inherent in this assumption may, in certain cases, be significant. The extent to which this is the case is investigated herein for building heights and terrain roughness conditions covering the range of interest in structural design.

16844. Huie, R. E., Long, N. J. T., Thrush, B. A., The quenching of chiorine fluorescence in the gas phase, Chem. Phys. Lett. 44, No. 3, 608-610 (Dec. 15, 1976).

Key words: chlorine fluorescence; gas phase; laser induced fluorescence.

Laser induced fluorescence has been observed from the B ${ }^{3} \mathrm{II}\left(\mathrm{O}_{u}{ }^{+}\right)$state of chlorine. Lifetimes have been measured from 19 to $208 \mathrm{~Pa}$, but the radiative lifetime is too long to be extracted from the data. A rate coefficient of $3.2 \times 10^{13} \mathrm{~cm}^{3}$ $\mathrm{mol}^{-1} \mathrm{~s}^{-1}$ was measured for quenching by $\mathrm{Cl}_{2}$ or $\mathrm{Ar}$, the removal process being collision induced predissociation of the ${ }^{3} \mathrm{I}\left(\mathrm{O}_{u}{ }^{+}\right)$ state.

16845. Finn, J. M., Crannell, H., Hallowell, P. L., O'Brien, J. T., Penner, S., Elastic electron scattering from the isotopes ${ }^{36} \mathrm{Ar}$ and ${ }^{40} \mathrm{Ar}, \mathrm{Nucl}$. Phys. A274, 28-44 (1976).

Key words: enriched targets; $E=65$ to $115 \mathrm{MeV}$; measured $\sigma(E, \theta)$; nuclear charge distributions; nuclear reactions; ${ }^{36.40} \operatorname{Ar}\left(e, e^{\prime}\right)$. 
The charge structure of ${ }^{36} \mathrm{Ar}$ and ${ }^{40} \mathrm{Ar}$ has been investigated using the technique of elastic electron scattering. Data were collected at the National Bureau of Standards Linear Accelerator with incident electron energies ranging from 65 to 115 $\mathrm{MeV}$ and a scattering angle of $110^{\circ}$. The data span a range of $q^{2}$ between 0.29 and $0.92 \mathrm{fm}^{-2}$. Phase shift fits to a two-parameter Fermi distribution yield model dependent rms charge-radius values of $3.33 \pm 0.02 \mathrm{fm}$ for ${ }^{36} \mathrm{Ar}$ and $3.39 \pm 0.02 \mathrm{fm}$ for ${ }^{40} \mathrm{Ar}$, where the quoted uncertainties are statistical only. These values are compared with the results of previous experiments on these nuclei.

16846. Burnett, E. D., Bassin, M. A., NBS results of hearing aid performance tests, Handbook of Hearing and Measurement 1977, IB 11-60, pp. 32-276 (Veterans Administration, Washington, DC, 1977).

Key words: hearing aids.

Data for hearing aid testing for the Veterans Administration for their use in Fiscal Year 1977 are presented. The methods used are those previously agreed upon with the Veterans Administration.

16847. Burnett, E. D., NBS hearing aid test procedures, Handbook of Hearing and Measurement 1977, IB 11-60, pp. 12-31 (Veterans Administration, Washington, DC, 1977).

Key words: anthropometric manikin; free-field measurements; hearing aid tests; or thotelephonic response.

This report discusses the current test procedures used by NBS to evaluate the electroacoustic properties of hearing aids. It includes the technical and practical reasons for performing the various tests in the manner described and in certain cases presents ideas and preliminary test methods for the evaluation of special-purpose hearing aids. However, the specific details of the electronic equipment used to perform the tests are not described.

16848. Courtens, E., Szöke, A., Time and spectral resolution in resonance scattering and resonance fluorescence, Phys. Rev. A 15, No. 4, 1588-1603 (Apr. 1977).

Key words: fluorescence; laser fields; theory; two-photon absorption; Raman scattering; Rayleigh scattering.

The theory of resonance Raman effect, resonantly enhanced two-photon absorption, and resonance fluorescence-valid also for strong fields-is treated in a unified and simplified way. Dressed states, Bloch equations, and perturbation theory are used to calculate line positions, and integrated intensities both for steady state and transient excitation. The case of adiabatic following is solved explicitly; it occurs when an off-resonance incident pulse is turned on and off slowly. It leads to the identification of Raman scattering, two-photon absorption, and Rayleigh scattering with an adiabatic process while fluorescence and consecutive two-photon absorption with nonadiabaticity. Time-dependent spectra are defined in a rigorous way. Our formulas agree in the various limits with those that appear in the literature.

16849. Corcoran, C. T., Langhoff, P. W., Moment-theory approximations for nonnegative spectral densities, J. Math. Phys. 18, No. 4, $651-657$ (Apr. 1977).

Key words: approximations; moment theory; spectral densities.

Moment-theory approximations constructed from finite numbers of spectral power moments are described for continuous, nonnegative spectral densities and associated Stieltjes integrals. Derivatives of the mean (Stieltjes) values of the $n$ th-order Tchebycheff bounds on nondecreasing distributions provide the appropriate approximations to the associated spectral densities. The $n$ th-order Tchebycheff density so defined is shown to be: real, nonnegative, and continuous on the real axis, to have $2 n$-. 4 continuous derivatives there, and to support $2 n-2$ positive-in-teger power moments. Related approximations to the associated Stieltjes integral are obtained from corresponding principalvalue quadratures. The Tchebycheff densities are convergent in the limit of large numbers of spectral moments for determined moment problems, but they are not solutions of reduced moment problems of appropriate finite order. An illustrative application in the case of normal-mode lattice vibrations in a diatomic chain indicates that the Tchebycheff densities are suitably convergent, and provide faithful images of the forbid.. den band gap and Van Hove singularities present.

16850. Szalata, Z. M., Finn, J. M., Flanz, J., Kline, F. J., Peterson, G. A., Lightbody, J. W., Jr., Maruyama, X. K., Penner, S., Low-momentum-transfer elastic electron scattering from ${ }^{3}$ He, Phys. Rev. C 15, No. 4, $1200-1203$ (Apr. 1977).

Key words: deduced rms charge radius; $\mathrm{E}=28.8-95.0$ $\mathrm{MeV}$; measured $\sigma(E)$ at $\theta=75^{\circ}$; nuclear reactions; ${ }^{3} \mathrm{He}$ $\left(\mathrm{e}, \mathrm{e}^{\prime}\right)$.

Elastic electron scattering cross sections for ${ }^{3} \mathrm{He}$ were measured relative to those of ${ }^{12} \mathrm{C}$ in the range of momentum transfer squared between 0.032 and $0.34 \mathrm{fm}^{-2}$. The ${ }^{3} \mathrm{He} \mathrm{rms}$ charge radius was determined from the data to be $1.89 \pm 0.05$ fm.

16851. Geist, J., Trends in the development of radiometry, Opt. Eng. 15, No. 6, 537-540 (Nov.-Dec. 1976).

Key words: blackbodies; electrically calibrated detectors; history of radiometry; Planck's constant; radiometric standards; radiometry; standard lamps; Stefan-Boltzmann constant.

The presentation of the history of radiometry is divided into two periods separated by 1959 , the year that the first laser was reported. In contrast to the coverage of the second period which relies heavily on the original sources, the coverage of the first period relies mostly on review material. The presentation is slanted toward work reported in the English language. This is particularly true of the second period. The presentation also tends to emphasize radiometric standards.

16852. Doyle, W. M., McIntosh, B. C., Geist, J., Implementation of a system of optical calibration based on pyroelectric radiometry, Opt. Eng. 15, No. 6, $541-548$ (Nov.-Dec. 1976).

Key words: detector based standards; electrically calibrated pyroelectric radiometer; optical calibration; optical radiation; pyroelectric radiometry.

This paper is a status report covering the development of detector-based standards for optical calibration. It briefly treats, in historical perspective, the philosophy and technology underlying the use of detectors as standards and assesses the impact of recent technological developments. Next, the development and operation of the Electrically Calibrated Pyroelectric Radiometer (ECPR) are described, and the methods used to characterize this instrument are outlined. Finally, we review the present capabilities of the ECPR and summarize some of the measurements to which it has been applied.

16853. Novotny, D. B., Photoresist exposure-Measurement and control, Proc. Developments in Semiconductor Microlithography, San Jose, CA, June 1-3, 1976, 80, 9-13 (Society of Photo-Optical Engineers, Palos Verdes Estates, CA, 1976).

Key words: exposure; exposure control; film thickness variation; irradiance measurements; photoresist; photoresist sensitivity; sensitivity index; Van Kreveld's additivity law. 
Single parameter irradiance measurements commonly used for the determination of photoresist exposure times are incapable of giving unique values of either the broad band irradiance from a mercury-arc lamp, or the photoresist exposure times. Resolution of these measurement incapabilities through a series of irradiance measurements of narrow, approximately monochromatic radiation bands is discussed. A basis for establishing photoresist sensitivity indices that can be used to calculate unambiguous exposure times by applying $V$ an Kreveld's additivity law to these narrow band irradiance measurements is suggested. The thickness variation of photoresist films is included in the method of calculating exposure time. Conditions that may simplify the calculations of exposure times or reduce the number of irradiance measurements when a mercury lamp is used as the exposure source are discussed. Suggestions are made for the use of these indices as photoresist specifications, and for the real-time automatic monitoring and control of exposure times in wafer fabrication where optical density variation in the photomasks and thickness variations in the photoresist films are automatically incorporated into the control by a microprocessor.

16854. Whealton, J. H., Burch, D. S., Phelps, A. V., Improved model for parallel-plate drift-tube experiments, Phys. Rev. A 15, No. 4, 1685-1695 (Apr. 1977).

Key words: diffusion; drift tube; electron; Monte Carlo; transport coefficient.

The validity of analysis of parallel-plate drift-tube experiments by use of diffusion theory is examined. Monte Carlo simulations demonstrate the inadequacy of such analyses for electron motion near an absorbing cathode. However, diffusion theory results are verified for situations in which cathodic absorption is negligible, provided that a parameter $\beta$, the ratio of energy relaxation distance to drift-tube length, is much smaller than unity. For experimental circumstances in which cathode effects may be distinguished from those of anodic absorption, circuit time constant, and ionization, the Monte Carlo results can be used to augment diffusion theory for interpretation of the observed transients in terms of transport coefficients.

16855. Buehler, M. G., David, J. M., Mattis, R. L., Phillips, W. E., Thurber, W. R., Planar test structures for characterizing impurities in silicon, (Extended Abstract), Proc. Electrochemical Society Spring Meeting, Toronto, Canada, May 11-16, 1975, 75-1, Abstract No. 171, 403-404 (May 1975).

Key words: defects; dopants; impurities; junctions; MOS capacitors; sheet resistors; silicon; test structures.

Various test structures such as sheet resistors, pn junctions, and MOS capacitors and their associated physical models have been developed to characterize dopants and defects in silicon. These structures address various needs within the semiconductor industry for (a) standardized and miniaturized test structures, (b) updated values for the dopant density versus resistivity relation, and (c) improved defect detection methods. Examples of their use include (a) an update of the dopant densityresistivity relation where a significant change from commonly used values has been found in p-silicon and (b) the detection of minute amounts of lifetime killing defects. determined from thermally stimulated current measurements.

16856. Simiu, E., Ellingwood, B., Code calibration of extreme wind return periods, J. Struct. Div. ASCE Tech. Notes 103, ST3, 725-729 (Mar. 1977).

Key words: codes; probability; statistics; structural design; wind.

Design wind speeds upon which the Uniform Building Code provisions are based represent the highest fastest mile wind speeds observed in a 39-year period at the recording stations. This study shows that the most likely value of the largest of $\mathbf{n}$ maximum yearly wind speeds is nearly equal to the wind speed corresponding to an n-year mean recurrence interval. UBC provisions can thus be directly compared to probabilistic provisions which are based on the return period concept.

16857. Carlsten, J. L., Szöke, A., Raymer, M. G., Collisional redistribution and saturation of near-resonance scattered light, Phys. Rev. A 15, No. 3, 1029-1045 (Mar. 1977).

Key words: collisions; near-resonant light scattering; redistribution; saturation st rontium.

This paper reports on our studies of near-resonant scattering of laser light in a collisional environment. A pulsed dye laser with a peak power of $55 \mathrm{MW} / \mathrm{cm}^{2}$ was tuned near the 460.73$\mathrm{nm}$ resonance line of strontium and the side emission was observed from an oven containing both strontium vapor and argon buffer gas. The emission was composed of three spectral components: Rayleigh scattering at the frequency of the laser $\omega_{L}$, fluorescence at the resonance frequency $\omega_{0}$ of strontium, and a third component at $2 \omega_{L}-\omega_{0}$. These three components have been studied as a function of the frequency and intensity of the laser and also as a function of the argon buffer gas pressure. While the Rayleigh emission was found to vary as $\Delta^{-2}$ ( $\Delta$ $\left.=\omega_{0}-\omega_{L}\right)$, the fluorescence component, which was produced by $\mathrm{Sr}$-Ar collisions, was found to be asymmetric with the sign of $\Delta$ as predicted by line-broadening theory. By measuring the ratio of the intensities of the fluorescence and Rayleigh components, we were able to measure directly the collisional redistribution function, important in the study of radiative transfer in stellar and planetary atmospheres. At high laser intensities all three components were found to saturate. The results were compared with the theoretical predictions of Mollow's steadystate theory. Theoretical fits for the high-intensity results were obtained when the collisional cross sections were taken to be considerably smaller than in our low-intensity measurements. We believe the discrepancy lies in the use of a steady-state theory for a transient experiment. Effects of radiative trapping and spatial averaging are also discussed.

16858. Mandel, J., The analysis of interlaboratory test data, Stand. News 5, No. 3, 17-20, 56 (Mar. 1977).

Key words: accuracy; analysis of variance; interlaboratory testing; precision; repeatability; reproducibility.

Precision and accuracy, as parameters for the evaluation of test results, are discussed. The precision is shown to involve both within- and between-laboratory variability. Therefore a proper evaluation of a test method requires that a properly designed interlaboratory study be conducted.

The paper deals with the design and analysis of the results of interlaboratory studies. It is shown that the conventional two-way analysis of variance can lead to erroneous values for the within- and between-laboratory components of variance. It is strongly recommended that the data be analyzed "level by level," i.e., separately for each material or level, by means of a one-way analysis of variance (within-between analysis). This method leads to unbiased estimates for the precision components and allows the latter to be evaluated as functions of the level. A numerical example is included.

16859. Rabinow, J., Patents-An inventor's viewpoint, (Proc. 50th Anniversary Meeting of the Patent and Trademark Institute of Canada, Ottawa, Canada, Sept. 15-17, 1976), Patent Trademark Inst. Can. J., pp. 836-853 (Feb. 1977).

Key words: Canada; copyrights; inventions; monopolies; patent law; patents. 
A committee of three Canadians has prepared a proposal for a new Patent Law for Canada and has published the Proposed Law and a Working Paper on it. A large section of the Working Paper is devoted to criticisms of patents in general. This talk was meant to refute these attacks.

The main attacks involved calling patents monopolies, stating that authors and composers create new art but inventors do not, and that patents are simply means to reduce innovation and extort tributes from society by inventors who create nothing new but simply find that which is "inherent in the nature of the world.'

16860. Bennett, H. S., Forman, R. A., Frequency dependence of photoacoustic spectroscopy: Surface- and bulk-absorption coefficients, J. Appl. Phys. 48, No. 4, $1432-1436$ (Apr. 1977).

Key words: bulk absorption; frequency dependence; laser materials; photoacoustic spectroscopy; surface absorption; weakly absorbing materials.

Researchers seek improved ways to measure separately the surface- and bulk-absorption coefficients of highly transparent materials. The case in which a laser beam modulated at angular frequency $\omega$ passes through the weakly absorbing windows of a gas cell which contains a nonabsorbing gas is investigated in this paper. In particular, the frequency dependences of the acoustic stresses in the gas which arise from the surface and bulk absorption are derived. An intermediate range of frequencies exists for which the acoustic stress due to surface absorption varies as $\omega^{-1}$ and has a $90^{\circ}$ phase shift relative to the modulated laser beam and for which the acoustic stress due to bulk absorption varies as $\omega^{-3 / 2}$ and has a $45^{\circ}$ phase shift. In ad dition, expressions for the acoustic stress and phase shift which are valid for all frequencies are given. These expressions enable one to develop numerical procedures by which the surface- and bulk-absorption coefficients may be determined separately. $\mathrm{Nu}$ merical examples for a representative laser glass and air (nitrogen) are given.

16861. Kamper, R. A., Superconducting devices for metrology and standards, Chapter 5 in Superconductor Applications: Squids and Machines, B. B. Schwartz and S. Foner, Eds., pp. 189-247 (Plenum Publ. Corp., New York, NY, 1977).

Key words: DC measurements; frequency; metrology; rf measurements; standards; superconductivity; thermometry.

This topic falls naturally into five almost independent parts, which I will discuss separately. They are: (1) Voltage standards; (2) Current comparators and measurements of ratios of current and voltage; (3) Measurements of RF power and attenuation; (4) Noise thermometry; (5) Measurements of frequency.

I shall assume the reader to be generally familiar with the properties of superconductors and the Josephson effect, which are discussed at length in other parts of this book.

16862. Reed, R. P., Mikesell, R. P., Clark, A. F., Low temperature tensile behavior of copper-stabilized niobium-titanium superconducting wire, (Proc. First Int. Cryogenic Materials Conf., Kingston, Ontario, Canada, July 22-25, 1975), Paper I-3 in Advances in Cryogenic Engineering, K. D. Timmerhaus, R. P. Reed, and A. F. Clark, Eds., 22, 463-471 (Plenum Publ. Corp., New York, NY, 1977).

Key words: composite; copper; low temperature; niobiumtitanium alloys; superconducting wire; tensile properties.

The tensile properties of multi-filamentary superconducting wire and its base components, $\mathrm{Cu}$ and $\mathrm{Nb}$ - $\mathrm{Ti}$, were measured at 298, 76 and $4 \mathrm{~K}$. Conventional tensile properties, yield strength, tensile strength, elongation and Young's modulus were obtained. Additionally, the influence of strain rate on tensile behavior and the stress-strain hysteresis effects of the supercon- ducting wire were studied. The Young's moduli of the wires were found to be lower than the bulk values. The tensile and yield strengths were well behaved; no discontinuous yielding was observed.

16863. Reed, R. P., Clark, A. F., van Reuth, E. C., A research program on the properties of structural materials at $4 \mathbf{K}$, (Proc. First Int. Cryogenic Materials Conf., Kingston, Ontario, Canada, July 22-25, 1975), Paper A-1 in Advances in Cryogenic Engineering, K. D. Timmerhaus, R. P. Reed, and A. F. Clark, Eds., 22, 1-8 (Plenum Publ. Corp., New York, NY, 1977).

Key words: low temperature; mechanical properties; research program; structural materials; thermal properties.

A research program to obtain and evaluate the low temperature properties of materials applicable to large scale superconducting machinery is described. The properties and materials measured are summarized and representative results included. The effects of processing and fabricating on low temperature behavior is also being studied. Discussion is included on the problems of rapid and efficient distribution of properties information and the response of this program to that need.

16864. Sparks, L. L., Magnetothermal conductivity of selected pure metals and alloys, (Proc. First Int. Cryogenic Materials Conf., Kingston, Ontario, Canada, July 22-25, 1975), Paper B-1 in Advances in Cryogenic Engineering, K. D. Timmerhaus, R. P. Reed, and A. F. Clark, Eds., 22, 119-127 (Plenum Publ. Corp., New York, NY, 1977).

Key words: copper; low temperature; magnetothermal conductivity; nickel alloy; stainless steel; thermal conductivity.

The magnetothermal conductivity program was initiated to determine the effect of a magnetic field on the thermal resistance of technically important metals. The experiments are done in magnetic fields up to $8 \mathrm{~T}$ and cover the temperature range from 4 to $20 \mathrm{~K}$. The results of this study are presented for a Ni-Cr-Fe alloy, AISI 310 stainless steel, oxygen-free copper, and a high purity copper specimen. A magnetic field typically increases the electronic thermal resistance and thus lowers the total thermal conductivity of a metal. The magnetic field effect at constant temperature is shown by the relative change in thermal resistance, $\Delta W / W_{H=0}$, where $\Delta W$ is defined as $W_{H \sim 0}-W_{H=0}$. Our experimental data show that the effect of an $8 \mathrm{~T}$ magnetic field on the $\mathrm{Ni}-\mathrm{Cr}-\mathrm{Fe}$ alloy is to increase $\Delta W / W_{H=0}$ by 0.08 at $5 \mathrm{~K}$ and 0.03 at $19 \mathrm{~K}$. The corresponding values for AISI 310 are 0.28 at $5 \mathrm{~K}$ and 0.10 at $19 \mathrm{~K}$. The thermal resistivity of the better conductors was found to be affected more strongly. An $8 \mathrm{~T}$ magnetic field causes $\Delta W / W_{H=0}$ to increase to 1.3 at $5.5 \mathrm{~K}$ and 0.8 at $19 \mathrm{~K}$ for oxygen-free copper; for the high purity copper, $\Delta W / W_{H=0}$ increases to 3.4 at $5.5 \mathrm{~K}$ and 2.7 at $20 \mathrm{~K}$.

16865. Schramm, R. E., Kasen, M. B., Static tensile properties of boron-aluminum and boron-epoxy composites at cryogenic temperatures, (Proc. First Int. Cryogenic Materials Conf., Kingston, Ontario, Canada, July 22-25, 1975), Paper C-2 in Advances in Cryogenic Engineering, K. D. Timmerhaus, R. P. Reed, and A. F. Clark, Eds., 22, $205-213$ (Plenum Publ. Corp., New York, NY, 1977).

Key words: advanced fiber composites; boron-aluminum; boron-epoxy; cryogenics; static mechanical properties.

State-of-the-art boron-aluminum and boron-epoxy composites have been mechanically characterized at 295,76 , and $4 \mathrm{~K}$. Static tensile properties include elastic and shear moduli, Poisson's ratio, yield and ultimate strengths, and elongation. The data are in a form useful in strength or stiffness limiting predictions of complex crossply components using macromechanical 
composite theory. Both composites performed well at cryogenic temperatures.

16866. McHenry, H. I., Fracture mechanics and its application to cryogenic structures, (Proc. First Int. Cryogenic Materials Conf., Kingston, Ontario, Canada, July 22-25, 1975), Paper A-2 in Advances in Cryogenic Engineering, K. D. Timmerhaus, R. P. Reed, and A. F. Clark, Eds., 22, 9-26 (Plenum Publ. Corp., New York, NY, 1977).

Key words: crack propagation; cryogenics; fracture mechanics; fracture toughness; material properties; structures.

A tutorial review of fracture mechanics is presented with emphasis on the application of this technology to cryogenic structures. The concepts of linear-elastic and elastic-plastic fracture mechanics are briefly reviewed. Test methods and representative data for fatigue crack growth and fracture toughness of structural alloys at cryogenic temperatures are summarized. The elements of a fracture control plan are presented and applications of fracture mechanics to cryogenic structures are described.

16867. Radford, H. E., Peterson, F. R., Jennings, D. A., Mucha, J. A., Heterodyne measurements of submillimeter laser spectrometer frequencies, IEEE J. Quant. Electron. Notes \& Lines QE-13, No. 3, 92-94 (Mar. 1977).

Key words: frequency measurement; infrared.

The frequencies of $46 \mathrm{CW}$ laser lines commonly used for submillimeter spectroscopy, with wavelengths between 0.1 and $0.7 \mathrm{~mm}$, have been measured by heterodyne methods. All the lines are optically pumped by a $\mathrm{CO}_{2}$ laser, with threshold pump powers of $3 \mathrm{~W}$ or less. The precision of measurement, limited by the laser linewidth, is typically \pm 1 part per million.

16868. Ekin, J. W., Fickett, F. R., Clark, A. F., Effect of stress on the critical current of NbTi multifilamentary composite wire, (Proc. First Int. Cryogenic Materials Conf., Kingston, Ontario, Canada, July 22-25, 1975), Paper 1-1 in Advances in Cryogenic Engineering, K. D. Timmerhaus, R. P. Reed, and A. F. Clark, Eds., 22, 449-452 (Plenum Publ. Corp., New York, NY, 1977).

Key words: critical currents; NbTi; stress effect; superconductor.

Measurements of the effect of stress on the critical currentmagnetic field characteristics of a NbTi:Cu (1:1.8) composite wire containing 180 filaments are described. The experimental apparatus employs a design allowing transverse field measurements in a simple solenoidal magnet. A series of measurements are reported at $4 \mathrm{~K}$ in fields to 8 Tesla which show a definite degradation of $I_{c}$ with applied stress, starting at about $1 / 3$ the breaking stress. The effect amounts to a 15-20 percent decrease in $I_{c}$ at $3 / 4$ of the breaking stress and rapidly increases at still larger stress levels. At each stress level, a substantial recovery toward the initial-unstressed $I_{c}$ value is observed after the stress is relieved.

16869. Ledbetter, H. M., Naimon, E. R., Weston, W. F., Lowtemperature elastic properties of invar, (Proc. First Int. Cryogenic Materials Conf., Kingston, Ontario, Canada, July 22-25, 1975), Paper B-7 in Advances in Cryogenic Engineering, K. D. Timmerhaus, R. P. Reed, and A. F. Clark, Eds., 22, 174-181 (Plenum Publ. Corp., New York, NY, 1977).

Key words: bulk modulus; compressibility; Debye temperature; elastic constant; invar; iron alloy; nickel alloy; Poisson's ratio; shear modulus; sound velocity; Young's modulus.
The elastic properties of a polycrystalline invar alloy were determined between room temperature and liquid-helium temperature by two methods: measurement of ultrasonic (10 $\mathrm{MHz})$ wave velocities with a pulse-echo technique, and measurement of resonance frequencies $(60 \mathrm{kHz})$ of cylindrical specimens with a composite piezoelectric-oscillator technique. The shear moduli obtained by the two methods are essentially the same. However, the other elastic constants (all of which have a dilatational component) differ both in magnitude and in temperature dependence. Present pulse-echo results agree closely with previous results obtained for both polycrystals and single crystais in a saturating magnetic field. The following elastic constants are reported: longitudinal modulus, Young's modulus, the shear modulus, the bulk modulus (reciprocal compressibility), and Poisson's ratio. The role of magnetic effects on invar's elastic properties is discussed briefly.

16870. Stevens, W. J., Hessel, M. M., Bertoncini, P. J., Wahl, A. C., Theoretical transition dipole moments and lifetimes for the $A^{1} \Sigma^{*} u \rightarrow X^{1} \Sigma^{+} g$ system of $\mathrm{Na}_{2}, J$. Chem. Phys. 66, No. 4, 1477-1482 (Feb. 15, 1977).

Key words: ab initio calculations; $A$-values; Franck-Condon factors; laser modeling; lifetime; multiconfiguration selfconsistent-field; potential energy curves; sodium molecule; transition dipole moment.

Multiconfiguration self-consistent field (MCSCF) calculations have been carried out on the $X^{1} \Sigma_{g}^{+}, A^{1} \Sigma_{u}^{+}$, and $B^{1} \Pi_{u}$ states of $\mathrm{Na}_{2}$. The calculated potential energy curves are in good agreement with the experimental $X$ and $A$ RKR curves of Hessel and Kusch. Both the $A \rightarrow X$ and $B \rightarrow X$ transition moments have been calculated as a function of nuclear separation using MCSCF wavefunctions. These calculations are in excellent agreement with the recent experimental determinations of the $B \rightarrow X$ transition moment. $A$ values and lifetimes of several $A$ state vibrational and rotational levels for the $A \rightarrow X$ transition have been calculated using the theoretical transition moment and the experimental potential curves of Hessel and Kusch. These again are in excellent agreement with the recently measured lifetimes.

16871. Haynes, W. M., Hiza, M. J., Measurements of the orthobaric liquid densities of methane, ethane, propane, isobutane, and normal butane, J. Chem. Thermodyn. 9, No. 2, 179187 (Feb. 1977).

Key words: density; deviation plots; ethane; experimental; isobutane; magnetic suspension densimeter; methane; normal butane; propane saturated liquid; tables.

The orthobaric liquid densities of the major components of natural gas have been determined with a magnetic suspension densimeter. This paper reports results for methane (105 to 160 $\mathrm{K}$ ), ethane ( 100 to $270 \mathrm{~K})$, propane ( 100 to $288 \mathrm{~K}$ ), isobutane $(115$ to $300 \mathrm{~K})$, and normal butane $(135$ to $300 \mathrm{~K})$. The imprecision of the measured densities is approximately 0.015 percent; the estimated overall uncertainty is 0.1 percent at low temperatures and decreases to 0.06 percent at $300 \mathrm{~K}$. A simple expression has been used to represent the densities as a function of temperature. Comprehensive comparisons with the experimental results of other investigators are presented.

16872. Zimmerman, J. E., SQUID instruments and shielding for low-level magnetic measurements, J. Appl. Phys. 48, No. 2, 702-710 (Feb. 1977).

Key words: biomagnetism; geomagnetism; instrumentation; Josephson effect; magnetometry; SQUID.

We have used a thick-walled aluminum enclosure to provide low-frequency shielding for biomagnetic studies with SQUID magnetic gradiometers. The shield provides an attenuation pro- 
portional to frequency above $1 / 3 \mathrm{~Hz}$. A 24-hole fractional-turn SQUID gradiometer has been used in the enclosure to carry out studies of magnetoencephalography on humans. An "asymmetric" configuration for a second-derivative gradiometer has been developed which provides a significant increase in sensitivity and resolution over more conventional symmetric arrays.

16873. Ekin, J. W., Mechanisms for critical-current degradation in $\mathrm{NbTi}$ and $\mathrm{Nb}_{3} \mathrm{Sn}$ multifilamentary wires, (Proc. IEEE Conf. Applied Superconductivity, Sanford, CA, Aug. 18-20, 1976), IEEE Trans. Magn. MAG-13, No. 1, 127-130 (Jan. 1977).

Key words: critical current; critical current degradation; degradation mechanisms; multifilamentary superconductors; $\mathrm{NbTi}$; $\mathrm{Nb}_{3} \mathrm{Sn}$; strain; stress.

Critical currents of $\mathrm{NbTi}$ and $\mathrm{Nb}_{3} \mathrm{Sn}$ multifilamentary wires have been studied in magnetic fields to $9 \mathrm{~T}$ as a function of mechanical load applied at $4 \mathrm{~K}$. Degradation of the critical current in $\mathrm{NbTi}$ is limited to about 30 percent with the effect becoming large only at strains above $\sim 1$ percent. The change in critical current with strain is much larger in $\mathrm{Nb}_{3} \mathrm{Sn}$, commencing at strains of 0.1 to 0.3 percent. For both superconductors, the first 20 to 30 percent decrease in critical current is almost totally reversible. A number of possible explanations of the observed degradation are considered, including filament breakage, heat generation by mechanical creep, degradation of the stabilizing matrix, and defect formation in the superconductor itself. Results of experiments to test the source of degradation are reported. Evidence for microcrack damage in the $\mathrm{Nb}_{3} \mathrm{Sn}$ reaction layer has been found and it is suggested that defect size variations on the order of a coherence length $(\sim 5$ $\mathrm{nm}$ ) can account for the reversibility of the degradation as well as low-strain enhancement effects.

16874. Peterson, R. L., McDonald, D. G., Picosecond pulses from Josephson junctions: Phenomenological and microscopic analyses, (Proc. IEEE Conf. Applied Superconductivity, Sanford, CA, Aug. 18-20, 1976), IEEE Trans. Magn. MAG-13, No. 1, 887-890 (Jan. 1977).

Key words: energy gap; Josephson junctions; picosecond pulses; superconducting electronics; superconductivity; voltage waveforms.

A Josephson junction modeled by the phenomenological current relation together with internal resistance can exhibit pulses in the voltage across the junction when driven by an oscillating current source. The pulses occur singly, in pairs, triplets, etc. with a repetition rate equal to twice the driving frequency. The inclusion of capacitance and inductance generally degrades the pulse characteristics, but attainable values for tunnel junctions are tolerable. With typical parameter values, the pulses have picosecond widths. The phenomenological model becomes suspect on such time scales, however, because typical gap frequencies are just under $10^{12} \mathrm{~Hz}$. Preliminary studies based on the microscopic tunnel-junction theory nevertheless show results qualitatively similar to those of the phenomenological model. The effects of resistor noise and current noise have also been studied. It is concluded that well developed ps voltage pulses can be created in physical Josephson junctions.

16875. Frederick, N. V., Sullivan, D. B., Adair, R. T., Advances in the use of SQUIDS for of attenuation measurement, (Proc. IEEE Conf. Applied Superconductivity, Sanford, CA, Aug. 18-20, 1976), IEEE Trans. Magn. MAG-13, No. 1, 361-364 (Jan. 1977).

Key words: attenuation; Josephson effect; quantum interference; radio frequency; SQUID; superconductivity.
The Squid system for $\mathrm{rf}$ attenuation measurement has been advanced by a number of significant changes. A redesign of the L-band SQUID has resulted in a significantly simpler geometry which provides an adjustable coupling for precise matching to the electronics. The redesigned SQUID contains a permanently adjusted point contact in a replaceable cartridge.

Attenuation measurement with this system relies heavily on proper signal processing in the room temperature components and a careful study of these conditions indicates a series of areas where error can be generated. These signal handling problems and appropriate solutions are discussed in detail.

16876. Sullivan, D. B., Frederick, N. V., Can superconductivity contribute to the determination of the absolute ampere?, (Proc. IEEE Conf. Applied Superconductivity, Sanford, CA, Aug. 18-20, 1976), IEEE Trans. Magn. MAG-13, No. 1, $396-$ 399 (Jan. 1977).

Key words: ampere definition; electrical units; fundamental constants; Josephson effect; levitation; superconductivity.

The absolute ampere is shown to be derivable from a static levitation of a superconducting mass. The magnetic force which salances the gravitational force can be obtained from a combination of inductance and linear position measurements. A unique feature of the concept is the use of the calculable capacitor for the inductance measurements. Besides the possibility of this specific approach other concepts involving superconductivity are also discussed.

16877. Hust, J. G., Thermal conductivity and electric resistivity standard reference materials: Tungsten ( 4 to $3000 \mathrm{~K}$ ), (Proc. 5th European Conf. on Thermophysical Properties of Solids at High Temperatures, Moscow, USSR, May 18-21, 1976), High Temp.-High Pressures 8, 377-390 (1976).

Key words: electrical resistivity; high temperature; Lorenz ratio; low temperature; standard reference material; thermal conductivity; thermopower; tungsten.

Thermal conductivity and electric resistivity data for arc-cast and sintered tungstens are compiled, analyzed, and correlated. Recommended values of thermal conductivity and electric resistivity for particular lots of tungsten are presented for the range 4 to $3000 \mathrm{~K}$. These values are based on low-temperature NBS measurements and higher-temperature measurements by participants of the AFML-AGARD project. The uncertainty of the thermal conductivity values below ambient is 2 percent and rises to 5 percent between ambient and $2000 \mathrm{~K}$. Above 2000 $K$ the uncertainty rises to a maximum of about 8 percent. The uncertainty of the electrical resistivity values is 2 percent over the entire temperature range.

16878. Hust, J. G., Giarratano, P. J., Thermal and electrical measurements on selected materials for low-temperature applications, ( Proc. First Int. Cryogenic Materials Conf., Kingston, Ontario, Canada, July 22-25, 1975), Paper B-2 in Advances in Cryogenic Engineering, K. D. Timmerhaus, R. P. Reed, and A. F. Clark, Eds., 22, 128-135 (Plenum Publ. Corp., New York, NY, 1977).

Key words: copper; electrical resistivity; iron alloys; Lorenz ratio; low temperature; nickel alloys; thermal conductivity; thermopower.

Thermal conductivity, electrical resistivity, thermo-power, and Lorenz ratio data have been obtained with a variable-temperature, multiproperty apparatus for high conductivity copper, a nickel base superalloy, and a low expansion alloy. Values of these properties are presented in graphical form at temperatures from 4 to $300 \mathrm{~K}$. The thermal conductivity data are accurate to 2 percent, which is well within material variability limits expected for production heats. Prediction techniques have been 
shown to yield conductivity values within 15 percent of experimental values for pure metals, such as high conductivity copper.

In addition, thermal conductivity values have been obtained, using a fixed-point apparatus, for two stainless steels at 6, 79, 196 , and $277 \mathrm{~K}$. These values, accurate to 10 percent, are presented in graphical form. The above data are compared to existing literature data on similar alloys.

16879. Reed, R. P., Tobler, R. L., Mikesell, R. P., The fracture toughness and fatigue crack growth rate of an Fe-Ni-Cr superalloy at 298, 76, and $4 \mathrm{~K}$, (Proc. First 1nt. Cryogenic Materials Conf., Kingston, Ontario, Canada, July 22-25, 1975), Paper A-7 in Advances in Cryogenic Engineering, K. D. Timmerhaus, R. P. Reed, and A. F. Clark, Eds., 22, 68-79 (Plenum Publ. Corp., New York, NY, 1977).

Key words: $J$-integral; plane strain fracture toughness; tensile fatigue crack growth rate.

Fatigue crack growth rate and fracture toughness data at 298, 76, and $4 \mathrm{~K}$ are presented for a precipitation hardenable, Fe-Ni-Cr superalloy, ASTM A453. Plane strain, linear-elastic fracture mechanics and $J$-integral test techniques were applied using compact specimens. The crack growth rate was significantly lower at low temperatures than at room temperature. The toughness parameter $K_{Q}$ and the critical value of the $J$-integral, $J_{I C}$, were determined. $K_{I C}(J)$, as converted from $J_{I C}$, decreased slightly with decreasing temperature. These results represent the first low temperature fatigue crack growth rate and toughness data for this alloy.

16880. Ledbetter, H. M., Poisson's ratio for central-force polycrystals, Z. Naturforsch. Teil A 31, No. 12, $1539-1542$ (Dec. 1976).

Key words: body-centered cubic solids; central-force solids; elastic constants; face-centered cubic solids; Poisson's ratio; polycrystals.

The Poisson ratio $\nu$ of a polycrystalline aggregate was calculated for both the face-centered cubic and the body-centered cubic cases. A general two-body central-force interatomatic potential was used. Deviations of $\nu$ from 0.25 were verified. A lower value of $\nu$ is predicted for the f.c.c. case than for the b.c.c. case. Observed values of $\nu$ for twenty-three cubic elements are discussed in terms of the predicted values. Effects of including volume-dependent electron-energy terms in the interatomic potential are discussed.

16881. Miller, R. C., Kidnay, A. J., Hiza, M. J., Liquid + vapor equilibria in methane + ethene and in methane + ethane from 150.00 to $190.00 \mathrm{~K}, J$. Chem. Thermodyn. 9, No. 2, 167-178 (1977).

Key words: ethane; ethene; methane; vapor + liquid equilibria.

Liquid + vapor equilibrium compositions and pressures are reported for methane + ethane at 160.000 and $180.00 \mathrm{~K}$ and for methane + ethene at 150.00, 160.00, 170.00, 180.00, and $190.00 \mathrm{~K}$. Liquid-phase $G^{E}$ values have been estimated from the experimental results. Liquid-mixture $G^{E}(x=0.5)$ values are compared with the results of previous investigations at temperatures less than $190 \mathrm{~K}$. For methane + ethane, $G^{E}$ values from 11 of the 16 isotherms analyzed agree within approximately 20 $\mathrm{J} \mathrm{mol}^{-1}$. Of the 13 available methane + ethene isotherms 11 yield $G^{E}(x=0.5)$ values that agree within the same limits.

16882. Bukowski, R. W., Field investigation of residential smoke detectors, Southern Bldg., pp. 28-31 (Apr.-May 1977).
Key words: detector sensitivity; detector siting; heat detectors; ionization smoke detectors; photoelectric smoke detectors; residential fires; smoke detectors; tenability levels.

A test program was undertaken to investigate the operation of residential smoke detectors under actual field conditions. The main objectives were to determine: 1) minimum sensitivity, 2 ) best location, and 3 ) escape time provided by a group of typical detectors. Instrumentation was used to determine theoretical response times of an "ideal" detector as a base line for evaluation of detector performance. The tests were conducted using smoldering or flaming ignition of sofas, chairs and mattresses in various rooms in two abandoned, single-family houses scheduled for demolition. Work was carried out during winter and summer seasons with central heating and cooling on and off.

In addition to a description of the tests and discussion of the results, the report contains all raw data for further analysis by the reader.

The tests indicate both photoelectric and ionization detectors at a sensitivity of approximately 1 percent per foot $(0.022$ OD per meter) provide adequate escape time from all the test fires when installed using the following guidelines: 1 . The detectors should be installed at the head of each stairway; 2 . Outside each separate sleeping area; 3 . At least one detector on every level of a multi-level home.

16883. Williamson, F. R., Olien, N. A., Cryogenic adhesives and sealants-Abstracted publications, NASA SP-3101, 158 pages (National Aeronautics and Space Administration, Washington, DC, 1977).

Key words: abstracted publications; adhesives and sealants; cryogenic adhesives and sealants; experimental data.

This survey is made up of information from the available reports and publications on Cryogenic Adhesives and sealants. The documents, listed alphabetically by first author, are original publications of experimental data on properties of adhesives and sealants at cryogenic temperatures, and review papers on cryogenic adhesives and their applications. An abstract has been prepared for each primary document cited, and the most important references are listed as found in the document. In addition, an author index and subject index are provided for the primary documents.

Also listed alphabetically by author are documents considered secondary in nature and include re-publications or variations of the primary documents, progress reports leading to the final reports included as primary documents, and experimental data on adhesive properties at temperatures between about $130 \mathrm{~K}$ and room temperature. The citations of the secondary documents include a comment or descriptive line as to the contents of the document.

16884. Harman, G. G., The use of acoustic emission in a test for beam lead bond integrity, Proc. 14th Annual IEEE Reliability Physics Symp., Las Vegas, NV, Apr. 20-22, 1976, pp. 86-97 (1976).

Key words: acoustic emission; automated tape bonding; beam lead devices; bugging height; microelectronics; nondestructive test.

The use of Acoustic Emission (AE) in a test for beam lead bond integrity has been investigated. AE refers to emission of broad band stress waves when materials are broken, cracked, or deformed. A major problem in the present work was to develop means of nondestructively stressing the delicate, irregularly extending beam leads. The most promising of the methods developed are a silicone rubber (SR) pull test, a push down test on SR encapsulated devices, and various probe methods of applying force to the beams without contacting the chip. AE 
bursts from weak bonds or beam anchors are detected with a substrate detector operating at $375 \mathrm{kHz}$ or a probe detector operating at $1.1 \mathrm{MHz}$ or both. The study has revealed considerable differences in the mechanical integrity of beam lead bond-anchor systems. General deterioration of the beam-anchor system begins at pull forces per beam of from approximately 1.0 to $2.5 \mathrm{gf}$, depending on the manufacturer's procedure. The forces applied to the beam-anchor system for all methods of stressing, except the pull test, are dependent upon the shape of the individual beams as they extend from the chip, as well as the uniformity of the bugging height. There are many other potential uses of $\mathrm{AE}$ in electronics, such as to insure the bonding integrity of flip chips, capacitor chips in hybrids, and bonds on automated tape-bonded integrated circuits. The latter two uses were experimentally demonstrated in the present work. Thus, it appears that AE will have an increasing role in assuring reliability in the microelectronics field.

16885. Meyerson, M. R., Appliance labeling and efficiency, Proc. Electro 77 Programs for Energy Conservation, New York, NY, Apr. 19-21, 1977, Paper 33/3, 1-7 (McGregor Warner, Washington, DC, 1977).

Key words: appliances; energy conservation; energy efficiency; energy improvement targets; labeling; test procedures.

The usage of energy in residences and by specific major appliances in residences are described and related to overall $\mathrm{Na}$ tional energy use. The Energy Policy and Conservation Act contains provisions designed to reduce consumption of energy by appliances. One provision consists of a labeling program to advise the consumers, at the point of sale, of the estimated annual operating costs of major appliances and a means of comparing these costs with competing brands. The other provision provides for the improvement of efficiency of specified appliances by an average amount of not less than 20 percent by the year 1980 as compared to 1972 . Certain key features of the Act are described and the prescribed roles of FEA, FTC, and NBS are explained. The procedures being used by NBS to establish the efficiency improvement goals for 1980 are presented and the key role that consumers will play in the success of the program is described.

16886. Gump, B. H., Hertz, H. S., May, W. E., Chesler, S. N., The hydrocarbon burden in the marine environment surrounding a refinery tanker jetty, J. Environ. Sci. Health A12, No. 3, 105-113 (1977).

Key words: benzo(a)pyrene; gas chromatography; gas chromatography-mass spectrometry; hydrocarbons; liquid chromatography; oil refinery; petroleum.

In an investigation of petroleum hydrocarbons in the vicinity of a refinery docking facility in a "clean" environment, water samples taken from the surface and at a 10-m depth and sediment samples taken from a nearby beach were found to have essentially no contamination, while bottom sediment had a low level hydrocarbon contamination. Of particular interest was the relative abundance of benzo(a)pyrene in the bottom sediment.

16887. Hoffman, J. D., Davis, G. T., Lauritzen, J. I., Jr., The rate of crystallization of linear polymers with chain folding, Chapter 7 in Treatise on Solid State Chemistry, N. B. Hannay, Ed., 3, $497-614$ (Plenum Press, New York, NY, 1976).

Key words: chain-folding; crystallization; growth rate; homogeneous nucleation; polymer; surface nucleation.

The article is an in-depth review of crystallization of polymers with chain-folding written specifically as a chapter in a book, which requires no abstract.
16888. Steinitz, R., Gebbie, K. B., Bar, V., The embedded feature model for the interpretation of chromospheric contrast profiles, Astrophys. J. 213, 269-277 (Apr. 1, 1977).

Key words: sun, atmosphere; sun, chromosphere; sun, spectroheliograms.

Contrast profiles obtained from chromospheric filtergrams and spectra of bright and dark mottles have to date been interpreted almost exclusively in terms of Beckers's cloud model. Here we demonstrate the failure of this model to account in a physically consistent way for the observed contrasts. As an alternative, we introduce an embedded-feature model, restricting our discussion in this paper to stationary features. Our model is then characterized by three independent parameters: the density of absorbing atoms, the geometrical depth, and the profile of the absorption coefficient. An analytic approximation to the contrast resulting from such a model reproduces well the observed behavior of all types of contrast profiles.

16889. Mayo, S., Galloway, K. F., Leedy, T. F., Radiation dose due to electron-gun metallization systems, (Proc. IEEE Annual Conf. on Nuclear and Space Effects, San Diego, CA, July 27-30, 1976), IEEE Trans. Nucl. Sci. NS-23, No. 6, 1875-1880 (Dec. 1976).

Key words: electron-gun evaporator; gate oxide film; metal evaporation; metallization; metal-oxide semiconductor; microelectronic device; radiation dose; silicon dioxide film.

Electron beam evaporation is often selected as a method for depositing the gate metal for metal-oxide-semiconductor (MOS) devices. X-rays generated by electron impact on the metal to be evaporated may produce damage in the gate oxide. Several experimenters have reported that radiation-hardened MOS devices metallized in electron-gun systems appear to degrade at a faster rate than devices fabricated identically except for the metallization technique used. In order to examine ways of minimizing the damage introduced by electron beam systems and to develop a basis for understanding the physical phenomena observed, the physics of the $x$-ray energy deposition during the metallization process was explored. Details of the calculational procedure, the data necessary to calculate the $x$-ray absorbed dose in the oxide layer due to the electron-gun deposition of aluminum and chromium, and the calculations are presented. The results of experimental measurements of the $x$ ray dose are included for comparison. The implications of the results including the differences in the radiation susceptibility of MOS devices prepared with different gate metals are discussed.

16890. Leight, W. G., Product safety, in what direction should we be going?, Prof. Safety 22, No. 5, 25-27 (May 1977).

Key words: consumer behavior; consumer product safety; human factors; misuse of products; systems analysis; use of products.

Product safety improvements entail interactions of legal, technical, and economic factors. The author explains "where we are and should be headed" from the vantage point of a technical researcher.

16891. Leedy, K. O., A bibliography on electron beam induced current analysis of semiconductor devices, Solid State Tech. 20, No. 2, 45-48 (Feb. 1977).

Key words: device inspection; electron-beam-induced current; microelectronics; $p-n$ junctions; scanning electron microscopy; semiconductor devices.

A bibliography has been compiled on the applications of the scanning electron microscope used in the electron-beam-in- 
duced-current mode in the analysis of semiconductor devices. Covering the period from December 1, 1963 when the first article appeared describing an application of EBIC through March, 1976, the literature survey included a search of the abstracts appearing in Electrical and Electronics Abstracts, Physics Abstracts and the Engineering Index.

16892. Geltman, S., Ionization of a model atom by a pulse of coherent radiation, J. Phys. B: Atom. Molec. Phys. 10, No. 5, $831-840$ (1977).

Key words: ionization; laser-induced breakdown; laser pulse; multiphoton absorption; tunnelling.

The time evolution of the ionization probability of a simple one-dimensional model atom under the influence of a harmonic electric field is studied by the numerical solution of the timedependent Schrödinger equation. The conditions are clarified under which tunnelling or multiphoton absorption may be regarded as appropriate mechanisms. The standard tunnelling formulae are found to give poor quantitative estimates of ionization probability. The duration of the radiation pulse is found to be of critical importance, as multiphoton absorption is seen to require a certain minimum time to develop. The overall behaviour predicted is consistent with measurements on the laser-induced breakdown of gases.

16893. Blackburn, D. L., Rubin, S., Rogers, G. J., Measurements of power transistor thermal instabilities, stable hotspots, and second-breakdown, (Proc. Int. Electron Devices Meeting, Washington, DC, Dec. 6-8, 1976), IEDM Tech. Digest, pp. $151-154$ (1976).

Key words: hot spots; measurement methods; power transistors; reliability; safe operating area limits; second breakdown; thermal instability.

The relationships of thermal instability, stable hot spots, and second breakdown in power transistors are discussed. A rationale is also given for using thermal instability as opposed to second breakdown as the specified limit of safe operation for power transistors. It is shown that the limit of thermal instability can be accurately predicted and the simple device measurements required to do this are described. A rapid, easy, nondestructive test is also described for experimentally determining this limit.

16894. Bullis, W. M., Galloway, K. F., Semiconductor electronics at the National Bureau of Standards: Programs and opportunities, Proc. $2 d$ IEEE (G-PHP)/ISHM University/Industry/Government Microelectronics Symp., University of New Mexico, Albuquerque, NM, Jan. 3-5, 1977, Session IX, pp. 11 (1977).

Key words: electronics; measurement methods; microelectronics; National Bureau of Standards; semiconductor devices; semiconductor materials; semiconductor process control.

The National Bureau of Standards (NBS) has had a long history in the fields of electricity and electronics. Many groups at NBS have made contributions which have enhanced the growth of the electronics community. The Semiconductor Technology Program, a part of the Electronics Technology Division, is specifically directed toward the development of measurement technology needed in the semiconductor electronics field. This paper discusses the nature of the research and development work involved and the avenues of interaction with industry, universities, and other government agencies.

16895. Ledford, A. E., Jr., Braun, W., Gas cell for photochemical studies, Rev. Sci. Instrum. 48, No. 5, 537-538 (May 1977).
Key words: apparatus; chromatography; experimental; laser; photochemistry.

A cell design suitable for chromatographic sampling of products is integrated into an apparatus suitable for performing ir, visible, and photochemical studies. The design of the cell and a schematic of the apparatus are presented and described.

16896. Fallır, J. E., Levine, J., The measurement of the positions of points on the earth's surface using an absolute gravimeter and a multi-wavelength geodimeter as complements to extraterrestrial techniques, (Proc. SALUR Symp., Austin, TX, June 1976), Paper in Scientific Applications of Lunar Laser Ranging, J. D. Mulholland, Ed., pp. 277-283 (D. Reidel Publ. Co., Dordrecht-Holland, 1977).

Key words: geodesy; gravimetry; lunar ranging; plate tectonics.

The usefulness of extraterrestrial techniques and in particular lunar laser ranging in obtaining the position of points on the earth's surface with an accuracy of several centimeters is now recognized. The positional information obtained in this way cannot be unambiguously interpreted without ancillary surface measurements. The use of a geodimeter with an accuracy of 5 parts in $10^{\mathrm{s}}$ (over a $50 \mathrm{~km}$ baseline) would permit all of the points within a radius of several hundred kilometers around a ranging station to be tied together with centimeter level accuracy, thereby eliminating any local phenomena that could be associated with single-point sites and the same time extending the coverage of extraterrestrially determined measurements. The use of an absolute.gravimeter with an accuracy of 3 parts in $10^{9}$ (which corresponds to a height sensitivity of about $1 \mathrm{~cm}$ ) would serve as a check on vertical motions and, in combination with extraterrestrially determined height data, yield information on internal mass motions. The implications of these groundbased measurement capabilities for extraterrestrially determined position measurements are discussed.

16897. Plante, E. R., Olson, C. D., Negas, T., Interaction of $\mathrm{K}_{2} \mathrm{O}$ with slag in open cycle, coal fired MHD, Proc. Sixth Int. Conf. on Magnetohydrodynamic Electrical Power Generation, Washington, DC, June 9-13, 1975, CONF750601-P2, II, 211 218 (1975).

Key words: activity of $\mathrm{K}_{2} \mathrm{O}$ in $\mathrm{K}_{2} \mathrm{O}-\mathrm{SiO}_{2}$ solutions; coalfired MHD; open-cycle MHD; seed-slag interaction; thermal decomposition of $\mathrm{K}_{2} \mathrm{O}-\mathrm{SiO}_{2}$ solutions; vapor pressure of $\mathrm{K}_{2} \mathrm{O}-\mathrm{Al}_{2} \mathrm{O}_{3}$ phases; vapor pressure of $\mathrm{K}_{2} \mathrm{O}-\mathrm{SiO}_{2}$ solutions.

Measurements of the potassium pressure over $\mathrm{K}_{2} \mathrm{O}-\mathrm{SiO}_{2}$ solutions and phases in the $\mathrm{K}_{2} \mathrm{O}-\mathrm{Al}_{2} \mathrm{O}_{3}$ system are reported. These data, together with suitable assumptions are used to estimate the extent of seed-slag interaction in open cycle-coal fired MHD by comparing the extrapolated measured activities in the two component solutions with those calculated for the plasma phase. The results indicate that a high degree of slag rejection at the combustor will be necessary in order to reduce seed losses to an acceptable level. A decreased conductivity of the plasma phase at temperatures below $2600 \mathrm{~K}$ and total pressures of about $5 \mathrm{~atm}$ also appears probable for the zero slag rejection system. The thin slag layer protecting the electrode and insulator structure of the MHD duct appears to be a problem area because of the expected high concentration of $\mathrm{K}_{2} \mathrm{O}$ dissolved at the relatively high pressures and cool wall temperatures. Some of the remaining problems will be resolved when experimental data on the three component system $\mathrm{K}_{2} \mathrm{O}-\mathrm{Al}_{2} \mathrm{O}_{3}-\mathrm{SiO}_{2}$ becomes available.

16898. Young, J. P., Ruff, A. W., Particle erosion measurements on metals, J. Eng. Mater. Technol. 99, 121-125 (Apr. 1977). 
Key words: erosion; metal; oxidation; particle; velocity dependence.

A method being used to measure the erosive wear of metals at different temperatures and under controlled environmental conditions is described. A commercial apparatus has been modified that can be used for tests at $500{ }^{\circ} \mathrm{C}$ and above and over a wide range of particle types, sizes, velocities, and concentrations. Test results from several iron and nickel base alloys are presented. Particular interest has been placed in the role of the oxide scale, in the particle velocity dependence and the impingement angle dependence of erosion rates, as well as the effect of varying particle concentration in the stream. Reproducibility among the tests of about 10 percent can be realized if care is exercised with regard to several important experimental parameters.

16899. Olver, F. W. J., Second-order differential equations with fractional transition points, Trans. Am. Math. Soc. 226, 227241 (1977).

Key words: asymptotic analysis; Bessel functions; error analysis; linear differential equations; transition point; turning point.

An investigation is made of the differential equation

$$
\begin{gathered}
d^{2} w / d x^{2}=\left\{u^{2}\left(x-x_{0}\right)^{\lambda} f(u, x)\right. \\
\left.+g(u, x) /\left(x-x_{0}\right)^{2}\right\} w,
\end{gathered}
$$

in which $u$ is a large real (or complex) parameter, $\lambda$ is a real constant such that $\lambda>-2, x$ is a real (or complex) variable, and $f(u, x)$ and $g(u, x)$ are continuous (or analytic) functions of $x$ in a real interval (or complex domain) containing $x_{0}$. The interval (or domain) need not be bounded. Previous results of Langer and Riekstins giving approximate solutions in terms of Bessel functions of order $1 /(\lambda+2)$ are extended and error bound supplied.

16900. Frederikse, H. P. R., Hosler, W. R., Electrodes and insulators: Design and materials considerations, Proc. I6th Symp. Engineering Aspects of Magnetohydrodynamics (MHD), University of Pittsburgh, Pittsburgh, PA, May 16-18, 1977, pp. IV.4.22-IV.4.28 (Pittsburgh Energy Research Center, U.S. Energy Research and Development Administration, Pittsburgh, PA, 1977).

Key words: design; electrode/insulators; netohydrodynamics; materials.

Electrode/insulator assemblies for MHD generators require a combination of careful design and appropriate materials. The first part of the paper lists the desired physical and chemical characteristics of ceramics and metals used in the fabrication of electrode systems. This is followed by a discussion of several different configurations, tested in a number of test rigs and MHD generators, which illustrates the various design problems.

16901. Hurley, C. W., Kreider, K. G., Applications of thermography in industry, Proc. Third Biennial Infrared Information Exchange, St. Louis, MO, Aug. 24-26, 1976, C. Warren, Ed., pp. 53.59 (AGA Corp., 550 County Ave., Secaucus, NJ, $1977)$.

Key words: energy conservation; energy surveys; infrared; nondestructive evaluation; thermographic surveys; thermography.

The Bureau of Standards has been conducting a project to develop a method for assessing heat losses in industrial equipment. This project is part of the NBS industrial energy conservation program. The $\mathbb{I R}$ surveys have included industrial facilities such as tire, cement, copper, brick, and paper plants as well as foundries and forging plants. The infrared survey was used to detect heat losses which require maintenance and repair or improvement. Several examples are presented. In addition the IR thermographic mapping was used to analyze the total heat losses of industrial furnaces as part of the energy balance on the furnace. This quantitative heat loss study is discussed as an inprogress report.

16902. Grot, R. A., Harrje, D. T., Johnston, L. C., Application of thermography for evaluating effectiveness of retrofit measures, Proc. Third Biennial Infrared Information Exchange, St. Louis, MO, Aug. 24-26, 1976, C. Warren, Ed., pp. 103-117 (AGA Corp., 550 County Ave., Secaucus, NJ, 1977).

Key words: buildings; energy conservation; evaluation; inspection; retrofit; thermography.

Retrofit measures in single family dwellings are considered an important part of the overall U.S. energy conservation program. Thermography was used to evaluate the effectiveness of a number of different retrofit measures normally available to the resident-owner. In this study, a group of townhouses was selected which, it was suspected, could benefit by commonly available retrofit measures. These houses were thermographically inspected before and after various retrofit measures were performed. Thermography was found to be an effective tool for evaluating these retrofit measures which decreased the energy consumption by about 25 percent.

16903. Davis, R. M., Evolution of computers and computing, Science 195, No. 4283, 1096-1102 (Mar. 18, 1977).

Key words: computer engineering; computer networks; computers; data processing; robots; software engineering.

The evolution of digital operation, stored program, automatic, electronic computers over the past 25 years has been accompanied by notable trends and changes. Engineering developments have produced computers ranging from very large systems capable of performing many complex calculations to very small microprocessors that can be used to control household appliances. The decreasing size and cost of computers and the development of computer networks have made access to computing power available to individuals and to small organizations. Techniques of programming computers have not changed as dramatically as the engineering features. Program correctness remains a problem, but programming developments have been oriented toward user convenience. The future looks bright for a wide variety of computer applications in scientific calculations, data processing and automatic control systems as man devises ways to use computers to extend his intellectual capabilities.

16904. Davis, R. M., Demanding more from computers, Comput. Dec., pp. 47-48 (Jan. 1976).

Key words: computer performance; computer software and programs; computer systems; real-time control systems.

Computers are beeoming the control elements of systems that initiate actions with little or no human intervention. Since the actions taken by these systems can have serious and far reaching effects, deficiencies in computer hardware and software design which contribute to unreliable results must be overcome. We must find means of making sure that systems are doing what they are supposed to and not performing any unintended functions. Success in overcoming the problems will determine the extent to which computers will be the pacing element in government and industry operations.

16905. Davis, R. M., When science and technology stumble, everyone suffers, (Proc. Rockefeller University 75th Anniversary Symp., New York, NY, Mar. 8, 1976), Paper in Beyond 
Tomorron: Trends and Prospects in Medical Science, Session III, pp. 87-103 (Rockefeller University, New York, NY, 1976).

Key words: institutional barriers to change; science and technology; scicntific freedom and responsibility; technological change.

This papcr looks at the decline of science and technology today and bricfly traces some historical developments which have impactcd on scicnce and technology. Rapid communications and the application of technology have been effective in specding up the rate of change in society. As a result, institutional barriers to thwart technological change and protect special intcrests have developed. Restoring public confidence in science and tcchnology so that they can bring about a better society will require changes in the interactions of government, science, technology, special-interest institutions and the individual. The issue of public control over the pace and direction of science must be settled, and attention must be paid to the need for scientific safeguards and preventive technology.

16906. Davis, R. M., Government information systems: Only the automated will survive, Gov. Data Syst. 5, No. 1, 14, 16, 27 (Mar.-Apr. 1976).

Key words: computers; government information collection; information policy; information processing; risk management.

The Federal Government collects and processes information to perform essential public service, to protect the public and to be accountable to the public. Many government functions, involving the collection of large amounts of data, would be impossible to accomplish without computers. However, the use of computers has aroused public concerns about loss of privacy and government intrusion into citizen's private lives. Information collection is often perceived as conflicting with individual rights. Some national attempts to balance individual rights with society's rights have resulted in legislation protecting privacy and regulating credit records. Areas such as privacy in medical records and welfare benefits remain to be addressed. The resolution of these and other conflicts will require the interaction of Congress, the Executive Branch, the information industry and the public. This paper suggests one approach to the resolution of these issues through the assessment of computer use in terms of the associated risks and benefits.

16907. Timmerhaus, K. D., Weitzel, D. H., Economic aspects of U.S. energy independence in the coming decade, (Proc. First Int. Cryogenic Materials Conf., Kingston, Ontario, Canada, July 22-25, 1975), Paper D-1 in Advances in Cryogenic Engineering, K. D. Timmerhaus, R. P. Reed, and A. F. Clark, Eds., 22, 166-179 (Plenum Publ. Corp., New York, NY, 1977).

Key words: economic; energy; research and development, energy.

There is no doubt that energy is a subject on the minds of many today. A great deal of what is being said about energy not only bears repeating, but requires careful evaluation and should be followed by constructive action. Energy research and development will play a central role in most of this nation's scientific, technological, and industrial endeavors for years, if not decades, to come. This is true not only because of the overwhelming importance of energy to the nation but because our energy problems-both immediate and long-range-are complex. It is also true because the urgency of dealing with these problems must be brought home to the public and to people at all levels of responsibility in government, industry, and education. These problems have not vanished with the end of the oil embargo and the disappearance of lines at the gas stations. The United States will be living with them and working to solve them for a long time. Before turning to some of the solutions that might be considered for the coming decade, it is useful to make a few observations to illustrate the national and global impact of the energy situation.

16908. Angel, W. T., Houck, J. C., Microcomputer temperature controller, (Proc. 3d Control Valve Symp. and Process Control Technology, Anaheim, CA, May 2-5, 1977), Paper in Final Control Elements 3, 139-143 (Instrument Society of America, Dittsburgh, PA, 1977).

Key words: AC bridge; microcomputer; synchronous detection; temperature controller; thermoelectric; thermometry.

A temperature controller has been developed that uses a microcomputer to synchronously detect a temperature deviation signal derived from a standard AC bridge, and to apply proportional and integral feedback control to heat source/sink via pulse width modulation. The controller has been interfaced with both resistance heaters and a thermoelectric heat pump. The principal advantage of digital control in this application is the ability the controller provides to realize long time constants in conjunction with low long-term setpoint drift for precisely controlling various thermal masses.

16909. Johnson, C. R., A Hadamard product involving $M$ matrices, Linear and Multilinear Algebra 4, 261-264 (1977).

Key words: diagonally dominant; diagonally symmetrizable; eigenvalue; Hadamard product; $M$-matrix.

We show that for any pair $M, N$ of $n M$-matrices, the Hadamard (entry-wise) product $M \cdot N^{-1}$ is again an $M$-matrix For a single $M$-matrix $M$, the matrix $M \cdot M^{-1}$ is also considered.

16910. Pearson, R., Jr., Lovas, F. J., Microwave spectrum and molecular structure of methylenimine $\left(\mathrm{CH}_{2} \mathrm{NH}\right), J$. Chem. Phys. 66, No. 9, 4149-4156 (May 1, 1977).

Key words: methylenimine; microwave spectroscopy; molecules; pyrolysis; rotational spectra; structure.

The microwave spectra of five new isotopic species of $\mathrm{CH}_{2} \mathrm{NH}$ have been measured in the pyrolysis products of aqueous solutions of methylamine and 1,2-diaminoethane. Rotational constants and moments of inertia have been determined for ${ }^{13} \mathrm{CH}_{2}{ }^{14} \mathrm{NH},{ }^{12} \mathrm{CH}_{2}{ }^{15} \mathrm{NH},{ }^{12} \mathrm{CH}_{2}{ }^{14} \mathrm{ND},{ }^{12} \mathrm{CD}_{2}{ }^{14} \mathrm{NH}$, and ${ }^{12} \mathrm{CD}_{2}{ }^{14} \mathrm{ND}$. These data have been combined with previous -measurements of ${ }^{12} \mathrm{CH}_{2}{ }^{14} \mathrm{NH}$ to give $r_{8}$-coordinates for the $\mathrm{C}$, $\mathrm{N}$, and imine- $\mathrm{H}$ atoms, and the following structural parameters: $r(\mathrm{CN})=1.273 \AA, r(\mathrm{NH})=1.023 \AA$, and $\varangle \mathrm{HNC}=110.5^{\circ}$. Methods for obtaining a complete structure, and uncertainties arising from the proximity of the $\mathrm{C}$ and $\mathrm{N}$ atoms to the principal $a$-axis are discussed. A pseudo-Kraitchman calculation constraining the $\mathrm{CH}$ distances to be equal gives following (planar) structure: $r(\mathrm{CN})=1.273 \AA, r(\mathrm{NH})=1.021 \AA, r(\mathrm{CH})$ $=1.09 \AA, \varangle \mathrm{HNC}=110.4^{\circ}, \varangle \mathrm{HCH}=117.0^{\circ}$, and $\varangle \mathrm{NCH}_{\text {cls }}$ $=125 \cdot 1^{\circ}$.

16911. Yap, W. T., Howell, B. F., Schaffer, R., Determination of the kinetic constants in a two-substrate enzymatic reaction, J. Chem. Ed. 54, 254-25 5 (Apr. 1977).

Key words: enzyme; initial velocity; kinetic constants; LDH; Michaelis constant; NADH; Zimm plot.

A graphical method is presented for the analysis of the initial velocity data in a two-substrate reaction. The reciprocal of the initial velocity is plotted versus a linear combination of the reciprocals of the two substrate concentrations. From the two extrapolated lines, at infinite concentration of each of the two substrates, the two Michaelis constants and the maximum 
velocity were determined. The method was illustrated, using data from the reaction of pyruvate with NADH, catalyzed by LDH.

16912. Lam, L. K., Gallagher, A., Hessel, M. M., The intensity distribution in the $\mathrm{Na}_{2}$ and $\mathrm{Li}_{2} A-X$ bands, J. Chem. Phys. 66, No. 8, 3550-3556 (Apr. 15, 1977).

Key words: $\mathrm{Li}_{2} ; \mathrm{Na}_{2}$; satellite; spectrum.

The accuracy of the quasistatic or classical Franck-Condon approximation for unresolved bound-bound molecular bands is investigated by comparison with appropriately averaged quantum mechanical calculations. Wavelength-averaged absorption and stimulated emission cross sections are calculated for the $A-X$ bands of $\mathrm{Na}_{2}$ and $\mathrm{Li}_{2}$, representing low resolution or collision broadened spectra, and comparisons are made with experimental spectra. These $A-X$ bands exhibit a red edge, due to a head of heads or a classical satellite, and a comparison of quantum mechanical, classical, and semiclassical satellite shapes is made. The overall quantum mechanical band shapes agree with the classical calculation, except for approximately periodic band structures and nonclassical behavior at the satellites. The emission spectrum resulting from white light or electron excitation of $\mathrm{Na}_{2}$, is also calculated and compared to that observed in an electrical discharge. Finally, emission spectra of $\mathbf{N a}_{2}$ for thermal distributions at various temperatures are compared to the fluorescence spectrum observed from excited dimers formed by an atom-molecule excitation transfer process

16913. Hubbard, C. R., Mighell, A. D., Ware, G. M., 4-hydroxy4H-furo[3,2-c]pyran-2(6H)-one (DLpatulin), Acto Cryst. B33, 928-931 (1977).

Key words: antibiotic; hydrogen bonding; patulin; refined structure; single crystal $x$-ray structure determination; 4 hydroxy-4H-furo( $3,2 c)$ pyran-2(6H)-one.

$\mathrm{C}_{7} \mathrm{H}_{6} \mathrm{O}_{4}, M_{r}=154.1$, monoclinic, $P 2 / n, a=9.008(2), b=$ 9.549(2), $c=7.786(2) \AA, \beta=94.80(2)^{\circ}, Z=4, D_{m}=1.53(2)$ (flotation), $D_{x}=1.535 \mathrm{~g} \mathrm{~cm}^{-3}$. The structure has been solved by direct methods and refined by least-squares techniques to a final $R$ value of 0.05 , based on 1365 reflections. Centrosymmetrically related molecules form dimers via a pair of hydrogen bonds connecting the hydroxyl $\mathrm{H}$ atom to the pyran ring $\mathrm{O}$ atom. The hydrogen-bond O...O distance is $2.810(2) \AA$ and the $\mathrm{OH}$...O angle is $167(2)^{\circ}$.

16914. Truhlar, D. G., Kuppermann, A., Dwyer, J., The importance of isotope-dependent transmission coefficients in calculating low-temperature isotope effects, Mol. Phys. 33, No. 3, 683-688 (1977).

Key words: collinear reactions; deuterium, collinear reactions; hydrogen, collinear reactions; kinetic isotope effects; potential surfaces; rate constants; transition state theory; transmission coefficient.

We compare conclusions which may be drawn from our previous work (Truhlar et al.), on the collinear $\mathrm{H}+\mathrm{H}_{2}$ reaction concerning practical calculations of isotope effects with conclusions drawn by $\mathrm{Wu}$ et al. We present calculations designed to elucidate the differences in conclusions. We suggest that one should not assume that accurate isotope effects for reactions involving $\mathbf{H}$ and $\mathrm{D}$ can be calculated from transition state theory using transmission coefficients equal to unity, especially at room temperature and lower temperatures.

16915. Bloss, R. L., Trends relating to verification of testing machines and weighing equipment, Proc. IMEKO 5th Int. Conf., Szeged, Hungary, Aug. 31, 1974, Preprint, pp. 1-19 (1974).
Key words: calibration; load cell; proving rings; testing machines; tolerance; verification.

Recent efforts in the United States pertaining to the verification of testing machines and the devices and methods used to determine their performance are discussed. A brief discussion of testing machine tolerances and the effect of calibrating device uncertainty is included.

16916. Herbst, J. F., Bak, P., Watson, R. E., Effective crystal fields in the rare earth pnictides, Physica 86-88 B\&C, Pt. 1, 123-124 (Jan.-Mar. 1977).

Key words: crystal field; pnictides; rare earth.

Various contributions to the effective $4 \mathrm{f}$ electron crystal fields in the rare earth pnictides are estimated and compared. These include the direct interaction with the ligand electrostatic field and effects associated with the $5 \mathrm{~d}$ band electrons.

16917. Lofquist, K. E. B., A positive displacement oscillatory water tunnel, Miscellaneous Report MR 77-1, 27 pages (U.S. Army, Corps of Engineers, Coastal Engineering Research Center, Ft. Belvoir, VA, Feb. 1977).

Key words: coastal processes; permeability effects; prototype tests; sand transport; water tunnel; waves.

The water tunnel described produces sinusoidal flow with peak velocities adjustable from 0 to at least 30 centimeters per second for any period between 3 and 25 seconds. The tunnel is of U-tube design with the middle horizontal part comprising the test section. The vertical end parts are two cylinders with tight-fitting pistons at one end, and two reservoirs open to air at the other. The pistons are driven by a variable-speed electric motor, with an adjustable counterweight permitting operation at resonance at any period.

16918. Linden, T. A., Protection: A nuisance or an opportunity?, Proc. COMPCON 76, Washington, DC, Sept. 7-10, 1976, pp. 30-36 (IEEE Computer Society, Long Beach, CA, 1976).

Key words: abstract data types; access controls; operating system protection; protection; protection mechanisms; reliable software; types.

The protection needed to support security is generally regarded as a nuisance; however, new protection systems promise not only to provide more flexible support for security but also to lead to software that is more reliable and less costly. Flexible protection can be used to control the inte ractions between software modules and thus simplify the problems encountered when modules are integrated into large software systems. Furthermore, it is closely linked with recent approaches to data abstraction where users are allowed to create and manipulate objects of user-defined types. Access controls can then be specified and enforced in terms of the problem-oriented concepts implemented by the user-defined types. These ideas are emerging from research on both operating systems and programming languages; and the access controls can be enforced by an operating system, by a language translator, or by both.

16919. Herbst, J. F., Angle-resolved photoemission from crystalfield-split adatom levels, Phys. Rev. B, 15, No. 8, 3720-3730 (Apr. 15, 1977).

Key words: adatom; crystal field; photoemission.

We investigate the angular distribution of photoelectrons emitted from atoms physisorbed on the surface of a metal. The crystalline electric field of the surface is represented by a small number of point charges in the vicinity of the adatom, and the splittings of $p$ and $d$ adatom levels in the crystal field are calculated. The spinorbit splitting of the adatom states is assumed to 
be large in comparison with the crystal-field effects. For adatom $p$ levels we consider both fourfold and bridge sites on a (100) surface of an fcc or bcc metal, and we include results for $d$ states in the fourfold configuration. Within the dipole approximation photoelectron distributions are calculated for these cases assuming normally incident, unpolarized light. The results demonstrate that the angular distributions are sensitive to substrate geometry. Implications of this work for recent ultraviolet photoemission experiments involving xenon and mercury adsorbed on a tungsten surface are discussed.

16920. Linden, T. A., Operating system structures to support security and reliable software, Comput. Surv. 8, No. 4, 409445 (Dec. 1976)

Key words: capability; capability-based addressing; computer security; extended-type objects; operating system structures; protection; reliable software; reliability; security; small protection domains; types.

Security has become an important and challenging goal in the design of computer systems. This survey focuses on two system structuring concepts that support security: small protection domains and extended-type objects. These two concepts are especially promising because they also support reliable software by encouraging and enforcing highly modular software structures-in both systems software and in applications programs. Small protection domains allow each subunit or module of a program to be executed in a restricted environment that can prevent unanticipated or undesirable actions by that module. Extended-type objects provide a vehicle for data abstraction by allowing objects of new types to be manipulated in terms of operations that are natural for these objects. This provides a way to extend system protection features so that protection can be enforced in terms of applications-oriented operations on objects. This survey also explains one approach toward implementing these concepts thoroughly and efficiently-an approach based on the concept of capabilities incorporated into the addressing structure of the computer. Capability-based addressing is seen as a practical way to support future requirements for security and reliable software without sacrificing requirements for performance, flexibility, and snaring.

16921. Packham, S. C., Frens, D. B., McCandless, J. B. Petajan, J. H., Birky, M. M., A chronic intra-arterial cannula and rapid micro-technique for carboxyhemoglobin determination, J. Combust. Toxicology 3, 471-478 (Nov. 1976).

Key words: carboxyhemoglobin; $\mathrm{CO}$ intoxication; intra-arterial cannula; spectrophotometer analysis.

A procedure for chronic placement of a cannula in the femoral artery of the rat is described. A rapid spectrophotometric technique for $\mathrm{COHb}$ analysis is outlined.

16922. Chi, J., DEPAF - A computer model for design and performance analysis of furmaces, Proc. Conf. on AIChE-ASME Heat Transfer, Salt Lake City, UT, Aug. 15-17, 1977, pp. 19 (American Society of Mechanical Engineers, New York, NY, 1977).

Key words: building heating system; computer simulation; energy conservation; furnace; operating cost; seasonal performance.

This report covers the development of a computer simulation program DEPAF (DEsign and Performance Analysis of Furnaces) for residential fossil-fuel-fired furnaces. DEPAF is based upon an analytical model which accounts for cyclic (on-andoff) operation of furnace burner and blower. Transmission of heat at on-cycle uses the theory of radiative and convective heat transfer; transmission of heat at off-cycle uses the theories of turbulent and free convective heat transfer. Confidence in DEPAF was established by the use of available experimental data on a gas-fired forced-warm-air furnace. While the theory of transient heat transfer in combustion is complex in nature, theoretical results based upon quasi-steady-state analysis are in excellent agreement with experiments. If the building heat loss is known, DEPAF can be used to calculate the annual performance and operating cost for residential heating systems with furnaces. Examples are given to illustrate applications of DEPAF to examine quantitatively the effect of design and operating variables on annual performance and operating costs of residential forced-warm-air furnaces. It was found that considerable savings in fuel and operating costs can often be achieved by performing certain modifications to existing furnaces.

16923. Benzinger, T. H., Mangum, B. W., Hill, J. E., The design, construction and operation of a scanning radiometer for measurement of plane radiant temperature in buildings, (Proc. ASHRAE Semi-annual Meeting, Seattle, WA, June 25-July 1, 1976), ASHRAE Trans. 82, 260-278 (1976).

Key words: comfort; measurement; radiation.

In order to accurately determine the effect of low-temperature radiation on the thermal comfort of building occupants, a new scanning radiometer has been designed and constructed. The instrument has been constructed using commercially available semiconductor thermopiles which have been arranged in a chessboard fashion with alternate thermopiles being coated with either a highly absorptive or highly reflective surface. The instrument has been designed to measure the effective temperature in a hemisphere facing the sensor over the temperature range normally encountered in building occupied spaces. It can be used in a stationary position or to "scan" an occupied space to determine the degree of asymmetry of the radiation.

16924. Raterink, H. J., Van de Stadt, H., Frankena, H. J., High-resolution measurements of molecular absorption line profiles at 10 micrometers, Opt. Commun. 20, No. 3, 415-417 (Mar. 1977).

Key words: ammonia; carbon dioxide; ethanol; measurement; molecular absorption; $10 \mu \mathrm{m}$ wavelength.

Absorption line profiles of $\mathrm{CO}_{2}, \mathrm{C}_{2} \mathrm{H}_{4}$ and $\mathrm{NH}_{3}$ have been measured around a wavelength of $10 \mu \mathrm{m}$ and under various conditions using a passive heterodyne detection technique with a resolution of $6 \times 10^{-4} \mathrm{~cm}^{-1}$.

16925. Moody, S. E., Lambropoulos, M., ac Stark effect in multiphoton ionization, Phys. Rev. A 15, No. 4, 1497-1501 (Apr. 1977).

Key words: ac Stark effect; ionization; multiphoton ionization.

Multiphoton ionization of atomic sodium has been studied experimentally for near resonance between the radiation field and several bound-bound transitions of the atom. It has been found that the atom-field interaction must be treated in a highly nonlinear way to describe successfully the observations, even when the absolute spectral power densities are relatively modest. Rabi frequencies as high as $10 \mathrm{GHz}$ are found to be directly observable with simple flashlamp-pumped tunable dye lasers.

16926. Hayward, E., Photon scattering in the energy range 5$30 \mathrm{MeV}$, (Lectures for the Erice Photonuclear School, Sicily, Italy, June 3-17, 1976), Paper in Lecture Notes in Physics No. 61, Photonuclear Reactions, J. Ehlers, K. Hepp, R. Kippenhahn, H. A. Weidenmüller, and J. Zittartz, Eds., pp. 340-406 (Springer-Verlag, Berlin, Germany, 1976). 
Key words: Delbrück scattering; Doppler broadening; electric quadrupole; giant resonances; photon scattering; polarized photons; resonance fluorescence.

Nuclear elastic photon scattering will be discussed including the resonance fluorescence of discrete energy levels and the scattering from the higher energy continuum. The effect of Doppler broadening and inelastic scattering on the former will be included and the angular distributions for polarized and unpolarized incident radiation will be outlined. The contributions and influence of Thomson, Rayleigh, and Delbrïck scattering will also be recognized.

The present status of the experiments will be summarized including the work using neutron capture $\gamma$-rays and tagged photons as sources. Areas for future experimentation will be pointed out. These will include the use of polarized beams as well as the polarization analysis of scattered beams.

16927. Watson, R. E., Bennett, L. H., Hyperfine fields at impurity sites in iron, Physica 86-88B, 435-436 (1977).

Key words: atomic volume; hyperfine fields; iron alloys; valence.

Controversy has recently revived concerning the correlation of hyperfine fields at impurity atom sites in ferromagnetic iron with atomic volume or with valence. Using a scheme to normalize to the free atom hyperfine field, we inspect the correlations of volume, valence and electronegativity with new normalized values.

16928. Tobler, R. L., Reed, R. P., Fatigue crack growth rates of structural alloys at $4 \mathrm{~K}$, (Proc. First Int. Cryogenic Materials Conf., Kingston, Ontario, Canada, July 22-25, 1975), Paper A-4 in Advances in Cryogenic Engineering, K. D. Timmerhaus, R. P. Reed, and A. F. Clark, Eds., 22, 35-46 (Plenum Publ. Corp., New York, NY, 1977).

Key words: aluminum alloys; crack propagation; fatigue; iron alloys; liquid helium; stainless steels; steels; superalloys; titanium alloys.

The fatigue crack growth rates (da/dN) of nine structural alloys tested in a liquid helium environment at a temperature of $4 \mathrm{~K}$ are presented and compared. Growth rates from $7 \times 10^{-5}$ to $2 \times 10^{-3} \mathrm{~mm} /$ cycle were measured for compact specimens 2.54 to $3.81 \mathrm{~cm}$ thick. The materials tested include: Ti-5Al2.5Sn, Ti-6Al-4V, A1S1 304, 310, and 316 stainless steels, A286 , Inconel $750,5083-0$ aluminum and 9 percent nickel steel. Results showed that stable face-centered cubic alloys having high elastic moduli displayed superior crack growth resistance at $4 \mathrm{~K}$, whereas materials with body-centered cubic or martensitic phases exhibited relatively high growth rates at this temperature. When compared on the basis of the strain intensity factor, $\Delta K / E$, the growth rates of alloys having close-packed crystal structures were in close agreement. An equation describing the crack growth rates of four stable fcc alloys is suggested as follows:

$$
\mathrm{da} / \mathrm{dN}=\mathrm{A}(\Delta \mathrm{K} / \mathrm{E})^{m}
$$

where the constants $\mathrm{A}$ and $\mathrm{m}$ have duplicate values depending on the range of $\Delta K / E$.

16929. Madey, T. E., Yates, J. T., Jr., Desorption methods as probes of kineties and bonding at surfaces, Surf. Sci. 63, 203231 (1977).

Key words: chemisorption; electron stimulated desorption; oxygen; sulphur hexafluoride; temperature programmed desorption; tungsten.

This paper is divided into two parts. Firstly, a review of desorption methods is presented, with emphasis on the use of temperature programmed desorption (TPD) and electron stimulated desorption (ESD) for understanding the bonding of adsorbed species to surfaces. Secondly, recent studies of the angular distribution of ESD ions from adsorbed layers on $\mathrm{W}(011)$ are discussed. The ESD of $\mathrm{O}^{+}$ions from oxygen adsorbed on a stepped $W(011)$ surface is shown to be sensitive to the presence of atom steps.

16930. Madey, T. E., Wagner, C. D., Joshi, A., Surface characterization of catalysts using electron spectroscopies: Results of a round-robin sponsored by ASTM Committee D-32 on catalysts, J. Electron Spectrosc. Relat. Phenom. 10, 359-388 (1977).

Key words: Auger electron spectroscopy; catalyst; electron binding energy; interlaboratory comparison; surface characterization; $x$-ray photoelectron spectroscopy.

We report the results of a round-robin of measurements designed to evaluate the utility of Auger Electron Spectroscopy (AES) and X-ray Photoelectron Spectroscopy (XPS or ESCA) in studies of powdered, insulating materials typically used as catalysts or catalyst supports. The round-robin was sponsored by ASTM Committee D-32 on Catalysts. Measurements were performed on high purity samples of silica gel $\left(\mathrm{SiO}_{2}\right)$, alumina $\left(\mathrm{Al}_{2} \mathrm{O}_{3}\right)$ and a sodium activated type $\mathrm{A}$ zeolite. Data on these samples were received from 12 laboratories using XPS and 8 laboratories using AES. The results indicate that the standard deviation in reported AES and XPS absolute line positions is much greater than the precision of any one measurement, indicating a great need for standardization of static charge referencing. In addition, there was a large spread in reported intensity ratios for instruments having nominally the same transmission characteristics and even of the same manufacture. The results demonstrate a need for standard calibration procedures for voltage scales and intensity response in the instruments.

16931. Surek, T., Coriell, S. R., Shape stability in float zoning of silicon crystals, J. Cryst. Growth 37, No. 3, 253-27l (Mar. 1977).

Key words: crystal growth; floating zone; meniscus; perturbation; shape stability; silicon.

The time evolution and stability of the dimensions of a solidifying crystal are examined for typical floating zone geometries. The stability criterion is based on the finding that the steadystate growth of crystals with constant cross section in a meniscus-controlled process requires that the angle $\phi$ between the meniscus and the growth axis equal $\phi_{0}$ (a constant; for silicon, $\phi_{0}=11^{\circ}$ ). Analyses are carried out of float zoning of a thin sheet in a horizontal plane and of a cylindrical crystal in the vertical direction; these systems are shown to usually exhibit an inherent tendency toward shape stabilization. A linear perturbation analysis is carried out for the general case where the resolidified and original crystal dimensions can be different at steady state, and necessary and sufficient conditions are derived for crystal shape stability in float zoning. For a stable system, perturbations are shown to lead to an exponentially decaying oscillation about steady state. Application of the analysis is made, throughout the paper, to float zoning of silicon crystals; special cases where the crystal shape is expected to be unstable are described.

16932. Bennett, L. H., McAlister, A. J., Cuthill, J. R., Erickson, N. E., Watson, R. E., Electronic and catalytic properties of refractory hard metals, J. Mol. Catalysis 2, 203-209 (1977).

Key words: catalysis; $\mathrm{Mo} ; \mathrm{Mo}_{2} \mathrm{C}$; refractory hard metals; valence bands; $\mathrm{W}$; WC; $\mathrm{x}$-ray photoemission. 
It has been observed experimentally that the compounds WC and $\mathrm{Mo}_{2} \mathrm{C}$ are catalytically active for hydrogen, whereas the host metals are inactive. We have studied previously the valence bands of $W$ and $W C$ by $x$-ray photoemission and found that the density of electron states at the Fermi level, $N\left(E_{F}\right)$, of $W C$ is materially higher than that of $W$. We report here a similar study of the valence bands of $\mathrm{Mo}$ and $\mathrm{MO}_{2} \mathrm{C}$; again, the compound is found to have higher $N\left(E_{F}\right)$ than the metal. Xray photoemission data relevant to such surface properties of WC as degree of oxidation are also presented.

16933. Haisch, B. M., Linsky, J. L., Lampton, M., Paresce, F., Margon, B., Stern, R., Extreme-ultraviolet observations of a flare on proxima centauri and implications concerning flarestar scaling theory, Astrophys. J. 213, L1 19-L123 (May 1, 1977).

Key words: extreme ultraviolet; flare-stellar; soft $x$ ray.

We report the first detection of EUV radiation from a UV Ceti-type flare star, Proxima Centauri, and derive an emission measure of $4.6 \times 10^{52} \mathrm{~cm}^{-3}$. This implies a total thermal $\mathrm{x}$-ray emission (1-250 $\AA$ ) of $L_{x}=7-18 \times 10^{29} \mathrm{ergs} \mathrm{s}^{-1}$. Using past $\mathrm{x}$ ray flare observations of $Y Z C M i$ and UV Ceti and a recombination model, we derive limits on $L_{x} / L_{\text {opt }}$ to test flare-star scaling theories. We conclude that $L_{x} / L_{\text {opt }}$ in the observed flare is at variance with Mullan's scaling law theory and may be highly variable among stellar flares.

16934. Cotton, I. W., Computer network interconnection, Proc. Second Berkeley Workshop on Computer Networks and Distributed Data Management, Berkeley, CA, May 25-27, 1977, pp. 3-18 (University of California, Berkeley, CA, 1977).

Key words: communications networks; computer networks; data communications; interconnection; networks; packet switching; standards.

This report examines the current situation regarding the interconnection of computer networks, especially packet switched networks (PSNs). Four major types of interconnections are surveyed: 1. Circuit Switched Network to PSN; 2. Star Network to PSN; 3. Simple Terminal to PSN; 4. PSN to PSN. The emphasis is on identifying the barriers to interconnection and on surveying approaches to a solution, rather than recommending any single course of action.

16935. Ruthberg, S., Gas infusion into doubled hermetic enclosures, IEEE Trans. Parts, Hybrids, Packaging PHP-13, No. 2, 110-116 (June 1977).

Key words: doubled hermetic enclosure; gas infusion of leaks; hermeticity; leak detection; semiconductor hermeticity.

In certain critical applications it is current practice to incorporate sealed electron devices within an outer hermetic enclosure for increased seal assurance. An exact solution is now given for the gas influx into such a doubled hermetic enclosure when each enclosure has a given leak size. This solution allows a comparison to be made between the leakage into a single isolated semiconductor package and that into the same package when it is protected by an outer enclosure. If the leaks are in the molecular flow regime, solutions for the pressure within the enclosures are of the form $P_{i}=A_{i} e^{-(\alpha-\beta) t}+B_{i} e^{-(\alpha-\beta) t}+P_{b}$ for $i=$ 1,2 , where $P_{b}$ is the external applied pressure at $t \geqslant 0$ and $\alpha, \beta$ are constants whose values depend only on the ratios of leak rates and of volumes. The general behavior is described in terms of a merit factor as a measure of the hermetic improvement for doubled enclosures over that of a single enclosure, and characteristics are derived for a broad spectrum of system dimensions. It is shown that a significant improvement in hermeticity over a long time span is not an a priori result of using an outer enclosure.
6936. Folts, H. C., Cotton, I. W., Interfaces: New standards catch up with technology, Data Commun. 6, No. 6, 31-40 (June 1977).

Key words: communications standards; data communications interfaces; data communications standards; interface standards; protocols.

Recent developments in data communications standards have been patterned on a hierarchical approach to communications system architecture. A number of independent levels have been identified, and standards development has proceeded at its own pace within each level. These levels are identified and recent progress at standardization is discussed for each.

16937. Kak, A. C., Jakowatz, C. V., Jr., Linzer, M., NDE of materials by computerized ultrasonic tomography, Proc. Second Conf. Automated Inspection and Product Control, Chicago, IL, Oct. 19-2I, 1976, pp. 235-246 (IIT Research Institute, Chicago, IL, 1976).

Key words: attenuation; computerized tomography; imaging; ultrasound; velocity.

Recent developments in computer assisted tomography have opened up many new opportunities in automated NDE of materials. Computerized tomography basically consists of digitally constructing cross-sectional images of objects using projection data. For medical and material applications, this projection data may be obtained by using either $\mathrm{x}$-ray or ultrasound. In this paper the basic principles of these techniques are first reviewed and then the potential applications of ultrasonic tomography to materials inspection are discussed.

16938. Trombka, J. I., Dyer, C. S., Evans, L. G., Bielefeld, M. J., Seltzer, S. M., Metzger, A. E., Reanalysis of the Apollo cosmic gamma-ray spectrum in the 0.3 to $10 \mathrm{MeV}$ energy region, Astrophys. J. 212, No. 3, Pt. 1, 925-935 (Mar. 15, 1977).

Key words: Apollo 16,17; background correction; cosmic gamma ray; flux isotropy; sodium iodide detector; spectral measurements.

Additional data obtained from the Apollo 16 and Apollo 17 missions, together with collateral calculations on background radiation effects, have made an improved subtraction of unwanted backgrounds from the diffuse cosmic $\gamma$-ray data previously reported from Apollo 15 possible. As a result, the 1 to $10 \mathrm{MeV}$ spectrum is lowered significantly and connects smoothly with recent data at other energies. The inflection reported previously is much less pronounced and has no more than a $1.5 \sigma$ significance. Sky occultation by the Apollo 16 spacecraft shows the bulk of the 0.3 to $1 \mathrm{MeV}$ radiation to be diffuse. The analysis of spurious backgrounds points to important improvements for future experiments designed for this spectral region.

16939. Mayo, S., Evans, W. H., Development of sodium contamination in semiconductor oxidation atmospheres at 1000 ${ }^{\circ} \mathrm{C}$, J. Electrochem. Soc. 124, No. 5, 780-785 (May 1977).

Key words: fused silica; microelectronic; MOS; oxidation furnace; silicon dioxide; sodium contamination; thermal oxidation.

The thermodynamic equilibria established in fused silica oxidation tubes operated at $1000{ }^{\circ} \mathrm{C}$ are analyzed. Transparent fused silica tubes used for thermal oxidation of silicon contain about 10 ppm sodium impurity. At oxidation temperatures sodium diffuses in fused silica, evaporates into the oxidation ambient, and reacts with residual water contaminating the oxidation atmosphere. During the oxidation cycle enough sodium is 
incorporated into the growing oxide film to be detected later by capacitance measurements in metal oxide semiconductor (MOS) structures. Reactions taking place during currently used in situ furnace cleaning procedures are analyzed. Calculations indicate that the amount of sodium removed from the fused silica tube wall through chlorine or hydrogen chloride cleaning is substantial. The reaction rate is regulated by diffusion of sodium in the fused silica. The use of iodine and hydrogen iodide as cleaning agents is discussed.

16940. Watson, R. E., Bennett, L. H., Calculation of atomic hyperfine-field coupling constants, Phys. Rev. B 15, No. 1, 502-503 (Jan. 1, 1977).

Key words: atomic beam; electronic structure; free atoms; hyperfine fields; relativistic Hartree-Fock theory.

The hyperfine fields characteristic of the free-atom valence $s$ electron are calculated to form a consistent set of values for normalization of hyperfine fields obtained by NMR, Mössbauer, and other techniques in solids.

16941. Lederer, P. S., Pressure transducer evaluation, (Proc. Workshop on Biomedical Pressure Measurements, CaseWestern Reserve University, Cleveland, $\mathrm{OH}$, Dec. 4-5, 1975 ), Paper in Indwelling and Implantable Pressure Transducers, D. G. Fleming, W. H. Ko, and M. R. Nauman, Eds., pp. 183191 (CRC Press, Inc., Cleveland, OH, 1977).

Key words: biomedical; evaluation; pressure measurement; pressure transducer; transducer.

In order to assure meaningful measurements with pressure transducers, their performance characteristics must be evaluated. Static and dynamic calibration techniques, as well as environmental and durability test procedures are discussed. Reference is made to on-going work at the National Bureau of Standards, as well as to the standardization activities of professional societies.

16942. Buehler, M. G., Thurber, W. R., Measurement of the resistivity of a thin square sample with a square four-probe array, Solid-State Electron. 20, No. 5-B, 403-406 (1977).

Key words: collector resistivity; epitaxial resistivity; fourprobe; resistivity; resistivity correction factors; semiconductor characterization; silicon; square array.

Geometrical correction factors are evaluated for the measurement of the resistivity of a square conducting sample whose thickness is small compared to the probe spacing of a square four-probe array. The correction factors allow the computation of the resistivity when the probes are not on the periphery of the square sample. The solution is based on the method of images and is written in a compact, easily-evaluated form. The resistivity measurement error encountered with the square sample is presented in graphical form for use in test structure design.

16943. Ruthberg, S., Hermetic test procedures and standards for semiconductor electronics, (Proc. Symp. on Nondestructive Testing Standards, Gaithersburg, MD, May 19-21, 1976), Am. Soc. Test. Mater. Spec. Tech. Publ. 624, Nondestructive Testing Standards-A Review, H. Berger, Ed., pp. 246-259 (June 1977).

Key words: hermetic seals; leakage; nondestructive tests; semiconductor devices; standards.

The hermetic testing of semiconductor devices is a challenging subject area because of the need for leak testing large numbers of sealed packages to very fine leak rates, where the packages are of a wide range of materials and internal volumes. The types of measurement methods, to be discussed are those presently in use and are represented in both military and voluntary standards. Four of these methods will be assessed briefly along with the relevant standards, as to advantages, disadvantages, range, precision, and agreement. The four methods are bubble, weight gain, helium leak detector, and radioisotope test procedures. Present interlaboratory test efforts that have been undertaken to provide suitable test data for guidance in the drafting of new American Society for Testing and Materials (ASTM) standards will be summarized. Future directions will be indicated.

16944. Gilsinn, J. F., Validation of an airport simulation model, Proc. Bicentennial Winter Simulation Conf., Gaithersburg, MD, June 6-8, 1976, H. J. Highland, T. J. Schriber, and R. G. Sargent, Eds., 1, 273-277 (Association for Computing Machinery, New York, NY, 1976).

Key words: airport simulation; air traffic control; aviation; models; simulation; transportation; validation of models.

This paper describes the validation of an airport simulation model, called DELCAP for DELay CAPacity, the two quantities which it measures, for use in estimating the traffic rates attainable at major busy U.S. airports. The simulation model outputs are compared to those of other models for simple cases to which both apply and to actual throughput data for several airports, with differences usually less than 6 to 8 percent.

16945. Watkins, S. W., Abrams, M. D., Remote terminal emulation in the procurement of teleprocessing systems, Proc. Natl. Computer Conf., Dallas, TX, June 13-16, 1977, 46, 723-727 (AFIPS Press, Montvale, NJ, 1977).

Key words: evaluation; interactive; measurement; performance evaluation; performance measurement; remote terminal emulation; Remote Terminal Emulator; teleprocessing.

This paper addresses some of the problems which exist when benchmarking interactive computing. The teleprocessing workload may be emulated by a program running internal to the System Under Test (SUT), known as an internal driver or internal stimulator. The limitations of internal drivers are discussed, especially with respect to procurement testing. The use of live operators and tape loops are also discussed, but these are also limited techniques. The most attractive alternative is to employ another, external, computer system to emulate the teleprocessing workload; this approach is called remote terminal emulation. The emulation constraints are delineated; terms applicable to the process are defined, including: Remote Terminal Emulator (RTE), scenario, script, and scene. Ten RTE's, representative of current capabilities, are briefly described.

16946. Finnegan, T. F., Wilson, J., Toots, J., High frequency properties of stable Nb-Nb oxide-Pb Josephson tunnel junctions, (Proc. Ist IC-SQUID Conf., Berlin, Germany, Oct. 58, 1976), Paper in Superconducting Quantum Interference Devices and Their Applications, H. D. Hahlbohn and H. Luebbig, Eds., pp. 381-394 (Walter de Gruyter \& Co., Berlin, Germany, 1977).

Key words: dielectric constant; Josephson effect; lead; microwaves; niobium; superconductivity; tunnelling.

Thin film Nb-Nb oxide-Pb Josephson junctions have been fabricated at the National Bureau of Standards in device configurations well suited for microwave-integrated-circuit applications. The device fabrication procedures will be described in detail. DC and microwave measurements have been used to characterize and monitor devices. Simple microwave measurements are shown to be a useful probe of the Nb-Nb oxide junction interface and confirm the existence of a thin layer of 
metallic NbO which can be a serious device limitation for many applications.

16947. Blair, B., Jesperson, J., Kamas, G., VLF precision timekeeping potential, (Proc. XV1 General Assembly of the International Union of Radio Science (URSI), Ottawa, Canada, Aug. 1969), Paper in Progress in Radio Science 1966-1969, J. A. Lane, J. W. Findlay, and C. E. White, Eds., 2, pp. 143-148 (International Union of Radio Science, Brussels, Belgium, 1971).

Key words: clock synchronizations; cycle identification; group delays; Omega timing; precision timekeeping; VLF antenna fields; VLF timing; VLF tracking coordination.

Timing needs exist today for synchronization of remote clocks to tens of microseconds or better. This paper discusses the potential of dual frequency VLF transmissions to fulfill those needs. The approach considers phase control of the transmission frequencies, phase relations of near field measurements to the far field reception, propagation of the transmitted signals, and the resulting time synchronization at a remote receiver. Specifically, studies were made of recent WWVL broadcasts as received at several distant points and compared with local cesium frequency standards. The transmission format of 19.9 and $20.0 \mathrm{kHz}$ signals ( $100 \mathrm{~Hz}$ frequency separation), broadcast at 10 -second alternate intervals, resulted in less than desirable cycle identification and time synchronization within several hundred microseconds. The format of 20.0 and 20.5 $\mathrm{kHz}$ time-shared signals ( $500 \mathrm{~Hz}$ frequency separation) gave positive cycle identification at several receiving sites. Day to day cycle identification is improved at both sites through a running average technique. Theoretical group delay predictions, which include dispersion corrections, are given for propagation to both magnetic east and west. Such predictions may provide coarse time bases for multiple frequency VLF timing. The considerations of this paper are directly applicable to the proposed Omega timing system.

16948. Mamrak, S. A., Kimbleton, S. R., Comparing equivalent network services through dynamic processing time prediction, Proc. 1977 Natl. Computer Conf., Dallas, TX, June 12-16, 1977, 46, 455-460 (AFIPS Press, Montvale, NJ, 1977).

Key words: computer networks; resource sharing; response time prediction.

Computer networks provide the potential for resource sharing. Realization of this potential requires knowledge of the available resources within the network. Moreover, if a given resource is available at more than one host, selection of the most appropriate host is required. This paper develops a dynamic means for host selection assuming that the evaluation metric is processing time. An experiment is described which provides an initial evaluation of the key component of the methodology on two separate systems. The paper concludes with a discussion of some overall insights into the applicability of the methodology and its implementation requirements.

16949. McLaughlin, W. L., Miller, A., Fidan, S., Pejtersen, K., Pedersen, W. B., Radiochromic plastic films for accurate measurement of radiation absorbed dose and dose distributions, Radiat. Phys. Chem. 10, 119-127 (1977).

Key words: cellulose acetate; dose distributions; dosimetry; dyed plastics; plastic films; polyvinyl acetate; polyvinyl butyral; polyvinyl chloride; polyvinyl pyrrolidone; radiation dosimetry; radiation processing; radiochromic dyes; triphenylmethane dyes.

Thin radiochromic dye films are useful for measuring large radiation absorbed doses $\left(10^{5}-10^{8}\right.$ rads) and for high-resolution imaging of dose patterns produced by penetrating radiation beams passing through nonhomogeneous media. Certain types of amino-substituted triarylmethane cyanides dissolved in polymeric solutions can be cast into flexible free-standing thin films of uniform thickness and reproducible response to ultraviolet and ionizing radiation. The increase in optical density versus energy deposited by radiation is linear over a wide range of doses and is for practical purposes independent of dose rate $\left(1-10^{14} \mathrm{rad} \mathrm{s}^{-1}\right)$. Upon irradiation of the film, the profile of the radiation field is registered as a permanent colored image of the dose distribution. Unlike most other types of dyed plastic dose meters, the optical density produced by irradiation is in most cases stable for periods of at least one year. Methods have been developed for casting various types of thin radiochromic plastic films and combinations of plastics (cellulose acetate, polyvinyl butyral, polyvinyl acetate, polyvinyl pyrrolidone and polyvinyl chloride) having radiation absorption characteristics corresponding to those of many polymeric systems in industrial radiation processing. The result is that errors due to energy dependence of response of the radiation sensor are effectively reduced, since the spectral sensitivity of the dose meter matches that of the polymer of interest, over a wide range of photon and electron energies (0.01-10 MeV).

16950. Voigt, P. A., Roberts, J. R., Measured Stark widths and shifts for neutral phosphorus lines, Phys. Rev. A 15, No. 3, 1006-1009 (Mar. 1977).

Key words: arc; Debye shielding; neutral phosphorus; Stark shifts; Stark widths.

Stark widths and shifts have been measured for six uv lines and three visible lines of neutral phosphorus in a wall-stabilized arc. The phosphorus is introduced into the arc in three forms: $\mathrm{PCl}_{3}$ vapor, atomized $\mathrm{H}_{2} \mathrm{PO}_{3}$, and $\mathrm{PF}_{3}$ gas. The results agree well with theory for both widths and shifts of the uv lines. It is suggested that the discrepancy with theory for the widths of the visible lines may be due to the neglect of Debye shielding in the theory.

16951. Bowman, C. D., Applications of neutron capture $\gamma$-ray spectroscopy, Proc. Second Int. Symp. on Neutron Capture Gamma Ray Spectroscopy and Related Topics, Petten, The Netherlands, Sept. 2-6, 1974, pp. $729-734$ (Reactor Centrum Nederland, Petten, The Netherlands, Mar. 1975).

Key words: applications past and future; $\gamma$-rays; neutron capture; spectroscopy.

Neutron capture $\gamma$-ray spectroscopy is discussed from the viewpoint of a basic science which is beginning to have a significant impact on applied science. Examples of this are cited in some detail. Probably trends in future applications of neutron capture $\boldsymbol{\gamma}$-ray spectroscopy are discussed along with other challenges in applications which related nuclear physics might wish to address in the future.

16952. Edelman, S., DeReggi, A. S., Comments on "Electroacoustic transducers with piezoelectric high polymer films", J. Audio Eng. Soc. 24, No. 7, 577-578 (Sept. 1976).

Key words: headphone; loudspeaker; microphone; piezoelectric polymer; sound source; vibration.

The subject paper describes how the small combined thickness and extensional vibrations of a piezoelectric polymer sheet can be used to generate a large pulsating movement by curving the sheet. An analysis based on more realistic assumptions results in a different description of the motion of a curved piezoelectric sheet pinned at the edges which agrees better with physical intuition.

16953. Hubbard, C. R., Smith, D. K., Experimental and calculated standards for quantitative analysis by powder diffrac- 
tion, Paper in Advances in X-Ray Analysis, H. F. McMurdie, C. S. Barrett, J. B. Newkirk, and C. O. Ruud, Eds., 20, 27 39 (Plenum Publ. Corp., New York, NY, 1977).

Key words: internal standard; polarization; powder diffraction; quantitative $x$-ray analysis; reference intensity ratio; $x$-ray intensity standards; $x$-ray powder diffraction.

Quantitative analysis by $x$-ray powder diffraction methods has become increasingly important in recent years with the availability of computer-controlled automatic powder diffractometers. All data gathering techniques require suitable reference standards to scale the measured data properly. One means of achieving this scaling is through the reference intensity ratio which is defined as the intensity ratio of the strongest diffraction maximum of a substance to the strongest maximum of a reference material in a 1:1 mixture by weight. These ratios may be measured or they may be calculated if the crystal structures of the materials are accurately known.

Although the ratio for a 1:1 mixture of a substance to a specific reference material (currently corundum) is a good basis for tabulating the reference intensity ratios, the actual measurement is often facilitated by using diffraction peaks other than the strongest ones, mixtures other than 1:1 or different reference materials. These measurements are appropriately corrected for tabulation. The tabulated ratios for the suggested set of experimental conditions-a diffractometer without any monochromators and employing $\mathrm{CuK} \alpha$ radiation-can be modified for different conditions using appropriate relationships. Carefully determined reference intensity ratios will prove invaluable in $\mathrm{x}$-ray quantitative analysis either indirectly as a check on experimental standards or directly in the analytical equations.

16954. Kemple, M. D., Spin coherence of Kramers ions in solids in zero external static magnetic field, (Proc. XIXth Congress Ampere, Heidelberg, W. Germany, Sept. 27-Oct. 1, 1976), Paper in Magnetic Resonance and Related Phenomena, $\mathrm{H}$. Brunner, K. H. Hausser, and D. Schweitzer, Eds., pp. 423. 426 (Groupement Ampere, Heidelberg, Geneva, Switzerland, 1976).

Key words: coherence; Kramers ions; nutation; spin echoes; spin locking; zero field magnetic resonance.

Observations of nutation, adiabatic passage, free induction decay, spin echoes, and spin locking, at temperatures 1.3-4.2 $\mathrm{K}$, of the near $2 \mathrm{GHz}$ zero applied static magnetic field magnetic resonance transition of ${ }^{143} \mathrm{Nd}^{+3}$ ions dilutely substituted for $\mathrm{La}^{+3}$ in crystals of $\mathrm{LaCl}_{3}$ are described.

16955. Light, J. C., Adiabatic perturbation approximation for time dependent collision processes, $J$. Chem. Phys. 66, No. 11 , 5241-5242 (June 1, 1977).

Key words: adiabatic perturbation approximation; collision theory; time dependent.

We shall show that unitary perturbation theory on an adiabatic basis set in an interaction representation yields quite accurate semiclassical transition probabilities over the entire range of the adiabaticity parameters.

16956. Harter, W. G., Patterson, C. W., Orbital level splitting in octahedral symmetry and $\mathrm{SF}_{6}$ rotational spectra. I. Qualitative features of high $J$ levels, $J$. Chem. Phys. 66, No. 11, 4872-4885 (June 1, 1977).

Key words: crystal field theory; group theory; high-resolution spectra; irreducible representation; isotope separation; molecular spectroscopy.
The interesting qualitative features of octahedral symmetry splitting of orbital levels with large angular momentum are derived using a simple quantum mechanical model. The clustering of certain octahedral group representations which has recently been observed in high resolution $\mathrm{SF}_{6}$ spectra is explained in detail. Semiquantitative formulas for splitting of the clusters are derived. An analogy with electron energy bands and Bloch waves is shown. The groundwork is laid for a quantitative theory which is given in the following article.

16957. Patterson, C. W., Harter, W. G., Orbital level splitting in octahedral symmetry and $\mathrm{SF}_{6}$ rotational spectra. II. Quantitative treatment of high $J$ levels, $J$. Chem. Phys. 66, No. 11 , 4886-4892 (June 1, 1977).

Key words: angular momentum; methane; rotational symmetry; sulfur hexafluoride.

We give a quantitative analysis for the clusters of octahedral terms which appear in the high resolution rotational spectra of $\mathrm{SF}_{6}$ for large angular momentum. We derive approximate expressions for the cluster energies and the splittings within each cluster which obviate the diagonalization of the octahedral deformation potential.

16958. Khoury, F., Passaglia, E., The morphology of crystalline synthetic polymers, Chapter 6 in Treatise on Solid State Chemistry, N. B. Mannay, Ed., 3, $335-340$ (Plenum Press, New York, NY, 1976).

Key words: chain folding; curved crystals; extended chain crystals; fold domains; fold surfaces; interlamellar links; morphology; polymer; sectorization; spheralites.

An overview of the morphology of crystalline polymers is given. The topics covered are: the requisites on polymer chains for crystallization; the morphology of polymers crystallized from solution; and the morphology of polymers crystallized from the melt at ordinary and at high pressures.

16959. Yap, W., Schaffer, R., Binding of dye to albumin studied by ultrafiltration, Clin. Chem. 23, 986-989 (1977).

Key words: continuous binding curve; dye binding; human albumin; membrane; reflection coefficient; ultrafiltration.

A procedure was developed that employs dynamic ultrafiltration for determining the binding of bromocresol green to human serum albumin. The procedure affords continuous data, instead of a few discreet points, for detailing the binding as a function of the concentration of the smaller molecule. The results are presented with a discussion of some of the major sources of uncertainties.

16960. Clarke, F. B. III, Ottoson, J., Fire death scenarios and firesafety planning, Fire J. 70, No. 3, 20-22, 117-118 (May 1976).

Key words: fire deaths; fire losses; fire statistics; home furnishings; program planning; residential fire deaths.

The purpose of this paper is to introduce the fire loss scenario as a tool for planning. Scenarios are defined in terms of categories of fire loss (death, injury or property loss) and the circumstances (occupancy type, ignition source, etc.) which surround each incident. Fire statistics from four sources are combined to provide a quantitative ranking of the most important scenarios for fire deaths. Fourteen scenarios account for approximately 66 percent of U.S. fire deaths. The most important of these is the residential fire deaths caused by ignition of furnishing items by careless smoking. This scenario scene accounts for 27 percent of fire deaths. The implications of these findings for planning for safety programs are discussed. 
16961. DeVoe, J. R., Instrument control by digital computers, (Proc. Int. Conf. Computers in Chemical Research and Education, Ljubljana/Zagreb, Yugoslavia, July 12-17, 1973), Paper in Computers in Chemical Research and Education, D. Hadzi, Ed., 1, 1/99-1/137 (American Elsevier Publ. Co., New York, NY, 1973).

Key words: computer control; laboratory automation; teleprocessor.

Digital computers now control and acquire data from a variety of scientific instruments. A major effort must be placed in specifying the computer-instrument interaction in detail. Implementation is best done so that versatility is not sacrificed. The Analytical Chemistry Division's computer system provides a type of versatility and utility that retains the user's scientific discipline, but augments it via the understanding of computer control.

16962. DiMarzio, E. A., Gibbs, J. H., Fleming. P. D. III, Sanchez, I. C., Effects of pressure on the equilibrium properties of glass-forming polymers, Macromolecules 9, 763-771 (Sept.-Oct. 1976).

Key words: glasses; kinetics; polymer glasses; pressure dependence.

The entropy theory (Gibbs-DiMarzio theory) of the glass transition is extended to incorporate the effects of pressure. The second order transition temperature $T_{2}$ increases with increasing pressure but approaches a finite asymptote at very high pressure (>10 kbars). This conclusion is unlike that of an isofree volume theory, according to which the transition temperature should increase without bound. The variation of $T_{2}$ with pressure is shown to satisfy the Ehrenfest relations $\mathrm{d} T_{2} / \mathrm{d} P$ $=T V \Delta \alpha / \Delta C_{p}=\Delta \beta / \Delta \alpha$, even though the theory appears, at first sight, to be a double order parameter theory of the transition. The point is that the apparent order parameters are not independent. A useful classification of order parameters is presented. The theory also predicts that the volume decreases along the transition line as pressure increases, in contradistinction to an isofree volume theory. This volume decrease is in accord with known experimental data and can also be used to explain the densification of glasses. Finally, it is suggested how the relevant kinetic parameters associated with this theory can be determined experimentally.

16963. Rhyne, J. J., Koon, N. C., Milstein, J. B., Alperin, H. A., Spin waves in ferrimagnetic $\mathrm{ErFe}_{2}$, Proc. Conf. on Neutron Scattering, Gatlinburg, TN, June 6-10, 1976, pp. 873-887 (Available from the National Technical Information Service, Springfield, VA, Sept. 1, 1976).

Key words: erbium; Laves phase; magnetic excitation; magnetism; rare earths; spin wavcs.

Spin excitations in a single crystal of the rare earth Laves phase compound $\mathrm{ErFe}_{2}$ have been studied using inelastic neutron scattering. Measurements were made in the ordered state at room temperature (Curie temperature $=574 \mathrm{~K}$ ) and revealed one acoustic and two optic modes. The lower optic mode is nondispersive with energy of $5 \mathrm{meV}$, and is nearly degenerate with the acoustic mode at the zone boundary. Dispersion in this mode is controlled by the rare earth-rare earth exchange interaction which was found to be nearly zero for this compound. The upper optic mode exhibits a gap of $8.75 \mathrm{meV}$ at the zone center and has a wave-vector dependence defined by the $\mathrm{Fe}-\mathrm{Fe}$ exchange and which is approximately equal to that in $\mathrm{Fe}$ metal. A nearest neighbor spin wave model has been developed for which the calculated spin wave energies are in excellent agreement with those observed for all three modes. The model also predicts three additional optic modes (two are degenerate) at energies above 100 niev which are not significantly populated.

16964. Glinka, C. J., Rowe, J. M., Rush, J. J., Rahman, A., Sinha, S. K., Flotow, H. E., Inelastic neutron scattering lineshapes in $\mathrm{PdD}_{.63}$, Proc. Conf. on Neutron Scattering, Gatlinburg, TN, June 6-10, 1976, pp. 536-542 (Available from the National Technical Information Service, Springfield, VA, Sept. 1, 1976).

Key words: defect crystal structures; inelastic neutron scattering; lattice dynamics; metal-hydrogen systems; palladium-deuteride $\left(\mathrm{PdD}_{0.63}\right)$; phonon lineshapes.

Previous measurements of the phonon dispersion curves in a single crystal of $\mathrm{PdD}_{.63}$ have been augmented by detailed inelastic neutron scattering measurements of the phonon lineshapes at $80 \mathrm{~K}$. The lineshapes observed at this temperature show substantial broadening and subsidiary structure. The data have been compared to calculated lineshapes based on a model in which the absence of translational symmetry inherent in the structure is approximately taken into account. The calculations indicate that the complexities of the observed lineshapes are intrinsic features of the "one phonon" response in this highly defected structure. In addition, the deuterium Debye-Waller factor has been obtained from the variation of the phonon intensity with scattering vector.

16965. Glinka, C. J., Rowe, J. M., Rush, J. J., Libowitz, G. G., Maeland, A., The lattice vibrations of $\mathrm{CeD}_{2.12}$, Solid State Commun. 22, 541-544 (1977).

Key words: cerium deuteride; inelastic neutron scattering; lattice dynamics; local mode vibrations; metal hydrides; phonon dispersion curves.

The complete phonon dispersion relation including both optic and acoustic modes has been measured along the major symmetry axes of a single crystal of $\mathrm{CeD}_{2.12}$ at $295 \mathrm{~K}$ by coherent neutron scattering. The results show the inadequacy of simple models previously used for the analysis of neutron incoherent scattering studies of rare earth dihydrides. The interstitial mode of vibration due to the excess deuterium (above $\mathrm{CeD}_{2}$ ) in octahedral sites has also been observed.

16966. Klein, R., Kelley, R. D., Combination and disproportionation of allylic radicals at low temperatures, J. Phys. Chem. 79, 1780-1 784 (1975).

Key words: allylic; combination; disproportionation; low temperature; radical.

The disproportionation-combination ratio for several allylic type radicals has been measured in the condensed phase at 90 K. Pairs of allylic radicals react exclusively by combination, with no disproportionation found within the limits of the analytical technique. Cross combination and disproportionation occurs between an allylic radical and an alkyl radical. In the cross disproportionation, the allylic radical acts exclusively as a hydrogen donor. This effect is attributed to the delocalization of the free spin, the hydrogen acceptor function being completely inhibited. Because of this, two allylic type radicals (or any radicals in which the density of the free spin is sufficiently delocalized) can only combine. The contribution of the resonant components of the allylic radicals to the combination products is found to be greatly dependent on steric effects.

16967. Watson, R. E., Bennett, L. H., Volume-corrected isomer shifts of transition-metal impurities: An orbital electronegativity scale, Phys. Rev. B 15, No. 11, 5136-5140 (June 1, 1977).

Key words: alloy theory; electronegativity; transition metal, Mössbauer effect. 
It is shown that, once volume effects are accounted for, a universal curve describes the Mössbauer isomer shifts of ${ }^{57} \mathrm{Fe}$, ${ }^{99} \mathrm{Ru},{ }^{181} \mathrm{Ta},{ }^{193} \mathrm{Ir},{ }^{195} \mathrm{Pt}$, and ${ }^{197} \mathrm{Au}$ impurity nuclei in a variety of hosts. The curve defines an "orbital" electronegativity associated with non- $d$ electron charge flow on or off these transition-metal atoms in alloys. The shape of the curve is remarkable in the extent to which it agrees with the "total" electronegativity scales of Pauling, Gordy-Thomas, and others. This agreement suggests that $d$ and non- $d$ charge flow are simply proportional to one another to an extent we find surprising.

16968. Hunter, $\dot{C}$., Relation between the dynamics and the flattening of elliptical galaxies, Astron. J. 82, No. 4, 271-282 (Apr. 1977).

Key words: anisotropy of mean square velocities; eccentricity of equidensity surface; elliptical galaxies; flattening; mass distribution function.

The interrelations between the eccentricity of equidensity surfaces, the anisotropy of mean square velocities, and the mass distribution function $f$ (assumed to be a function only of energy $E$ and angular momentum $J$ about the axis of symmetry) are studied. Distribution functions that are separable in $E$ and $J$, such as are often assumed, give rise to eccentricity profiles in which the eccentricity declines substantially in the central regions. Conversely, if the eccentricity is to remain relatively uniform in the central regions, then the dependence of $f$ on $J$ must grow in relative significance at high energies. Properties of finite truncated isothermal spheres are also investigated. When their distribution functions are truncated smoothly in phase space, their radii, in particular, are shown to be curiously sensitive to the central potential, and able to vary by more than a factor of 10 .

16969. Gilmore, W., Morris, M., Johnson, D. R., Lovas, F. J., Zuckerman, B., Tumer, B. E., Palmer, P., Observation of the $6_{16}-5_{15}$ transitions of acetaldehyde in Sagittarius B2, Astrophys. J. 204, 43-46 (Feb. 15, 1976).

Key words: acetaldehyde; internal rotation; interstellar molecules; mm wave transitions; overlapped lines; radio astronomy.

The $6_{16}-5_{15}$ transitions of acetaldehyde have been observed in the Sgr B2 molecular cloud. The large line width suggests that both the $A$ and $E$ symmetry states are present with essentially equal intensity. This is the first observation of acetaldehyde at millimeter wavelengths, and the intensity indicates that many other millimeter wave lines of acetaldehyde should be detectable.

16970. Rowe, J. M., Neutron scattering studies of the diffusion of hydrogen in metals, Proc. Conf. on Neutron Scattering, Gatlinburg, TN, June 6-10, 1976, pp. 491-506 (Available from the National Technical Information Service, Springfield, VA, Sept. 1, 1976).

Key words: diffusion; hydrogen; lattice dynamics; metals; netitron scattering; quasielastic scattering; review.

Some results of neutron quasielastic scattering studies of hydrogen diffusion in metals are presented and discussed. The limitations of the models presently available to interpret these data are presented. Several experimental results indicate reasons for the failure of the simple model to explain diffusion in any of the bcc metals even though the model does work well for fcc palladium. The areas where further research is needed are discussed and some recent research in these areas is also presented.

16971. Galloway, K. F., Leedy, K. O., Keery, W. J., Electronbeam-induced currents in simple device structures, Proc. 26th
Electronic Components Conf., San Francisco, CA, April 26-28, 1976, pp. 257-262 (1976).

Key words: device inspection; electron-beam-induced-current; microelectronics; $p-n$ junctions; scanning electron microscopy; semiconductor devices.

Electron-beam-induced current (EBIC) in semiconductor devices produced by the electron beam of a scanning electron microscope (SEM) can be used to image subsurface device features and to measure certain material parameters. This paper presents a simple model for estimating the magnitude of EBIC signals. EBIC signals from silicon $p-n$ junction diodes are compared with the predictions of the model. The application of EBIC to more complicated device structures is discussed.

16972. Rowe, J. M., Rush, J. J., Prince, E., Neutron diffraction study of the structure and phase transitions of alkali cyanide crystals, J. Chem. Phys. 66, No. 11, 5147-5149 (June 1, 1977).

Key words: antiferroelectric; $\mathrm{KCN}$; $\mathrm{NaCN}$; order parameter; structure.

The structures of sodium and potassium cyanide have been studied by neutron powder diffraction as a function of temperature between 6 and $300 \mathrm{~K}$. The orientation of the $\mathrm{CN}$ ions in the lowest temperature phase has been established, and the mechanism of the order-disorder phase transitions has been elucidated by a careful study of a superlattice line intensity in KCN.

16973. Fraker, A. C., Ruff, A. W., Metallic surgical implants: State of the art, J. Metals 29, No. 5, 1-7 (May 1977).

Key words: biocompatibility; cobalt-chromium; corrosion; implant requirements; mechanical properties; metal implants; stainless steel; standards; titanium.

Metallic surgical implants in use today have been discussed in terms of their properties and the implant requirements (biocompatibility, mechanical properties and environmental stability) imposed on them. Research of numerous workers is included in the review which lists 73 references. Emphasis is placed on the use of metals for orthopedic purposes but other uses are discussed briefly. Implant retrieval studies, standards and regulation are discussed.

16974. Kuriyama, M., Boettinger, W. J., Burdette, H. E., Crystal imperfections and magnetic domain walls in thick Czochralski-grown nickel single crystals, Paper in Advances in X-Ray Analysis, H. F. McMurdie, C. S. Barrett, J. B. Newkirk, and C. O. Ruud, Eds., 20, pp. 245-257 (Plenum Publ. Corp., New York, NY, 1977).

Key words: crystal growth; crystal perfection; diffraction topography; dynamical diffraction theory; ferromagnetic domain walls; nickel single crystals; x-ray dynamical diffraction.

To study the relationship between crystal growth conditions and resultant crystalline perfection, large nickel single crystals more than $12 \mathrm{~cm}$ long and 2 to $3 \mathrm{~cm}$ in diameter have been grown from the melt by the Czochralski method. Unlike semiconducting materials, one cannot easily thin metal crystals, without straining them, for the purpose of applying ordinary Lang topography with $\mu \mathrm{L} \sim 1$ where kinematical scattering in imperfect crystals is a good approximation. This situation with metal crystals necessitates the use of dynamical diffraction effects in imperfect crystals to permit sample crystals to be thick enough to demonstrate their imperfections as in the bulk.

The crystal perfection in as-grown nickel single crystals has, therefore, been assessed by $\mathrm{x}$-ray dynamical diffraction topog- 
raphy with an asymmetrical (double) crystal topographic (ACT) camera. Transmission topographs were obtained from crystals of thickness ranging from $0.37 \mathrm{~mm}(\mu L=18)$ to 1.03 $\mathrm{mm}(\mu \mathrm{L}=52)$ using $\{111\},(002)$ and (220) diffraction. The crystals grown under favorable conditions have shown strong anomalous transmission. The O-diffracted (transmitted) and the H-diffracted (Bragg-diffracted) beams display almost identical disruption images of crystal imperfections in the interior of the crystals. The types of imperfection and the degree of crystal perfection will be sorted by a set of crystal growth parameters, such as seed orientation and rotation rate.

In addition to the images of crystal imperfections, there are disruption images of $71^{\circ}, 109^{\circ}$ and $180^{\circ}$ magnetic domain walls in the topographs. These images in transmission topographs will be compared with those in surface topographs obtained with the surface reflection geometry. Contrast conditions and image formation mechanism will be discussed by a general extinction theory.

16975. Coursey,. B. M., Hutchinson, J. M. R., Unterweger, M. P., Calibration of $\mathrm{Ge}(\mathrm{Li})$ gamma-ray spectrometers for the measurement of radioactive noble gases, Int. J. Appl. Radiat. Isot. 28, 551-553 (1977).

Key words: environment; gamma-ray measurements; germanium-lithium detectors; noble gases; radioactivity; reactor effluents.

Assays of radioactive noble gases, in particular reactor gaseous effluents, are routinely made with $\mathrm{Ge}(\mathrm{Li})$ gamma-ray spectrometers. In the past, significant uncertainties in these assays have been associated with the calibration of the detector, that is, with the preparation of a curve showing full-energy-peak efficiency as a function of gamma-ray energy. A method of preparing such a curve, based on measurements made with gamma-ray point-source standards, is given here. An expression is given that relates the full-energy-peak efficiency for a point source, centered above a glass hemisphere, to that of a gaseous source in a spherical ampoule, for a given gamma-ray energy. Measurements made with standards of krypton-85, xenon-127, xenon- $131 \mathrm{~m}$ and xenon-133 demonstrate that the method is suitable for the intended purpose.

16976. Garvin, D., Hampson, R. F., Kurylo, M. J., Reaction rate data for the stratosphere: How good are they now?, Proc. Fourth Conf. on Climatic Impact Assessment Program, Cambridge, MA, Feb. 1975, pp. $391-397$ (U.S. Department of Transportation, Washington, DC, 1975).

Key words: chemical kinetics; data evaluation; data reliability; gas phase; photoabsorption cross section; photochemistry; quantum yield; rate constant; stratospheric chemistry.

The reaction-rate and photochemical data currently available for use in modeling of stratospheric chemistry are reviewed. They are characterized in terms of their quality and applicability. Of 46 "important" chemical reactions, the data for 33 are adequate. For 82 "less important" reactions, the data are generally less reliable, but in many cases sufficient. A similar pattern exists for photochemical processes. The data are adequate for 8 of 16 "important" processes and are adequate for 5 of 16 "less important" processes. A list of reactions for which more measurements are needed is supplied.

16977. Boettinger, W. J., Burdette, H. E., Farabaugh, E. N., Kuriyama, M., Some topographic observations of the effects of dynamical diffraction in imperfect metal crystals, Paper in $A d$ vances in X-Ray Analysis, H. F. McMurdie, C. S. Barrett, J. B. Newkirk, and C. O. Ruud, Eds., 20, 207-219 (Plenum Publ. Corp., New York, NY, 1977).
Key words: contrast conditions; diffraction topography; dynamical images; imperfect crystals; perfect crystals; $x$-ray dynamical diffraction.

$X$-ray diffraction topographs obtained in the anomalous transmission geometry contain images which are quite different from those obtained from thin crystals $(\mu L \leqslant 1)$. In this paper various topographic images which are unique to thick crystals $(\mu \mathrm{L}>10)$ will be presented and discussed in terms of dynamical diffraction in imperfect crystals. First, it is observed in topographs that images of crystal imperfections caused by disruption of the anomalous transmission effect are slightly broader or more diffuse in the $\mathrm{H}$-diffracted (Bragg-diffracted) beam than in the O-diffracted (transmitted beam). These observations have been made in both copper and nickel crystals. Such broadening can be explained by the presence of unique extinction terms in the expression for the intensity of the dynamically diffracted beam in an imperfect crystal. Second, it is observed that magnetic domain walls in thick nickel crystals are always imaged as deficiencies of the anomalous transmission background. This is to be contrasted with images of such walls in thin crystals which are either white or black and are caused primarily by mosaic type image formation from the adjacent domains. Third, unusual images will be shown which are deficient in $\mathrm{x}$-rays in the O-diffracted beam and enhanced in the $\mathrm{H}$-diffracted beam or vice versa. It will be shown experimentally in copper crystals that such images are caused by defects near the exit surface of the crystal. These images are thought to be caused by kinematical scattering of the already existing dynamically diffracted beam near the $x$-ray exit surface. Such surface defects are often artifacts of sample preparation and hence this information provides a useful tool for their identification. All of these topographic images have been obtained using asymmetric crystal topography. This paper will also include a brief comparison of this technique with more traditional topographic techniques.

16978. Bernstein, L. S., Abramowitz, S., Levin, I. W., Potential function for axial-equatorial fluorine atom exchange in $\mathrm{PF}_{5}$, $\mathrm{AsF}_{5}$, and $\mathrm{VF}_{5}, J$. Chem. Phys. 64, No. 8, 3228-3236 (Apr. 15, 1976).

Key words: $\mathrm{AsF}_{5}$; barriers; energy levels; gas phase; $\mathrm{PF}_{5}$; Raman; $\mathrm{VF}_{5}$.

Gas-phase Raman spectra of the $\nu_{7}$ fundamentals of $\mathrm{AsF}_{5}$ and $V_{5}$ were recorded for spectral resolutions approaching 1.5 $\mathrm{cm}^{-1}$. The vibrational transitions associated with $\nu_{7}$ for these systems, as well as for $\mathrm{PF}_{5}$, were interpreted in terms of a twodimensional anharmonic potential function constrained to a double minimum form for the motions leading to axial-equatorial fluorine atom exchange. The intramolecular exchange barrier heights, determined by the double minimum potentials, lie between 1139 and $995 \mathrm{~cm}^{-1}$ (3.26 to $2.84 \mathrm{kcal} / \mathrm{mol}$ where $1 \mathrm{kcal} / \mathrm{mol}=4.184 \mathrm{~kJ} / \mathrm{mol})$ for $\mathrm{PF}_{5}, 864$ and $755 \mathrm{~cm}^{-1}(2.47$ and $2.16 \mathrm{kcal} / \mathrm{mol}$ ) for $A s F_{5}$, and 593 and $428 \mathrm{~cm}^{-1}$ (1.54 and $1.22 \mathrm{kcal} / \mathrm{mol}$ ) for $V_{5}$. A discussion of the dynamics of the fluorine atom interchange pathways suggests that these trigonal bipyramidal $D_{3 h}$ molecules form $C_{4 \nu}$ intermediates by initially displacing the equatorial fluorine atoms and then by mixing in the axial fluorine distortions as the intramolecular exchange proceeds.

16979. Berger, R., An interpretation of the drop ball test in terms of a statistical model for fracture, $\mathrm{Am}$. J. Optom. Physiolog. Opt. 53, No. 8, 396-407 (Aug. 1976).

Key words: drop ball test; flaw distribution; fracture; impact resistance; ophthalmic lenses; statistics.

Some well-known statistical models for fracture were applied to the problem of impact of glass ophthalmic lenses. Parame- 
ters for a flaw distribution function were chosen to fit some previously published results of drop ball testing. The concept of an impact-resistant lens was reformulated in terms of minimizing the most severe flaws. Formulas were derived for the detection pararyeter, a convenient measure of the ability of any mechanical test to identify those lenses with the worst flaws. It was shown that the fraction of such lenses identified by the drop ball test is very small. As a side note, it was found that it is not significantly more difficult to expose "bad" lenses when they are tested in plastic bags. A method of obtaining useful information from the results of drop ball testing was outlined.

16980. Bowen, B. E., Cram, S. P., Effects of sample size on chromatographic behavior, J. Chromatogr. Sci. 12, 579-584 (Oct. 1974).

Key words: gas chromatography; molecular diffusion; moments; secondary flow.

High precision vapor phase sampling valves under computer control were used to study the effect of sample size on chromatographic peak shapes and diffusion phenomena in open tubular and wall-coated open tubular columns. Molecular diffusion is treated in terms of axial and Taylor diffusion and velocity profiles are interpreted in terms of the data. Secondary flow effects are considered in detail and are shown to be negligible for these columns compared to molecular, radial, and viscous diffusion.

16981. Mavrodineanu, R., Drews, U. W., NBS glass standards, Anal. Chem. Editors' Column 48, No. 7, 609A (1976).

Key words: absorbance; accuracy in spectrophotometry; glass filters; high-accuracy spectrophotometers; spectrophotometry; stability of transmittance; standard reference material; transfer standard; transmittance.

The transmittance accuracy of conventional spectrophotometers can be verified by means of transfer standards. Such standards are available from NBS in the form of glass filters (SRM 930). The integrity in time of the certified transmittance values depends on the stability of the glass and on the environmental conditions, including handling of the filters. Recently an unexpected instability of the glass was found in SRM $930 \mathrm{~b}$ which produced, in approximately 20 percent of these filters, a decrease in transmittance by up to 1.5 percent at $440 \mathrm{~nm}$ and $465 \mathrm{~nm}$ over a period of about one year. The purchasers of SRM $930 \mathrm{~b}$ have been informed of this fact and means have been suggested to remedy this situation.

16982. Neuhausen, R., Lightbody, J. W., Jr., Fivozinsky, S. P., Penner, S., Electron scattering studies of low-lying collective states of even Zn isotopes, Nucl. Phys. A263, 249-260 (1976).

Key words: anharmonic vibrator model; collective states; electron scattering; inelastic; two-phonon states; zinc 6466-68-70.

The inelastic electron scattering cross sections for the excitation of the low-lying collective states in the even $\mathrm{Zn}$ isotopes ${ }^{64} \mathrm{Zn},{ }^{66} \mathrm{Zn},{ }^{68} \mathrm{Zn}$ and ${ }^{70} \mathrm{Zn}$ have been measured in the momentum transfer region $q=0.3-1.1 \mathrm{fm}^{-1}$. Strong transitions to the first $2^{+}$and $3^{-}$states have been observed and the modified Tassie model with a two parameter Fermi charge distribution for the ground state was used to extract the values for the reduced transition probability $B,(E \lambda)$. Besides the investigation of these states, which in the framework of the vibrational model are considered as one-phonon states, special effort was made to measure the transition to the $2^{+}$two-phonon states in ${ }^{-1} \mathrm{Zn}$ $(\epsilon=1.80 \mathrm{MeV})$ and ${ }^{70} \mathrm{Zn}(\epsilon=1.76 \mathrm{MeV})$. We have applied the anharmonic vibrator model to these two nuclei and have extracted values for the static quadrupole moment of the first excited state.
16983. Singh, R. S., Trevino, S., Prask, H. J., Long wavelength $(\mathrm{K} \sim 0)$ ir active phonons of $\mathrm{NaHF}_{2}$ and $\mathrm{KHF}_{2}, J$. Chem. Phys. 58, No. 10, 4703-4704 (May 15, 1973).

Key words: infrared; $\mathrm{KHF}_{2}$; lattice modes; linear triatomic anions; $\mathrm{NaHF}_{2}$; polycrystals.

Far-infrared reflection spectra $\left(75-400 \mathrm{~cm}^{-1}\right)$ of pressed pellets of $\mathrm{NaHF}_{2}$ and $\mathrm{KHF}_{2}$ have been obtained at room temperature. There are two well-resolved bands in the spectrum of each sample. Kramer-Kronig analysis yielded the transverse and longitudinal optical phonons and assignments were made in analogy with results obtained for isomorphic metal-azide salts. For $\mathrm{NaHF}_{2}$, the modes are $210 \mathrm{~cm}^{-1}\left(\mathrm{~A}_{2 u}-\mathrm{TO}\right), 234 \mathrm{~cm}^{-1}\left(\mathrm{~A}_{2 u^{-}}\right.$ LO), $244 \mathrm{~cm}^{-1}\left(E_{u^{-}}-T O\right)$, and $292 \mathrm{~cm}^{-1}\left(E_{u^{-}}-L O\right)$. For $\mathrm{KHF}_{2}$, the modes are 134 and $174 \mathrm{~cm}^{-1}\left(E_{u^{-}}\right.$TO), and $158 \mathrm{~cm}^{-1}$ and 236 $\mathrm{cm}^{-1}\left(\mathrm{E}_{u^{-}}-\mathrm{LO}\right)$.

16984. Kosanić, M. M., Nenadović, M. T., Radał, B. B., Marković, V. M., McLaughlin, W. L., Liquid radiochromic dye dosimetry for continuous and pulsed radiation fields over a wide range of energy flux densities, Int. J. Appl. Radiat. Isot. 28, 313-321 (1977).

Key words: calorimetry; chemical dosimetry; dosimetry; dye dosimeters; electron beams; gamma rays; pararosaniline cyanide; pulse radiolysis; radiochromic dyes.

New studies of radiochromic dye dosimeters in liquid phase have shown that these systems may be used over a very wide range of absorbed dose rates. A dependence of response on dose rate occurs in both aqueous and organic radiochromic solutions only at dose rates exceeding about $10^{10} \mathrm{rad} \mathrm{s}^{-1} \cdot \mathrm{O}_{2}$ saturated solutions of pararosaniline cyanide in 2-methoxy ethanol show a linear response for absorbed doses up to $4 \times$

$10^{5} \mathrm{rad}$, without variation of dye yield with dose rate up to at least $10^{13} \mathrm{rad} \mathrm{s}^{-1}$. By adding nitrobenzene in small concentrations, the linear response can be extended to $1 \mathrm{Mrad}$, with only a slight change in dye formation yield with changing dose rate up to $10^{12} \mathrm{rad} \mathrm{s}^{-1}$. Hence these systems are suitable for applied dosimetry in either continuous gamma-ray fields or high-intensity pulsed accelerator beams (e.g., radiation processing or pulse radiolysis). The accuracy of dose measurement is \pm 3 percent, as long as the dye yield of the dosimeter solution is properly calibrated against a chemical or calorimetric standard system and as long as the concentration of the radiochromic dye precursor is accurately specified. The calibration may easily be carried out at relatively low radiation flux densities, as with ${ }^{60} \mathrm{Co}$ gamma radiation, and then the dosimeter may be used with the same $G$-value at extremely high dose rates.

16985. Abbundi, R., Segnan, R., Rhyne, J. J., Sweger, D. M., Hyperfine fields in the absence of magnetic order in Dy-Sc alloys, (Proc. 21st Annual A1P Conf. on Magnetism and Magnetic Materials, Philadelphia, PA, Dec. 9-12, 1975), Paper in Magnetism and Magnetic Materials-1975, J. J. Becker, C. H. Lander, and J. J. Rhyne, Eds., No. 29, pp. 352-353 (American lnstitute of Physics, New York, NY, 1976).

Key words: dysprosium; hyperfine fields; magnetism; rare earths; relaxation effects; scandium alloys.

$\mathrm{Tb}_{x} \mathrm{Sc}_{1-x}$ and $\mathrm{Gd}_{x} \mathrm{Sc}_{1-x}$ alloys have been shown to exhibit no long-range magnetic order for $x<.25$ (in $\mathrm{Tb}-\mathrm{Sc}$ ) from neutron scattering and magnetization experiments in contrast to $Y$ based alloys and conventional theory which predicts a vanishing of $T_{N}$ only as $x \rightarrow 0$. We have investigated the Dy hyperfine fields in a series of $\mathrm{Dy}_{\boldsymbol{r}} \mathrm{Sc}_{1-x}$ alloys in a similar range in which no $T_{N}$ is found (above $4 \mathrm{~K}$ ). Although no long-range order is present, the alloys do show a well-defined hyperfine splitting corresponding to a field approximately equal to that in pure Dy metal and independent of Dy concentration. This is present 
even in a 2 percent Dy alloy which is the lowest concentration measured. This surprising result suggests a spin-relaxation mechanism is operative which produces the observed hyperfine fields, but which is not accompanied by static long-range magnetic order.

16986. Raveché, H. J., Stuart, C. A., Bifurcation of solutions with crystalline symmetry, J. Math. Phys. 17, No. 10, 19491953 (Nov. 1976).

Key words: BBGKY hierarchy; bifurcation; crystal; free energy; lattice symmetry; stability.

We consider the BBGKY equation for the single particle probability density in a hard sphere system. We investigate whether there is bifurcation from the fluid phase to functions which have crystalline symmetry. We find that as the density of the fluid increases from zero, there is bifurcation in one, two, and three dimensions. The bifurcation is shown to be characteristic of metastability and in general it does not occur at the equilibrium coexistence of two phases. The direction of branching and the stability of solutions near bifurcation is also discussed.

16987. Berman, B. L., Gibson, B. F., O'Connell, J. S., Isospin shift of the energy of the giant resonance, Physics Letters 66B, No. 5, $405-409$ (Feb. 28, 1977).

Key words: giant resonance; hydrodynamic model; isospin; photonuclear; shell model; sum rules.

Systematics of the peak position of the photonuclear giant dipole resonance are examined to extract the dependence upon the isospin of the target nucleus. The energy shift with isospin $T$ at constant nuclear mass $A$ is of the same sign and magnitude as the shift with $A$ at constant $T$, in conflict with theoretical estimates.

16988. Fiori, C. E., Yakowitz, H., Newbury, D. E., Some techniques of signal processing in scanning electron microscopy, (Proc. Seventh Annual Scanning Electron Microscope Symp., Chicago, IL, April 4-11, 1974), Paper in Scanning Electron Microscopy/1974, O. M. Johari and 1. Corvin, Eds., Pt. 1, 167-174 (IIT Research Institute, Chicago, IL, 1974).

Key words: derivative operators; digital scan generator; isotropy; photographic processing; scanning electron microscopy; signal processing.

Six signal processing operators-differential signal amplification (black level), nonlinear amplification $(\gamma)$, the first time derivative and its absolute value, the second time derivative, and Y-modulation-are discussed. The effects of the time derivative operators on the apparent illumination and image isotropy are considered. The first time derivative can provide enhanced contrast at edges and the appearance of oblique illumination. The second time derivative and the absolute value of the first time derivative produce enhanced contrast at edges and the appearance of vertical illumination. In conventional unidirectionally scanned images, the time derivatives exhibit anisotropy-all detail parallel to the scan line is lost. By superimposing scans at right angles (orthogonal scanning), the information loss line is avoided for the second time derivative and the absolute value of the first derivative. In the case of the second derivative an isotropic operator results. Orthogonal scanning with the first time derivative rotates the line of information loss.

16989. Hunter, C., Tremaine, S., Collinear configurations of galaxies can be stable, Asiron. J. 82, No. 4, 262-270 (Apr. 1977).

Key words: galactic stability; galaxies; galaxies, clusters of.
Collinear configurations of point masses have long been known as possible, though unstable, solutions of the three-body problem. But collinear configurations consisting of a massive and extensive central primary with two satellites may be stable. One possible stabilizing mechanism is the tide induced in the primary by the satellites. Another is a reduction in the ratio of the primary's gravitational mass (as felt by the satellites) to its inertial mass. This effect arises if the primary extends beyond the orbits of the satellites. Both stabilizing mechanisms may be relevant to the dynamics of barred galaxies, configurations of external galaxies and their satellites, and to the Large Magellanic Cloud-Galaxy-Draco system.

16990. Kruger, J., Ambrose, J. R., Qualitative use of ellipsometry to study localized corrosion processes, (Proc. 3d Int. Conf. on Ellipsometry, Lincoln, NE, Sept. 23-25, 1975), Surf. Sci. 56, 394-412 (1976).

Key words: crevice corrosion; ellipsometry; localized corrosion; pitting; repassivation kinetics; stress corrosion.

Localized corrosion processes such as pitting, intergranular corrosion, crevice corrosion, and stress corrosion involve many aspects that are not amenable to a quantitative study by ellipsometry. This paper describes uses of ellipsometry that can, however, provide valuable insights into localized corrosion processes without having to determine the optical constants of absorbing films. The uses described are as follows: (1) the determination of induction times for pit initiation and the demonstration that changes occur in the passive film prior to pitting; (2) the measurement of the rate of repassivation, a process of importance to stress corrosion, for a metal surface whose protective film has been removed by abrasion (triboellipsometry); and (3) the identification of three stages leading to crevice corrosion by ellipsometric measurements made within a crevice.

16991. Ambler, E., 75 years of physics at NBS, Phys. Today, 7 pages (Aug. 1976).

Key words: American Physical Society; fundamental constants; National Bureau of Standards; nuclear physics; numerical analysis; physics; spectroscopy; thermal physics; 75 th anniversary.

The article contains a discussion of contributions of the $\mathrm{Na}$ tional Bureau of Standards to physics over its 75-year history and the close association between NBS and the American Physical Society. The contributions of NBS in four broad areas: nuclear physics, thermal physics (including cryogenics), spectroscopy (including collision parameters), and fundamental constants (including precision measurements).

16992. Voigt, P. A., Kornblith, R. L., Measurement of U I relative oscillator strengths, J. Opt. Soc. Am. 66, No. 5, $492-493$ (May 1976).

Key words: arc; oscillator strength; plasma; spectra; uranium.

Relative oscillator strengths have been measured for ten strong lines of $U$ I which may be useful in laser isotope separation of ${ }^{238} \mathrm{U}$ and ${ }^{235} \mathrm{U}$. The $\mathrm{U} I$ spectra was generated in a flow stabilized arc, which is essentially a free burning arc stabilized by streaming an inert buffer gas around one of the electrodes which is formed from a molten ball of uranium held in a tungsten cup. The relative oscillator strengths were placed on an absolute scale employing a recent lifetime determination for the $27887 \mathrm{~cm}^{-1}$ level of U I.

16993. Wiederhorn, S. M., Fuller, E. R., Jr., Bukowski, J. M., Robbins, C. R., Effect of hydrothermal environments on the erosion of castable refractories, (Proc. Winter Annual Meet- 
ing of the American Society of Mechanical Engineers, New York, NY, Dec. 5-10 1976), J. Eng. Mater. Technol. 99, 143146 (Apr. 1977).

Key words: coal gasification; environments; erosion; hydrothermal; refractories; strength.

Hydrothermal environments are expected to adversely affect the erosive resistance of castable refractories intended for use in high wear areas of coal gasification plants. The erosive wear behavior of two grades of refractories proposed for such use was studied at room temperature after exposure of the refractories to high-pressure steam. Wear occurs primarily in the cement phase that bonds the more wear-resistant aggregate. The wear resistance of the refractories depended on chemical interactions between the cement and the high pressure steam. Although chemical changes were observed to occur in both refractories, the wear resistance was found to decrease only in those cases for which the strength of the cement phase was substantially reduced.

16994. Unassigned.

16995. Reneker, D. H., Bolz, L. H., Effect of atomic oxygen on the surface morphology of polyethylene, J. Macromol. Sci.Chem. A 10, No. 3, 599-608 (1976).

Key words: atomic oxygen; chemiluminescent; corona discharge; dielectric breakdown; ozone attack.

The chemical species created in a low-pressure electrical discharge in oxygen attack the polymer at the surface, converting it to gaseous products. This process is interesting because: 1) the chemical changes on the resulting surface facilitate the formation of strong adhesive bonds and provide sites for the chemical attachment of other molecules, 2) significant morphological features lying below the surface may be revealed, 3) polymer can be cleanly removed from surfaces which are resistant to oxidation, and 4) dielectric breakdown frequently is preceded by the attack on the polymer of chemical species created in a corona discharge. Atomic oxygen is an important chemical species created in such a discharge. It reacts with organic substances rapidly at room temperature, but lives long enough in the low-pressure gas that it can be separated from many other reactive species created in the discharge. "Titration" with $\mathrm{NO}_{2}$ provides a straightforward chemiluminescent means for determining the concentration of atomic oxygen to which the sample is exposed. This paper characterizes the attack of atomic oxygen, perhaps in the presence of long lived but less reactive species such as excited $\mathrm{O}_{2}$ molecules, on polymer surfaces, using electron microscopic observations of known morphological features of polyethylene to observe the changes produced by atomic oxygen. Lamellar polyethylene crystals were attacked both at the edges and the fold surfaces. Layers many microns thick were removed from spherulitic samples and replicas obtained from the surfaces thus exposed. Thick samples were thinned to the point at which they were transparent to an electron beam and interior morphological features were directly observed.

16996. Treado, M. J., Development of reports and guidelines for law enforcement communications equipment, Proc. $1974 \mathrm{Car}$ nahan Conf., Lexington, KY, Apr. 1974, pp. 102-112 (1974).

Key words: communications; digital communications; guideline; law enforcement equipment report; Law Enforcement Standards Laboratory; mobile digital equipment; National Institute of Law Enforcement and Criminal Justice.

The Law Enforcement Standards Laboratory (LESL), was established by NBS for the National Institute of Law Enforcement and Criminal Justice (NILECJ) primarily to develop per- formance standards to assist law enforcement agencies in their equipment selection and procurement process. In addition to performance standards, LESL also is developing equipment reports, guidelines and glossaries for use by the law enforcement community. This paper uses a typical study effort, in this case one on mobile digital communications, to illustrate the development of a law enforcement equipment report.

16997. Kuriyama, M., Boettinger, W. J., Burdette, H. E., X-ray topographic observations of magnetic domains in Czochralskigrown nickel single crystals in anomalous transmission geometry, J. Appl. Phys. 47, No. 11, 5064-5068 (Nov. 1976).

Key words: anomalous transmission effect; asymmetric crystal topography; crystal imperfections; crystal perfection; Czochralski-grown nickel; dislocation clusters; dynamical diffraction; magnetic domains; magnetic domain walls; melt-grown crystals; nickel single crystals; $x$-ray diffraction topography.

The anomalous transmission effect has been observed in nickel single crystals grown by the Czochralski technique. Sample crystals prepared for $x$-ray topography are $1.5-2.5 \mathrm{~cm}$ in diameter and thicker than $0.4 \mathrm{~mm}$; the product of the ordinary linear absorption coefficient and thickness ranges from 17 to 45 for $\mathrm{Cu} K \boldsymbol{\alpha}$ radiation. Topographs taken with an asymmetriccrystal-topographic (ACT) camera have revealed extremely straight line images and rectangular arrangements of short linesegment images, along with the images of crystal imperfections. The line images change their arrangement upon application of magnetic fields. These images are attributed to magnetic domains in the interior of crystals. The formation of domain walls near the crystal surface is also observed and distinguished clearly from magnetic domains in the bulk with the use of the ACT camera.

16998. Leong-Hong, B., Marron, B., Data element dictionary/directory systems-A tool for data management, Proc. Sixteenth Annual Tech. Symp. Systems and Software. Operational Reliability and Performance Assurance, Gaithersburg, MD, June 2, 1977, P. A. Willis, Ed., pp. 17-20 (Association for Computing Machinery, New York, NY, 1977).

Key words: computer software; data base management system; data element dictionary/directory; data management; software tool.

A Data Element Dictionary/Directory (DED/D) is a software tool that provides a central repository of information about data resources. It can aid in achieving system operational reliability and performance assurance by reducing data redundancy, controlling access, and maintaining data integrity. This paper describes key features of DED/D's, and notes their advantages and disadvantages. Current usage patterns and the availability of systems are presented.

16999. Humphreys, J. C., Chappell, S. E., McLaughlin, W. L., Jarrett, R. D., Measurements of dose distributions in various materials irradiated by $10-\mathrm{MeV}$ electrons, (Proc. Int. Radiation Processing Conf., Puerto Rico, May 10-13, 1976), Radiat. Phys. Chem. 9, 749-761 (1977).

Key words: aluminum; beef muscle; carbon; depth-dose distributions; lateral-dose distributions; polystyrene; radiation dosimeters; radiation processing; radiochromic-dye films; $10-\mathrm{MeV}$ electrons.

Calibrated radiochromic dye films were used to measure depth-dose profiles and lateral absorbed dose distributions in several irradiated media. Measurements were made in carbon, aluminum, polystyrene, and beef muscle irradiated by incident electrons of about $10 \mathrm{MeV}$. The dye-film dosimeters were placed within the media in several geometrical configurations. 
In one arrangement, the dosimeters were used to integrate the dose distribution within the volume of irradiated beef packages. These measurements show a significant variation in dose near the lateral edges of the medium. The experimental depth-dose distributions are compared with Monte Carlo calculations and with reported experimental measurements. These data are of interest in radiation effects studies, radiation processing, and diagnostic and therapeutic radiology.

17000. McLaughlin, W. L., Radiation measurements and quality control, (Proc. Int. Radiation Processing Conf., Puerto Rico, May 10-13, 1976), Radiat. Phys. Chem. 9, 147-181 (1977).

Key words: dose distributions; dosimetry; electron beams; gamma radiation; plastic films; quality control; radiation processing; radiochromic dyes; sterilization.

Accurate measurements are essential to research leading to a successful radiation process and to the commissioning of the process and the facility. On the other hand, once the process is in production, the importance to quality control of measuring radiation quantities (i.e., absorbed dose, dose rate, dose distribution) rather than various other parameters of the process (i.e., conveyor speed, dwell time, radiation field characteristics, product dimensions) is not clearly established. When the safety of the product is determined by the magnitude of the administered dose, as in radiation steriilization, waste control, or food preservation, accuracy and precision of the measurement of the effective dose are vital. Since physical dose measurements are usually simpler, more reliable and reproducible than biological testing of the product, there is a trend toward using standardized dosimetry for quality control of some processes. In many industrial products, however, such as vulcanized rubber, textiles, plastics, coatings, films, wire and cable, the effective dose can be controlled satisfactorily by controlling process variables or by product testing itself. In the measurement of radiation dose and dose profiles by dosimetry, it is necessary to have suitable dose meter calibrations, to account for sources of error and imprecision, and to use correct statistical procedures in specifying dwell times or conveyor speeds and source and product parameters to achieve minimum and maximum doses within specifications.

17001. Farr, M. K., Trevino, S. F., Mode Gruneisen parameters of $\mathrm{KBr}$ determined by inelastic neutron scattering, Proc. Conf. on Neutron Scattering, Gatlinburg, TN, June 6-10, 1976, pp. 237-242 (Available from the National Technical Information Service, Springfield, VA, Sept. 1, 1976).

Key words: anharmonicity; dispersion curves; high pressure; $\mathrm{KBr}$; mode Gruneisen parameters; neutron scattering.

The room temperature acoustic phonon dispersion relations of $\mathrm{KBr}$ at 1 bar and $6.4 \mathrm{kbar}$ have been measured using inelastic neutron scattering techniques. The mode Gruneisen parameters, $\gamma(\vec{q}, j)$, for the measured modes have been calculated and are compared with several calculations based on various lattice dynamics models. The breathing shell model (BSM) and anharmonic deformation dipole model (ADD) calculations agree well with our acoustic mode measurements.

17002. Stenbakken, G., Isler, M., Mechanically actuated switches for burglar alarm systems, NILECJ-STD-0302.00, 18 pages (U.S. Department of Justice, Law Enforcement Assistance Administration, National Institute of Law Enforcement and Criminal Justice, Washington, DC, May 1974).

Key words: burglar alarm sensor; burglar alarm system; door switch; mechanically actuated switch; perimeter sensor; switch.

This standard establishes performance criteria for mechanically-actuated electrical switches intended for use in protective intrusion alarm circuits to monitor the position of doors, windows, etc. These devices cause the initiation of an alarm signal to a police panel, central station, or local audible alarm device. Included are requirements and test methods for performance, electrical properties and materials. The performance characteristics addressed are those that affect the false alarm susceptibility of the device. This standard does not provide performance criteria for the ability of these devices to resist attempts to defeat them through physical or surreptitious attack.

17003. Chesser, N. J., Prask, H. J., Quasi-elastic neutron scattering study of single crystal ammonium perchlorate, Proc. Conf. on Neutron Scattering, Gatlinburg, TN, June 6-10, 1976, pp. 295-302 (Available from the National Technical Information Service, Springfield, VA, Sept. 1, 1976).

Key words: activation energies; molecular orientations; $\mathrm{NH}_{4} \mathrm{ClO}_{4}$; quasi-elastic neutron scattering; residence times; single crystal.

The theoretical model for instantaneous jump reorientations about $C_{3}$ axes for $X Y_{4}$ groups has been extended to include the possibility of three distinct residence times among the four $Y$ sites. This is analogous to what is expected for orthorhombic $\mathrm{NH}_{4} \mathrm{ClO}_{4}$ in that two of the four $\mathrm{NH}_{4}$ proton sites are equivalent by symmetry. In terms of this model we have analyzed quasi-elastic neutron scattering data from single crystal $\mathrm{NH}_{4} \mathrm{ClO}_{4}$ in the temperature range 60-120K. Data were obtained using a three-axis spectrometer at relatively high resolution ( $F W H M=.084-.113 \mathrm{meV}$ ), and fit using a nonlinear least squares routine to obtain values for the relative elastic to quasi-elastic intensities as well as for quasi-elastic widths. Our results are in general agreement with earlier measurements on polycrystalline samples. However, analysis of measured line shapes at optimal points in reciprocal space suggests that the three distinct residence times expected are observed for the temperatures considered.

17004. Rush, J. J., Rowe, J. M., Glinka, C. J., Vagelatos, N., Flotow, H. E., Coherent neutron scattering study of the vibrations of interstitial deuterium in $a-V_{0.7}$, Proc. Conf. on Neutron Scattering, Gatlinburg, TN, June 6-10, 1976, pp. 543-549 (Available from the National Technical Information Service, Springfield, VA, Sept. 1, 1976).

Key words: band mode; elastic constants; interatomic forces; interstitial; lattice dynamics; metal hydrides.

The lattice dynamics of a single crystal of $\alpha(b c c) V_{0.7}$ has been investigated by coherent inelastic neutron scattering measurements at $295^{\circ} \mathrm{K}$. Since the scattering cross section of vanadium is almost entirely incoherent, this study offers a unique opportunity to directly measure the "band" modes associated with vibrational displacements of the light atom interstitials as a function of $\vec{q}$ and $\omega$. Transverse and longitudinal phonon groups were observed in the three symmetry directions at energies up to $27 \mathrm{meV}$. These are generally at higher energies than comparable modes measured in vanadium by $\mathrm{x}$-ray scattering. The vibrational "density of states" for $\mathrm{V}$ and $\mathrm{VD}_{\mathbf{0 . 7}}$ are also shown to be grossly different. Careful measurement of the "band mode" intensities for several different phonon branches as a function of $\vec{q}$ and $\omega$ indicate that the deuterium motions are strongly coupled to the metal lattice.

17005. Loevinger, R., Absorbed dose calibration system of the National Bureau of Standards, (Proc. Fourth int. Conf. on Medical Physics, Ottawa, Canada, July 25-30, 1976), Phys. Canada 32, Paper 10.1, 2 (July 1976).

Key words: absorbed dose; calibration; calorimeter; cobalt60 ; radiation standard. 
Ionization-chamber calibrations traceable to exposure standards have been provided for many years by the National Bureau of Standards (NBS). These calibrations have been limited to photon beams with energies up to that of cobalt-60. Since January 1976 NBS has offered calibration in a cobalt- 60 beam in terms of absorbed dose to water. These calibrations are traceable to two graphite calorimeters, which are the NBS standards of absorbed dose. The calibrations are performed in water at one meter from the source, at the center of a $10 \times$ $10 \mathrm{~cm}$ field, at a depth of $5 \mathrm{~cm}$. Calculation of absorbed dose for high-energy photon and electron beams can be carried out using conversion factors $\hat{C}_{\lambda}$ which are related in a simple manner to the usual conversion factors $\hat{C}_{\lambda}$ and $\mathrm{C}_{E}$. Comparison of the calibration factor in terms of absorbed dose with that in terms of exposure yields an estimate of the combined attenuation-displacement factor frequently represented by $A_{c}$ or $A_{e q}$, and conventionally given the value 0.985 for cobalt $-60 \gamma$ radiation.

17006. Parken, W. H., Jr., Beausoliel, R. W., Kelly, G. E., Factors affecting the performance of a residential air-to-air heat pump, (Proc. Symp. on Seasonal Operating Performance of Central Forced Air Heating and Cooling Systems, ASHRAE Annual Meeting, Chicago, IL, Feb. 13-17, 1977), ASHRAE Trans. 83, Pt. 1, 839-849 (1977).

Key words: air conditioning; comfort; heat pump; load-calculation; rating; residential; space heating; testing.

An experimental investigation was conducted to determine the performance of a 3-ton (1.055 E+04W) air-to-air heat pump. Coefficients of performance of the heat pump were determined in the laboratory under steady and cyclic conditions in both heating and cooling modes of operation for a range of simulated outdoor conditions. The results indicate a significant reduction in performance for both heating and cooling modes under cyclic operation. Full-load heating performance results were found to be slightly higher than the manufacturer's published ratings for outdoor temperatures above $42{ }^{\circ} \mathrm{F}$ ( 5.5 $\left.{ }^{\circ} \mathrm{C}\right)$. The results show a lower heating capacity and coefficient of performance than the manufacturer's published ratings for outdoor temperatures ranging from $42^{\circ} \mathrm{F}\left(5.5^{\circ} \mathrm{C}\right)$ to $17^{\circ} \mathrm{F}$ $\left(-8.3^{\circ} \mathrm{C}\right)$, tending towards agreement at the lower temperatures. This discrepancy in results for outdoor temperatures below $42{ }^{\circ} \mathrm{F}\left(5.5^{\circ} \mathrm{C}\right)$ is due to the effects of frosting and defrosting of the outdoor coil.

17007. Torchia, D. A., VanderHart, D. L., ${ }^{19} \mathrm{C}$ magnetic resonance evidence for anisotropic molecular motion in collagen fibrils, J. Mol. Biol. 104, 315-321 (1976).

Key words: collagen fibers; molecular motion; nmr; Overhauser effect; relaxation time; ${ }^{13} \mathrm{C}$.

Relaxation times and integrated intensities have been obtained from dipolar decoupled ${ }^{13} \mathrm{C}$ magnetic resonance spectra of reconstituted fibrils of chick calvaria collagen enriched at the glycine $C^{a}$ and $C^{\prime}$ positions. The data obtained are consistent with a model in which collagen molecules reorient about the long axis of the helix with a rotational diffusion constant $\left(R_{1}\right)$ of $\sim 10^{7} \mathrm{~s}^{-1}$, a value similar to that expected for the helix in solution. Data obtained from natural abundance ${ }^{13} \mathrm{C}$ spectra of native (crosslinked) calf achilles tendon and rat tail tendon provide evidence of rapid anisotropic reorientation for at least 75 percent of the carbons in these tissues. Hence, our preliminary data indicate that, in these materials, the intermolecular interactions in the fibrilar collagen lattice can accommodate rapid reorientation at a majority of carbon sites.

17008. Jewett, K. L., Brinckman, F. E., Bellama, J. M., Chemical factors influencing metal alkylation in water, ACS Symp. Series 18, Marine Chemistry in the Coastal Environment, Paper 17, 304-318 (1975).
Key words: alkylation; aqueous solution; coordination; mercury; metal complexes; organometals; photolysis; reaction rates; thallium; tin; transmethylation; water.

Understanding the role of metals in the environment requires examination of those factors involved in the dynamics of metal transformations. One such influence, ligand interactions, is involved in abiotic transalkylation between heavy metal species in aqueous solution. For example, in aqueous solution $\mathrm{Hg}\left(\mathrm{ClO}_{4}\right)_{2}$ will not react with $\left(\mathrm{CH}_{3}\right)_{3} \mathrm{SnClO}_{4}$. However, on substituting $\mathrm{Cl}^{-}$for $\mathrm{ClO}_{4}{ }^{-}$, the reaction proceeds to form $\left(\mathrm{CH}_{3}\right)_{2}$ $\mathrm{Sn}^{-2+}$ and $\mathrm{CH}_{3} \mathrm{Hg}^{+}$. Here the bimolecular rate $\mathrm{k}_{2}$ is directly proportional to $n\left[\mathrm{Cl}^{-}\right] /\left[\mathrm{Hg}^{2+}\right]$. Maximum $\mathrm{k}_{2}$ is observed when $\mathrm{n}=$ 4 , suggesting that $k_{2}$ is dependent on specific chloromercury species $\left[\mathrm{HgCl}_{n}\right]^{2-n}$. These results are consistent with the low activation energy $(14.2 \mathrm{kcal} / \mathrm{mol})$ previously determined for this transmethylation, i.e., reacting ions bear low or attractive charges. Comparison of relative concentrations of chloromercury (II) species, calculated for $\mathrm{pH}$ and $\mathrm{pCl}$ ranges observed both in the laboratory and the estuary, indicate that methylation most likely occurs on the $\mathrm{HgCl}_{3}{ }^{-}$ion.

Another factor influencing metal transformations is photoalkylation. If an aqueous solution of mercury acetate is irradiated at $253.7 \mathrm{~nm}, \mathrm{CH}_{3} \mathrm{Hg}^{+}$and $\left(\mathrm{CH}_{3}\right)_{2} \mathrm{Hg}$ along with gaseous products $\mathrm{CO}_{2}, \mathrm{C}_{2} \mathrm{H}_{8}$ and $\mathrm{Hg}$ are formed. Relative formation rates are determined for the methylated mercury species. The photolysis of $\mathrm{CH}_{3} \mathrm{HgAc}$ ( $\mathrm{Ac}=$ acetate), TlAc and unsuccessful attempts to photolyze $\mathrm{NaAc}$ are discussed and implications for environmental chemistry are considered.

17009. Coriell, S. R., Hardy, S. C., Cordes, M. R., Stability of liquid zones, J. Colloid Interface Sci. 60, No. 1, 126-136 (June 1, 1977).

Key words: floating zone; gravity; liquid zone; shape; stability; surface tension.

The criterion for the stability of a liquid zone of volume $V$ and length $L$ between two parallel circular coaxial plates of radius $R$ and $R_{u}$ is formulated via the calculus of variations. The liquid in the zone is static or uniformly rotating with angular velocity $\Omega$ and is subject to a gravitational acceleration $g$ along the axis of the plates. For $\Omega=0, V=\pi R^{2} L, R=R_{u}$, numerical computations give the maximum stable value of $L / R$ as a function of the Bond number $\epsilon \equiv \rho g R^{2} / \gamma$, where $\rho$ is the density difference between the liquid and the surrounding fluid and $\boldsymbol{\gamma}$ is the liquid-fluid surface tension. Experimental measurements of the stability of water zones are in good agreement with the numerical results. Experimental and theoretical results for horizontal liquid zones (gravitational field perpendicular to the axis of the plates) show that for $\epsilon<0.5$ horizontal zones are more stable than vertical zones.

17010. Brown, P., Clifton, J. R., Energy conservation through the use of waste materials in cement and concrete, Proc. Seminar on Energy and Resource Conservation in the Cement and Concrete Industry, Ottawa, Ontario, Canada, Nov. 8-9, 1976, V. M. Malhotra, E. E. Berry, and T. A. Wheat, Eds., Paper 3.2, pp. 3.2.1-3.2.33 (Canada Centre for Mineral and Energy Technology, Ottawa, Canada, 1977).

Key words: cement manufacture; energy conservation; fly ashes; mineral waste utilization; slags.

The utilization of suitable mineral-waste products can reduce the energy requirement in cement manufacture. Wastes and byproducts, when used as the raw materials in cement production, can reduce the energy requirements associated with raw materials processing and pyro-processing. Intergrinding waste materials with cement clinker or blending them with finished cement also reduces the energy consumption in the manufacture of cement, in this instance by replacing a portion of the 
portland cement clinker. The relative energy savings achieved through waste utilization by these methods are discussed. Factors affecting the selection of waste materials, such as compositional suitability, availability and cost, are considered along with the effects of market-related factors and consensus standards.

17011. Bennett, L. H., Swartzendruber, L. J., Reno, R. C., Nuclear hyperfine effects-overview, Proc. Workshop on Nondestructive Evaluation of Residual Stress, San Antonio, TX, Aug. 13-14, 1975, pp. 247-261 (Nondestructive Testing Information Analysis Center, Southwest Research Institute, San Antonio, TX, Feb. 1976).

Key words: Mössbauer effect; nuclear hyperfine techniques; nuclear magnetic resonance; perturbed angular correlation; residual stress.

An overview of nuclear hyperfine techniques (nuclear magnetic resonance, Mössbauer effect, and perturbed angular correlation) was presented at a recent U.S. Air Force Workshop held in San Antonio, Texas on Nondestructive Evaluation (NDE) of Residual Stress in Materials.

17012. Raveché, H. J., Stuart, C. A., Towards a molecular theory of freezing. II. Study of bifurcation as a function of density, J. Chem. Phys. 65, 2305-2312 (Sept. 15, 1976).

Key words: bifurcation; close-packed crystals; crystalline solutions; hard spheres; metastable states; molecular probability density.

We study, as a function of density, crystalline solutions for the single particle probability density which bifurcate from the fluid solution of a hard sphere system. The BBGKY equation is used to describe the fluid phase, with its closure taken from computer simulations. As the density increases from zero, crystalline solutions bifurcate from the fluid with a periodicity determined by the density. Bifurcation is found to be characteristic of metastable states, and in general it does not occur at the equilibrium coexistence of two phases. When compared to the known hard disk and hard sphere isotherms, the bifurcation points are seen to be remarkably consistent with the density at which the metastable extension of the crystalline branch meets the equilibrium fluid branch. Metastable crystalline states are also predicted in one dimension. The controversial Kirkwood instability criterion is interpreted in terms of our theory. We show that our analysis applies to a large class of potential energy functions. The possibility that the bifurcation near the jamming densities observed in the amorphous packing of incompressible spheres and disks is also discussed.

17013. Rosasco, G. J., Etz, E. S., The Raman microprobe: A new analytical tool, Res./Develop. 28, No. 6, 20-35 (June 1977).

Key words: airborne particles; microanalysis; micro-chemistry; microprobe; particulate matter; Raman spectroscopy.

A new Raman microprobe has been developed. This instrument enables routine measurement of the Raman spectra of individual, micrometer-sized particles. The essentials of the design of the instrument are briefly highlighted. Sample preparation and measurement techniques are outlined. The performance and practical utility of this new instrument are illustrated by results obtained on representative samples relevant to the characterization of airborne particulates. Preliminary results obtained in the study of urban dusts, microscopic fluid inclusions in minerals, and microparticles from cements are also highlighted.

17014. Anderson, W. E., Davis, R. S., Mopsik, F. I., Kryder, S. J., Khoury, F., Colson, J. P., Bolz, L. H., Measurements on insulating materials at cryogenic temperatures, Annual Report, Energy Research and Development Administration Energy Conservation Report CONS/2062-1, Part 1 and Part II, 135 pages (Available from the National Technical Information Service, Springfield, VA, Sept. 1976).

Key words: bridge measurements; cryogenic; dielectric loss; dissipation factor; epoxy insulation; high voltage; polymer tape insulation; superconducting cable; underground transmission.

This report details progress made to date on developing instrumentation and measurement methodology for studying highvoltage dielectric losses at cryogenic temperatures. The work described has been done in support of ERDA-funded ac superconducting transmission line projects at Brookhaven National Laboratory (BNL) and the Linde Division of the Union Carbide Corporation (UCC-Linde). Dissipation factor measurements have been made at a temperature of $4.2 \mathrm{~K}$ and at stresses up to $40 \mathrm{kV} / \mathrm{mm}$. Care has been taken to insure that errors in dissipation factor measurements are less than $\pm 1 \times$

$10^{-6}$. Sample dielectrics have included polymer tapes of interest to BNL and epoxy spacer material of interest to UCC-Linde. When dissipation factor measurements are made at high voltage, losses at sample interfaces become important. Flexible superconducting cables are designed to have many layers of coaxially wound plastic tape serving as the insulation. The spaces between tape layers will be impregnated with helium at pressures up to $1.5 \mathrm{MPa}$. Plans to investigate high-voltage dielectric losses under these conditions are discussed including a technique for measuring partial discharges using pulse-height analysis.

17015. Yonemura, G. T., Considerations and standards for visual inspection techniques, (Proc. Symp. on Nondestructive Testing Standards, Gaithersburg, MD, May 19-21, 1976), Am. Soc. Test. Mater. Spec. Tech. Publ. 624, Nondestructive Testing Standards-A Review, H. Berger, Ed., pp. 220-230 (June 1977).

Key words: modulation transfer function; nondestructive testing; vision; visual acuity; visual capacities.

When we look at the capacity of the human visual system we see that man can adjust to a wide variety of operating conditions. But, unless we have detailed information of the conditions for which these processes are to be standardized and quantitative descriptions of the tasks to be performed, the advantages to be obtained by visual science applications cannot be utilized optimally. The modulation transfer function would be an image evaluation technique applicable to nondestructive testing (NDT). Standardized tests to assess day-to-day performance as well as initial capacities should be developed. These tests should be derived from visual capacities correlated with the tasks to be performed.

17016. Berger, H., The National Bureau of Standards program in nondestructive evaluation, (Proc. Symp. on Nondestructive Testing Standards, Gaithersburg, MD, May 19-21, 1976), Am. Soc. Test. Mater. Spec. Tech. Publ. 624, Nondestructive Testing Standards-A Review, H. Berger, Ed., pp. 317-327 (June 1977).

Key words: acoustic emission; calibrations; electrical-eddy current measurements; microwaves; nondestructive evaluation; standard reference materials; standards; thermal testing; ultrasonics; visual testing; wear debris analysis.

The rationale and present technical content for the National Bureau of Standards (NBS) program in nondestructive evaluation (NDE) is presented. Needs for improved NDE measurement reliability and accuracy, needs that led to the establish- 
ment of this new program, are discussed. The present technical program is described. It includes work related to acoustic-ultrasonic, radiography, visual, electrical eddy current, microwave, penetrant and thermal testing, and wear debris analysis. The program content is summarized in two tables. Outputs from this program are indicated; these include standards and methods of measurement, calibration services, and standard reference materials.

17017. Eisenhower, E. H., Calibration of radiation sources for radiography, (Proc. Symp. on Nondestructive Testing Standards, Gaithersburg, MD, May 19-21, 1976), Am. Soc. Test. Mater. Spec. Tech. Publ. 624, Nondestructive Testing Standards-A Review, H. Berger, Ed., pp. 82-88 (June 1977).

Key words: calibration; gamma radiation; industrial radiography; national standards; radiation characteristics; radiation source; source calibration; test methods; $x$ rays.

A survey was conducted to find and evaluate published national standards for calibration of radiation sources used in industrial radiography. No standards were found on this specific subject, although several standards for medical radiography were discovered and summarized. The latter are inadequate for industrial radiography, but serve as general guidance on the subject. The need for an industrial standard was discussed, and a specific mechanism for developing such a standard was suggested if the need is considered to be sufficient.

17018. Huebner, R. H., Celotta, R. J., Mielczarek, S. R., Electron energy-Ioss analysis of carbon tetrafluoride and carbon tetrachloride (Extended Abstract), Argonne National Laboratory Report No. ANL-76-88, Part I. Radiological and Environmental Research Division Annual Report, pp. 1-3 (Argonne, IL, June 1975-Sept. 1976).

Key words: carbon tetrachloride; carbon tetrafluoride; electron impact; electron spectroscopy; oscillator strengths.

Oscillator strength distributions for $\mathrm{CF}_{4}$ and $\mathrm{CCl}_{4}$ were derived from the electron energy-loss spectra of $100 \mathrm{eV}$ incident electrons scattered at $0^{\circ}$.

17019. Huebner, R. H., O'Connor, M. E., Celotta, R. J., Mielczarek, S. R., Apparent oscillator strengths for water vapor (Extended Abstract), Argonne National Laboratory Report No. ANL-76-88, Part I. Radiological and Environmental Research Division Annual Report, pp. 4-9 (Argonne, IL, June 1975Sept. 1976).

Key words: electron impact; electron spectroscopy; oscillator strengths; water vapor.

Electron energy loss data are presented for 100-220 eV incident energies and oscillator strengths are obtained from the data.

17020. Roth, P. F., Simulation of computers: A tutorial introduction, Proc. Symp. on Simulation of Computer Systems, Boulder, CO, Aug. 12-14, 1975, H. J. Highland, Ed., pp. 35 (Association for Computing Machinery, New York, NY, 1975).

Key words: benchmark; computer performance; model simulation, computer.

This paper discusses the highlights of a tutorial on the simulation of computer systems. It deals with three major topics: the history and techniques of computer system models and simulations; the utility of applications of the technique; and some problems experienced during the maturation of the subject areas. Simulation, the process of using models to acquire data on computer systems is discussed in the context of benchmarking, a technique of using an actual system, as opposed to a model. The phases of a computer system life cycle are discussed, with relation to the applicability of simulation in each phase. Finally, there is a discussion of problems arising from users misconstruing the accuracies of simulation-derived data.

17021. Penn, D. R., Theory of electron energy-loss spectrum in core-level x-ray photoemission from solids, Phys. Rev. Lett. 38, No. 24, 1429-1432 (June 13, 1977).

Key words: energy loss; ESCA; solids; surfaces.

I present a theory of the electron energy-loss spectra observed in $x$-ray photoemission from the core levels of solids and report on calculations for the $2 s$ and $2 p$ core levels of $\mathrm{Al}, \mathrm{Mg}$, and $\mathrm{Na}$. The calculation takes intrinsic as well as extrinsic plasmons into account, and in all cases the agreement between theory and experiment is very good.

17022. Campagna, M., Pierce, D. T., Meier, F., Sattler, K., Siegmann, H. C., Emission of polarized electrons from solids, Paper in Advances in Electronics and Electron Physics 41, 113-165 (Academic Press Inc., New York, NY, 1976).

Key words: spin-polarized field emission; spin-polarized photoemission; surface magnetism.

A review is presented of the emission of spin-polarized electrons from solids with emphasis on ultraviolet photoemission. The experimental techniques for spin-polarized photoemission and field emission are described in detail including the detection of polarization by Mott scattering. A survey of results is given for $4 \mathrm{f}$ semiconductors and insulators such as the Europium chalcogenides, $3 \mathrm{~d}$ semiconductors and semimetals like magnetite and other simple ferrites and the catalyst $\mathrm{La}_{1-x} \mathrm{~Pb}_{x} \mathrm{MnO}_{3}$, 3d ferromagnets, and optically magnetized materials like GaAs. Preliminary spin-polarized field emission results from $\mathrm{Ni}$ are also presented.

17023. Hall, A. H., Simpson, J. A., Whetstone, J. R., Investigation of densities and thermal expansion coefficients applicable to petroleum measurement, Proc. 9th World Petroleum Congress, Tokyo, Japan, May Il-16, 1975, pp. 291-302 (American Petroleum Institute, Washington, DC, 1975).

Key words: petroleum measurement; silicon crystal density standards; volume reduction factors.

Measurement of bulk petroleum requires knowledge of the density and thermal expansion coefficient in order that volume at standard temperature can be calculated. The United States Bureau of Standards and the American Petroleum Institute are cooperating in a project to investigate these physical properties of current sources of crude petroleum and finished products. The measurements obtained at the Bureau will have an accuracy of better than 10 parts per miflion. and will tie to the "Système International" units for mass, length and temperature. Results are to be compared with the data base of the ASTMIP-API Petroleum Measurement Tables.

17024. Steiner, B. W., A survey of sources used for the accurate measurement of visible, near-infrared, and near uitraviolet radiation, Proc. Int. Commission on lllumination, 18th Session, London, England, Sept. 13, 1975, P-75-07, pp. 139-145 (Bureau Central de la Cie, Paris, Cedex 16, France, 1976).

Key words: photometry; radiometry; sources; standard.

A survey of photon sources used for accurate measurement throughout the world includes data on over 100 sources. Principal characteristics of the source emission, its sensitivity to environment, and physical characteristics are covered. Incandescent sources stable to better than 0.1 percent have been identified. The best discharge sources are about three times less 
stable. Complete characterization of the most stable sources remains to be performed. Although development of entirely new sources appears unnecessary, the incorporation of bases that would permit precise alignment would improve many measurements. The most suitable sources for one type of measurement may prove more widely useful. A few lasers stable to I percent are identified.

17025. Kimbleton, S. R., A fast approach to network data assignment, Proc. Second Workshop on Distributed Data Management and Computer Networks, University of California, Berkeley, CA, May 25-27, 1977, LBL 6416, pp. 245-256 (Lawrence Berkeley Lab., University of California, Berkeley, CA, 1977).

Key words: computer modeling systems; data; networks.

The increasingly volatile network data environments promised by the emergence of Network Operating Systems require computationally efficient approaches to network data assignment for effective data access. This paper introduces the class of Adaptive Cost Minimization policies having the properties of: computational simplicity provided by a table lookup based assignment approach; attractiveness to management through utilization of a process execution cost based formulation; and dynamic adaptiveness to changing access patterns. Exact forms of these policies are developed for environments in which the collection of accessing processes, but not necessarily the accessed data, are constrained to be resident on a single system. Asymptotically accurate approximate policies are developed for the case of multiple accessing processes located on multiple systems.

17026. Morrison, M. A., Lane, N. F., Collins, L. A., Low-energy electron-molecule scattering: Application of coupled-channel theory to $e-\mathrm{CO}_{2}$ collisions, Phys. Rev. A 15, No. 6, 2186 2201 (June 1977).

Key words: coupled-channel equations; $\mathrm{CO}_{2}$; electronmolecule collisions; static-model exchange-polarization potential.

A theoretical coupled-channels investigation of $e-\mathrm{CO}_{2}$ scattering is reported for incident electron energies from 0.07 to 10.0 $\mathrm{eV}$. The fixed-nuclei approximation is made with the molecule in the ground $X^{1} \Sigma_{0}{ }^{+}$state and the nuclei frozen at their equilibrium positions. The $e-\mathrm{CO}_{2}$ interaction potential consists of an $a b$ initio electrostatic Hartree potential, an approximate local exchange potential, and a semiempirical polarization potential. The coupled-channel equations are formulated in a body-fixed reference frame using single-center coordinates and are solved by means of an integral-equations algorithm. Convergence of the highly anisotropic interaction potential and of the expansion of the scattering function are discussed. The asymptotic decoupling approximation and the Born approximation are also studied and found to be unsatisfactory methods for computing quantitatively accurate cross sections for lowenergy $e-\mathrm{CO}_{2}$ collisions. Converged coupled-channel total integrated, momentum-transfer and differential cross sections are presented, and the former are compared with experimental results, with special attention given to low scattering energies $(\leq 0.1 \mathrm{eV})$.

17027. Collins, L. A., Norcross, D. W., Low-energy electron collisions with highly polar molecules: LiF, Phys. Rev. Lett. 38, No. 21, 1 208-1211 (May 23, 1977).

Key words: electron-molecule collisions; LiF; momentum transfer cross sections; polar molecules.

Close-coupling calculations of cross sections for rotational transitions have been performed using the full static Hartree potential surface plus a local approximation to the exchange in- teraction. While simpler approximations to the interaction potential are adequate for the total integrated cross section, accurate treatment of short-range interactions is essential for the momentum-transfer cross section. We find a resonance feature with $\Pi$ symmetry at about $2 \mathrm{eV}$ only in the static-exchangemodel calculations.

17028. Wiederhorn, S. M., Erosion behavior of ceramics, Proc. Workshop on Ceramics for Energy Applications, Columbus, OH, Nov. 24-25, 1975, CONF-751194, pp. 83-106 (Battelle Columbus Laboratories, Columbus, $\mathrm{OH}, 1975$ ).

Key words: ceramics; coal gasification; energy; erosion; high temperatures.

This review is concerned with the development of erosion resistant refractories for coal gasification applications. Because of their potential use of coal gasification systems, some current design practices used to solve erosion problems in the petrochemical industry are described. Then, theoretical treatments of erosion are discussed with reference to data obtained on both metals and ceramics. Finally, an overview of current erosion research is given, stressing the need for new equipment to study erosion in hostile environments.

17029. Aizenman, M., Smeyers, P., Weigert, A., Avoided crossing of modes of nonradial stellar oscillations, Astron. Astrophys. 58, $41-46$ (1977).

Key words: avoided crossings; coupled oscillators; nonradial oscillations.

The phenomenon of the interaction of two distinct types of oscillators is shown to occur in stars evolving away from the main sequence. This manifests itself in the occurrence of rapid shifts of frequency (bumping, avoided crossings) of the linear, adiabatic, nonradial modes of oscillation of the star. The physical origin of this behavior is discussed. The behavior of the $f$-mode near $l=1$ is shown to exhibit a sequence of such avoided crossings.

17030. Kahn, A. H., Theory of microwave eddy currents and paramagnetic resonance in materials of intermediate conductivity, Phys. Rev. B 16, No. 1, 64-72 (July 1, 1977).

Key words: eddy currents; organic conductors; paramagnetic resonance; TTF-TCNQ.

An analysis has been made of the eddy currents in a conducting solid in the shape of a long rectangular prism, with the applied rf magnetic field perpendicular to the length. The results are expressed in terms of a complex susceptibility. This, in turn, is related to the changes in resonant frequency and quality factor of a microwave cavity when the sample is introduced at the site of a magnetic field antinode. The calculations are performed for conductivities in the range of values for which the skin depth is comparable to the transverse dimensions of the sample. Solution is by the Rayleigh-Ritz method applied to a variational expression for the dipole moment of the sample. Several representative rectangular cross sections are treated. Also, the results for the cylinder in a transverse field are presented in closed form. In addition to the eddy-current loss and resonant-frequency shift, results are given for the modulation of the loss by paramagnetic resonance. The integrated resonance absorption intensity and the line shape anisotropy for Lorentzian lines are presented. The results are applied to the case of tetrathiafulvalinium-tetracyanoquinodimethane (TTF-TCNQ).

17031. Thomson, R. M., Exploring energy choices, Encyclopedia of Energy, D. N. Lapedes, Ed., pp. 25-33 (McGraw-Hill, Inc., New York, NY, 1976). 
Key words: energy choices; energy problem; energy resources; fossil fuels; nuclear power; solar energy.

This is a summary of analyses and projections by $\mathbf{M}$. K. Hubbert and others of the major energy resources in the United States and worldwide. Also current thinking on the relative merits and shortcomings of alternative energy sources is reviewed.

\section{Unassigned.}

17033. Misra, D. N., Bowen, R. L., Adhesive bonding of various materials to hard tooth tissues. 11. Chemisorption of an adduct (of the diglycydyl ether of bisphenol A with $N$-phenylglycine) on hydroxylapatite, J. Phys. Chem. 81, No. 9, 842846 (1977).

Key words: adhesive bonding to bone mineral; chemisorption of a dental varnish; configuration on surface; kinetics of adsorption from solution; rate law and areal regression of adsorbate; surface area and fixation of chelating rings.

Adsorption of a prototype synthetic dental varnish, a shortchain molecule with a chelating group on each end, was studied on synthetic hydroxylapatite from methylene chloride solution. The adsorption of the adduct is irreversible and the adsorbed amount remains constant from different concentrations of the solution. A rate law, based on an increasingly difficult gradual folding of the adsorbed molecules with an eventual fixation of the two chelating rings side by side, appears to explain all the kinetic features of the adsorption process. The tensile strength of polymer filled with hydroxylapatite was not changed by the presence of the adduct on the surface of the filler.

17034. Mathew, M., Schroeder, L. W., Dickens, B., Brown, W. E., The crystal structure of $\alpha-\mathrm{Ca}_{3}\left(\mathrm{PO}_{4}\right)_{2}, A c \ell a$ Crysı. B33, 1325-1333 (1977).

Key words: alpha-tricalcium phosphate; calcium phosphate; cation-anion columns; crystal structure; subcell; vacancies.

$\alpha-\mathrm{Ca}_{3}\left(\mathrm{PO}_{4}\right)_{2}$ crystallizes in the monoclinic space group $P Z_{1} / a$ with $a=12.887$ (2), $b=27.280$ (4), $c=15.219$ (2) $\AA, \beta=$ $126.20(1)^{\circ}$, and $Z=24$. An approximate subcell with $b^{\prime}=b / 3$ exists. The structure was solved by direct methods of phase determination and refined to $R=0.051$ and $R_{x}=0.049$ with 7002 reflections collected from a single crystal by counter methods. The structure consists of columns of cations, and columns of cations and anions with compensating cation vacancies, and is closely related to the structure of $\mathrm{K}_{3} \mathrm{Na}\left(\mathrm{SO}_{4}\right)_{2}$, the mineral glaserite. The calcium ions in $\alpha-\mathrm{Ca}_{3}\left(\mathrm{PO}_{4}\right)_{2}$ exhibit a wide range of coordination numbers and geometries.

17035. Fechter, J. V., Van Cott, H. P., The house that NBS built, J. Consumer Studies \& Home Econom. 1, No. 2, 101 108 (June 1977).

Key words: appliance research; behavioral laboratory; consumer product studies; human behavior research; Human Factors Laboratory; range energy consumption.

In 1974 the National Bureau of Standards established the Center for Consumer Product Technology to conduct product performance, safety and energy research. The Center's Human Factors Section operates a laboratory in a homelike setting for its studies of consumer product use. Video, audio, direct visual observation and computer compatible appliance data monitoring are among the data collection techniques a vailable. A study of the energy consumption used in cooking meals on gas and electric ovens illustrates how the facility is being used.

17036. Glass, R. A., Rubin, A. I., Emergency communications in high-rise buildings, Chapter 22 in Human Response to Tall
Buildings, D. J. Conway, Ed., CDS/34, 293-301 (Dowden, Hutchinson \& Ross, Inc., Stroudsburg, PA, 1977).

Key words: communications; disaster communication; emergency communications; fire communications; high-rise communications; high-rise emergency; information transfer; occupant needs; sensory stimuli.

The safety of occupants of high rise buildings during fire emergencies is often determined by the adequacy of the communications available to them-indicating how to respond. Visual signals (warning lights and directional signs) and auditory alarms and verbal messages are generally employed to serve this function. The actual signals now used in buildings have been developed over the years in a piecemeal fashion with minimal systematic research input. The adequacy of these signals have come into question in recent years, especially as a result of the potential for a major disaster associated with high-rise building fires. The paper traces the problems associated with communications systems presently in use from the standpoint of the occupant.

17037. Odom, J. V., Weights and measures play vital roles in metrication, Metric News 4, No. 3, 5, 11, 29 (May/June 1977).

Key words: education for metric; laws and regulations; metrication; metric system; National Conference on Weights and Measures; weights and measures.

This paper discusses the role weights and measures officials will play during the changeover to the metric system in the United States. Goals and objectives for the weights and measures community are outlined, and specific projects relating to the metric revision of Model Laws and Regulations and metric education for weights and measures officials is discussed.

17038. Schwarz, F. P., Determination of temperature dependence of solubilities of polycyclic aromatic hydrocarbons in aqueous solutions by a fluorescence method, J. Chem. Eng. Data 22, No. 3, 273-277 (July 1977).

Key words: aromatic hydrocarbons; heat of solution; salting-out effect; solubility.

The fluorescence intensities of saturated aqueous polycyclic aromatic hydrocarbon ( $\mathrm{PAH}$ ) solutions equilibrated at temperatures between 281 and $303 \mathrm{~K}$ are proportional to the PAH concentration. The fluorescence measurements are put on an absolute solubility scale by UV absorption measurements at $\mathbf{2 9 8 . 2}$ $\mathrm{K}$. This method was applied to the determination of the solubilities of naphthalene, 1-methylnaphthalene, 1-ethylnaphthalene, phenanthrene, anthracene, pyrene, and benzle]pyrene in water and in $0.5 \mathrm{~mol} \mathrm{~L}^{-1}$ sodium chloride solution. Enthalpies of solution of the PAH were calculated.

17039. Wiederhorn, S. M., Fracture of brittle materials at high temperatures, AFML-TR-76-139, 19 pages (Air Force Materials, Air Force Wright Aeronautical Laboratories, Air Force Systems Command, Wright-Patterson Air Force Base, OH, Aug. 1976).

Key words: acoustic emission; brittle materials; crack growth; cyclic loading; fracture mechanics; high temperature; proof testing; silicon carbide; silicon nitride.

This report summarizes the results of a program to study the high-temperature fracture properties of ceramic materials that are anticipated for use in turbine applications. As a result of this program; new techniques have been developed for the study of fracture at high temperatures; new theories have been developed for the application of fracture mechanics to design; and new experimental data on high temperature fracture have been generated. 
17040. Milton, H. J., Metrication: Take the tide at its flood, Concrete Constr. 22, No. 8, 429-431, 440-442 (Aug. 1977).

Key words: construction industry metrication; metrication bencfits; rationalization; technical issues in metrication.

This paper presents the impending change to metric (SI) measurcment in the construction community as an "opportunity" and a once-only chance for review, technical improvement and cost reduction. It deals with the analysis of precedent in the change to SI; defines some new terms, such as "hard conversion" to preferred sizes and descriptions; discusses metrication for benefit; and focuses on the opportunitics for rationalization associated with the change.

Four principal opportunities are identified; simplification, rationalization, harmonization and standardization, and each one is illustrated by a number of examples.

The paper recommends that metrication should be regarded as a "worthwhile challenge," rather than as a "problem," so that the approach to change is a vigorous and positive one instead of a defensive and negative one.

The benefits from opportunities realized should easily pay for the once only cost of the change.

17041. Newman, M., Sheingorn, M., Continuous solutions of a homogeneous functional equation, Aequationes Math. 13, No. $1 / 2,47-59$ (1975)

Key words: analytic functions with infinitely many branches; functional equations; Hurwitz's theorem.

It is shown that the functional equation

$$
\mathrm{f}(\mathrm{x})+\mathrm{f}(\mathrm{ax})+\mathrm{f}(\mathrm{bx})=0, \mathrm{l}<\mathrm{a}<\mathrm{b},
$$

has a nontrivial solution which is continuous for all real $x$ if and only if $b \neq a^{2}$. Generalizations for the equation

$$
\sum_{k=1}^{n} f\left(a_{k} \cdot x\right)=0,1=a_{1}<a_{2}<\ldots<a_{n},
$$

are also derived

17042. Berger, H., Ed., Nondestructive testing standards-A review, Am. Soc. Test. Mater. Spec. Tech. Publ. 624, 352 pages (American Society for Testing and Materials, Philadelphia, PA, 1977).

Key words: acoustic emission; inspection; leak testing: liquid penetrant; magnetic particle; measurements; nondestructive testing; optical; radiography; standards; ultrasonics; visual.

This 352-page book contains reviews, critiques, and general information on nondestructive testing standards. Background information on the standards preparation process and on the needs of various society and government organizations is followed by discussions of standards for specific nondestructive testing methods. These methods include radiography, ultrasonics, acoustic emission, liquid penetrant, magnetic particle, visual, optical, and leak testing. The final series of papers looks towards the future, for example, at needs for quantitative results and automated systems. Standards and specifications for nondestructive testing have evolved over a long period of time. The papers in this volume begin a long overdue examination of these standards. The problems of multiple standards and the confusion and inefficiency that brings with it are cited many times. Also, problems of reproducibility for many methods are indicated because variables associated with the methods are not under sufficient control. The book brings out these problems and hopefully will provide a stepping-off point for solutions and future improvements in nondestructive testing standards.

17043. Sanders, D. M., Haller, W. K., Effect of water vapor on sodium vaporization from two silica-based glasses, J. Am. Ceram. Soc. 60, No. 3-4, 138-141 (Mar.-Apr. 1977).
Key words: activity; glass; vaporization.

The influence of water vapor pressure on the equilibrium sodium vapor densities over well-stirred silica-based glass melts was investigated. Sodium was assumed to be present in the vapor as $\mathrm{Na}$ and $\mathrm{NaOH}$ molecules, and the activity of $\mathrm{Na}_{2} \mathrm{O}$ in the melt was calculated as a function of water vapor pressure above the melt.

17044. Todd, $T$. R., The infrared spectrum of ${ }^{12} \mathrm{C}^{32} \mathrm{~S}$ and ${ }^{12} \mathrm{C}^{34} \mathrm{~S}$, J. Mol. Spectrosc. 66, 162-167 (1977).

Key words: carbon monosulfide; Dunham coefficients; infrared absorption; molecular physics; short-lived molecular species; vibration-rotation spectra.

The 2-0 vibration-rotation bands of ${ }^{12} \mathrm{C}^{32} \mathrm{~S}$ and ${ }^{12} \mathrm{C}^{34} \mathrm{~S}$ near $2530 \mathrm{~cm}^{-1}$ have been measured with a high resolution spectrometer. The spectroscopic constants for these bands are given, as well as an improved set of Dunham coefficients for the $X^{1} \Sigma^{+}$state of ${ }^{12} C^{32} S$.

17045. Hertz, H. S., Coxon, B., Siedle, A. R., Disproportionation and pyrolysis of p-toluenesulfonylhydrazine, J. Organ. Chem. 42, No. 14, 2508-2509 (1977).

Key words: chemical ionization mass spectrometry; di-ptolyldisulfide-1,2-dioxide; mass spectrometry; nuclear magnetic resonance; $p$-toluenesulfonylhydrazine; 1,2-di(ptoluenesulfonyl)hydrazine.

A disproportionation of $p$-toluenesulfonylhydrazine, under acid conditions to give 1,2-di( $p$-toluenesulfonyl)hydrazine was observed. Pyrolysis of $p$-toluenesulfonylhydrazine at $140^{\circ}$ produced ammonium $p$-toluenesulfonate, di-p-tolyldisulfide-1,1dioxide, and $p$-toluenesulfonamide.

17046. Wiederhorn, S. M., Tighe, N. J., Evans, A. G., New design techniques for brittle materials, (Proc. 43d Meeting of the Structures and Materials Panel of AGARD, Neuilly sur Seine, France, Oct. 1976), Paper in AGARD Report No. 651. Mechanical Properties of Ceramics for High Temperature Applications, pp. $41-55$ (Technical Editing and Reproduction, Ltd., London, England, 1976).

Key words: ceramics; high temperature; proof testing; reliability.

Methods of design for improving the reliability of ceramics in structural applications are described. Based on the science of fracture mechanics, these methods provide a rational basis for estimating the lifetime of structural components that are subjected to applied loads. Data obtained by standard strength or fracture mechanics techniques are used to develop design diagrams from which component performance is evaluated. Three types of diagrams are described, depending on whether the critical flaw size in a component is estimated by nondestructive evaluation, proof testing, or statistical evaluation. The validity of the theory has been tested experimentally, and, on the whole, agreement between theory and experiment is satisfactory. However, additional experimentation is suggested to fully evaluate the limits of the theory.

17047. Forman, R. A., Weinstein, B. A., Piermarini, G., Hydrostatic pressure dependence of the doublet transitions of ruby, (Proc. Colloq. Int. du Centre National de la Recherche Scientifique, Lyon, France, June 28-July 3, 1976), Paper in Spectroscopie des Eléments de Transition et des Eléments Lourds dans les solides, No. 255, 51-57 (Editions du Centre National de la Recherche Scientifique, Paris, France, 1977).

Key words: $\mathrm{Cr}^{3+}$, crystal field spectra; $\mathrm{d}^{3}$ ion; optical spectra; ruby; transition metal ions; ultrahigh pressure. 
We studied the pressure dependence of the doublet transitions ${ }^{2} \mathrm{E},{ }^{2} \mathrm{~T}_{1}$, and ${ }^{2} \mathrm{~T}_{2}$ in ruby to hydrostatic pressures of 100 kbars. All measurements were performed in the diamond-anvil pressure cell utilizing a metal gasket and methanol-ethanol pressure fluid to insure a hydrostatic environment. The $\mathrm{R}$-line transitions have been found to shift toward the red linearly with pressure to pressures of $\mathbf{2 0 0}$ kbars in quasi-hydrostatic environments. By means of "hot" luminescence the $R^{\prime}\left({ }^{2} T_{1} \rightarrow{ }^{4} A_{2}\right)$ lines have also been studied and found to have a different linear dependence. The difference in the $R$ and $R^{\prime}$ shifts has allowed separation of the $R$ ' lines from the "hot" vibronics of the $R$ lines; an interesting resonance phenomenon is observed in this system and will be discussed. The $B\left({ }^{2} T_{2} \rightarrow{ }^{4} A_{2}\right)$ lines were studied by means of excitation spectra using a $\mathrm{cw}$ argon-pumped dye laser.

17048. Tilford, C. R:, Analytical procedure for determining lengths from fractional fringes, Appl. Opt. 16, No. 7, 18571860 (July 1977).

Key words: dimensional metrology; exact fringes; fractional fringe; interferometer; length measurement; partial fringe; wavelength measurement.

The development of stabilized multifrequency lasers makes fractional fringes an increasingly attractive technique for length measurement. Determination of an unknown length from the measured fractional fringes is aided by the development of analytical equations for the length and its uncertainty, and criteria are given for selecting the wavelengths.

17049. Mangum, B. W., The gallium melting-point standard: Its role in our temperature measurement system, Clin. Chem. 23, No. 4, $711-718$ (1977).

Key words: gallium; International Practical Temperature Scale of 1968; melting point standard; secondary fixed point; temperature fixed point; thermometry.

The latest internationally-adopted temperature scale, the International Practical Temperature Scale of 1968 (amended edition of 1975), is discussed in some detail and a brief description is given of its evolution. The melting point of high-purity gallium (stated to be at least $99.99999 \%$ pure) as a secondary temperature reference point is evaluated. I believe that this melting-point temperature of gallium should be adopted by the various medical professional societies and voluntary standards groups as the reaction temperature for enzyme reference methods in clinical enzymology. Gallium melting-point cells are available at the National Bureau of Standards as Standard Reference Material No. 1968.

17050. Mighell, A. D., The single crystal vs. the powder method for identification of crystalline materials, Paper in Advances in X-Ray Analysis, H. F. McMurdie, C. S. Barrett, J. B. Newkirk, and C. O. Ruud, Eds., 20, 53-62 (Plenum Publ. Corp., New York, NY, 1977).

Key words: identification; lattice; powder method; reduced cell; single crystal; symmetry.

Single crystal $x$-ray diffraction methods for the study of crystalline materials, although reliable, have been mainly confined to the academic laboratory because of the rather lengthy and complex procedure necessary to determine the unit cell and the space group. The situation has now changed. Several recent developments give single-crystal methods considerable potential for routine industrial use. They include growth of the data base, advances in lattice theory, and automation of the single-crystal $x$-ray diffractometer. To identify an unknown, one can start with a single crystal, mount it on the diffractometer, determine a refined primitve cell, reduce the cell, and check against a file of known reduced cells. The entire procedure can be automated. As a result, the single-crystal $x$-ray diffraction method can now complement the powder method for the routine analysis of crystalline materials.

17051. Hubbell, J. H., Photon mass attenuation and mass energy-absorption coefficients for $\mathrm{H}, \mathrm{C}, \mathrm{N}, \mathrm{O}, \mathrm{Ar}$, and seven mixtures from $0.1 \mathrm{keV}$ to $20 \mathrm{MeV}$, Radiat. Res. 70, 58-81 (1977).

Key words: attenuation coefficient; energy-absorption coefficient; gamma-ray; photon; $x$ ray.

Mass attenuation coefficients $\mu / \rho$ for $H, C, N, O$, and $A r$, developed at the National Bureau of Standards by the X-Ray and Ionizing Radiation Data Center from the latest theoretical and experimental cross-section data, are tabulated for photon energies from $0.1 \mathrm{keV}$ to $20 \mathrm{MeV}$, including the cesium-137 and cobalt-60 energies explicitly. Cross sections are listed, for the above elements, for the principal photon-atom interactions: coherent and incoherent scattering, atomic photoeffect, and positron-electron pair and triplet production; the energy-absorption cross sections for these interactions are also listed. From this cross-section data base, mass energy-absorption coefficients $\mu_{e n} / \rho$, taking into account bremsstrahlung losses and positron annihilation in flight, Compton-scattered and fluorescence photons, and mass-attenuation coefficients $\mu / \rho$, are tabulated for the above elements and for the mixtures: air, water, polystyrene, methyl methacrylate (Lucite, Perspex, Plexiglass, etc.), polyethylene, bakelite, and amber over the range from $0.1 \mathrm{keV}$ to $20 \mathrm{MeV}$. For application to cavity ionization detector metrology the ratio $\mu_{e n} / \rho$ in air to that in carbon and to that in the above six remaining mixtures is tabulated over the same energy range. The air and carbon $\mu_{e n} / \rho$ values and air/carbon ratios are compared with those in ICRU Report 17 and other earlier compilations.

17052. Kuhn, G. F., Model for the interaural time differences in the azimuthal plane, J. Acoust. Soc. Am. 62, No. 1, 157 167 (July 1977).

Key words: ears; head diffraction; hearing; interaural intensity differences; interaural time differences; localization; manikin.

An objective study of the steady-state interaural time difference (ITD) was performed on a manikin comprised of a head and torso. Data were taken for both a bare and clothed torso. The measured ITD's correspond reasonably accurately at the low and the high frequencies to the computed theoretical values for a rigid sphere of an effective radius $a$. The theoretical ratio of the low-frequency $(<500 \mathrm{~Hz})$ ITD to the highfrequency $(>2000 \mathrm{~Hz})$ ITD is $3 / 2$. The measured ITD is a minimum between 1.4 and $1.6 \mathrm{kHz}$ for angles of incidence, $\theta_{\text {inc, }}$, of sound between $15^{\circ}$ and $60^{\circ}$. At both the low and the high frequencies the data can be expressed by universal curves when the ITD is normalized by $\left(a / c_{0}\right) \sin \theta_{\text {inc }}$, where $c_{0}$ is the speed of sound in air and $\theta_{i n c}$ is the angle of incidence. Both the steadystate ITD and the interaural sound-pressure-level difference (ILD) show differences between measurements made with the bare torso and those with a clothed torso. These objectives results support the subjective measurements of past experiments, which showed that in man there was no localization improvement below approximately $500 \mathrm{~Hz}$, poor localization between 1000 and $2000 \mathrm{~Hz}$, and a change in the localization cue around $1400 \mathrm{~Hz}$ from ITD to ILD.

17053. Gornick, F., Passaglia, E., A dynamic model for a population of durable goods, Resource Recovery Conserva. 2, 193 $209(1976 / 1977)$.

Key words: age distributions; demography; durability; durable goods; matrix model; population dynamics; population 
growth rate; production rate; scrappage rate; stable-age population.

A dynamic model for a population of durable goods is presented. In the most general case the rate at which each individual member of the population delivers the service embodied in it is age-specific. If the total demand for services from goods of all ages is specified along with scrappage rates, the model predicts (1) the age distribution of a steady or stable-age distribution and (2) the time dependence of the approach to the steady state.

17054. Khayrallah, G. A., Smith, S. J., The cross section for production of the $3 \mathrm{~s}$ state of atomic hydrogen in dissociative excitation of $\mathrm{H}_{2}$ by electrons, Chem. Phys. Lett. 48, No. 2, 289-293 (June 1, 1977).

Key words: Balmer-alpha; collision; cross section; dissociation; electron; excitation; hydrogen.

A few measurements have been made on the relative contribution to the Balmer- $\alpha$ emission of the $3 \mathrm{~s}$ state of hydrogen atoms resulting from the dissociative excitation of $\mathrm{H}_{2}$ by electrons in the energy range 20 to $500 \mathrm{eV}$. Therefore measurements, however, are mutually inconsistent except between two measurements, one using the equilibrium technique and the other using the short-electron pulse technique. We have used the pulsed-electron-equilibrium method coupled with the timedelayed-observation technique to measure the contribution of the 3 s state of hydrogen atoms. Our experimental results agree with those found previously by means of the short-electronpulse technique as well as with other determinations at 50 and $110 \mathrm{eV}$, this confirming that less than 20 percent of the hydrogen atoms formed in the $n=3$ energy level are formed in the $3 \mathrm{~s}$ state.

17055. Thornton, D. D., The gallium melting-point standard: A determination of the liquid-solid equilibrium temperature of pure gallium on the International Practical Temperature Scale of 1968, Clin. Chem. 23, No. 4, 719-724 (1977).

Key words: fixed points; gallium; gallium melting point; melting; standards; temperature; thermistors; thermometry.

The sharpness and reproducibility of the gallium melting point were studied, and the melting temperature of gallium in terms of IPTS-68 was determined. Small melting-point cells designed for use with thermistors are described. Nine gallium cells including three levels of purity were used in 68 separate determinations of the melting point. The melting point of 99.99999 percent pure gallium in terms of IPTS-68 is found to be $29.771_{4} \pm 0.001_{4}{ }^{\circ} \mathrm{C}$; the melting range is less than 0.0005 ${ }^{\circ} \mathrm{C}$ and is reproducible to $\pm 0.0004{ }^{\circ} \mathrm{C}$.

17056. Haisch, B. M., Linsky, J. L., Weinstein, A., Shine, R. A., Analysis of the chromospheric spectrum of $\mathbf{O}$ i in Arcturus, Astrophys. J. 214, No. 3, $785-797$ (June 15, 1977).

Key words: Arcturus; chromospheres, stellar; line profiles, stellar; radiative transfer; ultraviolet spectra.

The ultraviolet and near-infrared spectra of $O_{i}$ in Arcturus are analyzed by a 15 level, 14 transition model for $O_{1}$ and the Ayres-Linsky model chromosphere. We find that the anomalously bright $O \operatorname{I\lambda } 1302,1305,1306$ resonance lines can be readily explained by a $L \beta$-pumped fluorescence mechanism as originally proposed by Bowen. Observed equivalent widths of the near-infrared triplet and singlet lines are also consistent with the model predictions, but the $\lambda \lambda 1355,1359$ intercombination lines and near-infrared quintet lines may pose a problem.
17057. Lias, S. G., Ausloos, P., Comments on "Entropy change in ion-molecule equilibria," J. Am. Chem. Soc. Commun. to Ed., 99, No. 14, 4831-4833 (July 6, 1977).

Key words: charge transfer; entropy; ion-molecule equilibria.

It is shown that for ion-molecule equilibria in which thermochemical information is derived from equilibrium constants determined at a single temperature, the estimation of $\Delta S$ must include the term $R \ln \left(Z_{r} / Z_{r}\right)$ where $Z_{f}$ and $Z_{r}$ are, respectively, the rate constants for the ion-molecule collisions in the forward and reverse directions. Representative ion-molecule equilibrium constants and forward and reverse rate constants illustrating the point are presented.

17058. Grundl, J., Eisenhauer, C., Fission rate measurements for materials neutron dosimetry in reactor environments, Proc. First ASTM-EURATOM Symp. on Reactor Dosimetry, Petten, The Netherlands, Sept. 22-26, 1975, EUR 5667 elf, Part 1, pp. 425-454 (Commission of the European Communities, Brussels, Belgium, 1977 ).

Key words: breeder reactor; fission; fission detector; materials; neutron dosimetry; reactor physics.

The use of fission detectors in materials neutron dosimetry in reactor environments offers unusual flexibility of application, a unique and useful variety of energy-dependent responses, and convenience of interpretation. In addition, because fission is the essential reaction rate of nuclear energy generation, fission cross sections are among the most accurate in existence. These characteristics of fission rate measurements will be described in the context of establishing neutron flux and fluence in reactor structures, beginning in-core and extending out to sensitive neutron environments at the reactor pressure vessel. An assessment of existing measurement methods and calibration schemes for characterizing neutron fluence spectra focuses on the interpretation of fission detector responses. Present day measurements practice and outlook in U.S. breeder reactor development programs and in the U.S. commercial power reactor industry are reviewed. Radiation effects testing of electronic components with degraded fission neutrons is included. Nearterm and expected accuracy requirements will be underscored insofar as they can be ascertained.

17059. Parker, W. J., Lee, B. T., A small-scale enclosure for characterizing the fire buildup potential of a room, Proc. Meeting to Honor Clay Preston Butler on the Occasion of his 70th Birthday, Experimental Methods in Fire Research, Menlo Park, CA, May 9-10, 1974, pp. 43-72 (Stanford Research Institute, Menlo Park, CA, 1974).

Key words: fire growth; fire tests; flashover; room fires; scale models; thermal radiation.

A 0.76 by $0.76 \mathrm{~m}$ ( 30 by 30 inch) enclosure with a $0.61 \mathrm{~m}$ ( 24 inch) high ceiling was used to model some fires in a $3 \times$ $3 \times 2.4$ meter $(10 \times 10 \times 8$ foot $)$ burnout room. Temperatures, oxygen concentrations, air velocity, and conductive and radiative heat fluxes were measured. The highest average air temperature in the upper part of the room was taken as a measure of the fire buildup potential of the room. Upper air temperatures attained in the model were similar in most cases to those in the full-scale compartment. From energy balance considerations this air temperature was related to the oxygen depletion in the room and was shown to correlate well with the oxygen content of the combustion gas and air exhausting from the model and full-scale room fires.

17060. Rossiter, W. J., Jr., Mathey, R. G., Effect of insulation on the surface temperature of roof membranes, Roofing Spec., pp. 28-39 (May 1976). 
Key words: built-up roofing; insulation; performance; radiative cooling; roofing; solar heating; surface temperature.

The surface temperatures of black, gray and white roofs were calculated for various thicknesses of insulation located between the membrane and roof deck. The calculations were performed using a steady-state heat balance equation to illustrate the increase in roof surface temperatures due to solar radiation.

The calculations indicate that the first increment (about 1 inch) of insulation causes a significant rise in the roof surface temperature due to solar radiation. Increasing the amount of insulation above this first increment to greater thicknesses does not appreciably increase the roof surface temperature.

17061. Rossiter, W. J., Jr., Mathey, R. G., Effect of insulation on the surface temperature of roof membranes, Roofing/Siding/Insulation, pp. 35-38, 136 (Apr. 1976).

Key words: built-up roofing; insulation; performance; radiative cooling; roofing; solar heating; surface temperature.

The surface temperatures of black, gray and white roofs were calculated for various thicknesses of insulation located between the membrane and roof deck. The calculations were performed using a steady-state heat balance equation to illustrate the increase in roof surface temperatures due to solar radiation.

The calculations indicate that the first increment (about 1 inch) of insulation causes a significant rise in the roof surface temperature due to solar radiation. Increasing the amount of insulation above this first increment to greater thicknesses does not appreciably increase the roof surface temperature.

17062. Burch, D., Ed., Technical guidelines for energy conservation, AFCEC-TR-77-12, 403 pages (Air Force Civil Engineering Center, Tyndall Air Force Base, FL, June 1977).

Key words: Air Force facilities; building energy conservation; energy management; evaluation and monitoring; survey of buildings.

This report provides detailed technical material on various energy conservation actions for existing Air Force facilities and utility systems. It is specifically tailored to serve as a working document for Base engineers and technical personnel. The report covers energy conservation for Air Force facilities, including the equipment for providing hot water, space heating and cooling, lighting, and humidification. It also covers central plant systems and underground distribution systems (hot water, steam, and chilled water). It does not cover energy conservation measures for tactical or mission-related equipment such as ground vehicles or fighter aircraft.

17063. Swyt, D. A., Rosberry, F. W., A comparison of some optical microscope measurements of photomask linewidths, Solid Stace Technol., pp. 70-75 (Aug. 1977).

Key words: dimensional standards; filar eyepiece; linewidth measurements; micrometer eyepiece; microscope calibration; optical microscope; photomasks; photomask metrology; optical microscope; shearing eyepiece.

Results of photomask linewidth measurements which depend systematically on the type or linespacing-calibrated optical microscopes used for the measurements have been observed during National Bureau of Standards work on developing calibrated photomask linewidth standards. Depending on the combination of microscope, measuring device, illumination type and object polarity present, repeatably regular differences in the apparent width of the same line, most often in the range from $+0.25 \mu \mathrm{m}$ to $-25 \mu \mathrm{m}$, were seen. Opaque lines and clear spaces from 1 to $10 \mu \mathrm{m}$ in width on chromium-on-glass photomask-like targets were measured. For the most part, a filar eyepiece microscope and an image-shearing eyepiece microscope were used. Some data for an automatic TV/microscope system and a second type of image-shearing microscope were obtained. Results support the contention that proper calibration of measuring instruments for photomask linewidth measurements requires true linewidth standards rather than line-spacing standards.

17064. Kuhn, G. F., Burnett, E. D., Acoustic pressure field alongside a manikin's head with a view towards in situ hearing-aid tests, J. Acoust. Soc. Am. 62, No. 2, $416-423$ (Aug. 1977).

Key words: audiometry; diffraction; head diffraction; hearing aids; instruments for hearing; manikin.

The frequency responses of hearing aids measured in a free field differ from those measured on the head of a person or a manikin due to the scattering of the sound by the head and the torso. In order to compare and interpret the response of hearing aids located on the head at various frequencies it is necessary to know precisely the spatial pressure distribution. The amplitude and phase of the acoustic pressure were measured alongside a manikin's head in increments ranging from 2 to 5 $\mathrm{mm}$ with frontal sound incidence. The acoustic driver was located in front of the manikin at distances of 1.0 and $3.5 \mathrm{~m}$ from the ear-canal axis. The test frequencies were the octave band center frequencies from 0.5 to $4.0 \mathrm{kHz}$ and the third-octave band center frequencies from 4.0 to $8.0 \mathrm{kHz}$. The sound pressure level varies smoothly, as a function of position, alongside the head for frequencies equal to or less than $2.0 \mathrm{kHz}$. At frequencies equal to or greater than $4.0 \mathrm{kHz}$ the pressure level changes rapidly with position. Particularly severe pressure minima were found to exist around the pinna at 6.3 and 8.0 $\mathrm{kHz}$. The smoothing effect of test signals using pink noise of 6 and 29 percent bandwidth on the acoustic pressure variation alongside the head and behind the pinna is also shown.

17065. Worley, S. D., Yates, J. T., Jr., A thermal desorption study of methyl formate from $\mathrm{W}(100)$ and its relevance to the catalytic production of methane, J. Catal. 48, 395-403 (1977).

Key words: chemisorption; methane; methyl formate; tungsten.

Previous work has suggested that methyl formate is a possible intermediate in the catalytic production of methane from formaldehyde on a tungsten (100) single crystal. To test this hypothesis, a study of methyl formate interaction with W(100) has been performed. The major products desorbed upon heating a saturated layer of methyl formate on W(100) were hydrogen and carbon monoxide. However, a significant yield of formaldehyde and small amounts of methane, carbon dioxide, and several organic products believed to be methyl formate, glycolaldehyde, and methyl alcohol were also observed. The thermal desorption products and their desorption kinetics from methyl formate adsorbed on $W(100)$ were very similar to those from formaldehyde on W(100). A sequence of reactions which might account for this similar behavior is suggested.

17066. Young, R. D., Length calibrations in the micrometer and. sub-micrometer range, Annals of the CIRP 25, No. 1, 245250 (Aug. 1977).

Key words: filar eyepiece; image-shearing eyepiece; integrated circuits; linewidth measurements; microelectronics; micrometrology; optical microscope; photoelectric microscope; photomask; scanning electron microscope.

Recent technological shifts toward microcircuits and other microtechnologies have generated unmet demands for length measurements in the micrometer and submicrometer range. The National Bureau of Standards is developing the measurement techniques and physical standards to provide the basis for 
extending the National Measurement System for Length to the micrometer range. The program involves the following activities: 1) development of a high accuracy scanning photometric microscope with data acquisition system, 2 ) systematic theoretical and experimental study of the errors in filar and shearing eyepiece measurements with optical microscopes, 3) development of electrically programmable, high resolution stages, 4) design and construction of interferometric stage for scanning electron microscope measurement of micrometer and submicrometer lines and spaces, 5) design and procurement of physical standards for calibration transfer, 6) optical evaluation of microscope objectives and 7) development of new optical instruments for linewidth measurement. Each component of the program will be described along with achievements to date. This paper is a synopsis of a report prepared at the end of the second year of this study.

17067. Tsumura, R., Straty, G. C., Speed of sound in saturated and compressed fluid ethane, Cryogenics 17, No. 4, 195-200 (Apr. 1977).

Key words: compressed fluid ethane; ethane, fluid; fluid ethane; sound; speed of sound.

The speed of sound in saturated and compressed fluid ethane has been measured in the temperature range 91 to $323.15 \mathrm{~K}$ and at pressures to $35 \mathrm{MPa}$. These data were combined with newly available $P \rho T$ data to obtain the isentropic compressibility and the ratio of the specific heats. The quality of the $P \rho T$ data has been examined by comparison of sound speeds calculated from these data with the measured sound speeds.

17068. Ledbetter, H. M., Read, D. T., Orthorhombic elastic constants of an NbTi/Cu composite superconductor, J. Appl. Phys. 48, No. 5, 1874-1879 (May 1977).

Key words: bulk modulus; composite; compressibility; copper; elastic constants; niobium-titanium; Poisson's ratio; pulse method; resonance method; shear modulus; sound velocity; Young's modulus.

Elastic properties of a niobium-titanium-filament coppermatrix composite superconductor were studied experimentally at room temperature. Ultrasonic pulse and resonance measurements showed the material has orthorhombic symmetry and, therefore, nine independent elastic constants. With respect to copper, $C_{11}, C_{22}$, and $C_{33}$ are about 7 percent lower; $C_{44}, C_{55}$, and $C_{66}$ are about 15 percent lower; the off-diagonal elastic constants are the same; and the bulk modulus is about 5 percent lower. Deviations from isotropic elastic behavior are small.

17069. Krauss, M., Julienne, P. S., Collision-induced $1\left({ }^{2} P_{1 / 2}\right)$ emission in argon and xenon, J. Chem. Phys. 67, No. 2, 669673 (July 15, 1977).

Key words: collision-induced; emission; interaction potential; iodine; perturbation theory; rate coefficient.

Long range perturbation theory is used to estimate the magnitude of the dipole transition moment leading to iodine ${ }^{2} P_{1 / 2}$ $\rightarrow{ }^{2} P_{3 / 2}$ emission during a collision with a rare gas atom. The leading term in the induced transition moment varies as $R^{-4}$ owing to the dipole-quadrupole term in the interaction potential. The two-body rate coefficient for collision-induced radiative decay of $I^{2} P_{1 / 2}$ is calculated using approximate model potentials for XeI and Arl. The coefficients are estimated to be $2 \times 10^{-19} \mathrm{~cm}^{3} \mathrm{sec}^{-1}$ and $6 \times 10^{-19} \mathrm{~cm}^{3} \mathrm{sec}^{-1}$ for $I^{2} P_{1 / 2}$ in $300^{\circ} \mathrm{K}$ Ar and $X e$, respectively.

17070. Howe, S. L., Risley, A. S., National Measurement System Time and Frequency-A micro study, NCSL Newsletter 15, No. 1, 16-20 (Apr. 1975).
Key words: frequency; National Measurement System; standards laboratories; survey; time.

Members of the National Conference of Standards Laboratories were surveyed to determine their needs for Time and Frequency technology and their use of NBS radio broadcasts. There was a 67.5 percent ( 106 labs) response to the NCSL questionnaire. Results showed that 92 percent of the standards labs use NBS broadcast services. It also revealed that these standards labs represent a total capital investment in T\&F equipment of $\$ 3.5$ million.

17071. Giarratano, P. J., Collier, R. S., Evaluation of capacitance densitometry for LNG mixtures with low nitrogen composition, Ind. Eng. Chem. Process Res. Dev. 16, No. 3, 330-336 (1977).

Key words: Clausius-Mosotti; densitometer (capacitance); density; dielectric constant; LNG; mixture(s).

Densities of typical LNG mixtures under saturation and subcooled conditions were calculated using a computer program which utilizes the method of corresponding states. The dielectric constant for each mixture was determined from the Clausius-Mosotti relationship assuming the excess $\mathrm{CM}$ function is zero. Examination of the resulting density-dielectric constant plots shows that for fixed nitrogen composition a nearly linear relationship exists between saturation density and dielectric constant under isobaric or isothermal conditions, independent of the hydrocarbon mixture. The results show, however, that the effect of the nitrogen composition on this linear relationship may be taken into account partially by a measurement of the mixture temperature. For the range of mixtures of this study it is possible to determine density to \pm 0.3 percent (intrinsic uncertainty) independent of knowledge of the hydrocarbon composition from an exact measurement of dielectric constant and temperature. Further improvements can be made if the fraction of nitrogen is known.

17072. Fickett, F. R., Structural materials for cryogenic applications, Proc. 6th Int. Cryogenic Engineering Conf., Grenoble, France, May $11-14,1976$, pp. 20-33 (IPC Science and Technology Press, Guildford, Surrey, England, 1976).

Key words: alloy; composite; cryogenics; electrical property; insulation; materials; mechanical property; metal; review; thermal property.

A general review of recent worldwide developments in the measurement of properties of materials used in structural applications at cryogenic temperatures is given. New alloy data and testing methods, particularly relating to crack growth, are discussed. The major emphasis is placed on the properties of a variety of composite materials now under consideration for various applications at low temperatures. Insulation materials and others which occasionally serve a structural purpose are also considered. An attempt is made to evaluate trends in these materials. Much of the literature in this field is contained in relatively obscure government reports and corporate publications. A brief bibliography is given as well as a guide to other sources of this literature.

17073. Evenson, K. M., Jennings, D. A., Petersen, F. R., Mucha, J. A., Jimenez, J. J., Charlton, R. M., Howard, C. J., Optically pumped FIR lasers: Frequency and power measurements and laser magnetic resonance spectroscopy, IEEE J. Quantum Electron. QE-13, No. 6, $442-444$ (June 1977).

Key words: FIR optically pumped lasers; frequency and power measurements; laser magnetic resonance spectroscopy. 
Optically pumped FIR lasers are currently in use in both frequency metrology and laser magnetic resonance spectroscopy programs in the NBS Boulder labs. The laser for use in frequency metrology is a CW $71 \mu \mathrm{m}$ methyl alcohol waveguide laser with over $100 \mathrm{~mW}$ output for frequency synthesis. Another laser with an intracavity absorption cell for laser spectroscopy has been constructed and is nearly transversely pumped. The metrology technique used to measure the frequency of these lasers is briefly reviewed and a unique power meter is described.

17074. Clark, A. F., Ekin, J., Defining critical current, IEEE Trans. Magn. MAG-13, No. 1, 38-40 (Jan. 1977).

Key words: critical current; definition; standards; superconductor.

The critical current of a practical superconductor can be defined in a variety of ways such as a specific voltage level, an apparent resistivity, or even the point of the irreversible superconducting-to-normal transition. The resultant values may differ very little or be meaningless for one given condition, but when comparing superconductors under a variety of conditions, such as different magnetic fields or applied stresses, these various definitions can give apparently different behavior. This is illustrated using data on the effects of stress on the critical current behavior in wires. As part of an initial effort at the National Bureau of Standards to develop standard practices and definitions for practical superconductors, several critical current criteria are proposed and discussed.

17075. Douglas, T. B., Krause, R. F., Jr., Evaluation of a simple static method for measuring vapor pressure, J. Chem. Thermodyn. 9, $511-522$ (1977).

Key words: argon-vapor contact; error analysis; iodine; molybdenum hexafluoride; new static technique; vapor pressure.

To complement transpiration and other methods when applied to partially dissociated or associated vapors, a direct static method was developed for measuring vapor pressures of around $1 \mathrm{kPa}$. A valve brings argon, originally at a little higher pressure, into direct contact with the pure vapor, whose pressure is very simply calculated from the reduction in pressure of the argon. Several types of systematic error were estimated; these include especially the effects of diffusion, viscosity, and steadystate gradients in gas temperature and molar mass, and indicate suitable dimensions of the capillary admitting the argon such that the vapor will remain confined essentially to its original volume during the time required for total-pressure equilibration. To test the method and apparatus, the vapor pressures of $l_{2}$ at 343 and $353 \mathrm{~K}$ (using saturated vapor) and that of $\mathrm{MoF}_{\mathrm{B}}$ at $237 \mathrm{~K}$ (using "superheated" vapor) were measured. The three mean values agree to better than 1 percent with the most reliable published values, which themselves probably have absolute uncertainties this great. Further refinement of the method to give a general accuracy of 0.1 percent seems feasible.

17076. Drullinger, R. E., Hessel, M. M., Smith, E. Q., Experimental studies of mercury molecules, J. Chem. Phys. 66, No. 12, 5656-5666 (June 15, 1977).

Key words: dimer; double resonance; mercury excimers; optically excited; spectra; two photon.

Optically excited fluorescence spectra in pure mercury vapor have been studied over the spectral range $240-600 \mathrm{~nm}$ for temperatures between $400-1000 \mathrm{~K}$ and densities between $5 \times 10^{16}$ $-2 \times 10^{19} \mathrm{~cm}^{-3}$. Absorption measurements were made over the spectral range $253-334 \mathrm{~nm}$, and both structured and continuum bands were observed. Several types of two photon experiments were also performed in order to probe the excited states of the mercury dimer. In addition, the mercury spectrum from mercury vapor-noble gas mixtures has also been studied for noble gas pressures up to $1 \mathrm{~atm}$.

17077. Edrich, J., Sullivan, D. B., McDonald, D. G., Results, potentials, and limitations of Josephson-mixer receivers at millimeter and long submillimeter wavelengths, IEEE Trans. Microwave Theory Tech. MTT-25, No. 6, 476-479 (June 1977).

Key words: heterodyne detection; Josephson effect; millimeter waves; mixing; receiver; superconductivity.

Millimeter-wave mixers using Josephson point contacts are described, which exhibit a conversion loss $L_{c}=9.5 \mathrm{~dB}$ and a noise temperature $T \sim 223 K$ for $\lambda \geqslant 0.95 \mathrm{~mm}$. Their potentials and limitations in noise, bandwidth, drive power, and stability for receiver applications are discussed.

17078. Daney, D. E., Ludtke, P. R., Jones, M. C., Thermal acoustic oscillations in current leads cooled with supercritical helium, IEEE Trans. Magn. MAG-13, No. 1, $412-415$ (Jan. 1977).

Key words: acoustic oscillations; current leads; experimental; stability; supercritical helium.

Observations are reported of pressure oscillations in model current leads cooled with supercritical helium. The oscillations are characterized and regions of the independent parameters in which the oscillations occurred are given. Different behavior depending on the design of each lead is noted. The effects of the thermodynamic state of the helium and the hydraulic diameter of each lead are in agreement with the theoretical predictions for simple tubes.

17079. Birmingham, B. W., Forecast of new metrological directions at NBS, NCSL Newsletter 18, No. 2, 12-15 (June 1977).

Key words: electromagnetic; interference; measurement; metrology; radiation; surface technology.

This manuscript was presented in the form of a speech made at the May 1977 Board of Directors meeting of the National Conference of Standards Laboratories. The speech covered some future directions of metrology at NBS.

17080. Beehler, R. E., Hanson, D. W., Davis, D. D., Recent changes and future trends in NBS time and frequency dissemination services, Proc. Seventh Annual Precise Time and Time Interval (PTTI) Applications and Planning Meeting, Goddard Space Flight Center, Greenbelt, $M D$, Dec. 24, 1975, X814-76-45, pp. 61-95 (1975).

Key words: NBS radio stations WWV/WWVH/WWVB; NBS time/frequency services; satellite timing; standard time/frequency broadcasts; television time/frequency dissemination; time/frequency calibrations; user equipment; user survey.

During the past two years a number of improvements have been made in the NBS Time and Frequency (T/F) Dissemination Services. These range from making the WWVB $60 \mathrm{kHz}$ broadcasts available on a continuous basis to implementing a new nationwide frequency calibration service using television techniques. NBS now provides regularly published calibrations of both the East Coast and the West Coast commercial TV network subcarrier frequencies for use as a transfer standard at the $10^{-11}$ accuracy level. Several versions of NBS-developed user equipment are described, covering a broad range of required user involvement, cost, and complexity. 
During the first half of 1975 the NBS conducted an extensive survey of WWV/WWVH users to obtain their views relating to possible reductions in the present broadcast services. A summary of the results of this survey, based on about 12,000 responses, is included along with a discussion of possible actions to be taken by NBS to reduce operating costs of these services. Future trends in NBS T/F dissemination services are discussed with special emphasis on the objectives and major milestones of the NBS program to disseminate T/F information via satellite.

17081. Arvidson, J. M., Brennan, J. A., Pressure measurement at low temperatures, (Proc. First Biennial Symp. on Instrumentation in the Cryogenic Industry, Houston, TX, Oct. II 14, 1976), ISA Trans. 1, 607-1-607-9 (1976).

Key words: accuracy; calibration; cryogenic; dynamic; frequency response; hysteresis; precision; pressure measurement; sensitivity; stability; thermal effects; zero-shift.

This paper discusses topics related to the questions 1) what types of pressure transducers show good potential for cryogenic use? 2) what are the output characteristics (stability, sensitivity, etc.) of a transducer when subjected to low temperature environments: and 3 ) are methods or apparatus available to cryogenically calibrate pressure transducers under static and dynamic conditions?

Some information is available on the low-temperature performance of a relatively few pressure transducer types; however, the information is either in the form of manufacturing specifications or unpublished reports. The results of this study clearly indicate that individual transducers, even from the same manufacturer, can exhibit totally different characteristics when subjected to identical cryogenic test procedures. The previous statement indicates the necessity of calibrating each transducer for use at low temperature.

Also included in the discussion is the description of a $\mathrm{Na}$ tional Bureau of Standards (NBS) static/dynamic low-temperature pressure transducer calibration facility, which is currently being developed.

17082. Arp, V., Stresses in superconducting solenoids, J. Appl. Phys. 48, No. 5, 2026-2036 (May 1977).

Key words: anisotropic materials; orthotropic materials; strain; stress; superconducting magnets.

This paper develops and summarizes analytical techniques for calculating radially dependent stress and strain in superconducting windings having anisotropic mechanical and thermal properties. The analysis considers stresses due to fabrication procedures, cooldown to helium temperature, and magnetic forces. Representative calculations for a particular superconducting coil are presented.

17083. Strobridge, T. R., Voth, R. O., Refrigeration technology for superconductors, IEEE Trans. Nucl. Sci. NS-24, No. 3, 1222-1226 (June 1977).

Key words: compressors; cryogenic refrigeration; efficiency; expanders; heat exchangers; particle accelerators; power transmission; reliability.

This paper reviews the large helium refrigerator purchases in the past several years; outlines the refrigerator research and development for the same period and presents a model and method for predicting the maximum practical helium temperature refrigerator efficiency obtainable today.

17084. Smith, E. W., Drullinger, R. E., Hessel, M. M., Cooper, J., A theoretical analysis of mercury molecules, J. Chem. Phys. 66, No. 12, 5667-5681 (June 15, 1977).
Key words: $A$-values; bound-free transitions; $\mathrm{Hg}_{2} ; \mathrm{Hg}_{3}$; potential curves; $335 \mathrm{~nm}$ mercury laser.

A theoretical analysis of experimental observations on bound-free electronic transitions in mercury molecules is presented. Potential curves and $A$ values are derived for these transitions and the possibility of emission from a mercury trimer is also discussed briefly. These data are then used to produce a simple model for an optically pumped $335 \mathrm{~nm}$ mercury laser. A table is given which predicts the small signal gain at $335 \mathrm{~nm}$ as a function of temperature, density, and the excimer density in the vapor.

17085. Read, D. T., Ledbetter, H. M., Temperature dependences of the elastic constants of precipitation-hardened aluminum alloys 2014 and 2219, J. Eng. Mater. Technol. 99, 181-184 (Apr. 1977).

Key words: aluminum alloys; bulk modulus; compressibility; Debye temperature; Poisson's ratio; precipitationhardening alloys; shear modulus; sound velocity; Young's modulus.

Elastic properties of precipitation-hardened aluminum alloys 2014 and 2219 were studied between 4 and $300 \mathrm{~K}$ ultrasonic pulse techniques. Both the longitudinal and transverse sound velocities were measured. Also reported are the Young's modulus, shear modulus, bulk modulus, and Poisson's ratio. For both alloys, the Young's moduli are about ten percent higher than for unalloyed aluminum, and they increase about ten percent on cooling from 300 to $4 \mathrm{~K}$. All the elastic constants show normal temperature dependence.

17086. Tobler, R. L., Fracture of structural alloys at temperatures approaching absolute zero, (Proc. 4th Int. Conf. of Fracture, Waterloo, Canada, June 19-24, 1977), Fracture 3, ICF4, 839-846 (1977).

Key words: aluminum alloys; ferritic steels; fracture toughness; low temperature; nickel alloys; titanium alloys.

The J-integral was used to evaluate and compare the low temperature fracture behavior of 14 commercial alloys, including ferritic steels, and aluminum-base, titanium-base and nickelbase alloys. The tests were performed at temperatures between 295 and $4 \mathrm{~K}$. These data, which can be used in fracture mechanics evaluations, suggest several generalizations that should aid in predicting the behavior of untested alloys.

17087. Read, D. T., Ledbetter, H. M., Elastic properties of a boron-aluminum composite at low temperatures, J. Appl. Phys. 48, No. 7, 2827-2831 (July 1977).

Key words: aluminum; boron-aluminum; bulk modulus; composite; compressibility; elastic constants; resonance method; shear modulus; torsional modulus; Young's modulus.

Elastic properties of a boron-filament-reinforced aluminummatrix composite were studied experimentally. Assuming transverse-isotropic elastic symmetry, five independent elastic constants were measured using a piezoelectric composite-oscillator method. Two constants, Young's modulus along the filament axis and the torsional modulus perpendicular to the filament axis, were determined between 300 and $4 \mathrm{~K}$. The composite's elastic-constant values are between the values of boron and aluminum, but closer to those of aluminum. Along the filament axis, Young's modulus is $2.30 \times 10^{11} \mathrm{~N} / \mathrm{m}^{2}$. Cooling from 300 to $4 \mathrm{~K}$ increases all the elastic stiffnesses by as much as 11 percent.

17088. Radebaugh, R., Electrical and thermal magnetoconductivities of single-crystal beryllium at low temperatures and its 
use as a heat switch, J. Low Temp. Phys. 27, Nos. 1/2, 91105 (1977).

Key words: beryllium; cryogenics; electrical conductivity; heat switch; Lorenz ratio; magnetic field; single crystal; thermal conductivity.

The effects of transverse magnetic fields up to $955 \mathrm{kA} / \mathrm{m}(12$ $\mathrm{kOe}$ ) on the electrical and thermal conductivities of singlecrystal beryllium have been measured between 2 and $300 \mathrm{~K}$. Most of the measurements were made on a sample with a resistance ratio of 1340 . This sample was pure enough so that the intrinsic electronic thermal resistivity could be measured for the first time. It was found to have the usual $T^{2}$ behavior. The current and heat flow were along the hexagonal $c$ axis of the crystal, while the thermal and electrical conductivities were studied as a function of the angle of the magnetic field in the basal plane. Below about $50 \mathrm{~K}$ the thermal conductivity could be reduced by several orders of magnitude by applying the magnetic field. The lattice conductivity, extrapolated from the measurements in the magnetic field, is given by $k=\gamma T^{2}$, where $\gamma=1.6 \times 10^{-4} \mathrm{~W} / \mathrm{cm} \mathrm{K}^{3}$. This value is in reasonable agreement with that obtained from measurements of beryllium alloys. The use of single-crystal beryllium as a heat switch for temperatures below about $30 \mathrm{~K}$ is discussed.

17089. McHenry, H. I., Reed, R. P., Fracture behavior of the heat-affected zone in $5 \% \mathrm{Ni}$ steel weldments, Weld. J. Res. Suppl., 9 pages (Apr. 1977).

Key words: cryogenic temperature; fatigue crack growth; fracture toughness; heat affected zone; J-integral; nickel steel; weldments.

The fracture properties of the base metal and the heat-affected zone (HAZ) of 5 percent $\mathrm{Ni}$ steel weldments were determined at room temperature, $111 \mathrm{~K}(-260 \mathrm{~F})$ and $76 \mathrm{~K}(-323$ F); emphasis was placed on tests at $111 \mathrm{~K}$, the minimum boiling point of liquefied natural gas (LNG). The $32 \mathrm{~mm}\left(1 \frac{1 / 4}{\mathrm{in} . \text {.) }}\right.$ thick test plates, which met the requirements of ASTM A645, were welded using the pulsed-power gas metal arc process at a heat input of $10.6 \mathrm{~kJ} / \mathrm{cm}$. The fatigue crack growth rates were determined for cracks growing through the thickness using four-point bend specimens. At $111 \mathrm{~K}$, the rates in the base metal were essentially the same as found by other investigators; however, the rates in the HAZ were up to 10 times faster than previously reported.

Fracture toughness tests were conducted under load-controlled conditions using $\mathrm{J}$-integral procedures. At $111 \mathrm{~K}$, the base metal and HAZ toughness values were 30 and 50 percent lower, respectively, than toughness values obtained previously for the same plate of test material under displacement-controlled conditions.

Fracture mechanics analyses using the results reported herein indicate that 5 percent $\mathrm{Ni}$ steel is suitable for LNG applications, but more conservative estimates of fatigue life and critical crack size are necessary.

17090. Tighe, N. J., Characterization of flaws produced by mechanical grinding of $\mathrm{Si}_{3} \mathrm{~N}_{4}$, Proc. 35th Ann. Proc. Electron Microscopy Society of America, Boston, MA, Aug. 18-26, 1977, pp. 144-145 (1977).

Key words: cracks; electron microscopy; grinding damage; oxidation; silicon nitride; surface flaws; thin foils.

Flaws near the ground surfaces of silicon nitride were characterized by electron microscopy. The grinding produced cracks and a high density of dislocation. The change in the flaw population by oxidation of the surface is described.

17091. Zimmerman, J. E., Radebaugh, R., Siegwarth, J. D., Possible cryocoolers for SQUID magnetometers, (Proc. Ist IC-
SQUID Conf., Berlin, Germany, Oct. 5-8, 1976), Paper in Superconducting Quantum Interference Devices and Their Applications, H. D. Hahlbohn and H. Luebbig, Eds., pp. 287. 296 (Walter de Gruyter \& Co., Berlin, Germany, New York, NY, 1977).

Key words: cryogenic refrigeration; magnetometry; SQUID; Stirling cycle.

In a study to determine if a cyclic cryogenic refrigerator is suitable for cooling SQUID magnetometers and similar instruments, we have used a specially designed Stirling machine with a three-stage displacer to achieve and maintain a temperature of $13 \mathrm{~K}$. The displacer and cylinder were made of low-susceptibility, nonconducting plastic to minimize magnetic interference. For the same reason, and also to minimize mechanical noise, the machine operates at low displacement and low speed, and it uses only about $10 \mathrm{~W}$ of mechanical power, requiring $50 \mathrm{~W}$ input to a typical small electric motor. Since the temperature achieved is within the range of $\mathrm{NbN}$ and $\mathrm{Nb}_{3} \mathrm{Sn}$ SQUIDs, it can, in principle, be used to cool a SQUID. The estimated magnetic signal from the reciprocating displacer may not seriously affect the magnetometer sensitivity, but the signal due to the cyclic pressure-induced geometric distortion of the SQUID mounting in the earth's field may be very difficult to eliminate.

17092. Sullivan, D. B., Frederick, N. V., Adair, R. T., RF power measurements using quantum interference in superconductors, (Proc. Ist IC-SQUID Conf., Berlin, Germany, Oct. 5-8, 1976), Paper in Superconducting Quantum Interference Devices and Their Applications, H. D. Hahlbohn and H. Luebbig, Eds., pp. 355-363 (Walter de Gruyter \& Co., Berlin, Germany, 1977).

Key words: Josephson effect; quantum interference; rf metrology; rf power; SQUID; superconductivity.

A SQUID system for high sensitivity and broad dynamic range measurement of $\mathrm{rf}$ power at $30 \mathrm{MHz}$ has been developed. The system is a modification of earlier concepts and consists of two SQUIDs, each sensing power in adjacent but slightly overlapping ranges, providing an overall dynamic range of 105 dB. A dc calibration of one of the SQUIDs provides a power uncertainty of less than $0.1 \mathrm{~dB}$ for the system at power levels as low as $-131 \mathrm{dBm}\left(\sim 8 \times 10^{-17}\right.$ watts $)$.

17093. Carter, G. C., Bennett, L. H., Kahan, D. J., Metallic shifts in NMR. A review of the theory and comprehensive critical data compilation of metallic materials, Progress in Materials Science, B. Chalmers, J. W. Christian, and T. B. Massalski, Eds., 20, Parts I-IV, 2350 pages (Pergamon Press, New York, NY, 1977).

Key words: compilation; critical evaluation; Knight shifts; magnetic moments; metals; nuclear quadrupole effects; nuclear relaxation.

Contains both a review of the pertinent theory on Knight shift and the critically evaluated sets of shift data on metallic materials. Related solid state physical properties data, such as structural data, phase diagrams, melting points, superconducting transition temperatures, magnetic transition temperatures, paramagnetic Pauli susceptibilities and compressibilities are also given. Each system, element, or alloy is considered separately, giving the data, a discussion of the rationale for their selection, and the pertinent references from which the data are taken. The elements are reviewed first, after which the alloys are considered.

The fourth volume of the book contains an addendum to the references published after each critical evaluation was completed. These references are annotated to describe the NMR properties contained in the paper. An alphabetical index 
of metals and alloys in which a particular nuclear resonance is observed or discussed in the evaluation is also given.

17094. Ledbetter, H. M., Anomalous elastic properties of a precipitation-hardened copper alloy, Met. Trans. 8A, No. 6, 1006-1007 (June 1977).

Key words: bulk modulus; compressibility; copper alloy; elastic constant; Poisson ratio; precipitation hardening; shear modulus; sound velocity; Young's modulus.

The room-temperature elastic constants of a polycrystalline precipitation-hardened copper-cadmium-chromium alloy were determined by a $10 \mathrm{MHz}$ pulse-echo method. With respect to copper the alloy has a fifteen-percent-lower bulk modulus, a fifteen-percent-higher shear modulus, and a fourteen-percentlower Poisson ratio. These changes, especially in the Poisson ratio, are much larger than those observed in the more familiar copper-beryllium precipitation-hardened alloy and compare to those usually obtained only by mechanical deformation or by phase transformation.

17095. Mathew, M., Schroeder, L. W., Jordan, T. H., The crystal structure of anhydrous stannous phosphate, $\mathrm{Sn}_{3}\left(\mathrm{PO}_{4}\right)_{2}$, Acta Cryst. B33, 1812-1816 (1977).

Key words: crystal structure; dimeric configuration; stannous compounds; stannous phosphate; tin coordination.

Anhydrous stannous phosphate, $\mathrm{Sn}_{3}\left(\mathrm{PO}_{4}\right)_{2}$, crystallizes in the monoclinic space group $P 2_{1} / c$ with $Z=4$. The unit-cell parameters at $25{ }^{\circ} \mathrm{C}$ are $a=11.092(8), b=4.830(4), c=16.401$ (10) $\AA$ and $\beta=94.28(5)^{\circ}$. The structure was solved by the heavy-atom method and refined by full-matrix least-squares techniques to $R_{u}(F)=0.034$ and $R(F)=0.047$ with 1813 reflections. The structure consists of alternating layers of $\mathbf{S n}^{\prime \prime}$ and $\mathrm{PO}_{4}$ ions parallel to the $a c$ plane. Two open channels parallel to [010] are formed by $\mathrm{Sn}^{\prime \prime}$ ions arranged in a helical fashion. Each $\mathrm{Sn}^{\prime \prime}$ ion is at the apex of a trigonal pyramid with the three nearest $\mathrm{O}$ atoms, each from a different $\mathrm{PO}_{4}$ group, forming the base. In one case, two $\mathrm{Sn}^{\prime \prime}$ ions enter into a dimeric configuration by sharing an O...O edge of the pyramid. The corresponding $\mathrm{Sn}-\mathrm{O}$ distances are $2.230(6)$ and 2.317 (6) $\AA$; the $\mathrm{O}-\mathrm{Sn}-\mathrm{O}$ angle of $69.6(2)^{\circ}$ is unusually small.

17096. Giarratano, P. J., Conference Report on Cryogenic Instrumentation Symposium held in Houston, TX, Oct. 11-14, 1976, Cryogenics 17, No. 3, 186 (Mar. 1977).

Key words: cryogenic; instrumentation.

A summary of papers presented at the Instrument Society of America International Conference and Exhibit is given.

17097. Schwartz, F. P., Wasik, S. P., A fluorescence method for the measurement of the partition coefficients of naphthalene, 1-methylnaphthalene, and 1 -ethylnaphthalene in water, $J$. Chem. Eng. Data 22, No. 3, 270-273 (July 1977).

Key words: enthalpy; fluorescence; heat of solution; naphthalene; partition coefficient; solubility; vapor pressure; 1 -ethylnaphthalene; 1 -methylnaphthalene.

A method is described for the determination of the partition coefficients of aromatic hydrocarbons in water by fluorescence measurements. The partition coefficients of water solutions of naphthalene, 1-methylnaphthalene, and 1-ethylnaphthalene between 8 and $31{ }^{\circ} \mathrm{C}$ were determined by this method. The solubilities of naphthalene in water over this temperature range were calculated from its partition coefficients.

17098. Barger, R. L., Rydberg constant measurement using cw dye laser and $\mathrm{H}^{*}$ atomic beam, Chapter in Atomic Masses and Fundamental Constants, J. H. Sanders and A. H. Wapstra,
Eds., 5, 565-570 (Plenum Publ. Corp., New York, NY, 1976).

Key words: Balmer $\alpha$ line; cw dye laser; Fabry-Perot interferometer; Rydberg constant.

An experiment is in progress to determine an accurate value of the Rydberg constant by measuring the wavelength of the Balmer $\alpha$ line. A high intensity atomic beam of $2 \mathrm{~S}$ hydrogen atoms will be used to reduce perturbations to a negligible level. Laser saturated absorption of the 2S-3P transition will be produced with a $\mathrm{cw}$ dye laser having a frequency stability of $6 \times 10^{-13}$, and the saturation peak will be detected by observing the Lyman $\alpha$ decay from an E-field quenching region. RF pumping between the $3 \mathrm{P}$ and $3 \mathrm{~S}$ levels, as suggested by Roberts and Fortson, should give resolution of hyperfine structure and prevent systematic errors due to overlapping components. With the dye laser locked to the Balmer $\alpha$ transition, the wavelength will be measured with the frequency-controlled Fabry-Perot interferometer which was used for the $\mathrm{CH}_{4} 3.39 \mu \mathrm{m}-\mathrm{Kr} 6057 \AA$ comparison. We expect to obtain an accuracy of about $10^{-10}$ with this experiment.

17099. Ledbetter, H. M., Ratio of the shear and Young's moduli for polycrystalline metallic elements, Mater. Sci. Eng. 27, 133136 (1977).

Key words: elastic constants; face-centered-cubic solids; polycrystals; shear modulus; Young's modulus.

By considering an aggregate of face-centered-cubic crystals and a general two-body central-force interatomic potential, it is shown that the shear modulus and Young's modulus of a crystalline aggregate are proportional. Their calculated ratio is 0.396 , close to the experimental value of 0.375 .

17100. West, J. B., Poland, H. M., Chemiluminescence from mixtures of $\mathrm{Ba}+\mathrm{CO}_{2}$ and $\mathrm{Ba}+\mathrm{CO}, J$. Chem. Phys. 66, No. 5 , 2139-2141 (Mar. 1, 1977).

Key words: barium reactions; chemiluminescence; heat pipe reaction.

Broad banded chemiluminescence has been detected from the reaction of $\mathrm{Ba}+\mathrm{CO}_{2}$ and $\mathrm{Ba}+\mathrm{CO}$ in a heat pipe. Extending from 500 to $1150 \mathrm{~nm}$, the spectrum of this flame exhibits several prominent peaks. The emitting species has not been identified; however, evidence favors a polyatomic molecule. The observation of such chemiluminescence from apparently endoergic reactions is of interest and importance for the understanding of chemiluminescent processes.

17101. Kusch, P., Hessel, M. M., An analysis of the $A^{1} \Sigma_{u}{ }^{+}$ $X^{\prime} \Sigma_{g}{ }^{+}$band system of ${ }^{7} \mathrm{Li}_{2}, J$. Chem. Phys. 67, No. 2, 586589 (July 16, 1977).

Key words: dissociation energy; Dunham coefficients; Franck Condon factors; molecular lithium; potential curve; spectroscopy.

A new analysis of the $A^{1} \Sigma_{u}{ }^{+}-X^{1} \Sigma_{g}{ }^{+}$band system of ${ }^{7} \mathrm{Li}_{2}$ has been made. The analysis extends from $\nu^{\prime}=0$ to $\nu^{\prime}=25$, from $\nu^{\prime \prime}=0$ to $\nu^{\prime \prime}=14$, and up to $J=78$. The dissociation energy of the $A$ state is found to be $8940 \mathrm{~cm}^{-1}$, considerably less than any earlier estimate of that energy. The RKR potential curves for the $A$ and $X$ states are given, together with the Franck-Condon factors for the $A-X$ transitions.

17102. Aizenman, M., Weigert, A., Stability properties of some stellar models in the Beta Cephei region, Astron. Astrophys. 56, 457-459 (Apr. 1977).

Key words: Beta Cephei stars; nonradial stability; pre-main sequence models. 
The non-radial quasi-adiabatic stability of very different types 'of stellar models lying in the region of the observed Beta Cephei stars has been calculated. The models are found to be stable. The accuracy and validity of the usual treatment of vibrational stability for these stars is discussed.

17103. Danos, M., Rafelski, J., Some consequences of Fermitype theory of weak interactions, Nuovo Cimento Lett. 19, No. 9, 339-343 (July 2, 1977).

Key words: effective neutral weak interactions; Fermi theory; finite field theory; neutral currents; weak coupling constants; weak interactions.

We consider qualitatively the consequences of a theory of weak interactions based on a Fermi-type interaction without vector mesons. We compute the renormalization of the Fermi coupling constant and obtain the strength of the induced, neutral current like, coupling.

17104. Clifton, J. R., Adobe building materials: Properties, problems, and preservation, Tech. Conservation, pp. 30-34 (Spring 1977).

Key words: adobe building materials; adobe soil; mechanical properties; moisture determination; preservation technology.

Earth, air, and water-three of the four elements of the ancient world-have been combined for several millennia to form a versatile building material. This product, sun-dried earth bricks, or adobe, was easy to make and use in pre-industrialized societies. No great technical skill or equipment was necessary. Fabrication required only mixing soil and water, shaping the mixture into forms, and exposing them to the atmosphere to set them. Once hardened, the bricks were ready to use.

The National Bureau of Standards is studying the properties of adobe to determine what problems may be associated with it, and how best to preserve adobe in old buildings.

17105. Sangster, R. C., Relevancy of measurements by a systems approach, Proc. 1972 Joint Measurement Conf., Boulder, CO, June 2l-23, 1972, pp. 31-37 (Instrument Society of America, Pittsburgh, PA, 1972).

Key words: metrology; systems.

The complexity of today's technological systems is so high that measurements made in the classical calibration sense, on specific isolated objects or portions of an overall system, may not be at all optimum for telling a client what his system is really doing. Metrology is undergoing an evolution paralleling that in electronics and other fields, to allow it to maintain relevancy by providing effective support to the systems engineer. Specific examples discussed relate to performance assessment in telecommunications systems, coal mine safety, plastic land mine detection, and other areas.

17106. Berger, H., Nondestructive evaluation (NDE) at the National Bureau of Standards (NBS), Nondestructive Testing Info. Anal. Ctr. Newsletter 5, No. 2, 1-4 (Aug. 1977).

Key words: acoustic; calibration; eddy current; microwave; nondestructive evaluation; penetrant; radiography; standards; thermal; ultrasonic; visual testing; wear debris.

The NBS-NDE Program is working to improve NDE measurement reliability and reproducibility, particularly in the areas of acoustic-ultrasonic, radiography, visual testing, electrical eddy-current testing, microwave method, penetrant testing, wear debris analysis and thermal testing. Calibration service for aluminum reference blocks is now available. Also available for sale are standard reference materials for coating thickness measurement and for calibration of densitometers. Short term fu- ture plans call for a loaner service for aluminum ultrasonic reference blocks, and calibration services for ultrasonic and acoustic emission transducers and for electrical conductivity. A recommended practice for thermal neutron radiography in collaboration with ASTM is in draft form.

17107. Marshall, H. E., Ruegg, R. T., Energy conservation through life-cycle costing, $J$. Archit. Ed. XXX, No. 3, 42-51 (Feb. 1977).

Key words: building design; cost; energy conservation; energy standards; fenestration; life-cycle costing; retrofitting; solar.

Architects, engineers, building operators and owners, and others who make decisions about the design and use of buildings need cost information about alternative energy conservation designs for old and new buildings. Specifically, they need to know the cost over time from introducing energy conserving techniques as compared to the cost savings over time from reduced energy bills. Life-cycle costing of energy conservation alternatives in buildings can be applied at the working level to reduce the owning and operating costs of buildings, to reduce energy consumption, and to encourage the optimal retrofit of old and design of new buildings with respect to rising fuel costs. This article provides practicing architects, architectural students, and others interested in the design process an overview of state-of-the-art methods for estimating the lifecycle cost (LCC) of alternative energy conservation techniques and a description of selected applications of LCC methods to energy conservation in buildings.

Retrofitting existing residential buildings for energy conservation is examined in LCC terms. The design of envelope features and subsystems for energy conservation in new buildings is explored in the context of LCC analysis. Finally, energy standards for buildings are examined in the LCC context to show why varying climates and fuel prices must be considered in developing economically efficient standards.

17108. Lewett, G. P., Evaluation of energy-related inventions, Int. Marketing Info. Series, Comm. News for the Foreign Serv. CNFS Spec. Issue, pp. 7-12 (U.S. Department of Commerce, Domestic \& International Business Administration, Bureau of International Commerce, Washington, DC, Mar./Apr. 1977).

Key words: energy; evaluation; innovation; invention; technology transfer.

A discussion and description of the NBS energy-related invention evaluation program. The program was legislated under the Federal Nonnuclear Energy Research and Development Act of 1974 and the Office of Energy-Related Inventions (OERI) began operating in April 1975. As of the date of publication OERI had received some 3700 inventions and had made 16 recommendations to ERDA.

17109. Amsden, A. A., Ginocchio, J. N., Harlow, F. H., Nix, J. R., Danos, M., Halbert, E. C., Smith, R. K., Jr., Comparison of macroscopic and microscopic calculations of highenergy ${ }^{20} \mathrm{Ne}+{ }^{238} \mathrm{U}$ collisions, Phys. Rev. Lett. 38, No. 19, 1055-1058 (May 9, 1977).

Key words: heavy ion collisions; inelastic scattering; Monte Carlo calculations; proton angular distributions; proton production; proton spectra.

For the reaction ${ }^{20} \mathrm{Ne}+{ }^{238} \mathrm{U}$ at a laboratory bombarding energy per nucleon of $250 \mathrm{MeV}$ we calculate the cross section $d^{2} \sigma / d E d \Omega$ for outgoing protons using four different approaches. These are relativistic fluid dynamics, classical many-body calculations with a hard-sphere nucleon-nucleon potential, and two versions of relativistic intranuclear-cascade calculations. These calculations reproduce some features of the experimental data, but some major discrepancies remain. 
17110. Trechscl, H. R., Research in energy conservation, J. Archit. Ed. XXX, No. 3, 31-33 (Feb. 1977).

Kcy words: building; building environment; energy conservation; engincering; human factor; resource impact factors.

The paper discusses past and current energy conservation research dealing with engineering, human factor, and building use factors. The paper also indicates critical research needs and identifies a number of specific issues related to energy conservation, specifically the need to consider the effect of energy conservation on building environment and on human occupants, the need for multidisciplinary and interdisciplinary research, and the requirement for accounting for the scarcity of individual energy forms or resource impact factors.

17111. Gross, J. G., Pielert, J. H., Building standards and codes for energy conservation, J. Archit. Ed. XXX, No. 3, 54-56 (Feb. 1977).

Key words: buildings; codes; energy conservation; regulatory community; standards.

Over the last few years, public attention has been increasingly attracted to problems related to the shortage of energy. A major area where the conservation of energy would be possible is in the design and construction of new buildings and the retrofitting of existing buildings. Building standards and codes, traditionally written for health and safety, are viewed as a mechanism for acconiplishing such conservation. The purpose of this paper is to review activities relative to this objective at the Federal level and within the various segments of the building regulatory community including State and local govern.nents, model building code groups, standards developing organizations and building regulators.

17112. Glinka, C. J., Minkiewicz, V. J., Passell, L., Absolute measurement of the critical scattering cross section in cobalt, (Proc. 21 st AlP Conf. on Magnetism and Magnetic Materials, Philadelphia, PA, Dec. 9-12, 1975), Paper in Magnetism and Magnetic Materials-1975, J. J. Becker, C. H. Lander, and J. J. Rhyne, Eds., No. 29, pp. 499-501 (American Institute of Physics, New York, NY, 1975).

Key words: absolute cross section measurement; cobalt; critical phenomena; interaction range; neutron scattering; spin correlation function.

Small-angle neutron scattering techniques have been used to study the angular distribution of the critical scattering from cobalt above $T_{r}$. These measurements have been put on an absolute scale by calibrating the critical scattering from cobalt. In this way the interaction range $r_{1}$, which appears in the classical and modified Ornstein-Zernike expressions for the asymptotic form of the spin pair correlation function and is related to the strength of the spin correlations, has been determined. We obtain $r_{1} / a=0.46 \pm 0.03$ for the ratio of the interaction range to the nearest-neighbor distance in cobalt. This result is in good agreement with theoretical predictions. Lack of agreement among previous determinations of the ratio $r_{1} / a$ made in iron failed to provide a definitive comparison with theory.

17113. Sorrows, H. E., Coping with future technology, Commerce Am. II, No. 20, 4-5 (Sept. 26, 1977); Surplus Record 54, No. 12, 38-40 (Dec. 1977 ).

Key words: free enterprise system; innovation; public private sector collaboration; technology growth; U.S. economy.

Technology has been a primary determinant of U.S. economic growth and is essential to the continued health and vigor of the U.S. free enterprise system. Adverse technology based trends are now stifling further U.S. technological growth and threaten our economic vitality. An aggressive collaboration between industry, government and academia is called for to attack developing problems. This partnership should identify and foster critically needed technology whose development is inhibited by lack of skills or by lack of necessary private sector incentives. Industry should lead in identifying bottlenecks to technological growth. Universities in addition to creating new knowledge should emphasize awareness of current industry and government needs in training engineers and managers and scientists. Where appropriate, the Federal Government should catalyze development and utilization of the desired new technologies. These efforts will provide many challenging opportunities to the U.S. technological community.

17114. Davis, R. M., Taking risks with computers, Proc. Symp. Man and the Computer, Dartmouth College, Hanover, NH, Nov. 30-Dec. I-2, 1976, pp. 28-34 (Kiewit Computation Center, Dartmouth College, Hanover, NH, 1976).

Key words: computer security; computer system performance; computer systems; individual privacy; risk management; safety of computer systems.

Computers, as other technological developments, have given rise to certain dangers or risks associated with their use. Public perceptions of these risks have been manifested as fears about dehumanization, invasion of privacy and damage to individuals through the improper use of information. In order to deal with these fears, we need to develop ways to set acceptable levels of risks and to judge the safety of computer systems. The determination of safety or an acceptable level of risk is a consensus derived process in which public concerns, dangers, vulnerabilities, and costs of safeguards and comparison of alternatives are all factored together to yield a result. Efforts to make computer systems safer and to set acceptable levels of risks can help to restore confidence in computers.

17115. Marshall, R. D., Full scale testing: Low rise, Proc. Workshop on Wind Load Requirements for Buildings, Northwestern Univ., Evanston, IL, June 3-4, 1976, pp. 159. 162 (1976).

\section{Key words: ANSI 58; low-rise buildings; wind study.}

This paper gives a brief description of the work being done by the Center for Building Technology in the area of wind forces on single family dwellings and the ANSI 58 code.

17116. Berlin, V. N., Weiss, R. G., The role of evaluation systems in the government policy and program change: $A$ cybermetic approach, Proc. Int. Conf. on Cybernetics and Society, Washington, DC, Sept. 19-21, 1977, pp. 17-22 (Institute of Electronics and Electrical Engineers, New York, NY, 1977).

Key words: administrative experimentation; evaluation; evaluation research; evaluation systems; policy analysis; social experimentation.

In a cybernetic model of the policy-making process, social program evaluation and administrative experimentation are feedback mechanisms. Such feedback is used to facilitate change in on-going government policies, programs, and processes. Problems associated with this methodology and an approach to the design of evaluation syste ms are described.

17117. Joel, L. S., Shier, D. R., Stein, M. L., Planes, cubes and center representable polytopes, Am. Math. Mo. 84, No. 5, 360-363 (May 1977).

Key words: convex set; data analysis; estimation; geometry; hypercube; hyperplane; polytope. 
Given an $n$-dimensional hypercube $C(n)$, is there a hyperplane that meets the interior of every facet of $C(n)$ ? Contrary to the impression given by the cases $n=1$ and $n=2$, the answer is "yes" for all $n>2$. Furthermore, for $n>3$, the hyperplane can also be chosen to contain any prescribed point of $C(n)$. Such results imply that the center of the smallest hyper-rectangle having sides parallel to the coordinate planes and enclosing a convex polytope $K$ does not necessarily lie in $K$. A practical estimation problem motivating the inquiry is described.

17118. Faulkner, D. J., Cepheid studies. I. Mode interaction in the beat Cepheid U Trianguli Australis, Astrophys. J. 216, 4956 (Aug. 15, 1977).

Key words: beat Cepheids; double-mode Cepheids; Fourier analysis of stellar variations; mocis interaction; stellar instabilities; U Trianguli Australis.

Photoelectric observations of the beat Cepheid U TrA previously reported by Oosterhoff and Jansen have been reanalyzed, using Fourier techniques. The two reported periods have been confirmed, and it has been shown that no further statistically significant periodicity is present. The two observed modes are subject to a strong mode interaction, but it is not yet clear whether this will have any implications for the beat masses derived for double-mode Cepheids. If $U \operatorname{TrA}$ is currently "mode switching," the change in relative mode amplitudes since these observations were made should be readily detectable.

17119. Peterlin, A., Individual bead contribution to intrinsic viscosity of polymers, Polymers Lett. 18, 747-749 (July 1977).

Key words: average gradient; intrinsic viscosity; nonrotating bead; single bead contribution to I.V.; torque on the bead.

The intrinsic viscosity calculation on the basis of the conventional necklace model of linear macromolecule completely neglects the contribution of the single beads. Actually, each bead contributes the same amount as a rigid sphere. This adds to intrinsic viscosity a constant term $2.5 / \rho$ with $\rho=(M / V)$ $=$ mass/volume of the segment represented by the bead. Actual interaction between the polymer and the solvent will modify the numerical value of this term which under specific conditions may even become negative.

17120. Brauer, G. M., Polymers in dentistry, (Proc. 100th Anniversary Prog. in Dental Materials, Ann Arbor, Ml, Oct. 1, 1975), Chapter 5 in Dental Materials Review, R. G. Craig, Ed., pp. 78-1 11 (University of Michigan Press, Ann Arbor, Ml, 1977).

Key words: adhesives; dental polymers; dental resins; dentures; impression materials; prosthetic materials; resin teeth; restoratives; sealants.

Plastics are employed successfully in many dental applications. Their properties make them especially valuable in the construction of dentures, plastic teeth and impression materials. The composite filling materials have been quite successful in areas where esthetics is of prime importance. Perhaps the biggest improvement in filling materials would be the development of a liner that bonds to tooth structure. The evidence today suggests that continuing progress will lead to clinically acceptable adhesive restoratives that will substantially improve the quality of dental services.

17121. Finnegan, T. F., Holdeman, L. B., Versatile multicontact thin-film superconducting switch, Rev. Sci. Instrum. 48, No. 9, 1212-1213 (Sept. 1977).
Key words: cryogenic electrical switch; mechanical switch; multiple contact switch; proximity effect; superconducting switch; thin-film.

A versatile mechanical superconducting switch which is suitable for use in various cryoelectronics applications has been developed. The switch design utilizes thin films for compactness and proximity layers of gold to prevent contact oxidation. A prototype four-pole, four-position switch is described in detail.

17122. Haus, J. W., Cullen, J. R., Dynamic order parameter fluctuations in a disordered system, Ann. NY Acad. Sci. 279, 45-46 (Oct. 15, 1976).

Key words: disordered system; dynamic susceptibility; Ginzburg-Landau free energy; relaxation time.

17123. Lafferty, W. J., Sams, R. L., The high resolution infrared spectrum of the $2 \nu_{2}+\nu_{3}$ and $\nu_{1}+\nu_{2}+\nu_{3}$ bands of ${ }^{14} \mathrm{~N}^{16} \mathrm{O}_{2}$ : Vibration and vibration-rotation constants of the electronic ground state of ${ }^{14} \mathrm{~N}^{16} \mathrm{O}_{2}, J$. Mol. Spectrosc. 66, 478-492 (1977).

Key words: combination bands; nitrogen dioxide; rotational constants; vibrational constants; vibration-rotation constants.

The $A$-type bands, $2 \nu_{2}+\nu_{3}$ and $\nu_{1}+\nu_{2}+\nu_{3}$, with band centers at 3092 and $3638 \mathrm{~cm}^{-1}$, respectively, of ${ }^{14} \mathrm{~N}^{16} \mathrm{O}_{2}$ have been measured with resolution of $0.03 \mathrm{~cm}^{-1}$ or better. Spectroscopic constants have been derived for the upper states of both bands. Infrared determined band constants have been combined with laser-excited resonance fluorescence data to obtain a set of vibration and vibration-rotation constants for the ground state of ${ }^{14} \mathrm{~N}^{16} \mathrm{O}_{2}$.

17124. Maki, A. G., Freund, S. M., Laser Stark spectroscopy of FCN, J. Mol. Spectrosc. 66, 493-499 (1977).

Key words: cyanogen fluoride; dipole moment; infrared spectroscopy; laser absorption; laser-Stark resonance; molecular spectra; Stark effect.

Using a $\mathrm{CO}_{2}$ laser, Stark shifted resonances have been measured for the C-F stretching fundamental $\left(\nu_{3}\right)$ of FCN near $9.3 \mathrm{\mu m}$, and for two nearby "hot" bands. The band centers measured are $1076.492007 \pm 0.000013 \mathrm{~cm}^{-1}$ for $00^{0} 1-00^{\circ} 0$, $1085.741046 \pm 0.000050 \mathrm{~cm}^{-1}$ for $01^{1} 1-0{ }^{1} 0$, and 1091.16222 $\pm 0.00015 \mathrm{~cm}^{-1}$ for $02^{\circ} 1-02^{\circ} 0$. The ground state dipole moment of FCN is found to be $2.1203 \pm 0.0010 \mathrm{D}$ and dipole moments are also given for the other states observed. Values are given for the rotational constant and $l$-doubling constant for the $01^{1} 1$ state.

17125. Kranbuehl, D. E., Verdier, P. H., Relaxation of the aspherical shapes of random-coil polymer chains, $J$. Chem. Phys. 67, No. 1, 361-365'(July 1, 1977).

Key words: excluded volume; Monte Carlo; polymer chain dynamics; random coil; random flight chain; relaxation times.

The conformations of random-coil polymer chains are known to be appreciably more aspherical than might have been expected intuitively. However, this instantaneous asphericity will only affect the measured physical properties of flexible chains in solution if the relaxation of the asphericity requires a time longer than the inherent sampling time of the experiment. It is therefore important, in the analysis of phenomena which depend upon chain shape, to know the time scale over which deviations from spherical symmetry persist. In this paper we extend our previous work on the relaxation of asphericity in chains without excluded volume interactions and present corresponding results for chains with excluded volume. Autocor- 
relation functions for the radius of gyration squared, its principal components, and the moments of inertia are determined using a dynamical model for linear polymer chains which simulates excluded volume effects. The results suggest that the asphericity of a random-flight chain is increased by the introduction of excluded volume interactions, and that the segment distribution will appear spherically symmetric only when it is averaged over a time comparable with or longer than the longest times in the relaxation-time spectrum of the chain.

17126. Dickson, G., Development of physical and mechanical testing, (Proc. 100th Anniversary Prog. in Dental Materials, Ann Arbor, MI, Oct. 1, 1975), Chapter 3 in Dental Materials Review, R. G. Craig, Ed., pp. 29-50 (University of Michigan Press, Ann Arbor, MI, 1977).

Key words: dental amalgam; dental materials; development of testing procedures; mechanical properties; physical properties; specification testing; testing of dental materials.

Instrumentation and experimental procedures used for determination of the physical and mechanical properties of dental materials have changed greatly in the past 100 years, but intelligent researchers 100 years ago were asking some of the same questions about the characteristics of their materials that are being asked today. Today there is a background of accumulated knowledge of dental materials and service conditions and a relationship with an extensive materials science that permit the questions to be asked more precisely. Technology is available for applying mechanical forces or other forms of excitation to materials in a more precise fashion, to measure the responses of the materials more accurately, and to analyze the data more rapidly and more completely than could the early researchers. Future developments in physical and mechanical testing for determination of basic properties and for evaluation of dental materials depend upon the advancement of this technology, but even more so upon the soundness of the physical principles and the attention to clinical relevance with which the technology is applied to dental problems.

17127. Davis, H., Piston gauge weight handler, Rev. Sci. Instrum. 48, No. 9, 1220-1221 (Sept. 1977).

Key words: gas compressibility factor; piston gauge weights; weight handler.

An electromechanical hydraulic lift has been developed and subsequently used to load and unload weight stacks from precision piston gauges without affecting the reliability or the operation of these gauges.

17128. Chen, S. T., Gallagher, A., Electron excitation of thallium $7^{2} S_{1 / 2}$ and $6^{2} D_{3 / 2,5 / 2}$ levels, Phys. Rev. $A$ 15, No. 3, 888 895 (Mar. 1977).

Key words: electron excitation; thalliurm.

We have measured the relative optical excitation functions of the $3776-\AA \quad\left(7^{2} S_{1 / 2} \rightarrow 6^{2} P_{1 / 2}\right), 2768-\AA \quad\left(6^{2} D_{3 / 2} \rightarrow 6^{2} P_{1 / 2}\right), 3529-\AA$ $\left(6^{2} D_{3 / 2} \rightarrow 6^{2} P_{3 / 2}\right)$, and $3519-\AA \quad\left(6^{2} D_{5 / 2} \rightarrow 6^{2} P_{3 / 2}\right)$ lines, and the polarization function of the $2768-\AA$ line, using crossed beams of electrons and thallium atoms, for electron energies from thresholds to $1500 \mathrm{eV}$. The electron energy resolution was $0.3 \mathrm{eV}$ for energies below $13 \mathrm{eV}$, and the atom beam was optically thin. By normalizing the resonance-line excitation functions to Born theory in the high-energy limit the $7^{2} S_{1 / 2}, 6^{2} D_{3 / 2}$, and $6^{2} D_{3 / 2}$ level-excitation cross sections are obtained. The $7^{2} S_{1 / 2}$-level excitation function rises very rapidly immediately above threshold, while the $6^{2} D_{3 / 2}$ level rises much more slowly. The $2768-\AA$ polarization function shows strong resonance at a few electron volts above the threshold. The $6^{2} D_{5 / 2}$ level excitation function peaks at lower energy as expected for a dipoleforbidden transition, but shows a small $E^{-1} \log _{10} E$ behavior at the high-energy limit.
17129. Leone, S. R., Kosnik, K. G., A tunable visible and ultraviolet laser on $\mathrm{S}_{2}\left(B^{3} \Sigma_{u}-X^{3} \Sigma_{p}{ }^{-}\right)$, Appl. Phys. Lett. 30, No. 7, 346-348 (Apr. 1, 1977).

Key words: gas laser; optical pumping; sulfur dimer; tunable laser; visible-ultraviolet laser.

Laser action has been achieved on the $B^{3} \Sigma_{u}{ }^{-}-X^{3} \Sigma_{g}{ }^{-}$transition of $S_{2}$ by optical pumping with a frequency-doubled dye laser and a nitrogen laser. The observed lasing is line tunable from 365 to $570 \mathrm{~nm}$. The $S_{2}$ molecule is a promising candidate for an efficient scalable ultraviolet laser system.

17130. Bakos, J. S., AC Stark effect and multiphoton processes in atoms, Physics Reports (Sec. C Physics Lett.) 31, No. 3, 209-235 (1977).

Key words: atomic spectra; electromagnetism; laser, highintensity; multiphoton absorption; optical interactions.

The strong light field of a laser induces multiphoton processes in atoms. Simultaneously, this light field causes distortion of the atomic spectra-it shifts, splits, and broadens the levels. These phenomena have to be taken into account in interpreting experimental results of multiphoton processes. The basic phenomenon of level distortion in a light field is reviewed and the effects caused by the level distortions in some multiphoton processes is discussed.

17131. Olson, W. B., Lovejoy, R. W., The infrared spectrum of the $\nu_{1}$ and $\nu_{4}$ bands of ${ }^{28} \mathrm{SiH}_{3} \mathrm{D}, \mathrm{J}$. Mol. Spectrosc. 66, 314330 (1977).

Key words: high resolution; infrared spectrum; monodeutero silane; SiH stretching vibrations; vibration-rotation interaction.

The spectrum of the $\nu_{1}$ and $\nu_{4} \mathrm{SiH}$ stretching bands of ${ }^{28} \mathrm{SiH}_{3} \mathrm{D}$ have been recorded and analyzed. The degenerate stretching mode is at $2188.504 \mathrm{~cm}^{-1}$, only $1.103 \mathrm{~cm}^{-1}$ above the symmetric stretching mode. Several accidental and essential resonances affect these bands but all have been successfully analyzed by diagonalization of the secular determinant complete through the second order of the transformed Hamiltonian. One accidental resonance leads to a number of forbidden transitions through which a value of the rotational constant $A_{0}$ has been obtained.

17132. Hayes, M. A., Norcross, D. W., Mann, J. B., Robb, W. D., Electron impact excitation of $\mathrm{Be}^{+}$: A benchmark study, $J$. Phys. B: Atom. Molec. Phys. Lett. 10, No. 11, L429-L434 (1977).

Key words: $\mathrm{Be}^{+}$; electron collisions; excitation.

Calculations of the cross section for excitation of the $2 p$ state of $\mathrm{Be}^{+}$, and for the polarization of the emitted radiation, have been performed using Coulomb-Born and close-coupling approximations. The results are compared with recent absolute measurements.

17133. Chapman, C., How to stop worrying and love benefit/cost analysis, Std. Eng. 29, No. 3, 54-56 (June 1977).

Key words: benefit/cost; building standards; cost/effectiveness; economics; safety standard; standards.

Economic analysis is useful in justifying standards efforts, setting priorities for standards work, and making decisions about specific standards. In using economic analysis, some basic laws should be kept in mind: (1) There is no free lunch; (2) There's always something you forgot; and (3) Money is a common measure of (almost) everything. This paper shows how to apply these and some other concepts to standards related problems. It gives hypothetical examples concerning mo- 
bile home fire safety standards and effluent measurement methods, and real examples from work by economists in the NBS Center for Building Technology. The CBT projects involve energy conservation in buildings, reduced sized venting, and ground fault circuit interrupters.

17134. Fickett, F. R., Controlled thermonuclear reactors. A prospective large-scale use of pure copper, INCRA Research Report, 44 pages (International Copper Research Association, New York, NY, Aug. 1976).

Key words: copper; cryogenic; fusion; magnets; superconductivity; thermonuclear.

The prospect of Controlled Thermonuclear Reactor (CTR) power plants operating before the tum of the century is a very real possibility. The magnetic confinement for the plasma in these systems will, most likely, be provided by superconducting magnets stabilized with pure copper. The paper provides an introduction to the principles of controlled fusion, followed by a discussion of various magnetic confinement schemes. The U.S. program in CTR is outlined in some detail and a tabular summary of the foreign effort is provided. The amounts and types of copper employed in the proposed power plant designs is given, as is a discussion of the data necessary for optimum design of the magnets.

17135. Fickett, F. R., A preliminary investigation of the behavior of high purity copper in high magnetic fields, Annual Report INCRA No. 186B, 55 pages (International Copper Research Association, New York, NY, Aug. 1974).

Key words: alloys; copper; electrical resistivity; iron; low temperature; susceptibility.

Measurements are reported on dilute copper iron alloys. The concentrations range from $1-1000$ atomic parts per million. The electrical resistivity and magnetic susceptibility of the specimens were measured at $4 \mathrm{~K}$. Also reported is an attempt at magnetic separation of iron impurities from molten copper.

17136. Haar, L., Powell, G., Klein, M., Wardell, J., Wilmot, G., A theoretical model for the equation of state for the system carbon dioxide and water, Proc. 13th JANNAF Combustion Meeting, Monterey, CA, Sept. 13-17, 1976, I, 199-212 (Naval Plant Representative, Naval Plant Representative Office, Laurel, MD, 1976).

Key words: ballistics; carbon dioxide; combustion gases; energy; equation of state; high pressure; high temperature; interaction virial coefficients; mixtures; molecular volumes; second virial coefficients; water.

We report here on the real-gas equation of state for mixtures containing water and carbon-dioxide. Results for the compressibility factor are given for the pressure range $0 \leqslant P \leqslant 10,000$ bar, and for values of temperature $850 \mathrm{~K} \leqslant \mathrm{~T} \leqslant 400 \mathrm{~K}$. The model is shown to be consistent with experimental data to within the accuracy of the data. The model is a logical extension of the theory for pure fluids, which was developed from a density expansion around a hard core equation of state. The parameters are well-defined physical quantities. These include the molecular volumes and the second virial coefficients for each of the interactions. Values for the second virial coefficients for the water-carbon-dioxide interaction were derived from the experimental mixture data, using the theoretical model and fitting the result to a Lennard-Jones 6-12 potential. We apply the results to assess the real-gas corrections to the thermodynamic properties for gun-propellant combustion gases.

17137. Siedle, A. R., Negas, T., Broussalian, J., Reactions of transition metal ions with the dithiotungstate(2-) ion, J. Inorg. Nucl. Chem. Notes 37, 2024-2025 (1975).
Key words: dithiotungstate; hydrolysis; infrared spectroscopy; rare earths; rare earth tungstate; tungstates; x-ray powder patterns.

The reaction between $\mathrm{Cr}^{+++}, \mathrm{Dy}^{+++}$or $\mathrm{Eu}^{+++}$with $\left(\mathrm{NH}_{4}\right)_{2} \mathrm{~W}$ $\mathrm{O}_{2} \mathrm{~S}_{2}$ in water leads to the formation of the corresponding transition metal tungstates $\mathrm{Cr}_{2}\left(\mathrm{WO}_{4}\right)_{3} \cdot 3 \mathrm{H}_{2} \mathrm{O}, \mathrm{Dy}_{2}\left(\mathrm{WO}_{4}\right)_{3} \cdot 6 \mathrm{H}_{2} \mathrm{O}$ and $\mathrm{Eu}_{2}\left(\mathrm{WO}_{4}\right)_{3} \cdot 17 \mathrm{H}_{2} \mathrm{O}$. On heating at $985^{\circ} \mathrm{C}, \mathrm{Cr}_{2}\left(\mathrm{WO}_{4}\right)_{3} \cdot 3 \mathrm{H}_{2} \mathrm{O}$ decomposes to $\mathrm{Cr}_{2} \mathrm{WO}_{6}$ and $\mathrm{WO}_{3}$ while the rare earth tungstate hydrates lost water without decomposition.

17138. Robertson, B., Potzick, J. E., Synchronous marker for measuring phase in the presence of noise, Rev. Sci. Instrum. 48, No. 10, 1290-1294 (Oct. 1977).

Key words: narrow pass filter; phase measurement; phase of noisy sinusoid; phase sensitive detector; synchronous detector; synchronous phase marker circuit.

A circuit has been constructed to mark the phase of a sinusoidal signal even when it is obscured by noise. The time jitter of the marker signal due to the noise can be reduced as much as desired in trade for slowed response time of the circuit. A theoretical description of the performance of the circuit and an error analysis are presented. Results of tests on the circuit agree approximately with the theoretical description.

17139. Ehrstein, J. R., Effect of specimen preparation on the calibration and interpretation of spreading resistance measurements, (Proc. Third Int. Symp. on Silicon Materials Science and Technology, Philadelphia, PA, May 9-13, 1977), Paper in Semiconductor Silicon 1977, H. R. Huff and E. Sirtl, Eds., 77-2, 377-386 (Electrochemical Society, Inc., Princeton, NJ, 1977).

Key words: metal-semiconductor contacts; resistivity; semiconductors; silicon; silicon polishing; spreading resistance calibration; spreading resistance measurements.

Spreading resistance is related to, but is not directly a measure of, specimen resistivity. When interpreting such data, the effect of resistivity gradients with depth can be accounted for by the use of various published correction factors, as appropriate. Direct consideration of the effect of contact material, load, and other less tangible parameters on metal-semiconductor barrier phenomena is circumvented by resorting to empirical calibration of spreading resistance on specimens of known resistivity. The form of the calibration relation depends on specimen crystal orientation, conductivity type, and surface preparation as well as on probe material, contact size, and load. This work is a study of the effect of surface preparation on the spreading resistance calibration of several principal combinations of silicon conductivity type and crystal orientation, and is done for several different probe materials at a single probe load. Results show that the effect which surface preparation has on spreading resistance measurements is clearly a function of the type of silicon considered. Results also indicate that certain probe dependences also exist at the moderate probe load used.

17140. Bullis, W. M., Vieweg-Gutberlet, F. G., Current trends in silicon characterization techniques, (Proc. Third Int. Symp. on Silicon Materials Science and Technology, Philadelphia, PA, May 9-13, 1977), Paper in Semiconductor Silicon 1977, H. R. Huff and E. Sirtl, Eds., 77-2, 360-366 (Electrochemical Society, lnc., Princeton, NJ, 1977).

Key words: chemical measurements; electrical measurements; electronics; profiling; silicon; trace analysis.

Good metrology is a critical factor both in the understanding of silicon material properties and in the design and production of silicon devices. Consequently, the semiconductor electronics field is at the forefront of a number of metrological areas, and 
advanced measurement techniques have been developed along with materials, processing, and device improvements. This introductory review provides a brief overview of recent developments in the multiplicity of electrical and physical analysis techniques available for characterizing silicon and places into a broader context those topics which are discussed in greater detail in the following papers.

17141. Hodgeson, J. A., How well can we measure significant deterioration of air quality, Proc. ASME Air Pollution Control Division Fifth Natl. Symp. Preventing Significant Deterioration: What Does It Mean? What Are Its Impacts? Pittsburgh, PA, May 11-12, 1977, pp. 30-45 (1977).

Key words: air quality; deterioration; measurements; particulates; regulations; sulfur dioxide.

Current reference methods for ambient sulfur dioxide $\left(\mathrm{SO}_{2}\right)$ and particulates are limited in their ability to measure the small incrémental increases in these pollutants allowed by Significant Deterioration regulations. The Pararosaniline Method for $\mathrm{SO}_{2}$ has inadequate sensitivity and the High-Volume Particulate Method gives misleading results in remote areas where windblown dusts are prevalent. Advanced methods which overcome these limitations are discussed.

17142. Olver, F. W. J., Connection formulas for second-order differential equations having an arbitrary number of turning points of arbitrary multiplicities, SIAM J. Math. Anal. 8, No. 4, 673-700 (Aug. 1977).

Key words: connection formulas; eigenvalue problems; Liouville-Green approximation; potential barrier; potential well; turning points; Whittaker functions; WKBJ approximation.

Consider the differential equation

$$
d^{2} w / d x^{2}=\left\{u^{2} f(x)+g(x)\right\} w, x \in(a, b),
$$

in which $(a, b)$ is a finite or infinite open interval, $u$ is a positive parameter, $f(x)$ is real and twice continuously differentiable, and $g(x)$ is continuous. It is well known that in any subinterval of $(a, b)$ not containing a turning point, that is, a zero of $f(x)$, uniform asymptotic solutions for large $u$ can be constructed in terms of the so-called Liouville-Green or WKBJ functions:

$$
f^{-1 / 4}(x) \exp \left\{ \pm u \int f^{1 / 2}(x) d x\right\} .
$$

If $(a, b)$ contains turning points, then differing combinations of the Liouville-Green functions have to be used in subintervals that are separated by a turning point in order to represent the same solution.

This paper solves the general problem of connecting the Liouville-Green approximations throughout the interval $(a, b)$ for any number of turning points of arbitrary multiplicities. Several illustrative examples are given, including an arbitrary number of turning points of even multiplicity, an arbitrary number of turning points of odd multiplicity, an eigenvalue problem involving four turning points of multiplicities $1,2,3$, and 4 , and a problem with two simple turning points and one multiple turning point that is solvable exactly in terms of Whittaker functions.

17143. Holt, H. K., Gain without population inversion in twoIevel atoms, Phys. Rev. A 16, No. 3, 1136-1 140 (Sept. 1977).

Key words: atoms; gain; population inversion; recoil.

For the case in which laser radiation interacts with two levels of an atom, it is shown that the re can be gain, even when there is no population inversion, because of recoil effects. The effect of recoil on certain precision measurements is also shown.
17144. Siedle, A. R., Activation of molecular hydrogen by a nido-metalloborane, J. Organometal. Chem. 97, C4-C6 (1975).

Key words: boron hydride; hydrogen; iridium; isotope exchange; metalloborane; oxidative addition.

Reaction of quaternary ammonium salts of $\left[\left(\mathrm{B}_{10}^{-} \mathrm{H}_{12}^{-}\right)\right.$ $\left.\operatorname{Ir}(\mathrm{CO})\left(\mathrm{PPh}_{3}\right)_{2}\right]^{-}$in dichloroethane with dideuterium at ambient temperature and pressure leads to reversible $\mathbf{H}-\mathbf{D}$ exchange at two terminal $\mathrm{B}-\mathrm{H}$ sites in the $\mathrm{B}_{10} \mathrm{H}_{12}$ ligand. Exchange is thought to occur at the 5-10 boron atoms.

17145. Burnett, E. D., Schweitzer, H. C., Attack and release times of automatic-gain-control hearing aids, J. Acoust. Soc. Am. 62, No. 3, 784-786 (Sept. 1977).

Key words: attack and release times; automatic gain control; compression; hearing aids.

The attack and release times were measured on each of three samples of 27 different models of compression-type hearing aids using the test conditions specified in ANSI Standard S322 (1976). The results indicate that almost all of the hearing aids tested have attack times less than or equal to $10 \mathrm{~ms}$. A little more than half of the hearing aids had release times of $50 \mathrm{~ms}$ or less. The range of the attack times varied from 1 to $23 \mathrm{~ms}$ and the release times from 5-600 ms.

17146. Botter, R., Pechine, J. M., Rosenstock, H. M., Photoionization of dimethyl ether and diethyl ether, Int. J. Mass Spectrom. Ion Phys. 25, 7-25 (1977).

Key words: appearance potential; diethyl ether; dimethyl ether; ionization potential; photoionization.

The ionization and fragmentation of dimethyl and diethyl ether have been studied by means of photoionization at room temperature and low temperature. The parent ion thresholds show evidence of hot band effects, and the adiabatic ionization potentials have been determined to be $10.01 \cdot \pm 0.01 \mathrm{eV}$ for dimethyl ether and $9.60 \pm 0.01 \mathrm{eV}$ for diethyl ether. The temperature dependence of thresholds for the primary fragmentation processes in both molecules can be accounted for by rotational and vibrational hot band effects. Heats of formation at absolute zero have been obtained for the species $\mathrm{CH}_{3} \mathrm{O}=\mathrm{CH}_{2}{ }^{+}$, $\mathrm{CH}_{3} \mathrm{CH}_{2} \mathrm{O}=\mathrm{CHCH}_{3}{ }^{+}$and $\mathrm{CH}_{2}=\mathrm{OCH}_{2} \mathrm{CH}_{3}{ }^{+}$. Evidence is obtained for important contributions of autoionization to ionization and fragmentation at higher energies.

17147. Li, S. S., Thurber, W. R., The dopant density and temperature dependence of electron mobility and resistivity in $n$ type silicon, Solid-State Electron. 20, 609-616 (1977).

Key words: dopant density; electron-electron scattering; electron mobility; ionized impurity scattering; lattice scattering; neutral impurity scattering; $n$-type silicon; resistivity; temperature.

Traditional analysis of electron mobilicy in $n$-type silicon neglects the effect of electron-electron scattering in the mobility calculations. As a result, theory fails to conform with experiment when dopant density exceeds $2 \times 10^{16} \mathrm{~cm}^{-3}$. In this work, an improved theoretical model for computing mobility and resistivity as functions of dopant density and temperature has been developed for $n$-type silicon. The model has been applied to phosphorus-doped silicon for dopant densities from $10^{13}$ to $10^{19} \mathrm{~cm}^{-3}$, and temperatures between 100 and $500 \mathrm{~K}$. The mobility was calculated analytically by appropriately combining lattice, ionized impurity and neutral impurity scattering contributions. The effect of electron-electron scattering was incorporated empirically for dopant densities greater than $2 \times 10^{16}$ $\mathrm{cm}^{-3}$. Additionally, the anisotropic scattering effect was in- 
cluded in the mobility formulations. Resistivity measurements on seven phosphorus-doped silicon wafers with dopant densities from $1.2 \times 10^{14}$ to $2.5 \times 10^{18} \mathrm{~cm}^{-3}$ were carried out for temperatures from 100 to $500 \mathrm{~K}$. Electron mobility at $300 \mathrm{~K}$ was deduced from resistivity and junction $C-V$ measurements for dopant densities from $10^{14}$ to $10^{18} \mathrm{~cm}^{-3}$. Agreement between theoretical calculations and experimental data for both electron mobility and resistivity of phosphorus-doped silicon was within \pm 7 percent in the range of dopant densities and temperatures studied.

17148. Stockbauer, R., A threshold photoelectron-photoion coincidence mass spectrometer for measuring ion kinetic energy release on fragmentation, Int. J. Mass Spectrom. Ion Phys. 25, 89-101 (1977).

Key words: acetone; coincidence; mass spectrometry; methane; photoionization; threshold photoelectron spectroscopy; time of flight mass spectrometry.

A threshold photoelectron-photoion coincidence mass spectrometer has been constructed to measure ion fragmentation and kinetic energy release on fragmentation as a function of the internal energy of the parent ion. The threshold photoelectron analysis uses a drift tube analyzer followed by a $127^{\circ}$ cylindrical plate analyzer for a nominal resolution of $20 \mathrm{meV}$. The ion mass and kinetic energy analysis uses a pulsed timeof-flight analyzer operated in a space focused mode. This insures that the spread in the flight time of ions of given mass is due primarily to the initial kinetic energy of the ion. The mass resolution is ca. 1 in 20 . To illustrate the potential of this instrument, results are presented for kinetic energy release as a function of internal energy for the fragmentation of acetone and methane ions.

17149. Kurylo, M. J., Flash photolysis resonance fluorescence investigation of the reaction of $\left.\mathbf{O}^{3} \mathrm{P}\right)$ atoms with $\mathrm{ClONO}_{2}$, Chem. Phys. Lett. 49, No. 3, 467-470 (Aug. 1, 1977).

Key words: chlorine nitrate; chlorofluorocarbons; oxygen atoms; rate constant; resonance fluorescence; stratosphere.

The flash photolysis resonance fluorescence technique has been used to measure the rate constant for the reaction of $\mathrm{O}\left({ }^{3} \mathrm{P}\right)$ atoms with $\mathrm{ClONO}_{2}$ at 10 torr total pressure over the temperature range $225-273 \mathrm{~K}$. The values obtained can be fit to the Arrhenius equation $k_{1}=(1.87 \pm 1.29) \times 10^{-12} \exp [-(692$ $\pm 167) / T] \mathrm{cm}^{3}$ molecule $\mathrm{s}^{-1}$. A composite Arrhenius expression is calculated from the combined results of the present study and a recent investigation by Molina et al. Because of the expanded data base this equation is considered more reliable and is recommended over the temperature range $213-295 \mathrm{~K}$ : $k_{1}=(3.03 \pm 1.56) \times 10^{-12} \exp [-(808 \pm 133) / T] \mathrm{cm}^{3}$ molecule ${ }^{-1} \mathrm{~s}^{-1}$. The uncertainties expressed are the standard deviations taken from a least squares analysis of the data and take into account the 95 percent confidence limits $( \pm 2 \sigma)$ of the individual points. Comparison of the loss rate for $\mathrm{ClONO}_{2}$ by oxygen atom reaction with the solar photolysis rate indicates that chemical reaction accounts for less than 15 percent of the $\mathrm{ClONO}_{2}$ removal at stratospheric altitudes between 20 and 30 km.

17150. Harman, G. G., The use of acoustic emission in a test for beam-lead, TAB, and hybrid chip capacitor bond integrity, IEEE. Trans. Parts, Hybrids, \&.Packaging PHP-13, No. 2, 116-127 (June 1977).

Key words: acoustic emission; automated tape bonding; beam lead devices; bugging height; microelectronics; nondestructive test.

The use of Acoustic Emission (AE) in a test for beam-lead bond and anchor integrity has been investigated. AE refers to the emission of broad-band stress waves when materials are broken, cracked, or deformed. A major problem in the present work was to develop means of nondestructively stressing the delicate, irregularly extending beam leads. The most promising of the methods developed are a silicone rubber (SR) pull test, a push down test on SR-encapsulated devices, and various probe methods of applying force to the beams without contacting the chip. AE bursts from weak bonds or beam anchors are detected with a substrate detector operating at $375 \mathrm{kHz}$ or a probe detector operating at $1.1 \mathrm{MHz}$ or both. The study has revealed considerable difference in the mechanical integrity of beam-lead bond-anchor systems. General deterioration of the beam-anchor system begins at pull forces per beam of approximately 1.0-2.5 gramsforce (gf), depending on the manufacturer's procedure. The forces applied to the beam-anchor system for all methods of stressing, except the pull test, are dependent upon the shape of the individual beams as they extend from the chip, as well as the uniformity of the bugging height. There are many other potential uses of $\mathrm{AE}$ in electronics, such as to insure the bonding integrity of flip chips, capacitor chips in hybrids, and bonds on tape automated bonded integrated circuits. The latter two uses were experimentally demonstrated in the present work. Thus it appears that AE will have an increasing role in assuring reliability in the microelectronics field.

17151. Krauss, M., The electronic structure of rare gas halide excimers, J. Chem. Phys. 67, No. 4, $1712-1719$ (Aug. 15, 1977).

Key words: dipole moment; excimer; excitation energy; perturbation formula; rare gas halide; Rittner model; transition moment.

The rare gas halide excimer states are analyzed in terms of an electrostatic model that includes mixing between the ionic excimer and neutral ground configurations. The energy splitting between the ${ }^{2} \Sigma$ and ${ }^{2} \Pi$ excimer states is strongly affected by this configuration mixing. A Rittner type energy expression is derived and parameterized for the $\mathrm{KrF}^{*}$ excimer energy curves, which are found in good agreement with the $a b$ initio curves of Dunning and Hay. Perturbation expressions are also derived for the dipole and transition moments of this system. The longrange formulas are compared with the available $a b$ initio literature. These expressions are then applied to a qualitative analysis of the transition moments of $\mathrm{KrF}^{*}$. The ${ }^{2} \Sigma^{+} \rightarrow{ }^{2} \Sigma^{+}$transition is found to be dominant, in agreement with the $a b$ initio results. The transition moment can actually be viewed as a small admixture of the large ionic dipole moment. Since the dipole moment varies as $R$ and the mixing coefficient as $\exp (-\alpha R)$, it is apparent that the transition moment will vary rapidly as a function of $R$ and also of the vibrational quantum number.

17152. Siedle, A. R., Dicarbollide complexes of rhodium and ruthenium, J. Organometal. Chem. 90, 249-256 (1975).

Key words: boron hydride; carborane; dicarbollide; metalloborane; metallocarborane; rhodium; ruthenium.

The 7,8- $\mathrm{B}_{9} \mathrm{C}_{2} \mathrm{H}_{11}{ }^{2-}$ ion reacts with $\left(\mathrm{Ph}_{3} \mathrm{P}\right)_{2} \mathrm{Rh}(\mathrm{CO}) \mathrm{Cl}$ to form $\left(\mathrm{B}_{9} \mathrm{C}_{2} \mathrm{H}_{11}\right)-\mathrm{Rh}(\mathrm{Cl})\left(\mathrm{Ph}_{3} \mathrm{P}\right)_{2}$. This rhodacarborane reacts with $\mathrm{NaBPh}_{4}$ to produce $\left(\mathrm{B}_{9} \mathrm{C}_{2} \mathrm{H}_{11}\right)-\mathrm{Rh}\left(\mathrm{Ph}_{3} \mathrm{P}\right)\left(\mathrm{Ph}_{4} \mathrm{~B}\right)$. The new metallocarboranes $\left[\left(\mathrm{B}_{9} \mathrm{C}_{2} \mathrm{H}_{11}\right) \mathrm{Rh}\left(\mathrm{Ph}_{3} \mathrm{P}\right)\left(\mathrm{C}_{6} \mathrm{H}_{6}\right)\right]_{2}$ and $\left(\mathrm{B}_{9} \mathrm{C}_{2} \mathrm{H}_{11}\right)$ $\mathrm{Rh}(\mathrm{H})\left(\mathrm{Ph}_{3} \mathrm{P}\right)$ were obtained from the reaction of $\mathrm{B}_{9} \mathrm{C}_{2} \mathrm{H}_{11}{ }^{2-}$ and (Phs $)_{3}$ RhCl. The ruthenacarboranes $\left(\overline{\mathrm{B}}_{9} \mathrm{C}_{2} \mathrm{H}_{11}\right)$ $\mathrm{Ru}(\mathrm{CO})\left(\mathrm{Ph}_{3} \mathrm{P}\right)_{2}$ and $\left(\mathrm{B}_{9} \mathrm{C}_{2} \mathrm{H}_{11}\right)-\mathrm{Ru}(\mathrm{CO})_{3} \cdot 0.5 \mathrm{C}_{6} \mathrm{H}_{6}$ were prepared from $\left(\mathrm{Ph}_{3} \mathrm{P}\right)_{2} \mathrm{Ru}(\mathrm{CO})_{2} \mathrm{Cl}_{2}$ and $\left[\mathrm{Ru}(\mathrm{CO})_{3} \mathrm{Cl}_{2}\right]_{2}$ respectively.

17153. Siedle, A. R., Oxidation of organometallic compounds with tetracyanoquinodimethan, J. Am. Chem. Soc. 97, 5931 (1975). 
Key words: chromium; infrared spectroscopy; magnetic susceptibility; molybdenum; tetracyanoquinodimethan; $\mathrm{x}$ ray photoelectron spectroscopy.

Reaction of $\left(\mathrm{CH}_{3} \mathrm{C}_{6} \mathrm{H}_{5}\right) \mathrm{Cr}(\mathrm{CO})_{3}$ and $\left(\mathrm{C}_{7} \mathrm{H}_{8}\right) \mathrm{Mo}(\mathrm{CO})_{4}$ with tetracyanoquinodimethan ( $\mathrm{TCNQ}$ ) leads to $\mathrm{Cr}\left(\mathrm{CH}_{3} \mathrm{CN}\right)_{2}$ $(\mathrm{TCNQ})_{2}$ and $\mathrm{Mo}(\mathrm{CO})_{2}\left(\mathrm{CH}_{3} \mathrm{CN}\right)_{2}$ (TCNQ) respectively in acetonitrile solvent. These materials are formulated as derivatives of the TCNQ dianion.

17154. Siedle, A. R., Johannesen, R. B., Reduction of the 1,3dithiolium cation with hexacarbonylvanadate(1-), J. Organ. Chem. 40, 2002 (1975).

Key words: coupling constants; hexacarbonylvanadate( $1-)$; NMR spectroscopy; reduction; $\mathrm{V}(\mathrm{CO})_{6}{ }_{6}^{-;}$1,3-dithiolium ion; 2,2'-bi( 1,3-dithiolyl).

Reductive coupling of the 1,3-dithiolium cation with sodium hexacarbonylvanadate(1-) afforded 2,2'-bi(1,3-dithiolyl). This dimer was characterized by ${ }^{13} \mathrm{C}$ and ${ }^{1} \mathrm{H}$ NMR spectroscopy.

17155. Brinckman, F. E., Parris, G. E., Blair, W. R., Jewett, K. L., Iverson, W. P., Bellama, J. M., Questions concerning environmental mobility of arsenic: Needs for a chemical data base and means for speciation of trace organoarsenicals, Environ. Health Perspec. 19, 11-24 (Aug. 1977).

Key words: analysis; aqueous chemistry; arsenic; atomic absorption spectrophotometry; biomethylation; electrochemistry; environment; gas chromatography; laserRaman; liquid chromatography; nuclear magnetic resonance; organoarsenic.

Biomethylation of metals, including arsenic, apparently occurs as a global process. Health control strategies therefore depend on accurate analysis of arsenic's environmental mobility. Determining to what extent biotransformations occur and how resultant organometal(loids) are sequestered in food chains requires sophistication beyond present-day total element determinations. Rather, active molecular forms of arsenic must be speciated for each environmental compartment, and it is necessary to quantify the dynamics of arsenic's mobility. Thus, new chemical facts are needed yielding rates of methylation or dimethylation of arsenic; partition coefficients of organoarsenicals between air, water, and organic phases; and arsenic redox chemistry in polar media. NBS research in this context is reviewed with examples of recent results emphasizing speciation methodology. Topic areas discussed are: the nature of aquated methylarsenic species (NMR and laser-Raman spectroscopy); transport of methylarsenicals from aqueous media (gas chromatography-graphite furnace AA detection applied to metabolic $\mathrm{Me}_{3} \mathrm{As}$ formation); and speciation of involatile organoarsenicals in aqueous media (demonstration of HPLC utilizing element-specific AA detection and appraisal of electrochemical detectors).

17156. Newbury, D. E., lon imaging in secondary ion mass spectrometry, (Proc. Society of Photo-Optical Instrumentation Engineers, Reston, VA, Apr. 18-21, 1977), Paper in Multidisciplinary Microscopy, R. L. Whitman, Ed., SPIE 104, 85-89 (1977).

Key words: ion imaging; ion microprobe; ion microscope; microanalysis; secondary ion mass spectrometry; surface analysis.

Secondary ion mass spectrometry (SIMS) is a surface analysis technique involving ion induced sputtering of a sample followed by mass spectrometry of the charged fraction of the emitted atoms. All elements and isotopes can be detected. Detectability limits range down to the parts per million level and quantitative analysis is possible by either empirical techniques or techniques based on physical models of secondary ion emission. Both surface and microanalysis can be carried out by SIMS. lon images can be prepared by either the ion microscope (direct imaging) or the ion microprobe (scanning and image mapping). Limiting resolutions are of the order of one micrometer. Ion images showing the distribution of intensities of elements and certain molecules can be obtained. Applications of ion imaging to the study of a copper beryllium alloy, a geological sample, and electronic materials are considered.

17157. Haber, S., The tanh rule for numerical integration, SIAM J. Numer. Anal. 14, No: 4, 668-685 (Sept. 1977).

Key words: Hardy space; numerical integration; numerical quadrature; piecewise analytic functions; quadrature; rational approximation; tanh rule; trapezoid rule.

The tanh rule for numerical integration is analyzed in the context of the Hardy space $H^{2}$. The optimal parameter choice is determined, and it is shown that the norm of the error functional is asymptotic to $C \exp (-(\pi / 2) \vee \bar{M})$, where $M$ is the number of points used and $C$ is a certain constant. The result is related to recent theorems on approximation of piecewise analytic functions by rational functions.

17158. Schneider, S. J., Jr., Materials research for clean utilization of coal: Quarterly progress report, Apr. 1-June 30, 1976, Energy Research and Development Administration FE-1749-8, 73 pages (Available from the National Technical Information Service, Springfield, VA, 1976).

Key words: ceramic corrosion; ceramic erosion; ceramic fracture; chemical degradation; coal gasification material; failure avoidance; metal corrosion; metal erosion; vaporization processes.

This progress report covers work on metal corrosion, metal erosion, ceramic deformation, fracture, erosion, and chemical degradation as related to coal gasification systems. This report also covers the failure avoidance program for ERDA coal conversion pilot plants.

17159. Schneider, S. J., Jr., Materials research for clean utilization of coal: Quarterly progress report, July 1-Sept. 30, 1976, Energy Research and Development Administration FE-3800-9, 32 pages (Available from the National Technical Information Service, Springfield, VA, 1976).

Key words: ceramic corrosion; ceramic erosion; ceramic fracture; chemical degradation; coal gasification material; failure avoidance; metal corrosion; metal erosion; vaporization processes

This progress report covers work on metal corrosion, metal erosion, ceramic deformation, fracture, erosion, and chemical degradation as related to coal gasification systems. This report also covers the failure avoidance program for ERDA coal conversion pilot plants.

17160. Hosler, W. R., Ed., The joint U.S.-U.S.S.R. test of the U.S. MHD electrode system in the U-02 MHD facility (Phase 1), Energy Research and Development Administration Final Report, ERDA-76//54, 262 pages (Available from the National Technical Information Service, Springfield, VA, 1976).

Key words: ceria; materials characterization; MHD(magnetohydrodynamics); power generation; testing; U.S.-U.S.S.R. cooperative program.

This report was jointly prepared for the Energy Research and Development Administration by the Battelle Pacific Northwest Laboratory, the National Bureau of Standards, the Westinghouse Research and Development Laboratory and the U.S.S.R. Institute of High Temperatures. The report presents 
the results of the first joint U.S.-U.S.S.R. test of U.S. MHD electrode materials in the U.S.S.R. U-02 MHD Facility. The electrode walls were designed and built by the Westinghouse Research and Development Laboratory.

The joint test was conducted in implementation of the understanding regarding open-cycle MHD cooperation reached between representatives of the U.S. and U.S.S.R. Joint Working Group for Energy held in Moscow, October 6, 1972, and endorsed as a cooperative program by the U.S.-U.S.S.R. Joint Committee for Scientific and Technical Cooperation at its meeting in Washington, D.C., March 21, 1973. Work on the program was affirmed by the U.S.-U.S.S.R. Joint Committee on Energy at its October 3-4, 1974 meeting in Washington, D.C.

17161. Ward, J., Cooper, J., Smith, E. W., Correlation effects in the theory of combined Doppler and pressure broadening-I. Classical theory, J. Quant. Spectrosc. Radiat. Transfer 14, 555-590 (1974)

Key words: analysis of correlated profiles; classical theory; Doppler broadening; one perturber limit; pressure broadening.

A classical Fourier amplitude theory of combined Doppler and pressure broadening in the impact approximation is developed which treats phase changes due to translation and collision on an equal basis. Radiator motion is accounted for properly by including speed dependence in the collision frequency and velocity dependence in the distribution function for phase shifts and final velocities as the result of a collision. The resulting theory is shown to be equivalent to a previous kinetic equation formulation of the problem. The one-perturber and classical analogue of the quantum one-interacting-level approximations are derived. In the latter case, a simple expression for the line shape in terms of speed dependent width and shift functions is obtained without approximation. Correlation effects are investigated by means of model speed dependent width and shift functions calculated for an inverse power interaction using straight line trajectories. The model shows no departure from a Voigt profile for the $r^{-3}$ interaction and for the $r^{-6}$ and $r^{-12}$ interactions the resulting profile is narrower in the core than the Voigt and in general asymmetric. Analysis of correlated profiles as Voigt profiles is shown under some conditions to lead to nonlinear density dependence in the width and shifts resulting in extrapolation anomalies and to significant errors in temperatures inferred from Doppler widths. Results are compared with previous work.

17162. Brennan, J. A., LaBrecque, J. F., Kneebone, C. H., Progress report on cryogenic flowmetering at the National Bureau of Standards, Proc. First Biennial Symp. Instrumentation in the Cryogenic Industry, Houston, TX, Oct. II-l4, 1976, 1, 621-1-621-16 (Instrument Society of America, Pittsburgh, PA, 1976).

Key words: liquid argon; liquid nitrogen; liquid oxygen; LNG; measurement; transfer standards.

Three years experience with cryogenic flowmeter transfer standards is reviewed with emphasis on their long term stability. Some statistically significant trends are identified and analyzed. Results of some brief flowmeter tests in liquid argon and liquid oxygen are also presented. Some early results from an LNG flowmetering program are also included.

17163. Moulder, J. C., Clark, A. F., Luminescence in metal flames irradiated with a $\mathrm{CO}_{2}$ laser, Chem. Phys. Lett. 49, No. 3, $471-474$ (Aug. 1, 1977).

Key words: calcium; $\mathrm{CO}_{2}$ laser; luminescence; magnesium; metal flames.
Rapid-scan spectrometry of calcium and magnesium flames ignited in air with a $\mathrm{CO}_{2}$ laser reveals luminescence excited by heterogeneous reactions on condensed metal oxide particles. The luminescence is stimulated by laser radiation. An explanation for this effect is proposed.

17164. Sawyer, D. E., Berning, D. W., Lewis, D. C., Laser scanning of active integrated circuits and discrete semiconductor devices, Solid State Teclinol., pp. 37-41, 48 (June 1977).

Key words: active devices; internal logic identification; laser scanning; logic flow identification; LSI testing; nondestructive tests; nonlinear region mapping; temperature mapping.

The device laser scanning work conducted in the Electronic Technology Division of the National Bureau of Standards (NBS) is described. The scanner constructed at NBS is sketched briefly; this is followed by illustrations demonstrating its usefulness for determining on a point-by-point basis the inner workings of active semiconductor devices. The scanner is non-damaging to all devices tried and it has been used to map d.c. and high-frequency gain variations in transistors, reveal areas of the device operating in a nonlinear manner, electronically map temperatures within devices, determine internal logic states in IC's and selectively change these states at will. It has also been used to perform hitherto impossible measurements on flip-chip bonded devices, that is, seeing the circuit electrical operation and the metallization pattern through the back side of the chip. Applications to other structures and devices including solar cells are suggested.

17165. David, J. M., Buehler, M. G., A numerical analysis of various cross sheet resistor test structures, Solid-State Electron. 20, No. 6, 539-543 (1977).

Key words: cross test structure; cross van der Pauw; numerical analysis; sheet resistance; sheet resistor test structure; test structures; van der Pauw.

Various four-terminal cross sheet resistor test structures were analyzed to determine the effect of the contact arm width and length on the measured sheet resistance. A nine-point finite difference approximation to the Laplace equation was used with a six-resistor equivalent circuit to solve for the sheet resistance measurement error. The error indicates the difference between the true sheet resistance and the sheet resistance calculated from the van der Pauw formula. The analysis demonstrates that many novel designs are possible. In particular, the Greek-cross sheet resistor is a valid van der Pauw test structure if the arm length is greater than the arm width. This test structure is important in that it allows the accurate measurement of the sheet resistance of a very small region whose width is limited only by the fabrication technology.

17166. Kirklin, D. R., Ritter, J. J., Abramowitz, S., Vibrational spectra and barrier to internal rotation of $\mathrm{BCl}_{2} \mathrm{SH}$ and $\mathbf{B C l}_{2} \mathrm{SD}$, J. Mol. Spectrosc. 67, 322-335 (1977).

Key words: $\mathrm{BCl}_{2} \mathrm{SD} ; \mathrm{BCl}_{2} \mathrm{SH}$; hindered rotation; infrared spectra; Raman spectra; vibrational analysis.

Recent interest in $\mathrm{SH}(\mathrm{D})$ derivatives of $\mathrm{BCl}_{3}$ prompted a vibrational study of $\mathrm{BCl}_{2} \mathrm{SH}$ and $\mathrm{BCl}_{2} \mathrm{SD}$. Raman spectra of the liquid and gas phases were recorded from 100 to $2700 \mathrm{~cm}^{-1}$. Infrared spectra of the vapors were recorded from 200 to 2700 $\mathrm{cm}^{-1}$. All nine fundamentals were observed and assigned for both molecules. The observation of seven polarized and two depolarized Raman bands confirms the planar configuration. The infrared vapor spectra shows the fundamental and three hot bands of the SH(D) torsional vibration. A comparison of our spectral results with an earlier study is presènted. The structure of the infrared torsional band allowed calculation of 
the barrier to internal rotation. Barrier values of 11.8 and 12.4 $\mathrm{kcal} / \mathrm{mole}$ were calculated for the protonated and deuterated molecules, respectively, utilizing the $V=\left(V_{2} / 2\right)(1-\cos 2 \phi)$ potential. Potential barrier values of 10.2 and $9.9 \mathrm{kcal} / \mathrm{mole}$ were obtained with the quartic potential, $V=A\left(z^{4}+B z^{2}\right)$. The two different potential barrier calculations afforded an evaluation of the choice of potentials for double minimum systems with high barriers. A barrier of about $11 \pm 3 \mathrm{kcal} / \mathrm{mole}$ is estimated for this species. Thermodynamic functions were also calculated.

17167. Barnard, A. J., Cooper, J., Smith, E. W., The broadening of He 1 lines including ion dynamic corrections, with application to $\lambda 4471 \AA$, J. Quant. Spectrosc. Radiat. Transfer 14, 1025-1077 (1974).

Key words: dynamic ion effects; forbidden lines; He I; $\lambda$ $4471 \AA$; Stark broadening.

A theory is developed for the broadening of $\mathrm{He} I$ lines with forbidden components which is valid at low densities (where the forbidden line is reasonably well isolated). This theory takes into account the effects of dynamic ion broadening. Application to $\lambda 4471 \AA$ gives good agreement with experiment and with a recent calculation of Lee; reasons for agreement with Lee are discussed in detail. Comprehensive tables for $4471 \AA$ are presented. These have been extended further into the line wings than previous tabulations. Static ion theory is found to be adequate for densities greater than $-5 \times 10^{15} \mathrm{~cm}^{-3}$. A simple numerical profile for allowed lines, taking into account dynamic ion effects, is also presented.

17168. Bowman, $R$. R., Some recent developments in the characterization and measurement of hazardous electromagnetic fields, Proc. Int. Symp. Biologic Effects and Health Hazards of Microwave Radiation, Oct. 15-18, 1973, Warsaw, Poland, pp. $217-227$ (1973).

Key words: electromagnetic fields; hazards; instrumentation; isotropic; measuring.

Exposure to hazardous electromagnetic fields often occurs in situations where the field has reactive near-field components, multipath components, and arbitrary polarization. The accurate measurement of such fields has been notoriously difficult yet must be made easily to provide adequate safety. Recently, several instruments have been developed that will measure the Hermitian magnitude $|E|$ of the electric component of complicated electromagnetic fields with extreme ease. Within their operating limits, the response of these instruments is essentially independent of angular orientation. The physics of the field sensors of these instruments is briefly discussed and the basic capabilities and limitations of each type of sensor are indicated.

17169. Eberly, J. H., Wodkiewicz, K., The time-dependent physical spectrum of light, J. Opt. Soc. Am. 67, No. 9, 12521260 (Sept. 1977).

Key words: coherence; correlation function; counting rate spectrum; nonstationary process; nonstationary spectrum; power spectrum; synthesized spectrum; time-dependent spectrum.

We investigate the time-dependent spectrum of light from an observational point of view and define a time-dependent "physical spectrum" of light based on the counting rate of a photodetector. The tunable element, the filter, that allows observation of different spectral components of the light is shown to play an essential role in the time-dependent spectrum. Its bandwidth cannot be taken arbitrarily narrow. We establish the connection between our physical spectrum and other time-dependent spectra associated with Page, Lampard, Silverman, and Kolmogorov, as well as with the Wiener-Khintchine power spectrum. Also, we show the conditions under which these earlier definitions can be used as the first approximations to the complete physical spectrum, and give an expression for the correction terms.

17170. deHoog, F. J., McNeil, J. R., Collins, G. J., Discharge studies of the Ne-Cu laser, J. Appl. Phys. 48. No. 9, 37013704 (Sept. 1977).

Key words: charge transfer; hollow cathode discharge; sputtering.

Spontaneous-emission and absorption studies of the $\mathrm{Ne}-\mathrm{Cu}$ hollow-cathode laser are summarized. The major discharge processes operative in the $\mathrm{Ne}-\mathrm{Cu}$ laser are outlined and the qualitative aspects of a proposed model of the $\mathrm{Ne}-\mathrm{Cu}$ laser are discussed. Emphasis is placed on cathode sputtering as a source of copper atoms, and we demonstrate that copper densities of $10^{14}$ atoms $/ \mathrm{cm}^{3}$ are created via discharge sputtering.

17171. Mihalas, D., Barnard, A. J., Cooper, J., Smith, E. W., He I $\lambda 4471$ profiles in B stars: Calculations with an improved line-broadening theory, Astrophys. J. 190,315-318 (June 1, 1974).

Key words: B-star spectra; forbidden lines; He I; radiative transfer; Stark broadening.

Theoretical profiles for the $\mathrm{He}$ I $\lambda 4471$ line in B-star spectra have been computed using an improved broadening theory of Barnard, Cooper, and Smith, together with level populations determined by a self-consistent solution by Auer and Mihalas of the coupled transfer and statistical-equilibrium equations. The broadening theory has been constructed to provide a more accurate description of the intensity and width of the forbidden $\left(2 p^{3} P^{n}-4 f^{3} F^{0}\right)$ transition as measured in laboratory experiments. The results presented in this paper show that the revision of the broadening theory leads to computed stellar profiles which are in much better agreement with observed profiles than any previously obtained.

17172. Mihalas, D., Barnard, A. J., Cooper, J., Smith, E. W., He I $\lambda \mathbf{4 9 2 2}$ profiles in B stars: Calculations with an improved line broadening theory, Astrophys. J. 197, 139-142 (Apr. I, 1975).

Key words: early type stars; helium forbidden lines; Stark broadening theory; stellar line profiles; transfer equations.

Theoretical profiles for the He I $\lambda 4922$ line in B star spectra have been computed using the improved broadening theory of Barnard, Cooper, and Smith, and the level populations calculated by Auer and Mihalas from a simultaneous self-consistent solution of the coupled transfer and statistical equilibrium equations. The revised broadening theory yields excellent agreement with laboratory measurements of the width and intensity of the forbidden $\left(2 p^{1} p^{n}-4 f^{n} F^{n}\right)$ transition. The results of this paper show that stellar profiles computed with the new theory are in excellent agreement with observed profiles, and the discrepancies between observation and theory that existed previously have now been removed.

17173. Bensema, W. D., A noise spectrum measurement system using the Fast Fourier Transform, IEEE Trans. Electromagn. Compat. EMC-19, No. 2, 37-43 (May 1977).

Key words: FFT; measurement system; RF noise spectrum; 3-D display.

A portable multichannel battery-operated measurement system was developed to measure the rms magnetic-field noise spectrum in the frequency range from $100 \mathrm{~Hz}$ to $375 \mathrm{kHz}$. During each measurement, the entire spectrum is measured simultaneously through the use of time-domain recordings which are 
later analyzed by Fast Fourier Transform (FFT) processing Dynamic ranges of $60 \mathrm{~dB}$ in a $125-\mathrm{Hz}$ bandwidth are obtained for spectra covering the range from $100 \mathrm{~Hz}$ to $100 \mathrm{kHz}$. The method also allows a three-dimensional display of the way spectrum occupancy changes with time.

Some advantages of the system are portability, rms measure ment, 100 percent probability of signal intercept, data gathering times measured in seconds or milliseconds, simultaneous coverage of several decades of frequency, no "picket fence" amplitude uncertainty with the associated potential 3-dB error, and increased frequency measurement resolution. Some examples of electromagnetic noise (measured in and above coal mines) are given, primarily to show the capability of the measuring system.

17174. Flanigan, W. F., Jr., Bowman, R. R., Lowell, W. R., Nonmetallic electrode system for recording EEG and ECG in electromagnetic fields, Physiol. Behavior Brief Commun. 18, $531-533$ (1977).

Key words: ECG; EEG; electromagnetic field; microwave radiation; nonmetallic electrode system; turtle.

The construction of a nonmetallic electrode/lead system for recording biopotentials in the presence of electromagnetic fields is described. The system is simple to prefabricate and about as versatile and easy to use as metallic electrodes and connecting wires. It has been used for acute and chronic EEG and ECG recordings from chelonians (turtles and tortoises) with consistently satisfactory results.

17175. Bensema, W. D., Amplitude, time, and frequency statistics of quasi-impulsive noise, Proc. 1977 EMC Symp., Montreux, Switzerland, June 28-30, 1977, pp. 347-352 (1977).

Key words: coal mine noise; digital data; electromagnetic interference; electromagnetic noise; emergency communications; Fast Fourier Transform; impulsive noise; magnetic field strength; measurement instrumentation; portable spectrum analyzer; spectral density; time-dependent spectral density.

A portable, multichannel battery-operated measurement system was developed to measure the rms magnetic-field noise spectrum in the frequency range from $100 \mathrm{~Hz}$ to $375 \mathrm{kHz}$. During each measurement, the entire spectrum is measured simultaneously through the use of time-domain recordings which are later analyzed by Fast Fourier Transform (FFT) processing. Dynamic ranges of $60 \mathrm{~dB}$ in a $125 \mathrm{~Hz}$ bandwidth are obtained for spectra covering the range from $100 \mathrm{~Hz}$ to $100 \mathrm{kHz}$. The method also allows a three-dimensional display of the way spectrum occupancy changes with time.

Some advantages of the system are portability, rms measurement, 100 percent probability of signal intercept, data gathering times measured in seconds or milliseconds, simultaneous coverage of several decades of frequency, no "picket fence" amplitude uncertainty with the associated potential $3 \mathrm{~dB}$ error, and increased frequency measurement resolution. Some examples of electromagnetic noise (measured in and above coal mines) are given, primarily to show the capability of the measuring system.

17176. Miles, L. B., The burning behavior of borderline fabrics, Proc. 5th Symp. on Textile Flamimability, New Orleans, LA, Apr. 20-21, 1977, 33 pages (LeBlanc Research Corp., New Orleans, LA, 1977).

Key words: burn injury potential; extinguishability; fire retardants; flammability hazard; FR treated cotton blends; FR treated cottons; ignitability; MAFT value; phosphorus; synthetic fabrics.
Under the proposed General Apparel Flammability Standard, the difference between class I fabrics, the "safest" class of fabrics, and the other classes is a maximum heat transfer rate (MAFT value) of less than $0.40 \mathrm{~J} \cdot \mathrm{cm}^{-2} \cdot \mathrm{s}^{-1}$ at any time during the test. For the present study, as add-ons or phosphorus levels were increased on flame-retardant treated cottons and cotton blends, these fabrics exhibited bi-modal clustering of their MAFT values above and below the 0.40 value. Previous work has indicated that this behavior is the result of high sensitivity to small changes in phosphorus levels over a narrow range as indicated by the response curve for MAFT values with increasing percent phosphorus. Any fabric which generated MAFT values on both sides of the $0.40 \mathrm{~J}$ level was defined as a "borderline" fabric.

Heat data over time for several borderline fabrics were collected using the Mushroom Apparel Flammability Tester (MAFT) and one other flammability apparatus, the Apparel Flammability Modeling Apparatus (AFMA). For the MAFT, two borderline treated cottons and two borderline treated polyester/cotton blends gave class 1 MAFT values that were less than those for two untreated borderline synthetics (polyester and acetate/nylon). But for non-class 1 MAFT values, the borderline cellulosics gave values greater than those for the borderline synthetics. MAFT values for the untreated cellulosic controls were much greater than MAFT values for the borderline treated cellulosics.

For the AFMA, heat data were compared to Derksen's injury curve to determine the percentage of sensors which surpassed heat levels considered sufficient for injury. In terms of sensor involvement, no differences were found between borderline synthetics and borderline cellulosics which did not self-extinguish. As in the MAFT tests, sensor involvement was much greater for the untreated controls than for the borderline treated cottons and blends.

Extinguishment by exposure to air flow for borderline specimens on the MAFT and by contact with a copper surface for specimens on the AFMA were studied. Extinguishment by air flow was more successful for borderline synthetics than for borderline cellulosics. On the other hand, extinguishment by contact with a large copper body was considerably more successful for the borderline cellulosics than for the borderline synthetics.

17177. Swann, P. R., Tighe, N. J., High voltage microscopy of the reduction of hematite to magnetite, Met. Trans. 8B, 479487 (Sepะ. 1977).

Key words: $\mathrm{Fe}_{2} \mathrm{O}_{3} ; \mathrm{Fe}_{2} \mathrm{O}_{4}$; gaseous reduction; hematite; high voltage electron microscopy; iron oxide; magnetite.

The microstructural changes associated with the formation of magnetite in hematite have been studied in specimens which have been partially reduced outside the microscope, thinned until electron transparent, and then examined in the normal way. Three types of structure have been observed in varying proportions which depend on the reduction temperature. At low temperatures, magnetite grows by the propagation of a cellular interface, the gas phase being transported to the cell boundary by a network of tunnels. At intermediate temperatures, magnetite plates are formed, whereas at high temperatures, both plate magnetite and blocky magnetite appear. It is proposed that the factor controlling the morphology which develops is the ratio of the cell boundary diffusivity to volume diffusivity of ferrous ions. It is noted that the decomposition morphologies of hematite and austenite have many similarities. The basic reason for this similarity is that both transformations involve substantial redistribution of elements in the solid state and the microstructures which develop are those that perform this redistribution the most efficiently at the temperatures involved. 
17178. Barger, R. L., Frequency stabilization of a cw dye laser, Laser Spectrosc., pp. 273-279 (June 1973).

Kcy words: dye lascr; frequency stabilization; iodine; saturatcd absorption.

A cw dyc laser has been frequency stabilized to a high finesse optical cavity with residual rms fluctuations less than $\mathbf{5 0}$ $\mathrm{kHz}$ for short timcs $(20 \mu \mathrm{sec}$ ) and $100 \mathrm{~Hz}$ for long times (10 sec.). Drift in the unstabilized optical cavity produced about $1-1 / 2 \mathrm{MHz} / \mathrm{min}$ drift in the laser frequency. The servo system is bricfly described, and a representative saturated absorption spectrum of $\mathrm{I}_{2}$ is shown.

17179. Easton, R. L., Fisher, L. C., Hanson, D. W., Hellwig, H. W., Rucger, L. J., Dissemination of time and frequency by satellite, Proc. IEEE 64, No. 10, 1482-1493 (Oct. 1976).

Key words: clock comparison; satellite time dissemination; standard frequency; standard time; time services; time transfer.

A survey is given of the field of satellite time dissemination covering past experience, present activities, and future planned services with their-respective precisions and accuracies. Transponder satellites, clock-carrying satellites, satellite systems, and two-way satellite links are discussed.

17180. Walls, F. L., Hellwig, H., A new kind of passively operating hydrogen frequency standard, Proc. 30th Annual Symp. on Frequency Control, Ft. Monmouth, NJ, June 1976, pp. $473-480$ ( 1976 ).

Key words: active hydrogen maser frequency standard: cavity pulling; cavity-Q; cavity servo; Crampton effect; frequency stability; hydrogen line $Q$; hydrogen line servo; magnetic field; passive hydrogen maser frequency standard; second-order Doppler; spin exchange; wall shift.

The philosophy behind a new design of a passively operating hydrogen frequency standard will be described. Basically the hydrogen atoms are stored in a conventional, coated quartz bulb, which is contained in a $T E_{n 11}$ cavity. The $\mathrm{H}$-atoms are interrogated by driving the traditional 1,0 to 0,0 transition with an external frequency source and comparing the amplitude and/or phase of the output signal from the cavity with the input signal. The goal of this design is to achieve long term frequency stability of better than 1 part in $10^{14}$ for measurement times from 1 day to 1 year. This is done by increasing the cavity linewidth and decreasing the hydrogen resonance linewidth as compared to typical values for an oscillating maser.

The possibility of significant size reductions based on the use of small dielectric cavities and lower beam intensities, at little or no sacrifice in long term stability, is pointed out.

A new cavity control servo is described which allows the rapid stabilization of the cavity resonance frequency to better than $10^{-14}$ in its effect of pulling the hydrogen resonance. The reduction of other systematic effects to below $10^{-14}$ fractional frequency uncertainty and instability is discussed, including spin exchange and magnetic interactions.

17181. Howe, D. A., The feasibility of applying the active TrTime system to automatic vehicle location, $J$. Inst. Navigation 21, No. 1, 9-15 (Spring 1974).

Key words: accuracy; hyperbolic system; range-range system; time and frequency dissemination; time code; TvTime system.

The National Bureau of Standaras Boulder Laboratory has studied the use of television as a carrier for accurate time and frequency signals. The usefulness of the TvTime System applied to locating cars and other vehicles automatically is examined.
Such a need exists in transit, police, taxi, utility and many commercial fleets. Past approaches to the problem are outlined. The NBS TvTime System and experimental results will be discussed. Two models of a car locating system are outlined, each having three parts: (1) a TV decoder in the car, (2) a radio link such as a mobile channel between car and central dispatch, and (3) a computer which determines the car's position. Results show that this system is capable of achieving a location accuracy of better than $60 \mathrm{~m}$ with 95 percent confidence. Some advantages and limitations of the system will be discussed and cost estimates for the equipment given.

17182. Smith, C. N., What time is it really?, Ind. Res. 19, No. 3, 70-74 (Mar. 1977).

Key words: atomic clocks; dissemination; frequency; geosynchronous satellite; measurement; standards; television; time.

Accurate timekeeping, and time and frequency measurements, are necessary to a wide range of scientific and technical activities in industry, commerce, and government. The National Bureau of Standards' research programs in time and frequency standards and measurements have recently produced significant advances in several areas of this field. New methods of disseminating accurate time and frequency information include the use of network television signals as transfer standards between NBS and the user, and the experimental use of geosynchronous satellites to relay time and frequency signals from NBS to users. New instrumentation for evaluating highquality clocks and for precisely measuring the time differences between them has been developed, along with a new portable atomic clock which provides much greater ease and economy of time transport than existing clocks.

17183. Gagnepain, J. J., Fundamental noise studies of quartz crystal resonators, Proc. 30th Annual Symp. on Frequency Control, Ft. Monmouth, NJ, June 1976, pp. $84-91$ (1976).

Key words: flicker noise; frequency random walk; quartz crystal resonators; resonance frequency fluctuation; temperature fluctuation.

The studies of quartz crystal oscillator frequency instabilities show they are not entirely due to electronics noise but the quartz resonator itself must be considered as a noise source. The previous investigations of resonator frequency noises (given by F. Walls) gave an important indication about their levels. This work presents the results of measurements of frequency fluctuations of quartz resonators used as passive fourports. The noise is characterized in the frequency domain.

Several noise sources contribute to the frequency fluctuations. Correlation with external perturbations as vibrations and temperature fluctuations are studied. In the power density spectra the noise at the lowest Fourier frequencies is related with thermal effects and mainly with thermal stresses. The flicker noise level is partially related with the resonator design. Different kinds of resonators at different frequencies are used with particular plating types and shapes.

17184. Wan, C. A., Computer simulation of water heater standby loss, Proc. 1977 ASME Winter Annual Meeting, Atlanta, GA, Nov. 27-Dec. 2, 1977, 15 pages (American Society of Mechanical Engineers, United Engineering Center, New York, NY, 1977).

Key words: alternating direction; computer simulation; cool down; energy savings; flue damper; heat transfer; implicit; insulation; laboratory measurements; modeling; standby loss; water heater.

A computer program called WHESTOD (Water Heater Energy Savings Through Operation and Design) is under develop- 
ment at the Center for Consumer Product Technology, National Bureau of Standards. The program solves the axisymmetric heat conduction equation, applicable to a water heater, in the cylindrical coordinate system using an implicit, alternating direction method. It will ultimately be implemented to simulate water heaters of various designs and operating conditions. It has been used to study the standby phase of an electric water heater and a gas water heater without pilot. Laboratory tests were also conducted for these two water heaters. Good agreement has been found between the computer simulations and laboratory measurements under comparable conditions. However, a more detailed model and further laboratory measurements are needed to achieve a complete water heater simulation as a versatile analysis tool.

17185. Walls, F. L., Stein, S. R., Gray, J. E., Glaze, D. J., Design considerations in state-of-the-art signal processing and phase noise measurement systems, Proc. 30th Annual Symp. on Frequency Control, Ft. Monmouth, NJ, June 1976, pp. 269-274 (1976).

Key words: correlation; double balanced mixer; isolation amplifier; phase-lock loop; phase noise.

A general method which allows one to estimate the phase noise of analog and digital signal handling equipment will be presented. As a specific example, this approach will be applied to a new buffer amplifier and the estimates compared with actual measurements. This amplifier achieves isolation of $>120$ $\mathrm{dB} @ \mathrm{MHz}$, has a phase noise floor $\left(\mathrm{S}_{\phi}\right)$ below $-170 \mathrm{~dB}$, and is on a printed circuit card $3.25 \mathrm{~cm}$ by $9 \mathrm{~cm}$.

Double balanced mixers are used extensively in noise measurement and signal processing equipment. Several circuits utilizing these devices will be discussed and data presented showing typical signal to noise realized. New circuits show 15 to $25 \mathrm{~dB}$ improvement over some traditional circuits. Single sideband noise floors $\left(S_{\phi}\right)_{i 2}$ lower than $-183 \mathrm{~dB}$ can be achieved using double balanced mixers. Even this isn't sufficient for all present requirements either in measurement or signal handling systems, however, an additional 10 to $40 \mathrm{~dB}$ reduction in the measurement noise can be achieved by the use of correlation techniques. The circuit diagram for a particularly simple embodiment of this will be shown along with experimental data.

Quite often it is desirable to phase lock two oscillators. Design considerations for choosing the unity gain point, and the slope of the gain roll-off will be given. In particular it will be shown that a gain slope of $-12 \mathrm{~dB} /$ octave which decreases to $-6 \mathrm{~dB} /$ octave at a point 1 to 3 octaves below the unity gain point has many advantages over single slope approaches.

17186. Brown, C. P., On-line bibliographic retrieval system use, Spec. Lib. 68, No. 4, 155-160 (Apr. 1977).

Key words: evaluation; National Bureau of Standards; online bibliographic retrieval systems.

On-line systems for bibliographic retrieval are becoming more widely used in special libraries. Yet, in spite of the convenience and speed of these systems, not all scientific users have shown enthusiasm. An evaluative survey conducted in one library implies a need for continued publicity and training to promote interest and familiarity among the user community.

17187. Imam, M. A., Gilmore, C. M., Fraker, A. C., Corrosionfatigue properties of the Ti-6A1-4V alloy, Proc. Conf. Environmental Degradation of Engineering Materials, Blacksburg, VA, Oct. 10-12, 1977, pp. 783-790 (College of Engineering, Virginia Tech, Blacksburg, VA, 1977).

Key words: corrosion; fatigue; microstructures; titanium alloys.
The high-strain, low frequency corrosion-fatigue properties of the Ti-6Al-4V alloy in two different conditions were determined. One group of specimens was tested in the mill annealed condition (two hours at $704{ }^{\circ} \mathrm{C}-760{ }^{\circ} \mathrm{C}$ ) and air cooled and another group was solution treated at $900{ }^{\circ} \mathrm{C}$ and water quenched prior to testing. Tests were conducted in Hanks' buffered saline solution at a temperature of $37{ }^{\circ} \mathrm{C}$ and solution $\mathrm{pH}$ of 7.4. Specimens were subjected to fully reversed torsion fatigue in a flowing solution at a shear strain of 0.018 and a frequency of $1 \mathrm{~Hz}$. The specimen electrode potential was monitored to follow the corrosion fatigue process. At the beginning of the corrosion-fatigue test, there is a drop in the electrode potential in the negative direction indicating the formation of many cracks in the oxide film. This is followed by a rise in the positive direction and a leveling off of the potential at a much more negative value than the material would exhibit if there were no mechanical action indicating repassivation of some cracks while others continue to propagate. The results showed that the corrosion-fatigue life of the material heat treated at $900{ }^{\circ} \mathrm{C}$ and water quenched is almost two times longer than that of the mill annealed material.

17188. Stevens, W. J., Krauss, M., The electronic structure of the ground and excited states of $\mathbf{M g}_{2}{ }^{+}$and $\mathbf{M g}, J$. Chem. Phys. 67, No. 5, 1977-1989 (Sept. 1, 1977).

Key words: ab initio; electronic structure; excimers; excited states; metal dimers; $\mathrm{Mg}_{2}$; multiconfiguration self-consistent-field.

The ground and excited valence states of $\mathrm{Mg}_{2}{ }^{+}$and $\mathrm{Mg}_{2}$ are calculated using the multiconfiguration self-consistent-field method. The energy curves of the $X 1 \Sigma_{g}+,{ }^{3} \Pi_{g},{ }^{3} \Sigma_{u}+,{ }^{3} \Pi_{u},{ }^{3} \Sigma_{g}+$, ${ }^{1} \Pi_{g},{ }^{1} \Sigma_{u}{ }^{+},{ }^{1} \Pi_{u}$, and $2^{1} \Sigma_{g}{ }^{+} \mu$ states of $\mathrm{Mg}_{2}$ and the ${ }^{2} \Sigma_{u}{ }^{+}$and ${ }^{2} \Pi_{\mu}$ curves of $\mathrm{Mg}_{2}{ }^{+}$are obtained for internuclear separations between 4 and 15 bohr. All of the excited states except the ${ }^{3} \Pi_{u}$ and ${ }^{3} \Sigma_{g}{ }^{+}$are found to be bound while the ground state is a weakly bound van der Waals molecule. Comparison between the calculated and experimentally known $X^{1} \Sigma_{g}{ }^{+}$and ${ }^{1} \Sigma_{u}{ }^{+}$energy curves shows good agreement for the equilibrium internuclear separation but the calculated $D_{e}\left(620 \mathrm{~cm}^{-1}\right)$ for the best approximation of the $X^{1} \Sigma_{v}{ }^{+}$state exceeds the experimental value by about 40 percent, and the calculated $D_{e}$ for the ${ }^{1} \Sigma_{u}{ }^{+}$ state is smaller than the experimental value of $9387 \mathrm{~cm}^{-1}$ by about $1800 \mathrm{~cm}^{-1}$. Analysis of the electronic structure of the excimers shows that the triplet states and the ${ }^{1} \Pi_{p}$ state are qualitatively described by covalent molecular orbital theory but all of the other bound singlets require more complicated descriptions including covalent configurational mixing, charge transfer, and Rydberg-covalent configuration mixing. Only the ${ }^{1} \Pi_{u}$ state can be unambiguously characterized as a charge transfer state. The $\mathrm{Mg}_{2}$ states were calculated to provide a model of the Group II excimer systems, which are candidates for the active media of lasers.

17189. Clark, F. O., Lovas, F. J., ${ }^{30} \mathrm{SiO}$ in the interstellar medium, Astrophys. J. 217, L47-L48 (Oct. 1, 1977).

Key words: interstellar sources; isotope ratio; molecular lines; radio astronomy; silicon monoxide; spectra.

The ${ }^{30} \mathrm{SiO}$ isotopic form of $\mathrm{SiO}$ has been detected in Orion and Sagittarius B2. The Orion isotopic abundances are decidedly terrestrial.

17190. Pallett, D. S., Cadoff, M. A., The national measurement system for acoustics, Sound Vib. 11, No. 10, 20-31 (Oct. 1977).

Key words: acoustical measurements; acoustics; national measurement system; noise; noise control; sound. 
Many recent acoustical measurement processes have been motivated by societal concern over noise and have broad relevance to our contemporary technological society. The emphasis of the study of the National Measurement System for Acoustics has been to determine the adequacy of these important physical measurements and to promote improvements within the measurement system. The relevant physical quantities are indicated, and the interactions occurring between participants as well as the roles of acoustical standardization institutions are specified. Finally, the status and trends of the System and the NBS role in adapting to changing technology are discussed.

17191. Hsu, N. N., Simmons, J. A., Hardy, S. C., An approach to acoustic emission signal analysis-Theory and experiment, Mater. Eval. 35, No. 10, 100-106 (Oct. 1977).

Key words: acoustic emission; acoustic emission simulator; capacitive transducer; Plate Green's function; signal analysis; wave propagation in Plate.

Acoustic emission (AE) signals are notorious for their complexity and irreproducibility. Because AE source characteristics are virtually unknown and the detected $\mathrm{AE}$ signals are colored by the propagation media, the sensor response, and the instrumentation settings, interpretations of test results such as spectral analysis or correlation studies are mostly qualitative and sometimes controversial; theories are either empirically derived or cannot be verified by experiments.

In this paper, we sketch an approach to the AE signal analysis problem. We first report the development of a theory which allows the computation of the displacement as a function of time at an arbitrary point on an infinite plate due to an arbitrary point source force function. The theory is based on a new Fourier inversion technique which yields exact formulas similar to those developed for seismological "ray" theories. We then report experimental results obtained on a $2.52 \mathrm{~cm}$ thick aluminum plate using a reproducible step function stress release pulse as a simulated AE signal and a wide band displacement capacitive transducer as a sensor. The measurements are in quantitative agreement with the predictions of theory.

We also discuss applications wherein the simulated signal, capacitive transducer and plate theory are used for AE source signature analysis and sensor calibration problems.

17192. Mosburg, E. R., Jr., Wilke, M. D., Excimer densities and destruction mechanisms in a high pressure pure mercury positive column, J. Chem. Phys. 66, No. 12, 5682-5693 (June 15, 1977).

Key words: dimers; discharge; lasers; mercury excimers; spectra; two photon.

A study of a pure mercury vapor dc discharge at gas densities of $0.75 \times 10^{18}$ to $10^{19} \mathrm{~cm}^{-3}$ and currents of $30-100 \mathrm{~mA}$ has allowed us to determine the densities of the atomic $6^{3} P_{0.1 .2}$ and $7^{3} S_{1}$ levels and the dimer ${ }^{3} 1_{u}$ level as well as the density of free electrons. We find the density of the ${ }^{3} 1_{u}$ level (which radiates the $335 \mathrm{~nm}$ band) to be several orders of magnitude below that needed for lasing on this transition. An analysis of the measured spacial profiles leads us to conclude that mercury trimers figure prominently into the kinetics of the system and that the destruction of these trimers is primarily by electron collisions. We also report evidence that the three-body rate for production of trimers from dimers greatly exceeds that for the formation of dimers from excited atoms. The procedures for analysis of the spacial profiles developed here constitute a new method for the semiquantitative determination of rate coefficients not otherwise accessible to measurement.

17193. Stephenson, J. C., Vibrational relaxation of NO $X^{2} \Pi(v$ $=1$ ) in the temperature range $100-300^{\circ} \mathrm{K}, \mathrm{J}$. Chem. Phys. 60, No. 11, $4289-4294$ (June 1974).
Key words: combustion; $\mathrm{CO}_{2}$ lasers; nitric oxide; optical pumping of molecules; vibrational relaxation.

Laser-excited fluorescence measurements have given rate constants for the vibrational deactivation of $\mathrm{NO}(v=1)$ by $\mathrm{NO}$, $\mathrm{He}$, and $\mathrm{N}_{2}$, and for the $V-V$ exchange between $\operatorname{CO}(v=1)$ and $\mathrm{NO}(v=1)$ in the temperature region 100-300 ${ }^{\circ} \mathrm{K}$. Relaxation was caused entirely by bimolecular collisions. Deactivation rates of $\mathrm{NO}(v=1)$ by $\mathrm{H}_{2} \mathrm{O}, \mathrm{D}_{2} \mathrm{O}, \mathrm{NO}_{2}, \mathrm{CH}_{4}, \mathrm{C}_{2} \mathrm{H}_{4}, \mathrm{C}_{2} \mathrm{H}_{6}$, and $\mathrm{C}_{4} \mathrm{H}_{10}$, and of $\mathrm{N}_{2}(v=1)$ by $\mathrm{NO}$ and $\mathrm{CO}(v=1)$ by $\mathrm{NO}_{2}$ and $\mathrm{N}_{2} \mathrm{O}_{4}$ were measured at $\mathrm{T}=298^{\circ} \mathrm{K}$.

17194. Stock, M., Smith, E. W., Drullinger, R. E., Hessel, M. M., Relaxation of the mercury $6^{3} P_{0}$ and $6^{3} P_{1}$ states, $J$. Chem . Phys. 67, No. 6, 2463-2469 (Sept. 15, 1977).

Key words: decay of resonance line; quenching rates; relaxation of mercury atoms; three body molecular formation: ${ }^{3} P_{0}$ and ${ }^{3} P_{1}$ atomic states; ${ }^{3} P_{0} \leftrightarrow{ }^{3} P_{1}$ collision rates.

The relaxation of $6^{3} P_{0}$ mercury atoms excited by a laser pulse was measured for densities ranging from $2 \times 10^{17}$ to $8 \times 10^{18}$ $\mathrm{cm}^{-3}$. The decay of the $253.7 \mathrm{~nm}$ resonance line was also measured for densities ranging from $5 \times 10^{16}$ to $10^{18} \mathrm{~cm}^{-3}$. The decay coefficients were analyzed to yield rate coefficients for three body molecular formation, the ${ }^{3} P_{1} \rightarrow{ }^{3} P_{0}$ collision rate and a collisional quenching rate for the ${ }^{3} P_{0}$ state. Small loss rates due to diffusion and radiation were also observed and found to be consistent with theoretical estimates of these quantities.

17195. Stevens, W. J., Gardner, M., Karo, A., Julienne, P., Theoretical determination of bound-free absorption cross sections in $\mathrm{Ar}_{2}{ }^{+}, J$. Chem. Phys. 67, No. 6, 2860-2867 (Sept. 15, 1977).

Key words: absorption cross-section; $\mathrm{Ar}_{2}{ }^{+}$; energy transfer; gain inhibitor; gas lasers; photodissociation; restricted Hartree-Fock; transition moment.

$A b$ initio calculations have been carried out for the potential energy curves and transition moments of the ${ }^{2} \Sigma_{u}{ }^{+},{ }^{2} \Pi_{g},{ }^{2} \Pi_{u}$, and ${ }^{2} \Sigma_{g}{ }^{+}$states of $\mathrm{Ar}_{2}{ }^{+}$which arise from the ${ }^{2} P+{ }^{1} S$ ion-atom asymptote. These data have been used in a theoretical calculation of the dissociative absorption cross sections from the bound ${ }^{2} \Sigma_{u}{ }^{+}$state to the repulsive ${ }^{2} \Pi_{g}$ and ${ }^{2} \Sigma_{g}{ }^{+}$states. The ${ }^{2} \Sigma_{u}{ }^{+}$ $\rightarrow{ }^{2} \Pi_{g}$ transition, which is dominated by spin-orbit effects, has a maximum absorption cross section of $2.6 \times 10^{-19} \mathrm{~cm}^{2}$ centered at $716 \mathrm{~nm}$ with a full width at half-maximum of $185 \mathrm{~nm}$ at room temperature. The ${ }^{2} \Sigma_{u}{ }^{+} \rightarrow{ }^{2} \Sigma_{g}{ }^{+}$transition is found to be much stronger with a maximum cross section of $0.5 \times 10^{-16} \mathrm{~cm}^{2}$ centered at $300 \mathrm{~nm}$ with a full width at half-maximum of 75 $\mathrm{nm}$ at room temperature.

17196. Levine, J., Harrison, J. C., Earth tide strain measurements in the Poorman mine near Boulder, Colorado, $J$. Geophys. Res. 81, No. 14, 2543-2555 (May 10, 1976).

Key words: cavity effects; earth tides; ocean loads; strainmeter.

Earth tide strains at a particular site are affected by the internal structure of the solid earth, ocean loads, local inhomogeneities in elastic constants due to geologic structure, topography near the observation site, and the cavity in which the measuring instrument is situated. All of these influences have been estimated quantitatively for the Poorman site for a diurnal $\left(\mathrm{O}_{1}\right)$ and a semidiurnal $\left(\mathrm{M}_{2}\right)$ tide. The predicted strains agree with those observed to within 5 percent for $M_{2}$ and 10 percent for $\mathrm{O}_{1}$ whereas without the topographic and geologic corrections there is an amplitude discrepancy of about 25 percent. The phase discrepancy is reduced from $-15^{\circ}$ to $-6^{\circ}$ for $O_{1}$. The residuals can be reduced further by using terms quadratic in the applied potential, which may imply a breakdown of linear 
tide theory, a deficiency in classical tidal calculations, or a local effect that modulates the tidal transfer function of our site.

Although the general features of strain tides are well understood, a quantitative comparison between theory and experiment has never, to our knowledge, yielded the sort of agreement obtained for gravity tides.

In this paper we show that by considering local topography and local int.omogeneities in the elastic constant, much of the discrepancy between classical tide theory and observations can be removed, at least for the $\mathrm{M}_{2}$ and $\mathrm{O}_{1}$ components. Although we have not analyzed the other minor tidal components, we are confident that the same sort of agreement would result from such an analysis.

17197. Misra, D. N., Bowen, R. L., Adhesive bonding of various materials to hard tooth tissues. XII. Adsorption of $N-12$ hydroxy-3-methacryloxypropy l)- $N$-phenylglycine (NPG-GMA) on hydroxyapatite, J. Colloid Interface Sci. 61, No. 1, 14-20 (Aug. 1977).

Key words: adhesion to polymers; adsorption from solutions; chemisorption; hydroxyapatite; irreversible vs reversible adsorption; surface-active comonomer.

Adsorption of an adhesion-promoting compound, N-(2hydroxy-3-methacryloxypropyl)-N-phenylglycine (NPG-GMA), was studied on synthetic hydroxyapatite from ethanol solution. The adsorption isotherm is very steep initially, followed by a step and then a Langmuir-type isotherm. The nature of adsorption is irreversible up to the step and reversible thereafter. The maximum amounts of the irreversibly adsorbed and the reversibly adsorbed materials are about the same. The irreversibly adsorbed material may be chemisorbed. If the irreversibility is effected by the chelating ligand groups of the molecule which rotates about the calcium ion site (centered on the nitrogen ligand) in a fully extended configuration, the area of the hydroxyapatite thus obtained corresponds to its BET $\left(\mathrm{N}_{2}\right)$ area. An additional reversible adsorption may take place on the irreversibly adsorbed apatite at higher concentrations if the irreversibly adsorbed molecules are reduced in their areal domain by a folding of their methacrylate groups. Polymer filled with synthetic hydroxyapatite covered with the irreversibly adsorbed NPG-GMA has a tensile strength about 50 percent greater than that of the polymer filled with untreated apatite.

17198. Bridges, J. M., Ott, W. R., Pitz, A., Einfeld, D., Stuck, D., Spectral radiance calibrations between $165-300 \mathrm{~nm}$ : An interlaboratory comparison, Appl. Opt. 16, No. 7, 1788-1790 (July 1977).

Key words: arc; calibration; deuterium; interlaboratory; lamp; radiance; radiometry; source; spectroscopy; standard; synchrotron; ultraviolet; wall-stabilized.

The spectral radiance of deuterium lamps calibrated by the Max Planck Institute fur Astronomie, the Physikalisch Technische Bundesanstalt, and the U.S. National Bureau of Standards are compared. The wavelength dependence of the measured spectral radiance based upon independent and different primary standards, agrees to within a \pm 3 percent error over the wavelength range from $165 \mathrm{~nm}$ to $300 \mathrm{~nm}$.

17199. Levine, J., Laser distance-measuring techniques, Ann. Rev. Earth Planet. Sci. 5, 357-369 (1977).

Key words: distance measurement; earth tides; laser strainmeter; surveying.

This is a review of the field of laser distance-measuring techniques. The discussion includes the results obtained using strainmeters, geodimeters, and various extraterrestrial techniques.
17200. Pezoldt, V. J., Persensky, J. J., Ramey, A. M., Human factors support of a lawn mower safety standard, Proc. Third Int. System Safety Conf., Washington, DC, Oct. 17-21, 1977, pp. 3-22 (1977).

Key words: anthropometric probes; consumer products; human factors; lawn mowers; psychophysics; reaction time; safety; standards.

Among the tasks performed by the National Bureau of Standards' Center for Consumer Product Technology is providing technical support to federal regulatory agencies. To illustrate this activity, three empirical studies performed by the Human Factors Section are summarized. Each of the studies was undertaken in support of the Consumer Product Safety Commission's development of a power lawn mower safety standard. The studies involve: (1) determination of an ergonomically sound time for blade stopping after release of a "dead-man" control; (2) development of an objective measure of the subjective judgement of "easy" as it relates to manually starting lawn mowers; and (3) evaluation of foot simulator probes for use in a blade contact performance test.

17201. Brauer, G. M., The present state and future of macromolecules for dental applications, Polym.-Plast. Technol. Eng. 9, No. 1, 87-121 (1977).

Key words: adhesives; dental applications; dental prosthetic materials; dental resins; future dental materials; macromolecules; plastics; polymers; sealants.

The oral region is subject to a small number of commonly occurring diseases, but a multitude of prosthetic devices involving macromolecular materials are required for the pertinent treatment. Plastics are especially valuable in the construction of dentures. Composite filling materials have been quite successful in areas where esthetics is of prime importance and have extended the useful life of the restoration. Adhesive liners that bond composites to tooth structure are greatly needed. New polymers will open vast horizons in maxillofacial prostheses and for implants.

Additional preventive procedures will result chiefly from research. These will include sealants or lacquers that will reduce or even eliminate caries. Provided the battle against periodontal disease can also be won, it will be possible for future generations to carry the natural dentition from cradle to grave.

17202. Brauer, G. M., Termini, D. J., Dickson, G., Analysis of the ingredients and determination of the residual components of acrylic bone cements, J. Biomed. Mater. Res. 11, 577-607 (1977).

Key words: analysis of acrylics; benzoyl peroxide determination; bone cement; chemical composition of bone cement; dimethyl-p-toluidine; hydroquinone leachable monomer; residual components in cements; residual methyl methacrylates.

Rapid and reliable methods for the characterization and quantitative determination of ingredients usually present in selfcuring methacrylate bone cements were developed using spectrophotometric, gas chromatographic (GC), and conventional gravimetric procedures. These procedures are applicable to noncrosslinked methacrylate resins. In the presence of some copolymers, polymer blends or crosslinking agents, or other ingredients which will result in the formation of insoluble methacrylate resins, some modification of the identification procedures and quantitative estimation of the resin components will be required. Molecular wight and molccular wcight distribution of the powder and cured cement were obtained from viscosity and gel-permeation measurements. Residual low 
molecular weight materials in the cured cement were determined for various storage times. Residual and water-leachable monomer and residual dimethyl-p-toluidine (DMPT) were measured by GC. In air, the monomer content of the cured resin decreased from 3.3 percent after $1 \mathrm{hr}$ to 2.4 percent after 215 days. When stored in water at $37^{\circ} \mathrm{C}$, over 65 percent of the extractable monomer is leached out within $10 \mathrm{~min}$. After $6 \mathrm{hr}$, the rate of diffusion of monomer into the aqueous phase is low. The cured cement contains as much as 0.6 percent DMPT, which does not leach out. Residual peroxide, estimated spectrophotometrically, amounts to 0.8 percent, but decreases to 0.14 percent after 15 months in water at $37^{\circ} \mathrm{C}$. A semiquantitative colorimetric test indicated that the hydroquinone content of specimens analyzed within $24 \mathrm{hr}$ after curing amounted to $9 \mathrm{ppm}$.

17203. Stein, S. R., Risley, A. S., Van de Stadt, H., Strumia, F., High speed frequency modulation of far infrared lasers using the Stark effect, Appl. Opt. 16, No. 7, 1893-1896 (July 1977).

Key words: far infrared laser; frequency modulation; Stark effect.

Electronic frequency tuning of an optically pumped far infrared waveguide laser has been achieved by using the Stark effect. Frequency modulation with a $50-\mathrm{kHz}$ modulation frequency and an index greater than 1 has been observed as well as a maximum modulation frequency of $300 \mathrm{kHz}$.

17204. Helbig, V., Kelleher, D. E., Wiese, W. L., Some measured regularities in the Stark broadening of neutral nitrogen lines, (Proc. VIII Int. Summer School and Symp. on the Physics of Ionized Gases, Dubrovnik, Yugoslavia, Sept. 1623, 1976), Extended Abstract 3.24 in Physics of lonized Gases 1976, pp. $412-415$ (J. Stefan Institute, Ljubljana, Yugoslavia, 1976).

Key words: multiplet; nitrogen lines; regularities; Stark broadening; supermultiplet; transition array; wall stabilized.

17205. Bean, V. E., NBS pressure transducer characterization program, Proc. Ninth Transducer Workshop, Ft. Walton Beach, FL, Apr. 26-28, 1977, pp. 186-208 (Secretariat, Range Commanders Council, White Sands Missile Range, NM, Apr. 22-24, 1977).

Key words: characterization; evaluation; performance; pressure; transducer.

As a step toward inproved pressure measurement, the NBS Pressure and Vacuum Section has developed a program designed to determine the long-term performance of pressure transducers. Among the parameters determined in the eight months test are: warm up, zero drift, supply voltage dependence, calibration, precision, pressure hysteresis, short and long term stability, shift of sensitivity and zero with temperature, temperature hysteresis, full scale drift, relaxation effects, effects due to pressure cycling, pressure fluid dependence, attitude dependence, etc. The philosophy of the program, the test schedule and examples of the data obtained are discussed.

17206. Wiese, W. L., Konjević, N., Regularities in the Stark widths of isolated lines, (Proc. VIII Int. Summer School and Symp. on the Physics of Ionized Gases, Dubrovnik, Yugoslavia, Sept. 16-23, 1976), Extended Abstract 3.25 in Physics of lonized Gases 1976, pp. 416-420 (J. Stefan Institute, Ljubljana, Yugoslavia, 1976).

Key words: isolated lines; multiplet; plasma broadening; regularities; Stark widths; supermultiplet; transition array.
17207. Kelley, R. D., Madey, T. E., Yates, J. T., Jr., Activity of tungsten as a methanation catalyst, J. Catal. 50, 301-305 (1977).

Key words: carbon monoxide; catalytic methanation; hydrogen; methane; tungsten.

The catalytic activity of tungsten has been investigated for the methane synthesis from $\mathrm{H}_{2}$ and $\mathrm{CO}$. Starting with atomically clean tungsten, the activity for catalytic methanation rivals that of $\mathrm{Ni}$, with tungsten being active at lower temperatures than Ni. These observations of high catalytic activity for tungsten suggest that the low activity seen in previous studies on tungsten catalysts may have been due to inadequate cleaning procedures.

17208. Abramowitz, S., Acquista, N., Levin, I. W., Infrared spectra of matrix isolated $\mathrm{FeO}_{2}$ : Evidence for a cyclic iron-0xygen complex, Chem. Phys. Lett. 50. No. 3, 423-426 (Sept. 15,1977 ).

Key words: $\mathrm{FeO} ; \mathrm{FeO}_{2}$ : infrared spectrum; structure; vibrational frequency.

Infrared matrix isolation techniques were used to study the reaction of $\mathrm{Fe}$ (vapor) with oxygen molecules. For various isotopically enriched oxygen samples, spectral transitions at $945.9,930.8$ and $911.4 \mathrm{~cm}^{-1}$ were assigned on the basis of their relatively large frequency shifts to the $\mathrm{O}-\mathrm{O}$ stretching modes of $\mathrm{Fe}^{16} \mathrm{O}_{2}, \mathrm{Fe}^{16} \mathrm{O}^{18} \mathrm{O}$ and $\mathrm{Fe}^{18} \mathrm{O}_{2}$, respectively. The low frequency Fe-O stretching modes were assigned to features at 517.1, 508.1 and $494.0 \mathrm{~cm}^{-1}$ for the same three isotopically substituted dioxygen complexes. Both the frequency behavior and intensity patterns involving the dioxygen ligand indicate a cyclic isosceles model for the $\mathrm{FeO}_{2}$ system.

17209. Bierbaum, V. M., Ellison, G. B., Futrell, J. H., Leone, $S$. R., Vibrational chemiluminescence from ion-molecule reactions: $\mathrm{O}^{-}+\mathrm{CO} \rightarrow \mathrm{CO}_{2} \nmid+e^{-}, J$. Chem. Phys. Lett. 67, No. 5, 2375-2376 (Sept. 1, 1977).

Key words: associative detachment; chemiluminescence; flowing afterglow; fluorescence; inf rared; ion-molecule.

Vibrational emission has been observed from the $\mathrm{CO}_{2}$ molecules produced in the associative detachment reaction, $\mathrm{O}^{-}$ $+\mathrm{CO} \rightarrow \mathrm{CO}_{2} \dagger+e^{-}\left(4.2 \mathrm{eV}\right.$ exothermic). The $\mathrm{O}^{-}$ions were produced from $\mathrm{O}_{2}$ in a modulated ion source of a flowing afterglow at densities approaching $10^{8} / \mathrm{cc}$. Following injection of $\mathrm{CO}$ downstream, infrared chemiluminescence was detected from the $\mathrm{CO}_{2}$ product at $4.3 \mu \mathrm{m}$ in the infrared. Over a wide range of emission currents and $\mathrm{O}_{2}$ pressures, the $\mathrm{CO}_{2}$ product vibrational emission intensity correlates well with the $\mathrm{O}^{-}$density. Initial estimates indicate that a substantial fraction of the $\mathrm{CO}_{2}$ molecules are born into excited vibrational states higher than (001). Reliable measurements can be made on vibrational deactivation rates of molecular ions and on vibrational population distributions in ion-molecule reactions using this technique.

17210. Danos, M., Williams, H. T., Separation of the $\Delta \Delta$ and $N N$ components of the deuteron by kinematics of high energy $\pi D$ reactions, Phys. Rev. C 16, No. 3, 1082-1086 (Sept. 1977).

Key words: angular correlations; deuteron; pions; $\Delta$ components; $\Delta$ nucleus dynamics; $\pi \mathrm{D}$ reactions.

The kinematics of the reaction $\pi+d \rightarrow \pi+N+$ anything is analyzed for $15 \mathrm{GeV}$ incoming pions. It is shown that by observing both the invariant mass and the angular correlations of backward $\pi N$ events one can insure that the observed particles arise from the decay of a spectator $\Delta$ in a quasifree scattering event, i.e., they give a quantitative estimate of the $\Delta \Delta$ admix- 
ture of the deuteron. Failure of experimental observation of such events would indicate a failure of the effective Lagrangian formalism.

17211. Walls, F. L., Design and results from a prototype passive hydrogen maser frequency standard, Proc. Conf. Precision Time and Time Interval, Washington, DC, Nov. 30-Dec. 2, 1976, pp. 369-380 (U.S. Naval Research Laboratory, Washington, DC, 1976).

Key words: amplitude modulation; cavity frequency; environmental sensitivity; frequency lock loop; long-term frequency stability; NBS time scale; phase modulation; (active-passive) hydrogen maser.

The basic design of a prototype passive hydrogen maser frequency standard is very briefly described and its unique features outlined. The latest results on its long-term stability and environmental sensitivity will be given. The present results indicate that $\sigma_{y}(\tau) \leq 2 \times 10^{-12} \tau^{-1 / 2}$ for averaging times between $40 \mathrm{~s}$ and $15000 \mathrm{~s}, \sigma_{y}(15000) \sim 1.4 \times 10^{-14}$. Over a fourteen-day period the rms daily time fluctuations was 2 ns while the least squares fit to a linear frequency drift over the fourteen days was $6 \times 10^{-16} / \mathrm{day}$, which is within the measurement noise. These results are particularly noteworthy for those interested in clocks for timekeeping applications as they were obtained without temperature control of any of the electronics and only a single oven on the cavity. Further improvements in the electronics including temperature stabilization of critical control circuits should reduce the daily variations by a factor of five to ten and also improve the already excellent long-term stability.

17212. Reader, J., Acquista, N., $4 s-4 p$ resonance transitions in highly charged $\mathrm{Cu}$ - and Zn-like ions, Phys. Rev. Lett. 39, No. 4, 184-187 (July 25, 1977).

Key words: ions; molybdenum; niobium; rubidium; spectra; structure; ultraviolet; yttriu m; zirconium.

The $4 s-4 p$ resonance transitions in the copperlike and zinclike ions from $\mathrm{Rb}$ to $\overline{\mathrm{Mo}}$ have been observed by means of a low-inductance open spark and a 10.7-m grazing-incidence spectrograph. Lines belonging to highly charged ions could be distinguished by their abnormally large widths. The observations confirm the identification of the resonance lines of Mo xi11 and Mo xiv in the Princeton University $S T$ tokamak by Hinnov, Johnson, Meservey, and Dimock.

17213. Evans, A. G., Linzer, M., Acoustic emission in brittle materials, Ann. Rev. Mater. Sci. 7, 179-208 (1977).

Key words: acoustic emission; amplitude distribution; brittle materials; ceramics; fracture.

This paper examines the acoustic emission from deformation and fracture processes in brittle materials. The origins of acoustic emission in such materials, their relation to the various test variables, and the deficiencies in our existing knowledge are described. Typical applications of acoustic emission are discussed.

17214. Graminski, E. L., Kirsch, R. A., Image analysis in paper manufacturing, Proc. IEEE Computer. Society Conference on Pattern Recognition and Image Processing, Troy, NY, June 68, 1977, pp. 137-143 (IEEE Computer Society, Long Beach, CA, 1977).

Key words: algorithms; fiber morphology; fibers; image analysis; pattern recognition; pulp characterization; pulps.

Significant energy savings in the paper industry can result from characterization of paper pulps by direct measurement of fiber morphology with automatic methods. We discuss the vari- ous fiber properties for which automatic image analysis applied to microscope images of pulps can yield savings of materials and energy. Computational algorithms applied to actual fiber data are shown to yield useful measurements for fiber length, curl, and potentially other properties. New fiber morphology measurement algorithms can include curl and length as special cases. Potentials for collaboration between the paper industry and the image analysis instrument industry are explored.

17215. Robertson, B., Effect of arbitrary temperature and flow profiles on the speed of sound in a pipe, J. Acoust. Soc. Am. 62, No. 4, 813-818 (Oct. 1977).

Key words: duct; fundamental mode; liquid; perfect gas; propagation; shear; transverse gradient; wavenumber.

An expression for the wave number of the fundamental mode in a uniform duct of arbitrary cross section is obtained correct to first order in $\mathrm{V} / c$ and in $c_{1} / c_{0}$, where $\mathrm{V}$ is the velocity of the fluid in the pipe and $c=c_{0}+c_{1}$ is the local sound speed with $c_{0}=$ constant. Correction terms are also obtained. The calculation applies to a fluid with the equation of state of an ideal gas or to a liquid and is valid for frequencies well below cutoff. The speed $c$ and velocity $\mathbf{V}$ can be arbitrary functions of position across the cross section given only $\nabla \cdot V=0$. For the gas, the wave number, which is a constant, can be expressed in terms of the average density and the total mass flow rate.

17216. Manger, C. L., Moore, J. H., Jr., Alexander, M. H., Evidence for the absence of complex formation between oxygen and olefins or fluorocarbons, Physiolog. Chem. 8, No. 6, 559-562 (Dec. 1976).

Key words: oxygen/fluorocarbon complex; oxygen/hydrocarbon complex; reversible oxygenation; second virial coefficients.

Second virial coefficients are measured for oxygen/ hydrocarbon and oxygen/fluorocarbon mixtures. The results indicate that the reversible oxygenation of fluorocarbon emulsions and olefinic fatty acids does not depend strongly upon attractive complex formation.

17217. Kahn, F. D., Supernova remnants, (Proc. 14th Int. Cosmic Ray Conf., Munich, Germany, Aug. 18-28, 1975), Conference Papers Volume 11. Invited Lectures and Rapporteur Papers, pp. 3566-3593 (Max-Planck-Institut für Extraterrestrische Physik, Munchen, Germany, 1975).

Key words: dynamics; galactic structure; interstellar medium; magnetic pressure; neutron; radiation; stellar explosion; supernova.

A supernova explosion probably begins with the sudden release of energy (about $10^{52} \mathrm{erg}$ ) in the dense neutron core of an extended star. The matter expelled from the core sweeps out through the envelope, heats the gas there and gives it a high outward velocity (about $10^{9} \mathrm{~cm} \mathrm{~s}^{-1}$ ). The expanding envelope radiates in the visible, reaching maximum brightness after some three weeks. It then dims over a period of months, and is kept hot during this time by a central source of energy. The radiative losses have little dynamical effect at this stage. Later the supernova ejecta interact with the surrounding interstellar matter. In Phase I of the interaction the majority of the mass in the remnant comes from the star; in Phase 11 the majority is interstellar gas. The latter phase ends when radiative losses from the remnant become dynamically important. There is a loss of pressure, the gas in the shell is compressed into filaments and the magnetic field amplified. The filamentary shell sweeps on until it is brought to rest by the interstellar medium, and by collision with neighboring supernova remnants. In this late stage magnetic pressure dominates the motion. Such old remnants may be identified with the galactic loop structures. 
Instabilities are present at various stages of the expansion. During the early motion through the stellar envelope they govern the mixing of the neutron gas with the envelope gas. During Phase I especially, and after Phase 11, they tend to distort the ambient magnetic field and perhaps accelerate charged particles. Finally the gas in the interior of the remnant takes a very long time to cool, and probably becomes the observed hot component of the interstellar medium.

17218. Gadzuk, J. W., Surface relaxation energies in core level spectroscopies of adsorbed atoms and molecules, Surf. Sci. 67, $77-88$ (1977).

Key words: adsorption; dielectric screening; photoelectron spectroscopy; relaxation.

Core level holes which are created in electron emission spectroscopies of atoms and molecules adsorbed or condensed onto metal surfaces induce a screening charge at the surface. The Coulomb interaction between the induced and the hole charge, called the extra-atomic relaxation energy, shifts the apparent binding energy of the ejected electron from the value inferred from an orbital energy. In this paper, linear response screening shifts are calculated for a number of different response functions which also allow for the polarizability of the adsorbed layers. The relation between classical image potential shifts and those obtained here is quantitatively compared. As an example, the $\mathrm{x}$-ray photoelectron spectrum of $\mathrm{SF}_{6}$ physisorbed on Ru surfaces is interpreted in terms of the present theory.

17219. Gadzuk, J. W., Plasmon satellites in x-ray photoemission spectra, J. Electron Spectrosc. Relat. Phenom. 11, 355-361 (1977).

Key words: photoemission; plasmons; satellites; XPS.

Controversy exists whether plasmon-satellite structure observed in core-level photoemission spectra arises from so-called intrinsic or extrinsic plasmon production. Owing to "interference" processes in which virtual plasmons produced by electrons (holes) are absorbed by holes (electrons), the holeplasmon coupling constant is significantly reduced in a way, predicted by Langreth, which varies inversely with the velocity of the photoexcited electron. Using synchrotron radiation, this coupling constant can be varied continuously with $h v$. An experiment is proposed for sorting out the role of intrinsic versus extrinsic processes in plasmon satellites.

17220. Crawford, M. L., Experimental evaluation of the radiation characteristics of dipole sources enclosed in a TEM transmission cell, Proc. Conf. on Precision Electromagnetic Measurements, Boulder, CO, June 28-July 1, 1976, pp. 57-59 (Institute of Electrical and Electronics Engineers, New York, NY, 1976).

Key words: measurements; radiated emission; radiation resistance; TEM cells.

This paper describes measurements to verify theoretical formulation of the changes in the radiation resistance of electronic equipment enclosed inside a special type shielded enclosure, a rectangular TEM cell. The measurements were made, assuming the device under test (DUT) could be modeled by dipole sources, using a monopole antenna mounted at various locations inside a typical cell. The predicted radiated power from the monopole antenna mounted inside the cell was within \pm 2 dB of the energy coupled to the cell's output ports. These results are contained in the paper and give credibility to the ability to relate such measurements to free space radiation conditions.

17221. Wacker, P. F., Newell, A. C., Advantages and disadvantages of planar, circular cylindrical, and spherical scanning and description of the NBS antenna scanning facilities, Proc. European Space Agency Symp., Noordwijk, The Netherlands, June 6-8, 1977, pp. 115-121 (ESA Scientific and Technical Publications Branch, ESTEC, Noordwijk, The Netherlands, 1977).

Key words: antenna patterns; cosite interference; cylindrical scanning; near-field scanning; planar scanning; scanning facilities; spherical scanning.

Near-field scanning yields high accuracy because of laboratory-type control, fitting with linear combinations of exact solutions of Maxwell's equations, high signal to noise ratio, averaging over $10^{4}$ or more measurements for each pattern value, full correction for proximity effects, and absence of ground and grazing angle reflections, as in an anechoic chamber. Further, it provides quite detailed pattern information, and it can yield phase and amplitude of each component of the electromagnetic six-vector for any distance, permitting computation of cosite interference. Not only is it independent of weather, it permits measurements to be made in a clean room and in atmospheric absorption bands. Planar, circular cylindrical, and spherical scanning are compared, and the NBS near-field scanning facilities are described, including new circular cylindrical and spherical facilities and what we believe to be the world's most accurate planar scanner.

17222. Wacker, P. F., Symmetry analysis applied to wave theory, Proc. Institute of Electrical and Electronics Engineers/Antennas and Propagation Society Int. Symp., Stanford, CA, June 20-24, 1977, pp. 169-172 (Braun-Brumfield, Inc., Ann Arbor, Ml, 1977).

Key words: computer programs; data reduction; eigenvalue equations; electromagnetic theory; group theory; near-field scanning; symmetry analysis.

Although symmetry analysis (SA) is little used in electromagnetic theory or engineering, it is one of the most powerful tools of physical science. Thus SA permits one to derive, from symmetry alone, Maxwell's equations and their exact complex vector spherical solutions, including transformation under coordinate rotation or translation, definitions of special functions, and orthogonalities between solutions and between the transformation coefficients. These two types of orthogonalities provide the basis for near-field spherical scanning with and without correction for the pattern of the measurement probe, including highly efficient computer programs. Being based upon relativistic invariance, SA provides deep and broad understanding. By pushing irrelevant details into the background, SA provides ready insight into complicated problems, say involving lossy, inhomogeneous, anisotropic, nonreciprocal, magnetoelectric media. These irrelevant details include mathematical formulation, many material properties, and, in large part, even the physical system, coordinate system, or whether the analysis is classical or quantum mechanical. This permits ready transfer of analysis and computer programs from one system to another. Thus, the mathematics of quantum mechanical selection rules may be used to reduce the effort required to determine scattering properties. Similarly, the noncrossing rule of spectroscopy may be applied to propagation constants of waveguides and resonant frequencies of cavities.

17223. Wacker, P. F., Recent results with spherical near-field antenna scanning at the National Bureau of Standards, Proc. European Space Agency Symp., Noordwijk, The Netherlands, June 6-8, 1977, pp. 159-164 (ESA Scientific and Technical Publications Branch, ESTEC, Noordwijk, The Netherlands, 1977).

Key words: antenna patterns; computer programs; nearfield scanning; spherical scanning. 
The author's Fast Fourier "Transform" multiplying matrix technique of processing near-field spherical scanning data has been programmed for the no-probe-correction case and is largely completed for the probe correction case, except for the complicated translational transformation of the probe pattern coefficients. (The elements of the multiplying matrices are constants independent of the angular and radial positions of the measurement points.) For an X-band antenna 23 wavelengths across with half-widths of $1.5-1.8^{\circ}$, computations were carried out in 2 minutes. For a scanning radius $\mathrm{R}=329.2 \mathrm{~cm}$, the far field is in good agreement with that accurately known from planar scanning. For $R=50.9 \mathrm{~cm}$, the agreement is less good, apparently due to lack of a probe correction. For $\Delta \boldsymbol{\Delta} \times \Delta \boldsymbol{\phi}=$ $2^{\circ} \times 6^{\circ}$ there is a small aliasing error at the larger radius, but essentially none at the smaller. Translation of the $\phi$ axis $0.36 \lambda$ from intersection with the $\theta$ axis produced only moderate errors.

17224. Newell, A. C., Repjar, A., Results of spherical near-field measurements on narrow-beam antennas, Proc. Conf. on Precision Electromagnetic Measurements, Boulder, $\mathrm{CO}$, June 28-July 1,1976, pp. 382-385 (Institute of Electrical and Electronics Engineers, New York, NY, 1976).

Key words: antennas; measurements; near-field; spherical.

The first phase of a program has been completed to develop spherical near-field measurement techniques. Tests were performed to determine.scan parameters, alignment procedures and estimates of errors. The results have shown that the required scan sector, the effect of the probe correction, and the required accuracy in knowing the radius of the measurement sphere $\mathbf{R}$ all decrease with $\mathbf{R}$. Comparisons of results have been made with planar near-field results which indicate the accuracy of the technique.

17225. Wacker, P. F., Symmetry analysis applied to scattering, inverse scattering, and antenna patterns: Measurements, moment method, and characteristic modes, Proc. Institute of Electrical and Electronics Engineers/Antennas and Propagation Society Int. Symp., Stanford, CA, June 20-2 , 1977, pp. $177-$ 180 (Braun-Brumfield, Inc., Ann Arbor, MI, 1977).

Key words: antenna patterns; characteristic modes; Garbacz characteristic modes; group theory; inverse scattering; moment methods; scattering; singularity expansion method; symmetry analysis.

Constructive procedures are given for making full use of known symmetries in reducing the measurement or computational effort required to determine (1) the scattering properties of any mathematically linear scatterer (say electromagnetic or linearized acoustic), (11) the transmitting or receiving properties of an antenna, and (III) the characteristic modes of: Garbacz, the singularity expansion method, and n-ports. (IV) Procedures are also given for determining all the symmetries of a scatterer (or scattering operator) from scattering properties, even when the inverse scattering problem has a nondenumerable infinity of exact solutions. For (1)-(III) the modes are so chosen and ordered that the scattering matrix is partitioned into submatrices, a large fraction of which are known a priori to have only zero elements and each of the others known except for a complex multiplicative constant. The measurement or computational effort for (1) and (II) is thus reduced to determining these multiplicative constants. The mathematics (which is fundamental to the selection rules of quantum mechanics) is rigorously exact and applies to (A) both finite and continuous groups, (B) active and passive scatterers and (C) media which are lossy, inhomogeneous, anisotropic, nonreciprocal, and magnetoelectric, subject only to the assumed symmetries.
17226. Levine, J., Comments on the review of "Strainmeter Technology," by P. H. Sydenham, Nature 257, No. 5526, 513 (Oct. 9, 1975).

Key words: laser strainmeter; saturated absorption.

Several of the conclusions of P. H. Sydenham re earth strain research are not acceptable. In particular conventional strain meters (i.e. quartz) have very serious problems in temperature and humidity control when it comes to the measurement of long period earth strain. These problems are relieved by using a laser strain meter. Some of the advantages and disadvantages of both types are discussed.

17227. Wait, D. F., Satellite earth terminal G/T measurements, Microwave J. 20, No. 4, 49, 51, 58 (Apr. 1977).

Key words: figure of merit; G/T; measurement accuracy; radio stars; satellite earth terminal; signal to noise; star flux.

A new measurement service of the National Bureau of Standards is the measurement of Figure of Merit $(\mathrm{G} / \mathrm{T})$ of satellite communications earth terminals. The G/T of the 10-meter earth terminal at Fucino, Italy, was recently measured at $2.2655 \mathrm{GHz}$, at low elevation angles to \pm 8 percent $( \pm 0.3 \mathrm{~dB}$ ). This measurement was one of the most carefully evaluated measurements of $\mathrm{G} / \mathrm{T}$ of any commercial earth terminal.

17228. Munro, R. G., A scaling theory of solids under hydrostatic pressure, J. Chem. Phys. 67, No. 7, 3146-3150 (Oct. 1, 1977).

Key words: frequency shifts; hydrostatic pressure; optical transitions; scaling theory.

A scaling theory is proposed for solids under hydrostatic pressures which do not undergo structural phase transitions or symmetry distortions or for which distortions may be neglected. The theory is tested with two adjustable parameters by computing the linear frequency shifts $(d v / d P)$ for the optical transitions ${ }^{4} A_{2}(F) \rightarrow{ }^{2} E,{ }^{2} T_{2},{ }^{4} T_{2}(F),{ }^{4} T_{1}(F),{ }^{2} T_{1}$ of $\mathrm{Cr}^{3+}$ ions in $\mathrm{Al}_{2} \mathrm{O}_{3}$. These results are further applied to $\mathrm{Al}_{2} \mathrm{O}_{3}: \mathrm{Ti}^{3+}, \mathrm{V}^{3+}$ with no additional parameter adjustments. Good agreement is found with all the data, including occurrences of both red and blue shifts. A general discussion of impurity ions isoelectronic to $\mathrm{Cr}^{3+}$ in $\mathrm{Al}_{2} \mathrm{O}_{3}$ is given. The evolution of the scaling theory into an effective potential representation of the externally applied pressure is also indicated.

17229. Weiss, A. W., Hartree-Fock line strengths for tne lithium, sodium and copper isoelectronic sequences, $J$. Quant. Spectrosc. Radiat. Transfer 18, No. 5-B, $481-490$ (1977).

Key words: atomic spectroscopy; Hartree-Fock; ions; line strength.

Hartree-Fock line strengths have been computed for the lowest $\Delta n=0$ transitions of ions in the lithium, sodium and copper isoelectronic sequences. Excitation energies were collected relativistically to lowest order in the Pauli approximation, and line strengths were corrected semiempirically using the Dirac correction factors of hydrogen-like ions. Systematic trends have been established and new data are presented for very highly ionized species.

17230. Hughes, E. E., Rook, H. L., Deardorff, E. R., Margeson, J. H., Fuerst, R. G., Performance of a nitrogen dioxide permeation device, Anal. Chem. 49, No. 12,'1823-1829 (Oct. 1977).

Key words: nitrogen dioxide; permeation tube; standard reference material. 
An in-depth study of the performance of a nitrogen dioxide permeation device, developed at NBS, has been conducted in cooperation with researchers at EPA. The study detailed conditions which would affect permeation rate and stability. Parameters such as temperature, humidity, nitrogen dioxide purity, and calibration procedures were investigated and their effect on rate characteristics was determined. Also, studies were conducted into the temperature memory effects so as to define the minimum temperature equilibration time necessary to obtain stable, reproducible rates. The results of this study have helped define the care necessary to use nitrogen dioxide permeation devices as primary gas standards.

17231. Berger, J., Levine, J., The spectrum of earth strain from $10^{-8}$ to $10^{2} \mathrm{~Hz}, J$. Geophys. Res. 79, No. 8, 1210-1214 (Mar. $10,1974)$.

Key words: earth strain; laser strainmeter; power spectrum.

We have measured the power spectrum of the earth strain fluctuations over 10 decades in frequency from $10^{-8}$ to $10^{2} \mathrm{~Hz}$ using data from three strain observatories. Although the strain meters were widely separated and of different design, they produced records whose power spectra are in close agreement with each other. We find that the composite power spectrum shows an approximate inverse square dependence on frequency over the entire band investigated.

17232. Cooper, J., Smith, E. W., Vidal, C. R., Influence of ion dynamics on $\mathrm{H} \alpha$ and $\mathrm{H} \beta$ at low densities, J. Phys. B: Atom. Molec. Phys. 7, No. 4, L101-L105 (Mar. 1974).

Key words: hydrogen $\mathrm{H} \alpha$ and $\mathrm{H} \beta$; ion dynamics; quasi static; Stark broadening; theoretical comparison.

Calculations for the Stark broadening of $\mathrm{H} \alpha$ and $\mathrm{H} \beta$ using a unified theory for both ions and electrons are presented in the density range $10^{14}$ to $10^{15} \mathrm{~cm}^{-3}$ at a temperature of $10^{4} \mathrm{~K}$ Although the theory is of marginal validity at these densities, it shows quite conclusively the influence of ion dynamics in reducing the dip at the centre of the $H \beta$ profile and the peak in the centre of the $\mathrm{H} \alpha$ profile.

17233. Richmond, J. C., A proposed standard for monochrome television cameras for courtroom use, Proc. SPIE Tech. Symp. East-Seminar on Optics in Security and Law Enforcement, Reston, VA, Apr. 2l-22, 1977, pp. 126-134 (Society of Photo-optical Instrumentation Engineers, Bellingham, WA, Oct. 1977).

Key words: contrast transfer function; distortion; limiting resolution; shading; signal-to-noise ratio; spectral response; standards; television cameras; total response.

This paper briefly describes a proposed Standard for Monochrome Television Cameras for Courtroom Use. In this brief description the physical parameters (size, weight, marking, user information, etc.) are ignored, and the operational parameters (format, sync signal, power requirements, connections, etc.) are mentioned only briefly. The performance parameters, 1$)$ relative spectral response, 2) total response, 3) signal-to-noise ratio, 4) limiting resolution, 5) contrast transfer function, 6) shading and 7) geometric distortion, are described in some detail. Minimum acceptance levels and methods of evaluation are given for each of the performance parameters.

17234. Komarek, E. L., An application of the six-port reflectometer to precision measurement of microwave one-port parameters, Proc. 1977 IEEE-MTT-S Int. Microwave Synip., San Diego, CA, June 21-23, 1977, pp. 56-57 (Institute of Electrical and Electronics Engineers, New York, NY, 1977).

Key words: microwave measurements; one-port microwave parameters; six-port concept.
The arbitrary six-port junction concept has been applied to an automated broadband system in the $1-18 \mathrm{GHz}$ frequency range for the measurement of microwave power and reflection coefficient. Performance evaluation results show an improvement in precision over other automated and manually operated measurement systems used at the National Bureau of Standards.

17235. Early, J. G., Elevated-temperature mechanical behavior of a carbon-manganese pressure vessel steel, J. Eng. Mater. Technol. 99, No. 4, 359-365 (Oct. 1977).

Key words: creep-rupture properties; elevated-temperature; fracture mode; Larson-Miller parameter; pressure vessel steel; tensile properties.

The short-time effects of stress and temperature on the mechanical properties of a carbon-manganese pressure vessel steel were investigated using room- and elevated-temperature tensile tests and short-time creep-rupture tests.

The tensile test results indicated that strain aging effects were not observed in the temperature range $1100 \mathrm{~F}$ to $1250 \mathrm{~F}$. Analysis of the creep-rupture data, in the range $1150 \mathrm{~F}$ to $1250 \mathrm{~F}$, by the Larson-Miller method using the procedures of Manson and Mendelson yielding a value of 20.7 for the material constant, $C$. In the temperature and stress regime studied, a linear relationship was observed between $\log$ (stress) and $\log$ (time-torupture).

Fractographic analyses revealed a common fracture mode in all specimens tested. The fracture mode is described as an intermediate type, containing features of both transgranular and intergranular fracture.

17236. Oman, R. C., Comparing the benefits and the costs - of electric typewriters and word processors, The Office 85 , No. 6, 77-79 (June 1977).

Key words: automatic typewriters; benefits; break even analysis; cost effectiveness; costs; productivity.

There is a very large differential between the cost of conventional electric and automatic typewriters. The ratio of the costs is usually on the order of 1 to 20 or 30 depending on the particular models involved. Despite the difference in cost, automatic typewriters as they are used in many office situations seldom substantially increase productivity and sometimes decrease it. Unless, automatic typewriters are used for rather special typing jobs, costs normally outweigh benefits. The article itemizes the benefits and costs of automatic typewriters and discusses the kind of typing situation where such typewriters can be beneficial. In addition, for those variables that can be easily quantified, a simple benefit/cost model using break-even analysis is presented. This model can be used as a guide to decision makers in determining whether the additional dollar investment in automatic typewriters can be economically justified through increased productivity.

17237. Engen, G. F., The six-port reflectometer: An alternative network analyzer, Proc. 1977 IEEE-MTT-S Int. Microwave Symp., San Diego, CA, June 21-23, 1977, pp. 44-46 (Institute of Electrical and Electronics Engineers, New York, NY, 1977).

Key words: automatic network analyzer; automation; microwave measurements; six-port.

Although the six-port measurement technique is rapidly gaining the attention of the microwave community, the theoretical development, to date, yields but limited practical insight into its operation.

Following a brief review of the prior art, such that the sixport techniques may be placed in proper perspective, this paper presents an alternative introduction leading to much better in- 
sight, and to design criteria for a six-port circuit which optimally exploits the concept.

17238. Huie, R. E., Long, N. J. T., Thrush, B. A., Laser induced fluorescence of $\mathrm{CFCI}$ and $\mathrm{CCI}_{2}$ in the gas phase, Chent. Phys. Lett. 51, No. 2, 197-200 (Oct. 15, 1977).

Key words: $\mathrm{CCl}_{2} ; \mathrm{CFCl}$; fluorescence; laser; lifetime; quenching rate.

The fluorescence of $\mathrm{CFCl}$ and $\mathrm{CCl}_{2}$ excited by a tunable dye laser has been observed in the gas phase. The radiative lifetimes are $644 \pm 18$ and $3810 \pm 300$ ns respectively consistent with matrix results. The quenching rate of $\mathrm{CCl}_{2}$ is greater than for $\mathrm{CFCl}$ and varies with the wavelength of excitation.

17239. Jesch, R. L., Bailey, R. A., Tausch, H. J., Characterization of a HF probe for integrated circuits measurements, Proc. Government Micro-circuit Applications Conf., Boulder, CO, June 25-27, 1974, pp. 120-121 (University of Colorado, Boulder, $\mathrm{CO}, 1974$ ).

Key words: parasitic; probe; probe assembly.

A special probe assembly is available which can make high frequency measurements on individual integrated circuit transistors. In order to determine and correct for the effects of the probe assemblies on transistor parameter measurements, a technique was developed to determine experimentally the element values in an equivalent circuit representing the probe assembly. Using the above model, correct two-port data can be obtained from probe/transistor measurements.

17240. Engen, G. F., An improved circuit for implementing the six-port technique of microwave measurements, Proc. 1977 IEEE-MTT-S Int. Microwave Symp. Digest, San Diego, CA, June 21-23, 1977, pp. 53-55 (Institute of Electrical and Electronics Engineers, New York, NY, 1977).

Key words: automatic network analyzer; automation; microwave measurements; six-port.

In a companion paper, circuit design criteria have been developed which will lead to optimal results in applying the six-port technique to the measurement of microwave parameters. This paper will describe what promises, in many situations, to become the "preferred" six-port circuit.

17241. Graminski, E. L., Effect of flexing on the mechanical properties of paper, Proc. Symp. The Fundaniental Properties of Paper Related to Its Uses, Cambridge, England, Sept. 1622, 1973, 24 pages (Technical Division, The British Paper and Board Industry Federation, London, England, 1973).

Key words: durability; flexing; paper.

Probable causes for the deterioration of the physical properties of paper as a result of repeated handling have been determined. A flexing test has been devised that evaluates the relative durability of paper.

Investigations with the scanning electron microscope indicate that the fibrillar component of paper deteriorates during flexing and is probably responsible for the decline in stiffness as well as the modulus of paper. Because of the ever-increasing use of automatic document handling equipment, stiffness retention with handling is essential, since limp documents are difficult, if not impossible, to process automatically. Unfortunately, stiffness declines rapidly as paper is flexed or handled.

The rates of deterioration for all other physical properties of paper during flexing are independent of each other and vary from one paper to another. The rate at which certain properties deteriorate is independent of the quality of the paper.

No correlation has been found between any paper property and durability.
17242. Cohen, P. I., Abramowitz, S., Broida, H. P., Chemisorptive Iuminescence from $\mathrm{Ba}$ and $\mathrm{Mg}$ films, Surface Sci. 69, 601604 ( 1977 ).

Key words: $\mathrm{Ba}$ and $\mathrm{Mg}$ films; chemiluminescence; chemisorption; codeposition; gas phase reaction.

The chemiluminescent reactions of $\mathrm{Ba}$ and $\mathrm{Mg}$ films, adsorbed on a gold plated copper surface maintained at liquid hydrogen temperature, with the oxidants $\mathrm{O}_{2}, \mathrm{O}_{3}, \mathrm{~N}_{2} \mathrm{O}, \mathrm{NO}_{2}$, and $\mathrm{SF}_{6}$ have been observed. Some spectral analysis of the glow emissions have been made.

17243. Weidman, M. P., A semi-automated sixport for measuring millimeter wave power and complex reflection coefficient, Proc. 1977 IEEE-MTT-S Int. Microwave Symp., San Diego, CA, June 2l-23, 1977, pp. 58-60 (Institute of Electrical and Electronics Engineers, New York, NY, 1977).

Key words: automation; millimeter wave; power measurement; reflection measu rement; six-port.

A six-port system has been developed and applied to the precision measurement of power and complex reflection coefficient in WR-15 (50-75 GHz) waveguide. The system is automated except for frequency and switching control for the signal source. This system provides a time saving factor of at least five as compared to a tuned reflectometer with little if any degradation in accuracy.

17244. Hoer, C. A., A microwave network analyzer using two 6-port reflectometers, Proc. 1977 IEEE-MTT-S Int. Microwave Synip., San Diego, CA, June 21-23, 1977, pp. 4749 (Institute of Electrical and Electronics Engineers, New York, NY, 1977).

Key words: impedance; microwaves; network analyzer; reflection coefficient; reflectometer; scattering parameters; self-calibration techniques; six-port junction.

Theory is presented for designing a microwave network analyzer which measures the circuit parameters of a 2-port device by connecting small portable 6-port reflectometers on each side of the 2-port. Several calibration techniques are described, including self-calibration.

17245. Hruska, G. R., Magrab, E. B., Penzes, W. B., Reply to "Comments on 'Environmental effects on microphones of various constructions", J. Acoust. Soc. Anı. 62, No. 5, 1314 (Nov. 1977).

Key words: calibration; ceramic; condenser; electret; humidity; microphones; reciprocity; sensitivity; temperature.

To answer the question as to whether or not the microphones were given sufficient time to "recover" from a particular humidity we elaborate further on the experimental procedure.

17246. Deslattes, R. D., Unification of the electromagnetic scale, Proc. XXth Colloq. Spectroscopicum Int./Anniversary and the $7 t h$ Int. Conf. on Atonic Spectroscopy, Prague, Czechoslovakia, Aug. 30-Sept. 7, 1977, pp. 267-284 (The Czechoslovak Spectroscopic Society of the Czechoslovak Academy of Sciences, Prague, Czechoslovakia, 1977).

Key words: electromagnetic spectra; gamma rays; secondary standards; $x$ rays.

Over the past ten years there have been several instances of notable progress in improving connections between different parts of the electromagnetic spectrum. These developments are reviewed and shown to already yield some of the results which might be hoped for from a well integrated wavelength or frequency scale defined by a single conventio.1. 
17247. Uriano, G. A., Gravatt, C. C., The role of reference materials and reference methods in chemical analysis, Crit. Rev. Anal. Chem. 6, No. 4, 361-411 (Oct. 1977).

Key words: accuracy; chemical analysis; measurement compatibility; measurement systems; reference method; standard reference material.

A critical review is made of the role of reference materials and reference methods in chemical analysis. Emphasis is placed on evaluating their use in achieving accurate and compatible measurements throughout large multi-laboratory networks rather than within individual analytical laboratories. The total systems approach to achieving measurement compatibility on a national scale is discussed in the context of recent applications in the fields of industrial, environmental, clinical and agricultural chemical analysis. The role of federal laboratories, regulatory agencies, voluntary standards organizations, professional societies and individual laboratories is examined in terms of their relationships to each other as well as to various components of the accuracy-based measurement system. A number of examples of the application of reference materials and reference methods to large measurement systems are given to illustrate the advantages and limitations of the systems approach to accurate measurements. For example, the use of reference materials to reduce between-laboratory variability of measurements is illustrated by a recent survey aimed at evaluating a network of 96 laboratories performing determinations of sulfur dioxide in air. Although reference materials and reference methods are found to be extremely important mechanisms for helping to achieve measurement compatibility, other components of the accuracy based measurement network such as interlaboratory and intralaboratory quality assurance programs are found to be equally important in achieving this goal. Some future directions and opportunities for applying these concepts are also given.

17248. Powell, C. J., Stein, R. J., Needham, P. B., Jr., Driscoll, $T$. J., Attenuation lengths of low-energy electrons in solids derived from the yield of proton-excited Auger electrons: Beryllium and aluminum, Phys. Rev. B 16, No. 4, 1370-1379 (Aug. 15, 1977).

Key words: absolute yield; aluminum; attenuation length; Auger electrons; Auger-electron spectroscopy; beryllium; electron; proton excitation; x-ray photoelectron spectroscopy.

Values are reported for the absolute yields of $K V V$ Auger electrons from beryllium and $L_{23} V V$ Auger electrons from alu minum excited by 60 - to $220-\mathrm{keV}$ proton bombardment. The measurements were made using semi-infinite evaporated samples, and the results were used to derive effective values of the inelastic attenuation lengths for low-energy Auger electrons in the surface regions of the samples. The attenuation lengths determined using this technique were $6.1 \AA$ for $100-\mathrm{eV}$ electrons in Be and $1.9 \AA$ for $67-\mathrm{eV}$ electrons in Al. These effective attenuation lengths are appropriate for use in Auger-electron spectroscopy and $\mathrm{x}$-ray photoelectron spectroscopy.

17249. Greene, R. L., Cooper, J., Smith, E. W., A unified theory of Stark broadening for hydrogenic ions-1. A general theory (including time ordering), J. Quant. Spectrosc. Radiat. Transfer 15, 1025-1036 (1975).

Key words: hydrogenic ions; Stark broadening; unified classical path theory; unified theory.

The formalism of the Unified Classical Path Theory of Stark broadening is extended (by use of a technique developed by Lisitsa and Sholin) to include the effects of time-ordering in the calculation of the required time-development operator. In addi- tion, hyperbolic classical paths are considered so that the theory is valid for hydrogenic ions (as well as for the straight line paths of neutral hydrogen).

17250. Abrams, M. D., Techniques for evaluating the effectiveness of interactive computer service, Proc. 1977 ACM Annual Conf., Seattle, WA, Oct. 16-19, 1977, pp. 452-458 (Association for Computing Machinery, New York, NY, 1977).

Key words: evaluating computer service; network measurement machine; remote terminal emulators; response time; throughput; turnaround time.

Three key system-independent functional measures of the effectiveness of interactive computer service are response time, turnaround time, and throughput. Measurement can be made under uncontrolled conditions using a communications monitor such as the NBS Network Measurement System and under controlled conditions using Remote Terminal Emulators. Additional measurement and test tools include accounting logs and programs, stopwatches, live operators, tape loops, and internal stimulators. A feasibility test is described; a collection of illustrative data is presented.

17251. Adams, J. W., Crawford, M. L., Shafer, J. F., Electromagnetic interference (EMI) measurements for automotive applications, Proc. SAE Automotive Congress Conf., Detroit, MI, Feb. 23-27, 1976, pp. 1-6 (Society of Automotive Engineers, Inc., Warrendale, PA, 1976).

Key words: electromagnetic measurements; interference; near-field probes; radiation; susceptibility; TEM cell.

This paper discusses present electromagnetic interference (EMI) measurement techniques and some of the problems associated with EMI measurements, especially relative to automotive problems. Improved measurement techniques are then discussed, including: 1) use of isotropic probes capable of measuring unperturbed, complex fields close to their sources and 2) transverse electromagnetic transmission cells with expanded applications for both susceptibility and emission measurements. Finally, some suggestions for minimizing automotive EMl problems are given.

17252. Abrams, M. D., Cotton, I. W., Watkins, S. W., Rosenthal, R., Rippy, D. E., The NBS computer network measurement system, IEEE Trans. Commun. COM-25, No. 10 , $1189-1198$ (Oct. 1977).

Key words: computer network measurement; data acquisition; interactive computer access; measurement; network measurement services; service; teleprocessing systems measurement.

The NBS Network Measurement System represents the implementation of an approach to the measurement of interactive computer networks, teleprocessing systems, and network services which focuses on the service delivered to users rather than on the internal operating efficiency of the system. The information obtained aids users in the quantitative evaluation of such systems and services. The Network Measurement System consists of a data acquisition system and a separate set of data analysis programs. This paper describes the approach to network measurement taken by this system, the models of usersystem dialogue employed, and technical summary of the implementation of the data acquisition system and the data analysis programs.

17253. Verdier, P. H., The scattering of light by uniformly curved rods. A model of semirigid rod macromolecules, Macromolecules 10, 913-918 (Sept.-Oct. 1977). 
Key words: bent rods; form factors; light scattering; macromolecules; rodlike; rodlike macromolecules; rods, bent; rods, semirigid; semirigid rods.

Uniformly curved rods may be used as a model of rodlike macromolecules which are not rigid enough to be straight rods in solution. The dependence of scattered light intensity upon scattering angle (form factor) has been obtained numerically for curved rods with angles of bend from 0 (straight rod) to $150^{\circ}$. The results have been used to synthesize "experimental" scattering data for rods with lengths from 1500 to $5000 \AA$, over the range of scattering angles accessible to conventional lightscattering photometers. The errors incurred in extrapolation of the inverse form factors to zero scattering angle are shown to be not excessive. Further, it is shown that in some circumstances the ratio of the scattered intensities at two supplementary angles is a function primarily of the contour length of the rod and does not depend strongly upon the angle of bend. Measuring such a ratio therefore gives an estimate of contour length and, if the relation between contour length and molecular weight is known, of molecular weight.

17254. Julienne, P. S., Theory of gain and saturation for collision-induced lasing transitions, J. Appl. Phys. 48, No. 10, 4140-4148 (Oct. 1977).

Key words: argon oxide excimer; free-free-laser saturation flux; gain coefficients; stimulated collision-induced emission.

Theoretical expressions are given for the inversion density, small-signal-gain coefficient, and saturation-energy flux which pertain to stimulated collision-induced emission, that is, the free-free and free-bound dipole emission from unbound excited states formed during a collision of an atomic metastable species and another atom. The probability of stimulated emission during a collision is assumed to remain much less than unity so that a Maxwellian velocity distribution of excited atoms is maintained. The gain and saturation are described in terms of a profile function $k(v)$, a frequency-dependent two-body rate coefficient per unit frequency. The final expressions are analogous to those for a homogeneously broadened two-level atom. The theory is applied to the collision-induced green continuum from oxygen ${ }^{1} S_{0}$ in argon.

17255. Wagner, H. L., McCrackin, F. L., Branching and molecular weight distribution of polyethylene SRM 1476, J. Appl. Polym. Sci. 21, 2833-2845 (1977).

Key words: branched polyethylene; fractionation; gel permeation chromatography; GPC; molecular weight distribution; polymer characterization; standard reference material 1476.

A method of determining the distribution of branching in a polymer is developed employing limiting viscosity numbers (intrinsic viscosity), gel permeation chromatography (GPC), and absolute molecular weight determinations of fractions of the whole polymer. A molecular weight calibration of the GPC column set is first determined employing these fractions. From the limiting viscosity number measurements of these fractions and their molecular weight distribution determined from the GPC chromatogram, the viscosity-molecular weight relationship is determined by a nonlinear least-squares fitting procedure. For the same molecular weight, the limiting viscosity number of the branched polymer is less than the limiting viscosity number of the linear polymer. From the ratio of the two, the number of branches per unit molecular weight of the branched polymer is calculated. This method was applied to SRM 1476 , the standard reference branched polyethylene issued by the $\mathrm{Na}$ tional Bureau of Standards. The branching density for the constituents of SRM 1476 rise from zero at molecular weights less than 10,000 to about 6 to $8 \times 10^{-5}$ at molecular weights of 50,000 and above. The branching of SRM 1476 was also determined by the method of Drott and Mendelson, giving a result in fair agreement with the above method.

17256. Crissman, J. M., Guttman, C. M., Zapas, L. J., Performance of plastic packaging for hazardous materials transportation. Part 1. Mechanical properties, Report No. DOT/MTB/OHMO-76/4, 51 pages (U.S. Department of Transportation, Materials Transportation Bureau, Office of Hazardous Materials Operations, Washington, DC, Oct. 1976).

Key words: container tests; hazardous materials ladings; mechanical properties; performance criteria; plastic packaging; stress-cracking; time-to-fail.

This report, prepared for the U.S. Department of Transportation, contains background information useful in evaluating the performance of plastic packagings for hazardous materials transportation, insofar as mechanical properties are concerned. Current DoT regulations and test methods are reviewed, as well as testing procedures from other organizations and countries. Also included are recommendations to modify current DoT regulations to make test methods more quantitative. Finally, experimental data are presented which represent the initial stage of a study it is hoped will ultimately lead to the establishment of criteria upon which the long time behavior of plastic containers can be predicted based on short time tests.

17257. Diamondstone, B. I., Burke, R. W., Some difficulties encountered in speciation studies of arsenic, Analyst Short Papers 102, 613-614 (Aug. 1977).

Key words: arsenic reduction; arsenic speciation; biological and organic materials; silver diethyldithiocarbamate method.

Speciation studies of arsenic (III) and arsenic (V) can be carried out in aqueous mixtures of the two using a variety of techniques. However, with the acid systems studied to date arsenic speciation cannot be measured in biological materials. These studies, in which known amounts of arsenic (III) and arsenic (V) were added to botanical materials, show that the digestion of the sample results in an alteration of the original oxidation states of arsenic.

17258. Fivozinsky, S. P., Lide, D. R., Jr., Communicating quantitative scientific knowledge, Tech. Commun., pp. 10-11 (Fourth Quarter 1977).

Key words: communication; information; interdisciplinary technology; physical property data; publish; science; standard reference data; technology.

The results of scientific research are of limited use for the advancement of technology unless a critical evaluation of these results is made to insure their reliability to workers in many varied areas. In turn, there must be an effective dissemination mechanism to insure an interdisciplinary transfer of knowledge.

17259. Schroeder, L. W., Dickens, B., Brown, W. E., Crystallographic studies of the role of $\mathrm{Mg}$ as a stabilizing impurity in $\boldsymbol{\beta}-\mathrm{Ca}_{3}\left(\mathrm{PO}_{4}\right)_{2}$. II. Refinement of $\mathrm{Mg}$-containing $\boldsymbol{\beta}-\mathrm{Ca}_{3}\left(\mathrm{PO}_{4}\right)_{2}, \boldsymbol{J}$. Solid State Chem. 22, 253-262 (1977).

Key words: beta-tricalcium phosphate; cation substitution; coordination; crystal structure; disorder; magnesium incorporation; phosphate; vacancies.

The crystal structures of five samples of $\mathrm{Mg}$-containing $\beta$-tricalcium or thophosphate, $\beta-\mathrm{Ca}_{3}\left(\mathrm{PO}_{4}\right)_{2}$, have been refined and the $\mathrm{Mg}$-impurity distribution has been examined. Typically, $\sim 7500$ reflections were measured and merged into a unique set 
of $\sim 2500$. Least-squares refinements with anisotropic temperature factors (and third cumulants for some atoms) produced weighted residuals, $R_{u}(F)$, in the region of 0.02 to 0.04 . Three of the five cation sites are always completely filled with calcium ions, a fourth site with $\mathrm{Ca}$ and $\mathrm{Mg}$ ions, and the fifth site contains $\mathrm{Ca}, \mathrm{Mg}$, and vacancies. Local order may exist because the sizes of the coordinations about the two $\mathrm{Mg}$-containing cation sites are directly related by the orientation of phosphate group $\mathrm{P}(2) \mathrm{O}_{4}$ such that a small ion in one site favors the incorporation of a small ion in the other site.

17260. Eckerle, K. L., Venable, W. H., Jr., 1976 remeasurement of NBS spectrophotometer-integrator filters, Color Res. Application 2, No. 3, 137-141 (Fall 1977).

Key words: chromaticity coordinates; color; filters; high accuracy; spectrophotometer; standards; transmittance; tristimulus values.

Sets of five colored-glass filters, identified as Standard Reference Materials 2101 through 2105 and intended for checking the performance of spectrophotometer-integrator systems, have been issued by NBS for many years. High-accuracy transmittance measurements were performed on a set of the colored filters designated Master Set No. 3 by using a reference spectrophotometer constructed at NBS. A comparison of the new values with the original data obtained in 1962 for Master Set No. 3 shows agreement to within the experimental uncertainties of the 1962 measurements.

17261. Kahn, A. H., Spal, R., Feldman, A., Eddy-current losses due to a surface crack in conducting material, J. Appl. Phys. 48, No. 11, 4454-4459 (Nov. 1977).

Key words: eddy currents; eddy current testing; electromagnetic testing; nondestructive testing.

Calculations are reported for the spatial distribution of magnetic fields in the neighborhood of a long surface crack in a conductor, where a uniform ac magnetic field is applied parallel to the length of the crack. The problem is resolved into tractable parts consisting of the cases of eddy currents near a semi-infinite crack with a sharp tip and eddy currents near a square corner. The semi-infinite crack problem is solved exactly by a modification of Sommerfeld's diffraction theory and the corner problem is treated by a Green's function obtained by the method of images. The composite solution is valid for a crack of depth equal to four times the electromagnetic skin depth or greater. From the solution, the Poynting vector is calculated and its integral over the surface computed. The change in power dissipation relative to the "uncracked" surface is given in a simple form.

17262. Bennett, L. H., McAlister, A. J., Watson, R. E., Interstitial compounds, Phys. Today 30, No. 9, 34-40 (Sept. 1977).

Key words: alloys; compounds; hardness; interstitial; metals; refractory.

The structure, properties, and bonding of interstitial compounds are reviewed, with tutorial emphasis on the many gaps in our knowledge and understanding of many of these properties, and their many potential technological applications.

17263. Geltman, S., Laser-induced ionising collisions in alkali vapours, J. Phys. B: Atom. Molec. Phys. 10, No. 15, 3057. 3074 (1977).

Key words: alkalis; atom collisions; multiphoton ionisation; Rabi shifts; radiative Penning ionization; tuneable lasers.

The semiclassical theory is developed for a simultaneous collisional and radiative process, and applied to the laser-induced ionisation in a collision of two excited alkali atoms (in their lowest $n^{2} \mathrm{P}$ states) in a laser field. Perturbation theory is used to evaluate the probability for this process in the case of straight-line paths at large impact parameter. The collision perturbation is taken to be the dipole-dipole interaction between the two atoms, which together with the dipole interaction with the radiation leads to the occurrence of $s$ and $d$ intermediate atomic states and $p$ and $f$ final states for the ejected electron. The form $P=\alpha / / \nu p^{5}$ results for the total ionisation probability, where $\alpha$ contains all the atomic information and has been evaluated for all the alkalis using the Coulomb and quantum defect approximations. Estimates of total cross sections are made by integrating over $\rho$ while allowing for saturation and trajectory effects. The ionisation rates for this process are compared with those for the direct two-photon ionisation. The laser-induced ionising collision process helps explain certain experimental observations in resonantly irradiated alkali vapours.

17264. Johnson, D. R., Lovas, F. J., Gottlieb, C. A., Gottlieb, E. W., Litvak, M. M., Guelin, M., Thaddeus, P., Detection of interstellar ethyl cyanide, Astrophys. J. 218, 370-376 (Dec. 1, 1977).

Key words: astronomy; ethyl cyanide; interstellar molecule; microwave emission; radio sources and rotational spectra.

Twenty-four millimeter-wave emission lines of ethyl cyanide $\left(\mathrm{CH}_{3} \mathrm{CH}_{2} \mathrm{CN}\right.$ ) have been detected in the Orion Nebula (OMC1) and seven in Sgr B2. To derive precise radial velocities from the astronomical data, the first laboratory measurement of the rotational spectrum of ethyl cyanide has been made at frequencies above $41 \mathrm{GHz}$. In OMC-1, the rotational temperature of ethyl cyanide is $90 \mathrm{~K}$ (in good agreement with other molecules), the local standard of rest radial velocity is $4.5 \pm$ $1.0 \mathrm{~km} \mathrm{~s}^{-1}$ (versus $8.5 \mathrm{~km} \mathrm{~s}^{-1}$ for most molecules), and the column density is $1.8 \times 10^{14} \mathrm{~cm}^{-2}$ (a surprisingly high figure for a complicated molecule). The high abundance of ethyl cyanide in the Orion Nebula suggests that ethane and perhaps larger saturated hydrocarbons may be common constituents of molecular clouds and have escaped detection only because they are nonpolar, or only weakly so.

17265. McAlister, A. J., Watson, R. E., Charge flow in transition metal carbides, Semicond. Insulators 2, 231-242 (1977).

Key words: charge transfer; chemical shifts; core levels; transition metal carbides; $x$-ray emission; $x$-ray photoemission.

To date, attempts to deduce transferred charge, $\delta$, in transition metal carbides from chemical shifts, $\Delta E_{B}$, of $x$-ray photoemission core lines have relied on analysis of $\Delta E_{B}$ in terms of interaction of $\delta$ with the core shell and the Madelung term consequent to charging of the remainder of the lattice when $\delta \neq 0$. Values of $\delta$ deduced on this basis were of plausible magnitude and of a sign consistent with one school of current thinking. But this approach is admittedly oversimplified. In the present work, we consider the consequences of going to a more complete analysis. Admitting the complications leads in the case of the carbides to an ill conditioned expression for $\Delta \mathrm{E}_{B}$ and to poorly determined values of $\delta$. Within these bounds, application of this expression to literature values of core shifts as well as new data obtained by us for WC and $\mathrm{Mo}_{2} \mathrm{C}$ leads to values of $\delta$ opposite in sign and smaller in magnitude than previously inferred, and to the conclusion that hitherto neglected volume effects, rather than transferred charge, make the dominant contribution to $\Delta \mathrm{E}_{B}$.

17266. Eisenhart, C., Contribution to invited discussion of "Do robust estimators work with real data?," by Stephen M. Stigler, Ann. Stat. 5, No. 6, 1085-1087 (Nov. 1977). 
Key words: A. A. Michelson; adaptive estimators: arithmetic mean; bias; estimators of location; median; $\mathbf{M}$ estimators; S. Newcomb; systematic errors; trimmed means; velocity of light.

Inasmuch as the actual causes and precise nature of the systematic errors affecting historic data sets, e.g. A. A. Michelson's and S. Newcomb's measurement of the velocity of light, are not known today, it is impossible to bring such data sets "into line" with modern measurements of the same quantity, or, alternatively, to "work backwards" from a currently accepted value of the quantity concerned (e.g. the velocity of light) to derive trustworthy determinations of the particular ("true"?) values that such historic data sets were striving to indicate. Consequently efforts, such as Stigler's, to compare the accuracies of alternative estimators of location applied to such historic data sets are dubious.

17267. Levine, J., Experiments of astrophysical significance using a laser strainmeter, (Proc. Laser Spectroscopy Conf., Vail, CO, June 25-29, 1973), Paper in Laser Spectroscopy, R. G. Brewer and A. Mooradian, Eds., pp. 643-652 (Plenum Press, New York, NY, 1974).

Key words: gravitational waves; laser; strainmeter.

A 30 meter laser strainmeter is currently being used to investigate the possibility of detecting extra terrestrial sources of gravitational waves using the earth as an antenna. The strainmeter consists of an evacuated Fabry-Perot interferometer, illuminated by a $3.39 \mu \mathrm{m}$ He-Ne laser. A second $3.39 \mu \mathrm{m}$ laser is stabilized by means of saturated absorption in methane, and its wavelength serves as a reference length for the system. We conclude that detection of signals from rotating binary star systems may be possible if some means could be found for reducing the earth noise, and we suggest ways in which this might be accomplished.

17268. Stewart, B. D., Improved $\beta$ scintillation counting, Health Phys. 33, No. 4, 343-344 (Oct. 1977).

Key words: low-level counting; plastic phosphors; scintillation counting; $\beta$-ray detection.

An improved method of low-level $\beta$ scintillation counting using thin plastic phosphors is described. The improved method reduces the uncertainty associated with detector efficiency measurements, and it reduces the cost per sample.

17269. Heydemann, P. L. M., Tilford, C. R., Hyland, R. W., Ultrasonic manometers for low and medium vacua under development at the National Bureau of Standards, J. Vac. Sci. Technol. 14, No. 1, 597-605 (Jan.-Feb. 1977).

Key words: interferometer; manometers; manometry; pressure standard; ultrasonic interferometer; vacuım measurement.

The first part of this paper describes the use of ultrasonic interferometry for the measurement of the lengths of manometer columns. The major known sources of errors of manometers are then analyzed, and design criteria are developed which reduce these errors below set limits. Finally, two ultrasonic manometers now being developed at the National Bureau of Standards for measurements in the low and medium vacuum ranges are described. The ultrasonic mercury manometer, with a range of $13 \mathrm{kPa}$, has been operated with a resolution of 1.4 $\mathrm{mPa}$.

17270. Costrell, L., CAMAC instrumentation and interface system for computer automated measurement and control, Proc. 8th Int. Conf. on $X$-ray Optics and Microanalysis, Boston, MA, Aug. 19, 1977, pp. 1-16 (1977),
Key words: CAMAC; computer interfacing; instrumentation, standards; interfacing.

The CAMAC instrumentation system for computer automated measurement and control is gaining wide international acceptance for industrial and laboratory applications. The system features a fully specified dataway together with modular functional units that are completely compatible with each other and that are available from diverse sources. The system is nonproprietary and can be freely used without license or restrictions of any kind.

17271. Wise, S. A., Chesler, S. N., Hertz, H. S., Hilpert, L. R., May, W. E., Chemically-bonded aminosilane stationary phase for the high-perfomance liquid chromatographic separation of polynuclear aromatic compounds, Anal. Chem. 49, No. 14, 2306-2310 (Dec. 1977).

Key words: fluorescence emission spectroscopy; gas chromatography-mass spectrometry; high-performance liquid chromatography; hydrocarbons; petroleum analysis; polynuclear aromatic hydrocarbons.

A commercially available, chemically-bonded aminosilane liquid chromatographic packing material, $\mu$ Bondapak $\mathrm{NH}_{2}$, was used as a substitute for silica or alumina for the normal-phase high-performance liquid chromatographic (HPLC) separation of aliphatic hydrocarbons and polynuclear aromatic compounds. The $\mu$ Bondapak $\mathbf{N H}_{2}$ provides a more distinct separation of polynuclear aromatic compounds based on the number of condensed rings than the classical adsorbents because the addition of alkyl groups to the aromatic rings has very little effect on their retention. The retention characteristics of polynuclear aromatic compounds on $\mu$ Bondapak $\mathrm{NH}_{2}$, classical adsorbents, and a reversed-phase packing material were compared. The application of $\mu$ Bondapak $\mathrm{NH}_{2}$ to isolate polynuclear aromatic compounds according to the number of condensed rings prior to analysis by gas chromatography-mass spectrometry (GC-MS) and/or reversed-phase HPLC with fluorescence ernission spectral identification is described.

17272. Howard, C. J., Evenson, K. M., Kinetics of the reaction of $\mathrm{HO}_{2}$ with $\mathrm{NO}$, Geophys. Res. Lett. 4, No. 10, 437-440 (Oct. 1977).

Key words: chemical reaction rate; $\mathrm{HO}_{2}$; hydroperoxyl; nitric oxide; NO.

The gas phase reaction of $\mathrm{HO}_{2}$ radicals with $\mathrm{NO}$ was studied using a discharge-flow system and laser-magnetic resonance detection. Concentrations of $\mathrm{HO}_{2}$ down to $2 \times 10^{9}$ molecules $/ \mathrm{cm}^{3}$ were detectable, thus allowing the reaction to be studied under pseudo-first-order kinetic conditions. The rate constant was measured using three independent kinetic schemes, one of which involved the detection of the reaction products $\mathrm{OH}$ and $\mathrm{NO}_{2}$. The three schemes gave results in excellent agreement. The rate constant, $k_{1}$, for the reaction

$$
\mathrm{HO}_{2}+\mathrm{NO} \rightarrow \mathrm{OH}+\mathrm{NO}_{2}
$$

is $(8.1 \pm 1.5) \times 10^{-12} \mathrm{~cm}^{3} / \mathrm{molecule} \cdot \mathrm{s}$ at $296 \mathrm{~K}$ and a pressure of $140-220 \mathrm{~Pa}(1.1-1.7$ torr $)$. The measurements also indicate that the rate constants for two other exothermic channels of the reaction are less than 2 percent of $k_{\underline{j}}$.

17273. Wise, S. A., Chesler, S. N., Gump, B. H., Hertz, H. S., May, W. E., Interlaboratory calibration for the analysis of petroleum levels in sediment, (Proc. Symp. on Fate and Effects of Petroleum Hydrocarbons in Marine Ecosystems and Organisms, Seattle, WA, Nov. 10-12, 1976), Chapter 35 in Interlaboratory Calibration for the Analysis of Petroleum Levels in Sediment, pp. 345-350 (Pergamon Press Inc., Elmsfort, NY, 1977). 
Key words: gas chromatography; gas chromatography-mass spectroscopy; hydrocarbons; intercalibration; petroleum analysis; trace analysis.

The large number of environmental analyses to be performed in the future necessitates the existence of a common basis for comparing the data. Otherwise data obtained from different laboratories would be of limited usefulness. Furthermore, unless the data can be put on an equivalent basis, environmental standards can neither be set nor enforced.

A sample, split between NBS and one other laboratory, was analyzed in order to determine the suitability of Katalla River sediment for a more extensive intercalibration exercise. The results of this limited intercomparison are discussed. The results encouraged us to initiate an enlarged intercalibration exercise which is now in progress. Comparison of the interlaboratory data should provide a measure of the analytical variability among the participating laboratories.

17274. Ives, L. K., Erosion of 310 stainless steel at $975^{\circ} \mathrm{C}$ in combustion gas atmospheres, J. Eng. Mater. Technol. 99, 126132 (Apr. 1977).

Key words: erosion-corrosion process; erosive wear; high temperature erosion; particle impingement; stainless steel.

Erosion tests were conducted on 310 stainless steel in combustion gas atmospheres at $975^{\circ} \mathrm{C}$. SiC particles of 100 mesh $(150 \mu \mathrm{m})$ size were employed over a velocity range of $15-70$ $\mathrm{m} / \mathrm{s}$ at a $90 \mathrm{deg}$ (perpendicular) angle of impingement. A comparison is made with results obtained at $25^{\circ} \mathrm{C}$ in air using the same test equipment. Scanning electron microscopy examination of the eroded surfaces revealed important information concerning the nature of the erosion-corrosion process. A multiple component test specimen is described for application in comparing alloys under nearly identical test conditions.

17275. Parker, R. L., Results of crystal growth in Skylab (and ASTP), (Proc. First European Conf. on Crystal Growth, ETH, Zurich, Switzerland, Sept. 12-18, 1976), Chapter 111.6 in 1976 Crystal Growth and Materials, K. Kaldis and H. J. Scheel, Eds., pp. 851-886 (North-Holland Publ. Co., Amsterdam, The Netherlands, 1977).

Key words: convection; crystal growth; microgravity; Skylab/ASTP; space processing.

A survey is presented of crystal growth experiments in microgravity, with an emphasis on Skylab experiments (19731974) but also with some discussion of Apollo-Soyuz Test Project experiments (1975).

On Skylab the experiments include vapor growth of IV-VI compounds including $\mathrm{GeSe}$ and $\mathrm{GeTe}$; directional solidification of a containerless melt of InSb; melt growth and segregation on Te-doped InSb; melt growth of InSb-GaSb alloys of several compositions; melt growth and microsegregation in Ge doped with $\mathrm{Ga}, \mathrm{Sb}$, or $\mathrm{B}$; and model liquid floating zone studies. On ASTP the experiments include melt growth and interface marking in $\mathrm{Ge}$ doped with $\mathrm{Ga}$ or $\mathrm{Sb}$; vapor growth of $\mathrm{GeSe}_{0.99} \mathrm{Te} \mathrm{e}_{0.01}$, $\mathrm{GeS}_{0.98 S_{0.02}}$ and related compositions; and growth of calcium tartrate, calcium carbonate and lead sulphate crystals by reactions in aqueous solutions.

A description of each experiment is given including such factors as temperatures and temperature gradients, cooling rates, growth rates and type of surrounding atmosphere.

A comparison is then given, where data are available, of the relative crystal perfection, homogeneity, size or other pertinent parameters obtained in these experiments with those obtained in control experiments performed on the earth (in one-g).

17276. Czernichowski, A., Hołys̀, A., Roberts, J. R., Transitio probabilities for the $3 s-4 p$ transitions of Nel, J. Phys. 38, 1065-1069 (Sept. 1977).
Key words: atomic spectra; configuration interaction; J-file sum rule; neon; transition probabilities; wall-stabilized arc.

Transition probabilities for the lines of the $3 \mathrm{~s}-4 \mathrm{p}$ transition array of Nel were measured in a wall-stabilized arc. The arc operated in neon $\left(<5 \% \mathrm{H}_{2}\right)$ at one atmosphere pressure and the relative transition probabilities of 27 lines emitted from this arc plasma were placed on an absolute scale using lifetimes of two different upper levels. The results are compared to other theoretical results and were checked with the $J$-file sum rule. The results presented here are inconsistent with the $J$-file sum rule.

17277. Boettinger, W. J., Burdette, H. E., Kuriyama, M., Observations of oblique magnetic domain walls in nickel single crystals by x-ray topography, Phil. Mag. 36, No. 4, 763-776 (1977).

Key words: dynamical diffraction; magnetic domains; nickel single crystals; $x$-ray diffraction; $x$-ray topography.

Unusual band images observed by dynamical diffraction $\mathrm{x}$-ray topography in nickel single crystals are elucidated by a model of very thin magnetic domains which extend obliquely through the thickness of the crystal. These thin domains have a magnetization direction which would cause free-pole formation on the crystal surface. In order to avoid these free poles, it is assumed that the magnetization direction of these thin domains rotates away from $\langle 111\rangle$ near the crystal surface. This rotation would cause curvature of the magnetic domain walls near the crystal surface. In this work such curvature is detected in the topographs by differences in the atomic displacement associated with the domain wall near the crystal surfaces and in the interior.

17278. Wise, S. A., May, W. E., Unusual experimental detectors for LC, Res./Develop. 28, No. 10, 54-62 (Oct. 1977).

Key words: cerium oxidation detector; liquid chromatography; liquid chromatography detectors; metal specific detector; photoionization detector; reaction detector.

A wide variety of detectors have been utilized in liquid chromatography to achieve both sensitivity and selectivity. This article examines some recent novel approaches in detection that might broaden LC applications in the future by providing alternatives to the commonly used detectors of today.

17279. Sengers, J. M. H. L., Critical behavior in fluids, Chapter $\mathrm{V}$ in High Pressure Technology, I. L. Span and J. Paauwe, Eds., II, 161-251 (Marcel Dekker, Inc., New York, NY, 1977).

Key words: critical exponents; critical región; fluid mixtures; fluids; scaling; thermodynamic properties; transport properties; universality.

A survey of critical-region anomalies of thermodynamic and transport properties is given. The critical behavior of Van der Waals' equation and of the Ising model is discussed. The concepts of critical exponents, scaling and universality of critical behavior are introduced. The use of these concepts in the description of critical behavior in one-component fluids is illustrated. The generalization to critical behavior in fluid mixtures is outlined.

17280. Leong-Hong, B., Marron, B., A technological tool and information management (Abstract only, paper is in microfiche), Proc. ASIS Annual Meeting: Information Management in the 1980's, Chicago, IL, Sept. 26-Oct. I, 1977, p. 3 (Knowledge Ind. Publ., Inc., White Plains, NY, 1977). 
Key words: computer software; data base management system; data element dictionary/directory; information management; software tool.

A Data Element Dictionary/Directory $(\mathrm{DED} / \mathrm{D})$ is a technological tool that supports information management. It functions as a central repository of information about data resources; and it helps in the implementation of information resources management by providing a mechanism for administering, controlling and retrieving stored information. Key features of DED/D's are presented, and advantages and disadvantages resulting from their use are noted. The options for building or buying systems and current availability of commercial systems are discussed.

17281. Wood, H. M., On-line password techniques, Proc. Trends and Applications: 1977-Computer Security and Integrity, Gaithersburg, MD, May 19, 1977, pp. 27-40 (IEEE Computer Society, Long Beach, CA, 1977).

Key words: computer security; controlled access; passwords; personal authentication.

This paper classifies the features of on-line password schemes according to password selection/assignment techniques lifetime, and content. Several password implementations are examined and their advantages and limitations discussed. The purpose of this review was not to judge any particular system as to overall security effectiveness, but rather to illustrate the wide range of implementations possible. Password protection is not considered.

17282. Mulholland, G. W., Lee, T. G., Baum, H. R., The coagulation of aerosols with broad initial size distributions, $J$. Colloid Interface Sci. 62, No. 3, 406-420 (Dec. 1977).

Key words: aerosols; asymptotic analysis; broad initial distribution; coagulation; electrical aerosol analyzer; selfpreserving; size distribution.

The effect of coagulation on an aerosol with a broad initial size distribution was calculated analytically for large and small particle sizes for arbitrary time with the assumption of a constant coagulation collision frequency. It was found for the class of algebraic initial distributions that in general there is no selfpreserving size distribution though for the special case of a Junge like algebraic size distribution there is a quasi selfpreserving form. The calculation also demonstrates that coagulation alone leads to dynamic equilibrium for large particle size without the need of additional physical processes such as particle sedimentation. The relevance of the calculations to real aerosols was tested by measuring the size distribution of smoke generated from smoldering "punk" and flaming $\alpha$-cellulose. The size distributions of both smoke aerosols are not only selfpreserving but also are very similar. There is quantitative agreement between the measured size distribution and the calculated quasi self-preserving form, $\psi=0.1(\eta+0.1)^{-2}$, where $\psi$ and $\eta$ are the reduced number distribution and reduced particle volume respectively.

17283. Quintiere, J., Growth of fire in building compartments, Am. Soc. Testing Mater. Spec. Tech. Publ. 614, pp. 131-167 (1977).

Key words: "flashover"; fluid flow; full-scale; heat transfer; literature review; mathematical models; room fire; scaling models; theoretical.

A review was made of both full-scale and scale model experiments concerned with fire growth and spread in building compartments. It appears that "flashover," i.e. the rapid transition to a fully-developed room fire, could be initiated by a fully involved chair fire alone, or by a large waste container ignition source against a combustible lining material. Scale model! results continue to provide valuable insight, but the validity of partial scaling results must be considered for each type of experiment. A quasi-steady idealized mathematical model was. developed to analyze the various parameters of fire develop-. ment in a room. These theoretical results show the significance of fuel properties, fire size and location, room and doorway. dimensions, and wall thermal properties. The limitations of a mathematical approach are also discussed.

17284. Burch, D. M., Siu, C. 1., Powell, F. J., Comparison of the thermal performance of three insulating materials commonly used to retrofit exterior frame walls in existing residences, (Proc. Annual Meeting of Com. B.1, IIF-IIR on Heat and Mass Transfer in Porous Structures, Washington, DC, Sept. 14-16, 1976), Bul. Inst. Int. Froid 2, 151-162 (1976).

Key words: condensation in walls; insulating properties; thermal conductivity; thermal insulation.

This paper describes experimental measurements conducted at the National Bureau of Standards to compare the thermal performance of three different insulating materials commonly used to retrofit the exterior frame walls of existing residential buildings. The insulation materials selected for study were cellulosic fiber, fibrous glass wool, and urea-formaldehyde foam. The thermal conductivities of the three materials were measured using the guarded-hot-plate apparatus according to Standard Method of Test ASTM C 177-71. Heat-transmission and moisture measurements were performed on a full-scale test wall that was exposed to simulated winter conditions in the laboratory. Similar measurements were also conducted on wall sections of a test house insulated with the various materials. Other performance properties such as shrinkage and settling are also reported.

17285. McCaffrey, B. J., Quintiere, J. G., Buoyancy driven countercurrent flows generated by a fire source, (Proc. Seminar on Turbulent Buoyant Convection, Dubrovnik, Yugoslavia, Aug. 1976), Paper in Heat Transfer and Turbulent Buoyant Convection, D. B. Spalding and N. Afgan, Eds., II, 457-472 (Hemisphere Publ. Corp., Washington, DC, 1977).

Key words: buoyant flow; corridor, countercurrent; fire; scaling; stratified flow; temperature; velocity measurements.

The velocity and temperature fields were determined for fire induced flows in corridors. The effects of scale, fire size, and doorway openings are presented. Detailed measurements illustrate the complex recirculating three dimensional character of the flow field. Mass flow rates are determined for the doorway openings and to determine the extent of entrainment. A critical Richardson number criterion was used to identify the mixed and stably stratified regions of the flow field.

17286. Powell, F. J., Hahn, M. H., Measurement of the frost' point of air in sealed insulating glass, (Proc. Annual Meeting of Com. B.1, IIF-IIR on Heat and Mass Transfer in Pornus Structures, Washington, DC, Sept. 14-16, 1976), Bul. Inst.' Int. Froid 2, 131-138 (1976).

Key words: ASTM Test Standard for insulating glass; frostpoint measuring apparatus; moisture condensation; seal durability and longevity; sealed insulating glass.

The background, objective and results of the Research Associate Program recently completed at the National Bureau of Standards (NBS) with the American Society for Testing and Materials (ASTM) is summarized. This program was concerned with the development of test methods and standards for use with factory-produced double-glazed insulating-glass window 
units. A permanently sealed air space between two or more panes of glass is desired to increase the resistance to the flow of heat through window glass and at the same time provide a unit that would not allow moisture condensation to form on the interior glass surfaces over the lifetime of the unit. In addition to interfering with vision, repeated moisture condensation in the form of liquid water or frost, with subsequent evaporation of the moisture, tends to leave a residue on these surfaces that are not accessible for cleaning. A new device for making nondestructive measurements (repeatable to within $0.5^{\circ} \mathrm{C}\left(1{ }^{\circ} \mathrm{F}\right.$ ) of the dew/frost point of the air-space in these sealed units is described (U.S. Patent 3,896,658) and the ASTM Standards produced in conjunction with the program are described and referenced (ASTM designation E546-75, E576-76, E-6 P1, E6 P2, and E-6 P3).

17287. King, D. S., Schenck, P. K., Smyth, K. C., Travis, J. C., Direct calibration of laser wavelength and bandwidth using the optogalvanic effect in hollow cathode lamps, Appl. Opt. 16, 2617-2619 (Oct. 1977).

Key words: bandwidth determination; discharge lamp; lasers; optogalvanic effect; spectroscopy; wavelength calibration.

A convenient and inexpensive new technique for the calibration of laser spectral wavelengths and linewidths is described. Electrical signals from commercial hollow cathode lamps resulting from the illumination of the discharge region with continuous-wave or pulsed laser sources in resonance with an electronic transition (opto-galvanic effect) were used for wavelength ( $\pm 10^{-4} \mathrm{~nm}$ in the range $260 \mathrm{~nm}$ to $655 \mathrm{~nm}$ ) and bandwidth calibrations (to $\pm 0.005 \mathrm{~nm}$ ). Extension of this technique to provide simultaneous calibration spectra while scanning laser wavelength is discussed.

17288. Abrams, M. D., Treu, S., A methodology for interactive computer service measurement, Commun. ACM 20, No. 12 , 936-944 (Dec. 1977).

Key words: computer service; external measurement; figure-of-merit; interactive system; measurement model; measurement, performance; measures; methodology; network measurement system.

A measurement methodology applicable to interactive computer service is described. Its primary purpose is to enable external, user-oriented assessment of computer performance, instead of the more frequently used internal system measurement techniques. The NBS Network Measurement System is employed as the external measurement tool. Example data have been collected and analyzed. A demonstration of the methodology, leading to a pragmatic figure-of-merit evaluation of results, is included.

17289. Achenbach, P. R., Heldenbrand, J. L., Development of performance-based energy conservation standards for buildings, Proc. Canadian Building Congress on Energy and Buildings, Toronto, Canada, Oct. 25-27, 1976, pp. 1-31 (1976).

Key words: codes and standards; energy conserving buildings; energy legislation; energy performance criteria; energy performance standards.

The criteria for energy conservation in new buildings, developed by the National Bureau of Standards at the request of the National Conference of States on Building Codes and Standards in February 1974 (NBSIR 74-452), were based on performance requirements for the components of a building and its mechanical and electrical systems, because that approach appeared to be the practical limit in the application of the performance concept at that time. Using the NBS docu- ment as a framework, the American Society of Heating, Refrigeration, and Air-Conditioning Engineers has subsequently developed ASHRAE Standard 90-75. However, the design professions have expressed a preference for specification of design annual energy budgets for whole buildings, as a more direct means of achieving freedom for trade-offs and innovations. NBS is now assisting the Department of Housing and Urban Development and the Energy Research and Development Administration in developing such performance standards for energy conservation in buildings, as required by Title 111 of Public Law 94-385. The performance concept being recommended by NBS is based on overall energy use and life-cycle cost of a building, supplemented by performance requirements related to thermal comfort, visual environment, indoor air quality, durability and health and safety considerations.

17290. Heldenbrand, J. L., Development and application of design performance standards for energy conservation in buildings, Ind. Forum. 8, No. 3, 9-20 (Aug. 1977).

Key words: building codes; energy conservation; energy efficiency; energy performance; model codes; standards.

One-third of the energy consumed in the United States is used to heat and cool buildings and to provide illumination, water heating, and other building services. About 40 percent of this energy can be saved through the effective application of existing technology, without reducing building performance. The first comprehensive and nationally applicable design standard for energy conservation in buildings, ASHRAE Standard 90-75, has recently been developed and applied, and it offers the opportunity for substantial energy savings. How this design standard was developed and applied provides an example of productive cooperation among many organizations. This example is of interest since such cooperation is essential if societal needs are to be met through the effective use of science and technology, and if remaining issues are to be resolved. Those involved included Federal and State governments and their agencies concerned with energy and building, construction, societies of the major design professions, industrial and energy trade associations, and building researchers.

17291. Fung, F. C. W., Smoke control by systematic pressurization, (Proc. ClB Symp., Hertfordshire, England, Nov. 4, 1975), Fire Res. 11, No. 4, 261-269 (Nov. 1975).

Key words: air-handling system; Chicago federal building; highrise; pressure profiles; Seattle federal building; smoke control; smoke simulation experiments; sulfur-hexafluoride; systematic pressurization.

An experimental investigation of smoke control in high-rise buildings by the "Systematic Pressurization" concept is presented here. This concept of smoke control involves the utilization of a modified building air-handling system. The building is generally divided vertically into several horizontal smoke control zones, each containing a predetermined number of floors. Upon smoke alarm the air-handling system is programmed to switch to smoke control mode by providing 100 percent exhaust to the smoke zone and 100 percent supply to the other zones. The idea is to simultaneously exhaust smoke from its zone of origin, and prevent smoke propagation to the other zones by pressurization.

Examples of the zoned or systematic pressurization smoke control concept are the Seattle and Chicago Federal Buildings. An extensive series of experiments, using the sulfurhexafluoride smoke simulation system, were performed to evaluate these buildings. During the experiments, complete stairwell and elevator shaft pressure profiles under normal and smoke control operations were also obtained. The effectiveness of the smoke control system as implemented in these federal buildings 
is discussed in the light of normalized sulfur-hexafluoride concentrations and the pressure profiles.

17292. Klose, J. Z., Voight, P. A., Mean lives and $g f$ values in U1, Phys. Rev. A 16, No. 5, 2032-2037 (Nov. 1977).

Key words: delayed coincidence; $g f$ value; imprisonment; lifetimes; mean life; resonance radiation; transition probability; uı; uranium.

Determinations of the mean lives of the 27887- and 16900$\mathrm{cm}^{-1}$ levels in $\mathrm{U} 1$ have been made, each at a single vapor density, using electronic excitation and a method of delayed coincidence. The lifetime values were obtained by optically detecting the decays of the $3584.9-$ and $5915.4-\AA$ resonance transitions, respectively. Using branching ratios obtained from known relative $f$ values, the averages of the measured lifetimes were corrected for imprisonment of the resonance radiation giving the following results: $\tau_{0}{ }^{27887}=10.9 \pm 0.8 \mathrm{~ns}$ and $\tau_{0}{ }^{16900}=205 \pm$ $20 \mathrm{~ns}$. These mean lives were then used to place a system of relative $g f$ values on two independent absolute scales, which were found to be in very close agreement. The lifetimes and $g f$ values are presented in comparison with the experimental results of others.

17293. Yonemura, G. T., Task lighting-Another view, Lighting Design Appl., pp. 27-30 (Nov. 1977).

Key words: energy conservation; illumination; illumination levels; lighting; task lighting.

The current North American lighting level recommendations are based on data derived from experiments in which the observers were required to detect the presence of a luminous disc. Experiments were conducted at real world levels, that is, the targets are seen 100 percent of the time but with differing levels of "goodness of seeing." I see better under condition A rather than $B$. Under these suprathreshold conditions the behavior of the eye is different from that obtained under threshold conditions. Experiments were conducted with gratings and alphabets as test objects. The threshold function is monotonic, that is, contrast required for detection decreases monotonically as luminance is increased, whereas the suprathreshold experiments result in a function with a minimum or optimum luminance level. The implementation of these findings as a reference base for recommending levels of illumination are discussed.

17294. Rosenstock, H. M., McCulloh, K. E., Lossing, F. P., On the mechanisms of $\mathrm{C}_{6} \mathrm{H}_{6}$ ionization and fragmentation, Int. J. Mass Spectrom. Ion Phys. 25, 327-341 (1977).

Key words: appearance potential; benzene; butatriene; heat of formation; ion; ionization potential; monoenergetic electron impact; photoionization; pyridine; vinylacetylene; 1,5hexadiyne; 2,4-hexadiyne.

Photoionization and electron monochromator studies have been carried out on benzene, 1,5-hexadiyne, 2,4-hexadiyne, pyridine and some $\mathrm{C}_{4} \mathrm{H}_{4}$ isomers to develop new information concerning the details of benzene ion fragmentation. Present results, together with those of other workers, indicate that a number of $\mathrm{C}_{6} \mathrm{H}_{6}{ }^{+}$ion isomers have energies comparable to that of the first excited state of the benzene ion. These could act as intermediate states in skeletal fragmentation of the benzene ion and account for the observed small kinetic shift. Results on vinyl acetylene and butatriene indicate that these ion structures are not formed at the fragmentation threshold in benzene. Results on 1,5-hexadiyne and pyridine indicate the formation of a new $\mathrm{C}_{4} \mathrm{H}_{4}{ }^{+}$ion structure, more stable than the two linear isomers. The evidence for lack of competition between hydrogen loss and skeletal fragmentation in the benzene ion is reviewed. Photoionization of benzene reveals autoionization contributions to parent ion and fragment ion production; assignments of the autoionizing levels are given. The photoionization behavior of 1,5-hexadiyne suggests that this also fragments via two pairs of noncompeting reactions, as postulated for benzene.

17295. Moldover, M. R., Gallagher, J. S., Phase equilibria in the critical region: An application of the rectilinear diameter and "1/3 power" laws to binary mixtures, Proc. Phase Equilibria and Fluid Properties in the Chemical Industry. Estimation and Correlation, Asilomar Conf. Grounds, Pacific Grove, CA, Jan. 16-21, 1977, T. S. Storvick and S. I. Sandler, Eds., pp. 498-509 (American Chemical Society, Washington, DC, 1977).

Key words: binary mixtures; critical locus; critical point; phase equilibria.

A model describing the VLE surface for mixtures in the critical region is described using the familiar " $1 / 3$ power law" and "law of rectilinear diameters." The success of this model is based upon the use of coefficients in these familiar laws which are function of a thermodynamic variable which has the same value in both the vapor and liquid phases. This differs from conventional thermodynamic models for mixtures which use coefficients which are functions of " $x$ ", the mole fraction of the mixture.

17296. Marshall, H. E., Ruegg, R. T., Wyly, R. S., Cost savings from reduced-sized venting, Plumbing Eng. Part 1, 5, No. 4, 35-38, 42 (July-Aug. 1977); Part 2, 5, No. 5, 45-46, 64, (Sept.-Oct. 1977).

Key words: cost savings; drainage-waste-vent; economics; life cycle; performance standards; pipe; plumbing; reducedsize vents; sanitary drainage system; venting.

Venting is required for all sanitary drain-waste-vent systems in buildings to maintain the traps of plumbing fixtures and thereby help prevent the entry of sewer gases into the building. Past research at NBS has shown that reduced-sized-venting (RSV), an innovative type of venting which utilizes dry vent pipes substantially smaller in size than those permitted by existing plumbing codes, meets the performance requirements imposed on conventional vent systems by the prescriptive requirements of codes for one and two-story houses. Builders, contractors, plumbers, and consumers of housing want to know the potential money savings from using RSV. Based on use of plastic pipe and depending on other assumptions made, estimates of potential savings per single-family household over the next 11 years are from $\$ 74$ to $\$ 129$, and for the nation as a whole, from $\$ 88$ million to $\$ 244$ million. Realization of these potential savings depends on how fast code authorities accept RSV in the plumbing codes and how fast builders and developers implement RSV technology once it is authorized in the codes.

17297. Brinckman, F. E., Blair, W. R., Jewett, K. L., Iverson, W. P., Application of a liquid chromatograph coupled with a flameless atomic absorption detector for speciation of trace organometallic compounds, J. Chromatogr. Sci. 15, $493-503$ (Nov. 1977).

Key words: arsenic; element-specific detector; flameless atomic absorption; flow monitoring; high-pressure liquid chromatography; lead; ligand; mercury; nanogram sensitivity; organometallic compounds; speciation; tin.

Use of a commercial flameless (graphite furnace) atomic absorption detector (GFAA) automatically coupled to a highpressure liquid chromatograph (HPLC) was demonstrated to provide element-specific separation and detection of organometallic compounds at nanogram concentrations in both 
protic and nonpolar solvents using conventional columns. Relative sensitivities of the HPLC-GFAA system for compounds of arsenic, lead, mercury, and tin were shown to be mainly functions of LC flow rate and relative AA sensitivity for each element. Separation of mixtures of organometal ions required both isochratic and gradient elution on reverse phase columns, but incorporation of certain charged or neutral ligand concentrations was necessary for achieving complete resolution of different organometal species. The GFAA detector can be operated in either a rapid sampling mode, providing higher resolution of the HPLC effluent, or in a batch survey mode which permits, with only slight $(5-10 \%)$ loss of effluent, recovery of sample fractions for additional analyses.

17298. Hastings, S. R., Performance evaluation of window strategies, Proc: RILEM/ASTM/CIB Symp. on Evaluation of the Performance of External Vertical Surfaces of Buildings, Otaniemi, Finland, Aug. 28-Sept. 2, 1977, II, 113-122 (Technical Research Centre of Finland, Helsinki, Finland, 1977).

Key words: daylighting; infiltration; insulation; passivesolar-heating; sun-shading; ventilation; windows.

Windows can be an important determinant of the energy comsumption of buildings. Properly designed windows can partially or wholly fulfill environmental requirements otherwise necessitating extensive purchased energy consumption by costly mechanical and illumination systems. The energy value of a window, considering the energy cost of replicating its contributions artificially, may even exceed the energy costs attributed to its limitations. To insure its value as a net asset, numerous design strategies are available to improve the conditions in which it performs. Adverse climatic forces can be mitigated through site design or use of exterior appendages. Interior accessories can compensate for the limitations of glass. Finally, building interior design can increase the utility of a window's contribution.

17299. Ruegg, R. T., Life-cycle cost evaluation of the personal patrol car program, J. Police Sci. Admin. 5, No. 3, 290-298 (Sept. 1977).

Key words: breakeven analysis; life-cycle costing; patrol cars; personal car plan; police fleet administration; takehome car program.

This paper provides assistance to the police fleet administrator in selecting an economically efficient vehicle program. It presents a general method for evaluating and comparing the costs and benefits of a personal patrol car program (PCP) and a multi-shift, pool car program (MSP). It identifies and illustrates with realistic data the cash flows associated with each of the two vehicle programs, and compares the life-cycle costs of a PCP with a MSP under alternative assumptions.

17300. Ruff, A. W., Young, J. P., Ives, L. K., Erosion measurements on metals at elevated temperatures, Proc. $2 d$ Int. Conf. on Mechanical Behavior of Materials, Boston, MA, Aug. 1620, 1976, 5 pages (1976).

Key words: erosion-corrosion process; erosive wear; high temperature erosion; particle impingement; stainless steel.

Studies have been conducted on the erosive wear of metals resulting from solid particle impingement under various environmental conditions at elevated temperatures. Specimens of several stainless steel and nickel alloys were exposed to a particle-gas stream. The particle flux; angle of attack; particle velocity, size, and type; surface temperature and other variables were controlled.

17301. Unassigned.
17302. Weber, S. F., Resource impact factors and the optimal energy conservation standard for buildings, Energy Bldgs. 1, No. 2, 1-13 (Oct. 1977).

Key words: building economics; economic efficiency; economics; energy; energy conservation; life-cycle cost; optimization; performance standards; resource impact factors; resources; social optimum; standards.

The effects of using "Resource Impact Factors" (RIFs) in the determination of an optimal energy conservation performance standard for buildings are assessed. R1Fs may be generally defined as indiccs constructed to reflect the full social costs of using various energy types. The major elements which RIF's should take into account are discussed as well as the appropriate method of formulating them. A cost minimization model for determining the optimal standard is used in conjunction with a range of RIF values so that a comparison can be made between a standard that is optimal from the private point of view (without RIFs) and one that is optimal from the social point of view (with RIFs). The comparison is made in terms of the amount of energy saved by each standard in climates of differing severity.

17303. Ellingwood, B., Shaver, J., Reliability of RC beams subjected to fire, J. Structural Div., ASCE 103, ST5, 1047-1059 (May 1977).

Key words: fire endurance; fire tests; probability theory; reinforced concrete; reliability; statistical analysis; structural engineering.

Methods for analytically predicting the behavior of reinforced concrete beams subjected to fire are presented. These incorporate the temperature-dependent strength degradation in the steel as well as thermal and creep strains. The parameters most important for predicting beam behavior are identified through a sensitivity study, and the application of reliability analysis in developing fire-resistant design procedures is discussed.

17304. Ellingwood, B., Statistical analysis of RC beam-column interaction, J. Structural Div., ASCE 103, ST7, 1377-1388 (July 1977).

Key words: probability; reinforced concrete; reliability; statistical analysis; structural engineering; uncertainty.

Analysis of uncertainties plays a central role in all reliabilitybased design procedures. Herein, the uncertainty in the resistance of reinforced concrete numbers subjected to combined bending and thrust is studied using Monte-Carlo techniques. The effects of load eccentricity, reinforcement ratio, and the contributions of individual uncertainties in the design parameters are examined. The results should aid in determining resistance factors for reinforced concrete design which are commensurate with the level of uncertainty using reliability-based concepts.

17305. Ellingwood, B., Culver, C., Analysis of live lvads in office buildings, J. Structural Div., ASCE 103, ST8, 1551-1560 (Aug. 1977).

Key words: buildings (codes); live loads; load surveys; probability theory; structural engineering.

An analysis of live loads in offices is presented, which applies probabilistic live load models to the results of a recent survey of U.S. office buildings conducted by the National Bureau of Standards. The results are compared to a study of live loads in offices in the United Kingdom and to the design loads currently specified by ANS1 A58.1-1972. On the basis of this study, a new expression for computing allowable reductions in live loads at large loaded areas is proposed. 
17306. Ellingwood, B., Harris, J. R., Reliability-based performance criteria for structures, Proc. Second Annual Engineering Mechanics Division Specialty Conf., Raleigh, NC, May 23-25, 1977, pp. 124-127 (American Society of Civil Engineers, New York, NY, 1977).

Key words: load factors; performance approach; performance criteria; reliability analysis; reliability-based design; resistance factors; structural engineering.

The performance concept systematizes the development of design criteria by first identifying specific performance attributes and then posing a series of criteria that would indicate an acceptable level of performance. In this study, performance criteria to assure adequate structural safety are presented. Reliability analysis techniques are used to develop load and resistance factors which assure that required levels of safety are attained. The load side of the design equation is developed so as to be applicable for a wide range of materials. This approach affords the designer an increased degree of flexibility, as similar levels of performance should be achieved regardless of which material is selected.

17307. Wood, H. M., The use of passwords for controlling access to remote computer systems and services, (Proc. Natl. Computer Conf. Dallas, TX, June 13-16, 1977), Paper in AFIPS Conference Proceedings 46, 27-33 (AFIPS Press, Montvale, NJ, 1977).

Key words: computer security; controlled access; passwords; personal authentication.

The widespread use of remote computer resources has made the problem of personal authentication most urgent. Systems without adequate access controls are vulnerable to threats including theft, fraud, and vandalism. Potential losses range from unauthorized use of computing time, to unauthorized modification or access to massive amounts of data. This paper examines the use of passwords for controlled access to computing resources. Password techniques, ways of protecting passwords, and attendant cost considerations are discussed. Similarities between passwords and data encryption keys are noted. General recommendations for the use of passwords are presented.

17308. Williamson, F. R., Cryogenic foam insulation-Abstracted publications, NASA Reference Publication 1002, 170 pages (National Aeronautics and Space Administration, Washington, DC, Sept. 1977).

Key words: abstracts; bibliography; cryogenic insulation; foam insulation; insulation; survey.

This survey is composed of information from the available reports and publications on Cryogenic Foam Insulation. One group of documents, listed alphabetically by first author, was chosen to include the most important or most informative papers on the properties and applications of foams. An abstract has been prepared for each document in this group, and the most important references are listed as found in the document.

Another group of documents, also listed alphabetically by author, generally includes less important papers than those in the first group. Some important papers are in the second group because information from them has been reviewed or repeated in documents included in the first group.

An author index and a subject index are provided. The indexes cover the authors and subjects of both groups of documents.

17309. Zahn, J. P., Tidal friction in close binary stars, Astron. Astrophys. 57, 383-394 (1977).

Key words: close binaries; stellar structure; x-ray binaries.
We examine various physical mechanisms which may produce tidal friction in close binary stars. We find that the most efficient in stars with convective envelopes is turbulent viscosity retarding the equilibrium tide, and in stars with radiative envelopes the action of radiative damping on the dynamical tide. Theoretical predictions based on these dissipative processes are in good agreement with the rotational velocities and orbital eccentricities observed in close binaries. The results are applied to the $\mathrm{X}$-ray binaries Her $\mathrm{X}-1$ and Cen $\mathrm{X}-3$.

17310. Weinstein, A., Moos, H. W., Linsky, J. L., A sensitive observation of the far-ultra-violet (1160-1700 $\AA$ ) spectrum of Arcturus and implications for its outer atmosphere, Astrophys. J. 218, 195-204 (Nov. 15, 1977).

Key words: stars, chromospheres; stars, coronae; stars, individual; stars, late type; ultraviolet spectra.

A low-resolution far-ultraviolet (1160-1700 $\AA$ ) spectrum of Arcturus ( $\alpha$ Boo, K2 IIIp) has been obtained by using a new very sensitive rocket-borne spectrograph with a multielement microchannel plate detector. $H \perp \lambda 1216, O \perp \lambda 1304$, and a broad unresolved emission near $1510 \AA$ were detected. A $2 \sigma$ feature is probably $O \geq \lambda 1356$. The ratio of $O=\lambda 1304$ to $O$, $\lambda 1356$ is similar to the solar ratio. This spectrum is very different from that of the Sun, with few emission features. The absence of certain emission lines in the spectrum of Arcturus implies either coronal temperatures outside the 20,000 to $350,000 \mathrm{~K}$ range (except for possibly $180,000 \pm 20,000 \mathrm{~K}$ ) or a lower coronal base pressure than previously assumed. A model of the chromosphere-corona transition region predicts fluxes too low to be detected at present. The observation was coordinated with a simultaneous determination of the Arcturus La fiux by the U2 detector on the Princeton Experimental Package aboard OAO-Copernicus. The two measurements agree within 10 percent of each other.

17311. Aizenman, M. L., Smeyers, P., An analysis of the linear, adiabatic oscillations of a star in terms of potential fields, $A s$ trophys. Space Sci. 48, 123-136 (1977).

Key words: nonradial modes; potential theory; stellar pulsation.

The linear adiabatic oscillations of a spherically symmetric star are analyzed in terms of potential fields. It is found that all displacement fields $\rho \xi$ can be described as either spheroidal or toroidal fields.

17312. Bennett, H. S., Cantrell, C. D., Absorbing precipitates in cadmium telluride: Estimates for catastrophic laser-damage thresholds, Appl. Opt. 16, No. 11, 2931-2933 (Nov. 1977).

Key words: cadmium telluride; elastic compliance tensor; elastic moduli; extrinsic damage thresholds; high-power lasers; infrared materials; tensile stress.

One problem frequently encountered in high-power laser systems is thermal extrinsic damage to the laser materials, which arises from absorbing inclusions. In this paper the maximum tensile stresses as a function of inclusion size, laser pulse width, and laser power are estimated for the common precipitates in CdTe.

17313. Bennett, H. S., Forman, R. A., Photoacoustic spectroscopy: A measurement technique for low absorption coefficients, Appl. Opt. 6, No. 11, 2834-2836 (Nov. 1977).

Key words: bulk absorption; frequency dependence; laser materials; photoacoustic spectroscopy; surface absorption; weakly absorbing materials.

The case in which a laser beam modulated at angular frequency $\omega$ passes through the weakly absorbing windows of 
a gas cell which contains a nonabsorbing gas is investigated in this paper. In particular, the frequency dependences of the acoustic stresses in the gas which arise from the surface and bulk absorption are derived. An intermediate range of frequencies exists for which the acoustic stress due to surface absorption varies approximately as $\omega^{-1}$ and has an approximate $90^{\circ}$ phase shift relative to the modulated laser beam and for which the acoustic stress due to bulk absorption varies approximately as $\omega^{-3 / 2}$ and has an approximate $45^{\circ}$ phase shift. Numerical ex. amples for a representative laser glass and air (nitrogen) are given.

17314. Eisenhart, C., Boscovich and the combination of observations, Chapter in Historical Studies in Probability and Statistics 2, 88-100 (Charles Griffin and Co., Ltd., London, England, 1977).

Key words: Boscovich, Roger Joseph (1711-1787); Cotes, Roger (1682-1716); Euier, Leonard (1707-1783); Figure of the Earth; fitting a linear equation; least sum of absolute deviations; Mayer, Tobias (1723-1762); method of averages; weighted mean; weighted median; zero sum of residuals.

Boscovich was the first to propose (1757) a completely objective procedure for determining the coefficients of a twoparameter linear equation $y=\alpha+\beta x$ from three or more observational points $\left(x_{i}, y_{i}\right), i=1,2,3, \ldots$. In keeping with the earlier Method of Averages, he required that the positive and negative deviations in the $y$-direction sum to zero, which forces it to pass through the centroid $(\bar{x}, \bar{y})$ of the data, i.e., be of the form $y=\bar{y}+\beta(x-\bar{x})$. In addition he proposed that the value $b$ chosen for $\beta$ be that for which the sum of the absolute deviations from the fitted line in the $y$-direction be a minimum. He later found and gave (1760) a geometric derivation of an algorithm for finding this "best" slope. Laplace (1789) adopted Boscovich's two criteria and gave an algebraic formulation and derivation of Boscovich's algorithm, from which it is evident that it can also be used to find the slope of a "least sum" line through an arbitrary point $\left(x_{0}, y_{0}\right)$. Like the median (in contrast to the mean) in the univariate case, the Boscovich line (in contrast to the Least Squares line) is insensitive to the more extreme observations. Some more recent work on fitting by least sums of absolute deviation is mentioned.

17315. Faulkner, D. J., Cepheid studies. II. A third period in the beat Cepheid TU Cassiopeiae, Astrophys. J. 218, 209-219 (Nov. 15, 1977).

Key words: Cepheids; beat Cepheids; double-mode Cepheids; mode interaction; pulsation; stellar instabilities; TU Cassiopeiae.

Two hundred and ninety photoelectric observations of the beat Cepheid TU Cas made by several investigators prior to 1960 have been reanalyzed by using Fourier techniques. The two previously reported periods (2d 13931 and $1 d .51833)$ have been confirmed, and a small-amplitude tertiary pulsation has been discoverd at $1^{\prime} \cdot 25246$. The amplitude gradation and period ratios of the pulsations suggest identification with the fundamental and first- and second-overtone radial modes. There is a strong mode interaction between the fundamental and first overtone. Application of the results of linear pulsation theory to the $P_{0} P_{1}$ pair yields a beat mass $\left(1.1 M_{0}\right)$ which has the usual discrepancy when compared with the evolutionary and pulsation masses. When the $P_{0} P_{2}$ pair is used, however, the beat mass is $3.4 M_{0}$, in substantial agreement with the pulsation mass. Evidence is mounting that beat Cepheids have "normal" Cepheid mass, so that we must look to some deficiency in our application of pulsation theory for resolution of the beat mass problem. It is suggested that period changes due to nonlinear mode interaction may be responsible.
17316. Harter, W. G., Patterson, C. W., Bands, clusters, and crystal field splitting: Understanding $\mathrm{SF}_{6}$ rotational levels, Int. J. Quantum Chem.: Quantum Chem. Symp. 11, 479-492 (1977).

Key words: crystal field theory; group theory; molecular spectroscopy; sulfur hexafluoride.

The elementary theory of electron bands for one-dimensional lattices is compared with a new approach to the theory of crystal-field splitting. Nomograms are given for determining the qualitative features of orbital level spectra for anisotropic crystal fields having polygonal $\left(D_{n}\right)$ or octahedral $(O)$ symmetry. The methods described are becoming an important part of the analysis of the rovibrational fine structure of $\mathrm{SF}_{6}$ and other symmetric molecules

17317. Hernández, A. J., Langhoff, P. W., On RayleighSchrödinger and Green's-function calculations of ionization potentials and electron affinities, Chem. Phys. Lett. 49, No. 3, 421-426 (Aug. 1, 1977).

Key words: electron affinities; Green's function; ionization potentials; Rayleigh-Schrödinger perturbation theory.

Connections between first-quantized Rayleigh-Schrödinger perturbation-theory and one-particle Green's-function calculations of the ionization potentials and electron affinities of atoms and molecules are reported.

17318. Koffend, J. B., Field, R. W., Guyer, D. R., Leone, S. R., Pulsed and CW optically pumped lasers for novel applications in spectroscopy and kinetics, (Proc. Third Int. Conf. on Laser Spectroscopy, Jackson, WY, July 3-6, 1977), Paper in Springer Series in Optical Sciences. Vol. 7: Laser Spectroscopy III, J. L. Hall and J. L. Carlsten, Eds., pp. 382-393 (Springer-Verlag, Berlin, Germany, 1977).

Key words: dimer laser; electronic transition laser; laser; laser kinetics; laser spectroscopy; optical pumping.

There is a recent explosion of interest in optically pumped gas phase electronic transition, diatomic lasers. At one time a laser-builder's laboratory curiosity, the subject of optically pumped diatomic lasers is rapidly developing into an important new field of research. There are three general, significant areas of exploration: spectroscopy, kinetics, and new laser devices. Optically pumped lasers provide new and unique methods to measure fundamental spectroscopic and kinetic details of molecular systems. They will make a significant impact in device applications in the future.

17319. Langhoff, P. W., Corcoran, C. T., Sims, J. S., Photoabsorption in atomic lithium, Phys. Rev. A 16, No. 4, 15131520 (Oct. 1977).

Key words: configuration interaction; cross sections; ionization cross sections; lithium; photoexcitation cross sections; Stieltjes-Tchebycheff technique.

Theoretical investigations employing the recently devised Stieltjes-Tchebycheff procedure and variational calculations in Hilbert space are reported of the photoexcitation and ionization cross sections in atomic lithium. The calculations include orbital configurations corresponding to both valence and $K$-shell electron excitations, allowing for core polarization and for configuration interaction in both the ground and excited states. Hylleraas correlation factors are employed to aid the convergence of the configuration-interaction expansions. The resulting discrete and continuum dipole spectra, and related dipole spectral sums, are in excellent agreement with previously reported polarized-orbital and many-body calculations, with the results of semiempirical investigations based on one-electron model 
potentials, with recent measurements of the static dipole polarizability, and with the results of a recent analysis of the experimentally determined $f$ numbers. Discrepancies between the theoretical and experimental photoionization cross section in the higher-energy valence region are attributed to systematic errors in the measured values, in accordance with previous observations. Although the Stieltjes-Tchebycheff technique is particularly suitable for studies for photoionization in molecular systems, the present results indicate that highly reliable cross sections are also obtained from the approach in applications to many-electron atomic systems when appropriate square-integrable wave functions are employed.

17320. Ledbetter, H. M., Low-temperature elastic properties of a precipitation-hardened copper alloy, Z. Metallkd. 68, No. 7, 506-509 (July 1977).

Key words: bulk modulus; compressibility; copper alloy; Debye temperature; elastic constants; Poisson's ratio; shear modulus; sound velocity; Young's modulus.

Elastic constants of a copper-cadmium-chromium precipitation-hardened alloy were measured between room temperature and liquid-helium temperature by ultrasonic-velocity methods. Compared to copper, the alloy has a much higher shear modulus, a much lower bulk modulus, and a seven-percent-higher Debye temperature. Despite different second-order elastic constants, the alloy's temperature derivatives are similar to copper's.

17321. Ledbetter, H. M., Anomalous low-temperature elastic behavior of a nitrogen-strengthened chromium-manganese stainless steel, Mater. Sci. Eng. 29, 255-260 (1977).

Key words: bulk modulus; compressibility; elastic constants; Poisson's ratio; pulse method; resonance method; shear modulus; sound velocity; stainless steel; Young's modulus.

Elastic constants of an Fe-21 Cr-6Ni-9Mn stainless steel were studied experimentally by both pulse and resonance methods. The room-temperature elastic constants are similar to those of AlSl 304. During cooling to liquid-nitrogen temperature ( 76 $\mathrm{K}$ ), all the elastic constants behave anomalously below $130 \mathrm{~K}$. As in Fe-Mn alloys, these anomalies are probably due to a Néel iransition. A further anomaly in the compressibility at $190 \mathrm{~K}$ suggests a second transition of unknown nature.

17322. Lewis, R. L., The use of three term recursion relations for numerical computations as applied to near-field spherical scanning, Proc. International Union of Radio Science (URSI) Int. Symip., Stanford, CA, June 20-24, 1977, pp. 224-226 (NSNC/URSI, Academy of Sciences, Washington, DC, 1977).

Key words: antennas; arrays; finite rotations; group representations; near-fields, recursion; scanning; spherical; spherical point group.

The near-field spherical scanning algorithms developed by Wacker require the computation of a large number of Fourier coefficients of the spherical point group's representation coefficients. Accurate and fast computations can be performed by three term recursion relations, as discussed by Gautschi. However, atiempting to use Fano and Racah's recursion relation for these quantities without applying the constraints of Gautschi's theory results in numerical instability. This problem is solved, resulting in a self-convergent recursive process which is accurate to within round off error limits of the computer.

17323. Libman, A. S., Weiss, R. G., Administrative experiment in public policy development, Proc. American Institute for Decision Sciences Ninth Annual Meeting, Chicago, IL, Oct.
19-2I, 1977, J. D. Stolen and J. J. Conway, Eds., pp. 395397 (1977).

Key words: administrative experimentation; evaluation; evaluation research; organizational design; policy analysis; program evaluation.

The Experimental Technology Incentives Program (ETIP) is the only program in the federal government which utilizes administrative experimentation as its primary modus operandi. Located in the Department of Commerce, ETIP seeks to. affect public policy and process to facilitate technological change in the private sector. The program operates in cooperation with federal, state, and local agencies which possess administrative responsibility for governmental regulatory, procurement, R\&D, and capital subsidy policies. Changes in policies are designed and implemented on an experimental basis with evaluations conducted to assess agency and commercial impacts. This paper describes the process which ETIP utilizes in this experimental approach to organization change.

17324. Linsky, J. L., The solar output and variability viewed in the broader context of stellar activity, Chapter in The Solar Output and Its Variation, O. R. White, Ed., pp. 477-515 (Colorado Associated University Press, Boulder, CO, Oct. 1977).

Key words: chromospheres, solar; chromospheres, stellar; coronae, solar; coronae, stellar; flares, solar; flares, stellar; magnetic cycles, solar; magnetic cycles, stellar; nonradiative heating; transition regions, solar; transition regions, stellar; ultraviolet spectra; visible spectra; $x$-ray spectra.

A critical review is presented of stellar analogues of solar phenomena and structures including chromospheres, transition regions, coronae, flares, cycles, and nonradiative heating of the outer layers of stars. The relevant diagnostics presently used or of potential use for deriving physical properties in various layers are discussed in detail.

An extensive bibliography is included.

17325. Mabie, C. P., Investments for chromium-based alloys, (Proc. Conf. on Alternatives to Gold Alloys in Dentistry, $\mathrm{Na}$ tional Institute of Health, Bethesda, MD, Jan. 24-26, 1977), DHEW Publication (NIH) 77-I227, pp. 186-201 (National Institute of Health, Bethesda, MD, 1977).

Key words: dental; expansion; investments; petrographic; thermal.

Optical microscopic, $x$-ray, differential thermal, and thermal dimensional change studies have been made on investments used for chromium-based alloys. These studies have revealed that reactions during burnout and casting bear critically upon investment performance. It has become apparent that there is a need to formulate investment systems which give better refractory performance during burnout and casting.

17326. Mahan, A. H., Smith, S. J., Observation of coherent excitation processes in e-H collisions, Phys. Rev. A 16, No. 5 , 1789-1792 (Nov. 1977).

Key words: coherence; electron excitation; hydrogen.

In a measurement of emission of Balmer- $\alpha$ flux from atomic hydrogen or deuterium excited by electron impact in a crossedbeam experiment, a longitudinal electric field which enhances the Balmer-a flux by Stark-mixing components of like $M_{J}$ within the $n=3$ shell, does so asymmetrically depending on whether the field is applied parallel or antiparallel to the electron beam. The effect is attributed to coherent excitation of states of opposite parity. 
17327. Martinez, R. 1., Huie, R. E., Herron, J. T., Mass spectrometric detection of dioxirane, $\mathrm{H}_{2} \widehat{\mathrm{COO}}$, and its decomposition products, $\mathrm{H}_{2}$ and $\mathrm{CO}$, from the reaction of ozone with ethylene, Chem. Phys. Lett. 51, No. 3, 457-459 (Nov. 1, 1977).

Key words: air pollution; chemical kinetics; dioxirane; ethylene; mass spectrometry; ozone.

Dioxirane has been detected in the gas phase, by means of photoionization mass spectrometry, as a product of the low temperature reaction of ozone with ethylene. Hydrogen and carbon monoxide are found to be products of the decomposition of dioxirane. The significance of these observations to atmospheric chemistry is discussed.

17328. Mattis, R. L., Buehler, M. G., A new method for calculating background dopant density from $p$-n junction capacitance-voltage measurements, J. Electrochem. Soc. 124, No. 12, 1918-1923 (Dec. 1977).

Key words: capacitance-voltage measurements; dopant density; Gaussian diffusion; p-n junction; semiconductors; silicon.

A new method is presented for calculating the average background dopant density within the depletion layer of a planar diffused p-n junction using capacitance-voltage $(C-V)$ measurements. The method has been successfully applied to specimens having a background dopant density as high as $10^{18}$ $\mathrm{cm}^{-3}$, and ideal data studies indicate that the method may be applicable to specimens having a background dopant density up to about $10^{19} \mathrm{~cm}^{-3}$. The average background dopant density is calculated by finding the Gaussian diffused layer as characterized by an effective surface dopant density, background dopant density, and junction depth which can best be fitted to all the $C-V$ data. It is not necessary to know the actual surface dopant density. The method is illustrated by calculations on both real and idealized $C-V$ data.

17329. Novotny, D. B., Sensitometry of photoresists for microelectronics, (Proc. SPSE Symp., New York, NY, Sept. 16-17, 1976), Photographic Sci. Eng. 21, No. 6, 351-355 (Nov./Dec. 1977).

Key words: exposure; exposure control; film thickness; irradiance measurements; photoresist; sensitivity index; sensitometry; Van Kreveld's additivity law.

Single parameter irradiance measurements commonly used for the determination of photoresist exposure times are incapable of giving unique values of either the broad-band irradiance from a mercury-arc lamp, or the photoresist exposure times. Resolution of these measurement incapabilities through a series of irradiance measurements of narrow, approximately monochromatic radiation bands is discussed. A basis for establishing photoresist sensitivity indices that can be used to calculate unambiguous exposure times by applying Van Kreveld's additivity law to these narrow band irradiance measurements is suggested. The thickness variation of photoresist films is included in the method of calculating exposure time. Suggestions are made for the use of these indices as photoresist specifications, and for the real-time automatic monitoring and control of exposure times in wafer fabrication where optical density variation in the photomasks and thickness variations in the photoresist films are automatically incorporated into the control by a microprocessor.

17330. Russell, T. J., Leedy, T. F., Mattis, R. L., A comparison of electrical and visual alignment test structures for evaluating photomask alignment in integrated circuit manufacturing, Proc. Int. Electron Devices Meeting, Washington, DC, Dec. 57, 1977, pp. 7A-7F (Institute of Electrical and Electronics Engineers, New York, NY, 1977).
Key words: electrical mask alignment; integrated circuit; photolithography; silicon; test pattern; visual alignment structure.

Various electrical alignment test structures were designed to conform to the NBS $2 \times N$ probe pad array and are thus compatible with a class of other modular test structures. The object of this study is to determine the feasibility of this new layout, to compare results with visual alignment test structures, and to establish the limits of resolution. The structures can be used to determine the misalignment of two photomask steps and are applicable to two conducting layers that contact each other at a contact window. The electrical data are displayed as wafer vector maps which are useful in quantifying mask alignment problems.

17331. Ruthberg, S., Neff, G. R., Martin, B. D., Radioisotope hermetic test precision, Proc. 1977 Int. Microelectronics Symp., Baltimore, MD, Oct. 24-26, 1977, pp. 131-137 (International Society for Hybrid Microelectronics, Montgomery, AL, 1977).

Key words: hermeticity; hermetic test standards; integrated circuits; radioisotope leak detection.

Leak testing is an essential element of the screening process for hermetic devices, where test methoids are designed to reject all devices with leak rates greater than some prescribed value; nevertheless, poor measurement correlations between test methods and between test installations continue to be a major problem. An effort within ASTM Committee F-1 on Electronics is being made to resolve such measurements problems. An interlaboratory comparison has been completed on the radioisotope test method using commercial test equipment and commercial glass-sealed ceramic packages (Cerdip). One hundred test packages with indicated leaks ranging from less than $1 \times 10^{-8} \mathrm{~atm} \cdot \mathrm{cm}^{3} / \mathrm{s}$ to about $5 \times 10^{-5} \mathrm{~atm} \cdot \mathrm{cm}^{3} / \mathrm{s}$ were tested sequentially by 11 laboratories using a 2 -step sequence in a specified procedure. These test results demonstrate conclusively that an interlaboratory comparison of hermetic packages can be accomplished under appropriate guidelines with a precision (one standard deviation) ranging from $0.5 \times 10^{-8}$ at $1 \times 10^{-6}$ $\mathrm{atm} \cdot \mathrm{cm}^{3} / \mathrm{s}$ to $3.2 \times 10^{-5}$ at $5 \times 10^{-5} \mathrm{~atm} \cdot \mathrm{cm}^{3} / \mathrm{s}$. It is demonstrated that this precision could be increased significantly through elimination of the individual laboratory biases that were found to occur.

\section{Unassigned.}

17333. Yaskin, L. A., Jones, M. C., Yeroshenko, V. M., Giarratano, P. J., Arp, V. D., A correlation for heat transfer to supercritical helium in turbulent flow in small channels, Cryogenics 17, No. 10, 549-552 (Oct. 1977).

Key words: channels, small; heat transfer; helium; turbulent flow.

This paper presents a new correlation for the deterioration in heat transfer to turbulent flows of helium, relative to standard constant property correlations. The correlating parameters are arrived at by analogy between the heat transfer process to a gas with high thermal expansion and that which takes place in the presence of gas injection through a porous wall, the idea having been originally proposed by Kruzhilin. The idea appears to be applicable to the ideal gas state as well as the supercritical state. Comparison with available experimental data is made. Not only is the correlation of the data good, but the actual injection equation may be used to predict deterioration by as much as an order of magnitude.

17334. Zimmerman, J. E., Sullivan, D. B., High-frequency Iimitations of the double-junction SQUID amplifier, Appl. Phys. Lett. 31, No. 5, 360-362 (Sept. 1977). 
Key words: amplifier; high-frcquency; Josephson junction; SQUID.

The double-junction SQUID is viewed as a parametric amplifier and mechanisms, which place an upper limit on the pump frequency (and thus gain), are investigated. Self-induced steps in the $I-V$ characteristics as well as damping of the Josephson oscillation are shown to be two limiting mechanisms.

17335. Burch, D. M., Kusuda, T., An infrared technique for measuring heat loss, Proc. RILEM/ASTM/CIB Symp. on Evaluation of Performance of External Vertical Surfaces of Buildings, Helsinki, Finland, Aug. 28-Sept. 2, 1977, pp. 62-72 (Technical Research Centre of Finland, Helsinki, Finland, 1977).

Key words: heat-flow reference pad; heat loss; infrared television system.

This paper describes a newly developed technique for estimating heat-loss rate utilizing an infrared television system. A device called a heat-flow reference pad was developed that makes it possible to estimate quantitatively the heat-loss rate at the surface of a building without the need for a conventional heat-flow meter to be mounted on the surface. The infrared measurement technique predicted heat-loss rates in the laboratory and field within approximately 12 percent.

17336. Evenson, K. M., Jennings, D. A., Petersen, F. R., Wells, J. S., Laser frequency measurements: A review, limitations, extension to $197 \mathrm{THz}(1.5 \mu \mathrm{m})$, (Proc. Third Int. Conf. on Laser Spectroscopy, Jackson, WY, July 3-6, 1977), Paper in Springer Series in Optical Sciences. Vol. 7: Laser Spectroscopy III, J. L. Hall and J. L. Carlsten, Eds., pp. 56-68 (SpringerVerlag, Berlin, Germany, 1977).

Key words: frequency measurement; frequency standards; helium neon laser; insulator metal diode; laser; speed of light; 1.5 microns.

The $\mathrm{CO}_{2}$ and $\mathrm{He}-\mathrm{Ne}$ lasers stabilized respectively with $\mathrm{CO}_{2}$ and $\mathrm{CH}_{4}$ are now accepted as frequency and wavelength standards at 9 to 12 , and $3.39 \mu \mathrm{m}$. This is due to their excellent frequency stability and accuracy, and the measurement of their frequencies. The measurement of both the frequency and wavelength of the $\mathrm{CH}_{4}$ device yielded a hundred fold increase in the accuracy of the speed of light. This paper reports the extension of direct frequency measurements to the $197 \mathrm{THz}(1.5$ $\mu \mathrm{m}) \mathrm{cw}$ line of a He-Ne laser, and reviews the current status of laser stabilization and speed of light measurements.

17337. Bergquist, J. C., Lee, S. A., Hall, J. L., Ramsey fringes in saturation spectroscopy, (Proc. Third Int. Conf. on Laser Spectroscopy, Jackson, WY, July 3-6, 1977), Paper in Springer Series in Optical Sciences. Vol. 7: Laser Spectroscopy III, J. L. Hall and J. L. Carlsten, Eds., pp. 142-148 (Springer-Verlag, Berlin, Germany, 1977).

Key words: coherence; fringes; interference; modulation; phase; Ramsey; saturation spectroscopy; transit-time.

Optical Ramsey fringes were observed in saturation spectroscopy with spatially separated light fields. The phase evolution of the Ramsey-type interaction between the atoms and the light fields, and the symmetry of the fringes are discussed. Techniques for application of the Ramsey method in precision spectroscopy by phase shift and modulation of the fringes are described.

17338. Lee, S. A., Hall, J. L., A traveling Michelson interferometer with phase-locked fringe interpolation, (Proc. Third Int. Conf. on Laser Spectroscopy, Jackson, WY, July 3-6, 1977), Paper in Springer Series in Optical Sciences. Vol. 7:
Laser Spectroscopy III, J. L. Hall and J. L. Carlsten, Eds., pp. 421-422 (Springer-Verlag, Berlin, Germany, 1977).

Key words: cw laser; interferometer; Michelson; phaselock; scanning; wavelength.

We describe an automatic scanning Michelson interferometer with a resolution extension scheme which utilizes a phaselocked oscillator in the fringe interpolation algorithm. The interferometer provides real-time wavelength display of single mode cw lasers with a demonstrated absolute accuracy of $2 \times$ $10^{-7}$.

17339. Freeman, C. M., Nudelman, S., Richmond, J. C., Eds., Optics in security and law enforcement (Book), Proc. Symp. on Optics in Security and Law Enforcement, Reston, VA, Apr. I8-2I, I977, 154 pages (Society of Photo-Optical Instrumentation Engineers, Bellingham, WA, 1977).

Key words: law enforcement; optics; security and law enforcement.

17340. Kusuda, T., Ellis, W., Vapor condensation in air-pervious insulation, (Proc. Annual Meeting of Com. B.1, IIF-lIR on Heat and Mass Transfer in Porous Structures, Washington, DC, Sept. 14-16, 1976), Bul. Inst. Int. Froid 2, 139-150 (1976).

Key words: air, moisture and heat transfer theory; cold storage insulation; fibrous-glass insulation; vapor condensation.

Theoretical and experimental studies were conducted on moisture accumulation problems in air-pervious insulation subjected to a steep temperature gradient. The principal test wall studied was a wooden partition for a cold storage installation consisting of warm-side vapor barrier, six inches of fibrous glass insulation, and a one-inch fibrous-glass interior finish board. Experimental data indicated that moisture accumulation became serious only when the vapor barrier was punctured both at the top and bottom of the test wall, thus causing a convective air in-flow at the top and out-flow at the bottom. The data further showed that with this type of leakage, most of the moisture accumulation occurred only at the top region of the wall.

A small-scale apparatus was used to test the moisture accumulation and drying-out performance of tube-type specimens that represent a portion of an insulated exterior wall subjected to simultaneous flow of air, moisture, and heat. These test results show that a slight air pressure differential across the insulation has much stronger influence on the vapor colitensation problem than the much higher water vapor pressure differential.

17341. Kusuda, T., SATG: A useful concept for window heat gain analysis, Proc. RILEM/ASTM/CIB Symp. on Evaluation of Performance of External Vertical Surfaces of Buildings, Helsinki, Finland, Aug. 28-Sept. 2, 1977, pp. 157-167 (Technical Research Centre of Finland, Helsinki, Finland 1977).

Key words: climatic data; cloud cover modifier; energy conservation; shading coefficient; solar heat gain; window design.

In an effort to evaluate the combined effect of solar heat gain and conduction heat transfer window through glass, a new concept called SATG (Sol-Air Temperature for Glass) is introduced. SATG is a combined index for outdoor temperature and the solar heat gain divided by the overall heat transfer coefficient. It represents a maximum possible temperature that space behind the window can attain, had there been no heat loss. Hourly SATG values for the single- and double-glaze windows of various orientations were determined by using ten 
years weather record of Washington, D.C. and were represented in the form of a frequency histogram. Also developed from these data are hourly solar-air degree hours as an index to evaluate the net heat transfer through windows.

17342. Buehler, M. G., Dopant profiles determined from enhancement mode MOSFET D-C measurements, Appl. Phys. Lett. 31, 848-850 (Dec. 1977).

Key words: direct-current; dopant density; ion implantation; MOSFET; silicon.

A new method is presented for the determination of the dopant profile in the gate region of a four-terminal enhancement mode metal-oxide-silicon field effect transistor (MOSFET). The method calls for the direct-current (D-C) measurement of the source-body voltage, $V_{S B}$, as a function of the gate-source voltage, $V_{G S}$, for a fixed minority carrier channel current. The profile depth is proportional to $\mathrm{dV}_{S B} / \mathrm{dV}_{G S}$ and the dopant density is inversely proportional to $\mathrm{d}^{2} \mathrm{~V}_{S B} / \mathrm{dV}_{G S^{2}}$. Only the oxide and silicon dielectric constants and oxide thickness are needed in the computations. The method is illustrated by the profile of a phosphorus layer implanted in an $n$-type silicon substrate.

17343. McLaughlin, W. L., Fundamentals of dosimetry, Chapter 1 in Manual of Food Irradiation Dosimetry, Technical Reports Series No. 178, pp. 1-34 (International Atomic Energy Agency, Vienna, Austria, 1977).

Key words: absorbed dose; calorimetry; dose distributions; dosimetry; electron beams; food irradiation; Fricke dosimetry; gamma rays; $x$ rays.

For food irradiation applications it is worthwhile to consider water as a reference material in which radiation absorbed can be measured by a reference dosimeter system, a water calorimeter or the more frequently used Fricke dosimeter, or by a calibrated routine dosimeter system that is also nearly water equivalent, such as ferrous cupric systems, acrylic (Perspex) or similar plastics, dyestuffs, or other organic systems. The correct calibration of the response of a dosimeter depends chiefly on the following observations: (1) If the absorbed dose is measured in a material whose radiation absorption characteristics (photon mass energy absorption cross sections or electron mass stopping powers) differ appreciably from those of water, appropriate corrections have to be made in order to convert the dose in one material to that in the other; (2) If the dose distribution is taken into account properly, that is, if the calibration of a dosimeter is carried out under electronic equilibrium conditions, the dosimeter system may be used at any given depth or position in an absorber in order to get a measurement of absorbed dose at that position.

17344. Collins, L. A., Norcross, D. W., Electron momentum transfer cross sections for polar molecules, (Proc. Conf. High Temperature Sciences Related to Open-Cycle, Coal-Fired MHD Systems, Argonne, IL, Apr. 4-6, 1977), Report ANL77-2l, pp. 86-90 (Argonne National Laboratory, Argonne, IL, Aug. 1977).

Key words: electron collisions; LiF; MHD; momentum transfer.

Rotational-excitation collisions between electrons and polar molecules such as $\mathrm{H}_{2} \mathrm{O}, \mathrm{SO}_{2}$ and $\mathrm{KOH}$ are thought to play an important role in determining the plasma conductivity of MHD generators. The molecule $\mathrm{KOH}$, even in small concentrations, may make a significant contribution to the total plasma reactivity due to its very large momentum transfer cross section. Our approach to developing general methods for calculating excitation and momentum transfer cross sections for electron collisions with strongly polar systems has been to carry out an exhaustive study using the close-coupling formulation for a typical molecule, LiF, in order to test the validity of approximating the full potential surface by simple model potentials; and should one or more of the potentials give accurate cross sections, to develop a systematic procedure for generating such model potentials. This is being performed in parallel with a study of the validity of various simpler approaches to the solution of the scattering problem.

17345. Blackburn, D. L., Koyama, R. Y., Oettinger, F. F., Rogers, G. J., Measurement techniques for high power semiconductor materials and devices: Annual report for the period January 1, 1976-December 31, 1976, Energy Conservation CONS/3800-2, 92 pages (National Technical Information Services, Springfield, VA, 1977).

Key words: d-c transmission; energy conservation; measurement methods; photovoltaic method; power-device grade silicon; resistivity variations; silicon; thermally stimulated capacitance; thermally stimulated current; thermally stimulated measurements; thyristor materials measurements; thyristor measurements.

This annual report describes NBS activities directed toward the development of measurement methods for semiconductor materials and devices which will lead to more effective use of high power semiconductor devices in applications for energy generation, transmission, conversion, and conservation. It responds to national needs arising from rapidly increasing demands for electricity and the present crisis in meeting longterm energy demands. Emphasis is on the development of measurement methods for thyristors and rectifier diodes.

The major tasks under this project are (1) to evaluate the feasibility of the photo-voltaic method as a rapid, nondestructive technique for characterizing the resistivity uniformity of high-resistivity, large-diameter silicon wafers and (2) to evaluate the use of thermally stimulated current and capacitance measurements as a means for characterizing lifetime controlling or leakage source defects in power device grade silicon wafers.

17346. Barnes, J. D., Martin, G. M., Performance of plastic packaging for hazardous materials transportation. Part II. Permeation, Report No. DOT/MTB/OHMO-76/5, 29 pages (National Technical Information Service, Springfield, VA, Oct. 1976).

Key words: hazardous materials; methods of test; permeation; plastics packagings; polyethylene; transportation.

Permeation as a mode of failure for plastics packagings is discussed. The materials properties which determine permeation performance are defined. Measurement methods aimed at determining values for the materials properties are surveyed.

A "matrix" scheme is introduced for evaluating the risks associated with the permeation failure of a package containing a hazardous materials lading. Permeation factors influencing reuse of plastic containers are described. Laboratory data from an evaluation of a simple method of test for eștimating the intrinsic property of a lading to permeate polyethylene is presented.

17347. Hill, J. E., Kelly, G. E., Peavy, B. A., A method of testing for rating thermal storage devices based on thermal performance, Solar Energy 19, 721-732 (1977).

Key words: standard test; thermal storage.

This paper describes a proposed test method for determining the "effective capacity" and heat loss characteristics of thermal storage devices. The prescribed series of tests should provide useful data for the rating of thermal storage devices based on thermal performance. The apparatuses and major components used in the tests have been prescribed so a liquid or air can be used as the transfer fluid. The series of tests to be con- 
ducted consist of one steady-state test to determine the heat loss characteristics and eight transient tests to determine the "effective capacity" for both heat storage and heat removal. During the transient tests, the entering fluid temperature is changed in a step-wise manner and amount of energy either stored or removed over a specified test time is determined. Sample experimental data are given in the paper to demonstrate the concept of the transient tests.

17348. Choi, C. S., Prask, H. J., Prince, E., Ammonium perchlorate: Reinvestigation of the crystal structure at $298 \mathrm{~K}$, Act. Crystallogr. B32, Pt. 10, 2919-2920 (Oct. 1976).

Key words: ammonium perchlorate; bond lengths and angles; crystal structure; rigid-body motion analysis; thermal motion of a perchlorate ion; $x$-ray diffraction.

The structure of ammonium perchlorate at $298 \mathrm{~K}$ has been refined with the $\mathrm{X}$-ray diffraction data of Peyronel \& Pignedoli [Acta Cryst. (1975), B31, 2052-2056]. A satisfactory refinement was achieved in space group Pnma, in agreement with earlier observations at low temperatures.

17349. Madey, T. E., Yates, J. T., Jr., Evidence for the conformation of $\mathrm{H}_{2} \mathrm{O}$ adsorbed on $\mathrm{Ru}(001)$, Chem. Phys. Lett. 51, No. 1, 77-83 (Oct. 1, 1977).

Key words: adsorption; angular distribution (ions); chemisorption; electron stimulated desorption; ruthenium; water.

The Electron Stimulated Desorption Ion Angular Distribution (ESDIAD) method has been used to study the adsorption of $\mathrm{H}_{2} \mathrm{O}$ by $\mathrm{Ru}(001)$. The results indicate that chemisorbed, undissociated $\mathrm{H}_{2} \mathrm{O}$ is bonded to $\mathrm{Ru}$ via the oxygen atom, and that interactions between neighboring molecules occur as coverage increases. The Utility of ESDIAD for structure determination in the absence of long range order is demonstrated.
17350. Munro, R. G., Green function theory of Curie and order-order transitions in ferromagnetic systems, J. Magnet. Magnetic. Mater. 5, 177-183 (1977).

Key words: canted phase; ferromagnetism; order-order transition; transition temperatures.

Dipolar critical temperatures in ferromagnetic systems with isotropic bilinear and biquadratic exchange are investigated by means of the Green function technique. Expressions are found for both the familiar Curie temperature, $T_{c}$, and the less well known order-order transition temperature, $T_{0}$, at which, under appropriate conditions, the magnetic ordering undergoes a change between fully aligned and canted ferromagnetism. At $T$ $=0$, a fully aligned state has $\left\langle s_{i}{ }^{2}\right\rangle=s$ for spin $s$ and all lattice sites $i$, while a canted state has $\left\langle s_{i}{ }^{2}\right\rangle<s$. It is shown independently of the Green function analysis that the $T=0$ ground state is fully aligned if $\alpha$, the ratio of biquadratic to bilinear exchange integrals, obeys $-[2 s(s-1)]^{-1}<a \leq\left[2 s^{2}-2 s+1\right]^{-1}$. The region below the lower limit is identified as the range in which canted ferromagnetism can occur and is a range that does not appear to have been considered previously via the Green function formalism.

The temperature dependence of the magnetic ordering is investigated by means of the double-time temperature-dependent Green function formalism. A new decoupling scheme is derived and used to reduce higher order Green functions to lowest order. It is found that a canted state, occurring at low temperatures, undergoes a transition to a fully aligned state at a temperature $T_{0}$ and subsequently becomes disordered at temperature $T_{c}$. Transitions to paramagnetism are found to be second order for $\alpha<\alpha_{c}$ and first order for $\alpha \geq \alpha_{c}$ where $\alpha_{c}$ is a critical value that depends on the atomic spin and weakly on the lattice structure. A phase diagram is given to illustrate the results, and a comparison is made with the corresponding results found in mean field theory. 


\section{LISTING OF NBS PAPERS BY MAJOR SUBJECT AREA}

This section provides a listing of 1976 papers organized by primary subject matter as follows:

Acoustics and Sound

Analytical Chemistry

Atomic and Molecular Studies

Building Technology

Computer Science and Technology

Health and Safety

Consumer Information and Protection

Electromagnetic Metrology

Electronic Technology

Energy Conservation and Production

Engineering, Product and Information Standards

Environmental Studies: Pollution Measurement

Failure Analysis

Fire Research

Fluids: Liquids, Gases and Plasmas

General Theoretical Chemistry and Physics

Instrumentation and Experimental Methods

Lasers and Their Applications

Low Temperature Science and Engineering

Mathematical and Statistical Methods

Measurement Science and Technology:

Policy and State-of-the-Art Surveys

Measurement Science and Technology:

Physical Standards and Fundamental Constants Metrology: Physical Measurements

Nuclear Physics and Radiation Technology
Mechanics: Design, Testing and Measurement

Operations Analysis and Applications

Processing and Performance of Materials

Properties of Materials: Electronic, Magnetic and Optical

Properties of Materials: Structural and Mechanical

Properties of Materials: Thermodynamic and Transport

Standard Reference Data

Standard Reference Materials

Surfaces and Interfaces

Thermodynamics and Chemical Kinetics

Technology Incentives

Other Subjects of General Interest

It permits users of this catalog to scan the Bureau's output by major subject category. The user should bear in mind that a paper is listed once by major subject even though it might well contain other secondary subject matters of interest. The keyword index permits the reader to determine the overall context of a paper, and provides an excellent secondary reference source.

The categories currently in use for classifying NBS publications are listed below and are followed by a listing of each paper by category. Full citations (including key-words and abstracts) will be found under the appropriate publication series, which is included in the paper title. Also of use will be the key-word index (mentioned above) and the author index. See Section 6 on page 340 for information on their organization and use. 


\section{Acoustics and Sound}

H122. Noise emission measurements for regulatory purposes, D. R. Flynn, W. A. Leasure, Jr., A. 1. Rubin, and M. A. Cadoff, Nat. Bur. Stand. (U.S.), Handb. 122, 193 pages (Mar. 1977) SN003-003-01750-7.

NBSIR 76-1179. Attack and release characteristics of compression hearing aids, E. D. Burnett and M. A. Bassin, 175 pages (Dec. 1976). Order from NTIS as PB276536.

16701. Hruska, G. R., Magrab, E. B., Penzes, W. B., Environmental effects on microphones of various constructions, $J$. Acoust. Soc. Am. 61, No. 1, 206-210 (Jan. 1977).

16702. Magrab, E. B., Natural frequencies of elastically supported orthotropic rectangular plates, J. Acoust. Soc. Am. 61, No. 1, 79-83 (Jan. 1977).

16735. Parks, S. 1., Linzer, M., Application of pulse compression techniques to medical ultrasound, (Proc. of the Society of Photo-Optical Instrumentation Engineers, Conf., Washington, DC, Sept. 16-19, 1976), Paper in Application of Optical Instrumentation in Medicine V, R. K. Cacak, et al., Eds., 96, 349-353 (Society of Photo-Optical Instrumentation Engineers, Palos Verdes Estates, CA, 1976).

16763. Pallett, D. S., Bartel, T. W., Voorhees, C. R., Recent reverberation room qualification studies at the National Bureau of Standards, Noise Control Eng. 7, No. 2, $71-80$ (Sept.Oct. 1976).

16764. Voorhees, C. R., Pallett, D. S., Laboratory measurements in acoustics, Noise Control Eng. 7, No. 2, $52-56$ (Sept.Oct. 1976).

16766. Holmer, C. 1., Qualification of an acoustic research facility for sound power determination, Noise Control Eng. 7, No. 2, 87-92 (Sept.-Oct. 1976).

17052. Kuhn, G. F., Model for the interaural time differences in the azimuthal plane, J. Acoust. Soc. Am. 62, No. 1, 157 167 (July 1977).

17064. Kuhn, G. F., Burnett, E. D., Acoustic pressure field alongside a manilisis's head with a view towards in situ hearing-aid tests, J. Acoust. Soc. Am. 62, No. 2, $416-423$ (Aug. 1977).

17145. Burnett, E. D., Schweitzer, H. C., Attack and release times of mutomatic-gain-control hearing aids, J. Acoust. Soc. Am. 62, No. 3, 784-786 (Sept. 1977).

17213. Evans, A. G., Linzer, M., Acoustic emission in brittle materials, Ann. Rev. Mater. Sci. 7, 179-208 (1977).

17215. Robertson, B., Effect of arbitrary temperature and flow profiles on the speed of sound in a.plpe, J. Acoust. Soc. Am. 62, No. 4, 813-818 (Oct. 1977).

17245. Hruska, G. R., Magrab, E. B., Penzes, W. B., Reply to "Comments on "Environmental effects or microphones of various constructions", J. Acoust. Soc. Am. 62, No. 5, 1314 (Nov. 1977).

\section{Analytical Chemistry}

Standard pH vaiues for the potassium hydrogen phthalate reference buffer solution from 0 to $60^{\circ} \mathrm{C}, \mathrm{H}$. B. Hetzer, R. A. Durst, R. A. Robinson, and R. G. Bates, J. Res. Nat. Bur. Stand. (U.S.), 81A (Phys. and Chem.), No. 1, 21-24 (Jan.Feb. 1977).

SP466. Standardivation in spectrophotometry and luminescence measurements. Proceedings of a Workshop Seminar held at the National Bureau of Standards, Gaithersburg, MD, Nov.
19-20, 1975, K. D. Mielenz, R. A. Velapoldi, and R. Mavrodineanu, Eds., Nat. Bur. Stand. (U.S.), Spec. Publ. 466, 155 pages (May 1977) SN003-003-01791-4.

Fluorescence quantum yield measurements, J. B. Birks, SP466, pp. 1-11 (May 1977).

Some methods of luminescence efficiency measurements, A. Bril and A. W. de Jager-Veenis, SP466, pp. 13-19 (May 1977).

On the actinometric measurement of absolute luminescence quantum yields, J. N. Demas and B. H. Blumenthal, SP466, pp. 21-24 (May 1977).

The calorimetric detection of excited states, J. B. Callis, SP466, pp. 25-31 (May 1977).

Fluorescence efficiency of laser dyes, K. H. Drexhage, SP466, pp. 33-40 (May 1977).

Diffuse reflectance spectroscopy; applications, standards, and calibration (with special reference to chromatography), $\mathbf{R}$. W. Frei, SP466, pp. 41-55 (May 1977).

The interpretation of diffuse reflectance spectra, H. G. Hecht, SP466, pp. 57-73 (May 1977).

Calibration of reflectance standards, W. Budde, SP466, pp. 75-85 (May 1977).

Understanding bidirectional reflectance and transmission for spoce applications, J. B. Schutt, SP466, pp. 87-93 (May 1977).

Standardization of light scattering measurement in conjunction with immunochemical analysis, G. J. Buffone, SP466, pp. 95-98 (May 1977).

Errors in spectrophotometry and calibration procedures to avoid them, A. G. Reule, SP466, pp. 99-114 (May 1977).

Standardization in transmission spectrophotometry in the visible and ultraviolet spectral regions, A. R. Robertson, SP466, pp. 117-120 (May 1977).

Acidic potassium dichromate solutions as ultraviolet absorbance standards, R. W. Burke and R. Mavrodineanu, SP466, pp. 121-126 (May 1977).

Considerations for the use of semi-transparent metallic thin films as potential transmittance standards in spectrophotometry, R. Mavrodineanu, SP466, pp. 127-131 (May 1977).

Structure-related optical characteristics of thin metallic films in the visible and ultraviolet, H. E. Bennett and J. L. Stanford, SP466, pp. 133-148 (May 1977).

NBSIR 77-1315. Simulated precipitation reference materials II, J. K. Taylor, E. R. Deardorff, and T. C. Rains, 26 pages (Sept. 1977). Order from NTIS as PB273945.

16673. Wasik, S., Chesler, S., Use of a nemntic liquid crystal for the gas-liquid chromatcographic separation of naphthalene homologues, J. Chromatogr. 122, $451-458$ (1976).

16699. Tsang, W., Walker, J. A., Instrument for the generation of renctive gases, Anal. Chem. 49, No. 1, 13-17 (Jan. 1977).

16760. Lutz, G. J., Activation analysis with a calliomium-252 source, (Proc. Educational Seminar on Use of Californium252 in Teaching and Research, Karlsruhe, Germany, Apr. 1418, 1975), IAEA-SR-3/3, Chapter in Some Physical, Dosimetry and Biomedical Aspects of Californium-252, pp. 7387 (International Atomic Energy Agency, Vienna, Austria, 1976).

16772. Durst, R. A., Tris(hydroxy methyl)aminomethane physialogic-pH buffer-Liquid-junction error, Clin. Chem. 23, No. 2, 298 (1977).

16777. Grant, W. H., Smith, L. E., Stromberg, R. R., Radiotracer techniques for protein adsorption measurements, J. Biomed. Mater. Res. Symp. 8, 33-38 ( 1977 ). 
16822. McCrackin, F. L., Calibration of gel permeation chromatography columns using polydisperse polymer standards, $J$. Appl. Polymer Sci. 21, 191 -198 (1977).

16921. Packham, S. C., Frens, D. B., McCandless, J. B., Petajan, J. H., Birky, M. M., A chronic intra-arterial cannula and rapid micro-technique for carboxyhemoglobin determination, J. Combust. Toxicology 3, $471-478$ (Nov. 1976).

16953. Hubbard, C. R., Smith, D. K., Experimental and calculated standards for quantitative analysis by powder diffraction, Paper in Advances in X-Ray Analysis, H. F. McMurdie, C. S. Barrett, J. B. Newkirk, and C. O. Ruud, Eds., 20, 2739 (Plenum Publ. Corp., New York, NY, 1977).

16980. Bowen, B. E., Cram, S. P., Effects of sample size on chromatographic behavior, J. Chromatogr. Sci. 12, 579-584 (Oct. 1974).

17050. Mighell, A. D., The single crystal vs. the powder method for identification of crystalline materials, Paper in Advances in X-Ray Analysis, H. F. McMurdie, C. S. Barrett, J. B. Newkirk, and C. O. Ruud, Eds., 20, 53-62 (Plenum Publ. Corp., New York, NY, 1977).

17230. Hughes, E. E., Rook, H. L., Deardorff, E. R., Margeson, J. H., Fuerst, R. G., Performance of a nitrogen dioxide permeation device, Anal. Chem. 49, No. 12, $1823-1829$ (Oct. 1977).

17247. Uriano, G. A., Gravatt, C. C., The role of reference materials and reference methods in chemical analysis, Crit. Rev. Anal. Chem. 6, No. 4, $361-411$ (Oct. 1977).

17257. Diamondstone, B. I., Burke, R. W., Some difficulties encountered in speciation studies of arsenic, Analyst Short Papers 102, 613-614 (Aug. 1977).

17271. Wise, S. A., Chesler, S. N., Hertz, H. S., Hilpert, L. R., May, W. E., Chemically-bonded aminosilane stationary phase for the high-performance liquid chromatographic separation of polynuclear aromatic compounds, Anal. Chem. 49, No. 14, 2306-2310 (Dec. 1977).

17278. Wise, S. A., May, W. E., Unusual experimental detectors for LC, Res./Develop. 28, No. 10, 54-62 (Oct. 1977).

17297. Brinckman, F. E., Blair, W. R., Jewett, K. L., Iverson, W. P., Application of a liquild chromatograph coupled with a flameless atomic absorption detector for speciation of trace organometallic compounds, J. Chromatogr. Sci. 15, 493-503 (Nov. 1977).

\section{Atomic and Molecular Studies}

Atlas of the $I_{2}$ spectrum from 19000 to $18000 \mathrm{~cm}^{-1}, \mathrm{~J}$. D. Simmons and J. T. Hougen, J. Res. Nat. Bur. Stand. (U.S.), $81 \mathrm{~A}$ (Phys. and Chem.), No. 1, 25-80 (Jan. Feb. 1977).

Isotope effects in the ascociation reactions of methyl and ethyl iodide cations, L. W. Sieck, J. Res. Nat. Bur. Stand. (U.S.), 81 A (Phys. and Chem.), Nos. 2 and 3, 267-271 (Mar.-June 1977).

Stimulated multiphoton bremsstrahlung in electron-ion collisions, S. Geltman, J. Res. Nat. Bur. Stand. (U.S.), 82, No. 3, 173 179 (Nov.-Dec. 1977).

SP363. Supplement 1. Bibliography on atoraic energy levels and spectra (July 1971 through June 1975), L. Hagan, Nat. Bur. Stand. (U.S.), Spec. Publ. 363 Suppl. I, 186 pages (Jan. 1977) SNO03-003-01673-0.

16659. Mehlman, G., Weiss, A. W., Esteva, J. M., Revised classification of $\mathrm{Mg}$ II levels between 59 and $63 \mathrm{eV}$, Astrophys. J. 209, 640-641 (Oct. 15, 1976).

16664. Lovas, F. J., Johnson, D. R., Buhl, D., Snyder, L. E., Millimeter emission lines in Orion A, Astrophys. J. 209, No. 3, 770-777 (Nov. 1, 1976).

16670. Ederer, D. L., Photoabsorption in inner-shells of atoms, (Proc. 2nd Int. Conf. on Inner Shell lonization Phenomena, Freiburg, Germany, Mar. 29-Apr. 2, 1976), Paper in Second International Conference on Inner Shell Ionization Phenomena.
W. Mehlhorn and R. Brenn, Eds., pp. 145-165 (Universität Freiburg, Freiburg, Fed. Rep. Germany, 1976).

16674. Collins, L. A., Lane, N. F., Quantum-mechanical calculations of rotational-excitation cross sections for $\mathbf{H C l}, \mathbf{D C l}, \mathbf{D F}$, and HF in slow collisions with He, Phys. Rev. A 14, No. 4, 1358-1367 (Oct. 1976).

16675. Clark, F. O., Asymmetric HCN line profiles from the Orion Nebula, Astrophys. J. 200, L1 15-L1 17 (Sept. 1, 1975).

16682. Morrison, M. A., Collins, L. A., Lane, N. F., Theoretical study of low-energy electron- $\mathrm{CO}_{2}$ scattering, Chem. Phys. Lett. 42, No. 2, 356-360 (Sept. 1, 1976).

16684. Krauss, M., Liu, B., The energy curve of $\mathrm{XeF}, \mathrm{X}^{2} \Sigma^{+}$, Chem. Phys. Lett. 44, No. 2, 257-260 (Dec. 1, 1976).

16689. Lafferty, W. J., Suenram, R. D., Johnson, D. R., Microwave spectrum of acetylene-d $2, J$. Mol. Spectrosc. 64, 147-156 (1977).

16703. Rebbert, R. E., Ausloos, P. J., Gas-phase photodecompasition of carbon tetrachloride, J. Photochem. 6, 265-276 (1976/77).

16709. Truhlar, D. G., Van-Catledge, F. A., Tests of INDO/1s and INDOXI/1s methods for the calculation of the static potential for electron scattering by $\mathrm{CO}, J$. Chem. Phys. 65, No. 12, 5536-5538 (Dec. 15, 1976).

16710. Wagner, H. L., Hoeve, C. A. J., The Mark-Houwink equation and chain dimensions of linear polyethylene in theta solvents, J. Polym. Sci. Polym. Symp. No. 54, 327-339 (1976).

16732. Chiu, H. Y., Adams, P. J., Linsky, J. L., Basri, G. S., Maran, S. P., Hobbs, R. W., High-resolution stellar vidicon spectrophotometry. I. Variable mass loss from arcturus and the hypothesis of giant convective elements, Astrophys. J. 211, No. 2, 453-462 (Jan. 15, 1977).

16736. Morton, M., Fetters, L. J., Homogeneous anionic polymerization of unsaturated monomers, Paper in Macromolecular Reviews, A. Peterlin, M. Goodman, S. Okamura, B. H. Zimm, and H. F. Mark, Eds., 2, 71-113 (Interscience Publishers, John Wiley \& Sons, New York, NY, 1967).

16740. Truhlar, D. G., Brandt, M. A., Srivastava, S. K., Trajmar, S., Chutjian, A., Quantum mechanical and crossed beam study of vibrational excitation of $\mathbf{N}_{2}$ by electron impact at 30 $75 \mathrm{eV}$, J. Chem. Phys. 66, No. 2, 655-663 (Jan. 15, 1977).

16752. Cheron, B., Scheps, R., Gallagher, A., Noble-gas broadening of the $6{ }^{2} P_{1 / 2}-7{ }^{2} S_{1 / 2}\left(377.6 \mathrm{~nm}\right.$ ) $6{ }^{2} P_{3 / 2}-7{ }^{2} S_{1 / 2}$ (535 inm) thallium lines, Phys. Rev. A 15, No. 2, 651-660 (Feb. 1977).

16757. Shiloh, M., Gayer, B., Brinckman, F. E., Preparation of nitrides by active nitrogen. II. $\mathrm{Si}_{3} \mathrm{~N}_{4}, J$. Electrochem. Soc. 124, No. 2, 295-300 (Feb. 1977).

16762. Jenkins, E. B., Snow, T. P., Upson, W. L., Starrfield, S. G., Gallagher, J. S., Friedjung, M., Linsky, J. L., Anderson, R., Henry, R. C., Moos, H. W., Copernicus observations of Nova Cygni 1975, Astrophys. J. 212, No. 1, 198-202 (Feb. 15, 1977).

16765. Lawton, S. A., Novick, S. E., Broida, H. P., Phelps, A. V., Quenching of optically pumped $\mathrm{O}_{2}\left(b^{1} \Sigma_{0}^{+}\right)$by ground state $\mathrm{O}_{2}$ molecules, J. Chem. Phys. Letters to the Editor 66, No. 3, 1381-1382 (Feb. 1, 1977).

16779. Lin, S. L., Bardsley, J. N., Monte Carlo simulation of Ion motion in drift tubes, J. Chem. Phys. 66, No. 2, 435-445 (Jan. 15, 1977).

16781. Okabe, H., Photodissociation of thiophosgene, J. Chem. Phys. 66, No. 5, 2058-2062 (Mar. 1, 1977).

16785. Manning, R. G., Kurylo, M. J., Flash photolysis resonance fluorescence investigation of the temperature dependencies of the reactions of $\left.\mathrm{Cl}^{2} \mathrm{P}\right)$ atoms with $\mathrm{CH}_{4}, \mathrm{CH}_{3} \mathrm{Cl}$, $\mathrm{CH}_{3} \mathrm{~F}, \mathrm{CH}_{3} \mathrm{~F}^{\dagger}$, and $\mathrm{C}_{2} \mathrm{H}_{6}, J$. Phys. Chem. 81, No. 4, 291-296 (1977). 
16799. Smith, E. W., Giraud, M., Calculations of rotational linewidths in $\mathrm{HCl}$ perturbed by argon, J. Chem. Phys. 66, No. 4, 1762-1764 (Feb. 15, 1977).

16800. Stock, M., Drullinger, R. E., Hessel, M. M., Comparison between electron beam and optically produced mercury excimer fluorescence, Chem. Phys. Lett. 45, No. 3, 592-594 (Feb. 1, 1977).

16802. Blais, N. C., Truhlar, D. G., Monte Carlo trajectory study of $\mathrm{Ar}+\mathrm{H}_{2}$ collisions. I. Potential energy surface and cross sections for dissociation, recombination, and inelastic scattering, J. Chem. Phys. 65, No. 12, 5335-5356 (Dec. 15, 1976).

16803. Blais, N. C., Truhlar, D. G., Monte Carlo trajectory study of $\mathrm{Ar}+\mathrm{H}_{2}$ collisions. II. Vibrational and rotational enhancement of cross sections for dissociation, J. Chem. Phys. 66, No. 2, $772-778$ (Jan. 15, 1977).

16804. Smeyers, P., Influence of magnetic fields on nonradial stellar oscillations, Proc. Solar and Stellar Pulsation Conf., Los Alamos, NM, Aug. 3-5, 1976, Pp. 140-149 (Los Alamos Scientific Laboratory, University of California, Los Alamos, NM, Oct. 1976).

16807. Faulkner, D. J., Mode interaction in U TrA, Proc. Solar and Stellar Pulsation Conf., Las Alamas, NM, Aug. 3-5, 1976, pp. 66-75 (Los Alamos Scientific Laboratory, University of California, Los Alamos, NM, Oct. 1976).

16809. Ayres, T. R., Linsky, J. L., Rodgers, A. W., Kurucz, R. L., Stellar model chromospheres. V. Alpha centauri A (G2 V) and alpha centauri B (KI V), Astrophys. J. 210, No. 1, Pt. 1, 199-210 (Nov. 15, 1976).

16810. Beaty, E. C., Hesselbacher, K. H., Hong, S. P., Moore, J. H., Triple-differential three-dimensiongl cross sections for low-energy electron impact ionization of belium, J. Phys. B: Atom. Molec. Phys. 10, No. 4, $611-620$ (1977).

16812. Stone, E. J., Lawrence, G. M., Fairchild, C. E., Kinetic energies and angular distributions of oxygen atom photofragments produced by photodissociation of $\mathrm{O}_{2}$ and $\mathrm{N}_{2} \mathrm{O}$ in the vacuum ultraviolet, J. Chem. Phys. 65, No. 12, 5083-5092 (Dec. 15, 1976).

16823. Maki, A. G., Sams, R. L., Pearson, R., Jr., Microwave and infrared spectra of isotopically substituted carbonyl selenide (OCSe), J. Mol. Spectrosc. 64, 452-459 (1977).

16824. Needham, P. B., Jr., Driscoll, T. J., Powell, C. J., Stein, R. J., Determination of the Be-Auger-electron attenuation length in Be using 160-keV protons, Appl. Phys. Lett. 30, No. 7, 357-359 (Apr. 1, 1977).

16826. Penn, D. R., Secondary-electron energy distribution in high-energy photoemission, J. Vac. Sci. Technol. 14, No. 1, 300-302 (Jan./Feb. 1977).

16844. Huie, R. E., Long, N. J. T., Thrush, B. A., The quenching of chlorine fluorescence in the gas phase, Chem. Phys. Lett. 44, No. 3, 608-610 (Dec. 15, 1976).

16848. Courtens, E., Szöke, A., Time and spectral resolution in resonance scattering and resonance fluorescence, Phys. Rev. A 15, No. 4, 1588-1603 (Apr. 1977).

16854. Whealton, J. H., Burch, D. S., Phelps, A. V., Improved model for parallel-plate drift-tube experiments, Phys. Rev. A 15, No. 4, 1685-1695 (Apr. 1977).

16870. Stevens, W. J., Hessel, M. M., Bertoncini, P. J., Wahl, A. C., Theoretical transition dipole moments and lifetimes for the $A^{1} \Sigma^{+}{ }_{u} \rightarrow X^{1} \Sigma^{+} g$ system of $\mathrm{Na}_{2}, J$. Chem. Phys. 66, No. 4, 1477-1482 (Feb. 15, 1977).

16887. Hoffman, J. D., Davis, G. T., Lauritzen, J. I., Jr., The rate of crystallization of linear polymers with chain folding, Chapter 7 in Treatise on Solid State Chemistry, N. B. Hannay, Ed., 3, $497-614$ (Plenum Press, New York, NY, 1976).

16888. Steinitz, R., Gebbie, K. B., Bar, V., The embedded feature model for the interpretation of chromospheric contrast profiles, Astrophys. J. 213, 269-277 (Apr. 1, 1977).
16892. Geltman, S., Ionization of a modei atom by a pulse of coherent radiation, J. Phys. B: Atom. Molec. Phys. 10, No. 5, $831-840$ (1977).

16910. Pearson, R., Jr., Lovas, F. J., Microwave spectrum and molecular structure of methylenimine $\left(\mathrm{CH}_{2} \mathrm{NH}\right), J$. Chem. Phys. 66, No. 9, 4149-4156 (May 1, 1977).

16912. Lam, L. K., Gallagher, A., Hessel, M. M., The intensity distribution in the $\mathrm{Na}_{2}$ and $\mathrm{Li}_{2} A-X$ bands, J. Chem. Phys. 66, No. 8, 3550-3556 (Apr. 15, 1977).

16914. Truhlar, D. G., Kuppermann, A., Dwyer, J., The importance of isotope-dependent transmission coefficients in calculating low-temperature isotope effects, Mol. Phys. 33, No. 3, 683-688 (1977).

16925. Moody, S. E., Lambropoulos, M., ac Stark effect in multiphoton ionization, Phys. Rev. A 15, No. 4, 1497-1501 (Apr. 1977).

16933. Haisch, B. M., Linsky, J. L., Lampton, M., Paresce, F., Margon, B., Stern, R., Extreme-ultraviolet observations of a flare on proxima centauri and implications concerning farestar scaling theory, Astrophys. J. 213, L119-L123 (May 1, 1977).

16940. Watson, R. E., Bennett, L. H., Calculation of atomic hyperfine-field coupling constants, Phys. Rev. B 15, No. 1, 502-503 (Jan. 1, 1977).

16950. Voigt, P. A., Roberts, J. R., Measured Stark widths and shifts for neutral phosphorus lines, Phys. Rev. A 15, No. 3, 1006-1009 (Mar. 1977).

16956. Harter, W. G., Patterson, C. W., Orbital level splitting in octahedral symmetry and $\mathrm{SF}_{6}$ rotational spectra. I. Qualitative features of high $J$ levels, $J$. Chem. Phys. 66, No. 11 , 4872-4885 (June 1, 1977).

16957. Patterson, C. W., Harter, W. G., Orbital level splitting in octahedral symmetry and $\mathrm{SF}_{\mathbf{6}}$ rotational spectra. II. Quantitative treatment of high $J$ levels, $J$. Chem. Phys. 66, No. 11 , 4886-4892 (June 1, 1977).

16962. DiMarzio, E. A., Gibbs, J. H., Fleming, P. D. III, Sanchez, I. C., Effects of pressure on the equilibrium properties of glass-forming polymers, Macromolecules 9, 763-771 (Sept.-Oct. 1976).

16966. Klein, R., Kelley, R. D., Combination and disproportionation of allylic radicals at low temperatures, J. Phys. Chem. 79, 1780-1784 (1975).

16969. Gilmore, W., Morris, M., Johnson, D. R., Lovas, F. J., Zuckerman, B., Turner, B. E., Palmer, P., Observation of the $6_{16}-5_{15}$ transitions of acetaldehyde in Sagittarius B2, Astrophys. J. 204, 43-46 (Feb. 15, 1976).

16978. Bernstein, L. S., Abramowitz, S., Levin, I. W., Potential function for axial-equatorial fuorine atom exchange in $\mathbf{P F}_{\mathrm{B}}$, $\mathrm{AsF}_{3}$, and $\mathrm{VF}_{5}, J$. Chem. Phys. 64, No. 8, 3228-3236 (Apr. 15, 1976).

16992. Voigt, P. A., Kornblith, R. L., Measurement of U I relative oscllator strengths, J. Opt. Soc. Am. 66, No. 5, $492-493$ (May 1976).

16995. Reneker, D. H., Bolz, L. H., Effect of atomic oxygen on the surface morphology of polyethylene, J. Macromol. Sci.Chem. A10, No. 3, 599-608 (1976).

17018. Huebner, R. H., Celotta, R. J., Mielczarek, S. R., Electron energy-loss analysis of carbon tetrafluoride and carbon tetrachloride (Extended Abstract), Argonne National Laboratory Report No. ANL-76-88, Part I. Radiological and Environmental Research Division Annual Report, pp. 1-3 (Argonne, IL, June 1975-Sept. 1976).

17019. Huebner, R. H., O'Connor, M. E., Celotta, R. J., Mielczarek, S. R., Apparent oscillator strengths for water vapor (Extended Abstract), Argonne National Laboratory Report No. ANL-76-88, Part I. Radiological and Environmental Research Division Annual Report, pp. 4-9 (Argonne, IL, June 1975Sept. 1976). 
17021. Penn, D. R., Theory of electron energy-loss spectrum In cone-level X-ray photoemission from solids, Phys. Rev. Lett. 38, No. 24, $1429-1432$ (June 13, 1977).

17026. Morrison, M. A., Lane, N. F., Collins, L. A., Low-energy electron-molecuie scattering: Application of coupled-channel theory to e-CO $\mathrm{CO}_{2}$ collisions, Phys. Rev. A 15, No. 6, 2186 2201 (June 1977).

17027. Collins, L. A., Norcross, D. W., Low-energy electron collisions with highly polar molecules: LiF, Phys. Rev. Lett. 38, No. 21, 1208-1211 (May 23, 1977).

17029. Aizenman, M., Smeyers, P., Weigert, A., Avoided crossing of modes of nonradial stellar ascillations, Astron. Astrophys. 58, 41-46 (1977).

17044. Todd, T. R., The infrared spectrum of ${ }^{12} \mathrm{C}^{32} \mathrm{~S}$ and ${ }^{12} \mathrm{C}^{34} \mathrm{~S}$, J. Mol. Spectrosc. 66, 162-167 (1977).

17045. Hertz, H. S., Coxon, B., Siedle, A. R., Disproportionation and pyrolysis of p-toluenesulfonylhydrazine, J. Organ. Chem. 42, No. 14, 2508-2509 (1977).

17054. Khayrallah, G. A., Smith, S. J., The cross section for production of the $3 \mathrm{~s}$ state of atomic hydrogen in dissociative excitation of $\mathrm{H}_{2}$ by electrons, Chem. Phys. Lett. 48, No. 2, 289-293 (June 1, 1977).

17056. Haisch, B. M., Linsky, J. L., Weinstein, A., Shine, R. A., Analysis of the chromospheric spectrum of $\mathbf{O} 1$ in Arcturus, Astrophys. J. 214, No. 3, $785-797$ (June 15, 1977).

17069. Krauss, M., Julienne, $P$. S., Collision-induced $1\left({ }^{2} P_{1 / 2}\right)$ emiscion in argon and xenon, J. Chem. Phys. 67, No. 2, 669 673 (July 15, 1977).

17076. Drullinger, R. E., Hessel, M. M., Smith, E. Q., Experimental studies of mercury molecules, J. Chem. Phys. 66, No. 12, 5656-5666 (June 15, 1977).

17084. Smith, E. W., Drullinger, R. E., Hessel, M. M., Cooper, J., A theoretical analysis of mercury molecules, J. Chem. Phys. 66, No. 12, 5667-5681 (June 15, 1977).

17101. Kusch, P., Hessel, M. M., An analysis of the $A^{1} \Sigma_{*}{ }^{+}$ $X^{\prime} \Sigma_{0}+$ band system of ${ }^{\top} L_{2}, J$. Chem. Phys. 67, No. 2, 586589 (July 16, 1977).

17118. Faulkner, D. J., Cepheid studies. I. Mode interaction In the beat Cepheid U Trianguli Australis, Astrophys. J. 216, 4956 (Aug. 15, 1977).

17119. Peterlin, A., Individual bead contribution to intrinsic viscosity of polymers, Polymers Lett. 18, 747-749 (July 1977).

17123. Lafferty, W. J., Sams, R. L., The high resolution infrared spectrum of the $2 \nu_{2}+\nu_{3}$ and $\nu_{1}+\nu_{2}+\nu_{3}$ bands of ${ }^{14} \mathrm{~N}^{16} \mathrm{O}_{2}$ : Vlbration and vibration-rotation constants of the electronic ground state of ${ }^{14} \mathrm{~N}^{18} \mathrm{O}_{2}, \mathrm{~J}$. Mol. Spectrasc. 66, 478-492 (1977).

17128. Chen, S. T., Gallagher, A., Electron excitation of thalllum $7^{2} S_{1 / 2}$ and $6^{2} D_{3 / 2,5 / 2}$ levels, Phys. Rev. A 15, No. 3, 888895 (Mar. 1977).

17131. Olson, W. B., Lovejoy, R. W., The infrared spectrum of the $\nu_{1}$ and $\nu_{4}$ bands of ${ }^{29} \mathrm{SlH}_{3} \mathrm{D}, \mathrm{J}$. Mol. Spectrosc. 66, 314 330 (1977).

17132. Hayes, M. A., Norcross, D. W., Mann, J. B., Robb, W. D., Electron impact excitation of $\mathrm{Be}^{+}$: A benchmark study, $J$. Phys. B: Atom. Molec. Phys. Lett. 10, No. 11, L429-L434 (1977).

17137. Siedle, A. R., Negas, T., Broussalian, J., Reactions of transition metal ions with the dithiotungstate(2-) lon, J. Inorg. Nucl. Chem. Notes 37, 2024-2025 (1975).

17144. Siedle, A. R., Activation of molecular hydrogen by a nido-metalloborane, J. Organometal. Chem. 97, C4-C6 (1975).

17146. Botter, R., Pechine, J. M., Rosenstock, H. M., Photoionization of dimethyl ether and diethyl ether, Int. J. Mass Spectrom. Ion Phys. 25, 7-25 (1977).

17148. Stockbauer, R., A threshold photoelectron-photoion coincidence mass spectrometer for measuring lon kinetic ener- gy release on fragmentation, Int. J. Mass Spectrom. Ion Phys. 25, 89-101 (1977).

17151. Krauss, M., The electronic structure of rare gas halide excimers, J. Chem. Phys. 67, No. 4, $1712-1719$ (Aug. 15, 1977).

17152. Siedle, A. R., Dicarbollide complexes of rhodium and ruthenium, J. Organometal. Chem. 90, 249-256 (1975).

17153. Siedle, A. R., Oxldation of organometallic compounds with tetracyanoquinodimethan, J. Am. Chem. Soc. 97, 5931 (1975).

17154. Siedle, A. R., Johannesen, R. B., Reduction of the 1,3dithiolium cation with hexacarbonylvanadate(1-); J. Organ. Chem. 40, 2002 (1975).

17166. Kirklin, D. R., Ritter, J. J., Abramowitz, S., Vlbrational spectra and barrier to intermal rotation of $\mathrm{BCl}_{2} \mathrm{SH}$ and $\mathrm{BCl}_{2} \mathrm{SD}, \mathrm{J}$. Mol. Spectrosc. 67, 322-335 (1977).

17167. Barnard, A. J., Cooper, J., Smith, E. W., The brosdening of He 1 lines including ion dynamic corrections, with application to $\lambda 4471 \AA, J$. Quant. Spectrosc. Radiat. Transfer 14, 1025-1077 (1974).

17171. Mihalas, D., Barnard, A. J., Cooper, J., Smith, E. W., He 1 1 4471 profiles in B stars: Calculations with an improved line-broadening theory, Astrophys. J. 190, $315-318$ (June 1, 1974).

17172. Mihalas, D., Barnard, A. J., Cooper, J., Smith, E. W., He 1 $\lambda \mathbf{4 9 2 2}$ profiles in B stars: Calculatlons with an improved line broadening theory, Astrophys. J. 197, 139-142 (Apr. 1, 1975).

17188. Stevens, W. J., Krauss, M., The electronic stracture of the ground and excited states of $\mathrm{Mg}_{2}{ }^{+}$and $\mathrm{Mg}, \mathrm{J}$. Chem. Phys. 67, No. 5, 1977-1989 (Sept. 1, 1977).

17189. Clark, F. O., Lovas, F. J., "resIO in the Interstellar medium, Astrophys. J. 217, L47-LA8 (Oct. 1, 1977).

17192. Mosburg, E. R., Jr., Wilke, M. D., Excimer densities and destruction mechanisms in a high pressure pure mercury positive column, J. Chem. Phys. 66, No. 12, 5682-5693 (June 15, 1977).

17194. Stock, M., Smith, E. W., Drullinger, R. E., Hessel, M. M., Relaxation of the mercury $6^{3} P_{0}$ and $6^{3} P_{1}$ states, $J$. Chem. Phys. 67, No. 6, 2463-2469 (Sept. 15, 1977).

17195. Stevens, W. J., Gardner, M., Karo, A., Julienne, P., Theoretical determination of bound-free absorption cross sections in $\mathrm{Ar}_{2}{ }^{+}$, J. Chem. Phys. 67, No. 6, 2860-2867 (Sept. 15, 1977).

17204. Helbig, V., Kelleher, D. E., Wiese, W. L., Some mensured regularities in the Stark broadening of neutral nitrogen lines, (Proc. VIII Int. Summer School and Symp. on the Physics of lonized Gases, Dubrovnik, Yugoslavia, Sept. 1623, 1976), Extended Abstract 3.24 in Physics of lonized Gases 1976, pp. $412-415$ (J. Stefan Institute, Ljubljana, Yugoslavia, 1976).

17206. Wiese, W. L., Konjevic, N., Regularities In the Stark widths of isolated lines, (Proc. VIII Int. Summer School and Symp. on the Physics of lonized Gases, Dubrovnik, Yugoslavia, Sept. 16-23, 1976), Extended Abstract 3.25 in Physics of Ionized Gases 1976, pp. 416-420 (J. Stefan Institute, Ljubljana, Yugoslavia, 1976).

17208. Abramowitz, S., Acquista, N., Levin, 1. W., Infrared spectra of matrix isolated $\mathrm{FeO}_{2}$ : Evidence for a cyclic Iron-oxygen complex, Chem. Phys. Lett. 50, No. 3, 423-426 (Sept. 15, 1977).

17209. Bierbaum, V. M., Ellison, G. B., Futrell, J. H., Leone, S. R., Vlbrational chemiluminescence from lon-molecule reactions: $\mathrm{O}^{-}+\mathrm{CO} \rightarrow \mathrm{CO}_{2}++e^{-}$, J. Chem. Phys. Lett. 67, No. 5, 2375-2376 (Sept. 1, 1977).

17212. Reader, J., Acquista, N., 4s-4p resonance transitions in highly charged $\mathrm{Cu}$ - and Zn-like lons, Phys. Rev. Lett. 39, No. 4, 184-187 (July 25, 1977). 
17219. Gadzuk, J. W., Plasmon satellites in x-ray photoemission spectra, J. Electron Spectrosc. Relat. Phenom. 11, 355-361 (1977).

17229. Weiss, A. W., Hartree-Fock line strengths for the lithium, sodium and copper isoelectronic sequences, J. Quant. Spectrosc. Radiat. Transfer 18, No. 5-B, $481-490$ (1977).

17232. Cooper, J., Smith, E. W., Vidal, C. R., Influence of ion dynamics on $H \alpha$ and $H \beta$ at low densities, J. Phys. B: Atom. Molec. Phys. 7, No. 4, L101-L105 (Mar. 1974).

17238. Huie, R. E., Long, N. J. T., Thrush, B. A., Laser induced fluorescence of $\mathrm{CFCl}$ and $\mathrm{CCl}_{2}$ in the gas phase, Chem. Phys. Lett. 51, No. 2, 197-200 (Oct. 15, 1977).

17249. Greene, R. L., Cooper, J., Smith, E. W., A unified theory of Stark broadening for hydrogenic ions-1. A general theory (including time ordering), J. Quant. Spectrasc. Radiat. Transfer 15, 1025-1036 (1975).

17264. Johnson, D. R., Lovas, F. J., Gottlieb, C. A., Gottlieb, E. W., Litvak, M. M., Guelin, M., Thaddeus, P., Detection of interstellar ethyl cyanide, Astrophys. J. 218, 370-376 (Dec. 1, 1977).

17276. Czernichowski, A., Holys̀, A., Roberts, J. R., Transition probabilities for the 3s-4p transitions of NeI, J. Phys. 38, 1065-1069 (Sept. 1977).

17292. Klose, J. Z., Voight, P. A., Mean lives and $g f$ values in U, Phys. Rev. A 16, No. 5, 2032-2037 (Nov. 1977).

17294. Rosenstock, H. M., McCulloh, K. E., Lossing, F. P., On the mechanisms of $\mathbf{C}_{\mathbf{8}} \mathbf{H}_{\mathbf{6}}$ ionization and fragmentation, Int. J. Mass Spectrom. Ion Phys. 25, 327-341 (1977).

17310. Weinstein, A., Moos, H. W., Linsky, J. L., A sensitive observation of the far-ultra-violet $(1160-1700 \AA)$ spectrum of Archurus and implications for its outer atrmosphere, Astrophys. J. 218, 195-204 (Nov. 15, 1977).

17316. Harter, W. G., Patterson, C. W., Bands, clusters, and crystal field splitting: Understanding $\mathrm{SF}_{8}$ rotational levels, Int. J. Quantum Chem.: Quantum Chem. Symp. 11, 479-492 (1977).

17317. Hernandez, A. J., Langhoff, P. W., On RayleighSchrödinger and Green's-function calculations of ionization potentials and electron affinities, Chem. Phys. Lett. 49, No. 3, 421-426 (Aug. 1, 1977).

17319. Langhoff, P. W., Corcoran, C. T., Sims, J. S., Photoabsorption in atomic lithium, Phys. Rev. A 16, No. 4, 1513 1520 (Oct. 1977).

17326. Mahan, A. H., Smith, S. J., Observation of coherent excitation processes in $e$-H collisions, Phys. Rev. A 16, No. 5, 1789-1792 (Nov. 1977).

17327. Martinez, R. I., Huie, R. E., Herron, J. T., Mass spectrometric detection of dioxirame, $\mathrm{H}_{2} \widehat{\mathrm{COO}}$, and its decomposition products, $\mathrm{H}_{2}$ and $\mathrm{CO}$, from the reaction of ozone with ethylene, Chem. Phys. Lett. 51, No. 3, 457-459 (Nov. 1, 1977).

\section{Building Technology}

SP446-1. Building technology project summaries 1976, M. Olmert, and CBT Management Group, Nat. Bur. Stand. (U.S.), Spec. Publ. 446-1, 83 pages (Sept. 1977) SN-003-003-018465.

SP457-1. Building technology publications 1976-Supplement 1, J. R. Debelius, Ed., Nat. Bur. Siand. (U.S.), Spec. Publ. 457. 1, 78 pages (June 1977) SNO03-003-01802-3.

SP470. Wind and seismic effects. Proceedings of the Seventh Joint Panel Conference of the U.S.-Japan Cooperative Program in Natural Resources, May 20-23, 1975, Tokyo, Japan, H. S. Lew, Ed., Nat. Bur. Stand. (U.S.), Spec. Publ. 470, 513 pages (Apr. 1977) SNO03-003-01762-1.

Present status of wind characteristics in Japan, $K$. Takeuchi, SP470, pp. I-1-I-17 (Apr. 1977).

A reexamimation of hurricane Camille, A. R. Hull, SP470, pp. 1-18-I-27 (Apr. 1977).
Fire tornado and its maximum wind-speed, $\mathrm{S}$. Soma and $\mathrm{K}$. Suda, SP470, Pp. I-28-I-41 (Apr. 1977).

A research project on the wind flow around tall buildings, T. Murota and K. Nakano, SP470, pp. I-42-I-49 (Apr. 1977).

Wind engineering research program supported by the $\mathrm{Na}$ tional Science Foundation, M. P. Gaus, SP470, pp. II-1-II10 (Apr. 1977).

Study of the wind pressure and the response of roof corners, T. Murota and M. Nakahara, SP470, pp. II-11-II-19 (Apr. 1977).

On the wind response of the Kanmon Bridge, T. Okubo, N. Narita, and K. Yokoyama, SP470, pp. II-20-II-46 (Apr. 1977).

Luling, Louisiana cable-stayed bridge wind tunnel section model tests, R. H. Gade, W. Podolny, Jr., and H. R. Bosch, SP470, pp. II-47-II-67 (Apr. 1977).

The regional distribution of the earthquake danger in Japan, S. Hattori, Y. Kitagawa, and T. Santo, SP470, Pp. III1-III-17 (Apr. 1977).

Quantification of seismicity, T. Terashima and T. Santo, SP470, pp. III-18-III-28 (Apr. 1977).

Maintenance of the strong-motion accelerograph and the data processing of the records, E. Kuribayashi, $H$. Tsuchida, and M. Watabe, SP470, pp. IV-1-IV-34 (Apr. 1977).

The United States strong-motion network: Field operations, R. P. Maley, SP470, pp. IV-35-IV-52 (Apr. 1977).

Strong-motion data management, C. Rojahn, SP470, pp. IV-53-IV-66 (Apr. 1977).

Brief review on liquefaction during earthquakes in Japan, E. Kuribayashi and F. Tatsuoka, SP470, pp. V-1-V-15 (Apr. 1977).

Vibration test on settlement of submerged sand layer, $K$. Sawada and Y. Koga, SP470, pp. V-16-V-35 (Apr. 1977).

Study on earthquake response of structures by considering non-deterministic varimbles, Y. Yamazaki and Y. Koizumi, SP470, Pp. VI-1 - VI-21 (Apr. 1977).

Least weight structures for threshold frequencies, $R$. D. McConnell, SP470, Pp. VI-22-VI-32 (Apr. 1977).

Ductile shear walls in earthquake-resistant multistory buildings, M. Fintel, SP470, pp. VI-33-VI-46 (Apr. 1977).

Surveillance of corps of engineers structures in earthquakeprone areas, K. O. O'Donnell, SP470, pp. VI-47-VI-63 (Apr. 1977).

School and hospital construction in California, J. F. Meehan, SP470, pp. VI-64-VI-73 (Apr. 1977).

Improved earthquake resistive design and construction of single-family rexidential dwellings, G. R. Fuller, SP470, pp. VI-74-VI-88 (Apr. 1977).

Dynamic tests of structures for oil tanks and nuclear power plants, S. Inaba, SP470, pp. VII-1-VII-6 (Apr. 1977).

Sheet pile foundation and its structural characteristics against horizontal loads, K. Kawakami, T. Okubo, K. Komada, and M. Okahara, SP470, pp. VII-7-VII-60 (Apr. 1977).

On specifications for earthquake-resistant design of highway bridges (January, 1971), K. Kawakami, E. Kuribayashi, T. Iwasaki, and Y. Iida, SP470, Pp. VIII-1-VIII-30 (Apr. 1977).

On specifications for earthquake-resistant design of the Honshu-Shikoku Bridges (JSCE 1974), I. Kawasaki and E. Kuribayashi, SP470, pp. VIII-31-VIII-4 1 (Apr. 1977).

Recent revision of design standards on seismic effects for port and harbour structures, S. Hayashi, H. Tsuchida, and S. Noda, SP470, pp. VIII-42-VIII-55 (Apr. 1977).

JSCE specifications for earthquake resistant design of submerged tunnels (1975), E. Kuribayashi and $M$. Tsuchida, SP470, pp. VIII-56-VIII-68 (Apr. 1977). 
Joint research program utilizing the large scale testing facilities (free discussion), M. Watabe, M. Hirosawa, and S. Nakata, SP470, pp. IX-1-IX-5 (Apr. 1977).

Earthquake disaster mitigation: $A$ joint research approach, C. C. Thiel and J. B. Scalzi, SP470, pp. IX-6-IX-16 (Apr. 1977).

High wind study in the Philippines, N. J. Raufaste, SP470, pp. X-1-X-11 (Apr. 1977).

Survey on seismology and earthquake engineering in India, Iran and Turkey, M. Watabe and $H$. Tokuhiro, SP470, pp. X-12-X-16 (Apr. 1977).

SP476. Opening the doors to better buildings, S. A. Kliment, Nat. Bur. Stand. (U.S.), Spec. Publ. 476, 32 pages (July 1977) SN003-003-01804.

SP477. Wind and seismic effects. Proceedings of the Eighth Joint Panel Conference of the U.S.-Japan Cooperative Program in Natural Resources, May 18-21, 1976, National Bureau of Standards, Gaithersburg, Md., H. S. Lew, Ed., Nat. Bur. Stand. (U.S.), Spec. Publ. 477, 626 pages (May 1977) SN003-003-01772-8.

Aspects of hurricane winds as recorded at an instrumented suspension bridge, R. H. Gade and R. H. Scanlan, SP477, pp. I-1-I-11 (May 1977).

Study on the wind effect on eaves, T. Murota, SP477, pp. I-12-I-20 (May 1977).

Measurements of wind loads and tie-down forces on mobile homes, R. D. Marshall and R. A. Crist, SP477, pp. I-21-I33 (May 1977).

On the wind resistant design specifications for the proposed Horshu-Shikoku bridges (1975), T. Okubo and N. Narita, SP477, pp. I-34-I-48 (May 1977).

Equivalent static wind loads for tall building design, $E$. Simiu, SP477, pp. I-49-I-65 (May 1977).

A wood house will resist wind forces, B. Bohannan, SP477, pp. 1-66-I-69 (May 1977).

Wind loads on low-rise buildings, N. J. Raufaste, Jr., SP477, pp. I-70-I-78 (May 1977).

Characteristics of the high wind at Hachijojima Island on the occasion of typhoon No. 7513, S. Soma, SP477, pp. II1-II-14 (May 1977).

High winds in the United States, 1975, A. R. Hull, T. D. Potter, and N. B. Guttman, SP477, pp. II-15-II-29 (May 1977).

Mean speed profiles of hurricane vinds, E. Simiu, V. C. Patel, and J. F. Nash, SP477, pp. I1-30-II-40 (May 1977).

Planning and design of strong-motion instrument networks,

R. B. Matthiesen, SP477, pp. III-1 -III-1 5 (May 1977).

Observation of earthquake response of ground with horizontal and vertical seismometer arrays, S. Hayashi, H. Tsuchida, and E. Kurata, SP477, pp. III-16-III-25 (May 1977).

Building strong-motion earthquake instrumentation, $C$. Rojahn, SP477, pp. III-26_-III-40 (May 1977).

Characteristics of underground seismic motions at four sites around Tokyo Bay, T. Iwasaki, S. Wakabayashi, and F. Tatsuoka, SP477, pp. III-41 -III-56 (May 1977).

Relationship between earthquake damage of existing wooden houses and seismic intensities, E. Kuribayashi, T. Tazaku, and T. Hadate, SP477, pp. IV-1-IV-17 (May 1977).

A method for calculating nonlinear seismic response in two dimensions, W. B. Joyner, SP477, pp. IV-18-IV-46 (May 1977).

A new scale representing the "quake-sensitivity" at a certain region, T. Terashima and T. Santo, SP477, pp. IV47-IV-54 (May 1977).

Damage to the civil engineering structures in Hachijojima Istand by typhoon 7513, T. Okubo, N. Narita, and $K$. Yokoyama, SP477, pp. V-1-V-20 (May 1977).

Cyclone Tracy, R. D. Marshall, SP477, pp. V-21-V-53 (May 1977).
On the damage to buildings in Hachijojima caused by typhoon No. 7513, T. Murota, SP477, pp. V-54-V-59 (May 1977).

Seismic response of reinforced concrete highway bridges, $\mathbf{J}$. Penzien, W. G. Godden, M. C. Chen, D. Williams, and K. Kawashima, SP477, pp. VI-1-VI-9 (May 1977).

An evaluation method for the earthquake resistant capacity of reinforced concrete and steel reinforced concrete columns, M. Ozaki and Y. Ishiyama, SP477, pp. VI-10-VI-27 (May 1977).

The earthquake engineering program of the National Science Foundation, J. B. Scalzi, SP477, pp. VI-28-VI-36 (May 1977).

Large-scale testing programs related to wind and seismic effects currently underway in Japan, S. Inaba, SP477, pp. VI37-VI-43 (May 1977).

Earthquake damiges to earth structures, K. Sawada, SP477, pp. VI-44-VI-49 (May 1977).

Dynamic test of a circuit breaker for transformer substation, S. Inaba and S. Kinoshita, SP477, pp. VI-50-VI-60 (May 1977).

Comprehensive seismic design provisions for buildings-A status report, C. G. Culver, SP477, pp. VI-61-VI-68 (May 1977).

Retrofitting of vulnerability in earthquake disaster mitigation problems, K. Ichihara, E. Kuribayashi, and T. Tazaki, SP477, pp. VI-69-VI-84 (May 1977).

Dynamic response characteristics of a model arch dam, C. D. Norman, R. D. Crowson, and J. P. Balsara, SP477, pp. VI-85-VI-1 17 (May 1977).

The measurement of the dymamic $k$-value in site and its application to design, T. Kunihiro, K. Yahagi, and M. Okahara, SP477, pp. VI-118-VI-140 (May 1977).

Laboratory investigation of undisturbed sampling and standard penetration tests on fine sands, M. F. Marcuson, S. S. Cooper, and M. A. Bieganousky, SP477, pp. VI-141-VI-157 (May 1977).

Dynamic soil properties with emphasis on comparison of laboratory tests and field measurements, T. Iwasaki and F. Tatsuoka, SP477, pp. VI-158-VI-178 (May 1977).

Design earthquakes, E. L. Krinitzsky and F. K. Chang, SP477, pp. VI-179-VI-191 (May 1977).

Relation between seismic coefifient and ground acceleration for gravity quaywall, S. Hayashi, S. Noda, and T. Uwabe, SP477, pp. VI-192-VI-198 (May 1977).

Investigation of earthquake resistance of structural (shear) wall buildings carried out at Portland Cement Association, $M$. Finkel, SP477, pp. VI-199-VI-219 (May 1977).

A philosophy for structural integrity of large panel buildings, M. Fintel and D. M. Schultz, SP477, pp. VI220-VI-251 (May 1977).

Wind and seismic design of United States nuclear power plants, L. C. Shao, R. J. Stuart, and C. H. Hofmayer, SP477, pp. VII-1 - VII-28 (May 1977).

Outline of basic philosophy and practices of aseismatic design for nuclear facilities in Japan, M. Watabe and Y. Ohsaki, SP477, pp. VII-29-VII-35 (May 1977).

Tornado-borne missiles, J. F. Costello, SP477, pp. VII36-VII-41 (May 1977).

Structural damage to bridges resulting from the Guatemaln earthquake, J. D. Cooper, SP477, pp. VIII-1-VIII-27 (May 1977).

SP490. Observations on the behavior. of buildings in the Romania earthquake of March 4, 1977, G. Fattal, E. Simiu, and C. Culver, Nat. Bur. Stand. (U.S.), Spec. Publ. 490, 168 pages (Sept. 1977) SN003-003-01841-4.

BSS62. Evaluation of structural properties of masonry in existing buildings, S. G. Fattal and L. E. Cattaneo, Nat. Bur. Stand. (U.S.), Bldg. Sci. Ser. 62, 127 pages (Mar. 1977) SN003-003-01738-8 
BSS94. Investigation of the Skyline Plaza Collapse in Fairfax County, Virginia, E. V. Leyendecker and S. G. Fattal, Nat. Bur. Stand. (U.S.), Bldg. Sci. Ser. 94, 91 pages (Feb. 1977) SN003-003-01696-9.

BSS98. Design methods for reducing the risk of progressive collapse in buildings, E. V. Leyendecker and B. R. Ellingwood, Nat. Bur. Stand. (U.S.), Bldg. Sci. Ser. 98, 68 pages (Apr. 1977) SN003-003-01765-5.

BSS100-1. Building to resist the effect of wind. Volume 1: Overview, R. D. Marshall, N. J. Raufaste, Jr., and S. A. Kliment, Nat. Bur. Stand. (U.S.), Bldg. Sci. Ser. 100-1, 34 pages (May 1977) SN003-003-01717-5.

BSS100-2. Building to resist the effect of wind. Volume 2: Estimation of extreme wind speeds and guide to the determination of wind forces, E. Simiu and R. D. Marshall, Nat. Bur. Stand. (U.S.), Bldg. Sci. Ser. 100-2, 29 pages (May 1977) SN003003-01718-3.

BSS100-3. Building to resist the effect of wind. Volume 3: A guide for improved masonry and timber connections in buildings, S. G. Fattal, G. E. Sherwood, and T. L. Wilkinson, Nat. Bur. Stand. (U.S.), Bldg. Sci. Ser. 100-3, 56 pages (May 1977) SN003-003-01719-1.

BSS100-4. Building to resist the effect of wind. Volume 4: Forecasting the economics of housing needs: A methodological guide, J. G. Kowalski, Nat. Bur. Stand. (U.S.), Bldg. Sci. Ser. 100-4, 36 pages (May 1977) SN003-003-01720-5.

BSS100-5. Building to resist the effect of wind. Volume 5: Housing in extreme winds: Socio-economic and architectural considerations, S. A. Kliment, Nat. Bur. Stand. (U.S.), Bldg. Sci. Ser. 100-5, 37 pages (May 1977) SN003-003-017?1-3.

BSS103. Exploratory study of glowing electrical connections, W. J. Meese and R. W. Beausoliel, Nat. Bur. Stand. (U.S.), Bldg. Sci. Ser. 103, 29 pages (Oct. 1977) SN003-003-01859-7.

BSS106. Earthquake resistant masonry construction: National workshop. Proceedings of a National Workshop held at the National Bureau of Standards, Boulder, CO, Sept. 13-16, 1976, R. A. Crist and L. E. Cattaneo, Eds., Nat. Bur. Stand. (U.S.), Bldg. Sci. Ser. 106, 372 pages (Sept. 1977) SN003003-01872-4.

A perspective view: Brick masonry construction in the U.S.A., A. H. Yorkdale, BSS106, pp. 9-16 (Sept. 1977).

A perspective view: Concrete masonry construction in the U.S.A., T. B. Redmond, BSS1 06, pp. 17-39 (Sept. 1977).

Earthquake resistant mssonry construction: A perspective view of needed research, R. A. Crist, BSS106, pp. 40-59 (Sept. 1977).

Seismic research on masonry-University of California, Berkeley, 1972-1977, R. L. Mayes, R. W. Clough, and Y. Omote, BSS106, pp. 60-90 (Sept. 1977).

Expected performance of uniform building code designed masonry buildings, $\mathbf{R}$. L. Mayes, R. W. Clough, Y. Omote, and S. W. Chen, BSS106, pp. 91-113 (Sept. 1977).

An experimental study of concrete masonry under seismictype loading, G. A. Hegemier, G. Krishnamoorthy, and R. O. Nunn, BSS106, pp. 114-153 (Sept. 1977).

An experimental study of connections in reinforced concrete masonry: Masonry structures under seismic loeding, J. Isenberg, G. A. Hegemier, and A. Anvar, BSS106, pp. 154-165 (Sept. 1977).

Masonry research and codes in the United Kingdom, W. B. Cranston, BSS106, pp. 166-176 (Sept. 1977).

The capacity of unreinforced masonry shear walls under membrane loads, S. G. Fattal, BSS106, pp. 177-197 (Sept. 1977).

Cansdian code requirements for masonry in earthquake zones, A. H. P. Maurenbrecher, BSS106, pp. 198-213 (Sept. 1977).

HEW activity in masonry design and construction, R. $M$. Webb, BSS106, pp. 215-217 (Sept. 1977).
NAVFAC interests in earthquake resistant masonry construction, J. V. Tyrrell, BSS106, p. 220 (Sept. 1977).

Summary of the Veterans Administration Engineering Program, P. M. Sears, BSS1 06, pp. 221-227 (Sept. 1977).

Seismic requirements of the Phoenix Construction Code, $\mathbf{R}$. C. Hildebrandt, BSS106, pp. 228-237 (Sept. 1977).

Concerns of the NYC Housing Authority in the design of multifamily masonry residential structures, E. Nadel, BSS106, pp. 238-242 (Sept. 1977).

Requirements of a seismic resistant masonry construction code, C. C. Lederer, BSS106, pp. 243-248 (Sept. 1977).

Some research needs of earthquake-resistant masonry, J. E. Amrhein, BSS106, pp. 255-258 (Sept. 1977).

Suggested researchable items relating to masonry construction, J. F. Meehan, BSS106, pp. 259-274 (Sept. 1977).

A view on some prerequisites for improved earthquake resistant masonry construction, M. E. Werner, BSS106, pp. 275-282 (Sept. 1977).

Arching in masonry walls subjected to out-of-plane forces, B. L. Gabrielsen and K. Kaplan, BSS106, pp. 283-313 (Sept. 1977).

Some thoughts on minimum requirements for the seismic design of load bearing masonry buildings, R. M. Gensert, BSS106, pp. 314-326 (Sept. 1977).

TN938. Recommended practice for the use of metric (SI) units in building design and construction, H. J. Milton, Nat. Bur. Stand. (U.S.), Tech. Note 938, 47 pages (Apr. 1977) SN003003-01761-2.

TN940. The representation and use of design specifications, $S$. J. Fenves and R. N. Wright, Nat. Bur. Stand. (U.S.), Tech. Note 940, 51 pages (June 1977) SNO03-003-01790-6.

TN941. Stone preservatives: Methods of laboratory testing and preliminary performance criteria, G. A. Sleater, Nat. Bur. Stand. (U.S.), Tech. Note 941, 79 pages (May 1977) SN003003-01727-2.

NBSIR 76-1184. Performance of branch circuit electrical terminations of copper and aluminum non-metallic sheathed cable, L. W. Masters, E. J. Clark, and E. J. Embree, 35 pages (Nov. 1976). Order from NTIS as PB267221.

NBSIR 76-1193. Earthquake related activities of the Center for Building Technology, C. G. Culver, 24 pages (Mar. 1977). Order from NTIS as PB265103.

NBSIR 77-1196. Wind tunnel studies of RP-US Bayanihan permanent school building, R. D. Marshall, 28 pages (Dec. 1977). Order from NTIS as PB274647.

NBSIR 77-1197. How houses can better resist high wind, S. Kliment, N. J. Raufaste, and R. D. Marshall, Coordinators, 12 pages (Feb. 1977). Order from NTIS as PB268081.

NBSIR 77-1233. U.S. team visit to France on health care facilities, S. Kramer and R. Kapsch, 56 pages (Apr. 1977). Order from NTIS as PB265436.

NBSIR 77-1244. Survey of uses of waste materials in construction in the United States, J. R. Clifton, P. W. Brown, and G. Frohnsdorff, 63 pages (July 1977). Order from NTIS as PB270854.

NBSIR 77-1256. Properties of 21 year old coal-tar pitch roofing membranes: A comparison with the NBS preliminary performance criteria, R. G. Mathey and W. J. Rossiter, Jr., 26 pages (June 1977). Order from NTIS as PB267845.

NBSIR 77-1261. Laboratory tests of thermoplastic plping assemblies subjected to water hammer and Intermittent hot water flow, D. E. Rorrer, J. R. Shaver, and R. S. Wyly, 51 pages (Aug. 1977). Order from NTIS as PB270867.

NBSIR 77-1263. Radiant heating in seamless flooring-A feasibility study, P. G. Campbell, M. A. Post, M. Godette, and W. E. Roberts, 30 pages (July 1977). Order from NTIS as PB273946.

NBSIR 77-1316. Performance criteria resource document for innovative construction, T. K. Faison, 165 pages (Nov. 1977). Order from NTIS as PB274404. 
NBSIR 77-1390. A preliminary examination of building regulations adopted by the states and major cities, P. W. Cooke and R. M. Eisenhard, 124 pages (Nov. 1977). Order from NTIS as PB274335.

NBS-GCR-77-87. Government-supported residential rehabilitation, M. C. McFarland, 55 pages (May 1977). Order from NTIS as PB268132.

NBS-GCR-77-88. Self-help housing construction: Effects of regulatory codes and standards, 121 pages (May 1977). Order from NTIS as PB268131.

16705. Fenves, S. J., Wright, R. N., The representation and use of design specifications, (Proc. Symp. on Structural and Geotechnical Mechanics, Urbana, IL, Oct. 2-3, 1975), Paper in Structural and Geotechnical Mechanics, W. J. Hall, Ed., Pp. 278-304 (Prentice-Hall, Inc., Englewood Cliffs, NJ, 1977).

16708. Culver, C. G., Live-load survey results for office buildings, J. Struct. Div. Proc. Am. Soc. Civil Eng. 102, No. ST12, 2269-2284 (Dec. 1976).

16843. Vaicaitis, R., Simiu, E., Nonlinear pressure terms and alongwind response, J. Struct. Div. ASCE Tech. Notes 103, ST4, 903-906 (Apr. 1977).

16856. Simiu, E., Ellingwood, B., Code calibration of extreme wind return periods, J. Struct. Div. ASCE Tech. Notes 103, ST3, 725-729 (Mar. 1977).

17060. Rossiter, W. J., Jr., Mathey, R. G., Effect of insulation on the surface temperature of roof membranes, Roofing Spec., pp. 28-39 (May 1976́).

17061. Rossiter, W. J., Jr., Mathey, R. G., Effect of insulation on the surface temperature of roof membranes, Roofing/Siding/Insulation, pp. 35-38, 136 (Apr. 1976).

171 15. Marshall, R. D., Full scale testing: Low rise, Proc. Workshop on Wind Load Requirements for Buildings, Northwestern Univ., Evanston, IL, June 3-4, 1976, pp. 159162 (1976).

17286. Powell, F. J., Hahn, M. H., Measurement of the frost point of air in sealed insulating glass, (Proc. Annual Meeting of Com. B.1, IIF-IIR on Heat and Mass Transfer in Porous Structures, Washington, DC, Sept. 14-16, 1976), Bul. Inst. Int. Froid 2, 131-138 (1976).

17293. Yonemura, G. T., Task lighting-Another view, Lighting Design Appl., pp. 27-30 (Nov. 1977).

17296. Marshall, H. E., Ruegg, R. T., Wyly, R. S., Cost savings from reduced-sized venting, Plumbing Eng. Part 1, 5, No. 4, 35-38, 42 (July-Aug. 1977); Part 2, 5, No. 5, 45-46, 64, (Sept.-Oct. 1977).

17298. Hastings, S. R., Performance evaluation of window strategies, Proc. RILEM/ASTM/CIB Symp. on Evaluatian of the Performance of External Vertical Surfaces of Buildings, Otaniemi, Finland, Aug. 28-Sept. 2, 1977, I, 113-122 (Technical Research Centre of Finland, Helsinki, Finland, 1977).

17305. Ellingwood, B., Culver, C., Analysis of live loeds in office buildings, J. Structural Div., ASCE 103, ST8, 1551-1560 (Aug. 1977).

\section{Computer Science and Technology}

SP500-1. Computer science \& technology: Foreign and domestic accomplishments in magnetic bubble device technology, R. B. J. Warnar and P. J. Calomeris, Nat. Bur. Stand. (U.S.), Spec. Publ. 500-l, 50 pages (Jan. 1977) SN003-00301724-8.

SP500-2. Computer science \& technology: Accessing individual records from personal data files using non-unique identifiers, G. B. Moore, J. L. Kuhns, J. L. Trefftzs, and C. A. Montgomery, Nat. Bur. Stand. (U.S.), Spec. Publ. 500-2, 203 pages (Feb. 1977) SNO03-003-01726-4.

SP500-3. Computer science \& technology: Technical profile of seven data element dictionary/directory systems, B. Leong-
Hong and B. Marron, Nat. Bur. Stand. (U.S.), Spec. Publ. 500-3, 45 pages (Feb. 1977) SNOO3-003-01725-6.

SP500-4. Computer science \& technology: Survey of remote terminal emulators, S. W. Watkins and M. D. Abrams, Nat. Bur. Stand. (U.S.), Spec. Publ. 500-4, 80 pages (Apr. 1977) SNO03-003-01 756-6.

SP500-5. Computer science \& technology: Impact of chargetransfer device technology on computer systems, R. B. J. Warnar, Nat. Bur. Stand. (U.S.), Spec. Publ. 500-5, 48 pages (Apr. 1977) SN003-003-01758-2.

SP500-6. Computer science \& technology: Computer network interconnection: Problems and prospects, 1. W. Cotton, Nat. Bur. Stand. (U.S.), Spec. Publ. 500-6, 83 pages (Apr. 1977) SN003-003-01757-4.

SP500-7. Computer science \& technology: Computers in the Federal Government: A compilation of statistics, M. M. Gray, Nat. Bur. Stand. (U.S.), Spec. Publ. 500-7, 41 pages (June 1977) SN003-003-01780-9.

SP500-8. Computer science \& technology: Workshop on standards for image pattern recognition. Proceedings of a Workshop held at the National Bureau of Standards, Gaithersburg, MD, June 3-4, 1976, J. M. Evans, Jr., R. Kirsch, and R. N. Nagel, Eds., Nat. Bur. Stand. (U.S.), Spec. Publ. 5008, 115 pages (May 1977) SN003-003-01771-0.

Introductory address, R. M. Davis, SP500-8, pp. 1-4 (May 1977).

The NATO RSG-4/SGIP tape format, J. S. Dehne, SP5008, pp. 11-25 (May 1977).

Tape formats, T. Pavlidis, SP500-8, pp. 26-27 (May 1977).

Earth observation image data format, J. Y. Sos, SP500-8, pp. 28-34 (May 1977).

On communicating about pictures, M. A. Fischler, SP5008, pp. 41-42 (May 1977).

Syntactic approach to the description of Image structure and content, K. S. Fu, SP500-8, p. 43 (May 1977).

Languages for image content and structure, J. F O'Callaghan, SP50O-8, p. 44 (May 1977).

Constructive descriptions of imsges, R. F. Sproull, SP5008, p. 45 (May 1977).

Instrument parameters in Image digitization, W. R. Huelskoetter, SP500-8, pp. 52-54 (May 1977).

Calibration of television micrascopes, K. Preston, Jr., SP500-8, pp. 56-57 (May 1977).

Digitization of ultrasonic signals for biomedical investigation, J. F. Greenleaf, SP500-8, pp. 59-62 (May 1977).

A suggestion for the calibration of digitized imagery, $W$. Frei, SP500-8, pp. 64-65 (May 1977).

Factors which influence acoustic images of medical objects, J. K. Zieniuk, SP500-8, pp. 67-69 (May 1977).

Documentation of the recording environment, $M$. Ritter and M. S. Maxwell, SP500-8, pp. 71-75 (May 1977).

Correcting gray scale distortions in photographic images, B. S. Baxter, SP500-8, pp. 77-79 (May 1977).

The reconding environment in pathology, L. Boccia, SP5008, p. 81 (May 1977).

Prototype images-Selection problems, R. Nagel, SP500-8, pp. 89-90 (May 1977).

Prototype radiographs, J. Sklansky, SP500-8, pp. 92-98 (May 1977).

Thoughts on standardization of parameters for Image evaluation, F. C. Billingsley, SP500-8, pp. 99-107 (May 1977).

SP500-9. Computer science \& technology: The use of passwords for controlled access to computer resources, H. M. Wood, Nat. Bur. Stand. (U.S.), Spec. Publ. 500-9, 59 pages (May 1977) SN003-003-01770-1.

SP500-10. Computer science \& technology: A data base management approach to privacy act compliance, $\mathbb{E}$. Fong, Nat. Bur. Stand. (U.S.), Spec. Publ. 500-10, 34 pages (June 1977) SN003-003-01787-6. 
SP500-11. Computer science \& technology: Computer software management: A primer for project management and quality control, D. W. Fife, Nat. Bur. Stand. (U.S.), Spec. Publ. 50011, 58 pages (July 1977) SN003-003-01795-7.

SP500-12. Computer science \& technology: Data compression-A comparison of methods, J. Aronson, Nat. Bur. Stand. (U.S.), Spec. Publ. 500-12, 39 pages (June 1977) SN003003-01797-3.

SP500-13. Computer science \& technology: Features of seven audit software packages-Frinciples and capabilities, A. J. Neumann, Nat. Bur. Stand. (U.S.), Spec. Publ. 500-13, 58 pages (July 1977) SN003-003-01807-4.

SP500-14. Computer science \& technology: Software tools: A building block approach, 1. T. Hardy, B. Leong-Hong, and D. W. Fife, Nat. Bur. Stand. (U.S.), Spec. Publ. 500-14, 66 pages (Aug. 1977) SN003-003-01823-6.

SP500-15. Computer science \& technology: Documentation of computer programs and automated data systerns. Proceedings of a Symposium held at the National Bureau of Standards, Gaithersburg, MD, Oct. 12, 1976, M. A. Krasny, Ed., Nat. Bur. Stand. (U.S.), Spec. Publ. 500-15, 66 pages (July 1977) SN003-003-01814-7.

Why document?, T. D. Puckorius, SP500-15, pp. 5-8 (July 1977).

Life cycle concepts and docurment types, R. A. Young, SP500-15, PP. 10-18 (July 1977).

Flexibility provisions and document type selection, R. R. Hegland, SP500-15, pp. 19-21 (July 1977).

Content guidelines, T. M. Kurihara, SP500-15, pp. 22-25 (July 1977).

USDA application management, R. V. Head, SP500-15, pp. 27-28 (July 1977).

Dacumentation standards-A management view, E. B. Smith, SP500-15, pp. 29-31 (July 1977).

Key elements in the ADP system development process at HUD, M. Goer, SP500-15, pp. 32-35 (July 1977).

Problems in using the documentation guideline, $R$. R. Hegland, SP500-15, Pp. 44-45 (July 1977).

FIPS PUB 38-Implementation philosophy in HEW, J. J. Strnad, SP500-15, Pp. $51-52$ (July 1977).

The role of the auditors in the development and evaluation of automated systems, P. L. Morrison, SP500-15, PP. 53-56 (July 1977).

SP500-16. Computer science \& technology: A survey of eleven govermment-developed data element dictionary/directory systems, H. McEwen, Coordinator for F1PS Task Group 17C-Data Element Dictionary/Directory, Nat. Bur. Stand. (U.S.), Spec. Publ. 500-16, 111 pages (Aug. 1977) SN003003-01817-1.

SP500-18. Computer science \& technology: Computer Performance Evaluation Users Group (CPEUG). Proceedings of the Thirteenth Meeting held at New Orleans, LA, Oct. 11 14, 1977, D. M. Conti and J. L. Walkowicz, Eds., Nat. Bur. Stand. (U.S.), Spec. Publ. 500-18, 241 pages (Sept. 1977) SNO03-003-01839-2.

Functional workload characteristics and computer response time in the design of on-line systems, J. D. Williams and J. S. Swenson, SP500-18, pp. 3-11 (Sept. 1977).

Functional workload characterization, J. E. McNeece and R. J. Sobecki, SP500-18, pp. 13-21 (Sept. 1977).

Some results on the clustering approach to workload modelling, A. K. Agrawala and J. M. Mohr, SP500-18, pp. J-38 (Sept. 1977).

Workload characterization and performance measurement for a CDC CYBER 74 computer system, J. R. Bear and T. E. Reeves, SP500-18, pp. 39-67 (Sept. 1977).

Selection of ADPS for the Air Force Academy: A case study, R. E. Waters, SP500-18, pp. $71-74$ (Sept. 1977).

Validation-All important in benchmarking, L. A. Johnson, SP500-18, pP. $75-83$ (Sept. 1977).
Determination of non-steady state conditions in performance measurement runs, N. N. Tendolkar, SP506-18, pp. 87-94 (Sept. 1977).

Capturing terminal traffic using a hardware monitor, T. M. Marter, SP500-18, pp. 95-105 (Sept. 1977).

A new tool for measuring response time, G. Carlson and D. Ferreira, SP500-18, pp. 107-115 (Sept. 1977).

Comparative study of task dispatching algorithms in an IBM MVT/ASP environment, S. E. Freeman and F. C. Green, SP500-18, Pp. 119-135 (Sept. 1977).

Computer performance comparisons, W. D. Bennett, SP500-18, pp. 137-142 (Sept. 1977).

A study on the effectiveness of data blocking in an MVS environment, R. E. Paulhamus and G. E. Ward, SP500-18, pp. 143-158 (Sept. 1977).

A new methodology for computer system data gathering, $R$. A. Orchard, SPSO0-18, pp. 159-182 (Sept. 1977).

The use of a validated event model in a comprehensive performance evaluation of an on-line minicomputer system, S. G. Gangwere, Jr., J. R. Hosler, and L. H. Stewart, SP500-18, pp. 185-211 (Sept. 1977).

Approximate evaluation of the effect of a bubble memory in a virtual memory system, W. T. K. Lin and A. B. Tonik, SP500-18, pp. 213-217 (Sept. 1977).

The use of measured utilizations in queuing network analysis, J. Bouhana, SP500-1 8, pp. 219-225 (Sept. 1977).

Applications of queuing models to ADP system performance prediction: A workshop summary, M. G. Spiegel, SP500-18, pp. 227-234 (Sept. 1977).

A simulation study of initiator/terminator policy in OS/MVT, E. Fiegl and N. Schneidewind, SP500-18, pp. $235-$ 248 (Sept. 1977).

SP500-19. Computer science \& technology: Audit and evaluation of computer security. Proceedings of the NBS Invitational Workshop held at Miami Beach, Florida, Mar. 22-24, 1977 , Z. G. Ruthberg and R. G. McKenzie, Eds., Nat. Bur. Stand. (U.S.), Spec. Publ. 500-19, 256 pages (Oct. 1977) SN003-003-01 848-1.

SP500-20. Computer science \& technology: Validating the correctness of hardware implementations of the NBS data encryption standard, J. Gait, Nat. Bur. Stand. (U.S.), Spec. Publ. 500-20, 46 pages (Nov. 1977) SN003-003-01861-9.

SP500-22. Computer science \& technology: Guide to computer program directories, A. G. Chattic, Compiler, Nat. Bur. Stand. (U.S.), Spec. Publ. 500-22, 168 pages (Dec. 1977) SN003-003-01867-8.

SP500-23. Computer science \& technology: An architecture for a robot hierarchical control system, A. J. Barbera, Nat. Bur. Stand. (U.S.), Spec. Publ. 500-23, 227 pages (Dec. 1977) SNO03-003-01874-1.

NBSIR 74-500. The CODASYL data base approach: A COBOL example of design and use of a personnel file, E. H. Sibley, 83 pages (Feb. 1974). Order from NTIS as PB265694.

NBSIR 76-1094. Standards for computer aided manufacturing, J. M. Evans, Jr., J. T. O'Neill, J. L. Little, J. S. Albus, A. J. Barbera, D. W. Fife, E. N. Fong, D. E. Gilsinn, F. E. Holberton, B. G. Lucas, G. E. Lyon, B. A. S. Marron, A. J. Neumann, M. V. Vickers, and J. C. Walker, 41 pages (July 1976). Order from NTIS as ADA030098.

NBSIR 76-1113. A ten year history of National Bureau of Standards activities under the Brooks Act (Public Law 89-306), G. Burns and S. Radack, Eds., 93 pages (Feb. 1977). Order from NT1S as PB263526.

NBSIR 77-1195. The world of EDP standards, M. F. Hill and J. L. Walkowicz, 154 pages (Dec. 1976). Order from NTIS as PB263771.

NBSIR 77-1228. Automatic data processing risk assessment, $S$. K. Reed, 37 pages (Mar. 1977). Order from NTIS as PB265950. 
NBSIR 77-1230. CROSSI-A Univac processor which assembles code for Interdata minicomputers, C. V. Young, 33 pages (Apr. 1977). Order from NTIS as PB269344.

NBSIR 77-1276. OMNITAB II user's reference manual-1977 supplement, D. Hogben and S. T. Peavy, 176 pages (July 1977). Order from NTIS as PB270855.

I NBSIR 77-1291. Report of the Workshop on Cryptography in Support of Computer Security, D. Branstad, J. Gait, and S. Katzke, 62 pages (Sept. 1977). Order from NTIS as PB27 1744.

NBS-GCR-77-89. Symbolic testing-Design techniques, costs and effectiveness, W. E. Howden, 168 pages (May 1977). Order from NTIS as PB268517.

16904. Davis, R. M., Demanding more from computers, Comput. Dec., pp. 47-48 (Jan. 1976).

16918. Linden, T. A., Protection: A nuisance or an opportunity?, Proc. COMPCON 76, Washington, DC, Sept. 7-10, 1976, pp. 30-36 (IEEE Computer Society, Long Beach, CA, 1976).

16920. Linden, T. A., Operating system structures to support security and reliable software, Comput. Surv. 8, No. 4, 409. 445 (Dec. 1976).

16934. Cotton, I. W., Computer network interconnection, Proc. Second Berkeley Workshop on Computer Networks and Distributed Data Management, Berkeley, CA, May 25-27, 1977. pp. 3-18 (University of California, Berkeley, CA, 1977).

16936. Folts, H. C., Cotton, I. W., Interfaces: New standards catch up with technology, Data Commun. 6, No. 6, 31-40 (June 1977).

16945. Watkins, S. W., Abrams, M. D., Remote terminal emulation in the procurement of teleprocessing systems, Proc. Natl. Computer Conf., Dallas, TX, June 13-16, 1977, 46, 723-727 (AFIPS Press, Montvale, NJ, 1977).

16948. Mamrak, S. A., Kimbleton, S. R., Comparing equivalent network services throwgh dynamic processing time prediction, Proc. 1977 Natl. Computer Conf., Dallas, TX, June 12-16, 1977, 46, 455-460 (AFIPS Press, Montvale, NJ, 1977).

16998. Leong-Hong, B., Marron, B., Data element dictionary/directory systems-A tool for data management, Proc. Sixteenth Annual Tech. Symp. Systems and Software. Operational Reliability and Performance Assurance, Gaithersburg, MD, June 2, 1977, P. A. Willis, Ed., Pp. 17-20 (Association for Computing Machinery, New York, NY, 1977).

17020. Roth, P. F., Simulation of computers: A tutorial introduction, Proc. Symp. on Simulation of Computer Systems, Boulder, CO, Aug. 12-14, 1975, H. J. Highland, Ed., pp. 35 (Association for Computing Machinery, New York, NY, 1975).

17025. Kimbleton, S. R., A fast approach to network data assignment, Proc. Second Workshop on Distributed Data Management and Computer Networks, University of California, Berkeley, CA, May 25-27, 1977, LBL 6416, pp. 245-256 (Lawrence Berkeley Lab., University of Califomia, Berkeley, CA, 1977).

17250. Abrams, M. D., Techniques for evaluating the effectiveness of interactive computer service, Proc. 1977 ACM Annual Conf., Seattle, WA, Oct. 16-19, 1977, pp. 452-458 (Association for Computing Machinery, New York, NY, 1977).

17252. Abrams, M. D., Cotton, I. W., Watkins, S. W., Rosenthal, R., Rippy, D. E., The NBS computer metwork measurement system, IEEE Trans. Commun. COM-25, No. 10, $1189-1198$ (Oct. 1977).

17280. Leong-Hong, B., Marron, B., A technological tool and information management (Abstract only, paper is in microfiche), Proc. ASIS Annual Meeting: Information Management in the $1980^{\prime} \mathrm{s}$, Chicago, 1L, Sept. 26-Oct. 1, 1977, p. 3 (Knowledge Ind. Publ., Inc., White Plains, NY, 1977).
17281. Wood, H. M., On-line password techniques, Proc. Trends and Applications: 1977-Computer Security and Integrity, Gaithersburg, MD, May 19, 1977, pp. 27-40 (IEEE Computer Society, Long Beach, CA, 1977).

17288. Abrams, M. D., Treu, S., A methodology for interactive computer service measurement, Commun. $A C M$ 20, No. 12, 936-944 (Dec. 1977).

17307. Wood, H. M., The use of passwords for controlling access to remote computer systems and services, (Proc. Natl. Computer Conf. Dallas, TX, June 13-16, 1977), Paper in AFIPS Conference Proceedings 46, 27-33 (AFIPS Press, Montvale, NJ, 1977).

\section{Health and Safety}

Solubility of $\mathrm{Ca}_{5}\left(\mathrm{PO}_{4}\right)_{3} \mathrm{OH}$ in the system $\mathrm{Ca}(\mathrm{OH})_{2}-\mathrm{H}_{8} \mathrm{PO}_{4}-\mathrm{H}_{2} \mathrm{O}$ at $5,15,25$, and $37^{\circ} \mathrm{C}, H$. McDowell, T. M. Gregory, and W. E. Brown, J. Res. Nat. Bur. Stand. (U.S.), $81 \mathrm{~A}$ (Phys. and Chem.), Nos. 2 and 3, 273-281 (Mar.-June 1977).

Monogr. 159. Visual range: Concepts, instrumental determination, and aviation applications, C. A. Douglas and R. L. Booker, Nat. Bur. Stand. (U.S.), Monogr. 159, 362 pages (June 1977) SNOO3-003-01782-5.

SP450. Blood pH, gases, and electrolytes. Proceedings of the Workshop on $\mathrm{pH}$ and Blood Gases, held at the National Bureau of Standards, Gaithersburg, MD, July 7-8, 1975, R. A. Durst, Ed., Nat. Bur. Stand. (U.S.), Spec. Publ. 450, 338 pages (June 1977) SN003-003-01792-2.

Definitions of acid-base quantities: Terminology, symbols, and SI units, O. Siggaard-Andersen, SP450, pp. 1-9 (June 1977).

The buffer value of plasma, erythrocyte fluid and whole blood, O. Siggaard-Andersen, M. Rørth, and D. A. P. Strickland, SP450, pp. 11-19 (June 1977).

Acid-base algorithms, O. Siggaard-Andersen, SP450, pp. 21-26 (June 1977).

Determination of total $\mathrm{CO}_{2}$ concentration in blood or plasma, P. Rispens, E. J. van Kampen, and W. G. Zijlstra, SP450, pp. 27-31 (June 1977).

The apparent overall first dissociation constant of $\mathrm{CO}_{2}$ in plasma, P. Rispens and W. G. Zijlstra, SP450, pp. 33-38 (June 1977).

Quantitative relationships between wotal $\mathrm{CO}_{2}$ concentration in blood and plasma, plasma bicarbonate concentration, plasma pH and carbon dioxide tension between $16-42^{\circ} \mathrm{C}, \mathrm{P}$. Rispens, J. P. Zock, and W. G. Zijlstra, SP450, pp. 39-45 (June 1977).

$P_{\mathrm{CO}_{2}}$ independent quantities, why or why not, $P$. Rispens, W. 'G. Zijlstra, and E. J. van Kampen, SP450, pp. 47-52 (June 1977).

Base excess. Why reopen the acid-base debate?, P. J. N. Howorth, SP450, pp. 53-56 (June 1977).

Use of in vivo $\mathrm{CO}_{2}$ titration curves in the physiological assessment of acid-base balance, P. J. N. Howorth, SP450, pp. 57-67 (June 1977).

Relative activity and SI units, B. F. Visser and A. H. J. Maas, SP450, pp. 69-72 (June 1977).

Semi-empirical acid-base program, B. F. Visser, A. J. Hoelen, J. A. Kreuger, and A. H. J. Maas, SP450, pp. 7374 (June 1977).

"Acid-base semantics"-A century of the Tower of Babel, H. F. Weisberg, SP450, pp. $75-89$ (June 1977).

Tri-slide ${ }^{T A}$ calculator for Henderson-Hiasselbalch equation and $\mathrm{CO}_{2} \mathrm{RREC}^{\circ} \mathrm{t}_{-} \mathrm{O}_{2}$ SLIDE $^{\mathrm{TM}}$ for temperature corrections of $\mathrm{pH}, \mathrm{PCO}_{2}$, and $\mathrm{PO}_{2}, \mathrm{H}$. F. Weisberg, SP450, pp. 91-101 (June 1977 ).

Aids for evaluation of acid-base imbalance-Diagrams, nomograms, and slide-rules, H. F. Weisberg, SP450, pp. 103117 (June 1977). 
The overall first ionization equation of carbonic acid as related to $\mathrm{CO}_{2}$ in gas phase: $\mathrm{A}$ new $\mathrm{p} K, \mathrm{~A}$. H. J. Maas and $\mathrm{B}$. F. Visser, SP450, pp. 119-126 (June 1977).

Towards a physiological nomenclature for in vivo disturbances of acid-base balance, J. J. Cohen, SP450, pp. 127-129 (June 1977).

Minimal acceptsnce criteria for acid-base nomograms, J. J. Cohen, SP450, pp. 131-132 (June 1977).

A physiological approach to acid-base diagnostics, P. Kildeberg and K. Engel, SP450, pp. 133-141 (June 1977).

$\mathrm{CO}_{2}$ solubility, $\mathrm{pK}^{\prime}$ and related factors in acid-base balance, W. H. Austin, SP45U, pp. 143-151 (June 1977).

Definition of oxygen saturation and characterization of oxygen-hemoglobin affinity, A. L. Malenfant, SP450, pp. 153162 (June 1977).

Problems associated with the definition of measured and calculated quantities in blood $\mathrm{pH}$ and gas analysis, $\mathrm{R}$. W. Burnett, SP450, pp. 163-165 (June 1977).

Arterial and venous blood samples in acid-base balance, $W$. H. Austin, SP450, pp. 167-170 (June 1977).

Blood sampling and handling in the determination of blood pH and blood gases, A. H. Richards, SP45O, pp. 171-173 (June 1977).

Non-analytical sources of laboratory error in pH and blood gas analysis, J. H. Ladenson, SP450, pp. $175-190$ (June 1977).

Instrument specifications, S. R. Gambino, SP450, pp. 191193 (June 1977).

Efifects of the liquid junction on $\mathrm{pH}$ measurement in blood; the $0.160 \mathrm{~mol} / \mathrm{l}$ sodium chloride bridge, A. H. J. Maas, SP450, pp. 195-200 (June 1977).

The critical care laboratory: A 10-year perspective, M. B. Laver and D. R. Misiano, SP450, pp. 201-206 (June 1977).

A theoretical and practical analysis of $\mathbf{P O}_{2}$ microelectrode behavior: The three-shell model, R. G. Buckles, H. Heitmann, and M. B. Laver, SP45O, pp. 207-225 (June 1977).

Dynamic response of a $\mathbf{p C O}_{2}$ electrode, S. J. Pace and $\mathbf{M}$. J. D. Brand, SP450, pp. 227-234 (June 1977).

Monitoring of oxygen pressure in human and animal blood, H. P. Kimmich and F. Kreuzer, SP450, pp. 235-238 (June 1977).

Alternative methods of $\mathrm{CO}_{2}$ measurement, with particular reference to contirucous recording, L. H. J. van Kempen and F. Kreuzer, SP450, pp. 239-246 (June 1977).

NBS standards for $\mathrm{pH}$ and ion activity measurements In biological fluids, R. A. Durst and R. G. Bates, SP450, pp. 247-255 (June 1977).

Use of carbon dioxide- and oxygen tonometered phosphatebicarbonate-chloride-glycerol-water mixtures for calibration and control of $\mathrm{pH}, \mathrm{pCO}_{2}$, and $\mathrm{pO}_{2}$ electrode systems, $\mathrm{A}$. $\mathrm{H}$. J. Maas, A. H. Veefkind, R. A. M. Van den Camp, A. J. Teunissen, A. B. T. J. Boink, and T. J. C. Ruigrok, SP450, pp. 257-265 (June 1977).

Calibration of blood gas analyzers, A. H. Runck, SP450, pp. 267-272 (June 1977).

Quality control, S. R. Gambino, SP450, pp. 273-274 (June 1977).

Quality control and standards, D. C. Noonan, SP450, pp. 275-278 (June 1977).

Development of reference methods: Blood gas analysis, A. L. Malenfant and K. D. Fallan, SP450, pp. 279-283 (June 1977).

Quality control and standards, S. K. Sørensen, SP450, pp. 285-287 (June 1977).

Development of reference methods, S. K. Sørensen, SP45O, Pp. 289-291 (June 1977).

Standardization of ion-selective electrodes for serum analysis, M. S. Mohan and R. G. Bates, SP450, pp. 293-299 (June 1977).
Electrolyte activities in human blood plasma, M. J. D. Brand and W. J. Scott, SP450, pp. 301-310 (June 1977).

The King's College Hospital ion-selective electrode serum electrolyte analyzer, A. D. Hirst, P. Gay, P. Richardson, and P. J. N. Howorth, SP450, pp. 31 1-314 (June 1977).

SP472. Retrieval and analysis of orthopaedlc implants. Proceedings of a Symposium held at the National Bureau of Standards, Gaithersburg, MD, Mar. 5, 1976, A. Weinstein, E. Horowitz, and A. W. Ruff, Eds., Nat. Bur. Stand. (U.S.), Spec. Publ. 472, 130 pages (Apr. 1977) SN003-003-017671.

Opening remarks, P. G. Laing, SP472, p. 1 (Apr. 1977).

Overview: Performance feedback via device retrieval and analysis, A. M. Weinstein, SP472, pp. 3-9 (Apr. 1977).

A review of metallurgical failure modes In orthopaedic implants, D. F. Williams, SP472, pp. 11-20 (Apr. 1977).

Models for systemic effects of metallic implants, $G$. K. Smith and J. Black, SP472, pp. 23-28 (Apr. 1977).

Tissue reaction to biomaterials, P. G. Laing, SP472, pp. 31 38 (Apr. 1977).

Clinical biomechanies, G. Piotrowski, SP472, pp. 41-48 (Apr. 1977).

Femoral stem performance, D. L. Bartel and S. C. Desormeaux, SP472, pp. $51-59$ (Apr. 1977).

Orthopaedic implant retrieval analysis, A. U. Daniels and H. K. Dunn, SP472, pp. $61-70$ (Apr. 1977).

Legal aspects of device retrieval, T. R. Lemon, SP472, pp. 73-79 (Apr. 1977).

SP480-1. LEAA police equipment survey of 1972, Volume I. The Need for Standards: Priorities for police equipment, $\mathbf{R}$. Ku, E. Bunten, and P. Klaus, Nat. Bur. Stand. (U.S.), Spec. Publ. 480-1, 166 pages (June 1977) SN003-003-01722-1.

SP480-2. LEAA police equipment survey of 1972, Volume $\mathbf{I}$. Communications equipment and supplies, S. Mumford, P. Klaus, E. Bunten, and R. Cunitz, Nat. Bur. Stand. (U.S.), Spec. Publ. 480-2, 127 pages (June 1977) SN003-003-017230.

SP480-3. LEAA police equipment survey of 1972, Volume III. Sirens and emergency warming lights, P. Klaus and E. Bunten, Nat. Bur. Stand. (U.S.), Spec. Publ. 480-3, 110 pages (June 1977) SNO03-003-01744-2.

SP480-4. LEAA police equipment survey of 1972, Volume IV. Alarms, security equipment, surveillance equipment, J. L. Eldreth, E. D. Bunten, and P. A. Klaus, Nat. Bur. Stand. (U.S.), Spec. Publ. 4804, 115 pages (June 1977) SN003003-01745-1.

SP480-5. LEAA police equipment survey of 1972, Volume V. Handguns and handgun ammunition, S. Bergman, E. Bunten, and P. Klaus, Nat. Bur. Stand. (U.S.), Spec. Publ. 480-5, 83 pages (June 1977) SN003-003-01747-7.

SP480-6. LEAA police equipment survey of 1972, Volume VI. Body armor and confiscated weapons, G. B. Hare, P. A. Klaus, and E. D. Bunten, Nat. Bur. Stand. (U.S.), Spec. Publ. 480-6, 77 pages (June 1977) SN003-003-01748-5.

SP480-7. LEAA police equlpment survey of 1972, Volume VII. Patrol cars, E. D. Bunten and P. A. Klaus, Nat. Bur. Stand. (U.S.), Spec. Publ. 480-7, 97 pages (June 1977) SN003-00301766-3.

SP480-8. A guide to voice scramblers for law enforcement agencies, R. E. Nelson, Nat. Bur. Stand. (U.S.), Spec. Publ. 4808, 44 pages (Dec. 1976) SN003-003-01 735-3.

SP480-13. Police communications equipment survey of $1976, \mathrm{~W}$. A. Shand and M. J. Treado, Nat. Bur. Stand. (U.S.), Spec. Publ. 480-13, 54 pages (Aug. 1977) SN003-003-01818-0.

SP480-18. Report on an Investigation of the high speed hazards of steel belted radial tires on police cars, J. J. Collard, Nat. Bur. Stand. (U.S.), Spec. Publ. 480-18, 40 pages (June 1977) SN003-003-01786-8. 
SP480-19. Digital data transmission tests on voice channels, Urban Sciences, Inc., Nat. Bur. Stand. (U.S.), Spec. Publ. 480-19, 63 pages (July 1977) SN003-003-01773-6.

SP480-21. The hazard of benzidine to criminal justice personnel, H. Steinberg, Nat. Bur. Stand. (U.S.), Spec Publ. 480-21, 16 pages (May 1977) SNOO3-003-01777-9.

SP480-22. Terms and definitions for door and window security, J. S. Stroik, Nat. Bur. Stand. (U.S.), Spec. Publ. 480-22, 16 pages (May 1977) SNO03-003-01774-4.

SP480-24. The role of behavioral science in physical security. Proceedings of the first annual symposium, Apr. 29-30, 1976, J. J. Kramer, Ed., Nat. Bur. Stand. (U.S.), Spec. Publ. 48024, 122 pages (Nov. 1977) SNOO3-003-01868-6.

Analyzing threats from terrorism, a working paper, E. D. Shaw, L. Hazlewood, R. E. Hayes, and D. R. Harris, SP48024, pp. 1-16 (Nov. 1977).

Federal Aviation Administration's behavioral research program for defense against hijacking, E. Pickrel, SP480-24, pp. 19-24 (Nov. 1977).

Perpetrator attributes in threat analysis, A. Fine, SP480-24, pp. 27-34 (Nov. 1977).

Profiles of computer criminals, S. Nycum, SP480-24, pp. 37-41 (Nov. 1977).

Some human factors that influence reliability of signal detection and identification in surveillance systems, $R$. Mackie, SP480-24, pp. 43-56 (Nov. 1977).

Human reliability factors, J. J. Cappucci, SP480-24, pp. 59-61 (Nov. 1977).

Human engineering in decision theory, K. A. Plant, SP48O24, pp. 63-73 (Nov. 1977).

Final report-Joint services perimeter barrier penetration evaluation, R. A. Fite and S. Kilpatrick, SP480-24, pp. 75106 (Nov. 1977).

Preliminary observations of complex fence and barrier assauils-Phase II, J. Kramer and P. Meguire, SP480-24, pp. 107-113 (Nov. 1977).

SP480-25. Image quality of monochrome television cameras, J. C. Richmond, Nat. Bur. Siand. (U.S.), Spec. Publ. 480-25, 14 pages (Oct. 1977) SNOO3-C03-01855-4.

SP480-26. The reduction of airborne lead in indoor firing ranges by using modified ammunition, A. A. Juhasz, Nat. Bur. Stand. (U.S.), Spec. Publ. 480-26, 27 pages (Nov. 1977) SNO03-003-0 1821-0.

SP480-27. Security lighting for nuclear weapons storage sites: A literature review and bibliography, P. G. Meguire, J. J. Kramer, and A. Stewart, Nat. Bur. Stand. (U.S.), Spec. Publ. 480-27, 38 pages (Nov. 1977) SNO03-003-01838-4.

SP482. Rare event/accident research methodology. Proceedings of a Workshop held at the National Bureau of Standards, Gaithersburg, MD, May 26-28, 1976, V. J. Pezoldt, Ed., Nat. Bur. Stand. (U.S.), Spec. Publ. 482, 112 pages (July 1977) SNO03-003-01800-7.

System safety engineering as the integrator of accident prevention activities, W. Hammer, SP482, pp. 1-10 (July 1977).

Investigative methods useful in safety, W. G. Johnson, SP482, pp. 11-23 (July 1977).

Hypothesis generation for rare events research, L. A. Benner, Jr., SP482, pp. 25-28 (July 1977).

Epidemiologic approaches to injury research, J. A. Waller, SP482, pp. 29-46 (July 1977).

Needed human research and new methodological considerations being forced by the law, G. A. Peters, SP482, pp. 4753 (July 1977).

Methods for studying complex homemaking tasks, R. E. Steidl, SP482, pp. 55-69 (July i977).

Data collection for hand tool injury: An approach, M. M. Ayoub, SP482, pp. 71-103 (July 1977).

Simulation in accident research, S. Rubinsky, SP482, pp. 105-109 (July 1977).
TN953. A new portable tester for the evaluation of the slip-resistance of walkway surfaces, R. J. Brungraber, Nat. Bur. Stand. (U.S.), Tech. Note 953, 51 pages (July 1977) SN003003-01796-5.

NBSIR 76-1005. A comparison of two testers in evaluating the slip-resistance of bathtub and shower base surfaces, R. J. Brungraber and T. J. R. Raper, 59 pages (Oct. 1977). Order from NTIS as PB273120.

NBSIR 76-1117. Exposure spectra from NBS vertical-beam ${ }^{60} \mathrm{Co}$ gamma-ray source, M. Ehrlich and C. G. Soares, 11 pages (Dec. 1976). Order from NTIS as PB269341.

NBSIR 76-1128. Interaction of blood proteins with solid surfaces, L. E. Smith, R. E. Dehl, W. H. Grant, R. R. Stromberg, and B. W. Morrissey, 44 pages (Oct. 1976). Order from NTIS as PB259199.

NBSIR 76-1146. A study of personal fall-safety equipment, $\mathbf{H}$. L. Steinberg, 219 pages (June 1977). Order from NTIS as PB269355.

NBSIR 76-1149. A second appraisal of methods for estimating self-reaction hazards, E. S. Domalski, 160 pages (Mar. 1977). Order from NTIS as PB266925.

NBSIR 76-1174. Skid resistance measurement test procedures for intercomparing FHWA national and regional reference systems, R. W. Kearns and J. F. Ward, 35 pages (Dec. 1976). Order from NTIS as PB262366.

NBSIR 76-1175. The static force calibration of a skid resistance measuring system, R. W. Kearns and J. F. Ward, 87 pages (Dec. 1976). Order from NTIS as PB276530.

NBSIR 77-1217. Safety problems associated with pressure containers, S. K. Wakamiya and N. J. Calvano, 42 pages (Mar. 1977). Order from NTIS as PB264691.

NBSIR 77-1218. Risks associated with certain sports activities; W. B. Beine, 106 pages (Jan. 1977). Order from NTIS as PB264666.

NBSIR 77-1246. Evaluation of the egress provisions of the HUD mobile home construction and safety standard, S. Adler, 78 pages (May 1977). Order from NTIS as PB268389.

NBSIR 77-1250. Analysis of housing data collected in a leadbased paint survey in Pittsburgh, Pennsylvania-Part I, D. R. Shier and W. G. Hall, 100 pages (May 1977). Order from NTIS as PB268150.

NBSIR 77-1251. Considerations in establishing performance criteria for structural firefighters' helmets, N. J. Calvano, 111 pages (May 1977). Order from NTIS as PB269531.

NBSIR 77-1262. Computerized site security monitor and response system, R. T. Moore, R. J. Carpenter, and A. L. Koenig, 45 pages (June 1, 1977). Order from NTIS as PB269346.

NBSIR 77-1293. Anslysis of housing data collected in a leadbased paint survey in Pittsburgh, Pennsylvania-Part I, D. R. Shier and W. G. Hall, 190 pages (June 1977). Order from NTIS as PB271745.

NBSIR 77-1294. Power lawn mowers: Evaluation of anthropometric foot probes, J. J. Persensky and A. M. Ramey, 57 pages (May 1977). Order from NTIS as PB272507.

NBSIR 77-1310. Microcalorimetric study of cardiac pacemakers and batteries, E. J. Prosen and J. C. Colbert, 21 pages (Sept. 1977). Order from NTIS as PB272690.

NBSIR 77-1313. An assessment of the technical literature on emergency egress from buildings, F. I. Stahl and J. Archea, 66 pages (Oct. 1977). Order from NTIS as PB273944.

NBS-GCR-77-91. Guidebook on anthropomorphic test dummy usage, D. H. Robbins, 84 pages (Mar. 1977). Order from NTIS as PB268904.

U.S. Patent 4,009,704. Cool-touch cooking surfaces, L. A. Marzetta, 4 pages (Mar. 1, 1977).

16666. Motz, J. W., Danos, M., The potential for exposure reduction in diagnostic radiology, Proc. Digest of the 4th Int. 
Conf. on Medical Physics, Special lssue of Physics in Canada, Ottawa, Canada, July 25-30, 1976, 32, 13.3 (Le DroitLeclerc, Ottawa, Canada, July 1976).

16706. Steinberg, H. L., Standard Reference Collections of forensic science materials: Status and needs, LESP-RPT$0601.00,90$ pages (U.S. Department of Justice, Law Enforcement Assistance Administration, National Institute of Law Enforcement and Criminal Justice, Washington, DC, Feb. 1977).

16714. Stroik, J. S., Physical security of door assemblies and components, NILECJ-STD-0306.00, 33 pages (U.S. Department of Justice, Law Enforcement Assistance Administration, National Institute of Law Enforcement and Criminal Justice, Washington, DC, May 1976).

16739. Brown, W. E., Gregory, T. M., Chow, L. C., Effects of fluoride on enamel solubility and cariostasis, Caries Res. 11, (Suppl. 1), 118-141 (1977).

16761. Richmond, J. C., A simple test for evaluating the spectral responsivity of monochrome television cameras, LESPRPT-0310.00, 24 pages (U.S. Department of Justice, Law Enforcement Assistance Administration, National Institute of Law Enforcement and Criminal Justice, Washington, DC, Feb. 1977)

16773. Scheide, E. P., The piezoelectric-crystal mercury dosimeter, Phys. Teach. 15, No. 1, 47-51 (Jan. 1977).

16787. Tung, M. S., Characterization and modification of permselective properties of apatite membranes, J. Dental Res. 55 , Spec. Issue D, D77-D85 (1976).

16830. Pella, P. A., Mills, R. M., A trace vapor generator for testing explosives vapor detectors, LESP-RPT-0604.00, 24 pages (U.S. Department of Justice, Law Enforcement Assistance Administration, National Institute of Law Enforcement and Criminal Justice, Washington, DC, Mar. 1977).

16831. Quindry, T. L., Stenbakken, G. N., Sound sensing units for intrusion alarm systems, NILECJ-STD-0308.00, 18 pages (U.S. Department of Justice, Law Enforcement Assistance Administration, National Institute of Law Enforcement and Criminal Justice, Washington, DC, Mar. 1977).

16846. Burnett, E. D., Bassin, M. A., NBS results of hearing aid performance tests, Handbook of Hearing and Measurement 1977, IB 11-60, pp. 32-276 (Veterans Administration, Washington, DC, 1977).

16847. Burnett, E. D., NAS hearing aid test procedures, Handbook of Hearing and Measurement 1977, IB 11-60, pp. 12-31 (Veterans Administration, Washington, DC, 1977).

16890. Leight, W. G., Product safety, in what direction should we be going?, Prof. Safety 22, No. 5, 25-27 (May 1977).

16941. Lederer, P. S., Pressure transducer evaluation, (Proc. Workshop on Biomedical Pressure Measurements, CaseWestern Reserve University, Cleveland, $\mathrm{OH}$, Dec. 4-5, 1975 ), Paper in Indwelling and Implantable Pressure Transducers, D. G. Fleming, W. H. Ko, and M. R. Nauman, Eds., pp. 183191 (CRC Press, Inc., Cleveland, OH, 1977).

16959. Yap, W., Schaffer, R., Binding of dye to albumin studied by ultrafiltration; Clin. Chem. 23, 986-989 (1977).

16973. Fraker, A. C., Ruff, A. W., Metallic surgical implants: State of the art, J. Metals 29, No. 5, 1-7 (May 1977).

16979. Berger, R., An interpretation of the drop ball test in terms of a statistical model for fracture, Am. J. Optom. Physiolog. Opt. 53, No. 8, 396-407 (Aug. 1976).

16996. Treado, M. J., Development of reports and guidelines for law enforcement communications equipment, Proc. 1974 Carnahan Conf., Lexington, KY, Apr. 1974, pp. 102-112 (1974).

17902. Stenbakken, G., IIsler, M., Mechanically actuated switches for burglar alarm systems, NILECJ-STD-0302.00, 18 pages (U.S. Department of Justice, Law Enforcement Assistance Administration, National Institute of Law Enforcement and Criminal Justice, Washington, DC, May 1974).
17033. Misra, D. N., Bowen, R. L., Adhesive bonding of various materials to hard tooth tissues. 11. Chemisorption of an adduct (of the diglycydyl ether of bisphenol $\mathbf{A}$ with $N$-phenylglycine) on hydroxylapatite, J. Phys. Chem. 81, No. 9, 842846 (1977).

17036. Glass, R. A., Rubin, A. I., Emergency communications in high-rise buildings, Chapter 22 in Human Response to Tall Buildings, D. J. Conway, Ed., CDS/34, 293-301 (Dowden, Hutchinson \& Ross, Inc., Stroudsburg, PA, 1977).

17049. Mangum, B. W., The gallium melting-point standard: Its role in our temperature measurement system, Clin. Chem. 23, No. 4, 711 -718 (1977).

17120. Brauer, G. M., Polymers in dentistry, (Proc. 100th Anniversary Prog. in Dental Materials, Ann Arbor, MI, Oct. 1, 1975), Chapter 5 in Dental Materials Review, R. G. Craig, Ed., pp. 78-111 (University of Michigan Press, Ann Arbor, MI, 1977).

17126. Dickson, G., Development of physical and mechanical testing, (Proc. 100th Anniversary Prog. in Dental Materials, Ann Arbor, Ml, Oct. 1, 1975 ), Chapter 3 in Dental Materials Review, R. G. Craig, Ed., pp. 29-50 (University of Michigan Press, Ann Arbor, MI, 1977).

17168. Bowman, R. R., Some recent developments in the characterization and nseasurement of hazardous electromagnetic fields, Proc. Int. Symp. Biologic Effects and Health Hazards of Microwave Radiation, Oct. 15-18, 1973, Warsaw, Poland, pp. 217-227 (1973).

17174. Flanigan, W. F., Jr., Bowman, R. R., Lowell, W. R., Nonmetallic electrode system for recording EEG and ECG in electromagnetic fields, Physiol. Behavior Brief Commun. 18, 531-533 (1977).

17197. Misra, D. N., Bowen, R. L., Adhesive bonding of various materials to hard tooth tissues. XII. Adsorption of $N-(2-$ hydroxy-3-methacryloxypropyl)- $N$-phenylglycine (NPG-GMA) on hydroxyapatite, J. Colloid Interface Sci. 61, No. 1, 14-20 (Aug. 1977).

17200. Pezoldt, V. J., Persensky, J. J., Ramey, A. M., Human factors support of a lawn mower safety standard, Proc. Third Int. System Safety Conf., Washington, DC, Oct. 17-21, 1977, pp. 3-22 (1977).

17201. Brauer, G. M., The present state and future of macromolecules for dental applications, Polym.-Plast. Technol. Eng. 9, No. 1, 87-121 (1977).

17202. Brauer, G. M., Termini, D. J., Dickson, G., Analysis of the ingredients and determination of the residual components of acrylic bone cements, J. Biomed. Mater. Res. 11, 577-607 (1977).

17233. Richmond, J. C., A proposed standard for monochrome television cameras for courtroom use, Proc. SPIE Tech. Symp. East-Seminar on Optics in Security and Law Enforcement, Reston, VA, Apr. 21-22, 1977, pp. 126-134 (Society of Photo-optical Instrumentation Engineers, Bellingham, WA, Oct. 1977).

17256. Crissman, J. M., Guttman, C. M., Zapas, L. J., Performance of plastic packaging for hazardous materials trans. portation. Part 1. Mechanical properties, Report No. DOT/MTB/OHMO-76/4, 51 pages (U.S. Department of Transportation, Materials Transportation Bureau, Office of Hazardous Materials Operations, Washington, DC, Oct. 1976).

17299. Ruegg, R. T., Life-cycle cast evaluation of the personal patrol car program, J. Police Sci. Admin. 5, No. 3, 290-298 (Sept. 1977).

17325. Mabie, C. P., Investments for chromium-based alloys, (Proc. Conf. on Alternatives to Gold Alloys in Dentistry, National Institute of Health, Bethesda, MD, Jan. 24-26, 1977), DHEW Publication (NIH) 77-1227, pp. 186-201 (National Institute of Health, Bethesda, MD, 1977). 
17339. Freeman, C. M., Nudelman, S., Richmond, J. C., Eds., Optics in security and law enforcement (Book), Proc. Symp. on Optics in Security and Law Enforcement, Reston, VA, Apr. 18-21, 1977, 154 pages (Society of Photo-Optical Instrumentation Engineers, Bellingham, WA, 1977).

17346. Barnes, J. D., Martin, G. M., Performance of plastic packaging for hazardous materials transportation. Part II. Permeation, Report No. DOT/MTB/OHMO-76/5, 29 pages (National Technical Information Service, Springfield, VA, Oct. 1976).

\section{Consumer Information and Protection}

SP471. Report of the 61st National Conference on Weights and Measures 1976, P. A. Raschella, Ed., Nat. Bur. Stand. (U.S.), Spec. Publ. 471, 304 pages (June 1977) SN003-003-018066.

Metrication-A one-time opportunity, R. L. Thompson, SP471, pp. 1.4 (June 1977).

A different view on tolerance application, O. K. Warnlof, SP471, pp. 5-12 (June 1977).

Tare weight in computer assisted checkout systems, H. Morris, SP471, pp. 13-16 (June 1977).

EPA gasoline vapor recovery progirams, R. L. Ajax, SP471, pp. 17-22 (June 1977).

Documentation of interpretations and methods of sale, E. W. Johnson, SP471, pp. 23-24 (June 1977).

What everyone should know about those Supreme Court cases having to do with moisture losses-As of the Fourth of July, 1976, M. S. Thompson, SP471, pp. 24-28 (June 1977).

Uniform retail meat identity standards, H. K. Johnson, SP471, pp. $29-43$ (June 1977)

An introduction to weights and measures for cordage products, W. H. Hagenbuch, SP471, pp. 44-48 (June 1977).

Report and recommendations to the National Conference on Weights and Measures on the measurement of kiln dried hardwood lumber, E. H. Gatewood, SP471, 49-52 (June 1977).

Metrication USA, M. E. O'Hagan, SP471, pp. 53-62 (June 1977).

The metrication of Seven-Up-The liter leader, B. H. Wells, SP471, pp. 63-68 (June 1977).

Metric training seminars, J. H. Landvater and M. Perkins, SP471, pp. 69-76 (June 1977).

A background for understanding sampling plans, M. G. Natrella, SP471, pp. 77-83 (June 1977).

National conference of State legislatures, T. Jensen, SP471, pp. 84-89 (June 1977).

National voluntary laboratory accreditation program, G. A. Rowland, SP471, pp. 90-102 (June 1977).

Consumer affairs forum (introduction), O. D. Mullinax, SP471, p. 103 (June 1977).

A new road for consumers, M. Dana, SP471, pp. 103-109 (June 1977).

Drained weight regulations, B. M. Gutterman, SP471, pp. 110-120 (June 1977).

What the consumer needs to know about metric, B. Beizer, SP471, pp. 120-124 (June 1977).

NBS and NCWM-Past, present, and future, E. Ambler, SP471, p. 128 (June 1977).

NBSIR 76-1092. Consumer product portability as related to wartanty rulemaking, J. J. Kramer and P. G. Meguire, 91 pages (Aug. 1976). Order from NTIS as PB265961.

NBSIR 77-1212. Life cycle costing: An assessment of practicability for consumer products, S. W. Stiefel, S. Justin Kim, and H. Hung, 66 pages (Dec. 1976). Order from NTIS as PB265697.

17035. Fechter, J. V., Van Cott, H. P., The house that NBS built, J. Consumer Studies \& Home Econom. 1, No. 2, 101 108 (June 1977).

\section{Electromagnetic Metrology}

TN692. Servo techniques in oscillators and measurement systems, F. L. Walls and S. R. Stein, Nat. Bur. Stand. (U.S.), Tech. Note 692, 23 pages (Dec. 1976) SN003-003-01734-5.

TN696. Near-field antenna measurements on a cylindrical surface: A source scattering-matrix formulation, A. D. Yaghjian, Nat. Bur. Stand. (U.S.), Tech. Note 696, 40 pages (July 1977) SN003-003-01850-3.

TN696, 1977 Revision. Near-field antenna measurements on a cylindrical surface: A source scattering-matrix formulation, A. D. Yaghjian, Nat. Bur. Stand.(U.S.), Tech. Note 696, (Revised Sept. 1977), 40 pages (Sept. 1977) SN003-00301850-3.

TN699. Spectrum Amplitude-Definition, generation and measurement, J. R. Andrews and M. G. Arthur, Nat. Bur. Stand. (U.S.), Tech. Note 699, 100 pages (Oct. 1977) SN003-003$01865-1$.

NBSIR 76-851. Electromagnetic remote sensing of inhomogeneous media, W. A. Bereuter and D. C. Chang, 22 pages (Jan. 1977). Order from NTIS as PB263124.

NBSIR 77-856. Proposed standards for ladar signatures, B. L. Danielson, 38 pages (Apr. 1977). Order from NTIS as ADA038725.

NBSIR 77-861. A relatively short cylindrical broadband antenna with tapered resistive loading for picosecond pulse measurements, M. Kanda, 47 pages (Aug. 1977). Order from NTIS as PB274057.

NBSIR 77-863. RF attenuation measurement system using a SQUID, R. T. Adair, N. V. Frederick, and D. B. Sullivan, 158 pages (Sept. 1977). Order from NTIS as PBADA046831.

NBSIR 77-866. NBS type IV rf power meter operation and maintenance, N. T. Larsen, 38 pages (Oct. 1977). Order from NTIS as PB274456.

NBSIR 77-868. The characteristics of broadband, isotropic electric field and magnetic field probes, M. Kanda, 34 pages (Nov. 1977). Order from NTIS as PB274457.

U.S. Patent $4,008,477$. Antenna with inherent filtering action, T. M. Babij, R. R. Bowman, and P. F. Wacker, 5 pages (Feb. 15, 1977).

U.S. Patent 4,008,610. Self-balancing D.C.-substitution measuring system, N. T. Larsen and G. R. Reeve, 9 pages (Feb. 22, 1977).

16663. Engen, G. F., Theorem giving limits for $\left|S_{22}\right|$ when $\left|S_{11}\right|$ and the two-port efficiency are known, IEEE Trans. Instrum. Meas. IM-20, No. 1, 78 (Feb. 1971).

16668. Crawford, M. L., Techniques for measurement of electromagnetic radiation and susceptibility of electronic equipment, Proc. Ist Symp. and Technical Exhibition on Electromagnetic Compatibility, Montrewx, Switzerland, May 20-22, 1975, pp. 38-44 (Electromagnetic Compatibility, Montreux, Switzerland, 1975).

16669. Kanda, M., An improved solid state noise source, Proc. Int. IEEE-MTT-S Microwave Symp., Cherry Hill, NJ, June 1416, 1976, pp. 224-226 (The Institute of Electrical and Electronics Engineers, Inc., Piscataway, NJ, June 1976).

16671. Wacker, P. F., Non-planar near field measurements: Spherical scanning, $A F A L-T R-75-38,55$ pages (Air Force Avionics Laboratory, Air Force Systems Command, WrightPatterson Air Force Base, OH, Apr. 1975).

16721. Gans, W. L., Present capabilities of the NBS Automatic Pulse Measurement System, IEEE Trans. Instrum. Meas. IM25, No. 4, 384-388 (Dec. 1976).

16722. Jesch, R. L., Repeatability of SMA coaxial connectors, IEEE Trans. Instrum. Meas. IM-25, No. 4, 314-320 (Dec. 1976).

16723. Larsen, N. T., A new self-balancing dc-substitution RF power meter, IEEE Trans. Instrum. Meas. IM-25, No. 4, 343347 (Dec. 1976). 
16724. Hoer, C. A., Roe, K. C., Allred, C. M., Measuring and minimizing diode detector nonlinearity, IEEE Trans. Instrum. Meas. IM-25, No. 4, 324-329 (Dec. 1976).

16725. Andrews, J. R., Impulse generator spectrum amplitude measurement techniques, IEEE Trans. Instrum. Meas. IM-25, No. 4, 380-384 (Dec. 1976).

16726. Engen, G. F., Determination of microwave phase and amplitude from power measurements, IEEE Trans. Instrum. Meas. IM-25, No. 4, 414-418 (Dec. 1976).

16727. Estin, A. J., Scattering parameters of SMA coaxial connector pairs, IEEE Trans. Instrum. Meas. IM-25, No. 4, 329. 334 (Dec. 1976).

16731. Riad, S. M., Nahman, N. S., Application of the homomorphic deconvolution for the separation of TDR sigmals occurring in overlapping time windows, IEEE Trans. Instrum. Meas. IM-25, No. 4; 388-391 (Dec. 1976).

16946. Finnegan, T. F., Wilson, J., Toots, J., High frequency properties of stable $\mathrm{Nb}-\mathrm{Nb}$ oxide-Pb Josephson tunnel junctions, (Proc. 1st IC-SQUID Conf., Berlin, Germany, Oct. 58, 1976), Paper in Superconducting Quantum Interference Devices and Their Applications, H. D. Hahlbohn and H. Luebbig, Eds., pp. 381-394 (Walter de Gruyter \& Co., Berlin, Germany, 1977).

17077. Edrich, J., Sullivan, D. B., McDonald, D. G., Results, potentials, and limitations of Josephson-mixer receivers at millimeter and long submillimeter wavelengths, IEEE Trans. Microwave Theory Tech. MTT-25, No. 6, 476-479 (June 1977).

17080. Beehler, R. E., Hanson, D. W., Davis, D. D., Recent changes and future trends in NBS time and frequency dissemination services, Proc. Seventh Annual Precise Time and Time Interval (PTTI) Applications and Planning Meeting, Goddard Space Flight Center, Greenbelt, MD, Dec. 2-4, 1975, X814-76-45, pp. 61-95 (1975).

17092. Sullivan, D. B., Frederick, N. V., Adair, R. T., RF power measurements using quantum interference in superconductors, (Proc. 1st IC-SQUID Conf., Berlin, Germany, Oct. 5-8, 1976), Paper in Superconducting Quantum Interference Devices and Their Applications, H. D. Hahlbohn and H. Luebbig, Eds., pp. 355-363 (Walter de Gruyter \& Co., Berlin, Germany, 1977).

17175. Bensema, W. D., Amplitude, time, and frequency statistics of quasi-impulsive noise, Proc. 1977 EMC Symp., Montreux, Switzerland, June 28-30, 1977, pp. 347-352 (1977).

17220. Crawford, M. L., Experimental evaluation of the radiation characteristics of dipole sources enclosed in a TEM transmission cell, Proc. Conf. on Precision Electromagnetic Measurements, Boulder, CO, June 28-July 1, 1976, pp. 57-59 (Institute of Electrical and Electronics Engineers, New York, NY, 1976).

17221. Wacker, P. F., Newell, A. C., Advantages and disadvantages of planar, circular cylindrical, and spherical scanning and description of the NBS antenna scanning facilities, Proc. European Space Agency Symp., Noordwijk, The Netherlands, June 6-8, 1977, pp. 115-121 (ESA Scientific and Technical Publications Branch, ESTEC, Noordwijk, The Netherlands, 1977).

17222. Wacker, P. F., Symmetry analysis applied to wave theory, Proc. Institute of Electrical and Electronics Engineers/Antennas and Propagation Society Int. Symp., Stanford, CA, June 20-24, 1977, pp. 169-172 (Braun-Brumfield, Inc., Ann Arbor, MI, 1977).

17223. Wacker, P. F., Recent results with spherical mear-field antenna scanning at the National Bureau of Standards, Proc. European Space Agency Symp., Noordwijk, The Netherlands, June 6-8, 1977, Pp. 159-164 (ESA Scientific and Technical Publications Branch, ESTEC, Noordwijk, The Netherlands, 1977).
17224. Newell, A. C., Repjar, A., Results of spherical near-field measurements on nartow-beam antennas, Proc. Conf. on Precision Electromagnetic Measurements, Boulder, CO, June 28-July 1, 1976, pp. 382-385 (Institute of Electrical and Electronics Engineers, New York, NY, 1976).

17225. Wacker, P. F., Symmetry analysis applied to scattering, inverse scattering, and antenna patterns: Measurements, moment method, and characteristic modes, Proc. Institute of Electrical and Electronics Engineers/Antennas and Propagation Society Int. Symp., Stanford, CA, June 20-24, 1977, pp. 177 180 (Braun-Brumfield, Inc., Ann Arbor, MI, 1977).

17227. Wait, D. F., Satellite earth terminal G/T measurements, Microwave J. 20, No. 4, 49, 51, 58 (Apr. 1977).

17234. Komarek, E. L., An application of the six-port reflectometer to precision measurement of microwave one-port parameters, Proc. 1977 IEEE-MTT-S Int. Microwave Symp., San Diego, CA, June 21-23, 1977, pp. 56-57 (Institute of Electrical and Electronics Engineers, New York, NY, 1977).

17237. Engen, G. F., The six-port reflectometer: An alternative network analyzer, Proc. 1977 IEEE-MTT-S Int. Microwave Symp., San Diego, CA, June 21-23, 1977, Pp. 44-46 (Institute of Electrical and Electronics Engineers, New York, NY, 1977).

17240. Engen, G. F., An improved circuit for implementing the six-port technique of microwave measurements, Proc. 1977 IEEE-MTT-S Int. Microwave Symp. Digest, San Diego, CA, June 21-23, 1977, pp. 53-55 (Institute of Electrical and Electronics Engineers, New York, NY, 1977).

17243. Weidman, M. P., A semi-automated sixport for measuring millimeter wave power and complex reflection coefficient, Proc. 1977 IEEE-MTT-S Int. Microwave Symp., San Diego, CA, June 21-23, 1977, pp. 58-60 (Institute of Electrical and Electronics Engineers, New York, NY, 1977).

17244. Hoer, C. A., A microwave network analyzer using two 6-port reflectometers, Proc. 1977 IEEE-MTT-S Int. Microwave Symp., San Diego, CA, June 21-23, 1977, pp. 4749 (Institute of Electrical and Electronics Engineers, New York, NY, 1977).

17251. Adams, J. W., Crawford, M. L., Shafer, J. F., Electromagnetic interference (EMI) measurements for automotive applications, Proc. SAE Automotive Congress Conf., Detroit, MI, Feb. 23-27, 1976, Pp. 1-6 (Society of Automotive Engineers, Inc., Warrendale, PA, 1976).

17322. Lewis, $R$. L., The use of three term recursion relations for numerical computations as applied to mear-field spherical scanning, Proc. International Union of Radio Science (URSI) Int. Symp., Stanford, CA, June 20-24, 1977, pp. 224-226 (NSNC/URSI, Academy of Sciences, Washington, DC, 1977).

17334. Zimmerman, J. E., Sullivan, D. B., High-frequency limitations of the double-junction SQUID amplifier, Appl. Phys. Lett. 31, No. 5, 360-362 (Sept. 1977).

\section{Electronic Technology}

SP400-24. Semiconductor measurement technology: A laser scanner for semiconduct or devices, D. E. Sawyer and D. W. Berning, Nat. Bur. Stand. (U.S.), Spec. Publ. 400-24, 72 pages (Feb. 1977) SNOO3-003-01739-6.

SP400-29. Semiconductor measurement technology. Progress report, January 1 to June 30, 1976, W. M. Bullis, Ed., Nat. Bur. Stand. (U.S.), Spec. Publ. 400-29, 119 pages (Apr. 1977) SN003-003-01759-1.

SP400-31. Semiconductor measurement technology: Techniques for measuring the integrity of passivation overcoats on integrated circuits, W. Kern and R. B. Comizzoli, Nat. Bur. Siand. (U.S.), Spec. Publ. 400-31, 120 pages (Mar. 1977) SN003-003-01753-1. 
SP400-33. Semiconductor measurement technology: The dopant density and temperature dependence of electron mobility and resistivity in n-type silicon, S. S. Li, Nat. Bur. Stand. (U.S.), Spec. Publ. 400-33, 36 pages (Mar. 1977) SN003-003-017426.

SP400-35. Semiconductor measurement technology: Notes on SEM examination of microelectronic devices, J. R. Devaney, K. O. Leedy, and W. J. Keery, Nat. Bur. Stand. (U.S.), Spec. Publ. 400-35, 54 pages (Apr. 1977) SN003-003-01755-8.

SP400-37. Semiconductor measurement technology: Suppression of premature dielectric breakdown for high-voltage capacitance measurements, A. M. Goodman, Nat. Bur. Stand. (U.S.), Spec. Publ. 400-37, 27 pages (July 1977) SN003-00301809-1.

SP400-39. Semiconductor measurement technology: Some aspects of dose measurement for accurate ion implantation, $D$. M. Jamba, Nat. Bur. Stand. (U.S.), Spec. Publ. 400-39, 44 pages (July 1977) SN003-003-01808.

SP400-40. Semiconductor measurement technology: A 25-kV bias-isolation unit for $1-\mathrm{MHz}$ capacitance and conductance measurements, A. M. Goodman, Nat. Bur. Stand. (U.S.), Spec. Publ. 400-40, 57 pages (Sept. 1977) SN003-003-018325.

SP400-41. Semiconductor measurement technology: A versatile high-voltage biss supply for extended range MS $C(V)$ and G(V) measurements, P. Kuczer, H. O. Hook, and A. M. Goodman, Nat. Bur. Stand. (U.S.), Spec. Publ. 400-41, 69 pages (Dec. 1977) SN003-003-01869-4.

SP400-42. Semiconductor measurement technology: Reliability technology for cardiac pacemakers II-A workshop report. Proceedings of a Workshop held at the National Bureau of Standards, Gaithersburg, MD, July 19-20, 1976, H. A. Schafft, Ed., Nat. Bur. Stand. (U.S.), Spec. Publ. 400-42, 45 pages (Aug. 1977) SN003-003-01815-5.

Process validation wafers for use in procuring reliable custom integrated circuit chips, M. G. Buehler, SP400-42, pp. 5-8 (Aug. 1977).

High reliability microcircuit procurement controls, $W$. J. Kitchen, Jr. and T. H. Brown, SP400-42, pp. 9-12 (Aug. 1977).

Mechanisms of dendritic growth, R. P. Frankenthal, SP4OO42, pp. 12-13 (Aug. 1977).

Use of epoxies in hybrid microcircuits, R. F. Redemske, SP400-42, pp. 14-15 (Aug. 1977).

Microcalorimetric study of cardiac pacemakers and batteries, E. J. Prosen and J. C. Colbert, SP400-42, pp. 16-18 (Aug. 1977).

Statistical methods for estimating the longevity of pacemaker batteries, D. J. Gerrard, SP400-42, pp. 18-19 (Aug. 1977).

Applications and pitfalls of reliability prediction, J. H. Maness and S. Kus, SP400-42, pp. 19-20 (Aug. 1977).

A reliability comparison of semiconductor and microcircuit technologies, H. A. Lauffenburger, SP400-42, pp. 20-22 (Aug. 1977).

Moisture measurement, leak rate, and reliability, R. E. Sulouff, SP400-42, pp. 22-24 (Aug. 1977).

The fundamentals of leak testing for cardiac pacemakers, $\mathrm{S}$. Ruthberg, SP400-42, pp. 25-30 (Aug. 1977).

Pacemaker leads-A physician's view, V. Parsonnet, SP4OO42, pp. 30-32 (Aug. 1977).

The performance of implantable pacing leads-A status report, P. P. Tarjan, SP400-42, pp. 33-37 (Aug. 1977).

SP400-44. Semiconductor measurement technology: Safe operating area limits for power transistors, D. L. Blackburn, Nat. Bur. Stand. (U.S.), Spec. Publ. 400-44, 20 pages (Sept. 1977) SNO03-003-01833-3.

NBSIR 77-1231. Measurement of transistor collector-emitter saturation voltage, K. O. Leedy, 55 pages (June 1977). Order from NTIS as PB267780.
NBSIR 77-1235. Some aspects of using a scanning electron microscope for total dose testing, K. F. Galloway and P. Roitman, 41 pages (Sept. 1977). Order from NTIS as PB273634.

NBSIR 77-1249. Measurement techniques for high power semiconductor materials and devices: Annual report, January 1 to December 31, 1976, D. L. Blackburn, R. Y. Koyama, F. F. Oettinger, and G. J. Rogers, 94 pages (May 1977). Order from NTIS as PB269345.

16853. Novotny, D. B., Photoresist exposure-Measurement and control, Proc. Developments in Semiconductor Microlithography, San Jose, CA, June 1-3, 1976, 80, 9-13 (Society of Photo-Optical Engineers, Palos Verdes Estates, CA, 1976).

16855. Buehler, M. G., David, J. M., Mattis, R. L., Phillips, W. E., Thurber, W. R., Planar test structures for characterizing impurities in silicon, (Extended Abstract), Proc. Electrochemical Society Spring Meeting, Toronto, Canada, May 11-16, 1975, 75-1, Abstract No. 171, 403-404 (May 1975).

16884. Harman, G. G., The use of acoustic emission in a test for beam lead bond integrity, Proc. 14th Annual IEEE Reliability Physics Symp., Las Vegas, NV, Apr. 20-22, 1976, pp. 86-97 (1976).

16889. Mayo, S., Galloway, K. F., Leedy, T. F., Radiation dose due to electron-gun metallization systems, (Proc. IEEE Annual Conf. on Nuclear and Space Effects, San Diego, CA, July 27-30, 1976), IEEE Trans. Nucl. Sci. NS-23, No. 6, 1875-1880 (Dec. 1976).

16891. Leedy, K. O., A bibliography on electron beam induced current analysis of semiconductor devices, Solid State Tech. 20, No. 2, 45-48 (Feb. 1977).

16893. Blackburn, D. L., Rubin, S., Rogers, G. J., Measurements of power transistor thermal instabilities, stable hotspots, and second-breakdown, (Proc. Int. Electron Devices Meeting, Washington, DC, Dec. 6-8, 1976), IEDM Tech. Digest, pp. 151-154 (1976).

16894. Bullis, W. M., Galloway, K. F., Semiconductor electronics at the National Burcau of Standards: Programs and opportunities, Proc. 2d IEEE (G-PHP)/ISHM University/Industry/Government Microelectronics Symp., University of New Mexico, Albuquerque, NM, Jan. 3-5, 1977, Session IX, pp. 11 (1977).

16935. Ruthberg, S., Gas infusion into doubled hermetic enclosures, IEEE Trans. Parts, Hybrids, Packaging PHP-13, No. 2, 110-116 (June 1977).

16939. Mayo, S., Evans, W. H., Development of sodium contamination in semiconductor oxidation atmospheres at 1000 ${ }^{\circ} \mathrm{C}$, J. Electrochem. Soc. 124, No. 5, $780-785$ (May 1977).

16942. Buehler, M. G., Thurber, W. R., Measurement of the resistivity of a thin square sample with a square four-probe array, Solid-State Electron. 20, No. 5-B, $403-406$ (1977).

16943. Ruthberg, S., Hermetic test procedures and standards for semiconductor electronics, (Proc. Symp. on Nondestructive Testing Standards, Gaithersburg, MD, May 19-21, 1976), Am. Soc. Test. Mater. Spec. Tech. Publ. 624, Nondestructive Testing Standards-A Review, H. Berger, Ed., pp. 246-259 (June 1977).

16971. Galloway, K. F., Leedy, K. O., Keery, W. J., Electronbearn-induced currents in simple device structures, Proc. 26th Electronic Components Conf., San Francisco, CA, April 26-28, 1976, pp. 257-262 (1976).

17139. Ehrstein, J. R., Effect of specimen preparation on the calibration and interpretation of spreading resistance measurements, (Proc. Third Int. Symp. on Silicon Materials Science and Technology, Philadelphia, PA, May 9-13, 1977), Papei in Semiconductor Silicon 1977, H. R. Huff and E. Sirtl, Eds., 77-2, 377-386 (Electrochemical Society, Inc., Princeton, NJ, 1977).

17140. Bullis, W. M., Vieweg-Gutberlet, F. G., Current trends in silicon characterization techniques, (Proc. Third Int. Symp. on Silicon Materials Science and Technology, Philadelphia, 
PA, May 9-13, 1977), Paper in Semiconductor Silicon 1977, H. R. Huff and E. Sirtl, Eds., 77-2, 360-366 (Electrochemical Society, Inc., Princeton, NJ, 1977).

17147. Li, S. S., Thurber, W. R., The dopant density and temperature dependence of electron mobility and resistivity in $n$ type silicon, Solid-State Electron. 20, 609-616 (1977).

17150. Harman, G. G., The use of acoustic emission in a test for beam-lead, TAB, and hybrid chip capacitor bond integrity, IEEE Trans. Parts, Hybrids, \& Packaging PHP-13, No. 2, 116-127 (June 1977).

17164. Sawyer, D. E., Berning, D. W., Lewis, D. C., Laser scanning of active integrated circuits and discrete semiconductor devices, Solid State Technol., pp. 37-41, 48 (June 1977).

17165. David, J. M., Buehler, M. G., A numerical analysis of various cross sheet resistor test structures, Solid-State Electron. 20, No. 6, 539-543 (1977).

17239. Jesch, R. L., Bailey, R. A., Tausch, H. J., Characterization of a HW probe for integrated circuits measurements, Proc. Government Micro-circuit Applications Conf., Boulder, CO, June 25-27, 1974, pp. 120-121 (University of Colorado, Boulder, CO, 1974).

17328. Mattis, R. L., Buehler, M. G., A new method for calculating background dopant density from p-n junction capacitance-voltage measurements, J. Electrochem. Soc. 124, No. 12, 1918-1923 (Dec. 1977).

17329. Novotny, D. B., Sensitometry of photoresists for microelectronics, (Proc. SPSE Symp., New York, NY, Sept. 16-17, 1976), Photographic Sci. Eng. 21, No. 6, 351-355 (Nov./Dec. 1977).

17330. Russell, T. J., Leedy, T. F., Mattis, R. L., A comparison of electrical and visual alignement test structures for evaluating photomask alignment in integrated circuit manufacturing, Proc. Int. Electron Devices Meeting, Washington, DC, Dec. 57, 1977, pp. 7A-7F (Institute of Electrical and Electronics Engineers, New York, NY, 1977).

17331. Ruthberg, S., Neff, G. R., Martin, B. D., Radioisotope hermetic test precision, Proc. 1977 Int. Microelectronics Symp., Baltimore, MD, Oct. 24-26, 1977, pp. 131-137 (International Society for Hybrid Microelectronics, Montgomery, AL, 1977).

17342. Buehler, M. G., Dopant profiles determined from enhancement mode MOSFET D-C measurements, Appl. Phys. Letc. 31, 848-850 (Dec. 1977).

17345. Blackburn, D. L., Koyama, R. Y., Oettinger, F. F., Rogers, G. J., Measurement techniques for high power semiconductor materials and devices: Annual report for the period January 1, 1976-1December 31, 1976, Energy Conservation CONS/3800-2, 92 pages (National Technical Information Services, Springfield, VA, 1977).

\section{Energy Conservation and Production}

Fundamentals of building heat transfer, T. Kusuda, J. Res. Nat. Bur. Stand. (U.S.), 82, No. 2, 97-106 (Sept.-Oct. 1977).

H121. Waste heat management guidebook, K. G. Kreider and M. B. McNeil, Eds., Nat. Bur. Stand. (U.S.), Handb. 121, 174 pages (Feb. 1 977) SN003-003-01669-1.

SP468. MIPG-Prevention of failures in coall conversion systems. Proceedings of the 24th Meeting of the Mechanical Failures Prevention Group, held at Battelle, Columbus Laboratories, Columbus, OH, Apr. 21-23, 1976, T. R. Shives and W. A. Willard, Eds., Nat. Bur. Stand. (U.S.), Spec. Publ. 468, 233 pages (Apr. 1977) SN003-003-01760-4.

Reliability, problems in cosel gesification and liquefection, $\mathbf{H}$. E. Frankel and J. R. Ogren, SP468, pp. 3-25 (Apr. 1977).

Economics of failures in energy generation systems. M. E. Lapides, SP468, pp. 27-39 (Apr. 1977).

Demonstration of a reliability methodology using two coal conversion plant models, J. R. Hoffman, W. T. Long, and R. L. Williams, SP468, pp. $41-48$ (Apr. 1977).
Critical materials problems in coal conversion, $R$. W. Staehle, SP468, pp. 50-78 (Apr. 1977).

The AGA-ERDA-MPC program on materials for the gastication of coal, A. O. Schaefer, SP468, pp. 80-92 (Apr. 1977).

Failure analysis of components from coal-gasification pllot plants, S. Greenberg and K. Natesan, SP468, pp. 97-106 (Apr. 1977).

Erosion problems in letdown valves, J. J. Mueller, SP468, pp. 107-118 (Apr. 1977).

ERDA information center for failure prevention in fossil energy plants, J. H. Smith and W. A. Willard, SP468, pp. 121-128 (Apr. 1977).

Steel plant coke-ovens: An energy conversion process with warpage problems, H. W. Lownie, Jr. and A. O. Hoffman, SP468, pp. 131-133 (Apr. 1977).

Selection of materials used in coal gasification plants, $M$. A. H. Howes, SP468, pp. 137-142 (Apr. 1977).

Particle erosion measurements on metals at elevated temperatures, L. K. Ives, J. P. Young, and A. W. Ruff, SP468, pp. 145-157 (Apr. 1977).

High-temperature corrosion, K. Natesan, SP468, pp. 159170 (Apr. 1977).

Development on nondestructive evaluation methods for coalconversion systems, W. A. Ellingson, G. C. Stanton, and N. P. Lapinski, SP468, pp. 172-181 (Apr. 1977).

Potential materials problems in coal gasification systems, $A$. M. Hall, SP468, pp. 183-188 (Apr. 1977).

Low ductility, high temperature failure of austenitic materials, F. B. Hamel, SP468, p. 191 (Apr. 1977).

The SRC plant, L. G. Samuels, SP468, pp. 192-194 (Apr. 1977).

Hligh Btu gasification pilot plant experience, A. J. Mac Nab, SP468, pp. 195-198 (Apr. 1977).

$\mathrm{CO}_{2}$ acceptor proces, C. A. Schulz, SP468, pp. 199-201 (Apr. 1977).

Consol pilot plant materials problems, J. F. Leterle, SP468, pp. 202-204 (Apr. 1977).

The synthane coal to gas pilot plant, R. Lewis, SP468, pp. 205-206 (Apr. 1977).

SP488. Measurements and standards for recycled all. Proceedings of a Workshop held at the National Bureau of Standards, Gaithersburg, MD, Nov. 22-23, 1976, D. A. Becker, Ed., Nat. Bur. Stand. (U.S.), Spec. Publ. 488, 140 pages (Aug. 1977) SN003-003-01831-7.

The NBS workshop objectives and the NBS recycled oil program, D. A. Becker, SP488, pp. 7-11 (Aug. 1977).

Burning used oil at a military installation, C. F. Schwarz, SP488, pp. 17-18 (Aug. 1977).

Fuel oil and the Defense Supply Agency, E. J. French, SP488, p. 19 (Aug. 1977).

Fuel oil specifications, B. L. Weller, SP488, pp. 21-26 (Aug. 1977).

Automotive crankcase drainings used for fuel, B. R. Williams, SP488, pp. 27-31 (Aug. 1977).

ASTM test methods for industrial oils, L. B. Sargent, Jr., SP488, pp. 37-38 (Aug. 1977).

Industrial ofl recycling at Chrysler, W. Katzenstein, SP488, pp. 39-40 (Aug. 1977).

Industrial oils: Descriptions, additives, and test methods, $J$. W. Swain, Jr., SP488, pp. 41-43 (Aug. 1977).

The use of recycled industrial and hydraulic olls at Ford, J. W. Hunt, SP488, pp. 45-46 (Aug. 1977).

Industrial lubricants, reclaimed olk, and test methods, C. J. Flake, SP488, pp. 47-49 (Aug. 1977).

DOD experiences in testing lube oils, T. C. Bowen, SP488, pp. 55-56 (Aug. 1977).

Waste oil recycling-An idea whose time has come, C. J. Thompson and M. L. Whisman, SP488, pp. 57-60 (Aug. 1977). 
Comments on additive response to different base oils, $T$. $P$. Sands, SP488, pp. 61-62 (Aug. 1977).

Activities of the ASTM used oil task force, W. W. Crouse, Jr., SP488, p. 63 (Aug. 1977).

Activities of the API used oil task force, B. W. Hutchings, SP488, pp. 65-67 (Aug. 1977).

Chevron research's experiences with re-refined oils, F. Sam, SP488, pp. 69-71 (Aug. 1977).

Engine sequence tests for determination of lube oil quality,

R. H. Kabel, SP488, pp. 73-75 (Aug. 1977).

Screening tests on lube oils, P. A. Asseff, SP488, pp. 7778 (Aug. 1977).

Laboratory testing on re-refined motor oil, B. R. Williams, SP488, pp. 79-87 (Aug. 1977).

Diesel lube oil test methods, J. A. MacLean, SP488, pp. 89-94 (Aug. 1977).

Recent used oil legislation, H. B. Kaufman, SP488, pp. 101 102 (Aug. 1977).

The lead problem associated with recycled oil, J. S. Cooper, SP488, pp. 103-104 (Aug. 1977).

Factors affecting used oil recovery/utilization and effects of proposed policy alfernatives, S. P. Maltezou, SP488, pp. 105107 (Aug. 1977).

Energy conservation aspects of re-refined oil, G. J. Mascetti, SP488, pp. 109-113 (Aug. 1977).

Marketing barriers for recycled oil, P. M. Cukor, SP488, pp. 115-121 (Aug. 1977).

SP489. Abstracted reports and articles of the HUD Modular Integrated Utility Systems (MIUS) Program, J. D. Ryan and B. Reznek, Eds., Nat. Bur. Stand. (U.S.), Spec. Publ. 489, 153 pages (Aug. 1977) SN003-003-01830-9.

SP491. Thermal analysis-Human comfort-Indoor environments. Proceedings of a Symposium held at the National Bureau of Standards, Gaithersburg, MD, Feb. 11, 1977, B. W. Mangum and J. E. Hill, Eds., Nat. Bur. Stand. (U.S.), Spec. Publ. 491, 197 pages (Sept. 1977) SN003-003-01849-0.

Thermal comfort in indoor environments, $P$. O. Fanger, SP491, pp. 3-17 (Sept. 1977).

The use of modeling human responses in the analysis of thermal comfort of indoor environments, N. Z. Azer and S. Hsu, SP491, pp. 18-40 (Sept. 1977).

Industrial heat stress monitoring, F. N. Dukes-Dobos, SP491, pp. 41-51 (Sept. 1977).

Establishment of the boundaries to comfort by analyzing discomfort, R. F. Goldman, SP491, pp. 52-64 (Sept. 1977).

Heat stress, work function and physiological heat exposure limits in man, A. R. Dasler, SP491, pp. 65-92 (Sept. 1977).

Effect of energy conservation guidelines on comfor, acceptability and health, A. P. Gagge and R. G. Nevins, SP491, pp. 93-116 (Sept. 1977).

Radiation measurement for thermal comfort assessment in the built environment, L. G. Berglund, SP491, pp. 117-130 (Sept. 1977).

Experimental analysis of thermal acceptability, R. R. Gonzalez, SP491, pp. 131-151 (Sept. 1977).

Rating of environments for human thermal comfort by "Resultant Surface Temperature," T. H. Benzinger, SP491, pp. 152-168 (Sept. 1977).

Aspects of indoor environments: Tolerable vs comfortable thermal environments, E. R. Buskirk and J. L. Loomis, SP491, Pp. 169-173 (Sept. 1977).

Axsessing productivity decrements in heat and cold: On-site simulation of industrial work in a mobile climate chamber, $D$. P. Wyon, SP491, pp. 174-189 (Sept. 1977).

BSS93. Dynamic performance of a residential air-to-air heat pump, G. E. Kelly and J. Bean, Nat. Bur. Stand. (U.S.), Bldg. Sci. Ser. 93, 18 pages (Mar. 1977) SN003-003-01691-8.

BSS96. Hourly solar radiation data for vertical and horizontal surfaces on average days in the United States and Canada, T.
Kusuda and K. Ishii, Nat. Bur. Stand. (U.S.), Bldg. Sci. Ser. 96, 412 pages (Apr. 1977) SN003-003-01698-5.

BSS97. Evaluation of ventilation requirements and energy consumption in existing New York City school buildings, S. T. Liu, C. M. Hunt, and F. J. Powell, Nat. Bur. Stand. (U.S.), Bldg. Sci. Ser. 97, 69 pages (Apr. 1977) SN003-003-017680.

BSS 104. Window design strategies to conserve energy, S. R. Hastings and R. W. Crenshaw, Nat. Bur. Stand. (U.S.), Bldg. Sci. Ser. 104, 209 pages (June 1977) SN003-003-01794-9.

TN933. An infrared technique for heat-loss measurement, D. $M$. Burch, T. Kusuda, and D. G. Blum, Nat. Bur. Stand. (U.S.), Tech. Note 933, 52 pages (Apr. 1977) SN003-003-01746-9.

TN946. Urea-formaldehyde based foam insulations: An assessment of their properties and performance, W. J. Rossiter, Jr., R. G. Mathey, D. M. Burch, and E. T. Pierce, Nat. Bur. Stand. (U.S.), Tech. Note 946, 92 pages (July 1977) SN003003-01801-5.

NBSIR 74-452. Design and evaluation criteria for energy conservation in new buildings, Staff of the Center for Building Technology, NBS, 107 pages (Revised Feb. 26, 1976). Order from NTIS as PB272511.

NBSIR 76-1088. Estimating the enerzy conservation potential of ventilation control through weather data analysis, T. Kusuda and J. W. Bean, 51 pages (Aug. 1977). Order from NTIS as PB273949.

NBSIR 76-1103. Some institutional factors affecting MUS-A case study and annotated bibliography, J. Elder, 65 pages (June 1977). Order from NTIS as PB268425.

NBSIR 76-1177. Comparison of computer-predicted and observed energy uses in a multi-family high-rise apartment building, J. P. Barnett and S. T. Liu, 37 pages (June 1977). Order from NTIS as PB267829.

NBSIR 76-1178. Air leakage and thermal performance of a MARK III relocatable Lewis building, C. W. Phillips, B. A. Peavy, and M. E. Kuklewicz, 42 pages (Dec. 1976). Order from NTIS as PB264211.

NBSIR 76-1182. The thermal performance of a two-bedroom mobile home, G. J. Teitsma and B. A. Peavy, 104 pages (Jan. 1977). Order from NTIS as PB263883.

NBSIR 77-852. Cryogenic fluids density reference system: Provisional accuracy statement, B. A. Younglove and J. D. Siegwarth, 31 pages (Jan. 1977). Order from NTIS as PB263776.

NBSIR 77-853. Helium research in support of superconducting power transmisxion-Annusl report (July 1975-September 1976), M. C. Jones, V. D. Arp, W. R. Parrish, D. E. Daney, P. R. Ludtke, N. V. Frederick, and B. A. Hands, 99 pages (Feb. 1977). Order from NTIS as PB265076.

NBSIR 77-1207. Performance of the engine-generators used in the Jersey City total enerzy plant, J. B. Coble, M. E. Kuklewicz, and J. H. Hebrank, 22 pages (Mar. 1977). Order from NTIS as PB264427.

NBSIR 77-1210. Equipment maintenance for energy conservation, J. Levy, 56 pages (Feb. 1977). Order from NTIS as PB264297.

NBSIR 77-1237. Transpiration heat transfer in thermal energy storage devices, B. A. Peavy and W. E. Dressler, 31 pages (May 1977). Order from NTIS as PB267281.

NBSIR 77-1243. Performance analysis of the Jersey City total energy site: Interim report, J. Hebrank, C. W. Hurley, J. D. Ryan, W. Obright, and W. Rippey, 175 pages (July 1977). Order from NTIS as PB269517.

NBSIR 77-1259. Building energy conservation programs-A preliminary examination of regulatory activities at the State level, P. W. Cooke and R. M. Eisenhard, 125 pages (June 1977). Order from NTIS as PB268873.

NBSIR 77-1270. Materials for fuel cells, L. H. Bennett, M. I. Cohen, A. L. Dragoo, A. D. Franklin, A. J. McAlister, and K. F. Young, 63 pages (May 1977). Order from NTIS as PB269518. 
NBSIR 77-1272. Intermediate standards for solar domestic hot water systems/HUD initiative, J. K. Holton, et al., 153 pages (July 1977). Order from NTIS as PB271758.

NBSIR 77-1274. Retrofitting an existing wood frame residence for energy conservation-An experimental study, D. M. Burch and C. M. Hunt, 159 pages (July 1977). Order from NTIS as PB269847.

NBSIR 77-1297. State solar energy legislation of 1976: A review of statutes relating to buildings, R. M. Eisenhard, 255 pages (Sept. 1977). Order from NTIS as PB273899.

NBSIR 77-1303. A simplified procedure for calculating the direct components of contrast rendition factor asd equivalent sphere illumination, J. B. Murdoch, 75 pages (Nov. 1977). Order from NTIS as PB274331.

NBSIR 77-1305. Provisional flat plate solar collector testing procedures, Solar Energy Program Team, Center for Building Technology, 56 pages (Sept. 1977). Order from NTIS as PB272500.

NBSIR 77-1307. A review of computer software applicable to the MRUS Program, W. L. Carroll and J. R. Schaefgen, Jr., 102 pages (Oct. 1977). Order from NTIS as PB273175.

NBSIR 77-1309. Three proposed typical house designs for energy conservation research, $S$. $R$. Hastings, 38 pages (Oct. 1977). Order from NTIS as PB274334.

16686. Dikkers, R. D., Development and implementation of standards for solar heating and cooling applications, Proc. Joint Solar Energy Conf. on Sharing the Sun 76 Solar Technology in the Seventies, Winnipeg, Manitoba, Canada, Aug. 15-20, 1976, 1, 83-90 (Pergamon Press, Elmsford, NY, 1976).

16733. Holton, J. K., Interfacing building design and solar energy research and standards, Proc. 1976 Joint Solar Energy Conf., on Sharing the Sun: Solar Technology in the Seventies, Winnipeg, Manitoba, Canada, Aug. 15-20, 1976, 9, 74-82 (Pergamon Press, Elmsford, NY, 1976).

16768. Brown, P. W., Berger, R. L., Clifton, J. R., Frohnsdorff, G., Limitations to fly ash use in blended cements, Proc. 4th Int. Ash Utilization Symp., St. Louis, MO, Mar. 24-25, 1976, pp. 518-529 (Energy Research \& Development Administration, Morgantown, WV, 1976).

16770. Kusuda, T., Energy calculations for energy conservation design of buildings, APEC J., pp. 18-22 (Automated Procedures for Engineering Consultants, Dayton, OH, Winter 1976-1977).

16782. Anderson, W. E., Davis, R. S., Measurement of ac insulation losses at cryogenic temperatures, IEEE Trans. Elec. Insulation El-12, No. 1, $51-54$ (Feb. 1977).

16885. Meyerson, M. R., Appliance labeling and efficiency, Proc. Electro 77 Programs for Energy Conservation, New York, NY, Apr. 19-21, 1977, Paper 33/3, 1-7 (McGregor Warner, Washington, DC, 1977).

16897. Plante, E. R., Olson, C. D., Negas, T., Interaction of $\mathrm{K}_{2} \mathrm{O}$ with slag im open cycle, coal fired MHD, Proc. Sixth Int. Conf. on Magnetohydrodynamic Electrical Power Generation, Washington, DC, June 9-13, 1975, CONF750601-P2, II, 211 218 (1975).

16900. Frederikse, H. P. R., Hosler, W. R., Electrodes and insulators: Design and materials considerations, Proc. 16th Symp. Engineering Aspects of Magnetohydrodynamics (MHD), University of Pittsburgh, Pittsburgh, PA, May 16-18, 1977, pp. IV.4.22-IV.4.28 (Pittsburgh Energy Research Center, U.S. Energy Research and Development Administration, Pittsburgh, PA, 1977).

16901. Hurley, C. W., Kreider, K. G., Applications of thermography in industry, Proc. Third Biennial Infrared Information Exchange, St. Louis, MO, Aug. 24-26, 1976, C. Warren, Ed., pp. 53-59 (AGA Corp., 550 County Ave., Secaucus, NJ, 1977).
16902. Grot, R. A., Harrje, D. T., Johnston, L. C., Application of thermography for evaluating effectiveness of retrofit measures, Proc. Third Biennial Infrared Information Exchange, St. Louis, MO, Aug. 24-26, 1976, C. Warren, Ed., pp. 103-117 (AGA Corp., 550 County Ave., Secaucus, NJ, 1977).

16907. Timmerhaus, K. D., Weitzel, D. H., Economic aspects of U.S. energy independence in the coming decade, (Proc. First Int. Cryogenic Materials Conf., Kingston, Ontario, Canada, July 22-25, 1975), Paper D-1 in Advances in Cryogenic Engineering, K. D. Timmerhaus, R. P. Reed, and A. F. Clark, Eds., 22, 166-179 (Plenum Publ. Corp., New York, NY, 1977).

16922. Chi, J., DEPAF - A computer model for design and performance analysis of furnaces, Proc. Conf. on AIChE-ASME Heat Transfer, Salt Lake City, UT, Aug. 15-17, 1977, pp. 19 (American Society of Mechanical Engineers, New York, NY, 1977).

16923. Benzinger, T. H., Mangurn, B. W., Hill, J. E., The design, construction and operation of a scanning radiometer for measurement of plane radiant temperathre in buildings, (Proc. ASHRAE Semi-annual Meeting, Seattle, WA, June 25-July 1, 1976), ASHRAE Trans. 82, 260-278 (1976).

17006. Parken, W. H., Jr., Beausoliel, R. W., Kelly, G. E., Factors affecting the performance of a residential air-to-air heat pump, (Proc. Symp. on Seasonal Operating Performance of Central Forced Air Heating and Cooling Systems, ASHRAE Annual Meeting, Chicago, IL, Feb. 13-17, 1977), ASHRAE Trans. 83, Pt. 1, 839-849 (1977).

17010. Brown, P., Clifton, J. R., Erergy conservation through the use of waste materials in cement and concrete, Proc. Seminar on Energy and Resource Conservation in the Cement and Concrete Industry, Ottawa, Ontario, Canada, Nov. 8-9, 1976, V. M. Malhotra, E. E. Berry, and T. A. Wheat, Eds., Paper 3.2, pp. 3.2.1-3.2.33 (Canada Centre for Mineral and Energy Technology, Ottawa, Canada, 1977).

17014. Anderson, W. E., Davis, R. S., Mopsik, F. I., Kryder, S. J., Khoury, F., Colson, J. P., Bolz, L. H., Measurements on insulating mmteriais at cryogenic temperatures, Annual Report, Energy Research and Development Administration Energy Conservation Report CONS/2062-1, Part I and Part II, 135 pages (Available from the National Technical Information Service, Springfield, VA, Sept. 1976).

17028. Wiederhorn, S. M., Erasion behavior of ceramies, Proc. Workshop on Ceramics for Energy Applications, Columbus, OH, Nov. 24-25, 1975, CONF-751194, pp. 83-106 (Battelle Columbus Laboratories, Columbus, $\mathrm{OH}, 1975$ ).

17031. Thomson, R. M., Exploring energy choices, Encyclopedia of Energy, D. N. Lapedes, Ed., pp. 25-33 (McGraw-Hill, Inc., New York, NY, 1976).

17062. Burch, D., Ed., Technical guidelines for energy conservetion, AFCEC-TR-77-12, 403 pages (Air Force Civil Engineering Center, Tyndall Air Force Base, FL, June 1977).

17107. Marshall, H. E., Ruegg, R. T., Energy conservation through life-cycle costing, J. Archit. Ed. XXX, No. 3, 42-51 (Feb. 1977).

17108. Lewett, G. P., Evaluation of energy-related inventions, Int. Marketing Info. Series, Comm. News for the Foreign Serv. CNFS Spec. Issue, pp. 7-12 (U.S. Department of Commerce, Domestic \& International Business Administration, Bureau of International Commerce, Washington, DC, Mar./Apr. 1977).

17110. Trechsel, H. R., Research in energy conservation, $J$. Archit. Ed. XXX, No. 3, 31-33 (Feb. 1977).

17111. Gross, J. G., Pielert, J. H., Building standards and codes for energy contservation, J. Archit. Ed. XXX, No. 3, 54-56 (Feb. 1977).

17158. Schneider, S. J., Jr., Materials research for clean utilization of coal: Quarterly progress report, Apr. 1-June 30, 1976, Energy Research and Development Administration FE-1749-8, 73 pages (Available from the National Technical Information Service, Springfield, VA, 1976). 
17159. Schneider, S. J., Jr., Materials research for clean utilization of coal: Quarterly progress report, July 1-Sept. 30, 1976 , Energy Research and Development Administration FE-3800-9, 32 pages (Available from the National Technical Information Service, Springfield, VA, 1976).

17160. Hosler, W. R., Ed., The joint U.S.-U.S.S.R. test of the U.S. MHD electrode system in the U-02 MHD facility (Phase 1), Energy Research and Development Administration Final Report, ERDA-76/154, 262 pages (Available from the $\mathrm{Na}$ tional Technical Information Service, Springfield, VA, 1976).

17176. Miles, L. B., The burning behavior of bonderline fabrics, Proc. 5th Symp. on Textile Flammability, New Orleans, LA, Apr. 20-21, 1977, 33 pages (LeBlanc Research Corp., New Orleans, LA, 1977).

17184. Wan, C. A., Computer simulation of water heater standby loss, Proc. 1977 ASME Winter Annual Meeting, Atlanta, GA, Nov. 27-Dec. 2, 1977, 15 pages (American Society of Mechanical Engineers, United Engineering Center, New York, NY, 1977).

17284. Burch, D. M., Siu, C. I., Powell, F. J., Comparison of the thermal performance of three insulating materials commonly used to retrofit exterior frame walls in existing residences, (Proc. Annual Meeting of Com. B.1, IIF-IIR on Heat and Mass Transfer in Porous Structures, Washington, DC, Sept. 14-16, 1976), Bul. Inst. Int. Froid 2, 151-162 (1976).

17289. Achenbach, P. R., Heldenbrand, J. L., Development of performance-based energy conservation standards for buildings, Proc. Canadian Building Congress on Energy and Buildings, Toronto, Canada, Oct. 25-27, 1976, pp. 1-31 (1976).

17290. Heldenbrand, J. L., Development and application of design performance standards for energy conservation in buildings, Ind. Forum. 8, No. 3, 9-20 (Aug. 1977).

17302. Weber, S. F., Resource impact factors and the optimal energy conservation standard for buildings, Energy Bldgs. 1, No. 2, 1-13 (Oct. 1977).

17335. Burch, D. M., Kusuda, T., An infrared technique for measuring heat loss, Proc. RILEM/ASTM/CIB Symp. on Evaluation of Performance of External Vertical Surfaces of Buildings, Helsinki, Finland, Aug. 28-Sept. 2, 1977, pp. 62-72 (Technical Research Centre of Finland, Helsinki, Finland, 1977).

17340. Kusuda, T., Ellis, W., Vapor condensation in air-pervious insulation, (Proc. Annual Meeting of Com. B.1, IIF-IIR on Heat and Mass Transfer in Porous Structures, Washington, DC, Sept. 14-16, 1976), Bul. Inst. Int. Froid 2, 139-150 (1976).

17341. Kusuda, T., SATG: A useful concept for window heat gain analysis, Proc. RILEM/ASTM/CIB Symp. on Evaluation of Performance of External Vertical Surfaces of Buildings, Helsinki, Finland, Aug. 28-Sept. 2, 1977, pp. 157-167 (Technical Research Centre of Finjand, Helsinki, Finland 1977).

17344. Collins, L. A., Norcross, D. W., Electron momentum transfer cross sections for polar molecules, (Proc. Conf. High Temperature Sciences Related to Open-Cycle, Coal-Fired MHD Systems, Argonne, IL, Apr. 4-6, 1977), Report ANL 77-21, pp. 86-90 (Argonne National Laboratory, Argonne, IL, Aug. 1977).

17347. Hill, J. E., Kelly, G. E., Peavy, B. A., A method of testing for rating thermal storage devices based on thermal performance, Solar Energy 19, 721 -732 (1977).

\section{Engineering, Product and Information Standards}

Monogr. 25, Section 14. Standard x-ray diffiraction powder patterns. Section 14-Data for 68 substances, M. C. Morris, H. F. McMurdie, E. H. Evans, B. Paretzkin, J. H. deGroot, and R. Newberry, Nat. Bur. Stand. (U.S.), Monogr. 25, Sec. 14, 143 pages (Sept. 1977) SN003-003-01842-2.
H123. American National Standard N537; Radiological safety standard for the design of radiographic and fluoroscopic industrial x-ray equipment. (ANSI N537-1976), E. H. Eisenhower, Chairman, ANSl Subcommittee N43-7, Nat. Bur. Stand. (U.S.), Handb. 123, 15 pages (Aug. 1977) SNO03003-01820-1.

SP440. COLOR-Universal language and dictionary of names, K. L. Kelly and D. B. Judd, Nat. Bur. Stand. (U.S.), Spec. Publ. 440, 184 pages (Dec. 1976) SN003-003-01705-1.

SP473. Research and innovation in the building regulatory process. Proceedings of the First NBS/NCSBCS Joint Conference held in Providence, RI, on Sept. 21-22, 1976, in conjunction with the Ninth Annual Meeting of the National Conference of States on Building Codes and Standards (NCSBCS), Inc., P. W. Cooke, Ed., Nat. Bur. Stand. (U.S.), Spec. Publ. 473, 504 pages (June 1977) SN003-003-017752.

Incentives and constraints in building and the regulatory process, U. P. Gauchat and D. L. Schodek, SP473, pp. 17. 33 (June 1977).

How environmental research may affect the technical provisions and enforcement of regulations, S. T. Margulis, SP473, pp. $35-53$ (June 1977).

Interior architecture by consent decree and court order, $W$. Kleeman, Jr. and R. Reeves, SP473, pp. 55-67 (June 1977).

Residential energy consumption: Socio-physical determinants of energy use in single family dwellings, B. M. Morrison, SP473, pp. 69-83 (June 1977).

Avoid tunnel vision in implementation of energy conservation building standards, W. J. van der Meer, SP473, pp. 85 101 (June 1977).

Standards for solar heating and cooling applications, R. D. Dikkers, SP473, pp. 103-112 (June 1977).

Regulatory barriers to the diffusion of innovation: Some evidence from building codes, S. Oster and J. M. Quigley, SP473, Pp. 113-135 (June 1977).

Effectiveness of U.S. municipal design review programs-Preliminary findings, S. Cohn, SP473, pp. 137-187 (June 1977)

Natural environmental carrying capecity and buflding regulation, P. G. Rowe, J. L. Gevirtz, and J. B. Blackburn, Jr., SP473, pp. 189-202 (June 1977).

Decision-aiding communications in the reglatory agency: The partisan uses of technical information, F. T. Ventre, SP473, pp. 203-223 (June 1977).

Oregon's experience in statewide code uniformity-Third year, W. M. Friday, SP473, pp. 225-240 (June 1977).

Regulation and communication in the inplementation of a building code for accessibility to the physically handicapped, T. J. R. Raper, SP473, pp. 241-251 (June 1977).

Catalogue of building safety instruments, R. S. Ferguson and C. C. Gordon, SP473, pp. 259-278 (June 1977).

Performance vs producer-controlled codes, $O$. Richards, SP473, pp. 279-284 (June 1977).

Logical analysis of building code provisions, J. R. Harris, SP473, pp. 285-316 (June 1977).

The evolution of the performance approsech in plumbing, $\mathbf{R}$. S. Wyly, L. S. Galowin, and M. J. Orloski, SP473, pp. 317 348 (June 1977)

A theoretical basis and implementation for computer assisted architectural design evaluation, D. A. Bryant and R. B. Dains, SP473, pp. 349-368 (June 1977).

The development of computer based systems for bullding codes, C. Masterson, SP473, pp. 369-375 (June 1977).

The use of computers and microfilm in the code enforcement program of the Chicago department of buildings, W. J. Burke and R. P. Moran, SP473, Pp. 377-382 (June 1977).

Improved communications between code officials and building design and construction groups through education, C. L. Charriere, SP473, pp. 383-389 (June 1977). 
Regulation and the housing industry, A. Trellis, SP473, pp. 391-396 (June 1977).

Economic impacts of building codes, J. S. McConnaughey, Jr., SP473, pp. 397-419 (June 1977).

Building codes: Preservation and rehabilitation, R. J. Kapsch, SP473, pp. 437-452 (June 1977).

Information structure of building codes and standards for the needs of existing buildings, B. Smith, SP473, pp. $453-489$ (June 1977).

Contractor understanding relative to rehab costs, R. S. Harrington, SP473, pp. $491-497$ (June 1977).

SP483. Index of U.S. nuclear standards, W. J. Slattery, Nat. Bur. Stand. (U.S.), Spec. Publ. 483, 127 pages (Aug. 1977) SNO03-003-01822-8.

FIPS PUB 10-2. Countries, dependencies, and areas of special sovereignty, H. E. McEwen, Standards Coordinator, Nat. Bur. Stand. (U.S.), Fed. Info. Process. Stand. Publ. (FIPS PUB) 10-2, 31 pages (Mar. 1977).

FIPS PUB 11-1. Dictionary for information processing, J. Walkowicz, Standards Coordinator, Nat. Bur. Stand. (U.S.), Fed. Info. Process. Stand. Publ. (FIPS PUB) $11-1,4$ pages (Sept. 1977).

FIPS PUB 16-1. Bit sequencing of the Code for Information Interchange in serial-by-bit data transmission, G. Clark, Standards Coordinator, Nat. Bur. Stand. (U.S.), Fed. Info. Process. Stand. Publ. (FIPS PUB) 16-1, 4 pages (1977).

FIPS PUB 17-1. Character structure and character parity sense for serial-by-bit data communication in the Code for Information Interchange, G. Clark, Standards Coordinator, Nat. Bur. Stand. (U.S.), Fed. Info. Process. Stand. Publ. (FIPS PUB) 17-1, 4 pages (1977).

FIPS PUB 18-1. Character structure and character parity sense for parallel-by-bit data communication in the code for information interchange, G. Clark, Standards Coordinator, Nat. Bur. Stand. (U.S.), Fed. Info. Process. Stand. Publ. (FIPS PUB) 18-1, 4 pages (1977).

FIPS PUB 22-1. Synchronous signaling rates between data terminal and data communication equipment, G. Clark, Standards Coordinator, Nat. Bur. Stand. (U.S.), Fed. Info. Process. Stand. Publ. (FIPS PUB) 22-1, 4 pages (1977).

FIPS PUB 42-1. Guidelines for benchmarking ADP systems in the competitive procurement enviroment, J. F. Wood, Ed., Nat. Bur. Stand. (U.S.), Fed. Info. Process. Stand. Publ. (FIPS PUB) 42-1, 27 pages (May 1977).

FIPS PUB 46. Data Encryption Standard, D. K. Branstad, Ed., Nat. Bur. Stand. (U.S.), Fed. Info. Process. Stand. Publ. (FIPS PUB) 46, 17 pages (1977).

FIPS PUB 47. Federal Standard COBOL Pocket Guide, Nat. Bur. Stand. (U.S.), Fed. Info. Process. Stand. Publ. (FIPS PUB) 47, 37 pages (1977).

FIPS PUB 48. Guidelines on evaluation of techniques for automated personal identification, P. Meissner, Nat. Bur. Stand. (U.S.), Fed. Info. Process. Stand. Publ. (FIPS PUB 48), 22 pages (Apr. 1977).

FIPS PUB 49. Guideline on computer performance management: An introduction, D. M. Conti, Nat. Bur. Stand. (U.S.), Fed. Info. Process. Stand. Publ. (FIPS PUB) 49, 14 pages (1977).

PS67-76. Marking of gold filled and rolled gold plate articles other than watchcases. (ANSI/VPS PS 67-76), C. W. Devereux, Technical Standards Coordinator, Nat. Bur. Stand. (U.S.), Prod. Stand. 67-76, 6 pages (Aug. 1977) SN003-00301813-9.

PS68-76. Marking of articles made of silver in combination with gold. (ANSI/VPS PS 68-76), C. W. Devereux, Technical Standards Coordinator, Nat. Bur. Stand. (U.S.), Prod. Stand. 68-76, 6 pages (Sept. 1977) SNOO3-003-01854-6.

PS69-76. Marking of articles made wholly or in part of platinum. (ANSI/VPS PS 69-76), C. W. Devereux, Technical Standards Coordinator, Nat. Bur. Stand. (U.S.), Prod. Stand. 69-76, 6 pages (Sept. 1977) SN003-003-01851-1.
PS70-76. Marking of articles made of karat gold. (ANSI/VPS PS 70-76), C. W. Devereux, Technical Standards Coordinator, Nat. Bur. Stand. (U.S.), Prod. Stand. 70-76, 6 pages (Sept. 1977) SN003-003-01853-8.

PS71-76. Marking of jewelry and novelties of silver. (ANS1/VPS PS 71-76), C. W. Devereux, Technical Standards Coordinator, Nat. Bur. Stand. (U.S.), Prod. Stand. 71-76, 4 pages (Aug. 1977) SN003-003-01852-0.

PS72-76. Toy Safety. (ANS1/VPS PS 72-76), J. M. Tascher, Technical Standards Coordinator, Nat. Bur. Stand. (U.S.), Prod. Stand. 72-76, 30 pages (Jan. 1977) SN003-003-017027.

PS73-77. Carbongted soft drink bottles. (ANSI/VPS PS 73-77), C. W. Devereux, Technical Standards Coordinator, Nat. Bur. Stand. (U.S.), Prod. Stand. 73-77, 11 pages (Nov. 1977) SN003-003-01 877-5.

TN948. Tabulation of voluntary standards and certification programs for consumer products, W. J. Slattery, Nat. Bur. Stand. (U.S.), Tech. Note 948, 187 pages (June 1977) SN003-003$01779-5$.

\section{Environmental Studies: Pollution Measurement}

Photodecompasition of chloromethanes adsorbed on silica surfaces, P. Ausloos, R. E. Rebbert, and L. Glasgow, J. Res. Nat. Bur. Stand. (U.S.), 82, No. 1, 1-8 (July-Aug. 1977).

SP464. Methods and standards for environmental measurement. Proceedings of the 8th Materials Research Symposium held at the National Bureau of Standards, Gaithersburg, MD 20234, Sept. 20-24, 1976, W. H. Kirchhoff, Ed., Nat. Bur. Stand. (U.S.), Spec. Publ. 464, 659 pages (Nov. 1977) SNO03-003-01 704-3.

Accuracy-An industrial viewpoint, W. O. Fitzgibbons, SP464, pp. 3-8 (Nov. 1977).

Ultraviolet photometer for ozone calibration, A. M. Bass, A. E. Ledford, Jr., and J. K. Whittaker, SP464, pp. 9-13 (Nov. 1977).

Accuracy of ozone calibration methods, R. J. Paur, SP464, pp. $15-19$ (Nov. 1977).

Interrelationships between primary calibration standards for nitric oxide, nitrogen dioxide and ozone as applied to test gas atmospheres generated by gas phase titration, D. G. Muldoon and A. M. Majahad, SP464, pp. 21-35 (Nov. 1977).

An analysis of the measurement accuracy and validity of results from the charcoal tube sampling technique, G. Moore, SP464, pp. 37-42 (Nov. 1977).

Achieving accuracy in environmental measurements using activation analysis, D. A. Becker, SP464, pp. 43-46 (Nov. 1977).

A comparison of factors affecting accuracy in atomic emission and atomic absorption spectrometry using a graphite furnace for trace metal analysis in water, M. S. Epstein, T. C. Rains, and T. C. O'Haver, SP464, pp. 47-51 (Nov. !977).

Improved accuracy in background corrected atomic absorption spectrometry, A. T. Zander and T. C. O'Haver, SP464, pp. 53-59 (Nov. 1977).

Standard addition uses and limitations in spectrophotometric analysis, R. Klein, Jr. and C. Hach, SP464, pp. 61-66 (Nov. 1977).

Unmet needs in the analysis of trace organics in water, W. T. Donaldson, SP464, pp. 69-72 (Nov. 1977).

GCIR-A versatile and powerful tool for analysis of pollutants, L. V. Azarraga, SP464, pp. $73-74$ (Nov. 1977).

The MSDC/EPA/NIH mass spectral search system, S. R. Heller, SP464, pp. 75-80 (Nov. 1977).

Methods for analysis of trace levels $(\mu \mathrm{g} / \mathrm{kg}$ ) of hydrocarbons in the marine environment, S. N. Chesler, B. H. Gump, H. S. Hertz, W. E. May, and S. A. Wise, SP464, pp. 81-85 (Nov. 1977). 
Potential carcinogens in water: GC/MS analysis, R. A. Hites, SP464, pp. 87-89 (Nov. 1977).

A new simple method for the recovery of trace organics from water, T. D. Kaczmarek, SP464, pp. 91-96 (Nov. 1977).

Determination of trace organic pollutants in water by spectrophotofluorescence after treatment with activated carbon, $J$. G. Montalvo, Jr. and C. G. Lee, SP464, pp. 97-100 (Nov. 1977).

Polyurethane foam plugs for concentration of trace quantities of benzo(a)pyrene from water, J. Saxena, J. Kozuchowski, and D. K. Basu, SP464, pp. 101-104 (Nov. 1977).

Thousands of metal analyses per man day-A reality In U.S. EPA's central regional laboratory: Multielement (23) analysis by an inductively coupled argon plasma atomic emission system (ICAP-AES), R. J. Ronan and G. Kunselman, SP464, pp. 107-111 (Nov. 1977).

Multielement analysis of river water, R. Schelenz, SP464, pp. 113-120 (Nov. 1977).

Multielement analysis in rainwater, J. G. van Raaphorst, J. Slanina, D. Borger, and W. A. Lingerak, SP464, pp. 121-123 (Nov. 1977).

Quantitative multi-element analysis of environmental samples by x-ray nuorescence spectrometry, P. A. Pella, K. Lorber, and K. F. J. Heinrich, SP464, pp. 125-127 (Nov. 1977).

Multielement analysis of air and water pollutants in gold mines by thermal and epithermal neutron activation, C. S. Erasmus, J. Sargeant, J. P. F. Sellschop, and J. I. W. Watterson, SP464, pp. 129-136 (Nov. 1977).

A multielement-direct reading method for the spectral andysis of sediment leachates, M. M. Moselhy, D. W. Boomer, J. N. Bishop, and P. L. Diosady, SP464, pp. 137-150 (Nov. 1977).

High efficlency solvent extraction of trace elements in aqueous media with bexafluoracetylacetone, M. Janghorbani, $M$. Ellinger, and K. Starke, SP464, pp. 151-156 (Nov. 1977).

Determination of trace and minor elements in the combustible fraction of urban refuse, W. J. Campbell, H. E. Marr, Ill, and S. L. Law, SP464, pp. 157-161 (Nov. 1977).

Physical characterization of aerosols, K. T. Whitby, SP464, pp. 165-173 (Nov. 1977).

Measurement of aerosol size distribution with a particle doppler shift spectrometer, I. Chabay, SP464, pp. 175-178 (Nov. 1977).

Instrumental analysis of light element compasition of atmospheric aerosols, E. S. Macias, SP464, pp. 179-188 (Nov. 1977).

X-R-D analysis of airborne asbestos preparation of calibration standards, M. Fatemi, E. Johnson, L. Birks, J. Gilfrich, and R. Whitlock, SP464, pp. 189-190 (Nov. 1977).

Respirable ambient aerosol mass concentration measurement with a battery-powered piezobalance, G. J. Sem, SP464, pp. 191-197 (Nov. 1977).

A cascade impaction instrument using quartz crystal microbalance sensing elements for "Real-Time" particle size distribution studies, D. Wallace and R. Chuan, SP464, pp. 199-211 (Nov. 1977).

A limitation on electrical measures of aerosols, W. H. Marlow, SP464, pp. 213-218 (Nov. 1977).

The use of a modified beta density function to characterize particle size distributions, A. S. Goldfarb and J. W. Gentry, SP464, pp. 219-226 (Nov. 1977).

In-situ monitoring with ion-selective electrodes-Advantages and pltfalls, or what the instructions didn't say, R. A. Durst, SP464, pp. 229-232 (Nov. 1977).

Problems of mercury determination in water samples, $\mathrm{S}$. Yamazaki, Y. Dokiya, and K. Fuwa, SP464, pp. 233-235 (Nov. 1977).
Sampling for water quality, W. R. Curtis, SP464, pp. 237 244 (Nov. 1977).

Monitoring bacterial survival in seawater using a diffusion chamber apparatus in situ, G. J. Vasconcelos, SP464, pp. 245-247 (Nov. 1977).

Clean laboratory methods to achieve contaminant-free processing and determination of ultra-trace samples in marine environmental studies, C. S. Wong, W. J. Cretney, J. Piuze, and P. Christensen, SP464, pp. 249-258 (Nov. 1977).

A modified procedure for determination of oil and grease in effluent waters, G. M. Hain and P. M. Kerschner, SP464, pp. 259-261 (Nov. 1977).

Variability of trace metals in bed sediments of the Po river: Implications for sampling, M. T. Ganzerli-Valentini, V. Maxia, S. Meloni, G. Queirazza, and E. Smedile, SP464, pp. 263-273 (Nov. 1977).

Application of laser technology to atmospheric monitoring, A. Mooradian, SP464, pp. 277-286 (Nov. 1977).

Laser monitoring techniques for trace gases, W. A. McClenny and G. M. Russwurm, SP464, pp. 287-290 (Nov. 1977).

Long-path monitoring with tunable lasers, E. D. Hinkley and R. T. Ku, SP464, pp. 291-294 (Nov. 1977).

Development of a two frequency downward looking airborme lidar system, J. A. Eckert, D. H. Bundy, and J. L. Peacock, SP464, pp. 295-300 (Nov. 1977).

Remote analysis of aerosols by differential scatter (disc) lidar systems, M. L. Wright, J. B. Pollack, and D. S. Colburn, SP464, pp. 301-303 (Nov. 1977).

Dial systems for monostatic sensing of atmospheric gases, $\mathrm{E}$. R. Murray, J. E. van der Laan, J. G. Hawley, R. D. Hake, Jr., and M. F. Williams, SP464, pp. 305-314 (Nov. 1977).

Coherent anti-Stokes Raman scattering in gases, J. J. Barrett, SP464, pp. 315-316 (Nov. 1977).

Highly selective, quantitative measurement of atmospheric pollutants using carbon monoxide and carbon dioxide lasers, D. M. Sweger, S. M. Freund, and J. C. Travis, SP464, pp. 317-320 (Nov. 1977).

Chemical characterization of aerosols: Progress and problems, W. E. Wilson, SP464, pp. 323-325 (Nov. 1977).

Detection of individual submicron sulfate particles, $Y$. Mamane and R. G. de Pena, SP464, pp. 327-334 (Nov. 1977).

An analysis of urban plume perticulates collected on Anderson 8-stage impactor stages, P. A. Russell, SP464, pp. 335336 (Nov. 1977).

Size discrimination and chemical composition of amblent irborne sulfate particles by diffusion sampling, $R$. L. Tanner and W. H. Marlow, SP464, pp. 337-342 (Nov. 1977).

The Identification of individual microparticles with a new micro-Raman spectrometer, E. S. Etz and G. J. Rosasco, SP464, pp. 343-346 (Nov. 1977).

A compact $x$-ray fluorescence sulfur analyzer, L. S. Birks, J. V. Gilfrich, and M. C. Peckerar, SP464, pp. 347-349 (Nov. 1977).

The x-ray Identification and semi-quantification of toxic lead compounds emitted into air by smelting operations, P. F. Lott and R. L. Foster, SP464, pp. 351-366 (Nov. 1977).

Flameless atomic absorption determinations of cadmium, lead and manganese In particle size fractionated aerosols, $M$. E. Peden, SP464, pp. 367-378 (Nov. 1977).

Amblent air quality monitoring, G. B. Morgan, SP464, Pp. 381-385 (Nov. 1977).

Applications of remote monitoring techniques in air enforcement programs, F. J. Biros, SP464, pp. 387-389 (Nov. 1977).

Individual air pollution monitors, S. C. Morris and M. G. Morgan, SP464, pp. 391-392 (Nov. 1977).

Intercalibration of nitrlc oxide/nitrogen dioxide/ozone monitors, D. H. Stedman and R. B. Harvey, SP464, pp. 393-396 (Nov. 1977). 
A reactive gas generator, W. Tsang and J. A. Walker, SP464, pp. 397-403 (Nov. 1977).

Semiconductor gas sensor equations for predicting performance characteristics, S. M. Toy, SP464, pp. 405-414 (Nov. 1977).

Monitoring nonmethane hydrocarbons in the atmosphere by photoionization, J. N. Driscoll, SP464, pp. 415-417 (Nov. 1977).

A study of vertical diffusion in the atmosphere using airborme gas chromatography and numerical modelling, R. S. Crabbe, SP464, pp. $419-433$ (Nov. 1977).

In situ quantitation of background halofluorocarbon levels, L. Elias, SP464, pp. 435-438 (Nov. 1977).

Origin and residence times of atmospheric pollutants: Application of ${ }^{14} \mathrm{C}$, L. A. Currie and R. B. Murphy, SP464, Pp. $439-447$ (Nov. 1977).

Chemical characterization of inorganic and organometallic constituents, R. S. Braman, SP464, pp. $451-458$ (Nov. 1977).

Analytical techniques for the study of the distribution and speciation of heavy metals in aquatic systems, H. J. Tobschall, N. Lawkowski, and K. Kritsotakis, SP464, pp. 459-460 (Nov. 1977).

Inorganic speciation of copper in estuarine environments, $D$. Burrell and M. L. Lee, SP464, pp. 461-465 (Nov. 1977).

Use of ion-specific electrodes in studying heavy metal transformation in aquatic ecosystem, S. Ramamoorthy and D. J. Kushner, SP464, pp. 467-471 (Nov. 1977).

Electrochemical studies of the methylmercury cation, R. A. Durst, F. E. Brinckman, K. L. Jewett, and J. E. Doody, SP464, pp. 473-483 (Nov. 1977).

An element-sperific technique for the analysis of organometallic compounds, Y. K. Chau and P. T. S. Wong, SP464, pp. 485-490 (Nov. 1977).

Chromatography-atomic spectroscopy combinations. Applications to metal species identification and determination, D. A. Segar and A. Y. Cantillo, SP464, pp. $491-493$ (Nov. 1977).

Changes in the chemical speciation of arsenic following ingestion by man, E. A. Crecelius, SP464, pp. 495-496 (Nov. 1977).

The determination of lead in aqueous solutions by the Delves cup technique and flameless atomic absorption spectrometry, H. J. Issaq, SP464, pp. 497-500 (Nov. 1977).

The status of reference materials for environmental analysis,

J. K. Taylor, SP464, pp. 503-507 (Nov. 1977).

Reference type samples for water/waste anaiyses in EPA, J. A. Winter, SP464, pp. 509-513 (Nov. 1977).

The preparation and analysis of trace elements in water standard reference material, J. R. Moody, H. L. Rook, P. J. Paulsen, T. C. Rains, 1. L. Barnes, and M. S. Epstein, SP464, pp. 515-518 (Nov. 1977).

The standard fineparticle, B. H. Kaye, SP464, pp. $519-526$ (Nov. 1977).

Thin film standards for $x$-ray and proton induced $x$-ray furorescence, D. N. Breiter, P. A. Pella, and K. F. J. Heinrich, SP464, pp. 527-529 (Nov. 1977).

Reference materials for automotive emissions testing, T. G. Eckman, SP464, pp. 531-534 (Nov. 1977).

Long term investigation of the stability of gaseous standard reference materials, E. E. Hughes and W. D. Dorko, SP464, pp. 535-539 (Nov. 1977).

Standard reference materials for the analysis of organic vapors in air, B. C. Cadoff, SP464, pp. 541 -543 (Nov. 1977).

Working reference materials for lead contamination analyses of air and water, A. C. Eckert, Jr. and D. M. Mongan, SP464, Pp. 545-551 (Nov. 1977).

Collaborative texting of air pollution methods, J. B. Clements, SP464, pp. 555-564 (Nov. 1977).
Interlaboratory comparison of neutron activation and atomic absorption analyses of size-classified stack fly ash, $J$. M. Ondov, R. C. Ragaini, R. E. Heft, G. L. Fisher, D. Silberman, and B. A. Prentice, SP464, pp. 565-572 (Nov. 1977).

Collaborative testing of a continuous chemiluminescent method for measurement of nitrogen dioxide In amblent air, J. H. Margeson, P. C. Constant, Jr., M. C. Sharp, and G. W. Scheil, SP464, pp. $573-574$ (Nov. 1977).

Collaborative testing of EPA method II, J. E. Knoll, M. R. Midgett, and G. W. Scheil, SP464, pp. 575-579 (Nov. 1977).

Evaiuation of interlaboratory comparison data by linear regression analysis, D. E. King, SP464, pp. 581-596 (Nov. 1977).

Potentiai enforcement uses of emission test collaborative studies, L. Paley and W. S. Smith, SP464, pp. 597-599 (Nov. 1977).

Ion chromatography-A new analytical technique for the assay of sulfate and nitrate in ambient aerosols, J. D. Mulik, R. Puckett, E. Sawicki, and D. Williams, SP464, pp. 603-607 (Nov. 1977).

The use of a gas chromatograph-microwave plasma detector for the detection of alkyl lead and selenium compounds in the atmosphere, D. C. Reamer, T. C. O'Haver, and W. H. Zoller, SP464, pp. 609-612 (Nov. 1977).

The Dutch Nationnl air pollution monitoring system-A focal and reference point, T. Schneider, SP464, pp. 613-615 (Nov. 1977).

Analysis and calibration techniques for measuring of airborne particulates and gaseous pollutants, 1. Delespaul, $H$. Peperstrate, and T. Rymen, SP464, pp. $617-623$ (Nov. 1977).

Factors governing the contents of metals in water, D. J. Swaine, SP464, pp. 625-626 (Nov. 1977).

Effects of water soluble components of refined oil on the fecundity of the copepod, Tigriopus Japonicus, C. Finney and A. D'Agostino, SP464, pp. 627-631 (Nov. 1977).

A comparison of electron microscope techniques for the identification of asbestos fibers, C. O. Ruud, P. A. Russell, C. S. Barrett, and R. L. Clark, SP464, pp. 635-636 (Nov. 1977).

Determination of reducing agents and solfate in airborne particulates by thermometric titration calorimetry, L. D. Hansen, D. J. Eatough, N. F. Mangelson, and R. M. Izatt, SP464, pp. 637-642 (Nov. 1977).

Determination of acidic and basic species in particulates by thermometric titration calorimetry, D. J. Eatough, L. D. Hansen, R. M. Izatt, and N. F. Mangelson, SP464, pp. 643-649 (Nov. 1977).

Single-particle analysis of the ash from the Dickerson coalfired power plant, J. A. Small and W. H. Zoller, SP464, pp. $651-658$ (Nov. 1977).

Laser-Raman monitoring of ambient sulfate aerosols, $R$. G. Stafford, R. K. Chang, and P. J. Kindlmann, SP464, pp. 659 667 (Nov. 1977).

Chemical characterization of particulates in real time by a light scattering method, C. C. Gravatt, SP464, pp. 669-671 (Nov. 1977).

The National voluntary laboratory accreditation program, T. R. Young, SP464, pp. 675-676 (Nov. 1977).

The National laboratory certification program for water supply, C. Hendricks, SP464, pp. 677-679 (Nov. 1977).

Laboratory accreditation, C. E. Hamilton, SP464, pp. 681 684 (Nov. 1977).

Certification of water and wastewater laboratories: A professional chemists view, H. G. Swope, SP464, pp. 685-687 (Nov. 1977).

Lessons to be learned from clinical laboratory accreditation, W. F. Vincent, SP464, pp. 689-691 (Nov. 1977). 
SP492. Procedures used at the National Bureau of Standards to determine selected trace elements in biological and botanical materials, R. Mavrodineanu, Ed., Nat. Bur. Stand. (U.S.), Spec. Publ. 492, 295 pages (Nov. 1977) SN003-003-018589.

Sample preparation, T. J. Murphy, SP492, pp. 5-8 (Nov. 1977).

Determination of arsenic, antimony and copper in biological and botanical materials using neutron activation analysis, $T$. E. Gills, SP492, pp. 9-12 (Nov. 1977).

Determination of platinum in biological and botanical materials using neutron activation analysis, D. A. Becker and T. E. Gills, SP492, pp. 12-14 (Nov. 1977).

Determination of vanadium and manganese in biological and botanical materials by neutron activation analysis, $\mathbf{S}$. $\mathbf{H}$. Harrison, SP492, pp. 15-19 (Nov. 1977).

Radiochemical separation for the determination of mercury and selenium in biological and botanical materials using neutron activation analysis, H. L. Rook, T. E. Gills, and G. J. Lutz, SP492, pp. 20-22 (Nov. 1977).

Determination of chromium in biological and botanical materials using neutron activation analysis, L. T. McClendon, SP492, pp. 23-26 (Nov. 1977).

Rapid, quantitative separation for the determination of selenium using neutron activation analysis, H. L. Rook, SP492, pp. 26-32 (Nov. 1977).

Determination of cadmium, copper, iron, lead, mercury, molybdenum, nickel, selenium, silver, tellurium, thallium, and zinc, P. J. Paulsen, SP492, pp. 33-48 (Nov. 1977).

Determination of beryllium, cadmium, copper, magnesium, manganese, mercury, nickel, and zinc by atomic absorption, and of calcium, potassium, rubidium, and sodium by flame emission spectrometry, in biological and botanical materials, T. C. Rains, SP492, pp. 49-65 (Nov. 1977).

Determination of calcium, potassium, and sodium in flour by emission tame spectrometry, J. R. Baldwin and $R$. Mavrodineanu, SP492, pp. 66-71 (Nov. 1977).

Procedures for the determination of arsenic, copper, and nickel by molecular absorption spectrometry, R. W. Burke and B. I. Diamondstone, SP492, pp. 73-84 (Nov. 1977).

Determination of beryllium by fluorescence spectrometry, $S$. A. Wicks and R. W. Burke, SP492, pp. 85-89 (Nov. 1977).

Analysis of botanical standard reference materials by cathode ray polarography, E. J. Maienthal, SP492, pp. 91 105 (Nov. 1977).

NBSIR 76-1169. Rationale and recommendations for changes and revisions to the HUD noise measurement systems specifications, D. S. Blomquist and M. A. Cadoff, 58 pages (Oct. 1977). Order from NTIS as PB273306.

NBSIR 76-1191. A survey of calibration techniques for atmospheric ozone monitors, J. A. Hodgeson, 30 pages (Dec. 1976). Order from NTIS as PB263534.

NBSIR 77-1227. Thermometry in the control of water quality, S. D. Wood, 21 pages (May 1977). Order from NTIS as PB267608.

16691. Green, R. B., Keller, R. A., Schenck, P. K., Travis, J. C., Luther, G. G., Opto-galvanic detection of species in flames, J. Am. Chem. Soc. 98, No. 26, $8517-8518$ (Dec. 22, 1976).

16729. Maienthal, E. J., Becker, D. A., A survey on current literature on sampling, sample handling, for environmental materials and long term storage, Interface 5, No. 4, 49-62 (1976).

16756. Hodgeson, J. A., Hughes, E. E., Schmidt, W. P., Bass, A. M., Methodology for standardization of atmospheric ozone measurements, Proc. Int. Conf. on Photochemical Oxidant Pollution and Its Control, Research Triangle Park, NC, Sept. 1217, 1976, EPA-600/3-77-001a, Ecological Research Series, 1, 3-12 (Environmental Sciences Research Laboratory, Research Triangle Park, NC, Jan. 1977).
16771. Scheide, E. P., Durst, R. A., Indirect determination of sulfate in natural waters by ion-selective electrode, Anal. Lett. 10, No. 1, 55-65 (1977).

16811. Parris, G. E., Blair, W. R., Brinckman, F. E., Chemical and physical considerations in the use of atomic absorption detectors coupled with a gas chromatograph for determination of trace organometallic gasps, Anal. Chem. 49, No. 3, 378-386 (Mar. 1977).

16886. Gump, B. H., Hertz, H. S., May, W. E., Chesler, S. N., The hydrocarbon burden in the marine environment surrounding a refinery tanker jetty, J. Environ. Sci. Health A12, No. 3, 105-1 13 (1977).

16976. Garvin, D., Hampson, R. F., Kurylo, M. J., - Reaction rate data for the stratosphere: How good are they now?, Proc. Fourth Conf. on Climatic Impact Assessment Program, Cambridge, MA, Feb. 1975, pp. 391-397 (U.S. Department of Transportation, Washington, DC, 1975).

17008. Jewett, K. L., Brinckman, F. E., Bellama, J. M., Chemical factors influencing metal alkylation in water, ACS Symp. Series 18, Marine Chemistry in the Coastal Environment, Paper 17, 304-318 (1975).

17013. Rosasco, G. J., Etz, E. S., The Raman microprobe: A new analytical tool, Res./Develop. 28, No. 6, 20-35 (June 1977).

17053. Gornick, F., Passaglia, E., A dynamic model for a population of durable goods, Resource Recovery Conserva. 2, 193 209 (1976/1977).

17141. Hodgeson, J. A., How well can we measure significant deterioration of air quality, Proc. ASME Air Pollution Control Division Fifth Natl. Symp. Preventing Significant Deterioration: What Does It Mean? What Are Its Impacts? Pittsburgh, PA, May Il-12, 1977, pp. $30-45$ (1977).

17149. Kurylo, M. J., Flash photolysis resonance fluorescence investigation of the reaction of $\mathrm{O}\left({ }^{3} \mathrm{P}\right)$ atoms with $\mathrm{ClONO}_{2}$, Chem. Phys. Lett. 49, No. 3, 467-470 (Aug. 1, 1977).

17155. Brinckman, F. E., Parris, G. E., Blair, W. R., Jewett, K. L., Iverson, W. P., Bellama, J. M., Questions concerning environmental mobility of arsenic: Needs for a chemical data base and means for speciation of trace organoarsenicals, Environ. Health Perspec. 19, 11-24 (Aug. 1977).

17216. Manger, C. L., Moore, J. H., Jr., Alexander, M. H., Evidence for the absence of complex formation between oxygen and otefins or fluorocarbons, Physiolog. Chem. 8, No. 6, 559-562 (Dec. 1976).

17273. Wise, S. A., Chesler, S. N., Gump, B. H., Hertz, H. S., May, W. E., Interlaboratory calibration for the analysis of petroleum levels in sediment, (Proc. Symp. on Fate and Effects of Petroleum Hydrocarbons in Marine Ecosystems and Organisms, Seattle, WA, Nov. 10-12, 1976), Chapter 35 in Interlaboratory Calibration for the Analysis of Petroleum Levels in Sediment, pp. 345-350 (Pergamon Press Inc., Elmsfort, NY, 1977).

\section{Failure Analysis}

NBSIR 74-594. Examination of failed four inch cast iron pipe natural gas main, Philadelphia Gas Works, Philadelphia, Pennsylvania, T. R. Shives, 24 pages (Oct. 1974). Order from NTIS as PB243546.

NBSIR 77-1275. Examination of cap screws from currency printing press flanges, T. R. Shives, 28 pages (June 1977). Order from NTIS as PB270523.

16715. Interrante, C. G., Early, J. G., Hicho, G. E., Analysis of findings of four tank-car accident reports, DOT Report No. FRA-OR\&D 75-50, 70 pages (Available as PB25 1097 from the National Technical Information Service, Springfield, VA 22161, Jan. 1975).

16716. Interrante, C. G., Impact properties of steels taken from four failed tank cars, DOT Report No. FRA-OR\&D 75-5I, 
157 pages (Available as PB255854 from the National Technical Information Service, Springfield, VA 22161, June 1976).

16717. Early, J. G., Interrante, C. G., A metallurgical investigation of a full-scale insulated rail tank car filled with LPG subjected to a fire environment, DOT Report No. FRA-OR\&D 75-52, 67 pages (Available as PB250587 from the National Technical Information Service, Springfield, VA 22161, Jan. 1975).

16718. Early, J. G., Mechanical properties of AAR M128-69-B steel plate samples taken from insulated fire tested tank car RAX 202, DOT Report No. FRA-OR\&D 76-74, 57 pages (Available as PB255907 from the National Technical Information Service, Springfield, VA 22161, June 1976).

16719. Interrante, C. G., Hicho, G. E., Harne, D. E., A metallurgical analysis of five steel plates taken from a tank car accident near Crescent City, Illinois, DOT Report No. FRAOR\&D 75-48, 87 pages (Available as PB250530 from the National Technical Information Service, Springfield, VA 22161, Mar. 1972).

16720. Interrante, C. G., Hicho, G. E., Metallungical analysis of a steel shell plate taken from a tank car accident near South Byron, N.Y., DOT Report No. FRA-OR\&D 75-47, 56 pages (Available as PB250063 from the National Technical Information Service, Springfield, VA 22161, Oct. 1971).

16737. Bright, R. G., Status and problems of fire detection for life salety in the United States, (Proc. Symp. National Academy of Sciences-National Research Council on Fire Detection for Life Safety, Washington, DC, Mar. 31-Apr. 1, 1975), Paper in Fire Detection and Life Safety, pp. 3-14 (1977).

\section{Fire Research}

Static pressure measurements of enclosure fires, B. J. McCaffrey and J. A. Rockett, J. Res. Nat. Bur. Stand. (U.S.), 82, No. 2, 107-117 (Sept.-Oct. 1977)

TN945. An investigation of the fire environment in the ASTM E 84 tunnel test, W. J. Parker, Nat. Bur. Stand. (U.S.), Tech. Note 945, 75 pages (Aug. 1977) SN003-003-01819-8.

NBSIR 76-1030. The effect of sample orientation in the smoke density chamber, L. Breden and M. Meisters, 32 pages (May 1976). Order from NTIS as PB263633.

NBSIR 76-1194. A study of fire spread in multi-family residences: The causes-The remedies, B. M. Vogel, 22 pages (Feb. 1977). Order from NTIS as PB264368.

NBSIR 77-1209. Control of smoke movement in buildings: A review, I. A. Benjamin, F. Fung, and L. Roth, 44 pages (July 1977). Order from NTIS as PB269866.

NBSIR 77-1222. Reproducibility of the radiant panel test method (ASTM E 162-67) using polyurethane foam, meoprene, and hardboard specimens, T. G. Lee, 40 pages (Mar. 1977). Order from NTIS as PB265089.

NBSIR 77-1225. Test and evaluation of the smoke control capabilities of the San Diego Veterars Administration Hospital, F. C. W. Fung and R. H. Zile, 167 pages (Apr. 1977). Order from NTIS as PB270856.

NBSIR 77-1234. Hazand characteristics of combustion products in fires: The state-of-the-art review, M. M. Birky, 49 pages (May 1977). Order from NTIS as PB267828.

NBSIR 77-1236. The measurement of fabric fammability parameters in experiments simulating human movement in burn accidents, E. A. Zawistowski, J. F. Krasny, E. Braun, R. Peacock, and N. Williams, 26 pages (June 1977). Order from NTIS as PB268902.

NBSIR 77-1260. A computer program for the thermal analysis of the fire endurance of construction walls, F. C. W. Fung, 62 pages (May 1977). Order from NTIS as PB2681 12.

NBSIR 77-1264. Fire research specialists: A directory, N. H. Jason, 139 pages (Sept. 1977). Order from NTIS as PB272475.
NBSIR 77-1265. An evaluation of fire properties of generic gypsum board products, J. R. Lawson, 30 pages (Aug. 1977). Order from NTIS as PB271097.

NBSIR 77-1277. Fire research publications, 1976, N. H. Jason, 16 pages (July 1977). Order from NTIS as PB269965.

NBSIR 77-1282. Investigation of the suitability of light duty pipe hangers for use in residential and care type sprinkler systems, W. D. Hayes, Jr. and R. L. P. Custer, 45 pages (Oct. 1977). Order from NTIS as PB273575.

NBSIR 77-1287. Analytical and experimental study of evaporative cooling and room fire suppression by corridor sprinkler system, S. T. Liu, 58 pages (Oct. 1977). Order from NTIS as PB273576.

NBSIR 77-1290. Combustion of mattresses exposed to flaming ignition sources. Part 1. Full-scale tests and hazard analysis, V. Babrauskas, 146 pages (Sept. 1977). Order from NTIS as PB272064.

NBSIR 77-1295. Tests on insulative barriers as a method of protecting neoprene core mattresses, J. N. Bresse, 30 pages (Nov. 1977). Order from NTIS as PB275170.

NBSIR 77-1302. A numerical technique to correct heat release rate calorimetry data for apparatus time delay, D. D. Evans and L. H. Breden, 25 pages (Nov. 1977). Order from NTIS as PB275 173.

NBSIR 77-1308. Annual conference on fire research, C. Huggett, Ed., 199 pages (Oct. 1977). Order from NTIS as PB273589.

NBSIR 77-1312. Physical properties of smokes pertinent to smoke detector technology, T. G. K. Lee and G. Mulholland, 46 pages (Nov. 1977). Order from NTIS as PB274330.

NBSIR 77-1318. The impact of a room fire on a corridor with considerations of fuel load, ventilation and scaling, J. Quintiere, B. McCaffrey, T. Kashiwagi, K. Den Braven, M. Harkleroad, J. Raines, and W. Rinkinen, 61 pages (Nov. 1977). Order from NTIS as PB273942.

NBSIR 77-1381. Preliminary report on evaluating alternatives for reducing upholstered furniture fire losses, B. Buchbinder, S. G. Helzer, and F. L. Offensend, 30 pages (Nov. 1977). Order from NTIS as PB273943.

NBS-GCR-76-77. A basic investigation of the extinguishability of various fabrics, L. B. Miles, 95 pages (Sept. 22, 1976). Order from NTIS as PB257767.

NBS-GCR-76-78. An investigation of certain design parameters of the mushroom apparel flammability tester, A. K. Stratton, 112 pages (July 1976). Order from NTIS as PB257836.

NBS-GCR-76-79. A problem in fire safety: Flame spreading acrass liquid fuels, F. L. Dryer, I. Glassman, W. A. Sirignano, 30 pages (Sept. 15, 1976). Order from NTIS as PB259127.

NBS-GCR-76-80. Scaling of radiative characteristics of turbulent diffusion thames, G. H. Markstein, 51 pages (June 1976). Order from NTIS as PB259126.

NBS-GCR-77-82. Detector sensitivity and siting requirements for dwellings-Phase 2, S. W. Harpe, T. E. Waterman, and W. J. Christian, 379 pages (Feb. 1977): Order from NTIS as PB263882.

NBS-GCR-77-83. Thermophysical properties of polystyrene and poly(vinyl chloride), C. Y. Ho, P. D. Desai, K. Y. Wu, T. N. Havill, and T. Y. Lee, 110 pages (Mar. 1977). Order from NTIS as PB265228.

NBS-GCR-77-84. UNDSAFE-1: A computer code for buoyant now in an enclosure, K. T. Yang and L. C. Chang, 103 pages (Mar. 1, 1977). Order from NTIS as PB267278.

NBS-GCR-77-85. Toxicity of plastic combustion products. Toxleological methodologies to assess the relative hazands of thermal decomposition products from polymeric materials, Y. Alarie and C. S. Barrow, 309 pages (Feb. 1976/1977). Order from NTIS as PB267233.

NBS-GCR-77-86. Environments of fire detectors-Phase 1: Effect of fire size, ceiling height and material. Volume 1. Mea- 
surements, G. Heskestad and M. A. Delichatsios, 206 pages (May 1977). Order from NTIS as PB272882.

NBS-GCR-77-90. Extinguishability as a component measure of flammability hazard, S. M. Spivak, 180 pages (Apr. 1977). Order from NTIS as PB269489.

NBS-GCR-77-92. Simulating human behavior in high-rise building fires: Modeling occupant movement through a fire-floor from initial alert to safe egress, F. I. Stahl, 55 pages (Aug. 1977). Order from NTIS as PB273166.

NBS-GCR-77-93. Human behavior in institutional fires and its design implications, L. Lerup, D. Cronrath, J. K. C. Liu, 185 pages (Feb. 28, 1977). Order from NTIS as PB27 1980.

NBS-GCR-77-94. Smoke as a determinant of human behavior in fire situations (project people), J. L. Bryan, 304 pages (June 30, 1977). Order from NTIS as PB271755.

NBS-GCR-77-95. Environments of fire detectors-Phase 1: Effect of fire size, ceiling height and material. Volume 2. Analysis, G. Heskestad and M. A. Delichatsios, 129 pages (July 1977). Order from NTIS as PB272883.

NBS-GCR-77-97. An experimental investigation of the heat transfer from a buoyant gas plume to a horizontal ceiling-Part 1. Unobstructed ceiling, C. C. Veldman, T. Kubota, and E. E. Zukoski, 115 pages (Sept. 1977). Order from NTIS as PB272069.

NBS-GCR-77-99. Prediction of fire hazard from fabrics and building materials, P. Durbetaki, W. C. Tincher, L. R. Lloyd, R. P. Lowery, W. J. Tingle, and V. L. Wolfe, Jr., 267 pages (Feb. 28, 1977). Order from NTIS as PB273977.

NBS-GCR-77-102. Vocal emergency slarms in hospitals and nursing facilities: Practice and potential, J. P. Keating and E. F. Loftus, 33 pages (July 1977). Order from NTIS as PB273165.

NBS-GCR-77-103. The goal oriented systems approach, J. Watts, 122 pages (July 12, 1977). Order from NTIS as PB273174.

16813. Krasny, J. F., Peacock, R. D., Comments on "Fiammability assessment of apparel fabries," Textile Chem. Colorists 9, No. 4, 32-33 (Apr. 1977).

16882. Bukowski, R. W., Field investigation of residential smoke detectors, Southern Bldg., pp. 28-31 (Apr.-May 1977).

16960. Clarke, F. B. III, Ottoson, J., Fire death scenarios and firesafety planning, Fire J. 70, No. 3, 20-22, 117-1 18 (May 1976).

17059. Parker, W. J., Lee, B. T., A small-scale enclosure for characterizing the fire buildup potential of a room, Proc. Meeting to Honor Clay Preston Butler on the Occasion of his 70th Birthday, Experimental Methods in Fire Research, Menlo Park, CA, May 9-10, 1974, pp. 43-72 (Stanford Research Institute, Menlo Park, CA, 1974).

17282. Mulholland, G. W., Lee, T. G., Baum, H. R., The coagulation of aerosols with broad initial size distributions, $J$. Colloid Interface Sci. 62, No. 3, 406-420 (Dec. 1977).

17283. Quintiere, J., Growth of fire in building compartments, Am. Soc. Testing Mater. Spec. Tech. Publ. 614, pp. 131-167 (1977).

17285. McCaffrey, B. J., Quintiere, J. G., Buoyancy driven countercurrent flows generated by a fire source, (Proc. Seminar on Turbulent Buoyant Convection, Dubrovnik, Yugoslavia, Aug. 1976), Paper in Heat Transfer and Turbulent Buoyant Convection, D. B. Spalding and N. Afgan, Eds., II, 457-472 (Hemisphere Publ. Corp., Washington, DC, 1977).

17291. Fung, F. C. W., Smoke control by systematic pressurization, (Proc. CIB Symp., Hertfordshire, England, Nov. 4, 1975), Fire Res. 11, No. 4, 261-269 (Nov. 1975).

\section{Fluids: Liquids, Gases and Plasmas}

The NBS two pressure humidity generator, Mark 2, S. Hasegawa and J. W. Little, J. Res. Nat. Bur. Stand. (U.S.), 81A (Phys. and Chem.), No. 1, $81-88$ (Jan.-Feb. 1977).
Humidity fixed points of binary saturated aqueous solutions, $L$. Greenspan, J. Res. Nat. Bur. Stand. (U.S.), $81 \mathrm{~A}$ (Phys. and Chem.), No. 1, 89-96 (Jan.-Feb. 1977).

Frequency dependence of intrinsic stress and birefringence tensor of bead/spring model of polymer solutions, A. Peterlin and J. T. Fong, J. Res. Nat. Bur. Stand. (U.S.), $81 \mathrm{~A}$ (Phys. and Chem.), No. 1, 97-107 (Jan.-Feb. 1977).

Evaporation of a liquid droplet, R. Kayser, Jr., and H. S. Bennett, J. Res. Nat. Bur. Stand. (U.S.), $81 \mathrm{~A}$ (Phys. and Chem.), Nos. 2 and 3, 257-266 (Mar.-June 1977).

Transport coefficients in the one-fluid approximation, H. J. M. Hanley, J. Res. Nat. Bur. Stand. (U.S.), 82, No. 3, 181-182 (Nov.-Dec. 1977).

Mathematical models of the transient heat flow to fuel droplets, H. S. Bennett and R. Kayser, Jr., J. Res. Nat. Bur. Stand. (U.S.), 82, No. 3, 183-195 (Nov.-Dec. 1977).

Laminar flow induced by a point source of heat, $H$. R. Baum, J. Res. Nat. Bur. Stand. (U.S.), $81 \mathrm{~B}$ (Math. Sci.), Nos. 1 and 2, 45-60 (Jan.-June 1977).

SP484, Volumes 1 and 2. Flow measurement in open channels and closed conduits. Proceedings of the Symposium on Flow Measurement in Open Channels and Closed Conduits held at the National Bureau of Standards in Gaithersburg. MD on Feb. 23-25, 1977, L. K. Irwin, Ed., Nat. Bur. Stand. (U.S.), Spec. Publ. 484, Vol. 1, 479 pages, Vol. 2, 490 pages (Oct. 1977) SNO03-003-01845-7.

Measuring the repeatability of flowmeters, A. T. J. Hayward, SP484, pp. 1-24 (Oct. 1977).

The Navy Liquid Flow Correlation Program, J. H. Tabler and C. G. Kullmann, SP484, pp. 25-32 (Oct. 1977).

A laboratory study of turbine meter uncertainty, G. E. Mattingly, P. E. Pontius, H. H. Allion, and E. F. Moore, SP484, pp. 33-54 (Oct. 1977).

Evolution of a modern petroleum measurement manual, L. M. Davis, SP484, pp. 55-60 (Oct. 1977).

Building blocks towards flowmeter reliability, D. Halmi, SP484, pp. $61-82$ (Oct. 1977).

Open channel flow monitoring or metering, that is the question, K. W. Martig, Jr., SP484, pp. 83-89 (Oct. 1977).

Instrument errors in open channel flow measurement systems, D. M. Grant, SP484, pp. 91-108 (Oct. 1977).

Marine dynamics and its effects on current measuring transducers, T. Mero, G. Appell, and R. S. McQuivey, SP484, pp. 109-122 (Oct. 1977).

Some error sources in Price and Pygmy current meter traverses, G. Kulin, SP484, pp. 123-144 (Oct. 1977).

Flow measurements in the canals of power plant closed loop cooling systems, J. F. O'Brien, J. Skridulis, J. Annett, G. W. Singley, and H. L. Koenig, SP484, pp. 145-172 (Oct. 1977).

Errors in flow measurement and their importance in infiltration/inflow analysis, D. L. Guthrie, D. R. Washington, and C. Vincenty, SP484, pp. 173-186 (Oct. 1977).

Rating broad-crested V-notch weirs with narrow, sloping approach channels and sediment deposits, J. F. Ruff, K. Saxton, and C. Dang, SP484, pp. 187-200 (Oct. 1977).

Compensating for construction errors in critical-tlow flumes and broad-crested weirs, J. A. Replogle, SP484, pp. 201-218 (Oct. 1977).

Numerical modeling of twodimensional flumes, $R$. W. Davis, SP484, pp. 219-242 (Oct. 1977).

The design of open channel acoustic flowmeters for specified accuracy: Sources of error and calibration test results, F. C. Lowell, Jr., SP484, pp. 243-266 (Oct. 1977).

Application considerations and performance capability of the time differential clamp-on ultrasonic flowmeter, J. Baumoel, SP484, pp. 267-276 (Oct. 1977).

Theoretical and experimental assessment of uncertainties in non-intrusive, ultrasonic flow measurement, R. F. Bruner, SP484, pp. 277-291 (Oct. 1977). 
A new ultrasonic flowmeter for the natural gas industry, $N$. E. Pedersen, J. E. Bradshaw, L. C. Lynnworth, and P. R. Morel, SP484, pp. 293-318 (Oct. 1977).

A new non-intrusive flowmeter, $R$. S. Flemons, SP484, pp. 319-333 (Oct. 1977).

Reconstructing three-dimensional fluid velocity vector and temperature fields from acoustic transmission measurements, S. A. Johnson, J. F. Greenleaf, M. Tanaka, and G. Flandro, SP484, pp. 335-359 (Oct. 1977).

Validation of use of dye-dilution method for flow measurement in large open and closed channel flows, W. H. Morgan, D. Kempf, and R. E. Phillips, SP484, pp. 361-394 (Oct. 1977 ).

Dilution method of discharge measurement in pipes, $E$. $R$. Holley, SP484, pp. 395-421 (Oct. 1977).

Application of a fluorescence technique to dye-concentration measurements in a turbulent jet, H. Liu, J. Lin, D. P. Delisi, and F. A. Robben, SP484, pp. 423-447 (Oct. 1977).

The application of Monte Carfo and Bayesian probability techniques to flow prediction and determination, F. J. Berté, SP484, pp. 447-470 (Oct. 1977).

Laser doppler anemometry for flow measurement, $\mathbf{W}$. W. Durgin and L. C. Neale, SP484, $471-477$ (Oct. 1977).

On improving the Pitot-tube determination of flows in large pipes, J. M. Robertson and M. E. Clark, SP484, pp. $479-489$ (Oct. 1977).

Numerical modeling of turbulent flow through thin orifice plates, R. W. Davis and G. E. Mattingly, SP484, pp. 491-522 (Oct. 1977)

Studies of pulsating incompressible flow through orifice meters, R. A. Bajura and M. T. Pellegrin, SP484, pp. 523-548 (Oct. 1977)

A vortex flowmeter-Calibration results and application experiences, R. W. Miller, J. P. DeCarlo, and J. T. Cullen, SP484, pp. 549-570 (Oct. 1977).

Temperature field measurements in turbulent thermals, $M$. Gad-el-Hak, SP484, pp. 571-596 (Oct. 1977).

Flow measurement up-date, R. B. Suhoke, SP484, pp. 597. 619 (Oct. 1977).

Near wall velocity measurements for wall shear inference in turbulent flows, F. J. Pierce, D. S. Gold, and E. 1. Dupont, SP484, pp. 621-648 (Oct. 1977).

On reduction of errors arising in hot-wire anemometry of thin turbulent shear layers, J. Gaviglio and J. P. Dussauge, SP484, pp. 649-658 (Oct. 1977).

Probe and method for simultancous measurements of "true" instantaneous temperature and three velocity components in turbulent flow, G. Fabris, SP484, pp. 659-685 (Oct. 1977).

Measurement of boundary layer transition using acoustic techniques, D. C. Sachs, T. F. V. Meagher, and V. D. Peckham, SP484, pp. $687-704$ (Oct. 1977).

Measurement of recirculating flow behind a cylinder with spray cooling, R. S. Rudland, SP484, pp. 705-718 (Oct. ¿977).

A new type of velocity probe, W. B. Brower, Jr. and A. Servoz, SP484, pp. $719-735$ (Oct. 1977).

The influence of turbulence on static and total pressure probes, V. E. Scottron, SP484, pp. 737-753 (Oct. 1977).

Determination and elimination of errors in velocity readings at ventilation tubing inlets, R. A. Haney, SP484, pp. 755-763 (Oct. 1977).

Indirect two-phase flow measurement: Analysis and reduction of methods errors, N. N. Kondic, SP484, pp. 765-782 (Oct. 1977).

Measurements of density and density gradient with an oscillating conductivity probe, D. P. Delisi and R. H. Kirchhoff, SP484, pp. 783-802 (Oct. 1977).

New techniques for automotive fuel flow measurements, $M$. Baker, SP484, pp. 803-820 (Oct. 1977).
Digital compensation techniques for pasitive-displacement and turbine flowmeters, R. Jennings, SP484, pp. 821-846 (Oct. 1977).

Viscosity effects on the turbine flowmeter, J. M. Ball, SP484, pp. $847-869$ (Oct. 1977).

Turbine meters for the measurement of gaseous hydrocarbons, P. J. LaNasa, SP484, pp. $871-880$ (Oct. 1977).

On a new method of gas flow measurement using cryogenic techniques, D. B. Mann and J. A. Brennan, SP484, pp. 881893 (Oct. 1977).

An anatomy of the international standards producing system-Flow measurement, L. K. Irwin, SP484, pp. 895-920 (Oct. 1977).

OIML and EEC, their impact on the international standards producing system, D. E. Edgerly, SP484, pp. 921-927 (Oct. 1977).

The interface between industrial, national and international standards, W. N. Seward, SP484, pp. 929-934 (Oct. 1977).

The adequacy of the data bases available for promulgating international standards, H. H. Dijstelbergen and N. V. N. Gasunie, SP484, Pp. $935-944$ (Oct. 1977).

Equitable implementation of national and international allocation programs (Summary of remarks to the panel). J. A. West, SP484, pp. 945-946 (Oct. 1977).

Ot form and substance for effective standards, E. A. Spencer, SP484, pp. 947-956 (Oct. 1977).

Comments on: Role of international standards in measuring and allocating hydrocarbons-A program for solution of our present problems, F. H. Abernathy, SP484, pp. $957-959$ (Oct. 1977).

TN693. Predicted values of the viscosity and thermal conductivity coefficlents of nitrous oxide, H. J. M. Hanley, Nat. Bur. Stand. (U.S.), Tech. Note 693, 64 pages (Mar. 1977) SN003003-01780-8.

TN943. Evaluation of automotive fuel flowmeters, B. Robertson and G. P. Baumgarten, Nat. Bur. Stand. (U.S.), Tech. Note 943, 95 pages (June 1977) SN003-003-01799-0.

NBSIR 76-994. A numerical solution of the time dependent partial differential equations which describe a one-dimensional, laminar, premixed tlame, R. L. Brown, 178 pages (Jan. 1976). Order from NTIS as PB263100.

NBSIR 77-1394. A computer code for the simulation of turbulent swirling flow through closed-conduit flow meters, $\mathbf{R}$. W. Davis and E. F. Moore, 12 pages (Dec. 1977). Order from NTIS as PB274650.

16749. Gadzuk, J. W., Vibrational excitation in photoemission spectroscopy of condensed molecules, Phys. Rev. B 14, No. 12, 5458-5465 (Dec. 15, 1976).

16786. Raveché, H. J., Metastable states in the Lennard-Jones fluid, Ann. N.Y. Acad. Sci. 279, 36-42 (Oct. 15, 1976).

16818. Wisdom, J., Hartquist, T. W., Lane, N. F., He(23S) bubble in liquid helium, Phys. Rev. B, Comments and Addenda 14, No. 9, $4205-4208$ (Nov. 1, 1976).

16820. Klebanoff, P. S., Frenkiel, F. N., On the small-scale turbulence structure, (Proc. Bat-Sheva Int. Seminar, Ben-Gurion Univ. of Negev, Beersheva, Israel, Mar. 17-20, 1975), Paper in MHD-Flows and Turbulence, H. Branover, Ed., pp. 147151 (Halsted Press, Div. John Wiley \& Sons, Inc., New York, NY, 1976).

16821. Klebanoff, P. S., McMichael, J. M., On MIHD pipe flow, (Proc. Bat-Sheva 1nt. Seminar, Ben-Gurion Univ. of Negev, Beersheva, Israel, Mar. 17-20, 1975), Paper in MHD-Flows and Turbulence, H. Branover, Ed., pp. 73-80 (Halsted Press, Div. John Wiley \& Sons, Inc., New York, NY, 1976).

16871. Haynes, W. M., Hiza, M. J., Measurements of the orthobaric liquid densities of methane, ethane, propane, isobutane, and normal butane, J. Chem. Thermodyn. 9, No. 2, 179 187 (Feb. 1977). 
16917. Lofquist, K. E. B., A pasitive displacement ascillatory water tunnel, Miscellaneous Report MR 77-1, 27 pages (U.S. Army, Corps of Engineers, Coastal Engineering Research Center, Ft. Belvoir, VA, Feb. 1977).

17009. Coriell, S. R., Hardy, S. C., Cordes, M. R., Stability of liquid zones, J. Colloid Interface Sci. 60, No. 1, 126-136 (June 1, 1977).

17067. Tsumura, R., Straty, G. C., Speed of sound in saturated and compressed fluid ethane, Cryogenics 17, No. 4, 195-200 (Apr. 1977).

17279. Sengers, J. M. H. L., Critical behavior in fluids, Chapter V in High Pressure Technology, I. L. Span and J. Paauwe, Eds., I, 161-251 (Marcel Dekker, Inc., New York, NY, 1977).

\section{General Theoretical Chemistry and Physics}

Monogr. 147, Suppl. 1. Relativistic many-body bound systems: Electromagnetic properties, M. Danos and V. Gillet, Nat. Bur. Stand. (U.S.), Monogr. 147, Suppl. 1, 52 pages (Apr. 1977) SNOO3-003-01754-0.

16711. Mountain, R. D., Generalized hydrodynamics, Adv. Mol. Relaxation Processes 9, 225-291 (1976).

16795. Holdeman, L. B., Holdeman, J. T., Jr., Magnetic torque on a shielded superconducting gyroscope, J. Appl. Phys. 47, No. 11, 4936-4943 (Nov. 1976).

16849. Corcoran, C. T., Langhoff, P. W., Moment-theory approximations for nonnegative spectral densities, J. Math. Phys. 18, No. 4, 651-657 (Apr. 1977).

16955. Light, J. C., Adiabatic perturbation approximation for time dependent collision processes, J. Chem. Phys. 66, No. 11 , 5241-5242 (June 1, 1977).

16968. Hunter, C., Relation between the dynamics and the flattening of elliptical galaxies, Astron. J. 82, No. 4, 271-282 (Apr. 1977).

16986. Raveché, H. J., Stuart, C. A., Bifurcation of solutions with crystalline symmetry, J. Math. Phys. 17, No. 10, 1949 1953 (Nov. 1976).

16989. Hunter, C., Tremaine, S., Collinear configurations of galadies can be stable, Astron. J. 82, No. 4, 262-270 (Apr. 1977).

17161. Ward, J., Cooper, J., Smith, E. W., Correlation effects in the theory of combined Doppler and pressure broedening-I. Classical theory, J. Quant. Spectrosc. Radiat. Transfer $14,555-590$ ( 1974 ).

17169. Eberly, J. H., Wodkiewicz, K., The timedependent physical spectrum of light, J. Opt. Soc. Am. 67, No. 9, 12521260 (Sept. 1977).

17311. Aizenman, M. L., Smeyers, P., An anolysis of the linear, adiabatic oscillations of a star in terms of potential fields, Astrophys. Space Sci. 48, 123-136 (1977).

\section{Instrumentation and Experimental Methods}

TN936. A FORTRAN program for desmearing small-angle $x$ ray seattering curves, J. Mazur, Nat. Bur. Stand. (U.S.), Tech. Note 936, 83 pages (Apr. 1977) SN003-003-01752-3.

TN958. Four versatile MDAS compatible modules, $M$. A. Lind and J. B. Fowler, Nat. Bur. Sland. (U.S.), Tech. Note 958, 34 pages (Nov. 1977) SN003-003-01866-0.

TN961. Experimental investigation of means for reducing the response of pressure transducers to thermal transients, J. S. Hilten, C. F. Vezzetti, J. F. Mayo-Wells, and P. S. Lederer, Nat. Bur. Stand. (U.S.), Tech. Note 961, 58 pages (Dec. 1977) SN003-003-01875-9.

NBSIR 73-291. A systematic study of vibration standards-Mounting effects, R. S. Koyanagi, J. D. Pollard, and J. D. Ramboz, 43 pages (Sept. 1973). Order from NTIS as PB272376.
NBSIR 76-1078. Piezoelectric polymer transducers for dynamic pressure measurements, A. S. DeReggi, S. Edelman, and S. C. Roth, 42 pages (June 1976). Order from NTIS as PB264125.

NBSIR 76-1 108. Fabrication of the barium fluoride film humidity sensor by industrial firms, F. E. Jones, 73 pages (Apr. 1977). Order from NTIS as PB269337.

U.S. Patent 4,001,681. Vector voltmeter, C. A. Hoer and G. F. Engen, 6 pages (Jan. 4, 1977).

16677. Costrell, L., Evolution, definition, and status of IEEE Standard 583: Standard modular instrumentation and digital interface system (CAMAC), Proc. Electro 76 Professional Program, Boston, MA, May 11-14, 1976, No. 29, Paper No. 4, 1-8 (Institute of Electrical and Electronics Engineers, Inc., New York, NY, 1976).

16678. Costrell, L., CAMAC instrumentation system-Introduction and general description, U.S. NIM Committee on CAMAC Tutorial Articles, (Computer Automated Measurement and Control), ERDA Report No. TID-26618, 8 pages (Energy Research and Development Administration, Washington, DC, Oct. 1976).

16679. Costrell, L., Highways for CAMAC systems-A brief introduction, U.S. NIM Committee on CAMAC Tutorial Articles, (Computer Automated Measurement and Control), ERDA Report No. TID-26618, 7 pages (Energy Research and Development Administration, Washington, DC, Oct. 1976).

16693. Hermach, F. L., Flach, D. R., An investigation of multijunction thermal converters, IEEE Trans. Instrum. Meas. IM-25, No. 4, 524-528 (Dec. 1976).

16694. Hermach, F. L., Ac-dc comparators for audio-frequency current and voltage measurements of high accuracy, IEEE Trans. Instrum. Meas. IM-25, No. 4, $489-494$ (Dec. 1976).

16704. Bright, D. S., Miniature helical stirrer, Anal. Chem. 49, No. 1, 191 (Jan. 1977).

16789. Lambropoulos, M., Moody, S. E., Destgn of a threestage alkali beam source, Rev. Sci. Instrum. 48, No. 2, 131134 (Feb. 1977).

16792. Haynes, W. M., Simplified magnetic suspension densimeter for absolute density measurements, Rev. Sci. Instrum. 48, No. 1, 39-41 (Jan. 1977).

16797. Radebaugh, R., Thermal conductance of indium solder joints at low temperatures, Rev. Sci. Instrum. 48, No. 1, 9394 (Jan. 1977).

16828. Spal, R. D., Production of uniform field gradients for magnetometers by means of current-carrying strips, J. Appl. Phys. 48, No. 3, 1338-1341 (Mar. 1977).

16839. Joy, D. C., Newbury, D. E., A bibliography on the observation of crystalline materials by use of diffraction effects in the scanning electron microscope, (Proc. Workshop on Analytical Electron Microscopy, Chicago, IL, Mar. 28-Apr. 1, 1977), Paper in Scanning Electron Microscopy I, 445-454 (IIT Research Institute, Chicago, IL, 1977).

16840. Newbury, D. E., Fundamentals of scanning electron microscopy for physicist: Contrast mechaniams, (Proc. Workshop on Analytical Electron Microscopy; Chicago, IL, Mar. 28-Apr. 1, 1977), Paper in Scanning Electron Microscopy I, 553-568 (IIT Research Institute, Chicago, IL, 1977).

16841. Heinrich, K. F. J., Elemental mapping in the microscopic domain, (Proc. Workshop on Analytical Electron Microscopy, Chicago, IL, Mar. 28-Apr. 1, 1977), Paper in Scanning Electron Micrascopy I, 605-614 (IIT Research Institute, Chicago, IL, 1977).

16842. Dickens, B., Pummer, W. J., Fynn, J. H., Automation of a thermogravimetry apparatus with a laboratory computer, (Proc. 3d Int. Symp. on Analytical Pyrolysis, Amsterdam, The Netherlands, Sept. 6-10, 1976), Paper in Analytical Pyrolysis, pp. 383-391 (Elsevier Scientific Publ. Co., Amsterdam, The Netherlands, 1977). 
16872. Zimmerman, J. E., SQUID instruments and shielding for low-level magnetic measurements, J. Appl. Phys. 48, No. 2, 702-710 (Feb. 1977).

16895. Ledford, A. E., Jr., Braun, W., Gas cell for photochemical studies, Rev. Sci. Instrum. 48, No. 5, 537-538 (May 1977).

16908. Angel, W. T., Houck, J. C., Microcomputer temperature controller, (Proc. 3d Control Valve Symp. and Process Control Technology, Anaheim, CA, May 2-5, 1977), Paper in Final Control Elements 3, 139-143 (Instrument Society of America, Pittsburgh, PA, 1977).

16952. Edelman, S., DeReggi, A. S., Comments on "Electroacoustic transducers with piezoelectric high polymer films," J. Audio Eng. Soc. 24, No. 7, $577-578$ (Sept. 1976).

16961. DeVoe, J. R., Instrument control by digital computers, (Proc. Int. Conf. Computers in Chemical Research and Education, Ljubljana/Zagreb, Yugoslavia, July 12-17, 1973), Paper in Computers in Chemical Research and Education, D. Hadzi, Ed., 1, 1/99-1/137 (American Elsevier Publ. Co., New York, NY, 1973)

17091. Zimmerman, J. E., Radebaugh, R., Siegwarth, J. D., Possible cryocoolers for SQUID nagnetometers, (Proc. 1st ICSQUID Conf., Berlin, Germany, Oct. 5-8, 1976), Paper in Superconducting Quantum Interference Devices and Their Applications, H. D. Hahlbohn and H. Luebbig, Eds., pp. 287 296 (Walter de Gruyter \& Co., Berlin, Germany, New York, NY, 1977).

17121. Finnegan, T. F., Holdeman, L. B., Versatile multicontact thin-film superconducting switch, Rev. Sci. Instrum. 48, No. 9, 1212-1213 (Sept. 1977).

17127. Davis, H., Piston gauge weight handler, Rev. Sci. Instrum. 48, No. 9, 1220-1221 (Sept. 1977).

17138. Robertson, B., Potzick, J. E., Synchronous marker for measuring phase in the presence of noise, Rev. Sci. Instrum. 48, No. 10, 1290-1294 (Oct. 1977).

17156. Newbury, D. E., Ion imaging in secondary ion mass spectrometry, (Proc. Society of Photo-Optical Instrumentation Engineers, Reston, VA, Apr. 18-21, 1977), Paper in Multidisciplinary Microscopy, R. L. Whitman, Ed., SPIE 104, 85-89 (1977).

17173. Bensema, W. D., A noise spectrum measurement system using the Fast Fourier Transform, IEEE Trans. Electromagn. Compat. EMC-19, No. 2, 37-43 (May 1977).

17181. Howe, D. A., The feasibility of applying the active TrTime system to automatic vehicle location, $J$. Inst. Navigation 21, No. 1, 9-15 (Spring 1974).

17183. Gagnepain, J. J., Fundamental moise studies of quartz crystal resonators, Proc. 30th Annual Symp. on Frequency Control, Ft. Monmouth, NJ, June 1976, pp. 84-91 (1976).

17185. Walls, F. L., Stein, S. R., Gray, J. E., Glaze, D. J., Design considerations in state-of-the-art signal processing and phase noise measurenrent systems, Proc. 30th Annual Symp. on Frequency Contral, Ft. Monmouth, NJ, June 1976, pp. 269-274 (1976).

17205. Bean, V. E., NBS pressure transducer characterization program, Proc. Ninth Transducer Workshop, Ft. Walton Beach, FL, Apr. 26-28, 1977, pp. 186-208 (Secretariat, Range Commanders Council, White Sands Missile Range, NM, Apr. 22-24, 1977).

17226. Levine, J., Comments on the review of "Strainmeter Technology," by P. H. Sydenham, Nature 257, No. 5526, 513 (Oct. 9, 1975).

17270. Costrell, L., CAMAC instrumentation and interface system for computer automated measurement and control, Proc. 8th Int. Conf. on $X$-ray Optics and Microanalysis, Boston, MA, Aug. 19,1977, pp. 1-16 (1977).

\section{Lasers and Their Applications}

TN685. A system for calibrating laser power meters for the range 5-1000 W, E. D. West and L. B. Schmidt, Nat. Bur. Stand. (U.S.), Tech. Note 685, 27 pages (May 1977) SN003003-01789-2.

NBSIR 77-858. Measurement procedures for the optical beam splitter attenuation device BA-1, B. L. Danielson, 24 pages (May 1977). Order from NTIS as PB272358.

U.S. Patent 4,025,406. Photochemical method for chlorine isotopic enrichment, M. Lamotte, H. J. Dewey, R. A. Keller, and J. J. Ritter, 4 pages (May 24, 1977).

16661. Lawton, R. A., Andrews, J. R., Electrical strobing of a photoconductor cuts sampling oscilloscope's risetime, Laser Focus Mag., pp. 62-65 (Nov. 1976).

16662. Dodge, M. J., Malitson, I. H., Refractive index of high purity $\mathrm{KCl}$ and $\mathrm{KI}$ doped $\mathrm{KCl}$, Proc. 5th Conf. on Infrared Laser Window Materials, Las Vegas, NV, Dec. 1-4, 1975, pp. 216-223 (Air Force Materials Laboratory, Wright-Patterson Air Force Base, OH, Feb. 1976).

16680. Ghigo, F. D., Shelus, P. J., Silverberg, E. C., Faller, J. E., Laser range measurements using non-Gaussian pulse shapes, Appl. Opt. 15, No. 11, 2621-2623 (Nov. 1976).

16695. Geltman, S., Theory of laser-induced inelastic collisions, J. Phys. B Letter to Editor 9, No. 18, L569-L574 (1976).

16728. Wells, J. S., Streit, G. E., Petersen, F. R., Absolute spinflip Raman laser frequency measurements with metal-insulator-metal diodes, Opt. Commun. 19, No. 2, 248-252 (Nov. 1976).

16746. Bennett, H. S., Cantrell, C. D., Inclusions in cadmium telluride: Estimates for damage thresholds, J. Appl. Phys. 48, No. 2, 522-529 (Feb. 1977).

16754. Lind, M. A., Measurement of the absolute spectral response of detectors, Proc. of the Technical Program-Electro-Optical Systems Design Conf. 1976-International Laser Exposition, New York, NY, Sept. 14-16, 1976, pp. 55-58 (1976).

16776. Bergquist, J. C., Lee, S. A., Hall, J. L., Saturated absorption with spatially separeted laser fields: Observation of optical "Ramsey" fringes, Phys. Rev. Lett. 38, No. 4, 159-162 (Jan. 24, 1977).

16783. Braun, W., Tsang, W., Mechanism of alkyl halide photolysis by a pulsed $\mathrm{CO}_{2}$ TEA laser, Chem. Phys. Lett. 44, No. 2, 354-359 (Dec. 1, 1976).

16796. Moulder, J. C., Clark, A. F., Time-resolved spectroscopy of laser-initiated metal combustion, (Proc. Unconventional Spectroscopy, San Diego, CA, Aug. 24-25, 1976), SPIE 82, 66-74 (Society of Photo-Optical Instrumentation Engineers, Palos Verdes Estates, CA, 1976).

16837. Lide, D. R., Jr., Sources of atomic and molecular data relevant to laser chemistry, Laser Focus 13, No. 2, pp. 5356 (Feb. 1977).

16857. Carlsten, J. L., Szöke, A., Raymer, M. G., Collisional redistribution and saturation of near-resonance scattered light, Phys. Rev. A 15, No. 3, 1029-1045 (Mar. 1977).

16860. Bennett, H. S., Forman, R. A., Frequency dependence of photoscoustic spectroscopy: Surface- and bulk-absorption coefficients, J. Appl. Phys. 48, No. 4, 1432-1436 (Apr. 1977).

16867. Radford, H. E., Peterson, F. R., Jennings, D. A., Mucha, J. A., Heterodyne measurements of submillimeter laser spectrometer frequencies, IEEE J. Quant. Electron. Notes \& Lines QE-13, No. 3, 92-94 (Mar. 1977).

16924. Raterink, H. J., Van de Stadt, H., Frankena, H. J., High-resolution measurements of molecular absorption line profiles at 10 micrometers, Opt. Commun. 20, No. 3, 415-417 (Mar. 1977).

17073. Evenson, K. M., Jennings, D. A., Petersen, F. R., Mucha, J. A., Jimenez, J. J., Chariton, R. M., Howard, C. J., Optically pumped FIR lasers: Frequency and power measure- 
ments and laser magnetic resonance spectroscopy, IEEE J. Quantum Electron. QE-13, No. 6, $442-444$ (June 1977).

17124. Maki, A. G., Freund, S. M., Laser Stark spectroscopy of FCN, J. Mol. Spectrosc. 66, 493-499 (1977).

17129. Leone, S. R., Kosnik, K. G., A tunable visible and ultraviolet laser on $S_{2}\left(B^{a} \Sigma_{u^{-}}-X^{3} \Sigma_{g}^{-}\right)$, Appl. Phys. Lett. 30, No. 7, 346-348 (Apr. 1, 1977).

17130. Bakos, J. S., AC Stark effect and multiphoton processes in atoms, Physics Reports (Sec. C Physics Lett.) 31, No. 3, 209-235 (1977).

17143. Holt, H. K., Gain without population inversion in twolevel atoms, Phys. Rev. A 16, No. 3, 1136-1140 (Sept. 1977).

17163. Moulder, J. C., Clark, A. F., Luminescence in metal thames irradiated with a $\mathrm{CO}_{2}$ laser, Chem. Phys. Lett. 49, No. 3, $471-474$ (Aug. 1, 1977).

17170. deHoog, F. J., McNeil, J. R., Collins, G. J., Dischange studies of the Ne-Cu laser, J. Appl. Phys. 48, No. 9, 37013704 (Sept. 1977).

17178. Barger, R. L., Frequency stabilization of a cw dye laser, Laser Spectrosc., pp. 273-279 (June 1973).

17196. Levine, J., Harrison, J. C., Earth tide strain measurements in the Poorman mine near Boulder, Colorado, J. Geophys. Res. 81, No. 14, 2543-2555 (May 10, 1976).

17199. Levine, J., Laser distance-measuring techniques, Ann. Rev. Earth Planet. Sci. 5, 357-369 (1977).

17203. Stein, S. R., Risley, A. S., Van de Stadt, H., Strumia, F., High speed frequency modulation of far infirared lasers using the Stark effect, Appl. Opt. 16, No. 7, 1893-1896 (July 1977).

17254. Julienne, P. S., Theory of gain and saturation for collision-induced lasing transitions, J. Appl. Phys. 48, No. 10, 4140-4148 (Oct. 1977).

17263. Geltman, S., Laser-induced ionising collisions in alkali vapours, J. Phys. B: Atom. Molec. Phys. 10, No. 15, $3057-$ 3074 (1977).

17267. Levine, J., Experiments of astrophysical significance using a laser strainmeter, (Proc. Laser Spectroscopy Conf., Vail, CO, June 25-29, 1973), Paper in Laser Spectroscopy, $\mathbf{R}$. G. Brewer and A. Mooradian, Eds., pp. 643-652 (Plenum Press, New York, NY, 1974).

17287. King, D. S., Schenck, P. K., Smyth, K. C., Travis, J. C., Direct calibration of laser wavelength and bandwidth using the optogalvanic effect in bollow cathode lamps, Appl. Opt. 16, 2617-2619 (Oct. 1977).

17312. Bennett, H. S., Cantrell, C. D., Absorbing precipitates in cadmiurn telluride: Estimates for catastrophic laser-damage thresholds, Appl. Opt. 16, No. 11, $2931-2933$ (Nov. 1977).

17318. Koffend, J. B., Field, R. W., Guyer, D. R., Leone, S. R., Pulsed and CW optically pumped lasers for novel applications in spectroscopy and kinetics, (Proc. Third Int. Conf. on Laser Spectroscopy, Jackson, WY, July 3-6, 1977), Paper in Springer Series in Optical Sciences. Vol. 7: Laser Spectroscopy III, J. L. Hall and J. L. Carlsten, Eds., pp. 382-393 (Springer-Verlag, Berlin, Germany, 1977).

17336. Evenson, K. M., Jennings, D. A., Petersen, F. R., Wells, J. S., Laser frequency measurements: $\mathbf{A}$ review, limitations, extension to $197 \mathrm{THz}(1.5 \mu \mathrm{m})$, (Proc. Third Int. Conf. on Laser Spectroscopy, Jackson, WY, July 3-6, 1977), Paper in Springer Series in Optical Sciences. Vol. 7: Laser Spectroscopy III, J. L. Hall and J. L. Carlsten, Eds., pp. 56-68 (SpringerVerlag, Berlin, Germany, 1977).

17337. Bergquist, J. C., Lee, S. A., Hall, J. L., Ramsey fringes in saturation spectroscopy, (Proc. Third Int. Conf. on Laser Spectroscopy, Jackson, WY, July 3-6, 1977), Paper in Springer Series in Optical Sciences. Vol. 7: Laser Spectroscopy III, J. L. Hall and J. L. Carlsten, Eds., pp. 142-148 (Springer-Verlag, Berlin, Germany, 1977).

17338. Lee, S. A., Hall, J. L., A traveling Michelson interferometer with phase-locked fringe interpolation, (Proc. Third
Int. Conf. on Laser Spectroscopy, Jackson, WY, July 3-6, 1977), Paper in Springer Series in Optical Sciences. Vol. 7: Laser Spectroscopy III, J. L. Hall and J. L. Carlsten, Eds., pp. 421-422 (Springer-Verlag, Berlin, Germany, 1977).

\section{Low Temperature Science and Engineering}

TN697. An evaluation of commercial densimeters for use in LNG, J. D. Siegwarth, B. A. Younglove, and J. F. LaBrecque, Nat. Bur. Stand. (U.S.), Tech. Note 697, 52 pages (Oct. 1977) SNO03-003-018627.

TN698. Cryogenic fiuids density reference system: Provisional accuracy statement, J. D. Siegwarth, B. A. Younglove, and J. F. LaBrecque, Nat. Bur. Stand. (U.S.), Tech. Note 698, 32 pages (Nov. 1977) SN003-003-01864-3.

NBSIR 76-847. Electrocaloric refrigeration for superconductors, R. Radebaugh, J. D. Siegwarth, W. N. Lawless, and A. J. Morrow, 195 pages (Feb. 1977). Order from NTIS as PB265007.

NBSIR 76-850. Liquid helium storage at high density and discharge at high flow rates, D. E. Daney, 54 pages (Dec. 1976). Order from NTIS as PB266945.

NBSIR 77-857. Cryogenic design and safety review NASA. Langley Research Center 0.3 Meter Transonic Cryogenic Tunnel, R. O. Voth and T. R. Strobridge, 28 pages (Apr. 1977). Order from NTIS as PB266944.

NBSIR 77-859. The thermodynamic properties of slush hydrogen and oxygen, H. M. Roder, 43 pages (Nov. 1977). Order from NTIS as PB274186.

NBSIR 77-862. Studies of hydrogen liquefier efficiency and the recovery of the liquefaction energy, $R$. O. Voth and $W$. $R$. Parrish, 62 pages (Aug. 1977). Order from NTIS as PB274058.

16791. Hanley, H. J. M., Prediction of the viscosity and thermal conductivity coefficients of mixtures, Cryogenics 16, No. 11, 643-651 (Nov. 1976).

16801. Tobler, R. L., Low temperature effects on the fracture behaviour of a nickel base superalloy, Cryogenics 16, No. 11, 669-674 (Nov. 1976).

16861. Kamper, R. A., Superconducting devices for metrology and standards, Chapter 5 in Superconductor Applications: Squids and Machines, B. B. Schwartz and S. Foner, Eds., pp. 189-247 (Plenum Publ. Corp., New York, NY, 1977).

16862. Reed, R. P., Mikesell, R. P., Clark, A. F., Low temperature tensile behavior of copper-stabilized niobium-titanium superconducting wire, (Proc. First Int. Cryogenic Materials Conf., Kingston, Ontario, Canada, July 22-25, 1975), Paper I-3 in Advances in Cryogenic Engineering, K. D. Timmerhaus, R. P. Reed, and A. F. Clark, Eds., 22, 463-471 (Plenum Publ. Corp., New York, NY, 1977).

16863. Reed, R. P., Clark, A. F., van Reuth, E. C., A research program on the properties of structural materials at $4 \mathrm{~K}$, (Proc. First Int. Cryogenic Materials Conf., Kingston, Ontario, Canada, July 22-25, 1975), Paper A-1 in Advances in Cryogenic Engineering, K. D. Timmerhaus, R. P. Reed, and A. F. Clark, Eds., 22, 1-8 (Plenum Publ. Corp., New York, NY, 1977).

16864. Sparks, L. L., Magnetothermal conductivity of selected pure metals and alloys, (Proc. First Int. Cryogenic Materials Conf., Kingston, Ontario, Canada, July 22-25, 1975), Paper B-1 in Advances in Cryogenic Engineering, K. D. Timmerhaus, R. P. Reed, and A. F. Clark, Eds., 22, 119-127 (Plenum Publ. Corp., New York, NY, 1977).

16865. Schramm, R. E., Kasen, M. B., Static tensile properties of boron-aluminum and boron-epoxy composites at cryogenic temperatures, (Proc. First Int. Cryogenic Materials Conf., Kingston, Ontario, Canada, July 22-25, 1975), Paper C-2 in Advances in Cryogenic Engineering, K. D. Timmerhaus, R. P. Reed, and A. F. Clark, Eds., 22, 205-213 (Plenum Publ. Corp., New York, NY, 1977). 
16866. McHenry, H. I., Fracture mechanics and its application to cryogenic structures, (Proc. First Int. Cryogenic Materials Conf., Kingston, Ontario, Canada, July 22-25, 1975), Paper A-2 in Advances in Cryogenic Engineering, K. D. Timmerhaus, R. P. Reed, and A. F. Clark, Eds., 22, 9-26 (Plenum Publ. Corp., New York, NY, 1977).

16868. Ekin, J. W., Fickett, F. R., Clark, A. F., Effect of stress on the critical curreni of NbTi multifilamentary composite wire, (Proc. First Int. Cryogenic Materials Conf., Kingston, Ontario, Canada, July 22-25, 1975), Paper 1-1 in Advances in Cryogenic Engineering, K. D. Timmerhaus, R. P. Reed, and A. F. Clark, Eds., 22, 449-452 (Plenum Publ. Corp., New York, NY, 1977).

16869. Ledbetter, H. M., Naimon, E. R., Weston, W. F., Lowtemperature elastic properties of invar, (Proc. First Int. Cryogenic Materials Conf., Kingston, Ontario, Canada, July 22-25, 1975), Paper B-7 in Advances in Cryogenic Engineering, K. D. Timmerhaus, R. P. Reed, and A. F. Clark, Eds., 22, 174-181 (Plenum Publ. Corp., New York, NY, 1977).

16873. Ekin, J. W., Mechanisms for critical-current degradation in $\mathrm{NbTi}$ and $\mathrm{Nb}_{3} \mathrm{Sn}$ multifilamentary wires, (Proc. IEEE Conf. Applied Superconductivity, Sanford, CA, Aug. 18-20, 1976), IEEE Trans. Magn. MAG-13, No. 1, 127-130 (Jan. 1977).

16878. Hust, J. G., Giarratano, P. J., Thermal and electrical measurements on selected materials for low-temperature applications, (Proc. First Int. Cryogenic Materials Conf., Kingston, Ontario, Canada, July 22-25, 1975), Paper B-2 in Advances in Cryogenic Engineering, K. D. Timmerhaus, R. P. Reed, and A. F. Clark, Eds., 22, 128-135 (Plenum Publ. Corp., New York, NY, 1977).

16879. Reed, R. P., Tobler, R. L., Mikesell, R. P., The fracture tounghness and fatigue crack growth rate of an $\mathrm{Fe}-\mathrm{Ni}-\mathrm{Cr}$ superalloy at 298, 76, and $4 \mathrm{~K}$, (Proc. First Int. Cryogenic Materials Conf., Kingston, Ontario, Canada, July 22-25, 1975), Paper A-7 in Advances in Cryogenic Engineering, K. D. Timmerhaus, R. P. Reed, and A. F. Clark, Eds., 22, 68-79 (Plenum Publ. Corp., New York, NY, 1977).

16883. Williamson, F. R., Olien, N. A., Cryogenic adhesives and sealants-Abstracted publications, NASA SP-3101, 158 pages (National Aeronautics and Space Administration, Washington, DC, 1977).

16928. Tobler, R. L., Reed, R. P., Fatigue crack growth rates of structural alloys at $4 \mathbf{K}$, (Proc. First Int. Cryogenic Materials Conf., Kingston, Ontario, Canada, July 22-25, 1975), Paper A-4 in Advances in Cryogenic Engineering. K. D. Timmerhaus, R. P. Reed, and A. F. Clark, Eds., 22, 35-46 (Plenum Publ. Corp., New York, NY, 1977).

17071. Giarratano, P. J., Collier, R. S., Evaluation of capacitance densitometry for LNG mixtures with low nitrogen composition, Ind. Eng. Chem. Process Res. Dev. 16, No. 3, 330-336 (1977).

17072. Fickett, F. R., Structural materials for cryogenic applications, Proc. 6th Int. Cryogenic Engineering Conf., Grenoble, France, May 11-14, 1976, pp. 20-33 (IPC Science and Technology Press, Guildford, Surrey, England, 1976).

17081. Arvidson, J. M., Brennan, J. A., Pressure measurement at low temperatures, (Proc. First Biennial Symp. on Instrumentation in the Cryogenic Industry, Houston, TX, Oct. 11 14, 1976), ISA Trans. 1, 607-1-607-9 (1976).

17082. Arp, V., Stresses in superconducting solenoids, J. Appl. Phys. 48, No. 5, 2026-2036 (May 1977).

17083. Strobridge, T. R., Voth, R. O., Refrigeration technology for supereonductors, IEEE Trans. Nucl. Sci. NS-24, No. 3, 1222-1226 (June 1977).

17086. Tobler, R. L., Fracture of structural alloys at temperatures approaching absolute zero, (Proc. 4th Int. Conf. of Fracture, Waterloo, Canada, June 19-24, 1977), Fracture 3 , ICF4, 839-846 (1977).
17087. Read, D. T., Ledbetter, H. M., Elastic properties of a boron-aluminum composite at low temperatures, J. Appl. Phys. 48, No. 7, 2827-2831 (July 1977).

17088. Radebaugh, R., Electrical and thermal magnetoconductivities of single-crystal beryllium at low temperatures and its use as a heat switch, J. Low Temp. Phys. 27, Nos. 1/2, 91105 (1977).

17096. Giarratano, P. J., Conference Report on Cryogenic Instrumentation Symposium held in Houston, TX, Oct. 11-14, 1976, Cryogenics 17, No. 3, 186 (Mar. 1977).

17134. Fickett, F. R., Controlled thermonuclear reactors. A prospective large-scale use of pure copper, INCRA Research Report, 44 pages (International Copper Research Association, New York, NY, Aug. 1976).

17162. Brennan, J. A., LaBrecque, J. F., Kneebone, C. H., Progress report on cryogenic flowmetering at the National Bureau of Standards, Proc. First Biennial Symp. Instrumentation in the Cryogenic Industry, Houston, TX, Oct. 11-14, 1976, 1, 621-1-621-16 (Instrument Society of America, Pittsburgh, PA, 1976).

17308. Williamson, F. R., Cryogenic foam insulation-Abstracted publications, NASA Reference Publication 1002, 170 pages (National Aeronautics and Space Administration, Washington, DC, Sept. 1977).

17320. Ledbetter, H. M., Low-temperature elastic properties of a precipitation-hardened copper alloy, Z. Metallkd. 68, No. 7, 506-509 (July 1977).

17321. Ledbetter, H. M., Anomalous low-temperature elastic behavior of a nitrogen-strengthened chromium-manganese stainless steel, Mater. Sci. Eng. 29, 255-260 (1977).

17333. Yaskin, L. A., Jones, M. C., Yeroshenko, V. M., Giarratano, P. J., Arp, V. D., A correlation for heat transfer to supercritical helium in turbulent now in small channels, Cryogenics 17, No. 10, 549-552 (Oct. 1977).

\section{Mathematical and Statistical Methods}

Minimum polynomials and control in linear systems, J. $\mathbf{Z}$. Hearon, J. Res. Nat. Bur. Stand. (U.S.), 82, No. 2, 129-132 (Sept.-Oct. 1977).

Eigenset generalizations of the eigenvalue concept, C. R. Johnson, J. Res. Nat. Bur. Stand. (U.S.), 82, No. 2, 133-136 (Sept.-Oct. 1977).

Enclaveless sets and MK-Systems, P. J. Slater, J. Res. Nat. Bur. Stand. (U.S.), 82, No. 3, 197-202 (Nov.-Dec. 1977).

Electromagnetism in non-Riemannian space, C. H. Page, J. Res. Nat. Bur. Stand. (U.S.), $81 B$ (Math. Sci.), Nos. 1 and 2, 1 3 (Jan.-June 1977).

Tables of one- and two-dimensional inverse Laplace transforms of complete elliptic integrals, S. Okui, J. Res. Nat. Bur. Stand. (U.S.), $81 B$ (Math. Sci.), Nos. 1 and 2, 5-39 (Jan.-June 1977).

Off-diagonal elements of normal matrices, R. Grone, J. Res. Nat. Bur. Stand. (U.S.), $81 B$ (Math. Sci.), Nos. 1 and 2, 41 44 (Jan.-June 1977).

Distant coordinates in matrix form, $K$. Goldberg, J. Res. Nat. Bur. Stand. (U.S.), $81 B$ (Math. Sci.), Nos. 1 and 2, 61-72 (Jan.-June 1977).

NBSIR 77-1253. Cost/benefit analysis of automated transit information systems, D. R. Shier and J. F. Gilsinn, 111 pages (June 1977). Order from NTIS as PB268424.

16660. Newman, M., Asymptotic formulas related to free products of cyclic groups, Math. Comp. 30, No. 136, 838-846 (Oct. 1976).

16676. Johnson, C. R., Multiplicativity and compatibility of generalized matrix norms, Linear Algebra and Appl. 16, 25 37 ( 1977 ).

16755. Johnson, C. R., The inertia of a product of two hermitian matrices, J. Math. Anal. Appl. 57, No. 1, 85-90 (Jan. 1977). 
16784. Goodman, S., Shier, D., On designing a reliable hierarchical structure, SIAM J. Appl. Math. 32, No. 2, 418 430 (Mar. 1977).

16805. Olver, F. W. J., Connection formulas for second-order differential equations with multiple turning points, SIAM J. Math. Anal. 8, No. 1, 127-154 (Feb. 1977).

16819. Johnson, C. R., Functional characterizations of the field of values and the convex hull of the spectrum, Proc. Am. Math. Soc. 61, No. 2, 201-204 (Dec. 1976).

16833. Wampler, R. H., On least squares algorithms, Am. Stat. Letter to Ed. 31, No. 1, 52-53 (Feb. 1977).

16836. Johnson, C. R., Locally compatible generalized matrix norms, Numer. Math. 27, $391-394$ (1977).

16899. Olver, F. W. J., Second-order differential equations with fractional transition points, Trans. Am. Math. Soc. 226, 227. 241 (1977).

16909. Johnson, C. R., A Hadamard product involving $M$ matrices, Linear and Multilinear Algebra 4, 261-264 (1977).

16944. Gilsinn, J. F., Validation of an airport simulation model, Proc. Bicentennial Winter Simulation Conf., Gaithersburg, MD, June 6-8, 1976, H. J. Highland, T. J. Schriber, and R. G. Sargent, Eds., 1, 273-277 (Association for Computing Machinery, New York, NY, 1976).

17041. Newman, M., Sheingorn, M., Continuous solutions of a homogeneous functional equation, Aequationes Math. 13, No. 1/2, 47-59 ( 1975 ).

17117. Joel, L. S., Shier, D. R., Stein, M. L., Planes, cubes and center representable polytopes, Am. Math. Mo. 84, No. 5, 360-363 (May 1977)

17142. Olver, F. W. J., Connection formulas for second-order differential equations having an arbitrary number of turning points of arbitrary multiplicities, SIAM J. Math. Anal. 8, No. 4, 673-700 (Aug. 1977).

17157. Haber, S., The tanh rule for numerical integration, SIAM J. Numer. Anal. 14, No. 4, 668-685 (Sept. 1977).

17266. Eisenhart, C., Contribution to invited discussion of "Do robust estimators work with real data?," by Stephen M. Stigler, Ann. Stat. 5, No. 6, 1085-1087 (Nov. 1977).

17314. Eisenhart, C., Boscovich and the combination of observations, Chapter in Historical Studies in Probability and Statistics 2, 88-100 (Charles Griffin and Co., Ltd., London, England, 1977).

\section{Measurement Science and Technology: Policy and State-of-the-Art Surveys}

SP463. Materials Information Programs-An interagency review of Federal agency activities on technical information about materials. Proceedings of a Conference held at the National Bureau of Standards, Gaithersburg, MD, Apr. 16 and 17, 1974, S. A. Rossmassler, Ed., Nat. Bur. Stand. (U.S.), Spec. Publ. 463, 271 pages (Jan. 1977) SN003-003-01701-9.

The National significance of materials information, F. P. Huddle, SP463, pp. 1.2.1-1.2.2 (Jan. 1977).

Review of agriculture information program materials information in the Forest Service, J. I. Zerbe, SP463, pp. 11.1.1ll. 1.4 (Jan. 1977)

The Current Research Information System (CRIS) as a source for materials information in the agricultural and allied sciences, P. L. Dopkowski, SP463, pp. Il.2.1-Il.2.10 (Jan. 1977).

How the Extension Service-Land Grant University-ARSUSDA information exchange functions, O. Bay, SP463, pp. II.3.1-II.3.4 (Jan. 1977).

Materials information in the Radiation Shielding Information Center, B. F. Maskewitz, D. K. Trubey, and R. W. Roussin, SP463, pp. III.1.1-III.I.10 (Jan. 1977).
Rare-Earth Information Center (RIC), K. A. Gschneidner, Jr. and B. L. Evans, SP463, pp. 1II.2.1-111.2.9 (Jan. 1977).

The Research Materials Information Center, T. F. Connolly and J. W. Cleland, SP463, pp. Ill.3.1-III.3.8 (Jan. 1977).

Materials information services of the Environmental Information System Office and the Toxic Materials Information Center, E. D. Copenhaver and G. U. Ulrikson, SP463, pp. III.4.1-111.4.15 (Jan. 1977).

Government-Industry Data Exchange Program, F. M. Nelson, SP463, pp. Ill.5.1-111.5.8 (Jan. 1977).

Introductory remarks, "The DoD Program for Technical Information about Materials," J. L. Blue, SP463, pp. IV.1.1IV.1.5 (Jan. 1977).

Metals and Ceramic Information Center, J. F. Lynch and H. D. Moran, SP463, pp. IV.2.1-lV.2.7 (Jan. 1977).

Plastics Technical Evaluation Center (PLASTEC), H. E. Pebly, SP463, pp. IV.3.1-IV.3.2 (Jan. 1977).

Thermophysical and Electronic Properties Information Analysis Center [TEPIAC] a DoD Information Analysis Center operated by Center for Information and Numerical Data Analysis and Synthesis [CINDAS], Y. S. Touloukian, SP463, pp. IV.4.1-IV.4.3 (Jan. 1977).

Machinability Data Center-Data Publications and Services,

J. F. Kahles, SP463, pp. IV.5.1-IV.5.8 (Jan. 1977).

Nondestructive Testing Information Analysis Center, G. Darcy, SP463, pp. IV.6.1-IV.6.2 (Jan. 1977).

Concrete Technology Information Analysis Center (CTIAC), B. Mather, SP463, pp. IV.7.1-IV.7.7 (Jan. 1977).

The Mechanical Properties Data Center Products, services and informational content, R. C. Braden, SP463, pp. IV.8.1IV.8.10 (Jan. 1977).

Water Recources Scientific Information Center (WRSIC), W. Z. Ignatieff, SP463, pp. V.1.1-V.1.6 (Jan. 1977).

Materials activity in the Office of Saline Water, F. $H$. Coley, SP463, Pp. V.2. 1-V.2.6 (Jan. 1977).

Bureau of Mines Information-Publication Program, R. P. Willing, SP463, pp. V.3.1-V.3.9 (Jan. 1977).

Materials information in the NASA Scientific and Technical Information System, F. G. Drobka, SP463, pp. VI.1.1-VI.1.7 (Jan. 1977).

The National Standard Reference Data System as a materials information resource, D. R. Lide, Jr., SP463, pp. VIl.1.1VII.1.15 (Jan. 1977).

The Flammable Fabric Accident Case and Testing System (FFACTS), A. K. Vickers, SP463, pp. Vil.2.1-Vil.2.11 (Jan. 1977).

National Technical Information Service-Its products and services, G. K. Kudravetz, SP463, pp. Vil.3.1-VII.3.5 (Jan. 1977).

Standard Reference Materials-The data and the material, R. W. Seward and H. T. Yolken, SP463, pp. VIl.4.1-VIl.4.14 (Jan. 1977).

NBS Standards Information Services-Description of data, information system and services, W. J. Slattery, SP463, pp. VIl.5.1-VII.5.9 (Jan. 1977).

The Library of Congress MARC system, L. J. Rather, SP463, pp. VIII.1.1-VIII.1.4 (Jan. 1977).

The National Referral Center, J. F. Price, SP463, pp. VIII.2.1-VIII.2.4 (Jan. 1977).

Increased demand for data and information in the materials cycle, E. Horowitz, SP463, pp. IX.1.1-IX.1.22 (Jan. 1977).

SP465. Science and technology in America-An assessment, E. Teller, N. Ramsey, W. O. Baker, H. Eyring, G. Birkhoff, A. Perlis, R. C. Seamans, Jr., S. Ramo, and R. M. Thomson, Ed., Nat. Bur. Stand. (U.S.), Spec. Publ. 465, 166 pages (June 1977) SN003-003-01728-1.

SP467. Activities of the National Bureau of Standards, $M$. Jacobs and S. A. Washbum, Eds., Nat. Bur. Stand. (U.S.), Spec. Publ. 467, 40 pages (Mar. 1977) SN003-003-0I716-7. 
NBSIR 75-936. The National Electromagnetic Measurement System, R. A. Kamper, 42 pages (June 1977). (Refer all requests to Electromagnetics Division, National Bureau of Standards, Boulder, CO 80302.).

NBSIR 75-938. The National Measurement System for Acoustics, D. S. Pallett and M. A. Cadoff, 95 pages (Mar. 1977). Order from NTIS as PB264290.

NBSIR 75-939. The National Measurement System for radiometry and photometry, H. J. Kostkowski, 32 pages (Nov. 1977). Order from NTIS as PB274643.

NBSIR 75-941. The National Measurement System for far ultraviolet radiometry, W. R. Ott, 74 pages (June 1977). Order from NTIS as PB269535.

NBSIR 75-945. The National Measurement System for Surface Properties, C. J. Powell, 81 pages (Mar. 1977). Order from NTIS as PB264258.

NBSIR 75-948. Economic analysis of the national measurement system, B. W. Poulson, Ed., 45 pages (Sept. 1977). Order from NTIS as PB274049.

NBSIR 75-949. Structure and functions of the national measurement system, R. C. Sangster, 140 pages (July 1977). Order from NTIS as PB274048.

NBSIR 76-1152. Report to AID on an NBS/AID workshop on standardization and measurement services, H. S. Peiser, J. Cornish, and C. C. Raley, Eds., 111 pages (Mar. 1977). Order from NTIS as PB265719.

NBSIR 76-1180. Standardization and measurement services in Guyana, H. S. Peiser, N. C. Beck, and K. S. Stephens, 100 pages (Feb. 1977). Order from NTIS as PB265087.

NBSIR 76-1 190. Report on an NBS/AID survey of standardization and measurement services in Thailand, H. S. Peiser and R. S. Marvin, Eds., 80 pages (Feb. 1977). Order from NTIS as PB264917.

16903. Davis, R. M., Evolution of computers and computing, Science 195, No. 4283, 1096-1 102 (Mar. 18, 1977).

16906. Davis, R. M., Government information systems: Oniy the automsted will survive, Gov. Data Syst. 5, No. 1, 14, 16, 27 (Mar.-Apr. 1976).

16991. Ambler, E., 75 years of physics at NBS, Phys. Today, 7 pages (Aug. 1976).

17016. Berger, H., The National Bureau of Standards program in nondestructive evaluation, (Proc. Symp. on Nondestructive Testing Standards, Gaithersburg, MD, May 19-21, 1976), Am. Soc. Test. Mater. Spec. Tech. Publ. 624, Nondestructive Testing Standards-A Review, H. Berger, Ed., pp. 317-327 (June 1977).

17070. Howe, S. L., Risley, A. S., National Measurement System Time and Frequency-A micro study, NCSL Newsletter 15, No. 1, 16-20 (Apr. 1975).

17079. Birmingham, B. W., Forecast of new metrological directions at NBS, NCSL Newsletter 18, No. 2, 12-15 (June 1977).

17105. Sangster, R. C., Relevancy of measurements by a systems approach, Proc. 1972 Joint Measurement Conf., Boulder, CO, June 21-23, 1972, pp. 31-37 (Instrument Society of America, Pittsburgh, PA, 1972).

17190. Pallett, D. S., Cadoff, M. A., The national measurement system for acoustics, Sound. Vib. 11, No. 10, 20-31 (OC' 1977).

\section{Measurement Science and Technology:}

\section{Physical Standards and Fundamental Constants}

On the atomic weight of gallium, G. Marineko, J. Res. Nat. Bur. Stand. (U.S.), $81 \mathrm{~A}$ (Phys. and Chem.), No. 1, 1-4 (Jan.-Feb. 1977).

SP330. The Intemational System of Units (SI), (Supersedes NBS Special Publication 330, 1974 Edition), Nat. Bur. Stand. (U.S.), Spec. Publ. 330, 46 pages (Aug. 1977) SN003-00301784-1.
NBSIR 77-1221. Proceedings of a symposium: Communicating for product improvement October 13-14, 1976, C. Hulick, Ed., 52 pages (Feb. 1977). Order from NTIS as PB264919.

16665. Madden, R. P., Hughey, L. R., Radiometry with synchrotron radiation, Proc. Synchrotron Radiation Facilities, Quebec Summer Workshop, Quebec, Canada, June 15-18, 1976, Chapter 10.4, pp. 10-51-10-77 (1976).

16698. Field, B. F., Hesterman, V. W., Laboratory voltage standard based on $2 \mathrm{e} / \mathrm{h}$, IEEE Trans. Instrum. Meas. IM-25, No. 4, 509-511 (Dec. 1976).

16759. Wineland, D. J., Allan, D. W., Glaze, D. J., Hellwig, H. W., Jarvis, S., Jr., Results on limitations in primary cesium standard operation, IEEE Trans. Instrum. Meas. IM-25, No. 4, 453-458 (Dec. 1976).

16775. Glaze, D. J., Hellwig, H., Allan, D. W., Jarvis, S., Jr., NBS-4 and NBS-6: The NBS primary frequency standards, Metrologia 13, 17-28 (Feb. 1977).

16778. Bridges, J. M., Ott, W. R., Vacuum ultraviolet radiometry. 3: The argon mini-arc as a new secondary standard of spectral radiance, Appl. Opt. 16, No. 2, 367-376 (Feb. 1977).

16876. Sullivan, D. B., Frederick, N. V., Can superconductivity contribute to the determination of the absolute ampere?, (Proc. IEEE Conf. Applied Superconductivity, Sanford, CA, Aug. 18-20, 1976), IEEE Trans. Magn. MAG-13, No. 1, 396399 (Jan. 1977).

17005. Loevinger, R., Absorbed dose calibration system of the National Bureau of Standards, (Proc. Fourth Int. Conf. on Medical Physics, Ottawa, Canada, July 25-30, 1976), Phys. Canada 32, Paper 10.1, 2 (July 1976).

17055. Thornton, D. D., The gallium melting-point standard: A determination of the liquid-solid equilibrium temperature of pure gallium on the Intemational Practical Temperature Scale of 1968, Clin. Chem. 23, No. 4, 719-724 (1977).

17098. Barger, R. L., Rydberg constant measurement using cw dye laser and $\mathbf{H}^{*}$ atomic beam, Chapter in Atomic Masses and Fundamental Constants, J. H. Sanders and A. H. Wapstra, Eds., 5, 565-570 (Plenum Publ. Corp., New York, NY, 1976).

17180. Walls, F. L., Hellwig, H., A new kind of passively operating hydrogen frequency standard, Proc. 30th Annual Symp. on Frequency Control, Ft. Monmouth, NJ, June 1976, pp. 473-480 (1976).

17211. Walls, F. L., Design and results from a prototype pascive hydrogen maser frequency standard, Proc. Conf. Precision Time and Time Interval, Washington, DC, Nov. 30-Dec. 2, 1976, pp. $369-380$ (U.S. Naval Research Laboratory, Washington, DC, 1976).

17246. Deslattes, R. D., Unification of the electromagnetic scale, Proc. XXth Colloq. Spectroscopicum Int./Anniversary and the 7 th Int. Conf. on Atomic Spectroscopy, Prague, Czechoslovakia, Aug. 30-Sept. 7, 1977, pp. 267-284 (The Czechoslovak Spectroscopic Society of the Czechoslovak Academy of Sciences, Prague, Czechoslovakia, 1977).

16681. Fong, J. T., Rehm, R. G., Graminski, E. L., Weibull statistics and a microscopic degradation model of paper, Tappi 60, No. 1, 156-159 (Jan. 1977).

\section{Metrology: Physical Measurements}

Establishing a scale of directional-hemispherical reflectance. Factor I: The Van den Akker Method, W. H. Venable, Jr., J. J. Hsia, and V. R. Weidner, J. Res. Nat. Bur. Stand. (U.S.), 82, No. 1, 29-55 (July-Aug. 1977).

Monogr. 160. Geometrical considerations and nomenclature for reflectance, F. E. Nicodemus, J. C. Richmond, J. J. Hsia, I. W. Ginsberg, and T. Limperis, Nat. Bur. Stand. (U.S.), Monogr. 160, 36 pages (Aug. 1977) SN003-003-01793. 
SP481. The gallium melting-point standard, B. W. Mangum and D. D. Thornton, Eds., Nat. Bur. Stand. (U.S.), Spec. Publ. 481, 35 pages (June 1977) SN003-003-01783-3.

TN594-13. Optical radiation measurements: The 1973 NBS scale of spectral irradiance, R. D. Saunders and J. B. Shumaker, Nat. Bur. Stand. (U.S.), Tech. Note 594-13, 36 pages (Apr. 1977) SN003-003-01709-4.

TN6 16, 2d Revision. Frequency standards and clocks: A tutorial introduction, H. Hellwig, Nat. Bur. Stand. (U.S.), Tech. Note 616 (2d Rev.), 70 pages (June 1977) SN003-003-01798-1.

TN695. Time and frequency user's manual, G. Kamas, Ed., Nat. Bur. Stand. (U.S.), Tech. Note 695, 217 pages (May 1977) SN003-003-01781-7.

TN910-3. Self-study manual on optical radiation measurements: Part I-Concepts, Chapter 6, F. E. Nicodemus, Ed., Nat. Bur. Stand. (U.S.), Tech. Note 910-3, 62 pages (June 1977) SN003-003-01785-0.

TN935. Measurement of energy irradiance from single pulse sources, A. R. Schaefer and E. F. Zalewski, Nat. Bur. Stand. (U.S.), Tech. Note 935, 32 pages (Feb. 1977) SN003-00301741-8.

TN950. The NBS detector response transfer and intercomparison package:- The instrumentation, M. A. Lind, E. F. Zalewski, and J. B. Fowler, Nat. Bur. Stand. (U.S.), Tech. Note 950, 23 pages (July 1977) SN003-003-01810-4.

TN952. Designs for the calibration of standards of mass, J. M. Cameron, M. C. Croarkin, and R. C. Raybold, Nat. Bur. Stand. (U.S.), Tech. Note 952, 64 pages (June 1977) SNO03. 003-1778-7.

TN954. Spectral radiometry: A new approach based on electrooptics, J. Geist, M. A. Lind, A. R. Schaefer, and E. F. Zalewski, Nat. Bur. Stand. (U.S.), Tech. Note 954, 23 pages (July 1977) SN003-003-01805-8.

TN956. FORTRAN program to determine length of gage blocks using single wavelength interferometry, R. N. Varner, Nat. Bur. Stand. (U.S.), Tech. Note 956, 55 pages (Sept. 1977) SN003-003-01840-6.

NBSIR 73-106. A system for computerized surface roughness measurement, D. A. Swyt, 61 pages (Feb. 1973). Order from NTIS as PB273940.

NBSIR 73-136. Measurements of cylindrical standards, R. C. Veale, 24 pages (Mar. 1973). Order from NTIS as PB273995.

NBSIR 73-196. Surface finish, friction and wear: The need for more than one parameter, D. A. Swyt, 28 pages (May 1973). Order from NTIS as PB273941.

NBSIR 73-219. Eight techniques for the optical measurement of surface roughness, R. D. Young, 39 pages (May 1973). Available from author.

NBSIR 73-232. A survey of the stability of optical nats, C. P. Reeve and R. C. Veale, 27 pages (June 1973). Order from NTIS as PB273947.

NBSIR 73-239. Gage block flatness and parallelism measurement, J. S. Beers and C. D. Tucker, 11 pages (Aug. 1973). Order from NTIS as PB273962.

NBSIR 74-601. A survey of the temporal stability of angle blocks, R. C. Veale and C. P. Reeve, 24 pages (Nov. 1974). Order from NTIS as PB273948.

NBSIR 76-999. Surveillance test procedures, H. W. Almer and J. Keller, Eds., 78 pages (May 1977). Order from NTIS as PB268130.

NBSIR 77-855. Quartz crystal oscillators with low acceleration sensitivity, J. J. Gagnepain and F. L. Walls, 16 pages (Mar. 1977). Order from NTIS as PB265075.

NBSIR 77-1240. Measurement assurance, J. M. Cameron, 16 pages (Apr. 1977). Order from NTIS as PB266238.

NBSIR 77-1278. The air density equation and the transfer of the mass unit, F. E. Jones, 31 pages (July 1977). Order from NTIS as PB270868.
NBSIR 77-1317. Calibration of high-voltage pulse measurement systems based on the Kerr effect, R. E. Hebner, Jr. and M. Misakian, 38 pages (Sept. 1977). Order from NTIS as PB274333.

U.S. Patent 4,014,166. Satellite controlled digital clock system, J. Y. Cateora, D. D. Davis, and D. W. Hanson, 13 pages (Mar. 29, 1977)

16683. McCamy, C. S., Theory of optical wedges as flux modulators, J. Opt. Soc. Am. 66, No. 12, 1350-1355 (Dec. 1976).

16697. Williams, E. S., Thermal current converters for accurate ac current measurement, IEEE Trans. Instrum. Meas. IM-25, No. 4, 519-523 (Dec. 1976).

16707. Morrow, J. J., NBS automated one-ohm resistance measurements, Quality Progress IX, No. 11, 22-25 (Nov. '1976).

16713. Childers, C. B., Dziuba, R. F., Lee, L. H., A resistive ratio standard for measuring direct voltages to $10 \mathrm{kV}, I E E E$ Trans. Instrum. Meas. IM-25, No. 4, 505-508 (Dec. 1976).

16750. Houck, J. C., Mercury-melting-line determination by latent heat method, J. Appl. Phys. 48, No. 2, 605-609 (Feb. 1977).

16788. Finnegan, T. F., Holdeman, L. B., Wahlsten, S., Microwave phenomena in thin-film Josephson junctions coupled to a contiguous microstrip resonator, IEEE Trans. Magn. MAG-13, No. 1, 392-395 (Jan. 1977).

16794. Hellwig, H., Design principles and characteristics of frequency and time standards, IEEE Trans. Nucl. Sci. NS-23, No. 6, 1629-1635 (Dec. 1976).

16851. Geist, J., Trends in the development of radiometry, Opt. Eng. 15, No. 6, 537-540 (Nov.-Dec. 1976).

16852. Doyle, W. M., McIntosh, B. C., Geist, J., Implementation of a system of optical calibration based on pyroelectric radiometry, Opt. Eng. 15, No. 6, $541-548$ (Nov.-Dec. 1976).

16858. Mandel, J., The analysis of interlaboratory test data, Stand. News 5, No. 3, 17-20, 56 (Mar. 1977).

16875. Frederick, N. V., Sullivan, D. B., Adair, R. T., Advances in the use of SQUIDS for rf attenuation measurement, (Proc. IEEE Conf. Applied Superconductivity, Sanford, CA, Aug. 18-20, 1976), IEEE Trans. Magn. MAG-13, No. I, 361-364 (Jan. 1977).

16896. Faller, J. E., Levine, J., The measurement of the positions of points on the earth's surface using an absolute gravimeter and a multi-wavelength geodimeter as complements to extraterrestrial techniques, (Proc. SALUR Symp., Austin, TX, June 1976), Paper in Scientific Applications of Lunar Laser Ranging, J. D. Mulholland, Ed., pp. 277-283 (D. Reidel Publ. Co., Dordrecht-Holland, 1977).

16947. Blair, B., Jesperson, J., Kamas, G., VLF precision timekeeping potential, (Proc. XVI General Assembly of the International Union of Radio Science (URSI), Ottawa, Canada, Aug. 1969), Paper in Progress in Radio Science 1966-1969, J. A. Lane, J. W. Findlay, and C. E. White, Eds., 2, pp. 143-148 (International Union of Radio Science, Brussels, Beigium, 1971).

16988. Fiori, C. E., Yakowitz, H., Newbury, D. E., Some techniques of signal processing in scanning electron microscopy, (Proc. Seventh Annual Scanning Electron Microscope Symp., Chicago, IL, April 4-11, 1974), Paper in Scanning Electron Microscopy/1974, O. M. Johari and I. Corvin, Eds., Pt. I, 167-174 (IIT Research Institute, Chicago, IL, 1974).

17023. Hall, A. H., Simpson, J. A., Whetstone, J. R., Investigation of densities and thermal expansion coefficients applicable to petroleum measurement, Proc. 9th World Petroleum Congress, Tokyo, Japan, May 11-16, 1975, pp. 291-302 (American Petroleum Institute, Washington, DC, 1975).

17024. Steiner, B. W., A survey of sources used for the accurate measurement of visible, near-infrared, and near ultraviolet radiation, Proc. Int. Commission on Illumination, 18th Session, Lonion, England, Sept. 13, 1975, P-75-07, pp. 139-145 (Bureau Central de la Cie, Paris, Cedex 16, France, 1976). 
17048. Tilford, C. R., Analytical procedure for determining lengths from fractional fringes, Appl. Opt. 16, No. 7, 18571860 (July 1977).

17063. Swyt, D. A., Rosberry, F. W., A comparison of some optical microscope measurements of photomask linewidths, Solid State Technol., pp. 70-75 (Aug. 1977).

17066. Young, R. D., Length calibrations in the micrometer and sub-micrometer range, Annals of the CIRP 25, No. 1, 245. 250 (Aug. 1977).

17179. Easton, R. L., Fisher, L. C., Hanson, D. W., Hellwig, H. W., Rueger, L. J., Dissemination of time and frequency by satellite, Proc. IEEE 64, No. 10, 1482-1493 (Oct. 1976).

17182. Smith, C. N., What time is it really?, Ind. Res. 19, No. 3, 70-74 (Mar. 1977).

17198. Bridges, J. M., Ott, W. R., Pitz, A., Einfeld, D., Stuck, D., Spectral radiance calibrations between $165-300 \mathrm{~nm}$ : An interlaboratory comparison, Appl. Opt. 16, No. 7, 1788-1790 (July 1977).

17214. Graminski, E. L., Kirsch, R. A., Image analysis in paper manufacturing, Proc. IEEE Computer Society Conference on Pattern Recognition and Image Processing, Troy, NY, June 68, 1977, pp. 137-143 (IEEE Computer Society, Long Beach, CA, 1977).

17269. Heydemann, P. L. M., Tilford, C. R., Hyland, R. W., Ultrasonic manometers for low and medium vacua under development at the Nationsl Bureau of Standards, J. Vac. Sci. Technol. 14, No. 1, 597-605 (Jan.-Feb. 1977).

\section{Nuclear Physics and Radiation Technology}

SP461. Radiation physics. Proceedings of the International Symposium on Radiation Physics, held at Bose Institute, Calcutta, India, Nov. 30-Dec. 4, 1974, A. M. Ghose, D. V. Gopinath, J. H. Hubbell, and S. C. Roy, Eds., Nat. Bur. Stand. (U.S.), Spec. Publ. 461, 268 pages (Jan. 1977) SN003003-01733-7.

Present status of photon cross section data $100 \mathrm{eV}$ to 100 GeV, J. H. Hubbell, SP46I, pp. 3-16 (Jan. 1977).

Semiempirical formulation of coherent scattering of gamma rays, S. C. Roy and A. M. Ghose, SP46I, pp. 17-19 (Jan. 1977).

Experimental photoionization cross sections of gamma ray photons for low, medium and high $\mathbf{Z}$ atoms, $B$. Sinha and $\mathbf{N}$. Chaudhuri, SP461, pp. 20-22 (Jan. 1977).

Inner bremsstrahlung accompanying electron capture in 'Be and ${ }^{51} \mathrm{C}$, H. Sanjeevaiah and B. Sanjeevaiah, SP461, pp. 2325 (Jan. 1977).

Inelastic scattering of $279 . \mathrm{KeV}$ gamma rays by bound electrons in heavy atoms, D. S. R. Murty, V. G. Reddy, E. Narasimhacharyulu, and S. T. Swamy, SP461, Pp. 26-28 (Jan. 1977).

Gamma ray attenuation coeficicient measurements at 1115 , 1173 and $1332 \mathrm{keV}$, S. Gopal and B. Sanjeevaiah, SP461, pp. 29-31 (Jan. 1977).

Radiation physics and nuclear technology, P. K. Iyengar, SP461, pp. 32-40 (Jan. 1977).

Variation of total to K-shell photoelectric cross section ratios with atomic number and photon energy, $\mathbf{R}$. Gowda and B. Sanjeevaiah, SP461, pp. 41-43 (Jan. 1977).

Optical model analysis of nonelastic interaction of $14.2 \mathrm{MeV}$ neutrons, B. Pal, A. Chatterjee, and A. M. Ghose, SP461, pp. 44-46 (Jan. 1977).

Geometric factors in radiation physics measurements, $A$. $\mathbf{M}$. Ghose, SP461, pp. 47-54 (Jan. 1977).

Measurement of angular distribution of incoherently scattered gamma rays from atoms, B. Sinha (Goswami) and N. Chaudhuri, SP461, pp. 55-56 (Jan. 1977).

Measurement and analysis of a few $14 \mathrm{MeV}$ neutron capture cross sections, M. Majumdar and B. Mitra, SP461, pp. 57-59 (Jan. 1977).
Intermediate energy approximation of the Bethe-Heitler formula for the bremsstrahlung cross-sections, K. Gopala and B. Sanjeevaiah, SP461, pp. 60-63 (Jan. 1977).

$A$ new method for the measurement of differential elastic scattering cross sections of fast neutrons, $S$. Nath, A. Chatterjee, and A. M. Ghose, SP461, pp. 64-66 (Jan. 1977).

Compton scattering of $1.12 \mathrm{MeV}$ gamma rays by $\mathrm{K}$-shell electrons, P. N. B. Prasad, G. Basavaraju, and P. P. Kane, SP461, pp. 67-69 (Jan. 1977).

Nuclear theory based cross sections of TH-232, TH-233 and U-233 and their applications in reactor technology, S. B. Garg and A. Kumar, SP461, pp. 70-73 (Jan. 1977).

The development of radiation shielding standards in USA, D. K. Trubey, SP461, pp. 74-78 (Jan. 1977).

Integral equation methods in radiation transport, $D . V$. Gopinath, SP461, pp. 79-86 (Jan. 1977).

Neutron transport problems in spherical geometry, D. C. Sahni, SP461, pp. 87-90 (Jan. 1977).

Transport of neutrons during reactor transients, $S$. K. Kapil, SP461, pp. 91-93 (Jan. 1977).

Criticality calculations by source-collision iteration technique for cylindrical systems, V. K. Sundaram and D. V. Gopinath, SP461, pp. 94-96 (Jan. 1977).

Stochastic method of calculations for fast systems, B. K. Godwal and M. P. Navalkar, SP461, pp. $97-99$ (Jan. 1977).

A random sampling technique for choosing scattering angles from arbitrary angular distributions in dosimetric and shielding computations, P. S. Nagarajan, C. P. Raghavendran, P. Sethulakshmi, and D. P. Bhatia, SP461, pp. 100-105 (Jan. 1977).

Monte Cario calculations on dose distributions from plane infinite oblique electron sources, C. R. Gopalakrishnan and V. Sundararaman, SP461, pp. $106-109$ (Jan. 1977).

Backscattering of gamma rays, T. Hyodo, SP461, pp. 110 118 (Jan. 1977).

Transmission of ${ }^{25} \mathrm{Cf}$ fission neutrons through various shields, Y. T. Song, SP461, pp. 119-123 (Jan. 1977).

Back-scattering (sky-shine) of gamma-rays from a 650 Curie cobalt -60 source by infinite air, J. Swarup and $A$. K. Ganguly, SP461, pp. 124-128 (Jan. 1977).

Backscattering of gamma rays by barriers from various media, D. B. Pozdneyev, SP461, pp. 129-131 (Jan. 1977).

Gamma ray streaming through annular cylindrical duct, $\mathrm{K}$. P. N. Murty, R. Vaidyanathan, and R. S. Singh, SP461, pp. 132-135 (Jan. 1977).

Multiple scattering of 12 to $40 \mathrm{MeV}$ heavy ions through small angles, B. W. Hooton, J. M. Freeman, and P. P. Kane, SP461, pp. 136-139 (Jan. 1977).

Charged particle transport in one-dimensional finite systems, G. Muthukrishnan, K. Santhanam, and D. V. Gopinath, SP461, pp. 140-143 (Jan. 1977).

Passage of heavy charged particles through matter, S. Mukherji and B. K. Srivastava, SP461, pp. 144-148 (Jan. 1977).

Neutron thermalization in hydrogenous moderators, L. S. Kothari, SP461, pp. 149-162 (Jan. 1977).

Neutron transport studies in fast reactor shieids, $R$. Vaidyanathan, K. P. N. Murty, and R. S. Singh, SP461, pp. 163-165 (Jan. 1977).

Shielding for the variable energy cyclotron at Calcutta, G. Muthukrishnan, H. Singh, and R. Mukherjee, SP461, pp. 166-170 (Jan. 1977).

Computer codes and data available from the radiation shielding information center, D. K. Trubey, B. F. Maskewitz, and R. W. Roussin, SP461, pp. 171-173 (Jan. 1977).

Gamma ray build-up factors for finite media, $K$. John and D. V. Gopinath, SP461, pp. 174-176 (Jan. 1977).

Physical principles of photon dosimetry, W. S. Snyder, SP461, Pp. 177-182 (Jan. 1977). 
Track theory applied to physical, chemical and biological systems, S. C. Sharma and R. Katz, SP46I, pp. 183-187 (Jan. 1977).

Spectrum shapes of low-energy photon sources, $R$. C. Sharma, S. Somasundaram, K. Unnikrishnan, and S. Datta, SP461, pp. 188-192 (Jan. 1977).

Dose function for beta dosimetry, S. J. Supe and S. Datta, SP461, pp. 193-196 (Jan. 1977).

Actual problems in photon dosimetry, D. F. Regulla and G. Drexler, SP461, pp. 197-208 (Jan. 1977).

Neutron dosimetry by thermoluminescence dosimeter, $Y$. Furuta and S. Tanaka, SP461, pp. 209-218 (Jan. 1977).

Effect of heat treatments on thermoluminescence of pure $\mathrm{Al}_{2} \mathrm{O}_{3}$, A. S. Basu and A. K. Ganguly, SP461, pp. 219-221 (Jan. 1977).

Thermoluminescence mechanisms in lithium nuoride, S. P. Kathuria, V. N. Bapat, C. M. Sunta, and V. K. Jain, SP46I, pp. 222-226 (Jan. 1977).

Thermoluminescence response of LiF to gamma rays, V. K. Jain and S. P. Kathuria, SP461, pp. 227-230 (Jan. 1977).

Change in TL sensitivity of quartz due to stress, M. David and A. K. Ganguly, SP461, pp. 231-233 (Jan. 1977).

ESR-TL correlation studies in $\mathrm{CaSO}_{4}(\mathrm{RE})$ phosphors, $\mathrm{K}$. S. V. Nambi, SP461, pp. 234-237 (Jan. 1977).

Neutron dose evaluation using calculated neutron spectra, $\mathbf{S}$. Makra, SP461, pp. 238-246 (Jan. 1977).

Utilization of plastic scintillator in the measurement of uncharged radiations, P. K. Sarkar and K. N. Kirthi, SP461, pp. 247-251 (Jan. 1977).

Neutron spectrometry by sandwich surface barrier technique, O. P. Joneja, SP461, pp. 252-254 (Jan. 1977).

Role of high resolution Ge(Li) detector in trace element stady in water activated with thermal neutrons, J. M. Chatterjee, E. Peeters, and M. A. Castiaux, SP461, pp. 255-256 (Jan. 1977).

SP493. Neutron standards and applications. Proceedings of the International Specialists Symposium on Neutron Standards and Applications held at the National Bureau of Standards, Gaithersburg, MD, Mar. 28-31, 1977, C. D. Bowman, A. D. Carlson, H. O. Liskien, and L. Stewart, Eds., Nat. Bur. Stand. (U.S.), Spec. Publ. 493, 379 pages (Oct. 1977) SNO03-00301847-3.

Survey of recent experiments for the 'Li-system, H. H Knitter, SP493, pp. 3-9 (Oct. 1977).

Angular anisotropy in the ${ }^{6} \mathrm{~L}(\mathrm{n}, \boldsymbol{\alpha})^{3} \mathrm{H}$ reaction below 100 keV, J. A. Harvey and I. G. Schröder, SP493, pp. 10-13 (Oct. 1977).

Experimental data base for the Li-7 system, H. Derrien and L. Edvardson, SP493, pp. 14-29 (Oct. 1977).

R-matrix analysis of the ' $\mathrm{Li}$ system, G. M. Hale, SP493, pp. 30-36 (Oct. 1977).

Special problems with 'Li glasses, G. P. Lamaze, SP493, pp. $37-42$ (Oct. 1977).

Instruments for use of $\mathrm{Li}$ as a standard, $\mathrm{L}$. W. Weston, SP493, pp. 43-46 (Oct. 1977).

Experiments and theory for differential n-p scattering, C. A. Uttley, SP493, pp. 47-53 (Oct. 1977).

Use of the $n, p$ scattering reaction for neutron fiux measurements, J. B. Czirr, SP493, Pp. 54-60 (Oct. 1977).

Surface barrier spectrometers for calibration of fast neutrons in MeV range, O. P. Joneja, R. V. Srikantaiah, M. R. Phiske, J. S. Coachman, and M. P. Navalkar, SP493, pp. 61-66 (Oct. 1977).

Review of ${ }^{10} \mathrm{~B}(\mathrm{n}, \mathrm{a})^{7} \mathrm{Li}$ cross-section measurements in the energy range from $10 \mathrm{keV}$ to $1 \mathrm{MeV}$, E. Wattecamps, SP493, pp. 67-84 (Oct. 1977).

Instruments for use of ${ }^{10} \mathrm{~B}$ as a standard, A. D. Carlson, SP493, pp. 85-92 (Oct. 1977).

Evaluation and use of carbon as a standard, J. C. Lachkar, SP493, pp. 93-100 (Oct. 1977).
Need for improved standards in neutron personnel dasimetry, J. A. Auxier, SP493, pp. 101-105 (Oct. 1977).

Standards in medical neutron dosimetry, J. J. Broerse, SP493, pp. 106-1 14 (Oct. 1977).

NBS facilities for standardization of neutron dosimetry from 0.001 to $14 \mathrm{MeV}$, O. A. Wasson, SP493, pp. 115-120 (Oct. 1977).

International neutron dosimetry intercomparisons, $R$. S. Caswell, SP493, pp. 121-127 (Oct. 1977).

Reactor core dosimetry standards, W. L. Zijp, SP493, pp. 128-136 (Oct. 1977).

Standards for dosimetry beyond the core, F. J. Rahn, K. E. Stahlkopf, T. U. Marston, R. Gold, and J. H. Roberts, SP493, pp. 137-145 (Oct. 1977).

Fission yields: Measurement techniques and data status, $\mathbf{W}$. J. Maeck, SP493, pp. 146-155 (Oct. 1977).

Fission reaction rate standards and applications, J. Grundl and C. Eisenhauer, SP493, pp. 156-164 (Oct. 1977).

Utility and use of neutron capture cross section standards and the status of the $A u(n, \gamma)$ standard, A. Paulsen, SP493, pp. 165-169 (Oct. 1977).

Remarks on the $2200 \mathrm{~m} / \mathrm{s}$ and $20^{\circ} \mathrm{C}$ Maxwellian neutron data for U-233, U-235, Pu-239 and Pu-241, H. D. Lemmel, SP493, pp. 170-173 (Oct. 1977).

Assessment of the "thermal mormalization technique" for measurement of neutron cross sections vs. energy, R. W. Peelle and G. de Saussure, SP493, pp. 174-181 (Oct. 1977).

Review of $\bar{\nu}$ for ${ }^{252} \mathrm{Cf}$ and thermal neutron fission, J. W. Boldeman, SP493, pp. 182-193 (Oct. 1977).

Measurement of the ${ }^{232} \mathrm{Cf}$ spontaneous fission neutron spectrum, M. V. Blinov, V. A. Vitenko, and V. T. Touse, SP493, pp. 194-197 (Oct. 1977).

Prompt fission neutron spectra, L. Stewart and C. M. Eisenhauer, SP493, pp. 198-205 (Oct. 1977).

On quantitative sample preparation of some heavy elements, A. H. Jaffey, SP493, pp. 206-211 (Oct. 1977).

Black and grey neutron detectors, F. Gabbard, SP493, pp. 212-220 (Oct. 1977).

Associated particle methods, M. M. Meier, SP493, pp. 221226 (Oct. 1977).

Associated gamma-ray technique for neutron fluence measurements, J. D. Brandenberger, SP493, pp. 227-233 (Oct. 1977).

Associated activity method, K. K. Sekharan, SP493, pp. 234-236 (Oct. 1977).

Accuracies and corrections in meutron bath techniques, E. J. Axton, SP493, pp. $237-243$ (Oct. 1977).

International comparison of hux density measurements for monoenergetic fast neutrons, V. D. Huynh, SP493, pp. 244 249 (Oct. 1977).

Calibration and use of filtered beams, R. B. Schwartz, SP493, pp. 250-254 (Oct. 1977).

Much ado about nothing: Deep minima in ${ }^{4 S c}$ and ${ }^{56} \mathrm{Fe}$ total neutron cross sections, R. E. Chrien, H. I. Liou, R. C. Block, U. N. Singh, and K. Kobayashi, SP493, pp. 255-260 (Oct. 1977).

The U-235 neutron fission cross section from 0.1 to 20.0 MeV, W. P. Poenitz, SP493, pp. 261-268 (Oct. 1977).

Propagation of uncertainties in fission cross section standards in the interpretation and utilization of critical benchmark measurements, C. R. Weisbin and R. W. Peelle, SP493, pp. 269-277 (Oct. 1977).

${ }^{237 \mathrm{~Np} \text { and }}{ }^{208} \mathrm{U}$ as possible standards for the $\mathrm{MeV}$ region, $\mathrm{S}$. Cierjacks, SP493, pp. 278-289 (Oct. 1977).

Standard integral measurement tacilities, A. Fabry, SP493, pp. 290-298 (Oct. 1977).

Integral measurement results in standard fields, D. M. Gilliam, SP493, pp. 299-303 (Oct. 1977). 
Absolute fission crass section measurements using fixed energy neutron sources, G. F. Knoll, SP493, pp. 304-310 (Oct. 1977).

Impact of ENDF standards on fast reactors, U. Farinelli, SP493, pp. 310-312 (Oct. 1977).

Absolute ${ }^{235} \mathrm{U},{ }^{238} \mathrm{U},{ }^{237} \mathrm{~Np}$ fast meutron fission cross-section measurements, V. M. Adamov, B. M. Alexandrov, I. D. Alkhazov, L. V. Drapchinsky, S. S. Kovalenko, O. I. Kostochkin, G. Y. Kudriavzev, L. Z. Malkin, K. A. Petrzhak, L. A. Pleskachevsky, A. V. Fomichev, and V. I. Shapakov, SP493, pp. 313-318 (Oct. 1977).

Neutron energy standards, G. D. James, SP493, pp. 319 328 (Oct. 1977).

Neutron transport calculations for the intermediate-energy standard meutron field (ISNF) at the National Bureau of Standards, C. M. Eisenhauer, J. A. Grundl, and A. Fabry, SP493, pp. 329-334 (Oct. 1977).

Standardization of fast pulse reactor dosimetry, A. H. Kazi, E. D. McGarry, and D. M. Gilliam, SP493, pp. 335-341 (Oct. 1977).

Dasimetry standards for neutrons above $10 \mathrm{MeV}, \mathrm{H}$. H. Barschall, SP493, pp. 342-346 (Oct. 1977).

TN955. Electromegnetic interactions from 5 to $500 \mathrm{MeV}$ and nuclear research-A position paper as of March 1977, L. C. Maximon, Nat. Bur. Stand. (U.S.), Tech. Note 955, 51 pages (Aug. 1977) SNOO3-003-01816-3.

TN957. Threshold photo and electroproduction of pions from nuclei, E. T. Dressler, Nat. Bur. Stand. (U.S.), Tech. Note 957, 38 pages (Sept. 1977) SN003-003-01834-0.

NBSIR 76-1135. Radiation-hardness testing of electronic devices: A survey of facility dosimetry practices, J. C. Humphreys and S. E. Chappell, 45 pages (Sept. 1976). Order from NTIS as PB263630.

NBSIR 77-1279. Cross sections and yields for high energy neutron source reactions, M. A. Lone, L. Stewart, A. D. Carlson, and C. D. Bowman, Eds., 40 pages (July 1977). Order from NTIS as PB270863.

Neutron spectra from deuteron and proton bombardment of thick lithium tangets, C. E. Nelson, F. O. Purser, P. Von Behren, and H. W. Newson, NBSIR 77-1279, pp. $1-4$ (July 1977).

Neutron spectral distributions from proton and deuteron bombardment of thick $L i$ and Be targets at 14.8, 18 and 23 MeV, M. A. Lone, NBSIR 77-1279, pp. 5-9 (July 1977).

35 and $65 \mathrm{MeV}$ protons and $35 \mathrm{MeV}$ deuterons on lithium and beryllium, M. Awschalom, NBSIR 77-1279, pp. 10-14 (July 1977).

Spectral measurements of 25 to $55 \mathrm{MeV}$ neutron bearns, S. W. Johnsen, NBSIR 77-1279, pp. 15-18 (July 1977).

Protons and deuterions on Be at $\mathrm{E}_{p}=100 \mathrm{MeV}$ and $\mathrm{E}_{d}=$ $80 \mathrm{MeV}$, G. H. Harrison, C. R. Cox, E. B. Kubiczek, and J. E. Robinson, NBSIR 77-1279, pp. 19-23 (July 1977).

Neutron yields and dosimetry for $\operatorname{Be}(d, n)$ and $L i(d, n)$ neutron sources at $\mathbf{E}_{d}=40 \mathrm{MeV}$. M. J. Saltmarsh, C. A. Ludemann, C. B. Fulmer, and R. C. Styles, NBSIR 77-1279, pp. 24-29 (July 1977).

Neutron spectra and doses from deuteron bombardment of light nuclei, H. H. Barschall, NBSIR 77-1279, p. 30 (July 1977).

Neutron spectral measurements and interpretation at the Naval Research Laboratory, L. S. August, P. Shapiro, and R. B. Theus, NBSIR 77-1279, pp. 31-34 (July 1977).

U.S. Patent 4,006,023. Photographic polymeric composition containing a leuco dye cyanide, W. L. McLaughlin, H. Levine, and M. Rosenstein, 9 pages (Feb. 1, 1977).

16687. Lindgren, R. A., Bendel, W. L., Jones, E. C., Jr., Fagg, L. W., Maruyama, X. K., Lightbody, J. W., Jr., Fivozinsky, S. P., Electroexcitation of the $T_{0}+1$ giant $M 1$ resonance in 5s,a07i, Phys. Rev. C 14, No. 5, 1789-1799 (Nov. 1976).
16790. Grundl, J. A., Spiegel, V., Eisenhauer, C. M., Heaton, H. T. II, Gilliam, D. M., Bigelow, J., A californium-252 fission spectrum irradiation facility for neutron reaction rate measurements, Nucl. Technol. 32, 315-319 (Mar. 1977).

16793. Heimbach, C. R., Lehman, D. R., O'Connell, J. S., Twobody electrodisintegration of ${ }^{3} \mathrm{He}$ : Faddeev calculation, Physics Lett. 66B, No. 1, 1-4 (Jan. 1977).

16806. Green, D. C., A CAMAC parallel branch driver for the Harris 6024/5 computer, IEEE Trans. Nucl. Sci. NS-24, No. 2, $931-932$ (Apr. 1977).

16814. Sparrow, J. H., Dick, C. E., Pulsed high intensity monoenergetic low energy $x$-ray source and absolute $x$-ray monitor, Nucl. Instrum. Methods 141, 283-292 (1977).

16845. Finn, J. M., Crannell, H., Hallowell, P. L., O'Brien, J. T., Penner, S., Elastic electron scattering from the isotopes ${ }^{38}$ Ar and ${ }^{40}$ Ar, Nucl. Phys. A274, 28-44 (1976).

16850. Szalata, Z. M., Finn, J. M., Flanz, J., Kline, F. J., Peterson, G. A., Lightbody, J. W., Jr., Maruyama, X. K., Penner, S., Low-momentum-transfer elastic electron scattering from ${ }^{3}$ He, Phys. Rev. C 15, No. 4, 1200-1203 (Apr. 1977).

16926. Hayward, E., Phot on scattering in the energy range 5$30 \mathrm{MeV}$, (Lectures for the Erice Photonuclear School, Sicily, Italy, June 3-17, 1976), Paper in Lecture Notes in Physics No. 61, Photonuclear Reactions, J. Ehlers, K. Hepp, R. Kippenhahn, H. A. Weidenmiiller, and J. Zittartz, Eds., pp. 340-406 (Springer-Verlag, Berlin, Germany, 1976).

16938. Trombka, J. I., Dyer, C. S., Evans, L. G., Bielefeld, M. J., Seltzer, S. M., Metzger, A. E., Reanalysis of the Apollo cosmic gamma-ray spectrum in the 0.3 to $10 \mathrm{MeV}$ energy region, Astrophys. J. 212, No. 3, Pt. 1, $925-935$ (Mar. 15, 1977).

16949. McLaughlin, W. L., Miller, A., Fidan, S., Pejtersen, K., Pedersen, W. B., Radiochromic plastic films for accurate measurement of radiation absorbed dose and dose distributions, Radiat. Phys. Chem. 10, 119-127 (1977).

16951. Bowman, C. D., Applications of neutron capture $\gamma$-ray spectroscopy, Proc. Second Int. Symp. on Neutron Capture Gamma Ray Spectroscopy and Related Topics, Petten, The Netherlands, Sept. 2-6, 1974, pp. 729-734 (Reactor Centrum Nederland, Petten, The Netherlands, Mar. 1975).

16975. Coursey, B. M., Hutchinson, J. M. R., Unterweger, M. P., Calibration of $\mathrm{Ge}(\mathrm{Li})$ gamma-ray spectrometers for the measurement of radioactive noble gases, Int. J. Appl. Radiat. Isot. 28, 551-553 (1977).

16982. Neuhausen, R., Lightbody, J. W., Jr., Fivozinsky, S. P., Penner, S., Electron scattering studies of low-lying collective states of even Zn isotopes, Nucl. Phys. A263, 249-260 (1976).

16984. Kosanic, M. M., Nenadović, M T., Radak, B. B., Markovič, V. M., McLaughlin, W. L., Liquid radiochromic dye dosimetry for continuous and pulsed radiation fields over a wide range of energy flux densities, Int. J. Appl. Radiat. Isot. 28, 313-321 (1977).

16987. Berman, B. L., Gibson, B. F., O'Connell, J. S., Isospin shift of the energy of the giant resonance, Physics Letters 66B, No. 5, 405-409 (Feb. 28, 1977).

16999. Humphreys, J. C., Chappell, S. E., McLaughlin, W. L., Jarrett, R. D., Meastrements of dose distributions in various materials irradiated by 10-MeV electrons, (Proc. Int. Radiation Processing Conf., Puerto Rico, May 10-13, 1976), Radiat. Phys. Chem. 9, 749-761 (1977).

17000. McLaughlin, W. L., Radiation measurements and quality control, (Proc. Int. Radiation Processing Conf., Puerto Rico, May 10-13, 1976), Radiat. Phys. Chem. 9, 147-181 (1977).

17051. Hubbell, J. H., Photon mass attenuation and mass energy-absorption coeficients for $\mathrm{H}, \mathrm{C}, \mathrm{N}, \mathrm{O}, \mathrm{Ar}$, and seven mixtures from $0.1 \mathrm{keV}$ to $20 \mathrm{MeV}$, Radiat. Res. 70, 58-81 (1977).

17058. Grundl, J., Eisenhauer, C., Fission rate measurements for materials neutron dosimetry in reactor environments, 
Proc. First ASTM-EURATOM Symp. on Reactor Dosimetry, Petten, The Netherlands, Sept. 22-26, 1975, EUR 5667 e/f, Part 1, pp. 425-454 (Commission of the European Communities, Brussels, Belgium, 1977).

17103. Danos, M., Rafelski, J., Some consequences of Fermitype theory of weak interactions, Nuovo Cimento Lett. 19, No. 9, 339-343 (July 2, 1977).

17109. Amsden, A. A., Ginocchio, J. N., Harlow, F. H., Nix, J. R., Danos, M., Halbert, E. C., Smith, R. K., Jr., Comparison of macroscopic and microscopic calculations of highenergy ${ }^{20} \mathrm{Ne}+{ }^{238} \mathrm{U}$ collisions, Phys. Rev. Lett. 38, No. 19, 1055-1058 (May 9, 1977).

17210. Danos, M., Williams, H. T., Separation of the $\Delta \Delta$ and NN components of the deuteron by kinematics of high energy $\pi D$ reactions, Phys. Rev. C 16, No. 3, 1082-1086 (Sept. 1977).

17268. Stewart, B. D., Improved $\boldsymbol{\beta}$ scintillation counting, Health Phys. 33, No. 4, 343-344 (Oct. 1977).

17343. McLaughlin, W. L., Fundamentals of dosimetry, Chapter 1 in Manual of Food Irradiation Dosimetry, Technical Reports Series No. 178, pp. 1-34 (International Atomic Energy Agency, Vienna, Austria, 1977).

\section{Mechanics: Design, Testing and Measurement}

NBSIR 76-1053. Component parts assembly with joints, adhesive-mechanical. Part 4. Analysis and test of bonded and weldbonded lap joints, R. A. Mitchell, R. M. Woolley, and S. M. Baker, 75 pages (Mar. 1976). Order from NTIS as ADA029426.

NBSIR 76-1145. Interlaboratory comparison of force calibrations using ASTM method E74-74. Phase I, R. W. Peterson and R. L. Bloss, 35 pages (Aug. 1976). Order from NTIS as PB265110.

NBSIR 77-1213. Skid resistance measurement tests of new FHWA reference systems at the Eastern Field Test Center, R. W. Kearns and J. F. Ward, 132 pages (Mar. 1977). Order from NTIS as PB265102.

NBSIR 77-1214. Evaluation of metal volumetric standards used in the measurement of liquid hydrocarbons: A report of a U.S. National Bureau of Standards and American Petroleum Institute research ascociate project, D. J. Hine, 204 pages (June 1977). Order from NTIS as PB269878.

NBSIR 77-1229. Accelerometer calibration-A comparison between CESTA and NBS, J. D. Pollard, 22 pages (Jan. 1977). Order from NTTS as PB265477.

NBSIR 77-1254. Transportation, handling and field service loads for air mobility shelter systems, C. W. C. Yancey, 74 pages (July 1977). Order from NTIS as PB269354.

16915. Bloss, R. L., Trends relating to verification of testing machines and weighing equipment, Proc. IMEKO Sth Int. Conf., Szeged, Hungary, Aug. 31, 1974, Preprint, pp. 1-19 (1974).

17303. Ellingwood, B., Shaver, J., Reliability of RC beams subjected to fire, J. Structural Div., ASCE 103, ST5, 1047-1059 (May 1977).

17304. Ellingwood, B., Statistical analysis of RC beam-column interaction, J. Structural Div., ASCE 103, ST7, 1377-1388 (July 1977).

17306. Ellingwood, B., Harris, J. R., Reliablity-based performance criteria for structures, Proc. Second Annual Engineering Mechanics Division Specialty Conf., Raleigh, NC, May 23-25, 1977, pp. 124-127 (American Society of Civil Engineers, New York, NY, 1977).

\section{Operations Analysis and Applications}

Minimax location problems with nonlinear costs, P. M. Dearing, J. Res. Nat. Bur. Stand. (U.S.), 82, No. 1, 65-72 (July-Aug. 1977).

A note on a nonlinear minimax location problem in tree networks, R. L. Francis, J. Res. Nat. Bur. Stand. (U.S.), 82, No. 1, 73-80 (July-Aug. 1977).

\section{Processing and Performance of Materials}

Monogr. 156. Stress corrosion cracking control measures, B. F. Brown, Nat. Bur. Stand. (U.S.), Monogr. 156, 81 pages (June 1977) SN003-003-01674-8.

Monogr. 158. Corrosion and protection of steel piles in a natural seawater environment, E. Escalante, W. P. Iverson, W. F. Gerinold, B. T. Sanderson, and R. L. Alumbaugh, Nat. Bur. Stand. (U.S.), Monogr. 158, 42 pages (June 1977) SN003003-01788-4.

SP487. MFPG-Engineering design. Proceedings of the 25th Meeting of the Mechanical Failures Prevention Group, held at the National Bureau of Standards, Gaithersburg, MD, Nov. 3-5, 1976, T. R. Shives and W. A. Willard, Eds., Nat. Bur. Stand. (U.S.), Spec. Publ. 487, 367 pages (Aug. 1977) SNO03-003-01 829-5.

The growing web around the designer, C. O. Smith, SP487, pp. 1-15 (Aug. 1977).

A systems approach to materials in design, B. P. Bardes, SP487, pp. 19-24 (Aug. 1977).

Probabilistic methods in design, E. B. Haugen, SP487, pp. 25-38 (Aug. 1977).

The finite element method in structural analysis, $H . G$. Schaeffer, SP487, pp. 41-61 (Aug. 1977).

NASTRAN thermal analyzer in interdisciplinary thermostructural analyses, H. P. Lee, SP487, pp. 62-81 (Aug. 1977).

The use of cathode ray tube graphics as a computer aided design tool, A. Branum, SP487, pp. 82-90 (Aug. 1977).

Review of the processing and properties of PAN graphitealuminum composites, R. T. Pepper, H. Gigerenzer, and T. A. Zack, SP487, pp. 93-107 (Aug. 1977).

Composite inlays for jet engines, $W$. Troha and K. Swain, SP487, pp. 108-120 (Aug. 1977).

Stress concentrations in composite materials, G. Kardos, SP487, pp. 121-134 (Aug. 1977).

Elastohydrodynamic lubrication, L. B. Sibley, SP487, pp. 137-153 (Aug. 1977).

Polyturoroalkyl-alkyl polysiloxane grease for instrument lubrication, J. B. Christian, SP487, pp. 154-171 (Aug. 1977).

Antiwear and lubricity additives for lubricants, S. M. Hsu, SP487, pp. 172-185 (Aug. 1977).

Piezoelectric polymers and their applications, S. Edelman, SP487, Pp. 189-196 (Aug. 1977).

Exoelectron emission-Past experience and future expectations, W. J. Baxter, SP487, pp. 197-209 (Aug. 1977).

Detecting structural degradation by acoustic emisxion, M. P. Kelly and R. J. Schlamp, SP487, pp. 210-238 (Aug. 1977).

Negligence charges in products liability law can be used in engineering as safety design criteria, R. R. Hagglund, SP487, pp. 241-246 (Aug. 1977).

Prescription to reduce products liability lasses. A. The defendant and products liability, J. P. Arness, SP487, pp. 247 252 (Aug. 1977).

Prescription to reduce products liability losses. B. The plaintiff and products liability, M. Heller, SP487, pp. 253-256 (Aug. 1977).

Safety analysis: Qualitative, quantitative and cost effective, H. D. Wolf, SP487, pp. 265-277 (Aug. 1977). 
A failure mode and effect analysis program to reduce mechanical failures, R. R. Landers, SP487, pp. 278-288 (Aug. 1977).

Fault tree analysis as a part of mechanical systems design, J. B. Fussell and D. P. Wagner, SP487, pp. 289-308 (Aug. 1977).

Ion plating-Concepts and applications, D. M. Mattox, SP487, pp. $311-323$ (Aug. 1977).

Sputtering, T. Spalvins, SP487, pp. $324-337$ (Aug. 1977).

SP494. MFPG. Detection, diagnosis and prognosis. Proceedings of the 26th Meeting of the Mechanical Failures Prevention Group held at the IIT Research Institute, Chicago, IL, May 17-19, 1977, T. R. Shives and W. A. Willard, Eds., Nat. Bur. Stand. (U.S.), Spec. Publ. 494, 296 pages (Sept. 1977) SNO03-003-01 844-9.

Statistical analysis of wear metal concentration measurements in oil; calculation of significant wear metal production rates, K. Scheller and K. J. Eisentraut, SP494, pp. 3-23 (Sept. 1977).

Effective fluid analysis of oil-wetted systems through proper planning and interpretation, R. K. Tessmann and G. E. Maroney, SP494, pp. 24-26 (Sept. 1977).

Oil analysis/wear particle analysis, P. B. Senholzi, SP494, pp. 27-32 (Sept. 1977).

Application of ferrographic Iube oil analysis to U.S.N. ship systems, G. F. Rester, SP494, pp. 33-48 (Sept. 1977).

Effectiveness of the real time ferrograph and other oil monitors as related to oil filtration, R. Valori, SP494, pp. 49-72 (Sept. 1977).

Ferrographic separation of organic compounds, E. R. Bowen and V. C. Westcott, SP494, pp. 73-74 (Sept. 1977).

Mechanical signature analysis as a first step in quantifying the characteristics of operating machinery, J. S. Mitchell, SP494, pp. 77-78 (Sept. 1977).

Spectrum analysis and machinery monitoring, G. F. Lang, SP494, pp. 79-81 (Sept. 1977).

Comparison of vibration signature analysis techniques, J. L. Frarey, SP494, pp. 82-83 (Sept. 1977).

The role of signal processing in machinery vibration analysis, J. H. Hamilton, SP494, pp. 93-96 (Sept. 1977).

Diagnostic techniques for steam turbines, R. L. Bannister, R. L. Osborne, and S. J. Jennings, SP494, pp. 97-116 (Sept. 1977).

Experimental determination of radial magnetic forces as a function of rotor offset in a large induction motor, $R$. $L$. Leon, SP494, pp. 117-120 (Sept. 1977).

A new chip detector-reliable, versatile, and inexpensive, $T$. Tauber, SP494, pp. 123-132 (Sept. 1977).

Another look at time waveform analysis, J. B. Catlin, SP494, pp. 133-137 (Sept. 1977).

The advent of sophisticated fierid power systems and its impact on preventative maintenance in the military, M. W. Wigton, SP494, pp. 138-145 (Sept. 1977).

Tire degradation monitoring, W. Lichodziejeswki, SP494, pp. 146-151 (Sept. 1977).

Use of microprocessons in analysis of acoustic emiscion weld monitoring data, R. N. Clark and T. A. Mathieson, SP494, pp. 152-166 (Sept. 1977).

Pictorial history of the development of proximity probes for use in high temperature liquid metals environment, $L$. Hoogenboom, SP494, pp. 167-187 (Sept. 1977).

Department of Transportation System for Train Accident Reduction (DOT-STAR), J. K. O'Steen, SP494, pp. 191-204 (Sept. 1977).

Comparison of vibration analysis techniques for rallroad roller bearing diagnostics, W. D. Waldron, SP494, pp. 205 222 (Sept. 1977).
Maintenance management through diagnosis, R. G. Salter, SP494, pp. 225-237 (Sept. 1977).

Vehicle monitoring system, S. C. Hadden, R. E. Hanson, and M. W. Stewich, SP494, pp. 238-248 (Sept. 1977).

Systemized diesel engine diagnostics, H. J. Mercik, Jr., SP494, pp. 249-258 (Sept. 1977).

NBSIR 76-1075. The structure of slow crack interfaces in silicon nitride, N. J. Tighe, 23 pages (May 1976). Order from NTIS as PB274653.

NBSIR 76-1 148. Characterizing the inter-fiber bond strengths of paper pulps in terms of a breaking energy, J. C. Smith and E. L. Graminski, 39 pages (Oct. 15, 1976). Order from NTIS as PB264689.

NBSIR 76-1170. The role of passive film growth kinetics and properties in stress corrosion and crevice corrosion susceptibility, J. Kruger and J. R. Ambrose, 56 pages (Nov. 1976). Order from NTIS as ADA034723.

NBSIR 77-1202. Application of proof tests to silicon nitride, $N$. J. Tighe, S. M. Wiederhorn, and L. R. Russell, 11 pages (Mar. 1977). Order from NTIS as PB276652.

NBSIR 77-1208. NBS space processing research, E. Passaglia and R. L. Parker, 115 pages (Feb. 1977). Order from NTIS as PB264286.

NBSIR 77-1232. Development of in-situ techniques for the detection and measurement of corrasion of copper concentric neutrals in underground environments, J. Kruger, U. Bertocci, E. Escalante, and J. L. Mullen, 71 pages (Apr. 1977). Order from NTIS as PB265672.

NBSIR 77-1396. Enosion of brittle materials by solid particle impact, B. J. Hockey, S. M. Wiederhorn, and H. Johnson, 27 pages (Nov. 1977). Order from NTIS as PB274648.

16672. Lawn, B. R., Fuller, E. R., Wiederhorn, S. M., Strength degradation of brittle surfaces: Sharp indenters, Am. Ceram. Soc. 58, No. 5-6, 193-197 (May-June 1976).

16685. Halsey, N., Marlowe, D. E., Mitchell, R. A., Mordfin, L., Non-metallic antenna-support materials pultruded rods for antenna guys, catenaries and communications structures, AFML-TR-76-42, 126 pages (Air Force Materials Laboratory, Wright-Patterson Air Force Base, OH, May 1976).

16690. Fraker, A. C., The microstructural influence of a 2 wt pet Mo addition to a Ti-1.5 wt pet Ni alloy, Metall. Trans. A Commun 7A, 1793-1796 (Nov. 1976).

16700. Interrante, C: G., Hicho, G. E., Removal of iron-sulfide deposits from fracture surfaces, Am. Soc. Test. Mater. Spec. Tech. Publ. 610, pp. 349-365 (1976).

16745. Gerhold, W. F., Corrosion behavior of ductile cast-iron pipe in soil environments, J. Am. Water Works Assoc. 68, No. 12, 5506-5510 (Dec. 1976).

16827. Ruff, A. W., Characterization of debris particles recovered from wearing systems, WEAR 42, 49-62 (1977).

16898. Young, J. P., Ruff, A. W., Particle erasion measurements on metals, J. Eng. Mater. Technol. 99, 121-125 (Apr. 1977).

16931. Surek, T., Coriell, S. R., Shape stability in float zoning of silicon crystals, J. Cryst. Growth 37, No. 3, 253-271 (Mar. 1977).

16937. Kak, A. C., Jakowatz, C. V., Jr., Linzer, M., NDE of materials by computerized ultrasonic tomography, Proc. Second Conf. Automated Inspection and Product Control, Chicago, IL, Oct. 19-21, 1976, pp. 235-246 (IIT Research Institute, Chicago, IL, 1976).

16990. Kruger, J., Ambrose, J. R., Qualitative use of ellipsometry to study localized corrasion processes, (Proc. 3d Int. Conf. on Ellipsometry, Lincoln, NE, Sept. 23-25, 1975), Surf. Sci. 56, 394-412 (1976). 
16993. Wiederhorn, S. M., Fuller, E. R., Jr., Bukowski, J. M., Robbins, C. R., Effect of hydrothermal environments on the erosion of castable refractories, (Proc. Winter Annual Meeting of the American Society of Mechanical Engineers, New York, NY, Dec. 5-10 1976), J. Eng. Mater. Technol. 99, 143146 (Apr. 1977).

17011. Bennett, L. H., Swartzendruber, L. J., Reno, R. C., Nuclear hyperfine effects-overview, Proc. Workshop on Nondestructive Evaluation of Residual Stress, San Antonio, TX, Aug. 13-14, 1975, pp. 247-261 (Nondestructive Testing Information Analysis Center, Southwest Research Institute, San Antonio, TX, Feb. 1976).

17015. Yonemura, G. T., Considerations and standards for visual inspection techniques, (Proc. Symp. on Nondestructive Testing Standards, Gaithersburg, MD, May 19-21, 1976), Am. Soc. Test. Mater. Spec. Tech. Publ. 624, Nondestructive Testing Standards-A Review, H. Berger, Ed., pp. 220-230 (June 1977).

17017. Eisenhower, E. H., Calibration of radiation sources for radiography, (Proc. Symp. on Nondestructive Testing Standards, Gaithersburg, MD, May 19-21, 1976), Am. Soc. Test. Mater. Spec. Tech. Publ. 624, Nondestructive Testing Standards-A Review, H. Berger, Ed., pp. 82-88 (June 1977).

17039. Wiederhom, S. M., Fracture of brittle materials at high temperatures, AFML-TR-76-139, 19 pages (Air Force Materials, Air Force Wright Aeronautical Laboratories, Air Force Systems Command, Wright-Patterson Air Force Base, OH, Aug. 1976).

17042. Berger, H., Ed., Nondestructive testing standards-A review, Am. Sac. Test. Mater. Spec. Tech. Publ. 624, 352 pages (American Society for Testing and Materials, Philadelphia, PA, 1977).

17043. Sanders, D. M., Haller, W. K., Effect of water vapor on sodium vaporization from two silica-based glasses, J. Am. Ceram. Soc. 60, No. 3-4, 138-141 (Mar.-Apr. 1977).

17046. Wiederhorn, S. M., Tighe, N. J., Evans, A. G., New design techniques for brittle materials, (Proc. 43d Meeting of the Structures and Materials Panel of AGARD, Neuilly sur Seine, France, Oct. 1976), Paper in AGARD Report No. 651 . Mechanical Properties of Ceramics for High Temperature Applications, pp. 41-55 (Technical Editing and Reproduction, Ltd., London, England, 1976).

17085. Read, D. T., Ledbetter, H. M., Temperature dependences of the elastic constants of precipitation-hardened aluminum alloys 2014 and 2219, J. Eng. Mater. Technol. 99, 181-184 (Apr. 1977).

17089. McHenry, H. I., Reed, R. P., Fracture behavior of the heat-affected zone in $5 \% \mathrm{Ni}$ steel weldments, Weld. J. Res. Suppl., 9 pages (Apr. 1977).

17090. Tighe, N. J., Characterization of thaws produced by mechanical grinding of $\mathrm{Si}_{3} \mathrm{~N}_{4}$, Proc. 35th Ann. Proc. Electron Micrascopy Society of America, Boston, MA, Aug. 18-26, 1977, pp. 144-145 (1977).

17106. Berger, H., Nondestructive evaluation (NDE) at the National Bureau of Standards (NBS), Nondestructive Testing Info. Anal. Ctr. Newsletter 5, No. 2, 1-4 (Aug. 1977).

17187. Imam, M. A., Gilmore, C. M., Fraker, A. C., Corrosionfatigue properties of the Ti-6A1-4V alloy, Proc. Conf. Environmental Degradation of Engineering Materials, Blacksburg, VA, Oct. 10-12, 1977, pp. 783-790 (College of Engineering, Virginia Tech, Blacksburg, VA, 1977).

17191. Hsu, N. N., Simmons, J. A., Hardy, S. C., An approach to acoustic emission signal analysis-Theory and experiment, Mater. Eval. 35, No. 10, 100-106 (Oct. 1977).

17235. Early, J. G., Elevated-temperature mechanical behavior of a carbon-manganese pressure vessel steel, J. Eng. Mater. Technol. 99, No. 4, 359-365 (Oct. 1977).

17241. Graminski, E. L., Effect of flexing on the mechanical properties of paper, Proc. Symp. The Fundamental Properties of Paper Related to Its Uses, Cambridge, England, Sept. 1622, 1973, 24 pages (Technical Division, The British Paper and Board Industry Federation, London, England, 1973).

17274. Ives, L. K., Erosion of 310 stainless steel at $975^{\circ} \mathrm{C}$ in combustion gas atmospheres, J. Eng. Mater. Technol. 99, 126132 (Apr. 1977).

17275. Parker, R. L., Results of crystal growth in Skylab (and ASTP), (Proc. First European Conf. on Crystal Growth, ETH, Zurich, Switzerland, Sept. 12-18, 1976), Chapter 111.6 in 1976 Crystal Growth and Materials, K. Kaldis and H. J. Scheel, Eds., pp. 851-886 (North-Holland Publ. Co., Amsterdam, The Netherlands, 1977).

17300. Ruff, A. W., Young, J. P., Ives, L. K., Erosion measurements on metals at elevated temperatures, Proc. $2 d$ Int. Conf. on Mechanical Behavior of Materials, Boston, MA, Aug. 1620, 1976, 5 pages (1976).

\section{Properties of Materials: Electronic, Magnetic and Optical}

Thermophysical measurements on $90 \mathrm{Ti}-6 \mathrm{AI}-4 \mathrm{~V}$ alloy above 1450 K using a transient (subsecond) technique, A. Cezairliyan, J. L. McClure, and R. Taylor, J. Res. Nat. Bur. Stand. (U.S.), 81A (Phys. and Chem.), Nos. 2 and 3, 251-256 (Mar.-June 1977).

Melting point, normal spectral emittance (at the melting point), and electrical resistivity (above $1900 \mathrm{~K}$ ) of titanium by a pulse heating method, A. Cezairliyan and A. P. Miiller, J. Res. Nat. Bur. Stand. (U.S.), 82, No. 2, 119-122 (Sept.-Oct. 1977).

NBSIR 76-1186. Piezoelectricity and pyroelectricity in crystolline polymers, G. T. Davis and M. G. Broadhurst, 57 pages (Dec. 1976). Order from NTIS as PB264893.

NBSIR 77-1219. Optical materials characterization, A. Feldman, D. Horowitz, R. M. Waxler, M. J. Dodge, and W. K. Gladden, 37 pages (Mar. 1977). Order from NTIS as PB264692.

NBSIR 77-1304 (ARPA). Optical materials characterization, A. Feldman, D. Horowitz, R. M. Waxler, M. J. Dodge, and W. K. Gladden, 43 pages (Aug. 1977). Order from NTIS as PB272478.

16730. Waxler, R. M., Horowitz, D., Feldman, A., Precision interferometer for measuring photoelastic constants, Appl. Opt. 16, No. 1, 20-22 (Jan. 1977).

16748. Penn, D. R., Electron mean free paths for free-electronlike materials, Phys. Rev. B 13, No. 12, 5248-5254 (June 15, 1976).

16751. Tsai, D. H., MacDonald, R. A., An atomistic view of shock wave propagation in a solid, (Proc. 5th European Conf. on Thermophysical Properties of Solids at High Temperatures, Moscow, USSR, May 18-21, 1976), High Temp. High Pressures 8, 403-418 (1976).

16767. Cezairliyan, A., McClure, J. L., Temperature and energy of $\alpha \rightarrow \beta$ transformation in hafnium-3\% zirconium, High Temp. High Pressures 8, $461-467$ (1976).

16798. Siegwarth, J. D., Polarization and dielectric constant of SrTiO glass ceramics at low temperatures, J. Appl. Phys. 48, No. 1, 1-4 (Jan. 1977).

16815. Bennett, H. S., Forman, R. A., Relative dominance of bulk or surface absorption in highly transparent materials by transient methods, J. Appl. Phys. 48, No. 3, 1217-1222 (Mar. 1977).

16816. Ekin, J. W., Clark, A. F., Effect of strain on the critical current of $\mathrm{Nb}_{3} \mathrm{Sn}$ and $\mathrm{NbTi}$ multifilamentary composite wires, (Proc. Joint MMM-Intermag Conf., Pittsburgh, PA, June 15 18, 1976), AlP Conf. Proc. No. 34, Magnetism and Magnetic Materials-1976, J. J. Becker and G. H. Lander, Eds., pp. 81-83 (American Institute of Physics, New York, NY, 1976). 
16835. Alperin, H. A., Cullen, J. R., Clark, A. E., Callen, E., Amorphous magnetism in bulk samples of terbium iron alloys, Physica 86-88B, 767-769 (1977).

16874. Peterson, R. L., McDonald, D. G., Picosecond pulses from Josephson junctions: Phenomenological and microscopic analyses, (Proc. 1EEE Conf. Applied Superconductivity, Sanford, CA, Aug. 18-20, 1976), IEEE Trans. Magn. MAG-13, No. 1, 887-890 (Jan. 1977).

16877. Hust, J. G., Thermal conductivity and electric resistivity standard reference materials: Tungsten ( 4 to $3000 \mathrm{~K}$ ), (Proc. 5th European Conf. on Thermophysical Properties of Solids at High Temperatures, Moscow, USSR, May 18-21, 1976), High Temp.-High Pressures 8, 377-390 (1976).

16916. Herbst, J. F., Bak, P., Watson, R. E., Effective crystal fields in the rare earth pnictides, Physica $86-88$ B\&C, Pt. 1, 123-124 (Jan.-Mar. 1977).

16919. Herbst, J. F., Angle-resolved photoemission from crystalfield-split adatom levels, Phys. Rev. B, 15, No. 8, 3720-3730 (Apr. 15, 1977).

16927. Watson, R. E., Bennett, L. H., Hyperfine fields at impurity sites in iren, Physica 86-88B, $435-436$ (1977).

16932. Bennett, L. H., McAlister, A. J., Cuthill, J. R., Erickson, N. E., Watson, R. E., Electronic and catalytic properties of refractory hard metals, J. Mol. Catalysis 2, 203-209 (1977).

16954. Kemple, M. D., Spin coherence of Kramers ions in solids in zero external static magnetic field, (Proc. XIXth Congress Ampere, Heidelberg, W. Germany, Sept. 27-Oct. 1, 1976), Paper in Magnetic Resonance and Related Phenomena, H. Brunner, K. H. Hausser, and D. Schweitzer, Eds., pp. 423426 (Groupement Ampere, Heidelberg, Geneva, Switzerland, 1976).

16963. Rhyne, J. J., Koon, N. C., Milstein, J. B., Alperin, H. A., Spin waves in ferrimagnetic $\mathrm{ErFe}_{2}$, Proc. Conf. on Neutron Scattering, Gatlinburg, TN, June 6-10, 1976, pp. 873-887 (Available from the National Technical Information Service, Springfield, VA, Sept. 1, 1976).

16964. Glinka, C. J., Rowe, J. M., Rush, J. J., Rahman, A., Sinha, S. K., Flotow, H. E., Inelastic neutron scattering

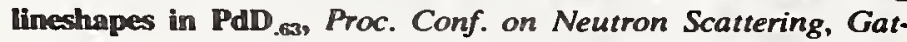
linburg, TN, June 6-10, 1976, pp. 536-542 (Available from the National Technical Information Service, Springfield, VA, Sept. 1, 1976).

16965. Glinka, C. J., Rowe, J. M., Rush, J. J., Libowitz, G. G., Maeland, A., The lattice vibrations of $\mathrm{CeD}_{2.12}$, Solid State Commun. 22, $541-544$ (1977).

16967. Watson, R. E., Bennett, L. H., Volume-corrected isomer shifts of transition-metal impurities: An orbital electronegativity scale, Phys. Rev. B 15, No. 11, 5136-5140 (June 1, 1977).

16974. Kuriyama, M., Boettinger, W. J., Burdette, H. E., Crystal imperfections and magnetic domain walls in thick Czochralski-grown nickel single crystals, Paper in Advances in X-Ray Analysis, H. F. McMurdie, C. S. Barrett, J. B. Newkirk, and C. O. Ruud, Eds., 20, pp. 245-257 (Plenum Publ. Corp., New York, NY, 1977).

16977. Boettinger, W. J., Burdette, H. E., Farabaugh, E. N., Kuriyama, M., Some topographic observations of the effects of dynamical diffraction in imperfect metal crystals, Paper in Advances in X-Ray Analysis, H. F. McMurdie, C. S. Barrett, J. B. Newkirk, and C. O. Ruud, Eds., 20, 207-219 (Plenum Publ. Corp., New York, NY, 1977).

16983. Singh, R. S., Trevino, S., Prask, H. J., Long wavelength $(\mathrm{K} \sim \mathbf{0})$ ir active phonons of $\mathrm{NaHF}_{2}$ and $\mathrm{KHF}_{2}, J$. Chem. Phys. 58, No. 10, 4703-4704 (May 15, 1973).

16985. Abbundi, R., Segnan, R., Rhyne, J. J., Sweger, D. M., Hyperfine fields in the absence of magnetic order in Dy-Sc alloys, (Proc. 21 st Annual AlP Conf. on Magnetism and Magnetic Materials, Philadelphia, PA, Dec. 9-12, 1975), Paper in Magnetism and Magnetic Materials-1975, J. J. Becker, C. H.
Lander, and J. J. Rhyne, Eds., No. 29, pp. $352-353$ (American Institute of Physics, New York, NY, 1976).

16997. Kuriyama, M., Boettinger, W. J., Burdette, H. E., X-ray topographic observations of magnetic domains in Czochralsklgrown nickel single crystals in anomalous transmission geometry, J. Appl. Phys. 47, No. 11, $5064-5068$ (Nov. 1976).

17001. Farr, M. K., Trevino, S. F., Mode Gruneisen parameters of $\mathrm{KBr}$ determined by inelastic neutron scattering, Proc. Conf. on Neutron Scattering, Gatlinburg, TN, June 6-10, 1976, pp. 237-242 (Available from the National Technical Information Service, Springfield, VA, Sept. 1, 1976).

17003. Chesser, N. J., Prask, H. J., Qunsi-elastic neutron scattering study of single crystal ammonium perchlorate, Proc. Conf. on Neutron Scattering, Gatlinburg, TN, June 6.10, 1976, pp. 295-302 (Available from the National Technical Information Service, Springfield, VA, Sept. 1, 1976).

17004. Rush, J. J., Rowe, J. M., Glinka, C. J., Vagelatos, N., Flotow, H. E., Coherent neutron scattering study of the vibrations of interstitial deuterium in $\alpha-V_{0.7}$, Proc. Conf. on Neutron Scattering, Gatlinburg, TN, June 6-10, 1976, pp. 543-549 (Available from the National Technical Information Service, Springfield, VA, Sept. 1, 1976).

17007. Torchia, D. A., VanderHart, D. L., ${ }^{13} \mathrm{C}$ magnetic resonance evidence for anisotropic molecular motion in collagen fibrils, J. Mol. Biol. 104, 31 5-321 (1976).

17022. Campagna, M., Pierce, D. T., Meier, F., Sattler, K., Siegmann, H. C., Emission of polarized electrons from solids, Paper in Advances in Electronics and Electron Physics 41, 113-165 (Academic Press Inc., New York, NY, 1976).

17030. Kahn, A. H., Theory of microwave eddy currents and paramagnetic resonance in materials of intermediate conductivity, Phys. Rev. B 16, No. 1, 64-72 (July 1, 1977).

17034. Mathew, M., Schroeder, L. W., Dickens, B., Brown, W. E., The crystal structure of $\alpha-\mathrm{Ca}_{3}\left(\mathrm{PO}_{4}\right)_{2}$, Acta Cryst. B33, $1325-1333$ (1977).

17047. Forman, R. A., Weinstein, B. A., Piermarini, G., Hydrostatic pressure dependence of the doublet transitions of ruby, (Proc. Colloq. Int. du Centre National de la Recherche Scientifique, Lyon, France, June 28-July 3, 1976), Paper in Spectroscopie des Eléments de Transition et des Eléments Lourds dans les solides, No. 255, 51-57 (Editions du Centre National de la Recherche Scientifique, Paris, France, 1977).

17074. Clark, A. F., Ekin, J., Defining critical current, IEEE Trans. Magn. MAG-13, No. 1, 38-40 (Jan. 1977).

17078. Daney, D. E., Ludtke, P. R., Jones, M. C., Thermal acoustic oscillations in current leads cooled with supercritical helium, IEEE Trans. Magn. MAG-13, No. 1, $412-415$ (Jan. 1977).

17093. Carter, G. C., Bennett, L. H., Kahan, D. J., Metallic shifts in NMR. A review of the theory and comprehensive critical data compilation of metallic materials, Progress in Materials Science, B. Chalmers, J. W. Christian, and T. B. Massalski, Eds., 20, Parts I-IV, 2350 pages (Pergamon Press, New York, NY, 1977).

17100. West, J. B., Poland, H. M., Chemiluminescence from mixtures of $\mathrm{Ba}+\mathrm{CO}_{2}$ and $\mathrm{Ba}+\mathrm{CO}, J$. Chem. Phys. 66, No. 5, 2139-2141 (Mar. 1, 1977).

17112. Glinka, C. J., Minkiewicz, V. J., Passell, L., Absolute measurement of the critical scattering cross section in cobalt, (Proc. 21 st AIP Conf. on Magnetism and Magnetic Materials, Philadelphia, PA, Dec. 9-12, 1975), Paper in Magnetism and Magnetic Materials-1975, J. J. Becker, C. H. Lander, and J. J. Rhyne, Eds., No. 29, pp. 499-501 (American Institute of Physics, New York, NY, 1975).

17135. Fickett, F. R., A preliminary investigation of the behavior of high purity copper in high magnetic fields, Annual Report INCRA No. I86B, 55 pages (International Copper Research Association, New York, NY, Aug. 1974). 
17248. Powell, C. J., Stein, R. J., Needham, P. B., Jr., Driscoll, T. J., Attenuation lengths of low-energy electrons in solids derived from the yield of proton-excited Auger electrons: Beryllium and aluminum, Phys. Rev. B 16, No. 4, 1370-1379 (Aug. 15, 1977).

17261. Kahn, A. H., Spal, R., Feldman, A., Eddy-current losses due to a surface crack in conducting material, J. Appl. Phys. 48, No. 11, 4454-4459 (Nov. 1977).

17262. Bennett, L. H., McAlister, A. J., Watson, R. E., Interstitial compounds, Phys. Today 30, No. 9, 34-40 (Sept. 1977).

17265. McAlister, A. J., Watson, R. E., Charge flow in transition metal carbides, Semicond. Insulators 2, 231 -242 (1977).

17313. Bennett, H. S., Forman, R. A., Photoacoustic spectroscopy: A measurement technique for low absorption coefficients, Appl. Opt. 6, No. 11, 2834-2836 (Nov. 1977).

17350. Munro, R. G., Green function theory of Curie and order-order transitions in ferromagnetic systems, J. Magnet. Magnetic. Mater. 5, 177-183 (1977).

\section{Properties of Materials:}

\section{Structural and Mechanical}

Thermodynamics of the densification process for polymer glasses, J. E. McKinney and R. Simha, J. Res. Nat. Bur. Stand. (U.S.), 81A (Phys. and Chem.), Nos. 2 and 3, 283 297 (Mar.-June 1977).

Uniaxial extension and compression in stress-strain relations of rubber, L. A. Wood, J. Res. Nat. Bur. Stand. (U.S.), 82, No. 1, 57-63 (July-Aug. 1977).

Phase equilibria and crystal chemistry of rubidium niobates and rubidium tantalates, D. B. Minor, R. S. Roth, H. S. Parker, and W. S. Brower, J. Res. Nat. Bur. Stand. (U.S.), 82, No. 3, 151-165 (Nov.-Dec. 1977).

Investigation of calcium aluminate cement phases under high gaseous pressure, J. L. Waring, R. S. Roth, W. S. Brower, and C. A. Harding, J. Res. Nat. Bur. Stand. (U.S.), 82, No. 3, 167-172 (Nov.-Dec. 1977).

SP486. User evaluation of "Phase Diagrams for Ceramists" and implications for related data and research programs, $R$. S. Roth, L. P. Cook, T. Negas, G. W. Cleek, and J. B. Wachtman, Jr., Nat. Bur. Stand. (U.S.), Spec. Publ. 486, 70 pages (Aug. 1977) SNO03-003-01827-9.

NBSIR 77-1239. Workshop on applications of phase diagrams in metallurgy and ceramies, L. H. Bennett and G. C. Carter, 235 pages (Apr. 1977). Order from NTIS as PB269281.

16688. Staffa, J. A., Zervos, C., Mighell, A. D., Hubbard, C. R., S-carboxymethyl-L-cysteine sulfoxide (configuration 2R:4R), Acta Cryst. B32, Part 11, $3132-3135$ (Nov. 1976).

16696. Rubin, R. J., Mazur, J., Weiss, G. H., Spans of polymer chains, Pure Appl. Chem. 46, 143-148 (1976).

16738. Waterstrat, R. M., Manuszewski, R. C., The niobiumosmium constitution diagram, J. Less-Common Met. 51, 55 67 (1977).

16741. Jordan, T. H., Schroeder, L. W., Dickens, B., Brown, W. E., Crystal structure of stannous hydroxide phosphate, a reaction product of stannous fluoride and apatite, Inorg. Chem. 15, No. 8, 1810-1814 (1976).

16742. Schroeder, L. W., Prince, E., Hydrogen-bonded dimers in Tin(II) hydrogen phosphate, Acta Cryst. B32, Part 12 , 3309-3311 (Dec. 1976).

16774. McKinney, J. E., Application of hole theory to estimate the pressure-induced densification of polymers, Ann. N.Y. Acad. Sci. 279, 88-93 (Oct. 15, 1976).

16817. Han, C. C., Mozer, B., Conformation of PS-PMMA diblock copolymer in toluene by small angle neutron scattering, Macromolecules 10, No. 1, 44-51 (Jan./Feb. 1977).
16832. Waterstrat, R. M., Müller, J., Ternary A15-phase regions in the $\mathrm{Nb}-\mathrm{Sn}-\mathrm{Si}$ and $\mathrm{Nb}-\mathrm{Sn}$-As systems, J. Less-Common Metals 52, 271-277 (1977).

16834. Waterstrat, R. M., Manuszewski, R. C., The vanadiumrhodium constitution diagram, J. Less-Common Metals 52, 293-305 (1977).

16880. Ledbetter, H. M., Poisson's ratio for central-force polycrystals, $Z$. Naturforsch. Teil A 31, No. 12, $1539-1542$ (Dec. 1976)

16913. Hubbard, C. R., Mighell, A. D., Ware, G. M., 4-hydroxy-4H-furo[3,2-c]pyran-2(6H)-one (DL-patulin), Acta Cryst. B33, 928-931 (1977).

16958. Khoury, F., Passaglia, E., The morphology of crystalline synthetic polymers, Chapter 6 in Treatise on Solid State Chemistry, N. B. Hannay, Ed., 3, 335-340 (Plenum Press, New York, NY, 1976).

16972. Rowe, J. M., Rush, J. J., Prince, E., Neutron diffraction study of the structure and phase transitions of alkali cyanide crystals, J. Chem. Phys. 66, No. 11, 5147-5149 (June 1, 1977).

17012. Raveché, H. J., Stuart, C. A., Towards a molecular theory of freezing. II. Study of bifurcation as a function of density, J. Chem. Phys. 65, 2305-2312 (Sept. 15, 1976).

17068. Ledbetter, H. M., Read, D. T., Orthorhombic elastic constants of an $\mathrm{NbTi} / \mathrm{Cu}$ composite superconductor, J. Appl. Phys. 48, No. 5, 1874-1879 (May 1977).

17094. Ledbetter, H. M., Anomalous elastic properties of a precipitation-hardened copper alloy, Met. Trans. 8A, No. 6, 1006-1007 (June 1977).

17095. Mathew, M., Schroeder, L. W., Jordan, T. 'H., The crystal structure of anhydrous stannous phosphate, $\mathrm{Sn}_{3}\left(\mathbf{P O}_{4}\right)_{2}$, Acta Cryst. B33, 1812-1816 (1977).

17099. Ledbetter, H. M., Ratio of the shear and Young's moduli for polycrystalline metallic elements, Mater. Sci. Eng. 27, 133 136 (1977).

17125. Kranbuehl, D. E., Verdier, P. H., Relaxation of the aspherical shapes of random-coil polymer chains, J. Chem. Phys. 67, No. 1, 361-365 (July 1, 1977).

17177. Swann, P. R., Tighe, N. J., High voltage microscopy of the reduction of hematite to magnetite, Met. Trans. 8B, 479487 (Sept. 1977).

17228. Munro, R. G., A scaling theory of solids under hydrostatic pressure, J. Chem. Phys. 67, No. 7, 3146-3150 (Oct. 1,1977 ).

17253. Verdier, P. H., The scattering of light by uniformly curved rods. A model of semirigid rod macromolecules, Macromolecules 10, 913-918 (Sept.-Oct. 1977).

17255. Wagner, H. L., McCrackin, F. L., Branching and molecular weight distribution of polyethylene SRM 1476, $J$. Appl. Polym. Sci. 21, 2833-2845 (1977).

17259. Schroeder, L. W., Dickens, B., Brown, W. E., Crystallographic studies of the role of $\mathbf{M g}$ as a stabilizing impurity in $\boldsymbol{\beta}-\mathrm{Ca}_{3}\left(\mathrm{PO}_{4}\right)_{2}$. II. Refinement of $\mathrm{Mg}$-containing $\boldsymbol{\beta}-\mathrm{Ca}_{3}\left(\mathrm{PO}_{4}\right)_{2}, J$. Solid State Chem. 22, 253-262 (1977).

17277. Boettinger, W. J., Burdette, H. E., Kuriyama, M., Observations of oblique,magnetic domain walls in nickel single crystals by x-ray topography, Phil. Mag. 36, No. 4, 763-776 (1977).

17348. Choi, C. S., Prask, H. J., Prince, E., Ammonium perchlorate: Reinvestigation of the crystal structure at $298 \mathrm{~K}$, Act. Crystallogr. B32, Pt. 10, 2919-2920 (Oct. 1976).

\section{Properties of Materials:}

\section{Thermodynamic and Transport}

Diffusion with discontinuous swelling. III. Type II diffusion as a particular solution of the conventional diffusion equation, $\mathrm{A}$. 
Peterlin, J. Res. Nat. Bur. Stand. (U.S.), 81A (Phys. and Chem.), Nos. 2 and 3, 243-250 (Mar.-June 1977).

16970. Rowe, J. M., Neutron scattering studies of the diffusion of hydrogen In metals, Proc. Conf. on Neutron Scattering, Gatlinburg, TN, June 6-10, 1976, pp. 491-506 (Available from the National Technical Information Service, Springfield, VA, Sept. 1, 1976).

\section{Standard Reference Data}

Diffusion in copper and copper alloys. Part V. Diffusion in systems involving elements of group VA, D. B. Butrymowicz, J. R. Manning, and M. E. Read, J. Phys. Chem. Ref. Data 6, No. 1, 1-50 (1977).

The calculated thermodynamic properties of superfluid helium4, J. S. Brooks and R. J. Donnelly, J. Phys. Chem. Ref. Data 6, No. 1, 51-104 (1977).

Thermodynamic properties of normal and deuterated methanols, S. S. Chen, R. C. Wilhoit, and B. J. Zwolinski, J. Phys. Chem. Ref. Data 6, No. 1, 105-1 12 (1977).

The spectrum of molecular nitrogen, A. Lofthus and P. H. Krupenie, J. Phys. Chem. Ref. Data 6, No. 1, 113-307 (1977).

Energy levels of chromium, $\mathrm{Cr}$ i through $\mathrm{Cr}$ xxiv, J. Sugar and C. Corliss, J. Phys. Chem. Ref. Data 6, No. 2, 317-384 (1977).

The activity and osmotic coefficients of aqueous calcium chloride at 298.15 K, B. R. Staples and R. L. Nuttall, J. Phys. Chem. Ref. Data 6, No. 2, 385-408 (1977).

Molten salts: Volume 4, part 3. Bromides and mixtures; iodides and mixtures. Electrical conductance, density, viscosity, and surface tension data, G. J. Janz, R. P. T. Tomkins, C. B. Allen, J. R. Downey, Jr., and S. K. Singer, J. Phys. Chem. Ref. Data 6, No. 2, $409-596$ (1977).

The viscosity and thermal conductivity coefficients for dense gaseous and liquid methane, H. J. M. Hanley, W. M. Haynes, and R. D. McCarty, J. Phys. Chem. Ref. Data 6, No. 2, $597-$ 610 (1977).

Phase diagrams and thermodynamic properties of ternary copper-silver systems, Y. A. Chang, D. Goldberg, and J. P. Neumann, J. Phys. Chem. Ref. Data 6, No. 3, 621-674 (1977).

Crystal data space-group tables, A. D. Mighell, H. M. Ondik, and B. B. Molino, J. Phys. Chem. Ref. Data 6, No. 3, 675 830 (1977).

Energy levels of one electron atoms, G. W. Erickson, J. Phys. Chem. Ref. Data 6, No. 3, $831-870$ (1977).

Rate constants for reactions of $\mathbf{C l O}_{x}$ of atmospheric interest, $\mathrm{R}$. T. Watson, J. Phys. Chem. Ref. Data 6, No. 3, 871-918 (1977).

NMR spectral data: A compilation of aromatic proton chemical shifts in mono- and di-substituted benzenes, B. L. Shapiro and L. E. Mohrmann, J. Phys. Chem. Ref. Data 6, No. 3, 919 992 ( 1977).

Tables of molecular vibrational frequencies-Consolidated Volume II, T. Shimanouchi, J. Phys. Chem. Ref. Data 6, No. 3, 993-1 102 ( 1977).

Effects of lsotopic composition, temperature, pressure, and dissolved gases on the density of liquid water, G. S. Kell, J. Phys. Chem. Ref. Data 6, No. 4, $1109-1132$ (1977).

Viscosity of water substance-mew International Formulation and lts background, A. Nagashima, J. Phys. Chem. Ref. Data 6, No. 4, 1133-1166 (1977).

A correlation of the existing viscosity and thermal conductivity data of gaseous and liquid ethane, H. J. M. Hanley, K. E. Gubbins, and S. Murad, J. Phys. Chem. Ref. Data 6, No. 4, 1167-1180 (1977).

Elastic properties of zinc: A compilation and a review, H. M. Ledbetter, J. Phys. Chem. Ref. Data 6, No. 4, 1181-1204 (1977).
Behavior of the AB-type compounds at high pressures and high temperatures, L. Merrill, J. Phys. Chem. Ref. Data 6, No. 4, 1205-1252 (1977).

Energy levels of manganese, Mn 1 through Mn xxv, C. Corliss and J. Sugar, J. Phys. Chem. Ref. Data 6, No. 4, 1253-1330 (1977).

SP485. A bibliography of sources of experimental data leading to activity or osmotic coefficients for polyvalent electrolytes in aqueous solution, R. N. Goldberg, B. R. Staples, R. L. Nuttall, and R. Arbuckle, Nat. Bur. Stand. (U.S.), Spec. Publ. 485, 53 pages (July 1977) SNO03-003-01812-1.

NSRDS-NBS59. Selected specific rates of reactions of transients from water in aqueous solution. III. Hydroxyl radical and perhydroxyl radical and their radical ions, Farhataziz and A. B. Ross, Nat. Stand. Ref. Data Ser., Nat. Bur. Stand. (U.S.). 59, 122 pages (Jan. 1977) SN003-003-01731-1.

16667. Beeghly, H. F., Mears, T. W., Michaelis, R. E., Standard materials for analysis and testing, Paper in Treatise on Analytical Chemistry, I. M. Kolthoff and P. M. Elving, Eds., 3, Part III, 1-45 (John Wiley \& Sons, 1976).

16692. Rossmassler, S. A., The National Standard Reference Data System, Proc. AGARD Conf. on Advancements in Retrieval Technology as Related to Information Systems, Arlington, VA, Oct. 20-21, 1976, AGARD-CP-207, 10-1-104 (Available from National Technical Information Service, Springfield, VA 22161, Dec. 1976).

17258. Fivozinsky, S. P., Lide, D. R., Jr., Communicating quantitative scientific knowledge, Tech. Commun., pp. 10-11 (Fourth Quarter 1977).

\section{Standard Reference Materials}

SP260-54. Standard reference materials: Certification and use of acidic potassium dichromate solutions as an ultraviolet absorbance standard-SRM 935, R. W. Burke and R. Mavrodineanu, Nat. Bur. Stand. (U.S.), Spec. Publ. 260-54, 157 pages (Aug. 1977) SN003-003-01828-7.

SP260-55. Standard reference materials: Enthalpy and heat capacity standard reference material: Molybdenum SRM 781, from 273 to $2800 \mathrm{~K}$, D. A. Ditmars, A. Cezairliyan, S. Ishihara, and T. B. Douglas, Nat. Bur. Stand. (U.S.), Spec. Publ. 260-55, 80 pages (Sept. 1977) SN003-003-01836-8.

TN947. Critical evaluation of data in the physical sciences-A status report on the National Standard Reference Data System, January 1977, S. A. Rossmassler, Ed., Nat. Bur. Stand. (U.S.), Tech. Note 947, 84 pages (May 1977) SN003003-01776-1.

16981. Mavrodineanu, R., Drews, U. W., NBS glass standards, Anal. Chem. Editors' Column 48, No. 7, 609A (1976).

17260. Eckerle, K. L., Venable, W. H., Jr., 1976 remeasurement of NBS spectrophotometer-integrator filters, Color Res. Application 2, No. 3, 137-141 (Fall 1977).

\section{Surfaces and Interfaces}

SP475. The electron factor In catalysis on metals. Proceedings of a workshop held at the National Bureau of Standards, Gaithersburg, MD, Dec. 8-9, 1975, L. H. Bennett, Ed., Nat. Bur. Stand. (U.S.), Spec. Publ. 475,217 pages (Apr. 1977) SN003-003-01764.

Welcome, E. Ambler, SP475, p. 1 (Apr. 1977).

Overview of the workshop, L. H. Bennett, SP475, pp. 3-4 (Apr. 1977).

Catalysis by metals: Concepts, factors and reactions, $M$. Boudart, SP475, PP. 5-12 (Apr. 1977).

Experimental techniques, J. Katzer, R. Park, T. Rhodin, J. T. Yates, and G. Haller, Panel members, SP475, p. 13 (Apr. 1977). 
Experimental methods in heterogenous catalysis, J. T. Yates, Jr., SP475, pp. 15-29 (Apr. 1977).

Investigation of support catalysis by $x$-ray absorption spectroscopy, F. W. Lytle, SP475, pp. 34-41 (Apr. 1977).

Catalysis by alloys and bimetallic clusters, J. H. Sinfelt, SP475, pp. 56-67 (Apr. 1977).

Surface composition of nickel-copper alloys, V. Ponec, SP475, pp. 71-80 (Apr. 1977).

Heat of formation of 3d and 4d transition metal hydrides, G. D. Gelatt, J. A. Weiss, and H. Ehrenrich, SP475, pp. 8386 (Apr. 1977).

Geometric factors in chemisorption and catalysis on metals, G. Ertl, SP475, pp. 94-118 (Apr. 1977).

The geometry of solid surfaces, C. B. Duke, SP475, pp. 127-130 (Apr. 1977).

Bonding properties of stepped transition metal surfaces, G. S. Painter, R. O. Jones, and P. J. Jennings, SP475, pp. 136149 (Apr. 1977).

The role of model Hamiltonians in chemisorption and catalysis, J. W. Gadzuk, SP475, pp. 154-161 (Apr. 1977).

Theory for chemisorption and catalysis, A. B. Anderson, SP475, pp. 166-170 (Apr. 1977).

A comparison of SCF-Xa and extended Huckel methods for metal clusters, R. P. Messmer, C. W. Tucker, Jr., and K. H. Johnson, SP475, pp. 174-177 (Apr. 1977).

A new role for theory in surface science; D. R. Hamann, SP475, pp. 183-192 (Apr. 1977).

16744. Stein, R. J., Electron transmission measurements of electron mean free path in supported thin films from $1-5 \mathrm{keV}$, Surf. Sci. 60, 436-444 (1976).

16747. Gadzuk, J. W., Angle resolved Auger surface spectroscopy, Surf. Sci. 60, 76-84 (1976).

16780. Hardy, S. C., A grain boundary groove measurement of the surface tension between ice and water, Philos. Mag. 35, No. 2, $471-484$ (Feb. 1977).

16808. Vorburger, T. V., Sandstrom, D. R., Waclawski, B. J., The displacement of hydrogen by carbon monoxide on the (100) face of tungsten: A photoemission and thermal desorption study, Surface Sci. 60, $211-230$ (1976).

16829. Vorburger, T. V., Waclawski, B. J., Plummer, E. W., Evidence for the distortion of $\mathrm{C}_{2} \mathrm{H}_{4}$ and $\mathrm{C}_{2} \mathrm{H}_{2}$ chemisorbed on W(100), Chem. Phys. Lett. 46, No. 1, $42-47$ (Feb. 15, 1977).

16929. Madey, T. E., Yates, J. T., Jr., Desorption methods as probes of kineties and bonding at surfaces, Surf. Sci. 63, 203231 (1977).

16930. Madey, T. E., Wagner, C. D., Joshi, A., Surface characterization of catalysts using electron spectroscopies: Results of a round-robin sponsored by ASTM Committee D-32 on catalysts, J. Electron Spectrosc. Relat. Phenom. 10, 359-388 (1977).

17065. Worley, S. D., Yates, J. T., Jr., A thermal desorption study of methyl formate from $W(100)$ and its relevance to the catalytic production of methane, J. Catal. 48, 395-403 (1977). 17207. Kelley, R. D., Madey, T. E., Yates, J. T., Jr., Activity of tungsten as a methanation catalyst, J. Catal. 50, 301-305 (1977).

17218. Gadzuk, J. W., Surface relaxation energies in core level spectroscopies of adsorbed atoms and molecules, Surf. Sci. 67, 77-88 (1977).

17242. Cohen, P. I., Abramowitz, S., Broida, H. P., Chemisorptive luminescence from $\mathrm{Bg}$ and $\mathrm{Mg}$ films, Surface Sci. 69, 601604 ( 1977).

17349. Madey, T. E., Yates, J. T., Jr., Evidence for the conformation of $\mathrm{H}_{2} \mathrm{O}$ adsorbed on $\mathrm{Ru}(001)$, Chem. Phys. Lett. 51, No. 1, 77-83 (Oct. 1, 1977).

\section{Thermodynamics and Chemical Kinetics}

Vapor pressure formulation for ice, A. Wexler, J. Res. Nat. Bur. Stand. (U.S.), 81A (Phys. and Chem.), No. 1, 5-20 (Jan.-Feb. 1977).

Heat capacity and thermodynamic properties of poly(vinyl chloride), S. S. Chang, J. Res. Nat. Bur. Stand. (U.S.), 82, No. 1, 9-18 (July-Aug. 1977).

Enthalpy of solution of sodium nitrite, J. C. Cases, V. B. Parker, and M. V. Kilday, J. Res. Nat. Bur. Stand. (U.S.), 82, No. 1, 19-28 (July-Aug. 1977).

A method for the numerical evaluation of the second virial coefficient for polyatomic molecules, P. M. Holland, J. F. Ely, H. J. M. Hanley, J. Res. Nat. Bur. Stand. (U.S.), 82, No. 2, 123. 127 (Sept.-Oct. 1977).

SP478. Nitrogen oxychlorides: A bibliography on data for physical and chemical properties of CINO, $\mathrm{CINO}_{2}$, and $\mathrm{CINO}_{3}, \mathrm{~F}$. Westley, Nat. Bur. Stand. (U.S.), Spec. Publ. 478, 54 pages (Aug. 1977) SN003-003-01824-4.

TN937. Estimation of net enthalpies of combustion of some aviation fuels expressed in the International System of Units (SI), R. L. Nuttall and G. T. Armstrong, Nat. Bur. Stand. (U.S.), Tech. Note 937, 63 pages (Apr. 1977) SN003-003-01763-9.

NBSIR 77-860. Provisional thermodymamic functions of propane, from 85 to $700 \mathrm{~K}$ at pressures to $700 \mathrm{bar}, \mathrm{R}$. D. Goodwin, 240 pages (July 1977). Order from NTIS as PB272355.

NBSIR 77-1300. A computer-assisted evaluation of the thermochemical data of the compounds of thorium, D. D. Wagman, R. H. Schumm, and V. B. Parker, 94 pages (Aug. 1977). Order from NTIS as PB273171.

16769. Chang, S. S., Stored energy in poly(vinyl chloride) from pelletizing process, J. Chem. Thermodyn. 9, 189-197 (1977).

16825. Pella, P. A., Measurement of the vapor pressures of TNT, 2,4-DNT, 2,6-DNT, and EGDN, J. Chem. Thermodyn. 9, 301-305 (1977).

16838. Laufer, A. H., Bass, A. M., Reaction between triplet methylene and $\mathrm{CO}_{2}$ : Rate constant determination, Chem. Phys. Lett. 46, No. 1, 151-155 (Feb. 15, 1977).

16881. Miller, R. C., Kidnay, A. J., Hiza, M. J., Liquid + vapor equilibria in methane + ethene and in methane + ethane from 150.00 to $190.00 \mathrm{~K}, J$. Chem. Thermodyn. 9, No. 2, 167-178 (1977).

16911. Yap, W. T., Howell, B. F., Schaffer, R., Determination of the kinetic constants in a two-substrate enzymatic reaction, J. Chem. Ed. 54, 254-255 (Apr. 1977).

17038. Schwarz, F. P., Determination of temperature dependence of solubilities of polycyclic aromatic hydrocarbons in aqueous solutions by a fluorescence method, J. Chem. Eng. Data 22, No. 3, 273-277 (July 1977).

17057. Lias, S. G., Ausloos, P., Comments on "Entropy change in ion-molecule equilibria," J. Am. Chem. Soc. Commun. to Ed., 99, No. 14, 4831-4833 (July 6, 1977).

17075. Douglas, T. B., Krause, R. F., Jr., Evaluation of a simple static method for measuring vapor pressure, J. Chem. Thermadyn. 9, $511-522$ (1977).

17097. Schwartz, F. P., Wasik, S. P., A fluorescence method for the measurement of the partition coefificients of naphthalene, 1-methylnaphthalene, and 1-ethylnaphthalene in water, $J$. Chem. Eng. Data 22, No. 3, 270-273 (July 1977).

17122. Haus, J. W., Cullen, J. R., Dynamic order parameter fluctuations in a disordered system, Ann. NY Acad. Sci. 279, 45-46 (Oct. 15, 1976).

17136. Haar, L., Powell, G., Klein, M., Wardell, J., Wilmot, G., A theoretical model for the equation of state for the system carbon dioxide and water, Proc. 13th JANNAF Combustion Meeting, Monterey, CA, Sept. 13-17, 1976, I, 199-212 (Naval 
Plant Representative, Naval Plant Representative Office, Laurel, MD, 1976).

17193. Stephenson, J. C., Vibrational relaxation of NO $X^{2} \Pi(v$ $=1$ ) in the temperature range $100-300^{\circ} \mathrm{K}, \mathrm{J}$. Chem. Phys. 60, No. 11, 4289-4294 (June 1974).

17272. Howard, C. J., Evenson, K. M., Kinetics of the reaction of $\mathrm{HO}_{2}$ with NO, Geophys. Res. Lett. 4, No. 10, 437-440 (Oct. 1977).

17295. Moldover, M. R., Gallagher, J. S., Phase equilibria in the critical region: An application of the rectilinear diameter and "1/3 power" laws to binary mixtures, Proc. Phase Equilibria and Fluid Properties in the Chemical Industry. Estimation and Correlation, Asilomar Conf. Grounds, Pacific Grove, CA, Jan. 16-21, 1977, T. S. Storvick and S. I. Sandler, Eds., pp. 498-509 (American Chemical Society, Washington, DC, 1977).

\section{Technology Incentives}

NBS-GCR-ETIP 76-24. A framework for analyzing commodity supply restrictions, 242 pages (Sept. 1976). Order from NTIS as PB258093.

NBS-GCR-ETIP 76-25. Cartelization in the world cobalt market: Economic analysis and policy implications, 96 pages (Sept. 1976). Order from NTIS as PB264386.

NBS-GCR-ETIP 76-26. Value incentive program. Energy conservation compressors for computer room air conditioning systems, 39 pages (Oct. 1976). Order from NTIS as PB259998.

NBS-GCR-ETIP 76-27. Value incentive program. Reduce welding/brazing on wardrobe hinge, 41 pages (Oct. 1976). Order from NTIS as PB260523.

NBS-GCR-ETIP 76-28. Policy implications of producer country supply restrictions: The world platinum and palladium markets, 153 pages (Sept. 1976). Order from NTIS as PB264387.

NBS-GCR-ETIP 76-29. Policy implications of producer country supply restrictions: The world manganese market, 210 pages (Sept. 1976). Order from NTIS as PB264388.

NBS-GCR-ETIP 76-30. Policy implications of producer country supply restrictions: The world copper market, 121 pages (Aug. 1976). Order from NTIS as PB264389.

NBS-GCR-ETIP 76-31. Policy implications of producer country supply restrictions: The world chromite market, 247 pages (Oct. 1976). Order from NTIS as PB264390.

NBS-GCR-ETIP 76-32. Policy implications of producer country supply restrictions: The world aluminum/bauxite market, 275 pages (Mar. 1977). Order from NTIS as PB264391.

NBS-GCR-ETIP 76-33. Policy implications of producer country supply restrictions: The world energy market, 382 pages (Nov. 1976). Order from NTIS as PB264392.

NBS-GCR-ETIP 76-34. Developing incentives for pest control methods. Proceedings of a conference Oct. 26-27, 1976, 92 pages (Jan. 1976). Order from NTIS as PB263275.

NBS-GCR-ETIP 76-35. Post-marketing surveillance of new drugs: A preliminary review of the current state-of-the-art, $W$. M. Wardell, M. C. Tsianco, H. T. Davis, and S. N. Anavekar, 46 pages (Dec. 1976). Order from NTIS as PB263273.

NBS-GCR-ETIP 77-36. Policy implications of producer country supply restrictions: Overview and summary, 264 pages (Feb. 1977). Order from NTIS as PB264393.

NBS-GCR-ETIP 77-37. Life cycle costing-Case studies, C. Hulick, Ed., 107 pages (May 1, 1977). Order from NTIS as PB268162.

NBS-GCR-ETIP 77-38. Commodity supply policies, 211 pages (Aug. 1977). Order from NTIS as PB272700.

NBS-GCR-ETIP 77-39. Prototype procurement: A case study in experimental technology check wrapping machines of the U.S.
Treasury Depertment, 30 pages (Nov. 1977). Order from NTIS as PB273950.

17116. Berlin, V. N., Weiss, R. G., The role of evaluation systems in the government policy and program change: $A$ cybernetic approach, Proc. Int. Conf. on Cybernetics and Society, Washington, DC, Sept. 19-21, 1977, pp. 17-22 (Institute of Electronics and Electrical Engineers, New York, NY, 1977).

17323. Libman, A. S., Weiss, R. G., Administrative experiment in public policy development, Proc. American Institute for Decision Sciences Ninth Annual Meeting, Chicago, IL, Oct. 19-21, 1977, J. D. Stolen and J. J. Conway, Eds., pp. $395-$ 397 (1977).

\section{Other Subjects of General Interest}

Monogr. 155. From sundials to atomic clocks-Understanding time and frequency, J. Jespersen and J. Fitz-Randolph, Nat. Bur. Stand. (U.S.), Mongr. 155, 177 pages (Dec. 1977) SN003-003-01650-1.

SP305. Supplement 8. Publications of the National Bureau of Standards 1976 catalog. A compilation of abstracts and key word and author indexes, B. L. Burris, Ed., Nat. Bur. Stand. (U.S.), Spec. Publ. 305 Suppl. 8, 728 pages (June 1977) SN003-003-01743-4.

SP458. Metrication and dimensional coordination-A selected bibliography, R. E. Clark and C. L. Roat, Nat. Bur. Stand. (U.S.), Spec. Publ. 458, 32 pages (Apr. 1977) SN003-00301684-5.

SP469. A policy analysis of citizen rights issues in health data systems, A. F. Westin and F. Isbell, Ed., Nat. Bur. Stand. (U.S.), Spec. Publ. 469, 48 pages (Jan. 1977) SN003-00301730-2.

SP479. Corrosion and metal artifacts-A dialogue between conservators and archaeologists and corrosion scientists, B. F. Brown, H. C. Burnett, W. T. Chase, M. Goodway, J. Kruger, and M. Pourbaix, Eds., Nat. Bur. Stand. (U.S.), Spec. Publ. 479, 252 pages (July 1977) SNO03-003-01826-1.

Electrochemical corrosion and reduction, M. Pourbaix, SP479, pp. 1-16 (July 1977).

Corrosion product characterization, N. A. Nielsen, SP479, pp. 17-37 (July 1977).

Principles of gaseous reduction of corrosion products, C. E. Birchenall and R. A. Meussner, SP479, pp. 39-57 (July 1977).

Some brief remarks on electrocbemical reduction, J. Kruger, SP479, pp. 59-65 (July 1977).

Measures for preventing corrosion of metals, R. T. Foley, SP479, pp. 67-76 (July 1977).

A review of the history and practice of patination, P. D. Weil, SP479, pp. 77-92 (July 1977).

The production of artificial patimation on copper, D. C. Hemming, SP479, pp. 93-102 (July.1977).

Beta iron oxide hydroxide formation in localized active corrosion of iron artifacts, F. Zucchi, G. Morigi, and V. Bertolasi, SP479, pp. 103-105 (July 1977).

The current status of the treatment of corroded metal artifacts, R. M. Organ, SP479, pp. 107-142 (July 1977).

Some constructive corrodings, C. S. Smith, SP479, pp. 143153 (July 1977).

Conservation of rusty iron objects by hydrogen reduction, L. Barkman, SP479, Pp. 155-166 (July 1977).

Restoration of large gilded statues using various electrocbemical and metallurgical techniques, F. Ogburn, E. Passaglia, H. C. Burnett, J. Kruger, and M. L. Pickelsimer, SP479, pp. 167-178 (July 1977).

Problems of retrieval and retention of artifacts in field excavations, W. Trousdale, SP479, pp. 179-189 (July 1977). 
SP500-17. Computer science \& technology: Copyright in computer-readable works: Policy impacts of technological change, R. G. Saltman, Nat. Bur. Stand. (U.S.), Spec. Publ. 500-17, 267 pages (Oct. 1977) SNO03-003-01843-1.

TN934. Preservation of historic adobe structures-A status report, J. R. Clifton, Nat. Bur. Stand. (U.S.), Tech. Note 934, 35 pages (Feb. 1977) SNOO3-003-01740-0.

TN939. NBS reactor: Summary of activities July 1975 to June 1976, F. J. Shorten, Ed., Nat. Bur. Stand. (U.S.), Tech. Note 939, 140 pages (May 1977) SNO03-003-01769-8.

TN960. A survey of the National Metric Speakers Bureau, J. M. Tascher, Nat. Bur. Stand. (U.S.), Tech. Note 960, 56 pages (Nov. 1977) SN003-003-01860-1.

NBSIR 76-1125. Catalog of artifacts on display in the NBS Museum, H. L. Mason, Ed., 292 pages (Nov. 1977). Order from NTIS as PB273666.

NBSIR 77-1215. NBS serial holdings-1977, J. C. Tucker, Ed., 242 pages (Apr. 1977). Order from NTTS as PB269534.

NBSIR 77-1257. An analysis of employee publics and employee communication programs in the National Bureau of Standards, J. E. Grunig, 43 pages (June 1977). Order from NTIS as PB271973.

16712. Brown, P. W., Clifton, J. R., Nondestructive techniques for evaluating metallic artifacts of historical interest, Bull. Assoc. Preserv. Technol. VIII, No. 4, 2-21 (1976).

16734. Tucker, J. C., Alternative models of the decision-making process and their implications for information packaging, Proc. 39th Annual Meeting of the American Society for Information Science on Information-Politics, San Francisco, CA, Oct. 4-9, 1976, 13, 10 pages (American Society for Information Science, Washington, DC, 1976).

16743. Henderson, M. M., The Federal sector, Chapter in The Information Age: Its Development, Its Impact, D. P. Hammer, Ed., pp. 91-121 (The Scarecrow Press, Inc., Metuchen, NJ, 1976).

16758. Hummer, D. G., Line formation in expanding atmospheres, (Proc. LAU Symp. No. 70, on Be and Shell Stars, Bass River, MA, Sept. 1975), Paper in Be and Shell Stars, A. Slettebak, Ed., pp. 281-312 (Reidel, Dordrecht-Holland, 1976).

16859. Rabinow, J., Patents-An inventor's viewpoint, (Proc. 50th Anniversary Meeting of the Patent and Trademark Institute of Canada, Ottawa, Canada, Sept. 15-17, 1976), Patent Trademark Inst. Can. J., pp. 836-853 (Feb. 1977).

16905. Davis, R. M., When science and technology stumble, everyone suffers, (Proc. Rockefeller University 75th Anniversary Symp., New York, NY, Mar. 8, 1976), Paper in Beyond
Tomorrow. Trends and Prospects in Medical Science, Session III, pp. 87-103 (Rockefeller University, New York, NY, 1976).

17037. Odom, J. V., Weights and measures play vital roles in metrication, Metric News 4, No. 3, 5, 11,29 (May/June 1977).

17040. Milton, H. J., Metrication: Take the tide at its flood, Concrete Constr. 22, No. 8, 429-431, 440-442 (Aug. 1977).

17102. Aizenman, M., Weigert, A., Stability properties of some stellar models in the Beta Cephei region, Astron. Astrophys. 56, 457-459 (Apr. 1977).

17104. Clifton, J. R., Adobe building materials: Properties, problems, and preservation, Tech. Conservation, pp. 30-34 (Spring 1977).

17113. Sorrows, H. E., Coping with future technology, Commerce Am. II, No. 20, 4-5 (Sept. 26, 1977); Surplus Record 54, No. 12, 38-40 (Dec. 1977).

17114. Davis, R. M., Taking risks with computers, Proc. Symp. Man and the Computer, Dartmouth College, Hanover, NH, Nov. 30-Dec. 1-2, 1976, pp. 28-34 (Kiewit Computation Center, Dartmouth College, Hanover, NH, 1976).

17133. Chapman, C., How to stop worrying and love benefit/cost analysis, Std. Eng. 29, No. 3, 54-56 (June 1977).

17186. Brown, C. P., On-line bibliographic retrieval system use, Spec. Lib. 68, No. 4, 155-160 (Apr. 1977).

17217. Kahn, F. D., Supernova remnants, (Proc. 14th Int. Cosmic Ray Conf., Munich, Germany, Aug. 18-28, 1975), Conference Papers Volume 11. Invited Lectures and Rapporteur Papers, pp. 3566-3593 (Max-Planck-Institut fuir Extraterrestrische Physik, Munchen, Germany, 1975).

17231. Berger, J., Levine, J., The spectrum of earth strain from $10^{-8}$ to $10^{2} \mathrm{~Hz}, J$. Geophys. Res. 79, No. 8, $1210-1214$ (Mar. 10,1974 ).

17236. Oman, R. C., Comparing the benefits and the costs of electric typewriters and word processors, The Office 85, No. 6, 77-79 (June 1977).

17309. Zahn, J. P., Tidal friction in close binary stars, Astron. Astrophys. 57, 383-394 (1977).

17315. Faulkner, D. J., Cepheid studies. II. A third period in the beat Cepheid TU Cassiopeiae, Astrophys. J. 218, 209-219 (Nov. 15, 1977).

17324. Linsky, J. L., The solar output and variability viewed in the broader context of stellar activity, Chapter in The Solar Output and Its Variation, O. R. White, Ed., Pp. 477-515 (Colorado Associated University Press, Boulder, CO, Oct. 1977). 


\section{INDEXES}

\subsection{HOW TO USE THE INDEXES}

In addition to the usual author index, a subject index is provided in the form of a permuted key work index. In this type of index the key words in each publication or paper are arranged by shifting each group of key words along the horizontal printing line so that each key word in turn has an opportunity to appear alphabetically. The user is thus able to locate papers of interest to him through the subject-related words he finds in the key word index.

The index symbols used in the author and key word indexes are explained in the following three tables. These tables also give the pages on which the abstracts of the various publication series: begin.

Table A. Symbols for the Periodicals

\begin{tabular}{|c|c|c|c|c|c|}
\hline $\begin{array}{c}\text { NBS Journal } \\
\text { of Research }\end{array}$ & \multicolumn{3}{|c|}{ Index Symbol } & Issue Date & $\begin{array}{c}\text { Page } \\
\text { Number }\end{array}$ \\
\hline Section A & $\begin{array}{l}\text { Vol. } \\
\text { J. Res. } 81 \\
\text { J. Res. } 81\end{array}$ & $\begin{array}{c}\text { Sec. } \\
\text { A } \\
\text { A }\end{array}$ & $\begin{array}{c}\text { No. } \\
1 \\
2 \& 3\end{array}$ & $\begin{array}{l}\text { January-February } 1977 \\
\text { March-June } 1977\end{array}$ & $\begin{array}{l}41 \\
42\end{array}$ \\
\hline Section B & J. Res. 81 & B & $1 \& 2$ & January-June 1977 & 44 \\
\hline $\begin{array}{l}\text { Effective July } \\
1977 \text {, issued } \\
\text { as one Section }\end{array}$ & $\{$ J. Res. 82 & - & $\begin{array}{l}1 \\
2 \\
3\end{array}$ & $\begin{array}{l}\text { July-August } 1977 \\
\text { September-October } 1977 \\
\text { November-December } 1977\end{array}$ & 45 \\
\hline
\end{tabular}

Journal of Physical and Chemical Reference Data

J. Phys. Chem. Ref. Data

\begin{tabular}{|c|c|c|c|}
\hline \multicolumn{2}{|c|}{ Index Symbol } & Issue Date & $\begin{array}{c}\text { Page } \\
\text { Number }\end{array}$ \\
\hline $\begin{array}{cc}\text { Vol. } & \\
\text { JCPRD } & 6 \\
\text { JCPRD } & 6 \\
\text { JCPRD } & 6 \\
\text { JCPRD } & 6\end{array}$ & $\begin{array}{c}\text { No. } \\
1 \\
2 \\
3 \\
4\end{array}$ & $\begin{array}{l}1977 \\
1977 \\
1977 \\
1977\end{array}$ & $\begin{array}{l}48 \\
48 \\
49 \\
50\end{array}$ \\
\hline
\end{tabular}

\begin{tabular}{c|c|r|l|c}
\hline \hline & \multicolumn{2}{|c|}{} & \multicolumn{1}{|c}{ Issue Date } & $\begin{array}{c}\text { Page } \\
\text { Number }\end{array}$ \\
\hline & \multicolumn{2}{|c|}{ Index Symbol } & & \\
DIM/NBS & Vol. & No. & & 52 \\
DIM/NBS & 61 & 1 & January 1977 & 52 \\
DIM/NBS & 61 & 2 & February 1977 & March 1977 \\
DIM/NBS & 61 & 4 & April 1977 & 52 \\
DIM/NBS & 61 & 5 & May 1977 & 53 \\
DIM/NBS & 61 & 6 & June 1977 & 53 \\
DIM/NBS & 61 & 7 & July 1977 & 53 \\
DIM/NBS & 61 & 8 & August 1977 & 53 \\
DIM/NBS & 61 & 9 & September 1977 & 53 \\
DIM/NBS & 61 & 10 & October 1977 & 54 \\
DIM/NBS & 61 & 11 & November 1977 & 54 \\
DIM/NBS & 61 & 12 & December 1977 & 54 \\
\hline
\end{tabular}


B. Symbols for the Nonperiodicals

\begin{tabular}{l|l|c}
\hline \multicolumn{1}{c|}{ NBS Nonperiodical Series } & \multicolumn{1}{|c|}{ Index Symbol } & Page Number \\
\hline Monographs & Monogr. & 55 \\
Handbooks & H & 57 \\
Special Publications & SP & 58 \\
Applied Mathematics Series & AMS & 137 \\
National Standard Reference Data Series & NSRDS & 137 \\
Building Science Series & BSS & 138 \\
Federal Information Processing Standards & FIPS PUBS & 144 \\
Product Standards & PS & 146 \\
Technical Notes & TN & 154 \\
Consumer Information Series & NSS & 155 \\
NBS Interagency Reports & NBSIR & 182 \\
Grantee/Contractor Reports and Patents & GCR & \\
\hline
\end{tabular}

Table C. Symbols for the Papers Published by Others (1977)

\begin{tabular}{c|c|c}
\hline \hline \multicolumn{1}{c|}{$\begin{array}{c}\text { NBS Papers Published by Others } \\
\text { (1977) }\end{array}$} & Index Symbol & Page Number \\
\hline $\begin{array}{l}\text { Professional Journals, Books, Book Chapters, } \\
\text { Proceedings, etc. }\end{array}$ & $\begin{array}{c}\text { Five-Digit numbers, 16659 } \\
\text { through } 17350\end{array}$ & 191 \\
\hline
\end{tabular}




\subsection{AUTHOR INDEX}

\section{A}

Abaundi, R., Segnan, R., Rhyne, J. J., SWeger, D. M., 16985. ABERNATHY, F. H., SP484, pp. 957-959 (Oct. 1977). AbramowtTZ, S., ACQUista, N., LeVIN, I. W., 17208. Abramowitz, S., Broida, H. P., Cohen, P. I., 17242. AbramowitZ, S., KIRKLIN, D. R., RITTER, J. J., 17166. ABRAMOWITZ, S., LEVIN, I. W., BERNSTEIN, L. S., 16978. ABRAMS, M. D., 17250 .

Arrams, M. D., Cotton, I. W., Watkins, S. W., Rosenthal, R., RIPPY, D. E., 17252.

Abrams, M. D., Treu, S., 17288.

ABRAMS, M. D., WatKins, S. W., SP500-4.

ABRAMS, M. D., Watkins, S. W., 16945.

ACHENBaCH, P. R., Heldengrand, J. L., 17289.

ACquista, N., LeVin, I. W., Abramowitz, S., 17208.

ACQUiSTA, N., READER, J., 17212.

Adair, R. T., Frederick, N. V., Sullivan, D. B., 16875.

Adair, R. T., Frederick, N. V., Sullivan, D. B., NBSIR 77 863.

Adair, R. T., Sullivan, D. B., Frederick, N. V., 17092.

Adamov, V. M., Alexandrov, B. M., Alkhazov, I. D., Drapchinsky, L. V., Kovalenko, S. S., Kostochikin, O. I., Kudriavzev, G. Y., Malkin, L. Z., Petrzhak, K. A., Pleskachevsky, L. A., Fomichev, A. V., Shapakov, V. I., SP493, Pp. 313-318 (Oct. 1977).

Adams, J. W., CraWTORd, M. L., Shafer, J. F., 17251.

Adams, P. J., LinsKy, J. L., Basri, G. S., Maran, S. P., Hobbs, R. W., CHIU, H. Y., 16732.

ADLER, S., NBSIR 77-1246.

Agrawala, A. K., Mohr, J. M., SP500-18, pp. 23-38 (Sept. 1977).

Aizenman, M., Smeyers, P., Weigert, A., 17029.

AIZENMAN, M., Weigert, A., 17102.

AIzenman, M. L., Smeyers, P., 17311 .

AuX, R. L., SP471, pp. 17-22 (June 1977).

AlARIE, Y., BARROW, C. S., NBS-GCR-77-85.

Albus, J. S., Barbera, A. J., Fife, D. W., Fong, E. N., GilSinN, D. E., Holberton, F. E., Lucas, B. G., Lyon, G. E., Marron, B. A. S., NeumanN, A. J., Vickers, M. V., Walker, J. C., Evans, J. M., JR., O'Neill, J. T., Little, J. L., NBSIR 76-1094.

Alexander, M. H., Manger, C. L., MOORe, J. H., JR., 17216.

Alexandrov, B. M., Alkhazov, I. D., Drapchinsky, L. V., Kovalenko, S. S., Kostochion, O. I., Kudriavzev, G. Y., Malkin, L. Z., Petrzihak, K. A., Pleskachevsky, L. A., Fomichev, A. V., ShapaKov, V. I., Adamov, V. M., SP493, pp. 313-318 (Oct. 1977).

Alkhazov, I. D., Drapchinsky, L. V., Kovalenko, S. S., Kostochkin, O. I., Kudria vzev, G. Y., Malkin, L. Z., Petrzhak, K. A., Pleskachevsky, L. A., Fomichev, A. V., ShapaKov, V. I., Adamov, V. M., Alexandrov, B. -M., SP493, pp. 313-318 (Oct. 1977).

Allan, D. W., Glaze, D. J., Hellmig, H. W., JaRvis, S., JR., WINELAND, D. J., 16759.

Allan; D. W., Jarvis, S., JR., Glaze, D. J., Hellwig, H., 16775.

Allen, C. B., Downey, J. R., JR., Singer, S. K., Janz, G. J., TOMKINS, R. P. T., JPCRD 6, No. 2, 409-596 (1977).

Allion, H. H., Moore, E. F., Mattingly, G. E., Pontius, P. E., SP484, pp. 33-54 (Oct. 1977).

Allred, C. M., Hoer, C. A., Roe, K. C., 16724.

AlMER, H. W., KELLER,J., NBSIR 76-999.

Alperin, H. A., Cullen, J. R., Clark, A. E., Callen, E., 16835 .

Alperin, H. A., Rhyne, J. J., KoOn, N. C., Mrstein, J. B., 16963.

alumbaugh, R. L., Escalante, F., Iverson, W. P., Gerhold, W. F., SANDERSON, B. T., Monogr. 158.

AMBLER, E., SP47I, p. 128 (June 1977).
AMBLER, E., SP475, p. 1 (Apr. 1977).

AMBLER, E., 16991 .

AMBrose, J. R., KRUGER, J., NBSIR 76-1170.

AMBrose, J. R., KRUGER, J., 16990.

AMRHEIN, J. E., BSSI06, pp. 255-258 (Sept. 1977).

Amsden, A. A., Ginocchio, J. N., Harlow, F. H., Nix, J. R.,

Danos, M., Halbert, E. C., Smith, R. K., JR., 17109.

Anavekar, S. N., Wardell, W. M., Tsianco, M. C., Davis, H. T., NBS-GCR-ETIP 76-35.

ANDERSON, A. B., SP475, pp. 166-170 (Apr. 1977).

Anderson, R., Henry, R. C., MoOs, H. W., Jenkins, E. B., Snow, T. P., Upson, W. L., Starrfield, S. G., Gallagher, J. S., Friedjung, M., LiNSKY, J. L., 16762.

ANDERSON, W. E., DAVIS, R. S., 16782.

Anderson, W. E., Davis, R. S., MopsiK, F. I., KRYDer, S. J.,

Khoury, F., COLSON, J. P., BOLz, L. H., 17014.

ANDREWS, J. R., 16725.

ANDREWS, J. R., ARTHUR, M. G., TN699.

ANDREWS, J. R., LAWTON, R. A., 16661.

ANGEL, W. T., HOUCK, J. C., 16908.

AnNett, J., Singley, G. W., Koenig, H. L., O'Brien, J. F., SKRIDULIS, J., SP484, pp. 145-172 (Oct. 1977).

AnVar, A., Isenberg, J., Hegemier, G. A., BSSI06, pp. 154. 165 (Sept. 1977).

APPell, G., MCQuivey, R. S., MERO, T., SP484, pp. 109-122 (Oct. 1977).

Arbuckle, R., Goldberg, R. N., Staples, B. R., Nuttall, R. L., SP485.

ARCHEA, J., STAHL, F. I., NBSIR 77-1313.

ARMSTRONG, G. T., NUTtALL, R. L., TN937.

ARNess, J. P., SP487, pp. 247-252 (Aug. 1977).

ARONSON, J., SP500-12.

ARP, V., 17082.

ArP, V. D., Parrish, W. R., Daney, D. E., LudTKe, P. R., Frederick, N. V., HANDS, B. A., JONES, M. C., NBSIR 77853.

ARP, V. D., YASKIN, L. A., Jones, M. C., Yeroshenko, V. M., Giarratano, P. J., 17333.

ARTHUR, M. G., ANDREWS, J. R., TN699.

ARvidson, J. M., BrenNan, J. A., 17081.

ASSEFF, P. A., SP488, pp. 77-78 (Aug. 1977).

August, L. S., Shapiro, P., Theus, R. B., NBSIR 77-1279, pp. 31-34 (July 1977).

Ausloos, P., Lias, S. G., 17057.

Ausloos, P., Rebbert, R. E., Glasgow, L., J. Res. 82, No. 1, $1-8$ (1977).

Ausloos, P. J., Rebeert, R. E., 16703.

Ausrin, W. H., SP450, pp. 143-151 (June 1977).

AuSTTN, W. H., SP450, pp. 167-170 (June 1977).

AuXIER, J. A., SP493, pp. 101-105 (Oct. 1977).

AwSCHALOM, M., NBSIR 77-1279, pp. 10-14 (July 1977).

Axton, E. J., SP493, pp. 237-243 (Oct. 1977).

AYOUB, M. M., SP482, pp. 71-103 (July 1977).

AYres, T. R., LINSKY, J. L., RODGers, A. W., KuRUCZ, R. L., 16809.

Azarraga, L. V., SP464, pp. 73-74 (Nov. 1977).

AZER, N. Z., Hsu, S., SP491, pp. $18-40$ (Sept. 1977).

\section{B}

Babu, T. M., Bowman, R. R., Wacker, P. F., U.S. Patent 4,008,477.

BABRAUSKAS, V., NBSIR 77-1290.

Balley, R. A., TAUSCH, H. J., JESCH, R. L., 17239.

Bajura, R. A., Pellegrin, M. T., SP484, pp. 523-548 (Oct. 1977).

BaK, P., Watson, R. E., Herbst, J. F., 16916.

BAKER, M., SP484, pp. 803-820 (Oct. 1977).

BAKer, S. M., Mrtchell, R. A., WoOlley, R. M., NBSIR 761053. 
Baker, W. O., Eyring, H., Birkhoff, G., Perlis, A., Seamans, R. C., JR., Ramo, S., Thomson, R. M., Teller, E., Ramsey, N., SP465.

BAKOS, J. S., 17130.

Baldwin, J. R., Mavrodineanu, R., SP492, pp. 66-71 (Nov. 1977).

BALL, J. M., SP484, pp. 847-869 (Oct. 1977).

Balsara, J. P., Norman, C. D., Crowson, R. D., SP477, pp. V-85-VI-117 (May 1977).

BanNister, R. L., OSborne, R. L., Jennings, S. J., SP494, pp. 97-116 (Sept. 1977).

Bapat, V. N., Sunta, C. M., Jain, V. K., Kathuria, S. P., SP461, pp. 222-226 (Jan. 1977).

Bar, V., Steinitz, R., Gebbie, K. B., 16888.

BARBERA, A. J., SP500-23.

Barbera, A. J., Fife, D. W., Fong, E. N., Gilsinn, D. E., Holberton, F. E., Lucas, B. G., Lyon, G. E., Marron, B. A. S., Neumann, A. J., Vickers, M. V., Walker, J. C., Evans, J. M., JR., O'NeחL, J. T., LitTle, J. L., Albus, J. S., NBSIR 76-1094.

BARDES, B. P., SP487, pp. 19-24 (Aug. 1977).

BARDSLEY, J. N., LIN, S. L., 16779.

, BARGER, R. L., 17098.

BARGER, R. L., 17178.

BARKMAN, L., SP479, pp. 155-166 (July 1977).

Barnard, A. J., CoOper, J., SMTth, E. W., 17167.

Barnard, A. J., CoOper, J., SMith, E. W., Mirhalas, D., $17 ! 71$.

Barnard, A. J., CoOper, J., Smith, E. W., Mihalas, D., 17172.

BARNES, I. L., EPSTEIN, M. S., MOODY, J. R., ROOK, H. L., Paulsen, P. J., Rains, T. C., SP464, pp. 515-518 (Nov. 1977).

BARnes, J. D., MARtin, G. M., 17346.

BARNeTt, J. P., LIU, S. T., NBSIR 76-1177.

Barrett, C. S., Clark, R. L., Ruud, C. O., Russell, P. A., SP464, PP. 635-636 (Nov. 1977).

BARRETT, J. J., SP464, pp. 31 5-316 (Nov. 1977).

BARROW, C. S., AlARIE, Y., NBS-GCR-77-85.

BarschaLl, H. H., NBSIR 77-1279, p. 30 (July 1977).

Barschall, H. H., SP493, pp. 342-346 (Oct. 1977).

Bartel, D. L., Desormeaux, S. G., SP472, pp. 51-59 (Apr. 1977).

Bartel, T. W., Voorhees, C. R., Pallett, D. S., 16763.

Basavaranu, G., Kane, P. P., Prasad, P. N. B., SP461, pp. 67-69 (Jan. 1977).

Basri, G. S., Maran, S. P., Hobbs, R. W., Chiu, H. Y., Adams, P. J., LINSKY, J. L., 16732.

Bass, A. M., Hodgeson, J. A., Hughes, E. E., Schmid, W. P., 16756.

Bass, A. M., Laufer, A. H., 16838.

BASS, A. M., LedFord, A. E., JR., WhitTAKER, J. K., SP464, pp. 9-13 (Nov. 1977).

BASSIN, M. A., BuRNeTt, E. D., NBSIR 76-1179.

BASSIN, M. A., BuRNeTt, E. D., 16846.

Basu, A. S., Ganguly, A. K., SP461, pp. 219-221 (Jan. 1977).

Basu, D. K., SAXENa, J., KozUChowsKi, J., SP464, pp. 101-104 (Nov. 1977).

BATES, R. G., DURST, R. A., SP450, pp. 247-255 (June 1977).

Bates, R. G., Hetzer, H. B., Durst, R. A., Robinson, R. A., J. Res. 81A No. 1, 21-24 (1977).

BAtes, R. G., MohaN, M. S., SP450, pp. 293-299 (June 1977).

BAUM, H. R., J. Res. $81 B$ Nos. 1 and 2, 45-60 (1977).

Baum, H. R., Mulholland, G. W., Lee, T. G., 17282.

Baumgarten, G. P., Robertson, B., TN943.

BAUMOEL, J., SP484, pp. 267-276 (Oct. 1977).

BAXTER, B. S., SP500-8, pp. 77-79 (May 1977).

BAXTER, W. J., SP487, pp. 197-209 (Aug. 1977).

BAY, O., SP463, pp. II.3.1-II.3.4 (Jan. 1977).

BEAN, J., KeLLY, G. E., BSS93.
BEAN, J. W., Kusuda, T., NBSIR 76-1088.

BEAN, V. E., 17205.

BeAR, J. R., ReEves, T. E., SP500-18, pp. 39-67 (Sept. 1977).

Beaty, E. C., Hesselbacher, K. H., Hong, S. P., MoOre, J. H., 16810.

Beausoliel, R. W., Kelly, G. E., Parken, W. H., Jr., 17006.

Beausoliel, R. W., Meese, W. J., BSSI03.

Beck, N. C., Stephens, K. S., Peiser, H. S., NBSIR 76-1180.

BeCKer, D. A., SP464, pp. 43-46 (Nov. 1977).

BECKER, D. A., SP488.

BECKER, D. A., SP488, pp. 7-11 (Aug. 1977).

Becker, D. A., Gills, T. E., SP492, pp. 12-14 (Nov. 1977).

Becker, D. A., Maienthal, E. J., 16729.

Beeghly, H. F., Mears, T. W., Michaelis, R. E., 16667.

Beehler, R. E., Hanson, D. 'W., Davis, D. D., 17080.

BeERS, J. S., TUCKER, C. D., NBSIR 73-239.

BEINE, W. B., NBSIR 77-1218.

BEIZER, B., SP471, pp. 120-124 (June 1977).

Bellama, J. M., Brinckman, F. E., Parris, G. E., Blair, W. R., JeWETt, K. L., IVERSON, W. P., I7155.

Bellama, J. M., JeWett, K. L., Brinckman, F. E., 17008.

Bendel, W. L., Jones, E. C., JR., FagG, L. W., Maruyama, X. K., Lightbody, J. W., JR., Fivozinsky, S. P., Lindgren, R. A., 16687.

Benjamin, I. A., Fung, F., Roth, L., NBSIR 77-1209.

BENNER, L. A., JR., SP482, pp. 25-28 (July 1977).

BenNeTt, H. E., STANFORD, J. L., SP466, pp. 133-148 (May 1977).

Bennett, H. S., Cantrell, C. D., 16746.

Bennett, H. S., Cantrell, C. D., 17312.

BENNETT, H. S., Forman, R. A., 16815.

BENNETT, H. S., Forman, R. A., 16860.

BENNETT, H. S., Forman, R. A., 17313.

Bennett, H. S., Kayser, R., JR., J. Res. 81A Nos. 2 and 3. 257-266 (1977).

BenNeTt, H. S., KAYSER, R., JR., J. Res. 82, No. 3, 183-195 (1977).

BENNETT, L. H., SP475.

BENNETT, L. H., SP475, pp. 3-4 (Apr. 1977).

BenNett, L. H., Carter, G. C., NBSIR 77-1239.

Bennett, L. H., Cohen, M. I., Dragoo, A. L., Franklin, A. D., MCAlister, A. J., Young, K. F., NBSIR 77-1270.

BenNetT, L. H., Kahan, D. J., Carter, G. C., 17093.

Bennett, L. H., McAlister, A. J., Cuthill, J. R., Erickson, N. E., WATSON, R. E., 16932.

Bennett, L. H., McAlister, A. J., Watson, R. E., 17262.

BenNett, L. H., SWARTZENDRUber, L. J., Reno, R. C., 17011.

BENNETT, L. H., WATSON, R. E., 16927.

BENNETT, L. H., WATSON, R. E., 16940.

BENNETT, L. H., WATSON, R. E., 16967.

BENNETT, W. D., SP500-18, pp. 137-142 (Sept. 1977).

BENSEMA, W. D., 17173.

BENSEMA, W. D., 17175.

BENZINGER, T. H., SP491, pp. 152-168 (Sept. 1977).

Benzinger, T. H., Mangum, B. W., Hill, J. E., 16923.

Bereuter, W. A., Chang, D. C., NBSIR 76-851.

Berger, H., 17016.

Berger, H., 17042.

Berger, H., 17106.

Berger, J., LeVine, J., 17231.

BERGER, R., 16979.

Berger, R. L., Clifton, J. R., Frohnsdorf, G., Brown, P. W., 16768.

Berglund, L. G., SP491, pp. 117-130 (Sept. 1977).

Bergman, S., Bunten, E., Klaus, P., SP480-5.

Bergquist, J. C., LeE, S. A., Hall, J. L., 16776.

Bergquist, J. C., LeE, S. A., Hall, J. L., 17337.

BerLIN, V. N., WeISS, R. G., 17116.

Berman, B. L., Gibson, B. F., O'Connell, J. S., 16987.

Berning, D. W., LeWIS, D. C., SAWYer, D. E., 17164. 
Berning, D. W., Sawyer, D. E., SP400-24.

Bernstein, L. S., Abramowitz, S., LeVin, I. W., 16978.

BERTÉ, F. J., SP484, pp. 447-470 (Oct. 1977).

Bertocci, U., Escalante, E., Mullen, J. L., Kruger, J., NBSIR 77-1232.

Bertolasi, V., Zucchi, F., Morigi, G., SP479, pp. 103-105 (July 1977).

Bertoncini, P. J., Wahl, A. C., Stevens, W. J., Hessel, M. M., 16870 .

Bhatia, D. P., Nagarajan, P. S., Raghavendran, C. P., Sethulakshmi, P., SP461, pp. 100-105 (Jan. 1977).

Bieganousky, M. A., Marcuson, M. F., CoOper, S. S., SP477, pp. VI-141-VI-157 (May 1977).

Bielefeld, M. J., Seltzer, S. M., Metzger, A. E., Trombka, J. I., Dyer, C. S., Evans, L. G., 16938.

Bierbaum, V. M., Ellison, G. B., Futrell, J. H., Leone, S. R., 17209.

Bigelow, J., Grundl, J. A., Spiegel, V., Eisenhauer, C. M., Heaton, H. T. II, Gilliam, D. M., 16790.

Billingsley, F. C., SP500-8, pp. 99-107 (May 1977).

Birchenall, C. E., Meussner, R. A., SP479, pp. 39-57 (July 1977).

Birkhoff, G., Perlis, A., Seamans, R. C., JR., Ramo, S., Thomson, R. M., Teller, E., Ramsey, N., Baker, W. O., EYRING, H., SP465.

Birks, J. B., SP466, pp. 1-11 (May 1977).

Birks, L., Gilfrich, J., Whitlock, R., FAtemi, M., Johnson, E., SP464, pp. 189-190 (Nov. 1977).

Birks, L. S., Gilfrich, J. V., Peckerar, M. C., SP464, pp. 347 349 (Nov. 1977).

BIRKY, M. M., NBSIR 77-1234.

Birky, M. M., Packham, S. C., Frens, D. B., McCandless, J. B., Petajan, J. H., 16921 .

Birmingham, B. W., 17079 .

Biros, F. J., SP464, pp. 387-389 (Nov. 1977).

Bishop, J. N., Diosady, P. L., Moselhy, M. M., BoOmer, D. W., SP464, pp. 137-150 (Nov. 1977).

BlaCK, J., SMITH, G. K., SP472, pp. 23-28 (Apr. 1977).

BLACKBURN, D. L., SP400-44.

Blackburn, D. L., Koyama, R. Y., Oettinger, F. F., Rogers, G. J., 17345 .

Blackburn, D. L., Koyama, R. Y., Oettinger, F. F., Rogers, G. J., NBSIR 77-1249.

Blackburn, D. L., Rubin, S., Rogers, G. J., 16893.

Blackburn, J. B., JR., Rowe, P. G., Gevirtz, J. L., SP473, pp. 189-202 (June 1977).

Blair, B., Jesperson, J., Kamas, G., 16947.

Blair, W. R., Brinckman, F. E., Parris, G. E., 16811 .

Blair, W. R., Jewett, K. L., Iverson, W. P., Bellama, J. M., Brinckman, F. E., Parris, G. E., 17155.

Blair, W. R., Jewett, K. L., Iverson, W. P., Brinckman, F. E., 17297.

Blais, N. C., Truhlar, D. G., 16802.

Blais, N. C., Truhllar, D. G., 16803.

Blinov, M. V., Vitenko, V. A., TOUSE, V. T., SP493, pp. $194-$ 197 (Oct. 1977).

Block, R. C., Singh, U. N., Kobayashi, K., Chrien, R. E., Liou, H. I., SP493, pp. 255-260 (Oct. 1977).

Blomquist, D. S., CADoff, M. A., NBSIR 76-1169.

Bloss, R. L., 16915.

Bloss, R. L., Peterson, R. W., NBSIR 76-1145.

BLUE, J. L., SP463, pp. IV.1.1-IV.1.5 (Jan. 1977).

BLUM, D. G., BURCH, D. M., KusUdA, T., TN933.

Blumenthal, B. H., Demas, J. N., SP466, pp. $21-24$ (May 1977).

BOCCIA, L., SP500-8, p. 81 (May 1977).

Boettinger, W. J., Burdette, H. E., Kuriyama, M., 16974.

Boettinger, W. J., Burdette, H. E., Farabaugh, E. N., KuRIYAMA, M., 16977.

Boettinger, W. J., Burdette, H. E., Kuriyama, M., 16997.
BoetTtinger, W. J., BurdetTe, H. E., KuriYama, M., 17277.

BohaNNAN, B., SP477, pp. I-66-I-69 (May 1977).

Boink, A. B. T. J., RuIG ROK, T. J. C., MAAS, A. H. J., VeEFKIND, A. H., VAN dEN Camp, R. A. M., Teunissen, A. J., SP450, pp. 257-265 (June 1977).

Boldeman, J. W., SP493, pp. 182-193 (Oct. 1977).

Bolz, L. H., ANDERSON, W. E., Davis, R. S., Mopsik, F. I. Kryder, S. J., Khoury, F., Colson, J. P., 17014.

BOLZ, L. H., RENEKeR, D. H., 16995.

BOOKer, R. L., Douglas, C. A., Monogr. 159.

BoOmer, D. W., Bishop, J. N., Diosady, P. L., Moselhy, M. M., SP464, pp. 137-150 (Nov. 1977).

Borger, D., Lingerak, W. A., van RaAphorst, J. G., Slanina, J., SP464, pp. $121-123$ (Nov. 1977).

Bosch, H. R., Gade, R. H., Podolny, W., JR., SP470, pp. II47-II-67 (Apr. 1977).

Botter, R., Pechine, J. M., Rosenstock, H. M., 17146.

BOUDART, M., SP475, pp. 5-12 (Apr. 1977).

BOUHANA, J., SP500-18, pp. 219-225 (Sept. 1977).

BOWEn, B. E., Cram, S. P., 16980.

BOWEN, E. R., WeSTCOTT, V. C., SP494, pp. 73-74 (Sept 1977).

BOWEN, R. L., MisRa, D. N., 17033.

BOWEN, R. L., MISRA, D. N., 17197.

BOWEN, T. C., SP488, pp. 55-56 (Aug. 1977).

BOWMAN, C. D., 16951.

Bowman, C. D., Carlson, A. D., Liskien, H. O., Stewart, L., SP493:

Bowman, C. D., Lone, M. A., Stewart, L., Carlson, A. D., NBSIR 77-1279.

BOWMAN, R. R., 17168.

Bowman, R. R., Lowell, W. R., Flanigan, W. F., JR., 17174.

Bowman, R. R., Wacker, P. F., BabU, T. M., U.S. Patent 4,008,477.

BRADEN, R. C., SP463, pp. IV.8.1-IV.8.10 (Jan. 1977).

Bradshaw, J. E., Linnworth, L. C., Morel, P. R., Pedersen, N. E., SP484, pp. 293-318 (Oct. 1977).

BRAMAN, R. S., SP464, pp. $451-458$ (Nov. 1977).

Brand, M. J. D., PACE, S. J., SP450, pp. 227-234 (June 1977).

Brand, M. J. D., ScOTt, W. J., SP450, pp. $301-310$ (June 1977).

BRANDENBERGER, J. D., SP493, pp. 227-233 (Oct. 1977).

Brandt, M. A., Srivastava, S. K., Trajmar, S., Chutjian, A., Trumlar, D. G., 16740.

Branstad, D., GaIT, J., KatZKe, S., NBSIR 77-1291.

BRANSTAD, D. K., FIPS PUB 46.

BraNuM, A., SP487, pp. 82-90 (Aug. 1977).

BRAUER, G. M., 17120.

BraUer, G. M., 17201 .

Brauer, G. M., Termini, D. J., Dickson, G., 17202.

Braun, E., Peacock, R., Whlliams, N., Zawistowski, E. A., KRASMY, J. F., NBSIR 77-1236.

BraUn, W., LedFord, A. E., JR., 16895.

Braun, W., TSANG, W., 16783.

Breden, L., MEISTERS, M., NBSIR 76-1030.

BREDEN, L. H., EVANS, D. D., NBSIR 77-1302.

Breiter, D. N., Pella, P. A., Heinrich, K. F. J., SP464, pp. 527-529 (Nov. 1977).

Brennan, J. A., Arvidson, J. M., 17081.

Brennan, J. A., LaBrecque, J. F., KNeebone, C. H., 17162.

Brennan, J. A., MANN, D. B., SP484, pp. $881-893$ (Oct. 1977).

BRESSE, J. N., NBSIR 77-1295.

Bridges, J. M., OTt, W. R., 16778.

Bridges, J. M., OTt, W. R., Pitz, A., Einfeld, D., Stuck, D., 17198.

BRIGHT, D. S., 16704.

BRIGHT, R. G., 16737.

Bril, A., DE JAGER-VeEnIS, A. W., SP466, pp. 13-19 (May 1977).

Brinckman, F. E., Bellama, J. M., JeWETt, K. L., 17008. 
Brinckman, F. E., Blair, W. R., Jewett, K. L., Iverson, W. P., 17297.

Brinckman, F. E., Jewett, K. L., Doody, J. E., Durst, R. A., SP464, pp. 473-483 (Nov. 1977).

Brinckman, F. E., Parris, G. E., Blair, W. R., 16811 .

Brinckman, F. E., Parris, G. E., Blair, W. R., Jewett, K. L., Iverson, W. P., Bellama, J. M., 17155.

Brinckman, F. E., Shiloh, M., Gayer, B., 16757.

Broadhurst, M. G., Davis, G. T., NBSIR 76-1186.

Broerse, J. J., SP493, pp. 106-114 (Oct. 1977).

Broida, H. P., Cohen, P. I., Abramowitz, S., 17242.

Broida, H. P., Phelps, A. V., Lawton, S. A., Novick, S. E., 16765.

Brooks, J. S., Donnelly, R. J., JPCRD 6, No. 1, 51-104 (1977).

Broussalian, J., Siedle, A. R., Negas, T., 17137.

Brower, W. B., JR., Servoz, A., SP484, pp. $719-735$ (OCt. 1977).

Brower, W. S., Harding, C. A., Waring, J. L., Roth, R. S., J. Res. 82, No. 3, 167-172 (1977).

Brower, W. S., Minor, D. B., Roth, R. S., Parker, H. S., J. Res. 82, No. 3, $151-165$ (1977).

Brown, B. F., Monogr. 156.

Brown, B. F., Burnett, H. C., Chase, W. T., Goodway, M., Kruger, J., Pourbaix, M., SP479.

Brown, C. P., 17186.

Brown, P., Clifton, J. R., 17010.

Brown, P. W., Berger, R. L., Clifton, J. R., FrohnsdorfF, G., 16768.

Brown, P. W., Clifton, J. R., 16712

Brown, P. W., FrohnsdorfF, G., Clifton, J. R., NBSIR 77-1244.

BROWN, R. L., NBSIR 76-994.

Brown, T. H., KrTCHEN, W. J.JR., SP400-42, pp. 9-12 (Aug. 1977).

Brown, W. E., Gregory, T. M., Chow, L. C., 16739.

Brown, W. E., Jordan, T. H., Schroeder, L. W., Dickens, B., 16741

Brown, W. E., Mathew, M., Schroeder, L. W., Dickens, B., 17034.

Brown, W. E., McDowell, H., Gregory, T. M., J. Res. 81A Nos. 2 and 3, 273-281 (1977).

Brown, W. E., SCHroeder, L. W., Dickens, B., 17259.

BRUNER, R. F., SP484, pp. 277-291 (Oct. 1977).

BRUNGRABER, R. J., TN953.

BRUNGRABER, R. J., RAPER, T. J. R., NBSIR 76-1005.

BRYAN, J. L., NBS-GCR-77-94.

BRyant, D. A., Dains, R. B., SP473, pp. 349-368 (June 1977),

Buchbinder, B., Helzer, S. G., OfFEnSEND, F. L., NBSIR $77-1381$.

Buckies, R. G., HeitmanN, H., Laver, M. B., SP450, pp. 207. 225 (June 1977).

BUDDE, W., SP466, pp. 75-85 (May 1977).

BUEHLER, M. G., SP400-42, pp. 5-8 (Aug. 1977).

BUEHLER, M. G., 17342.

Buehler, M. G., DAVtd, J. M., 17165.

Buehler, M. G., David, J. M., Mattis, R. L., Phillips, W. E. THURBER, W. R., 16855.

Buehler, M. G., Mattis, R. L., 17328.

BuEhler, M. G., Thurber, W. R., 16942.

BUFFONE, G. J., SP466, pp. $95-98$ (May 1977).

BuHL, D., SNYder, L. E., Lovas, F. J., JOHNSON, D. R., 16664.

Búkowski, J. M., Robiins, C. R., Wiederhorn, S. M., Fuller, E. R., JR., 16993.

BukowskI, R. W., 16882.

Bullis, W. M., SP400-29.

Bullis, W. M., Galloway, K. F., 16894.

Bulus, W. M., VieWEG-Gưtberlet, F. G., 17140.

Bundy, D. H., PEACOCK, J. L., ECKert, J. A., SP464, pp. $295-$ 300 (Nov. 1977).
Bunten, E., Cunttz, R., Mumford, S., Klaus, P., SP480-2.

Bunten, E., Klaus, P., SP480-3.

Bunten, E., Klaus, P., Bergman, S., SP480-5.

Bunten, E., Klaus, P., Ku, R., SP480-1.

Bunten, E. D., Hare, G. B., Klaus, P. A., SP480-6.

Bunten, E. D., Klaus, P. A., SP480-7.

Bunten, E. D., Klaus, P. A., Eldreth, J. L., SP480-4.

BURCH, D., 17062.

BuRCH, D. M., HuNT, C. M., NBSIR 77-1274.

BURCH, D. M., KuSUdA, T., 17335.

BurCh, D. M., Kusuda, T., BluM, D. G., TN933.

Burch, D. M., Pierce, E. T., Rossiter, W. J., Jr., Mathey, R. G., $T N 946$.

Burch, D. M., Siu, C. I., Powell, F. J., 17284.

Burch, D. S., Phelps, A. V., Whealton, J. H., 16854.

Burdette, H. E., Farabaugh, E. N., Kuriyama, M. BOETTINGER, W. J., 16977.

Burdette, H. E., Kuriyama, M., Boettinger, W. J., 16974.

Burdette, H. E., Kuriyama, M., Boettinger, W. J., 16997.

Burdette, H. E., Kuriyama, M., Boettinger, W. J., 17277.

BURKE, R. W., DIAMONDSTONe, B. I., 17257.

BURKe, R. W., Diamondstone, B. I., SP492, pp. 73-84 (Nov. 1977).

Burke, R. W., Mavrodineanu, R., SP260-54.

BURKe, R. W., MaVrodineanu, R., SP466, pp. 121-126 (May 1977).

BURKE, R. W., Wicks, S. A., SP492, pp. $85-89$ (Nov. 1977).

BURKe, W. J., MORAN, R. P., SP473, pp. $377-382$ (June 1977).

BURNETT, E. D., 16847.

BuRNeTt, E. D., BASSIN, M. A., NBSIR 76-1179.

BurnetT, E. D., BASSIN, M. A., 16846.

BurNetT, E. D., KuHN, G. F., 17064.

Burnett, E. D., SChWEITZER, H. C., 17145.

Burnett, H. C., Chase, W. T., Goodway, M., Kruger, J., Pourbaix, M., Brown, B. F., SP479.

Burnett, H. C., Kruger, J., Pickelsimer, M. L., Ogburn, F., Passaglia, E., SP479, pp. 167-178 (July 1977).

BURNETT, R. W., SP450, pp. 163-165 (June 1977).

BURNS, G., RADACK, S., NBSIR 76-1113.

Burrell, D., LeE, M. L., SP464, pp. $461-465$ (Nov. 1977).

BURRIS, B. L., SP305. Supplement 8.

BuskiRK, E. R., LoOMIS, J. L., SP491, pp. 169-173 (Sept. 1977).

Butrymowicz, D. B., Manning, J. R., ReAd, M. E., JPCRD 6, No. 1, 1-50 (1977).

\section{C}

CadofF, B. C., SP464, pp. $541-543$ (Nov. 1977).

CAdoff, M. A., Blomquist, D. S., NBSIR 76-1169.

Cadoff, M. A., Flynn, D. R., Leasure, W. A., JR., Rubin, A. 1., $\mathrm{H} 122$

Cadoff, M. A., Pallett, D. S., NBSIR 75-938.

Cadoff, M. A., Pallett, D. S., 17190.

Callen, E., Alperin, H. A., Cullen, J. R., Clark, A. E., 16835.

Callis, J. B., SP466, pp. 25-31 (May 1977).

Calomeris, P. J., Warnar, R. B. J., SPS00-1.

Calvano, N. J., NBSIR 77-1251.

Calvano, N. J., WakamiYa, S. K., NBSIR 77-1217.

Cameron, J. M., NBSIR 77-1240.

Cameron, J. M., Croarkin, $\cdot$ M. C., Raybold, R. C., TN952.

Campagna, M., Pierce, D. T., Meier, F., Sattler, K., SiegMANN, H. C., 17022.

Campbell, P. G., Post, M. A., Godette, M., Roberts, W. E., NBSIR 77-1263.

Campbell, W. J., Marr, H. E. III., LAw, S. L., SP464, pp. 157. 161 (Nov. 1977).

Cantillo, A. Y., Segar, D. A., SP464, pp. $491-493$ (Nov. 1977).

Cantrell, C. D., Bennett, H. S., 16746. 
Cantrell, C. D., Bennett, H. S., 17312.

CAPPUCCI, J. J., SP480-24, pp. 59-61 (Nov. 1977).

Carlson, A. D., SP493, pp. 85-92 (Oct. 1977).

Carlson, A. D., Bowman, C. D., Lone, M. A., Stewart, L., NBSIR 77-1279.

Carlson, A. D., liskien, H. O., Stewart, L., Bowman, C. D., SP493.

Carlson, G., Ferreira, D., SP500-18, pp. $107-115$ (Sept. 1977).

Carlsten, J. L., Szöke, A., Raymer, M. G., 16857.

Carpenter, R. J., Koenig, A. L., MoOre, R. T., NBSIR 771262.

Carroll, W. L., Schaefgen, J. R., JR., NBSIR 77-1307.

Carter, G. C., Bennett, L. H., NBSIR 77-1239.

Carter, G. C., Bennett, L. H., Kahan, D. J., 17093.

Cases, J. C., Parker, V. B., Kilday, M. V., J. Res. 82, No. I, 19-28 (1977).

Castiaux, M. A., Chatteruee, J. M., Peeters, E., SP461, pp. 255-256 (Jan. 1977).

Caswell, R. S., SP493, pp. 121-127 (Oct. 1977).

Cateora, J. V., Davis, D. D., Hanson, D. W., U.S. Patent $4,014,166$

Catlin, J. B., SP494, pp. 133-137 (Sept. 1977).

Cattaneo, L. E., Crist, R. A., BSSI06.

Cattaneo, L. E., Fattal, S. G., BSS62.

Celotta, R. J., Mielczarek, S. R., Huebner, R. H., 17018.

Celotta, R. J., Mielczarek, S. R., Huebner, R. H., O'ConNOR, M. E., 17019.

Cezairlyyan, A., Ishihara, S., Douglas, T. B., Dttmars, D. A., SP260-55.

Cezairliyan, A., McClure, J. L., 16767.

Cezairliyan, A., McClure, J. L., Taylor, R., J. Res. 81 A Nos. 2 and 3, 251-256 (1977).

Cezairliyan, A., Muller, A. P., J. Res. 82, No. 2, 119-122 (1977).

ChaBAY, I., SP464, pp. 175-178 (Nov. 1977).

Chang, D. C., Bereuter, W. A., NBSIR 76-851.

Chang, F. K., Krinitzsky, E. L., SP477, pp. VI-179-VI-191 (May 1977).

Chang, L. C., Yang, K. T., NBS-GCR-77-84.

Chang, R. K., Kindlmann, P. J., Stafford, R. G., SP464, pp. 659-667 (Nov. 1977).

Chang, S. S., J. Res. 82, No. 1, 9-18 (1977).

Chang, S. S., 16769.

Chang, Y. A., Goldberg, D., Neumann, J. P., JPCRD 6, No. 3, 621-674 (1977).

Chapman, C., 17133.

Chappell, S. E., Humphreys, J. C., NBSIR 76-1135.

Chappell, S. E., Mclaughlin, W. L., Jarkett, R. D., HuMPhREYS, J. C., 16999.

Charlton, R. M., Howard, C. J., Evenson, K. M., Jennings, D. A., Petersen, F. R., Mucha, J. A., Jimenez, J. J., 17073.

Charriere, C. L., SP473, pp. 383-389 (June 1977).

Chase, W. T., Goodway, M., Kruger, J., Pourbaix, M., Brown, B. F., BURNETT, H. C., SP479.

Chatterjee, A., Ghose, A. M., Nath, S., SP461, pp. 64-66 (Jan. 1977).

Chatteruee, A., Ghose, A. M., Pal, B., SP461, pp. 44-46 (Jan. 1977).

Chatteruee, J. M., Peeters, E., Castiaux, M. A., SP461, pp. 255-256 (Jan. 1977).

Chattic, A. G., SP500-22.

Chau, Y. K., Wong, P. T. S., SP464, pp. $485-490$ (Nov. 1977).

Chaudhuri, N., SinHa, B., SP461, pp. 20-22 (Jan. 1977).

Chaudhuri, N., Sinha (Goswami), B., SP461, pp. 55-56 (Jan. 1977).

Chen, M. C., Willams, D., Ka washima, K., Penzien, J., GodDEN, W. G., SP477, pp. VI-1 - VI-9 (May 1977).

Chen, S. S., Wilhoit, R. C., Zwolinsk, B. J., JPCRD 6, No. $1,105-112$ (1977).
Chen, S. T., Gallagher, A., 17128.

Chen, S. W., Mayes, R. L., Clough, R. W., Omote, Y., BSS106, pp. 91-113 (Sept. 1977).

Cheron, B., Scheps, R., Gallagher, A., 16752.

Chesler, S., Wasik, S., 16673.

Chesler, S. N., Gump, B. H., Hertz, H. S., MaY, W. E., 16886.

Chesler, S. N., Gump, B. H., Hertz, H. S., May, W. E., Wise, S. A., 17273 .

Chesler, S. N., Gump, B. H., Hertz, H. S., May, W. E., Wise, S. A., SP464, pp. $81-85$ (Nov. 1977).

Chesler, S. N., Hertz, H. S., Hilpert, L. R., May, W. E., WISE, S. A., 17271.

Chesser, N. J., Prask, H. J., 17003.

CHI, J., 16922.

Childers, C. B., Dziuba, R. F., Lee, L. H., 16713.

Chiu, H. Y., Adams, P. J., Linsky, J. L., Basri, G. S., Maran, S. P., Hobrs, R. W., 16732.

Choi, C. S., Prask, H. J., Prince, E., 17348.

Chow, L. C., Brown, W. E., Gregory, T. M., 16739.

Chrien, R. E., Liou, H. I., Block, R. C., Singh, U. N., KOBAYASHI, K., SP493, pp. 255-260 (Oct. 1977).

Christensen, P., Wong, C. S., Cretney, W. J., Piuze, J., SP464, pp. 249-258 (Nov. 1977).

Christian, J. B., SP487, pp. 154-171 (Aug. 1977).

Christian, W. J., Harpe, S. W., Waterman, T. E., NBS-GCR77-82.

Chuan, R., Wallace, D., SP464, pp. 199-211 (Nov. 1977).

Chutuian, A., Truhlar, D. G., Brandt, M. A., Srivastava, S. K., Trajmar, S., 16740.

Cieruacks, S., SP493, pp. 278-289 (Oct. 1977).

Clark, A. E., Callen, E., Alperin, H. A., Cullén, J. R., 16835.

Clark, A. F., EkIN, J., 17074.

Clark, A. F., Ekin, J. W., 16816.

Clark, A. F., Ekin, J. W., Fickett, F. R., 16868.

Clark, A. F., Moulder, J. C., 16796.

Clark, A. F., Moulder, J. C., 17163.

Clark, A. F., Reed, R. P., Mikesell, R. P., 16862.

Clark, A. F., van Reuth, E. C., Reed, R. P., 16863.

Clark, E. J., Embree, E. J., Masters, L. W., NBSIR 76-1184.

Clark, F. O., 16675.

Clark, F. O., Lovas, F. J., 17189.

Clark, G., FIPS PUB 16-1.

Clark, G., FIPS PUB 17-1.

Clark, G., FIPS PUB 18-1.

ClaRK, G., FIPS PUB $22-1$.

Clark, M. E., Robertson, J. M., SP484, pp. $479-489$ (Oct. 1977).

Clark, R. E., RoAt, C. L., SP458.

Clark, R. L., Ruud, C. O., Russell, P. A., Barrett, C. S., SP464, pp. 635-636 (Nov. 1977).

Clark, R. N., Mathieson, T. A., SP494, pp. 152-166 (Sept. 1977).

Clarke, F. B. III, Ottoson, J., 16960.

Cleek, G. W., Wachtman, J. B., JR., Roth, R. S., Cook, L. P., Negas, T., SP486.

Cleland, J. W., Connolly, T. F., SP463, pp. III.3.1-III.3.8 (Jan. 1977).

Clements, J. B., SP464, pp. 555-564 (Nov. 1977).

Clifton, J. R., TN934.

Clifton, J. R., 17104.

Clifton, J. R., Brown, P., 17010.

Clifton, J. R., Brown, P. W., 16712.

Clifton, J. R., Brown, P. W., FrohnsdorfF, G., NBSIR $77-1244$.

Clifton, J. R., Frohnsdorf, G., Brown, P. W., Berger, R. L., 16768.

Clough, R. W., Omote, Y.; Chen, S. W., Mayes, R. L., BSS106, pp. 91-113 (Sept. 1977). 
Clough, R. W., OMote, Y., Mayes, R. L., BSS106, pp. 60-90 (Sept. 1977).

Coachman, J. S., Navalkar, M. P., Joneja, O. P., SrikanTAIAH, R. V., PHISKE, M. R., SP493, pp. 61-66 (Oct. 1977).

Coble, J. B., KuKleWicz, M. E., Hebrank, J. H., NBSIR $77-$ 1207.

COHEN, J. J., SP450, pp. 127-129 (June 1977).

COHEN, J. J., SP450, pp. 131-132 (June 1977).

Cohen, M. I., Dragoo, A. L., Franklin, A. D., McAlister, A. J., YOUNG, K. F., BenNeTt, L. H., NBSIR 77-1270.

Cohen, P. I., Abramowitz, S., Broida, H. P., 17242.

COHN, S., SP473, pp. 137-187 (June 1977).

Colbert, J. C., Prosen, E. J., NBSIR 77-1310.

Colbert, J. C., Prosen, E. J., SP400-42, pp. 16-18 (Aug. 1977).

Colburn, D. S., Wright, M. L., Pollack, J. B., SP464, pp. 301-303 (Nov. 1977).

COLEY, F. H., SP463, pp. V.2.1 -V.2.6 (Jan. 1977).

Collard, J. J., SP480-18.

Collier, R. S., Glarratano, P. J., 17071.

Collins, G. J., DEHoOG, F. J., MCNeIL, J. R., 17170.

Collins, L. A., LANE, N. F., 16674.

Collins, L. A., Lane, N. F., Morrison, 'M. A., 16682.

Collins, L. A., Morrison, M. A., LANE, N. F., 17026.

COLlins, L. A., NorCross, D. W., 17027.

COLlins, L. A., NorCross, D. W., 17344.

Colson, J. P., Bolz, L. H., Anderson, W. E., Davis, R. S., MOPSIK, F. I., KRYDER, S. J., KHOURY, F., 17014.

COMIZZOLI, R. B., KeRN, W., SP400-31.

Connolly, T. F., Cleland, J. W., SP463, pp. III.3.1-III.3.8 (Jan. 1977).

Constant, P. C., JR., Sharp, M. C., Scheil, G. W., Margeson, J. H., SP464, pp. 573-574 (Nov. 1977).

CONTT, D. M., FIPS PUB 49.

CONT, D. M., Walkowicz, J. L., SP500-18.

CoOk, L. P., Negas, T., Cleek, G. W., WaChtman, J. B., JR., ROTH, R. S., SP486.

COOKE, P. W., SP473.

COOKE, P. W., EISENHARD, R. M., NBSIR 77-1259.

COOKE, P. W., EISENHARD, R. M., NBSIR 77-1390.

COOPER, J., SMITH, E. W., BARNARD, A. J., 17167.

CoOper, J., Smith, E. W., Drullinger, R. E., Hessel, M. M., 17084.

COOPER, J., SMITH, E. W., GReENE, R. L., 17249.

CoOper, J., Smith, E. W., Mihalas, D., Barnard, A. J., 17171.

Cooper, J., Smith, E. W., Mihalas, D., Barnard, A. J., 17172.

COOPER, J., SMITH, E. W., VidAl, C. R., 17232.

COOPER, J., SMITH, E. W., WARD, J., 17161.

COOPER, J. D., SP477, pp. VIII-1 -VIII-27 (May 1977).

COOPER, J. S., SP488, pp. 103-104 (Aug. 1977).

CoOper, S. S., Bieganousky, M. A., Marcuson, M. F., SP477, pp. VI-141-VI-157 (May 1977).

Copenhaver, E. D., Ulrikson, G. U., SP463, pp. III.4.1 III.4.15 (Jan. 1977).

Corcoran, C. T., LANGHOFF, P. W., 16849.

Corcoran, C. T., Sims, J. S., LanghofF, P. W., 17319.

Cordes, M. R., Coriell, S. R., Hardy, S. C., 17009.

Coriell, S. R., Hardy, S. C., CoRdes, M. R., 17009.

CORIELl, S. R., SUREK, T., 16931.

CORliss, C., SUGAR, J., JPCRD 6, No. 2, $317-384$ (1977).

CORliss, C., SUGAR, J., JPCRD 6, No. 4, 1253-1330 (1977).

Cornish, J., Raley, C. C., Peiser, H. S., NBSIR 76-1152.

COSTEllo, J. F., SP477, pp. VII-36-VII-41 (May 1977).

COSTRELL, L., 16677.

COSTRELL, L., 16678.

COSTRELL, L., 16679.

COSTREll, L., 17270.

CotTon, I. W., SP500-6.
CotTon, I. W., 16934.

Cotton, I. W., Folts, H. C., 16936.

Cotton, I. W., Watkins, S. W., Rosenthal, R., Rippy, D. E., ABRAMS, M. D., 17252 .

Coursey, B. M., Hutchinson, J. M. R., Unterweger, M. P., 16975.

COURTENS, E., SzöKe, A., 16848.

Cox, C. R., Kubiczek, E. B., Robinson, J. E., Harrison, G. H., NBSIR 77-1279, pp. 19-23 (July 1977).

Coxon, B., Siedle, A. R., Hertz, H. S., 17045.

Crabbe, R. S., SP464, pp. 419-433 (Nov. 1977).

Cram, S. P., Bowen, B. E., 16980.

Crannell, H., Hallowell, P. L., O'Brien, J. T., Penner, S., FInN, J. M., 16845.

Cranston, W. B., BSS106, pp. 166-176 (Sept. 1977).

CRAWFORd, M. L., 16668.

CraWford, M. L., 17220.

Crawford, M. L., Shafer, J. F., Adams, J. W., 17251.

Crecelius, E. A., SP464, pp. 495-496 (Nov. 1977).

Crensha w, R. W., Hastings, S. R., BSSI04.

Cretney, W. J., Piuze, J., Christensen, P., Wong, C. S., SP464, pp. 249-258 (Nov. 1977).

Crissman, J. M., Guttman, C. M., ZaPas, L. J., 17256.

CRIST, R. A., BSSI06, pp. 40-59 (Sept. 1977).

Crist, R. A., Cattaneo, L. E., BSS 106.

Crist, R. A., Marshall, R. D., SP477, pp. I-21-I-33 (May 1977).

Croarkin, M. C., Raybold, R. C., Cameron, J. M., TN952.

Cronrath, D., LiU, J. K. C., Lerup, L., NBS-GCR-77-93.

Crouse, W. W., JR., SP488, p. 63 (Aug. 1977).

Crowson, R. D., Balsara, J. P., Norman, C. D., SP477, pp. V1-85-VI-117 (May 1977).

Cukor, P. M., SP488, pp. 115-121 (Aug. 1977).

Cullen, J. R., Clark, A. E., Callen, E., Alperin, H. A., 16835.

Cullen, J. R., Haus, J. W., 17122.

Cullen, J. T., Miller, R. W., DeCarlo, J. P., SP484, pp. 549 570 (Oct. 1977).

Culver, C., Ellingwood, B., 17305.

Culver, C., Fattal, G., Simiu, E., SP490.

Culver, C. G., NBSIR 76-1193.

Culver, C. G., SP477, pp. V1-61-V1-68 (May 1977).

Culver, C. G., 16708.

Cunitz, R., Mumford, S., Klaus, P., Bunten, E., SP480-2.

Currie, L. A., MURPhy, R. B., SP464, pp. $439-447$ (Nov. 1977).

CURTIS, W. R., SP464, pp. 237-244 (Nov. 1977).

Custer, R. L. P., HAYES, W. D., JR., NBSIR 77-1282.

Cuthill, J. R., Erickson, N. E., Watson, R. E., Bennett, L.

H., MCAlister, A. J., 16932.

Czernichowski, A., Holys', A., Roberts, J. R., 17276.

Czirr, J. B., SP493, pp. 54-60 (Oct. 1977).

\section{D}

D'Agostino, A., Finney, C., SP464, pp. 627-631 (Nov. 1977).

Dains, R. B., Bryant, D. A., SP473, pp. 349-368 (June 1977).

DANA, M., SP471, pp. 103-109 (June 1977).

DANEY, D. E., NBSIR 76-850.

DANeY, D. E., LudTKE, P. R., Frederick, N. V., Hands, B. A., Jones, M. C., ARP, V. D., PARrish, W. R., NBSIR 77-853.

DANEY, D. E., LudTKE, P. R., Jones, M. C., 17078.

Dang, C., RufF, J. F., SAXTON, K., SP484, pp. $187-200$ (Oct. 1977).

Daniels, A. U., Dunn, H. K., SP472, pp. $61-70$ (Apr. 1977).

DANIELSON, B. L., NBSIR 77-856.

DANIELSON, B. L., NBSIR 77-858.

Danos, M., Gillet, V., Monogr. 147, Suppl. 1 .

Danos, M., Halbert, E. C., SMith, R. K., JR., AMSDEN, A. A., Ginocchio, J. N., HaRlow, F. H., Nix, J. R., 17109. 
Danos, M., Motz, J. W., 16666.

DANOS, M., RAFELSKI, J., 17103.

Danos, M., Williams, H. T., 17210.

DARCY, G., SP463, pp. IV.6.1-IV.6.2 (Jan. 1977).

DASLER, A. R., SP491, pp. 65-92 (Sept. 1977).

Datta, S., Sharma, R. C., Somasundaram, S., UnNikrishnan, K., SP461, pp. 188-192 (Jan. 1977).

DatTa, S., SuPE, S. J., SP461, pp. 193-196 (Jan. 1977).

DAVID, J. M., Buehler, M. G., 17165.

David, J. M., Mattis, R. L., Phillips, W. E., Thurber, W. R., BUEHLER,M. G., 16855 .

David, M., Ganguly, A. K., SP461, pp. $231-233$ (Jan. 1977).

Davis, D. D., Beehler, R. E., Hanson, D. W., 17080.

Davis, D. D., Hanson, D. W., Cateora, J. V., U.S. Patent $4,014,166$.

Davis, G. T., Broadhurst, M. G., NBSIR 76-1 186.

Davis, G. T., Laurizen, J. I., JR., Hoffman, J. D., 16887.

Davis, H., 17127.

Davis, H. T., Anavekar, S. N., Wardell, W. M., Tsianco, M. C., NBS-GCR-ETIP 76-35.

Davis, L. M., SP484, pp. 55-60 (Oct. 1977).

Davis, R. M., SP500-8, pp. 1-4 (May 1977).

Davis, R. M., 16903.

DAvis, R. M., 16904.

Davis, R. M., 16905.

Davis, R. M., 16906.

Davis, R. M., 17114 .

DAVIS, R. S., ANDERSON, W. E., 16782.

Davis, R. S., MOPSIK, F. I., KRYDER, S. J., KhOURY, F., COLSON, J. P., BOlz, L. H., ANDerson, W. E., 17014.

DAVIS, R. W., SP484, pp. $219-242$ (Oct. 1977).

Davis, R. W., Mattingly, G. E., SP484, pp. $491-522$ (Oct. 1977).

DAVIS, R. W., MOORE, E. F., NBSIR 77-1394.

de Jager-Veenis, A. W., Bril, A., SP466, pp. 13-19 (May 1977).

de Pena, R. G., Mamane, Y., SP464, pp. $327-334$ (Nov. 1977).

de Saussure, G., Peelle, R. W., SP493, pp. 174-181 (Oct. 1977).

Deardorf, E. R., Margeson, J. H., Fuerst, R. G., Hughes, E. E., ROOK, H. L., 17230.

DEARDORF, E. R., RAINS, T. C., TAYLOR, J. K., NBSIR 77 1315.

Dearing, P. M., J. Res. 82, No. 1, 65-72 (1977).

Debelius, J. R., SP457-I.

deCarlo, J. P., Cullen, J. T., Miller, R. W., SP484, pp. 549 570 (Oct. 1977).

deGroot, J. H., Newberry, R., Morris, M. C., McMurdie, H. F., Evans, E. H., Paretzkin, B., Monogr. 25, Section 14.

Dehl, R. E., Grant, W. H., Stromberg, R. R., Morrissey, B. W., SMITH, L. E., NBSIR 76-1128.

DEHNE, J. S., SP500-8, pp. 11-25 (May 1977).

DEHoOg, F. J., MCNeII, J. R., Collins, G. J., 17170.

Delespaul, I., Peperstrate, H., RYMen, T., SP464, pp. 617. 623 (Nov. 1977).

Delichatsios, M. A., Heskestad, G., NBS-GCR-77-86.

Delichatsios, M. A., Heskestad, G., NBS-GCR-77-95.

Delisi, D. P., KiRChHOFF, R. H., SP484, pp. 783-802 (Oct. 1977).

Delisi; D. P., Robien, F. A., LiU, H., Lin, J., SP484, pp. 423447 (Oct. 1977).

Demas, J. N., Blumenthal, B. H., SP466, pp. $21-24$ (May 1977).

Den Braven, K., Harkleroad, M., Raines, J., Rinkinen, W., Quinttere, J., MCCaffrey, B., KashiwaGi, T., NBSIR 77. 1318.

DeReggi, A. S., Edelman, S., 16952.

DeReggi, A. S., Edelman, S., Roth, S. C., NBSIR 76-1078.

Derrien, H., Edvardson, L., SP493, pp. 14-29 (Oct. 1977).
Desai, P. D., Wu, K. Y., Havill, T. N., LeE, T. Y., Ho, C. Y., NBS-GCR-77-83.

DeslatTES, R. D., 17246.

Desormeaux, S. G., Bartel, D. L., SP472, pp. $51-59$ (Apr. 1977).

Devaney, J. R., Leedy, K. O., Keery, W. J., SP400-35.

DeVereuX, C. W., PS67-76.

DevereuX, C. W., PS68-76.

DevereuX, C. W., PS69-76.

Devereux, C. W., PS70-76.

Devereux, C. W., PS7I-76.

DeVereuX, C. W., PS73-77.

DEVOE, J. R., 16961 .

Dewey, H. J., Keller, R. A., Rrtter, J. J., Lamotte, M., U.S. Patent 4,025,406.

Diamondstone, B. I., BURKE, R. W., 17257.

Diamondstone, B. I., BuRKe, R. W., SP492, pp. $73-84$ (Nov. 1977).

Dick, C. E., Sparrow, J. H., 16814.

Dickens, B., Brown, W. E., JoRdan, T. H., Schroeder, L. W., 16741.

Dickens, B., Brown, W. E., Mathew, M., Schroeder, L. W., 17034.

Dickens, B., Brown, W. E., Schroeder, L. W., 17259.

Dickens, B., Pummer, W. J., Flynn, J. H., 16842.

Dickson, G., 17126.

Dickson, G., Brauer, G. M., Termini, D. J., 17202.

Dustelbergen, H. H., Gasunie, N. V. N., SP484, pp. 935-944 (Oct. 1977).

DikKERS, R. D., SP473, pp. 103-1 12 (June 1977).

DikKers, R. D., 16686.

Dimarzio, E. A., Gibbs, J. H., Fleming, P. D. III, Sanchez, I. C., 16962.

Diosady, P. L., Moselhy, M. M., BOOMer, D. W., Bishop, J. N., SP464, pp. 137-150 (Nov. 1977).

Dtmars, D. A., Cezairliyan, A., Ishmhara, S., Douglas, T. B., SP260-55.

Dodge, M. J., Gladden, W. K., Feldman, A., Horowitz, D., WAXIER, R. M., NBSIR 77-I304 (ARPA).

Dodge, M. J., Gladden, W. K., Feldman, A., Waxler, R. M., HOROWITZ, D., 16730.

DODGE, M. J., Malitson, I. H., 16662.

DOKTYA, Y., FUWA, K., YAMAZAKI, S., SP464, pp. 233-235 (Nov. 1977).

DOMALSKI, E. S., NBSIR .76-1149.

Donaldson, W. T., SP464, pp. 69-72 (Nov. 1977).

DONNElly, R. J., BROOKS, J. S., JPCRD 6, No. 1, 51-104 (1977).

Doody, J. E., Durst, R. A., Brinckman, F. E., Jewett, K. L., SP464, pp. 473-483 (Nov. 1977).

DOPKOWSKI, P. L., SP463, pp. II.2.1-II.2.10 (Jan. 1977).

Dorko, W. D., Hughes, E. E., SP464, pp. $535-539$ (Nov. 1977).

DOUglas, C. A., Booker, R. L., Monogr. 159.

Douglas, T. B., Dimmars, D. A., Cezairliyan, A., Ishimara, S., SP260-55.

Douglas, T. B., Krause, R. F., JR., 17075.

Downey, J. R., JR., Singer, S. K., Janz, G. J., Tomkins, R. P. T., Allen, C. B., JPCRD 6, No. 2, $409-596$ (1977).

DOYLe, W. M., MCINTOSh, B. C., Geist, J., 16852.

Dragoo, A. L., Franklin, A. D., Mcalister, A. J., Young, K. F., BenNetT, L. H., COHEN, M. I., NBSIR 77-1270.

Drapchinsky, L. V., Kovalenko, S. S., Kostochkin, O. I., Kudriavzev, G. Y., Malkin, L. Z., Petrzihak, K. A., Pleskachevsky, L. A., Fomichev, A. V., Shapakov, V. I., Adamov, V. M., Alexandrov, B. M., Alkhazov, 1. D., SP493, pp. 313-318 (Oct. 1977).

DRESSLER, E. T., TN957.

Dressler, W. E., PeAvy, B. A., NBSIR 77-1237.

Drews, U. W., MaVrodineanu, R., 16981 . 
Drexhage, K. H., SP466, pp. 33-40 (May 1977).

Drexler, G., Regulla, D. F., SP461, pp. 197-208 (Jan. 1977).

Driscoll, J. N., SP464, pp. $415-417$ (Nov. 1977).

Driscoll, T. J., Powell, C. J., Stein, R. J., Needham, P. B., JR., 16824.

Driscoll, T. J., Powell, C. J., Stein, R. J., Needham, P. B., JR., 17248.

DrobKa, F. G., SP463, pp. VI.1.1-VI.1.7 (Jan. 1977).

Drullinger, R. E., Hessel, M. M., StOCK, M., 16800.

Drullinger, R. E., Hessel, M. M., SMITH, E. Q., 17076.

Drullinger, R. E., Hessel, M. M., CoOper, J., Smith, E. W., 17084.

Drullinger, R. E., Hessel, M. M., Stock, M., Smith, E. W., 17194.

Dryer, F. L., Glassman, I., Sirignano, W. A., NBS-GCR-7679.

DukE, C. B., SP475, pp. 127-130 (Apr. 1977).

DUKES-Dobos, F. N., SP491, pp. 41-51 (Sept. 1977).

DuNN, H. K., DANIELS, A. U., SP472, pp. $61-70$ (Apr. 1977).

Dupont, E. I., PIerce, F. J., Gold, D. S., SP484, pp. 621-648 (Oct. 1977).

Durbetak, P., Tincher, W. C., Lloyd, L. R., LoWery, R. P., Tingle, W. J., WOLFE, V. L., JR., NBS-GCR-77-99.

Durgin, W. W., Neale, L. C., SP484, $471-477$ (OCt. 1977).

DURST, R. A., SP450.

DURST, R. A., SP464, pp. 229-232 (Nov. 1977).

DURST, R. A., 16772.

Durst, R. A., BATES, R. G., SP450, pp. 247-255 (June 1977).

DuRst, R. A., Brinckman, F. E., JeWETt, K. L., DOODY, J. E., SP464, pp. 473-483 (Nov. 1977).

Durst, R. A., Robinson, R. A., Bates, R. G., Hetzer, H. B., J. Res. 81A No. 1, 21-24 (1977).

DURST, R. A., SCheide, E. P., 16771.

Dussauge, J. P., Gaviglio, J., SP484, pp. 649-658 (Oct. 1977).

DWyer, J., Truhlar, D. G., KuppermanN, A., 16914.

Dyer, C. S., Evans, L. G., Bielefeld, M. J., Seltzer, S. M., Metzger, A. E., TrombKa, J. I., 16938.

Dziuba, R. F., Lee, L. H., Childers, C. B., 16713.

\section{E}

EARLY, J. G., 16718 .

EARLY, J. G., 17235.

EARLy, J. G., Hicho, G. E., INTERRANTE, C. G., 16715

EARLY, J. G., INTERRANTE, C. G., 16717.

Easton, R. L., Fisher, L. C., Hanson, D. W., Hellwig, H. W., RUEGER, L. J., 17179.

Eatough, D. J., Hansen, L. D., IzatT, R. M., Mangelson, N. F., SP464, pp. 643-649 (Nov. 1977).

Eatough, D. J., Mangelson, N. F., Izatt, R. M., Hansen, L. D., SP464, pp. 637-642 (Nov. 1977).

EBERLY, J. H., WODKIEWICZ, K., 17169.

Eckerle, K. L., Venable, W. H., JR., 17260.

ECkert, A. C., JR., Mongan, D. M., SP464, pp. 545-551 (Nov. 1977).

Eckert, J. A., Bundy, D. H., Peacock, J. L., SP464, pp. $295-$ 300 (Nov. 1977).

EcKMAN, T. G., SP464, pp. 531-534 (Nov. 1977).

Edelman, S., SP487, pp. 189-196 (Aug. 1977).

Edelman, S., DeReggi, A. S., 16952.

Edelman, S., Roth, S. C., DeReggi, A. S., NBSIR 76-1078.

EDERER, D. L., 16670.

EDGERLY, D. E., SP484, pp. $921-927$ (Oct. 1977).

EDrich, J., Sullivan, D. B., McDonald, D. G., 17077.

Edvardson, L., Derrien, H., SP493, pp. 14-29 (Oct. 1977).

Ehrenrich, H., Gelatt, G. D., Weiss, J. A., SP475, pp. 83 86 (Apr. 1977).

EHrLICH, M., SOARES, C. G., NBSIR 76-1117.

EHRSTEIN, J. R., 17139.
Einfeld, D., Stuck, D., Bridges, J. M., Orr, W. R., PITz, A., 17198.

EISENHARD, R. M., NBSIR 77-1297.

EISENHARD, R. M., COOKE, P. W., NBSIR 77-1259.

EISENHARD, R. M., COOKE, P. W., NBSIR 77-1390.

EISENHART, C., 17266.

EISENHART, C., 17314.

Eisenhauer, C., Grundl, J., SP493, pp. 156-164 (Oct. 1977).

Eisenhauer, C., Grundl, J., 17058.

Eisenhauer, C. M., Grundl, J. A., Fabry, A., SP493, pp. 329. 334 (Oct. 1977).

Eisenhauer, C. M., Heation, H. T. II, Gillam, D. M., Bigelow, J., Grundl, J. A., Spiegel, V., 16790.

Eisenhauer, C. M., Stewart, L., SP493, pp. 198-205 (Oct. 1977).

EISENHOWER, E. H., H123.

EISENHOWER, E. H., 17017.

Eisentraut, K. J., Scheller, K., SP494, pp. 3-23 (Sept. 1977).

EkIn, J., Clark, A. F., 17074.

EKIN, J. W., 16873.

EkIn, J. W., Clark, A. F., 16816.

EkIN, J. W., FicketT, F. R., ClARK, A. F., 16868.

ELDER, J., NBSIR 76-I103.

Eldreth, J. L., Bunten, E. D., Klaus, P. A., SP480-4.

Elias, L., SP464, pp. $435-438$ (Nov. 1977).

Ellinger, M., Starke, K., Janghorbani, M., SP464, pp. 151156 (Nov. 1977).

Ellingson, W. A., Stanton, G. C., Lapinski, N. P., SP468, pp. 172-181 (Apr. 1977).

Ellingwood, B., 17304.

Ellingwood, B., Culver, C., 17305.

Ellingwood, B., Harris, J. R., 17306.

Ellingwood, B., Shaver, J., 17303.

Ellingwood, B., Simiu, E., 16856.

EllingwOOD, B. R., LeYeNDECKER, E. V., BSS98.

Ellis, W., Kusuda, T., 17340.

Ellison, G. B., Futrell, J. H., Leone, S. R., Bierbaum, V. M., 17209.

Ely, J. F., Hanley, H. J. M., Holland, P. M., J. Res. 82, No. 2, 123-127 (1977).

Embree, E. J., Masters, L. W., Clark, E. J., NBSIR 76-1184.

Engel, K., Kildeberg, P., SP450, pp. 133-141 (June 1977).

ENGEN, G. F., 16663.

ENGEN, G. F., 16726.

ENGEN, G. F., 17237.

ENGEN, G. F., 17240.

Engen, G. F., Hoer, C. A., U.S. Patent 4,001,681.

Epstein, M. S., MoOdy, J. R., ROOK, H. L., Paulsen, P. J., Rains, T. C., Barnes, I. L., SP464, pp. $515-518$ (Nov. 1977).

Epstein, M. S., Rains, T. C., O'Haver, T. C., SP464, pp. 4751 (Nov. 1977).

Erasmus, C. S., Sargeant, J., Sellschop, J. P. F., Watterson, J. I. W., SP464, pp. 129-136 (Nov. 1977).

ERICKSON, G. W., JPCRD 6, No. 3, 831-870 (1977).

Erickson, N. E., Watson, R. E., Bennett, L. H., Mcalister, A. J., Cutrill, J. R., 16932.

ERTL, G., SP475, pp. 94-118 (Apr. 1977).

Escalante, E., Iverson, W. P., Gerhold, W. F., Sanderson, B. T., Alumbaugh, R. L., Monogr. 158.

Escalante, E., Mullen, J. L., Kruger, J., Bertocci, U., NBSIR 77-1232.

Esteva, J. M., Mehlman, G., Weiss, A. W., 16659.

EstiN, A. J., 16727.

ETZ, E. S., Rosasco, G. J., SP464, pp. 343-346 (Nov. 1977).

Etz, E. S., Rosasco, G. J., 17013.

Evans, A. G., Linzer, M., 17213.

Evans, A. G., Wiederhorn, S. M., Tighe, N. J., 17046.

Evans, B. L., Gschneidner, K. A., JR., SP463, pp. III.2.1III.2.9 (Jan. 1977).

Evans, D. D., BredEN, L. H., NBSIR 77-1302. 
Evans, A. G., Wiederhorn, S. M., Tighe, N. J., 16753.

Evans, E. H., Paretzkin, B., deGroot, J. H., Newberry, R., Morris, M. C., McMurdie, H. F., Monogr. 25, Section 14.

Evans, J. M., JR., KIRSCh, R., NAGEL, R. N., SP500-8.

Evans, J. M., JR., O'Neill, J. T., LitTle, J. L., Albus, J. S., Barbera, A. J., Fife, D. W., Fong, E. N., Gilsinn, D. E., holberton, F. E., lucas, B. G., Lyon, G. E., Marron, B. A. S., NeumanN, A. J., Vickers, M. V., Walker, J. C., NBSIR 76-1094.

Evans, L. G., Bielefeld, M. J., Seltzer, S. M., Metzger, A. E., TrombKa, J. I., DYer, C. S., 16938

Evans, W. H., MaYo, S., 16939.

Evenson, K. M., Howard, C. J., 17272.

Evenson, K. M., Jennings, D. A., Petersen, F. R., Mucha, J. A., Jimenez, J. J., Charlton, R. M., Howard, C. J., 17073.

Evenson, K. M., Jennings, D. A., Petersen, F. R., Wells, J. S., 17336.

Eyring, H., Birkhoff, G., Perlis, A., Seamans, R. C., JR., Ramo, S., Thomson, R. M., Teller, E., Ramsey, N., Baker, W. O., SP465.

\section{F}

FABRIS, G., SP484, pp. $659-685$ (Oct. 1977).

FABRY, A., SP493, pp. $290-298$ (Oct. 1977).

Fabry, A., Eisenhauer, C. M., Grundl, J. A., SP493, pp. 329 334 (Oct. 1977).

FagG, L. W., Maruyama, X. K., Lightbody, J. W., JR., FivozinsKy, S. P., Lindgren, R. A., Bendel, W. L., Jones, E. C., JR., 16687.

Fairchild, C. E., Stone, E. J., Lawrence, G. M., 16812.

FaISON, T. K., NBSIR 77-1316.

Fallan, K. D., Malenfant, A. L., SP450, pp. 279-283 (June 1977).

Faller, J. E., Ghigo, F. D., Shelus, P. J., Silverberg, E. C., 16680.

FAller, J. E., LeVine, J., 16896.

Fanger, P. O., SP491, pp. 3-17 (Sept. 1977).

Farabaugh, E. N., Kuryama, M., Boettinger, W. J., BurDETTE, H. E., 16977.

Farhataziz, RosS, A. B., NSRDS-NBS59.

FARINELli, U., SP493, pp. 31 0-312 (Oct. 1977).

FarR, M. K., Trevino, S. F., 17001 .

FATEMi, M., Johinson, E., Birks, L., Gilfrich, J., Whitlock, R., SP464, pp. $189-190$ (Nov. 1977).

Fattal, G., Simiu, E., Culver, C., SP490.

FATTAL, S. G., BSS106, pp. 177-197 (Sept. 1977).

Fattal, S. G., Cattaneo, L. E., BSS62.

FATTAL, S. G., LEYENDECKER, E. V., BSS94.

Fattal, S. G., Sherwood, G. E., Wilkinson, T. L., BSS1003.

FAULKNER, D. J., 16807.

FAULKNER, D. J., 17118

FAULKNER, D. J., 17315.

Fechter, J. V., VAN COTt, H. P., 17035.

Feldman, A., Horowitz, D., WaxLeR, R. M., NBSIR 77-1219.

Feldman, A., Horowttz, D., Waxler, R. M., DOdge, M. J., GladdeN, W. K., NBSIR 77-1304 (ARPA).

Feldman, A., KahN, A. H., SPA L, R., 17261.

Feldman, A., Waxler, R. M., Horowitz, D., DoDge, M. J., GLADDEN, W. K., 16730 .

Fenves, S. J., Wright, R. N., TN940.

Fenves, S. J., WRIGHT, R. N., 16705.

Ferguson, R. S., Gordon, C. C., SP473, pp. 259-278 (June 1977).

Ferreira, D., Carlson, G., SP500-18, pp. $107-115$ (Sept. 1977).

Fetters, L. J., MORTON, M., 16736.

FICKETT, F. R., 17072.

FICKETT, F. R., 17134 .

FICKETT, F. R., 17135 .
Fickett, F. R., Clark, A. F., EkIN, J. W., 16868.

Fidan, S., Pejtersen, K., Pedersen, W. B., Mclaughlin, W. L., Miller, A., 16949.

FIEGL, E., SCHNeIDEWIND, N., SP500-18, pp. 235-248 (Sept. 1977).

Field, B. F., Hesterman, V. W., 16698.

Field, R. W., GuYer, D. R., LeONe, S. R., Koffend, J. B., 17318.

FIFE, D. W., SP500-11.

Fife, D. W., Fong, E. N., GilsinN, D. E., Holberton, F. E., lucas, B. G., Lyon, G. E., Marron, B. A. S., Neumann, A. J., Vickers, M. V., Walker, J. C., EvanS, J. M., JR., O'Neill, J. T., LitTle, J. L., Albus, J. S., Barbera, A. J., NBSIR 76-1094.

Fife, D. W., HARdy, I. T., LeONG-Hong, B., SP500-14.

FINE, A., SP480-24, pp. 27-34 (Nov. 1977).

FINKEL, M., SP477, pp. VI-199-VI-219 (May 1977).

Finn, J. M., Crannell, H., Hallowell, P. L., O'Brien, J. T., PenNer, S., 16845.

Finn, J. M., Flanz, J., Kline, F. J., Peterson, G. A., Lighibody, J. W., JR., Maruyama, X. K., Penner, S., Szalata, Z. M., 16850.

Finnegan, T. F., Moldeman, L. B., Wahlsten, S., 16788.

FinNegan, T. F., Holdeman, L. B., 17121 .

FinNegan, T. F., Wilson, J., TOOTS, J., 16946.

FinNey, C., D'Agostino, A., SP464, pp. 627-631 (Nov. 1977).

FINTEL, M., SP470, pp. VI-33-VI-46 (Apr. 1977).

FinTel, M., SchultZ, D. M., SP477, pp. VI-220-VI-25 1 (May 1977).

FIorl, C. E., YaKowrtz, H., NewbURY, D. E., 16988.

Fischler, M. A., SP500-8, pp. 41-42 (May 1977).

Fisher, G. L., Silberman, D., Prentice, B. A., Ondov, J. M., Ragaini, R. C., Heft, R. E., SP464, pp. $565-572$ (Nov. 1977).

Fisher, L. C., hanson, D. W., Hellwig, H. W., Rueger, L. J., EASTON, R. L., 17179.

Fite, R. A., KILPATRick, S., SP480-24, pp. 75-106 (Nov. 1977). Fitzgibions, W. O., SP464, pp. 3-8 (Nov. 1977).

Fitz-Randolph, J., Jespersen, J., Monogr. 155.

Frvozinsky, S. P., LIDE, D. R., JR., 17258.

Fivozinsky, S. P., Lindgren, R. A., Bendel, W. L., Jones, E. C., JR., FAGG, L. W., MARUYAMA, X. K., Lightbody, J. W., JR., 16687

Frvozinsky, S. P., Penner, S., Neuhausen, R., Lightbody, J. W., JR., 16982.

Flach, D. R., Hermach, F. L., 16693.

Flake, C. J., SP488, pp. 47-49 (Aug. 1977).

Flandro, G., Johnson, S. A., Greenleaf, J. F., Tanaka, M., SP484, pp. 335-359 (Oct. 1977).

Flanigan, W. F., JR., Bowman, R. R., Lowell, W. R., 17174.

Flanz, J., Kiline, F. J., Peterson, G. A., Lightbody, J. W., JR., Maruyama, X. K., Penner, S., Szalata, Z. M., Finn, J. M., 16850.

Fleming, P. D. III, Sanchez, I. C., Dimarzio, E. A., Gibes, J. H., 16962.

FLEMONS, R. S., SP484, pp. 319-333 (Oct. 1977).

Flotow, H. E., Glinka, C. J., Rowe, J. M., Rush, J. J., RAHMAN, A., Sinha, S. K., 16964.

Flotow, H. E., Rush, J. J., Rowe, J. M., Glinka, C. J., VAGelatos, N., 17004.

Flynn, D. R., Leasure, W. A., JR., Rubin, A. I., Cadoff, M. A., $H 122$.

Flynn, J. H., Dickens, B., Pummer, W. J., 16842.

FOLEY, R. T., SP479, pp. 67-76 (July 1977).

Folts, H. C.,Cotton, I: W., 16936.

Fomichev, A. V., Shapakov, V. I., Adamov, V. M., AlexanDROV, B. M., ALKhazov, I. D., DRAPChINSKY, L. 'V., Kovalenko, S. S., Kostochikin, O. I., KudRIA vzev, G.' Y., Malkin, L. Z., PetrzhaK, K. A., Pleskachevsky, L. A., SP493, Pp. 313-318 (Oct. 1977). 
Fong, E. N., Gilsinn, D. E., Holberton, F. E., Lucas, B. G., Lyon, G. E., Marron, B. A. S., Neumann, A. J., Vickers, M. V., Walker, J. C., Evans, J. M., JR., O'Neill, J. T., LITTLE, J. L., Albus, J. S., BARbera, A. J., FifE, D. W., NBSIR 76-1094.

Fong, J. T., Peterlin, A., J. Res. 81A No. 1, 97-107 (1977).

Fong, J. T., ReHM, R. G., Graminski, E. L., 16681 .

Forman, R. A., BENNETT, H. S., 16815.

Forman, R. A., BENNETt, H. S., 16860.

Forman, R. A., BenNetT, H. S., 17313.

Forman, R. A., Weinstein, B. A., Piermarini, G., 17047.

Foster, R. L., LotT, P. F., SP464, pp. 351-366 (Nov. 1977).

FOWLER, J. B., LIND, M. A., TN958.

Fowler, J. B., Lind, M. A., ZalewsKı, E. F., TN950.

Fraker, A. C., 16690.

Fraker, A. C., IMAM, M. A., Gilmore, C. M., 17187.

Fraker, A. C., RUFF, A. W., 16973.

Francis, R. L., J. Res. 82, No. 1, 73-80 (1977).

Frankel, H. E., OGReN, J. R., SP468, pp. 3-25 (Apr. 1977).

Frankena, H. J., Raterink, H. J., VAN de StadT, H., 16924.

FRANKENTHAL, R. P., SP400-42, pp. 12-13 (Aug. 1977).

Franklin, A. D., McAlister, A. J., Young, K. F.,Bennett, L. H., Cohen, M. I., DRAGOO, A. L., NBSIR 77-1270.

FRAREY, J. L., SP494, pp. 82-83 (Sept. 1977).

Frederick, N. V., Adair, R. T., Sullivan, D. B., 17092.

Frederick, N. V., Hands, B. A., Jones, M. C., ARP, V. D., PARRISH, W. R., DANEY, D. E., LUDTKE, P. R., NBSIR 77853.

Frederick, N. V., Sullivan, D. B., Adair, R. T., 16875.

Frederick, N. V., Sullivan, D. B., 16876.

Frederick, N. V., Sullivan, D. B., AdaIR, R. T., NBSIR $77-$ 863.

Frederikse, H. P. R., Hosler, W. R., 16900.

Freeman, C. M., Nudelman, S., Richmond, J. C., 17339.

Freeman, J. M., Kane, P. P., Hooton, B. W., SP461, pp. 136139 (Jan. 1977).

Freeman, S. E., Green, F. C., SP500-18, pp. $119-135$ (Sept. 1977).

FReI, R. W., SP466, pp. 41-55 (May 1977).

FreI, W., SPS00-8, pp. 64-65 (May 1977).

FrenCH, E. J., SP488, p. 19 (Aug. 1977).

Frenkel, F. N., KLebanoff, P. S., 16820.

Frens, D. B., McCandless, J. B., Petajan, J. H., Birky, M. M., РaCkHaM, S. C., 16921.

Freund, S. M., Mak, A. G., 17124.

Freund, S. M., Travis, J. C., Sweger, D. M., SP464, pp. 317 320 (Nov. 1977).

FrIDAY, W. M., SP473, pp. 225-240 (June 1977).

Friedjung, M., Linsky, J. L., Anderson, R., Henry, R. C., Moos, H. W., Jenitins, E. B., Snow, T. P., Upson, W. L., Starrfield, S. G., Gallagher, J. S., 16762.

Frohinsdorf, G., Brown, P. W., Berger, R. L., Clifton, J. R., 16768.

Frohnsdorff, G., Clifton, J. R., Brown, P. W., NBSIR 77-1244.

Fu, K. S., SP500-8, p. 43 (May 1977).

Fuerst, R. G., Hughes, E. E., ROOK, H. L., DeardorfF, E. R., MARGESON, J. H., 17230.

Fuller, E. R., WIEderhorn, S. M., LAWN, B. R., 16672.

Fuller, E. R., JR., Bukowsk, J. M., Robbins, C. R., WIEDERHORN, S. M., 16993.

Fuller, G. R., SP470, pp. VI-74-VI-88 (Apr. 1977).

Fulmer, C. B., Styles, R. C., Saltmarsh, M. J., LudemanN,

C. A., NBSIR 77-1279, pp. 24-29 (July 1977).

FUNG, F., ROTH, L., BENJAMIN, I. A., NBSIR 77-1209.

FUNG, F. C. W., NBSIR 77-1260.

FUNG, F. C. W., 17291.

FUNG, F. C. W., Zile, R. H., NBSIR 77-1225.

Furuta, Y., TANAKA, S., SP461, pp. 209-218 (Jan. 1977).
Fussell, J. B., WaGne R, D. P., SP487, pp. 289-308 (Aug. 1977).

Futrell, J. H., Leone, S. R., Bierbaum, V. M., Ellison, G. B., 17209.

FuWA, K., YamazakI, S., DokIYa, Y., SP464, pp. 233-235 (Nov. 1977).

\section{G}

GabBard, F., SP493, pp. $212-220$ (Oct. 1977).

Gabrielsen, B. L., KaPlan, K., BSS106, pp. 283-313 (Sept. 1977).

Gade, R. H., Podolny, W., JR., BOSCH, H. R., SP470, pp. II47-II-67 (Apr. 1977).

Gade, R. H., SCANLAN, R. H., SP477, pp. I-1-I-11 (May 1977).

GAD-EL-HAK, M., SP484, pp. $571-596$ (Oct. 1977).

GADZUK, J. W., SP475, pp. 154-161 (Apr. 1977).

GADzUK, J. W., 16747.

GADZUK, J. W., 16749.

GADzUK, J. W., 17218 .

GADZUK, J. W., 17219.

Gagge, A. P., Nevins, R. G., SP491, pp. 93-1 16 (Sept. 1977).

Gagnepain, J. J., 17183.

GaGnePain, J. J., Walls, F. L., NBSIR 77-855.

GATT, J., SPSOO-20.

GATT, J., KATZKE, S., BRANSTAD, D., NBSIR 77-1291.

Gallagher, A., Chen, S. T., 17128.

Gallagher, A., Cheron, B., Scheps, R., 16752.

Gallagher, A., Hessel, M. M., LaM, L. K., 16912.

Gallagher, J. S., Friedjung, M., Linsky, J. L., Anderson, R., Henry, R. C., Moos, H. W., Jenkins, E. B., Snow, T. P., UPSON, W. L., STARRFIEld, S. G., 16762.

Gallagher, J. S., Moldover, M. R., 17295.

Galloway, K. F., Bullis, W. M., 16894.

Galloway, K. F., Leedy, K. O., KeERY, W. J., 16971.

Galloway, K. F., Leedy, T. F., Mayo, S., 16889.

Galloway, K. F., ROTTMaN, P., NBSIR 77-1235.

GaLOWIN, L. S., ORLOSK1, M. J., WYLY, R. S., SP473, pp. 317 348 (June 1977).

GaMbnNo, S. R., SP450, pp. 191-193 (June 1977).

GaMBino, S. R., SP450, pp. 273-274 (June 1977).

Ganguly, A. K., BaSU, A. S., SP461, pp. 219-221 (Jan. 1977).

Ganguly, A. K., David, M., SP461, pp. 231-233 (Jan. 1977).

Ganguly, A. K., SWARUP, J., SP461, pp. 124-128 (Jan. 1977).

Gangwere, S. G., JR., HOSLER, J. R., Stewart, L. H., SPSOO18, pp. 185-211 (Sept. 1977).

GANS, W. L., 16721.

Ganzerli-Valentini, M. T., MaxaA, V., Meloni, S., QueirazZA, G., SMEdLE, E., SP464, pp. 263-273 (Nov. 1977).

Gardner, M., Karo, A., Julienne, P., Stevens, W. J., 17195.

GARG, S. B., KUMAR, A., SP461, pp. $70-73$ (Jan. 1977).

Garvin, D., Hampson, R. F., Kurylo, M. J, 16976.

Gasunie, N. V. N., DustelberGen, H. H., SP484, pp. 935-944 (Oct. 1977).

GatewOOD, E. H., SP471, 49-52 (JUNE 1977).

Gauchat, U. P., Schodek, D. L., SP473, pp. $17-33$ (June 1977).

GaUS, M. P., SP470, pp. II-1-III-10 (Apr. 1977).

Gaviglio, J., Dussauge, J. P., SP484, pp. 649-658 (Oct. 1977).

Gay, P., Richardson, P., Howorth, P. J. N., Hirst, A. D., SP450, pp. $311-314$ (June 1977).

Gayer, B., Brinckman, F. E., Shiloh, M., 16757.

GebBIE, K. B., BAR, V., SteintTz, R., 16888.

GeIST, J., 16851 .

Geist, J., DOYLE, W. M., McINTOSH, B. C., 16852.

Geist, J., Lind, M. A., Schaefer, A. R., Zalewski, E. F., TN954. 
Gelatt, G. D., Weiss, J. A., EhrenRich, H., SP475, pp. 8386 (Apr. 1977).

Geltman, S., J. Res. 82, No. 3, $173-179$ (1977).

GeLTMAN, S., 16695.

Geltman, S., 16892.

Geltman, S., 17263.

GenSERT, R. M., BSSI06, pp. $314-326$ (Sept. 1977).

Gentry, J. W., Goldfarb, A. S., SP464, pp. 219-226 (Nov. 1977).

Gerhold, W. F., 16745.

Gerhold, W. F., Sanderson, B. T., Alumbaugh, R. L., EscaLANTE, E., IVERSON, W. P., Monogr. 158.

GerRARD, D. J., SP400-42, pp. 18-19 (Aug. 1977).

Gevirtz, J. L., Blackburn, J. B., JR., Rowe, P. G., SP473, pp. 189-202 (June 1977).

Ghigo, F. D., Shelus, P. J., Silverberg, E. C., Faller, J. E., 16680.

GHOSE, A. M., SP461, pp. 47-54 (Jan. 1977).

Ghose, A. M., Gopinath, D. V., Hubbell, J. H., Roy, S. C., SP461.

Ghose, A. M., Nath, S., Chatterjee, A., SP461, pp. 64-66 (Jan. 1977).

Ghose, A. M., Pal, B., Chatteree, A., SP461, pp. 44-46 (Jan. 1977).

Ghose, A. M., Roy, S. C., SP461, pp. 17-19 (Jan. 1977).

Giarratano, P. J., 17096.

Giarratano, P. J., ARP, V. D., Yaskin, L. A., Jones, M. C., YeroshenKo, V. M., 17333.

Giarratano, P. J., Collier, R. S., 17071.

Giarratano, P. J., Hust, J. G., 16878.

Gibbs, J. H., Fleming, P. D. III, Sancher, I. C., Dimarzio, E. A., 16962.

Gibson, B. F., O'Connell, J. S., Berman, B. L., 16987.

Gigerenzer, H., Zack, T. A., Pepper, R. T., SP487, pp. 93 107 (Aug. 1977).

Gilfrich, J., Whitlock, R., Fatemi, M., Johnson, E., Birks, L., SP464, pp. 189-190 (Nov. 1977).

Gilfrich, J. V., Peckerar, M. C., Birks, L. S., SP464, pp. 347 349 (Nov. 1977).

Gillet, V., Danos, M., Monogr. 147, Suppl. 1.

GllliaM, D. M., SP493, pp. 299-303 (Oct. 1977).

Gllliam, D. M., Kazl, A. H., McGarry, E. D., SP493, pp. 335341 (Oct. 1977).

GiLLs, T. E., SP492, pp. 9-12 (Nov. 1977).

Gills, T. E., Becker, D. A., SP492, pp. 12-14 (Nov. 1977).

GilLs, T. E., LUTZ, G. J., ROOK, H. L., SP492, pp. $20-22$ (Nov. 1977).

GILMore, C. M., Fraker, A. C., IMAM, M. A., 17187.

Gilmore, W., Morris, M., JohnSON, D. R., Lovas, F. J., Zuckerman, B., Turner, B. E., Palmer, P., 16969.

Gilsinn, D. E., Holberton, F. E., Lucas, B. G., Lyon, G. E., Marron, B. A, S., NeumanN, A. J., Vickers, M. V., Walker, J. C., Evans, J. M., JR., OTerll, J. T., LTtrle, J. L., Albus, J. S., Barbera, A. J., Fife, D. W., Fong, E. N., NBSIR 76-1094.

GILSINN, J. F., 16944.

GILSINN, J. F., SHIER, D. R., NBSIR 77-1253.

Ginocchio, J. N., Harlow, F. H., Nix, J. R., Danos, M., HalBERT, E. C., SMTth, R. K., JR., AMSDEN, A. A., 17109.

Ginsberg, I. W., Limperis, T., Nicodemus, F. E., Richmond, J. C., Hsia, J. J., Monogr. 160.

GiRAUD, M., SMTH, E. W., 16799.

Gladden, W. K., Feldman, A., Horowttz, D., Waxler, R. M., DODGE, M. J., NBSIR 77-1304 (ARPA).

Gladden, W. K., Feldman, A., Waxler, R. M., Horowitz, D., DODGE, M. J., 16730 .

Glasgow, L., Ausloos, P., Rebbert, R. E., J. Res. 82, No. 1, $1-8$ (1977).

Glass, R. A., RuBin, A. I., 17036.
Glassman, I., SiRignano, W. A., Dryer, F. L., NBS-GCR-7679.

Glaze, D. J., Hellwig, H., Allan, D. W., Jarvis, S., JR., 16775.

Glaze, D. J., Hellwig, H. W., Jarvis, S., JR., Wineland, D. J., Allan, D. W., 16759.

Glaze, D. J., Walls, F. L., Stein, S. R., Gray, J. E., 17185.

Glinka, C. J., Minkiewicz, V. J., PAssell, L., 17112.

Glinka, C. J., Rowe, J. M., Rush, J. J., Rahman, A., Sinha, S. K., Flotow, H. E., 16964.

Glinka, C. J., Rowe, J. M., Rush, J. J., Libowitz, G. G., MaELAND, A., 16965.

Glinka, C. J., Vagelatos, N., Flotow, H. E., Rush, J. J., ROWE, J. M., 17004.

Godden, W. G., Chen, M. C., Williams, D., Kawashima, K., PENZIEN, J., SP477, pp. VI-1 -VI-9 (May 1977).

GodetTe, M., Roberts, W. E., Campbell, P. G., POSt, M. A., NBSIR 77-1263.

Godwal, B. K., Navalkar, M. P., SP461, pp. $97-99$ (Jan. 1977).

GOER, M., SP500-15, pp. 32-35 (July 1977).

Gold, D. S., Dupont, E. I., Pierce, F. J., SP484, pp. 621-648 (Oct. 1977).

Gold, R., Roberts, J. H., RahN, F. J., Stahlkopf, K. E., MARSTON, T. U., SP493, pp. 137-145 (Oct. 1977).

Goldberg, D., Neumann, J. P., Chang, Y. A., JPCRD 6, No. 3, 621-674 (1977).

GoldberG, K., J. Res. $81 B$ Nos. 1 and 2, 61-72 (1977).

Goldberg, R. N., Staples, B. R., Nuttall, R. L., Arbuckle, R., SP485.

Goldfarb, A. S., Gentry, J. W., SP464, pp. $219-226$ (Nov. 1977).

GOLDMAN, R. F., SP491, pp. 52-64 (Sept. 1977).

Gonzalez, R. R., SP491, pp. 131-151 (Sept. 1977).

GOODMAN, A. M., SP400-37.

GOODMAN, A. M., SP400-40.

GOOdMAN, A. M., KuCZER, P., HOOK, H. O., SP400-41.

GoOdman, S., SHIER, D., 16784.

Goodway, M., Kruger, J., Pourbaix, M., Brown, B. F., BurNEtT, H. C., Chase, W. T., SP479.

GOODWIN, R. D., NBSIR 77-860.

Gopal, S., SANJeEvaiah, B., SP461, pp. 29-31 (Jan. 1977).

Gopala, K., SANJEEVAIAH, B., SP461, pp. 60-63 (Jan. 1977).

Gopalakrishnan, C. R., Sundararaman, V., SP461, pp. 106109 (Jan. 1977).

GOPINATH, D. V., SP461, pp. $79-86$ (Jan. 1977).

Gopinath, D. V., Hubbell, J. H., RoY, S. C., Ghose, A. M., SP461.

GOPINATH, D. V., JOHN, K., SP461, pp. $174-176$ (Jan. 1977).

Gopinath, D. V., MUthukrishinan, G., Santhanam, K., SP461, pp. $140-143$ (Jan. 1977).

GopINATH, D. V., SUNDARAM, V. K., SP461, pp. $94-96$ (Jan. 1977).

Gordon, C. C., Ferguson, R. S., SP473, pp. 259-278 (June 1977).

Gornick, F., Passaglia, E., 17053.

GotTlieb, C. A., Gottuieb, E. W., Litvak, M. M., Guelin, M., Thaddeus, P., Johnson, D. R., Lovas, F. J., 17264.

Gottlieb, E. W., Litvak, M. M., Guelin, M., Thaddeus, P., Johnson, D. R., Lovas, F. J., GotTlieb, C. A., 17264.

Gowda, R., Sanjeevaiah, B., SP461, pp. $41-43$ (Jan. 1977).

GRAMINSKI, E. L., 17241 .

GraminsKi, E. L., FONG, J. T., REHM, R. G., 16681 .

GraminsKi, E. L., KIRSCH, R. A., 17214.

GrAMINSKI, E. L., SMITH, J. C., NBSIR 76-1148.

GraNT, D. M., SP484, pp. 91-108 (Oct. 1977).

Grant, W. H., SMTth, L. E., StromberG, R. R., 16777.

Grant, W. H., Stromberg, R. R., Morrissey, B. W., SMtth, L. E., DEHL, R. E., NBSIR 76-1128.

Gravatt, C. C., SP464, pp. 669-671 (Nov. 1977).

Gravatt, C. C., Uriano, G. A., 17247. 
Gray, J. E., Glaze, D. J., Walls, F. L., Stein, S. R., 17185.

GRAY, M. M., SP500-7.

GREEN, D. C., 16806.

Green, F. C., Freeman, S. E., SP500-18, pp. $119-135$ (Sept. 1977).

Green, R. B., Keller, R. A., Schenck, P. K., Travis, J. C., LUTHER, G. G., 16691 .

GreenberG, S., NATESAN, K., SP468, pp. 97-106 (Apr. 1977).

Greene, R. L., COOPER, J., SMItH, E. W., 17249.

Greenleaf, J. F., SP500-8, pp. 59-62 (May 1977).

Greenleaf, J. F., Tanaka, M., Flandro, G., Johnson, S. A., SP484, pp. 335-359 (Oct. 1977).

Greenspan, L., J. Res. 81A No. 1, 89-96 (1977).

Gregory, T. M., Brown, W. E., MCDowell, H., J. Res. 81 A Nos. 2 and 3, 273-281 (1977).

Gregory, T. M., Chow, L. C., Brown, W. E., 16739.

Grone, R., J. Res. 81B Nos. 1 and 2, 41-44 (1977).

Gross, J. G., Pielert, J. H., 17111 .

Grot, R. A., HarrJe, D. T., Johnston, L. C., 16902.

GrundL, J., EISENHAUER, C., SP493, pp. 156-164 (Oct. 1977).

GrundL, J., Eisenhauer, C., 17058.

Grundl, J. A., Fabry, A., Eisenhauer, C. M., SP493, pp. 329 334 (Oct. 1977).

Grundl, J. A., Spiegel, V., Eisenhauer, C. M., Heaton, H. T. I, Gilliam, D. M., Bigelow, J., 16790.

GRUNIG, J. E., NBSIR 77-1257.

GSChNeIdner, K. A., JR., Evans, B. L., SP463, pp. III.2.1III. 2.9 (Jan. 1977).

Gubbins, K. E., Murad, S., Hanley, H. J. M., JPCRD 6, No. 4, $1167-1180$ (1977).

Guelin, M., Thaddeus, P., Johnson, D. R., Lovas, F. J., GotTLieb, C. A., Gottlieb, E. W., LTtVak, M. M., 17264.

Gump, B. H., Hertz, H. S., May, W. E., Chesler, S. N., 16886.

Gump, B. H., Hertz, H. S., May, W. E., Wise, S. A., Chesler, S. N., 17273.

Gump, B. H., Hertz, H. S., May, W. E., Wise, S. A., Chesler, S. N., SP464, pp. 81-85 (Nov. 1977).

Guthrie, D. L., Washington, D. R., Vincenty, C., SP484, pp. 173-186 (Oct. 1977).

GutTerman, B. M., SP471, pp. 110-120 (June 1977).

Guttman, C. M., Zapas, L. J., Crissman, J. M., 17256.

Guttman, N. B., Hull, A. R., Potter, T. D., SP477, pp. II15-II-29 (May 1977).

Guyer, D. R., Leone, S. R., Koffend, J. B., Field, R. W., 17318.

\section{H}

Hanr, L., Powell, G., Klein, M., Wardell, J., Wilmot, G., 17136.

HABER, S., 17157.

HACH, C., KLEIN, R., JR., SP464, pp. 61-66 (Nov. 1977).

Hadate, T., Kuribayash, E., TaZaku, T., SP477, pp. IV1-IV-17 (May 1977).

Hadden, S. C., Hanson, R. E., Stewich, M. W., SP494, pp. 238-248 (Sept. 1977).

HAGAN, L., SP363. Supplement 1.

HagenbuCh, W. H., SP471, pp. 44-48 (June 1977).

Hagglund, R. R., SP487, pp. 241-246 (Aug. 1977).

HahN, M. H., Powell, F. J., 17286.

HaIn, G. M., Kerschner, P. M., SP464, pp. 259-261 (Nov. 1977).

Haisch, B. M., Linsky, J. L., Lampton, M., Paresce, F., MarGON, B., STERN, R., 16933.

Haisch, B. M., Linsky, J. L., Weinstein, A., Shine, R. A., 17056.

Hake, R. D., JR., Williams, M. F., Murray, E. R., Van der LAaN, J. E., HaWley, J. G., SP464, pp. 305-314 (Nov. 1977).
Halbert, E. C., Smith, R. K., JR., AmSden, A. A., Ginocchio, J. N., HaRlow, F. H., Nix, J. R., Danos, M., 17109.

HALE, G. M., SP493, pp. 30-36 (Oct. 1977).

HALl, A. H., Simpson, J. A., Whetstone, J. R., 17023.

HALL, A. M., SP468, pp. 183-188 (Apr. 1977).

Hall, J. L., Bergquist, J. C., Lee,S. A., 16776.

Hall, J. L., Bergouist, J. C., Lee, S. A., 17337.

HALL, J. L., LEE, S. A., 17338.

HALl, W. G., SHIER, D. R., NBSIR 77-1250.

HALl, W. G., SHIER, D. R., NBSIR.77-1293.

haller, G., Katzer, J., Park, R., Rhodin, T., Yates, J. T., SP475, p. 13 (Apr. 1977).

Haller, W. K., SANDERS, D. M., 17043.

Hallowell, P. L., O'Brien, J. T., Penner, S., Finn, J. M., Crannell, H., 16845.

Halm, D., SP484, pp. $61-82$ (Oct. 1977).

Halsey, N., Marlowe, D. E., Mitchell, R. A., Mordfin, L., 16685.

HAMANN, D. R., SP475, pp. 183-192 (Apr. 1977).

HAMEL, F. B., SP468, p. 191 (Apr. 1977).

HaMiton, C. E., SP464, pp. 681-684 (Nov. 1977).

Hamiton, J. H., SP494, pp. 93-96 (Sept. 1977).

HAMMER, W., SP482, pp. 1-10 (July 1977).

Hampson, R. F., Kurylo, M. J., Garvin, D., 16976.

HaN, C. C., MOZER, B., 16817.

Hands, B. A., Jones, M. C., ARP, V. D., PARrish, W. R., Daney, D. E., Ludtke, P. R., Frederick, N. V., NBSIR 77 853.

HANEY, R. A., SP484, Pp. $755-763$ (Oct. 1977).

Hanley, H. J. M., J. Res. 82, No. 3, $181-182$ (1977).

HANLEY, H. J. M., TN693.

HANLEY, H. J. M., 16791.

Hanley, H. J. M., Gubbins, K. E., Murad, S., JPCRD 6, No. 4, $1167-1180$ (1977).

Hanley, H. J. M., haynes, W. M., MCCaRty, R. D., JPCRD 6, No. 2, 597-610 (1977).

Hanley, H. J. M., Holland, P. M., Ely, J. F., J. Res. 82, No. 2, 123-127 (1977).

hansen, L. D., Eatough, D. J., Mangelson, N. F., lzatt, R. M., SP464, pp. 637-642 (Nov. 1977).

hansen, L. D., lzatt, R. M., Mangelson, N. F., Eatough, D. J., SP464, pp. 643-649 (Nov. 1977).

Hanson, D. W., Cateora, J. V., Davis, D. D., U.S. Patent $4,014,166$.

Hanson, D. W., Davis, D. D., Beehler, R. E., 17080.

hanson, D. W., Hellwig, H. W., Rueger, L. J., Easton, R. L., Fisher, L. C., 17179.

hanson, R. E., Stewich, M. W., Hadden, S. C., SP494, pp. 238-248 (Sept. 1977).

Harding, C. A., Waring, J. L., Roth, R. S., Brower, W. S., J. Res. 82, No. 3, 167-172 (1977).

Hardy, I. T., LeONG-Hong, B., Fife, D. W., SP500-14.

HARDY, S. C., 16780.

Hardy, S. C., Cordes, M. R., Coriell, S. R., 17009.

Hardy, S. C., Hsu, N. N., Snmmons, J. A., 17191.

hare, G. B., Klaus, P. A., Bunten, E. D., SP480-6.

Harkleroad, M., Raines, J., Rinkinen, W., Quintiere, J., MCCaffrey, B., Kashiwagi, T., DeN Braven, K., NBSIR 77 1318.

harlow, F. H., Nix, J. R., Danos, M., Halbert, E. C., Smith, R. K., JR., AMSDEN, A. A., GiNOCCHO, J. N., 17109.

HARMAN, G. G., 16884.

HARMAN, G. G., 17150.

harne, D. E., Interrante, C. G., Hicho, G. E., 16719.

Harpe, S. W., Waterman, T. E., Christian, W. J., NBS-GCR77-82.

haRrington, R. S., SP473, pp. $491-497$ (June 1977).

harris, D. R., Shaw, E. D., Hazlewood, L., Hayes, R. E., SP480-24, Pp. 1-16 (Nov. 1977).

HARRIS, J. R., SP473, Pp. 285-316 (June 1977). 
Harris, J, R., Ellingwood, B., 17306

harrison, G. H., Cox, C. R., Kubiczek, E. B., Robinson, J. E., NBSIR 77-1279, pp. 19-23 (July 1977).

Harrison, J. C., Levine, J., 17196.

HARRISON, S. H., SP492, pp. 15-19 (Nov. 1977).

Harrue, D. T., Johnston, L. C., Grot, R. A., 16902.

harter, W. G., Patterson, C. W., 16956.

Harter, W. G., Patterson, C. W., 16957.

Harter, W. G., Patterson, C. W., 17316.

Hartquist, T. W., Lane, N. F., Wisdom, J., 16818.

Harvey, J. A., Schröder, I. G., SP493, pp. 10-13 (Oct. 1977).

Harvey, R. B., Stedman, D. H., SP464, pp. 393-396 (Nov. 1977).

Hasegawa, S., Little, J. W., J. Res. 81A No. 1, $81-88$ (1977).

HASTINGS, S. R., NBSIR 77-1309.

Hastings, S. R., 17298.

Hastings, S. R., Crenshaw, R. W., BSS104.

Hattori, S., Kitagawa, Y., Santo, T., SP470, pp. III-1-III-17 (Apr. 1977).

Haugen, E. B., SP487, pp. 25-38 (Aug. 1977)

Haus, J. W., Cullen, J. R., 17122.

Havill, T. N., Lee, T. Y., Ho, C. Y., Desai, P. D., WU, K. Y., NBS-GCR-77-83.

Hawley, J. G., Hake, R. D., Jr., Williams, M. F., Murray, E. R., van DER LAaN, J. E., SP464, pp. 305-314 (Nov. 1977).

Hayashi, S., Noda, S., Uware, T., SP477, pp. VI-192-VI-198 (May 1977).

Hayashi, S., Tsuchida, H., Kurata, E., SP477, pp. III-16-III25 (May 1977).

HaYashi, S., Tsuchida, H., Noda, S., SP470, pp. VIII42-VIII-55 (Apr. 1977)

Hayes, M. A., Norcross, D. W., Mann, J. B., Robb, W. D., 17132.

Hayes, R. E., Harris, D. R., Shaw, E. D., Hazlewood, L., SP480-24, pp. 1-16 (Nov. 1977).

Hayes, W. D., JR., Custer, R. L. P., NBSIR 77-1282.

HAYNES, W. M., 16792.

HAYNes, W. M., Hiza, M. J., 16871 .

Haynes, W. M., MCCARTy, R. D., Hanley, H. J. M., JPCRD 6, No. 2, 597-610 (1977).

HaYWARD, A. T. J., SP484, pp. 1-24 (Oct. 1977).

HAYWARD, E., 16926.

Hazlewood, L., Hayes, R. E., Harris, D. R., Shaw, E. D., SP480-24, pp. 1-16 (Nov. 1977).

Head, R. V., SP500-15, pp. 27-28 (July 1977)

HeAron, J. Z., J. Res. 82, No. 2, 129-132 (1977).

Heaton, H. T. II, Gilliam, D. M., Bigelow, J., Grundl, J. A., Spiegel, V., Eisenhauer, C. M., 16790.

Hebner, R. E., JR., MiSAKIAN, M., NBSIR 77-1317.

Hebrank, J., Hurley, C. W., Ryan, J. D., Obright, W., RipPEY, W., NBSIR 77-1243.

Hebrank, J. H., Coble, J. B., Kuklewicz, M. E., NBSIR 77 1207.

НеснT, H. G., SP466, pp. 57-73 (May 1977).

Heft, R. E., Fisher, G. L., Silberman, D., Prentice, B. A., Ondov, J. M., Ragain,, R. C., SP464, pp. $565-572$ (Nov. 1977).

Hegemier, G. A., AnVAR, A., ISEnberg, J., BSSI06, pp. 154165 (Sept. 1977).

Hegemier, G. A., Krishnamoorthy, G., NunN, R. O., BSSI06, pp. 114-153 (Sept. 1977).

HEglaND, R. R., SP500-15, pp. 19-21 (July 1977).

Hegland, R. R., SP500-15, pp. $44-45$ (July 1977).

Heimbach, C. R., Lehman, D. R., O'Connell, J. S., 16793.

HEINRICH, K. F. J., 16841 .

Heinrich, K. F. J., Breiter, D. N., Pella, P. A., SP464, pp. 527-529 (Nov. 1977)

Heinrich, K. F. J., Pella, P. A., Lorber, K., SP464, pp. 125 127 (Nov. 1977).
Heitmann, H., Laver, M. B., Buckles, R. G., SP450, pp. 207 225 (June 1977).

Helbig, V., Kelleher, D. E., Wiese, W. L., 17204.

Heldenbrand, J. L., 17290.

Heldenbrand, J. L., Achenbach, P. R., 17289.

Heller, M., SP487, pp. 253-256 (Aug. 1977).

Heller, S. R., SP464, pp. 75-80 (Nov. 1977).

Hellwig, H., TN616, $2 d$ Revision.

Hellwig, H., 16794.

Hellwig, H., Allan, D. W., Jarvis, S., Jr., Glaze, D. J., 16775.

Hellwig, H., Walls, F. L., 17180.

Hellwig, H. W., Jarvis, S., JR., Wineland, D. J., Allan, D. W., Glaze, D. J., 16759.

Hellwig, H. W., Rueger, L. J., Easton, R. L., Fisher, L. C., HANSON, D. W., 17179.

Helzer, S. G., OfFensend, F. L., Buchbinder, B., NBSIR 77-1381.

Hemming, D. C., SP479, pp. 93-102 (July 1977).

Henderson, M. M., 16743.

HeNDRICKS, C., SP464, pp. 677-679 (Nov. 1977).

Henry, R. C., Moos, H. W., Jenkins, E. B., Snow, T. P., Upson, W. L., Starkfield, S. G., Gallagher, J. S., FriedJUNG, M., LINSKY, J. L., ANDERSON, R., 16762.

Herbst, J. F., 16919.

Herbst, J. F., BaK, P., Watson, R. E., 16916.

Hermach, F. L., 16694.

Hermach, F. L., Flach, D. R., 16693.

Hernandez, A. J., Langhoff, P. W., 17317.

Herron, J. T., Martinez, R. I., Huie, R. E., 17327.

Hertz, H. S., Coxon, B., Siedle, A. R., 17045.

Hertz, H. S., Hilpert, L. R., May, W. E., Wise, S. A., Chesler, S. N., 17271 .

Hertz, H. S., May, W. E., Chesler, S. N., Gump, B. H., 16886.

Hertz, H. S., May, W. E., Wise, S. A., Chesler, S. N., Gump, B. H., 17273 .

Hertz, H. S., May, W. E., Wise, S. A., Chesler, S. N., Gump, B. H., SP464, pp. 81-85 (Nov. 1977).

Heskestad, G., Delichatsios, M. A., NBS-GCR-77-86.

Heskestad, G., Delichatsios, M. A., NBS-GCR-77-95.

Hessel, M. M., Bertoncini, P. J., Wahl, A. C., Stevens, W. J., 16870 .

Hessel, M. M., CoOper, J., Smith, E. W., Drullinger, R. E., 17084.

Hessel, M. M., KusCh, P., 17101 .

Hessel, M. M., Lam, L. K., Gallagher, A., 16912.

Hessel, M. M., Smith, E. Q., Drullinger, R. E., 17076.

Hessel, M. M., Stock, M., Drullinger, R. E., 16800.

Hessel, M. M., Stock, M., Smith, E. W., Drullinger, R. E., 17194.

Hesselbacher, K. H., Hong, S. P., Moore, J. H., Beaty, E. C., 16810 .

Hesterman, V. W., Field, B. F., 16698.

Hetzer, H. B., Durst, R. A., Robinson, R. A., BAtes, R. G., J. Res. 81A No. 1, 21-24 (1977).

Heydemann, P. L. M., Tilford, C. R., Hyland, R. W., 17269.

Hicho, G. E., Harne, D. E., InTerRante, C. G., 16719

Hicho, G. E., INTERrante, C. G., 16700.

Hicho, G. E., Interrante, C. G., 16720.

Hicho, G. E., Interrante, C. G., Early, J. G., 1671 S.

Hildebrandt, R. C., BSS 106, pp. 228-237 (Sept. 1977).

Hill, J. E., Benzinger, T. H., Mangum, B. W., 16923.

Hill, J. E., Kelly, G. E., Peavy, B. A., 17347.

Hill, J. E., Mangum, B. W., SP491.

HiLl, M. F., Walkowicz, J. L., NBSIR 77-1195.

Hilpert, L. R., May, W. E., Wise, S. A., Chesler, S. N., HERTZ, H. S., 17271.

Hilten, J. S., Vezzett, C. F., Mayo-Wells, J. F., Lederer, P. S., TN961.

HINE, D. J., NBSIR 77-1214. 
Hinkley, E. D., KU, R. T., SP464, pp. $291-294$ (Nov. 1977)

Hirosawa, M., Nakata, S., Watabe, M., SP470, pp. IX-1-IX5 (Apr. 1977).

Hirst, A. D., Gay, P., Richardson, P., Howorth, P. J. N., SP450, pp. $311-314$ (June 1977).

Hites, R. A., SP464, pp. 87-89 (Nov. 1977).

HizA, M. J., HaYNES, W. M., 16871 .

Hiza, M. J., Miller, R. C., Kidnay, A. J., 16881.

Ho, C. Y., Desai, P. D., WU, K. Y., Havill, T. N., Lee, T. Y., NBS-GCR-77-83.

Hóbis, R. W., ChiU, H. Y., Adams, P. J., Linsky, J. L., BaSRi, G. S., Maran, S. P., 16732.

HOCKEY, B. J., WIEDERHORN, S. M., JOHNSON, H., NBSIR 77 1396.

HODGESON, J. A., NBSIR 76-1191.

Hodgeson, J. A., 17141.

Hodgeson, J. A., Hughes, E. E., Schmidt, W. P., Bass, A. M. 16756.

Hoelen, A. J., Kreuger, J. A., MaAs, A. H. J., Visser, B. F., SP450, pp. 73-74 (June 1977).

Hoer, C. A., 17244.

Hoer, C. A., Engen, G. F., U.S. Patent 4,001,681.

Hoer, C. A., Roe, K. C., Allred, C. M., 16724.

Hoeve, C. A. J., WAgNeR, H. L., 16710.

HofmMan, , A. O., LoWnie, H. W., JR., SP468, pp. 131-133 (Apr. 1977).

Hoffman, J. D., Davis, G. T., Lauritzen, J. I., JR., 16887.

Hofmman, J. R., Long, W. T., Williams, R. L., SP468, pp. 41-48 (Apr. 1977).

Hofmayer, C. H., Shao, L. C., Stuart, R. J., SP477, pp. VII1-VTI-28 (May 1977).

Hogren, D., Peavy, S. T., NBSIR 77-1276.

Holberton, F. E., Lucas, B. G., Lyon, G. E., Marron, B. A. S., Neumann, A. J., Vickers, M. V., Walker, J. C., Evans, J. M., JR., O'Neill, J. T., LitTle, J. L., Albus, J. S., BARBERA, A. J., Fife, D. W., Fong, E. N., Gilsinn, D. E., NBSIR 76-1094.

Holdeman, J. T., JR., Holdeman, L. B., 16795.

Holdeman, L. B., Finnegan, T. F., 17121.

Holdeman, L. B., Holdeman, J. T., JR., 16795.

Holdeman, L. B., Wahlsten, S., Finnegan, T. F., 16788.

Holland, P. M., Ely, J. F., Hanley, H. J. M., J. Res. 82, No. 2, $123-127$ (1977).

Holley, E. R., SP484, pp. 395-421 (Oct. 1977).

HOLMER, C. I., 16766.

HOLT, H. K., 17143.

HOLTON, J. K., NBSIR 77-1272.

HOLtON, J. K., 16733.

Holys, A., Roberts, J. R., Czernichowski, A., 17276.

Hong, S. P., Moore, J. H., Beaty, E. C., Hesselbacher, K. H., 16810.

HoOgenboOM, L., SP494, pp. 167-187 (Sept. 1977).

Hook, H. O., GoOdMaN, A. M., KuCZer, P., SP400-41.

Hooton, B. W., Freeman, J. M., Kane, P. P., SP461, pp. 136 139 (Jan. 1977).

Horowitz, D., Dodge, M. J., Gladden, W. K., Feldman, A., WAXLER, R. M., 16730.

Horowitz, D., WaXler, R. M., Dodge, M. J., Gladden, W. K., Feldman, A., NBSIR 77-1304 (ARPA).

Horowitz, D., WaXler, R. M., Feldman, A., NBSIR 77-1219. HoRowITZ, E., SP463, pp. IX.1.1-IX.1.22 (Jan. 1977).

Horowitz, E., RUFF, A. W., WeINSTEIN, A., SP472.

Hosler, J. R., Stewart, L. H., Gangwere, S. G., JR., SP50018, pp. 185-211 (Sept. 1977).

HOSLER, W. R., 17160 .

Hosler, W. R., Frederikse, H. P. R., 16900.

Houck, J. C., 16750.

Houck, J. C., ANGel, W. T., 16908.

Hougen, J. T., Simmons, J. D., J. Res. 81A No. 1, 25-80 (1977).

Howard, C. J., Evenson, K. M., 17272.
Howard, C. J., Evenson, K. M., Jennings, D. A., Petersen, F. R., Mucha, J. A., Jimenez, J. J., Charlton, R. M., 17073. HOWDEN, W. E., NBS-GCR-77-89.

HOWE, D. A., 17181 .

Howe, S. L., Risley, A. S., 17070.

Howell, B. F., Schaffer, R., YAP, W. T., 16911.

HoweS, M. A. H., SP468, pp. 137-142 (Apr. 1977).

HowORTH, P. J. N., SP450, pp. 53-56 (June 1977).

HowORTH, P. J. N., SP450, pp. 57-67 (June 1977).

Howorth, P. J. N., Hirst, A. D., GAY, P., Richardson, P., SP45O, pp. 311 -314 (June 1977).

Hruska, G. R., Magrab, E. B., Penzes, W. B., 16701

Hruska, G. R., Magrab, E. B., Penzes, W. B., 17245.

Hsia, J. J., Ginsberg, I. W., Limperis, T., Nicodemus, F. E., RichMond, J. C., Monogr. 160.

Hsia, J. J., Weidner, V. R., Venable, W. H., JR., J. Res. 82, No. 1, 29-55 (1977).

Hsu, N. N., Simmons, J. A., HaRdy, S. C., 17191 .

Hsu, S., Azer, N. Z., SP491, pp. $18-40$ (Sept. 1977).

Hsu, S. M., SP487, pp. 172-185 (Aug. 1977).

Hubbard, C. R., Mighell, A. D., Ware, G. M., 16913.

HubBard, C. R., SMith, D. K., 16953.

Hubbard, C. R., Staffa, J. A., Zervos, C., Mighell, A. D., 16688.

HuBbeLl, J. H., SP461, pp. 3-16 (Jan. 1977).

HuBBell, J. H., 17051 .

Hubeell, J. H., Roy, S. C., Ghose, A. M., Gopinath, D. V., SP461.

HuDDle, F. P., SP463, pp. I.2.1-I.2.2 (Jan. 1977).

Huebner, R. H., Celotta, R. J., Mielczarek, S. R., 17018.

Huebner, R. H., O'Connor, M. E., Celotta, R. J., MielcZAREK, S. R., 17019

HUELSKOETTER, W. R., SP500-8, Pp. 52-54 (May 1977).

HUGGETT, C., NBSIR 77-1308.

Hughes, E. E., DORKo, W. D., SP464, pp. $535-539$ (Nov. 1977 ).

Hughes, E. E., Rook, H. L., Deardorff, E. R., Margeson, J. H., Fuerst, R. G., 17230.

Hughes, E. E., Schmidt, W. P., Bass, A. M., Hodgeson, J. A., 16756.

Hughey, L. R., Madden, R. P., 16665.

Hute, R. E., Herron, J. T., Martinez, R. I., 17327.

Huie, R. E., LoNg, N. J. T., Thrush, B. A., 16844.

Huie, R. E., LoNG, N. J. T., Thrush, B. A., 17238.

HULICK, C., NBS-GCR-ETIP 77-37.

HuLICK, C., NBSIR 77-1221.

Hull, A. R., SP470, pp. I-18-I-27 (Apr. 1977).

Hull, A. R., Potter, T. D., Guttman, N. B., SP477, pp. II15-II-29 (May 1977).

HUMMER, D. G., 16758.

Humphreys, J. C., Chappell, S. E., Mclaughlin, W. L., JarRETT, R. D., 16999.

Humphreys, J. C., Chappell, S. E., NBSIR 76-1135.

HuNG, H., STIEFEL, S. W., JUSTIN KIM, S., NBSIR 77-1212.

HuNT, C. M., BuRCH, D. M., NBSIR 77-1274.

HuNT, C. M., POWEll, F. J., LiU, S. T., BSS97.

HUNT, J. W., SP488, pp. $45-46$ (Aug. 1977).

HUNTER, C., 16968.

Hunter, C., Tremaine, S., 16989.

Hurley, C. W., Kreider, K. G., 16901.

Hurley, C. W., Ryan, J. D., Obright, W., Rippey, W., HEBRANK, J., NBSIR 77-1243.

HusT, J. G., 16877.

Hust, J. G., Giarratano, P. J., 16878.

Hutchings, B. W., SP488, pp. 65-67 (Aug. 1977).

Hutchinson, J. M. R., Unterweger, M. P., Coursey, B. M., 16975.

HUYNH, V. D., SP493, pp. 244-249 (Oct. 1977).

Hyland, R. W., Heydemann, P. L. M., Tilford, C. R., 17269.

HYODO, T., SP461, pp. 1 10-1 18 (Jan. 1977). 
ICHIHARA, K., Kuribayashi, E., Tazaki, T., Sl'477, pp. VI69-VI-84 (May 1977).

IGNATIEFF, W. Z., Sl463, pp. V.1.1-V.1.6 (Jan. 1977).

IIDa, Y., KaWaKami, K., Kuribayashi, E., IWasaki, T., SP470, pp. VIII-1-VIII-30 (Apr. 1977).

IMAM, M. A., Gilmore, C. M., Fraker, A. C., 17187

INABA, S., Sl'470, pp. VII-1-VII-6 (Apr. 1977).

INABA, S., SP477, pp. VI-37-VI-43 (May 1977).

INABA, S., KinOSHITA, S., SP477, pp. VI-50-VI-60 (May 1977).

INTERRANTE, C. G., 16716.

INTERrante, C. G., Early, J. G., 16717.

Interrante, C. G., Early, J. G., Нicho, G. E., 16715.

INTERRANTE, C. G., Нicho, G. E., 16700.

INTERRANTE, C. G., Нicho, G. E., 16720.

Interrante, C. G., Hicho, G. E., Harne, D. E., 16719.

IRWIN, L. K., SP484, pp. 895-920 (Oct. 1977).

IRWIN, L. K., SP484, Volumes $l$ and 2.

ISBELL, F., WESTIN, A. F., SP469.

ISENBERG, J., Hegemier, G. A., ANVAR, A., BSSI06, pp. 154. 165 (Sept. 1977).

Ishihara, S., Douglas, T. B., Ditmars, D. A., Cezairliyan, A., SP260-55.

IsHil, K., KuSUDA, T., BSS96.

ISHIYAMA, Y., OZAK1, M., SP477, pp. VI-10-VI-27 (May 1977).

ISLeR, M., STEnbakKen, G., 17002

ISSAQ, H. J., SP464, pp. 497-500 (Nov. 1977).

Iverson, W. P., Bellama, J. M., Brinckman, F. E., Parris, G. E., Blair, W. R., JeWETt, K. L., 17155 .

Iverson, W. P., Brinckman, F. E., Blair, W. R., Jewet, K L., 17297

Iverson, W. P., Gerhold, W. F., Sanderson, B. T., Alumbaugh, R. L., Escalante, E., Monogr. 158.

IVES, L. K., 17274

IVES, L. K., RUfF, A. W., Young, J. P., 17300.

IVES, L. K., Young, J. P., RufF, A. W., SP468, pp. 145-157 (Apr. 1977).

IWASAKı, T., IIDa, Y., KaWaKaMi, K., KURIBayashi, E., SP470, pp. VIII-1-VIII-30 (Apr. 1977).

IWASAKI, T., TATSUOKa, F., SP477, pp. VI-158-VI-178 (May 1977).

IWaSaki, T., Wakabayashi, S., Tatsuoka, F., SP477, pp. III41-III-56 (May 1977).

IYENGAR, P. K., SP461, pp. $32-40$ (Jan. 1977).

Izatt, R. M., Hansen, L. D., Eatough, D. J., Mangelson, N F., SP464, pp. 637-642 (Nov. 1977).

Izatt, R. M., Mangelson, N. F., Eatough, D. J., Hansen, L. D., SP464, pp. 643-649 (Nov. 1977).

\section{J}

Jacobs, M., WaShburn, S. A., SP467.

JAFFEY, A. H., SP493, pp. 206-211 (Oct. 1977).

JaIN, V. K., KathURIA, S. P., SP46I, pp. 227-230 (Jan. 1977)

Jain, V. K., Kathuria, S. P., Bapat, V. N., Sunta, C. M., SP461, pp. 222-226 (Jan. 1977).

JAKowatz, C. V., JR., Linzer, M., KaK, A. C., 16937.

JAMBA, D. M., SP400-39.

JAMES, G. D., SP493, pp. $319-328$ (Oct. 1977).

Janghorbani, M., Ellinger, M., Starke, K., SP464, pp. 151 156 (Nov. 1977).

Janz, G. J., Tomkins, R. P. T., Allen, C. B., Downey, J. R., JR., SINGER, S. K., JPCRD 6, No. 2, 409-596 (1977).

Jarrett, R. D., Humphreys, J. C., Chappell, S. E., McLaughlin, W. L., 16999.

Jarvis, S., Jr., Glaze, D. J., Hellwig, H., Allan, D. W., 16775 .
Jarvis, S., JR., Winfland, D. J., Allan, D. W., Glaze, D. J., HELlWIG, H. W., 16759.

JASON, N. H., NBSIR 77-1264.

JASON, N. H., NBSIR 77-1277.

Jenkins, E. B., Snow, T. P., Upson, W. L., Starrfield, S. G., Gallagher, J. S., Friedjung, M., Linsky, J. L., Anderson, R., HenRy, R. C., MoOS, H. W., 16762.

Jennings, D. A., Mucha, J. A., Radford, H. E., Peterson, F. R., 16867

Jennings, D. A., Petersen, F. R., Mucha, J. A., Jimenez, J. J., Charlton, R. M., Howard, C. J., Evenson, K. M., 17073.

Jennings, D. A., Petersen, F. R., Wells, J. S., Evenson, K. M., 17336 .

Jennings, P. J., Painter, G. S., Jones, R. O., SP475, pp. 136149 (Apr. 1977).

JENNINGS, R., SP484, pp. 821-846 (Oct. 1977).

Jennings, S. J., Bannister, R. L., Osborne, R. L., SP494, pp. 97-116 (Sept. 1977).

JENSEN, T., SP47I, pp. 84-89 (June 1977).

JESCH, R. L., 16722.

Jesch, R. L., Bailey, R. A., TAusch, H. J., 17239.

Jespersen, J., Fitz-RandolPh, J., Monogr. 155.

Jesperson, J., Kamas, G., Blair, B., 16947.

Jewett, K. L., Brinckman, F. E., Bellama, J. M., 17008.

Jewett, K. L., Doody, J. E., Durst, R. A., Brinckman, F. E., SP464, pp. 473-483 (Nov. 1977).

Jewett, K. L., Iverson, W. P., Bellama, J. M., Brinckman, F. E., Parris, G. E., Blair, W. R., 17155.

Jewett, K. L., Iverson, W. P., Brinckman, F. E., Blair, W. R., 17297.

Jimenez, J. J., Charlton, R. M., Howard, C. J., Evenson, K. M., Jennings, D. A., Petersen, F. R., Mucha, J. A., 17073.

Joel, L. S., Shier, D. R., Stein, M. L., 17117 .

JohanNesen, R. B., Siedle, A. R., 17154.

JoHN, K., GOPINATH, D. V., SP46I, pp. 174-176 (Jan. 1977).

JOHNSEN, S. W., NBSIR 77-1279, pp. $15-18$ (July 1977).

JoHNSON, C. R., J. Res. 82, No. 2, 133-136 (1977).

JoHNSON, C. R., 16676.

JOHNSON, C. R., 16755.

JOHNSON, C. R., 16819 .

JOHNSON, C. R., 16836.

JOHNSON, C. R., 16909.

Johnson, D. R., BUhl, D., SNyder, L. E., Lovas, F. J., 16664.

JohnSON, D. R., LaFFerTy, W. J., SuenRam, R. D., 16689.

Johnson, D. R., Lovas, F. J., Gottlieb, C. A., Gottlieb, E. W., Litvak, M. M., Guelin, M., Thaddeus, P., 17264.

Johnson, D. R., Lovas, F. J., Zuckerman, B., Turner, B. E., Palmer, P., Gilmore, W., Morris, M., 16969.

Johnson, E., Birks, L., Gilfrich, J., Whitlock, R., Fatemi, M., SP464, pp. 189-190 (Nov. 1977).

JoHNSON, E. W., SP47I, pp. 23-24 (June 1977).

JOHNSON, H., HOCKEY, B. J., WIEDERHORN, S. M., NBSIR 77 1396.

JOHNSON, H. K., SP47I, pp. 29-43 (June 1977).

Johnson, K. H., Messmer, R. P., Tucker, C. W., JR., SP475, pp. 174-177 (Apr. 1977).

JOHNSON, L. A., SPSO0-18, pp. $75-83$ (Sept. 1977).

Johnson, S. A., Greenleaf, J. F., Tanaka, M., Flandro, G., SP484, pp. 335-359 (Oct. 1977).

JoHNSON, W. G., SP482, pp. 11-23 (July 1977).

Johnston, L. C., Grot, R. A., HARrJe, D. T., 16902.

JONEJA, O. P., SP461, pp. 252-254 (Jan. 1977).

Joneja, O. P., Srikantalah, R. V., Phiske, M. R., Coachman, J. S., Navalkar, M. P., SP493, pp. 61-66 (Oct. 1977).

Jones, E. C., JR., FaGG, L. W., Maruyama, X. K., Lightbody, J. W., JR., Fivozinsky, S. P., Lindgren, R. A., Bendel, W. L., 16687.

JONES, F. E., NBSIR 76-1 108.

JONES, F. E., NBSIR 77-1278. 
Jones, M. C., ArP, V. D., Parrish, W. R., Daney, D. E., Ludtke, P. R., Frederick, N. V., HaNds, B. A., NBSIR 77. 853.

Jones, M. C., DANey, D. E., LUdTKe, P. R., 17078.

Jones, M. C., Yeroshenko, V. M., Giarratano, P. J., ArP, V. D., YASKIN, L. A., 17333.

Jones, R. O., Jennings, P. J., Painter, G. S., SP475, pp. $136-$ 149 (Apr. 1977).

Jordan, T. H., MATHEW, M., Schroeder, L. W., 17095.

Jordan, T. H., Schroeder, L. W., Dickens, B., Brown, W. E., 16741.

Joshi, A., Madey, T. E., Wagner, C. D., 16930.

JoY, D. C., NeWbURY, D. E., 16839.

JOYNER, W. B., SP477, pp. IV-18-IV-46 (May 1977).

JUDD, D. B., KELlY, K. L., SP440.

JUHASZ, A. A., SP480-26.

Julienne, P., Stevens, W. J., Gardner, M., Karo, A., 17195.

JULIENNE, P: S., 17254.

Julienne, P. S., Krauss, M., 17069.

Justin Kim, S., Hung, H., STIEfel, S. W., NBSIR 77-1212.

\section{$\mathbf{K}$}

KabEL, R. H., SP488, pp. 73-75 (Aug. 1977).

KaCZMAREK, T. D., SP464, pp. $91-96$ (Nov. 1977).

Kahan, D. J., Carter, G. C., BennetT, L. H., 17093.

KAHLES, J. F., SP463, pp. IV.5.1-IV.5.8 (Jan. 1977).

KAHN, A. H., 17030.

Kahn, A. H., Spal, R., Feldman, A., 17261.

KAHN, F. D., 17217.

KaK, A. C., JAKowatz, C. V., JR., Linzer, M., 16937.

KaMAS, G., TN695.

Kamas, G., Blair, B., Jesperson, J., 16947.

KAMPER, R. A., NBSIR 75-936.

KAMPER, R. A., 16861 .

KANDA, M., NBSIR 77-861.

KANDA, M., NBSIR 77-868.

KANDA, M., 16669.

Kane, P. P., Hooton, B. W., Freeman, J. M., SP46I, pp. 136 139 (Jan. 1977).

Kane, P. P., Prasad, P. N. B., Basavarau, G., SP461, pp. 67-69 (Jan. 1977).

KAPIL, S. K., SP461, pp. 91 -93 (Jan. 1977).

Kaplan, K., Gabrielsen, B. L., BSS106, pp. 283-313 (Sèpt. 1977).

KaPSCH, R., KRAMER, S., NBSIR 77-1233.

KAPSCH, R. J., SP473, pp. 437-452 (June 1977).

Kardos, G., SP487, pp. $121-134$ (Aug. 1977).

Karo, A., Julienne, P., Ste vens, W. J., Gardner, M., 17195.

Kasen, M. B., Schramm, R. E., 16865.

Kashiwagi, T., Den Braven, K., Harkleroad, M., Raines, J., RINKINEN, W., Quintiere, J., MCCAFFrey, B., NBSIR 771318 .

Kathuria, S. P., Bapat, V. N., Sunta, C. M., Jain, V. K., SP461, pp. 222-226 (Jan. 1977).

Kathuria, S. P., Jain, V. K., SP461, pp. 227-230 (Jan. 1977).

KatZ, R., ShaRma, S. C., SP461, pp. 183-187 (Jan. 1977).

KatZenstein, W., SP488, pp. 39-40 (Aug. 1977).

Katzer, J., Park, R., Rhodin, T., Yates, J. T., Haller, G., $S P 475$, p. 13 (Apr. 1977).

Katzke, S., Branstad, D., Gait, J., NBSIR 77-1291.

KaUfMaN, H. B., SP488, pp. 101-102 (Aug. 1977).

KaWaKami, K., KURIbaYashi, E., IwaSaki, T., IIDA, Y., SP470, pp. VIII-1 - VIII-30 (Apr. 1977).

Kawakami, K., OKUbo, T., Komada, K., Okahara, M., SP470, pp. VII-7-VII-60 (Apr. 1977).

Kawasaki, I., Kuribayashi, E., SP470, pp. VIII-31-VIII-41 (Apr. 1977).

Kawashima, K., Penzien, J., Godden, W. G., Chen, M. C., Williams, D., SP477, pp. VI-1 -VI-9 (May 1977).
KAYE, B. H., SP464, pp. $519-526$ (Nov. 1977).

Kayser, R., Jr., Bennett, H. S., J. Res. 81A Nos. 2 and 3, 257-266 (1977).

KAYSER, R., JR., BENNETT, H. S., J. Res. 82, No. 3, 183-195 (1977).

Kazi, A. H., McGarry, E. D., Gilliam, D. M., SP493, pp. 335 341 (Oct. 1977).

KEARNS, R. W., WARD, J. F., NBSIR 76-1174.

KEARNS, R. W., WARD, J. F., NBSIR 76-1175.

KEARNS, R. W., WARD, J. F., NBSIR 77-1213.

Keating, J. P., Loftus, E. F., NBS-GCR-77-102.

KeERY, W. J., Devaney, J. R., Leedy, K. O., SP400-35.

KeERy, W. J., Galloway, K. F., Leedy, K. O., 16971.

Kell, G. S., JPCRD 6, No. 4, 1109-1132 (1977).

Kelleher, D. E., Wiese, W. L., Helbig, V., 17204.

Keller, J., Almer, H. W., NBSIR 76-999.

Keller, R. A., Ritter, J. J., Lamotte, M., Dewey, H. J., U.S. Patent 4,025,406

Keller, R. A., Schenck, P. K., Travis, J. C., Luther, G. G., GreEN, R. B., 16691 .

Kelley, R. D., Klein, R., 16966.

Kelley, R. D., Madey, T. E., Yates, J. T., JR., 17207.

Kelly, G. E., BeAN, J., BSS93.

Kelly, G. E., Parken, W. H., Jr., Beausoliel, R. W., 17006.

Kelly, G. E., Peavy, B. A., Hill, J. E., 17347.

KELLY, K. L., JudD, D. B., SP440.

Kelly, M. P., Schlamp, R. J., SP487, pp. $210-238$ (Aug 1977).

Kempf, D., Phillips, R. E., Morgan, W. H., SP484, pp. 361 394 (Oct. 1977).

KEMPLE, M. D., 16954.

KeRN, W., Comizzoli, R. B., SP400-31.

Kerschner, P. M., HAIN, G. M., SP464, pp. 259-261 (Nov. 1977).

Khayrallah, G. A., Smith, S. J., 17054

Khoury, F., Colson, J. P., Bolz, L. H., Anderson, W. E., DAVIS, R. S., MOPSIK, F. I., KRYDER, S. J., 17014.

Khoury, F., Passaglia, E., 16958

Kidnay, A. J., Hiza, M. J., Miller, R. C., 16881 .

Kilday, M. V., Cases, J. C., Parker, V. B., J. Res. 82, No. 1, 19-28 (1977).

Kildeberg, P., Engel, K., SP450, pp. 133-141 (June 1977).

KilPatrick, S., Fite, R. A., SP480-24, pp. 75-106 (Nov. 1977).

KIMBLETON, S. R., 17025

Kimbleton, S. R., MAMraK, S. A., 16948.

Kimmich, H. P., Kreuzer, F., SP450, pp. 235-238 (June 1977).

Kindlmann, P. J., Stafford, R. G., Chang, R. K., SP464, pp. 659-667 (Nov. 1977).

KING, D. E., SP464, pp. 581-596 (Nov. 1977).

King, D. S., Schenck, P. K., Smyth, K. C., Travis, J. C., 17287.

Kinoshita, S., INABA, S., SP477, pp. VI-50-VI-60 (May 1977).

Kirchhoff, R. H., Delisi, D. P., SP484, pp. 783-802 (Oct. 1977).

KIRCHHOFF, W. H., SP464.

Kirklin, D. R., Ritter, J. J., Abramowitz, S., 17166.

Kirsch, R., Nagel, R. N., EvanS, J. M., JR., SP500-8.

KirSCH, R. A., GRAMINSKI, E. L., 17214 .

KIRTHI, K. N., SARKar, P. K., SP461, pp. 247-251 (Jan. 1977).

Kitagawa, Y., Santo, T., Hattori, S., SP470, pp. III-1-III-17 (Apr. 1977)

Kitchen, W. J., JR., Brown, T. H., SP400-42, pp. 9-12 (Aug. 1977).

Klaus, P., Bergman, S., Bunten, E., SP480-5.

Klaus, P., Bunten, E., SP480-3.

Klaus, P., Bunten, E., Cunitz, R., Mumford, S., SP480-2.

Klaus, P., Ku, R., Bunten, E., SP480-I.

Klaus, P. A., Bunten, E. D., SP480-7.

Klaus, P. A., Bunten, E. D., Hare, G. B., SP480-6. 
Klaus, P. A., Eldreth, J. L., Bunten, E. D., SP480 4 .

Klebanoff, P. S., Frenkiel, F. N., 16820.

Klebanoff, P. S., MCMichael, J. M., 16821.

KLEEMAN, W., JR., ReEves, R., SP473, pp. 55-67 (June 1977).

Klein, M., Wardell, J., Wilmot, G., HaAr, L., Powell, G., 17136.

Klein, R., Kelley, R. D., 16966.

KIEIN, R., JR., HACH, C., SP464, PP. 61-66 (Nov. 1977).

KiIment, S., Raufaste, N. J., Marshall, R. D., NBSIR 77. 1197.

KLIMENT, S. A:, BSS100-5.

KLIMENT, S. A., SP476.

Kliment, S. A., Marshall, R. D., Raufaste, N. J., JR., BSS100-1.

Kine, F. J., Peterson, G. A., Lightbody, J. W., JR., Maruyama, X. K., Penner, S., Szalata, Z. M., Finn, J. M., Flanz, J., 16850.

KLOSE, J. Z., VoIGHT, P. A., 17292.

Kneebone, C. H., Brennan, J. A., LaBrecQue, J. F., 17162.

KNITTER, H. H., SP493, pp. 3-9 (Oct. 1977).

KNoll, G. F., SP493, pp. 304-3 10 (Oct. 1977).

KNOLl, J. E., MIDGETT, M. R., SChEIL, G. W., SP464, pp. $575-$ 579 (Nov. 1977).

Kobayashi, K., Chrien, R. E., Liou, H. I., Block, R. C., SINGH, U. N., SP493, pp. 255-260 (Oct. 1977).

Koenig, A. L., MoORE, R. T., Carpenter, R. J., NBSIR 77. 1262.

Koenig, H. L., O'Brien, J. F., Skridulis, J., ANNETt, J., Singley, G. W., SP484, pp. 145-172 (Oct. 1977).

KOFFEnd, J. B., Field, R. W., GuYer, D. R., LeONE, S. R., 17318 .

KoGa, Y., SAWAdA, K., SP470, pp. V-16-V-35 (Apr. 1977).

KOIZUMI, Y., YAMAZAKI, Y., SP470, pp. VI-1-VI-21 (Apr. 1977).

Komada, K., Okahara, M., Kawakam, K., OKubo, T., SP470, pp. VII-7-VII-60 (Apr. 1977).

KOMAREK, E. L., 17234.

KONDIC, N. N., SP484, pp. $765-782$ (Oct. 1977 ).

Konjević N., WIESE, W. L., 17206.

KoOn, N. C., Milstein, J. B., Alperin, H. A., Rhyne, J. J., 16963.

KORNBLITH, R. L., VOIGT, P. A., 16992.

Kosanić, M. M., Nenadović, M. T., Radak, B. B., Marković, V. M., MCLaughlin, W. L., 16984.

KOSNIK, K. G., LEONE, S. R., 17129.

KostKowski, H. J., NBSIR 75-939.

Kostochikin, O. I., Kudriavzev, G. Y., Malkin, L. Z., Petrzhak, K. A., Pleskachevsky, L. A., Fomichev, A. V., Shapakov, V. I., Adamov, V. M., Alexandrov, B. M., AlKhazov, I. D., Drapchinsky, L. V., Kovalenko, S. S., SP493, Pp. 313-318 (Oct. 1977).

KOTHARI, L. S., SP461, pp. 149-162 (Jan. 1977).

Kovalenko, S. S., Kostochkin, O. I., KudRiavzev, G. Y., Malkin, L. Z., Petrzhak, K. A., Pleskachevsky, L. A., Fomichev, A. V., Shapakov, V. I., Adamov, V. M., AlexanDROV, B. M., AlKhiazov, I. D., DRAPChINSKY, L. V., SP493, pp. 313-318 (Oct. 1977).

KOWALSKI, J. G., BSS100-4.

Koyama, R. Y., OetTinger, F. F., Rogers, G. J., Blackburn, D. L., 17345.

Koyama, R. Y., OetTinger, F. F., Rogers, G. J., Blackburn, D. L., NBSIR 77-1249.

Koyanagi, R. S., Pollard, J. D., Ramboz, J. D., NBSIR 73 291.

Kozuchowski, J., Basu, D. K., Saxena, J., SP464, pp. 101-104 (Nov. 1977).

Kramer, J., Meguire, P., SP480-24, pp. $107-113$ (Nov. 1977). KRAMER, J. J., SP480-24.

Kramer, J. J., MEgUIRE, P. G., NBSIR 76-1092.

Kramer, J. J., Stewart, A., Meguire, P. G., SP480-27.
KRAMER, S., KAPSCH, R., NBSIR 77-1233.

Kranbuehl, D. E., Verdier, P. H., 17125.

Krasny, J. F., Braun, E., Peacock, R., Williams, N., ZAWISTOWSKI, E. A., NBSIR 77-1236.

Krasny, J. F., PEACOCK, R. D., 16813.

KRASNY, M. A., SP500-15.

Krause, R. F., JR., Douglas, T. B., 17075.

KRAUSS, M., 17151 .

Krauss, M., JulienNe, P. S., 17069.

KRAUSS, M., LiU, B., 16684.

Krauss, M., Stevens, W. J., 17188.

Kreider, K. G., HURLEY, C. W., 16901.

KREIDER, K. G., MCNEIL, M. B., H121.

Kreuger, J. A., MAas, A. H. J., Visser, B. F., Hoelen, A. J., SP45O, PP. 73-74 (June 1977).

Kreuzer, F., Kimmich, H. P., SP450, pp. 235-238 (June 1977).

Kreuzer, F., van KeMPEN, L. H. J., SP450, pp. 239-246 (June 1977).

Krinitzsky, E. L., Chang, F. K., SP477, pp. VI-179-VI-191 (May 1977).

Krishnamoorthy, G., NunN, R. O., Hegemier, G. A., BSSI06, pp. 114-153 (Sept. 1977).

Kritsotakis, K., TObSchall, H. J., Lawkowski, N., SP464, pp. 459.460 (Nov. 1977).

KRUGER, J., SP479, pp. 59-65 (July 1977).

Kruger, J., AMbrose, J. R., NBSIR 76-1 170.

KRUGer, J., AMBrose, J. R., 16990.

Kruger, J., Bertocci, U., Escalante, E., Mullen, J. L., NBSIR 77-1232.

Kruger, J., Pickelsimer, M. L., Ogburn, F., Passaglia, E., BURNETT, H. C., SP479, Pp. 167-178 (July 1977).

Kruger, J., Pourbaix, M., Brown, B. F., Burnett, H. C., Chase, W. T., GoOdWay, M., SP479.

Krupenie, P. H., Lofthus, A., JPCRD 6, No. 1, 113-307 (1977).

Kryder, S. J., Khoury, F., Colson, J. P., Bolz, L. H., ANderSON, W. E., Davis, R. S., Morsik, F. I., 17014.

Ku, R., Bunten, E., KLAUS, P., SP480-1.

KU, R. T., HiNKLEY, E. D., SP464, Pp. 291-294 (Nov. 1977).

Kubiczex, E. B., Robinson, J. E., Harrison, G. H., Cox, C. R., NBSIR 77-1279, Pp. 19-23 (July 1977).

KüOTA, T., ZuKosia, E. E., VeldMan, C. C., NBS-GCR-77-97.

KucZer, P., HOOK, H. O., GOOdMaN, A. M., SP400-41.

KudRaveTZ, G. K., SP463, pp. VII.3.1-VII.3.5 (Jan. 1977).

Kudriavzev, G. Y., Malkin, L. Z., PetrzhaK, K. A., Pleskachevsky, L. A., Fomichev, A. V., Shapakov, V. I., Adamov, V. M., Alexandrov, B. M., Alkhazov, I. D., Drapchinsky, L. V., Kovalenko, S. S., Kostochikin, O. I., SP493, pp. 313-318 (Oct. 1977).

KuHN, G. F., 17052.

KUHN, G. F., BURNETT. E. D., 17064.

KuhNS, J. L., TRefftzs, J. L., Montgomery, C. A., MoOre, G. B., SP5OO-2.

Kuklewicz, M. E., Hebrank, J. H., Coble, J. B., NBSIR 77 1207.

Kuklewicz, M. E., Phillips, C. W., Peavy, B. A., NBSiR 761178.

Kutin, G., SP484, pp. 123-144 (Oct. 1977).

Kullmann, C. G., TableR, J. H., SP484, pp. 25-32 (Oct. 1977).

Kumar, A., Garg, S. B., SP461, pp. 70-73 (Jan. 1977).

KuniHRo, T., YaHAGI, K., OKaHARA, M., SP477, pP. VI118 -VI-140 (May 1977).

Kunselman, G., Ronan, R. J., SP464, pp. 107-111 (Nov. 1977).

Kuppermann, A., DWyer, J., Truhlar, D. G., 16914.

Kurata, E., Hayashi, S., Tsuchida, H., SP477, pp. III-16-III25 (May 1977).

Kuribayashi, E., Iwasaki, T., Ihda, Y., Kawakami, K., SP470, pp. VIII-1-VIII-30 (Apr. 1977). 
Kuribayashi, E., KaWASAKI, I., SP470, pp. VIII-31-VIII-41 (Apr. 1977).

KuRIBayashi, E., Tatsuoka, F., SP470, pp. V-1-V-15 (Apr. 1977).

Kuribayashi, E., TAZaKI, T., ICHIHARA, K., SP477, pp. VI69-VI-84 (May 1977).

Kuribayashi, E., Tazaku, T., Hadate, T., SP477, pp. IV1-IV-17 (May 1977).

KurIBAyaShI, E., Tsuchida, H., SP470, pp. VIII-56-VIII-68 (Apr. 1977).

Kuribayashi, E., Tsuchida, H., Watabe, M., SP470, pp. IV1-IV-34 (Apr. 1977).

KuRIHARA, T. M., SP500-15, pp. 22-25 (July 1977).

Kuriy ama, M., Boettinger, W. J., Burdette, H. E., 16974.

Kurtyama, M., Boettinger, W. J., Burdette, H. E., Farabaugh, E. N., 16977.

Kuriyama, M., Boettinger, W. J., Burdette, H. E., 16997.

Kuriyama, M., BoetTinger, W. J., BuRdeTte, H. E., 17277.

KuruCZ, R. L., AYReS, T. R., LINSKY, J. L., RODGERS, A. W., 16809.

KURYLO, M. J., 17149.

KuRYLo, M. J., GarVin, D., Hampson, R. F., 16976.

KuRYLO, M. J., MANNING, R. G., 16785.

KuS, S., MANESS, J. H., SP400-42, pp. 19-20 (Aug. 1977).

KusCh, P., Hessel, M. M., 17101.

KUSHNER, D. J., RAMAMOORTHY, S., SP464, pp. 467-471 (Nov. 1977).

KusUdA, T., J. Res. 82, No. 2, 97-106 (1977).

KUSUDA, T., 16770.

KUSUDA, T., 17341.

KUSUDA, T., BEAN, J. W., NBSIR 76-1088.

Kusuda, T., Blum, D. G., BuRCH, D. M., TN933.

KuSUdA, T., BurCH, D. M., 17335.

Kusuda, T., Ellis, W., 17340.

KUSUDA, T., ISHII, K., BSS96.

\section{$\mathbf{L}$}

LaBrecque, J. F., Kneebone, C. H., Brennan, J. A., 17162.

LaBrecque, J. F., Siegwarth, J. D., Younglove, B. A., TN697.

LaBrecque, J. F., Siegwarth, J. D., Younglove, B. A., TN698.

LACHKAR, J. C., SP493, pp. 93-100 (Oct. 1977).

LADENSON, J. H., SP450, pp. 175-190 (June 1977).

LAFFERTY, W. J., SAMS, R. L., 17123.

LAFFERTY, W. J., SUENRAM, R. D., JOHNSON, D. R., 16689.

LAING, P. G., SP472, p. 1 (Apr. 1977).

LAING, P. G., SP472, pp. 31-38 (Apr. 1977).

Lam, L. K., Gallagher, A., Hessel, M. M., 16912.

LAMAZE, G. P., SP493, pp. 37-42 (Oct. 1977).

LAMBropoulos, M., MOOdY, S. E., 16789.

LAMBropoulos, M., MOODY, S. E., 16925.

Lamotte, M., Dewey, H. J., KelleR, R. A., Ritter, J. J., U.S. Patent 4,025,406.

lampton, M., Paresce, F., Margon, B., Stern, R., Haisch, B. M., LINSKY, J. L., 16933.

LANASA, P. J., SP484, pp. 871-880 (Oct. 1977).

LANDERS, R. R., SP487, pp. 278-288 (Aug. 1977).

Landvater, J. H., Perkins, M., SP471, pp. 69-76 (June 1977).

LANE, N. F., Collins, L. A., 16674.

Lane, N. F., Collins, L. A., Morrison, M. A., 17026.

Lane, N. F., Morrison, M. A., Collins, L. A., 16682.

LANE, N. F., WiSDOM, J., HARTQUIST, T. W., 16818.

LANG, G. F., SP494, pp. 79-81 (Sept. 1977).

Langhoff, P. W., Corcoran, C. T., 16849.

Langhoff, P. W., Corcoran, C. T., Sims, J. S., 17319.

Langhoff, P. W., Hernandez, A. J., 17317.

LAPIDES, M. E., SP468, pp. 27-39 (Apr. 1977).

Lapinski, N. P., Ellingson, W. A., Stanton, G. C., SP468, pp. 172-181 (Apr. 1977).
LARSEN, N. T., NBSIR 77-866.

LARSEN, N. T., 16723.

Larsen, N. T., Reeve, G. R., U.S. Patent 4,008,610.

LAUfER, A. H., BASS, A. M., 16838.

LAUFFENBURGER, H. A., SP400-42, pp. 20-22 (Aug. 1977).

LaUritzen, J. I., JR., HoffMan, J. D., Davis, G. T., 16887.

Laver, M. B., Buckles, R. G., Heitmann, H., SP450, pp. 207. 225 (June 1977).

LAVER, M. B., Misiano, D. R., SP450, pp. 201-206 (June 1977).

Law, S. L., Campbell, W. J., MarR, H. E. III., SP464, pp. $157-$ 161 (Nov. 1977).

Lawkowski, N., Kritsotakis, K., Tobschall, H. J., SP464, pp. 459-460 (Nov. 1977).

Lawless, W. N., Morrow, A. J., Radebaugh, R., Siegwarth, J. D., NBSIR 76-847.

LaWn, B. R., Fuller, E. R., Wiederhorn, S. M., 16672.

Lawrence, G. M., Fairchild, C. E., Stone, E. J., 16812.

LAWSON, J. R., NBSIR 77-1265.

LAWTON, R. A., ANDREWS, J. R., 16661.

Lawton, S. A., Novick, S. E., Brotda, H. P., Phelps, A. V., 16765.

Leasure, W. A., Jr., Rubin, A. I., Cadoff, M. A., Flynn, D. R., H122.

LEDBETTER, H. M., JPCRD 6, No. 4, $1181-1204$ (1977).

LEDBETTER, H. M., 16880.

LEDBETTER, H. M., 17094.

LEDBETTER, H. M., 17099.

LEDBETTER, H. M., 17320.

LEDBETTER, H. M., 17321.

Ledbetrer, H. M., Naimon, E. R., Weston, W. F., 16869.

LEDBETTER, H. M., READ, D. T., 17068.

LeDbeTter, H. M., ReAD, D. T., 17085.

LEDBETTER, H. M., READ, D. T., 17087.

LeDERER, C. C., BSS106, pp. 243-248 (Sept. 1977).

LEDERER, P. S., 16941.

Lederer, P. S., Hilten, J. S., Vezzetti, C. F., Mayo-Wells, J. F., TN961.

LEDFord, A. E., JR., Braun, W., 16895.

LeDFORD, A. E., JR., WhITTAKer, J. K., BASS, A. M., SP464, pp. 9-13 (Nov. 1977).

Lee, B. T., Parker, W. J., 17059.

Lee, C. G., Montalvo, J. G., JR., SP464, pp. 97-100 (Nov. 1977).

LEE, H. P., SP487, Pp. $62-81$ (Aug. 1977).

LeE, L. H., Childers, C. B., Dziuba, R. F., 16713.

LeE, M. L., BurRell, D., SP464, pp. $461-465$ (Nov. 1977).

LeE, S. A., Hall, J. L., 17338.

Lee, S. A., Hall, J. L., Bergquist, J. C., 16776.

Lee, S. A., Hall, J. L., Bergquist, J. C., 17337.

LEE, T. G., NBSIR 77-1222.

LeE, T. G., Baum, H. R., Mulholland, G. W., 17282.

LeE, T. G. K., Mulholland, G., NBSIR 77-1312.

LeE, T. Y., Ho, C. Y., Desai, P. D., WU, K. Y., Havill, T. N., NBS-GCR-77-83.

LEEDY, K. O., NBSIR 77-1231.

LEEDY, K. O., 16891.

Leedy, K. O., Keery, W. J., DeVaney, J. R., SP400-35.

LeEdy, K. O., Keery, W. J., Galloway, K. F., 16971.

Leedy, T. F., MATtIS, R. L., RuSSEll, T. J., 17330.

Leedy, T. F., Mayo, S., Galloway, K. F., 16889.

Lehman, D. R., O'Connell, J. S., Heimbach, C. R., 16793.

LEIGHT, W. G., 16890.

LEMMEL, H. D., SP493, pp. 170-173 (Oct. 1977).

LEMON, T. R., SP472, pp. 73-79 (Apr. 1977).

LEON, R. L., SP494, pp. $117-120$ (Sept. 1977).

Leone, S. R., Bierbaum, V. M., Eluison, G. B., Futrell, J. H., 17209.

Leone, S. R., Koffend, J. B., Field, R. W., Guyer, D. R., 17318.

LEONE, S. R., KosNIK, K. G., 17129. 
Leong-Hong, B., Fife, D. W., HaRdy, I. T., SP500-14.

LEONG-HONG, B., MARRON, B., SPSO0-3.

LeONG-Hong, B., MARron, B., 16998.

Leong-Hong, B., Marron, B., 17280.

Lerup, L., Cronrath, D., LiU, J. K. C., NBS-GCR-77-93.

LETERLE, J. F., SP468, pp. 202-204 (Apr. 1977).

LeVin, I. W., Abramowitz, S., AcQuista, N., 17208.

LeVIN, I. W., Bernstein, L. S., Abramowitz, S., 16978.

Levine, H., Rosenstein, M., Mclaughlin, W. L., U.S. Patent $4,006,023$.

LEVINE, J., 17199.

LEVINE, J., 17226.

LEVINE, J., 17267.

LEVINE, J., BERGER, J., 17231.

LEVINE, J., FAller, J. E., 16896.

LeVINE, J., HaRRISON, J. C., 17196.

LEVY, J., NBSIR 77-1210.

LEW, H. S., SP470.

LEW, H. S., SP477.

LEWETT, G. P., 17108.

Lewis, D. C., SAWYer, D. E., Berning, D. W., 17164.

LEwIS, R., SP468, pp. 205-206 (Apr. 1977).

LEWIS, R. L., 17322.

LeYeNDECKER, E. V., EllingwOOd, B. R., BSS98.

LEYENDECKER, E. V., FATTAL, S. G., BSS94.

L, S. S., SP400-33.

LI, S. S., Thurber, W. R., 17147

Lias, S. G., Ausloos, P., 17057.

LIBMAN, A. S., WeIsS, R. G., 17323.

Libowitz, G. G., Maeland, A., Glinka, C. J., Rowe, J. M., RuSH, J. J., 16965.

LICHODZIEJESWKI, W., SP494, pp. 146-151 (Sept. 1977).

LIDE, D. R., JR., SP463, pp. VII.1.1-VII.1.15 (Jan. 1977).

LIDE, D. R., JR., 16837.

LIDE, D. R., JR., FivozInsKY, S. P., 17258.

LIGHT, J. C., 16955.

Lightbody, J. W., JR., FIVOZINSKY, S. P., LindGREN, R. A., Bendel, W. L., Jones, E. C., JR., Fagg, L. W., Maruyama, X. K., 16687 .

Lightrody, J. W., JR., Fivozinsky, S. P., Penner, S., NeuHAUSEN, R., 16982.

Lughtibody, J. W., Jr., Maruyama, X. K., Penner, S., Szalata, Z. M., Finn, J. M., Flanz, J., Kline, F. J., Peterson, G. A., 16850.

LIMPERIS, T., Nicodemus, F. E., Richmond, J. C., Hsia, J. J., Ginsberg, I. W., Monogr. 160.

Lin, J., Delisi, D. P., Robben, F. A., Liu, H., SP484, pp. 423447 (Oct. 1977).

LIN, S. L., BARDSLeY, J. N., 16779.

LIN, W. T. K., TonIK, A. B., SP500-18, pp. 213-217 (Sept. 1977).

LIND, M. A., 16,54 .

LIND, M. A., Fowler, I. B., TN958.

Lind, M. A., Schaefer, A. R., Zalewski, E: F., Geist, J., TN954.

LIND, M. A., ZalewSKI, E. F., FowleR, J. B., TN950.

LINDEN, T. A., 16918.

LINDEN, T. A., 16920.

LindGren, R. A., Bendel, W. L., Jones, E. C., JR., FAGG, L. W., Maruyama, X. K., Lighteody, J. W., JR., Fivozinsky, S. P., 16687.

Lingerak, W. A., van RaAphorst, J. G., Slanina, J., Borger, D., SP464, pp. 121-123 (Nov. 1977).

LINSKY, J. L., 17324.

Linsky, J. L., Amderson, R., Henry, R. C., MoOs, H. W., Jenkins, E. B., Snow, T. P., Upson, W. L., Starrfield, S. G., Gallagher, J. S., Friedjung, M., 16762.

Linsky, J. L., Basri, G. S., Maran, S. P., Hobbs, R. W., ChiU, H. Y., ADAMS, P. J., 16732.
Linsky, J. L., Lampton, M., Paresce, F., Margon, B., Stern, R., Haisch, B. M., 16933.

LinSKY, J. L., Rodgers, A. W., KuruCz, R. L., AYres, T. R., 16809.

LinSKY, J. L., WeINSTEIN, A., MoOS, H. W., 17310.

Linsky, J. L., Weinstein, A., Shine, R. A., Haisch, B. M., 17056.

Linzer, M., Evans, A. G., 17213.

Linzer, M., KaK, A. C., Jakowatz, C. V., JR., 16937.

Linzer, M., PARKS, S. I., 16735.

Liou, H. I., Block, R. C., Singh, U. N., Kobayashi, K., Chrien, R. E., SP493, pp. $255-260$ (Oct. 1977).

Liskien, H. O., Stewart, L., Bowman, C. D., Carlson, A. D., $S P 493$.

Little, J. L., Albus, J. S., Barbera, A. J., Fife, D. W., Fong, E. N., Gilsinn, D. E., Holberton, F. E., lucas, B. G., Lyon, G. E., Marron, B. A. S., NeumanN, A. J., Vickers, M. V., Walker, J. C., Evans, J. M., JR., O'Neill, J. T., NBSIR 76-1094.

Little, J. W., Hasegawa, S., J. Res. 81A No. 1, $81-88$ (1977).

Litvax, M. M., Guelin, M., Thaddeus, P., Johnson, D. R., Lovas, F. J., Gottlieb, C. A., Gottlieb, E. W., 17264.

LiU, B., Krauss, M., 16684.

LiU, H., LIN, J., Delisi, D. P., Robben, F. A., SP484, pp. 423 447 (Oct. 1977).

LiU, J. K. C., Lerup, L., Cronrath, D., NBS-GCR-77-93.

LIU, S. T., NBSIR 77-1287.

LIU, S. T., BARNETT, J. P., NBSIR 76-1177.

LiU, S. T., HuNt, C. M., Powell, F. J., BSS97.

Lloyd, L. R., LOWERY, R. P., TINGle, W. J., WOlFe, V. L., JR., Durbetak, P., TINCHER, W. C., NBS-GCR-77-99.

LOEVINGER, R., 17005.

LOFQUIST, K. E. B., 16917.

LoftuUs, A., KRUPENIE, P. H., JPCRD 6, No. 1, 113-307 (1977).

Loftus, E. F., KeAting, J. P., NBS-GCR-77-102.

LONE, M. A., NBSIR 77-1279, pp. 5-9 (July 1977).

Lone, M. A., Stewart, L., Carlson, A. D., Bowman, C. D., NBSIR 77-1279.

Long, N. J. T., Thrush, B. A., Hute, R. E., 16844.

LONG, N. J. T., Thrush, B. A., HuIE, R. E., 17238.

Long, W. T., Williams, R. L., Hoffman, J. R., SP468, pp. 41-48 (Apr. 1977).

LoOMis, J. L., BuskiRK, E. R., SP491, pp. $169-173$ (Sept. 1977).

Lorber, K., Heinrich, K. F. J., Pella, P. A., SP464, pp. 125 127 (Nov. 1977).

Lossing, F. P., Rosenstock, H. M., McCulloh, K. E., 17294.

LOTT, P. F., FOSTER, R. L., SP464, pp. 351-366 (Nov. 1977).

Lovas, F. J., Clark, F. O., 17189.

Lovas, F. J., Gottlieb, C. A., Gottuleb, E. W., Litvak, M. M., Guelin, M., Thaddeus, P., Johinson, D. R., 17264.

Lovas, F. J., Johnson, D. R., BuHL, D., SNYder, L. E., 16664.

Lovas, F. J., Pearson, R., JR., 16910.

Lovas, F. J., Zuckerman, B., Turner, B. E., Palmer, P., GilMORE, W., MORRIS, M., JOHNSON, D. R., 16969.

LOVEJOY, R. W., OLSON, W. B., 17131.

LOWELl, F. C., JR., SP484, pp. 243-266 (Oct. 1977).

Lowell, W. R., Flanigan, W. F., JR., Bowman, R. R., 17174.

LOWERY, R. P., Tingle, W. J., WOlfe, V. L., JR., DURBetaki, P., TINCHER, W. C., LLOYD, L. R., NBS-GCR-77-99.

LOWNIE, H. W., JR., HofFman, A. O., SP468, pp. 131-133 (Apr. 1977).

Lucas, B. G., Lyon, G. E., Marron, B. A. S., Neumann, A. J., Vickers, M. V.,; Walker, J. C., Evans, J. M., JR., O'Neill, J. T., Little, J. L., Albus, J. S., Barbera, A. J., Fife, D. W., Fong, E. N., Gilsinn, D. E., Holberton, F. E., NBSIR 76-1094.

Ludemann, C. A., Fulmer, C. B., Styles, R. C., Saltmarsh, M. J., NBSIR 77-1279, pp. 24-29 (July 1977). 
LudTKe, P. R., Frederick, N. V., Hands, B. A., Jones, M. C., ARP, V. D., PARrish, W. R., DANEY, D. E., NBSIR 77-853.

LudTKE, P. R., Jones, M. C., DANEY, D. E., 17078.

Luther, G. G., Green, R. B., Keller, R. A., Schenck, P. K., Travis, J. C., 16691 .

LUTZ, G. J., 16760.

LuTz, G. J., RoOK, H. L., Gills, T. E., SP492, pp. 20-22 (Nov. 1977).

LYNCH, J. F., MORAN, H. D., SP463, pp. IV.2.1-IV.2.7 (Jan. 1977).

Linnworth, L. C., Morel, P. R., Pedersen, N. E., Bradshaw, J. E., SP484, pp. 293-318 (Oct. 1977).

Lyon, G. E., Marron, B. A. S., Neumann, A. J., Vickers, M. V., Walker, J. C., Evans, J. M., JR., O'Neill, J. T., LitTle, J. L., Albus, J. S., Barbera, A. J., Fife, D. W., Fong, E. N., Gilsinn, D. E., Holberton, F. E., Lucas, B. G., NBSIR 76-1094.

LYTLE, F. W., SP475, pp. 34-41 (Apr. 1977).

\section{$\mathbf{M}$}

MAAS, A. H. J., SP450, pp. 195-200 (June 1977).

MaAs, A. H. J., VeefKind, A. H., VAN DEN CAMP, R. A. M., Teunissen, A. J., Boink, A. B. T. J., Ruigrok, T. J. C., SP450, Pp. 257-265 (June 1977).

MAAS, A. H. J., VISSER, B. F., SP450, pp. 69-72 (June 1977).

MAAS, A. H. J., VisSER, B. F., SP450, pp. $119-126$ (June 1977).

MaAs, A. H. J., Visser, B. F., Hoelen, A. J., Kreuger, J. A., SP450, pp. 73-74 (June 1977).

Mabie, C. P., 17325.

MAC NAB, A. J., SP468, pp. 195-198 (Apr. 1977).

MacDonald, R. A., Tsai, D. H., 16751.

MAClAS, E. S., SP464, pp. 179-188 (Nov. 1977).

MACKIE, R., SP480-24, pp. 43-56 (Nov. 1977).

MACLEAN, J. A., SP488, pp. 89-94 (Aug. 1977).

MAdDEN, R. P., Hughey, L. R., 16665.

Madey, T. E., Wagner, C. D., Joshi, A., 16930.

MADEY, T. E., YATES, J. T., JR., 16929.

MADEY, T. E., YATES, J. T., JR., 17349.

MAdEY, T. E., YATES, J. T., JR., KelleY, R. D., 17207.

MAECK, W. J., SP493, pp. 146-155 (Oct. 1977).

Maeland, A., Glinka, C. J., Rowe, J. M., Rush, J. J., LiBowTrz, G. G., 16965.

MAGrab, E. B., 16702.

Magrab, E. B., Penzes, W. B., Hruska, G. R., 16701.

Magrai, E. B., Penzes, W. B., Hruska, G. R., 17245.

Mahan, A. H., SMITH, S. J., 17326.

MatentHal, E. J., SP492, pp. 91-105 (Nov. 1977).

Matentthal, E. J., Becker, D. A., 16729.

Majahad, A. M., Muldoon, D. G., SP464, pp. 21-35 (Nov. 1977).

MAJUmdar, M., Mitra, B., SP461, pp. 57-59 (Jan. 1977).

MAKI, A. G., Freund, S. M., 17124.

Makx, A. G., SAms, R. L., Pearson, R., JR., 16823.

MAKRA, S., SP461, pp. 238-246 (Jan. 1977).

Malenfant, A. L., SP450, pp. 153-162 (June 1977).

Malenfant, A. L., Fallan, K. D., SP450, pp. 279-283 (June 1977).

MAlEY, R. P., SP470, pp. IV-35-IV-52 (Apr. 1977).

Malitson, I. H., DODGE, M. J., 16662.

Malkin, L. Z., Petrzhak, K. A., Pleskachevsky, L. A., Fomichev, A. V., Shapakov, V. I., Adamov, V. M., AlexanDRov, B. M., Alkhazov, I. D., Drapchinsky, L. V., Kovalenko, S. S., Kostochiein, O. I., Kudriavzev, G. Y., SP493, pp. 313-318 (Oct. 1977).

Maltezou, S. P., SP488, pp. 105-107 (Aug. 1977).

Mamane, Y., de Pena, R. G., SP464, pp. 327-334 (Nov. 1977).

Mamrak, S. A., Kimbleton, S. R., 16948.

MANDEL, J., 16858.
Maness, J. H., Kus, S., SP400-42, pp. 19-20 (Aug. 1977)

Mangelson, N. F., Eatough, D. J., Hansen, L. D., Izatt, R. M., SP464, pp. 643-649 (Nov. 1977).

Mangelson, N. F., Izatt, R. M., Hansen, L. D., Eatough, D. J., SP464, pp. 637-642 (Nov. 1977).

Manger, C. L., Moore, J. H., JR., Alexander, M. H., 17216.

Mangum, B. W., 17049.

Mangum, B. W., Hill, J. E., SP491.

Mangum, B. W., Hill, J. E., Benzinger, T. H., 16923.

Mangum, B. W., Thornton, D. D., SP481.

MANN, D. B., BrenNan, J. A., SP484, pp. $881-893$ (Oct. 1977).

ManN, J. B., RobB, W. D., Hayes, M. A., Norcross, D. W., 17132.

MANning, J. R., READ, M. E., Butrymowicz, D. B., JPCRD 6, No. 1, 1-50 (1977).

ManNing, R. G., KurYlo, M. J., 16785.

Manuszewski, R. C., Waterstrat, R. M., 16738.

MANusze WSKi, R. C., Waterstrat, R. M., 16834.

Maran, S. P., Hobes, R. W., Chiu, H. Y., Adams, P. J., LinSKY, J. L., BASRI, G. S., 16732.

Marcuson, M. F., Cooper, S. S., Bieganousky, M. A., SP477, pp. VI-141 - VI-157 (May 1977).

Margeson, J. H., Constant, P. C., JR., Sharp, M. C., Scheil, G. W., SP464, Pp. 573-574 (Nov. 1977).

Margeson, J. H., Fuerst, R. G., Hughes, E. E., Rook, H. L., DEARDORFF, E. R., 17230 .

Margon, B., Stern, R., Haisch, B. M., Linsky, J. L., LampTON, M., PARESCE, F., 16933.

Margulis, S. T., SP473, pp. 35-53 (June 1977).

Marinenko, G., J. Res. 81 A No. 1, 1-4 (1977).

Marković, V. M., Mclaughlin, W. L., Kosanić, M. M., Nenadović, M. T., RADAK, B. B., 16984.

MARKSTEIN, G. H., NBS-GCR-76-80.

MARLOW, W. H., SP464, pp. 213-218 (Nov. 1977).

Marlow, W. H., TANnER, R. L., SP464, pp. 337-342 (Nov. 1977).

Marlowe, D. E., Mrtchell, R. A., Mordfin, L., Halsey, N., 16685.

Maroney, G. E., Tessmann, R. K., SP494, pp. 24-26 (Sept. 1977).

Marr, H. E. III., Law, S. L., Campbell, W. J., SP464, pp. 157161 (Nov. 1977).

Marron, B., LeONG-Hong, B., SP500-3.

MARRON, B., LeONG-HONG, B., 16998.

MArRon, B., LeONG-Hong, B., 17280.

Marron, B. A. S., Neumann, A. J., Vickers, M. V., Walker, J. C., Evans, J. M., JR., O'Neill, J. T., Little, J. L., Albus, J. S., Barbera, A. J., Fife, D. W., Fong, E. N., Gilsinn, D. E., Holberton, F. E., Lucas, B. G., Lyon, G. E., NBSIR 76-1094.

Marshall, H. E., Ruegg, R. T., 17107.

Marshall, H. E., Ruegg, R. T., Wyly, R. S., 17296.

Marshall, R. D., NBSIR 77-1196.

Marshall, R. D., SP477, pp. V-21-V-53 (May 1977).

Marshall, R. D., 17115 .

Marshall, R. D., Crist, R. A., SP477, pp. I-21-I-33 (May 1977).

Marshall, R. D., Kliment, S., Raufaste, N. J., NBSIR 77. 1197.

Marshall, R. D., Raufaste, N. J., JR., Kliment, S. A., BSS100-1.

Marshall, R. D., Simiu, E., BSS100-2.

Marston, T. U., Gold, R., Roberts, J. H., Rahn, F. J., StahlKOPF, K. E., SP493, pp. 137-145 (Oct. 1977).

MARTER, T. M., SP500-18, pp. 95-105 (Sept. 1977).

MARTiG, K. W., JR., SP484, pp. 83-89 (Oct. 1977).

Martin, B. D., Ruthiber G, S., NefF, G. R., 17331.

Martin, G. M., Barnes, J. D., 17346.

Martinez, R. I., Hute, R. E., Herron, J. T., 17327. 
Maruyama, X. K., Lightbody, J. W., JR., Fivozinsky, S. P., Lindgren, R. A., Bendel, W. L., Jones, E. C., JR., FAGG, L. W., 16687.

Maruyama, X. K., Penner, S., Szalata, Z. M., Finn, J. M., Flanz, J., Kline, F. J., Peterson, G. A., Lightbody, J. W., JR., 16850.

MARvin, R. S., Peiser, H. S., NBSIR 76-1190.

Marzetta, L. A., U.S. Patent 4,009,704.

MASCETT, G. J., SP488, pp. 109-113 (Aug. 1977).

MASkEWITZ, B. F., Roussin, R. W., TRUBEY, D. K., SP461, pp. 171-173 (Jan. 1977).

Maskewttz, B. F., Trubey, D. K., Roussin, R. W., SP463, pp. III.1.1-III.1.10 (Jan. 1977).

MASON, H. L., NBSIR 76-1125.

Masters, L. W., Clark, E. J., Embree, E. J., NBSIR 76-1184.

MASTERSON, C., SP473, pp. 369-375 (June 1977).

MATHER, B., SP463, pp. IV.7.1-IV.7.7 (Jan. 1977).

Mathew, M., Schroeder, L. W., Dickens, B., Brown, W. E., 17034.

Mathew, M., Schroeder, L. W., Jordan, T. H., 17095.

Mathey, R. G., Burch, D. M., Pierce, E. T., Rossiter, W. J., JR., TN946.

MATHEY, R. G., Rossiter, W. J., JR., 17060.

MATHEY, R. G., ROSSITER, W. J., JR., 17061 .

MAthey, R. G., Rossiter, W. J., JR., NBSIR 77-1256.

Mathueson, T. A., Clark, R. N., SP494, pp. 152-166 (Sept. 1977).

MATTHIESEN, R. B., SP477, pp. III-1-III-1 5 (May 1977).

Mattingly, G. E., Davis, R. W., SP484, pp. $491-522$ (Oct. 1977).

Mattingly, G. E., Pontius, P. E., Allion, H. H., Moore, E. F., SP484, pp. 33-54 (Oct. 1977).

MAtTIS, R. L., BUEhleR, M. G., 17328.

Mattis, R. L., Phillips, W. E., Thurber, W. R., Buehler, M. G., DAvid, J. M., 16855.

MATtIS, R. L., RusSell, T. J., LeEdy, T. F., 17330.

MatTox, D. M., SP487, pp. $311-323$ (Aug. 1977).

Maurenbrecher, A. H. P., BSSI06, pp. 198-213 (Sept. 1977).

MaVRodineanu, R., SP466, pp. 127-131 (May 1977).

MaVrodineanu, R., SP492.

Mavrodineanu, R., Baldwin, J. R., SP492, pp. 66-71 (Nov. 1977).

Mavrodineanu, R., Burke, R. W., SP260-54.

MaVrodineanu, R., BURKe, R. W., SP466, pp. 121-126 (May 1977).

Mavrodineanu, R., Drews, U. W., 16981 .

Mavrodineanu, R., Mielenz, K. D., Velapoldi, R. A., SP466.

Maxia, V., Meloni, S., Queirazza, G., Smedile, E., GanzerliVAlentin, M. T., SP464, pp. 263-273 (Nov. 1977).

MAXIMON, L. C., TN955.

MaXWell, M. S., RitTeR, M., SP500-8, pp. 71-75 (May 1977).

May, W. E., Cuesler, S. N., Gump, B. H., Hertz, H. S., 16886

MAY, W. E., WISE, S. A., 17278.

May, W. E., Wise, S. A., Chesler, S. N., Hertz, H. S., HilPERT, L. R., 17271 .

May, W. E., Wise, S. A., Chesler, S. N., Gump, B. H., Hertz, H. S., 17273.

May, W. E., Wise, S. A., Chesler, S. N., Gump, B. H., Hertz, H. S., SP464, pp. $81-85$ (Nov. 1977).

Mayes, R. L., Clough, R. W., Omote, Y., BSSI06, pp. 60-90 (Sept. 1977).

Mayes, R. L., Clough, R. W., Omote, Y., Chen, S. W., BSSI06, pp. 91-113 (Sept. 1977).

Mayo, S., Evans, W. H., 16939.

Mayo, S., Galloway, K. F., Leedy, T. F., 16889.

Mayo-Wells, J. F., Lederer, P. S., Hilten, J. S., Vezzetti, C. F., TN961.

MAZUR, J., TN936.

MAZUR, J., Weiss, G. H., RubiN, R. J., 16696.
McAlister, A. J., Cuthill, J. R., Erickson, N. E., Watson, R. E., BENNETT, L. H., 16932.

McAlister, A. J., Watson, R. E., 17265.

MCAlister, A. J., WAtSON, R. E., BenNetT, L. H., 17262.

McAlister, A. J., Young, K. F., BenNett, L. H., Cohen, M. I., Dragoo, A. L., FrankIIN, A. D., NBSIR 77-1270.

McCaffrey, B., Kashiwagi, T., Den Braven, K., Harkleroad, M., RAINES, J., RINKINEN, W., QUINTIERE, J., NBSIR 77-1318. MCCAFFreY, B. J., QUINTIERE, J. G., 17285.

MCCaffrey, B. J., RocketT, J. A., J. Res. 82, No. 2, 107-117 (1977).

MCCAMY, C. S., 16683.

McCandless, J. B., Petajan, J. H., Birky, M. M., Packham, S. C., Frens, D. B., 16921.

McCarty, R. D., Hanley, H. J. M., Haynes, W. M., JPCRD 6, No. 2, 597-610 (1977).

MCClendon, L. T., SP492, pp. 23-26 (Nov. 1977).

MCClenny, W. A., RusswurM, G. M., SP464, pp. 287-290 (Nov. 1977).

McClure, J. L., Cezairliyan, A., 16767.

McClure, J. L., Taylor, R., Cezairliyan, A., J. Res. 81 A Nos. 2 and 3, 251-256 (1977).

MCConnaughey, J. S., JR., SP473, pp. $397-419$ (June 1977).

MCConnell, R. D., SP470, pp. VI-22-VI-32 (Apr. 1977).

MCCRACKIN, F. L., 16822.

MCCrackin, F. L., WAgner, H. L., 17255.

McCulloh, K. E., Lossing, F. P., Rosenstock, H. M., 17294.

McDonald, D. G., Edrich, J., Sullivan, D. B., 17077.

McDonald, D. G., Peterson, R. L., 16874.

MCDOWell, H., Gregory, T. M., Brown, W. E., J. Res. 81 A Nos. 2 and 3, 273-281 (1977).

MCEWEN, H., SP500-16.

MCEWEN, H. E., FIPS PUB 10-2.

MCFARLAND, M. C., NBS-GCR-77-87.

MCGarry, E. D., Gilliam, D. M., Kaza, A. H., SP493, pp. 335341 (Oct. 1977).

MCHENRY, H. I., 16866.

MCHENRY, H. I., REED, R. P., 17089

McIntosh, B. C., Geist, J., Doyle, W. M., 16852.

MCKenzie, R. G., RUTHBERG, Z. G., SP500-19.

MCKINNEY, J. E., 16774.

McKinney, J. E., Simha, R., J. Res. 81 A Nos. 2 and 3, 283297 (1977).

MCLaughlin, W. L., 17000

MCLaughlin, W. L., 17343

Mclaughlin, W. L., Jarrett, R. D., Humphreys, J. C., ChapPELL, S. E., 16999.

Mclaughlin, W. L., Kosanic, M. M., Nenadovic, M. T., Radak, B. B., Markovic, V. M., 16984.

Mclaughlin, W. L., Levine, H., Rosenstein, M., U.S. Patent 4,006,023.

Mclaughlin, W. L., Miller, A., Fidan, S., Pejtersen, K., Pedersen, W. B., 16949.

McMichael, J. M., Klebanoff, P. S., 16821 .

McMurdie, H. F., Evans, E. H., Paretzkin, B., deGroot, J. H., NewberRy, R., Morris, M. C., Monogr. 25, Section 14.

MCNeECE, J. E., SOBECKI, R. J., SP500-18, pp. 13-21 (Sept. 1977).

MCNeil, J. R., Collins, G. J., DeHoog, F. J., 17170.

MCNeIL, M. B., KReIDER, K. G., HI2l.

MCQuivey, R. S., Mero, T., APPELl, G., SP484, pp. 109-122 (Oct. 1977).

Meagher, T. F. V., Peckham, V. D., Sachs, D. C., SP484, pP. 687-704 (Oct. 1977).

Mears, T. W., Michaelis, R. E., Beeghly, H. F., 16667.

MeEhaN, J. F., BSS106, pp. 259-274 (Sept. 1977).

Meehan, J. F., SP470, pp. VI-64-VI-73 (Apr. 1977).

Meese, W. J., Beausoliel, R. W., BSSI03.

Meguire, P., KraMer, J., SP480-24, pp. 107-1 13 (Nov. 1977).

Meguire, P. G., KRAMER, J. J., NBSIR 76-1092. 
Meguire, P. G., Kramer, J. J., Stewart, A., SP480-27.

Mehlman, G., Weiss, A. W., Esteva, J. M., 16659.

Meier, F., Sattler, K., Siegmann, H. C., Campagna, M., PIERCE, D. T., 17022.

MEIER, M. M., SP493, pp. 221-226 (Oct. 1977).

MEISSNER, P., FIPS PUB 48.

Meisters, M., Breden, L., NBSIR 76-1030.

Meloni, S., Queirazza, G., Smedile, E., Ganzerli-Valentini, M. T., MAXIA, V., SP464, pp. 263-273 (Nov. 1977).

MERCIK, H. J., JR., SP494, pp. 249-258 (Sept. 1977).

Mero, T., APPELl, G., MCQuiveY, R. S., SP484, Pp. 109-122 (Oct. 1977).

MERRILL, L., JPCRD 6, No. 4, $1205-1252$ (1977).

MESSMER, R. P., TUCKER, C. W., JR., JOHNSON, K. H., SP475, pp. 174-177 (Apr. 1977).

Metzger, A. E., Trombka, J. I., Dyer, C. S., Evans, L. G., Bielefeld, M. J., Seltzer, S. M., 16938.

Meussner, R. A., BirChenall, C. E., SP479, pp. $39-57$ (July 1977).

MEYERSON, M. R., 16885.

Miller, J., WAterstrat, R. M., 16832.

Michaelis, R. E., Beeghly, H. F., Mears, T. W., 16667.

MidGetT, M. R., SCHeIL, G. W., KNOLL, J. E., SP464, pp. 575. 579 (Nov. 1977).

Mielczarex, S. R., Huebner, R. H., Celotta, R. J., 17018.

Mirlczarex, S. R., Huebner, R. H., o'Connor, M. E., CelotTA, R. J., 17019.

Mielenz, K. D., Velapoldi, R. A., Mavrodineanu, R., SP466.

Mighell, A. D., 17050.

Mighell, A. D., Hubbard, C. R., Staffa, J. A., Zervos, C., 16688.

Mighell, A. D., Ondik, H. M., Molino, B. B., JPCRD 6, No. 3, 675-830 (1977).

Mighell, A. D., Ware, G. M., Hubbard, C. R., 16913.

Mihalas, D., Barnard, A. J., Cooper, J., Smith, E. W., 17171 .

Mithalas, D., Barnard, A. J., Cooper, J., Smith, E. W., 17172.

Mitller, A. P., Cezairliyan, A., J. Res. 82, No. 2, 119-122 (1977).

Mikesell, R. P., Clark, A. F., Reed, R. P., 16862.

Mikesell, R. P., REed, R. P., TOBLER, R. L., 16879.

MILES, L. B., NBS-GCR-76-77.

Miles, L. B., 17176 .

Miller, A., Fidan, S., Pejtersen, K., Pedersen, W. B., MClaughlin, W. L., 16949.

Miller, R. C., Kronay, A. J., Hiza, M. J., 16881.

Miller, R. W., DeCarlo, J. P., Cullen, J. T., SP484, pp. 549570 (Oct. 1977).

Mills, R. M., Pella, P. A., 16830.

Milstein, J. B., Alperin, H. A., RHYNe, J. J., KOON, N. C., 16963.

Milton, H. J., TN938.

Milton, H. J., 17040.

Minkiewicz, V. J., PAssell, L., Glinka, C. J., 17112.

Minor, D. B., ROTH, R. S., PARKer, H. S., BroWer, W. S., J. Res. 82, No. 3, 151-165 (1977).

MISAKIAN, M., HEBNER, R. E., JR., NBSIR 77-1317.

Misiano, D. R., LAVER, M. B., SP450, pp. 201-206 (June 1977).

MisRA, D. N., BOWEN, R. L., 17033.

MISRA, D. N., BOWEN, R. L., 17197.

MrTChELl, J. S., SP494, pp. 77-78 (Sept. 1977).

Mrtchell, R. A., Mordfin, L., Halsey, N., Marlowe, D. E., 16685.

Mrtchell, R. A., WoOlley, R. M., BAKer, S. M., NBSIR 761053.

MITRA, B., MAJUMdAR, M., SP461, pp. 57-59 (Jan. 1977).

MohaN, M. S., BATES, R. G., SP450, pp. 293-299 (June 1977).

Mohr, J. M., Agrawala, A. K., SP500-18, pp. 23-38 (Sept. 1977).
Mohrmann, L. E., Shapiro, B. L., JPCRD 6, No. 3, 919-992 (1977).

Moldover, M. R., Gallagher, J. S., 17295.

Molino, B. B., Mighell, A. D., Ondik, H. M., JPCRD 6, No. 3, 675-830 (1977).

Mongan, D. M., Eckert, A. C., JR., SP464, pp. 545-551 (Nov. 1977).

Montalvo, J. G., JR., LeE, C. G., SP464, pp. 97-100 (Nov. 1977).

Montgomery, C. A., Moore, G. B., Kuhns, J. L., Trefftzs, J. L., SP5O0-2.

MoOdy, J. R., Rook, H. L., Paulsen, P. J., Rains, T. C., BARNes, I. L., EPSTEIN, M. S., SP464, pp. $515-518$ (Nov. 1977).

MOOdY, S. E., LAmbropoulos, M., 16789.

MOODY, S. E., LAMBropoulos, M., 16925.

MoOradian, A., SP464, pp. 277-286 (Nov. 1977).

MOORE, E. F., DAVIS, R. W., NBSIR 77-1394.

Moore, E. F., Mattingly, G. E., Pontius, P. E., Allion, H. H., SP484, pp. 33-54 (Oct. 1977).

MoORE, G., SP464, pp. $37-42$ (Nov. 1977).

Moore, G. B., Kuhns, J. L., Trefftzs, J. L., Montgomery, C. A., SP500-2.

Moore, J. H., Beaty, E. C., Hesselbacher, K. H., Hong, S. P., 16810 .

Moore, J. H., JR., Alexander, M. H., Manger, C. L., 17216.

MOORE, R. T., Carpenter, R. J., KoenIG, A. L., NBSIR 77. 1262.

Moos, H. W., Jenknns, E. B., Snow, T. P., Upson, W. L., Starrfield, S. G., Gallagher, J. S., Friedjung, M., Linsky, J. L., ANDERSON, R., HeNRY, R. C., 16762.

MoOS, H. W., LINSKY, J. L., WeINSTEIN, A., 17310.

Mopsik, F. I., KRYDer, S. J., KhOURY, F., COLSON, J. P., BOlz, L. H., ANDERSON, W. E., DAVIS, R. S., 17014

MORAN, H. D., LYNCH, J. F., SP463, pp. IV.2.1-IV.2.7 (Jan. 1977).

MORAN, R. P., BURKE, W. J., SP473, pp. 377-382 (June 1977).

Mordfin, L., Halsey, N., Marlowe, D. E., Mrtchell, R. A., 16685.

Morel, P. R., Pedersen, N. E., Bradshaw, J. E., Lynnworth, L. C., SP484, pp. 293-318 (Oct. 1977).

MORGAN, G. B., SP464, pp. 381-385 (Nov. 1977).

Morgan, M. G., MORRIS, S. C., SP464, pp. $391-392$ (Nov. 1977).

Morgan, W. H., Kempf, D., Phillifs, R. E., SP484, pp. 361 394 (Oct. 1977).

Morigi, G., Bertolast, V., Zucchi, F., SP479, pp. 103-105 (July 1977).

MORRIS, H., SP47I, pp. 13-16 (June 1977).

MORRIS, M., JoHnSON, D. R., Lovas, F. J., ZuCKerman, B., Turner, B. E., Palmer, P., Gilmore, W., 16969.

Morris, M. C., McMurdie, H. F., Evans, E. H., Paretzin, B., DEGroot, J. H., Ne WberRy, R., Monogr. 25, Section 14.

MorRis, S. C., Morgan, M. G., SP464, pp. 391-392 (Nov. 1977).

MORRISON, B. M., SP473, pp. 69-83 (June 1977).

Morrison, M. A., Collins, L. A., Lane, N. F., 16682.

MORRISON, M. A., LANE, N. F., Collins, L. A., 17026.

MORRISON, P. L., SPSO0-15, pp. 53-56 (July 1977).

Morrissey, B. W., Smith, L. E., Dehl, R. E., Grant, W. H., STROMBERG, R. R., NBSIR 76-1128.

MorRow, A. J., RADEba UGH, R., SiegW ARTH, J. D., LaWless, W. N., NBSIR 76-847.

MORROW, J. J., 16707.

Morton, M., FetTers, L. J., 16736.

Mosburg, E. R., JR., Wilke, M. D., 17192

MOSelhy, M. M., BOOMER, D. W., BishOP, J. N., Diosady, P. L., SP464, Pp. 137-150 (Nov. 1977).

Motz, J. W., DANOS, M., 16666.

Moulder, J. C., Clark, A. F., 16796.

Moulder, J. C., Clark, A. F., 17163. 
Mountain, R. D., 16711 .

MOZER, B., HAN, C. C., 16817.

Mucha, J. A., Jimenez, J. J., Charlton, R. M., Howard, C. J., Evenson, K. M., Jennings, D. A., Petersen, F. R., 17073.

Mucha, J. A., Radford, H. E., Peterson, F. R., Jennings, D. A., 16867.

Mueller, J. J., SP468, pp. 107-118 (Apr. 1977).

Mukheriee, R., Muthukrishnan, G., Singh, H., SP461, pp. 166-170 (Jan. 1977).

MukHeri, S., Srivastava, B. K., SP461, Pp. 144-148 (Jan. 1977).

Muldoon, D. G., Majahad, A. M., SP464, pp. 21-35 (Nov. 1977).

Mulholland, G., Lee, T. G. K., NBSIR 77-1312.

Mulholland,G. W., Lee, T. G., Baum, H. R., 17282.

Mulik, J. D., Puckett, R., Sawicki, E., Williams, D., SP464, Pp. 603-607 (Nov. 1977).

Mullen, J. L., Kruger, J., Bertocci, U., Escalante, E., NBSIR 77-1232.

MullinaX, O. D., SP471, p. 103 (June 1977).

Mumford, S., Klaus, P., Bunten, E., Cunitz, R., SP480-2.

MUNRO, R. G., 17228.

MUNRO, R. G., 17350.

Murad, S., Hanley, H. J. M., Gubiins, K. E., JPCRD 6, No. 4, 1167-1180 (1977).

MURDOCH, J. B., NBSIR 77-1303.

MUROTA, T., SP477, Pp. I-12-I-20 (May 1977).

MuROTA, T., SP477, pp. V-54-V-59 (May 1977).

Murota, T., Nakahara, M., SP470, pp. II-11-II-19 (Apr. 1977).

Murota, T., NaKano, K., SP470, pp. I-42-I-49 (Apr. 1977).

MurPhy, R. B., Currie, L. A., SP464, Pp. $439-447$ (Nov. 1977).

MURPHY, T. J., SP492, pp. 5-8 (Nov. 1977).

Murray, E. R., van der laAN, J. E., HaWley, J. G., Hake, R. D., JR., Williams, M. F., SP464, pp. 305-314 (Nov. 1977).

MurTy, D. S. R., Reddy, V. G., Narasimhacharyulu, E., SWAMY, S. T., SP461, Pp. 26-28 (Jan. 1977).

MurTy, K. P. N., Singh, R. S., Vaidyanathan, R., SP461, Pp. 163-165 (Jan. 1977).

Murty, K. P. N., Vaidyanathan, R., Singh, R. S., SP461, Pp. 132-135 (Jan. 1977).

Muthukrishnan, G., Santhanam, K., Gopinath, D. V., SP461, pp. 140-143 (Jan. 1977).

Muthukrishnan, G., Singh, H., Mukheruee, R., SP461, pp. 166-170 (Jan. 1977).

\section{$\mathbf{N}$}

NADEL, E., BSS106, pp. 238-242 (Sept. 1977).

Nagarajan, P. S., Raghavendran, C. P., Sethulakshmi, P., Bhatia, D. P., SP461, pp. 100-105 (Jan. 1977).

NAGASHIMA, A., JPCRD 6, No. 4, 1133-1166 (1977).

NAGEL, R., SP500-8, pP. 89-90 (May 1977).

NAGEL, R. N., EvaNS, J. M., JR., KIRSCH, R., SP500-8.

NAHMAN, N. S., Riad, S. M., 16731.

NAMMON, E. R., Weston, W. F., LedBetTer, H. M., 16869.

Nakahara, M., Murota, T., SP470, pp. II-11-II-19 (Apr. 1977).

Nakano, K., MUROTA, T., SP470, pP. I-42-I-49 (Apr. 1977).

Nakata, S., Watabe, M., Hirosawa, M., SP470, pp. IX-1-IX5 (Apr. 1977).

NAMBI, K. S. V., SP461, Pp. 234-237 (Jan. 1977).

Narasimhacharyulu, E., Swamy, S. T., Murty, D. S. R., REDDY, V. G., SP461, pp. 26-28 (Jan. 1977).

NARTTA, N., OKubo, T., SP477, Pp. I-34-I-48 (May 1977).

NartTa, N., Yokoyama, K., OKUbO, T., SP470, pp. II-20-II46 (Apr. 1977).
Narita, N., Yokoyama, K., OKubo, T., SP477, pp. V-1-V-20 (May 1977).

Nash, J. F., Simiu, E., Patel, V. C., SP477, pp. II-30-II-40 (May 1977).

NATESAN, K., SP468, pp. 159-170 (Apr. 1977).

Natesan, K., Greenberg, S., SP468, pp. 97-106 (Apr. 1977).

Nath, S., Chatteriee, A., Ghose, A. M., SP461, pp. 64-66 (Jan. 1977).

Natrella, M. G., SP47I, pp. 77-83 (June 1977).

Navalkar, M. P., Godwal, B. K., SP461, pp. 97-99 (Jan. 1977).

Navalkar, M. P., Joneja, O. P., Srikantaiah, R. V., Phiske, M. R., Coachman, J. S., SP493, pp. 61-66 (Oct. 1977).

Neale, L. C., Durgin, W. W., SP484, $471-477$ (OCt. 1977).

Needham, P. B., JR., Driscoll, T. J., Powell, C. J., Stein, R. J., 16824 .

Needham, P. B., JR., Driscoll, T. J., Powell, C. J., Stein, R. J., 17248.

NefF, G. R., Martin, B. D., Ruthberg, S., 17331 .

Negas, T., Broussalian, J., Siedle, A. R., 17137.

Negas, T., Cleek, G. W., Wachtman, J. B., JR., Roth, R. S., COOK, L. P., SP486.

Negas, T., Plante, E. R., Olson, C. D., 16897.

Nelson, C. E., Purser, F. O., Von Behren, P., Newson, H. W., NBSIR 77-1279, pp. 1-4 (July 1977).

Nelson, F. M., SP463, pP. III.5.1-III.5.8 (Jan. 1977).

NELSON, R. E., SP480-8.

Nenadović, M. T., Radak, B. B., Marković, V. M., Mclaughlin, W. L., Kosanić, M. M., 16984.

Neuhausen, R., Lightbody, J. W., JR., Fivozinsky, S. P., PenNer, S., 16982.

NEUMANN, A. J., SPS00-13.

NeumanN, A. J., Vickers, M. V., Walker, J. C., Evans, J. M., Jr., O'Neill, J. T., Little, J. L., Albus, J. S., Barbera, A. J., Fife, D. W., Fong, E. N., Gilsinn, D. E., Holberton, F. E., Lucas, B. G., Lyon, G. E., Marron, B. A. S., NBSIR 76-1094.

Neumann, J. P., Chang, Y. A., Goldberg, D., JPCRD 6, No. 3, 621-674 (1977).

Nevins, R. G., Gagge, A. P., SP491, pp. 93-116 (Sept. 1977).

Newberry, R., Morris, M. C., McMurdie, H. F., Evans, E.

H., Paretzkin, B., DeGroot, J. H., Monogr. 25, Section 14.

NEWBURY, D. E., 16840.

Newbury, D. E., 17156.

NeWBury, D. E., FIORI, C. E., YakowTtZ, H., 16988.

NeWBuRY, D. E., JoY, D. C., 16839.

Newell, A. C., Repjar, A., 17224.

Newell, A. C., WACKer, P. F., 17221 .

NeWMAN, M., 16660.

Newman, M., Sheingorn, M., 17041.

Newson, H. W., Nelson, C. E., Purser, F. O., Von Behren, P., NBSIR 77-1279, Pp. 1-4 (July 1977).

NiCODEMUS, F. E., TN910-3.

Nicodemus, F. E., Richmond, J. C., Hsia, J. J., Ginsaerg, I. W., LIMPERIS, T., Monogr. 160.

Nielsen, N. A., SP479, pp. 17-37 (July 1977).

Nix, J. R., Danos, M., Halbert, E. C., Smith, R. K., JR., AMSDEN, A. A., Ginocchio, J. N., HaRlow, F. H., 17109.

Noda, S., Hayashi, S., Tsuchida, H., SP470, pp. VIII42-VIII-55 (Apr. 1977).

Noda, S., UWabe, T., Ha YaShi, S., SP477, pp. VI-192-VI-198 (May 1977).

NOONAN, D. C., SP45O, pp. 275-278 (June 1977).

Norcross, D. W., Collins, L. A., 17027.

Norcross, D. W., Collins, L. A., 17344.

Norcross, D. W., ManN, J. B., Robb, W. D., Hayes, M. A., 17132.

Norman, C. D., Crowson, R. D., Balsara, J. P., SP477, Pp. VI-85-VI-1 17 (May 1977). 
Novick, S. E., Broida, H. P., Phelps, A. V., Lawton, S. A., 16765.

NovotNY, D. B., 16853.

NovotNY, D. B., 17329.

Nudelman, S., Richmond, J. C., Freeman, C. M., 17339.

NunN, R. O., Hegemier, G. A., KRIShNamoorthy, G., BSSI06, pp. 114-153 (Sept. 1977).

Nuttall, R. L., Arbuckle, R., Goldberg, R. N., Staples, B. R., SP485.

Nuttall, R. L., ARMSTrong, G. T., TN937.

Nuttall, R. L., Staples, B. R., JPCRD 6, No. 2, 385-408 (1977).

NycUM, S., SP480-24, pp. 37-41 (Nov. 1977).

\section{O}

O'Brien, J. F., Skridulis, J., Annett, J., Singley, G. W., KOENIG, H. L., SP484, pp. 145-172 (Oct. 1977).

O'Brien, J. T., Penner, S., Finn, J. M., Crannell, H., HalLOWELL, P. L., 16845

Obright, W., Rippey, W., Hebrank, J., Hurley, C. W., Ryan, J. D., NBSIR 77-1243.

O'Callaghan, J. F., SP500-8, p. 44 (May 1977).

O'Connell, J. S., Berman, B. L., Gibson, B. F., 16987.

O'Connell, J. S., Heimbach, C. R., Lehman, D. R., 16793.

O'Connor, M. E., Celotta, R. J., Mielczarek, S. R., HUEBNER, R. H., 17019.

ODOM, J. V., 17037.

O'DONNELL, K. O., SP470, pp. VI-47-VI-63 (Apr. 1977).

Oettinger, F. F., Rogers, G. J., Blackburn, D. L., Koyama, R. Y., 17345 .

Oettinger, F. F., Rogers, G. J., Blackburn, D. L., Koyama, R. Y., NBSIR 77-1249.

OfFEnSENd, F. L., BUChBinder, B., Helzer, S. G., NBSIR 77-1381.

Ogburn, F., Passaglia, E., Burnett, H. C., Kruger, J., PiCKelsimer, M. L., SP479, pp. 167-178 (July 1977).

OGren, J. R., Frankel, H. E., SP468, pp. 3-25 (Apr. 1977).

O'HAGAN, M. E., SP471, pp. 53-62 (June 1977).

O'Haver, T. C., Epstein, M. S., Rains, T. C., SP464, pp. 4751 (Nov. 1977).

O'Haver, T. C., Zander, A. T., SP464, pp. $53-59$ (Nov. 1977).

O'Haver, T. C., Zoller, W. H., Reamer, D. C., SP464, pp. 609-612 (Nov. 1977).

OHSAKI, Y., WaTABE, M., SP477, pp. VII-29-VII-35 (May 1977).

OKABE, H., 16781 .

Okahara, M., Kawakami, K., OKubo, T., Komada, K., SP470, pp. VII-7-VII-60 (Apr. 1977).

OKahaRA, M., KunihIRo, T., YallagI, K., SP477, pp. VI118-VI-140 (May 1977).

OKubo, Т., Komada, K., OKahaRa, M., KaWaKami, K., SP470, pp. VII-7-VII-60 (Apr. 1977).

OKUBO, T., NARITA, N., SP477, pp. I-34-I-48 (May 1977).

OKubo, T., Narita, N., YOKOYaMa, K., SP470, pp. II-20-II46 (Apr. 1977).

OKubo, T., Narita, N., Yokoyama, K., SP477, pp. V-1-V-20 (May 1977).

Oкu, S., J. Res. $81 \mathrm{~B}$ Nos. 1 and 2, 5-39 (1977).

Olien, N. A., Williamson, F. R., 16883.

OLMERT, M., SP446-1.

Olson, C. D., Negas, T., Plante, E. R., 16897.

OLSON, W. B., LOVEJOY, R. W., 17131.

OLVER, F. W. J., 16805.

Olver, F. W. J., 16899.

Olver, F. W. J., 17142

OMAN, R. C., 17236.

Omote, Y., Chen, S. W., Mayes, R. L., Clough, R. W., BSS106, pp. 91-113 (Sept. 1977).
OмоTe, Y., Mayes, R. L., Clough, R. W., BSSI06, pp. 60-90 (Sept. 1977).

Ondix, H. M., Molino, B. B., Mighell, A. D., JPCRD 6, No. 3, 675-830 (1977).

Ondov, J. M., Ragaini, R. C., Heft, R. E., Fisher, G. L., Silberman, D., Prentice, B. A., SP464, pp. 565-572 (Nov. 1977).

O'Neill, J. T., Little, J. L., Albus, J. S., Barbera, A. J., Fife, D. W., Fong, E. N., Gilsinn, D. E., Holberton, F. E., Lucas, B. G., Lyon, G. E., Marron, B. A. S., Neumann, A. J., Vickers, M. V., Walker, J. C., Evans, J. M., JR., NBSIR 76-1094.

OrChaRd, R. A., SP500-18, pp. 159-182 (Sept. 1977).

OrǴaN, R. M., SP479, pp. 107-142 (July 1977).

OrLosk, M. J., WyLy, R. S., Galowin, L. S., SP473, pp. 317 348 (June 1977).

Osborne, R. L., Jennings, S. J., Bannister, R. L., SP494, pp. 97-116 (Sept. 1977).

O'SteEn, J. K., SP494, pp. 191-204 (Sept. 1977).

OSTER, S., Quigley, J. M., SP473, pp. 113-135 (June 1977).

OTT, W. R., NBSIR 75-941.

OTT, W. R., BRIDGES, J. M., 16778.

OTt, W. R., PItz, A., Einfeld, D., Stuck, D., Bridges, J. M., 17198.

OZAKI, M., IshiYaMA, Y., SP477, pp. VI-10-VI-27 (May 1977).

\section{$\mathbf{P}$}

PaCe, S. J., BRAND, M. J. D., SP450, pp. 227-234 (June 1977).

Packham, S. C., Frens, D. B., McCandless, J. B., Petajan, J. H., BiRKY, M. M., 16921.

PAGe, C. H., J. Res. 81B Nos. 1 and 2, 1-3.(1977).

Painter, G. S., Jones, R. O., Jennings, P. J., SP475, pp. 136149 (Apr. 1977).

Pal, B., Chatterjee, A., Ghose, A. M., SP461, pp. $44-46$ (Jan. 1977).

Paley, L., Smith, W. S., SP464, pp. 597-599 (Nov. 1977).

Pallett, D. S., Bartel, T. W., Voorhees, C. R., 16763.

PalletT, D. S., CAdoff, M. A., NBSIR 75-938.

Pallett, D. S., CADOFF, M. A., 17190.

Pallett, D. S., VoORhees, C. R., 16764.

Palmer, P., Gilmore, W., Morris, M., Johnson, D. R., Lovas, F. J., ZuCKerman, B., Turner, B. E., 16969.

Paresce, F., Margon, B., Stern, R., Haisch, B. M., Linsky, J. L., LAMPTON, M., 16933.

Paretzkin, B., deGroot, J. H., Newberry, R., Morris, M. C., McMurdie, H. F., Evans, E. H., Monogr. 25, Section 14.

Park, R., Rhodin, T., Yates, J. T., Haller, G., Katzer, J., SP475, p. 13 (Apr. 1977).

Parken, W. H., JR., Beausoliel, R. W., Kelly, G. E., 17006.

Parker, H. S., Brower, W. S., Minor, D. B., Roth, R. S., J. Res. 82, No. 3, 151-165 (1977).

PARKER, R. L., 17275.

Parker, R. L., Passaglia, E., NBSIR 77-1208.

Parker, V. B., Kilday, M. V., Cases, J. C., J. Res. 82, No. 1, 19-28 (1977).

Parker, V. B., Wagman, D. D., Schumm, R. H., NBSIR 77. 1300 .

PARKer, W. J., TN945.

Parker, W. J., Lee, B. T., 17059.

PARKS, S. I., Linzer, M., 16735.

Parris, G. E., Blair, W. R., Brinckman, F. E., 16811 .

Parris, G. E., Blair, W. R., Jewett, K. L., Iverson, W. P., Bellama, J. M., Brinckman, F. E., 17155.

Parrish, W. R., Daney, D. E., Ludtke, P. R., Frederick, N. V., HANDS, B. A., JONES, M. C., ARP, V. D., NBSIR 77-853.

PARRISH, W. R., VOTH, R. O., NBSIR 77-862.

Parsonnet, V., SP400-42, pp. 30-32 (Aug. 1977).

Passaglia, E., Burnett, H. C., Kruger, J., Pickelsimer, M. L., OGBuRN, F., SP479, pp. 167-178 (July 1977).

Passaglia, E., Gornick, F., 17053. 
Passaglia, E., Khoury, F., 16958.

Passaglia, E., Parker, R. L., NBSIR 77-1208.

Passell, L., Glinka, C. J., Minkiewicz, V. J., 17112.

Patel, V. C., Nash, J. F., Simiu, E., SP477, pp. II-30-II40(May 1977).

Patterson, C. W., harter, W. G., 16956.

Patterson, C. W., Harter, W. G., 16957.

Patterson, C. W., Harter, W. G., 17316.

Paulhamus, R. E., Ward, G. E., SP500-18, pp. 143-158 (Sept. 1977).

PAulsen, A., SP493, pp. 165-169 (Oct. 1977).

PAULSEN, P. J., SP492, pp. 33-48 (Nov. 1977).

Paulsen, P. J., Rains, T. C., Barnes, I. L., Epstein, M. S. MOODY, J., R., RoOK, H. L., SP464, pp. $515-518$ (Nov. 1977).

PAUR, R. J., SP464, pp. 15-19 (Nov. 1977).

Pavlidis, T., SP500-8, pp. 26-27 (May 1977).

Peacock, J. L., Eckert, J. A., Bundy, D. H., SP464, pp. 295300 (Nov. 1977).

Peacock, R., Williams, N., Zamistowski, E. A., Krasny, J. F., BRAUN, E., NBSIR 77-1236.

Peacock, R. D., Krasny, J. F., 16813.

Pearson, R., JR., Lovas, F. J., 16910.

Pearson, R., JR., Maki, A. G., Sams, R. L., 16823.

Peavy, B. A., Dressler, W. E., NBSIR 77-1237.

Peavy, B. A., Hill, J. E., Kelly, G. E., 17347.

Peavy, B. A., Kuklewicz, M. E., Phillips, C. W., NBSiR 761178.

Peavy, B. A., TertSma, G. J., NBSIR 76-1182.

PeAvy, S. T., Hogben, D., NBSIR 77-1276.

Pebly, H. E., SP463, pp. IV.3.1-IV.3.2 (Jan. 1977).

Pechine, J. M., Rosenstock, H. M., Botter, R., 17146.

Peckerar, M. C., Birks, L. S., Gilfrich, J. V., SP464, pp. $347-$ 349 (Nov. 1977).

Peckham, V. D., Sachs, D. C., Meagher, T. F. V., SP484, pp. 687-704 (Oct. 1977).

PEden, M. E., SP464, pp. 367-378 (Nov. 1977 ).

Pedersen, N. E., Bradshaw, J. E., Lynnworth, L. C., Morel, P. R., SP484, pp. 293-318 (Oct. 1977).

Pedersen, W. B., Mclaughlin, W. L., Miller, A., Fidan, S., Pejtersen, K., 16949.

Peelle, R. W., de Saussure, G., SP493, pp. 174-181 (Oct. 1977).

Peelle, R. W., Weisbin, C. R., SP493, pp. 269-277 (Oct. 1977).

Peeters, E., Castiaux, M. A., Chatteruee, J. M., SP461, pp. 255-256 (Jan. 1977).

Peiser, H. S., Beck, N. C., Stephens, K. S., NBSIR 76-1180.

Peiser, H. S., Cornish, J., Raley, C. C., NBSIR 76-1152.

Peiser, H. S., Marvin, R. S., NBSIR 76-1190.

Pejtersen, K., Pedersen, W. B., Mclaughlin, W. L., Miller, A., Fidan, S., 16949.

Pella, P. A., 16825.

Pella, P. A., Heinrich, K. F. J., Bretter, D. N., SP464, pp. 527-529 (Nov. 1977).

Pella, P. A., Lorber, K., Heinrich, K. F. J., SP464, pp. 125 127 (Nov. 1977).

Pella, P. A., Mills, R. M., 16830.

Pellegrin, M. T., Bajura, R. A., SP484, pp. 523-548 (Oct. 1977).

PENN, D. R., 16748.

PENN, D. R., 16826.

PENN, D. R., 17021.

Penner, S., Finn, J. M., Crannell, H., Hallowell, P. L., O'Brien, J. T., 16845.

Penner, S., Neuhausen, R., Lightbody, J. W., JR., FivozinSKY, S. P., 16982.

Penner, S., Szalata, Z. M., Finn, J. M., Flanz, J., Kline, F. J., Peterson, G. A., Lightbody, J. W., JR., Maruyama, X. K., 16850.
Penzes, W. B., Hruska, G. R., Magrab, E. B., 16701.

Penzes, W. B., Hruska, G. R., Magrab, E. B., 17245.

Penzien, J., Godden, W. G., Chen, M. C., Williams, D.,

KaWashima, K., SP477, pp. VI-1-VI-9 (May 1977).

Peperstrate, H., Rymen, T., Delespaul, I., SP464, pp. 617 623 (Nov. 1977).

Pepper, R. T., Gigerenzer, H., ZaCk, T. A., SP487, pp. 93107 (Aug. 1977).

Perkins, M., Landvater, J. H., SP471, pp. 69-76 (June 1977).

Perlis, A., Seamans, R. C., JR., Ramo, S., Thomson, R. M., Teller, E., Ramsey, N., Baker, W. O., Eyring, H., BirkHOFF, G., SP465.

Persensky, J. J., Ramey, A. M., NBSIR 77-1294.

Persensky, J. J., Ramey, A. M., Pezoldt, V. J., 17200.

Petajan, J. H., Birky, M. M., Packham, S. C., Frens, D. B., McCandless, J. B., 16921.

Peterlin, A., J. Res. 81A Nos. 2 and 3, 243-250 (1977).

Peterlin, A., 17119.

Peterlin, A., Fong, J. T., J. Res. 81A No. 1, 97-107 (1977).

Peters, G. A., SP482, pp. 47-53 (July 1977).

Petersen, F. R., Mucha, J. A., Jimenez, J. J., Charlton, R. M., Howard, C. J., Evenson, K. M., Jennings, D. A., 17073.

Petersen, F. R., Wells, J. S., Evenson, K. M., Jennings, D. A., 17336.

Petersen, F. R., Wells, J. S., Strett, G. E., 16728.

Peterson, F. R., Jennings, D. A., Mucha, J. A., Radford, H. E., 16867.

Peterson, G. A., Lightbody, J. W., JR., Maruyama, X. K., Penner, S., Szalata, Z. M., finn, J. M., Flanz, J., Kline, F. J., 16850.

Peterson, R. L., McDonald, D. G., 16874.

Peterson, R. W., Bloss, R. L., NBSIR 76-1145.

Petrzhak, K. A., Pleskachevsky, L. A., Fomichev, A. V., Shapakov, V. I., Adamov, V. M., Alexandrov, B. M., Alkhazov, I. D., Drapchinsky, L. V., Kovalenko, S. S., KostochKin, O. I., Kudriavzev, G. Y., MalKiN, L. Z., SP493, pp. 313-318 (Oct. 1977).

Pezoldt, V. J., SP482.

Pezoldt, V. J., Persensky, J. J., Ramey, A. M., 17200.

Phelps, A. V., Lawton, S. A., Novick, S. E., Broida, H. P., 16765.

Phelps, A. V., Whealton, J. H., Burch, D. S., 16854.

Phillips, C. W., PeAvy, B. A., KuKlewicz, M. E., NBSIR 761178.

Phillips, R. E., Morgan, W. H., Kempf, D., SP484, pp. 361 394 (Oct. 1977).

Phillips, W. E., Thurber, W. R., Buehler, M. G., David, J. M., MatTtS, R. L., 16855.

Phiske, M. R., Coachman, J. S., Navalkar, M. P., Joneja, $O$. P., Srikantaiah, R. V., SP493, pp. 61 -66 (Oct. 1977).

Pickelsimer, M. L., Ogburn, F., Passaglia, E., Burnett, $H$. C., Kruger, J., SP479, pp. 167-178 (July 1977).

Pickrel, E., SP480-24, pp. 19-24 (Nov. 1977).

Pielert, J. H., Gross, J. G., 17111.

Pierce, D. T., Meier, F., Sattler, K., Siegmann, H. C., CamPAGNA, M., 17022.

Pierce, E. T., Rossiter, W. J., Jr., Mathey, R. G., Burch, D. M., TN946.

Pierce, F. J., Gold, D. S., Dupont, E. I., SP484, pp. 621-648 (Oct. 1977).

Piermarini, G., Forman, R. A., Weinstein, B. A., 17047.

Plotrowski, G., SP472, pp. $41-48$ (Apr. 1977).

Pitz, A., Einfeld, D., Stuck, D., Bridges, J. M., OTt, W. R., 17198.

Piuze, J., Christensen, P., Wong, C. S., Cretney, W. J., SP464, pp. 249-258 (Nov. 1977).

Plant, K. A., SP480-24, pp. 63-73 (Nov. 1977).

Plante, E. R., Olson, C. D., Negas, T., 16897. 
Pleskachevsky, L. A., Fomichev, A. V., Shapakov, V. I., Adamov, V. M., Alexandrov, B. M., Alkhazov, I. D., Drapchinsky, L. V., Kovalenko, S. S., Kostochkin, O. I., Kudriavzev, G. Y., Malkin, L. Z., Petrzhak, K. A., SP493, pp. 313-318 (Oct. 1977).

Plummer, E. W., Vorburger, T. V., Waclawski, B. J., 16829.

Podolny, W., JR., Bosch, H. R., GADE, R. H., SP470, pp. II47-II-67 (Apr. 1977).

POENITZ, W. P., SP493, pp. 261-268 (Oct. 1977).

POland, H. M., West, J. B., 17100.

Pollack, J. B., Colburn, D. S., Wright, M. L., SP464, pp. 301-303 (Nov. 1977).

POLLARD, J. D., NBSIR 77-1229.

Pollard, J. D., Ramboz, J. D., Koyanagi, R. S., NBSIR 73291.

PONEC, V., SP475, pp. 71-80 (Apr. 1977).

Pontius, P. E., Allion, H. H., Moore, E. F., Mattingly, G. E., SP484, pp. 33-54 (Oct. 1977).

Post, M. A., Godette, M., Roberts, W. E., Campbell, P. G., NBSIR 77-1263.

PotTer, T. D., GutTman, N. B., Hull, A. R., SP477, pp. II15-II-29 (May 1977).

POTZICK, J. E., ROBERTSON, B., 17138.

POULSON, B. W., NBSIR 75-948.

Pourbaix, M., SP479, pp. 1-16 (July 1977).

Pourbaix, M., Brown, B. F., Burnett, H. C., Chase, W. T., Goodway, M., Kruger, J., SP479:

POWELL, C. J., NBSIR 75-945.

Powell, C. J., Stein, R. J., Needham, P. B., JR., Driscoll, T. J., 16824.

Powell, C. J., Stein, R. J., Needham, P. B., JR., Driscoll, T. $\mathrm{J} ., 17248$.

Powell, F. J., Burch, D. M., SiU, C. I., 17284.

POWELl, F. J., HAHN, M. H., 17286.

Powell, F. J., LiU, S. T., Hunt, C. M., BSS97.

Powell, G., Klein, M., Wardell, J., Wilmot, G., HaAr, L., 17136.

PozdneyeV, D. B., SP461, pp. 129-13! (Jan. 1977).

Prasad, P. N. B., Basavarau, G., Kane, P. P., SP461, pp. 67-69 (Jan. 1977).

Prask, H. J., Chesser, N. J., 17003.

Prask, H. J., Prince, E., Chot, C. S., 17348.

Prask, H. J., Singh, R. S., Trevino, S., 16983.

Prentice, B. A., Ondov, J. M., Ragaini, R. C., Heft, R. E., Fisher, G. L., Silberman, D., SP464, pp. $565-572$ (Nov. 1977).

PReston, K., JR., SP500-8, pp. 56-57 (May 1977).

Price, J. F., SP463, pp. VIII.2.1-VIII.2.4 (Jan. 1977).

Prince, E., Choi, C. S., Prask, H. J., 17348.

Prince, E., Rowe, J. M., Rush, J. J., 16972.

Prince, E., Schroeder, L. W., 16742.

Prosen, E. J., Colbert, J. C., NBSIR 77-1310.

Prosen, E. J., Colbert, J. C., SP400-42, pp. 16-18 (Aug. 1977).

Puckett, R., Sawicki, E., Williams, D., Mưllk, J. D., SP464, pp. 603-607 (Nov. 1977).

PuCKorius, T. D., SP500-15, pp. 5-8 (July 1977).

Pummer, W. J., Flynn, J. H., Dickens, B., 16842.

Purser, F. O., Von Behren, P., Newson, H. W., Nelson, C. E., NBSIR 77-1279, pp. 1-4 (July 1977).

\section{Q}

Queirazza, G., Smedile, E., Ganzerli-Valentini, M. T., Maxia, V., Meloni, S., SP464, pp. 263-273 (Nov. 1977). Quigley, J. M., OSTER, S., SP473, pp. $113-135$ (June 1977). Quindry, T. L., STENBAKken, G. N., 16831.

QUINTIERE, J., 17283.
Quintiere, J., McCaffrey, B., Kashiwagi, T., Den Braven, K., Harkleroad, M., Raines, J., Rinkinen, W., NBSIR 771318.

Quintiere, J. G., MCCAFfrey, B. J., 17285.

\section{$\mathbf{R}$}

RabinOW, J., 16859.

RADACK, S., BURNS, G., NBSIR 76-1113.

Radak, B. B., Markovic, V. M., Mclaughlin, W. L., Kosanic, M. M., Nenadovic, M. T., 16984.

RADEBAUgh, R., 16797.

RADEBAUgh, R., 17088.

Radebaugh, R., Siegwarth, J. D., Lawless, W. N., Morrow, A. J., NBSIR 76-847.

Radebaugh, R., SiegwarTh, J. D., Zimmerman, J. E., 17091.

Radford, H. E., Peterson, F. R., Jennings, D. A., Mucha, J. A., 16867.

Rafelski, J., Danos, M., 17103.

Ragaini, R. C., Heft, R. E., Fisher, G. L., Silberman, D., Prentice, B. A., ONdov, J. M., SP464, pp. 565-572 (Nov. 1977).

Raghavendran, C. P., Sethulakshmi, P., Bhatta, D. P., Nagarajan, P. S., SP461, pp. 100-105 (Jan. 1977).

Rahman, A., Sinha, S. K., Flotow, H. E., Glinka, C. J., ROWE, J. M., RuSH, J. J., 16964.

Rahn, F. J., Stahlkopf, K. E., Marston, T. U., Gold, R., ROBERTS, J. H., SP493, pp. 137-145 (Oct. 1977).

Raines, J., Rinkinen, W., QuintIERE, J., MCCafFrey, B., Kashiwagi, T., Den Braven, K., Harkleroad, M., NBSIR 77-1318.

RaINS, T. C., SP492, pp. $49-65$ (Nov. 1977).

Rains, T. C., Barnes, I. L., EPSTEIn, M. S., MoOdy, J. R., RoOK, H. L., Paulsen, P. J., SP464, pp. $515-518$ (Nov. 1977).

Rains, T. C., O'Haver, T. C., Epstein, M. S., SP464, pp. 47. 51 (Nov. 1977).

Rains, T. C., Taylor, J. K., DeardorfF, E. R., NBSIR 77 1315.

Raley, C. C., Peiser, H. S., Cornish, J., NBSIR 76-1152.

RamamoorThy, S., KuShneR, D. J., SP464, pp. 467-471 (Nov. 1977).

Ramboz, J. D., Koyanagi, R. S., Pollard, J. D., NBSIR 73. 291.

Ramey, A. M., Persensky, J. J., NBSIR 77-1294.

Ramey, A. M., Pezoldt, V. J., Persensky, J. J., 17200.

Ramo, S., Thomson, R. M., Teller, E., Ramsey, N., Baker, W. O., Eyring, H., Birkhoff, G., Perlis, A., Seamans, R. C., JR., SP465.

Ramsey, N., Baker, W. O., Eyring, H., Birkhoff, G., Perlis, A., Seamans, R. C., JR., Ramo, S., Thomson, R. M., Teller, E., SP465.

RAPER, T. J. R., SP473, pp. 241-251 (June 1977).

RAPER, T. J. R., BRUNGRABER, R. J., NBSIR 76-1005.

RASCHELla, P. A., SP471.

Raterink, H. J., Van de Stadt, H., Frankena, H. J., 16924.

RATHER, L. J., SP463, pp. VIII.1.1-VIII.1.4 (Jan. 1977).

Raufaste, N. J., SP470, pp. X-1-X-11 (Apr. 1977).

Raufaste, N. J., Marshall, R. D., Kliment, S., NBSIR 77. 1197.

RAUFASTE, N. J., JR., SP477, pp. I-70-I-78 (May 1977).

Raufaste, N. J., JR., Kliment, S. A., Marshall, R. D., BSS100-1.

RAVECHÉ, H. J., 16786.

RAVECHÉ, H. J., STUART, C. A., 16986.

RaVeché, H. J., Stuart, C. A., 17012.

Raybold, R. C., Cameron, J. M., Croarkin, M. C., TN952.

Raymer, M. G., Carlsten, J. L., SzöKe, A., 16857.

READ, D. T., LeDBeTter, H. M., 17068.

READ, D. T., LedBetTER, H. M., 17085. 
ReAD, D. T., LeDbeTTER, H. M., 17087.

ReAD, M. E., ButrymowiCz, D. B., MANning, J. R., JPCRD 6, No. 1, 1-50 (1977).

READER, J., ACQUiSTA, N., 17212.

ReAmer, D. C., O'HAVer, T. C., ZOller, W. H., SP464, pp. 609-612 (Nov. 1977).

Rebbert, R. E., Ausloos, P. J., 16703.

Rebbert, R. E., Glasgow, L., Ausloos, P., J. Res. 82, No. 1, $1-8$ (1977).

Reddy, V. G., Narasimhacharyulu, E., Swamy, S. T., MUrty, D. S. R., SP46I, pp. 26-28 (Jan. 1977).

REDEMSKE, R. F., SP400-42, pp. 14-15 (Aug. 1977).

REDMOND, T. B., BSSI06, pp. 17-39 (Sept. 1977).

Reed, R. P., Clark, A. F., van Reuth, E. C., 16863.

REed, R. P., MCHeNRY, H. I., 17089.

Reed, R. P., Mikeseli, R. P., Clark, A. F., 16862.

Reed, R. P., Tobler, R. L., 16928.

Reed, R. P., Tobler, R. L., Mikesell, R. P., 16879.

REED, S. K., NBSIR 77-1228.

Reeve, C. P., Veale, R. C., NBSIR 73-232.

ReEve, C. P., Veale, R. C., NBSIR 74-601.

Reeve, G. R., Larsen, N. T., U.S. Patent 4,008,610.

Reeves, R., KLeEman, W., JR., SP473, pp. $55-67$ (June 1977).

ReEves, T. E., BeAR, J. R., SP500-18, pp. 39-67 (Sept. 1977).

Regulla, D. F., Drexler, G., SP461, pp. 197-208 (Jan. 1977).

RehM, R. G., Graminski, E. L., Fong, J. T., 16681.

RENEKER, D. H., BOLZ, L. H., 16995.

ReNo, R. C., BenNett, L. H., SWARTzendruber, L. J., 17011.

Repjar, A., NewEll, A. C., 17224.

RePlogle, J. A., SP484, pp. $201-218$ (Oct. 1977).

RFSTER, G. F., SP494, pp. 33-48 (Sept. 1977).

Reure, A. G., SP466, pp. 99-114 (May 1977).

REZNEK, B., RYAN, J. D., SP489.

Rhodin, T., Yates, J. T., Haller, G., Katzer, J., Park, R., SP475, p. 13 (Apr. 1977).

RhYNe, J. J., KoON, N. C., Milstein, J. B., Alperin, H. A., 16963.

Rryne, J. J., Sweger, D. M., Abbundi, R., Segnan, R., 16985.

Riad, S. M., NaHMaN, N. S., 16731.

RichaRd, A. H., SP450, pp. $171-173$ (June 1977).

RichardS, O., SP473, pp. 279-284 (June 1977).

Richardson, P., Howorth, P. J. N., Hirst, A. D., Gay, P., SP450, pp. $311-314$ (June 1977).

RICHMOND, J. C., SP480-25.

Richmond, J. C., 16761.

RiCHMOND, J. C., 17233.

Ruchmond, J. C., Freeman, C. M., Nudelman, S., 17339.

Richmond, J. C., HsiA, J. J., Ginsberg, I. W., Limperis, T., Nicodemus, F. E., Monogr. 160.

RINKINEN, W., Quintiere, J., MCCAFFrey, B., Kashiwagi, T., Den Braven, K., Harkleroad, M., Raines, J., NBSIR 77 1318.

Rippey, W., Hebrank, J., Hurley, C. W., Ryan, J. D., OBRIGHT, W., NBSIR 77-1243.

Rippy, D. E., Abrams, M. D., Cotton, I. W., WatkIns, S. W., ROSENTHAL, R., 17252.

Risley, A. S., Howe, S. L., 17070.

Risley, A. S., Van de Stadt, H., Strumia, F., Stein, S. R., 17203.

Rispens, P., van Kampen, E. J., Zulstra, W. G., SP450, pp. 27-31 (June 1977).

Rispens, P., Zulstra, W. G., SP450, pp. 33-38 (June 1977).

Rispens, P., Zulstra, W. G., van Kampen, E. J., SP450, pp. 47-52 (June 1977).

Rispens, P., Zock, J. P., Zulstra, W. G., SP450, pp. 39-45 (June 1977).

Rrtter, J. J., Abramowtrz, S., KiRKIIN, D. R., 17166.

Ritter, J. J., Lamotte, M., DeWey, H. J., KelleR, R. A., U.S. Patent 4,025,406.

RTtTer, M., MAXWELl, M. S., SP500-8, pp. 7 1-75 (May 1977).
Roat, C. L., Clark, R. E., SP458.

Robb, W. D., Hayes, M. A., Norcross, D. W., ManN, J. B., 17132.

Robren, F. A., LiU, H., LIN, J., Delisi, D. P., SP484, pp. 423. 447 (Oct. 1977).

Robbins, C. R., Wiederhorn, S. M., Fuller, E. R., JR., BuKOWSKI, J. M., 16993.

RoBbins, D. H., NBS-GCR-77-91.

Roberts, J. H., Rahn, F. J., Stahlkopf, K. E., Marston, T. U., Gold, R., SP493, pp. 137-145 (Oct. 1977).

Roberts, J. R., Czernichowski, A., Holys, A., 17276.

ROBERTS, J. R., VOIGT, P. A., 16950.

Roberts, W. E., Campbell, P. G., Post, M. A., Godette, M., NBSIR 77-1263.

ROBERTSON, A. R., SP466, pp. $117-120$ (May 1977).

ROBERTSON, B., 17215.

Robertson, B., Baumgarten, G. P., TN943.

Robertson, B., Potzick, J. E., 17138.

Robertson, J. M., Clark, M. E., SP484, pp. $479-489$ (Oct. 1977).

Robinson, J. E., Harrison, G. H., Cox, C. R., Kubiczek, E. B., NBSIR 77-1279, pp. 19-23 (July 1977).

Robinson, R. A., Bates, R. G., Hetzer, H. B., Durst, R. A., J. Res. 81A No. 1, 21-24 (1977).

RoCketT, J. A., MCCAFFrEY, B. J., J. Res. 82, No. 2, 107-117 (1977).

RODER, H. M., NBSIR 77-859.

Rodgers, A. W., Kurucz, R. L., AYres, T. R., LINSKY, J. L., 16809.

Roe, K. C., Allred, C. M., Hoer, C. A., 16724.

Rogers, G. J., Blackburn, D. L., Koyama, R. Y., Oettinger, F. F., 17345.

Rogers, G. J., Blackburn, D. L., Koyama, R. Y., Oettinger, F. F., NBSIR 77-1249.

Rogers, G. J., Blackburn, D. L., Rubin, S., 16893.

ROTTMAN, P., GaLlowaY, K. F., NBSIR 77-1235.

ROJAHN, C., SP470, pp. IV-53-IV-66 (Apr. 1977).

ROJAHN, C., SP477, pp. III-26-III-40 (May 1977).

Ronan, R. J., Kunselman, G., SP464, pp. 107-111 (Nov. 1977).

ROOK, H. L., SP492, pp. 26-32 (Nov. 1977).

RoOK, H. L., Deardorf, E. R., Margeson, J. H., Fuerst, R. G., Hughes, E. E., 17230.

RoOK, H. L., Gills, T. E., LuTz, G. J., SP492, pp. 20-22 (Nov. 1977).

Rook, H. L., Paulsen, P. J., Rains, T. C., Barnes, I. L., EpSTEIN, M. S., MOODY, J. R., SP464, pp. $515-518$ (Nov. 1977).

RORRER, D. E., Shaver, J. R., Wyly, R. S., NBSIR 77-1261.

RФRTH, M., Strickland, D. A. P., SiggaAr-ANdersen, O., SP450, pp. 11-19 (June 1977).

Rosasco, G. J., ETZ, E. S., SP464, pp. 343-346 (Nov. 1977).

Rosasco, G. J., ETZ, E. S., 17013.

ROSBERRY, F. W., SWYT, D. A., 17063.

Rosenstein, M., Mclaughlin, W. L., Levine, H., U.S. Patent 4,006,023.

Rosenstock, H. M., Botter, R., Pechine, J. M., 17146.

Rosenstock, H. M., MCCulloh, K. E., Lossing, F. P., 17294.

Rosenthal, R., Rippy, D. E., Abrams, M. D., Cotton, I. W., WATKINS, S. W., 17252.

Ross, A. B., FARHATAZIZ, NSRDS-NBSS9.

ROSSITER, W. J., JR., MATHEY, R. G., 17060.

Rosstrer, W. J., JR., MATHEY, R. G., 17061.

Rossiter, W. J., JR., Mathey, R. G., BurCh, D. M., Pierce, E. T., TN946.

ROSSTTER, W. J., JR., MATHEy, R. G., NBSIR 77-1256.

ROSSMASSLER, S. A., SP463.

Rossmassler, S. A., TN947.

ROSSMASSleR, S. A., 16692.

Roth, L., Benumin, I. A., Fung, F., NBSIR 77-1209. 
Roth, P. F., 17020.

Roth, R. S., Brower, W. S., Harding, C. A., Waring, J. L., J. Res. 82, No. 3, 167-172 (1977).

Roth, R. S., COOK, L. P., Negas, T., Cleek, G. W., WaChtMAN, J. B., JR., SP486.

Roth, R. S., Parker, H. S., Brower, W. S., Minor, D. B., J. Res. 82, No. 3, 151-165 (1977).

Roth, S. C., DeReggi, A. S., Edelman, S., NBSIR 76-1078.

Roussin, R. W., MaskewtT, B. F., Trubey, D. K., SP463, pp. III.1.1-III.1.10 (Jan. 1977).

Roussin, R. W., Truaey, D. K., Maskewitz, B. F., SP461, pp. 171-173 (Jan. 1977).

Rowe, J. M., 16970.

Rowe, J. M., Glinka, C. J., Vagelatos, N., Flotow, H. E., RUSH, J. J., 17004.

Rowe, J. M., Rush, J. J., Libowitz, G. G., Maeland, A., GlinKA, C. J., 16965.

Rowe, J. M., Rush, J. J., Prince, E., 16972.

Rowe, J. M., Rush, J. J., Rahman, A., Sinha, S. K., Flotow, H. E., Glinka, C. J., 16964.

Rowe, P. G., Gevirtz, J. L., Blackburn, J. B., JR., SP473, pp. 189-202 (June 1977).

RowLAND, G. A., SP471, pp. 90-102 (June 1977).

Roy, S. C., Ghose, A. M., SP461, pp. 17-19 (Jan. 1977).

Roy, S. C., Ghose, A. M., Gopinath, D. V., Hubbell, J. H., SP461.

Rubin, A. I., Cadoff, M. A., Flynn, D. R., Leasure, W. A., JR., H122.

RuBin, A. I., Glass, R. A., 17036.

Rubin, R. J., Mazur, J., Weiss, G. H., 16696.

RuBin, S., Rogers, G. J., BlACKBURN, D. L., 16893.

RUBINSKY, S., SP482, pp. 105-109 (July 1977).

RUDLAND, R. S., SP484, pp. 705-718 (Oct. 1977).

Rueger, L. J., Easton, R. L., Fisher, L. C., Hanson, D. W., Hellwig, H. W., 17179.

RUEGG, R. T., 17299.

RUEGg, R. T., MARShall, H. E., 17107.

RUEGG, R. T., WYLY, R. S., Marshall, H. E., 17296.

RUFF, A. W., 16827.

RufF, A. W., Fraker, A. C., 16973.

RuFf, A. W., Ives, L. K., YOUNG, J. P., SP468, pp. 145-157 (Apr. 1977).

RuFr, A. W., WeINSTEIN, A., Horowtz, E., SP472.

RUF, A. W., YOUNG, J. P., 16898.

RuFf, A. W., Young, J. P., IVES, L. K., 17300.

RUfF, J. F., SAXTON, K., DANG, C., SP484, pp. 187-200 (Oct. 1977).

RuigroK, T. J. C., MAAS, A. H. J., VeEFKIND, A. H., VAN DEN Camp, R. A. M., Teunissen, A. J., Bonnk, A. B. T. J., SP450, pp. 257-265 (June 1977).

RuNCK, A. H., SP450, pp. 267-272 (June 1977).

Rush, J. J., Libowitz, G. G., Maeland, A., Glinka, C. J., RowE, J. M., 16965.

Rush, J. J., Prince, E., Rowe, J. M., 16972.

Rush, J. J., Rahman, A., Sinha, S. K., Flotow, H. E., Glinka, C. J., ROWE, J. M., 16964.

Rush, J. J., Rowe, J. M., Glinka, C. J., Vagelatos, N., Flotow, H. E., 17004.

RusSell, L. R., Tighe, N. J., WIEderhorN, S. M., NBSIR 771202.

RUSSELL, P. A., SP464, pp. 335-336 (Nov. 1977).

Russell, P. A., Barrett, C. S., Clark, R. L., RuUd, C. O., SP464, pp. 635-636 (Nov. 1977).

RusSell, T. J., LeEDY, T. F., MattTS, R. L., 17330.

Russwurm, G. M., McClenny, W. A., SP464, pp. 287-290 (Nov. 1977).

RuTHBERG, S., SP400-42, pp. 25-30 (Aug. 1977).

RUTHBERG, S., 16935.

RUTHBERG, S., 16943.

RuthiberG, S., NeFF, G. R.. MARTIN, B. D., 17331.
RuthberG, Z. G., MCKenzie, R. G., SPSO0-19.

Ruud, C. O., Russell, P. A., Barrett, C. S., Clark, R. L., SP464, pp. 635-636 (Nov. 1977).

Ryan, J. D., Obright, W., Rippey, W., Hebrank, J., Hurley, C. W., NBSIR 77-1243.

Ryan, J. D., REZNEK, B., SP489.

Rymen, T., Delespaul, I., Peperstrate, H., SP464, pp. 617623 (Nov. 1977).

S

Sachs, D. C., Meagher, T. F. V., Peckham, V. D., SP484, pp. 687-704 (Oct. 1977).

SAHN1, D. C., SP461, pp. 87-90 (Jan. 1977).

SALTER, R. G., SP494, pp. 225-237 (Sept. 1977).

SALTMAN, R. G., SP500-17.

Saltmarsh, M. J., Ludemann, C. A., Fulmer, C. B., Styles, R. C., NBSIR 77-1279, pp. 24-29 (July 1977).

SAM, F., SP488, pp. 69-71 (Aug. 1977).

SAMS, R. L., LAFFERTY, W. J., 17123.

Sams, R. L., Pearson, R., JR., MAKI, A. G., 16823.

SAMUELS, L. G., SP468, pp. 192-194 (Apr. 1977).

Sanders, D. M., Haller, W. K., 17043.

Sanderson, B. T., Alumbaugh, R. L., Escalante, E., iverson, W. P., Gerhold, W. F., Monogr. 158.

SANDS, T. P., SP488, pp. 61-62 (Aug. 1977).

Sandstrom, D. R., WaClawski, B. J., Vorburger, T. V., 16808.

SANGSTER, R. C., NBSIR 75-949.

SANGSTER, R. C., 17105

Sanjeevaiah, B., Gopal, S., SP461, pp. 29-31 (Jan. 1977).

Sanjeevaiah, B., Gopala, K., SP461, pp. 60-63 (Jan. 1977).

Sanjeevalah, B., Gowda, R., SP461, pp. $41-43$ (Jan. 1977).

Sanjeevaiah, B., Samjeevaiah, H., SP461, pp. 23-25 (Jan. 1977).

Sanjeevaiah, H., Sanjeevaiah, B., SP461, pp. 23-25 (Jan. 1977).

Santhanam, K., Gopinath, D. V., Muthukrishnan, G., SP461, pp. 140-143 (Jan. 1977).

Santo, T., Hattori, S., Krtagawa, Y., SP470, pp. III-1-III-17 (Apr. 1977).

Santo, T., Terashima, T., SP470, pp. III-18-III-28 (Apr. 1977).

Santo, T., Terashima, T., SP477, pp. IV-47-IV-54 (May 1977).

Sargeant, J., Sellschop, J. P. F., Watterson, J. I. W., Erasmus, C. S., SP464, pp. 129-136 (Nov. 1977).

SARGENT, L. B., JR., SP488, pp. 37-38 (Aug. 1977).

SARKAR, P. K., KIRTHI, K. N., SP461, pp. 247-251 (Jan. 1977).

Sattler, K., Siegmann, H. C., Campagna, M., Pierce, D. T., MEIER, F., 17022.

SAUNDERS, R. D., Shumaker, J. B., TN594-13.

SAWADA, K., SP477, pp. VI-44-VI-49 (May 1977).

SAWADA, K., KOGA, Y., SP470, pp. V-16-V-35 (Apr. 1977).

Sawicki, E., Williams, D., Mulik, J. D., Puckett, R., SP464, pp. 603-607 (Nov. 1977).

SAWYER, D. E., BERNING, D. W., SP400-24.

Sawyer, D. E., Berning, D. W., Lewis, D. C., 17164.

SAXENA, J., KozUCHOWSK1, J., BASU, D. K., SP464, pp. 1,01-104 (Nov. 1977).

SAXTON, K., DANG, C., RuFF, J. F., SP484, pp. 187-200 (Oct. 1977).

SCALZI, J. B., SP477, pp. VI-28-VI-36 (May 1977).

Scalzi, J. B., Thiel, C. C., SP470, pp. IX-6-IX-16 (Apr. 1977).

SCANlaN, R. H., Gade, R. H., SP477, pp. I-1-I-11 (May 1977).

SChAEFER, A. O., SP468, pp. 80-92 (Apr. 1977).

SChAEFER, A. R., ZALEWSKI, E. F., TN935. 
Schaefer, A. R., Zalewski, E. F., Geist, J., Lind, M. A., TN954.

SCHAEFFER, H. G., SP487, pp. 41-61 (Aug. 1977).

SchaefGen, J. R., JR., Carroll, W. L., NBSIR 77-1307.

SCHAFFER, R., YAP, W., 16959.

SchafFer, R., YAP, W. T., Howell, B. F., 16911.

SCHAFFT, H. A., SP400-42.

SCHEIDE, E. P., 16773.

SChEIDE, E. P., 'JURST, R. A., 16771.

Scheil, G. W., KNOll, J. E., MidGetT, M. R., SP464, pp. $575-$ 579 (Nov. 1977).

Scheil, G. W., Margeson, J. H., Constant, P. C., Jr., Sharp, M. C., SP464, pp. 573-574 (Nov. 1977).

SCHELENZ, R., SP464, pp. 113-120 (Nov. 1977).

SChEller, K., Eisentraut, K. J., SP494, pp. 3-23 (Sept. 1977).

Schenck, P. K., Smyth, K. C., Travis, J. C., KING, D. S., 17287.

Schinck, P. K., Travis, J. C., Luther, G. G., Green, R. B., KELler, R. A., 16691.

Scheps, R., Gallagher, A., Cheron, B., 16752.

SCHLAMP, R. J., Kelly, M. P., SP487, pp. 210-238 (Aug. 1977).

SCHMIDT, L. B., WEST, E. D., TN685.

Schmidt, W. P., Bass, A. M., Hodgeson, J. A., Hughes, E. E., 16756.

SCHNEIDER, S. J., JR., 17158.

SCHNEIDER, S. J., JR., 17159.

SCHINEIDER, T., SP464, pp. 613-615 (Nov. 1977).

SCHNEIDEWINd, N., Fiegl, E., SP500-18, pp. 235-248 (Sept. 1977).

Schodex, D. L., Gauchat, U. P., SP473, pp. 17-33 (June 1977).

SCHRAMM, R. E., KASEN, M. B., 16865.

SCHRöder, I. G., HARVey, J. A., SP493, pp. 10-13 (Oct. 1977).

Schroeder, L. W., Dickens, B., Brown, W. E., Jordan, T. H., 16741.

Schroeder, L. W., Dickens, B., Brown, W. E., Mathew, M., 17034.

Schroeder, L. W., Dickens, B., Brown, W. E., 17259.

SCHROEder, L. W., Jordan, T. H., MATHEW, M., 17095.

Schroeder, L. W., Prince, E., 16742.

SchultZ, D. M., FinTel, M., SP477, pp. VI-220-VI-251 (May 1977).

Schulz, C. A., SP468, pp. 199-201 (Apr. 1977).

SCHUMM, R. H., PARKer, V. B., WAGMAN, D. D., NBSIR 77 1300.

SchuTt, J. B., SP466, pp. 87-93 (May 1977).

SCHWARTZ, F. P., WASIK, S. P., 17097.

SCHWARTZ, R. B., SP493, pp. 250-254 (Oct. 1977).

SCHWARZ, C. F., SP488, pp. 17-18 (Aug. 1977).

SCHWARZ, F. P., 17038.

SChWertzer, H. C., BuRnetT, E. D., 17145.

ScotT, W. J., Brand, M. J. D., SP450, pp. $301-310$ (June 1977).

SCOTTRON, V. E., SP484, pp. 737-753 (Oct. 1977).

Seamans, R. C., Jr., Ramo, S., Thomson, R. M., Teller, E., Ramsey, N., Baker, W. O., Eyring, H., Birkhoff, G., PerLIS, A., SP465.

SEARS, P. M., BSSI06, pp. 221-227 (Sept. 1977).

Segar, D. A., Cantillo, A. Y., SP464, pp. 491493 (Nov. 1977).

Segnan, R., Rhyne, J. J., SWeger, D. M., Abbundi, R., 16985.

SekHaran, K. K., SP493, pp. 234-236 (Oct. 1977).

Sellschop, J. P. F., Watterson, J. I. W., Erasmus, C. S., SarGEANT, J., SP464, pp. 129-136 (Nov. 1977).

Seltzer, S. M., Metzger, A. E., Trombka, J. I., DYer, C. S., Evans, L. G., Bielefeld, M. J., 16938.

SEM, G. J., SP464, pp. 191-197 (Nov. 1977).

SENGERS, J. M. H. L., 17279.

SENHOLZi, P. B., SP494, pp. 27-32 (Sept. 1977).
Servoz, A., Brower, W. B., JR., SP484, pp. $719-735$ (OCt. 1977).

Sethulakshmi, P., Bhatia, D. P., Nagarajan, P. S RAGHaVendRaN, C. P., SP461, pp. 100-105 (Jan. 1977).

SEWARD, R. W., YOLKEN, H. T., SP463, pp. VII.4.1-VII.4.14 (Jan. 1977).

SEWARD, W. N., SP484, pp. 929-934 (Oct. 1977).

Shafer, J. F., Adams, J. W., CraWford, M. L., 17251.

Shand, W.A., Treado, M. J., SP480-13.

Shao, L. C., Stuart, R. J., Hofmayer, C. H., SP477, pp. VII1-VII-28 (May 1977).

Shapakov, V. I., Adamov, V. M., Alexandrov, B. M., Alkhazov, I. D., Drapchinsky, L. V., Kovalenko, S. S., Kostochian, O. I., Kudriavzev, G. Y., Malkin, L. Z., Petrzhak, K. A., Pleskachevsky, L. A., Fomichev, A. V., SP493, pp. 313-318 (Oct. 1977).

ShapiRo, B. L., MohrmanN, L. E., JPCRD 6, No. 3, 919-992 (1977).

Shapiro, P., Theus, R. B., August, L. S., NBSIR 77-1279, pp. 31-34 (July 1977).

Sharma, R. C., Somasundaram, S., Unnikrishnan, K., Datta, S., SP461, pp. 188-192 (Jan. 1977).

Sharma, S. C., KaTZ, R., SP461, pp. 183-187 (Jan. 1977).

Sharp, M. C., Scheil, G. W., Margeson, J. H., Constant, P. C., JR., SP464, pp. 573-574 (Nov. 1977).

Shaver, J., EllingwOOd, B., 17303.

SHAVER, J. R., WYLY, R. S., RORRER, D. E., NBSIR 77-1261.

Shaw, E. D., Hazlewood, L., Hayes, R. E., Harris, D. R., SP480-24, pp. 1-16 (Nov. 1977).

SheINGorN, M., NeWMaN, M., 17041.

Shelus, P. J., Silverberg, E. C., Faller, J. E., Ghigo, F. D., 16680 .

Sherwood, G. E., Wilkinson, T. L., Fattal, S. G., BSS1003.

ShiER, D., GoOdman, S., 16784.

SHIER, D. R., GILSINN, J. F., NBSIR 77-1253.

SHIER, D. R., HALL, W. G., NBSIR 77-1250.

SHIER, D. R., HALl, W. G., NBSIR 77-1293.

SHIER, D. R., STEIN, M. L., JOEL, L. S., 17117.

Shrloh, M., GaYer, B., Brinckman, F. E., 16757.

SHIMANOUCHI, T., JPCRD 6, No. 3, 993-1102 (1977).

ShIne, R. A., Haisch, B. M., Linsky, J. L., Weinstein, A., 17056.

SHIVES, T. R., NBSIR 74-594.

SHIVES, T. R., NBSIR 77-1275.

SHIVES, T. R., WILlaRd, W. A., SP468.

ShIVES, T. R., WILlaRD, W. A., SP487.

Shives, T. R., Willard, W. A., SP494.

SHORTEN, F. J., TN939.

Shumaker, J. B., SAUNDERS, R. D., TN594-13.

Sibley, E. H., NBSIR 74-500.

SibleY, L. B., SP487, pp. 137-153 (Aug. 1977).

SiECK, L. W., J. Res. 81A Nos. 2 and 3, 267-271 (1977).

SIEDLE, A. R., 17144.

SIEDLE, A. R., 17152 .

SIEDLE, A. R., 17153.

Siedle, A. R., Hertz, H. S., Coxon, B., 17045.

Siedle, A. R., JoHannesen, R. B., 17154.

Siedle, A. R., Negas, T., Broussalian, J., 17137.

Siegmann, H. C., Campagna, M., Pierce, D. T., Meier, F., SATTLER, K., 17022.

SIEGWARTH, J. D., 16798.

Siegwarth, J. D., Lawless, W. N., Morrow, A. J., RADEBAUGH, R., NBSIR 76-847.

Siegwarth, J. D., Younglove, B. A., LaBrecque, J. F., TN697.

Siegwarth, J. D., Younglove, B. A., LaBrecque, J. F., TN698.

SiegWarth, J. D., Younglove, B. A., NBSIR 77-852.

SiegWarth, J. D., Zimmerman, J. E., Ra debaugh, R., 17091. 
SigGAARD-ANDERSEN, O., SP450, pp. 1-9 (June 1977).

SiggAARD-ANDERSEN, O., SP450, pp. 21-26 (June 1977).

SiggaArd-Andersen, O., RøRth, M., Strickland, D. A. P., SP450, pp. 11-19 (June 1977).

Silberman, D., Prentice, B. A., Ondov, J. M., Ragaini, R. C., HeFt, R. E., Fisher, G. L., SP464, pp. 565-572 (Nov. 1977).

Silverberg, E. C., Faller, J. E., Ghigo, F. D., Shelus, P. J., 16680.

SIMHA, R., MCKINNEY, J. E., J. Res. 81 A Nos. 2 and 3, 283297 ( 1977).

Simu, E., SP477, pp. 1-49-1-65 (May 1977).

Simiu, E., Culver, C., Fattal, G., SP490.

Simiu, E., EllingwoOd, B., 16856.

Simiu, E., Marshall, R. D., BSS100-2.

Simiu, E., Patel, V. C., Nash, J. F., SP477, pp. П-30-П-40 (May 1977).

Simiu, E., Vaicaitis, R., 16843.

Simmons, J. A., HaRdy, S. C., Hsu, N. N., 17191.

Simmons, J. D., Hougen, J. T., J. Res. 81A No. 1, 25-80 (1977).

Simpson, J. A., Whitstone, J. R., Hall, A. H., 17023.

Sims, J. S., Langhoff, P. W., Corcoran, C. T., 17319.

SINFELT, J. H., SP475, pp. 56-67 (Apr. 1977).

Singer, S. K., Janz, G. J., Tominins, R. P. T., Allen, C. B., DOWNEY, J. R., JR., JPCRD 6, No. 2, 409-596 (1977).

Singh, H., MukHERJEe, R., MuthukRishNaN, G., SP461, pp. 166-170 (Jan. 1977).

Singh, R. S., Murty, K. P. N., Vaidyanathan, R., SP461, pp. 132-135 (Jan. 1977).

Singh, R. S., Trevino, S., Prask, H. J., 16983.

Singh, R. S., VaIdyanathan, R., Murty, K. P. N., SP461, pp. 163-165 (Jan. 1977).

Singh, U. N., Kobayashi, K., Chrien, R. E., Liou, H. I., Block, R. C., SP493, pp. 255-260 (Oct. 1977).

Singley, G. W., Koenig, H. L., O'Brien, J. F., Skridulis, J., ANNETT, J., SP484, pp. 145-172 (Oct. 1977).

Sinha, B., Chaudhuri, N., SP461, pp. 20-22 (Jan. 1977).

Sinha, S. K., Flotow, H. E., Glinka, C. J., Rowe, J. M., RUSH, J. J., RAHMAN, A., 16964.

Sinha (Goswami), B., Chaudhuri, N., SP461, pp. 55-56 (Jan. 1977).

'Sirugnano, W. A., Dryer, F. L., Glassman, I., NBS-GCR-7679.

Siu, C. 1., Powell, F. J., BurCh, D. M., 17284.

SKLANSKY, J., SP500-8, pp. 92-98 (May 1977).

Skridulis, J., ANNetT, J., Singley, G. W., Koenig, H. L., O'BRIEN, J. F., SP484, pp. $145-172$ (Oct. 1977).

Slanina, J., BORger, D., LINGERAK, W. A., VAN RAaphorst, J. G., SP464, pp. 121-123 (Nov. 1977).

Slater, P. J., J. Res. 82, No. 3, 197-202 (1977).

SLATTERY, W. J., SP463, pp. VII.5.1-VII.5.9 (Jan. 1977).

SLATTERY, W. J., SP483.

SLATTERY, W. J., TN948.

SLEATER, G. A., TN941.

SMALL, J. A., ZOLLER, W. H., SP464, pp. 651-658 (Nov. 1977).

Smedile, E., Ganzerli-Valentini, M. T., Maxia, V., Meloni, S., QueirazZA, G., SP464, pp. 263-273 (Nov. 1977).

SMEYERS, P., 16804.

SMEYERS, P., AIZENMAN, M. L., 17311.

SMEYers, P., Weigert, A., AIZENMAN, M., 17029.

SMTrH, B., SP473, pp. 453-489 (June 1977).

SMITH, C. N., 17182.

SMTrt, C. O., SP487, pp. 1-15 (Aug. 1977).

SMITH, C. S., SP479, pp. 143-153 (July 1977).

SMTth, D. K., HubBaRd, C. R., 16953.

SMITH, E. B., SP500-15, pp. 29-31 (July 1977).

SMith, E. Q., Drullinger, R. E., Hessel, M. M., 17076.

SMTth, E. W., Barnard, A. J., COOPER, J., 17167.

Smith, E. W., Drullinger, R. E., Hessel, M. M., CoOper, J., 17084.
Smith, E. W., Drullinger, R. E., Hessel, M. M., Stock, M., 17194.

Smith, E. W., Giraud, M., 16799.

SMith, E. W., Greene, R. L., CoOper, J., 17249.

Smith, E. W., Mihalas, D., Barnard, A. J., CoOper, J., 17171 .

Smith, E. W., Mihalas, D., Barnard, A. J., Cooper, J., 17172.

Smith, E. W., Vidal, C. R., COOPER, J., 17232.

SMITH, E. W., WARD, J., COOPER, J., 17161.

SMITH, G. K., BlACK, J., SP472, pp. 23-28 (Apr. 1977).

SMITH, J. C., GRAMINSKI, E. L., NBSIR 76-1148.

SMITH, J. H., WILlaRd, W. A., SP468, pp. 121-128 (Apr. 1977).

Smith, L. E., Dehl, R. E., Grant, W. H., Stromberg, R. R., MORRISSEY, B. W., NBSIR 76-1128.

SMTth, L. E., StromberG, R. R., Grant, W. H., 16777.

SMTth, R. K., JR., AMSDEN, A. A., Ginocchlo, J. N., HaRlow,

F. H., Nix, J. R., Danos, M., Halbert, E. C., 17109.

SMith, S. J., KHAYrallah, G. A., 17054.

SMITH, S. J., MAHAN, A. H., 17326.

SMTth, W. S., Paley, L., SP464, pp. 597-599 (Nov. 1977).

Smyth, K. C., Travis, J. C., King, D. S., Schenck, P. K., 17287.

Snow, T. P., Upson, W. L., Starrfield, S. G., Gallagher, J. S., Friedjung, M., Linsky, J. L., Anderson, R., Henry, R. C., Moos, H. W., Jenkins, E. B., 16762.

SNyder, L. E., Lovas, F. J., JohnSON, D. R., BuHL, D., 16664.

SNYDER, W. S., SP461, pp. 177-182 (Jan. 1977).

SOARES, C. G., EHRLICH, M., NBSIR 76-1117.

SOBECKI, R. J., MCNeECE, J. E., SP500-18, pp. 13-21 (Sept. 1977).

SOMA, S., SP477, pp. II-1-П-14 (May 1977).

SOMA, S., SUDA, K., SP470, pp. I-28-1-41 (Apr. 1977).

Somasundaram, S., Unnikrishnan, K., Datta, S., Sharma, R. C., SP461, pp. 188-192 (Jan. 1977).

SONG, Y. T., SP461, pp. 119-123 (Jan. 1977).

SøRENSEN, S. K., SP450, pp. 285-287 (June 1977).

SøRENSEN, S. K., SP450, pp. 289-291 (June 1977).

SORROWs, H. E., 17113.

Sos, J. Y., SP500-8, pp. 28-34 (May 1977).

Spal, R., Feldman, A., KahN, A. H., 17261.

SPAL, R. D., 16828.

SPAlVINS, T., SP487, pp. 324-337 (Aug. 1977).

SPARKS, L. L., 16864.

SParRow, J. H., Dick, C. E., 16814.

SPENCER, E. A., SP484, pp. 947-956 (Oct. 1977).

SPIEGEL, M. G., SPS00-18, pp. 227-234 (Sept. 1977).

Spiegel, V., Eisenhauer, C. M., Heaton, H. T. II, Gilliam, D. M., Bigelow, J., Grundl, J. A., 16790.

SPIVAK, S. M., NBS-GCR-77-90.

SPROULL, R. F., SPS00-8, p. 45 (May 1977).

Srmkantaiah, R. V., Phiske, M. R., Coachman, J. S., NavalKAR, M. P., Joneja, O. P., SP493, pp. $61-66$ (Oct. 1977).

Srivastava, B. K., MukHerJl, S., SP461, pp. 144-148 (Jan. 1977).

Srivastava, S. K., Trammar, S., Chutjan, A., Truhlar, D. G., BRANDT, M. A., 16740.

Staehle, R. W., SP468, pp. $50-78$ (Apr. 1977).

Staffa, J. A., Zervos, C., Mighell, A. D., Hubbard, C. R., 16688.

Stafrord, R. G., Chang, R. K., KindlmanN, P. J., SP464, pp. 659-667 (Nov. 1977).

STAHL, F. I., NBS-GCR-77-92.

STAHL, F. I., ARCHEA, J., NBSIR 77-1313.

Stahliopf, K. E., Marston, T. U., Gold, R., Roberts, J. H., RAHN, F. J., SP493, pp. 137-145 (Oct. 1977).

STANFORD, J. L., BENNETT, H. E., SP466, pp. 133-148 (May 1977). 
Stanton, G. C., Lapinski, N. P., Ellingson, W. A., SP468, pp. 172-181 (Apr. 1977).

STAPles, B. R., Nuttall, R. L., JPCRD 6, No. 2, 385-408 (1977).

Staples, B. R., Nuttall, R. L., Arbuckle, R., Goldberg, R. N., SP485.

Starke, K., Janghorbani, M., Ellinger, M., SP464, pp. 151 156 (Nov. 1977).

Starrfield, S. G., Gallagher, J. S., Friedjung, M., Linsky, J. L., Anderson, R., Henry, R. C., MoOs, H. W., Jenkins, E. I $\because$., SNOW, T. P., UPSON, W. L., 16762.

Stedman, D. H., HaRVEy, R. B., SP464, pp. 393-396 (Nov. 1977).

STEIDL, R. E., SP482, pp. 55-69 (July 1977).

Stein, M. L., Joel, L. S., SHIER, D. R., 17117.

STEIN, R. J., 16744.

Stein, R. J., Needham, P. B., JR., Driscoll, T. J., Powell, C. J., 16824.

Stein, R. J., Needham, P. B., Jr., Driscoll, T. J., Powell, C. J., 17248.

Stein, S. R., Gray, J. E., Glaze, D. J., Walls, F. L., 17185.

Stein, S. R., Risley, A. S., Van de Stadt, H., Strumia, F., 17203.

Stein, S. R., Walls, F. L., TN692.

STEINBERG, H., SP480-21.

STEINBERG, H. L., NBSIR 76-I 146 .

STEINBERG, H. L., 16706.

STEINER, B. W., 17024.

Steinitz, R., Gebbie, K. B., BAR, V., 16888.

STENBAKKEN, G., ISLeR, M., 17002.

STENBAKKen, G. N., QUINDRY, T. L., I683I.

Stephens, K. S., Peiser, H. S., Beck, N. C., NBSIR 76-1180.

STEPHENSON, J. C., 17193.

Stern, R., Haisch, B. M., Linsky, J. L., Lampton, M., Paresce, F., Margon, B., 16933.

Stevens, W. J., Gardner, M., Karo, A., Julienne, P., 17195.

Stevens, W. J., Hessel, M. M., Bertoncini, P. J., WAhl, A. C., 16870.

Stevens, W. J., Krauss, M., 17188.

Stewart, A., Meguire, P. G., Kramer, J. J., SP480-27.

STEWART, B. D., 17268.

Stewart, L., Bowman, C. D., Carlson, A. D., liskien, H. O., SP493.

Stewart, L., Carlson, A. D., Bowman, C. D., Lone, M. A., NBSIR 77-1279.

Stewart, L., Eisenhauer, C. M., SP493, pp. 198-205 (Oct. 1977).

Stewart, L. H., Gangwere, S. G., Jr., Hosler, J. R., SP50018, pp. 185-211 (Sept. 1977).

Stewich, M. W., Hadden, S. C., Hanson, R. E., SP494, pp. 238-248 (Sept. 1977).

STtefel, S. W., JuSTin KIM, S., HuNG, H., NBSIR 77-1212.

Stock, M., Drullinger, R. E., Hessel, M. M., 16800.

Stock, M., Smith, E. W., Drullinger, R. E.; Hessel, M. M., 17194.

STOCKBAUER, R., 17148.

Stone, E. J., Lawrence, G. M., Falrchild, C. E., 16812.

Stratton, A. K., NBS-GCR-76-78.

Straty, G. C., TSUMURA, R., 17067.

Streit, G. E., Petersen, F. R., Wells, J. S., 16728.

Strickiand, D. A. P., SiggaArd-Andersen, O., R $\phi$ RTh, M., SP450, pp. 11-19 (June 1977).

STRNAD, J. J., SPS00-15, pp. 51 -52 (July 1977).

Strobridge, T. R., Voth, R. O., NBSIR 77-857.

STROBRIDGE, T. R., VOTH, R. O., 17083.

STROIK, J. S., SP480-22.

STROIK, J. S., 16714.

StromberG, R. R., Grant, W. H., SMith, L. E., 16777.

Stromberg, R. R., Morrissey, B. W., Smith, L. E., Dehl, R. E., GRANT, W. H., NBSIR 76-1128.
Strumia, F., Stein, S. R., Risley, A. S., Van de Stadt, H., 17203.

Stuart, C. A., Raveché, H. J., 16986.

Stuart, C. A., RAveché, H. J., 17012.

Stuart, R. J., Hofmayer, C. H., Shao, L. C., SP477, pp. VII1-VII-28 (May 1977).

Stuck, D., Bridges, J. M., Ott, W. R., Pitz, A., Einfeld, D., 17198.

Styles, R. C., Saltmarsh, M. J., ludemann, C. A., Fulmer, C. B., NBSIR 77-1279, pp. 24-29 (July 1977).

SUdA, K., SOMA, S., SP470, pp. I-28-I-41 (Apr. 1977).

SUENRAM, R. D., JohnSON, D. R., LAFFe RTY, W. J., 16689.

Sugar, J., Corliss, C., JPCRD 6, No. 2, $317-384$ (1977).

Sugar, J., Corliss, C., JPCRD 6, No. 4, 1253-1330 (1977).

SuHOKE, R. B., SP484, pp. 597-619 (Oct. 1977).

Sullivan, D. B., Adair, R. T., Frederick, N. V., 16875.

Sullivan, D. B., Adair, R. T., Frederick, N. V., NBSIR 77. 863.

Sullivan, D. B., Frederick, N. V., 16876.

Sullivan, D. B., Frederick, N. V., Adair, R. T., 17092.

Sullivan, D. B., McDonald, D. G., EdRich, J., 17077.

Sullivan, D. B., Zimmerman, J. E., 17334.

SuloufF, R. E., SP40042, pp. 22-24 (Aug. 1977).

Sundaram, V. K., Gopinath, D. V., SP461, pp. $94-96$ (Jan. 1977).

Sundararaman, V., Gopalakrishnan, C. R., SP461, pp. 106109 (Jan. 1977).

Sunta, C. M., Jain, V. K., Kathuria, S. P., Bapat, V. N., SP461, Pp. 222-226 (Jan. 1977).

SUPE, S. J., DATTA, S., SP461, pp. 193-196 (Jan. 1977).

SUREK, T., Coriell, S. R., 16931.

SwaIN, J. W., JR., SP488, pp. $41-43$ (Aug. 1977).

SwaIN, K., Troha, W., SP487, pp. 108-1 20 (Aug. 1977).

SWAINE, D. J., SP464, pp. 625-626 (Nov. 1977).

Swamy, S. T., Murty, D. S. R., Reddy, V. G., NarasimhaCHARYULU, E., SP461, pp. 26-28 (Jan. 1977).

Swann, P. R., Tighe, N. J., 17177.

Swartzendruber, L. J., Reno, R. C., Bennett, L. H., 17011.

Swarup, J., Ganguly, A. K., SP46I, pp. 124-128 (Jan. 1977).

SWeger, D. M., Abbundi, R., Segnan, R., RhyNe, J. J., 16985.

Sweger, D. M., Freund, S. M., Travis, J. C., SP464, pp. 317 . 320 (Nov. 1977).

Swenson, J. S., Williams, J. D., SP500-18, pp. 3-11 (Sept. 1977).

SWOPE, H. G., SP464, pp. 685-687 (Nov. 1977).

SWYT, D. A., NBSIR 73-106.

SWYT, D. A., NBSIR 73-196.

SWYT, D. A., ROSBERRY, F. W., 17063.

Szalata, Z. M., Finn, J. M., Flanz, J., Kline, F. J., Peterson, G. A., Lightbody, J. W., JR., Maruyama, X. K., Penner, S., 16850 .

SzöKe, A., Courtens, E., 16848.

SZöke, A., Raymer, M. G., Carlsten, J. L., 16857.

\section{$\mathbf{T}$}

Tabler, J. H., Kullmann, C. G., SP484, pp. 25-32 (Oct 1977).

TAKEUCHI, K., SP470, pp. 1-1-I-17 (Apr. 1977).

Tanaka, M., Flandro, G., Johnson, S. A., Greenleaf, J. F. SP484, Pp. 335-359 (Oct. 1977).

TANAKA, S., FURUTA, Y., SP461, pp. 209-218 (Jan. 1977).

TANNER, R. L., MARLOW, W. H., SP464, pp. 337-342 (Nov 1977).

TARAN, P. P., SP400-42, pp. 33-37 (Aug. 1977).

TASChER, J. M., PS72-76.

TASCHER, J. M., TN960.

TATSUOKA, F., IWASAKI, T., SP477, pp. VI-158-VI-178 (Ma) 1977). 
TATSUOKa, F., IWASAKI, T., WaKabaYashi, S., SP477, pp. III41-III-56 (May 1977).

Tatsuoka, F., Kuribayashi, E., SP470, pp. V-1-V-15 (Apr. 1977).

TAUBER, T., SP494, pp. 123-132 (Sept. 1977).

TAusch, H. J., Jesch, R. L., Bailey, R. A., 17239.

TAYLOR, J. K., SP464, pp. 503-507 (Nov. 1977).

TAYloR, J. K., DeARdoRf, E. R., RAINS, T. C., NBSIR $77-$ 1315.

Taylor, R., Cezalrliyan, A., McClure, J. L., J. Res. 81 A Nos. 2 and 3, 251-256 (1977).

TaZAKI, T., ICHIHARA, K., KuRIBayashI, E., SP477, pp. VI69-VI-84 (May 1977).

Tazaku, T., Hadate, T., Kuribayashi, E., SP477, pp. IV1-IV-17 (May 1977).

Teitsma, G. J., Peavy, B. A., NBSIR 76-1/82.

Teller, E., Ramsey, N., Baker, W. O., Eyring, H., Birkhoff, G., Perlis, A., Seamans, R. C., JR., Ramo, S., Thomson, R. M., SP465.

TENDOLKaR, N. N., SP500-18, pp. 87-94 (Sept. 1977).

Terashima, T., SaNTO, T., SP470, pp. III-18-III-28 (Apr. 1977).

TERAShima, T., SANTO, T., SP477, pp. IV-47-IV-54 (May 1977).

Termini, D. J., Dickson, G., Brauer, G. M., 17202.

Tessmann, R. K., Maroney, G. E., SP494, pp. 24-26 (Sept. 1977).

Teunissen, A. J., Boink, A. B. T. J., Ruigrok, T. J. C., MAAs, A. H. J., VeEFIND, A. H., VAN DEN CAMP, R. A. M., SP450, pp. 257-265 (June 1977).

Thaddeus, P., Johnson, D. R., Lovas, F. J., Gottlieb, C. A., GotTtieb, E. W., Litvak, M. M., Guelin, M., 17264.

Theus, R. B., August, L. S., Shapiro, P., NBSIR 77-1279, pp. 31-34 (July 1977).

Thiel, C. C., ScalzI, J. B., SP470, pp. IX-6-IX-16 (Apr. 1977).

Thompson, C. J., Whisman, M. L., SP488, pp. 57-60 (Aug. 1977).

ThOMPSON, M. S., SP471, pp. 24-28 (June 1977).

THOMPSON, R. L., SP47I, pp. 1 -4 (June 1977).

THOMSON, R. M., 17031 .

Thomson, R. M., Teller, E., Ramsey, N., Baker, W. O., Eyring, H., Birkhoff, G., Perlis, A., Seamans, R. C., JR., RAMO, S., SP465.

THORNTON, D. D., 17055.

Thornton, D. D., Mangum, B. W., SP481.

Thrush, B. A., HuIE, R. E., LONG, N. J. T., 16844.

Thrush, B. A., HuIE, R. E., LONG, N. J. T., 17238.

THURBer, W. R., BUEHLER, M. G., 16942.

Thurber, W. R., Buehler, M. G., DAvi, J. M., Mattis, R. L., Phillips, W. E., 16855.

THURBER, W. R., LI, S. S., 17147.

TIGHE, N. J., NBSIR 76-1075.

Tighe, N. J., 17090.

Tighe, N. J., Evans, A. G., Wiederhorn, S. M., 17046.

Thghe, N. J., SWanN, P. R., 17177.

TIGHE, N. J., WIEDERHORN, S. M., RUSSELl, L. R., NBSIR $77-$ 1202.

ThLFORD, C. R., 17048.

Thrord, C. R., Hyland, R. W., Heydemann, P. L. M., 17269.

Tommerhaus, K. D., Wertzel, D. H., 16907.

TINCher, W. C., Lloyd, L. R., LOWERY, R. P., Tingle, W. J., WOlFe, V. L., JR., DURBeTAKI, P., NBS-GCR-77-99.

Tingle, W. J., Wolfe, V. L., JR., Durbetaki, P., Tincher, W. C., LLOYD, L. R., LOWERY, R. P., NBS-GCR-77-99.

TOBLER, R. L., 16801.

TOBLER, R. L., 17086.

Tobler, R. L., Mikesell, R. P., Reed, R. P., 16879.

TOBLER, R. L., REED, R. P., 16928.

Tobschall, H. J., Lawkowski, N., KRITSOTAKIS, K., SP464, pp. 459-460 (Nov. 1977).
TODD, T. R., 17044.

ToKuHiro, H., WATABE, M., SP470, pp. X-12-X-16 (Apr. 1977).

Tomkins, R. P. T., Allen, C. B., Downey, J. R., JR., Singer, S. K., JANZ, G. J., JPCRD 6, No. 2, 409-596 (1977).

Tonik, A. B., LiN, W. T. K., SPSO0-18, pp. 213-217 (Sept. 1977).

Toots, J., Finnegan, T. F., Wilson, J., 16946.

TORChiA, D. A., VANDERHART, D. L., 17007.

TOULOUKIAN, Y. S., SP463, pp. IV.4.1-IV.4.3 (Jan. 1977).

Touse, V. T., Blinov, M. V., Vtrenko, V. A., SP493, pp. 194197 (Oct. 1977).

ToY, S. M., SP464, pp. $405-414$ (Nov. 1977).

Trajmar, S., Chutjian, A., Truhlar, D. G., Brandt, M. A., Srivastava, S. K., 16740.

Travis, J. C., King, D. S., Schenck, P. K., SMYth, K. C., 17287.

Travis, J. C., Luther, G. G., Green, R. B., Keller, R. A., SCHENCK, P. K., 16691.

Travis, J. C., Sweger, D. M., Freund, S. M., SP464, pp. 317 320 (Nov. 1977).

TrEADO, M. J., 16996.

Treado, M. J., Shand, W. A., SP480-13.

TrechSEL, H. R., 17110 .

Trefftzs, J. L., Montgomery, C. A., Moore, G. B., Kuhns, J. L., SP5O0-2.

Trellis, A., SP473, pp. 391-396 (June 1977).

Tremaine, S., Hunter, C., 16989.

Treu, S., Abrams, M. D., 17288.

Trevino, S., Prask, H. J., Singh, R. S., 16983.

Trevino, S. F., Farr, M. K., 17001.

Troha, W., Swain, K., SP487, pp. 108-1 20 (Aug. 1977).

Trombka, J. I., Dyer, C. S., Evans, L. G., Bielefeld, M. J., Seltzer, S. M., Metzger, A. E., 16938.

Trousdale, W., SP479, pp. $179-189$ (July 1977).

TRUBEY, D. K., SP461, pp. 74-78 (Jan. 1977).

Trubey, D. K., Maskewitz, B. F., Roussin, R. W., SP461, pp. 171-173 (Jan. 1977).

Trubey, D. K., Roussin, R. W., MaskewtTz, B. F., SP463, pp. III.1.1-III.1.10 (Jan. 1977).

Truhlar, D. G., Blais, N. C., 16802.

TruHlar, D. G., Blais, N. C., 16803.

Truhlar, D. G., Brandt, M. A., Srivastava, S. K., Tramar, S., Chutuian, A., 16740.

Truhlar, D. G., Kuppermann, A., DWyer, J., 16914.

Truhlar, D. G., Van-Catledge, F. A., 16709.

TSAI, D. H., MACDONALD, R. A., 16751 .

TSANG, W., Braun, W., 16783.

TSANG, W., Walker, J. A., SP464, pp. $397-403$ (Nov. 1977).

TSANG, W., WALKer, J. A., 16699.

Tsianco, M. C., Davis, H. T., Anavekar, S. N., Wardell, W. M., NBS-GCR-ETIP 76-35.

Tsuchida, H., Kurata, E., Hayasha, S., SP477, pp. III-16-III25 (May 1977).

Tsuchida, H., KuRBayasha, E., SP470, pp. VIII-56-VIII-68 (Apr. 1977).

Tsuchida, H., Noda, S., Hayasha, S., SP470, pp. VIII42-VIII-55 (Apr. 1977).

Tsuchida, H., Watabe, M., Kuribayashr, E., SP470, pp. IV1-IV-34 (Apr. 1977).

TSUmura, R., Straty, G. C., 17067.

TUCKER, C. D., BEERS, J. S., NBSIR 73-239.

TuCker, C. W., JR., JohnSON, K. H., Messmer, R. P., SP475, pp. 174-177 (Apr. 1977).

TUCKER, J. C., NBSIR 77-1215.

TUCKER, J. C., 16734.

TUNG, M. S., 16787.

Turner, B. E., Palmer, P., Gllmore, W., Morris, M., JohnSON, D. R., Lovas, F. J., ZuCKERMAN, B., 16969.

TYRRELl, J. V., BSS106, p. 220 (Sept. 1977). 


\section{$\mathbf{U}$}

Ulrikson, G. U., Copenhaver, E. D., SP463, pp. III.4.1 III.4.15 (Jan. 1977).

Unnikrishnan, K., Datta, S., Sharma, R. C., Somasundaram, S., SP461, Pp. 188-192 (Jan. 1977).

Unterweger, M. P., Coursey, B. M., Hutchinson, J. M. R., 16975.

Upson, W. L., Starrfield, S. G., Gallagher, J. S., Friedjung, M., Linsky, J. L., Anderson, R., Henry, R. C., MoOs, H. W., Jenkins, E. B., Snow, T. P., 16762.

Uriano, G. A., Gravatt, C. C., 17247.

UTTLEY, C. A., SP493, pp. 47-53 (Oct. 1977).

Uwabe, T., Hayashi, S., Noda, S., SP477, pp. VI-192-VI-198 (May 1977).

\section{$\mathbf{V}$}

Vagelatos, N., Flotow, H. E., Rush, J. J., Rowe, J. M., GlinKa, C. J., 17004.

VAICATTIS, R., SimiU, E., 16843.

Vaidyanathan, R., MURTy, K. P. N., Singh, R. S., SP461, Pp. 163-165 (Jan. 1977).

Vaidyanathan, R., Singh, R. S., Murty, K. P. N., SP461, pp. 132-135 (Jan. 1977).

VALORI, R., SP494, Pp. 49-72 (Sept. 1977).

Van CotT, H. P., Fechter, J. V., 17035.

Van de Stadt, H., Frankena, H. J., Raterink, H. J., 16924.

Van de Stadt, H., Strumia, F., Stein, S. R., Risley, A. S., 17203.

Van den Camp, R. A. M., Teunissen, A. J., Boink, A. B. T. J., RUigroK, T. J. C., MAAS, A. H. J., VeEFIIND, A. H., SP450, pp. 257-265 (June 1977).

VAN der LAan, J. E., Hawley, J. G., Hake, R. D., JR., WilLIAMS, M. F., MURRAY, E. R., SP464, pp. 305-314 (Nov. 1977).

VAN DER MEER, W. J., SP473, pp. 85-101 (June 1977).

van Kampen, E. J., Rispens, P., Zulstra, W. G., SP450, pp. 47-52 (June 1977).

van Kampen, E. J., Zulstra, W. G., Rispens, P., SP450, pp. 27-31 (June 1977).

vaN KEMPEN, L. H. J., KREuZER, F., SP450, pp. 239-246 (June 1977).

VAN RAaPhorst, J. G., Slanina, J., Borger, D., Lingerak, W. A., SP464, pp. 121-123 (Nov. 1977).

van Reuth, E. C., Reed, R. P., Clark, A. F., 16863.

Van-Catledge, F. A., Truhlar, D. G., 16709.

VANDERHART, D. L., TORChiA, D. A., 17007.

VARNER, R. N., TN956.

VASCONCELOS, G. J., SP464, pp. 245-247 (Nov. 1977).

VEALE, R. C., NBSIR 73-136.

VeAle, R. C., ReEve, C. P., NBSIR 73-232.

Veale, R. C., ReEve, C. P., NBSIR 74-601.

Veefikind, A. H., Van den Camp, R. A. M., Teunissen, A. J., Boink, A. B. T. J., Ruigrok, T. J. C., MAAs, A. H. J., SP450, Pp. 257-265 (June 1977).

Velapoldi, R. A., Mavrodineanu, R., Mielenz, K. D., SP466.

Veldman, C. C., Kubota, T., ZuKoski, E. E., NBS-GCR-77-97.

VENABLE, W. H., JR., EcKerle, K. L., 17260.

Venable, W. H., JR., Hsia, J. J., Weidner, V. R., J. Res. 82, No. 1, 29-55 (1977).

VENTRE, F. T., SP473, pp. 203-223 (June 1977).

VERDIER, P. H., 17253.

Verdier, P. H., Kranbuehl, D. E., 17125.

Vezzett, C. F., Mayo-Wells, J. F., Lederer, P. S., Hilten, J. S., TN 961 .

VICKERS, A. K., SP463, pp. VII.2.1-VII.2.11 (Jan. 1977).

Vickers, M. V., Walker, J. C., Evans, J. M., JR., O'Neill, J. T., Little, J. L., Albus, J. S., Barbera, A. J., Fife, D. W.,
Fong, E. N., Gilsinn, D. E., Holberton, F. E., Lucas, B G., Lyon, G. E., Marron, B. A. S., Neumann, A. J., NBSIR 76-1094.

VIDAL, C. R., COOPER, J., SMITH, E. W., 17232.

VIEWEG-Gutrerlet, F. G., Bullis, W. M., 17140.

VINCENT, W. F., SP464, pp. 689-691 (Nov. 1977).

VinCENTY, C., GuThrie, D. L., Washington, D. R., SP484, pp 173-186 (Oct. 1977).

Visser, B. F., Hoelen, A. J., Kreuger, J. A., MaAs, A. H. J., SP450, pp. 73-74 (June 1977).

VISSER, B. F., MAAS, A. H. J., SP450, pp. 69-72 (June 1977).

VISSER, B. F., MAAS, A. H. J., SP450, pp. 119-126 (June 1977).

Vitenko, V. A., Touse, V. T., Blinov, M. V., SP493, pp. 194. 197 (Oct. 1977).

VOGEL, B. M., NBSIR 76-1194.

VOIGHT, P. A., KLOSE, J. Z., 17292.

VOIGT, P. A., KoRnblith, R. L., 16992.

VOIGT, P. A., ROBERTS, J. R., 16950.

Von Behren, P., Newson, H. W., Nelson, C. E., Purser, F. O., NBSIR 77-1279, pp. 1-4 (July 1977).

Voorhees, C. R., Pallett, D. S., 16764.

Voorhees, C. R., Pallett, D. S., Bartel, T. W., 16763.

VORBURGER, T. V., SANDSTROM, D. R., WACLAWSKI, B. J, 16808.

Vorburger, T. V., Waclawski, B. J., Plummer, E. W., 16829

VOTh, R. O., PARrish, W. R., NBSIR 77-862.

VOTH, R. O., STROBRIDGe, T. R., NBSIR 77-857.

VOTH, R. O., STROBRIDGE, T. R., 17083.

\section{W}

Wachtman, J. B., JR., Roth, R. S., CoOk, L. P., Negas, T., Cleek, G. W., SP486.

WACKER, P. F., 16671 .

WACKER, P. F., 17222.

WACKER, P. F., 17223.

WACKER, P. F., 17225 .

WACKer, P. F., Babu, T. M., Bowman, R. R., U.S. Patent 4,008,477.

WACKer, P. F., Newell, A. C., 17221 .

Waclawsid, B. J., Plummer, E. W., Vorburger, T. V., 16829

WAClawski, B. J., Vorburger, T. V., SANDSTrom, D. R. 16808.

Wagman, D. D., Schumm, R. H., Parker, V. B., NBSIR 771300.

WAGner, C. D., Joshi, A., Madey, T. E., 16930.

WAGNer, D. P., Fussell, J. B., SP487, pp. 289-308 (Aug. 1977).

Wagner, H. L., Hoeve, C. A. J., 16710.

WAGNER, H. L., MCCRACKIN, F. L., 17255.

Wayl, A. C., Stevens, W. J., Hessel, M. M., Bertoncin, P. J., 16870.

Wahlsten, S., Finnegan, T. F., Holdeman, L. B., 16788.

WATT, D. F., 17227.

WakabayashI, S., TATSUOKa, F., IwaSaki, T., SP477, pp. III41-III-56 (May 1977).

WakamiYa, S. K., Calvano, N. J., NBSIR 77-1217.

WALDRON, W. D., SP494, pp. 205-222 (Sept. 1977).

WALKeR, J. A., TSANG, W., SP464, pp. $397-403$ (Nov. 1977).

WALKer, J. A., TSANG, W., 16699.

Walker, J. C., Evans, J. M., JR., O'Neill, J. T., Little, J. L. Albus, J. S., Barbera, A. J., Fife, D. W., Fong, E. N., GilSinn, D. E., Holberton, F. E., Lucas, B. G., Lyon, G. E. Marron, B. A. S., Neumann, A. J., Vickers, M. V., NBSIR 76-1094.

WALKOWICZ, J., FIPS PUB $11-I$.

Walkowicz, J. L., CONTI, D. M., SP500-18.

WALKOWICZ, J. L., HiLl, M. F., NBSIR 77-1195.

Wallace, D., Chuan, R., SP464, pp. 199-211 (Nov. 1977). 
WALLER, J. A., SP482, pp. 29-46 (July 1977).

WALLS, F. L., 17211 .

Walls, F. L., Gagnepain, J. J., NBSIR 77-855.

Walls, F. L., Hellwig, H., 17180.

Walls, F. L., Stein, S. R., TN692.

Walls, F. L., Stein, S. R., Gray, J. E., Glaze, D. J., 17185.

WAMPLER, R. H., 16833.

WAN, C. A., 17184 .

Ward, G. E., Paulhamus, R. E., SP500-18, pp. 143-158 (Sept. 1977).

WARD, J., COOPER, J., SMITH, E. W., 17161.

WARD, J. F., KEARNS, R. W., NBSIR 76-1174.

WARD, J. F., KEARNS, R. W., NBSIR 76-1175.

WARD, J. F., KEARNS, R. W., NBSIR 77-1213.

Wardell, J., Wilmot, G., HaAR, L., Powell, G., Klein, M., 17136.

Wardell, W. M., Tsianco, M. C., Davis, H. T., Anavekar, S. N., NBS-GCR-ETIP 76-35.

Ware, G. M., Hubbard, C. R., Mighell, A. D., 16913.

Waring, J. L., Roth, R. S., Brower, W. S., Harding, C. A., J. Res. 82, No. 3, 167-172 (1977).

WARNAR, R. B. J., SPSOO-5.

Warnar, R. B. J., Calomeris, P. J., SP500-I.

WARNLOF, O. K., SP47I, pp. 5-12 (June 1977).

WASHBURN, S. A., JACOBS, M., SP467.

Washington, D. R., Vincenty, C., Guthrie, D. L., SP484, pp. 173-186 (Oct. 1977).

WASIK, S., Chesler, S., 16673.

WASIK, S. P., SCHWARTZ, F. P., 17097.

WASSON, O. A., SP493, pp. 115-120 (Oct. 1977).

Watabe, M., Hirosawa, M., Nakata, S., SP470, pp. IX-1-IX5 (Apr. 1977).

Watabe, M., Kuribayashi, E., Tsuchida, H., SP470, pp. IV1-IV-34 (Apr. 1977).

WaTABE, M., OHSAKI, Y., SP477, pp. VII-29-VII-35 (May 1977).

Watare, M., ToKuHIRO, H., SP470, pp. X-12-X-16 (Apr. 1977).

Waterman, T. E., Christian, W. J., Harpe, S. W., NBS-GCR$77-82$.

WATERS, R. E., SP500-18, pp. $71-74$ (Sept. 1977).

Waterstrat, R. M., Manuszewski, R. C., 16738.

Waterstrat, R. M., MANUSzeWSK, R. C., 16834.

'Waterstrat, R. M., Müller, J., 16832.

WatKInS, S. W., ABraMS, M. D., SP5004.

Watkins, S. W., Abrams, M. D., 16945.

Watkins, S. W., Rosenthal, R., Rippy, D. E., Abrams, M. D., COTTON, I. W., 17252.

WATSON, R. E., BENNETT, L. H., 16927.

WATSON, R. E., BENNETT, L. H., 16940.

WATSON, R. E., BenNetT, L. H., 16967.

Watson, R. E., Bennett, L. H., McAlister, A. J., Cuthill, J. R., ERICKSON, N. E., 16932.

WAtson, R. E., Bennett, L. H., McAlister, A. J., 17262.

WATSON, R. E., HeRBST, J. F., BAK, P., 16916.

WATSON, R. E., MCALISTER, A. J., 17265.

WATSON, R. T., JPCRD 6, No. 3, $871-918$ (1977).

WATTECAMPS, E., SP493, pp. 67-84 (Oct. 1977).

WatTerson, J. I. W., ERasmus, C. S., SARgeant, J., SELLSChOP, J. P. F., SP464, pp. 129-136 (Nov. 1977).

WATTS, J., NBS-GCR-77-103.

Waxler, R. M., Dodge, M. J., Gladden, W. K., Feldman, A.., HOROWITZ, D., NBSIR 77-1304 (ARPA).

WAXLER, R. M., FeldMan, A., HOROWTTZ, D., NBSIR 77-1219.

WaXler, R. M., Horowitz, D., Dodge, M. J., Gladden, W. K., Feldman, A., 16730.

WEBB, R. M., BSSI06, pp. $215-217$ (Sept. 1977).

WEBER, S. F., 17302.

WEIDMAN, M. P., 17243.

Weidner, V. R., Venable, W. H., JR., Hsia, J. J., J. Res. 82, No. 1, 29-55 (1977).
Weigert, A., Aizenman, M., 17102.

Weigert, A., Aizenman, M., Smeyers, P., 17029.

WEIL, P. D., SP479, pp. 77-92 (July 1977).

Weinstein, A., HoRowitz, E., RuFf, A. W., SP472.

Weinstein, A., MoOs, H. W., Linsky, J. L., 17310.

Weinstein, A., Shine, R. A., Haisch, B. M., Linsky, J. L. 17056.

WeINSTEIN, A. M., SP472, pp. 3-9 (Apr. 1977).

Weinstein, B. A., Piermarini, G., Forman, R. A., 17047.

WeISBerg, H. F., SP45O, pp. 103-117 (June 1977).

WeISBERG, H. F., SP450, pp. $75-89$ (June 1977).

WeiSBERG, H. F., SP450, pp. 91-101 (June 1977).

Weisbin, C. R., Peelle, R. W., SP493, pp. 269-277 (Oct. 1977).

WeISS, A. W., 17229.

Weiss, A. W., Esteva, J. M., Mehlman, G., 16659.

Weiss, G. H., RUBIN, R. J., MAZUR, J., 16696.

Weiss, J. A., Ehrenrich, H., Gelatt, G. D., SP475, pp. 8386 (Apr. 1977).

Weiss, R. G., Berlin, V. N., 17116.

Weiss, R. G., LibMaN, A. S., 17323.

Wertzel, D. H., Timmerhaus, K. D., 16907.

WELLER, B. L., SP488, pp. 21-26 (Aug. 1977).

WeLLS, B. H., SP47I, pp. 63-68 (June 1977).

Wells, J. S., Evenson, K. M., Jennings, D. A., Petersen, F. R., 17336.

Wells, J. S., Streit, G. E., Petersen, F. R., 16728.

WERNER, M. E., BSSI06, pp. 275-282 (Sept. 1977).

WEST, E. D., SCHMIDT, L. B., TN685.

WEST, J. A., SP484, pp. 945-946 (Oct. 1977 ).

West, J. B., POland; H. M., 17100.

Westcott, V. C., Bowen, E. R., SP494, pp. 73-74 (Sept. 1977).

Westin, A. F., IsBell, F., SP469.

WESTLEY, F., SP478.

WESTON, L. W., SP493, pp. 43-46 (Oct. 1977).

Weston, W. F., LedbetTer, H. M., Naimon, E. R., 16869.

WEXLER, A., J. Res. 81A No. 1, 5-20 (1977).

Whealton, J. H., Burch, D. S., Phelps, A. V., 16854.

Whetstone, J. R., HALL, A. H., Simpson, J. A., 17023.

Whisman, M. L., Thompson, C. J., SP488, pp. 57-60 (Aug. 1977).

WhITBY, K. T., SP464, pp. $165-173$ (Nov. 1977).

WhItLOCK, R., FATEMI, M., JohnSON, E., BiRKS, L., GILFICh, J., SP464, pp. 189-190 (Nov. 1977).

Whittaker, J. K., Bass, A. M., Ledford, A. E., JR., SP464, pp. 9-1 3 (Nov. 1977).

WICKS, S. A., BURKE, R. W., SP492, pp. $85-89$ (Nov. 1977).

WIEDERHORN, S. M., 17028.

WIEDERHORN, S. M., 17039.

Wiederhorn, S. M., Fuller, E. R., Jr., BuKowski, J. M., RobBINS, C. R., 16993.

WiederhorN, S. M., JohnSON, H., Hockey, B. J., NBSIR 77. 1396.

WIEderhorn, S. M., LAWN, B. R., FUller, E. R., 16672.

WIEDERHORN, S. M., RuSSELl, L. R., TIGHE, N. J., NBSIR 771202.

Wiederhorn, S. M., Tighe, N. J., Evans, A. G., 17046.

Wiese, W. L., Helbig, V., Kelleher, D. E., 17204.

WIESE, W. L., KONJEVIĆ, N., 17206.

WIGTON, M. W., SP494, pp. 138-145 (Sept. 1977).

Wilhort, R. C., Zwolinsk, B. J., Chen, S. S., JPCRD 6, No. 1, 105-112 (1977).

Wilke, M. D., Mosburg, E. R., JR., 17192.

Wilkinson, T. L., Fattal, S. G., Sherwood, G. E., BSSI003.

Willard, W. A., ShIVEs, T. R., SP468.

WILlard, W. A., SHIVES, T. R., SP487.

Willard, W. A., SHives, T. R., SP494. 
Willard, W. A., SMITH, J. H., SP468, pp. 121-128 (Apr. 1977).

WilliaMS, B. R., SP488, pp. 27-31 (Aug. 1977).

WilliaMS, B. R., SP488, pp. 79-87 (Aug. 1977).

Williams, D., Kawashima, K., Penzien, J., Godden, W. G., CHEN, M. C., SP477, pp. VI-1 - VI-9 (May 1977).

Williams, D., Mulik, J. D., Puckett, R., Sawicki, E., SP464, Pp. 603-607 (Nov. 1977).

WilliaMS, D. F., SP472, pp. 11-20 (Apr. 1977).

Williams, E. S., 16697.

Williams, H. T., Danos, M., 17210.

Williams, J. D., Swenson, J. S., SP500-18, pp. 3-11 (Sept. 1977).

Williams, M. F., Murray, E. R., van der laan, J. E., HAWLEY, J. G., HAKE, R. D., JR., SP464, pp. 305-314 (Nov. 1977).

Williams, N., Zawistowski, E. A., Krasny, J. F., Braun, E., PEACOCK, R., NBSIR 77-1236.

Williams, R. L., Hoffman, J. R., Long, W. T., SP468, pp. 41-48 (Apr. 1977).

Williamson, F. R., 17308.

Williamson, F. R., Olien, N. A., 16883.

WILLING, R. P., SP463, pp. V.3.1-V.3.9 (Jan. 1977).

Wilmor, G., HaAr, L., Powell, G., Klein, M., Wardell, J., 17136.

Wilson, J., Toots, J., Finnegan, T. F., 16946.

WILSON, W. E., SP464, pp. 323-325 (Nov. 1977).

Wineland, D. J., Allan, D. W., Glaze, D. J., Hellmi, H. W., JARVIS, S., JR., 16759.

WINTER, J. A., SP464, pp. 509-513 (Nov. 1977).

Wisdom, J., HaRtQuist, T. W., LANE, N. F., 16818.

Wise, S. A., Chesler, S. N., Gump, B. H., Hertz, H. S., May, W. E., 17273 .

Wise, S. A., Chesler, S. N., Gump, B. H., Hertz, H. S., May, W. E., SP464, pp. 81-85 (Nov. 1977).

Wise, S. A., Chesler, S. N., Hertz, H. S., Hilpert, L. R., MAY, W. E., 17271 .

WiSE, S. A., MaY, W. E., 17278.

WODKIEWICZ, K., EBERLY, J. H., 17169.

WOLF, H. D., SP487, pp. 265-277 (Aug. 1977).

WOlfe, V. L., JR., Durbetaki, P., Tincher, W. C., Lloyd, L. R., LOWERY, R. P., TINGle, W. J., NBS-GCR-77-99.

Wong, C. S., Cretney, W. J., Piuze, J., Christensen, P., SP464, Pp. 249-258 (Nov. 1977).

Wong, P. T. S., Chau, Y. K., SP464, pp. $485-490$ (Nov. 1977).

WOOD, H. M., SP500-9.

WoOD, H. M., 17281.

WoOD, H. M., 17307.

WOOD, J. F., FIPS PUB 42-1.

Wood, L. A., J. Res. 82, No. 1, $57-63$ (1977).

WOOD, S. D., NBSIR 77-1227.

WOOlley, R. M., BAKER, S. M., Mrtchell, R. A., NBSIR 76 1053.

WORLEY, S. D., YATES, J. T., JR., 17065.

Wright, M. L., Pollack, J. B., Colburn, D. S., SP464, pp. 301-303 (Nov. 1977).

WRIGHT, R. N., FENVES, S. J., TN940.

WRIGHT, R. N., FENVES, S. J., 16705.

Wu, K. Y., Ha vill, T. N., Lee, T. Y., Ho, C. Y., Desai, P. D., NBS-GCR-77-83

Wrly, R. S., Galowin, L. S., Orloski, M. J., SP473, pp. 317 348 (June 1977).

WYly, R. S., MARSHAll, H. E., RUEGg, R. T., 17296.

WYLY, R. S., RORRER, D. E., SHAVER, J. R., NBSIR 77-1261.

WYON, D. P., SP491, pp. 174-189 (Sept. 1977).

YAGHUIAN, A. D., TN696.

YAGHIIAN, A. D., TN696, 1977 Revision.
YaHAGI, K., OKahara, M., KunihiRo, T., SP477, pp. V118-VI-140 (May 1977).

YaKowtTZ, H., NewBURY, D. E., FIORI, C. E., 16988.

YAMAZAKI, S., DOKIYA, Y., FUWA, K., SP464, pp. 233-235 (Nov. 1977).

YAMAZAKI, Y., KoIzUMI, Y., SP470, pp. VI-1-VI-21 (Apr. 1977).

YANCEY, C. W. C., NBSIR 77-1254.

YANG, K. T., ChANG, L. C., NBS-GCR-77-84.

YAP, W., SCHAFFER, R., 16959.

YAP, W. T., HoWEll, B. F., SChafFer, R., 16911.

Yaskin, L. A., Jones, M. C., Yeroshenko, V. M., GiarRatano, P. J., ARP, V. D., 17333.

Yates, J. T., Haller, G., Katzer, J., Park, R., Rhodin, T., SP475, p. 13 (Apr. 1977).

YATES, J. T., JR., SP475, pp. 15-29 (Apr. 1977).

YATTS, J. T., JR., KELley, R. D., MADEY, T. E., 17207.

YATES, J. T., JR., MADEY, T. E., 16929.

YATES, J. T., JR., MAdEY, T. E., 17349.

YATES, J. T., JR., WORLEY, S. D., 17065

Yeroshenko, V. M., Giarratano, P. J., ARP, V. D., Yaskin, L. A., JONES, M. C., 17333.

Yokoyama, K., OKubo, T., NaRITA, N., SP470, pp. II-20-II46 (Apr. 1977).

Yokoyama, K., OKubo, T., Narita, N., SP477, pp. V-1-V-20 (May 1977).

YOlKen, H. T., SeWARd, R. W., SP463, pp. VIl.4.1-VII.4.14 (Jan. 1977).

YONEMURA, G. T., 17015.

YONEMURA, G. T., 17293.

YORKDALE, A. H., BSS106, pp. 9-16 (Sept. 1977).

YOUNG, C. V., NBSIR 77-1230.

YOUNG, J. P., IVES, L. K., RUFF, A. W., 17300.

YOUNG, J. P., RuFF, A. W., 16898.

YOUNG, J. P., RUFF, A. W., IVES, L. K., SP468, pp. 145-157 (Apr. 1977).

Young, K. F., Bennett, L. H., Cohen, M. I., Dragoo, A. L. FrankLIN, A. D., MCALISTER, A. J., NBSIR 77-1270.

YOUNG, R. A., SP500-15, pp. 10-18 (July 1977).

YouNG, R. D., NBSIR 73-219.

YOUNG, R. D., 17066.

YouNG, T. R., SP464, pp. 675-676 (Nov. 1977).

Younglove, B. A., LaBrecque, J. F., Siegwarth, J. D., TN697.

Younglove, B. A., LaBrecque, J. F., Siegwarth, J. D., TN698.

Younglove, B. A., Siegwarth, J. D., NBSIR 77-852.

\section{$\mathbf{Z}$}

ZaCk, T. A., Pepper, R. T., Gigerenzer, H., SP487, pp. 93. 107 (Aug. 1977).

ZAHN, J. P., 17309.

ZAlewSKi, E. F., Fowler, J. B., LIND, M. A., TN950.

ZalewsKi, E. F., Geist, J., LiND, M. A., Schaefer, A. R., TN954.

Zalewski, E. F., SChaefer, A. R., TN935.

ZaNder, A. T., O'HA ver, T. C., SP464, pp. 53-59 (Nov. 1977).

Zapas, L. J., Crissman, J. M., Guttman, C. M., 17256.

Zawistowsk, E. A., Krasny, J. F., Braun, E., Peacock, R. WILLIAMS, N., NBSIR 77-1236.

ZERBE, J. I., SP463, pp. II.1.1-П.1.4 (Jan. 1977).

Zervos, C., Mighell, A. D., Hubbard, C. R., Staffa, J. A., 16688.

ZIENIUK, J. K., SP500-8, pp. 67-69 (May 1977).

Zulstra, W. G., RispenS, P., SP450, pp. 33-38 (June 1977).

Zulstra, W. G., Rispens, P., van Kampen, E. J., SP450, pp. 27-31 (June 1977).

Zulstra, W. G., Rispens, P., Zock, J. P., SP450, pp. 39-45 (June 1977). 
Zulstra, W. G., van Kampen, E. J., Rispens, P., SP450, pp. 47-52 (June 1977).

Zup, W. L., SP493, pp. 128-136 (Oct. 1977).

ZiLE, R. H., Fung, F. C. W., NBSIR 77-1225.

ZIMMERMAN, J. E., 16872.

Zimmerman, J. E., Radebaugh, R., Siegwarth, J. D., 17091.

Zimmerman, J. E., Sullivan, D. B., 17334.

Zock, J. P., Zulstra, W. G., Rispens, P., SP450, pp. 39-45 (June 1977).
Zoller, W. H., Reamer, D. C., O'Haver, T. C., SP464, pp. 609-612 (Nov. 1977).

Zoller, W. H., SMALl, J. A., SP464, pp. 651 -658 (Nov. 1977). Zucchi, F., Morigi, G., Bertolasi, V., SP479, pp. 103-105 (July 1977).

Zuckerman, B., Turner, B. E., Palmer, P., Gilmore, W., MoRRIS, M., JohNSON, D. R., Lovas, F. J., 16969.

Zukosk, E. E., Veldman, C. C., KubOTA, T., NBS-GCR-77-97. ZwOlinski, B. J., Chen, S. S., Wilhoit, R. C., JPCRD 6, No. $1,105-112$ (1977). 


\subsection{KEY WORD INDEX}

\section{A}

A. A. Michelson; adaptive estimators; arithmetic mean; bias; estimators of location; median; M-estimators; S. Newcomb; systematic errors; trimmed means; velocity of light; 17266 .

AA roughness; surface autocorrelation; surface finish; surface finish average wavelength; surface periodicity; NBSIR 73. 196.

$\alpha$-activity; absolute counting; aliquotting; analysis (plutonium, uranium); isotope dilution; santple preparation; specific activity; SP493, pp. 206-211 (Oct. 1977).

Ab initio; electronic structure; excimers; excited states; metal dimers; $\mathrm{Mg}_{2}$; multiconfiguration self-consistent-field; 17188

Ab initio calculations; $A$-values; Franck-Condon factors; laser modeling; lifetime; multiconfiguration self-consistent-field; potential energy curves; sodium molecule; transition dipole moment; 16870 .

Abnormal loading; alternate path; building code; design criteria; probability; progressive collapse; reliability; structural engineering; uncertainty; BSS98.

Absolute absorptivities; continuum models; diffuse reflectance; radiative transfer; reflectance spectra; scattering coefficients; statistical models; SP466, pp. 57-73 (May 1977).

Absolute configuration; amino acid derivative; crystal structure; $S$-carboxymethyl-L-cysteine sulfoxide; $\mathrm{x}$-ray determination; zwitterion; 16688 .

Absolute counting; aliquotting; analysis (plutonium, uranium); isotope dilution; sample preparation; specific activity; $\alpha$-activity; SP493, pp. 206-211 (Oct. 1977).

Absolute cross section measurement; cobalt; critical phenomena; interaction range; neutron scattering; spin correlation function; 17112 .

Absolute cross sections; neutron sources; SP493, pp. 304-310 (Oct. 1977).

Absolute measurements; barium ferrite buoy; densimeter; experimental; liquid, magnetic; modification; suspension; 16792

Absolute measurements; fission cross sections; fission spectrum neutrons; 14.8-MeV neutrons; ${ }^{225} \mathrm{U} ;{ }^{238} \mathrm{U} ;{ }^{237} \mathrm{~Np} ;{ }^{252} \mathrm{Cf} ; S P 493$, pp. 313-318 (Oct. 1977).

Absolute quantum efficiency; absolute quantum yieid; calorimetry; luminescence; photoacoustic spectrometer; piezocalorimeter; transducers; triplet formation; SP466, pp. 25-31 (May 1977).

Absolute quantum yield; calorimetry; luminescence; photoacoustic spectrometer; piezocalorimeter; transducers; triplet formation; absolute quantum efficiency; SP466, pp. 25-31 (May 1977).

Absolute radiant power measurements; detector radiometry; detector response transfer instrumentation; radiometers; silicon detectors; TN950.

Absolute radiometry; detector; electrically calibrated detectors; laser power measurements; pyroelectric detectors; radiometry; silicon cell; silicon detector; silicon photodetector; TN954.

Absolute reflectance; diffuse reflectance; error analysis; reflectance; reflectance factor; spectrophotometry; J. Res. 82, No. 1, 29-55 (1977).

Absolute spectral response; detector uniformity; linearity; photodetectors; silicon detectors; 16754.

Absolute $\mathrm{x}$-ray detectors; electron excitations; monoenergetic $\mathrm{x}$ rays; pulsed $\mathrm{x}$-ray source; $\mathrm{x}$-ray detector calibration; $1.5-8$ $\mathrm{keV} \times$ rays; 16814 .

Absolute yield; aluminum; attenuation length; Auger electrons; Auger-electron spectroscopy; beryllium; electron; proton excitation; $\mathrm{x}$-ray photoelectron spectroscopy; 17248.

Absolute yield; chemical actinometry; correction factors; luminescence; quantum-flat actinometer; quantum yield; SP466, pp. 21-24 (May 1977).
Absorbance; accuracy in spectrophotometry; glass filters; high accuracy spectrophotometers; spectrophotometry; stability of transmittance; standard reference material; transfer standard; transmittance; 16981 .

Absorbance linearity; accuracy of transmittance or absorbance scale; acidic potassium dichromate solutions; calibration of ultraviolet spectrometers; certification of apparent specific absorbance; isosbestic wavelengths; liquid filters; standard reference material; SP260-54.

Absorbance linearity; accuracy; acidic potassium dichromate solutions; calibration of ultraviolet spectrophotometers; liquid filters; transfer standards; ultraviolet absorbance standards; SP466, pp. 121-126 (May 1977).

Absorbed dose; calibration; calorimeter; cobalt-60; radiation standard; 17005.

Absorbed dose; calorimetry; dose distributions; dosimetry; electron beams; food irradiation; Fricke dosimetry; gamma rays; $\mathrm{x}$ rays; 17343 .

Absorption; accuracy; cross section; fast neutrons; geometric factors; photon; polarimeter; radiation physics; scattering; spectrometers; SP461, pp. 47-54 (Jan. 1977).

Absorption; barothermal gas cell; bulk absorption; highly transparent; infrared materials; optical materials; surface absorption; 16815.

Absorption; dielectric layers; irregularities; metallic thin films; microirregularities; overcoating; plasmons; scatter; SP466, pp. 133-148 (May 1977).

Absorption chillers; boiler performance; central utility plant; diesel engine; engine-generator efficiency; heat recovery; performance; total energy systems; NBSIR 77-1243.

Absorption cross section; carbon tetrachloride; chlorine atom; photochemistry; primary processes; quantum yields; troposphere; ultraviolet; 16703.

Absorption cross-section; $\mathrm{Ar}_{2}{ }^{+}$; energy transfer; gain inhibitor; gas lasers; photodissociation; restricted Hartree-Fock; transition moment; 17195 .

Absorption spectra; chemical kinetics; chlorine; chlorine oxides; chlorocarbon; chlorofluorocarbon; data compilation and evaluation; nitrosyl chloride; rate constant; JPCRD 6, No. 3 $871-918$ (1977).

Abstract data types; access controls; operating system protection; protection; protection mechanisms; reliable software; types; 16918.

Abstracted publications; adhesives and sealants; cryogenic adhesives and sealants; experimental data; 16883.

Abstracted reports and articles; HUD Modular Integrated Utility Systems (MIUS) Program; total energy; utility systems; SP489.

Abstracts; bibliography; cryogenic insulation; foam insulation; insulation; survey; 17308 .

Abstracts, NBS publications; key words; publications; SP305. Supplement 8.

AB-type compounds; calibration; critically evaluated data; crystallographic data; experimental melting curves; high pressure; solid-solid phase boundaries; JPCRD 6, No. 4, 1205 1252 ( 1977 ).

AC bridge; microcomputer; synchronous detection; temperature controller; thermoelectric; thermometry; 16908.

Ac current measurement; ac-dc comparator; ac-dc transfer standard; ac voltage measurement; thermal converter; 16694

Ac current measurements; ac-dc comparator; ac-dc transfer standard; ac voltage measurement; multijunction converter; thermal converter; 16693 .

AC high voltage; AC voltmeter calibrator; marine studies; microelectronic industry; monitoring system; photodetectors; radiopharmaceuticals; ultraviolet radiation; windows; DIMINBS 61, No. 12, 1-32 (1977).

AC impedance; automated electrochemical analysis; ceramic electrolytes; ceria-yttria; cyclic voltommetry; electrocatalysis; 
equivalent circuit; fuel cells; microprocessor; network analyzer; phosphoric acid electrolyte; refractory hard metals; NBSIR 77-1270.

Ac Stark effect; ionization; multiphoton ionization; 16925.

Ac voltage measurement; multijunction converter; thermal converter; ac current measurements; ac-dc comparator; ac-dc transfer standard; 16693 .

Ac voltage measurement; thermal converter; ac current measurement; ac-dc comparator; ac-dc transfer standard; 16694.

AC voltmeter calibrator; marine studies; microelectronic industry; monitoring system; photodetectors; radiopharmaceuticals; ultraviolet radiation; windows; $\mathrm{AC}$ high voltage; DIM/NBS 61 , No. 12, 1-32 (1977).

Accelerated laboratory testing; performance criteria; stone decay; stone preservatives; TN94I.

Accelerated testing; consumer products; cost estimation; life cycle costing; life cycle performance; life testing, and performance testing; NBSIR 77-1212.

Acceleration; accelerogram; gravity quaywall; rock motion; seismic coefficient; SP477, PP. VI-192-VI-198 (May 1977).

Acceleration; airplanes; cargo; dynamic loads; equivalent static force; gravity load; handling devices; handling loads; military field shelters; probability distributions; shocks, snow load; static load; trains; transportation; trucks; vibrations; wind load; NBSIR 77-I254.

Acceleration calibration; mounting variable; vibration; NBSIR 73-291.

Acceleration field; acceleration sensitivity; compound crystal resonator; crystallographic axis; nonlinear elastic effect; resonance frequency; NBSIR 77-855.

Acceleration records; dynamic behavior; earthquakes; response spectra; soils; SP477, pp. I11-41-111-56 (May 1977).

Acceleration sensitivity; compound crystal resonator; crystallographic axis; nonlinear elastic effect; resonance frequency; acceleration field; NBSIR 77-855.

Accelerogram; gravity quaywall; rock motion; seismic coefficient; acceleration; SP477, pp. VI-192-V1-198 (May 1977).

Accelerograph; bridges; buildings; codes; disaster; dynamic analysis; earthquakes; ground failures; hydraulic structures; seismicity; soils; standards; structural response; vessels and wind; SP470.

Accelerograph; bridges; buildings; codes; disaster; dynamic analysis; earthquakes; ground failures; nuclear facilities; seismicity; soils; standards; structural response; winds; SP477.

Accelerographs; data processing; earthquake records; strongmotion data; SP470, pp. IV-53-1V-66 (Apr. 1977).

Accelerographs; earthquake data; earthquake records; field observations; strong-motion accelerographs; SP470, pp. IV1-IV-34 (Apr. 1977).

Accelerographs; earthquake data; earthquake records; field stations; strong-motion network; SP470, pp. IV-35-1V-52 (Apr. 1977).

Accelerometers; calibration; measurements; vibration; vibration exciters; vibration standards; NBSIR 77-1229.

Access controls; operating system protection; protection; protection mechanisms; reliable software; types; abstract data types; 16918 .

Accessibility standards; building code; code administration; communication; enabling legislation; physically handicapped; regulation; SP473, pp. 241-251 (June 1977).

Accident; apparel; burn injury; fabric flammability; fabrics; fire; garments; heat transfer; injury hazard; simulation; NBSIR 77 i236.

Accident; associated factors; injuries; literature; NEISS; recommendations; review; safety; sports; NBSIR 77-1218.

Accident prevention; hazard analysis; risks; safety; SP487, pp. 265-277 (Aug. 1977).

Accident reduction, skidding; highway safety; measurement, skid resistance; pavement skid resistance; skid resistance measurement; tire-pavement interface forces; wet pavement skid resistance; NBSIR 76-1175.

Accident reduction, skidding; correlation, skid resistance; highway safety; measurement, skid resistance; pavement, skid resistance; pavement wetting system; skid resistance, measurement; tire-pavement interface forces; wet pavement skid resistance; NBSIR 77-1213.

Accident research; human factors; methodology; rare events; safety; system safety; SP482.

Accidental polymerization; CHETAH predictive scheme; hazard evaluation; test data; test methods; thermal explosion theory; NBSIR 76-1/49.

Accidents; benefit-cost analysis; building codes; building economics; building regulations; economic impact; electric shock; ground fault circuit interrupters; national electric code; safety regulations; standards; SP473, pp. 397-419 (June 1977).

Accounting data; computer performance; computer resource unit; probability density function; statistics; turnaround; workload; SP500-18, pp. 39-67 (Sept. 1977).

Accuracy; acidic potassium dichromate solutions; calibration of ultraviolet spectrophotometers; liquid filters; transfer standards; ultraviolet absorbance standards; absorbance linearity; SP466, pp. 121 - 126 (May 1977).

Accuracy; aerosol; air; collaborative testing; laboratory accreditation; laser technology; multielement analysis; pollutants; speciation; Standard Reference Materials; trace organics; water; SP464.

Accuracy; analysis of variance; interlaboratory testing; precision; repeatability; reproducibility; 16858 .

Accuracy; $\mathrm{Au}(\mathrm{n}, \boldsymbol{\gamma})$ cross section; cross section fluctuations; measurement; neutron capture cross section; normalization; reference standard; review; SP493, pp. 165-169 (Oct. 1977).

Accuracy; calibration; characteristic factor ( $\mathrm{K}$ or $\mathrm{C}$ ); curve fitting; pickoffs (magnetic and RF); turbine flowmeter; universal curve; viscosity measurement; SP484, pp. 847-869 (Oct. 1977).

Accuracy; calibration; cryogenic; dynamic; frequency response; hysteresis; precision; pressure measurement; sensitivity; stability; thermal effects; zero-shift; 17081 .

Accuracy; calibration; flow conditioning; meter performance; perturbations; precision; turbine meter; uncertainty; SP484, pp. 33-54 (Oct. 1977).

Accuracy; certification; precision; SRM; standard reference data; standard reference materials; SP463, pp. V11.4.1VII.4.14 (Jan. 1977).

Accuracy; chemical analysis; measurement compatibility; measurement systems; reference method; standard reference material; 17247.

Accuracy; critical parameters; diffuse reflectance; fluorescence; instrumentation; luminescence; quantum yield; spectrophotometry; standard reference materials; staridardization; SP466.

Accuracy; cross section; fast neutrons; geometric factors; photon; polarimeter; radiation physics; scattering; spectrometers; absorption; SP461, pp. 47-54 (Jan. 1977).

Accuracy; design analysis; equipment specification; field standard; gravimetric calibration; liquid retention or clingage tests; precision; prover; Research Associate Program; standards inspection procedure; temperature correction; test measure; NBSIR 77-1214.

Accuracy; hyperbolic system; range-range system; time and frequency dissemination; time code; TvTime system; 17181 .

Accuracy in spectrophotometry; glass filters; high-accuracy spectrophotometers; spectrophotometry; stability of transmittance; standard reference material; transfer standard; transmittance; absorbance; 16981 .

Accuracy of transmittance or absorbance scale; acidic potassium dichromate solutions; calibration of ultraviolet spec- 
trometers; certification of apparent specific absorbance; isosbestic wavelengths; liquid filters; standard reference material; transfer standards; SP260-54.

Accurate ion beam current measurement; current integrators; ion beam scanning; ion implantation; ion implantation dose measurement and control; secondary particle suppression; SP400-39.

Accurate neutron energy determination; energy standards; SP493, pp. 319-328 (Oct. 1977).

Ac-dc comparator; ac-dc transfer standard; ac voltage measurement; multijunction converter; thermal converter; ac current measurements; 16693

Ac-dc comparator; ac-dc transfer standard; ac voltage measurement; thermal converter; ac current measurement; 16694.

Ac-dc difference; current comparator; current measurements; thermoelement; 16697.

Ac-dc transfer standard; ac voltage measurement; multijunction converter; thermal converter; ac current measurements; acdc comparator; 16693.

Ac-dc transfer standard; ac voltage measurement; thermal converter; ac current measurement; ac-dc comparator; 16694.

Acetaldehyde; acrolein; calibration; diffusion cell; formaldehyde; instrumentation; pyrolysis; reactive gases; 16699.

Acetaldehyde; internal rotation; interstellar molecules; $\mathbf{m m}$ wave transitions; overlapped lines; radio astronomy; 16969.

Acetone; coincidence; mass spectrometry; methane; photoionization; threshold photoelectron spectroscopy; time of flight mass spectrometry; 17148 .

Acetylene; adsorption; chemisorption; dehydrogenation; ethylene; photoemission; tungsten; ultraviolet photoelectron spectroscopy; 16829.

Acetylene- $d_{2}$; $l$-type doubling constants; microwave spectrum; rotational constants; Stark effect; vibrational transition moment; 16689.

Acid-base status; blood electrolytes; blood gases; blood pH; calcium; carbon dioxide; hydrogen ion concentration; nomograms; oxygen; $\mathrm{PCO}_{2} ; \mathrm{pH}$; potassium; $\mathrm{PO}_{2}$; sodium; SP45O.

Acidic potassium dichromate solutions; calibration of ultraviolet spectrometers; certification of apparent specific absorbance; isosbestic wavelengths; liquid filters; standard reference material; transfer standards; absorbance linearity; $S P 260-54$

Acidic potassium dichromate solutions; calibration of ultraviolet spectrophotometers; liquid filters; transfer standards; ultraviolet absorbance standards; absorbance linearity; accuracy; SP466, pp. 121-126 (May 1977).

Acidity; emf; pH; phthalate buffer; potassium hydrogen phthalate; standard for pH; J. Res. 81A No. 1, 21-24 (1977).

Acoustic; calibration; eddy current; microwave; nondestructive evaluation; penetrant; radiography; standards; thermal; ultrasonic; visual testing; wear debris; 17106 .

Acoustic emission; acoustic emission simulator; capacitive transducer; Plate Green's function; signal analysis; wave propagation in Plate; 17191 .

Acoustic emission; amplitude distribution; brittle materials; ceramics; fracture; 17213

Acoustic emission; Auger electron spectroscopy; beam-lead bonds; capacitance-voltage methods; carrier mobility; C-MOS circuits; dopant profiles; electrical properties; electronics; four-probe method; hermeticity; ion implantation; Irvin's curves; leak tests; SP4OO-29.

Acoustic emission; automated tape bonding; beam lead devices; bugging height; microelectronics; nondestructive test; 16884 .

Acoustic emission; automated tape bonding; beam lead devices; bugging height; microelectronics; nondestructive test; 17150 .

Acoustic emission; brittle materials; crack growth; cyclic loading; fracture mechanics; high temperature; proof testing; silicon carbide; silicon nitride; 17039 .
Acoustic emission; calibrations; electrical-eddy current measurements; microwaves; nondestructive evaluation; standard reference materials; standards; thermal testing; ultrasonics; visual testing; wear debris analysis; 17016 .

Acoustic emission; crack growth; drill pipe; failure; Kaiser Ef. fect; pressure vessels; sources; SP487, pp. 210-238 (Aug. 1977).

Acoustic emission; damage detection; failure prevention; noise spectrum; piezoelectric polymer; vibration sensor; SP487, pp. 189-196 (Aug. 1977).

Acoustic emission; inspection; leak testing; liquid penetrant; magnetic particle; measurements; nondestructive testing; optical; radiography; standards; ultrasonics; visual; 17042 .

Acoustic emission simulator; capacitive transducer; Plate Green's function; signal analysis; wave propagation in Plate; acoustic emission; 17191 .

Acoustic flow meters; closed conduit flows; current meters; dye-dilution methods; errors in flow measurement; flow measurement; fluid flow modeling; fluid velocity; flumes; gas flow standard; hot-wire anemometry; international flow standards: SP484, Volumes 1 and 2.

Acoustic flow rate; acoustic velocity; flow rate; liquid flow rate; liquid velocity; open channel flow rate; open channel velocity; SP484, pp. 243-266 (Oct. 1977).

Acoustic monitor; BLAM; boundary layer transition; hypersonic velocities; SP484, pp. 687-704 (Oct. 1977).

Acoustic oscillations; current leads; experimental; stability; supercritical helium; 17078 .

Acoustic rays; flow measurement; ultrasonic flowmeter; SP484, pp. 277-291 (Oct. 1977).

Acoustic test facility; noise; noise measurement; reverberation room; sound power measurement; standard test procedures for sound power measu rement; 16766 .

Acoustic transmission measurements; algebraic reconstruction techniques; temperature fields; SP484, pp. 335-359 (Oct. 1977).

Acoustic velocity; flow rate; liquid flow rate; liquid velocity; open channel flow rate; open channel velocity; acoustic flow rate; SP484, pp. 243-266 (Oct. 1977).

Acoustical measurements; acoustics; acoustics facility; automated sound measurement; computer-controlled instrumentation; reverberation room; reverberation room qualification; sound power; 16763.

Acoustical measurements; acoustics; acoustics facilities; laboratory facilities; noise measurement; sound measurement; 16764.

Acoustical measurements; acoustics; national measurement system; noise; noise control; sound; 17190 .

Acoustical measurements; acoustics; audiometry; national measurement system; noise; noise control; noise emissions; sound; sound level meters; NBSIR 75-938.

Acoustics; acoustics facilities; laboratory facilities; noise measurement; sound measurement; acoustical measurements; 16764.

Acoustics; acoustics facility; automated sound measurement; computer-controlled instrumentation; reverberation room; reverberation room qualification; sound power; acoustical measurements; 16763.

Acoustics; appliances; atmospheric; durability; electrical; environment; housing technology; HVAC; innovative construction; maintainability; materials; minimum property standards; performance criteria; performance evaluation; plumbing; safety; structures; test methods; NBSIR 77-1316.

Acoustics; audiometry; national measụrement system; noise; noise control; noise emissions; sound; sound level meters; acoustical measurements; NBSIR 75-938.

Acoustics; community noise; environmental impact; noise; noise exposure measurement system; sound; NBSIR 76-1169. 
Acoustics; environmental pollution; machinery and equipment; noise; noise abatement and control; noise emission; regulation; sound; $H I 22$.

Acoustics; national measurement system; noise; noise control; sound; acoustical measurements; 17190 .

Acoustics facilities; laboratory facilities; noise measurement; sound measurement; acoustical measurements; acoustics; 16764

Acoustics facility; automated sound measurement; computercontrolled instrumentation; reverberation room; reverberation room qualification; sound power; acoustical measurements; acoustics; 16763.

Acrolein; calibration; diffusion cell; formaldehyde; instrumentation; pyrolysis; reactive gases; acetaldehyde; 16699.

Activation; analysis; element; gamma rays; $\mathrm{Ge}(\mathrm{Li})$ detector; neutron; nondestructive; resolution; spectrometry; water; SP461, pp. 255-256 (Jan. 1977).

Activation; Bragg-Gray; dosimetry; energy per ion pair; fluence; kerma factor; neutrons; SP493, pp. 342-346 (Oct. 1977).

Activation; capture reaction; cross section; measurement; neutron; $\beta$-counting error; SP461, pp. 57-59 (Jan. 1977).

Activation analysis; californium-252; inland waters and sediments; in vivo analysis; mineral exploration; nuclear safeguards; oceanography; on-stream analysis; well logging; 16760.

Activation analysis; crystal structure; diffraction; isotopes; molecular dynamics; neutron; nuclear reactor; radiation; TN939.

Activation energies; molecular orientations; $\mathrm{NH}_{4} \mathrm{ClO}_{4}$; quasielastic neutron scattering; residence times; single crystal; 17003.

Activation parameters; active nitrogen; iodine; kinetics; microwave discharge; nitride; plasma; reaction mechanism; silicon; synthesis; thin film; vapor transport; 16757.

Active devices; internal logic identification; laser scanning; logic flow identification; LSI testing; nondestructive tests; nonlinear region mapping; temperature mapping; 17164 .

Active hydrogen maser frequency standard; cavity pulling; cavity-Q; cavity servo; Crampton effect; frequency stability; hydrogen line Q; hydrogen line servo; magnetic field; passive hydrogen maser frequency standard; second-order Doppler; spin exchange; wall shift; 17180 .

Active nitrogen; iodine; kinetics; microwave discharge; nitride; plasma; reaction mechanism; silicon; synthesis; thin film; vapor transport; activation parameters; 16757.

Activity; glass; vaporization; 17043.

Activity coefficient; calcium chloride; critical evaluation; electrolyte; excess free energy; osmotic coefficient; solutions; thermodynamic properties; JPCRD 6, No. 2, 385-408 (1977).

Activity coefficients; aqueous systems; bibliography; electrochemistry; isopiestic; osmotic coefficients; thermochemistry; vapor pressure; $S P 485$.

Activity of $\mathrm{K}_{2} \mathrm{O}$ in $\mathrm{K}_{2} \mathrm{O}-\mathrm{SiO}_{2}$ solutions; coal-fired $\mathrm{MHD}$; opencycle MHD; seed-slag interaction; thermal decomposition of $\mathrm{K}_{2} \mathrm{O}-\mathrm{SiO}_{2}$ solutions; 16897 .

Acute lethality; Douglas Fir; inhalation; mice; polyurethane; pulmonary irritation; PVC; respiratory rate; sensory irritation; stress index; thermal decomposition products; toxicity; NBSGCR-77-85

Adaptive; automation; computer; control; goal-oriented; hierarchical control; robot; sensors; SPSO0-23.

Adaptive estimators; arithmetic mean; bias; estimators of location; median; M-estimators; S. Newcomb; systematic errors; trimmed means; velocity of light; A. A. Michelson; 17266.

Adaptive reuse; architecture; building codes; building regulations; building safety; construction; performance; preservation; rehabilitation; renovation; SP473, pp. 437-452 (June 1977).

Adatom; crystal field; photoemission; 16919.
Adhesion; coatings; films; gas discharges; sputtering; SP487, pp. 311-323 (Aug. 1977).

Adhesion to polymers; adsorption from solutions; chemisorption; hydroxyapatite; irreversible vs reversible adsorption; surface-active comonomer; 17197.

Adhesive bonding to bone mineral; chemisorption of a dental varnish; configuration on surface; kinetics of adsorption from solution; rate law and areal regression of adsorbate; surface area and fixation of chelating rings; 17033 .

Adhesive-bonded joints; bonded joints; cyclic loading; debond analysis; double-lap-joint analysis; fatigue tests; finite element analysis; joints; nonlinear analysis; single-lap-joint analysis; single-lap-joint bending; spotwelded joints; weldbonded joints; NBSIR 76-I053.

Adhesives; composites; computerized information system; foams; plastics information; Plastics Technical Evaluation Center; specifications; technical reports; testing methods; tooling; SP463, pp. IV.3.1-IV.3.2 (Jan. 1977).

Adhesives; dental applications; dental prosthetic materials; dental resins; future dental materials; macromolecules; plastics; polymers; sealants; 17201 .

Adhesives; dental polymers; dental resins; dentures; impression materials; prosthetic materials; resin teeth; restoratives; sealants; 17120 .

Adhesives and sealants; cryogenic adhesives and sealants; experimental data; abstracted publications; 16883.

Adiabatic perturbation approximation; collision theory; time dependent; 16955.

Adiabatic temperature drift; enthalpy; glass transition; heat capacity; pelletization; poly(vinyl chloride), pressure densification; relaxation; stored energy; strain energy; 16769.

Adjustment; benchmark; cross-sections; fast reactors; integral experiments; standards; SP493, pp. $310-312$ (Oct. 1977).

Administrative experimentation; evaluation; evaluation research; evaluation systems; policy analysis; social experimentation; 17116.

Administrative experimentation; evaluation; evaluation research; organizational design; policy analysis; program evaluation; 17323.

Administrative procedures; building codes; building regulations; buildings; economic impacts; environmental considerations; innovative practices; regulatory research; standards development; SP473.

Adobe; air pollution; corrosion; electrical; energy management; graphic pen; halocarbons; infrared lasers; international standard; neutron xeroradiography; problem-solving; radiation safety; smoke detectors; solar heating; SRM's; DIM/NBS 61 , No. 3, 1-32 (1977).

Adobe building materials; adobe soil; mechanical properties; moisture determination; preservation technology; 17104.

Adobe building materials; adobe soil; mechanical properties; moisture determination; preservation technology; TN934.

Adobe soil; mechanical properties; moisture determination; preservation technology; adobe building materials; 17104 .

Adobe soil; mechanical properties; moisture determination; preservation technology; adobe building materials; TN934.

ADP; automated data processing; computer software; data element dictionary; data element dictionary/directory; data management; software tool; SP500-16.

ADP availability; annual loss expectancy; application system vulnerability; computer security; data confidentiality; data integrity; data security; physical security; procedural security; risk analysis; risk assessment; systems security; NBSIR 771228.

ADP costs; Federal ADP statistics; Federal Government computers; Federal minicomputers; statistics; SP500-7.

ADP life cycle; computer performance evaluation; computer performance measurement; computer performance prediction; computer system acquisition; conference proceedings; 
CPEUG; hardware monitoring; on-line system evaluation; prediction methods; queuing models; SP500-18.

ADP security; computer networks; controlled accessibility; encryption; evaluation criteria; key; password; personal identification; terminals; verification; FIPS PUB 48.

ADP security; computer security; encryption; Federal Information Processing Standard; FIPS PUB 46.

ADP standards; Brooks Act; computer science research; computers in the Federal Government; scientific and technological advisory services; NBSIR 76-1113.

ADP standards; computers; data elements and codes; data processing; Federal Information Processing Standards; geography; information processing standards; information system; representations and codes; standards; statistical data; FIPS PUB 10-2.

ADP standards; international standardization; national standardization; national standards bodies; practice; procedures; regional standardization; standardization; standards development; NBSIR 77-1195.

Adsorption; angle resolved; Auger; chemisorption; electron spectroscopy; surfaces; 16747.

Adsorption; angular distribution (ions); chemisorption; electron stimulated desorption; ruthenium; water; 17349.

Adsorption; blood protein; ellipsometry; implants; polymer adsorption; protein adsorption; synthetic implants; NBSIR 761128 .

Adsorption; chemisorption; dehydrogenation; ethylene; photoemission; tungsten; ultraviolet photoelectron spectroscopy; acetylene; 16829.

Adsorption; dielectric screening; photoelectron spectroscopy; relaxation; 17218 .

Adsorption; molecules; photoelectron spectroscopy; surfaces; vibrational excitation; 16749.

Adsorption; proteins; radiotracer; techniques; 16777.

Adsorption from solutions; chemisorption; hydroxyapatite; irreversible vs reversible adsorption; surface-active comonomer; adhesion to polymers; 17197.

Advanced fiber composites; boron-aluminum; boron-epoxy; cryogenics; static mechanical properties; 16865.

Adversary scenarios; automated response systems; distributed processing; monitoring systems; physical security; sensor systems; NBSIR 77-1262.

Adverse reaction detection; biostatistics; drug regulation; pharmaceutical regulation; phase IV; post marketing surveillance; regulatory experiments; system design; NBS-GCR-ETIP 7635 .

Aerodynamics; boundary layers; buildings; turbulence; wind loads; wind tunnels; NBSIR 77-1196.

Aerodynamics; building (codes); pressure; spectra; structural engineering; tall buildings; turbulence; wind; 16843 .

Aerodynamics; buildings; full-scale testing; mobile homes; wind loads; SP477, pp. 1-21-I-33 (May 1977).

Aerosol; air; collaborative testing; laboratory accreditation; laser technology; multielement analysis; pollutants; speciation; Standard Reference Materials; trace organics; water; accuracy; SP464.

Aerosol; mass concentration; number concentration; size distribution; smoke; smoke detector; test method; UL 217; NBSIR 77-1312.

Aerosols; asymptotic analysis; broad initial distribution; coagulation; electrical aerosol analyzer; self-preserving; size distribution; 17282.

Aerospace; computer information system; international aerospace abstracts; materials; mechanical properties; metallic materials; nonmetallic materials; physical properties; RECON; scientific and technical aerospace reports; SP463, pp. VI.1.1-VI.1.7 (Jan. 1977).

Age distributions; demography; durability; durable goods; matrix model; population dynamics; population growth rate; production rate; scrappage rate; stable-age population; 17053.

Agricultural materials; agricultural research; biological properties; chemical properties; engineering properties; food products; information retrieval systems; management information systems; materials; nonfood products; SP463, pp. II.2.1-II.2.10 (Jan. 1977).

Agricultural research; biological properties; chemical properties; engineering properties; food products; information retrieval systems; management information systems; materials; nonfood products; physical properties; $S P 463$, pp. II.2.1II.2.10 (Jan. 1977).

Agricultural research service; agriculture; extension service; information services; land grant university; SP463, pp. II.3.1II.3.4 (Jan. 1977).

Agriculture; extension service; information services; land grant university; agricultural research service; SP463, pp. I1.3.1II.3.4 (Jan. 1977).

AID; assistance; developing economies; foreign relations; industrializing nations; international relations; LDS's; measurement services; standardization; NBSIR 76-1152.

AIDS; bark; forest products; glues and gluing; information service; lumber; mechanical properties; paper; pulp; timber; wood; wood products; SP463, pp. II.1.1-II.1.4 (Jan. 1977).

Air; collaborative testing; laboratory accreditation; laser technology; multielement analysis; pollutants; speciation; Standard Reference Materials; trace organics; water; accuracy; aerosol; $S P 464$.

Air buoyancy; air density; mass unit transfer; real gas equation; NBSIR 77-1278.

Air cc.ıditioning; comfort; heat pump; load-calculation; rating; residential; space heating; testing; 17006.

Air conditioning requirements; energy conservation; intermittent ventilation; ventilation control; weather data analysis; NBSIR 76-1088.

Air density; mass unit transfer; real gas equation; air buoyancy; NBSIR 77-1278.

Air dose; arbitrary shaped field; back-scatter factor; Clarks' method; depth dose; dosimetry; surface dose; SP461, pp. 193-196 (Jan. 1977).

Air flow; extinguishability; extinguishment; fabric flammability; fibers; heat flux; heat sinks; oxygen concentration; textiles; NBS-GCR-77-90.

Air Force Academy; benchmark tests; development of benchmarks; live test demonstrations; selection of ADPS; SP500-18, pp. $71-74$ (Sept. 1977).

Air Force facilities; building energy conservation; energy management; evaluation and monitoring; survey of buildings; 17062.

Air infiltration; condensation in buildings; energy conservation; energy measurements; fuel savings; heat-loss reduction; insulation properties; residential heat loss; retrofitting houses; thermal conductivity; thermal insulation; thermography; NBSIR 77-1274.

Air infiltration; energy conservation; mobile home; part-load efficiency; thermography; NBSIR 76-1182.

Air leakage; building design; energy conservation; fenestration; HVAC systems; illumination; insulation; lighting; performance standard; thermal performance; ventilation; water heating; NBSIR 74-452.

Air leakage of buildings; building heat transfer; honeycomb panel construction; relocatable buildings; wind-load racking; NBSIR 76-1178.

Air, moisture and heat transfer theory; cold storage insulation; fibrous-glass insulation; vapor condensation; 17340.

Air pollution; analysis; ecology; energy; environmental impact; land pollution; mutagenicity; toxic materials; toxicology; trace contaminants; water pollution; SP463, pp. III.4.1III.4.15 (Jan. 1977). 
Air pollution; attic ventilation; data encryption; dental materials; fire safety; metric; miniature electric field; organic sulfur; radiometric detector; smog formation; SRM's; DIM/NBS 61, No. 11, 1-32 (1977).

Air pollution; calibration; iodometry; monitoring; ozone; ultraviolet photometry; NBSIR 76-1191.

Air pollution; chemical kinetics; dioxirane; ethylene; mass spectrometry; ozone; 17327.

Air pollution; corrosion; electrical; energy management; graphic pen; halocarbons; infrared lasers; international standard; neutron xeroradiography; problem-solving; radiation safety; smoke detectors; solar heating; SRM's; adobe; DIM/NBS 61, No. 3, 1-32 (1977).

Air quality; deterioration; measurements; particulates; regulations; sulfur dioxide; 17141 .

Air traffic control; aviation; models; simulation; transportation; validation of models; airport simulation; 16944 .

Air velocity; error elimination; vane anemometer; velocity readings; ventilation tubing; SP484, pp. $755-763$ (Oct. 1977).

Airborne lead; ammunition; firing ranges; law enforcement; lead; lead poisoning; SP480-26.

Airborne particles; microanalysis; micro-chemistry; microprobe; particulate matter; Raman spectroscopy; 17013.

Air-handling system; Chicago federal building; highrise; pressure profiles; Seattle federal building; smoke control; smoke simulation experiments; sulfur-hexafluoride; systematic pressurization; 17291 .

Air-handling units; building pressure profile; computer simulation; elevator shaft pressure profiles; parametric analysis; simulated smoke concentration; smoke control; smoke movement; smoke simulation; systematic pressurization; NBSIR 77-1225.

Air-leakage; dynamic heat transfer; energy analysis; heat and cooling loads; heat loss and heat gain; multi-room problems; J. Res. 82, No. 2, 97-106 (1977).

Airplanes; cargo; dynamic loads; equivalent static force; gravity load; handling devices; handling loads; military field shelters; probability distributions; shocks, snow load; static load; trains; transportation; trucks; vibrations; wind load; acceleration; NBSIR 77-1254.

Airport simulation; air traffic control; aviation; models; simulation; transportation; validation of models; 16944.

Air-tightness; daylighting; energy-conservation; insulation; shading; solar-heating; ventilation; windows; BSS104.

Alarm; architecture; design implication; emergency actions; emergency communicative; emergency decisions; escape; fires; human behavior; human response; life safety; mapping; model; nursing homes; rescue; verbal communicative; NBSGCR-77-93.

Alarm; audio alarm; burglar alarm; intrusion alarm; intrusion detector; sound sensing; standard; 16831 .

Alarm systems; cameras; police; police equipment; security equipment; surveillance equipment; $S P 480-4$.

Alaska pipeline; calibration; CMAC; computers; consumer sounding boards; data; electron probe microanalysis; laser ionization; metrication; noise; nondestructive evaluation; research associate program; standards; DIM/NBS 61 , No. 1 , $1-32$ (1977).

Albedo; angular; backscattering; barrier; differentials; distribution; gamma rays; integral; medium; Monte Carlo; SP461, pp. 129-131 (Jan. 1977).

Albedo; backscattering; distribution; dose rate; gamma rays; Monte Carlo; photon; SP461, pp. $110-118$ (Jan. 1977).

ALERT; calibration procedures; engineering technical data, metrology; failure mode; failure rate, quality, reliability, safety; technology transfer; urgent data request; SP463, pp. III.5.1-III.5.8 (Jan. 1977).

Algebra of normal functions; correlation; probability; random variable; reliability; SP487, pp. 25-38 (Aug. 1977).
Algebraic reconstruction techniques; temperature fields; acoustic transmission measurements; SP484, pp. 335-359 (Oct. 1977).

Algorithm; Lennard-Jones; metastable states; Monte Carlo; 16786.

Algorithms; fiber morphology; fibers; image analysis; pattern recognition; pulp characterization; pulps; 17214 .

Aliquotting; analysis (plutonium, uranium); isotope dilution; sample preparation; specific activity; $\alpha$-activity; absolute counting; SP493, pp. 206-211 (Oct. 1977).

Alkalis; atomic collisions; multiphoton ionization; Rabi shifts; radiative Penning ionization; tuneable lasers; 17263 .

Alkyl halides; $\mathrm{CO}_{2}$ laser; infrared; kinetics; mechanisms; photochemistry; pyrolysis; 16783.

Alkyl iodides; ion-molecule reactions; isotope effects; mass spectrometry; photoionization; rate constants; J. Res. 81A Nos. 2 and 3, 267-271 (1977).

Alkylation; aqueous solution; coordination; mercury; metal complexes; organometals; photolysis; reaction rates; thallium; tin; transmethylation; water; 17008.

Allegheny County; data transmission tests, digital data; mobile digital equipment; modulation technique; transmission rate; voice channel; SP480-19.

Allocating hydrocarbons; hydrocarbon measurement; international standards; SP484, pp. 957-959 (Oct. 1977).

Allowable bolt loads, end distance, edge distance and spacing; drift; face shells, reinforcing splices; high lift grouting; shotcrete, surface wave instrumentation; veneer anchorage; BSS106, pp. 259-274 (Sept. 1977).

Alloy; composite; cryogenics; electrical property; insulation; materials; mechanical property; metal; review; thermal property; 17072.

Alloy theory; electronegativity; transition metal, Mössbauer effect; 16967.

Alloys; antimony; arsenic; bismuth; copper; diffusion; electromigration; liquid metals; nitrogen; phosphorus; ternary diffusion; thermomigration; JPCRD 6, No. 1, 1-50 ( 1977 ).

Alloys; compounds; hardness; interstitial; metals; refractory; 17262.

Alloys; copper; electrical resistivity; iron; low temperature; susceptibility; 17135

Alluvial deposits; earthquakes; epicentral distance; liquefaction; settlement; soils; SP470, pp. V-1-V-15 (Apr. 1977).

Allylic; combination; disproportionation; low temperature; radical; 16966.

Alpha; boron; branching ratio; compilation; cross-section; elastic; lithium; measurements; neutron; total; SP493, pp. 67. 84 (Oct. 1977).

Alpha-tricalcium phosphate; calcium phosphate; cation-anion columns; crystal structure; subcell; vacancies; 17034 .

Alternate path; building code; design criteria; probability; progressive collapse; reliability; structural engineering; uncertainty; abnormal loading; BSS98.

Alternating direction; computer simulation; cool down; energy savings; flue damper; heat transfer; implicit; insulation; laboratory measurements; modeling; standby loss; water heater; 17184

Alternatives; ASHRAE 90-75; building standards; buildings; energy conservation; minimum property standards; multiple glazing; "U" values; SP473, pp. 85-101 (June 1977).

Alternatives; building codes; building process; constraints; costs; incentives; regulation; SP473, pp. 17-33 (June 1977).

Alumina cements; $\mathrm{CaO} \cdot \mathrm{Al}_{2} \mathrm{O}_{3} \cdot \mathrm{H}_{2} \mathrm{O}$; coal gasification; refractory cements; J. Res. 82, No. 3, 167-172 (1977).

Aluminium; carbon; collision; copper; distribution; dose; electron; Gaussian; Monte Carlo; scattering; SP461, pp. 106-109 (Jan. 1977).

Aluminium oxide; glow; heat treatment; impurity; temperature; thermoluminescence; SP461, pp. 219-221 (Jan. 1977). 
Aluminum; attenuation length; Auger electrons; Auger-electron spectroscopy; beryllium; electron; proton excitation; $x$-ray photoelectron spectroscopy; absolute yield; 17248 .

Aluminum; beef muscle; carbon; depth-dose distributions; lateral-dose distributions; polystyrene; radiation dosimeters; radiation processing; radiochromic-dye films; $10-\mathrm{MeV}$ electrons; 16999.

Aluminum; boron-aluminum; bulk modulus; composite; compressibility; elastic constants; resonance method; shear modulus; torsional modulus; Young's modulus; 17087.

Aluminum alloys; bulk modulus; compressibility; Debye temperature; Poisson's ratio; precipitation-hardening alloys; shear modulus; sound velocity; Young's modulus; 17085 .

Aluminum alloys; copper alloys; high strength steels; nickel alloys; stainless steels; stress corrosion cracking; titanium alloys; Monogr. 156.

Aluminum alloys; crack propagation; fatigue; iron alloys; liquid helium; stainless steels; steels; superalloys; titanium alloys; 16928.

Aluminum alloys; ferritic steels; fracture toughness; low temperature; nickel alloys; titanium alloys; 17086.

Aluminum stabilization; copper stabilization; critical current; critical-current degradation; multifilamentary wires; $\mathbf{N b}_{3} \mathrm{Sn}$; NbTi; strain; stress; 16816.

Aluminum wiring; branch circuits; copper wiring; military buildings; NBSIR 76-1184.

American Ceramic Society; ceramics; phase diagrams; "Phase Diagrams for Ceramists"; phase equilibria; user evaluation; SP486.

American electroplaters'; calorimeter; cryogenic flow measurement; dental restorations; deep ocean research; federal science; governmental environment; laser energy; space flight; spectroscopy; SRM; television captioning; DIM/NBS 61 , No. 4, 1-32 (1977).

American National Standards Institute; computerized information system; engineering standards; mandatory standards; national standards; plastics standards; standards; standards information service; voluntary standards; SP463, pp. VII.5.IVIl.5.9 (Jan. 1977).

American Nuclear Society; radiation; shielding; standard; SP461, pp. 74-78 (Jan. 1977).

American Physical Society; fundamental constants; National Bureau of Standards; nuclear physics; numerical analysis; physics; spectroscopy; thermal physics; 75 th anniversary; 16991

American Standard Code for Information Interchange; ASCII; communications; data communications equipment; data processing terminal equipment; data transmission; Federal Information Processing Standards; serial-by-bit; serial-bycharacter; FIPS PUB 16-1.

American Standard Code for Information Interchange; ASClI; character parity sense; character structure; communications; data transmission; Federal Information Processing Standards; serial-by-bit; telecommunications; teleprocessing; FIPS PUB 17-1.

American Standard Code for Information Interchange; ASCll; character structure; communications; data transmission; Federal Information Processing Standards; parallel-by-bit; parity sense; serial-by-character; telecommunications; teleprocessing; FIPS PUB 18-1.

Amino acid derivative; crystal structure; $S$-carboxymethyl-Lcysteine sulfoxide; $x$-ray determination; zwitterion; absolute configuration; 16688.

Aminocoumarins; carbazine dyes; deuterium effect; fluorescence quantum yield; laser dyes; molecular structure; oxazine dyes; quenching; xanthene dyes; SP466, pp. 33-40 (May 1977).

Ammonia; carbon dioxide; ethanoI; measurement; molecular absorption; $10 \mu \mathrm{m}$ wavelength; 16924.
Ammonium perchlorate; bond lengths and angles; crystal structure; rigid-body motion analysis; thermal motion of a perchlorate ion; x-ray diffraction; 17348 .

Ammunition; firing ranges; law enforcement; lead; lead poisoning; airborne lead; SP480-26.

Ammunition; handguns; police; police equipment; standards; SP480-5.

Amorphous alloys; iron; magnetization measurements; neutron diffraction; terbium; 16835 .

Amorphous materials; bubble; field-access; garnet; guide-pattern; magnetoresistance; nonvolatility; orthoferrite; photolithography; uniaxial structures; SP500-1.

Ampere definition; electrical units; fundamental constants; Josephson effect; levitation; superconductivity; 16876.

Amplifier; high-frequency; Josephson junction; SQUID; 17334.

Amplitude distribution; brittle materials; ceramics; fracture; acoustic emission; 17213.

Amplitude modulation; cavity frequency; environmental sensitivity; frequency lock loop; long-term frequency stability; NBS time scale; phase modulation; (active-passive) hydrogen maser; 17211 .

Analysis; aqueous chemistry; arsenic; atomic absorption spectrophotometry; biomethylation; electrochemistry; environment; gas chromatography; laser-Raman; liquid chromatography; nuclear magnetic resonance; organoarsenic; 17155.

Analysis; buoyancy; laminar flow; plume; pressure distribution; streamlines; temperature distribution; J. Res. $81 \mathrm{~B}$ Nos. I and 2, 45-60 (1977).

Analysis; compressive strength; deflection; design; flexural strength; masonry walls; racking strength; seismic loading; shear strength; shear wall; stiffness; BSS62.

Analysis; ecology; energy; environmental impact; land pollution; mutagenicity; tox ic materials; toxicology; trace contaminants; water pollution; air pollution; SP463, pp. III.4.IIll.4. I 5 (Jan. 1977).

Analysis; element; gamma rays; $\mathrm{Ge}(\mathrm{Li})$ detector; neutron; nondestructive; resolution; spectrometry; water; activation; SP461, pp. 255-256 (Jan. 1977).

Analysis; implants; metallic; orthopaedic; retrieval; SP472.

Analysis of acrylics; benzoyl peroxide determination; bone cement; chemical composition of bone cement; dimethyl-ptoluidine; hydroquinone leachable monomer; residual components in cements; residual methyl methacrylates; 17202.

Analysis of correlated profiles; classical theory; Doppler broadening; one perturber limit; pressure broadening; 17161 .

Analysis of variance; interlaboratory testing; precision; repeatability; reproducibility; accuracy; 16858 .

Analysis (plutonium, uranium); isotope dilution; sample preparation; specific activity; $\alpha$-activity; absolute counting; aliquotting; SP493, pp. 206-211 (Oct. I977).

Analytic functions with infinitely many branches; functional equations; Hurwitz's theorem; 17041.

Analytical disciplines; analytical procedures; atomic absorption spectrometry; biological materials; blanks; botanical materials; chemical species; flame emission spectrometry; fluorescence spectrometry; molecular absorption spectrometry; neutron activation analysis; SP492.

Analytical formula; coherent scattering; cross section; gamma rays; photons; Rayleigh scattering; SP461, pp. 17-19 (Jan. I977).

Analytical procedure; bibliographies; computerized information system; concrete; concrete technology; construction material; construction methods; portland cement; state-of-the-art summaries; technical reports; test methods; SP463, pp. IV.7.1IV.7.7 (Jan. 1977).

Analytical procedures; atomic absorption spectrometry; biological materials; blanks; botanical materials; chemical species; flame emission spectrometry; fluorescence spectrometry; molecular absorption spectrometry; neutron activation analysis; polarography; pure reagents; SP492. 
Anchor bolts; bond; damping; ductility; earthquake resistance; energy absorption; modulus of elasticity; partial reinforcing; risk; shear modulus; testing; ultimate strength; BSSIO6, pp. 255-258 (Sept. 1977).

Anemometer; cylinder; frequency; hot film anemometer; recirculating flow; spray; two component flow; vortex street; wake flow; SP484, pp. 705-718 (Oct. 1977).

Angle; centre of mass; coefficients; computations, cross-section; Legendre polynomial; neutron; random sampling; scattering; shielding; SP461, pp. 100-105 (Jan. 1977).

Angle block; between time variation; calibration; measuring system; stability; standard deviation; statistical analysis; NBSIR 74-601.

Angle resolved; Auger; chemisorption; electron spectroscopy; surfaces; adsorption; 16747.

Angular; backscattering; barrier; differentials; distribution; gamma rays; integral; medium; Monte Carlo; albedo; SP461, pp. 129-131 (Jan. 1977).

Angular correlations; deuteron; pions; $\Delta$ components; $\Delta$ nucleus dynamics; $\pi \mathrm{D}$ reactions; 17210 .

Angular distribution; chlorine; foils; ions; iron, oxygen; measurement; Moliere theory; multiple; scattering; SP461, pp. 136-139 (Jan. 1977).

Angular distribution; cross section; gamma rays; photon; scáttering, incoherent; $x$ rays; SP461, pp. 55-56 (Jan. 1977).

Angular distribution; fast neutrons; linac; reactor filtered beam; standard; ${ }^{6} \mathrm{Li}(\mathrm{n}, \alpha) \mathrm{T}$; SP493, pp. 10-13 (Oct. 1977).

Angular distribution (ions); chemisorption; electron stimulated desorption; ruthenium; water; adsorption; 17349.

Angular momentum; methane; rotational symmetry; sulfur hexafluoride; 16957

Anharmonic crystal; computer simulation; energy transport; equation of state; interatomic potential; molecular dynamics; second sound; shock wave; stress relaxation; structural relaxation; thermal relaxation; 16751 .

Anharmonic vibrator model; collective states; electron scattering; inelastic; two-phonon states; zinc 64-66-68-70; 16982.

Anharmonicity; dispersion curves; high pressure; $\mathrm{KBr}$; mode Gruneisen parameters; neutron scattering; 17001 .

Anholonomic; constraint; electromagnetism; Hamilton; Maxwell; momentum; Poynting; variational; J. Res. 81B Nos. 1 and 2, 1-3 (1977).

Aniline point; API gravity; aviation fuels; enthalpy of combustion; fuels; gasoline; gravity; heat content; heat of combustion; kerosine; TN937.

ANISN; code; configuration; dose equivalent; energy; gamma rays; neutron; scattering; shield; transmission; ${ }^{252}$ Cf; SP461, pp. 119-123 (Jan. 1977).

Anisotropic interactions; $\mathrm{HCl}-\mathrm{Ar}$; linear molecules; rotational line widths; semiempirical potential; theoretical potential; 16799.

Anisotropic materials; orthotropic materials; strain; stress; superconducting magnets; 17082 .

Anisotropy; charged particle; computer code; energy-angle; integral; legendre polynomial; scattering; semi analytical; spatial; transmission; SP461, pp. 140-143 (Jan. 1977).

Anisotropy; composite laminates; failure; strain concentration; stress concentration; SP487, pp. 121-134 (Aug. 1977).

Anisotropy of mean square velocities; eccentricity of equidensity surface; elliptical galaxies; flattening; mass distribution function; 16968 .

Annual loss expectancy; application system vulnerability; computer security; data confidentiality; data integrity; data security; physical security; procedural security; risk analysis; risk assessment; systems security; ADP availability; NBSIR 77.1228.

Annual report; computer; energy; environmental; measurement; product safety; research; science; standards; technology; SP467.
Annual reports; diffusion in metals; fire; journals; library holdings, NBS Library; NBS periodicals; periodicals; proceedings; serials; standards; transactions; NBSIR 77-1215.

Annular; computation; duct; gamma ray; integration; kernel; radiation; streaming; SP461, pp. 132-135 (Jan. 1977).

Anomalous transmission effect; asymmetric crystal topography; crystal imperfections; crystal perfection; Czochralski-grown nickel; dislocation clusters; dynamical diffraction; magnetic domains; magnetic domain walls; melt-grown crystals; nickel single crystals; 16997.

ANSI 58; low-rise buildings; wind study; 17115 .

Antenna; antenna frequency response; dielectric sheath; filtering antenna; resistive shield; U.S. Patent 4,008,477.

Antenna frequency response; dielectric sheath; filtering antenna; resistive shield; antenna; U.S. Patent 4,008,477.

Antenna patterns; characteristic modes; Garbacz characteristic modes; group theory; inverse scattering; moment methods; scattering; singularity expansion method; symmetry analysis; 17225.

Antenna patterns; computer programs; near-field scanning; spherical scanning; 17223.

Antenna patterns; cosite interference; cylindrical scanning; near-field scanning; planar scanning; scanning facilities; spherical scanning; 17221 .

Antennas; arrays; coordinate transformations; data processing; group representations; measurements; near field; nonplanar; patterns; scanning; spherical; symmetry; 16671 .

Antennas; arrays; finite rotations; group representations; nearfields, recursion; scanning; spherical; spherical point group; 17322.

Antennas; measurements; near-field; spherical; 17224 .

Anthropometric manikin; free-field measurements; hearing aid tests; orthotelephonic response; 16847.

Anthropometric probes; consumer products; human factors; lawn mowers; psychophysics; reaction time; safety; standards; 17200.

Anthropometry; biomechanics; carrying; consumer product portability; ergonomics; human factors; lifting; manual materials handling; physiology; psychophysics; safety; warranty; NBSIR 76-1092.

Anthropomorphic dummies; building safety; dummies; guidebook; testing; NBS-GCR-77-91.

Antibiotic; hydrogen bonding; patulin; refined structure; single crystal $x$-ray structure determination; 4-hydroxy-4Hfuro $(3,2 c)$ pyran-2(6H)-one; 16913.

Antibodies; antigens; biological polymers; immunochemical analysis; light scattering; polymers; proteins; solid standards; SP466, pp. 95-98 (May 1977).

Antiferroelectric; $\mathrm{KCN}$; $\mathrm{NaCN}$; order parameter; structure; 16972.

Antigens; biological polymers; immunochemical analysis; light scattering; polymers; proteins; solid standards; antibodies; SP466, pp. 95-98 (May 1977).

Antimony; arsenic; bismuth; copper; diffusion; electromigration; liquid metals; nitrogen; phosphorus; ternary diffusion; thermomigration; alloys; JPCRD 6, No. 1, 1-50 (1977).

Antimony dialkyldithiocarbamate; antiwear; bearing lubrication; extreme pressure; fluorinated ethylenepropylene; gear lubrication; grease; polyfluoroalkyl-alkyl polysiloxane; polytetrafluoroethylene; SP487, pp. 154-171 (Aug. 1977).

Antiwear; bearing lubrication; extreme pressure; fluorinated ethylenepropylene; gear lubrication; grease; polyfluoroalkylalkyl polysiloxane; polytetrafluoroethylene; antimony dialkyldithiocarbamate; SP487, pp. 154-171 (Aug. 1977).

Antiwear additives; interaction; lubricant; metals; properties; tricresyl phosphate; zinc dithiophosphate; SP487, pp. 172185 (Aug. 1977).

Apartment building; collapse; concrete; concrete strength; construction; flexure; progressive collapse; shear; strength; BSS94. 
Apartments; building codes; fire; firc resistivity; firestopping; fire walls; garden apartments; multi-family residences; NBSIR 76-1194.

Apatites; caries mechanism; caries prevention; membrane potentials; permselective properties; surface properties; 16787.

API gravity; aviation fuels; enthalpy of combustion; fuels; gasoline; gravity; heat content; heat of combustion; kerosine; aniline point; TN937.

Apollo 16,17; background correction; cosmic gamma ray; flux isotropy; sodium iodide detector; spectral measurements; 16938.

Apparatus; chromatography; experimental; laser; photochemistry; 16895.

Apparel; burn injury; fabric flammability; fabrics; fire; garments; heat transfer; injury hazard; simulation; accident; NBSIR 77-1236.

Apparel; fabrics; flammability testing; heat transfer rates; Mushroom Apparel Flammability Tester; standards; test development; textiles; NBS-GCR-76-78.

Apparel fires; burn injury; fabric flammability; FFACTS; flammability standards; Flammable Fabrics Act; ignition sources; SP463, pp. VII.2.1-VII.2.11 (Jan. 1977).

Apparent mass; buoyancy; buoyancy correction; change; comparison; difference; mass; records; set; surveillance limits; surveillance test; test interval; true mass; value; weighing design; weights; NBSIR 76-999.

Appearance potential; benzene; butatriene; heat of formation; ion; ionization potential; monoenergetic electron impact; photoionization; pyridine; vinylacetylene; 1,5-hexadiyne; 2,4hexadiyne; 17294 .

Appearance potential; diethyl ether; dimethyl ether; ionization potential; photoionization; /7/46.

Appliance research; behavioral laboratory; consumer product studies; human behavior research; Human Factors Laboratory; range energy consumption; 17035 .

Appliances; atmospheric; durability; electrical; environment; housing technology; HVAC; innovative construction; maintainability; materials; minimum property standards; performance criteria; performance evaluation; plumbing; safety; structures; test methods; acoustics; NBSIR 77-1316.

Appliances; energy conservation; energy efficiency; energy improvement targets; labeling; test procedures; 16885 .

Application of standards; international standards; measurcment standards; national standards; SP484, pp. 929-934 (Oct. 1977).

Application system vulnerability; computer security; data confidentiality; data integrity; data security; physical security; procedural security; risk analysis; risk assessment; systems security; ADP availability; annual loss expectancy; NBSIR 77-1228.

Applications past and future; $\gamma$-rays; neutron capture; spectroscopy; 16951 .

Applied microeconomic framework; commodity supply crises; econometric analysis; economic impacts; efficiency impacts; income distribution effects; policy alternatives; NBS-GCRETIP 76-24.

Applied microeconomic framework; commodity supply crises; econometric analysis; economic impacts; efficiency impacts; income distribution effects; policy alternatives; NBS-GCRETIP 76-32.

Applied microeconomic framework; commodity supply crises; econometric analysis; economic impacts; efficiency impacts; income distribution effects; policy alternatives; NBS-GCRETIP 76-33.

Applied microeconomic framework; commodity supply crises; econometric analysis; economic impacts; efficiency impacts; income distribution effects; policy alternatives; NBS-GCRETIP 77-36.
Approach channels; broad-crested V-notch weirs; calibration; small watersheds; stream gages; streamflow measurements; weirs; SP484, pp. 187-200 (Oct. 1977).

Approximation; bremsstrahlung; cross section; electron; intermediate energy; photons; SP461, pp. 60-63 (Jan. 1977).

Approximations; diffusion; neutron; NIOBE; Rapsodie; reactor; shielding; transport calculation; SP461, pp. 163-165 (Jan. 1977).

Approximations; fast-thermal couple reactor; neutron; reactor transients; solution; time-dependent; transport; transport equation; SP46I, pp. 9 1-93 (Jan. 1977).

Approximations; moment theory; spectral densities; 16849.

Apsara; energy distribution; gamma ray; iterative; neutron; plastic; recoil; scintillator; UNFOLD; SP461, pp. 247-251 (Jan. 1977).

Aqueous chemistry; arsenic; atomic absorption spectrophotometry; biomethylation; electrochemistry; environment; gas chromatography; laser-Raman; liquid chromatography; nuclear magnetic resonance; organoarsenic; analysis; 17155.

Aqueous solution; chemical kinetics; data compilation; hydroxyl radical; oxide radical ion; perhydroxyl radical; radiation chemistry; rates; superoxide ion; NSRDS-NBS59.

Aqueous solution; coordination; mercury; metal complexes; organometals; photolysis; reaction rates; thallium; tin; transmethylation; water; alkylation; 17008 .

Aqueous solution; equilibrium; humidity; relative humidity; salt; saturated salt solution; vapor pressure; water vapor; J. Res. 81A No. 1, 89-96 (1977).

Aqueous solutions of gases; compressibility; equation of state; heavy water; isotopic waters; partial molar volume of aqueous gases; PVT; thermal expansivity; water; JPCRD 6, No. 4, $1109-1132$ (1977).

Aqueous systems; bibliography; electrochemistry; isopiestic; osmotic coefficients; thermochemistry; vapor pressure; activity coefficients; SP485.

Aramid; composite materials; end fittings for FRP rod; environmental resistance of FRP rods; fiber-reinforced plastic (FRP); glass; guys, antenna; pultrusion; reinforced plastics; stress rupture of FRP rod; test methods; weatherability of FRP rods; 16685.

Arbitrary shaped field; back-scatter factor; Clarks' method; depth dose; dosimetry; surface dose; air dose; SP461, pp. 193-196 (Jan. 1977).

Arc; calibration; deuterium; interlaboratory; lamp; radiance; radiometry; source; spectroscopy; standard; synchrotron; ultraviolet; wall-stabilized; 17198 .

Arc; Debye shielding; neutral phosphorus; Stark shifts; Stark widths; 16950.

Arc; oscillator strength; plasma; spectra; uranium; 16992.

Arch dam; deflections; dynamic tests; model; structural analysis; velocities; vibrations; SP477, pp. VI-85-VI-117 (May 1977).

Archaeological finds, preservation of; conservation of metal artifacts; corrosion, inhibiting of; corrosion, treatment methods; metal artifacts, restoration of; patina, artificially produced; patina, natural; $S P 479$.

Arching; masonry walls; BSSI06, pp. 283-313 (Sept. 1977).

Architectural; design; housing; low income; low-rise buildings; sites and services; socio-economic; structural design; wind-resistant; BSSIOO-5.

Architectural controls; buildings; design review; land use; municipalities; regulation; site design; SP473, pp. 137-187 (June 1977).

Architectural criteria; automated system; building codes; buildings; computer applications; criteria maintenance design evaluation; design guides; SP473, pp. 349-368 (June 1977).

Architectural psychology; architectural research; building codes; building design; building fires; building regulatory 
standards; emergency egress; exit capacity; fire safety; human performance; occupational safety; regulatory data; NBSIR 77-1313.

Architectural research; building codes; building design; building fires; building regulatory standards; emergency egress; exit capacity; fire safety; human performance; occupational safety; regulatory data; architectural psychology; NBSIR 77 1313.

Architecture; building codes; building regulations; building safety; construction; performance; preservation; rehabilitation; renovation; adaptive reuse; $S P 473$, pp. 437-452 (June 1977).

Architecture; building technology; construction; health facilities; hospitals; medical facilities; medical planning; NBSIR 77-1233:

Architecture; buildings; connectors; design criteria; fasteners; wind; NBSIR 77-1197.

Architecture; buildings; design; energy; legislation; solar; standards; State; NBSIR 77-1297.

Architecture; design implication; emergency actions; emergency communicative; emergency decisions; escape; fires; human behavior; human response; life safety; mapping; model; nursing homes; rescue; verbal communicative; alarm; NBSGCR-77-93.

Arcing/sparking; branch circuit; contact resistance; electrical connections; fire hazard; glowing electrical connections; BSSIO3.

Arcturus; chromospheres, stellar; line profiles, stellar; radiative transfer; ultraviolet spectra; 17056.

Argon; collisions; dissociation; hydrogen; inelastic; molecular potential; recombination; scattering; theoretical; theory; 16802.

Argon; cross section; dissociation collisions; hydrogen; theory; vibrational and rotational enhancement; 16803.

Argon; light source; mini-arc; radiometry; spectral radiance; standard; ultraviolet; 16778.

Argon gas discharge noise source; silicon avalanche diode; solid state noise source; stability; 16669.

Argon oxide excimer; free-free-laser saturation flux; gain coefficients; stimulated collision-induced emission; 17254 .

Argon-vapor contact; error analysis; iodine; molybdenum hexafluoride; new static technique; vapor pressure; 17075 .

Arithmetic mean; bias; estimators of location; median; M-estimators; S. Newcomb; systematic errors; trimmed means; velocity of light; A. A. Michelson; adaptive estimators; 17266.

Army Materials and Mechanics Research Center; electromagnetics; materials testing; nondestructive testing; Nondestructive Testing Newsletter; radiography; technical reports; ultrasonics; SP463, pp. IV.6.1-IV.6.2 (Jan. 1977).

Aromatic hydrocarbons; heat of solution; salting-out effect; solubility; 17038 .

Aromatic proton chemical shifts; mono- and di-substituted benzenes; NMR spectral data; JPCRD 6, No. 3, 919-992 (1977).

Arrays; coordinate transformations; data processing; group representations; measurements; near field; nonplanar; patterns; scanning; spherical; symmetry; antennas; 16671 .

Arrays; earthquakes; ground motion; records; results; seismometers; SP477, pp. III-16-III-25 (May 1977).

Arrays; finite rotations; group representations; near-fields, recursion; scanning; spherical; spherical point group; antennas; 17322.

Arsenic; atomic absorption; gas chromatography; organometal; selenium; tin; 16811 .

Arsenic; atomic absorption spectrophotometry; biomethylation; electrochemistry; environment; gas chromatography; laserRaman; liquid chromatography; nuclear magnetic resonance; organoarsenic; analysis; aqueous chemistry; 17155.
Arsenic; bismuth; copper; diffusion; electromigration; liquid metals; nitrogen; phosphorus; ternary diffusion; thermomigration; alloys; antimony; JPCRD 6, No. 1, 1-50 (1977).

Arsenic; element-specific detector; flameless atomic absorption; flow monitoring; high-pressure liquid chromatography; lead; ligand; mercury; nanogram sensitivity; organometallic compounds; speciation; tin; 17297.

Arsenic reduction; arsenic speciation; biological and organic materials; silver diethyldithiocarbamate method; 17257 .

Arsenic speciation; biological and organic materials; silver diethyldithiocarbamate method; arsenic reduction; 17257.

Arson; bibliographies; building fires; carpets; construction materials; fire departments; fire detection systems; fire tests; flame research; flammability tests; interior fumishings; mobile homes; polyurethanes; smoke detectors; standards; textiles; toxicity; NBSIR 77-1277.

$\mathrm{Ar}_{2}{ }^{+}$; energy transfer; gain inhibitor; gas lasers; photodissociation; restricted Hartree-Fock; transition moment; absorption cross-section; 17195 .

ASCII; character parity sense; character structure; communications; data transmission; Federal Information Processing Standards; serial-by-bit; telecommunications; teleprocessing; American Standard Code for Information Interchange; FIPS PUB 17-1.

ASCII; character structure; communications; data transmission; Federal Information Processing Standards; parallel-by-bit; parity sense; serial-by-character; telecommunications; teleprocessing; American Standard Code for Information Interchange; FIPS PUB $18-1$

ASCII; communications; data communications equipment; data processing terminal equipment; data transmission; Federal Information Processing Standards; serial-by-bit; serial-bycharacter; telecommunications; teleprocessing; FIPS PUB 16 $l$.

Aseismic design; dynamic tests; nuclear reactors; oil tanks; power plants; shake table; SP470, pp. VII-1-VII-6 (Apr. 1977).

Aseismic design criteria; design provisions; earthquakes; specifications; structural engineering; tunnels; SP470, pp. VIII56-VIII-68 (Apr. 1977).

ASFIT; build-up factor; empirical; energy; gamma ray; mean free path; SP461, pp. 174-176 (Jan. 1977).

$\mathrm{AsF}_{5}$; barriers; energy levels; gas phase; $\mathrm{PF}_{5}$; Raman; $\mathrm{VF}_{5}$; 16978.

ASHRAE 90-75; building standards; buildings; energy conservation; minimum property standards; multiple glazing; " $U$ " values; alternatives; SP473, pp. 85-101 (June 1977).

Assembler; cross-assembler; machine code; relocatable code; NBSIR 77-1230.

Assessment of fatigue damage; exoelectron emission; failure prediction; laser scanner; oxide rupture; surface deformation; SP487, pp. 197-209 (Aug. 1977).

Assistance; developing economies; foreign relations; industrializing nations; international relations; LDS's; measurement services; standardization; AID; NBSIR 76-1152.

Associated factors; injuries; literature; NEISS; recommendations; review; safety; sports; accident; NBSIR 77-1218.

Associative detachment; chemiluminescence; flowing afterglow; fluorescence; infrared; ion-molecule; 17209.

ASTM E 162; coefficient of variation; flame spread tests; flexible polyurethane; hardboard; interlaboratory evaluation; neoprene; radiant panel test; round robin; test method; NBSIR 77-1222.

ASTM E 84; fire tests; flame spread; heat flux; heat release rate; oxygen depletion; smoke; Steiner Tunnel Test; TN945.

ASTM Test Standard for insulating glass; frost-point measuring apparatus; moisture condensation; seal durability and longevity; sealed insulating glass; 17286 . 
Astronomy; automation; clocks; communication; frequency; history; mathematics; navigation; physics; time; time broadcasts; time scales; Monogr. 155.

Astronomy; ethyl cyanide; interstellar molecule; microwave emission; radio sources and rotational spectra; 17264 .

Asymmetric coordination; crystal structure; $\mathrm{Sn}$ bonding; tin hydroxy phosphate; tin phosphate; 16741 .

Asymmetric crystal topography; crystal imperfections; crystal perfection; Czochralski-grown nickel; dislocation clusters; dynamical diffraction; magnetic domains; magnetic domain walls; melt-grown crystals; nickel single crystals; $x$-ray diffraction topography; 16997.

Asymptotic analysis; Bessel functions; boundary-value problem; connection formula; diffraction theory; error analysis; Liouville-Green approximation; ordinary differential equation; turning point; 16805.

Asymptotic analysis; Bessel functions; error analysis; linear differential equátions; transition point; turning point; 16899.

Asymptotic analysis; broad initial distribution; coagulation; electrical aerosol analyzer; self-preserving; size distribution; aerosols; 17282

Asymptotic formulas; classical modular group; cyclic groups; free groups; free products; tables; 16660.

Atmospheric; durability; electrical; environment; housing technology; HVAC; innovative construction; maintainability; materials; minimum property standards; performance criteria; performance evaluation; plumbing; safety; structures; test methods; acoustics; appliances; NBSIR 77-1316.

Atomic; experimental; lifetimes; $\mathrm{N}_{2} \mathrm{O}$; oxygen; radiation; timeof-flight; 16812

Atomic absorption; gas chromatography; organometal; selenium; tin; arsenic; 16811 .

Atomic absorption spectrometry; biological materials; blanks; botanical materials; chemical species; flame emission spectrometry; fluorescence spectrometry; molecular absorption spectrometry; neutron activation analysis; polarography; pure reagents; sample preparation; SP492.

Atomic absorption spectrophotometry; biomethylation; electrochemistry; environment; gas chromatography; laserRaman; liquid chromatography; nuclear magnetic resonance; organoarsenic; analysis; aqueous chemistry; arsenic; 17155.

Atomic and molecular data; chemical kinetics data; energy data; environmental data; industrial process data; materials utilization data; mechanical properties; nuclear data; physical science data; solid state data; standard reference data; thermodynamic data; TN947.

Atomic beam; effusive oven; sodium beam; 16789 .

Atomic beam; electronic structure; free atoms; hyperfine fields; relativistic Hartree-Fock theory; 16940.

Atomic clocks; dissemination; frequency; geosynchronous satellite; measurement; standards; television; time; 17182 .

Atomic collision; excitation transfer; laser stimulation; orbiting; saturation; selection rules; van der Waals; 16695.

Atomic collisions; multiphoton ionization; Rabi shifts; radiative Penning ionization; tuneable lasers; alkalis; 17263.

Atomic energy levels; atomic spectra; chromium; JPCRD 6, No. 2, 317-384 (1977).

Atomic energy levels; atomic spectra; manganese; JPCRD 6, No. 4, 1253-1330 (1977).

Atomic energy levels; atomic spectra; bibliography; energy levels, atomic; spectra, atomic; wavelengths, atoms and ions; SP363. Supplement 1.

Atomic form factor; attenuation coefficients; cross sections; gamma rays, incoherent scattering function; pair production; photoelectric effect; photons; $x$ rays; SP461, pp. 3-16 (Jan 1977).

Atomic frequency standard; frequency discrimination; frequency domain stability; frequency-lock loop; phase-lock loop; phase noise; servo techniques; time domain stability; TN692.
Atomic number; cross section; K-shell; measurement; photoelectric effect; photon; SP461, pp. 41-43 (Jan. 1977).

Atomic number contrast; electron beam induced conductivity (EBIC) contrast; electron channeling contrast; magnetic contrast; scanning electron microscopy; topographic contrast; voltage contrast; 16840 .

Atomic ordering; constitution diagram; niobium alloys; osmium alloys; phase diagram; 16738

Atomic ordering; constitution diagram; phase diagram; phase transformations; rhodium alloys; vanadium alloys; 16834 .

Atomic oxygen; chemiluminescent; corona discharge; dielectric breakdown; ozone attack; 16995.

Atomic processes; line identifications; 16659

Atomic spectra; bibliography; energy levels, atomic; spectra, atomic; wavelengths, atoms and ions; a.omic energy levels; SP363. Supplement 1.

Atomic spectra; chromium; atomic energy levels; JPCRD 6, No. 2, 317-384 (1977).

Atomic spectra; configuration interaction; $J$-file sum rule; neon; transition probabilities; wall-stabilized arc; 17276.

Atomic spectra; data sources; laser chemistry; molecular spectra; 16837.

Atomic spectra; electromagnetism; laser, high-intensity; multiphoton absorption; optical interactions; 17130 .

Atomic spectra; manganese; atomic energy levels; JPCRD 6 , No. 4, 1253-1330 (1977).

Atomic spectroscopy; Hartree-Fock; ions; line strength; 17229.

Atomic structure; electron structure; energy levels; fine structure; hydrogenic atoms; Lamb shift; level shifts; quantum electrodynamics; radiative corrections; relativistic corrections; JPCRD 6, No. 3, 831-870 (1977).

Atomic volume; hyperfine fields; iron alloys; valence; 16927.

Atomic weight; coulometry; electrochemical equivalent; gallium arsenide; gallium atomic weight; stoichiometry; J. Res. $81 \mathrm{~A}$ No. 1, 1-4 (1977).

Atom-molecule scattering; collisions of $\mathrm{He}$ with diatomic hydrides; heavy particle collisions; rotational excitation in atom-molecule scattering; 16674 .

Atoms; gain; population inversion; recoil; 17143.

Atoms, correlation; configuration interaction; exchange interaction; inner shells; photoabsorption; 16670.

Attack and release characteristics; compression; hearing aids; NBSIR 76-1179.

Attack and release times; automatic gain control; compression; hearing aids; 17145 .

Attenuation; computerized tomography; imaging; ultrasound; velocity; 16937.

Attenuation; Josephson effect; quantum interference; radio frequency; SQUID; superconductivity; 16875 .

Attenuation; laser attenuation; optical be am splitter; NBSIR 77858.

Attenuation coefficient; counting sequence; cross section; gamma ray; photon; SP461, pp. 29-31 (Jan. 1977).

Attenuation coefficient; energy-absorption coefficient; gammaray; photon; $x$ ray; 17051 .

Attenuation coefficients; cross sections; gamma rays, incoherent scattering function; pair production; photoelectric effect; photons; $x$ rays; atomic form factor; SP461, pp. 3-16 (Jan. 1977).

Attenuation length; Auger electrons; Auger-electron spectroscopy; beryllium; electron; proton excitation; x-ray photoelectron spectroscopy; absolute yield; aluminum; 17248.

Attenuation length; Auger-electron yield; beryllium; electron scattering; proton bombardment; 16824 .

Attic ventilation; data encryption; dental materials; fire safety; metric; miniature electric field; organic sulfur; radiometric detector; smog formation; SRM's; air pollution; DIM/NBS 61, No. 11, 1-32 (1977). 
Audio alarm; burglar alarm; intrusion alarm; intrusion detector; sound sensing; standard; alarm; 16831.

Audiometry; diffraction; head diffraction; hearing aids; instruments for hearing; manikin; 17064.

Audiometry; national measurement system; noise; noise control; noise emissions; sound; sound level meters; acoustical measurements; acoustics; NBSIR 75-938.

Audit packages; audit routines; audit software; auditing; auditing standards; computer assisted auditing; computer auditing; SP500-13.

Audit routines; audit software; auditing; auditing standards; computer assisted auditing; computer auditing; audit packages; SP500-13.

Audit software; auditing; auditing standards; computer assisted auditing; computer auditing; audit packages; audit routines; SP500-13

Audit standards; audit techniques; audit tools; audit training; communications security; computer controls; computer security; data integrity; interactive audit; internal audit; postprocessing audit; program integrity; SP500-19.

Audit techniques; audit tools; audit training; communications security; computer controls; computer security; data integrity; interactive audit; internal audit; post-processing audit; program integrity; audit standards; SP500-19.

Audit tools; audit training; communications security; computer controls; computer security; data integrity; interactive audit; internal audit; post-processing audit; program integrity; audit standards; audit techniques; SP5O0-19.

Audit training; communications security; computer controls; computer security; data integrity; interactive audit; internal audit; post-processing audit; program integrity; audit standards; audit techniques; audit tools; SP500-19.

Auditing; auditing standards; computer assisted auditing; computer auditing; audit packages; audit routines; audit software; SP500-13.

Auditing standards; computer assisted auditing; computer auditing; audit packages; audit routines; audit software; auditing; SP500-13.

Auger; chemisorption; electron spectroscopy; surfaces; adsorption; angle resolved; 16747.

Auger electron spectroscopy; beam-lead bonds; capacitancevoltage methods; carrier mobility; C-MOS circuits; dopant profiles; electrical properties; electronics; four-probe method; hermeticity; ion implantation; Irvin's curves; leak tests; linewidth measurement; SP400-29.

Auger electron spectroscopy; catalyst; electron binding energy; interlaboratory comparison; surface characterization; $\mathbf{x}$-ray photoelectron spectroscopy; 16930.

Auger electrons; Auger-electron spectroscopy; beryllium; electron; proton excitation; $x$-ray photoelectron spectroscopy; absolute yield; aluminum; attenuation length; 17248 .

Auger-electron spectroscopy; beryllium; electron; proton excitation; x-ray photoelectron spectroscopy; absolute yield; aluminum; attenuation length; Auger electrons; 17248 .

Auger-electron spectroscopy (AES); electron attenuation lengths; electron spectroscopy for chemical analysis (ESCA); electron transmission through thin films; inelastic electron mean free path; supported thin films; 16744.

Auger-electron yield; beryllium; electron scattering; proton bombardment; attenuation length; 16824 .

Auto-correlation; convective velocity; cross-correlation; exit concentration; exit velocity; flow visualization; fluorescence; fluorescent dye; laser; laser dye-fluorescence technique; mean concentration; mean velocity; measuring volume; SP484, pp. 423-447 (Oct. 1977).

Automated data processing; computer software; data element dictionary; data element dictionary/directory; data management; software tool; ADP; SP500-16.
Automated data systems; computer programs; documentation; documentation content guidelines; FIPS guidelines; software, symposium proceedings; SP500-15.

Automated electrochemical analysis; ceramic electrolytes; ceriayttria; cyclic voltommetry; electrocatalysis; equivalent circuit; fuel cells; microprocessor; network analyzer; phosphoric acid electrolyte; refractory hard metals; AC impedance; NBSIR 77-1270.

Automated measurement; pulse; rise time; sampling oscilloscope; spectrum amplitude; time domain; transient; 16721 .

Automated resistance measurement; automation; dc current comparator; digital nanovoltmeter; resistance; resistance measurements; 16707.

Automated response systems; distributed processing; monitoring systems; physical security; sensor systems; adversary scenarios; NBSIR 77-1262.

Automated sound measurement; computer-controlled instrumentation; reverberation room; reverberation room qualification; sound power; acoustical measurements; acoustics; acoustics facility; 16763 .

Automated system; building codes; buildings; computer applications; criteria maintenance design evaluation; design guides; architectural criteria; SP473, pp.349-368 (June 1977).

Automated tape bonding; beam lead devices; bugging height; microelectronics; nondestructive test; acoustic emission; 16884.

Automated tape bonding; beam lead devices; bugging height; microelectronics; nondestructive test; acoustic emission; 17150 .

Automatic gain control; compression; hearing aids; attack and release times; 17145 .

Automatic network analyzer; automation; microwave; microwave measurement; six-port; 16726.

Automatic network analyzer; automation; microwave measurements; six-port; 17237.

Automatic network analyzer; automation; microwave measurements; six-port; 17240.

Automatic printing; Calcomp plotting; data editing; interactive; labels; numerical analysis; OMNITAB II computing system; probability plotting; selection of variables in linear regression; statistical plotting; stem-and-leaf displays; table making; NBSIR 77-1276.

Automatic sprinklers; care type occupancies; fire endurance; load failure; pipe hangers; residential occupancies; NBSIR 77-1282.

Automatic sprinklers; compartment fire; corridor sprinkler systems; droplet size; droplet trajectory; evaporative cooling; fire suppression; full-scale test; gas temperature; oxygen content; recirculating flow; reduced scale model test; scaling criteria; NBSIR 77-1287.

Automatic typewriters; benefits; break even analysis; cost effectiveness; costs; productivity; 17236.

Automation; calibration; data formats; documentation; image content language; image processing; pattem recognition; prototype images; standards; SP500-8.

Automation; clocks; communication; frequency; history; mathematics; navigation; physics; time; time broadcasts; time scales; astronomy; Monogr. 155.

Automation; computer; control; goal-oriented; hierarchical control; rcbot; sensors; adaptive; SP500-23.

Automation; cost/benefit; models; queuing; telephone systems; transit information; transportation; NBSIR 77-1253.

Automation; dc current comparator; digital nanovoltmeter; resistance; resistance measurements; automated resistance measurement; 16707.

Automation; microwave; microwave measurement; six-port; automatic network analyzer; 16726 .

Automation; micr.vave measurements; six-port; automatic network analyzer; 17237 . 
Automation; microwave measurements; six-port; automatic network analyzer; 17240.

Automation; millimeter wave; power measurement; reflection measurement; six-port; 17243.

Automotive environment; automotive fuel flowmeters; effect of environment on flowmeter performance; flowmeter calibration; flowmeter evaluation; procedure for testing flowmeters; TN943.

Automotive fuel; flow measurement errors; fuel economy measurements; fuel flow measurements; in-line flow transducer; SP484, pp. 803-820 (Oct. 1977).

Automotive fuel flowmeters; effect of environment on flowmeter performance; flowmeter calibration; flowmeter evaluation; procedure for testing flowmeters; automotive environment; TN943.

$\mathrm{Au}(\mathrm{n}, \gamma)$ cross section; cross section fluctuations; measurement; neutron capture cross section; normalization; reference standard; review; accuracy; SP493, pp. 165-169 (Oct. 1977):

Availability; basis statistics; offered load; performance; SP500. 18, pp. $137-142$ (Sept. 1977).

Availability; crystal growth; crystal structure; electronic properties; magnetic properties; optical properties; phase diagrams; research materials; thermal properties; SP463, pp. III.3.1III.3.8 (Jan. 1977)

Availability; fault tree analysis; probabilistic analysis; reliability; systems analysis; SP487, pp. 289-308 (Aug. 1977).

A-values; bound-free transitions; $\mathrm{Hg}_{2} ; \mathrm{Hg}_{3}$; potential curves; 335 nm mercury laser; 17084.

A-values; Franck-Condon factors; laser modeling; lifetime; multiconfiguration self-consistent-field; potential energy curves; sodium molecule; transition dipole moment; ab initio calculations; 16870.

Average gradient; intrinsic viscosity; nonrotating bead; single bead contribution to I.V.; torque on the bead; 17119

Aviation; models; simulation; transportation; validation of models; airport simulation; air traffic control; 16944.

Aviation fuels; enthalpy of combustion; fuels; gasoline; gravity; heat content; heat of combustion; kerosine; aniline point; API gravity; TN937.

Avoided crossings; coupled oscillators; nonradial oscillations; 17029.

A15 phase; constitution diagram; niobium alloys; phase diagram; superconductivity; ternary alloys; 16832 .

\section{B}

Ba and Mg films; chemiluminescence; chemisorption; codeposition; gas phase reaction; 17242 .

Back scattering; gamma rays; sky-shine; spectrum; ${ }^{60} \mathrm{Co}$; $\mathrm{SP461}$, pp. 124-128 (Jan. 1977).

Background correction; cosmic gamma ray; flux isotropy; sodium iodide detector; spectral measurements; Apollo 16,17; 16938 .

Back-scatter factor; Clarks' method; depth dose; dosimetry; surface dose; air dose; arbitrary shaped field; SP461, pp. $193-$ 196 (Jan. 1977).

Backscattered emission; EBIC; microelectronic devices; scanning electron microscope; secondary emission; voltage contrast; SP400-35.

Backscattering; barrier; differentials; distribution; gamma rays; integral; medium; Monte Carlo; albedo; angular; SP46I, pp. 129-131 (Jan. 1977).

Backscattering; distribution; dose rate; gamma rays; Monte Carlo; photon; albedo; SP461, pp. 110 -1 18 (Jan. 1977).

$\mathrm{BaF}_{2} ; \mathrm{CaF}_{2} ; \mathrm{KBr}$; KCl; Lexan; LiF; NaF; Plexiglas 55; refractive index; $\mathrm{SrF}_{2}$; thermal coefficient of refractive index; $\mathrm{ZnS}$; ZnSe; NBSIR 77-1304 (ARPA)

$\mathrm{BaF}_{2} ; \mathrm{CaF}_{2} ; \mathrm{KBr} ; \mathrm{KCl}$; LiF; NaF; refractive index; $\mathrm{SrF}_{2}$; thermal coefficient of refractive index; ZnSe; NBSIR 77-1219.
Ballistic protective equipment; body armor; confiscated weapons; police; standards; SP480-6.

Ballistics; carbon dioxide; combustion gases; energy; equation of state; high pressure; high temperature; interaction virial coefficients; mixtures; molecular volumes; second virial coefficients; water; 17136 .

Balmer $\alpha$ line; cw dye laser; Fabry-Perot interferometer; Rydberg constant; 17098.

Balmer-alpha; collision; cross section; dissociation; electron; excitation; hydrogen; 17054.

Band mode; elastic constants; interatomic forces; interstitial; lattice dynamics; metal hydrides; 17004.

Bandwidth; calibration; errors in spectrophotometry; interferences; multiple reflections; photometric linearity; polarization; sample characteristics; stray light; wavelength accuracy; SP466, pp. 99-114 (May 1977).

Bandwidth determination; discharge lamp; lasers; optogalvanic effect; spectroscopy; wavelength calibration; 17287.

Barium ferrite buoy; densimeter; experimental; liquid, magnetic; modification; suspension; absolute measurements; 16792.

Barium fluoride; calibration equations; fast response; films; humidity sensor; industrial fabrication; isotherm equations; physical adsorption; relative humidity; routine radiosonde application; NBSIR 76-1108.

Barium reactions; chemiluminescence; heat pipe reaction; 17100.

Barium sulfate; diffuse reflectance spectra; magnesium oxide; opal glass; radiant flux; reflectance standards; standards calibration; SP466, pp. 75-85 (May 1977).

Bark; forest products; glues and gluing; information service; lumber; mechanical properties; paper; pulp; timber; wood; wood products; AIDS; SP463, pp. II.1.1-II.1.4 (Jan. 1977).

Barothermal gas cell; bulk absorption; highly transparent; infrared materials; optical materials; surface absorption; absorption; 16815

Barrier; differentials; distribution; gamma rays; integral; medium; Monte Carlo; albedo; angular; backscattering; SP46I, pp. 129-131 (Jan. 1977).

Barriers; energy levels; gas phase; $\mathrm{PF}_{5} ;$ Raman; $\mathrm{VF}_{5} ; \mathrm{AsF}_{5}$; 16978.

Barycentric coordinates; distance coordinates; Euclidean plane; matrices of order three; triangle of reference; J. Res. $81 B$ Nos. 1 and 2,61-72 (1977).

Basic physical data; medical; mixed $\mathbf{n}-\boldsymbol{\gamma}$ fields; neutron dosimetry; standards; SP493, pp. 106-114 (Oct. 1977).

Basic principles; computer calculations; computer modeling; experimental methods; smoke control methods; smoke movement; smoke simulation; state-of-the-art review; NBSIR 77 1209.

Basis statistics; offered load; performance; availability; SPSOO18, pp. 137-142 (Sept. 1977).

Bath techniques; manganese sulphate baths; neutron; SP493, pp. 237-243 (Oct. 1977).

Batteries; cardiac pacemakers; hermeticity; hybrid devices; leak testing; measurement technology; microcalorimetry; pacemaker leads; process control; reliability; screen tests; semiconductor devices; SP400-42.

Battery; microcalorimetry; pacemaker; power cell; selfdischarge; NBSIR 77-1310.

Bauxite; chromite; commodity supply policies; contingency planning; energy (petroleum); manganese; NBS-GCR-ETIP 77-38.

Bayes' Rule; flow determination; flow prediction; Monte Carlo; statistics; stratified sampling; SP484, pp. 447-470 (Oct. 1977).

BBGKY hierarchy; bifurcation; crystal; free energy; lattice symmetry; stability; 16986.

$\mathrm{BCl}_{2} \mathrm{SD} ; \mathrm{BCl}_{2} \mathrm{SH}$; hindered rotation; infrared spectra; Raman spectra; vibrational analysis; 17166. 
$\mathrm{BCl}_{2} \mathrm{SH}$; hindered rotation; infrared spectra; Raman spectra; vibrational analysis; $\mathrm{BCl}_{2} \mathrm{SD} ; 17166$.

Be; Li; neutron sources; thick-target yields; NBSIR 77-1279, pp. 10-14 (July 1977).

Bead-spring model; eigenvalues; frequency response; intrinsic optical tensor; intrinsic stress tensor; polymer solution; $J$. Res. 81A No. 1, 97-107 (1977).

Beam lead devices; bugging height; microelectronics; nondestructive test; acoustic emission; automated tape bonding; 16884.

Beam lead devices; bugging height; microelectronics; nondestructive test; acoustic emission; automated tape bonding; 17150

Beam-lead bonds; capacitance-voltage methods; carrier mobility; C-MOS circuits; dopant profiles; electrical properties; electronics; four-probe method; hermeticity; ion implantation; Irvin's curves; leak tests; line-width measurement; measurement methods; SP400-29.

Bearing lubrication; extreme pressure; fluorinated ethylenepropylene; gear lubrication; grease; polyfluoroalkylalkyl polysiloxane; polytetrafluoroethylene; antimony dialkyldithiocarbamate; antiwear; SP487, pp. 154-171 (Aug. 1977).

Bearings; computer programs; elastohydrodynamics; failure analysis; film thickness; gears; Hertz contacts; lubrication; rheology; starvation; traction; SP487, pp. 137-I53 (Aug. 1977).

Beat Cepheids; double-mode Cepheids; Fourier analysis of stelIar variations; mode interaction; stellar instabilities; U Trianguli Australis; 16807.

Beat Cepheids; double-mode Cepheids; Fourier analysis of stelIar variations; mode interaction; stellar instabilities; U Trianguli Australis; 17118 .

Beat Cepheids; double-mode Cepheids; mode interaction; pulsation; stellar instabilities; TU Cassiopeiae; Cepheids; 17315.

Bedding; beds; compartment fires; firesafety engineering; fire tests; health care facilities; hospitals; mattresses; prisons; NBSIR 77-1290.

Bedrock; modeling; rheological; seismic response; two-dimensions; SP477, pp. IV-18-IV-46 (May 1977).

Beds; compartment fires; firesafety engineering; fire tests; health care facilities; hospitals; mattresses; prisons; bedding; NBSIR 77-I290.

Beef muscle; carbon; depth-dose distributions; lateral-dose distributions; polystyrene; radiation dosimeters; radiation processing; radiochromic-dye films; $10-\mathrm{MeV}$ electrons; aluminum; 16999.

Behavioral laboratory; consumer product studies; human behavior research; Human Factors Laboratory; range energy consumption; appliance research; 17035.

Behavioral science; human factors; human reliability; perpetrator attributes; physical security; psychological deterrence; sophisticated crime; threat analysis; terrorism; vigilance; SP48024.

Benchmark; computer performance; model simulation, computer; 17020 .

Benchmark; cross-sections; fast reactors; integral experiments; standards; adjustment; SP493, pp. 310-312 (Oct. 1977).

Benchmark audit procedures; benchmarking; benchmarks associated with government procurement of computers; validation; SP500-18, pp. 75-83 (Sept. 1977).

Benchmark mix demonstration; computer selection; Federal Information Processing Standard; workload representation; benchmarking; FIPS PUB 42-1.

Benchmark spectrum; discrete ordinates; intermediate energy; measurement assurance; neutron standard; reaction rates; SP493, pp. 329-334 (Oct. 1977).
Benchmark tests; development of benchmarks; live test demonstrations; selection of ADPS; Air Force Academy; SP500-18, pp. 71-74 (Sept. 1977).

Benchmarking; benchmark mix demonstration; computer selection; Federal Information Processing Standard; workload representation; FIPS PUB 42-1.

Benchmarking; benchmarks associated with government procurement of computers; validation; benchmark audit procedures; SPSO0-18, pp. 75-83 (Sept. 1977).

Benchmarking; computer procurement; computer selection; workload characterization; SP500-18, pp. 13-21 (Sept. 1977).

Benchmarking; dispatching algorithms; synthetic benchmarking; SP500-18, pp. 119-135 (Sept. 1977).

Benchmarks associated with government procurement of computers; validation; benchmark audit procedures; benchmarking; SP500-18, pp. 75-83 (Sept. 1977).

Benefit-cost analysis; building codes; building economics; building regulations; economic impact; electric shock; ground fault circuit interrupters; national electric code; safety regulations; standards; accidents; SP473, pp. 397-419 (June 1977).

Benefits; break even analysis; cost effectiveness; costs; productivity; automatic typewriters; 17236.

Benefit/cost; building standards; cost/effectiveness; economics; safety standard; standards; 17133 .

Bent rods; form factors; light scattering; macromolecules; rodlike; rodlike macromolecules; rods, bent; rods, semirigid; semirigid rods; 17253.

Benzene; butatriene; heat of formation; ion; ionization potential; monoenergetic electron impact; photoionization; pyridine; vinylacetylene; 1,5-hexadiyne; 2,4-hexadiyne; appearancc potential; 17294 .

Benzidine hazard; blood testing; carcinogen; fingerprints; forensic science; hazardous materials; SP480-21.

Benzoyl peroxide determination; bone cement; chemical composition of bone cement; dimethyl-p-toluidine; hydroquinone leachable monomer; residual components in cements; residual methyl methacrylates; analysis of acrylics; 17202 .

Benzo(a)pyrene; gas chromatography; gas chromatographymass spectrometry; hydrocarbons; liquid chromatography; oil refinery; petroleum; 16886.

Beryllium; ceramics; cryogenics; dielectric-constant; electrets; electrocaloric effect; entropy; ferroelectrics; glass-ceramics; heat switches; magnetothermal conductivity; polarization; potassium tantalate; refrigeration; specific heat; strontium titanate; NBSIR 76-847.

Beryllium; copper; cryogenics; indium; joints; solder; thermal conductance; 16797.

Beryllium; cryogenics; electrical conductivity; heat switch; Lorenz ratio; magnetic field; single crystal; thermal conductivity; 17088 .

Beryllium; electron; proton excitation; $x$-ray photoelectron spectroscopy; absolute yield; aluminum; attenuation length; Auger electrons; Auger-electron spectroscopy; 17248.

Beryllium; electron scattering; proton bombardment; attenuation length; Auger-electron yield; 16824.

BESM-6; JEZEBEL; Markov process; neutron; PURNIMA; Rossi- $\alpha$; slowing down; stochastic; SP461, pp. $97-99$ (Jan. 1977).

Bessel functions; boundary-value problem; connection formula; diffraction theory; error analysis; Liouville-Green approximation; ordinary differential equation; turning point; asymptotic analysis; 16805 .

Bessel functions; error analysis; linear differential equations; transition point; turning point; asymptotic analysis; 16899.

Beta Cephei stars; nonradial stability; pre-main sequence models; 17102

Beta-tricalcium phosphate; cation substitution; coordination; crystal structure; disorder; magnesium incorporation; phosphate; vacancies; 17259. 
Between time variation; calibration; measuring system; stability; standard deviation; statistical analysis; angle block; NBSIR $74-601$.

$\mathrm{Be}^{+}$; electron collisions; excitation; 17132

$B e(d, n)$ source; $B e(p, n)$ source; $C(d, n)$ source; $D(d, n)$ source; dosimetry; $\operatorname{Li}(d, n)$ source; $\operatorname{Li}(p, n)$ source; neutron angular distributions; neutron energy distributions; neutrons; nuclear reactions; thick-target yields; NBSIR 77-1279.

$B e(p, n)$ source; $C(d, n)$ source; $D(d, n)$ source; dosimetry; $\operatorname{Li}(d, n)$ source; $\operatorname{Li}(p, n)$ source; neutron angular distributions; neutron energy distributions; neutrons; nuclear reactions; thick-target yields; $B e(d, n)$ source; NBSIR 77-1279.

Bias; estimators of location; median; M-estimators; S. Newcomb; systematic errors; trimmed means; velocity of light; A. A. Michelson; adaptive estimators; arithmetic mean; 17266 .

Bias uncertainty; frequency accuracy; frequency bias; frequency stability; primary frequency standard; time dispersion; 16775 .

Bias-isolation unit; capacitance and conductance measurements at high applied-bias voltage; capacitance/conductance-meter; capacitance-voltage measurements; electronics; extendedrange $C(V)$ and $G(V)$ measurements; high voltage $C(V)$ and G(V) measurements; SP4OO-4O.

Bibliographic information; data bases; information retrieval; library automation; machine-readable; MARC; standards; SP463, pp. VIII.1.1-VIII.1.4 (Jan. 1977).

Bibliographies; building fires; carpets; construction materials; fire departments; fire detection systems; fire tests; flame research; flammability tests; interior furnishings; mobile homes; polyurethanes; smoke detectors; standards; textiles; toxicity; arson; NBSIR 77-1277.

Bibliographies; computerized information system; concrete; concrete technology; construction material; construction methods; portland cement; state-of-the-art summaries; technical reports; test methods; analytical procedure; SP463, pp. IV.7.1-IV.7.7 (Jan. 1977).

Bibliography; building technology publications; Center for Building Technology; key word-author indexes; publication abstracts; SP457-1.

Bibliography; chemical kinetics; chemistry; chlorine nitrate; molecular properties; nitrosyl chloride; nitryl chloride; physical properties; spectral properties; thermodynamic properties; SP4 78

Bibliography; cryogenic insulation; foam insulation; insulation; survey; abstracts; 17308.

Bibliography; electrochemistry; isopiestic; osmotic coefficients; thermochemistry; vapor pressure; activity coefficients; aqueous systems; SP485.

Bibliography; energy levels, atomic; spectra, atomic; wavelengths, atoms and ions; atomic energy levels; atomic spectra; SP363. Supplement 1.

Bidirectional radiometry; canopies; diffuse reflectance; diffuse transmission; ,reflectance standards; scattering surfaces; SP466, pp. 87-93 (May 1977).

Bidirectional reflectance-distribution function; diffuse reflectance; directional reflectance; nomenclature of reflectance; optical reflection; reflectance; reflectance factor; reflectance geometry; reflectance nomenclature; reflection; specular reflectance; Monogr. 160.

Bifurcation; close-packed crystals; crystalline solutions; hard spheres; metastable states; molecular probability density; 17012.

Bifurcation; crystal; free energy; lattice symmetry; stability; BBGKY hierarchy; 16986

Binary mixtures; critical locus; critical point; phase equilibria; 17295

Biocompatibility; cobalt-chromium; corrosion; implant requirements; mechanical properties; metal implants; stainless steel; standards; titanium; 16973.
Biological and organic materials; silver diethyldithiocarbamate method; arsenic reduction; arsenic speciation; 17257.

Biological assessment; chemical analysis; combustion products; fire fatalities; smoke inhalation; toxicity; NBSIR 77-1234.

Biological materials; blanks; botanical materials; chemical species; flame emission spectrometry; fluorescence spectrometry; molecular absotption spectrometry; neutron activation analysis; polarography; pure reagents; sample preparation; SP492.

Biological polymers; immunochemical analysis; light scattering; polymers; proteins; solid standards; antibodies; antigens; SP466, pp. 95-98 (May 1977).

Biological properties; chemical properties; engineering properties; food products; information retrieval systems; management information systems; materials; nonfood products: physical properties; research information; SP463, pp. II.2.1 II.2.10 (Jan. 1977).

Biomagnetism; geomagnetism; instrumentation; Josephson effect; magnetometry; SQUID; 16872

Biomechanics; carrying; consumer product portability; ergonomics; human factors; lifting; manual materials handling; physiology; psychophysics; safety; warranty; anthropometry; NBSIR 76-1092.

Biomedical; evaluation; pressure measurement; pressure transducer; transducer; 16941 .

Biomethylation; electrochemistry; environment; gas chromatography; laser-Raman; liquid chromatography; nuclear magnetic resonance; organoarsenic; analysis; aqueous chemistry; arsenic; atomic absorption spectrophotometry; 17155 .

Biostatistics; drug regulation; pharmaceutical regulation; phase IV; post marketing surveillance; regulatory experiments; system design; adverse reaction detection; NBS-GCR-ETIP 76-35.

Biphenyl; chain dimensions; dodecanol; linear polyethylene; Mark-Houwink equation; NBS Standard Reference Material 1475; theta solvents; 3,3,5-trimethylhexyl acetate; 16710 .

Bismuth; copper; diffusion; electromigration; liquid metals; nitrogen; phosphorus; temary diffusion; thermomigration; alloys; antimony; arsenic; JPCRD 6, No. 1, 1-50 (1977).

Bituminous roof membranes; built-up roof membranes; coal-tar pitch; performance criteria; physical and engineering properties; test methods; NBSIR 77-1256.

Black and grey neutron detectors; neutron flux measurement; review; SP493, pp. 212-220 (Oct. 1977).

Blackbodies; electrically calibrated detectors; history of radiometry; Planck's constant; radiometric standards; radiometry; standard lamps; Stefan-Boltzmann constant; 16851 .

Blade flutter control; composite materials; jet engines; SP487, pp. 108-120 (Aug. 1977).

BLAM; boundary layer transition; hypersonic velocities; acoustic monitor; SP484, pp. 687-704 (Oct. 1977).

Blanks; botanical materials; chemical species; flame emission spectrometry; fluorescence spectrometry; molecular absorption spectrometry; neutron activation analysis; polarography; pure reagents; sample preparation; spark source mass spectrometric isotope dilution; tissues; SP492.

Blended cements; fly ash; specifications; 16768 .

Block copolymers; homogeneous anionic polymerization; monodisperse polymers; unsaturated monomers; 16736.

Blocking factor; data record; multiple regression; processing time; regression model; SP500-18, pp. 143-158 (Sept. 1977).

Blood electrolytes; blood gases; blood $\mathrm{pH}$; calcium; carbon dioxide; hydrogen ion concentration; nomograms; oxygen; $\mathrm{PCO}_{2}$; $\mathrm{pH}$; potassium; $\mathrm{PO}_{2}$; sodium; acid-base status; SP45O.

Blood gases; blood $\mathrm{pH}$; calcium; carbon dioxide; hydrogen ion concentration; nomograms; oxygen; $\mathrm{PCO}_{2} ; \mathrm{pH}$; potassium; $\mathrm{PO}_{2}$; sodium; acid-base status; blood electrolytes; SP450.

Blood lead; children; data analysis; housing; lead paint; lead poisoning; surveys; NBSIR 77-1293. 
Blood $\mathrm{pH}$; calcium; carbon dioxide; hydrogen ion concentration; nomograms; oxygen; $\mathrm{PCO}_{2} ; \mathrm{pH}$; potassium; $\mathrm{PO}_{2}$; sodium; acid-base status; blood electrolytes; blood gases; SP450.

Blood protein; ellipsometry; implants; polymer adsorption; protein adsorption; synthetic implants; adsorption; NBSIR 76-1128.

Blood testing; carcinogen; fingerprints; forensic science; hazardous materials; benzidine hazard; $S P 480-21$.

Body armor; confiscated weapons; police; standards; ballistic protective equipment; SP480-6.

Body belts; body harness; fall-arrest equipment; fall-safety systems; impact accelerations; impact forces; lanyards; linemen's equipment; load-extension data; occupational safety and health; performance standard; regulation; tensile testing; worker safety equipment; NBSIR 76-1146.

Body hamess; fall-arrest equipment; fall-safety systems; impact accelerations; impact forces; lanyards; linemen's equipment; load-extension data; occupational safety and health; performance standard; regulation; tensile testing; worker safety equipment; body belts; NBSIR 76-1146.

Body shadow; contrast rendition; hand calculator; illuminating engineering; light design; luminaire effectiveness; luminance factor; office lighting; sphere illumination; NBSIR 77-1303.

Body-centered cubic solids; central-force solids; elastic constants; face-centered cubic solids; Poisson's ratio; polycrystals; 16880 .

Boiler performance; central utility plant; diesel engine; enginegenerator efficiency; heat recovery; performance; total energy systems; absorption chillers; NBSIR 77-1243.

Boilers; economics; energy conservation; instrumentation; recuperators; waste; $\mathrm{H} 12 \mathrm{I}$.

Bolometer; dc substitution; microwave; power meter; NBSIR 77-866.

Bolometer; D.C.-substitution technique; differential operational amplifiers; microwave power meter; self-balancing two amplifier power meter; U.S. Patent 4,008,610.

Bolometer; microwave; power measurement; 16723.

Bond; damping; ductility; earthquake resistance; energy absorption; modulus of elasticity; partial reinforcing; risk; shear modulus; testing; ultimate strength; anchor bolts; BSS106, pp. 255-258 (Sept. 1977).

Bond distances; carbonyl selenide; energy levels; force field; infrared; microwave; molecular structure; spectra; spectroscopy; 16823.

Bond lengths and angles; crystal structure; rigid-body motion analysis; thermal motion of a perchlorate ion; $x$-ray diffraction; ammonium perchlorate; 17348 .

Bonded joints; cyclic loading; debond analysis; double-lap-joint analysis; fatigue tests; finite element analysis; joints; nonlinear analysis; single-lap-joint analysis; single-lap-joint bending; spotwelded joints; weldbonded joints; adhesive-bonded joints; NBSIR 76-1053.

Bone cement; chemical composition of bone cement; dimethylp-toluidine; hydroquinone leachable monomer; residual components in cements; residual methyl methacrylates; analysis of acrylics; benzoyl peroxide determination; 17202.

Boolean random sampling; computer system monitoring; data gathering; SP500-18, pp. 159-182 (Sept. 1977).

Bore hole; k property; property; soil; stiffness; testing; SP477, pp. VI-118-VI-140 (May 1977).

Boron; branching ratio; compilation; cross-section; elastic; lithium; measurements; neutron; total; alpha; SP493, pp. 67-84 (Oct. 1977).

Boron hydride; carborane; dicarbollide; metalloborane; metallocarborane; rhodium; ruthenium; 17152.

Boron hydride; hydrogen; iridium; isotope exchange; metalloborane; oxidative addition; 17144 .

Boron scintillators; $\mathrm{Ge}(\mathrm{Li})$; ionization chambers; $\mathrm{NaI}$; neutron flux determination; proportional counters; solid-state detectors; standard cross section; SP493, pp. 85-92 (Oct. 1977).
Boron-aluminum; boron-epoxy; cryogenics; static mechanical properties; advanced fiber composites; 16865 .

Boron-aluminum; bulk modulus; composite; compressibility; elastic constants; resonance method; shear modulus; torsional modulus; Young's modulus; aluminum; 17087.

Boron-epoxy; cryogenics; static mechanical properties; advanced fiber composites; boron-aluminum; 16865 .

Boscovich, Roger Joseph (1711-1787); Cotes, Roger (16821716); Euler, Leonard (1707-1783); Figure of the Earth; fitting a linear equation; least sum of absolute deviations; Mayer, Tobias (1723-1762); method of averages; weighted mean; 17314.

Botanical materials; chemical species; flame emission spectrometry; fluorescence spectrometry; molecular absorption spectrometry; neutron activation analysis; polarography; pure reagents; sample preparation; spark source mass spectrometric isotope dilution; tissues; SP492.

Bound electrons; cross section; gamma rays; inelastic scattering; K-shell electron; photon; $x$ ray; SP461, pp. 26-28 (Jan. 1977).

Bound set; convex hull; eigenvalue-eigenvector equation; root of unity; J. Res. 82, No. 2, 133-136 (1977).

Boundary layer; hurricanes; loads (forces); natural analysis; tall buildings; wind profiles; SP477, Pp. II-30-II-40 (May 1977).

Boundary layer transition; hypersonic velocities; acoustic monitor; BLAM; SP484, pp. 687-704 (Oct. 1977).

Boundary layers; buildings; turbulence; wind loads; wind tunnels; aerodynamics; NBSIR 77-1196.

Boundary-layer; higher-order moments; hot-wire anemometry; log-normal distribution; small-scale turbulence; 16820.

Boundary-value problem; connection formula; diffraction theory; error analysis; Liouville-Green approximation; ordinary differential equation; turning .point; asymptotic analysis; Bessel functions; 16805 .

Bound-free transitions; $\mathrm{Hg}_{2} ; \mathrm{Hg}_{3}$; potential curves; $335 \mathrm{~nm}$ mercury laser; $A$-values; 17084 .

Bragg-Gray; dosimetry; energy per ion pair; fluence; kerma factor; neutrons; activation; SP493, pp. 342-346 (Oct. 1977).

Branch circuit; contact resistance; electrical connections; fire hazard; glowing electrical connections; arcing/sparking; BSSI03.

Branch circuits; copper wiring; military buildings; aluminum wiring; NBSIR 76-1184

Branch driver; CAMAC; CAMAC standards; computer interfaces; digital interfaces; Harris computer; 16806.

Branched polyethylene; fractionation; gel permeation chromatography; GPC; molecular weight distribution; polymer characterization; standard reference material 1476; 17255 .

Branching ratio; compilation; cross-section; elastic; lithium; measurements; neutron; total; alpha; boron; SP493, pp. 6784 (Oct. 1977).

Break even analysis; cost effectiveness; costs; productivity; automatic typewriters; benefits; 17236 .

Breakeven analysis; life-cycle costing; patrol cars; personal car plan; police fleet administration; take-home car program; 17299.

Breaking energy; inter-fiber bond strength; mixed waste paper; paper recycling; pulp characterization; $2.5 \mathrm{~g} / \mathrm{m}^{2}$ handsheets; NBSIR 76-1148.

Breeder reactor; fission; fission detector; materials; neutron dosimetry; reactor physics; 17058 .

Bremsstrahlung; cross section; electron; intermediate energy; photons; approximation; SP461, pp. 60-63 (Jan. 1977).

Bremsstrahlung; electron-ion collisions; free-free transitions; multiphoton processes; plasma absorption; J. Res. 82, No. 3, 173-179 (1977).

Bremsstrahlung spectrum tip; Delbrück scattering; electromagnetic interactions; electron scattering; radiative corrections; total photon absorption cross sections; virtual photon theory; TN955. 
Brick; clay masonry; concrete block; concrete masonry; failure modes; load capacity; masonry walls; shear walls; splitting strength; ultimate capacity; BSS106, pp. 177-197 (Sept. 1977).

Bricks; buildings; Canada; concrete blocks; design standards; earthquake resistant structures; masonry; BSS106, pp. 198213 (Sept. 1977).

Bridge; cabled stayed; displacements; flutter; models; wind angles; wind tunnel; SP470, pp. II-47-II-67 (Apr. 1977).

Bridge measurements; cryogenic; dielectric loss; dissipation factor; epoxy insulation; high voltage; polymer tape insulation; superconducting cable; underground transmission; 17014 .

Bridges; buildings; codes; disaster; dynamic analysis; earthquakes; ground failures; hydraulic structures; seismicity; soils; standards; structural response; vessels and wind; accelerograph; SP470.

Bridges; buildings; codes; disaster; dynamic analysis; earthquakes; ground failures; nuclear facilities; seismicity; soils; standards; structural response; winds; accelerograph; SP477.

Bridges; design; experiments; nonlinear response; reinforced concrete; SP477, pp. VI-1 - VI-9 (May 1977).

Bridges; displacements; field tests; wind measurements; winds; wind speed; SP470, pp. II-20-II-46 (Apr. 1977).

Bridges; earthquake damage; Guatemala earthquake; SP477, pp. VIII-1 - VIII-27 (May 1977).

Bridges; earthquake design; earthquake forces; seismic provisions; specifications; SP470, pp. VIII-31-VIII-4I (Apr. 1977).

Bridges; specifications; wind; SP477, pp. I-34-I-48 (May 1977).

Brittle fracture; cast iron gas pipe; graphitic corrosion; steadite; NBSIR 74-594.

Brittle materials; ceramics; ceramic turbine; proof testing; silicon nitride; strength; NBSIR 77-1202.

Brittle materials; ceramics; fracture; acoustic emission; amplitude distribution; 17213.

Brittle materials; crack growth; cyclic loading; fracture mechanics; high temperature; proof testing; silicon carbide; silicon nitride; acoustic emission; 17039.

Brittle solids; ceramic surfaces; degradation; fracture; indentation; strength; 16672

Broad initial distribution; coagulation; electrical aerosol analyzer; self-preserving; size distribution; aerosols; asymptotic analysis; 17282 .

Broadband antenna; measurements; picosecond pulse; resistive loading; the method of moments; NBSIR 77-861.

Broadband probe; dipole antenna; dynamic range; electric field probe; isotropic probe; loop antenna; magnetic field probe; tangential sensitivity; NBSIR 77-868.

Broad-crested V-notch weirs; calibration; small watersheds; stream gages; streamflow measurements; weirs; approach channels; SP484, pp. 187-200 (Oct. 1977).

Broad-crested weirs; errors; flow measurement; flumes; openchannel flow; SP484, pp. 201-218 (Oct. 1977).

Bromides; data compilation; density; electrical conductance; iodides; molten salt mixtures; standard reference data; surface tension; viscosity; JPCRD 6, No. 2, 409-596 (1977).

Brooks Act; computer science research; computers in the Federal Government; scientific and technological advisory services; ADP standards; NBSIR 76-1/13.

B-star spectra; forbidden lines; He 1; radiative transfer; Stark broadening; 17171 .

Bubble; field-access; garnet; guide-pattern; magnetoresistance; nonvolatility; orthoferrite; photolithography; uniaxial structures; amorphous materials; SP500-1.

Bubble memory; performance evaluation; system modeling; virtual memory system; SP500-18, pp. 213-217 (Sept. 1977).
Bucket-brigade; buried channel; Canada; charge-coupled device; Great Britain; imager CCD's; Japan; peristaltic CCD's; surface channel; The Federal Republic of Germany; The Netherlands; transfer channel; SPSOO-5.

Bugging height; microelectronics; nondestructive test; acoustic emission; automated tape bonding; beam lead devices; 16884.

Bugging height; microelectronics; nondestructive test; acoustic emission; automated tape bonding; beam lead devices; 17150.

Builder-developer; construction; consumers; cost analysis; cost benefits; housing; regulation; SP473, pp. 391-396 (June 1977).

Building; building environment; energy conservation; engineering; human factor; resource impact factors; 17110 .

Building; wind; wind effects; wind loads; wind observation; wind speed; SP470, pp. I-42-I-49 (Apr. 1977).

Building blocks; programming aids; software tools; syntax analysis; text editing; SP5OO-l4.

Building code; building permits; computers; enforcement; information retrieval; inspection; management control; microfilm; SP473, pp. 377-382 (June 1977).

Building code; code administration; communication; enabling legislation; physically handicapped; regulation; accessibility standards; SP473, pp. 241-251 (June 1977).

Building code; design criteria; probability; progressive collapse; reliability; structural engineering; uncertainty; abnormal loading; alternate path; $B S S 98$.

Building code structure; existing buildings; historic preservation; performance attributes; performance evaluation; building codes and standards; SP473, pp. 453-489 (June 1977).

Building codes; building design; building fires; building regulatory standards; emergency egress; exit capacity; fire safety; human performance; occupational safety; regulatory data; architectural psychology; architectural research; NBSIR 771313.

Building codes; building economics; building regulations; economic impact; electric shock; ground fault circuit interrupters; national electric code; safety regulations; standards; accidents; benefit-cost analysis; SP473, pp. 397-419 (June 1977).

Building codes; building process; constraints; costs; incentives; regulation; alternatives; SP473, pp. 17-33 (June 1977).

Building codes; building regulations; design criteria; earthquakes; hospitals; schools; SP470, pp. VI-64-VI-73 (Apr. 1977).

Building codes; building regulations; buildings; economic impacts; environmental considerations; innovative practices; regulatory research; standards development; administrative procedures; SP473.

Building codes; building regulations; building safety; construction; performance; preservation; rehabilitation; renovation; adaptive reuse; architecture; SP473, pp. 437-452 (June 1977).

Building codes; building regulation; do-it-yourself; home construction; housing; rehabilitation; remodeling; renewal; renovation; self-help; standards; NBS-GCR-77-88.

Building codes; building safety; control; instruments; knowledge; legislation; life safety; regulation; standards; SP473, pp. 259-278 (June 1977).

Building codes; buildings; construction; dwellings; earthquakes; seismic design criteria; SP470, pp. VI-74-VI-88 (Apr. 1977).

Building codes; buildings; computer applications; criteria maintenance design evaluation; design guides; architectural criteria; automated system; SP473, pp. 349-368 (June 1977).

Building codes; buildings; codes and standards; housing; hurricanes; pressure coefficients; probability distribution functions; risk; statistical analysis; storms; structural engineering; tropical storms; wind loads; wind speeds; BSS100-2. 
Building codes; buildings; design; earthquakes; structural engineering; SP477, pp. Vl-6I-Vl-68 (May 1977).

Building codes; carrying capacity; environment; land use; natural system; performance standards; regulatory process; SP473, pp. 189-202 (June 1977).

Building codes; community development; construction costs; contractors; housing; rehabilitation; standards; SP473, pp. 491-497 (June 1977).

Building codes; computer model; decision table; decision theory; networks; specifications; standards; system engineering; SP473, pp. 285-316 (June 1977).

Building codes; computer programming; decision tables; graph theory; performance specifications; standards; 16705 .

Building codes; computer programming; decision tables; graph theory; performance specifications; standards; TN94O.

Building codes; concrete testing; evaluation; innovations; inplace testing; performance approach; regulatory domination; standards development; SP473, pp. 279-284 (June 1977,).

Building codes; decision making; public policy; regulation; SP473, pp. 203-223 (June 1977).

Building codes; earthquakes; natural disasters; structural engineering; buildings; $S P 490$.

Building codes; energy conservation; energy efficiency; energy performance; model codes; standards; 17290.

Building codes; fire; fire resistivity; firestopping; fire walls; garden apartments; multi-family residences; apartments; NBSIR 76-II94.

Building codes; housing; rehabilitation; remodeling; residential; urban renewal; NBS-GCR-77-87.

Building codes and standards; construction industry; dimensional coordination; metrication; metric system; modular coordination; SI; SP458.

Building codes and standards; building code structure; existing buildings; historic preservation; performance attributes; performance evaluation; SP473, pp. 453-489 (June 1977).

Building codes and standards; design criteria; earthquake resistance; masonry construction; seismic design; structural design; structural engineering; structural research; BSSIO6.

Building codes and standards; design criteria; earthquake resistance; limit states design; masonry construction; materials testing standardization; mathematical models; rehabilitation; retrofit; seismic design; structural design; BSS106, pp. 40-59 (Sept. 1977).

Building collapse; computer security; cryogenic temperature; dentistry; dielectric measurements; dye lasers; dynamic calibration; electron microscopy; electronic technology; energy conservation; interferometric wavemeter; metric; DIMINBS 6I, No. 2, 1-32 (1977).

Building construction; building regulations; cities; code uniformity; enforcement; legislation; rules and regulations; statewide codes; summary tables; NBSIR 77-1390.

Building construction groups; certification; code enforcement officials; communications; criteria; education programs; professional competence; SP473, pp. 383-389 (June 1977).

Building design; building fires; building regulatory standards; emergency egress; exit capacity; fire safety; human performance; occupational safety; regulatory data; architectural psychology; architectural research; building codes; NBSIR 77-1313.

Building design; cost; energy conservation; energy standards; fenestration; life-cycle costing; retrofitting; solar; 17107.

Building design; energy conservation; fenestration; HVAC systems; illumination; insulation; lighting; performance standard; thermal performance; ventilation; water heating; air leakage; NBSIR 74-452.

Building economics; building regulations; economic impact; electric shock; ground fault circuit interrupters; national electric code; safety regulations; standards; accidents; benefitcost analysis; building codes; SP473, pp. 397-419 (June 1977).
Building economics; economic efficiency; economics; energy; energy conservation; life-cycle cost; optimization; performance standards; resource impact factors; resources; social optimum; standards; 17302.

Building energy analysis; computerized energy analysis; energy consumption; heating and cooling loads; NBSIR 76-II77.

Building energy conservation; energy management; evaluation and monitoring; survey of buildings; Air Force facilities; I 7062.

Building envelope; energy conservation base; insulation; residential design practices; typical construction characteristics; typical new house materials; windows; NBSIR 77-I309.

Building environment; energy conservation; engineering; human factor; resource impact factors; building; 17110 .

Building fires; building regulatory standards; emergency egress; exit capacity; fire safety; human performance; occupational safety; regulatory data; architectural psychology; architectural research; building codes; building design; NBSIR 77 I3I3.

Building fires; carpets; construction materials; fire departments; fire detection systems; fire tests; flame research; flammability tests; interior furnishings; mobile homes; polyurethanes; smoke detectors; standards; textiles; toxicity; arson; bibliographies; NBSIR 77-I277.

Building fires; egress; fire alarms; fire incidents; fire investigations; fires; human behavior; project people; residential buildings; smoke; statistical analysis; NBS-GCR-77-94.

Building fires; fire behavior; high-rise buildings; occupant behavior in fires; simulated behavior; NBS-GCR-77-92.

Building fires; fire detection devices; heat detectors; ionization chamber detectors; photoelectric detectors; smoke detectors; 16737.

Building heat transfer; honeycomb panel construction; relocatable buildings; wind-load racking; air leakage of buildings; NBSIR 76-II78.

Building heating system; computer simulation; energy conservation; furnace; operating cost; seasonal performance; $I 6922$.

Building official; building regulation; education; housing demand; innovation; regulatory barriers; residential construction; unionization; SP473, pp. 113-135 (June 1977).

Building performance; building process; building systems; construction management; design/build; life-cycle costing; project procurement; SP476.

Building permits; computers; enforcement; information retrieval; inspection; management control; microfilm; building code; SP473, pp. 377-382 (June 1977).

Building pressure profile; computer simulation; elevator shaft pressure profiles; parametric analysis; simulated smoke concentration; smoke control; smoke movement; smoke simulation; systematic pressurization; air-handling units; NBSIR 77 . 1225.

Building process; building systems; construction management; design/build; life-cycle costing; project procurement; building performance; $S P 476$.

Building process; constraints; costs; incentives; regulation; alternatives; building codes; SP473, pp. 17-33 (June 1977).

Building regulation; code administration; enforcement; funding; local government; model codes; state-local relations; statewide codes; uniformity; SP473, pp. 225-240 (June 1977).

Building regulation; computer-based systems; computer technology; information processing; performance evaluation; plan review; research and development; SP473, pp. 369-375 (June 1977).

Building regulation; do-it-yourself; home construction; housing; rehabilitation; remodeling; renewal; renovation; self-help; standards; building codes; NBS-GCR-77-88.

Building regulation; education; housing demand; innovation; regulatory barriers; residential construction; unionization; building official; SP473, pp. 113-135 (June 1977). 
Building regulations; buildings; economic impacts; environmental considerations; innovative practices; regulatory research; standards development; administrative procedures; building codes; SP4 73.

Building regulations; building safety; construction; performance; preservation; rehabilitation; renovation; adaptive reuse; architecture; building codes; SP473, pp. 437-452 (June 1977).

Building regulations; cities; code uniformity; enforcement; legislation; rules and regulations; statewide codes; summary tables; building construction; NBSIR 77-1390.

Building regulations; design criteria; earthquakes; hospitals; schools; building codes; SP470, pp. VI-64-VI-73 (Apr. 1977).

Building regulations; economic impact; electric shock; ground fault circuit interrupters; national electric code; safety regulations; standards; accidents; benefit-cost analysis; building codes; building economics; SP473, pp. 397-419 (June 1977).

Building regulatory standards; emergency egress; exit capacity; fire safety; human performance; occupational safety; regulatory data; architectural psychology; architectural research; building codes; building design; building fires; NBSIR 77 1313.

Building research; building technology; codes; criteria; project summaries; standards; technical bases; SP446-I.

Building research; chemistry; combustion research; design concepts; directories; fire prevention; fire research; hazard analysis; physics; NBSIR 77-1264.

Building safety; construction; performance; preservation; rehabilitation; renovation; adaptive reuse; architecture; building codes; building regulations; SP473, pp. 437-452 (June 1977).

Building safety; control; instruments; knowledge; legislation; life safety; regulation; standards; building codes; SP473, pp. 259 . 278 (June 1977).

Building safety; dummies; guidebook; testing; anthropomorphic dummies; NBS-GCR-77-91.

Building standards; buildings; energy conservation; minimum property standards; multiple glazing; "U" values; alternatives; ASHRAE 90-75; SP473, pp. 85-101 (June 1977).

Building standards; cost/effectiveness; economics; safety standard; standards; benefit/cost; 17133 .

Building systems; construction management; design/build; lifecycle costing; project procurement; building performance; building process; SP476.

Building technology; codes; criteria; project summaries; standards; technical bases; building research; SP446-I.

Building technology; construction; health facilities; hospitals; medical facilities; medical planning; architecture; NBSIR 77. 1233.

Building technology publications; Center for Building Technology; key word-author indexes; publication abstracts; bibliography; SP457-I.

Building (codes); pressure; spectra; structural engineering; tall buildings; turbulence; wind; aerodynamics; 16843 .

Buildings; building codes; earthquakes; natural disasters; structural engineering; SP490.

Buildings; Canada; concrete blocks; design standards; earthquake resistant structures; masonry; bricks; BSSI06, pp. 198-213 (Sept. 1977).

Buildings; codes; disaster; dynamic analysis; earthquakes; ground failures; hydraulic structures; seismicity; soils; standards; structural response; vessels and wind; accelerograph; bridges; SP470.

Buildings; codes; disaster; dynamic analysis; earthquakes; ground failures; nuclear facilities; seismicity; soils; standards; structural response; winds; accelerograph; bridges; SP477.

Buildings; codes; energy conservation; regulatory community; standards; 17111 .
Buildings; codes and standards; housing; hurricanes; pressure coefficients; probability distribution functions; risk; statistical analysis; storms; structural engineering; tropical storms; wind loads; wind speeds; building codes; BSS100-2.

Buildings; collapse; concrete; panels; structural integrity; SP477, pp. VI-220-VI-251 (May 1977).

Buildings; computer applications; criteria maintenance design evaluation; design guides; architectural criteria; automated system; building codes; SP473, pp. 349-368 (June 1977).

Buildings; connectors; design criteria; fasteners; wind; architecture; NBSIR 77-1197.

Buildings; construction; dwellings; earthquakes; seismic design criteria; building codes; SP470, pp. VI-74-VI-88 (Apr. 1977).

Buildings; cooling; heating; laboratory accreditation; performance criteria; solar energy; standards; 16686.

Buildings; cooling; heating; performance criteria; solar collectors; solar energy; standards; SP473, pp. 103-112 (June 1977).

Buildings; cyclones; disasters; structural engineering; tides; wind; SP477, pp. V-21-V-53 (May 1977).

Buildings; damage; dynamic response; earthquakes; safety; shear wall; stiffness; SP470, pp. VI-33-VI-46 (Apr. 1977).

Buildings; design; disaster mitigation; earthquakes; engineering; NBSIR 76-1193.

Buildings; design; earthquakes; structural engineering; building codes; SP477, pp. VI-61-VI-68 (May 1977).

Buildings; design; energy; legislation; solar; standards; State; architecture; NBSIR 77-1297.

Buildings; design review; land use; municipalities; regulation; site design; architectural controls; SP473, pp. 137-187 (June 1977).

Buildings; dynamic effects; high winds; roofs; typhoon; wind pressure; SP470, pp. II-1-II-19 (Apr. 1977).

Buildings; earthquakes; research; structural engineering; structures; SP470, pp. IX-6-1X-16 (Apr. 1977).

Buildings; ease of ignition; fire tests; gypsum board; potential heat; properties; rate of flame spread; rate of heat release; scanning electron microscope (SEM); NBSIR 77-1265.

Buildings; economic impacts; environmental considerations; innovative practices; regulatory research; standards development; administrative procedures; building codes; building regulations; SP473.

Buildings; energy conservation; evaluation; inspection; retrofit; thermography; 16902.

Buildings; energy conservation; minimum property standards; multiple glazing; "U" values; altematives; ASHRAE 90-75; building standards; SP473, pp. 85-101 (June 1977).

Buildings; energy conservation; enforcement; legislation; regulations; solar energy; standards; state-of-the-art study; NBSIR 77-1259.

Buildings; fire protection; fire safety; goal oriented systems approach; systems analysis; NBS-GCR-77-103.

Buildings; full-scale testing; mobile homes; wind loads; aerodynamics; SP477, pp. I-21-I-33 (May 1977).

Buildings; instruments; strong motion; SP477, pp. III-26-III-40 (May 1977).

Buildings; live loads; load surveys; structural engineering; 16708 .

Buildings; turbulence; wind loads; wind tunnels; aerodynamics; boundary layers; NBSIR 77-1196.

Buildings (codes); live loads; load surveys; probability theory; structural engineering; 17305.

Build-up factor; empirical; energy; gamma ray; mean free path; ASFIT; SP461, pp. 174-176 (Jan. 1977).

Built-up roof membranes; coal-tar pitch; performance criteria; physical and engineering properties; test methods; bituminous roof membranes; NBSIR 77-I256.

Built-up roofing; insulation; performance; radiative cooling; roofing; solar heating; surface temperature; 17060 . 
Built-up roofing; insulation; performance; radiative cooling; roofing; solar heating; surface temperature; 17061 .

Bulk absorption; frequency dependence; laser materials; photoacoustic spectroscopy; surface absorption; weakly absorbing materials; 16860 .

Bulk absorption; frequency dependence; laser materials; photoacoustic spectroscopy; surface absorption; weakly absorbing materials; 17313 .

Bulk absorption; highly transparent; infrared materials; optical materials; surface absorption; absorption; barothermal gas cell; 16815 .

Bulk modulus; composite; compressibility; copper; elastic constants; niobium-titanium; Poisson's ratio; pulse method; resonance method; shear modulus; sound velocity; Young's modulus; 17068.

Bulk modulus; composite; compressibility; elastic constants; resonance method; shear modulus; torsional modulus; Young's modulus; aluminum; boron-aluminum; 17087 .

Bulk modulus; compressibility; Debye temperature; elastic constant; invar; iron alloy; nickel alloy; Poisson's ratio; shear modulus; sound velocity; Young's modulus; 16869.

Bulk modulus; compressibility; Debye temperature; Poisson's ratio; precipitation-hardening alloys; shear modulus; sound velocity; Young's modulus; aluminum alloys; 17085 .

Bulk modulus; compressibility; copper alloy; elastic constant; Poisson ratio; precipitation hardening; shear modulus; sound velocity; Young's modulus; 17094.

Bulk modulus; compressibility; copper alloy; Debye temperature; elastic constants; Poisson's ratio; shear modulus; sound velocity; Young's modulus; 17320.

Bulk modulus; compressibility; Debye temperature; elastic constants; Poisson's ratio; shear modulus; single-crystal elastic coefficients; sound velocities; Young's modulus; zinc; JPCRD 6, No. 4, 1181-1204 (1977).

Bulk modulus; compressibility; elastic constants; Poisson's ratio; pulse method; resonance method; shear modulus; sound velocity; stainless steel; Young's modulus; 17321 .

Buoyancy; buoyancy correction; change; comparison; difference; mass; records; set; surveillance limits; surveillance test; test interval; true mass; value; weighing design; weights; apparent mass; NBSIR 76-999.

Buoyancy; laminar flow; plume; pressure distribution; streamlines; temperature distribution; analysis; J. Res. $81 \mathrm{~B}$ Nos. 1 and 2, 45-60 (1977).

Buoyancy correction; change; comparison; difference; mass; records; set; surveillance limits; surveillance test; test interval; true mass; value; weighing design; weights; apparent mass; buoyancy; NBSIR 76-999.

Buoyancy pressure; enclosure fires; entrainment; fire induced flows; models; physical scale; plumes; J. Res. 82, No. 2, 107 117 (1977).

Buoyant flow; compartment fires; corridor fires; fire code; fire science; fire spread model; NBS-GCR-77-84.

Buoyant flow; corridor, countercurrent; fire; scaling; stratified flow; temperature; velocity measurements; 17285 .

Buoyant plumes; ceilings; compartment fires; fire plumes; heat transfer; room fires; scale models; NBS-GCR-77-97.

Buoyant thermals; entrainment coefficient; fire-balls; turbulent thermals; vortex bubbles; SP484, pp. $571-596$ (Oct. 1977).

Bureau of Mines; energy; health and safety; metallurgy; mining; Office of Mineral Information; SP463, pp. V.3.1-V.3.9 (Jan. 1977).

Burglar alarm; intrusion alarm; intrusion detector; sound sensing; standard; alarm; audio alarm; 16831 .

Burglar alarm sensor; burglar alarm system; door switch; mechanically actuated switch; perimeter sensor; switch; 17002.

Burglar alarm system; door switch; mechanically actuated switch; perimeter sensor; switch; burglar alarm sensor; 17002.
Burglary resistance; door assemblies; door components; doors; frames; hardware; hinges; locks; security standards; $167 / 4$.

Buried cables; copper concentric neutral wires; corrosion detection methods; corrosion tests; current-potential measurements; underground corrosion; NBSIR 77-1232.

Buried channel; Canada; charge-coupled device; Great Britain; imager CCD's; Japan; peristaltic CCD's; surface channel; The Federal Republic of Germany; The Netherlands; transfer channel; bucket-brigade; SPSOO-5.

Burn injury; fabric flammability; FFACTS; flammability standards; Flammable Fabrics Act; ignition sources; apparel fires; SP463, pp. V11.2.1-V11.2.11 (Jan. 1977).

Burn injury; fabric flammability; fabrics; fire; garments; heat transfer; injury hazard; simulation; accident; apparel; NBSIR 77-1236.

Burn injury; flammability; Mushroom Flammability Tester; test methods; 16813 .

Burn injury potential; extinguishability; fire retardants; flammability hazard; FR treated cotton blends; FR treated cottons; ignitability; MAFT value; phosphorus; synthetic fabrics; 17176

Burn-out; helium-cooled current leads; helium flow facility; helium impurities; microwave pressure transducer; thermalacoustic oscillations; NBSIR 77-853.

Butatriene; heat of formation; ion; ionization potential; monoenergetic electron impact; photoionization; pyridine; vinylacetylene; 1,5-hexadiyne; 2,4-hexadiyne; appearance potential; benzene; 17294

\section{C}

Ca II emission; stars, chromospheres; stars, individual; stars, late type; stars, mass loss; 16732.

Cabled stayed; displacements; flutter; models; wind angles; wind tunnel; bridge; SP470, pp. II-47-II-67 (Apr. 1977).

Cadmium telluride; elastic compliance tensor; elastic moduli; extrinsic damage thresholds; high-power lasers; infrared materials; tensile stress; 16746.

Cadmium telluride; elastic compliance tensor; elastic moduli; extrinsic damage thresholds; high-power lasers; infrared materials; tensile stress; 17312

$\mathrm{CaF}_{2} ; \mathrm{KBr}$; $\mathrm{KCl}$; Lexan; LiF; NaF; Plexiglas 55; refractive index; $\mathrm{SrF}_{2}$; thermal coefficient of refractive index; $\mathrm{ZnS}$; $\mathrm{ZnSe} ; \mathrm{BaF}_{2} ; N B S I R$ 77-1304 (ARPA).

$\mathrm{CaF}_{2} ; \mathrm{KBr}$; KCl; LiF; NaF; refractive index; $\mathrm{SrF}_{2}$; thermal coefficient of refractive index; $\mathrm{ZnSe} \mathrm{BaF}_{2} ;$ NBSIR 77-1219.

Calcium; carbon dioxide; hydrogen ion concentration; nomograms; oxygen; $\mathrm{PCO}_{2} ; \mathrm{pH}$; potassium; $\mathrm{PO}_{2}$; sodium; acid-base status; blood electrolytes; blood gases; blood pH; SP45O.

Calcium; $\mathrm{CO}_{2}$ laser; luminescence; magnesium; metal flames; 17163.

Calcium chloride; critical evaluation; electrolyte; excess free energy; osmotic coefficient; solutions; thermodynamic properties; activity coefficient; JPCRD 6, No. 2, 385-408 (1977)

Calcium phosphate; cation-anion columns; crystal structure; subcell; vacancies; alpha-tricalcium phosphate; 17034 .

Calcomp plotting; data editing; interactive; labels; numerical analysis; OMNITAB II computing system; probability plotting; selection of variables in linear regression; statistical plotting; stem-and-leaf displays; table making; automatic printing; NBSIR 77-1276.

Calculated $\sigma(\theta)$; experimental $\sigma(\theta)$; model predictions; nuclear reactions $\mathrm{np}$ scattering $\mathrm{E} \leqslant 30 \mathrm{MeV}$; phase shift analyses; SP493, pp. 47-53 (Oct. 1977).

Calculation; concrete; cyclotron; design; earth shield; neutron spectra; shielding; shield thickness; SP461, pp. 166-170 (Jan. 1977). 
Calculation; cross section; optical model; reactor technology; scattering-elastic, inelastic, total; thorium; uranium; SP461, pp. $70-73$ (Jan. 1977).

Calibration; californium-252; cross sections; design; errors; fission neutrons; irradiation devices; measuring methods; neutron reactions; neutron sources; 16790.

Calibration; calorimeter; cobalt-60; radiation standard; absorbed dose; 17005 .

Calibration; ceramic; condenser; electret; humidity; microphones; reciprocity; sensitivity; temperature; 16701 .

Calibration; ceramic; condenser; electret; humidity; microphones; reciprocity; sensitivity; temperature; 17245 .

Calibration; characteristic factor ( $\mathrm{K}$ or $\mathrm{C}$ ); curve fitting; pickoffs (magnetic and RF); turbine flowmeter; universal curve; viscosity measurement; accuracy; SP484, pp. 847-869 (Oct. 1977).

Calibration; CMAC; computers; consumer sounding boards; data; electron probe microanalysis; laser ionization; metrication; noise; nondestructive evaluation; research associate program; standards; Alaska pipeline; DIM/NBS 61 , No. 1, 1-32 (1977).

Calibration; column broadening, GPC; gel permeation chromatography; nonlinear regression; 16822.

Calibration; consumers; energy; energy savings; grain moisture; mass spectra; radiation sterilizing; screw thread standards; SHIVA laser; silicon; timekeeping; ultraviolet radiation; DIM/NBS 61, No. 9, 1-32 (1977).

Calibration; critically evaluated data; crystallographic data; experimental melting curves; high pressure; solid-solid phase boundaries; AB-type compounds; JPCRD 6, No. 4, 12051252 (1977).

Calibration; cryogenic; dynamic; frequency response; hysteresis; precision; pressure measurement; sensitivity; stability; thermal effects; zero-shift; accuracy; 17081

Calibration; cylinders; plug gages; rolls; wire standards; NBSIR $73-136$

Calibration; data formats; documentation; image content language; image processing; pattern recognition; prototype images; standards; automation; SP500-8.

Calibration; density; photography; reflectance; transmittance; wedges; 16683

Calibration; detection; dosimetry; facilities; fluence; flux; moderation; monitor; neutron; shielding; sources; standardization; SP493, pp. 115-120 (Oct. 1977).

Calibration; deuterium; interlaboratory; lamp; radiance; radiometry; source; spectroscopy; standard; synchrotron; ultraviolet; wall-stabilized; arc; 17198 .

Calibration; dew point; humidity; hygrometer; mixing ratio; relative humidity; two-pressure generator; volume ratio; water vapor; J. Res. 81A No. 1, 81-88 (1977).

Calibration; dielectrics; dividers; electric fields; electro-optics; high voltage measurement; insulating fluids; Kerr effect; nitrobenzene; pulse measurement; space charge; NBSIR 77. 1317.

Calibration; diffusion cell; formaldehyde; instrumentation; pyrolysis; reactive gases; acetaldehyde; acrolein; 16699.

Calibration; eddy current; microwave; nondestructive evaluation; penetrant; radiography; standards; thermal; ultrasonic; visual testing; wear debris; acoustic; 17106.

Calibration; efficiency; neutron beams; neutron flux; neutrons; ${ }^{3} \mathrm{H},{ }^{2} \mathrm{H},{ }^{4} \mathrm{He},{ }^{3} \mathrm{He}$, protons; SP493, pp. 221-226 (Oct. 1977).

Calibration; electromagnetic interference; fast Fourier transform; impulse generator; radiometer; sampling oscilloscope; spectrum amplitude; spectrum analyzer; spectrum intensity; 16725.

Calibration; errors in spectrophotometry; interferences; multiple reflections; photometric linearity; polarization; sample characteristics; stray light; wavelength accuracy; bandwidth; SP466, pp. 99-114 (May 1977).
Calibration; flow conditioning; meter performance; perturbations; precision; turbine meter; uncertainty; accuracy; SP484, pp. 33-54 (Oct. 1977).

Calibration; gamma radiation; industrial radiography; national standards; radiation characteristics; radiation source; source calibration; test methods; $x$ rays; 17017.

Calibration; iodometry; monitoring; ozone; ultraviolet photometry; air pollution; NBSIR 76-1 191.

Calibration; load cell; proving rings; testing machines; tolerance; verification; 16915

Calibration; measurements; vibration; vibration exciters; vibration standards; accelerometers; NBSIR 77-1229.

Calibration; measuring system; stability; standard deviation; statistical analysis; angle block; between time variation; NBSIR 74-601.

Calibration; optical flat, profile; stability; standard deviation; -NBSIR 73-232.

Calibration; Pitot-static tube; Reynolds number; sphere flow; transition; trip-wire probe; turbulent boundary layer; SP484, pp. 719-735 (Oct. 1977).

Calibration; small watersheds; stream gages; streamflow measurements; weirs; approach channels; broad-crested V-notch weirs; SP484, pp. 187-200 (Oct. 1977).

Calibration equations; fast response; films; humidity sensor; industrial fabrication; isotherm equations; physical adsorption; relative humidity; routine radiosonde application; barium fluoride; NBSIR 76-1108.

Calibration facilities; photodiodes; radiometry; spectrometer calibration; synchrotron radiation; transfer standard detectors; 16665 .

Calibration of ultraviolet spectrometers; certification of apparent specific absorbance; isosbestic wavelengths; liquid filters; standard reference material; transfer standards; absorbance linearity; accuracy of transmittance or absorbance scale; SP260-54.

Calibration of ultraviolet spectrophotometers; liquid filters; transfer standards; ultraviolet absorbance standards; absorbance linearity; accuracy; acidic potassium dichromate solutions; SP466, pp. 121-126 (May 1977).

Calibration procedures; engineering technical data, metrology; failure mode; failure rate, quality, reliability, safety; technology transfer; urgent data request; ALERT; SP463, pp. IIII.5.1III.5.8 (Jan. 1977).

Calibrations; electrical-eddy current measurements; microwaves; nondestructive evaluation; standard reference materials; standards; thermal testing; ultrasonics; visual testing; wear debris analysis; acoustic emission; 17016.

Calibrations; interpolation formula; irradiance drift formula; projected solid angle; spectral irradiance; standards; TN59413.

Californium-252; cross sections; design; errors; fission neutrons; irradiation devices; measuring methods; neutron reactions; neutron sources; calibration; 16790.

Californium-252; dosimetry; neutron flux standard; pulse reactor calibration; radiation effects; SP493, pp. 335-341 (Oct. 1977).

Californium-252; inland waters and sediments; in vivo analysis; mineral exploration; nuclear safeguards; oceanography; onstream analysis; well logging; activation analysis; 16760 .

Californium-252; Maxwellian spectrum; plutonium-239; prompt fission spectrum; uranium-235; Watt spectrum; SP493, pp. 198-205 (Oct. 1977).

Calorimeter; cobalt-60; radiation standard; absorbed dose; calibration; 17005 .

Calorimeter; cryogenic flow measurement; dental restorations; deep ocean research; federal science; governmental environment; laser energy; space flight; spectroscopy; SRM; television captioning; thermophysical; weights and measures: DIMINBS 61, No. 4, 1-32 (1977). 
Calorimeter; laser calorimeter; laser energy; laser power; TN685.

Calorimetry; chemical dosimetry; dosimetry; dye dosimeters; electron beams; gamma rays; pararosaniline cyanide; pulse radiolysis; radiochromic dyes; 16984 .

Calorimetry; color names; color-order systems; Munsell Color System; Universal Color Language; variable accuracy of color designations; centroid colors; color; color designations; SP440.

Calorimetry; dose distributions; dosimetry; electron beams; food irradiation; Fricke dosimetry; gamma rays; $x$ rays; absorbed dose; 17343.

Calorimetry; enthalpy relaxation; glass transition; heat capacity; polymer; poly(vinyl chloride); pressure effects; thermodynamic properties; J. Res. 82, No. 1, 9-18 (1977).

Calorimetry; heat release rate; response time; time delay; NBSIR 77-1302.

Calorimetry; luminescence; photoacoustic spectrometer; piezocalorimeter; transducers; triplet formation; absolute quantum efficiency; absolute quantum yield; SP466, pp. 25-31 (May 1977).

Calorimetry, soln.; $\mathrm{NaNO}_{2}$, enthalpy of dilution; $\mathrm{NaNO}_{2}$, enthalpy of soln.; $\mathrm{NaNO}_{2}$, relative apparent molar heat content; $\mathrm{NaNO}_{2}$, enthalpies of transition and fusion; J. Res. 82, No. 1, 19-28 (1977).

CAM architectures; computer aided manufacturing; computer systems; standards; system integration; voluntary standards; NBSIR 76-1094.

CAMAC; CAMAC standards; computer interfaces; digital interfaces; Harris computer; branch driver; 16806.

CAMAC; computer interfacing; instrumentation; interfacing; standards; 16677.

CAMAC; computer interfacing; instrumentation, standards; interfacing; 17270 .

CAMAC; Dataway; instrumentation; modules; nuclear; standards; 16678.

CAMAC; highway; interface; instrumentation; standards; 16679.

CAMAC standards; computer interfaces; digital interfaces; Harris computer; branch driver; CAMAC; 16806.

Cameras; police; police equipment; security equipment; surveillance equipment; alarm systems; SP480-4.

Canada; charge-coupled device; Great Britain; imager CCD's; Japan; peristaltic CCD's; surface channel; The Federal Republic of Germany; The Netherlands; transfer channel; bucket-brigade; buried channel; SP500-5.

Canada; concrete blocks; design standards; earthquake resistant structures; masonry; bricks; buildings; BSS106, pp. 198-213 (Sept. 1977).

Canada; copyrights; inventions; monopolies; patent law; patents; 16859.

Canopies; diffuse reflectance; diffuse transmission; reflectance standards; scattering surfaces; bidirectional radiometry; SP466, pp. 87-93 (May 1977).

Canted phase; ferromagnetism; order-order transition; transition temperatures; 17350 .

$\mathrm{CaO} \cdot \mathrm{Al}_{2} \mathrm{O}_{3} \cdot \mathrm{H}_{2} \mathrm{O}$; coal gasification; refractory cements; alumina cements; J. Res. 82, No. 3, 167-172 (1977).

Cap screw failures; cyclic loading; fatigue; fatigue failure; NBSIR 77-1275

Capability; capability-based addressing; computer security; extended-type objects; operating system structures; protection; reliable software; reliability; security; small protection domains; types; 16920.

Capability-based addressing; computer security; extended-type objects; operating system structures; protection; reliable software; reliability; security; small protection domains; types; capability; 16920.
Capacitance and conductance measurements at high appliedbias voltage; capacitance/conductance-meter; capacitancevoltage measurements; electronics; extended-range $C(V)$ and $\mathrm{G}(\mathrm{V})$ measurements; high voltage $\mathrm{C}(\mathrm{V})$ and $\mathrm{G}(\mathrm{V})$ measurements; MIS capacitors; $S P 400-40$.

Capacitance-voltage measurements; dopant density; Gaussian diffusion; p-n junction; semiconductors; silicon; 17328 .

Capacitance-voltage measurements; dielectric breakdown suppression; discharge suppression; electronics; extended-range MIS C (V) measurements; high-voltage C (V) measurements; MIS capacitor; premature dielectric breakdown; semiconductor devices; SP4OO-37.

Capacitance-voltage measurements; electronics; extended-range $C(V)$ and $G(V)$ measurements; high voltage $C(V)$ and $G(V)$ measurements; MIS capacitors; modified MIS C(V) measurements; semiconductor devices; silicon-on-sapphire measurements; SOS measurements; SP4OO 40.

Capacitance-voltage methods; carrier mobility; C-MOS circuits; dopant profiles; electrical properties; electronics; four-probe method; hermeticity; ion implantation; Irvin's curves; leak tests; line-width measurement; measurement methods; microelectronics; SP400-29.

Capacitance/conductance-meter; capacitance-voltage measurements; electronics; extended-ránge $\mathrm{C}(\mathrm{V})$ and $\mathrm{G}(\mathrm{V})$ measurements; high voltage $C(V)$ and $G(V)$ measurements; MIS capacitors; modified MIS C(V) measurements; semiconductor devices; SP400.40.

Capacitive transducer; Plate Green's function; signal analysis; wave propagation in Plate; acoustic emission; acoustic emission simulator; 17191 .

Capture reaction; cross section; measurement; neutron; $\boldsymbol{\beta}$ counting error; activation; SP461, pp. 57-59 (Jan. 1977).

Carbazine dyes; deuterium effect; fluorescence quantum yield; laser dyes; molecular structure; oxazine dyes; quenching; xanthene dyes; aminocoumarins; SP466, pp. 33-40 (May 1977).

Carbon; collision; copper; distribution; dose; electron; Gaussian; Monte Carlo; scattering; aluminium; SP461, pp. 106109 (Jan. 1977).

Carbon; depth-dose distributions; lateral-dose distributions; polystyrene; radiation dosimeters; radiation processing; radiochromic-dye films; $10-\mathrm{MeV}$ electrons; aluminum; beef muscle; 16999.

Carbon; elastic scattering cross section; evaluation; optical model; R-function analysis; standard; total cross section; SP493, pp. 93-100 (Oct. 1977).

Carbon dioxide; combustion gases; energy; equation of state; high pressure; high temperature; interaction virial coefficients; mixtures; molecular volumes; second virial coefficients; water; ballistics; 17136.

Carbon dioxide; corresponding states; mixtures; nitrous oxide; prediction; thermal conductivity; transport property; viscosity; TN693.

Carbon dioxide; ethanol; measurement; molecular absorption; $10 \mu \mathrm{m}$ wavelength; ammonia; 16924.

Carbon dioxide; hydrogen ion concentration; nomograms; oxygen; $\mathrm{PCO}_{2} ; \mathrm{pH}$; potassium; $\mathrm{PO}_{2}$; sodium; acid-base status; blood electrolytes; blood gases; blood pH; calcium; SP450.

Carbon monosulfide; Dunham coefficients; infrared absorption; molecular physics; short-lived molecular species; vibrationrotation spectra; 17044 .

Carbon monoxide; catalytic methanation; hydrogen; methane; tungsten; 17207.

Carbon monoxide; chemisorption; coadsorption; desorption; displacement; hydrogen; photoemission; thermal desorption; tungsten; ultraviolet photoelectron spectroscopy; 16808.

Carbon monoxide molecules; dipole moment; electron scattering; electrostatic potential; intermediate neglect of differential overlap (INDO); molecular orbital theory; quantum chemistry; static potential; 16709. 
Carbon steel; corrosion; ductile cast-iron; soils; statistical analysis; underground; 16745 .

Carbon tetrachloride; carbon tetrafluoride; electron impact; electron spectroscopy; oscillator strengths; 17018 .

Carbon tetrachloride; chlorine atom; photochemistry; primary processes; quantum yields; troposphere; ultraviolet; absorption cross section; 16703.

Carbon tetrafluoride; electron impact; electron spectroscopy; oscillator strengths; carbon tetrachloride; 17018 .

Carbonyl selenide; energy levels; force field; infrared; microwave; molecular structure; spectra; spectroscopy; bond distances; 16823.

Carborane; dicarbollide; metalloborane; metallocarborane; rhodium; ruthenium; boron hydride; 17152 .

Carboxyhemoglobin; $\mathrm{CO}$ intoxication; intra-arterial cannula; spectrophotometer analysis; 16921 .

Carcinogen; fingerprints; forensic science; hazardous materials; benzidine hazard; blood testing; SP480-2l.

Cardiac pacemakers; hermeticity; hybrid devices; leak testing; measurement technology; microcalorimetry; pacemaker leads; process control; reliability; screen tests; semiconductor devices; batteries; SP400-42.

Care type occupancies; fire endurance; load failure; pipe hangers; residential occupancies; automatic sprinklers; NBSIR 77-1282.

Cargo; dynamic loads; equivalent static force; gravity load; handling devices; handling loads; military field shelters; probability distributions; shocks, snow load; static load; trains; transportation; trucks; vibrations; wind load; acceleration; airplanes; NBSIR 77-1254.

Caries mechanism; caries prevention; membrane potentials; permselective properties; surface properties; apatites; 16787.

Caries prevention; membrane potentials; permselective properties; surface properties; apatites; caries mechanism; 16787.

Carpets; construction materials; fire departments; fire detection systems; fire tests; flame research; flammability tests; interior furnishings; mobile homes; polyurethanes; smoke detectors; standards; textiles; toxicity; arson; bibliographies; building fires; NBSIR 77-1277.

Carrier mobility; C-MOS circuits; dopant profiles; electrical properties; electronics; four-probe method; hermeticity; ion implantation; Irvin's curves; leak tests; line-width measurement; measurement methods; microelectronics; optical flyingspot scanner; SP4OO-29.

Carrying; consumer product portability; ergonomics; human factors; lifting; manual materials handling; physiology; psychophysics; safety; warranty; anthropometry; biomechanics; NBSIR 76-1092.

Carrying capacity; environment; land use; natural system; performance standards; regulatory process; building codes: SP473, pp. 189-202 (June 1977).

Cartels; economic policy options; foreign supply disruptions; stockpiling; technology; U.S. demand structure; NBS-GCRETIP 76-25.

Cartels; economic policy options; foreign supply disruptions; stockpiling; technology; U.S. demand structure; NBS-GCRETIP 76-28.

Cartels; economic policy options; foreign supply disruptions; stockpiling; technology options; U.S. demand structure; NBSGCR-ETIP 76-29.

Cartels; economic policy options; foreign supply disruptions; stockpiling; technology options; U.S. demand structure; NBSGCR-ETIP 76-30.

Cartels; economic policy options; foreign supply disruptions; stockpiling technology options; U.S. demand structure; NBSGCR-ETIP 76-3I.

$\mathrm{CaSO}_{4}$; correlation; dose; ESR; gamma ray; glow curve; irradiation; TL; SP461, pp. 234-237 (Jan. 1977).

Cast iron gas pipe; graphitic corrosion; steadite; brittle fracture; NBSIR 74-594.
Catalysis; characterization; chemisorption; electronic factor; geometric factor; metals; surfaces; SP475.

Catalysis; $\mathrm{Mo} ; \mathrm{MO}_{2} \mathrm{C}$; refractory hard metals; valence bands; $\mathrm{W}$; WC; x-ray photoemission; 16932.

Catalyst; electron binding energy; interlaboratory comparison; surface characterization; $\mathrm{x}$-ray photoelectron spectroscopy; Auger electron spectroscopy; 16930 .

Catalytic methanation; hydrogen; methane; tungsten; carbon monoxide; 17207.

Cathode.ray tubes; computer aided design; design; graphics; SP487, pp. 82-90 (Aug. 1977).

Cathode-ray excitation; luminescence; luminescence standards; phosphors; quantum efficiencies; radiant efficiencies; UV excitation; x-ray excitation; SP466, pp. 13-19 (May 1977).

Cathodic protection; coating systems; corrosion protection; offshore corrosion; sand corrosion; seawater corrosion; splash zone corrosion; Monogr. 158.

Cation substitution; coordination; crystal structure; disorder; magnesium incorporation; phosphate; vacancies; beta-tricalcium phosphate; 17259 .

Cation-anion columns; crystal structure; subcell; vacancies; alpha-tricalcium phosphate; calcium phosphate; 17034 .

Cautionary labeling for toys; hazardous characteristics of toys; safety, toy; toy safety; use and reasonably foreseeable abuse testing for toys; PS72-76.

Cavity effects; earth tides; ocean loads; strainmeter; 17196.

Cavity frequency; environmental sensitivity; frequency lock loop; long-term frequency stability; NBS time scale; phase modulation; (active-passive) hydrogen maser; amplitude modulation; 17211 .

Cavity pulling; cavity-Q; cavity servo; Crampton effect; frequency stability; hydrogen line $Q$; hydrogen line servo; magnetic field; passive hydrogen maser frequency standard; second-order Doppler; spin exchange; wall shift; active hydrogen maser frequency standard; 17180 .

Cavity servo; Crampton effect; frequency stability; hydrogen line Q; hydrogen line servo; magnetic field; passive hydrogen maser frequency standard; second-order Doppler; spin exchange; wall shift; active hydrogen maser frequency standard; cavity pulling; cavity-Q; 17180 .

Cavity-Q; cavity servo; Crampton effect; frequency stability; hydrogen line Q; hydrogen line servo; magnetic field; passive hydrogen maser frequency standard; second-order Doppler; spin exchange; wall shift; active hydrogen maser frequency standard; cavity pulling; 17180 .

$\mathrm{CCl}_{2}$; $\mathrm{CFCl}$; fluorescence; laser; lifetime; quenching rate; 17238 .

Ceiling height; ceilings; cotton; detector location; detectors; fire detectors; polyurethanes; polyvinyl chloride; room fires; rooms; smoldering; wood; NBS-GCR-77-86.

Ceiling height; ceilings; cotton; detector location; fire detectors; fire growth; flaming fires; heat detectors; polyurethanes; polyvinyl chloride; smoke detectors; smoldering fires; temperature rise; wood; NBS-GCR-77-95.

Ceilings; compartment fires; fire plumes; heat transfer; room fires; scale models; buoyant plumes; NBS-GCR-77-97.

Ceilings; cotton; detector location; detectors; fire detectors; polyurethanes; polyvinyl chloride; room fires; rooms; smoldering; wood; ceiling height; NBS-GCR-77-86.

Ceilings; cotton; detector location; fire detectors; fire growth; flaming fires; heat detectors; polyurethanes; polyvinyl chloride; smoke detectors; smoldering fires; temperature rise; wood; ceiling height; NBS-GCR-77-95.

Ceilometer; runway visual range; scattering; transmissometer; visibility; visual range; Monogr. 159.

Cell; delta ray; dose; ions; LET; model; neutron; OER; one-hit detector; pion; radiation; track; SP461, pp. 183-187 (Jan. 1977).

Cellular plastics; foam insulation; insulation; materials properties; performance; urea-formaldehyde; TN946. 
Cellulose acetate; dose distributions; dosimetry; dyed plastics; plastic films; polyvinyl acetate; polyvinyl butyral; polyvinyl chloride; polyvinyl pyrrolidone; radiation dosimetry; radiation processing; radiochromic dyes; triphenylmethane dyes; 16949.

Cellulosic materials; char; convective heat transfer; fabric flammability; fabrics; fire hazards; ignition time; pyrolysis; radiant heating; thermal radiation; thermoplastics; NBS-GCR77-99.

Cement manufacture; energy conservation; fly ashes; mineral waste utilization; slags; 17010 .

Center for Building Technology; key word-author indexes; publication abstracts; bibliography; building technology publications; SP457-1.

Central utility plant; diesel engine; engine-generator efficiency; heat recovery; performance; total energy systems; absorption chillers; boiler performance; NBSIR 77-I243.

Céntral-force solids; elastic constants; face-centered cubic solids; Poisson's ratio; polycrystals; body-centered cubic solids; 16880

Centre of mass; coefficients; computations, cross-section; Legendre polynomial; neutron; random sampling; scattering; shielding; angle; SP461, pp. $100-105$ (Jan. 1977).

Centroid colors; color; color designations; calorimetry; color names; color-order systems; Munsell Color System; Universal Color Language; variable accuracy of color designations; SP440.

Cepheids; beat Cepheids; double-mode Cepheids; mode interaction; pulsation; stellar instabilities; TU Cassiopeiae; 17315.

Ceramic; condenser; electret; humidity; microphones; reciprocity; sensitivity; temperature; calibration; 16701 .

Ceramic; condenser; electret; humidity; microphones; reciprocity; sensitivity; temperature; calibration; $I 7245$.

Ceramic corrosion; ceramic erosion; ceramic frącture; chemical degradation; coal gasification material; failure avoidance; metal corrosion; metal erosion; vaporization processes; 17158.

Ceramic corrosion; ceramic erosion; ceramic fracture; chemical degradation; coal gasification material; failure avoidance; metal corrosion; metal erosion; vaporization processes; 17159.

Ceramic electrolytes; ceria-yttria; cyclic voltommetry; electrocatalysis; equivalent circuit; fuel cells; microprocessor; network analyzer; phosphoric acid electrolyte; refractory hard metals; AC impedance; automated electrochemical analysis; NBSIR 77-1270.

Ceramic erosion; ceramic fracture; chemical degradation; coal gasification material; failure avoidance; metal corrosion; metal erosion; vaporization processes; ceramic corrosion; 17158.

Ceramic erosion; ceramic fracture; chemical degradation; coal gasification material; failure avoidance; metal corrosion; metal erosion; vaporization processes; ceramic corrosion; 17159.

Ceramic fracture; chemical degradation; coal gasification material; failure avoidance; metal corrosion; metal erosion; vaporization processes; ceramic corrosion; ceramic erosion; 17158.

Ceramic fracture; chemical degradation; coal gasification material; failure avoidance; metal corrosion; metal erosion; vaporization processes; ceramic corrosion; ceramic erosion; 17159.

Ceramic surfaces; degradation; fracture; indentation; strength; brittle solids; 16672 .

Ceramic technology; current awareness services; databooks; information analysis center; inquiry services; metals technology; structural materials; technical reports; SP463, pp. IV.2.1IV.2.7 (Jan. 1977).

Ceramic turbine; proof testing; silicon nitride; strength; brittle materials; ceramics; NBSIR 77-1202.
Ceramics; ceramic turbine; proof testing; silicon nitride; strength; brittle materials; NBSIR 77-1202.

Ceramics; coal gasification; energy; erosion; high temperatures; 17028.

Ceramics; cryogenics; dielectric-constant; electrets; electrocaloric effect; entropy; ferroelectrics; glass-ceramics; heat switches; magnetothermal conductivity; polarization; potassium tantalate; refrigeration; specific heat; strontium titanate; beryllium; NBSIR 76-847.

Ceramics; erosion; fracture; plastic flow; solid particle impact; transmission electron microscopy; NBSIR 77-1396.

Ceramics; fracture; acoustic emission; amplitude distribution; brittle materials; 17213 .

Ceramics; high temperature; proof testing; reliability; 17046.

Ceramics; phase diagrams; "Phase Diagrams for Ceramists"; phase equilibria; user evaluation; American Ceramic Society; SP486.

Ceria; materials characterization; MHD (magnetohydrodynamics); power generation; testing; U.S.-U.S.S.R. cooperative program; 17160

Ceria-yttria; cyclic voltommetry; electrocatalysis; equivalent circuit; fuel cells; microprocessor; network analyzer; phosphoric acid electrolyte; refractory hard metals; AC impedance; automated electrochemical analysis; ceramic electrolytes; NBSIR 77- 1270

Cerium deuteride; inelastic neutron scattering; lattice dynamics; local mode vibrations; metal hydrides; phonon dispersion curves; 16965.

Cerium oxidation detector; liquid chromatography; liquid chromatography detectors; metal specific detector; photoionization detector; reaction detector; 17278 .

Certification; code enforcement officials; communications; criteria; education programs; professional competence; building construction groups; SP473, pp. 383-389 (June 1977).

Certification; precision; SRM; standard reference data; standard reference materials; accuracy; SP463, pp. VII.4.I-VII.4.14 (Jan. 1977).

Certification of apparent specific absorbance; isosbestic wavelengths; liquid filters; standard reference material; transfer standards; absorbance linearity; accuracy of transmittance or absorbance scale; acidic potassium dichromate solutions; SP260-54.

Certification programs; consumer products; household products; industry standards; international recommendations; national standards; product standards; recommended practices; specifications; test methods; TN948.

Cesium beam; clocks (atomic); crystal oscillator; frequency accuracy; frequency stability; frequency standards; hydrogen maser; quartz crystal; rubidium gas cell; timekeeping; TN616, $2 d$ Revision.

Cesium standard; clock, operating; magnetic shielding; microwave feed; primary cesium standard; 16759 .

$\mathrm{CFCl}$; fluorescence; laser; lifetime; quenching rate; $\mathrm{CCl}_{2}$; 17238 .

Chain dimensions; dodecanol; linear polyethylene; Mark-Houwink equation; NBS Standard Reference Material 1475; theta solvents; 3,3,5-trimethylhexyl acetate; biphenyl; 16710 .

Chain folding; curved crystals; extended chain crystals; fold domains; fold surfaces; interlamellar links; morphology; polymer; sectorization; spheralites; 16958.

Chain-folding; crystallization; growth rate; homogeneous nucleation; polymer; surface nucleation; 16887.

Change; comparison; difference; mass; records; set; surveillance limits; surveillance test; test interval; true mass; value; weighing design; weights; apparent mass; buoyancy; buoyancy correction; NBSIR 76-999.

Channels, small; heat transfer; helium; turbulent flow; $I 7333$. 
Char; convective heat transfer; fabric flammability; fabrics; fire hazards; ignition time; pyrolysis; radiant heating; thermal radiation; thermoplastics; cellulosic materials; NBS-GCR-77. 99.

Character parity sense; character structure; communications; data transmission; Federal Information Processing Standards; serial-by-bit; telecommunications; teleprocessing; American Standard Code for Information Interchange; ASCII; FIPS PUB 17-1.

Character structure; communications; data transmission; Federal Information Processing Standards; serial-by-bit; telecommunications; teleprocessing; American Standard Code for Information Interchange; ASCII; character parity sense; FIPS PUB 17.1.

Character structure; communications; data transmission; Federal Information Processing Standards; parallel-by-bit; parity sense; serial-by-character; telecommunications; teleprocessing; American Standard Code for Information Interchange; ASCII; FIPS PUB 18-1.

Characteristic factor ( $\mathrm{K}$ or $\mathrm{C}$ ); curve fitting; pickoffs (magnetic and RF); turbine flowmeter; universal curve; viscosity measurement; accuracy; calibration; SP484, pp. 847-869 (Oct. I977).

Characteristic modes; Garbacz characteristic modes; group theory; inverse scattering; moment methods; scattering; singularity expansion method; symmetry analysis; antenna patterns; 17225.

Characterization; chemisorption; electronic factor; geometric factor; metals; surfaces; catalysis; SP475.

Characterization; evaluation; performance; pressure; transducer; 17205.

Charge; charged particle; collision; electron; ionic charge; ionization potential; stopping power; stripped particle; velocity; SP461, pp. 144-148 (Jan. 1977).

Charge distribution; charge transfer; corona poling; dipole orientation; piezoelectricity; polarization; polyvinylidene fluoride; pyroelectricity; vinylidene fluoride copolymer; NBSIR 76-1186.

Charge transfer; chemical shifts; core levels; transition metal carbides; $x$-ray emission; $x$-ray photoemission; 17265.

Charge transfer; corona poling; dipole orientation; piezoelectricity; polarization; polyvinylidene fluoride; pyroelectricity; vinylidene fluoride copolymer; charge distribution; NBSIR 76-1186.

Charge transfer; dissociation energy; energy curve; overlap; van der Waals; XeF; 16684.

Charge transfer; entropy; ion-molecule equilibria; 17057.

Charge transfer; hollow cathode discharge; sputtering; 17170 .

Charge-coupled device; Great Britain; imager CCD's; Japan; peristaltic CCD's; surface channel; The Federal Republic of Germany; The Netherlands; transfer channel; bucket-brigade; buried channel; Canada; SP500-5.

Charged particle; collision; electron; ionic charge; ionization potential; stopping power; stripped particle; velocity; charge; SP461, pp. I 44-148 (Jan. 1977).

Charged particle; computer code; energy-angle; integral; legendre polynomial; scattering; semi analytical; spatial; transmission; anisotropy; SP461, pp. 140-143 (Jan. 1977).

Charged particle; dosimeter; dosimetry; efficiency; gamma ray; kerma; neutron; SP461, pp. 209-218 (Jan. 1977).

Check wrapping equipment; experimental procurement; experimental technology incentives program; procurement experiment; prototype procurement; technological innovation; NBS-GCR-ETIP 77-39.

Checking prepackaged commodities; computer assisted checkout systems; consumer affairs; cordage products; drained weight; laws and reguiations; metrication; national laboratory accreditation; retail meat identity standards; tolerance application; vapor recovery; SP47I.
Checklist for design; design; factors in design; requirements in design; SP487, pp. 1-15 (Aug. 1977).

Chemical; critical evaluation; mechanical; numerical data; physical properties; thermodynamics; transport; $S P 463$, pp. VII.1.1-VII.1.15 (Jan. 1977).

Chemical actinometry; correction factors; luminescence; quantum-flat actinometer; quantum yield; absolute yield; $S P 466$, pp. 21-24 (May 1977).

Chemical analysis; combustion products; fire fatalities; smoke inhalation; toxicity; biological assessment; NBSIR 77-1234.

Chemical analysis; environmental samples; long-term storage; microbiologicals; organics; pesticides; radionuclides; sample handling; sampling; trace elements; 16729.

Chemical analysis; measurement systems; physical measurement units; standard reference materials; 16667.

Chemical analysis; measurement compatibility; measurement systems; reference method; standard reference material; accuracy; 17247.

Chemical analysis; rainwater analysis; reference materials; NBSIR 77-1315.

Chemical composition of bone cement; dimethyl-p-toluidine; hydroquinone leachable monomer; residual components in cements; residual methyl methacrylates; analysis of acrylics; benzoyl peroxide determination; bone cement; 17202 .

Chemical degradation; coal gasification material; failure avoidance; metal corrosion; metal erosion; vaporization processes; ceramic corrosion; ceramic erosion; ceramic fracture; 17158.

Chemical degradation; coal gasification material; failure avoidance; metal corrosion; metal erosion; vaporization processes; ceramic corrosion; ceramic erosion; ceramic fracture; 17159.

Chemical dosimetry; dosimetry; dye dosimeters; electron beams; gamma rays; pararosaniline cyanide; pulse radiolysis; radiochromic dyes; calorimetry; 16984.

Chemical ionization mass spectrometry; di-p-tolyldisulfide-1,2dioxide; mass spectrometry; nuclear magnetic resonance; $p$ toluenesulfonylhydrazine; - 1,2-di( $p$-toluenesulfonyl)hydrazine; 17045.

Chemical kinetics; chemistry; chlorine nitrate; molecular properties; nitrosyl chloride; nitryl chloride; physical properties; spectral properties; thermodynamic properties; bibliography; SP478.

Chemical kinetics; chlorine; chlorine oxides; chlorocarbon; chlorofluorocarbon; data compilation and evaluation; nitrosyl chloride; rate constant; absorption spectra; JPCRD 6, No. 3, 871.918 (1977).

Chemical kinetics; chlorine atoms; flash photolysis; hydrogen metathesis methanes; resonance fluorescence; vibrational excitation; 16785 .

Chemical kinetics; data compilation; hydroxyl radical; oxide radical ion; perhydroxyl radical; radiation chemistry; rates; superoxide ion; aqueous solution; NSRDS-NBS59.

Chemical kinetics; data evaluation; data reliability; gas phase; photoabsorption cross section; photochemistry; quantum yield; rate constant; stratospheric chemistry; 16976.

Chemical kinetics; dioxirane; ethylene; mass spectrometry; ozone; air pollution; 17327.

Chemical kinetics data; energy data; environmental data; industrial process data; materials utilization data; mechanical properties; nuclear data; physical science data; solid state data; standard reference data; thermodynamic data; transport properties; TN947.

Chemical measurements; electrical measurements; electronics; profiling; silicon; trace analysis; 17140 .

Chemical potential; dental caries; enamel; fluorapatite; fluoride; hydroxyapatite; solubility; 16739.

Chemical properties; engineering properties; food products; information retrieval systems; management information 
systems; materials; nonfood products; physical properties; research information; agricultural materials; SP463, pp. 11.2.1-11.2.10 (Jan. 1977).

Chemical reaction rate; $\mathrm{HO}_{2}$; hydroperoxyl; nitric oxide; $\mathrm{NO}$; 17272.

Chemical shifts; core levels; transition metal carbides; x-ray emission; x-ray photoemission; charge transfer; 17265.

Chemical species; flame emission spectrometry; fluorescence spectrometry; molecular absorption spectrometry; neutron activation analysis; polarography; pure reagents; sample preparation; spark source mass spectrometric isotope dilution; tissues; analytical disciplines; SP492.

Chemiluminescence; chemisorption; codeposition; gas phase reaction; $\mathrm{Ba}$ and $\mathrm{Mg}$ films; 17242 .

Chemiluminescence; flowing afterglow; fluorescence; infrared; ion-molecule; associative detachment; 17209 .

Chemiluminescence; heat pipe reaction; barium reactions; 17100.

Chemiluminescent; corona discharge; dielectric breakdown; ozone attack; atomic oxygen; 16995.

Chemisorption; coadsorption; desorption; displacement; hydrogen; photoemission; thermal desorption; tungsten; ultraviolet photoelectron spectroscopy; carbon monoxide; 16808.

Chemisorption; codeposition; gas phase reaction; $\mathrm{Ba}$ and $\mathbf{M g}$ films; chemiluminescence; 17242 .

Chemisorption; dehydrogenation; ethylene; photoemission; tungsten; ultraviolet photoelectron spectroscopy; acetylene; adsorption; 16829.

Chemisorption; electron spectroscopy; surfaces; adsorption; angle resolved; Auger; 16747.

Chemisorption; electron stimulated desorption; oxygen; sulphur hexafluoride; temperature programmed desorption; tungsten; 16929.

Chemisorption; electron stimulated desorption; ruthenium; water; adsorption; angular distribution (ions); 17349.

Chemisorption; electronic factor; geometric factor; metals; surfaces; catalysis; characterization; SP4 75.

Chemisorption; hydroxyapatite; irreversible vs reversible adsorption; surface-active comonomer; adhesion to polymers; adsorption from solutions; 17197.

Chemisorption; methane; methyl formate; tungsten; 17065.

Chemisorption of a dental varnish; configuration on surface; kinetics of adsorption from solution; rate law and areal regression of adsorbate; surface area and fixation of chelating rings; adhesive bonding to bone mineral; 17033 .

Chemistry; chlorine nitrate; molecular properties; nitrosyl chloride; nitryl chloride; physical properties; spectral properties; thermodynamic properties; bibliography; chemical kinetics; SP478.

Chemistry; combustion research; design concepts; directories; fire prevention; fire research; hazard analysis; physics; building research; NBSIR 77-1264.

CHETAH predictive scheme; hazard evaluation; test data; test methods; thermal explosion theory; accidental polymerization; NBSIR 76-1149.

Chicago federal building; highrise; pressure profiles; Seattle federal building; smoke control; smoke simulation experiments; sulfur-hexafluoride; systematic pressurization; air-handling system; 17291 .

Children; data analysis; housing; lead paint; lead poisoning; surveys; x-ray fluorescence; NBSIR 77-1250.

Children; data analysis; housing; lead paint; lead poisoning; surveys; blood lead; NBSIR 77-1293.

Chirp radar; medical diagnosis; pulse compression; signal processing; ultrasound; 16735.

Chlorine; chlorine oxides; chlorocarbon; chlorofluorocarbon; data compilation and evaluation; nitrosyl chloride; rate constant; absorption spectra; chemical kinetics; JPCRD 6, No. 3, $871-918$ (1977).
Chlorine; foils; ions; iron, oxygen; measurement; Moliere theory; multiple; scattering; angular distribution; SP461, pp. 136-139 (Jan. 1977).

Chlorine atom; photochemistry; primary processes; quantum yields; troposphere; ultraviolet; absorption cross section; carbon tetrachloride; 16703.

Chlorine atoms; flash photolysis; hydrogen metathesis methanes; resonance fluorescence; vibrational excitation; chemical kinetics; 16785.

Chlorine fluorescence; gas phase; laser induced fluorescence; 16844.

Chlorine isotope separation; isotope enrichment; laser isotope separation; photochemical enrichment; thiophosgene; U.S. Patent 4,025,406.

Chlorine nitrate; chlorofluorocarbons; oxygen atoms; rate constant; resonance fluorescence; stratosphere; 17149 .

Chlorine nitrate; molecular properties; nitrosyl chloride; nitryl chloride; physical properties; spectral properties; thermodynamic properties; bibliography; chemical kinetics; chemistry; SP478.

Chlorine oxides; chlorocarbon; chlorofluorocarbon; data compilation and evaluation; nitrosyl chloride; rate constant; absorption spectra; chemical kinetics; chlorine; JPCRD 6, No. 3, $871-918$ (1977).

Chlorocarbon; chlorofluorocarbon; data compilation and evaluation; nitrosyl chloride; rate constant; absorption spectra; chemical kinetics; chlorine; chlorine oxides; JPCRD 6, No. 3, $871-918$ (1977).

Chlorofluorocarbon; data compilation and evaluation; nitrosyl chloride; rate constant; absorption spectra; chemical kinetics; chlorine; chlorine oxides; chlorocarbon; JPCRD 6, No. 3 , $871-918$ (1977).

Chlorofluorocarbons; oxygen atoms; rate constant; resonance fluorescence; stratosphere; chlorine nitrate; 17149 .

Chloromethanes, photochemistry; quantum yields; quartz; sand; surface reactions; tropospheric sink; J. Res. 82, No. 1, 1-8 (1977).

Cholesky decomposition; Givens transformations; GramSchmidt orthogonalization; Householder transformations; least squares algorithms; regression; statistics; 16833.

Chromaticity coordinates; color; filters; high accuracy; spectrophotometer; standards; transmittance; tristimulus values; 17260.

Chromatography; color matching; color measurement; diffuse reflectance; Kubelka-Munk function; reflectance; reflectance standards; thin layer chromatography; SP466, pp. 41-55 (May 1977).

Chromatography; experimental; laser; photochemistry; apparatus; 16895 .

Chromite; commodity supply policies; contingency planning; energy (petroleum); manganese; bauxite; NBS-GCR-ETIP 77-38.

Chromium; atomic energy levels; atomic spectra; $J P C R D$ 6, No. 2. 317-384 (1977).

Chromium; infrared spectroscopy; magnetic susceptibility; molybdenum; tetracyanoquinodimethan; $x$-ray photoelectron spectroscopy; 17153.

Chromospheres, solar; chromospheres, stellar; coronae, solar; coronae, stellar; flares, solar; flares, stellar; magnetic cycles, solar; magnetic cycles, stellar; nonradiative heating; transition regions, solar; transition regions, stellar; ultraviolet spectra; visible spectra; 17324 .

Chromospheres, stellar; coronae, solar; coronae, stellar; flares, solar; flares, stellar; magnetic cycles, solar; magnetic cycles, stellar; nonradiative heating; transition regions, solar; transition regions, stellar; ultraviolet spectra; visible spectra; $x$-ray spectra; 17324.

Chromospheres, stellar; line profiles, stellar; radiative transfer; ultraviolet spectra; Arcturus; 17056. 
Circuit breaker; data; expcriment; shake table; testing; transformer; SP477, pp. VI-50_-VI-60 (May 1977).

Cities; codc uniformity; enforcement; legislation; rules and regulations; statewide codes; summary tables; building construction; building regulations; NBSIR 77-1390

Citizen rights; computers, confidentiality; data systems; health records; information policy, management principles; medical rccords; privacy; recordkeeping practices; security; SP469.

Clamp-on ultrasonic flowmeter; flowmetering; ultrasonic flowmeter; SP484, pp. 267-276 (Oct. 1977).

Clarks' method; depth dose; dosimetry; surface dose; air dose; arbitrary shaped field; back-scatter factor; SP46I, pp. 193 196 (Jan. 1977).

Classical modular group; cyclic groups; free groups; free products; tables; asymptotic formulas; 16660 .

Classical theory; Doppler broadening; one perturber limit; pressure broadening; analysis of correlated profiles; 17161 .

Classification; damage; intensity; seismic; wooden house; SP477, pp. IV-I -IV-17 (May 1977).

Clausius-Clapeyron equation; saturation vapor pressure over ice; thermal properties of ice; vapor pressurc; vapor pressure at the triple point; vapor pressure of ice; water vapor; J. Res. 81A No. 1, 5-20 (1977).

Clausius-Mosotti; densitometer (capacitance); density; dielectric constant; LNG; mixture(s); 17071.

Clay masonry; concrete block; concrete masonry; failure modes; load capacity; masonry walls; shear walls; splitting strength; ultimate capacity; brick; BSS106, pp. 177.197 (Sept. 1977).

Climatic data; cloud cover modifier; energy conservation; shading coefficient; solar heat gain; window design; 17341 .

Clinical laboratory; fixed-point; gallium; melting-point standard; temperature; thermometric fixed-point; SP481.

Clinical $\mathrm{pH}$; liquid junction; $\mathrm{pH}$ analyzers; $\mathrm{pH}$ error; $\mathrm{pH}$; physiologic pH; tris pH buffer; 16772 .

Clock comparison; satellite time dissemination; standard frequency; standard time; time services; time transfer; 17179.

Clock comparison and reset; digital clock; satellite clock system; satellite controlled clock; satellite time code reception; U.S. Patent 4,014,166.

Clock, operating; magnetic shielding; microwave feed; primary cesium standard; cesium standard; 16759.

Clock synchronizations; cycle identification; group delays; Omega timing; precision timekeeping; VLF antenna fields; VLF timing; VLF tracking coordination; 16947

Clocks; communication; frequency; history; mathematics; navigation; physics; time; time broadcasts; time scales; astronomy; automation; Monogr. 155.

Clocks (atomic); crystal oscillator; frequency accuracy; frequency stability; frequency standards; hydrogen maser; quartz crystal; rubidium gas cell; timekeeping; cesium beam; TN616, 2d Revision.

Close binaries; stellar structure; x-ray binaries; 17309.

Close-coupling calculations; crossed beams; cross sections; differential cross sections; electron scattering; inelastic scattering; nitrogen molecules; resonances; scattering; vibrational excitation; 16740 .

Closed conduit flow; flow measurement; international standards; open channel flow; petroleum product standards; SP484, pp. 895-920 (Oct. 1977).

Closed conduit flow; instrumentation; measuring flow; metering flow; monitoring flow; open channel flow; public law 92-500; sewerage flow; wastewater flow; SP484, pp. 83-89 (Oct. 1977).

Closed conduit flows; current meters; dye-dilution methods; errors in flow measurement; flow measurement; fluid flow modeling; fluid velocity; flumes; gas flow standard; hot-wire anemometry; international flow standards; laser anemometry; open channel flows; SP484, Volumes $l$ and 2.
Closed conduit meter; differential pressure; flow measurement: mathematical modeling; meter performance; orifice meter; turbulence flow; SP484, pp. 491-522 (Oct. 1977).

Closed-loop cooling system; cooling lake; dye dilution method error analysis; flow rate measurement; open channel flow measurement; power plant; spray canal; stage-discharge equa tion; velocity-area method; weir equation; SP484, pp. 145 172 (Oct. 1977).

Close-packed crystals; crystalline solutions; hard spheres; metastable states; molecular probability density; bifurcation; 17012.

Clothing; cold discomfort; energy conservation; humidity; tem. perature; thermal acceptability; SP491, pp. 131-151 (Sept. 1977).

Clothing effects; comfort; heat storage; work effects; SP491, pp. 52-64 (Sept. 1977).

Clothing insulation; effective temperature (ET*); energy con. servation; summer temperature guidelines; thermal accepta. bility; thermal preference survey; winter temperature; SP491, pp. 93-116 (Sept. 1977).

Cloud cover modifier; energy conservation; shading coefficient; solar heat gain; window design; climatic data; 17341 .

Clustering; workload characterization; SP500-18, pp. 23-38 (Sept. 1977).

CMAC; computers; consumer sounding boards; data; electron probe microanalysis; laser ionization; metrication; noise; nondestructive evaluation; research associate program; standards; Alaska pipeline; calibration; DIM/NBS 61 , No. $1,1.32$ (1977).

C-MOS circuits; dopant profiles; electrical properties; electronics; four-probe method; hermeticity; ion implantation; Irvin's curves; leak tests; line-width measurement; measurement methods; microelectronics; optical flying-spot scanner; SP400-29.

$\mathrm{CO}$; combustion; $\mathrm{CO}_{2}$; methylene; rate constant; 16838 .

$\mathrm{CO}$ intoxication; intra-arterial cannula; spectrophotometer analysis; carboxyhemoglobin; 16921 .

Coadsorption; desorption; displacement; hydrogen; photoemission; thermal desorption; tungsten; ultraviolet photoelectron spectroscopy; carbon monoxide; chemisorption; 16808 .

Coagulation; electrical aerosol analyzer; self-preserving; size distribution; aerosols; asymptotic analysis; broad initial dis. tribution; 17282 .

Coal by-products; construction materials; industrial wastes; mining wastes; municipal waste; slags; waste materials; NBSIR 77-1244.

Coal conversion; coal gasification; coal liquefaction; corrosion; failure analysis; failure prevention; quality assurance; reliability; SP468.

Coal conversion; consumer products; cryogenic; crystalline materials; dosimeter calibrations; energy; energy related inventions; heterodyne receiver; international standards code; NCSL; NMR knight shifts; neutron beams; DIM/NBS 61 , No. 7. 1-32 (1977).

Coal gasification; coal liquefaction; corrosion; failure analysis: failure prevention; quality assurance; reliability; coal conversion; SP468.

Coal gasification; energy; erosion; high temperatures; ceramics; 17028.

Coal gasification; environments; erosion; hydrothermal; refractories; strength; 16993 .

Coal gasification; refractory cements; alumina cements; $\mathrm{CaO} \cdot \mathrm{Al}_{2} \mathrm{OB3}$ H $\mathrm{O} ; J$. Res. 82, No. 3, 167-172 (1977).

Coal gasification material; failure avoidance; metal corrosion; metal erosion; vaporization processes; ceramic corrosion; ceramic erosion; ceramic fracture; chemical degradation; 17158 .

Coal gasification material; failure avoidance; metal corrosion; metal erosion; vaporization processes; ceramic corrosion; 
ceramic erosion; ceramic fracture; chemical degradation; 17159.

Coal liquefaction; corrosion; failure analysis; failure prevention; quality assurance; reliability; coal conversion; coal gasification; SP468.

Coal mine noise; digital data; electromagnetic interference; electromagnetic noise; emergency communications; Fast Fourier Transform; impulsive noise; magnetic field strength; measurement instrumentation; portable spectrum analyzer; spectral density; 17175 .

Coal-fired MHD; open-cycle MHD; seed-slag interaction; thermal decomposition of $\mathrm{K}_{2} \mathrm{O}-\mathrm{SiO}_{2}$ solutions; vapor pressure of $\mathrm{K}_{2} \mathrm{O}-\mathrm{Al}_{2} \mathrm{O}_{3}$ phases; 16897.

Coal-tar pitch; performance criteria; physical and engineering properties; test methods; bituminous roof membranes; builtup roof membranes; NBSIR 77-1256.

Coastal processes; permeability effects; prototype tests; sand transport; water tunnel; waves; 16917.

Coating materials; composite materials; design; failure avoidance; failure prevention; lubricants; materials of design; product liability; reliability of design; techniques of design; validation of design; $S P 487$.

Coating systems; corrosion protection; offshore corrosion; sand corrosion; seawater corrosion; splash zone corrosion; cathodic protection; Monogr. 158.

Coatings; delayed response; dynamic; dynamic response; pressure step; pressure transducer; protective coatings; shock tube; tape; thermal protection; thermal radiant-energy response; thermal transient response; transducer; zero shift; TN961.

Coatings; films; gas discharges; sputtering; adhesion; SP487, pp. 311-323 (Aug. 1977).

Coaxial connectors; microwave connectors; RF connectors; scattering parameters; 16727.

Cobalt; critical phenomena; interaction range; neutron scattering; spin correlation function; absolute cross section measurement; 17112 .

Cobalt-chromium; corrosion; implant requirements; mechanical properties; metal implants; stainless steel; standards; titanium; biocompatibility; 16973.

Cobalt-60; radiation standard; absorbed dose; calibration; calorimeter; 17005.

COBOL; COBOL programming aids; Federal Standard COBOL; programming aids; programming languages; FIPS PUB 47.

COBOL; CODASYL; data base; data definition; data definition language; data structure applications; NBSIR 74-500.

COBOL programming aids; Federal Standard COBOL; programming aids; programming languages; COBOL; FIPS PUB 47.

CODASYL; data base; data definition; data definition language; data structure applications; COBOL; NBSIR 74-500.

Code; configuration; dose equivalent; energy; gamma rays; neutron; scattering; shield; transmission; ${ }^{252} \mathrm{Cf}$; ANISN; SP461, pp. 119-123 (Jan. 1977).

Code administration; communication; enabling legislation; physically handicapped; regulation; accessibility standards; building code; SP473, pp. 241-251 (June 1977).

Code administration; enforcement; funding; local government; model codes; state-local relations; statewide codes; uniformity; building regulation; SP473, pp. 225-240 (June 1977).

Code enforcement officials; communications; criteria; education programs; professional competence; building construction groups; certification; SP473, pp. 383-389 (June 1977).

Code uniformity; enforcement; legislation; rules and regulations; statewide codes; summary tables; building construction; building regulations; cities; NBSIR 77-1390.

Codeposition; gas phase reaction; $\mathrm{Ba}$ and $\mathrm{Mg}$ films; chemiluminescence; chemisorption; 17242.
Codes; criteria; project summaries; standards; technical bases; building research; building technology; SP446-1.

Codes; design; dynamic analysis; masonry; shear walls; BSS106, pp. $91-113$ (Sept. 1977).

Codes; disaster; dynamic analysis; earthquakes; ground failures; hydraulic structures; seismicity; soils; standards; structural response; vessels and wind; accelerograph; bridges; buildings; SP470.

Codes; disaster; dynamic analysis; earthquakes; ground failures; nuclear facilities; seismicity; soils; standards; structural response; winds; accele rograph; bridges; buildings; SP477.

Codes; energy conservation; regulatory community; standards; buildings; 17111

Codes; probability; statistics; structural design; wind; 16856.

Codes and standards; connectors; fasteners; low-rise buildings; masonry walls' structural design; technology transfer; timber roofs; timber walls; wind effects; BSSIOO-3.

Codes and standards; disaster mitigation; housing; low-rise buildings; socio-economics; structural connections; wind loads; SP477, pp. I-70-I-78 (May 1977).

Codes and standards; disaster mitigation; housing; low-rise buildings; socio-economics; structural connections; technology transfer; wind loads; BSS100-1.

Codes and standards; energy conserving buildings; energy legislation; energy performance criteria; energy performance standards; 17289 .

Codes and standards; environmental studies; fire safety; health dangers; research needs; SP473, pp. 35-53 (June 1977).

Codes and standards; housing; hurricanes; pressure coefficients; probability distribution functions; risk; statistical analysis; storms; structural engineering; tropical storms; wind loads; wind speeds; building codes; buildings; BSS100-2.

Coding; coding theory; computer storage; data compaction; data compression; data elements; data management; data processing; information management; information theory; SP500-12.

Coding; communication systems; fire alarm systems; health care facilities; hospital communication systems; hospital fires; hospital personnel; human behavior; nursing home fires; nursing staff; standards; voice communication; NBS-GCR-77. 102.

Coding theory; computer storage; data compaction; data compression; data elements; data management; data processing; information management; information theory; coding; SP5OO12.

Coefficient of variation; flame spread tests; flexible polyurethane; hardboard; interlaboratory evaluation; neoprene; radiant panel test; round robin; test method; ASTM E 162; NBSIR 77-1222.

Coefficients; computations, cross-section; Legendre polynomial; neutron; random sampling; scattering; shielding; angle; centre of mass; SP461, pp. 100-105 (Jan. 1977).

Coherence; correlation function; counting rate spectrum; nonstationary process; nonstationary spectrum; power spectrum; synthesized spectrum; time-dependent spectrum; 17169.

Coherence; electron excitation; hydrogen; 17326.

Coherence; fringes; interference; modulation; phase; Ramsey; saturation spectroscopy; transit-time; 17337.

Coherence; Kramers ions; nutation; spin echoes; spin locking; zero field magnetic resonance; 16954.

Coherent microwave emission; e/h voltage standard; Josephson junction; microstrip resonator; microwave coupling; parametric plasma oscillation; thin-film device; 16788 .

Coherent scattering; cross section; gamma rays; photons; Rayleigh scattering; analytical formula; SP461, pp. 17-19 (Jan. 1977).

Coherent scattering; cross sections; gamma ray; incoherent scattering; pair-production; photoionization; SP46I, pp. 2022 (Jan. 1977). 
"Coin" or "Coin Silver," marking of; jewelry, "Silver," marking of; novelties, "Silver," marking of; "Sterling Silver," "Silver," or "Solid Silver," marking of; PS71-76.

Coincidence; electron capture; excited state; gamma ray; ground state; inner bremsstrahlung; Jauch plot; spectrum transition; SP461, pp. 23-25 (Jan. 1977).

Coincidence; mass spectrometry; methane; photoionization; threshold photoelectron spectroscopy; time of flight mass spectromctry; acetone; 17148 .

Cold discomfort; energy conservation; humidity; tempcrature; thermal acceptability; clothing; SP491, pp. 131-151 (Sept. 1977).

Cold storage insulation; fibrous-glass insulation; vapor condensation; air, moisture and heat transfer theory; 17340 .

Collaborative testing; laboratory accreditation; laser technology; multielement analysis; pollutants; speciation; Standard Reference Materials; trace organics; water; accuracy; aerosol; air; SP464.

Collagen fibers; molecular motion; nmr; Overhauser effect; relaxation time; ${ }^{13} \mathrm{C} ; 17007$.

Collapse; concrete; concrete strength; construction; flexure; progressive collapse; shear; strength; apartment building; BSS94.

Collapse; concrete; panels; structural integrity; buildings; SP477, pp. VI-220-VI-25I (May 1977).

Collective states; electron scattering; inelastic; two-phonon states; zinc 64-66-68-70; anharmonic vibrator model; 16982

Collector resistivity; epitaxial resistivity; four-probe; resistivity; resistivity correction factors; semiconductor characterization; silicon; square array; 16942 .

Collector-emitter; saturation voltage; transistor measurement; transistor measurement repeatability; NBSIR 77-1231.

Collimator; exposure spectra; gamma-rays; scattered radiation; source housing; spectrometry; ${ }^{60} \mathrm{Co}$ gamma-ray source; NBSIR 76-1117.

Collinear reactions; deuterium, collinear reactions; hydrogen, collinear reactions; kinetic isotope effects; potential surfaces; rate constants; transition state theory; transmission coefficient; 16914

Collision; copper; distribution; dose; electron; Gaussian; Monte Carlo; scattering; aluminium; carbon; SP461, pp. 106-109 (Jan. 1977).

Collision; cross section; dissociation; electron; excitation; hydrogen; Balmer-alpha; 17054.

Collision; cylindrical; energy; integral; iterative; neutron; transmission matrix; criticality; SP461, pp. 94-96 (Jan. 1977).

Collision; electron; ionic charge; ionization potential; stopping power; stripped particle; velocity; charge; charged particle; SP461, pp. I44-148 (Jan. 1977).

Collision theory; time dependent; adiabatic perturbation approximation; 16955 .

Collision-induced; emission; interaction potential; iodine; perturbation theory; rate coefficient; 17069

Collisions; dissociation; hydrogen; inelastic; molecular potential; recombination; scattering; theoretical; theory; argon; 16802.

Collisions; near-resonant light scattering; redistribution; saturation strontium; 16857

Collisions of He with diatomic hydrides; heavy particle collisions; rotational excitation in atom-molecule scattering: atom-molecule scattering; 16674 .

Color; color designations; calorimetry; color names; color-order systems; Munsell Color System; Universal Color Language; variable accuracy of color designations; centroid colors; SP440.

Color; filters; high accuracy; spectrophotometer; standards; transmittance; tristimulus values; chromaticity coordinates; 17260 .

Color designations; calorimetry; color names; color-order systems; Munsell Color System; Universal Color Language; variable accuracy of color designations; centroid colors: color; $S P 440$.

Color matching; color measurement; diffuse reflectance; $\mathrm{Ku}$. belka-Munk function; reflectance; reflectance standards; thin layer chromatography; chromatography; SP466, pp. 41-55 (May 1977).

Color measurement; diffuse reflectance; Kubelka-Munk function; reflectance; reflectance standards; thin layer chromatog raphy; chromatography; color matching; SP466, pp. 41-55 (May 1977)

Color names; color-order systems; Munsell Color System; Universal Color Language; variable accuracy of color designations; centroid colors; color; color designations: calorimetry; $S P 440$.

Color-order systems; Munsell Color System; Universal Color Language; variable accuracy of color designations; centroid colors; color; color designations; calorimetry; color names: SP440

Column broadening, GPC; gel permeation chromatography; nonlinear regression; calibration; 16822

Columns; concrete; earthquake; hysteretic envelope; reinforced; strength; SP477, pp. VI-10-Vl-27 (May 1977).

Combination; disproportionation; low temperature; radical; al. Iylic; 16966.

Combination bands; nitrogen dioxide; rotational constants; vibrational constants; vibration-rotation constants; 17123 .

Combustion; $\mathrm{CO}_{2}$; methylene; rate constant; $\mathrm{CO} ; 16838$.

Combustion; $\mathrm{CO}_{2}$ lasers; nitric oxide; optical pumping of molecules; vibrational relaxation; 17193 .

Combustion; differential equations; flame chemistry; flame modeling; laminar flames; numerical solution of flame equations; NBSIR 76-994.

Combustion; emulsified fuel droplet; fuel droplet; heat flow; micro-explosion; preheat; J. Res. 82, No. 3, 183-195 (1977).

Combustion gases; energy; equation of state; high pressure; high temperature; interaction virial coefficients; mixtures; molecular volumes; second virial coefficients; water; ballistics; carbon dioxide; 17136 .

Combustion models; flame spread; fluid flow; laser doppler velocimetry; liquid fuels; solid fuels; surface tension; NBSGCR-76-79.

Combustion products; fire fatalities; smoke inhalation; toxicity; biological assessment; chemical analysis; NBSIR 77-1234.

Combustion products; fire hazards; fire modeling; fire research; human behavior in fires; NBSIR 77-1308.

Combustion research; design concepts; directories; fire prevention; fire research; hazard analysis; physics; building research; chemistry; NBSIR 77-1264.

Comfort; heat pump; load-calculation; rating; residential; space heating; testing; air conditioning; 17006.

Comfort; heat storage; work effects; clothing effects; SP491. pp. 52-64 (Sept. 1977).

Comfort; measurement; radiation; 16923.

Commerce; Defense; E.R.D.A.; Federal agencies; interagency review; Interior; Library of Congress; materials; materials data; materials information; N.A.S.A.; U.S.D.A; SP463.

Commodity supply crises; econometric analysis; economic impacts; efficiency impacts; income distribution effects; policy alternatives; applied microeconomic framework; NBS-GCRETIP 76-24.

Commodity supply crises; econometric analysis; economic impacts; efficiency impacts; income distribution effects; policy alternatives; applied microeconomic framework; NBS-GCR. ETIP 76-32,

Commodity supply crises; econometric analysis; economic impacts; efficiency impacts; income distribution effects; policy alternatives; applied microeconomic framework; NBS-GCR. ETIP 76-33. 
Commodity supply crises; econometric analysis; economic impacts; efficiency impacts; income distribution effects; policy alternatives; applicd microcconomic framework; NBS-GCRE7IP 77-36.

Commodity supply policies; contingency planning; energy (petroleum); manganese; bauxite; chromite; NBS-GCR-ETIP 77-38.

Communication; enabling legislation; physically handicapped; rcgulation; accessibility standards; building code; code administration; SP473, pp. 241-251 (June 1977).

Communication; frequency; history; mathematics; navigation; physics; time; time broadcasts; time scales; astronomy; automation; clocks; Monogr. 155.

Communication; information; interdisciplinary technology; physical property data; publish; science; standard reference data; technology; 17258

Conmunication among scientists; coordination of research organizations; employee communication; information needs; information processing; information seeking; internal media; NBSIR 77-1257.

Communication of research and standards; National Bureau of Standards; solar energy standards; standards users; 16733 .

Communication systems; fire alarm systems; health care facilities; hospital communication systems; hospital fires; hospital personnel; human behavior; nursing home fires; nursing staff; standards; voice communication; coding; NBS-GCR-77-102.

Communications; criteria; education programs; professional competence; building construction groups; certification; code enforcement officials; SP473, pp. 383-389 (June 1977).

Communications; data communications equipment; data processing terminal equipment; data transmission; Federal Information Processing Standards; serial-by-bit; serial-bycharacter; telecommunications; teleprocessing; FIPS PUB I6l.

Communications; data transmission; Federal Information Processing Standards; serial-by-bit; telecommunications; teleprocessing; American Standard Code for Information Interchange; ASCII; character parity sense; character structure; FIPS PUB 17-1.

Communications; data transmission; Federal Information Processing Standards; parallel-by-bit; parity sense; serial-bycharacter; telecommunications; teleprocessing; American Standard Code for Information Interchange; ASCII; character structure; FIPS PUB 18-1.

Communications; digital communications; guideline; law enforcement equipment report; Law Enforcement Standards Laboratory; mobile digital equipment; National Institute of Law Enforcement and Criminal Justice; 16996.

Communications; disaster communication; emergency communications; fire communications; high-rise communications; high-rise emergency; information transfer; occupant needs; sensory stimuli; 17036 .

Communications; mobile radio; police; police equipment; portable radio; standards; $S P 480-2$.

Communications equipment priorities; equipment standards; Law Enforcement Standards Laboratory; police equipment; reports and guidelines; survey; $S P 480-13$.

Communications networks; computer networks; data communications; interconnection; networks; packet switching; standards; 16934.

Communications networks; computer networks; data communications; interconnection; networks; packet switching; standards; SP500-6.

Communications security; computer controls; computer security; data integrity; interactive audit; internal audit; postprocessing audit; program integrity; audit standards; audit techniques; audit tools; audit training; SP500-19.

Communications security; computer security; cryptography; encryption standard; interface requirements; Monte-Carlo testing; testbed; test cases; validating correctness; SP500-20.
Communications standards; data communications interfaces; data communications standards; ' interface standards; protocols; 16936.

Community development; construction costs; contractors; housing; rehabilitation; standards; building codes; SP473, pp. 491497 (June 1977).

Community noise; environmcntal impact; noise; noise exposure measurement system; sound; acoustics; NBSIR 76-1169.

Comparative evaluation; cross sections; fission spectra; integrals; neutrons; radioactivation; resonance integrals; spectral functions; SP493, pp. 128-136 (Oct. 1977)

Comparison; difference; mass; records; set; surveillance limits; surveillance test; test interval; true mass; value; weighing design; weights; apparent mass; buoyancy; buoyancy correction; change; NBSIR 76-999.

Compartment fire; corridor sprinkler systems; droplet size; droplet trajectory; evaporative cooling; fire suppression; fullscale test; gas temperature; oxygen content; recirculating flow; reduced scale model test; scaling criteria; spray water flow rate; water spray; NBSIR 77-1287.

Compartment fires; corridor fires; fire code; fire science; fire spread model; buoyant flow; NBS-GCR-77-84.

Compartment fires; fire plumes; heat transfer; room fires; scale models; buoyant plumes; ceilings; NBS-GCR-77-97.

Compartment fires; fire-retardants; insulation; mattresses; shipboard; thermal conductivity; NBSIR 77-1295.

Compartment fires; firesafety engineering; fire tests; health care facilities; hospitals; mattresses; prisons; bedding; beds; NBSIR 77-1290.

Compatible; generalized matrix norm; Hadamard product; multiplicative; spectral radius; vector norm; 16676.

Compatible; generalized matrix norm; multiplicative; spectral radius; unit ball; vector norm; 16836 .

Compilation; critical evaluation; Knight shifts; magnetic moments; metals; nuclear quadrupole effects; nuclear relaxation; 17093.

Compilation; cross-section; elastic; lithium; measurements; neutron; total; alpha; boron; branching ratio; SP493, pp. 67 84 (Oct. 1977).

Complete elliptic integrals; inverse Laplace transforms; J. Res. 81 B Nos. 1 and 2, 5-39 (1977).

Component efficiency; cryogenics; efficiency; energy recovery; hydrogen; liquefier; NBSIR 77-862.

Composite; compressibility; copper; elastic constants; niobiumtitanium; Poisson's ratio; pulse method; resonance method; shear modulus; sound velocity; Young's modulus; bulk modulus; 17068.

Composite; compressibility; elastic constants; resonance method; shear modulus; torsional modulus; Young's modulus; aluminum; boron-aluminum; bulk modulus; 17087 .

Composite; copper; low temperature; niobium-titanium alloys; superconducting wire; tensile properties; 16862 .

Composite; cryogenics; electrical property; insulation; materials; mechanical property; metal; review; thermal property; alloy; 17072 .

Composite building constructions; convection; experimental data; fire endurance; heat generation or absorption; numerical solutions; one-dimensional; radiation; thermal conduction; transient heat transfer; NBSIR 77-1260.

Composite laminates; failure; strain concentration; stress concentration; anisotropy; SP487, pp. $121-134$ (Aug. 1977).

Composite material; fabrication techniques; graphite fibers-aluminum; mechanical behavior; pultrusion/drawing; wire preform; SP487, pp. 93-107 (Aug. 1977).

Composite materials; design; failure avoidance; failure prevention; lubricants; materials of design; product liability; reliability of design; techniques of design; validation of design; coating materials; $S P 487$. 
Composite materials; end fittings for FRP rod; environmental resistance of FRP rods; fiber-reinforced plastic (FRP); glass; guys, antenna; pultrusion; reinforced plastics; stress rupture of FRP rod; test methods; weatherability of FRP rods; aramid; 16685 .

Composite materials; jet engines; blade flutter control; SP487, pp. 108-120 (Aug. 1977).

Composites; computerized information system; foams; plastics information; Plastics Technical Evaluation Center; specifications; technical reports; testing methods; tooling; adhesives; SP463, pp. IV.3.1-IV.3.2 (Jan. 1977).

Compositional analysis; instrumental methods; metallic artifacts; microstructural analysis; nondestructive evaluation techniques; 16712.

Compound crystal resonator; crystallographic axis; nonlinear elastic effect; resonance frequency; acceleration field; acceleration sensitivity; NBSIR 77-855.

Compounds; hardness; interstitial; metals; refractory; alloys; 17262

Compressed fluid ethane; ethane, fluid; fluid ethane; sound; speed of sound; 17067

Compressibility; copper; elastic constants; niobium-titanium; Poisson's ratio; pulse method; resonance method; shear modulus; sound velocity; Young's modulus; bulk modulus; composite; 17068 .

Compressibility; copper alloy; elastic constant; Poisson ratio; precipitation hardening; shear modulus; sound velocity; Young's modulus; bulk modulus; 17094.

Compressibility; copper alloy; Debye temperature; elastic constants; Poisson's ratio; shear modulus; sound velocity; Young's modulus; bulk modulus; 17320 .

Compressibility; Debye temperature; elastic constant; invar; iron alloy; nickel alloy; Poisson's ratio; shear modulus; sound velocity; Young's modulus; bulk modulus; 16869 .

Compressibility; Debye temperature; Poisson's ratio; precipitation-hardening alloys; shear modulus; sound velocity; Young's modulus; aluminum alloys; bulk modulus; 17085 .

Compressibility; Debye temperature; elastic constants; Poisson's ratio; shear modulus; single-crystal elastic coefficients; sound velocities; Young's modulus; zinc; bulk modulus; JPCRD 6, No. 4, 1181-1204 (1977).

Compressibility; densification; glass; glass transition; hole theory; liquid; polymer; pressure; thermodynamic; 16774 .

Compressibility; densification; glass; glass transition; liquid; polymer; pressure; PVT; pyrolysis; refractive index; thermal expansion; thermodynamic; J. Res. 81 A Nos. 2 and 3, 283297 ( 1977).

Compressibility; elastic constants; resonance method; shear modulus; torsional modulus; Young's modulus; aluminum; boron-aluminum; bulk modulus; composite; 17087.

Compressibility; elastic constants; Poisson's ratio; pulse method; resonance method; shear modulus; sound velocity; stainless steel; Young's modulus; bulk modulus; 17321 .

Compressibility; equation of state; heavy water; isotopic waters; partial molar volume of aqueous gases; PVT; thermal expansivity; water; aqueous solutions of gases; JPCRD 6, No. 4, $1109-1132$ ( 1977 ).

Compressible cooking surfaces; hot plates; thermal safety covering; warming trays; U.S. Patent 4,009,704.

Compression; hearing aids; attack and release times; automatic gain control; 17145 .

Compression; hearing aids; attack and release characteristics; NBSIR 76-1179.

Compressive strength; deflection; design; flexural strength; masonry walls; racking strength; seismic loading; shear strength; shear wall; stiffness; analysis; BSS62.

Compressors; cryogenic refrigeration; efficiency; expanders; heat exchangers; particle accelerators; power transmission; reliability; 17083.
Compton scattering; differential cross section; electron binding; gamma rays; K-shell; photons; SP461, pp. $67-69$ (Jan. 1977).

Computation; duct; gamima ray; integration; kernel; radiation; streaming; annular; SP461, pp. 132-135 (Jan. 1977).

Computations, cross-section; Legendre polynomial; neutron; random sampling; scattering; shielding; angle; centre of mass; coefficients; SP461, pp. 100-105 (Jan. 1977).

Computed thermodynamic properties; entropy; equation of state; excitation spectrum; helium-4; normal fluid helium-4; phonons; protons; specific heat; superfluid helium-4; JPCRD 6, No. 1, 51-104 (1977).

Computer; computer program; copyright; data base; economic efficiency; information technology; policy analysis; policymaking; public goods; technological change; transaction costs; SP500-17.

Computer; control; goal-oriented; hierarchical control; robot; sensors; adaptive; automation; SP500-23.

Computer; energy; environmental; measurement; product safety; research; science; standards; technology; annual report; SP467.

Computer; energy; radiation; solar; BSS96.

Computer aided design; design; graphics; cathode ray tubes; SP487, pp. 82-90 (Aug. 1977).

Computer aided manufacturing; computer systems; standards; system integration; voluntary standards; CAM architectures; NBSIR 76-1094.

Computer applications; criteria maintenance design evaluation; design guides; architectural criteria; automated system; building codes; builidings; SP473, pp. 349-368 (June 1977).

Computer assisted auditing; computer auditing; audit packages; audit routines; audit software; auditing; auditing standards; SP500-13.

Computer assisted check-out systems; consumer affairs; cordage products; drained weight; laws and regulations; metrication; national laboratory accreditation; retail meat identity standards; tolerance application; vapor recovery; weights and measures; SP471.

Computer auditing; audit packages; audit routines; audit software; auditing; auditing standards; computer assisted auditing; SP5O0-13.

Computer calculations; computer modeling; experimental methods; smoke control methods; smoke movement; smoke simulation; state-of-the-art review; basic principles; NBSIR 77-1209.

Computer code; data library; information; radiation; radiation analysis; RSIC; shielding; SP461, pp. 171-173 (Jan. 1977).

Computer code; dose; dosimetry; monitor; neutron; shielding; spectrum; SP461, pp. 238-246 (Jan. 1977).

Computer code; energy-angle; integral; legendre polynomial; scattering; semi analytical; spatial; transmission; anisotropy; charged particle; SP461, pp. 140-143 (Jan. 1977).

Computer codes; materials properties; nuclear data; radiation transport; reactor; RSIC; shielding; weapons; SP463, pp. III.1.1-III.1.10 (Jan. 1977).

Computer control; laboratory automation; teleprocessor; 16961 .

Computer controls; computer security; data integrity; interactive audit; internal audit; post-processing audit; program integrity; audit standards; audit techniques; audit tools; audit training; communications security; SP500-19.

Computer engineering; computer networks; computers; data processing; robots; software engineering; 16903.

Computer information. system; international aerospace abstracts; materials; mechanical properties; metallic materials; nonmetallic materials; physical properties; RECON; scientific and technical aerospace reports; thesaurus; SP463, pp. VI.I.1-VI.1.7 (Jan. 1977).

Computer interfaces; digital interfaces; Harris computer; branch driver; CAMAC; CAMAC standards; 16806 
Computer interfacing; instrumentation; interfacing; standards; CAMAC; 16677.

Computer interfacing; instrumentation, standards; interfacing; CAMAC; 17270 .

Computer management; computer programming; computer project control; computer software; software engineering; software quality; software reliability; SPSOO-II.

Computer memories; computer performance; inventor; molecular identity; preserving stone; pressure measurements; rfpower meter; roofing; safety; security alarms; SRM's; time and frequency; ultraviolet; DIM/NBS 61, No. 8, 1-32 (1977).

Computer model; decision table; decision theory; networks; specifications; standards; system engineering; building codes; SP473, pp. 285-316 (June 1977).

Computer modeling; experimental methods; smoke control methods; smoke movement; smoke simulation; state-of-theart review; basic principles; computer calculations; NBSIR 77-1209.

Computer modeling systems; data; networks; 17025 .

Computer network measurement; data acquisition; interactive computer access; measurement; network measurement services; service; teleprocessing systems measurement; 17252 .

Computer networking; computer security; controlled access; identification; passwords; personal authentication; SP500-9.

Computer networks; computers; data processing; robots; software engineering; computer engineering; 16903.

Computer networks; controlled accessibility; encryption; evaluation criteria; key; password; personal identification; terminals; verification; ADP security; FIPS PUB 48.

Computer networks; data communications; interconnection; networks; packet switching; standards; communications networks; 16934.

Computer networks; data communications; interconnection; networks; packet switching; standards; communications networks; SP500-6.

Computer networks; resource sharing; response time prediction; 16948.

Computer performance; computer resource unit; probability density function; statistics; turnaround; workload; accounting data; SP500-18, pp. 39-67 (Sept. 1977).

Computer performance; computer software and programs; computer systems; real-time control systems; 16904.

Computer performance; inventor; molecular identity; preserving stone; pressure measurements; rf-power meter; roofing; safety; security alarms; SRM's; time and frequency; ultraviolet; computer memories; $D / M / N B S 61$, No. $8,1-32$ (1977).

Computer performance; model simulation, computer; benchmark; 17020.

Computer performance evaluation; computer performance measurement; computer performance prediction; computer system acquisition; conference proceedings; CPEUG; hardware monitoring; on-line system evaluation; prediction methods; queuing models; simulation; SP500-18.

Computer performance evaluation; computer performance management; Federal Information Processing Standards; performance measures; FIPS PUB 49.

Computer performance management; Federal Information Processing Standards; performance measures; computer performance evaluation; FIPS PUB 49.

Computer performance measurement; computer performance prediction; computer system acquisition; conference proceedings; CPEUG; hardware monitoring; on-line system evaluation; prediction methods; queuing models; simulation; software monitoring; workload definition; SP500-18.

Computer performance prediction; computer system acquisition; conference proceedings; CPEUG; hardware monitoring; on-line system evaluation; prediction methods; queuing models; simulation; software monitoring; workload definition; ADP life cycle; SPSO0-18.
Computer predictions; critical evaluations; data compilations; industrial needs; phase diagrams; theory of phase diagrams; thermodynamics; NBSIR 77-1239.

Computer procurement; computer selection; workload characterization; benchmarking; SP500-18, pp. 13-21 (Sept. 1977).

Computer program; copyright; data base; economic efficiency; information technology; policy analysis; policymaking; public goods; technological change; transaction costs; computer; SP500-17.

Computer program index; Federal Software Exchange Program; proprietary software; public domain software; software exchange; software guide; software index; software sharing; SP500-22.

Computer programming; computer project control; computer software; software engineering; software quality; software reliability; computer management; SP5OO-II.

Computer programming; cost analysis; software engineering; software reliability; software testing; symbolic evaluation; symbolic testing; NBS-GCR-77-89.

Computer programming; decision tables; graph theory; performance specifications; standards; building codes; 16705 .

Computer programming; decision tables; graph theory; performance specifications; standards; building codes; TN94O.

Computer programs; cooling; energy analysis; financial analysis; heating; load calculation; MIUS; modular integrated utility system; simulation; utility services; NBSIR 77-1307.

Computer programs; data reduction; eigenvalue equations; electromagnetic theory; group theory; near-field scanning; symmetry analysis; 17222 .

Computer programs; documentation; documentation content guidelines; FIPS guidelines; software, symposium proceedings; automated data systems; SP500-15.

Computer programs; elastohydrodynamics; failure analysis; film thickness; gears; Hertz contacts; lubrication; rheology; starvation; traction; bearings; SP487, pp. 137-153 (Aug. 1977).

Computer programs; enthalpy; entropy; hydrogen; internal energy; liquid; oxygen; PVT; quality; slush; solid; vapor; NBSIR 77-859.

Computer programs; near-field scanning; spherical scanning; antenna patterns; 17223 .

Computer project control; computer software; software engineering; software quality; software reliability; computer management; computer programming; SP500-11.

Computer resource unit; probability density function; statistics; turnaround; workload; accounting data; computer performance; SP500-18, pp. 39-67 (Sept. 1977).

Computer response time; human factors; on-line systems; system design; task variables; workload characteristics; SP500-18, pp. 3-11 (Sept. 1977).

Computer science research; computers in the Federal Government; scientific and technological advisory services; ADP standards; Brooks Act; NBSIR 76-1113.

Computer security; computer system performance; computer systems; individual privacy; risk management; safety of computer systems; 17114 .

Computer security; controlled access; passwords; personal authentication; 17281 .

Computer security; controlled access; passwords; personal authentication; 17307.

Computer security; controlled access; identification; passwords; personal authentication; computer networking; SPS00-9.

Computer security; cryogenic temperature; dentistry; dielectric measurements; dye lasers; dynamic calibration; electron microscopy; electronic technology; energy conservation; interferometric wavemeter; metric; pressure transducers; DIM/NBS 61, No. 2, 1-32 (1977).

Computer security; cryptography; encryption standard; interface requirements; Monte-Carlo testing; testbed; test cases; validating correctness; communications security; SP5OO-20. 
Computer security; data confidentiality; data integrity; data security; physical security; procedural security; risk analysis; risk assessment; systems security; ADP availability; annual loss expectancy; application system vulnerability; NBSIR 77. 1228.

Computer security; data integrity; interactive audit; intemal audit; post-processing audit; program integrity; audit standards; audit techniques; audit tools; audit training; communications security; computer controls; SP500-19.

Computer security; encryption; Federal Information Processing Standard; ADP security; FIPS PUB 46.

Computer security; extended-type objects; operating system structures; protection; reliable software; reliability; security; small protection domains; types; capability; capability-based addressing; 16920.

Computer selection; Federal Information Processing Standard; workload representation; benchmarking; benchmark mix demonstration; FIPS PUB 42-1.

Computer selection; workload characterization; benchmarking; computer procurement; SP500-18, pp. 13-21 (Sept. 1977).

Computer service; external measurement; figure-of-merit; interactive system; measurement model; measurement, performance; measures; methodology; network measurement system; 17288 .

Computer simulation; cool down; energy savings; flue damper; heat transfer; implicit; insulation; laboratory measurements; modeling; standby loss; water heater; alternating direction; 17184.

Computer simulation; elevator shaft pressure profiles; parametric analysis; simulated smoke concentration; smoke control; smoke movement; smoke simulation; systematic pressurization; air-handling units; building pressure profile; NBSIR 77 1225.

Computer simulation; energy conservation; furnace; operating cost; seasonal performance; building heating system; 16922 .

Computer simulation; energy transport; equation of state; interatomic potential; molecular dynamics; second sound; shock wave; stress relaxation; structural relaxation; thermal relaxation; anharmonic crystal; 16751 .

Computer software; data base management system; data element dictionary/directory; data management; software tool; 16998.

Computer software; data base management system; data element dictionary/directory; information management; software tool; 17280 .

Computer software; data base management systems; data element dictionary; data element dictionary/directory; software tool; SP500-3.

Computer software; data element dictionary; data element dictionary/directory; data management; software tool; ADP; automated data processing; SP500-16.

Computer software; software engineering; software quality; software reliability; computer management; computer programming; computer project control; SP500-11.

Computer software and programs; computer systems; real-time control systems; computer performance; 16904.

Computer storage; data compaction; data compression; data elements; data management; data processing; information management; information theory; coding; coding theory; SP500-12.

Computer system acquisition; conference proceedings; CPEUG; hardware monitoring; on-line system evaluation; prediction methods; queuing models; simulation; software monitoring; workload definition; ADP life cycle; computer performance evaluation; SP5O0-18.

Computer system monitoring; data gathering; boolean random sampling; SP500-18, pp. 159-182 (Sept. 1977).

Computer system performance; computer systems; individual privacy; risk management; safety of computer systems; computer security; 17114 .
Computer systems; individual privacy; risk management; safety of computer systems; computer security; computer system performance; 17114 .

Computer systems; real-time control systems; computer performance; computer software and programs; 16904 .

Computer systems; standards; system integration; voluntary standards; CAM architectures; computer aided manufacturing; NBSIR 76-1094.

Computer technology; information processing; performance evaluation; plan review; research and development; building regulation; computer-based systems; SP473, pp. 369-375 (June 1977).

Computer use; conservation; data; earth's measurement; energy; health .records; hydrogen; law enforcement; liquefied natural gas; metric tons; polyethylene; sound; spinach; SRM; systems and software; telecommunications; DIM/NBS 6l, No. 5, 1-32 (1977).

Computer utilization; data base functions; data base management systems; Privacy Act of 1974; privacy compliance techniques; SPSO0-10.

Computer-based systems; computer technology; information processing; performance evaluation; plan review; research and development; building regulation; SP473, pp. 369-375 (June 1977).

Computer-communication networks; configuration analysis; model validation; performance management; performance prediction; queuing networks; sizing studies; system design; SP500-18, pp. 227-234 (Sept. 1977).

Computer-controlled instrumentation; reverberation room; reverberation room qualification; sound power; acoustical measurements; acoustics; acoustics facility; automated sound measurement; 16763.

Computerized data; data elements; equity; federal technology; fire modeling; heat; hydrocarbon; ionized molybdenum; measurement assurance; metric; neutron diffraction; recycling oil; research and innovation; safety; ultrasonic tissue; DIM/NBS 61 , No. 6, 1-32 (1977)

Computerized energy analysis; energy conservation standards; new building design; retrofit design; 16770 .

Computerized energy analysis; energy consumption; heating and cooling loads; building energy analysis; NBSIR 76-1177.

Computerized experiment; experiment automation; off-the-shelf automation; polymer degradation; rapid response furnace; thermogravimetry; 16842 .

Computerized information system; foams; plastics information; Plastics Technical Evaluation Center; specifications; technical reports; testing methods; tooling; adhesives; composites; SP463, pp. IV.3.1 -IV.3.2 (Jan. 1977).

Computerized information system; data bank; electrical properties; electronic properties; magnetic properties; optical properties; Retrieval Guide; technical reports; SP463, pp. IV.4.1 IV.4.3 (Jan. 1977).

Computerized information system; concrete; concrete technology; construction material; construction methods; portland cement; state-of-the-art summaries; technical reports; test methods; analytical procedure; bibliographies; SP463, pp. IV.7.1-IV.7.7 (Jan. 1977).

Computerized information system; document dissemination; governmént reports; NTIS; patent licensing; technical reports; SP463, pp. VII.3.1-VII.3.5 (Jan. 1977).

Computerized information system; engineering standards; mandatory standards; national standards; plastics 'standards; standards; standards information service; voluntary standards; American National Standards Institute; SP463, pp. VII.5.1VII.5.9 (Jan. 1977).

Computerized information system; directories; information resource; National Referral Center; referral; scientific and technical information; thesaurus; SP463, pp. VIII.2.1-VIII.2.4 (Jan. 1977). 
Computerized thermal simulation; $\mathrm{CO}_{2}$ concentration; energy conservation in schools; energy consumption; energy utilization in schools; oxygen content; reduced ventilation rate; school operation schedule; ventilation test; BSS97.

Computerized tomography; imaging; ultrasound; velocity; attenuation; 16937.

Computers; consumer sounding boards; data; electron probe microanalysis; laser ionization; metrication; noise; nondestructive evaluation; research associate program; standards; Alaska pipeline; calibration; CMAC; DIM/NBS 61 , No. 1 , 1-32 (1977).

Computers; data elements and codes; data processing; Federal Information Processing Standards; geography; information processing standards; information system; representations and codes; standards; statistical data; ADP standards; FIPS PUB 10-2.

Computers; data processing; definitions; dictionary for information processing; Federal Information Processing Standards Publication; information processing; terms; vocabulary; FIPS PUB $11-1$.

Computers; data processing; robots; software engineering; computer engineering; computer networks; 16903.

Computers; enforcement; information retrieval; inspection; management control; microfilm; building code; building permits; SP473, pp. $377-382$ (June 1977).

Computers; government information collection; information policy; information processing; risk management; 16906.

Computers, confidentiality; data systems; health records; information policy, management principles; medical records; privacy; recordkeeping practices; security; citizen rights; SP469.

Computers in the Federal Government; scientific and technological advisory services; ADP standards; Brooks Act; computer science research; NBSIR 76-11/13.

Concentrated loads; design criteria; mode of failure; racking resistance; structural performance; uniform loads; SP477, pp. I-66-I-69 (May 1977).

Concentration dependent diffusion coefficient; concentration front; discontinuous swelling; unconventional diffusion; velocity of concentration front propagation; J. Res. 81 A Nos. 2 and 3, 243-250 (1977).

Concentration front; discontinuous swelling; unconventional diffusion; velocity of concentration front propagation; concentration dependent diffusion coefficient; J. Res. 81A Nos. 2 and 3, 243-250 (1977).

Concrete; concrete strength; construction; flexure; progressive collapse; shear; strength; apartment building; collapse; BSS94.

Concrete; concrete technology; construction material; construction methods; portland cement; state-of-the-art summaries; technical reports; test methods; analytical procedure; bibliographies; computerized information system; SP463, pp. IV.7.I-IV.7.7 (Jan. 1977).

Concrete; cyclotron; design; earth shield; neutron spectra; shielding; shield thickness; calculation; SP461, pp. 166-170 (Jan. 1977).

Concrete; earthquake; hysteretic envelope; reinforced; strength; columns; SP477, pp. VI-10-VI-27 (May 1977).

Concrete; panels; structural integrity; buildings; collapse; SP477, pp. VI-220-VI-251 (May 1977).

Concrete block; concrete masonry; failure modes; load capacity; masonry walls; shear walls; splitting strength; ultimate capacity; brick; clay masonry; BSS106, pp. $177-197$ (Sept. 1977).

Concrete blocks; design standards; earthquake resistant structures; masonry; bricks; buildings; Canada; BSSI06, pp. 198213 (Sept. 1977).

Concrete masonry; failure modes; load capacity; masonry walls; shear walls; splitting strength; ultimate capacity; brick; clay masonry; concrete block; BSS106, pp. 177-197 (Sept. 1977).
Concrete strength; construction; flexure; progressive collapse; shear; strength; apartment building; collapse; concrete; BSS94.

Concrete technology; construction material; construction methods; portland cement; state-of-the-art summaries; technical reports; test methods; analytical procedure; bibliographies; computerized information system; concrete; SP463, pp. IV.7.1-IV.7.7 (Jan. 1977).

Concrete testing; evaluation; innovations; in-place testing; performance approach; regulatory domination; standards development; building codes; SP473, pp. 279-284 (June 1977).

Condensation in buildings; energy conservation; energy measurements; fuel savings; heat-loss reduction; insulation properties; residential heat loss; retrofitting houses; thermal conductivity; thermal insulation; thermography; air infiltration; NBSIR 77-1274.

Condensation in walls; insulating properties; thermal conductivity; thermal insulation; 17284 .

Condenser; electret; humidity; microphones; reciprocity; sensitivity; temperature; calibration; ceramic; 16701 .

Condenser; electret; humidity; microphones; reciprocity; sensitivity; temperature; calibration; ceramic; 17245.

Conductivity probe; density; density gradient; experimental; internal wave; laboratory; oscillating probe; SP484, Pp. 783802 (Oct. 1977).

Conference proceedings; CPEUG; hardware monitoring; on-line system evaluation; prediction methods; queuing models; simulation; software monitoring; workload definition; ADP life cycle; computer performance evaluation; computer performance measurement; SPS00-18.

Configuration; dose equivalent; energy; gamma rays; neutron; scattering; shield; transmission; ${ }^{252} \mathrm{Cf}$; ANISN; code; SP461, pp. 119-123 (Jan. 1977).

Configuration analysis; model validation; performance management; performance prediction; queuing networks; sizing studies; system design; computer-communication networks; SPS00-18, pp. 227-234 (Sept. 1977).

Configuration interaction; cross sections; ionization cross sections; lithium; photoexcitation cross sections; StieltjesTchebycheff technique; 17319 .

Configuration interaction; exchange interaction; inner shells; photoabsorption; atoms, correlation; 16670.

Configuration interaction; $J$-file sum rule; neon; transition probabilities; wall-stabilized arc; atomic spectra; 17276

Configuration on surface; kinetics of adsorption from solution; rate law and areal regression of adsorbate; surface area and fixation of chelating rings; adhesive bonding to bone mineral; chemisorption of a dental varnish; 17033 .

Confiscated weapons; police; standards; ballistic protective equipment; body armor; SP480-6.

Confluent hypergeometric functions; droplet; moving boundary problem; preheat; transient heat conduction; J. Res. 81A Nos. 2 and 3, 257-266 (1977).

Conformation; deuterated polystyrene-poly(methylmethacrylate); diblock copolymer; radius of gyration; small angle neutron scattering; 16817.

Connection formula; diffraction theory; error analysis; Liouville-Green approximation; ordinary differential equation; turning point; asymptotic analysis; Bessel functions; boundary-value problem; 16805.

Connection formulas; eigenvalue problems; Liouville-Green approximation; potential barrier; potential well; turning points; Whittaker functions; WKBJ approximation; 17142 .

Connections; houses; masonry; piers; research; seismic; shear walls; spandrel beams; BSS106, pp. 60-90 (Sept. 1977).

Connectors; design criteria; fasteners; wind; architecture; buildings; NBSIR 77-1197. 
Connectors; fasteners; low-rise buildings; masonry walls' structural design; technology transfer; timber roofs; timber walls; wind effects; codes and standards; BSSIOO-3.

Conservation; data; earth's measurement; energy; health records; hydrogen; law enforcement; liquefied natural gas; metric tons; polyethylene; sound; spinach; SRM; systems and software; telecommunications; computer use; DIM/NBS 61 , No. 5, 1-32 (1977).

Conservation of metal artifacts; corrosion, inhibiting of; corrosion, treatment methods; metal artifacts, restoration of; patina, artificially produced; patina, natural; archaeological finds, preservation of; SP479.

Constitution diagram; niobium alloys; osmium alloys; phase diagram; atomic ordering; 16738.

Constitution diagram; niobium alloys; phase diagram; superconductivity; ternary alloys; A15 phase; 16832.

Constitution diagram; phase diagram; phase transformations; rhodium alloys; vanadium alloys; atomic ordering; 16834.

Constrained extrema of quadratic forms; numerical range; $J$. Res. $81 \mathrm{~B}$ Nos. 1 and 2, $41-44$ (1977).

Constraint; electromagnetism; Hamilton; Maxwell; momentum; Poynting; variational; anholonomic; J. Res. 81B Nos. 1 and 2, $1-3$ (1977).

Constraints; costs; incentives; regulation; alternatives; building codes; building process; SP473, pp. 17-33 (June 1977).

Construction; consumers; cost analysis; cost benefits; housing; regulation; builder-developer; SP473, pp. $391-396$ (June 1977).

Construction; dams; earthquake; earth structures; roads; survey; SP477, pp. VI-44-VI-49 (May 1977).

Construction; dwellings; earthquakes; seismic design criteria; building codes; buildings; SP470, pp. VI-74-VI-88 (Apr. 1977).

Construction; flexure; progressive collapse; shear; strength; apartment building; collapse; concrete; concrete strength; BSS94.

Construction; health facilities; hospitals; medical facilities; medical planning; architecture; building technology; NBSIR 77-1233.

Construction; performance; preservation; rehabilitation; renovation; adaptive reuse; architecture; building codes; building regulations; building safety; SP473, pp. 437-452 (June 1977).

Construction costs; contractors; housing; rehabilitation; standards; building codes; community development; SP473, pp. 491-497 (June 1977).

Construction industry; dimensional coordination; metrication; metric system; modular coordination; SI; building codes and standards; $S P 458$.

Construction industry metrication; metrication benefits; rationalization; technical issues in metrication; 17040 .

Construction management; design/build; life-cycle costing; project procurement; building performance; building process; building systems; $S P 476$.

Construction material; construction methods; portland cement; state-of-the-art summaries; technical reports; test methods; analytical procedure; bibliographies; computerized information system; concrete; concrete technology; SP463, pp. IV.7.1-IV.7.7 (Jan. 1977).

Construction materials; fire departments; fire detection systems; fire tests; flame research; flammability tests; interior furnishings; mobile homes; polyurethanes; smoke detectors; standards; textiles; toxicity; arson; bibliographies; building fires; carpets; NBSIR 77-1277.

Construction materials; industrial wastes; mining wastes; municipal waste; slags; waste materials; coal by-products; NBSIR 77-1244.

Construction methods; portland cement; state-of-the-art summaries; technical reports; test methods; analytical procedure; bibliographies; computerized information system; concrete; concrete technology; construction material; SP463, pp. IV.7.I-IV.7.7 (Jan. 1977).

Consumer affairs; cordage products; drained weight; laws and regulations; metrication; national laboratory accreditation; retail meat identity standards; tolerance application; vapor recovery; weights and measures; checking prepackaged commodities; SP471.

Consumer behavior; consumer product safety; human factors; misuse of products; systems analysis; use of products; 16890 .

Consumer product portability; ergonomics; human factors; lifting; manual materials handling; physiology; psychophysics; safety; warranty; anthropometry; biomechanics; carrying; NBSIR 76-1092.

Consumer product safety; human factors; misuse of products; systems analysis; use of products; consumer behavior; 16890 .

Consumer product studies; human behavior research; Human Factors Laboratory; range energy consumption; appliance research; behavioral laboratory; 17035 .

Consumer products; cost estimation; life cycle costing; life cycle performance; life testing, and performance testing; accelerated testing; NBSIR 77-1212.

Consumer products; cryogenic; crystalline materials; dosimeter calibrations; energy; energy related inventions; heterodyne receiver; international standards code; NCSL; NMR knight shifts; neutron beams; piezo-flex micropositioning; DIM/NBS 61 , No. 7, 1-32 (1977).

Consumer products; generic probes; human factors; lawn mowers; safety; standards; NBSIR 77-1294.

Consumer products; household products; industry standards; international recommendations; national standards; product standards; recommended - practices; specifications; test methods; certification programs; TN948.

Consumer products; human factors; lawn mowers; psychophysics; reaction time; safety; standards; anthropometric probes; 17200 .

Consumer sounding boards; data; electron probe microanalysis; laser ionization; metrication; noise; nondestructive evaluation; research associate program; standards; Alaska pipeline; calibration; CMAC; computers; DIM/NBS 61 , No. 1, 1-32 (1977).

Consumers; cost analysis; cost benefits; housing; regulation; builder-developer; construction; SP473, pp. 391-396 (June 1977).

Consumers; energy; energy savings; grain moisture; mass spectra; radiation sterilizing; screw thread standards; SHIVA laser; silicon; timekeeping; ultraviolet radiation; calibration; DIM/NBS 61, No. 9, 1-32 (1977).

Contact resistance; electrical connections; fire hazard; glowing electrical connections; arcing/sparking; branch circuit; BSS103.

Container; corrosion; explosion; extinguisher; fire; gas; injury; liquefied; petroleum; standards; NBSIR 77-1217.

Container tests; hazardous materials ladings; mechanical properties; performance criteria; plastic packaging; stresscracking; time-to-fail; 17256.

Contingency planning; energy (petroleum); manganese; bauxite; chromite; commodity supply policies; NBS-GCR-ETIP 77-38.

Continuous binding curve; dye binding; human albumin; membrane; reflection coefficient; ultrafiltration; 16959.

Continuum models; diffuse reflectance; radiative transfer; reflectance spectra; scattering coefficients; statistical models; absolute absorptivities; SP466, pp. 57-73 (May 1977).

Contractors; housing; rehabilitation; standards; building codes; community development; construction costs; SP473, PP. 491497 (June 1977).

Contrast; contrast transfer function; image quality; limiting resolution; relative spectral response; signal-to-noise ratio; square wave patterns; television cameras; SP480-25. 
Contrast; detection; illumination; incapacitation; psychological deterrence; recognition; security lighting; security systems; visibility level; visual processes; SP480-27.

Contrast conditions; diffraction topography; dynamical images; imperfect crystals; perfect crystals; $x$-ray dynamical diffraction; 16977.

Contrast rendition; hand calculator; illuminating engineering; light design; luminaire effectiveness; luminance factor; office lighting; sphere illumination; body shadow; NBSIR 77-1303.

Contrast transfer function; distortion; limiting resolution; shading; signal-to-noise ratio; spectral response; standards; television cameras; total response; 17233 .

Contrast transfer function; image quality; limiting resolution; relative spectral response; signal-to-noise ratio; square wave patterns; television cameras; contrast; SP480-25.

Control; goal-oriented; hierarchical control; robot; sensors; adaptive; automation; computer; SPSOO-23.

Control; instruments; knowledge; legislation; life safety; regulation; standards; building codes; building safety; SP473, pp. 259-278 (June 1977)

Control theory; linear algebra; matrix; minimum polynomials; $J$. Res. 82, No. 2, 129-1 32 (1977).

Controlled access; identification; passwords; personal authentication; computer networking; computer security; SP500-9.

Controlled access; passwords; personal authentication; computer security; 17281 .

Controlled access; passwords; personal authentication; computer security; 17307.

Controlled accessibility; encryption; evaluation criteria; key; password; personal identification; terminals; verification; ADP security; computer networks; FIPS PUB 48.

Convection; crystal growth; crystal perfection; microgravity; purification; space processing; NBSIR 77-1208.

Convection; crystal growth; microgravity; Skylab/ASTP; space processing; 17275.

Convection; experimental data; fire endurance; heat generation or absorption; numerical solutions; one-dimensional; radiation; thermal conduction; transient heat transfer; composite building constructions; NBSIR 77-1260.

Convective heat transfer; fabric flammability; fabrics; fire hazards; ignition time; pyrolysis; radiant heating; thermal radiation; thermoplastics; cellulosic materials; char; NBSGCR-77-99.

Convective velocity; cross-correlation; exit concentration; exit velocity; flow visualization; fluorescence; fluorescent dye; laser; laser dye-fluorescence technique; mean concentration; mean velocity; measuring volume; remote sensing; SP484, pp. 423-447 (Oct. 1977).

Convex hull; eigenvalue; field of values; positive semidefinite; semistable; 16819.

Convex hull; eigenvalue-eigenvector equation; root of unity; bound set; J. Res. 82, No. 2, 133-136 (1977).

Convex set; data analysis; estimation; geometry; hypercube; hyperplane; polytope; 17117 .

Cool down; energy savings; flue damper; heat transfer; implicit; insulation; laboratory measurements; modeling; standby loss; water heater; alternating direction; computer simulation; 17184.

Cooling; energy analysis; financial analysis; heating; load calculation; MIUS; modular integrated utility system; simulation; utility services; computer programs; NBSIR 77-1307.

Cooling; heating; laboratory accreditation; performance criteria; solar energy; standards; buildings; 16686.

Cooling; heating; performance criteria; solar collectors; solar energy; standards; buildings; SP473, pp. 103-112 (June 1977).

Cooling and heating coefficients of performance; effective seasonal heating COP; heat pumps; heat pumps and energy conservation; part-load performance; seasonal performance factor; BSS93.
Cooling lake; dye dilution method; error analysis; flow rate measurement; open channel flow measurement; power plant; spray canal; stage-discharge equation; velocity-area method; weir equation; closed-loop cooling system; SP484, pp. 145172 (Oct. 1977).

Coordinate transformations; data processing; group representations; measurements; near field; nonplanar; patterns; scanning; spherical; symmetry; antennas; arrays; 16671 .

Coordination; crystal structure; disorder; magnesium incorporation; phosphate; vacancies; beta-tricalcium phosphate; cation substitution; 17259.

Coordination; mercury; metal complexes; organometals; photolysis; reaction rates; thallium; tin; transmethylation; water; alkylation; aqueous solution; 17008 .

Coordination of research organizations; employee communication; information needs; information processing; information seeking; internal media; communication among scientists; NBSIR 77-1257.

Copper; cryogenic; fusion; magnets; superconductivity; thermonuclear; 17134 .

Copper; cryogenics; indium; joints; solder; thermal conductance; beryllium; 16797.

Copper; diffusion; electromigration; liquid metals; nitrogen; phosphorus; ternary diffusion; thermomigration; alloys; antimony; arsenic; bismuth; JPCRD 6, No. 1, 1-50 (1977).

Copper; distribution; dose; electron; Gaussian; Monte Carlo; scattering; aluminium; carbon; collision; SP461, pp. 106-109 (Jan. 1977).

Copper; elastic constants; niobium-titanium; Poisson's ratio; pulse method; resonance method; shear modulus; sound velocity; Young's modulus; bulk modulus; composite; compressibility; 17068 .

Copper; electrical resistivity; iron alloys; Lorenz ratio; low temperature; nickel alloys; thermal conductivity; thermopower; 16878.

Copper; electrical resistivity; iron; low temperature; susceptibility; alloys; 17135

Copper; low temperature; magnetothermal conductivity; nickel alloy; stainless steel; thermal conductivity; 16864 .

Copper; low temperature; niobium-titanium alloys; superconducting wire; tensile properties; composite; 16862

Copper alloy; Debye temperature; elastic constants; Poisson's ratio; shear modulus; sound velocity; Young's modulus; bulk modulus; compressibility; 17320 .

Copper alloy; elastic constant; Poisson ratio; precipitation hardening; shear modulus; sound velocity; Young's modulus; bulk modulus; compressibility; 17094 .

Copper alloys; high strength steels; nickel alloys; stainless steels; stress corrosion cracking; titanium alloys; aluminum alloys; Monogr. 156.

Copper concentric neutral wires; corrosion detection methods; corrosion tests; current-potential measurements; underground corrosion; buried cables; NBSIR 77-1232.

Copper stabilization; critical current; critical-current degradation; multifilamentary wires; $\mathrm{Nb}_{3} \mathrm{Sn}$; $\mathrm{NbTi}$; strain; stress; aluminum stabilization; 16816 .

Copper wiring; military buildings; aluminum wiring; branch circuits; NBSIR 76-1184.

Copyright; data base; economic efficiency; information technology; policy analysis; policymaking; public goods; technological change; transaction costs; computer; computer program; SP5OO-17.

Copyrights; inventions; monopolies; patent law; patents; Canada; 16859.

Cordage products; drained weight; laws and regulations; metrication; national laboratory accreditation; retail meat identity standards; tolerance application; vapor recovery; weights and measures; checking prepackaged commodities; computer assisted check-out systems; SP47I. 
Core levels; transition metal carbides; $\mathrm{x}$-ray emission; $\mathrm{x}$-ray photoemission; charge transfer; chemical shifts; 17265 .

Core temperature; energy conservation; modeling; OSHA Standards; thermal sensation; WBGT; SP49I, pp. 18-40 (Sept. 1977).

Corona charging decoration; dielectric defect detection; electrophoretic decoration; integrated circuit quality control; selective chemical etching; semiconductor device reliability; SP400-3I.

Corona discharge; dielectric breakdown; ozone attack; atomic oxygen; chemiluminescent; 16995.

Corona poling; dipole orientation; piezoelectricity; polarization; polyvinylidene fluoride; pyroelectricity; vinylidene fluoride copolymer; charge distribution; charge transfer; NBSIR 761186.

Coronae, solar; coronae, stellar; flares, solar; flares, stellar; magnetic cycles, solar; magnetic cycles, stellar; nonradiative heating; transition regions, solar; transition regions, stellar; ultraviolet spectra; visible spectra; $x$-ray spectra; chromospheres, solar; 17324.

Coronae, stellar; flares, solar; flares, stellar; magnetic cycles, solar; magnetic cycles, stellar; nonradiative heating; transition regions, solar; transition regions, stellar; ultraviolet spectra; visible spectra; $x$-ray spectra; chromospheres, solar; chromospheres, stellar; 17324 .

Correction factors; luminescence; quantum-flat actinometer; quantum yield; absolute yield; chemical actinometry; SP466, pp. 21-24 (May 1977).

Correlation; critical point anomaly; methane; tables; thermal conductivity coefficient; viscosity coefficient; JPCRD 6, No. 2, 597-610 (1977).

Correlation; dose; ESR; gamma ray; glow curve; irradiation; TL; $\mathrm{CaSO}_{4}$; SP46I, pp. $234-237$ (Jan. 1977).

Correlation; double balanced mixer; isolation amplifier; phaselock loop; phase noise; 17185 .

Correlation; probability; random variable; reliability; algebra of normal functions; SP487, pp. 25-38 (Aug. 1977).

Correlation function; counting rate spectrum; nonstationary process; nonstationary spectrum; power spectrum; synthesized spectrum; time-dependent spectrum; coherence; 17169.

Correlation function; density fluctuations; fluctuations; hydrodynamics; light scattering; liquid state; molecular dynamics; neutron scattering; shear wave; statistical mechanics; time correlation function; transverse current; ultrasonics; 16711 .

Correlation, skid resistance; highway safety; measurement, skid resistance; pavement, skid resistance; pavement wetting system; skid resistance, measurement; tire-pavement interface forces; wet pavement skid resistance; accident reduction, skidding; NBSIR 77-1213.

Corresponding states; dense liquid; mixture; modified Enskog theory; prediction; thermal conductivity coefficient; viscosity coefficient; 16791

Corresponding states; mixtures; nitrous oxide; prediction; thermal conductivity; transport property; viscosity; carbon dioxide; TN693.

Corridor, countercurrent; fire; scaling; stratified flow; temperature; velocity measurements; buoyant flow; $I 7285$.

Corridor fires; fire code; fire science; fire spread model; buoyant flow; compartment fires; NBS-GCR-77-84.

Corridor sprinkler systems; droplet size; droplet trajectory; evaporative cooling; fire suppression; full-scale test; gas temperature; oxygen content; recirculating flow; reduced scale model test; scaling criteria; spray water flow rate; water spray; NBSIR 77-I287.

Corridors; fuel load; heat transfer; room fires; scaling; ventilation; NBSIR 77-13/8.

Corrosion; desalination; distillation; hot sea water and materials; SP463, pp. V.2.1-V.2.6 (Jan. 1977).
Corrosion; ductile cast-iron; soils; statistical analysis; underground; carbon steel; 16745.

Corrosion; electrical; energy management; graphic pen; halocarbons; infrared lasers; international standard; neutron xeroradiography; problem-solving; radiation safety; smoke detectors; solar heating; SRM's; adobe; air pollution; DIM/NBS 61 , No. 3, 1-32 (1977).

Corrosion; explosion; extinguisher; fire; gas; injury; liquefied; petroleum; standards; container; NBSIR 77-1217.

Corrosion; failure analysis; failure prevention; quality assurance; reliability; coal conversion; coal gasification; coal liquefaction; SP468.

Corrosion; fatigue; microstructures; titanium alloys; 17187.

Corrosion; implant requirements; mechanical properties; metal implants; stainless steel; standards; titanium; biocompatibility; cobalt-chromium; 16973.

Corrosion detection methods; corrosion tests; current-potential measurements; underground corrosion; buried cables; copper concentric neutral wires; NBSIR 77-1232.

Corrosion, inhibiting of; corrosion, treatment methods; metal artifacts, restoration of; patina, artificially produced; patina, natural; archaeological finds, preservation of; conservation of metal artifacts; $S P 479$.

Corrosion protection; offshore corrosion; sand corrosion; seawater corrosion; splash zone corrosion; cathodic protection; coating systems; Monogr. 158.

Corrosion resistant alloys; microstructures; molybdenum additions; precipitation; titanium alloys; transmission electron microscopy; 16690.

Corrosion tests; current-potential measurements; underground corrosion; buried cables; copper concentric neutral wires; corrosion detection methods; NBSIR 77-I232.

Corrosion, treatment methods; metal artifacts, restoration of; patina, artificially produced; patina, natural; archaeological finds, preservation of; conservation of metal artifacts; corrosion, inhibiting of; SP4 79.

Cosite interference; cylindrical scanning; near-field scanning; planar scanning; scanning facilities; spherical scanning; antenna patterns; 17221 .

Cosmic gamma ray; flux isotropy; sodium iodide detector; spectral measurements; Apollo 16,17; background correction; 16938.

Cost; energy conservation; energy standards; fenestration; lifecycle costing; retrofitting; solar; building design; 17107 .

Cost analysis; cost benefits; housing; regulation; builderdeveloper; construction; consumers; SP473, pp. 391-396 (June 1977).

Cost analysis; software engineering; software reliability; software testing; symbolic evaluation; symbolic testing; computer programming; NBS-GCR-77-89.

Cost benefits; housing; regulation; builder-developer; construction; consumers; cost analysis; SP473, pp. 391-396 (June 1977).

Cost effectiveness; costs; productivity; automatic typewriters; benefits; break even analysis; 17236 .

Cost effectiveness; ground motion; network design; strong-motion record; SP477, pp. III-1 -III-15 (May 1977).

Cost estimation; life cycle costing; life cycle performance; life testing, and performance testing; accelerated testing; consumer products; NBSIR 77-1212.

Cost plus loss; decision analysis; fire; furniture fire; losses; residential fire; standard; upholstered furniture; NBSIR 77. I38I.

Cost savings; drainage-waste-vent; economics; life cycle; performance standards; pipe; plumbing; reduced-size vents; sanitary drainage system; venting; 17296.

Costs; existing structures; optimization; retrofitting; seismic; SP477, pp. VI-69-VI-84 (May 1977).

Costs; incentives; regulation; alternatives; building codes; building process; constraints; SP473, pp. 17-33 (June 1977). 
Costs; productivity; automatic typewriters; benefits; break even analysis; cost effectiveness; $l 7236$.

Cost/benefit; models; queuing; telephone systems; transit information; transportation; automation; NBSIR 77-1253.

Cost/effectiveness; economics; safety standard; standards; benefit/cost; building standards; 17133 .

Cotes, Roger (1682-1716); Euler, Leonard (1707-1783); Figure of the Earth; fitting a linear equation; least sum of absolute deviations; Mayer, Tobias (1723-1762); method of averages; weighted mean; weighted median; zero sum of residuals; 17314 .

Cottage industry; developing countries; Guyana; less developed countries; measurement services; standardization; testing facilities; NBSIR 76-1180

Cotton; detector location; detectors; fire detectors; polyurethanes; polyvinyl chloride; room fires; rooms; smoldering; wood; ceiling height; ceilings; NBS-GCR-77-86.

Cotton; detector location; fire detectors; fire growth; flaming fires; heat detectors; polyurethanes; polyvinyl chloride; smoke detectors; smoldering fires; temperature rise; wood; ceiling height; ceilings; NBS-GCR-77-95.

Coulomb excitation; electron scattering; Faddeev equations; helium-three; monopole transition; separable potential; 16793.

Coulometry; electrochemical equivalent; gallium arsenide; gallium atomic weight; stoichiometry; atomic weight; J. Res. 81A No. 1, $1-4$ (1977).

Counting rate spectrum; nonstationary process; nonstationary spectrum; power spectrum; synthesized spectrum; time-dependent spectrum; coherence; correlation function; 17169 .

Counting sequence; cross section; gamma ray; photon; attenuation coefficient; SP461, pp. 29-31 (Jan. 1977).

Coupled oscillators; nonradial oscillations; avoided crossings; 17029.

Coupled-channel equations; $\mathrm{CO}_{2}$; electron-molecule collisions; static-model exchange-polarization potential; 17026.

Coupling constants; hexacarbonylvanadate(1-); NMR spectroscopy; reduction; $\mathrm{V}(\mathrm{CO})_{6}^{-} ; 1$,3-dithiolium ion; $2,2^{\prime}$-bi(1,3dithiolyl); 17154 .

Court orders; human behavior; institutional occupancies; interior design; physical environment; regulation; research; standards; SP473, pp. 55-67 (June 1977).

$\mathrm{CO}_{2}$; electron-molecule collisions; static-model exchangepolarization potential; coupled-channel equations; 17026 .

$\mathrm{CO}_{2}$; methylene; rate constant; $\mathrm{CO}$; combustion; 16838 .

$\mathrm{CO}_{2}$ concentration; energy conservation in schools; energy consumption; energy utilization in schools; oxygen content; reduced ventilation rate; school operation schedule; ventilation test; computerized thermal simulation; BSS97.

$\mathrm{CO}_{2}$ laser; infrared; kinetics; mechanisms; photochemistry; pyrolysis; alkyl halides; 16783 .

$\mathrm{CO}_{2}$ laser; luminescence; magnesium; metal flames; calcium; 17163.

$\mathrm{CO}_{2}$ lasers; nitric oxide; optical pumping of molecules; vibrational relaxation; combustion; 17193 .

CPEUG; hardware monitoring; on-line system evaluation; prediction methods; queuing models; simulation; software monitoring; workload definition; ADP life cycle; computer performance evaluation; computer performance measurement; computer performance prediction; SP5O0-18.

Crack growth; cyclic loading; fracture mechanics; high temperature; proof testing; silicon carbide; silicon nitride; acoustic emission; brittle materials; 17039 .

Crack growth; drill pipe; failure; Kaiser Effect; pressure vessels; sources; acoustic emission; SP487, pp. 210-238 (Aug. 1977).

Crack propagation; cryogenics; fracture mechanics; fracture toughness; material properties; structures; 16866.

Crack propagation; ductility; failure; fractography; fracture tests; hydrogen; steels; stress corrosion; 16700.
Crack propagation; fatigue; iron alloys; liquid helium; stainless steels; steels; superalloys; titanium alloys; aluminum alloys; 16928 .

Cracks; electron microscopy; fracture interfaces; plastic deformation; silicon nitride; turbine materials; NBSIR 76-1075.

Cracks; electron microscopy; grinding damage; oxidation; silicon nitride; surface flaws; thin foils; 17090 .

Crampton effect; frequençy stability; hydrogen line $Q$; hydrogen line servo; magnetic. field; passive hydrogen maser frequency standard; second-order Doppler; spin exchange; wall shift; active hydrogen maser frequency standard; cavity pulling; cavity-Q; cavity servo; 17180 .

Credit authorization system; critical resource; disk modelling; event model; measurement; modelling; resource dependency; system capacity; validation; SPS00-18, pp. 185-211 (Sept. 1977).

Creep-rupture properties; elevated-temperature; fracture mode; Larson-Miller parameter; pressure vessel steel; tensile properties; 17235.

Crevice corrosion; ellipsometry; localized corrosion; pitting; repassivation kinetics; stress corrosion; 16990.

Crevice corrosion; iron-molybdenum alloys; localized corrosion; repassivation; sensitization; stainless steel; NBSIR 76-1170.

Criminalistics; evidential materials; forensic reference collections; forensic science; reference materials; standard reference collections; 16706 .

Criteria; education programs; professional competence; building construction groups; certification; code enforcement officials; communications; SP473, pp. 383-389 (June 1977).

Criteria; project summaries; standards; technical bases; building research; building technology; codes; SP446-I.

Criteria, accuracy; criteria, performance; dose equivalent; elements, transuranic; glove box; intercomparison; neutrons, high energy; neutrons, low energy; non-uniform exposures; quality factor; standards; SP493, pp. 101-105 (Oct. 1977).

Criteria maintenance design evaluation; design guides; architectural criteria; automated system; building codes; buildings; computer applications; SP473, pp. 349-368 (June 1977).

Criteria, performance; dose equivalent; elements, transuranic; glove box; intercomparison; neutrons, high energy; neutrons, low energy; non-uniform exposures; quality factor; standards; criteria, accuracy; SP493, pp. 101-105 (Oct. 1977).

Critical current; critical current degradation; degradation mechanisms; multifilamentary superconductors; $\mathrm{NbTi} ; \mathrm{Nb}_{3} \mathrm{Sn}$; strain; stress; 16873.

Critical current; critical-current degradation; multifilamentary wires; $\mathrm{Nb}_{3} \mathrm{Sn}$; $\mathrm{NbTi}$; strain; stress; aluminum stabilization; copper stabilization; 16816 .

Critical current; definition; standards; superconductor; 17074 .

Critical current degradation; degradation mechanisms; multifilamentary superconductors; $\mathrm{NbTi}$ $\mathrm{Nb}_{3} \mathrm{Sn}$; strain; stress; critical current; 16873.

Critical currents; NbTi; stress effect; superconductor; 16868 .

Critical evaluation; electrolyte; excess free energy; osmotic coefficient; solutions; thermodynamic properties; activity coefficient; calcium chloride; JPCRD 6, No. 2, 385-408 (1977)

Critical evaluation; Knight shifts; magnetic moments; metals; nuclear quadrupole effects; nuclear relaxation; compilation; 17093.

Critical evaluation; mechanical; numerical data; physical properties; thermodynamics; transport; chemical; SP463, pp. VII.1.1-VII.1.15 (Jan. 1977).

Critical evaluations; data compilations; industrial needs; phase diagrams; theory of phase diagrams; thermodynamics; computer predictions; NBSIR 77-1239.

Critical exponents; critical region; fluid mixtures; fluids; scaling; thermodynamic properties; transport properties; universality; 17279 . 
Critical item list; failure mode and effect analysis; failure reduction; reliability; system safety; SP487, pp. 278-288 (Aug. 1977).

Critical locus; critical point; phase equilibria; binary mixtures; 17295.

Critical parameters; diffuse reflectance; fluorescence; instrumentation; luminescence; quantum yield; spectrophotometry; standard reference materials; standardization; accuracy; SP466.

Critical phenomena; interaction range; neutron scattering; spin correlation function; absolute cross section measurement; cobalt; 17112 .

Critical point; mixture; one-fluid theory; plait point; thermal conductivity coefficient; viscosity coefficient; $J$. Res. 82, No. 3, $181-182$ (1977).

Critical point; phase equilibria; binary mixtures; critical locus; 17295.

Critical point anomaly; methane; tables; thermal conductivity coefficient; viscosity coefficient; correlation; JPCRD 6, No. 2, 597-610 (1977).

Critical point enhancement; data evaluation; ethane; thermal conductivity coefficient; viscosity coefficient; JPCRD 6, No. $4,1167-1180$ ( 1977 ).

Critical region; fluid mixtures; fluids; scaling; thermodynamic properties; transport properties; universality; critical exponents; 17279.

Critical resource; disk modelling; event model; measurement; modelling; resource dependency; system capacity; validation; credit authorization system; SPSO0-18, pp. 185-211 (Sept. 1977).

Critical review; Franck-Condon integrals; molecular constants; molecular nitrogen; potential energy curves; radiative lifetimes; JPCRD 6, No. 1, $113-307$ (1977).

Critical-current degradation; multifilamentary wires; $\mathbf{N b}_{3} \mathrm{Sn}$; $\mathrm{NbTi}$; strain; stress; aluminum stabilization; copper stabilization; critical current; 16816.

Criticality; collision; cylindrical; energy; integral; iterative; neutron; transmission matrix; SP461, pp. 94-96 (Jan. 1977).

Critically evaluated data; crystallographic data; experimental melting curves; high pressure; solid-solid phase boundaries; AB-type compounds; calibration; JPCRD 6, No. 4, 12051252 (1977).

Critically evaluated data; International Formulation; steam; viscosity of water and steam; water; JPCRD 6, No. 4, 1133 1166 (1977).

Critically evaluated data; phase diagrams; ternary copper-silver alloy systems; thermodynamic properties; JPCRD 6, No. 3, $621-674$ (1977).

Criticals; cross section; ENDF/B; fission; standards; uncertainties; SP493, pp. 269-277 (Oct. 1977).

Cross section; differential; elastic; multiple bias technique; neutron; scattering; SP461, pp. 64-66 (Jan. 1977).

Cross section; differential; electron; helium; ionization; measurements; 16810 .

Cross section; diffusion; kernel; lattice vibration; model; moderator; neutron; scattering; thermalization; SP461, pp. 149-162 (Jan. 1977).

Cross section; dissociation; electron; excitation; hydrogen; Balmer-alpha; collision; 17054.

Cross section; dissociation collisions; hydrogen; theory; vibrational and rotational enhancement; argon; 16803.

Cross section; electron; intermediate energy; photons; approximation; bremsstrahlung; SP461, pp. 60-63 (Jan. 1977).

Cross section; ENDF/B; fission; standards; uncertainties; criticals; SP493, pp. 269-277 (Oct. 1977).

Cross section; energy transfer; gamma rays; moderator; neutron; radiation damage; reactor; scattering; spectrometer; SP461, pp. 32-40 (Jan. 1977).
Cross section; fast neutrons; geometric factors; photon; polarimeter; radiation physics; scattering; spectrometers; absorption; accuracy; SP461, pp. 47-54 (Jan. 1977).

Cross section; gamma ray; photon; attenuation coefficient; counting sequence; SP461, pp. 29-3I (Jan. 1977).

Cross section; gamma rays; inelastic scattering; $\mathrm{K}$-shell electron; photon; $x$ ray; bound electrons; SP461, pp. 26-28 (Jan. 1977).

Cross section; gamma rays; photons; Rayleigh scattering; analytical formula; coherent scattering; SP461, pp. 17-19 (Jan. 1977).

Cross section; gamma rays; photon; scattering, incoherent; $x$ rays; angular distribution; SP461, pp. 55-56 (Jan. 1977).

Cross section; K-shell; measurement; photoelectric effect; photon; atomic number; SP461, pp. 41 -43 (Jan. 1977).

Cross section; measurement; neutron; $\beta$-counting error; activation; capture reaction; SP461, pp. 57-59 (Jan. 1977).

Cross section; multiple bias; neutron; nonelastic; optical model; parameter; polynomial extrapolation; sphere transmission; SP461, pp. 44-46 (Jan. 1977).

Cross section; neutron; normalization; resonance; shape; standards; thermal; ${ }^{6} \mathrm{Li}(\mathrm{n}, \alpha) ;{ }^{10} \mathrm{~B}(\mathrm{n}, \alpha) ;{ }^{235} \mathrm{U}(\mathrm{n}, \mathrm{f}) ; S P 493$, pp. 174 181 (Oct. 1977).

Cross section; optical model; reactor technology; scatteringelastic, inelastic, total; thoriunn; uranium; calculation; SP46I, pp. $70-73$ (Jan. 1977).

Cross section fluctuations; measurement; neutron capture cross section; normalization; reference standard; review; accuracy; Au(n,y) cross section; SP493, pp. $165-169$ (Oct. 1977).

Cross section standards; dosimetry; fission; flux; measuring techniques; neutrons; standards; SP493.

Cross sections; design; errors; fission neutrons; irradiation devices; measuring methods; neutron reactions; neutron sources; calibration; californium-252; 16790.

Cross sections; detector efficiency; neutron fluence; SP493, pp. 227-233 (Oct. 1977).

Cross sections; differential cross sections; electron scattering; inelastic scattering; nitrogen molecules; resonances; scattering; vibrational excitation; close-coupling calculations; crossed beams; 16740.

Cross sections; dosimetry; electrons; neutrons; photons, radiation physics; symposium; SP461.

Cross sections; ENDF/B; fission; integral measurements; standard neutron fields; SP493, pp. 290-298 (Oct. 1977).

Cross sections; fission; neutron reactions; neutron spectrum; reactor fuels; reactor materials; SP493, pp. 156-164 (Oct. 1977).

Cross sections; fission spectra; integrals; neutrons; radioactivation; resonance integrals; spectral functions; comparative evaluation; SP493, pp. 128-136 (Oct. 1977).

Cross sections; fission yields; neutrons; nuclear data; standard fields; SP493, pp. 299-303 (Oct. 1977).

Cross sections; gamma ray; incoherent scattering; pair-production; photoionization; coherent scattering; SP461, pp. 20-22 (Jan. 1977).

Cross sections; gamma rays, incoherent scattering function; pair production; photoelectric effect; photons; $x$ rays; atomic form factor; attenuation coefficients; SP461, pp. 3-16 (Jan. 1977).

Cross sections; ionization cross sections; lithium; photoexcitation cross sections; Stieltjes-Tchebycheff technique; configuration interaction; 17319 .

Cross test structure; cross van der Pauw; numerical analysis; sheet resistance; sheet resistor test structure; test structures; van der Pauw; 17165 .

Cross van der Pauw; numerical analysis; sheet resistance; sheet resistor test structure; test structures; van der Pauw; cross test structure; 17165 .

Cross-assembler; machine code; relocatable code; assembler; NBSIR 77-1230. 
Cross-correlation; exit concentration; exit velocity; flow visualization; fluorescence; fluorescent dye; laser; laser dyefluorescence technique; mean concentration; mean velocity; measuring volume; remote sensing; $S P 484$, pp. $423-447$ (Oct. 1977).

Cross-correlation analysis; liquid velocity measurement; non-intrusive flowmeter; ultrasonic beams; SP484, pp. 319-333 (Oct. 1977).

Crossed beams; cross sections; differential cross sections; electron scattering; inelastic scattering; nitrogen molecules; resonances; scattering; vibrational excitation; close-coupling calculations; 16740 .

Cross-section; elastic; lithium; measurements; neutron; total; alpha; boron; branching ratio; compilation; SP493, pp. 67-84 (Oct. 1977).

Cross-sections; fast reactors; integral experiments; standards; adjustment; benchmark; SP493, pp. 310-312 (Oct. 1977).

Cryocooler; EMI problems; energy problems; energy savings; exchange program; lead detection; metric; oxygen; technology; DIM/NBS 61, No. 10, 1-32 (1977).

Cryogenic; crystalline materials; dosimeter calibrations; energy; energy related inventions; heterodyne receiver; international standards code; NCSL; NMR knight shifts; neutron beams; piezo-flex micropositioning; pressure; DIM/NBS 61 , No. 7 , 1-32 (1977).

Cryogenic; design; nitrogen; safety; wind-tunnel; NBSIR 77. 857.

Cryogenic; dielectric loss; dissipation factor; high voltage; low temperature polymer; 16782 .

Cryogenic; dielectric loss; dissipation factor; epoxy insulation; high voltage; polymer tape insulation; superconducting cable; underground transmission; bridge measurements; 17014 .

Cryogenic; dynamic; frequency response; hysteresis; precision; pressure measurement; sensitivity; stability; thermal effects; zero-shift; accuracy; calibration; 17081 .

Cryogenic; flow; gas; liquid; mass flow; measurement; SP484, pp. 881-893 (Oct. 1977).

Cryogenic; fusion; magnets; superconductivity; thermonuclear; copper; 17134.

Cryogenic; instrumentation; 17096.

Cryogenic adhesives and sealants; experimental data; abstracted publications; adhesives and sealants; 16883 .

Cryogenic densimeters; density reference system; liquid methane; LNG; TN697.

Cryogenic electrical switch; mechanical switch; multiple contact switch; proximity effect; superconducting switch; thinfilm; 17121 .

Cryogenic flow measurement; dental restorations; deep ocean research; federal science; governmental environment; laser energy; space flight; spectroscopy; SRM; television captioning; thermophysical; weights and measures; DIM/NBS 61 , No. 4, 1-32 (1977).

Cryogenic helium supply system; cryogenic storage; helium; helium supply system; high density helium storage; liquid helium storage; supercritical helium; NBSIR 76-850.

Cryogenic insulation; foam insulation; insulation; survey; abstracts; bibliography; 17308 .

Cryogenic refrigeration; efficiency; expanders; heat exchangers; particle accelerators; power transmission; reliability; compressors; 17083.

Cryogenic refrigeration; magnetometry; SQUID; Stirling cycle; 17091 .

Cryogenic storage; helium; helium supply system; high density helium storage; liquid helium storage; supercritical helium; cryogenic helium supply system; NBSIR 76-850.

Cryogenic temperature; dentistry; dielectric measurements; dye lasers; dynamic calibration; electron microscopy; electronic technology; energy conservation; interferometric wavemeter; metric; pressure transducers; synchrotron radiation; DIM/NBS 61, No. 2, 1.32 (1977).
Cryogenic temperature; fatigue crack growth; fracture toughness; heat affected zone; J-integral; nickel steel; weldments; 17089.

Cryogenics; dielectric-constant; electrets; electrocaloric effect; entropy; ferroelectrics; glass-ceramics; heat switches; magnetothermal conductivity; polarization; potassium tantalate; refrigeration; specific heat; strontium titanate; beryllium: ceramics; NBSIR 76-847.

Cryogenics; efficiency; energy recovery; hydrogen; liquefier; component efficiency; NBSIR 77-862.

Cryogenics; electrical conductivity; heat switch; Lorenz ratio; magnetic field; single crystal; thermal conductivity; beryllium; 17088.

Cryogenics; electrical property; insulation; materials; mechanical property; metal; review; thermal property; alloy; composite; 17072

Cryogenics; fracture mechanics; fracture toughness; material properties; structures; crack propagation; 16866.

Cryogenics; indium; joints; solder; thermal conductance; beryllium; copper; 16797.

Cryogenics; static mechanical properties; advanced fiber composites; boron-aluminu m; boron-epoxy; 16865

Cryptanalysis; cryptography; encryption; key management; known plaintext attack; security; work factor; NBSIR 77. 1291 .

Cryptography; encryption; key management; known plaintext attack; security; work factor; cryptanalysis; NBSIR 77-1291.

Cryptography; encryption standard; interface requirements; Monte-Carlo testing; testbed; test cases; validating correctness; communications security; computer security; SP500-20.

Crystal; free energy; lattice symmetry; stability; BBGKY hierarchy; bifurcation; 16986.

Crystal; isostructural materials; lattice; point group; polymorphism; space group; symmetry; JPCRD 6, No. 3, 675-830 (1977).

Crystal chemistry; ionic conductivity; nonstoichiometry; phase equilibria; rubidium niobate; rubidium tantalate; J. Res. 82, No. 3, 151-165 (1977).

Crystal field; photoemission; adatom; 16919.

Crystal field; pnictides; rare earth; 16916.

Crystal field theory; group theory; high-resolution spectra; irreducible representation; isotope separation; molecular spectroscopy; 16956.

Crystal field theory; group theory; molecular spectroscopy; sulfur hexafluoride; 17316 .

Crystal growth; crystal perfection; diffraction topography; dynamical diffraction theory; ferromagnetic domain walls; nickel single crystals; $x$-ray dynamical diffraction; 16974.

Crystal growth; crystal perfection; microgravity; purification; space processing; convection; NBSIR 77-1208.

Crystal growth; crystal structure; electronic properties; magnetic properties; optical properties; phase diagrams; research materials; thermal properties; availability; SP463, pp. III.3.1III.3.8 (Jan. 1977).

Crystal growth; floating zone; meniscus; perturbation; shape stability; silicon; 16931 .

Crystal growth; microgravity; Skylab/ASTP; space processing; convection; 17275 .

Crystal imperfections; crystal perfection; Czochralski-grown nickel; dislocation clusters; dynamical diffraction; magnetic domains; magnetic domain walls; melt-grown crystals; nickel single crystals; $x$-ray diffraction topography; anomalous transmission effect; 16997.

Crystal orientation determination; crystallographic contrast: electron channeling contrast; microstructural analysis; scanning electron microscope; selected area electron channeling pattern; 16839.

Crystal oscillator; frequency accuracy; frequency stability; frequency standards; hydrogen maser; quartz crystal; rubidi- 
um gas cell; timekeeping; cesium beam; clocks (atomic); TN616, 2d Revision.

Crystal perfection; Czochralski-grown nickel; dislocation clusters; dynamical diffraction; magnetic domains; magnetic domain walls; melt-grown crystals; nickel single crystals; $x$ ray diffraction topography; anomalous transmission effect; asymmetric crystal topography; 16997.

Crystal perfection; diffraction topography; dynamical diffraction theory; ferromagnetic domain walls; nickel single crystals; x-ray dynamical diffraction; crystal growth; 16974 .

Crystal perfection; microgravity; purification; space processing; convection; crystal growth; NBSIR 77-1208.

Crystal structure; diffraction; isotopes; molecular dynamics; neutron; nuclear reactor; radiation; activation analysis; TN939.

Crystal structure; dimeric configuration; stannous compounds; stannous phosphate; tin coordination; 17095.

Crystal structure; disorder; magnesium incorporation; phosphate; vacancies; beta-tricalcium phosphate; cation substitution; coordination; 17259.

Crystal structure; electronic properties; magnetic properties; optical properties; phase diagrams; research materials; thermal properties; availability; crystal growth; SP463, pp. III.3.1III.3.8 (Jan. 1977).

Crystal structure; integrated intensities; lattice constants; peak intensities; powder patterns; reference intensities; standard; $\mathrm{x}$-ray diffraction; Monogr. 25, Section 14.

Crystal structure; rigid-body motion analysis; thermal motion of a perchlorate ion; $x$-ray diffraction; ammonium perchlorate; bond lengths and angles; 17348 .

Crystal structure; $S$-carboxymcthyl-L-cysteine sulfoxide; $\mathrm{x}$-ray determination; zwitterion; absolute configuration; amino acid derivative; 16688 .

Crystal structure; Sn bonding; tin hydroxy phosphate; tin phosphate; asymmetric coordination; 16741 .

Crystal structure; subcell; vacancies; alpha-tricalcium phosphate; calcium phosphate; cation-anion columns; 17034.

Crystalline materials; dosimeter calibrations; energy; energy related inventions; heterodyne receiver; international standards code; NCSL; NMR knight shifts; neutron beams; piezo-flex micropositioning; pressure; thermodynamic tables; DIM/NBS 61 , No. 7, 1-32 (1977).

Crystalline solutions; hard spheres; metastable states; molecular probability density; bifurcation; close-packed crystals; 17012 .

Crystallization; growth rate; homogeneous nucleation; polymer; surface nucleation; chain-folding; 16887.

Crystallographic axis; nonlinear elastic effect; resonance frequency; acceleration field; acceleration sensitivity; compound crystal resonator; NBSIR 77-855.

Crystallographic contrast; electron channeling contrast; microstructural analysis; scanning electron microscope; selected area electron channeling pattern; crystal orientation determination; 16839.

Crystallographic data; experimental melting curves; high pressure; solid-solid phase boundaries; AB-type compounds; calibration; critically evaluated data; JPCRD 6, No. 4, 1205 1252 (1977).

Crystals; fused silica; interferometers; optics; photoelasticity; 16730:

$\mathrm{Cr}^{3+}$, crystal field spectra; $\mathrm{d}^{3}$ ion; optical spectra; ruby; transition metal ions; ultrahigh pressure; 17047.

$\operatorname{CS}\left(A^{1} \pi\right)$; photodissociation; thiophosgene; $\Delta H f^{\circ}$ (SCC1); $\Delta H f^{\circ}$ $\left(\mathrm{SCCl}_{2}\right) ; 16781$.

Current awareness services; databooks; information analysis center; inquiry services; metals technology; structural materials; technical reports; ceramic technology; SP463, pp. IV.2.1IV.2.7 (Jan. 1977).

Current comparator; current measurements; therroelement; ac-dc difference; 16697.
Current integrators; ion beam scanning; ion implantation; ion implantation dose measurement and control; secondary particle suppression; accurate ion beam current measurement; SP400-39.

Current leads; experimental; stability; supercritical helium; acoustic oscillations; 17078 .

Current measurements; thermoelement; ac-dc difference; current comparator; 16697.

Current measuring transducers; current velocities; dynamic response characteristics; fluctuating flow characteristics; marine environment; SP484, pp. 109-122 (Oct. 1977).

Current meter calibrations; current meters, water; flow measurement; Price meter suspensions; Pygmy meter performance; velocity-area method; SP484, pp. 123-144 (Oct. 1977).

Current meters; dye-dilution methods; errors in flow measurement; flow measurement; fluid flow modeling; fluid velocity; flumes; gas flow standard; hot-wire anemometry; international flow standards; laser anemometry; open channel flows; orifice meters; SP484, Volumes 1 and 2.

Current meters, water; flow measurement; Price meter suspensions; Pygmy meter performance; velocity-area method; current meter calibrations; SP484, pp. 123-144 (Oct. 1977).

Current research; ductility; full scale testing; high-rise masonry; scale factors; shear walls; BSS106, pp. 314-326 (Sept. 1977).

Current velocities; dynamic response characteristics; fluctuating flow characteristics; marine environment; current measuring transducers; SP484, pp. 109-122 (Oct. 1977).

Current-potential measurements; underground corrosion; buried cables; copper concentric neutral wires; corrosion detection methods; corrosion tests; NBSIR 77-1232.

Curve fitting; energy irradiance; flashtube; pulsed source; radiometry; TN935.

Curve fitting; pickoffs (magnetic and RF); turbine flowmeter; universal curve; viscosity measurement; accuracy; calibration; characteristic factor ( $\mathrm{K}$ or $\mathrm{C}$ ); SP484, pp. 847-869 (Oct. 1977).

Curved crystals; extended chain crystals; fold domains; fold surfaces; interlamellar links; morphology; polymer; sectorization; spheralites; chain folding; 16958.

Cuvette; helix; mixer; spectrophotometry; stirrer; vortex; 16704

Cw dye laser; Fabry-Perot interferometer; Rydberg constant; Balmer $\alpha$ line; 17098.

Cw laser; interferometer; Michelson; phase-lock; scanning; wavelength; 17338 .

Cyanogen fluoride; dipole moment; infrared spectroscopy; laser absorption; laser-Stark resonance; molecular spectra; Stark effect; 17124.

Cycle identification; group delays; Omega timing; precision timekeeping; VLF antenna fields; VLF timing; VLF tracking coordination; clock synchronizations; 16947.

Cyclic groups; free groups; free products; tables; asymptotic formulas; classical modular group; 16660.

Cyclic loading; debond analysis; double-lap-joint analysis; fatigue tests; finite element analysis; joints; nonlinear analysis; single-lap-joint analysis; single-lap-joint bending; spotwelded joints; weldbonded joints; adhesive-bonded joints; bonded joints; NBSIR 76-1053.

Cyclic loading; fatigue; fatigue failure; cap screw failures; NBSIR 77-1275.

Cyclic loading; fracture mechanics; high temperature; proof testing; silicon carbide; silicon nitride; acoustic emission; brittle materials; crack growth; 17039.

Cyclic voltommetry; electrocatalysis; equivalent circuit; fuel cells; microprocessor; network analyzer; phosphoric acid electrolyte; refractory hard metals; AC impedance; automated electrochemical analysis; ceramic electrolytes; ceria-yttria; NBSIR 77-1270. 
Cyclones; disasters; structural engineering; tides; wind; buildings; SP477, pp. V-21-V-53 (May 1977).

Cyclotron; design; earth shield; neutron spectra; shielding; shield thickness; calculation; concrete; SP461, pp. 166-170 (Jan. 1977).

Cylinder; frequency; hot film anemometer; recirculating flow; spray; two component flow; vortex street; wake flow; anemometer; SP484, pp. 705-718 (Oct. 1977).

Cylinders; plug gages; rolls; wire standards; calibration; NBSIR 73-136.

Cylindrical; energy; integral; iterative; neutron; transmission matrix; criticality; collision; SP461, pp. 94-96 (Jan. 1977).

Cylindrical scanning; near-field measurements; source-scattering matrix; TN696.

Cy'indrical scanning; near-field measurements; scattering matrix; TN696, 1977 Revision.

Cylindrical scanning; near-field scanning; planar scanning; scanning facilities; spherical scanning; antenna patterns; cosite interference; 17221 .

Czochralski-grown nickel; dislocation clusters; dynamical diffraction; magnetic domains; magnetic domain walls; meltgrown crystals; nickel single crystals; $x$-ray diffraction topography; anomalous transmission effect; asymmetric crystal topography; crystal imperfections; 16997.

$C(d, n)$ source; D(d,n) source; dosimetry; Li(d,n) source; $\mathrm{Li}(\mathrm{p}, \mathrm{n})$ source; neutron angular distributions; neutron energy distributions; neutrons; nuclear reactions; thick-target yields; $\operatorname{Be}(\mathrm{d}, \mathrm{n})$ source; $\mathrm{Be}(\mathrm{p}, \mathrm{n})$ source; NBSIR 77-1279.

\section{D}

Damage; dynamic response; earthquakes; safety; shear wall; stiffness; buildings; SP470, pp. VI-33-VI-46 (Apr. 1977).

Damage; effects; houses; typhoon; wind speeds; SP477, pp. II1-II-14 (May 1977).

Damage; intensity; seismic; wooden house; classification; SP477, pp. IV-1-IV-17 (May 1977).

Damage; structures; typhoon; wind; wind effects; SP477, pp. V-1 - V-20 (May 1977).

Damage; typhoon; wind; wind effects; SP477, pp. V-54-V-59 (May 1977).

Damage detection; failure prevention; noise spectrum; piezoelectric polymer; vibration sensor; acoustic emission; SP487, pp. 189-196 (Aug. 1977).

Damping; ductility; earthquake resistance; energy absorption; modulus of elasticity; partial reinforcing; risk; shear modulus; testing; ultimate strength; anchor bolts; bond; BSS106, pp. 255-258 (Sept. 1977).

Dams; earthquake; earth structures; roads; survey; construction; SP477, pp. VI-44-VI-49 (May 1977).

Data; displacements; intensity; seismic records; velocity; SP477, pp. VI-179-VI-191 (May 1977).

Data; earth's measurement; energy; health records; hydrogen; law enforcement; liquefied natural gas; metric tons; polyethylene; sound; spinach; SRM; systems and software; telecommunications; computer use; conservation; DIM/NBS 61 , No. 5, 1-32 (1977).

Data; electron probe microanalysis; laser ionization; metrication; noise; nondestructive evaluation; research associate program; standards; Alaska pipeline; calibration; CMAC; computers; consumer sounding boards; DIM/NBS 61 , No. 1, 1-32 (1977).

Data; evaluations; status; U-235 (n,f); 0.1-20.0 MeV; SP493, pp. 261-268 (Oct. 1977).

Data; experiment; shake table; testing; transformer; circuit breaker; SP477, pp. VI-50_-VI-60 (May 1977).

Data; networks; computer modeling systems; 17025.

Data acquisition; interactive computer access; measurement; network measurement services; service; teleprocessing systems measurement; computer network measurement; 17252.

Data acquisition system; MIDAS; MIDAS amplifier controller; MIDAS digital to analog converter; MIDAS modules; MIDAS stepping motor indexer; MIDAS up/down counter; TN958.

Data analysis; estimation; geometry; hypercube; hyperplane; polytope; convex set; 17117 .

Data analysis; housing; lead paint; lead poisoning; surveys; $x$-ray fluorescence; children; NBSIR 77-1250.

Data analysis; housing; lead paint; lead poisoning; surveys; blood lead; children; NBSIR 77-1293.

Data bank; electrical properties; electronic properties; magnetic properties; optical properties; Retrieval Guide; technical reports; Thermophysical and Electronic Properties Information Analysis Center; SP463, pp. IV.4.1-IV.4.3 (Jan. 1977).

Data banks; information analysis centers; Machinability Data Center; machining costs; machining data banks; Machining Data Handbook; machining data publications; SP463, pP. IV.5.1-IV.5.8 (Jan. 1977).

Data base; data definition; data definition language; data structure applications; COBOL; CODASYL; NBSIR 74-500.

Data base; economic efficiency; information technology; policy analysis; policymaking; public goods; technological change; transaction costs; computer; computer program; copyright; SP5O0-17.

Data base functions; data base management systems; Privacy Act of 1974; privacy compliance techniques; computer utilization; SP500-10.

Data base management system; data element dictionary/directory; data management; software tool; computer software; 16998

Data base management system; data element dictionary/directory; information management; software tool; computer software; 17280.

Data base management systems; data element dictionary; data element dictionary/directory; software tool; computer software; SPSOO-3.

Data base management systems; Privacy Act of 1974; privacy compliance techniques; computer utilization; data base functions; SP500-10.

Data bases; EEC regulations; flow rate; international standards; orifice plates; SP484, pp. 935-944 (Oct. 1977).

Data bases; information retrieval; library automation; machinereadable; MARC; standards; bibliographic information; SP463, pp. VIII.1.I-VIII.1.4 (Jan. 1977).

Data communication equipment; data processing terminal equipment; data transmission (voice band); Federal Information Processing Standards; synchronous signaling rates; teleprocessing; FIPS PUB 22-1.

Data communications; interconnection; networks; packet switching; standards; communications networks; computer networks; 16934.

Data communications; interconnection; networks; packet switching; standards; communications networks; computer networks; SP500-6.

Data communications equipment; data processing terminal equipment; data transmission; Federal Information Processing Standards; serial-by-bit; serial-by-character; telecommunications; teleprocessing; FIPS PUB 16-1.

Data communications interfaces; data communications standards; interface standards; protocols; communications standards; 16936.

Data communications standards; interface standards; protocols; communications standards; data communications interfaces; 16936.

Data compaction; data compression; data elements; data management; data processing; information management; information theory; coding; coding theory; computer storage; SPSOO-12. 
Data compilation; data evaluation; information retrieval; NSRDS; Omnidata; reference data; 16692.

Data compilation; density; electrical conductance; iodides; molten salt mixtures; standard reference data; surface tension; viscosity; bromides; JPCRD 6, No. 2, 409-596 (1977).

Data compilation; hydroxyl radical; oxide radical ion; perhydroxyl radical; radiation chemistry; rates; superoxide ion; aqueous solution; chemical kinetics; NSRDS-NBS59.

Data compilation and evaluation; nitrosyl chloride; rate constant; absorption spectra; chemical kinetics; chlorine; chlorine oxides; chlorocarbon; chlorofluorocarbon; JPCRD 6 , No. 3, $871-918$ (1977).

Data compilations; fission yield measurement techniques, counting, mass spectrometry; fission yields, thermal, fast, absolute, relative; fission yields versus neutron energy; SP493, pp. 146-155 (Oct. 1977).

Data compilations; industrial needs; phase diagrams; theory of phase diagrams; thermodynamics; computer predictions; critical evaluations; NBSIR 77-1239.

Data compression; data elements; data management; data processing; information management; information theory; coding; coding theory; computer storage; data compaction; SP5O0-12.

Data confidentiality; data integrity; data security; physical security; procedural security; risk analysis; risk assessment; systems security; ADP availability; annual loss expectancy; application system vulnerability; computer security; NBSIR 77-1228.

Data definition; data definition language; data structure applications; COBOL; CODASYL; data base; NBSIR 74-500.

Data definition language; data structure applications; COBOL; CODASYL; data base; data definition; NBSIR 74-500.

Data editing; interactive; labels; numerical analysis; OMNTAB II computing system; probability plotting; selection of variables in linear regression; statistical plotting; stem-and-leaf displays; table making; automatic printing; Calcomp plotting; NBSIR 77-1276.

Data element dictionary; data element dictionary/directory; software tool; computer software; data base management systems; SP500-3.

Data element dictionary; data element dictionary/directory; data management; software tool; ADP; automated data processing; computer software; SP5O0-16.

Data element dictionary/directory; data management; software tool; computer software; data base management system; 16998.

Data element dictionary/directory; information management; software tool; computer software; data base management system; 17280 .

Data element dictionary/directory; software tool; computer software; data base management systems; data element dictionary; SP500-3.

Data element dictionary/directory; data management; software tool; ADP; automated data processing; computer software; data element dictionary; SP500-16.

Data elements; data management; data processing; information management; information theory; coding; coding theory; computer storage; data compaction; data compression; SP500-12.

Data elements; equity; federal technology; fire modeling; heat; hydrocarbon; ionized molybdenum; measurement assurance; metric; neutron diffraction; recycling oil; research and innovation; safety; ultrasonic tissue; computerized data; DIM/NBS 61, No. 6, 1-32 (1977).

Data elements and codes; data processing; Federal Information Processing Standards; geography; information processing standards; information system; representations and codes; standards; statistical data; ADP standards; computers; FIPS PUB 10-2.
Data encryption; dental materials; fire safety; metric; miniature electric field; organic sulfur; radiometric detector; smog formation; SRM's; air pollution; attic ventilation; DIM/NBS 61, No. 1 1, 1-32 (1977).

Data evaluation; data reliability; gas phase; photoabsorption cross section; photochemistry; quantum yield; rate constant; stratospheric chemistry; chemical kinetics; 16976.

Data evaluation; enthalpy; entropy; Gibbs energy; thermochemical data networks; thermochemical tables; thorium compounds; NBSIR 77-1300.

Data evaluation; ethane; thermal conductivity coefficient; viscosity coefficient; critical point enhancement; JPCRD 6, No. 4, 1167-1180 (1977).

Data evaluation; information retrieval; NSRDS; Omnidata; reference data; data compilation; 16692.

Data formats; documentation; image content language; image processing; pattern recognition; prototype images; standards; automation; calibration; SPSOO-8.

Data gathering; boolean random sampling; computer system monitoring; SP500-18, pp. 159-182 (Sept. 1977).

Data input bus; DATANET 355 ; data output bus; high-speed line adaptor; HIS 6080; interactive terminal; probe point development; programmable monitor; stimulator; terminal data; SP500-18, pp. 95-105 (Sept. 1977).

Data integrity; data security; physical security; procedural security; risk analysis; risk assessment; systems security; ADP availability; annual loss expectancy; application system vulnerability; computer security; data confidentiality; NBSIR 771228.

Data integrity; interactive audit; internal audit; post-processing audit; program integrity; audit standards; audit techniques; audit tools; audit training; communications security; computer controls; computer security; SP500-19.

Data library; information; radiation; radiation analysis; RSIC; shielding; computer code; SP461, pp. 171-173 (Jan. 1977).

Data management; data processing; information management; information theory; coding; coding theory; computer storage; data compaction; data compression; data elements; SP50012.

Data management; software tool; ADP; automated data processing; computer software; data element dictionary; data element dictionary/directory; SP500-16.

Data management; software tool; computer software; data base management system; data element dictionary/directory; 16998.

Data output bus; high-speed line adaptor; HIS 6080; interactive terminal; probe point development; programmable monitor; stimulator; terminal data; data input bus; DATANET 355; SP500-18, pp. 95-105 (Sept. 1977).

Data processing; definitions; dictionary for information processing; Federal Information Processing Standards Publication; information processing; terms; vocabulary; computers; FIPS PUB 11-1.

Data processing; earthquake records; strong-motion data; accelerographs; SP470, pp. IV-53-IV-66 (Apr. 1977).

Data processing; Federal Information Processing Standards; geography; information processing standards; information system; representations and codes; standards; statistical data; ADP standards; computers; data elements and codes; FIPS PUB 10-2.

Data processing; group representations; measurements; near field; nonplanar; patterns; scanning; spherical; symmetry; antennas; arrays; coordinate transformations; 16671 :

Data processing; information management; information theory; coding; coding theory; computer storage; data compaction; data compression; data elements; data management; SP50012.

Data processing; robots; software engineering; computer engineering; computer networks; computers; 16903. 
Data processing terminal equipment; data transmission; Federal Information Processing Standards; serial-by-bit; serial-bycharacter; telecommunications; teleprocessing; American Standard Code for Information Interchange; ASCll; communications; FIPS PUB 16-1.

Data processing terminal equipment; data transmission (voice band); Federal Information Processing Standards; synchronous signaling rates; teleprocessing; data communication equipment; FIPS PUB 22-1.

Data record; multiple regression; processing time; regression model; blocking factor; SP500-18, pp. 143-1 58 (Sept. 1977).

Data reduction; eigenvalue equations; electromagnetic theory; group theory; near-field scanning; symmetry analysis; computer programs; 17222

Data reliability; gas phase; photoabsorption cross section; photochemistry; quantum yield; rate constant; stratospheric chemistry; chemical kinetics; data evaluation; 16976.

Data retrieval; file validation; name lookup; nonunique identifiers; personal data files; Privacy Act; probability model; fetrieval; SP500-2.

Data security; physical security; procedural security; risk analysis; risk assessment; systems security; ADP availability; annual loss expectancy; application system vulnerability; computer security; data confidentiality; data integrity; NBSIR 771228.

Data sources; laser chemistry; molecular spectra; atomic spectra; 16837 .

Data storage/retrieval; handbooks; mechanical properties; Mechanical Properties Data Center; structural metals and alloys; technical information; user awareness; SP463, pp. IV.8.1-IV.8.10 (Jan. 1977).

Data structure applications; COBOL; CODASYL; data base; data definition; data definition language; NBSIR 74-500.

Data systems; health records; information policy, management principles; medical records; privacy; recordkeeping practices; security; citizen rights; computers, confidentiality; SP469.

Data transmission; Federal Information Processing Standards; serial-by-bit; serial-by-character; telecommunications; teleprocessing; American Standard Code for Information Interchange; ASCII; communications; data communications equipment; FIPS PUB 16-1.

Data transmission; Federal Information Processing Standards; serial-by-bit; telecommunications; teleprocessing; American Standard Code for Information Interchange; ASCII; character parity sense; character structure; communications; FIPS PUB $17-1$.

Data transmission; Federal Information Processing Standards; parallel-by-bit; parity sense; serial-by-character; telecommunications; teleprocessing; American Standard Code for Information Interchange; ASCII; character structure; communications; FIPS PUB 18-1.

Data transmission tests, digital data; mobile digital equipment; modulation technique; transmission rate; voice channel; Allegheny County; SP480-19.

Data transmission (voice band); Federal Information Processing Standards; synchronous signaling rates; teleprocessing; data communication equipment; data processing terminal equipment; FIPS PUB 22-1.

Databooks; information analysis center; inquiry services; metals technology; structural materials; technical reports; ceramic technology; current awareness services; SP463, pp. IV.2.1IV.2.7 (Jan. 1977).

DATANET 355; data output bus; high-speed line adaptor; HIS 6080; interactive terminal; probe point development; programmable monitor; stimulator; terminal data; data input bus; SP500-18, pp. 95-105 (Sept. 1977).

Dataway; instrumentation; modules; nuclear; standards; CAMAC; 16678.

Daylighting; energy-conservation; insulation; shading; solarheating; ventilation; windows; air-tightness; BSS104.
Daylighting; infiltration; insulation; passive-solar-heating; sunshading; ventilation; windows; 17298 .

Dc current comparator; digital nanovoltmeter; resistance; resistance measurements; automated resistance measurement; automation; 16707.

DC measurements; frequency; metrology; if measurements; standards; superconductivity; thermometry; 16861 .

Dc substitution; microwave; power meter; bolometer; NBSIR 77-866.

D-c transmission; energy conservation; measurement methods; photovoltaic method; power-device grade silicon; resistivity variations; silicon; thermally stimulated capacitance; thermally stimulated current; thermally stimulated measurements; thyristor materials measurements; 17345 .

D-c transmission; energy conservation; measurement methods; photovoltaic method; power-device grade silicon; resistivity variations; silicon; thermally stimulated capacitance; thermally stimulated current; thermally stimulated measurements; NBSIR 77-1249.

D.C.-substitution technique; differential operational amplifiers; microwave power meter; self-balancing two amplifier power meter; bolometer; U.S. Patent 4,008,610.

DDC; Defense Documentation Center; DoD technical information; Information Analysis Centers; technical information; SP463, pp. IV.1.1-IV.1.5 (Jan. 1977).

Debond analysis; double-lap-joint analysis; fatigue tests; finite element analysis; joints; nonlinear analysis; single-lap-joint analysis; single-lap-joint bending; spotwelded joints; weldbonded joints; adhesive-bonded joints; bonded joints; cyclic loading; NBSIR 76-1053.

Debris; electron microscopy; particles; wear; x-ray emission; 16827.

Debye shielding; neutral phosphorus; Stark shifts; Stark widths; arc; 16950.

Debye temperature; elastic constant; invar; iron alloy; nickel alloy; Poisson's ratio; shear modulus; sound velocity; Young's modulus; bulk modulus; compressibility; 16869.

Debye temperature; elastic constants; Poisson's ratio; shear modulus; sound velocity; Young's modulus; bulk modulus; compressibility; copper alloy; 17320 .

Debye temperature; elastic constants; Poisson's ratio; shear modulus; single-crystal elastic coefficients; sound velocities; Young's modulus; zinc; bulk modulus; compressibility; JPCRD 6, No. 4, 1181-1204 (1977).

Debye temperature; Poisson's ratio; precipitation-hardening alloys; shear modulus; sound velocity; Young's modulus; aluminum alloys; bulk modulus; compressibility; 17085 .

Decay of resonance line; quenching rates; relaxation of mercury atoms; three body molecular formation; ${ }^{3} P_{0}$ and ${ }^{3} P_{1}$ atomic states; ${ }^{3} P_{0} \rightarrow{ }^{3} P_{1}$ collision rates; 17194 .

Decision analysis; fire; furniture fire; losses; residential fire; standard; upholstered furniture; cost plus loss; NBSIR 771381 .

Decision maker; decision model; information packaging; information processing; managment information; 16734 .

Decision making; public policy; regulation; building codes; SP473, pp. 203-223 (June 1977).

Decision model; information packaging; information processing; managment information; decision maker; 16734.

Decision table; decision theory; networks; specifications; standards; system engineering; building codes; computer model; SP473, pp. 285-316 (June 1977).

Decision tables; graph theory; performance specifications; standards; building codes; computer programming; 16705 .

Decision tables; graph theory; performance specifications; standards; building codes; computer programming; TN94O.

Decision theory; networks; specifications; standards; system engineering; building codes; computer model; decision table; SP473, pp. 285-316 (June 1977). 
Deduced neutron resonance parameters; neutron total cross sections; ${ }^{45} \mathrm{Sc}$ measured from 0.4 to $22 \mathrm{keV} ;{ }^{56} \mathrm{Fe}$ measured from 0.4 to $1000 \mathrm{keV}$; SP493, pp. 255-260 (Oct. 1977).

Deduced rms charge radius; $\mathrm{E}=28.8-95.0 \mathrm{MeV}$; measured $\sigma(E)$ at $\theta=75^{\circ}$; nuclear reactions; ${ }^{3} \mathrm{He}\left(\mathrm{e}, \mathrm{e}^{\prime}\right) ; 16850$.

Deep ocean research; federal science; governmental environment; laser energy; space flight; spectroscopy; SRM; television captioning; thermophysical; weights and measures; American electroplaters'; calorimeter; DIM/NBS 6I, No. 4, 1-32 (1977).

Defect crystal structures; inelastic neutron scattering; lattice dynamics; metal-hydrogen systems; palladium-deuteride $\left(\mathrm{PdD}_{\mathbf{0 . 6 3}}\right)$; phonon lineshapes; 16964.

Defects; dopants; impurities; junctions; MOS capacitors; sheet resistors; silicon; test structures; 16855.

Defendant and products liability; liability losses; products liability losses; SP487, pp. 247-252 (Aug. 1977).

Defense; E.R.D.A.; Federal agencies; interagency review; Interior; Library of Congress; materials; materials data; materials information; N.A.S.A.; U.S.D.A; Commerce; SP463.

Defense Documentation Center; DoD technical information; Information Analysis Centers; technical information; DDC; SP463, pp. IV.1.1-IV.1.5 (Jan. 1977).

Definition; standards; superconductor; critical current; 17074.

Definitions; dictionary for information processing; Federal Information Processing Standards Publication; information processing; terms; vocabulary; computers; data processing; FIPS PUB $11-1$.

Definitions; doors; glossary; security terms; windows; SP480-22.

Deflection; design; flexural strength; masonry walls; racking strength; seismic loading; shear strength; shear wall; stiffness; analysis; compressive strength; BSS62.

Deflections; dynamic tests; model; structural analysis; velocities; vibrations; arch dam; SP477, pp. VI-85-VI-117 (May 1977).

Degradation; fracture; indentation; strength; brittle solids; ceramic surfaces; 16672 .

Degradation mechanisms; multifilamentary superconductors; $\mathrm{NbTi}$; $\mathrm{Nb}_{3} \mathrm{Sn}$; strain; stress; critical current; critical current degradation; 16873 .

Dehydrogenation; ethylene; photoemission; tungsten; ultraviolet photoelectron spectroscopy; acetylene; adsorption; chemisorption; 16829.

Delayed coincidence; $g f$ value; imprisonment; lifetimes; mean life; resonance radiation; transition probability; ur; uranium; 17292.

Delayed response; dynamic; dynamic response; pressure step; pressure transducer; protective coatings; shock tube; tape; thermal protection; thermal radiant-energy response; thermal transient response; transducer; zero shift; coatings; TN961.

Delbrück scattering; Doppler broadening; electric quadrupole; giant resonances; photon scattering; polarized photons; resonance fluorescence; 16926.

Delbrück scattering; electromagnetic interactions; electron scattering; radiative corrections; total photon absorption cross sections; virtual photon theory; bremsstrahlung spectrum tip; TN955.

Delta ray; dose; ions; LET; model; neutron; OER; one-hit detector; pion; radiation; track; cell; SP46I, pp. 183-187 (Jan. 1977).

Demography; durability; durable goods; matrix model; population dynamics; population growth rate; production rate; scrappage rate; stable-age population; age distributions; 17053.

Dense liquid; mixture; modified Enskog theory; prediction; thermal conductivity coefficient; viscosity coefficient; corresponding states; 16791 .
Densification; glass; glass transition; hole theory; liquid; polymer; pressure; thermodynamic; compressibility; 16774.

Densification; glass; glass transition; liquid; polymer; pressure; $P V T$; pyrolysis; refractive index; thermal expansion; thermodynamic; compressibility; J. Res. 81A Nos. 2 and 3, 283297 (1977).

Densimeter; experimental; liquid, magnetic; modification; suspension; absolute measurements; barium ferrite buoy; 16792.

Densimeters; density reference system; liquid methane; LNG; TN698.

Densimeters; density reference system; liquid methane; LNG; NBSIR 77-852.

Densities; enthalpies; entropies; equation of state; internal energies; isobars; isochores; isotherms; Joule-Thomson inversion; latent heats of vaporization; melting line; orthobaric densities; propane; specific heats; speeds of sound; vapor pressure; NBSIR 77-860.

Densitometer (capacitance); density; dielectric constant; LNG; mixture(s); Clausius-Mosotti; 17071.

Density; density gradient; experimental; internal wave; laboratory; oscillating probe; conductivity probe; SP484, pp. 783-802 (Oct. 1977).

Density; deviation plots; ethane; experimental; isobutane; magnetic suspension densimeter; methane; normal butane; propane saturated liquid; tables; 16871 .

Density; dielectric constant; LNG; mixture(s); Clausius-Mosotti; densitometer (capacitance); 17071.

Density; electrical conductance; iodides; molten salt mixtures; standard reference data; surface tension; viscosity; bromides; data compilation; JPCRD 6, No. 2, 409-596 (1977).

Density; liquefaction; sand; soils; tests; undisturbed sampling; SP477, pp. VI-141 - VI-157 (May 1977).

Density; photography; reflectance; transmittance; wedges; calibration; 16683.

Density fluctuations; fluctuations; hydrodynamics; light scattering; liquid state; molecular dynamics; neutron scattering; shear wave; statistical mechanics; time correlation function; transverse current; ultrasonics; correlation function; 16711 .

Density gradient; experimental; internal wave; laboratory; oscillating probe; conductivity probe; density; SP484, pp. 783-802 (Oct. 1977).

Density reference system; liquid methane; LNG; cryogenic densimeters; TN697.

Density reference system; liquid methane; LNG; densimeters; TN698.

Density reference system; liquid methane; LNG; densimeters; NBSIR 77-852.

Density transform; expansion coefficient; Green's function; neutron; spherical; symmetric; transport; SP46I, pp. 87-90 (Jan. 1977).

Dental; expansion; investments; petrographic; thermal; 17325.

Dental amalgam; dental materials; development of testing procedures; mechanical properties; physical properties; specification testing; testing of dental materials; 17126 .

Dental applications; dental prosthetic materials; dental resins; future dental materials; macromolecules; plastics; polymers; sealants; adhesives; 17201 .

Dental caries; enamel; fluorapatite; fluoride; hydroxyapatite; solubility; chemical potential; 16739.

Dental materials; development of testing procedures; mechanical properties; physical properties; specification testing; testing of dental materials; dental amalgam; 17126 .

Dental materials; fire safety; metric; miniature electric field; organic sulfur; radiometric detector; smog formation; SRM's; air pollution; attic ventilation; data encryption; DIM/NBS 61 , No. 1 1, 1-32 (1977).

Dental polymers; dental resins; dentures; impression materials; prosthetic materials; resin teeth; restoratives; sealants; adhesives; 17120. 
Dental prosthetic materials; dental resins; future dental materials; macromolecules; plastics; polymers; sealants; adhesives; dental applications; 17201 .

Dental resins; dentures; impression materials; prosthetic materials; resin teeth; restoratives; sealants; adhesives; dental polymers; 17120 .

Dental resins; future dental materials; macromolecules; plastics; polymers; sealants; adhesives; dental applications; dental prosthetic materials; $1720 I$.

Dental restorations; deep ocean research; federal science; governmental environment; laser energy; space flight; spectroscopy; SRM; television captioning; thermophysical; weights and measures; American electroplaters'; calorimeter; DIMINBS 61, No. 4, 1-32 (1977).

Dentistry; dielectric measurements; dye lasers; dynamic calibration; electron microscopy; electronic technology; energy conservation; interferometric wavemeter; metric; pressure transducers; synchrotron radiation; building collapse; DIM/NBS 61 , No. 2, 1-32 (1977).

Dentures; impression materials; prosthetic materials; resin teeth; restoratives; sealants; adhesives; dental polymers; dental resins; $I 7 I 20$.

Depth dose; dosimetry; surface dose; air dose; arbitrary shaped field; back-scatter factor; Clarks' method; SP46I, Pp. 193 196 (Jan. 1977).

Depth-dose distributions; lateral-dose distributions; polystyrene; radiation dosimeters; radiation processing; radiochromic-dye films; 10-MeV electrons; aluminum; beef muscle; carbon; 16999.

Derivative operators; digital scan generator; isotropy; photographic processing; scanning electron microscopy; signal processing; 16988.

Desalination; distillation; hot sea water and materials; corrosion; SP463, Pp. V.2.1-V.2.6 (Jan. 1977).

Description of method; possible improvements; uncertainties in efficiency; SP493, pp. 234-236 (Oct. 1977).

Design; disaster mitigation; earthquakes; engineering; buildings; NBSIR 76-1/93.

Design; dynamic analysis; masonry; shear walls; codes; BSSI06, pp. 91-113 (Sept. 1977).

Design; earth shield; neutron spectra; shielding; shield thickness; calculation; concrete; cyclotron; SP461, PP. 166170 (Jan. 1977).

Design; earthquakes; harbours; ports; specifications; structures; SP470, Pp. VIII-42-VIII-55 (Apr. 1977).

Design; earthquakes; structural engineering; building codes; buildings; SP477, pp. VI-61 - VI-68 (May 1977).

Design; electrode/insulators; magnetohydrodynamics; materials; 16900.

Design; energy; legislation; solar; standards; State; architecture; buildings; NBSIR 77-1297.

Design; equivalent loads; tall buildings; wind loads; SP477, Pp. I-49-I-65 (May 1977).

Design; errors; fission neutrons; irradiation devices; measuring methods; neutron reactions; neutron sources; calibration; californium-252; cross sections; 16790.

Design; experiments; nonlinear response; reinforced concrete; bridges; SP477, pp. VI-1 - VI-9 (May 1977).

Design; factors in design; requirements in design; checklist for design; SP487, pp. 1-15 (Aug. 1977).

Design; failure avoidance; failure prevention; lubricants; materials of design; product liability; reliability of design; techniques of design; validation of design; coating materials; composite materials; $S P 487$.

Design; flexural strength; masonry walls; racking strength; seismic loading; shear strength; shear wall; stiffness; analysis; compressive strength; deflection; BSS62.

Design; graphics; cathode ray tubes; computer aided design; SP487, pp. 82-90 (Aug. 1977).
Design; housing; low income; low-rise buildings; sites and services; socio-economic; structural design; wind-resistant; architectural; BSSI00-5.

Design; nitrogen; safety; wind-tunnel; cryogenic; NBSIR 77. 857.

Design analysis; equipment specification; field standard; gravimetric calibration; liquid retention or clingage tests; precision; prover; Research Associate Program; standards inspection procedure; temperature correction; test measure; test measure evaluation; NBSIR 77-I 214 .

Design concepts; directories; fire prevention; fire research; hazard analysis; physics; building research; chemistry; combustion research; NBSIR 77-I264.

Design considerations; field testing; fuel gas measurement; fundamentals; gaseous hydrocarbons; installation; performance characteristics; turbine meter; SP484, pp. $871-880$ (Oct. 1977).

Design criteria; earthquake resistance; masonry construction; seismic design; structural design; structural engineering; structural research; building codes and standards; BSSI06.

Design criteria; earthquake resistance; limit states design; masonry construction; materials testing standardization; mathematical models; rehabilitation; retrofit; seismic design; structural design; structural research; BSSI06, pp. 40-59 (Sept. 1977).

Design criteria; earthquakes; hospitals; schools; building codes; building regulations; SP470; pp. VI-64-VI-73 (Apr. 1977).

Design criteria; fasteners; wind; architecture; buildings; connectors; NBSIR 77-1197.

Design criteria; mode of failure; rasking resistance; structural performance; uniform loads; concentrated loads; SP477, PP. I-66-I-69 (May 1977).

Design criteria; probability; progressive collapse; reliability; structural engineering; uncertainty; abnormal loading; alternate path; building code; BSS98.

Design guides; architectural criteria; automated system; building codes; buildings; computer applications; criteria maịntenance design evaluation; SP473, pp. 349-368 (June 1977).

Design guides; nuclear facilities; SP477, Pp. VII-29-VII-35 (May 1977).

Design implication; emergency actions; emergency communicative; emergency decisions; escape; fires; human behavior; human response; life safety; mapping; model; nursing homes; rescue; verbal communicative; alarm; architecture; NBSGCR-77-93.

Design of experiments; least squares; mass calibration; statistical design; weighing design; TN952.

Design procedures; earthquake excitation of structures; earthquake resistant structures; reinforcing details; structural walls; SP477, PP. VI-199-VI-219 (May 1977).

Design provisions; earthquakes; specifications; structural engineering; tunnels; aseismic design criteria; SP470, pp. VIII56-VIII-68 (Apr. 1977).

Design review; land use; municipalities; regulation; site design; architectural controls; buildings; SP473, Pp. 137-187 (June 1977).

Design standard; fluoroscopy; national standard; radiation safety; radiography; $x$-ray equipment; $x$-ray safety; $x$-ray tube; HI23.

Design standards; earthquake resistant structures; masonry; bricks; buildings; Canada; concrete blocks; BSSI06, pp. 198213 (Sept. 1977).

Design/build; life-cycle costing; project procurement; building performance; building prccess; building systems; construction management; SP476.

Desorption; displacement; hydrogen; photoemission; thermal desorption; tungsten; ultraviolet photoelectron spectroscopy; carbon monoxide; chemisorption; coadsorption; 16808. 
Detection; dosimetry; facilities; fluence; flux; moderation; monitor; neutron; shielding; sources; standardization; calibration; SP493, pp. 115-120 (Oct. 1977).

Detection; illumination; incapacitation; psychological deterrence; recognition; security lighting; security systems; visibility level; visual processes; contrast; SP480-27.

Detector; electrically calibrated detectors; laser power measurements; pyroelectric detectors; radiometry; silicon cell; silicon detector; silicon photodetector; absolute radiometry; TN954.

Detector; energy leakage; Monte Carlo; neutron; sandwich; spectrometry; surface barrier; ${ }^{6} \mathrm{LiF}$; SP461, pp. $252-254$ (Jan. 1977).

Detector; Monte Carlo; perspex; photon energy; pulse height; resolution; scattering media; tissue; water; SP461, pp. 188192 (Jan. 1977).

Detector based standards; electrically calibrated pyroelectric radiometer; optical calibration; optical radiation; pyroelectric radiometry; 16852.

Detector efficiency; neutron fluence; cross sections; SP493, pp. 227-233 (Oct. 1977).

Detector location; detectors; fire detectors; polyurethanes; polyvinyl chloride; room fíres; rooms; smoldering; wood; ceiling height; ceilings; cotton; NBS-GCR-77-86.

Detector location; fire detectors; fire growth; flaming fires; heat detectors; polyurethanes; polyvinyl chloride; smoke detéctors; smoldering fires; temperature rise; wood; ceiling height; ceilings; cotton; NBS-GCR-77-95.

Detector radiometry; detector response transfer instrumentation; radiometers; silicon detectors; absolute radiant power measurements; TN950.

Detector response transfer instrumentation; radiometers; silicon detectors; absolute radiant power measurements; detector radiometry; TN950.

Detector sensitivity; detector siting; heat detectors; ionization smoke detectors; photoelectric smoke detectors; residential fires; smoke detectors; tenability levels; 16882.

Detector sensitivity; detector siting; escape time; fire tests; gas detectors; heat detectors; residential fires; smoke detectors; NBS-GCR-77-82.

Detector siting; escape time; fire tests; gas detectors; heat detectors; residential fires; smoke detectors; detector sensitivity; NBS-GCR-77-82.

Detector siting; heat detectors; ionization smoke detectors; photoelectric smoke detectors; residential fires; smoke detectors; tenability levels; detector sensitivity; 16882 .

Detector uniformity; linearity; photodetectors; silicon detectors; absolute spectral response; 16754 .

Detectors; fire detectors; polyurethanes; polyvinyl chloride; room fires; rooms; smoldering; wood; ceiling height; ceilings; cotton; detector location; NBS-GCR-77-86.

Detectors; flux; neutrons; proton-recoil; scattering; standards; SP493, pp. 54-60 (Oct. 1977).

Detectors; National Measurement System; photometry; radiometry; sources; standards; survey; NBSIR 75-939.

Detectors; National Measurement System; radiometry; sources; survey; ultraviolet; NBSIR 75-941.

Deterioration; measurements; particulates; regulations; sulfur dioxide; air quality; 17141

Deterministic; dynamics; earthquake; probability; random vibrations; safety; structures; SP470, pp. VI-1-VI-21 (A pr. 1977).

Deuterated polystyrene-poly(methylmethacrylate); diblock copolymer; radius of gyration; small angle neutron scattering; conformation; 16817.

Deuterium; interlaboratory; lamp; radiance; radiometry; source; spectroscopy; standard; synchrotron; ultraviolet; wall-stabilized; arc; calibration; 17198.

Deuterium, collinear reactions; hydrogen, collinear reactions; kinetic isotope effects; potential surfaces; rate constants; transition state theory; transmission coefficient; collinear reactions; 16914.

Deuterium effect; fluorescence quantum yield; laser dyes; molecular structure; oxazine dyes; quenching; xanthene dyes; aminocoumarins; carbazine dyes; SP466, pp. 33-40 (May 1977).

Deuteron; pions; $\Delta$ components; $\Delta$ nucleus dynamics; $\pi D$ reactions; angular correlations; 17210 .

Deuterons; ionization; neutron spectra; NBSIR 77-1279, p. 30 (July 1977).

Developing countries; Guyana; less developed countries; measurement services; standardization; testing facilities; cottage industry; NBSIR 76-1180.

Developing economies; foreign relations; industrializing nations; international relations; LDS's; measurement services; standardization; AID; assistance; NBSIR 76-1152.

Development; forecasts; growth; housing needs; projections; BSS100-4.

Development of benchmarks; live test demonstrations; selection of ADPS; Air Force Academy; benchmark tests; SP500-18, pp. $71-74$ (Sept. 1977).

Development of testing procedures; mechanical properties; physical properties; specification testing; testing of dental materials; dental amalgam; dental materials; 17126 .

Deviation plots; ethane; experimental; isobutane; magnetic suspension densimeter; methane; normal butane; propane saturated liquid; tables; density; 16871 .

Device inspection; electron-beam-induced current; microelectronics; $p-n$ junctions; scanning electron microscopy; semiconductor devices; 16891 .

Device inspection; electron-beam-induced-current; microelectronics; $p-n$ junctions; scanning electron microscopy; semiconductor devices; 16971 .

Dew point; humidity; hygrometer; mixing ratio; relative humidity; two-pressure generator; volume ratio; water vapor; calibration; J. Res. 81A No. 1, 81-88 (1977).

Diagnostic radiography; exposure reduction; imaging information content; image processing; mammography; $x$-ray radiography; 16666.

Diagonally dominant; diagonally symmetrizable; eigenvalue; Hadamard product; $M$-matrix; 16909.

Diagonally symmetrizable; eigenvalue; Hadamard product; $M$ matrix; diagonally dominant; 16909.

Diblock copolymer; radius of gyration; small angle neutron scattering; conformation; deuterated polystyrenepoly(methylmethacrylate); 16817 .

Dicarbollide; metalloborane; metallocarborane; rhodium; ruthenium; boron hydride; carborane; 17152 .

Dictionary for information processing; Federal Information Processing Standards Publication; information processing; terms; vocabulary; computers; data processing; definitions; FIPS PUB 11-1.

Dielectric breakdown; ozone attack; atomic oxygen; chemiluminescent; corona discharge; 16995.

Dielectric breakdown suppression; discharge suppression; electronics; extended-range MIS C (V) measurements; high-voltage $C$ (V) measurements; MIS capacitor; premature dielectric breakdown; semiconductor devices; capacitance-voltage measurements; SP400-37.

Dielectric constant; dielectric relaxation; electret; glass ceramic; polarization; strontium titanate; 16798.

Dielectric constant; Josephson effect; lead; microwaves; niobium; superconductivity; tunnelling; 16946.

Dielectric constant; LNG; mixture(s); Clausius-Mosotti; densitometer (capacitance); density; 17071 .

Dielectric defect detection; electrophoretic decoration; integrated circuit quality control; selective chemical etching; semiconductor device reliability; corona charging decoration; SP400-31. 
Dielectric layers; irregularities; metallic thin films; microirregularities; overcoating; plasmons; scatter; absorption; SP466, pp. 133-148 (May 1977).

Dielectric loss; dissipation factor; high voltage; low temperature polymer; cryogenic; 16782 .

Dielectric loss; dissipation factor; epoxy insulation; high voltage; polymer tape insulation; superconducting cable; underground transmission; bridge measurements; cryogenic; 17014

Dielectric measurements; dye lasers; dynamic calibration; electron microscopy; electronic technology; energy conservation; interferometric wavemeter; metric; pressure transducers; synchrotron radiation; building collapse; computer security: DIM/NBS 61, No. 2, 1-32 (1977).

Dielectric relaxation; electret; glass ceramic; polarization; strontium titanate; dielectric constant; 16798.

Dielectric screening; photoelectron spectroscopy; relaxation; adsorption; 17218 .

Dielectric sheath; filtering antenna; resistive shield; antenna; antenna frequency response; U.S. Patent 4,008,477.

Dielectric-constant; electrets; electrocaloric effect; entropy; ferroelectrics; glass-ceramics; heat switches; magnetothermal conductivity; polarization; potassium tantalate; refrigeration; specific heat; strontium titanate; beryllium; ceramics; cryogenics; NBSIR 76-847.

Dielectrics; dividers; electric fields; electro-optics; high voltage measurement; insulating fluids; Kerr effect; nitrobenzene; pulse measurement; space charge; calibration; NBSIR 77 1317.

Diesel engine; engine-generator efficiency; heat recovery; performance; total energy systems; absorption chillers; boiler performance; central utility plant; NBSIR 77-1243.

Diesel engine performance; engine-generator efficiency; enginegenerator performance; heat recovery; total energy systems; NBSIR 77-1207.

Diethyl ether; dimethyl ether; ionization potential; photoionization; appearance potential; 17146 .

Difference; mass; records; set; surveillance limits; surveillance test; test interval; true mass; value; weighing design; weights; apparent mass; buoyancy; buoyancy correction; change; comparison; NBSIR 76-999.

Differential; elastic; multiple bias technique; neutron; scattering; cross section; SP461, pp. 64-66 (Jan. 1977).

Differential; electron; helium; ionization; measurements; cross section; 16810 .

Differential cross section; electron binding; gamma rays; Kshell; photons; Compton scattering; SP461, pp. 67-69 (Jan. 1977).

Differential cross sections; electron scattering; inelastic scattering; nitrogen molecules; resonances; scattering; vibrational excitation; close-coupling calculations; crossed beams; cross sections; 16740

Differential equations; flame chemistry; flame modeling; laminar flames; numerical solution of flame equations; combustion; NBSIR 76-994.

Differential operational amplifiers; microwave power meter; self-balancing two amplifier power meter; bolometer; D.C.substitution technique; U.S. Patent 4,008,610.

Differential pressure; flow measurement; mathematical modeling; meter performance; orifice meter; turbulence flow; closed conduit meter; SP484, pp. 491-522 (Oct. 1977).

Differential pressure; flow metering error; flow oscillations; jet flow; orifice meters; pulsating flow measurements; pulsations; turbulence; vortex; SP484, pp. 523-548 (Oct. 1977).

Differentials; distribution; gamma rays; integral; medium; Monte Carlo; albedo; angular; backscattering; barrier; SP46I, pp. 129-131 (Jan. 1977).

Diffraction; head diffraction; hearing aids; instruments for hearing; manikin; audiometry; 17064.
Diffraction; isotopes; molecular dynamics; neutron; nuclear reactor; radiation; activation analysis; crystal structure; TN939.

Diffraction theory; error analysis; Liouville-Green approximation; ordinary differential equation; turning point; asymptotic analysis; Bessel functions; boundary-value problem; connection formula; 16805 .

Diffraction topography; dynamical diffraction theory; ferromagnetic domain walls; nickel single crystals; $x$-ray dynamical diffraction; crystal growth; crystal perfection; 16974.

Diffraction topography; dynamical images; imperfect crystals; perfect crystals; $x$-ray dynamical diffraction; contrast conditions; 16977.

Diffuse reflectance; diffuse transmission; reflectance standards; scattering surfaces; bidirectional radiometry; canopies; SP466, pp. 87-93 (May 1977).

Diffuse reflectance; directional reflectance; nomenclature of reflectance; optical reflection; reflectance; reflectance factor; reflectance geometry; reflectance nomenclature; reflection; specular reflectance; sub-surface scattering; Monogr. 160.

Diffuse reflectance; error analysis; reflectance; reflectance factor; spectrophotometry; absolute reflectance; J. Res. 82, No. 1, 29-55 (1977).

Diffuse reflectance; fluorescence; instrumentation; luminescence; quantum yield; spectrophotometry; standard reference materials; standardization; accuracy; critical parameters; SP466.

Diffuse reflectance; Kubelka-Munk function; reflectance; reflectance standards; thin layer chromatography; chromatography; color matching; color measurement; SP466, pp. 41-55 (May 1977).

Diffuse reflectance; radiative transfer; reflectance spectra; scattering coefficients; statistical models; absolute absorptivities; continuum models; SP466, pp. 57-73 (May 1977).

Diffuse reflectance spectra; magnesium oxide; opal glass; radiant flux; reflectance standards; standards calibration; barium sulfate; SP466, pp. 75-85 (May 1977).

Diffuse transmission; reflectance standards; scattering surfaces; bidirectional radiometry; canopies; diffuse reflectance; SP466, pp. 87-93 (May 1977).

Diffuser; interference filters; spectral responsivity; spectral transmittance; television camera tubes; television cameras; test methods; 16761 .

Diffusion; drift tube; electron; Monte Carlo; transport coefficient; 16854.

Diffusion; electromigration; liquid metals; nitrogen; phosphorus; ternary diffusion; thermomigration; alloys; antimony; arsenic; bismuth; copper; JPCRD 6, No. 1, 1-50 (1977).

Diffusion; hydrogen; lattice dynamics; metals; neutron scattering; quasielastic scattering; review; 16970.

Diffusion; kernel; lattice vibration; model; moderator; neutron; scattering; thermalization; cross section; SP461, pp. 149-162 (Jan. 1977).

Diffusion; neutron; NIOBE; Rapsodie; reactor; shielding; transport calculation; approximations; SP461, pp. 163-165 (Jan. 1977).

Diffusion cell; formaldehyde; instrumentation; pyrolysis; reactive gases; acetaldehyde; acrolein; calibration; 16699.

Diffusion in metals; fire; journals; library holdings, NBS Library; NBS periodicals; periodicals; proceedings; serials; standards; transactions; annual reports; NBSIR 77-12I5.

Digital clock; satellite clock system; satellite controlled clock; satellite time code reception; clock comparison and reset; U.S. Patent 4,014,166.

Digital communications; guideline; law enforcement equipment report; Law Enforcement Standards Laboratory; mobile digital equipment; National Institute of Law Enforcement and Criminal Justice; communications; 16996. 
Digital compensation techniques; fossil fuel limitations; linear specific gravity compensation; positive displacement flowmeters; turbine flowmeters; SP484, pp. $821-846$ (Oct. 1977).

Digital data; electromagnetic interference; electromagnetic noise; emergency communications; Fast Fourier Transform; impulsive noise; magnetic field strength; measurement instrumentation; portable spectrum analyzer; spectral density; timedependent spectral density; 17175 .

Digital interfaces; Harris computer; branch driver; CAMAC; CAMAC standards; computer interfaces; 16806.

Digital nanovoltmeter; resistance; resistance measurements; automated resistance measurement; automation; dc current comparator; 16707.

Digital scan generator; isotropy; photographic processing; scanning electron microscopy; signal processing; derivative operators; 16988.

Dilution method; discharge measurement in pipes; method of mixtures; mixing; tracer technique; SP484, pp. 395-421 (Oct. 1977).

Dimensional coordination; metrication; metric system; modular coordination; Sl; building codes and standards; construction industry; SP458.

Dimensional metrology; exact fringes; fractional fringe; interferometer; length measurement; partial fringe; wavelength measurement; 17048.

Dimensional standards; filar eyepiece; linewidth measurements; micrometer eyepiece; microscope calibration; optical microscope; photomasks; photomask metrology; optical microscope; shearing eyepiece; 17063.

Dimer; double resonance; mercury excimers; optically excited; spectra; two photon; 17076.

Dimer laser; electronic transition laser; laser; laser kinetics; laser spectroscopy; optical pumping; 17318.

Dimeric configuration; stannous compounds; stannous phosphate; tin coordination; crystal structure; 17095.

Dimers; discharge; lasers; mercury excimers; spectra; two photon; 17192.

Dimethyl ether; ionization potential; photoionization; appearance potential; diethyl ether; 17146 .

Dimethyl-p-toluidine; hydroquinone leachable monomer; residual components in cements; residual methyl methacrylates; analysis of acrylics; benzoyl peroxide determination; bone cement; chemical composition of bone cement; 17202 .

Diode detector; diode model; temperature compensation; 16724.

Diode model; temperature compensation; diode detector; 16724.

Dioxirane; ethylene; mass spectrometry; ozone; air pollution; chemical kinetics; 17327.

Dipolar gas; numerical integration; polyatomic molecule; Pople expansion; quadrupolar gas; second virial coefficient; J. Res. 82, No. 2, 123-127 (1977).

Dipole antenna; dynamic range; electric field probe; isotropic probe; loop antenna; magnetic field probe; tangential sensitivity; broadband probe; NBSIR 77-868.

Dipole moment; electron scattering; electrostatic potential; intermediate neglect of differential overlap (INDO); molecular orbital theory; quantum chemistry; static potential; carbon monoxide molecules; 16709.

Dipole moment; excimer; excitation energy; perturbation formula; rare gas halide; Rittner model; transition moment; 17151 .

Dipole moment; infrared spectroscopy; laser absorption; laserStark resonance; molecular spectra; Stark effect; cyanogen fluoride; 17124.

Dipole orientation; piezoelectricity; polarization; polyvinylidene fluoride; pyroelectricity; vinylidene fluoride copolymer; charge distribution; charge transfer; corona poling; NBSIR 76-1186.
Di-p-tolyldisulfide-1,2-dioxide; mass spectrometry; nuclear magnetic resonance; $p$-toluenesulfonylhydrazine; 1,2-di( $p$ toluenesulfonyl)hydrazine; chemical ionization mass spectrometry; 17045 .

Direct voltage measurements; high voltage measurements; Kelvin-Varley divider; ratio standard; voltage dividers; volt boxes; 16713 .

Direct-current; dopant density; ion implantation; MOSFET; silicon; 17342.

Directional radiant temperature; mean radiant temperature; radiation measurement; radiometer; thermal comfort; thermal radiation; SP491, pp. 117-130 (Sept. 1977).

Directional reflectance; nomenclature of reflectance; optical reflection; reflectance; reflectance factor; reflectance geometry; reflectance nomenclature; reflection; specular reflectance; sub-surface scattering; bidirectional reflectancedistribution function; Monogr. 160.

Directories; fire prevention; fire research; hazard analysis; physics; building research; chemistry; combustion research; design concepts; NBSIR 77-1264.

Directories; information resource; National Referral Center; referral; scientific and technical information; thesaurus; computerized information system; SP463, pp. VIII.2.1-VIII.2.4 (Jan. 1977).

Disaster; dynamic analysis; earthquakes; ground failures; hydraulic structures; seismicity; soils; standards; structural response; vessels and wind; accelerograph; bridges; buildings; codes; SP470.

Disaster; dynamic analysis; earthquakes; ground failures; nuclear facilities; seismicity; soils; standards; structural response; winds; accelerograph; bridges; buildings; codes; SP477.

Disaster communication; emergency communications; fire communications; high-rise communications; high-rise emergency; information transfer; occupant needs; sensory stimuli; communications; 17036.

Disaster mitigation; earthquakes; engineering; buildings; design; NBSIR 76-1193.

Disaster mitigation; housing; low-rise buildings; socioeconomics; structural connections; wind loads; codes and standards; SP477, pp. I-70-I-78 (May 1977).

Disaster mitigation; housing; low-rise buildings; socioeconomics; structural connections; technology transfer; wind loads; codes and standards; BSS100-1.

Disasters; structural engineering; tides; wind; buildings; cyclones; SP477, pp. V-21-V-53 (May 1977).

Discharge; lasers; mercury excimers; spectra; two photon; dimers; 17192.

Discharge lamp; lasers; optogalvanic effect; spectroscopy; wavelength calibration; bandwidth determination; 17287 .

Discharge measurement in pipes; method of mixtures; mixing; tracer technique; dilution method; SP484, pp. 395-42 1 (Oct. 1977).

Discharge suppression; electronics; extended-range MIS C (V) measurements; high-voltage $\mathrm{C}$ (V) measurements; MIS capacitor; premature dielectric breakdown; semiconductor devices; capacitance-voltage measurements; dielectric breakdown suppression; SP400-37.

Discontinuous swelling; unconventional diffusion; velocity of concentration front propagation; concentration dependent diffusion coefficient; concentration front; J. Res. 81 A Nos. 2 and 3, 243-250 (1977).

Discrete ordinates; intermediate energy; measurement assurance; neutron standard; reaction rates; benchmark spectrum; SP493, pp. 329-334 (Oct. 1977).

Disk modelling; event model; measurement; modelling; resource dependency; system capacity; validation; credit authorization system; critical resource; SPSOO-18, pp. $185-$ 211 (Sept. 1977). 
Dislocation clusters; dynamical diffraction; magnetic domains; magnetic domain walls; melt-grown crystals; nickel single crystals; $x$-ray diffraction topography; anomalous transmission effect; asymmetric crystal topography; crystal imperfections; crystal perfection; 16997.

Disorder; magnesium incorporation; phosphate; vacancies; betatricalcium phosphate; cation substitution; coordination; crystal structure; 17259 .

Disordered system; dynamic susceptibility; Ginzburg-Landau free energy; relaxation time; 17122 .

Dispatching algorithms; synthetic benchmarking; benchmarking; SPSO0-18, pp. 119-135 (Sept. 1977).

Dispersion curves; high pressure; $\mathrm{KBr}$; mode Gruneisen parameters; neutron scattering; anharmonicity; 17001 .

Displacement; hydrogen; photoemission; thermal desorption; -tungsten; ultraviolet photoelectron spectroscopy; carbon monoxide; chemisorption; coadsorption; desorption; 16808.

Displacements; field tests; wind measurements; winds; wind speed; bridges; SP470, pp. Il-20-11-46 (Apr. 1977).

Displacements; flutter; models; wind angles; wind tunnel; bridge; cabled stayed; SP470, pp. II-47-1I-67 (Apr. 1977).

Displacements; intensity; seismic records; velocity; data; SP477, pp. VI-179-V1-191 (May 1977).

Disproportionation; low temperature; radical; allylic; combination; 16966.

Dissemination; frequency; geosynchronous satellite; measurement; standards; television; time; atomic clocks; 17182.

Dissipation factor; epoxy insulation; high voltage; polymer tape insulation; superconducting cable; underground transmission; bridge measurements; cryogenic; dielectric loss; 17014.

Dissipation factor; high voltage; low temperature polymer; cryogenic; dielectric loss; 16782.

Dissociation; electron; excitation; hydrogen; Balmer-alpha; collision; cross section; 17054 .

Dissociation; hydrogen; inelastic; molecular potential; recombination; scattering; theoretical; theory; argon; collisions; 16802.

Dissociation collisions; hydrogen; theory; vibrational and rotational enhancement; argon; cross section; 16803.

Dissociation energy; Dunham coefficients; Franck Condon factors; molecular lithium; potential curve; spectroscopy; 17101 .

Dissociation energy; energy curve; overlap; van der Waals; XeF; charge transfer; 16684.

Dissolution; hydroxyapatite; ion pairs; solubility; solubility isotherms; solubility product; thermal coefficient of solubility; thermodynamics; tooth mineral; J. Res. 81A Nos. 2 and 3, 273-281 (1977).

Distance coordinates; Euclidean plane; matrices of order three; triangle of reference; barycentric coordinates; J. Res. $81 \mathrm{~B}$ Nos. 1 and 2, 61-72 (1977).

Distance measurement; earth tides; laser strainmeter; surveying; 17199.

Distillation; hot sea water and materials; corrosion; desalination; SP463, pp. V.2.1-V.2.6 (Jan. 1977).

Distortion; limiting resolution; shading; signal-to-noise ratio; spectral response; standards; television cameras; total response; contrast transfer function; 17233.

Distributed processing; monitoring systems; physical security; sensor systems; adversary scenarios; automated response systems; NBSIR 77-1262.

Distribution; dose; electron; Gaussian; Monte Carlo; scattering; aluminium; carbon; collision; copper; SP461, pp. 106-109 (Jan. 1977).

Distribution; dose rate; gamma rays; Monte Carlo; photon; albedo; backscattering; SP461, pp. $110-118$ (Jan. 1977).

Distribution; gamma rays; integral; medium; Monte Carlo; albedo; angular; backscattering; barrier; differentials; SP461, pp. 129-131 (Jan. 1977).

Distributions; neutrons; resolution; spectra; uncertainties; yield; NBSIR 77-1279, pp. 15-18 (July 1977).
Dithiotungstate; hydrolysis; infrared spectroscopy; rare earths; rare earth tungstate; tungstates; $\mathrm{x}$-ray powder patterns; 17137.

Dividers; electric fields; electro-optics; high voltage measurement; insulating fluids; Kerr effect; nitrobenzene; pulse measurement; space charge; calibration; dielectrics; NBSIR 77 1317.

DNT; EGDN; electron-capture gas chromatography; measurements; TNT; vapor pressures; 16825.

DNT; EGDN; explosive detection; limits of detection; sensitivity test; TNT; vapor generator; vapor pressure; 16830 .

Document dissemination; government reports; NTIS; patent licensing; technical reports; computerized information system; SP463, pp. V11.3.1-V11.3.5 (Jan. 1977).

Documentation; documentation content guidelines; F1PS guidelines; software, symposium proceedings; automated data systems; computer programs; SP500-15.

Documentation; image content language; image processing; pattern recognition; prototype images; standards; automation; calibration; data formats; SPSO0-8.

Documentation content guidelines; FIPS guidelines; software, symposium proceedings; automated data systems; computer programs; documentation; SPSO0-1S.

DoD technical information; Information Analysis Centers; technical information; DDC; Defense Documentation Center; SP463, pp. IV.1.1-IV.1.5 (Jan. 1977).

Dodecanol; linear polyethylene; Mark-Houwink equation; NBS Standard Reference Material 1475; theta solvents; 3,3,5trimethylhexyl acetate; biphenyl; chain dimensions; 16710 .

Do-it-yourself; home construction; housing; rehabilitation; remodeling; renewal; renovation; self-help; standards; building codes; building regulation; NBS-GCR-77-88.

Dominating set; enclaveless set; graph; hypergraph; König System; KM-System; Menger System; MK-System; J. Res. 82, No. 3, 197-202 (1977).

Door assemblies; door components; doors; frames; hardware; hinges; locks; security standards; burglary resistance; 16714 .

Door components; doors; frames; hardware; hinges; locks; security standards; burglary resistance; door assemblies; 16714.

Door switch; mechanically actuated switch; perimeter sensor; switch; burglar alarm sensor; burglar alarm system; 17002.

Doors; frames; hardware; hinges; locks; security standards; burglary resistance; door assemblies; door components; 16714.

Doors; glossary; security terms; windows; definitions; SP480-22.

Dopant density; electron mobility; ionized impurity scattering mobility; lattice mobility; neutral impurity scattering mobility; n-type silicon; resistivity; scattering mechanisms; temperature; $S P 400-33$.

Dopant density; electron-electron scattering; electron mobility; ionized impurity scattering; lattice scattering; neutral impurity scattering; $n$-type silicon; resistivity; temperature; 17147.

Dopant density; Gaussian diffusion; p-n junction; semiconductors; silicon; capacitance-voltage measurements; 17328.

Dopant density; ion implantation; MOSFET; silicon; direct-current; 17342.

Dopant profiles; electrical properties; electronics; four-probe method; hermeticity; ion implantation; Irvin's curves; leak tests; line-width measurement; measurement methods; microelectronics; optical flying-spot scanner; oxidation particle impact noise detection test; SP4OO-29.

Dopants; impurities; junctions; MOS capacitors; sheet resistors; silicon; test structures; defects; 16855 .

Doppler broadening; electric quadrupole; giant resonances; photon scattering; polarized photons; resonance fluorescence; Delbrïck scattering; 16926.

Doppler broadening; one perturber limit; pressure broadening; analysis of correlated profiles; classical theory; 17161 .

Dose; dosimetry; monitor; neutron; shielding; spectrum; computer code; SP461, pp. 238-246 (Jan. 1977). 
Dose; dosimetry; Monte Carlo; organ; phantom; photon; reciprocity theorem; source; target; tissue; SP461, pp. 177 182 (Jan. 1977).

Dose; electron; Gaussian; Monte Carlo; scattering; aluminium; carbon; collision; copper; distribution; SP461, pp. 106-109 (Jan. 1977).

Dose; ESR; gamma ray; glow curve; irradiation; TL; $\mathrm{CaSO}_{4}$; correlation; SP461, pp. 234-237 (Jan. 1977).

Dose; gamma rays; $\mathrm{LiF}$; response; sensitivity; supralinear; thermoluminescence; SP461, pp. 227-230 (Jan. 1977).

Dose; ions; LET; model; neutron; OER; one-hit detector; pion; radiation; track; cell; delta ray; SP461, pp. 183-187 (Jan. 1977).

Dose distributions; dosimetry; dyed plastics; plastic films; polyvinyl acetate; polyvinyl butyral; polyvinyl chloride; polyvinyl pyrrolidone; radiation dosimetry; radiation processing; radiochromic dyes; triphenylmethane dyes; cellulose acetate; 16949 .

Dose distributions; dosimetry; electron beams; gamma radiation; plastic films; quality control; radiation processing; radiochromic dyes; sterilization; 17000 .

Dose distributions; dosimetry; electron beams; food irradiation; Fricke dosimetry; gamma rays; $x$ rays; absorbed dose; calorimetry; 17343.

Dose equivalent; elements, transuranic; glove box; intercomparison; neutrons, high energy; neutrons, low energy; nonuniform exposures; quality factor; standards; criteria, accuracy; criteria, performance; SP493, pp. 101-105 (Oct. 1977).

Dose equivalent; energy; gamma rays; neutron; scattering; shield; transmission; 252 Cf; ANISN; code; configuration; SP461, pp. 119-123 (Jan. 1977).

Dose rate; gamma rays; Monte Carlo; photon; albedo; backscattering; distribution; SP461, pp. $110-118$ (Jan. 1977).

Dosimeter; dosimetry; efficiency; gamma ray; kerma; neutron; charged particle; SP461, pp. 209-218 (Jan. 1977).

Dosimeter calibration; electronic devices; ionizing radiation; radiation dosimetry; radiation hardness testing; radiation sources; thermoluminescence dosimeters; total dose; NBSIR 76-1135.

Dosimeter calibration; monoenergetic neutrons; neutron beams; neutrons; resonant scatterer; SP493, pp. 250-254 (Oct. 1977).

Dosimeter calibrations; energy; energy related inventions; heterodyne receiver; international standards code; NCSL; NMR knight shifts; neutron beams; piezo-flex micropositioning; pressure; thermodynamic tables; coal conversion; DIM/NBS 61, No. 7, 1-32 (1977).

Dosimetry; dye dosimeters; electron beams; gamma rays; pararosaniline cyanide; pulse radiolysis; radiochromic dyes; calorimetry; chemical dosimetry; 16984 .

Dosimetry; dyed plastics; plastic films; polyvinyl acetate; polyvinyl butyral; polyvinyl chloride; polyvinyl pyrrolidone; radiation dosimetry; radiation processing; radiochromic dyes; triphenylmethane dyes; cellulose acetate; dose distributions; 16949.

Dosimetry: $\mathrm{E}_{d}=40 \mathrm{MeV} ; \mathrm{E}_{n}>2 \mathrm{MeV}$; measured thick-target neutron yields, $\mathrm{Be}(\mathrm{d}, \mathrm{n}), \mathrm{Li}(\mathrm{d}, \mathrm{n}) ; \theta=0-90^{\circ} ; N B S I R$ 77-1279, pp. 24-29 (July 1977).

Dosimetry; efficiency; gamma ray; kerma; neutron; charged particle; dosimeter; SP461, pp. 209-218 (Jan. 1977).

Dosimetry; electron beams; food irradiation; Fricke dosimetry; gamma rays; $x$ rays; absorbed dose; calorimetry; dose distributions; 17343 .

Dosimetry; electron beams; gamma radiation; plastic films; quality control; radiation processing; radiochromic dyes; sterilization; dose distributions; 17000 .

Dosimetry; electrons; neutrons; photons, radiation physics; symposium; cross sections; SP461.
Dosimetry; energy per ion pair; fluence; kerma factor; neutrons; activation; Bragg-Gray; SP493, pp. 342-346 (Oct. 1977).

Dosimetry; energy spectra; high energy; LET; neutrons; yields; NBSIR 77-1279, pp. 19-23 (July 1977).

Dosimetry; facilities; fluence; flux; moderation; monitor; neutron; shielding; sources; standardization; calibration; detection; SP493, pp. 115-120 (Oct. 1977).

Dosimetry; fission; flux; measuring techniques; neutrons; standards; cross section standards; SP493.

Dosimetry; licensing; measurements; nuclear power; SP493, pp. 137-145 (Oct. 1977).

Dosimetry; $\mathrm{Li}(\mathrm{d}, \mathrm{n})$ source; $\mathrm{Li}(\mathrm{p}, \mathrm{n})$ source; neutron angular distributions; neutron energy distributions; neutrons; nuclear reactions; thick-target yields; $\operatorname{Be}(d, n)$ source; $B e(p, n)$ source; $\mathrm{C}(\mathrm{d}, \mathrm{n})$ source; $\mathrm{D}(\mathrm{d}, \mathrm{n})$ source; NBSIR 77-1279.

Dosimetry; monitor; neutron; shielding; spectrum; computer code; dose; SP461, pp. 238-246 (Jan. 1977).

Dosimetry; Monte Carlo; organ; phantom; photon; reciprocity theorem; source; target; tissue; dose; SP461, pp. 177-182 (Jan. 1977).

Dosimetry; neutron flux standard; pulse reactor calibration; radiation effects; californium-252; SP493, pp. 335-341 (Oct. 1977).

Dosimetry; surface dose; air dose; arbitrary shaped field; backscatter factor; Clarks' method; depth dose; SP461, pp. 193196 (Jan. 1977).

Dosimetry units; photon dosimetry; radiation; solid state dosimetry; SP461, pp. 197-208 (Jan. 1977).

Double balanced mixer; isolation amplifier; phase-lock loop; phase noise; correlation; 17185 .

Double resonance; mercury excimers; optically excited; spectra; two photon; dimer; 17076.

Doubled hermetic enclosure; gas infusion of leaks; hermeticity; leak detection; semiconductor hermeticity; 16935.

Double-lap-joint analysis; fatigue tests; finite element analysis; joints; nonlinear analysis; single-lap-joint analysis; single-lapjoint bending; spotwelded joints; weldbonded joints; adhesivebonded joints; bonded joints; cyclic loading; debond analysis; NBSIR 76-1053.

Double-mode Cepheids; Fourier analysis of stellar variations; mode interaction; stellar instabilities; $U$ Trianguli Australis; beat Cepheids; 16807.

Double-mode Cepheids; Fourier analysis of stellar variations; mode interaction; stellar instabilities; $U$ Trianguli Australis; beat Cepheids; 17118 .

Double-mode Cepheids; mode interaction; pulsation; stellar instabilities; TU Cassiopeiae; Cepheids; beat Cepheids; 17315.

Douglas Fir; inhalation; mice; polyurethane; pulmonary irritation; PVC; respiratory rate; sensory irritation; stress index; thermal decomposition products; toxicity; acute lethality; $N B S-G C R-77-85$.

Drainage-waste-vent; economics; life cycle; performance standards; pipe; plumbing; reduced-size vents; sanitary drainage system; venting; cost savings; 17296 .

Drained weight; laws and regulations; metrication; national laboratory accreditation; retail meat identity standards; tolerance application; vapor recovery; weights and measures; checking prepackaged commodities; computer assisted check-out systems; consumer affairs; SP471.

$\boldsymbol{\gamma}$-rays; neutron capture; spectroscopy; applications past and future; 16951 .

Drift; face shells, reinforcing splices; high lift grouting; shotcrete, surface wave instrumentation; veneer anchorage; allowable bolt loads, end distance, edge distance and spacing; BSS106, pp. 259-274 (Sept. 1977).

Drift tube; electron; Monte Carlo; transport coefficient; diffusion; 16854.

Drift tube; ion; Monte-Carlo; swarm; theory; velocity distribution; 16779. 
Drill pipe; failure; Kaiser Effect; pressure vessels; sources; acoustic emission; crack growth; SP487, pp. 210-238 (Aug. 1977).

Drop ball test; flaw distribution; fracture; impact resistance; ophthalmic lenses; statistics; 16979.

Drop calorimetry; emittance; enthalpy; heat capacity; highspeed measurements; high temperature; molybdenum; pulse calorimetry; standard reference material; thermodynamic functions; SP260-55.

Droplet; moving boundary problem; preheat; transient heat conduction; confluent hypergeometric functions; J. Res. 81A Nos. 2 and 3, 257-266 (1977).

Droplet size; droplet trajectory; evaporative cooling; fire suppression; full-scale test; gas temperature; oxygen content; recirculating flow; reduced scale model test; scaling criteria; spray water flow rate; water spray; automatic sprinklers; compartment fire; NBSIR 77-1287.

Droplet trajectory; evaporative cooling; fire suppression; fullscale test; gas temperature; oxygen content; recirculating flow; reduced scale model test; scaling criteria; spray water flow rate; water spray; automatic sprinklers; compartment fire; NBSIR 77-1287.

Drug regulation; pharmaceutical regulation; phase IV; post marketing surveillance; regulatory experiments; system design; adverse reaction detection; biostatistics; NBS-GCRETIP 76-35.

Duct; fundamental mode; liquid; perfect gas; propagation; shear; transverse gradient; wavenumber; 17215 .

Duct; gamma ray; integration; kernel; radiation; streaming; annular; computation; SP461, pp. 132-135 (Jan. 1977).

Ductile cast-iron; soils; statistical analysis; underground; carbon steel; corrosion; 16745.

Ductility; earthquake resistance; energy absorption; modulus of elasticity; partial reinforcing; risk; shear modulus; testing; ultimate strength; anchor bolts; bond; damping; BSS106, pp. 255-258 (Sept. 1977).

Ductility; failure; fractography; fracture tests; hydrogen; steels; stress corrosion; crack propagation; 16700.

Ductility; full scale testing; high-rise masonry; scale factors; shear walls; current research; BSS106, pp. 314-326 (Sept. 1977).

Dummies; guidebook; testing; anthropomorphic dummies; building safety; NBS-GCR-77-91.

Dunham coefficients; Franck Condon factors; molecular lithium; potential curve; spectroscopy; dissociation energy; 17101.

Dunham coefficients; infrared absorption; molecular physics; short-lived molecular species; vibration-rotation spectra; carbon monosulfide; 17044 .

Durability; durable goods; matrix model; population dynamics; population growth rate; production rate; scrappage rate; stable-age population; age distributions; demography; 17053.

Durability; electrical; environment; housing technology; HVAC; innovative construction; maintainability; materials; minimum property standards; performance criteria; performance evaluation; plumbing; safety; structures; test methods; acoustics; appliances; atmospheric; NBSIR 77-1316.

Durability; fatigue; fiber length; flexing; low cycle fatigue; mechanical properties; microstructure; modelling; paper; pore size; statistical analysis; Weibull distribution; 16681 .

Durability; flexing; paper; 17241 .

Durability/reliability; fire safety; rating criteria; solar collectors; structural performance; testing procedures; thermal performance; NBSIR 77-1305.

Durable goods; matrix model; population dynamics; population growth rate; production rate; scrappage rate; stable-age population; age distributions; demography; durability; 17053 .

Dwellings; earthquakes; seismic design criteria; building codes; buildings; construction; SP470, pp. VI-74-VI-88 (Apr. 1977).
Dye binding; human albumin; membrane; reflection coefficient; ultrafiltration; continuous binding curve; 16959.

Dye dilution method; error analysis; flow rate measurement; open channel flow measurement; power plant; spray canal; stage-discharge equation; velocity-area method; weir equation; closed-loop cooling system; cooling lake; SP484, pp. 145-172 (Oct. 1977).

Dye dilution method; flume calibration; turbidity variations; validity testing; water soluble tracers; SP484, pp. 361-394 (Oct. 1977).

Dye dosimeters; electron beams; gamma rays; pararosaniline cyanide; pulse radiolysis; radiochromic dyes; calorimetry; chemical dosimetry; dosimetry; 16984.

Dye laser; flame analysis; flame fluorescence; laser; opto-galvanic effect; spectroscopy; tunable laser; 16691.

Dye laser; frequency stabilization; iodine; saturated absorption; 17178

Dye lasers; dynamic calibration; electron microscopy; electronic technology; energy conservation; interferometric wavemeter; metric; pressure transducers; synchrotron radiation; building collapse; computer security; cryogenic temperature; DIM/NBS 61, No. 2, 1-32 (1977).

Dyed plastics; plastic films; polyvinyl acetate; polyvinyl butyral; polyvinyl chloride; polyvinyl pyrrolidone; radiation dosimetry; radiation processing; radiochromic dyes; triphenylmethane dyes; cellulose acetate; dose distributions; dosimetry; 16949.

Dye-dilution methods; errors in flow measurement; flow measurement; fluid flow modeling; fluid velocity; flumes; gas flow standard; hot-wire anemometry; international flow standards; laser anemometry; open channel flows; orifice meters; pitotstatic meters; SP484, Volumes 1 and 2.

Dynamic; dynamic response; pressure step; pressure transducer; protective coatings; shock tube; tape; thermal protection; thermal radiant-energy response; thermal transient response; transducer; zero shift; coatings; delayed response; TN961.

Dynamic; frequency response; hysteresis; precision; pressure measurement; sensitivity; stability; thermal effects; zero-shift; accuracy; calibration; cryogenic; 17081 .

Dynamic analysis; earthquakes; ground failures; hydraulic structures; seismicity; soils; standards; structural response; vessels and wind; accelerograph; bridges; buildings; codes; disaster; SP470.

Dynamic analysis; earthquakes; ground failures; nuclear facilities; seismicity; soils; standards; structural response; winds; accelerograph; bridges; buildings; codes; disaster; SP477.

Dynamic analysis; masonry; shear walls; codes; design; BSS106, pp. 91-113 (Sept. 1977).

Dynamic behavior; earthquakes; response spectra; soils; acceleration records; SP477, pp. III-4I-III-56 (May 1977).

Dynamic calibration; electron microscopy; electronic technology; energy conservation; interferometric wavemeter; metric; pressure transducers; synchrotron radiation; building collapse; computer security; cryogenic temperature; dentistry; DIM/NBS 61, No. 2, 1-32 (1977).

Dynamic effects; high winds; roofs; typhoon; wind pressure; buildings; SP470, pp. II-1 -II-19 (Apr. 1977).

Dynamic heat transfer; energy analysis; heat and cooling loads; heat loss and heat gain; multi-room problems; air-leakage; $J$. Res. 82, No. 2, 97-106 (1977).

Dynamic ion effects; forbidden lines; He $1 ; \lambda 4471 \AA$; Stark broadening; 17167.

Dynamic loads; equivalent static force; gravity load; handling devices; handling loads; military field shelters; probability distributions; shocks, snow load; static load; trains; transportation; trucks; vibrations; wind load; acceleration; airplanes; cargo; NBSIR 77-1254.

Dynamic programming; economic analysis; energy conservation; equipment maintenance; Markow decision process; policy improvement algorithm; NBSIR 77-1210. 
Dynamic programming; graph; network; organization; probability; reliability; trees; 16784 .

Dynamic range; electric field probe; isotropic probe; loop antenna; magnetic field probe; tangential sensitivity; broadband probe; dipole antenna; NBSIR 77-868.

Dynamic response; earthquakes; safety; shear wall; stiffness; buildings; damage; SP470, pp. VI-33-VI-46 (Apr. 1977).

Dynamic response; pressure step; pressure transducer; protective coatings; shock tube; tape; thermal protection; thermal radiant-energy response; thermal transient response; transducer; zero shift; coatings; delayed response; dynamic; TN961.

Dynamic response characteristics; fluctuating flow characteristics; marine environment; current measuring transducers; current velocities; SP484, pp. 109-122 (Oct. 1977).

Dynamic susceptibility; Ginzburg-Landau free energy; relaxation time; disordered system; 17122.

Dynamic testing; lateral load simulation; models; shake tables; testing; SP470, pp. IX-1 -IX-5 (Apr. 1977).

Dynamic tests; model; structural analysis; velocities; vibrations; arch dam; deflections; SP477, pp. VI-85-VI-117 (May 1977).

Dynamic tests; nuclear reactors; oil tanks; power plants; shake table; aseismic design; SP470, pp. VII-1 - VII-6 (Apr. 1977).

Dynamical diffraction; magnetic domains; magnetic domain walls; melt-grown crystals; nickel single crystals; x-ray diffraction topography; anomalous transmission effect; asymmetric crystal topography; crystal imperfections; crystal perfection; Czochralski-grown nickel; 16997.

Dynamical diffraction; magnetic domains; nickel single crystals; x-ray diffraction; x-ray topography; 17277.

Dynamical diffraction theory; ferromagnetic domain walls; nickel single crystals; x-ray dynamical diffraction; crystal growth; crystal perfection; diffraction topography; 16974 .

Dynamical images; imperfect crystals; perfect crystals; $x$-ray dynamical diffraction; contrast conditions; diffraction topography; 16977

Dynamics; earthquake; probability; random vibrations; safety; structures; deterministic; SP470, pp. VI-1-VI-21 (Apr. 1977).

Dynamics; failure; roofs; wind; SP477, pp. I-12-I-20 (May 1977).

Dynamics; field tests; laboratory tests; relationships; soil properties; SP477, pp. VI-158-VI-1 78 (May 1977).

Dynamics; galactic structure; interstellar medium; magnetic pressure; neutron; radiation; stellar explosion; supernova; 17217.

Dynamics; missiles; power plants; structural engineering; tornadoes; trajectories; SP477, pp. VII-36-VII-41 (May 1977).

Dysprosium; hyperfine fields; magnetism; rare earths; relaxation effects; scandium alloys; 16985 .

$D^{3}$ ion; optical spectra; ruby; transition metal ions; ultrahigh pressure; $\mathrm{Cr}^{3+}$, crystal field spectra; 17047.

$D(d, n)$ source; dosimetry; $\mathrm{Li}(d, n)$ source; $\mathrm{Li}(p, n)$ source; neutron angular distributions; neutron energy distributions; neutrons; nuclear reactions; thick-target yields; $B e(d, n)$ source; $B e(p, n)$ source; $C(d, n)$ source; NBSIR 77-I279.

\section{$\mathbf{E}$}

Early type stars; helium forbidden lines; Stark broadening theory; stellar line profiles; transfer equations; 17172 .

Ears; head diffraction; hearing; interaural intensity differences; interaural time differences; localization; manikin; 17052.

Earth shield; neutron spectra; shielding; shield thickness; calculation; concrete; cyclotron; design; SP461, pp. 166-170 (Jan. 1977).

Earth strain; laser strainmeter; power spectrum; 17231.

Earth structures; roads; survey; construction; dams; earthquake; SP477, pp. VI-44-VI-49 (May 1977).
Earth tides; laser strainmeter; surveying; distance measurement; 17199.

Earth tides; ocean loads; strainmeter; cavity effects; 17196.

Earthquake; earth structures; roads; survey; construction; dams; SP477, pp. VI-44_VI-49 (May 1977).

Earthquake; hysteretic envelope; reinforced; strength; columns; concrete; SP477, pp. VI-10-VI-27 (May 1977).

Earthquake; index; quake-sensitivity; seismic index; seismicity; SP477, pp. IV-47-IV-54 (May 1977).

Earthquake; probability; random vibrations; safety; structures; deterministic; dynamics; SP470, pp. VI-1-VI-21 (Apr. 1977).

Earthquake; program; research; seismic; SP477, pp. VI-28-VI36 (May 1977).

Earthquake; research programs; seismic; testing; wind; SP477, pp. VI-37-VI-43 (May 1977).

Earthquake damage; Guatemala earthquake; bridges; SP477, pp. VIII-I -VIII-27 (May 1977).

Earthquake damage analysis; masonry; rheology, material; BSSIO6, pp. 114-153 (Sept. 1977).

Earthquake data; earthquake records; field observations; strong-motion accelerographs; accelerographs; SP470, pp. IV-1-IV-34 (Apr. 1977).

Earthquake data; earthquake records; field stations; strong-motion network; accelerographs; SP470, pp. IV-35-IV-52 (Apr. 1977).

Earthquake design; earthquake forces; seismic provisions; specifications; bridges; SP470, pp. VIII-31-VIII-4I (Apr. 1977).

Earthquake distribution; earthquakes; field data; frequency maps; ground displacement; Japan; SP470, pp. III-1 -III-17 (Apr. 1977).

Earthquake distributions; epicenters; maps; seismicity index; SP470, pp. III-18-III-28 (Apr. 1977).

Earthquake engineering; earthquakes; education; India; Iran; training; Turkey; SP470, pp. X-12-X-16 (Apr. 1977).

Earthquake excitation of structures; earthquake resistant structures; reinforcing details; structural walls; design procedures; SP477, pp. VI-199-VI-219 (May 1977).

Earthquake forces; seismic provisions; specifications; bridges; earthquake design; SP470, pp. VIII-31 - VIII-4I (Apr. 1977).

Earthquake records; field observations; strong-motion accelerographs; accelerographs; earthquake data; $S P 470$, pp. IV1-IV-34 (Apr. 1977).

Earthquake records; field stations; strong-motion network; accelerographs; earthquake data; SP470, pp. IV-35-IV-52 (Apr. 1977).

Earthquake records; strong-motion data; accelerographs; data processing; SP470, pp. IV-53-IV-66 (Apr. 1977).

Earthquake resistance; energy absorption; modulus of elasticity; partial reinforcing; risk; shear modulus; testing; ultimate strength; anchor bolts; bond; damping; ducțility; BSSI06, pp. 255-258 (Sept. 1977).

Earthquake resistance; limit states design; masonry construction; materials testing standardization; mathematical models; rehabilitation; retrofit; seismic design; structural design; structural research; building codes and standards; BSSI06, pp. 40-59 (Sept. 1977).

Earthquake resistance; masonry construction; seismic design; structural design; structural engineering; structural research; building codes and standards; design criteria; BSSIO6.

Earthquake resistant structures; reinforcing details; structural walls; design procedures; earthquake excitation of structures; SP477, pp. VI-199-VI-219 (May 1977).

Earthquake resistant structures; masonry; bricks; buildings; Canada; concrete blocks; design standards; BSS106, pp. 198213 (Sept. 1977).

Earthquakes; education; India; Iran; training; Turkey; earthquake engineering; SP470, pp. X-12-X-16 (Apr. 1977). 
Earthquakes; engineering; buildings; design; disaster mitigation; NBSIR 76-1193.

Earthquakes; epicentral distance; liquefaction; settlement; soils; alluvial deposits; SP470, pp. V-1-V-15 (Apr. 1977).

Earthquakes; field data; frequency maps; ground displacement; Japan; earthquake distribution; SP470, pp. 111-1-111-17 (Apr. 1977).

Earthquakes; ground failures; hydraulic structures; seismicity; soils; standards; structural response; vessels and wind; accelerograph; bridges; buildings; codes; disaster; dynamic analysis; SP470.

Earthquakes; ground failures; nuclear facilities; seismicity; soils; standards; structural response; winds; accelerograph; bridges; buildings; codes; disaster; dynamic analysis; SP477.

Earthquakes; ground motion; records; results; seismometers; arrays; SP477, pp. 111-16-111-25 (May 1977).

Earthquakes; harbours; ports; specifications; structures; design; SP470, pp. VIIl-42-VIII-55 (Apr. 1977).

Earthquakes; highway bridges; seismic provisions; specifications; structural engineering; SP470, pp. V111-1-VII1-30 (Apr. 1977).

Earthquakes; hospitals; schools; building codes; building regulations; design criteria; SP470, pp. V1-64_VI-73 (Apr. 1977).

Earthquakes; hydraulic structures; inspection; instrumentation; strong-motion accelerographs; SP470, pp. V1-47-VI-63 (Apr. 1977).

Earthquakes; liquefaction; sand layer; shake table; vibration tests; void ratios; SP470, pp. V-16-V-35 (Apr. 1977).

Earthquakes; natural disasters; structural engineering; buildings; building codes; SP490.

Earthquakes; research; structural engineering; structures; buildings; SP470, pp. 1X-6-1X-16 (Apr. 1977).

Earthquakes; response spectra; soils; acceleration records; dynamic behavior; SP477, pp. I11-41-111-56 (May 1977).

Earthquakes; safety; shear wall; stiffness; buildings; damage; dynamic response; SP470, pp. VI-33-V1-46 (Apr. 1977).

Earthquakes; seismic design criteria; building codes; buildings; construction; dwellings; SP470, pp. VI-74-VI-88 (Apr. 1977).

Earthquakes; specifications; structural engineering; tunnels; aseismic design criteria; design provisions; SP470, pp. V11156-VII1-68 (Apr. 1977).

Earthquakes; structural engineering; building codes; buildings; design; SP477, pp. VI-61 - V1-68 (May 1977).

Earth's measurement; energy; health records; hydrogen; law enforcement; liquefied natural gas; metric tons; polyethylene; sound; spinach; SRM; systems and software; telecommunications; computer use; conservation; data; DIM/NBS 61, No. 5 , $1-32$ (1977).

Ease of ignition; fire tests; gypsum board; potential heat; properties; rate of flame spread; rate of heat release; scanning electron microscope (SEM); buildings; NBSIR 77-1265.

EBIC; microelectronic devices; scanning electron microscope; secondary emission; voltage contrast; backscattered emission; SP400-35.

Eccentricity of equidensity surface; elliptical galaxies; flattening; mass distribution function; anisotropy of mean square velocities; 16968.

ECG; EEG; electromagnetic field; microwave radiation; nonmetallic electrode system; turtle; 17174 .

Ecology; energy; environmental impact; land pollution; mutagenicity; toxic materials; toxicology; trace contaminants; water pollution; air pollution; analysis; SP463, pp. I11.4.11II.4.15 (Jan. 1977).

Econometric analysis; economic impacts; efficiency impacts; income distribution effects; policy alternatives; applied microeconomic framework; commodity supply crises; NBSGCR-ETIP 76-24.
Econometric analysis; economic impacts; efficiency impacts; income distribution effects; policy alternatives; applied microeconomic framework; commodity supply crises; NBSGCR-ETIP 76-32.

Econometric analysis; economic impacts; efficiency impacts; income distribution effects; policy alternatives; applied microeconomic framework; commodity supply crises; NBSGCR-ETIP 76-33.

Econometric analysis; economic impacts; efficiency impacts; income distribution effects; policy alternatives; applied microeconomic framework; commodity supply crises; NBSGCR-ETIP 77-36.

Economic; energy; research and development, energy; 16907.

Economic analysis; energy conservation; equipment maintenance; Markow decision process; policy improvement algorithm; dynamic programming; NBSIR 77-1210.

Economic efficiency; economics; energy; energy conservation; life-cycle cost; optimization; performance standards; resource impact factors; resources; social optimum; standards; building economics; 17302.

Economic efficiency; information technology; policy analysis; policymaking; public goods; technological change; transaction costs; computer; computer program; copyright; data base; SP500-17.

Economic impact; electric shock; ground fault circuit interrupters; national electric code; safety regulations; standards; accidents; benefit-cost analysis; building codes; building economics; building regulations; SP473, pp. 397-419 (June 1977).

Economic impacts; efficiency impacts; income distribution effects; policy alternatives; applied microeconomic framework; commodity supply crises; econometric analysis; NBS-GCRETIP 76-24.

Economic impacts; efficiency impacts; income distribution effects; policy alternatives; applied microeconomic framework; commodity supply crises; econometric analysis; NBS-GCRETIP 76-32.

Economic impacts; efficiency impacts; income distribution effects; policy alternatives; applied microeconomic framework; commodity supply crises; econometric analysis; NBS-GCRETIP 76-33.

Economic impacts; efficiency impacts; income distribution effects; policy alternatives; applied microeconomic framework; commodity supply crises; econometric analysis; NBS-GCRETIP 77-36.

Economic impacts; environmental considerations; innovative practices; regulatory research; standards development; administrative procedures; building codes; building regulations; buildings; SP473.

Economic policy options; foreign supply disruptions; stockpiling; technology; U.S. demand structure; cartels; NBS-GCRETIP 76-25.

Economic policy options; foreign supply disruptions; stockpiling; technology; U.S. demand structu re; carțels; NBS-GCRETIP 76-28.

Economic policy options; foreign supply disruptions; stockpiling; technology options; U.S. demand structure; cartels; NBSGCR-ETIP 76-29.

Economic policy options; foreign supply disruptions; stockpiling; technology options; U.S. demand structure; cartels; NBSGCR-ETIP 76-30.

Economic policy options; foreign supply disruptions; stockpiling technology options; U.S. demand structure; cartels; NBSGCR-ETIP 76-31.

Economics; energy; energy conservation; life-cycle cost; optimization; performance standards; resource impact factors; resources; social optimum; standards; building economics; economic efficiency; 17302 .

Economics; energy conservation; instrumentation; recuperators; waste; boilers; H121. 
Economics; information; NBS; national measurement system; NBSIR 75-948.

Economics; life cycle; performance standards; pipe; plumbing; reduced-size vents; sanitary drainage system; venting; cost savings; drainage-waste-vent; 17296.

Economics; safety standard; standards; benefit/cost; building standards; cost/effectiveness; 17133.

Eddy current; microwave; nondestructive evaluation; penetrant; radiography; standards; thermal; ultrasonic; visual testing; wear debris; acoustic; calibration; 17106.

Eddy current testing; electromagnetic testing; nondestructive testing; eddy currents; 17261 .

Eddy currents; eddy current testing; electromagnetic testing; nondestructive testing; 17261 .

Eddy currents; organic conductors; paramagnetic resonance; TTF-TCNQ; 17030.

Education; housing demand; innovation; regulatory barriers; residential construction; unionization; building official; building regulation; SP473, pp. 113-135 (June 1977).

Education; India; Iran; training; Turkey; earthquake engineering; earthquakes; SP470, pp. X-12-X-16 (Apr. 1977).

Education; research; research programs; wind engineering; wind studies; SP470, pp. I1-1-II-10 (Apr. 1977).

Education for metric; laws and regulations; metrication; metric system; National Conference on Weights and Measures; weights and measures; 17037.

Education programs; professional competence; building construction groups; certification; code enforcement officials; communications; criteria; SP473, pp. 383-389 (June 1977).

$E_{d}=8,12,15 \mathrm{MeV}, E_{p}=15 \mathrm{MeV}$; energy spectra, yields; neutrons; thick target; time-of-flight; NBSIR 77-1279, pp. 14 (July 1977).

EEC regulations; flow rate; international standards; orifice plates; data bases; SP484, pp. 935-944 (Oct. 1977).

EEG; electromagnetic field; microwave radiation; nonmetallic electrode system; turtle; ECG; 17174.

Effect of environment on flowmeter performance; flowmeter calibration; flowmeter evaluation; procedure for testing flowmeters; automotive environment; automotive fuel flowmeters; TN943.

Effective Lagrangian; electroproduction; impulse approximation; photoproduction; pseudoscalar and pseudovector coupling; threshold pion production; TN957.

Effective neutral weak interactions; Fermi theory; finite field theory; neutral currents; weak coupling constants; weak interactions; 17103.

Effective seasonal heating COP; heat pumps; heat pumps and energy conservation; part-load performance; seasonal performance factor; cooling and heating coefficients of performance; BSS93.

Effective temperature $\left(E T^{*}\right)$; energy conservation; summer temperature guidelines; thermal acceptability; thermal preference survey; winter temperature; clothing insulation; SP491, pp. 93-116 (Sept. 1977).

Effects; houses; typhoon; wind speeds; damage; SP477, Pp. II1-II-14 (May 1977).

Efficiency; energy recovery; hydrogen; liquefier; component efficiency; cryogenics; NBSIR 77-862:

Efficiency; expanders; heat exchangers; particle accelerators; power transmission; reliability; compressors; cryogenic refrigeration; 17083 .

Efficiency; gamma ray; kerma; neutron; charged particle; dosimeter; dosimetry; SP461, pp. 209-218 (Jan. 1977).

Efficiency; neutron beams; neutron flux; neutrons; ${ }^{3} \mathrm{H},{ }^{2} \mathrm{H},{ }^{4} \mathrm{He}$, ${ }^{3} \mathrm{He}$, protons; calibration; SP493, pp. $221-226$ (Oct. 1977).

Efficiency impacts; income distribution effects; policy alternatives; applied microeconomic framework; commodity supply crises; econometric analysis; economic impacts; NBS-GCRETIP 76-24.
Efficiency impacts; income distribution effects; policy altematives; applied microeconomic framework; commodity supply crises; econometric analysis; economic impacts; NBS-GCRETIP 76-32.

Efficiency impacts; income distribution effects; policy alternatives; applied microeconomic framework; commodity supply crises; econometric analysis; economic impacts; NBS-GCRETIP 76-33.

Efficiency impacts; income distribution effects; policy alternatives; applied microeconomic framework; commodity supply crises; econometric analysis; economic impacts; NBS-GCRETIP 77-36.

Effusive oven; sodium beam; atomic beam; 16789.

EGDN; electron-capture gas chromatography; measurements; TNT; vapor pressures; DNT; 16825.

EGDN; explosive detection; limits of detection; sensitivity test; TNT; vapor generator; vapor pressure; DNT; 16830 .

Egress; fire alarms; fire incidents; fire investigations; fires; human behavior; project people; residential buildings; smoke; statistical analysis; building fires; NBS-GCR-77-94.

Eigenvalue; field of values; positive semidefinite; semistable; convex hull; 16819.

Eigenvalue; Hadamard product; $M$-matrix; diagonally dominant; diagonally symmetrizable; 16909.

Eigenvalue; hermitian matrix; inertia; stability; 16755.

Eigenvalue equations; electromagnetic theory; group theory; near-field scanning; symmetry analysis; computer programs; data reduction; 17222 .

Eigenvalue problems; Liouville-Green approximation; potential barrier; potential well; tuming points; Whittaker functions; WKBJ approximation; connection formulas; 17142 .

Eigenvalue-eigenvector equation; root of unity; bound set; convex hull; J. Res. 82, No. 2, 133-136 (1977).

Eigenvalues; frequency response; intrinsic optical tensor; intrinsic stress tensor; polymer solution; bead-spring model; J. Res. 81A No. 1, 97-107 (1977).

Elastic; lithium; measurements; neutron; total; alpha; boron; branching ratio; compilation; cross-section; SP493, pp. 67-84 (Oct. 1977).

Elastic; multiple bias technique; neutron; scattering; cross section; differential; SP461, pp. 64-66 (Jan. 1977).

Elastic compliance tensor; elastic moduli; extrinsic damage thresholds; high-power lasers; infrared materials; tensile stress; cadmium telluride; 16746.

Elastic compliance tensor; elastic moduli; extrinsic damage thresholds; high-power lasers; infrared materials; tensile stress; cadmium telluride; 17312.

Elastic constant; invar; iron alloy; nickel alloy; Poisson's ratio; shear modulus; sound velocity; Young's modulus; bulk modulus; compressibility; Debye temperature; 16869.

Elastic constant; Poisson ratio; precipitation hardening; shear modulus; sound velocity; Young's modulus; bulk modulus; compressibility; copper alloy; 17094.

Elastic constants; face-centered cubic solids; Poisson's ratio; polycrystals; body-centered cubic solids; central-force solids; 16880 .

Elastic constants; face-centered-cubic solids; polycrystals; shear modulus; Young's modulus; 17099.

Elastic constants; interatomic forces; interstitial; lattice dynamics; metal hydrides; band mode; 17004.

Elastic constants; niobium-titanium; Poisson's ratio; pulse method; resonance method; shear modulus; sound velocity; Young's modulus; bulk modulus; composite; compressibility; copper; 17068.

Elastic constants; Poisson's ratio; shear modulus; sound velocity; Young's modulus; bulk modulus; compressibility; copper alloy; Debye temperature; 17320.

Elastic constants; Poisson's ratio; pulse method; resonance method; shear modulus; sound velocity; stainless steel; Young's modulus; bulk modulus; compressibility; 17321. 
Elastic constants; Poisson's ratio; shear modulus; single-crystal elastic coefficients; sound velocities; Young's modulus; zinc; bulk modulus; compressibility; Debye temperature; JPCRD 6 , No. 4, $1181-1204$ (1977).

Elastic constants; resonance method; shear modulus; torsional modulus; Young's modulus; aluminum; boron-aluminum; bulk modulus; composite; compressibility; 17087.

Elastic moduli; extrinsic damage thresholds; high-power lasers; infrared materials; tensile stress; cadmium telluride; elastic compliance tensor; 16746.

Elastic moduli; extrinsic damage thresholds; high-power lasers; infrared materials; tensile stress; cadmium telluride; elastic compliance tensor; 17312 .

Elastic scattering; neutrons; review of measurements; $\mathrm{Li}(\mathrm{n}, \alpha)$;

${ }^{6} \mathrm{Li}$ total; ' Li system; SP493, pp. 14-29 (Oct. 1977).

Elastic scattering cross section; evaluation; optical model; Rfunction analysis; standard; total cross section; carbon; SP493, pp. 93-100 (Oct. 1977).

Elastohydrodynamics; failure analysis; film thickness; gears; Hertz contacts; lubrication; rheology; starvation; traction; bearings; computer programs; SP487, pp. 137-153 (Aug. 1977).

Electret; glass ceramic; polarization; strontium titanate; dielectric constant; dielectric relaxation; 16798.

Electret; humidity; microphones; reciprocity; sensitivity; temperature; calibration; ceramic; condenser; 16701.

Electret; humidity; microphones; reciprocity; sensitivity; temperature; calibration; ceramic; condenser; 17245 .

Electrets; electrocaloric effect; entropy; ferroelectrics; glassceramics; heat switches; magnetothermal conductivity; polarization; potassium tantalate; refrigeration; specific heat; strontium titanate; beryllium; ceramics; cryogenics; dielectricconstant; NBSIR 76-847.

Electric field probe; isotropic probe; loop antenna; magnetic field probe; tangential sensitivity; broadband probe; dipole antenna; dynamic range; NBSIR 77-868.

Electric fields; electro-optics; high voltage measurement; insulating fluids; Kerr effect; nitrobenzene; pulse measurement; space charge; calibration; dielectrics; dividers; NBSIR 771317.

Electric quadrupole; giant resonances; photon scattering; polarized photons; resonance fluorescence; Delbrück scattering; Doppler broadening; 16926.

Electric shock; ground fault circuit interrupters; national electric code; safety regulations; standards; accidents; benefitcost analysis; building codes; building economics; building regulations; economic impact; SP473, pp. 397-419 (June 1977).

Electrical; energy management; graphic pen; halocarbons; infrared lasers; international standard; neutron xeroradiography; problem-solving; radiation safety; smoke detectors; solar heating; SRM's; adobe; air pollution; corrosion; DIM/NBS 61, No. 3, 1-32 (1977).

Electrical; environment; housing technology; HVAC; innovative construction; maintainability; materials; minimum property standards; performance criteria; performance evaluation; plumbing; safety; structures; test methods; acoustics; appliances; atmospheric; durability; NBSIR 77-1316.

Electrical aerosol analyzer; self-preserving; size distribution; aerosols; asymptotic analysis; broad initial distribution; coagulation; 17282.

Electrical conductance; iodides; molten salt mixtures; standard reference data; surface tension; viscosity; bromides; data compilation; density; JPCRD 6, No. 2, 409-596 (1977).

Electrical conductivity; heat switch; Lorenz ratio; magnetic field; single crystal; thermal conductivity; beryllium; cryogenics; 17088.

Electrical connections; fire hazard; glowing electrical connections; arcing/sparking; branch circuit; contact resistance; BSS103.
Electrical heating elements; materials performance; radiant panel-seamless flooring system; seamless flooring; temperature characteristics; NBSIR 77-1263.

Electrical mask alignment; integrated circuit; photolithography; silicon; test pattern; visual alignment structure; 17330.

Electrical measurements; electronics; profiling; silicon; trace analysis; chemical measurements; 17140 .

Electrical properties; electronics; four-probe method; hermeticity; ion implantation; Irvin's curves; leak tests; line-width measurement; measurement methods; microelectronics; optical flying-spot scanner; oxidation particle impact noise detection test; $S P 400-29$.

Electrical properties; electronic properties; magnetic properties; optical properties; Retrieval Guide; technical reports; Thermophysical and Electronic Properties Information Analysis Center; SP463, pp. IV.4.1-IV.4.3 (Jan. 1977).

Electrical property; insulation; materials; mechanical property; metal; review; thermal property; alloy; composite; cryogenics; 17072.

Electrical resistivity; emittance; high-speed measurement; high temperature; melting point; radiance temperature; titanium; J. Res. 82, No. 2, 11 9-122 (1977).

Electrical resistivity; heat capacity; high-speed measurements; high temperatures; melting; normal spectral emittance; radiance temperature; specific heat capacity; thermal radiation properties; thermodynamics; J. Res. 81 A Nos. 2 and 3, 251256 (1977).

Electrical resistivity; high temperature; Lorenz ratio; low temperature; standard reference material; thermal conductivity; thermopower; tungsten; 16877.

Electrical resistivity; iron; low temperature; susceptibility; alloys; copper; 17135.

Electrical resistivity; iron alloys; Lorenz ratio; low temperature; nickel alloys; thermal conductivity; thermopower; copper; 16878.

Electrical units; fundamental constants; Josephson effect; levitation; superconductivity; ampere definition; 16876.

Electrical-eddy current measurements; microwaves; nondestructive evaluation; standard reference materials; standards; thermal testing; ultrasonics; visual testing; wear debris analysis; acoustic emission; calibrations; 17016.

Electrically calibrated detectors; history of radiometry; Planck's constant; radiometric standards; radiometry; standard lamps; Stefan-Boltzmann constant; blackbodies; 16851 .

Electrically calibrated detectors; laser power measurements; pyroelectric detectors; radiometry; silicon cell; silicon detector; silicon photodetector; absolute radiometry; detector; TN954.

Electrically calibrated pyroelectric radiometer; optical calibration; optical radiation; pyroelectric radiometry; detector based standards; 16852 .

Electrocaloric effect; entropy; ferroelectrics; glass-ceramics; heat switches; magnetothermal conductivity; polarization; potassium tantalate; refrigeration; specific heat; strontium titanate; beryllium; ce ramics; cryogenics; dielectric-constant; electrets; NBSIR 76-847.

Electrocatalysis; equivalent circuit; fuel cells; microprocessor; network analyzer; phosphoric acid electrolyte; refractory hard metals; AC impedance; automated electrochemical analysis; ceramic electrolytes; ceria-yttria; cyclic voltommetry; NBSIR 77-1270.

Electrochemical equivalent; gallium arsenide; gallium atomic weight; stoichiometry; atomic weight; coulometry; J. Res. 81A No. 1, $1-4$ (1977).

Electrochemistry; environment; gas chromatography; laserRaman; liquid chromatography; nuclear magnetic resonance; organoarsenic; analysis; aqueous chemistry; arsenic; atomic absorption spectrophotometry; biomethylation; 17155 . 
Electrochemistry; isopiestic; osmotic coefficients; thermochemistry; vapor pressure; activity coefficients; aqueous systems; bibliography; SP485.

Electrode/insulators; magnetohydrodynamics; materials; design; 16900.

Electrodynamics; gyroscope; London moment; magnetic torque; relativity; satellite experiment; superconducting; 16795.

Electrolyte; excess free energy; osmotic coefficient; solutions; thermodynamic properties; activity coefficient; calcium chloride; critical evaluation; JPCRD 6, No. 2, 385-408 (1977).

Electromagnetic; interference; measurement; metrology; radiation; surface technology; 17079.

Electromagnetic field; microwave radiation; nonmetallic electrode system; turtle; iCG; EEG; 17174.

Electromagnetic fields; hazards; instrumentation; isotropic; measuring; 17168 .

Electromagnetic interactions; electron scattering; radiative corrections; total photon absorption cross sections; virtual photon theory; bremsstrahlung spectrum tip; Delbrück scattering; $T N 955$.

Electromagnetic interference; fast Fourier transform; impulse generator; radiometer; sampling oscilloscope; spectrum amplitude; spectrum analyzer; spectrum intensity; calibration; 16725 .

Electromagnetic interference; electromagnetic noise; emergency communications; Fast Fourier Transform; impulsive noise; magnetic field strength; measurement instrumentation; portable spectrum analyzer; spectral density; time-dependent spectral density; coal mine noise; 17175 .

Electromagnetic interference; Fourier transformation; impulse; impulse generator; spectrum amplitude; TN699.

Electromagnetic measurements; interference; near-field probes; radiation; susceptibility; TEM ccll; 17251 .

Electromagnetic noise; emergency communications; Fast Fourier Transform; impulsive noise; magnetic field strength; measurement instrumentation; portable spectrum analyzer; spectral density; time-dependent spectral density; coal mine noise; digital data; 17175 .

Electromagnetic properties; form factors; magnetic moments; quadrupole moments; quantum field theory; relativistic many body systems; vector dominance; Monogr. 147, Suppl. 1.

Electromagnetic quantities; laser; microwave; National Measurement System; radio measurements; NBSIR 75-936.

Electromagnetic spectra; gamma rays; secondary standards; $x$ rays; 17246.

Electromagnetic testing; nondestructive testing; eddy currents; eddy current testing; 17261 .

Electromagnetic theory; group theory; near-field scanning; symmetry analysis; computer programs; data reduction; eigenvalue equations; 17222 .

Electromagnetics; materials testing; nondestructive testing; Nondestructive Testing Newsletter; radiography; technical reports; ultrasonics; Army Materials and Mechanics Research Center; SP463, Pp. IV.6.1-IV.6.2 (Jan. 1977).

Electromagnetism; Hamilton; Maxwell; momentum; Poynting; variational; anholonomic; constraint; J. Res. $81 \mathrm{~B}$ Nos. 1 and 2, 1-3 (1977).

Electromagnetism; laser, high-intensity; multiphoton absorption; optical interactions; atomic spectra; 17130 .

Electromigration; liquid metals; nitrogen; phosphorus; ternary diffusion; thermomigration; alloys; antimony; arsenic; bismuth; copper; diffusion; JPCRD 6, No. 1, 1-50 (1977).

Electron; excitation; hydrogen; Balmer-alpha; collision; cross section; dissociation; 17054 .

Electron; Gaussian; Monte Carlo; scattering; aluminium; carbon; collision; copper; distribution; dose; SP46I, pp. 106-109 (Jan. 1977).

Electron; helium; ionization; measurements; cross section; differential; 16810.
Electron; intermediate energy; photons; approximation; bremsstrahlung; cross section; SP461, pp. 60-63 (Jan. 1977).

Electron; ionic charge; ionization potential; stopping power; stripped particle; velocity; charge; charged particle; collision; SP461, pp. 144-148 (Jan. 1977).

Electron; Monte Carlo; transport coefficient; diffusion; drift tube; 16854 .

Electron; proton excitation; $x$-ray photoelectron spectroscopy; absolute yield; aluminum; attenuation length; Auger electrons; Auger-electron spectroscopy; beryllium; 17248 .

Electron affinities; Green's function; ionization potentials; Rayleigh-Schrödinger perturbation theory; 17317.

Electron attenuation lengths; electron spectroscopy for chemical analysis (ESCA); electron transmission through thin films; inelastic electron mean free path; supported thin films; Auger-electron spectroscopy (AES); 16744 .

Electron beam energy deposition; ionizing radiation effects; radiation dose; radiation testing; scanning electron microscope; semiconductor devices; NBSIR 77-1235.

Electron beam induced conductivity (EBIC) contrast; electron channeling contrast; magnetic contrast; scanning electron microscopy; topographic contrast; voltage contrast; atomic number contrast; 16840.

Electron beams; food irradiation; Fricke dosimetry; gamma rays; $x$ rays; absorbed dose; calorimetry; dose distributions; dosimetry; 17343.

Electron beams; gamma radiation; plastic films; quality control; radiation processing; radiochromic dyes; sterilization; dose distributions; dosimetry; 17000.

Electron beams; gamma rays; pararosaniline cyanide; pulse radiolysis; radiochromic dyes; calorimetry; chemical dosimetry; dosimetry; dye dosimeters; 16984.

Electron binding; gamma rays; K-shell; photons; Compton scattering; differential cross section; SP461, pp. 67-69 (Jan. 1977).

Electron binding energy; interlaboratory comparison; surface characterization; $\mathrm{x}$-ray photoelectron spectroscopy; Auger electron spectroscopy; catalyst; 16930.

Electron capture; excited state; gamma ray; ground state; inner bremsstrahlung; Jauch plot; spectrum; transition; coincidence; SP461, pp. 23-25 (Jan. 1977).

Electron channeling contrast; microstructural analysis; scanning electron microscope; selected area electron channeling pattern; crystal orientation determination; crystallographic contrast; 16839.

Electron channeling contrast; magnetic contrast; scanning electron microscopy; topographic contrast; voltage contrast; atomic number contrast; electron beam induced conductivity (EBIC) contrast; 16840.

Electron collisions; excitation; $\mathrm{Be}^{+} ; 17132$.

Electron collisions; LiF; MHD; momentum transfer; 17344.

Electron excitation; hydrogen; zoherence; 17326.

Electron excitation; thallium; 17128.

Electron excitations; monoenergetic $\mathrm{x}$ rays; pulsed $\mathrm{x}$-ray source; $\mathrm{x}$-ray detector calibration; $1.5-8 \mathrm{keV} x$ rays; absolute $\mathrm{x}$-ray detectors; 16814

Electron impact; electron spectroscopy; oscillator strengths; carbon tetrachloride; carbon tetrafluoride; 17018 .

Electron impact; electron spectroscopy; oscillator strengths; water vapor; 17019.

Electron mean free path; free-electron-like metal; 100 to several $1000 \mathrm{eV} ; 16748$.

Electron microscopy; electronic technology; energy conservation; interferometric wavemeter; metric; pressure transducers; synchrotron radiation; building collapse; computer security; cryogenic temperature; dentistry; DIM/NBS 61 , No. 2, 1-32 (1977).

Electron microscopy; fracture interfaces; plastic deformation; silicon nitride; turbine materials; cracks; NBSIR 76-1075. 
Electron microscopy; grinding damage; oxidation; silicon nitride; surface flaws; thin foils; cracks; 17090.

Electron microscopy; particles; wear; x-ray emission; debris; 16827.

Electron mobility; ionized impurity scattering; lattice scattering; neutral impurity scattering; n-type silicon; resistivity; temperature; dopant density; electron-electron scattering; 17147.

Electron mobility; ionized impurity scattering mobility; lattice mobility; neutral impurity scattering mobility; $n$-type silicon; resistivity; scattering mechanisms; temperature; dopant density: SP400-33.

Electron probe; image formation; ion probe; microanalysis; microscopy; scanning; $x$-ray spectroscopy; 16841.

Electron probe microanalysis; laser ionization; metrication; noise; nondestructive evaluation; research associate program; standards; Alaska pipeline; calibration; CMAC; computers; consumer sounding boards; data; DIM/NBS 61, No. 1, 1-32 (1977).

Electron scattering; electrostatic potential; intermediate neglect of differential overlap (INDO); molecular orbital theory; quantum chemistry; static potential; carbon monoxide molecules; dipole moment; 16709.

Electron scattering; Faddeev equations; helium-three; monopole transition; separable potential; Coulomb excitation; 16793.

Electron scattering; inelastic; isospin; magnetic; multipolarity; sum rule; 16687.

Electron scattering; inelastic scattering; nitrogen molecules; resonances; scattering; vibrational excitation; close-coupling calculations; crossed beams; cross sections; differential cross sections; 16740.

Electron scattering; inelastic; two-phonon states; zinc 64-66-6870; anharmonic vibrator model; collective states; 16982.

Electron scattering; proton bombardment; attenuation length; Auger-electron yield; beryllium; 16824 .

Electron scattering; radiative corrections; total photon absorption cross sections; virtual photon theory; bremsstrahlung spectrum tip; Delbrück scattering; electromagnetic interactions; TN955.

Electron spectroscopy; oscillator strengths; carbon tetrachloride; carbon tetrafluoride; electron impact; 17018.

Electron spectroscopy; oscillator strengths; water vapor; electron impact; 17019.

Electron spectroscopy; surfaces; adsorption; angle resolved; Auger; chemisorption; 16747.

Electron spectroscopy for chemical analysis (ESCA); electron transmission through thin films; inelastic electron mean free path; supported thin films; Auger-electron spectroscopy (AES); electron attenuation lengths; 16744.

Electron stimulated desorption; oxygen; sulphur hexafluoride; temperature programmed desorption; tungsten; chemisorption; 16929.

Electron stimulated desorption; ruthenium; water; adsorption; angular distribution (ions); chemisorption; 17349.

Electron structure; energy levels; fine structure; hydrogenic atoms; Lamb shift; level shifts; quantum electrodynamics; radiative corrections; relativistic corrections; atomic structure; JPCRD 6, No. 3, 831-870 (1977).

Electron transmission through thin films; inelastic electron mean free path; supported thin films; Auger-electron spectroscopy (AES); electron attenuation lengths; electron spectroscopy for chemical analysis (ESCA); 16744.

Electron-beam-induced current; microelectronics; $\boldsymbol{p}$ - $\boldsymbol{n}$ junctions; scanning electron microscopy; semiconductor devices; device inspection; 16891 .

Electron-beam-induced-current; microelectronics; $p$ - $n$ junctions; scanning electron microscopy; semiconductor devices; device inspection; 16971 .

Electron-capture gas chromatography; measurements; TNT; vapor pressures; DNT; EGDN; 16825.
Electronegativity; transition metal, Mössbauer effect; alloy theory; 16967.

Electron-electron scattering; electron mobility; ionized impurity scattering; lattice scattering; neutral impurity scattering; $n$ type silicon; resistivity; temperature; dopant density; 17147 .

Electron-gun evaporator; gate oxide film; metal evaporation; metallization; metal-oxide semiconductor; microelectronic device; radiation dose; silicon dioxide film; 16889 .

Electronic devices; ionizing radiation; radiation dosimetry; radiation hardness testing; radiation sources; thermoluminescence dosimeters; total dose; dosimeter calibration; NBSIR 76-1135.

Electronic equipment; EMC measurements; low-Q enclosures; radiated susceptibility; TEM transmission cell; 16668 .

Electronic factor; geometric factor; metals; surfaces; catalysis; characterization; chemisorption; SP475.

Electronic properties; magnetic properties; optical properties; phase diagrams; research materials; thermal properties; availability; crystal growth; crystal structure; SP463, pP. III.3.1-III.3.8 (Jan. 1977).

Electronic properties; magnetic properties; optical properties; Retrieval Guide; technical reports; Thermophysical and Electronic Properties Information Analysis Center; thermophysical properties; SP463, pp. IV.4.1-IV.4.3 (Jan. 1977).

Electronic reliability; electronics; laser scanner; measurement method; mixer; optics; pre-amplifier; radio receiver; semiconductor device studies; SP400-24.

Electronic structure; excimers; excited states; metal dimers; $\mathrm{Mg}_{2}$; multiconfiguration self-consistent-field; ab initio; 17188 .

Electronic structure; free atoms; hyperfine fields; relativistic Hartree-Fock theory; atomic beam; 16940.

Electronic technology; energy conservation; interferometric wavemeter; metric; pressure transducers; synchrotron radiation; building collapse; computer security; cryogenic temperature; dentistry; dielectric measurements; dye lasers; DIM/NBS 61, No. 2, 1-32 (1977).

Electronic transition laser; laser; laser kinetics; laser spectroscopy; optical pumping; dimer laser; 17318.

Electronics; extended-range $C(V)$ and $G(V)$ measurements; high voltage $C(V)$ and $G(V)$ measurements; MIS capacitors; modified MIS C(V) measurements; semiconductor devices; silicon-on-sapphire measurements; SOS measurements; biasisolation unit; SP4O0-40.

Electronics; extended-range MIS C (V) measurements; highvoltage C (V) measurements; MIS capacitor; premature dielectric breakdown; semiconductor devices; capacitancevoltage measurements; dielectric breakdown suppression; discharge suppression; SP400-37.

Electronics; four-probe method; hermeticity; ion implantation; Irvin's curves; leak tests; line-width measurement; measurement methods; microelectronics; optical flying-spot scanner; oxidation particle impact noise detection test; passivation overcoats; SP400-29.

Electronics; laser scanner; measurement method; mixer; optics; pre-amplifier; radio receiver; semiconductor device studies; electronic reliability; SP400-24.

Electronics; measurement methods; microelectronics; National Bureau of Standards; semiconductor devices; semiconductor materials; semiconductor process cont rol; 16894.

Electronics; profiling; silicon; trace analysis; chemical measurements; electrical measurements; 17140 .

Electron-ion collisions; free-free transitions; multiphoton processes; plasma absorption; bremsstrahlung; J. Res. 82, No. 3, $173-179$ (1977).

Electron-molecule collisions; static-model exchange-polarization potential; coupled-channel equations; $\mathrm{CO}_{2} ; 17026$.

Electron-molecule collisions; LiF; momentum transfer cross sections; polar molecules; 17027 .

Electrons; neutrons; photons, radiation physics; symposium; cross sections; dosimetry; SP461. 
Electro-optics; high voltage measurement; insulating fluids; Kerr effect; nitrobenzene; pulse measurement; space charge; calibration; dielectrics; dividers; electric fields; NBSIR 77 1317.

Electrophoretic decoration; integrated circuit quality control; selective chemical etching; semiconductor device reliability; corona charging decoration; dielectric defect detection; SP400-3I.

Electroproduction; impulse approximation; photoproduction; pseudoscalar and pseudovector coupling; threshold pion production; effective Lagrangian; TN957.

Electrostatic potential; intermediate neglect of differential overlap (INDO); molecular orbital theory; quantum chemistry; static potential; carbon monoxide molecules; dipole moment; electron scattering; 16709.

Element; gamma rays; $\mathrm{Ge}(\mathrm{Li})$ detector; neutron; nondestructive; resolution; spectrometry; water; activation; analysis; SP46I, pp. 255-256 (Jan. 1977).

Elements, transuranic; glove box; intercomparison; neutrons, high energy; neutrons, low energy; non-uniform exposures; quality factor; standards; criteria, accuracy; criteria, performance; dose equivalent; SP493, pp. 101-105 (Oct. 1977).

Element-specific detector; flameless atomic absorption; flow monitoring; high-pressure liquid chromatography; lead; ligand; mercury; nanogram sensitivity; organometallic compounds; speciation; tin; arsenic; 17297.

Elevated-temperature; fracture mode; Larson-Miller parameter; pressure vessel steel; tensile properties; creep-rupture properties; 17235.

Elevator shaft pressure profiles; parametric analysis; simulated smoke concentration; smoke control; smoke movement; smoke simulation; systematic pressurization; air-handling units; building pressure profile; computer simulation; NBSIR 77-1225.

Ellipsometry; implants; polymer adsorption; protein adsorption; synthetic implants; adsorption; blood protein; NBSIR 761128 .

Ellipsometry; localized corrosion; pitting; repassivation kinetics; stress corrosion; crevice corrosion; 16990.

Elliptical galaxies; flattening; mass distribution function; anisotropy of mean square velocities; eccentricity of equidensity surface; 16968.

EMC measurements; low-Q enclosures; radiated susceptibility; TEM transmission cell; electronic equipment; 16668 .

Emergency actions; emergency communicative; emergency decisions; escape; fires; human behavior; human response; life safety; mapping; model; nursing homes; rescue; verbal communicative; alarm; architecture; design implication; NBSGCR-77-93.

Emergency communications; Fast Fourier Transform; impulsive noise; magnetic field strength; measurement instrumentation; portable spectrum analyzer; spectral density; time-dependent spectral density; coal mine noise; digital data; electromagnetic interference; 17175 .

Emergency communications; fire communications; high-rise communications; high-rise emergency; information transfer; occupant needs; sensory stimuli; communications; disaster communication; 17036.

Emergency communicative; emergency decisions; escape; fires; human behavior; human response; life safety; mapping; model; nursing homes; rescue; verbal communicative; alarm; architecture; design implication; emergency actions; NBSGCR-77-93.

Emergency decisions; escape; fires; human behavior; human response; life safety; mapping; model; nursing homes; rescue; verbal communicative; alarm; architecture; design implication; emergency actions; emergency communicative; NBSGCR-77-93.
Emergency egress; exit capacity; fire safety; human performance; occupational safety; regulatory data; architectural psychology; architectural research; building codes; building design; building fires; building regulatory standards; NBSIR $77-1313$.

Emergency egress; HUD; mobile home; racking; research; safety; standard; window; NBSIR 77-1246.

Emergency warning lights; police equipment; sirens; standards; SP480-3.

Emf; pH; phthalate buffer; potassium hydrogen phthalate; standard for pH; acidity; J. Res. 81A No. 1, 21-24 (1977).

EMI problems; energy problems; energy savings; exchange program; lead detection; metric; oxygen; technology; cryocooler; DIM/NBS 61, No. 10, 1-32 (1977).

Emission; interaction potential; iodine; perturbation theory; rate coefficient; collision-induced; 17069.

Emittance; enthalpy; heat capacity; high-speed measurements; high temperature; molybdenum; pulse calorimetry; standard reference material; thermodynamic functions; drop calorimetry; SP260-55.

Emittance; high-speed measurement; high temperature; melting point; radiance temperature; titanium; electrical resistivity; $J$. Res. 82, No. 2, 119-122 (1977).

Empirical; energy; gamma ray; mean free path; ASFIT; buildup factor; SP461, pp. 174-176 (Jan. 1977).

Employee communication; information needs; information processing; information seeking; internal media; communication among scientists; coordination of research organizations; NBSIR 77-1257.

Emulsified fuel droplet; fuel droplet; heat flow; micro-explosion; preheat; combustion; J. Res. 82, No. 3, 183-195 (1977).

Enabling legislation; physically handicapped; regulation; accessibility standards; building code; code administration; communication; SP473, pp. 241-251 (June 1977).

Enamel; fluorapatite; fluoride; hydroxyapatite; solubility; chemical potential; dental caries; 16739.

Enclaveless set; graph; hypergraph; König System; KM-System; Menger System; MK-System; dominating set; J. Res. 82, No. 3, 197-202 (1977).

Enclosure fires; entrainment; fire induced flows; models; physical scale; plumes; buoyancy pressure; J. Res. 82, No. 2, 107 117 (1977).

Encryption; evaluation criteria; key; password; personal identification; terminals; verification; ADP security; computer networks; controlled accessibility; FIPS PUB 48.

Encryption; Federal Information Processing Standard; ADP security; computer security; FIPS PUB 46.

Encryption; key management; known plaintext attack; security; work factor; cryptanalysis; cryptography; NBSIR 77-1291.

Encryption standard; interface requirements; Monte-Carlo testing; testbed; test cases; validating correctness; communications security; computer security; cryptography; SP50O-20.

End fittings for FRP rod; environmental resistance of FRP rods; fiber-reinforced plastic (FRP); glass; guys, antenna; pultrusion; reinforced plastics; stress rupture of FRP rod; test methods; weatherability of FRP rods; aramid; composite materials; 16685.

ENDF/B; fission; integral measurements; standard neutron fields; cross sections; SP493, pp. 290-298 (Oct. 1977).

ENDF/B; fission; standards; uncertainties; criticals; cross section; SP493, pp. 269-277 (Oct. 1977).

Energy; energy conservation; life-cycle cost; optimization; performance standards; resource impact factors; resources; social optimum; standards; building economics; economic efficiency; economics; 17302 .

Energy; energy related inventions; heterodyne receiver; international standards code; NCSL; NMR knight shifts; neutron beams; piezo-flex micropositioning; pressure; thermodynamic tables; coal conversion; consumer products; cryogenic; DIM/NBS 61, No. 7, 1-32 (1977). 
Energy; energy savings; grain moisture; mass spectra; radiation sterilizing; screw thread standards; SHIVA laser; silicon; timekeeping; ultraviolet radiation; calibration; consumers; DIM/NBS 61, No. 9, 1-32 (1977).

Energy; environmental; measurement; product safety; research; science; standards; technology; annual report; computer; SP467.

Energy; environmental impact; land pollution; mutagenicity; toxic materials; toxicology; trace contaminants; water pollution; air pollution; analysis; ecology; SP463, pp. Ill.4.1Ill.4.15 (Jan. 1977).

Energy; environmental quality; management; materials information; national programs; policy; technology assessment; SP463, pp. I.2.1-I.2.2 (Jan. 1977).

Energy; equation of state; high pressure; high temperature; interaction virial coefficients; mixtures; molecular volumes; second virial coefficients; water; ballistics; carbon dioxide; combustion gases; 17136 .

Energy; erosion; high temperatures; ceramics; coal gasification; 17028.

Energy; evaluation; innovation; invention; technology transfer; 17108.

Energy; gamma ray; mean free path; ASFIT; build-up factor; empirical; SP461, pp. 174-176 (Jan. 1977).

Energy; gamma rays; neutron; scattering; shield; transmission; ${ }^{252}$ Cf; ANISN; code; configuration; dose equivalent; SP46I, pp. 119-123 (Jan. 1977).

Energy; health and safety; metallurgy; mining; Office of Mineral Information; Bureau of Mines; SP463, pp. V.3.1-V.3.9 (Jan. 1977 ).

Energy; health records; hydrogen; law enforcement; liquefied natural gas; metric tons; polyethylene; sound; spinach; SRM; systems and software; telecommunications; computer use; conservation; data; earth's measurement; DIM/NBS 61, No. 5, 1-32 (1977).

Energy; integral; iterative; neutron; transmission matrix; criticality; collision; cylindrical; SP461, pp. 94-96 (Jan. 1977).

Energy; legislation; solar; standards; State; architecture; buildings; design; NBSIR 77-1297.

Energy; radiation; solar; computer; BSS96.

Energy; research and development, energy; economic; 16907.

Energy absorption; modulus of elasticity; partial reinforcing; risk; shear modulus; testing; ultimate strength; anchor bolts; bond; damping; ductility; earthquake resistance; BSS106, pp. 255-258 (Sept. 1977).

Energy analysis; financial analysis; heating; load calculation; MIUS; modular integrated utility system; simulation; utility services; computer programs; cooling; NBSIR 77-1307.

Energy analysis; heat and cooling loads; heat loss and heat gain; multi-room problems; air-leakage; dynamic heat transfer; $J$. Res. 82, No. 2, 97-106 (1977).

Energy and flux calibration; fast neutrons; isotropic neutrons; $\mathrm{Li}^{6}$ sandwich surface barrier spectrometer; proton recoil surface barrier spectrometer; SP493, pp. 61-66 (Oct. 1977).

Energy choices; energy problem; energy resources; fossil fuels; nuclear power; solar energy; 17031 .

Energy conservation; energy efficiency; energy improvement targets; labeling; test procedures; appliances; 16885.

Energy conservation; energy efficiency; energy performance; model codes; standards; building codes; 17290 .

Energy conservation; energy measurements; fuel savings; heatloss reduction; insulation properties; residential heat loss; retrofitting houses; thermal conductivity; thermal insulation; thermography; air infiltration; condensation in buildings; NBSIR 77-1274.

Energy conservation; energy surveys; infrared; nondestructive evaluation; thermographic surveys; thermography; 16901.

Energy conservation; energy standards; fenestration; life-cycle costing; retrofitting; solar; building design; cost; 17107.
Energy conservation; enforcement; legislation; regulations; solar energy; standards; state-of-the-art study; buildings; NBSIR 77-1259.

Energy conservation; engineering; human factor; resource impact factors; building; building environment; 17110 .

Energy conservation; equipment maintenance; Markow decision process; policy improvement algorithm; dynamic programming; economic analysis; NBSIR 77-1210.

Energy conservation; evaluation; inspection; retrofit; thermography; buildings; 16902 .

Energy conservation; fenestration; HVAC systems; illumination; insulation; lighting; performance standard; thermal performance; ventilation; water heating; air leakage; building design; NBSIR 74-452.

Energy conservation; fly ashes; mineral waste utilization; slags; cement manufacture; 17010 .

Energy conservation; furnace; operating cost; seasonal performance; building heating system; computer simulation; 16922.

Energy conservation; humidity; temperature; thermal acceptability; clothing; cold discomfort; SP491, pp. 131-151 (Sept. 1977).

Energy conservation; illumination; illum ination levels; lighting; task lighting; 17293

Energy conservation; instrumentation; recuperators; waste; boilers; economics; HI2I.

Energy conservation; interferometric wavemeter; metric; pressure transducers; synchrotron radiation; building collapse; computer security; cryogenic temperature; dentistry; dielectric measurements; dye lasers; dynamic calibration; DIM/NBS 61 , No. 2, 1-32 (1977).

Energy conservation; intermittent ventilation; ventilation control; weather data analysis; air conditioning requirements; NBSIR 76-1088.

Energy conservation; life-cycle cost; optimization; performance standards; resource impact factors; resources; social optimum; standards; building economics; economic efficiency; eeonomics; energy; 17302.

Energy conservation; measurement methods; photovoltaic method; power-device grade silicon; resistivity variations; silicon; thermally stimulated capacitance; thermally stimulated current; thermally stimulated measurements; thyristor materials measurements; 17345 .

Energy conservation; measurement methods; photovoltaic method; power-device grade silicon; resistivity variations; silicon; thermally stimulated capacitance; thermally stimulated current; thermally stimulated measurements; thyristor materials measurements; NBSIR 77-1249.

Energy conservation; minimum property standards; multiple glazing; "U" values; alternatives; ASHRAE 90-75; building standards; buildings; SP473, pp. 85-101 (June 1977).

Energy conservation; mobile home; part-load efficiency; thermography; air infiltration; NBSIR 76-1 182.

Energy conservation; modeling; OSHA Standards; thermal sensation; WBGT; core temperature; SP491, PP. 18-40 (Sept. 1977).

Energy conservation; regulatory community; standards; buildings; codes; 17111 .

Energy conservation; shading coefficient; solar heat gain; window design; climatic data; cloud cover modifier; 17341 .

Energy conservation; summer temperature guidelines; thermal acceptability; thermal preference survey; winter temperature; clothing insulation; effective temperature $\left(E T^{*}\right) ; S P 491, \mathrm{pp}$. 93-116 (Sept. 1977).

Energy conservation base; insulation; residential design practices; typical construction characteristics; typical new house materials; windows; building envelope; NBSIR 77-1309.

Energy conservation in buildings; heat stress; human comfort; indoor environment; mean radiant temperature; thermal comfort; SP49I. 
Energy conservation in schools; energy consumption; energy utilization in schools; oxygen content; reduced ventilation rate; school operation schedule; ventilation test; computerized thermal simulation; $\mathrm{CO}_{2}$ concentration; BSS97.

Energy conservation research; heat and cold stress; mobile climate chamber; SP491, pp. 174-189 (Sept. 1977).

Energy conservation standards; new building design; retrofit design; computerized energy analysis; 16770.

Energy conserving buildings; energy legislation; energy performance criteria; energy performance standards; codes and standards; 17289.

Energy consumption; energy utilization in schools; oxygen content; reduced ventilation rate; school operation schedule; ventilation test; computerized thermal simulation; $\mathrm{CO}_{2}$ concentration; energy conservation in schools; BSS97.

Energy consumption; heating and cooling loads; building energy analysis; computerized energy analysis; NBSIR 76-1177.

Energy consumption; input/output models; lifestyle factors; physical environment; residential housing; socio-physical determinants; systems theory; SP473, pp. 69-83 (June 1977).

Energy curve; overlap; van der Waals; XeF; charge transfer; dissociation energy; 16684.

Energy data; environmental data; industrial process data; materials utilization data; mechanical properties; nuclear data; physical science data; solid state data; standard reference data; thermodynamic data; transport properties; atomic and molecular data; TN947.

Energy distribution; gamma ray; iterative; neutron; plastic; recoil; scintillator; UNFOLD; Apsara; SP461, pp. 247-251 (Jan. 1977).

Energy distribution; photoemission; secondary electron; 16826.

Energy efficiency; energy improvement targets; labeling; test procedures; appliances; energy conservation; 16885.

Energy efficiency; energy performance; model codes; standards; building codes; energy conservation; 17290

Energy gap; Josephson junctions; picosecond pulses; superconducting electronics; superconductivity; voltage waveforms; 16874.

Energy improvement targets; labeling; test procedures; appliances; energy conservation; energy efficiency; 16885.

Energy irradiance; flashtube; pulsed source; radiometry; curve fitting; TN935.

Energy leakage; Monte Carlo; neutron; sandwich; spectrometry; surface barrier; ${ }^{6} \mathrm{LiF}$; detector; SP461, pp. 252-254 (Jan. 1977).

Energy legislation; energy performance criteria; energy performance standards; codes and standards; energy conserving buildings; 17289 .

Energy levels; fine structure; hydrogenic atoms; Lamb shift; level shifts; quantum electrodynamics; radiative corrections; relativistic corrections; atomic structure; electron structure; JPCRD 6, No. 3, 831-870 (1977).

Energy levels; force field; infrared; microwave; molecular structure; spectra; spectroscopy; bond distances; carbonyl selenide; 16823.

Energy levels; gas phase; $\mathrm{PF}_{5}$; Raman; $\mathrm{VF}_{5}$; $\mathrm{AsF}_{5}$; barriers; 16978.

Energy levels, atomic; spectra, atomic; wavelengths, atoms and ions; atomic energy levels; atomic spectra; bibliography; SP363. Supplement 1 .

Energy loss; ESCA; solids; surfaces; 17021.

Energy management; evaluation and monitoring; survey of buildings; Air Force facilities; building energy conservation; 17062.

Energy management; graphic pen; halocarbons; infrared lasers; international standard; neutron xeroradiography; problemsolving; radiation safety; smoke detectors; solar heating; SRM's; adobe; air pollution; corrosion; electrical; DIM/NBS 61 , No. 3, 1-32 (1977).
Energy measurements; fuel savings; heat-loss reduction; insulation properties; residential heat loss; retrofitting houses; thermal conductivity; thermal insulation; thermography; air infiltration; condensation in buildings; energy conservation; NBSIR 77-1274.

Energy per ion pair; fluence; kerma factor; neutrons; activation; Bragg-Gray; dosimetry; SP493, pp. 342-346 (Oct. 1977).

Energy performance; model codes; standards; building codes; energy conservation; energy efficiency; 17290.

Energy performance criteria; energy performance standards; codes and standards; energy conserving buildings; energy legislation; 17289.

Energy performance standards; codes and standards; energy conserving buildings; energy legislation; energy performance criteria; 17289.

Energy problem; energy resources; fossil fuels; nuclear power; solar energy; energy choices; 17031 .

Energy problems; energy savings; exchange program; lead detection; metric; oxygen; technology; cryocooler; EMI problems; DIM/NBS 61, No. 10, 1-32 (1977).

Energy recovery; hydrogen; liquefier; component efficiency; cryogenics; efficiency; NBSIR 77-862.

Energy related inventions; heterodyne receiver; international standards code; NCSL; NMR knight shifts; neutron beams; piezo-flex micropositioning; pressure; thermodynamic tables; coal conversion; consumer products; cryogenic; DIM/NBS 61 , No. 7, 1-32 (1977)

Energy resources; fossil fuels; nuclear power; solar energy; energy choices; energy problem; 17031 .

Energy savings; exchange program; lead detection; metric; oxygen; technology; cryocooler; EMI problems; energy problems; DIM/NBS 61, No. 10, I-32 (1977).

Energy savings; flue damper; heat transfer; implicit; insulation; laboratory measurements; modeling; standby loss; water heater; alternating direction; computer simulation; cool down; 17184 .

Energy savings; grain moisture; mass spectra; radiation sterilizing; screw thread standards; SHIVA laser; silicon; timekeeping; ultraviolet radiation; calibration; consumers; energy; DIM/NBS 61, No. 9, 1-32 (1977).

Energy spectra; high energy; LET; neutrons; yields; dosimetry; NBSIR 77-1279, pp. 19-23 (July 1977).

Energy spectra; neutrons; Rossi-counter measurements; Serber theory; thick target; time-of-flight; ${ }^{9} \mathrm{Be}(\mathrm{d}, \mathrm{n}){ }^{10} \mathrm{~B} ;{ }^{9} \mathrm{Be}\left({ }^{3} \mathrm{H}\right.$ e,n) ${ }^{11}$ C; NBSIR 77-1279, pp. 31-34 (July 1977).

Energy spectra, yields; neutrons; thick target; time-of-flight; ${ }^{7} \mathrm{Li}(\mathrm{d}, \mathrm{n})^{8} \mathrm{Be},{ }^{7} \mathrm{Li}(\mathrm{p}, \mathrm{n})^{7} \mathrm{Be} ; \quad N B S I R \quad 77-1279$, pp. $1-4$ (July 1977).

Energy standards; accurate neutron energy determination; SP493, pp. 319-328 (Oct. 1977).

Energy standards; fenestration; life-cycle costing; retrofitting; solar; building design; cost; energy conservation; 17107.

Energy surveys; infrared; nondestructive evaluation; thermugraphic surveys; thermography; energy conservation; 16901 .

Energy transfer; gain inhibitor; gas lasers; photodissociation; restricted Hartree-Fock; transition moment; absorption crosssection; $\mathrm{Ar}_{2}{ }^{+} ; 17195$.

Energy transfer; gamma rays; moderator; neutron; radiation damage; reactor; scattering; spectrometer; cross section; SP461, pp. 32-40 (Jan. 1977).

Energy transport; equation of state; interatomic potential; molecular dynamics; second sound; shock wave; stress relaxation; structural relaxation; thermal relaxation; anharmonic crystal; computer simulation; 16751 .

Energy utilization in schools; oxygen content; reduced ventilation rate; school operation schedule; ventilation test; computerized thermal simulation; $\mathrm{CO}_{2}$ concentration; energy conservation in schools; energy consumption; BSS97. 
Energy (petroleum); manganese; bauxite; chromite; commodity supply policies; contingency planning; NBS-GCR-ETIP 77 38.

Energy-absorption coefficient; gamma-ray; photon; $x$ ray; attenuation coefficient; 17051 .

Energy-angle; integral; legendre polynomial; scattering; semi analytical; spatial; transmission; anisotropy; charged particle; computer code; SP461, pp. 140-143 (Jan. 1977).

Energy-conservation; insulation; shading; solar-heating; ventilation; windows; air-tightness; daylighting; BSS104.

Enforcement; funding; local government; model codes; statelocal relations; statewide codes; uniformity; building regulation; code administration; SP473, pp. 225-240 (June 1977).

Enforcement; information retrieval; inspection; management control; microfilm; building code; building permits; computers; SP473, pp. 377-382 (June 1977).

Enforcement; legislation; regulations; solar energy; standards; state-of-the-art study; buildings; energy conservation; NBSIR 77-1259.

Enforcement; legislation; rules and regulations; statewide codes; summary tables; building construction; building regulations; cities; code uniformity; NBSIR 77-1390.

Engine oil; fuel oil; hydraulic oil; industrial oils; lubricating oil; oil specifications; petroleum standards; petroleum test methods; recycled oil; re-refined oil; used oil; waste oil; SP488.

Engineering; buildings; design; disaster mitigation; earthquakes; NBSIR 76-1193.

Engineering; human factor; resource impact factors; building; building environment; energy conservation; 17110 .

Engineering design; manufacturing processes; materials selection; systems approach to design; SP487, pp. 19-24 (Aug. 1977).

Engineering properties; food products; information retrieval systems; management information systems; materials; nonfood products; physical properties; research information; agricultural materials; agricultural research; SP463, pp. II.2.1-11.2.10 (Jan. 1977).

Engineering standards; mandatory standards; national standards; plastics standards; standards; standards information service; voluntary standards; American National Standards Institute; computerized information system; SP463, pp. VI1.5.1-VII.5.9 (Jan. 1977).

Engineering standards, index of; index of nuclear standards; KWIC index of standards; SP483.

Engineering technical data, metrology; failure mode; failure rate, quality, reliability, safety; technology transfer; urgent data request; ALERT; calibration procedures; SP463, pp. III.5.1-111.5.8 (Jan. 1977).

Engine-generator efficiency; engine-generator performance; heat recovery; total energy systems; diesel engine performance; NBSIR 77-1207.

Engine-generator efficiency; heat recovery; performance; total energy systems; absorption chillers; boiler performance; central utility plant; diesel engine; NBSIR 77-1243.

Engine-generator performance; heat recovery; total energy systems; diesel engine performance; engine-generator efficiency; NBSIR 77-1207.

Enriched targets; $\mathrm{E}=65$ to $115 \mathrm{MeV}$; measured $\sigma(\mathrm{E}, \boldsymbol{\theta})$; nuclear charge distributions; nuclear reactions; ${ }^{36.40} \mathrm{Ar}\left(\mathrm{e}, \mathrm{e}^{\prime}\right)$; 16845 .

$E_{n}>2 \mathrm{MeV}$; measured thick-target neutron yields, $\operatorname{Be}(d, n)$, $\mathrm{Li}(\mathrm{d}, \mathrm{n}) ; \theta=0-90^{\circ}$; dosimetry: $\mathrm{E}_{d}=40 \mathrm{MeV} ;$ NBSIR 771279, pp. 24-29 (July 1977).

Enthalpies; entropies; equation of state; internal energies; isobars; isochores; isotherms; Joule-Thomson inversion; latent heats of vaporization; melting line; orthobaric densities; propane; specific heats; speeds of sound; vapor pressure; densities; NBSIR 77-860.
Enthalpy; entropy; Gibbs energy; thermochemical data networks; thermochemical tables; thorium compounds; data evaluation; NBSIR 77-1300.

Enthalpy; entropy; hydrogen; internal energy; liquid; oxygen; PVT; quality; slush; solid; vapor; computer programs; NBSIR 77-859.

Enthalpy; fluorescence; heat of solution; naphthalene; partition coefficient; solubility; vapor pressure; 1-ethylnaphthalene; 1 methylnaphthalene; 17097.

Fnthalpy; glass transition; heat capacity; pelletization; poly (vinyl chloride), pressure densification; relaxation; stored energy; strain energy; adiabatic temperature drift; 16769.

Enthalpy; heat capacity; high-speed measurements; high temperature; molybdenum; pulse calorimetry; standard reference material; thermodynamic functions; drop calorimetry; emittance; SP260-55.

Enthalpy of combustion; fuels; gasoline; gravity; heat content; heat of combustion; kerosine; aniline point; API gravity; aviation fuels; TN937.

Enthalpy of formation; Gibbs energy of formation; ideal gas thermodynamic properties; intermolecular association; normal and deuterated methanols; potential barrier to internal rotation; principal and reduced moments of inertia; JPCRD 6, No. 1, 105-112 (1977).

Enthalpy relaxation; glass transition; heat capacity; polymer; poly(vinyl chloride); pressure effects; thermodynamic properties; calorimetry; J. Res. 82, No. 1, 9-18 (1977).

Entrainment; fire induced flows; models; physical scale; plumes; buoyancy pressure; enclosure fires; J. Res. 82, No. 2, 107117 (1977).

Entrainment coefficient; fire-balls; turbulent thermals; vortex bubbles; buoyant thermals; SP484, pp. $571-596$ (Oct. 1977).

Entropies; equation of state; internal energies; isobars; isochores; isotherms; Joule-Thomson inversion; latent heats of vaporization; melting line; orthobaric densities; propane; specific heats; speeds of sound; vapor pressure; densities; enthalpies; NBSIR 77-860.

Entropy; equation of state; excitation spectrum; helium-4; normal fluid helium-4; phonons; protons; specific heat; superfluid helium-4; computed thermodynamic properties; JPCRD 6, No. 1, 51-104 (1977).

Entropy; ferroelectrics; glass-ceramics; heat switches; magnetothermal conductivity; polarization; potassium tantalate; refrigeration; specific heat; strontium titanate; beryllium; ceramics; cryogenics; dielectric-constant; electrets; electrocaloric effect; NBSIR 76-847.

Entropy; Gibbs energy; thermochemical data networks; thermochemical tables; thorium compounds; data evaluation; enthalpy; NBSIR 77-1300.

Entropy; hydrogen; internal energy; liquid; oxygen; PVT; quality; slush; solid; vapor; computer programs; enthalpy; NBSIR 77-859.

Entropy; ion-molecule equilibria; charge transfer; 17057.

Environment; gamma-ray measurements; germanium-lithium detectors; noble gases; radioactivity; reactor effluents; 16975.

Environment; gas chromatography; laser-Raman; liquid chromatography; nuclear magnetic resonance; organoarsenic; analysis; aqueous chemistry; arsenic; atomic absorption spectrophotometry; biomethylation; electrochemistry; 17155.

Environment; housing technology; HVAC; innovative construction; maintainability; materials; minimum property standards; performance criteria; performance evaluation; plumbing; safety; structures; test methods; acoustics; appliances; atmospheric; durability; electrical; NBSIR 77-1316.

Environment; land use; natural system; performance standards; regulatory process; building codes; carrying capacity; SP473, pp. 189-202 (June 1977).

Environmental; measurement; product safety; research; science; standards; technology; annual report; computer; energy; SP467. 
Environmental analysis; industrial hygiene; mercury vapor; personal dosimeter; piezoelectric sensors; quartz crystal microbalance; 16773 .

Environmental analysis; ion-selective electrode; lcad electrode; natural waters; rainwater; seawater; sulfate; 16771 .

Environmental considerations; innovative practices; regulatory research; standards development; administrative procedures; building codes; building regulations; buildings; economic impacts; $S P 473$.

Environmental control; temperature and performance; temperature control; thermal comfort; thermal sensation; thermal tolerance; work conditions; SP491, pp. 169-173 (Sept. 1977).

Environmental data; industrial process data; materials utilization data; mechanical properties; nuclear data; physical science data; solid state data; standard reference data; thermodynamic data; transport properties; atomic and molecular data; chemical kinetics data; TN947.

Environmental impact; land pollution; mutagenicity; toxic materials; toxicology; trace contaminants; water pollution; air pollution; analysis; ecology; energy; SP463, pp. IIl.4.1-111.4.15 (Jan. 1977).

Environmental impact; noise; noise exposure measurement system; sound; acoustics; community noise; NBSIR 76-1169.

Environmental monitoring; heat stress control; heat stress indices; heat stress monitoring; industrial heat stress; metabolic heat load; SP491, pp. 41-51 (Sept. 1977).

Environmental pollution; machinery and equipment; noise; noise abatement and control; noise emission; regulation; sound; acoustics; HI22.

Environmental quality; management; materials information; national programs; policy; technology assessment; energy; SP463, pp. 1.2.1-1.2.2 (Jan. 1977).

Environmental resistance of FRP rods; fiber-reinforced plastic (FRP); glass; guys, antenna; pultrusion; reinforced plastics; stress rupture of FRP rod; test methods; weatherability of FRP rods; aramid; composite materials; end fittings for FRP rod; 16685.

Environmental samples; long-term storage; microbiologicals; organics; pesticides; radionuclides; sample handling; sampling; trace elements; chemical analysis; 16729.

Environmental sensitivity; frequency lock loop; long-term frequency stability; NBS time scale; phase modulation; (active-passive) hydrogen maser; amplitude modulation; cavity frequency; 17211

Environmental studies; fire safety; health dangers; research needs; codes and standards; SP473, pp. 35-53 (June 1977).

Environments; erosion; hydrothermal; refractories; strength; coal gasification; 16993

Enzyme; initial velocity; kinetic constants; LDH; Michaelis constant; NADH; Zimm plot; 16911 .

$\mathrm{E}_{n}=$ 0.1-20 MeV; summary of experimental results; ${ }^{237} \mathrm{~Np}$, ${ }^{238} \mathrm{U}(\mathrm{n}, \mathrm{f})$ as neutron standards; SP493, pp. 278-289 (Oct. 1977).

Epicenters; maps; seismicity index; earthquake distributions; SP470, pp. III-18-III-28 (Apr. 1977).

Epicentral distance; liquefaction; settlement; soils; alluvial deposits; earthquakes; SP470, pp. V-1-V-15 (Apr. 1977).

Epitaxial resistivity; four-probe; resistivity; resistivity correction factors; semiconductor characterization; silicon; square array; collector resistivity; 16942 .

Epoxy insulation; high voltage; polymer tape insulation; superconducting cable; underground transmission; bridge measurements; cryogenic; dielectric loss; dissipation factor; 17014.

Equation of state; excitation spectrum; helium-4; normal fluid helium-4; phonons; protons; specific heat; superfluid helium4; computed thermodynamic properties; entropy; JPCRD 6 , No. 1, $51-104$ (1977)
Equation of state; heavy water; isotopic waters; partial molar volume of aqueous gases; $P V T$; thermal expansivity; water; aqueous solutions of gases; conipressibility; JPCRD 6, No. 4, $1109-1132$ (1977).

Equation of state; high pressure; high temperature; interaction virial coefficients; mixtures; molecular volumes; second virial coefficients; water; ballistics; carbon dioxide; combustion gases; energy; 17136.

Equation of state; interatomic potential; molecular dynamics; second sound; shock wave; stress relaxation; structural relaxation; thermal relaxation; anharmonic crystal; computer simulation; energy transport; 16751.

Equation of state; internal energies; isobars; isochores; isotherms; Joule-Thomson inversion; latent heats of vaporization; melting line; orthobaric densities; propane; specific heats; speeds of sound; vapor pressure; densities; enthalpies; entropies; NBSIR 77-860.

Equilibrium; humidity; relative humidity; salt; saturated salt solution; vapor pressure; water vapor; aqueous solution; $J$. Res. 81 A No. 1, 89-96 (1977).

Equipment maintenance; Markow decision process; policy improvement algorithm; dynamic programming; economic analysis; energy conservation; NBSiR 77-1210.

Equipment specification; field standard; gravimetric calibration; liquid retention or clingage tests; precision; prover; Research Associate Program; standards inspection procedure; temperature correction; test measure; test measure evaluation; "to contain"; NBSIR 77-1214.

Equipment standards; Law Enforcement Standards Laboratory; police equipment; reports and guidelines; survey; communications equipment priorities; SP480-13.

Equity; federal technology; fire modeling; heat; hydrocarbon; ionized molybdenum; measurement assurance; metric; neutron diffraction; recycling oil; research and innovation; safety; ultrasonic tiscue; computerized data; data elements; DIM/NBS 61, No. 6, 1 -32 (1977).

Equivalent circuit; fuel cells; microprocessor; network analyzer; phosphoric acid electrolyte; refractory hard metals; AC impedance; automated electrochemical analysis; ceramic electrolytes; ceria-yttria; cyclic voltommetry; electrocatalysis; NBSIR 77-1270.

Equivalent loads; tall buildings; wind loads; design; SP477, pp. I-49-1-65 (May 1977).

Equivalent static force; gravity load; handling devices; handling loads; military field shelters; probability distributions; shocks, snow load; static load; trains; transportation; trucks; vibrations; wind load; acceleration; airplanes; cargo; dynamic loads; NBSIR 77-1254.

Erbium; Laves phase; magnetic excitation; magnetism; rare earths; spin waves; 16963 .

E.R.D.A.; Federal agencies; interagency review; Interior; Library of Congress; materials; materials data; materials information; N.A.S.A.; U.S.D.A; Commerce; Defense; SP463.

Ergonomics; human factors; lifting; manual materials handling; physiology; psychophysics; safety; warranty; anthropometry; biomechanics; carrying; consumer product portability; NBSIR 76-1092.

Erosion; fracture; plastic flow; solid particle impact; transmission electron microscopy; ceramics; NBSIR 77-1396.

Erosion; high temperatures; ceramics; coal gasification; energy; 17028.

Erosion; hydrothermal; refractories; strength; coal gasification; environments; 16993.

Erosion; metal; oxidation; particle; velocity dependence; 16898.

Erosion-corrosion process; erosive wear; high temperature erosion; particle impingement; stainless steel; 17274 .

Erosion-corrosion process; erosive wear; high temperature erosion; particle impingement; stainless steel; 17300.

Erosive wear; high temperature erosion; particle impingement; stainless steel; erosion-corrosion process; 17274 . 
Erosive wear; high temperature erosion; particle impingement; stainless steel; erosion-corrosion process; 17300.

Error analysis; flow rate measurement; open channel flow measurement; power plant; spray canal; stage-discharge equation; velocity-area method; weir equation; closed-loop cooling system; cooling lake; dye dilution method; SP484, pp. 145 172 (Oct. 1977).

Error analysis; iodine; molybdenum hexafluoride; new static technique; vapor pressure; argon-vapor contact; 17075.

Error analysis; linear differential equations; transition point; turning point; asymptotic analysis; Bessel functions; 16899.

Error analysis; Liouville-Green approximation; ordinary differential equation; turning point; asymptotic analysis; Bessel functions; boundary-value problem; connection formula; diffraction theory; 16805 .

Error analysis; reflectance; reflectance factor; spectrophotometry; absolute reflectance; diffuse reflectance; $J$. Res. 82, No. 1, 29-55 (1977).

Error elimination; vane anemometer; velocity readings; ventilation tubing; air velocity; SP484, pp. $755-763$ (Oct. 1977).

Error reduction; flow measurement techniques; flow vs. temperature techniques; pressure drops; thermal devices; SP484, pp. 597-619 (Oct. 1977).

Error reduction; hot-wire anemometry; supersonic flows; thin turbulent shear layers; SP484, pp. 649-658 (Oct. 1977).

Error reduction; indirect flow measurement; turbulent twophase flow; two-phase flow; SP484, pp. $765-782$ (Oct. 1977).

Error reduction strategy; flow measurement errors; infiltration/inflow analysis; Parshall flume; SP484, pp. 173-186 (Oct. 1977).

Errors; fission neutrons; irradiation devices; measuring methods; neutron reactions; neutron sources; calibration; californium-252; cross sections; design;.16790.

Errors; flow measurement; flumes; open-channel flow; broadcrested weirs; SP484, pp. 201-218 (Oct. 1977).

Errors in flow measurement; flow measurement; fluid flow modeling; fluid velocity; flumes; gas flow standard; hot-wire anemometry; international flow standards; laser anemometry; open channel flows; orifice meters; pitot-static meters; turbine meters; weirs; SP484, Volumes 1 and 2.

Errors in spectrophotometry; interferences; multiple reflections; photometric linearity; polarization; sample characteristics; stray light; wavelength accuracy; bandwidth; calibration; SP466, pp. 99-114 (May 1977).

Errors in spectrophotometry; photometric scale; slit width; spectral transmission; spectrophotometer standards; stray light; wavelength scale; SP466, pp. 117-120 (May 1977).

ESCA; solids; surfaces; energy loss; 17021 .

Escape; fires; human behavior; human response; life safety; mapping; model; nursing homes; rescue; verbal communicative; alarm; architecture; design implication; emergency actions; emergency communicative; emergency decisions; NBS GCR-77-93.

Escape time; fire tests; gas detectors; heat detectors; residential fires; smoke detectors; detector sensitivity; detector siting; NBS-GCR-77-82.

ESR; gamma ray; glow curve; irradiation; TL; $\mathrm{CaSO}_{4}$; correlation; dose; SP461, pp. 234-237 (Jan. 1977).

Estimation; geometry; hypercube; hyperplane; polytope; convex set; data analysis; 17117.

Estimators of location; median; M-estimators; S. Newcomb; systematic errors; trimmed means; velocity of light; A. A. Michelson; adaptive estimators; arithmetic mean; bias; 17266.

Ethane; ethene; methane; vapor + liquid equilibria; 16881 .

Ethane; experimental; isobutane; magnetic suspension densimeter; methane; normal butane; propane saturated liquid; tables; density; deviation plots; 16871 .
Ethane; thermal conductivity coefficient; viscosity coefficient; critical point enhancement; data evaluation; JPCRD 6, No. 4, $1167-1180$ (1977).

Ethane, fluid; fluid ethane; sound; speed of sound; compressed fluid ethane; 17067.

Ethanol; measurement; molecular absorption; $10 \mu \mathrm{m}$ wavelength; ammonia; carbon dioxide; 16924.

Ethene; methane; vapor + liquid equilibria; ethane; 16881 .

Ethyl cyanide; interstellar molecule; microwave emission; radio sources and rotational spectra; astronomy; 17264.

Ethylene; mass spectrometry; ozone; air pollution; chemical kinetics; dioxirane; 17327.

Ethylene; photoemission; tungsten; ultraviolet photoelectron spectroscopy; acetylene; adsorption; chemisorption; dehydrogenation; 16829.

Euclidean plane; matrices of order three; triangle of reference; barycentric coordinates; distance coordinates; J. Res. $81 \mathrm{~B}$ Nos. 1 and 2, 61-72 (1977).

Euler, Leonard (1707-1783); Figure of the Earth; fitting a linear equation; least sum of absolute deviations; Mayer, Tobias (1723-1762); method of averages; weighted mean; weighted median; zero sum of residuals; Boscovich, Roger Joseph (1711-1787); 17314.

Evaluating computer service; network measurement machine; remote terminal emulators; response time; throughput; turnaround time; 17250 .

Evaluation; evaluation research; evaluation systems; policy analysis; social experimentation; administrative experimentation; 17116.

Evaluation; evaluation research; organizational design; policy analysis; program evaluation; administrative experimentation; 17323.

Evaluation; innovation; invention; technology transfer; energy; 17108.

Evaluation; innovations; in-place testing; performance approach; regulatory domination; standards development; building codes; concrete testing; SP473, pp. 279-284 (June 1977).

Evaluation; inspection; retrofit; thermography; buildings; energy conservation; 16902.

Evaluation; interactive; measurement; performance evaluation; performance measurement; remote terminal emulation; Remote Terminal Emulator; teleprocessing; 16945.

Evaluation; interactive; measurement; performance evaluation; performance measurement; remote terminal emulation; remote terminal emulators; teleprocessing; SPSOO-4.

Evaluation; National Bureau of Standards; on-line bibliographic retrieval systems; 17186 .

Evaluation; optical model; R-function analysis; standard; total cross section; carbon; elastic scattering cross section; SP493, pp. 93-100 (Oct. 1977).

Evaluation; performance; pressure; transducer; characterization; 17205.

Evaluation; pressure measurement; pressure transducer; transducer; biomedical; 16941

Evaluation and monitoring; survey of buildings; Air Force facilities; building energy conservation; energy management; 17062.

Evaluation criteria; key; password; personal identification; terminals; verification; ADP security; computer networks; controlled accessibility; encryption; FIPS PUB 48.

Evaluation research; evaluation systems; policy analysis; social experimentation; administrative experimentation; evaluation; 17116.

Evaluation research; organizational design; policy analysis; program evaluation; administrative experimentation; evaluation; 17323.

Evaluation systems; policy analysis; social experimentation; administrative experimentation; evaluation; evaluation research; 17116. 
Evaluations; status; U-235 (n,f); 0.1-20.0 MeV; data; SP493, pp. 261-268 (Oct. 1977).

Evaporated metal-on-quartz; filters, transmittance; neutral filters; standard reference materials; transmittance characteristics; ultraviolet-visible filters; SP466, pp. 127-131 (May 1977).

Evaporative cooling; fire suppression; full-scale test; gas temperature; oxygen content; recirculating flow; reduced scale model test; scaling criteria; spray water flow rate; water spray; automatic sprinklers; compartment fire; corridor sprinkler systems; NBSIR 77-1287.

Event model; measurement; modelling; resource dependency; system capacity; validation; credit authorization system; critical resource; disk modelling; SP500-18, pp. 185-211 (Sept. 1977).

Evidential materials; forensic reference collections; forensic science; reference materials; standard reference collections; criminalistics; 16706.

Exact fringes; fractional fringe; interferometer; length measurement; partial fringe; wavelength measurement; dimensional metrology; 17048.

Excess free energy; osmotic coefficient; solutions; thermodynamic properties; activity coefficient; calcium chloride; critical evaluation; electrolyte; JPCRD 6, No. 2, 385-408 (1977).

Exchange interaction; inner shells; photoabsorption; atoms, correlation; configuration interaction; 16670.

Exchange program; lead detection; metric; oxygen; technology; cryocooler; EMl problems; energy problems; energy savings; DIM/NBS 61, No. 10, 1-32 (1977).

Excimer; excitation energy; perturbation formula; rare gas halide; Rittner model; transition moment; dipole moment; 17151.

Excimers; excited states; metal dimers; $\mathbf{M g}_{2}$; multiconfiguration self-consistent-field; ab initio; electronic structure; 17188.

Excitation; $\mathrm{Be}^{+}$; electron collisions; 17132 .

Excitation; hydrogen; Balmer-alpha; collision; cross section; dissociation; electron; 17054.

Excitation energy; perturbation formula; rare gas halide; Rittner model; transition moment; dipole moment; excimer; 17151 .

Excitation spectrum; helium-4; normal fluid helium-4; phonons; protons; specific heat; superfluid helium-4; computed thermodynamic properties; entropy; equation of state; JPCRD 6, No. 1, 51-104 (1977).

Excitation transfer; laser stimulation; orbiting; saturation; selection rules; van der Waals; atomic collision; 16695.

Excited state; gamma ray; ground state; inner bremsstrahlung; Jauch plot; spectrum; transition; coincidence; electron capture; SP461, pp. 23-25 (Jan. 1977).

Excited states; metal dimers; $\mathrm{Mg}_{2}$; multiconfiguration self-consistent-field; ab initio; electronic structure; excimers; 17188.

Excluded volume; Monte Carlo; polymer chain dynamics; random coil; random flight chain; relaxation times; 17125 .

Existing buildings; historic preservation; performance attributes; performance evaluation; building codes and standards; building code structure; SP473, pp. 453-489 (June 1977).

Existing structures; optimization; retrofitting; seismic; costs; SP477, pp. VI-69-VI-84 (May 1977).

Exit capacity; fire safety; human performance; occupational safety; regulatory data; architectural psychology; architectural research; building codes; building design; building fires; building regulatory standards; emergency egress; NBSIR 771313.

Exit concentration; exit velocity; flow visualization; fluorescence; fluorescent dye; laser; laser dye-fluorescence technique; mean concentration; mean velocity; measuring volume; remote sensing; root-mean-square concentration; SP484, pp. $423-447$ (Oct. 1977).
Exit velocity; flow visualization; fluorescence; fluorescent dye; laser; laser dye-fluorescence technique; mean concentration; mean velocity; measuring volume; remote sensing; rootmean-square concentration; Schmidt number; SP484, Pp. 423-447 (Oct. 1977).

Exoelectron emission; failure prediction; laser scanner; oxide rupture; surface deformation; assessment of fatigue damage; SP487, pp. 197-209 (Aug. 1977).

Expanders; heat exchangers; particle accelerators; power transmission; reliability; compressors; cryogenic refrigeration; efficiency; 17083.

Expansion; investments; petrographic; thermal; dental; 17325.

Expansion coefficient; Green's function; neutron; spherical; symmetric; transport; density transform; SP461, pp. 87-90 (Jan. 1977).

Experiment; shake table; testing; transformer; circuit breaker; data; SP477, pp. VI-50-VI-60 (May 1977).

Experiment automation; off-the-shelf automation; polymer degradation; rapid response furnace; thermogravimetry; computerized experiment; 16842 .

Experimental; internal wave; laboratory; oscillating probe; conductivity probe; density; density gradient; SP484, pp. 783 . 802 (Oct. 1977).

Experimental; isobutane; magnetic suspension densimeter; methane; normal butane; propane saturated liquid; tables; density; deviation plots; ethane; 16871 .

Experimental; laser; photochemistry; apparatus; chromatography; 16895.

Experimental; lifetimes; $\mathrm{N}_{2} \mathrm{O}$; oxygen; radiation; time-of-flight; atomic; 16812 .

Experimental; liquid, magnetic; modification; suspension; absolute measurements; barium ferrite buoy; densimeter; 16792.

Experimental; stability; supercritical helium; acoustic oscillations; current leads; 17078.

Experimental data; abstracted publications; adhesives and sealants; cryogenic adhesives and sealants; 16883.

Experimental data; fire endurance; heat generation or absorption; numerical solutions; one-dimensional; radiation; thermal conduction; transient heat transfer; composite building constructions; convection; NBSIR 77-1260.

Experimental melting curves; high pressure; solid-solid phase boundaries; AB-type compounds; calibration; critically evaluated data; crystallographic data; JPCRD 6, No. 4, 1205-1252 (1977).

Experimental methods; smoke control methods; smoke movement; smoke simulation; state-of-the-art review; basic principles; computer calculations; computer modeling; NBSIR 771209.

Experimental $\sigma(\theta)$; model predictions; nuclear reactions np scattering $E \leqslant 30 \mathrm{MeV}$; phase shift analyses; calculated $\sigma(\theta)$; SP493, pp. 47-53 (Oct. 1977).

Experimental procurement; experimental technology incentives program; procurement experiment; prototype procurement; technological innovation; check wrapping equipment; NBSGCR-ETIP 77-39.

Experimental Technology Incentives Program (ETIP); Federal Supply Service; life cycle costing; procurement policy; specifications; value incentive; NBS-GCR-ETIP 76-26.

Experimental Technology Incentives Program (ETIP); Federal Supply Service; life cycle costing; procurement policy; specifications; value incentive; NBS-GCR-ETIP 76-27.

Experimental technology incentives program; procurement experiment; prototype procurement; technological innovation; check wrapping equipment; experimental procurement; NBSGCR-ETIP 77-39.

Experiments; nonlinear response; reinforced concrete; bridges; design; SP477, pp. VI- I - VI-9 (May 1977).

Explosion; extinguisher; fire; gas; injury; liquefied; petroleum; standards; container; corrosion; NBSIR 77-1217. 
Explosive detection; limits of detection; sensitivity test; TNT; vapor generator; vapor pressure; DNT; EGDN; 16830.

Exposure; exposure control; film thickness variation; irradiance measurements; photoresist; photoresist sensitivity; sensitivity index; Van Kreveld's additivity law; 16853.

Exposure; exposure control; film thickness; irradiance measurements; photoresist; sensitivity index; sensitometry; Van Kreveld's additivity law; 17329.

Exposure control; film thickness variation; irradiance measurements; photoresist; photoresist sensitivity; sensitivity index; Van Kreveld's additivity law; exposure; 16853.

Exposure control; film thickness; irradiance measurements; photoresist; sensitivity index; sensitometry; Van Kreveld's additivity law; exposure; 17329.

Exposure limits; heat stress; thermal analysis; SP49I, pp. 65.92 (Sept. 1977).

Exposure reduction; imaging information content; image processing; mammography; $\mathrm{x}$-ray radiography; diagnostic radiography; 16666.

Exposure spectra; gamma-rays; scattered radiation; source housing; spectrometry; ${ }^{60} \mathrm{Co}$ gamma-ray source; collimator; NBSIR 76-11117.

Extended chain crystals; fold domains; fold surfaces; interlamellar links; morphology; polymer; sectorization; spheralites; chain folding; curved crystals; 16958.

Extended-range $C(V)$ and $G(V)$ measurements; high voltage $C(V)$ and $G(V)$ measurements; MIS capacitors; modified MIS C(V) measurements; senviconductor devices; silicon-onsapphire measurements; SOS measurements; bias-isolation unit; $S P 400-40$.

Extended-range MIS C (V) measurements; high-voltage C (V) measurements; MIS capacitor; premature dielectric breakdown; semiconductor devices; capacitance-voltage measurements; dielectric breakdown suppression; discharge suppression; electronics; SP400-37.

Extended-type objects; operating system structures; protection; reliable software; reliability; security; small protection domains; types; capability; capability-based addressing; computer security; 16920.

Extension and compression in rubber; Martin-Roth-Stiehler equation; modulus of rubber; Mooney-Rivlin equation; rubber; stress-strain relations; stress-strain relations in rubber; J. Res. 82, No. 1, 57-63 (1977).

Zxtension service; information services; land grant university; agricultural research service; agriculture; SP463, pp. II.3.1II.3.4 (Jan. 1977).

External measurement; figure-of-merit; interactive system; measurement model; measurement, performance; measures; methodology; network measurement system; computer service; 17288.

External particle detectors; gaseous ionization detectors; instruments; scintillation detectors; ${ }^{6} \mathrm{Li}(\mathrm{n}, \alpha)^{3} \mathrm{H}$; SP493, pp. $43-46$ (Oct. 1977).

Extinguishability; extinguishment; fabric flammability; fibers; heat flux; heat sinks; oxygen concentration; textiles; air flow; NBS-GCR-77-90.

Extinguishability; fabric flammability; flammability ranking; heat flux; heat transfer rate; linear burning rate; NBS-GCR76-77.

Extinguishability; fire retardants; flammability hazard; FR treated cotton blends; FR treated cottons; ignitability; MAFT value; phosphorus; synthetic fabrics; burn injury potential; 17176

Extinguisher; fire; gas; injury; liquefied; petroleum; standards; container; corrosion; explosion; NBSIR 77-1217.

Extinguishment; fabric flammability; fibers; heat flux; heat sinks; oxygen concentration; textiles; air flow; extinguishability; NBS-GCR-77-90.
Extra-tropical storms; hurricanes; thunderstorms; tornadoes; wind; wind damage; SP477, Pp. II-15-II-29 (May 1977).

Extreme pressure; fluorinated ethylenepropylene; gear lubrication; grease; polyfluoroalkyl-alkyl polysiloxane; polytetrafluoroethylene; antimony dialkyldithiocarbamate; antiwear; bearing lubrication; SP487, pp. 154-171 (Aug. 1977).

Extreme ultraviolet; flare-stellar; soft $x$ ray; 16933.

Extrinsic damage thresholds; high-power lasers; infrared materials; tensile stress; cadmium telluride; elastic compliance tensor; elastic moduli; 16746.

Extrinsic damage thresholds; high-power lasers; infrared materials; tensile stress; cadmium telluride; elastic compliance tensor; elastic moduli; 17312.

$\mathrm{E}=14.8,18,23 \mathrm{MeV}$; measured neutron spectral distributions for $\mathrm{E}_{\mathrm{n}}>0.3 \mathrm{MeV}$; nuclear reactions; NBSIR 77-1279, pp. 5-9 (July 1977).

$E=28.8-95.0 \mathrm{MeV}$; measured $\sigma(E)$ at $\theta=75^{\circ}$; nuclear reactions; ${ }^{3} \mathrm{He}\left(\mathrm{e}, \mathrm{e}^{\prime}\right)$; deduced rms charge radius; 16850 .

$\mathrm{E}=65$ to $115 \mathrm{MeV}$; measured $\sigma(\mathrm{E}, \theta)$; nuclear charge distributions; nuclear reactions; ${ }^{36.40} \operatorname{Ar}\left(e, e^{\prime}\right)$; enriched targets; 16845.

E/h voltage standard; Josephson junction; microstrip resonator; microwave coupling; parametric plasma oscillation; thin-film device; coherent microwave emission; 16788.

\section{F}

Fabric flammability; fabrics; fire; garments; heat transfer; injury hazard; simulation; accident; apparel; burn injury; NBSIR 77 1236.

Fabric flammability; fabrics; fire hazards; ignition time; pyrolysis; radiant heating; thermal radiation; thermoplastics; cellulosic materials; char; convective heat transfer; NBS-GCR-77. 99.

Fabric flammability; FFACTS; flammability standards; Flammable Fabrics Act; ignition sources; apparel fires; bum injury; SP463, pp. VII.2.1-VII.2.11 (Jan. 1977).

Fabric flammability; fibers; heat flux; heat sinks; oxygen concentration; textiles; air flow; extinguishability; extinguishment; NBS-GCR-77-90.

Fabric flammability; flammability ranking; heat flux; heat transfer rate; linear burning rate; extinguishability; NBSGCR-76-77.

Fabrication techniques; graphite fibers-aluminum; mechanical behavior; pultrusion/drawing; wire preform; composite material; SP487, pp. 93-107 (Aug. 1977).

Fabrics; fire; garments; heat transfer; injury hazard; simulation; accident; apparel; burn injury; fabric flammability; NBSIR 77-1236.

Fabrics; fire hazards; ignition time; pyrolysis; radiant heating; thermal radiation; thermoplastics; cellulosic materials; char; convective heat transfer; fabric flammability; NBS-GCR-7799.

Fabrics; flammability testing; heat transfer rates; Mushroom Apparel Flammability Tester; standards; test development; textiles; apparel; NBS-GCR-76-78.

Fabry-Perot interferometer; Rydberg constant; Balmer $\alpha$ line; cw dye laser; 17098.

Face shells, reinforcing splices; high lift grouting; shotcrete, surface wave instrumentation; veneer anchorage; allowable bolt loads, end distance, ed ge distance and spacing; drift; BSSI06, pp. 259-274 (Sept. 1977).

Face-centered cubic solids; Poisson's ratio; polycrystals; bodycentered cubic solids; central-force solids; elastic constants; 16880 .

Face-centered-cubic solids; polycrystals; shear modulus; Young's modulus; elastic constants; 17099. 
Facilities; fluence; flux; moderation; monitor; neutron; shielding; sources; standardization; calibration; detection; dosimetry; SP493, pp. 115-120 (Oct. 1977).

Facility location; location theory; minimax; networks; J. Res. 82, No. 1, 65-72 (1977).

Facility location; location theory; minimax; networks; J. Res. 82, No. 1, 73-80 (1977).

Factors in design; requirements in design; checklist for design; design; SP487, pp. 1-15 (Aug. 1977).

Faddeev equations; helium-three; monopole transition; separable potential; Coulomb excitation; electron scattering; 16793.

Failure; fractography; fracture tests; hydrogen; steels; stress corrosion; crack propagation; ductility; 16700.

Failure; Kaiser Effect; pressure vessels; sources; acoustic emission; crack growth; drill pipe; SP487, pp. 210-238 (Aug. 1977).

Failure; roofs; wind; dynamics; SP477, pp. I-12-I-20 (May 1977).

Failure; strain concentration; stress concentration; anisotropy; composite laminates; SP487, pp. 121-134 (Aug. 1977).

Failure analysis; failure prevention; quality assurance; reliability; coal conversion; coal gasification; coal liquefaction; corrosion; SP468.

Failure analysis; film thickness; gears; Hertz contacts; lubrication; rheology; starvation; traction; bearings; computer programs; elastohydrodynamics; SP487, pp. $137-153$ (Aug. 1977).

Failure avoidance; failure prevention; lubricants; materials of design; product liability; reliability of design; techniques of design; validation of design; coating materials; composite materials; design; SP487.

Failure avoidance; metal corrosion; metal erosion; vaporization processes; ceramic corrosion; ceramic erosion; ceramic fracture; chemical degradation; coal gasification material; 17158.

Failure avoidance; metal corrosion; metal erosion; vaporization processes; ceramic corrosion; ceramic erosion; ceramic fracture; chemical degradation; coal gasification material; 17159.

Failure detection; failure diagnosis; failure prevention; ferrography; land vehicle diagnostics; oil analysis; railroad system diagnostics; signature analysis; wear; SP494.

Failure diagnosis; failure prevention; ferrography; land vehicle diagnostics; oil analysis; railroad system diagnostics; signature analysis; wear; failure detection; SP494.

Failure mode; failure rate, quality, reliability, safety; technology transfer; urgent data request; ALERT; calibration procedures; engineering technical data, metrology; SP463, pp. III.5.1-III.5.8 (Jan. 1977).

Failure mode and effect analysis; failure reduction; reliability; system safety; critical item list; SP487, pp. 278-288 (Aug. 1977).

Failure modes; load capacity; masonry walls; shear walls; splitting strength; ultimate capacity; brick; clay masonry; concrete block; concrete masonry; BSS106, pp. 177-197 (Sept. 1977).

Failure prediction; laser scanner; oxide rupture; surface deformation; assessment of fatigue damage; exoelectron emission; SP487, pp. 197-209 (Aug. 1977).

Failure prevention; ferrography; land vehicle diagnostics; oil analysis; railroad system diagnostics; signature analysis; wear; failure detection; failure diagnosis; SP494.

Failure prevention; lubricants; materials of design; product liability; reliability of design; techniques of design; validation of design; coating materials; composite materials; design; failure avoidance; $S P 487$.

Failure prevention; noise spectrum; piezoelectric polymer; vibration sensor; acoustic emission; damage detection; SP487, pp. 189-196 (A1 's. 1977).

Failure prevention; quality assurance; reliability; coal conversion; coal gasification; coal liquefaction; corrosion; failure analysis; $S P 468$.
Failure rate, quality, reliability, safety; technology transfer; urgent data request; ALERT; calibration procedures; engineering technical data, metrology; failure mode; SP463, pp. III.5.1-III.5.8 (Jan. 1977).

Failure reduction; reliability; system safety; critical item list; failure mode and effect analysis; SP487, pp. 278-288 (Aug. 1977).

Fall-arrest equipment; fall-safety systems; impact accelerations; impact forces; lanyards; linemen's equipment; load-extension data; occupational safety and health; performance standard; regulation; tensile testing; worker safety equipment; body belts; body harness; NBSIR 76-1146.

Fall-safety systems; impact accelerations; impact forces; lanyards; linemen's equipment; Ioad-extension data; occupational safety and health; performance standard; regulation; tensile testing; worker safety equipment; body belts; body harness; fall-arrest equipment; NBSIR 76-1 146.

Far infrared laser; frequency modulation; Stark effect; 17203.

Faraday magnetometer design; homogeneity; magnet design; magnetic field gradients; magnetometer design; 16828.

Fast Fourier transform; impulse generator; radiometer; sampling oscilloscope; spectrum amplitude; spectrum analyzer; spectrum intensity; calibration; electromagnetic interference; 16725.

Fast Fourier Transform; impulsive noise; magnetic field strength; measurement instrumentation; portable spectrum analyzer; spectral density; time-dependent spectral density; coal mine noise; digital data; electromagnetic interference; electromagnetic noise; 17175 .

Fast neutron flux density; international comparison; SP493, pp. 244-249 (Oct. 1977).

Fast neutrons; geometric factors; photon; polarimeter; radiation physics; scattering; spectrometers; absorption; accuracy; cross section; SP461, pp. 47-54 (Jan. 1977).

Fast neutrons; isotropic neutrons; $\mathrm{Li}^{\mathbf{6}}$ sandwich surface barrier spectrometer; proton recoil surface barrier spectrometer; energy and flux calibration; SP493, pp. 61-66 (Oct. 1977).

Fast neutrons; linac; reactor filtered beam; standard; ${ }^{6} \mathrm{Li}(\mathrm{n}, \alpha)$ T; angular distribution; SP493, pp. 10-13 (Oct. 1977).

Fast reactors; integral experiments; standards; adjustment; benchmark; cross-sections; SP493, pp. 310-312 (Oct. 1977).

Fast response; films; humidity sensor; industrial fabrication; isotherm equations; physical adsorption; relative humidity; routine radiosonde application; barium fluoride; calibration equations; NBSIR 76-I108.

Fasteners; low-rise buildings; masonry walls' structural design; technology transfer; timber roofs; timber walls; wind effects; codes and standards; connectors; BSS100-3.

Fasteners; wind; architecture; buildings; connectors; design criteria; NBSIR 77-1197.

Fast-thermal couple reactor; neutron; reactor transients; solution; time-dependent; transport; transport equation; approximations; SP461, pp. $91-93$ (Jan. 1977).

Fatigue; fatigue failure; cap screw failures; cyclic loading; NBSIR 77-1275.

Fatigue; fiber length; flexing; low cycle fatigue; mechanical properties; microstructure; modelling; paper; pore size; statistical analysis; Weibull distribution; durability; 16681 .

Fatigue; fracture; low temperature tests; mechanical properties; nickel alloys; superalloys; 16801 .

Fatigue; iron alloys; liquid helium; stainless steels; steels; superalloys; titanium alloys; aluminum alloys; crack propagation; 16928.

Fatigue; microstructures; titanium alloys; corrosion; 17187.

Fatigue crack growth; fracture toughness; heat affected zone; J-integral; nickel steel; weldments; cryogenic temperature; 17089.

Fatigue failure; cap screw failures; cyclic loading; fatigue; NBSIR 77-1275. 
Fatigue tests; finite element analysis; joints; nonlinear analysis; single-lap-joint analysis; single-lap-joint bending; spotwelded joints; weldbonded joints; adhesive-bonded joints; bonded joints; cyclic loading; debond analysis; double-lap-joint analysis; NBSIR 76-1053.

Fault tree analysis; probabilistic analysis; reliability; systems analysis; availability; SP487, pp. 289-308 (Aug. 1977).

Federal ADP statistics; Federal Government computers; Federal minicomputers; statistics; ADP costs; SP500-7.

Federal agencies; interagency review; Interior; Library of Congress; materials; materials data; materials information; N.A.S.A.; U.S.D.A; Commerce; Defense; E.R.D.A.; SP463.

Federal Government computers; Federal minicomputers; statistics; ADP costs; Federal ADP statistics; SP500-7.

Federal Information Processing Standards; geography; information processing standards; information system; representations and codes; standards; statistical data; ADP standards; computers; data elements and codes; data processing; FIPS PUB 10-2.

Federal Information Processing Standards Publication; information processing; terms; vocabulary; computers; data processing; definitions; dictionary for information processing; FIPS PUB $11-1$

Federal Information Processing Standards; serial-by-bit; serialby-character; telecommunications; teleprocessing; American Standard Code for Information Interchange; ASCII; communications; data communications equipment; FIPS PUB 16-1.

Federal Information Processing Standards; serial-by-bit; telecommunications; teleprocessing; American Standard Code for Information Interchange; ASCII; character parity sense; character structure; communications; data transmission; FIPS PUB 17-I.

Federal Information Processing Standards; parallel-by-bit; parity sense; serial-by-character; telecommunications; teleprocessing; American Standard Code for Information Interchange; ASCII; character structure; communications; data transmission; FIPS PUB 18-1.

Federal Information Processing Standards; synchronous signaling rates; teleprocessing; data communication equipment; data processing terminal equipment; data transmission (voice band); FIPS PUB 22-1.

Federal Information Processing Standard; workload representation; benchmarking; benchmark mix demonstration; computer selection; FIPS PUB 42-1.

Federal Information Processing Standard; ADP security; computer security; encryption; FIPS PUB 46.

Federal Information Processing Standards; performance measures; computer performance evaluation; computer performance management; FIPS PUB 49.

Federal library and information activities; library and information sciences; review; 16743.

Federal minicomputers; statistics; ADP costs; Federal ADP statistics; Federal Government computers; SP500-7.

Federal science; governmental environment; laser energy; space flight; spectroscopy; SRM; television captioning; thermophysical; weights and measures; American electroplaters'; calorimeter; cryogenic flow measurement; DIMINBS 6I, No. 4, 1-32 (1977).

Federal Software Exchange Program; proprietary software; public domain software; software exchange; software guide; software index; software sharing; computer program index; SP500-22.

Federal Standard COBOL; programming aids; programming languages; 'COBOL; COBOL programming aids; FIPS PUB 47.
Federal Supply Service; life cycle costing; procurement policy; specifications; value incentive; Experimental Technology Incentives Program (ETIP); NBS-GCR-ETIP 76-26.

Federal Supply Service; life cycle costing; procurement policy; specifications; value incentive; Experimental Technology Incentives Program (ETIP); NBS-GCR-ETIP 76-27.

Federal technology; fire modeling; heat; hydrocarbon; ionized molybdenum; measurement assurance; metric; neutron diffraction; recycling oil; research and innovation; safety; ultrasonic tissue; computerized data; data elements; equity; DIM/NBS 6I, No. 6, 1-32 (1977).

Fenestration; HVAC systems; illumination; insulation; lighting; performance standard; thermal performance; ventilation; water heating; air leakage; building design; energy conservation; NBSIR 74-452.

Fenestration; life-cycle costing; retrofitting; solar; building design; cost; energy conservation; energy standards; 17107.

$\mathrm{FeO} ; \mathrm{FeO}_{2}$ : infrared spectrum; structure; vibrational frequency; 17208.

$\mathrm{FeO}_{2}$ : infrared spectrum; structure; vibrational frequency; $\mathrm{FeO}$; 17208.

Fermi theory; finite field theory; neutral currents; weak coupling constants; weak interactions; effective neutral weak interactions; 17103.

Ferritic steels; fracture toughness; low temperature; nickel alloys; titanium alloys; aluminum alloys; 17086.

Ferroelectrics; glass-ceramics; heat switches; magnetothermal conductivity; polarization; potassium tantalate; refrigeration; specific heat; strontium titanate; beryllium; ceramics; cryogenics; dielectric-constant; electrets; electrocaloric effect; entropy; NBSIR 76-847.

Ferrography; land vehicle diagnostics; oil analysis; railroad system diagnostics; signature analysis; wear; failure detection; failure diagnosis; failure prevention; SP494.

Ferromagnetic domain walls; nickel single crystals; $x$-ray dynamical diffraction; crystal growth; crystal perfection; diffraction topography; dynamical diffraction theory; 16974.

Ferromagnetism; order-order transition; transition temperatures; canted phase; 17350.

$\mathrm{Fe}_{2} \mathrm{O}_{3} ; \mathrm{Fe}_{2} \mathrm{O}_{4}$; gaseous reduction; hematite; high voltage electron microscopy; iron oxide; magnetite; 17177.

$\mathrm{Fe}_{2} \mathrm{O}_{4}$; gaseous reduction; hematite; high voltage electron microscopy; iron oxide; magnetite; $\mathrm{Fe}_{2} \mathrm{O}_{3} ; 17177$.

FFACTS; flammability standards; Flammable Fabrics Act; ignition sources; apparel fires; burn injury; fabric flammability; SP463, pp. VII.2.1-VII.2.11 (Jan. 1977).

FFT; measurement system; RF noise spectrum; 3-D display; 17173 .

Fiber length; flexing; low cycle fatigue; mechanical properties; microstructure; modelling; paper; pore size; statistical analysis; Weibull distribution; durability; fatigue; 16681 .

Fiber morphology; fibers; image analysis; pattern recognition; pulp characterization; pulps; algorithms; 17214 .

Fiber-reinforced plastic (FRP); glass; guys, antenna; pultrusion; reinforced plastics; stress rupture of FRP rod; test methods; weatherability of FRP rods; aramid; composite materials; end fittings for FRP rod; environmental resistance of FRP rods; 16685 .

Fibers; heat flux; heat sinks; oxygen concentration; textiles; air flow; extinguishability; extinguishment; fabric flammability; NBS-GCR-77-90.

Fibers; image analysis; pattern recognition; pulp characterization; pulps; algorithms; fiber morphology; 17214.

Fibrous-glass insulation; vapor condensation; air, moisture and heat transfer theory; cold storage insulation; 17340 .

Field data; frequency maps; ground displacement; Japan; earthquake distribution; earthquakes; SP470, pp. III- I-III-17 (Apr. 1977). 
Field measurements; model; towers; wind; wind observation; wind tunnel; SP470, pp. 1-1-[-17 (Apr. 1977).

Field observations; strong-motion accelerographs; accelerographs; earthquake data; earthquake records; SP470, pp. IV1-IV-34 (Apr. 1977).

Field of values; positive semidefinite; semistable; convex hull; eigenvalue; 16819 .

Field standard; gravimetric calibration; liquid retention or clingage tests; precision; prover; Research Associate Program; standards inspection procedure; temperature correction; test measure; test measure evaluation; "to contain"; "to deliver"; NBSIR 77-1214.

Field stations; strong-motion network; accelerographs; earthquake data; earthquake records; $S P 470$, pp. IV-35-IV52 (Apr. 1977).

Field studies; high winds; instrumentation; Philippines; wind tunnel test; SP470, pp. X-1-X-11 (Apr. 1977).

Field testing; fuel gas measurement; fundamentals; gaseous hydrocarbons; installation; performance characteristics; turbine meter; design considerations; SP484, pp. 871-880 (Oct. 1977).

Field tests; laboratory tests; relationships; soil properties; dynamics; SP477, pp. V1-158-VI-178 (May 1977).

Field tests; wind measurements; winds; wind speed; bridges; displacements; SP470, pp. II-20-II-46 (Apr. 1977).

Field-access; garnet; guide-pattern; magnetoresistance; nonvolatility; orthoferrite; photolithography; uniaxial structures; amorphous materials; bubble; SP500-1.

Figure of merit; $\mathrm{G} / \mathrm{T}$; measurement accuracy; radio stars; satellite earth terminal; signal to noise; star flux; 17227.

Figure of the Earth; fitting a linear equation; least sum of absolute deviations; Mayer, Tobias (1723-1762); method of averages; weighted mean; weighted median; zero sum of residuals; Boscovich, Roger Joseph (1711-1787); Cotes, Roger (1682-1716); 17314 .

Figure-of-merit; interactive system; measurement model; measurement, performance; measures; methodology; network measurement system; computer service; external measurement; 17288.

Filar eyepiece; image-shearing eyepiece; integrated circuits; linewidth measurements; microelectronics; micrometrology; optical microscope; photoelectric microscope; photomask; scanning electron microscope; 17066.

Filar eyepiece; linewidth measurements; micrometer eyepiece; microscope calibration; optical microscope; photomasks; photomask metrology; optical microscope; shearing eyepiece; dimensional standards; 17063

File validation; name lookup; nonunique identifiers; personal data files; Privacy Act; probability model; retrieval; data retrieval; SP500-2.

Film thickness; gears; Hertz contacts; lubrication; rheology; starvation; traction; bearings; computer programs; elastohydrodynamics; failure analysis; SP487, pp. 137-153 (Aug. 1977).

Film thickness; irradiance measurements; photoresist; sensitivity index; sensitometry; Van Kreveld's additivity law; exposure; exposure control; 17329.

Film thickness variation; irradiance measurements; photoresist; photoresist sensitivity; sensitivity index; Van Kreveld's additivity law; exposure; exposure control; 16853

Films; gas discharges; sputtering; adhesion; coatings; SP487, pp. 311-323 (Aug. 1977).

Films; humidity sensor; industrial fabrication; isotherm equations; physical adsorption; relative humidity; routine radiosonde application; barium fluoride; calibration equations; fast response; NBSIR 76-1108.

Filtering antenna; resistive shield; antenna; antenna frequency response; dielectric sheath; U.S. Patent 4,008,477.
Filters; high accuracy; spectrophotometer; standards; transmittance; tristimulus values; chromaticity coordinates; color; 17260.

Filters, transmittance; neutral filters; standard reference materials; transmittance characteristics; ultraviolet-visible filters: evaporated metal-on-quartz; SP466, pp. 127-131 (May 1977).

Financial analysis; heating; load calculation; MIUS; modular integrated utility system; simulation; utility services; computer programs; cooling; energy analysis; NBSIR 77-1307.

Fine structure; hydrogenic atoms; Lamb shift; level shifts; quantum electrodynamics; radiative corrections; relativistic corrections; atomic structure; electron structure; energy levels; JPCRD 6, No. 3, 831-870 (1977).

Fingerprints; forensic science; hazardous materials; benzidine hazard; blood testing; carcinogen; SP480-21.

Finite element analysis; joints; nonlinear analysis; single-lapjoint analysis; single-lap-joint bending; spotwelded joints; weldbonded joints; adhesive-bonded joints; bonded joints; cyclic loading; debond analysis; double-lap-joint analysis; fatigue tests; NBSIR 76-1053.

Finite element method; structural analysis; SP487, pp. 41-61 (Aug. 1977).

Finite field theory; neutral currents; weak coupling constants; weak interactions; effective neutral weak interactions; Fermi theory; 17103.

Finite rotations; group representations; near-fields, recursion; scanning; spherical; spherical point group; antennas; arrays; 17322.

Finite-element method; general purpose heat transfer computer program; interdisciplinary thermo-structural analyses; SP487, pp. 62-81 (Aug. 1977).

FIPS guidelines; software, symposium proceedings; automated data systems; computer programs; documentation; documentation content guidelines; SP500-15.

FIR optically pumped lasers; frequency and power measurements; laser magnetic resonance spectroscopy; 17073 .

Fire; fire resistivity; firestopping; fire walls; garden apartments; multi-family residences; apartments; building codes; NBSIR 76-1194.

Fire; furniture fire; losses; residential fire; standard; upholstered furniture; cost plus loss; decision analysis; NBSIR 77-1381.

Fire; garments; heat transfer; injury hazard; simulation; accident; apparel; burn injury; fabric flammability; fabrics; NBSIR 77-1236.

Fire; gas; injury; liquefied; petroleum; standards; container; corrosion; explosion; extinguisher; NBSIR 77-1217.

Fire; journals; library holdings, NBS Library; NBS periodicals; periodicals; proceedings; serials; standards; transactions; annual reports; diffusion in metals; NBSIR 77-1215.

Fire; scaling; stratified flow; temperature; velocity measurements; buoyant flow; corridor, countercurrent; 17285 .

Fire alarm systems; health care facilities; hospital communication systems; hospital fires; hospital personnel; human behavior; nursing home fires; nursing staff; standards; voice communication; coding; communication systems; NBS-GCR77-102.

Fire alarms; fire incidents; fire investigations; fires; human behavior; project people; residential buildings; smoke; statistical analysis; building fires; egress; NBS-GCR-77-94.

Fire behavior; high-rise buildings; occupant behavior in fires; simulated behavior; building fires; NBS-GCR-77-92.

Fire code; fire science; fire spread model; buoyant flow; compartment fires; corridor fires; NBS-GCR-77-84.

Fire communications; high-rise communications; high-rise emergency; information transfer; occupant needs; sensory stimuli; communications; disaster communication; emergency communications; 17036.

Fire deaths; fire losses; fire statistics; home furnishings; program planning; residential fire deaths; 16960 
Fire departments; fire detection systems; fire tests; flame research; flammability tests; interior furnishings; mobile homes; polyurethanes; smoke detectors; standards; textiles; toxicity; arson; bibliographies; building fires; carpets; construction materials; NBSIR 77-1277.

Fire detection devices; heat detectors; ionization chamber detectors; photoelectric detectors; smoke detectors; building fires; 16737.

Fire detection systems; fire tests; flame research; flammability tests; interior furnishings; mobile homes; polyurethanes; smoke detectors; standards; textiles; toxicity; arson; bibliographies; building fires; carpets; construction materials; fire departments; NBSIR 77-1277.

Fire detectors; fire growth; flaming fires; heat detectors; polyurethanes; polyvinyl chloride; smoke detectors; smoldering fires; temperature rise; wood; ceiling height; ceilings; cotton; detector location; NBS-GCR-77-95.

Fire detectors; polyurethanes; polyvinyl chloride; room fires; rooms; smoldering; wood; ceiling height; ceilings; cotton; detector location; detectors; NBS-GCR-77-86.

Fire endurance; fire tests; probability theory; reinforced concrete; reliability; statistical analysis; structural engineering; 17303 .

Fire endurance; heat generation or absorption; numerical solutions; one-dimensional; radiation; thermal conduction; transient heat transfer; composite building constructions; convection; experimental data; NBSIR 77-1260.

Fire endurance; load failure; pipe hangers; residential occupancies; automatic sprinklers; care type occupancies; NBSIR 771282.

Fire fatalities; smoke inhalation; toxicity; biological assessment; chemical analysis; combustion products; NBSIR 77-1234.

Fire growth; fire tests; flashover; room fires; scale models; thermal radiation; 17059 .

Fire growth; flaming fires; heat detectors; polyurethanes; polyvinyl chloride; smoke detectors; smoldering fires; temperature rise; wood; ceiling height; ceilings; cotton; detector location; fire detectors; NBS-GCR-77-95.

Fire hazard; glowing electrical connections; arcing/sparking; branch circuit; contact resistance; electrical connections; BSS103.

Fire hazards; fire modeling; fire research; human behavior in fires; combustion products; NBSIR 77-1308.

Fire hazards; ignition time; pyrolysis; radiant heating; thermal radiation; thermoplastics; cellulosic materials; char; convective heat transfer; fabric flammability; fabrics; NBS-GCR-7799.

Fire helmet; head injury; head protection; heat resistance; helmet; impact; penetration resistance; test methods; NBSIR 771251.

Fire incidents; fire investigations; fires; human behavior; project people; residential buildings; smoke; statistical analysis; building fires; egress; fire alarms; NBS-GCR-77-94.

Fire induced flows; models; physical scale; plumes; buoyancy pressure; enclosure fires; entrainment; J. Res. 82, No. 2, 107 117 (1977).

Fire investigations; fires; human behavior; project people; residential buildings; smoke; statistical analysis; building fires; egress; fire alarms; fire incidents; NBS-GCR-77-94.

Fire losses; fire statistics; home furnishings; program planning; residential fire deaths; fire deaths; 16960.

Fire modeling; fire research; human behavior in fires; combustion products; fire hazards; NBSIR 77-1308.

Fire modeling; heat; hydrocarbon; ionized molybdenum; measurement assurance; metric; neutron diffraction; recycling oil; research and innovation; safety; ultrasonic tissue; computerized data; data elements; equity; federal technology; DIM/NBS 61, No. 6, 1-32 (1977).
Fire performance; horizontal and vertical smoke measurements; smoke; smoke density chamber; smoke suppressants; NBSIR 76-1030.

Fire plumes; heat transfer; room fires; scale models; buoyant plumes; ceilings; compartment fires; NBS-GCR-77-97.

Fire prevention; fire research; hazard analysis; physics; building research; chemistry; combustion research; design concepts; directories; NBSIR 77-1264.

Fire protection; fire safety; goal oriented systems approach; systems analysis; buildings; NBS-GCR-77-103.

Fire research; hazard analysis; physics; building research; chemistry; combustion research; design concepts; directories; fire prevention; NBSIR 77-1264.

Fire research; human behavior in fires; combustion products; fire hazards; fire modeling; NBSIR 77-1308.

Fire research; polymers; polystyrene; poly(vinyl chloride); specific heat; thermal conductivity; thermal diffusivity; NBSGCR-77-83.

Fire resistivity; firestopping; fire walls; garden apartments; multi-family residences; apartments; building codes; fire; NBSIR 76-1194.

Fire retardants; flammability hazard; FR treated cotton blends; FR treated cottons; ignitability; MAFT value; phosphorus; synthetic fabrics; burn injury potential; extinguishability; 17176.

Fire safety; goal oriented systems approach; systems analysis; buildings; fire protection; NBS-GCR-77-103.

Fire safety; health dangers; research needs; codes and standards; environmental studies; SP473, pp. 35-53 (June 1977).

Fire safety; human performance; occupational safety; regulatory data; architectural psychology; architectural research; building codes; building design; building fires; building regulatory standards; emergency egress; exit capacity; NBSIR 77-1313.

Fire safety; metric; miniature electric field; organic sulfur; radiometric detector; smog formation; SRM's; air pollution; attic ventilation; data encryption; dental materials; DIM/NBS 61 , No. 11, 1-32 (1977).

Fire safety; rating criteria; solar collectors; structural performance; testing procedures; thermal performance; durability/reliability; NBSIR 77-1305.

Fire science; fire spread model; buoyant flow; compartment fires; corridor fires; fire code; NBS-GCR-77-84.

Fire spread model; buoyant flow; compartment fires; corridor fires; fire code; fire science; NBS-GCR-77-84.

Fire statistics; home furnishings; program planning; residential fire deaths; fire deaths; fire losses; 16960.

Fire suppression; full-scale test; gas temperature; oxygen content; recirculating flow; reduced scale model test; scaling criteria; spray water flow rate; water spray; automatic sprinklers; compartment fire; corridor sprinkler systems; droplet size; droplet trajectory; NBSIR 77-1287.

Fire tests; flame research; flammability tests; interior furnishings; mobile homes; polyurethanes; smoke detectors; standards; textiles; toxicity; arson; bibliographies; building fires; carpets; construction materials; fire departments; fire detection systems; NBSIR 77-1277.

Fire tests; flame spread; heat flux; heat release rate; oxygen depletion; smoke; Steiner Tunnel Test; ASTM E 84; TN945.

Fire tests; flashover; room fires; scale models; thermal radiation; fire growth; 17059 .

Fire tests; gas detectors; heat detectors; residential fires; smoke detectors; detector sensitivity; detector siting; escape time; NBS-GCR-77-82.

Fire tests; gypsum board; potential heat; properties; rate of flame spread; rate of heat release; scanning electron microscope (SEM); buildings; ease of ignition; NBSIR 771265.

Fire tests; health care facilities; hospitals; mattresses; prisons; bedding; beds; compartment fires; firesafety engineering; NBSIR 77-1290. 
Fire tests; probability theory; reinforced concrete; reliability; statistical analysis; structural engineering; fire endurance; 17303.

Fire tormados; tomado model; tomados; wind speed; fires; SP470, pp. I-28-I-41 (Apr. 1977).

Fire walls; garden apartments; multi-family residences; apartments; building codes; fire; fire resistivity; firestopping; NBSIR 76-1194.

Fire-balls; turbulent thermals; vortex bubbles; buoyant thermals; entrainment coefficient; SP484, pp. 571-596 (Oct. 1977).

Fire-retardants; insulation; mattresses; shipboard; thermal conductivity; compartment fires; NBSIR 77-1295.

Fires; fire tornados; tornado model; tomados; wind speed; SP470, pp. I-28-I-4I (Apr. 1977).

Fires; human behavior; human response; life safety; mapping; model; nursing homes; rescue; verbal communicative; alarm; architecture; design implication; emergency actions; emergency communicative; emergency decisions; escape; NBSGCR-77-93.

Fires; human behavior; project people; residential buildings; smoke; statistical analysis; building fires; egress; fire alarms; fire incidents; fire investigations; NBS-GCR-77-94.

Firesafety engineering; fire tests; health care facilities; hospitals; mattresses; prisons; bedding; beds; compartment fires; NBSIR 77-1290.

Firestopping; fire walls; garden apartments; multi-family residences; apartments; building codes; fire; fire resistivity; NBSIR 76-1194.

Firing ranges; law enforcement; lead; lead poisoning; airborne lead; ammunition; SP480-26.

Fission; fission detector; materials; neutron dosimetry; reactor physics; breeder reactor; 17058 .

Fission; flux; measuring techniques; neutrons; standards; cross section standards; dosimetry; SP493.

Fission; integral measurements; standard neutron fields; cross sections; ENDF/B; SP493, pp. 290-298 (Oct. 1977).

Fission; neutron reactions; neutron spectrum; reactor fuels; reactor materials; cross sections; SP493, pp. 156-164 (Oct. 1977).

Fission; standards; uncertainties; criticals; cross section; ENDF/B; SP493, pp. 269-277 (Oct. 1977).

Fission cross sections; fission spectrum neutrons; $14.8-\mathrm{MeV}$ neutrons; ${ }^{225} \mathrm{U}$; ${ }^{238} \mathrm{U}$; ${ }^{237} \mathrm{~Np}$; ${ }^{252} \mathrm{Cf}$; absolute measurements; SP493, pp. 313-318 (Oct. 1977).

Fission detector; materials; neutron dosimetry; reactor physics; breeder reactor; fission; 17058 .

Fission neutron spectrum; neutron detectors; neutron standard; time-of-flight; ${ }^{252} \mathrm{Cf}$; SP493, pp. $194-197$ (Oct. 1977).

Fission neutrons; irradiation devices; measuring methods; neutron reactions; neutron sources; calibration; californium252; cross sections; design; errors; 16790.

Fission spectra; integrals; neutrons; radioactivation; resonance integrals; spectral functions; comparative evaluation; cross sections; SP493, pp. 128-136 (Oct. 1977).

Fission spectrum neutrons; $14.8-\mathrm{MeV}$ neutrons; ${ }^{235} \mathrm{U}$; ${ }^{238} \mathrm{U}$; ${ }^{237} \mathrm{~Np}$; ${ }^{252} \mathrm{Cf}$; absolute measurements; fission cross sections; SP493, pp. 313-318 (Oct. 1977).

Fission standards; neutron nuclear data evaluation; Pu-239; Pu239 half-life; Pu-241; thermal neutron cross-sections; U-233; U-235; fission-neutron yields; SP493, pp. 170-173 (Oct. 1977).

Fission yield measurement techniques, counting, mass spectrometry; fission yields, thermal, fast, absolute, relative; fission yields versus neutron energy; data compilations; SP493, pp. 146-1 55 (Oct. 1977).

Fission yields; neutrons; nuclear data; standard fields; cross sections; SP493, pp. 299-303 (Oct. 1977).
Fission yields, thermal, fast, absolute, relative; fission yields versus neutron energy; data compilations; fission yield measurement techniques, counting, mass spectrometry; SP493, pp. 146-155 (Oct. 1977).

Fission yields versus neutron energy; data compilations; fission yield measurement techniques, counting, mass spectrometry; fission yields, thermal, fast, absolute, relative; SP493, pp. 146-155 (Oct. 1977).

Fission-neutron yields; fission standards; neutron nuclear data evaluation; $\mathrm{Pu}-239$; $\mathrm{Pu}-239$ half-life; $\mathrm{Pu}-241$; thermal neutron cross-sections; U-233; U-235; SP493, pp. 170-173 (Oct. 1977).

Fitting a linear equation; least sum of absolute deviations; Mayer, Tobias (1723-1762); method of averages; weighted mean; weighted median; zero sum of residuals; Boscovich, Roger Joseph (1711-1787); Cotes, Roger (1682-1716); 17314.

Fixed points; gallium; gallium melting point; melting; standards; temperature; thermistors; thermometry; 17055.

Fixed-point; gallium; melting-point standard; temperature; thermometric fixed-point; clinical laboratory; SP481.

Flame analysis; flame fluorescence; laser; opto-galvanic effect; spectroscopy; tunable laser; dye laser; 16691.

Flame chemistry; flame modeling; laminar flames; numerical solution of flame equations; combustion; differential equations; NBSIR 76-994.

Flame emission spectrometry; fluorescence spectrometry; molecular absorption spectrometry; neutron activation analysis; polarography; pure reagents; sample preparation; spark source mass spectrometric isotope dilution; tissues; analytical disciplines; analytical procedures; SP492.

Flame fluorescence; laser; opto-galvanic effect; spectroscopy; tunable laser; dye laser; flame analysis; 16691 .

Flame modeling; laminar flames; numerical solution of flame equations; combustion; differential equations; flame chemistry; NBSIR 76-994.

Flame radiation; radiant flux density; radiation measurement; radiative heat transfer; turbulent flames; NBS-GCR-76-80.

Flame research; flammability tests; interior fumishings; mobile homes; polyurethanes; smoke detectors; standards; textiles; toxicity; arson; bibliographies; building fires; carpets; construction materials; fire departments; fire detection systems; fire tests; NBSIR 77-1277.

Flame spread; fluid flow; laser doppler velocimetry; liquid fuels; solid fuels; surface tension; combustion models; NBS-GCR76-79.

Flame spread; heat flux; heat release rate; oxygen depletion; smoke; Steiner Tunnel Test; ASTM E 84; fire tests; TN945.

Flame spread tests; flexible polyurethane; hardboard; interlaboratory evaluation; neoprene; radiant panel test; round robin; test method; ASTM E 162; coefficient of variation; NBSIR 77-1222.

Flameless atomic absorption; flow monitoring; high-pressure liquid chromatography; lead; ligand; mercury; nanogram sensitivity; organometallic compounds; speciation; tin; arsenic; element-specific detector; 17297.

Flaming fires; heat detectors; polyurethanes; polyvinyl chloride; smoke detectors; smoldering fires; temperature rise; wood; ceiling height; ceilings; cotton; detector location; fire detectors; fire growth; NBS-GCR-77-95.

Flammability; Mushroom Flammability Tester; test methods; burn injury; 16813 .

Flammability hazard; FR treated cotton blends; FR treated cottons; ignitability; MAFT value; phosphorus; synthetic fabrics; burn injury potential; extinguishability; fire retardants; 17176 .

Flammability ranking; heat flux; heat transfer rate; linear burning rate; extinguishability; fabric flammability; NBS-GCR-7677. 
Flammability standards; Flammable Fabrics Act; ignition sources; apparel fires; burn injury; fabric flammability; FFACTS; SP463, pp. VIl.2.1-VI1.2.11 (Jan. 1977).

Flammability testing; heat transfer rates; Mushroom Apparel Flammability Tester; standards; test development; textiles; apparel; fabrics; NBS-GCR-76-78.

Flammability tests; interior furnishings; mobile homes; polyurethanes; smoke detectors; standards; textiles; toxicity; arson; bibliographies; building fires; carpets; construction materials; fire departments; fire detection systems; fire tests; flame research; NBSIR 77-1277.

Flammable Fabrics Act; ignition sources; apparel fires; burn injury; fabric flammability; FFACTS; flammability standards; SP463, pp. V1l.2.1-V11.2.11 (Jan. 1977).

Flare stars; stellar chromospheres; stellar evolution; stellar photospheres; stellar spectra; stellar transition regions; 16809.

Flares, solar; flares, stellar; magnetic cycles, solar; magnetic cycles, stellar; nonradiative heating; transition regions, solar; transition regions, stellar; ultraviolet spectra; visible spectra; x-ray spectra; chromospheres, solar; chromospheres, stellar; coronae, solar; 17324.

Flares, stellar; magnetic cycles, solar; magnetic cycles, stellar; nonradiative heating; transition regions, solar; transition regions, stellar; ultraviolet spectra; visible spectra; $x$-ray spectra; chromospheres, solar; chromospheres, stellar; coronae, solar; coronae, stellar; 17324.

Flare-stellar; soft x ray; extreme ultraviolet; 16933.

Flash photolysis; hydrogen metathesis methanes; resonance fluorescence; vibrational excitation; chemical kinetics; chlorine atoms; 16785 .

"flashover"; fluid flow; full-scale; heat transfer; literature review; mathematical models; room fire; scaling models; theoretical; 17283.

Flashover; room fires; scale models; thermal radiation; fire growth; fire tests; 17059.

Flashtube; pulsed source; radiometry; curve fitting; energy irradiance; TN935.

Flatness; gage blocks; interferometry; length measurement; parallelism; NBSIR 73-239.

Flattening; mass distribution function; anisotropy of mean square velocities; eccentricity of equidensity surface; elliptical galaxies; 16968.

Flaw distribution; fracture; impact resistance; ophthalmic lenses; statistics; drop ball test; 16979.

Flexible polyurethane; hardboard; interlaboratory evaluation; neoprene; radiant panel test; round robin; test method; ASTM E 162; coefficient of variation; flame spread tests; NBSIR 77-1222.

Flexing; low cycle fatigue; mechanical properties; microstructure; modelling; paper; pore size; statistical analysis; Weibull distribution; durability; fatigue; fiber length; 16681 .

Flexing; paper; durability; 17241.

Flexural strength; masonry walls; racking strength; seismic loading; shear strength; shear wall; stiffness; analysis; compressive strength; deflection; design; BSS62.

Flexure; progressive collapse; shear; strength; apartment building; collapse; concrete; concrete strength; construction; BSS94.

Flicker noise; frequency random walk; quartz crystal resonators; resonance frequency fluctuation; temperature fluctuation; 17183 .

Floating zone; gravity; liquid zone; shape; stability; surface tension; 17009.

Floating zone; meniscus; perturbation; shape stability; silicon; crystal growth; 16931 .
Floor treatments; shoe sole and heel materials; slip-resistance tester; walkway surfaces; waxes and polishes; flooring; TN953.

Flooring; floor treatments; shoe sole and heel materials; slip-resistance tester; walkway surfaces; waxes and polishes; TN953.

Flow; gas; liquid; mass flow; measurement; cryogenic; SP484, pp. 881-893 (Oct. 1977).

Flow conditioning; meter performance; perturbations; precision; turbine meter; uncertainty; accuracy; calibration; SP484, pp. 33-54 (Oct. 1977).

Flow determination; flow prediction; Monte Carlo; statistics; stratified sampling; Bayes' Rule; SP484, pp. 447-470 (Oct. 1977).

Flow in large pipes; flow metering; pipe flow; Pitot tubes; velocity indication; SP484, pp. $479-489$ (Oct. 1977).

Flow measurement; fluid flow modeling; fluid velocity; flumes; gas flow standard; hot-wire anemometry; international flow standards; laser anemometry; open channel flows; orifice meters; pitot-static meters; turbine meters; weirs; acoustic flow meters; SP484, Volumes $I$ and 2.

Flow measurement; flumes; open-channel flow; broad-crested weirs; errors; SP484, pp. 201 -218 (Oct. 1977).

Flow measurement; He Ne laser; laser doppler anemometry; SP484, 471-477 (Oct. 1977).

Flow measurement; industry; intergovernmental; international standards; legal metrology; measurement; trade facilitation; SP484, pp. $921-927$ (Oct. 1977).

Flow measurement; international standards; open channel flow; petroleum product standards; closed conduit flow; SP484, pp. 895-920 (Oct. 1977).

Flow measurement; ISO; methods of tests; need for international standardization; product specifications; SP484, pp. 947-956 (Oct. 1977).

Flow measurement; mathematical modeling; meter performance; orifice meter; turbulence flow; closed conduit meter; differential pressure; SP484, pp. $491-522$ (Oct. 1977).

Flow measurement; Price meter suspensions; Pygmy meter performance; velocity-area method; current meter calibrations; current meters, water; SP484, pp. 123-144 (Oct. 1977).

Flow measurement; ultrasonic flowmeter; acoustic rays; SP484, pp. 277-291 (Oct. 1977).

Flow measurement errors; fuel economy measurements; fuel flow measurements; in-line flow transducer; automotive fuel; SP484, pp. 803-820 (Oct. 1977).

Flow measurement errors; infiltration/inflow analysis; Parshall flume; error reduction strategy; SP484, pp. 173-186 (Oct. 1977).

Flow measurement techniques; flow vs. temperature techniques; pressure drops; thermal devices; error reduction; SP484, pp. 597-619 (Oct. 1977).

Flow measurement, water; flow meters; instruments, flow measurement; level measurement; level-to-flow rate conversion; liquid flow; open channel flow measurement; secondary measuring device; SP484, pp. 91-108 (Oct. 1977).

Flow measurements; flow properties; flow meter reliability; reliability; SP484, pp. 61-82 (Oct. 1977).

Flow meter; meter performance; numerical modeling; turbulent flow; NBSIR 77-1394.

Flow metering; pipe flow; Pitot tubes; velocity indication; flow in large pipes; $S P 484$, pp. $479-489$ (Oct. 1977).

Flow metering error; flow oscillations; jet flow; orifice meters; pulsating flow measurements; pulsations; turbulence; vortex; differential pressure; SP484, pp. 523-548 (Oct. 1977).

Flow meters; instruments, flow measurement; level measurement; level-to-flow rate conversion; liquid flow; open channel flow measurement; secondary measuring device; flow measurement, water; SP484, pp. 91 -108 (Oct. 1977).

Flow monitoring; high-pressure liquid chromatography; lead; ligand; mercury; nanogram sensitivity; organometallic com- 
pounds; speciation; tin; arsenic; element-specific detector; flameless atomic absorption; 17297.

Flow oscillations; jet flow; orifice meters; pulsating flow measurements; pulsations; turbulence; vortex; differential pressure; flow metering error; SP484, pp. 523-548 (Oct. 1977).

Flow prediction; Monte Carlo; statistics; stratified sampling; Bayes' Rule; flow determination; SP484, pp. 447-470 (Oct. 1977).

Flow properties; flowmeter reliability; reliability; flow measurements; SP484, pp. 61-82 (Oct. 1977).

Flow rate; international standards; orifice plates; data bases; EEC regulations; SP484, pp. 935-944 (Oct. 1977).

Flow rate; liquid flow rate; liquid velocity; open channel flow rate; open channel velocity; acoustic flow rate; acoustic velocity; SP484, pp. 243-266 (Oct. 1977).

Flow rate measurement; open channel flow measurement; power plant; spray canal; stage-discharge equation; velocityarea method; weir equation; closed-loop cooling system; cooling lake; dye dilution method; error analysis; SP484, pp. 145-172 (Oct. 1977).

Flow visualization; fluorescence; fluorescent dye; laser; laser dye-fluorescence technique; mean concentration; mean velocity; measuring volume; remote sensing; root-meansquare concentration; Schmidt number; simultaneous measurements; SP484, pp. 423-447 (Oct. 1977).

Flow vs. temperature techniques; pressure drops; thermal devices; error reduction; flow measurement techniques; SP484, pp. 597-619 (Oct. 1977).

Flowing afterglow; fluorescence; infrared; ion-molecule; associative detachment; chemiluminescence; 17209.

Flowmeter calibration; flowmeter drift; flowmeter measurements; flowmeter repeatability; SP484, pp. 1-24 (Oct. 1977).

Flowmeter calibration; flowmeter evaluation; procedure for testing flowmeters; automotive environment; automotive fuel flowmeters; effect of environment on flowmeter performance; TN943.

Flowmeter drift; flowmeter measurements; flowmeter repeatability; flowmeter calibration; SP484, pp. 1-24 (Oct. 1977).

Flowmeter evaluation; procedure for testing flowmeters; automotive environment; automotive fuel flowmeters; effect of environment on flowmeter performance; flowmeter calibration; TN943.

Flowmeter for natural gas; ultrasonic flowmeter; ultrasonic pulses; SP484, pp. 293-318 (Oct. 1977).

Flowmeter measurements; flowmeter repeatability; flowmeter calibration; flowmeter drift; SP484, pp. 1-24 (Oct. 1977).

Flowmeter reliability; reliability; flow measurements; flow properties; SP484, pp. 61-82 (Oct. 1977).

Flowmeter repeatability; flowmeter calibration; flowmeter drift; flowmeter measurements; SP484, pp. 1-24 (Oct. 1977).

Flowmetering; ultrasonic flowmeter; clamp-on ultrasonic flowmeter; SP484, pp. 267-276 (Oct. 1977).

Fluctuating flow characteristics; marine environment; current measuring transducers; current velocities; dynamic response characteristics; SP484, pp. 109-122 (Oct. 1977).

Fluctuations; hydrodynamics; light scattering; liquid state; molecular dynamics; neutron scattering; shear wave; statistical mechanics; time correlation function; transverse current; ultrasonics; correlation function; density fluctuations; 16711 .

Flue damper; heat transfer; implicit; insulation; laboratory measurements; modeling; standby loss; water heater; alternating direction; computer simulation; cool down; energy savings; 17184.

Fluence; flux; moderation; monitor; neutron; shielding; sources; standardization; calibration; detection; dosimetry; facilities; SP493, pp. 115-120 (Oct. 1977).

Fluence; kerma factor; neutrons; activation; Bragg-Gray; dosimetry; energy per ion pair; SP493, pp. 342-346 (Oct. 1977).
Fluid ethane; sound; speed of sound; compressed fluid ethane; ethane, fluid; 17067.

Fluid flow; full-scale; heat transfer; literature review; mathematical models; room fire; scaling models; theoretical; "flashover"; 17283.

Fluid flow; laser doppler velocimetry; liquid fuels; solid fuels; surface tension; combustion models; flame spread; NBSGCR-76-79.

Fluid flow modeling; fluid velocity; flumes; gas flow standard; hot-wire anemometry; international flow standards; laser anemometry; open channel flows; orifice meters; pitot-static meters; turbine meters; weirs; acoustic flow meters; closed conduit flows; SP484, Volumes 1 and 2.

Fluid mechanics; nonisothermal flow; three velocity components in turbulent flow; true instantaneous temperatures; turbulent 'flow; SP484, pp. 659-685 (Oct. 1977).

Fluid mixtures; fluids; scaling; thermodynamic properties; transport properties; universality; critical exponents; critical region; 17279.

Fluid velocity; flumes; gas flow standard; hot-wire anemometry; international flow standards; laser anemometry; open channel flows; orifice meters; pitot-static meters; turbine meters; weirs; acoustic flow meters; closed conduit flows; current meters; SP484, Volumes 1 and 2.

Fluids; scaling; thermodynamic properties; transport properties; universality; critical exponents; critical region; fluid mixtures; 17279.

Flume calibration; turbidity variations; validity testing; water soluble tracers; dye dilution method; SP484, pp. 361-394 (Oct. 1977).

Flumes; gas flow standard; hot-wire anemometry; international flow standards; laser anemometry; open channel flows; orifice meters; pitot-static meters; turbine meters; weirs; acoustic flow meters; closed conduit flows; current meters; dye-dilution methods; SP484, Volumes 1 and 2.

Flumes; hydraulic models; hydraulics; numerical models; openchannel flow; weirs; SP484, pp. 219-242 (Oct. 1977).

Flumes; open-channel flow; broad-crested weirs; errors; flow measurement; SP484, pp. 201-218 (Oct. 1977).

Fluorapatite; fluoride; hydroxyapatite; solubility; chemical potential; dental caries; enamel; 16739.

Fluorescence; fluorescent dye; laser; laser dye-fluorescence technique; mean concentration; mean velocity; measuring volume; remote sensing; root-mean-square concentration; Schmidt number; simultaneous measurements; spectra; water jet; SP484, pp. 423-447 (Oct. 1977).

Fluorescence; heat of solution; naphthalene; partition coefficient; solubility; vapor pressure; 1-ethylnaphthalene; 1methylnaphthalene; enthalpy; 17097.

Fluorescence; infrared; ion-molecule; associative detachment; chemiluminescence; flowing afterglow; 17209.

Fluorescence; instrumentation; luminescence; quantum yield; spectrophotometry; standard reference materials; standardization; accuracy; critical parameters; diffuse reflectance; SP466.

Fluorescence; laser; lifetime; quenching rate; $\mathrm{CCl}_{2}$; $\mathrm{CFCl}$; 17238.

Fluorescence; laser fields; theory; two-photon absorption; Raman scattering; Rayleigh scattering; 16848.

Fluorescence emission spectroscopy; gas chromatography-mass spectrometry; high-performance liquid chromatography; hydrocarbons; petroleum analysis; polynuclear aromatic hydrocarbons; 17271 .

Fluorescence lifetime; fluorescence quantum efficiency; fluorescence quantum yields; fluorescence spectrum; fluorescence standards; molecular fluorescence parameters; observed (technical) fluorescence parameters; polarization; SP466, pp. 1-11 (May 1977). 
Fluorescence quantum efficiency; fluorescence quantum yields; fluorescence spectrum; fluorescence standards; molecular fluorescence parameters; observed (technical) fluorescence parameters; polarization; SP466, pp. 1-11 (May 1977).

Fluorescence quantum yield; laser dyes; molecular structure; oxazine dyes; quenching; xanthene dyes; aminocoumarins; carbazine dyes; deuterium effect; SP466, pp. 33-40 (May 1977).

Fluorescence quantum yields; fluorescence spectrum; fluorescence standards; molecular fluorescence parameters; observed (technical) fluorescence parameters; polarization; radiative and non-radiative transition probabilities; SP466, pp. 1-11 (May 1977).

Fluorescence spectrometry; molecular absorption spectrometry; neutron activation analysis; polarography; pure reagents; sample preparation; spark source mass spectrometric isotope dilution; tissues; analytical disciplines; analytical procedures; atomic absorption spectrometry; SP492.

Fluorescence spectrum; fluorescence standards; molecular fluorescence parameters; observed (technical) fluorescence parameters; polarization; radiative and non-radiative transition probabilities; real fluorescence parameters; SP466, pp. 1-11 (May 1977).

Fluorescence standards; molecular fluorescence parameters; observed (technical) fluorescence parameters; polarization; radiative and non-radiative transition probabilities; real fluorescence parameters; fluorescence lifetime; SP466, pp. 111 (May 1977).

Fluorescent dye; laser; laser dye-fluorescence technique; mean concentration; mean velocity; measuring volume; remote sensing; root-mean-square concentration; Schmidt number; simultaneous measurements; spectra; water jet; auto-correlation; SP484, pp. 423-447 (Oct. 1977).

Fluoride; hydroxyapatite; solubility; chemical potential; dental caries; enamel; fluorapatite; 16739.

Fluorinated ethylenepropylene; gear lubrication; grease; polyfluoroalkyl-alkyl polysiloxane; polytetrafluoroethylene; antimony dialkyldithiocarbamate; antiwear; bearing lubrication; extreme pressure; SP487, pp. 154-171 (Aug. 1977).

Fluoroscopy; national standard; radiation safety; radiography; $\mathrm{x}$-ray equipment; x-ray safety; x-ray tube; design standard; H123.

Flutter; models; wind angles; wind tunnel; bridge; cabled stayed; displacements; SP470, pp. Il-47-11-67 (Apr. 1977).

Flux; measuring techniques; neutrons; standards; cross section standards; dosimetry; fission; SP493.

Flux; moderation; monitor; neutron; shielding; sources; standardization; calibration; detection; dosimetry; facilities; fluence; SP493, pp. 115-120 (Oct. 1977).

Flux; neutrons; proton-recoil; scattering; standards; detectors; SP493, pp. 54-60 (Oct. 1977).

Flux isotropy; sodium iodide detector; spectral measurements; Apollo 16,17; background correction; cosmic gamma ray; 16938.

Fly ash; specifications; blended cements; 16768.

Fly ashes; mineral waste utilization; slags; cement manufacture; energy conservation; 17010.

Foam insulation; insulation; materials properties; performance; urea-formaldehyde; cellular plastics; TN946.

Foam insulation; insulation; survey; abstracts; bibliography; cryogenic insulation; 17308.

Foams; plastics information; Plastics Technical Evaluation Center; specifications; technical reports; testing methods; tooling; adhesives; composites; computerized information system; SP463, pp. IV.3.1-IV.3.2 (Jan. 1977).

Foils; ions; iron, oxygen; measurement; Moliere theory; multiple; scattering; angular distribution; chlorine; SP461, Pp. 136 139 (Jan. 1977).
Fold domains; fold surfaces; interlamellar links; morphology; polymer; sectorization; spheralites; chain folding; curved crystals; extended chain crystals; 16958.

Fold surfaces; interlamellar links; morphology; polymer; sectorization; spheralites; chain folding; curved crystals; extended chain crystals; fold domains; 16958 .

Food irradiation; Fricke dosimetry; gamma rays; $x$ rays; absorbed dose; calorimetry; dose distributions; dosimetry; electron beams; 17343.

Food products; information retrieval systems; management information systems; materials; nonfood products; physical properties; research information; agricultural materials; agricultural research; biological properties; SP463, pp. 11.2.1-11.2.10 (Jan. 1977).

Forbidden lines; He I; radiative transfer; Stark broadening; Bstar spectra; 17171.

Forbidden lines; He 1 ; $\lambda 4471 \AA$; Stark broadening; dynamic ion effects; 17167

Force; force calibration; interlaboratory comparison; load cell; static force; NBSIR 76-1145.

Force calibration; interlaboratory comparison; load cell; static force; force; NBSIR 76-1145.

Force field; infrared; microwave; molecular structure; spectra; spectroscopy; bond distances; carbonyl selenide; energy levels; 16823 .

Forecasts; growth; housing needs; projections; development; BSS100-4.

Foreign relations; industrializing nations; international relations; LDS's; measurement services; standardization; AID; assistance; developing economies; NBSIR 76-1152.

Foreign supply disruptions; stockpiling; technology; U.S. demand structure; cartels; economic policy options; NBS-GCRETIP 76-25.

Foreign supply disruptions; stockpiling; technology; U.S. demand structure; cartels; economic policy options; NBS-GCRETIP 76-28.

Foreign supply disruptions; stockpiling; technology options; U.S. demand structure; cartels; economic policy options; NBS-GCR-ETIP 76-29.

Foreign supply disruptions; stockpiling; technology options; U.S. demand structure; cartels; economic policy options; NBS-GCR-ETIP 76-30.

Foreign supply disruptions; stockpiling technology options; U.S. demand structure; cartels; economic policy options; NBSGCR-ETIP 76-31.

Forensic reference collections; forensic science; reference materials; standard reference collections; criminalistics; evidential materials; 16706.

Forensic science; hazardous materials; benzidine hazard; blood testing; carcinogen; fingerprints; SP480-21.

Forensic science; reference materials; standard reference collections; criminalistics; evidential materials; forensic reference collections; 16706.

Forest products; glues and gluing; information service; lumber; mechanical properties; paper; pulp; timber; wood; wood products; AIDS; bark; SP463, pp. 11.1.1-11.1.4 (Jan. 1977).

Form factors; light scattering; macromolecules; rodlike; rodlike macromolecules; rods, bent; rods, semirigid; semirigid rods; bent rods; 17253 .

Form factors; magnetic moments; quadrupole moments; quantum field theory; relativistic many body systems; vector dominance; electromagnetic properties; Monogr. 147, Suppl. l.

Formaldehyde; instrumentation; pyrolysis; reactive gases; acetaldehyde; acrolein; calibration; diffusion cell; 16699.

FORTRAN computer program; gage blocks; interferometry; TN956.

FORTRAN program; integral equation; interpolating polynomial; numerical stability; slit correction; small angle scattering; unsmearing; TN936. 
Fossil fuel limitations; linear specific gravity compensation; positive displacement flowmeters; turbine flowmeters; digital compensation techniques; SP484, pp. 821-846 (Oct. 1977).

Fossil fuels; nuclear power; solar energy; energy choices; energy problem; energy resources; 17031 .

Foundation; lateral loads; sheet piles; structural analysis; tests; SP470, pp. V11-7-V11-60 (Apr. 1977).

Fourier analysis of stellar variations; mode interaction; stellar instabilities; U Trianguli Australis; beat Cepheids; doublemode Cepheids; 16807.

Fourier analysis of stellar variations; mode interaction; stellar instabilities; U Trianguli Australis; beat Cepheids; doublemode Cepheids; 17118.

Fourier transformation; impulse; impulse generator; spectrum amplitude; electromagnetic interference; TN699.

Four-probe; rcsistivity; resistivity correction factors; semiconductor characterization; silicon; square array; collector resistivity; epitaxial resistivity; 16942.

Four-probe method; hermeticity; ion implantation; Irvin's curves; leak tests; line-width measurement; measurement methods; microelectronics; optical flying-spot scanner; oxidation particle impact noise detection test; passivation overcoats; photovoltaic method; SP400-29.

FR treated cotton blends; FR treated cottons; ignitability; MAFT value; phosphorus; synthetic fabrics; burn injury potential; extinguishability; fire retardants; flammability hazard; 17176 .

FR treated cottons; ignitability; MAFT value; phosphorus; synthetic fabrics; burn injury potential; extinguishability; fire retardants; flammability hazard; FR treated cotton blends; 17176.

Fractional fringe; interferometer; length measurement; partial fringe; wavelength measurement; dimensional metrology; exact fringes; 17048 .

Fractionation; gel permeation chromatography; GPC; molecular weight distribution; polymer characterization; standard reference material 1476; branched polyethylene; 17255.

Fractography; fracture tests; hydrogen; steels; stress corrosion; crack propagation; ductility; failure; 16700.

Fracture; acoustic emission; amplitude distribution; brittle materials; ceramics; 17213 .

Fracture; impact resistance; ophthalmic lenses; statistics; drop ball test; flaw distribution; 16979 .

Fracture; indentation; strength; brittle solids; ceramic surfaces; degradation; 16672

Fracture; low temperature tests; mechanical properties; nickel alloys; superalloys; fatigue; 16801 .

Fracture; plastic flow; solid particle impact; transmission electron microscopy; ceramics; erosion; NBSIR 77-1396.

Fracture interfaces; plastic deformation; silicon nitride; turbine materials; cracks; electron microscopy; NBSIR 76-1075.

Fracture mechanics; fracture toughness; material properties; structures; crack propagation; cryogenics; 16866.

Fracture mechanics; high temperature; proof testing; silicon carbide; silicon nitride; acoustic emission; brittle materials; crack growth; cyclic loading; 17039.

Fracture mode; Larson-Miller parameter; pressure vessel steel; tensile properties; creep-rupture properties; elevated-temperature; 17235.

Fracture tests; hydrogen; steels; stress corrosion; crack propagation; ductility; failure; fractography; 16700 .

Fracture toughness; heat affected zone; J-integral; nickel steel; weldments; cryogenic temperature; fatigue crack growth; 17089.

Fracture toughness; low temperature; nickel alloys; titanium alloys; aluminum alloys; ferritic steels; 17086.

Fracture toughness; material properties; structures; crack propagation; cryogenics; fracture mechanics; 16866.

Frames; hardware; hinges; locks; security standards; burglary resistance; door assemblies; door components; doors; 16714.
Franck Condon factors; molecular lithium; potential curve; spectroscopy; dissociation energy; Dunham coefficients; 17101.

Franck-Condon factors; laser modeling; lifetime; multiconfiguration self-consistent-field; potential energy curves; sodium molecule; transition dipole moment; ab initio calculations; $A$ values; 16870 .

Franck-Condon integrals; molecular constants; molecular nitrogen; potential energy curves; radiative lifetimes; critical review; JPCRD 6, No. 1, 113-307 (1977).

Free atoms; hyperfine fields; relativistic Hartree-Fock theory; atomic beam; electronic structure; 16940.

Free energy; lattice symmetry; stability; BBGKY hierarchy; bifurcation; crystal; 16986.

Free enterprise system; innovation; public private sector collaboration; technology growth; U.S. economy; 17113.

Free groups; free products; tables; asymptotic formulas; classical modular group; cyclic groups; 16660.

Free products; tables; asymptotic formulas; classical modular group; cyclic groups; free groups; 16660.

Free-electron-like metal; 100 to several $1000 \mathrm{eV}$; electron mean free path; 16748 .

Free-field measurements; hearing aid tests; orthotelephonic response; anthropometric manikin; 16847.

Free-free transitions; multiphoton processes; plasma absorption; bremsstrahlung; electron-ion collisions; J. Res. 82, No. 3, 173-179 (1977).

Free-free-laser saturation flux; gain coefficients; stimulated collision-induced emission; argon oxide excimer; 17254.

Frequency; geosynchronous satellite; measurement; standards; television; time; atomic clocks; dissemination; 17182.

Frequency; history; mathematics; navigation; physics; time; time broadcasts; time scales; astronomy; automation; clocks; communication; Monogr. 155.

Frequency; hot film anemometer; recirculating flow; spray; two component flow; vortex street; wake flow; anemometer; cylinder; SP484, pp. 705-718 (Oct. 1977).

Frequency; metrology; rf measurements; standards; superconductivity; thermometry; DC measurements; 16861 .

Frequency; National Measurement System; standards laboratories; survey; time; 17070 .

Frequency; standards, time; time standards; 16794.

Frequency accuracy; frequency bias; frequency stability; primary frequency standard; time dispersion; bias uncertainty; 16775.

Frequency accuracy; frequency stability; frequency standards; hydrogen maser; quartz crystal; rubidium gas cell; timekeeping; cesium beam; clocks (atomic); crystal oscillator; TN616, $2 d$ Revision.

Frequency and power measurements; laser magnetic resonance spectroscopy; FIR optically pumped lasers; 17073.

Frequency bias; frequency stability; primary frequency standard; time dispersion; bias uncertainty; frequency accuracy; 16775.

Frequency calibration; high frequency; Loran-C; low frequency; radio broadcasts; standard frequencies; television color subcarrier; time and frequency calibration methods; time calibration; time signals; TN695.

Frequency dependence; laser materials; photoacoustic spectroscopy; surface absorption; weakly absorbing materials; bulk absorption; 16860 .

Frequency dependence; laser materials; photoacoustic spectroscopy; surface absorption; weakly absorbing materials; bulk absorption; 17313 .

Frequency discrimination; frequency domain stability; frequency-lock loop; phase-lock loop; phase noise; servo techniques; time domain stability; atomic frequency standard; TN692.

Frequency domain stability; frequency-lock loop; phase-lock loop; phase noise; servo techniques; time domain stability; atomic frequency standard; frequency discrimination; TN692. 
Frequency lock loop; long-term frequency stability; NBS time scale; phase modulation; (active-passive) hydrogen maser; amplitude modulation; cavity frequency; environmental sensitivity; 17211 .

Frequency maps; ground displacement; Japan; earthquake distribution; earthquakes; field data; SP470, pp. 1II-1-IIl-17 (Apr. 1977).

Frequency measurement; frequency standards; helium neon laser; insulator metal diode; laser; speed of light; 1.5 microns; 17336.

Frequency measurement; infrared; 16867.

Frequency measurements on tunable lasers; IFS with a tunable laser; infrared frequency synthesis; SFRL frequency measurement; spin flip Raman laser; 16728.

Frequency modulation; Stark effect; far infrared laser; 17203.

Frequency random walk; quartz crystal resonators; resonance frequency fluctuation; temperature fluctuation; flicker noise; 17183.

Frequency response; hysteresis; precision; pressure measurement; sensitivity; stability; thermal effects; zero-shift; accuracy; calibration; cryogenic; dynamic; 17081 .

Frequency response; intrinsic optical tensor; intrinsic stress tensor; polymer solution; bead-spring model; eigenvalues; J. Res. 81A No. 1, 97-107 (1977).

Frequency response; least weight; optimization; structures; SP470, Pp. VI-22 - VI-32 (Apr. 1977).

Frequency shifts; hydrostatic pressure; optical transitions; scaling theory; 17228 .

Frequency stability; frequency standards; hydrogen maser; quartz crystal; rubidium gas cell; timekeeping; cesium beam; clocks (atomic); crystal oscillator; frequency accuracy; TN616, 2d Revision.

Frequency stability; hydrogen line $Q$; hydrogen line servo; magnetic field; passive hydrogen maser frequency standard; second-order Doppler; spin exchange; wall shift; active hydrogen maser frequency standard; cavity pulling; cavity-Q; cavity servo; Crampton effect; 17180 .

Frequency stability; primary frequency standard; time dispersion; bias uncertainty; frequency accuracy; frequency bias; 16775 .

Frequency stabilization; iodine; saturated absorption; dye laser; 17178.

Frequency standards; helium neon laser; insulator metal diode; laser; speed of light; 1.5 microns; frequency measurement; 17336.

Frequency standards; hydrogen maser; quartz crystal; rubidium gas cell; timekeeping; cesium beam; clocks (atomic); crystal oscillator; frequency accuracy; frequency stability; TN616, $2 d$ Revision.

Frequency-lock loop; phase-lock loop; phase noise; servo techniques; time domain stability; atomic frequency standard; frequency discrimination; frequency domain stability; TN692.

Fricke dosimetry; gamma rays; $x$ rays; absorbed dose; calorimetry; dose distributions; dosimetry; electron beams; food irradiation; 17343.

Friction, pavement; highway safety; measurement, skid resistance; pavement, skid resistance; test procedures, skid resistance measuring systems; tire-pavement interface forces; NBSIR 76-1174.

Fringes; interference; modulation; phase; Ramsey; saturation spectroscopy; transit-time; coherence; 17337.

Frost-point measuring apparatus; moisture condensation; seal durability and longevity; sealed insulating glass; ASTM Test Standard for insulating glass; 17286 .

Fuel cells; microprocessor; network analyzer; phosphoric acid electrolyte; refractory hard metals; AC impedance; automated electrochemical analysis; ceramic electrolytes; ceria-yttria; cyclic voltommetry; electrocatalysis; equivalent circuit; NBSIR 77-1270.
Fuel droplet; heat flow; micro-explosion; preheat; combustion; emulsified fuel droplet; J. Res. 82, No. 3, 183-195 (1977).

Fuel economy measurements; fuel flow measurements; in-line flow transducer; automotive fuel; flow measurement errors; SP484, pp. 803-820 (Oct. 1977).

Fuel flow measurements; in-line flow transducer; automotive fuel; flow measurement errors; fuel economy measurements; SP484, pp. 803-820 (Oct. 1977).

Fuel gas measurement; fundamentals; gaseous hydrocarbons; installation; performance characteristics; turbine meter; design considerations; field testing; SP484, pp. 871-880 (Oct. 1977).

Fuel load; heat transfer; room fires; scaling; ventilation; corridors; NBSIR 77-1318.

Fuel oil; hydraulic oil; industrial oils; lubricating oil; oil specifications; petroleum standards; petroleum test methods; recycled oil; re-refined oil; used oil; waste oil; engine oil; SP488.

Fuel savings; heat-loss reduction; insulation properties; residential heat loss; retrofitting houses; thermal conductivity; thermal insulation; thermography; air infiltration; condensation in buildings; energy conservation; energy measurements; NBSIR 77-1274.

Fuels; gasoline; gravity; heat content; heat of combustion; kerosine; aniline point; API gravity; aviation fuels; enthalpy of combustion; TN937.

Full scale testing; high-rise masonry; scale factors; shear walls; current research; ductility; BSS106, pp. 314-326 (Sept. 1977).

Full-scale; heat transfer; literature review; mathematical models; room fire; scaling models; theoretical; "flashover"; fluid flow; 17283 .

Full-scale test; gas temperature; oxygen content; recirculating flow; reduced scale model test; scaling criteria; spray water flow rate; water spray; automatic sprinklers; compartment fire; corridor sprinkler systems; droplet size; droplet trajectory; NBSIR 77-1287.

Full-scale testing; mobile homes; wind loads; aerodynamics; buildings; SP477, pp. I-21-1-33 (May 1977).

Functional equations; Hurwitz's theorem; analytic functions with infinitely many branches; 17041 .

Fundamental constants; Josephson effect; levitation; superconductivity; ampere definition; electrical units; 16876.

Fundamental constants; National Bureau of Standards; nuclear physics; numerical analysis; physics; spectroscopy; thermal physics; 75th anniversary; American Physical Society; 16991.

Fundamental frequencies; infrared spectra; polyatomic molecules; Raman spectra; vibrational frequencies; JPCRD 6 , No. 3, 993-1102 (1977).

Fundamental mode; liquid; perfect gas; propagation; shear; transverse gradient; wavenumber; duct; 17215 .

Fundamentals; gaseous hydrocarbons; installation; performance characteristics; turbine meter; design considerations; field testing; fuel gas measurement; SP484, pp. 871-880 (Oct. 1977).

Funding; local government; model codes; state-local relations; statewide codes; uniformity; building regulation; code administration; enforcement; SP473, pp. 225-240 (June 1977).

Furnace; operating cost; seasonal performance; building heating system; computer simulation; energy conservation; 16922.

Furniture fire; losses; residential fire; standard; upholstered furniture; cost plus loss; decision analysis; fire; NBSIR 77-1381.

Fused silica; interferometers; optics; photoelasticity; crystals; 16730.

Fused silica; microelectronic; MOS; oxidation fumace; silicon dioxide; sodium contamination; thermal oxidation; 16939.

Fusion; magnets; superconductivity; thermonuclear; copper; cryogenic; 17134.

Future dental materials; macromolecules; plastics; polymers; sealants; adhesives; dental applications; dental prosthetic materials; dental resins; 17201 . 


\section{G}

Gage blocks; interferometry; FORTRAN computer program; TN956.

Gage blocks; interferometry; length measurement; parallelism; flatness; NBSIR 73-239.

Gain; population inversion; recoil; atoms; 17143 .

Gain coefficients; stimulated collision-induced emission; argon oxide excimer; free-free-laser saturation flux; 17254.

Gain inhibitor; gas lasers; photodissociation; restricted HartreeFock; transition moment; absorption cross-section; $\mathrm{Ar}_{2}{ }^{+}$; energy transfer; 17195 .

Galactic stability; galaxies; galaxies, clusters of; 16989.

Galactic structure; interstellar medium; magnetic pressure; neutron; radiation; stellar explosion; supernova; dynamics; 17217

Galaxies; galaxies, clusters of; galactic stability; 16989.

Galaxies, clusters of; galactic stability; galaxies; 16989.

Galerkin; natural frequencies; orthotropic; plates; rotary inertia; transverse shear; vibration; 16702.

Gallium; gallium melting point; melting; standards; temperature; thermistors; thermometry; fixed points; 17055.

Gallium; International Practical Temperature Scale of 1968; melting point standard; secondary fixed point; temperature fixed point; thermometry; 17049.

Gallium; melting-point standard; temperature; thermometric fixed-point; clinical laboratory; fixed-point; SP48I.

Gallium arscnide; gallium atomic weight; stoichiometry; atomic weight; coulometry; electrochemical equivalent; J. Res. 81A No. 1, 1-4 (1977).

Gallium atomic weight; stoichiometry; atomic weight; coulometry; electrochemical equivalent; gallium arsenide; J. Res. 81 A No. 1, 1-4 (1977).

Gallium melting point; melting; standards; temperature; thermistors; thermometry; fixed points; gallium; 17055.

Gamma radiation; industrial radiography; national standards; radiation characteristics; radiation source; source calibration; test methods; $x$ rays; calibration; 17017 .

Gamma radiation; plastic films; quality control; radiation processing; radiochromic dyes; sterilization; dose distributions; dosimetry; electron beams; 17000.

Gamma ray; glow curve; irradiation; $\mathrm{TL} ; \mathrm{CaSO}_{4}$; correlation; dose; ESR; SP461, pp. 234-237 (Jan. 1977).

Gamma ray; ground state; inner bremsstrahlung; Jauch plot; spectrum; transition; coincidence; electron capture; excited state; SP461, pp. 23-25 (Jan. 1977).

Gamma ray; incoherent scattering; pair-production; photoionization; coherent scattering; cross sections; SP46I, pp. 20-22 (Jan. 1977).

Gamma ray; integration; kernel; radiation; streaming; annular; computation; duct; SP461, pp. 132-135 (Jan. 1977).

Gamma ray; iterative; neutron; plastic; recoil; scintillator; UNFOLD; Apsara; energy distribution; SP461, pp. 247-251 (Jan. 1977).

Gamma ray; kerma; neutron; charged particle; dosimeter; dosimetry; efficiency; SP461, pp. 209-218 (Jan. 1977).

Gamma ray; mean free path; ASFIT; build-up factor; empirical; energy; SP461, pp. 174-176 (Jan. 1977).

Gamma ray; photon; attenuation coefficient; counting sequence; cross section; SP46 I, pp. 29-31 (Jan. 1977).

Gamma rays; Ge( $\mathrm{Li})$ detector; neutron; nondestructive; resolution; spectrometry; water; activation; analysis; element; SP461, pp. 255-256 (Jan. 1977).

Gamma rays; inelastic scattering; $\mathrm{K}$-shell electron; photon; $\mathrm{x}$ ray; bound electrons; cross section; SP461, pp. 26-28 (Jan. 1977).

Gamma rays; integral; medium; Monte Carlo; albedo; angular; backscattering; barrier; differentials; distribution; SP461, pp. 129-131 (Jan. 1977).
Gamma rays; ionizing radiation; leuco dye cyanide; radiation dosimeter; radiation sensor; triphenylmethane cyanide dye precursor; ultraviolet; x rays; U.S. Patent 4,006,023.

Gamma rays; irradiation; LiF; optical absorption; spectral distribution; thermoluminescence; SP461, pp. 222-226 (Jan. 1977).

Gamma rays; K-shell; photons; Compton scattering; differential cross section; electron binding; SP461, pp. 67-69 (Jan. 1977).

Gamma rays; LiF; response; sensitivity; supralinear; thermoluminescence; dose; SP461, pp. 227-230 (Jan. 1977).

Gamma rays; moderator; neutron; radiation damage; reactor; scattering; spectrometer; cross section; energy transfer; SP461, pp. $32-40$ (Jan. 1977).

Gamma rays; Monte Carlo; photon; albedo; backscattering; distribution; dose rate; SP461, pp. $110-118$ (Jan. 1977).

Gamma rays; neutron; scattering; shield; transmission; ${ }^{252} \mathrm{Cf}$; ANISN; code; configuration; dose equivalent; energy; SP461, pp. 119-123 (Jan. 1977).

Gamma rays; pararosaniline cyanide; pulse radiolysis; radiochromic dyes; calorimetry; chemical dosimetry; dosimetry; dye dosimeters; electron beams; 16984.

Gamma rays; photon; scattering, incoherent; $x$ rays; angular distribution; cross section; SP461, pp. 55-56 (Jan. 1977).

Gamma rays; photons; Rayleigh scattering; analytical formula; coherent scattering; cross section; SP461, pp. 17-19 (Jan. 1977).

Gamma rays; secondary standards; x rays; electromagnetic spectra; 17246.

Gamma rays; sky-shine; spectrum; ${ }^{60} \mathrm{Co}$; back scattering; SP461, pp. 124-128 (Jan. 1977).

Gamma rays; $x$ rays; absorbed dose; calorimetry; dose distributions; dosimetry; electron beams; food irradiation; Fricke dosimetry; 17343.

Gamma rays, incoherent scattering function; pair production; photoelectric effect; photons; $x$ rays; atomic form factor; attenuation coefficients; cross sections; SP461, pp. 3-16 (Jan. 1977).

Gamma-ray; photon; $x$ ray; attenuation coefficient; energy-absorption coefficient; 17051 .

Gamma-ray measurements; germanium-lithium detectors; noble gases; radioactivity; reactor effluents; environment; 16975 .

Gamma-rays; scattered radiation; source housing; spectrometry; ${ }^{\circ}$ Co gamma-ray source; collimator; exposure spectra; NBSIR 76-1117.

Garbacz characteristic modes; group theory; inverse scattering; moment methods; scattering; singularity expansion method; symmetry analysis; antenna patterns; characteristic modes; 17225 .

Garden apartments; multi-family residences; apartments; building codes; fire; fire resistivity; firestopping; fire walls; $N B S I R$ 76-1194.

Garments; heat transfer; injury hazard; simulation; accident; apparel; burn injury; fabric flammability; fabrics; fire; NBSIR 77-1236.

Garnet; guide-pattern; magnetoresistance; nonvolatility; orthoferrite; photolithography; uniaxial structures; amorphous materials; bubble; field-access; SPSOO- 1 .

Gas; injury; liquefied; petroleum; standards; container; corrosion; explosion; extinguisher; fire; NBSIR 77-1217.

Gas; liquid; mass flow; measurement; cryogenic; flow; SP484, pp. $881-893$ (Oct. 1977).

Gas chromatography; gas chromatography-mass spectrometry; hydrocarbons; liquid chromatography; oil refinery; petroleum; benzo(a)pyrene; 16886.

Gas chromatography; gas chromatography-mass spectroscopy; hydrocarbons; intercalibration; petroleum analysis; trace analysis; 17273 . 
Gas chromatography; laser-Raman; liquid chromatography; nuclear magnetic resonance; organoarsenic; analysis; aqueous chemistry; arsenic; atomic absorption spectrophotometry; biomethylation; electrochemistry; environment; 17155 .

Gas chromatography; molecular diffusion; moments; secondary flow; 16980 .

Gas chromatography; organometal; selenium; tin; arsenic; atomic absorption; 16811 .

Gas chromatography-mass spectrometry; hydrocarbons; liquid chromatography; oil refinery; petroleum; benzo(a)pyrene; gas chromatography; 16886.

Gas chromatography-mass spectrometry; high-performance liquid chromatography; hydrocarbons; petroleum analysis; polynuclear aromatic hydrocarbons; fluorescence emission spectroscopy; 17271 .

Gas chromatography-mass spectroscopy; hydrocarbons; intercalibration; petroleum analysis; trace analysis; gas chromatography; 17273.

Gas compressibility factor; piston gauge weights; weight handler; 17127.

Gas detectors; heat detectors; residential fires; smoke detectors; detector sensitivity; detector siting; escape time; fire tests; NBS-GCR-77-82.

Gas discharges; sputtering; adhesion; coatings; films; SP487, pp. 311-323 (Aug. 1977).

Gas flow standard; hot-wire anemometry; international flow standards; laser anemometry; open channel flows; orifice meters; pitot-static meters; turbine meters; weirs; acoustic flow meters; closed conduit flows; current meters; dye-dilution methods; SP484, Volumes 1 and 2.

Gas infusion of leaks; hermeticity; leak detection; semiconductor hermeticity; doubled hermetic enclosure; 16935.

Gas laser; optical pumping; sulfur dimer; tunable laser; visibleultraviolet laser; 17129.

Gas lasers; photodissociation; restricted Hartree-Fock; transition moment; absorption cross-section; $\mathrm{Ar}_{2}{ }^{+}$; energy transfer; gain inhibitor; 17195 .

Gas phase; laser induced fluorescence; chlorine fluorescence; 16844.

Gas phase; $\mathrm{PF}_{5}$; Raman; $\mathrm{VF}_{5}$; $\mathrm{AsF}_{5}$; barriers; energy levels; 16978.

Gas phase; photoabsorption cross section; photochemistry; quantum yield; rate constant; stratospheric chemistry; chemical kinetics; data evaluation; data reliability; 16976.

Gas phase reaction; $\mathrm{Ba}$ and $\mathrm{Mg}$ films; chemiluminescence; chemisorption; codeposition; 17242 .

Gas temperature; oxygen content; recirculating flow; reduced scale model test; scaling criteria; spray water flow rate; water spray; automatic sprinklers; compartment fire; corridor sprinkler systems; droplet size; droplet trajectory; evaporative cooling; NBSIR 77-1287.

Gaseous hydrocarbons; installation; performance characteristics; turbine meter; design considerations; field testing; fuel gas measurement; fundamentals; SP484, pp. 871-880 (Oct. 1977).

Gaseous ionization detectors; instruments; scintillation detectors; ${ }^{6} \mathrm{Li}(\mathrm{n}, \alpha)^{3} \mathrm{H}$; external particle detectors; SP493, pp. 4346 (Oct. 1977).

Gaseous reduction; hematite; high voltage electron microscopy; iron oxide; magnetite; $\mathrm{Fe}_{2} \mathrm{O}_{3} ; \mathrm{Fe}_{2} \mathrm{O}_{4} ; 17177$.

Gas-liquid chromatography; liquid crystal; naphthalene homologues; nematic phase; supercooled phase; 16673.

Gasoline; gravity; heat content; heat of combustion; kerosine; aniline point; API gravity; aviation fuels; enthalpy of combustion; fuels; TN937.

Gate oxide film; metal evaporation; metallization; metal-oxide semiconductor; microelectronic device; radiation dose; silicon dioxide film; electron-gun evaporator; 16889 .
Gaussian; Monte Carlo; scattering; aluminium; carbon; collision; copper; distribution; dose; electron; SP461, pp. 106-109 (Jan. 1977).

Gaussian diffusion; p-n junction; semiconductors; silicon; capacitance-voltage measurements; dopant density; 17328 .

Gear lubrication; grease; polyfluoroalkyl-alkyl polysiloxane; polytetrafluoroethylene; antimony dialkyldithiocarbamate; antiwear; bearing lubrication; extreme pressure; fluorinated ethylenepropylene; SP487, pp. 154-171 (Aug. 1977).

Gears; Hertz contacts; lubrication; rheology; starvation; traction; bearings; computer programs; elastohydrodynamics; failure analysis; film thickness; SP487, pp. 137-153 (Aug. 1977).

Gel permeation chromatography; nonlinear regression; calibration; column broadening, GPC; 16822 .

Gel permeation chromatography; GPC; molecular weight distribution; polymer characterization; standard reference material 1476; branched polyethylene; fractionation; 17255 .

General Conference on Weights and Measures; International System of Units; SI; Système International des Unités; Units of Measurements; SP330.

General purpose heat transfer computer program; interdisciplinary thermo-structural analyses; finite-element method; SP487, pp. 62-81 (Aug. 1977).

Generalized matrix norm; Hadamard product; multiplicative; spectral radius; vector norm; compatible; 16676.

Generalized matrix norm; multiplicative; spectral radius; unit ball; vector norm; compatible; 16836 .

Generic probes; human factors; lawn mowers; safety; standards; consumer products; NBSIR 77-1294.

Geodesy; gravimetry; lunar ranging; plate tectonics; 16896.

Geography; information processing standards; information system; representations and codes; standards; statistical data; ADP standards; computers; data elements and codes; data processing; Federal Information Processing Standards; FIPS PUB 10-2.

Geomagnetism; instrumentation; Josephson effect; magnetometry; SQUID; biomagnetism; 16872.

Geometric factor; metals; surfaces; catalysis; characterization; chemisorption; electronic factor; SP475.

Geometric factors; photon; polarimeter; radiation physics; scattering; spectrometers; absorption; accuracy; cross section; fast neutrons; SP46I, pp. 47-54 (Jan. 1977).

Geometry; hypercube; hyperplane; polytope; convex set; data analysis; estimation; 17117 .

Geosynchronous satellite; measurement; standards; television; time; atomic clocks; dissemination; frequency; 17182 .

Germanium-lithium detectors; noble gases; radioactivity; reactor effluents; environment; gamma-ray measurements; 16975.

$\mathrm{Ge}(\mathrm{Li})$; ionization chambers; NaI; neutron flux determination; proportional counters; solid-state detectors; standard cross section; ${ }^{10} \mathrm{~B}\left(\mathrm{n}, \alpha_{0}+\alpha_{1} \gamma\right)^{7} \mathrm{Li}$; SP493, pp. 85-92 (Oct. 1977).

$\mathrm{Ge}(\mathrm{Li})$ detector; neutron; nondestructive; resolution; spectrometry; water; activation; analysis; element; gamma rays; SP461, pp. 255-256 (Jan. 1977).

gf value; imprisonment; lifetimes; mean life; resonance radiation; transition probability; ur; uranium; delayed coincidence; 17292.

Giant resonance; hydrodynamic model; isospin; photonuclear; shell model; sum rules; 16987.

Giant resonances; photon scattering; polarized photons; resonance fluorescence; Delbrück scattering; Doppler broadening; electric quadrupole; 16926.

Gibbs energy; thermochemical data networks; thermochemical tables; thorium compounds; data evaluation; enthalpy; entropy; NBSiR 77-1300

Gibbs energy of formation; ideal gas thermodynamic properties; intermolecular association; normal and deuterated methanols; potential barrier to internal rotation; principal and reduced 
moments of inertia; structural parameters; JPCRD 6, No. 1 , 105-112 (1977).

Ginzburg-Landau free energy; relaxation time; disordered system; dynamic susceptibility; $17 / 22$.

Givens transformations; Gram-Schmidt orthogonalization; Householder transformations; least squares algorithms; regression; statistics; Cholesky decomposition; 16833.

Glass; glass transition; hole theory; liquid; polymer; pressure; thermodynamic; compressibility; densification; 16774.

Glass; glass transition; liquid; polymer; pressure; PVT; pyrolysis; refractive index; thermal expansion; thermodynamic; compressibility; densification; J. Res. 81A Nos. 2 and 3, 283-297 (1977).

Glass; guys, antenna; pultrusion; reinforced plastics; stress rupture of FRP rod; test methods; weatherability of FRP rods; aramid; composite materials; end fittings for FRP rod; environmental resistance of FRP rods; fiber-reinforced plastic (FRP); 16685.

Glass; vaporization; activity; 17043.

Glass ceramic; polarization; strontium titanate; dielectric constant; dielectric relaxation; electret; 16798 .

Glass filters; high-accuracy spectrophotometers; spectrophotometry; stability of transmittance; standard reference material; transfer standard; transmittance; absorbance; accuracy in spectrophotometry; 16981

Glass, returnable and nonreturnable bottles; glass, soda-lime-silica; manufacturing requirements; PS73-77.

Glass scintillators; Monte Carlo; multiple scattering; neutron detection; photomultipliers; ${ }^{6} \mathrm{Li}(\mathrm{n}, \alpha) \mathrm{T} ;$ SP493, pp. $37-42$ (Oct. 1977).

Glass, soda-lime-silica; manufacturing requirements; glass, returnable and nonreturnable bottles; PS73-77.

Glass transition; heat capacity; pelletization; poly(vinyl chloride), pressure densification; relaxation; stored energy; strain energy; adiabatic temperature drift; enthalpy; 16769.

Glass transition; heat capacity; polymer; poly(vinyl chloride); pressure effects; thermodynamic properties; calorimetry; enthalpy relaxation; J. Res. 82, No. 1, 9-18 (1977).

Glass transition; hole theory; liquid; polymer; pressure; thermodynamic; compressibility; densification; glass; 16774 .

Glass transition; liquid; polymer; pressure; PVT; pyrolysis; refractive index; thermal expansion; thermodynamic; compressibility; densification; glass; J. Res. $81 \mathrm{~A}$ Nos. 2 and 3 , 283-297 (1977)

Glass-ceramics; heat switches; magnetothermal conductivity; polarization; potassium tantalate; refrigeration; specific heat; strontium titanate; beryllium; ceramics; cryogenics; dielectricconstant; electrets; electrocaloric effect; entropy; ferroelectrics; NBSIR 76-847.

Glasses; kinetics; polymer glasses; pressure dependence; 16962. Glossary; security terms; windows; definitions; doors; SP480-22.

Glove box; intercomparison; neutrons, high energy; neutrons, low energy; non-uniform exposures; quality factor; standards; criteria, accuracy; criteria, performance; dose equivalent; elements, transuranic; SP493, pp. 101-105 (Oct. 1977).

Glow; heat treatment; impurity; temperature; thermoluminescence; aluminium oxide; SP461, pp. 219-221 (Jan. 1977).

Glow curve; irradiation; TL; $\mathrm{CaSO}_{4}$; correlation; dose; ESR; gamma ray; SP461, pp. 234-237 (Jan. 1977).

Glowing electrical connections; arcing/sparking; branch circuit; contact resistance; electrical connections; fire hazard; BSS103.

Glues and gluing; information service; lumber; mechanical properties; paper; pulp; timber; wood; wood products; AIDS; bark; forest products; SP463, pp. 11.1.1-11.1.4 (Jan. 1977).

Goal oriented systems approach; systems analysis; buildings; fire protection; fire safety; NBS-GCR-77-103.

Goal-oriented; hierarchical. control; robot; sensors; adaptive; automation; computer; control; SP5OO-23.
"Gold Filled," marking of; "Gold Overlay," marking of; "Gold Plate," marking of; "Rolled Gold Plate," marking of; jewelry, marking of; PS67-76.

"Gold Overlay," marking of; " Gold Plate," marking of; " Rolled Gold Plate," marking of; jewelry, marking of; "Gold Filled," marking of; PS67-76.

"Gold Plate," marking of; "Rolled Gold Plate," marking of; jewelry, marking of; "Gold Filled," marking of; "Gold Overlay," marking of; PS67-76.

Government information collection; information policy; information processing; risk management; computers; 16906.

Government reports; NTIS; patent licensing; technical reports; computerized information system; document dissemination; SP463, pp. VII.3.1-V11.3.5 (Jan. 1977).

Governmental environment; laser energy; space flight; spectroscopy; SRM; television captioning; thermophysical; weights and measures; American electroplaters'; calorimeter; cryogenic flow measurement; dental restorations; DIM/NBS 61 , No. 4, 1-32 (1977).

GPC; molecular weight distribution; polymer characterization; standard reference material 1476; branched polyethylene; fractionation; gel permeation chromatography; 17255 .

Grain boundary groove; ice-water interface; ice-water surface tension; Nash-Glicksman theory; surface energy; 16780.

Grain moisture; mass spectra; radiation sterilizing; screw thread standards; SHIVA laser; silicon; timekeeping; ultraviolet radiation; calibration; consumers; energy; energy savings; DIM/NBS 61, No. 9, 1-32 (1977).

Gram-Schmidt orthogonalization; Householder transformations; least squares algorithms; regression; statistics; Cholesky decomposition; Givens transformations; 16833.

Graph; hypergraph; König System; KM-System; Menger System; MK-System; dominating set; enclaveless set; J. Res. 82, No. 3, 197-202 (1977).

Graph; network; organization; probability; reliability; trees; dynamic programming; 16784 .

Graph theory; performance specifications; standards; building codes; computer programming; decision tables; 16705.

Graph theory; performance specifications; standards; building codes; computer programming; decision tables; TN940.

Graphic pen; halocarbons; infrared lasers; international standard; neutron xeroradiography; problem-solving; radiation safety; smoke detectors; solar heating; SRM's; adobe; air pollution; corrosion; electrical; energy management; DIM/NBS 61 , No. 3, 1-32 (1977).

Graphics; cathode ray tubes; computer aided design; design; SP487, pp. 82-90 (Aug. 1977).

Graphite fibers-aluminum; mechanical behavior; pultrusion/drawing; wire preform; composite material; fabrication techniques; SP487, Pp. 93-107 (Aug. 1977).

Graphitic corrosion; steadite; brittle fracture; cast iron gas pipe; NBSIR 74-594.

Gravimetric calibration; liquid retention or clingage tests; precision; prover; Research Associate Program; standards inspection procedure; temperature correction; test measure; test measure evaluation; "to contain"; "to deliver"; volumetric calibration; NBSIR 77-1214.

Gravimetry; lunar ranging; plate tectonics; geodesy; 16896.

Gravitational waves; laser; strainmeter; 17267

Gravity; heat content; heat of combustion; kerosine; aniline point; API gravity; aviation fuels; enthalpy of combustion; fuels; gasoline; TN937.

Gravity; liquid zone; shape; stability; surface tension; floating zone; 17009 .

Gravity load; handling devices; handling loads; military field shelters; probability distributions; shocks, snow load; static load; trains; transportation; trucks; vibrations; wind load; acceleration; airplanes; cargo; dynamic loads; equivalent static force; NBSIR 77-1254. 
Gravity quaywall; rock motion; seismic coefficient; acceleration; accelerogram; SP477, pp. V1-192-V1-198 (May I977).

Grease; polyfluoroalkyl-alkyl polysiloxane; polytetrafluoroethylene; antimony dialkyldithiocarbamate; antiwear; bearing lubrication; extreme pressure; fluorinated ethylenepropylene; gear lubrication; SP487, pp. 154-171 (Aug. 1977).

Great Britain; imager CCD's; Japan; peristaltic CCD's; surface channel; The Federal Republic of Germany; The Netherlands; transfer channel; bucket-brigade; buried channel; Canada; charge-coupled device; SPSO0-5.

Green's function; ionization potentials; Rayleigh-Schrödinger perturbation theory; electron affinities; 17317.

Green's function; neutron; spherical; symmetric; transport; density transform; expansion coefficient; SP461, pp. 87-90 (Jan. 1977).

Grinding damage; oxidation; silicon nitride; surface flaws; thin foils; cracks; electron microscopy; 17090.

Ground displacement; Japan; earthquake distribution; earthquakes; field data; frequency maps; SP470, pp. III1-Ill-17 (Apr. 1977).

Ground failures; hydraulic structures; seismicity; soils; standards; structural response; vessels and wind; accelerograph; bridges; buildings; codes; disaster; dynamic analysis; earthquakes; SP470.

Ground failures; nuclear facilities; seismicity; soils; standards; structural response; winds; accelerograph; bridges; buildings; codes; disaster; dynamic analysis; earthquakes; SP477.

Ground fault circuit interrupters; national electric code; safety regulations; standards; accidents; benefit-cost analysis; building codes; building economics; building regulations; economic impact; electric shock; SP473, pp. $397-419$ (June 1977).

Ground motion; network design; strong-motion record; cost effectiveness; SP477, pp. III-1 - III-15 (May 1977).

Ground motion; records; results; seismometers; arrays; earthquakes; SP477, pp. III-16-III-25 (May 1977).

Ground state; inner bremsstrahlung; Jauch plot; spectrum; transition; coincidence; electron capture; excited state; gamma ray; SP461, pp. 23-25 (Jan. 1977).

Group delays; Omega timing; precision timekeeping; VLF antenna fields; VLF timing; VLF tracking coordination; clock synchronizations; cycle identification; 16947.

Group representations; measurements; near field; nonplanar; patterns; scanning; spherical; symmetry; antennas; arrays; coordinate transformations; data processing; 16671 .

Group representations; near-fields, recursion; scanning; spherical; spherical point group; antennas; arrays; finite rotations; 17322.

Group theory; high-resolution spectra; irreducible representation; isotope separation; molecular spectroscopy; crystal field theory; 16956.

Group theory; inverse scattering; moment methods; scattering; singularity expansion method; symmetry analysis; antenna patterns; characteristic modes; Garbacz characteristic modes; 17225.

Group theory; molecular spectroscopy; sulfur hexafluoride; crystal field theory; 17316.

Group theory; near-field scanning; symmetry analysis; computer programs; data reduction; eigenvalue equations; electromagnetic theory; 17222

Growth; housing needs; projections; development; forecasts; BSSI00-4.

Growth rate; homogeneous nucleation; polymer; surface nucleation; chain-folding; crystallization; 16887.

Guatemala earthquake; bridges; earthquake damage; SP477, Pp. VIII-1 - VIII-27 (May 1977).

Guidebook; testing; anthropomorphic dummies; building safety; dummies; NBS-GCR-77-91.
Guideline; law enforcement equipment report; Law Enforcement Standards Laboratory; mobile digital equipment; National Institute of Law Enforcement and Criminal Justice; communications; digital communications; 16996.

Guide-pattern; magnetoresistance; nonvolatility; orthoferrite; photolithography; uniaxial structures; amorphous materials; bubble; field-access; gamet; SPSO0-1.

Guyana; less developed countries; measurement services; standardization; testing facilities; cottage industry; developing countries; NBSIR 76-1180.

Guys, antenna; pultrusion; reinforced plastics; stress rupture of FRP rod; test methods; weatherability of FRP rods; aramid; composite materials; end fittings for FRP rod; environmental resistance of FRP rods; fiber-reinforced plastic (FRP); glass; 16685.

Gypsum board; potential heat; properties; rate of flame spread; rate of heat release; scanning electron microscope (SEM); buildings; ease of ignition; fire tests; NBSIR 77-1265.

Gyroscope; London moment; magnetic torque; relativity; satellite experiment; superconducting; electrodynamics; 16795.

G/T; measurement accuracy; radio stars; satellite earth terminal; signal to noise; star flux; figure of merit; 17227 .

\section{H}

Hadamard product; $M$-matrix; diagonally dominant; diagonally symmetrizable; eigenvalue; 16909.

Hadamard product; multiplicative; spectral radius; vector norm; compatible; generalized matrix norm; 16676.

Hafnium; high-speed measurements; high temperature; solidsolid phase transformation; thermodynamics; 16767.

Halocarbons; infrared lasers; international standard; neutron xeroradiography; problem-solving; radiation safety; smoke detectors; solar heating; SRM's; adobe; air pollution; corrosion; electrical; energy management; graphic pen; DIM/NBS 61 , No. 3, 1-32 (1977).

Hamilton; Maxwell; momentum; Poynting; variational; anholonomic; constraint; electromagnetism; J. Res. 81 B Nos. I and 2, 1-3 (1977).

Hand calculator; illuminating engineering; light design; luminaire effectiveness; luminance factor; office lighting; sphere illumination; body shadow; contrast rendition; NBSIR 77-1303.

Handbooks; mechanical properties; Mechanical Properties Data Center; structural metals and alloys; technical information; user awareness; data storage/retrieval; SP463, pp. IV.8.1IV.8.10 (Jan. I977).

Handguns; police; police equipment; standards; ammunition; SP480-5.

Handling devices; handling loads; military field shelters; probability distributions; shocks, snow load; static load; trains; transportation; trucks; vibrations; wind load; acceleration; airplanes; cargo; dynamic loads; equivalent static force; gravity load; NBSIR 77-1254.

Handling loads; military field shelters; probability distributions; shocks, snow load; static load; trains; transportation; trucks; vibrations; wind load; acceleration; airplanes; cargo; dynamic loads; equivalent static force; gravity load; handling devices; NBSIR 77-1254.

Harbours; ports; specifications; structures; design; earthquakes; SP470, Pp. VIII-42-VIII-55 (Apr. 1977).

Hard spheres; metastable states; molecular probability density; bifurcation; close-packed crystals; crystalline solutions; 17012.

Hardboard; interlaboratory evaluation; neoprene; radiant panel test; round robin; test method; ASTM E 162; coefficient of variation; flame spread tests; flexible polyurethane; NBSIR 77-1222.

Hardness; interstitial; metals; refractory; alloys; compounds; 1726?. 
Hardware; hinges; locks; security standards; burglary resistance; door assemblies; door components; doors; frames; 16714.

Hardware monitoring; on-line system evaluation; prediction methods; queuing models; simulation; software monitoring; workload definition; ADP life cycle; computer performance evaluation; computer performance measurement; computer performance prediction; SP500-18.

Hardy space; numerical integration; numerical quadrature; piecewise analytic functions; quadrature; rational approximation; tanh rule; trapezoid rule; 17157.

Harris computer; branch driver; CAMAC; CAMAC standards; computer interfaces; digital interfaces; 16806.

Hartree-Fock; ions; line strength; atomic spectroscopy; 17229.

Hazard analysis; physics; building research; chemistry; combustion research; design concepts; directories; fire prevention; fire research; NBSIR 77-1264.

Hazard analysis; risks; safety; accident prevention; SP487, PP. 265-277 (Aug. 1977).

Hazard evaluation; test data; test methods; thermal explosion theory; accidental polymerization; CHETAH predictive scheme; NBSIR 76-1149.

Hazardous characteristics of toys; safety, toy; toy safety; use and reasonably foreseeable abuse testing for toys; cautionary labeling for toys; PS72-76.

Hazardous materials; benzidine hazard; blood testing; carcinogen; fingerprints; forensic science; SP480-21.

Hazardous materials; methods of test; permeation; plastics packagings; polyethylene; transportation; 17346.

Hazardous materials ladings; mechanical properties; performance criteria; plastic packaging; stress-cracking; time-tofail; container tests; 17256 .

Hazards; instrumentation; isotropic; measuring; electromagnetic fields; 17168.

HCl-Ar; linear molecules; rotational line widths; semiempirical potential; theoretical potential; anisotropic interactions; 16799.

He 1 ; radiative transfer; Stark broadening; B-star spectra; forbidden lines; 17171 .

He 1 ; $\lambda 4471 \AA$; Stark broadening; dynamic ion effects; forbidden lines; 17167.

He Ne laser; laser doppler anemometry; flow measurement; SP484, 471-477 (Oct. 1977).

Head diffraction; hearing; interaural intensity differences; interaural time differences; localization; manikin; ears; 17052.

Head diffraction; hearing aids; instruments for hearing; manikin; audiometry; diffraction; 17064.

Head injury; head protection; heat resistance; helmet; impact; penetration resistance; test methods; fire helmet; NBSIR 77 1251 .

Head protection; heat resistance; helmet; impact; penetration resistance; test methods; fire helmet; head injury; NBSIR 77 1251

Headphone; loudspeaker; microphone; piezoelectric polymer; sound source; vibration; 16952.

Health and safety; metallurgy; mining; Office of Mineral Information; Bureau of Mines; energy; SP463, pp. V.3.1-V.3.9 (Jan. 1977).

Health care facilities; hospitals; mattresses; prisons; bedding; beds; compartment fires; firesafety engineering; fire tests; NBSIR 77-1290.

Health care facilities; hospital communication systems; hospital fires; hospital personnel; human behavior; nursing home fires; nursing staff; standards; voice communication; coding; communication systems; fire alarm systems; NBS-GCR-77-102.

Health dangers; research needs; codes and standards; environmental studies; fire safety; SP473, pp. 35-53 (June 1977).

Health facilities; hospitals; medical facilities; medical planning; architecture; building technology; construction; NBSIR 771233.
Health records; hydrogen; law enforcement; liquefied natural gas; metric tons; polyethylene; sound; spinach; SRM; systems and software; telecommunications; computer use; conservation; data; earth's measurement; energy; DIM/NBS 61 , No. 5 , $1-32$ (1977).

Health records; information policy, management principles; medical records; privacy; recordkeeping practices; security; citizen rights; computers, confidentiality; data systems; SP469.

Hearing; interaural intensity differences; interaural time differences; localization; manikin; ears; head diffraction; 17052.

Hearing aid tests; orthotelephonic response; anthropometric manikin; free-field measurements; 16847.

Hearing aids; attack and release characteristics; compression; NBSIR 76-1179.

Hearing aids; attack and release times; automatic gain control; compression; 17145 .

Hearing aids; instruments for hearing; manikin; audiometry; diffraction; head diffraction; 17064 .

Hearing aids; 16846.

Heat; hydrocarbon; ionized molybdenum; measurement assurance; metric; neutron diffraction; recycling oil; research and innovation; safety; ultrasonic tissue; computerized data; data elements; equity; federal technology; fire modeling; DIM/NBS 61, No. 6, 1-32 (1977).

Heat affected zone; J-integral; nickel steel; weldments; cryogenic temperature; fatigue crack growth; fracture toughness; 17089.

Heat and cold stress; mobile climate chamber; energy conservation research; SP491, Pp. 174-189 (Sept. 1977).

Heat and cooling loads; heat loss and heat gain; multi-room problems; air-leakage; dynamic heat transfer; energy analysis; J. Res. 82, No. 2, 97-106 (1977).

Heat capacity; high-speed measurements; high temperatures; melting; normal spectral emittance; radiance temperature; specific heat capacity; thermal radiation properties; thermodynamics; titanium alloy; J. Res. 81A Nos. 2 and 3, 251256 (1977).

Heat capacity; high-speed measurements; high temperature; molybdenum; pulse calorimetry; standard reference material; thermodynamic functions; drop calorimetry; emittance; enthalpy; SP260-55.

Heat capacity; pelletization; poly(vinyl chloride), pressure densification; relaxation; stored energy; strain energy; adiabatic temperature drift; enthalpy; glass transition; 16769.

Heat capacity; polymer; poly(vinyl chloride); pressure effects; thermodynamic properties; calorimetry; enthalpy relaxation; glass transition; J. Res. 82, No. 1, 9-18 (1977).

Heat content; heat of combustion; kerosine; aniline point; API gravity; aviation fuels; enthalpy of combustion; fuels; gasoline; gravity; TN937.

Heat detectors; ionization chamber detectors; photoelectric detectors; smoke detectors; building fires; fire detection devices; 16737

Heat detectors; ionization smoke detectors; photoelectric smoke detectors; residential fires; smoke detectors; tenability levels; detector sensitivity; detector siting; 16882.

Heat detectors; polyurethanes; polyvinyl chloride; smoke detectors; smoldering fires; temperature rise; wood; ceiling height; ceilings; cotton; detector location; fire detectors; fire growth; flaming fires; NBS-GCR-77-95.

Heat detectors; residential fires; smoke detectors; detector sensitivity; detector siting; escape time; fire tests; gas detectors; NBS-GCR-77-82.

Heat exchangers; particle accelerators; power transmission; reliability; compressors; cryogenic refrigeration; efficiency; expanders; 17083.

Heat flow; micro-explosion; preheat; combustion; emulsified fuel droplet; fuel droplet; J. Res. 82, No. 3, 183-195 (1977). 
Heat flux; heat release rate; oxygen depletion; smoke; Steiner Tunnel Test; ASTM E 84; fire tests; flame spread; TN945.

Heat flux; heat sinks; oxygen concentration; textiles; air flow; extinguishability; extinguishment; fabric flammability; fibers; NBS-GCR-77-90.

Heat flux; heat transfer rate; linear burning rate; extinguishability; fabric flammability; flammability ranking; NBS-GCR76-77.

Heat generation or absorption; numerical solutions; one-dimensional; radiation; thermal conduction; transient heat transfer; composite building constructions; convection; experimental data; fire endurance; NBSIR 77-1260.

Heat loss; infrared television system; heat-flow reference pad; 17335.

Heat loss and heat gain; multi-room problems; air-leakage; dynamic heat transfer; energy analysis; heat and cooling loads; J. Res. 82, No. 2, 97-106 (1977).

Heat of combustion; kerosine; aniline point; API gravity; aviation fuels; enthalpy of combustion; fuels; gasoline; gravity; heat content; TN937.

Heat of formation; ion; ionization potential; monoenergetic electron impact; photoionization; pyridine; vinylacetylene; 1,5-hexadiyne; 2,4-hexadiyne; appearance potential; benzene; butatriene; 17294 .

Heat of solution; naphthalene; partition coefficient; solubility; vapor pressure; 1-ethylnaphthalene; 1-methylnaphthalene; enthalpy; fluorescence; 17097.

Heat of solution; salting-out effect; solubility; aromatic hydrocarbons; 17038.

Heat pipe reaction; barium reactions; chemiluminescence; 17100.

Heat pump; load-calculation; rating; residential; space heating; testing; air conditioning; comfort; 17006.

Heat pumps; heat pumps and energy conservation; part-load performance; seasonal performance factor; cooling and heating coefficients of performance; effective seasonal heating COP; BSS93.

Heat pumps and energy conservation; part-load performance; seasonal performance factor; cooling and heating coefficients of performance; effective seasonal heating COP; heat pumps; BSS93.

Heat recovery; performance; total energy systems; absorption chillers; boiler performance; central utility plant; diesel engine; engine-generator efficiency; NBSIR 77-1243.

Heat recovery; total energy systems; diesel engine performance; engine-generator efficiency; engine-generator performance; NBSIR 77-1207.

Heat release rate; oxygen depletion; smoke; Steiner Tunnel Test; ASTM E 84; fire tests; flame spread; heat flux; TN945.

Heat release rate; response time; time delay; calorimetry; NBSIR 77-1302.

Heat resistance; helmet; impact; penetration resistance; test methods; fire helmet; head injury; head protection; NBSIR 77-1251.

Heat sinks; oxygen concentration; textiles; air flow; extinguishability; extinguishment; fabric flammability; fibers; heat flux; NBS-GCR-77-90.

Heat storage; work effects; clothing effects; comfort; SP491, pp. 52-64 (Sept. 1977).

Heat stress; human comfort; indoor environment; mean radiant temperature; thermal comfort; energy conservation in buildings; SP491.

Heat stress; thermal analysis; exposure limits; SP49I, pp. 65-92 (Sept. 1977).

Heat stress control; heat stress indices; heat stress monitoring; industrial heat stress; metabolic heat load; environmental monitoring; SP491, pp. 41-51 (Sept. 1977).

Heat stress indices; heat stress monitoring; industrial heat stress; metabolic heat load; environmental monitoring; heat stress control; SP491, pp. 41-51 (Sept. 1977).
Heat stress monitoring; industrial heat stress; metabolic heat load; environmental monitoring; heat stress control; heat stress indices; SP491, pp. $41-51$ (Sept. 1977).

Heat switch; Lorenz ratio; magnetic field; single crystal; thermal conductivity; beryllium; cryogenics; electrical conductivity; 17088 .

Heat switches; magnetothermal conductivity; polarization; potassium tantalate; refrigeration; specific heat; strontium titanate; beryllium; ceramics; cryogenics; dielectric-constant; electrets; electrocaloric effect; entropy; ferroelectrics; glassceramics; NBSIR 76-847.

Heat transfer; helium; turbulent flow; channels, small; $I 7333$.

Heat transfer; implicit; insulation; laboratory measurements; modeling; standby loss; water heater; alternating direction; computer simulation; cool down; energy savings; flue damper; 17184.

Heat transfer; injury hazard; simulation; accident; apparel; burn injury; fabric flammability; fabrics; fire; garments; NBSIR 77. 1236.

Heat transfer; literature review; mathematical models; room fire; scaling models; theoretical; "flashover"; fluid flow; fullscale; 17283

Heat transfer; room fires; scaling; ventilation; corridors; fuel load; NBSIR 77-1318.

Heat transfer; room fires; scale models; buoyant plumes; ceilings; compartment fires; fire plumes; NBS-GCR-77-97.

Heat transfer rate; linear burning rate; extinguishability; fabric flammability; flammability ranking; heat flux; NBS-GCR-7677.

Heat transfer rates; Mushroom Apparel Flammability Tester; standards; test development; textiles; apparel; fabrics; flammability testing; NBS-GCR-76-78.

Heat treatment; impurity; temperature; thermoluminescence; aluminium oxide; glow; SP461, pp. 219-221 (Jan. 1977).

Heat-flow measurements; infrared heat-loss measurement technique; measurement technology; thermography; TN933.

Heat-flow reference pad; heat loss; infrared television system; 17335 .

Heating; laboratory accreditation; performance criteria; solar energy; standards; buildings; cooling; 16686.

Heating; load calculation; MIUS; modular integrated utility system; simulation; utility services; computer programs; cooling; energy analysis; financial analysis; NBSIR 77-1307.

Heating; performance criteria; solar collectors; solar energy; standards; buildings; cooling; SP473, pp. 103-112 (June 1977).

Heating and cooling loads; building energy analysis; computerized energy analysis; energy consumption;-NBSIR 761177.

Heat-loss reduction; insulation properties; residential heat loss; retrofitting houses; thermal conductivity; thermal insulation; thermography; air infiltration; condensation in buildings; energy conservation; energy measurements; fuel savings; NBSIR 77-1274.

Heavy ion collisions; inelastic scattering; Monte Carlo calculations; proton angular distributions; proton production; proton spectra; 17109.

Heavy particle collisions; rotational excitation in atom-molecule scattering; atom-molecule scattering; collisions of $\mathrm{He}$ with diatomic hydrides; 16674.

Heavy water; isotopic waters; partial molar volume of aqueous gases; PVT; thermal expansivity; water; aqueous solutions of gases; compressibility; equation of state; JPCRD 6, No. 4, 1109-1132 (1977).

Helium; helium supply system; high density helium storage; liquid helium storage; supercritical helium; cryogenic helium supply system; cryogenic storage; NBSIR 76-850.

Helium; ionization; measurements; cross section; differential; electron; 16810.

Helium; turbulent flow; channels, small; heat transfer; 17333. 
Helium absorption; liquid helium bubble; metastable helium atoms; 16818.

Helium flow facility; helium impurities; microwave pressure transducer; thermal-acoustic oscillations; burn-out; heliumcooled current leads; NBSIR 77-853.

Helium forbidden lines; Stark broadening theory; stellar line profiles; transfer equations; early type stars; 17172 .

Helium impurities; microwave pressure transducer; thermalacoustic oscillations; burn-out; helium-cooled current leads; helium flow facility; NBSIR 77-853.

Helium neon laser; insulator metal diode; laser; speed of light; 1.5 microns; frequency measurement; frequency standards; 17336.

Helium supply system; high density helium storage; liquid helium storage; supercritical helium; cryogenic helium supply system; cryogenic storage; helium; NBSIR 76-850.

Helium-cooled current leads; helium flow facility; helium impurities; microwave pressure transducer; thermal-acoustic oscillations; burn-out; NBSIR 77-853.

Helium-three; monopole transition; separable potential; Coulomb excitation; electron scattering; Faddeev equations; 16793.

Helium-4; normal fluid helium-4; phonons; protons; specific heat; superfluid helium-4; computed thermodynamic properties; entropy; equation of state; excitation spectrum; JPCRD 6, No. 1, 51-104 (1977).

Helix; mixer; spectrophotometry; stirrer; vortex; cuvette; 16704.

Helmet; impact; penetration resistance; test methods; fire helmet; head injury; head protection; heat resistance; NBSIR 77-1251.

Hematite; high voltage electron unicroscopy; iron oxide; magnetite; $\mathrm{Fe}_{2} \mathrm{O}_{3} ; \mathrm{Fe}_{2} \mathrm{O}_{4}$; gaseous reduction; 17177 .

Hermetic seals; leakage; nondestructive tests; semiconductor devices; standards; 16943 .

Hermetic test standards; integrated circuits; radioisotope leak detection; hermeticity; 17331 .

Hermeticity; hermetic test standards; integrated circuits; radioisotope leak detection; 17331 .

Hermeticity; hybrid devices; leak testing; measurement technology; microcalorimetry; pacemaker leads; process control; reliability; screen tests; semiconductor devices; batteries; cardiac pacemakers; SP400-42.

Hermeticity; ion implantation; Irvin's curves; leak tests; linewidth measurement; measurement methods; microelectronics; optical flying-spot scanner; oxidation particle impact noise detection test; passivation overcoats; photovoltaic method; power-device grade silicon; SP400-29.

Hermeticity; leak detection; semiconductor hermeticity; doubled hermetic enclosure; gas infusion of leaks; 16935.

Hermitian matrix; inertia; stability; eigenvalue; 16755.

Hertz contacts; lubrication; rheology; starvation; traction; bearings; computer programs; elastohydrodynamics; failure analysis; film thickness; gears; SP487, pp. 137-153 (Aug. 1977).

Heterodyne detection; Josephson effect; millimeter waves; mixing; receiver; superconductivity; 17077.

Heterodyne receiver; international standards code; NCSL; NMR knight shifts; neutron beams; piezo-flex micropositioning; pressure; thermodynamic tables; coal conversion; consumer products; cryogenic; crystalline materials; DIM/NBS 61 , No. 7, 1-32 (1977).

Hexacarbonylvanadate( 1-); NMR spectroscopy; reduction; $\mathrm{V}(\mathrm{CO})_{6}^{-;}$1,3-dithiolium ion; 2,2'-bi(1,3-dithiolyl); coupling constants; 17154 .

$\mathrm{Hg}_{2} ; \mathrm{Hg}_{3}$; potential curves; $335 \mathrm{~nm}$ mercury laser; $A$-values; bound-free transitions; 17084 .

$\mathrm{Hg}_{3}$; potential curves; $335 \mathrm{~nm}$ mercury laser; A-values; boundfree transitions; $\mathrm{Hg}_{2} ; 17084$.
Hierarchical control; robot; sensors; adaptive; automation; computer; control; goal-oriented; SP500-23.

High accuracy; spectrophotometer; standards; transmittance; tristimulus values; chromaticity coordinates; color; filters; 17260 .

High density helium storage; liquid helium storage; supercritical helium; cryogenic helium supply system; cryogenic storage; helium; helium supply system; NBSIR 76-850.

High energy; LET; neutrons; yields; dosimetry; energy spectra; NBSIR 77-1279, pp. 19-23 (July 1977).

High frequency; Loran-C; low frequency; radio broadcasts; standard frequencies; television color subcarrier; time and frequency calibration methods; time calibration; time signals; frequency calibration; TN695.

High lift grouting; shotcrete, surface wave instrumentation; veneer anchorage; allowable bolt loads, end distance, edge distance and spacing; drift; face shells, reinforcing splices; BSSI06, pp. 259-274 (Sept. 1977).

High pressure; high temperature; interaction virial coefficients; mixtures; molecular volumes; second virial coefficients; water; ballistics; carbon dioxide; combustion gases; energy; equation of state; 17136 .

High pressure; $\mathrm{KBr}$; mode Gruneisen parameters; neutron scattering; anharmonicity; dispersion curves; 17001 .

High pressure; latent heat detection; melting and freezing equilibrium; mercury; 16750.

High pressure; solid-solid phase boundaries; AB-type compounds; calibration; critically evaluated data; crystallographic data; experimental melting curves; JPCRD 6, No. 4, 1205 1252 (1977).

High resolution; infrared spectrum; monodeutero silane; $\mathrm{SiH}$ stretching vibrations; vibration-rotation interaction; 17131 .

High speed aerodynamics; radiative transfer; spectral line formation; stellar atmospheres; 16758.

High speed tire hazard; police patrol car tires; radial tire failures; SP480-18.

High strength steels; nickel alloys; stainless steels; stress corrosion cracking; titanium alloys; aluminum alloys; copper alloys; Monogr. 156.

High temperature; interaction virial coefficients; mixtures; molecular volumes; second virial coefficients; water; ballistics; carbon dioxide; combustion gases; energy; equation of state; high pressure; 17136.

High temperature; Lorenz ratio; low temperature; standard reference material; thermal conductivity; thermopower; tungsten; electrical resistivity; 16877.

High temperature; melting point; radiance temperature; titanium; electrical resistivity; emittance; high-speed measurement; J. Res. 82, No. 2, 119-122 (1977).

High temperature; molybdenum; pulse calorimetry; standard reference material; thermodynamic functions; drop calorimetry; emittance; enthalpy; heat capacity; high-speed measurements; SP260-55.

High temperature; proof testing; silicon carbide; silicon nitride; acoustic emission; brittle materials; crack growth; cyclic loading; fracture mechanics; 17039 .

High temperature; proof testing; reliability; ceramics; 17046.

High temperature; solid-solid phase transformation; thermodynamics; hafnium; high-speed measurements; 16767.

High temperature erosion; particle impingement; stainless steel; erosion-corrosion process; erosive wear; 17274 .

High temperature erosion; particle impingement; stainless steel; erosion-corrosion process; erosive wear; 17300.

High temperatures; ceramics; coal gasification; enetgy; erosion; 17028 .

High temperatures; melting; normal spectral emittance; radiance temperature; specific heat capacity; thermal radiation properties; thermodynamics; titanium alloy; electrical resistivity; heat capacity; J. Res. 81A Nos. 2 and 3, 251-256 (1977). 
High voltage; low temperature polymer; cryogenic; dielectric loss; dissipation factor; 16782.

High voltage; polymer tape insulation; superconducting cable; underground transmission; bridge measurements; cryogenic; dielectric loss; dissipation factor; epoxy insulation; 17014 .

High voltage $C(V)$ and $G(V)$ measurements; MIS capacitors; modified MIS C(V) measurements; semiconductor devices; silicon-on-sapphire measurements; SOS measurements; biasisolation unit; capacitance and conductance measurements at high applied-bias voltage; $S P 400-40$.

High voltage electron microscopy; iron oxide; magnetite; $\mathrm{Fe}_{2} \mathrm{O}_{3}$; $\mathrm{Fe}_{2} \mathrm{O}_{4}$; gaseous reduction; hematite; 17177 .

High voltage measurement; insulating fluids; Kerr effect; nitrobenzene; pulse measurement; space charge; calibration; dielectrics; dividers; electric fields; electro-optics; NBSIR 77 1317.

High voltage measurements; Kelvin-Varley divider; ratio standard; voltage dividers; volt boxes; direct voltage measurements; 16713.

High winds; instrumentation; Philippines; wind tunnel test; field studies; SP470, pp. X-1-X-11 (Apr. 1977).

High winds; roofs; typhoon; wind pressure; buildings; dynamic effects; SP470, pp. II-1-I1-19 (Apr. 1977).

High-accuracy spectrophotometers; spectrophotometry; stability of transmittance; standard reference material; transfer standard; transmittance; absorbance; accuracy in spectrophotometry; glass filters; 16981 .

Higher-order moments; hot-wire anemometry; log-normal distribution; small-scale turbulence; boundary-layer; 16820 .

High-frequency; Josephson junction; SQUID; amplifier; 17334.

Highly transparent; infrared materials; optical materials; surface absorption; absorption; barothermal gas cell; bulk absorption; 16815 .

High-performance liquid chromatography; hydrocarbons; petroleum analysis; polynuclear aromatic hydrocarbons; fluorescence emission spectroscopy; gas chromatographymass spectrometry; 17271 .

High-power lasers; infrared materials; tensile stress; cadmium telluride; elastic compliance tensor; elastic moduli; extrinsic damage thresholds; 16746.

High-power lasers; infrared materials; tensile stress; cadmium telluride; elastic compliance tensor; elastic moduli; extrinsic damage thresholds; 17312 .

High-pressure liquid chromatography; lead; ligand; mercury; nanogram sensitivity; organometallic compounds; speciation; tin; arsenic; element-specific detector; flameless atomic absorption; flow monitoring; 17297.

High-resolution spectra; irreducible representation; isotope separation; molecular spectroscopy; crystal field theory; group theory; 16956.

High-resolution spectrum; iodine spectrum; line identification atlas; rovibronic assignments; spectral analysis; visible absorption spectroscopy; J. Res. 81A No. 1, 25-80 (1977).

Highrise; pressure profiles; Seattle federal building; smoke control; smoke simulation experiments; sulfur-hexafluoride; systematic pressurization; air-handling system; Chicago federal building; 17291 .

High-rise buildings; occupant behavior in fires; simulated behavior; building fires; fire behavior; NBS-GCR-77-92.

High-rise communications; high-rise emergency; information transfer; occupant needs; sensory stimuli; communications; disaster communication; emergency communications; fire communications; 17036.

High-rise emergency; information transfer; occupant needs; sensory stimuli; communications; disaster communication; emergency communications; fire communications; high-rise communications; 17036 .

High-rise masonry; scale factors; shear walls; current research; ductility; full scale testing; BSS106, pp. 314-326 (Sept. 1977).
High-speed line adaptor; HIS 6080; interactive terminal; probe point development; programmable monitor; stimulator; terminal data; data input bus; DATANET 355; data output bus; SP500-18, pp. 95-105 (Sept. 1977).

High-speed measurement; high temperature; melting point; radiance temperature; titanium; electrical resistivity; emittance; J. Res. 82, No. 2, $119-122$ (1977).

High-speed measurements; high temperature; solid-solid phase transformation; thermodynamics; hafnium; 16767.

High-speed measurements; high temperatures; melting; normal spectral emittance; radiance temperature; specific heat capacity; thermal radiation properties; thermodynamics; titanium alloy; electrical resistivity; J. Res. $81 \mathrm{~A}$ Nos. 2 and 3, 251-256 (1977).

High-speed measurements; high temperature; molybdenum; pulse calorimetry; standard reference material; thermodynamic functions; drop calorimetry; emittance; enthalpy; heat capacity; SP260-55.

High-voltage bias supply; high-voltage $C(V)$ and $G(V)$ measurements; high-voltage function generator; high-voltage sweep; semiconductor devices; silicon-on-sapphire measurements; SP400-41.

High-voltage C (V) measurements; MIS capacitor; premature dielectric breakdown; semiconductor devices; capacitancevoltage measurements; dielectric breakdown suppression; discharge suppression; electronics; extended-range MIS C (V) measurements; SP400-37.

High-voltage C(V) and G(V) measurements; high-voltage function generator; high-voltage sweep; semiconductor devices; silicon-on-sapphire measurements; high-voltage bias supply; $S P 400-41$.

High-voltage function generator; high-voltage sweep; semiconductor devices; silicon-on-sapphire measurements; high-voltage bias supply; high-voltage $\mathrm{C}(\mathrm{V})$ and $\mathrm{G}(\mathrm{V})$ measurements; $S P 400-41$.

High-voltage sweep; semiconductor devices; silicon-on-sapphire measurements; high-voltage bias supply; high-voltage $\mathrm{C}(\mathrm{V})$ and G(V) measurements; high-voltage function generator; SP400-41.

Highway; interface; instrumentation; standards; CAMAC; 16679.

Highway bridges; seismic provisions; specifications; structural engineering; earthquakes; SP470, pp. VIII-1-VIl1-30 (Apr. 1977).

Highway safety; measurement, skid resistance; pavement, skid resistance; test procedures, skid resistance measuring systems; tire-pavement interface forces; friction, pavement; NBSIR 76-1174.

Highway safety; measurement, skid resistance; pavement skid resistance; skid resistance measurement; tire-pavement interface forces; wet pavement skid resistance; accident reduction, skidding; NBSIR 76-II75.

Highway safety; measurement, skid resistance; pavement, skid resistance; pavement wetting system; skid resistance, measurement; tire-pavement interface forces; wet pavement skid resistance; accident reduction, skidding; correlation, skid resistance; NBSIR 77-1213.

Hindered rotation; infrared spectra; Raman spectra; vibrational analysis; $\mathrm{BCl}_{2} \mathrm{SD} ; \mathrm{BCl}_{2} \mathrm{SH} ; 17166$.

Hinges; locks; security standards; burglary resistance; door assemblies; door components; doors; frames; hardware; 16714.

H1S 6080; interactive terminal; probe point development; programmable monitor; stimulator; terminal data; data input bus; DATANET 355; data output bus; high-speed line adaptor; SP500-18, pp. 95-105 (Sept. 1977).

Historic preservation; performance attributes; performance evaluation; building codes and standards; building code structure; existing buildings; SP473, pp. $453-489$ (June 1977). 
History; mathematics; navigation; physics; time; time broadcasts; time scales; astronomy; automation; clocks; communication; frequency; Monogr. 155.

History of radiometry; Planck's constant; radiometric standards; radiometry; standard lamps; Stefan-Boltzmann constant; blackbodies; electrically calibrated detectors; 16851 .

History of science; measurement instruments; measurement standards; National Bureau of Standards; national measurement standards; physical measurement; weights and measures; NBSIR 76-1125.

Hole theory; liquid; polymer; pressure; thermodynamic; compressibility; densification; glass; glass transition; 16774 .

Hollow cathode discharge; sputtering; charge transfer; 17170.

Home construction; housing; rehabilitation; remodeling; renewal; renovation; self-help; standards; building codes; building regulation; do-it-yourself; NBS-GCR-77-88.

Home furnishings; program planning; residential fire deaths; fire deaths; fire losses; fire statistics; 16960 .

Homogeneity; magnet design; magnetic field gradients; magnetometer design; Faraday magnetometer design; 16828.

Homogeneous anionic polymerization; monodisperse polymers; unsaturated monomers; block copolymers; 16736.

Homogeneous nucleation; polymer; surface nucleation; chainfolding; crystallization; growth rate; 16887.

Homomorphic deconvolution; time domain reflectometry; 16731 .

Honeycomb panel construction; relocatable buildings; windload racking; air leakage of buildings; building heat transfer; NBSIR 76-1178.

Horizontal and vertical smoke measurements; smoke; smoke density chamber; smoke suppressants; fire performance; NBSIR 76-1030.

Hospital communication systems; hospital fires; hospital personnel; human behavior; nursing home fires; nursing staff; standards; voice communication; coding; communication systems; fire alarm systems; health care facilities; NBS-GCR-77-102.

Hospital fires; hospital personnel; human behavior; nursing home fires; nursing staff; standards; voice communication; coding; communication systems; fire alarm systems; health care facilities; hospital communication systems; NBS-GCR77-102.

Hospital personnel; human behavior; nursing home fires; nursing staff; standards; voice communication; coding; communication systems; fire alarm systems; health care facilities; hospital communication systems; hospital fires; NBS-GCR-77102.

Hospitals; mattresses; prisons; bedding; beds; compartment fires; firesafety engineering; fire tests; health care facilities; NBSIR 77-1290.

Hospitals; medical facilities; medical planning; architecture; building technology; construction; health facilities; NBSIR 77-1233.

Hospitals; schools; building codes; building regulations; design criteria; earthquakes; SP470, pp. VI-64-VI-73 (Apr. 1977).

Hot film anemometer; recirculating flow; spray; two component flow; vortex street; wake flow; anemometer; cylinder; frequency; SP484, pp. $705-718$ (Oct. 1977).

Hot plates; thermal safety covering; warming trays; compressible cooking surfaces; U.S. Patent 4,009,704.

Hot sea water and materials; corrosion; desalination; distillation; SP463, pp. V.2.1-V.2.6 (Jan. 1977).

Hot spots; junction temperature; measurement technology; nondestructive test; reliability; safe operating limits; second breakdown; semiconductor devices; thermal characterization; thermal instability; thermal resistance; transistors; SP400-44.

Hot spots; measurement methods; power transistors; reliability; safe operating area limits; second breakdown; thermal instability; 16893 .
Hot-wire anemometry; international flow standards; laser anemometry; open channel flows; orifice meters; pitot-static meters; turbine meters; weirs; acoustic flow meters; closed conduit flows; current meters; dye-dilution methods; errors in flow measurement; SP484, Volumes 1 and 2.

Hot-wire anemometry; log-normal distribution; small-scale turbulence; boundary-layer; higher-order moments; 16820 .

Hot-wire anemometry; supersonic flows; thin turbulent shear layers; error reduction; SP484, pp. 649-658 (Oct. 1977).

Household products; industry standards; international recommendations; national standards; product standards; recommended practices; specifications; test methods; certification programs; consumer products; TN948.

Householder transformations; least squares algorithms; regression; statistics; Cholesky decomposition; Givens transformations; Gram-Schmidt orthogonalization; 16833.

Houses; masonry; piers; research; seismic; shear walls; spandrel beams; connections; BSSI06, pp. 60-90 (Sept. 1977).

Houses; typhoon; wind speeds; damage; effects; SP477, pp. II1-II-1 4 (May 1977).

Housing; hurricanes; pressure coefficients; probability distribution functions; risk; statistical analysis; storms; structural engineering; tropical storms; wind loads; wind speeds; building codes; buildings; codes and standards; BSS100-2.

Housing; lead paint; lead poisoning; surveys; $x$-ray fluorescence; children; data analysis; NBSIR 77-1250.

Housing; lead paint; lead poisoning; surveys; blood lead; children; data analysis; NBSIR 77-I293.

Housing; low income; low-rise buildings; sites and services; socio-economic; structural design; wind-resistant; architectural; design; BSSI00-5.

Housing; low-rise buildings; socio-economics; structural connections; wind loads; codes and standards; disaster mitigation; SP477, pp. I-70-I-78 (May 1977).

Housing; low-rise buildings; socio-economics; structural connections; technology transfer; wind loads; codes and standards; disaster mitigation; BSSIOO-I.

Housing; regulation; builder-developer; construction; consumers; cost analysis; cost benefits; SP473, pp. 391-396 (June 1977).

Housing; rehabilitation; remodeling; residential; urban renewal; building codes; NBS-GCR-77-87.

Housing; rehabilitation; remodeling; renewal; renovation; selfhelp; standards; building codes; building regulation; do-ityourself; home construction; NBS-GCR-77-88.

Housing; rehabilitation; standards; building codes; community development; construction costs; contractors; SP473, pp. 491-497 (June 1977).

Housing demand; innovation; regulatory barriers; residential construction; unionization; building official; building regulation; education; SP473, pp. 113-135 (June 1977).

Housing needs; projections; development; forecasts; growth; BSS 1004.

Housing technology; HVAC; innovative construction; maintainability; materials; minimum property standards; performance criteria; performance evaluation; plumbing; safety; structures; test methods; acoustics; appliances; atmospheric; durability; electrical; environment; NBSIR 77-1316.

$\mathrm{HO}_{2}$; hydroperoxyl; nitric oxide; $\mathrm{NO}$; chemical reaction rate; 17272.

HUD; mobile home; racking; research; safety; standard; window; emergency egress; NBSIR 77-1246.

HUD Modular Integrated Utility Systems (MIUS) Program; total energy; utility systems; abstracted reports and articles; SP489.

Human albumin; membrane; reflection coefficient; ultrafiltration; continuous binding curve; dye binding; 16959.

Human behavior; human response; life safety; mapping; model; nursing homes; rescue; verbal communicative; alarm; 
architecture; design implication; emergency actions; emergency communicative; emergency decisions; escape; fires; NBS-GCR-77-93.

Human behavior; institutional occupancies; interior design; physical environment; regulation; research; standards; court orders; SP473, pp. 55-67 (June 1977).

Human behavior; nursing home fires; nursing staff; standards; voice communication; coding; communication systems; fire alarm systems; health care facilities; hospital communication systems; hospital fires; hospital personnel; NBS-GCR-77-102.

Human behavior; project people; residential buildings; smoke; statistical analysis; building fires; egress; fire alarms; fire incidents; fire investigations; fires; NBS-GCR-77-94.

Human behavior in fires; combustion products; fire hazards; fire modeling; fire research; NBSIR 77-1308.

Human behavior research; Human Factors Laboratory; range energy consumption; appliance research; behavioral laboratory; consumer product studies; 17035.

Human comfort; indoor climate; indoor environment; thermal comfort; thermal environment; thermal neutrality; SP491, pp. 3-17 (Sept. 1977).

Human comfort; indoor erivironment; mean radiant temperature; thermal comfort; energy conservation in buildings; heat stress; SP491.

Human factor; resource impact factors; building; building environment; energy conservation; engineering; 17110 .

Human factors; human reliability; perpetrator attributes; physical security; psychological deterrence; sophisticated crime; threat analysis; terrorism; vigilance; behavioral science; SP480-24.

Human factors; lawn mowers; psychophysics; reaction time; safety; standards; anthropometric probes; consumer products; 17200.

Human factors; lawn mowers; safety; standards; consumer products; generic probes; NBSIR 77-1294.

Human factors; lifting; manual materials handling; physiology; psychophysics; safety; warranty; anthropometry; biomechanics; carrying; consumer product portability; ergonomics; NBSIR 76-1092.

Human factors; methodology; rare events; safety; system safety; accident research; SP482.

Human factors; misuse of products; systems analysis; use of products; consumer behavior; consumer product safety; 16890.

Human factors; on-line systems; system design; task variables; workload characteristics; computer response time; SP500-18, pp. 3-11 (Sept. 1977).

Human Factors Laboratory; range energy consumption; appliance research; behavioral laboratory; consumer product studies; human behavior research; 17035.

Human performance; occupational safety; regulatory data; architectural psychology; architectural research; building codes; building design; building fires; building regulatory standards; emergency egress; exit capacity; fire safety; NBSIR 77-1313.

Human reliability; perpetrator attributes; physical security; psychological deterrence; sophisticated crime; threat analysis; terrorism; vigilance; behavioral science; human factors; SP480-24.

Human response; life safety; mapping; model; nursing homes; rescue; verbal communicative; alarm; architecture; design implication; emergency actions; emergency communicative; emergency decisions; escape; fires; human behavior; NBSGCR-77-93.

Humidity; hygrometer; mixing ratio; relative humidity; twopressure generator; volume ratio; water vapor; calibration; dew point; J. Res. 81A No. 1, 81-88 (1977).

Humidity; microphones; reciprocity; sensitivity; temperature; calibration; ceramic; condenser; electret; 16701 .
Humidity; microphones; reciprocity; sensitivity; temperature; calibration; ceramic; condenser; electret; 17245.

Humidity; relative humidity; salt; saturated salt solution; vapor pressure; water vapor; aqueous solution; equilibrium; J. Res. 81 A No. 1, 89-96 (1977).

Humidity; temperature; thermal acceptability; clothing; cold discomfort; energy conservation; SP491, pp. 131-151 (Sept. 1977).

Humidity sensor; industrial fabrication; isotherm equations; physical adsorption; relative humidity; routine radiosonde application; barium fluoride; calibration equations; fast response; films; NBSIR 76-1108.

Hurricane; storm surge; tropical storms; wind; wind data; wind speed; SP470, pp. I-18-I-27 (Apr. 1977).

Hurricanes; loads (forces); natural analysis; tall buildings; wind profiles; boundary layer; SP477, pp. II-30-II-40 (May 1977).

Hurricanes; pressure coefficients; probability distribution functions; risk; statistical analysis; storms; structural engineering; tropical storms; wind loads; wind speeds; building codes; buildings; codes and standards; housing; BSS100-2.

Hurricanes; thunderstorms; tornadoes; wind; wind damage; extra-tropical storms; SP477, pp. II-15-II-29 (May 1977).

Hurwitz's theorem; analytic functions with infinitely many branches; functional equations; 17041 .

HVAC; innovative construction; maintainability; materials; minimum property standards; performance criteria; performance evaluation; plumbing; safety; structures; test methods; acoustics; appliances; atmospheric; durability; electrical; environment; housing technology; NBSIR 77-1316.

HVAC systems; illumination; insulation; lighting; performance standard; thermal performance; ventilation; water heating; air leakage; building design; energy conservation; fenestration; NBSIR 74-452.

Hybrid devices; leak testing; measurement technology; microcalorimetry; pacemaker leads; process control; reliability; screen tests; semiconductor devices; batteries; cardiac pacemakers; hermeticity; SP400-42.

Hydraulic models; hydraulics; numerical models; open-channel flow; weirs; flumes; SP484, pp. 219-242 (Oct. 1977).

Hydraulic oil; industrial oils; lubricating oil; oil specifications; petroleum standards; petroleum test methods; recycled oil; re-refined oil; used oil; waste oil; engine oil; fuel oil; SP488.

Hydraulic structures; inspection; instrumentation; strong-motion accelerographs; earthquakes; SP470, pp. VI-47-VI-63 (Apr. 1977).

Hydraulic structures; seismicity; soils; standards; structural response; vessels and wind; accelerograph; bridges; buildings; codes; disaster; dynamic analysis; earthquakes; ground failures; $S P 470$.

Hydraulics; numerical models; open-channel flow; weirs; flumes; hydraulic models; SP484, pp. 21 19-242 (Oct. 1977).

Hydrocarbon; ionized molybdenum; measurement assurance; metric; neutron diffraction; recycling oil; research and innovation; safety; ultrasonic tissue; computerized data; data elements; equity; federal technology; fire modeling; heat; DIMINBS 61, No. 6, 1-32 (1977).

Hydrocarbon measurement; international standards; allocating hydrocarbons; SP484, pp. 957-959 (Oct. 1977).

Hydrocarbons; intercalibration; petroleum analysis; trace analysis; gas chromatography; gas chromatography-mass spectroscopy; 17273.

Hydrocarbons; liquid chromatography; oil refinery; petroleum; benzo(a)pyrene; gas chromatography; gas chromatographymass spectrometry; 16886.

Hydrocarbons; petroleum analysis; polynuclear aromatic hydrocarbons; fluorescence emission spectroscopy; gas chromatography-mass spectrometry; high-performance liquid chromatography; 17271 . 
Hydrodynamic model; isospin; photonuclear; shell model; sum rules; giant resonance; 16987.

Hydrodynamics; light scattering; liquid state; molecular dynamics; neutron scattering; shear wave; statistical mechanics; time correlation function; transverse current; ultrasonics; correlation function; density fluctuations; fluctuations; 16711 .

Hydrogen; Baimer-alpha; collision; cross section; dissociation; electron; excitation; 17054.

Hydrogen; coherence; electron excitation; 17326.

Hydrogen; inelastic; molecular potential; recombination; scattering; theoretical; theory; argon; collisions; dissociation; 16802 .

Hydrogen; internal energy; liquid; oxygen; PVT; quality; slush; solid; vapor; computer programs; enthalpy; entropy; NBSIR 77-859.

Hydrogen; iridium; isotope exchange; metalloborane; oxidative addition; boron hydride; 17144 .

Hydrogen; lattice dynamics; metals; neutron scattering; quasielastic scattering; review; diffusion; 16970 .

Hydrogen; law enforcement; liquefied natural gas; metric tons; polyethylene; sound; spinach; SRM; systems and software; telecommunications; computer use; conservation; data; earth's measurement; energy; health records; DIM/NBS 61 , No. 5, 1-32 (1977).

Hydrogen; liquefier; component efficiency; cryogenics; efficiency; energy recovery; NBSIR 77-862.

Hydrogen; methane; tungsten; carbon monoxide; catalytic methanation; 17207

Hydrogen; photoemission; thermal desorption; tungsten; ultraviolet photoelectron spectroscopy; carbon monoxide; chemisorption; coadsorption; desorption; displacement; 16808 .

Hydrogen; steels; stress corrosion; crack propagation; ductility; failure; fractography; fracture tests; 16700 .

Hydrogen; theory; vibrational and rotational enhancement; argon; cross section; dissociation collisions; 16803.

Hydrogen bonding; patulin; refined structure; single crystal $\mathrm{x}$ ray structure determination; 4-hydroxy-4H-furo $(3,2 c)$ pyran2(6H)-one; antibiotic; 16913

Hydrogen, collinear reactions; kinetic isotope effects; potential surfaces; rate constants; transition state theory; transmission coefficient; collinear reactions; deuterium, collinear reactions; 16914

Hydrogen $H \alpha$ and $H \beta$; ion dynamics; quasi static; Stark broadening; theoretical comparison; 17232 .

Hydrogen ion concentration; nomograms; oxygen; $\mathrm{PCO}_{2} ; \mathrm{pH}$; potassium; $\mathrm{PO}_{2}$; sodium; acid-base status; blood electrolytes; blood gases; blood pH; calcium; carbon dioxide; SP45O.

Hydrogen line Q; hydrogen line servo; magnetic field; passive hydrogen maser frequency standard; second-order Doppler; spin exchange; wall shift; active hydrogen maser frequency standard; cavity pulling; cavity-Q; cavity servo; Crampton effect; frequency stability; 17180 .

Hydrogen line servo; magnetic field; passive hydrogen maser frequency standard; second-order Doppler; spin exchange; wall shift; active hydrogen maser frequency standard; cavity pulling; cavity-O; cavity servo; Crampton effect; frequency stability; hydrogen line $\mathrm{Q} ; 17180$.

Hydrogen maser; quartz crystal; rubidium gas cell; timekeeping; cesium beam; clocks (atomic); crystal oscillator; frequency accuracy; frequency stability; frequency standards; TN616, 2d Revision.

Hydrogen metathesis methanes; resonance fluorescence; vibrational excitation; chemical kinetics; chlorine atoms; flash photolysis; 16785.

Hydrogen-bonded dimers; neutron diffraction; stannous hydrogen phosphate; 16742 .

Hydrogenic atoms; Lamb shift; level shifts; quantum electrodynamics; radiative corrections; relativistic corrections; atomic structure; electron structure; energy levels; fine structure; JPCRD 6, No. 3, 831-870 (1977).

Hydrogenic ions; Stark broadening; unified classical path theory; unified theory; 17249.

Hydrolysis; infrared spectroscopy; rare earths; rare earth tungstate; tungstates; $\mathrm{x}$-ray powder patterns; dithiotungstate; 17137.

Hydroperoxyl; nitric oxide; $\mathrm{NO}$; chemical reaction rate; $\mathrm{HO}_{2}$; 17272.

Hydroquinone leachable monomer; residual components in cements; residual methyl methacrylates; analysis of acrylics; benzoyl peroxide determination; bone cement; chemical composition of bone cement; dimethyl-p-toluidine; 17202 .

Hydrostatic pressure; optical transitions; scaling theory; frequency shifts; 17228 .

Hydrothermal; refractories; strength; coal gasification; environments; erosion; 16993.

Hydroxyapatite; ion pairs; solubility; solubility isotherms; solubility product; thermal coefficient of solubility; thermodynamics; tooth mineral; dissolution; I. Res. $81 \mathrm{~A}$ Nos. 2 and 3, 273-281 (1977).

Hydroxyapatite; irreversible vs reversible adsorption; surfaceactive comonomer; adhesion to polymers; adsorption from solutions; chemisorption; 17197.

Hydroxyapatite; solubility; chemical potential; dental caries; enamel; fluorapatite; fluoride; 16739.

Hydroxyl radical; oxide radical ion; perhydroxyl radical; radiation chemistry; rates; superoxide ion; aqueous solution; chemical kinetics; data compilation; NSRDS-NBS59.

Hygrometer; mixing ratio; relative humidity; two-pressure generator; volume ratio; water vapor; calibration; dew point; humidity; J. Res. 81A No. 1, 81-88 (1977).

Hyperbolic system; range-range system; time and frequency dissemination; time code; TvTime system; accuracy; 17181 .

Hypercube; hyperplane; polytope; convex set; data analysis; estimation; geometry; 17117.

Hyperfine fields; iron alloys; valence; atomic volume; 16927.

Hyperfine fields; magnetism; rare earths; relaxation effects; scandium alloys; dysprosium; 16985

Hyperfine fields; relativistic Hartree-Fock theory; atomic beam; electronic structure; free atoms; 16940.

Hypergraph; König System; KM-System; Menger System; MKSystem; dominating set; enclaveless set; graph; J. Res. 82, No. 3, 197-202 (1977).

Hyperplane; polytope; convex set; data analysis; estimation; geometry; hypercube; 17117.

Hypersonic velocities; acoustic monitor; BLAM; boundary layer transition; SP484, pp. 687-704 (Oct. 1977).

Hysteresis; precision; pressure measurement; sensitivity; stability; thermal effects; zero-shift; accuracy; calibration; cryogenic; dynamic; frequency response; 17081 .

Hysteretic envelope; reinforced; strength; columns; concrete; earthquake; SP477, pp. VI-10-VI-27 (May 1977).

\section{I}

IBM OS/MVT; initiator policy; job scheduling; simulation; SP500-18, pp. 235-248 (Sept. 1977).

Ice-water interface; ice-water surface tension; Nash-Glicksman theory; surface energy; grain boundary groove; 16780.

Ice-water surface tension; Nash-Glicksman theory; surface energy; grain boundary groove; ice-water interface; 16780.

Ideal gas thermodynamic properties; intermolecular association; normal and deuterated methanols; potential barrier to internal rotation; principal and reduced moments of inertia; structural parameters; vibrational fundamentals; JPCRD 6, No. 1, 105-112 (1977).

Identification; lattice; powder method; reduced cell; single crystal; symmetry; 17050 . 
Identification; passwords; personal authentication; computer networking; computer security; controlled access; SP500-9.

IFS with a tunable laser; infrared frequency synthesis; SFRL frequency measurement; spin flip Raman laser; frequency measurements on tunable lasers; 16728 .

Ignitability; MAFT value; phosphorus; synthetic fabrics; burn injury potential; extinguishability; fire retardants; flammability hazard; FR treated cotton blends; FR treated cottons; 17176.

Ignition sources; apparel fires; burn injury; fabric flammability; FFACTS; flammability standards; Flammable Fabrics Act; SP463, pp. VII.2.1-VII.2.11 (Jan. 1977).

Ignition time; pyrolysis; radiant heating; thermal radiation; thermoplastics; cellulosic materials; char; convective heat transfer; fabric flammability; fabrics; fire hazards; NBS-GCR77-99.

Illuminating engineering; light design; luminaire effectiveness; luminance factor; office lighting; sphere illumination; body shadow; contrast rendition; hand calculator; NBSIR 77-1303.

Illumination; illumination levels; lighting; task lighting; energy conservation; 17293.

Illumination; incapacitation; psychological deterrence; recognition; security lighting; security systems; visibility level; visual processes; contrast; dctection; SP480-27.

Illumination; insulation; lighting; performance standard; thermal performance; ventilation; water heating; air leakage; building design; energy conservation; fenestration; HVAC systems; NBSIR 74-452.

Illumination levels; lighting; task lighting; energy conservation; illumination; 17293.

Image analysis; pattern recognition; pulp characterization; pulps; algorithms; fiber morphology; fibers; 17214 .

Image content language; image processing; pattern recognition; prototype images; standards; automation; calibration; data formats; documentation; SP500-8.

Image formation; ion probe; microanalysis; microscopy; scanning; $x$-ray spectroscopy; electron probe; 16841

Image processing; mammography; $x$-ray radiography; diagnostic radiography; exposurc reduction; imaging information content; 16666.

Image processing; pattern recognition; prototype images; standards; automation; calibration; data formats; documentation; image content language; SP5OO-8.

Image quality; limiting resolution; relative spectral response; signal-to-noise ratio; square wave patterns; television cameras; contrast; contrast transfer function; SP480-25.

Imager CCD's; Japan; peristaltic CCD's; surface channel; The Federal Republic of Germany; The Netherlands; transfer channel; bucket-brigade; buried channe!; Canada; chargecoupled device; Great Britain; SP500-5.

Image-shearing eyepiece; integrated circuits; linewidth measurements; microelectronics; micrometrology; optical microscope; photoelectric microscope; photomask; scanning electron microscope; filar eyepiece; 17066 .

Imaging; ultrasound; velocity; attenuation; computerized tomography; 16937.

Imaging information content; image processing; mammography; $\mathrm{x}$-ray radiography; diagnostic radiography; exposure reduction; 16666.

Immunochemical analysis; light scattering; polymers; proteins; solid standards; antibodies; antigens; biological polymers; SP466, pp. $95-98$ (May 1977).

Impact; penetration resistance; test methods; fire helmet; head injury; head protection; heat resistance; helmet; NBSIR 77 1251 .

Impact accelerations; impact forces; lanyards; linemen's equipment; load-extension data; occupational safety and health; performance standard; regulation; tensile testing; worker safety equipment; body belts; body harness; fall-arrest equipment; fall-safety systems; NBSIR 76-1146.
Impact forces; lanyards; linemen's equipment; load-extension data; occupational safety and health; performance standard; regulation; tensile testing; worker safety equipment; body belts; body harness; fall-arrest equipment; fall-safety systems; impact accelerations; NBSIR 76-I146.

Impact of government on the economy; pesticides; R\&D incentives; regulation; technology; NBS-GCR-ETIP 76-34.

Impact pressure probe; Pitot tubes; static pressure probe; turbulence; turbulent boundary layers; velocity measurement; SP484, pp. 737-753 (Oct. 1977).

Impact resistance; ophthalmic lenses; statistics; drop ball test; flaw distribution; fracture; 16979.

Impedance; microwaves; network analyzer; reflection coefficient; reflectometer; scattering parameters; self-calibration techniques; six-port junction; 17244.

Imperfect crystals; perfect crystals; $x$-ray dynamical diffraction; contrast conditions; diffraction topography; dynamical images; 16977.

Implant requirements; mechanical properties; metal implants; stainless steel; standards; titanium; biocompatibility; cobaltchromium; corrosion; 16973.

Implants; metallic; orthopaedic; retrieval; analysis; SP472.

Implants; polymer adsorption; protein adsorption; synthetic implants; adsorption; blood protein; ellipsometry; NBSIR 761128.

Implementation of allocation programs; international allocation programs; International Energy Agency; national allocation programs; SP484, pp. 945-946 (Oct. 1977).

Implicit; insulation; laboratory measurements; modeling; standby loss; water heater; altemating direction; computer simulation; cool down; energy savings; flue damper; heat transfer; 17184 .

Impression materials; prosthetic materials; resin teeth; restoratives; sealants; adhesives; dental polymers; dental resins; dentures; 17120 .

Imprisonment; lifetimes; mean life; resonance radiation; transition probability; uı; uranium; delayed coincidence; $g f$ value; 17292.

Impulse; impulse generator; spectrum amplitude; electromagnetic interference; Fourier transformation; TN699.

Impulse approximation; photoproduction; pseudoscalar and pseudovector coupling; threshold pion production; effective Lagrangian; electroproduction; TN957.

Impulse generator; radiometer; sampling oscilloscope; spectrum amplitude; spectrum analyzer; spectrum intensity; calibration; electromagnetic interference; fast Fourier transform; 16725.

Impulse generator; spectrum amplitude; electromagnetic interference; Fourier transformation; impulse; TN699.

Impulsive noise; magnetic field strength; measurement instrumentation; portable spectrum analyzer; spectral density; timedependent spectral density; coal mine noise; digital data; electromagnetic interference; electromagnetic noise; emergency communications; 17175 .

Impurities; junctions; MOS capacitors; sheet resistors; silicon; test structures; defects; dopants; 16855.

Impurity; temperature; thermoluminescence; aluminium oxide; glow; heat treatment; SP461, pp. 219-221 (Jan. 1977).

In vivo analysis; mineral exploration; nuclear safeguards; oceanography; on-stream analysis; well logging; activation analysis; californium-252; inland waters and sediments; 16760.

Incapacitation; psychological deterrence; recognition; security lighting; security systems; visibility level; visual processes; contrast; detection; illumination; SP480-27.

Incentives; regulation; altematives; building codes; building process; constraints; costs; SP473, pp. 17-33 (June 1977).

Incoherent scattering; pair-production; photoionization; coherent scattering; cross sections; gamma ray; SP461, pp. 20-22 (Jan. 1977). 
Income distribution effects; policy alternatives; applied microeconomic framework; commodity supply crises; econometric analysis; economic impacts; efficiency impacts; NBS-GCR-ETIP 76-24.

Income distribution effects; policy alternatives; applied microeconomic framework; commodity supply crises; econometric analysis; economic impacts; efficiency impacts; NBS-GCR-ETIP 76-32.

Income distribution effects; policy alternatives; applied microeconomic framework; commodity supply crises; econometric analysis; economic impacts; efficiency impacts; NBS-GCR-ETIP 76-33.

Income distribution effects; policy alternatives; applied microeconomic framework; commodity supply crises; econometric analysis; economic impacts; efficiency impacts; NBS-GCR-ETIP 77-36.

Indentation; strength; brittle solids; ceramic surfaces; degradation; fracture; 16672 .

Index; quake-sensitivity; seismic index; seismicity; earthquake; SP477, pp. IV-47-IV-54 (May 1977).

Index of nuclear standards; KWIC index of standards; engineering standards, index of; SP483.

India; Iran; training; Turkey; earthquake engineering; earthquakes; education; SP470, pp. X-12-X-16 (Apr. 1977).

Indirect flow measurement; turbulent two-phase flow; twophase flow; error reduction; SP484, pp. $765-782$ (Oct. 1977).

Indium; joints; solder; thermal conductance; beryllium; copper; cryogenics; 16797.

Individual privacy; risk management; safety of computer systems; computer security; computer system performance; computer systems; $17 / 14$.

Indoor climate; indoor environment; thermal comfort; thermal environment; thermal neutrality; human comfort; SP49I, pp. 3-17 (Sept. 1977).

Indoor environment; mean radiant temperature; thermal comfort; energy conservation in buildings; heat stress; human comfort; SP49I.

Indoor environment; thermal comfort; thermal environment; thermal neutrality; human comfort; indoor climate; SP491, pp. 3-17 (Sept. 1977).

Indoor environmental measurement; rating of indoor environments; thermal comfort; SP491, pp. 152-168 (Sept. 1977).

Industrial fabrication; isotherm equations; physical adsorption; relative humidity; routine radiosonde application; barium fluoride; calibration equations; fast response; films; humidity sensor; NBSIR 76-IIO8.

Industrial heat stress; metabolic heat load; environmental monitoring; heat stress control; heat stress indices; heat stress monitoring; SP49I, pp. 41-51 (Sept. 1977).

Industrial hygiene; mercury vapor; personal dosimeter; piezoelectric sensors; quartz crystal microbalance; environmental analysis; 16773 .

Industrial needs; phase diagrams; theory of phase diagrams; thermodynamics; computer predictions; critical evaluations; data compilations; NBSIR 77-I239.

Industrial oils; lubricating oil; oil specifications; petroleum standards; petroleum test methods; recycled oil; re-refined oil; used oil; waste oil; engine oil; fuel oil; hydraulic oil; SP488.

Industrial process data; materials utilization data; mechanical properties; nuclear data; physical science data; solid state data; standard reference data; thermodynamic data; transport properties; atomic and molecular data; chemical kinetics data; energy data; TN947.

Industrial radiography; national standards; radiation characteristics; radiation source; source calibration; test methods; $x$ rays; calibration; gamma radiation; 17017 .

Industrial wastes; mining wastes; municipal waste; slags; waste materials; coal by-products; construction materials; NBSIR $77-1244$
Industrializing nations; international relations; LDS's; measurement services; standardization; AID; assistance; developing economies; foreign relations; NBSIR 76-II52.

Industry; intergovernmental; international standards; legal metrology; measurement; trade facilitation; flow measurement; SP484, pp. $921-927$ (Oct. 1977).

Industry standards; international recommendations; national standards; product standards; recommended practices; specifications; test methods; certification programs; consumer products; household products; TN948.

Inelastic; isospin; magnetic; multipolarity; sum rule; electron scattering; 16687.

Inelastic; molecular potential; recombination; scattering; theoretical; theory; argon; collisions; dissociation; hydrogen; 16802.

Inelastic; two-phonon states; zinc 64-66-68-70; anharmonic vibrator model; collective states; electron scattering; 16982.

Inelastic electron mean free path; supported thin films; Augerelectron spectroscopy (AES); electron attenuation lengths; electron spectroscopy for chemical analysis (ESCA); electron transmission through thin films; 16744 .

Inelastic neutron scattering; lattice dynamics; metal-hydrogen systems; palladium-deuteride $\left(\operatorname{PdD}_{0.63}\right)$; phonon lineshapes; defect crystal structures; $I 6964$.

Inelastic neutron scattering; lattice dynamics; local mode vibrations; metal hydrides; phonon dispersion curves; cerium deuteride; 16965.

Inelastic scattering; $\mathbf{K}$-shell electron; photon; $\mathbf{x}$ ray; bound electrons; cross section; gamma rays; SP46I, pp. 26-28 (Jan. 1977).

Inelastic scattering; Monte Carlo calculations; proton angular distributions; proton production; proton spectra; heavy ion collisions; I7I09.

Inelastic scattering; nitrogen molecules; resonances; scattering; vibrational excitation; close-coupling calculations; crossed beams; cross sections; differential cross sections; electron scattering; 16740 .

Inertia; stability; eigenvalue; hermitian matrix; 16755.

Infiltration; insulation; passive-solar-heating; sun-shading; ventilation; windows; daylighting; $I 7298$.

Infiltration/inflow analysis; Parshall flume; error reduction strategy; flow measurement errors; SP484, pp. 173-186 (Oct. 1977).

Information; interdisciplinary technology; physical property data; publish; science; standard reference data; technology; communication; 17258 .

Information; NBS; national measurement system; economics; NBSIR 75-948.

Information; radiation; radiation analysis; RSIC; shielding; computer code; data library; SP46I, pp. $171-173$ (Jan. 1977).

Information analysis center; inquiry services; metals technology; structural materials; technical reports; ceramic technology; current awareness services; databooks; SP463, pp. IV.2.1IV.2.7 (Jan. 1977).

Information Analysis Centers; technical information; DDC; Defense Documentation Center; DoD technical information; SP463, pp. IV.1.1-IV.1.5 (Jan. 1977).

Information analysis centers; Machinability Data Center; machining costs; machining data banks; Machining Data Handbook; machining data publications; data banks; SP463, pp. IV.5.1-IV.5.8 (Jan. 1977).

Information center; rare earths; SP463, pp. III.2.1-III.2.9 (Jan. 1977).

Information demand; materials information and data system; national commission on materials policy; technology transfer; total materials cycle; SP463, pp. IX.1.1-IX.1.22 (Jan. 1977).

Information exchange; information management; information network; information retrieval; information services; information systems; specialized information center; water resources information; SP463, pp. V.1.1-V.1.6 (Jan. 1977). 
Information management; information network; information retrieval; information services; information systems; specialized information center; water resources information; information exchange; SP463, pp. V.1.1-V.1.6 (Jan. 1977).

Information management; information theory; coding; coding theory; computer storage; data compaction; data compression; data elements; data management; data processing; SP500-12.

Information management; software tool; computer software; data base management system; data element dictionary/directory; 17280 .

Information needs; information processing; information seeking; internal media; communication among scientists; coordination of research organizations; employee communication; NBSIR 77-1257.

Information network; information retrieval; information services; information systems; specialized information center; water resources information; information exchange; information management; SP463, pp. V.1.1-V.1.6 (Jan. 1977).

Information packaging; information processing; managment information; decision maker; decision model; 16734.

Information policy; information processing; risk management; computers; government information collection; 16906.

Information policy, management principles; medical records; privacy; recordkeeping practices; security; citizen rights; computers, confidentiality; data systems; health records; SP469.

Information processing; information seeking; internal media; communication among scientists; coordination of research organizations; employee communication; information needs; NBSIR 77-1257.

Information processing; managment information; decision maker; decision model; information packaging; 16734 .

Information processing; performance evaluation; plan review; research and development; building regulation; computerbased systems; computer technology; SP473, pp. 369-375 (June 1977).

Information processing; risk management; computers; government information collection; information policy; 16906.

Information processing; terms; vocabulary; computers; data processing; definitions; dictionary for information processing; Federal Information Processing Standards Publication; FIPS PUB 11-1.

Information processing standards; information system; representations and codes; standards; statistical data; ADP standards; computers; data elements and codes; data processing; Federal Information Processing Standards; geography; FIPS PUB 10 2 .

Information resource; National Referral Center; referral; scientific and technical information; thesaurus; computerized information system; directories; SP463, pp. VIII.2.1-VIII.2.4 (Jan. 1977).

Information retrieval; information services; information systems; specialized information center; water resources information; information exchange; information management; information network; SP463, pp. V.1.1-V.1.6 (Jan. 1977).

Information retrieval; inspection; management control; microfilm; building code; building permits; computers; enforcement; SP473, pp. 377-382 (June 1977).

Information retrieval; library automation; machine-readable; MARC; standards; bibliographic information; data bases; SP463, pp. VIII.1.1-VIII.1.4 (Jan. 1977).

Information retrieval; NSRDS; Omnidata; reference data; data compilation; data evaluation; 16692.

Information retrieval systems; management information systems; materials; nonfood products; physical properties; research information; agricultural materials; agricultural research; biological properties; chemical properties; SP463, pp. II.2.1-II.2.10 (Jan. 1977).
Information seeking; internal media; communication among scientists; coordination of research organizations; employee communication; information needs; information processing; NBSIR 77-1257.

Information service; lumber; mechanical properties; paper; pulp; timber; wood; wood products; AIDS; bark; forest products; glues and gluing; SP463, pp. II.1.1-1I.1.4 (Jan. 1977).

Information services; information systems; specialized information center; water resources information; information exchange; information management; information network; information retrieval; SP463, pp. V.1.1-V.1.6 (Jan. 1977).

Information services; land grant university; agricultural research service; agriculture; extension service; SP463, pp. II.3.1-11.3.4 (Jan. 1977).

Information system; representations and codes; standards; statistical data; ADP standards; computers; data elements and codes; data processing; Federal Information Processing Standards; geography; information processing standards; FIPS PUB 10-2.

Information systems; specialized information center; water resources information; information exchange; information management; information network; information retrieval; information services; SP463, pp. V.1.1-V.1.6 (Jan. 1977).

Information technology; policy analysis; policymaking; public goods; technological change; transaction costs; computer; computer program; copyright; data base; economic efficiency; SP500-17.

Information theory; coding; coding theory; computer storage; data compaction; data compression; data elements; data management; data processing; information management; SP500-12.

Information transfer; occupant needs; sensory stimuli; communications; disaster communication; emergency communications; fire communications; high-rise communications; highrise emergency; 17036.

Infrared; frequency measurement; 16867.

Infrared; ion-molecule; associative detachment; chemiluminescence; flowing afterglow; fluorescence; 17209.

Infrared; $\mathrm{KHF}_{2}$; lattice modes; linear triatomic anions; $\mathrm{NaHF}_{2}$; polycrystals; 16983.

Infrared; kinetics; mechanisms; photochemistry; pyrolysis; alkyl halides; $\mathrm{CO}_{2}$ laser; 16783.

Infrared; microwave; molecular structure; spectra; spectroscopy; bond distances; carbonyl selenide; energy levels; force field; 16823.

Infrared; nondestructive evaluation; thermographic surveys; thermography; energy conservation; energy surveys; 16901 .

Infrared absorption; molecular physics; short-lived molecular species; vibration-rotation spectra; carbon monosulfide; Dunham coefficients; 17044 .

Infrared frequency synthesis; SFRL frequency measurement; spin flip Raman laser; frequency measurements on tunable lasers; IFS with a tunable laser; 16728 .

Infrared heat-loss measurement technique; measurement technology; thermography; heat-flow measurements; TN933.

Infrared lasers; international standard; neutron xeroradiography; problem-solving; radiation safety; smoke detectors; solar heating; SRM's; adobe; air pollution; corrosion; electrical; energy management; graphic pen; halocarbons; DIM/NBS 61, No. 3, 1-32 (1977).

Infrared materials; optical materials; surface absorption; absorption; barothermal gas cell; bulk absorption; highly transparent; 16815.

Infrared materials; tensile stress; cadmium telluride; elastic compliance tensor; elastic moduli; extrinsic damage thresholds; high-power lasers; 16746.

Infrared materials; tensile stress; cadmium telluride; elastic compliance tensor; elastic moduli; extrinsic damage thresholds; high-power lasers; 17312. 
Infrared spectra; polyatomic molecules; Raman spectra; vibrational frequencies; fundamental frequencies; JPCRD 6, No. 3 , 993-1102 (1977).

Infrared spectra; Raman spectra; vibrational analysis; $\mathrm{BCl}_{2} \mathrm{SD}$; $\mathrm{BCl}_{2} \mathrm{SH}$; hindered rotation; 17166 .

Infrared spectroscopy; laser absorption; laser-Stark resonance; molecular spectra; Stark effect; cyanogen fluoride; dipole moment; 17124.

Ifrared spectroscopy; magnetic susceptibility; molybdenum; tetracyanoquinodimethan; $\mathrm{x}$-ray photoelectron spectroscopy; chromium; 17153.

Infrared spectroscopy; rare earths; rare earth tungstate; tungstates; x-ray powder patterns; dithiotungstate; hydrolysis; 17137.

Infrared spectrum; monodeutero silane; SiH stretching vibrations; vibration-rotation interaction; high resolution; 17131 .

Infrared television system; heat-flow reference pad; heat loss; 17335.

Inhalation; mice; polyurethane; pulmonary irritation; PVC; respiratory rate; sensory irritation; stress index; thermal decomposition products; toxicity; acute lethality; Douglas Fir; NBS-GCR-77-85.

Inhomogeneous dielectrics; profile inversion; NBSIR 76-85I.

Initial velocity; kinetic constants; LDH; Michaelis constant; NADH; Zimm plot; enzyme; 16911 .

Initiator policy; job scheduling; simulation; IBM OS/MVT; SP500-18, pp. 235-248 (Sept. 1977).

Injuries; literature; NEISS; recommendations; review; safety; sports; accident; associated factors; NBSIR 77-1218.

Injury; liquefied; petroleum; standards; container; corrosion; explosion; extinguisher; fire; gas; NBSIR 77-1217.

Injury hazard; simulation; accident; apparel; burn injury; fabric flammability; fabrics; fire; garments; heat transfer; NBSIR 771236.

Inland waters and sediments; in vivo analysis; mineral exploration; nuclear safeguards; oceanography; on-stream analysis; well logging; activation analysis; californium-252; 16760 .

In-line flow transducer; automotive fuel; flow measurement errors; fuel economy measurements; fuel flow measurements; SP484, Pp. 803-820 (Oct. 1977).

Inner bremsstrahlung; Jauch plot; spectrum; transition; coincidence; electron capture; excited state; gamma ray; ground state; SP461, pp. 23-25 (Jan. 1977).

Inner shells; photoabsorption; atoms, correlation; configuration interaction; exchange interaction; 16670.

Innovation; invention; technology transfer; energy; evaluation; 17108.

Innovation; public private sector collaboration; technology growth; U.S. economy; free enterprise system; 17113.

Innovation; regulatory barriers; residential construction; unionization; building official; building regulation; education; housing demand; SP473, pp. 113-135 (June 1977).

Innovations; in-place testing; performance approach; regulatory domination; standards development; building codes; concrete testing; evaluation; SP473, pp. 279-284 (June 1977).

Innovative construction; maintainability; materials; minimum property standards; performance criteria; performance evaluation; plumbing; safety; structures; test methods; acoustics; appliances; atmospheric; durability; electrical; environment; housing technology; HVAC; NBSIR 77-1316.

Innovative practices; regulatory research; standards development; administrative procedures; building codes; building regulations; buildings; economic impacts; environmental considerations; SP473.

In-place testing; performance approach; regulatory domination; standards development; building codes; concrete testing; evaluation; innovations; SP473, Pp. 279-284 (June 1977).

Input/output models; lifestyle factors; physical environment; residential housing; socio-physical determinants; systems theory; energy consumption; SP.473, pp. 69-83 (June 1977).
Inquiry services; metals technology; structural materials; technical reports; ceramic technology; current awareness services; databooks; information analysis center; SP463, pp. IV.2.1IV.2.7 (Jan. 1977).

Insertion loss; reflection coefficient; repeatability; SMA connectors; 16722 .

Inspection; instrumentation; strong-motion accelerographs; earthquakes; hydraulic structures; SP470, pp. Vl-47-Vl-63 (Apr. 1977).

Inspection; leak testing; liquid penetrant; magnetic particle; measurements; nondestructive testing; optical; radiography; standards; ultrasonics; visual; acoustic emission; 17042 .

Inspection; management control; microfilm; building code; building permits; computers; enforcement; information retrieval; SP473, pp. 377-382 (June 1977).

Inspection; retrofit; thermography; buildings; energy conservation; evaluation; 16902 .

Installation; performance characteristics; turbine meter; design considerations; field testing; fuel gas measurement; fundamentals; gaseous hydrocarbons; SP484, pp. 871-880 (Oct. 1977).

Institutional barriers to change; science and technology; scientific freedom and responsibility; technological change; 16905.

Institutional factors; Modular Integrated Utility System; total energy; utility system; NBSIR 76-1103.

Institutional occupancies; interior design; physical environment; regulation; research; standards; court orders; human behavior; SP473, PP. 55-67 (June 1977).

Instrumental methods; metallic artifacts; microstructural analysis; nondestructive evaluation techniques; compositional analysis; 16712 .

Instrumentation; cryogenic; 17096.

Instrumentation; interfacing; standards; CAMAC; computer interfacing; 16677

Instrumentation; isotropic; measuring; electromagnetic fields; hazards; 17168 .

Instrumentation; Josephson effect; magnetometry; SQUID; biomagnetism; geomagnetism; 16872 .

Instrumentation; luminescence; quantum yield; spectrophotometry; standard reference materials; standardization; accuracy; critical parameters; diffuse reflectance; fluorescence; SP466.

Instrumentation; measurement standards; National Bureau of Standards; national measurement system; standardization organizations; standard reference data; weights and measures; NBSIR 75-949.

Instrumentation; measuring flow; metering flow; monitoring flow; open channel flow; public law 92-500; sewerage flow; wastewater flow; closed conduit flow; SP484, pp. 83-89 (Oct. 1977).

Instrumentation; modules; nucleàr; standards; CAMAC; Dataway; 16678.

Instrumentation; Philippines; wind tunnel test; field studies; high winds; SP470, pp. X-1-X-11 (Apr. 1977).

Instrumentation; pyrolysis; reactive gases; acetaldehyde; acrolein; calibration; diffusion cell; formaldehyde; 16699.

Instrumentation; recuperators; waste; boilers; economics; energy conservation; $\mathrm{H} 12 \mathrm{I}$.

Instrumentation; standards; CAMAC; highway; interface; 16679.

Instrumentation; strong-motion accelerographs; earthquakes; hydraulic structures; inspection; SP470, PP. VI-47-VI-63 (Apr. 1977).

Instrumentation, standards; interfacing; CAMAC; computer interfacing; 17270 .

Instruments; knowledge; legislation; life safety; regulation; standards; building codes; building safety; control; SP473, pp. 259-278 (June 1977). 
Instruments; scintillation detectors; ${ }^{6} \mathrm{Li}(\mathrm{n}, \boldsymbol{\alpha})^{3} \mathrm{H}$; external particle detectors; gaseous ionization detectors; SP493, pp. 43-46 (Oct. 1977).

Instruments; strong motion; buildings; SP477, pp. 11I-26-111-40 (May 1977).

Instruments, flow measurement; level measurement; level-toflow rate conversion; liquid flow; open channel flow measurement; secondary measuring device; flow measurement, water; flow meters; SP484, pp. $91-108$ (Oct. 1977).

Instruments for hearing; manikin; audiometry; diffraction; head diffraction; hearing aids; 17064

Insulating fluids; Kerr effect; nitrobenzene; pulse measurement; space charge; calibration; dielectrics; dividers; electric fields; electro-optics; high voltage measurement; NBSIR 77-1317.

Insulating properties; thermal conductivity; thermal insulation; condensation in walls; 17284 .

Insulation; laboratory measurements; modeling; standby loss; water heater; alternating direction; computer simulation; cool down; energy savings; flue damper; heat transfer; implicit; 17184 .

Insulation; lighting; performance standard; thermal performance; ventilation; water heating; air leakage; building design; energy conservation; fenestration; HVAC systems; illumination; NBSIR 74-452.

Insulation; materials; mechanical property; metal; review; thermal property; alloy; composite; cryogenics; electrical property; 17072 .

Insulation; materials properties; performance; urea-formaldehyde; cellular plastics; foam insulation; TN946.

Insulation; mattresses; shipboard; thermal conductivity; compartment fires; fire-retardants; NBSIR 77-1295.

Insulation; passive-solar-heating; sun-shading; ventilation; windows; daylighting; infiltration; 17298 .

Insulation; performance; radiative cooling; roofing; solar heating; surface temperature; built-up roofing; 17060 .

Insulation; performance; radiative cooling; roofing; solar heating; surface temperature; built-up roofing; 17061 .

Insulation; residential design practices; typical construction characteristics; typical new house materials; windows; building envelope; energy conservation base; NBSIR 77-1309.

Insulation; shading; solar-heating; ventilation; windows; airtightness; daylighting; energy-conservation; BSS104.

lnsulation; survey; abstracts; bibliography; cryogenic insulation; foam insulation; 17308.

Insulation properties; residential heat loss; retrofitting houses; thermal conductivity; thermal insulation; thermography; air infiltration; condensation in buildings; energy conservation; energy measurements; fuel savings; heat-loss reduction; NBSIR 77-1274.

Insulator metal diode; laser; speed of light; 1.5 microns; frequency measurement; frequency standards; helium neon laser; 17336.

Integral; iterative; neutron; transmission matrix; criticality; collision; cylindrical; energy; SP461, pp. 94-96 (Jan. 1977).

Integral; legendre polynomial; scattering; semi analytical; spatial; transmission; anisotropy; charged particle; computer code; energy-angle; SP461, pp. 140-143 (Jan. 1977).

Integral; medium; Monte Carlo; albedo; angular; backscattering; barrier; differentials; distribution; gamma rays; SP461, pp. 129-131 (Jan. 1977).

Integral equation; interpolating polynomial; numerical stability; slit correction; small angle scattering; unsmearing; FORTRAN program; TN936.

Integral equation; radiation; scattering; semi-numerical; transport; SP461, pp. $79-86$ (Jan. 1977).

Integral experiments; standards; adjustment; benchmark; crosssections; fast reactors; SP493, pp. 310-312 (Oct. 1977).

Integral measurements; standard neutron fields; cross sections; ENDF/B; fission; SP493, pp. 290-298 (Oct. 1977).
Integrals; neutrons; radioactivation; resonance integrals; spectral functions; comparative evaluation; cross sections; fission spectra; SP493, pp. 128-136 (Oct. 1977).

Integrated circuit; photolithography; silicon; test pattern; visual alignment structure; electrical mask alignment; 17330.

Integrated circuit quality control; selective chemical etching; semiconductor device reliability; corona charging decoration; dielectric defect detection; electrophoretic decoration; SPAOO-31.

Integrated circuits; linewidth measurements; microelectronics; micrometrology; optical microscope; photoelectric microscope; photomask; scanning electron microscope; filar eyepiece; image-shearing eyepiece; 17066.

Integrated circuits; radioisotope leak detection; hermeticity; hermetic test standards; 17331 .

Integrated intensities; lattice constants; peak intensities; powder patterns; reference intensities; standard; $x$-ray diffraction; crystal structure; Monogr. 25, Section 14.

Integration; kernel; radiation; streaming; annular; computation; duct; gamma ray; SP461, pp. 132-135 (Jan. 1977).

Intensity; seismic; wooden house; classification; damage; SP477, pp. IV-1-1V-17 (May 1977).

Intensity; seismic records; velocity; data; displacements; SP477, pp. VI-179-VI-191 (May 1977).

Interaction; lubricant; metals; properties; tricresyl phosphate; zinc dithiophosphate; antiwear additives; SP487, pp. 172-185 (Aug. 1977).

Interaction potential; iodine; perturbation theory; rate coefficient; collision-induced; emission; 17069.

Interaction range; neutron scattering; spin correlation function; absolute cross section measurement; cobalt; critical phenomena; 17112 .

Interaction virial coefficients; mixtures; molecular volumes; second virial coefficients; water; ballistics; carbon dioxide; combustion gases; energy; equation of state; high pressure; high temperature; 17136.

Interactive; labels; numerical analysis; OMNITAB II computing system; probability plotting; selection of variables in linear regression; statistical plotting; stem-and-leaf displays; table making; automatic printing; Calcomp plotting; data editing; NBSIR 77-1276.

Interactive; measurement; performance evaluation; performance measurement; remote terminal emulation; Remote Terminal Emulator; teleprocessing; evaluation; 16945.

Interactive; measurement; performance evaluation; performance measurement; remote terminal emulation; remote terminal emulators; teleprocessing; evaluation; SP500-4.

Interactive audit; internal audit; post-processing audit; program integrity; audit standards; audit techniques; audit tools; audit training; communications security; computer controls; computer security; data integrity; SP500-19.

Interactive computer access; measurement; network measurement services; service; teleprocessing systems measurement; computer network measurement; data acquisition; 17252.

Interactive computer system; performance measurement; renewal theory; statistical analysis; steady state; SPSOO-18, pp. 87-94 (Sept. 1977).

Interactive system; measurement model; measurement, performance; measures; methodology; network measurement system; computer service; external measurement; figure-ofmerit; 17288 .

Interactive terminal; probe point development; programmable monitor; stimulator; terminal data; data input bus; DATANET 355; data output bus; high-speed line adaptor; HIS 6080; SP500-18, pp. 95-105 (Sept. 1977).

Interagency review; Interior; Library of Congress; materials; materials data; materials information; N.A.S.A.; U.S.D.A; Commerce; Defense; E.R.D.A.; Federal agencies; SP463.

Interatomic forces; interstitial; lattice dynamics; metal hydrides; band mode; elastic constants; 17004. 
Interatomic potential; molecular dynamics; second sound; shock wave; stress relaxation; structural relaxation; thermal relaxation; anharmonic crystal; computer simulation; energy transport; equation of state; 16751 .

Interaural intensity differences; interaural time differences; localization; manikin; ears; head diffraction; hearing; 17052.

Interaural time differences; localization; manikin; ears; head diffraction; hearing; interaural intensity differences; 17052 .

Intercalibration; petroleum analysis; trace analysis; gas chromatography; gas chromatography-mass spectroscopy; hydrocarbons; 17273.

Intercomparison; neutrons, high energy; neutrons, low energy; non-uniform exposures; quality factor; standards; criteria, accuracy; criteria, performance; dose equivalent; elements, transuranic; glove box; SP493, pp. $101-105$ (Oct. 1977).

Intercomparisons; medical; neutron dosimetry; radiation effects; standards; SP493, pp. $121-127$ (Oct. 1977).

Interconnection; networks; packet switching; standards; communications networks; computer networks; data communications; 16934

Interconnection; networks; packet switching; standards; communications networks; computer networks; data communications; SP500-6.

Interdisciplinary technology; physical property data; publish; science; standard reference data; technology; communication; information; 17258 .

Interdisciplinary thermo-structural analyses; finite-element method; general purpose heat transfer computer program; SP487, pp. 62-81 (Aug. 1977).

Interface; instrumentation; standards; CAMAC; highway; 16679.

Interface requirements; Monte-Carlo testing; testbed; test cases; validating correctness; communications security; computer security; cryptography; encryption standard; SP500-20.

Interface standards; protocols; communications standards; data communications interfaces; data communications standards; 16936.

Interfacing; CAMAC; computer interfacing; instrumentation, standards; 17270

Interfacing; standards; CAMAC; computer interfacing; instrumentation; 16677

Interference; measurement; metrology; radiation; surface technology; electromagnetic; 17079.

Interference; modulation; phase; Ramsey; saturation spectroscopy; transit-time; coherence; fringes; 17337.

Interference; near-field probes; radiation; susceptibility; TEM cell; electromagnetic measurements; 17251 .

Interference filters; spectral responsivity; spectral transmittance; television camera tubes; television cameras; test methods; diffuser; 16761

Interferences; multiple reflections; photometric linearity; polarization; sample characteristics; stray light; wavelength accuracy; bandwidth; calibration; errors in spectrophotometry; SP466, pp. 99-1 14 (May 1977).

Interferometer; length measurement; partial fringe; wavelength measurement; dimensional metrology; exact fringes; fractional fringe; 17048

Interferometer; manometers; manometry; pressure standard; ultrasonic interferometer; vacuum measurement; 17269.

Interferometer; Michelson; phase-lock; scanning; wavelength; cw laser; 17338.

Interferometers; optics; photoelasticity; crystals; fused silica; 16730.

Interferometric wavemeter; metric; pressure transducers; synchrotron radiation; building collapse; computer security; cryogenic temperature; dentistry; dielectric measurements; dye lasers; dynamic calibration; electron microscopy; DIM/NBS 61, No. 2, 1-32 (1977).

Interferometry; FORTRAN computer program; gage blocks; TN956.
Interferometry; length measurement; parallelism; flatness; gage blocks; NBSIR 73-239.

Inter-fiber bond strength; mixed waste paper; paper recycling; pulp characterization; $2.5 \mathrm{~g} / \mathrm{m}^{2}$ handsheets; breaking energy; NBSIR 76-1148.

Intergovernmental; international standards; legal metrology; measurement; trade facilitation; flow measurement; industry; SP484, pp. $921-927$ (Oct. 1977).

Interior; Library of Congress; materials; materials data; materials information; N.A.S.A.; U.S.D.A; Commerce; Defense; E.R.D.A.; Federal agencies; interagency review; SP463.

Interior design; physical environment; regulation; research; standards; court orders; human behavior; institutional occupancies; SP473, pp. 55-67 (June 1977).

Interior furnishings; mobile homes; polyurethanes; smoke detectors; standards; textiles; toxicity; arson; bibliographies; building fires; carpets; construction materials; fire departments; fire detection systems; fire tests; flame research; flammability tests; NBSIR 77-1277.

Interlaboratory; lamp; radiance; radiometry; source; spectroscopy; standard; synchrotron; ultraviolet; wall-stabilized; arc; calibration; deuterium; 17198.

Interlaboratory comparison; load cell; static force; force; force calibration; NBSIR 76-1/45.

Interlaboratory comparison; surface characterization; $\mathrm{x}$-ray photoelectron spectroscopy; Auger electron spectroscopy; catalyst; electron binding energy; 16930.

Interlaboratory evaluation; neoprene; radiant panel test; round robin; test method; ASTM E 162; coefficient of variation; flame spread tests; flexible polyurethane; hardboard; NBSIR 77-1222.

Interlaboratory testing; precision; repeatability; reproducibility; accuracy; analysis of variance; 16858 .

Interlamellar links; morphology; polymer; sectorization; spheralites; chain folding; curved crystals; extended chain crystals; fold domains; fold surfaces; 16958.

Intermediate energy; measurement assurance; neutron standard; reaction rates; benchmark spectrum; discrete ordinates; SP493, pp. 329-334 (Oct. 1977).

Intermediate energy; photons; approximation; bremsstrahlung; cross section; electron; SP461, pp. 60-63 (Jan. 1977).

Intermediate neglect of differential overlap (INDO); molecular orbital theory; quantum chemistry; static potential; carbon monoxide molecules; dipole moment; electron scattering; electrostatic potential; 16709.

Intermittent hot water exposure tests of thermoplastic pipe; pressure shock in thermoplastic pipe; water hammer in thermoplastic pipe; NBSIR 77-1261.

Intermittent ventilation; ventilation control; weather data analysis; air conditioning requirements; energy conservation; NBSIR 76-1088.

Intermolecular association; normal and deuterated methanols; potential barrier to internal rotation; principal and reduced moments of inertia; structural parameters; vibrational fundamentals; JPCRD 6, No. 1, 105-112 (1977).

Internal audit; post-processing audit; program integrity; audit standards; audit techniques; audit tools; audit training; communications security; computer controls; computer security; data integrity; interactive audit; SPSOO-19.

Internal energies; isobars; isochores; isotherms; Joule-Thomson inversion; latent heats of vaporization; melting line; orthobaric densities; propane; specific heats; speeds of sound; vapor pressure; densities; enthalpies; entropies; ęquation of state; NBSIR 77-860.

Internal energy; liquid; oxygen; PVT; quality; slush; solid; vapor; computer programs; enthalpy; entropy; hydrogen; NBSIR 77-859.

Internal logic identification; laser scanning; logic flow identification; LSI testing; nondestructive tests; nonlinear region mapping; temperature mapping; active devices; 17164 . 
Internal media; communication among scientists; coordination of research organizations; employee communication; information needs; information processing; information seeking; NBSIR 77-1257.

Internal rotation; interstellar molecules; $\mathrm{mm}$ wave transitions; overlapped lines; radio astronomy; acetaldehyde; 16969.

Internal standard; polarization; powder diffraction; quantitative $x$-ray analysis; reference intensity ratio; $x$-ray intensity standards; $x$-ray powder diffraction; 16953.

Internal wave; laboratory; oscillating probe; conductivity probe; density; density gradient; experimental; SP484, pp. 783-802 (Oct. 1977).

International aerospace abstracts; materials; mechanical properties; metallic materials; nonmetallic materials; physical properties; RECON; scientific and technical aerospace reports; thesaurus; aerospace; SP463, pp. VI.1.1-VI.1.7 (Jan. 1977).

International allocation programs; International Energy Agency; national allocation programs; implementation of allocation programs; SP484, pp. 945-946 (Oct. 1977).

International comparison; fast neutron flux density; SP493, pp. 244-249 (Oct. 1977).

International Energy Agency; national allocation programs; implementation of allocation programs; international allocation programs; SP484, pp. 945-946 (Oct. 1977).

International flow standards; laser anemometry; open channel flows; orifice meters; pitot-static meters; turbine meters; weirs; acoustic flow meters; closed conduit flows; current meters; dye-dilution methods; errors in flow measurement; flow measurement; SP484, Volumes 1 and 2.

International Formulation; steam; viscosity of water and steam; water; critically evaluated data; JPCRD 6, No. 4, 1133-1166 (1977).

International Practical Temperature Scale of 1968; melting point standard; secondary fixed point; temperature fixed point; thermometry; gallium; 17049.

International recommendations; national standards; product standards; recommended practices; specifications; test methods; certification programs; consumer products; household products; industry standards; TN948.

International relations; LDS's; measurement services; standardization; AID; assistance; developing economies; foreign relations; industrializing nations; NBSIR 76-1152.

International standard; neutron xeroradiography; problem-solving; radiation safety; smoke detectors; solar heating; SRM's; adobe; air pollution; corrosion; electrical; energy management; graphic pen; halocarbons; infrared lasers; DIM/NBS 61 , No. 3, 1-32 (1977).

International standardization; national standardization; national standards bodies; practice; procedures; regional standardization; standardization; standards development; ADP standards; NBSIR 77-1195.

International standards; allocating hydrocarbons; hydrocarbon measurement; SP484, pp. 957-959 (Oct. 1977).

International standards; legal metrology; measurement; trade facilitation; flow measurement; industry; intergovernmental; SP484, pp. $921-927$ (Oct. 1977).

International standards; measurement standards; national standards; application of standards; SP484, pp. $929-934$ (Oct. 1977).

International standards; open channel flow; petroleum product standards; closed conduit flow; flow measurement; SP484, pp. 895-920 (Oct. 1977).

International standards; orifice plates; data bases; EEC regulations; flow rate; SP484, pp. 935-944 (Oct. 1977).

International standards code; NCSL; NMR knight shift neutron beams; piezo-flex micropositioning; pressure; thermodynamic tables; coal conversion; consumer products; cryogenic; crystalline materials; dosimeter calibrations; energy; DIM/NBS 61, No. 7, 1-32 (1977).
International System of Units; Sl; Système International des Unités; Units of Measurements; General Conference on Weights and Measures; SP330.

International System of Units (SI); metric design and construction; recommended SI practice; TN938.

Interpolating polynomial; numerical stability; slit correction; small angle scattering; unsmearing; FORTRAN program; integral equation; TN936.

Interpolation formula; irradiance drift formula; projected solid angle; spectral irradiance; standards; calibrations; TN594-13.

Interstellar medium; magnetic pressure; neutron; radiation; stellar explosion; supernova; dynamics; galactic structure; 17217.

Interstellar molecule; microwave emission; radio sources and rotational spectra; astronomy; ethyl cyanide; 17264.

Interstellar, molecules; line identifications; nebulae, individual; radio sources, lines; 16664 .

Interstellar molecules; $\mathrm{mm}$ wave transitions; overlapped lines; radio astronomy; acetaldehyde; internal rotation; 16969.

Interstellar sources; isotope ratio; molecular lines; radio astronomy; silicon monoxide; spectra; 17189.

Interstitial; lattice dynamics; metal hydrides; band mode; elastic constants; interatomic forces; 17004

Interstitial; metals; refractory; alloys; compounds; hardness; 17262.

Intra-arterial cannula; spectrophotometer analysis; carboxyhemoglobin; CO intoxication; 16921.

Intrinsic optical tensor; intrinsic stress tensor; polymer solution; bead-spring model; eigenvalues; frequency response; J. Res. 81A No. 1, 97-107 (1977).

Intrinsic stress tensor; polymer solution; bead-spring model; eigenvalues; frequency response; intrinsic optical tensor; $J$. Res. 81A No. 1, 97-107 (1977).

Intrinsic viscosity; nonrotating bead; single bead contribution to I.V.; torque on the bead; average gradient; 17119 .

Intrusion alarm; intrusion detector; sound sensing; standard; alarm; audio alarm; burglar alarm; 16831 .

Intrusion detector; sound sensing; standard; alarm; audio alarm; burglar alarm; intrusion alarm; 16831 .

Invar; iron alloy; nickel alloy; Poisson's ratio; shear modulus; sound velocity; Young's modulus; bulk modulus; compressibility; Debye temperature; elastic constant; 16869.

Invention; technology transfer; energy; evaluation; innovation; 17108.

Inventions; monopolies; patent law; patents; Canada; copyrights; 16859.

Inventor; molecular identity; preserving stone; pressure measurements; rf-power meter; roofing; safety; security alarms; SRM's; time and frequency; ultraviolet; computer memories; computer performance; DIM/NBS 61, No. 8, 1-32 (1977).

Inverse Laplace transforms; complete elliptic integrals; J. Res. 81B Nos. 1 and 2, 5-39 (1977).

Inverse scattering; moment methods; scattering; singularity expansion method; symmetry analysis; antenna patterns; characteristic modes; Garbacz characteristic modes; group theory; 17225.

Investments; petrographic; thermal; dental; expansion; 17325.

Iodides; molten salt mixtures; standard reference data; surface tension; viscosity; bromides; data compilation; density; electrical conductance; JPCRD 6, No. 2, 409-596 (1977).

lodine; kinetics; microwave discharge; nitride; plasma; reaction mechanism; silicon; synthesis; thin film; vapor transport; activation parameters; active nitrogen; 16757.

lodine; molybdenum hexafluoride; new static technique; vapor pressure; argon-vapor contact; error analysis; 17075.

Iodine; perturbation theory; rate coefficient; collision-induced; emission; interaction potential; 17069.

Iodine; saturated absorption; dye laser; frequency stabilization; 17178. 
lodine spectrum; line identification atlas; rovibronic assignments; spectral analysis; visible absorption spectroscopy; high-resolution spectrum; J. Res. 81A No. 1, 25-80 (1977).

Iodometry; monitoring; ozone; ultraviolet photometry; air pollution; calibration; NBSIR 76-1191.

Ion; ionization potential; monoenergetic electron impact; photoionization; pyridine; vinylacetylene; 1,5-hexadiyne; 2,4 hexadiyne; appearance potential; benzene; butatriene; heat of formation; 17294.

Ion; Monte-Carlo; swarm; theory; velocity distribution; drift tube; 16779.

Ion beam scanning; ion implantation; ion implantation dose measurement and control; secondary particle suppression; accurate ion beam current measurement; current integrators; SP400-39.

Ion dynamics; quasi static; Stark broadening; theoretical comparison; hydrogen $H \alpha$ and $H \beta ; 17232$.

Ion imaging; ion microprobe; ion microscope; microanalysis; secondary ion mass spectrometry; surface analysis; 17156.

Ion implantation; ion implantation dose measurement and control; secondary particle suppression; accurate ion beam current measurement; current integrators; ion beam scanning; SP400-39.

Ion implantation; Irvin's curves; Ieak tests; line-width measurement; measurement methods; microelectronics; optical flyingspot scanner; oxidation particle impact noise detection test; passivation overcoats; photovoltaic method; power-device grade silicon; SP400-29.

Ion implantation; MOSFET; silicon; direct-current; dopant density; 17342

Ion implantation dose measurement and control; secondary particle suppression; accurate ion beam current measurement; current integrators; ion beam scanning; ion implantation; SP400-39.

Ion microprobe; ion microscope; microanalysis; secondary ion mass spectrometry; surface analysis; ion imaging; 17156.

Ion microscope; microanalysis; secondary ion mass spectrometry; surface analysis; ion imaging; ion microprobe; 17156.

Ion pairs; solubility; solubility isotherms; solubility product; thermal coefficient of solubility; thermodynamics; tooth mineral; dissolution; hydroxyapatite; J. Res. 81A Nos. 2 and 3, 273-281 (1977).

Ion probe; microanalysis; microscopy; scanning; x-ray spectroscopy; electron probe; image formation; 16841 .

Ionic charge; ionization potential; stopping power; stripped particle; velocity; charge; charged particle; collision; electron; SP461, pp. 144-148 (Jan. 1977).

Ionic conductivity; nonstoichiometry; phase equilibria; rubidium niobate; rubidium tantalate; crystal chemistry; J. Res. 82, No. 3, 151-165 (1977).

Ionization; laser-induced breakdown; laser pulse; multiphoton absorption; tunnelling; 16892 .

Ionization; measurements; cross section; differential; electron; helium; 16810.

Ionization; multiphoton ionization; ac Stark effect; 16925.

Ionization; neutron spectra; deuterons; NBSIR 77-1279, p. 30 (July 1977).

Ionization chamber detectors; photoelectric detectors; smoke detectors; building fires; fire detection devices; heat detectors; 16737.

Ionization chambers; NaI; neutron flux determination; proportional counters; solid-state detectors; standard cross section; ${ }^{10} \mathrm{~B}\left(\mathrm{n}, \alpha_{0}+\alpha_{1} \gamma\right)^{7} \mathrm{Li}$; SP493, pp. 85-92 (Oct. 1977).

Ionization cross sections; lithium; photoexcitation cross sections; Stieltjes-Tchebycheff technique; configuration interaction; cross sections; 17319 .

Ionization potential; monoenergetic electron impact; photoionization; pyridine; vinylacetylene; 1,5-hexadiyne; 2,4- hexadiyne; appearance potential; benzene; butatriene; heat of formation; ion; 17294 .

Ionization potential; photoionization; appearance potential; diethyl ether; dimethyl ether; $17 / 46$.

Ionization potential; stopping power; stripped particle; velocity; charge; charged particle; collision; electron; ionic charge; SP461, PP. 1 44-1 48 (Jan. 1977).

Ionization potentials; Rayleigh-Schrödinger perturbation theory; electron affinities; Green's function; 17317.

Ionization smoke detectors; photoelectric smoke detectors; residential fires; smoke detectors; tenability levels; detector sensitivity; detector siting; heat detectors; 16882 .

Ionized impurity scattering; lattice scattering; neutral impurity scattering; n-type silicon; resistivity; temperature; dopant density; electron-electron scattering; electron mobility; 17147.

Ionized impurity scattering mobility; lattice mobility; neutral impurity scattering mobility; $n$-type silicon; resistivity; scattering mechanisms; temperature; dopant density; electron mobility; SP400-33.

Ionized molybdenum; measurement assurance; metric; neutron diffraction; recycling oil; research and innovation; safety; ultrasonic tissue; computerized data; data elements; equity; federal technology; fire modeling; heat; hydrocarbon; DIM/NBS 61, No. 6, 1-32 (1977).

Ionizing radiation; leuco dye cyanide; radiation dosimeter; radiation sensor; triphenylmethane cyanide dye precursor; ultraviolet; x rays; gamma rays; U.S. Patent 4,006,023.

Ionizing radiation; radiation dosimetry; radiation hardness testing; radiation sources; thermoluminescence dosimeters; total dose; dosimeter calibration; electronic devices; NBSIR 761135.

Ionizing radiation effects; radiation dose; radiation testing; scanning electron microscope; semiconductor devices; electron beam energy deposition; NBSIR 77-1235.

Ion-molecule; associative detachment; chemiluminescence; flowing afterglow; fluorescence; infrared; 17209.

Ion-molecule equilibria; charge transfer; entropy; 17057.

Ion-molecule reactions; isotope effects; mass spectrometry; photoionization; rate constants; alkyl iodides; J. Res. 81A Nos. 2 and 3, 267-271 (1977).

Ions; iron, oxygen; measurement; Moliere theory; multiple; scattering; angular distribution; chlorine; foils; SP461, PP. 136-139 (Jan. 1977).

Ions; LET; model; neutron; OER; one-hit detector; pion; radiation; track; cell; delta ray; dose; SP461, pp. 183-187 (Jan. 1977).

lons; line strength; atomic spectroscopy; Hartree-Fock; 17229.

Ions; molybdenum; niobium; rubidium; spectra; structure; ultraviolet; yttrium; zirconium; 17212.

Ion-selective electrode; Iead electrode; natural waters; rainwater; seawater; sulfate; environmental analysis; 16771 .

Iran; training; Turkey; earthquake engineering; earthquakes; education; India; SP470, pp. X-12-X-16 (Apr. 1977).

Iridium; isotope exchange; metalloborane; oxidative addition; boron hydride; hydrogen; 17144 .

"Iridium," marking of; jewelry, marking of; "Osmium," marking of; "Palladium," marking of; "Platinum," marking of; "Rhodium," marking of; "Ruthenium," marking of; PS69-76.

Iron; low temperature; susceptibility; alloys; copper; electrical resistivity; 17135.

Iron; magnetization measurements; neutron diffraction; terbium; amorphous alloys; 16835.

Iron alloy; nickel alloy; Poisson's ratio; shear modulus; sound velocity; Young's modulus; bulk modulus; compressibility; Debye temperature; elastic constant; invar; 16869.

Iron alloys; liquid helium; stainless steels; steels; superalloys; titanium alloys; aluminum alloys; crack propagation; fatigue; 16928. 
Iron alloys; Lorenz ratio; low temperature; nickel alloys; thermal conductivity; thermopower; copper; electrical resistivity; 16878 .

Iron alloys; valence; atomic volume; hyperfine fields; 16927.

Iron oxide; magnetite; $\mathrm{Fe}_{2} \mathrm{O}_{3} ; \mathrm{Fe}_{2} \mathrm{O}_{4}$; gaseous reduction; hematite; high voltage electron microscopy; 17177.

Iron, oxygen; measurement; Moliere theory; multiple; scattering; angular distribution; chlorine; foils; ions; SP461, pp. 136139 (Jan. 1977).

Iron-molybdenum alloys; localized corrosion; repassivation; sensitization; stainless steel; crevice corrosion; NBSIR 76-1170.

Irradiance drift formula; projected solid angle; spectral irradiance; standards; calibrations; interpolation formula; TN59413.

Irradiance measurements; photoresist; photoresist sensitivity; sensitivity index; Van Kreveld's additivity law; exposure; exposure control; film thickness variation; 16853 .

Irradiance measurements; photoresist; sensitivity index; sensitometry; Van Kreveld's additivity law; exposure; exposure control; film thickness; 17329.

Irradiation; LiF; optical absorption; spectral distribution; thermoluminescence; gamma rays; SP461, pp. 222-226 (Jan. 1977).

Irradiation; $\mathrm{TL} ; \mathrm{CaSO}_{4}$; correlation; dose; ESR; gamma ray; glow curve; SP461, pp. 234-237 (Jan. 1977).

Irradiation devices; measuring methods; neutron reactions; neutron sources; calibration; califomium-252; cross sections; design; errors; fission neutrons; 16790.

Irreducible representation; isotope separation; molecular spectroscopy; crystal field theory; group theory; high-resolution spectra; 16956.

Irregularities; metallic thin films; microirregularities; overcoating; plasmons; scatter; absorption; dielectric layers; SP466, pp. 133-148 (May 1977).

Irreversible vs reversible adsorption; surface-active comonomer; adhesion to polymers; adsorption from solutions; chemisorption; hydroxyapatite; 17197.

Irvin's curves; leak tests; line-width measurement; measurement methods; microelectronics; optical flying-spot scanner; oxidation particle impact noise detection test; passivation overcoats; photovoltaic method; power-device grade silicon; radioisotope method; $S P 400-29$.

ISO; methods of tests; need for international standardization; product specifications; flow measurement; SP484, pp. 947. 956 (Oct. 1977).

Isobars; isochores; isotherms; Joule-Thomson inversion; latent heats of vaporization; melting line; orthobaric densities; propane; specific heats; speeds of sound; vapor pressure; densities; enthalpies; entropies; equation of state; internal energies; NBSIR 77-860.

Isobutane; magnetic suspension densimeter; methane; normal butane; propane saturated liquid; tables; density; deviation plots; ethane; experimental; 16871 .

Isochores; isotherms; Joule-Thomson inversion; latent heats of vaporization; melting line; orthobaric densities; propane; specific heats; speeds of sound; vapor pressure; densities; enthalpies; entropies; equation of state; internal energies; isobars; NBSIR 77-860.

Isolated lines; multiplet; plasma broadening; regularities; Stark widths; supermultiplet; transition array; 17206.

Isolation amplifier; phase-lock loop; phase noise; correlation; double balanced mixer; 17185 .

Isopiestic; osmotic coefficients; thermochemistry; vapor pressure; activity coefficients; aqueous systems; bibliography; electrochemistry; SP485.

Isosbestic wavelengths; liquid filters; standard reference material; transfer standards; absorbance linearity; accuracy of transmittance or absorbance scale; acidic potassium dichromate solutions; calibration of ultraviolet spectrometers; SP260-54.
Isospin; magnetic; multipolarity; sum rule; electron scattering; inelastic; 16687.

Isospin; photonuclear; shell model; sum rules; giant resonance; hydrodynamic model; 16987.

Isostructural materials; lattice; point group; polymorphism; space group; symmetry; crystal; JPCRD 6, No. 3, 675-830 (1977).

Isotherm equations; physical adsorption; relative humidity; routine radiosonde application; barium fluoride; calibration equations; fast response; films; humidity sensor; industrial fabrication; NBSIR 76-1108.

Isotherms; Joule-Thomson inversion; latent heats of vaporization; melting line; orthobaric densities; propane; specific heats; speeds of sound; vapor pressure; densities; enthalpies; entropies; equation of state; internal energies; isobars; isochores; NBSIR 77-860.

Isotope dilution; sample preparation; specific activity; $\alpha$-activity; absolute counting; aliquotting; analysis (plutonium, uranium); SP493, pp. 206-211 (Oct. 1977).

Isotope effects; mass spectrometry; photoionization; rate constants; alkyl iodides; ion-molecule reactions; J. Res. 81 A Nos. 2 and 3, 267-271 (1977).

Isotope enrichment; laser isotope separation; photochemical enrichment; thiophosgene; chlorine isotope separation; U.S. Patent 4,025,406.

Isotope exchange; metalloborane; oxidative addition; boron hydride; hydrogen; iridium; 17144.

Isotope ratio; molecular lines; radio astronomy; silicon monoxide; spectra; interstellar sources; 17189.

Isotope separation; molecular spectroscopy; crystal field theory; group theory; high-resolution spectra; irreducible representation; 16956.

Isotopes; molecular dynamics; neutron; nuclear reactor; radiation; activation analysis; crystal structu re; diffraction; TN939.

Isotopic waters; partial molar volume of aqueous gases; PVT; thermal expansivity; water; aqueous solutions of gases; compressibility; equation of state; heavy water; JPCRD 6, No. 4, 1109-1132 (1977).

Isotropic; measuring; electromagnetic fields; hazards; instrumentation; 17168.

Isotropic neutrons; $\mathrm{Li}^{\mathbf{6}}$ sandwich surface barrier spectrometer; proton recoil surface barrier spectrometer; energy and flux calibration; fast neutrons; SP493, pp. 61-66 (Oct. 1977).

Isotropic probe; loop antenna; magnetic field probe; tangential sensitivity; broadband probe; dipole antenna; dynamic range; electric field probe; NBSIR 77-868.

Isotropy; photographic processing; scanning electron microscopy; signal processing; derivative operators; digital scan generator; 16988

Iterative; neutron; plastic; recoil; scintillator; UNFOLD; Apsara; energy distribution; gamma ray; SP461, pp. 247-251 (Jan. 1977).

Iterative; neutron; transmission matrix; criticality; collision; cylindrical; energy; integral; SP461, pp. $94-96$ (Jan. 1977).

\section{J}

Japan; earthquake distribution; earthquakes; field data; frequency maps; ground displacement; SP470, pp. III-1-III17 (Apr. 1977).

Japan; peristaltic CCD's; surface channel; The Federal Republic of Germany; The Netherlands; transfer channel; bucket-brigade; buried channel; Canada; charge-coupled device; Great Britain; imager CCD's; SP500-5.

Jauch plot; spectrum; transition; coincidence; electron capture; excited state; gamma ray; ground state; inner bremsstrahlung; SP461, pp. 23-25 (Jan. 1977).

Jet engines; blade flutter control; composite materials; SP487, pp. 108-120 (Aug. 1977). 
Jet flow; orifice meters; pulsating flow measurements; pulsations; turbulence; vortex; differential pressure; flow metering error; flow oscillations; SP484, pp. 523-548 (Oct. 1977).

Jewelry; "Silver/Gold," marking of; PS68-76.

Jewelry, marking of; "Gold Filled," marking of; "Gold Overlay," marking of; "Gold Plate," marking of; "Rolled Gold Plate," marking of; PS67-76.

Jewelry, marking of; "Karat," "Karat gold," “Kt," “Kt gold," "K," or "K gold," marking of; PS70-76.

Jewelry, marking of; "Osmium," marking of; "Palladium," marking of; "Platinum," marking of; "Rhodium," marking of; "Ruthenium," marking of; "Iridium," marking of; PS69-76.

Jeweiry, "Silver," marking of; novelties, "Silver," marking of; "Sterling Silver," "Silver," or "Solid Silver," marking of; "Coin" or "Coin Silver," marking of; PS7I-76.

JEZEBEL; Markov process; neutron; PURNIMA; Rossi- $\alpha$; slowing down; stochastic; BESM-6; SP461, pp. 97-99 (Jan. 1977).

$J$-file sum rule; neon; transition probabilities; wall-stabilized arc; atomic spectra; configuration interaction; 17276 .

J-integral; nickel steel; weldments; cryogenic temperature; fatigue crack growth; fracture toughness; heat affected zone; 17089.

$J$-integral; plane strain fracture toughness; tensile fatigue crack growth rate; 16879 .

Job scheduling; simulation; IBM OS/MVT; initiator policy; SP500-18, pp. 235-248 (Sept. 1977).

Joints; nonlinear analysis; single-lap-joint analysis; single-lapjoint bending; spotwelded joints; weldbonded joints; adhesivebonded joints; bonded joints; cyclic loading; debond analysis; double-lap-joint analysis; fatigue tests; finite element analysis; NBSIR 76-1053.

Joints; solder; thermal conductance; beryllium; copper; cryogenics; indium; 16797.

Josephson effect; lead; microwaves; niobium; superconductivity; tunnelling; dielectric constant; 16946.

Josephson effect; levitation; superconductivity; ampere definition; electrical units; fundamental constants; 16876.

Josephson effect; magnetometry; SQUID; biomagnetism; geomagnetism; instrumentation; 16872.

Josephson effect; millimeter waves; mixing; receiver; superconductivity; heterodyne detection; 17077.

Josephson effect; quantum interference; radio frequency; SQUID; superconductivity; attenuation; 16875 .

Josephson effect; quantum interference; rf metrology; rf power; SQUID; superconductivity; 17092 .

Josephson junction; microstrip resonator; microwave coupling; parametric plasma oscillation; thin-film device; coherent microwave emission; e/h voltage standard; 16788 .

Josephson junction; quantum interference; rf attenuation; superconductivity; NBSIR 77-863.

Josephson junction; SQUID; amplifier; high-frequency; 17334 .

Josephson junction; standard cell; superconducting; voltage measurement; voltage reference; 16698 .

Josephson junctions; picosecond pulses; superconducting electronics; superconductivity; voltage waveforms; energy gap; 16874.

Joule-Thomson inversion; latent heats of vaporization; melting line; orthobaric densities; propane; specific heats; speeds of sound; vapor pressure; densities; enthalpies; entropies; equation of state; internal energies; isobars; isochores; isotherms; NBSIR 77-860.

Journals; library holdings, NBS Library; NBS periodicals; periodicals; proceedings; serials; standards; transactions; annual reports; diffusion in metals; fire; $N B S I R$ 77-1215.

Junction temperature; measurement technology; nondestructive test; reliability; safe operating limits; second breakdown; semiconductor devices; thermal characterization; thermal instability; thermal resistance; transistors; hot spots; SP400-44.

Junctions; MOS capacitors; sheet resistors; silicon; test structures; defects; dopants; impurities; 16855.
K property; property; soil; stiffness; testing; bore hole; SP477, pp. VI-118-VI-140 (May 1977).

Kaiser Effect; pressure vessels; sources; acoustic emission; crack growth; drill pipe; failure; SP487, pp. 210-238 (Aug. 1977).

"Karat," "Karat gold," “Kt," “Kt gold," “K," or “K gold," marking of; jewelry, marking of; PS70-76.

$\mathrm{KBr}$; KCl; Lexan; LiF; $\mathrm{NaF}$; Plexiglas 55; refractive index; $\mathrm{SrF}_{2}$; thermal coefficient of refractive index; $\mathrm{ZnS} ; \mathrm{ZnSe} ; \mathrm{BaF}_{2}$; $\mathrm{CaF}_{2} ;$ NBSIR 77-1304 (ARPA).

$\mathrm{KBr} ; \mathrm{KCl}$; $\mathrm{LiF} ; \mathrm{NaF}$; refractive index; $\mathrm{SrF}_{2}$; thermal coefficient of refractive index; $\mathrm{ZnSe} ; \mathrm{BaF}_{2} ; \mathrm{CaF}_{2} ;$ NBSIR 77-1219.

$\mathrm{KBr}$; mode Gruneisen parameters; neutron scattering; anharmonicity; dispersion curves; high pressure; 17001 .

$\mathrm{KCl}$; Lexan; LiF; NaF; Plexiglas 55; refractive index; $\mathrm{SrF}_{2}$; thermal coefficient of refractive index; $\mathrm{ZnS} ; \mathrm{ZnSe} ; \mathrm{BaF}_{2} ; \mathrm{CaF}_{2}$; $\mathrm{KBr}$; NBSIR 77-1304 (ARPA).

$\mathrm{KCl}$; $\mathrm{LiF}$; $\mathrm{NaF}$; refractive index; $\mathrm{SrF}_{2}$; thermal coefficient of refractive index; $\mathrm{ZnSe}$; $\mathrm{BaF}_{2} ; \mathrm{CaF}_{2} ; \mathrm{KBr} ;$ NBSIR 77-1219.

$\mathrm{KCN}$; $\mathrm{NaCN}$; order parameter; structure; antiferroelectric; 16972.

Kelvin-Varley divider; ratio standard; voltage dividers; volt boxes; direct voltage measurements; high voltage measurements; 16713

Kerma; neutron; charged particle; dosimeter; dosimetry; efficiency; gamma ray; SP461, pp. 209-218 (Jan. 1977).

Kerma factor; neutrons; activation; Bragg-Gray; dosimetry; energy per ion pair; fluence; SP493, pp. 342-346 (Oct. 1977).

Kernel; lattice vibration; model; moderator; neutron; scattering; thermalization; cross section; diffusion; SP461, pp. 149-162 (Jan. 1977).

Kernel; radiation; streaming; annular; computation; duct; gamma ray; integration; SP461, pp. 132-135 (Jan. 1977).

Kerosine; aniline point; API gravity; aviation fuels; enthalpy of combustion; fuels; gasoline; gravity; heat content; heat of combustion; TN937.

Kerr effect; nitrobenzene; pulse measurement; space charge; calibration; dielectrics; dividers; electric fields; electro-optics; high voltage measurement; insulating fluids; NBSIR 77-1317.

Key; password; personal identification; terminals; verification; ADP security; computer networks; controlled accessibility; encryption; evaluation criteria; FIPS PUB 48.

Key management; known plaintext attack; security; work factor; cryptanalysis; cryptography; encryption; NBSIR 77-1291.

Key word-author indexes; publication abstracts; bibliography; building technology publications; Center for Building Technology; SP457-1.

Key words; publications; abstracts, NBS publications; SP305. Supplement 8.

$\mathrm{KHF}_{2}$; lattice modes; linear triatomic anions; $\mathbf{N a H F}_{2}$; polycrystals; infrared; 16983.

Kinetic constants; LDH; Michaelis constant; NADH; Zimm plot; enzyme; initial velocity; 16911 .

Kinetic isotope effects; potential surfaces; rate constants; transition state theory; transmission coefficient; collinear reactions; deuterium, collinear reactions; hydrogen, collinear reactions; 16914.

Kinetics; mechanisms; photochemistry; pyrolysis; alkyl halides; $\mathrm{CO}_{2}$ laser; infrared; 16783 .

Kinetics; Mercury excimers; time resolved spectroscopy; 16800.

Kinetics; microwave discharge; nitride; plasma; reaction mechanism; silicon; synthesis; thin film; vapor transport; activation parameters; active nitrogen; iodine; 16757 .

Kinetics; polymer glasses; pressure dependence; glasses; 16962.

Kinetics of adsorption from solution; rate law and areal regression of adsorbate; surface area and fixation of chelating rings; 
adhesive bonding to bone mineral; chemisorption of a dental varnish; configuration on surface; 17033 .

KM-System; Menger System; MK-System; dominating set; enclaveless set; graph; hypergraph; König System; J. Res. 82, No. 3, 197-202 (1977).

König System; KM-System; Menger System; MK-System; dominating set; enclaveless set; graph; hypergraph; J. Res. 82, No. 3, 197-202 (1977).

Knight shifts; magnetic moments; metals; nuclear quadrupole effects; nuclear relaxation; compilation; critical evaluation; 17093.

Knowledge; legislation; life safety; regulation; standards; building codes; building safety; control; instruments; SP473, pp. 259-278 (June 1977).

Known plaintext attack; security; work factor; cryptanalysis; cryptography; encryption; key management; NBSIR 77-1291.

Kollsman tester; NBS-Brungraber tester; safety of bathrooms; slip-resistance of bathtub and shower base surfaces; slip-resistance testers; NBSIR 76-1005.

Kramers ions; nutation; spin echoes; spin locking; zero field magnetic resonance; coherence; 16954.

K-shell; measurement; photoelectric effect; photon; atomic number; cross section; SP461, pp. 41-43 (Jan. 1977).

K-shell; photons; Compton scattering; differential cross section; electron binding; gamma rays; SP461, pp. 67-69 (Jan. 1977).

K-shell electron; photon; $x$ ray; bound electrons; cross section; gamma rays; inelastic scattering; SP461, pp. 26-28 (Jan. 1977).

Kubelka-Munk function; reflectance; reflectance standards; thin layer chromatography; chromatography; color matching; color measurement; diffuse reflectance; SP466, pp. 41-55 (May 1977).

KWIC index of standards; engineering standards, index of; index of nuclear standards; SP483.

\section{$\mathbf{L}$}

Labeling; test procedures; appliances; energy conservation; energy efficiency; energy improvement targets; 16885 .

Labels; numerical analysis; OMNITAB II computing system; probability plotting; selection of variables in linear regression; statistical plotting; stem-and-leaf displays; table making; automatic printing; Calcomp plotting; data editing; interactive; NBSIR 77-1276.

Laboratory; oscillating probe; conductivity probe; density; density gradient; experimental; internal wave; SP484, pp. 783802 (Oct. 1977).

Laboratory accreditation; laser technology; multielement analysis; pollutants; speciation; Standard Reference Materials; trace organics; water; accuracy; aerosol; air; collaborative testing; SP464.

Laboratory accreditation; performance criteria; solar energy; standards; buildings; cooling; heating; 16686.

Laboratory automation; teleprocessor; computer control; 16961.

Laboratory facilities; noise measurement; sound measurement; acoustical measurements; acoustics; acoustics facilities; 16764.

Laboratory measurements; modeling; standby loss; water heater; alternating direction; computer simulation; cool down; energy savings; flue damper; heat transfer; implicit; insulation; 17184 .

Laboratory tests; relationships; soil properties; dynamics; field tests; SP477, pp. VI-158-V1-178 (May 1977).

Lamb shift; level shifts; quantum electrodynamics; radiative corrections; relativistic corrections; atomic structure; electron structure; energy levels; fine structure; hydrogenic atoms; JPCRD 6, No. 3, 831-870 (1977).

Laminar flames; numerical solution of flame equations; combustion; differential equations; flame chemistry; flame modeling; NBSIR 76-994.

Laminar flow; plume; pressure distribution; streamlines; temperature distribution; analysis; buoyancy; J. Res. 81 B Nos. 1 and 2, 45-60 (1977).

Lamp; radiance; radiometry; source; spectroscopy; standard; synchrotron; ultraviolet; wall-stabilized; arc; calibration; deuterium; interlaboratory; 17198 .

Land grant university; agricultural research service; agriculture; extension service; information services; SP463, pp. II.3.1II.3.4 (Jan. 1977).

Land pollution; mutagenicity; toxic materials; toxicology; trace contaminants; water pollution; air pollution; analysis; ecology; energy; environmental impact; SP463, pp. III.4.1-III.4.15 (Jan. 1977).

Land use; municipalities; regulation; site design; architectural controls; buildings; design review; SP473, pp. 137-187 (June 1977).

Land use; natural system; performance standards; regulatory process; building codes; carrying capacity; environment; SP473, pp. 189-202 (June 1977).

Land vehicle diagnostics; oil analysis; railroad system diagnostics; signature analysis; wear; failure detection; failure diagnosis; failure prevention; ferrography; SP494.

Lanyards; linemen's equipment; load-extension data; occupational safety and health; performance standard; regulation; tensile testing; worker safety equipment; body belts; body hamess; fall-arrest equipment; fall-safety systems; impact accelerations; impact forces; NBSIR 76-1146.

Larson-Miller parameter; pressure vessel steel; tensile properties; creep-rupture properties; elevated-temperature; fracture mode; 17235.

Laser; laser dye-fluorescence technique; mean concentration; mean velocity; measuring volume; remote sensing; rootmean-square concentration; Schmidt number; simultaneous measurements; spectra; water jet; auto-correlation; SP484, pp. 423-447 (Oct. 1977).

Laser; laser kinetics; laser spectroscopy; optical pumping; dimer laser; electronic transition laser; 17318 .

Laser; lifetime; quenching rate; $\mathrm{CCl}_{2}$; $\mathrm{CFCl}$; fluorescence; 17238.

Laser; metastable; oxygen molecules; photoluminescence; quenching; 16765.

Laser; microwave; National Measurement System; radio measurements; electromagnetic quantities; NBSIR 75-936.

Laser; opto-galvanic effect; spectroscopy; tunable laser; dye laser; flame analysis; flame fluorescence; 16691.

Laser; photochemistry; apparatus; chromatography; experimental; 16895 .

Laser; speed of light; 1.5 microns; frequency measurement; frequency standards; helium neon laser; insulator metal diode; 17336.

Laser; strainmeter; gravitational waves; 17267.

Laser absorption; laser-Stark resonance; molecular spectra; Stark effect; cyanogen fluoride; dipole moment; infrared spectroscopy; 17124.

Laser anemometry; open channel flows; orifice meters; pitotstatic meters; turbine meters; weirs; acoustic flow meters; closed conduit flows; current meters; dye-dilution methods; errors in flow measurement; flow measurement; fluid flow modeling; SP484, Volumes 1 and 2.

Laser attenuation; optical beam splitter; attenuation; NBSIR 77-858.

Laser calorimeter; laser energy; laser power; calorimeter; TN685. 
Laser chemistry; molecular spectra; atomic spectra; data sources; 16837.

Laser doppler anemometry; flow measurement; He Ne laser; SP484, 471-477 (Oct. 1977).

Laser doppler velocimetry; liquid fuels; solid fuels; surface tension; combustion models; flame spread; fluid flow; NBS-GCR76-79.

Laser dye-fluorescence technique; mean concentration; mean velocity; measuring volume; remote sensing; root-meansquare concentration; Schmidt number; simultaneous measurements; spectra; water jet; auto-correlation; convective velocity; SP484, pp. 423-447 (Oct. 1977).

Laser dyes; molecular structure; oxazine dyes; quenching; xanthene dyes; aminocoumarins; carbazine dyes; deuterium effect; fluorescence quantum yield; SP466, pp. 33-40 (May 1977).

Laser effects; luminescence; metal combustion; spectroscopy; titanium alloys; 16796.

Laser energy; laser power; calorimeter; laser calorimeter; TN685.

Laser energy; space flight; spectroscopy; SRM; television captioning; thermophysical; weights and measures; American electroplaters'; calorimeter; cryogenic flow measurement; dental restorations; deep ocean research; federal science; DIM/NBS 6I, No. 4, 1-32 (1977).

Laser fields; theory; two-photon absorption; Raman scattering; Rayleigh scattering; fluorescence; 16848.

Laser, high-intensity; multiphoton absorption; optical interactions; atomic spectra; electromagnetism; 17130.

Laser induced fluorescence; chlorine fluorescence; gas phase; 16844.

Laser ionization; metrication; noise; nondestructive evaluation; research associate program; standards; Alaska pipeline; calibration; CMAC; computers; consumer sounding boards; data; electron probe microanalysis; DIM/NBS 61 , No. 1, 132 (1977).

Laser isotope separation; photochemical enrichment; thiophosgene; chlorine isotope separation; isotope enrichment; U.S. Patent 4,025,406.

Laser kinetics; laser spectroscopy; optical pumping; dimer laser; electronic transition laser; laser; 17318 .

Laser magnetic resonance spectroscopy; FIR optically pumped lasers; frequency and power measurements; 17073 .

Laser materials; photoacoustic spectroscopy; surface absorption; weakly absorbing materials; bulk absorption; frequency dependence; 16860.

Laser materials; photoacoustic spectroscopy; surface absorption; weakly absorbing materials; bulk absorption; frequency dependence; 17313 .

Laser modeling; lifetime; multiconfiguration self-consistentfield; potential energy curves; sodium molecule; transition dipole moment; ab initio calculations; A-values; Franck-Condon factors; 16870 .

Laser power; calorimeter; laser calorimeter; laser energy; TN685.

Laser power measurements; pyroelectric detectors; radiometry; silicon cell; silicon detector; silicon photodetector; absolute radiometry; detector; electrically calibrated detectors; TN954.

Laser pulse; multiphoton absorption; tunnelling; ionization; laser-induced breakdown; 16892 .

Laser radar; laser radar signatures; target standards; NBSIR 77856.

Laser radar signatures; target standards; laser radar; NBSIR 77856.

Laser range measurement; pulse shapes; ranging systems; 16680.

Laser scanner; measurement method; mixer; optics; pre-amplifier; radio receiver; semiconductor device studies; electronic reliability; electronics; $5 r 400-24$.
Laser scanner; oxide rupture; surface deformation; assessment of fatigue damage; exoelectron emission; failure prediction; SP487, pp. 197-209 (Aug. 1977).

Laser scanning; logic flow identification; LSI testing; nondestructive tests; nonlinear region mapping; temperature mapping; active devices; internal logic identification; 17164.

Laser spectroscopy; optical pumping; dimer laser; electronic transition laser; laser; laser kinetics; 17318 .

Laser stimulation; orbiting; saturation; selection rules; van der Waals; atomic collision; excitation transfer; 16695.

Laser strainmeter; power spectrum; earth strain; 17231 .

Laser strainmeter; saturated absorption; 17226.

Laser strainmeter; surveying; distance measurement; earth tides; 17199.

Laser technology; multielement analysis; pollutants; speciation; Standard Reference Materials; trace organics; water; accuracy; aerosol; air; collaborative testing; laboratory accreditation; SP464.

Laser-induced breakdown; laser pulse; multiphoton absorption; tunnelling; ionization; 16892.

Laser-Raman; liquid chromatography; nuclear magnetic resonance; organoarsenic; analysis; aqueous chemistry; arsenic; atomic absorption spectrophotometry; biomethylation; electrochemistry; environment; gas chromatography; 17155.

Lasers; mercury excimers; spectra; two photon; dimers; discharge; 17192 .

Lasers; optogalvanic effect; spectroscopy; wavelength calibration; bandwidth determination; discharge lamp; 17287.

Laser-Stark resonance; molecular spectra; Stark effect; cyanogen fluoride; dipole moment; infrared spectroscopy; laser absorption; 17124 .

Latent heat detection; melting 'and freezing equilibrium; mercury; high pressure; 16750.

Latent heats of vaporization; melting line; orthobaric densities; propane; specific heats; speeds of sound; vapor pressure; densities; enthalpies; entropies; equation of state; internal energies; isobars; isochores; isotherms; Joule-Thomson inversion; NBSIR 77-860.

Lateral load simulation; models; shake tables; testing; dynamic testing; SP470, pp. IX-1-IX-5 (Apr. 1977).

Lateral loads; sheet piles; structural analysis; tests; foundation; SP470, pp. VII-7-VII-60 (Apr. 1977).

Lateral-dose distributions; polystyrene; radiation dosimeters; radiation processing; radiochromie-dye films; $10-\mathrm{MeV}$ electrons; aluminum; beef muscle; carbon; depth-dose distributions; 16999.

Lattice; point group; polymorphism; space group; symmetry; crystal; isostructural materials; JPCRD 6, No. 3, 675-830 (1977).

Lattice; powder method; reduced cell; single crystal; symmetry; identification; 17050.

Lattice constants; peak intensities; powder patterns; reference intensities; standard; $x$-ray diffraction; crystal structure; integrated intensities; Monogr. 25, Section 14.

Lattice dynamics; local mode vibrations; metal hydrides; phonon dispersion curves; cerium deuteride; inelastic neutron scattering; 16965 .

Lattice dynamics; metal hydrides; band mode; elastic constants; interatomic forces; interstitial; 17004 .

Lattice dynamics; metal-hydrogen systems; palladium-deuteride ( $\left(\mathrm{Pd}_{\mathbf{0 . 6 3}}\right)$; phonon lineshapes; defect crystal structures; inelastic neutron scattering; 16964.

Lattice dynamics; metals; neutron scattering; quasielastic scattering; review; diffusion; hydrogen; 16970.

Lattice mobility; neutral impurity scattering mobility; $n$-type silicon; resistivity; scattering mechanisms; temperature; dopant density; electron mobility; ionized impurity scattering mobility; SP400-33.

Lattice modes; linear triatomic anions; $\mathrm{NaHF}_{2}$; polycrystals; infrared; $\mathrm{KHF}_{2} ; 16983$. 
Lattice scattering; neutral impurity scattering; $\boldsymbol{n}$-type silicon; resistivity; temperature; dopant density; electron-electron scattering; electron mobility; ionized impurity scattering; 17147.

Lattice symmetry; stability; BBGKY hierarchy; bifurcation; crystal; free energy; 16986.

Lattice vibration; model; moderator; neutron; scattering; thermalization; cross section; diffusion; kernel; SP461, pp. 149. 162 (Jan. 1977).

Laves phase; magnetic excitation; magnetism; rare earths; spin waves; erbium; 16963.

Law enforcement; lead; lead poisoning; airborne lead; ammunition; firing ranges; $S P 480-26$.

Law enforcement; liquefied natural gas; metric tons; polyethylene; sound; spinach; SRM; systems and software; telecommunications; computer use; conservation; data; earth's measurement; energy; health records; hydrogen; DIM/NBS 61, No. 5, 1-32 (1977).

Law enforcement: optics; security and law enforcement; 17339. Law enforcement equipment report; Law Enforcement Standards Laboratory; mobile digital equipment; National Institute of Law Enforcement and Criminal Justice; communications; digital communications; guideline; 16996.

Law Enforcement Standards Laboratory; mobile digital equipment; National Institute of Law Enforcement and Criminal Justice; communications; digital communications; guideline; law enforcement equipment report; 16996.

Law Enforcement Standards Laboratory; police equipment; reports and guidelines; survey; communications equipment priorities; equipment standards; $S P 480-13$.

Lawn mowers; psychophysics; reaction time; safety; standards; anthropometric probes; consumer products; human factors; 17200.

Lawn mowers; safety; standards; consumer products; generic probes; human factors; NBSIR 77-1294.

Laws and regulations; metrication; metric system; National Conference on Weights and Measures; weights and measures; education for metric; 17037 .

Laws and regulations; metrication; national laboratory accreditation; retail meat identity standards; tolerance application; vapor recovery; weights and measures; checking prepackaged commodities; computer assisted. check-out systems; consumer affairs; cordage products; $S P 471$.

LDH; Michaelis constant; NADH; Zimm plot; enzyme; initial velocity; kinetic constants; 16911 .

LDS's; measurement services; standardization; AID; assistance; developing economies; foreign relations; industrializing nations; international relations; NBSIR 76-I152.

Lead; lead poisoning; airborne lead; ammunition; firing ranges; law enforcement; SP480-26.

Lead; ligand; mercury; nanogram sensitivity; organometallic compounds; speciation; tin; arsenic; element-specific detector; flameless atomic absorption; flow monitoring; high-pressure liquid chromatography; 17297.

Lead; microwaves; niobium; superconductivity; tunnelling dielectric constant; Josephson effect; 16946.

Lead detection; metric; oxygen; technology; cryocooler; EMI problems; energy problems; energy savings; exchange program; DIM/NBS 61. No. 10, 1-32 (1977).

Lead electrode; natural waters; rainwater; seawater; sulfate; environmental analysis; ion-selective electrode; 16771 .

Lead paint; lead poisoning; surveys; $x$-ray fluorescence; children; data analysis; housing; NBSIR 77-1250.

Lead paint; lead poisoning; surveys; blood lead; children; data analysis; housing; NBSIR 77-1293.

Lead poisoning; airborne lead; ammunition; firing ranges; law enforcement; lead; $S P 480-26$.

Lead poisoning; surveys; blood lead; children; data analysis; housing; lead paint; NBSIR 77-1293.

Lead poisoning; surveys; $x$-ray fluorescence; children; data analysis; housing; lead paint; NBSIR 77-1250.
Leak detection; semiconductor hermeticity; doubled hermetic enclosure; gas infusion of leaks; hermeticity; 16935.

Leak testing; liquid penetrant; magnetic particle; measurements; nondestructive testing; optical; radiography; standards; ultrasonics; visual; acoustic emission; inspection; 17042.

Leak testing; measurement technology; microcalorimetry; pacemaker leads; process control; reliability; screen tests; semiconductor devices; batteries; cardiac pacemakers; hermeticity; hybrid devices; $S P 400-42$.

Leak tests; line-width measurement; measurement methods; microelectronics; optical flying-spot scanner; oxidation particle impact noise detection test; passivation overcoats; photovoltaic method; power-device grade silicon; radioisotope method; resistivity; $S P 400-29$.

Leakage; nondestructive tests; semiconductor devices; standards; hermetic seals; 16943.

Least squares; mass calibration; statistical design; weighing design; design of experiments; TN952.

Least squares algorithms; regression; statistics; Cholesky decomposition; Givens transformations; Gram-Schmidt orthogonalization; Householder transformations; 16833.

Least sum of absolute deviations; Mayer, Tobias (1723-1762); method of averages; weighted mean; weighted median; zero sum of residuals; Boscovich, Roger Joseph (1711-1787); Cotes, Roger (1682-1716); Euler, Leonard (1707-1783); 17314.

Least weight; optimization; structures; frequency response; SP470, pp. VI-22-VI-32 (Apr. 1977).

Legal metrology; measurement; trade facilitation; flow measurement; industry; intergovernmental; international standards; SP484, pp. $921-927$ (Oct. 1977).

Legendre polynomial; neutron; random sampling; scattering; shielding; angle; centre of mass; coefficients; computations, cross-section; SP461, pp. 100-105 (Jan. 1977).

Legendre polynomial; scattering; semi analytical; spatial; transmission; anisotropy; charged particle; computer code; energyangle; integral; SP461, pp. 140-143 (Jan. 1977).

Legislation; life safety; regulation; standards; building codes; building safety; control; instruments; knowledge; SP473, pp. 259-278 (June 1977).

Legislation; regulations; solar energy; standards; state-of-the-art study; buildings; energy conservation; enforcement; NBSIR 77-1259.

Legislation; rules and regulations; statewide codes; summary tables; building construction; building regulations; cities; code uniformity; enforcement; NBSIR 77-1390.

Legislation; solar; standards; State; architecture; buildings; design; energy; NBSIR 77-1297.

Length measurement; parallelism; flatness; gage blocks; interferometry; NBSIR 73-239.

Length measurement; partial fringe; wavelength measurement; dimensional metrology; exact fringes; fractional fringe; interferometer; 17048.

Lennard-Jones; metastable states; Monte Carlo; algorithm; 16786.

LESL; NILECJ; privacy; scramblers; speech scramblers; voice privacy; voice scramblers; SP480-8.

Less developed countries; measurement services; standardization; testing facilities; cottage industry; developing countries; Guyana; NBSIR 76-1180.

LET; model; neutron; OER; one-hit detector; pion; radiation; track; cell; delta ray; dose; ions; SP461, pp. 183-187 (Jan. 1977).

LET; neutrons; yields; dosimetry; energy spectra; high energy; NBSIR 77-1279, pp. 19-23 (July 1977).

Leuco dye cyanide; radiation dosimeter; radiation sensor; triphenylmethane cyanide dye precursor; ultraviolet; $x$ rays; gamma rays; ionizing radiation; U.S. Patent 4,006,023. 
Level measurement; level-to-flow rate conversion; liquid flow; open channel flow measurement; secondary measuring device; flow measurement, water; flow meters; instruments, flow measurement; SP484, pp. 91-108 (Oct. 1977).

Level shifts; quantum electrodynamics; radiative corrections; relativistic corrections; atomic structure; electron structure; energy levels; fine structure; hydrogenic atoms; Lamb shift; JPCRD 6, No. 3, $831-870$ (1977).

Level-to-flow rate conversion; liquid flow; open channel flow measurement; secondary measuring device; flow measurement, water; flow meters; instruments, flow measurement; level measurement; SP484, pp. 91-108 (Oct. 1977).

Levitation; superconductivity; ampere definition; electrical units; fundamental constants; Josephson effect; 16876.

Lexan; LiF; NaF; Plexiglas 55; refractive index; $\mathrm{SrF}_{2}$; thermal coefficient of refractive index; $\mathrm{ZnS} ; \mathrm{ZnSe} ; \mathrm{BaF}_{2} ; \mathrm{CaF}_{2} ; \mathrm{KBr}$; $\mathrm{KCl}$; NBSIR 77-1304 (ARPA).

$\mathrm{Li}$; neutron sources; thick-target yields; Be; NBSIR 77-1279, pp. 10-14 (July 1977).

Liability losses; plaintiff and products liability; products liability losses; SP487, pp. 253-256 (Aug. 1977).

Liability losses; products liability losses; defendant and products liability; SP487, pp. 247-252 (Aug. 1977).

Library and information sciences; review; Federal library and information activities; 16743.

Library automation; machine-readable; MARC; standards; bibliographic information; data bases; information retrieval; SP463, pp. VIII.1.1-VIII.1.4 (Jan. 1977).

Library holdings, NBS Library; NBS periodicals; periodicals; proceedings; serials; standards; transactions; annual reports; diffusion in metals; fire; journals; NBSIR 77-1215.

Library of Congress; materials; materials data; materials information; N.A.S.A.; U.S.D.A; Commerce; Defense; E.R.D.A.; Federal agencies; interagency review; Interior; SP463.

Licensing; measurements; nuclear power; dosimetry; SP493, pp. 137-145 (Oct. 1977).

LiF; MHD; momentum transfer; electron collisions; 17344.

LiF; momentum transfer cross sections; polar molecules; electron-molecule collisions; 17027.

LiF; NaF; Plexiglas 55; refractive index; $\mathrm{SrF}_{2}$; thermal coefficient of refractive index; $\mathrm{ZnS} ; \mathrm{ZnSe} ; \mathrm{BaF}_{2} ; \mathrm{CaF}_{2} ; \mathrm{KBr} ; \mathrm{KCl}$; Lexan; NBSIR 77-1304 (ARPA).

LiF; $\mathrm{NaF}$; refractive index; $\mathrm{SrF}_{2}$; thermal coefficient of refractive index; $\mathrm{ZnSe} ; \mathrm{BaF}_{2} ; \mathrm{CaF}_{2} ; \mathrm{KBr}$; KCl; NBSIR 77-1219.

LiF; optical absorption; spectral distribution; thermoluminescence; gamma rays; irradiation; SP461, pp. 222-226 (Jan. 1977).

LiF; response; sensitivity; supralinear; thermoluminescence; dose; gamma rays; SP461, Pp. 227-230 (Jan. 1977).

Life cycle; performance standards; pipe; plumbing; reduced-size vents; sanitary drainage system; venting; cost savings; drainage-waste-vent; economics; 17296.

Life cycle costing; life cycle performance; life testing, and performance testing; accelerated testing; consumer products; cost estimation; NBSIR 77-1212.

Life cycle costing; printer ribbons; procurement experiment; refrigerator-freezers; water heaters; window air conditioners; NBS-GCR-ETIP 77-37.

Life cycle costing; procurement policy; specifications; value incentive; Experimental Technology Incentives Program (ETIP); Federal Supply Service; NBS-GCR-ETIP 76-26.

Life cycle costing; procurement policy; specifications; value incentive; Experimental Technology Incentives Program (ETIP); Federal Supply Service; NBS-GCR-ETIP 76-27.

Life cycle performance; life testing, and performance testing; accelerated testing; consumer products; cost estimation; life cycle costing; NBSIR 77-1212.

Life safety; mapping; model; nursing homes; rescue; verbal communicative; alarm; architecture; design implication; emergency actions; emergency communicative; emergency decisions; escape; fires; human behavior; human response; NBS-GCR-77-93.

Life safety; regulation; standards; building codes; building safety; control; instruments; knowledge; legislation; SP473, pp. 259-278 (June 1977).

Life testing, and performance testing; accelerated testing; consumer products; cost estimation; life cycle costing; life cycle performance; NBSIR 77-1212.

Life-cycle cost; optimization; performance standards; resource impact factors; resources; social optimum; standards; building economics; economic efficiency; economics; energy; energy conservation; 17302.

Life-cycle costing; patrol cars; personal car plan; police fleet administration; take-home car program; breakeven analysis; 17299.

Life-cycle costing; project procurement; building performance; building process; building systems; construction management; design/build; SP476.

Life-cycle costing; retrofitting; solar; building design; cost; energy conservation; energy standards; fenestration; 17107.

Lifestyle factors; physical environment; residential housing; socio-physical determinants; systems theory; energy consumption; input/output models; SP473, pp. 69-83 (June 1977).

Lifetime; multiconfiguration self-consistent-field; potential energy curves; sodium molecule; transition dipole moment; ab initio calculations; $A$-values; Franck-Condon factors; laser modeling; 16870.

Lifetime; quenching rate; $\mathrm{CCl}_{2} ; \mathbf{C F C l}$; fluorescence; laser; 17238.

Lifetimes; mean life; resonance radiation; transition probability; Ut; uranium; delayed coincidence; $g f$ value; imprisonment; 17292.

Lifetimes; $\mathrm{N}_{2} \mathrm{O}$; oxygen; radiation; time-of-flight; atomic; experimental; 16812 .

Lifting; manual materials handling; physiology; psychophysics; safety; warranty; anthropometry; biomechanics; carrying; consumer product portability; ergonomics; human factors; NBSIR 76-1092.

Ligand; mercury; nanogram sensitivity; organometallic compounds; speciation; tin; arsenic; element-specific detector; flameless atomic absorption; flow monitoring; high-pressure liquid chromatography; lead; 17297.

Light design; luminaire effectiveness; luminance factor; office lighting; sphere illumination; body shadow; contrast rendition; hand calculator; illuminating engineering; NBSIR 771303.

Light scattering; liquid state; molecular dynamics; neutron scattering; shear wave; sțatistical mechanics; time correlation function; transverse current; ultrasonics; correlation function; density fluctuations; fluctuations; hydrodynamics; 16711 .

Light scattering; macromolecules; rodlike; rodlike macromolecules; rods, bent; rods, semirigid; semirigid rods; bent rods; form factors; 17253 .

Light scattering; optical measurement of roughness; surface finish; surface roughness; NBSIR 73-219.

Light scattering; polymers; proteins; solid standards; antibodies; antigens; biological polymers; immunochemical analysis; SP466, pp. 95-98 (May 1977).

Light source; mini-arc; radiometry; spectral radiance; standard; ultraviolet; argon; 16778 .

Lighting; performance standard; thermal performance; ventilation; water heating; air leakage; building design; energy conservation; fenestration; HVAC systems; illumination; insulation; NBSIR 74-452.

Lighting; task lighting; energy conservation; illumination; illumination levels; 17293.

Limit states design; masonry construction; materials testing standardization; mathematical models; rehabilitation; retrofit; 
seismic design; structural design; structural research; building codes and standards; design criteria; BSS106, pp. 40-59 (Sept. 1977).

Limiting resolution; relative spectral response; signal-to-noise ratio; square wave patterns; television cameras; contrast; contrast transfer function; image quality; $S P 480-25$.

Limiting resolution; shading; signal-to-noise ratio; spectral response; standards; television cameras; total response; contrast transfer function; distortion; 17233.

Limits of detection; sensitivity test; TNT; vapor generator; vapor pressure; DNT; EGDN; explosive detection; 16830.

Linac; reactor filtered beam; standard; ${ }^{6} \mathrm{Li}(\mathrm{n}, \alpha) \mathrm{T}$; angular distribution; fast neutrons; SP493, pp. 10-13 (Oct. 1977).

Line broadening; satellites; thallium; 16752.

Line identification atlas; rovibronic assignments; spectral analysis; visible absorption spectroscopy; high-resolution spectrum; iodine spectrum; J. Res. 81 A No. 1, 25-80 (1977).

Line identifications; atomic processes; 16659.

Line identifications; nebulae, individual; radio sources, lines; interstellar, molecules; 16664.

Line profiles, stellar; radiative transfer; ultraviolet spectra; Arcturus; chromospheres, stellar; 17056.

Line strength; atomic spectroscopy; Hartree-Fock; ions; 17229.

Linear algebra; matrix; minimum polynomials; control theory; J. Res. 82, No. 2, 129-132 (1977).

Linear burning rate; extinguishability; fabric flammability; flammability ranking; heat flux; heat transfer rate; NBS-GCR76-77.

Linear differential equations; transition point; turning point; asymptotic analysis; Bessel functions; error analysis; 16899.

Linear molecules; rotational line widths; semiempirical potential; theoretical potential; anisotropic interactions; $\mathrm{HCl}-\mathrm{Ar}$; 16799.

Linear polyethylene; Mark-Houwink equation; NBS Standard Reference Material 1475; theta solvents; 3,3,5-trimethylhexyl acetate; biphenyl; chain dimensions; dodecanol; 16710 .

Linear specific gravity compensation; positive displacement flowmeters; turbine flowmeters; digital compensation techniques; fossil fuel limitations; SP484, pp. 821-846 (Oct. 1977).

Linear triatomic anions; $\mathrm{NaHF}_{2}$; polycrystals; infrared; $\mathrm{KHF}_{2}$; lattice modes; 16983.

Linearity; photodetectors; silicon detectors; absolute spectral response; detector uniformity; 16754.

Linearity; shedding frequency; vortex flowmeter; vortex generating element; vortex shedding; SP484, pp. 549-570 (Oct. 1977).

Linemen's equipment; load-extension data; occupational safety and health; performance standard; regulation; tensile testing; worker safety equipment; body belts; body harness; fall-arrest equipment; fall-safety systems; impact accelerations; impact forces; lanyards; NBSIR 76-1146.

Line-width measurement; measurement methods; microelectronics; optical flying-spot scanner; oxidation particle impact noise detection test; passivation overcoats; photovoltaic method; power-device grade silicon; radioisotope method; resistivity; resistivity variations; SP400-29.

Linewidth measurements; micrometer eyepiece; microscope calibration; optical microscope; photomasks; photomask metrology; optical microscope; shearing eyepiece; dimensional standards; filar eyepiece; 17063 .

Linewidth measurements; microelectronics; micrometrology; optical microscope; photoelectric microscope; photomask; scanning electron microscope; filar eyepiece; image-shearing eyepiece; integrated circuits; 17066 .

Liouville-Green approximation; ordinary differential equation; turning point; asymptotic analysis; Bessel functions; boundary-value problem; connection formula; diffraction theory; error analysis; 16805.
Liouville-Green approximation; potential barrier; potential well; turning points; Whittaker functions; WKBJ approximation; connection formulas; eigenvalue problems; 17142 .

Liquefaction; sand; soils; tests; undisturbed sampling; density; SP477, pp. VI-141-V1-157 (May 1977).

Liquefaction; sand layer; shake table; vibration tests; void ratios; earthquakes; SP470, pp. V-16-V-35 (Apr. 1977).

Liquefaction; settlement; soils; alluvial deposits; earthquakes; epicentral distance; SP470, pp. V-1-V-15 (Apr. 1977).

Liquefied; petroleum; standards; container; corrosion; explosion; extinguisher; fire; gas; injury; NBSIR 77-1217.

Liquefied natural gas; metric tons; polyethylene; sound; spinach; SRM; systems and software; telecommunications; computer use; conservation; data; earth's measurement; energy; health records; hydrogen; law enforcement; DIM/NBS 61, No. 5, 1-32 (1977).

Liquefier; component efficiency; cryogenics; efficiency; energy recovery; hydrogen; NBSIR 77-862.

Liquid; mass flow; measurement; cryogenic; flow; gas; SP484, pp. 881-893 (Oct. 1977).

Liquid; oxygen; PVT; quality; slush; solid; vapor; computer programs; enthalpy; entropy; hydrogen; internal energy; NBSIR 77-859.

Liquid; perfect gas; propagation; shear; transverse gradient; wavenumber; duct; fundamental mode; 17215 .

Liquid; polymer; pressure; PVT; pyrolysis; refractive index; thermal expansion; thermodynamic; compressibility; densification; glass; glass transition; J. Res. 81 A Nos. 2 and 3, 283297 (1977).

Liquid; polymer; pressure; thermodynamic; compressibility; densification; glass; glass transition; hole theory; 16774.

Liquid argon; liquid nitrogen; liquid oxygen; LNG; measurement; transfer standards; 17162 .

Liquid chromatography; liquid chromatography detectors; metal specific detector; photoionization detector; reaction detector; cerium oxidation detector; 17278 .

Liquid chromatography; nuclear magnetic resonance; organoarsenic; analysis; aqueous chemistry; arsenic; atomic absorption spectrophotometry; biomethylation; electrochemistry; environment; gas chromatography; laser-Raman; 17155.

Liquid chromatography; oil refinery; petroleum; benzo(a)pyrene; gas chromatography; gas chromatographymass spectrometry; hydrocarbons; 16886 .

Liquid chromatography detectors; metal specific detector; photoionization detector; reaction detector; cerium oxidation detector; liquid chromatography; 17278.

Liquid crystal; naphthalene homologues; nematic phase; supercooled phase; gas-liquid chromatography; 16673.

Liquid filters; standard reference material; transfer standards; absorbance linearity; accuracy of transmittance or absorbance scale; acidic potassium dichromate solutions; calibration of ultraviolet spectrometers; certification of apparent specific absorbance; SP260-54.

Liquid filters; transfer standards; ultraviolet absorbance standards; absorbance linearity; accuracy; acidic potassium dichromate solutions; calibration of ultraviolet spectrophotometers; SP466, pp. 121-126 (May 1977).

Liquid flow; open channel flow measurement; secondary measuring device; flow measurement, water; flow meters; instruments, flow measurement; level measurement; level-to-flow rate conversion; SP484, pp. 91-108 (Oct. 1977).

Liquid flow rate; liquid velocity; open channel flow rate; open channel velocity; acoustic flow rate; acoustic velocity; flow rate; SP484, pp. 243-266 (Oct. 1977).

Liquid fuels; solid fuels; surface tension; combustion models; flame spread; fluid flow; laser doppler velocimetry; NBSGCR-76-79.

Liquid helium; stainless steels; steels; superalloys; titanium alloys; aluminum alloys; crack propagation; fatigue; iron alloys; 16928. 
Liquid helium bubble; metastable helium atoms; helium absorption; 16818 .

Liquid helium storage; supercritical helium; cryogenic helium supply system; cryogenic storage; helium; helium supply system; high density helium storage; NBSIR 76-850.

Liquid junction; $\mathrm{pH}$ analyzers; $\mathrm{pH}$ error; $\mathrm{pH}$; physiologic $\mathrm{pH}$; tris $\mathrm{pH}$ buffer; clinical $\mathrm{pH} ; 16772$.

Liquid, magnetic; modification; suspension; absolute measurements; barium ferrite buoy; densimeter; experimental; 16792 .

Liquid metals; magnetohydrodynamics; pipe flow; resistance coefficients; turbulence; 16821 .

Liquid metals; nitrogen; phosphorus; ternary diffusion; thermomigration; alloys; antimony; arsenic; bismuth; copper; diffusion; electromigration; JPCRD 6, No. 1, 1-50 (1977).

Liquid methane; LNG; cryogenic densimeters; density reference system; TN697.

Liquid methane; LNG; densimeters; density reference system; TN698.

Liquid methane; LNG; densimeters; density reference system; NBSIR 77-852.

Liquid nitrogen; liquid oxygen; LNG; measurement; transfer standards; liquid argon; 17162.

Liquid oxygen; LNG; measurement; transfer standards; liquid argon; liquid nitrogen; 17162 .

Liquid penetrant; magnetic particle; measurements; nondestructive testing; optical; radiography; standards; ultrasonics; visual; acoustic emission; inspection; leak testing; 17042.

Liquid retention or clingage tests; precision; prover; Research Associate Program; standards inspection procedure; temperature correction; test measure; test measure evaluation; "to contain"; "to deliver"; volumetric calibration; accuracy; NBSIR 77-1214.

Liquid state; molecular dynamics; neutron scattering; shear wave; statistical mechanics; time correlation function; transverse current; ultrasonics; correlation function; density fluctuations; fluctuations; hydrodynamics; light scattering; 16711 .

Liquid velocity; open channel flow rate; open channel velocity; acoustic flow rate; acoustic velocity; flow rate; liquid flow rate; SP484, pp. 243-266 (Oct. 1977).

Liquid velocity measurement; non-intrusive flowmeter; ultrasonic beams; cross-correlation analysis; SP484, pp. 319 333 (Oct. 1977).

Liquid zone; shape; stability; surface tension; floating zone; gravity; 17009.

Literature; NEISS; recommendations; review; safety; sports; accident; associated factors; injuries; NBSIR 77-1218.

Literature review; mathematical models; room fire; scaling models; theoretical; "flashover"; fluid flow; full-scale; heat transfer; 17283 .

Lithium; measurements; neutron; total; alpha; boron; branching ratio; compilation; cross-section; elastic; SP493, pp. 67-84 (Oct. 1977).

Lithium; photoexcitation cross sections; Stieltjes-Tchebycheff technique; configuration interaction; cross sections; ionization cross sections; 17319 .

Live loads; load surveys; probability theory; structural engineering; buildings (codes); 17305.

Live loads; load surveys; structural engineering; buildings; 16708.

Live test demonstrations; selection of ADPS; Air Force Academy; benchmark tests; development of benchmarks; SP500-18, pp. 71-74 (Sept. 1977).

$\mathrm{Li}_{2} ; \mathrm{Na}_{2}$; satellite; spectrum; 16912 .

$\mathrm{Li}(\mathrm{d}, \mathrm{n})$ source; $\mathrm{Li}(\mathrm{p}, \mathrm{n})$ source; neutron angular distributions; neutron energy distributions; neutrons; nuclear reactions; thick-target yields; $B e(d, n)$ source; $B e(p, n)$ source; $C(d, n)$ source; $\mathrm{D}(\mathrm{d}, \mathrm{n})$ source; dosimetry; NBSIR 77-1279.

$\mathrm{Li}(\mathrm{p}, \mathrm{n})$ source; neutron angular distributions; neutron energy distributions; neutrons; nuclear reactions: thick-target yields;
$\operatorname{Be}(d, n)$ source; $B e(p, n)$ source; $C(d, n)$ source; $D(d, n)$ source; dosimetry; $\mathrm{Li}(\mathrm{d}, \mathrm{n})$ source; NBSIR 77-1279.

$\mathrm{Li}^{6}$ sandwich surface barrier spectrometer; proton recoil surface barrier spectrometer; energy and flux calibration; fast neutrons; isotropic neutrons; SP493, pp. 61-66 (Oct. 1977).

LNG; cryogenic densimeters; density reference system; liquid methane; TN697.

LNG; densimeters; density reference system; liquid methane; TN698.

LNG; densimeters; density reference system; liquid methane; NBSIR 77-852.

LNG; measurement; transfer standards; liquid argon; liquid nitrogen; liquid oxygen; 17162 .

LNG; mixture(s); Clausius-Mosotti; densitometer (capacitançe); density; dielectric constant; 17071 .

Load calculation; MIUS; modular integrated utility system; simulation; utility services; computer programs; cooling; energy analysis; financial analysis; heating; NBSIR 77-1307.

Load capacity; masonry walls; shear walls; splitting strength; ultimate capacity; brick; clay masonry; concrete block; concrete masonry; failure modes; BSS106, pp. 177-197 (Sept. 1977).

Load cell; proving rings; testing machines; tolerance; verification; calibration; 16915 .

Load cell; static force; force; force calibration; interlaboratory comparison; NBSIR 76-1145.

Load factors; performance approach; performance criteria; reliability analysis; reliability-based design; resistance factors; structural engineering; 17306.

Load failure; pipe hangers; residential occupancies; automatic sprinklers; care type occupancies; fire endurance; NBSIR 771282.

Load surveys; probability theory; structural engineering; buildings (codes); live loads; 17305.

Load surveys; structural engineering; buildings; live loads; 16708.

Load-calculation; rating; residential; space heating; testing; air conditioning; comfort; heat pump; 17006.

Load-extension data; occupational safety and health; performance standard; regulation; tensile testing; worker safety equipment; body belts; body harness; fall-arrest equipment; fall-safety systems; impact accelerations; impact forces; lanyards; linemen's equipment; NBSIR 76-1146.

Loads (forces); natural analysis; tall buildings; wind profiles; boundary layer; hurricanes; SP477, pp. II-30-II-40 (May 1977).

Local government; model codes; state-local relations; statewide codes; uniformity; building regulation; code administration; enforcement; funding; SP473, pp. 225-240 (June 1977).

Local mode vibrations; metal hydrides; phonon dispersion curves; cerium deuteride; inelastic neutron scattering; lattice dynamics; 16965.

Localization; manikin; ears; head diffraction; hearing; interaural intensity differences; interaural time differences; 17052 .

Localized corrosion; pitting; repassivation kinetics; stress corrosion; crevice corrosion; ellipsometry; 16990.

Localized corrosion; repassivation; sensitization; stainless steel; crevice corrosion; iron-molybdenum alloys; NBSIR 76-1170.

Location theory; minimax; networks; facility location; J. Res. 82, No.' 1, 65-72 (1977).

Location theory; minimax; networks; facility location; J. Res. 82, No. 1, 73-80 (1977).

Locks; security standards; burglary resistance; door assemblies; door components; doors; frames; hardware; hinges; 16714.

Logic flow identification; LSI testing; nondestructive tests; nonlinear region mapping; temperature mapping; active devices; internal logic identification; laser scanning; I7I64.

Log-normal distribution; small-scale turbulence; boundarylayer; higher-order moments; hot-wire anemometry; 16820. 
London moment; magnetic torque; relativity; satellite experiment; superconducting; electrodynamics; gyroscope; 16795.

Long-term frequency stability; NBS time scale; phase modulation; (active-passive) hydrogen maser; amplitude modulation; cavity frequency; environmental sensitivity; frequency lock loop; 17211 .

Long-term storage; microbiologicals; organics; pesticides; radionuclides; sample handling; sampling; trace elements; chemical analysis; environmental samples; 16729.

Loop antenna; magnetic field probe; tangential sensitivity; broadband probe; dipole antenna; dynamic range; electric field probe; isotropic probe; NBSIR 77-868.

Loran-C; low frequency; radio broadcasts; standard frequencies; television color subcarrier; time and frequency calibration methods; time calibration; time signals; frequency calibration; high frequency; TN695.

Lorenz ratio; low temperature; standard reference material; thermal conductivity; thermopower; tungsten; electrical resistivity; high temperature; 16877.

Lorenz ratio; low temperature; nickel alloys; thermal conductivity; thermopower; copper; electrical resistivity; iron alloys; 16878.

Lorenz ratio; magnetic field; single crystal; thermal conductivity; beryllium; cryogenics; electrical conductivity; heat switch; 17088.

Losses; residential fire; standard; upholstered furniture; cost plus loss; decision analysis; fire; furniture fire; NBSIR 771381 .

Lossless two-port; scattering parameters; 16663.

Loudspeaker; microphone; piezoelectric polymer; sound source; vibration; headphone; 16952.

Low cycle fatigue; mechanical properties; microstructure; modelling; paper; pore size; statistical analysis; Weibull distribution; durability; fatigue; fiber length; flexing; 16681 .

Low frequency; radio broadcasts; standard frequencies; television color subcarrier; time and frequency calibration methods; time calibration; time signals; frequency calibration; high frequency; Loran-C; TN695.

Low income; low-rise buildings; sites and services; socioeconomic; structural design; wind-resistant; architectural; design; housing; BSS100-5.

Low temperature; magnetothermal conductivity; nickel alloy; stainless steel; thermal conductivity; copper; 16864 .

Low temperature; mechanical properties; research program; structural materials; thermal properties; 16863.

Low temperature; nickel alloys; thermal conductivity; thermopower; copper; electrical resistivity; iron alloys; Lorenz ratio; 16878 .

Low temperature; nickel alloys; titanium alloys; aluminum alloys; ferritic steels; fracture toughness; 17086.

Low temperature; niobium-titanium alloys; superconducting wire; tensile properties; composite; copper; 16862 .

Low temperature; radical; allylic; combination; disproportionation; 16966.

Low temperature; standard reference material; thermal conductivity; thermopower; tungsten; electrical resistivity; high temperature; Lorenz ratio; 16877.

Low temperature; susceptibility; alloys; copper; electrical resistivity; iron; 17135 .

Low temperature polymer; cryogenic; dielectric loss; dissipation factor; high voltage; 16782 .

Low temperature tests; mechanical properties; nickel alloys; superalloys; fatigue; fracture; 16801 .

Low-level counting; plastic phosphors; scintillation counting; $\beta$ ray detection; $l 7268$.

Low-Q enclosures; radiated susceptibility; TEM transmission cell; electronic equipment; EMC measurements; 16668.

Low-rise buildings; masonry walls' structural design; technology transfer; timber roofs; timber walls; wind effects; codes and standards; connectors; fastenare. bcrinn ?
Low-rise buildings; sites and services; socio-economic; structural design; wind-resistant; architectural; design; housing; low income; BSSIO0-5.

Low-rise buildings; socio-economics; structural connections; wind loads; codes and standards; disaster mitigation; housing; SP477, pp. 1-70-I-78 (May 1977).

Low-rise buildings; socio-economics; structural connections; technology transfer; wind loads; codes and standards; disaster mitigation; housing; BSS100-1.

Low-rise buildings; wind study; ANS1 $58 ; 17115$.

LSI testing; nondestructive tests; nonlinear region mapping; temperature mapping; active devices; internal logic identification; laser scanning; logic flow identification; 17164.

L-type doubling constants; microwave spectrum; rotational constants; Stark effect; vibrational transition moment; acetylene$d_{2} ; 16689$.

Lubricant; metals; properties; tricresyl phosphate; zinc dithiophosphate; antiwear additives; interaction; SP487, Pp. 172-185 (Aug. 1977).

Lubricants; materials of design; product liability; reliability of design; techniques of design; validation of design; coating materials; composite materials; design; failure avoidance; failure prevention; SP487.

Lubricating oil; oil specifications; petroleum standards; petroleum test methods; recycled oil; re-refined oil; used oil; waste oil; engine oil; fuel oil; hydraulic oil; industrial oils; SP488.

Lubrication; rheology; starvation; traction; bearings; computer programs; elastohydrodynamics; failure analysis; film thickness; gears; Hertz contacts; SP487, pp. 137-153 (Aug. 1977).

Lumber; mechanical properties; paper; pulp; timber; wood; wood products; AIDS; bark; forest products; glues and gluing; information service; SP463, pp. II.1.1-1I.1.4 (Jan. 1977).

Luminaire effectiveness; luminance factor; office lighting; sphere illumination; body shadow; contrast rendition; hand calculator; illuminating engineering; light design; NBSIR 77 1303.

Luminance factor; office lighting; sphere illumination; body shadow; contrast rendition; hand calculator; illuminating engineering; light design; luminaire effectiveness; NBSIR 771303.

Luminescence; luminescence standards; phosphors; quantum efficiencies; radiant efficiencies; UV excitation; x-ray excitation; cathode-ray excitation; SP466, pP. 13-19 (May 1977).

Luminescence; magnesium; metal flames; calcium; $\mathrm{CO}_{2}$ laser; 17163.

Luminescence; metal combustion; spectroscopy; titanium alloys; laser effects; 16796.

Luminescence; photoacoustic spectrometer; piezocalorimeter; transducers; triplet formation; absolute quantum efficiency; absolute quantum yield; calorimetry; SP466, PP. 25-31 (May 1977).

Luminescence; quantum yield; spectrophotometry; standard reference materials; standardization; accuracy; critical parameters; diffuse reflectance; fluorescence; instrumentation; SP466.

Luminescence; quantum-flat actinometer; quantum yield; absolute yield; chemical actinometry; correction factors; SP466, pp. 21-24 (May 1977).

Luminescence standards; phosphors; quantum efficiencies; radiant efficiencies; UV excitation; $x$-ray excitation; cathode-ray excitation; luminescence; SP466, pp. 13-19 (May 1977).

Lunar ranging; plate tectonics; geodesy; gravimetry; 16896.

\section{M}

Machinability Data Center; machining costs; machining data banks; Machining Data Handbook; machining data publications; data banks; information analysis centers; SP463, pP. IV.5.1-IV.5.8 (Jan. 1977). 
Machine code; relocatable code; assembler; cross-assembler; NBSIR 77-1230.

Machine-readable; MARC; standards; bibliographic information; data bases; information retrieval; library automation; SP463, pp. VIII.1.1-VIll.1.4 (Jan. 1977).

Machinery and equipment; noise; noise abatement and control; noise emission; regulation; sound; acoustics; environmental pollution; $H 122$

Machining costs; machining data banks; Machining Data Handbook; machining data publications; data banks; information analysis centers; Machinability Data Center; SP463, pp. IV.5.1-IV.5.8 (Jan. 1977).

Machining data banks; Machining Data Handbook; machining data publications; data banks; information analysis centers; Machinability Data Center; machining costs; SP463, pp. IV.5.1-IV.5.8 (Jan. 1977).

Machining Data Handbook; machining data publications; data banks; information analysis centers; Machinability DataCenter; machining costs; machining data banks; SP463, pp. IV.5.1 -IV.5.8 (Jan. 1977).

Machining data publications; data banks; information analysis centers; Machinability Data Center; machining costs; machining data banks; Machining Data Handbook; SP463, pp. IV.5.1-IV.5.8 (Jan. 1977).

Macromolecules; plastics; polymers; sealants; adhesives; dental applications; dental prosthetic materials; dental resins; future dental materials; 17201

Macromolecules; rodlike; rodlike macromolecules; rods, bent; rods, semirigid; semirigid rods; bent rods; form factors; light scattering; 17253 .

MAFT value; phosphorus; synthetic fabrics; burn injury potential; extinguishability; fire retardants; flammability hazard; FR treated cotton blends; FR treated cottons; ignitability; 17176 .

Magnesium; metal flames; calcium; $\mathrm{CO}_{2}$ laser; luminescence; 17163.

Magnesium incorporation; phosphate; vacancies; beta-tricalcium phosphate; cation substitution; coordination; crystal structure; disorder; 17259.

Magnesium oxide; opal glass; radiant flux; reflectance standards; standards calibration; barium sulfate; diffuse reflectance spectra; SP466, pp. 75-85 (May 1977).

Magnet design; magnetic field gradients; magnetometer design; Faraday magnetometer design; homogeneity; 16828

Magnetic; multipolarity; sum rule; electron scattering; inelastic; isospin; 16687

Magnetic contrast; scanning electron microscopy; topographic contrast; voltage contrast; atomic number contrast; electron beam induced conductivity (EBIC) contrast; electron channeling contrast; 16840 .

Magnetic cycles, solar; magnetic cycles, stellar; nonradiative heating; transition regions, solar; transition regions, stellar; ultraviolet spectra; visible spectra; x-ray spectra; chromospheres, solar; chromospheres, stellar; coronae, solar; coronae, stellar; flares, solar; 17324

Magnetic cycles, stellar; nonradiative heating; transition regions, solar; transition regions, stellar; ultraviolet spectra; visible spectra; $\mathrm{x}$-ray spectra; chromospheres, solar; chromospheres, stellar; coronae, solar; coronae, stellar; flares, solar; flares, stellar; 17324 .

Magnetic dornain walls; melt-grown crystals; nickel single crystals; $\mathrm{x}$-ray diffraction topography; anomalous transmission effect; asymmetric crystal topography; crystal imperfections; crystal perfection; Czochralski-grown nickel; dislocation clusters; dynamical diffraction; 16997.

Magnetic domains; magnetic domain walls; melt-grown crystals; nickel single crystals; $x$-ray diffraction topography; anomalous transmission effect; asymmetric crystal topography; crystal imperfections; crystal perfection; Czochralski-grown nickel; dislocation clusters; 16997.
Magnetic domains; nickel single crystals; $x$-ray diffraction; $x$-ray topography; dynamical diffraction; 17277.

Magnetic excitation; magnetism; rare earths; spin waves; erbium; Laves phase; 16963.

Magnetic field; passive hydrogen maser frequency standard; second-order Doppler; spin exchange; wall shift; active hydrogen maser frequency standard; cavity pulling; cavity-Q; cavity servo; Crampton effect; frequency stability; hydrogen line Q; hydrogen line servo; 17180 .

Magnetic field; single crystal; thermal conductivity; beryllium; cryogenics; electrical conductivity; heat switch; Lorenz ratio; 17088.

Magnetic field gradients; magnetometer design; Faraday magnetometer design; homogeneity; magnet design; 16828.

Magnetic field probe; tangential sensitivity; broadband probe; dipole antenna; dynamic range; electric field probe; isotropic probe; loop antenna; NBSIR 77-868.

Magnetic field strength; measurement instrumentation; portable spectrum analyzer; spectral density; time-dependent spectral density; coal mine noise; digital data; electromagnetic interference; electromagnetic noise; emergency communications; Fast Fourier Transform; 17175 .

Magnetic moments; metals; nuclear quadrupole effects; nuclear relaxation; compilation; critical evaluation; Knight shifts; 17093.

Magnetic moments; quadrupole moments; quantum field theory; relativistic many body systems; vector dominance; electromagnetic properties; form factors; Monogr. 147, Suppl. l.

Magnetic particle; measurements; nondestructive testing; optical; radiography; standards; ultrasonics; visual; acoustic emission; inspection; leak testing; liquid penetrant; 17042 .

Magnetic pressure; neutron; radiation; stellar explosion; supernova; dynamics; galactic structure; interstellar medium; 17217.

Magnetic properties; optical properties; phase diagrams; research materials; thermal properties; availability; crystal growth; crystal structure; electronic properties; SP463, pp. III.3.1-III.3.8 (Jan. 1977).

Magnetic properties; optical properties; Retrieval Guide; technical reports; Thermophysical and Electronic Properties Information Analysis Center; thermophysical properties; computerized information system; SP463, pp. IV.4.1-IV.4.3 (Jan. 1977).

Magnetic shielding; microwave feed; primary cesium standard; cesium standard; clock, operating; 16759.

Magnetic susceptibility; molybdenum; tetracyanoquinodimethan; $x$-ray photoelectron spectroscopy; chromium; infrared spectroscopy; 17153 .

Magnetic suspension densimeter; methane; normal butane; propane saturated liquid; tables; density; deviation plots; ethane; experimental; isobutane; 16871

Magnetic torque; relativity; satellite experiment; superconducting; electrodynamics; gyroscope; London moment; 16795.

Magnetism; rare earths; relaxation effects; scandium alloys; dysprosium; hyperfine fields; 16985 .

Magnetism; rare earths; spin waves; erbium; Laves phase; magnetic excitation; 16963.

Magnetite; $\mathrm{Fe}_{2} \mathrm{O}_{3} ; \mathrm{Fe}_{2} \mathrm{O}_{4}$; gaseous reduction; hematite; high voltage electron microscopy; iron oxide; 17177 .

Magnetization measurements; neutron diffraction; terbium; amorphous alloys; iron; 16835.

Magnetohydrodynamics; materials; design; electrode/insulators; 16900.

Magnetohydrodynamics; pipe flow; resistance coefficients; turbulence; liquid metals; 16821 .

Magnetometer design; Faraday magnetometer design; homogeneity; magnet design; magnetic field gradients; 16828 .

Magnetometry; SQUID; biomagnetism; geomagnetism; instrumentation; Josephson effect; 16872. 
Magnetometry; SQUID; Stirling cycle; cryogenic refrigeration; 17091.

Magnetoresistance; nonvolatility; orthoferrite; photolithography; uniaxial structures; amorphous materials; bubble; field-access; garnet; guide-pattern; SPSOO-1.

Magnetothermal conductivity; nickel alloy; stainless steel; thermal conductivity; copper; low temperature; 16864 .

Magnetothermal conductivity; polarization; potassium tantalate; refrigeration; specific heat; strontium titanate; beryllium; ceramics; cryogenics; dielectric-constant; electrets; electrocaloric effect; entropy; ferroelectrics; glass-ceramics; heat switches; NBSIR 76-847.

Magnets; superconductivity; thermonuclear; copper; cryogenic; fusion; 17134 .

Maintainability; materials; minimum property standards; performance criteria; performance evaluation; plumbing; safety; structures; test methods; acoustics; appliances; atmospheric; durability; electrical; environment; housing technology; HVAC; innovative construction; NBSIR 77-1316.

Mammography; $x$-ray radiography; diagnostic radiography; exposure reduction; imaging information content; image processing; 16666.

Management; materials information; national programs; policy; technology assessment; energy; environmental quality; SP463, pp. I.2.1-I.2.2 (Jan. 1977).

Management control; microfilm; building code; building permits; computers; enforcement; information retrieval; inspection; SP473, pp. 377-382 (June 1977).

Management information systems; materials; nonfood products; physical properties; research information; agricultural materials; agricultural research; biological properties; chemical properties; engineering properties; SP463, pp. II.2.I-II.2.10 (Jan. I977).

Managment information; decision maker; decision model; information packaging; information processing; 16734.

Mandatory standards; national standards; plastics standards; standards; standards information service; voluntary standards; American National Standards Institute; computerized information system; engineering standards; SP463, pp. VII.5.1VII.5.9 (Jan. 1977).

Manganese; atomic energy levels; atomic spectra; JPCRD 6, No. 4, 1253-1330 (1977).

Manganese; bauxite; chromite; commodity supply policies; contingency planning; energy (petroleum); NBS-GCR-ETIP 77. 38.

Manganese sulphate baths; neutron; bath techniques; SP493, pp. 237-243 (Oct. 1977).

Manikin; audiometry; diffraction; head diffraction; hearing aids; instruments for hearing; 17064 .

Manikin; ears; head diffraction; hearing; interaural intensity differences; interaural time differences; localization; 17052.

Manometers; manometry; pressure standard; uItrasonic interferometer; vacuum measurement; interferometer; 17269.

Manometry; pressure standard; ultrasonic interferometer; vacuum measurement; interferometer; manometers; 17269.

Manual materials handling; physiology; psychophysics; safety; warranty; anthropometry; biomechanics; carrying; consumer product portability; ergonomics; human factors; lifting; NBSIR 76-1092.

Manufacturing processes; materials selection; systems approach to design; engineering design; SP487, pp. 19-24 (Aug. I977).

Manufacturing requirements; glass, returnable and nonreturnable bottles; glass, soda-lime-silica; PS73-77.

Mapping; model; nursing homes; rescue; verbal communicative; alarm; architecture; design implication; emergency actions; emergency communicative; emergency decisions; escape; fires; human behavior; human response; life safety; NBSGCR-77-93.

Maps; seismicity index; earthquake distributions; epicenters; SP470, pp. III-18-III-28 (Apr. 1977).
MARC; standards; bibliographic information; data bases; information retrieval; library automation; machine-readable; SP463, pp. VIII.1.1-VIII.1.4 (Jan. 1977).

Marine environment; current measuring transducers; current velocities; dynamic response characteristics; fluctuating flow characteristics; SP484, pp. 109-122 (Oct. 1977).

Marine studies; microelectronic industry; monitoring system; photodetectors; radiopharmaceuticals; ultraviolet radiation; windows; $\mathrm{AC}$ high voltage; $\mathrm{AC}$ voltmeter calibrator; DIMINBS 61, No. 12, 1-32 (1977).

Mark-Houwink equation; NBS Standard Reference Material 1475; theta solvents; 3,3,5-trimethylhexyl acetate; biphenyl; chain dimensions; dodecanol; linear polyethylene; 16710 .

Markov process; neutron; PURNIMA; Rossi- $\alpha$; slowing down; stochastic; BESM-6; JEZEBEL; SP461, pp. 97-99 (Jan. 1977).

Markow decision process; policy improvement algorithm; dynamic programming; economic analysis; energy conservation; equipment maintenance; NBSIR 77-1210.

Martin-Roth-Stiehler equation; modulus of rubber; MooneyRivlin equation; rubber; stress-strain relations; stress-strain relations in rubber; uniaxial extension and compression in rubber; J. Res. 82, No. 1, 57-63 (1977).

Masonry; bricks; buildings; Canada; concrete blocks; design standards; earthquake resistant structures; BSS106, pp. 198213 (Sept. 1977).

Masonry; masonry panels; seismic loading; BSS106, pp. 154165 (Sept. 1977).

Masonry; piers; research; seismic; shear walls; spandrel beams; connections; houses; BSS106, pp. 60-90 (Sept. 1977).

Masonry; rheology, material; earthquake damage analysis; BSS106, pp. 114-I 53 (Sept. 1977).

Masonry; shear walls; codes; design; dynamic analysis; BSS106, pp. $91-113$ (Sept. 1977).

Masonry codes, United Kingdom; masonry research; BSS106, pp. 166-176 (Sept. I977).

Masonry construction; materials testing standardization; mathematical models; rehabilitation; retrotit; seismic design; structural design; structural research; building codes and standards; design criteria; earthquake resistance; BSS106, pp. 4059 (Sept. I977).

Masonry construction; seismic design; structural design; structural engineering; structural research; building codes and standards; design criteria; earthquake resistance; BSSI06.

Masonry panels; seismic loading; masonry; BSS106, pp. 154165 (Sept. 1977).

Masonry research; masonry codes, United Kingdom; BSS106, pp. I66-176 (Sept. 1977).

Masonry walls; arching; BSS106, pp. 283-3I3 (Sept. 1977).

Masonry walls; racking strength; seismic loading; shear strength; shear wall; stiffness; analysis; compressive strength; deflection; design; flexural strength; BSS62.

Masonry walls; shear walls; splitting strength; ultimate capacity; brick; clay masonry; concrete block; concrete masonry; failure modes; load capacity; BSS106, pp. I77-197 (Sept. 1977).

Masonry walls' structural design; technology transfer; timber roofs; timber walls; wind effects; codes and standards; connectors; fasteners; low-rise buildings; BSS100-3.

Mass; records; set; surveillance limits; surveillance test; test interval; true mass; value; weighing design; weights; apparent mass; buoyancy; buoyancy correction; change; comparison; difference; NBSIR 76-999.

Mass calibration; statistical design; weighing design; design of experiments; least squares; TN952.

Mass concentration; number concentration; size distribution; smoke; smoke detector; test method; UL 217; aerosol; NBSIR 77-1312. 
Mass distribution function; anisotropy of mean square velocities; eccentricity of equidensity surface; elliptical galaxies; flattening; 16968 .

Mass flow; measurement; cryogenic; flow; gas; liquid; SP484, pp. 881-893 (Oct. 1977).

Mass spectra; radiation sterilizing; screw thread standards; SHIVA laser; silicon; timekeeping; ultraviolet radiation; calibration; consumers; energy; energy savings; grain moisture; DIM/NBS 61, No. 9, 1-32 (1977).

Mass spectrometry; methane; photoionization; threshold photoelectron spectroscopy; time of flight mass spectrometry; acetone; coincidence; 17148 .

Mass spectrometry; nuclear magnetic resonance; $p$-toluenesulfonylhydrazine; 1,2-di( $p$-toluenesulfonyl)hydrazine; chemical ionization mass spectrometry; di-p-tolyldisulfide-1,2-dioxide; 17045.

Mass spectrometry; ozone; air pollution; chemical kinetics; dioxirane; ethylene; 17327.

Mass spectrometry; photoionization; rate constants; alkyl iodides; ion-molecule reactions; isotope effects; J. Res. 81 A Nos. 2 and 3, 267-271 (1977).

Mass unit transfer; real gas equation; air buoyancy; air density; NBSIR 77-1278.

Material properties; structures; crack propagation; cryogenics; fracture mechanics; fracture toughness; 16866.

Materials; design; electrode/insulators; magnetohydrodynamics; 16900.

Materials; materials data; materials information; N.A.S.A.; U.S.D.A; Commerce; Defense; E.R.D.A.; Federal agencies; interagency review; Interior; Library of Congress; SP463.

Materials; mechanical properties; metallic materials; nonmetallic materials; physical properties; RECON; scientific and technical aerospace reports; thesaurus; aerospace; computer information system; SP463, pp. V1.1.1-VI.1.7 (Jan. 1977).

Materials; mechanical property; metal; review; thermal property; alloy; composite; cryogenics; electrical property; insulation; 17072.

Materials; minimum property standards; performance criteria; performance evaluation; plumbing; safety; structures; test methods; acoustics; appliances; atmospheric; durability; electrical; environment; housing technology; HVAC; innovative construction; maintainability; NBSIR 77-1316.

Materials; neutron dosimetry; reactor physics; breeder reactor; fission; fission detector; 17058 .

Materials; nonfood products; physical properties; research information; agricultural materials; agricultural research; biological properties; chemical properties; engineering properties; food products; SP463, pp. II.2.1-II.2.10 (Jan. 1977).

Materials characterization; MHD(magnetohydrodynamics); power generation; testing; U.S.-U.S.S.R. cooperative program; ceria; 17160 .

Materials data; materials information; N.A.S.A.; U.S.D.A; Commerce; Defense; E.R.D.A.; Federal agencies; interagency review; Interior; Library of Congress; materials; SP463.

Materials information; N.A.S.A.; U.S.D.A; Commerce; Defense; E.R.D.A.; Federal agencies; interagency review; Interior; Library of Congress; materials; materials data; SP463.

Materials information; national programs; policy; technology assessment; energy; environmental quality; management; SP463, pp. 1.2.1-1.2.2 (Jan. 1977).

Materials information and data system; national commission on materials policy; technology transfer; total materials cycle; information demand; SP463, pp. IX.1.1-IX.1.22 (Jan. 1977).

Materials of design; product liability; reliability of design; techniques of design; validation of design; coating materials; composite materials; design; failure avoidance; failure prevention; lubricants; SP487.

Materials performance; radiant panel-seamless flooring system; seamless flooring; temperature characteristics; electrical heating elements; NBSIR 77-1263.
Materials properties; nuclear data; radiation transport; reactor; RSIC; shielding; weapons; computer codes; SP463, pp. III.1. I-III.1.10 (Jan. 1977).

Materials properties; performance; urea-formaldehyde; cellular plastics; foam insulation; insulation; TN946.

Materials selection; systems approach to design; engineering design; manufacturing processes; SP487, pp. 19-24 (Aug. 1977).

Materials testing; nondestructive testing; Nondestructive Testing Newsletter; radiography; technical reports; ultrasonics; Army Materials and Mechanics Research Center; electromagnetics; SP463, pp. IV.6.1-IV.6.2 (Jan. 1977).

Materials testing standardization; mathematical models; rehabilitation; retrofit; seismic design; structural design; structural research; building codes and standards; design criteria; earthquake resistance; limit states design; BSS106, pp. 40-59 (Sept. 1977).

Materials utilization data; mechanical properties; nuclear data; physical science data; solid state data; standard reference data; thermodynamic data; transport properties; atomic and molecular data; chemical kinetics data; energy data; environmental data; TN947.

Mathematical modeling; meter performance; orifice meter; turbulence flow; closed conduit meter; differential pressure; flow measurement; SP484, pp. 491-522 (Oct. 1977).

Mathematical models; rehabilitation; retrofit; seismic design; structural design; structural research; building codes and standards; design criteria; earthquake resistance; limit states design; masonry construction; BSS106, pp. 40-59 (Sept. 1977).

Mathematical models; room fire; scaling models; theoretical; "flashover"; fluid flow; full-scale; heat transfer; literature review; 17283 .

Mathematics; navigation; physics; time; time broadcasts; time scales; astronomy; automation; clocks; communication; frequency; history; Monogr. 155.

Matrices of order three; triangle of reference; barycentric coordinates; distance coordinates; Euclidean plane; J. Res. 81B Nos. 1 and 2, 61-72 (1977).

Matrix; minimum polynomials; control theory; linear algebra; $J$. Res. 82, No. 2, 129-132 (1977).

Matrix model; population dynamics; population growth rate; production rate; scrappage rate; stable-age population; age distributions; demography; durability; durable goods; 17053 .

Mattresses; prisons; bedding; beds; compartment fires; firesafety engineering; fire tests; health care facilities; hospitals; NBSIR $77-1290$

Mattresses; shipboard; thermal conductivity; compartment fires; fire-retardants; insulation; NBSIR 77-1295.

Maxwell; momentum; Poynting; variational; anholonomic; constraint; electromagnetism; Hamilton; J. Res. $81 B$ Nos. 1 and 2, 1 -3 (1977).

Maxwellian spectrum; plutonium-239; prompt fission spectrum; uranium-235; Watt spectrum; californium-252; SP493, pp. 198-205 (Oct. 1977).

Mayer, Tobias (1723-1762); method of averages; weighted mean; weighted median; zero sum of residuals; Boscovich, Roger Joseph (1711-1787); Cotes, Roger (1682-1716); Euler, Leonard (1707-1783); Figure of the Earth; fitting a linear equation; 17314.

Mean concentration; mean velocity; measuring volume; remote sensing; root-mean-square concentration; Schmidt number; simultaneous measurements; spectra; water jet; auto-correlation; convective velocity; cross-correlation; SP484, pp. 423447 (Oct. 1977).

Mean free path; ASFIT; build-up factor; empirical; energy; garnma ray; SP461, pp. 174-176 (Jan. 1977).

Mean life; resonance radiation; transition probability; ur; uranium; delayed coincidence; $g f$ value; imprisonment; lifetimes; 17292. 
Mean radiant temperature; radiation measurement; radiometer; thermal comfort; thermal radiation; directional radiant temperature; SP491, pp. 117-130 (Sept. 1977).

Mean radiant temperature; thermal comfort; energy conservation in buildings; heat stress; human comfort; indoor environment; $S P 491$.

Mean velocity; measuring volume; remote sensing; root-meansquare concentration; Schmidt number; simultaneous measurements; spectra; water jet; auto-correlation; convective velocity; cross-correlation; exit concentration; exit velocity; SP484, pp. 423-447 (Oct. 1977).

Measured $\sigma(\mathrm{E}, \theta)$; nuclear charge distributions; nuclear reactions; ${ }^{36.40} \mathrm{Ar}\left(\mathrm{e}, \mathrm{e}^{\prime}\right)$; enriched targets; $\mathrm{E}=65$ to $115 \mathrm{MeV}$; 16845 .

Measured $\sigma(E)$ at $\theta=75^{\circ}$; nuclear reactions; ${ }^{3} \mathrm{He}\left(\mathrm{e}, \mathrm{e}^{\prime}\right)$; deduced rms charge radius; $\mathrm{E}=28.8-95.0 \mathrm{MeV} ; 16850$.

Measured neutron spectral distributions for $E_{n}>0.3 \mathrm{MeV}$; nuclear reactions; $\theta=0^{\circ}, 10^{\circ}, 20^{\circ}, 30^{\circ}, 40^{\circ}$; NBSIR 77-1279, pp. 5-9 (July 1977).

Measured thick-target neutron yields, $B e(d, n), \operatorname{Li}(d, n) ; \theta=0$ 90\%; dosimetry: $\mathrm{E}_{d}=40 \mathrm{MeV} ; \mathrm{E}_{n}>2 \mathrm{MeV} ;$ NBSIR 77-1279, pp. 24-29 (July 1977).

Measurement; cryogenic; flow; gas; liquid; mass flow; SP484, pp. 881-893 (Oct. 1977).

Measurement; metrology; radiation; surface technology; electromagnetic; interference; 17079.

Measurement; modelling; resource dependency; system capacity; validation; credit authorization system; critical resource; disk modelling; event model; SP500-18, pp. 185-211 (Sept. 1977).

Measurement; molecular absorption; $10 \mu \mathrm{m}$ wavelength; ammonia; carbon dioxide; ethanol; 16924.

Measurement; Moliere theory; multiple; scattering; angular distribution; chlorine; foils; ions; iron, oxygen; SP461, pp. 136139 (Jan. 1977).

Measurement; network measurement services; service; teleprocessing systems measurement; computer network measurement; data acquisition; interactive computer access; 17252.

Measurement; neutron; $\beta$-counting error; activation; capture reaction; cross section; $S P 461$, pp. 57-59 (Jan. 1977).

Measurement; neutron capture cross section; normalization; reference standard; review; accuracy; $\operatorname{Au}(n, \gamma)$ cross section; cross section fluctuations; SP493, pp. 165-169 (Oct. 1977).

Measurement; performance evaluation; performance measurement; remote terminal emulation; Remote Terminal Emulator; teleprocessing; evaluation; interactive; 16945.

Measurement; performance evaluation; performance measurement; remote terminal emulation; remote terminal emulators; teleprocessing; evaluation; interactive; SPSOO-4.

Measurement; photoelectric effect; photon; atomic number; cross section; K-shell; SP461, pp. 41-43 (Jan. 1977).

Measurement; product safety; research; science; standards; technology; annual report; computer; energy; environmental; SP467.

Measurement; radiation; comfort; 16923.

Measurement; standards; television; time; atomic clocks; dissemination; frequency; geosynchronous satellite; 17182 .

Measurement; trade facilitation; flow measurement; industry; intergovernmental; international standards; legal metrology; SP484, pp. $921-927$ (Oct. 1977).

Measurement; transfer standards; liquid argon; liquid nitrogen; liquid oxygen; LNG; 17162.

Measurement accuracy; radio stars; satellite earth terminal; signal to noise; star flux; figure of merit; $G / T ; 17227$.

Measurement assurance; metric; neutron diffraction; recycling oil; research and innovation; safety; ultrasonic tissue; computerized data; data elements; equity; federal technology; fire modeling; heat; hydrocarbon; ionized molybdenum; DIM/NBS 61, No. 6, 1-32 (1977).
Measurement assurance; neutron standard; reaction rates; benchmark spectrum; discrete ordinates; intermediate energy; SP493, pp. 329-334 (Oct. 1977).

Measurement assurance; systematic error; uncertainty; NBSIR 77-1240.

Measurement compatibility; measurement systems; reference method; standard reference material; accuracy; chemical analysis; 17247.

Measurement instrumentation; portable spectrum analyzer; spectral density; time-dependent spectral density; coal mine noise; digital data; electromagnetic interference; electromagnetic noise; emergency communications; Fast Fourier Transform; impulsive noise; 17175.

Measurement instruments; measurement standards; National Bureau of Standards; national measurement standards; physical measurement; weights and measures; history of science; NBSIR 76-1125.

Measurement method; mixer; optics; pre-amplifier; radio receiver; semiconductor device studies; electronic reliability; electronics; laser scanner; SP400-24.

Measurement methods; microelectronics; National Bureau of Standards; semiconductor devices; semiconductor materials; semiconductor process control; electronics; 16894 .

Measurement methods; microelectronics; optical flying-spot scanner; oxidation particle impact noise detection test; passivation overcoats; photovoltaic method; power-device grade silicon; radioisotope method; resistivity; resistivity variations; SP400-29.

Measurement methods; photovoltaic method; power-device grade silicon; resistivity variations; silicon; thermally stimulated capacitance; thermally stimulated current; thermally stimulated measurements; thyristor materials measurements; thyristor measurements; d-c transmission; 17345 .

Measurement methods; photovoltaic method; power-device grade silicon; resistivity variations; silicon; thermally stimulated capacitance; thermally stimulated current; thermally stimulated measurements; thyristor materials measurements; thyristor measurements; NBSIR 77-1249.

Measurement methods; power transistors; reliability; safe operating area limits; second breakdown; thermal instability; hot spots; 16893.

Measurement model; measurement, performance; measures; methodology; network measurement system; computer service; external measurement; figure-of-merit; interactive system; 17288 .

Measurement, performance; measures; methodology; network measurement system; computer service; external measurement; figure-of-merit; interactive system; measurement model; 17288 .

Measurement practices; metering; oil measurement documents; petroleum measuring; tank gaging; SP484, pp. 55-60 (Oct. 1977).

Measurement services; standardization; AID; assistance; developing economies; foreign relations; industrializing nations; international relations; LDS's; NBSIR 76-1152.

Measurement services; standardization; testing facilities; cottage industry; developing countries; Guyana; less developed countries; NBSIR 76-1180.

Measurement, skid resistance; pavement, skid resistance; test procedures, skid resistance measuring systems; tire-pavement interface forces; friction, pavement; highway safety; NBSIR 76-1174.

Measurement, skid resistance; pavement skid resistance; skid resistance measurement; tire-pavement interface forces; wet pavement skid resistance; accident reduction, skidding; highway safety; NBSIR 76-1175.

Measurement, skid resistance; pavement, skid resistance; pavement wetting system; skid resistance, measurement; tïre-pavement interface forces; wet pavement skid resistance; accident 
reduction, skidding; correlation, skid resistance; highway safety; NBSIR 77-1213.

Measurement standards; national standards; application of standards; international standards; SP484, pp. 929-934 (Oct. 1977).

Measurement standards; National Bureau of Standards; national measurement system; standardization organizations; standard reference data; weights and measures; instrumentation; NBSIR 75-949.

Measurement standards; National Bureau of Standards; national measurement standards; physical measurement; weights and measures; history of science; measurement instruments; NBSIR 76-1125.

Measurement system; RF noise spectrum; 3-D display; FFT; 17173.

Measurement systems; physical measurement units; standard reference materials; chemical analysis; 16667.

Measurement systems; reference method; standard reference material; accuracy; chemical analysis; measurement compatibility; 17247.

Measurement technology; microcalorimetry; pacemaker leads; process control; reliability; screen tests; semiconductor devices; batteries; cardiac pacemakers; hermeticity; hybrid devices; leak testing; SP400-42.

Measurement technology; nondestructive test; reliability; safe operating limits; second breakdown; semiconductor devices; thermal characterization; thermal instability; thermal resistance; transistors; hot spots; junction temperature; SP40044.

Measurement technology; thermography; heat-flow measurements; infrared heat-loss measurement technique; TN933.

Measurements; cross section; differential; electron; helium; ionization; 16810.

Measurements; near field; nonplanar; patterns; scanning; spherical; symmetry; antennas; arrays; coordinate transformations; data processing; group representations; 16671 .

Measurements; near-field; spherical; antennas; 17224 .

Measurements; neutron; total; alpha; boron; branching ratio; compilation; cross-section; elastic; lithium; SP493, pp. 67-84 (Oct. 1977).

Measurements; nondestructive testing; optical; radiography; standards; ultrasonics; visual; acoustic emission; inspection; leak testing; liquid penetrant; magnetic particle; 17042.

Measurements; nuclear power; dosimetry; licensing; SP493, pp. 137-145 (Oct. 1977).

Measurements; particulates; regulations; sulfur dioxide; air quality; deterioration; 17141

Measurements; picosecond pulse; resistive loading; the method of moments; broadband antenna; NBSIR 77-861.

Measurements; quality control; standardization; testing facilities; Thailand; NBSIR 76-1190.

Measurements; radiated emission; radiation resistance; TEM cells; 17220 .

Measurements; TNT; vapor pressures; DNT; EGDN; electron-capture gas chromatography; 16825 .

Measurements; vibration; vibration exciters; vibration standards; accelerometers; calibration; NBSIR 77-1229.

Measurements review; polarization; ${ }^{3} \mathrm{H}\left(\alpha,{ }^{6} \mathrm{Li}\right) \mathrm{n},{ }^{4} \mathrm{He}(\mathrm{t}, \mathrm{t}){ }^{4} \mathrm{He} ;{ }^{6} \mathrm{Li}$ neutron cross sections; $\mathrm{Ti}$ system; SP493, pp. 3.9 (Oct. 1977).

Measures; methodology; network measurement system; computer service; external measurement; figure-of-merit; interactive system; measurement model; measurement, performance; 17288 .

Measuring; electromagnetic fields; hazards; instrumentation; isotropic; 17168.

Measuring flow; metering flow; monitoring flow; open channel flow; public law 92-500; sewerage flow; wastewater flow; closed conduit flow; instrumentation; SP484, pp. 83-89 (Oct. 1977).
Measuring methods; neutron reactions; neutron sources; calibration; californium-252; cross sections; design; errors; fission neutrons; irradiation devices; 16790.

Measuring response time; software monitor; SP500-18, pp. 107 115 (Sept. 1977).

Measuring system; stability; standard deviation; statistical analysis; angle block; between time variation; calibration; NBSIR 74-601.

Measuring techniques; neutrons; standards; cross section standards; dosimetry; fission; flux; SP493.

Measuring volume; remote sensing; root-mean-square concentration; Schmidt number; simultaneous measurements; spectra; water jet; auto-correlation; convective velocity; cross-correlation; exit concentration; exit velocity; SP484, pp. 423-447 (Oct. 1977).

Mechanical; numerical data; physical properties; thermodynamics; transport; chemical; critical evaluation; SP463, pp. VII.1.1-VII.1.15 (Jan. 1977).

Mechanical behavior; pultrusion/drawing; wire preform; composite material; fabrication techniques; graphite fibers-aluminum; SP487, pp. 93-107 (Aug. 1977).

Mechanical properties; Mechanical Properties Data Center; structural metals and alloys; technical information; user awareness; data storage/retrieval; handbooks; SP463, pp. IV.8.1-IV.8.10 (Jan. 1977).

Mechanical properties; metal implants; stainless steel; standards; titanium; biocompatibility; cobalt-chromium; corrosion; implant requirements; 16973.

Mechanical properties; metallic materials; nonmetallic materials; physical properties; RECON; scientific and technical aerospace reports; thesaurus; aerospace; computer information system; international aerospace abstracts; SP463, pp. VI.1.1-VI.1.7 (Jan. 1977).

Mechanical properties; microstructure; modelling; paper; pore size; statistical analysis; Weibull distribution; durability; fatigue; fiber length; flexing; low cycle fatigue; 16681 .

Mechanical properties; moisture determination; preservation technology; adobe building materials; adobe soil; 17104 .

Mechanical properties; moisture determination; preservation technology; adobe building materials; adobe soil; TN934.

Mechanical properties; nickel alloys; superalloys; fatigue; fracture; low temperature tests; 16801 .

Mechanical properties; nuclear data; physical science data; solid state data; standard reference data; thermodynamic data; transport properties; atomic and molecular data; chemical kinetics data; energy data; environmental data; industrial process data; TN947.

Mechanical properties; paper; pulp; timber; wood; wood products; AIDS; bark; forest products; glues and gluing; information service; lumber; SP463, pp. II.1.1-lI.1.4 (Jan. 1977).

Mechanical properties; performance criteria; plastic packaging; stress-cracking; time-to-fail; container tests; hazardous materials ladings; 17256.

Mechanical properties; physical properties; specification testing; testing of dental materials; dental amalgam; dental materials; development of testing procedures; 17126.

Mechanical properties; research program; structural materials; thermal properties; low temperature; 16863.

Mechanical Properties Data Center; structural metals and alloys; technical information; user awareness; data storage/retrieval; handbooks; mechanical properties; SP463, pp. IV.8.1-IV.8.10 (Jan. 1977).

Mechanical property; metal; review; thermal property; alloy; composite; cryogenics; electrical property; insulation; materials; 17072.

Mechanical switch; multiple contact switch; proximity effect; superconducting switch; thin-film; cryogenic electrical switch; 17121 . 
Mechanically actuated switch; perimeter sensor; switch; burglar alarm sensor; burglar alarm system; door switch; 17002 .

Mechanisms; photochemistry; pyrolysis; alkyl halides; $\mathrm{CO}_{2}$ laser; infrared; kinetics; 16783.

Median; M-estimators; S. Newcomb; systematic errors; trimmed means; velocity of light; A. A. Michelson; adaptive estimators; arithmetic mean; bias; estimators of location; 17266.

Medical; mixed $n-\gamma$ fields; neutron dosimetry; standards; basic physical data; SP493, pp. 106-114 (Oct. 1977).

Medical; neutron dosimetry; radiation effects; standards; intercomparisons; SP493, pp. 121 -127 (Oct. 1977).

Medical diagnosis; pulse compression; signal processing; ultrasound; chirp radar; 16735.

Medical facilities; medical planning; architecture; building technology; construction; health facilities; hospitals; NBSIR 77-1233.

Medical planning; architecture; building technology; construction; health facilities; hospitals; medical facilities; NBSIR 771233.

Medical records; privacy; recordkeeping practices; security; citizen rights; computers, confidentiality; data systems; health records; information policy, management principles; SP469.

Medium; Monte Carlo; albedo; angular; backscattering; barrier; differentials; distribution; gamma rays; integral; SP461, pp. 129-131 (Jan. 1977).

Melt-grown crystals; nickel single crystals; x-ray diffraction topography; anomalous transmission effect; asymmetric crystal topography; crystal imperfections; crystal perfection; Czochralski-grown nickel; dislocation clusters; dynamical diffraction; magnetic domains; 16997.

Melting; normal spectral emittance; radiance temperature; specific heat capacity; thermal radiation properties; thermodynamics; titanium alloy; electrical resistivity; heat capacity; high-speed measurements; J. Res. 81 A Nos. 2 and 3, 251256 (1977).

Melting; standards; temperature; thermistors; thermometry; fixed points; gallium; gallium melting point; 17055 .

Melting and freezing equilibrium; mercury; high pressure; latent heat detection; 16750 .

Melting line; orthobaric densities; propane; specific heats; speeds of sound; vapor pressure; densities; enthalpies; entropies; equation of state; internal energies; isobars; isochores; isotherms; Joule-Thomson inversion; latent heats of vaporization; NBSIR 77-860.

Melting point; radiance temperature; titanium; electrical resistivity; emittance; high-speed measurement; high temperature; J. Res. 82, No. 2, $119-122$ (1977).

Melting point standard; secondary fixed point; temperature fixed point; thermometry; gallium; International Practical Temperature Scale of 1968; 17049

Melting-point standard; temperature; thermometric fixed-point; clinical laboratory; fixed-point; gallium; SP481.

Membrane; reflection coefficient; ultrafiltration; continuous binding curve; dye binding; human albumin; 16959.

Membrane potentials; permselective properties; surface properties; apatites; caries mechanism; caries prevention; 16787.

Menger System; MK-System; dominating set; enclaveless set; graph; hypergraph; König Systcm; KM-System; J. Res. 82, No. 3, 197-202 (1977).

Meniscus; perturbation; shape stability; silicon; crystal growth; floating zone; 16931 .

Mercury; high pressure; latent heat detection; melting and freezing equilibrium; 16750 .

Mercury; metal complexes; organometals; photolysis; reaction rates; thallium; tin; transmethylation; water; alkylation; aqueous solution; coordination; 17008.

Mercury; nanogram sensitivity; organometallic compounds; speciation; tin; arsenic; element-specific detector; flameless atomic absorption; flow monitoring; high-pressure liquid chromatography; lead; ligand; 17297.
Mercury excimers; optically excited; spectra; two photon; dimer; double resonance; 17076.

Mercury excimers; spectra; two photon; dimers; discharge; lasers; 17192.

Mercury excimers; time resolved spectroscopy; kinetics; 16800.

Mercury vapor; personal dosimeter; piezoelectric sensors; quartz crystal microbalance; environmental analysis; industrial hygiene; 16773 .

M-estimators; S. Newcomb; systematic errors; trimmed means; velocity of light; A. A. Michelson; adaptive estimators; arithmetic mean; bias; estimators of location; median; 17266.

Metabolic heat load; environmental monitoring; heat stress control; heat stress indices; heat stress monitoring; industrial heat stress; SP491, pp. 41-51 (Sept. 1977).

Metal; oxidation; particle; velocity dependence; erosion; 16898.

Metal; review; thermal property; alloy; composite; cryogenics; electrical property; insulation; materials; mechanical property; 17072 .

Metal artifacts, restoration of; patina, artificially produced; patina, natural; archaeological finds, preservation of; conservation of metal artifacts; corrosion, inhibiting of; corrosion, treatment methods; SP479.

Metal combustion; spectroscopy; titanium alloys; laser effects; luminescence; 16796.

Metal complexes; organometals; photolysis; reaction rates; thallium; tin; transmethylation; water; alkylation; aqueous solution; coordination; mercury; 17008.

Metal corrosion; metal erosion; vaporization processes; ceramic corrosion; ceramic erosion; ceramic fracture; chemical degradation; coal gasification material; failure avoidance; 17158.

Metal corrosion; metal erosion; vaporization processes; ceramic corrosion; ceramic erosion; ceramic fracture; chemical degradation; coal gasification material; failure avoidance; 17159.

Metal dimers; $\mathrm{Mg}_{2}$; multiconfiguration self-consistent-field; $\mathrm{ab}$ initio; electronic structure; excimers; excited states; 17188.

Metal erosion; vaporization processes; ceramic corrosion; ceramic erosion; ceramic fracture; chemical degradation; coal gasification material; failure avoidance; metal corrosion; 17158 .

Metal erosion; vaporization processes; ceramic corrosion; ceramic erosion; ceramic fracture; chemical degradation; coal gasification material; failure avoidance; metal corrosion; 17159.

Metal evaporation; metallization; metal-oxide semiconductor; microelectronic device; radiation dose; silicon dioxide film; electron-gun evaporator; gate oxide film; 16889.

Metal flames; calcium; $\mathrm{CO}_{2}$ laser; luminescence; magnesium; 17163.

Metal hydrides; band mode; elastic constants; interatomic forces; interstitial; lattice dynamics; 17004.

Metal hydrides; phonon dispersion curves; cerium deuteride; inelastic neutron scattering; lattice dynamics; local mode vibrations; 16965.

Metal implants; stainless steel; standards; titanium; biocompatibility; cobalt-chromium; corrosion; implant requirements; mechanical properties; 16973.

Metal specific detector; photoionization detector; reaction deiector; cerium oxidation detector; liquid chromatography; liquid chromatography detectors; 17278.

Metal-hydrogen systems; palladium-deuteride $\left(\mathrm{PdD}_{0.63}\right)$; phonon lineshapes; defect crystal structures; inelastic neutron scattering; lattice dynamics; 16964 .

Metallic; orthopaedic; retrieval; analysis; implants; SP472.

Metallic artifacts; microstructural analysis; nondestructive evaluation techniques; compositional analysis; instrumental methods; 16712 . 
Metallic materials; nonmetallic materials; physical properties; RECON; scientific and technical aerospace reports; thesaurus; aerospace; computer information system; international aerospace abstracts; materials; SP463, pp. VI.1.1-VI.1.7 (Jan. 1977).

Metallic thin films; microirregularities; overcoating; plasmons; scatter; absorption; dielectric layers; irregularities; SP466, pp. 133-148 (May 1977).

Metallization; metal-oxide semiconductor; microelectronic device; radiation dose; silicon dioxide film; electron-gun evaporator; gate oxide film; metal evaporation; 16889.

Metalloborane; metallocarborane; rhodium; ruthenium; boron hydride; carborane; dicarbollide; 17152.

Metalloborane; oxidative addition; boron hydride; hydrogen; iridium; isotope exchange; 17144.

Metallocarborane; rhodium; ruthenium; boron hydride; carborane; dicarbollide; metalloborane; 17152 .

Metallurgical; tank cars; 16716.

Metallurgical; tank cars; 16717.

Metallurgical; tank cars; 16718 .

Metallurgy; mining; Office of Mineral Information; Bureau of Mines; energy; health and safety; SP463, pp. V.3.1-V.3.9 (Jan. 1977).

Metallurgy; tank cars; 16715.

Metallurgy; tank cars; 16719.

Metallurgy; tank cars; 16720.

Metal-oxide semiconductor; microelectronic device; radiation dose; silicon dioxide film; electron-gun evaporator; gate oxide film; metal evaporation; metallization; 16889.

Metals; neutron scattering; quasielastic scattering; review; diffusion; hydrogen; lattice dynamics; 16970.

Metals; nuclear quadrupole effects; nuclear relaxation; compilation; critical evaluation; Knight shifts; magnetic moments; 17093.

Metals; properties; tricresyl phosphate; zinc dithiophosphate; antiwear additives; interaction; lubricant; SP487, pp. 172-185 (Aug. 1977).

Metals; refractory; alloys; compounds; hardness; interstitial; 17262.

Metals; surfaces; catalysis; characterization; chemisorption; electronic factor; geometric factor; SP475.

Metals technology; structural materials; technical reports; ceramic technology; current awareness services; databooks; information analysis center; inquiry services; SP463, pp. IV.2.1-IV.2.7 (Jan. 1977).

Metal-semiconductor contacts; resistivity; semiconductors; silicon; silicon polishing; spreading resistance calibration; spreading resistance measurements; 17139.

Metastable; oxygen molecules; photoluminescence; quenching; laser; 16765.

Metastable helium atoms; helium absorption; liquid helium bubble; 16818.

Metastable states; molecular probability density; bifurcation; close-packed crystals; crystalline solutions; hard spheres; 17012.

Metastable states; Monte Carlo; algorithm; Lennard-Jones; 16786.

Meter performance; numerical modeling; turbulent flow; flow meter; NBSIR 77-1394.

Meter performance; orifice meter; turbulence flow; closed conduit meter; differential pressure; flow measurement; mathematical modeling; SP484, pp. $491-522$ (Oct. 1977).

Meter performance; perturbations; precision; turbine meter; uncertainty; accuracy; calibration; flow conditioning; SP484, pp. 33-54 (Oct. 1977).

Metering; oil measurement documents; petroleum measuring; tank gaging; measurement practices; SP484, pp. 55-60 (Oct. 1977).
Metering flow; monitoring flow; open channel flow; public law 92-500; sewerage flow; wastewater flow; closed conduit flow; instrumentation; measuring flow; SP484, pp. 83-89 (Oct. 1977).

Methane; methyl formate; tungsten; chemisorption; 17065.

Methane; normal butane; propane saturated liquid; tables; density; deviation plots; ethane; experimental; isobutane; magnetic suspension densimeter; 16871 .

Methane; photoionization; threshold photoelectron spectroscopy; time of flight mass spectrometry; acetone; coincidence; mass spectrometry; 17148 .

Methane; rotational symmetry; sulfur hexafluoride; angular momentum; 16957.

Methane; tables; thermal conductivity coefficient; viscosity coefficient; correlation; critical point anomaly; JPCRD 6, No. 2, 597-610 (1977).

Methane; tungsten; carbon monoxide; catalytic methanation; hydrogen; 17207.

Methane; vapor . liquid equilibria; ethane; ethene; 16881 .

Method of averages; weighted mean; weighted median; zero sum of residuals; Boscovich, Roger Joseph (1711-1787); Cotes, Roger (1682-1716); Euler, Leonard (1707-1783); Figure of the Earth; fitting a linear equation; least sum of absolute deviations; 17314 .

Method of mixtures; mixing; tracer technique; dilution method; discharge measurement in pipes; SP484, pp. 395-421 (Oct. 1977).

Methodology; network measurement system; computer service; external measurement; figure-of-merit; interactive system; measurement model; measurement, performance; measures; 17288.

Methodology; rare events; safety; system safety; accident research; human factors; SP482.

Methods of test; permeation; plastics packagings; polyethylene; transportation; hazardous materials; 17346.

Methods of tests; need for international standardization; product specifications; flow measurement; ISO; SP484, pp. 947-956 (Oct. 1977).

Methyl formate; tungsten; chemisorption; methane; 17065.

Methylene; rate constant; $\mathrm{CO}$; combustion; $\mathrm{CO}_{2} ; 16838$.

Methylenimine; microwave spectroscopy; molecules; pyrolysis; rotational spectra; structure; 16910.

Metric; miniature electric field; organic sulfur; radiometric detector; smog formation; SRM's; air pollution; attic ventilation; data encryption; dental materials; fire safety; DIM/NBS 61, No. 11, 1-32 (1977).

Metric; neutron diffraction; recycling oil; research and innovation; safety; ultrasonic tissue; computerized data; data elements; equity; federal technology; fire modeling; heat; hydrocarbon; ionized molybdenum; measurement assurance; DIM/NBS 61, No. 6, 1-32 (1977).

Metric; oxygen; technology; cryocooler; EMI problems; energy problems; energy savings; exchange program; lead detection; DIM/NBS 61, No. 10, 1-32 (1977).

Metric; pressure transducers; synchrotron radiation; building collapse; computer security; cryogenic temperature; dentistry; dielectric measurements; dye lasers; dynamic calibration; electron microscopy; electronic technology; DIM/NBS 6I, No. 2, 1-32 (1977).

Metric design and construction; recommended SI practice; International System of Units (S1); TN938.

Metric information, sources of; metric speakers; Metric Speakers Bureau, National; National Metric Speakers Bureau; TN960.

Metric speakers; Metric Speakers Bureau, National; National Metric Speakers Bureau; metric information, sources of; TN960.

Metric Speakers Bureau, National; National Metric Speakers Bureau; metric information, sources of; metric speakers; TN960. 
Metric system; modular coordination; Sl; building codes and standards; construction industry; dimensional coordination; metrication; SP458.

Metric system; National Conference on Weights and Measures; weights and measures; education for metric; laws and regulations; metrication; 17037.

Metric tons; polyethylene; sound; spinach; SRM; systems and software; telecommunications; computer use; conservation; data; earth's measurement; energy; health records; hydrogen; law enforcement; liquefied natural gas; DIM/NBS 61 , No. 5 , 1-32 (1977).

Metrication; metric system; modular coordination; Sl; building codes and standards; construction industry; dimensional coordination; SP458.

Metrication; metric system; National Conference on Weights and Measures; weights and measures; education for metric; laws and regulations; 17037.

Metrication; national laboratory accreditation; retail meat identity standards; tolerance application; vapor recovery; weights and measures; checking prepackaged commodities; computer assisted check-out systems; consumer affairs; cordage products; drained weight; SP471.

Metrication; noise; nondestructive evaluation; research associate program; standards; Alaska pipeline; calibration; CMAC; computers; consumer sounding boards; data; electron probe microanalysis; laser ionization; DIM/NBS 61, No. 1, 1-32 (1977).

Metrication benefits; rationalization; technical issues in metrication; construction industry metrication; 17040.

Metrology; radiation; surface technology; electromagnetic; interference; measurement; 17079.

Metrology; rf measurements; standards; superconductivity; thermometry; DC measurements; frequency; 16861 .

Metrology; systems; 17105.

Metrology system; Navy Flow Correlation Program; turbine flowmeters; volumetric standards; SP484, pp. 25-32 (Oct. 1977).

$\mathrm{Mg}_{2}$; multiconfiguration self-consistent-field; ab initio; electronic structure; excimers; excited states; metal dimers; 17188 .

MHD; momentum transfer; electron collisions; LiF; 17344.

MHD(magnetohydrodynamics); power generation; testing; U.S.U.S.S.R. cooperative program; ceria; materials characterization; 17160.

Mice; polyurethane; pulmonary irritation; PVC; respiratory rate; sensory irritation; stress index; thermal decomposition products; toxicity; acute lethality; Douglas Fir; inhalation; NBS-GCR-77-85.

Michaelis constant; NADH; Zimm plot; enzyme; initial velocity; kinetic constants; LDH; 16911 .

Michelson; phase-lock; scanning; wavelength; cw laser; interferometer; 17338.

Microanalysis; micro-chemistry; microprobe; particulate matter; Raman spectroscopy; airborne particles; 17013.

Microanalysis; microscopy; scanning; x-ray spectroscopy; electron probe; image formation; ion probe; 16841 .

Microanalysis; secondary ion mass spectrometry; surface analysis; ion imaging; ion microprobe; ion microscope; 17156.

Microbiologicals; organics; pesticides; radionuclides; sample handling; sampling; trace elements; chemical analysis; environmental samples; long-term storage; 16729.

Microcalorimetry; pacemaker; power cell; self-discharge; battery; NBSIR 77-1310.

Microcalorimetry; pacemaker leads; process control; reliability; screen tests; semiconductor devices; batteries; cardiac pacemakers; hermeticity; hybrid devices; leak testing; measurement technology; SP400-42.

Micro-chemistry; microprobe; particulate matter; Raman spectroscopy; airborne particles; microanalysis; 17013.
Microcomputer; synchronous detection; temperature controller; thermoelectric; thermometry; AC bridge; 16908.

Microelectronic; MOS; oxidation furnace; silicon dioxide; sodium contamination; thermal oxidation; fused silica; 16939.

Microelectronic device; radiation dose; silicon dioxide film; electron-gun evaporator; gate oxide film; metal evaporation; metallization; metal-oxide semiconductor; 16889.

Microelectronic devices; scanning electron microscope; secondary emission; voltage contrast; backscattered emission; EBIC; SP400-35.

Microelectronic industry; monitoring system; photodetectors; radiopharmaceuticals; ultraviolet radiation; windows; AC high voltage; AC voltmeter calibrator; marine studies; DIM/NBS 61, No. 12, 1-32 (1977).

Microelectronics; micrometrology; optical microscope; photoelectric microscope; photomask; scanning electron microscope; filar eyepiece; image-shearing eyepiece; integrated circuits; linewidth measurements; 17066.

Microelectronics; National Bureau of Standards; semiconductor devices; semiconductor materials; semiconductor process control; electronics; measurement methods; 16894.

Microelectronics; nondestructive test; acoustic emission; automated tape bonding; beam lead devices; bugging height; 16884.

Microelectronics; nondestructive test; acoustic emission; automated tape bonding; beam lead devices; bugging height; 17150.

Microelectronics; optical flying-spot scanner; oxidation particle impact noise detection test; passivation overcoats; photovoltaic method; power-device grade silicon; radioisotope method; resistivity; resistivity variations; safe operating area, transistor; SP400-29.

Microelectronics; $p$ - $n$ junctions; scanning electron microscopy; semiconductor devices; device inspection; electron-beam-induced current; 16891 .

Microelectronics; $\boldsymbol{p}-\boldsymbol{n}$ junctions; scanning electron microscopy; semiconductor devices; device inspection; electron-beam-induced-current; 16971 .

Micro-explosion; preheat; combustion; emulsified fuel droplet; fuel droplet; heat flow; J. Res. 82, No. 3, 183-195 (1977).

Microfilm; building code; building permits; computers; enforcement; information retrieval; inspection; management control; SP473, pp. 377-382 (June 1977).

Microgravity; purification; space processing; convection; crystal growth; crystal perfection; NBSIR 77-1208.

Microgravity; Skylab/ASTP; space processing; convection; crystal growth; 17275.

Microirregularities; overcoating; plasmons; scatter; absorption; dielectric layers; irregularities; metallic thin films; SP466, pp. 133-148 (May 1977).

Micrometer eyepiece; microscope calibration; optical microscope; photomasks; photomask metrology; optical microscope; shearing eyepiece; dimensional standards; filar eyepiece; linewidth measurements; 17063.

Micrometrology; optical microscope; photoelectric microscope; photomask; scanning electron microscope; filar eyepiece; image-shearing eyepiece; integrated circuits; linewidth measurements; microelectronics; 17066.

Microphone; piezoelectric polymer; sound source; vibration; headphone; loudspeaker; 16952.

Microphones; reciprocity; sensitivity; temperature; calibration; ceramic; condenser; electret; humidity; 16701 .

Microphones; reciprocity; sensitivity; temperature; calibration; ceramic; condenser; electret; humidity; 17245.

Microprobe; particulate matter; Raman spectroscopy; airborne particles; microanalysis; micro-chemistry; 17013.

Microprocessor; network analyzer; phosphoric acid electrolyte; refractory hard metals; AC impedance; automated electrochemical analysis; ceramic electrolytes: ceria-yttria; cyclic 
voltommetry; electrocatalysis; equivalent circuit; fuel cells; NBSIR 77-1270.

Microscope calibration; optical microscope; photomasks; photomask metrology; optical microscope; shearing eyepiece; dimensional standards; filar eyepiece; linewidth measurements; micrometer eyepiece; 17063.

Microscopy; scanning; x-ray spectroscopy; electron probe; image formation; ion probe; microanalysis; 16841 .

Microstrip resonator; microwave coupling; parametric plasma oscillation; thin-film device; coherent microwave emission; e/h voltage standard; Josephson junction; 16788.

Microstructural analysis; nondestructive evaluation techniques; compositional analysis; instrumental methods; metallic artifacts; 16712 .

Microstructural analysis; scanning electron microscope; selected area electron channeling pattern; crystal orientation determination; crystallographic contrast; electron channeling contrast; 16839.

Microstructure; modelling; paper; pore size; statistical analysis; Weibull distribution; durability; fatigue; fiber length; flexing; low cycle fatigue; mechanical properties; 16681 .

Microstructures; molybdenum additions; precipitation; titanium alloys; transmission electron microscopy; corrosion resistant alloys; 16690.

Microstructures; titanium alloys; corrosion; fatigue; 17187.

Microwave; microwave measurement; six-port; automatic network analyzer; automation; 16726.

Microwave; molecular structure; spectra; spectroscopy; bond distances; carbonyl selenide; energy levels; force field; infrared; 16823.

Microwave; National Measurement System; radio measurements; electromagnetic quantities; laser; NBSIR 75-936.

Microwave; nondestructive evaluation; penetrant; radiography; standards; thermal; ultrasonic; visual testing; wear debris; acoustic; calibration; eddy current; 17106.

Microwave; power measurement; bolometer; 16723.

Microwave; power meter; bolometer; dc substitution; NBSIR 77-866.

Microwave connectors; RF connectors; scattering parameters; coaxial connectors; 16727.

Microwave coupling; parametric plasma oscillation; thin-film device; coherent microwave emission; e/h voltage standard; Josephson junction; microstrip resonator; 16788 .

Microwave discharge; nitride; plasma; reaction mechanism; silicon; synthesis; thin film; vapor transport; activation parameters; active nitrogen; iodine; kinetics; 16757.

Microwave emission; radio sources and rotational spectra; astronomy; ethyl cyanide; interstellar molecule; 17264 .

Microwave feed; primary cesium standard; cesium standard; clock, operating; magnetic shielding; 16759.

Microwave measurement; six-port; automatic network analyzer; automation; microwave; 16726.

Microwave measurements; one-port microwave parameters; sixport concept; 17234 .

Microwave measurements; six-port; automatic network analyzer; automation; 17237.

Microwave measurements; six-port; automatic network analyzer; automation; 17240.

Microwave power meter; self-balancing two amplifier power meter; bolometer; D.C.-substitution technique; differential operational amplifiers; U.S. Patent 4,008,610.

Microwave pressure transducer; thermal-acoustic oscillations; burn-out; helium-cooled current leads; helium flow facility; helium impurities; NBSIR 77-853.

Microwave radiation; nonmetallic electrode system; turtle; ECG; EEG; electromagnetic field; 17174.

Microwave spectroscopy; molecules; pyrolysis; rotational spectra; structure; methylenimine; 16910.
Microwave spectrum; rotational constants; Stark effect; vibrational transition moment; acetylene- $d_{2}$; l-type doubling constants; 16689.

Microwave voltmeter; phase angle measurements; six-port voltmeter; vector voltmeter; U.S. Patent 4,001,681.

Microwaves; network analyzer; reflection coefficient; reflectometer; scattering parameters; self-calibration techniques; six-port junction; impedance; 17244.

Microwaves; niobium; superconductivity; tunnelling; dielectric constant; Josephson effect; lead; 16946.

Microwaves; nondestructive evaluation; standard reference materials; standards; thermal testing; ultrasonics; visual testing; wear debris analysis; acoustic emission; calibrations; electrical-eddy current measurements; 17016.

MIDAS; MIDAS amplifier controller; MIDAS digital to analog converter; MIDAS modules; MIDAS stepping motor indexer; MIDAS up/down counter; data acquisition system; TN958.

MIDAS amplifier controller; MIDAS digital to analog converter; MIDAS modules; MIDAS stepping motor indexer; MIDAS up/down counter; data acquisition system; MIDAS; TN958.

MIDAS digital to analog converter; MIDAS modules; MIDAS stepping motor indexer; MIDAS up/down counter; data acquisition system; MIDAS; MIDAS amplifier controller; TN958.

MIDAS modules; MIDAS stepping motor indexer; MIDAS up/down counter; data acquisition system; MIDAS; MIDAS amplifier controller; MIDAS digital to analog converter; TN958.

MIDAS stepping motor indexer; MIDAS up/down counter; data acquisition system; MIDAS; MIDAS amplifier controller; MIDAS digital to analog converter; MIDAS modules; TN958.

MIDAS up/down counter; data acquisition system; MIDAS; MIDAS amplifier controller; MIDAS digital to analog converter; MIDAS modules; MIDAS stepping motor indexer; TN958.

Military buildings; aluminum wiring; branch circuits; copper wiring; NBSIR 76-1184.

Military field shelters; probability distributions; shocks, snow load; static load; trains; transportation; trucks; vibrations; wind load; acceleration; airplanes; cargo; dynamic loads; equivalent static force; gravity load; handling devices; handling loads; NBSIR 77-1254.

Millimeter wave; power measurement; reflection measurement; six-port; automation; 17243.

Millimeter waves; mixing; receiver; superconductivity; heterodyne detection; Josephson effect; 17077.

Mineral exploration; nuclear safeguards; oceanography; onstream analysis; well logging; activation analysis; californium252; inland waters and sediments; in vivo analysis; 16760.

Mineral waste utilization; slags; cement manufacture; energy conservation; fly ashes; 17010 .

Mini-arc; radiometry; spectral radiance; standard; ultraviolet; argon; light source; 16778.

Miniature electric field; organic sulfur; radiometric detector; smog formation; SRM's; air pollution; attic ventilation; data encryption; dental materials; fire safety; metric; $D I M / N B S$ 61, No. 11, 1-32 (1977).

Minimax; networks; facility location; location theory; J. Res. 82, No. 1, 65-72 (1977).

Minimax; networks; facility location; location theory; J. Res. 82, No. 1, 73-80 (1977).

Minimum polynomials; control theory; linear algebra; matrix; $J$. Res. 82, No. 2, 129-132 (1977).

Minimum property standards; multiple glazing; "U" values; alternatives; ASHRAE 90-75; building standards; buildings; energy conservation; SP473, pp. 85-101 (June 1977).

Minimum property standards; performance criteria; performance evaluation; plumbing; safety; structures: ton 
methods; acoustics; appliances; atmosphenc; durabılity; electrical; environment; housing technology; HVAC; innovative construction; maintainability; materials; NBSIR 77-1316.

Mining; Office of Mineral Information; Bureau of Mines; energy; health and safety; metallurgy; SP463, pp. V.3.1-V.3.9 (Jan. 1977).

Mining wastes; municipal waste; slags; waste materials; coal byproducts; construction materials; industrial wastes; NBSIR 77-1244.

MIS capacitor; premature dielectric breakdown; semiconductor devices; capacitance-voltage measurements; dielectric breakdown suppression; discharge suppression; electronics; extended-range MIS C (V) measurements; high-voltage C (V) measurements; SP400-37.

MIS capacitors; modified MIS C(V) measurements; semiconductor devices; silicon-on-sapphire measurements; SOS measurements; bias-isolation unit; capacitance and conductance measurements at high applied-bias voltage; capacitance/conductance-meter; SP400-40.

Missiles; power plants; structural engineering; tornadoes; trajectories; dynamics; SP477, pp. VI1-36-VI1-41 (May 1977).

Misuse of products; systems analysis; use of products; consumer behavior; consumer product safety; human factors; 16890 .

MIUS; modular integrated utility system; simulation; utility services; computer programs; cooling; energy analysis; financial analysis; heating; load calculation; NBSIR 77-1307.

Mixed $n-\gamma$ fields; neutron dosimetry; standards; basic physical data; medical; SP493, pp. 106-114 (Oct. 1977).

Mixed waste paper; paper recycling; pulp characterization; 2.5 $\mathrm{g} / \mathrm{m}^{2}$ handsheets; breaking energy; inter-fiber bond strength; NBSIR 76-1148.

Mixer; optics; pre-amplifier; radio receiver; semiconductor device studies; electronic reliability; electronics; laser scanner; measurement method; SP400-24.

Mixer; spectrophotometry; stirrer; vortex; cuvette; helix; 16704.

Mixing; receiver; superconductivity; heterodyne detection; Josephson effect; millimeter waves; 17077.

Mixing; tracer technique; dilution method; discharge measurement in pipes; method of mixtures; SP484, pp. 395-421 (Oct. 1977).

Mixing ratio; relative humidity; two-pressure generator; volume ratio; water vapor; calibration; dew point; humidity; hygrometer; J. Res. 81A No. 1, 81-88 (1977).

Mixture; modified Enskog theory; prediction; thermal conductivity coefficient; viscosity coefficient; corresponding states; dense liquid; 16791.

Mixture; one-fluid theory; plait point; thermal conductivity coefficient; viscosity coefficient; critical point; J. Res. 82, No. 3, $181-182$ (1977).

Mixtures; molecular volumes; second virial coefficients; water; ballistics; carbon dioxide; combustion gases; energy; equation of state; high pressure; high temperature; interaction virial coefficients; 17136 .

Mixtures; nitrous oxide; prediction; thermal conductivity; transport property; viscosity; carbon dioxide; corresponding states; TN693.

Mixture(s); Clausius-Mosotti; densitometer (capacitance); density; dielectric constant; LNG; 17071.

MK-System; dominating set; enclaveless set; graph; hypergraph; König System; KM-System; Menger System; J. Res. 82, No. 3, 197-202 (1977).

Mm wave transitions; overlapped lines; radio astronomy; acetaldehyde; internal rotation; interstellar molecules; 16969.

M-matrix; diagonally dominant; diagonally symmetrizable; eigenvalue; Hadamard product; 16909.

Mo; $\mathrm{Mo}_{2} \mathrm{C}$; refractory hard metals; valence bands; $\mathrm{W}$; WC; $\mathrm{x}$ ray photoemission; catalysis; 16932 .

Mobile climate chamber; energy conservation research; heat and cold stress; SP491, pp. $174-189$ (Sept. 1977).
Mobile digital equipment; modulation technique; transmission rate; voice channel; Allegheny County; data transmission tests, digital data; SP480-19.

Mobile digital equipment; National Institute of Law Enforcement and Criminal Justice; communications; digital communications; guideline; law enforcement equipment report; Law Enforcement Standards Laboratory; 16996.

Mobile home; part-load efficiency; thermography; air infiltration; energy conservation; NBSIR 76-1182.

Mobile home; racking; research; safety; standard; window; emergency egress; HUD; NBSIR 77-1246.

Mobile homes; polyurethanes; smoke detectors; standards; textiles; toxicity; arson; bibliographies; building fires; carpets; construction materials; fire departments; fire detection systems; fire tests; flame research; flammability tests; interior furnishings; NBSIR 77-1277.

Mobile homes; wind loads; aerodynamics; buildings; full-scale testing; SP477, pp. 1-21-1-33 (May 1977).

Mobile radio; police; police equipment; portable radio; standards; communications; $S P 480-2$.

Mode Grumeisen parameters; neutron scattering; anharmonicity; dispersion curves; high pressure; $\mathrm{KBr} ; 17001$.

Mode interaction; pulsation; stellar instabilities; TU Cassiopeiae; Cepheids; beat Cepheids; double-mode Cepheids; 17315.

Mode interaction; stellar instabilities; U Trianguli Australis; beat Cepheids; double-mode Cepheids; Fourier analysis of stellar variations; 16807.

Mode interaction; stellar instabilities; U Trianguli Australis; beat Cepheids; double-mode Cepheids; Fourier analysis of stellar variations; 17118 .

Mode of failure; racking resistance; structural performance; uniform loads; concentrated loads; design criteria; SP477, pp. I-66-I-69 (May 1977).

Model; moderator; neutron; scattering; thermalization; cross section; diffusion; kernel; lattice vibration; SP461, pp. 149 162 (Jan. 1977).

Model; neutron; OER; one-hit detector; pion; radiation; track; cell; delta ray; dose; ions; LET; SP461, pp. 183-187 (Jan. 1977).

Model; nursing homes; rescue; verbal communicative; alarm; architecture; design implication; emergency actions; emergency communicative; emergency decisions; escape; fires; human behavior; human response; life safety; mapping; NBSGCR-77-93.

Modei; structural analysis; velocities; vibrations; arch dam; deflections; dynamic tests; SP477, pp. VI-85-VI-117 (May 1977).

Model; towers; wind; wind observation; wind tunnel; field measurements; SP470, pp. 1-1-1-17 (Apr. 1977).

Model codes; standards; building codes; energy conservation; energy efficiency; energy performance; 17290.

Model codes; state-local relations; statewide codes; uniformity; building regulation; code administration; enforcement; funding; local government; SP473, pp. 225-240 (June 1977).

Model predictions; nuclear reactions np scattering $E \leqslant 30$ $\mathrm{MeV}$; phase shift analyses; calculated $\sigma(\theta)$; experimental $\sigma(\theta)$; SP493, pp. 47-53 (Oct. 1977).

Model simulation, computer; benchmark; computer performance; 17020 .

Model validation; performance management; performance prediction; queuing networks; sizing studies; system design; computer-communication networks; configuration analysis; SP500-18, pp. 227-234 (Sept. 1977).

Modeling; OSHA Standards; thermal sensation; WBGT; core temperature; energy conservation; SP491, pp. 18-40 (Sept. 1977).

Modeling; rheological; seismic response; two-dimensions; bedrock; SP477, pp. IV-18-IV-46 (May 1977). 
Modeling; standby loss; water heater; alternating direction; computer simulation; cool down; energy savings; flue damper; heat transfer; implicit; insulation; laboratory measurements; 17184 .

Modelling; paper; pore size; statistical analysis; Weibull distribution; durability; fatigue; fiber length; flexing; low cycle fatigue; mechanical properties; microstructure; 16681 .

Modelling; resource dependency; system capacity; validation; credit authorization system; critical resource; disk modelling; event model; measurement; SP500-18, pp. 185-211 (Sept. 1977).

Models; physical scale; plumes; buoyancy pressure; enclosure fires; entrainment; fire induced flows; J. Res. 82, No. 2, 107 117 (1977).

Models; queuing; telephone systems; transit information; transportation; automation; cost/benefit; NBSIR 77-1253.

Models; shake tables; testing; dynamic testing; lateral load simulation; SP470, pp. IX-1 - IX-5 (Apr. 1977).

Models; simulation; transportation; validation of models; airport simulation; air traffic control; aviation; 16944.

Models; wind angles; wind tunnel; bridge; cabled stayed; displacements; flutter; SP470, pP. II-47-II-67 (Apr. 1977).

Moderation; monitor; neutron; shielding; sources; standardization; calibration; detection; dosimetry; facilities; fluence; flux; SP493, pp. $115-120$ (Oct. 1977).

Moderator; neutron; radiation damage; reactor; scattering; spectrometer; cross section; energy transfer; gamma rays; SP461, pp. 32-40 (Jan. 1977).

Moderator; neutron; scattering; thermalization; cross section; diffusion; kernel; lattice vibration; model; SP461, pp. 149162 (Jan. 1977).

Modification; suspension; absolute measurements; barium ferrite buoy; densimeter; experimental; liquid, magnetic; 16792.

Modified Enskog theory; prediction; thermal conductivity coefficient; viscosity coefficient; corresponding states; dense liquid; mixture; 16791 .

Modified MIS C(V) measurements; semiconductor devices; silicon-on-sapphire measurements; SOS measurements; biasisolation unit; capacitance and conductance measurements at high applied-bias voltage; capacitance/conductance-meter; capacitance-voltage measurements; SP400-40.

Modular coordination; SI; building codes and standards; construction industry; dimensional coordination; metrication; metric system; SP458.

Modular Integrated Utility System; total energy; utility system; institutional factors; NBSIR 76-1/103.

Modular integrated utility system; simulation; utility services; computer programs; cooling; energy analysis; financial analysis; heating; load calculation; MIUS; NBSIR 77-1307.

Modulation; phase; Ramsey; saturation spectroscopy; transittime; coherence; fringes; interference; 17337.

Modulation technique; transmission rate; voice channel; Allegheny County; data transmission tests, digital data; mobile digital equipment; SP480-19.

Modulation transfer function; nondestructive testing; vision; visual acuity; visual capacities; 17015.

Modules; nuclear; standards; CAMAC; Dataway; instrumentation; 16678.

Modulus of elasticity; partial reinforcing; risk; shear modulus; testing; ultimate strength; anchor bolts; bond; damping; ductility; earthquake resistance; energy absorption; BSS106, pp. 255-258 (Sept. 1977).

Modulus of rubber; Mooney-Rivlin equation; rubber; stressstrain relations; stress-strain relations in rubber; uniaxial extension and compression in rubber; extension and compression in rubber; J. Res. 82, No. 1, 57-63 (1977).

Moisture condensation; seal durability and longevity; sealed insulating glass; ASTM Test Standard for insulating glass; frostpoint measuring apparatus; 17286 .
Moisture determination; preservation technology; adobe building materials; adobe soil; mechanical properties; 17104.

Moisture determination; preservation technology; adobe building materials; adobe soil; mechanical properties; TN934.

Molecular absorption; $10 \mu \mathrm{m}$ wavelength; ammonia; carbon dioxide; ethanol; measurement; 16924.

Molecular absorption spectrometry; neutron activation analysis; polarography; pure reagents; sample preparation; spark source mass spectrometric isotope dilution; tissues; analytical disciplines; analytical procedures; atomic absorption spectrometry; biological materials; SP492.

Molecular constants; molecular nitrogen; potential energy curves; radiative lifetimes; critical review; Franck-Condon integrals; JPCRD 6, No. 1, 113 3-307 (1977).

Molecular diffusion; moments; secondary flow; gas chromatography; 16980.

Molecular dynamics; neutron; nuclear reactor; radiation; activation analysis; crystal structure; diffraction; isotopes; TN939.

Molecular dynamics; neutron scattering; shear wave; statistical mechanics; time correlation function; transverse current; ultrasonics; correlation function; density fluctuations; fluctuations; hydrodynamics; light scattering; liquid state; 16711 .

Molecular dynamics; second sound; shock wave; stress relaxation; structural relaxation; thermal relaxation; anharmonic crystal; computer simulation; energy transport; equation of state; interatomic potential; 16751 .

Molecular fluorescence parameters; observed (technical) fluorescence parameters; polarization; radiative and nonradiative transition probabilities; real fluorescence parameters; fluorescence lifetime; fluorescence quantum efficiency; SP466, Pp. 1-11 (May 1977).

Molecular identity; preserving stone; pressure measurements; rf-power meter; roofing; safety; security alarms; SRM's; time and frequency; ultraviolet; computer memories; computer performance; inventor; DIM/NBS 61, No. 8, 1-32 (1977).

Molecular lines; radio astronomy; silicon monoxide; spectra; interstellar sources; isotope ratio; 17189.

Molecular lithium; potential curve; spectroscopy; dissociation energy; Dunham coefficients; Franck Condon factors; 17101.

Molecular motion; nmr; Overhauser effect; relaxation time; ${ }^{13} \mathrm{C}$; collagen fibers; 17007.

Molecular nitrogen; potential energy curves; radiative lifetimes; critical review; Franck-Condon integrals; molecular constants; JPCRD 6, No. 1, 113-307 (1977).

Molecular orbital theory; quantum chemistry; static potential; carbon monoxide molecules; dipole moment; electron scattering; electrostatic potential; intermediate neglect of differential overlap (INDO); 16709.

Molecular orientations; $\mathrm{NH}_{4} \mathrm{ClO}_{4}$; quasi-elastic neutron scattering; residence times; single crystal; activation energies; 17003.

Molecular physics; short-lived molecular species; vibration-rotation spectra; carbon monosulfide; Dunham coefficients; infrared absorption; 17044.

Molecular potential; recombination; scattering; theoretical; theory; argon; collisions; dissociation; hydrogen; inelastic; 16802 .

Molecular probability density; bifurcation; close-packed crystals; crystalline solutions; hard spheres; metastable states; 17012.

Molecular properties; nitrosyl chloride; nitryl chloride; physical properties; spectral properties; thermodynamic properties; bibliography; chemical kinetics; chemistry; chlorine nitrate; SP478.

Molecular spectra; atomic spectra; data sources; laser chemistry; 16837.

Molecular spectra; Stark effect; cyanogen fluoride; dipole moment; infrared spectroscopy; laser absorption; laser-Stark resonance; 17124 . 
Molecular spectroscopy; crystal field theory; group theory; high-resolution spectra; irreducible representation; isotope separation; 16956.

Molecular spectroscopy; sulfur hexafluoride; crystal field theory; group theory; 17316 .

Molecular structure; oxazine dyes; quenching; xanthene dyes; aminocoumarins; carbazine dyes; deuterium effect; fluorescence quantum yield; laser dyes; SP466, pp. 33-40 (May 1977).

Molecular structure; spectra; spectroscopy; bond distances; carbonyl selenide; energy levels; force field; infrared; microwave; 16823 .

Molecular volumes; second virial coefficients; water; ballistics; carbon dioxide; combustion gases; energy; equation of state; high pressure; high temperature; interaction virial coefficients; mixtures; 17136.

Molecular weight distribution; polymer characterization; standard reference material 1476; branched polyethylene; fractionation; gel permeation chromatography; GPC; 17255 .

Molecules; photoelectron spectroscopy; surfaces; vibrational excitation; adsorption; 16749.

Molecules; pyrolysis; rotational spectra; structure; methylenimine; microwave spectroscopy; 16910 .

Molecules, interstellar; Orion Nebula; 16675.

Moliere theory; multiple; scattering; angular distribution; chlorine; foils; ions; iron, oxygen; measurement; SP461, pp. 136-139 (Jan. 1977).

Molten salt mixtures; standard reference data; surface tension; viscosity; bromides; data compilation; density; electrical conductance; iodides; JPCRD 6, No. 2, 409-596 (1977).

Molybdenum; niobium; rubidium; spectra; structure; ultraviolet; yttrium; zirconium; ions; 17212 .

Molybdenum; pulse calorimetry; standard reference material; thermodynamic functions; drop calorimetry; emittance; enthalpy; heat capacity; high-speed measurements; high temperature; SP260-55.

Molybdenum; tetracyanoquinodimethan; x-ray photoelectron spectroscopy; chromium; infrared spectroscopy; magnetic susceptibility; 17153.

Molybdenum additions; precipitation; titanium alloys; transmission electron microscopy; corrosion resistant alloys; microstructures; 16690 .

Molybdenum hexafluoride; new static technique; vapor pressure; argon-vapor contact; error analysis; iodine; 17075.

Moment methods; scattering; singularity expansion method; symmetry analysis; antenna patterns; characteristic modes; Garbacz characteristic modes; group theory; inverse scattering; 17225 .

Moment theory; spectral densities; approximations; 16849.

Moments; secondary flow; gas chromatography; molecular diffusion; 16980.

Momentum; Poynting; variational; anholonomic; constraint; electromagnetism; Hamilton; Maxwell; J. Res. 81B Nos. 1 and 2, 1-3 (1977).

Momentum transfer; electron collisions; LiF; MHD; 17344.

Momentum transfer cross sections; polar molecules; electronmolecule collisions; LiF; 17027.

Monitor; neutron; shielding; spectrum; computer code; dose; dosimetry; SP461, pp. 238-246 (Jan. 1977).

Monitor; neutron; shielding; sources; standardization; calibration; detection; dosimetry; facilities; fluence; flux; moderation; SP493, pp. 115-120 (Oct. 1977).

Monitoring; ozone; ultraviolet photometry; air pollution; calibration; iodometry; NBSIR 76-1191.

Monitoring flow; open channel flow; public law 92-500; sewerage flow; wastewater flow; closed conduit flow; instrumentation; measuring flow; metering flow; SP484, pp. 83-89 (Oct. 1977).
Monitoring system; photodetectors; radiopharmaceuticals; ultraviolet radiation; windows; $\mathrm{AC}$ high voltage; $\mathrm{AC}$ voltmeter calibrator; marine studies; microelectronic industry; DIM/NBS 61, No. 12, 1-32 (1977).

Monitoring systems; physical security; sensor systems; adversary scenarios; automated response systems; distributed processing; NBSIR 77-1262.

Mono- and di-substituted benzenes; NMR spectral data; aromatic proton chemical shifts; JPCRD 6, No. 3, 919-992 (1977).

Monodeutero silane; $\mathrm{SiH}$ stretching vibrations; vibration-rotation interaction; high resolution; infrared spectrum; 17131 .

Monodisperse polymers; unsaturated monomers; block copolymers; homogeneous anionic polymerization; 16736.

Monoenergetic electron impact; photoionization; pyridine; vinylacetylene; 1,5-hexadiyne; 2,4-hexadiyne; appearance potential; benzene; butatriene; heat of formation; ion; ionization potential; 17294.

Monoenergetic neutrons; neutron beams; neutrons; resonant scatterer; dosimeter calibration; SP493, pp. 250-254 (Oct. 1977).

Monoenergetic $x$ rays; pulsed $x$-ray source; $x$-ray detector calibration; 1.5-8 keV $x$ rays; absolute $x$-ray detectors; electron excitations; 16814 .

Monopole transition; separable potential; Coulomb excitation; electron scattering; Faddeev equations; helium-three; 16793.

Monopolies; patent law; patents; Canada; copyrights; inventions; 16859.

Monte Carlo; albedo; angular; backscattering; barrier; differentials; distribution; gamma rays; integral; medium; SP461, pp. 129-131 (Jan. 1977).

Monte Carlo; algorithm; Lennard-Jones; metastable states; 16786.

Monte Carlo; multiple scattering; neutron detection; photomultipliers; ${ }^{\circ} \mathrm{Li}(\mathrm{n}, \alpha) \mathrm{T}$; glass scintillators; SP493, pp. $37-42$ (Oct. 1977).

Monte Carlo; neutron; sandwich; spectrometry; surface barrier; ${ }^{6} \mathrm{LiF}$; detector; energy leakage; SP461, pp. 252-254 (Jan. 1977).

Monte Carlo; organ; phantom; photon; reciprocity theorem; source; target; tissue; dose; dosimetry; SP461, pp. 177-182 (Jan. 1977).

Monte Carlo; perspex; photon energy; pulse height; resolution; scattering media; tissue; water; detector; SP461, pp. 188-192 (Jan. 1977).

Monte Carlo; photon; albedo; backscattering; distribution; dose rate; gamma rays; SP461, pp. 110-118 (Jan. 1977).

Monte Carlo; polymer chain dynamics; random coil; random flight chain; relaxation times; excluded volume; 17125 .

Monte Carlo; scattering; aluminium; carbon; collision; copper; distribution; dose; electron; Gaussian; SP461, pp. 106-109 (Jan. 1977).

Monte Carlo; statistics; stratified sampling; Bayes' Rule; flow determination; flow prediction; SP484, pp. 447-470 (Oct. 1977).

Monte Carlo; transport coefficient; diffusion; drift tube; electron; 16854.

Monte Carlo calculations; proton angular distributions; proton production; proton spectra; heavy ion collisions; inelastic scattering; 17109.

Monte-Carlo; swarm; theory; velocity distribution; drift tube; ion; 16779 .

Monte-Carlo testing; testbed; test cases; validating correctness; communications security; computer security; cryptography; encryption standard; interface requirements; SP500-20.

Mooney-Rivlin equation; rubber; stress-strain relations; stressstrain relations in rubber; uniaxial extension and compression in rubber; extension and compression in rubber; MartinRoth-Stiehler equation; J. Res. 82, No. 1, $57-63$ (1977). 
Morphology; polymer; sectorization; spheralites; chain folding; curved crystals; extended chain crystals; fold domains; fold surfaces; interlamellar links; 16958.

MOS; oxidation furnace; silicon dioxide; sodium contamination; thermal oxidation; fused silica; microelectronic; 16939.

MOS capacitors; sheet resistors; silicon; test structures; defects; dopants; impurities; junctions; 16855.

MOSFET; silicon; direct-current; dopant density; ion implantation; 17342.

Mounting variable; vibration; acceleration calibration; NBSIR 73-291.

Moving boundary problem; preheat; transient heat conduction; confluent iypergeometric functions; droplet; J. Res. 81A Nos. 2 and 3, 257-266 (1977).

$\mathrm{Mo}_{2} \mathrm{C}$; refractory hard metals; valence bands; W; WC; $\mathrm{x}$-ray photoemission; catalysis; Mo; 16932.

$M^{*}$ ssbauer effect; nuclear hyperfine techniques; nuclear magnetic resonance; perturbed angular correlation; residual stress; 17011 .

Mueller matrix; polarization; polarizer; retarder; Stokes parameters; TN910-3.

Multiconfiguration self-consistent-field; potential energy curves; sodium molecule; transition dipole moment; ab initio calculations; $A$-values; Franck-Condon factors; laser modeling; lifetime; 16870 .

Multiconfiguration self-consistent-field; ab initio; electronic structure; excimers; excited states; metal dimers; $\mathbf{M g}_{9} ; 17188$.

Multielement analysis; pollutants; speciation; Standard Reference Materials; trace organics; water; accuracy; aerosol; air; collaborative testing; laboratory accreditation; laser technology; SP464.

Multi-family residences; apartments; building codes; fire; fire resistivity; firestopping; fire walls; garden apartments; NBSIR 76-1194.

Multifilamentary superconductors; $\mathrm{NbTi}$; $\mathrm{Nb}_{3} \mathrm{Sn}$; strain; stress; critical current; critical current degradation; degradation mechanisms; 16873.

Multifilamentary wires; $\mathrm{Nb}_{3} \mathrm{Sn}$; $\mathrm{NbTi}$; strain; stress; aluminum stabilization; copper stabilization; critical current; criticalcurrent degradation; 16816.

Multijunction converter; thermal converter; ac current measurements; ac-dc comparator; ac-dc transfer standard; ac voltage measurement; 16693.

Multiphoton absorption; optical interactions; atomic spectra; electromagnetism; laser, high-intensity; 17130.

Multiphoton absorption; tunnelling; ionization; laser-induced breakdown; laser pulse; 16892

Multiphoton ionization; ac Stark effect; ionization; 16925.

Multiphoton ionization; Rabi shifts; radiative Penning ionization; tuneable lasers; alkalis; atomic collisions; 17263.

Multiphoton processes; plasma absorption; bremsstrahlung; electron-ion collisions; free-free transitions; J. Res. 82, No. 3, 173-179 (1977).

Multiple; scattering; angular distribution; chlorine; foils; ions; iron, oxygen; measurement; Moliere theory; SP461, pp. 136139 (Jan. 1977).

Multiple bias; neutron; nonelastic; optical model; parameter; polynomial extrapolation; sphere transmission; cross section; SP461, pp. 44-46 (Jan. 1977).

Multiple bias technique; neutron; scattering; cross section; differential; elastic; SP461, pp. 64-66 (Jan. 1977).

Multiple contact switch; proximity effect; superconducting switch; thin-film; cryogenic electrical switch; mechanical switch; 17121.

Multiple glazing; "U" values; alternatives; ASHRAE 90-75; building standards; buildings; energy conservation; minimum property standards; SP473, pp. 85-101 (June 1977).

Multiple reflections; photometric linearity; polarization; sample characteristics; stray light; wavelength accuracy; bandwidth; calibration; errors in spectrophotometry; interferences: SP466, pp. 99-114 (May 1977).

Multiple regression; processing time; regression model; blocking factor; data record; SP500-18, pp. 143-158 (Sept. 1977).

Multiple scattering; neutron detection; photomultipliers; ${ }^{6} \mathrm{Li}(\mathrm{n}, \alpha) \mathrm{T}$; glass scintillators; Monte Carlo; SP493, pp. 37-42 (Oct. 1977).

Multiplet; nitrogen lines; regularities; Stark broadening; supermultiplet; transition array; wall stabilized; 17204.

Multiplet; plasma broadening; regularities; Stark widths; supermultiplet; transition array; isolated lines; 17206.

Multiplicative; spectral radius; vector norm; compatible; generalized matrix norm; Hadamard product; 16676.

Multiplicative; spectral radius; unit ball; vector norm; compatible; generalized matrix norm; 16836.

Multipolarity; sum rule; electron scattering; inelastic; isospin; magnetic; 16687.

Multi-room problems; air-leakage; dynamic heat transfer; energy analysis; heat and cooling loads; heat loss and heat gain; J. Res. 82, No. 2, 97-106 (1977).

Municipal waste; slags; waste materials; coal by-products; construction materials; industrial wastes; mining wastes; NBSIR 77-1244

Municipalities; regulation; site design; architectural controls; buildings; design review; land use; SP473, pp. 137-187 (June 1977).

Munsell Color System; Universal Color Language; variable accuracy of color designations; centroid colors; color; color designations; calorimetry; color names; color-order systems; SP440.

Mushroom Apparel Flammability Tester; standards; test development; textiles; apparel; fabrics; flammability testing; heat transfer rates; NBS-GCR-76-78.

Mushroom Flammability Tester; test methods; burn injury; flammability; 16813 .

Mutagenicity; toxic materials; toxicology; trace contaminants; water pollution; air pollution; analysis; ecology; energy; environmental impact; land pollution; SP463, pp. III.4.1-III.4.15 (Jan. 1977).

\section{$\mathbf{N}$}

$\mathrm{NaCN}$; order parameter; structure; antiferroelectric; $\mathrm{KCN}$; 16972.

NADH; Zimm plot; enzyme; initial velocity; kinetic constants; LDH; Michaelis constant; 16911 .

$\mathrm{NaF}$; Plexiglas 55; refractive index; $\mathrm{SrF}_{2}$; thermal coefficient of refractive index; $\mathrm{ZnS} ; \mathrm{ZnSe} ; \mathrm{BaF}_{2} ; \mathrm{CaF}_{2} ; \mathrm{KBr} ; \mathrm{KCl}$; Lexan; LiF; NBSIR 77-1304 (ARPA).

$\mathrm{NaF}$; refractive index; $\mathrm{SrF}_{2}$; thermal coefficient of refractive index; $\mathrm{ZnSe} ; \mathrm{BaF}_{2} ; \mathrm{CaF}_{2} ; \mathrm{KBr} ; \mathrm{KCl}$; LiF; NBSIR 77-1219.

$\mathrm{NaHF}_{2}$; polycrystals; infrared; $\mathrm{KHF}_{2}$; lattice modes; linear triatomic anions; 16983.

Nal; neutron flux determination; proportional counters; solidstate detectors; standard cross section; ${ }^{10} \mathrm{~B}\left(\mathrm{n}, \alpha_{0}+\alpha_{1} \gamma\right)^{7} \mathrm{Li}$; SP493, pp. 85-92 (Oct. 1977).

Name lookup; nonunique identifiers; personal data files; Privacy Act; probability model; retrieval; data retrieval; file validation; SP500-2.

Nanogram sensitivity; organometallic compounds; speciation; tin; arsenic; element-specific detector; flameless atomic absorption; flow monitoring; high-pressure liquid chromatography; lead; ligand; mercury; 17297.

$\mathrm{NaNO}_{2}$, enthalpies of transition and fusion; $\mathrm{NaNO}_{2}$, melting temperature; calorimetry, soln.; $\mathrm{NaNO}_{2}$, enthalpy of dilution; $\mathrm{NaNO}_{2}$, enthalpy of soln.; J. Res. 82, No. 1, 19-28 (1977).

$\mathrm{NaNO}_{2}$, enthalpy of dilution; $\mathrm{NaNO}_{2}$, en thalpy of soln.; $\mathrm{NaNO}_{2}$, relative apparent molar heat content; $\mathrm{NaNO}_{2}$, enthalpies of transition and fusion; J. Res. 82, No. 1, 19-28 (1977). 
$\mathrm{NaNO}_{2}$, enthalpy of soln.; $\mathrm{NaNO}_{2}$, relative apparent molar heat content; $\mathrm{NaNO}_{2}$, enthalpies of transition and fusion; $\mathrm{NaNO}_{2}$, melting temperature; calorimetry, soln.; J. Res. 82, No. 1, 19-28 (1977).

$\mathrm{NaNO}_{2}$, melting temperature; calorimetry, soln.; $\mathrm{NaNO}_{2}$, enthalpy of dilution; $\mathrm{NaNO}_{2}$, enthalpy of soln.; $\mathrm{NaNO}_{2}$, relative apparent molar heat content; J. Res. 82, No. 1, 19-28 (1977).

$\mathrm{NaNO}_{2}$, relative apparent molar heat content; $\mathrm{NaNO}_{2}$, enthalpies of transition and fusion; $\mathrm{NaNO}_{2}$, melting temperature; calorimetry, soln.; $\mathrm{NaNO}_{2}$, enthalpy of dilution; J. Res. 82, No. 1, 19-28 (1977).

Naphthalene; partition coefficient; solubility; vapor pressure; 1 ethylnaphthalene; 1-methylnaphthalene; enthalpy; fluorescence; heat of solution; 17097.

Naphthalene homologues; nematic phase; supercooled phase; gas-liquid chromatography; liquid crystal; 16673.

Narrow pass filter; phase measurement; phase of noisy sinusoid; phase sensitive detector; synchronous detector; synchronous phase marker circuit; 17138 .

N.A.S.A.; U.S.D.A; Commerce; Defense; E.R.D.A.; Federal agencies; interagency review; Interior; Library of Congress; materials; materials data; materials information; SP463.

Nash-Glicksman theory; surface energy; grain boundary groove; ice-water interface; ice-water surface tension; 16780 .

National allocation programs; implementation of allocation programs; international allocation programs; International Energy Agency; SP484, pp. 945-946 (Oct. 1977).

National Bureau of Standards; physical sciences; science and technology in America; technology; 75th anniversary; SP465.

National Bureau of Standards; national measurement system; standardization organizations; standard reference data; weights and measures; instrumentation; measurement standards; NBSIR 75-949.

National Bureau of Standards; national measurement standards; physical measurement; weights and measures; history of science; measurement instruments; measurement standards; NBSIR 76-1125.

National Bureau of Standards; solar energy standards; standards users; communication of research and standards; 16733.

National Bureau of Standards; semiconductor devices; semiconductor materials; semiconductor process control; electronics; measurement methods; microelectronics; 16894.

National Bureau of Standards; nuclear physics; numerical analysis; physics; spectroscopy; thermal physics; 75th anniversary; American Physical Society; fundamental constants; 16991 .

National Bureau of Standards; on-line bibliographic retrieval systems; evaluation; 17186 .

National commission on materials policy; technology transfer; total materials cycle; information demand; materials information and data system; SP463, pp. IX.1.1-IX.1.22 (Jan. 1977).

National Conference on Weights and Measures; weights and measures; education for metric; laws and regulations; metrication; metric system; 17037.

National electric code; safety regulations; standards; accidents; benefit-cost analysis; building codes; building economics; building regulations; economic impact; electric shock; ground fault circuit interrupters; SP473, pp. 397-419 (June 1977).

National Institute of Law Enforcement and Criminal Justice; communications; digital communications; guideline; law enforcement equipment report; Law Enforcement Standards Laboratory; mobile digital equipment; 16996.

National laboratory accreditation; retail meat identity standards; tolerance application; vapor recovery; weights and measures; checking prepackaged commodities; computer assisted check-out systems; consumer affairs; cordage products; drained weight; laws and regulations; SP47I.

National measurement standards; physical measurement; weights and measures; history of science; measurement in- struments; measurement standards; National Bureau of Standards; NBSIR 76-1125.

National Measurement System; radio measurements; electromagnetic quantities; laser; microwave; NBSIR 75-936.

National measurement system; noise; noise control; noise emissions; sound; sound level meters; acoustical measurements; acoustics; audiometry; NBSIR 75-938.

National Measurement System; photometry; radiometry; sources; standards; survey; detectors; NBSIR 75-939.

National Measurement System; radiometry; sources; survey; ultraviolet; detectors; NBSIR 75-941.

National measurement system; economics; information; NBS; NBSIR 75-948.

National Measurement System; standards laboratories; survey; time; frequency; 17070 .

National measurement system; noise; noise control; sound; acoustical measurements; acoustics; 17190.

National measurement system; standardization organizations; standard reference data; weights and measures; instrumentation; measurement standards; National Bureau of Standards; NBSIR 75-949.

National Measurement System for Surface Properties; surface atomic structure; surface characterization; surface composition; surface electronic structure; surface properties; NBSIR 75-945.

National Metric Speakers Bureau; metric information, sources of; metric speakers; Metric Speakers Bureau, National; TN960.

National programs; policy; technology assessment; energy; environmental quality; management; materials information; SP463, pp. 1.2.1-I.2.2 (Jan. 1977).

National Referral Center; referral; scientific and technical information; thesaurus; computerized information system; directories; information resource; SP463, pp. VIII.2.1VIII.2.4 (Jan. 1977).

National standard; radiation safety; radiography; $x$-ray equipment; $x$-ray safety; $x$-ray tube; design standard; fluoroscopy; HI 23.

National standardization; national standards bodies; practice; procedures; regional standardization; standardization; standards development; ADP standards; international standardization; NBSIR 77-1195.

National standards; application of standards; international standards; measurement standards; SP484, pp. $929-934$ (Oct. 1977).

National standards; plastics standards; standards; standards information service; voluntary standards; American National Standards Institute; computerized information system; engineering standards; mandatory standards; SP463, pp. VII.5.1-VII.5.9 (Jan. 1977).

National standards; product standards; recommended practices; specifications; test methods; certification programs; consumer products; household products; industry standards; international recommendations; TN948.

National standards; radiation characteristics; radiation source; source calibration; test methods; $x$ rays; calibration; gamma radiation; industrial radiography; 17017.

National standards bodies; practice; procedures; regional standardization; standardization; standards development; ADP standards; international standardization; national standardization; NBSIR 77-1195.

Natural analysis; tall buildings; wind profiles; boundary layer; hurricanes; loads (forces); SP477, pp. II-30-1I-40 (May 1977).

Natural disasters; structural engineering; buildings; building codes; earthquakes; SP490.

Natural frequencies; orthotropic; plates; rotary inertia; transverse shear; vibration; Galerkin; 16702. 
Natural system; performance standards; regulatory process; building codes; carrying capacity; environment; land use; SP473, pp. 189-202 (June 1977).

Natural waters; rainwater; seawater; sulfate; environmental analysis; ion-selective electrode; lead electrode; 16771 .

Navigation; physics; time; time broadcasts; time scales; astronomy; automation; clocks; communication; frequency; history; mathematics; Monogr. 155.

Navy Flow Correlation Program; turbine flowmeters; volumetric standards; metrology system; SP484, pp. 25-32 (Oct. 1977).

$\mathrm{Na}_{2}$; satellite; spectrum; $\mathrm{Li}_{2} ; 16912$.

NBS; national measurement system; economics; information; NBSIR 75-948.

NBS periodicals; periodicals; proceedings; serials; standards; transactions; annual reports; diffusion in metals; fire; journals; library holdings, NBS Library; NBSIR 77-1215.

NBS radio stations WWV/WWVH/WWVB; NBS time/frequency services; satellite timing; standard time/frequency broadcasts; television time/frequency dissemination; time/frequency calibrations; user equipment; user survey; 17080.

NBS Standard Reference Material 1475; theta solvents; 3,3,5trimethylhexyl acetate; biphenyl; chain dimensions; dodecanol; linear polyethylene; Mark-Houwink equation; 16710.

NBS time scale; phase modulation; (active-passive) hydrogen maser; amplitude modulation; cavity frequency; environmental sensitivity; frequency lock loop; long-term frequency stability; 17211 .

NBS time/frequency services; satellite timing; standard time/frequency broadcasts; television time/frequency dissemination; time/frequency calibrations; user equipment; user survey; NBS radio stations WWV/WWVH/WWVB; 17080.

NBS-Brungraber tester; safety of bathrooms; slip-resistance of bathtub and shower base surfaces; slip-resistance testers; Kollsman tester; NBSIR 76-1005.

$\mathrm{NbTi}$; $\mathrm{Nb}_{3} \mathrm{Sn}$; strain; stress; critical current; critical current degradation; degradation mechanisms; multifilamentary superconductors; 16873 .

NbTi; strain; stress; aluminum stabilization; copper stabilization; critical current; critical-current degradation; multifilamentary wires; $\mathrm{Nb}_{3} \mathrm{Sn} ; 16816$.

$\mathrm{NbTi}$; stress effect; superconductor; critical currents; 16868 .

$\mathrm{Nb}_{3} \mathrm{Sn}$; $\mathrm{NbTi}$; strain; stress; aluminum stabilization; copper stabilization; critical current; critical-current degradation; multifilamentary wires; 16816 .

$\mathrm{Nb}_{3} \mathrm{Sn}$; strain; stress; critical current; critical current degradation; degradation mechanisms; multifilamentary superconductors; $\mathrm{NbTi}$; 16873.

NCSL; NMR knight shifts; neutron beams; piezo-flex micropositioning; pressure; thermodynamic tables; coal conversion; consumer products; cryogenic; crystalline materials; dosimeter calibrations; energy; energy related inventions; DIM/NBS 61, No. 7, 1-32 (1977).

Near field; nonplanar; patterns; scanning; spherical; symmetry; antennas; arrays; coordinate transformations; data processing; group representations; measurements; 16671 .

Near-field; spherical; antennas; measu rements; 17224.

Near-field measurements; scattering matrix; cylindrical scanning; TN696, 1977 Revision.

Near-field measurements; source-scattering matrix; cylindrical scanning; TN696.

Near-field probes; radiation; susceptibility; TEM cell; electromagnetic measurements; interference; 17251 .

Near-field scanning; planar scanning; scanning facilities; spherical scanning; antenna patterns; cosite interference; cylindrical scanning; 17221 .

Near-field scanning; spherical scanning; antenna patterns; computer programs; 17223.
Near-field scanning; symmetry analysis; computer programs; data reduction; eigenvalue equations; electromagnetic theory; group theory; 17222 .

Near-fields, recursion; scanning; spherical; spherical point group; antennas; arrays; finite rotations; group representations; 17322

Near-resonant light scattering; redistribution; saturation strontium; collisions; 16857.

Nebulae, individual; radio sources, lines; interstellar, molecules; line identifications; 16664.

Need for international standardization; product specifications; flow measurement; ISO; methods of tests; SP484, pp. 947. 956 (Oct. 1977).

NEISS; recommendations; review; safety; sports; accident; associated factors; injuries; literature; NBSIR 77-1218.

Nematic phase; supercooled phase; gas-liquid chromatography; liquid crystal; naphthalene homologues; 16673.

Neon; transition probabilities; wall-stabilized arc; atomic spectra; configuration interaction; $J$-file sum rule; 17276 .

Neoprene; radiant panel test; round robin; test method; ASTM E 162; coefficient of variation; flame spread tests; flexible polyurethane; hardboard; interlaboratory evaluation; NBSIR 77-1222.

Network; organization; probability; reliability; trees; dynamic programming; graph; 16784.

Network analyzer; phosphoric acid electrolyte; refractory hard metals; AC impedance; automated electrochemical analysis; ceramic electrolytes; ceria-yttria; cyclic voltommetry; electrocatalysis; equivalent circuit; fuel cells; microprocessor; NBSIR 77-1270.

Network analyzer; reflection coefficient; reflectometer; scattering parameters; self-calibration techniques; six-port junction; impedance; microwaves; 17244.

Network design; strong-motion record; cost effectiveness; ground motion; SP477, pp. III-1 -III-1 5 (May 1977).

Network measurement machine; remote terminal emulators; response time; throughput; turnaround time; evaluating computer service; 17250 .

Network measurement services; service; teleprocessing systems measurement; computer network measurement; data acquisition; interactive computer access; measurement; 17252 .

Network measurement system; computer service; external measurement; figure-of-merit; interactive system; measurement model; measurement, performance; measures; methodology; 17288

Networks; computer modeling systems; data; 17025 .

Networks; facility location; location theory; minimax; J. Res. 82, No. 1, 65-72 (1977).

Networks; facility location; location theory; minimax; J. Res. 82, No. 1, 73.80 (1977).

Networks; packet switching; standards; communications networks; computer networks; data communications; interconnection; 16934.

Networks; packet switching; standards; communications networks; computer networks; data communications; interconnection; SP5OO-6.

Networks; specifications; standards; system engineering; building codes; computer model; decision table; decision theory; SP473, pp. 285-316 (June 1977).

Neutral currents; weak coupling constants; weak interactions; effective neutral weak interactions; Fermi theory; finite field theory; 17103.

Neutral filters; standard reference materials; transmittance characteristics; ultraviolet-visible filters; evaporated metal-onquartz; filters, transmittance; SP466, pp. 127-131(May 1977).

Neutral impurity scattering; $n$-type silicon; resistivity; temperature; dopant density; electron-electron scattering; electron mobility; ionized impurity scattering; lattice scattering; 17147. 
Neutral impurity scattering mobility; $n$-type silicon; resistivity; scattering mechanisms; temperature; dopant density; electron mobility; ionized impurity scattering mobility; lattice mobility; $S P 400-33$.

Neutral phosphorus; Stark shifts; Stark widths; arc; Debye shielding; 16950.

Neutron; bath techniques; manganese sulphate baths; SP493, pp. 237-243 (Oct. 1977).

Neutron; charged particle; dosimeter; dosimetry; efficiency; gamma ray; kerma; SP461, pp. 209-218 (Jan. 1977).

Neutron; NIOBE; Rapsodie; reactor; shielding; transport calculation; approximations; diffusion; SP461, pp. 163-165 (Jan. 1977).

Neutron; nondestructive; resolution; spectrometry; water; activation; analysis; element; gamma rays; $\mathrm{Ge}(\mathrm{Li})$ detector; SP461, pp. 255-256 (Jan. 1977).

Neutron; nonelastic; optical model; parameter; polynomial extrapolation; sphere transmission; cross section; multiple bias; SP461, pp. 44-46 (Jan. 1977).

Neutron; normalization; resonance; shape; standards; thermal; ${ }^{6} \mathrm{Li}(\mathrm{n}, \alpha) ;{ }^{10} \mathrm{~B}(\mathrm{n}, \alpha) ;{ }^{235} \mathrm{U}(\mathrm{n}, \mathrm{f})$; cross section; SP493, pp. 174181 (Oct. 1977).

Neutron; nuclear reactor; radiation; activation analysis; crystal structure; diffraction; isotopes; molecular dynamics; TN939.

Neutron; OER; one-hit detector; pion; radiation; track; cell; delta ray; dose; ions; LET; model; SP461, pp. 183-187 (Jan. 1977).

Neutron; plastic; recoil; scintillator; UNFOLD; Apsara; energy distribution; gamma ray; iterative; SP461, pp. 247-251 (Jan. 1977).

Neutron; PURNIMA; Rossi- $\alpha$; slowing down; stochastic; BESM6; JEZEBEL; Markov process; SP461, pp. 97-99 (Jan. 1977).

Neutron; radiation; stellar explosion; supernova; dynamics; galactic structure; interstellar medium; magnetic pressure; 17217.

Neutron; radiation damage; reactor; scattering; spectrometer; cross section; energy transfer; gamma rays; moderator; SP461, pp. 32-40 (Jan. 1977).

Neutron; random sampling; scattering; shielding; angle; centre of mass; coefficients; computations, cross-section; Legendre polynomial; SP461, pp. 100-105 (Jan. 1977).

Neutron; reactor transients; solution; time-dependent; transport; transport equation; approximations; fast-thermal couple reactor; SP461, Pp. 91-93 (Jan. 1977).

Neutron; sandwich; spectrometry; surface barrier; ${ }^{6} \mathrm{LiF}$; detector; energy leakage; Monte Carlo; SP461, pp. 252-254 (Jan. 1977).

Neutron; scattering; cross section; differential; elastic; multiple bias technique; SP461, pp. 64-66 (Jan. 1977).

Neutron; scattering; shield; transmission; ${ }^{252}$ Cf; ANISN; code; configuration; dose equivalent; energy; gamma rays; SP461, pp. 119-123 (Jan. 1977).

Neutron; scattering; thermalization; cross section; diffusion; kernel; lattice vibration; model; moderator; SP461, pp. 149 . 162 (Jan. 1977).

Neutron; $\boldsymbol{\beta}$-counting error; activation; capture reaction; cross section; measurement; SP461, pp. 57-59 (Jan. 1977).

Neutron; shielding; sources; standardization; calibration; detection; dosimetry; facilities; fluence; flux; moderation; monitor; SP493, pp. 115-120 (Oct. 1977).

Neutron; shielding; spectrum; computer code; dose; dosimetry; monitor; SP461, pp. 238-246 (Jan. 1977).

Neutron; spherical; symmetric; transport; density transform; expansion coefficient; Green's function; SP461, pp. 87-90 (Jan. 1977).

Neutron; total; alpha; boron; branching ratio; compilation; cross-section; elastic; lithium; measurements; SP493, pp. 6784 (Oct. 1977).

Neutron; transmission matrix; criticality; collision; cylindrical; energy; integral; iterative; SP461, pp. 94-96 (Jan. 1977).
Neutron activation analysis; polarography; pure reagents; sample preparation; spark source mass spectrometric isotope dilution; tissues; analytical disciplines; analytical procedures; atomic absorption spectrometry; biological materials; blanks; botanical materials; SP492.

Neutron angular distributions; neutron energy distributions; neutrons; nuclear reactions; thick-target yields; $B e(d, n)$ source; $B e(p, n)$ source; $C(d, n)$ source; $D(d, n)$. source; dosimetry; $\mathrm{Li}(\mathrm{d}, \mathrm{n})$ source; $\mathrm{Li}(\mathrm{p}, \mathrm{n})$ source; NBSIR 77-1279.

Neutron beams; neutron flux; neutrons; ${ }^{3} \mathrm{H},{ }^{2} \mathrm{H},{ }^{4} \mathrm{He},{ }^{3} \mathrm{He}$, protons; calibration; efficiency; SP493, pp. 221-226 (Oct. 1977).

Neutron beams; neutrons; resonant scatterer; dosimeter calibration; monoenergetic neutrons; SP493, pp. 250-254 (Oct. 1977).

Neutron beams; piezo-flex micropositioning; pressure; thermodynamic tables; coal conversion; consumer products; cryogenic; crystalline materials; dosimeter calibrations; energy; energy related inventions; heterodyne receiver; DIM/NBS 61 , No. 7, 1-32 (1977).

Neutron capture; spectroscopy; applications past and future; $\gamma$ rays; 16951

Neutron capture cross section; normalization; reference standard; review; accuracy; $\mathrm{Au}(\mathrm{n}, \gamma)$ cross section; cross section fluctuations; measurement; SP493, pp. 165-169 (Oct. 1977).

Neutron detection; photomultipliers; ${ }^{6} \mathrm{Li}(\mathrm{n}, \alpha) \mathrm{T}$; glass scintillators; Monte Carlo; multiple scattering; SP493, pp. 37-42 (Oct. 1977).

Neutron detectors; neutron standard; time-of-flight; ${ }^{252} \mathrm{Cf}$; fission neutron spectrum; SP493, pp. 194-197 (Oct. 1977).

Neutron diffraction; recycling oil; research and innovation; safety; ultrasonic tissue; computerized data; data elements; equity; federal technology; fire modeling; heat; hydrocarbon; ionized molybdenum; measurement assurance; metric; DIM/NBS 61, No. 6, 1-32 (1977).

Neutron diffraction; stannous hydrogen phosphate; hydrogenbonded dimers; 16742

Neutron diffraction; terbium; amorphous alloys; iron; magnetization measurements; 16835 .

Neutron dosimetry; radiation effects; standards; intercomparisons; medical; SP493, pp. 121-127 (Oct. 1977).

Neutron dosimetry; react or physics; breeder reactor; fission; fission detector; materials; 17058 .

Neutron dosimetry; standards; basic physical data; medical; mixed n- $\gamma$ fields; SP493, pp. 106-114 (Oct. 1977).

Neutron energy distributions; neutrons; nuclear reactions; thick-target yields; $B e(d, n)$ source; $B e(p, n)$ source; $C(d, n)$ source; $D(d, n)$ source; dosimetry; $\operatorname{Li}(d, n)$ source; $\operatorname{Li}(p, n)$ source; neutron angular distributions; NBSIR 77-1279.

Neutron fluence; cross sections; detector efficiency; SP493, pp. 227-233 (Oct. 1977).

Neutron flux; neutrons; ${ }^{3} \mathrm{H},{ }^{2} \mathrm{H},{ }^{4} \mathrm{He},{ }^{3} \mathrm{He}$, protons; calibration; efficiency; neutron beams; SP493, pp. 221-226 (Oct. 1977).

Neutron flux determination; proportional counters; solid-state detectors; standard cross section; ${ }^{10} \mathrm{~B}\left(\mathrm{n}, \alpha_{0}+\alpha_{1} \gamma\right)^{7} \mathrm{Li} ; S P 493$, pp. 85-92 (Oct. 1977).

Neutron flux measurement; review; black and grey neutron detectors; SP493, pp. 212-220 (Oct. 1977).

Neutron flux standard; pulse reactor calibration; radiation effects; californium-252; dosimetry; SP493, pp. 335-341 (Oct. 1977).

Neutron nuclear data evaluation; Pu-239; Pu-239 half-life; Pu241; thermal neutron cross-sections; U-233; U-235; fissionneutron yields; fission standards; SP493, pP. 170-173 (Oct. 1977).

Neutron reactions; neutron sources; calibration; californium252; cross sections; design; errors; fission neutrons; irradiation devices; measuring methods; 16790. 
Neutron reactions; neutron spectrum; reactor fuels; reactor materials; cross sections; fission; SP493, pp. 156-164 (Oct. 1977).

Neutron scattering; anharmonicity; dispersion curves; high pressure; KBr; mode Gruneisen parameters; 17001 .

Neutron scattering; quasielastic scattering; review; diffusion; hydrogen; lattice dynamics; metals; 16970.

Neutron scattering; shear wave; statistical mechanics; time correlation function; transverse current; ultrasonics; correlation function; density fluctuations; fluctuations; hydrodynamics; light scattering; liquid state; molecular dynamics; 16711 .

Neutron scattering; spin correlation function; absolute cross section measurement; cobalt; critical phenomena; interaction range; 17112 .

Neutron sources; absolute cross sections; SP493, pp. 304-310 (Oct. 1977).

Neutron sources; calibration; californium-252; cross sections; design; errors; fission neutrons; irradiation devices; measuring methods; neutron reactions; 16790.

Neutron sources; thick-target yields; Be; Li; NBSIR 77-1279, pp. 10-14 (July 1977).

Neutron spectra; deuterons; ionization; NBSIR 77-1279, p. 30 (July 1977).

Neutron spectra; shielding; shield thickness; calculation; concrete; cyclotron; design; earth shield; SP461, pp. 166-170 (Jan. 1977).

Neutron spectrum; reactor fuels; reactor materials; cross sections; fission; neutron reactions: SP493, pp. 156-164 (Oct. 1977).

Neutron standard; reaction rates; benchmark spectrum; discrete ordinates; intermediate energy; measurement assurance; SP493, pp. 329-334 (Oct. 1977).

Neutron standard; time-of-flight; ${ }^{252} \mathrm{Cf}$; fission neutron spectrum; neutron detectors; SP493, pp. 194-197 (Oct. 1977).

Neutron standards; $\nu$; ${ }^{233.255} \mathrm{U}(\mathrm{n}, \mathrm{f}) ;{ }^{209.241} \mathrm{Pu}(\mathrm{n}, \mathrm{f}) ;{ }^{252} \mathrm{Cf} ; \mathrm{SP493}$, pp. 182-193 (Oct. 1977).

Neutron total cross sections; ${ }^{45} \mathrm{Sc}$ measured from 0.4 to 22 $\mathrm{keV}$; ${ }^{56} \mathrm{Fe}$ measured from 0.4 to $1000 \mathrm{keV}$; deduced neutron resonance parameters; SP493, pp. 255-260 (Oct. 1977).

Neutron xeroradiography; problem-solving; radiation safety; smoke detectors; solar heating; SRM's; adobe; air pollution; corrosion; electrical; energy management; graphic pen; halocarbons; infrared lasers; international standard; DIM/NBS 61, No. 3, 1-32 (1977).

Neutrons; activation; Bragg-Gray; dosimetry; energy per ion pair; fluence; kerma factor; SP493, pp. 342-346 (Oct. 1977).

Neutrons; nuclear data; standard fields; cross sections; fission yields; SP493, pp. 299-303 (Oct. 1977).

Neutrons; nuclear reactions; thick-target yields; $B e(d, n)$ source; $B e(p, n)$ source; $C(d, n)$ source; $D(d, n)$ source; dosimetry; $\mathbf{L i}(d, n)$ source; $\mathbf{L i}(p, n)$ source; neutron angular distributions; neutron energy distributions; NBSIR 77-1279.

Neutrons; photons, radiation physics; symposium; cross sections; dosimetry; electrons; SP461.

Neutrons; proton-recoil; scattering; standards; detectors; flux; SP493, pp. 54-60 (Oct. 1977).

Neutrons; radioactivation; resonance integrals; spectral functions; comparative evaluation; cross sections; fission spectra; integrals; SP493, pp. 128-136 (Oct. 1977).

Neutrons; resolution; spectra; uncertainties; yield; distributions; NBSIR 77-1279, pp. 15-18 (July 1977).

Neutrons; resonant scatterer; dosimeter calibration; monoenergetic neutrons; neutron beams; SP493, pp. 250-254 (Oct. 1977).

Neutrons; review of measurements; ${ }^{6} \mathrm{Li}(\mathrm{n}, \boldsymbol{\alpha})$; ${ }^{6} \mathrm{Li}$ total; ${ }^{\top} \mathrm{Li}$ system; elastic scattering; SP493, pp. 14-29 (Oct. 1977).

Neutrons; Rossi-counter measurements; Serber theory; thick target; time-of-flight; ${ }^{9} \mathrm{Be}(\mathrm{d}, \mathrm{n}){ }^{10} \mathrm{~B} ;{ }^{9} \mathrm{Be}\left({ }^{3} \mathrm{He}, \mathrm{n}\right){ }^{11} \mathrm{C}$; energy spectra; NBSIR 77-1279, pp. 31 -34 (July 1977).
Neutrons; standards; cross section standards; dosimetry; fission; flux; measuring techniques; SP493.

Neutrons; thick target; time-of-flight; ${ }^{7} \mathrm{Li}(\mathrm{d}, \mathbf{n})^{8} \mathrm{Be},{ }^{7} \mathrm{Li}(\mathbf{p}, \mathbf{n})^{7} \mathrm{Be}$; $\mathrm{E}_{d}=8,12,15 \mathrm{MeV}, \mathrm{E}_{p}=15 \mathrm{MeV} ;$ NBSIR 77-1279, pp. I4 (July 1977).

Neutrons; yields; dosimetry; energy spectra; high energy; LET; NBSIR 77-1279, pp. 19-23 (July 1977).

Neutrons; ${ }^{3} \mathrm{H},{ }^{2} \mathrm{H},{ }^{4} \mathrm{He},{ }^{3} \mathrm{He}$, protons; calibration; efficiency; neutron beams; neutron flux; SP493, Pp. 221-226 (Oct. 1977).

Neutrons, high energy; neutrons, low energy; non-uniform exposures; quality factor; standards; criteria, accuracy; criteria, performance; dose equivalent; elements, transuranic; glove box; intercomparison; SP493, pp. $101-105$ (Oct. 1977).

Neutrons, low energy; non-uniform exposures; quality factor; standards; criteria, accuracy; criteria, performance; dose equivalent; elements, transuranic; glove box; intercomparison; neutrons, high energy; SP493, pp. 101-105 (Oct. 1977).

New building design; retrofit design; computerized energy analysis; energy conservation standards; 16770.

New static technique; vapor pressure; argon-vapor contact; error analysis; iodine; molybdenum hexafluoride; 17075 .

$\mathrm{NH}_{4} \mathrm{ClO}_{4}$; quasi-elastic neutron scattering; residence times; single crystal; activation energies; molecular orientations; 17003.

Nickel alloy; Poisson's ratio; shear modulus; sound velocity; Young's modulus; bulk modulus; compressibility; Debye temperature; elastic constant; invar; iron alloy; 16869

Nickel alloy; stainless steel; thermal conductivity; copper; low temperature; magnetothermal conductivity; 16864 .

Nickel alloys; stainless steels; stress corrosion cracking; titanium alloys; aluminum alloys; copper alloys; high strength steels; Monogr. 156.

Nickel alloys; superalloys; fatigue; fracture; low temperature tests; mechanical properties; 16801 .

Nickel alloys; thermal conductivity; thermopower; copper; electrical resistivity; iron alloys; Lorenz ratio; low temperature; 16878.

Nickel alloys; titanium alloys; aluminum alloys; ferritic steels; fracture toughness; low temperature; 17086.

Nickel single crystals; $x$-ray dynamical diffraction; crystal growth; crystal perfection; diffraction topography; dynamical diffraction theory; ferromagnetic domain walls; 16974 .

Nickel single crystals; $x$-ray diffraction topography; anomalous transmission effect; asymmetric crystal topography; crystal imperfections; crystal perfection; Czochralski-grown nickel; dislocation clusters; dy namical diffraction; magnetic domains; magnetic domain walls; 16997.

Nickel single crystals; $x$-ray diffraction; $x$-ray topography; dynamical diffraction; magnetic domains; 17277.

Nickel steel; weldments; cryogenic temperature; fatigue crack growth; fracture toughness; heat affected zone; J-integral; 17089.

NILECJ; privacy; scramblers; speech scramblers; voice privacy; voice scramblers; LESL; SP480-8.

NIOBE; Rapsodie; reactor; shielding; transport calculation; approximations; diffusion; neutron; SP461, pp. 163-165 (Jan. 1977).

Niobium; rubidium; spectra; structure; ultraviolet; yttrium; zirconium; ions; molybdenum; 17212.

Niobium; superconductivity; tunnelling; dielectric constant; Josephson effect; lead; microwaves; 16946.

Niobium alloys; osmium alloys; phase diagram; atomic ordering; constitution diagram; 16738.

Niobium alloys; phase diagram; superconductivity; ternary alloys; A 15 phase; constitution diagram; 16832.

Niobium-titanium; Poisson's ratio; pulse method; resonance method; shear modulus; sound velocity; Young's modulus; 
bulk modulus; composite; compressibility; copper; elastic constants; 17068 .

Viobium-titanium alloys; superconducting wire; tensile properties; composite; copper; low temperature; 16862 .

Vitric oxide; NO; chemical reaction rate; $\mathrm{HO}_{2}$; hydroperoxyl; 17272.

vitric oxide; optical pumping of molecules; vibrational relaxation; combustion; $\mathrm{CO}_{2}$ lasers; 17193.

Nitride; plasma; reaction mechanism; silicon; synthesis; thin film; vapor transport; activation parameters; active nitrogen; iodine; kinetics; microwave discharge; 16757.

vitrobenzene; pulse measurement; space charge; calibration; dielectrics; dividers; electric fields; electro-optics; high voltage measurement; insulating fluids; Kert effect; NBSIR 771317.

Jitrogen; phosphorus; ternary diffusion; thermomigration; alloys; antimony; arsenic; bismuth; copper; diffusion; electromigration; liquid metals; JPCRD 6, No. 1, 1-50 (1977).

Jitrogen; safety; wind-tunnel; cryogenic; design; NBSIR 77 857.

Vitrogen dioxide; permeation tube; standard reference material; 17230.

Jitrogen dioxide; rotational constants; vibrational constants; vibration-rotation constants; combination bands; 17123 .

vitrogen lines; regularities; Stark broadening; supermultiplet; transition array; wall stabilized; multiplet; 17204 .

vitrogen molecules; resonances; scattering; vibrational excitation; close-coupling calculations; crossed beams; cross sections; differential cross sections; electron scattering; inelastic scattering; 16740.

vitrosyl chloride; nitryl chloride; physical properties; spectral properties; thermodynamic properties; bibliography; chemical kinetics; chemistry; chlorine nitrate; molecular properties; SP478.

Vitrosyl chloride; rate constant; absorption spectra; chemical kinetics; chlorine; chlorine oxides; chlorocarbon; chlorofluorocarbon; data compilation and evaluation; JPCRD 6, No. 3, $871-918$ (1977).

Vitrous oxide; prediction; thermal conductivity; transport property; viscosity; carbon dioxide; corresponding states; mixtures; TN693.

Vitryl chloride; physical properties; spectral properties; thermodynamic properties; bibliography; chemical kinetics; chemistry; chlorine nitrate; molecular properties; nitrosyl chloride; SP478.

Nmr; Overhauser effect; relaxation time; ${ }^{13} \mathrm{C}$; collagen fibers; molecular motion; 17007.

VMR knight shifts; neutron beams; piezo-flex micropositioning; pressure; thermodynamic tables; coal conversion; consumer products; cryogenic; crystalline materials; dosimeter calibrations; energy; energy related inventions; DIM/NBS 61 , No. 7 , 1-32 (1977).

VMR spectral data; aromatic proton chemical shifts; mono- and di-substituted benzenes; JPCRD 6, No. 3, 919-992 (1977).

VMR spectroscopy; reduction; $\mathrm{V}(\mathrm{CO})_{6_{-}}^{-}$; 1,3-dithiolium ion; 2,2'-bi(1,3-dithiolyl); coupling constants; hexacarbonylvanadate(1-); 17154 .

NO; chemical reaction rate; $\mathrm{HO}_{2}$; hydroperoxyl; nitric oxide; 17272.

Voble gases; radioactivity; reactor effluents; environment; gamma-ray measurements; germanium-lithium detectors; 16975.

Noise; noise abatement and control; noise emission; regulation; sound; acoustics; environmental pollution; machinery and equipment; $H 122$.

Noise; noise control; noise emissions; sound; sound level meters; acoustical measurements; acoustics; audiometry; national measurement system; NBSIR 75-938.

Noise; noise control; sound; acoustical measurements; acoustics; national measurement system; 17190.
Noise; noise exposure measurement system; sound; acoustics; community noise; environmental impact; NBSIR 76-1169.

Noise; noise measurement; reverberation room; sound power measurement; standard test procedures for sound power measurement; acoustic test facility; 16766.

Noise; nondestructive evaluation; research associate program; standards; Alaska pipeline; calibration; CMAC; computers; consumer sounding boards; data; electron probe microanalysis; laser ionization; metrication; DIM/NBS 61 , No. 1, 1-32 (1977).

Noise abatement and control; noise emission; regulation; sound; acoustics; environmental pollution; machinery and equipment; noise; HI22.

Noise control; noise emissions; sound; sound level meters; acoustical measurements; acoustics; audiometry; national measurement system; noise; NBSIR 75-938.

Noise control; sound; acoustical measurements; acoustics; national measurement system; noise; 17190 .

Noise emission; regulation; sound; acoustics; environmental pollution; machinery and equipment; noise; noise abatement and control; HI22.

Noise emissions; sound; sound level meters; acoustical measurements; acoustics; audiometry; national measurement system; noise; noise control; NBSIR 75-938.

Noise exposure measurement system; sound; acoustics; community noise; environmental impact; noise; NBSIR 76-1169.

Noise measurement; reverberation room; sound power measurement; standard test procedures for sound power measurement; acoustic test facility; noise; 16766.

Noise measurement; sound measurement; acoustical measurements; acoustics; acoustics facilities; laboratory facilities; 16764.

Noise spectrum; piezoelectric polymer; vibration sensor; acoustic emission; damage detection; failure prevention; SP487, pp. 189-196 (Aug. 1977).

Nomenclature of reflectance; optical reflection; reflectance; reflectance factor; reflectance geometry; reflectance nomenclature; reflection; specular reflectance; sub-surface scattering; bidirectional reflectance-distribution function; diffuse reflectance; Monogr. 160.

Nomograms; oxygen; $\mathrm{PCO}_{2} ; \mathrm{pH}$; potassium; $\mathrm{PO}_{2}$; sodium; acidbase status; blood electrolytes; blood gases; blood $\mathrm{pH}$; calcium; carbon dioxide; hydrogen ion concentration; SP45O.

Nondestructive; resolution; spectrometry; water; activation; analysis; element; gamma rays; $\mathrm{Ge}(\mathrm{Li})$ detector; neutron; SP461, pp. 255-256 (Jan. 1977).

Nondestructive evaluation; penetrant; radiography; standards; thermal; ultrasonic; visual testing; wear debris; acoustic; calibration; eddy current; microwave; 17106 .

Nondestructive evaluation; research associate program; standards; Alaska pipeline; calibration; CMAC; computers; consumer sounding boards; data; electron probe microanalysis; laser ionization; metrication; noise; DIM/NBS 61 , No. 1, 132 (1977).

Nondestructive evaluation; standard reference materials; standards; thermal testing; ultrasonics; visual testing; wear debris analysis; acoustic emission; calibrations; electrical-eddy current measurements; microwaves; 17016 .

Nondestructive evaluation; thermographic surveys; thermography; energy conservation; energy surveys; infrared; 16901 .

Nondestructive evaluation techniques; compositional analysis; instrumental methods; metallic artifacts; microstructural analysis; 16712 .

Nondestructive test; acoustic emission; automated tape bonding; beam lead devices; bugging height; microelectronics; 16884.

Nondestructive test; acoustic emission; automated tape bonding; beam lead devices; bugging height; microelectronics; 17150. 
Nondestructive test; reliability; safe operating limits; second breakdown; semiconductor devices; thermal characterization; thermal instability; thermal resistance; transistors; hot spots; junction temperature; measurement technology; SP400-44.

Nondestructive testing; eddy currents; eddy current testing; electromagnetic testing; 17261 .

Nondestructive testing; Nondestructive Testing Newsletter; radiography; technical reports; ultrasonics; Army Materials and Mechanics Research Center; electromagnetics; materials testing; SP463, pp. IV.6.1-IV.6.2 (Jan. 1977).

Nondestructive testing; optical; radiography; standards; ultrasonics; visual; acoustic emission; inspection; leak testing; liquid penetrant; magnetic particle; measurements; 17042.

Nondestructive testing; vision; visual acuity; visual capacities; modulation transfer function; 17015 .

Nondestructive Testing Newsletter; radiography; technical reports; ultrasonics; Army Materials and Mechanics Research Center; electromagnetics; materials testing; nondestructive testing; SP463, pp. IV.6.1-IV.6.2 (Jan. 1977).

Nondestructive tests; nonlinear region mapping; temperature mapping; active devices; internal logic identification; laser scanning; logic flow identification; LSI testing; 17164.

Nondestructive tests; semiconductor devices; standards; hermetic seals; leakage; 16943.

Nonelastic; optical model; parameter; polynomial extrapolation; sphere transmission; cross section; multiple bias; neutron; SP461, pp. 44-46 (Jan. 1977).

Nonfood products; physical properties; research information; agricultural materials; agricultural research; biological properties; chemical properties; engineering properties; food products; information retrieval systems; SP463, pp. 11.2.1II.2.10 (Jan. 1977).

Non-intrusive flowmeter; ultrasonic beams; cross-correlation analysis; liquid velocity measurement; SP484, pp. 319-333 (Oct. 1977).

Nonisothermal flow; three velocity components in turbulent flow; true instantaneous temperatures; turbulent flow; fluid mechanics; SP484, pp. 659-685 (Oct. 1977).

Nonlinear analysis; single-lap-joint analysis; single-lap-joint bending; spotwelded joints; weldbonded joints; adhesivebonded joints; bonded joints; cyclic loading; debond analysis; double-lap-joint analysis; fatigue tests; finite element analysis; joints; NBSIR 76-1053.

Nonlinear elastic effect; resonance frequency; acceleration field; acceleration sensitivity; compound crystal resonator; crystallographic axis; NBSIR 77-855.

Nonlinear region mapping; temperature mapping; active devices; internal logic identification; laser scanning; logic flow identification; LSI testing; nondestructive tests; 17164 .

Nonlinear regression; calibration; column broadening, GPC; gel permeation chromatography; 16822 .

Nonlinear response; reinforced concrete; bridges; design; experiments; SP477, pp. VI-1 - VI-9 (May 1977).

Nonlinear spectroscopy; Ramsey fringes; saturated absorption; 16776.

Nonmetallic electrode system; turtle; ECG; EEG; electromagnetic field; microwave radiation; 17174 .

Nonmetallic materials; physical properties; RECON; scientific and technical aerospace reports; thesaurus; aerospace; computer information system; international aerospace abstracts; materials; mechanical properties; SP463, pp. VI.1.1-VI.1.7 (Jan. 1977).

Nonplanar; patterns; scanning; spherical; symmetry; antennas; arrays; coordinate transformations; data processing; group representations; measurements; near field; 16671 .

Nonradial; perturbation theory; stellar oscillations; weak magnetic fields; 16804

Nonradial modes; potential theory; stellar pulsation; 17311 .

Nonradial oscillations; avoided crossings; coupled oscillators; 17029.
Nonradial stability; pre-main sequence models; Beta Cephei stars; 17102

Nonradiative heating; transition regions, solar; transition regions, stellar; ultraviolet spectra; visible spectra; $x$-ray spectra; chromospheres, solar; chromospheres, stellar; coronae, solar; coronae, stellar; flares, solar; flares, stellar; magnetic cycles, solar; 17324.

Nonrotating bead; single bead contribution to 1.V.; torque on the bead; average gradient; intrinsic viscosity; 17119.

Nonstationary process; nonstationary spectrum; power spectrum; synthesized spectrum; time-dependent spectrum; coherence; correlation function; counting rate spectrum; 17169.

Nonstationary spectrum; power spectrum; synthesized spectrum; time-dependent spectrum; coherence; correlation function; counting rate spectrum; nonstationary process; 17169.

Nonstoichiometry; phase equilibria; rubidium niobate; rubidium tantalate; crystal chemistry; ionic conductivity; J. Res. 82, No. 3, 151-165 (1977).

Non-uniform exposures; quality factor; standards; criteria, accuracy; criteria, performance; dose equivalent; elements, transuranic; glove box; intercomparison; neutrons, high energy; neutrons, low energy; SP493, pp. 101-105 (Oct. 1977).

Nonunique identifiers; personal data files; Privacy Act; probability model; retrieval; data retrieval; file.validation; name lookup; SP500-2.

Nonvolatility; orthoferrite; photolithography; uniaxial structures; amorphous materials; bubble; field-access; garnet; guide-pattern; magnetoresistance; SP500-1.

Normal and deuterated methanols; potential barrier to internal rotation; principal and reduced moments of inertia; structural parameters; vibrational fundamentals; virial coefficients of the equation of state; enthalpy of formation; JPCRD 6, No. 1, 105-112 (1977).

Normal butane; propane saturated liquid; tables; density; deviation plots; ethane; experimental; isobutane; magnetic suspension densimeter; methane; 16871 .

Normal fluid helium-4; phonons; protons; specific heat; superfluid helium-4; computed thermodynamic properties; entropy; equation of state; excitation spectrum; helium-4; JPCRD 6, No. 1, 51-104 (1977).

Normal spectral emittance; radiance temperature; specific heat capacity; thermal radiation properties; thermodynamics; titanium alloy; electrical resistivity; heat capacity; high-speed measurements; high temperatures; J. Res. 81A Nos. 2 and 3, 251 -256 (1977).

Normalization; reference standard; review; accuracy; $\mathrm{Au}(\mathrm{n}, \boldsymbol{\gamma})$ cross section; cross section fluctuations; measurement; neutron capture cross section; SP493, pp. 165-169 (Oct. 1977).

Normalization; resonance; shape; standards; thermal; ${ }^{\circ} \mathrm{Li}(\mathrm{n}, \alpha)$; ${ }^{10} \mathrm{~B}(\mathrm{n}, \alpha)$; ${ }^{225} \mathrm{U}(\mathrm{n}, \mathrm{f})$; cross section; neutron; SP493, pp. 174. 181 (Oct. 1977).

Novae; OAO-3; spectra-ultraviolet; 16762.

Novelties, "Silver," marking of; "Sterling Silver," "Silver," or "Solid Silver," marking of; "Coin" or "Coin Silver," marking of; jewelry, "Silver," marking of; PS7 I-76.

NSRDS; Omnidata; reference data; data compilation; data evaluation; information retrieval; 16692.

NTTS; patent licensing; technical reports; computerized information system; document dissemination; government reports; SP463, pp. VII.3.1-VI1.3.5 (Jan. 1977).

n-type silicon; resistivity; scattering mechanisms; temperature; dopant density; electron mobility; ionized impurity scattering mobility; lattice mobility; neutral impurity scattering mobility; SP400-33.

n-type silicon; resistivity; temperature; dopant density; electronelectron scattering; electron mobility; ionized impurity scattering; lattice scattering; neutral impurity scattering; 17147 . 
Nuclear; standards; CAMAC; Dataway; instrumentation; modules; 16678 .

Nuclear charge distributions; nuclear reactions; ${ }^{36,40} \operatorname{Ar}\left(e, e^{\prime}\right)$; enriched targets; $E=65$ to $115 \mathrm{MeV}$; measured $\sigma(E, \theta)$; 16845.

Nuclear data; physical science data; solid state data; standard reference data; thermodynamic data; transport properties; atomic and molecular data; chemical kinetics data; energy data; environmental data; industrial process data; materials utilization data; TN947.

Nuclear data; radiation transport; reactor; RSIC; shielding; weapons; computer codes; materials properties; SP463, pp. III.1.1-III.1.10 (Jan. 1977).

Nuclear data; standard fields; cross sections; fission yields; neutrons; SP493, pp. 299-303 (Oct. 1977).

Nuclear facilities; design guides; SP477, pp. VII-29-VII-35 (May 1977).

Nuclear facilities; seismicity; soils; standards; structural response; winds; accelerograph; bridges; buildings; codes; disaster; dynamic analysis; earthquakes; ground failures; SP477.

Nuclear hyperfine techniques; nuclear magnetic resonance; perturbed angular correlation; residual stress; Mössbauer effect; 17011 .

Nuclear magnetic resonance; organoarsenic; analysis; aqueous chemistry; arsenic; atomic absorption spectrophotometry; biomethylation; electrochemistry; environment; gas chromatography; laser-Raman; liquid chromatography; 17155.

Nuclear magnetic resonance; perturbed angular correlation; residual stress; Mössbauer effect; nuclear hyperfine techniques; 17011.

Nuclear magnetic resonance; p-toluenesulfonylhydrazine; 1,2di(p-toluenesulfonyl)hydrazine; chemical ionization mass spectrometry; di-p-tolyldisulfide-1,2-dioxide; mass spectrometry; 17045.

Nuclear physics; numerical analysis; physics; spectroscopy; thermal physics; 75th anniversary; American Physical Society; fundamental constants; National Bureau of Standards; 16991.

Nuclear power; dosimetry; licensing; measurements; SP493, pp. 137-145 (Oct. 1977).

Nuclear power; solar energy; energy choices; energy problem; energy resources; fossil fuels; 17031 .

Nuclear power plant; seismic effects; tornado; wind; SP477, pp. VII-1-VII-28 (May 1977).

Nuclear quadrupole effects; nuclear relaxation; compilation; critical evaluation; Knight shifts; magnetic moments; metals; 17093

Nuclear reactions; $\theta=0^{\circ}, 10^{\circ}, 20^{\circ}, 30^{\circ}, 40^{\circ} ;$ NBSIR 77-1279, pp. 5-9 (July 1977).

Nuclear reactions; thick-target yields; $B e(d, n)$ source; $B e(p, n)$ source; $C(d, n)$ source; $D(d, n)$ source; dosimetry; $L i(d, n)$ source; $\mathrm{Li}(\mathrm{p}, \mathrm{n})$ source; neutron angular distributions; neutron energy distributions; neutrons; NBSIR 77-1279.

Nuclear reactions; ${ }^{3} \mathrm{He}$ (e,e'); deduced $\mathrm{mms}$ charge radius; $\mathbf{E}=$ $28.8-95.0 \mathrm{MeV}$; measured $\sigma(\mathrm{E})$ at $\theta=75^{\circ} ; 16850$.

Nuclear reactions; ${ }^{36.40} \mathrm{Ar}\left(\mathrm{e}, \mathrm{e}^{\prime}\right)$; enriched targets; $\mathrm{E}=65$ to 115 $\mathrm{MeV}$; measured $\sigma(\mathrm{E}, \theta)$; nuclear charge distributions; 16845.

Nuclear reactions np scattering $E \leqslant 30 \mathrm{MeV}$; phase shift analyses; calculated $\sigma(\theta)$; experimental $\sigma(\theta)$; model predictions; SP493, pp. 47-53 (Oct. 1977).

Nuclear reactor; radiation; activation analysis; crystal structure; diffraction; isotopes; molecular dynamics; neutron; TN939.

Nuclear reactors; oil tanks; power plants; shake table; aseismic design; dynamic tests; SP470, pp. VII-1 - VII-6 (Apr. 1977).

Nuclear relaxation; compilation; critical evaluation; Knight shifts; magnetic moments; metals; nuclear quadrupole effects; 17093.

Nuclear safeguards; oceanography; on-stream analysis; well logging; activation analysis; californium-252; inland waters and sediments; in vivo analysis; mineral exploration; 16760.
Number concentration; size distribution; smoke; smoke detector; test method; UL 217; aerosol; mass concentration; NBSIR 77-1312.

Numerical analysis; OMNITAB II computing system; probability plotting; selection of variables in linear regression; statistical plotting; stem-and-leaf displays; table making; automatic printing; Calcomp plotting; data editing; interactive; labels; NBSIR 77-1276.

Numerical analysis; physics; spectroscopy; thermal physics; 75th anniversary; American Physical Society; fundamental constants; National Bureau of Standards; nuclear physics; 16991 .

Numerical analysis; sheet resistance; sheet resistor test structure; test structures; van der Pauw; cross test structure; cross van der Pauw; 17165.

Numerical data; physical properties; thermodynamics; transport; chemical; critical evaluation; mechanical; SP463, pp. VII.1.1-VII.1.15 (Jan. 1977).

Numerical integration; numerical quadrature; piecewise analytic functions; quadrature; rational approximation; tanh rule; trapezoid rule; Hardy space; 17157

Numerical integration; polyatomic molecule; Pople expansion; quadrupolar gas; second virial coefficient; dipolar gas; J. Res. 82, No. 2, 123-127 (1977).

Numerical modeling; turbulent flow; flow meter; meter performance; NBSIR 77-1394.

Numerical models; open-channel flow; weirs; flumes; hydraulic models; hydraulics; SP484, pp. 219-242 (Oct. 1977).

Numerical quadrature; piecewise analytic functions; quadrature; rational approximation; tanh rule; trapezoid rule; Hardy space; numerical integration; 17157.

Numerical range; constrained extrema of quadratic forms; $J$. Res. 81 B Nos. 1 and 2, $41-44$ (1977).

Numerical solution of flame equations; combustion; differential equations; flame chemistry; flame modeling; laminar flames; NBSIR 76-994.

Numerical solutions; one-dimensional; radiation; thermal conduction; transient heat transfer; composite building constructions; convection; experimental data; fire endurance; heat generation or absorption; NBSIR 77-1260.

Numerical stability; slit correction; small angle scattering; unsmearing; FORTRAN program; integral equation; interpolating polynomial; TN936.

Nursing home fires; nursing staff; standards; voice communication; coding; communication systems; fire alarm systems; health care facilities; hospital communication systems; hospital fires; hospital personnel; human behavior; NBSGCR-77-102.

Nursing homes; rescue; verbal communicative; alarm; architecture; design implication; emergency actions; emergency communicative; emergency decisions; escape; fires; human behavior; human response; life safety; mapping; model; NBSGCR-77-93.

Nursing staff; standards; voice communication; coding; communication systems; fire alarm systems; health care facilities; hospital communication systems; hospital fires; hospital personnel; human behavior; nursing home fires; NBS-GCR-77102.

Nutation; spin echoes; spin locking; zero field magnetic resonance; coherence; Kramers ions; 16954.

$\mathrm{N}_{2} \mathrm{O}$; oxygen; radiation; time-of-flight; atomic; experimental; lifetimes; 16812 .

\section{O}

OAO-3; spectra-ultraviolet; Novae; 16762.

Observed (technical) fluorescence parameters; polarization; radiative and non-radiative transition probabilities; real fluorescence parameters; fluorescence lifetime; fluorescence 
quantum efficiency; fluorescence quantum yields; SP466, pp. 1-11 (May 1977).

Occupant behavior in fires; simulated behavior; building fires; fire behavior; high-rise buildings; NBS-GCR-77-92.

Occupant needs; sensory stimuli; communications; disaster communication; emergency communications; fire communications; high-rise communications; high-rise emergency; information transfer; 17036.

Occupational safety; regulatory data; architectural psychology; architectural research; building codes; building design; building fires; building regulatory standards; emergency egress; exit capacity; fire safety; human performance; NBSIR 771313.

Occupational safety and health; performance standard; regulation; tensile testing; worker safety equipment; body belts; body harness; fall-arrest equipment; fall-safety systems; impact accelerations; impact forces; lanyards; linemen's equipment; load-extension data; NBSIR 76-1146.

Ocean loads; strainmeter; cavity effects; earth tides; 17196.

Oceanography; on-stream analysis; well logging; activation analysis; californium-252; inland waters and sediments; in vivo analysis; mineral exploration; nuclear safeguards; 16760.

OER; one-hit detector; pion; radiation; track; cell; delta ray; dose; ions; LET; model; neutron; SP461, pp. 183-187 (Jan. 1977).

Offered load; performance; availability; basis statistics; SP50018, pp. 137-142 (Sept. 1977).

Office lighting; sphere illumination; body shadow; contrast rendition; hand calculator; illuminating engineering; light design; luminaire effectiveness; luminance factor; NBSIR 77 1303.

Office of Mineral 1nformation; Bureau of Mines; energy; health and safety; metallurgy; mining; SP463, pp. V.3.1-V.3.9 (Jan. 1977).

Offshore corrosion; sand corrosion; seawater corrosion; splash zone corrosion; cathodic protection; coating systems; corrosion protection; Monogr. 158.

Off-the-shelf automation; polymer degradation; rapid response furnace; thermogravimetry; computerized experiment; experiment automation; 16842.

Oil analysis; railioad system diagnostics; signature analysis; wear; failure detection; failure diagnosis; failure prevention; ferrography; land vehicle diagnostics; SP494.

Oil measurement documents; petroleum measuring; tank gaging; measurement practices; metering; SP484, pp. 55-60 (Oct. 1977).

Oil refinery; petroleum; benzo(a)pyrene; gas chromatography; gas chromatography-mass spectrometry; hydrocarbons; liquid chromatography; 16886.

Oil specifications; petroleum standards; petroleum test methods; récycled oil; re-refined oil; used oil; waste oil; engine oil; fuel oil; hydraulic oil; industrial oils; lubricating oil; SP488.

Oil tanks; power plants; shake table; aseismic design; dynamic tests; nuclear reactors; SP470, pp. VII-1-V11-6 (Apr. 1977).

Omega timing; precision timekeeping; VLF antenna fields; VLF timing; VLF tracking coordination; clock synchronizations; cycle identification; group delays; 16947.

Omnidata; reference data; data compilation; data evaluation; information retrieval; NSRDS; 16692.

OMNITAB II computing system; probability plotting; selection of variables in linear regression; statistical plotting; stem-andleaf displays; table making; automatic printing; Calcomp plotting; data editing; interactive; labels; numerical analysis; NBSIR $\because \because 1276$.

One perturber limit; pressure broadening; analysis of correlated profiles; classical theory; Doppler broadening; 17161 .

One-dimensional; radiation; thermal conduction; transient heat transfer; composite building constructions; convection; ex- perimental data; fire endurance; heat generation or absorption; numerical solutions; NBSIR 77-1260.

One-fluid theory; plait point; thermal conductivity coefficient; viscosity coefficient; critical point; mixture; J. Res. 82, No. 3, $181-182$ (1977).

One-hit detector; pion; radiation; track; cell; delta ray; dose; ions; LET; model; neutron; OER; SP461, pp. 183-187 (Jan. 1977).

One-port microwave parameters; six-port concept; microwave measurements; 17234 .

On-line bibliographic retrieval systems; evaluation; National Bureau of Standards; 17186.

On-line system evaluation; prediction methods; queuing models; simulation; software monitoring; workload definition; ADP life cycle; computer performance evaluation; computer performance measurement; computer performance prediction; computer system acquisition; SP500-18.

On-line systems; system design; task variables; workload characteristics; computer response time; human factors; SP500-18, pp. 3-11 (Sept. 1977).

On-stream analysis; well logging; activation analysis; californium-252; inland waters and sediments; in vivo analysis; mineral exploration; nuclear safeguards; oceanography; 16760.

Opal glass; radiant flux; reflectance standards; standards calibration; barium sulfate; diffuse reflectance spectra; magnesium oxide; SP466, pp. 75-85 (May 1977).

Open channel flow; petroleum product standards; closed conduit flow; flow measurement; international standards; SP484, pp. 895-920 (Oct. 1977).

Open channel flow; public law 92-500; sewerage flow; wastewater flow; closed conduit flow; instrumentation; measuring flow; metering flow; monitoring flow; SP484, pp. 83-89 (Oct. 1977).

Open channel flow measurement; secondary measuring device; flow measurement, water; flow meters; instruments, flow measurement; level measurement; level-to-flow rate conversion; liquid flow; SP484, pp. 91-108 (Oct. 1977).

Open channel flow measurement; power plant; spray canal; stage-discharge equation; velocity-area method; weir equation; closed-loop cooling system; cooling lake; dye dilution method; error analysis; flow rate measurement; SP484, pp. 145-172 (Oct. 1977).

Open channel flow rate; open channel velocity; acoustic flow rate; acoustic velocity; flow rate; liquid flow rate; liquid velocity; SP484, pp. 243-266 (Oct. 1977).

Open channel flows; orifice meters; pitot-static meters; turbine meters; weirs; acoustic flow meters; closed conduit flows; current meters; dye-dilution methods; errors in flow measurement; flow measurement; fluid flow modeling; fluid velocity; flumes; SP484, Volumes 1 and 2.

Open channel velocity; acoustic flow rate; acoustic velocity; flow rate; liquid flow rate; liquid velocity; open channel flow rate; SP484, pp. 243-266 (Oct. 1977).

Open-channel flow; broad-crested weirs; errors; flow measurement; flumes; SP484, pp. 201-218 (Oct. 1977).

Open-channel flow; weirs; flumes; hydraulic models; hydraulics; numerical models; SP484, pp. 219-242 (Oct. 1977).

Open-cycle MHD; seed-slag interaction; thermal decomposition of $\mathrm{K}_{2} \mathrm{O}-\mathrm{SiO}_{2}$ solutions; vapor pressure of $\mathrm{K}_{2} \mathrm{O}-\mathrm{Al}_{2} \mathrm{O}_{3}$ phases; vapor pressure of $\mathrm{K}_{2} \mathrm{O}-\mathrm{SiO}_{2}$ solutions; 16897 .

Operating cost; seasonal performance; building heating system; computer simulation; energy conservation; furnace; 16922.

Operating system protection; protection; protection mechanisms; reliable software; types; abstract data types; access controls; 16918 .

Operating system structures; protection; reliable software; reliability; security; small protection domains; types; capability; capability-based addressing; computer security; extended-type objects; 16920. 
Operational analysis; queuing networks; queuing theory; utilization; SP500-18, pp. $219-225$ (Sept. 1977).

Ophthalmic lenses; statistics; drop ball test; flaw distribution; fracture; impact resistance; 16979.

Optical; oscilloscope; photoconductor; sampling; waveforms; 16661.

Optical; radiography; standards; ultrasonics; visual; acoustic emission; inspection; leak testing; liquid penetrant; magnetic particle; measurements; nondestructive testing; 17042 .

Optical absorption; spectral distribution; thermoluminescence; gamma rays; irradiation; LiF; SP461, pp. 222-226 (Jan. 1977).

Optical beam splitter; attenuation; laser attenuation; NBSIR 77 858.

Optical calibration; optical radiation; pyroelectric radiometry; detector based standards; electrically calibrated pyroelectric radiometer; 16852 .

Optical flat, profile; stability; standard deviation; calibration; NBSIR 73-232.

Optical flying-spot scanner; oxidation particle impact noise detection test; passivation overcoats; photovoltaic method; power-device grade silicon; radioisotope method; resistivity; resistivity variations; safe operating area, transistor; scanning acoustic microscope; $S P 400-29$.

Optical interactions; atomic spectra; electromagnetism; laser, high-intensity; multiphoton absorption; 17130.

Optical materials; surface absorption; absorption; barothermal gas cell; bulk absorption; highly transparent; infrared materials; 16815 .

Optical measurement of roughness; surface finish; surface roughness; light scattering; NBSIR 73-219.

Optical microscope; photoelectric microscope; photomask; scanning electron microscope; filar eyepiece; image-shearing eyepiece; integrated circuits; linewidth measurements; microelectronics; micrometrology; 17066.

Optical microscope; photomasks; photomask metrology; optical microscope; shearing eyepiece; dimensional standards; filar eyepiece; linewidth measurements; micrometer eyepiece; microscope calibration; 17063.

Optical microscope; shearing eyepiece; dimensional standards; filar eyepiece; linewidth measurements; micrometer eyepiece; microscope calibration; optical microscope; photomasks; photomask metrology; 17063.

Optical model; parameter; polynomial extrapolation; sphere transmission; cross section; multiple bias; neutron; nonelastic; SP461, pp. 44-46 (Jan. 1977).

Optical model; reactor technology; scattering-elastic, inelastic, total; thorium; uranium; calculation; cross section; SP46I, pp. 70-73 (Jan. 1977).

Optical model; R-function analysis; standard; total cross section; carbon; elastic scattering cross section; evaluation; SP493, pp. 93-100 (Oct. 1977).

Optical properties; phase diagrams; research materials; thermal properties; availability; crystal growth; crystal structure; electronic properties; magnetic properties; SP463, pp. III.3.1III.3.8 (Jan. 1977).

Optical properties; Retrieval Guide; technical reports; Thermophysical and Electronic Properties Information Analysis Center; thermophysical properties; computerized information system; data bank; SP463, pp. IV.4.1-IV.4.3 (Jan. 1977).

Optical pumping; dimer laser; electronic transition laser; laser; laser kinetics; laser spectroscopy; 17318.

Optical pumping; sulfur dimer; tunable laser; visible-ultraviolet laser; gas laser; 17129.

Optical pumping of molecules; vibrational relaxation; combustion; $\mathrm{CO}_{2}$ lasers; nitric oxide; 17193 .

Optical radiation; pyroelectric radiometry; detector based standards; electrically calibrated pyroelectric radiometer; optical calibration; 16852 .
Optical reflection; reflectance; reflectance factor; reflectance geometry; reflectance nomenclature; reflection; specular reflectance; sub-surface scattering; bidirectional reflectancedistribution function; diffuse reflectance; directional reflectance; Monogr. 160.

Optical spectra; ruby; transition metal ions; ultrahigh pressure; $\mathrm{Cr}^{3+}$, crystal field spectra; $\mathrm{d}^{3}$ ion; 17047 .

Optical transitions; scaling theory; frequency shifts; hydrostatic pressure; 17228.

Optically excited; spectra; two photon; dimer; double resonance; mercury excimers; 17076.

Optics; photoelasticity; crystals; fused silica; interferometers; 16730.

Optics; pre-amplifier; radio receiver; semiconductor device studies; electronic reliability; electronics; laser scanner; measurement method; mixer; SP400-24.

Optics; security and law enforcement; law enforcement; 17339.

Optimization; performance standards; resource impact factors; resources; social optimum; standards; building economics; economic efficiency; economics; energy; energy conservation; life-cycle cost; 17302.

Optimization; retrofitting; seismic; costs; existing structures; SP477, pp. VI-69-VI-84 (May 1977).

Optimization; structures; frequency response; least weight; SP470, pp. VI-22-VI-32 (Apr. 1977).

Opto-galvanic effect; spectroscopy; tunable laser; dye laser; flame analysis; flame fluorescence; laser; 16691.

Optogalvanic effect; spectroscopy; wavelength calibration; bandwidth determination; discharge lamp; lasers; 17287.

Orbiting; saturation; selection rules; van der Waals; atomic collision; excitation transfer; laser stimulation; 16695.

Order parameter; structure; antiferroelectric; KCN; $\mathrm{NaCN}$; 16972.

Order-order transition; transition temperatures; canted phase; ferromagnetism; 17350.

Ordinary differential equation; turning point; asymptotic analysis; Bessel functions; boundary-value problem; connection formula; diffraction theory; error analysis; Liouville-Green approximation; 16805 .

Organ; phantom; photon; reciprocity theorem; source; target; tissue; dose; dosimetry; Monte Carlo; SP461, pp. 177-182 (Jan. 1977).

Organic conductors; paramagnetic resonance; TTF-TCNQ; eddy currents; 17030.

Organic sulfur; radiometric detector; smog formation; SRM's; air pollution; attic ventilation; data encryption; dental materials; fire safety; metric; miniature electric field; DIMINBS 61, No. 11, 1-32 (1977).

Organics; pesticides; radionuclides; sample handling; sampling; trace elements; chemical analysis; environmental samples; long-term storage; microbiologicals; 16729.

Organization; probability; reliability; trees; dynamic programming; graph; network; 16784.

Organizational design; policy analysis; program evaluation; administrative experimentation; evaluation; evaluation research; 17323

Organoarsenic; analysis; aqueous chemistry; arsenic; atomic absorption spectrophotometry; biomethylation; electrochemistry; environment; gas chromatography; laser-Raman; liquid chromatography; nuclear magnetic resonance; 17155 .

Organometal; selenium; tin; arsenic; atomic absorption; gas chromatography; 16811 .

Organometallic compounds; speciation; tin; arsenic; elementspecific detector; flameless atomic absorption; flow monitoring; high-pressure liquid chromatography; lead; ligand; mercury; nanogram sensitivity; 17297.

Organometals; photolysis; reaction rates; thallium; tin; transmethylation; water; alkylation; aqueous solution; coordination; mercury; metal complexes; 17008. 
Orifice meter; turbulence flow; closed conduit meter; diffcrential pressure; flow measurement; mathematical modeling; meter performance; SP484, pp. 491-522 (Oct. 1977).

Orifice meters; pitot-static meters; turbine meters; weirs; acoustic flow meters; closed conduit flows; current meters; dye-dilution methods; errors in flow measurement; flow measurement; fluid flow modeling; fluid velocity; flumes; gas flow standard; SP484, Volumes 1 and 2

Orifice meters; pulsating flow measurements; pulsations; turbulence; vortex; differential pressure; flow metering error; flow oscillations; jet flow; SP484, pp. 523-548 (Oct. 1977).

Orifice plates; data bases; EEC regulations; flow rate; international standards; SP484, pp. 935-944 (Oct. 1977).

Orion Nebula; molecules, interstellar; 16675.

Orthobaric densities; propane; specific heats; speeds of sound; vapor pressure; densities; enthalpies; entropies; equation of state; internal energies; isobars; isochores; isotherms; JouleThomson inversion; latent heats of vaporization; melting line; NBSIR 77-860.

Orthoferrite; photolithography; uniaxial structures; amorphous materials; bubble; field-access; garnet; guide-pattern; magnetoresistance; nonvolatility; SP500-1.

Orthopaedic; retrieval; analysis; implants; metallic; SP472.

Orthotelephonic response; anthropometric manikin; free-field measurements; hearing aid tests; 16847.

Orthotropic; plates; rotary inertia; transverse shear; vibration; Galerkin; natural frequencies; 16702.

Orthotropic materials; strain; stress; superconducting magnets; anisotropic materials; 17082.

Oscillating probe; conductivity probe; density; density gradient; experimental; internal wave; laboratory; SP484, pp. 783-802 (Oct. 1977).

Oscillator strength; plasma; spectra; uranium; arc; 16992.

Oscillator strengths; carbon tetrachloride; carbon tetrafluoride; electron impact; electron spectroscopy; 17018.

Oscillator strengths; water vapor; electron impact; electron spectroscopy; 17019.

Oscilloscope; photoconductor; sampling; waveforms; optical; 16661 .

OSHA Standards; thermal sensation; WBGT; core temperature; energy conservation; modeling; SP491, pp. 18-40 (Sept. 1977).

Osmium alloys; phase diagram; atomic ordering; constitution diagram; niobium alloys; 16738.

"Osmium," marking of; "Palladium," marking of; "Platinum," marking of; "Rhodium," marking of; "Ruthenium," marking of; "Iridium," marking of; jewelry, marking of; PS69-76.

Osmotic coefficient; solutions; thermodynamic properties; activity coefficient; calcium chloride; critical evaluation; electrolyte; excess free energy; JPCRD 6, No. 2, 385-408 (1977).

Osmotic coefficients; thermochemistry; vapor pressure; activity coefficients; aqueous systems; bibliography; electrochemistry; isopiestic; SP485.

Overcoating; plasmons; scatter; absorption; dielectric layers; irregularities; metallic thin films; microirregularities; SP466, pp. 133-148 (May 1977).

Overhauser effect; relaxation time; ${ }^{13} \mathrm{C}$; collagen fibers; molecular motion; nmr; 17007.

Overlap; van der Waals; XeF; charge transfer; dissociation energy; energy curve; 16684 .

Overlapped lines; radio astronomy; acetaldehyde; internal rotation; interstellar molecules; mm wave transitions; 16969.

Oxazine dyes; quenching; xanthene dyes; aminocoumarins; carbazine dyes; deuterium effect; fluorescence quantum yield; laser dyes; molccular structure; SP466, pp. 33-40 (May 1977).

Oxidation; particle; velocity dependence; erosion; metal; 16898.

Oxidation; silicon nitride; surface flaws; thin foils; cracks; electron microscopy; grinding damage; 17090.
Oxidation furnace; silicon dioxide; sodium contamination; thermal oxidation; fuscd silica; microelectronic; MOS; 16939.

Oxidation particle impact noise detection test; passivation overcoats; photovoltaic method; power-device grade silicon; radioisotope method; resistivity; resistivity variations; safe operating area, transistor; scanning acoustic microscope; scanning electron microscope; $S P 400-29$.

Oxidative addition; boron hydride; hydrogen; iridium; isotope exchange; metalloborane; 17144 .

Oxide radical ion; perhydroxyl radical; radiation chemistry; rates; superoxide ion; aqueous solution; chemical kinetics; data compilation; hydroxyl radical; NSRDS-NBS59.

Oxide rupture; surface deformation; assessment of fatigue damage; exoelectron emission; failure prediction; laser scanner; SP487, pp. 197-209 (Aug. 1977).

Oxygen; $\mathrm{PCO}_{2} ; \mathrm{pH}$; potassium; $\mathrm{PO}_{2}$; sodium; acid-base status; blood electrolytes; blood gases; blood $\mathrm{pH}$; calcium; carbon dioxide; hydrogen ion concentration; nomograms; SP4SO.

Oxygen; PVT; quality; slush; solid; vapor; computer programs; enthalpy; entropy; hydrogen; internal energy; liquid; NBSIR 77-859.

Oxygen; radiation; time-of-flight; atomic; experimental; lifetimes; $\mathrm{N}_{2} \mathrm{O} ; 16812$.

Oxygen; sulphur hexafluoride; temperature programmed desorption; tungsten; chemisorption; electron stimulated desorption; 16929.

Oxygen; technology; cryocooler; EMI problems; energy problems; energy savings; exchange program; lead detection; metric; DIM/NBS 61, No. 10, 1-32 (1977).

Oxygen atoms; rate constant; resonance fluorescence; stratosphere; chlorine nitrate; chlorofluorocarbons; 17149.

Oxygen concentration; textiles; air flow; extinguishability; extinguishment; fabric flammability; fibers; heat flux; heat sinks; NBS-GCR-77-90.

Oxygen content; recirculating flow; rcduced scale model test; scaling criteria; spray water flow rate; water spray; automatic sprinklers; compartment fire; corridor sprinkler systems; droplet size; droplet trajectory; evaporative cooling; fire suppression; NBSIR 77-1287.

Oxygen content; reduced ventilation rate; school operation schedule; ventilation test; computerized thermal simulation; $\mathrm{CO}_{2}$ concentration; energy conservation in schools; energy consumption; energy utilization in schools; BSS97.

Oxygen depletion; smoke; Steiner Tunnel Test; ASTM E 84; fire tests; flame spread; heat flux; heat release rate; TN945.

Oxygen molecules; photoluminescence; quenching; laser; metastable; 16765.

Oxygen/fluorocarbon complex; oxygen/hydrocarbon complex; reversible oxygenation; second virial coefficients; 17216 .

Oxygen/hydrocarbon complex; reversible oxygenation; second virial coefficients; oxygen/fluorocarbon complex; 17216.

Ozone; air pollution; chemical kinetics; dioxirane; ethylene; mass spectrometry; 17327.

Ozone; potassium iodide; techniques; ultraviolet photometer; 16756.

Ozone; ultraviolet photometry; air pollution; calibration; iodometry; monitoring; NBSIR 76-1191.

Ozone attack; atomic oxygen; chemiluminescent; corona discharge; dielectric breakdown; 16995.

\section{$\mathbf{P}$}

Pacemaker; power cell; self-discharge; battery; microcalorimetry; NBSIR 77-1310.

Pacemaker leads; process control; reliability; screen tests; semiconductor devices; batreries; cardiac pacemakers; hermeticity; hybrid devices; leak testing; measurement technology; microcalorimetry; SP4OO-42. 
Packet switching; standards; communications networks; computer networks; data communications; interconnection; networks; 16934.

Packet switching; standards; communications networks; computer networks; data communications; interconnection; networks; SP500-6.

Pair production; photoelectric effect; photons; $x$ rays; atomic form factor; attenuation coefficients; cross sections; gamma rays, incoherent scattering function; SP46I, pp. 3-16 (Jan. 1977).

Pair-production; photoionization; coherent scattering; cross sections; gamma ray; incoherent scattering; SP461, pp. 20-22 (Jan. 1977).

"Palladium," marking of; "Platinum," marking of; "Rhodium," marking of; "Ruthenium," marking of; "Iridium," marking of; jewelry, marking of; "Osmium," marking of; PS69-76.

Palladium-deuteride $\left(\mathrm{PdD}_{0.63}\right)$; phonon lineshapes; defect crystal structures; inelastic neutron scattering; lattice dynamics; metal-hydrogen systems; 16964.

Panels; structural integrity; buildings; collapse; concrete; SP477, pp. VI-220-VI-251 (May 1977).

Paper; durability; flexing; 17241

Paper; pore size; statistical analysis; Weibull distribution; durability; fatigue; fiber length; flexing; low cycle fatigue; mechanical properties; microstructure; modelling; 16681 .

Paper; pulp; timber; wood; wood products; AIDS; bark; forest products; glues and gluing; information service; lumber; mechanical properties; SP463, pp. II.1.1-II.1.4 (Jan. 1977).

Paper recycling; pulp characterization; $2.5 \mathrm{~g} / \mathrm{m}^{2}$ handsheets; breaking energy; inter-fiber bond strength; mixed waste paper; NBSIR 76-1148.

Parallel-by-bit; parity sense; serial-by-character; telecommunications; teleprocessing; American Standard Code for Information Interchange; ASCII; character structure; communications; data transmission; Federal Information Processing Standards; FIPS PUB 18-1.

Parallelism; flatness; gage blocks; interferometry; length measurement; NBSIR 73-239.

Paramagnetic resonance; TTF-TCNQ; eddy currents; organic conductors; 17030.

Parameter; polynomial extrapolation; sphere transmission; cross section; multiple bias; neutron; nonelastic; optical model; SP461, pp. 44-46 (Jan. 1977).

Parametric analysis; simulated smoke concentration; smoke control; smoke movement; smoke simulation; systematic pressurization; air-handling units; building pressure profile; computer simulation; elevator shaft pressure profiles; NBSIR $77-1225$.

Parametric plasma oscillation; thin-film device; coherent microwave emission; e/h voltage standard; Josephson junction; microstrip resonator; microwave coupling; 16788.

Pararosaniline cyanide; pulse radiolysis; radiochromic dyes; calorimetry; chemical dosimetry; dosimetry; dye dosimeters; electron beams; gamma rays; 16984.

Parasitic; probe; probe assembly; 17239.

Parity sense; serial-by-character; telecommunications; teleprocessing; American Standard Code for Information Interchange; ASCII; character structure; communications; data transmission; Federal Information Processing Standards; parallel-by-bit; FIPS PUB 18-1.

Parshall flume; error reduction strategy; flow measurement errors; infiltration/inflow analysis; SP484, pp. 173-186 (Oct. 1977).

Partial fringe; wavelength measurement; dimensional metrology; exact fringes; fractional fringe; interferometer; length measurement; 17048.

Partial molar volume of aqueous gases; PVT; thermal expansivity; water; aqueous solutions of gases; compressibility; equation of state; heavy water; isotopic waters; JPCRD 6, No. 4, 1109-1132 (1977).
Partial reinforcing; risk; shear modulus; testing; ultimate strength; anchor bolts; bond; damping; ductility; earthquake resistance; energy absorption; modulus of elasticity; BSSI06, pp. 255-258 (Sept. 1977).

Particle; velocity dependence; erosion; metal; oxidation; 16898.

Particle accelerators; power transmission; reliability; compressors; cryogenic refrigeration; efficiency; expanders; heat exchangers; 17083.

Particle impingement; stainless steel; erosion-corrosion process; erosive wear; high temperature erosion; 17274 .

Particle impingement; stainless steel; erosion-corrosion process; erosive wear; high temperature erosion; 17300.

Particles; wear; x-ray emission; debris; electron microscopy; 16827.

Particulate matter; Raman spectroscopy; airbome particles; microanalysis; micro-chemistry; microprobe; 17013

Particulates; regulations; sulfur dioxide; air quality; deterioration; measurements; 17141.

Partition coefficient; solubility; vapor pressure; 1-ethylnaphthalene; 1-methylnaphthalene; enthalpy; fluorescence; heat of solution; naphthalene; 17097.

Part-load efficiency; thermography; air infiltration; energy conservation; mobile home; NBSIR 76-1182.

Part-load performance; seasonal performance factor; cooling and heating coefficients of performance; effective seasonal heating COP; heat pumps; heat pumps and energy conservation; BSS93.

Passivation overcoats; photovoltaic method; power-device grade silicon; radioisotope method; resistivity; resistivity variations; safe operating area, transistor; scanning acoustic microscope; scanning electron microscope; scanning low energy electron probe; $S P 400-29$.

Passive hydrogen maser frequency standard; second-order Doppler; spin exchange; wall shift; active hydrogen maser frequency standard; cavity pulling; cavity-Q; cavity servo; Crampton effect; frequency stability; hydrogen line $Q$; hydrogen line servo; magnetic field; 17180 .

Passive-solar-heating; sun-shading; ventilation; windows; daylighting; infiltration; insulation; 17298.

Password; personal identification; terminals; verification; ADP security; computer networks; controlled accessibility; encryption; evaluation criteria; key; FIPS PUB 48.

Passwords; personal authentication; computer security; controlled access; 17281 .

Passwords; personal authentication; computer security; controlled access; 17307.

Passwords; personal authentication; computer networking; computer security; controlled access; identification; SP500-9.

Patent law; patents; Canada; copyrights; inventions; monopolies; 16859.

Patent licensing; technical reports; computerized information system; document dissemination; government reports; NTIS; SP463, pp. VII.3.1-VII.3.5 (Jan. 1977).

Patents; Canada; copyrights; inventions; monopolies; patent law; 16859.

Patina, artificially produced; patina, natural; archaeological finds, preservation of; conservation of metal artifacts; corrosion, inhibiting of; corrosion, treatment methods; metal artifacts, restoration of; SP479.

Patina, natural; archaeological finds, preservation of; conservation of metal artifacts; corrosion, inhibiting of; corrosion, treatment methods; metal artifacts, restoration of; patina, artificially produced; SP479.

Patrol cars; personal car plan; police fleet administration; takehome car program; breakeven analysis; life-cycle costing; 17299.

Patrolcar; police; police vehicles; standards; SP480-7.

Pattem recognition; prototype images; standards; automation; calibration; data formats; documentation; image content language; image processing; SP500-8. 
Pattern recognition; pulp characterization; pulps; algorithms; fiber morphology; fibers; image analysis; 17214 .

Patterns; scanning; spherical; symmetry; antennas; arrays; coordinate transformations; data processing; group representations; measurements; near field; nonplanar; 16671 .

Patulin; refined structure; single crystal $x$-ray structure determination; 4-hydroxy-4H-furo $(3,2 c)$ pyran-2(6H)-one; antibiotic; hydrogen bonding; 16913 .

Pavement, skid resistance; pavement wetting system; skid resistance, measurement; tire-pavement interface forces; wet pavement skid resistance; accident reduction, skidding; correlation, skid resistance; highway safety; measurement, skid resistance; NBSIR 77-1213.

Pavement skid resistance; skid resistance measurement; tirepavement interface forces; wet pavement skid resistance; accident reduction, skidding; highway safety; measurement, skid resistance; NBSIR 76-1175.

Pavement, skid resistance; test procedures, skid resistance measuring systems; tire-pavement interface forces; friction, pavement; highway safety; measurement, skid resistance; NBSIR 76-1174.

Pavement wetting system; skid resistance, measurement; tirepavement interface forces; wet pavement skid resistance; accident reduction, skidding; correlation, skid resistance; highway safety; measurement, skid resistance; pavement, skid resistance; NBSIR 77-1213.

$\mathrm{PCO}_{2} ; \mathrm{pH}$; potassium; $\mathrm{PO}_{2}$; sodium; acid-base status; blood electrolytes; blood gases; blood pH; calcium; carbon dioxide; hydrogen ion concentration; nomograms; oxygen; SP450.

Peak intensities; powder patterns; reference intensities; standard; $x$-ray diffraction; crystal structure; integrated intensities; lattice constants; Monogr. 25, Section 14.

Pelletization; poly(vinyl chloride), pressure densification; relaxation; stored energy; strain energy; adiabatic temperature drift; enthalpy; glass transition; heat capacity; 16769.

Penetrant; radiography; standards; thermal; ultrasonic; visual testing; wear debris; acoustic; calibration; eddy current; microwave; nondestructive evaluation; 17106.

Penetration resistance; test methods; fire helmet; head injury; head protection; heat resistance; helmet; impact; NBSIR 77. 1251.

Perfect crystals; $x$-ray dynamical diffraction; contrast conditions; diffraction topography; dynamical images; imperfect crystals; 16977.

Perfect gas; propagation; shear; transverse gradient; wavenumber; duct; fundamental mode; liquid; 17215 .

Performance; availability; basis statistics; offered load; SP500. 18, pp. 137-142 (Sept. 1977).

Performance; preservation; rehabilitation; renovation; adaptive reuse; architecture; building codes; building regulations; building safety; construction; SP473, pp. 437-452 (June 1977).

Performance; pressure; transducer; characterization; evaluation; 17205.

Performance; radiative cooling; roofing; solar heating; surface temperature; built-up roofing; insulation; $I 7060$.

Performance; radiative cooling; roofing; solar heating; surface temperature; built-up roofing; insulation; 17061 .

Performance; total energy systems; absorption chillers; boiler performance; central utility plant; diesel engine; enginegenerator efficiency; heat recovery; NBSIR 77-1243.

Performance; urea-formaldehyde; cellular plastics; foam insulation; insulation; materials properties; TN946.

Performance approach; performance criteria; reliability analysis; reliability-based design; resistance factors; structural engineering; load factors; 17306

Performance approach; performance characteristics; performance criteria; performance evaluation; performance testing; plumbing research; plumbing research needs; reducedsize venting; SP473, pp. 317-348 (June 1977).
Performance approach; regulatory domination; standards development; building codes; concrete testing; evaluation; innovations; in-place testing; SP473, pp. 279-284 (June 1977).

Performance attributes; performance evaluation; building codes and standards; building code structure; existing buildings; historic preservation; SP473, pp. 453-489 (June 1977).

Performance characteristics; performance criteria; performance evaluation; performance testing; plumbing research; plumbing research needs; reduced-size venting; performance approach; SP473, pp. 317-348 (June 1977).

Performance characteristics; turbine meter; design considerations; field testing; fuel gas measurement; fundamentals; gaseous hydrocarbons; installation; SP484, pp. 871-880 (Oct. 1977).

Performance criteria; performance evaluation; performance testing; plumbing research; plumbing research needs; reduced-size venting; performance approach; performance characteristics; SP473, pp. 317-348 (June 1977).

Performance criteria; performance evaluation; plumbing; safety; structures; test methods; acoustics; appliances; atmospheric; durability; electrical; environment; housing technology; HVAC; innovative construction; maintainability; materials; minimum property standards; NBSIR 77-1316.

Performance criteria; physical and engineering properties; test methods; bituminous roof membranes; built-up roof membranes; coal-tar pitch; NBSIR 77-1256.

Performance criteria; plastic packaging; stress-cracking; timeto-fail; container tests; hazardous materials ladings; mechanical properties; 17256.

Performance criteria; reliability analysis; reliability-based design; resistance factors; structural engineering; load factors; performance approach; 17306.

Performance criteria; solar collectors; solar energy; standards; buildings; cooling; heating; SP473, pp. 103-112 (June 1977).

Performance criteria; solar energy; standards; buildings; cooling; heating; laboratory accreditation; 16686.

Performance criteria; stone decay; stone preservatives; accelerated laboratory testing; TN941.

Performance evaluation; building codes and standards; building code structure; existing buildings; historic preservation; performance attributes; SP473, pp. 453-489 (June 1977).

Performance evaluation; performance measurement; remote terminal emulation; Remote Terminal Emulator; teleprocessing; evaluation; interactive; measurement; 16945.

Performance evaluation; performance testing; plumbing research; plumbing research needs; reduced-size venting; performance approach; performance characteristics; performance criteria; SP473, pp. 317-348 (June 1977).

Performance evaluation; performance measurement; remote terminal emulation; remote terminal emulators; teleprocessing; evaluation; interactive; measurement; SP500. 4.

Performance evaluation; plan review; research and development; building regulation; computer-based systems; computer technology; information processing; SP473, pp. 369-375 (June 1977).

Performance evaluation; plumbing; safety; structures; test methods; acoustics; appliances; atmospheric; durability; electrical; environment; housing technology; HVAC; innovative construction; maintainability; materials; minimum property standards; performance criteria; NBSIR 77-1316.

Performance evaluation; system modeling; virtual memory system; bubble memory; SP500-18, pp. 213-217 (Sept. 1977).

Performance management; performance prediction; queuing networks; sizing studies; system design; computer-communication networks; configuration analysis; model validation; SP500-I8, pp. 227-234 (Sept. 1977). 
Performance measurement; remote terminal emulation; Remote Terminal Emulator; teleprocessing; evaluation; interactive; measurement; performance evaluation; 16945.

Performance measurement; remote terminal emulation; remote terminal emulators; teleprocessing; evaluation; interactive; measurement; performance evaluation; SPSO0-4.

Performance measurement; renewal theory; statistical analysis; steady state; interactive computer system; SPS00-18, pp. 87 94 (Sept. 1977).

Performance measures; computer performance evaluation; computer performance management; Federal Information Processing Standards; FIPS PUB 49.

Performance prediction; queuing networks; sizing studies; system design; computer-communication networks; configuration analysis; model validation; performance management; SP500-18, pp. 227-234 (Sept. 1977).

Performance specifications; standards; building codes; computer programming; decision tables; graph theory; 16705.

Performance specifications; standards; building codes; computer programming; decision tables; graph theory; TN940.

Performance standard; regulation; tensile testing; worker safety equipment; body belts; body harness; fall-arrest equipment; fall-safety systems; impact accelerations; impact forces; lanyards; linemen's equipment; load-extension data; occupational safety and health; NBSIR 76-1146.

Performance standard; thermal performance; ventilation; water heating; air leakage; building design; energy conservation; fenestration; HVAC systems; illumination; insulation; lighting; NBSIR 74-452.

Performance standards; pipe; plumbing; reduced-size vents; sanitary drainage system; venting; cost savings; drainagewaste-vent; economics; life cycle; 17296.

Performance standards; regulatory process; building codes; carrying capacity; environment; land use; natural system; SP473, pp. 189-202 (June 1977).

Performance standards; resource impact factors; resources; social optimum; standards; building economics; economic efficiency; economics; energy; energy conservation; life-cycle cost; optimization; 17302.

Performance testing; plumbing research; plumbing research needs; reduced-size venting; performance approach; performance characteristics; performance criteria; performance evaluation; SP473, pp. 317-348 (June 1977).

Perhydroxyl radical; radiation chemistry; rates; superoxide ion; aqueous solution; chemical kinetics; data compilation; hydroxyl radical; oxide radical ion; NSRDS-NBS59.

Perimeter sensor; switch; burglar alarm sensor; burglar alarm system; door switch; mechanically actuated switch; 17002 .

Periodicals; proceedings; serials; standards; transactions; annual reports; diffusion in metals; fire; journals; library holdings, NBS Library; NBS periodicals; NBSIR 77-1215.

Peristaltic CCD's; surface channel; The Federal Republic of Germany; The Netherlands; transfer channel; bucket-brigade; buried channel; Canada; charge-coupled device; Great Britain; imager CCD's; Japan; SP500-5.

Permeability effects; prototype tests; sand transport; water tunnel; waves; coastal processes; 16917.

Permeation; plastics packagings; polyethylene; transportation; hazardous materials; methods of test; 17346.

Permeation tube; standard reference material; nitrogen dioxide; 17230.

Permselective properties; surface properties; apatites; caries mechanism; caries prevention; membrane potentials; 16787.

Perpetrator attributes; physical security; psychological deterrence; sophisticated crime; threat analysis; terrorism; vigilance; behavioral science; human factors; human reliability; SP480-24.

Personal authentication; computer security; controlled access; passwords; 17281 .
Personal authentication; computer security; controlled access; passwords; 17307.

Personal authentication; computer networking; computer security; controlled access; identification; passwords; SP50O. 9.

Personal car plan; police fleet administration; take-home car program; breakeven analysis; life-cycle costing; patrol cars; 17299.

Personal data files; Privacy Act; probability model; retrieval; data retrieval; file validation; name lookup; nonunique identifiers; SPSO0-2.

Personal dosimeter; piezoelectric sensors; quartz crystal microbalance; environmental analysis; industrial hygiene; mercury vapor; 16773 .

Personal identification; terminals; verification; ADP security; computer networks; controlled accessibility; encryption; evaluation criteria; key; password; FIPS PUB 48.

Perspex; photon energy; pulse height; resolution; scattering media; tissue; water; detector; Monte Carlo; SP461, pp. 188 192 (Jan. 1977).

Perturbation; shape stability; silicon; crystal growth; floating zone; meniscus; 16931 .

Perturbation formula; rare gas halide; Rittner model; transition moment; dipole moment; excimer; excitation energy; 17151 .

Perturbation theory; rate coefficient; collision-induced; emission; interaction potential; iodine; 17069.

Perturbation theory; stellar oscillations; weak magnetic fields; nonradial; 16804.

Perturbations; precision; turbine meter; uncertainty; accuracy; calibration; flow conditioning; meter performance; SP484, pp. 33-54 (Oct. 1977).

Perturbed angular correlation; residual stress; Mössbauer effect; nuclear hyperfine techniques; nuclear magnetic resonance; 17011.

Pesticides; radionuclides; sample handling; sampling; trace elements; chemical analysis; environmental samples; long-term storage; microbiologicals; organics; 16729.

Pesticides; R\&D incentives; regulation; technology; impact of government on the economy; NBS-GCR-ETIP 76-34.

Petrographic; thermal; dental; expansion; investments; 17325.

Petroleum; benzo(a)pyrene; gas chromatography; gas chromatography-mass spectrometry; hydrocarbons; liquid chromatography; oil refinery; 16886 .

Petroleum; standards; container; corrosion; explosion; extinguisher; fire; gas; injury; liquefied; NBSIR 77-1217.

Petroleum analysis; polynuclear aromatic hydrocarbons; fluorescence emission spectroscopy; gas chromatographymass spectrometry; high-performance liquid chromatography; hydrocarbons; 17271 .

Petroleum analysis; trace analysis; gas chromatography; gas chromatography-mass spectroscopy; hydrocarbons; intercalibration; 17273 .

Petroleum measurement; silicon crystal density standards; volume reduction factors; 17023 .

Petroleum measuring; tank gaging; measurement practices; metering; oil measurement documents; SP484, pp. 55-60 (Oct. 1977).

Petroleum product standards; closed conduit flow; flow measurement; international standards; open channel flow; SP484, pp. 895-920 (Oct. 1977).

Petroleum standards; petroleum test methods; recycled oil; rerefined oil; used oil; waste oil; engine oil; fuel oil; hydraulic oil; industrial oils; lubricating oil; oil specifications; SP488.

Petroleum test methods; recycled oil; re-refined oil; used oil; waste oil; engine oil; fuel oil; hydraulic oil; industrial oils; lubricating oil; oil specifications; petroleum standards; $S P 488$.

$\mathrm{PF}_{5}$; Raman; $\mathrm{VF}_{5} ; \mathrm{AsF}_{3}$; barriers; energy levels; gas phase; 16978.

PH; phthalate buffer; potassium hydrogen phthalate; standard for pH; acidity; emf; J. Res. 81A No. 1, $21-24$ (1977). 
$\mathrm{PH}$; physiologic $\mathrm{pH}$; tris $\mathrm{pH}$ buffer; clinical $\mathrm{pH}$; liquid junction; pH analyzers; pH error; 16772 .

$\mathrm{PH}$; potassium; $\mathrm{PO}_{2}$; sodium; acid-base status; blood electrolytes; blood gases; blood $\mathrm{pH}$; calcium; carbon dioxide; hydrogen ion concentration; nomograms; oxygen; $\mathrm{PCO}_{2}$; SP450.

PH analyzers; pH error; $\mathrm{pH}$; physiologic $\mathrm{pH}$; tris $\mathrm{pH}$ buffer; clinical pH; liquid junction; 16772 .

PH error; $\mathrm{pH}$; physiologic $\mathrm{pH}$; tris $\mathrm{pH}$ buffer; clinical $\mathrm{pH}$; liquid junction; $\mathrm{pH}$ analyzers; 16772

Phantom; photon; reciprocity theorem; source; target; tissue; dose; dosimetry; Monte Carlo; organ; SP461, pp. 177-182 (Jan. 1977).

Pharmaceutical regulation; phase IV; post marketing surveillance; regulatory experiments; system design; adverse reaction detection; biostatistics; drug regulation; NBS-GCR-ETIP 76-35.

Phase; Ramsey; saturation spectroscopy; transit-time; coherence; fringes; interference; modulation; 17337.

Phase angle measurements; six-port voltmeter; vector voltmeter; microwave voltmeter; U.S. Patent 4,001,681.

Phase diagram; atomic ordering; constitution diagram; niobium alloys; osmium alloys; 16738 .

Phase diagram; phase transformations; rhodium alloys; vanadium alloys; atomic ordering; constitution diagram; 16834 .

Phase diagram; superconductivity; ternary alloys; A15 phase; constitution diagram; niobium alloys; 16832.

Phase diagrams; "Phase Diagrams for Ceramists"; phase equilibria; user evaluation; American Ceramic Society; ceramics; SP486.

Phase diagrams; research materials; thermal properties; availability; crystal growth; crystal structure; electronic properties; magnetic properties; optical properties; SP463, pp. III.3.1II1.3.8 (Jan. 1977).

Phase diagrams; ternary copper-silver alloy systems; thermodynamic properties; critically evaluated data; JPCRD 6 , No. 3, 621-674 (1977).

Phase diagrams; theory of phase diagrams; thermodynamics; computer predictions; critical evaluations; data compilations; industrial needs; NBSIR 77-I 239.

"Phase Diagrams for Ceramists"; phase equilibria; user evaluation; American Ceramic Society; ceramics; phase diagrams; SP486.

Phase equilibria; binary mixtures; critical locus; critical point; 17295.

Phase equilibria; rubidium niobate; rubidium tantalate; crystal chemistry; ionic conductivity; nonstoichiometry; J. Res. 82, No. 3, 151-165 (1977).

Phase equilibria; user evaluation; American Ceramic Society; ceramics; phase diagrams; "Phase Diagrams for Ceramists"; SP486.

Phase 1V; post marketing surveillance; regulatory experiments; system design; adverse reaction detection; biostatistics; drug regulation; pharmaceutical regulation; NBS-GCR-ETIP 76-35.

Phase measurement; phase of noisy sinusoid; phase sensitive detector; synchronous detector; synchronous phase marker circuit; narrow pass filter; 17138 .

Phase modulation; (active-passive) hydrogen maser; amplitude modulation; cavity frequency; environmental sensitivity; frequency lock loop; long-term frequency stability; NBS time scale; $172 I I$.

Phase noise; correlation; double balanced mixer; isolation amplifier; phase-lock loop; 17185

Phase noise; servo techniques; time domain stability; atomic frequency standard; frequency discrimination; frequency domain stability; frequency-lock loop; phase-lock loop; TN692.

Phase of noisy sinusoid; phase sensitive detector; synchronous detector; synchronous phase marker circuit; narrow pass filter; phase measurement; 17138 .
Phase sensitive detector; synchronous detector; synchronous phase marker circuit; narrow pass filter; phase measurement; phase of noisy sinusoid; 17138 .

Phase shift analyses; calculated $\sigma(\theta)$; experimental $\sigma(\theta)$; model predictions; nuclear reactions np scattering $E \leqslant 30 \mathrm{MeV}$; SP493, pp. 47-53 (Oct. 1977).

Phase transformations; rhodium alloys; vanadium alloys; atomic ordering; constitution diagram; phase diagram; 16834 .

Phase-lock; scanning; wavelength; cw laser; interferometer; Michelson; 17338.

Phase-lock loop; phase noise; correlation; double balanced mixer; isolation amplifier; 17185 .

Phase-lock loop; phase noise; servo techniques; time domain stability; atomic frequency standard; frequency discrimina. tion; frequency domain stability; frequency-lock loop; TN692.

Philippines; wind tunnel test; field studies; high winds; instru. mentation; SP470, pp. X-1-X-11 (Apr. 1977).

Phonon dispersion curves; cerium deuteride; inelastic neutron scattering; lattice dynamics; local mode vibrations; metal hydrides; 16965.

Phonon lineshapes; defect crystal structures; inelastic neutron scattering; lattice dynamics; metal-hydrogen systems; palladium-deuteride $\left(\mathrm{PdD}_{0.63}\right) ; 16964$.

Phonons; protons; specific heat; superfluid helium-4; computed thermodynamic properties; entropy; equation of state; excitation spectrum; helium-4; normal fluid helium-4; JPCRD 6, No. 1, 51-104 (1977).

Phosphare; vacancies; beta-tricalcium phosphate; cation substitution; coordination; crystal structure; disorder; magnesium incorporation; 17259.

Phosphoric acid electrolyte; refractory hard metals; AC impedance; automated electrochemical analysis; ceramic electrolytes; ceria-yttria; cyclic voltommetry; electrocatalysis; equivalent circuit; fuel cells; microprocessor; network analyzer; NBSIR 77-1270.

Phosphors; quantum efficiencies; radiant efficiencies; UV excitation; $x$-ray excitation; cathode-ray excitation; lu. minescence; luminescence standards; SP466, pp. 13-19 (May 1977).

Phosphorus; synthetic fabrics; burn injury potential; extin guishability; fire retardants; flammability hazard; FR treated cotton blends; FR treated cottons; ignitability; MAFT value; 17176.

Phosphorus; ternary diffusion; thermomigration; alloys; an timony; arsenic; bismuth; copper; diffusion; electromigration; liquid metals; nitrogen; JPCRD 6, No. 1, 1-50 (1977).

Photoabsorption; atoms, correlation; configuration interaction; exchange interaction; inner shells; 16670.

Photoabsorption cross section; photochemistry; quantum yield; rate constant; stratospheric chemistry; chemical kinetics; data evaluation; data reliability; gas phase; 16976.

Photoacoustic spectrometer; piezocalorimeter; transducers; triplet formation; absolute quantum efficiency; absolute quantum yield; calorimetry; luminescence; SP466, pp. 25-31 (May 1977).

Photoacoustic spectroscopy; surface absorption; weakly absorbing materials; bulk absorption; frequency dependence; laset materials; 16860 .

Photoacoustic spectroscopy; surface absorption; weakly absorbing materials; bulk absorption; frequency dependence; laser materials; 17313 .

Photochemical enrichment; thiophosgene; chlorine isotope separation; isotope enrichment; laser isotope separation; U.S. Patent 4,025,406.

Photochemistry; apparatus; chromatography; experimental laser; 16895.

Photochemistry; primary processes; quantum yields; troposphere; ultraviolet; absorption cross section; carbo: tetrachloride; chlorine atom; 16703. 
Photochemistry; pyrolysis; alkyl halides; $\mathrm{CO}_{2}$ laser; infrared; kinetics; mechanisms; 16783.

Photochemistry; quantum yield; rate constant; stratospheric chemistry; chemical kinetics; data evaluation; data reliability; gas phase; photoabsorption cross section; 16976.

Photoconductor; sampling; waveforms; optical; oscilloscope; 16661 .

Photodetectors; radiopharmaceuticals; ultraviolet radiation; windows; $\mathrm{AC}$ high voltage; $\mathrm{AC}$ voltmeter calibrator; marine studies; microelectronic industry; monitoring system; DIM/NBS 6I, No. 12, 1-32 (1977).

Photodetectors; silicon detectors; absolute spectral response; detector uniformity; linearity; 16754.

Photodiodes; radiometry; spectrometer calibration; synchrotron radiation; transfer standard detectors; calibration facilities; 16665.

Photodissociation; restricted Hartree-Fock; transition moment; absorption cross-section; $\mathrm{Ar}_{2}{ }^{+}$; energy transfer; gain inhibitor; gas lasers; 17195.

Photodissociation; thiophosgene; $\Delta H f^{\circ}$ (SCCl); $\Delta H f^{\circ}\left(\mathrm{SCCl}_{2}\right)$; $\operatorname{CS}\left(A^{1} \pi\right) ; 16781$

Photoelasticity; crystals; fused silica; interferometers; optics; 16730.

Photoelectric detectors; smoke detectors; building fires; fire detection devices; heat detectors; ionization chamber detectors; 16737.

Photoelectric effect; photon; atomic number; cross section; Kshell; measurement; SP461, pp. $41-43$ (Jan. 1977).

Photoelectric effect; photons; $x$ rays; atomic form factor; attenuation coefficients; cross sections; gamma rays, incoherent scattering function; pair production; SP461, pp. 3-16 (Jan. 1977).

Photoelectric microscope; photomask; scanning electron microscope; filar eyepiece; image-shearing eyepiece; integrated circuits; linewidth measurements; microelectronics; micrometrology; optical microscope; 17066.

Photoelectric smoke detectors; residential fires; smoke detectors; tenability levels; detector sensitivity; detector siting; heat detectors; ionization smoke detectors; 16882 .

Photoelectron spectroscopy; relaxation; adsorption; dielectric screening; 17218.

Photoelectron spectroscopy; surfaces; vibrational excitation; adsorption; molecules; 16749.

Photoemission; adatom; crystal field; 16919.

Photoemission; plasmons; satellites; XPS; 17219.

Photoemission; secondary electron; energy distribution; 16826.

Photoemission; thermal desorption; tungsten; ultraviolet photoelectron spectroscopy; carbon monoxide; chemisorption; coadsorption; desorption; displacement; hydrogen; 16808.

Photoemission; tungsten; ultraviolet photoelectron spectroscopy; acetylene; adsorption; chemisorption; dehydrogenation; ethylene; 16829 .

Photoexcitation cross sections; Stieltjes-Tchebycheff technique; configuration interaction; cross sections; ionization cross sections; lithium; 17319.

Photographic processing; scanning electron microscopy; signal processing; derivative operators; digital scan generator; isotropy; 16988 .

Photography; reflectance; transmittance; wedges; calibration; density; 16683.

Photoionization; appearance potential; diethyl ether; dimethyl ether; ionization potential; 17146.

Photoionization; coherent scattering; cross sections; gamma ray; incoherent scattering; pair-production; SP461, pp. 20-22 (Jan. 1977).

Photoionization; pyridine; vinylacetylene; 1,5-hexadiyne; 2,4hexadiyne; appearance potential; benzene; butatriene; heat of formation; ion; ionization potential; monoenergetic electron impact; 17294.
Photoionization; rate constants; alkyl iodides; ion-molecule reactions; isotope effects; mass spectrometry; J. Res. 81A Nos. 2 and 3, 267-271 (1977).

Photoionization; threshold photoelectron spectroscopy; time of flight mass spectrometry; acetone; coincidence; mass spectrometry; methane; 17148 .

Photoionization detector; reaction detector; cerium oxidation detector; liquid chromatography; liquid chromatography detectors; metal specific detector; 17278 .

Photolithography; silicon; test pattern; visual alignment structure; electrical mask alignment; integrated circuit; 17330.

Photolithography; uniaxial structures; amorphous materials; bubble; field-access; garnet; guide-pattern; magnetoresistance; nonvolatility; orthoferrite; SP5OO-1.

Photoluminescence; quenching; laser; metastable; oxygen molecules; 16765.

Photolysis; reaction rates; thallium; tin; transmethylation; water; alkylation; aqueous solution; coordination; mercury; metal complexes; organometals; 17008.

Photomask; scanning electron microscope; filar eyepiece; image-shearing eyepiece; integrated circuits; linewidth measurements; microelectronics; micrometrology; optical microscope; photoelectric microscope; 17066.

Photomask metrology; optical microscope; shearing eyepiece; dimensional standards; filar eyepiece; linewidth measurements; micrometer eyepiece; microscope calibration; optical microscope; photomasks; 17063.

Photomasks; photomask metrology; optical microscope; shearing eyepiece; dimensional standards; filar eyepiece; linewidth measurements; micrometer eyepiece; microscope calibration; optical microscope; 17063 .

Photometric linearity; polarization; sample characteristics; stray light; wavelength accuracy; bandwidth; calibration; errors in spectrophotometry; interferences; multiple reflections; SP466, pp. 99-114 (May 1977).

Photometric scale; slit width; spectral transmission; spectrophotometer standards; stray light; wavelength scale; errors in spectrophotometry; SP466, pp. 117-120 (May 1977).

Photometry; radiometry; sources; standard; 17024 .

Photometry; radiometry; sources; standards; survey; detectors; National Measurement System; NBSIR 75-939.

Photomultipliers; ' $\mathrm{Li}(\mathrm{n}, \boldsymbol{\alpha}) \mathrm{T}$; glass scintillators; Monte Carlo; multiple scattering; neutron detection; SP493, pp. 37-42 (Oct. 1977).

Photon; albedo; backscattering; distribution; dose rate; gamma rays; Monte Carlo; SP461, pp. 110-118 (Jan. 1977).

Photon; atomic number; cross section; K-shell; measurement; photoelectric effect; SP461, pp. 41-43 (Jan. 1977).

Photon; attenuation coefficient; counting sequence; cross section; gamma ray; SP461, pp. 29-31 (Jan. 1977).

Photon; polarimeter; radiation physics; scattering; spectrometers; absorption; accuracy; cross section; fast neutrons; geometric factors; SP461, pp. 47-54 (Jan. 1977).

Photon; reciprocity theorem; source; target; tissue; dose; dosimetry; Monte Carlo; organ; phantom; SP461, pp. 177182 (Jan. 1977).

Photon; scattering, incoherent; $x$ rays; angular distribution; cross section; gamma rays; SP461, Pp. $55-56$ (Jan. 1977).

Photon; $x$ ray; attenuation coefficient; energy-absorption coefficient; gamma-ray; 17051 .

Photon; $x$ ray; bound electrons; cross section; gamma rays; inelastic scattering; K-shell electron; SP461, pp. 26-28 (Jan. 1977).

Photon dosimetry; radiation; solid state dosimetry; dosimetry units; SP461, pp. 197-208 (Jan. 1977).

Photon energy; pulse height; resolution; scattering media; tissue; water; detector; Monte Carlo; perspex; SP461, pp. 188192 (Jan. 1977). 
Photon scattering; polarized photons; resonance fluorescence; Delbrück scattering; Doppler broadening; electric quadrupole; giant resonances; 16926.

Photons; approximation; bremsstrahlung; cross section; electron; intermediate energy; SP461, pp. 60-63 (Jan. 1977).

Photons; Compton scattering; differential cross seetion; electron binding; gamma rays; K-shell; SP461, pp. 67-69 (Jan. 1977).

Photons; Rayleigh scattering; analytical formula; coherent scattering; cross section; gamma rays; SP461, pp. $17-19$ (Jan. 1977).

Photons; $x$ rays; atomic form factor; attenuation coefficients; cross sections; gamma rays, incoherent scattering function; pair production; photoelectric effect; SP461, pp. 3-16 (Jan. 1977).

Photons, radiation physics; symposium; cross sections; dosimetry; electrons; neutrons; SP46I.

Photonuclear; shell model; sum rules; giant resonance; hydrodynamic model; isospin; 16987.

Photoproduction; pseudoscalar and pseudovector coupling; threshold pion production; effective Lagrangian; electroproduction; impulse approximation; TN957.

Photoresist; photoresist sensitivity; sensitivity index; Van Kreveld's additivity law; exposure; exposure control; film thickness variation; irradiance measurements; 16853.

Photoresist; sensitivity index; sensitometry; Van Kreveld's additivity law; exposure; exposure control; film thickness; irradiance measurements; 17329.

Photoresist sensitivity; sensitivity index; Van Kreveld's additivity law; exposure; exposure control; film thickness variation; irradiance measurements; photoresist; 16853.

Photovoltaic method; power-device grade silicon; resistivity variations; silicon; thermally stimulated capacitance; thermally stimulated current; thermally stimulated measurements; thyristor materials measurements; thyristor measurements; dc transmission; energy conservation; 17345 .

Photovoltaic method; power-device grade silicon; radioisotope method; resistivity; resistivity variations; safe operating area, transistor; scanning acoustic microscope; scanning electron microscope; scanning low energy electron probe; semiconductor devices; SP400-29.

Photovoltaic method; power-device grade silicon; resistivity variations; silicon; thermally stimulated capacitance; thermally stimulated current; thermally stimulated measurements; thyristor materials measurements; thyristor measurements; $d$ c transmission; NBSIR 77-1249.

Phthalate buffer; potassium hydrogen phthalate; standard for pH; acidity; emf; pH; J. Res. 81A No. 1, $21-24$ (1977).

Physical adsorption; relative humidity; routine radiosonde application; barium fluoride; calibration equations; fast response; films; humidity sensor; industrial fabrication; isotherm equations; NBSIR 76-1108.

Physical and engineering properties; test methods; bituminous roof membranes; built-up roof membranes; coal-tar pitch; performance criteria; NBSIR 77-I256.

Physical environment; regulation; research; standards; court orders; human behavior; institutional occupancies; interior design; SP473, pp. 55-67 (June 1977).

Physical environment; residential housing; socio-physical determinants; systems theory; energy consumption; input/output models; lifestyle factors; SP473, pp. 69-83 (June 1977).

Physical measurement; weights and measures; history of science; measurement instruments; measurement standards; National Bureau of Standards; national measurement standards; NBSIR 76-III25.

Physical measurement units; standard reference materials; chemical analysis; measurement systems; 16667.

Physical properties; RECON; scientific and technical aerospace reports; thesaurus; aerospace; computer information system; international aerospace abstracts; materials; mechanical properties; metallic materials; SP463, pp. VI.1.1-VI.1.7 (Jan. 1977).

Physical properties; research information; agricultural materials; agricultural research; biological properties; chemical properties; engineering properties; food products; information retrieval systems; SP463, pp. II.2.1-II.2.10 (Jan. 1977).

Physical properties; specification testing; testing of dental materials; dental amalgam; dental materials; development of testing procedures; mechanical properties; 17126.

Physical properties; spectral properties; thermodynamic properties; bibliography; chemical kinetics; chemistry; chlorine nitrate; molecular properties; nitrosyl chloride; nitryl chloride; SP478.

Physical properties; thermodynamics; transport; chemical; critical evaluation; mechanical; numerical data; SP463, pp. VII.1.1-VII.1.15 (Jan. 1977).

Physical property data; publish; science; standard reference data; technology; communication; information; interdisciplinary technology; 17258 .

Physical scale; plumes; buoyancy pressure; enclosure fires; entrainment; fire induced flows; models; J. Res. 82, No. 2, 107 117 (1977).

Physical science data; solid state data; standard reference data; thermodynamic data; transport properties; atomic and molecular data; chemical kinetics data; energy data; environmental data; industrial process data; materials utilization data; mechanical properties; TN947.

Physical sciences; science and technology in America; technology; 75th anniversary; National Bureau of Standards; SP465.

Physical security; procedural security; risk analysis; risk assessment; systems security; ADP availability; annual loss expectancy; application system vulnerability; computer security; data confidentiality; data integrity; data security; NBSIR 771228.

Physical security; psychological deterrence; sophisticated crime; threat analysis; terrorism; vigilance; behavioral science; human factors; human reliability; perpetrator attributes; SP480-24.

Physical security; sensor systems; adversary scenarios; automated response systems; distributed processing; monitoring systems; NBSIR 77-1262.

Physically handicapped; regulation; accessibility standards; building code; code administration; communication; enabling legislation; SP473, pp. 241-251 (June 1977).

Physics; building research; chemistry; combustion research; design concepts; directories; fire prevention; fire research; hazard analysis; NBSIR 77-1264.

Physics; spectroscopy; thermal physics; 75th anniversary; American Physical Society; fundamental constants; National Bureau of Standards; nuclear physics; numerical analysis; 16991 .

Physics; time; time broadcasts; time scales; astronomy; automation; clocks; communication; frequency; history; mathematics; navigation; Monogr. 155.

Physiologic $\mathrm{pH}$; tris $\mathrm{pH}$ buffer; clinical $\mathrm{pH}$; liquid junction; $\mathrm{pH}$ analyzers; $\mathrm{pH}$ error; $\mathrm{pH} ; 16772$.

Physiology; psychophysics; safety; warranty; anthropometry; biomechanics; carrying; consumer product portability; ergonomics; human factors; lifting; manual materials handling; NBSIR 76-1092.

Pickoffs (magnetic and RF); turbine flowmeter; universal curve; viscosity measurement; accuracy; calibration; characteristic factor ( $K$ or $C$ ); curve fitting; SP484, pp. 847-869 (Oct. 1977).

Picosecond pulse; resistive loading; the method of moments; broadband antenna; measurements; NBSIR 77-861. 
Picosecond pulses; superconducting electronics; superconductivity; voltage waveforms; energy gap; Josephson junctions; 16874 .

Piecewise analytic functions; quadrature; rational approximation; tanh rule; trapezoid rule; Hardy space; numerical integration; numerical quadrature; 17157.

Piers; research; seismic; shear walls; spandrel beams; connections; houses; masonry; BSS106, pp. 60-90 (Sept. 1977).

Piezocalorimeter; transducers; triplet formation; absolute quantum efficiency; absolute quantum yield; calorimetry; luminescence; photoacoustic spectrometer; SP466, pp. 25-31 (May I977).

Piezoelectric; polymer; polyvinylidene fluoride; pressure sensor; pyroelectric; transducer; NBSIR 76-1078.

Piezoelectric polymer; sound source; vibration; headphone; loudspeaker; microphone; 16952.

Piezoelectric polymer; vibration sensor; acoustic emission; damage detection; failure prevention; noise spectrum; SP487, pp. 189-196 (Aug. 1977).

Piezoelectric sensors; quartz crystal microbalance; environmental analysis; industrial hygiene; mercury vapor; personal dosimeter; 16773 .

Piezoelectricity; polarization; polyvinylidene fluoride; pyroelectricity; vinylidene fluoride copolymer; charge distribution; charge transfer; corona poling; dipole orientation; NBSIR 761186.

Piezo-flex micropositioning; pressure; thermodynamic tables; coal conversion; consumer products; cryogenic; crystalline materials; dosimeter calibrations; energy; energy related inventions; heterodyne receiver; international standards code; DIM/NBS 61, No. 7, 1-32 ( I 977).

Pion; radiation; track; cell; delta ray; dose; ions; LET; model; neutron; OER; one-hit detector; SP461, pp. 183-187 (Jan. 1977).

Pions; $\Delta$ components; $\Delta$ nucleus dynamics; $\pi D$ reactions; angular correlations; deuteron; 17210 .

Pipe; plumbing; reduced-size vents; sanitary drainage system; venting; cost savings; drainage-waste-vent; economics; life cycle; performance standards; 17296.

Pipe flow; Pitot tubes; velocity indication; flow in large pipes; flow metering; SP484, pp. 479-489 (Oct. 1977).

Pipe flow; resistance coefficients; turbulence; liquid metals; magnetohydrodynamics; 16821 .

Pipe hangers; residential occupancies; automatic sprinklers; care type occupancies; fire endurance; load failure; NBSIR 77-1282.

Piston gauge weights; weight handler; gas compressibility factor; 17127.

Pitot tubes; static pressure probe; turbulence; turbulent boundary layers; velocity measurement; impact pressure probe; SP484, pp. 737-753 (Oct. 1977).

Pitot tubes; velocity indication; flow in large pipes; flow metering; pipe flow; SP484, pp. $479-489$ (Oct. 1977).

Pitot-static meters; turbine meters; weirs; acoustic flow meters; closed conduit flows; current meters; dye-dilution methods; errors in flow measurement; flow measurement; fluid flow modeling; fluid velocity; flumes; gas flow standard; hot-wire anemometry; SP484, Volumes 1 and 2.

Pitot-static tube; Reynolds number; sphere flow; transition; tripwire probe; turbulent boundary layer; calibration; SP484, pp. 719-735 (Oct. 1977).

Pitting; repassivation kinetics; stress corrosion; crevice corrosion; ellipsometry; localized corrosion; 16990.

Plaintiff and products liability; products liability losses; liability losses; SP487, pp. 253-256 (Aug. 1977).

Plait point; thermal conductivity coefficient; viscosity coefficient; critical point; mixture; one-fluid theory; J. Res. 82, No. $3,181-182$ (1977).
Plan review; research and development; building regulation; computer-based systems; computer technology; information processing; performance evaluation; SP473, pp. $369-375$ (June 1977).

Planar scanning; scanning facilities; spherical scanning; antenna patterns; cosite interference; cylindrical scanning; near-field scanning; 17221 .

Planck's constant; radiometric standards; radiometry; standard lamps; Stefan-Boltzmann constant; blackbodies; electrically calibrated detectors; history of radiometry; 16851 .

Plane strain fracture toughness; tensile fatigue crack growth rate; $J$-integral; 16879 .

Plasma; reaction mechanism; silicon; synthesis; thin film; vapor transport; activation parameters; active nitrogen; iodine; kinetics; microwave discharge; nitride; 16757.

Plasma; spectra; uranium; arc; oscillator strength; 16992.

Plasma absorption; bremsstrahlung; electron-ion collisions; freefree transitions; multiphoton processes; J. Res. 82, No. 3, 173-179 (1977).

Plasma broadening; regularities; Stark widths; supermultiplet; transition array; isolated lines; multiplet; 17206.

Plasmons; satellites; XPS; photoemission; 17219.

Plasmons; scatter; absorption; dielectric layers; irregularities; metallic thin films; microirregularities; overcoating; SP466, pp. 133-I 48 (May 1977).

Plastic; recoil; scintillator; UNFOLD; Apsara; energy distribution; gamma ray; iterative; neutron; SP461, pp. 247-251 (Jan. I977).

Plastic deformation; silicon nitride; turbine materials; cracks; electron microscopy; fracture interfaces; NBSIR 76-1075.

Plastic films; polyvinyl acetate; polyvinyl butyral; polyvinyl chloride; polyvinyl pyrrolidone; radiation dosimetry; radiation processing; radiochromic dyes; triphenylmethane dyes; cellulose acetate; dose distributions; dosimetry; dyed plastics: 16949.

Plastic films; quality control; radiation processing; radiochromic dyes; sterilization; dose distributions; dosimetry; electron beams; gamma radiation; 17000 .

Plastic flow; solid particle impact; transmission electron microscopy; ceramics; erosion; fracture; NBSIR 77-1396.

Plastic packaging; stress-cracking; time-to-fail; container tests; hazardous materials ladings; mechanical properties; performance criteria; 17256.

Plastic phosphors; scintillation counting; $\beta$-ray detection; lowlevel counting; 17268 .

Plastics; polymers; sealants; adhesives; dental applications; dental prosthetic materials; dental resins; future dental materials; macromolecules; 17201 .

Plastics information; Plastics Technical Evaluation Center; specifications; technical reports; testing methods; tooling; adhesives; composites; computerized information system; foams; SP463, pp. IV.3.1-IV.3.2 (Jan. 1977).

Plastics packagings; polyethylene; transportation; hazardous materials; methods of test; permeation; 17346.

Plastics standards; standards; standards information service; voluntary standards; American National Standards Institute; computerized information system; engineering standards; mandatory standards; national standards; SP463, pp. VII.5.1VII.5.9 (Jan. 1977).

Plastics Technical Evaluation Center; specifications; technical reports; testing methods; tooling; adhesives; composites; computerized information system; foams; plastics information; SP463, pp. IV.3.1-IV.3.2 (Jan. 1977).

Plate Green's function; signal analysis; wave propagation in Plate; acoustic emission; acoustic emission simulator; capacitive transducer; 17191

Plate tectonics; geodesy; gravimetry; lunar ranging; 16896.

Plates; rotary inertia; transverse shear; vibration; Galerkin; natural frequencies; or thotropic; 16702.

"Platinum," marking of; "Rhodium," marking of; "Ruthenium," marking of; "Iridium," marking of; jewelry, marking of; "Osmium," marking of; "Palladium," marking of; PS69-76. 
Plexiglas 55; refractive index; $\mathrm{SrF}_{2}$; thermal coefficient of refractive index; $\mathrm{ZnS} ; \mathrm{ZnSe} ; \mathrm{BaF}_{2} ; \mathrm{CaF}_{2} ; \mathrm{KBr} ; \mathrm{KCl}$; Lexan; LiF; NaF; NBSIR 77-1304 (ARPA).

Plug gages; rolls; wire standards; calibration; cylinders; NBSIR 73-136.

Plumbing; reduced-size vents; sanitary drainage system; venting; cost savings; drainage-waste-vent; economics; life cycle; performance standards; pipe; 17296.

Plumbing; safety; structures; test methods; acoustics; appliances; atmospheric; durability; electrical; environment; housing technology; HVAC; innovative construction; maintainability; materials; minimum property standards; performance criteria; performance evaluation; NBSIR 77-1316.

Plumbing research; plumbing research needs; reduced-size venting; performance approach; performance characteristics; performancs criteria; performance evaluation; performance testing; SP473, pp. 317-348 (June 1977).

Plumbing research needs; reduced-size venting; performance approach; performance characteristics; performance criteria; performance evaluation; performance testing; plumbing research; SP473, pp. 317-348 (June 1977).

Plume; pressure distribution; streamlines; temperature distribution; analysis; buoyancy; laminar flow; J. Res. $81 \mathrm{~B}$ Nos. 1 and 2, 45-60 (1977).

Plumes; buoyancy pressure; enclosure fires; entrainment; fire induced flows; models; physical scale; J. Res. 82, No. 2, 107 117 (1977).

Plutonium-239; prompt fission spectrum; uranium-235; Watt spectrum; californium-252; Maxwellian spectrum; SP493, pp. 198-205 (Oct. 1977).

P-n junction; semiconductors; silicon; capacitance-voltage measurements; dopant density; Gaussian diffusion; 17328.

p-n junctions; scanning electron microscopy; semiconductor devices; device inspection; electron-beam-induced current; microelectronics; 16891.

p-n junctions; scanning electron microscopy; semiconductor devices; device inspection; electron-beam-induced-current; microelectronics; 16971 .

Pnictides; rare earth; crystal field; 16916.

Point group; polymorphism; space group; symmetry; crystal; isostructural materials; lattice; JPCRD 6, No. 3, 675-830 (1977).

Poisson ratio; precipitation hardening; shear modulus; sound velocity; Young's modulus; bulk modulus; compressibility; copper alloy; elastic constant; 17094.

Poisson's ratio; polycrystals; body-centered cubic solids; central-force solids; elastic constants; face-centered cubic solids; 16880 .

Poisson's ratio; precipitation-hardening alloys; shear modulus; sound velocity; Young's modulus; aluminum alloys; bulk modulus; compressibility; Debye temperature; 17085.

Poisson's ratio; pulse method; resonance method; shear modulus; sound velocity; Young's modulus; bulk modulus; composite; compressibility; copper; elastic constants; niobiumtitanium; 17068.

Poisson's ratio; pulse method; resonance method; shear modulus; sound velocity; stainless steel; Young's modulus; bulk modulus; compressibility; elastic constants; 17321 .

Poisson's ratio; shear modulus; single-crystal elastic coefficients; sound velocities; Young's modulus; zinc; bulk modulus; compressibility; Debye temperature; elastic constants; JPCRD 6, No. 4, 1181-1204 (1977).

Poisson's ratio; shear modulus; sound velocity; Young's modulus; bulk modulus; compressibility; Debye temperature; elastic constant; invar; iron alloy; nickel alloy; 16869 .

Poisson's ratio; shear modulus; sound velocity; Young's modulus; bulk modulus; compressibility; copper alloy; Debye temperature; elastic constants; 17320 .

Polar molecules; electron-molecule collisions; LiF; momentum transfer cross sections; 17027.
Polarimeter; radiation physics; scattering; spectrometers; absorption; accuracy; cross section; fast neutrons; geometric factors; photon; SP461, pp. 47-54 (Jan. 1977).

Polarization; polarizer; retarder; Stokes parameters; Mueller matrix; TN910-3.

Polarization; polyvinylidene fluoride; pyroelectricity; vinylidene fluoride copolymer; charge distribution; charge transfer; corona poling; dipole orientation; piezoelectricity; NBSIR 761186.

Polarization; potassium tantalate; refrigeration; specific heat; strontium titanate; beryllium; ceramics; cryogenics; dielectricconstant; electrets; electrocaloric effect; entropy; ferroelectrics; glass-ceramics; heat switches; magnetothermal conductivity; NBSIR 76-847.

Polarization; powder diffraction; quantitative $x$-ray analysis; reference intensity ratio; $x$-ray intensity standards; $x$-ray powder diffraction; internal standard; 16953.

Polarization; radiative and non-radiative transition probabilities; real fluorescence parameters; fluorescence lifetime; fluorescence quantum efficiency; fluorescence quantum yields; fluorescence spectrum; fluorescence standards; SP466, pp. 1-11 (May 1977).

Polarization; sample characteristics; stray light; wavelength accuracy; bandwidth; calibration; errors in spectrophotometry; interferences; multiple reflections; photometric linearity; SP466, pp. 99-114 (May 1977).

Polarization; strontium titanate; dielectric constant; dielectric relaxation; electret; glass ceramic; 16798.

Polarization; ${ }^{3} \mathrm{H}\left(\alpha,{ }^{6} \mathrm{Li}\right) \mathrm{n},{ }^{4} \mathrm{He}(\mathrm{t}, \mathrm{t}){ }^{4} \mathrm{He}$; ${ }^{6} \mathrm{Li}$ neutron cross sections; ${ }^{7} \mathrm{Li}$ system; measurements review; SP493, pp. 3-9 (Oct. 1977).

Polarized photons; resonance fluorescence; Delbrück scattering; Doppler broadening; electric quadrupole; giant resonances; photon scattering; 16926.

Polarizer; retarder; Stokes parameters; Mueller matrix; polarization; TN910-3.

Polarography; pure reagents; sample preparation; spark source mass spectrometric isotope dilution; tissues; analytical disciplines; analytical procedures; atomic absorption spectrometry; biological materials; blanks; botanical materials; chemical species; SP492.

Police; police equipment; portable radio; standards; communications; mobile radio; $S P 480-2$.

Police; police equipment; security equipment; surveillance equipment; alarm systems; cameras; SP480-4.

Police; police equipment; standards; SP480-I.

Police; police equipment; standards; ammunition; handguns; SP480-5.

Police; police vehicles; standards; patrolcar; SP480-7.

Police; standards; ballistic protective equipment; body armor; confiscated weapons; SP480-6.

Police equipment; portable radio; standards; communications; mobile radio; police; $S P 480-2$.

Police equipment; reports and guidelines; survey; communications equipment priorities; equipment standards; Law Enforcement Standards Laboratory; SP480-13.

Police equipment; security equipment; surveillance equipment; alarm systems; cameras; police; SP480 4 .

Police equipment; sirens; standards; emergency warning lights; SP480-3.

Police equipment; standards; police; SP480-1.

Police equipment; standards; ammunition; handguns; police; SP480-5.

Police fleet administration; take-home car program; breakeven analysis; life-cycle costing; patrol cars; personal car plan; 17299.

Police patrol car tires; radial tire failures; high speed tire hazard; SP480-18.

Police vehicles; standards; patrolcar; police; SP480-7. 
Policy; technology assessment; energy; environmental quality management; materials information; national programs; SP463, Pp. I.2.1-I.2.2 (Jan. 1977).

Policy alternatives; applied microeconomic framework; commodity supply crises; econometric analysis; economic impacts; efficiency impacts; income distribution effects; NBS. GCR-ETIP 76-24

Policy alternatives; applied microeconomic framework; commodity supply crises; econometric analysis; economic impacts; efficiency impacts; income distribution effects; NBSGCR-ETIP 76-32.

Policy alternatives; applied microeconomic framework; commodity supply' crises; econometric analysis; economic impacts; efficiency impacts; income distribution effects; NBSGCR-ETIP 76-33.

Policy alternatives; applied microeconomic framework; commodity supply crises; econometric analysis; economic impacts; efficiency impacts; income distribution effects; NBSGCR-ETIP 77-36.

Policy analysis; policymaking; public goods; technological change; transaction costs; computer; computer program; copyright; data base; economic efficiency; information technology; SP500-17.

Policy analysis; program evaluation; administrative experimentation; evaluation; evaluation research; organizational design; 17323.

Policy analysis; social experimentation; administrative experimentation; evaluation; evaluation research; evaluation systems; 17116.

Policy improvement algorithm; dynamic programming; economic analysis; energy conservation; equipment maintenance; Markow decision process; NBSIR 77-1210.

Policymaking; public goods; technological change; transaction costs; computer; computer program; copyright; data base; economic efficiency; information technology; policy analysis; SP500-17.

Pollutants; speciation; Standard Reference Materials; trace organics; water; accuracy; aerosol; air; collaborative testing; laboratory accreditation; laser technology; multielement analysis; SP464.

Pollution; standards committees; temperature measurements; thermal pollution; thermometry; water analysis; water pollution; NBSIR 77-1227.

Polyatomic molecule; Pople expansion; quadrupolar gas; second virial coefficient; dipolar gas; numerical integration; J. Res. 82, No. 2, 123-127 (1977).

Polyatomic molecules; Raman spectra; vibrational frequencies; fundamental frequencies; infrared spectra; JPCRD 6, No. 3, 993-1 102 (1977).

Polycrystals; body-centered cubic solids; central-force solids; elastic constants; face-centered cubic solids; Poisson's ratio; 16880.

Polycrystals; infrared; $\mathrm{KHF}_{2}$; lattice modes; linear triatomic anions; $\mathrm{NaHF}_{2} ; 16983$.

Polycrystals; shear modulus; Young's modulus; elastic constants; face-centered-cubic solids; 17099.

Polyethylene; sound; spinach; SRM; systems and software; telecommunications; computer use; conservation; data; earth's measurement; energy; health records; hydrogen; law enforcement; liquefied natural gas; metric tons; DIMINBS 61 , No. 5, 1-32 (1977).

Polyethylene; transportation; hazardous materials; methods of test; permeation; plastics packagings; 17346 .

Polyfluoroalkyl-alkyl polysiloxane; polytetrafluoroethylene; antimony dialkyldithiocarbamate; antiwear; bearing lubrication; extreme pressure; fluorinated ethylenepropylene; gear lubrication; grease; SP487, pp. 154-171 (Aug. 1977).

Polymer; polyvinylidene fluoride; pressure sensor; pyroelectric; transducer; piezoelectric; NBSIR 76-1078.
Polymer; poly(vinyl chloride); pressure effects; thermodynamic properties; calorimetry; enthalpy relaxation; glass transition; heat capacity; J. Res. 82, No. 1, 9-18 (1977).

Polymer; pressure; $P V T$; pyrolysis; refractive index; thermal expansion; thermodynamic; compressibility; densification; glass; glass transition; liquid; J. Res. 81A Nos. 2 and 3, 283-297 (1977).

Polymer; pressure; thermodynamic; compressibility; densification; glass; glass transition; hole theory; liquid; 16774 .

Polymer; sectorization; spheralites; chain folding; curved crystals; extended chain crystals; fold domains; fold surfaces; interlamellar links; morphology; 16958.

Polymer; surface nucleation; chain-folding; crystallization; growth rate; homogeneous nucleation; 16887.

Polymer adsorption; protein adsorption; synthetic implants; adsorption; blood protein; ellipsometry; implants; NBSIR 761128.

Polymer chain dynamics; random coil; random flight chain; relaxation times; excluded volume; Monte Carlo; 17125.

Polymer chain statistics; random walk statistics; spans of polymer chains; 16696.

Polymer characterization; standard reference material 1476; branched polyethylene; fractionation; gel permeation chromatography; GPC; molecular weight distribution; 17255.

Polymer degradation; rapid response furnace; thermogravimetry; computerized experiment; experiment automation; off-the-shelf automation; 16842.

Polymer glasses; pressure dependence; glasses; kinetics; 16962.

Polymer solution; bead-spring model; eigenvalues; frequency response; intrinsic optical tensor; intrinsic stress tensor; $J$. Res. 81A No. 1, 97-107 (1977).

Polymer tape insulation; superconducting cable; underground transmission; bridge measurements; cryogenic; dielectric loss; dissipation factor; epoxy insulation; high voltage; 17014.

Polymers; polystyrene; poly(vinyl chloride); specific heat; thermal conductivity; thermal diffusivity; fire research; NBSGCR-77-83.

Polymers; proteins; solid standards; antibodies; antigens; biological polymers; immunochemical analysis; light scattering; SP466, pp. 95-98 (May 1977).

Polymers; sealants; adhesives; dental applications; dental prosthetic materials; dental resins; future dental materials; macromolecules; plastics; 17201 .

Polymorphism; space group; symmetry; crystal; isostructural materials; lattice; point group; JPCRD 6, No. 3, 675-830 (1977).

Polynomial extrapolation; sphere transmission; cross section; multiple bias; neutron; nonelastic; optical model; parameter; SP461, pp. 44-46 (Jan. 1977).

Polynuclear aromatic hydrocarbons; fluorescence emission spectroscopy; gas chromatography-mass spectrometry; highperformance liquid chromatography; hydrocarbons; petroleum analysis; 17271 .

Polystyrene; poly(vinyl chloride); specific heat; thermal conductivity; thermal diffusivity; fire research; polymers; NBSGCR-77-83.

Polystyrene; radiation dosimeters; radiation processing; radiochromic-dye films; $10-\mathrm{MeV}$ electrons; aluminum; beef muscle; carbon; depth-dose distributions; lateral-dose distributions; 16999.

Polytetrafluoroethylene; antimony dialkyldithiocarbamate; antiwear; bearing lubrication; extreme pressure; fluorinated ethylenepropylene; gear lubrication; grease; polyfluoroalkylalkyl polysiloxane; SP487, pp. 154-171 (Aug. 1977).

Polytope; convex set; data analysis; estimation; geometry; hypercube; hyperplane; 17117.

Polyurethane; pulmonary irritation; PVC; respiratory rate; sensory irritation; stress index; thermal decomposition products; toxicity; acute lethality; Douglas Fir; inhalation; mice; NBSGCR-77-85. 
Polyurethanes; polyvinyl chloride; room fires; rooms; smoldering; wood; ceiling height; ceilings; cotton; detector location; detectors; fire detectors; NBS-GCR-77-86.

Polyurethanes; polyvinyl chloride; smoke detectors; smoldering fires; temperature rise; wood; ceiling height; ceilings; cotton; detector location; fire detectors; fire growth; flaming fires; heat detectors; NBS-GCR-77-95.

Polyurethanes; smoke detectors; standards; textiles; toxicity; arson; bibliographies; building fires; carpets; construction materials; fire departments; fire detection systems; fire tests; flame research; flammability tests; interior furnishings; mobile homes; NBSIR 77-1277.

Polyvinyl acetate; polyvinyl butyral; polyvinyl chloride; polyvinyl pyrrolidone; radiation dosimetry; radiation processing; radiochromic dyes; triphenylmethane dyes; cellulose acetate; dose distributions; dosimetry; dyed plastics; plastic films; 16949.

Polyvinyl butyral; polyvinyl chloride; polyvinyl pyrrolidone; radiation dosimetry; radiation processing; radiochromic dyes; triphenylmethane dyes; cellulose acetate; dose distributions; dosimetry; dyed plastics; plastic films; polyvinyl acetate; 16949.

Polyvinyl chloride; polyvinyl pyrrolidone; radiation dosimetry; radiation processing; radiochromic dyes; triphenylmethane dyes; cellulose acetate; dose distributions; dosimetry; dyed plastics; plastic films; polyvinyl acetate; polyvinyl butyral; 16949.

Polyvinyl chloride; room fires; rooms; smoldering; wood; ceiling height; ceilings; cotton; detector location; detectors; fire detectors; polyurethanes; NBS-GCR-77-86.

Polyvinyl chloride; smoke detectors; smoldering fires; temperature rise; wood; ceiling height; ceilings; cotton; detector location; fire detectors; fire growth; flaming fires; heat detectors; polyurethanes; NBS-GCR-77-95.

Polyvinyl pyrrolidone; radiation dosimetry; radiation processing; radiochromic dyes; triphenylmethane dyes; cellulose acetate; dose distributions; dosimetry; dyed plastics; plastic films; polyvinyl acetate; polyvinyl butyral; polyvinyl chloride; 16949.

Polyvinylidene fluoride; pressure sensor; pyroelectric; transducer; piezoelectric; polymer; NBSIR 76-1078.

Polyvinylidene fluoride; pyroelectricity; vinylidene fluoride copolymer; charge distribution; charge transfer; corona poling; dipole orientation; piezoelectricity; polarization; NBSIR 76-1186.

Poly(vinyl chloride); pressure effects; thermodynamic properties; calorimetry; enthalpy relaxation; glass transition; heat capacity; polymer; J. Res. 82, No. 1, 9-18 (1977).

Poly(vinyl chloride); specific heat; thermal conductivity; thermal diffusivity; fire research; polymers; polystyrene; NBSGCR-77-83.

Poly(vinyl chloride), pressure densification; relaxation; stored energy; strain energy; adiabatic temperature drift; enthalpy; glass transition; heat capacity; pelletization; 16769.

Pople expansion; quadrupolar gas; second virial coefficient; dipolar gas; numerical integration; polyatomic molecule; $J$. Res. 82, No. 2, 123-127 (1977).

Population dynamics; population growth rate; production rate; scrappage rate; stable-age population; age distributions; demography; durability; durable goods; matrix model; 17053.

Population growth rate; production rate; scrappage rate; stableage population; age distributions; demography; durability; durable goods; matrix model; population dynamics; 17053.

Population inversion; recoil; atoms; gain; 17143.

Pore size; statistical analysis; Weibull distribution; durability; fatigue; fiber length; flexing; low cycle fatigue; mechanical properties; microstructure; modelling; paper; 16681 .

Porous media; thermal energy storage; transpiration heat transfer; NBSIR 77-1237.
Portable radio; standards; communications; mobile radio; police; police equipment; SP480-2.

Portable spectrum analyzer; spectral density; time-dependent spectral density; coal mine noise; digital data; electromagnetic interference; electromagnetic noise; emergency communications; Fast Fourier Transform; impulsive noise; magnetic field strength; 17175 .

Portland cement; state-of-the-art summaries; technical reports; test methods; analytical procedure; bibliographies; computerized information system; concrete; concrete technology; construction material; construction methods; SP463, pp. IV.7.1-1V.7.7 (Jan. 1977).

Ports; specifications; structures; design; earthquakes; harbours; SP470, pp. Vill-42-VIll-55 (Apr. 1977).

Positive displacement flowmeters; turbine flowmeters; digital compensation techniques; fossil fuel limitations; linear specific gravity compensation; SP484, pp. 821-846 (Oct. 1977).

Positive semidefinite; semistable; convex hull; eigenvalue; field of values; 16819.

Possible improvements; uncertainties in efficiency; description of method; SP493, pp. 234-236 (Oct. 1977).

Post marketing surveillance; regulatory experiments; system design; adverse reaction detection; biostatistics; drug regulation; pharmaceutical regulation; phase IV; NBS-GCR-ETIP .76-35.

Post-processing audit; program integrity; audit standards; audit techniques; audit tools; audit training; communications security; computer controls; computer security; data integrity; interactive audit; internal audit; SP500-19.

Potassium; $\mathrm{PO}_{2}$; sodium; acid-base status; blood electrolytes; blood gases; blood $\mathrm{pH}$; calcium; carbon dioxide; hydrogen ion concentration; nomograms; oxygen; $\mathrm{PCO}_{2}$; pH; SP45O.

Potassium chloride; refractive index; temperature coefficient of index; 16662.

Potassium hydrogen phthalate; standard for $\mathrm{pH}$; acidity; emf; pH; phthalate buffer; J. Res. 81A No. 1, $21-24$ (1977).

Potassium iodide; techniques; ultraviolet photometer; ozone; 16756.

Potassium tantalate; refrigeration; specific heat; strontium titanate; beryllium; ceramics; cryogenics; dielectric-constant; electrets; electrocaloric effect; entropy; ferroelectrics; glassceramics; heat switches; magnetothermal conductivity; polarization; NBSIR 76-847.

Potential barrier; potential well; turning points; Whittaker functions; WKBJ approximation; connection formulas; eigenvalue problems; Liouville-Green approximation; 17142.

Potential barrier to internal rotation; principal and reduced moments of inertia; structural parameters; vibrational fundamentals; virial coefficients of the equation of state; enthalpy of formation; Gibbs energy of formation; JPCRD 6, No. 1, 105112 (1977).

Potential curve; spectroscopy; dissociation energy; Dunham coefficients; Franck Condon factors; molecular lithium; 17101 .

Potential curves; $335 \mathrm{~nm}$ mercury laser; $A$-values; bound-free transitions; $\mathrm{Hg}_{2} ; \mathrm{Hg}_{3} ; 17084$.

Potential energy curves; radiative lifetimes; critical review; Franck-Condon integrals; molecular constants; molecular nitrogen; JPCRD 6, No. 1, $113-307$ (1977).

Potential energy curves; sodium molecule; transition dipole moment; ab initio calculations; $\boldsymbol{A}$-values; Franck-Condon factors; laser modeling; lifetime; multiconfiguration self-consistent-field; 16870.

Potential heat; properties; rate of flame spread; rate of heat release; scanning electron microscope (SEM); buildings; ease of ignition; fire tests; gypsum board; NBSIR 77-1265.

Potential surfaces; rate constants; transition state theory; transmission coefficient; collinear reactions; deuterium, collinear 
reactions; hydrogen, collinear reactions; kinetic isotope effects; 16914.

Potential theory; stellar pulsation; nonradial modes; 17311 .

Potential well; turning points; Whittaker functions; WKBJ approximation; connection formulas; eigenvalue problems; Liouville-Green approximation; potential barrier; 17142 .

Powder diffraction; quantitative $\mathrm{x}$-ray analysis; reference intensity ratio; $x$-ray intensity standards; $x$-ray powder diffraction; internal standard; polarization; 16953.

Powder method; reduced cell; single crystal; symmetry; identification; lattice; 17050

Powder patterns; reference intensities; standard; $x$-ray diffraction; crystal structure; integrated intensities; lattice constants; peak intensities; Monogr. 25, Section 14.

Power cell; self-discharge; battery; microcalorimetry; pacemaker; NBSIR 77-1310.

Power generation; testing; U.S.-U.S.S.R. cooperative program; ceria; materials characterization; MHD (magnetohydrodynamics); 17160.

Power measurement; bolometer; microwave; 16723 .

Power measurement; reflection measurement; six-port; automation; millimeter wave; 17243 .

Power meter; bolometer; dc substitution; microwave; NBSIR 77-866.

Power plant; spray canal; stage-discharge equation; velocityarea method; weir equation; closed-loop cooling system; cooling lake; dye dilution method; error analysis; flow rate measurement; open channel flow measurement; SP484, Pp. 145-172 (Oct. 1977).

Power plants; shake table; aseismic design; dynamic tests; nuclear reactors; oil tanks; SP470, pp. VII-1-VII-6 (Apr. 1977).

Power plants; structural engineering; tornadoes; trajectories; dynamics; missiles; SP477, pp. VII-36_VII-41 (May 1977).

Power spectrum; earth strain; laser strainmeter; 17231 .

Power spectrum; synthesized spectrum; time-dependent spectrum; coherence; correlation function; counting rate spectrum; nonstationary process; nonstationary spectrum; 17169.

Power transistors; reliability; safe operating area limits; second breakdown; thermal instability; hot spots; measurement methods; 16893.

Power transmission; reliability; compressors; cryogenic refrigeration; efficiency; expanders; heat exchangers; particle accelerators; 17083 .

Power-device grade silicon; radioisotope method; resistivity; resistivity variations; safe operating area, transistor; scanning acoustic microscope; scanning electron microscope; scanning low energy electron probe; semiconductor devices; semiconductor materials; SP400-29.

Power-device grade silicon; resistivity variations; silicon; thermally stimulated capacitance; thermally stimulated current; thermally stimulated measurements; thyristor materials measurements; thyristor measurements; $d-c$ transmission; energy conservation; measurement methods; 17345 .

Power-device grade silicon; resistivity variations; silicon; thermally stimulated capacitance; thermally stimulated current; thermally stimulated measurements; thyristor materials measurements; thyristor measurements; d-c transmission; energy conservation; NBSIR 77-1249.

Poynting; variational; anholonomic; constraint; electromagnetism; Hamilton; Maxwell; momentum; J. Res. $81 B$ Nos. 1 and $2,1-3$ (1977).

$\mathrm{PO}_{2}$; sodium; acid-base status; blood electrolytes; blood gases; blood pH; calcium; carbon dioxide; hydrogen ion concentration; nomograms; oxygen; $\mathrm{PCO}_{2}$; $\mathrm{pH}$; potassium; SP450.

Practice; procedures; regional standardization; standardization; standards development; ADP standards; international standardization; national standardization; national standards bodies; NBSIR 77-1195.
Pre-amplifier; radio receiver; semiconductor device studies; electronic reliability; electronics; laser scanner; measurement method; mixer; optics; SP400-24.

Precipitation; titanium alloys; transmission electron microscopy; corrosion resistant alloys; microstructures; molybdenum additions; 16690.

Precipitation hardening; shear modulus; sound velocity; Young's modulus; bulk modulus; compressibility; copper alloy; elastic constant; Poisson ratio; 17094.

Precipitation-hardening alloys; shear modulus; sound velocity; Young's modulus; aluminum alloys; bulk modulus; compressibility; Debye temperature; Poisson's ratio; 17085.

Precision; pressure measurement; sensitivity; stability; thermal effects; zero-shift; accuracy; calibration; cryogenic; dynamic; frequency response; hysteresis; 17081

Precision; prover; Research Associate Program; standards inspection procedure; temperature correction; test measure; test measure evaluation; "to contain"; "to deliver"; volumetric calibration; accuracy; design analysis; equipment specification; NBSIR 77-1214.

Precision; repeatability; reproducibility; accuracy; analysis of variance; interlaboratory testing; 16858 .

Precision; SRM; standard reference data; standard reference materials; accuracy; certification; SP463, pp. VII.4.1-VII.4.14 (Jan. 1977).

Precision; turbine meter; uncertainty; accuracy; calibration; flow conditioning; meter performance; perturbations; SP484, pp. 33-54 (Oct. 1977).

Precision timekeeping; VLF antenna fields; VLF timing; VLF tracking coordination; clock synchronizations; cycle identification; group delays; Omega timing; 16947.

Prediction; thermal conductivity; transport property; viscosity; carbon dioxide; corresponding states; mixtures; nitrous oxide; TN693.

Prediction; thermal conductivity coefficient; viscosity coefficient; corresponding states; dense liquid; mixture; modified Enskog theory; 16791 .

Prediction methods; queuing models; simulation; software monitoring; workload definition; ADP life cycle; computer performance evaluation; computer performance measurement; computer performance prediction; computer system acquisition; conference proceedings; CPEUG; SP500-18.

Preheat; combustion; emulsified fuel droplet; fuel droplet; heat flow; micro-explosion; J. Res. 82, No. 3, 183-195 (1977).

Preheat; transient heat conduction; confluent hypergeometric functions; droplet; moving boundary problem; J. Res. 81A Nos. 2 and 3, 257-266 (1977).

Pre-main sequence models; Beta Cephei stars; nonradial stability; 17102 .

Premature dielectric breakdown; semiconductor devices; capacitance-voltage measurements; dielectric breakdown suppression; discharge suppression; electronics; extended-range MIS C (V) measurements; high-voltage C (V) measurements; MIS capacitor; $S P 400-37$.

Preservation; rehabilitation; renovation; adaptive reuse; architecture; building codes; building regulations; building safety; construction; performance; SP473, pp. 437-452 (June 1977).

Preservation technology; adobe building materials; adobe soil; mechanical properties; moisture determination; 17104 .

Preservation technology; adobe building materials; adobe soil; mechanical properties; moisture determination; TN934.

Preserving stone; pressure measurements; rf-power meter; roofing; safety; security alarms; SRM's; time and frequency; ultraviolet; computer memories; computer performance; inventor; molecular identity; DIM/NBS 61, No. 8, 1-32 (1977).

Pressure; PVT; pyrolysis; refractive index; thermal expansion; thermodynamic; compressibility; densification; glass; glass transition; liquid; polymer; J. Res. 81 A Nos. 2 and 3, 283297 (1977). 
Pressure; spectra; structural engineering; tall buildings; turbulence; wind; aerodynamics; building (codes); 16843.

Pressure; thermodynamic; compressibility; densification; glass; glass transition; hole theory; liquid; polymer; 16774.

Pressure; thermodynamic tables; coal conversion; consumer products; cryogenic; crystalline materials; dosimeter calibrations; energy; energy related inventions; heterodyne receiver; international standards code; NCSL; NMR knight shifts; DIM/NBS 61, No. 7, 1-32 (1977).

Pressure; transducer; characterization; evaluation; performance; 17205.

Pressure broadening; analysis of correlated profiles; classical theory; Doppler broadening; one perturber limit; 17161 .

Pressure coefficients; probability distribution functions; risk; statistical analysis; storms; structural engineering; tropical storms; wind loads; wind speeds; building codes; buildings; codes and standards; housing; hurricanes; BSS100-2.

Pressure dependence; glasses; kinetics; polymer glasses; 16962.

Pressure distribution; streamlines; temperature distribution; analysis; buoyancy; laminar flow; plume; J. Res. 81B Nos. 1 and 2, 45-60 (1977).

Pressure drops; thermal devices; error reduction; flow measurement techniques; flow vs. temperature techniques; SP484, pp. 597-619 (Oct. 1977).

Pressure effects; thermodynamic properties; calorimetry; enthalpy relaxation; glass transition; heat capacity; polymer; poly(vinyl chloride); J. Res. 82, No. 1, 9-18 (1977).

Pressure measurement; pressure transducer; transducer; biomedical; evaluation; 16941 .

Pressure measurement; sensitivity; stability; thermal effects; zero-shift; accuracy; calibration; cryogenic; dynamic; frequency response; hysteresis; precision; 17081 .

Pressure measurements; rf-power meter; roofing; safety; security alarms; SRM's; time and frequency; ultraviolet; computer memories; computer performance; inventor; molecular identity; preserving stone; DIM/NBS 61, No. 8, 1-32 (1977).

Pressure profiles; Seattle federal building; smoke control; smoke simulation experiments; sulfur-hexafluoride; systematic pressurization; air-handling system; Chicago federal building; highrise; 17291 .

Pressure sensor; pyroelectric; transducer; piezoelectric; polymer; polyvinylidene fluoride; NBSIR 76-1078.

Pressure shock in thermoplastic pipe; water hammer in thermoplastic pipe; intermittent hot water exposure tests of thermoplastic pipe; NBSIR 77-1261.

Pressure standard; ultrasonic interferometer; vacuum measurement; interferometer; manometers; manometry; 17269.

Pressure step; pressure transducer; protective coatings; shock tube; tape; thermal protection; thermal radiant-energy response; thermal transient response; transducer; zero shift; coatings; delayed response; dynamic; dynamic response; TN961.

Pressure transducer; protective coatings; shock tube; tape; thermal protection; thermal radiant-energy response; thermal transient response; transducer; zero shift; coatings; delayed response; dynamic; dynamic response; pressure step; TN961.

Pressure transducer; transducer; biomedical; evaluation; pressure measurement; 16941.

Pressure transducers; synchrotron radiation; building collapse; computer security; cryogenic temperature; dentistry; dielectric measurements; dye lasers; dynamic calibration; electron microscopy; electronic technology; energy conservation; DIM/NBS 61, No. 2, 1-32 (1977).

Pressure vessel steel; tensile properties; creep-rupture properties; elevated-temperature; fracture mode; Larson-Miller parameter; 17235.

Pressure vessels; sources; acoustic emission; crack growth; drill pipe; failure; Kaiser Effect; SP487, pp. 210-238 (Aug. 1977).
Price meter suspensions; Pygmy meter performance; velocityarea method; current meter calibrations; current meters, water; flow measurement; SP484, pp. 123-144 (Oct. 1977).

Primary cesium standard; cesium standard; clock, operating; magnetic shielding; microwave feed; 16759.

Primary frequency standard; time dispersion; bias uncertainty; frequency accuracy; frequency bias; frequency stability; 16775.

Primary processes; quantum yields; troposphere; ultraviolet; absorption cross section; carbon tetrachloride; chlorine atom; photochemistry; 16703.

Principal and reduced moments of inertia; structural parameters; vibrational fundamentals; virial coefficients of the equation of state; enthalpy of formation; Gibbs energy of formation; ideal gas thermodynamic properties; JPCRD 6, No. 1, 105-112 (1977).

Printer ribbons; procurement experiment; refrigerator-freezers; water heaters; window air conditioners; life cycle costing; NBS-GCR-ETIP 77-37.

Prisons; bedding; beds; compartment fires; firesafety engineering; fire tests; health care facilities; hospitals; mattresses; NBSIR 77-1290.

Privacy; recordkeeping practices; security; citizen rights; computers, confidentiality; data systems; health records; information policy, management principles; medical records; SP469.

Privacy; scramblers; speech scramblers; voice privacy; voice scramblers; LESL; NILECJ; SP480-8.

Privacy Act; probability model; retrieval; data retrieval; file validation; name lookup; nonunique identifiers; personal data files; SP500-2.

Privacy Act of 1974; privacy compliance techniques; computer utilization; data base functions; data base management systems; SP500-10.

Privacy compliance techniques; computer utilization; data base functions; data base management systems; Privacy Act of 1974; SP500-10.

Probabilistic analysis; reliability; systems analysis; availability; fault tree analysis; SP487, pp. 289-308 (Aug. 1977).

Probability; progressive collapse; reliability; structural engineering; uncertainty; abnormal loading; alternate path; building code; design criteria; BSS98.

Probability; random variable; reliability; algebra of normal functions; correlation; SP487, pp. 25-38 (Aug. 1977).

Probability; random vibrations; safety; structures; deterministic; dynamics; earthquake; SP470, pp. VI-1-VI-21 (Apr. 1977).

Probability; reinforced concrete; reliability; statistical analysis; structural engineering; uncertainty; 17304.

Probability; reliability; trees; dynamic programming; graph; network; organization; 16784.

Probability; statistics; structural design; wind; codes; 16856.

Probability density function; statistics; turnaround; workload; accounting data; computer performance; computer resource unit; SP500-18, pp. 39-67 (Sept. 1977).

Probability distribution functions; risk; statistical analysis; storms; structural engineering; tropical storms; wind loads; wind speeds; building codes; buildings; codes and standards; housing; hurricanes; pressure coefficients; BSS100-2.

Probability distributions; shocks, snow load; static load; trains; transportation; trucks; vibrations; wind load; acceleration; airplanes; cargo; dynamic loads; equivalent static force; gravity load; handling devices; handling loads; military field shelters; NBSIR 77-1254.

Probability model; retrieval; data retrieval; file validation; name lookup; nonunique identifiers; personal data files; Privacy Act; SP500-2.

Probability plotting; selection of variables in linear regression; statistical plotting; stem-and-leaf displays; table making; automatic printing; Calcomp plotting; data editing; interactive; labels; numerical analysis; OMNITAB II computing system; NBSIR 77-1276. 
Probability theory; reinforced concrete; reliability; statistical analysis; structural engineering; fire endurance; fire tests; 17303.

Probability theory; structural engineering; buildings (codes); live loads; load surveys; 17305.

Probe; probe assembly; parasitic; 17239.

Probe assembly; parasitic; probe; 17239.

Probe point development; programmable monitor; stimulator; terminal data; data input bus; DATANET 355; data output bus; high-speed line adaptor; HIS 6080; interactive terminal; SP500-18, pp. 95-105 (Sept. 1977).

Problem-solving; radiation safety; smoke detectors; solar heating; SRM's; adobe; air pollution; corrosion; electrical; energy management; graphic pen; halocarbons; infrared lasers; international standard; neutron xeroradiography; DIM/NBS 61 , No. 3, 1-32 (1977).

Procedural security; risk analysis; risk assessment; systems security; ADP availability; annual loss expectancy; application system vulnerability; computer security; data confidentiality; data integrity; data security; physical security; NBSIR 77-1228:

Procedure for testing flowmeters; automotive environment; automotive fuel flowmeters; effect of environment on flowmeter performance; flowmeter calibration; flowmeter evaluation; TN943.

Procedures; regional standardization; standardization; standards development; ADP standards; international standardization; national standardization; national standards bodies; practice; NBSIR 77-1195.

Proceedings; serials; standards; transactions; annual reports; diffusion in metals; fire; joumals; library holdings, NBS Library; NBS periodicals; periodicals; NBSIR 77-1215.

Process control; reliability; screen tests; semiconductor devices; batteries; cardiac pacemakers; hermeticity; hybrid devices; leak testing; measurement technology; microcalorimetry; pacemaker leads; SP400-42.

Processing time; regression model; blocking factor; data record; multiple regression; SP500-18, pp. 143-158 (Sept. 1977).

Procurement experiment; prototype procurement; technological innovation; check wrapping equipment; experimental procurement; experimental technology incentives program; NBS-GCR-ETIP 77-39.

Procurement experiment; refrigerator-freezers; water heaters; window air conditioners; life cycle costing; printer ribbons; NBS-GCR-ETIP 77-37.

Procurement incentives; product improvement system; product innovation; user need; NBSIR 77-1221.

Procurement policy; specifications; value incentive; Experimental Technology Incentives Program (ETIP); Federal Supply Service; life cycle costing; NBS-GCR-ETIP 76-26.

Procurement policy; specifications; value incentive; Experimental Technology Incentives Program (ETIP); Federal Supply Service; life cycle costing; NBS-GCR-ETIP 76-27.

Product improvement system; product innovation; user need; procurement incentives; NBSIR 77-1221.

Product innovation; user need; procurement incentives; product improvement system; NBSIR 77-1221.

Product liability; reliability of design; techniques of design; validation of design; coating materials; composite materials; design; failure avoidance; failure prevention; lubricants; materials of design; SP487.

Product liability; safety; SP487, pp. 241-246 (Aug. 1977).

Product safety; research; science; standards; technology; annual report; computer; energy; environmental; measurement; SP467.

Product specifications; flow measurement; ISO; methods of tests; need for international standardization; SP484, pp. 947 956 (Oct. 1977).
Product standards; recommended practices; specifications; test methods; certification programs; consumer products; household products; industry standards; international recommendations; national standards; TN948.

Production rate; scrappage rate; stable-age population; age distributions; demography; durability; durable goods; matrix model; population dynamics; population growth rate; 17053.

Productivity; automatic typewriters; benefits; break even analysis; cost effectiveness; costs; 17236.

Products liability losses; defendant and products liability; liability losses; SP487, pp. 247-252 (Aug. 1977).

Products liability losses; liability losses; plaintiff and products liability; SP487, pp. 253-256 (Aug. 1977).

Professional competence; building construction groups; certification; code enforcement officials; communications; criteria; education programs; SP473, pp. 383-389 (June 1977).

Profile inversion; inhomogeneous dielectrics; NBSIR 76-85I.

Profiling; silicon; trace analysis; chemical measurements; electrical measurements; electronics; 17140 .

Program; research; seismic; earthquake; SP477, pp. V1-28-V136 (May 1977).

Program evaluation; administrative experimentation; evaluation; evaluation research; organizational design; policy analysis; 17323.

Program integrity; audit standards; audit techniques; audit tools; audit training; communications security; computer controls; computer security; data integrity; interactive audit; internal audit; post-processing audit; SP500-19.

Program planning; residential fire deaths; fire deaths; fire losses; fire statistics; home furnishings; 16960.

Programmable monitor; stimulator; terminal data; data input bus; DATANET 355; data output bus; high-speed line adaptor; IHIS 6080; interactive terminal; probe point development; SP500-18, pp. 95-105 (Sept. 1977).

Programming aids; programming languages; COBOL; COBOL programming aids; Federal Standard COBOL; FIPS PUB 47.

Programming aids; software tools; syntax analysis; text editing; building blocks; SP5OO-14.

Programming languages; COBOL; COBOL programming aids; Federal Standard COBOL; programming aids; FIPS PUB 47.

Progressive collapse; reliability; structural engineering; uncertainty; abnormal loading; alternate path; building code; design criteria; probability; BSS98.

Progressive collapse; shear; strength; apartment building; collapse; concrete; concrete strength; construction; flexure; BSS94.

Project people; residential buildings; smoke; statistical analysis; building fires; egress; fire alarms; fire incidents; fire investigations; fires; human behavior; NBS-GCR-77-94.

Project procurement; building performance; building process; building systems; construction management; design/build; life-cycle costing; SP476.

Project summaries; standards; technical bases; building research; building tech nology; codes; criteria; SP446-I.

Projected solid angle; spectral irradiance; standards; calibrations; interpolation formula; irradiance drift formula; TN59413.

Projections; development; forecasts; growth; housing needs; BSSI $00-4$.

Prompt fission spectrum; uranium-235; Watt spectrum; californium-252; Maxwellian spectrum; plutonium-239; SP493, pp. 198-205 (Oct. 1977).

Proof testing; reliability; ceramics; high temperature; 17046.

Proof testing; silicon carbide; silicon nitride; acoustic emission; brittle materials; crack growth; cyclic loading; fracture mechanics; high temperature; 17039.

Proof testing; silicon nitride; strength; brittle materials; ceramics; ceramic turbine; NBSIR 77-I202.

Propagation; shear; transverse gradient; wavenumber; duct; fundamental mode; liquid; perfect gas; 17215. 
Propane; specific heats; speeds of sound; vapor pressure; densities; enthalpies; entropies; equation of state; internal energies; isobars; isochores; isotherms; Joule-Thomson inversion; latent heats of vaporization; melting line; orthobaric densities; NBSIR 77-860.

Propane saturated liquid; tables; density; deviation plots; ethane; experimental; isobutane; magnetic suspension densimeter; methane; normal butane; 16871 .

Properties; rate of flame spread; rate of heat release; scanning electron microscope (SEM); buildings; ease of ignition; fire tests; gypsum board; potential heat; NBSIR 77-1265.

Properties; tricresyl phosphate; zinc dithiophosphate; antiwear additives; interaction; lubricant; metals; SP487, pp. 172-185 (Aug. 1977).

Property; soil; stiffness; testing; bore hole; k property; SP477. pp. VI-1 18-VI-140 (May 1977).

Proportional counters; solid-state detectors; standard cross section; ${ }^{10} \mathrm{~B}\left(\mathrm{n}, \alpha_{0}+\alpha_{1} \gamma\right)^{7} \mathrm{Li} ;{ }^{10} \mathrm{~B}\left(\mathrm{n}, \alpha_{1} \gamma\right)^{7} \mathrm{Li} ; S P 493$, pp. $85-92$ (Oct. 1977).

Proprietary software; public domain software; software exchange; software guide; software index; software sharing; computer program index; Federal Software Exchange Program; SP500-22.

Prosthetic materials; resin teeth; restoratives; sealants; adhesives; dental polymers; dental resins; dentures; impression materials; 17120 .

Protection; protection mechanisms; reliable software; types; abstract data types; access controls; operating system protection; 16918.

Protection; reliable software; reliability; security; small protection domains; types; capability; capability-based addressing; computer security; extended-type objects; operating system structures; 16920.

Protection mechanisms; reliable software; types; abstract data types; access controls; operating system protection; protection; 16918.

Protective coatings; shock tube; tape; thermal protection; thermal radiant-energy response; thermal transient response; transducer; zero shift; coatings; delayed response; dynamic; dynamic response; pressure step; pressure transducer; TN961.

Protective coatings; sputtering; thin films; SP487, pp. 324-337 (Aug. 1977).

Protein adsorption; synthetic implants; adsorption; blood protein; ellipsometry; implants; polymer adsorption; NBSIR 76-1128.

Proteins; radiotracer; techniques; adsorption; 16777.

Proteins; solid standards; antibodies; antigens; biological polymers; immunochemical analysis; light scattering; polymers; SP466, pp. 95-98 (May 1977).

Protocols; communications standards; data communications interfaces; data communications standards; interface standards; 16936.

Proton angular distributions; proton production; proton spectra; heavy ion collisions; inelastic scattering; Monte Carlo calculations; 17109.

Proton bombardment; attenuation length; Auger-electron yield; beryllium; electron scattering; 16824 .

Proton excitation; $x$-ray photoelectron spectroscopy; absolute yield; aluminum; attenuation length; Auger electrons; Augerelectron spectroscopy; beryllium; electron; 17248 .

Proton production; proton spectra; heavy ion collisions; inelastic scattering; Monte Carlo calculations; proton angular distributions; 17109 .

Proton recoil surface barrier spectrometer; energy and flux calibration; fast neutrons; isotropic neutrons; $\mathbf{L i}^{6}$ sandwich surface barrier spectrometer; SP493, pp. 61-66 (Oct. 1977).

Proton spectra; heavy ion collisions; inelastic scattering; Monte Carlo calculations; proton angular distributions; proton production; 17109.
Proton-recoil; scattering; standards; detectors; flux; neutrons; SP493, pp. 54-60 (Oct. 1977).

Protons; specific heat; superfluid helium-4; computed thermodynamic properties; entropy; equation of state; excitation spectrum; helium-4; normal fluid helium-4; phonons; JPCRD 6, No. 1, 51-104 (1977).

Prototype images; standards; automation; calibration; data formats; documentation; image content language; image processing; pattern recognition; SP500-8.

Prototype procurement; technological innovation; check wrapping equipment; experimental procurement; experimental technology incentives program; procurement experiment; NBS-GCR-ETIP 77-39.

Prototype tests; sand transport; water tunnel; waves; coastal processes; permeability effects; 16917.

Prover; Research Associate Program; standards inspection procedure; temperature correction; test measure; test measure evaluation; "to contain"; "to deliver"; volumetric calibration; accuracy; design analysis; equipment specification; field standard; NBSIR 77-1214.

Proving rings; testing machines; tolerance; verification; calibration; load cell; 16915 .

Proximity effect; superconducting switch; thin-film; cryogenic electrical switch; mechanical switch; multiple contact switch; 17121 .

Pseudoscalar and pseudovector coupling; threshold pion production; effective Lagrangian; electroproduction; impulse approximation; photoproduction; TN957.

Psychological deterrence; recognition; security lighting; security systems; visibility level; visual processes; contrast; detection; illumination; incapacitation; SP480-27.

Psychological deterrence; sophisticated crime; threat analysis; terrorism; vigilance; behavioral science; human factors; human reliability; perpetrator attributes; physical security; SP480-24.

Psychophysics; reaction time; safety; standards; anthropometric probes; consumer products; human factors; lawn mowers; 17200.

Psychophysics; safety; warranty; anthropometry; biomechanics; carrying; consumer product portability; ergonomics; human factors; lifting; manual materials handling; physiology; NBSIR 76-1092.

$p$-toluenesulfonylhydrazine; 1,2-di( $p$-toluenesulfonyl)hydrazine; chemical ionization mass spectrometry; di-p-tolyldisulfide-1,2dioxide; mass spectrometry; nuclear magnetic resonance; 17045.

Public domain software; software exchange; software guide; software index; software sharing; computer program index; Federal Software Exchange Program; proprietary software; SP500-22.

Public goods; technological change; transaction costs; computer; computer program; copyright; data base; economic efficiency; information technology; policy analysis; policymaking; SPSO0-17.

Public law 92-500; sewerage flow; wastewater flow; closed conduit flow; instrumentation; measuring flow; metering flow; monitoring flow; open channel flow; SP484, pp. 83-89 (Oct. 1977).

Public policy; regulation; building codes; decision making; SP473, pp. 203-223 (June 1977).

Public private sector collaboration; technology growth; U.S. economy; free enterprise system; innovation; 17113 .

Publication abstracts; bibliography; building technology publications; Center for Building Technology; key word-author indexes; SP457-I.

Publications; abstracts, NBS publications; key words; SP305. Supplement 8.

Publish; science; standard reference data; technology; communication; information; interdisciplinary technology; physical property data; 17258 . 
Pulmonary irritation; PVC; respiratory rate; sensory irritation; stress index; thermal decomposition products; toxicity; acute lethality; Douglas Fir; inhalation; mice; polyurethane; NBSGCR-77-85.

Pulp; timber; wood; wood products; AIDS; bark; forest products; glues and gluing; information service; lumber; mechanical properties; paper; SP463, pp. II.1.1-II.1.4 (Jan. 1977).

Pulp characterization; pulps; algorithms; fiber morphology; fibers; image analysis; pattern recognition; 17214 .

Pulp characterization; $2.5 \mathrm{~g} / \mathrm{m}^{2}$ handsheets; breaking energy; inter-fiber bond strength; mixed waste paper; paper recycling; NBSIR 76-1148.

Pulps; algorithms; fiber morphology; fibers; image analysis; pattern recognition; pulp characterization; 17214

Pulsating flow measurements; pulsations; turbulence; vortex; differential pressure; flow metering error; flow oscillations; jet flow; orifice meters; SP484, pp. 523-548 (Oct. 1977).

Pulsation; stellar instabilities; TU Cassiopeiae; Cepheids; beat Cepheids; double-mode Cepheids; mode interaction; 17315.

Pulsations; turbulence; vortex; differential pressure; flow metering error; flow oscillations; jet flow; orifice meters; pulsating flow measurements; SP484, pp. 523-548 (Oct. 1977).

Pulse; rise time; sampling oscilloscope; spectrum amplitude; time domain; transient; automated measurement; 16721 .

Pulse calorimetry; standard reference material; thermodynamic functions; drop calorimetry; emittance; enthalpy; heat capacity; high-speed measurements; high temperature; molybdenum; SP260-55.

Pulse compression; signal processing; ultrasound; chirp radar; medical diagnosis; 16735.

Pulse height; resolution; scattering media; tissue; water; detector; Monte Carlo; perspex; photon energy; SP461, pp. 188 192 (Jan. 1977).

Pulse measurement; space charge; calibration; dielectrics; dividers; electric fields; electro-optics; high voltage measurement; insulating fluids; Kerr effect; nitrobenzene; NBSIR 77 1317.

Pulse method; resonance method; shear modulus; sound velocity; Young's modulus; bulk modulus; composite; compressibility; copper; elastic constants; niobium-titanium; Poisson's ratio; 17068 .

Pulse method; resonance method; shear modulus; sound velocity; stainless steel; Young's modulus; bulk modulus; compressibility; elastic constants; Poisson's ratio; 17321.

Pulse radiolysis; radiochromic dyes; calorimetry; chemical dosimetry; dosimetry; dye dosimeters; electron beams; gamma rays; pararosaniline cyanide; 16984.

Pulse reactor calibration; radiation effects; californium-252; dosimetry; neutron flux standard; SP493, pp. 335-34l (Oct. 1977).

Pulse shapes; ranging systems; laser range measurement; 16680.

Pulsed source; radiometry; curve fitting; energy irradiance; flashtube; TN935.

Pulsed x-ray source; $x$-ray detector calibration; $1.5-8 \mathrm{keV} \times$ rays; absolute $\mathrm{x}$-ray detectors; electron excitations; monoenergetic $x$ rays; 16814 .

Pultrusion; reinforced plastics; stress rupture of FRP rod; test methods; weatherability of FRP rods; aramid; composite materials; end fittings for FRP rod; environmental resistance of FRP rods; fiber-reinforced plastic (FRP); glass; guys, antenna; 16685 .

Pultrusion/drawing; wire preform; composite material; fabrication techniques; graphite fibers-aluminum; mechanical behavior; SP487, pp. 93-107 (Aug. 1977).

Pure reagents; sample preparation; spark source mass spectrometric isotope dilution; tissues; analytical disciplines; analytical procedures; atomic absorption spectrometry; biological materials; blanks; botanical materials; chemical species; flame emission spectrometry; SP492.
Purification; space processing; convection; crystal growth; crystal perfection; microgravity; NBSIR 77-1208.

PURNIMA; Rossi- $\alpha$; slowing down; stochastic; BESM-6; JEZEBEL; Markov process; neutron; SP461, pp. 97-99 (Jan. 1977).

Pu-239; Pu-239 half-life; Pu-24l; thermal neutron cross-sections; U-233; U-235; fission-neutron yields; fission standards; neutron nuclear data evaluation; SP493, pp. 170-173 (Oct. 1977).

Pu-239 half-life; Pu-241; thermal neutron cross-sections; U-233; U-235; fission-neutron yields; fission standards; neutron nuclear data evaluation; Pu-239; SP493, pp. 170-173 (Oct. 1977).

Pu-241; thermal neutron cross-sections; U-233; U-235; fissionneutron yields; fission standards; neutron nuclear data evaluation; Pu-239; Pu-239 half-life; SP493, pp. 170-173 (Oct. 1977).

PVC; respiratory rate; sensory irritation; stress index; thermal decomposition products; toxicity; acute lethality; Douglas Fir; inhalation; mice; polyurethane; pulmonary irritation; NBSGCR-77-85.

PVT; pyrolysis; refractive index; thermal expansion; thermodynamic; compressibility; densification; glass; glass transition; liquid; polymer; pressure; J. Res. $81 \mathrm{~A}$ Nos. 2 and 3, 283-297 (1977).

PVT; quality; slush; solid; vapor; computer programs; enthalpy; entropy; hydrogen; internal energy; liquid; oxygen; NBSIR 77-859.

$P V T$; thermal expansivity; water; aqueous solutions of gases; compressibility; equation of state; heavy water; isotopic waters; partial molar volume of aqueous gases; JPCRD 6, No. 4, $1109-1132$ (1977).

Pygmy meter performance; velocity-area method; current meter calibrations; current meters, water; flow measurement; Price meter suspensions; SP484, pp. 123-1 44 (Oct. 1977).

Pyridine; vinylacetylene; 1,5-hexadiyne; 2,4-hexadiyne; appearance potential; benzene; butatriene; heat of formation; ion; ionization potential; monoenergetic electron impact; photoionization; 17294

Pyroelectric; transducer; piezoelectric; polymer; polyvinylidene fluoride; pressure sensor; NBSIR 76-1078.

Pyroelectric detectors; radiometry; silicon cell; silicon detector; silicon photodetector; absolute radiometry; detector; electrically calibrated detectors; laser power measurements; TN954.

Pyroelectric radiometry; detector based standards; electrically calibrated pyroelectric radiometer; optical calibration; optical radiation; 16852 .

Pyroelectricity; vinylidene fluoride copolymer; charge distribution; charge transfer; corona poling; dipole orientation; piezoelectricity; polarization; polyvinylidene fluoride; NBSIR 76-1186.

Pyrolysis; alkyl halides; $\mathrm{CO}_{2}$ laser; infrared; kinetics; mechanisms; photochemistry; 16783.

Pyrolysis; radiant heating; thermal radiation; thermoplastics; cellulosic materials; char; convective heat transfer; fabric flammability; fabrics; fire hazards; ignition time; NBS-GCR77-99.

Pyrolysis; reactive gases; acetaldehyde; acrolein; calibration; diffusion cell; formaldehyde; instrumentation; 16699.

Pyrolysis; refractive index; thermal expansion; thermodynamic; compressibility; densification; glass; glass transition; liquid; polymer; pressure; $P V T$; J. Res. 81A Nos. 2 and 3, 283-297 (1977).

Pyrolysis; rotational spectra; structure; methylenimine; microwave spectroscopy; molecules; 16910 . 
Quadrature; rational approximation; tanh rule; trapezoid rule; Hardy space; numerical integration; numerical quadrature; piecewise analytic functions; 17157 .

Quadrupolar gas; second virial coefficient; dipolar gas; numerical integration; polyatomic molecule; Pople expansion; J. Res. 82, No. 2, 123-127 (1977).

Quadrupole moments; quantum field theory; relativistic many body systems; vector dominance; electromagnetic properties; form factors; magnetic moments; Monogr. 147, Suppl. 1.

Quake-sensitivity; seismic index; seismicity; earthquake; index; SP477, Pp. IV-47-IV-54 (May 1977).

Quality; slush; solid; vapor; computer programs; enthalpy; entropy; hydrogen; internal energy; liquid; oxygen; PVT; NBSIR 77-859.

Quality assurance; reliability; coal conversion; coal gasification; coal liquefaction; corrosion; failure analysis; failure prevention; SP468.

Quality control; radiation processing; radiochromic dyes; sterilization; dose distributions; dosimetry; electron beams; gamma radiation; plastic films; 17000.

Quality control; standardization; testing facilities; Thailand; measurements; NBSIR 76-1190.

Quality factor; standards; criteria, accuracy; criteria, performance; dose equivalent; elements, transuranic; glove box; intercomparison; neutrons, high energy; neutrons, low energy; non-uniform exposures; SP493, pp. $101-105$ (Oct. 1977).

Quantitative $x$-ray analysis; reference intensity ratio; $x$-ray intensity standards; $x$-ray powder diffraction; internal standard; polarization; powder diffraction; 16953.

Quantum chemistry; static potential; carbon monoxide molecules; dipole moment; electron scattering; electrostatic potential; intermediate neglect of differential overlap (INDO); molecular orbital theory; 16709.

Quantum efficiencies; radiant efficiencies; UV excitation; $x$-ray excitation; cathode-ray excitation; luminescence; luminescence standards; phosphors; SP466, Pp. 13-19 (May 1977).

Quantum electrodynamics; radiative corrections; relativistic corrections; atomic structure; electron structure; energy levels; fine structure; hydrogenic atoms; Lamb shift; level shifts; JPCRD 6, No. 3, 831-870 (1977).

Quantum field theory; relativistic many body systems; vector dominance; electromagnetic properties; form factors; magnetic moments; quadrupole moments; Monogr. 147, Suppl. 1.

Quantum interference; radio frequency; SQUID; superconductivity; attenuation; Josephson effect; 16875 .

Quantum interference; if attenuation; superconductivity; Josephson junction; NBSIR 77-863.

Quantum interference; if metrology; rf power; SQUID; superconductivity; Josephson effect; 17092.

Quantum yield; absolute yield; chemical actinometry; correction factors; luminescence; quantum-flat actinometer; SP466, pp. 21-24 (May 1977).

Quantum yield; rate constant; stratospheric chemistry; chemical kinetics; data evaluation; data reliability; gas phase; photoabsorption cross section; photochemistry; 16976.

Quantum yield; spectrophotometry; standard reference materials; standardization; accuracy; critical parameters; diffuse reflectance; fluorescence; instrumentation; luminescence; SP466.

Quantum yields; quartz; sand; surface reactions; tropospheric sink; chloromethanes, photochemistry; J. Res. 82, No. 1, 1 8 (1977).

Quantum yields; troposphere; ultraviolet; absorption cross section; carbon tetrachloride; chlorine atom; photochemistry; primary processes; 16703.

Quantum-flat actinometer; quantum yield; absolute yield; chemical actinometry; correction factors; luminescence; SP466, Pp. 21-24 (May 1977).
Quartz; sand; surface reactions; tropospheric sink; chloromethanes, photochemistry; quantum yields; J. Res. 82, No. 1, 1-8 (1977).

Quartz; sensitivity; stress; thermoluminism; SP461, Pp. 231-233 (Jan. 1977).

Quartz crystal; rubidium gas cell; timekeeping; cesium beam; clocks (atomic); crystal oscillator; frequency accuracy; frequency stability; frequency standards; hydrogen maser; TN6 16, 2d Revision.

Quartz crystal microbalance; environmental analysis; industrial hygiene; mercury vapor; personal dosimeter; piezoelectric sensors; 16773.

Quartz crystal resonators; resonance frequency fluctuation; temperature fluctuation; flicker noise; frequency random walk; 17183.

Quasi static; Stark broadening; theoretical comparison; hydrogen $\mathrm{H} \alpha$ and $\mathrm{H} \beta$; ion dynamics; 17232 .

Quasi-elastic neutron scattering; residence times; single crystal; activation energies; molecular orientations; $\mathrm{NH}_{4} \mathrm{ClO}_{4} ; 17003$.

Quasielastic scattering; review; diffusion; hydrogen; lattice dynamics; metals; neutron scattering; 16970.

Quenching; laser; metastable; oxygen molecules; photoluminescence; 16765 .

Quenching; xanthene dyes; aminocoumarins; carbazine dyes; deuterium effect; fluorescence quantum yield; laser dyes; molecular structure; oxazine dyes; SP466, pp. 33-40 (May 1977).

Quenching rate; $\mathrm{CCl}_{2} ; \mathbf{C F C l}$; fluorescence; laser; lifetime; 17238.

Quenching rates; relaxation of mercury atoms; three body molecular formation; ${ }^{3} P_{0}$ and ${ }^{3} P_{1}$ atomic states; ${ }^{3} P_{0} \rightarrow{ }^{3} P_{1}$ collision rates; decay of resonance line; 17194 .

Queuing; telephone systems; transit information; transportation; automation; cost/benefit; models; NBSIR 77-1253.

Queuing models; simulation; software monitoring; workload definition; ADP life cycle; computer performance evaluation; computer performance measurement; computer performance prediction; computer system acquisition; conference proceedings; CPEUG; hardware monitoring; SP500-18.

Queuing networks; queuing theory; utilization; operational analysis; SP500-18, pp. 219-225 (Sept. 1977).

Queuing networks; sizing studies; system design; computer-communication networks; configuration analysis; model validation; performance management; performance prediction; SP500-18, PP. 227-234 (Sept. 1977).

Queuing theory; utilization; operational analysis; queuing networks; SP500-18, pp. 219-225 (Sept. 1977).

\section{$\mathbf{R}$}

Rabi shifts; radiative Penning ionization; tuneable lasers; alkalis; atomic collisions; multiphoton ionization; 17263.

Racking; research; safety; standard; window; emergency egress; HUD; mobile home; NBSIR 77-1246.

Racking resistance; structural performance; uniform loads; concentrated loads; design criteria; mode of failure; SP477, pp. I-66-I-69 (May 1977).

Racking strength; seismic loading; shear strength; shear wall; stiffness; analysis; compressive strength; deflection; design; flexural strength; masonry walls; BSS62.

Radial tire failures; high speed tire hazard; police patrol car tires; SP480-18.

Radiance; radiometry; source; spectroscopy; standard; synchrotron; ultraviolet; wall-stabilized; arc; calibration; deuterium; interlaboratory; lamp; 17198.

Radiance temperature; specific heat capacity; thermal radiation properties; thermodynamics; titanium alloy; electrical resistivity; heat capacity; high-speed measurements; high temperatures; melting; J. Res. 81A Nos. 2 and 3, 251-256 (1977). 
Radiance temperature; titanium; electrical resistivity; emittance; high-speed measurement; high temperature; melting point; $J$. Res. 82, No. 2, 119-122 (1977).

Radiant efficiencies; UV excitation; $x$-ray excitation; cathoderay excitation; luminescence; luminescence standards; phosphors; quantum efficiencies; SP466, pp. 13-19 (May 1977).

Radiant flux; reflectance standards; standards calibration; barium sulfate; diffuse reflectance spectra; magnesium oxide; opal glass; SP466, pp. 75-85 (May 1977).

Radiant flux density; radiation measurement; radiative heat transfer; turbulent flames; flame radiation; NBS-GCR-76-80.

Radiant heating; thermal radiation; thermoplastics; cellulosic materials; char; convective heat transfer; fabric flammability; fabrics; fire hazards; ignition time; pyrolysis; NBS-GCR-7799.

Radiant panel test; round robin; test method; ASTM E 162; coefficient of variation; flame spread tests; flexible polyurethane; hardboard; interlaboratory evaluation; neoprene; NBSIR 77-1222.

Radiant panel-seamless flooring system; seamless flooring; temperature characteristics; electrical heating elements; materials performance; NBSIR 77-1263.

Radiated emission; radiation resistance; TEM cells; measurements; 17220.

Radiated susceptibility; TEM transmission cell; electronic equipment; EMC measurements; low-Q enclosures; 16668.

Radiation; activation analysis; crystal structure; diffraction; isotopes; molecular dynamics; neutron; nuclear reactor; TN939.

Radiation; comfort; measurement; 16923.

Radiation; radiation analysis; RSIC; shielding; computer code; data library; information; SP461, pp. 171-173 (Jan. 1977).

Radiation; scattering; semi-numerical; transport; integral equation; SP461, pp. 79-86 (Jan. 1977).

Radiation; shielding; standard; American Nuclear Society; SP461, pp. 74-78 (Jan. 1977).

Radiation; solar; computer; energy; BSS96.

Radiation; solid state dosimetry; dosimetry units; photon dosimetry; SP461, pp. 197-208 (Jan. 1977).

Radiation; stellar explosion; supernova; dynamics; galactic structure; interstellar medium; magnetic pressure; neutron; 17217.

Radiation; streaming; annular; computation; duct; gamma ray; integration; kemel; SP461, pp. 132-135 (Jan. 1977).

Radiation; surface technology; electromagnetic; interference; measurement; metrology; 17079 .

Radiation; susceptibility; TEM cell; electromagnetic measurements; interference; near-field probes; 17251 .

Radiation; thermal conduction; transient heat transfer; composite building constructions; convection; experimental data; fire endurance; heat generation or absorption; numerical solutions; one-dimensional; NBSIR 77-1260.

Radiation; time-of-flight; atomic; experimental; lifetimes; $\mathrm{N}_{2} \mathrm{O}$; oxygen; 16812 .

Radiation; track; cell; delta ray; dose; ions; LET; model; neutron; OER; one-hit detector; pion; SP461, pp. 183-187 (Jan. 1977).

Radiation analysis; RSIC; shielding; computer code; data library; information; radiation; SP461, pp. 171-173 (Jan. 1977).

Radiation characteristics; radiation source; source calibration; test methods; $\mathrm{x}$ rays; calibration; gamma radiation; industrial radiography; national standards; 17017.

Radiation chemistry; rates; superoxide ion; aqueous solution; chemical kinetics; data compilation; hydroxyl radical; oxide radical ion; perhydroxyl radical; NSRDS-NBS59.

Radiation damage; reactor; scattering; spectrometer; cross section; energy transfer; gamma rays; moderator; neutron; SP461, pp. 32-40 (Jan. 1977).
Radiation dose; radiation testing; scanning electron microscope; semiconductor devices; electron beam energy deposition; ionizing radiation effects; NBSIR 77-1235.

Radiation dosimeter; radiation sensor; triphenylmethane cyanide dye precursor; ultraviolet; $x$ rays; gamma rays; ionizing radiation; leuco dye cyanide; U.S. Patent 4,006,023.

Radiation dosimeters; radiation processing; radiochromic-dye films; 10-MeV electrons; aluminum; beef muscle; carbon; depth-dose distributions; lateral-dose distributions; polystyrene; 16999.

Radiation dosimetry; radiation hardness testing; radiation sources; thermoluminescence dosimeters; total dose; dosimeter calibration; electronic devices; ionizing radiation; NBSIR 76-1135.

Radiation dosimetry; radiation processing; radiochromic dyes; triphenylmethane dyes; cellulose acetate; dose distributions; dosimetry; dyed plastics; plastic films; polyvinyl acetate; polyvinyl butyral; polyvinyl chloride; polyvinyl pyrrolidone; 16949.

Radiation effects; californium-252; dosimetry; neutron flux standard; pulse reactor calibration; SP493, pp. 335-341 (Oct. 1977).

Radiation effects; standards; intercomparisons; medical; neutron dosimetry; SP493, pp. 121-127 (Oct. 1977).

Radiation hardness testing; radiation sources; thermoluminescence dosimeters; total dose; dosimeter calibration; electronic devices; ionizing radiation; radiation dosimetry; NBSIR 76-1135.

Radiation measurement; radiative heat transfer; turbulent flames; flame radiation; radiant flux density; NBS-GCR-7680.

Radiation measurement; radiometer; thermal comfort; thermal radiation; directional radiant temperature; mean radiant temperature; SP491, pp. 117.130 (Sept. 1977).

Radiation physics; scattering; spectrometers; absorption; accuracy; cross section; fast neutrons; geometric factors; photon; polarimeter; SP46I, pp. 47-54 (Jan. 1977).

Radiation processing; radiochromic dyes; triphenylmethane dyes; cellulose acetate; dose distributions; dosimetry; dyed plastics; plastic films; polyvinyl acetate; polyvinyl butyral; polyvinyl chloride; polyvinyl pyrrolidone; radiation dosimetry; 16949.

Radiation processing; radiochromic-dye films; $10-\mathrm{MeV}$ electrons; aluminum; beef muscle; carbon; depth-dose distributions; lateral-dose distributions; polystyrene; radiation dosimeters; 16999.

Radiation processing; radiochromic dyes; sterilization; dose distributions; dosimetry; electron beams; gamma radiation; plastic films; quality control; 17000 .

Radiation resistance; TEM cells; measurements; radiated emission; $I 7220$.

Radiation safety; radiography; $x$-ray equipment; $x$-ray safety; $x$ ray tube; design standard; fluoroscopy; national standard; H123.

Radiation safety; smoke detectors; solar heating; SRM's; adobe; air pollution; corrosion; electrical; energy management; graphic pen; halocarbons; infrared lasers; international standard; neutron xeroradiography; problem-solving; DIM/NBS 61 , No. 3, 1-32 (1977).

Radiation sensor; triphenylmethane cyanide dye precursor; ultraviolet; $\mathrm{x}$ rays; gamma rays; ionizing radiation; leuco dye cyanide; radiation dosimeter; U.S. Patent 4,006,023.

Radiation source; source calibration; test methods; $\mathrm{x}$ rays; calibration; gamma radiation; industrial radiography; national standards; radiation characteristics; 17017.

Radiation sources; thermoluminescence dosimeters; total dose; dosimeter calibration; electronic devices; ionizing radiation; radiation dosimetry; radiation hardness testing; NBSIR 761135. 
Radiation standard; absorbed dose; calibration; calorimeter; cobalt-60; 17005 .

Radiation sterilizing; screw thread standards; SHIVA laser; silicon; timekeeping; ultraviolet radiation; calibration; consumers; energy; energy savings; grain moisture; mass spectra; DIM/NBS 61, No. 9, 1-32 (1977).

Radiation testing; scanning electron microscope; semiconductor devices; electron beam energy deposition; ionizing radiation effects; radiation dose; NBSIR 77-1235.

Radiation transport; reactor; RSIC; shielding; weapons; computer codes; materials properties; nuclear data; SP463, pp. III.1.1-III.1.10 (Jan. 1977).

Radiative and non-radiative transition probabilities; real fluorescence parameters; fluorescence lifetime; fluorescence quantum efficiency; fluorescence quantum yields; fluorescence spectrum; fluorescence standards; SP466, pp. 111 (May 1977).

Radiative cooling; roofing; solar heating; surface temperature; built-up roofing; insulation; performance; 17060.

Radiative cooling; roofing; solar heating; surface temperature; built-up roofing; insulation; performance; 17061 .

Radiative corrections; relativistic corrections; atomic structure; electron structure; energy levels; fine structure; hydrogenic atoms; Lamb shift; level shifts; quantum electrodynamics; JPCRD 6, No. 3, 831-870 (1977).

Radiative corrections; total photon absorption cross sections; virtual photon theory; bremsstrahlung spectrum tip; Delbrück scattering; electromagnetic interactions; electron scattering; TN955.

Radiative heat transfer; turbulent flames; flame radiation; radiant flux density; radiation measurement; NBS-GCR-76-80.

Radiative lifetimes; critical review; Franck-Condon integrals; molecular constants; molecular nitrogen; potential energy curves; JPCRD 6, No. 1, 113-307 (1977).

Radiative Penning ionization; tuneable lasers; alkalis; atomic collisions; multiphoton ionization; Rabi shifts; 17263.

Radiative transfer; reflectance spectra; scattering coefficients; statistical models; absolute absorptivities; continuum models; diffuse reflectance; SP466, pp. 57-73 (May 1977).

Radiative transfer; spectral line formation; stellar atmospheres; high speed aerodynamics; 16758.

Radiative transfer; Stark broadening; B-star spectra; forbidden lines; He 1; 17171 .

Radiative transfer; ultraviolet spectra; Arcturus; chromospheres, stellar; line profiles, stellar; 17056 .

Radical; allylic; combination; disproportionation; low temperature; 16966.

Radio astronomy; acetaldehyde; internal rotation; interstellar molecules; mm wave transitions; overlapped lines; 16969.

Radio astronomy; silicon monoxide; spectra; interstellar sources; isotope ratio; molecular lines; 17189.

Radio broadcasts; standard frequencies; television color subcarrier; time and frequency calibration methods; time calibration; time signals; frequency calibration; high frequency; Loran-C; low frequency; TN695.

Radio frequency; SQUID; superconductivity; attenuation; Josephson effect; quantum interference; 16875.

Radio measurements; electromagnetic quantities; laser; microwave; National Measurement System; NBSIR 75-936.

Radio receiver; semiconductor device studies; electronic reliability; electronics; laser scanner; measurement method; mixer; optics; pre-amplifier; SP400-24.

Radio sources and rotational spectra; astronomy; ethyl cyanide; interstellar molecule; microwave emission; 17264.

Radio sources, lines; interstellar, molecules; line identifications; nebulae, individual; $/ 6664$.

Radio stars; satellite earth terminal; signal to noise; star flux; figure of merit; G/T; measurement accuracy; 17227.
Radioactivation; resonance integrals; spectral functions; comparative evaluation; cross sections; fission spectra; integrals; neutrons; SP493, pp. 128-136 (Oct. 1977).

Radioactivity; reactor effluents; environment; gamma-ray measurements; germanium-lithium detectors; noble gases; I6975.

Radiochromic dyes; calorimetry; chemical dosimetry; dosimetry; dye dosimeters; electron beams; gamma rays; pararosaniline cyanide; pulse radiolysis; 16984 .

Radiochromic dyes; sterilization; dose distributions; dosimetry; electron beams; gamma radiation; plastic films; quality control; radiation processing; 17000 .

Radiochromic dyes; triphenylmethane dyes; cellulose acetate; dose distributions; dosimetry; dyed plastics; plastic films; polyvinyl acetate; polyvinyl butyral; polyvinyl chloride; polyvinyl pyrrolidone; radiation dosimetry; radiation processing; 16949.

Radiochromic-dye films; 10-MeV electrons; aluminum; beef muscle; carbon; depth-dose distributions; lateral-dose distributions; polystyrene; radiation dosimeters; radiation processing; 16999.

Radiography; standards; thermal; ultrasonic; visual testing; wear debris; acoustic; calibration; eddy current; microwave; nondestructive evaluation; penetrant; 17106.

Radiography; standards; ultrasonics; visual; acoustic emission; inspection; leak testing; liquid penetrant; magnetic particle; measurements; nondestructive testing; optical; 17042.

Radiography; technical reports; ultrasonics; Army Materials and Mechanics Research Center; electromagnetics; materials testing; nondestructive testing; Nondestructive Testing Newsletter; SP463, pp. IV.6.1-IV.6.2 (Jan. 1977).

Radiography; $x$-ray equipment; $x$-ray safety; $x$-ray tube; design standard; fluoroscopy; national standard; radiation safety; HI23.

Radioisotope leak detection; hermeticity; hermetic test standards; integrated circuits; 17331 .

Radioisotope method; resistivity; resistivity variations; safe operating area, transistor; scanning acoustic microscope; scanning electron microscope; scanning low energy electron probe; semiconductor devices; semiconductor materials; semiconductor process control; silicon; SP400-29.

Radiometer; sampling oscilloscope; spectrum amplitude; spectrum analyzer; spectrum intensity; calibration; electromagnetic interference; fast Fourier transform; impulse generator; 16725.

Radiometer; thermal comfort; thermal radiation; directional radiant temperature; mean radiant temperature; radiation measurement; SP491, pp. 117-130 (Sept. 1977).

Radiometers; silicon detectors; absolute radiant power measurements; detector radiometry; detector response transfer instrumentation; TN950.

Radiometric detector; smog formation; SRM's; air pollution; attic ventilation; data encryption; dental materials; fire safety; metric; miniature electric field; organic sulfur; DIM/NBS $6 I$, No. 11, 1-32 (1977).

Radiometric standards; radiometry; standard lamps; StefanBoltzmann constant; blackbodies; electrically calibrated detectors; history of radiometry; Planck's constant; 16851 .

Radiometry; curve fitting; energy irradiance; flashtube; pulsed source; TN935.

Radiometry; silicon cell; silicon detector; silicon photodetector; absolute radiometry; detector; electrically calibrated detectors; laser power measurements; pyroelectric detectors; TN954.

Radiometry; source; spectroscopy; standard; synchrotron; ultraviolet; wall-stabilized; arc; calibration; deuterium; interlaboratory; lamp; radiance; 17198 .

Radiometry; sources; standard; photometry; 17024 .

Radiometry; sources; standards; survey; detectors; National Measurement System; photometry; NBSIR 75-939. 
Radiometry; sources; survey; ultraviolet; detectors; National Measurement System; NBSIR 75-94I.

Radiometry; spectral radiance; standard; ultraviolet; argon; light source; mini-arc; 16778 .

Radiometry; spectrometer calibration; synchrotron radiation; transfer standard detectors; calibration facilities; photodiodes; 16665.

Radiometry; standard lamps; Stefan-Boltzmann constant; blackbodies; electrically calibrated detectors; history of radiometry; Planck's constant; radiometric standards; 16851 .

Radionuclides; sample handling; sampling; trace elements; chemical analysis; environmental samples; long-term storage; microbiologicals; organics; pesticides; 16729.

Radiopharmaceuticals; ultraviolet radiation; windows; $\mathrm{AC}$ high voltage; AC voltmeter calibrator; marine studies; microelectronic industry; monitoring system; photodetectors; DIM/NBS 61 , No. 12, 1-32 (1977).

Radiotracer; techniques; adsorption; proteins; 16777.

Radius of gyration; small angle neutron scattering; conformation; deuterated polystyrene-poly(methylmethacrylate); diblock copolymer; 16817.

Railroad system diagnostics; signature analysis; wear; failure detection; failure diagnosis; failure prevention; ferrography; land vehicle diagnostics; oil analysis; SP494.

Rainwater; seawater; sulfate; environmental analysis; ion-selective electrode; lead electrode; natural waters; 16771 .

Rainwater analysis; reference materials; chemical analysis; NBSIR 77-1315.

Raman; VF $;$ AsF $F_{5}$; barriers; energy levels; gas phase; $\mathrm{PF}_{5}$; 16978.

Raman scattering; Rayleigh scattering; fluorescence; laser fields; theory; two-photon absorption; 16848 .

Raman spectra; vibrational analysis; $\mathrm{BCl}_{2} \mathrm{SD} ; \mathrm{BCl}_{2} \mathrm{SH}$; hindered rotation; infrared spectra; 17166.

Raman spectra; vibrational frequencies; fundamental frequencies; infrared spectra; polyatomic molecules; JPCRD 6, No. 3, 993-1102 (1977).

Raman spectroscopy; airborne particles; microanalysis; microchemistry; microprobe; particulate matter; 17013.

Ramsey; saturation spectroscopy; transit-time; coherence; fringes; interference; modulation; phase; 17337.

Ramsey fringes; saturated absorption; nonlinear spectroscopy; 16776.

Random coil; random flight chain; relaxation times; excluded volume; Monte Carlo; polymer chain dynamics; 17125.

Random flight chain; relaxation times; excluded volume; Monte Carlo; polymer chain dynamics; random coil; 17125.

Random sampling; scattering; shielding; angle; centre of mass; coefficients; computations, cross-section; Legendre polynomial; neutron; SP461, pp. 100-105 (Jan. 1977).

Random variable; reliability; algebra of normal functions; correlation; probability; SP487, pp. 25-38 (Aug. 1977).

Random vibrations; safety; structures; deterministic; dynamics; earthquake; probability; SP470, pp. VI-1-VI-21 (Apr. 1977).

Random walk statistics; spans of polymer chains; polymer chain statistics; 16696.

Range energy consumption; appliance research; behavioral laboratory; consumer product studies; human behavior research; Human Factors Laboratory; 17035.

Range-range system; time and frequency dissemination; time code; TvTime system; accuracy; hyperbolic system; 17181.

Ranging systems; laser range measurement; pulse shapes; 16680.

Rapid response furnace; thermogravimetry; computerized experiment; experiment automation; off-the-shelf automation; polymer degradation; 16842 .

Rapsodie; reactor; shielding; transport calculation; approximations; diffusion; neutron; NIOBE; SP46I, PP. 163-165 (Jan. 1977).
Rare earth; crystal field; pnictides; 16916.

Rare earth tungstate; tungstates; $\mathrm{x}$-ray powder patterns; dithiotungstate; hydrolysis; infrared spectroscopy; rare earths; 17137.

Rare earths; information center; SP463, pp. IIl.2.1-111.2.9 (Jan. 1977).

Rare earths; rare earth tungstate; tungstates; x-ray powder patterns; dithiotungstate; hydrolysis; infrared spectroscopy; 17137.

Rare earths; relaxation effects; scandium alloys; dysprosium; hyperfine fields; magnetism; 16985.

Rare earths; spin waves; erbium; Laves phase; magnetic excitation; magnetism; 16963.

Rare events; safety; system safety; accident research; human factors; methodology; SP482.

Rare gas halide; Rittner model; transition moment; dipole moment; excimer; excitation energy; perturbation formula; 17151

Rate coefficient; collision-induced; emission; interaction potential; iodine; perturbation theory; 17069.

Rate constant; absorption spectra; chemical kinetics; chlorine; chlorine oxides; chlorocarbon; chlorofluorocarbon; data compilation and evaluation; nitrosyl chloride; JPCRD 6, No. 3 , $871-918$ (1977).

Rate constant; $\mathrm{CO}$; combustion; $\mathrm{CO}_{2}$; methylene; 16838 .

Rate constant; resonance fluorescence; stratosphere; chlorine nitrate; chlorofluorocarbons; oxygen atoms; 17149 .

Rate constant; stratospheric chemistry; chemical kinetics; data evaluation; data reliability; gas phase; photoabsorption cross section; photochemistry; quantum yield; 16976 .

Rate constants; alkyl iodides; ion-molecule reactions; isotope effects; mass spectrometry; photoionization; J. Res. 81A Nos. 2 and 3, 267-271 (1977).

Rate constants; transition state theory; transmission coefficient; collinear reactions; deuterium, collinear reactions; hydrogen, collinear reactions; kinetic isotope effects; potential surfaces; 16914.

Rate law and areal regression of adsorbate; surface area and fixation of chelating rings; adhesive bonding to bone mineral; chemisorption of a dental varnish; configuration on surface; kinetics of adsorption from solution; 17033.

Rate of flame spread; rate of heat release; scanning electron microscope (SEM); buildings; ease of ignition; fire tests; gypsum board; potential heat; properties; NBSIR 77-1265.

Rate of heat release; scanning electron microscope (SEM); buildings; ease of ignition; fire tests; gypsum board; potential heat; properties; rate of flame spread; NBSIR 77-I265.

Rates; superoxide ion; aqueous solution; chemical kinetics; data compilation; hydroxyl radical; oxide radical ion; perhydroxyl radical; radiation chemistry; NSRDS-NBS59.

Rating; residential; space heating; testing; air conditioning; comfort; heat pump; load-calculation; 17006.

Rating criteria; solar collectors; structural performance; testing procedures; thermal performance; durability/reliability; fire safety; NBSIR 77-1305.

Rating of indoor environments; thermal comfort; indoor environmental measurement; SP49I, pp. 152-168 (Sept. 1977).

Ratio standard; voltage dividers; volt boxes; direct voltage measurements; high voltage measurements; Kelvin-Varley divider; 16713.

Rational approximation; tanh rule; trapezoid rule; Hardy space; numerical integration; numerical quadrature; piecewise analytic functions; quadrature; 17157.

Rationalization; technical issues in metrication; construction industry metrication; metrication benefits; 17040 .

Rayleigh scattering; analytical formula; coherent scattering; cross section; gamma rays; photons; SP46I, pp. 17-19 (Jan. 1977).

Rayleigh scattering; fluorescence; laser fields; theory; twophoton absorption; Raman scattering; 16848. 
Rayleigh-Schrödinger perturbation theory; electron affinities; Green's function; ionization potentials; 17317 .

Reaction detector; cerium oxidation detector; liquid chromatography; liquid chromatography detectors; metal specific detector; photoionization detector; 17278 .

Reaction mechanism; silicon; synthesis; thin film; vapor transport; activation parameters; active nitrogen; iodine; kinetics; microwave discharge; nitride; plasma; 16757.

Reaction rates; benchmark spectrum; discrete ordinates; intermediate energy; measurement assurance; neutron standard; SP493, pp. 329-334 (Oct. 1977).

Reaction rates; thallium; tin; transmethylation; water; alkylation; aqueous solution; coordination; mercury; metal complexes; organometals; photolysis; 17008 .

Reaction time; safety; standards; anthropometric probes; consumer products; human factors; lawn mowers; psychophysics; 17200.

Reactive gases; acetaldehyde; acrolein; calibration; diffusion cell; formaldehyde; instrumentation; pyrolysis; 16699.

Reactor; RSIC; shielding; weapons; computer codes; materials properties; nuclear data; radiation transport; SP463, pp. III.1.1 -III.1.10 (Jan. 1977).

Reactor; scattering; spectrometer; cross section; energy transfer; gamma rays; moderator; neutron; radiation damage; SP461, pp. 32-40 (Jan. 1977).

Reactor; shielding; transport calculation; approximations; diffusion; neutron; NIOBE; Rapsodie; SP461, pp. 163-165 (Jan. 1977).

Reactor effluents; environment; gamma-ray measurements; germanium-lithium detectors; noble gases; radioactivity; 16975 .

Reactor filtered beam; standard; ${ }^{6} \mathrm{Li}(\mathrm{n}, \alpha) \mathrm{T}$; angular distribution; fast neutrons; linac; SP493, pp. 10-13 (Oct. 1977).

Reactor fuels; reactor materials; cross sections; fission; neutron reactions; neutron spectrum; SP493, pp. 156-164 (Oct. 1977).

Reactor materials; cross sections; fission; neutron reactions; neutron spectrum; reactor fuels; SP493, pp. 156-164 (Oct. 1977).

Reactor physics; breeder reactor; fission; fission detector; materials; neutron dosimetry; 17058.

Reactor technology; scattering-elastic, inelastic, total; thorium; uranium; calculation; cross section; optical model; SP461, pp. 70-73 (Jan. 1977).

Reactor transients; solution; time-dependent; transport; transport equation; approximations; fast-thermal couple reactor; neutron; SP461, pp. 91-93 (Jan. 1977).

Real fluorescence parameters; fluorescence lifetime; fluorescence quantum efficiency; fluorescence quantum yields; fluorescence spectrum; fluorescence standards; molecular fluorescence parameters; observed (technical) fluorescence parameters; SP466, pp. 1-11 (May 1977).

Real gas equation; air buoyancy; air density; mass unit transfer; NBSIR 77-1278.

Real-time control systems; computer performance; computer software and programs; computer systems; 16904

Receiver; superconductivity; heterodyne detection; Josephson effect; millimeter waves; mixing; 17077.

Reciprocity; sensitivity; temperature; calibration; ceramic; condenser; electret; humidity; microphones; 16701.

Reciprocity; sensitivity; temperature; calibration; ceramic; condenser; electret; humidity; microphones; 17245.

Reciprocity theorem; source; target; tissue; dose; dosimetry; Monte Carlo; organ; phantom; photon; SP461, pp. 177-182 (Jan. 1977).

Recirculating flow; reduced scale model test; scaling criteria; spray water flow rate; water spray; automatic sprinklers; compartment fire; corridor sprinkler systems; droplet size; droplet trajectory; evaporative cooling; fire suppression; fullscale test; NBSIR 77-1287.
Recirculating flow; spray; two component flow; vortex street; wake flow; anemometer; cylinder; frequency; hot film anemometer; SP484, pp. 705-718 (Oct. 1977).

Recognition; security lighting; security systems; visibility level; visual processes; contrast; detection; illumination; incapacitation; psychological deterrence; SP480-27.

Recoil; atoms; gain; population inversion; 17143.

Recoil; scintillator; UNFOLD; Apsara; energy distribution; gamma ray; iterative; neutron; plastic; SP461, pp. 247-251 (Jan. 1977).

Recombination; scattering; theoretical; theory; argon; collisions; dissociation; hydrogen; inelastic; molecular potential; 16802.

Recommendations; review; safety; sports; accident; associated factors; injuries; literat ure; NEISS; NBSIR 77-1218.

Recommended practices; specifications; test methods; certification programs; consumer products; household products; industry standards; international recommendations; national standards; product standards; TN948.

Recommended SI practice; International System of Units (SI); metric design and construction; TN938.

RECON; scientific and technical aerospace reports; thesaurus; aerospace; computer information system; international aerospace abstracts; materials; mechanical properties; metallic materials; nonmetaltic materials; SP463, pp. VI.1.1-VI.1.7 (Jan. 1977).

Recordkeeping practices; security; citizen rights; computers, confidentiality; data systems; health records; information policy, management principles; medical records; privacy; SP469.

Records; results; seismometers; arrays; earthquakes; ground motion; SP477, pp. III-16-III-25 (May 1977).

Records; set; surveillance limits; surveillance test; test interval; true mass; value; weighing design; weights; apparent mass; buoyancy; buoyancy correction; change; comparison; difference; mass; NBSIR 76-999.

Recuperators; waste; boilers; economics; energy conservation; instrumentation; $\mathrm{HI} 2 \mathrm{l}$.

Recycled oil; re-refined oil; used oil; waste oil; engine oil; fuel oil; hydraulic oil; industrial oils; lubricating oil; oil specifications; petroleum standards; petroleum test methods; SP488.

Recycling oil; research and innovation; safety; ultrasonic tissue; computerized data; data elements; equity; federal technology; fire modeling; heat; hydrocarbon; ionized molybdenum; measurement assurance; metric; neutron diffraction; DIM/NBS 61, No. 6, 1-32 (1977).

Redistribution; saturation strontium; collisions; near-resonant light scattering; 16857.

Reduced cell; single crystal; symmetry; identification; lattice; powder method; 17050 .

Reduced scale model test; scaling criteria; spray water flow rate; water spray; automatic sprinklers; compartment fire; corridor sprinkler systems; droplet size; droplet trajectory; evaporative cooling; fire suppression; full-scale test; gas temperature; NBSIR 77-1287.

Reduced ventilation rate; school operation schedule; ventilation test; computerized thermal simulation; $\mathrm{CO}_{2}$ concentration; energy conservation in schoois; energy consumption; energy utilization in schools; oxygen content; BSS97.

Reduced-size venting; performance approach; performance characteristics; performance criteria; performance evaluation; performance testing; plumbing research; plumbing research needs; SP473, pp. 317-348 (June 1977).

Reduced-size vents; sanitary drainage system; venting; cost savings; drainage-waste-vent; economics; life cycle; performance standards; pipe; plumbing; 17296.

Reduction; V(CO) $)_{-}^{-;}$1,3-dithiolium ion; 2,2'-bi(1,3-dithiolyl); coupling constants; hexacarbonylvanadate(1-); NMR spectroscopy; 17154.

Reference data; data compilation; data evaluation; information retrieval; NSRDS; Omnidata; 16692. 
Reference intensitics; standard; x-ray diffraction; crystal structure; integrated intensities; lattice constants; peak intensities; powder patterns; Monogr. 25, Section 14.

Reference intensity ratio; $x$-ray intensity standards; $x$-ray powder diffraction; internal standard; polarization; powder diffraction; quantitative $x$-ray analysis; 16953.

Reference materials; chemical analysis; rainwater analysis; NBSIR 77-1315.

Reference materials; standard reference collections; criminalistics; evidential materials; forensic reference collections; forensic science; 16706.

Reference method; standard reference material; accuracy; chemical analysis; measurement compatibility; measurement systems; 17247.

Reference standard; review; accuracy; $A u(n, \gamma)$ cross section; cross section fluctuations; measurement; neutron capture cross section; normalization; SP493, pp. 165-169 (Oct. 1977).

Referral; scientific and technical information; thesaurus; computerized information system; directories; information resource; National Referral Center; SP463, pp. VIII.2.1VIII.2.4 (Jan. 1977).

Refined structure; single crystal $x$-ray structure determination; 4-hydroxy-4H-furo( $3,2 c)$ pyran-2(6H)-one; antibiotic; hydrogen bonding; patulin; 16913 .

Reflectance; reflectance factor; spectrophotometry; absolute reflectance; diffuse reflectance; error analysis; J. Res. 82, No. 1, 29-55 (1977).

Reflectance; reflectance factor; reflectance geometry; reflectance nomenclature; reflection; specular reflectance; sub-surface scattering; bidirectional reflectance-distribution function; diffuse reflectance; directional reflectance; nomenclature of reflectance; Monogr. 160.

Reflectance; reflectance standards; thin layer chromatography; chromatography; color matching; color measurement; diffuse reflectance; Kubelka-Munk function; SP466, pp. 41-55 (May 1977).

Reflectance; transmittance; wedges; calibration; density; photography; 16683 .

Reflectance factor; reflectance geometry; reflectance nomenclature; reflection; specular reflectance; sub-surface scattering; bidirectional reflectance-distribution function; diffuse reflectance; directional reflectance; nomenclature of reflectance; optical reflection; Monogr. 160.

Reflectance factor; spectrophotometry; absolute reflectance; diffuse reflectance; error analysis; reflectance; J. Res. 82, No. 1, 29-55 (1977).

Reflectance geometry; reflectance nomenclature; reflection; specular reflectance; sub-surface scattering; bidirectional reflectance-distribution function; diffuse reflectance; directional reflectance; nomenclature of reflectance; optical reflection; reflectance; Monogr. 160.

Reflectance nomenclature; reflection; specular reflectance; subsurface scattering; bidirectional reflectance-distribution function; diffuse reflectance; directional reflectance; nomenclature of reflectance; optical reflection; reflectance; reflectance factor; Monogr. 160.

Reflectance spectra; scattering coefficients; statistical models; absolute absorptivities; continuum models; diffuse reflectance; radiative transfer; SP466, pp. 57-73 (May 1977).

Reflectance standards; scattering surfaces; bidirectional radiometry; canopies; diffuse reflectance; diffuse transmission; SP466, pp. 87-93 (May 1977).

Reflectance standards; standards calibration; barium sulfate; diffuse reflectance spectra; magnesium oxide; opal glass; radiant flux; SP466, pp. 75-85 (May 1977).

Reflectance standards; thin layer chromatography; chromatography; color matching; color measurement; diffuse reflectance; Kubelka-Munk function; reflectance; SP466, pp. 41-55 (May 1977).
Reflection; specular reflectance; sub-surface scattering; bidirectional reflectance-distribution function; diffuse reflectance; directional reflectance; nomenclature of reflectance; optical reflection; reflectance; reflectance factor; reflectance geometry; Monogr. 160.

Reflection coefficient; reflectometer; scattering parameters; self-calibration techniques; six-port junction; impedance; microwaves; network analyzer; 17244 .

Reflection coefficient; repeatability; SMA connectors; insertion loss; 16722.

Reflection coefficient; ultrafiltration; continuous binding curve; dye binding; human albumin; membrane; 16959 .

Reflection measurement; six-port; automation; millimeter wave; power measurement; 17243

Reflectometer; scattering parameters; self-calibration techniques; six-port junction; impedance; microwaves; network analyzer; reflection coefficient; 17244 .

Refractive index; $\mathrm{SrF}_{2}$; thermal coefficient of refractive index; $\mathrm{ZnSe} ; \mathrm{BaF}_{2} ; \mathrm{CaF}_{2} ; \mathrm{KBr} ; \mathrm{KCl} ; \mathrm{LiF} ; \mathrm{NaF} ; \mathrm{NBSIR} 77-1219$.

Refractive index; $\mathrm{SrF}_{2}$; thermal coefficient of refractive index; $\mathrm{ZnS}$; ZnSe; $\mathrm{BaF}_{2} ; \mathrm{CaF}_{2} ; \mathrm{KBr}$; $\mathrm{KCl}$; Lexan; LiF; $\mathrm{NaF}$; Plexiglas 55; NBSIR 77-1304 (ARPA).

Refractive index; temperature coefficient of index; potassium chloride; 16662

Refractive index; thermal expansion; thermodynamic; compressibility; densification; glass; glass transition; liquid; polymer; pressure; PVT; pyrolysis; J. Res. 81A Nos. 2 and 3, 283-297 (1977).

Refractories; strength; coal gasification; environments; erosion; hydrothermal; 16993.

Refractory; alloys; compounds; hardness; interstitial; metals; 17262

Refractory cements; alumina cements; $\mathrm{CaO} \cdot \mathrm{Al}_{2} \mathrm{O}_{3} \cdot \mathrm{H}_{2} \mathrm{O}$; coal gasification; J. Res. 82, No. 3, 167-172 (1977).

Refractory hard metals; AC impedance; automated electrochemical analysis; ceramic electrolytes; ceria-yttria; cyclic voltommetry; electrocatalysis; equivalent circuit; fuel cells; microprocessor; network analyzer; phosphoric acid electrolyte; NBSIR 77-1270.

Refractory hard metals; valence bands; W; WC; x-ray photoemission; catalysis; Mo; $\mathrm{Mo}_{2} \mathrm{C} ; 16932$.

Refrigeration; specific heat; strontium titanate; beryllium; ceramics; cryogenics; dielectric-constant; electrets; electrocaloric effect; entropy; ferroelectrics; glass-ceramics; heat switches; magnetothermal conductivity; polarization; potassium tantalate; NBSIR 76-847.

Refrigerator-freezers; water heaters; window air conditioners; life cycle costing; printer ribbons; procurement experiment; NBS-GCR-ETIP 77-37.

Regional standardization; standardization; standards development; ADP standards; intemational standardization; national standardization; national standards bodies; practice; procedures; NBSIR 77-1195.

Regression; statistics; Cholesky decomposition; Givens transformations; Gram-Schmidt orthogonalization; Householder transformations; least squares algorithms; 16833.

Regression model; blocking factor; data record; multiple regression; processing time; SP500-18, pp. 143-158 (Sept. 1977).

Regularities; Stark broadening; supermultiplet; transition array; wall stabilized; multiplet; nitrogen lines; 17204 .

Regularities; Stark widths; supermultiplet; transition array; isolated lines; multiplet; plasma broadening; 17206.

Regulation; accessibility standards; building code; code administration; communication; enabling legislation; physically handicapped; SP473, pp. 241-251 (June 1977).

Regulation; alternatives; building codes; building process; constraints; costs; incentives; SP473, pp. 17-33 (June 1977).

Regulation; builder-developer; construction; consumers; cost analysis; cost benefits; housing; SP473, pp. 391-396 (June 1977). 
Regulation; building codes; decision making; public policy; SP473, pp. 203-223 (June 1977).

Regulation; research; standards; court orders; human behavior; institutional occupancies; interior design; physical environment; SP473, pp. 55-67 (June 1977).

Regulation; site design; architectural controls; buildings; design review; land use; municipalities; SP473, pp. 137-187 (June 1977).

Regulation; sound; acoustics; environmental pollution; machinery and equipment; noise; noise abatement and control; noise emission; H122.

Regulation; standards; building codes; building safety; control; instruments; knowledge; legislation; life safety; SP473, pp. 259-278 (June 1977).

Regulation; technology; impact of government on the economy; pesticides; R\&D incentives; NBS-GCR-ETIP 76-34.

Regulation; tensile testing; worker safety equipment; body belts; body harness; fall-arrest equipment; fall-safety systems; impact accelerations; impact forces; lanyards; linemen's equipment; load-extension data; occupational safety and health; performance standard; NBSIR 76-1146.

Regulations; solar energy; standards; state-of-the-art study; buildings; energy conservation; enforcement; legislation; NBSIR 77-1259.

Regulations; sulfur dioxide; air quality; deterioration; measurements; particulates; 17141

Regulatory barriers; residential construction; unionization; building official; building regulation; education; housing demand; innovation; SP473, pp. 113-135 (June 1977).

Regulatory community; standards; buildings; codes; energy conservation; 17111 .

Regulatory data; architectural psychology; architectural research; building codes; building design; building fires; building regulatory standards; emergency egress; exit capacity; fire safety; human performance; occupational safety; NBSIR 77-1313.

Regulatory domination; standards development; building codes; concrete testing; evaluation; innovations; in-place testing; performance approach; SP473, pp. 279-284 (June 1977).

Regulatory experiments; system design; adverse reaction detection; biostatistics; drug regulation; pharmaceutical regulation; phase IV; post marketing surveillance; NBS-GCR-ETIP 7635.

Regulatory process; building codes; carrying capacity; environment; land use; natural system; performance standards; SP473, pp. 189-202 (June 1977).

Regulatory research; standards development; administrative procedures; building codes; building regulations; buildings; economic impacts; environmental considerations; innovative practices; SP473.

Rehabilitation; remodeling; residential; urban renewal; building codes; housing; NBS-GCR-77-87.

Rehabilitation; remodeling; renewal; renovation; self-help; standards; building codes; building regulation; do-it-yourself; home construction; housing; NBS-GCR-77-88.

Rehabilitation; renovation; adaptive reuse; architecture; building codes; building regulations; building safety; construction; performance; preservation; SP473, pp. 437-452 (June 1977).

Rehabilitation; retrofit; seismic design; structural design; structural research; building codes and standards; design criteria; earthquake resistance; limit states design; masonry construction; materials testing standardization; BSS106, pp. 40-59 (Sept. 1977).

Rehabilitation; standards; building codes; community development; construction costs; contractors; housing; SP473, pp. $491-497$ (June 1977).

Reinforced; strength; columns; concrete; earthquake; hysteretic envelope; SP477, pp. VI-10-VI-27 (May 1977).

Reinforced concrete; bridges; design; experiments; nonlinear response; SP477, pp. VI-1-VI-9 (May 1977 ).
Reinforced concrete; reliability; statistical analysis; structural engineering; fire endurance; fire tests; probability theory; 17303.

Reinforced concrete; reliability; statistical analysis; structural engineering; uncertainty; probability; 17304.

Reinforced plastics; stress rupture of FRP rod; test methods; weatherability of FRP rods; aramid; composite materials; end fittings for FRP rod; environmental resistance of FRP rods; fiber-reinforced plastic (FRP); glass; guys, antenna; pultrusion; 16685.

Reinforcing details; structural walls; design procedures; earthquake excitation of structures; earthquake resistant structures; SP477, pp. VI-199-VI-219 (May 1977).

Relationships; soil properties; dynamics; field tests; laboratory tests; SP477, pp. VI-158-VI-178 (May 1977).

Relative humidity; routine radiosonde application; barium fluoride; calibration equations; fast response; films; humidity sensor; industrial fabrication; isotherm equations; physical adsorption; NBSIR 76-1108.

Relative humidity; salt; saturated salt solution; vapor pressure; water vapor; aqueous solution; equilibrium; humidity; J. Res. 81A No. 1, 89-96 (1977).

Relative humidity; two-pressure generator; volume ratio; water vapor; calibration; dew point; humidity; hygrometer; mixing ratio; J. Res. 81A No. 1, 81-88 (1977).

Relative spectral response; signal-to-noise ratio; square wave patterns; television cameras; contrast; contrast transfer function; image quality; limiting resolution; SP480-25.

Relativistic corrections; atomic structure; electron structure; energy levels; fine structure; hydrogenic atoms; Lamb shift; level shifts; quantum electrodynamics; radiative corrections; JPCRD 6, No. 3, 831-870 (1977).

Relativistic Hartree-Fock theory; atomic beam; electronic structure; free atoms; hyperfine fields; 16940.

Relativistic many body systems; vector dominance; electromagnetic properties; form factors; magnetic moments; quadrupole moments; quantum field theory; Monogr. 147, Suppl. 1.

Relativity; satellite experiment; superconducting; electrodynamics; gyroscope; London moment; magnetic torque; 16795.

Relaxation; adsorption; dielectric screening; photoelectron spectroscopy; 17218.

Relaxation; stored energy; strain energy; adiabatic temperature drift; enthalpy; glass transition; heat capacity; pelletization; poly(vinyl chloride), pressure densification; 16769.

Relaxation effects; scandium alloys; dysprosium; hyperfine fields; magnetism; rare earths; 16985.

Relaxation of mercury atoms; three body molecular formation; ${ }^{3} P_{0}$ and ${ }^{3} P_{1}$ atomic states; ${ }^{3} P_{0} \rightarrow{ }^{3} P_{1}$ collision rates; decay of resonance line; quenching rates; 17194 .

Relaxation time; disordered system; dynamic susceptibility; Ginzburg-Landau free energy; 17122.

Relaxation time; ${ }^{13} \mathrm{C}$; collagen fibers; molecular motion; $\mathrm{nmr}$; Overhauser effect; 17007.

Relaxation times; excluded volume; Monte Carlo; polymer chain dynamics; random coil; random flight chain; 17125.

Reliability; algebra of normal functions; correlation; probability; random variable; SP487, pp. 25-38 (Aug. 1977).

Reliability; ceramics; high temperature; proof testing; 17046.

Reliability; coal conversion; coal gasification; coal liquefaction; corrosion; failure analysis; failure prevention; quality assurance; SP468.

Reliability; compressors; cryogenic refrigeration; efficiency; expanders; heat exchangers; particle accelerators; power transmission; 17083.

Reliability; flow measurements; flow properties; flowmeter reliability; SP484, pp. $61-82$ (Oct. 1977).

Reliability; safe operating area limits; second breakdown; thermal instability; hot spots; measurement methods; power transistors; 16893 . 
Reliability; safe operating limits; second breakdown; semiconductor devices; thermal characterization; thermal instability; thermal resistance; transistors; hot spots; junction temperature; measurement technology; nondestructive test; SP4OO44.

Reliability; screen tests; semiconductor devices; batteries; cardiac pacemakers; hermeticity; hybrid devices; leak testing; measurement tcchnology; microcalorimetry; pacemaker leads; process control; $S P 400-42$.

Reliability; security; small protection domains; types; capability; capability-based addressing; computer security; extended-type objects; operating system structures; protection; reliable software; 16920.

Reliability; statistical analysis; structural engineering; fire endurance; fire tests; probability theory; reinforced concrete; 17303.

Reliability; statistical analysis; structural engineering; uncertainty; probability; reinforced concrete; 17304.

Reliability; structural engineering; uncertainty; abnormal loading; alternate path; building code; design criteria; probability; progressive collapse; BSS98.

Reliability; system safety; critical item list; failure mode and effect analysis; failure reduction; SP487, pp. 278-288 (Aug. 1977).

Reliability; systems analysis; availability; fault tree analysis; probabilistic analysis; SP487, pp. 289-308 (Aug. 1977).

Reliability; trees; dynamic programming; graph; network; organization; probability; 16784 .

Reliability analysis; reliability-based design; resistance factors; structural engineering; load factors; performance approach; performance criteria; 17306 .

Reliability of design; techniques of design; validation of design; coating materials; composite materials; design; failure avoidance; failure prevention; lubricants; materials of design; product liability; SP487.

Reliability-based design; resistance factors; structural engineering; load factors; performance approach; performance criteria; reliability analysis; 17306.

Reliable software; reliability; security; small protection domains; types; capability; capability-based addressing; computer security; extended-type objects; operating system structures; protection; 16920

Reliable software; types; abstract data types; access controls; operating system protection; protection; protection mechanisms; 16918.

Relocatable buildings; wind-load racking; air leakage of buildings; building heat transfer; honeycomb panel construction; NBSIR 76-1178.

Relocatable code; assembler; cross-assembler; machine code; NBSIR 77-1230.

Remodeling; renewal; renovation; self-help; standards; building codes; building regulation; do-it-yourself; home construction; housing; rehabilitation; NBS-GCR-77-88.

Remodeling; residential; urban renewal; building codes; housing; rehabilitation; NBS-GCR-77-87.

Remate sensing; root-mean-square concentration; Schmidt number; simultaneous measurements; spectra; water jet; autocorrelation; convective velocity; cross-correlation; exit concentration; exit velocity; flow visualization; fluorescence; SP484, pp. 423-447 (Oct. 1977).

Remote terminal emulation; Remote Terminal Emulator; teleprocessing; evaluation; interactive; measurement; performance evaluation; performance measurement; 16945.

Remote terminal emulation; remote terminal emulators; teleprocessing; evaluation; interactive; measurement; performance evaluation; performance measurement; SP500-4.

Remote Terminal Emulator; teleprocessing; evaluation; interactive; measurement; performance evaluation; performance measurement; remote terminal emulation; 16945.
Remote terminal emulators; response time; throughput; turnaround time; evaluating computer service; network measurement machine; 17250 .

Remote terminal emulators; teleprocessing; evaluation; interactive; measurement; performance evaluation; performance measurement; remote terminal emulation; SP500-4.

Renewal; renovation; self-help; standards; building codes; building regulation; do-it-yourself; home construction; housing; rehabilitation; remodeling; NBS-GCR-77-88.

Renewal theory; statistical analysis; steady state; interactive computer system; performance measurement; SP500-18, pp. 87-94 (Sept. 1977).

Renovation; adaptive reuse; architecture; building codes; building regulations; building safety; construction; performance; preservation; rehabilitation; SP473, pp. 437-452 (June 1977).

Renovation; self-help; standards; building codes; building regulation; do-it-yourself; home construction; housing; rehabilitation; remodeling; renewal; NBS-GCR-77-88.

Repassivation; sensitization; stainless steel; crevice corrosion; iron-molybdenum alloys; localized corrosion; NBSIR 761170.

Repassivation kinetics; stress corrosion; crevice corrosion; ellipsometry; localized corrosion; pitting; 16990.

Repeatability; reproducibility; accuracy; analysis of variance; interlaboratory testing; precision; 16858.

Repeatability; SMA connectors; insertion loss; reflection coefficient; 16722 .

Reports and guidelines; survey; communications equipment priorities; equipment standards; Law Enforcement Standards Laboratory; police equipment; SP480-13.

Representations and codes; standards; statistical data; ADP standards; computers; data elements and codes; data processing; Federal Information Processing Standards; geography; information processing standards; information system; FIPS PUB $10-2$.

Reproducibility; accuracy; analysis of variance; interlaboratory testing; precision; repeatability; 16858.

Requirements in design; checklist for design; design; factors in design; SP487, pp. 1-15 (Aug. 1977).

Re-refined oil; used oil; waste oil; engine oil; fuel oil; hydraulic oil; industrial oils; lubricating oil; oil specifications; petroleum standards; petroleum test methods; recycled oil; SP488.

Rescue; verbal communicative; alarm; architecture; design implication; emergency actions; emergency communicative; emergency decisions; escape; fires; human behavior; human response; life safety; mapping; model; nursing homes; NBSGCR-77-93.

Research; research programs; wind engineering; wind studies; education; SP470, pp. II-1 -II-10 (Apr. 1977).

Research; safety; standard; window; emergency egress; HUD; mobile home; racking; NBSIR 77-1246.

Research; science; standards; technology; annual report; computer; energy; environmental; measurement; product safety; SP467.

Research; seismic; earthquake; program; SP477, pp. VI-28-VI36 (May 1977).

Research; seismic; shear walls; spandre! beams; connections; houses; masonry; piers; BSS106, pp. 60-90 (Sept. 1977).

Research; standards; court orders; human behavior; institutional occupancies; interior design; physical environment; regulation; SP473, PP. 55-67 (June 1977).

Research; structural engineering; structures; buildings; earthquakes; SP470, pp. IX-6-IX-16 (Apr. 1977).

Research and development; building regulation; computerbased systems; computer technology; information processing; performance evaluation; plan revicw; SP473, pp. 369-375 (June 1977).

Research and development, energy; economic; energy; 16907. 
Research and innovation; safety; ultrasonic tissue; computerized data; data elements; equity; federal technology; fire modeling; heat; hydrocarbon; ionized molybdenum; measurement assurance; metric; neutron diffraction; recycling oil; DIM/NBS 61, No. 6, 1-32 (1977).

Research associate program; standards; Alaska pipeline; calibration; CMA ; ; computers; consumer sounding boards; data; electron probe microanalysis; laser ionization; metrication; noise; nondestructive evaluation; DIM/NBS 61 , No. 1 , 1-32 (1977).

Research Associate Program; standards inspection procedure; temperature correction; test measure; test measure evaluation; "to contain"; "to deliver"; volumetric calibration; accuracy; design analysis; equipment specification; field standard; NBSIR 77-1214.

Research information; agricultural materials; agricultural research; biological properties; chemical properties; engineering properties; food products; information retrieval systems; management information systems; materials; SP463, pp. II.2.1-11.2.10 (Jan. 1977).

Research materials; thermal properties; availability; crystal growth; crystal structure; electronic properties; magnetic properties; optical properties; phase diagrams; SP463, pp. 111.3.1III.3.8 (Jan. 1977).

Research needs; codes and standards; environmental studies; fire safety; health dangers; SP473, pp. 35-53 (June 1977).

Research program; structural materials; thermal properties; low temperature; mechanical properties; 16863.

Research programs; seismic; testing; wind; earthquake; SP477, pp. VI-37-VI-43(May 1977).

Research programs; wind engineering; wind studies; education; research; SP470, pp. II-1-II-10 (Apr. 1977).

Residence times; single crystal; activation energies; molecular orientations; $\mathrm{NH}_{4} \mathrm{ClO}_{4} ;$ quasi-elastic neutron scattering; 17003.

Residential; space heating; testing; air conditioning; comfort; heat pump; load-calculation; rating; 17006.

Residential; urban renewal; building codes; housing; rehabilitation; remodeling; NBS-GCR-77-87.

Residential buildings; smoke; statistical analysis; building fires; egress; fire alarms; fire incidents; fire investigations; fires; human behavior; project people; NBS-GCR-77-94.

Residential construction; unionization; building official; building regulation; education; housing demand; innovation; regulatory barriers; SP473, pp. 113-135 (June 1977).

Residential design practices; typical construction characteristics; typical new house materials; windows; building envelope; energy conservation base; insulation; NBSIR 771309.

Residential fire; standard; upholstered furniture; cost plus loss; decision analysis; fire; furniture fire; losses; NBSIR 77-1381.

Residential fire deaths; fire deaths; fire losses; fire statistics; home furnishings; program planning; 16960.

Residential fires; smoke detectors; tenability levels; detector sensitivity; detector siting; heat detectors; ionization smoke detectors; photoelectric smoke detectors; 16882.

Residential fires; smoke detectors; detector sensitivity; detector siting; escape time; fire tests; gas detectors; heat detectors; NBS-GCR-77-82.

Residential heat loss; retrofitting houses; thermal conductivity; thermal insulation; thermography; air infiltration; condensation in buildings; energy conservation; energy measurements; fuel savings; heat-loss reduction; insulation properties; $N B S / R$ 77-1274.

Residential housing; socio-physical determinants; systems theory; energy consumption; input/output models; lifestyle factors; physical environment; SP473, pp. 69-83 (June 1977).

Residential occupancies; automatic sprinklers; care type occupancies; fire endurance; load failure; pipe hangers; NBSIR 77-1282.
Residual components in cements; residual methyl methacrylates; analysis of acrylics; benzoyl peroxide determination; bone cement; chemical composition of bone cement; dimethyl-p-toluidine; hydroquinone leachable monomer; 17202.

Residual methyl methacrylates; analysis of acrylics; benzoyl peroxide determination; bone cement; chemical composition of bone cement; dimethyl-p-toluidine; hydroquinone leachable monomer; residual components in cements; 17202 .

Residual stress; Mössbauer effect; nuclear hyperfine techniques; nuclear magnetic resonance; perturbed angular correlation; 17011.

Resin teeth; restoratives; sealants; adhesives; dental polymers; dental resins; dentures; impression materials; prosthetic materials; 17120 .

Resistance; resistance measurements; automated resistance measurement; automation; dc current comparator; digital nanovoltmeter; 16707.

Resistance coefficients; turbulence; liquid metals; magnetohydrodynamics; pipe flow; 16821 .

Resistance factors; structural engineering; load factors; performance approach; performance criteria; reliability analysis; reliability-based design; 17306 .

Resistance measurements; automated resistance measurement; automation; dc current comparator; digital nanovoltmeter; resistance; 16707.

Resistive loading; the method of moments; broadband antenna; measurements; picosecond pulse; NBSIR 77-861.

Resistive shield; antenna; antenna frequency response; dielectric sheath; filtering antenna; U.S. Patent 4,008,477.

Resistivity; resistivity correction factors; semiconductor characterization; silicon; square array; collector resistivity; epitaxial resistivity; four-probe; 16942.

Resistivity; resistivity variations; safe operating area, transistor; scanning acoustic microscope; scanning electron microscope; scanning low energy electron probe; semiconductor devices; semiconductor materials; semiconductor process control; silicon; silicon dioxide; SP400-29.

Resistivity; scattering mechanisms; temperature; dopant density; electron mobility; ionized impurity scattering mobility; lattice mobility; neutral impurity scattering mobility; $n$-type silicon; SP400-33.

Resistivity; semiconductors; silicon; silicon polishing; spreading resistance calibration; spreading resistance measurements; metal-semiconductor contacts; 17139.

Resistivity; temperature; dopant density; electron-electron scattering; electron mobility; ionized impurity scattering; lattice scattering; neutral impurity scattering; n-type silicon; 17147.

Resistivity correction factors; semiconductor characterization; silicon; square array; collector resistivity; epitaxial resistivity; four-probe; resistivity; 16942.

Resistivity variations; safe operating area, transistor; scanning acoustic microscope; scanning electron microscope; scanning low energy electron probe; semiconductor devices; semiconductor materials; semiconductor process control; silicon; silicon dioxide; SP4O0-29.

Resistivity variations; silicon; thermally stimulated capacitance; thermally stimulated current; thermally stimulated measurements; thyristor materials measurements; thyristor measurements; d-c transmission; energy conservation; measurement methods; photovoltaic method; 17345 .

Resistivity variations; silicon; thermally stimulated capacitance; thermally stimulated current; thermally stimulated measurements; thyristor materials measurements; thyristor measurements; d-c transmission; energy conservation; measurement methods; NBSIR 77-1249.

Resolution; scattering media; tissue; water; detector; Monte Carlo; perspex; photon energy; pulse height; SP461, pp. 188192 (Jan. 1977). 
Resolution; spectra; uncertainties; yield; distributions; neutrons; NBSIR 77-1279, pp. 15-18 (July 1977).

Resolution; spectrometry; water; activation; analysis; element; gamma rays; $\mathrm{Ge}(\mathrm{Li})$ detector; neutron; nondestructive; SP461, pp. 255-256 (Jan. 1977).

Resonance; shape; standards; thermal; ${ }^{6} \mathrm{Li}(\mathrm{n}, \alpha) ;{ }^{10} \mathrm{~B}(\mathrm{n}, \alpha)$; ${ }^{235} \mathrm{U}(\mathrm{n}, \mathrm{f})$; cross section; neutron; normalization; SP493, pp. 174-181 (Oct. 1977).

Resonance fluorescence; Delbrück scattering; Doppler broadening; electric quadrupole; giant resonances; photon scattering; polarized photons; 16926 .

Resonance fluorescence; stratosphere; chlorine nitrate; chlorofluorocarbons; oxygen atoms; rate constant; 17149.

Resonance fluorescence; vibrational excitation; chemical kinetics; chlorine atoms; flash photolysis; hydrogen metathesis methanes; 16785.

Resonance frequency; acceleration field; acceleration sensitivity; compound crystal resonator; crystallographic axis; nonlinear elastic effect; NBSIR 77-855.

Resonance frequency fluctuation; temperature fluctuation; flicker noise; frequency random walk; quartz crystal resonators; 17183.

Resonance integrals; spectral functions; comparative evaluation; cross sections; fission spectra; integrals; neutrons; radioactivation; SP493, pp. 128-136 (Oct. 1977).

Resonance method; shear modulus; sound velocity; Young's modulus; bulk modulus; composite; compressibility; copper; elastic constants; niobium-titanium; Poisson's ratio; pulse method; 17068.

Resonance method; shear modulus; torsional modulus; Young's modulus; aluminum; boron-aluminum; bulk modulus; composite; compressibility; elastic constants; 17087.

Resonance method; shear modulus; sound velocity; stainless steel; Young's modulus; bulk modulus; compressibility; elastic constants; Poisson's ratio; pulse method; 17321

Resonance parameters; R-matrix; standard; ${ }^{6} \mathrm{Li}(\mathrm{n}, \mathrm{t})$; ${ }^{7} \mathrm{Li}$ system; SP493, pp. 30-36 (Oct. 1977).

Resonance radiation; transition probability; ui; uranium; delayed coincidence; $g f$ value; imprisonment; lifetimes; mean life; 17292.

Resonances; scattering; vibrational excitation; close-coupling calculations; crossed beams; cross sections; differential cross sections; electron scattering; inelastic scattering; nitrogen molecules; 16740.

Resonant scatterer; dosimeter calibration; monoenergetic neutrons; neutron beams; neutrons; SP493, pp. 250-254 (Oct. 1977).

Resource dependency; system capacity; validation; credit authorization system; critical resource; disk modelling; event model; measurement; modelling; SP500-18, pp. 185-211 (Sept. 1977).

Resource impact factors; building; building environment; energy conservation; engineering; human factor; 17110 .

Resource impact factors; resources; social optimum; standards; building economics; economic efficiency; economics; energy; energy conservation; life-cycle cost; optimization; performance standards; 17302.

Resource sharing; response time prediction; computer networks; 16948.

Resources; social optimum; standards; building economics; economic efficiency; economics; energy; energy conservation; life-cycle cost; optimization; performance standards; resource impact factors; 17302 .

Respiratory rate; sensory irritation; stress index; thermal decomposition products; toxicity; acute lethality; Douglas Fir; inhalation; mice; polyurethane; pulmonary irritation; PVC; NBS-GCR-77-85.

Response; sensitivity; supralinear; thermoluminescence; dose; gamma rays; LiF; SP461, pp. 227-230 (Jan. 1977).
Response spectra; soils; acceleration records; dynamic behavior; earthquakes; SP477, pp. 111-41-111-56 (May 1977).

Response time; throughput; turnaround time; evaluating computer service; network measurement machine; remote terminal emulators; 17250 .

Response time; time delay; calorimetry; heat release rate; NBSIR 77-1302.

Response time prediction; computer networks; resource sharing; 16948.

Restoratives; sealants; adhesives; dental polymers; dental resins; dentures; impression materials; prosthetic materials; resin teeth; 17120 .

Restricted Hartree-Fock; transition moment; absorption crosssection; $\mathrm{Ar}_{2}{ }^{+}$; energy transfer; gain inhibitor; gas lasers; photodissociation; 17195 .

Results; seismometers; arrays; earthquakes; ground motion; records; SP477, pp. III-16-III-25 (May 1977).

Retail meat identity standards; tolerance application; vapor recovery; weights and measures; checking prepackaged commodities; computer assisted check-out systems; consumer affairs; cordage products; drained weight; laws and regulations; metrication; SP471.

Retarder; Stokes parameters; Mueller matrix; polarization; polarizer; TN910-3.

Retrieval; analysis; implants; metallic; or thopaedic; SP472.

Retrieval; data retrieval; file validation; name lookup; nonunique identifiers; personal data files; Privacy Act; probability model; SPSOO-2.

Retrieval Guide; technical reports; Thermophysical and Electronic Properties Information Analysis Center; thermophysical properties; computerized information system; data bank; electrical properties; SP463, pp. IV.4.1 -IV.4.3 (Jan. 1977).

Retrofit; seismic design; structural design; structural research; building codes and standards; design criteria; earthquake resistance; limit states design; masonry construction; materials testing standardization; mathematical models; BSSI06, pp. 40-59 (Sept. 1977).

Retrofit; thermography; buildings; energy conservation; evaluation; inspection; 16902.

Retrofit design; computerized energy analysis; energy conservation standards; new building design; 16770.

Retrofitting; seismic; costs; existing structures; optimization; SP477, pp. VI-69-VI-84 (May 1977).

Retrofitting; solar; building design; cost; energy conservation; energy standards; fenestration; life-cycle costing; 17107.

Retrofitting houses; thermal conductivity; thermal insulation; thermography; air infiltration; condensation in buildings; energy conservation; energy measurements; fuel savings; heat-loss reduction; insulation properties; residential heat loss; NBSIR 77-1274.

Reverberation room; reverberation room qualification; sound power; acoustical measurements; acoustics; acoustics facility; automated sound measurement; computer-controlled instrumentation; 16763.

Reverberation room; sound power measurement; standard test procedures for sound power measurement; acoustic test facility; noise; noise measurement; 16766.

Reverberation room qualification; sound power; acoustical measurements; acoustics; acoustics facility; automated sound measurement; computer-controlled instrumentation; reverberation room; 16763 .

Reversible oxygenation; second virial coefficients; oxygen/fluorocarbon complex; oxygen/hydrocarbon complex; 17216.

Review; accuracy; $A u(n, \gamma)$ cross section; cross section fluctuations; measurement; neutron capture cross section; normalization; reference standard; SP493, pp. $165-169$ (Oct. 1977).

Review; black and grey neutron detectors; neutron flux measurement; SP493, pp. $212-220$ (Oct. 1977). 
Review; diffusion; hydrogen; lattice dynamics; metals; neutron scattering; quasielastic scattering; 16970.

Review; Federal library and information activities; library and information sciences; 16743.

Review; safety; sports; accident; associated factors; injuries; literature; NEISS; recommendations; NBSIR 77-1218.

Review; thermal property; alloy; composite; cryogenics; electrical property; insulation; materials; mechanical property; metal; 17072.

Review of measurements; ${ }^{6} \mathrm{Li}(\mathrm{n}, \alpha) ;{ }^{6} \mathrm{Li}$ total; ${ }^{7} \mathrm{Li}$ system; elastic scattering; neutrons; SP493, pp. 14-29 (Oct. 1977).

Reynolds number; sphere flow; trarisition; trip-wire probe; turbulent boundary layer; calibration; Pitot-static tube; SP484, pp. 719-735 (Oct. 1977).

Rf attenuation; superconductivity; Josephson junction; quantum interference; NBSIR 77-863.

RF connectors; scattering parameters; coaxial connectors; microwave connectors; 16727.

Rf measurements; standards; superconductivity; thermometry; DC measurements; frequency; metrology; 16861 .

Rf metrology; if power; SQUID; superconductivity; Josephson effect; quantum interference; 17092.

RF noise spectrum; 3-D display; FFT; measurement system; 17173.

Rf power; SQUID; superconductivity; Josephson effect; quantum interference; rf metrology; 17092.

Rf-power meter; roofing; safety; security alarms; SRM's; time and frequency; ultraviolet; computer memories; computer performance; inventor; molecular identity; preserving stone; pressure measurements; DIM/NBS 61, No. 8, 1-32 (1977).

R-function analysis; standard; total cross section; carbon; elastic scattering cross section; evaluation; optical model; SP493, Pp. 93-100 (Oct. 1977).

Rheological; seismic response; two-dimensions; bedrock; modeling; SP477, Pp. IV-18-IV-46 (May 1977).

Rheology; starvation; traction; bearings; computer programs; elastohydrodynamics; failure analysis; film thickness; gears; Hertz contacts; lubrication; SP487, pp. 137-153 (Aug. 1977).

Rheology, material; earthquake damage analysis; masonry; BSS106, pp. 114-153 (Sept. 1977).

Rhodium; ruthenium; boron hydride; carborane; dicarbollide; metalloborane; metallocarborane; 17152 .

Rhodium alloys; vanadium alloys; atomic ordering; constitution diagram; phase diagram; phase transformations; 16834

"Rhodium," marking of; "Ruthenium," marking of; "Iridium," marking of; jewelry, marking of; "Osmium," marking of; "Palladium," marking of; "Platinum," marking of; PS69-76.

Rigid-body motion analysis; thermal motion of a perchlorate ion; x-ray diffraction; ammonium perchlorate; bond lengths and angles; crystal structure; 17348 .

Rise time; sampling oscilloscope; spectrum amplitude; time domain; transient; automated measurement; pulse; 16721 .

Risk; shear modulus; testing; ultimate strength; anchor bolts; bond; damping; ductility; earthquake resistance; energy absorption; modulus of elasticity; partial reinforcing; BSS106, pp. 255-258 (Sept. 1977).

Risk; statistical analysis; storms; structural engineering; tropical storms; wind loads; wind speeds; building codes; buildings; codes and standards; housing; hurricanes; pressure coefficients; probability distribution functions; BSS100-2.

Risk analysis; risk assessment; systems security; ADP availability; annual loss expectancy; application system vulnerability; computer security; data confidentiality; data integrity; data security; physical security; procedural security; NBSIR 771228.

Risk assessment; systems security; ADP availability; annual loss expectancy; application system vulnerability; computer security; data confidentiality; data integrity; data security; physical security; procedural security; risk analysis; NBSIR 77-1228.
Risk management; computers; government information collection; information policy; information processing; 16906.

Risk management; safety of computer systems; computer security; computer system performance; computer systems; individual privacy; 17114 .

Risks; safety; accident prevention; hazard analysis; SP487, pp. 265-277 (Aug. 1977).

Rittner model; transition moment; dipole moment; excimer; excitation energy; perturbation formula; rare gas halide; 17151 .

R-matrix; standard; ${ }^{6} \mathrm{Li}(\mathrm{n}, \mathrm{t})$; ${ }^{7} \mathrm{Li}$ system; resonance parameters; SP493, pp. 30-36 (Oct. 1977).

Roads; survey; construction; dams; earthquake; earth structures; SP477, Pp. VI-44_VI-49 (May 1977).

Robot; sensors; adaptive; automation; computer; control; goaloriented; hierarchical control; SP500-23.

Robots; software engineering; computer engineering; computer networks; computers; data processing; 16903.

Rock motion; seismic coefficient; acceleration; accelerogram; gravity quaywall; SP477, pp. VI-192-VI-198 (May 1977).

Rodlike; rodlike macromolecules; rods, bent; rods, semirigid; semirigid rods; bent rods; form factors; light scattering; macromolecules; 17253.

Rodlike macromolecules; rods, bent; rods, semirigid; semirigid rods; bent rods; form factors; light scattering; macromolecules; rodlike; 17253.

Rods, bent; rods, semirigid; semirigid rods; bent rods; form factors; light scattering; macromolecules; rodlike; rodlike macromolecules; 17253 .

Rods, semirigid; semirigid rods; bent rods; form factors; light scattering; macromolecules; rodlike; rodlike macromolecules; rods, bent; 17253.

"Rolled Gold Plate," marking of; jewelry, marking of; "Gold Filled," marking of; "Gold Overlay," marking of; "Gold Plate," marking of; PS67-76.

Rolls; wire standards; calibration; cylinders; plug gages; NBSIR 73-136.

Roofing; safety; security alarms; SRM's; time and frequency; ultraviolet; computer memories; computer performance; inventor; molecular identity; preserving stone; pressure measurements; rf-power meter; DIM/NBS 61, No. 8, 1-32 (1977).

Roofing; solar heating; surface temperature; built-up roofing; insulation; performance; radiative cooling; 17060 .

Roofing; solar heating; surface temperature; built-up roofing; insulation; performance; radiative cooling; 17061 .

Roofs; typhoon; wind pressure; buildings; dynamic effects; high winds; SP470, Pp. II-1 -II-19 (Apr. 1977).

Roofs; wind; dynamics; failure; SP477, PP. I-12-I-20 (May 1977).

Room fire; scaling models; theoretical; "flashover"; fluid flow; full-scale; heat transfer; literature review; mathematical models; 17283 .

Room fires; rooms; smoldering; wood; ceiling height; ceilings; cotton; detector location; detectors; fire detectors; polyurethanes; polyvinyl chloride; NBS-GCR-77-86.

Room fires; scale models; buoyant plumes; ceilings; compartment fires; fire plumes; heat transfer; NBS-GCR-77-97.

Room fires; scale models; thermal radiation; fire growth; fire tests; flashover; 17059.

Room fires; scaling; ventilation; corridors; fuel load; heat transfer; NBSIR 77-1318.

Rooms; smoldering; wood; ceiling height; ceilings; cotton; detector location; detectors; fire detectors; polyurethanes; polyvinyl chloride; room fires; NBS-GCR-77-86.

Root of unity; bound set; convex hull; eigenvalue-eigenvector equation; J. Res. 82, No. 2, 133-136 (1977).

Root-mean-square concentration; Schmidt number; simultaneous measurements; spectra; water jet; auto-correlation; convective velocity; cross-correlation; exit concentration; exit velocity; flow visualization; fluorescence; fluorescent dye; SP484, pp. 423-447 (Oct. 1977). 
Rossi- $\alpha$; slowing down; stochastic; BESM-6; JEZEBEL; Markov process; neutron; PURNIMA; SP461, pp. 97-99 (Jan. 1977).

Rossi-counter measurements; Serber theory; thick target; timeof-flight; ${ }^{9} \mathrm{Be}(\mathrm{d}, \mathrm{n}){ }^{10} \mathrm{~B} ; \quad{ }^{9} \mathrm{Be}\left({ }^{3} \mathrm{He}, \mathrm{n}\right){ }^{11} \mathrm{C}$; energy spectra; neutrons; NBSIR 77-1279, pp. 31-34 (July 1977).

Rotary inertia; transverse shear; vibration; Galerkin; natural frequencies; orthotropic; plates; 16702.

Rotational constants; Stark effect; vibrational transition moment; acetylene- $d_{2}$; l-type doubling constants; microwave spectrum; 16689.

Rotational constants; vibrational constants; vibration-rotation constants; combination bands; nitrogen dioxide; 17123.

Rotational excitation in atom-molecule scattering; atommolecule scattering; collisions of He with diatomic hydrides; heavy particle collisions; 16674 .

Rotational line widths; semiempirical potential; theoretical potential; anisotropic interactions; $\mathbf{H C l}-\mathbf{A r}$; linear molecules; 16799.

Rotational spectra; structure; methylenimine; microwave spectroscopy; molecules; pyrolysis; 16910.

Rotational symmetry; sulfur hexafluoride; angular momentum; methane; 16957.

Round robin; test method; ASTM E 162; coefficient of variation; flame spread tests; flexible polyurethane; hardboard; interlaboratory evaluation; neoprene; radiant panel test; NBSIR $77-1222$

Routine radiosonde application; barium fluoride; calibration equations; fast response; films; humidity sensor; industrial fabrication; isotherm equations; physical adsorption; relative humidity; NBSIR 76-1108.

Rovibronic assignments; spectral analysis; visible absorption spectroscopy; high-resolution spectrum; iodine spectrum; line identification atlas; J. Res. 81A No. 1, 25-80 (1977).

RSIC; shielding; computer code; data library; information; radiation; radiation analysis; SP461, pp. 171-173 (Jan. 1977).

RSIC; shielding; weapons; computer codes; materials properties; nuclear data; radiation transport; reactor; SP463, pp. III.1.1-III.1.10 (Jan. 1977).

Rubber; stress-strain relations; stress-strain relations in rubber; uniaxial extension and compression in rubber; extension and compression in rubber; Martin-Roth-Stiehler equation; modulus of rubber; J. Res. 82, No. 1, 57-63 (1977).

Rubidium; spectra; structure; ultraviolet; yttrium; zirconium; ions; molybdenum; niobium; 17212 .

Rubidium gas cell; timekeeping; cesium beam; clocks (atomic); crystal oscillator; frequency accuracy; frequency stability; frequency standards; hydrogen maser; quartz crystal; TN616, 2d Revision.

Rubidium niobate; rubidium tantalate; crystal chemistry; ionic conductivity; nonstoichiometry; phase equilibria; J. Res. 82, No. 3, 151-165 (1977).

Rubidium tantalate; crystal chemistry; ionic conductivity; nonstoichiometry; phase equilibria; rubidium niobate; J. Res. 82, No. 3, $151-165$ (1977).

Ruby; transition metal ions; ultrahigh pressure; $\mathrm{Cr}^{3+}$, crystal field spectra; $\mathrm{d}^{3}$ ion; optical spectra; 17047.

Rules and regulations; statewide codes; summary tables; building construction; building regulations; cities; code uniformity; enforcement; legislation; NBSIR 77-1390.

Runway visual range; scattering; transmissometer; visibility; visual range; ceilometer; Monogr. 159.

Ruthenium; boron hydride; carborane; dicarbollide; metalloborane; metallocarborane; rhodium; 17152.

Ruthenium; water; adsorption; angular distribution (ions); chemisorption; electron stimulated desorption; 17349.

"Ruthenium," marking of; "Iridium," marking of; jewelry, marking of; "Osmium," marking of; "Palladium," marking of; "Platinum," marking of; "Rhodium," marking of; PS69-76.

Rydberg constant; Balmer $\alpha$ line; cw dye laser; Fabry-Perot interferometer; 17098.
R\&D incentives; regulation; technology; impact of government on the economy; pesticides; NBS-GCR-ETIP 76-34.

\section{$\mathbf{S}$}

S. Newcomb; systematic errors; trimmed means; velocity of light; A. A. Michelson; adaptive estimators; arithmetic mean; bias; estimators of location; median; M-estimators; 17266.

Safe operating area limits; second breakdown; thermal instability; hot spots; measurement methods; power transistors; reliability; 16893 .

Safe operating area, transistor; scanning acoustic microscope; scanning electron microscope; scanning low energy electron probe; semiconductor devices; semiconductor materials; semiconductor process control; silicon; silicon dioxide; silicon on sapphire; SP400-29.

Safe operating limits; second breakdown; semiconductor devices; thermal characterization; thermal instability; thermal resistance; transistors; hot spots; junction temperature; measurement technology; nondestructive test; reliability; SP4OO44.

Safety; accident prevention; hazard analysis; risks; SP487, pp. 265-277 (Aug. 1977)

Safety; product liability; SP487, pp. 241-246 (Aug. 1977).

Safety; security alarms; SRM's; time and frequency; ultraviolet; computer memories; computer performance; inventor; molecular identity; preserving stone; pressure measurements; rf-power meter; roofing; DIM/NBS 61, No. 8, 1-32 (1977).

Safety; shear wall; stiffness; buildings; damage; dynamic response; earthquakes; SP470, pp. VI-33-VI-46 (Apr. 1977).

Safety; sports; accident; associated factors; injuries; literature; NEISS; recommendations; review; NBSIR 77-1218.

Safety; standard; window; emergency egress; HUD; mobile home; racking; research; NBSIR 77-1246.

Safety; standards; anthropometric probes; consumer products; human factors; lawn mowers; psychophysics; reaction time; 17200.

Safety; standards; consumer products; generic probes; human factors; lawn mowers; NBSIR 77-1294.

Safety; structures; deterministic; dynamics; earthquake; probability; random vibrations; SP470, pp. VI-1-VI-21 (Apr. 1977).

Safety; structures; test methods; acoustics; appliances; atmospheric; durability; electrical; environment; housing technology; HVAC; innovative construction; maintainability; materials; minimum property standards; performance criteria; performance evaluation; plumbing; NBSIR 77-1316.

Safety; system safety; accident research; human factors; methodology; rare events; SP482.

Safety; ultrasonic tissue; computerized data; data elements; equity; federal technology; fire modeling; heat; hydrocarbon; ionized molybdenum; measurement assurance; metric; neutron diffraction; recycling oil; research and innovation; DIM/NBS 61, No. 6, 1-32 (1977).

Safety; warranty; anthropometry; biomechanics; carrying; consumer product portability; ergonomics; human factors; lifting; manual materials handling; physiology; psychophysics; NBSIR 76-1092.

Safety; wind-tunnel; cryogenic; design; nitrogen; NBSIR 77 857.

Safety of bathrooms; slip-resistance of bathtub and shower base surfaces; slip-resistance testers; Kollsman tester; NBS-Brungraber tester; NBSIR 76-1005.

Safety of computer systems; computer security; computer system performance; computer systems; individual privacy; risk management; 17114 .

Safety regulations; standards; accidents; benefit-cost analysis; building codes; building economics; building regulations; 
economic impact; electric shock; ground fault circuit interrupters; national electric code; SP473, pp. 397-419 (June 1977).

Safety standard; standards; benefit/cost; building standards; cost/effectiveness; economics; 17133.

Safety, toy; toy safety; use and reasonably foreseeable abuse testing for toys; cautionary labeling for toys; hazardous characteristics of toys; PS72-76.

Salt; saturated salt solution; vapor pressure; water vapor; aqueous solution; equilibrium; humidity; relative humidity; J. Res. 81A No. 1, 89-96 (1977).

Salting-out effect; solubility; aromatic hydrocarbons; heat of solution; 17038 .

Sample characteristics; stray light; wavelength accuracy; bandwidth; calibration; errors in spectrophotometry; interferences; multiple reflections; photometric linearity; polarization; SP466, pp. 99-1 14 (May 1977).

Sample handling; sampling; trace elements; chemical analysis; environmental samples; long-term storage; microbiologicals; organics; pesticides; radionuclides; 16729.

Sample preparation; spark source mass spectrometric isotope dilution; tissues; analytical disciplines; analytical procedures; atomic absorption spectrometry; biological materials; blanks; botanical materials; chemical species; flame emission spectrometry; SP492.

Sample preparation; specific activity; $\alpha$-activity; absolute counting; aliquotting; analysis (plutonium, uranium); isotope dilution; SP493, pp. 206-211 (Oct. 1977).

Sampling; trace elements; chemical analysis; environmental samples; long-term storage; microbiologicals; organics; pesticides; radionuclides; sample handling; 16729.

Sampling; waveforms; optical; oscilloscope; photoconductor; 16661 .

Sampling oscilloscope; spectrum amplitude; time domain; transient; automated measurement; pulse; rise time; 16721 .

Sampling oscilloscope; spectrum amplitude; spectrum analyzer; spectrum intensity; calibration; electromagnetic interference; fast Fourier transform; impulse generator; radiometer; 16725.

Sand; soils; tests; undisturbed sampling; density; liquefaction; SP477, Pp. Vl-141-VI-1 57 (May 1977).

Sand; surface reactions; tropospheric sink; chloromethanes, photochemistry; quantum yields; quartz; J. Res. 82, No. 1, $1-8$ ( 1977).

Sand corrosion; seawater corrosion; splash zone corrosion; cathodic protection; coating systems; corrosion protection; offshore corrosion; Monogr. 158.

Sand layer; shake table; vibration tests; void ratios; earthquakes; liquefaction; SP470, pp. V-16-V-35 (Apr. 1977).

Sand transport; water tunnel; waves; coastal processes; permeability effects; prototype tests; 16917.

Sandwich; spéctrometry; surface barrier; ${ }^{6} \mathrm{LiF}$; detector; energy leakage; Monte Carlo; neutron; SP461, Pp. 252-254 (Jan. 1977).

Sanitary drainage system; venting; cost savings; drainage-wastevent; economics; life cycle; performance standards; pipe; plumbing; reduced-size vents; 17296.

Satellite; spectrum; $\mathrm{Li}_{2} ; \mathrm{Na}_{2} ; 16912$.

Satellite clock system; satellite controlled clock; satellite time code reception; clock comparison and reset; digital clock; U.S. Patent 4,014,166.

Satellite controlled clock; satellite time code reception; clock comparison and reset; digital clock; satellite clock system; U.S. Patent 4,014,166.

Satellite earth terminal; signal to noise; star flux; figure of merit; G/T; measurement accuracy; radio stars; 17227 .

Satellite experiment; superconducting; electrodynamics; gyroscope; London moment; magnetic torque; relativity; 16795.
Satellite time code reception; clock comparison and reset; digital clock; satellite clock system; satellite controlled clock; U.S. Patent 4,014,166.

Satellite time dissemination; standard frequency; standard time; time services; time transfer; clock comparison; 17179.

Satellite timing; standard time/frequency broadcasts; television time/frequency dissemination; time/frequency calibrations; user equipment; user survey; NBS radio stations WWV/WWVH/WWVB; NBS time/frequency services; 17080.

Satellites; thallium; line broadening; 16752 .

Satellites; XPS; photoemission; plasmons; 17219.

Saturated absorption; dye laser; frequency stabilization; iodine; 17178.

Saturated absorption; laser strainmeter; 17226.

Saturated absorption; nonlinear spectroscopy; Ramsey fringes; 16776.

Saturated salt solution; vapor pressure; water vapor; aqueous solution; equilibrium; humidity; relative humidity; salt; J. Res. 81A No. 1, 89-96 (1977).

Saturation; selection rules; van der Waals; atomic collision; excitation transfer; laser stimulation; orbiting; 16695.

Saturation spectroscopy; transit-time; coherence; fringes; interference; modulation; phase; Ramsey; 17337.

Saturation strontium; collisions; near-resonant light scattering; redistribution; 16857.

Saturation vapor pressure over ice; thermal properties of ice; vapor pressure; vapor pressure at the triple point; vapor pressure of ice; water vapor; Clausius-Clapeyron equation; J. Res. 81 A No. 1, 5-20 (1977).

Saturation voltage; transistor measurement; transistor measurement repeatability; collector-emitter; NBSIR 77-I231.

Scale factors; shear walls; current research; ductility; full scale testing; high-rise masonry; BSS106, pp. 314-326 (Sept. 1977).

Scale models; buoyant plumes; ceilings; compartment fires; fire plumes; heat transfer; room fires; NBS-GCR-77-97.

Scale models; thermal radiation; fire growth; fire tests; flashover; room fires; 17059.

Scaling; stratified flow; temperature; velocity measurements; buoyant flow; corridor, countercurrent; fire; 17285 .

Scaling; thermodynamic properties; transport properties; universality; critical exponents; critical region; fluid mixtures; fluids; 17279.

Scaling; ventilation; corridors; fuel load; heat transfer; room fires; NBSIR 77-1318.

Scaling criteria; spray water flow rate; water spray; automatic sprinklers; compartment fire; corridor sprinkler systems; droplet size; droplet trajectory; evaporative cooling; fire suppression; full-scale test; gas temperature; oxygen content; recirculating flow; NBSIR 77-1287.

Scaling models; theoretical; "flashover"; fluid flow; full-scale; heat transfer; literature review; mathematical models; room fire; 17283 .

Scaling theory; frequency shifts; hydrostatic pressure; optical transitions; 17228 .

Scandium alloys; dysprosium; hyperfine fields; magnetism; rare earths; relaxation effects; 16985 .

Scanning; spherical; spherical point group; antennas; arrays; finite rotations; group representations; near-fields, recursion; 17322.

Scanning; spherical; symmetry; antennas; arrays; coordinate transformations; data processing; group representations; measurements; near field; nonplanar; patterns; 16671 .

Scanning; wavelength; cw laser; interferometer; Michelson; phase-lock; 17338.

Scanning; $x$-ray spectroscopy; electron probe; image formation; ion probe; microanalysis; microscopy; 16841 .

Scanning acoustic microscope; scanning electron microscope; scanning low energy electron probe; semiconductor devices; 
semiconductor materials; semiconductor process control; silicon; silicon dioxide; silicon on sapphire; sodium contamination; spreading resistance; $S P 400-29$.

Scanning electron microscope; scanning low energy electron probe; semiconductor devices; semiconductor materials; semiconductor process control; silicon; silicon dioxide; silicon on sapphire; sodium contamination; spreading resistance; surface roughness; test patterns; SP400-29.

Scanning electron microscope; secondary emission; voltage contrast; backscattered emission; EBIC; microelectronic devices; SP400-35.

Scanning electron microscope; selected area electron channeling pattern; crystal orientation determination; crystallographic contrast; electron channeling contrast; microstructural analysis; 16839.

Scanning electron microscope; filar eyepiece; image-shearing eyepiece; integrated circuits; linewidth measurements; microelectronics; micrometrology; optical microscope; photoelectric microscope; photomask; 17066.

Scanning electron microscope; semiconductor devices; electron beam energy deposition; ionizing radiation effects; radiation dose; radiation testing; NBSIR 77-1235.

Scanning electron microscope (SEM); buildings; ease of ignition; fire tests; gypsum board; potential heat; properties; rate of flame spread; rate of heat release; NBSIR 77-1265.

Scanning electron microscopy; topographic contrast; voltage contrast; atomic number contrast; electron beam induced conductivity (EBIC) contrast; electron channeling contrast; magnetic contrast; 16840.

Scanning electron microscopy; semiconductor devices; device inspection; electron-beam-induced current; microelectronics; p- $n$ junctions; 16891.

Scanning electron microscopy; semiconductor devices; device inspection; electron-beam-induced-current; microelectronics; $p-n$ junctions; 16971 .

Scanning electron microscopy; signal processing; derivative operators; digital scan generator; isotropy; photographic processing; 16988.

Scanning facilities; spherical scanning; antenna patterns; cosite interference; cylindrical scanning; near-field scanning; planar scanning; 17221 .

Scanning low energy electron probe; semiconductor devices; semiconductor materials; semiconductor process control; silicon; silicon dioxide; silicon on sapphire; sodium contamination; spreading resistance; surface roughness; test patterns; thermally stimulated current; SP400-29.

$S$-carboxymethyl-L-cysteine sulfoxide; $x$-ray determination; zwitterion; absolute configuration; amino acid derivative; crystal structure; 16688 .

Scatter; absorption; dielectric layers; irregularities; metallic thin films; microirregularities; overcoating; plasmons; SP466, PP. 133-148 (May 1977).

Scattered radiation; source housing; spectrometry; ${ }^{60} \mathrm{Co}$ gammaray source; collimator; exposure spectra; gamma-rays; NBSIR 76-1117.

Scattering; aluminium; carbon; collision; copper; distribution; dose; electron; Gaussian; Monte Carlo; SP461, Pp. 106-109 (Jan. 1977).

Scattering; angular distribution; chlorine; foils; ions; iron, oxygen; measurement; Moliere theory; multiple; SP461, PP. 136-139 (Jan. 1977)

Scattering; cross section; differential; elastic; multiple bias technique; neutron; SP461, pp. 64-66 (Jan. 1977).

Scattering; semi analytical; spatial; transmission; anisotropy; charged particle; computer code; energy-angle; integral; legendre polynomial; SP461, Pp. $140-143$ (Jan. 1977).

Scattering; semi-numerical; transport; integral equation; radiation; SP461, Pp. 79-86 (Jan. 1977).
Scattering; shield; transmission; ${ }^{232} \mathrm{Cf}$; ANISN; code; configuration; dose equivalent; energy; gamma rays; neutron; SP461, Pp. 119-123 (Jan. 1977).

Scattering; shielding; angle; centre of mass; coefficients; computations, cross-section; Legendre polynomial; neutron; random sampling; SP461, Pp. 100-105 (Jan. 1977).

Scattering; singularity expansion method; symmetry analysis; antenna patterns; characteristic modes; Garbacz characteristic modes; group theory; inverse scattering; moment methods; 17225 .

Scattering; spectrometer; cross section; energy transfer; gamma rays; moderator; neutron; radiation damage; reactor; SP461, Pp. 32-40 (Jan. 1977).

Scattering; spectrometers; absorption; accuracy; cross section; fast neutrons; geometric factors; photon; polarimeter; radiation physics; SP461, pp. 47-54 (Jan. 1977).

Scattering; standards; detectors; flux; neutrons; proton-recoil; SP493, pp. 54-60 (Oct. 1977).

Scattering; theoretical; theory; argon; collisions; dissociation; hydrogen; inelastic; molecular potential; recombination; 16802.

Scattering; thermalization; cross section; diffusion; kernel; lattice vibration; model; moderator; neutron; SP461, Pp. 149162 (Jan. 1977).

Scattering; transmissometer; visibility; visual range; ceilometer; runway visual range; Monogr. 159.

Scattering; vibrational excitation; close-coupling calculations; crossed beams; cross sections; differential cross sections; electron scattering; inelastic scattering; nitrogen molecules; resonances; 16740 .

Scattering coefficients; statistical models; absolute absorptivities; continuum models; diffuse reflectance; radiative transfer; reflectance spectra; SP466, Pp. 57-73 (May 1977).

Scattering, incoherent; $x$ rays; angular distribution; cross section; gamma rays; photon; SP461, Pp. 55-56 (Jan. 1977).

Scattering matrix; cylindrical scanning; near-field measurements; TN696, 1977 Revision.

Scattering mechanisms; temperature; dopant density; electron mobility; ionized impurity scattering mobility; lattice mobility; neutral impurity scattering mobility; $n$-type silicon; resistivity; SP400-33.

Scattering media; tissue; water; detector; Monte Carlo; perspex; photon energy; pulse height; resolution; SP461, Pp. 188-192 (Jan. 1977).

Scattering parameters; coaxial connectors; microwave connectors; RF connectors; 16727.

Scattering parameters; lossless two-port; 16663.

Scattering parameters; self-calibration techniques; six-port junction; impedance; microwaves; network analyzer; reflection coefficient; reflectometer; 17244.

Scattering surfaces; bidirectional radiometry; canopies; diffuse reflectance; diffuse transmission; reflectance standards; SP466, PP. 87-93 (May 1977).

Scattering-elastic, inelastic, total; thorium; uranium; calculation; cross section; optical model; reactor technology; SP461, PP. 70-73 (Jan. 1977).

Schmidt number; simultaneous measurements; spectra; water jet; auto-correlation; convective velocity; cross-correlation; exit concentration; exit velocity; flow visualization; fluorescence; fluorescent dye; laser; SP484, PP. 423-447 (Oct. 1977).

School operation schedule; ventilation test; computerized thermal simulation; $\mathrm{CO}_{2}$ concentration; energy conservation in schools; energy consumption; energy utilization in schools; oxygen content; reduced ventilation rate; BSS97.

Schools; building codes; building regulations; design criteria; earthquakes; hospitals; SP470, Pp. VI-64-VI-73 (Apr. 1977). 
Science; standard reference data; technology; communication; information; interdisciplinary technology; physical property data; publish; 17258 .

Science; standards; technology; annual report; computer; energy; environmental; measurement; product safety; research; SP467.

Science and technology; scientific freedom and responsibility; technological change; institutional barriers to change; 16905.

Science and technology in America; technology; 75th anniversary; National Bureau of Standards; physical sciences; SP465.

Scientific and technical aerospace reports; thesaurus; aerospace; computer information system; international aerospace abstracts; materials; mechanical properties; metallic materials; nonmetallic materials; physical properties; SP463, pp. V1.1.1-V1.1.7 (Jan. 1977).

Scientific and technical information; thesaurus; computerized information system; directories; information resource; $\mathrm{Na}$ tional Referral Center; referral; SP463, pp. VI11.2.1-V111.2.4 (Jan. 1977).

Scientific and technological advisory services; ADP standards; Brooks Act; computer science research; computers in the Federal Government; NBSIR 76-1113.

Scientific freedom and responsibility; technological change; institutional barriers to change; science and technology; 16905.

Scintillation counting; $\beta$-ray detection; low-level counting; plastic phosphors; 17268.

Scintillation detectors; ${ }^{6} \mathrm{Li}(\mathrm{n}, \alpha)^{3} \mathrm{H}$; external particle detectors; gaseous ionization detectors; instruments; SP493, pp. 43-46 (Oct. 1977).

Scintillator; UNFOLD; Apsara; energy distribution; gamma ray; iterative; neutron; plastic; recoil; SP46I, pp. 247-251 (Jan. 1977).

$\beta$-counting error; activation; capture reaction; cross section; measurement; neutron; SP461, pp. 57-59 (Jan. 1977).

Scramblers; speech scramblers; voice privacy; voice scramblers; LESL; N1LECJ; privacy; SP480-8.

Scrappage rate; stable-age population; age distributions; demography; durability; durable goods; matrix model; population dynamics; population growth rate; production rate; 17053 .

Screen tests; semiconductor devices; batteries; cardiac pacemakers; hermeticity; hybrid devices; leak testing; measurement technology; microcalorimetry; pacemaker leads; process control; reliability; SP400-42.

Screw thread standards; SHIVA laser; silicon; timekeeping; ultraviolet radiation; calibration; consumers; energy; energy savings; grain moisture; mass spectra; radiation sterilizing; DIMINBS 6I, No. 9, 1-32 (1977).

Seal durability and longevity; sealed insulating glass; ASTM Test Standard for insulating glass; frost-point measuring apparatus; moisture condensation; 17286 .

Sealants; adhesives; dental applications; dental prosthetic materials; dental resins; future dental materials; macromolecules; plastics; polymers; 17201 .

Sealants; adhesives; dental polymers; dental resins; dentures; impression materials; prosthetic materials; resin teeth; restoratives; 17120.

Sealed insulating glass; ASTM Test Standard for insulating glass; frost-point measuring apparatus; moisture condensation; seal durability and longevity; 17286.

Seamless flooring; temperature characteristics; electrical heating elements; materials performance; radiant panel-seamless flooring system; NBSIR 77-1263.

Seasonal performance; building heating system; computer simulation; energy conservation; furnace; operating cost; 16922.

Seasonal perfori:-ance factor; cooling and heating coefficients of performance; effective seasonal heating COP; heat pumps; heat pumps and energy conservation; part-load performance; BSS93.
Seattle federal building; smoke control; smoke simulation experiments; sulfur-hexafluoride; systematic pressurization; airhandling system; Chicago federal building; highrise; pressure profiles; 17291 .

Seawater; sulfate; environmental analysis; ion-selective electrode; lead electrode; natural waters; rainwater; 16771 .

Seawater corrosion; splash zone corrosion; cathodic protection; coating systems; corrosion protection; offshore corrosion; sand corrosion; Monogr. 158.

Second breakdown; semiconductor devices; thermal characterization; thermal instability; thermal resistance; transistors; hot spots; junction temperature; measurement technology; nondestructive test; reliability; safe operating limits; SP40O44.

Second breakdown; thermal instability; hot spots; measurement methods; power transistors; reliability; safe operating area limits; 16893 .

Second sound; shock wave; stress relaxation; structural relaxation; thermal relaxation; anharmonic crystal; computer simulation; energy transport; equation of state; interatomic potential; molecular dynamics; 16751.

Second virial coefficient; dipolar gas; numerical integration; polyatomic molecule; Pople expansion; quadrupolar gas; $J$. Res. 82, No. 2, 123-127 (1977).

Second virial coefficients; oxygen/fluorocarbon complex; oxygen/hydrocarbon complex; reversible oxygenation; 17216.

Second virial coefficients; water; ballistics; carbon dioxide; combustion gases; energy; equation of state; high pressure; high temperature; interaction virial coefficients; mixtures; molecular volumes; 17136 .

Secondary electron; energy distribution; photoemission; 16826.

Secondary emission; voltage contrast; backscattered emission; EBIC; microelectronic devices; scanning electron microscope; SP400-35.

Secondary fixed point; temperature fixed point; thermometry; gallium; International Practical Temperature Scale of 1968; melting point standard; 17049 .

Secondary flow; gas chromatography; molecular diffusion; moments; 16980.

Secondary ion mass spectrometry; surface analysis; ion imaging; ion microprobe; ion microscope; microanalysis; 17156.

Secondary measuring device; flow measurement, water; flow meters; instruments, flow measurement; level measurement; level-to-flow rate conversion; liquid flow; open channel flow measurement; SP484, pp. 91-108 (Oct. 1977).

Secondary particle suppression; accurate ion beam current measurement; current integrators; ion beam scanning; ion implantation; ion implantation dose measurement and control; SP400-39.

Secondary standards; $\mathrm{x}$ rays; electromagnetic spectra; gamma rays; 17246 .

Second-order Doppler; spin exchange; wall shift; active hydrogen maser frequency standard; cavity pulling; cavity-Q; cavity servo; Crampton effect; frequency stability; hydrogen line Q; hydrogen line servo; magnetic field; passive hydrogen maser frequency standard; 17180 .

Sectorization; spheralites; chain folding; curved crystals; extended chain crystais; fold domains; fold surfaces; interlamellar links; morphology; polymer; 16958.

Security; citizen rights; computers, confidentiality; data systems; health records; information policy, management principles; medical records; privacy; recordkeeping practices; SP469.

Security; small protection domains; types; capability; capabilitybased addressing; computer security; extended-type objects; operating system structures; protection; reliable software; reliability; 16920.

Security; work factor; cryptanalysis; cryptography; encryption; key management; known plaintext attack; NBSIR 77-1291. 
Security alarms; SRM's; time and frequency; ultraviolet; computer memories; computer performance; inventor; molecular identity; preserving stone; pressure measurements; rf-power meter; roofing; safety; DIM/NBS 61, No. 8, 1-32 (1977).

Security and law enforcement; law enforcement; optics; 17339.

Security equipment; surveillance equipment; alarm systems; cameras; police; police equipment; $S P 480-4$.

Security lighting; security systems; visibility level; visual processes; contrast; detection; illumination; incapacitation; psychological deterrence; recognition; SP480-27.

Security standards; burglary resistance; door assemblies; door components; doors; frames; hardware; hinges; locks; 16714.

Security systems; visibility level; visual processes; contrast; detection; illumination; incapacitation; psychological deterrence; recognition; security lighting; $S P 480-27$.

Security terms; windows; definitions; doors; glossary; SP480-22.

Seed-slag interaction; thermal decomposition of $\mathrm{K}_{2} \mathrm{O}-\mathrm{SiO}_{2}$ solutions; vapor pressure of $\mathrm{K}_{2} \mathrm{O}-\mathrm{Al}_{2} \mathrm{O}_{3}$ phases; vapor pressure of $\mathrm{K}_{2} \mathrm{O}-\mathrm{SiO}_{2}$ solutions; 16897 .

Seismic; costs; existing structures; optimization; retrofitting; SP477, pp. VI-69-VI-84 (May 1977).

Seismic; earthquake; program; research; SP477, pp. VI-28-VI36 (May 1977).

Seismic; shear walls; spandrel beams; connections; houses; masonry; piers; research; BSS106, pp. 60-90 (Sept. 1977).

Seismic; testing; wind; earthquake; research programs; SP477, pp. V1-37-VI-43 (May 1977).

Seismic; wooden house; classification; damage; intensity; SP477, pp. IV-1 -IV-17 (May 1977).

Seismic coefficient; acceleration; accelerogram; gravity quaywall; rock motion; SP477, pp. VI-192-VI-198 (May 1977).

Seismic design; structural design; structural engineering; structural research; building codes and standards; design criteria; earthquake resistance; masonry construction; BSSIO6.

Seismic design; structural design; structural research; building codes and standards; design criteria; earthquake resistance; limit states design; masonry construction; materials testing standardization; mathematical models; rehabilitation; BSSI06, pp. 40-59 (Sept. 1977).

Seismic design criteria; building codes; buildings; construction; dwellings; earthquakes; SP470, pp. VI-74-VI-88 (Apr. 1977).

Seismic effects; tornado; wind; nuclear power plant; SP477, pp. VII-1 - VII-28 (May 1977).

Seismic index; seismicity; earthquake; index; quake-sensitivity; SP477, pp. IV-47-IV-54 (May 1977).

Seismic loading; masonry; masonry panels; BSSI06, pp. 154. 165 (Sept. 1977).

Seismic loading; shear strength; shear wall; stiffness; analysis; compressive strength; deflection; design; flexural strength; masonry walls; racking strength; BSS62.

Seismic provisions; specifications; structural engineering; earthquakes; highway bridges; SP470, pp. VIII-1-VIII-30 (Apr. 1977).

Seismic provisions; specifications; bridges; earthquake design; earthquake forces; SP470, pp. VIII-31-VIII-41 (Apr. 1977).

Seismic records; velocity; data; displacements; intensity; SP477, pp. VI-179-VI-191 (May 1977).

Seismic response; two-dimensions; bedrock; modeling; rheological; SṔ477, pp. IV-18-IV-46 (May 1977).

Seismicity; earthquake; index; quake-sensitivity; seismic index; SP477, pp. IV-47-IV-54 (May 1977).

Seismicity; soils; standards; structural response; vessels and wind; accelerograph; bridges; buildings; codes; disaster; dynamic analysis; earthquakes; ground failures; hydraulic structures; SP470.

Seismicity; soils; standards; structural response; winds; accelerograph; bridges; buildings; codes; disaster; dynamic analysis; earthquakes; ground failures; nuclear facilities; SP477.
Seismicity index; earthquake distributions; epicenters; maps; SP470, pp. III-18-Ill-28 (Apr. 1977).

Seismometers; arrays; earthquakes; ground motion; records; results; SP477, pp. III-16-III-25 (May 1977).

Selected area electron channeling pattern; crystal orientation determination; crystallographic contrast; electron channeling contrast; microstructural analysis; scanning electron microscope; 16839.

Selection of ADPS; Air Force Academy; benchmark tests; development of benchmarks; live test demonstrations; SP50O18, pp. $71-74$ (Sept. 1977).

Selection of variables in linear regression; statistical plotting; stem-and-leaf displays; table making; automatic printing; Calcomp plotting; data editing; interactive; labels; numerical analysis; OMNITAB II computing system; probability plotting; NBSIR 77-1276.

Selection rules; van der Waals; atomic collision; excitation transfer; laser stimulation; orbiting; saturation; 16695.

Selective chemical etching; semiconductor device reliability; corona charging decoration; dielectric defect detection; electrophoretic decoration; integrated circuit quality control; SP400-31.

Selenium; tin; arsenic; atomic absorption; gas chromatography; organometal; 16811

Self-balancing two amplifier power meter; bolometer; D.C.-substitution technique; differential operational amplifiers; microwave power meter; U.S. Patent 4,008,610.

Self-calibration techniques; six-port junction; impedance; microwaves; network analyzer; reflection coefficient; reflectometer; scattering parameters; 17244.

Self-discharge; battery; microcalorimetry; pacemaker; power cell; NBSIR 77-1310.

Self-help; standards; building codes; building regulation; do-ityourself; home construction; housing; rehabilitation; remodeling; renewal; renovation; NBS-GCR-77-88.

Self-preserving; size distribution; aerosols; asymptotic analysis; broad initial distribution; coagulation; electrical aerosol analyzer; 17282 .

Semi analytical; spatial; transmission; anisotropy; charged particle; computer code; energy-angle; integral; legendre polynomial; scattering; SP461, pp. 140-143 (Jan. 1977).

Semiconductor characterization; silicon; square array; collector resistivity; epitaxial resistivity; four-probe; resistivity; resistivity correction factors; 16942 .

Semiconductor device reliability; corona charging decoration; dielectric defect detection; electrophoretic decoration; integrated circuit quality control; selective chemical etching; SP400-31.

Semiconductor device studies; electronic reliability; electronics; laser scanner; measurement method; mixer; optics; pre-amplifier; radio receiver; $S P 400-24$.

Semiconductor devices; batteries; cardiac pacemakers; hermeticity; hybrid devices; leak testing; measurement technology; microcalorimetry; pacemaker leads; process control; reliability; screen tests; SP400-42.

Semiconductor devices; capacitance-voltage measurements; dielectric breakdown suppression; discharge suppression; electronics; extended-range MIS C (V) measurements; highvoltage $\mathrm{C}$ (V) measurements; MIS capacitor; premature dielectric breakdown; SP400-37.

Semiconductor devices; device inspection; electron-beam-induced current; microelectronics; $p$ - $n$ junctions; scanning electron microscopy; 16891 .

Semiconductor devices; device inspection; electron-beam-induced-current; microelectronics; $\boldsymbol{p}-\boldsymbol{n}$ junctions; scanning electron microscopy; 16971 .

Semiconductor devices; electron beam energy deposition; ionizing radiation effects; radiation dose; radiation testing; scanning electron microscope; NBSIR 77-1235. 
Semiconductor devices; semiconductor materials; semiconductor process control; electronics; measurement methods; microelectronics; National Bureau of Standards; 16894.

Semiconductor devices; semiconductor materials; semiconductor process control; silicon; silicon dioxide; silicon on sapphire; sodium contamination; spreading resistance; surface roughness; test patterns; thermally stimulated current; transistors, power; TTL circuits; SP400-29.

Semiconductor devices; silicon-on-sapphire measurements; SOS measurements; bias-isolation unit; capacitance and conductance measurements at high applied-bias voltage; capacitance/conductance-meter; capacitance-voltage measurements; electronics; SP400-40.

Semiconductor devices; silicon-on-sapphire measurements; high-voltage bias supply; high-voltage $C(V)$ and $G(V)$ measurements; high-voltage function generator; high-voltage sweep; SP400-4I.

Semiconductor devices; standards; hermetic seals; leakage; nondestructive tests; 16943

Semiconductor devices; thermal characterization; thermal instability; thermal resistance; transistors; hot spots; junction temperature; measurement technology; nondestructive test; reliability; safe operating limits; second breakdown; SP4OO-44.

Semiconductor hermeticity; doubled hermetic enclosure; gas infusion of leaks; hermeticity; leak detection; 16935.

Semiconductor materials; semiconductor process control; electronics; measurement methods; microelectronics; National Bureau of Standards; semiconductor devices; 16894.

Semiconductor materials; semiconductor process control; silicon; silicon dioxide; silicon on sapphire; sodium contamination; spreading resistance; surface roughness; test patterns; thermally stimulated current; transistors, power; TTL circuits; ultrasonic wire bonding; SP400-29.

Semiconductor process control; electronics; measurement methods; microelectronics; National Bureau of Standards; semiconductor devices; semiconductor materials; 16894 .

Semiconductor process control; silicon; silicon dioxide; silicon on sapphire; sodium contamination; spreading resistance; surface roughness; test patterns; thermally stimulated current; transistors, power; TTL circuits; ultrasonic wire bonding; ultraviolet reflectance; $S P 400-29$.

Semiconductors; silicon; capacitance-voltage measurements; dopant density; Gaussian diffusion; p-n junction; 17328.

Semiconductors; silicon; silicon polishing; spreading resistance calibration; spreading resistance measurements; metalsemiconductor contacts; resistivity; 17139 .

Semiempirical potential; theoretical potential; anisotropic interactions; $\mathrm{HCl}-\mathrm{Ar}$; linear molecules; rotational line widths; 16799.

Semi-numerical; transport; integral equation; radiation; scattering; SP46I, pp. 79.86 (Jan. 1977).

Semirigid rods; bent rods; form factors; light scattering; macromolecules; rodlike; rodlike macromolecules; rods, bent; rods, semirigid; 17253 .

Semistable; convex hull; eigenvalue; field of values; positive semidefinite; 16819.

Sensitivity; stability; thermal effects; zero-shift; accuracy; calibration; cryogenic; dynamic; frequency response; hysteresis; precision; pressure measurement; 17081 .

Sensitivity; stress; thermoluminism; quartz; SP461, pp. 231-233 (Jan. 1977).

Sensitivity; supralinear; thermoluminescence; dose; gamma rays; LiF; response; SP461, pp. 227-230 (Jan. 1977).

Sensitivity; temperature; calibration; ceramic; condenser; electret; humidity; microphones; reciprocity; 16701 .

Senritivity; temperature; calibration; ceramic; condenser; electret; humidity; microphones; reciprocity; 17245 .

Sensitivity index; sensitometry; Van Kreveld's additivity law; exposure; exposure control; film thickness; irradiance measurements; photoresist; 17329.
Sensitivity index; Van Kreveld's additivity law; exposure; exposure control; film thickness variation; irradiance measurements; photoresist; photoresist sensitivity; 16853.

Sensitivity test; TNT; vapor generator; vapor pressure; DNT; EGDN; explosive detection; limits of detection; 16830 .

Sensitization; stainless steel; crevice corrosion; iron-molybdenum alloys; localized corrosion; repassivation; NBSIR 761170 .

Sensitometry; Van Kreveld's additivity law; exposure; exposure control; film thickness; irradiance measurements; photoresist; sensitivity index; 17329.

Sensor systems; adversary scenarios; automated response systems; distributed processing; monitoring systems; physical security; NBSIR 77-1262.

Sensors; adaptive; automation; computer; control; goaloriented; hierarchical control; robot; SP5O0-23.

Sensory irritation; stress index; thermal decomposition products; toxicity; acute lethality; Douglas Fir; inhalation; mice; polyurethane; pulmonary irritation; PVC; respiratory rate; NBS-GCR-77-85.

Sensory stimuli; communications; disaster communication; emergency communications; fire communications; high-rise communications; high-rise emergency; information transfer; occupant needs; 17036.

Separable potential; Coulomb excitation; electron scattering; Faddeev equations; helium-three; monopole transition; 16793.

Serber theory; thick target; tlme-of-flight; ${ }^{8} \mathrm{Be}(\mathrm{d}, \mathrm{n}){ }^{10} \mathrm{~B} ;{ }^{8} \mathrm{Be}\left({ }^{3} \mathrm{H}\right.$ n) ${ }^{\text {II }}$ C; energy spectra; neutrons; Rossi-counter measurements; NBSIR 77-1279, pp. 31-34 (July 1977).

Serial-by-bit; serial-by-character; telecommunications; teleprocessing; American Standard Code for Information Interchange; ASCII; communications; data communications equipment; data processing terminal equipment; data transmission; FIPS PUB 16-1.

Serial-by-bit; telecommunications; teleprocessing; American Standard Code for Information Interchange; ASCII; character parity sense; character structure; communications; data transmission; Federal Information Processing Standards; FIPS PUB 17-1.

Serial-by-character; telecommunications; teleprocessing; American Standard Code for Information Interchange; ASCII; communications; data communications equipment; data processing terminal equipment; data transmission; FIPS PUB 16-1.

Serial-by-character; telecommunications; teleprocessing; American Standard Code for Information Interchange; ASCII; character structure; communications; data transmission; Federal Information Processing Standards; parallel-by-bit; parity sense; FIPS PUB $18-1$.

Serials; standards; transactions; annual reports; diffusion in metals; fire; journals; library holdings, NBS Library; NBS periodicals; periodicals; proceedings; NBSIR 77-1215.

Service; teleprocessing systems measurement; computer network measurement; data acquisition; interactive computer access; measurement; network measur ement services; 17252 .

Servo techniques; time domain stability; atomic frequency standard; frequency discrimination; frequency domain stability; frequency-lock loop; phase-lock loop; phase noise; TN692.

Set; surveillance limits; surveillance test; test interval; true mass; value; weighing design; weights; apparent mass; buoyancy; buoyancy correction; change; comparison; difference; mass; records; NBSIR 76-999.

Settlement; soils; alluvial deposits; earthquakes; epicentral distance; liquefaction; SP470, pp. V-1 -V-15 (Apr. 1977).

Sewerage flow; wastewater flow; closed conduit flow; instrumentation; measuring flow; metering flow; monitoring flow; open channel flow; public law 92-500; SP484, pp. 83-89 (Oct. 1977). 
SFRL frequency measurement; spin flip Raman laser; frequency measurements on tunable lasers; IFS with a tunable laser; infrared frequency synthesis; 16728 .

Shading; signal-to-noise ratio; spectral response; standards; television cameras; total response; contrast transfer function; distortion; limiting resolution; 17233 .

Shading; solar-heating; ventilation; windows; air-tightness; daylighting; energy-conservation; insulation; BSS104.

Shading coefficient; solar heat gain; window design; climatic data; cloud cover modifier; energy conservation; 17341 .

Shake table; aseismic design; dynamic tests; nuclear reactors; oil tanks; power plants; SP470, pp. VII-1--VIl-6 (Apr. 1977).

Shake table; testing; transformer; circuit breaker; data; experiment; SP477, pp. VI-50_-_VI-60 (May 1977).

Shake table; vibration tests; void ratios; earthquakes; liquefaction; sand layer; SP470, pp. V-16-V-35 (Apr. 1977).

Shake tables; testing; dynamic testing; lateral load simulation; models; SP470, pp. IX-1-IX-5 (Apr. 1977).

Shape; stability; surface tension; floating zone; gravity; liquid zone; 17009 .

Shape; standards; thermal; ${ }^{6} \mathrm{Li}(\mathrm{n}, \alpha) ;{ }^{10} \mathrm{~B}(\mathrm{n}, \alpha) ;{ }^{235} \mathrm{U}(\mathrm{n}, \mathrm{f})$; cross section; neutron; normalization; resonance; SP493, pp. 174 181 (Oct. 1977).

Shape stability; silicon; crystal growth; floating zone; meniscus; perturbation; 16931 .

Shear; strength; apartment building; collapse; concrete; concrete strength; construction; flexure; progressive collapse; BSS94.

Shear; transverse gradient; wavenumber; duct; fundamental mode; liquid; perfect gas; propagation; 17215 .

Shear modulus; single-crystal elastic coefficients; sound velocities; Young's modulus; zinc; bulk modulus; compressibility; Debye temperature; elastic constants; Poisson's ratio; JPCRD 6, No. 4, 1181-1204 (1977).

Shear modulus; sound velocity; Young's modulus; bulk modulus; compressibility; Debye temperature; elastic constant; invar; iron alloy; nickel alloy; Poisson's ratio; 16869.

Shear modulus; sound velocity; Young's modulus; bulk modulus; composite; compressibility; copper; elastic constants; niobium-titanium; Poisson's ratio; pulse method; resonance method; 17068 .

Shear modulus; sound velocity; Young's modulus; aluminum alloys; bulk modulus; compressibility; Debye temperature; Poisson's ratio; precipitation-hardening alloys; 17085 .

Shear modulus; sound velocity; Young's modulus; bulk modulus; compressibility; copper alloy; elastic constant; Poisson ratio; precipitation hardening; 17094 .

Shear modulus; sound velocity; Young's modulus; bulk modulus; compressibility; copper alloy; Debye temperature; elastic constants; Poisson's ratio; 17320.

Shear modulus; sound velocity; stainless steel; Young's modulus; bulk modulus; compressibility; elastic constants; Poisson's ratio; pulse method; resonance method; 17321 .

Shear modulus; testing; ultimate strength; anchor bolts; bond; damping; ductility; earthquake resistance; energy absorption; modulus of elasticity; partial reinforcing; risk; BSSI06, pp. 255-258 (Sept. 1977).

Shear modulus; torsional modulus; Young's modulus; aluminum; boron-aluminum; bulk modulus; composite; compressibility; elastic constants; resonance method; 17087.

Shear modulus; Young's modulus; elastic constants; face-centered-cubic solids; polycrystals; 17099.

Shear strength; shear wall; stiffness; analysis; compressive strength; deflection; design; flexural strength; masonry walls; racking strength; seismic loading; $B S S 62$.

Shear wall; stiffness; analysis; compressive strength; deflection; design; flexural strength; masonry walls; racking strength; seismic loading; shear strength; BSS62.
Shear wall; stiffness; buildings; damage; dynamic response; earthquakes; safety; SP470, pp. Vl-33-Vl-46 (Apr. 1977).

Shear walls; codes; design; dynamic analysis; masonry; BSS106, pp. $91-113$ (Sept. 1977).

Shear walls; current research; ductility; full scale testing; highrise masonry; scale factors; BSS106, pp. 314-326 (Sept. 1977).

Shear walls; spandrel beams; connections; houses; masonry; piers; research; seismic; BSS106, pp. 60-90 (Sept. 1977).

Shear walls; splitting strength; ultimate capacity; brick; clay masonry; concrete block; concrete masonry; failure modes; load capacity; masonry walls; BSS106, pp. 177-197 (Sept. 1977).

Shear wave; statistical mechanics; time correlation function; transverse current; ultrasonics; correlation function; density fluctuations; fluctuations; hydrodynamics; light scattering; liquid state; molecular dynamics; neutron scattering; 16711 .

Shearing eyepiece; dimensional standards; filar eyepiece; linewidth measurements; micrometer eyepiece; microscope calibration; optical microscope; photomasks; photomask metrology; optical microscope; 17063.

Shedding frequency; vortex flowmeter; vortex generating element; vortex shedding; linearity; SP484, pp. 549-570 (Oct. 1977).

Sheet piles; structural analysis; tests; foundation; lateral loads; SP470, pp. VII-7-VII-60 (Apr. 1977).

Sheet resistance; sheet resistor test structure; test structures; van der Pauw; cross test structure; cross van der Pauw; numerical analysis; 17165 .

Sheet resistor test structure; test structures; van der Pauw; cross test structure; cross van der Pauw; numerical analysis; sheet resistance; 17165 .

Sheet resistors; silicon; test structures; defects; dopants; impurities; junctions; MOS capacitors; 16855.

Shell model; sum rules; giant resonance; hydrodynamic model; isospin; photonuclear; 16987.

Shield; transmission; ${ }^{252}$ Cf; ANISN; code; configuration; dose equivalent; energy; gamma rays; neutron; scattering; SP46I, pp. 119-123 (Jan. 1977).

Shield thickness; calculation; concrete; cyclotron; design; earth shield; neutron spectra; shielding; SP461, pp. 166-170 (Jan. 1977).

Shielding; angle; centre of mass; coefficients; computations, cross-section; Legendre polynomial; neutron; random sampling; scattering; SP461, pp. 100-105 (Jan. 1977).

Shielding; computer code; data library; information; radiation; radiation analysis; RSIC; SP461, pp. 171-173 (Jan. 1977).

Shielding; shield thickness; calculation; concrete; cyclotron; design; earth shield; neutron spectra; SP461, pp. 166-170 (Jan. 1977).

Shielding; sources; standardization; calibration; detection; dosimetry; facilities; fluence; flux; moderation; monitor; neutron; SP493, pp. 115-120 (Oct. 1977).

Shielding; spectrum; computer code; dose; dosimetry; monitor; neutron; SP461, pp. 238-246 (Jan. 1977).

Shielding; standard; American Nuclear Society; radiation; SP461, pp. 74-78 (Jan. 1977).

Shielding; transport calculation; approximations; diffusion; neutron; NIOBE; Rapsodie; reactor; SP461, pp. 163-165 (Jan. 1977).

Shielding; weapons; computer codes; materials properties; nuclear data; radiation transport; reactor; RSIC; SP463, pp. 111.1.1-111.1.10 (Jan. 1977).

Shipboard; thermal conductivity; compartment fires; fire-retardants; insulation; mattresses; NBSIR 77-1295.

SHIVA laser; silicon; timekeeping; ultraviolet radiation; calibration; consumers; energy; energy savings; grain moisture; mass spectra; radiation sterilizing; screw thread standards; DIM/NBS 61, No. 9, 1-32 (1977). 
Shock tube; tape; thermal protection; thermal radiant-energy response; thermal transient response; transducer; zero shift; coatings; delayed response; dynamic; dynamic response; pressure step; pressure transducer; protective coatings; TN961.

Shock wave; stress relaxation; structural relaxation; thermal relaxation; anharmonic crystal; computer simulation; energy transport; equation of state; interatomic potential; molecular dynamics; second sound; 16751 .

Shocks, snow load; static load; trains; transportation; trucks; vibrations; wind load; acceleration; airplanes; cargo; dynamic loads; equivalent static force; gravity load; handling devices; handling loads; military field shelters; probability distributions; NBSIR 77-1254.

Shoe sole and heel materials; slip-resistance tester; walkway surfaces; waxes and polishes; flooring; floor treatments; TN953.

Short-lived molecular species; vibration-rotation spectra; carbon monosulfide; Dunham coefficients; infrared absorption; molecular physics; 17044.

Shotcrete, surface wave instrumentation; veneer anchorage; allowable bolt loads, end distance, edge distance and spacing; drift; face shells, reinforcing splices; high lift grouting; BSS106, pp. 259-274 (Sept. 1977).

Sl; building codes and standards; construction industry; dimensional coordination; metrication; metric system; modular coordination; SP458.

SI; Système International des Unités; Units of Measurements; General Conference on Weights and Measures; International System of Units; SP330.

Signal analysis; wave propagation in Plate; acoustic emission; acoustic emission simulator; capacitive transducer; Plate Green's function; 17191 .

Signal processing; derivative operators; digital scan generator; isotropy; photographic processing; scanning electron microscopy; 16988.

Signal processing; ultrasound; chirp radar; medical diagnosis; pulse compression; 16735 .

Signal to noise; star flux; figure of merit; G/T; measurement accuracy; radio stars; satellite earth terminal; 17227.

Signal-to-noise ratio; spectral response; standards; television cameras; total response; contrast transfer function; distortion; limiting resolution; shading; 17233.

Signal-to-noise ratio; square wave pattems; television cameras; contrast; contrast transfer function; image quality; limiting resolution; relative spectral response; SP480-25.

Signature analysis; wear; failure detection; failure diagnosis; failure prevention; ferrography; land vehicle diagnostics; oil analysis; railroad system diagnostics; SP494.

SiH stretching vibrations; vibration-rotation interaction; high resolution; infrared spectrum; monodeutero silane; 17131 .

Silicon; capacitance-voltage measurements; dopant density; Gaussian diffusion; p-n junction; semiconductors; 17328.

Silicon; crystal growth; floating zone; meniscus; perturbation; shape stability; 16931 .

Silicon; direct-current; dopant density; ion implantation; MOSFET; 17342.

Silicon; silicon dioxide; silicon on sapphire; sodium contamination; spreading resistance; surface roughness; test patterns; thermally stimulated current; transistors, power; TTL circuits; ultrasonic wire bonding; ultraviolet reflectance; $x$-ray damag; acoustic emission; SP400-29.

Silicon; silicon polishing; spreading resistance calibration; spreading resistance measurements; metal-semiconductor contacts; resistivity; semiconductors; 17139.

Silicon; square array; collector resistivity; epitaxial resistivity; four-probe; resistivity; resistivity correction factors; semiconductor characterization; 16942.

Silicon; synthesis; thin film; vapor transport; activation parameters; active nitrogen; iodine; kinetics; microwave discharge; nitride; plasma; reaction mechanism; 16757.
Silicon; test pattern; visual alignment structure; electrical mask alignment; integrated circuit; photolithography; 17330.

Silicon; test structures; defects; dopants; impurities; junctions; MOS capacitors; sheet resistors; 16855 .

Silicon; thermally stimulated capacitance; thermally stimulated c'irrent; thermally stimulated measurements; thyristor matenals measurements; thyristor measurements; d-c transmission; energy conservation; measurement methods; photovoltaic method; power-device grade silicon; 17345 .

Silicon; thermally stimulated capacitance; thermally stimulated current; thermally stimulated measurements; thyristor materals measurements; thyristor measurements; d-c transmission; energy conservation; measurement methods; photovoltaic method; NBSIR 77-1249.

Silicon; timekeeping; ultraviolet radiation; calibration; consumers; energy; energy savings; grain moisture; mass spectra; radiation sterilizing; screw thread standards; SHIVA laser; DIMINBS 61, No. 9, 1-32 (1977).

Silicon; trace analysis; chemical measurements; electrical measurements; electronics; profiling; 17140.

Silicon avalanche diode; solid state noise source; stability; argon gas discharge noise source; 16669.

Silicon carbide; silicon nitride; acoustic emission; brittle matenals; crack growth; cyclic loading; fracture mechanics; high temperature; proof testing; 17039.

Silicon cell; silicon detector; silicon photodetector; absolute radiometry; detector; electrically calibrated detectors; laser power measurements; pyroelectric detectors; radiometry; TN954.

Silicon crystal density standards; volume reduction factors; petroleum measurement; 17023.

Silicon detector; silicon photodetector; absolute radiometry; detector; slectrically calibrated detectors; laser power measurements; pyroelectric detectors; radiometry; silicon cell TN954

Silicon detectors; absolute radiant power measurements; detector radiometry; detector response transfer instrumentation radiometers; TN950.

Silicon detectors; absolute spectral response; detector uniformity; linearity; photodetectors; 16754.

Silicon dioxide; silicon on sapphire; sodium contamination; spreading resistance; surface roughness; test patterns; thermally stimulated current; transistors, power; TTL circuits; ultrasonic wire bonding; ultraviolet reflectance; $x$-ray damag acoustic emission; SP400-29.

Silicon dioxide; sodium contamination; thermal oxidation; fused silica; microelectronic; MOS; oxidation furnace; 16939.

Silicon dioxide film; electron-gun evaporator; gate oxide film; metal evaporation; metallization; metal-oxide semiconductor; microelectronic device; radiation dose; 16889.

Silicon monoxide; spectra; interstellar sources; isotope ratio; molecular lines; radio astronomy; 17189.

Silicon nitride; acoustic emission; brittle materials; crack growth; cyclic loading; fracture mechanics; high temperature proof testing; silicon carbide; 17039.

Silicon nitride; strength; brittle materials; ceramics; ceramic turbine; proof testing; NBSIR 77-1202.

Silicon nitride; surface flaws; thin foils; cracks; electron microscopy; grinding damage; oxidation; 17090.

Silicon nitride; turbine materials; cracks; electron microscopy; fracture interfaces; plastic deformation; NBSIR 76-1075.

Silicon on sapphire; sodium contamination; spreading resistance; surface roughness; test patterns; thermally stimulated current; transistors, power; TTL circuits; ultrasonic wire bonding; ultraviolet reflectance; $x$-ray damag; acoustic emission; SP400-29.

Silicon photodetector; absolute radiometry; detector; electrically calibrated detectors; laser power measurements; pyroelectric detectors; radiometry; silicon cell; silicon detector; TN954. 
Silicon polishing; spreading resistance calibration; spreading resistance measurements; metal-semiconductor contacts; resistivity; semiconductors; silicon; 17139.

Silicon-on-sapphire measurements; SOS measurements; biasisolation unit; capacitance and conductance measurements at high applied-bias voltage; capacitance/conductance-meter; capacitance-voltage measurements; electronics; extendedrange $C(V)$ and $G(V)$ measurements; SP400-40.

Silicon-on-sapphire measurements; high-voltage bias supply; high-voltage $C(V)$ and $G(V)$ measurements; high-voltage function generator; high-voltage sweep; semiconductor devices; SP400-4I.

Silver diethyldithiocarbamate method; arsenic reduction; arsenic speciation; biological and organic materials; 17257.

"Silver/Gold," marking of; jewelry; PS68-76.

Simulated behavior; building fires; fire behavior; high-rise buildings; occupant behavior in fires; NBS-GCR-77-92.

Simulated smoke concentration; smoke control; smoke movement; smoke simulation; systematic pressurization; air-handling units; building pressure profile; computer simulation; elevator shaft pressure profiles; parametric analysis; NBSIR 77-1225.

Simulation; accident; apparel; burn injury; fabric flammability; fabrics; fire; garments; heat transfer; injury hazard; NBSIR $77-1236$

Simulation; IBM OS/MVT; initiator policy; job scheduling; SP500-18, pp. 235-248 (Sept. 1977).

Simulation; software monitoring; workload definition; ADP life cycle; computer performance evaluation; computer performance measurement; computer performance prediction; computer system acquisition; conference proceedings; CPEUG; hardware monitoring; SP500-18.

Simulation; transportation; validation of models; airport simulation; air traffic control; aviation; models; 16944.

Simulation; utility services; computer programs; cooling; energy analysis; financial analysis; heating; load calculation; MIUS; modular integrated utility system; NBSIR 77-1307.

Simultaneous measurements; spectra; water jet; auto-correlation; convective velocity; cross-correlation; exit concentration; exit velocity; flow visualization; fluorescence; fluorescent dye; laser; laser dye-fluorescence technique; SP484, pp. 423-447 (Oct. 1977).

Single bead contribution to I.V.; torque on the bead; average gradient; intrinsic viscosity; nonrotating bead; 17119 .

Single crystal; activation energies; molecular orientations; $\mathrm{NH}_{4} \mathrm{ClO}_{4}$; quasi-elastic neutron scattering; residence times; 17003.

Single crystal; symmetry; identification; lattice; powder method; reduced cell; 17050 .

Single crystal; thermal conductivity; beryllium; cryogenics; electrical conductivity; heat switch; Lorenz ratio; magnetic field; 17088.

Single crystal $\mathrm{x}$-ray structure determination; 4-hydroxy-4Hfuro $(3,2 c)$ pyran-2 $(6 H)$-one; antibiotic; hydrogen bonding; patulin; refined structure; 16913 .

Single-crystal elastic coefficients; sound velocities; Young's modulus; zinc; bulk modulus; compressibility; Debye temperature; elastic constants; Poisson's ratio; shear modulus; JPCRD 6, No. 4, 1181-1204 (1977).

Single-lap-joint analysis; single-lap-joint bending; spotwelded joints; weldbonded joints; adhesive-bonded joints; bonded joints; cyclic loading; debond analysis; double-lap-joint analysis; fatigue tests; finite element analysis; joints; nonlinear analysis; NBSIR 76-1053.

Single-lap-joint bending; spotwelded joints; weldbonded joints; adhesive-bonded joints; bonded joints; cyclic loading; debond analysis; double-lap-joint analysis; fatigue tests; finite element analysis; joints; nonlinear analysis; single-lap-joint analysis; NBSIR 76-1053.
Singularity expansion method; symmetry analysis; antenna patterns; characteristic modes; Garbacz characteristic modes; group theory; inverse scattering; moment methods; scattering; 17225 .

Sirens; standards; emergency warning lights; police equipment; SP480-3.

Site design; architectural controls; buildings; design review; land use; municipalities; regulation; SP473, pp. 137-187 (June 1977).

Sites and services; socio-economic; structural design; wind-resistant; architectural; design; housing; low income; low-rise buildings; BSS 100-5.

Six-port; automatic network analyzer; automation; microwave; microwave measurement; 16726.

Six-port; automatic network analyzer; automation; microwave measurements; 17237

Six-port; automatic network analyzer; automation; microwave measurements; 17240

Six-port; automation; millimeter wave; power measurement; reflection measurement; 17243.

Six-port concept; microwave measurements; one-port microwave parameters; 17234 .

Six-port junction; impedance; microwaves; network analyzer; reflection coefficient; reflectometer; scattering parameters; self-calibration techniques; 17244 .

Six-port voltmeter; vector voltmeter; microwave voltmeter; phase angle measurements; U.S. Patent 4,001,681.

Size distribution; aerosols; asymptotic analysis; broad initial distribution; coagulation; electrical aerosol analyzer; selfpreserving; 17282.

Size distribution; smoke; smoke detector; test method; UL 217; aerosol; mass concentration; number concentration; NBSIR 77-1312.

Sizing studies; system design; computer-communication networks; configuration analysis; model validation; performance management; performance prediction; queuing networks; SP500-18, pp. 227-234 (Sept. 1977).

Skid resistance measurement; tire-pavement interface forces; wet pavement skid resistance; accident reduction, skidding; highway safety; measurement, skid resistance; pavement skid resistance; NBSIR 76-I175.

Skid resistance, measurement; tire-pavement interface forces; wet pavement skid resistance; accident reduction, skidding; correlation, skid resistance; highway safety; measurement, skid resistance; pavement, skid resistance; pavement wetting system; NBSIR 77-1213.

Skylab/ASTP; space processing; convection; crystal growth; microgravity; 17275 .

Sky-shine; spectrum; ${ }^{60} \mathrm{Co}$; back scattering; gamma rays; SP461, pp. 124-128 (Jan. 1977).

Slags; cement manufacture; energy conservation; fly ashes; mineral waste utilization; 17010 .

Slags; waste materials; coal by-products; construction materials; industrial wastes; mining wastes; municipal waste; NBSIR 77 . 1244.

Slip-resistance of bathtub and shower base surfaces; slip-resistance testers; Kollsman tester; NBS-Brungraber tester; safety of bathrooms; NBSIR 76-1005.

Slip-resistance tester; walkway surfaces; waxes and polishes; flooring; floor treatments; shoe sole and heel materials; TN953.

Slip-resistance testers; Kollsman tester; NBS-Brungraber tester; safety of bathrooms; slip-resistance of bathtub and shower base surfaces; NBSIR 76-1005.

Slit correction; small angle scattering; unsmearing; FORTRAN program; integral equation; interpolating polynomial; numerical stability; TN936.

Slit width; spectral transmission; spectrophotometer standards; stray light; wavelength scale; errors in spectrophotometry; photometric scale; SP466, pp. 117-120 (May 1977). 
Slowing down; stochastic; BESM-6; JEZEBEL; Markov process; neutron; PURNIMA; Rossi- $\alpha$; SP461, pp. 97-99 (Jan. 1977).

Slush; solid; vapor; computer programs; enthalpy; entropy; hydrogen; internal energy; liquid; oxygen; PVT; quality; NBSIR 77-859.

SMA connectors; insertion loss; reflection coefficient; repeatability; 16722 .

Small angle neutron scattering; conformation; deuterated polystyrene-poly(methylmethacrylate); diblock copolymer; radius of gyration; 16817 .

Small angle scattering; unsmearing; FORTRAN program; integral equation; interpolating polynomial; numerical stability; slit correction; TN936.

Small protection domains; types; capability; capability-based addressing; computer security; extended-type objects; operating system structures; protection; reliable software; reliability; security; 16920.

Small watersheds; stream gages; streamflow measurements; weirs; approach channels; broad-crested V-notch weirs; calibration; SP484, pp. 187-200 (Oct. 1977).

Small-scale turbulence; boundary-layer; higher-order moments; hot-wire anemometry; log-normal distribution; 16820 .

Smog formation; SRM's; air pollution; attic ventilation; data encryption; dental materials; fire safety; metric; miniature electric field; organic sulfur; radiometric detector; DIM/NBS 61 , No. 11, 1-32 (1977).

Smoke; smoke density chamber; smoke suppressants; fire performance; horizontal and vertical smoke measurements; NBSIR 76-1030.

Smoke; smoke detector; test method; UL 217; aerosol; mass concentration; number concentration; size distribution; NBSIR 77-1312.

Smoke; statistical analysis; building fires; egress; fire alarms; fire incidents; fire investigations; fires; human behavior; project people; residential buildings; NBS-GCR-77-94.

Smoke; Steiner Tunnel Test; ASTM E 84; fire tests; flame spread; heat flux; heat release rate; oxygen depletion; TN945.

Smoke control; smoke movement; smoke simulation; systematic pressurization; air-handling units; building pressure profile; computer simulation; elevator shaft pressure profiles; parametric analysis; simulated smoke concentration; NBSIR 77-1225

Smoke control; smoke simulation experiments; sulfur-hexafluoride; systematic pressurization; air-handling system; Chicago federal building; highrise; pressure profiles; Seattle federal building; 17291 .

Smoke control methods; smoke movement; smoke simulation; state-of-the-art review; basic principles; computer calculations; computer modeling; experimental methods; NBSIR 77. 1209

Smoke density chamber; smoke suppressants; fire performance; horizontal and vertical smoke measurements; smoke; NBSIR 76-1030.

Smoke detector; test method; UL 217; aerosol; mass concentration; number concentration; size distribution; smoke; NBSIR 77-1312

Smoke detectors; building fires; fire detection devices; heat detectors; ionization chamber detectors; photoelectric detectors; 16737.

Smoke detectors; detector sensitivity; detector siting; escape time; fire tests; gas detectors; heat detectors; residential fires; NBS-GCR-77-82.

Smoke detectors; smoldering fires; temperature rise; wood; ceiling height; ceilings; cotton; detector location; fire detectors; fire growth; flaming fires; heat detectors; polyurethanes; polyvinyl chloride; NBS-GCR-77-95.

Smoke detectors; solar heating; SRM's; adobe; air pollution; corrosion; electrical; energy management; graphic pen; halocarbons; infrared lasers; international standard; neutron xeroradiography; problem-solving; radiation safety; DIM/NBS 61 , No. 3, 1-32 (1977).

Smoke detectors; standards; textiles; toxicity; arson; bibliographies; building fires; carpets; construction materials; fire departments; fire detection systems; fire tests; flame research; flammability tests; interior furnishings; mobile homes; polyurethanes; NBSIR 77-1277.

Smoke detectors; tenability levels; detector sensitivity; detector siting; heat detectors; ionization smoke detectors; photoelectric smoke detectors; residential fires; 16882 .

Smoke inhalation; toxicity; biological assessment; chemical analysis; combustion products; fire fatalities; NBSIR 77-1234.

Smoke movement; smoke simulation; state-of-the-art review; basic principles; computer calculations; computer modeling; experimental methods; smoke control methods; NBSIR 77. 1209.

Smoke movement; smoke simulation; systematic pressurization; air-handling units; building pressure profile; computer simulation; elevator shaft pressure profiles; parametric analysis; simulated smoke concentration; smoke control; NBSIR 77. 1225.

Smoke simulation; state-of-the-art review; basic principles; computer calculations; computer modeling; experimental methods; smoke control methods; smoke movement; NBSIR 77-1209.

Smoke simulation; systematic pressurization; air-handling units; building pressure profile; computer simulation; elevator shaft pressure profiles; parametric analysis; simulated smoke concentration; smoke control; smoke movement; NBSIR 771225.

Smoke simulation experiments; sulfur-hexafluoride; systematic pressurization; air-handling system; Chicago federal building; highrise; pressure profiles; Seattle federal building; smoke control; 17291 .

Smoke suppressants; fire performance; horizontal and vertical smoke measurements; smoke; smoke density chamber; NBSIR 76-1030.

Smoldering; wood; ceiling height; ceilings; cotton; detector location; detectors; fire detectors; polyurethanes; polyvinyl chloride; room fires; rooms; NBS-GCR-77-86.

Smoldering fires; temperature rise; wood; ceiling height; ceilings; cotton; detector location; fire detectors; fire growth; flaming fires; heat detectors; polyurethanes; polyvinyl chloride; smoke detectors; NBS-GCR-77-95.

Sn bonding; tin hydroxy phosphate; tin phosphate; asymmetric coordination; crystal structure; 16741 .

Social experimentation; administrative experimentation; evaluation; evaluation research; evaluation systems; policy analysis; 17116

Social optimum; standards; building economics; economic efficiency; economics; energy; energy conservation; life-cycle cost; optimization; performance standards; resource impact factors; resources; 17302

Socio-economic; structural design; wind-resistant; architectural; design; housing; low income; low-rise buildings; sites and services; BSSI00-5.

Socio-economics; structural connections; wind-loads; codes and standards; disaster mitigation; housing; low-rise buildings; SP477, pp. I-70-I-78 (May 1977).

Socio-economics; structural connections; technology transfer; wind loads; codes and standards; disaster mitigation; housing low-rise buildings; BSS100- 1 .

Socio-physical determinants; systems theory; energy consumption; input/output models; lifestyle factors; physical environ ment; residential housing; SP473, pp. 69-83 (June 1977).

Sodium; acid-base status; blood electrolytes; blood gases; blood pH; calcium; carbon dioxide; hydrogen ion - concentration nomograms; oxygen; $\mathrm{PCO}_{2} ; \mathrm{pH}$; potassium; $\mathrm{PO}_{2} ; \mathrm{SP} 450$.

Sodium beam; atomic beam; effusive oven; 16789 . 
Sodium contamination; spreading resistance; surface roughness; test patterns; thermally stimulated current; transistors, power; TTL circuits; ultrasonic wire bonding; ultraviolet reflectance; x-ray damag; acoustic emission; Auger electron spectroscopy; beam-lead bonds; SP400-29.

Sodium contamination; thermal oxidation; fused silica; microelectronic; MOS; oxidation furnace; silicon dioxide; 16939.

Sodium iodide detector; spectral measurements; Apollo 16,17; background correction; cosmic gamma ray; flux isotropy; 16938.

Sodium molecule; transition dipole moment; ab initio calculations; $A$-values; Franck-Condon factors; laser modeling; lifetime; multiconfiguration self-consistent-field; potential energy curves; 16870.

Soft x ray; extreme ultraviolet; flare-stellar; 16933 .

Software engineering; computer engineering; computer networks; computers; data processing; robots; 16903.

Software engineering; software quality; software reliability; computer management; computer programming; computer project control; computer software; SPS00-11.

Software engineering; software reliability; software testing; symbolic evaluation; symbolic testing; computer programming; cost analysis; NBS-GCR-77-89.

Software exchange; software guide; software index; software sharing; computer program index; Federal Software Exchange Program; proprietary software; public domain software; SP500-22.

Software guide; software index; software sharing; computer program index; Federal Software Exchange Program; proprietary software; public domain software; software exchange; SPSOO22.

Software index; software sharing; computer program index; Federal Software Exchange Program; proprietary software; public domain software; software exchange; software guide; SP500-22.

Software monitor; measuring response time; SPS00-18, pp. $107-$ 115 (Sept. 1977).

Software monitoring; workload definition; ADP life cycle; computer performance evaluation; computer performance measurement; computer performance prediction; computer system acquisition; conference proceedings; CPEUG; hardware monitoring; on-line system evaluation; SP500-18.

Software quality; software reliability; computer management; computer programming; computer project control; computer software; software engineering; SPSO0-II

Software reliability; computer management; computer programming; computer project control; computer software; software engineering; software quality; SP500-11.

Software reliability; software testing; symbolic evaluation; symbolic testing; computer programming; cost analysis; software engineering; NBS-GCR-77-89.

Software sharing; computer program index; Federal Software Exchange Program; proprietary software; public domain software; software exchange; software guide; software index; SP500-22.

Software, symposium proceedings; automated data systems; computer programs; documentation; documentation content guidelines; FIPS guidelines; SP500-15.

Software testing; symbolic evaluation; symbolic testing; computer programming; cost analysis; software engineering; software reliability; NBS-GCR-77-89.

Software tool; ADP; automated data processing; computer software; data element dictionary; data element dictionary/directory; data management; SPSO0-16.

Software tool; computer software; data base management system; data element dictionary/directory; data management; 16998.
Software tool; computer software; data base management system; data element dictionary/directory; information management; 17280 .

Software tool; computer software; data base management systems; data element dictionary; data element dictionary/directory; SP500-3.

Software tools; syntax analysis; text editing; building blocks; programming aids; SP500-14.

Soil; stiffness; testing; bore hole; k property; property; SP477, pp. VI-1 18-VI-140 (May 1977).

Soil properties; dynamics; field tests; laboratory tests; relationships; SP477, pp. VI-158-VI-178 (May 1977).

Soils; acceleration records; dynamic behavior; earthquakes; response spectra; SP477, pp. III-4 I - III-56 (May 1977).

Soils; alluvial deposits; earthquakes; epicentral distance; liquefaction; settlement; SP470, pp. V-1-V-1 S (Apr. 1977).

Soils; standards; structural response; vessels and wind; accelerograph; bridges; buildings; codes; disaster; dynamic analysis; earthquakes; ground failures; hydraulic structures; seismicity; SP470.

Soils; standards; structural response; winds; accelerograph; bridges; buildings; codes; disaster; dynamic analysis; earthquakes; ground failures; nuclear facilities; seismicity; SP477.

Soils; statistical analysis; underground; carbon steel; corrosion; ductile cast-iron; 16745 .

Soils; tests; undisturbed sampling; density; liquefaction; sand; SP477, pp. VI-141 - VI-157 (May 1977).

Solar; building design; cost; energy conservation; energy standards; fenestration; life-cycle costing; retrofitting; 17107.

Solar; computer; energy; radiation; BSS96.

Solar; standards; State; architecture; buildings; design; energy; legislation; NBSIR 77-1297.

Solar buildings; solar collectors; solar domestic hot water systems; standards; thermal storage; NBSIR 77-1272.

Solar collectors; solar domestic hot water systems; standards; thermal storage; solar buildings; NBSIR 77-1272.

Solar collectors; solar energy; standards; buildings; cooling; heating; performance criteria; SP473, pp. 103-112 (June 1977).

Solar collectors; structural performance; testing procedures; thermal performance; durability/reliability; fire safety; rating criteria; NBSIR 77-1305.

Solar domestic hot water systems; standards; thermal storage; solar buildings; solar collectors; NBSIR 77-1272.

Solar energy; energy choices; energy problem; energy resources; fossil fuels; nuclear power; 17031 .

Solar energy; standards; buildings; cooling; heating; laboratory accreditation; performance criteria; 16686.

Solar energy; standards; buildings; cooling; heating; performance criteria; solar collectors; SP473, pp. 103-112 (June 1977).

Solar energy; standards; state-of-the-art study; buildings; energy conservation; enforcement; legislation; regulations; NBSIR 77-1259.

Solar energy standards; standards users; communication of research and standards; National Bureau of Standards; 16733.

Solar heat gain; window design; climatic data; cloud cover modifier; energy conservation; shading coefficient; 17341 .

Solar heating; SRM's; adobe; air pollution; corrosion; electrical; energy management; graphic pen; halocarbons; infrared lasers; international standard; neutron xeroradiography; problem-solving; radiation safety; smoke detectors; DIM/NBS 61 , No. 3, 1-32 (1977).

Solar heating; surface temperature; built-up roofing; insulation; performance; radiative cooling; roofing; 17060.

Solar heating; surface temperature; built-up roofing; insulation; performance; radiative cooling; roofing; 17061 . 
Solar-heating; ventilation; windows; air-tightness; daylighting; energy-conservation; insulation; shading; BSS104.

Solder; thermal conductance; beryllium; copper; cryogenics; indium; joints; 16797.

Solid; vapor; computer programs; enthalpy; entropy; hydrogen; internal energy; liquid; oxygen; PVT; quality; slush; NBSIR 77-859.

Solid fuels; surface tension; combustion models; flame spread; fluid flow; laser doppler velocimetry; liquid fuels; NBS-GCR76-79.

Solid particle impact; transmission electron microscopy; ceramics; erosion; fracture; plastic flow; NBSIR 77-1396.

Solid standards; antibodies; antigens; biological polymers; immunochemical analysis; light scattering; polymers; proteins; SP466, Pp. 95-98 (May 1977).

Solid state data; standard reference data; thermodynamic data; transport properties; atomic and molecular data; chemical kinetics data; energy data; environmental data; industrial process data; materials utilization data; mechanical properties; nuclear data; TN947

Solid state dosimetry; dosimetry units; photon dosimetry; radiation; SP461, Pp. 197-208 (Jan. 1977).

Solid state noise source; stability; argon gas discharge noise source; silicon avalanche diode; 16669

Solids; surfaces; energy loss; ESCA; 17021

Solid-solid phase boundaries; AB-type compounds; calibration; critically evaluated data; crystallographic data; experimental melting curves; high pressure; JPCRD 6, No. 4, 1205-1252 (1977).

Solid-solid phase transformation; thermodynamics; hafnium; high-speed measurements; high temperature; 16767.

Solid-state detectors; standard cross section; ${ }^{10} \mathrm{~B}\left(\mathrm{n}, \alpha_{0}+\alpha_{1} \gamma\right)^{7} \mathrm{Li}$; ${ }^{10} \mathrm{~B}\left(\mathrm{n}, \alpha_{1} \gamma\right)^{7} \mathrm{Li}$; boron scintillators; $\mathrm{Ge}(\mathrm{Li})$; SP493, pp. $85-92$ (Oct. 1977).

Solubility; aromatic hydrocarbons; heat of solution; salting-out effect; 17038.

Solubility; chemical potential; dental caries; enamel; fluorapatite; fluoride; hydroxyapatite; 16739.

Solubility; solubility isotherms; solubility product; thermal coefficient of solubility; thermodynamics; tooth mineral; dissolution; hydroxyapatite; ion pairs; J. Res. 81A Nos. 2 and 3, 273-281 (1977).

Solubility; vapor pressure; 1-ethylnaphthalene; 1-methylnaphthalene; enthalpy; fluorescence; heat of solution; naphthalene; partition coefficient; 17097.

Solubility isotherms; solubility product; thermal coefficient of solubility; thermodynamics; tooth mineral; dissolution; hydroxyapatite; ion pairs; solubility; J. Res. $81 \mathrm{~A}$ Nos. 2 and 3, 273-281 (1977)

Solubility product; thermal coefficient of solubility; thermodynamics; tooth mineral; dissolution; hydroxyapatite; ion pairs; solubility; solubility isotherms; J. Res. 81 A Nos. 2 and 3, 273-281 (1977).

Solution; time-dependent; transport; transport equation; approximations; fast-thermal couple reactor; neutron; reactor transients; SP461, pp. $91-93$ (Jan. 1977).

Solutions; thermodynamic properties; activity coefficient; calcium chloride; critical evaluation; electrolyte; excess free energy; osmotic coefficient; JPCRD 6, No. 2, 385-408 (1977).

Sophisticated crime; threat analysis; terrorism; vigilance; behavioral science; human factors; human reliability; perpetrator attributes; physical security; psychological deterrence; SP480-24.

SOS measurements; bias-isolation unit; capacitance and conductance measurements at high applied-bias voltage; capacitance/conductance-meter; capacitance-voltage measurements; electronics; extended-range $C(V)$ and $G(V)$ measurements; SP400-40.

Sound; acoustical measurements; acoustics; national measurement system; noise; noise control; 17190
Sound; acoustics; community noise; environmental impact; noise; noise exposure measurement system; NBSIR 76-1169.

Sound; acoustics; environmental pollution; machinery and equipment; noise; noise abatement and control; noise emission; regulation; $H 122$.

Sound; sound level meters; acoustical measurements; acoustics; audiometry; national measurement system; noise; noise control; noise emissions; NBSIR 75-938.

Sound; speed of sound; compressed fluid ethane; ethane, fluid; fluid ethane; 17067.

Sound; spinach; SRM; systems and software; telecommunications; computer use; conservation; data; earth's measurement; energy; health records; hydrogen; law enforcement; liquefied natural gas; metric tons; polyethylene; DIM/NBS 61 , No. 5 , 1-32 (1977).

Sound level meters; acoustical measurements; acoustics; audiometry; national measurement system; noise; noise control; noise emissions; sound; NBSIR 75-938.

Sound measurement; acoustical measurements; acoustics; acoustics facilities; laboratory facilities; noise measurement; 16764.

Sound power; acoustical measurements; acoustics; acoustics facility; automated sound measurement; computer-controlled instrumentation; reverberation room; reverberation room qualification; 16763.

Sound power measurement; standard test procedures for sound power measurement; acoustic test facility; noise; noise measurement; reverberation room; 16766 .

Sound sensing; standard; alarm; audio alarm; burglar alarm; intrusion alarm; intrusion detector; 16831 .

Sound source; vibration; headphone; loudspeaker; microphone; piezoelectric polymer; 16952.

Sound velocities; Young's modulus; zinc; bulk modulus; compressibility; Debye temperature; elastic constants; Poisson's ratio; shear modulus; single-crystal elastic coefficients; JPCRD 6, No. 4, 1181-1204 (1977).

Sound velocity; stainless steel; Young's modulus; bulk modulus; compressibility; elastic constants; Poisson's ratio; pulse method; resonance method; shear modulus; 17321 .

Sound velocity; Young's modulus; bulk modulus; compressibility; Debye temperature; elastic constant; invar; iron alloy; nickel alloy; Poisson's ratio; shear modulus; 16869.

Sound velocity; Young's modulus; bulk modulus; composite; compressibility; copper; elastic constants; niobium-titanium; Poisson's ratio; pulse method; resonance method; shear modulus; 17068 .

Sound velocity; Young's modulus; aluminum alloys; bulk modulus; compressibility; Debye temperature; Poisson's ratio; precipitation-hardening alloys; shear modulus; 17085 .

Sound velocity; Young's modulus; bulk modulus; compressibility; copper alloy; elastic constant; Poisson ratio; precipitation hardening; shear modulus; 17094.

Sound velocity; Young's modulus; bulk modulus; compressibility; copper alloy; Debye temperature; elastic constants; Poisson's ratio; shear modulus; 17320.

Source; spectroscopy; standard; synchrotron; ultraviolet; wallstabilized; arc; calibration; deuterium; interlaboratory; lamp; radiance; radiometry; 17198 .

Source; target; tissue; dose; dosimetry; Monte Carlo; organ; phantom; photon; reciprocity theorem; SP461, pp. 177-182 (Jan. 1977).

Source calibration; test methods; $x$ rays; calibration; gamma radiation; industrial radiography; national standards; radiation characteristics; radiation source; 17017.

Source housing; spectrometry; ${ }^{\circ} \mathrm{Co}$ gamma-ray source; collimator; exposure spectra; gamma-rays; scattered radiation; NBSIR 76-1117.

Sources; acoustic emission; crack growth; drill pipe; failure; Kaiser Effect; pressure vessels; SP487, pp. 210-238 (Aug. 1977). 
Sources; standard; photometry; radiometry; 17024.

Sources; standardization; calibration; detection; dosimetry; facilities; fluence; flux; moderation; monitor; neutron; shielding; SP493, pp. 115-120 (Oct. 1977).

Sources; standards; survey; detectors; National Measurement System; photometry; radiometry; NBSIR 75-939.

Sources; survey; ultraviolet; detectors; National Measurement System; radiometry; NBSIR 75-941.

Source-scattering matrix; cylindrical scanning; near-field measurements; TN696.

Space charge; calibration; dielectrics; dividers; electric fields; electro-optics; high voltage measurement; insulating fluids; Kerr effect; nitrobenzene; pulse measurement; NBSIR 771317.

Space flight; spectroscopy; SRM; television captioning; thermophysical; weights and measures; American electroplaters'; calorimeter; cryogenic flow measurement; dental restorations; deep ocean research; federal science; DIM/NBS 61 , No. 4, 1-32 (1977).

Space group; symmetry; crystal; isosiructural materials; lattice; point group; polymorphism; JPCRD 6, No. 3, 675-830 (I977).

Space heating; testing; air conditioning; comfort; heat pump; load-calculation; rating; residential; 17006 .

Space processing; convection; crystal growth; microgravity; Skylab/ASTP; 17275 .

Space processing; convection; crystal growth; crystal perfection; microgravity; purification; NBSIR 77-1208.

Spandrel beams; connections; houses; masonry; piers; research; seismic; shear walls; BSS106, pp. 60-90 (Sept. 1977).

Spans of polymer chains; polymer chain statistics; random walk statistics; 16696.

Spark source mass spectrometric isotope dilution; tissues; analytical disciplines; analytical procedures; atomic absorption spectrometry; biological materials; blanks; botanical materials; chemical species; flame emission spectrometry; fluorescence spectrometry; SP492.

Spatial; transmission; anisotropy; charged particle; computer code; energy-angle; integral; legendre polynomial; scattering; semi analytical; SP461, pp. 140-143 (Jan. 1977).

Specialized information center; water resources information; information exchange; information management; information network; information retrieval; information services; information systems; SP463, pp. V.1.1-V.1.6 (Jan. 1977).

Speciation; Standard Reference Materials; trace organics; water; accuracy; aerosol; air; collaborative testing; laboratory accreditation; laser technology; multielement analysis; pollutants; SP464.

Speciation; tin; arsenic; element-specific detector; flameless atomic absorption; flow monitoring; high-pressure liquid chromatography; lead; ligand; mercury; nanogram sensitivity; organometallic compounds; 17297.

Specific activity; $\alpha$-activity; absolute counting; aliquotting; analysis (plutonium, uranium); isotope dilution; sample preparation; SP493, pp. 206-211 (Oct. 1977).

Specific heat; strontium titanate; beryllium; ceramics; cryogenics; dielectric-constant; electrets; electrocaloric effect; entropy; ferroelectrics; glass-ceramics; heat switches; magnetothermal conductivity; polarization; potassium tantalate; refrigeration; NBSIR 76-847.

Specific heat; superfluid helium-4; computed thermodynamic properties; entropy; equation of state; excitation spectrum; helium-4; normal fluid helium-4; phonons; protons; JPCRD 6, No. I, 51-104 (1977).

Specific heat; thermal conductivity; thermal diffusivity; fire research; polymers; polystyrene; poly(vinyl chloride); NBSGCR-77-83.

Specific heat capacity; thermal radiation properties; thermodynamics; titanium alloy; electrical resistivity; heat capaci- ty; high-speed measurements; high temperatures; melting; normal spectral emittance; J. Res. 81 A Nos. 2 and 3, 251256 (1977).

Specific heats; speeds of sound; vapor pressure; densities; enthalpies; entropies; equation of state; internal energies; isobars; isochores; isotherms; Joule-Thomson inversion; latent heats of vaporization; melting line; orthobaric densities; propane; NBSIK 77-860.

Specification testing; testing of dental materials; dental amalgam; dental materials; developmen: of testing procedures; mechanical properties; physical properties; 17126 .

Specifications; blended cements; fly ash; 16768.

Specifications; bridges; earthquake design; earthquake forces; seismic provisions; SP470, pp. VIII-31-VIIl-4l (Apr. 1977).

Specifications; standards; system engineering; building codes; computer model; decision table; decision theory; networks; SP473, pp. 285-316 (June 1977).

Specifications; structural engineering; earthquakes; highway bridges; seismic provisions; SP470, pp. VIII-1-VIIl-30 (Apr. 1977).

Specifications; structural engineering; tunnels; aseismic design criteria; design provisions; earthquakes; SP470, pp. VIII56-VIII-68 (Apr. 1977).

Specifications; structures; design; earthquakes; harbours; ports; SP470, pp. VIII-42-VIII-55 (Apr. 1977).

Specifications; technical reports; testing methods; tooling; adhesives; composites; computerized information system; foams; plastics information; Plastics Technical Evaluation Center; SP463, pp. IV.3.1-IV.3.2 (Jan. 1977).

Specifications; test methods; certification programs; consumer products; household products; industry standards; international recommendations; national standards; product standards; recommended practices; TN948.

Specifications; value incentive; Experimental Technology Incentives Program (ETIP); Federal Supply Service; life cycle costing; procurement policy; NBS-GCR-ETIP 76-26.

Specifications; value incentive; Experimental Technology Incentives Program (ETIP); Federal Supply Service; life cycle costing; procurement policy; NBS-GCR-ETIP 76-27.

Specifications; wind; bridges; SP477, pp. I-34-I-48 (May 1977).

Spectra; interstellar sources; isotope ratio; molecular lines; radio astronomy; silicon monoxide; 17189 .

Spectra; spectroscopy; bond distances; carbonyl selenide; energy levels; force field; infrared; microwave; molecular structure; 16823.

Spectra; structural engineering; tall buildings; turbulence; wind; aerodynamics; building (codes); pressure; 16843.

Spectra; structure; ultraviolet; yttrium; zirconium; ions; molybdenum; niobium; rubidium; 17212 .

Spectra; two photon; dimer; double resonance; mercury excimers; optically excited; 17076.

Spectra; two photon; dimers; discharge; lasers; mercury excimers; 17192.

Spectra; uncertainties; yield; distributions; neutrons; resolution; NBSIR 77-1279, pp. 15-18 (July 1977).

Spectra; uranium; arc; oscillator strength; plasma; 16992.

Spectra; water jet; auto-correlation; convective velocity; crosscorrelation; exit concentration; exit velocity; flow visualization; fluorescence; fluorescent dye; laser; laser dyefluorescence technique; mean concentration; mean velocity; SP484, pp. 423-447 (Oct. 1977).

Spectra, atomic; wavelengths, atoms and ions; atomic energy levels; atomic spectra; bibliography; energy levels, atomic; SP363. Supplement 1.

Spectral analysis; visible absorption spectroscopy; high-resolution spectrum; iodine spectrum; line identification atlas; rovibronic assignments; J. Res. 81A No. 1, 25-80 (1977).

Spectral densities; approximations; moment theory; 16849. 
Spectral density; time-dependent spectral density; coal mine noise; digital data; electromagnetic interference; electromagnetic noise; emergency communications; Fast Fourier Transform; impulsive noise; magnetic field strength; measurement instrumentation; 17175 .

Spectral distribution; thermoluminescence; gamma rays; irradiation; LiF; optical absorption; SP461, pp. 222-226 (Jan. 1977).

Spectral functions; comparative evaluation; cross sections; fission spectra; integrals; neutrons; radioactivation; resonance integrals; SP493, pp. 128-136 (Oct. 1977).

Spectral irradiance; standards; calibrations; interpolation formula; irradiance drift formula; projected solid angle; TN594-13.

Spectral line formation; stellar atmospheres; high speed aerodynamics; radiative transfer; 16758 .

Spectral measurements; Apollo 16,17; background correction; cosmic gamma ray; flux isotropy; sodium iodide detector; 16938.

Spectral properties; thermodynamic properties; bibliography; chemical kinetics; chemistry; chlorine nitrate; molecular properties; nitrosyl chloride; nitryl chloride; physical properties; SP478.

Spectral radiance; standard; ultraviolet; argon; light source; mini-arc; radiometry; 16778 .

Spectral radius; unit ball; vector norm; compatible; generalized matrix norm; multiplicative; 16836.

Spectral radius; vector norm; compatible; generalized matrix norm; Hadamard product; multiplicative; 16676.

Spectral response; standards; television cameras; total response; contrast transfer function; distortion; limiting resolution; shading; signal-to-noise ratio; 17233 .

Spectral responsivity; spectral transmittance; television camera tubes; television cameras; test methods; diffuser; interference filters; 16761 .

Spectral transmission; spectrophotometer standards; stray light; wavelength scale; errors in spectrophotometry; photometric scale; slit width; SP466, pp. 117-120 (May 1977).

Spectral transmittance; television camera tubes; television cameras; test methods; diffuser; interference filters; spectral responsivity; 16761 .

Spectra-ultraviolet; Novae; OAO-3; 16762.

Spectrometer; cross section; energy transfer; gamma rays; moderator; neutron; radiation damage; reactor; scattering; SP461, pp. 32-40 (Jan. 1977).

Spectrometer calibration; synchrotron radiation; transfer standard detectors; calibration facilities; photodiodes; radiometry; 16665 .

Spectrometers; absorption; accuracy; cross section; fast neutrons; geometric factors; photon; polarimeter; radiation physics; scattering; SP461, pp. 47-54 (Jan. 1977).

Spectrometry; surface barrier; ${ }^{\circ L i F}$; detector; energy leakage; Monte Carlo; neutron; sandwich; SP461, pp. 252-254 (Jan. 1977).

Spectrometry; water; activation; analysis; element; gamma rays; $\mathrm{Ge}(\mathrm{Li})$ detector; neutron; nondestructive; resolution; SP46I, pp. 255-256 (Jan. 1977).

Spectrometry; ${ }^{\circ}$ Co gamma-ray source; collimator; exposure spectra; gamma-rays; scattered radiation; source housing; NBSIR 76-1117.

Spectrophotometer; standards; transmittance; tristimulus values; chromaticity coordinates; color; filters; high accuracy; 17260.

Spectrophotometer analysis; carboxyhemoglobin; $\mathrm{CO}$ intoxication; intra-arterial cannula; 16921 .

Spectrophotometer standards; stray light; wavelength scale; errors in spectrophotometry; photometric scale; slit width; spectral transmission; SP466, pp. 117-120 (May 1977).

Spectrophotometry; absolute reflectance; diffuse reflectance; error analysis; reflectance; reflectance factor; J. Res. 82, No. 1, 29-55 (1977).
Spectrophotometry; stability of transmittance; standard reference material; transfer standard; transmittance; absorbance; accuracy in spectrophotometry; glass filters; highaccuracy spectrophotometers; 16981 .

Spectrophotometry; standard reference materials; standardization; accuracy; critical parameters; diffuse reflectance; fluorescence; instrumentation; luminescence; quantum yield; SP466.

Spectrophotometry; stirrer; vortex; cuvette; helix; mixer; 16704.

Spectroscopy; applications past and future; $\gamma$-rays; neutron capture; 16951 .

Spectroscopy; bond distances; carbonyl selenide; energy levels; force field; infrared; microwave; molecular structure; spectra; 16823.

Spectroscopy; dissociation energy; Dunham coefficients; Franck Condon factors; molecular lithium; potential curve; 17101 .

Spectroscopy; SRM; television captioning; thermophysical; weights and measures; American electroplaters'; calorimeter; cryogenic flow measurement; dental restorations; deep ocean research; federal science; governmental environment; DIM/NBS 6I, No. 4, 1-32 (1977).

Spectroscopy; standard; synchrotron; ultraviolet; wall-stabilized; arc; calibration; deuterium; interlaboratory; lamp; radiance; radiometry; source; 17198 .

Spectroscopy; thermal physics; 75th anniversary; American Physical Society; fundamental constants; National Bureau of Standards; nuclear physics; numerical analysis; physics; 16991 .

Spectroscopy; titanium alloys; laser effects; luminescence; metal combustion; 16796.

Spectroscopy; tunable laser; dye laser; flame analysis; flame fluorescence; laser; opto-galvanic effect; 16691 .

Spectroscopy; wavelength calibration; bandwidth determination; discharge lamp; lasers; optogalvanic effect; 17287.

Spectrum; computer code; dose; dosimetry; monitor; neutron; shielding; SP461, pp. 238-246 (Jan. 1977).

Spectrum; $\mathrm{Li}_{2} ; \mathrm{Na}_{2} ;$ satellite; 16912 .

Spectrum; transition; coincidence; electron capture; excited state; gamma ray; ground state; inner bremsstrahlung; Jauch plot; SP461, pp. 23-25 (Jan. 1977).

Spectrum; ${ }^{60} \mathrm{Co}$; back scattering; gamma rays; sky-shine; SP46I, pp. 124-128 (Jan. 1977).

Spectrum amplitude; electromagnetic interference; Fourier transformation; impulse; impulse generator; TN699.

Spectrum amplitude; spectrum analyzer; spectrum intensity; calibration; electromagnetic interference; fast Fourier transform; impulse generator; radiometer; sampling oscilloscope; 16725.

Spectrum amplitude; time domain; transient; automated measurement; pulse; rise time; sampling oscilloscope; 16721 .

Spectrum analyzer; spectrum intensity; calibration; electromagnetic interference; fast Fourier transform; impulse generator; radiometer; sampling oscilloscope; spectrum amplitude; 16725.

Spectrum intensity; calibration; electromagnetic interference; fast Fourier transform; impulse generator; radiometer; sampling oscilloscope; spectrum amplitude; spectrum analyzer; 16725.

Specular reflectance; sub-surface scattering; bidirectional reflectance-distribution function; diffuse reflectance; directional reflectance; nomenclature of reflectance; optical reflection; reflectance; reflectance factor; reflectance geometry; reflectance nomenclature; Monogr. 160.

Speech scramblers; voice privacy; voice scramblers; LESL; NILECJ; privacy; scramblers; SP480-8.

Speed of light; 1.5 microns; frequency measurement; frequency standards; helium neon laser; insulator metal diode; laser; 17336.

Speed of sound; compressed fluid ethane; ethane, fluid; fluid ethane; sound; 17067. 
Speeds of sound; vapor pressure; densities; enthalpies; entropies; equation of state; internal energies; isobars; isochores; isotherms; Joule-Thomson inversion; latent heats of vaporization; melting line; orthobaric densities; propane; specific heats; NBSIR 77-860.

Spheralites; chain folding; curved crystals; extended chain crystals; fold domains; fold surfaces; interlamellar links; morphology; polymer; sectorization; 16958.

Sphere flow; transition; trip-wire probe; turbulent boundary layer; calibration; Pitot-static tube; Reynolds number; SP484, pp. $719-735$ (Oct. 1977).

Sphere illumination; body shadow; contrast rendition; hand calculator; illuminating engineering; light design; luminaire effectiveness; luminance factor; office lighting; NBSIR 77 1303.

Sphere transmission; cross section; multiple bias; neutron; nonelastic; optical model; parameter; polynomial extrapolation; SP461, pp. 44-46 (Jan. 1977).

Spherical; antennas; measurements; near-field; 17224.

Spherical; spherical point group; antennas; arrays; finite rotations; group representations; near-fields, recursion; scanning; 17322.

Spherical; symmetric; transport; density transform; expansion coefficient; Green's function; neutron; SP461, pp. 87-90 (Jan. 1977).

Spherical; symmetry; antennas; arrays; coordinate transformations; data processing; group representations; measurements; near field; nonplanar; patterns; scanning; 16671.

Spherical point group; antennas; arrays; finite rotations; group representations; near-fields, recursion; scanning; spherical; 17322.

Spherical scanning; antenna patterns; cosite interference; cylindrical scanning; near-field scanning; planar scanning; scanning facilities; 17221 .

Spherical scanning; antenna patterns; computer programs; nearfield scanning; 17223 .

Spin correlation function; absolute cross section measurement; cobalt; critical phenomena; interaction range; neutron scattering; 17112 .

Spin echoes; spin locking; zero field magnetic resonance; coherence; Kramers ions; nutation; 16954.

Spin exchange; wall shift; active hydrogen maser frequency standard; cavity pulling; cavity-Q; cavity servo; Crampton effect; frequency stability; hydrogen line $Q$; hydrogen line servo; magnetic field; passive hydrogen maser frequency standard; second-order Doppler; 17180.

Spin flip Raman laser; frequency measurements on tunable lasers; IFS with a tunable laser; infrared frequency synthesis; SFRL frequency measurement; 16728.

Spin locking; zero field magnetic resonance; coherence; Kramers ions; nutation; spin echoes; 16954.

Spin waves; erbium; Laves phase; magnetic excitation; magnetism; rare earths; 16963 .

Spinach; SRM; systems and software; telecommunications; computer use; conservation; data; earth's measurement; energy; health records; hydrogen; law enforcement; liquefied natural gas; metric tons; polyethylene; sound; DIMINBS 61, No. 5, 1-32 (1977).

Spin-polarized field emission; spin-polarized photoemission; surface magnetism; 17022.

Spin-polarized photoemission; surface magnetism; spinpolarized field emission; 17022 .

Splash zone corrosion; cathodic protection; coating systems; corrosion protection; offshore corrosion; sand corrosion; seawater corrosion; Monogr. 158.

Splitting strength; ultimate capacity; brick; clay masonry; concrete block; concrete masonry; failure modes; load capacity; masonry walls; shear walls; BSS106, pp. 177-197 (Sept. 1977).
Sports; accident; associated factors; injuries; literature; NEISS; recommendations; review; safety; NBSIR 77-1218.

Spotwelded joints; weldbonded joints; adhesive-bonded joints; bonded joints; cyclic loading; debond analysis; double-lapjoint analysis; fatigue tests; finite element analysis; joints; nonlinear analysis; single-lap-joint analysis; single-lap-joint bending; NBSIR 76-1053.

Spray; two component flow; vortex street; wake flow; anemometer; cylinder; frequency; hot film anemometer; recirculating flow; SP484, pp. $705-718$ (Oct. 1977).

Spray canal; stage-discharge equation; velocity-area method; weir equation; closed-loop cooling system; cooling lake; dye dilution method; error analysis; flow rate measurement; open channel flow measurement; power plant; SP484, pp. 145-172 (Oct. 1977).

Spray water flow rate; water spray; automatic sprinklers; compartment fire; corridor sprinkler systems; droplet size; droplet trajectory; evaporative cooling; fire suppression; full-scale test; gas temperature; oxygen content; recirculating flow; NBSIR 77-1287.

Spreading resistance; surface roughness; test patterns; thermally stimulated current; transistors, power; TTL circuits; ultrasonic wire bonding; ultraviolet reflectance; $\mathrm{x}$-ray damage; acoustic emission; Auger electron spectroscopy; beam-lead bonds; SP400-29.

Spreading resistance calibration; spreading resistance measurements; metal-semiconductor contacts; resistivity; semiconductors; silicon; silicon polishing; 17139.

Spreading resistance measurements; metal-semiconductor contacts; resistivity; semiconductors; silicon; silicon polishing; spreading resistance calibration; 17139.

Sputtering; adhesion; coatings; films; gas discharges; SP487, pp. 311-323 (Aug. 1977).

Sputtering; charge transfer; hollow cathode discharge; 17170.

Sputtering; thin films; protective coatings; SP487, pp. 324-337 (Aug. 1977).

Square array; collector resistivity; epitaxial resistivity; fourprobe; resistivity; resistivity correction factors; semiconductor characterization; silicon; 16942.

Square wave patterns; television cameras; contrast; contrast transfer function; image quality; limiting resolution; relative spectral response; signal-to-noise ratio; SP480-25.

SQUID; amplifier; high-frequency; Josephson junction; 17334.

SQUID; biomagnetism; geomagnetism; instrumentation; Josephson effect; magnetometry; 16872.

SQUID; Stirling cycle; cryogenic refrigeration; magnetometry; 17091.

SQUID; superconductivity; attenuation; Josephson effect; quantum interference; radio frequency; 16875.

SQUID; superconductivity; Josephson effect; quantum interference; rf metrology; if power; 17092.

$\beta$-ray detection; low-level counting; plastic phosphors; scintillation counting; 17268.

$\mathrm{SrF}_{2}$; thermal coefficient of refractive index; $\mathrm{ZnSe} ; \mathrm{BaF}_{2} ; \mathrm{CaF}_{2}$; $\mathrm{KBr} ; \mathrm{KCl}$; LiF; NaF; refractive index; NBSIR 77-1219.

$\mathrm{SrF}_{2}$; thermal coefficient of refractive index; $\mathrm{ZnS} ; \mathrm{ZnSe} ; \mathrm{BaF}_{2}$; $\mathrm{CaF}_{2} ; \mathrm{KBr} ; \mathrm{KCl}$; Lexan; LiF; NaF; Plexiglas 55; refractive index; NBSIR 77-1304 (ARPA).

SRM; standard reference data; standard reference materials; accuracy; certification; precision; SP463, pp. VII.4.1-VII.4.14 (Jan. 1977).

SRM; systems and software; telecommunications; computer use; conservation; data; earth's measurement; energy; health records; hydrogen; law enforcement; liquefied natural gas; metric tons; polyethylene; sound; spinach; DIM/NBS 61, No. 5, $1-32$ ( 1977).

SRM; television captioning; thermophysical; weights and measures; American electroplaters'; calorimeter; cryogenic flow measurement; dental restorations; deep ocean research; 
federal science; governmental environment; laser energy; DIM/NBS 61, No. 4, 1-32 (1977).

SRM's; adobe; air pollution; corrosion; electrical; energy management; graphic pen; halocarbons; infrared lasers; international standard; neutron xeroradiography; problem-solving; radiation safety; smoke detectors; solar heating; DIM/NBS 61 , No. 3, 1-32 (1977).

SRM's; air pollution; attic ventilation; data encryption; dental materials; fire safety; metric; miniature electric field; organic sulfur; radiometric detector; smog formation; DIM/NBS 61 , No. 1 1, 1-32 (1977).

SRM's; time and frequency; ultraviolet; computer memories; computer performance; inventor; molecular identity; preserving stone; pressure measurements; rf-power meter; roofing; safety; security alarms; DIM/NBS 61, No. 8, 1-32 (1977).

Stability; argon gas discharge noise source; silicon avalanche diode; solid state noise source; 16669.

Stability; BBGKY hierarchy; bifurcation; crystal; free energy; lattice symmetry; 16986

Stability; eigenvalue; hermitian matrix; inertia; 16755 .

Stability; standard deviation; calibration; optical flat, profile; NBSIR 73-232

Stability; standard deviation; statistical analysis; angle block; between time variation; calibration; measuring system; NBSIR 74-601

Stability; supercritical helium; acoustic oscillations; current leads; experimental; 17078.

Stability; surface tension; floating zone; gravity; liquid zone; shape; 17009.

Stability; thermal effects; zero-shift; accuracy; calibration; cryogenic; dynamic; frequency response; hysteresis; precision; pressure measurement; sensitivity; 17081 .

Stability of transmittance; standard reference material; transfer standard; transmittance; absorbance; accuracy in spectrophotometry; glass filters; high-accuracy spectrophotometers; spectrophotometry; 16981 .

Stable-age population; age distributions; demography; durability; durable goods; matrix model; population dynamics; population growth rate; production rate; scrappage rate; 17053.

Stage-discharge equation; velocity-area method; weir equation; closed-loop cooling system; cooling lake; dye dilution method; error analysis; flow rate measurement; open channel flow measurement; power plant; spray canal; SP484, pp. 145172 (Oct. 1977).

Stainless steel; crevice corrosion; iron-molybdenum alloys; localized corrosion; repassivation; sensitization; NBSIR 76 1170.

Stainless steel; erosion-corrosion process; erosive wear; high temperature erosion; particle impingement; 17274.

Stainless steel; erosion-corrosion process; erosive wear; high temperature erosion; particle impingement; 17300 .

Stainless steel; standards; titanium; biocompatibility; cobaltchromium; corrosion; implant requirements; mechanical properties; metal implants; 16973 .

Stainless steel; thermal conductivity; copper; low temperature; magnetothermal conductivity; nickel alloy; 16864 .

Stainless steel; Young's modulus; bulk modulus; compressibility; elastic constants; Poisson's ratio; pulse method; resonance method; shear modulus; sound velocity; 17321 .

Stainless steels; steels; superalloys; titanium alloys; aluminum alloys; crack propagation; fatigue; iron alloys; liquid helium; 16928.

Stainless steels; stress corrosion cracking; titanium alloys; aluminum alloys; copper alloys; high strength steels; nickel alloys; Monogr. 156.

Standard; alarm; audio alarm; burglar alarm; intrusion alarm; intrusion detector; sound sensing; 16831 .

Standard; American Nuclear Society; radiation; shielding; SP461, pp. 74-78 (Jan. 1977).

Standard; photometry; radiometry; sources; 17024 .
Standard; synchrotron; ultraviolet; wall-stabilized; arc; calibration; deuterium; interlaboratory; lamp; radiance; radiometry; source; spectroscopy; 17198.

Standard; total cross section; carbon; elastic scattering cross section; evaluation; optical model; R-function analysis; SP493, pp. 93-100 (Oct. 1977).

Standard; ultraviolet; argon; light source; mini-arc; radiometry; spectral radiance; 16778 .

Standard; upholstered furniture; cost plus loss; decision analysis; fire; furniture fire; losses; residential fire; NBSIR 771381 .

Standard; window; emergency egress; HUD; mobile home; racking; research; safety; NBSIR 77-1246.

Standard; $x$-ray diffraction; crystal structure; integrated intensities; lattice constants; peak intensities; powder patterns; reference intensities; Monogr. 25, Section 14.

Standard; ${ }^{6} \mathrm{Li}(\mathrm{n}, \boldsymbol{\alpha}) \mathrm{T}$; angular distribution; fast neutrons; linac; reactor filtered beam; SP493, pp. 10-13 (Oct. 1977).

Standard; ${ }^{6} \mathrm{Li}(\mathrm{n}, \mathrm{t})$; ${ }^{7} \mathrm{Li}$ system; resonance parameters; R-matrix; SP493, pp. 30-36 (Oct. 1977).

Standard cell; superconducting; voltage measurement; voltage reference; Josephson junction; 16698.

Standard cross section; ${ }^{10} \mathrm{~B}\left(\mathrm{n}, \alpha_{0}+\alpha_{1} \gamma\right)^{7} \mathrm{Li} ;{ }^{10} \mathrm{~B}\left(\mathrm{n}, \alpha_{1} \gamma\right)^{7} \mathrm{Li}$; boron scintillators; $\mathrm{Ge}(\mathrm{Li})$; ionization chambers; NaI; SP493, pp. 85-92 (Oct. 1977).

Standard deviation; calibration; optical flat, profile; stability; NBSIR 73-232.

Standard deviation; statistical analysis; angle block; between time variation; calibration; measuring system; stability; NBSIR 74-601.

Standard fields; cross sections; fission yields; neutrons; nuclear data; SP493, pp. 299-303 (Oct. 1977).

Standard for $\mathrm{pH}$; acidity; emf; pH; phthalate buffer; potassium hydrogen phthalate; J. Res. 81A No. 1, 21-24 (1977).

Standard frequencies; television color subcarrier; time and frequency calibration methods; time calibration; time signals; frequency calibration; high frequency; Loran-C; low frequency; radio broadcasts; TN695.

Standard frequency; standard time; time services; time transfer; clock comparison; satellite time dissemination; 17179.

Standard lamps;Stefan-Boltzmann constant; blackbodies; electrically calibrated detectors; history of radiometry; Planck's constant; radiometric standards; radiometry; 16851 .

Standard neutron fields; cross sections; ENDF/B; fission; integral measurements; SP493, pp. 290-298 (Oct. 1977).

Standard reference collections; criminalistics; evidential materials; forensic reference collections; forensic science; reference materials; 16706.

Standard reference data; standard reference materials; accuracy; certification; precision; SRM; SP463, pp. VII.4.1-VII.4.14 (Jan. 1977).

Standard reference data; surface tension; viscosity; bromides; data compilation; density; electrical conductance; iodides; molten salt mixtures; JPCRD 6, No. 2, 409-596 (1977).

Standard reference data; technology; communication; information; interdisciplinary technology; physical property data; publish; science; 17258 .

Standard reference data; thermodynamic data; transport properties; atomic and molecular data; chemical kinetics data; energy data; environmental data; industrial process data; materials utilization data; mechanical properties; nuclear data; physical science data; TN947.

Standard reference data; weights and measures; instrumentation; measurement standards; National Bureau of Standards; national measurement system; standardization organizations; NBSIR 75-949.

Standard reference material; thermal conductivity; thermopower; tungsten; electrical resistivity; high temperature; Lorenz ratio; low temperature; 16877. 
Standard reference material; transfer standard; transmittance; absorbance; accuracy in spectrophotometry; glass filters; high-accuracy spectrophotometers; spectrophotometry; stability of transmittance; 16981 .

Standard reference material; nitrogen dioxide; permeation tube; 17230.

Standard reference material; accuracy; chemical analysis; measurement compatibility; measurement systems; reference method; 17247.

Standard reference material; transfer standards; absorbance linearity; accuracy of transmittance or absorbance scale; acidic potassium dichromate solutions; calibration of ultraviolet spectrometers; certification of apparent specific absorbance; isosbestic wavelengths; SP260-54.

Standard reference material; thermodynamic functions; drop calorimetry; emittance; enthalpy; heat capacity; high-speed measurements; high temperature; molybdenum; pulse calorimetry; SP260-55.

Standard reference material 1476; branched polyethylene; fractionation; gel permeation chromatography; GPC; molecular weight distribution; polymer characterization; 17255 .

Standard reference materials; accuracy; certification; precision; SRM; standard reference data; SP463, pp. VII.4.1-VII.4.14 (Jan. 1977).

Standard reference materials; chemical analysis; measurement systems; physical measurement units; 16667.

Standard reference materials; standards; thermal testing; ultrasonics; visual testing; wear debris analysis; acoustic emission; calibrations; electrical-eddy current measurements; microwaves; nondestructive evaluation; 17016 .

Standard Reference Materials; trace organics; water; accuracy; aerosol; air; collaborative testing; laboratory accreditation; laser technology; multielement analysis; pollutants; speciation; SP464.

Standard reference materials; standardization; accuracy; critical parameters; diffuse reflectance; fluorescence; instrumentation; luminescence; quantum yield; spectrophotometry; SP466.

Standard reference materials; transmittance characteristics; ultraviolet-visible filters; evaporated metal-on-quartz; filters, transmittance; neutral filters; SP466, pp. 127-131 (May 1977).

Standard test; thermal storage; 17347.

Standard test procedures for sound power measurement; acoustic test facility; noise; noise measurement; reverberation room; sound power measurement; 16766.

Standard time; time services; time transfer; clock comparison; satellite time dissemination; standard frequency; 17179.

Standard time/frequency broadcasts; television time/frequency dissemination; time/frequency calibrations; user equipment; user survey; NBS radio stations WWV/WWVH/WWVB; NBS time/frequency services; satellite timing; 17080.

Standardization; accuracy; critical parameters; diffuse reflectance; fluorescence; instrumentation; luminescence; quantum yield; spectrophotometry; standard reference materials; SP466.

Standardization; AID; assistance; developing economies; foreign relations; industrializing nations; international relations; LDS's; measurement services; NBSIR 76-1152.

Standardization; calibration; detection; dosimetry; facilities; fluence; flux; moderation; monitor; neutron; shielding; sources; SP493, pp. 115-120 (Oct. 1977).

Standardization; standards development; ADP standards; international standardization; national standardization; national standards bodies; practice; procedures; regional standardization; NBSIR 77-1195.

Standardization; testing facilities; cottage industry; developing countries; Guyana; less developed countries; measurement services; NBSIR 76-1180.
Standardization; testing facilities; Thailand; measurements; quality control; NBSIR 76-1190.

Standardization organizations; standard reference data; weights and measures; instrumentation; measurement standards; National Bureau of Standards; national measurement system; NBSIR 75-949.

Standards; accidents; benefit-cost analysis; building codes; building economics; building regulations; economic impact; electric shock; ground fault circuit interrupters; national electric code; safety regulations; SP473, pp. 397-419 (June 1977).

Standards; adjustment; benchmark; cross-sections; fast reactors; integral experiments; SP493, pp. $310-312$ (Oct. 1977).

Standards; Alaska pipeline; calibration; CMAC; computers; consumer sounding boards; data; electron probe microanalysis; laser ionization; metrication; noise; nondestructive evaluation; research associate program; DIM/NBS 61 , No. 1 , $1-32$ (1977).

Standards; ammunition; handguns; police; police equipment; SP480-5.

Standards; anthropometric probes; consumer products; human factors; lawn mowers; psychophysics; reaction time; safety; 17200

Standards; automation; calibration; data formats; documentation; image content language; image processing; pattern recognition; prototype images; SP500-8.

Standards; ballistic protective equipment; body armor; confiscated weapons; police; SP480-6.

Standards; basic physical data; medical; mixed $\mathrm{n}-\boldsymbol{\gamma}$ fields; neutron dosimetry; SP493, pp. 106-114 (Oct. 1977).

Standards; benefit/cost; building standards; cost/effectiveness; economics; safety standard; 17133 .

Standards; bibliographic information; data bases; information retrieval; library automation; machine-readable; MARC; SP463, pp. VIII.1.1-VIII.1.4 (Jan. 1977)

Standards; building codes; building safety; control; instruments; knowledge; legislation; life safety; regulation; SP473, pp. 259. 278 (June 1977).

Standards; building codes; building regulation; do-it-yourself; home construction; housing; rehabilitation; remodeling; renewal; renovation; self-help; NBS-GCR-77-88.

Standards; building codes; community development; construction costs; contractors; housing; rehabilitation; SP473, pp. 491-497 (June 1977).

Standards; building codes; computer programming; decision tables; graph theory; performance specifications; 16705 .

Standards; building codes; computer programming; decision tables; graph theory; performance specifications; TN940.

Standards; building codes; energy conservation; energy efficiency; energy performance; model codes; 17290.

Standards; building economics; economic efficiency; economics; energy; energy conservation; life-cycle cost; optimization; performance standards; resource impact factors; resources; social optimum; 17302.

Standards; buildings; codes; energy conservation; regulatory community; 17111 .

Standards; buildings; cooling; heating; laboratory accreditation; performance criteria; solar energy; 16686.

Standards; buildings; cooling; heating; performance criteria; solar collectors; solar energy; SP473, pp. 103-112 (June 1977).

Standards; calibrations; interpolation formula; irradiance drift formula; projected solid angle; spectral irradiance; TN594-13.

Standards; CAMAC; computer interfacing; instrumentation; interfacing; 16677.

Standards; CAMAC; Dataway; instrumentation; modules; nuclear; 16678.

Standards; CAMAC; highway; interface; instrumentation; 16679. 
Standards; communications; mobile radio; police; police equipment; portable radio; $S P 480-2$.

Standards; communications networks; computer networks; data communications; interconnection; networks; packet switching; 16934.

Standards; communications networks; computer networks; data communications; interconnection; networks; packet switching; SP500-6.

Standards; consumer products; generic probes; human factors; lawn mowers; safety; NBSIR 77-1294.

Standards; container; corrosion; explosion; extinguisher; fire; gas; injury; liquefied; petroleum; NBSIR 77-1217.

Standards; court orders; human behavior; institutional occupancies; interior design; physical environment; regulation; research; SP473, pp. 55-67 (June 1977).

Standards; criteria, accuracy; criteria, performance; dose equivalent; elements, transuranic; glove box; intercomparison; neutrons, high energy; neutrons, low energy; nonuniform exposures; quality factor; SP493, pp. 101-105 (Oct. 1977).

Standards; cross section standards; dosimetry; fission; flux; measuring techniques; neutrons; SP493.

Standards; detectors; flux; neutrons; proton-recoil; scattering; SP493, pp. 54-60 (Oct. 1977).

Standards; emergency warning lights; police equipment; sirens; SP480-3.

Standards; hermetic seals; leakage; nondestructive tests; semiconductor devices; 16943.

Standards; intercomparisons; medical; neutron dosimetry; radiation effects; SP493, pp. 121-127 (Oct. 1977).

Standards; patrolcar; police; police vehicles; SP480-7.

Standards; police; police equipment; SP480-1.

Standards; standards information service; voluntary standards; American National Standards Institute; computerized information system; engineering standards; mandatory standards; national standards; plastics standards; SP463, pp. VII.5.1VII.5.9 (Jan. 1977).

Standards; State; architecture; buildings; design; energy; legislation; solar; NBSIR 77-1297.

Standards; state-of-the-art study; buildings; energy conservation; enforcement; legislation; regulations; solar energy; NBSIR 77-1259.

Standards; statistical data; ADP standards; computers; data elements and codes; data processing; Federal Information Processing Standards; geography; information processing standards; information system; representations and codes; FIPS PUB 10-2.

Standards; structural response; vessels and wind; accelerograph; bridges; buildings; codes; disaster; dynamic analysis; earthquakes; ground failures; hydraulic structures; seismicity; soils; SP470.

Standards; structural response; winds; accelerograph; bridges; buildings; codes; disaster; dynamic analysis; earthquakes; ground failures; nuclear facilities; seismicity; soils; SP477.

Standards; superconductivity; thermometry; DC measurements; frequency; metrology; rf measurements; 16861 .

Standards; superconductor; critical current; definition; 17074 .

Standards; survey; detectors; National Measurement System; photometry; radiometry; sources; NBSIR 75-939.

Standards; system engineering; building codes; computer model; decision table; decision theory; networks; specifications; SP473, pp. 285-316 (June 1977).

Standards; system integration; voluntary standards; CAM architectures; computer aided manufacturing; computer systems; NBSIR 76-1094.

Standards; technical bases; building research; building technology; codes; criteria; project summaries; SP446-1.

Standards; technology; annual report; computer; energy; environmental; measurement; product safety; research; science; SP467.
Standards; television; time; atomic clocks; dissemination; frequency; geosynchronous satellite; measurement; 17182 .

Standards; television cameras; total response; contrast transfer function; distortion; limiting resolution; shading; signal-tonoise ratio; spectral response; 17233 .

Standards; temperature; thermistors; thermometry; fixed points; gallium; gallium melting point; melting; 17055 .

Standards; test development; textiles; apparel; fabrics; flammability testing; heat transfer rates; Mushroom Apparel Flammability Tester; NBS-GCR-76-78.

Standards; textiles; toxicity; arson; bibliographies; building fires; carpets; construction materials; fire departments; fire detection systems; fire tests; flame research; flammability tests; interior furnishings; mobile homes; polyurethanes; smoke detectors; NBSIR 77-1277.

Standards; thermal; ultrasonic; visual testing; wear debris; acoustic; calibration; eddy current; microwave; nondestructive evaluation; penetrant; radiography; 17106.

Standards; thermal; ${ }^{6} \mathrm{Li}(\mathrm{n}, \alpha) ;{ }^{10} \mathrm{~B}(\mathrm{n}, \alpha) ;{ }^{235} \mathrm{U}(\mathrm{n}, \mathrm{f})$; cross section; neutron; normalization; resonance; shape; SP493, pp. 174 181 (Oct. 1977).

Standards; thermal storage; solar buildings; solar collectors; solar domestic hot water systems; NBSIR 77-1272.

Standards; thermal testing; ultrasonics; visual testing; wear debris analysis; acoustic emission; calibrations; electricaleddy current measurements; microwaves; nondestructive evaluation; standard reference materials; 17016 .

Standards; titanium; biocompatibility; cobalt-chromium; corrosion; implant requirements; mechanical properties; metal implants; stainless steel; 16973.

Standards; transactions; annual reports; diffusion in metals; fire; journals; library holdings, NBS Library; NBS periodicals; periodicals; proceedings; serials; NBSIR 77-1215.

Standards; transmittance; tristimulus values; chromaticity coordinates; color; filters; high accuracy; spectrophotometer; 17260 .

Standards; ultrasonics; visual; acoustic emission; inspection; leak testing; liquid penetrant; magnetic particle; measurements; nondestructive testing; optical; radiography; 17042.

Standards; uncertainties; criticals; cross section; ENDF/B; fission; SP493, pp. 269-277 (Oct. 1977).

Standards; voice communication; coding; communication systems; fire alarm systems; health care facilities; hospital communication systems; hospital fires; hospital personnel; human behavior; nursing home fires; nursing staff; $N B S-G C R$ 77-102.

Standards calibration; barium sulfate; diffuse reflectance spectra; magnesium oxide; opal glass; radiant flux; reflectance standards; SP466, pp. 75-85 (May 1977).

Standards committees; temperature measurements; thermal pollution; thermometry; wạter analysis; water pollution; pollution; NBSIR 77-1227.

Standards development; administrative procedures; building codes; building regulations; buildings; economic impacts; environmental considerations; innovative practices; regulatory research; SP473.

Standards development; ADP standards; international standardization; national standardization; national standards bodies; practice; procedures; regional standardization; standardization; NBSIR 77-1195.

Standards development; building codes; concrete testing; evaluation; innovations; in-place testing; performance approach; regulatory domination; SP473, pp. 279-284 (June 1977).

Standards information service; voluntary standards; American National Standards Institute; computerized information system; engineering standards; mandatory standards; national standards; plastics standards; standards; SP463, pp. VII.5.1 VII.5.9 (Jan. 1977). 
Standards inspection procedure; temperature correction; test measure; test measure evaluation; "to contain"; "to deliver"; volumetric calibration; accuracy; design analysis; equipment specification; field standard; gravimetric calibration; NBSIR 77-1214.

Standards laboratories; survey; time; frequency; National Measurement System; 17070.

Standards, time; time standards; frequency; 16794.

Standards users; communication of research and standards; National Bureau of Standards; solar energy standards; 16733.

Standby loss; water heater; alternating direction; computer simulation; cool down; energy savings; flue damper; heat transfer; implicit; insulation; laboratory measurements; modeling; 17184.

Stannous compounds; stannous phosphate; tin coordination; crystal structure; dimeric configuration; 17095.

Stannous hydrogen phosphate; hydrogen-bonded dimers; neutron diffraction; 16742 .

Stannous phosphate; tin coordination; crystal structure; dimeric configuration; stannous compounds; 17095.

Star flux; figure of merit; $\mathrm{G} / \mathrm{T}$; measurement accuracy; radio stars; satellite earth terminal; signal to noise; 17227.

Stark broadening; B-star spectra; forbidden lines; He I; radiative transfer; 17171 .

Stark broadening; dynamic ion effects; forbidden lines; He I; $\lambda 4471 \AA ; 17167$.

Stark broadening; supermultiplet; transition array; wall stabilized; multiplet; nitrogen lines; regularities; 17204.

Stark broadening; theoretical comparison; hydrogen $\mathrm{H} \alpha$ and $\mathbf{H} \beta$; ion dynamics; quasi static; 17232.

Stark broadening; unified classical path theory; unified theory; hydrogenic ions; 17249.

Stark broadening theory; stellar line profiles; transfer equations; early type stars; helium forbidden lines; 17172 .

Stark effect; cyanogen fluoride; dipole moment; infrared spectroscopy; laser absorption; laser-Stark resonance; molecular spectra; 17124 .

Stark effect; far infrared laser; frequency modulation; 17203.

Stark effect; vibrational transition moment; acetylene- $d_{2}$; $l$-type doubling constants; microwave spectrum; rotational constants; 16689.

Stark shifts; Stark widths; arc; Debye shielding; neutral phosphorus; 16950.

Stark widths; arc; Debye shielding; neutral phosphorus; Stark shifts; 16950.

Stark widths; supermultiplet; transition array; isolated lines; multiplet; plasma broadening; regularities; 17206 .

Stars, chromospheres; stars, coronae; stars, individual; stars, late type; ultraviolet spectra; 17310.

Stars, chromospheres; stars, individual; stars, late type; stars, mass loss; Ca Il emission; 16732.

Stars, coronae; stars, individual; stars, late type; ultraviolet spectra; stars, chromospheres; 17310.

Stars, individual; stars, late type; stars, mass loss; Ca II emission; stars, chromospheres; 16732 .

Stars, individual; stars, late type; ultraviolet spectra; stars, chromospheres; stars, coronae; 17310.

Stars, late type; stars, mass loss; Ca ut emission; stars, chromospheres; stars, individual; 16732.

Stars, late type; ultraviolet spectra; stars, chromospheres; stars, coronae; stars, individual; 17310 .

Stars, mass loss; Ca II emission; stars, chromospheres; stars, individual; stars, late type; 16732.

Starvation; traction; bearings; computer programs; elastohydrodynamics; failure analysis; film thickness; gears; Hertz contacts; lubrication; rheology; SP487, pp. 137-153 (Aug. 1977).

State; architecture; buildings; design; energy; legislation; solar; standards; NBSIR 77-1297.
State-local relations; statewide codes; uniformity; building regulation; code administration; enforcement; funding; local government; model codes; SP473, pp. 225-240 (June 1977).

State-of-the-art review; basic principles; computer calculations; computer modeling; experimental methods; smoke control methods; smoke movement; smoke simulation; NBSIR 771209.

State-of-the-art study; buildings; energy conservation; enforcement; legislation; regulations; solar energy; standards; NBSIR 77-1259.

State-of-the-art summaries; technical reports; test methods; analytical procedure; bibliographies; computerized information system; concrete; concrete technology; construction material; construction methods; portland cement; SP463, pp. IV.7.1-1V.7.7 (Jan. 1977).

Statewide codes; summary tables; building construction; building regulations; cities; code uniformity; enforcement; legislation; rules and regulations; NBSIR 77-1390.

Statewide codes; uniformity; building regulation; code administration; enforcement; funding; local government; model codes; state-local relations; SP473, pp. 225-240 (June 1977).

Static force; force; force calibration; interlaboratory comparison; load cell; NBSIR 76-1 145.

Static load; trains; transportation; trucks; vibrations; wind load; acceleration; airplanes; cargo; dynamic loads; equivalent static force; gravity load; handling devices; handling loads; military field shelters; probability distributions; shocks, snow load; NBSIR 77-1254.

Static mechanical properties; advanced fiber composites; boron-aluminum; boron-epoxy; cryogenics; 16865 .

Static potential; carbon monoxide molecules; dipole moment; electron scattering; electrostatic potential; intermediate neglect of differential overlap (INDO); molecular orbital theory; quantum chemistry; 16709.

Static pressure probe; turbulence; turbulent boundary layers; velocity measurement; impact pressure probe; Pitot tubes; SP484, pp. 737-753 (Oct. 1977).

Static-model exchange-polarization potential; coupled-channel equations; $\mathrm{CO}_{2}$; electron-molecule collisions; 17026.

Statistical analysis; angle block; between time variation; calibration; measuring system; stability; standard deviation; NBSIR $74-601$.

Statistical analysis; building fires; egress; fire alarms; fire incidents; fire investigations; fires; human behavior; project people; residential buildings; smoke; NBS-GCR-77-94.

Statistical analysis; steady state; interactive computer system; performance measurement; renewal theory; SP500-18, pp. 87-94 (Sept. 1977).

Statistical analysis; storms; structural engineering; tropical storms; wind loads; wind speeds; building codes; buildings; codes and standards; housing; hurricanes; pressure coefficients; probability distribution functions; risk; BSS100-2.

Statistical analysis; structural engineering; fire endurance; fire tests; probability theory; reinforced concrete; reliability; 17303.

Statistical analysis; structural engineering; uncertainty; probability; reinforced concrete; reliability; 17304 .

Statistical analysis; underground; carbon steel; corrosion; ductile cast-iron; soils; 16745 .

Statistical analysis; Weibull distribution; durability; fatigue; fiber length; flexing; low cycle fatigue; mechanical properties; microstructure; modelling; paper; pore size; 16681 .

Statistical data; ADP standards; computers; data elements and codes; data processing; Federal Information Processing Standards; geography; information processing standards; information system; representations and codes; standards; FIPS PUB $10-2$.

Statistical design; weighing design; design of experiments; least squares; mass calibration; TN952. 
Statistical mechanics; time correlation function; transverse current; ultrasonics; correlation function; density fluctuations; fluctuations; hydrodynamics; light scattering; liquid state; molecular dynamics; neutron scattering; shear wave; 16711 .

Statistical models; absolute absorptivities; continuum models; diffuse reflectance; radiative transfer; reflectance spectra; scattering coefficients; SP466, pp. 57-73 (May 1977).

Statistical plotting; stem-and-leaf displays; table making; automatic printing; Calcomp plotting; data editing; interactive; labels; numerical analysis; OMNITAB II computing system; probability plotting; selection of variables in linear regression; NBSIR 77-1276.

Statistics; ADP costs; Federal ADP statistics; Federal Government computers; Federal minicomputers; SP500-7.

Statistics; Cholesky decomposition; Givens transformations; Gram-Schmidt orthogonalization; Householder transformations; least squares algorithms; regression; 16833.

Statistics; drop ball test; flaw distribution; fracture; impact resistance; ophthalmic lenses; 16979.

Statistics; stratified sampling; Bayes' Rule; flow determination; flow prediction; Monte Carlo; SP484, pp. 447-470 (Oct. 1977).

Statistics; structural design; wind; codes; probability; 16856.

Statistics; turnaround; workload; accounting data; computer performance; computer resource unit; probability density function; SP500-18, pp. 39-67 (Sept. 1977).

Status; U-235 (n,f); 0.1-20.0 MeV; data; evaluations; SP493. pp. 261-268 (Oct. 1977).

Steadite; brittle fracture; cast iron gas pipe; graphitic corrosion; NBSIR 74-594.

Steady state; interactive computer system; performance measurement; renewal theory; statistical analysis; SP500-18, pp. 87-94 (Sept. 1977).

Steam; viscosity of water and steam; water; critically evaluated data; International Formulation; JPCRD 6, No. 4, $1133-1166$ (1977).

Steels; stress corrosion; crack propagation; ductility; failure; fractography; fracture tests; hydrogen; 16700.

Steels; superalloys; titanium alloys; aluminum alloys; crack propagation; fatigue; iron alloys; liquid helium; stainless steels; 16928.

Stefan-Boltzmann constant; blackbodies; electrically calibrated detectors; history of radiometry; Planck's constant; radiometric standards; radiometry; standard lamps; 16851.

Steiner Tunnel Test; ASTM E 84; fire tests; flame spread; heat flux; heat release rate; oxygen depletion; smoke; TN945.

Stellar atmospheres; high speed aerodynamics; radiative transfer; spectral line formation; 16758.

Stellar chromospheres; stellar evolution; stellar photospheres; stellar spectra; stellar transition regions; flare stars; 16809.

Stellar evolution; stellar photospheres; stellar spectra; stellar transition regions; flare stars; stellar chromospheres; 16809.

Stellar explosion; supernova; dynamics; galactic structure; interstellar medium; magnetic pressure; neutron; radiation; 17217.

Stellar instabilities; TU Cassiopeiae; Cepheids; beat Cepheids; double-mode Cepheids; mode interaction; pulsation; 17315.

Stellar instabilities; U Trianguli Australis; beat Cepheids; double-mode Cepheids; Fourier analysis of stellar variations; mode interaction; 16807.

Stellar instabilities; U Trianguli Australis; beat Cepheids; double-mode Cepheids; Fourier analysis of stellar variations; mode interaction; 17118 .

Stellar line profiles; transfer equations; early type stars; helium forbidden lines; Stark broadening theory; 17172.

Stellar oscillations; weak magnetic fields; nonradial; perturbation theory; 16804

Stellar photospheres; stellar spectra; stellar transition regions; flare stars; stellar chromospheres; stellar evolution; 16809.

Stellar pulsation; nonradial modes; potential theory; 17311 .
Stellar spectra; stellar transition regions; flare stars; stellar chromospheres; stellar evolution; stellar photospheres; 16809.

Stellar structure; $\mathrm{x}$-ray binaries; close binaries; 17309.

Stellar transition regions; flare stars; stellar chromospheres; stellar evolution; stellar photospheres; stellar spectra; 16809.

Stem-and-leaf displays; table making; automatic printing; Calcomp plotting; data editing; interactive; labels; numerical analysis; OMNITAB II computing system; probability plotting; selection of variables in linear regression; statistical plotting; NBSIR 77-1276.

Sterilization; dose distributions; dosimetry; electron beams; gamma radiation; plastic films; quality control; radiation processing; radiochromic dyes; 17000 .

"Sterling Silver," "Silver," or "Solid Silver," marking of; "Coin" or "Coin Silver," marking of; jewelry, "Silver," marking of; novelties, "Silver," marking of; PS71-76.

Stieltjes-Tchebycheff technique; configuration interaction; cross sections; ionization cross sections; lithium; photoexcitation cross sections; 17319.

Stiffness; analysis; compressive strength; deflection; design; flexural strength; masonry walls; racking strength; seismic loading; shear strength; shear wall; BSS62.

Stiffness; buildings; damage; dynamic response; earthquakes; safety; shear wall; SP470, pp. VI-33-VI-46 (Apr. 1977).

Stiffness; testing; bore hole; k property; property; soil; SP477, pp. VI-1 18-VI-140 (May 1977).

Stimulated collision-induced emission; argon oxide excimer; free-free-laser saturation flux; gain coefficients; 17254 .

Stimulator; terminal data; data input bus; DATANET 355; data output bus; high-speed line adaptor; HIS 6080; interactive terminal; probe point development; programmable monitor; SP500-18, pp. 95-105 (Sept. 1977).

Stirling cycle; cryogenic refrigeration; magnetometry; SQUID; 17091.

Stirrer; vortex; cuvette; helix; mixer; spectrophotometry; 16704.

Stochastic; BESM-6; JEZEBEL; Markov process; neutron; PURNIMA; Rossi- $\alpha$; slowing down; SP461, pp. $97-99$ (Jan. 1977).

Stockpiling; technology; U.S. demand structure; cartels; economic policy options; foreign supply disruptions; NBSGCR-ETIP 76-25.

Stockpiling; technology; U.S. demand structure; cartels; economic policy options; foreign supply disruptions; NBSGCR-ETIP 76-28.

Stockpiling; technology options; U.S. demand structure; cartels; economic policy options; foreign supply disruptions; NBSGCR-ETIP 76-29.

Stockpiling; technology options; U.S. demand structure; cartels; economic policy options; foreign supply disruptions; NBSGCR-ETIP 76-30.

Stockpiling technology options; U.S. demand structure; cartels; economic policy options; foreign supply disruptions; NBSGCR-ETIP 76-31.

Stoichiometry; atomic weight; coulometry; electrochemical equivalent; gallium arsenide; gallium atomic weight; J. Res. 81 A No. 1, 1-4 (1977).

Stokes parameters; Mueller matrix; polarization; polarizer; retarder; TN910-3.

Stone decay; stone preservatives; accelerated laboratory testing; performance criteria; TN941.

Stone preservatives; accelerated laboratory testing; performance criteria; stone decay; TN941.

Stopping power; stripped particle; velocity; charge; charged particle; collision; electron; ionic charge; ionization potential; SP461, pp. 144-148 (Jan. 1977).

Stored energy; strain energy; adiabatic temperature drift; enthalpy; glass transition; heat capacity; pelletization; poly(vinyl chloride), pressure densification; relaxation; 16769. 
Storm surge; tropical storms; wind; wind data; wind speed; hurricane; SP470, pp. I-18-I-27 (Apr. 1977).

Storms; structural engineering; tropical storms; wind loads; wind speeds; building codes; buildings; codes and standards; housing; hurricanes; pressure coefficients; probability distribution functions; risk; statistical analysis; BSS100-2.

Strain; stress; aluminum stabilization; copper stabilization; critical current; critical-current degradation; multifilamentary wires; $\mathrm{Nb}_{3} \mathrm{Sn}$; $\mathrm{NbTi} ; 16816$.

Strain; stress; critical current; critical current degradation; degradation mechanisms; multifilamentary superconductors; $\mathrm{NbTi} ; \mathrm{Nb}_{3} \mathrm{Sn} ; 16873$.

Strain; stress; superconducting magnets; anisotropic materials; orthotropic materials; 17082.

Strain concentration; stress concentration; anisotropy; composite laminates; failure; SP487, pp. 121-134 (Aug. 1977).

Strain energy; adiabatic temperature drift; enthalpy; glass transition; heat capacity; pelletization; poly(vinyl chloride), pressure densification; relaxation; stored energy; 16769.

Strainmeter; cavity effects; earth tides; ocean loads; 17196.

Strainmeter; gravitational waves; laser; 17267.

Stratified flow; temperature; velocity measurements; buoyant flow; corridor, countercurrent; fire; scaling; 17285 .

Stratified sampling; Bayes' Rule; flow determination; flow prediction; Monte Carlo; statistics; SP484, pp. 447-470 (Oct. 1977).

Stratosphere; chlorine nitrate; chlorofluorocarbons; oxygen atoms; rate constant; resonance fluorescence; 17149 .

Stratospheric chemistry; chemical kinetics; data evaluation; data reliability; gas phase; photoabsorption cross section; photochemistry; quantum yield; rate constant; 16976.

Stray light; wavelength accuracy; bandwidth; calibration; errors in spectrophotometry; interferences; multiple reflections; photometric linearity; polarization; sample characteristics; SP466, pp. 99-114 (May 1977).

Stray light; wavelength scale; errors in spectrophotometry; photometric scale; slit width; spectral transmission; spectrophotometer standards; SP466, pp. 117-120 (May 1977).

Stream gages; streamflow measurements; weirs; approach channels; broad-crested V-notch weirs; calibration; small watersheds; SP484, pp. $187-200$ (Oct. 1977).

Streamflow measurements; weirs; approach channels; broadcrested V-notch weirs; calibration; small watersheds; stream gages; SP484, pp. 187-200 (Oct. 1977).

Streaming; annular; computation; duct; gamma ray; integration; kernel; radiation; SP461, pp. 132-135 (Jan. 1977).

Streamlines; temperature distribution; analysis; buoyancy; laminar flow; plume; pressure distribution; J. Res. 81B Nos. 1 and 2, 45-60 (1977).

Strength; apartment building; collapse; concrete; concrete strength; construction; flexure; progressive collapse; shear; BSS94.

Strength; brittle materials; ceramics; ceramic turbine; proof testing; silicon nitride; NBSIR 77-1202.

Strength; brittle solids; ceramic surfaces; degradation; fracture; indentation; 16672.

Strength; coal gasification; environments; erosion; hydrothermal; refractories; 16993.

Strength; columns; concrete; earthquake; hysteretic envelope; reinforced; SP477, pp. VI-10-VI-27 (May 1977).

Stress; aluminum stabilization; copper stabilization; critical current; critical-current degradation; multifilamentary wires; $\mathrm{Nb}_{3} \mathrm{Sn}$; NbTi; strain; 16816.

Stress; critical current; critical current degradation; degradation mechanisms; multifilamentary superconductors; $\mathrm{NbTi} ; \mathrm{Nb}_{3} \mathrm{Sn}$; strain; 16873.

Stress; superconducting magnets; anisotropic materials; orthotropic materials; strain; 17082.

Stress; thermoluminism; quartz; sensitivity; SP461, pp. 231-233 (Jan. 1977).
Stress concentration; anisotropy; composite laminates; failure; strain concentration; SP487, pp. 121-134 (Aug. 1977).

Stress corrosion; crack propagation; ductility; failure; fractography; fracture tests; hydrogen; steels; 16700.

Stress corrosion; crevice corrosion; ellipsometry; localized corrosion; pitting; repassivation kinetics; 16990.

Stress corrosion cracking; titanium alloys; aluminum alloys; copper alloys; high strength steels; nickel alloys; stainless steels; Monogr. 156.

Stress effect; superconductor; critical currents; NbTi; 16868.

Stress index; thermal decomposition products; toxicity; acute lethality; Douglas Fir; inhalation; mice; polyurethane; pulmonary irritation; PVC; respiratory rate; sensory irritation; NBSGCR-77-85.

Stress relaxation; structural relaxation; thermal relaxation; anharmonic crystal; computer simulation; energy transport; equation of state; interatomic potential; molecular dynamics; second sound; shock wave; 16751 .

Stress rupture of FRP rod; test methods; weatherability of FRP rods; aramid; composite materials; end fittings for FRP rod; environmental resistance of FRP rods; fiber-reinforced plastic (FRP); glass; guys, antenna; pultrusion; reinforced plastics; 16685 .

Stress-cracking; time-to-fail; container tests; hazardous materials ladings; mechanical properties; performance criteria; plastic packaging; 17256

Stress-strain relations; stress-strain relations in rubber; uniaxial extension and compression in rubber; extension and compression in rubber; Martin-Roth-Stiehler equation; modulus of rubber; Mooney-Rivlin equation; J. Res. 82, No. 1, 57-63 (1977).

Stress-strain relations in rubber; uniaxial extension and compression in rubber; extension and compression in rubber; Martin-Roth-Stiehler equation; modulus of rubber; MooneyRivlin equation; rubber; J. Res. 82, No. 1, 57-63 (1977).

Stripped particle; velocity; charge; charged particle; collision; electron; ionic charge; ionization potential; stopping power; SP461, Pp. 144-148 (Jan. 1977).

Strong motion; buildings; instruments; SP477, pp. III-26-III-40 (May 1977).

Strong-motion accelerographs; accelerographs; earthquake data; earthquake records; field observations; SP470, pp. IV1-IV-34 (Apr. 1977).

Strong-motion accelerographs; earthquakes; hydraulic structures; inspection; instrumentation; SP470, pp. VI-47-VI-63 (Apr. 1977).

Strong-motion data; accelerographs; data processing; earthquake records; SP470, pp. IV-53-IV-66 (Apr. 1977).

Strong-motion network; accelerographs; earthquake data; earthquake records; field stations; SP470, pp. IV-35-IV-52 (Apr. 1977).

Strong-motion record; cost effectiveness; ground motion; network design; SP477, pp. III-1 -III-15 (May 1977).

Strontium titanate; beryllium; ceramics; cryogenics; dielectricconstant; electrets; electrocaloric effect; entropy; ferroelectrics; glass-ceramics; heat switches; magnetothermal conductivity; polarization; potassium tantalate; refrigeration; specific heat; NBSIR 76-847.

Strontium titanate; dielectric constant; dielectric relaxation; electret; glass ceramic; polarization; 16798 .

Structural analysis; finite element method; SP487, pp. 41-61 (Aug. 1977).

Structural analysis; tests; foundation; lateral loads; sheet piles; SP470, pp. VII-7-VII-60 (Apr. 1977).

Structural analysis; velocities; vibrations; arch dam; deflections; dynamic tests; model; SP477, pp. VI-85-VI-117 (May 1977).

Structural connections; technology transfer; wind loads; codes and standards; disaster mitigation; housing; low-rise buildings; socio-economics; BSSI00-1. 
Structural connections; wind loads; codes and standards; disaster mitigation; housing; low-rise buildings; socio-economics; SP477, pp. 1-70-1-78 (May 1977).

Structural design; structural engineering; structural research; building codes and standards; design criteria; earthquake resistance; masonry construction; seismic design; BSSIO6.

Structural design; structural research; building codes and standards; design criteria; earthquake resistance; limit states design; masonry construction; materials testing standardization; mathematical models; rehabilitation; retrofit; BSSI06, pp. $40-59$ (Sept. 1977).

Structural design; wind; codes; probability; statistics; 16856.

Structural design; wind-resistant; architectural; design; housing; low income; low-rise buildings; sites and services; socioeconomic; BSSIOO-5.

Structural engineering; building codes; buildings; design; earthquakes; SP477, pp. VI-61 - VI-68 (May 1977).

Structural engineering; buildings; live loads; load surveys; 16708.

Structural engineering; buildings; building codes; earthquakes; natural disasters; SP490.

Structural engineering; buildings (codes); live loads; load surveys; probability theory; 17305 .

Structural engineering; earthquakes; highway bridges; seismic provisions; specifications; SP470, pp. VIII-I-VIIl-30 (Apr. 1977).

Structural engineering; fire endurance; fire tests; probability theory; reinforced concrete; reliability; statistical analysis; 17303.

Structural engineering; load factors; performance approach; performance criteria; reliability analysis; reliability-based design; resistance factors; 17306.

Structural engineering; structures; buildings; earthquakes; research; SP470, pp. 1X-6-IX-16 (Apr. 1977).

Structural engineering; structural research; building codes and standards; design criteria; earthquake resistance; masonry construction; seismic design; structural design; BSSI06.

Structural engineering; tall buildings; turbulence; wind; aerodynamics; building (codes); pressure; spectra; 16843.

Structural engineering; tides; wind; buildings; cyclones; disasters; SP477, Pp. V-21 - V-53 (May 1977).

Structural engineering; tomadoes; trajectories; dynamics; missiles; power plants; SP477, pp. VII-36-VII-4l (May 1977).

Structural engineering; tropical storms; wind loads; wind speeds; building codes; buildings; codes and standards; housing; hurricanes; pressure coefficients; probability distribution functions; risk; statistical analysis; storms; BSSI00-2.

Structural engineering; tunnels; aseismic design criteria; design provisions; earthquakes; specifications; SP470, pp. VIII56-VIIl-68 (Apr. 1977).

Structural engineering; uncertainty; probability; reinforced concrete; reliability; statistical analysis; 17304 .

Structural engineering; uncertainty; abnormal loading; alternate path; building code; design criteria; probability; progressive collapse; reliability; BSS98.

Structural integrity; buildings; collapse; concrete; panels; SP477, Pp. VI-220_-VI-25 I (May 1977).

Structural materials; technical reports; ceramic technology; current awareness services; databooks; information analysis center; inquiry services; metals technology; SP463, pp. IV.2.1-IV.2.7 (Jan. 1977).

Structural materials; thermal properties; low temperature; mechanical properties; research program; 16863.

Structural metals and alloys; technical information; user awareness; data storage/retrieval; handbooks; mechanical properties; Mechanical Properties Data Center; SP463, pp. IV.8.1IV.8.10 (Jan. 1977).

Structural parameters; vibrational fundamentals; virial coefficients of the equation of state; enthalpy of formation; Gibbs energy of formation; ideal gas thermodynamic properties; intermolecular association; JPCRD 6, No. 1, 105-112 (1977).

Structural performance; testing procedures; thermal performance; durability/reliability; fire safety; rating criteria; solar collectors; NBSIR 77-I305.

Structural performance; uniform loads; concentrated loads; design criteria; mode of failure; racking resistance; SP477, pp. I-66-1-69 (May 1977).

Structural relaxation; thermal relaxation; anharmonic crystal; computer simulation; energy transport; equation of state; interatomic potential; molecular dynamics; second sound; shock wave; stress relaxation; 16751 .

Structural research; building codes and standards; design criteria; earthquake resistance; masonry construction; seismic design; structural design; structural engineering; BSSIO6.

Structural research; building codes and standards; design criteria; earthquake resistance; limit states design; masonry construction; materials testing standardization; mathematical models; rehabilitation; retrofit; seismic design; BSSI06, pp. 40-59 (Sept. 1977).

Structural response; vessels and wind; accelerograph; bridges; buildings; codes; disaster; dynamic analysis; earthquakes; ground failures; hydraulic structures; seismicity; soils; standards; SP470.

Structural response; winds; accelerograph; bridges; buildings; codes; disaster; dynamic analysis; earthquakes; ground failures; nuclear facilities; seismicity; soils; standards; SP477.

Structural walls; design procedures; earthquake excitation of structures; earthquake resistant structures; reinforcing details; SP477, pp. VI-199_-Vl-219 (May 1977).

Structure; antiferroelectric; $\mathrm{KCN}$; $\mathrm{NaCN}$; order parameter; 16972.

Structure; methylerimine; microwave spectroscopy; molecules; pyrolysis; rotational spectra; 16910 .

Structure; ultraviolet; yttrium; zirconium; ions; molybdenum; niobium; rubidium; spectra; 17212 .

Structure; vibrational frequency; $\mathrm{FeO} ; \mathrm{FeO}_{2}$ : infrared spectrum; 17208.

Structures; buildings; earthquakes; research; structural engineering; SP470, pp. IX-6-1X-16 (Apr. 1977).

Structures; crack propagation; cryogenics; fracture mechanics; fracture toughness; material properties; 16866.

Structures; design; earthquakes; harbours; ports; specifications; SP470, pp. VIIl-42-VIII-55 (Apr. 1977).

Structures; deterministic; dynamics; earthquake; probability; random vibrations; safety; SP470, pp. VI-1-VI-2l (Apr. 1977).

Structures; frequency response; least weight; optimization; SP470, pp. VI-22-VI-32 (Apr. 1977).

Structures; test methods; acoustics; appliances; atmospheric; durability; electrical; environment; housing technology; HVAC; innovative construction; maintainability; materials; minimum property standards; performance criteria; performance evaluation; plumbing; safety; NBSIR 77-1316.

Structures; typhoon; wind; wind effects; damage; SP477, pp. V-1-V-20 (May 1977).

Subcell; vacancies; alpha-tricalcium phosphate; calcium phosphate; cation-anion columns; crystal structure; 17034 .

Sub-surface scattering; bidirectional reflectance-distribution function; diffuse reflectance; directional reflectance; nomenclature of reflectance; optical reflection; reflectance; reflectance factor; reflectance geometry; reflectance nomenclature; reflection; Monogr. 160.

Sulfate; environmental analysis; ion-selective electrode; lead electrode; natural waters; rainwater; seawater; 16771 .

Sulfur dimer; tunable laser; visible-ultraviolet laser; gas laser; optical pumping; 17129 .

Sulfur dioxide; air quality; deterioration; measurements; particulates; regulations; 17141 . 
Sulfur hexafluoride; angular momentum; methane; rotational symmetry; 16957.

Sulfur hexafluoride; crystal field theory; group theory; molecular spectroscopy; 17316 .

Sulfur-hexafluoride; systematic pressurization; air-handling system; Chicago federal building; highrise; pressure profiles; Seattle federal building; smoke control; smoke simulation experiments; 17291 .

Sulphur hexafluoride; temperature programmed desorption; tungsten; chemisorption; electron stimulated desorption; oxygen; 16929.

Sum rule; electron scattering; inelastic; isospin; magnetic; multipolarity; 16687.

Sum rules; giant resonance; hydrodynamic model; isospin; photonuclear; shell model; 16987.

Summary of experimental results; ${ }^{237} \mathrm{~Np},{ }^{238} \mathrm{U}(\mathrm{n}, \mathrm{f})$ as neutron standards; $\mathrm{E}_{n}=$ 0.1-20 MeV; SP493, pp. 278-289 (Oct. 1977).

Summary tables; building construction; building regulations; cities; code uniformity; enforcement; legislation; rules and regulations; statewide codes; NBSIR 77-1390.

Summer temperature guidelines; thermal acceptability; thermal preference survey; winter temperature; clothing insulation; effective temperature (ET*); energy conservation; SP491, Pp. 93-116 (Sept. 1977).

Sun, atmosphere; sun, chromosphere; sun, spectroheliograms; 16888.

Sun, chromosphere; sun, spectroheliograms; sun, atmosphere; 16888 .

Sun, spectroheliograms; sun, atmosphere; sun, chromosphere; 16888 .

Sun-shading; ventilation; windows; daylighting; infiltration; insulation; passive-solar-heating; 17298.

Superalloys; fatigue; fracture; low temperature tests; mechanical properties; nickel alloys; 16801 .

Superalloys; titanium alloys; aluminum alloys; crack propagation; fatigue; iron alloys; liquid helium; stainless steels; steels; 16928.

Superconducting; electrodynamics; gyroscope; London moment; magnetic torque; relativity; satellite experiment; 16795.

Superconducting; voltage measurement; voltage reference; Josephson junction; standard cell; 16698.

Superconducting cable; underground transmission; bridge measurements; cryogenic; dielectric loss; dissipation factor; epoxy insulation; high voltage; polymer tape insulation; 17014.

Superconducting electronics; superconductivity; voltage waveforms; energy gap; Josephson junctions; picosecond pulses; 16874.

Superconducting magnets; anisotropic materials; orthotropic materials; strain; stress; 17082 .

Superconducting switch; thin-film; cryogenic electrical switch; mechanical switch; multiple contact switch; proximity effect; 17121.

Superconducting wire; tensile properties; composite; copper; low temperature; niobium-titanium alloys; 16862 .

Superconductivity; ampere definition; electrical units; fundamental constants; Josephson effect; levitation; 16876.

Superconductivity; attenuation; Josephson effect; quantum interference; radio frequency; SQUID; 16875.

Superconductivity; heterodyne detection; Josephson effect; millimeter waves; mixing; receiver; 17077.

Superconductivity; Josephson effect; quantum interference; if metrology; rf power; SQUID; 17092.

Superconductivity; Josephson junction; quantum interference; rf attenuation; NBSIR 77-863.

Superconductivity; ternary alloys; A15 phase; constitution diagram; niobium alloys; phase diagram; 16832 .

Superconductivity; thermometry; DC measurements; frequency; metrology; rf measurements; standards; 16861 .
Superconductivity; thermonuclear; copper; cryogenic; fusion; magnets; 17134 .

Superconductivity; tunnelling; dielectric constant; Josephson effect; lead; microwaves; niobium; 16946.

Superconductivity; voltage waveforms; energy gap; Josephson junctions; picosecond pulses; superconducting electronics; 16874.

Superconductor; critical currents; NbTi; stress effect; 16868.

Superconductor; critical current; definition; standards; 17074.

Supercooled phase; gas-liquid chromatography; liquid crystal; naphthalene homologues; nematic phase; 16673.

Supercritical helium; acoustic oscillations; current leads; experimental; stability; 17078 .

Supercritical helium; cryogenic helium supply system; cryogenic storage; helium; helium supply system; high density helium storage; liquid helium storage; NBSIR 76-850.

Superfluid helium-4; computed thermodynamic properties; entropy; equation of state; excitation spectrum; helium-4; normal fluid helium-4; phonons; protons; specific heat; JPCRD 6, No. 1, 51-104 (1977).

Supermultiplet; transition array; wall stabilized; multiplet; nitrogen lines; regularities; Stark broadening; 17204.

Supermultiplet; transition array; isolated lines; multiplet; plasma broadening; regularities; Stark widths; 17206.

Supernova; dynamics; galactic structure; interstellar medium; magnetic pressure; neutron; radiation; stellar explosion; 17217.

Superoxide ion; aqueous solution; chemical kinetics; data compilation; hydroxyl radical; oxide radical ion; perhydroxyl radical; radiation chemistry; rates; NSRDS-NBS59.

Supersonic flows; thin turbulent shear layers; error reduction; hot-wire anemometry; SP484, pp. 649-658 (Oct. 1977).

Supported thin films; Auger-electron spectroscopy (AES); electron attenuation lengths; electron spectroscopy for chemical analysis (ESCA); electron transmission through thin films; inelastic electron mean free path; 16744 .

Supralinear; thermoluminescence; dose; gamma rays; LiF; response; sensitivity; SP461, Pp. 227-230 (Jan. 1977).

Surface absorption; absorption; barothermal gas cell; bulk absorption; highly transparent; infrared materials; optical materials; 16815 .

Surface absorption; weakly absorbing materials; bulk absorption; frequency dependence; laser materials; photoacoustic spectroscopy; 16860.

Surface absorption; weakly absorbing materials; bulk absorption; frequency dependence; laser materials; photoacoustic spectroscopy; 17313 .

Surface analysis; ion imaging; ion microprobe; ion microscope; microanalysis; secondary ion mass spectrometry; 17156 .

Surface area and fixation of chelating rings; adhesive bonding to bone mineral; chemisorption of a dental varnish; configuration on surface; kinetics of adsorption from solution; rate law and areal regression of adsorbate; 17033.

Surface atomic structure; surface characterization; surface composition; surface electronic structure; surface properties; $\mathrm{Na}$ tional Measurement System for Surface Properties; NBSIR $75-945$.

Surface autocorrelation; surface finish; surface finish average wavelength; surface periodicity; AA roughness; NBSIR 73196.

Surface barrier; ${ }^{6} \mathrm{LiF}$; detector; energy leakage; Monte Carlo; neutron; sandwich; spectrometry; SP461, pp. 252-254 (Jan. 1977).

Surface channel; The Federal Republic of Germany; The Netherlands; transfer channel; bucket-brigade; buried channel; Canada; charge-coupled device; Great Britain; imager CCD's; Japan; peristaltic CCD's; SPSO0-5.

Surface characterization; surface composition; surface electronic structure; surface properties; National Measurement 
System for Surface Properties; surface atomic structure; NBSIR 75-945.

Surface characterization; $x$-ray photoelectron spectroscopy; Auger electron spectroscopy; catalyst; electron binding energy; interlaboratory comparison; 16930.

Surface composition; surface electronic structure; surface properties; National Measurement System for Surface Properties; surface atomic structure; surface characterization; NBSIR 75945.

Surface deformation; assessment of fatigue damage; exoelectron emission; failure prediction; laser scanner; oxide rupture; SP487, pp. 197-209 (Aug. 1977).

Surface dose; air dose; arbitrary shaped field; back-scatter factor; Clarks' method; depth dose; dosimetry; SP461, Pp. 193 196 (Jan. 1977).

Surface electronic structure; surface properties; National Measurement System for Surface Properties; surface atomic structure; surface characterization; surface composition; NBSIR 75-945.

Surface energy; grain boundary groove; ice-water interface; icewater surface tension; Nash-Glicksman theory; 16780.

Surface finish; surface finish average wavelength; surface periodicity; AA roughness; surface autocorrelation; NBSIR 73-196.

Surface finish; surface roughness; light scattering; optical measurement of roughness; NBSIR 73-219.

Surface finish average wavelength; surface periodicity; AA roughness; surface autocorrelation; surface finish; NBSIR 73 196.

Surface flaws; thin foils; cracks; electron microscopy; grinding damage; oxidation; silicon nitride; 17090 .

Surface magnetism; spin-polarized field emission; spin-polarized photoemission; 17022.

Surface nucleation; chain-folding; crystallization; growth rate; homogeneous nucleation; polymer; 16887

Surface periodicity; AA roughness; surface autocorrelation; surface finish; surface finish average wavelength; NBSIR 73-196.

Surface profile instrumentation; surface roughness calibrations; surface roughness measurement; NBSIR 73-106.

Surface properties; apatites; caries mechanism; caries prevention; membrane potentials; permselective properties; 16787.

Surface properties; National Measurement System for Surface Properties; surface atomic structure; surface characterization; surface composition; surface electronic structure; NBSIR 75945.

Surface reactions; tropospheric sink; chloromethanes, photochemistry; quantum yields; quartz; sand; J. Res. 82, No. 1, 1-8 (1977).

Surface roughness; light scattering; optical measurement of roughness; surface finish; NBSIR 73-219.

Surface roughness; test patterns; thermally stimulated current; transistors, power; TTL circuits; ultrasonic wire bonding; ultraviolet reflectance; $x$-ray damag; acoustic emission; Auger electron spectroscopy; beam-lead bonds; capacitance-voltage methods; SP400-29.

Surface roughness calibrations; surface roughness measurement; surface profile instrumentation; NBSIR 73-106.

Surface roughness measurement; surface profile instrumentation; surface roughness calibrations; NBSIR 73-106.

Surface technology; electromagnetic; interference; measurement; metrology; radiation; 17079 .

Surface temperature; built-up roofing; insulation; performance; radiative cooling; roofing; solar heating; 17060 .

Surface temperature; built-up roofing; insulation; performance; radiative cooling; roofing; solar heating; 17061 .

Surface tension; combustion models; flame spread; fluid flow; laser doppler velocimetry; liquid fuels; solid fuels; NBS-GCR76-79.

Surface tension; floating zone; gravity; liquid zone; shape; stability; 17009 .
Surface tension; viscosity; bromides; data compilation; density; electrical conductance; iodides; molten salt mixtures; standard reference data; JPCRD 6, No. 2, $409-596$ (1977).

Surface-active comonomer; adhesion to polymers; adsorption from solutions; chemisorption; hydroxyapatite; irreversible vs reversible adsorption; 17197 .

Surfaces; adsorption; angle resolved; Auger; chemisorption; electron spectroscopy; 16747.

Surfaces; catalysis; characterization; chemisorption; electronic factor; geometric factor; metals; SP475.

Surfaces; energy loss; ESCA; solids; 17021.

Surfaces; vibrational excitation; adsorption; molecules; photoelectron spectroscopy; 16749.

Surveillance equipment; alarm systems; cameras; police; police equipment; security equipment; SP480-4.

Surveillance limits; surveillance test; test interval; true mass; value; weighing design; weights; apparent mass; buoyancy; buoyancy correction; change; comparison; difference; mass; records; set; NBSIR 76-999.

Surveillance test; test interval; true mass; value; weighing design; weights; apparent mass; buoyancy; buoyancy correction; change; comparison; difference; mass; records; set; surveillance limits; NBSIR 76-999.

Survey; abstracts; bibliography; cryogenic insulation; foam insulation; insulation; 17308.

Survey; communications equipment priorities; equipment standards; Law Enforcement Standards Laboratory; police equipment; reports and guidelines; SP480-13.

Survey; construction; dams; earthquake; earth structures; roads; SP477, pp. VI-44_VI-49 (May 1977).

Survey; detectors; National Measurement System; photometry; radiometry; sources; standards; NBSIR 75-939.

Survey; time; frequency; National Measurement System; standards laboratories; 17070.

Survey; ultraviolet; detectors; National Measurement System; radiometry; sources; NBSIR 75-941.

Survey of buildings; Air Force facilities; building energy conservation; energy management; evaluation and monitoring; 17062

Surveying; distance measurement; earth tides; laser strainmeter; 17199.

Surveys; blood lead; children; data analysis; housing; lead paint; lead poisoning; NBSIR 77-1293.

Surveys; $x$-ray fluorescence; children; data analysis; housing; lead paint; lead poisoning; NBSIR 77-1250.

Susceptibility; alloys; copper; electrical resistivity; iron; low temperature; 17135 .

Susceptibility; TEM cell; electromagnetic measurements; interference; near-field probes; radiation; 17251.

Suspension; absolute measurements; barium ferrite buoy; densimeter; experimental; liquid, magnetic; modification; 16792.

Swarm; theory; velocity distribution; drift tube; ion; MonteCarlo; 16779.

Switch; burglar alarm sensor; burglar alarm system; door switch; mechanically actuated switch; perimeter sensor; 17002.

Symbolic evaluation; symbolic testing; computer programming; cost analysis; software engineering; software reliability; software testing; NBS-GCR-77-89.

Symbolic testing; computer programming; cost analysis; software engineering; software reliability; software testing; symbolic evaluation; NBS-GCR-77-89.

Symmetric; transport; density transform; expansion coefficient; Green's function; neutron; spherical; SP461, pp. 87-90 (Jan. 1977).

Symmetry; antennas; arrays; coordinate transformations; data processing; group representations; measurements; near field; nonplanar; patterns; scanning; spherical; 16671 . 
Symmetry; crystal; isostructural materials; lattice; point group; polymorphism; space group; JPCRD 6, No. 3, 675-830 (1977).

Symmetry; identification; lattice; powder method; reduced cell; single crystal; 17050.

Symmetry analysis; antenna patterns; characteristic modes; Garbacz characteristic modes; group theory; inverse scattering; moment methods; scattering; singularity expansion method; 17225 .

Symmetry analysis; computer programs; data reduction; eigenvalue equations; electromagnetic theory; group theory; nearfield scanning; 17222 .

Symposium; cross sections; dosimetry; electrons; neutrons; photons, radiation physics; SP461.

Synchronous detection; temperature controller; thermoelectric; thermometry; AC bridge; microcomputer; 16908.

Synchronous detector; synchronous phase marker circuit; narrow pass filter; phase measurement; phase of noisy sinusoid; phase sensitive detector; 17138 .

Synchronous phase marker circuit; narrow pass filter; phase measurement; phase of noisy sinusoid; phase sensitive detector; synchronous detector; 17138 .

Synchronous signaling rates; teleprocessing; data cormmunication equipment; data processing terminal equipment; data transmission (voice band); Federal Information Processing Standards; FIPS PUB 22-1.

Synchrotron; ultraviolet; wall-stabilized; arc; calibration; deuterium; interlaboratory; lamp; radiance; radiometry; source; spectroscopy; standard; 17198.

Synchrotron radiation; building collapse; computer security; cryogenic temperature; dentistry; dielectric measurements; dye lasers; dynamic calibration; electron microscopy; electronic technology; energy conservation; DIM/NBS 61, No. 2, $1-32$ (1977).

Synchrotron radiation; transfer standard detectors; calibration facilities; photodiodes; radiometry; spectrometer calibration; 16665.

Syntax analysis; text editing; building blocks; programming aids; software tools; SP500-14.

Synthesis; thin film; vapor transport; activation parameters; active nitrogen; iodine; kinetics; microwave discharge; nitride; plasma; reaction mechanism; silicon; 16757.

Synthesized spectrum; time-dependent spectrum; coherence; correlation function; counting rate spectrum; nonstationary process; nonstationary spectrum; power spectrum; 17169.

Synthetic benchmarking; benchmarking; dispatching algorithms; SP500-18, pp. 119-135 (Sept. 1977).

Synthetic fabrics; burn injury potential; extinguishability; fire retardants; flammability hazard; FR treated cotton blends; FR treated cottons; ignitability; MAFT value; phosphorus; 17176.

Synthetic implants; adsorption; blood protein; ellipsometry; implants; polymer adsorption; protein adsorption; NBSIR 761128.

System capacity; validation; credit authorization system; critical resource; disk modelling; event model; measurement; modelling; resource dependency; SP500-18, pp. 185-211 (Sept. 1977).

System design; adverse reaction detection; biostatistics; drug regulation; pharmaceutical regulation; phase IV; post marketing surveillance; regulatory experiments; NBS-GCR-ETIP 7635.

System design; computer-communication networks; configuration analysis; model validation; performance management; performance prediction; queuing networks; sizing studies; SP500-18, pp. 227-234 (Sept. 1977).

System design; task variables; workload characteristics; computer response time; human factors; on-line systems; SP50018, pp. 3-11 (Sept. 1977).
System engineering; building codes; computer model; decision table; decision theory; networks; specifications; standards; SP473, pp. 285-316 (June 1977).

System integration; voluntary standards; CAM architectures; computer aided manufacturing; computer systems; standards; NBSIR 76-1094.

System modeling; virtual memory system; bubble memory; performance evaluation; SP500-18, pp. 213-217 (Sept. 1977).

System safety; accident research; human factors; methodology; rare events; safety; $S P 482$.

System safety; critical item list; failure mode and effect analysis; failure reduction; reliability; SP487, pp. 278-288 (Aug. 1977).

Systematic error; uncertainty; measurement assurance; NBSIR 77-1240.

Systematic errors; trimmed means; velocity of light; A. A. Michelson; adaptive estimators; arithmetic mean; bias; estimators of location; median; M-estimators; S. Newcomb; 17266.

Systematic pressurization; air-handling system; Chicago federal building; highrise; pressure profiles; Seattle federal building; smoke control; smoke simulation experiments; sulfur-hexafluoride; 17291 .

Systematic pressurization; air-handling units; building pressure profile; computer simulation; elevator shaft pressure profiles; parametric analysis; simulated smoke concentration; smoke control; smoke movement; smoke simulation; NBSIR 771225.

Systems; metrology; 17105 .

Systems analysis; availability; fault tree analysis; probabilistic analysis; reliability; SP487, pp. 289-308 (Aug. 1977).

Systems analysis; buildings; fire protection; fire safety; goal oriented systems approach; NBS-GCR-77-103.

Systems analysis; use of products; consumer behavior; consumer product safety; human factors; misuse of products; 16890 .

Systems and software; telecommunications; computer use; conservation; data; earth's measurement; energy; health records; hydrogen; law enforcement; liquefied natural gas; metric tons; polyethylene; sound; spinach; SRM; DIM/NBS 61, No. 5, 1-32 (1977).

Systems approach to design; engineering design; manufacturing processes; materials selection; SP487, pp. 19-24 (Aug. 1977).

Systems security; ADP availability; annual loss expectancy; application system vulnerability; computer security; data confidentiality; data integrity; data security; physical security; procedural security; risk analysis; risk assessment; NBSIR 771228.

Systems theory; energy consumption; input/output models; lifestyle factors; physical environment; residential housing; socio-physical determinants; SP473, pp. $69-83$ (June 1977).

Système International des Unités; Units of Measurements; General Conference on Weights and Measures; International System of Units; SI; SP330.

\section{T}

Table making; automatic printing; Calcomp plotting; data editing; interactive; labels; numerical analysis; OMNITAB II computing system; probability plotting; selection of variables in linear regression; statistical plotting; stem-and-leaf displays; NBSIR 77-1276.

Tables; asymptotic formulas; classical modular group; cyclic groups; free groups; free products; 16660 .

Tables; density; deviation plots; ethane; experimental; isobutane; magnetic suspension densimeter; methane; normal butane; propane saturated liquid; 16871 .

Tables; thermal conductivity coefficient; viscosity coefficient; correlation; critical point anomaly; methane; JPCRD 6, No. 2, 597-610 (1977). 
Take-home car program; breakeven analysis; life-cycle costing; patrol cars; personal car plan; police fleet administration; 17299.

Tall buildings; turbulence; wind; aerodynamics; building (codes); pressure; spectra; structural engineering; 16843.

Tall buildings; wind loads; design; equivalent loads; SP477, pP. I-49-I-65 (May 1977).

Tall buildings; wind profiles; boundary layer; hurricanes; loads (forces); natural analysis; SP477, Pp. II-30-II-40 (May 1977).

Tangential sensitivity; broadband probe; dipole antenna; dynamic range; electric field probe; isotropic probe; loop antenna; magnetic field probe; NBSIR 77-868.

Tanh rule; trapezoid rule; Hardy space; numerical integration; numerical quadrature; piecewise analytic functions; quadrature; rational approximation; 17157.

Tank cars; metallurgical; 16716.

Tank cars; metallurgical; 16717.

Tank cars; metallurgical; 16718 .

Tank cars; metallurgy; 16715.

Tank cars; metallurgy; 16719.

Tank cars; metallurgy; 16720.

Tank gaging; measurement practices; metering; oil measurement documents; petroleum measuring; SP484, PP. 55-60 (Oct. 1977).

Tape; thermal protection; thermal radiant-energy response; thermal transient response; transducer; zero shift; coatings; delayed response; dynamic; dynamic response; pressure step; pressure transducer; protective coatings; shock tube; TN961.

Target; tissue; dose; dosimetry; Monte Carlo; organ; phantom; photon; reciprocity theorem; source; SP461, pp. 177-182 (Jan. 1977).

Target standards; laser radar; laser radar signatures; NBSIR 77 856.

Task lighting; energy conservation; illumination; illumination levels; lighting; 17293.

Task variables; workload characteristics; computer response time; human factors; on-line systems; system design; SP50018, pp. 3-11 (Sept. 1977).

Technical bases; building research; building technology; codes; criteria; project summaries; standards; SP446-1.

Technical information; DDC; Defense Documentation Center; DoD technical information; Information Analysis Centers; SP463, PP. IV.1.1-IV.1.5 (Jan. 1977).

Technical information; user awareness; data storage/retrieval; handbooks; mechanical properties; Mechanical Properties Data Center; structural metals and alloys; SP463, PP. IV.8.1IV.8.10 (Jan. 1977).

Technical issues in metrication; construction industry metrication; metrication benefits; rationalization; 17040 .

Technical reports; ceramic technology; current awareness services; databooks; information analysis center; inquiry services; metals technology; structural materials; SP463, PP. IV.2.1-IV.2.7 (Jan. 1977)

Technical reports; computerized information system; document dissemination; government reports; NTIS; patent licensing; SP463, pp. VII.3.1-VII.3.5 (Jan. 1977).

Technical reports; test methods; analytical procedure; bibliographies; computerized information system; concrete; concrete technology; construction material; construction methods; portland cement; state-of-the-art summaries; SP463, pp. IV.7.1IV.7.7 (Jan. 1977).

Technical reports; testing methods; tooling; adhesives; composites; computerized information system; foams; plastics information; Plastics Technical Evaluation Center; specifications; SP463, pp. IV.3.1-IV.3.2 (Jan. 1977).

Technical reports; Thermophysical and Electronic Properties Information Analysis Center; thermophysical properties; computerized information system; data bank; electrical proper- ties; electronic properties; SP463, PP. IV.4.1-IV.4.3 (Jan. 1977).

Technical reports; ultrasonics; Army Materials and Mechanics Research Center; electromagnetics; materials testing; nondestructive testing; Nondestructive Testing Newsletter; radiography; SP463, pp. IV.6.1-IV.6.2 (Jan. 1977).

Techniques; adsorption; proteins; radiotracer; 16777.

Techniques; ultraviolet photometer; ozone; potassium iodide; 16756.

Techniques of design; validation of design; coating materials; composite materials; design; failure avoidance; failure prevention; lubricants; materials of design; product liability; reliability of design; SP487.

Technological change; institutional barriers to change; science and technology; scientific freedom and responsibility; 16905.

Technological change; transaction costs; computer; computer program; copyright; data base; economic efficiency; information technology; policy analysis; policymaking; public goods; SP500-17.

Technological innovation; check wrapping equipment; experimental procurement; experimental technology incentives program; procurement experiment; prototype procurement; NBS-GCR-ETIP 77-39.

Technology; annual report; computer; energy; environmental; measurement; product safety; research; science; standards; SP467.

Technology; communication; information; interdisciplinary technology; physical property data; publish; science; standard reference data; 17258 .

Technology; cryocooler; EMI problems; energy problems; energy savings; exchange program; lead detection; metric; oxygen; DIM/NBS 61, No. 10, 1-32 (1977).

Technology; impact of government on the economy; pesticides; R\&D incentives; regulation; NBS-GCR-ETIP 76-34.

Technology; U.S. demand structure; cartels; economic policy options; foreign supply disruptions; stockpiling; NBS-GCRETIP 76-25.

Technology; U.S. demand structure; cartels; economic policy options; foreign supply disruptions; stockpiling; NBS-GCRETIP 76-28.

Technology; 75th anniversary; National Bureau of Standards; physical sciences; science and technology in America; SP465.

Technology assessment; energy; environmental quality; management; materials information; national programs; policy; SP463, pp. I.2.1-I.2.2 (Jan. 1977).

Technology growth; U.S. economy; free enterprise system; innovation; public private sector collaboration; 17113.

Technology options; U.S. demand structure; cartels; economic policy options; foreign supply disruptions; stockpiling; NBSGCR-ETIP 76-29.

Technology options; U.S. demand structure; cartels; economic policy options; foreign supply disruptions; stockpiling; NBSGCR-ETIP 76-30

Technology transfer; energy; evaluation; innovation; invention; 17108 .

Technology transfer; timber roofs; timber walls; wind effects; codes and standards; connectors; fasteners; low-rise buildings; masonry walls' structural design; BSSI 00-3.

Technology transfer; total materials cycle; information demand; materials information and data system; national commission on materials policy; SP463, PP. IX.1.1-IX.1.22 (Jan. 1977).

Technology transfer; urgent data request; ALERT; calibration procedures; engineering technical data, metrology; failure mode; failure rate, quality, reliability, safety; SP463, pp. III.5.1 -III.5.8 (Jan. 1977).

Technology transfer; wind loads; codes and standards; disaster mitigation; housing; low-rise buildings; socio-economics; structural connections; BSSIOO-I. 
Telecommunications; computer use; conservation; data; earth's measurement; energy; health records; hydrogen; law enforcement; liquefied natural gas; metric tons; polyethylene; sound; spinach; SRM; systems and software; DIM/NBS 61, No. 5, 1-32 (1977).

Telecommunications; teleprocessing; American Standard Code for Information Interchange; ASCIl; communications; data communications equipment; data processing terminal equipment; data transmission; Federal Information Processing Standards; FIPS PUB 16-1.

Telecommunications; teleprocessing; American Standard Code for Information Interchange; ASCll; character parity sense; character structure; communications; data transmission; Federal Information Processing Standards; serial-by-bit; FIPS PUB 17-1.

Telecommunications; teleprocessing; American Standard Code for Information Interchange; ASCIl; character structure; communications; data transmission; Federal Information Processing Standards; parallel-by-bit; parity sense; serial-bycharacter; FIPS PUB $18-1$.

Telephone systems; transit information; transportation; automation; cost/benefit; models; queuing; NBSIR 77-1253.

Teleprocessing; American Standard Code for Information Interchange; ASCII; communications; data communications equipment; data processing terminal equipment; data transmission; Federal Information Processing Standards; serial-bybit; FIPS PUB 16-1.

Teleprocessing; American Standard Code for Information Interchange; ASCII; character parity sense; character structure; communications; data transmission; Federal Information Processing Standards; serial-by-bit; telecommunications; FIPS PUB 17-1.

Teleprocessing; American Standard Code for Information Interchange; ASCII; character structure; communications; data transmission; Federal Information Processing Standards; parallel-by-bit; parity sense; serial-by-character; telecommunications; FIPS PUB 18-1.

Teleprocessing; data communication equipment; data processing terminal equipment; data transmission (voice band); Federal Information Processing Standards; synchronous signaling rates; FIPS PUB 22-1.

Teleprocessing; evaluation; interactive; measurement; performance evaluation; performance measurement; remote terminal emulation; Remote Terminal Emulator; 16945.

Teleprocessing; evaluation; interactive; measurement; performance evaluation; performance measurement; remote terminal emulation; remote terminal emulators; SPSOO-4.

Teleprocessing systems measurement; computer network measurement; data acquisition; interactive computer access; measurement; network measurement services; service; 17252 .

Teleprocessor; computer control; laboratory automation; 16961.

Television; time; atomic clocks; dissemination; frequency; geosynchronous satellite; measurement; standards; 17182.

Television camera tubes; television cameras; test methods; diffuser; interference filters; spectral responsivity; spectral transmittance; 16761 .

Television cameras; contrast; contrast transfer function; image quality; limiting resolution; relative spectral response; signalto-noise ratio; square wave patterns; SP480-25.

Television cameras; test methods; diffuser; interference filters; spectral responsivity; spectral transmittance; television camera tubes; 16761 .

Television cameras; total response; contrast transfer function; distortion; limiting resolution; shading; signal-to-noise ratio; spectral response; standards; 17233.

Television captioning; thermophysical; weights and measures; American electroplaters'; calorimeter; cryogenic flow measurement; dental restorations; deep ocean research; federal science; governmental environment; laser energy; DIM/NBS 61 , No. 4, 1-32 (1977).

Television color subcarrier; time and frequency calibration methods; time calibration; time signals; frequency calibration; high frequency; Loran-C; low frequency; radio broadcasts; standard frequencies; TN695.

Television time/frequency dissemination; time/frequency calibrations; user equipment; user survey; NBS radio stations WWV/WWVH/WWVB; NBS time/frequency services; satellite timing; standard time/frequency broadcasts; 17080 .

TEM cell; electromagnetic measurements; interference; nearfield probes; radiation; susceptibility; 17251 .

TEM cells; measurements; radiated emission; radiation resistance; 17220.

TEM transmission cell; electronic equipment; EMC measurements; low-Q enclosures; radiated susceptibility; 16668.

Temperature; calibration; ceramic; condenser; electret; humidity; microphones; reciprocity; sensitivity; 16701 .

Temperature; calibration; ceramic; condenser; electret; humidity; microphones; reciprocity; sensitivity; 17245 .

Temperature; dopant density; electron-electron scattering; electron mobility; ionized impurity scattering; lattice scattering; neutral impurity scattering; $n$-type silicon; resistivity; 17147.

Temperature; dopant density; electron mobility; ionized impurity scattering mobility; lattice mobility; neutral impurity scattering mobility; n-type silicon; resistivity; scattering mechanisms; SP400-33.

Temperature; thermal acceptability; clothing; cold discomfort; energy conservation; humidity; SP491, Pp. 131-151 (Sept. 1977).

Temperature; thermistors; thermometry; fixed points; gallium; gallium melting point; melting; standards; 17055.

Temperature; thermoluminescence; aluminium oxide; glow; heat treatment; impurity; SP461, pp. 219-221 (Jan. 1977).

Temperature; thermometric fixed-point; clinical laboratory; fixed-point; gallium; melting-point standard; $S P 481$.

Temperature; velocity measurements; buoyant flow; corridor, countercurrent; fire; scaling; stratified flow; 17285.

Temperature and performance; temperature control; thermal comfort; thermal sensation; thermal tolerance; work conditions; environmental control; SP491, pp. 169-173 (Sept. 1977).

Temperature characteristics; electrical heating elements; materials performance; radiant panel-seamless flooring system; seamless flooring; NBSIR 77-1 263.

Temperature coefficient of index; potassium chloride; refractive index; 16662.

Temperature compensation; diode detector; diode model; 16724.

Temperature control; thermal comfort; thermal sensation; thermal tolerance; work conditions; environmental control; temperature and performance; SP491, pp. 169-173 (Sept. 1977).

Temperature controller; thermoelectric; thermometry; AC bridge; microcomputer; synchronous detection; 16908 .

Temperature correction; test measure; test measure evaluation; "to contain"; "to deliver"; volumetric calibration; accuracy; design analysis; equipment specification; field standard; gravimetric calibration; liquid retention or clingage tests; precision; NBSIR 77-1214.

Temperature distribution; analysis; buoyancy; laminar flow; plume; pressure distribution; streamlines; J. Res. 81B Nos. 1 and 2, 45-60 (1977).

Temperature fields; acoustic transmission measurements; algebraic reconstruction techniques; SP484, pp. 335-359 (Oct. 1977).

Temperature fixed point; thermometry; gallium; International Practical Temperature Scale of 1968; melting point standard; secondary fixed point; 17049. 
Temperature fluctuation; flicker noise; frequency random walk; quartz crystal resonators; resonance frequency fluctuation; 17183

Temperature mapping; active devices; internal logic identification; laser scanning; logic flow identification; LSI testing; nondestructive tests; nonlinear region mapping; 17164 .

Temperature measurements; thermal pollution; thermometry; water analysis; water pollution; pollution; standards committees; NBSIR 77-1227.

Temperature programmed desorption; tungsten; chemisorption; electron stimulated desorption; oxygen; sulphur hexafluoride; 16929.

Temperature rise; wood; ceiling height; ceilings; cotton; detector location; fire detectors; fire growth; flaming fires; heat detectors; polyurethanes; polyvinyl chloride; smoke detectors; smoldering fires; NBS-GCR-77-95.

Tenability levels; detector sensitivity; detector siting; heat detectors; ionization smoke detectors; photoelectric smoke detectors; residential fires; smoke detectors; 16882.

Tensile fatigue crack growth rate; $J$-integral; plane strain fracture toughness; 16879.

Tensile properties; composite; copper; low temperature; niobium-titanium alloys; superconducting wire; 16862 .

Tensile properties; creep-rupture properties; elevated-temperature; fracture mode; Larson-Miller parameter; pressure vessel steel; 17235 .

Tensile stress; cadmium telluride; elastic compliance tensor; elastic moduli; extrinsic damage thresholds; high-power lasers; infrared materials; 16746.

Tensile stress; cadmium telluride; elastic compliance tensor; elastic moduli; extrinsic damage thresholds; high-power lasers; infrared materials; 17312 .

Tensile testing; worker safety equipment; body belts; body harness; fall-arrest equipment; fall-safety systems; impact accelerations; impact forces; lanyards; linemen's equipment; load-extension data; occupational safety and health; performance standard; regulation; NBSIR 76-1146.

Terbium; amorphous alloys; iron; magnetization measurements; neutron diffraction; 16835 .

Terminal data; data input bus; DATANET 355; data output bus; high-speed line adaptor; HIS 6080; interactive terminal; probe point development; programmable monitor; stimulator; SP500-18, pp. 95-105 (Sept. 1977).

Terminals; verification; ADP security; computer networks; controlled accessibility; encryption; evaluation criteria; key; password; personal identification; FIPS PUB 48.

Terms; vocabulary; computers; data processing; definitions; dictionary for information processing; Federal Information Processing Standards Publication; information processing; FIPS PUB 11-1.

Ternary alloys; A15 phase; constitution diagram; niobium alloys; phase diagram; superconductivity; 16832.

Temary copper-silver alloy systems; thermodynamic properties; critically evaluated data; phase diagrams; JPCRD 6, No. 3 , $621-674$ (1977).

Ternary diffusion; thermomigration; alloys; antimony; arsenic; bismuth; copper; diffusion; electromigration; liquid metals; nitrogen; phosphorus; JPCRD 6, No. 1, 1-50 (1977).

Terrorism; vigilance; behavioral science; human factors; human reliability; perpetrator attributes; physical security; psychological deterrence; sophisticated crime; threat analysis; SP480-24.

Test cases; validating correctness; communications security; computer security; cryptography; encryption standard; interface requirements; Monte-Carlo testing; testbed; SP500-20.

Test data; test methods; thermal explosion theory; accidental polymerization; CHETAH predictive scheme; hazard evaluation; NBSIR 76-1/49.
Test development; textiles; apparel; fabrics; flammability testing; heat transfer rates; Mushroom Apparel Flammability Tester; standards; NBS-GCR-76-78.

Test interval; true mass; value; weighing design; weights; apparent mass; buoyancy; buoyancy correction; change; comparison; difference; mass; records; set; surveillance limits; surveillance test; NBSIR 76-999.

Test measure; test measure evaluation; "to contain"; "to deliver"; volumetric calibration; accuracy; design analysis; equipment specification; field standard; gravimetric calibration; liquid retention or clingage tests; precision; prover; NBSIR 77-1214.

Test measure evaluation; "to contain"; "to deliver"; volumetric calibration; accuracy; design analysis; equipment specification; field standard; gravimetric calibration; liquid retention or clingage tests; precision; prover; Research Associate Program; NBS/R 77-1214.

Test method; ASTM E 162; coefficient of variation; flame spread tests; flexible polyurethane; hardboard; interlaboratory evaluation; neoprene; radiant panel test; round robin; NBSIR 77-1222.

Test method; UL 217; aerosol; mass concentration; number concentration; size distribution; smoke; smoke detector; NBSIR 77-1312.

Test methods; acoustics; appliances; atmospheric; durability; electrical; environment; housing technology; HVAC; innovative construction; maintainability; materials; minimum property standards; performance criteria; performance evaluation; plumbing; safety; structures; NBSIR 77-1316.

Test methods; analytical procedure; bibliographies; computerized information system; concrete; concrete technology; construction material; construction methods; portland cement; state-of-the-art summaries; technical reports; SP463, pp. IV.7.1-IV.7.7 (Jan. 1977).

Test methods; bituminous roof membranes; built-up roof membranes; coal-tar pitch; performance criteria; physical and engineering properties; NBSIR 77-1256.

Test methods; burn injury; flammability; Mushroom Flammability Tester; 16813 .

Test methods; certification programs; consumer products; household products; industry standards; international recommendations; national standards; product standards; recommended practices; specifications; TN948.

Test methods; diffuser; interference filters; spectral responsivity; spectral transmittance; television camera tubes; television cameras; 16761 .

Test methods; fire helmet; head injury; head protection; heat resistance; helmet; impact; penetration resistance; NBSIR 77 1251 .

Test methods; thermal explosion theory; accidental polymerization; CHETAH predictive scheme; hazard evaluation; test data; NBSIR 76-1/49.

Test methods; weatherability of FRP rods; aramid; composite materials; end fittings for FRP rod; environmental resistance of FRP rods; fiber-reinforced plastic (FRP); glass; guys, antenna; pultrusion; reinforced plastics; stress rupture of FRP rod; 16685.

Test methods; $\mathrm{x}$ rays; calibration; gamma radiation; industrial radiography; national standards; radiation characteristics; radiation source; source calibration; 17017 .

Test pattern; visual alignment structure; electrical mask alignment; integrated circuit; photolithography; silicon; 17330.

Test patterns; thermally stimulated current; transistors, power; TTL circuits; ultrasonic wire bonding; ultraviolet reflectance; $x$-ray damag; acoustic emission; Auger electron spectroscopy; beam-lead bonds; capacitance-voltage methods; carrier mobility; SP400-29.

Test procedures; appliances; energy conservation; energy efficiency; energy improvement targets; labeling; 16885 . 
Test procedures, skid resistance measuring systems; tire-pavement interface forces; friction, pavement; highway safety; measurement, skid resistance; pavement, skid resistance; NBSIR 76-1174.

Test structures; defects; dopants; impurities; junctions; MOS capacitors; sheet resistors; silicon; 16855.

Test structures; van der Pauw; cross test structure; cross van der Pauw; numerical analysis; sheet resistance; sheet resistor test structure; 17165 .

Testbed; test cases; validating correctness; communications security; computer security; cryptography; encryption standard; interface requirements; Monte-Carlo testing; SP500-20.

Testing; air conditioning; comfort; heat pump; load-calculation; rating; residential; space heating; 17006 .

Testing; anthropomorphic dummies; building safety; dummies; guidebook; NBS-GCR-77-91.

Testing; bore hole; k property; property; soil; stiffness; SP477, pp. VI-118-VI-140 (May 1977).

Testing; dynamic testing; lateral load simulation; models; shake tables; SP470, pp. IX-1-IX-5 (Apr. 1977).

Testing; transformer; circuit breaker; data; experiment; shake table; SP477, pp. VI-50-VI-60 (May 1977).

Testing; ultimate strength; anchor bolts; bond; damping; ductility; earthquake resistance; energy absorption; modulus of elasticity; partial reinforcing; risk; shear modulus; BSSI06, pp. 255-258 (Sept. 1977).

Testing; U.S.-U.S.S.R. cooperative program; ceria; materials characterization; $\mathrm{MHD}$ (magnetohydrodynamics); power generation; 17160 .

Testing; wind; earthquake; research programs; seismic; SP477, pp. VI-37-VI-43 (May 1977).

Testing facilities; cottage industry; developing countries; Guyana; less developed countries; measurement services; standardization; NBSIR 76-1180.

Testing facilities; Thailand; measurements; quality control; standardization; NBS!R 76-1190.

Testing machines; tolerance; verification; calibration; load cell; proving rings; 16915 .

Testing methods; tooling; adhesives; composites; computerized information system; foams; plastics information; Plastics Technical Evaluation Center; specifications; technical reports; SP463, pp. IV.3.1-IV.3.2 (Jan. 1977).

Testing of dental materials; dental amalgam; dental materials; development of testing procedures; mechanical properties; physical properties; specification testing; 17126.

Testing procedures; thermal performance; durability/reliability; fire safety; rating criteria; solar collectors; structural performance; NBSIR 77-1305.

Tests; foundation; lateral loads; sheet piles; structural analysis; SP470, pp. VII-7-VII-60 (Apr. 1977).

Tests; undisturbed sampling; density; liquefaction; sand; soils; SP477, pp. VI-141 - VI-157 (May 1977).

Tetracyanoquinodimethan; $x$-ray photoelectron spectroscopy; chromium; infrared spectroscopy; magnetic susceptibility; molybdenum; 17153 .

Text editing; building blocks; programming aids; software tools; syntax analysis; SP500-14.

Textiles; air flow; extinguishability; extinguishment; fabric flammability; fibers; heat flux; heat sinks; oxygen concentration; NBS-GCR-77-90.

Textiles; apparel; fabrics; flammability testing; heat transfer rates; Mushroom Apparel Flammability Tester; standards; test development; NBS-GCR-76-78.

Textiles; toxicity; arson; bibliographies; building fires; carpets; construction materials; fire departments; fire detection systems; fire tests; flame research; flammability tests; interior furnishings; mobile homes; polyurethanes; smoke detectors; standards; NBSIR 77-1277.

Thailand; measurements; quality control; standardization; testing facilities; NBSIR 76-1190.
Thallium; electron excitation; 17128.

Thallium; line broadening; satellites; 16752.

Thallium; tin; transmethylation; water; alkylation; aqueous solution; coordination; mercury; metal complexes; organometals; photolysis; reaction rates; 17008 .

The Federal Republic of Germany; The Netherlands; transfer channel; bucket-brigade; buried channel; Canada; chargecoupled device; Great Britain; imager CCD's; Japan; peristaltic CCD's; surface channel; SPS00-5.

The method of moments; broadband antenna; measurements; picosecond pulse; resistive loading; NBSIR 77-86I.

The Netherlands; transfer channel; bucket-brigade; buried channel; Canada; charge-coupled device; Great Britain; imager CCD's; Japan; peristaltic CCD's; surface channel; The Federal Republic of Germany; SP500-5.

Theoretical; "flashover"; fluid flow; full-scale; heat transfer; literature review; mathematical models; room fire; scaling models; 17283 .

Theoretical; theory; argon; collisions; dissociation; hydrogen; inelastic; molecular potential; recombination; scattering; 16802.

Theoretical comparison; hydrogen $\mathrm{H} \alpha$ and $\mathbf{H} \beta$; ion dynamics; quasi static; Stark broadening; 17232 .

Theoretical elastic e- $\mathrm{CO}_{2}$ scattering; theoretical electron- $\mathrm{CO}_{2}$ scattering; theoretical electron-molecule scattering; 16682.

Theoretical electron- $\mathrm{CO}_{2}$ scattering; theoretical electronmolecule scattering; theoretical elastic e- $\mathrm{CO}_{2}$ scattering; 16682.

Theoretical electron-molecule scattering; theoretical elastic e$\mathrm{CO}_{2}$ scattering; theoretical electron- $\mathrm{CO}_{2}$ scattering; 16682.

Theoretical potential; anisotropic interactions; $\mathrm{HCi}$-Ar; linear molecules; rotational line widths; semiempirical potential; 16799.

Theory; argon; collisions; dissociation; hydrogen; inelastic; molecular potential; recombination; scattering; theoretical; 16802.

Theory; two-photon absorption; Raman scattering; Rayleigh scattering; fluorescence; laser fields; 16848.

Theory; velocity distribution; drift tube; ion; Monte-Carlo; swarm; 16779.

Theory; vibrational and rotational enhancement; argon; cross section; dissociation collisions; hydrogen; 16803.

Theory of phase diagrams; thermodynamics; computer predictions; critical evaluations; data compilations; industrial needs; phase diagrams; NBSIR 77-1239.

Thermal; dental; expansion; investments; petrographic; 17325.

Thermal; ultrasonic; visual testing; wear debris; acoustic; calibration; eddy current; microwave; nondestructive evaluation; penetrant; radiography; standards; 17106 .

Thermal; ${ }^{6} \mathrm{Li}(\mathrm{n}, \alpha) ;{ }^{10} \mathrm{~B}(\mathrm{n}, \alpha)$; ${ }^{235} \mathrm{U}(\mathrm{n}, \mathrm{f})$; cross section; neutron; normalization; resonance; shape; standards; SP493, pp. 174181 (Oct. 1977).

Thermal acceptability; clothing; cold discomfort; energy conservation; humidity; temperature; SP491, pp. 131-151 (Sept. 1977).

Thermal acceptability; thermal preference survey; winter temperature; clothing insulation; effective temperature (ET*); energy conservation; summer temperature guidelines; SP491, pp. 93-116 (Sept. 1977).

Thermal analysis; exposure limits; heat stress; SP491, pp. 6592 (Sept. 1977).

Thermal characterization; thermal instability; thermal resistance; transistors; hot spots; junction temperature; measurement technology; nondestructive test; reliability; safe operating limits; second breakdown; semiconductor devices; SP400-44.

Thermal coefficient of refractive index; $\mathrm{ZnSe} ; \mathrm{BaF}_{2} ; \mathrm{CaF}_{2} ; \mathrm{KBr}$; $\mathrm{KCl}$; LiF; NaF; refractive index; $\mathrm{SrF}_{2} ;$ NBSIR 77-1219. 
Thermal coefficient of refractive index; $\mathrm{ZnS} ; \mathrm{ZnSe} ; \mathrm{BaF}_{2} ; \mathrm{CaF}_{2}$; $\mathrm{KBr}$; $\mathrm{KCl}$; Lexan; LiF; NaF; Plexiglas 55; refractive index; $\mathrm{SrF}_{2} ; N B S I R$ 77-1304 (ARPA).

Thermal coefficient of solubility; thermodynamics; tooth mineral; dissolution; hydroxyapatite; ion pairs; solubility; solubility isotherms; solubility product; J. Res. 81A Nos. 2 and 3, 273-281 (1977).

Thermal comfort; energy conservation in buildings; heat stress; human comfort; indoor environment; mean radiant temperature; SP491.

Thermal comfort; indoor environmental measurement; rating of indoor environments; SP491, pp. 152-168 (Sept. 1977).

Thermal comfort; thermal environment; thermal neutrality; human comfort; indoor climate; indoor environment; SP49I, pp. 3-17 (Sept. 1977).

Thermal comfort; thermal radiation; directional radiant temperature; mean radiant temperature; radiation measurement; radiometer; SP491, pp. 117-130 (Sept. 1977).

Thermal comfort; thermal sensation; thermal tolerance; work conditions; environmental control; temperature and performance; temperature control; SP491, pp. 169-173 (Sept. 1977).

Thermal conductance; beryllium; copper; cryogenics; indium; joints; solder; 16797.

Thermal conduction; transient heat transfer; composite building constructions; convection; experimental data; fire endurance; heat generation or absorption; numerical solutions; onedimensional; radiation; NBSIR 77-1260.

Thermal conductivity; beryllium; cryogenics; electrical conductivity; heat switch; Lorenz ratio; magnetic field; single crystal; 17088.

Thermal conductivity; compartment fires; fire-retardants; insulation; mattresses; shipboard; NBSIR 77-1295.

Thermal conductivity; copper; low temperature; magnetothermal conductivity; nickel alloy; stainless steel; 16864 .

Thermal conductivity; thermal insulation; condensation in walls; insulating properties; 17284 .

Thermal conductivity; thermal insulation; thermography; air infiltration; condensation in buildings; energy conservation; energy measurements; fuel savings; heat-loss reduction; insulation properties; residential heat loss; retrofitting houses; NBSIR 77-1274.

Thermal conductivity; thermal diffusivity; fire research; polymers; polystyrene; poly(vinyl chloride); specific heat; NBS-GCR-77-83.

Thermal conductivity; thermopower; tungsten; electrical resistivity; high temperature; Lorenz ratio; low temperature; standard reference material; 16877

Thermal conductivity; thermopower; copper; electrical resistivity; iron alloys; Lorenz ratio; low temperature; nickel alloys; 16878 .

Thermal conductivity; transport property; viscosity; carbon dioxide; corresponding states; mixtures; nitrous oxide; prediction; TN693.

Thermal conductivity coefficient; viscosity coefficient; corresponding states; dense liquid; mixture; modified Enskog theory; prediction; 16791 .

Thermal conductivity coefficient; viscosity coefficient; critical point; mixture; one-fluid theory; plait point; J. Res. 82, No. 3, 181-182 (1977).

Thermal conductivity coefficient; viscosity coefficient; correlation; critical point anomaly; methane; tables; JPCRD 6, No. 2, 597-610 (1977).

Thermal conductivity coefficient; viscosity coefficient; critical point enhancement; data evaluation; ethane; JPCRD 6, No. $4,1167-1180$ (1977).

Thermal converter; ac current measurements; ac-dc comparator; ac-dc transfer standard; ac voltage measurement; multijunction converter; 16693.
Thermal converter; ac current measurement; ac-dc comparator; ac-dc transfer standard; ac voltage measurement; 16694.

Thermal decomposition of $\mathrm{K}_{2} \mathrm{O}-\mathrm{SiO}_{2}$ solutions; vapor pressure of $\mathrm{K}_{2} \mathrm{O}-\mathrm{Al}_{2} \mathrm{O}_{3}$ phases; vapor pressure of $\mathrm{K}_{2} \mathrm{O}-\mathrm{SiO}_{2}$ solutions; 16897.

Thermal decomposition products; toxicity; acute lethality; Douglas Fir; inhalation; mice; polyure thane; pulmonary irritation; PVC; respiratory rate; sensory irritation; stress index; NBS-GCR-77-85.

Thermal desorption; tungsten; ultraviolet photoelectron spectroscopy; carbon monoxide; chemisorption; coadsorption; desorption; displacement; hydrogen; photoemission; 16808.

Thermal devices; error reduction; flow measurement techniques; flow vs. temperature techniques; pressure drops; SP484, pp. 597-619 (Oct. 1977).

Thermal diffusivity; fire research; polymers; polystyrene; poly(vinyl chloride); specific heat; thermal conductivity; NBS-GCR-77-83.

Thermal effects; zero-shift; accuracy; calibration; cryogenic; dynamic; frequency response; hysteresis; precision; pressure measurement; sensitivity; stability; 17081 .

Thermal energy storage; transpiration heat transfer; porous media; NBSIR 77-1237.

Thermal environment; thermal neutrality; human comfort; indoor climate; indoor environment; thermal comfort; SP491, pp. 3-17 (Sept. 1977).

Thermal expansion; thermodynamic; compressibility; densification; glass; glass transition; liquid; polymer; pressure; PVT; pyrolysis; refractive index; J. Res. 81A Nos. 2 and 3, 283-297 (1977).

Thermal expansivity; water; aqueous solutions of gases; compressibility; equation of state; heavy water; isotopic waters; partial molar volume of aqueous gases; PVT; JPCRD 6, No. 4, 1109-1132 (1977).

Thermal explosion theory; accidental polymerization; CHETAH predictive scheme; hazard evaluation; test data; test methods; NBSIR 76-1149.

Thermal instability; hot spots; measurement methods; power transistors; reliability; safe operating area limits; second breakdown; 16893.

Thermal instability; thermal resistance; transistors; hot spots; junction temperature; measurement technology; nondestructive test; reliability; safe operating limits; second breakdown; semiconductor devices; thermal characterization; SP400-44.

Thermal insulation; condensation in walls; insulating properties; thermal conductivity; 17284 .

Thermal insulation; thermography; air infiltration; condensation in buildings; energy conservation; energy measurements; fuel savings; heat-loss reduction; insulation properties; residential heat loss; retrofitting houses; thermal conductivity; NBSIR 77-1274.

Thermal motion of a perchlorate ion; x-ray diffraction; ammonium perchlorate; bond lengths and angles; crystal structure; rigid-body motion analysis; 17348 .

Thermal neutrality; human comfort; indoor climate; indoor environment; thermal comfort; thermal environment; SP491, pp. 3-17 (Sept. 1977).

Thermal neutron cross-sections; U-233; U-235; fission-neutron yields; fission standards; neutron nuclear data evaluation; $\mathrm{Pu}$ 239; Pu-239 half-life; Pu-241; SP493, pp. 170-173 (Oct. 1977).

Thermal oxidation; fused silica; microelectronic; MOS; oxidation furnace; silicon dioxide; sodium contamination; 16939.

Thermal performance; durability/reliability; fire safety; rating criteria; solar collectors; structural performance; testing procedures; NBSIR 77-1305.

Thermal performance; ventilation; water heating; air leakage; building design; energy conservation; fenestration; HVAC systems; illumination; insulation; lighting; performance standard; NBSIR 74-452. 
Thermal physics; 75th anniversary; American Physical Society; fundamental constants; National Bureau of Standards; nuclear physics; numerical analysis; physics; spectroscopy; 16991.

Thermal pollution; thermometry; water analysis; water pollution; pollution; standards committees; temperature measurements; NBSIR 77-1227.

Thermal preference survey; winter temperature; clothing insulation; effective temperature (ET*); energy conservation; summer temperature guidelines; thermal acceptability; SP491, pp. 93-116 (Sept. 1977).

Thermal properties; availability; crystal growth; crystal structure; electronic properties; magnetic properties; optical properties; phase diagrams; research materials; SP463, pp. III.3.1-III.3.8 (Jan. 1977).

Thermal properties; low temperature; mechanical properties; research program; structural materials; 16863.

Thermal properties of ice; vapor pressure; vapor pressure at the triple point; vapor pressure of ice; water vapor; ClausiusClapeyron equation; saturation vapor pressure over ice; $J$. Res. 81A No. 1, 5-20 (1977).

Thermal property; alloy; composite; cryogenics; electrical property; insulation; materials; mechanical property; metal; review; 17072.

Thermal protection; thermal radiant-energy response; thermal transient response; transducer; zero shift; coatings; delayed response; dynamic; dynamic response; pressure step; pressure transducer; protective coatings; shock tube; tape; TN961.

Thermal radiant-energy response; thermal transient response; transducer; zero shift; coatings; delayed response; dynamic; dynamic response; pressure step; pressure transducer; protective coatings; shock tube; tape; thermal protection; TN961.

Thermal radiation; directional radiant temperature; mean radiant temperature; radiation measurement; radiometer; thermal comfort; SP491, pp. $117-130$ (Sept. 1977).

Thermal radiation; fire growth; fire tests; flashover; room fires; scale models; 17059.

Thermal radiation; thermoplastics; cellulosic materials; char; convective heat transfer; fabric flammability; fabrics; fire hazards; ignition time; pyrolysis; radiant heating; NBS-GCR77-99.

Thermal radiation properties; thermodynamics; titanium alloy; electrical resistivity; heat capacity; high-speed measurements; high temperatures; melting; normal spectral emittance; radiance temperature; J. Res. 81A Nos. 2 and 3, 251-256 (1977).

Thermal relaxation; anharmonic crystal; computer simulation; energy transport; equation of state; interatomic potential; molecular dynamics; second sound; shock wave; stress relaxation; structural relaxation; 16751 .

Thermal resistance; transistors; hot spots; junction temperature; measurement technology; nondestructive test; reliability; safe operating limits; second breakdown; semiconductor devices; thermal characterization; thermal instability; SP400-44.

Thermal safety covering; warming trays; compressible cooking surfaces; hot plates; U.S. Patent 4,009,704.

Thermal sensation; thermal tolerance; work conditions; environmental control; temperature and performance; temperature control; thermal comfort; SP491, pp. 169-173 (Sept. 1977).

Thermal sensation; WBGT; core temperature; energy conservation; modeling; OSHA Standards; SP491, pp. 18-40 (Sept. 1977).

Thermal storage; solar buildings; solar collectors; solar domestic hot water systems; standards; NBSIR 77-1272.

Thermal storage; standard test; 17347.

Thermal testing; ultrasonics; visual testing; wear debris analysis; acoustic emission; calibrations; electrical-eddy current measurements; microwaves; nondestructive evaluation; standard reference materials; standards; 17016.
Thermal tolerance; work conditions; environmental control; temperature and performance; temperature control; thermal comfort; thermal sensation; SP491, pp. 169-173 (Sept. 1977).

Thermal transient response; transducer; zero shift; coatings; delayed response; dynamic; dynamic response; pressure step; pressure transducer; protective coatings; shock tube; tape; thermal protection; thermal radiant-energy response; TN961.

Thermal-acoustic oscillations; burn-out; helium-cooled current leads; helium flow facility; helium impurities; microwave pressure transducer; NBSIR 77-853.

Thermalization; cross section; diffusion; kernel; lattice vibration; model; moderator; neutron; scattering; SP46I, pp. 149162 (Jan. 1977).

Thermally stimulated capacitance; thermally stimulated current; thermally stimulated measurements; thyristor materials measurements; thyristor measurements; d-c transmission; energy conservation; measurement methods; photovoltaic method; power-device grade silicon; 17345 .

Thermally stimulated capacitance; thermally stimulated current; thermally stimulated measurements; thyristor materials measurements; thyristor measurements; d-c transmission; energy conservation; measurement methods; photovoltaic method; power-device grade silicon; NBSIR 77-1249.

Thermally stimulated current; thermally stimulated measurements; thyristor materials measurements; thyristor measurements; d-c transmission; energy conservation; measurement methods; photovoltaic method; power-device grade silicon; resistivity variations; silicon; 17345 .

Thermally stimulated current; transistors, power; TTL circuits; ultrasonic wire bonding; ultraviolet reflectance; $x$-ray damag; acoustic emission; Auger electron spectroscopy; beam-lead bonds; capacitance-voltage methods; carrier mobility; C-MOS circuits; SP400-29.

Thermally stimulated current; thermally stimulated measurements; thyristor materials measurements; thyristor measurements; d-c transmission; energy conservation; measurement methods; photovoltaic method; power-device grade silicon; resistivity variations; silicon; NBSIR 77-1249.

Thermally stimulated measurements; thyristor materials measurements; thyristor measurements; d-c transmission; energy conservation; measurement methods; photovoltaic method; power-device grade silicon; resistivity variations; silicon; thermally stimulated capacitance; 17345 .

Thermally stimulated measurements; thyristor materials measurements; thyristor measurements; d-c transmission; energy conservation; measurement methods; photovoltaic method; power-device grade silicon; resistivity variations; silicon; thermally stimulated capacitance; NBSIR 77-1249.

Thermistors; thermometry; fixed points; gallium; gallium melting point; melting; standards; temperature; 17055 .

Thermochemical data networks; thermochemical tables; thorium compounds; data evaluation; enthalpy; entropy; Gibbs energy; NBSIR 77-1300.

Thermochemical tables; thorium compounds; data evaluation; enthalpy; entropy; Gibbs energy; thermochemical data networks; NBSIR 77-1300.

Thermochemistry; vapor pressure; activity coefficients; aqueous systems; bibliography; electrochemistry; isopiestic; osmotic coefficients; SP485.

Thermodynamic; compressibility; densification; glass; glass transition; hole theory; liquid; polymer; pressure; 16774.

Thermodynamic; compressibility; densification; glass; glass transition; liquid; polymer; pressure; PVT; pyrolysis; refractive index; thermal expansion; J. Res. 81A Nos. 2 and 3, 283297 (1977).

Thermodynamic data; transport properties; atomic and molecular data; chemical kinetics data; energy data; environmental data; industrial process data; materials utilization data; 
mechanical properties; nuclear data; physical science data; solid state data; TN947.

Thermodynamic functions; drop calorimetry; emittance; enthalpy; heat capacity; high-speed measurements; high temperature; molybdenum; pulse calorimetry; standard reference material; SP260-55.

Thermodynamic properties; activity coefficient; calcium chloride; critical evaluation; electrolyte; excess free energy; osmotic coefficient; solutions; JPCRD 6, No. 2, 385-408 (1977).

Thermodynamic properties; bibliography; chemical kinetics; chemistry; chlorine nitrate; molecular properties; nitrosyl chloride; nitryl chloride; physical properties; spectral properties; $S P 478$.

Thermodynamic properties; calorimetry; enthalpy relaxation; glass transition; heat capacity; polymer; poly(vinyl chloride); pressure effects; J. Res. 82, No. 1, 9-18 (1977).

Thermodynamic properties; critically evaluated data; phase diagrams; ternary copper-silver alloy systems; JPCRD 6, No. 3, $621-674$ (1977).

Thermodynamic properties; transport properties; universality; critical exponents; critical region; fluid mixtures; fluids; scaling; 17279.

Thermodynamic tables; coal conversion; consumer products; cryogenic; crystalline materials; dosimeter calibrations; energy; energy related inventions; heterodyne receiver; international standards code; NCSL; NMR knight shifts; DIM/NBS 61 , No. 7, 1-32 (1977).

Thermodynamics; computer predictions; critical evaluations; data compilations; industrial needs; phase diagrams; theory of phase diagrams; NBSIR 77-1239.

Thermodynamics; hafnium; high-speed measurements; high temperature; solid-solid phase transformation; 16767.

Thermodynamics; titanium alloy; electrical resistivity; heat capacity; high-speed measurements; high temperatures; melting; normal spectral emittance; radiance temperature; specific heat capacity; J. Res. 81A Nos. 2 and 3, 251-256 (1977).

Thermodynamics; tooth mineral; dissolution; hydroxyapatite; ion pairs; solubility; solubility isotherms; solubility product; thermal coefficient of solubility; J. Res. 81A Nos. 2 and 3 , 273-281 (1977).

Thermodynamiçs; transport; chemical; critical evaluation; mechanical; numerical data; physical properties; SP463, pp. VII.1.1-VII.1.15 (Jan. 1977).

Thermoelectric; thermometry; AC bridge; microcomputer; synchronous detection; temperature controller; 16908.

Thermoelement; ac-dc difference; current comparator; current measurements; 16697.

Thermographic surveys; thermography; energy conservation; energy surveys; infrared; nondestructive evaluation; 16901 .

Thermography; air infiltration; energy conservation; mobile home; part-load efficiency; NBSIR 76-1182.

Thermography; air infiltration; condensation in buildings; energy conservation; energy measurements; fuel savings; heat-loss reduction; insulation properties; residential heat loss; retrofitting houses; thermal conductivity; thermal insulation; NBSIR 77-1274.

Thermography; buildings; energy conservation; evaluation; inspection; retrofit; 16902 .

Thermography; energy conservation; energy surveys; infrared; nondestructive evaluation; thermographic surveys; 16901 .

Thermography; heat-flow measurements; infrared heat-loss measurement technique; measurement technology; TN933.

Thermogravimetry; computerized experiment; experiment automation; off-the-shelf automation; polymer degradation; rapid response furnace; 16842

Thermoluminescence; aluminium oxide; glow; heat treatment; impurity; temperature; SP461, pp. 219-221 (Jan. 1977).
Thermoluminescence; dose; gamma rays; LiF; response; sensitivity; supralinear; SP461, Pp. 227-230 (Jan. 1977).

Thermoluminescence; gamma rays; irradiation; LiF; optical absorption; spectral distribution; SP461, Pp. 222-226 (Jan. 1977).

Thermoluminescence dosimeters; total dose; dosimeter calibration; electronic devices; ionizing radiation; radiation dosimetry; radiation hardness testing; radiation sources; NBSIR 76-1135.

Thermoluminism; quartz; sensitivity; stress; SP461, pp. 231-233 (Jan. 1977).

Thermometric fixed-point; clinical laboratory; fixed-point; gallium; melting-point standard; temperature; SP48I.

Thermometry; AC bridge; microcomputer; synchronous detection; temperature controller; thermoelectric; 16908.

Thermometry; DC measurements; frequency; metrology; rf measurements; standards; superconductivity; 16861 .

Thermometry; fixed points; gallium; gallium melting point; melting; standards; temperature; thermistors; 17055.

Thermometry; gallium; International Practical Temperature Scale of 1968; melting point standard; secondary fixed point; temperature fixed point; 17049.

Thermometry; water analysis; water pollution; pollution; standards committees; temperature measurements; thermal pollution; NBSIR 77-1227.

Thermomigration; alloys; antimony; arsenic; bismuth; copper; diffusion; electromigration; liquid metals; nitrogen; phosphorus; ternary diffusion; JPCRD 6, No. 1, 1-50 (1977).

Thermonuclear; copper; cryogenic; fusion; magnets; superconductivity; 17134.

Thermophysical; weights and measures; American electroplaters'; calorimeter; cryogenic flow measurement; dental restorations; deep ocean research; federal science; governmental environment; laser energy; space flight; spectroscopy; SRM; DIMINBS 61, No. 4, 1-32 (1977).

Thermophysical and Electronic Properties Information Analysis Center; thermophysical properties; computerized information system; data bank; electrical properties; electronic properties; magnetic properties; SP463, Pp. IV.4.1-IV.4.3 (Jan. 1977).

Thermophysical properties; computerized information system; data bank; electrical properties; electronic properties; magnetic properties; optical properties; Retrieval Guide; technical reports; SP463, pp. IV.4.1-IV.4.3 (Jan. 1977).

Thermoplastics; cellulosic materials; char; convective heat transfer; fabric flammability; fabrics; fire hazards; ignition time; pyrolysis; radiant heating; thermal radiation; NBS-GCR77-99.

Thermopower; copper; electrical resistivity; iron alloys; Lorenz ratio; low temperature; nickel alloys; thermal conductivity; 16878 .

Thermopower; tungsten; electrical resistivity; high temperature; Lorenz ratio; low temperature; standard reference material; thermal conductivity; 16877 .

Thesaurus; aerospace; computer information system; international aerospace abstracts; materials; mechanical properties; metallic materials; nonmetallic materials; physical properties; RECON; SP463, pp. VI.1.1-VI. 1.7 (Jan. 1977).

Thesaurus; computerized information system; directories; information resource; National Referral Center; referral; scientific and technical information; SP463, pP. VIIl.2.1-VIII.2.4 (Jan. 1977).

Theta solvents; 3,3,5-trimethylhexyl acetate; biphenyl; chain dimensions; dodecanol; linear polyethylene; Mark-Houwink equation; NBS Standard Reference Material 1475; 16710.

Thick target; time-of-flight; ${ }^{7} \mathrm{Li}(\mathrm{d}, \mathrm{n})^{8} \mathrm{Be},{ }^{7} \mathrm{Li}(\mathrm{p}, \mathrm{n})^{7} \mathrm{Be} ; \mathrm{E}_{d}=8$, 12, $15 \mathrm{MeV}, \mathrm{E}_{p}=15 \mathrm{MeV}$; NBSIR 77-1279, pp. 1-4 (July 1977).

Thick target; time-of-flight; ${ }^{9} \mathrm{Be}(\mathrm{d}, \mathrm{n}){ }^{10} \mathrm{~B} ;{ }^{9} \mathrm{Be}\left({ }^{3} \mathrm{He}, \mathrm{n}\right)^{11} \mathrm{C}$; energy spectra; neutrons; Rossi-counter measurements; Serber theory; NBSIR 77-1279, pp. 31-34 (July 1977). 
Thick-target yields; Be; Li; neutron sources; NBSIR 77-1279, pp. 10-14 (July 1977).

Thick-target yields; $\operatorname{Be}(d, n)$ source; $B e(p, n)$ source; $C(d, n)$ source; $D(d, n)$ source; dosimetry; $\operatorname{Li}(d, n)$ source; $\operatorname{Li}(p, n)$ source; neutron angular distributions; neutron energy distributions; neutrons; nuclear reactions; NBSIR 77-1279.

Thin film; vapor transport; activation parameters; active nitrogen; iodine; kinetics; microwave discharge; nitride; plasma; reaction mechanism; silicon; synthesis; 16757.

Thin films; protective coatings; sputtering; SP487, pp. 324-337 (Aug. 1977).

Thin foils; cracks; electron microscopy; grinding damage; oxidation; silicon nitride; surface flaws; 17090 .

Thin layer chromatography; chromatography; color matching; color measurement; diffuse reflectance; Kubelka-Munk function; reflectance; reflectance standards; SP466, pp. 41-55 (May 1977).

Thin turbulent shear layers; error reduction; hot-wire anemometry; supersonic flows; SP484, pp. 649-658 (Oct. 1977).

Thin-film; cryogenic electrical switch; mechanical switch; multiple contact switch; proximity effect; superconducting switch; 17121 .

Thin-film device; coherent microwave emission; e/h voltage standard; Josephson junction; microstrip resonator; microwave coupling; parametric plasma oscillation; 16788.

Thiophosgene; chlorine isotope separation; isotope enrichment; laser isotope separation; photochemical enrichment; U.S. Patent 4,025,406.

Thiophosgene; $\Delta H f^{\circ}(\mathrm{SCCl}) ; \Delta H f^{\circ}\left(\mathrm{SCCl}_{2}\right) ; \mathrm{CS}\left(A^{1} \pi\right)$; photodissociation; 16781 .

Thorium; uranium; calculation; cross section; optical model; reactor technology; scattering-elastic, inelastic, total; SP46I, pp. $70-73$ (Jan. 1977).

Thorium compounds; data evaluation; enthalpy; entropy; Gibbs energy; thermochemical data networks; thermochemical tables; NBSIR 77-1300.

Threat analysis; terrorism; vigilance; behavioral science; human factors; human reliability; perpetrator attributes; physical security; psychological deterrence; sophisticated crime; SP480-24.

Three body molecular formation; ${ }^{3} P_{0}$ and ${ }^{3} P_{1}$ atomic states; ${ }^{3} P_{0}$ $\rightarrow{ }^{3} P_{1}$ collision rates; decay of resonance line; quenching rates; relaxation of mercury atoms; 17194 .

Three velocity components in turbulent flow; true instantaneous temperatures; turbulent flow; fluid mechanics; nonisothermal flow; SP484, pp. 659-685 (Oct. 1977).

Threshold photoelectron spectroscopy; time of flight mass spectrometry; acetone; coincidence; mass spectrometry; methane; photoionization; 17148 .

Threshold pion production; effective Lagrangian; electroproduction; impulse approximation; photoproduction; pseudoscalar and pseudovector coupling; TN957.

Throughput; turnaround time; evaluating computer service; network measurement machine; remote terminal emulators; response time; 17250 .

Thunderstorms; tornadoes; wind; wind damage; extra-tropical storms; hurricanes; SP477, PP. II-15-II-29 (May 1977).

Thyristor materials measurements; thyristor measurements; d-c transmission; energy conservation; measurement methods; photovoltaic method; power-device grade silicon; resistivity variations; silicon; thermally stimulated capacitance; thermally stimulated current; 17345 .

Thyristor materials measurements; thyristor measurements; d-c transmission; energy conservation; measurement methods; photovoltaic method; power-device grade silicon; resistivity variations; silicon; thermally stimulated capacitance; thermally stimulated current; NBSIR 77-1249.
Thyristor measurements; d-c transmission; energy conservation; measurement methods; photovoltaic method; power-device grade silicon; resistivity variations; silicon; thermally stimulated capacitance; thermally stimulated current; thermally stimulated measurements; 17345.

Thyristor measurements; d-c transmission; energy conservation; measurement methods; photovoltaic method; power-device grade silicon; resistivity variations; silicon; thermally stimulated capacitance; thermally stimulated current; thermally stimulated measurements; NBSIR 77-1249.

Tides; wind; buildings; cyclones; disasters; structural engineering; SP477, pp. V-21-V-53 (May 1977).

Timber; wood; wood products; AlDS; bark; forest products; glues and gluing; information service; lumber; mechanical properties; paper; pulp; SP463, pp. I1.1.1-11.1.4 (Jan. 1977).

Timber roofs; timber walls; wind effects; codes and standards; connectors; fasteners; low-rise buildings; masonry walls' structural design; technology transfer; BSSI00-3.

Timber walls; wind effects; codes and standards; connectors; fasteners; low-rise buildings; masonry walls' structural design; technology transfer; timber roofs; BSSI00-3

Time; atomic clocks; dissemination; frequency; geosynchronous satellite; measurement; standards; television; 17182 .

Time; frequency; National Measurement System; standards laboratories; survey; 17070 .

Time; time broadcasts; time scales; astronomy; automation; clocks; communication; frequency; history; mathematics; navigation; physics; Monogr. 155.

Time and frequency; ultraviolet; computer memories; computer performance; inventor; molecular identity; preserving stone; pressure measurements; rf-power meter; roofing; safety; security alarms; SRM's; DIM/NBS 61, No. 8, 1-32 (1977).

Time and frequency calibration methods; time calibration; time signals; frequency calibration; high frequency; Loran-C; low frequency; radio broadcasts; standard frequencies; television color subcarrier; TN695.

Time and frequency dissemination; time code; TvTime system; accuracy; hyperbolic system; range-range system; 17181 .

Time broadcasts; time scales; astronomy; automation; clocks; communication; frequency; history; mathematics; navigation; physics; time; Monogr. 155.

Time calibration; time signals; frequency calibration; high frequency; Loran-C; low frequency; radio broadcasts; standard frequencies; television color subcarrier; time and frequency calibration methods; TN695.

Time code; TvTime system; accuracy; hyperbolic system; range-range system; time and frequency dissemination; 17181 .

Time correlation function; transverse current; ultrasonics; correlation function; density fluctuations; fluctuations; hydrodynamics; light scattering; liquid state; molecular dynamics; neutron scattering; shear wave; statistical mechanics; 16711

Time delay; calorimetry; heat release rate; response time; NBSIR 77-1302.

Time dependent; adiabatic perturbation approximation; collision theory; 16955.

Time dispersion; bias uncertainty; frequency accuracy; frequency bias; frequency stability; primary frequency standard; 16775.

Time domain; transient; automated measurement; pulse; rise time; sampling oscilloscope; spectrum amplitude; 16721 .

Time domain reflectometry; homomorphic deconvolution; 16731 .

Time domain stability; atomic frequency standard; frequency discrimination; frequency domain stability; frequency-lock loop; phase-lock loop; phase noise; servo techniques; TN692.

Time of flight mass spectrometry; acetone; coincidence; mass spectrometry; methane; photoionization; threshold photoelectron spectroscopy; 17148 . 
Time resolved spectroscopy; kinetics; Mercury excimers; 16800.

Time scales; astronomy; automation; clocks; communication; frequency; history; mathematics; navigation; physics; time; time broadcasts; Monogr. 155.

Time services; time transfer; clock comparison; satellite time dissemination; standard frequency; standard time; 17179.

Time signals; frequency calibration; high frequency; Loran-C; low frequency; radio broadcasts; standard frequencies; television color subcarrier; time and frequency calibration methods; time calibration; TN695.

Time standards; frequency; standards, time; 16794.

Time transfer; clock comparison; satellite time dissemination; standard frequency; standard time; time services; 17179.

Time-dependent; transport; transport equation; approximations; fast-thermal couple reactor; neutron; reactor transients; solution; SP461, pp. 91-93 (Jan. 1977).

Time-dependent spectral density; coal mine noise; digital data; electromagnetic interference; electromagnetic noise; emergency communications; Fast Fourier Transform; impulsive noise; magnetic field strength; measurement instrumentation; portable spectrum analyzer; 17175 .

Time-dependent spectrum; coherence; correlation function; counting rate spectrum; nonstationary process; nonstationary spectrum; power spectrum; synthesized spectrum; 17169 .

Timekeeping; cesium beam; clocks (atomic); crystal oscillator; frequency accuracy; frequency stability; frequency standards; hydrogen maser; quartz crystal; rubidium gas cell; TN616, 2d Revision.

Timekeeping; ultraviolet radiation; calibration; consumers; energy; energy savings; grain moisture; mass spectra; radiation sterilizing; screw thread standards; SHIVA laser; silicon; DIM/NBS 61, No. 9, 1-32 (1977).

Time-of-flight; atomic; experimental; lifetimes; $\mathrm{N}_{2} \mathrm{O}$; oxygen; radiation; 16812 .

Time-of-flight; ${ }^{252} \mathrm{Cf}$; fission neutron spectrum; neutron detectors; neutron standard; SP493, pp. 194-197 (Oct. 1977).

Time-of-flight; ${ }^{7} \mathrm{Li}(\mathrm{d}, \mathrm{n})^{8} \mathrm{Be},{ }^{7} \mathrm{Li}(\mathrm{p}, \mathrm{n})^{7} \mathrm{Be} ; \mathrm{E}_{d}=8,12,15 \mathrm{MeV}$, $\mathrm{E}_{\mathrm{p}}=15 \mathrm{MeV}$; energy spectra, yields; NBSIR 77-1279, pp. $1-4$ (July 1977).

Time-of-flight; ${ }^{9} \mathrm{Be}(\mathrm{d}, \mathrm{n}){ }^{10} \mathrm{~B} ;{ }^{9} \mathrm{Be}\left({ }^{3} \mathrm{He}, \mathrm{n}\right)^{11} \mathrm{C}$; energy spectra; neutrons; Rossi-counter measurements; Serber theory; thick target; NBSIR 77-1279, pp. 31-34 (July 1977).

Time-to-fail; container tests; hazardous materials ladings; mechanical properties; performance criteria; plastic packaging; stress-cracking; 17256.

Time/frequency calibrations; user equipment; user survey; NBS radio stations WWV/WWVH/WWVB; NBS time/frequency services; satellite timing; standard time/frequency broadcasts; television time/frequency dissemination; 17080 .

Tin; arsenic; atomic absorption; gas chromatography; organometal; selenium; 16811 .

Tin; arsenic; element-specific detector; flameless atomic absorption; flow monitoring; high-pressure liquid chromatography; lead; ligand; mercury; nanogram sensitivity; organometallic compounds; speciation; 17297.

Tin; transmethylation; water; alkylation; aqueous solution; coordination; mercury; metal complexes; organometals; photolysis; reaction rates; thallium; 17008 .

Tin coordination; crystal structure; dimeric configuration; stannous compounds; stannous phosphate; 17095.

Tin hydroxy phosphate; tin phosphate; asymmetric coordination; crystal structure; $\mathrm{Sn}$ bonding; 16741 .

Tin phosphate; asymmetric coordination; crystal structure; Sn bonding; tin hydroxy phosphate; 16741 .

Tire-pavement interface forces; friction, pavement; highway safety; measurement, skid resistance; pavement, skid resistance; test procedures, skid resistance measuring systems; NBSIR 76-1174.
Tire-pavement interface forces; wet pavement skid resistance; accident reduction, skidding; highway safety; measurement, skid resistance; pavement skid resistance; skid resistance measurement; NBSIR 76-1175.

Tire-pavement interface forces; wet pavement skid resistance; accident reduction, skidding; correlation, skid resistance; highway safety; measurement, skid resistance; pavement, skid resistance; pavement wetting system; skid resistance, measurement; NBSIR 77-1213.

Tissue; dose; dosimetry; Monte Carlo; organ; phantom; photon; reciprocity theorem; source; target; SP461, pp. 177-182 (Jan 1977).

Tissue; water; detector; Monte Carlo; perspex; photon energy; pulse height; resolution; scattering media; SP461, pp. 188 192 (Jan. 1977).

Tissues; analytical disciplines; analytical procedures; atomic absorption spectrometry; biological materials; blanks; botanical materials; chemical species; flame emission spectrometry fluorescence spectrometry; molecular absorption spectrometry; neutron activation analysis; SP492.

Titanium; biocompatibility; cobalt-chromium; corrosion; implant requirements; mechanical properties; metal implants; stainless steel; standards; 16973.

Titanium; electrical resistivity; emittance; high-speed measurement; high temperature; melting point; radiance temperature; J. Res. 82, No. 2, 119-122 (1977).

Titanium alloy; electrical resistivity; heat capacity; high-speed measurements; high temperatures; melting; normal spectral emittance; radiance temperature; specific heat capacity; thermal radiation properties; J. Res. 81A Nos. 2 and 3, 251-256 (1977).

Titanium alloys; aluminum alloys; crack propagation; fatigue; iron alloys; liquid helium; stainless steels; steels; superalloys; 16928.

Titanium alloys; aluminum alloys; ferritic steels; fracture toughness; low temperature; nickel alloys; 17086.

Titanium alloys; aluminum alloys; copper alloys; high strength steels; nickel alloys; stainless steels; stress corrosion cracking; Monogr. 156.

Titanium alloys; corrosion; fatigue; microstructures; 17187.

Titanium alloys; laser effects; luminescence; metal combustion spectroscopy; 16796.

Titanium alloys; transmission electron microscopy; corrosion resistant alloys; microstructures; molybdenum additions; precipitation; 16690.

TL; $\mathrm{CaSO}_{4}$; correlation; dose; ESR; gamma ray; glow curve; irradiation; SP461, pp. 234-237 (Jan. 1977).

TNT; vapor generator; vapor pressure; DNT; EGDN; explosive detection; limits of detection; sensitivity test; 16830 .

TNT; vapor pressures; DNT; EGDN; electron-capture gas chromatography; measurements; 16825 .

"to contain"; "to deliver"; volumetric calibration; accuracy; design analysis; equipment specification; field standard; gravimetric calibration; liquid retention or clingage tests; precision; prover; Research Associate Program; NBSIR 77. 1214.

"to deliver"; volumetric calibration; accuracy; design analysis; equipment specification; field standard; gravimetric calibration; liquid retention or clingage tests; precision; prover, Research Associate Program; standards inspection procedure; NBSIR 77-1214.

Tolerance; verification; calibration; load cell; proving rings; testing machines; 16915.

Tolerance application; vapor recovery; weights and measures; checking prepackaged commodities; computer assisted check-out systems; consumer affairs; cordage products; drained weight; laws and regulations; metrication; national laboratory accreditation; SP47I. 
Tooling; adhesives; composites; computerized information system; foams; plastics information; Plastics Technical Evaluation Center; specifications; technical reports; testing methods; SP463, pp. IV.3.1-IV.3.2 (Jan. 1977).

Tooth mineral; dissolution; hydroxyapatite; ion pairs; solubility; solubility isotherms; solubility product; thermal coefficient of solubility; thermodynamics; J. Res. 81A Nos. 2 and 3, 273281 (1977).

Topographic contrast; voltage contrast; atomic number contrast; electron beam induced conductivity (EBIC) contrast; electron channeling contrast; magnetic contrast; scanning electron microscopy; 16840.

Tomado; wind; nuclear power plant; seismic effects; SP477, pp. VII-I-V11-28 (May 1977).

Tornado model; tornados; wind speed; fires; fire tornados; SP470, Pp. I-28-I-41 (Apr. 1977).

Tornadoes; trajectories; dynamics; missiles; power plants; structural engineering; SP477, pp. VII-36-VII-41 (May 1977).

Tornadoes; wind; wind damage; extra-tropical storms; hurricanes; thunderstorms; SP477, pp. II-15-II-29 (May 1977).

Tornados; wind speed; fires; fire tornados; tornado model; SP470, pp. I-28-I-41 (Apr. 1977).

Torque on the bead; average gradient; intrinsic viscosity; nonrotating bead; single bead contribution to I.V.; 17119.

Torsional modulus; Young's modulus; aluminum; boron-aluminum; bulk modulus; composite; compressibility; elastic constants; resonance method; shear modulus; 17087.

Total; alpha; boron; branching ratio; compilation; cross-section; elastic; lithium; measurements; neutron; SP493, pp. 67-84 (Oct. 1977).

Total cross section; carbon; elastic scattering cross section; evaluation; optical modeI; R-function analysis; standard; SP493, pp. 93-100 (Oct. 1977).

Total dose; dosimeter calibration; electronic devices; ionizing radiation; radiation dosimetry; radiation hardness testing; radiation sources; thermoluminescence dosimeters; NBSIR 76-1135.

Total energy; utility system; institutional factors; Modular Integrated Utility System; NBSIR 76-1103.

Total energy; utility systems; abstracted reports and articles; HUD Modular Integrated Utility Systems (MIUS) Program; SP489.

Total energy systems; absorption chillers; boiler performance; central utility plant; diesel engine; engine-generator efficiency; heat recovery; performance; NBSIR 77-1243.

Total energy systems; diesel engine performance; enginegenerator efficiency; engine-generator performance; heat recovery; NBSIR 77-1207.

Total materials cycle; information demand; materials information and data system; national commission on materials policy; technology transfer; SP463, pp. IX.I.I-IX.I.22 (Jan. 1977).

Total photon absorption cross sections; virtual photon theory; bremsstrahlung spectrum tip; Delbrück scattering; electromagnetic interactions; electron scattering; radiative corrections; TN955.

Total response; contrast transfer function; distortion; limiting resolution; shading; signal-to-noise ratio; spectral response; standards; television cameras; 17233.

; Towers; wind; wind observation; wind tunnel; field measurements; model; SP470, pp. I-1-I-17 (Apr. 1977).

Toxic materials; toxicology; trace contaminants; water pollution; air pollution; analysis; ecology; energy; environmental impact; land pollution; mutagenicity; SP463, pp. III.4.111I.4.15 (Jan. 1977).

Toxicity; acute lethality; Douglas Fir; inhalation; mice; polyurethane; pulmonary irritation; PVC; respiratory rate; sensory irritation; stress index; thermal decomposition products; NBSGCR-77-85.
Toxicity; arson; bibliographies; building fires; carpets; construction materials; fire departments; fire detection systems; fire tests; flame research; flammability tests; interior furnishings; mobile homes; polyurethanes; smoke detectors; standards; textiles; NBSIR 77-1277.

Toxicity; biological assessment; chemical analysis; combustion products; fire fatalities; smoke inhalation; NBSIR 77-1234.

Toxicology; trace contaminants; water pollution; air pollution; analysis; ecology; energy; environmental impact; land pollution; mutagenicity; toxic materials; SP463, pp. III.4.1-III.4.15 (Jan. 1977).

Toy safety; use and reasonably foreseeable abuse testing for toys; cautionary labeling for toys; hazardous characteristics of toys; safety, toy; PS72-76.

Trace analysis; chemical measurements; electrical measurements; electronics; profiling; silicon; 17140 .

Trace analysis; gas chromatography; gas chromatography-mass spectroscopy; hydrocarbons; intercalibration; petroleum analysis; 17273 .

Trace contaminants; water pollution; air pollution; analysis; ecology; energy; environmental impact; land pollution; mutagenicity; toxic materials; toxicology; SP463, pp. III.4.1 III.4.15 (Jan. 1977).

Trace elements; chemical analysis; environmental samples; Iong-term storage; microbiologicals; organics; pesticides; radionuclides; sample handling; sampling; 16729.

Trace organics; water; accuracy; aerosol; air; collaborative testing; laboratory accreditation; laser. technology; multielement analysis; pollutants; speciation; Standard Reference Materials; SP464.

Tracer technique; dilution method; discharge measurement in pipes; method of mixtures; mixing; SP484, pp. 395-42 I (Oct. 1977).

Track; cell; delta ray; dose; ions; LET; model; neutron; OER; one-hit detector; pion; radiation; SP461, pp. 183-187 (Jan. 1977).

Traction; bearings; computer programs; elastohydrodynamics; failure analysis; film thickness; gears; Hertz contacts; lubrication; rheology; starvation; SP487, pp. 137-153 (Aug. 1977).

Trade facilitation; flow measurement; industry; intergovernmental; international standards; legal metrology; measurement; SP484, pp. $921-927$ (Oct. 1977).

Training; Turkey; earthquake engineering; earthquakes; education; India; Iran; SP470, pp. X-12-X-16 (Apr. 1977).

Trains; transportation; trucks; vibrations; wind load; acceleration; airplanes; cargo; dynamic loads; equivalent static force; gravity load; handling devices; handling loads; military field shelters; probability distributions; shocks, snow load; static load; NBSIR 77-1254.

Trajectories; dynamics; missiles; power plants; structural engineering; tomadoes; SP477, pp. VII-36-VII-4I (May I977).

Transaction costs; computer; computer program; copyright; data base; economic efficiency; information technology; policy analysis; policymaking; public goods; technological change; SP500-17.

Transactions; annual reports; diffusion in metals; fire; journals; library holdings, NBS Library; NBS periodicals; periodicals; proceedings; serials; standards; NBSIR 77-1215.

Transducer; biomedical; evaluation; pressure measurement; pressure transducer; 16941 .

Transducer; characterization; evaluation; performance; pressure; 17205.

Transducer; piezoelectric; polymer; polyvinylidene fluoride; pressure sensor; pyroelectric; NBSIR 76-1078.

Transducer; zero shift; coatings; delayed response; dynamic; dynamic response; pressure step; pressure transducer; protective coatings; shock tube; tape; thermal protection; thermal radiant-energy response; thermal transient response; TN961. 
Transducers; triplet formation; absolute quantum efficiency; absolute quantum yield; calorimetry; luminescence; photoacoustic spectrometer; piezocalorimeter; SP466, pp. 25 31 (May 1977).

Transfer channel; bucket-brigade; buried channel; Canada; charge-coupled device; Great Britain; imager CCD's; Japan; peristaltic CCD's; surface channel; The Federal Republic of Germany; The Netherlands; SP500-5.

Transfer equations; early type stars; helium forbidden lines; Stark broadening theory; stellar line profiles; 17172 .

Transfer standard; transmittance; absorbance; accuracy in spectrophotometry; glass filters; high-accuracy spectrophotometers; spectrophotomctry; stability of transmittance; standard reference material; 16981 .

Transfer standard detectors; calibration facilities; photodiodes; radiometry; spectrometer calibration; synchrotron radiation; 16665.

Transfer standards; absorbance linearity; accuracy of transmittance or absorbance scale; acidic potassium dichromate solutions; calibration of ultraviolet spectrometers; certification of apparent specific absorbance; isosbestic wavelengths; liquid filters; $S P 260-54$.

Transfer standards; liquid argon; liquid nitrogen; liquid oxygen; LNG; measurement; 17162 .

Transfer standards; ultraviolet absorbance standards; absorbance linearity; accuracy; acidic potassium dichromate solutions; calibration of ultraviolet spectrophotometers; liquid filters; SP466, pp. 121-126 (May 1977).

Transformer; circuit breaker; data; experiment; shake table; testing; SP477, pp. VI-50_-VI-60 (May 1977).

Transient; automated measurement; pulse; rise time; sampling oscilloscope; spectrum amplitude; time domain; 16721.

Transient heat conduction; confluent hypergeometric functions; droplet; moving boundary problem; preheat; J. Res. 81A Nos. 2 and 3, 257-266 (1977).

Transient heat transfer; composite building constructions; convection; experimental data; fire endurance; heat generation or absorption; numerical solutions; one-dimensional; radiation; thermal conduction; NBSIR 77-1260.

Transistor measurement; transistor measurement repeatability; collector-emitter; saturation voltage; NBSIR 77-1231.

Transistors; hot spots; junction temperature; measurement technology; nondestructive test; reliability; safe operating limits; second breakdown; semiconductor devices; thermal characterization; thermal instability; thermal resistance; SP400-44.

Transistors, power; TTL circuits; ultrasonic wire bonding; ultraviolet reflectance; $x$-ray damag; acoustic emission; Auger electron spectroscopy; beam-lead bonds; capacitance-voltage methods; carrier mobility; C-MOS circuits; dopant profiles; electrical properties; SP400-29.

Transit information; transportation; automation; cost/benefit; models; queuing; telephone systems; NBSIR 77-1253.

Transition; coincidence; electron capture; excited state; gamma ray; ground state; inner bremsstrahlung; Jauch plot; spectrum; SP461, pp. 23-25 (Jan. 1977).

Transition; trip-wire probe; turbulent boundary layer; calibration; Pitot-static tube; Reynolds number; sphere flow; SP484. pp. 719-735 (Oct. 1977).

Transition array; isolated lines; multiplet; plasma broadening; regularities; Stark widths; supermultiplet; $I 7206$.

Transition array; wall stabilized; multiplet; nitrogen lines; regularities; Stark broadening; supermultiplet; 17204.

Transition dipole moment; ab initio calculations; $A$-values; Franck-Condon factors; laser modeling; lifetime; multiconfiguration self-consistent-field; potential energy curves; sodium molecule; 16870.

Transition metal carbides; $\mathrm{x}$-ray emission; $\mathrm{x}$-ray photoemission; charge transfer; chemical shifts; core levels; 17265 .
Transition metal ions; ultrahigh pressure; $\mathrm{Cr}^{3+}$, crystal field spectra; $\mathrm{d}^{3}$ ion; optical spectra; ruby; 17047.

Transition metal, Mössbauer effect; alloy theory; electronegativity; 16967.

Transition moment; absorption cross-section; $\mathrm{Ar}_{2}{ }^{+}$; energy transfer; gain inhibitor; gas lasers; photodissociation; restricted Hartree-Fock; 17195.

Transition moment; dipole moment; excimer; excitation energy; perturbation formula; rare gas halide; Rittner model; 17151 .

Transition point; turning point; asymptotic analysis; Bessel functions; error analysis; linear differential equations; 16899.

Transition probabilities; wall-stabilized arc; atomic spectra; configuration interaction; $J$-file sum rule; neon; 17276 .

Transition probability; UI; uranium; delayed coincidence; $g f$ value; imprisonment; lifetimes; mean life; resonance radiation; 17292 .

Transition regions, solar; transition regions, stellar; ultraviolet spectra; visible spectra; x-ray spectra; chromospheres, solar; chromospheres, stellar; coronae, solar; coronae, stellar; flares, solar; flares, stellar; magnetic cycles, solar; magnetic cycles, stellar; 17324.

Transition regions, stellar; ultraviolet spectra; visible spectra; x-ray spectra; chromospheres, solar; chromospheres, stellar; coronae, solar; coronae, stellar; flares, solar; flares, stellar; magnetic cycles, solar; magnetic cycles, stellar; nonradiative heating; 17324 .

Transition state theory; transmission coefficient; collinear reactions; deuterium, collinear reactions; hydrogen, collinear reactions; kinetic isotope effects; potential surfaces; rate constants; 16914 .

Transition temperatures; canted phase; ferromagnetism; orderorder transition; 17350.

Transit-time; coherence; fringes; interference; modulation; phase; Ramsey; saturation spectroscopy; 17337.

Transmethylation; water; alkylation; aqueous solution; coordination; mercury; metal complexes; organometals; photolysis; reaction rates; thallium; tin; 17008 .

Transmission; anisotropy; charged particle; computer code; energy-angle; integral; legendre polynomial; scattering; semi analytical; spatial; SP461, pp. 140-143 (Jan. 1977).

Transmission; ${ }^{252} \mathrm{Cf}$; ANISN; code; configuration; dose equivalent; energy; gamma rays; neutron; scattering; shield; SP461, pp. $119-123$ (Jan. 1977).

Transmission coefficient; collinear reactions; deuterium, collinear reactions; hydrogen, collinear reactions; kinetic isotope effects; potential surfaces; rate constants; transition state theory; 16914.

Transmission electron microscopy; corrosion resistant alloys; microstructures; molybdenum additions; precipitation; titanium alloys; 16690.

Transmission electron microscopy; ceramics; erosion; fracture; plastic flow; solid particle impact; NBSIR 77-1396.

Transmission matrix; criticality; collision; cylindrical; energy; integral; iterative; neutron; SP46I, pp. 94-96 (Jan. 1977).

Transmission rate; voice channel; Allegheny County; data transmission tests, digital data; mobile digital equipment; modulation technique; SP480-19.

Transmissometer; visibility; visual range; ceilometer; runway visual range; scattering; Monogr. 159.

Transmittance; absorbance; accuracy in spectrophotometry: glass filters; high-accuracy spectrophotometers; spectrophotometry; stability of transmittance; standard reference material; transfer standard; 16981 .

Transmittance; tristimulus values; chromaticity coordinates; color; filters; high accuracy; spectrophotometer; standards; 17260.

Transmittance; wedges; calibration; density; photography; reflectance; 16683 . 
Transmittance characteristics; ultraviolet-visible filters; evaporated metal-on-quartz; filters, transmittance; neutral filters; standard reference materials; SP466, pp. 127-131 (May 1977).

Transpiration heat transfer; porous media; thermal energy storage; NBSIR 77-1237.

Transport; chemical; critical evaluation; mechanical; numerical data; physical properties; thermodynamics; SP463, pp. VII.1.1-VIl.1.15 (Jan. 1977).

Transport; density transform; expansion coefficient; Green's function; neutron; spherical; symmetric; SP461, pp. 87-90 (Jan. 1977).

Transport; integral equation; radiation; scattering; semi-numerical; SP461, pp. 79-86 (Jan. 1977).

Transport; transport equation; approximations; fast-thermal couple reactor; neutron; reactor transients; solution; time-dependent; SP461, pp. 91-93 (Jan. 1977).

Transport calculation; approximations; diffusion; neutron; NIOBE; Rapsodie; reactor; shielding; SP461, pp. 163-165 (Jan. 1977).

Transport coefficient; diffusion; drift tube; electron; Monte Carlo; 16854.

Transport equation; approximations; fast-thermal couple reactor; neutron; reactor transients; solution; time-dependent; transport; SP461, pp. 91-93 (Jan. 1977).

Transport properties; atomic and molecular data; chemical kinetics data; energy data; environmental data; industrial proccss data; materials utilization data; mechanical properties; nuclear data; physical science data; solid state data; standard reference data; TN947.

Transport properties; universality; critical exponents; critical region; fluid mixtures; fluids; scaling; thermodynamic properties; 17279

Transport property; viscosity; carbon dioxide; corresponding states; mixtures; nitrous oxide; prediction; thermal conductivity; TN693.

Transportation; automation; cost/benefit; models; queuing; telephone systems; transit information; NBSIR 77-1253.

Transportation; hazardous materials; methods of test; permeation; plastics packagings; polyethylene; 17346 .

Transportation; trucks; vibrations; wind load; acceleration; airplanes; cargo; dynamic loads; equivalent static force; gravity load; handling devices; handling loads; military field shelters; probability distributions; shocks, snow load; static load; trains; NBSIR 77-1254.

Transportation; validation of models; airport simulation; air traffic control; aviation; models; simulation; 16944.

Transverse current; ultrasonics; correlation function; density fluctuations; fluctuations; hydrodynamics; light scattering; liquid state; molecular dynamics; neutron scattering; shear wave; statistical mechanics; time correlation function; 16711 .

Transverse gradient; wavenumber; duct; fundamental mode; liquid; perfect gas; propagation; shear; 17215.

Transverse shear; vibration; Galerkin; natural frequencies; orthotropic; plates; rotary inertia; 16702.

Trapezoid rule; Hardy space; numerical integration; numerical quadrature; piecewise analytic functions; quadrature; rational approximation; tanh rule; 17157.

Trees; dynamic programming; graph; network; organization; probability; reliability; 16784 .

Triangle of reference; barycentric coordinates; distance coordinates; Euclidean plane; matrices of order three; J. Res. 81B Nos. I and 2, 61-72 (1977).

Tricresyl phosphate; zinc dithiophosphate; antiwear additives; interaction; lubricant; metals; properties; SP487, pp. 172-185 (Aug. 1977).

Trimmed means; velocity of light; A. A. Michelson; adaptive estimators; arithmetic mean; bias; estimators of location; median; M-estimators; S. Newcomb; systematic errors; 17266.
Triphenylmethane cyanide dye precursor; ultraviolet; $\mathrm{x}$ rays; gamma rays; ionizing radiation; leuco dye cyanide; radiation dosimeter; radiation sensor; U.S. Patent 4,006,023.

Triphenylmethane dyes; cellulose acetate; dose distributions; dosimetry; dyed plastics; plastic films; polyvinyl acetate; polyvinyl butyral; polyvinyl chloride; polyvinyl pyrrolidone; radiation dosimetry; radiation processing; radiochromic dyes; 16949.

Triplet formation; absolute quantum efficiency; absolute quantum yield; calorimetry; luminescence; photoacoustic spectrometer; piezocalorimeter; transducers; SP466, pp. 25-31 (May 1977).

Trip-wire probe; turbulent boundary layer; calibration; Pitotstatic tube; Reynolds number; sphere flow; transition; SP484, pp. $719-735$ (Oct. 1977).

Tris $\mathrm{pH}$ buffer; clinical $\mathrm{pH}$; liquid junction; $\mathrm{pH}$ analyzers; $\mathrm{pH}$ error; $\mathrm{pH}$; physiologic $\mathrm{pH} ; 16772$.

Tristimulus values; chromaticity coordinates; color; filters; high accuracy; spectrophotometer; standards; transmittance; 17260

Tropical storms; wind; wind data; wind speed; hurricane; storm surge; SP470, pp. I-18-I-27 (Apr. 1977).

Tropical storms; wind loads; wind speeds; building codes; buildings; codes and standards; housing; hurricanes; pressure coefficients; probability distribution functions; risk; statistical analysis; storms; structural engineering; BSS100-2.

Troposphere; ultraviolet; absorption cross section; carbon tetrachloride; chlorine atom; photochemistry; primary processes; quantum yields; 16703 .

Tropospheric sink; chloromethanes, photochemistry; quantum yields; quartz; sand; surface reactions; J. Res. 82, No. 1, 18 (1977).

Trucks; vibrations; wind load; acceleration; airplanes; cargo; dynamic loads; equivalent static force; gravity load; handling devices; handling loads; military field shelters; probability distributions; shocks, snow load; static load; trains; transportation; NBSIR 77-1254.

True instantaneous temperatures; turbulent flow; fluid mechanics; nonisothermal flow; three velocity components in turbulent flow; SP484, pp. 659-685 (Oct. 1977).

True mass; value; weighing design; weights; apparent mass; buoyancy; buoyancy correction; change; comparison; difference; mass; records; set; surveillance limits; surveillance test; test interval; NBSIR 76-999.

TTF-TCNQ; eddy currents; organic conductors; paramagnetic resonance; 17030 .

TTL circuits; ultrasonic wire bonding; ultraviolet reflectance; x-ray damag; acoustic emission; Auger electron spectroscopy; beam-lead bonds; capacitance-voltage methods; carrier mobility; C-MOS circuits; dopant profiles; electrical properties; electronics; SP400-29.

TU Cassiopeiae; Cepheids; beat Cepheids; double-mode Cepheids; mode interaction; pulsation; stellar instabilities; 17315.

Tunable laser; dye laser; flame analysis; flame fluorescence; laser; opto-galvanic effect; spectroscopy; 16691.

Tunable laser; visible-ultraviolet laser; gas laser; optical pumping; sulfur dimer; 17129 .

Tuneable lasers; alkalis; atomic collisions; multiphoton ionization; Rabi shifts; radiative Penning ionization; 17263.

Tungstates; x-ray powder patterns; dithiotungstate; hydrolysis; infrared spectroscopy; rare earths; rare earth tungstate; 17137.

Tungsten; carbon monoxide; catalytic methanation; hydrogen; methane; 17207.

Tungsten; chemisorption; electron stimulated desorption; oxygen; sulphur hexafluoride; temperature programmed desorption; 16929.

Tungsten; chemisorption; methane; methyl formate; 17065 . 
Tungsten; electrical resistivity; high temperature; Lorenz ratio; low temperature; standard reference material; thermal conductivity; thermopower; 16877.

Tungsten; ultraviolet photoelectron spectroscopy; carbon monoxide; chemisorption; coadsorption; desorption; displacement; hydrogen; photoemission; thermal desorption; 16808 .

Tungsten; ultraviolet photoelectron spectroscopy; acetylene; adsorption; chemisorption; dehydrogenation; ethylene; photoemission; 16829

Tunnelling; 'dielectric constant; Josephson effect; lead; microwaves; niobium; superconductivity; 16946.

Tunnelling; ionization; laser-induced breakdown; laser pulse; multiphoton absorption; 16892 .

Tunnels; aseismic design criteria; design provisions; earthquakes; specifications; structural engineering; SP470, pp. VIII-56-VIII-68 (Apr. 1977).

Turbidity variations; validity testing; water soluble tracers; dye dilution method; flume calibration; SP484, pp. 361-394 (Oct. 1977).

Turbine flowmeter; universal curve; viscosity measurement; accuracy; calibration; characteristic factor ( $\mathbf{K}$ or $\mathbf{C}$ ); curve fitting; pickoffs (magnetic and RF); SP484, pp. $847-869$ (Oct. 1977).

Turbine flowmeters; digital compensation techniques; fossil fuel limitations; linear specific gravity compensation; positive displacement flowmeters; SP484, pp. 821-846 (Oct. 1977).

Turbine flowmeters; volumetric standards; metrology system; Navy Flow Correlation Program; SP484, pp. 25-32 (Oct. 1977).

Turbine materials; cracks; electron microscopy; fracture interfaces; plastic deformation; silicon nitride; NBSIR 76-1075.

Turbine meter; design considerations; field testing; fuel gas measurement; fundamentals; gaseous hydrocarbons; installation; performance characteristics; SP484, pp. 871-880 (Oct. 1977).

Turbine meter; uncertainty; accuracy; calibration; flow conditioning; meter performance; perturbations; precision; SP484, pp. 33-54 (Oct. 1977).

Turbine meters; weirs; acoustic flow meters; closed conduit flows; current meters; dye-dilution methods; errors in flow measurement; flow measurement; fluid flow modeling; fluid velocity; flumes; gas flow standard; hot-wire anemometry; SP484, Volumes $I$ and 2.

Turbulence; liquid metals; magnetohydrodynamics; pipe flow; resistance coefficients; 16821

Turbulence; turbulent boundary layers; velocity measurement; impact pressure probe; Pitot tubes; static pressure probe; SP484, pp. 737-753 (Oct. 1977).

Turbulence; vortex; differential pressure; flow metering error; flow oscillations; jet flow; orifice meters; pulsating flow measurements; pulsations; SP484, pp. 523-548 (Oct. 1977).

Turbulence; wind; aerodynamics; building (codes); pressure; spectra; structural engineering; tall buildings; 16843 .

Turbulence; wind loads; wind tunnels; aerodynamics; boundary layers; buildings; NBSIR 77-1196

Turbulence flow; closed conduit meter; differential pressure; flow measurement; mathematical modeling; meter performance; orifice meter; SP484, pp. 491 -522 (Oct. 1977).

Turbulent boundary layer; calibration; Pitot-static tube; Reynolds number; sphere flow; transition; trip-wire probe; SP484, pp. $719-735$ (Oct. 1977).

Turbulent boundary layers; velocity measurement; impact pressure probe; Pitot tubes; static pressure probe; turbulence; SP484, pp. 737-753 (Oct. 1977).

Turbulent flames; flame radiation; radiant flux density; radiation measurement; radiative heat transfer; NBS-GCR-76-80.

Turbulent flow; channels, small; heat transfer; helium; 17333.

Turbulent flow; flow meter; meter performance; numerical modeling; NBSIR 77-1394.
Turbulent flow; fluid mechanics; nonisothermal flow; three velocity components in turbulent flow; true instantaneous temperatures; SP484, pp. 659-685 (Oct. 1977).

Turbulent flow; velocity profiles; wall shear inference; wall velocity measurements; SP484, pp. 621-648 (Oct. 1977).

Turbulent thermals; vortex bubbles; buoyant thermals; entrainment coefficient; fire-balls; SP484, pp. 571-596 (Oct. 1977).

Turbulent two-phase flow; two-phase flow; error reduction; indirect flow measurement; SP484, pp. $765-782$ (Oct. 1977).

Turkey; earthquake engineering; earthquakes; education; India Iran; training; SP470, pp. X-12-X-16 (Apr. 1977).

Turnaround; workload; accounting data; computer performance; computer resource unit; probability density function; statistics; SP500-18, pp. 39-67 (Sept. 1977).

Turnaround time; evaluating computer service; network measurement machine; remote terminal emulators; response time; throughput; 17250 .

Turning point; asymptotic analysis; Bessel functions; boundary. value problem; connection formula; diffraction theory; error analysis; Liouville-Green approximation; ordinary differential equation; 16805 .

Turning point; asymptotic analysis; Bessel functions; error analysis; linear differential equations; transition point; 16899.

Turning points; Whittaker functions; WKBJ approximation; connection formulas; eigenvalue problems; Liouville-Green approximation; potential barrier; potential well; 17142 .

Turtle; ECG; EEG; electromagnetic field; microwave radiation; nonmetallic electrode system; 17174 .

TvTime system; accuracy; hyperbolic system; range-range system; time and frequency dissemination; time code; 17181 .

Two component flow; vortex street; wake flow; anemometer; cylinder; frequency; hot film anemometer; recirculating flow; spray; SP484, pp. 705-718 (Oct. 1977 ).

Two photon; dimer; double resonance; mercury excimers; optically excited; spectra; 17076 .

Two photon; dimers; discharge; lasers; mercury excimers; spectra; 17192

Two-dimensions; bedrock; modeling; rheological; seismic response; SP477, pp. IV-18-IV-46 (May 1977).

Two-phase flow; error reduction; indirect flow measurement; turbulent two-phase flow; SP484, pp. 765-782 (Oct. 1977).

Two-phonon states; zinc 64-66-68-70; anharmonic vibrator model; collective states; electron scattering; inelastic; 16982.

Two-photon absorption; Raman scattering; Rayleigh scattering; fluorescence; laser fields; theory; 16848 .

Two-pressure generator; volume ratio; water vapor; calibration; dew point; humidity; hygrometer; mixing ratio; relative humidity; J. Res. 81 A No. 1, $81-88$ (1977).

Types; abstract data types; access controls; operating system protection; protection; protection mechanisms; reliable software; 16918 .

Types; capability; capability-based addressing; computer secunty; extended-type objects; operating system structures; protection; reliable software; reliability; security; sriall protection domains; 16920

Typhoon; wind; wind effects; damage; structures; SP477, pp. V-1-V-20 (May 1977).

Typhoon; wind; wind effects; damage; S P477, pp. V-54-V-59 (May 1977).

Typhoon; wind pressure; buildings; dynamic effects; high winds; roofs; SP470, pp. II-1-II-19 (Apr. 1977).

Typhoon; wind speeds; damage; effects; houses; SP477, pp. Il1-II-14 (May 1977).

Typical construction characteristics; typical new house materials; windows; building envelope; energy conservation base; insulation; residential design practices; NBSIR 77-1309.

Typical new house materials; windows; building envelope; energy conservation base; insulation; residential design practices; typical construction characteristics; NBSIR 77-1309. 
U Trianguli Australis; beat Cepheids; double-mode Cepheids; Fourier analysis of stellar variations; mode interaction; stellar instabilities; 16807.

U Trianguli Australis; beat Cepheids; double-mode Cepheids; Fourier analysis of stellar variations; mode interaction; stellar instabilities; 17118 .

"U" values; alternatives; ASHRAE 90-75; building standards; buildings; energy conservation; minimum property standards; multiple glazing; SP473, pp. 85-101 (June 1977).

ü; uranium; delayed coincidence; $g f$ value; imprisonment; lifetimes; mean life; resonance radiation; transition probability; 17292 .

UL 217; aerosol; mass concentration; number concentration; size distribution; smoke; smoke detector; test method; NBSIR 77-1312.

Ultimate capacity; brick; clay masonry; concrete block; concrete masonry; failure modes; load capacity; masonry walls; shear walls; splitting strength; BSS106, pp. 177-197 (Sept. 1977).

Ultimate strength; anchor bolts; bond; damping; ductility; earthquake resistance; energy absorption; modulus of elasticity; partial reinforcing; risk; shear modulus; testing; BSS106, pp. 255-258 (Sept. 1977).

Ultrafiltration; continuous binding curve; dye binding; human albumin; membrane; reflection coefficient; 16959.

Ultrahigh pressure; $\mathrm{Cr}^{3+}$, crystal field spectra; $\mathrm{d}^{3}$ ion; optical spectra; ruby; transition metal ions; 17047.

Ultrasonic; visual testing; wear debris; acoustic; calibration; eddy current; microwave; nondestructive evaluation; penetrant; radiography; standards; thermal; 17106.

Ultrasonic beams; cross-correlation analysis; liquid velocity measurement; non-intrusive flowmeter; SP484, pp. 319-333 (Oct. 1977).

Ultrasonic flowmeter; acoustic rays; flow measurement; SP484, pp. 277-291 (Oct. 1977).

Utrasonic flowmeter; clamp-on ultrasonic flowmeter; flowmetering; SP484, pp. 267-276 (Oct. 1977).

Ultrasonic flowmeter; ultrasonic pulses; flowmeter for natural gas; SP484, pp. 293-318 (Oct. 1977).

Ultrasonic interferometer; vacuum measurement; interferometer; manometers; manometry; pressure standard; 17269.

Uitrasonic pulses; flowmeter for natural gas; ultrasonic flowmeter; SP484, pp. 293-318 (Oct. 1977).

Ultrasonic tissue; computerized data; data elements; equity; federal technology; fire modeling; heat; hydrocarbon; ionized molybdenum; measurement assurance; metric; neutron diffraction; recycling oil; research and innovation; safety; DIMINBS 61, No. 6, 1-32 (1977).

Ultrasonic wire bonding; ultraviolet reflectance; x-ray damag; acoustic emission; Auger electron spectroscopy; beam-lead bonds; capacitance-voltage methods; carrier mobility; C-MOS circuits; dopant profiles; electrical properties; electronics; four-probe method; SP400-29.

Ultrasonics; Army Materials and Mechanics Research Center; electromagnetics; materials testing; nondestructive testing; Nondestructive Testing Newsletter; radiography; technical reports; SP463, pp. IV.6.1-IV.6.2 (Jan. 1977).

Ultrasonics; correlation function; density fluctuations; fluctuations; hydrodynamics; light scattering; liquid state; molecular dynamics; neutron scattering; shear wave; statistical mechanics; time correlation function; transverse current; 16711.

Ultrasonics; visual; acoustic emission; inspection; leak testing; liquid penetrant; magnetic particle; measurements; nondestructive testing; optical; radiography; standards; 17042.

Ultrasonics; visual testing; wear debris analysis; acoustic emission; calibrations; electrical-eddy current measurements; microwaves; nondestructive evaluation; standard reference materials; standards; thermal testing; 17016.

Ultrasound; chirp radar; medical diagnosis; pulse compression; signal processing; 16735 .

Ultrasound; velocity; attenuation; computerized tomography; imaging; 16937.

Ultraviolet; absorption cross section; carbon tetrachloride; chlorine atom; photochemistry; primary processes; quantum yields; troposphere; 16703 .

Ultraviolet; argon; light source; mini-arc; radiometry; spectral radiance; standard; 16778 .

Ultraviolet; computer memories; computer performance; inventor; molecular identity; preserving stone; pressure measurements; rf-power meter; roofing; safety; security alarms; SRM's; time and frequency; DIM/NBS 61, No. 8, 1-32 (1977).

Ultraviolet; detectors; National Measurement System; radiometry; sources; survey; NBSIR 75-941.

Ultraviolet; wall-stabilized; arc; calibration; deuterium; interlaboratory; lamp; radiance; radiometry; source; spectroscopy; standard; synchrotron; 17198.

Ultraviolet; $x$ rays; gamma rays; ionizing radiation; leuco dye cyanide; radiation dosimeter; radiation sensor; triphenylmethane cyanide dye precurșor; U.S. Patent 4,006,023.

Ultraviolet; yttrium; zirconium; ions; molybdenum; niobium; rubidium; spectra; structure; 17212 .

Ultraviolet absorbance standards; absorbance linearity; accuracy; acidic potassium dichromate solutions; calibration of ultraviolet spectrophotometers; liquid filters; transfer standards; SP466, pp. 121-126 (May 1977).

Ultraviolet photoelectron spectroscopy; carbon monoxide; chemisorption; coadsorption; desorption; displacement; hydrogen; photoemission; thermal desorption; tungsten; 16808.

Ultraviolet photoelectron spectroscopy; acetylene; adsorption; chemisorption; dehydrogenation; ethylene; photoemission; tungsten; 16829.

Ultraviolet photometer; ozone; potassium iodide; techniques; 16756.

Ultraviolet photometry; air pollution; calibration; iodometry; monitoring; ozone; NBSIR 76-1191.

Ultraviolet radiation; calibration; consumers; energy; energy savings; grain moisture; mass spectra; radiation sterilizing; screw thread standards; SHIVA laser; silicon; timekeeping; DIM/NBS 61, No. 9, 1-32 (1977).

Ultraviolet radiation; windows; $\mathrm{AC}$ high voltage; $\mathrm{AC}$ voltmeter calibrator; marine studies; microelectronic industry; monitoring system; photodetectors; radiopharmaceuticals; DIM/NBS 61 , No. 12, 1-32 (1977).

Ultraviolet reflectance; $x$-ray damag; acoustic emission; Auger electron spectroscopy; beam-lead bonds; capacitance-voltage methods; carrier mobility; C-MOS circuits; dopant profiles; electrical properties; electronics; four-probe method; hermeticity; ion implantation; SP400-29.

Ultraviolet spectra; Arcturus; chromospheres, stellar; line profiles, stellar; radiative transfer; 17056.

Ultraviolet spectra; stars, chromospheres; stars, coronae; stars, individual; stars, late type; 17310.

Ultraviolet spectra; visible spectra; x-ray spectra; chromospheres, solar; chromospheres, stellar; coronae, solar; coronae, stellar; flares, solar; flares, stellar; magnetic cycles, solar; magnetic cycles, stellar; nonradiative heating; transition regions, solar; 17324.

Ultraviolet-visible filters; evaporated metal-on-quartz; filters, transmittance; neutral filters; standard reference materials; transmittance characteristics; SP466, pp. 127-131 (May 1977).

Uncertainties; criticals; cross section; ENDF/B; fission; standards; SP493, pp. 269-277 (Oct. 1977). 
Uncertainties; yield; distributions; neutrons; resolution; spectra; NBSIR 77-1279, pp. 15-18 (July 1977).

Uncertainties in efficiency; description of mcthod; possible improvements; SP493, pp. 234-236 (Oct. 1977).

Uncertainty; abnormal loading; alternate path; building code; design criteria; probability; progressive collapse; reliability; structural engineering; BSS98.

Uncertainty; accuracy; calibration; flow conditioning; meter performance; perturbations; precision; turbine meter; SP484, pp. 33-54 (Oct. 1977).

Uncertainty; measurement assurance; systematic error; NBSIR 77-1240.

Uncertainty; probability; reinforced concrete; reliability; statistical analysis; structural engineering; 17304.

Unconventional diffusion; velocity of concentration front propagation; concentration dependent diffusion coefficient; concentration front; discontinuous swelling; J. Res. 81A Nos. 2 and 3, 243-250 (1977).

Underground; carbon steel; corrosion; ductile cast-iron; soils; statistical analysis; 16745 .

Underground corrosion; buricd cables; copper concentric neutral wires; corrosion detection methods; corrosion tests; current-potential measurements; NBSIR 77-1232.

Underground transmission; bridge measurements; cryogenic; dielectric loss; dissipation factor; epoxy insulation; high voltage; polymer tape insulation; superconducting cable; 17014 .

Undisturbed sampling; density; liquefaction; sand; soils; tests; SP477, pp. VI-141 - VI-157 (May 1977).

UNFOLD; Apsara; energy distribution; gamma ray; iterative; neutron; plastic; recoil; scintillator; SP461, pp. 247-251 (Jan. 1977).

Uniaxial extension and compression in rubber; extension and compression in rubber; Martin-Roth-Stiehler equation; modulus of rubber; Mooney-Rivlin equation; rubber; stress-strain relations; J. Res. 82, No. 1, 57-63 (1977).

Uniaxial structures; amorphous materials; bubble; field-access; garnet; guide-pattern; magnetoresistance; nonvolatility; orthoferrite; photolithography; SP500-I.

Unified classical path theory; unified theory; hydrogenic ions; Stark broadening; 17249 .

Unified theory; hydrogenic ions; Stark broadening; unified classical path theory; 17249 .

Uniform loads; concentrated loads; design criteria; mode of failure; racking resistance; structural performance; SP477, pp. I-66-I-69 (May 1977).

Uniformity; building regulation; code administration; enforcement; funding; local government; model codes; state-local relations; statewide codes; SP473, pp. 225-240 (June 1977).

Unionization; building official; building regulation; education; housing demand; innovation; regulatory barriers; residential construction; SP473, pp. 113-135 (June 1977).

Unit ball; vector norm; compatible; generalized matrix norm; multiplicative; spectral radius; 16836.

Units of Measurements; General Conference on Weights and Measures; International System of Units; SI; Système International des Unités; SP330.

Universal Color Language; variable accuracy of color designations; centroid colors; color; color designations; calorimetry; color names; color-order systems; Munsell Color System; SP440.

Universal curve; viscosity measurement; accuracy; calibration; characteristic factor ( $\mathrm{K}$ or $\mathrm{C}$ ); curve fitting; pickoffs (magnetic and RF); turbine flowmeter; SP484, pp. 847-869 (Oct. 1977).

Universality: critical exponents; critical region; fluid mixtures; fluids; scaling; thermodynamic properties; transport properties; 17279.

Unsaturated monomers; block copolymers; homogeneous anionic polymerization; monodisperse polymers; 16736 .
Unsmearing; FORTRAN program; integral equation; interpolating polynomial; numerical stability; slit correction; small angle scattering; $T N 936$.

Upholstered furniture; cost plus loss; decision analysis; fire; furniture fire; losses; residential fire; standard; NBSIR 77-1381.

Uranium; arc; oscillator strength; plasma; spectra; 16992.

Uranium; calculation; cross section; optical model; reactor technology; scattering-elastic, inelastic, total; thorium; SP461, pp. 70-73 (Jan. 1977).

Uranium; delayed coincidence; $g f$ value; imprisonment; lifetimes; mean life; resonance radiation; transition probability; uı; 17292.

Uranium-235; Watt spectrum; californium-252; Maxwellian spectrum; plutonium-239; prompt fission spectrum; SP493, pp. 198-205 (Oct. 1977).

Urban renewal; building codes; housing; rehabilitation; remodeling; residential; NBS-GCR-77-87.

Urea-formaldehyde; cellular plastics; foam insulation; insulation; materials properties; performance; TN946.

Urgent data request; ALERT; calibration procedures; engineering technical data, metrology; failure mode; failure rate, quality, reliability, safety; technology transfer; SP463, pp. III.5.1-III.5.8 (Jan. 1977).

U.S. demand structure; cartels; economic policy options; foreign supply disruptions; stockpiling; technology; NBSGCR-ETIP 76-25.

U.S. demand structure; cartels; economic policy options; foreign supply disruptions; stockpiling; technology; NBSGCR-ETIP 76-28.

U.S. demand structure; cartels; economic policy options; foreign supply disruptions; stockpiling; technology options; NBS-GCR-ETIP 76-29.

U.S. demand structure; cartels; economic policy options; foreign supply disruptions; stockpiling; technology options; NBS-GCR-ETIP 76-30.

U.S. demand structure; cartels; economic policy options; foreign supply disruptions; stockpiling technology options; NBS-GCR-ETIP 76-3I.

U.S. economy; free enterprise system; innovation; public private sector collaboration; technology growth; 17113.

U.S.D.A; Commerce; Defense; E.R.D.A.; Federal agencies; interagency review; Interior; Library of Congress; materials; materials data; materials information; N.A.S.A.; SP463.

Use and reasonably foreseeable abuse testing for toys; cautionary labeling for toys; hazardous characteristics of toys; safety, toy; toy safety; PS72-76.

Use of products; consumer behavior; consumer product safety; human factors; misuse of products; systems analysis; 16890.

Used oil; waste oil; engine oil; fuel oil; hydraulic oil; industrial oils; lubricating oil; oil specifications; petroleum standards; petroleum test methods; recycled oil; re-refined oil; SP488.

User awareness; data storage/retrieval; handbooks; mechanical properties; Mechanical Properties Data Center; structural metals and alloys; technical information; SP463, pp. IV.8.1IV.8.10 (Jan. 1977).

User equipment; user survey; NBS radio stations WWV/WWVH/WWVB; NBS time/frequency services; satellite timing; standard time/frequency broadcasts; television time/frequency dissemination; time/frequency calibrations; 17080 .

User evaluation; American Ceramic Society; ceramics; phase diagrams; "Phase Diagrams for Ceramists"; phase equilibria: SP486.

User need; procurement incentives; product improvement system; product innovation; NBSIR 77-1221.

User survey;. NBS radio stations WWV/WWVH/WWVB; NBS time/frequency services; satellite timing; standard time/frequency broadcasts; television time/frequency dissemination; time/frequency calibrations; user equipment 17080. 
U.S.-U.S.S.R. cooperative program; ceria; materials characterization; MHD(magnetohydrodynamics); power generation; testing; 17160.

Utility services; computer programs; cooling; energy analysis; financial analysis; heating; load calculation; MIUS; modular integrated utility system; simulation; NBSIR 77-1307.

Utility system; institutional factors; Modular Integrated Utility System; total energy; NBSIR 76-1103.

Utility systems; abstracted reports and articles; HUD Modular Integrated Utility Systems (MIUS) Program; total energy; SP489.

Utilization; operational analysis; queuing networks; queuing theory; SP500-18, pp. 219-225 (Sept. 1977).

UV excitation; $\mathrm{x}$-ray excitation; cathode-ray excitation; luminescence; luminescence standards; phosphors; quantum efficiencies; radiant efficiencies; SP466, pp. 13-19 (May 1977).

U-233; U-235; fission-neutron yields; fission standards; neutron nuclear data evaluation; Pu-239; Pu-239 half-life; Pu-241; thermal neutron cross-sections; SP493, pp. 170-173 (Oct. 1977).

U-235; fission-neutron yields; fission standards; neutron nuclear data evaluation; Pu-239; Pu-239 half-life; Pu-241; thermal neutron cross-sections; U-233; SP493, pp. 170-173 (Oct. 1977).

U-235 (n,f); 0.1-20.0 MeV; data; evaluations; status; SP493, pp. 261-268 (Oct. 1977).

\section{V}

Vacancies; alpha-tricalcium phosphate; calcium phosphate; cation-anion columns; crystal structure; subcell; 17034.

Vacancies; beta-tricalcium phosphate; cation substitution; coordination; crystal structure; disorder; magnesium incorporation; phosphate; 17259 .

Vacuum measurement; interferometer; manometers; manometry; pressure standard; ultrasonic interferometer; 17269.

Valence; atomic volume; hyperfine fields; iron alloys; 16927.

Valence bands; W; WC; x-ray photoemission; catalysis; Mo; $\mathrm{Mo}_{2} \mathrm{C}$; refractory hard metals; 16932.

Validating correctness; communications security; computer security; cryptography; encryption standard; interface requirements; Monte-Carlo testing; testbed; test cases; SP500-20.

Validation; benchmark audit procedures; benchmarking; benchmarks associated with government procurement of computers; SP500-18, pp. 75-83 (Sept. 1977).

Validation; credit authorization system; critical resource; disk modelling; event model; measurement; modelling; resource dependency; system capacity; SP500-18, pp. 185-211 (Sept. 1977).

Validation of design; coating materials; composite materials; design; failure avoidance; failure prevention; lubricants; materials of design; product liability; reliability of design; techniques of design; SP487.

Validation of models; airport simulation; air traffic control; aviation; models; simulation; transportation; 16944.

Validity testing; water soluble tracers; dye dilution method; flume calibration; turbidity variations; SP484, pp. 361-394 (Oct. 1977).

Value; weighing design; weights; apparent mass; buoyancy; buoyancy correction; change; comparison; difference; mass; records; set; surveillance limits; surveillance test; test interval; true mass; NBSIR 76-999.

Value incentive; Experimental Technology Incentives Program (ETIP); Federal Supply Service; life cycle costing; procurement policy; specifications; NBS-GCR-ETIP 76-26.

Value incentive; Experimental Technology Incentives Program (ETTP); Federal Supply Service; life cycle costing; procurement policy; specifications; NBS-GCR-ETIP 76-27.
Van der Pauw; cross test structure; cross van der Pauw; numerical analysis; sheet resistance; sheet resistor test structure; test structures; 17165 .

Van der Waals; atomic collision; excitation transfer; laser stimulation; orbiting; saturation; selection rules; 16695.

Van der Waals; XeF; charge transfer; dissociation energy; energy curve; overlap; 16684 .

Van Kreveld's additivity law; exposure; exposure control; film thickness variation; irradiance measurements; photoresist; photoresist sensitivity; sensitivity index; 16853.

Van Kreveld's additivity law; exposure; exposure control; film thickness; irradiance measurements; photoresist; sensitivity index; sensitometry; 17329.

Vanadium alloys; atomic ordering; constitution diagram; phase diagram; phase transformations; rhodium alloys; 16834 .

Vane anemometer; velocity readings; ventilation tubing; air velocity; error elimination; SP484, pp. $755-763$ (Oct. 1977).

Vapor; computer programs; enthalpy; entropy; hydrogen; internal energy; liquid; oxygen; PVT; quality; slush; solid; NBSIR 77-859.

Vapor condensation; air, moisture and heat transfer theory; cold storage insulation; fibrous-glass insulation; 17340 .

Vapor generator; vapor pressure; DNT; EGDN; explosive detection; limits of detection; sensitivity test; TNT; 16830 .

Vapor pressure; activity coefficients; aqueous systems; bibliography; electrochemistry; isopiestic; osmotic coefficients; thermochemistry; SP485.

Vapor pressure; argon-vapor contact; error analysis; iodine; molybdenum hexafluoride; new static technique; 17075.

Vapor pressure; densities; enthalpies; entropies; equation of state; internal energies; isobars; isochores; isotherms; JouleThomson inversion; latent heats of vaporization; melting line; orthobaric densities; propane; specific heats; speeds of sound; NBSIR 77-860.

Vapor pressure; DNT; EGDN; explosive detection; limits of detection; sensitivity test; TNT; vapor generator; 16830 .

Vapor pressure; vapor pressure at the triple point; vapor pressure of ice; water vapor; Clausius-Clapeyron equation; saturation vapor pressure over ice; thermal properties of ice; $J$. Res. 81A No. 1, 5-20 (1977).

Vapor pressure; water vapor; aqueous solution; equilibrium; humidity; relative humidity; salt; saturated salt solution; J. Res. 81A No. 1, 89-96 (1977).

Vapor pressure; 1-ethylnaphthalene; 1-methylnaphthalene; enthalpy; fluorescence; heat of solution; naphthalene; partition coefficient; solubility; 17097.

Vapor pressure at the triple point; vapor pressure of ice; water vapor; Clausius-Clapeyron equation; saturation vapor pressure over ice; thermal properties of ice; vapor pressure; $J$. Res. 81A No. 1, 5-20 (1977).

Vapor pressure of ice; water vapor; Clausius-Clapeyron equation; saturation vapor pressure over ice; thermal properties of ice; vapor pressure; vapor pressure at the triple point; J. Res. 81A No. 1, 5-20 (1977).

Vapor pressure of $\mathrm{K}_{2} \mathrm{O}-\mathrm{Al}_{2} \mathrm{O}_{3}$ phases; vapor pressure of $\mathrm{K}_{2} \mathrm{O}$ $\mathrm{SiO}_{2}$ solutions; activity of $\mathrm{K}_{2} \mathrm{O}$ in $\mathrm{K}_{2} \mathrm{O}-\mathrm{SiO}_{2}$ solutions; coalfired MHD; open-cycle MHD; 16897.

Vapor pressure of $\mathrm{K}_{2} \mathrm{O}-\mathrm{SiO}_{2}$ solutions; activity of $\mathrm{K}_{2} \mathrm{O}$ in $\mathrm{K}_{2} \mathrm{O}$ $\mathrm{SiO}_{2}$ solutions; coal-fired MHD; open-cycle MHD; seed-slag interaction; 16897

Vapor pressures; DNT; EGDN; electron-capture gas chromatography; measurements; TNT; 16825 .

Vapor recovery; weights and measures; checking prepackaged commodities; computer assisted check-out systems; consumer affairs; cordage products; drained weight; laws and regulations; metrication; national laboratory accreditation; retail meat identity standards; SP47I.

Vapor transport; activation parameters; active nitrogen; iodine; kinetics; microwave discharge; nitride; plasma; reaction mechanism; silicon; synthesis; thin film; 16757 . 
Vapor + liquid equilibria; ethane; ethene; methane; 16881 .

Vaporization; activity; glass; 17043.

Vaporization processes; ceramic corrosion; ceramic erosion; ceramic fracture; chemical degradation; coal gasification material; failure avoidance; metal corrosion; metal erosion; 17158

Vaporization processes; ceramic corrosion; ceramic erosion; ceramic fracture; chemical degradation; coal gasification material; failure avoidance; metal corrosion; metal erosion; 17159.

Variable accuracy of color designations; centroid colors; color; color designations; calorimetry; color names; color-order systems; Munsell Color System; Universal Color Language; SP440.

Variational; anholonomic; constraint; electromagnetism; Hamilton; Maxwell; momentum; Poynting; J. Res. 81B Nos. 1 and 2, 1-3 (1977).

Vector dominance; electromagnetic properties; form factors; magnetic moments; quadrupole moments; quantum field theory; relativistic many body systems; Monogr. 147, Suppl. I.

Vector norm; compatible; generalized matrix norm; Hadamard product; multiplicative; spectral radius; 16676 .

Vector norm; compatible; generalized matrix norm; multiplicative; spectral radius; unit ball; 16836 .

Vector voltmeter; microwave voltmeter; phase angle measurements; six-port voltmeter; U.S. Patent 4,001,681.

Velocities; vibrations; arch dam; deflections; dynamic tests; model; structural analysis; SP477, pp. VI-85-VI-117 (May 1977).

Velocity; attenuation; computerized tomography; imaging; ultrasound; 16937.

Velocity; charge; charged particle; collision; electron; ionic charge; ionization potential; stopping power; stripped particle; SP461, pp. 144-148 (Jan. 1977).

Velocity; data; displacements; intensity; seismic records; SP477, pp. VI-179-VI-191 (May 1977).

Velocity dependence; erosion; metal; oxidation; particle; 16898.

Velocity distribution; drift tube; ion; Monte-Carlo; swarm; theory; 16779.

Velocity indication; flow in large pipes; flow metering; pipe flow; Pitot tubes; SP484, pp. 479-489 (Oct. 1977).

Velocity measurement; impact pressure probe; Pitot tubes; static pressure probe; turbulence; turbulent boundary layers; SP484, pp. $737-753$ (Oct. 1977).

Velocity measurements; buoyant flow; corridor, countercurrent; fire; scaling; stratified flow; temperature; 17285 .

Velocity of concentration front propagation; concentration dependent diffusion coefficient; concentration front; discontinuous swelling; unconventional diffusion; J. Res. 81A Nos. 2 and 3, 243-250 (1977).

Velocity of light; A. A. Michelson; adaptive estimators; arithmetic mean; bias; estimators of location; median; M-estimators; S. Newcomb; systematic errors; trimmed means; 17266.

Velocity profiles; wall shear inference; wall velocity measurements; turbulent flow; SP484, pp. 621-648 (Oct. 1977).

Velocity readings; ventilation tubing; air velocity; error elimination; vane anemometer; SP484, pp. $755-763$ (Oct. 1977).

Velocity-area method; current meter calibrations; current meters, water; flow measurement; Price meter suspensions; Pygmy meter performance; SP484, pp. 123-144 (Oct. 1977).

Velocity-area method; weir equation; closed-loop cooling system; cooling lake; dye dilution method; error analysis; flow rate measurement; open channel flow measurement; power plant; spray canal; stage-discharge equation; SP484, pp. 145-172 (Oct. 1977).
Veneer anchorage; allowable bolt loads, end distance, edge distance and spacing; drift; face shells, reinforcing splices; high lift grouting; shotcrete, surface wave instrumentation; BSS106, pp. 259-274 (Sept. 1977).

Ventilation; corridors; fuel load; heat transfer; room fires; scaling; NBSIR 77-1318.

Ventilation; water heating; air leakage; building design; energy conservation; fenestration; HVAC systems; illumination; insulation; lighting; performance standard; thermal performance; NBSIR 74-452.

Ventilation; windows; air-tightness; daylighting; energy-conservation; insulation; shading; solar-heating; BSSI04.

Ventilation; windows; daylighting; infiltration; insulation; passive-solar-heating; sun-shading; 17298.

Ventilation control; weather data analysis; air conditioning requirements; energy conservation; intermittent ventilation; NBSIR 76-1088.

Ventilation test; computerized thermal simulation; $\mathrm{CO}_{2}$ concentration; energy conservation in schools; energy consumption; energy utilization in schools; oxygen content; reduced ventilation rate; school operation schedule; BSS97.

Ventilation tubing; air velocity; error elimination; vane anemometer; velocity readings; SP484, pp. $755-763$ (Oct. 1977).

Venting; cost savings; drainage-waste-vent; economics; life cycle; performance standards; pipe; plumbing; reduced-size vents; sanitary drainage system; 17296 .

Verbal communicative; alarm; architecture; design implication; emergency actions; emergency communicative; emergency decisions; escape; fires; human behavior; human response; life safety; mapping; model; nursing homes; rescue; NBSGCR-77-93.

Verification; ADP security; computer networks; controlled accessibility; encryption; evaluation criteria; key; password; personal identification; terminals; FIPS PUB 48.

Verification; calibration; load cell; proving rings; testing machines; tolerance; 16915 .

Vessels and wind; accelerograph; bridges; buildings; codes; disaster; dynamic analysis; earthquakes; ground failures; hydraulic structures; seismicity; soils; standards; structural response; SP470.

$\mathrm{VF}_{5}$; AsF ; barriers; energy levels; gas phase; $\mathrm{PF}_{5}$; Raman; 16978.

Vibration; acceleration calibration; mounting variable; NBSIR 73-291.

Vibration; Galerkin; natural frequencies; orthotropic; plates; rotary inertia; transverse shear; 16702.

Vibration; headphone; loudspeaker; microphone; piezoelectric polymer; sound source; 16952.

Vibration; vibration exciters; vibration standards; accelerometers; calibration; measurements; NBSIR 77-1229.

Vibration exciters; vibration standards; accelerometers; calibration; measurements; vibration; NBSIR 77-1229.

Vibration sensor; acoustic emission; damage detection; failure prevention; noise spectrum; piezoelectric polymer; SP487, pp. 189-196 (Aug. 1977).

Vibration standards; accelerometers; calibration; measurements; vibration; vibration exciters; NBSIR 77-I229.

Vibration tests; void ratios; earthquakes; liquefaction; sand layer; shake table; SP470, pp. V-16-V-35 (Apr. 1977).

Vibrational analysis; $\mathrm{BCl}_{2} \mathrm{SD} ; \mathrm{BCl}_{2} \mathrm{SH}$; hindered rotation; infrared spectra; Raman spectra; 17166.

Vibrational and rotational enhancement; argon; cross section; dissociation collisions; hydrogen; theory; 16803.

Vibrational constants; vibration-rotation constants; combination bands; nitrogen dioxide; rotational constants; 17123 .

Vibrational excitation; adsorption; molecules; photoelectron spectroscopy; surfaces; 16749. 
Vibrational excitation; chemical kinetics; chlorine atoms; flash photolysis; hydrogen metathesis methanes; resonance fluorescence; 16785 .

Vibrational excitation; close-coupling calculations; crossed beams; cross sections; differential cross sections; electron scattering; inelastic scattering; nitrogen molecules; resonances; scattering; 16740 .

Vibrational frequencies; fundamental frequencies; infrared spectra; polyatomic molecules; Raman spectra; JPCRD 6, No. 3, 993-1102 (1977).

Vibrational frequency; $\mathrm{FeO} ; \mathrm{FeO}_{2}$ : infrared spectrum; structure; 17208.

Vibrational fundamentals; virial coefficients of the equation of state; enthalpy of formation; Gibbs energy of formation; ideal gas thermodynamic properties; intermolecular association; normal and deuterated methanols; JPCRD 6, No. 1, 105-1 12 (1977).

Vibrational relaxation; combustion; $\mathrm{CO}_{2}$ lasers; nitric oxide; optical pumping of molecules; 17193.

Vibrational transition moment; acetylene- $d_{2}$; $l$-type doubling constants; microwave spectrum; rotational constants; Stark effect; 16689 .

Vibration-rotation constants; combination bands; nitrogen dioxide; rotational constants; vibrational constants; 17123 .

Vibration-rotation interaction; high resolution; infrared spectrum; monodeutero silane; SiH stretching vibrations; 17131 .

Vibration-rotation spectra; carbon monosulfide; Dunham coefficients; infrared absorption; molecular physics; short-lived molecular species; 17044.

Vibrations; arch dam; deflections; dynamic tests; model; structural analysis; velocities; SP477, pp. VI-85-VI-117 (May 1977).

Vibrations; wind load; acceleration; airplanes; cargo; dynamic loads; equivalent static force; gravity load; handling devices; handling loads; military field shelters; probability distributions; shocks, snow load; static load; trains; transportation; trucks; NBSIR 77-1254.

Vigilance; behavioral science; human factors; human reliability; perpetrator attributes; physical security; psychological deterrence; sophisticated crime; threat analysis; terrorism; SP48024.

Vinylacetylene; 1,5-hexadiyne; 2,4-hexadiyne; appearance potential; benzene; butatriene; heat of formation; ion; ionization potential; monoenergetic electron impact; photoionization; pyridine; 17294.

Vinylidene fluoride copolymer; charge distribution; charge transfer; corona poling; dipole orientation; piezoelectricity; polarization; polyvinylidene fluoride; pyroelectricity; NBSIR 76-1186.

Virial coefficients of the equation of state; enthalpy of formation; Gibbs energy of formation; ideal gas thermodynamic properties; intermolecular association; normal and deuterated methanols; potential barrier to internal rotation; JPCRD 6, No. 1, 105-112 (1977).

Virtual memory system; bubble memory; performance evaluation; system modeling; SP500-18, pp. 213-217 (Sept. 1977).

Virtual photon theory; bremsstrahlung spectrum tip; Delbrück scattering; electromagnetic interactions; electron scattering; radiative corrections; total photon absorption cross sections; TN955.

Viscosity; bromides; data compilation; density; electrical conductance; iodides; molten salt mixtures; standard reference data; surface tension; JPCRD 6, No. 2, $409-596$ ( 1977 ).

Viscosity; carbon dioxide; corresponding states; mixtures; nitrous oxide; prediction; thermal conductivity; transport property; TN693.

Viscosity coefficient; correlation; critical point anomaly; methane; tables; thermal conductivity coefficient; JPCRD 6, No. 2, 597-610 (1977).
Viscosity coefficient; corresponding states; dense liquid; mixture; modified Enskog theory; prediction; thermal conductivity coefficient; 16791 .

Viscosity coefficient; critical point; mixture; one-fluid theory; plait point; thermal conductivity coefficient; J. Res. 82, No. 3, 181-182 (1977).

Viscosity coefficient; critical point enhancement; data evaluation; ethane; thermal conductivity coefficient; JPCRD 6, No. 4, $1167-1180$ (1977).

Viscosity measurement; accuracy; calibration; characteristic factor ( $\mathrm{K}$ or $\mathrm{C}$ ); curve fitting; pickoffs (magnetic and $\mathrm{RF}$ ); turbine flowmeter; universal curve; SP484, pp. 847-869 (Oct. 1977).

Viscosity of water and steam; water; critically evaluated data; International Formulation; steam; JPCRD 6, No. 4, 1133. 1166 (1977).

Visibility; visual range; ceilometer; runway visual range; scattering; transmissometer; Monogr. 159.

Visibility level; visual processes; contrast; detection; illumination; incapacitation; psychological deterrence; recognition; security lighting; security systems; SP480-27.

Visible absorption spectroscopy; high-resolution spectrum; iodine spectrum; line identification atlas; rovibronic assignments; spectral analysis; J. Res. 81 A No. 1, 25-80 (1977).

Visible spectra; $x$-ray spectra; chromospheres, solar; chromospheres, stellar; coronae, solar; coronae, stellar; flares, solar; flares, stellar; magnetic cycles, solar; magnetic cycles, stellar; nonradiative heating; transition regions, solar; transition regions, stellar; 17324.

Visible-ultraviolet laser; gas laser; optical pumping; sulfur dimer; tunable laser; 17129

Vision; visual acuity; visual capacities; modulation transfer function; nondestructive testing; 17015 .

Visual; acoustic emission; inspection; leak testing; liquid penetrant; magnetic particle; measurements; nondestructive testing; optical; radiography; standards; ultrasonics; 17042.

Visual acuity; visual capacities; modulation transfer function: nondestructive testing; vision; 17015.

Visual alignment structure; electrical mask alignment; integrated circuit; photolithography; silicon; test pattern; 17330.

Visual capacities; modulation transfer function; nondestructive testing; vision; visual acuity; 17015 .

Visual processes; contrast; detection; illumination; incapacitation; psychological deterrence; recognition; security lighting; security systems; visibility level; SP480-27.

Visual range; ceilometer; runway visual range; scattering; transmissometer; visibility; Monogr. 159.

Visual testing; wear debris; acoustic; calibration; eddy current; microwave; nondestructive evaluation; penetrant; radiography; standards; thermal; ultrasonic; 17106.

Visual testing; wear debris analysis; acoustic emission; calibrations; electrical-eddy current measurements; microwaves; nondestructive evaluation; standard reference materials; standards; thermal testing; ultrasonics; 17016.

VLF antenna fields; VLF timing; VLF tracking coordination; clock synchronizations; cycle identification; group delays; Omega timing; precision timekeeping; 16947.

VLF timing; VLF tracking coordination; clock synchronizations; cycle identification; group delays; Omega timing; precision timekeeping; VLF antenna fields; 16947.

VLF tracking coordination; clock synchronizations; cycle identification; group delays; Omega timing; precision timekeeping; VLF antenna fields; VLF timing; 16947.

Vocabulary; computers; data processing; definitions; dictionary for information processing; Federal Information Processing Standards Publication; information processing; terms; FIPS PUB $11-1$. 
Voice channel; Allegheny County; data transmission tests, digital data; mobile digital equipment; modulation technique; transmission rate; $S P 480-19$.

Voice communication; coding; communication systems; fire alarm systems; health care facilities; hospital communication systems; hospital fires; hospital personnel; human behavior; nursing home fires; nursing staff; standards; NBS-GCR-77102.

Voice privacy; voice scramblers; LESL; NILECJ; privacy; scramblers; speech scramblers; SP480-8.

Voice scramblers; LESL; NILECJ; privacy; scramblers; speech scramblers; voice privacy; $S P 480-8$.

Void ratios; earthquakes; liquefaction; sand layer; shake table; vibration tests; SP470, pp. V-16-V-35 (Apr. 1977).

Volt boxes; direct voltage measurements; high voltage measurements; Kelvin-Varley divider; ratio standard; voltage dividers; 16713 .

Voltage contrast; atomic number contrast; electron beam induced conductivity (EBIC) contrast; electron channeling contrast; magnetic contrast; scanning electron microscopy; topographic contrast; 16840 .

Voltage contrast; backscattered emission; EBIC; microelectronic devices; scanning electron microscope; secondary emission; SP400-35.

Voltage dividers; volt boxes; direct voltage measurements; high voltage measurements; Kelvin-Varley divider; ratio standard; 16713.

Voltage measurement; voltage reference; Josephson junction; standard cell; superconducting; 16698.

Voltage reference; Josephson junction; standard cell; superconducting; voltage measurement; 16698.

Voltage waveforms; energy gap; Josephson junctions; picosecond pulses; superconducting electronics; superconductivity; 16874

Volume ratio; water vapor; calibration; dew point; humidity; hygrometer; mixing ratio; relative humidity; two-pressure generator; J. Res. 81A No. 1, 81-88 (1977).

Volume reduction factors; petroleum measurement; silicon crystal density standards; 17023.

Volumetric calibration; accuracy; design analysis; equipment specification; field standard; gravimetric calibration; liquid retention or clingage tests; precision; prover; Research Associate Program; standards inspection procedure; temperature correction; NBSIR 77-1214.

Volumetric standards; metrology system; Navy Flow Correlation Program; turbine flowmeters; SP484, pp. 25-32 (Oct. 1977).

Voluntary standards; American National Standards Institute; computerized information system; engineering standards; mandatory standards; national standards; plastics standards; standards; standards information service; SP463, pp. VII.5.1 VII.5.9 (Jan. 1977).

Voluntary standards; CAM architectures; computer aided manufacturing; computer systems; standards; system integration; NBSIR 76-1094.

Vortex; cuvette; helix; mixer; spectrophotometry; stirrer; 16704

Vortex; differential pressure; flow metering error; flow oscillations; jet flow; orifice meters; pulsating flow measurements; pulsations; turbulence; SP484, pp. 523-548 (Oct. 1977).

Vortex bubbles; buoyant thermals; entrainment coefficient; fireballs; turbulent thermals; SP484, pp. $571-596$ (Oct. 1977).

Vortex flowmeter; vortex generating element; vortex shedding; linearity; shedding frequency; SP484, pp. 549-570 (Oct. 1977).

Vortex generating element; vortex shedding; linearity; shedding frequency; vortex flowmeter; SP484, pp. 549-570 (Oct. 1977).
Vortex shedding; linearity; shedding frequency; vortex flowmeter; vortex generating element; SP484, pp. 549-570 (Oct. 1977).

Vortex street; wake flow; anemometer; cylinder; frequency; hot film anemometer; recirculating flow; spray; two component flow; SP484, pp. 705-718 (Oct. 1977).

$\mathrm{V}(\mathrm{CO})_{6_{-}}^{-;}$1,3-dithiolium ion; 2,2'-bi(1,3-dithiolyl); coupling constants; hexacarbonylvanadate(1-); NMR spectroscopy; reduction; 17154 .

\section{W}

W; WC; x-ray photoemission; catalysis; $\mathrm{Mo}$; $\mathrm{Mo}_{2} \mathrm{C}$; refractory hard metals; valence bands; 16932 .

Wake flow; anemometer; cylinder; frequency; hot film anemometer; recirculating flow; spray; two component flow; vortex street; SP484, pp. 705-718 (Oct. 1977).

Walkway surfaces; waxes and polishes; flooring; floor treatments; shoe sole and heel materials; slip-resistance tester; TN953.

Wall shear inference; wall velocity measurements; turbulent flow; velocity profiles; SP484, pp. 621-648 (Oct. 1977).

Wall shift; active hydrogen maser frequency standard; cavity pulling; cavity-Q; cavity servo; Crampton effect; frequency stability; hydrogen line $Q$; hydrogen line servo; magnetic field; passive hydrogen maser frequency standard; secondorder Doppler; spin exchange; 17180 .

Wall stabilized; multiplet; nitrogen lines; regularities; Stark broadening; supermultiplet; transition array; 17204 .

Wall velocity measurements; turbulent flow; velocity profiles; wall shear inference; SP484, pp. 621-648 (Oct. 1977).

Wall-stabilized; arc; calibration; deuterium; interlaboratory; lamp; radiance; radiometry; source; spectroscopy; standard; synchrotron; ultraviolet; 17198 .

Wall-stabilized arc; atomic spectra; configuration interaction; $J$-file sum rule; neon; transition probabilities; 17276.

Warming trays; compressible cooking surfaces; hot plates; thermal safety covering; U.S. Patent 4,009,704.

Warranty; anthropometry; biomechanics; carrying; consumer product portability; ergonomics; human factors; lifting; manual materials handling; physiology; psychophysics; safety; NBSIR 76-1092.

Waste; boilers; economics; energy conservation; instrumentation; recuperators; $H / 21$.

Waste materials; coal by-products; construction materials; industrial wastes; mining wastes; municipal waste; slags; NBSIR 77-1244.

Waste oil; engine oil; fuel oil; hydraulic oil; industrial oils; lubricating oil; oil specifications; petroleum standards; petroleum test methods; recycled oil; re-refined oil; used oil; SP488.

Wastewater flow; closed conduit flow; instrumentation; measuring flow; metering flow; monitoring flow; open channel flow; public law 92-500; sewerage flow; SP484, pp. 83-89 (Oct. 1977).

Water; accuracy; aerosol; air; collaborative testing; laboratory accreditation; laser technology; multielement analysis; pollutants; speciation; Standard Reference Materials; trace organics; SP464.

Water; activation; analysis; element; gamma rays; $\mathrm{Ge}(\mathrm{Li})$ detector; neutron; nondestructive; resolution; spectrometry; SP461, pp. 255-256 (Jan. 1977).

Water; adsorption; angular distribution (ions); chemisorption; electron stimulated desorption; ruthenium; 17349 .

Water; alkylation; aqueous solution; coordination; mercury; metal complexes; organometals; photolysis; reaction rates; thallium; tin; transmeth ylation; 17008 .

Water; aqueous solutions of gases; compressibility; equation of state; heavy water; isotopic waters; partial molar volume of 
aqueous gases; PVT; thermal expansivity; JPCRD 6, No. 4, $1109-1132$ (1977).

Water; ballistics; carbon dioxide; combustion gases; energy; equation of state; high pressure; high temperature; interaction virial coefficicnts; mixtures; molecular volumes; second virial coefficients; 17136 .

Water; critically evaluated data; International Formulation; steam; viscosity of water and steam; JPCRD 6, No. 4, 1133 1166 (1977).

Water; detector; Monte Carlo; perspex; photon energy; pulse height; resolution; scattering media; tissue; SP46I, pp. 188 I92 (Jan. 1977).

Water analysis; water pollution; pollution; standards committees; temperature measurements; thermal pollution; thermometry; NBSIR 77-1227.

Water hammer in thermoplastic pipe; intermittent hot water exposure tests of thermoplastic pipe; pressure shock in thermoplastic pipe; NBSIR 77-1261.

Water heater; alternating direction; computer simulation; cool down; energy savings; flue damper; heat transfer; implicit; insulation; laboratory measurements; modeling; standby loss; 17184 .

Water heaters; window air conditioners; life cycle costing; printer ribbons; procurement experiment; refrigeratorfreezers; NBS-GCR-ETIP 77-37.

Water heating; air leakage; building design; energy conservation; fenestration; HVAC systems; illumination; insulation; lighting; performance standard; thermal performance; ventilation; NBSIR 74-452.

Water jet; auto-correlation; convective velocity; cross-correlation; exit concentration; exit velocity; flow visualization; fluorescence; fluorescent dye; laser; laser dye-fluorescence technique; mean concentration; mean velocity; SP484, pp. 423-447 (Oct. 1977).

Water pollution; air pollution; analysis; ecology; energy; environmental impact; land pollution; mutagenicity; toxic materials; toxicology; trace contaminants; SP463, pp. III.4.IIII.4.15 (Jan. 1977).

Water pollution; pollution; standards committees; temperature measurements; thermal pollution; thermometry; water analysis; NBSIR 77-1227.

Water resources information; information exchange; information management; information network; information retrieval; information services; information systems; specialized information center; SP463, pp. V.1.1-V.1.6 (Jan. 1977).

Water soluble tracers; dye dilution method; flume calibration; turbidity variations; validity testing; SP484, pp. 361-394 (Oct. 1977).

Water spray; automatic sprinklers; compartment fire; corridor sprinkler systems; droplet size; droplet trajectory; evaporative cooling; fire suppression; full-scale test; gas temperature; oxygen content; recirculating flow; reduced scale model test; scaling criteria; NBSIR 77-1287.

Water tunnel; waves; coastal processes; permeability effects; prototype tests; sand transport; 16917 .

Water vapor; aqueous solution; equilibrium; humidity; relative humidity; salt; saturated salt solution; vapor pressure; J. Res. 81A No. 1, 89-96 (1977).

Water vapor; calibration; dew point; humidity; hygrometer; mixing ratio; relative humidity; two-pressure generator; volume ratio; J. Res. 81 A No. 1, 81-88 (1977).

Water vapor; Clausius-Clapeyron equation; saturation vapor pressure over ice; thermal properties of ice; vapor pressure; vapor pressure at the triple point; vapor pressure of ice; $J$. Res. 81A No. I, 5-20 (1977).

Water vapor; 'electron impact; electron spectroscopy; oscillator strengths; 17019.

Watt spectrum; califomium-252; Maxwellian spectrum; plutonium-239; prompt fission spectrum; uranium-235; SP493, pp. 198-205 (Oct. 1977).
Wave propagation in Plate; acoustic emission; acoustic emission simulator; capacitive transducer; Plate Green's function; signal analysis; 17191

Waveforms; optical; oscilloscope; photoconductor; sampling; 16661 .

Wavelength; cw laser; interferometer; Michelson; phase-lock; scanning; 17338 .

Wavelength accuracy; bandwidth; calibration; errors in spectrophotometry; interferences; multiple reflections; photometric linearity; polarization; sample characteristics; stray light; SP466, pp. 99-114 (May 1977).

Wavelength calibration; bandwidth determination; discharge lamp; lasers; optogalvanic effect; spectroscopy; 17287.

Wavelength measurement; dimensional metrology; exact fringes; fractional fringe; interferometer; length measurement; partial fringe; 17048 .

Wavelength scale; errors in spectrophotometry; photometric scale; slit width; spectral transmission; spectrophotometer standards; stray light; SP466, pp. 117-120 (May 1977).

Wavelengths, atoms and ions; atomic energy levels; atomic spectra; bibliography; energy levels, atomic; spectra, atomic; SP363. Supplement I.

Wavenumber; duct; fundamental mode; liquid; perfect gas; propagation; shear; transverse gradient; 17215.

Waves; coastal processes; permeability effects; prototype tests; sand transport; water tunnel; 16917.

Waxes and polishes; flooring; floor treatments; shoe sole and heel materials; slip-resistance tester; walkway surfaces; TN953.

WBGT; core temperature; energy conservation; modeling; OSHA Standards; thermal sensation; SP491, pp. 18-40 (Sept. 1977).

WC; x-ray photoemission; catalysis; $\mathrm{Mo} ; \mathrm{Mo}_{2} \mathrm{C}$; refractory hard metals; valence bands; W; 16932 .

Weak coupling constants; weak interactions; effective neutral weak interactions; Fermi theory; finite field theory; neutral currents; 17103

Weak interactions; effective neutral weak interactions; Fermi theory; finite field theory; neutral currents; weak coupling constants; 17103.

Weak magnetic fields; nonradial; perturbation theory; stellar oscillations; 16804 .

Weakly absorbing materials; bulk absorption; frequency dependence; laser materials; photoacoustic spectroscopy; surface absorption; 16860 .

Weakly absorbing materials; bulk absorption; frequency dependence; laser materials; photoacoustic spectroscopy; surface absorption; 17313.

Weapons; computer codes; materials properties; nuclear data; radiation transport; reactor; RSIC; shielding; SP463, pp. III.1.1-III.1.10 (Jan. 1977).

Wear; failure detection; failure diagnosis; failure prevention; ferrography; land vehicle diagnostics; oil analysis; railroad system diagnostics; signature analysis; SP494.

Wear; x-ray emission; debris; electron microscopy; particles; 16827.

Wear debris; acoustic; calibration; eddy current; microwave; nondestructive evaluation; penetrant; radiography; standards; thermal; ultrasonic; visual testing; 17106.

Wear debris analysis; acoustic emission; calibrations; electricaleddy current measurements; microwaves; nondestructive evaluation; standard reference materials; standards; thermal testing; ultrasonics; visual testing; 17016 .

Weather data analysis; air conditioning requirements; energy conservation; intermittent ventilation; ventilation control; NBSIR 76-1088.

Weatherability of FRP rods; aramid; composite materials; end fittings for FRP rod; environmental resistance of FRP rods; fiber-reinforced plastic (FRP); glass; guys, antenna; pultru- 
sion; reinforced plastics; stress rupture of FRP rod; test methods; 16685.

Wedges; calibration; density; photography; reflectance; transmittance; 16683

Weibull distribution; durability; fatigue; fiber length; flexing; low cycle fatigue; mechanical properties; microstructure; modelling; paper; pore size; statistical analysis; 16681 .

W ighing design; design of experiments; least squares; mass calibration; statistical design; TN952.

Weighing design; weights; apparent mass; buoyancy; buoyancy correction; change; comparison; difference; mass; records; set; surveillance limits; surveillance test; test interval; true mass; value; NBSIR 76-999.

Weight handler; gas compressibility factor; piston gauge weights; 17127.

Weighted mean; weighted median; zero sum of residuals; Boscovich, Roger Joseph (1711-1787); Cotes, Roger (1682. 1716); Euler, Leonard (1707-1783); Figure of the Earth; fitting a linear equation; least sum of absolute deviations; 17314 .

Weighted median; zero sum of residuals; Boscovich, Roger Joseph (1711-1787); Cotes, Roger (1682-1716); Euler, Leonard (1707-1783); Figure of the Earth; fitting a linear equation; least sum of absolute deviations; Mayer, Tobias (1723-1762); 17314 .

Weights; apparent mass; buoyancy; buoyancy correction; change; comparison; difference; mass; records; set; surveillance limits; surveillance test; test interval; true mass; value; weighing design; NBSIR 76-999.

Weights and measures; American electroplaters'; calorimeter; cryogenic flow measurement; dental restorations; deep ocean research; federal science; governmental environment; laser energy; space flight; spectroscopy; SRM; DIMINBS 6I, No. 4, $1-32$ ( 1977 ).

Weights and measures; checking prepackaged commodities; computer assisted check-out systems; consumer affairs; cordage products; drained weight; laws and regulations; metrication; national laboratory accreditation; retail meat identity standards; tolerance application; SP471.

Weights and measures; education for metric; laws and regulations; metrication; metric system; National Conference on Weights and Measures; 17037.

Weights and measures; history of science; measurement instruments; measurement standards; National Bureau of Standards; national measurement standards; physical measurement; NBSIR 76-1125.

Weights and measures; instrumentation; measurement standards; National Bureau of Standards; national measurement system; standardization organizations; standard reference data; NBSIR 75-949.

Weir equation; closed-loop cooling system; cooling lake; dye dilution method; error analysis; flow rate measurement; open channel flow measurement; power plant; spray canal; stagedischarge equation; velocity-area method; SP484, pp. 145 172 (Oct. 1977).

Weirs; acoustic flow meters; closed conduit flows; current meters; dye-dilution methods; errors in flow measurement; flow measurement; fluid flow modeling; fluid velocity; flumes; gas flow standard; hot-wire anemometry; international flow standards; SP484, Volumes 1 and 2.

Weirs; approach channels; broad-crested V-notch weirs; calibration; small watersheds; stream gages; streamflow measurements; SP484, pp. 187-200 (Oct. 1977).

Weirs; flumes; hydraulic models; hydraulics; numerical models; open-channel flow; SP484, pp. $219-242$ (Oct. 1977).

Weldbonded joints; adhesive-bonded joints; bonded joints; cyclic loading; debond analysis; double-lap-joint analysis; fatigue tests; finite element analysis; joints; nonlinear analysis; single-lap-joint analysis; single-lap-joint bending; spotwelded joints; NBSIR 76-1053.
Weldments; cryogenic temperature; fatigue crack growth; fracture toughness; heat affected zone; J-integral; nickel steel; 17089.

Well logging; activation analysis; californium-252; inland waters and sediments; in vivo analysis; mineral exploration; nuclear safeguards; oceanography; on-stream analysis; 16760 .

Wet pavement skid resistance; accident reduction, skidding; highway safety; measurement, skid resistance; pavement skid resistance; skid resistance measurement; tire-pavement interface forces; NBSIR 76-1175.

Wet pavement skid resistance; accident reduction, skidding; correlation, skid resistance; highway safety; measurement, skid resistance; pavement, skid resistance; pavement wetting system; skid resistance, measurement; tire-pavement interface forces; NBSIR 77-1213.

Whittaker functions; WKBJ approximation; connection formulas; eigenvalue problems; Liouville-Green approximation; potential barrier; potential well; turning points; 17142 .

Wind; aerodynamics; building (codes); pressure; spectra; structural engineering; tall buildings; turbulence; 16843 .

Wind; architecture; buildings; connectors; design criteria; fasteners; NBSIR 77-1197.

Wind; bridges; specifications; SP477, Pp. I-34-I-48 (May 1977).

Wind; buildings; cyclones; disasters; structural engineering; tides; SP477, pp. V-21 - V-53 (May 1977).

Wind; codes; probability; statistics; structural design; 16856.

Wind; dynamics; failure; roofs; SP477, PP. I-12-I-20 (May 1977).

Wind; earthquake; research programs; seismic; testing; SP477, pp. VI-37-VI-43 (May 1977).

Wind; nuclear power plant; seismic effects; tornado; SP477, pp. VII-1 - VII-28 (May 1977).

Wind; wind damage; extra-tropical storms; hurricanes; thunderstorms; tornadoes; SP477, pp. II-15-II-29 (May 1977).

Wind; wind data; wind speed; hurricane; storm surge; tropical storms; SP470, pp. 1-18-I-27 (Apr. 1977).

Wind; wind effects; damage; structures; typhoon; SP477, PP. V-1-V-20 (May 1977).

Wind; wind effects; damage; typhoon; SP477, pp. V-54-V-59 (May 1977).

Wind; wind effects; wind loads; wind observation; wind speed; building; SP470, pp. I-42-I-49 (Apr. 1977).

Wind; wind observation; wind tunnel; field measurements; model; towers; SP470, pp. I-1-I-17 (Apr. 1977).

Wind; wind velocity spectra; SP477, Pp. I-1 -I-II (May 1977).

Wind angles; wind tunnel; bridge; cabled stayed; displacements; flutter; models; SP470, pP. II-47-ПI-67 (Apr. 1977).

Wind damage; extra-tropical storms; hurricanes; thunderstorms; tornadoes; wind; SP477, PP. II-15-II-29 (May 1977).

Wind data; wind speed; hurricane; storm surge; tropical storms; wind; SP470, pp. I-18-I-27 (Apr. 1977).

Wind effects; codes and standards; connectors; fasteners; lowrise buildings; masonry walls' structural design; technology transfer; timber roofs; timber walls; BSSI00-3

Wind effects; damage; structures; typhoon; wind; SP477, pp. V-1-V-20 (May 1977).

Wind effects; damage; typhoon; wind; SP477, pp. V-54-V-59 (May 1977).

Wind effects; wind loads; wind observation; wind speed; building; wind; SP470, pp. 1-42-I-49 (Apr. 1977).

Wind engineering; wind studies; education; research; research programs; SP470, pp. II-1-II-10 (Apr. 1977).

Wind load; acceleration; airplanes; cargo; dynamic loads; equivalent static force; gravity load; handling devices; handling loads; military field shelters; probability distributions; shocks, snow load; static load; trains; transportation; trucks; vibrations; NBSIR 77-1254.

Wind loads; aerodynamics; buildings; full-scale testing; mobile homes; SP477, Pp. I-21 -I-33 (May 1977). 
Wind loads; codes and standards; disaster mitigation; housing; low-rise buildings; socio-economics; structural connections; SP477, pp. I-70-I-78 (May 1977).

Wind loads; codes and standards; disaster mitigation; housing; low-rise buildings; socio-economics; structural connections; technology transfer; BSS100-1.

Wind loads; design; equivalent loads; tall buildings; SP477, pp. I-49-I-65 (May 1977).

Wind loads; wind observation; wind speed; building; wind; wind effects; SP470, pp. I-42-I-49 (Apr. 1977).

Wind loads; wind speeds; building codes; buildings; codes and standards; housing; hurricanes; pressure coefficients; probability distribution functions; risk; statistical analysis; storms; structural engineering; tropical storms; BSS100-2.

Wind loads; wind tunnels; aerodynamics; boundary layers; buildings; turbulence; NBSIR 77-1196.

Wind measurements; winds; wind speed; bridges; displacements; field tests; SP470, pp. II-20-II-46 (Apr. 1977).

Wind observation; wind speed; building; wind; wind effects; wind loads; SP470, pp. 1-42-I-49 (Apr. 1977).

Wind observation; wind tunnel; field measurements; model; towers; wind; SP470, pp. I-1-I-17 (Apr. 1977).

Wind pressure; buildings; dynamic effects; high winds; roofs; typhoon; SP470, pp. II-1-II-19 (Apr. 1977).

Wind profiles; boundary layer; hurricanes; loads (forces); natural analysis; tall buildings; SP477, pp. II-30-II-40 (May 1977).

Wind speed; bridges; displacements; field tests; wind measurements; winds; SP470, pp. II-20-II-46 (Apr. I977).

Wind speed; building; wind; wind effects; wind loads; wind observation; SP470, pp. I-42-I-49 (Apr. 1977).

Wind speed; fires; fire tornados; tornado model; tornados; SP470, pp. I-28-I-41 (Apr. 1977).

Wind speed; hurricane; storm surge; tropical storms; wind; wind data; SP470, pp. I-18-I-27 (Apr. 1977).

Wind speeds; building codes; buildings; codes and standards; housing; hurricanes; pressure coefficients; probability distribution functions; risk; statistical analysis; storms; structural engineering; tropical storms; wind loads; BSS100-2.

Wind speeds; damage; effects; houses; typhoon; SP477, pp. II1-II-14 (May 1977).

Wind studies; education; research; research programs; wind engineering; SP470, pp. II-1-II-IO (Apr. 1977).

Wind study; ANSI 58; low-rise buildings; 17115.

Wind tunnel; bridge; cabled stayed; displacements; flutter; models; wind angles; SP470, pp. II-47-II-67 (Apr. 1977).

Wind tunnel; field measurements; model; towers; wind; wind observation; SP470, pp. I-1 - I-I 7 (Apr. I977).

Wind tunnel test; field studies; high winds; instrumentation; Philippines; SP470, pp. X-1-X-1 1 (Apr. 1977).

Wind tunnels; aerodynamics; boundary layers; buildings; turbulence; wind loads; NBSIR 77-1196.

Wind velocity spectra; wind; SP477, pp. I-1-I-11 (May 1977).

Wind-load racking; air leakage of buildings; building heat transfer; honeycomb panel construction; relocatable buildings; NBSIR $76-1178$.

Window; emergency egress; HUD; mobile home; racking; research; safety; standard; NBSIR 77-1246.

Window air conditioners; life cycle costing; printer ribbons; procurement experiment; refrigerator-freezers; water heaters; NBS-GCR-ETIP 77-37.

Window design; climatic data; cloud cover modifier; energy conservation; shading coefficient; solar heat gain; 17341 .

Windows; AC high voltage; AC voltmeter calibrator; marine studies; microelectronic industry; monitoring system; photodetectors; radiopharmaceuticals; ultraviolet radiation; DIM/NBS 61, No. 12, 1-32 ( 1977).

Windows; air-tightness; daylighting; energy-conservation; insulation; shading; solar-heating; ventilation; BSS104.
Windows; building envelope; energy conservation base; insulation; residential design practices; typical construction characteristics; typical new house materials; NBSIR 77-1309.

Windows; daylighting; infiltration; insulation; passive-solar-heating; sun-shading; ventilation; 17298.

Windows; definitions; doors; glossary; security terms; SP480-22.

Wind-resistant; architectural; design; housing; low income; lowrise buildings; sites and services; socio-economic; structural design; BSS100-5.

Winds; accelerograph; bridges; buildings; codes; disaster; dynamic analysis; earthquakes; ground failures; nuclear facilities; seismicity; soils; standards; structural response; $S P 477$.

Winds; wind speed; bridges; displacements; field tests; wind measurements; SP470, pp. II-20-II-46 (Apr. 1977).

Wind-tunnel; cryogenic; design; nitrogen; safety; NBSIR 77 857.

Winter temperature; clothing insulation; effective temperature $\left(E T^{*}\right)$; energy conservation; summer temperature guidelines; thermal acceptability; thermal preference survey; SP491, pp. 93-116 (Sept. 1977).

Wire preform; composite material; fabrication techniques; graphite fibers-aluminum; mechanical behavior; pultrusion/drawing; SP487, pp. 93-107 (Aug. 1977).

Wire standards; calibration; cylinders; plug gages; rolls; NBSIR 73-136.

WKBJ approximation; connection formulas; eigenvalue problems; Liouville-Green approximation; potential barrier; potential well; turning points; Whittaker functions; 17142.

Wood; ceiling height; ceilings; cotton; detector location; detectors; fire detectors; polyurethanes; polyvinyl chloride; room fires; rooms; smoldering; NBS-GCR-77-86.

Wood; ceiling height; ceilings; cotton; detector location; fire detectors; fire growth; flaming fires; heat detectors; polyurethanes; polyvinyl chloride; smoke detectors; smoldering fires; temperature rise; NBS-GCR-77-95.

Wood; wood products; AIDS; bark; forest products; glues and gluing; information service; lumber; mechanical properties; paper; pulp; timber; SP463, pp. II.1.1-II.1.4 (Jan. 1977).

Wood products; AIDS; bark; forest products; glues and gluing; information service; lumber; mechanical properties; paper; pulp; timber; wood; SP463, pp. II.1.1-II.1.4 (Jan. 1977).

Wooden house; classification; damage; intensity; seismic; SP477, pp. IV-1 -IV-17 (May 1977).

Work conditions; environmental control; temperature and performance; temperature control; thermal comfort; thermal sensation; thermal tolerance; SP491, pp. 169-173 (Sept. 1977).

Work effects; clothing effects; comfort; heat storage; SP491, pp. 52-64 (Sept. 1977).

Work factor; cryptanalysis; cryptography; encryption; key management; known plaintext attack; security; NBSIR 771291.

Worker safety equipment; body belts; body harness; fall-arrest equipment; fall-safety systems; impact accelerations; impact forces; lanyards; linemen's equipment; load-extension data; occupational safety and health; performance standard; regulation; tensile testing; NBSIR 76-1146.

Workload; accounting data; computer performance; computer resource unit; probability density function; statistics; turnaround; SP500-18, pp. 39-67 (Sept. 1977).

Workload characteristics; computer response time; human factors; on-line systems; system design; task variables; SP500-18, pp. 3-11 (Sept. 1977).

Workload characterization; benchmarking; computer procurement; computer selection; SP500-18, pp. 13-21 (Sept. 1977).

Workload characterization; clustering; SP500-18, pp. 23-38 (Sept. 1977).

Workload definition; ADP life cycle; computer performance evaluation; computer performance measurement; computer 
performance prediction; computer system acquisition; conference proceedings; CPEUG; hardware monitoring; on-line system evaluation; prediction methods; SP500-18.

Workload representation; benchmarking; benchmark mix demonstration; computer selection; Federal Information Processing Standard; FIPS PUB 42-1.

\section{$\mathbf{X}$}

$\nu$; ${ }^{233.235} \mathrm{U}(\mathrm{n}, \mathrm{f}) ;{ }^{239.241} \mathrm{Pu}(\mathrm{n}, \mathrm{f}) ;{ }^{252} \mathrm{Cf}$; neutron standards; SP493, pp. $182-193^{\circ}$ (Oct. 1977).

$X$ ray; attenuation coefficient; energy-absorption coefficient; gamma-ray; photon; 17051.

$\mathrm{X}$ ray; bound electrons; cross section; gamma rays; inelastic scattering; K-shell electron; photon; SP461, pp. 26-28 (Jan. 1977).

X rays; absorbed dose; calorimetry; dose distributions; dosimetry; electron beams; food irradiation; Fricke dosimetry; gamma rays; 17343 .

$\mathrm{X}$ rays; angular distribution; cross section; gamma rays; photon; scattering, incoherent; SP461, pp. 55-56 (Jan. 1977).

$X$ rays; atomic form factor; attenuation coefficients; cross sections; gamma rays, incoherent scattering function; pair production; photoelectric effect; photons; SP461, pp. 3-16 (Jan. 1977).

$\mathrm{X}$ rays; calibration; gamma radiation; industrial radiography; national standards; radiation characteristics; radiation source; source calibration; test methods; 17017.

$\mathrm{X}$ rays; electromagnetic spectra; gamma rays; secondary standards; 17246.

$X$ rays; gamma rays; ionizing radiation; leuco dye cyanide; radiation dosimeter; radiation sensor; triphenylmethane cyanide dye precursor; ultraviolet; U.S. Patent 4,006,023.

$X$ anthene dyes; aminocoumarins; carbazine dyes; deuterium effect; fluorescence quantum yield; laser dyes; molecular structure; oxazine dyes; quenching; SP466, pp. 33-40 (May 1977).

$\mathrm{XeF}$; charge transfer; dissociation energy; energy curve; overlap; van der Waals; 16684.

XPS; photoemission; plasmons; satellites; 17219.

$\mathrm{X}$-ray binaries; close binaries; stellar structure; 17309.

$\mathrm{X}$-ray damag; acoustic emission; Auger electron spectroscopy; beam-lead bonds; capacitance-voltage methods; carrier mobility; C-MOS circuits; dopant profiles; electrical properties; electronics; four-probe method; hermeticity; ion implantation; Irvin's curves; SP400-29.

$\mathrm{X}$-ray detector calibration; $1.5-8 \mathrm{keV} \mathrm{x}$ rays; absolute $\mathrm{x}$-ray detectors; electron excitations; monoenergetic $\mathrm{x}$ rays; pulsed $\mathrm{x}$ ray source; 16814.

$\mathrm{X}$-ray determination; zwitterion; absolute configuration; amino acid derivative; crystal structure; $S$-carboxymethyl-L-cysteine sulfoxide; 16688.

$\mathrm{X}$-ray diffraction; ammonium perchlorate; bond lengths and angles; crystal structure; rigid-body motion analysis; thermal motion of a perchlorate ion; 17348 .

$\mathrm{X}$-ray diffraction; crystal structure; integrated intensities; lattice constants; peak intensities; powder patterns; reference intensities; standard; Monogr. 25, Section 14.

$\mathrm{X}$-ray diffraction; $\mathrm{x}$-ray topography; dynamical diffraction; magnetic domains; nickel single crystals; 17277.

$\mathrm{X}$-ray diffraction topography; anomalous transmission effect; asymmetric crystal topography; crystal imperfections; crystal perfection; Czochralski-grown nickel; dislocation clusters; dynamical diffraction; magnetic domains; magnetic domain walls; melt-grown crystals; 16997.

X-ray dynamical diffraction; crystal growth; crystal perfection; diffraction topography; dynamical diffraction theory; ferromagnetic domain walls; nickel single crystals; 16974 .

$\mathrm{X}$-ray dynamical diffraction; contrast conditions; diffraction topography; dynamical images; imperfect crystals; perfect crystals; 16977.
X-ray emission; debris; electron microscopy; particles; wear; 16827.

$\mathrm{X}$-ray emission; $\mathrm{x}$-ray photoemission; charge transfer; chemical shifts; core levels; transition metal carbides; 17265.

$\mathrm{X}$-ray equipment; $\mathrm{x}$-ray safety; $\mathrm{x}$-ray tube; design standard; fluoroscopy; national standard; radiation safety; radiography; HI23.

$\mathrm{X}$-ray excitation; cathode-ray excitation; luminescence; luminescence standards; phosphors; quantum efficiencies; radiant efficiencies; UV excitation; SP466, pp. 13-19 (May 1977).

$X$-ray fluorescence; children; data analysis; housing; lead paint; lead poisoning; surveys; NBSIR 77-1250.

$\mathrm{X}$-ray intensity standards; $\mathrm{X}$-ray powder diffraction; internal standard; polarization; powder diffraction; quantitative $x$-ray analysis; reference intensity ratio; 16953.

$\mathrm{X}$-ray photoelectron spectroscopy; Auger electron spectroscopy; catalyst; electron binding energy; interlaboratory comparison; surface characterization; 16930.

$\mathrm{X}$-ray photoelectron spectroscopy; chromium; infrared spectroscopy; magnetic susceptibility; molybdenum; tetracyanoquinodimethan; 17153.

$\mathrm{X}$-ray photoelectron spectroscopy; absolute yield; aluminum; attenuation length; Auger electrons; Auger-electron spectroscopy; beryllium; electron; proton excitation; 17248 .

X-ray photoemission; catalysis; $\mathrm{Mo} ; \mathrm{Mo}_{2} \mathrm{C}$; refractory hard metals; valence bands; W; WC; 16932.

$\mathrm{X}$-ray photoemission; charge transfer; chemical shifts; core levels; transition metal carbides; $\mathrm{x}$-ray emission; 17265 .

$\mathrm{X}$-ray powder diffraction; internal standard; polarization; powder diffraction; quantitative $x$-ray analysis; reference intensity ratio; $x$-ray intensity standards; 16953.

$\mathrm{X}$-ray powder patterns; dithiotungstate; hydrolysis; infrared spectroscopy; rare earths; rare earth tungstate; tungstates; 17137.

$\mathrm{X}$-ray radiography; diagnostic radiography; exposure reduction; imaging information content; image processing; mammography; 16666.

$\mathrm{X}$-ray safety; $\mathrm{x}$-ray tube; design standard; fluoroscopy; national standard; radiation safety; radiography; $x$-ray equipment; HI23.

X-ray spectra; chromospheres, solar; chromospheres, stellar; coronae, solar; coronae, stellar; flares, solar; flares, stellar; magnetic cycles, solar; magnetic cycles, stellar; nonradiative heating; transition regions, solar; transition regions, stellar; ultraviolet spectra; 17324.

$\mathrm{X}$-ray spectroscopy; electron probe; image formation; ion probe; microanalysis; microscopy; scanning; 16841 .

$\mathrm{X}$-ray topography; dynamical diffraction; magnetic domains; nickel single crystals; $x$-ray diffraction; 17277 .

$X$-ray tube; design standard; fluoroscopy; national standard; radiation safety; radiography; $x$-ray equipment; $x$-ray safety; HI23.

\section{Y}

Yield; distributions; neutrons; resolution; spectra; uncertainties; NBSIR 77-1279, pp. 1 5-18 (July 1977).

Yields; dosimetry; energy spectra; high energy; LET; neutrons; NBSIR 77-1279, pp. 19-23 (July 1977).

Young's modulus; aluminum; boron-aluminum; bulk modulus; composite; compressibility; elastic constants; resonance method; shear modulus; torsional modulus; 17087.

Young's modulus; aluminum alloys; bulk modulus; compressibility; Debye temperature; Poisson's ratio; precipitationhardening alloys; shear modulus; sound velocity; 17085 .

Young's modulus; bulk modulus; compressibility; Debye temperature; elastic constant; invar; iron alloy; nickel alloy; Poisson's ratio; shear modulus; sound velocity; 16869. 
Young's modulus; bulk modulus; composite; compressibility; copper; elastic constants; niobium-titanium; Poisson's ratio; pulse method; resonance method; shear modulus; sound velocity; 17068 .

Young's modulus; bulk modulus; compressibility; copper alloy; elastic constant; Poisson ratio; precipitation hardening; shear modulus; sound velocity; 17094 .

Young's modulus; bulk modulus; compressibility; copper alloy; Debye temperature; elastic constants; Poisson's ratio; shear modulus; sound velocity; 17320.

Young's modulus; bulk modulus; compressibility; elastic constants; Poisson's ratio; pulse method; resonance method; shear modulus; sound velocity; stainless steel; 17321 .

Young's modulus; elastic constants; face-centered-cubic solids; polycrystals; shear modulus; 17099.

Young's modulus; zinc; bulk modulus; compressibility; Debye temperature; elastic constants; Poisson's ratio; shear modulus; single-crystal elastic coefficients; sound velocities; JPCRD 6, No. 4, 1181-1204 (1977).

Yttrium; zirconium; ions; molybdenum; niobium; rubidium; spectra; structure; ultraviolet; 17212 .

\section{$\mathbf{Z}$}

Zero field magnetic resonance; coherence; Kramers ions; nutation; spin echoes; spin locking; 16954.

Zero shift; coatings; delayed response; dynamic; dynamic response; pressure step; pressure transducer; protective coatings; shock tube; tape; thermal protection; thermal radiant-energy response; thermal transient response; transducer; TN961.

Zero sum of residuals; Boscovich, Roger Joseph (1711-1787); Cotes, Roger (1682-1716); Euler, Leonard (1707-1783); Figure of the Earth; fitting a linear equation; least sum of absolute deviations; Mayer, Tobias (1723-1762); 17314.

Zero-shift; accuracy; calibration; cryogenic; dynamic; frequency response; hysteresis; precision; pressure measurement; sensitivity; stability; thermal effects; 17081 .

Zimm plot; enzyme; initial velocity; kinetic constants; LDH; Michaelis constant; NADH; 16911 .

Zinc; bulk modulus; compressibility; Debye temperature; elastic constants; Poisson's ratio; shear modulus; single-crystal elastic coefficients; sound velocities; Young's modulus; JPCRD 6, No. 4, 1181-1204 (1977).

Zinc dithiophosphate; antiwear additives; interaction; lubricant; metals; properties; tricresyl phosphate; SP487, pp. 172-185 (Aug. 1977).

Zinc 64-66-68-70; anharmonic vibrator model; collective states; electron scattering; inelastic; two-phonon states; 16982.

Zirconium; ions; molybdenum; niobium; rubidium; spectra; structure; ultraviolet; yttrium; 17212 .

$\mathrm{ZnS}$; ZnSe; $\mathrm{BaF}_{2} ; \mathrm{CaF}_{2} ; \mathrm{KBr}$; $\mathrm{KCl}$; Lexan; LiF; NaF; Plexiglas 55; refractive index; $\mathrm{SrF}_{2}$; thermal coefficient of refractive index; NBSIR 77-1304 (ARPA).

$\mathrm{ZnSe} ; \mathrm{BaF}_{2} ; \mathrm{CaF}_{2} ; \mathrm{KBr} ; \mathrm{KCl} ; \mathrm{LiF} ; \mathrm{NaF}$; refractive index; $\mathrm{SrF}_{2}$; thermal coefficient of refractive index; NBSIR 77-1219.

$\mathrm{ZnSe} ; \mathrm{BaF}_{2} ; \mathrm{CaF}_{2} ; \mathrm{KBr} ; \mathrm{KCl}$; Lexan; LiF; NaF; Plexiglas 55; refractive index; $\mathrm{SrF}_{2}$; thermal coefficient of refractive index; $\mathrm{ZnS}$; NBSIR 77-1304 (ARPA).

Zwitterion; absolute configuration; amino acid derivative; crystal structure; $S$-carboxymethyl-L-cysteine sulfoxide; $\mathrm{x}$-ray determination; 16688 .

0.1-20.0 MeV; data; evaluations; status; U-235 (n,f); SP493, pp. 261-268 (Oct. 1977).

1-ethylnaphthalene; $\quad 1$-methylnaphthalene; enthalpy; fluorescence; heat of solution; naphthalene; partition coefficient; solubility; vapor pressure; 17097.

1-methylnaphthalene; enthalpy; fluorescence; heat of solution; naphthalene; partition coefficient; solubility; vapor pressure; 1-ethylnaphthalene; 17097.
$10 \mu \mathrm{m}$ wavelength; ammonia; carbon dioxide; ethanol; measurement; molecular absorption; 16924.

${ }^{10} \mathrm{~B}\left(\mathrm{n}, \alpha_{0}+\alpha_{1} \gamma\right)^{7} \mathrm{Li} ;{ }^{10} \mathrm{~B}\left(\mathrm{n}, \alpha_{1} \gamma\right)^{7} \mathrm{Li}$; boron scintillators; $\mathrm{Ge}(\mathrm{Li})$; ionization chambers; Nal; SP493, pp. 85-92 (Oct. 1977).

${ }^{10} \mathrm{~B}\left(\mathrm{n}, \alpha_{1} \gamma\right)^{7} \mathrm{Li}$; boron scintillators; $\mathrm{Ge}(\mathrm{Li})$; ionization chambers; Nal; neutron flux determination; proportional counters; solidstate detectors; standard cross section; SP493, pp. $85-92$ (Oct. 1977).

${ }^{10} \mathrm{~B}(\mathrm{n}, \boldsymbol{\alpha})$; ${ }^{235} \mathrm{U}(\mathrm{n}, \mathrm{f})$; cross section; neutron; normalization; resonance; shape; standards; thermal; ${ }^{6} \mathrm{Li}(\mathrm{n}, \alpha)$; SP493, pp. 174-181 (Oct. 1977).

10-MeV electrons; aluminum; beef muscle; carbon; depth-dose distributions; lateral-dose distributions; polystyrene; radiation dosimeters; radiation processing; radiochromic-dye films; 16999.

100 to several $1000 \mathrm{eV}$; electron mean free path; free-electronlike metal; 16748 .

1,2-di(p-toluenesulfonyl)hydrazine; chemical ionization mass spectrometry; di-p-tolyldisulfide-1,2-dioxide; mass spectrometry; nuclear magnetic resonance; $p$-toluenesulfonylhydrazine; 17045.

${ }^{13} \mathrm{C}$; collagen fibers; molecular motion; $\mathrm{nmr}$; Overhauser effect; relaxation time; 17007 .

1,3-dithiolium ion; 2,2'-bi(1,3-dithiolyl); coupling constants; hexacarbonylvanadate(1-); NM $\dot{R}$ spectroscopy; reduction; $\mathrm{V}(\mathrm{CO})_{6-;}^{-;} 17154$.

14.8-MeV neutrons; ${ }^{235} \mathrm{U}$; ${ }^{238} \mathrm{U}$; ${ }^{237} \mathrm{~Np}$; ${ }^{252} \mathrm{Cf}$; absolute measurements; fission cross sections; fission spectrum neutrons; SP493, pp. 313-318 (Oct. 1977).

1.5 microns; frequency measurement; frequency standards; helium neon laser; insulator metal diode; laser; speed of light; 17336.

1,5-hexadiyne; 2,4-hexadiyne; appearance potential; benzene; butatriene; heat of formation; ion; ionization potential; monoenergetic electron impact; photoionization; pyridine; vinylacetylene; 17294 .

1.5-8 keV $x$ rays; absolute $x$-ray detectors; electron excitations; monoenergetic $x$ rays; pulsed $x$-ray source; $x$-ray detector calibration; 16814 .

2,2'-bi(1,3-dithiolyl); coupling constants; hexacarbonylvanadate(1-); NMR spectroscopy; reduction; $\mathrm{V}(\mathrm{CO})_{6 .}^{-}$; 1,3dithiolium ion; 17154 .

${ }^{233.235} \mathrm{U}(\mathrm{n}, \mathrm{f})$; ${ }^{239.241} \mathrm{Pu}(\mathrm{n}, \mathrm{f})$; ${ }^{252} \mathrm{Cf}$; neutron standards; v; SP493, pp. 182-193 (Oct. 1977).

${ }^{205} \mathrm{U}$; ${ }^{258} \mathrm{U}$; ${ }^{237} \mathrm{~Np}$; ${ }^{252} \mathrm{Cf}$; absolute measurements; fission cross sections; fission spectrum neutrons; $14.8-\mathrm{MeV}$ neutrons; SP493, pp. 313-318 (Oct. 1977).

${ }^{2235} \mathrm{U}(\mathrm{n}, \mathrm{f})$; cross section; neutron; normalization; resonance; shape; standards; thermal; ${ }^{6} \mathrm{Li}(\mathrm{n}, \alpha) ;{ }^{10} \mathrm{~B}(\mathrm{n}, \alpha)$; SP493, pp. 174-181 (Oct. 1977).

${ }^{237} \mathrm{~Np}$; ${ }^{252} \mathrm{Cf}$; absolute measurements; fission cross sections; fission spectrum neutrons; $14.8-\mathrm{MeV}$ neutrons; ${ }^{235} \mathrm{U} ;{ }^{238} \mathrm{U}$; SP493, pp. 313-318 (Oct. 1977).

${ }^{237} \mathrm{~Np},{ }^{208} \mathrm{U}(\mathrm{n}, \mathrm{f})$ as neutron standards; $\mathrm{E}_{\mathrm{n}}=0.1-20 \mathrm{MeV}$; summary of experimental results; SP493, pp. 278-289 (Oct. 1977).

${ }^{238} \mathrm{U} ;{ }^{237} \mathrm{~Np} ;{ }^{252} \mathrm{Cf}$; absolute measuremehts; fission cross sections; fission spectrum neutrons; $14.8-\mathrm{MeV}$ neutrons; ${ }^{235} \mathrm{U} ;$ SP493, pp. 313-318 (Oct. 1977).

${ }^{209.241} \mathrm{Pu}(\mathrm{n}, \mathrm{f}) ;{ }^{252} \mathrm{Cf}$; neutron standards; $\nu$; ${ }^{203.253} \mathrm{U}(\mathrm{n}, \mathrm{f}) ; S P 493$, pp. 182-193 (Oct. 1977).

2,4-hexadiyne; appearance potential; benzene; butatriene; heat of formation; ion; ionization potential; monoenergetic electron impact; photoionization; pyridine; vinylacetylene; 1,5hexadiyne; 17295 .

$2.5 \mathrm{~g} / \mathrm{m}^{2}$ handsheets; breaking energy; in ter-fiber bond strength; mixed waste paper; paper recycling; pulp characterization; NBSIR 76-1148. 
252 Cf; ANISN; code; configuration; dose equivalent; energy; gamma rays; neutron; scattering; shield; transmission; SP461, pp. 119-123 (Jan. 1977).

${ }^{252} \mathrm{Cf}$; absolute measurements; fission cross sections; fission spectrum neutrons; 14.8-MeV neutrons; ${ }^{235} \mathrm{U} ;{ }^{238} \mathrm{U} ;{ }^{237} \mathrm{~Np}$; SP493, pp. 313-318 (Oct. 1977).

${ }^{252} \mathrm{Cf}$; fission neutron spectrum; neutron detectors; neutron standard; time-of-flight; SP493, pp. 194-197 (Oct. 1977).

${ }^{252} \mathrm{Cf}$; neutron standards; $\nu$; ${ }^{233.225} \mathrm{U}(\mathrm{n}, \mathrm{f}) ;{ }^{239.241} \mathrm{Pu}(\mathrm{n}, \mathrm{f}) ; S P 493$, pp. 182-193 (Oct. 1977).

3-D display; FFT; measurement system; RF noise spectrum; 17173.

${ }^{3} \mathrm{H},{ }^{2} \mathrm{H},{ }^{4} \mathrm{He},{ }^{3} \mathrm{He}$, protons; calibration; efficiency; neutron beams; neutron flux; neutrons; SP493, pp. 221-226 (Oct. 1977).

${ }^{3} \mathrm{He}\left(\mathrm{e}, \mathrm{e}^{\prime}\right)$; deduced $\mathrm{rms}$ charge radius; $\mathrm{E}=28.8-95.0 \mathrm{MeV}$; measured $\sigma(\mathrm{E})$ at $\theta=75^{\circ}$; nuclear reactions; 16850 .

${ }^{3} \mathrm{H}\left(\alpha,{ }^{6} \mathrm{Li}\right) \mathrm{n},{ }^{4} \mathrm{He}(\mathrm{t}, \mathrm{t}){ }^{4} \mathrm{He}$; ${ }^{6} \mathrm{Li}$ neutron cross sections; ${ }^{7} \mathrm{Li}$ system; measurements review; polarization; SP493, pp. 3-9 (Oct. 1977).

${ }^{3} P_{0}$ and ${ }^{3} P_{1}$ atomic states; ${ }^{3} P_{0} \rightarrow{ }^{3} P_{1}$ collision rates; decay of resonance line; quenching rates; relaxation of mercury atoms; three body molecular formation; 17194 .

${ }^{3} P_{0} \rightarrow{ }^{3} P_{1}$ collision rates; decay of resonance line; quenching rates; relaxation of mercury atoms; three body molecular formation; ${ }^{3} P_{0}$ and ${ }^{3} P_{1}$ atomic states; 17194 .

$335 \mathrm{~nm}$ mercury laser; $A$-values; bound-free transitions; $\mathrm{Hg}_{2}$; $\mathrm{Hg}_{3}$; potential curves; 17084 .

3,3,5-trimethylhexyl acetate; biphenyl; chain dimensions; dodecanol; linear polyethylene; Mark-Houwink equation; NBS Standard Reference Material 1475; theta solvents; 16710.

${ }^{36.40} \mathrm{Ar}\left(\mathrm{e}, \mathrm{e}^{\prime}\right)$; enriched targets; $\mathrm{E}=65$ to $115 \mathrm{MeV}$; measured $\sigma(\mathrm{E}, \theta)$; nuclear charge distributions; nuclear reactions; 16845 .

(active-passive) hydrogen maser; amplitude modulation; cavity frequency; environmental sensitivity; frequency lock loop; long-term frequency stability; NBS time scale; phase modulation; 17211 .

4-hydroxy-4H-furo $(3,2 c)$ pyran-2(6H)-one; antibiotic; hydrogen bonding; patulin; refined structure; single crystal $\mathrm{x}$-ray structure determination; 16913 .

$\lambda 4471 \AA$; Stark broadening; dynamic ion effects; forbidden lines; He $1 ; 17167$

${ }^{45} \mathrm{Sc}$ measured from 0.4 to $22 \mathrm{keV}$; ${ }^{56} \mathrm{Fe}$ measured from 0.4 to $1000 \mathrm{keV}$; deduced neutron resonance parameters; neutron total cross sections; SP493, pp. 255-260 (Oct. 1977).

${ }^{56} \mathrm{Fe}$ measured from 0.4 to $1000 \mathrm{keV}$; deduced neutron resonance parameters; neutron total cross sections; ${ }^{45} \mathrm{Sc}$ measured from 0.4 to $22 \mathrm{keV}$; SP493, pp. 255-260 (Oct. 1977).

${ }^{6} \mathrm{Li}$ neutron cross sections; ${ }^{7} \mathrm{Li}$ system; measurements review; polarization; ${ }^{3} \mathrm{H}\left(\alpha,{ }^{6} \mathrm{Li}\right) \mathrm{n},{ }^{4} \mathrm{He}(\mathrm{t}, \mathrm{t}){ }^{4} \mathrm{He}$; $S P 493$, pp. 3-9 (Oct. 1977).
${ }^{6} \mathrm{Li}$ total; ${ }^{7} \mathrm{Li}$ system; elastic scattering; neutrons; review of measurements; ${ }^{6} \mathrm{Li}(\mathrm{n}, \alpha)$; SP493, pp. 14-29 (Oct. 1977).

'LiF; detector; energy leakage; Monte Carlo; neutron; sandwich; spectrometry; surface barrier; SP461, pp. 252-254 (Jan. 1977)

${ }^{6} \mathrm{Li}(\mathrm{n}, \boldsymbol{\alpha}) ;{ }^{10} \mathrm{~B}(\mathrm{n}, \boldsymbol{\alpha}) ;{ }^{205} \mathrm{U}(\mathrm{n}, \mathrm{f})$; cross section; neutron; normalization; resonance; shape; standards; thermal; SP493, pp. 174181 (Oct. 1977).

${ }^{6} \mathrm{Li}(\mathrm{n}, \alpha)$; ${ }^{6} \mathrm{Li}$ total; ${ }^{7} \mathrm{Li}$ system; elastic scattering; neutrons; review of measurements; SP493, pp. 14-29 (Oct. 1977).

${ }^{6} \mathrm{Li}(\mathrm{n}, \boldsymbol{\alpha}) \mathrm{T}$; angular distribution; fast neutrons; linac; reactor filtered beam; standard; SP493, pp. 10-13 (Oct. 1977).

${ }^{6} \mathrm{Li}(\mathrm{n}, \boldsymbol{\alpha}) \mathrm{T}$; glass scintillators; Monte Carlo; multiple scattering; neutron detection; photomultipliers; SP493, pp. 37-42 (Oct. 1977).

${ }^{6} \mathrm{Li}(\mathrm{n}, \boldsymbol{\alpha})^{3} \mathrm{H}$; external particle detectors; gaseous ionization detectors; instruments; scintillation detectors; SP493, pp. 43-46 (Oct. 1977).

${ }^{6} \mathrm{Li}(\mathrm{n}, \mathrm{t}) ;{ }^{7} \mathrm{Li}$ system; resonance parameters; R-matrix; standard; SP493, pp. 30-36 (Oct. 1977).

${ }^{\circ} \mathrm{Co}$; back scattering; gamma rays; sky-shine; spectrum; SP461, pp. 124-128 (Jan. 1977).

${ }^{60} \mathrm{Co}$ gamma-ray source; collimator; exposure spectra; gammarays; scattered radiation; source housing; spectrometry; NBSIR 76-1117.

${ }^{\top} \mathrm{Li}$ system; elastic scattering; neutrons; review of measurements; ${ }^{6} \mathrm{Li}(\mathrm{n}, \alpha) ;{ }^{6} \mathrm{Li}$ total; SP493, pp. 14-29 (Oct. 1977).

${ }^{7} \mathrm{Li}$ system; measurements review; polarization; ${ }^{3} \mathrm{H}\left(\alpha,{ }^{6} \mathrm{Li}\right) \mathrm{n}$, ${ }^{4} \mathrm{He}(\mathrm{t}, \mathrm{t}){ }^{4} \mathrm{He}$; ${ }^{6} \mathrm{Li}$ neutron cross sections; SP493, pp. 3-9 (Oct. 1977).

${ }^{7} \mathrm{Li}$ system; resonance parameters; R-matrix; standard; ${ }^{6} \mathrm{Li}(\mathrm{n}, \mathrm{t})$; SP493, pp. 30-36 (Oct. 1977).

${ }^{7} \mathrm{Li}(\mathrm{d}, \mathrm{n})^{6} \mathrm{Be},{ }^{7} \mathrm{Li}(\mathrm{p}, \mathrm{n})^{7} \mathrm{Be} ; \mathrm{E}_{d}=8,12,15 \mathrm{MeV}, \mathrm{E}_{p}=15 \mathrm{MeV}$; energy spectra, yields; neutrons; NBSIR 77-1279, pp. 1-4 (July 1977).

${ }^{7} \mathrm{Li}\left({ }_{p}{ }^{d}, \mathrm{n}\right),{ }^{9} \mathrm{Be}\left({ }_{p}{ }^{d}, \mathrm{n}\right) ; \mathrm{E}=14.8,18,23 \mathrm{MeV}$; measured neutron spectral distributions for $\mathrm{E}_{n}>0.3 \mathrm{MeV}$; NBSIR 77-1279, pp. 5-9 (July 1977).

75th anniversary; American Physical Society; fundamental constants; National Bureau of Standards; nuclear physics; numerical analysis; physics; spectroscopy; thermal physics; 16991.

75th anniversary; National Bureau of Standards; physical sciences; science and technology in America; technology; $S P 465$.

${ }^{9} \mathrm{Be}(\mathrm{d}, \mathrm{n})^{10} \mathrm{~B} ;{ }^{9} \mathrm{Be}\left({ }^{3} \mathrm{He}, \mathrm{n}\right){ }^{11} \mathrm{C}$; energy spectra; neutrons; Rossicounter measurements; Serber theory; thick target; time-offlight; NBSIR 77-1279, pp. 31-34 (July 1977).

${ }^{9} \mathrm{Be}\left({ }^{3} \mathrm{He}, \mathrm{n}\right){ }^{11} \mathrm{C}$; energy spectra; neutrons; Rossi-counter measurements; Serber theory; thick target; time-of-flight; ${ }^{9} \mathrm{Be}(\mathrm{d}, \mathrm{n})^{10} \mathrm{~B}$; NBSIR 77-1279, pp. 31-34 (July 1977). 


\section{APPENDIX A. LIST OF DEPOSITORY LIBRARIES IN THE UNITED STATES}

\section{ALABAMA}

Alexander City: Alexander City State Junior College, Thomas D. Russell Library (1967).

Auburn: Auburn University, Ralph Brown Draughon Library (1907).

3irmingham:

Birmingham Public Library (1895).

Birmingham-Southern College Library (1932).

Jefferson State Junior College, James B. Allen Library (1970).

Samford University, Harwell G. Davis Library (1884).

Enterprise: Enterprise State Junior College Library (1967).

Florence: University of North Alabama, Collier Library (1932). Jadsden: Gadsden Public Library (1963).

Huntsville: University of Alabama, Huntsville Campus Library (1964).

lacksonville: Jacksonville State University, Ramona Wood Library (1929).

Maxwell A.F. Base: Air University Library (1963).

Mobile:

Mobile Public Library (1963).

Spring Hill College, Thomas Byrne Memorial Library (1937).

University of South Alabama Library (1968).

Montgomery:

Alabama State Department of Archives and History Library (1884).

Alabama Supreme Court Library (1884).

Auburn University at Montgomery Library (1971) - REGIONAL.

Normal: Alabama Agricultural and Mechanical College, Drake Memorial Library (1963).

St. Bernard: St. Bernard College Library (1962).

Troy: Troy State University, Lurleen B. Wallace Educational Resources Center (1963).

Tuskegee Institute: Tuskegee Institute, Hollis Burke Frissell Library (1907).

University:

University of Alabama, School of Law Library (1967).

University of Alabama Library (1860)-REGIONAL.

\section{ALASKA}

Anchorage:

Anchorage Higher Education Consortium Library (1961).

Supreme Court of Alaska Library (1973).

College: University of Alaska, Elmer E. Rasmuson Library (1922).

Juneau: Alaska State Library (1964).

Ketchikan: Ketchikan Community College Library (1970).

\section{ARIZONA}

Coolidge: Central Arizona College, Instructional Materials Center (1973).

Flagstaff: Northern Arizona University Library (1937).
Phoenix:

Department of Library and Archives (unknown)-REGIONAL.

Phoenix Public Library (1917).

Prescott: Yavapai College Library (1976).

Tempe: Arizona State University, Matthews Library (1944).

Thatcher: Eastern Arizona Junior College Library (1963).

Tucson:

Tucson Public Library (1970).

University of Arizona Library (1907) - REGIONAL.

Yuma: Yuma City-County Library (1963).

\section{ARKANSAS}

Arkadelphia: Ouachita Baptist University, Riley Library (1963).

Batesville: Arkansas College Library (1963).

Clarksville: College of the Ozarks Library (1925).

Conway: Hendrix College, O. C. Bailey Library (1903).

Fayetteville: University of Arkansas Library (1907).

Little Rock:

Arkansas Supreme Court Library (1962).

Little Rock Public Library (1953).

University of Arkansas at Little Rock Library (1973).

Magnolia: Southern Arkansas University, Mogale Library (1956).

Monticello: University of Arkansas at Monticello Library (1956).

Pine Bluff: University of Arkansas, Watson Memorial Library (1976).

Russellville: Arkansas Tech University, Tomlinson Library (1925).

Searcy: Harding College, Beaumont Memorial Library (1963).

State College: Arkansas State University, Dean B. Ellis Library (1913).

Walnut Ridge: Southern Baptist College, Felix Goodson Library (1967).

\section{CALIFORNIA}

Anaheim: Anaheim Public Library (1963).

Arcadia: Arcadia Public Library (1975).

Arcata: Humboldt State College Library (1963).

Bakersfield:

California State College, Bakersfield Library (1974).

Kern County Library System (1943).

Berkeley:

University of California, General Library (1907).

University of California, Law Library, Earl Warren Legal Center (1963).

Carson: Carson Regional Library (1973).

Chico: Chico State University Libráry (1962).

Claremont: Pomona College Documents Collection, Honnold Library (1913).

Compton: Compton Library (1972).

Culver City: Culver City Library (1966).

Davis:

University of California at Davis Library (1953). 
University of California at Davis, School of Law Library (1972).

Dominguez Hills: California State College, Dominguez Hills, Educational Resources Center (1973).

Downey: Downey City Library (1963).

Fresno:

Fresno County Free Library (1920).

California State University Library (1962).

Fullerton: California State University at Fullerton Library (1963).

Garden Grove: Garden Grove Regional Library (1963).

Gardena: Gardena Public Library (1966).

Hayward: California State College at Hayward Library (1963).

Huntington Park: Huntington Park Library, San Antonio Region (1970).

Inglewood: Inglewood Public Library (1963).

Irvine: University of California at Irvine Library (1963).

La Jolla: University of California, San Diego, University Library (1963).

Lakewood: Angelo Iacoboni Public Library (1970).

Lancaster: Lancaster Regional Library (1967).

Long Beach:

California State College at Long Beach Library (1962).

Long Beach Public Library (1933).

Los Angeles:

California State College at Los Angeles, John F. Kennedy Memorial Library (1956).

Los Angeles County Law Library (1963).

Los Angeles Public Library (1891).

Loyola University of Los Angeles Library (1933).

Occidental College, Mary Norton Clapp Library (1941).

Pepperdine University Library (1963).

South western University, School of Law Library (1975).

University of California at Los Angeles Library (1932).

University of California at Los Angeles, Law Library (1958).

University of Southern California Library (1933).

Menlo Park: Department of the Interior, Geological Survey Library (1962).

Montebello: Montebello Library (1966).

Monterey: Naval Postgraduate School Library (1963).

Monterey Park: Bruggemeyer Memorial Library (1964).

Northridge: California State University at Northridge Library (1958).

Norwalk: Los Cerritos Regional Library (1973).

Oakland:

Mills College Library (1966).

Oakland Public Library (1923).

Ontario: Ontario City Library (1974).

Pasadena:

California Institute of Technology, Millikan Memorial Library (1933).

Pasadena Public Library (1963).

Pleasant Hill: Contra Costa County Library (1964).

Redding: Shasta County Library (1956).

Redlands: University of Redlands, Armacost Library (1933).

Redwood City: Redwood City Public Library (1966).

Reseda: West Valley Regional Branch Library (1966).

Richmond: Richmond Public Library (1943).

Riverside:

Riverside Public Library (1947).

University of California at Riverside Library (1963).

Sacramento:

California State Library (1895) - REGIONAL.

Sacramento City-County Library (1880).

Sacramento County Law Library (1963).

Sacramento State College Library (1963).

San Bernardino: San Bernardino County Free Library (1964).

San Diego:

San Diego State University, Love Library (1962).

San Diego County Law Library (1973).

San Diego County Library (1966).

San Diego Public Library (1895).
University of San Diego Law Library (1967).

San Francisco:

Mechanics' Institute Library (1889).

San Francisco Public Library (1889).

San Francisco State College, Social Science and Business Library (1955).

Supreme Court of California Library (1972).

U.S. Court of Appeals for Ninth Circuit Library (1971).

University of San Francisco, Richard A. Gleeson Library (1963).

San Jose: San Jose State College Library (1962).

San Leandro: San Leandro Community Library Center (1961).

San Luis Obispo: California Polytechnic State University Library (1969).

San Rafael: Marin County Free Library (1975).

Santa Ana:

Orange County Law Library (1975).

Santa Ana Public Library (1959).

Santa Barbara: University of California at Santa Barbara Libra. ry $(1960)$.

Santa Clara: University of Santa Clara, Orradre Library (1963).

Santa Cruz: University of California at Santa Cruz Library (1963).

Santa Rosa: Santa Rosa-Sonoma County Public Library (1896).

Stanford: Stanford University Libraries (1895).

Stockton: Public Library of Stockton and San Joaquin County (1884)

Thousand Oaks: California Lutheran College Library (1964).

Torrance: Torrance Civic Center Library (1969).

Turlock: Stanislaus State College Library (1964).

Valencia: Valencia Regional Library (1972).

Van Nuys: Los Angeles Valley College Library (1970).

Ventura: Ventura County Library Services Agency (1975).

Visalia: Tulare County Free Library (1967).

Walnut: Mount San Antonio College Library (1966).

West Covina: West Covina Library (1966).

Whittier: Whittier College, Wardman Library (1963).

\section{CANAL ZONE}

Balboa Heights: Canal Zone Library-Museum (1963)

\section{COLORADO}

Alamosa: Adams State College Learning Resources Center (1963).

Boulder: University of Colorado Libraries (1879)-RE. GIONAL.

Colorado Springs:

Colorado College, Charles Leaming Tutt Librạry (1880).

University of Colorado, Colorado Springs Library (1974).

Denver:

Colorado State Library (unknown).

Denver Public Library (1884) - REGIONAL.

Department of Interior, Bureau of Reclamation Library (1962).

Regis College, Dayton Memorial Library (1915).

University of Denver, Penrose Library (1909).

U.S. Court of Appeals for Tenth Circuit Library (1973).

Fort Collins: Colorado State University Library (1907).

Golden: Colorado School of Mines, Arthur Lakes Library (1939).

Greeley: University of Northern Colorado Library (1966).

Gunnison: Western State College, Leslie J. Savage Library (1932).

La Junta: Otero Junior College, Wheeler Library (1963).

Lakewood: Jefferson County Public Library, Lakewood Regional Jibrary (1968). 
Pueblo:

Puebio Regional Library (1893).

University Southern Colorado Library (1965).

U.S. Air Force Academy: Academy Library (1956).

\section{CONNECTICUT}

Bridgeport: Bridgeport Public Library (1884).

Danbury: Western Connecticut State College, Ruth A. Haas Library (1967).

Danielson: Quinebaug Valley Community College (1975).

Enfield: Enfield Public Library (1967).

Hartford:

Connecticut State Library (unknown) - REGIONAL.

Hartford Public Library (1945).

Trinity College Library (1895).

Middletown: Wesleyan University Library (1906).

Mystic: Marine Historical Association, Inc., G. W. Blunt White Library (1964).

New Britain: Central Connecticut State College, Elihu Burritt Library (1973).

New Haven:

Southern Connecticut State College Library (1968).

Yale University Library (1859).

New London:

Connecticut College Library (1926).

U.S. Coast Guard Academy Library (1939).

Stamford: Stamford Public Library (1973).

Storrs: University of Connecticut, Wilbur Cross Library (1907).

Waterbury: Silas Bronson Library (1869).

West Haven: University of New Haven Library (1971).

\section{DELAWARE}

Dover:

Delaware State College, William C. Jason Library (1962).

State Department of Community Affairs and Economic Development, Division of Libraries (1972).

State Law Library in Kent County (unknown).

Georgetown:

Delaware Technical and Community College, Southern Branch Library (1968).

Sussex County Law Library (1976).

Newark:

University of Delaware, Morris Library (1907).

Delaware Law School Library (1976).

Wilmington:

New Castle County Law Library (1974).

Wilmington Institute and New Castle County Library (1861).

\section{DISTRICT OF COLUMBIA}

Washington:

Advisory Commission on Intergovernmental Relations Library.

Civil Aeronautics Board Library (1975).

Civil Service Commission Library (1963).

Department of Commerce Library (1955).

Department of Health, Education, and Welfare Library (1954).

Department of Housing and Urban Development Library (1969).

Department of the Interior Central Library (1895).

Department of Justice Main Library (1895).

Department of Labor Library (1976).

Department of State Library (1895).
Department of State, Office of Legal Advisor, Law Library (1966).

Department of Transportation, National Highway Traffic Safety Administration Library (1968).

District of Columbia Public Library (1943).

Federal City College Library (1970).

Federal Deposit Insurance Corporation Library (1972).

Federal Election Commission Library (1975).

Federal Reserve System Law Library (1976).

General Accounting Office Library (1975).

General Services Administration Library (1975).

Georgetown University Library (1969).

Indian Claims Commission Library (1968).

National War College Library (1895).

Navy Department Library (1895).

Navy Department, Office of Judge Advocate General Library (1963).

Office of Management and Budget Library (1965).

Office of The Adjutant General, Department of Army Library (1969).

Postal Service Library (1895).

Treasury Department Library (1895).

U.S. Court of Appeals, Judge's Library (1975).

Veterans' Administration, Central Office Library (1967).

\section{FLORIDA}

Boca Raton: Florida Atlantic University Library (1963).

Clearwater: Clearwater Public Library (1972).

Coral Gables: University of Miami Library (1939).

Daytona Beach: Volusia County Public Libraries (1963).

DeLand: Stetson University, duPont-Ball Library (1887).

Fort Lauderdale:

Broward County Library (1967).

Nova University Library (1967).

Gainesville: University of Florida Libraries (1907)-REGIONAL.

Jacksonville:

Haydon Burns Library (1914).

Jacksonville University, Swisher Library (1962).

University of North Florida Library (1972).

Lakeland: Lakeland Public Library (1928).

Leesburg: Lake-Sumter Community College Library (1963).

Melbourne: Florida Institute of Technology Library (1963).

Miami:

Florida International University Library (1970).

Miami Public Library (1952).

Opa Locka: Biscayne College Library (1966).

Orlando: Florida Technological University Library (1966).

Palatka: St. Johns River Junior College Library (1963).

Pensacola: University of West Florida, John C. Pace Library (1966).

Port Charlotte: Charlotte County Library System (1973).

St. Petersburg:

St. Petersburg Public Library (1965).

Stetson University College Law Library (1975).

Sarasota: Sarasota Public Library (1970).

Tallahassee:

Florida Agricultural and Mechanical University, Coleman Memorial Library (1936).

State Library of Florida (1929).

Florida State University, R. M. Stozier Library (1941).

Florida Supreme Court Library (1974).

Tampa:

Tampa Public Library (1965).

University of South Florida Library (1962).

University of Tampa, Merle Kelce Library (1953).

Winter Park: Rollins College, Mills Memorial Library (1909). 


\section{GEORGIA}

Albany: Albany Public Library (1964).

Americus: Georgia Southwestern College, James Earl Carter Library (1966).

Athens: University of Georgia Libraries (1907).

Atlanta:

Atlanta Public Library (1880).

Atlanta University, Trevor Arnett Library (1962).

Emory University, Robert W. Woodruff Library (1928).

Emory University, School of Law Library (1968).

Georgia Institute of Technology, Price Gilbert Memorial Library (1963).

Georgia State Library (unknown).

Georgia State University Library (1970).

Augusta: Augusta College Library (1962).

Brunswick: Brunswick Public Library (1965).

Carrollton: West Georgia College, Sanford Library (1962).

Columbus: Columbus College, Simon Schwob Memorial Library (1975).

Dahlonega: North Georgia College Library (1939).

Decatur: Dekalb Community College-South Campus, Learning Resources Center (1973).

Gaines ville: Chestatee Regional Library (1968).

Macon: Mercer University Library (1964).

Marietta: Kennesaw Junior College Library (1968).

Milledgeville: Georgia College at Milledgeville, Ina Dillard Russell Library (1950).

Mount Berry: Berry College, Memorial Library (1970).

Savannah: Savannah Public and Chatham-Effingham Liberty Regional Library (1857).

Statesboro: Georgia Southern College, Rosenwald Library (1939).

Valdosta: Valdosta State College, Richard Holmes Powell Library (1956).

\section{GUAM}

Agana: Nieves M. Flores Memorial Library (1962).

\section{HAWAII}

Hilo: University of Hawaii, Hilo Campus Library (1962).

Honolulu:

Chaminade College of Honolulu Library (1965).

Hawaii Medical Library, Inc. (1968).

Hawaii State Library (1929).

Municipal Reference Library of the City and County of Honolulu (1965).

Supreme Court Law Library (1973).

University of Hawaii Library (1907).

Laie: Church College of Hawaii, Woolley Library (1964).

Lihue: Kauai Public Library (1967).

Pearl City: Leeward Community College Library (1967).

Wailuku: Maui Public Library (1962).

\section{IDAHO}

Boise:

Boise State College Library (1966).

Boise Public Library and Information Center (1929).

Idaho State Law Library (unknown).

Idaho State Library (1971).
Caldwell: College of Idaho, Terteling Library (1930).

Moscow: University of Idaho Library (1907) - REGIONAL.

Pocatello: Idaho State University Library (1908).

Rexburg: Ricks College, David O. McKay Library (1946).

Twin Falls: College of Southern Idaho Library (1970).

\section{ILLINOIS}

Bloomington: Illinois Wesleyan University Libraries (1964).

Carbondale: Southern Illinois University Library (1932).

Carlinville: Blackburn College Library (1954).

Carterville: Shawnee Library System (1971).

Champaign: University of Illinois Law Library, College of Law (1965).

Charleston: Eastern Illinois University, Booth Library (1962).

Chicago:

Chicago Public Library (1876).

Chicago State University Library (1954).

DePaul University, Lincoln Park Campus Library (1975).

Field Museum of Natural History Library (1963).

John Crerar Library (1909).

Loyola University of Chicago, E. M. Cudahy Memonal Library (1966).

Northeastern Illinois University Library (1961).

University of Chicago Law Library (1964).

University of Chicago Library (1897).

University of Illinois, Chicago Circle Campus Library (1957).

Decatur: Decatur Public Library (1954).

De Kalb: Northern Illinois University, Swen Franklin Parson Library (1960).

Edwardsville: Southern Illinois University, Lovejoy Library (1959).

Elsah: Principia College, Marshall Brooks Library (1957).

Evanston: Northwestern University Library (1876).

Freeport: Freeport Public Library (1905).

Galesburg: Galesburg Public Library (1896).

Jacksonville: MacMurray College, Henry Pfeiffer Library (1929).

Kankakee: Olivet Nazarene College, Benner Library and Resource Center (1946).

Lake Forest: Lake Forest College, Donnelley Library (1962).

Lebanon: McKendree College, Holman Library (1968).

Lisle: Illinois Benedictine College, Theodore F. Lownik Library (1911).

Lockport: Lewis University Library (1952).

Macomb: Western Illinois University Memorial Library (1962).

Moline: Black Hawk College, Learning Resources Center (1970).

Monmouth: Monmouth College Library (1860).

Morton Grove: Oakton Community College Library (1976).

Mt. Carmel: Wabash Valley College Library (1975).

Normal: Illinois State University, Milner Library (1877).

Oak Park: Oak Park Public Library (1963).

Oglesby: Illinois Valley Community College Library (1976).

Palos Hills: Moraine Valley Community College Library (1972).

Park Forest South: Governors State University Library (1974) Peoria:

Bradley University, Cullom Davis Library (1963).

Peoria Public Library (1883).

River Forest: Rosary College Library (1966).

Rockford: Rockford Public Library (unknown).

Springfield: Illinois State Library (unknown) - REGIONAL.

Urbana: University of Illinois Library (1907).

Wheaton: Wheaton College Library (1964).

Woodstock: Woodstock Public Library (1963) 


\section{INDIANA}

Anderson: Anderson College, Charles E. Wilson Library (1959). Bloomington: Indiana University Library (1881).

Crawfordsville: Wabash College, Lilly Library (1906).

Evansville:

Evansville and Vanderburgh County Public Library (1928).

Indiana State University, Evansville Campus Library (1969).

Fort Wayne:

Indiana-Purdue Universities, Regional Campus Library (1965).

Public Library of Fort Wayne and Allen County (1896).

Franklin: Franklin College Library (1976).

Gary:

Gary Public Library (1943).

Indiana University, Northwest Campus Library (1966).

Greencastle: De Pauw University, Roy O. West Library (1879).

Hammond: Hammond Public Library (1964).

Hanover: Hanover College Library (1892).

Huntington: Huntington College Library (1964).

Indianapolis:

Butler University, Irwin Library (1965).

Indiana State Library (unknown) - REGIONAL.

Indiana Supreme Court Law Library (1975).

Indiana University, Law Library (1967).

Indianapolis-Marion County Public Library (1906).

Kokomo: Indiana University, Kokomo Regional Campus Library (1969).

Lafayette: Purdue University Library (1907).

Muncie:

Ball State University Library (1959).

Muncie Public Library (1906).

New Albany: Indiana University, Southeastern Campus Library (1965).

Notre Dame: University of Notre Dame, Memorial Library (1883).

Rensselaer: St. Joseph's College Library (1964).

Richmond:

Earlham College, Lilly Library (1964).

Morrison-Reeves Library (1906).

South Bend: Indiana University at South Bend Library (1965).

Terre Haute: Indiana State University, Cunningham Memorial Library (1906).

Valparaiso: Valparaiso University, Moellering Memorial Library (1930).

\section{IOWA}

Ames: Iowa State University of Science and Technology Library (1907).

Cedar Falls: University of Northern Iowa Library (1946).

Council Bluffs:

Free Public Library (1885).

Iowa Western Community College, Hoover Media Library (1972).

Davenport: Davenport Public Library (1973).

Des Moines:

Drake University, Cowles Library (1966).

Drake University Law Library (1972).

Iowa State Traveling Library (unknown).

Public Library of Des Moines (1888).

Dubuque:

Carnegie-Stout Public Library (unknown).

Loras College, Wahlert Memorial Library (1967).

Fayette: Upper Iowa College, Henderson-Wilder Library (1974).

Grinnell: Grinnell College, Burling Library (1874).
Iowa City:

University of Iowa, Law Library (1968).

University of Iowa Library (1884) - REGIONAL.

Lamoni: Graceland College, Frederick Madison Smith Library (1927).

Mason City: North Iowa Area Community College Library (1976).

Mount Vernon: Cornell College, Russell D. Cole Library (1896).

Orange City: Northwestern College, Ramaker Library (1970).

Sioux City: Sioux City Public Library (1894).

\section{KANSAS}

Atchison: Benedictine College Library (1965).

Baldwin City: Baker University Library (1908).

Colby: Colby Community Junior College Library (1968).

Emporia: Kansas State College, William Allen White Library (1909).

Hays: Fort Hays Kansas State College, Forsyth Library (1926).

Hutchinson: Hutchinson Public Library (1963).

Lawrence:

University of Kansas, Watson Library (1869)-REGIONAL.

University of Kansas Law Library (1971).

Manhattan: Kansas State University, Farrell Library (1907).

Pittsburg: Kansas State College of Pittsburg, Porter Library (1952).

Salina: Kansas Wesleyan University, Memorial Library (1930).

Topeka:

Kansas State Historical Society Library (1877).

Kansas State Library (unknown).

Kansas Supreme Court Law Library (1975).

Washburn University of Topeka, Law Library (1971).

Wichita: Wichita State University Library (1901).

\section{KENTUCKY}

Ashland: Ashland Public Library (1946).

Barbourville: Union College, Abigail E. Weeks Memorial Library (1958).

Bowling Green: Western Kentucky University, Cravens Graduate Center and Library (1934).

Covington: Thomas More College Library (1970).

Danville: Centre College, Grace Doherty Library (1884).

Frankfort:

Kentucky Department of Libraries (1967).

Kentucky State University, Blazer Library (1972).

State Law Library (unknown).

Highland Heights: Northern Kentucky State College Library (1973).

Hopkinsville: Hopkinsville Community College Library (1976).

Lexington:

University of Kentucky, Law Library (1968).

University of Kentucky, Margaret I. King Library (1907) - REGIONAL.

Louisville:

Louisville Free Public Library (1904).

University of Louisville, Belknap Campus Library (1925).

University of Louisville Law Library (1975).

Morehead: Morehead State University, Johnson Camden Library (1955).

Murray: Murray State University Library (1924).

Owensboro: Kentucky Wesleyan College Library (1966).

Richmond: Eastern Kentucky University, John Grant Crabbe Library (1966). 


\section{LOUISIANA}

Baton Rouge:

Louisiana State Library (1976).

Louisiana State University Law Library (1929).

Louisiana State University Library (1907) - REGIONAL.

Southern University Library (1952).

Eunice: Louisiana State University at Eunice, Le Doux Library (1969).

Hammond: Southeastern Louisiana University, Sims Memorial Library (1966).

Lafayette: University of Southwestern Louisiana Library (1938).

Lake Charles: McNeese State University, Frazar Memorial Library (1941).

Monroe: Northeast Louisiana University, Sandel Library (1963).

Natchitoches: Northwestern State University, Watson Memorial Library (1887).

New Orleans:

Isaac Delgado College, Moss Technical Library (1968).

Law Library of Louisiana (unknown).

University of New Orleans Library (1963).

Loyola University Library (1942).

New Orleans Public Library (1883).

Southern University in New Orleans Library (1962).

Tulane University, Howard-Tilton Memorial Library (1942)

Tulane University Law Library (1976).

U.S. Court of Appeals, Fifth Circuit Library (1973).

Pineville: Louisiana College, Richard W. Norton Memorial Library (1969).

Ruston: Louisiana Technical University Library (1896) - REGIONAL.

Shreveport:

Louisiana State University at Shreveport Library (1967).

Shreve Memorial Library (1923).

Thibodaux: Francis T. Nicholls State University, Leonidas Polk Library (1962).

\section{MAINE}

Augusta:

Maine Law and Legislative Reference Library (1973).

Maine State Library (unknown).

Bangor: Bangor Public Library (1884).

Brunswick: Bowdoin College, Hawthorne-Longfellow Library (1884).

Castine: Maine Maritime Academy, Nutting Memorial Library (1969).

Lewiston: Bates College Library (1883).

Orono: University of Maine, Raymond H. Fogler Library (1907)-REGIONAL.

Portland:

Portland Public Library (1884).

University of Maine Law Library (1964).

Springvale: Nasson College Library (1961).

Waterville: Colby College Library (1884).

\section{MARYLAND}

Annapolis:

Maryland State Library (unknown).

U.S. Naval Academy, Nimitz Library (1895).

Baltimore:

Enoch Pratt Free Library (1887).

Johns Hopkins University, Milton S. Eisenhower Library (1882).
Morgan State College, Soper Library (1940).

University of Baltimore, Langsdale Library (1973).

University of Maryland, Baltimore County Library (1971).

University of Maryland, School of Law Library (1969).

Bel Air: Harford Community College Library (1967).

Beltsville: Department of Agriculture, National Agricultural Library (1895).

Chestertown: Washington College, Chester M. Miller Library (1891).

College Park: University of Maryland, McKeldin Library (1925)-REGIONAL.

Cumberland: Allegany Community College Library (1974).

Frostburg: Frostburg State College Library (1967).

Germantown: Energy Research \& Development Adm. Library (1963).

Patuxent River: Naval Air Station Library (1968).

Rockville: Montgomery County Department of Public Libranies (1951).

Salisbury: Salisbury State College, Blackwell Library (1965).

Towson: Goucher College, Julia Rogers Library (1966).

Westminster: Western Maryland College Library (1896).

\section{MASSACHUSETTS}

Amherst:

Amherst College Library (1884).

University of Massachusetts, Goodell Library (1907).

Belmont: Belmont Memorial Library (1968).

Boston:

Boston Athenaeum Library (unknown).

Boston College, Bapst Library (1963).

Boston Public Library (1859)-REGIONAL.

Northeastern University, Dodge Library (1962).

State Library of Massachusetts (unknown):

Brookline: Public Library of Brookline (1925).

Cambridge:

Harvard College Library (1860).

Massachusetts Institute of Technology Libraries (1946).

Chicopee: Our Lady of the Elms College Library (1969).

Lowell: Lowell Technological Institute, Alumni Memonal Library (1952).

Lynn: Lynn Public Library (1953).

Marlborough: Marlborough Public Library (1971).

Medford: Tufts University Library (1899).

Milton: Curry College Library (1972).

New Bedford: New Bedford Free Public Library (1858).

North Dartmouth: Southeastern Massachusetts University Library (1965).

North Easton: Stonehill College, Cushing-Martin Library (1962).

Springfield: Springfield City Library (1966).

Waltham: Brandeis University, Goldfarb Library (1965).

Wellesley: Wellesley College Library (1943).

Wenham: Gordon College, Winn Library (1963).

Williamstown: Williams College Library (unknown).

Worcester:

American Antiquarian Society Library (1814).

University of Massachusetts, Medical Center Library (1972).

Worcester Public Library (1859).

\section{MICHIGAN}

Albion: Albion College, Stockwell Memorial Library (1966).

Allendale: Grand Valley State College Library (1963).

Alma: Alma College, Monteith Library (1963). 


\section{Ann Arbor:}

Great Lakes Basin Commission Library (1971).

University of Michigan, Harlan Hatcher Library (1884).

Benton Harbor: Benton Harbor Public Library (1907).

Bloomfield Hills: Cranbrook Institute of Science Library (1940).

Dearborn:

Henry Ford Centennial Library (1969).

Henry Ford Community College Library (1957).

Detroit:

Detroit Public Library (1868) - REGIONAL.

Marygrove College Library (1965).

Mercy College of Detroit Library (1965).

University of Detroit Library (1884).

Wayne State University Law Library (1971).

Wayne State University, G. Flint Purdy Library (1937).

Dowagiac: Southwestern Michigan College Library (1971).

East Lansing:

Michigan State University, Law Library (1971).

Michigan State University Library (1907).

Escanaba: Michigan State Library, Upper Peninsula Branch (1964).

Farmington: Martin Luther King Learning Resources Center, Oakland Community College (1968).

Flint:

Charles Stewart Mott Library (1959).

Flint Public Library (1967).

Grand Rapids:

Grand Rapids Public Library (1876).

Calvin College Library (1967).

Houghton: Michigan Technological University Library (1876).

Jackson: Jackson Public Library (1965).

Kalamazoo:

Kalamazoo Library System (1907).

Western Michigan University, Dwight B. Waldo Library (1963).

Lansing: Michigan State Library (unknown) - REGIONAL.

Livonia: Schoolcraft College Library (1962).

Marquette: Northern Michigan University, Olsen Library (1963).

Monroe: Monroe County Library System (1974).

Mt. Clemens: Macomb County Library (1968).

Mt. Pleasant: Central Michigan University Library (1958).

Muskegon: Hackley Public Library (1894).

Olivet: Olivet College Library (1974).

Petoskey: North Central Michigan College Library (1962).

Port Huron: Saint Clair County Library System (1876).

Rochester: Oakland University, Kresge Library (1964).

Saginaw: Hoyt Public Library (1890).

Traverse City: Northwestern Michigan College, Mark Osterlin Library (1964).

University Center: Delta College Library (1963).

Warren: Warren Public Library, Arthur J. Miller Branch (1973).

Wayne: Wayne Oakland Federated Library System (1957).

Ypsilanti: Eastern Michigan University Library (1965).

\section{MINNESOTA}

Bemidji: Bemidji State College, A. C. Clark Library (1963).

Collegeville: St. John's University, Alcuin Library (1954).

Duluth: Duluth Public Library (1909).

Mankato: Mankato State College Memorial Library (1962).

Minneapolis:

Anoka County Library (1971).

Hennepin County Libraries (1971).

Minneapolis Public Library (1893).

University of Minnesota, Wilson Library (1907)-REGIONAL.
Moorhead: Moorhead State College Library (1956).

Morris: University of Minnesota at Morris Library (1963).

Northfield:

Carleton College Library (1930).

St. Olaf College, Rolvaag Memorial Library (1930).

St. Cloud: St. Cloud State College Library (1962).

St. Paul:

Minnesota Historical Society Library (1867).

Minnesota State Law Library (unknown).

St. Paul Public Library (1914).

University of Minnesota, St. Paul Campus Library (1974).

Saint Peter: Gustavus Adolphus College Library (1941).

Stillwater: Stillwater Public Library (1893).

Willmar: Crow River Regional Library (1958).

Winona: Winona State University, Maxwell Library (1969).

\section{MISSISSIPPI}

Cleveland: Delta State University, W. B. Roberts Library (1975).

Columbus: Mississippi State College for Women, J. C. Fant Memorial Library (1920).

Hattiesburg: University of Southern Mississippi Library (1935).

Jackson:

Jackson State College Library (1968).

Millsaps College, Millsaps-Wilson Library (1963).

Mississippi Library Commission (1947).

Mississippi State Law Library (unknown).

Lorman: Alcorn Agricultural and Mechanical College Library (1970).

State College: Mississippi State University, Mitchell Memorial Library (1907).

University:

University of Mississippi Library (1833) - REGIONAL.

University of Mississippi, School of Law Library (1967).

\section{MISSOURI}

Cape Girardeau: Southeast Missouri State College, Kent Library (1916).

Columbia: University of Missouri Library (1862).

Fayette: Central Methodist College Library (1962).

Fulton: Westminster College, Reeves Library (1875).

Jefferson City:

Lincoln University, Inman E. Page Library (1944).

Missouri State Library (1963).

Missouri Supreme Court Library (unknown).

Joplin: Missouri Southern State College Library (1966).

Kansas City:

Kansas City Public Library (1881).

Rockhurst College Library (1917).

University of Missouri at Kansas City, General Library (1938).

Kirksville: Northeast Missouri State Teachers College, Pickler Memorial Library (1966).

Liberty: William Jewell College Library (1900).

Rolla: University of Missouri at Rolla Library (1907).

St. Charles: Lindenwood College, Margaret Leggat Butler Library (1973).

St. Joseph: St. Joseph Public Library (1891).

St. Louis:

St. Louis County Library (1970).

St. Louis Public Library (1866).

St. Louis University, Law Library (1967).

St. Louis University, Pius XII Memorial Library (1866). 
University of Missouri at St. Louis, Thomas Jefferson Library (1966).

U.S. Court of Appeals, Eighth Circuit Library (1972).

Washington University, John M. Olin Library (1906).

Springfield:

Drury College, Walker Library (1874).

Southwest Missouri State College Library (1963).

Warrensburg: Central Missouri State College, Ward Edwards Library (1914).

\section{MONTANA}

Billings: Eastern Montana College Library (1924).

Bozeman: Montana State University Library (1907).

Butte: Montana College of Mineral Science and Technology Library (1901).

Helena:

Carroll College Library (1974).

Montana Historical Society Library (unknown).

Montana State Library (1966).

Missoula: University of Montana Library (1909)-REGIONAL.

\section{NEBRASKA}

Blair: Dana College, Dana-LIFE Library (1924).

Crete: Doane College, Whitin Library (1944).

Fremont: Midland Lutheran College Library (1924).

Kearney: Kearney State College, Calvin T. Ryan Library (1962).

Lincoln:

Nebraska Publications Clearinghouse, Nebraska Library Commission (1972) - REGIONAL.

Nebraska State Library (unknown).

University of Nebraska, Don L. Love Memorial Library (1907).

Omaha:

Creighton University, Alumni Library (1964).

Omaha Public Library (1880).

University of Nebraska at Omaha, University Library (1939).

Scottsbluff: Scottsbluff Public Library (1925).

Wayne: Wayne State College, U.S. Conn Library (1970).

\section{NEVADA}

Carson City:

Nevada State Library (unknown).

Nevada Supreme Court Library (1973).

Las Vegas:

Clark County Library District Library (1974).

University of Nevada at Las Vegas, James R. Dickinson Library (1959).

Reno:

Nevada State Historical Society Library (1974).

Eiversity of Nevada Library (1907)-REGIONAL.

\section{NEW HAMPSHIRE}

Concord:

Franklin Pierce Law Center Library (1973).

New Hampshire State Library (unknown).

Durham: University of New Hampshire Library (1907).
Franconia: Franconia College Library (1972).

Hanover: Dartmouth College, Baker Library (1884).

Henniker: New England College Library (1966).

Manchester:

Manchester City Library (1884).

New Hampshire College, H.A.B. Shapiro Memorial Libra. ry (1976).

St. Anselm's College, Geise Library (1963).

Nashua: Nashua Public Library (1971).

\section{NEW JERSEY}

Bayonne: Bayonne Free Public Library (1909).

Bloomfield: Free Public Library of Bloomfield (1965).

Bridgeton: Cumberland County Library (1966).

Camden: Rutgers University-Camden Library (1966).

Convent Station: College of St. Elizabeth, Mahoney Library (1938).

Dover: County College of Morris Library, Learning Resources Center (1975).

East Orange: East Orange Public Library (1966).

Elizabeth: Free Public Library of Elizabeth (1895).

Glassboro: Glassboro State College, Savitz Learning Resource Center (1963).

Hackensack: Johnson Free Public Library (1966).

Irvington: Free Public Library of Irvington (1966).

Jersey City:

Free Public Library of Jersey City (1879).

Jersey City State College, Forrest A. Irwin Library (1963).

Lawrenceville: Rider College Library (1975).

Madison: Drew University, Rose Memorial Library (1939).

Mahwah: Ramapo College Library (1971).

Mount Holly: Burlington County Library (1966).

New Brunswick:

Free Public Library (1908).

Rutgers University Library (1907).

Newark:

Newark Public Library (1906) - REGIONAL.

Rutgers-The State University, John Cotton Dana Library (1966).

Passaic: Passaic Public Library (1964).

Phillipsburg: Phillipsburg Free Public Library (1976).

Plainfield: Plainfield Public Library (1971).

Pomona: Stockton State College Library (1972).

Princeton: Princeton University Library (1884).

Rutherford: Fairleigh Dickinson University, Messler Library (1953).

Shrewsbury: Monmouth County Library (1968).

South Orange: Seton Hall University, McLaughlin Library (1947).

Teaneck: Fairleigh Dickinson University, Teaneck Campus Library (1963).

Toms River: Ocean County College Learning Resources Center (1966)

Trenton:

New Jersey State Library, Law and Reference Bureau, De. partment of Education (unknown).

Trenton Free Public Library (1902).

Union: Kean College of New Jersey, Nancy Thompson Library (1973).

Upper Montclair: Montclair State College, Harry A. Sprague Library (1967).

Wayne: Wayne Public Library (1972).

West Long Branch: Monmouth College, Guggenheim Memorial Library (1963).

Woodbridge: Free Public Library of Woodbridge (1965). 


\section{NEW MEXICO}

Albuquerque:

University of New Mexico, Medical Sciences Library (1973).

University of New Mexico, School of Law Library (1973).

University of New Mexico, Zimmerman Library (1896) - REGIONAL.

Hobbs: New Mexico Junior College, Pannell Library (1969).

Las Cruces: New Mexico State University Library (1907).

Las Vegas: New Mexico Highlands University, Donnelly Library (1913).

Portales: Eastern New Mexico University Library (1962).

Santa Fe:

New Mexico State Library (1960) - REGIONAL.

Supreme Court Law Library (unknown).

Silver City: Western New Mexico University, Miller Library (1972).

\section{NEW YORK}

Albany:

New York State Library (unknown) - REGIONAL.

State University of New York at Albany Library (1964).

Auburn: Seymour Library (1972).

Bayside: Queensborough Community College Library (1972).

Binghamton: State University of New York at Binghamton Library (1962).

Brockport: State University of New York, Drake Memorial Library (1967).

Bronx:

Herbert H. Lehman College Library (1967).

New York Public Library, Mott Haven Branch (1973).

Bronxville: Sarah Lawrence College Library (1969).

Brooklyn:

Brooklyn College Library (1936).

Brooklyn Law School, Law Library (1974).

Brooklyn Public Library (1908).

Polytechnic Institute of Brooklyn, Spicer Library (1963).

Pratt Institute Library (1891).

State University of New York, Downstate Medical Center Library (1958).

Buffalo:

Buffalo and Erie County Public Library (1895).

State University of New York at Buffalo, Lockwood Memorial Library (1963).

Canton: St. Lawrence University, Owen D. Young Library (1920).

Corning: Corning Community College, Arthur A. Houghton, Jr. Library (1963).

Cortland: State University of New York, College at Cortland, Memorial Library (1964).

Delhi: State University Agricultural and Technical College Library (1970).

Douglaston: Cathedral College Library (1971).

East Islip: East Islip Public Library (1974).

Elmira: Elmira College, Gannett-Tripp Learning Center (1956).

Farmingdale: State University Agricultural and Technical Institute at Farmingdale Library (1917).

Flushing: Queens College, Paul Klapper Library (1939).

Garden City:

Adelphi University, Swirbul Library (1966).

Nassau Library System (1965).

Geneseo: State University College, Milne Library (1967).

Greenvale: C. W. Post College, B. Davis Schwartz Memorial Library (1965).

Hamilton: Colgate University Library (1902).
Hempstead: Hofstra University Library (1964).

Ithaca:

Cornell University Library (1907).

New York State Colleges of Agriculture and Home Economics, Albert R. Mann Library (1943).

Jamaica:

Queens Borough Public Library (1926).

St. John's University Library (1956).

Kings Point: U.S. Merchant Marine Academy Library (1962).

Mount Vernon: Mount Vernon Public Library (1962).

New Paltz: State University Collage Library (1965).

New York City:

City University of New York, City College Library (1884).

College of Insurance, Ecker Library (1965).

Columbia University Libraries (1882).

Cooper Union Library (1930).

Fordham University Library (1937).

Medical Library Center of New York (1976).

New York Law Institute Library (1909).

New York Public Library (Astor Branch) (1907).

New York Public Library (Lenox Branch) (1884).

New York University Libraries (1967).

New York University, Law Library (1973).

State University of New York, Maritime College Library (1947).

Newburgh: Newburgh Free Library (1909).

Niagara Falls: Niagara Falls Public Library (1976).

Oakdale: Dowling College Library (1965).

Oneonta: State University College, James M. Milne Library (1966).

Oswego: State University College, Penfield Library (1966).

Plattsburgh: State University College, Benjamin F. Feinberg Library (1967).

Potsdam:

Clarkson College of Technology, Harriet Call Burnap Memorial Library (1938).

State University College, Frederick W. Crumb Memorial Library (1964).

Poughkeepsie: Vassar College Library (1943).

Purchase: State University of New York, College at Purchase Library (1969).

Rochester:

Rochester Public Library (1963).

University of Rochester Library (1880).

St. Bonaventure: St. Bonaventure College, Friedsam Memorial Library (1938).

Saratoga Springs: Skidmore College Library (1964).

Schenectady: Union College, Schaffer Library (1901).

Southampton: Southampton College Library (1973).

Staten Island (Grymes Hill): Wagner College, Horrmann Library (1953).

Stony Brook: State University of New York at Stony Brook Library (1963).

Syracuse: Syracuse University Library (1878).

Troy: Troy Public Library (1869).

Utica: Utica Public Library (1885).

West Point: U.S. Military Academy Library (unknown).

Yonkers:

Yonkers Public Library (1910).

Yorktown Heights: Mercy College at Fox Meadow Library.

\section{NORTH CAROLINA}

Asheville: University of North Carolina at Asheville, D. Hiden Ramsey Library (1965).

Boiling Springs: Gardner-Webb College, Dover Memorial Library (1974). 
Boone: Appalachian State University Library (1963).

Buies Creek: Campbell College, Carrie Rich Memorial Library (1965).

Chapel Hill: University of North Carolina Library (1884) - REGIONAL.

Charlotte:

Public Library of Charlotte and Mecklenburg County (1964).

Queens College, Everette Library (1927).

University of North Carolina at Charlotte, Atkins Library (1964).

Cullowhee: Western Carolina University, Hunter Library (1953).

Davidson: Davidson College, Hugh A. \& Jane Grey Memorial

Durham: Library (1893).

Duke University, William R. Perkins Library (1890).

North Carolina Central University, James E. Shepard Memorial Library (1973).

Elon College: Elon College Library (1971).

Fayetteville: Fayetteville State University, Chesnutt Library (1971).

Greensboro:

North Carolina Agricultural and Technical State University, F. D. Bluford Library (1937).

University of North Carolina at Greensboro, Walter Clinton Jackson Library (1963).

Greenville: East Carolina University, J. Y. Joyner Library (1951).

Laurinburg: St. Andrews Presbyterian College, DeTamble Library (1969).

Lexington: Davidson County Public Library System (1971).

Mount Olive: Mount Olive College, Moye Library (1971).

Murfreesboro: Chowan College, Whitaker Library (1963).

Pembroke: Pembroke State University Library (1965).

Raleigh:

North Carolina State Library (unknown).

North Carolina State University, D. H. Hill Library (1923).

North Carolina Supreme Court Library (1972).

Wake County Public Libraries (1969).

Rocky Mount: North Carolina Wesleyan College Library (1969).

Salisbury: Catawba College Library (1925).

Wilmington: University of North Carolina at Wilmington, William M. Randall Library (1965).

Wilson: Atlantic Christian College, Clarence L. Hardy Library (1930).

Winston-Salem:

Forsyth County Public Library System (1954).

Wake Forest University, Z. Smith Reynolds Library (1902).

\section{NORTH DAKOTA}

\section{Bismarck:}

State Historical Society of North Dakota (1907).

North Dakota State Law Library (unknown).

State Library Commission Library (1971).

Veterans Memorial Public Library (1967).

Dickinson: Dickinson State College Library (1968).

Fargo:

Fargo Public Library (1964).

North Dakota State University Library (1907)-REGIONAL, in cooperation with University of North Dakota, Chester Fritz Library at Grand Forks.

Grand Forks: University of North Dakota, Chester Fritz Library (1890).
Minot: Minot State College, Memorial Library (1925).

Valley City: State College Library (1913).

\section{OHIO}

Ada: Ohio Northern University, J. P. Taggart Law Library (1965).

Akron:

Akron Public Library (1952).

University of Akron Library (1963).

Alliance: Mount Union College Library (1888).

Ashland: Ashland College Library (1938).

Athens: Ohio University Library (1886).

Batavia: Clermont General and Technical College Library (1973).

Bluffton: Bluffton College, Musselman Library (1951).

Bowling Green: Bowling Green State University Library (1933).

Canton: Malone College, Everett L. Cattell Library (1970).

Chardon: Geauga County Public Library (1971).

Cincinnati:

Public Library of Cincinnati and Hamilton County (1884). University of Cincinnati Library (1929).

Cleveland:

Case Western Reserve University, Freiberger Library (1913).

Cleveland Heights-University Heights Public Library (1970).

Cleveland Public Library (1886).

Cleveland State University Library (1966).

John Carroll University, Grasselli Library (1963).

Municipal Reference Library (1970).

Columbus:

Capital University Library (1968).

Columbus Public Library (1885).

Ohio State Library (unknown) - REGIONAL.

Ohio State University Library (1907).

Ohio Supreme Court Law Library (1973).

Dayton:

Dayton and Montgomery County Public Library (1909).

University of Dayton, Albert Emanuel Library (1969).

Wright State University Library (1965).

Delaware: Ohio Wesleyan University, L. A. Beeghly Library (1845).

Elyria: Elyria Public Library (1966).

Findlay: Findlay College, Shafer Library (1969).

Gambier: Kenyon College Library (1873).

Granville: Denison University Library (1884).

Hiram: Hiram College, Teachout-Price Memorial Library (1874).

Kent: Kent State University Library (1962).

Marietta: Marietta College, Dawes Memorial Library (1884).

Middletown: Miami University at Middletown, Gardner-Harvey Library (1970).

New Concord: Muskingum College Library (1966).

Oberlin: Oberlin College Library (1858).

Oxford: Miami University, Alumni Library (1909).

Portsmouth: Portsmouth Public Library (unknown).

Rio Grande: Rio Grande College, Jeanette Albiez Davis Library (1966).

Springfield: Warder Public Library (1884).

Steubenville:

College of Steubenville, Starvaggi Memorial Library (1971)

Public Library of Steubenville and Jefferson County (1950).

Tiffin: Heidelberg College, Beeghly Library (1964).

Toledo:

Toledo-Lucas County Public Library (1884).

University of Toledo Library (1963). 
Westerville: Otterbein College, Centennial Library (1967). Wooster: College of Wooster, the Andrews Library (1966). Youngstown:

Public Library of Youngstown and Mahoning County (1923).

Youngstown State University Library (1971).

\section{OKLAHOMA}

Ada: East Central State College, Linscheid Library (1914).

Alva: Northwestern State College Library (1907).

Bartlesville: United States ERDA-BERC Library (1962).

Bethany: Bethany Nazarene College, R. T. Williams Library (1971).

Durant: Southeastern State College Library (1929).

Edmond: Central State University Library (1934).

Enid: Public Library of Enid and Garfield County (1908).

Langston: Langston University, G. Lamar Harrison Library (1941).

Muskogee: Muskogee Public Library (1971).

Norman: University of Oklahoma Libraries (1893).

Oklahoma City:

Oklahoma County Libraries (1974).

Oklahoma City University Library (1963).

Oklahoma Department of Libraries (1893) - REGIONAL.

Shawnee: Oklahoma Baptist University Library (1933).

Stillwater: Oklahoma State University Library (1907).

Tahlequah: Northeastern State College, John Vaughan Library (1923).

Tulsa:

Tulsa City-County Library (1963).

University of Tulsa, McFarlin Library (1929).

Weatherford: Southwestern Oklahoma State University, Al Harris Library (1958).

\section{OREGON}

Ashland: Southern Oregon College Library (1953).

Corvallis: Oregon State University Library (1907).

Eugene: University of Oregon Library (1883).

Forest Grove: Pacific University Library (1897).

La Grande: Eastern Oregon College, Walter M. Pierce Library (1954).

McMinnville: Linfield College, Northup Library (1965).

Monmouth: Oregon College of Education Library (1967).

Portland:

Department of the Interior, Bonneville Power Administration Library (1962).

Lewis and Clark College, Aubrey R. Watzek Library (1967).

Library Association of Portland (1884).

Portland State University Library (1963) - REGIONAL.

Reed College Library (1912).

Salem:

Oregon State Library (unknown).

Oregon Supreme Court Library (1974).

Willamette University Library (1969).

\section{PENNSYLVANIA}

Allentown: Muhlenberg College, Haas Library (1939).

Altoona: Altoona Public Library (1969).

Bethlehem: Lehigh University, Linderman Library (1876).

Blue Bell: Montgomery County Community College, Learning

Resources Center Library (1975).
Carlisle: Dickinson College, Boyd Lee Spahr Library (1947).

Cheyney: Cheyney State College, Leslie Pinckney Hill Library (1947).

Collegeville: Ursinus College, Myrin Library (1963).

Doylestown: Bucks County Free Library, Center County Library (1970).

East Stroudsburg: East Stroudsburg State College, Kemp Library (1966).

Erie: Erie Public Library (1897).

Greenville: Thiel College, Langenheim Memorial Library (1963).

Harrisburg: State Library of Pennsylvania (unknown)-REGIONAL.

Haverford: Haverford College Library (1897).

Hazleton: Hazleton Area Public Library (1964).

Indiana: Indiana University of Pennsylvania, Rhodes R. Stabley Library (1962).

Johnstown: Cambria Public Library (1965).

Lancaster: Franklin and Marshall College, Fackenthal Library (1895).

Lewisburg: Bucknell University, Ellen Clarke Bertrand Library (1963).

Mansfield: Mansfield State College Library (1968).

Meadville: Allegheny College, Reis Library (1907).

Millersville: Millersville State College, Ganser Library (1966).

Monessen: Monessen Public Library (1969).

New Castle: New Castle Free Public Library (1963).

Newtown: Bucks County Community College Library (1968).

Norristown: Montgomery County-Norristown Public Library (1969).

Philadelphia:

Drexel University Library (1963).

Free Library of Philadelphia (1897).

St. Joseph's College Library (1974).

Temple University, Samuel Paley Library (1947).

U.S. Court of Appeals, Third Circuit (1973).

University of Pennsylvania, Biddle Law Library (1974).

University of Pennsylvania Library (1886).

Pittsburgh:

Bureau of Mines, Pittsburgh Research Center Library (1962).

Carnegie Library of Pittsburgh, Allegheny Regional Branch (1924).

Carnegie Library of Pittsburgh (1895).

La Roche College, John J. Wright Library (1974).

University of Pittsburgh, Hillman Library (1910).

Pottsville: Pottsville Free Public Library (1967).

Reading: Reading Public Library (1901).

Scranton: Scranton Public Library (1895).

Shippensburg: Shippensburg State College, Ezra Lehman Memorial Library (1973).

Slippery Rock: Slippery Rock State College, Maltby Library (1965).

Swarthmore: Swarthmore College Library (1923).

University Park: Pennsylvania State University Library (1907).

Villanova: Villanova University, School of Law Library (1964).

Warren: Warren Library Association; Warren Public Library (1885).

Washington: Washington and Jefferson College, Memorial Library (1884).

Waynesburg: Waynesburg College Library (1964).

West Chester: West Chester State College, Francis Harvey Green Library (1967).

Wilkes-Barre: King's College, Corgan Library (1949).

Williamsport: Lycoming College Library (1970).

York: York Junior College Library (1963).

Youngwood: Westmoreland County Community College, Learning Resource Center (1972). 


\section{PUERTO RICO}

Mayaguez: University of Puerto Rico, Mayaguez Campus Library (1928).

Ponce: Catholic University of Puerto Rico Library (1966).

Rio Piedras: University of Puerto Rico General Library (1928).

\section{RHODE ISLAND}

Kingston: University of Rhode Island Library (1907).

Newport: Naval War College Library (1963).

Providence:

Brown University, John D. Rockefeller, Jr. Library (unknown).

Providence College, Phillips Memorial Library (1969).

Providence Public Library (1884).

Rhode Island College Library (1965).

Rhode Island State Library (before 1895).

Warwick: Warwick Public Library (1966).

Westerly: Westerly Public Library (1909).

\section{SOUTH CAROLINA}

Charleston:

Baptist College at Charleston Library (1967).

College of Charleston Library (1869).

The Citadel Memorial Library (1962).

Clemson: Clemson University Library (1893).

Columbia:

Benedict College, Learning Resources Center (1969).

South Carolina State Library (before 1895).

University of South Carolina Undergraduate Library (1884).

Conway: University of South Carolina, Coastal Carolina Regional Campus Library (1974).

Due West: Erskine College, McCain Library (1968).

Florence:

Florence County Library (1967).

Francis Marion College, James A. Rogers Library (1970).

Greenville:

Furman University Library (1962)

Greenville County Library (1966).

Greenwood: Lander College Library (1967).

Orangeburg: South Carolina State College, Whittaker Library (1953).

Rock Hill: Winthrop College Library (1896).

Spartanburg: Spartanburg County Public Library (1967).

\section{SOUTH DAKOTA}

Aberdeen: Northern State College Library (1963).

Brookings: South Dakota State University, Lincoln Memorial Library (1889).

Pierre: South Dakota State Library (1973).

Rapid City:

Rapid City Public Library (1963).

South Dakota School of Mines and Technology Library (1963).

Sioux Falls:

Augustana College, Mikkelsen Library and Learning Resources Center (1969).

Sioux Falls Public Library (1903).

Spearfish: Black Hills State College Library (1942).

Vermillion: University of South Dakota, I. D. Weeks Library (1889).

Yankton: Yankton College, Corliss Lay Library (1904).

\section{TENNESSEE}

Bristol: King College Library (1970).

Chattanooga:

Chattanooga-Hamilton County Bicentennial Library (1907).

TVA Technical Library (1976).

Clarksville: Austin Peay State University, Felix G. Woodward Library (1945).

Cleveland: Cleveland State Community College Library (1973). Columbia: Columbia State Community College Library (1973).

Cookeville: Tennessee Technological University, Jere Whitson Memorial Library (1969).

Jackson: Lambuth College, Luther L. Gobbel Library (1967).

Jefferson City: Carson-Newman College Library (1964).

Johnson City: East Tennessee State University, Sherrod Library (1942).

Knoxville:

Public Library of Knoxville and Knox County, Lawson McGhee Library (1973).

University of Tennessee Law Library (1971).

University of Tennessee Library (1907).

Martin: University of Tennessee at Martin Library (1957).

Memphis:

Memphis and Shelby County Public Library and Information Center (1896).

Memphis State University, John W. Brister Library (1966).

Murfreesboro: Middle Tennessee State University, Andrew L. Todd Library (1912).

Nashville:

Fisk University Library (1965).

Joint University Libraries (1884).

Public Library of Nashville and Davidson County (1884).

Tennessee State Law Library (1976).

Tennessee State Library and Archives, State Library Division (unknown).

Tennessee State University, Martha M. Brown Memorial Library (1972).

Sewanee: University of the South, Jesse Ball duPont Library (1873).

\section{TEXAS}

Abilene: Hardin-Simmons University Library (1940).

Arlington:

Arlington Public Library (1970).

University of Texas at Arlington Library (1963). Austin:

Texas State Law Library (1972).

Texas State Library (unknown) - REGIONAL.

University of Texas at Austin Library (1884).

University of Texas, Lyndon B. Johnson School of Public Affairs Library (1966).

University of Texas, School of Law Library (1965).

Baytown: Lee College Library (1970).

Beaumont: Lamar University Library (1957).

Brownwood: Howard Payne College, Walker Memorial Library (1964).

Canyon: West Texas State University Library (1928).

College Station: Texas Agricultural and Mechanical University Library (1907).

Commerce: East Texas State University Library (1937).

Corpus Christi: Texas A\&I University at Corpus Christi Library (1976).

Corsicana: Navarro Junior College Library (1965).

Dallas:

Bishop College, Zale Library (1966).

Dallas Baptist College Library (1967). 
Dallas Public Library (1900).

Southern Methodist University, Fondren Library (1925).

University of Texas Health Science Center Library at Dallas (1975).

Denton: North Texas State University Library (1948).

Edinburg: Pan American University Library (1959).

El Paso:

El Paso Public Library (1906).

University of Texas at El Paso Library (1966).

Fort Worth:

Fort Worth Public Library (1905).

Texas Christian University, Mary Couts Burnett Library (1916).

Galveston: Rosenberg Library (1909).

Houston:

Houston Public Library (1884).

North Harris County College, Learning Resource Center (1974).

Rice University, Fondren Library (1967).

University of Houston Library (1957).

Huntsville: Sam Houston State University, Estill Library (1949).

Irving: Irving Municipal Library (1974).

Kingsville: Texas Arts and Industries University Library (1944).

Lake Jackson: Brazosport College Library (1969).

Laredo: Laredo Junior College Library (1970).

Longview: Nicholson Memorial Public Library (1961).

Lubbock: Texas Tech University Library (1935)-REGIONAL.

Marshall: Wiley College, Cole Library (1962).

Mesquite: Mesquite Public Library (1975).

Nacogdoches: Stephen F. Austin State University Library (1965).

Plainview: Wayland Baptist College, Van Howeling Memorial Library (1963).

Richardson: University of Texas at Dallas Library (1972).

San Angelo: Angelo State University, Porter Henderson Library (1964).

San Antonio:

San Antonio College Library (1972).

San Antonio Public Library, Business and Science Department (1899).

St. Mary's University Library (1964).

Trinity University Library (1964).

University of Texas at San Antonio Library (1973).

San Marcos: Southwest Texas State University Library (1955).

Seguin: Texas Lutheran College, Blumberg Memorial Library (1970).

Sherman: Austin College, Arthur Hopkins Library (1963).

Texarkana: Texarkana Community College, Palmer Memorial Library (1963).

Victoria: University of Houston, Victoria Center Library (1973).

Waco: Baylor University Library (1905).

Wichita Falls: Midwestern University, Moffett Library (1963).

\section{UTAH}

Cedar City: Southern Utah State College Library (1964).

Ephraim: Snow College, Lucy A. Phillips Library (1963).

Logan: Utah State University, Merrill Library and Learning Resources Center (1907) - REGIONAL.

Ogden: Weber State College Library (1962).

Provo:

Brigham Young University, Lee Library (1908).

Brigham Young University Law Library (1972).
Salt Lake City:

Utah State Supreme Court Law Library (1975).

University of Utah, Eccles Medical Sciences Library (1970).

University of Utah, Law Library (1966).

University of Utah, Marriott Library (1893).

Utah State Library Commission, Documents Library (unknown).

\section{VERMONT}

Burlington: University of Vermont, Bailey Library (1907).

Castleton: Castleton State College, Calvin Coolidge Library (1969).

Johnson: Johnson State College, John Dewey Library (1955).

Lyndonville: Lyndon State College, Samuel Reed Hall Library (1969).

Middlebury: Middlebury College, Egbert Start Library (1884).

Montpelier: Vermont Department of Libraries (before 1895).

Northfield: Norwich University Library (1908).

Putney: Windham College, Dorothy Culbertson Marvin Memorial Library (1965).

\section{VIRGIN ISLANDS}

Charlotte Amalie (St. Thomas): College of the Virgin Islands, Ralph M. Paiewonsky Library (1973).

St. Thomas Public Library (1968).

Christiansted (St. Croix): Christiansted Public Library (1974).

\section{VIRGINIA}

Blacksburg: Virginia Polytechnic Institute, Newman Library (1907).

Bridgewater: Bridgewater College, Alexander Mack Memorial Library (1902).

Charlottesville:

University of Virginia, Alderman Library (1910)-REGIONAL.

University of Virginia Law Library (1964).

Chesapeake: Chesapeake Public Library System (1970).

Danville: Danville Community College Library (1969).

Emory: Emory and Henry College Library (1884).

Fairfax: George Mason College of the University of Virginia, Fenwick Library (1960).

Fredericksburg: Mary Washington College, E. Lee Trinkle Library (1940).

Hampden-Sydney: Hampden-Sydney College, Eggleston Library (1891).

Harrisonburg: Madison College, Madison Memorial Library (1973).

Hollins College: Hollins College, Fishburn Library (1967).

Lexington:

Virginia Military Institute, Preston Library (1874).

Washington and Lee University, Cyrus Hall McCormick Library (1910).

Martinsville: Patrick Henry Community College Library (1971). Norfolk:

Armed Forces Staff College Library (1963).

Norfolk Public Library (1895).

Old Dominion University Library (1963).

Petersburg: Virginia State College, Johnston Memorial Library (1907).

Quantico:

Federal Bureau of Investigation Academy Library (1970).

Marine Corps Schools, James Carson Breckinridge Library (1967). 
Reston: Department of the Interior, Geological Survey Library (1962).

Richmond:

State Law Library (1973).

University of Richmond, Boatwright Memorial Library (1900).

U.S. Court of Appeals, Fourth Circuit Library (1973).

Virginia Commonwealth University, James Branch Cabell Library (1971).

Virginia State Library (unknown).

Roanoke: Roanoke Public Library (1964).

Salem: Roanoke College Library (1886).

Williamshurg: William and Mary College Library (1936).

Wise: Clinch Valley College, John Cook Wyllie Library (1971).

\section{WASHINGTON}

Bellingham: Western Washington State College, Wilson Library (1963).

Cheney: Eastern Washington State College Library (1966).

Ellensburg: Central Washington State College Library (1962).

Everett: Everett Public Library (1914).

Olympia:

Evergreen State College Library (1972).

Washington State Library (unknown) - REGIONAL.

Port Angeles: North Olympic Library System (1965).

Pullman: Washington State University Library (1907).

Seattle:

Seattle Public Library (1908).

University of Washington Library (1890).

University of Washington, School of Law Library (1969).

Spokane: Spokane Public Library (1910).

Tacoma:

Tacoma Public Library (1894).

University of Puget Sound, Collins Memorial Library (1938).

Vancouver: Fort Vancouver Regional Library (1962).

Walla Walla: Whitman College, Penrose Memorial Library (1890).

\section{WEST VIRGINIA}

Athens: Concord College Library (1924).

Bluefield: Bluefield State College Library (1972).

Charleston:

Kanawha County Public Library (1952).

West Virginia Library Commission (unknown).

Elkins: Davis and Elkins College Library (1913).

Fairmont: Fairmont State College Library (1884).

Glenville: Glenville State College, Robert F. Kidd Library (1966).

Huntington: Marshall University Library (1925).

Institute: West Virginia State College Library (1907).

Morgantown: West Virginia University Library (1907)-REGIONAL.

Salem: Salem College Library (1921).

Shepherdstown: Shepherd College Library (1971).
Weirton: Mary H. Weir Public Library (1963).

\section{WISCONSIN}

Appleton: Lawrence University, Seeley G. Mudd Library (1869).

Beloit: Beloit College Libraries (1888).

Eau Claire: University of Wisconsin, Eau Claire, William D. McIntyre Library (1951).

Fond du Lac: Fond du Lac Public Library (1966).

Green Bay: University of Wisconsin at Green Bay Library (1968).

La Crosse:

La Crosse Public Library (1883).

University of Wisconsin-La Crosse, Murphy Library (1965).

Madison:

Department of Public Instruction, Division for Library Services, Reference and Loan Library (1965).

Madison Public Library (1965).

State Historical Society Library (1870) - REGIONAL, in cooperation with University of Wisconsin, Memorial Library.

University of Wisconsin, Memorial Library (1939).

Wisconsin State Library (unknown).

Milwaukee:

Alverno College Library (1971).

Milwaukee County Law Library (1934).

Milwaukee Public Library (1861) - REGIONAL.

Mount Mary College Library (1964).

University of Wisconsin-Milwaukee Library (1960).

Oshkosh: University of Wisconsin-Oshkosh, Forrest R. Polk Library (1956).

Platteville: University of Wisconsin-Platteville, Elton S. Karrmann Library (1964).

Racine: Racine Public Library (1898).

River Falls: University of Wisconsin-River Falls, Chalmer Davee Library (1962).

Stevens Point: University of Wisconsin-Stevens Point, Learning Resources Center (1951).

Superior:

Superior Public Library (1908).

University of Wisconsin-Superior, Jim Dan Hill Library (1935).

Waukesha: Waukesha Public Library (1966).

Wausau: Marathon County Public Library (1971).

Whitewater: University of Wisconsin-Whitewater, Harold Andersen Library (1963).

\section{WYOMING}

Casper: Natrona County Public Library (1929).

Cheyenne: Wyoming State Library (unknown)-REGIONAL. Laramie: University of Wyoming, Coe Library (1907).

Powell: Northwest Community College Library (1967).

Riverton: Central Wyoming College Library (1969).

Rock Springs: Western Wyoming College Library (1969).

Sheridan: Sheridan College, Mary Brown Kooi Library (1963). 


\section{APPENDIX B. LIST OF DISTRICT OFFICES OF THE U.S. DEPARTMENT OF COMMERCE}

\section{ALABAMA}

Birmingham-Gayle C. Shelton, Jr., Director, Suite 200-201, 908 South 20th Street, 35205, Area Code 205 Tel 254-1331, FTS 229-1331

\section{ALASKA}

Anchorage-Sara L. Haslett, Director, 412 Hill Building, 632 Sixth Avenue 99501, Area Code 907 Tel 265-5307, FTS Dial 8-399-0150, Ask for $265-5307$

\section{ARIZONA}

Phoenix-Donald W. Fry, Director, Suite 2950 Valley Bank Center, 201 North Central Avenue 85073, Area Code 602 Tel 261-3285, FTS 2613285

\section{ARKANSAS}

- Little Rock (Dallas, Texas District)1100 North University, Suite 109 72207, Area Code 501 Tel 378-5157, FTS $740-5157$

\section{CALIFORNIA}

Los Angeles-Eric C. Silberstein, Director, Room 800, 11777 San Vicente Boulevard 90049, Area Code 213 Tel 824-7591, FTS 799-7591

-San Diego-233 A Street, Sulte 310 92101, Area Code 714 Tel 293-5395, FTS 895-5395

San Francisco-Philip M. Creighton, Director, Federal Building, Box 36013, 450 Golden Gate Avenue 94102, Area Code 415 Tel 556-5860, FTS 556-5868

\section{COLORADO}

Denver-Norman Lawson, Director, Room 165, New Customhouse, 19th \& Stout Street 80202, Area Code 303 Tel 837-3246, FTS 327-3246

\section{CONNECTICUT}

Harfford-Richard C. Kilbourn, Director, Room 610-B, Federal Office Building, 450 Main Street 06103, Area Code 203 Tel 244-3530, FTS 2443530

\section{FLORIDA}

Miami-Roger J. LaRoche, Director, Room 821, City National Bank Bullding, 25 West Flagler Street 33130 , Area Code 305 Tel 350-5267, FTS 350-5267

- Clearwater-128 North Osceola Avenue 33515, Area Code 813 Tel 446-4081

-Jacksonville-815 S. Main Street, Suite 100, 32207, Area Code 904 Tel 791-2796, FTS 946-2796 -Tallahassee-Collins BIdg., Rm. G-20 32304, Area Code 904 Tel 488-6469, FTS 946-4320

-DENOTES TRADE SPECIALIST -ODENOTES CHANGE.
GEORGIA

Atlanta-David S. Williamson, Director, Suite 600, 1365 Peachtree Street, N.E. 30309 , Area Code 404 Tel 8817000, FTS 257-7000

Savannah-James W. Mclntire, Director, 222 U.S. Courthouse \& P.O Box 9746, 125-29 Bull Street 31402, Area Code 912 Tel 232-4321, Ext. 204, FTS 248-4204

\section{HAWAII}

Honolulu-John S. Davies, Director, 4106 Federal Building, P.O. Box 50026, 300 Ala Moana Boulevard, 96850. Area Code 808 Tel 546-8694 FTS Dial 8, 556-0220, Ask for 5468694

\section{ILLINOIS}

Chicago-Gerald M. Marks, Director, 1406 Mid Continental Plaza Building, 55 East Monroe Street 60603, Area Code 312 Tel $353-4450$, FTS 3534450

\section{INDIANA}

Indianapolis-Mel R. Sherar, Director, 357 U.S. Courthouse \& Federal Office Building, 46 East Ohio Street 46204. Area Code 317 Tel 269-6214, FTS 331-6214

\section{IOWA}

Des Moines-Jesse N. Durden, Director, 817 Federal Building, 210 Walnut Street 50309, Area Code 515 Tel 284-4222, FTS 862-4222

\section{KENTUCKY}

-Frankfort (Memphis, Tennessee District)-Capitol Plaza Office Tower, Room 2425, 40601, Area Code 502 $875-4421$

\section{LOUISIANA}

New Orleans-Edwin A. Leland, Jr., Director, 432 International Trade Mart, No. 2 Canal Street 70130, Area Code 504 Tel 589-6546, FTS 682-6546

\section{MAINE}

-Portland (Boston, Massachusetts District)-Maine State Pier, 40 Commercial Street 04111, Area Code 207 Tel 773-5608, FTS 833-3407

\section{MARYLAND}

Baltimore-Carroll F. Hopkins, Director, 415 U.S. Customhouse, Gay and Lombard Streets 21202, Area Code 301 Tel $962-3560$, FTS $922-3560$
MASSACHUSETTS

Boston-Francis J. O'Connor, Director 10th Floor, 441 Stuart Street 02116, Area Code 617 Tel 223-2312, FTS 223-2312

\section{MICHIGAN}

Detroit-William L. Welch, Director, 445 Federal Building, 231 West Lafayette 48226, Area Code 313 Tel 2263650 , FTS $226-3650$

-Grand Rapids-350 Ottawa Street N.W. 49503, Area Code 616 Tel 456-2411/33 FTS $372-2411$

\section{MINNESOTA}

Minneapolis-Glenn A. Matson, Director, 218 Federal Building, 110 South Fourth Street 55401, Area Code 612 Tel 725-2133, FTS 725-2133

\section{MISSISSIPPI}

- Jackson (Birmingham, Alabama District)-P.O. Box 849, 1202 Walter Sillers Building 39205, Area Code 601 Tel $969-4388$, FTS 490-4388

\section{MISSOURI}

St. Louis-Donald R. Loso, Director, 120 South Central Avenue 63105, Area Code 314 Tel 425-3302-4, FTS 279-3302

-Kansas City-Room 1840, 601 East 12th Street 64106, Area Code 816 Tel $374-3142$, FTS $758-3142$

\section{MONTANA}

-Butte (Cheyenne, Wyoming District) -225 S. Idaho Street, Room 101 P.O. Box 3809, 59701, Area:Code 406 Tel 723-6561, Ext. 2317, FTS 585-2317

\section{NEBRASKA}

Omaha-George H. Payne, Director, Capitol Plaza, Suite 703A, 1815 Capitol Avenue 68102, Area Code 402 Tel 221-3665, FTS $864-3665$

\section{NEVADA}

- Reno-Joseph J. Jeremy, Director, 777 W. 2nd Street, Room 120, 89503 , Area Code 702 Tel 784-5203, FTS 470-5203

\section{NEW JERSEY}

Newark-Clifford R. Lincoln, Director, 4th Floor, Gateway Building, Market Street \& Penn Plaza 07102, Area Code 201 Tel 645-6214, FTS 341-6214

\section{NEW MEXICO}

Albuquerque-William E. Dwyer, DIrector, 505 Marquette Ave., NW, Suite 1015, 87102, Area Code 505 Tel 7662386, FTS $474-2386$ 
NEW YORK

Buffalo-Robert F. Magee, Director, 1312 Federal Building, 111 West $\mathrm{Hu}$ ron Street 14202, Area Code 716 Tel 846-4191, FTS 437-4191

New York-Arthur C. Rutzen, DIrector, Room 3718, Federal Office Building, 26 Federal Plaza, Foley Square 10007, Area Code 212 Tel 264-0634, FTS 264-0600

\section{NORTH CAROLINA}

Greensboro-Joel B. New, Director, 203 Federal Building, West Market Street, P.O. Box 1950 27402, Area Code 919 Tel 378-5345, FTS 699-5345

-Asheville-151 Haywood Street 28802, Area Code 704 Tel 2541981, FTS $672-0342$

\section{OHIO}

Cincinnati-Gordon B. Thomas, Director, 10504 Federal Office Buiiding, 550 Main Street 45202, Area Code 513 Tel 684-2944, FTS 684-2944

Cleveland-Charles B. Stebbins, Director, Room 600, 666 Euclid Avenue 44114, Area Code 216 Tel 522-4750, FTS 293-4750

\section{OKLAHOMA}

-Oklahoma City (Dallas, Texas District)-4020 Lincoln Boulevard 73105, Area Code 405 Tel 231-53Q2, FTS $736-5302$

\section{OREGON}

Portland - Lloyd R. Porter, Dlrector, Room 618, 1220 S.W. 3rd Avenue 97204, Area Code 503 Tel 221-3001, FTS 423-3001
PENNSYLVANIA

Philadelphia-Patrick P. McCabe, Director, 9448 Federal Bullding, 600 Arch Street 19106, Area Code 215 Tel 597-2850, FTS 597-2866

Pitisburgh-William M. Bradley, Trade Specialist-in-Charge, 2002 Federal Building, 1000 Liberty Avenue 15222, Area Code 412 Tel 644-2850, FTS $722-2850$

\section{PUERTO RICO}

San Juan (Hato Rey)-Enrlque Vilella, Director, Room 659-Federal Building 00918, Area Code 809 Tel 753-4555, Ext. 555, FTS Dial 9 4726620, Ask for 753-4555

\section{RHODE ISLAND}

-Providence (Boston, Massachusetts District)-1. Weybossett Hill 02903, Area Code 401 Tel 277-2605, ext. 22, FTS $838-4482$

\section{SOUTH CAROLINA}

Columbla-Philip A. Ouzts, Director, 2611 Forest Drive, Forest Center 29204, Area Code 803 Tel 765-5345, FTS 677-5345

-Charleston-Suite 631, Federal Building, 334 Meetlng Street 29403 Area Code 803 Tel 577-4361, FTS $677-4361$

\section{TENNESSEE}

Memphis-Bradford H. Rice, Director, Room 710, 147 Jefferson Avenue 38103, Area Code 901 Tel 521-3213, FTS 222-3213

-Nashville-4014 Aberdeen Road, 37216. Area Code 615 Tel 297. 5233, FTS 852-5161

\section{TEXAS}

Dallas-C. Carmon Stiles, Director, Room 7A5, 1100 Commerce Street 75242 Area Code 214 Tel 749-1515, FTS $749-1513$
Houston-Felicito C. Guerrero, DI. rector, 2625 Federal Bldg., Court. house, 515 Rusk Street 77002, Areal Code 713 Tel 226-4231, FTS 527-423

-San Antonio-University of Texa at San Antonio, Div. of Continuing Education 78285, Area Code 512 Tel 229-5875, FTS 229-5875

\section{UTAH}

Salt Lake City-George M. Blessing, Jr., Director, 1203 Federal Bullding 125 South State Street 84138, Area Code 801 Tel 524-5116, FTS 588-5116 VIRGINIA

Aichmond-(Vacant), 8010 Federal Bullding, 400 North 8th Street 23240 Area Code 804 Tel 782-2246, FTS 925-2246

-Fairfax-8550 Arlington Blvd. 22031, Area Code 703 560-6460 FTS 235-1519

\section{WASHINGTON}

Seattle-Judson S. Wonderly, Director, Room 706, Lake Union Building, 1700 Westlake Avenue North 98109, Area Code 206 Tel 442-5615, FTS 399-5615

\section{WEST VIRGINIA}

- Charleston-Roger L. Fortner, Director, 3000 New Federal Building 500 Quarrier Street 25301, Area Code 304 Tel 343-6181, ext. 375, FTS 924. 1375

\section{WISCONSIN}

Milwaukee-Russell $\mathrm{H}$. Leitch, Director, Federal BIdg/U.S. Courthouse, 517 East Wisconsin Avenue 53202, Area Code 414 Tel. 291-3473, FTS $362-3473$

\section{WYOMING}

Cheyenne-Lowell O. Burns, Director 6022 O'Mahoney Federal Center, 212 Capitol Avenue 82001, Area Code 307 Tel 778-2220, ext. 2151, FTS 3282151 
NBS.114A (REV. 11.77$)$

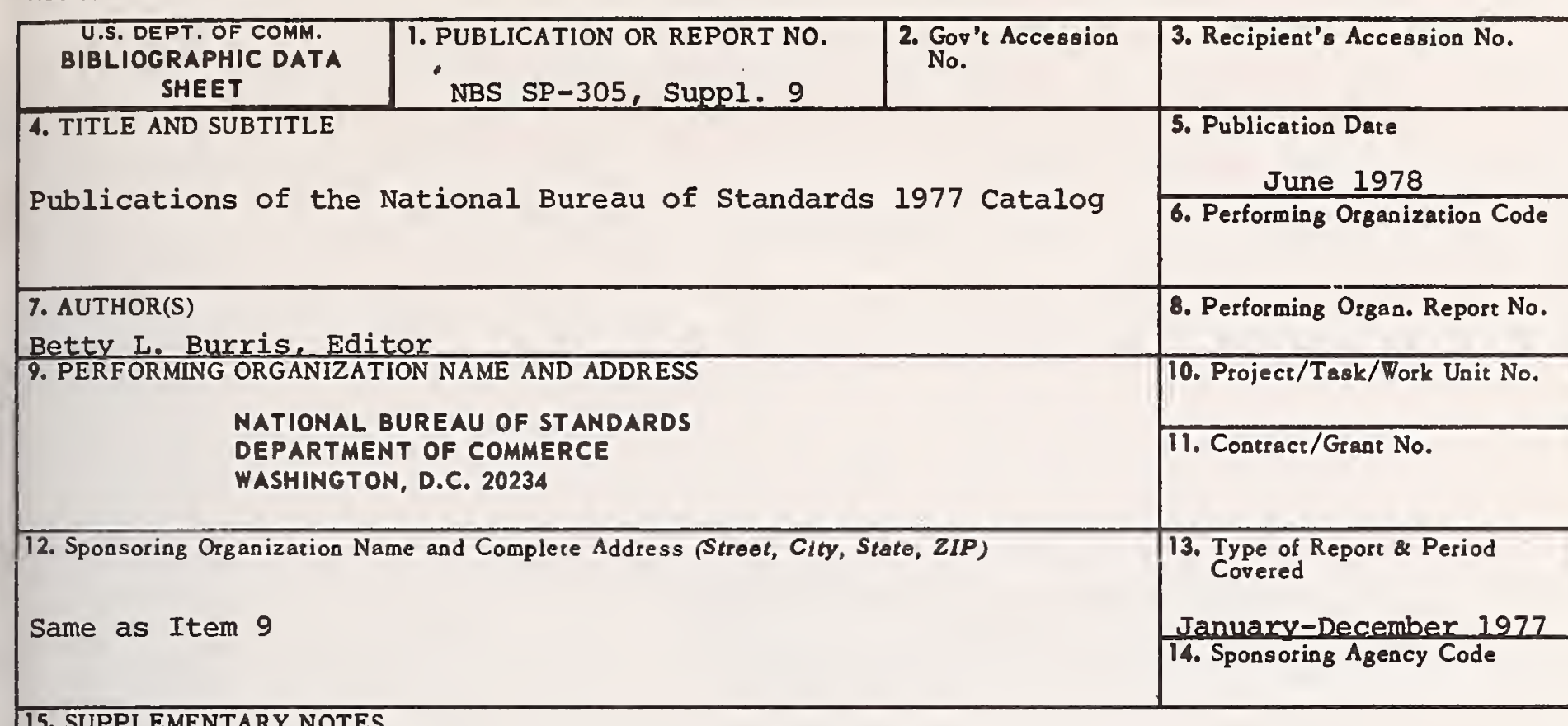

\section{SUPPLEMENTARY NOTES}

Library of Congress Catalog Card No. 48-47112

16. ABSTRACT (A 200-word or less factual summary of most significant information. If document includes a significant bibllography or literature survey, mention it here.)

This supplement to Special Publication 305 supplements 1 through 8 of the National Bureau of Standards lists the publications of the Bureau issued between January 1 December 31, 1977. It includes an abstract of each publication (plus some earlier papers omitted from Special Publication 305 Supplement 8), key-word and author indexes; and general information and instructions about NBS publications.

Miscellaneous Publication 240 (covering the period July 1, 1957 through June 30, 1960) and its supplement (covering the period July 1, 1960 through June 30, 1966), Special Publication 305 (covering the period July 1966 through December 1967), and Special Publication 305 Supplement 1 (covering the period 1968-1969), Special Publication 305 Supplenent 2 (covering the period 1970), Special Publication 305 Supplement 3 (covering the period 1971), Special Publication 305 Supplement 4 (covering the period 1972), Special Publication 305 Supplement 5 (covering the period 1973), Special Publication 305 Supplement 6 (covering the period 1974), Special Publication 305 Supplement 7 (covering the period 1975), Special Publication 305 supplement 8 (covering the period 1976), remain in effect. Two earlier lists, Circular 460 (Publications of the National Bureau of Standards, 1901 to June 1947) and its supplement (Supplementary List of Publications of the National Bureau of Standards, July 1, 1947 to June 30, 1957) are also still in effect.

17. KEY WORDS (six to twelve entries; alphabetical order; capitalize only the first letter of the first key word unless a propor name; separated by semicolons)

Abstracts, NBS publications; key words; publications.
18. AVAILABILITY
X Unlimited

For Official Distribution. Do Not Release to NTIS

G Order From Sup. of Doc., U.S. Government Printing Offjce Washington, D.C. 20402, SD Stock No. SN003-003 - $81951-8$

Order From National Technical Information Service (NTIS) Springfield, Virginia 22151

\begin{tabular}{|l|c|}
\hline $\begin{array}{l}\text { 19. SECURITY CLASS } \\
\text { (THIS REPURT) }\end{array}$ & 21. NO. OF PAGES \\
UNCL ASSIFIED & 616 \\
\hline $\begin{array}{l}\text { 20. SECURITY CLASS } \\
\text { (THIS PAGE) }\end{array}$ & 22. Price \\
UNCLASSIFIED & $\$ 7.50$ \\
\hline
\end{tabular}





\section{Announcement of New Publicatione of the \\ National Bureau of Standards}

Superintendent of Documents, Government Printing Office,

Washington, D. C. 20402

\section{Dear Sir:}

Please add my name to the announcement list of new publications as issued by the National Bureau of Standards. Name.

Company.

Address.

City. State. Zip Code

(Notification Key N519) 




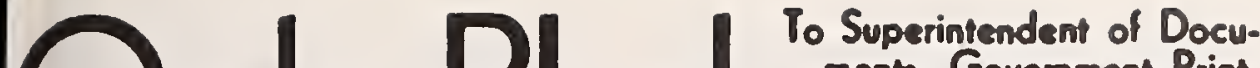 ments, Govemment Print- ing Office, Woshington, D.C. 20402}

Dote 19

Nome

Siroet oddrew

Cin

Siote

Zip Cods con un or eur. or poca

Eneloind

Ta be mailed

lorer

Subcription

Refond

Coupon Refund

Porroge

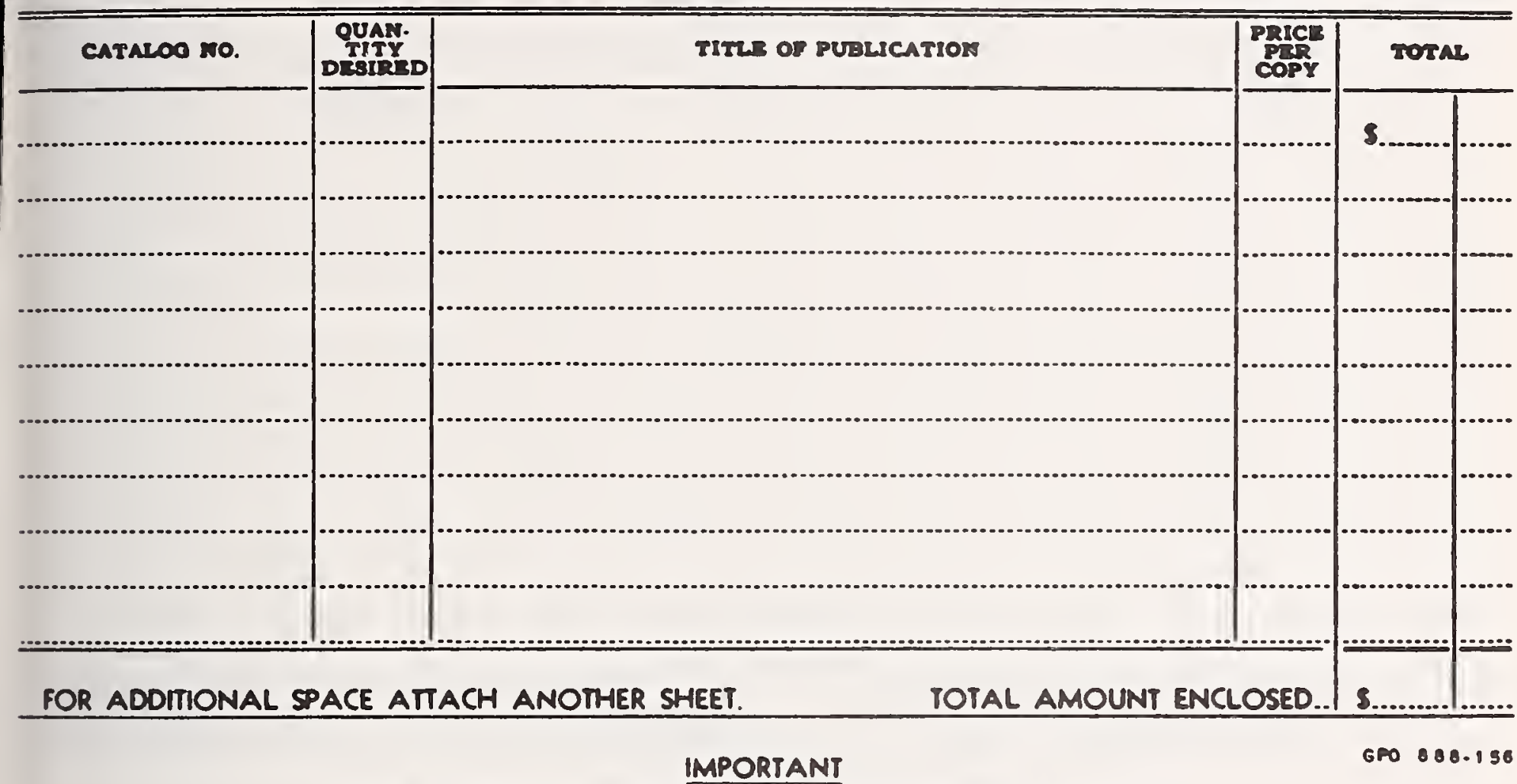

Please Inelude your ZIP CODE when filling out the mailing label below.

U.S. GOVERNMENT PRINTING OFFICE PUBLIC DOCUMENTS DEPARTMENT WASHINGTON, D.C. 20402 OFFICIAL BUSINESS
POSTAGE AND FEES PATD U.S. GOVERNMENT PRINTING OF RZCE 375 SPECLAL FOURTH-CLASS RATE BOOK

Name

Street address 



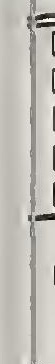

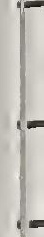

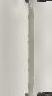

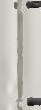

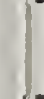


MAIL ORDER TO:

NIS

Matiand Technical Information Service

U. S. OEPARTIMENT OF COMMERCE

5265 Port Royal Rosd, Springtield Vs. 22151

Date

Ship to: (Enter if different from address at len.)

Name

Address

City, State, ZIP

\section{TELEX 89.9405}

Attention:

$\square$ Charge my NTIS deposit account no.
$\square$ Send me an application for an NTIS deposit account.
$\square$ Purchase order no.
$\square$ Check enclosed for $\$$
$\square$ Bill me (not applicable to foreign customers) add 50 per title.

Wherever a foreign sales price is NOT specified in the listings, all foreign buyers must add the following charges to each order.

$\$ 2.50$ for each document $\$ 1.50$ for each microfiche

FOR DDC USERS OHLY

DDC USER CODE

CONTRACT MUMBER (UAST 6 CHARACTERS ONLV

Please allow two weeks for delivery on your order.

If ordering without a document number, by title only, add a week.

$\square$ Magnetic Tape

7 track

$200 \mathrm{BPI}$ odd parity

800 BPI $\square$ even parity

$\square 9$ track -800 BPI odd parity only

\section{Document Number}

(If ordered by title, see reverse side first)

\section{Titles ordered are from:}

$\square$ Weekly Government Abstracts.

titles

$\square$ NTISearch,

$\square$ Government Reports Topical Announcements

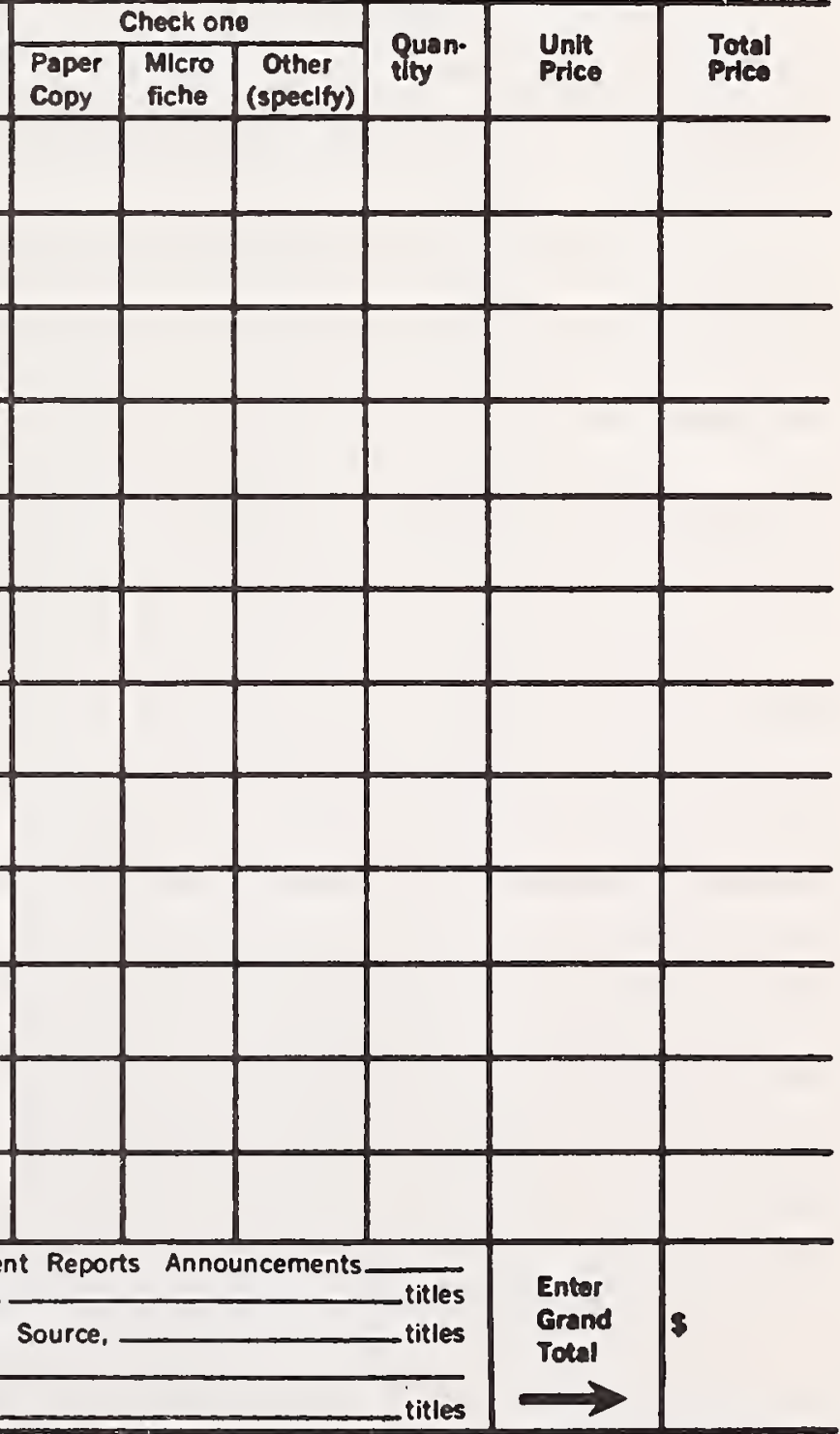




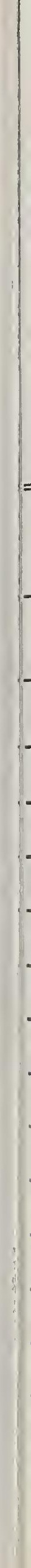


MAIL ORDER TO:

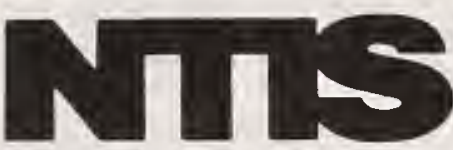

National Technical Information Service

U. S. DEPARTMENT OF COMMERCE

5285 Port Royal Road, Springfield Vo. 22151

Date

Ship to: (Enter if different from address at left.)

Name

Address

City, State, ZIP

\section{TELEX 89.9405}

Attention

$\square$ Charge my NTIS deposit account no.

$\square$ Send me an application for an NTIS deposit account.

$\square$ Purchase order no.

$\square$ Check enclosed for $\$$

$\square$ Bill me (not applicable to foreign customers) add 50 per title.

Wherever a foreign sales price is NOT speci. fied in the listings, all foreign buyers must add the following charges to each order. $\$ 2.50$ for each document $\$ 1.50$ for each microfiche
FOR DOC USERS OALY

DDC USER CODE

CONTRACT NUMBER

MAST 6 CHARACTERS OMLY

Please allow two weeks for delivery on your order.

If ordering without a document number, by title only, add a week.

$\square$ Magnetic Tape $\square 7$ track $\square 556$ BPI odd parity

(tape)

556 BPI $\square$ even parity

9 track -800 BPI odd parity oniy

Document Number

(If ordered by title, see reverse side first)
Titles ordered are from:

$\square$ Weekly Government Abstracts, _

NTIS earch, titles

$\square$ Government Reports Topical Announcements, titles

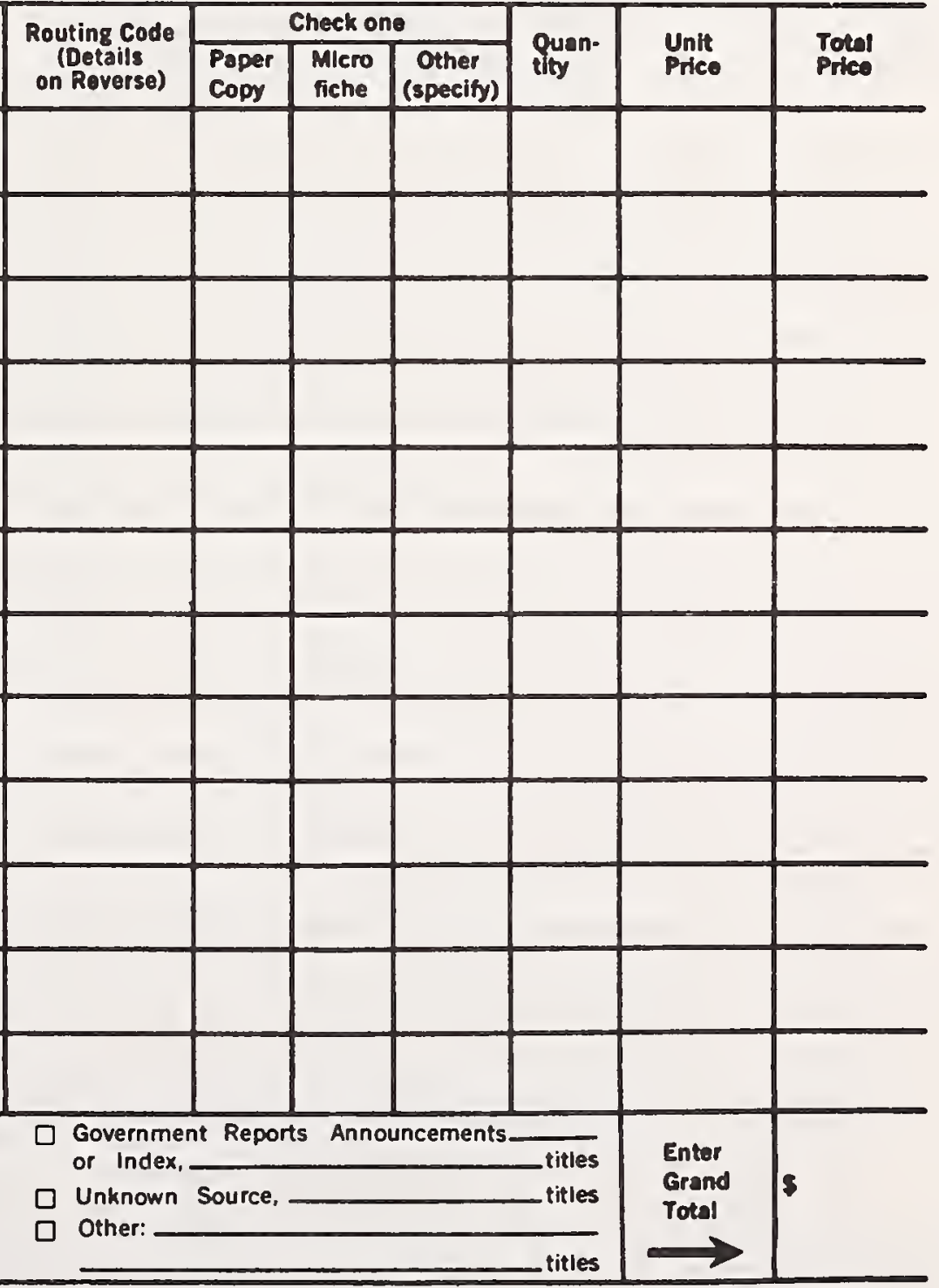

USCOMMODC $12323 . P 73$ 

MAIL ORDER TO:

NIS

Motioned Techaical Information Service U. S. DEPARTMENT OF COMMERCE

secs Port Royal Roed, Springfield Vs. 22151

Date

Ship to: (Enter if different from address at loft.)

Name

Address

City. State, ZIP

TELEX 89.9405

Attention:

\begin{tabular}{l}
\hline Charge my NTIS deposit account no. \\
$\square$ Send me an application for an NTIS deposit account. \\
$\square$ Purchase order no. \\
$\square$ Check enclosed for $\$$ \\
$\square$ Bill me (not applicable to foreign customers) add 50e per title.
\end{tabular}

Wherever a foreign sales price is NOT specified in the listings, all foreign buyers must add the following charges to each order.

$\$ 2.50$ for each document

$\$ 1.50$ for each microfiche

Bill me (not applicable to foreign customers) add 50 e per title.

Please allow two weeks for delivery on your order.

If ordering without a document number, by title only, add a week.

(If ordered by title, see reverse side first)
Magnetic Tape
(tape)
Thtes ordered are from:

$\square$ Weekly Government Abstracts,

titles

$\square$ NTISearch

$\square$ Government Reports Topical Announcements,

titles

titles
FOR DOC USERS ONLY

DOC USER CODE

CONTRACT MUMBER (LAST 6 CHARACTERS OMLV

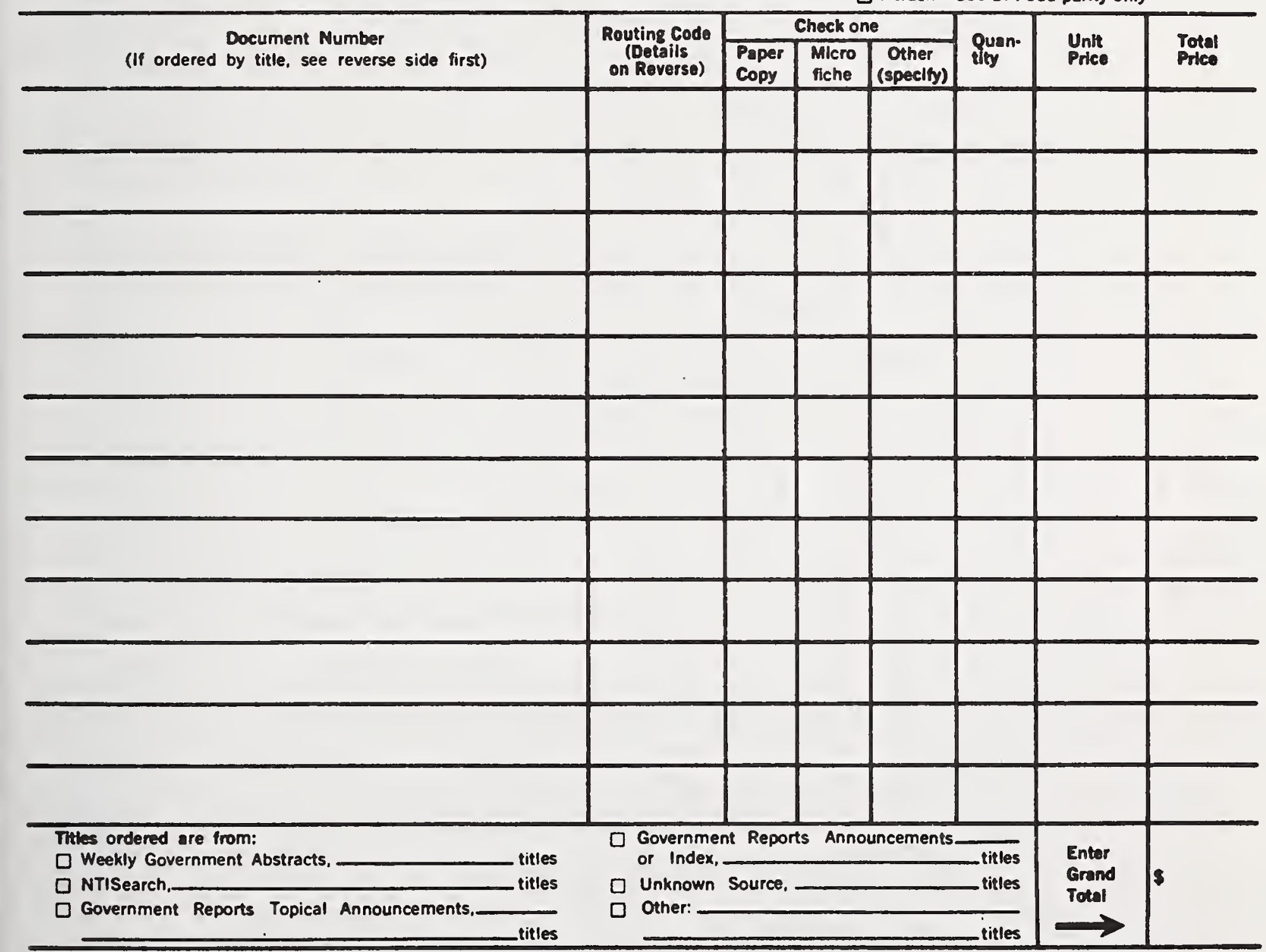

$\square 200 \mathrm{BPI}$

$\square 556$ BP, $\square$ odd parity

800 BPI $\square$ even parity

$\square 7$ track

$\square 800 \mathrm{BPI}$ even parity

$\square 9$ track $-800 \mathrm{BPI}$ odd parity only 




\section{EDGE INDEX}

\section{Descriptive}

NBS Periodical and Non-Periodical Publications

Purchase Procedures and Document Availability

Citations (index code is shown within parentheses)

Journal of Research, Section A(J81A, January-June 1977)

Journal of Research, Section B(J81B, January-June 1977)

Journal of Research (J82, July-December 1977)

Journal of Physical and Chemical Reference Data(JPCRD)

DIMENSIONS/NBS (DIM/NBS)

Monographs (Monogr.)

Handbooks (H)

Special Publications (SP)

Applied Mathematics Series (AMS)

National Standard Reference Data Series (NSRDS)

Building Science Series (BBS)

Federal Information Processing Standards Publications (FIPS PUBS)

Product Standards (PS)

Technical Notes (TN)

Consumer Information Series (CIS)

NBS Interagency Reports (NBSIR)

Grantee/Contractor Reports and Patents (GCR)

NBS Papers Published in Non-NBS Media [5-digit arabic number]

Listing of NBS Papers by Major Subject Areas

How To Use the Indexes

Author Index

Key Word Index

Depository Libraries in the United States 



